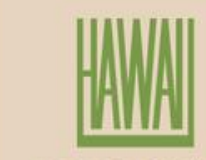

UNIVERSITY of

HAWAI'I

PRESS

\title{
ANCIENT TAHITIAN SOCIETY
}


ANCIENT TAHITIAN SOCIETY 


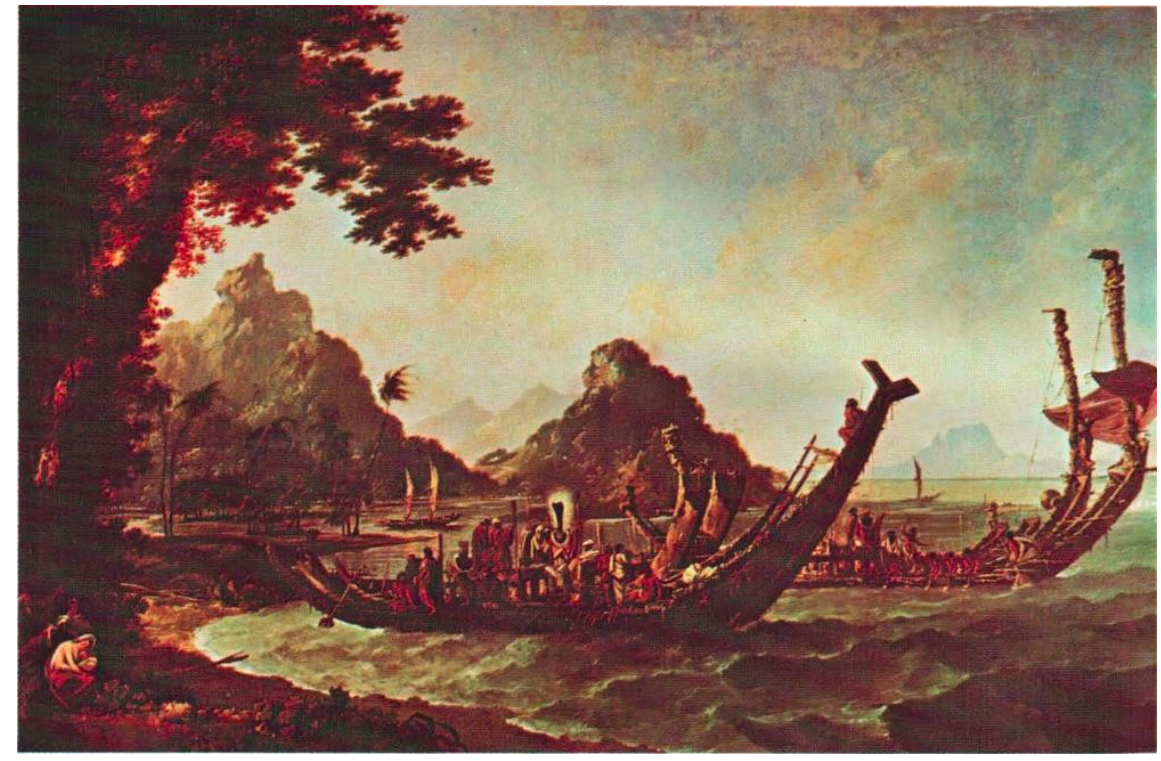

"The War Boats of the Island of Otahiete and the Society Isles, with a view of part of the Harbour of Ohamanene in the Island of Ulietea one of the Society Islands." Painting by W. Hodges, Cook's second voyage. Admiralty House, London. 



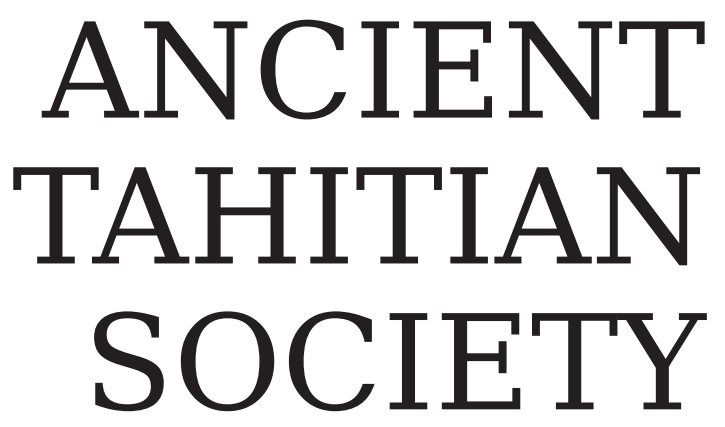

DOUGLAS L. OLIVER 


\section{HWWA \\ UNIVERSITY of HAWAI'I PRESS \\ OPEN ACCES}

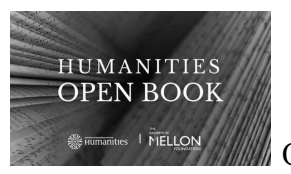

Open Access edition funded by the National Endowment for the Humanities / Andrew W. Mellon Foundation Humanities Open Book Program.

\section{(c) $(1) \Theta()_{\mathrm{BY}} \mathrm{NC}$} NonCommercial-NoDerivatives 4.0 International (CC BY-NC-ND 4.0), which permits readers to freely download and share the work in print or electronic format for non-commercial purposes, so long as credit is given to the author. Derivative works and commercial uses require permission from the publisher. For details, see https://creativecommons.org/licenses/by-nc-nd/4.0/. The Creative Commons license described above does not apply to any material that is separately copyrighted.

Open Access ISBNs:

9780824884536 (PDF)

9780824884543 (EPUB)

This version created: 25 September, 2019

Please visit www.hawaiiopen.org for more Open Access works from University of Hawai'i Press.

Copyright (c) 1974 by The University Press of Hawaii All rights reserved 
To Kenneth Emory, prehistorian, Raymond Firth, ethnographer, and the late John Beaglehole, who have infused new life into the study of Polynesian culture 



\section{volume 1 CONTENTS}

Prefatory Remarks and Acknowledgments xi

Chapter 1 Introduction 1

Chapter 2 Geography and Population 7

THE PRE-MAOHI SETTING 7

Topography 7; Climate 16; Tides 19; Soils 19; Phytogeography 20; Fauna 25; Summary 26

POPULATION 26

Numbers 26; Composition 39; Physical Characteristics 40

THE SETTING IN $1767 \quad 42$

Chapter 3 Cosmology 47

SOCIAL ENTITIES 47

Cosmogony 47; Principles of Classification 54; Spirits 56; Humans

62; Social Groups 65

RELATIONS BETWEEN SPIRITS AND HUMANS 65

Sacredness and Similar Concepts 66; Omens, Auguries, and Dreams 69; Images and Talismans 71; Human Oracles 78; Prayer and Offering 83; Dancing and

Prodigious Acts 93; Priests 94; Marae 95; Religious Ritual 106

Chapter 4 The Daily Cycle 123

DAILY ROUTINE 123

DIURNAL TIME RECKONING 128

Chapter 5 Primary Tools and Crafts 133

PRIMARY TOOLS 133

Human Body as a Tool 133; "Natural" Objects as Tools 134; Fabricated

Primary Tools 135

CORDAGE 139

BARK CLOTH 143

PLAITWARE AND NETTING 149

Chapter 6 Grooming 152

EVERYDAY CLOTHING 152

TOILETTE 155

FATTENING AND SKIN BLEACHING

TATTOO AND SUPERCISION 159 
Chapter 7 Buildings 162

DWELLINGS 162

MARAE 177

Chapter 8 Boats And Travel 194

BOATS 194

BOAT TRAVEL 207

NAVIGATION 215

METEOROLOGY 218

TRAVEL RITUAL 218

Chapter 9 Food 220

EATING AND COOKING 220

CIRCULATION OF FOOD 229

FOOD PLANTS 234

Breadfruit 234; Coconuts 244; Wild Food Plants 245; Cultivated Food Plants 248

PLANT-FOOD DISTRIBUTION 253

KAVA 256

FOOD-PLANT RITUAL 259

ANNUAL-CYCLE TIME RECKONING 264

DOMESTIC ANIMALS 270

Pigs 270; Dogs 276; Chickens 277; Rats 278

HUNTING 278

FISHING 281

Fishing Techniques 284; Seasonal Factors in Fishing 303; Locational

Factors in Fishing 308; Social Factors in Fishing 309; Fishing Ritual 310

Chapter 10 Diversions 315

GAMES AND SPORTS 315

STORIES, RIDDLES, AND JESTS

323

MUSIC 326

DANCE 332

DRAMA 339

TOURING AND VISITING 343

Chapter 11 Sexuality 350

COITUS 350

"PROMISCUITY" 354

CHOOSING A PARTNER 358

TIMES AND PLACES 361

"SEDUCTION" 364

SEX TRAINING 368

HOMOSEXUALITY 369

Chapter 12 Warfare 375

WEAPONS AND UNIFORMS 376

TRAINING 381 
MOBILIZATION 383

FIGHTING PERSONNEL 387

FREQUENCY OF WARFARE 387

FIGHTING ON LAND 389

PEACEMAKING 396

FIGHTING AT SEA 400

VEHIATUA'S WAR 405

Chapter 13 The Individual: From Conception to Afterlife 409

CONCEPTION 409

BIRTH 413

INFANTICIDE 424

NURTURANCE AND SOCIALIZATION 427

MATURATION RITES 431

Tattoo 431; Supercision 434; Fattening 434; Coming-of-Age 437; Āmo'a 437

CONNUBIALITY 445

"Marriage" 445; Nuptials 447; Arranging Marriages 453; Polygamy 463

FORMAL FRIENDSHIP 465

OLD AGE AND INFIRMITY 466

SICKNESS AND DEATH 469

Harming 472; Curing 474; Death 485; Body Disposal 507; Case Studies:

The Deaths of Vehiatua II and of Mahau 511

JOURNEY OF THE SOUL 521

Notes 529 


\section{volume 2 CONTENTS}

Chapter 14 Introduction to Social Relations 579

DIMENSIONS OF INTERACTION 580

Terminology 581; Time 583; Space 584; Governance 585;

Transaction 586; Emotion 589

KINDS OF INTERACTION 591

SANCTIONS 592

Chapter 15 Sex and Age 597

MALENESS AND FEMALENESS 597

AGE 607

Infancy 609; Childhood 609; Youth 610; Maturity 613; Old Age 613

Chapter 16 Consanguinity: Common-Descent Units 616

COMMON DESCENT 616

KIN-CONGREGATIONS 622

Composition 624; Marae-Names and Offices 626; Chiefs and Tutelars

627; Chiefs and Other Members 632; Kin-Congregation Titles and Marae Stones 640

CHANGES IN KIN-CONGREGATION STRUCTURE 648

THE OPOA COGNATIC STOCK 660

Leeward Islands 660; Tahiti-Mo'orea 674

RANK 686

Chapter 17 Consanguineal Roles 688

ADJACENT GENEALOGICAL LEVELS 690

SAME GENEALOGICAL LEVEL 726

NONADJACENT GENEALOGICAL LEVELS 743

Chapter 18 Class 749

SOCIAL STRATIFICATION 749

Ari'i 759

Manahune 765

Ra'atira 769

RECRUITMENT 771

ORIGINS OF CLASS STRATIFICATION 777

ATTRIBUTES OF CLASS 782 
CLASS-BASED PATTERNS OF INTERACTION 791

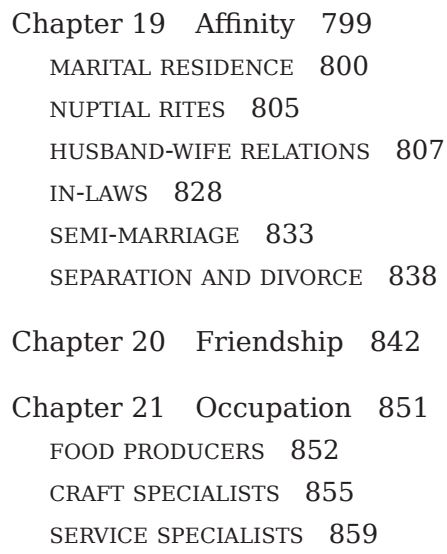

Tahu'a Tatau (Tatatau), Tahu'a Tehe 861; Tapua Miri 862; Teuteu 862; Ghost Guardians 862; Prostitutes 863; Entertainers 863; Teachers 864; Taura, or Tahu'a Atua 866; Priests 869; Fighters 876 SKILL 879

Chapter 22 Cults 881

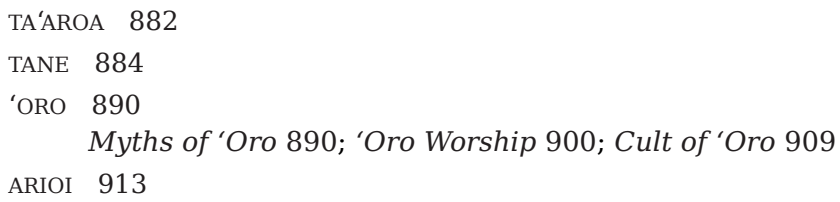

Chapter 23 Proximity and Force 965

RESIDENTIAL PROXIMITY 965

TERRITORIAL UNITS 966

Households 966; Neighborhoods 967; Larger Territorial Units 970;

Orders of Territorial-Unit Complexity 976; The Nature of Territorial-Unit Interrelations 978

TRIBES 982

Force 982; Size 985; Composition 986

TRIBAL ACTIVITIES 987

Warring 987; Intertribal Visting 993; Work Projects 995; Levy of Objects 1001; Worship 1011; Fattening of Youths 1014; Carnivals 1014; Rites for the Chief 1015

ROUTES TO TRIBAL CHIEFTAINSHIP 1024

OTHER TRIBAL OFFICES 1027

SYMBOLS OF CHIEFTAINSHIP 1037

Hau 1049

CHIEFS AND SOCIAL ORDER 1053 
Theft 1054; Lese Majesty 1059; Social Justice 1061; Constraints on Chiefly Authority 1064

THE PRECEPTS OF TETUNAE 1067

ADVANTAGES OF TRIBAL MEMBERSHIP 1070

Chapter 24 Summary, Synthesis, Evolution 1074

ENDS AND MEANS 1074

Life Goals 1074; Physical Resources 1078; Labor 1078; Technology 1079;

Social-relational Techniques 1079

SOCIAL UNITS AND ROLES 1092

Consanguinity 1093; Class 1098; Affinity 1099; Friendship 1101;

Occupation 1102; Cult 1105; Arioi 1106; Tribe 1108; Sex and Age 1110

SYNTHESIS 1114

Comparisons of Intrarelations of Social Groups 1114; Relative Positions

of Boundaries of Social Groups 1115; Consanguinity and Class 1117;

Tribe and Class 1118; Statuses 1118; Symbols 1119; Property 1120

EVOLUTION OF MAOHI SOCIETY TO 17671121

Notes 1133 


\section{volume 3 CONTENTS}

Chapter 25 Tribal Polity at Beginning of Early European Era 1171

TAHITI 1173

Seaward Teva 1174; Hitia'a 1176; Mahaena, Tiarei, Ha'apaiano'o,

Ha'apape 1177; Poreonu'u 1179; Fa'a'a (Te Fana) 1191; Puna'auia (Mano

Tahi) 1193; Pa'ea (Mano Rua) 1196; Landward Teva 1198

MO‘OREA 1203

LEEWARD ISLANDS 1207

'ORO IMAGES AND FEATHER GIRDLES 1213

Chapter 26 The Emergence of the Pomares 1217

THE PAPARA DEBACLE 1217

CONTEST BETWEEN NORTH AND SOUTH 1225

NEW ALIGNMENTS 1232

Chapter 27 Tahiti and Mo'orea 1237

THE MO'OREAN SUCCESSION WAR 1239

TE TO'OFA'S REVENGE 1250

Chapter 28 Wars of the Bounty Mutineers 1256

Chapter 29 Rank versus Power 1272

AGGRANDIZEMENT BY KINSHIP 1272

THE Matilda INCIDENT 1281

OTHER CHANGES IN MAOHI LIFE 1284

Chapter 30 The Missionaries Arrive 1288

THE POLITICAL SITUATION IN $1797 \quad 1288$

SON AGAINST FATHER 1295

“DISAFFECTION OF THE COMMONALITY" 1304

THE IMAGE OF 'ORO 1307

Chapter 31 Fall of the Pomares 1314

FRAGILE VICTORY 1314

QUALIFIED DEFEAT 1320

Chapter 32 And Rise Again 1333

Hau Manahune 1333

REINFORCEMENTS 1336 
CONVERSION 1339

JEHOVAH VERSUS 'ORO 1342

“NEW STATE OF THINGS” 1349

Notes 1351

Bibliography 1367

Subject Index 1385

Place Index 1405

Name Index 1411 


\section{PREFATORY REMARKS AND ACKNOWLEDGMENTS}

I began this book about twenty years ago. Having decided to carry out a field study of a contemporary Society Islands community - for contrast with a study done in Melanesia some fifteen years earlier - I set aside a summer to prepare an ethnographic reconstruction of pre-European Tahiti in order to see how much of the past had survived into the present. As one "specialist," who shall be nameless, advised me, “... it shouldn't be much of a job, since most of the information is already recorded and digested in a handful of books."

The incredibility of that advice turned out to be exceeded only by the naïveté of my credulity. By the end of that summer I had indeed read the "handful of books" alluded to, but in doing so I had accumulated many more questions than answers. For example, it had become clear to me that many of the generalizations then current about ancient Tahitian social relations (the focus of my inquiries) were in reality scholars' inventions that had come to acquire "authenticity" more through reassertion than through retesting with primary sources. Also, during that frustrating summer I discovered the existence of masses of unpublished primary sources that had hitherto been either untapped or tapped only piecemeal.

Finally however, after some fifteen years and many interruptions, including two periods of fieldwork in the Society Islands and resumption of research in Melanesia, the goal was approached as near as I have the knowledge, or more decisively the will, to reach it. In proceeding thus far - which I readily acknowledge is not far. enough - I have become heavily indebted for help received from many individuals and institutions. It is now my pleasure to list them.

First, for the financial support that helped to provide me with free time, travel, research assistance, typing, and so forth, I am indebted to the Anthropology Department of Harvard University, the East-West Center at the University of Hawaii, the National Science Foundation, and the Tri-Institutional Pacific Program.

The libraries and librarians who were most useful and helpful were Harvard's Peabody Museum Library (and Margaret Currier), the Bishop 
Museum Library (and Margaret Titcomb), the University of Hawaii Pacific Collection (presided over by Janet Bell and Renée Heyum), and the Mitchell Library of the Library of New South Wales.

A book describing ancient Tahiti must of course include extensive quotes and paraphrases from primary sources, published and unpublished. For permission to use such material grateful acknowledgment is made to the following publishers and archives: the Bishop Museum, the London Missionary Society Corporation, the Hakluyt Society, Cambridge University Press, the Golden Cockerel Press, the Polynesian Society, Société des études océaniennes, the National Library of Australia, the Mitchell Library, and Angus and Robertson, Ltd. Less extensive but very useful material was quoted from copyrighted publications of the University of Washington Press, Columbia University Press, and the Franz Steiner Verlag of Wiesbaden.

The illustrations which, I hope, help to expand and enliven the text derive from many collections, and have been provided through the services of many generous custodians. In the first rank are the British Museum (the Trustees thereof in general, and B.A.L. Cranstone and Edward Telesford in particular), the London Missionary Society Corporation (especially Irene Fletcher and E.H.G. Blacklock), the Mitchell Library (especially Suzanne Mourot), and the Bishop Museum (particularly Roland Force, Kenneth Emory, and especially Yosihiko Sinoto, who generously supplied photographs of several of the ancient stone structures he and his associates have studied and in part reconstructed). Other institutions and individuals that have generously contributed illustrations are The Art Institute of Chicago, Mr. and Mrs. Henri Kamer, Raymond Wielgus, the Bernisches Historisches Museum, the British Museum of Natural History, Cambridge University Museum (especially Robert Maclehose), the Field Museum of Natural History (especially Donald Collier), The Museum of Primitive Art (New York), the National Library of Australia, the National Maritime Museum (Greenwich, England), the Peabody Museum of Harvard University, the Peabody Museum (Salem, Massachusetts), The University Museum of the University of Pennsylvania, Admiralty House (London), and the Etnografiska Museet (Stockholm). In addition, the illustrations include copies of several previously published photographs and drawings of objects found in the following collections: the British Museum, the Hunterian Museum of the University of Glasgow, the National Museum of Ireland, the Pitt-Rivers Museum (Oxford), the Cambridge University Museum, Greenwich Hospital (Greenwich, England), the Mitchell Library (Sydney), the Institut für Völkerkunde (Göttingen), Peabody Museum (Salem), American Museum of Natural History (New York), Museum für Natur- und Völkerkunde (Basel), Museum für Völkerkunde (Vienna), National Museum (Washington), and the Honolulu Academy of Arts. I have also to thank the four 
skillful artists who prepared illustrations for this book, either drawing the objects themselves or copying illustrations of them: Niel Crozier, who drew the maps used in these volumes, A. Smith-Brunet, G. C. Smith, and George Sasaku.

The selection and documentation of most of these illustrations was the work of Roger Rose, now curator at the Bishop Museum. I am deeply indebted to Dr. Rose for his invaluable assistance and eagerly look forward to the publication of his comprehensive manuscript on the material culture of ancient Tahiti.

A work of this size and length of gestation embodies the assistance and encouragement of many persons in addition to the kinds of contributions heretofore acknowledged. Chief among those who directly and materially aided in the research were Robin Hooper, Nan Gaynor, Ann Jay, Robert Jay, Joy Rabin, and Marguerite Robinson. I have also profited greatly from the knowledge and insights provided by several of my colleagues, some of them former students, and all of them specialists in various aspects of Polynesian history or anthropology: Eugene Anderson, the late John Beaglehole, Bengt Danielsson, Greg Dening, Kenneth Emory, Ben Finney, Raymond Firth, Derek Freeman, Irving Goldman, Roger Green, Neil Gunson, E.S.C. Handy, Antony Hooper, Paul Kay, Robert Levy, Harry Maude, Richard Moench, Colin Newbury, H. René Papy, Marshall Sahlins, and Yosihiko Sinoto.

Harking back to the eras under scrutiny, I wish to pay special tribute to the ethnographic reporting of four of the early visitors to Tahiti: Bligh, Morrison, Orsmond, and Rodriguez. (The missionary Knott may have been better informed about Tahitian life than any of these four, but his knowledge is recorded mainly in the writings of others.)

It is also fitting to acknowledge here the great service rendered to Tahitian studies by Patrick O'Reilly and Édouard Reitman, in their monumental Bibliographie de Tahiti et de la Polynésie française (1967). Unfortunately for me, this work appeared after completion of my manuscript; had it been available a few years earlier it would have reduced my own labors immeasurably.

In addition to the above, I wish to thank several persons for their help in connection with my field studies in contemporary Tahiti - studies which, though not the basis of the present book, may have helped some in the attempt to comprehend life in Tahiti in earlier eras. Chief among these are Dr. and Mrs. Bengt Danielsson, Jean Guiart, Henri Jacquier, Mr. and Mrs. M. R. Kellam, J. Laguesse, Emile Massal, and Aurora Natua. Above all, I am deeply indebted to R. G. White, who shared with me his profound knowledge of the Tahitian language during my fieldwork in Tahiti and during the preparation of this work. In this connection, I am also moved to acknowledge gratefully the assistance, deliberate or otherwise, provided me by the Polynesian residents of Huahine and Mo'orea, the sites of my field studies. 
Although themselves unaware, they undoubtedly exemplified many continuities with that long-forgotten past, which they labeled, doubtless with some mixed feelings, the "Heathen Era" (tau etene).

Last but (as the saying goes) certainly not least, I wish to acknowledge with gratitude the services of the two persons most largely and directly responsible for the book in this final form: to my wife, Ann R. Oliver, who bore with me helpfully and patiently during the years it took to write it, and to my editor, Iris M. Wiley, who helped me recast it in a more comprehensible form.

Now, a word about the book's dedication. Each of the three scholars to whom this work is dedicated has been preeminent in his respective field in the recent revival of scholarly interest in pre-European Polynesia. With regard to Tahiti particularly, however, the names of F. Garanger, Roger Green, and Yosihiko Sinoto must be added to the list of scholars who have made very important contributions to the prehistory of that archipelago. Robert Levy's recent report (Tahitians: Mind and Experience in the Society Islands [Chicago \& London: University of Chicago Press, 1973]) on the thought processes and emotional organization of contemporary Tahitians also signals a revival of competent scholarship on this aspect of ancient Polynesian life. Though the individuals he observed were living nearly two centuries later than those seen by Cook and Bligh, it would be surprising indeed if none of their mental and emotional behaviors were survivals of a pre-European past. Similarly, recent descriptions of contemporary Tahitian communities and customs (e.g., by B. Finney, A. Hooper, M. Jullien, P. Kay, A. Lavondes, Y. Lemaitre, M. Panoff, Fr. Ravault, G. Ringon, and Cl. Robineau) undoubtedly contain ancient continuities, which more probing and comparison will someday reveal.

Turning now to some aspects of the text itself, the reader will undoubtedly note many inconsistencies in the spellings of Tahitian words - a fault that I am painfully conscious of but have been unable to correct. The problem derives from several circumstances. First of all, during the eras under study, the recordings we have of Tahitian words and texts were done by Europeans wholly unsophisticated in linguistic science in general and in phonetics and phonemics in particular. Consequently, not only did these writers perceive and record native words in different ways, but most of them did not even grasp the phonemic significance of such fundamental features of Tahitian as vowel length and the glottal consonant. Of course, if the words in question were still current today, and demonstrably unchanged in meanings, it would be a simple matter to go back over the old texts and "correct" the spellings, including insertion of glottals and of diacritics for vowel length.

Unfortunately, the language has changed, and changed very much in lexical inventory and semantics, and possibly in syntax and morphology as well. (For example, in an unsystematic but suggestive exercise, I read 
aloud to a group of four adults, all past forty, a list of about five hundred words from randomly selected pages of the Davies' (i.e., LMS) dictionary, which was published in 1851. From this list my informants recognized less than one hundred, and reached consensus of meanings for only about half of these.) As it has not been possible to "correct" the old recordings with a high enough degree of certainty, I decided to leave most of them as originally written, simplifying spellings and adding glottals and vowel length macrons only in exceptional cases.

I also made no effort to "correct" misspellings and other errors in the quoted English texts, mainly to preserve the antique flavor of the various writers' styles. In at least one case, however, "correction" was dispensed with because I simply did not understand the writer's intended sense. I refer to some of William Orsmond's "translations," and particularly those describing the Arioi. Some of these native texts, along with their "translations," have been included for purposes of documentation; but not even a linguist as expert as R. G. White has been able to make much sense of some of the passages' obsolete words.

Finally, with respect to the French and German language materials quoted or paraphrased in the text, all translations are mine unless otherwise noted.

\section{Honolulu}

December 1973 



\section{VOLUME 1 ETHNOGRAPHY}





\section{CHAPTER 1 INTRODUCTION}

"Tahiti is far famed yet too little known." Thus wrote J.M. Orsmond in 1848 (Henry 1928:I), and the same assertion can be made in 1972. Thousands of pages had been published about Tahiti and its neighboring islands when Orsmond uttered his judgment, and tens of thousands have been published since that time, but a unified, comprehensive, and detailed description of the pre-European ways of life of the inhabitants of those Islands is yet to appear in print. The present work, lengthy as it is, makes no such claim to comprehensiveness; rather, it is concerned mainly with the social relations of those inhabitants, and it serves up only enough about their technology, their religion, their aesthetic expressions, and so forth, to place descriptions of their social relations in context and render them more comprehensible.

I began this work many years ago, mainly to provide me and my coresearchers with a background - an ethnographic base line - or anthropological studies I was carrying out in some present-day communities in the Society Islands. As our library endeavors progressed, however, I became convinced that a study of the kind and scope now being presented would be a useful thing in itself for several reasons.

First, the picture that began to take shape was of a way of life of surprising richness, complexity, vitality, and sophistication. The institutions of this society invite comparison less with most Pacific island societies that I know about, from personal observation and from reading, than with societies that historians have come to call "civilizations." It seemed to me then, as it continues to do so now, that so populous and variegated a society as this once was deserves, and even demands, scholarly reconstruction quite apart from any scientific purposes that might therewith be served. For modern man, living in a world trending toward uniformity, some humanistic interests might be aroused and gratified by contemplation of this ancient Tahitian way of life.

Moreover, another inducement is added to the humanistic reasons for this reconstruction by the very fact that the subject is Tahiti. Ever since the Dolphin, Endeavour, and Boudeuse returned to Europe from these Islands two centuries ago, Tahiti has captured and held the interest of the Western 
world, serving variously as a model for philosophers, an image for poets, and a mecca for romantics. ${ }^{1}$

The scientific purposes that may be served by my reconstruction derive mainly from Tahiti's ethnological situation - that is, membership in a large "genus" of Pacific island societies demonstrably interrelated historically, and probably "genetically," by many linguistic and other cultural ties. This situation, therefore, permits and encourages comparative study aimed at understanding how and why variations came about in customs that were once alike. Needless to say, scholars have grasped this opportunity with eagerness, and scores of studies comparing everything from tools and crafts to social stratification and cosmology have been published. All this would be very fine for the science of man provided the "facts" on which such comparisons were made were true.

When the comparisons I speak of have to do with such tangible, durable objects as stone tools and reconstructable temple pyramids, all well and good. But when scholars seek to compare such intangibles as "chieftainship" or "social stratification" or "sacredness," the results can be no more credible than the information and interpretations thereof on which they are based. As a result of my long and near-exhaustive study of primary materials on ancient Tahiti, I have come to doubt or discredit much of the "information" about Tahiti used in such comparisons.

One explanation for the shortcomings of many comparisons lies in the nature of the materials used by their authors - that is, almost wholly published and largely secondary materials. "Comparativists" cannot reasonably be expected to carry out the immense amount of pioneer archival research or the detailed sorting of published primary sources required for all societies in their comparisons; they should, however, be expected to exercise critical judgment about the interpretations formed in the sources they do use. It was the errors perpetrated in these latter interpretations that have led astray so many authors of comparative studies involving ancient Tahiti. Moreover, many errors have, through time and frequent repetition, acquired the respectability and unassailability of scientific dogma.

(A conclusion I have arrived at as a result of the situation just described is the desirability of postponing further comparisons until each society to be compared has been exhaustively studied; although I do not for a moment expect that a suggestion as radical as that will be accepted!)

Another explanation for the shortcomings of many comparative studies of Polynesia-wide scope is to be found in the tendency of writers to impute identical meanings to behaviors or objects of different societies because they look or sound alike. It may, of course, turn out that some things are identical in all significant respects, but that must be demonstrated and cannot safely be assumed, particularly in Polynesian societies, which share such large numbers of entities that look or sound alike. 
A third reason for compiling this study has been the growing interest of historians in Tahiti and its neighbors. Most of this interest has focused, appropriately, on post-European developments there, but understanding of those developments requires some knowledge of the indigenous form of society on which the European influences played. No scholar trained mainly in the historian's craft could or should be expected to double as ethnographer (whose craft is as specialized as the historian's).

Finally, I address this study to those present-day Tahitians who would like to cut through the innumerable myths that now befog their view of their own past. Unless Tahiti proves to be different from most Pacific island polities, its indigenous peoples will eventually come to have more desire to manage their own lives and more eagerness to learn about their past.

The first Europeans known to have set eyes on Tahiti were Captain Samuel Wallis and the crew of H.M.S. Dolphin. The Dolphin reached the Islands on June 19, 1767 and remained among them until July 28; thereafter these Islands were visited by European vessels in the following order:

Boudeuse (and storeship Étoile), Louis de Bougainville commanding: remained at Hitia'a, Tahiti April 2 to 14, 1768.

H.M. Bark Endeavour, James Cook commanding: anchored at Matavai, Tahiti April 12 to July 12, 1769; brief visits to Huahine and Ra'iatea.

Aguila (Spanish), Don Domingo Boenechea commanding: anchored off Tai'arapu, Tahiti November 8 to December 20, 1772.

H.M.S. Resolution, James Cook commanding (accompanied by H.M.S. Adventure, Tobias Furneaux commanding): visited Tai'arapu and Hitia'a, Tahiti August 15 to 24, 1773; anchored at Matavai August 15 to September 1, 1773. In 1774 Cook returned to Tahiti and anchored at Matavai from April 22 to May 14. Thereafter brief visits to Huahine and Ra'iateaTaha'a.

Aguila and Jupiter, Don Domingo Boenechea commanding: remained off Tai'arapu November 15, 1774 to January 28, 1775, except for a brief visit to Ra'iatea. Upon departure for home four Spaniards-two priests and two attendants - were left to establish a Catholic mission. On October 30, 1775, Aguila returned, spent another twelve days at Tai'arapu, and left for home with the mission party aboard.

H.M.S. Resolution, James Cook commanding (accompanied by H.M.S. Discovery, Charles Clerke commanding): anchored off Tai'arapu August 13 to 23, 1777, and at Matavai August 24 to September 29; brief visits to Mo'orea, Huahine, Ra'iatea, Taha'a, and Porapora.

H.M.S. Lady Penrhyn, Lieutenant John Watts commanding: anchored at Matavai July 10 to 24, 1788; brief visit to Huahine.

H.M.S. Bounty, William Bligh commanding: anchored at Matavai October 
26,1788 , to collect breadfruit plantings. En route home the vessel was captured by part of its crew, and Bligh and some of his supporters were set adrift in a boat. On June 6, 1789 Bounty returned to Tahiti but left for Tubuai on June 23. The vessel returned on September 22, left ashore sixteen of its crew, and departed immediately for what turned out to be Pitcairn. Those "mutineers" left ashore then remained on Tahiti until captured and taken home on the H.M.S. Pandora.

Mercury, John Henry Cox commanding: anchored at Matavai August 13 to September 2, 1789; brief visit to Tetiaroa.

H.M.S. Pandora, Edward Edwards commanding: anchored at Matavai March 23 to May 8, 1791.

H.M.S. Discovery, George Vancouver commanding (accompanied by Chatham, Lieutenant William R. Broughton commanding): anchored at Matavai December 27-30, 1791 to January 24, 1792.

Whaleship Matilda, Matthew Weatherhead commanding: anchored briefly at Matavai in February 1792. Shortly afterwards Matilda was wrecked in the Tuamotus, but her captain and crew returned safely to Tahiti in small boats and remained there until taken off by subsequent vessels.

Schooner Jenny, Captain Baker commanding: anchored at Matavai March 25 to $31,1792$.

Prince William Henry, (captain unknown): anchored at Matavai March 26 to 29, 1792.

H.M.S. Providence, William Bligh commanding (accompanied by Assistant, Lieutenant Nathaniel Portlock commanding): anchored at Matavai April 7 to July 19, 1792, to collect a new load of breadfruit plantings.

Daedalus (storeship for Discovery and Chatham), Thomas New commanding: anchored at Matavai briefly in February 1793.

During the first quarter-century of European visits to these Islands, the persons involved were in fact visitors and little more, except for the lengthier stays of the Spanish mission group and the Bounty "mutineers," and of a small handful of beachcombers. The arrival of the Duff on March 4, 1797, however, marked the beginning of a new kind of contact between the Islanders and Europeans, for this vessel landed a band of Protestant missionaries, whose purpose was to remain and win converts. Thereafter, European (and later, Australian and American) vessels visited the Islands with increasing frequency. By 1815 the effects, direct and indirect, of all these alien contacts had become potent enough to bring about radical changes in the Islanders' political system and in many of their religious ideas.

In line with the events just outlined, volumes 1 and 2 of this work are a reconstruction of these Islanders' way of life as I believe it to have been just before it began to be transformed by European influence-a 
period I label the Late Indigenous Era. Volume 3 covers events in Tahiti and Mo'orea from about 1767 to $1815-$ a period I label the Early European Era.

Inasmuch as these Islanders had no system of writing, obtaining reliable information about the Late Indigenous Era poses something of a problem, to say the least. Aside from certain tangible objects, the only kinds of traits undeniably ascribable to that era are those seen and reported by the very first Europeans to visit the Islands. These visits themselves, however, started the process of radical change, and the visitors were poorly qualified to perceive or describe the indigenous customs they encountered. Subsequent visitors, such as Morrison and Bligh, and later on such missionaries as Davies, Orsmond, and Ellis, recorded, at the time of their respective visits, large quantities of what appear to be reliable data about or from the Islanders; but the question that arises is whether these data can be ascribed to the Late Indigenous Era as well. I cannot suggest any simple formula for answering this question and have had to rely on my own informed guesswork, the credibility of which the reader will have to decide.

Included in the general question just touched on are some more specific, but equally perplexing, questions having to do with linguistic data. It was not until about 1800 that any systematic and at least partly competent attempts were made to study and record the native language. Thus we are deprived of what could have been a very valuable source of information about many customs that had by that time changed. The systems of orthography in the pioneer attempts took little or no account of two important phonemic features of the indigenous language, namely, vowel length (long and short) and the glottal-stop consonant. Consequently, when having to work with untranslated native texts it is often impossible to know which of several possible references was originally meant. Adding further to the difficulties of translating many of the texts recorded a century or more ago is the fact that the indigenous language has in the interim undergone extensive changes, not only in terms of word loss but, evidently, word meanings as well.

Finally, something must be said about the main subject matter of this book-that is, ancient Tahitian society. By "ancient" I mean the eras already referred to: Late Indigenous and Early European. By "society" I refer to the kind of aggregate formerly constituted by all the inhabitants of what has come to be labeled the "Society Islands," the archipelago that extends from Maupiti at the northwest to Me'etia at the southeast. Although communication between some of the islands was in ancient times rendered difficult by stretches of empty and perilous sea, none of them was as isolated, socially, from the rest as were all of them from other archipelagoes. Accompanying this social unity was a cultural one. As James Morrison wrote from Tahiti in 1789 or 1790 : 
The Manners and Customs of the other Islands [besides Tahiti] are as Near the same as those of Different Countys in the Same Kingdom, and their produce nearly the Same \& the Inhabitants of all the Society Isles are one and the same people-Taheite is by Much the largest and most powerful when the Strength of the Island is united, and is therefore acknowledged Mistress Paramount of the whole. They all distinguish their Language, Customs \&c. by the Name of Taheite as well at home as when they are at Taheite and there are but few Men of Property who do not visit Taheite once in their lifetime and many visit it frequently. (1935:238)

By "Mistress Paramount" Morrison was evidently referring to Tahiti's greater size and larger population, and not to any actual or asserted political paramountcy, which he well knew did not obtain.

Morrison's statement also provides an ethnographic rationale for the title I have given to this book-that is, Ancient Tahitian Society. But having thus used the term Tahitian for the book's title I shall not use it in this sense again. Instead, for the sake of economy and precision, I shall henceforth use the word Maohi to refer to the people and customs of the archipelago in general, and reserve the words Tahiti and Tahitian (or Mo'orean, Ra'iatean, etc.) for use when specifying the inhabitants and culture of any one island. Maohi (phonemically, mā'ohi) was these Islanders' word for persons, customs, objects, and so forth, native to their archipelago, as distinct from those of elsewhere (see LMS Dictionary). In time the word came to include other Polynesian-speaking islanders, as distinct from Europeans; but during the Late Indigenous Era, and at least the early years of the Early European Era, Maohi seems to have referred specifically to the indigenous inhabitants and culture of this one archipelago. 


\section{CHAPTER 2 GEOGRAPHY AND POPULATION}

\section{The Pre-MaOHI SetTing}

The main islands of the Society archipelago extend for approximately 480 $\mathrm{km}$ along a northwest to southeast axis, the center being located at latitude $17^{\circ}$ south and longitude $152^{\circ} 30^{\prime}$ west. $^{1}$ The widest break in this chain of islands is only $120 \mathrm{~km}$, separating Tahiti from Me'etia, whereas all the islands are separated from neighboring archipelagoes by distances of $200 \mathrm{~km}$ or more. Even Tahiti and Me'etia are within sight of each other, from their heights. (See figs. 2-1 and 2-2, p. 9.)

By modern convention the archipelago is divided into an eastern (or Windward) sector and a western (or Leeward) sector, but this division now has more administrative than geographic rationale.

Tetiaroa and Tupai (Motu Iti) are atolls, low islands; the other eight islands are volcanic (nonactive), high islands-although Mai'ao, the one nearest the center, rises only 185 meters above its wide atoll-like lagoons. Tahiti itself is the largest of the Society Islands; it measures $52 \mathrm{~km}$ along its northwest-southeast axis and $30 \mathrm{~km}$ across its greatest breadth. Second largest is Ra'iatea-Taha'a, actually two distinct islands encircled by the same barrier reef. (Figs. 2-3 through 2-12, maps of the islands, are found on pp. 10-14.) Topographical data for these and the six other high islands making up the Society archipelago (from northwest to southeast) are presented in Table 1.

These figures on island areas are somewhat misleading on two counts: being only two-dimensional they understate considerably the sloping surfaces of these mountainous islands; and they do not include the extensive lagoon areas within the barrier reefs that surround most of the islands.

\section{Topography}

The Society Islands are the remnants of cones raised by successive extrusions of lava from the ocean floor, and many of the physical differences among them are to be accounted for by their differences in geologic age. Oldest of all are the atolls, Motu Iti (Tupai) and Tetiaroa. Next oldest is Mai'ao, whose central volcanic cone has been reduced to a low rounded 
TABLE 1 Topographical Data for High Islands of Society Archipelago

\begin{tabular}{lcc}
\hline Island & $\begin{array}{c}\text { Highest Elevation } \\
\text { (meters) }\end{array}$ & $\begin{array}{c}\text { Area } \\
\text { (square km) }\end{array}$ \\
\hline Maupiti (Maurua) & 213 & 12 \\
Porapora (Vavau) & 725 & 38 \\
Ra'iatea (Havai'i) & 1,033 & 238 \\
Taha'a (Uporu) & 549 & 82 \\
Huahine & 680 & 74 \\
Mai'ao (Tupuae Manu, Sir Charles & 185 & $8.9 *$ \\
$\quad$ Saunders Island) & 1,212 & 132.5 \\
Mo'orea (Aimeo, York Island) & 2,237 & 1,040 \\
Tahiti (King Georges Island) & 455 & 2.33 \\
Me‘etia (Osnaburg Island) & & \\
\hline
\end{tabular}

* Finney 1964:21. All other elevation and area figures in this list are from Papy 1954, vol. I.

hill by eons of erosion and subsidence. The remaining islands appear to be members of a more recent arc of volcanic activity, which took place during Pliocene and early Pleistocene times, with successive mountainous eruptions from northwest to southeast. Thus, Maupiti, at the northwestern end of this arc, appears oldest, and Me'etia, at the southeastern end, most recent. Generally speaking the older the island the more eroded its mountains and the more extensively developed its reefs-both fringing and barrier. The factor of relative age shows up also in differences in soil composition and in vegetation. The nature of all these differences, and their relevance to the structure of the native society, will be set forth in due course.

Tahiti rests near the southeastern, or youngest, end of the more recent arc. It consists of two massifs joined by a low narrow isthmus. The larger and nearly rhomboid part of the island (Tahiti Nui 'Greater Tahiti') averages about $30 \mathrm{~km}$ in diameter and reaches an altitude of 2,237 meters; the smaller, lozenge-shaped part (Tahiti Iti 'Lesser Tahiti', or Tai'arapu) is about onethird as large in area and its highest peak reaches 1,323 meters above sea level. Pictures can describe far better than words the general shape of Tahiti, but some topographic features need to be specified.

The 3,000-meter volcanic cone which once comprised Greater Tahiti has been lowered and truncated some 800 meters by subsidence and erosion, and its flanks have been cut into by water and wind. The winds that prevail throughout most of the year in these latitudes, the well-known southeast trades (which, however, vary in direction from north-northeast 


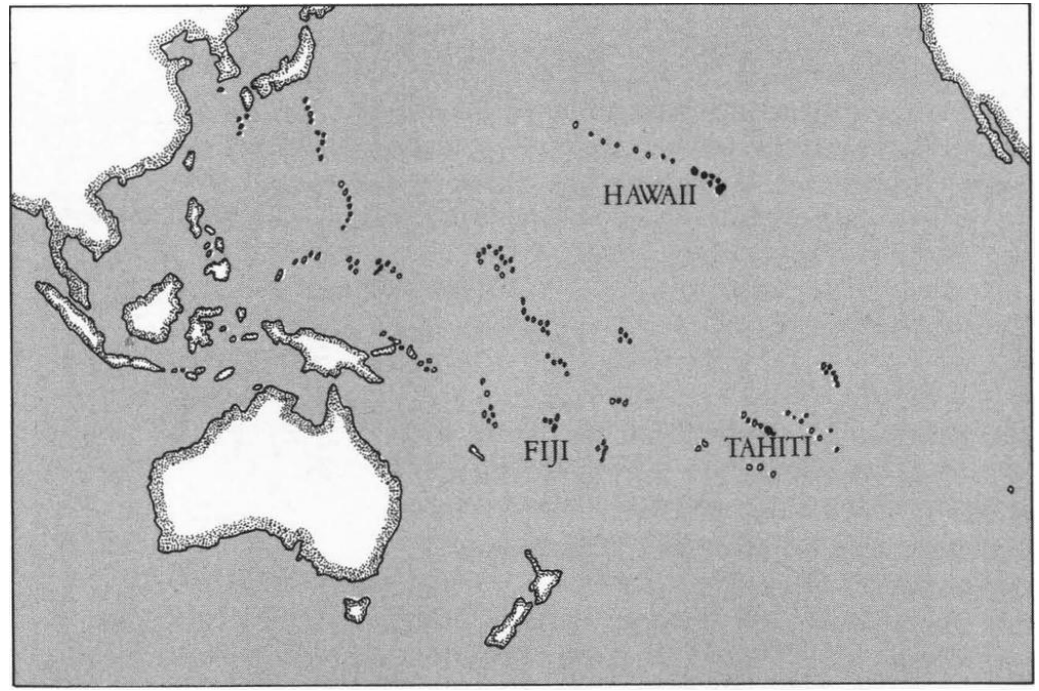

FIgure 2-1. Pacific Basin

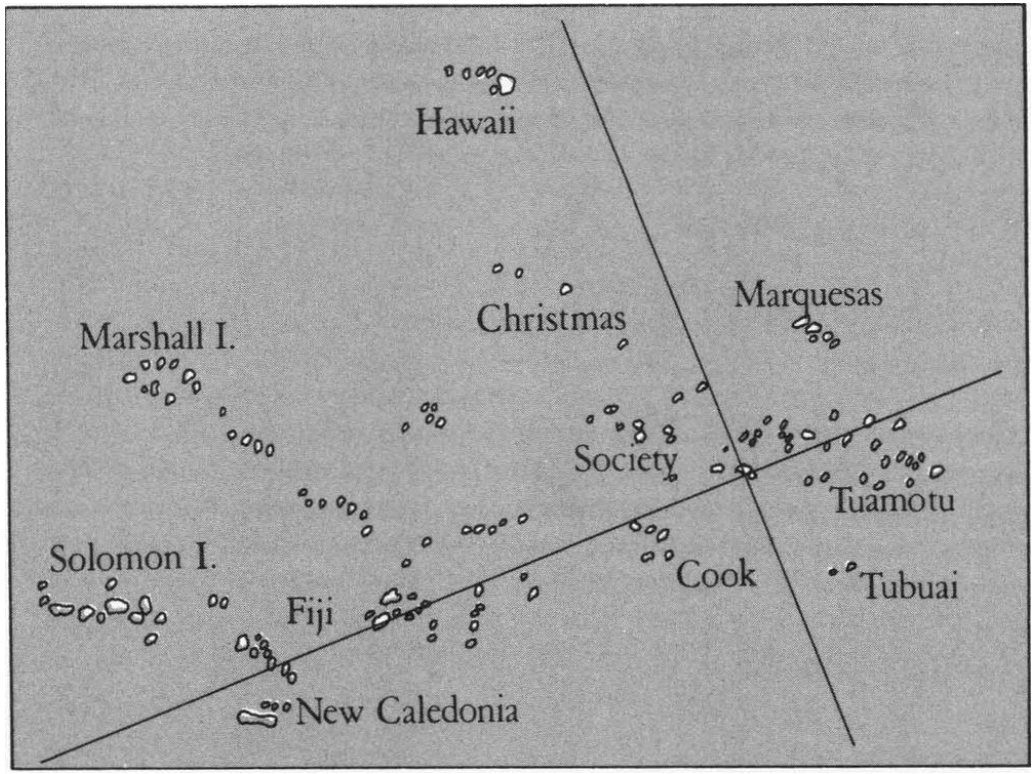

FIGURE 2-2. East Central Polynesia 


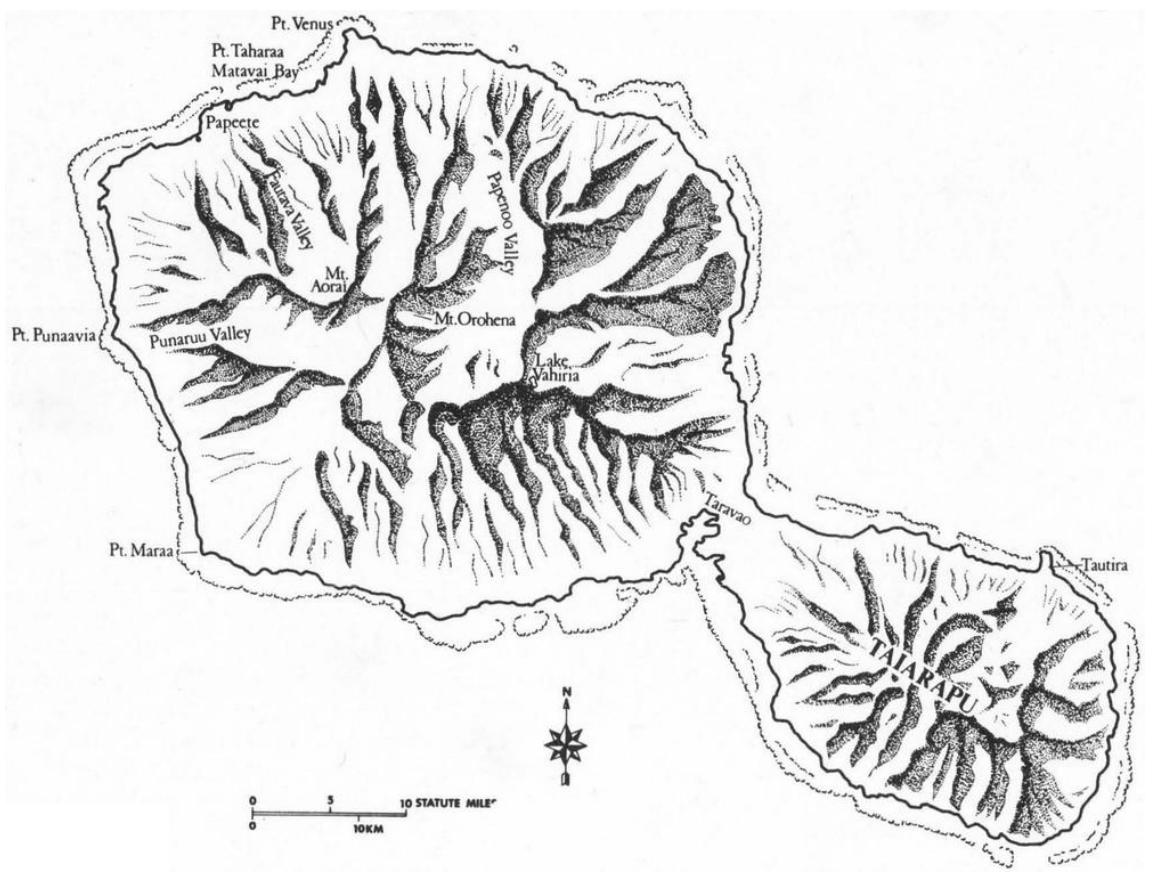

FIGURE 2-3. Tahiti 


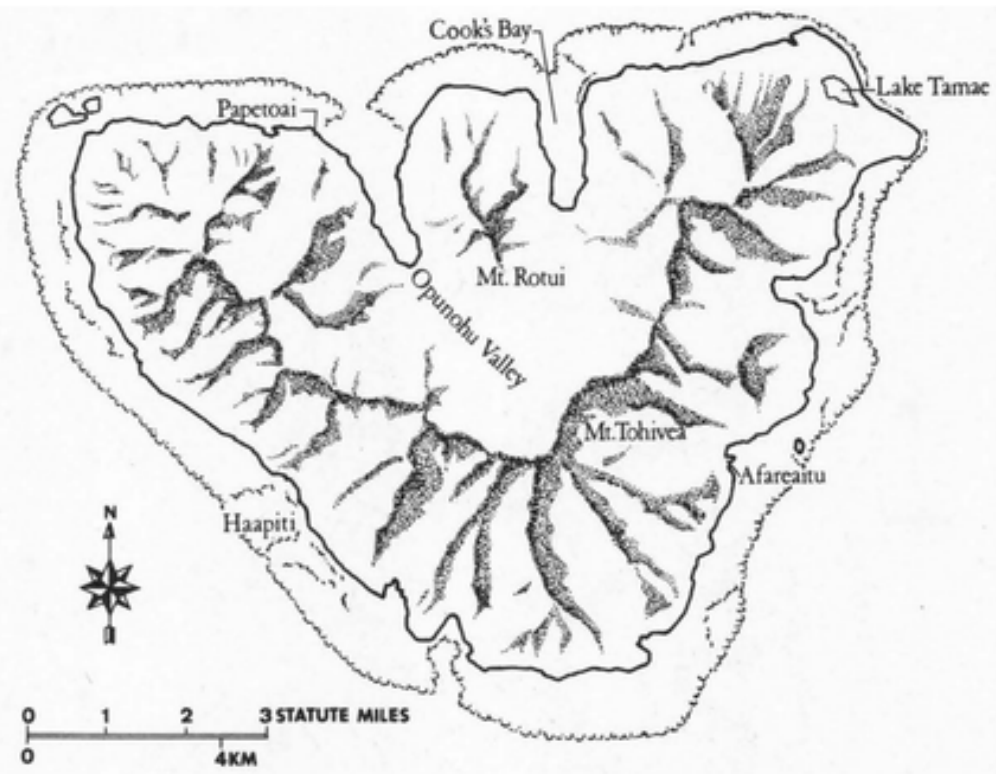

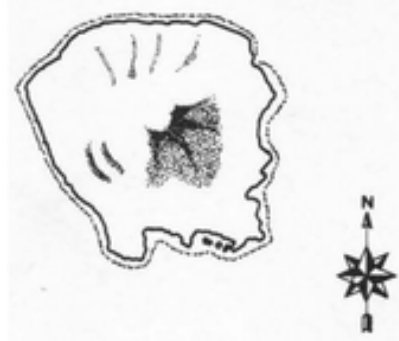

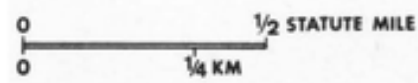

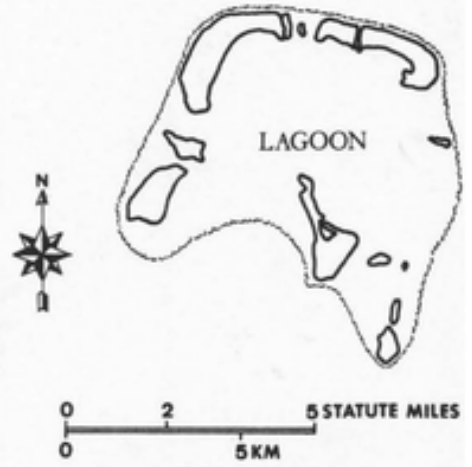

Figure 2-6. Tetiaroa 


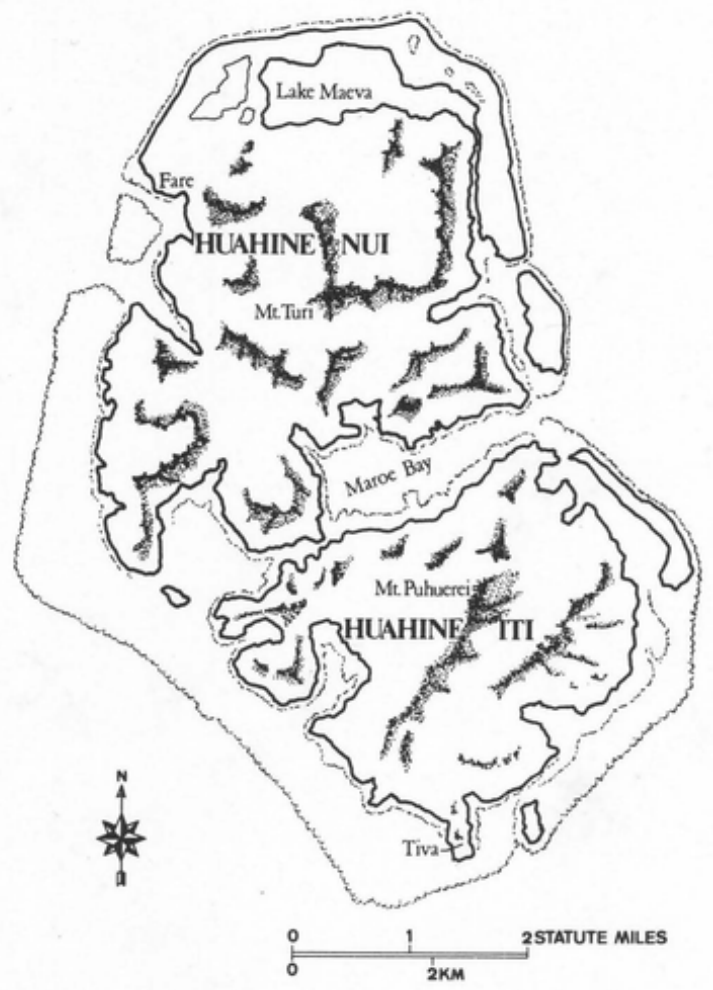

Figure 2-7, Huahine 


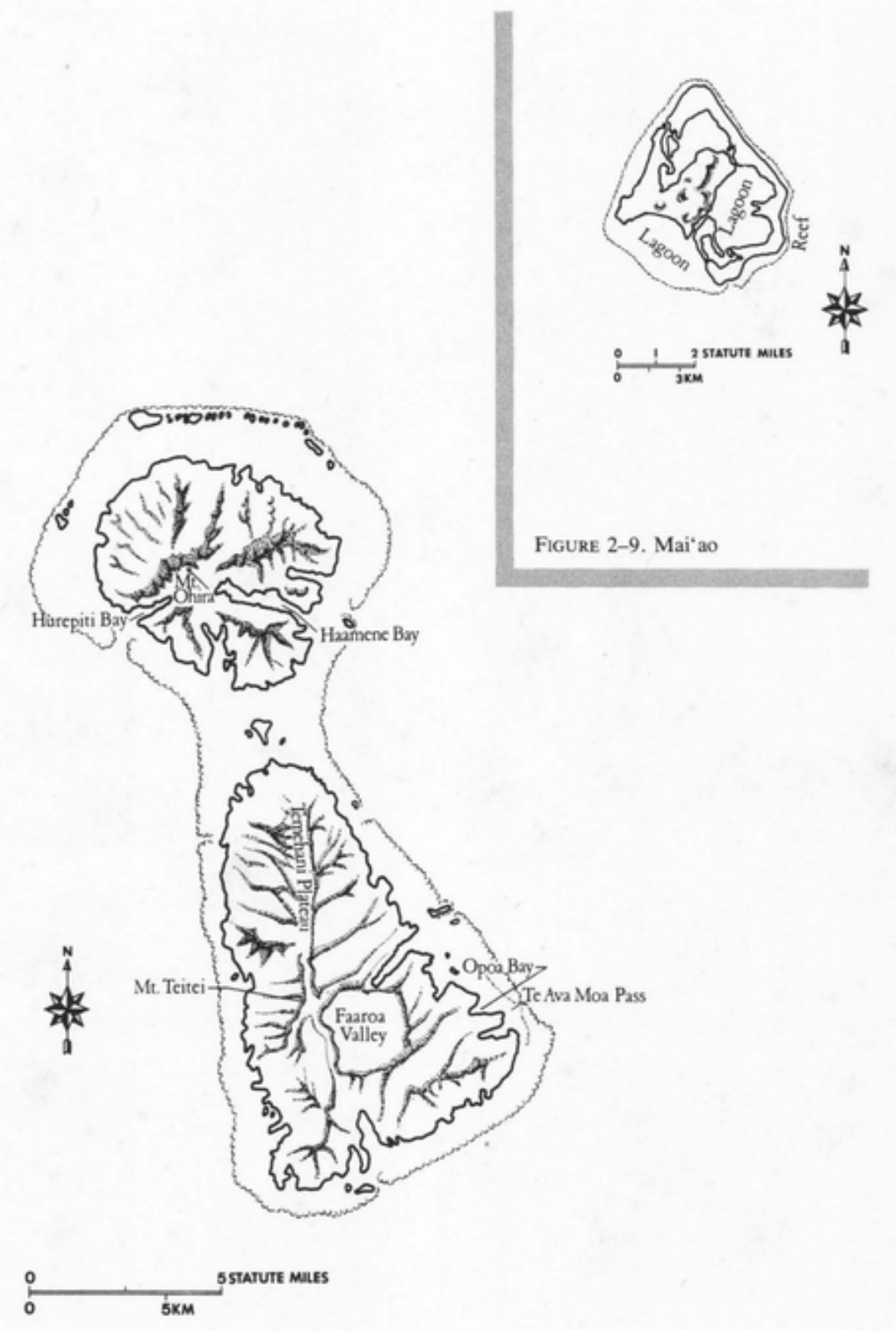

Figure 2-8. Ra'iatea and Taha'a 


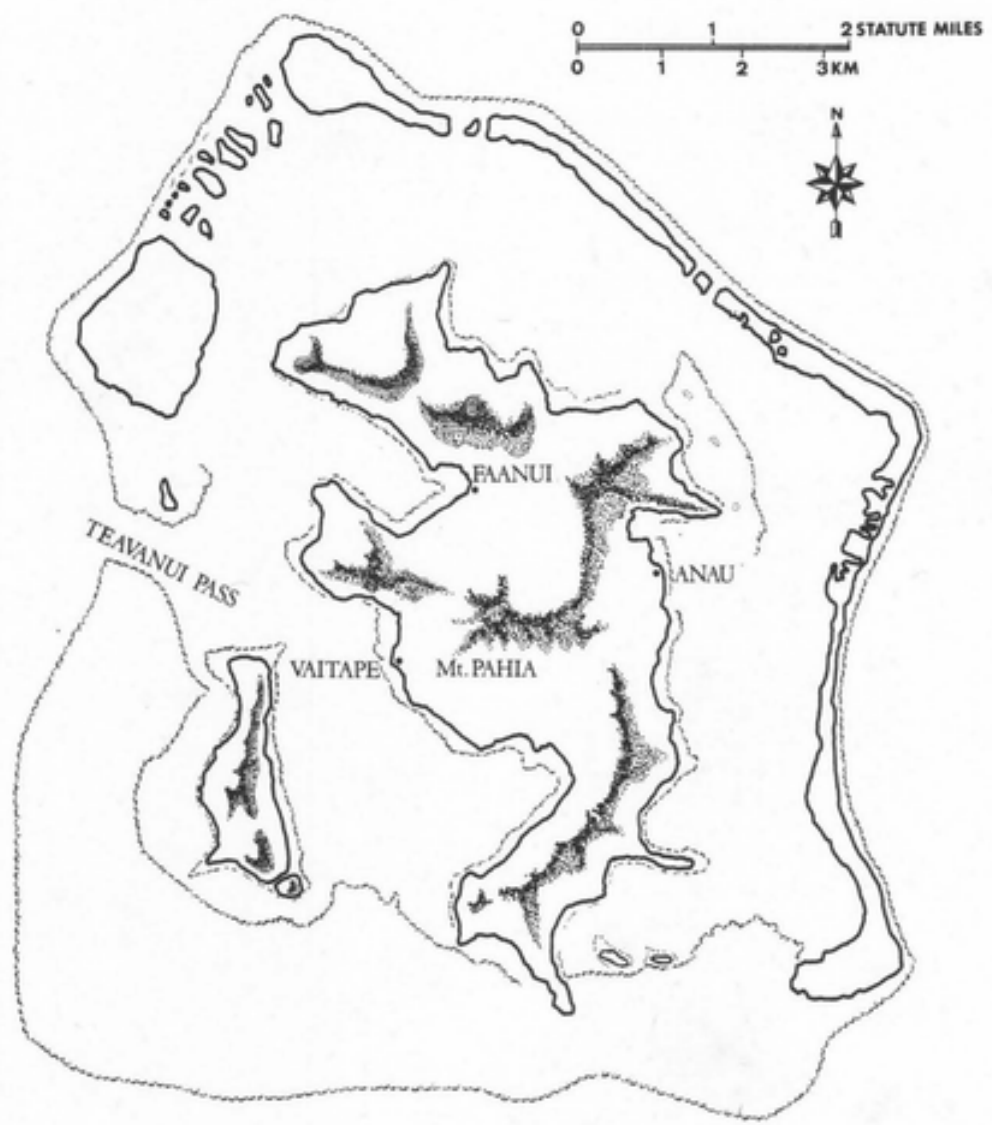

Figure 2-10. Porapora

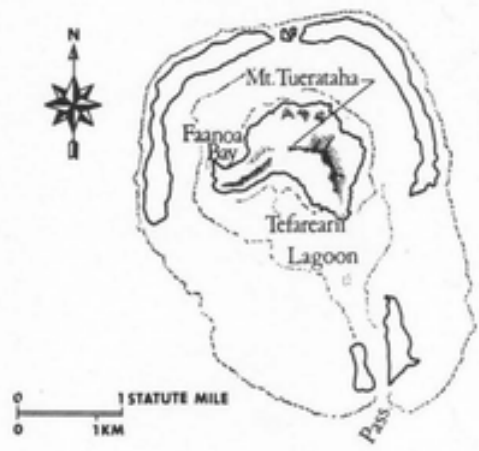

FIGURE 2-11. Maupiti
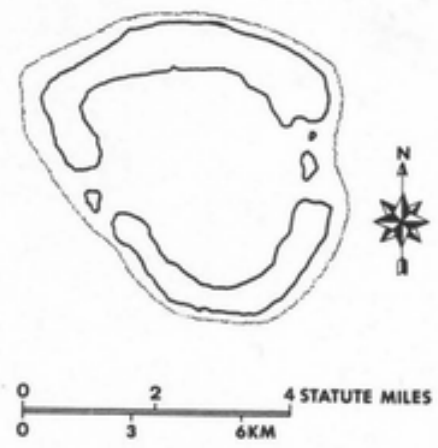

Figure 2-12. Tupai 
to southeast), have had the indirect effect of aggrading the leeward slopes and of widening the flat coastal belt at their base. At the same time the heavier seas along the windward coasts have somewhat inhibited the development of coral, in contrast to the more protected leeward shores, which are bordered by almost continuous barrier and fringe reefs. Similar general considerations apply to Lesser Tahiti.

As already implied, the flanks of Tahiti's two central massifs are indented with scores of more or less radial valleys. Most of these valleys are shallow, narrow, and steep-sided; and their streams, which vary greatly in depth from time to time, debouch directly and rapidly into swamp, lagoon, or sea. In the case of some deeper valleys, their floors level out farther inland and their streams back up behind bars of sand and coral rubble, forming relatively wide estuarial plains. Viewed from some distance at sea, some of the lower flanks of the massifs appear gently sloping and even, but closer inspection reveals most of these to be cut into sharp interfluvial ridges, with the notable exception of the wide saddle formed by the Isthmus of Taravao, which links Greater and Lesser Tahiti. Tahiti's mountainous interior is broken by two large plateaus, of 400 and 700 meters altitude respectively, but their inaccessibility has rendered them unimportant in human terms.

Marine topography was almost as important as that of the land to the amphibious Maohis, and it varies greatly from place to place. At one extreme is the coast at the southeastern tip of Lesser Tahiti, where steep headlands plunge straight into deep water and where oceanic waves and swells break with great force directly against the cliffs. At the other topographic extreme is the protected southern coastline of the isthmus, with its flat swampy shores and broad, shallow, muddy lagoon and bays. The broken line of barrier reef off the northeastern and eastern coasts protects only about half the shore from the steady onshore winds and waves, and the few lagoons are deep and relatively turbulent. In contrast, the western and southern coasts, protected by an almost continuous line of barrier reef, are bordered by lagoons of medium depths, clear waters, and surfaces which are ordinarily calm.

Turning now to the other high islands of the archipelago, various local peculiarities of size, position, and geology-as well as the factor of relative age-have led to the development of many distinct landscapes.

Mai'ao (Tupuae Manu, Sir Charles Saunders Island), the oldest-relic of an earlier volcanic chain-consists of a low, centrally located hill surrounded by wide flat plains and broad, shallow, landlocked lagoons.

Maupiti (Maurua), the westernmost and oldest of the principal chain of islands, has a higher and more rugged central core and a deeper moat or lagoon to which there is a deep but narrow pass through the surrounding reef.

Next in age and location is Porapora, much like Maupiti in conformation but more than twice the latter's diameter overall. (Fig. 2-13.) 
Southeast of Porapora and only $17 \mathrm{~km}$ distant are Taha'a and Ra'iatea, enclosed within a common barrier reef and separated by a mere $4 \mathrm{~km}$ of shallow lagoon. Ra'iatea approaches Tahiti in the height of its mountains, and both Ra'iatea and Taha'a are indented by several deep bays.

Huahine is like Ra'iatea-Taha'a in form but is much smaller in size, and the gap between its two islands narrows to a few meters in places. Also, the large lagoon at its northern end, so-called Lake Maeva, is landlocked save for a very long narrow tidal channel. (Fig. 2-14.)

Mo'orea's (Eimeo, Aimeo) most distinctive geographic feature is its vast central bowllike valley, which opens out into two deep bays of the northern coast (fig. 2-15).

Finally, the characteristics which distinguish Me'etia, the youngest and smallest island of the archipelago, are its reef-free shores, steep flanks, and generally rugged terrain.

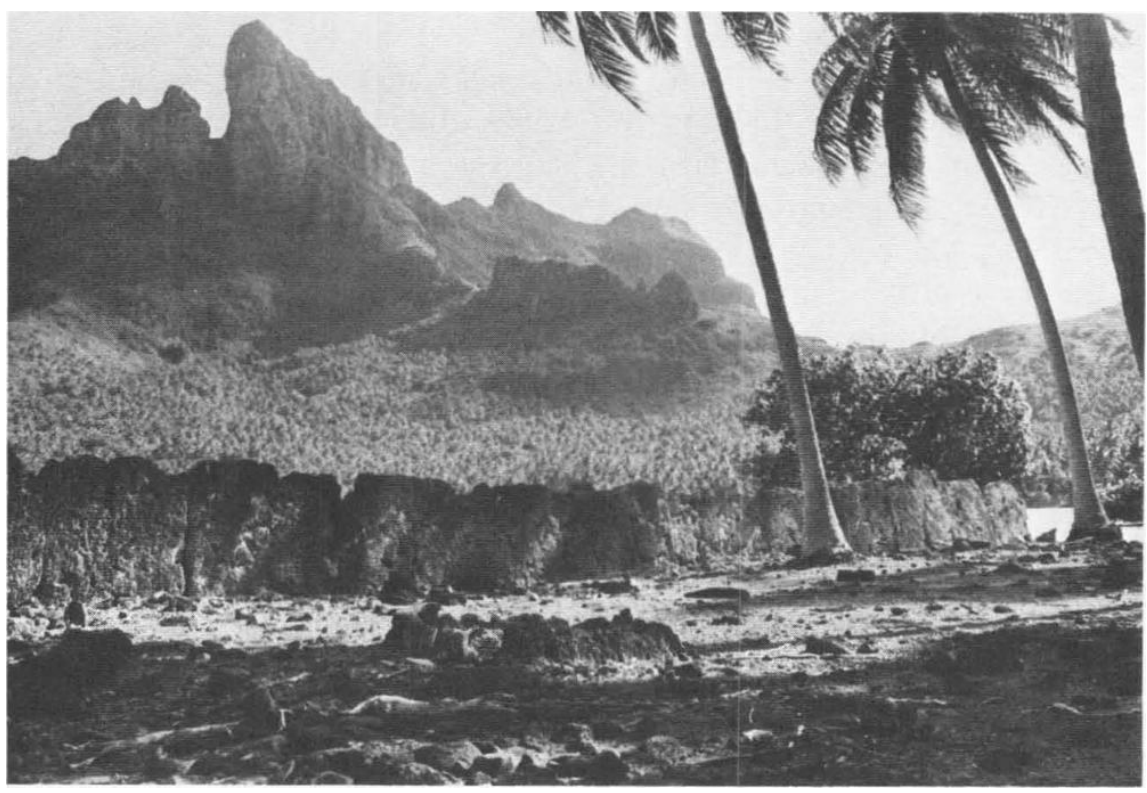

FIGURE 2-13. View of central peaks of Porapora with remnants of temple (marae Aehautai) in foreground. Photo by Y. Sinoto, Bishop Museum.

\section{Climate}

Since meteorological statistics seldom convey whole impressions, it should be stated at the outset that the climate of Tahiti and its neighboring islands strikes many visitors from Europe and America as paradisical: 


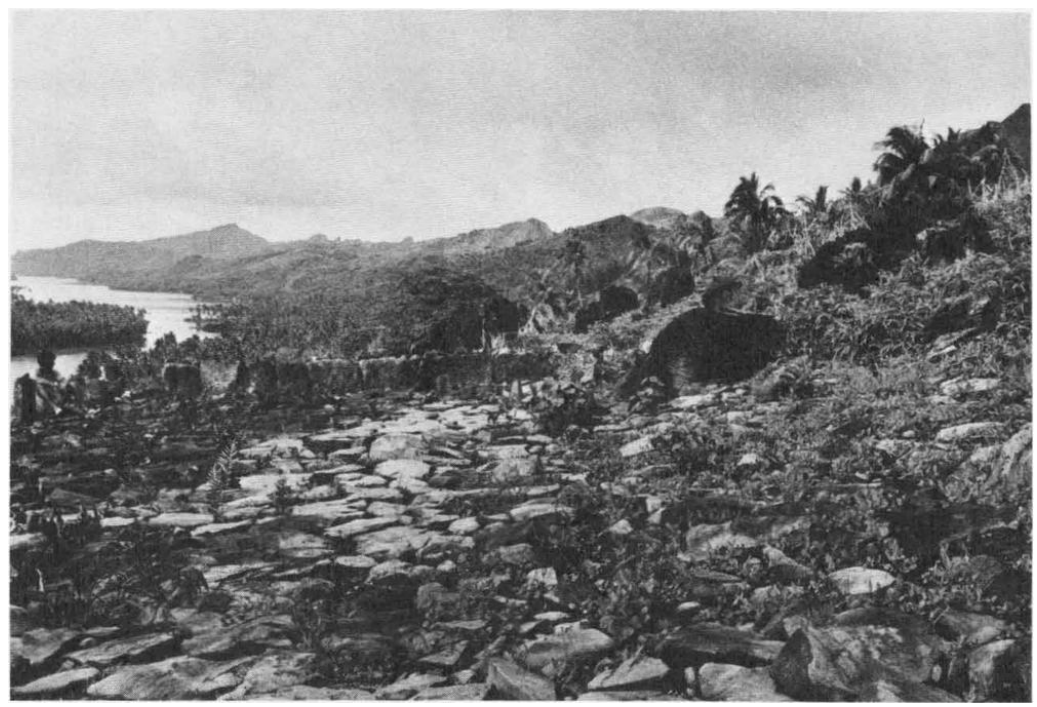

FIGURE 2-14. View of northern end of Huahine, with remnants of temple (at Paepae Ofata, Maeva) in foreground.

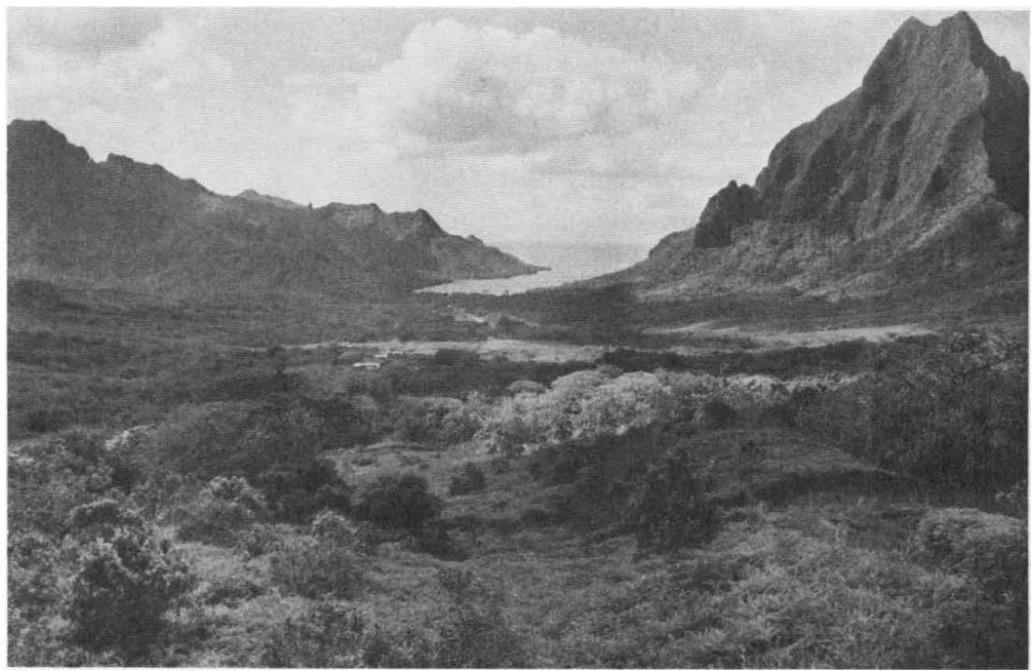

Figure 2-15. View of Opunohu Bay and Valley, Mo'orea. Photo by Y. Sinoto, Bishop Museum. 
semitropical warmth tempered by nearly year-round ocean breezes or cooling rain. Without subscribing entirely to this view (and without implying a personal desire to dwell in Paradise!), it is nevertheless true that these Islands are favored with an absence of climatic excesses. Residents now distinguish between a hot season, from about November to April, and a cool season, from about May to October. The latter marks the period of the steadier southeasterly trade winds and is relatively dry, while the former is characterized by change-ability in wind direction, more rainfall, and higher humidity. The contrast is not quite so sharp as this may seem to indicate, for even during the so-called hot and wet season the average monthly maximum temperature of $31.6^{\circ} \mathrm{C}$ is only $2.2^{\circ} \mathrm{C}$ higher than that of the cool season, and the precipitation averages only about double. Also, local variations in climate are sharper and perhaps more pertinent to our subject matter. For example, the three or so meters of rain which annually falls on Tahiti's exposed isthmus is more than one-and-one-half times the annual precipitation at Pape'ete, on the protected northwest coast; and places can be found, say along Tahiti's western shore, which differ even more from the isthmus not only in precipitation but in temperature and insolation as well. More will be indicated about these differences when I attempt to classify natural areas, but a word should first be said about the winds, which have had such far-reaching effects on human activities in these Islands.

The prevailing surface winds of this region of the Pacific vary in direction and in velocity. Unless deflected they tend to blow from the north-northeast during January and February, then veer toward the southeast through August or September, and then veer back again. It is during the southeast phase that they blow with greatest strength and regularity, usually ranging between 20 and $40 \mathrm{~km}$ an hour over the surface of the open sea. This is a time of clear sunny days and cool nights. But it is only at sea or along unobstructed windward coasts that such clear-cut conditions prevail. Apart from the varied and highly distinctive wind patterns to be found in deep valleys and on mountain slopes, at many places along the coasts-particularly the leeward ones-mountains, capes, and nearby islands serve to deflect the prevailing winds into patterns quite at variance with the one just described.

At times during each year strong rain-laden winds from the west (north-northwest to south-southwest) take over from the trades for days at a time. These counter-trades blow most steadily and frequently from January through March, but occur at other times of the year as well. In addition to these more or less steady winds of widespread occurrence, many places on the larger islands are subjected to a cool thermally produced breeze off the mountains at night which gives way to a brisk onshore breeze during the day.

Finally, there are the cyclonic storms. These Islands lie outside the so-called typhoon zones, but they do occasionally receive winds of devastat- 
ing force. According to one record, for the years 1819 through 1906 there occurred only ten storms of hurricane strength-in comparison with Fiji, where during an eighty-three-year period there was an average of two hurricanes a year. During the period 1940 through 1950 the three worst winds experienced on Tahiti attained recorded velocities of 72, 85, and $95 \mathrm{~km}$ per hour; they uprooted coastal trees, ruined gardens, and destroyed many buildings. The high waters which accompany such winds have their force lessened somewhat by barrier reefs, and, in any case, by going a little way inland one can usually escape both high water and wind.

\section{Tides}

One of the most noteworthy features of the physical environment of these Islands is the meagerness of their tides. The average amplitude is about 40 cm during spring tides and almost nil at neap tides. ${ }^{2}$

\section{Soils}

The soils of the high islands derive mainly from decomposition of their basaltic foundations and their vegetation, mixed here and there with calcareous sand and larger coralline fragments. ${ }^{3}$

The land surfaces of the atoll islands consist of fine calcareous sand mixed with coralline debris and in a few places with guano and thin layers of humus. Similar soils occur on the islets dotting the offshore reefs of the high islands and also make up the mainland beaches along some shores well protected by barrier reefs. In contrast, many beaches along unprotected shores are composed wholly of fine black sand derived from decomposition of basaltic rock. There are still some beaches made up of mixtures of basaltic sand, calcareous sand, and coralline debris.

A second major category of soils includes those covering the coastal plains and the lower and middle reaches of valley floors. These are more or less black in color and embody large proportions of lateritic clays, but in addition they contain many mineral elements along with organic matter. Farther inland on the fern-covered and wooded lower slopes are found red lateritic soils which are somewhat dryer and poorer in mineral and organic content than are those of the coastal plains. Still higher up the mountain flanks are found nearly unmixed lateritic clays, terminating in the mountain tops or in naked basaltic peaks and cliffs. But neither these nor the highly distinctive soils found in high-altitude depressions are directly pertinent to our concerns.

Though hardly to be classed with soils, mention should be made of two other kinds of ground surfaces which were relevant to Maohi life, namely, the extensive beds of basaltic rocks and boulders spread over the estuaries of the larger streams, and the more or less exposed deposits of reef limestone fringing the shores at many places. 


\section{Phytogeography}

Vegetation provides the most comprehensive means for classifying natural zones-especially when dealing with the habitat of a people so heavily dependent upon plants as the Maohis were.

The two atoll complexes within the living area of at least some of the ancient Maohis were Tetiaroa, $41 \mathrm{~km}$ north of Tahiti, and Tupai (Motu Iti), about $12 \mathrm{~km}$ north of Porapora. Consider what potentialities these atolls possessed in terms of human utilization. First of all they were dry land, providing more or less safe haven from the dangers of the sea; although more exposed to the high winds and waves than most parts of the high islands, there is no legendary or historical record of their having been wholly devastated by cyclone or tidal wave. Second, potable fresh water was obtainable there by rain catchment and, on Tetiaroa, from a spring on one of the islets. Third, great quantities of fish and other marine foods were available in their lagoons. But what about food plants?

The native vegetation of both atolls was relatively poor-richer perhaps than that of Central Pacific atolls, such as Canton and Phoenix, but sparser than any permanently inhabited self-subsistent atoll of Polynesia. The indigenous vegetation consisted of grasses, ferns, shrubs, and a few trees and coconut palms. Only the latter, and the small edible nut of the heliotrope (Cordia subcordata), or tou, were used for food, although nearly every species present had other uses: for dye, construction, and so forth. On the face of it, then, these atoll complexes were not richly enough endowed in natural resources to encourage permanent self-subsistent occupation, although we know from historical evidence that they did serve special purposes, which will be described later on. But these purposes did not depend upon any distinctive feature of the atolls' vegetation; every kind of plant found growing on the atolls grew also along the coasts of the high islands, whose several prehuman "natural zones" may now be considered.

By the time Europeans first sighted these Islands the Maohis and their ancestors had already transformed the plant cover of large parts of them by clearing areas for cultivation and settlement, by accidental firing, by use of the primitive vegetation for food and building materials, and by introduction of new plants. Later on I shall describe the Islands' vegetation during the latter part of the eighteenth century, but first let us consider what it was like when the Maohis' ancestors first arrived about a millennium before then.

According to H. René Papy's invaluable monograph (1954), the most authoritative reconstruction of the Islands' plant life, the indigenous prehuman landscape was divided into three major vegetation zones: coastal, mesotropical, and wet-tropical. ${ }^{4}$ While I use the past tense throughout this 
chapter in writing about the prehuman landscape, some of the description of course applies equally well to later eras.

\section{COASTAL}

This zone extended from the foot of the mountain flanks to the lagoon or ocean, and included the floors of valleys in their lower reaches. It varied greatly in width from a few meters to several kilometers. It consisted typically of a so-called adlittoral plain, composed mainly of decomposed basalt more or less mixed with alluvia; a line of beach, composed of basaltic or coralline sand, pure or mixed; and a narrow transition area between the two. In places the muddy estuaries of streams varied this pattern, and, along stretches of coast unprotected by reef, the beaches abutted directly against the flanks of the hills. Along indentations of some of the well-protected shores were also to be found swampy mud flats, but these were usually quite narrow, partly as a result of the slight variation in tide levels. Salty air affected the vegetation of this coastal belt to some distance inland, but subsoil water remained fresh up to the ocean's edge.

The principal associations of indigenous plants found in the coastal zone before human agents, including the ancient Maohis, began to transform it were the following: ${ }^{5}$

Submangrove. The "true" mangrove tree (Rhizophora) typical of so many Pacific shores was either absent from or exceedingly rare in the Society Islands. In the kind of settings where mangrove elsewhere thrives-muddy flats along protected coasts and estuaries-there grew the following plants: a fern (Acrostichum) which appears to inhibit the growth of "true" mangrove; certain grasses (Lepturus, Paspalum); and five economically noteworthy trees-Hibiscus, Thespesia, Barringtonia, Calophyllum, and Hernandia. Each of these trees proved to be useful to the colonizing Maohis, and all but one of them grew in other settings as well.

Littoral. (In this narrow, saline-dominated strip of shoreline were found all the typical submangrove trees except Hernandia, which may, however, have occurred on Maupiti, and all the so-called atoll trees except Guettarda; in addition there were stands of Tahitian chestnut (Inocarpus), ironwood ( $\mathrm{Ca}$ suarina), and Ximenia. Growing in the coral sand and debris of this subzone were the seaside purslane (Sesuvium), a white-flowered shrub (Scaevola), the large sea bean (Mucuna), and two other leguminous plants, Sophora and Canavalia.

Generally speaking, the black-sand beaches were poorer in vegetation than the corralline ones, having normally produced only sedges (Cyperaceae) and Aeschynomene. 
Adlittoral plain. This most extensive part of the coastal zone, extending from the littoral to the bottom of the slopes and into the valleys, is the "coconut zone" of today. Human occupation has transformed it more than any other part of these Islands so that the listing of its virgin vegetation involves some speculative reconstruction, although the identity of the principal forms seems based on reliable evidence.

Some of the trees typical of the littoral-Hibiscus, Calophyllum, Inocarpus, and Barringtonia-grew here also. In addition, we meet for the first time in our survey two species of the well-known screw pine (Pandanus tectorius and P. tahitensis), the medicinally important Morinda, the fragrant butterfly pandanus (Freycinetia victoriperrea), the tall slender Neonauclea, and the small banyan (Ficus prolixa). The last three thrive best in wetter ground. Clinging to some of these trees and the bases of cliffs there are today (and probably were in earliest Maohi times) thick growths of a convolvulus vine (Ipomea peltata).

Shrubby and herbaceous plants were said by Papy to have been represented by few species not found also in other subzones (1954:II, 194). In general, sedges and ferns were more common in the wetter parts, grasses and legumes in the dryer parts. Several other species of small trees, shrubs, herbs, creepers, and the like-including vervens, spurges, euphorbias, lindens, and nightshades-inhabited this subzone; and many of them were utilized by the Maohis as medicinals and incidental foods.

Summarizing the botanical features of this adlittoral part of the coastal zone, Papy wrote:

It seems reasonable to conclude that prior to the arrival of the Polynesians, the dryer parts of this zone were dominated by stands of Hibiscus tiliaceus and Pandanus, in which were perhaps found a few scattered coconut palms. Also abundant were certain plants that have since then nearly or wholly disappeared from this zone-i.e., Calophyllum inophyllum, Thespesia populnea, Cordia subcordata, Ficus prolixa, Erythrina indica, and Dodonea viscosa-as well as certain others now limited to the mesotropical belt.

At that same time the [rainier] windward parts of the adlittoral zone were characterized by analogous but higher and denser stands of Barringtonia speciosa [a myrtle; the Maohis' hutu]. (1954:II, 196-197)

\section{MESOTROPICAL}

With respect to Tahiti itself this undifferentiated zone is limited to the sunny slopes behind the western and northwestern coasts (Point Mara'a to Point Tahara'a), and from the adlittoral zone to an altitude of about 300 meters. Elsewhere it is confined to the lower slopes of the northern ends of Ra'iatea and Tana'a, to the steeper leeward flanks of Porapora and Maupiti, and to the central plateau of Maupiti and possibly Mai'ao. In other words, this zone has a climate characterized by intense sunshine and by moderate rainfall 
and humidity-somewhat less than the coastal plains and considerably less than higher altitudes. ${ }^{6}$ But, as Papy emphasized, in the Society Islands this zone is not as sharply differentiated, in climate or, as we shall see, in vegetation, from neighboring zones as is the case in the Hawaiian Islands.

The dominant tree of the mesotropical zone was at one time the large acacia (Serianthes), a favorite wood for canoes. In addition, several shrubs and subfrutescent plants, including Planchonella, Abrus, Buettneria, Timonius, Wikstroemia, Glochidion, and Alphitonia, grew sporadically throughout the zone. The last four of these grew in the neighboring wet-tropical zone also, and Timonius grew on the atolls as well.

The ground cover of this mesotropical zone consisted of several species of legumes, grasses, compositae, woody herbs, a widely distributed fern (Gleichenia), and club moss (Lycopodium).

Of special ethnological interest is the "native cotton" (Gossypium purpurascens), or vavai, which is no longer found in these Islands but which is said to have once been abundant, presumably in this mesotropical zone.

\section{WET-TROPICAL}

Following Papy, this zone may be divided into four more or less distinctive natural areas: lower reaches of valleys, plateaus and middle slopes of mountains, rain forests, and mountain summits.

Lower reaches of valleys (subzone 1). This type of natural area occurs in the following locations:

Tahiti-the valleys separating the mesotropical slopes, i.e., the western and northwestern sides of the island from Point Mara'a to Point Tahara'a.

Mo'orea and elsewhere on Tahiti-those valleys and slopes from sea level to 300 through 500 meters in altitude, having relatively wet climates, i.e., all those of Mo'orea, those on the eastern side of Tahiti from Point Tahara'a to Tautira, and those on the southern side of Tahiti from Point Mara'a to Teahupo'o.

Ra'iatea-valleys and slopes up to 300 meters on the eastern side, and those extending from 50 through 300 meters in altitude at the northern end. On the southern and western sides of the island the upper boundaries of this type of area are much lower in altitude.

Huahine, almost all of the inland, most of Taha'a, and the eastern side of Me'etia-in these places one also found some vegetation elsewhere more characteristic of subzone 2 (see below).

Maupiti and inland Porapora-the intermixture of vegetation elsewhere characteristic of subzones 1 and 2 is complete and ubiquitous.

Indigenous species truly distinctive of this subzone were not numerous, 
the most characteristic having been the Tahitian mango (Spondias), or vi, the smaller reva tree (Cerbera), the ritually important ti plant (Taetsia), and the "native ginger" (Amomum). Among the other plants characteristic of the subzone, though not distinctively so, were Hibiscus, Melastoma, and Aleurites (candlenut).

Plateaus and middle slopes of mountains (subzone 2). Papy distinguished three types of vegetative landscapes in this subzone: myrtle forests, moors and pseudosavannahs, and steep high slopes, (a) Myrtle forests. The myrtle trees (Metrosideros) characteristic of this type of landscape reached heights of 7 to 8 meters, (b) Moors and pseudosavannahs. This type of landscape developed in the same middle altitudes as the myrtle forests, but in places where myrtle forests did not develop or were extinguished as the result of soil impoverishment or, later on, brush burning. Its distinctive feature is its thick covering of the anuhe fern (Gleichenia), in which were occasional stands of Lycopodium. In a few places the fern cover was broken by growth of grasses and sedges, and by clumps of the ubiquitous Hibiscus, Pandanus, Melastoma, Decaspermum, and Casuarina. (c) Steep high slopes. On Tahiti, at altitudes of 700 through 1,000 meters the fissures in the bare basalt slopes were often populated by plants of myrtle forest type.

Rain forests (subzone 3). This subzone does not occur on Me'etia, Porapora, Maupiti, or Mai'ao; on Tana'a and Huahine small patches of it occur at the heads of the larger valleys on the windward side. Elsewhere it is represented in sunless places subject to heavy precipitation:

Tahiti-the cloud-covered slopes 900 through 1,500 meters in altitude; parts of the larger valleys (above 600 meters on the dry side, above 300 meters in the moderately wet areas, and above 20 meters in the very wet areas); the southeastern coast and the northeastern-central areas of the peninsula.

Mo'orea-less well drained parts of the eastern and southern slopes and valleys; the comparable valley depths elsewhere.

Ra'iatea-rain-drenched slopes and valleys of the southern two-thirds of the islands up to altitudes of about 600 meters.

The most characteristically distinctive plants of this subzone were the mountain fern tree and the butterfly pandanus. Other pandanus plants found here in quantity occurred also in other zones.

Among the thick tangled vegetation of the rain forests were numerous species of large and small trees, shrubs, creepers, ferns, epiphytes, and so forth. Some were found elsewhere, and some were distinctive of this zone.

Mountain summits of Tahiti and Ra'iatea (subzone 4). The most plentiful 
plants found at these high altitudes were myrtle (Metrosideros), saxifrage (Weinmannia), ferns, epiphytes, and lycopodes.

Particularly relevant to our concerns because of their importance in Maohi technology are three plant members of the wet-tropical zone; these are giant bamboo, mountain plantain, and Tahitian chestnut. The latter was certainly growing in these Islands prior to human occupation; concerning the origin of the others, expert opinion is divided (Papy 1954:II, 222ff).

Giant bamboo ('ofe: Schizostachyum glaucifolium) occurs in almost pure groves of different dimensions on the windward slopes and wet valley bottoms. Mountain plantains ( $f e^{\prime} i$ : Musa fehi), of which there are many varieties, once grew plentifully in large thickets high up the mountain slopes at 600 to 900 meters. After generations of collecting, these original stands became quite depleted, and the Maohis turned more to cultivating plantains nearer to their dwellings. Tahitian chestnuts (māpē: Inocarpus edulis), another important Maohi food, continue to grow in almost pure groves in the lower and middle reaches of wet valleys, as well as in comparably moist protected parts of the coastal plains.

Some seaweeds were occasionally used by the Maohis as a food supplement; otherwise marine vegetation was not an important factor in Maohi life and hence is not directly relevant to my description.

\section{Fauna}

The prehuman terrestrial and freshwater fauna of these Islands was characterized by poverty in number of species. As far as one can determine there were no mammals at all, and reptiles were represented only by the blue skink (Lygosima cyanurum) and three species of geckos. Perhaps the most noteworthy freshwater fish were perches (Kuhlia marginato), gobies (Eleotris fusca), a pipefish (Syngnathus conspicillatos), and three species of eel (Anguilla megastoma, A. mauritania, A. ossura). Land and freshwater molluscs were more varied, but crustaceans limited to these habitats were numerous in numbers but few in species, notably, land crabs and freshwater prawns. The saltwater fauna was abundant and heterogeneous. The central importance of this fauna in native thought and activities will be related in succeeding chapters.

When Europeans arrived they found centipedes, scorpions, spiders, house flies, and two kinds of mosquitos-the Culex fatigaus, and the filariabearing Ardes polynesiensis-but it is not certain which of these predated humans on these Islands. 
The more noteworthy groups of native birds that inhabited these Islands prior to human occupation included frigate birds, tropic birds, boobies, ducks, terns, sandpipers, curlews, pigeons, parakeets, cuckoos, kingfishers, shrikes, and Old World warblers. Some of these were to figure importantly in Maohi life.

\section{Summary}

Such then was the natural setting comprising these Islands when humans first set foot on them-or, at least, so that setting would have been perceived by a Western-trained naturalist. How the Islands looked to the first human settlers is of course impossible to reconstruct, for, by the time Europeans arrived some ten or more centuries later to record their observations, the inhabitants had already transformed parts of that setting and perhaps their own perceptions of it as well. Two factors do, however, seem credible. First of all, except for those arriving directly from generation-long residence on atolls, these landfalls did not present the arriving canoe passengers with much that was strikingly new and different-topographically, botanically, or zoologically. In other words, the new settlers were presented with physical resources which they were already prepared to exploit, in terms of prior knowledge and well-tested techniques. Second, although some of the canoes that ended up on these shores may have arrived with nothing more than a few starving survivors, over the course of centuries there evidently came other canoes bearing exogenous plants and animals, which eventually helped serve to transform large portions of the virgin setting into the landscape seen by Wallis, Cook, Bougainville, and other explorers. But before attempting to reconstruct that more recent landscape, let us see what can be concluded about the size and composition of the human population living in that landscape in 1767.

\section{POPULATION}

The Island [of Tahiti] will have about 10,000 inhabitants at the lowest computation (formed during the launch's journey all round it). (From Don Domingo Boenechea, Journal, 1772, in Corney 1913:329)

... the whole Island [of Tahiti] cannot contain less than two hundred and four thousand inhabitants. (From James Cook, Journal, May 1774, in Beaglehole 1961:409)

... with which authoritative and quite typical discrepancy one confronts the task of trying to discover how many people were living on these Islands at the time Europeans first arrived, to minister to their decimation. ${ }^{7}$

\section{Numbers}

The first "official" census of Tahiti Island's native population was carried out by English missionaries in 1829. It is unlikely that these scrupulous 
men, who knew the geography and the people so well, committed any large errors of omission or double-counting. The number arrived at was 8,674. ${ }^{8}$ But, between the first European guess, made in 1767 by Robertson-“... upward of a hundred thousant Men Women and Children," (Robertson 1948:234) - and the missionaries' conscientious tally, a number of other European visitors engaged in this pastime, with the results shown in Table 2.

Robertson's guess was made solely on the basis of estimates of the numbers of natives who had swarmed to Matavai Bay to see the first Europeans to reach their shores. From this kind of extrapolation it is only surprising that his guess was not higher.

The source of Cook's 1769 figure was the Ra'iatean priest, Tupaia, who sailed on the homeward voyage of the Endeavour, as far as Batavia, where he died. Tupaia was a highly intelligent man who served the leaders of Tahiti's Papara tribe as high priest and counselor and was thus in a good position to know of what he spoke:

Tupia informs us that the whole Island can Muster 6780 Fighting Men by which some Judgment may be form'd of the number of inhabitants, each district furnishes a certain number which the Chief is obliged to bring into the Field when Summons'd by the Eare de hi [ari'i rahi] or King of the Island either to make War or repell an invation. (Beaglehole 1955:120nl)

As we shall see, Cook's comprehension of the island's political organization, including his notions about its having a "king," was faulty on many counts. He may also have garbled Tupaia's estimate of "Fighting Men"-but probably not overly much.

Tupaia's estimate was also reported by Cook's shipmate, Sir Joseph Banks:

The districts which [an $a r^{\prime}{ }^{\prime}$ ] Possess are obligd in time of a general attack to furnish each their Quota of soldiers for the service of the Publick. Those of the Principal districts which Tupia recolected when added together amounted to 6680 men to which army it is probable that the small Quotas of the rest would not make any great addition. (Beaglehole 1962:I, 385)

As Beaglehole pointed out, however, Banks' figure of 6,680 is inconsistent with another entry in his diary which lists the respective quotas of fourteen "districts" as follows:

Forces of Otahite 6780

$\begin{array}{ll}\text { Oteihouroo [Atehuru] } & 400 \\ \text { Parapara [Papara] } & 900 \text { [?] } \\ \text { Wyuridde [Vaiuriri] } & 300 \\ \text { Opora [Poreonu'u:Pare-Arue?] } & 800 \\ \text { O'whaa [Mahaena?] } & 200\end{array}$




$\begin{array}{ll}\text { Tettahu [Tetaha; Fa'a'a] } & 200 \\ \text { Mattavii [Matavai] } & 200 \\ \text { Whapiano [Ha'apaino'o] } & 200 \\ \text { Whidia [Hitia'a] } & 600 \\ \text { Whahite [Afa'ahiti] } & 400 \text { [?] } \\ \text { Tiarreboo [Tai'arapu] } & 1800 \\ \text { Wyourou [Vairao] } & 200 \\ \text { Matawii [Mata'oae] } & 400 \\ \text { Wyaru [Vaiari] } & 180\end{array}$

The numbers with question marks are so badly written as to be questionable, but were interpreted by McArthur as given above (1968:237).

The identification of Banks' district names also involves some uncertainties. I have placed in brackets the identifications proposed by McArthur; all but two of these seem to be fairly straightforward, and even these two, Opora and O'whaa, seem to be indicated by the process of elimination. ${ }^{9}$ The listing of Afa'ahiti, Vairao, and Mata'oae in addition to Tai'arapu is somewhat puzzling inasmuch as all these and other peninsula districts were usually lumped together under Tai'arapu, but in this context the latter name evidently indicates only Tautira and Teahupo'o.

A somewhat more serious uncertainty concerns the so-called districts which figured in many early European accounts but which are not included in Banks' list, namely, Tiarei, Pueu Toahotu, and Atimaono. Either Banks (ex Tupaia) deliberately excluded these four sparsely populated territories from his principal districts, or they were included in the figures for Mahaena, Afa'ahiti, Vairao, and Papaia, respectively, as suggested by McArthur (1968:239). I shall return to this important Tupaia-Banks list later, but first let us consider the other eighteenth-century estimates of Tahiti's population.

Boenechea's figure derived mainly from an estimate provided by some of his crew who circumnavigated the island in a launch, mapping harbors and headlands, and touching ashore here and there. Rodriguez arrived at his estimate on the basis of his ten-and-a-half-months' residence on the island, spent mostly at Tautira, on the Tai'arapu peninsula, but including many overland visits to neighboring regions and two trips around Greater Tahiti, partly overland and partly in canoes skirting the shore. The only recorded evidence of any count having been made by him was one that took place in Mata'oae, where the crowd that greeted him was so great “... I thought I would like to see how many of them there were, as nearly as might be; so I desired the people to arrange themselves on a piece of open ground, and they did accordingly, with much merriment. I made them out to number rather more than a thousand souls." (Corney 1919:52) 


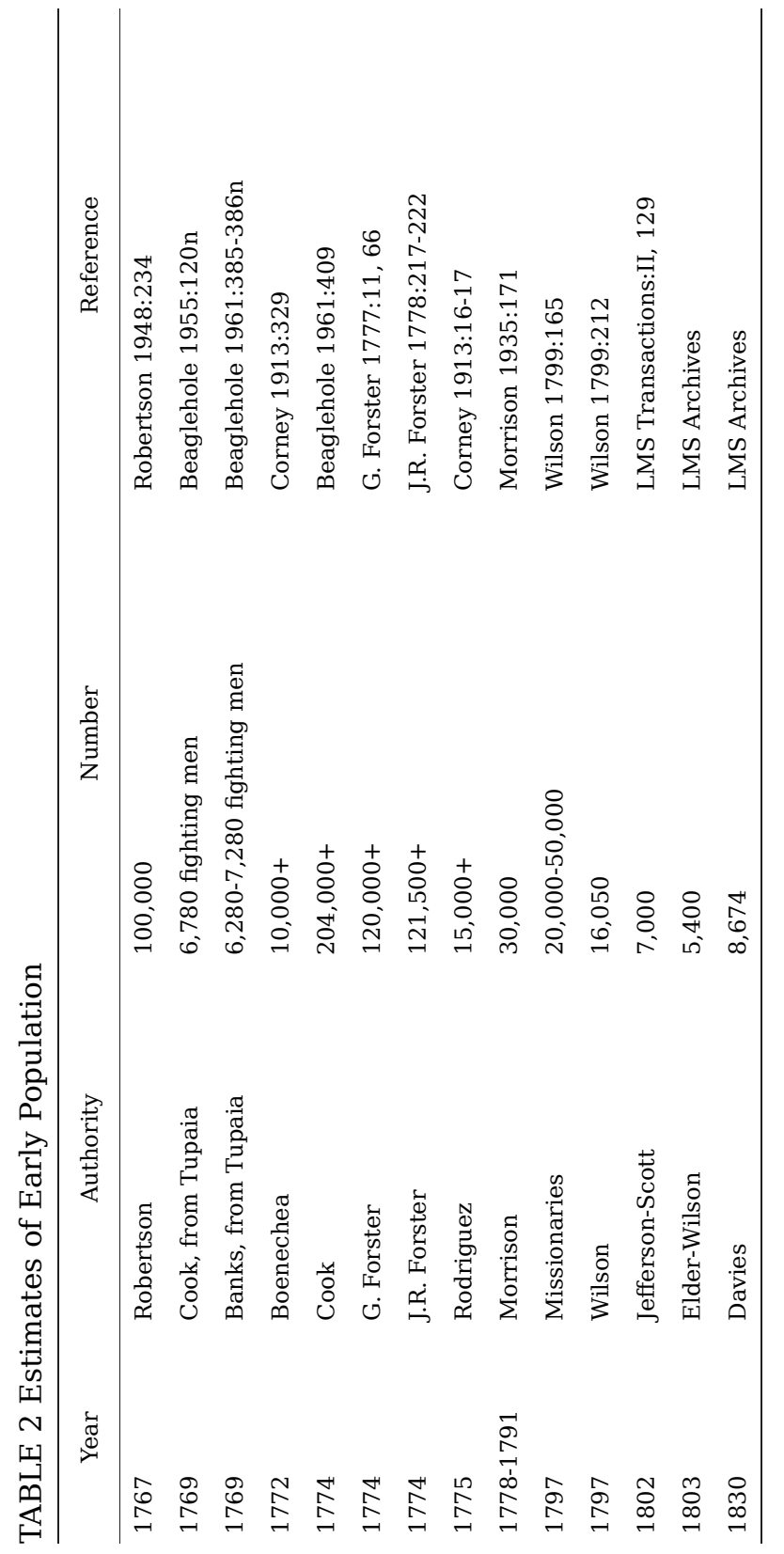


The Spanish padres for whom Rodriguez acted as interpreter guessed on one occasion the island's population to be over 8,000 , and on another occasion over 12,000 (Corney 1915:79, 203). Concerning their guesses it was reported by Don Manuel de Amat, Viceroy of Peru: "This interpreter [Rodriguez] assured me that the place is thickly peopled, and was of opinion that the inhabitants exceed fifteen thousand persons. The Missionary Padres can give no estimate with any sort of accuracy, as they never went beyond the immediate precincts of their hospice." (Corney 1913:16-17)

Cook's 1774 estimate was derived by multiplying by three (his guess concerning the ratio of warriors to total population) the number of fighting men the island could muster, this latter figure having been arrived at partly by observation and partly by multiplication. In April and May 1774, a large number of canoes paraded near Matavai, purportedly in preparation for an attack on nearby Mo'orea. On April 26, Cook wrote of having seen 160 large war canoes and 170 smaller supporting vessels; these he reported as having belonged to the districts of Attahouru and Ahopatea, and to have been commanded by a chiefly admiral named Towha [Te To'ofa]. At that time his estimate of the complement of each war and supporting canoe was forty and eight men respectively, or a total of 7,760 men, which, however, he considered an underestimate. Next, he reported having seen on April 30 a fleet of ten or more war canoes, this time from the "district" of Matavai [a division of Ha'apape]; these he claimed were "... thinly manned ... the most being not above thirty and the least Sixteen or Eighteen." At last, on May 14 he reported having seen a fleet of forty war canoes belonging to the "district" of Tettaha [Fa'a'a]. Taking Tettaha ("... one of the smallest districts") as a safe average, he then went on to estimate the total island population by multiplying the number of Tettaha's war canoes by the number of "districts" (according to Cook, 24 on Greater Tahiti, 19 on the peninsula)-that is, "If we allow forty men to each Canoe according to my former computation it will require Sixty eight Thousand able bodied men and as these cannot amount to One third part the number of both Sex the whole Island cannot contain less than two hundred and four thousand inhabitants." In addition, he added that this estimate did not take into account the men required to man the escort vessels, “... which cannot require less than two thousand," nor the possibility that the peninsula contained as many people as did the mainland. (Beaglehole 1961:390, 409) ${ }^{10}$

G. Forster's estimate was based on the same naval review as was Cook's, and on the same false assumptions about Tahiti's political geography.

The number of districts in both peninsulas amounts to forty-three; we assumed at a medium, that each could equip only twenty war-canoes, and we supposed each of these to be manned only with thirty-five men. The sum of men employed in the fleet, exclusive of the attending boats, would then be no less 
than thirty thousand; and these we assume as the fourth part of the whole nation. What makes this computation still more moderate is, that we suppose these thirty thousand to be the whole number of persons capable of bearing arms, or fit for service; and that the common proportion of these men, to the rest of the people, is much smaller than one fourth, in all the countries of Europe. (G. Forster 1777:II, 66)

J.R. Forster, father of George, based his estimate on the aforesaid naval review also, and on the same incorrect notion about the island's political geography; but his calculations were more tortuous and were "supported" by estimates of the island's population-supporting power in terms of its supposed economic resources (J. Forster 1778:217ff).

Aside from the tally made by him at Mata'oae we are not informed how Morrison calculated his figure, but judging from other parts of his ethnographic description he had opportunity to arrive at an approximation more credible than those of 1774 by Cook and the Forsters.

Shortly after arriving at Tahiti in 1797, three of the English missionaries traveled about Greater Tahiti for a fortnight to look over the scene of their labors. Their report stated: "The accounts of former navigators as to the populousness of the country are greatly exaggerated. We think that not a fourth part so many will be found as Captain Cook supposes, perhaps not a tenth" (Wilson 1799:165). No details are given concerning the method by which they arrived at this estimate, but much of the way they were accompanied by a prominent chief, who, while possibly having had political reasons for underrating the numbers of followers of his potential enemies, could scarcely have gone traveling abroad without attracting considerable attention.

But even their modest estimate was considered excessive by the ship's chief officer, William Wilson, who traveled around the island in order to "... try some method of estimating the number of people in each district" (Wilson 1799:179). He employed a Swedish beachcomber, Peter, as interpreter and hence was not altogether insulated by ignorance; moreover, his "method" was rigidly systematic. According to a Tahitian informant, a man "... having a shrewd, intelligent countenance," met at the beginning of their tour, each "district" [fenua] was composed of a number of "matteynas" [mata'eina'a] and "tees" [ti'i].

[The former was] ... a principal house, distinguished either by a degree of rank in its ancient or present owner, or by a portion of land being attached to it; and sometimes on account of its central situation to a few other houses: that the matteyna sets up a tee (or image) at the morai [marae], which entitles it to the liberty of worshipping there; and the other houses in the department of the matteyna claim a part in the same privilege, and are thence called tees: that in some matteynas there are eight or nine persons in the family, in others but two or three; and that it frequently happens, that a matteyna or a tee is totally deserted. Therefore, from this account, and what I afterwards saw of the thin population, I allow but six persons to each matteyna, and the same to a tee, as the latter is often oc- 
cupied by a larger family than the former, and as both terms do sometimes apply to the same house; consequently, as often as this occurs, there will be an error of six in excess. (Wilson 1799:184)

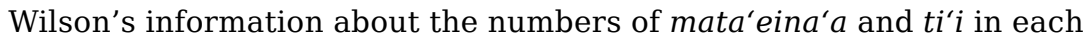
"district" was obtained by questioning prominent local natives-a practice perhaps as short in reliability as his method of calculation was short in validity-but he at least saw large portions of the coastal area and hence was able to obtain impressionistic confirmation of some of the figures given him.

What of substance may be salvaged from these various estimates? In my opinion the only ones that warrant serious consideration are Tupaia's 1769 figures on fighting men, Cook's 1774 count of naval vessels, Wilson's 1797 survey, and the missionary estimates of 1802 and 1803.

Banks' version of Tupaia's figures on fighting men deserves special attention. As principal adviser to the leaders of Papara, and thus deeply immersed in the intertribal politics of that era, Tupaia would have had a fairly realistic notion of the fighting strength of the various contending parties. The figures in question are, of course, too rounded to be credible, but the tribal percentages are not excessively inconsistent with those of later censuses. There is an exception with respect to the peninsula, which according to Tupaia's count mustered a fighting force approximating 40 percent of the whole island's total, as compared with later censuses which attribute to the peninsula only about 20 to 25 percent of the island's total population. On the other hand, Tupaia's total figure for all the island's fighting men is at sharp variance with Cook's count at the famous naval review of 1774 provided, that is, that Cook's "fleet" did indeed derive solely from Atehuru.

The war canoes Cook saw-and presumably counted-on April 26, 1774, carried an estimated 7,760 men. Cook identified this fleet as that of the districts of Attahouru [Atehuru] and Ahopatea. From evidence on Cook's map, and from later more authoritative evidence, Ahopatea was merely a section of the tribal district of $\mathrm{Pa}$ 'ea, which along with Puna'auia, made up Atehuru. But, inasmuch as this fleet was commanded mainly by an "admiral" named Te To'ofa, it is likely that it also included vessels from Fa'a'a, whose most prominent tribal chief Te To'ofa was. (Except for Cook's implication, there is nothing to gainsay the possibility that the Fa'a'a fleet of forty canoes seen on May 14 had also been part of the April 26 assembly.)

As for the fleet of ten war canoes seen by Cook on April 30, and identified by him as belong to Matavai, that is, Ha'apape, these were "thinly manned," and according to his estimates contained about 200 to 250 men.

In other words, Cook's fleet figure for Ha'apape is nearly identical with Tupaia's 1769 estimate concerning that district's fighting men; but his fleet figure for Atehuru (plus Fa'a'a) exceeds Tupaia’s by 7,160! Sev- 
eral explanations may be offered for this discrepancy; the one I consider most likely is that the fleet Cook saw contained contingents not only from Atehuru and Fa'a'a but also from most other tribes of Tahiti-Landward Teva (Papara, Vaiari, Vaiuriri), Seaward Teva (Tautira, Teahupo'o, Vairao, Mata'oae, Afa'ahiti, Pueu), Hitia'a, Tierei, Mahaena, and Ha'apaino'o. For one thing, the figure of 7,760 or so men contained in this fleet is not greatly different from that of 5,780 listed for those districts by Tupaia. And perhaps of more weight, there is some evidence that all or most of Tahiti's tribal districts were indeed united in the attack upon Mo'orea, for which the fleet review was a prologue.

In any case, for lack of any better information, I accept a figure of about 9,000 for the number of Tahiti's fighting men-my estimate being a compromise between Tupaia's all-too-approximate one and Cook's fairly reliable but probably incorrectly attributed count. Having taken this position, I am still left with the question of what proportion of the island's total population was constituted by those fighting men. As we saw above, Cook put the proportion at less than one-third, and G. Forster at "the fourth part of the whole nation." Morrison also put the proportion at "near one third," but there is a possibility that his figure was derived from Cook's published account as much as from his own observations. In view of many kinds of evidence, which will be scattered throughout the remainder of this work, I am inclined to accept Forster's figure, which, when combined with Tupaia's, would result in the approximations for Tahiti's population from about 1767 to 1774 shown in Table 3.

No reader could be more conscious than I of the imperfections, in data and in assumptions, of these figures, but they are the best I can produce. It may be said in defense of them that they are not contradicted by other data-archaeological, ethnographic, or historical-of which I know. Moreover, allowing for the well-documented decrease due to introduced disease in the intervening years, my figure of 35,000 for 1767 through 1774 is not greatly at variance with Morrison's "Near 30,000" for 1788 through 1791.

I turn now to Wilson's figure of 16,050, which, it will be recalled, was compiled during a tour of the island in 1797 and was based on a rough household count. I present also in Table 3 the results of this census. We cannot be sure that the so-called district names therein listed refer to exactly the same territorial units in all cases. Moreover, I leave for later any discussion of the significance of this comparison, and of the details regarding the missionary censuses listed in Table 2 .

When we turn from Tahiti to the other islands of the Society archipelago in our effort to determine their pre-European population numbers, we move 
from fantasy, wild guesses, and conflicting evidence to no early evidence at all-except in the case of Me'etia, the small steep rock of an island at the extreme southeastern end of the chain. When the Spaniards called there in 1772 some of them walked over most of the island and evidently saw most of its inhabitants, whom they reported to number about 200 (Corney 1913:296). ${ }^{11}$

TABLE 3 Population Estimates of Island of Tahiti

\begin{tabular}{lrr}
\hline \multicolumn{1}{c}{ District } & Wilson (1797) & $\begin{array}{r}\text { Oliver, based on Tupaia } \\
(1767-1774)\end{array}$ \\
\hline Atehuru & 1,608 & 2,088 \\
Fa'a'a & 852 & 1,044 \\
Pare-Arue & 1,290 & 4,176 \\
Ha'apape & 822 & 1,044 \\
Ha'apaino'o & 1,860 & 1,044 \\
Mahaena-Tierei & 990 & 1,044 \\
Hitia'a & 1,254 & 3,132 \\
Afa'ahiti-Pueu & 618 & 2,088 \\
Tautira-Teahupo'o & 2,760 & 9,396 \\
Vairao-Taohotu & 360 & 1,044 \\
Mata'oae & 270 & 2,088 \\
Vaiari & 444 & 940 \\
Vaiuriri & 1,044 & 1,553 \\
Papara-Atimaono & 1,878 & 4,685 \\
$\quad$ TOTAL & 16,050 & 35,366 \\
\hline
\end{tabular}

The estimates of population up to 1825 that I have found for other islands of the archipelago are listed in Table 4. I have included some post-1815 figures because they provide a basis better than guesswork for estimating the size of population of the Late Indigenous Era.

Mo'orea. J. Forster's estimate is pure fantasy:

Imeo [Aimeo, Eimeo, Mo'orea] is a little, but well-cultivated isle, subject to the king of T-Obreonoo [Te Poreonu'u]. According to the accounts of the Taheiteans, it opposed and beat off the whole force of Te-Arraboo [Taiarapu]; and the great armaments we observed going forward in T-Obreonoo [i.e., the naval assembly seen by Cook, and mentioned above], for the reduction of Imeo, prove that they have no mean idea of their strength; notwithstanding this, we shall allow them no more than one fourth of the population of T-Obreonoo, i.e. 20,250.... (1778:221-222) 
In 1802 and 1803, two missionaries walked around Mo'orea preaching to all who would listen and probably formed a fairly realistic impression of the island's total population (Jefferson, Journal, 1 December 1802, LMS Archives). I have found no record of their estimate, but their colleague Jefferson, writing some months later, and probably drawing on information obtained from them, put the island's population at "not more than 2000 people" (Jefferson to LMS, 29 August 1803, LMS Archives). Gyles, an expert sent by the LMS directors to develop the Islands' sugar production, formed his estimate of Mo'orea's population during his brief residence there. There is no evidence that it was based on any kind of systematic count. (Newbury 1961:222-223)

Tetiaroa. These atoll islets, directly under the control of the ruling dynasty of Pare, served as a resort for members of that family and their retinue, who went there from time to time to convalesce from illness and from kava ('ava) debilitation, or to escape from the pressures of politics at home. The permanent population appears to have been very small, and it is likely to have included some Tuamotuan castaways. Wilson's estimate of the population was based on hearsay and is clearly inaccurate:

Towards evening we saw Tethurōa, low land, about twenty-four miles from Otaheite. It consists of six or seven islets very near each other, not many feet above the level of the sea, covered with cocoa-nuts, but no bread-fruit, which they are not allowed to cultivate. It belongs to the King [Pomare II], but Mānne Manne claims it. The natives, about three thousand, are employed in fishing for the chiefs at Otaheite, and bring back bread-fruit and other things in exchange. (Wilson 1799:89)

In August 1803, the missionaries Elder and Wilson visited the atoll and made a more realistic estimate; since they were well aware of the atoll's nature as a resort, and specifically wrote "inhabitants," we are probably justified in concluding that these latter were more or less permanent residents of the place:

There are five Islands of the group called Tatooroa inhabited: Rayona the southernmost \& the highest land, is abt. 2 miles in circumference, \& contains 28 inhabitants: perhaps this Isld. may be 12 or 14 feet above the level of the sea. Rematoo lies about a mile to the northward of the above; is 3 miles in circumference, $\&$ contains between $20 \& 30$ inhabitants. Two miles northwest of Rematoo is Onehoa; it is about 2 miles round. Two miles to the Eastward of the last mentioned is Motooroa: this \& Onehoa contains 35 inhabitants. To the eastward of Motooroa lies Horoa-terra: it is abt. 6 miles round \& contains 50 people. Besides these there are 6 uninhabited islands, the largest of which does not appear to be a mile round. These Islands form a circle: there is a reef round them, but no good entrance through it: within the reef is deep water, sufficient for a ship to lie at anchor in. The produce of these Islands are cocoanuts \& a few bushes \& short grass, the soil is sandy \& does not appear worth cultivating. The generality of the people who live on them, belong to Otaheite, very few are natives of the place; from what we could learn there never 


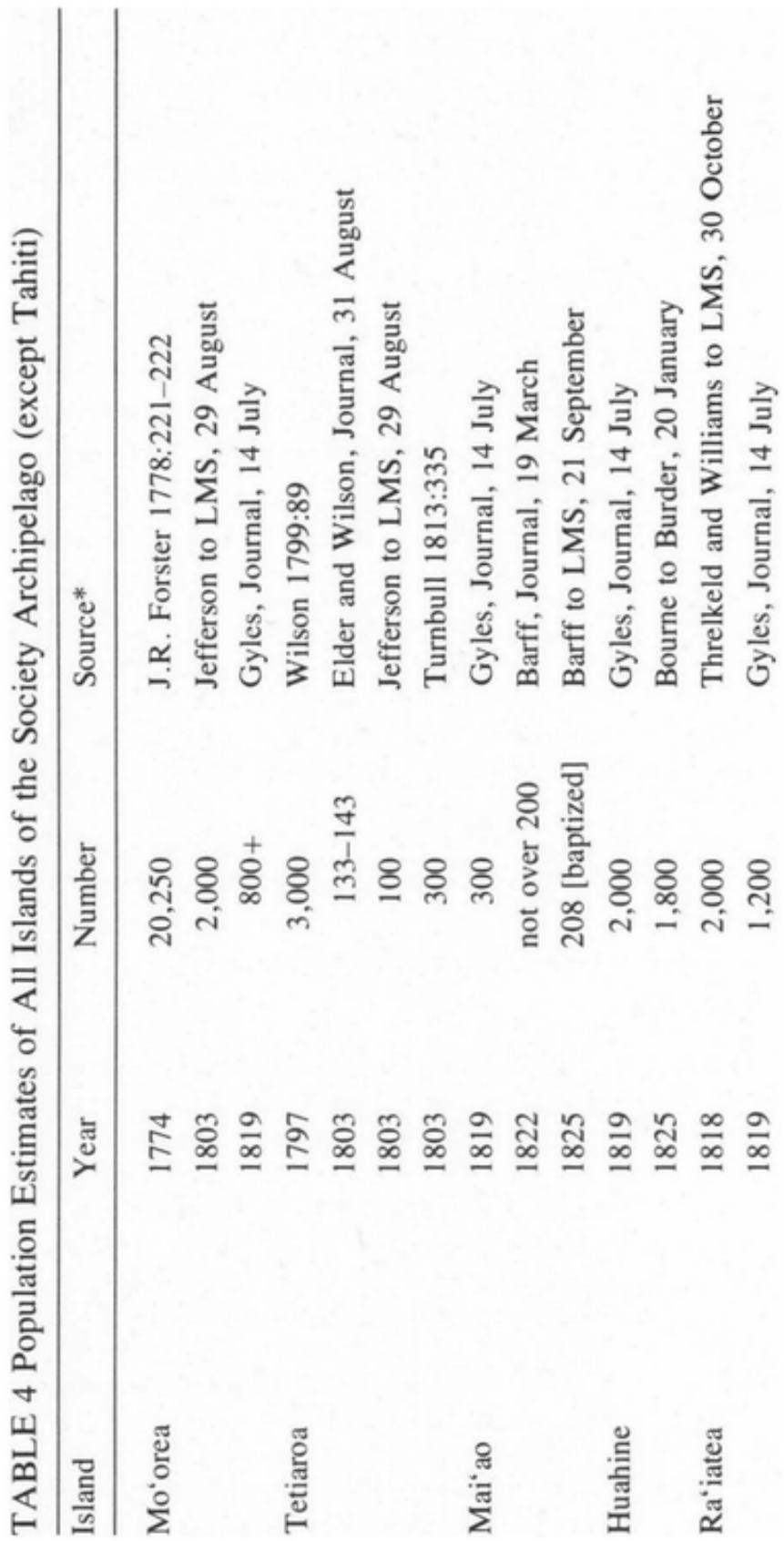




$$
\begin{aligned}
& \stackrel{Ð}{\circlearrowright} \\
& \text { \& }
\end{aligned}
$$

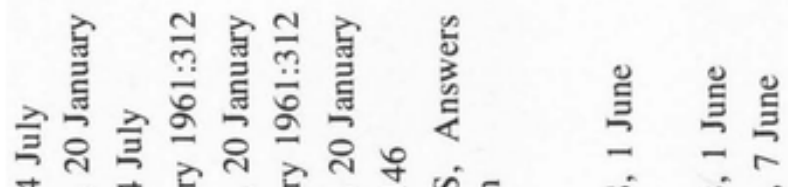

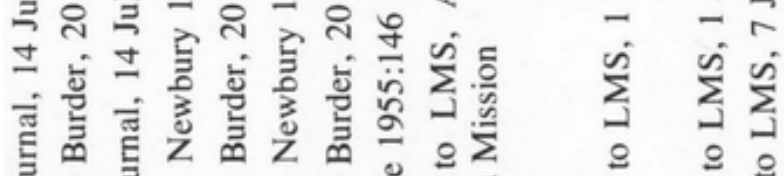

$$
\begin{aligned}
& \text { 을 }
\end{aligned}
$$

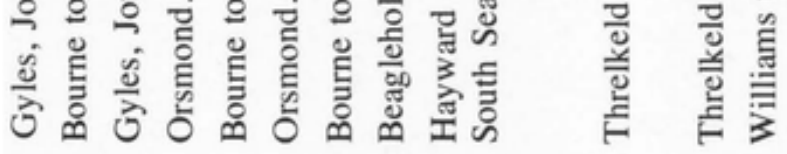

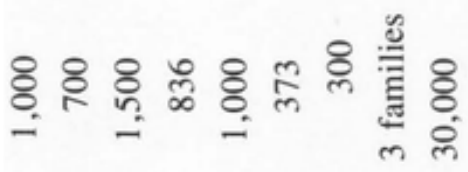

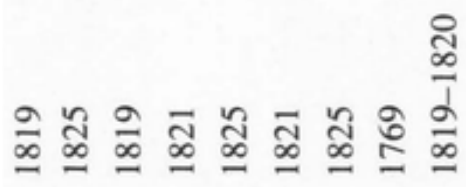

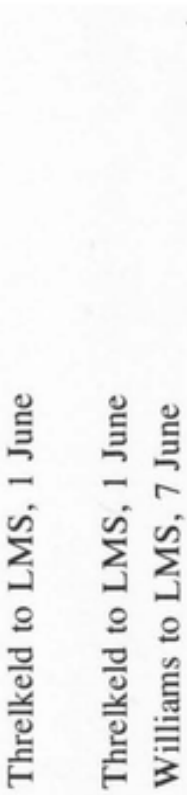

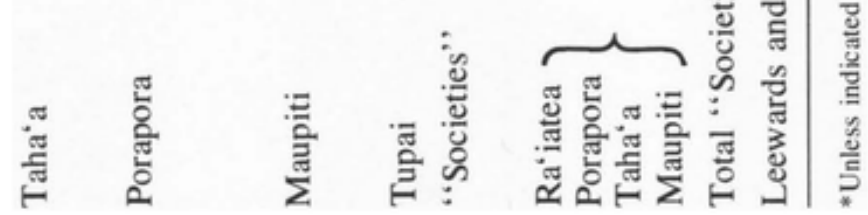


did many people live there, they say, that some are dead, \& others drowned in coming to Otaheite. (Elder and Wilson, Journal, 18-31 August 1803, LMS Archives)

The estimates of Jefferson and Turnbull are less reliable, having been based on hearsay. Turnbull's, especially, is rather curiously inconsistent, since it was based on information obtained from Elder and Wilson. Turnbull wrote: "Mr. Elder and Mr. Wilson had just returned from the Mottos [motu, islet], whither they had been conveyed by our boat on the 18th of August. They reported that the population did not exceed three hundred." (1813:335)

Mai'ao. I cannot discover the basis of Gyles' estimate. Barff's 1822 estimate was based on a visit to the island, as were his estimates of 1825.

Huahine. Again, I do not know the source of Gyles' estimate, but Bourne was stationed in the Leeward Islands and presumably had a fair notion of the populations thereabout. In July 1820, the missionaries Davies, Ellis, and Barff reported from Huahine:

The preaching of the word has been chiefly at our place of residence near Fare harbour, ... the number of the hearers has often been from 1200 to 1600 , most of the people of Maeva and Huahine iti having removed to this neighbourhood, it supersedes the necessity of visiting those places, and in like manner the schools also at those places have been suspended for the present. (Davies, Ellis, and Barff to Burder, 15 July 1820, LMS Archives)

The inference that may be drawn from this passage is that the "hearers" included most of the adults on the island, but how many children were among these "hearers" is impossible to say.

Ra'iatea. The estimate of Threlkeld and Williams, contained in their report of 30 October 1818, was based on local residence and an ardent search for people to convert. The search, it may be added, had been largely unsuccessful up to that point: "No one is yet baptized save 2 or 3 hundred who were baptized one day at Eimeo by a Drunken Sailor" (Threlkeld and Williams to LMS, 30 October 1818, LMS Archives).

Taha'a. Bourne's 1825 estimate for Tana'a was based on his residence there and hence is probably fairly reliable.

Porapora and Maupiti. Both of these islands were under Orsmond's charge, and his estimates of their populations are about as reliable as one is likely to get for communities such as these.

Tupai, or Motu Iti, was subsequently deserted, but in 1769 Cook described it in the following terms:

Between 5 and 6 oClock PM as we were standing to the Northward we discover'd 
a Small low Island lying NBW or NNW distant 4 or 5 Leagues from Bolabola, this Island is call'd Tubai. Tupia says that it produceth nothing but a few Cocoa-nuts; that there are only three Families live upon it, but that the people from these Islands resort thither to catch fish. (Beaglehole 1955:146)

There was considerable going and coming between Mo'orea and Tahiti, between Mo'orea and the Leeward Islands in general, and among the Leeward Islands themselves. It is impossible to establish the extent to which this movement was recognized in the forming of various population estimates, but my guess is that the later missionary censuses would have excluded any large influxes of visitors.

More critical is the question of the relationship between these later figures and the populations of 1767. Mo'orea was closely involved in Tahiti's devastating wars and probably suffered just as directly and heavily from European-introduced disease. The other islands may have suffered somewhat less from introduced disease but were racked by many large-scale wars of their own. On balance, however, my guess is that the Leeward populations suffered less of a decline, during the five decades after 1767, than did those of Tahiti and Mo'orea.

For most of the Leeward Islands this guess is supported in part by geographic circumstances; that is, except for Ra'iatea, these islands could not have supported vastly larger populations than those living there-certainly not eight times as many (the most plausible estimate for Tahiti), and perhaps not even twice as many. Ra'iatea is, however, puzzling in this respect. It is by far the largest of the Leeward Islands and could conceivably have supported a population many times larger than the "less than 2000" reported by Threlkeld and Wilson in 1818; yet there is no positive evidence that such was ever the case. ${ }^{12}$

\section{Composition}

In view of the state of our knowledge about these Islands' population size in 1767, it is not surprising that there is little or no firm evidence concerning the composition of that population. Captain Wilson asserted that there was a numerical preponderance of males but provided no numbers and no basis for his estimate: “... both parties do oftener make up their minds to save the male than the female, which partiality accounts for the disproportion of the sexes, ..." (1799:192). More specific estimates place the proportion of males to females at one to three, or one to four, or even one to ten-but these relate to a much later time and are, in any case, highly impressionistic. In describing Mo'orea in 1818, one member of the LMS mission wrote: "The females are very few, I suppose not one to three males" (Gyles to Sleigh, 23 November 1818, LMS Archives). In a general survey of this mission field in 1819-1820, Hayward wrote: “... the pro- 
portion of the sexes [is] one woman to 3 or 4 men ..." (Hayward to LMS, Answers to Queries re South Sea Mission, 1819 or 1820, LMS Archives).

Data on age composition are virtually nonexistent. Orsmond, writing in 1821, reported that the Porapora population consisted of 545 "adults" and 291 "children," but that is about all we have to go on. Data on mortality and longevity are not much better, being limited to casual remarks about the high prevalence of infant death or to statements like the following: "Many were alive in 1791 who remembered the loss of one of Roggewein's squadron at an island [Makatea?] north of Otaheite, in 1722." (Wilson 1799:328).

In this connection, Morrison's statement that “... it appears to me that they live to a Good old age ..." (1935:231) may be contrasted with Varela's, that "... they are not long-lived, for we saw very few old people" (Corney 1915:289).

\section{Physical Characteristics}

Captain Cook's matter-of-fact description of the Maohis is as good as any:

With respect to their persons the men in general are tall, strong limb'd and well shaped, one of the tallest we saw measured Six feet 3 Inches and a half, ${ }^{[13]}$ the superior women are in every respect as large as Europeans but the inferior sort are in general small owing possibbly to their early amours which they are more addicted to then their superiors. They are of various colours, those of the inferior sort who are obliged to be much exposed to the sun and air are of a very dark brown, the Superiors again who spend most of their time in thier Houses or under shelter are not browner than people who are born or reside long in the West Indias nay some of the women are almost as fair as Europeans. Their hair is almost universaly black thick and strong.... They have all fine white teeth and for the most part short flat noses and thick lips, yet their features are agreable and their gate gracefull.... (Beaglehole 1955:123-124)

Other early voyagers were less stinting, some even rapturous, in their admiration of the physiques and countenances of the Maohis; even the staid chroniclers of the first missionary band found them not wholly unpleasing in their ways.

The natural colour of the inhabitants is olive, inclining to copper. Some are very dark, as the fishermen, who are most exposed to the sun and sea; but the women, who carefully clothe themselves, and avoid the sun-beams, are but a shade or two darker than an European brunette. Their eyes are black and sparkling; their teeth white and even; their skin soft and delicate; their limbs finely turned; their hair jetty, perfumed, and ornamented with flowers; but we did not think their features beautiful, as, by continual pressure from infancy, which they call touroome, they widen the face with their hands, distend the mouth, and flatten the nose and forehead, which gives them a too masculine look; and they are in general large, and wide over the shoulders; we were therefore disappointed in the judgment we had formed from the report of preceding visitors; and though here and there was to be seen a young person who might be esteemed comely, we saw few who, in fact, 
could be called beauties; yet they possess eminent feminine graces: their faces are never darkened with a scowl, or covered with a cloud of sullenness or suspicion. (Wilson 1799:327)

Another impression was provided by William Wales who accompanied Cook on his second voyage.

With regard to the Personal Beauties of the Otahitean Ladies, I believe it would be most prudent to remain entirely silent; since by a contrary proceedure I must expose in the grossest manner my own want of tast, or that of those Gentlemen who have asserted that 'they may vie with the greatest beauties of Europe', and that 'the English Women appeared Verry ordinery on their first arrival there' from this celebrated Cythera: but it is no new thing for the itch of writing to get the better of prudence; it will not therefore be wondered at if I run all risks of this kind to have the pleasure of describing their persons; at least, so far as there appears to be any national characteristic in it. In the first place then, their stature is very small, and their features although rather regular have a masculine turn. Their Complexion is a light Olive, or rather a deadish Yellow; their hair is of a glossy black and cut short in the bowl-dish fashion of the Country People in England; but had here, I think, a pretty effect, as it corresponded more with the simplicity of their Dress than any other form would. Their Eyes are exceeding black and lively but rather too prominent for my liking. Their noses are flat especially towards the lower end and their nostrils in consequence wide, as are also their mouths. Their lips are rather thick than otherwise; but their teeth are remarkable close, white, and even. The Breasts of the young ones before they have had Children are very round and beautifull, but those of the old ones hang down to their Navals. I have no occasion to call in the Aids of Imagination to describe every part of them, down to their very toes, as there were plenty of them who were not solicitous to hide any of their beauties from our Eyes; but it may be best to stop here, and proceed to say a little in defence of their Characters, which have, in my opinion, been as much depreciated as their beauties have been Magnifyed. (Beaglehole 1961:796) ${ }^{14}$

Some of the early visitors commented upon the obesity of many Maohis, male and female, including one man who measured 54 inches around the waist, and 313/4 inches around the thigh (G. Forster 1777:I, 390-391). As we shall see, there were institutionalized measures undertaken to fatten people, as a means of enhancing their comeliness; but quite apart from that, the usual diet and activity regimes of many Maohis seem to have produced nearly the same results.

One of the most vividly expressed impressions of Maohi physique is Anderson's contrast between them and the Friendly Islanders, Tongans, whom he and his shipmates had visited en route to Tahiti:

Nothing could make a stronger impression, at first sight, on our arrival here [Tahiti], than the remarkable contrast between the robust make and dark colour of the people of Tongataboo, and a sort of delicacy and whiteness, which distinguish the inhabitants of Otaheite. It was even some time before that difference could preponderate in favour of the Otaheiteans; and then only, perhaps, because we became accustomed to them, the marks which had recommended the others began 
to be forgotten. Their women, however, struck us as superior in every respect; and as possessing all those delicate characteristics, which distinguish them from the other sex in many countries. The beard which the men here wear long, and the hair which is not cut so short, as is the fashion at Tongataboo, made also a great difference; and we could not help thinking, that, on every occasion, they shewed a greater degree of timidity and fickleness. The muscular appearance, so common amongst the Friendly Islanders, and which seems a consequence of their being accustomed to much action, is lost here, where the superior fertility of their country enables the inhabitants to lead a more indolent life; and its place is supplied by a plumpness and smoothness of the skin; which, though, perhaps, more consonant with our ideas of beauty, is no real advantage; as it seems attended with a kind of languor in all their motions, not observable in the others. This observation is fully verified, in their boxing and wrestling, which may be called little better than the feeble efforts of children, if compared to the vigour with which these exercises are performed at the Friendly Islands. (Cook 1784:146-147)

Various physical anomalies were also noted by early visitors, including occurrences of albinism, and of dwarfism:

During our stay in these Islands I saw some not more than 5 or 6 who were a total exception to all I have said before. They were whiter even than us but of a dead Colour like that of the nose of a white horse; their eyes hair eyebrows and beards were also white; they were universaly short sighted and lookd always unwholesome, their skins scurfy and scaly and eyes often full of Rheum. As they had no two of them any connextions with one another I conclude that the difference of colour \&c. was totaly accidental and did not at all run in families. (Beaglehole 1962:I, 335) ${ }^{15}$

They brought before me [Rodriguez] a dwarf, whom I measured and found a bare vara [a Spanish measure: .836 meters] in height, three quartas [cuarta, i.e., one quarter of a vara] in girth round the belly, a geme [span: about 8 inches] the legs, the head very large, and a gruff voice, the entire body hairy, and scarcely able to walk for weariness. His father measures five cuartas in height, and, by his looks, is now forty years of age, a little more or less. I set the son down at fourteen to sixteen years, although the natives say that his beard will soon appear, and he will then grow no more. The mother is dead\& they say she was about the same size as the son, and for this reason they declare that he will not grow any taller. (Corney 1919:90)

I saw a Dwarf about Eight Years old-the Boys head was very large, the body tolerably proportioned, but the thighs, and Legs particularly were very short. His Height was 31 Inches, and all the People agreed that he would never be any taller. His name was Tommah, but he was commonly called Hai'ah, (or Dwarf.) He was without four of the upper fore teeth all the rest were perfect. (Bligh 1792:142b)

\section{The SETTING IN 1767}

Seen from a distance at sea these Islands must have looked much the same to the European "discoverers" in 1767 as they did to their Polynesian discoverers a millennium or so earlier. A few scattered houses and stone structures, together with many more coconut palms, were visible along the shores, but, by looking inland from the decks of their ships, Wallis and Cook 
and Bougainville would have seen much the same kind of landscapes that greeted the first Polynesian settlers. Closer observation ashore, however, would have revealed some rather extensive changes, at least in the adlittoral and lower-valley parts of the coastal zone, the lower slopes of the dry-tropical zone, and the lower reaches of valleys in the wet-tropical zone.

First, many areas of the adlittoral and lower-valley subzones had been cleared of their primitive vegetation and replaced with houses, religious centers, and groves and gardens of introduced plants-mainly breadfruit, taro, tarua (Xanthosoma sagittifolium), sweet potato, yam, arrowroot, sugarcane, paper mulberry, "bitter taro" (Alocasia macrorrhiza: 'ape), and "giant taro" (Cyrtosperma nadeaudianum: 'ape veo). Some of these new plants, notably breadfruit and 'ape, had "escaped" from gardens and groves and had become established in other settings.

Second, several kinds of useful indigenous plants had been encouraged to proliferate by deliberate planting and protection, mainly in the coastal and lower-valley areas. The principal ones of these were the coconut palm, mountain plantain, banana, kava, ti, and turmeric.

Third, considerable inroads had been made into natural growth of certain plants, for food, construction, and other purposes. For example, natural stands of mountain plantain were drawn upon heavily and probably reduced in numbers. Also, men had to go farther and farther inland in search of suitable trees for canoe hulls and probably for ordinary house timbers as well.

Fourth, the pigs introduced by the Polynesians, and particularly the feral ones, had succeeded in destroying some of the original plants in some areas, but much more destructive in this respect were the bush fires set by humans, accidentally or in connection with pig hunting, garden clearing, and warfare. The sources contain some vivid descriptions of such fires.

There has been a large fire in the mountains opposite Pare since Thursday last, yesterday evening it reached a large plantation of cocoanut trees, that were planted by the kings father about 17 years ago-there were some hundreds much damaged and the greater part of which perhaps will never grow again. (Youl et al., Journal 11 October 1806, LMS Archives)

For several days and nights past there has been a strong great fire in the lower hills of Matavae, which consumed almost every tree and shrub before it, a plantation of cocoa nuts upon one of the hills, planted about three or four years ago by some of the brethren is supposed to be entirely consumed. (Davies, Journal, 27 August 1807, LMS Archives)

In some cases the original plants of fire-devastated areas were able to reestablish themselves; such was the case with the Gleichenia fern cover over much of the dry-tropical zone slopes. Elsewhere, in burnt-out portions of the wet-tropical zone (particularly on the middle slopes) myrtle (Metrosideros), melastomas, and dodoneas moved in. ${ }^{16}$

In summary, by the time Europeans began to arrive on the scene, the 
Maohis had, deliberately or otherwise, brought about extensive changes in certain parts of the Islands-mainly in the adlittoral parts of the coastal zone, the lower slopes of the dry-tropical zone, and the lower parts of the wet-tropical zone-areas which European visitors were to describe as parklike, even reminiscent of "the Elysium fields" (Bougainville 1772:38). In Banks' words:

No countrey can boast such delightfull walks as this, the whole plains where the people live are coverd with groves of Breadfruit and cocoa nut trees without underwood; these are intersected in all directions by the paths which go from one house to the other, so the whole countrey is a shade than which nothing can be more gratefull in a climate where the sun has so powerfull an influence. (Beaglehole 1962:I, 340)

On the other hand, they effected few or no changes in submangrove areas or on atolls or atoll-like offshore islets; neither had their colonization resulted in any extensive changes in areas directly bordering sea and lagoon. The extensive rain forests had been altered slightly by Maohis foraging for mountain plantains and timber, but most of the mountainous interiors remained unvisited and unchanged. In other words, only about one-fifth of the Islands' land areas had been more or less affected by Maohi settlement.

The early European visitors to the Islands found the indigenes dwelling in "households" scattered mainly about the coastal plain and the lower and middle reaches of the valleys. Such households typically consisted of a single sleeping house along with a separate cookhouse, although a few also included an extra shelter or two for sleeping, working, or entertaining. In addition, in many if not most cases the structures making up a household unit included a marae, a place set aside and specially constructed for worship. Nearly all these households were separated from one another by gardens and orchards. Some, in fact, stood hundreds of yards distant from all other dwellings; but most individual households were clustered, spatially and socially, into "neighborhoods" each consisting of from two to ten or so households.

The larger-than-average establishments of certain socially prominent persons, containing extra quarters for servants and hangers-on, were described by some Europeans as "villages," but they were in actuality merely enlarged single households. In certain areas of high-yield economic resources the households and neighborhoods were clustered closely enough together to warrant, perhaps, labeling them "villages"; but such aggregates were the rare exception and not the rule.

In addition to the household buildings just mentioned, and the gardens and groves associated with them, the early European visitors to these Islands found numerous other structures located apart from households, or in some cases spatially separated even from neighborhoods. These included archery platforms and an occasional more or less secular meetinghouse, but usually such structures were marae, serving congregations of larger-thanneighborhood size. 
The earliest European visitors have left no maps and few verbal descriptions of actual settlements and only the most general indications of population densities:

The most thickly populated localities are the District of Papala [Papara], the District of Tallarabu [Taiarapu], and the western side where the arii Otu resides [i.e., Pare]. (Corney 1915:79)

9th day [9 July 1775]:-It broke clear and calm. I started off by land, with all the arii and their kinfolk, it being the custom to go as far as or beyond the confines of their district, in order to renew there the guest's supplies and take leave of him, with much weeping, which was done accordingly; and thus, as I passed through it by land, I saw the whole of Opare, which is a very populous and smiling district. Better houses were met with than elsewhere in the island; the land is of good quality, and very wide extent, for it includes well-peopled valleys stocked on their lower slopes with good-sized plantations, though the hills are not so thickly wooded as those belonging to Vehiatua in his part of the country. (Corney 1919:169)

I started for the district of Papara, which adjoins that of Atehuru. This last is the largest district of all in the island and is pretty densely peopled.... (Corney 1919:172)

... [Taravao Isthmus] is only thinly peopled, because the natives declare that they constantly see the Tupapau or Evil One there. (Corney 1919:49)

The extent of valley settlement is indicated in the following:

Fr. Geronimo went with the Interpreter up the Ohatutira [Tautira] gully, where a great many people live, but in scattered fashion. (Corney 1915:321)

This district of Apayano [Papeno'o, consisting mainly of the valley of that name] is large and populous; and its coast line not bad, on the whole, but it has not the protection of an outer reef. (Corney 1919:167)

We proceeded about [six miles up the valley of the Matavai River] and had houses pretty plentifully on each side the river, the vally being all this way 3 or 400 yards across. We were now shewn a house which we were told would be the last we should see. (Beaglehole 1962:I, 307)

The only specific reference I can find to an inland hillside residence is Bligh's description of that of the $\operatorname{ari} i$ Tynah [Tina]:

This afternoon I took a Walk with Tynah to the Hills where his Country residence is to sow Indian Corn. It may very properly be called his Seat, for he has a neat House and a Plantation of all the produce of the Country. Ground provisions such as Yams and sweet Potatoes were in great abundance, but they had not yet began to flower, and of course not in season, however he directed a few Potatoes to be dug for me. A Great many Cocoa Nutt Trees which he has planted within these five Years from the Nutt in Rows, are in great perfection, and he has very fine Clusters of Breadfruit Trees also of his own planting. The Situation is delightfull with a fine View of Oparre and Matavai. Tetturoah [the atoll Tetiaroa, some 41 $\mathrm{km}$ north of the coast at this point] can also be seen. The soil is exceedingly rich and good so that every thing grows luxuriantly. (Bligh 1789:II, 40)

On smaller islands, with narrower coastal plains and only shallow 
steep-sided valleys, the populations had to thin out extensively and use higher ground for growing food crops:

The Island of Huheine is Hilly and very uneven, with several curious projecting Rocks about the summits of some of the Hills. It is surrounded by flat Land which abounds with Cocoa Nutts and Breadfruit, and is also cultivated on the rising Grounds. (Bligh 1789:II, 84)

Forster explained "... the superior affluence and luxury of the Taheitians," in comparison with natives of Huahine, as due to the inferiority of Huahine's natural resources, "... where the ambient plain is so narrow and inconsiderable, that the natives are obliged to cultivate the hills" (1777:II, 119).

The earliest and most authoritative figures available concerning the spatial distribution of Tahiti's population were given in Table 3. Another account of population distribution was recorded by missionaries in 1797, during their circuit of Tahiti, but the value of this estimate is limited in two ways. In the first place, the count was by district only, and, in most cases, was based on hearsay. Second, it was taken thirty years after Wallis' visit, by which time the island's total population had been reduced to an estimated 16,050. Later descriptions of actual settlements are not applicable to the era under study because they involve radical changes wrought by the missionaries, who successfully undertook to concentrate the remnants of the natives into neighborhoods around the mission stations.

In fact, archaeology provides the best evidence available about the actual distribution of the pre-European Maohis; and even this is evidence of an indirect kind. Stone remains of structures have been found throughout the adlittoral zone-the farthest inland reported to be about $15 \mathrm{~km}$ from the coast near the head of the Papeno'o Valley. They have been found also along the water's edge, and a few on hillsides and plateaus outside the adlittoral zone; but most of these latter relate to nonresidential structures: to temples, council platforms, archery ranges, and fortresses, many of which may well have been purposely distant from places of residence. A few stone remains, particularly the stone curbings of round-ended houses, may have been either residences or public buildings; but these are also limited to the adlittoral zone. 


\section{CHAPTER 3 COSMOLOGY}

This account of Maohi life begins with descriptions and behavioral exemplifications of these Islanders' beliefs about the nature of their universe and their positions in it. To those readers who on theoretical grounds might favor some other order of ethnographic presentation-say, the explication of technology prior to that of cosmography-I say that in my own opinion the beliefs people entertain about themselves and their environment at any one moment are the most decisive factor in determining how they act toward that environment at that time. This is not to assert that exogenous factors have not helped change, over time, the beliefs held by the Maohis, for they have undoubtedly done so; but when attempting to portray and comprehend how the Maohis of 1767 caught fish (or contracted marriages, or dealt with biological death, etc.), their perceptions about the gods of fishing (or about social stratification, or ghosts) provide more immediately relevant keys to our understanding than does information about natural or technological factors that in the past may have helped to shape those perceptions and practices concerning fishing (or marriage, or funerals).

\section{SOCIAL ENTITIES}

\section{Cosmogony}

What were the Maohis' pre-European beliefs concerning the beginnings of their universe?

Anyone attempting to answer this question is confronted with problems of authenticity and variability. Allegedly "authentic" data on such beliefs were collected over a period of at least a century. In fact, "native" and, supposedly, pre-European beliefs are still being recorded today. (Compare such statements as, "The following myth was told by old X who learned it from his grandfather, the last sage of the district.") Some of these myths are so patently Bible-inspired as to present no problem regarding derivation, but in other cases, especially myths about floods and about strife in heaven, it is next to impossible to decide whether biblical similarities are remarkable convergences or disguised borrowings. One possible way out of this dilemma would be to utilize only those accounts collected before the 
missionaries began active proselytism, about 1800; but one must consider that, with the possible exception of accounts by Rodriguez and Morrison, only after 1800 were any accounts collected by Europeans familiar enough with the language to record or translate these interviews to any reliable degree. Moreover, by utilizing only the premissionary data one would have to depend upon brief fragments and ignore the large corpus of materials recorded much later by such missionaries as Jefferson, Knott, Davies, and Ellis, and by such laymen as Moerenhout and de Bovis.

My criteria for authenticity are quite simpleminded. I place heaviest reliance upon the writers just mentioned because I believe them to have been conversant enough with European ideas, including biblical themes, to recognize them as such, and intellectually honest enough to so identify them. Also, comparison with data from other Polynesian societies can provide some indirect corroboration for what is or is not pre-European. (In the present context I am concerned only with beliefs authentically pre-European, since I am trying to reconstruct Maohi suppositions about their society before these began to be altered by contact with aliens. A Christianized Maohi's formulation about the Genesis is no less "authentic" and ethnographically useful-but for other purposes.)

The problem of variability is quite different. Different versions of particular subjects vary so widely, from place to place and from informant to informant, that one might question the feasibility of trying to reconstruct the Maohi cosmogony and cosmology. ${ }^{1}$ The answer to this is that such variation, within certain limits of course, was the hallmark of Maohi beliefs, in terms of place and time. Even within the brief period that I have tapped for reconstruction there seem to have been local changes in some beliefs quite apart from those induced by the presence of Europeans.

All this conflicts with a view many Europeans have entertained about ancient Polynesia which envisaged each society as having a more or less official corpus of sacred lore that was faithfully preserved from generation to generation by priests and sages skilled in memorization. Rote memorization was a deliberately fostered and highly valued skill in some Polynesian societies, including Maohi society, and this did indeed serve to protect some traditions and formulae from rapid change. ${ }^{2}$ Moreover, some versions of myths were "official," but "official" with respect to this or that social unit, and not to Maohi society as a whole.

Some Polynesian cosmogonies are said to picture the universe developing out of nothingness by a kind of self-generating evolutionary process. There may be fragments of such a view in Maohi beliefs, ${ }^{3}$ but by far the most frequent and best developed Maohi cosmogonic theme concerns a primal spirit, Ta'aroa, who initiated the known universe by incantation ( $r a h u$ ) or by personification of his own attributes or by sexual reproduction with beings created by him. ${ }^{4}$ 
A creation chant dictated to Orsmond in 1822 on Porapora, and later heard also at Mo'orea, combines many characteristic themes. I summarize below the action described in the chant, freely paraphrased and severely abbreviated from Henry (1928:336-338). ${ }^{5}$

In the beginning there was only Ta'aroa, who had no forebears, who created himself and all other first beings and things. For countless ages Ta'aroa existed alone, floating in space ('aere) and darkness ( $p \bar{o})$ within egglike shells. Finally wearying of his solitude, Ta'aroa broke out of his shells. One of these shells was Rumia, which became his house (fare), the dome of the gods' sky which enclosed the world $(a o)$, then vegetatively growing. The other shell became the world's great foundation (tumu), consisting of stratum rock ( Ta'aroa were several personlike attributes: memory (mehara), thought (mana'o), steadfast gaze (tutonu), and observation (hi'ohi'o).

Ta'aroa then caused the land's Great Foundation to become husband (tane) and its Stratum Rock to become wife (vahine), and he placed his spirit (värua), his very essence (meho'i nona iho), inside Foundation and hailed him as ari'i. Ta'aroa then bade Foundation and Stratum Rock to go to each other and cohabit, but they refused. Ta'aroa continued for eons to dwell in the enclosed dark sky and conjured forth (rahu) many other gods (atua); it was only later that he made man (ta'ata), with the help of his artisan-god, Tu. Ta'aroa shook off the red and yellow feathers growing from his own body and these became plants growing on the land. Meanwhile the octopus, Foundation of Earthly Heaven, held the sky close to the earth, keeping out all light.

Another version relates that Ta'aroa had a consort, Ofeufeumaitera'i, who like himself emerged unassisted out of the $p \bar{o}$, and from whom he begat 'Oro. 'Oro then begat two sons of his own from another atua of unspecified origin, and these six "... constituted the whole of their highest rank of divinities, according to the traditions of the priests of Tahiti." ${ }^{\prime 6}$

Still another version relates that Ta'aroa's first act was to create a daughter, Hina, with whom he subsequently begat (fänau) 'Oro, after she had assisted him in making the heavens, earth, sea, and many other atua.

One could go on at some length repeating, and attempting to analyze, the many variations among the recorded versions of Creation ${ }^{7}-$ an intriguing study in itself, but one too specialized for this book's objectives. Instead, I shall be content to emphasize that such variations existed (and probably much more so than the surviving documents indicate) and to point out, though not very systematically, some of the more obvious themes that are directly related to our interests.

In most versions of the Creation, mankind ( $t a^{\prime} a t a$ ) appears rather late, after numerous other entities-major and minor gods, meteorological phenomena, physiographic features, flora, fauna, and so forth-had been formed. Out of the innumerable chants and narrative accounts describing these events it is possible to distinguish seven formative processes:

1. Incantation $(r a h u)$. By this means, Ta'aroa called into being many 
kinds of entities, including lesser gods, some of whom also possessed and occasionally made use of this kind of creative power.

2. Fabrication (rave, hamani). By this means some entities were made out of others. For example, Ta'aroa fabricated many gods out of the parts of his own body or out of some of his own attributes, and these in turn fabricated other entities.

3. Sexual reproduction (fänau). Ta'aroa cohabited with his own creation, Stratum Rock, and from this union was born Hina, the Moon Goddess. Again, Ta'aroa caused the shadow of a breadfruit tree-one of his numerous manifestations-to pass over his offspring Hina, and the god 'Oro was thus born. (One noteworthy feature of many of these accounts is the prevalence of what the ancient Maohis themselves regarded as "incest"; male spirits cohabit with their own sisters, daughters, granddaughters, and even mothers.)

4. Division. For example, some gods in a fit of anger broke up the land into many islands.

5. Fishing up islands from the sea. This kind of action was usually attributed to the demigod Maui. In a variant of this theme, islands are described simply as having been "cast up" by the sea.

6. Growth (tupu) from other entities. Thus, the staple plants grew out of the body of a man; or Ti'i and Hina are said to have caused-to-grow (tupu) common people for the earth (Henry 1928:403).

7. Transformation. For example, one married couple gave birth to a head, which turned into the first coconut; or, during a time of famine, a man converted himself into a breadfruit tree to save his wife and children from starvation.

Finally, some entities are said merely to have arrived or appeared, without indication of how or whence. ${ }^{8}$

Events involving formation of the major gods or categories of gods, the principal natural phenomena, the larger land features, the main classes of animals, plants, and so forth, were implied to have taken place in the remote past. On the other hand, many other acts of creation or of transformation were believed to be ongoing, including, of course, the seasonal reappearance of many food plants and animals, which was in no sense a wholly "automatic" process.

But creation was not enough; entities had to be brought into proper relationships, a process that is described in several myths. One of these concerns strife between Darkness, Famine, Sleep, on one side, and Light, Plenty, Wakefulness, on the other, with the latter prevailing and introducing a general reconciliation. (It is possible but I believe not probable that this may have been based on a biblical theme.) Another recurrent myth theme concerns the firm fixing in place of the land by means of the growth of 
roots, termed ari'i in this context-a metaphor having interesting social implications, which are discussed below. Still another theme concerns snaring the sun for the purpose of lengthening the day. Of all myth themes one of the most frequently recorded concerns the separation of Sky from Earth, sometimes imagined to be a couple in embrace, but more often described as being held together by an octopus. When this mighty feat of separation was accomplished light replaced darkness between Sky and Earth, and pillars (pou) were erected to hold Sky aloft.

Finally, I reproduce in its entirety a text recorded by Orsmond and titled (by him, probably) "Order Finally Established." The purpose in including such a lengthy, detailed text in what is otherwise intended as an epitome of Maohi cosmogonic beliefs is twofold. First, I wish to suggest how comprehensive such beliefs were; and second, I offer this example to indicate how detailed were the Maohis' perceptions of their physical surroundings, including items that seem to have played no part, useful or otherwise, in the "practical" business of maintaining life. ${ }^{9}$

The presence of Tane among the gods (atua) introduces some uncertainty concerning beliefs about the origin of mankind, since tane is used most commonly to label the male human being. Also, some writers refer to Tane as a demigod (atua-ta'ata). Nevertheless, the more explicit accounts of mankind's origin concern a being named Ti'i. A myth dictated to Orsmond in 1822 and again in 1833 by informants from Mai'ao and Tahiti combines several of the more characteristic themes on this subject.

\section{CREATION OF MAN}

Te mata o Tû ma Ta‘aroa i nana i raro i te piha taata. Ua apo'opo'o a'era raua:

"Ua tupu te fenua, ua tupu te ra'i, e ua tupu te moana; ua í ana'a ia i te mea oraora. Ua api te piha atua $\mathrm{i}$ te atua, na hea rà te piha taata e au ai?"

“E hamani rà i te taata!” A rahu ra Ta'aroa i raro i te aro o ha'eha'a, tu maira o Ti'i ho'e roa ra taata. O te taata matamua roa 'ino ia i te ao nei. O Ti'i ahu one. Ti'i ma‘a-ra'a uta. Ti'i ma'ara'a i tai, Ti'i haamou-huna, Ti'i fa'aina toi. E 'ao 'uo te Ti'i, e 'Ao fa'auru i te pô e te ao i ta Ti'i e fa'aue atu.

O Na-pô-tîtî e o Na-po-tàtà te rahua mai e Ta'aroa ei hoa varua ino na Ti'i i te pô, ape'e mai nei i te ao nei.
The eyes of Tû (Stability) with Ta'aroa (The-unique-one) looked down into the room for man. They consulted together:

"Land has grown, the sky has grown, and the ocean has grown; all these are filled with living creatures. The room for gods is filled with gods, and now what shall be done for the room for man?"

"We must now make man" [was the decision].

So Ta'aroa conjured up from below, and there stood forth Ti'i (Fetcher), only one man. He was the very first man in this world. He was Ti'i, clothed in sand, Ti'i the propagator inland; Ti'i, the propagator seaward; Ti'i, secret destroyer; Ti'i, the axe sharpener. $\mathrm{Ti}^{\prime} \mathrm{i}$ had a white heron, that bewitched by day and by night all whom he bid it enter.

Na-po-titi (Lingering-night) and Napo-tata (Retarded-night) were conjured forth by the Ta'aroa as demon friends for $\mathrm{Ti}^{\prime} \mathrm{i}$ in darkness, and they followed him into this world. 
A noho Te-fatu i te vahine, ia Faahotu, fanau mai ra o Hina-te-'u'uti-maha'i-tuamea, O Hina ai tua, Hina ai aro; e mata i mua e e mata i muri to Hina, atua vahine fanau taata matamua roa i te ao nei.

A noho tamahine o Ti'i-ia Hina te'u'uti-mahai-tua-mea, oia o te 'ai tua e te 'ai aro, fanau a'era ta raua, o Uru-o-te-oa-ti'a; hee te tua, o Hina-'ere'ere-manua, muri iho o Hina-nui-fa'ahara-ma'au, o Rua-faa-ra'i maira. I amui te hua'ai o Ti'i e o Hina i te hua'ai o te nu'u atua ei tane e ei vahine i tereira tau, i te pô ra.

O Ti'i e o Hina, i tu ra'i piri, na fariua i te ao ei tata'u no te ao, ei tupuraa taata rii ia no te ao, i te piha taata. Ua api a'era te piha taata i te taata, a ite Ta'aroa a faarire.

I te rahiraa o te taata, fanau maira te pe'ape'a; fanau ta te pe'apea, o te pa'ara; fanau ta te pa'ari, o te tau, fanau a'era ta te tau, o te tahitohito.

A fanau mai ta Ti'i e ta Hina-maha'itua-mea tamarii, te ari'i nui maro 'ura; e hua'ai na te atua mai te pô mai. A tû mai te taata i rahua e Ti'i ma Hina-mana'i-tua-mea, oia te taata ri'i, te manahune o te ao nei. A noho te ari'i nui i te taata ri'i, fanau maira te hui-ra'atira o te ao nei. A noho te hui ari'i i te hui-ra'atira fanau maira te ari'i ri'i o te ao nei.

O te outu rorao te 'ai'a fenua o te hui ari'i; tei reira te marae nui o te fenua, e 'ore e mo'e. O te 'o'o'a hohonu te 'ai'a fenua o te hui raatira. A í te fenua $i$ te taata a ràrà $i$ te mau vahi ato'a. Tei tai e tei uta te fenua o te taata ri'i, e piri haere ia fenua i to te feia mana.
Te-fatu (The-lord) dwelt with his wife, Faahotu (Be-fruitful), and they begat Hinate-u'uti-maha'i-tua-mea (Gray-to-extractand-mitigate-many-things), Hina who ate from before and from behind; a front face and a back face had Hina the goddess, who was the first woman born in this world.

Ti'i took to wife in her girlhood, Hina-te'u'uti-mahai-tua-mea, she who ate from before and from behind, and they begat Uru-o-te-oati'a (Inspired-of-the-house-of-high-chiefs); there followed Hina-'ere'ere-manua (Hinablack-and-hasty-tempered); next came Hinanui-faahara-ma'au (Hina-the-great-and-sulky), and then was born Raa-faa-ra'i (Source-ofkings). The children of Ti'i and Hina intermarried with the gods at that period, in darkness.

When Ti'i and Hina stood in the close sky, and turned to the earth to call to the world, it was to create common people for the world, in the department of man. Thus the room for man was filled with people, and Ta'aroa saw it and applauded.

When people multiplied, trouble was produced; trouble begat wisdom; wisdom begat cunning; cunning begat mockery.

When Ti'i and Hina-maha'i-tua-mea (Hina-mitigator-of-many-things) begat children they became the high royal family of the 'ura girdle; they were descendants of the gods from darkness. When people stood forth conjured into being by Ti'i and Hinamaha'i-tua-mea, they became the common people, the plebians of the world. When the royal family espoused common people, they begat the gentry of the world. When the royal family espoused the gentry, they begat the nobility of the world.

The long capes were the inheritance of royalty and the nobility; there stood the great temples of the land which could not be hidden. Deep bays were the inheritance of the gentry. As the land got thickly populated, the people spread everywhere. On the seashore and inland were the lands of the plebeians bordering on the lands of the great.

(Henry 1928:402-403)

Maohi cynicism is revealed in the lines about mankind, trouble, wisdom, cunning, and mockery, but for our purposes the point of central interest in this myth is its explanation of marriage-class differences.

De Bovis also referred to the misalliance theme of human origin: "As for man (kind), it is universally believed that they had been engendered by 
gods who mated beneath themselves and thereby the race degenerated" (1909:45-46); but he added no details. In other versions, by Ellis (1829:I, 113) and d'Urville (1834:I, 564), Ta'aroa and Hina begat Ti'i and Hinaereeremonoi, who in turn begat Ta'ata. Ta'ata and his grandmother Hina then begat Ouru and Fana, the progenitors of humanity.

Still other versions similar to this one specify Opoa, on Ra'iatea, as the place where human beings first appeared-a theme related to the widespread belief in the primacy of Opoa, as the main center of 'Oro worship and the ancestral home (ai'a tupuna) of some of the archipelago's highest-ranking kin-Titles. ${ }^{10}$ Parallel to this belief is an account of the growing (tupu) of other islands out of Havai'i (an ancient name for Ra'iatea): first Vavau (Porapora), then Tupai, then Maurua (Maupiti), then Mapiha'a, and so on. ${ }^{11}$ In this connection it is noteworthy that Tahiti, largest by far of the Society Islands, appeared late on the scene; originally a part of land connecting Ra'iatea and Taha'a, it moved southeastward in the form of a fish. Neither ari'i nor gods accompanied the "warriors" (toa, 'aito) who remained on the fish-island and formed its population. After many generations the warrior chiefs tried to cut the sinews of their fishisland to stabilize it, but having no gods to assist them they failed. They called out for gods but none responded. Then they sailed to Tubuai and obtained an axe dedicated to a sea god, and being possessed (uru) by the latter's powers the axe cut the sinews.

Supplementing this account, Miss Henry wrote that warrior chiefs became warrior kings over plebeian Tahiti, and gradually their families intermarried and became one with the royal [red-girdle ari'i] family of Opoa in the motherland. They landed at Mo'orea and at Tahiti's southern peninsula (Lesser Tahiti) but not in Greater Tahiti itself, whose populace called angrily for them to come. At length the gods swept over all Tahiti, whose people fled in terror and hid in caves and ravines. For a while the gods terrorized the populace, demanding the heads of the slain warriors. In the midst of their fear the people prayed and then they raised their voices beseeching the gods not to destroy them. They repented for having called angrily upon the gods to come. Then the multitudes of gods had compassion upon these mortal beings and did them no harm. Soon the people of Tahiti and Mo'orea erected temples and dedicated them to the gods, and they felt themselves protected by the spirit world as in ancient times in Havai'i. (Henry 1928:443-444)

If the indigenous authenticity of this account can be accepted in spite of its biblical phrasing, then we have here a highly suggestive version of the relations between gods and at least the lower classes of mankind.

Gods created many of mankind's customs, and men themselves invented some of their most important and useful ones, such as making fire by friction. But perhaps most inventive and venturesome of all were such 
demigods as Maui, Hiro, Honoura, and Rata. Some of the longest accounts recorded tell the adventures of these Beings-their travels to far islands, their contests with gods and other spirits, their miraculous feats of strength and craftsmanship. The very fact of their part-humanity seems to have engaged the sympathy and stimulated the fantasy of the Maohis.

As stated earlier, this cosmogonic epitome is a composite one, put together from a number of myths, cult dogmas, and so forth. It is unlikely that any one Maohi could have reproduced all the ideas summarized, or would have put them together in just this form. There were, however, a number of individuals, male and female, who made a specialty of learning and teaching large portions of the society's accumulated ideas about the universe; these were the tahu'a parau tumu fenua (experts in knowledge about the origin of the earth), or vaha rau (cave of many openings), or, as I shall label them, "sages."

Sages are said to have learned their store of information in schools (fare hapi'ira'a 'houses of learning'), which were established in several places throughout the Islands. Learning was by rote memory, usually in chant form, and the subjects taught included myths, "history," genealogy, calendar, geography, astronomy, and enigmas and similes. Extensive knowledge of the kind just listed had usually to be learned through hard and persistent effort, but there was a shortcut:

When a very learned man was about to expire and wished to transmit his knowledge to his son, even though the son was very young, he would say, "My son, stay by me and draw my last breath into thy mouth and swallow it that my learning may become thine." So when the moment came, the son would open his mouth over his father's and receive his last breath. It was affirmed that this means never failed to produce the precious knowledge. A scholar of this kind was called atiti-pau or ae-pau (all knowledge absorbed). It is said that he thus came in touch with the spirit of his deceased father, which visited and taught him all his knowledge, in deep sleep sometimes bordering upon trances. (Henry 1928:290)

I turn now to a more detailed description of the principal entities believed by the Maohis to make up their universe.

\section{Principles of Classification}

There is evidence aplenty that some Maohis were keen observers of their physical surroundings, and that at least some of them engaged more than casually in speculation and generalization about their universe. ${ }^{12}$ In fact, sages occupied positions of honor and privilege, and it may well be that there were native Aristotles, or at least Linnaeuses, among them. But it is extremely unlikely that the doctrines of any individual or any one "school" would have enjoyed universal currency, for detailed uniformity of belief was not a prominent feature of Maohi life and bigotry about such matters was practically nonexistent. 
Lacking explicit and comprehensive statements on these matters, I am left with the task of constructing them from inference, using for this purpose a wide range of behavioral and textual data.

To begin with, in my judgment the Society Islands data do not support E.S.C. Handy's thesis that these Polynesians regarded the universe as a psychic dynamism manifesting itself physically, that all objective phenomena of nature had their origin in the psychic dynamism, that concrete nature in all its parts was also in a sense regarded as a reservoir of dynamic power, and that its different parts were the mediums of transmission of this force. Handy informed us that "The most conclusive evidence of the existence in the native mind of the idea of the psychic dynamism of nature lies in the mana concept itself" (1927:26). As in the case of the postulated World Soul concept (see note 4, this chapter), no recorded texts or accounts of behavior that I know of provide evidence that the Maohis entertained such a generalized, all-embracing, energetic, animatistic view of their universe. Building stones for such a metaphysic may perhaps be inferred from some of their beliefs and actions, including some recorded usages of the word mana, but I believe that the highly refined comprehensive view enunciated above is the construct of the philosophically minded ethnologist and not, even implicitly, of the Maohis themselves. It may well be that some remote cultural ancestors of the Maohis shared such a metaphysic, but the data collected on the Maohis during the eras I am describing do not permit such a reconstruction.

This is not to say that the Maohis did not intellectually analyze and, up to a point, synthesize the manifold phenomena around and within them; for this they did to a considerable degree. But rather than attempt a full treatment of this matter, which would be a major task requiring a lengthy volume, I shall present here an outline of Maohi classifications more or less directly relevant to my concern with social relations. ${ }^{13}$

Rather than being “... a psychic dynamism manifesting itself physically," nature for the ancient Maohis consisted of innumerable individual entities, some of which were intrinsically animate and some intrinsically inanimate but capable of animation. What constituted an individual entity is not entirely clear. The great primal Stratum Rock was in itself an entity-in fact, an important spirit-and certain individual rocks and rocky outcrops were made animate by spirits, but it is not clear how large or distinctive a rock had to be to become individually animated in this way. The same uncertainty prevails with respect to soil, sand, water, wind, plants, and the like. It is fairly certain, however, that every animal being exhibiting movement of its own was considered to be a separate and obviously animate entity. Thus, although the individual entities in the universe may be said to have been intrinsically either animate or inanimate this classification does not 
correspond altogether with Western organic-inorganic or with plantanimal categories. There was on the one hand a general distinction drawn between man or man-like beings and all other animals-at least in terms of certain distinctive names for some body parts (e.g., head, brain, lungs, penis). On the other hand, myths record several instances of more or less permanent transformation of one of these contrasting entities into the other, and of descent of one from the other.

Much more explicit was the distinction between mortal mankind (ta'ata) and all kinds of "spirits"-gods, ghosts, and demigods; each is, for example, said to occupy different rooms (piha) of the universe. In the beginning some ta'ata were 'conjured into being' (rahu) and others were born (fänua) by means of sexual reproduction among spirits, but in time most ta'ata came to be born of other ta'ata. Some spirits were and continued to be born of other spirits, but many others originated or continued to originate in other ways: by conjuring, by transformation of the souls of deceased ta'ata, and so on. As we shall see, the soul (värua) of a living ta'ata was capable of extracorporeal movement, but there is no doubt that "spirits" were in general capable of greater and more varied kinds of activities than were ta'ata. Finally, the bodies (tino) of all ta'ata were believed to be destined to expire and disintegrate; this may also have been the fate of some souls. Even some spirits, such as those slain, and presumably extinguished, by the demigod Rata, could die (Henry 1928:481ff); but most spirits were potentially immortal.

\section{Spirits}

In some texts the word atua appears to have the general meaning of spirit, as contrasted with ta'ata, or human; but other usages permit a classification of spirits into atua (god) and 'oromātua (ghost), plus an intermediate category, atua-ta'ata (demigod). ${ }^{14}$ I can perceive no absolute distinctions between, say, atua and 'oromātua as a group in terms of power, but some atua are more powerful than any 'oromātua (or atua-ta'ata).

By far the most powerful and versatile of atua was Ta'aroa. In most cosmogonic accounts (but not in all), he was the primal, first individualized entity, the being without parents, the creator of most other categories of entities. He made many other atua out of his own attributes (huru) or out of parts of his shells; he conjured others into being, and then mated with some of these to produce still others. Many other parts of the universe, not themselves atua, were created directly or indirectly by Ta'aroa. He-this atua is usually implied to be male-did not create all things or all orderly relationships among things, but he did begin these processes; and he created the other atua who carried on the acts of creation.

After Ta'aroa, among the myriads of other atua they believed in, the Maohis implicitly or explicitly distinguished several ranks and categories, according to function or effectiveness or relationship with Ta'aroa. 
First and literally highest-they occupied the topmost levels of the heavens $^{15}$-were such atua as Tu, Tane, 'Oro, and Atea, including presumably some of Ta'aroa's own personified attributes. ${ }^{16} \mathrm{Tu}$ stood above the hosts of such gods because he served as hands for Ta'aroa ("O te atua ia i hau a'e i te nu'u atua, no te mea ei rima 'oia no Ta'aroa" [Henry 1928:355]); that is, he was Ta'aroa's chief artisan in the fashioning of many primal entities. Tane also was accorded very high standing among Ta'aroa's creations-even higher than that accorded exalted Tumu (Foundation): "Tumu had little temples [marae]; [Ta'aroa saw to it that] Tane had great ones. Tumu had a few priests; Tane had many priests" (Henry 1928:398). Some writers viewed Tane and Ta'aroa as having been equals, as supreme deities of separate cults, comprising older or more recent immigrant populations, respectively. Even were this the case, however, the evidence at our disposal indicates far-reaching syncretism, with Ta'aroa accorded primal position.

'Oro, whose cult was dominant during the era under study, played a lesser role during the great epoch of creation than did many other atua, and he owes his subsequent exalted position to his identity with the Arioi sect and his close connections with Ra'iatea, the purported source of the highestranking kin-Titles held by humans.

After these deities somewhat weaker in effectiveness and usually more specialized in function, were innumerable atua, such as Hina (goddess of the moon as well as sometime spouse of Ta'aroa), Ro'o (fame, prestige, principal messenger of Tane), Hiro (god of thieves), Tipa (principal god of healing), and $\mathrm{Ti}^{\prime} \mathrm{i}$ (progenitor of mankind and principal god of sorcery).

Still less effective, and even more highly specialized, were the innumerable minor $a t u a^{17}$ that rendered $p \bar{o}$, the spirits' room (piha) of the universe, far more populous than $a o$, the room of mankind. ${ }^{18}$ These included localized spirits holding sway over specific areas of land and sea; tutelars of specific social units-territorial, kin, occupational, and so forth; familiars of individuals; patrons of events and of activities (e.g., childbearing, voyaging, tapa making, archery); and others.

In what shape or character, did the Maohis conceive of their atua? The answer to this intricate question is obscured by the nature of the evidence, which consists mainly of texts and of generalizations by ethnographically naïve or linguistically incompetent observers. With respect to textual evidence the universal problem of translation is complicated, in this case, by the terseness of expression and by the multiple references carried by some of the key words-all of which allow the translator wide latitude for felicitous phrasing, often at the expense of analysis. Consider, for example, the characterization of Ta'aroa given in one of the creation chants (dictated to Orsmond in 1822 and presumably translated by him):

Ta'aroa's natures were myriads; he was Ta'aroa above, Ta'aroa below, 
Ta'aroa in stone. Ta'aroa was a god's house; his backbone was the ridgepole, his ribs were the supporters. These were Ta'aroa's (attributes):

Great-Ta'aroa, the Truth, Turner-of-the-earth, the Great-Ta'aroa who ended sins and evil, the Great-Ta'aroa Foundation, the Great-Ta'aroa of boundless glory, Ta'aroa of sure bidding, Ta'aroa of the clear sky, Ta'aroa who propagated, Ta'aroa who stood over the passage of the reef, Ta'aroa the extirpator, the great Ta'aroa whose curse was death. (Henry 1928:336)

On the basis of attributions such as the above (which are fairly typical of those recorded for other major deities), could one characterize the Maohi concept of this atua as "substantial" or "unsubstantial," as "spiritual" or "material"? With respect to mankind, the words tino and vārua corresponded fairly closely with the English words 'body' and 'soul', used contrastively. After death the vārua usually survived to become an individualized spirit called an 'oromàtua. Moreover, texts occasionally contain references to the acts of "good" or of "bad" vārua, and in some instances atua are described as having vārua of their own, but there is no evidence pointing to a belief that atua were in general like or identical with vārua-stuff.

In any event, all atua possessed (or consisted of) mana (power, might, influence [LMS Dictionary]) in large measure, along with the attribute of ra'a (sacredness):

E mana nui roa to te nu'u atua, E mata ra'a to te atua, E hou'u te ta'ata, e fatiou te mau ra'au, e oríorío, e mahe'ahe'a roa, e mimi'o ino to te fenua e to te moana i te mana o to'na rima, i te aho o to'na paoa ihu.
All the hosts of gods had great power. Their glance was holy. Man crouched, trees bent down, all on land and in the sea withered, grew pale, and shrank under the power of their hands, before the breath of their nostrils.

(Henry 1928:394)

However vague their conceptions may have been regarding the shape or matter of atua in their "natural" state, the Maohis entertained fairly clear-cut notions about how such spirits looked and acted when they were communicating with humans.

First and most directly, some atua seem to have been conceived of as existing "naturally" in some specific and visible form: for example, a shark, a giant eel, a large octopus, a huge rock. Second, some atua occasionally transformed themselves into certain characteristic forms-usually but not always zoomorphic. And third, all or most atua had the ability to possess (uru i roto, 'enter into') some object or animate being, including humans, and communicate with humans through the voices of mediums, or some other characteristic behavior.

In summary, there appear to have been three types of atua manifestations: say, permanent shark-gods, gods occasionally changed into sharks, and gods entered into sharks; this is one possible interpretation. In actuality, the Maohis themselves may have entertained less clear-cut distinctions than those I here propose. Linguistically, for example, they 
have distinguished specifically two kinds of atua manifestations, to'o and ata. In addition, the term nohora'a (the sitting, seat) was also applied generally to places or objects where spirits occasionally stayed. $T o^{\prime} O$ was the generic name for a type of fabricated and more or less anthropomorphic "image" into which an atua's presence (mehoi) was occasionally invoked when it became necessary to communicate with it. In contrast, an ata was a natural object or being. The LMS Dictionary defines ata as "a cloud, a shadow"; according to Henry, however, the term also signified anything animate or inanimate that was regarded as "... an incarnation of a god that had been duly invoked to enter it" (1928:392). But Henry did not indicate who or what does the invoking; and the list of ata given by her includes all three of the types of atua-manifestations distinguished above-that is, atua in their "natural" forms, occasional atua transformations, and atua mediums-as well as ghosts.

In any case, it may be useful to list a few ata (out of the scores recorded in Henry's volume alone) that were regarded as embodiments of atua; such a list will provide more evidence of the extraordinary proliferation of Maohi "polytheism." I will begin with birds, listing first their names, then the atua associated with them, and then the special meaning, if any, attributed to their behavior:

Domestic rooster (moa oni), ata of Ruaitefa'atoa (Source-of-warriors). His voice crying from a valley was an ominous sign to warriors.

Light-yellow thrush ('omama 'o-pua-fau), ata of 'Oroitemarotea ('Oro in his manifestation of Warrior-of-the-yellow-girdle).

Darker-colored thrush ('omana'o-uri), ata of Tamatea (Blond-child), the god of salamanders.

Red-feathered duck (mo'ora-'ura), ata of 'Orovehi'ura ('Oro in his manifestation of Red-feather-covered).

Wild duck (mo'ora-ōviri), ata of "sylvan elves."

Surf duck (toroa), ata of Hau, god of peace.

Vari-colored parakeet (tāvae), ata of Tu, god of stability.

Black parakeet (tētē, named for its cry, "tete"), ata of "artisan elves" of hills, which was its habitat.

Long-tailed, variegated parakeet (tarara, also named for its cry), ata of "artistic" sylvan elves.

Bird of paradise (arevareva), ata of Ta'aroa. When it cried "oti' $i$, oti' $i$," near people's houses, those who heard it would say, "ta rua, ta rua" (repeat, repeat), and if it did not do so, it was a sign that Ta'aroa was angry, and that the sick of the family would surely die. This bird is heard most often in rainy weather, and its cry prolonged thus, "oti' $i$, oti' $i$, $t^{\prime}{ }^{\prime} i, t^{\prime} i, t^{\prime} i, t^{\prime} i{ }^{\prime}$, ," is always indicative of the approach of rain.

Woodpecker (ruro), ata of Ra'a, god of sacredness in his manifestation 
of Being-angry. Its typical behavior was to rob fowls of their feathers for its nest.

Black-feathered swallow ('ope'a), ata of the female atua of the air.

Reef egret ('ótu'u), ata of Ru'anu'u (Source-of-armies). When anyone offended this bird, people's necks got twisted around so that the face looked behind.

Black-and-white speckled rail $(o \bar{a})$, ata of Oāhīvari (Blackness-fishing-inmud), god of quagmire.

Tahitian rail (meho, hiding-in-bush), ata of Tu in his manifestation of moonlit sky. The meho's cry is "ho," which is the characteristic sound made by $\mathrm{Tu}$.

Gray plover ('uriti), a denizen of river banks, ata of water gods.

"Whistling" plover (torea), ata of Temeharo, god of strangulation.

Common albatross (putu, ruru), an ata of Ta'aroa, especially on atolls. This bird was appealed to when canoes became swamped at sea.

Sooty albatross (putu-minamu), ata of Bordering-rock-of-canoes. It lived on dangerous reefs and warned canoes away from them.

White sea swallow (pira'e-te'a) ata of Tane-in-light. It protected people from accidents by, say, breaking their fall from trees. Also served as a messenger of peace.

Booby ('euao), ata of Tu in his manifestation of Smiter-of-the-sea. When this bird sat on a turbulent sea the waters became calm.

(Adapted from Henry 1928:384ff)

Thus every type of bird distinguished by the Maohis was the ata of some one or more atua. Similar kinds of association were attributed to nearly all other animate beings distinguished by the Maohis, and to many inanimate objects as well. In some cases the logic behind the association seems clear: for example, the rail that inhabited a swamp with the atua of that swamp; the booby seen resting on a calm sea surface with the atua who calmed the sea; the great spotted octopus $\left(f e^{\prime} e\right)$ with the atua who once held heaven and earth together; and the red-feathered bird with red-favoring 'Oro. In other cases however the data are insufficient or the logic behind the association is no longer clear-clear, that is, according to any principle of classification for which we now have the key. In some instances, all the individuals of an ata "species" seem to have been considered potential or actual embodiments of its atua, whereas in other instances only certain ones so qualified-for example, not all crabs but only those inhabiting marae (Henry 1928:392).

When an ata was believed to be in the state of actually embodying an atua it was of course accorded the attention and respect normally due the atua, regardless of the treatment ordinarily shown the ata. For example, the domesticated male pig was ordinarily shown anything but respect, but when one of them became possessed by 'Oro in the latter's man-slaying 
role, a characteristic manifestation, people trembled and expected disaster to strike the land (Henry 1928:383). There were, however, certain ata accorded respect even when not so possessed; for example, such was the great spotted octopus, the ata of Tumu, although it may well be that this and similar ata were more or less permanently possessed by their atua or were their "natural" embodiments.

Some ata, like the atua they embodied, were accorded recognition, attention, and respect by people everywhere-for example, the frigate bird ('otaha), ata of warrior 'Oro. Others were sacrosanct, more or less, only to particular aggregates of people having special ties to the atua thus embodied; dragonflies, for example, were ata of Hiro, god of thieves, and when a thief entered a house for robbery he released a dragonfly which dazed the victims; or, in places where the purple cockles served to embody locally affiliated atua, people there avoided eating them for fear of death. ${ }^{19}$ Finally, some animals or objects served regularly to embody an individual's own spirit-familiar, and usually the individual "... did not let another know what he or she had chosen as a medium of communication with a patron spirit, while the object chosen [the ata] became a sacred incumbrance to its worshipper" (Henry 1928:392).

The second major category of spirits consisted of ghosts ('oromātua), ${ }^{20}$ the active souls of deceased humans. (I am unable to discover whether the belief existed that animals, other than humans, ever survived in ghost form.) As we shall see, every human had a soul (vārua), which survived its body's physical death at least for a time. But not all souls survived indefinitely; some were destroyed sooner or later after death. Of those that did survive indefinitely, some continued to exist in other realms and some reentered the realm of the living as ghosts.

In one passage, Henry wrote that souls released from "purgatory" became one of three types of ghosts: "good ghosts" that reentered their own skulls and watched continuously over the welfare of their surviving kin; "rambling ghosts" that took only occasional interest in the affairs of their surviving kin; and fierce "long-toothed ghosts" that were consistently malignant toward humans, kinsmen or otherwise (1928:201-202). In other contexts this same writer reported beliefs to the effect that some souls were transformed after death or entered into certain animals (also called ata); for example, persons drowned at sea, into sharks or dolphins, infants, into periwinkles. It is not clear, however, whether we are dealing here with different species of ghosts or with different kinds of classification-the latter based on form of ghostly embodiment and the former on mode of behavior.

Also, as in the case of atua, the distinction between ghost-becomeanimal (or other object), ghost-transformed (occasionally)-into-animal (or object), and ghost-entered (occasionally)-into-animal (or object), is not al- 
ways clear; but as suggested earlier this kind of distinction may have been irrelevant, or at least unimportant, to the Maohis themselves.

In any case, ghosts were active participants in humans' lives. Generally speaking, they were less powerful and less versatile than gods, although there were certain 'oromàtua more powerful than many of the lesser atua. Also, in general, ghosts tended more than gods to be directly concerned with everyday human affairs-for example, as tutelars of specific families, vengeful hunters of particular locales, or familiars of individual magicians. As family tutelars they often occupied their own skulls, which were kept by relatives after disposing of the rest of the body. As sorcerers' familiars they were induced to occupy small wooden or stone images called $t^{\prime} i$ (fetcher; as distinct from $t o^{\prime} o$, the image-seat of a god).

Finally, I draw attention to the third major category of spirits recognized by the Maohis, the demigods (atua-ta'ata), to distinguish them from sky gods (atua i te ra'i). These popular myth personalities differed from sky atua in having been born mainly of human parents and in having lived their marvelous lives as humans, although they possessed many of the attributes of atua; characteristically, they won their most spectacular successes against sky atua. Some of them entered ultimately the pantheon of still-active atua, while others seem to have been regarded as beings only of the past.

\section{Humans}

With experience gained from the practice of embalming and from dismembering the bodies of sacrificial victims and slain enemies, the Maohis evidently possessed fairly detailed knowledge of human anatomy; but this did not extend to physiology. I have already noted their distinction between body (tino) and soul (vārua): the former invariably disintegrated after "death," the latter usually survived the body and unless specifically extirpated could go on existing forever. Most accounts placed the soul within the body during the waking state-dreams having constituted the experiences of the soul's wandering outside the body during sleep and trance. A contrary view, placing the soul normally outside the body, which it visited only during dreaming, is recorded in only one account (LMS Transactions: II, 126). Outside the body, the soul ordinarily assumed the appearance of its affiliated body, but it is not clear what it looked like or where it resided when within the body. It is recorded that the soul left the body by way of the cranium (Henry 1928:291), and some association with breath is indicated by a belief that the soul left the dying body through the mouth. Taken with the belief that the heir of a dying person could acquire some of the latter's knowledge by inhaling his expiring breath, ${ }^{21}$ this could signify either that knowledge was considered to be an attribute of the soul or that it was an independent entity.

In common with most other Polynesians, the Maohis treated the head 
with much respect, but I am unable to find an explicitly stated rationale for this in Maohi terms. Certainly, the head was not the site of thought (mana'o) or emotions (horuhoru), both of which were located in the stomach $(\bar{o} p \bar{u})$ and intestines (' $\left.{ }^{\prime} ' a u\right)$ or, in a more general sense, in the vitals (manava). ${ }^{22}$

A more puzzling problem is presented by the concept of iho, generally translated as the essence or nature of a thing or person (LMS Dictionary). For example, in connection with exuviae sorcery, the tupu, the tangible part of the victim's body-hair, nail parings, and the like-used by the sorcerer to lead his spirit accomplice to the victim, is said to contain some of the latter's iho. In various other usages iho can be translated as a general term for the reflexive: Teuru iho (Teuru himself); or for proximity: piha iho (beside, next to), iho nei (just now, lately); as well as "prime characteristic": iho ari'i (the dignity and office of an $\operatorname{ari}^{\prime} i$ ); and even "individuality" or "soul": in the myth of Fa'ahoutu recorded by Orsmond (Henry 1928:373) the iho of that deity's deceased infants reentered her womb in order to be reborn. Here, as in many other instances, the available evidence on Maohi beliefs does not permit us to distinguish between concrete reference and poetic metaphor.

The Maohis doubtless had suppositions about reproduction and physiology, but I can discover few explicit formulations about such matters. Verbally, ōra (life, health, to live) was used in opposition to pohe and mate (death, dead, sickness, injury); I suspect that the difference between these states was not merely a question of the presence or absence of the soul, but I am unable to find just what the difference was conceived to be.

Conception was believed to result mainly from sexual intercourse, but there is little information available concerning Maohi theories about the substances or processes involved, except possibly the notion about iho just described. Abortion was so widely practiced that the Maohis must have possessed fairly detailed knowledge of fetal anatomy, but no such information is recorded. Also, inasmuch as some prematurely born infants were considered to have had souls, it may be that the soul was believed to be present in the infant's body before birth; but ideas about the source of the soul and the time of its entry or development are not recorded. Complicating this issue is a puzzling statement from Henry, relating that a newborn infant "... was allowed to cry long and breathe freely so as to receive full life (iho) from its mother ..." before its cord was severed (1928:183). Moreover, in connection with infanticide, which was frequently practiced, if the infant “... survived until it had properly drawn its breath and opened its eyes, its life was spared, as it was then regarded as having its own iho (personality) and as having a claim on this life" (Henry 1928:275).

Whatever the nature and source of the individual's vārua and iho, once 
these entities or attributes are present and the umbilicus severed the individual human is complete, although the cord and placenta, carefully hidden in the family marae, were believed to contain at least some of the individual's "essence" (Henry 1928:184).

Following birth, the infant and its mother were secluded, for reasons which will be discussed later. In any case, the restrictions surrounding a newborn child, and one or both of its parents, could be removed only by successive performances of a certain kind of rite, called àmo'a. In some instances these rites were concluded, and the principals thereby freed of ritual constraints, within a few months or years; in other instances the final freeing was deliberately postponed for many years.

Explicit Maohi formulations about the physical process of nurturance and maturation are nowhere recorded in the primary sources. Both sexes were tattooed, and boys were supercised at a time Westerners might associate with puberty, but I have failed to find any specifically Maohi explanations for this concurrence. In fact, I can discover little evidence of native statements regarding the course of life, except that in time people, like plants, simply fade and wither (óriorio), unless spirits intervene.

Death (pohe, mate) was the condition characterized by the permanent departure of the soul and the rotting away of the softer parts of the body. Once the decay began it was believed that the process could never be reversed, although it was temporarily arrested in exceptional circumstances when the soul was allowed by spirits to return to the body. As long as there was any body remaining, however, there continued to be a link between it and the soul-for example, the skull became a "natural" medium for the soul when it returned to its earthly haunts; and, if an enemy obtained any portion of the bodily remains, he could use it to secure control over the departed soul, just as the sorcerer used exuviae to destroy a living victim. For these, reasons, together, possibly, with fear of "contamination," it was necessary to bury or hide the bodily remains out of the reach of malicious persons, and this included clothing and other things which were in close contact with the deceased. Some corpses were embalmed and thus preserved for a few months, but this I infer was done out of respect for the soul hovering nearby and not with any hope of preserving the vitality of the decaying body.

Spirits were capable of injuring or destroying humans either by damaging their bodies or by capturing or destroying their souls. A soul could be captured while it wandered outside the body during sleep; or it could be kidnapped from the body. To harm the body a spirit could enter it and damage its vitals by eating or piercing them; or a spirit could cause an accident or help guide an enemy's weapons.

Beliefs about the fate of a human's soul were exceedingly varied, but most of them revolved around a central set of themes in which the soul 
journeyed to one of two kinds of afterworlds - a paradise or a limbo (via a purgatory). After a period in either of these places most souls became free to return on occasion to their mortal haunts, many of them to exercise influence, as ghosts ('oromätua), over human lives, especially over the lives of their surviving kinfolk.

Before leaving the topic of Maohi conceptions regarding the nature of mankind, I must underline once again the matter of the central importance of social cosmography, namely, the several points of similarity of identity between humans and spirits. While in the foregoing I have emphasized differences between the two species of beings, one should not lose sight of their many resemblances, not only in behavior but in their beginnings and endings as well. For example, in some myths the pedigrees of Maohi mankind as a whole, or of particular genetic lines, lead back uninterrupted to spirits. And many or most human souls become spirits after "death." Moreover, the various kinds of social units into which the Maohis conceptually divided their society were composed of humans and spirits.

\section{Social Groups}

I noted in my preliminary remarks on Maohi settlement patterns the existence of households and neighborhoods, which constituted the most visible palpable kinds of enduring social groupings in the Islands. It can be said that the Maohis themselves accorded conceptual reality to households and neighborhood groupings-less perhaps to the former than to the latter-in terms not only of their living human members but of their spirit tutelars as well. In addition, the Maohis viewed themselves as belonging to several other kinds of social units-descent lines, kin-congregations, marriage classes, guilds, tribes, and less secular cults and sects.

There is evidence that the Maohis conceived of themselves, the indigenes of this archipelago, as constituting a distinctive segment of humanity. It is an open question how far beyond their own Islands they believed humanity to have extended, but certainly beyond the Western Tuamotus. The Maohis, who had fairly frequent contact with the inhabitants of the Western Tuamotus, considered themselves, as a people, distinctively superior to the latter in many ways. For example, in writing about some Tuamotuan castaways on Tahiti, Rodriguez noted: "They appear a somewhat timorous people, for they showed a lack of spirit even in their dances, and are not so animated as our natives, who therefore made fun of them and were for mimicking their slowness" (Corney 1919:134).

\section{RELATIONS BETWEEN SPIRITS AND HumanS}

In the very vague sense in which the terms were used, it may be said that humans and spirits normally existed in different spheres, or "rooms" 
(piha), of the universe-the former in the $p \bar{o}$, the latter in the ao. Interaction between spirits and humans was however fairly frequent, and, in the suppositions of the Maohis both spirits and humans were members of the same society. One basic assumption underlying this interaction was that spirits and humans were impelled by the same appetites and guided by the same motives. Complicating this, however, was another equally basic assumption that spirits were more versatile, more mobile, and in general more powerful than humans and that they were (or possessed) more $r a^{\prime} a$.

\section{Sacredness and Similar Concepts}

The differences between spirits and humans were perhaps best epitomized, conceptually, in the words $r a^{\prime} a, m o^{\prime} a$, noa, and tapu. To anyone versed in Polynesian ethnography these words or their near cognates will be familiar, and perhaps in connection with some Polynesian societies perfectly intelligible. ${ }^{23}$ Unfortunately, their precise meanings in the language used by the Maohis cannot be reconstructed from the texts and translations now available. Having already noted the hazards involved in attempting to illuminate Maohi obscurities with data from, say, New Zealand or Hawaii or Rarotonga, I shall have to do what I can with these terms on the basis of the available local data and leave to others the pleasures of grander interpretations.

$M o^{\prime} a$ and $r a^{\prime} a$ are used almost interchangeably in the sources in ways that imply both holy and sacred, although a small case might be made for $m o^{\prime} a$ being somewhat closer to holy in certain contexts. ${ }^{24}$ In any case, in view of the well-nigh impossibility of separating and assigning meanings to $r a^{\prime} a$ and $m o^{\prime} a$ with any sharp degree of accuracy, throughout this book they will both be translated as sacred.

In this broad sense all spirits were sacred, as was everything in more or less direct association with spirits: the precincts and paraphernalia of marae ${ }^{25}$ all persons engaging in prayer and sacrifice, the cast-off trappings of to'o, the persons and names of holders of high-ranking kin-Titles (in view, probably, of their being in a more direct line of descent from the gods), and so forth. Spirits varied as widely in their degrees of sacredness as they did in their power, and so, respectively, did the things associated with spirits. For example, the god 'Oro (and his marae, rituals, images, etc.) was incomparably more sacred than any commoner's household tutelar spirit; the head of a kin-Titleholder's firstborn son was more sacred than that of a second-born. It may even be that the bodies of the incumbents of some high-ranking kinTitles were more sacred than some lesser gods and ghosts, but in general spirits were more sacred than humans.

Due to unspecified mechanisms, it was generally dangerous for a human to be too near an entity having more sacredness (or being more sacred) than himself. It is not clear just how such effects were believed to 
have been brought about, but it would be reasonable to assume some kind of direct spirit intervention. The belief, said to prevail in some Polynesian societies, that the sacred entities were imbued with a kind of pervasive supernatural "electricity" that in itself damaged less heavily "charged" individuals is an intriguing one to search for, ${ }^{26}$ but I have found no reliable evidence for it in the sources on the Maohis.

By reason of the fact that entities were sacred and dangerous, they were also tapu, that is, restricted, dedicated to use in sacred ritual, set aside from normal uses. These glosses of tapu closely parallel meanings of the term in other Polynesian societies, but the Maohis used tapu in some other senses as well. ${ }^{27}$ Moreover, they used another word, rahui, to denote the restrictions, usually spirit sanctioned, periodically laid on hogs, fruit, fish, and so forth, for conservation and other purposes. Because of the specific nature of these meanings, my practice throughout this book will be to use tapu and rahui, instead of attempting to translate them.

Entities lacking sacredness were noa-that is common, profane, or, as the term will be translated hereafter, secular. For example, women were secular to the extent that they were not allowed to enter enclosures of most marae. An exception was sometimes made in the case of women holding kinTitles of very high rank. Also, during marriage ceremonies at family marae women were present but kept from direct contact with the marae's courtyard by means of mats spread upon the ground. Most men were also in a condition of secularity most of the time, but could with appropriate ritual preparation enter sacred precincts and engage in sacred activities, at the conclusion of which it was sometimes necessary for them to divest themselves of sacredness before resuming normal occupations.

Some aspects of the distinction made by the Maohis between sacred and secular are indicated in a text describing the concluding episode of a major marae rite, wherein the presiding priest addressed the attending spirits in these words:

Dismissal! Grand dismissal to make ordinary [noa]!

Let sacredness [tapu] remain here [in the temple], that we become ordinary [noa].

Let holiness $\left[\mathrm{ra}^{\prime} \mathrm{a}\right]$ be thine, O god, let the priesthood hold the sanctification [mo'a] of the sovereign and congregation. We are now retiring to use our hands and become vile [ha'aha'a]: we shall do domestic work, wear flowers, paint ourselves yellow with mati, blow fire, curse, give each other blows, practise black art [sorcery], caress [make love], put on unconsecrated clothes [ahu noa], eat pork, cavalla fish, shark, bananas; and drink ava; look not upon us in anger for this, O god!

Remain thou here, in this holy place [vahi mo'a], turn thy face to Pô, look not upon the deeds of men. (Henry, 1928:172)

As noted above, it is clear from many conventions that sacredness was dangerous to persons in a state of secularity; food prepared in a marae was 
unsafe for women, and a person engaged in sacred activities had to be fed by another lest the sacredness adhering to his hands render the food too sacred for his stomach. Conversely, secularity seems in some situations to have impaired sacredness; for example, if a woman touched a corpse destined for sacrifice to a god, the corpse was thereby rendered unsuitable for sacrifice.

Further examples of the conceptual antithesis, sacred $\left(\mathrm{ra}^{\prime} \mathrm{a} / \mathrm{mo}^{\prime} \mathrm{a} /\right.$ tapu)-secular (noa), will be given throughout this book, but now let us turn to some other words used by the Maohis in their references to spirit-human interaction. First, the word mana the LMS Dictionary translates quite straightforwardly as power, might, influence; powerful, mighty, affluent; to be in power, possess influence; but some other writers expand it into a major cosmological concept. Words approximating mana, which appear in many Oceanic languages, have proved to be among the most troublesome to translate. As Raymond Firth noted in his study of the word's meaning on Tikopia, some writers have lifted it out of its ethnographic context and transformed it into a "... technical term describing a specialized abstraction of the theoretical anthropologist," with little or no reference to its various native meanings (1940:487). Still other writers have extended its purported meaning in one native language to its occurrences in other languages, on the unproven assumption that it had much the same meaning elsewhere. Firth's compilation of the various generic translations indicates the range (1940:484):

The following selection from the various meanings (not all exclusive) that have been attributed to mana shows the confusion; it also illustrates the theoretical preconceptions of the various authors. Mana has been translated as:

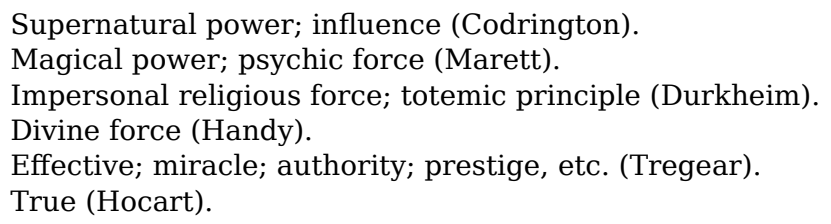

I would not be so seriously concerned with this matter were it not for the practice of some writers on the Maohis to impute to their usages of mana meanings derived from other languages or from philosophical invention, even to the extent of employing such meanings as an explanatory principle for larger realms of belief and practice.

In actual practice, the word mana occurs infrequently in utterances attributable to the Maohis themselves. One of the few textual occurrences of the word that I can find is a precept which adjures the populace to treat their tribal council (hiva) with respect-its members being e pupu mana, that is, a group having legitimate authority, positive power, and so on (E. Salmon 1937:29). Somewhat similar in meaning (to me, at least) is the gen- 
eral reference to rulers as feia (people) mana. Both these applictions of mana to persons could imply political power or supernatural power or both. When used with reference to objects, however, the supernatural aspect of the word is more evident; for example, in a traditional account of an expedition from Ra'iatea to Tahiti, the canoe is described as having been "well laced and ornamented with sacred sennit [coconut fiber cordage], so that it was said to be possessed with great power or magnetism (mana)" (Henry 1928:129). Again, in a chant aimed at consecrating an adze prior to its fashioning a canoe hull, the canoe builders' tutelar spirits were asked to make the adze light in weight, to consecrate (taputapu) it, to impel (tuitui) it, to complete (fa'aoti) it, and to give power (mana) to it (Henry 1928:147).

I shall later say more about mana, particularly in connection with occupational skill, but I must confess here and now that my data are not sufficient to permit me to carry out the kind of analysis that Firth did on Tikopia, which alone can lead to credible translations of this intriguing set of cognates.

Still other Maohi words concerning interaction between spirits and humans are repo and hara. Tentatively they may be glossed as dirt/defilement, and error, respectively; but, as later passages will indicate, I have found it impossible to reach any credible precision in my translations of these words.

\section{Omens, Auguries, and Dreams}

Spirits communicated with humans in various ways: by their recognized effects upon events in general, through omens, through the winds rustling the leaves of certain trees, through the actions of their ata, through divinatory signs, through dreams, and through human mediums. Consideration of these various ways should throw light not only upon how spirits "spoke" to humans but also upon the question of how spirits required humans to behave.

First, spirits communicated with humans through means of their recognized effects upon events in general. Bodily injury or illness was almost invariably interpreted as a sign that spirits were displeased with the victims; and similarly with crop failures, storm damage, defeat in warfare, and so forth. In fact, nearly all of life's failures-and conversely, its successes-were influenced by spirits and signified either their disapproval or approval of human actions or omissions.

Some omens explicitly constituted messages from spirits to humans. As Henry (1928) showed, for example: "A comet was supposed to be a god forerunning war or sickness" (p. 227); "Heavy rain [during a certain ceremony] was supposed to show displeasure of that god [Ra'a], and no rain was considered ominous of some approaching evil, which in either case, the priests endeavored to ward off by prayer" (p. 160). Henry 
recorded numerous other "omens" which related to interactions of men, although one may assume that the "messages" in question were transmitted by spirits, for example: "If a man was caught in a whirlwind, it showed that the king had sealed his fate for [sacrifice]" (p. 227); and "A cold hand or nose was an omen of approaching war" (p. 227).

Trees especially favored by spirits for communicating with humans were the tamanu (Calophyllum inophyllum), miro (Thespesia populnea), and 'aito (Casuarina equisetifolia). These trees grew in many settings and were used for a number of ordinary, secular purposes; but those mainly regarded as spirit-mediums were the ones growing within marae precincts. When the leaves of the latter were heard to rustle, it was taken as a sign that one or more spirits were present, but it is not clear from the evidence available whether such rustling was interpreted as assent or dissent to questions asked the spirits, or as auspicious or unfavorable omens for events to come.

Spirits embodied in their ata communicated with humans by sounds or other movements characteristic of the creature or object in its natural form. Presumably any human was capable of hearing or seeing these messages, although special knowledge was required to interpret their meanings.

Interpreting the messages of spirits through what might be called experimental divination also required specialized knowledge. Animals were killed for this purpose and messages were interpreted from their manner of dying or from their appearance immediately after death. In the case of a pig, for example, the Maohi considered it an ill-omen if its backbone were found to be defective or if its ears stood up straight (de Bovis 1909:55). Divining by means of an animal's entrails was more complicated:

By this time, the pig, that had been killed, was cleaned, and the entrails taken out. These happened to have a considerable share of those convulsive motions, which often appear, in different parts, after an animal is killed; and this was considered by the spectators as a very favourable omen to the expedition, on account of which the sacrifices had been offered. After being exposed for some time, that those who chose, might examine their appearances, the entrails were carried to the priests, and laid down before them. While one of their number prayed, another inspected the entrails more narrowly, and kept turning them gently with a stick. When they had been sufficiently examined, they were thrown into the fire and left to consume. (Cook 1784:38)

De Bovis asserted that animals used for divining were afterwards thrown away outside the marae as rubbish, but this is unlikely on grounds of their sacredness, and is moreover denied in reports by other writers.

Human offerings also served for divinatory purposes, but nothing is reported concerning the signs interpreted.

Another method of experimental divination reported in the sources concerned coconuts:

They had also a singular method of cutting a cocoa-nut, and, by minutely examin- 
ing its parts, of ascertaining their portentous indications. These ceremonies were generally practised in the temple.

There were others, however, performed elsewhere, as the patu, which consisted in dividing a ripe cocoa-nut into two equal parts, taking the half opposite to that to which the stalk was attached, and proceeding with it in a canoe to some distance from the shore; here the priest offered his prayers; and then placing the cocoa-nut in the sea, continuing his prayers, and narrowly watching its descent, he thereby pretended to ascertain the result of any measures in which those by whom he was employed were interested. The patu was frequently resorted to while negociations for peace were carried on between parties who had been engaged in war. Divination was employed to discover the cause or author of sickness, or to ascertain the fate of a fleet or a canoe that might have commenced a distant or hazardous voyage. (Ellis 1829:II, 239-240) ${ }^{28}$

Spirits communicated with humans in dreams by revealing their wishes or information to a sleeper's conscious soul while the soul was either stationary, in the sleeper's body, or wandering around outside it. At times the revelation was deliberately sought after by the human, at other times it came about unsolicited and unexpectedly. Any individual was capable of receiving such dream-revelations, but there were a few for whom serving one or several spirits was a regular profession:

... they have an equal confidence in dreams, which they suppose to be communications either from their God, or from the spirits of their departed friends, enabling those favoured with them to foretell future events; but this kind of knowledge is confined to particular people.... Amongst them, however, the dreamers possess a reputation little inferior to that of their inspired priests and priestesses.... (Cook 1784:166)

There were several different ways by which the gods communicated their answers [to humans' questions] or their wishes, but the most common way was in the form of dreams experienced [by humans] while asleep in marae. (Moerenhout 1837:I, 513)

\section{Images and Talismans}

The "images" through which spirits interacted with humans were of two fairly distinct types. Ti'i (fetcher) was the usual label for those in which spirits sojourned more or less continuously to perform services for their human patrons, whereas $t^{\prime} o$ were those into which spirits were occasionally invoked for purposes of more general worship; insofar as the former spirits were mainly ghosts and the latter mainly gods this distinction also applies to $t i^{\prime} i$ and $t o^{\prime} o$ respectively, although there were exceptions. ${ }^{29}$

$\mathrm{Ti}^{\prime} i$ spirits served mainly as agents for sorcerers or diviners, or as protectors of their human associates. An individual desiring the services of a $t^{\prime} i$ spirit first carved, or commissioned the carving of, an anthropomorphic image in wood or stone, and then by verbal petition and tangible offering, persuaded a spirit to enter it (figs 3-1 through 3-3). In some cases the receptacle used for this purpose was the skull of the spirit (ghost) thus invoked. The relationship established consisted of an exchange of goods: the spirit carried 

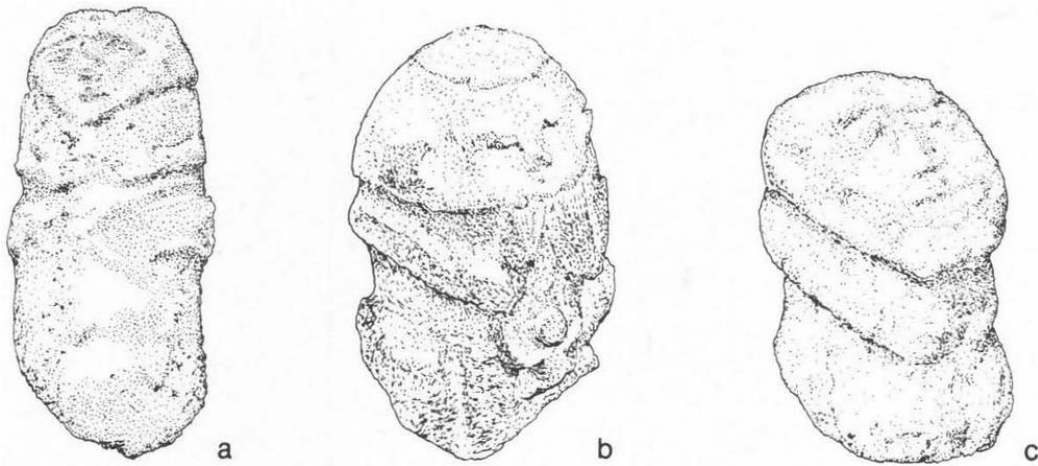

FIGURE 3-1. Stone figures: $a$, height $51 \mathrm{~cm}$. Peabody Museum, Salem; $b$, height $53 \mathrm{~cm}$. Drawn from illustration in Danielsson 1957; $c$, height $34 \mathrm{~cm}$. Peabody Museum, Salem.
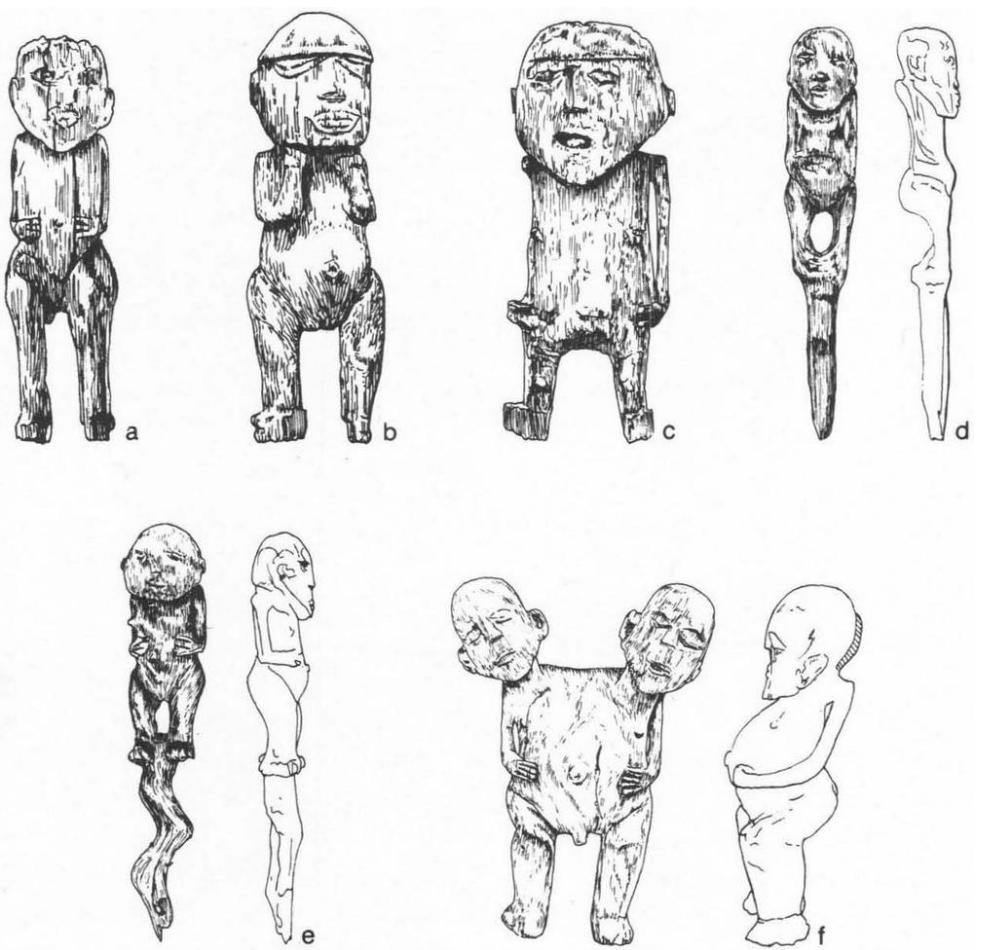

FIGURE 3-2. Wood figures: $a$, height $49 \mathrm{~cm}$. Museum für Natur- und Völkerkunde, Basel; $b$, height $10.2 \mathrm{~cm}$. British Museum; $c$, height $40 \mathrm{~cm}$. Hunterian Museum, University of Glasgow; $d$, front and side views, total length $18.5 \mathrm{~cm}$. British Museum; $e$, front and side views, total length $15.8 \mathrm{~cm}$. British Museum; $f$, two-headed figure, front and side views, height $58.5 \mathrm{~cm}$. British Museum. 

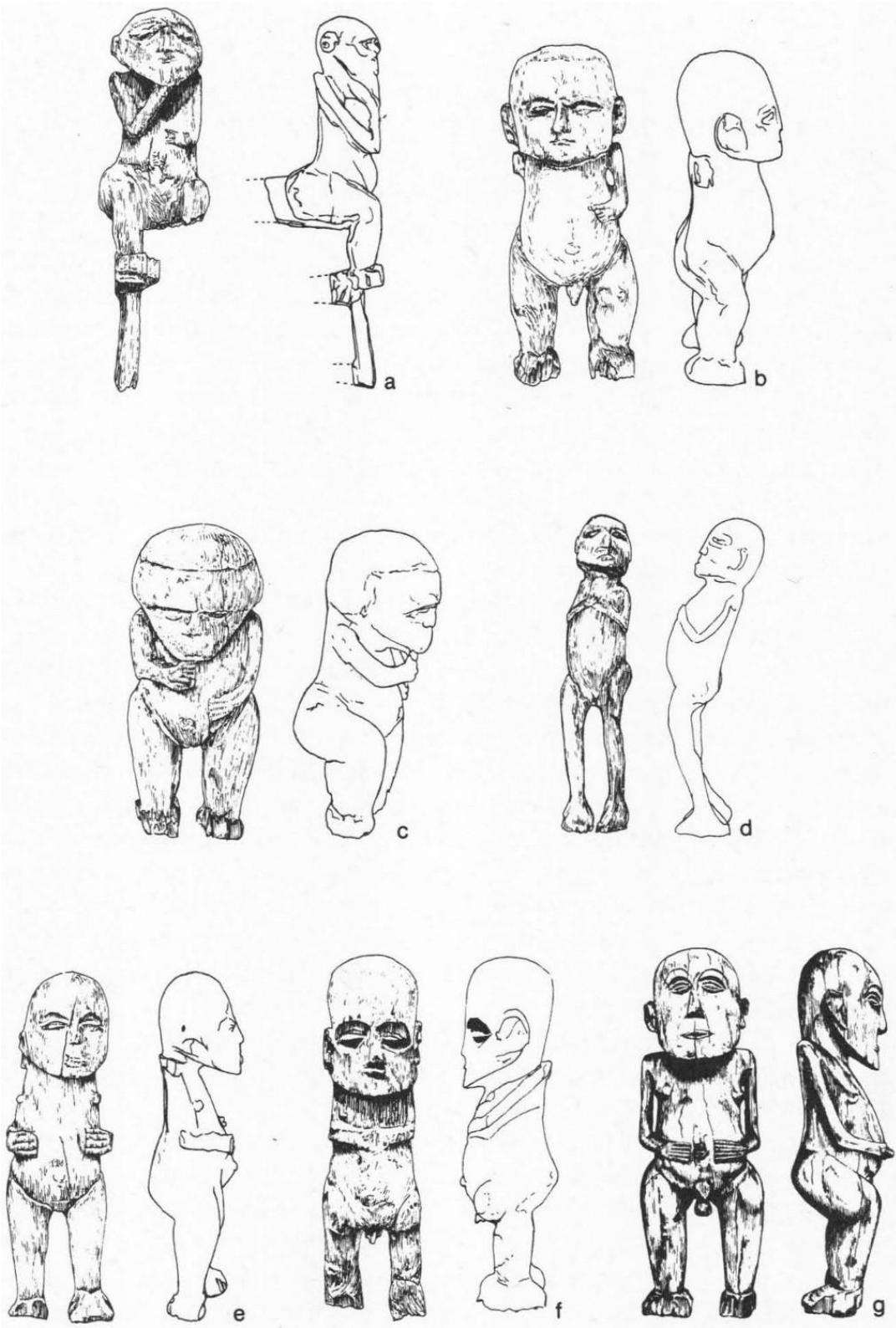

FIGURE 3-3. Wood figures (front and side views): $a$, total length $203 \mathrm{~mm}$. National Museum of Ireland; $b$, height $34 \mathrm{~cm}$. Pitt-Rivers Museum, Oxford; $c$, height $32 \mathrm{~cm}$. PittRivers Museum, Oxford; $d$, height $180 \mathrm{~mm}$. British Museum; $e$, height $48 \mathrm{~cm}$. British Museum; $f$, height $46.5 \mathrm{~cm}$. British Museum; $g$, height $57 \mathrm{~cm}$. Bishop Museum. 
out instructions from the human in return for tangible offerings, respectful handling, and periodic refurbishing, and remained in service as long as these were forthcoming. Moreover, not only could humans institute and maintain this kind of relationship with a spirit but they could also terminate the relationship on their own initiative by disposing of the image (or skull).

Sorcery was the principal kind of service performed by ti'i spirits, and the most common techniques used by them in such undertakings was to capture the intended victim's soul or to enter his body and destroy his vitals. Some forms of blame-fixing divination were also carried out by means of ti'i spirits, who were commissioned to capture and reveal to the diviner the identity of the culprit. In addition, many $t i{ }^{\prime} i$ spirits had "standing orders" to protect their human associates' property and persons, usually by harming any malefactor. Noteworthy in this regard were the $t^{\prime} i$ spirits sojourning in single or multiple images set up along territorial boundaries or near the residences of eminent persons.

$T^{\prime} o^{30}$ were in general larger than $t i^{\prime} i$. They were made of wood or stone or wickerwork, and, although most of them appear to have been anthropomorphic or zoomorphic, a few-including some of those harboring principal gods-were mere cylinders of wood or wickerwork. Henry implied a terminological distinction between wooden statues, $t o^{\prime} o$, and those made of wickerwork, huamanu (1928:153); but the LMS Dictionary translated huamanu as "a bunch of red feathers taken to an artificer when a canoe was to be built." In this connection, Cook described a figure seen by him which may have been a god-image but seems also to have been used as a representation in connection with more secular dramatic performances: "From hence we proceeded farther and met with a very extraordinary curiosity call'd Mahuwe and said by the Natives to be used in their Heiva's or publick entertainments, probably as punch is in a Puppet Show. It was the figure of a man...." (Beaglehole 1955:111-112.) Banks, in describing this same figure, wrote that "... it was the only one of the kind in Otahite" (Beaglehole 1962:I, 302).

A prominent, even indispensable, part of the equipment of a to'o consisted of red and yellow feathers. The feathers were either attached to the exterior of the $t^{\prime} o$ or kept in recesses inside. According to Moerenhout the reason to'o were less realistically anthropomorphic-in fact, in some instances, not even intended to be anthropomorphic-is that it was the feathers attached to such $t^{\prime} o$ and not the to'o themselves that served as "the true emblems of divinity" (1837:I, 471). In April 1792 Bligh witnessed a sacrifice dedicated to the god 'Oro and utilizing an "image" of that god: "The Red Bundle [embodying] their Etuah [atua] (which they called Oro) was nothing more than a number of Yellow and Red feathers, and four rolls about 18 Inches long platted over with Cocoa Nutt fibres, to which they gave the Name of some inferior Deities" (1792:138). One meaning that may be 
inferred from this somewhat obscure passage is that the "Oro "image" in question consisted entirely of feathers. Feathers were also attached to $t i^{\prime} i$ images, or used independently of images. In fact, so important were feathers in spirit-human interaction that they require additional comment.

The red head-feathers of the green parakeet (Cyanoramphus zealandicus) (Beaglehole 1961:411) and, to a slightly less degree, certain yellow feathers were the most highly treasured objects in use among the ancient Maohis. Some indication of the demand for them is contained in the journals of early European visitors:

When we were at Amsterdam [Tongatapu Island, Tonga], among other Curiosities we Collected some red Parrot Feathers which were highly Valued by these people; When this came to be known in the isle [of Tahiti] all the Principal people of both Sex endeavour'd by every means in their power to Ingratiate themselves into our favour in order to obtain these Valuable Jewels by bring(ing) us Hogs and every other thing the Island produced, and generally for Tiyo (Friendship) but they always took care to let us know that Oora (red Feathers) were to be a part of the return we were to make. (Beaglehole 1961:382-383)

So very solicitous \& zealously desirous are our good friends here for the attaining of these red Feathers and so thoroughly convinc'd of their efficacy with their Sovereign Deities that they will very chearfully oblige us in good natur'd but rather unhallow'd rites for the possession of them to render back religious Ceremonies by way of Propitiation to their Jolly Gods. (Clerke, in Beaglehole 1961:383n) ${ }^{31}$

Feathers were used in a variety of ways, which will in due course be listed, but underlying all these uses was the belief that feathers were highly valued by the spirits themselves. Why they were so highly regarded is not entirely clear, but it is at least suggestive that Ta'aroa himself was originally covered with feathers, which he used for clothing the newly made earth in trees, shrubs, and creepers (Henry 1928:339). Indeed, it might almost seem that feathers independently, inherently partook of some of the attribute of sacredness; but Moerenhout asserted that they first had to be consecrated by gods in marae rites (1837:I, 472-473).

Once consecrated, feathers were an almost invariable item in the equipment needed for prayer. In one respect it appears that they were considered the principal means for attracting the attention of spirits to the business at hand. This was accomplished by holding up the feathers in full view. In another respect they served to transmit, by contact, some of the spirits' sacredness to entities requiring consecration. Either a single feather was used for these purposes, or a bunch of them bound together by sennit, or clusters tied to sticks of wood (Bligh 1792:173). When not in use, such feathers were ordinarily kept in bamboo containers. Moerenhout and Cook wrote as follows concerning some of their uses:

These feathers they make up in little bunches consisting of eight or ten and fix them to the end of a small cord about three or four Inches long, which is made of the strong out side fibers of the Cocoanut, twisted so hard that it is like a piece 
of twisted wire and serves as a handle to the bunch. Thus prepared they are used as Symbols of the Eatua's [atua] or Divinities in all their religious ceremonies. I have very often seen them hold one of these bunches and some times only two or three feathers between the fore finger and thumb and say a prayer, not one word of which I could ever understand. (Beaglehole 1961:411)

... threatened by danger of some kind they hasten to seek them, believing that their presence would suffice as a guarantee of the aid; and at sea, when a storm is approaching, they hold them toward the horizon from which the storm is coming, and order it to retire, either in the name of these emblems, or in the name of the divinities which they represent. (Moerenhout 1837:I, 474, as translated by E.S.C. Handy 1927:126)

The greatest concentration of sacred feathers was in the form of feather girdles (maro), consisting of long belts of thread-strengthened tapa to which were attached hundreds of feathers. The largest girdle reported in the sources was twenty-one feet long and six inches wide, and probably contained thousands of rare feathers (Henry 1928:189). Such girdles were owned by chiefly dynasties and were emblematic of the society's highest-ranking kin-Titles, whose incumbents were thus nearly godlike in sacredness.

It must be left to imagination to reconstruct how the hundreds of $t^{\prime} o$ came to be created, for evidence in this matter is slim. Presumably the fabrication and consecration of socially important $t o^{\prime} o$ for the major gods were commissioned by individuals holding high-ranking kin-Titles who were desirous of gaining additional spirit reinforcements. In other cases the to' $o$ of a minor spirit (and of a politically unimportant social unit) would have waxed in ritual importance along with the political fortunes of its congregation, and thereby required a more imposing shell and outer trappings. A third type of development, reported by Ellis (1829:II, 205-206), was that followed by some owners of sacred feathers who, if the spirit (or spirits) invoked by their feathers were consistent in responding favorably to their prayers, honored the spirit by providing a $t^{\prime} o$ to encase the feathers-and perhaps even a small god house for the $t^{\prime} o$ as well.

Ellis also provided a revealing account of his conversations with a to' $O$ carver (tahu'a tarai to'o):

I had repeated conversations with a tahua-tarai-too, a maker of gods, whom I met with on a visit to Raiatea. As he appeared a serious inquirer after truth, and I could place some confidence in what he related. I was anxious to know his own opinion as to the idols it had been his business to make,--whether he really believed they were the powerful beings which the natives supposed; and if so, what constituted their great power over the other parts of the tree from which they were hewn? He assured me, that although at times he thought it was all deception, and only practised his trade to obtain the property he received for his work; yet at other times he really thought the gods he himself had made, were powerful beings. It was not, he said, from the alteration his tools had effected in the appearance of the wood, or the carving with which they were ornamented, but because they had been taken to the temple, and were filled with the atua, that they became so powerful. (1829:II, 204) 
Some to'o were kept in dwellings but most of them (in contrast to $t^{\prime} i$ ) were deposited in marae, where they were stored in shelters (fare ia manaha 'house of sacred treasures') ${ }^{32}$ along with other sacred paraphernalia, such as drums and conches. Marae attendants occasionally slept in these shelters. Important to' $o$ were kept within these shelters in small god houses (fare atua) of their own:

Ta'aroa made the first fare-atua (god's house or ark) out of his own body, which he easily replaced with another body for himself. This fare-atua was supposed to have been the model for the house of a god for all time. It was a neat little ark made of sacred polished wood, with arched roof covered with fara [pandanus] thatch, square at each end and having a level floor. Its dimensions were about four feet long, two and a half feet wide, and three feet high, varying in size according to the form of the god that was placed in it. One end was closed. The other end had a circular entrance for the god, with a close-fitting stopper of sacred cloth. To this ark were attached cords of sacred sennit, which were passed under it to either side, forming a loop at each corner, through which polished poles of miro wood were passed that extended far enough for two men at each end to bear upon their shoulders. The ark containing the god rested between. In the same manner, the Israelites carried their Ark of the Covenant. This little house was placed in a recess in the fare-ia-manaha upon a stand about four feet high, supported with four curved and nicely carved, polished legs, forming two arches. (Henry 1928:136)

Henry went on to say that each god house was named after some attribute of its to'o's god: for example, the Bed of the Lord Ta'aroa, the Bed of Tane in Bird's Down (1928:136).

On occasions when the $t^{\prime} o$ of a major god was transported away from its home marae, to participate in a grand ceremony or to reinforce its devotees in battle, it was placed in its god house on its own specially built and consecrated canoe, va'a-roa-i-te-mata'i (long-canoe-in-the-wind). Such canoes usually had elevated prows and sterns decorated with high-relief $t i$ ' $i$ figures (receptacles, probably, for guard-of-honor spirits) and were otherwise embellished and supernaturally strengthened with feathers and pennants.

There were several methods used for inducing a god to enter its $t o^{\prime} o$. One was to summon it verbally, usually by means of a series of loud cries: ho! ho! ho! ho! Since spirits often traveled on winds, another method was to fan the air vigorously. But for more formal occasions involving major gods the usual practice was to send spirit messengers to invite them. For every major god there was one or more of such messengers (ärere), and the important marae usually contained a number of statues, to' $O$ or $t i^{\prime} i$, where such messengers sojourned. In addition, the inducement to any such summons was occasionally enhanced by offerings of pigs, dogs, fish, or best of all a human; the ghost of the sacrificed creature was thereby commissioned to invite the gods to enter their $t^{\prime} o$ and partake of the feast provided by the creature's own body.

According to Moerenhout, on occasions like the ones just described, 
the most usual forms in which gods voiced their responses to humans' queries were by the cries of the birds and by the wind's rustling of leaves (1837:I, 513-514).

In the case of the major gods, when their immediate collaboration was no longer required it was necessary to dismiss them, in order to free (fa'anoa 'render secular') a place and its people from the dangers and restrictions resulting from such close proximity with the gods' sacredness $\left(\mathrm{ra}^{\prime} \mathrm{a}\right)$.

In order to maintain $t o^{\prime} o$ (and possibly some $t i^{\prime} i$ as well) as suitable habitations for their spirit sojourners it was essential that they be reconsecrated periodically in special ceremonies, called paiatua, which will be described below.

Finally, as in the case of $t i^{\prime} i$, it was possible to dissociate oneself from an unsatisfactory god, by discarding its $t^{\prime} O$ :

When members of a family were stricken with long, protracted illness and with death and the prayers for their recovery to the gods (or goddesses) of their ancestral marae proved ineffectual, the family would hold counsel together and say, "This god is no longer helping us; he is a man-devouring god. Let us cast him off and seek the favor of another deity!"

Then the officiating family priest or head of the family, as the case might have been, according to the rank of the family, would go to the marae to cast off the god (pô'ara'a tu i te atua), saying:

Tera te po‘a, te po'a tu nei au ia 'oe! Eiaha 'oe e uru fa'ahou mai i roto iau nei; eiaha vau ei nohora'a fa'ahou no 'oe; eiaha vau e 'ite fa'ahou ia 'oe; eiaha 'oe e 'ite fa'ahou mai iau. E haere 'oe e 'imi e atu i te tahi taura no 'oe, i te tahi utu'afare e atu. Eiaha vau eiaha roa! Ua poihu vau ia 'oe-ua ri'ari'a a'era vau ia 'oe! Te va atu nei au ia 'oe. E haere roa 'oe i te Vai-tu-pô, i te aro o Ta'aroa, to 'oe na metua, Ta'aroa te metua o te mau atua 'atoa. Eiha 'oe e ho'i fa'ahou mai iau nei. Inaha te huia, te pohepohe nei i te ma'i; te rave hia nei e 'oe, e atua ri'ari'a roa 'oe e te 'ai ta'ata!
There is casting off, I am casting thee off! Do not come in to possess me again; let me not be a seat for thee again! let me not know thee again; do thou not know me again. Go and seek some other medium for thyself in another home. Let it not be me, not at all! I am wearied of thee-I am terrified with thee! I am expelling thee. Go even to the Vai-tu-po (River-in-darkness), into the presence of Ta'aroa, thy father, Ta'aroa, the father of all gods. Return not again to me. Behold the family, they are stricken with sickness; thou art taking them, thou art a terrible man-devouring god!

After this proceeding, another god was chosen to take his place, and so on, until the evil in the family ceased. A new image to represent the new god was made and inaugurated at the first pa'i-atua that followed the event. If the priest or family imagined themselves haunted by the discarded god, in dreams or otherwise, the image was removed from its grave to a new one and if necessary moved again and again until the minds of those interested were set at rest. (Henry 1928:178)

\section{Human Oracles}

The inspiration of prophets is the main pillar of religion; if this were overthrown the whole system would fall. (Davies, Journal, 10 December 1808, LMS Archives).

Perhaps the most direct procedure used by spirits to communicate with 
humans was that of possession (uruhia), that is, actually entering into a human's body and speaking with his voice. Such spirit-possession varied greatly in duration and in degree of involvement. At one extreme was the momentary visitation manifested by the involuntary shout of some individual at, say, a wake or a marae ritual. At the other extreme was the example provided by a few individuals who were so frequently and exclusively possessed by some spirit or another as to be identified continuously with the spirit itself; such a one was Etari, whom Cook described as follows:

After the Ship was Moored Omai and I went a Shore to pay a visit to a man which he said was the God of Bolabola [Porapora]: we found him seated under one of those small Awnings they carry in their traveling Canoes; he was an elderly man and had lost the use of his legs so that he was carried from place to place on a ha(n)d barrow. Some call'd him Olla, the same name as the God of Bolabola, but his proper name was Etary. From Omai's account of this Man I expected to have seen him adored as a God, but excepting some young Plantain trees laying before him and upon the Awning, I saw nothing by which he might be distinguished from other Chiefs. Omai presented him with a small tuft of red feathers tied to the end of a small stick and after a little conversation on indifferent matters, Omais attention was drawn to an old Woman the Sister of his Mother .... (Beaglehole 1967:188).

According to Moerenhout there were several individuals identified with spirits:

There were always in all these islands certain individuals who represented or personified the gods. In some instances it was a leading chief, or even the paramount himself who acted as such, but more usually it was a priest or a sub-chief, or even a person of little consequence-for social status did not have much bearing on who should be a [god's oracle]. (Moerenhout 1837:I, 479)

Ellis, in a brief statement, claimed that idiots “... were always considered as inspired" (1829:II, 193), but this is the only direct reference I have been able to discover to this identification.

In between these extremes there were numerous individuals-mainly males, but some females as well-who became possessed often enough to serve as professional oracles, or taura. These specialists were known also as tahu'a atua to differentiate them from tahu'a pure (prayer specialists). Morrison gave a vivid account of the behavior of a taura asked to divine some spirit's knowledge, advice, or prediction:

When they are Consulted with respect to the Event of War \&c. they dress themselves in a fantastical form and decorate themselves with Red and Black Feathers, of which they suppose the Deity to be imoderately fond as he always makes use of Birds when he decends on earth and having his Head bound with Rowavva [ rau 'ava, kava leaves] he goes into a close place screend in near the Morai for that purpose, or into some thick bush where he remains a few Minutes, and comes out sneezing two or three times, when he begins to look wild, his eyes staring, and his 
body distorted into many forms and in a moment he seems to have undergone a most amazing Change-these postures they attribute to the contest between their own soul, and that of the Deity endeavoring to take its habitation which it at last effects and they appear as if stupid and do not know any person. His Colleague, who is Generally a Tahowwa [tahu'a, or probably tahu'a pure], then Compliments him by the Name of the Deity which he professes to be inspired with, and asks him such questions as he or the party Conserned wish to have Answered \& he returns him answers in a low squeaking tone of voice and makes large demands of the Party Concerned but should he be questioned while strugling with the Diety he somtimes utters half sentances in a Curious Manner as if both souls endeavourd to speak at the same time and somtimes speaks with his natural, and somtimes in a Squeaking Voice-When the Spirit leaves him he begins to Gape and Yawn and often falls backward with a loud shriek and lays speechless some Minutes, when he awakes as if from a sleep and his body being reocupied by his own Soul He resumes his own voice, and seems to know nothing of what has passd, he Generally times it at the flight of one of the Birds from the Morai and his Colleague does not forget to inform him of what Demands the Deity has made \& those Concerned seldom fail to furnish him with evry thing he required, if they have it, or Can by any Means get it. (Morrison 1935:181-182)

The "large demands" made by the taura of his client evidently referred to offerings to be made to the spirit-including, probably, some compensation for the taura himself.

Ellis, writing decades later (and in less picturesque English) corroborated Morrison's account and added some details:

As soon as the god was supposed to have entered the priest, the latter became violently agitated, and worked himself up to the highest pitch of apparent frenzy, the muscles of the limbs seemed convulsed, the body swelled, the countenance became terrific, the features distorted, and the eyes wild and strained. In this state he often rolled on the earth, foaming at the mouth, as if labouring under the influence of the divinity by whom he was possessed, and, in shrill cries, and violent and often indistinct sounds, revealed the will of the god. The priests, who were attending, and versed in the mysteries, received, and reported to the people, the declarations which had been thus received.

When the priest had uttered the response of the oracle, the violent paroxysm gradually subsided, and comparative composure ensued. The god did not, however, always leave him as soon as the communication had been made. Sometimes the same taura, or priest, continued for two or three days possessed by the spirit or deity; a piece of peculiar native cloth, worn round one arm, was an indication of inspiration, or of the indwelling of the god in the individual who wore it. ${ }^{[33]}$ The acts of the man during this period were considered as those of the god, and hence the greatest attention was paid to his expressions, and the whole of his deportment. (Ellis 1829:II, 235-236)

Another account, by the missionary Davies, writing about Huahine, reveals the material side of a "prophet's" message:

Two canoes ... from Raiatea ... In one of them there is a Prophet of the god Tane, in the course of the day he was inspired, ran to the Sea, \& sat down in the Water some distance from the Shore, where he declared to the peo- 
ple, who assembled on the Shore in great numbers, that he was going to Tahaete. (Journal, 3 December 1808, LMS Archives)

The house of the god Hoata which is to be built in a marae close by us is going on $\&$ the work stopped of ours. In the evening there were prayers in the Marae \& offerings made to Oro, Tane \&c \& the prophet of Tane mentioned Dec 3rd was again inspired, he said, speaking in the name of Tane, that he had been at Taheete \& that there was War there. Pomare being so apprehensive of danger that he went on board the boat out at sea to sleep every night, in the day returning on shore. How far the god is telling the truth remains to be proved, he has been absent near a week most of which time he spent as it is supposed at Taheete viewing the state of affairs there. (9 December 1808)

... The people here are more superstitious than the Taheiteans and more exact in the observance of religious ceremonies, \& the injunctions of the prophets. Four at least of these are present in our neighborhood, Viz. 2 of Tane, 1 of Oro who has his hand wrapt in cloth, like Metea in Taheite whenever he pretends to inspiration, \& another prophet of Tohu a shark god. This morning most of the people of the island were assembled at a Marae near our dwelling making prayers and offerings to the god. Arepaea gave 2 large hogs to a prophet of Tane, who is also a priest in order that he might pray for his recovery, \& that the god might make known by the prophet the crime for which he is affected. The other prophet of Tane \& the prophet of Oro were inspired in the course of the day, the contents of their Oracles were that more offerings are to be made to the gods, canoes $\&$ houses built, crimes atoned for by offerings of hogs, cloth \&c \&c. The people seem to exult in the multitude of their Prophets \& the certainty they have of knowing the will of their gods. (10 December 1808)

Ariipaea [a prominent chief] taken ill again, from drinking new spirits made from the Ti root. He knows it makes him ill, but persists in drinking it, \& has had a quantity made here two or three times by means of a worm $\&$ pot he and Edea brought from Tanete. Arapaes's illness as usual set the priest to Work, many prayers were made to Oro, Tane, Tepa \&c. many plantains were placed about the house where he lay, \& others were carried about by the Priests some were taken to the Marae \& also 2 or 3 pigs who were made to squeal loudly that the attention of the gods if possible might be attracted, the sacred Drums were also beating at the same time. While these things were transacting the prophet of Tane mentioned Dec. 3 was inspired he was first seized with strange convulsions, he trembled greatly shook himself, ran out of the house where Arepaea was, stooped to the ground put his head \& shoulders under the end of a small Canoe that was near at hand rising it up \& shaking it and at the same time grunting and groaning with all his might, after remaining so for a while he came out from under the Canoe took his right hand \& struck vehemently upon his breast several times, then did the same with his left, he then fell to the ground tore it with his hands taking up handfuls of earth \& throwing them down again. All this while he did not speak one articulate word, but at last he became more composed \& the Oracle came out, he spoke in the name of Tane \& as Tane himself, mentioned Arepaeas illness called him an ungovernable son blamed his conduct in several instances, particularly his not being so generous \& liberal as he ought in giving hogs \&c for the gods $\&$ the delay that had occured in building the gods house, \& in ambiguous terms said what was looked upon as a promise of his recovery, however 
he admonished him \& the other Chiefs to be more punctual in the performance of prayers, offerings \& other religious ceremonies, \& to leave this part of the island with the Uru \&c. for the gods \& the Priests. Soon after another Prophet was inspired but the particulars we have not learned. (13 January 1809)

According to Henry and Moerenhout, individuals so possessed manifested some remarkable changes in their own behavior:

Under the influence of spirits they delivered messages to the people (most of which were so ambiguous that they could be understood in diverse ways) and became so strong that they could do things impossible to them at other times. During these spells they wore a strip of sacred cloth round the left arm, as a sign that they must not be disturbed. Kings Pomare II and Tamatoa III and the early missionaries testified to having seen priests while possessed in this way thrust hand and arm up to the shoulder, without injury, into the solid ground of hardtrodden pathways. They foamed at the mouth, had their eyeballs distorted and their limbs convulsed, and uttered hideous shrieks and ejaculations. Captain Henry once saw a priest, after making such a display take hold of a great canoe, which ordinarily required three or four men to launch, push it into the water, and set it adrift with great ease. The man then plunged into the sea, held his head under water for a long time, and then sat up among the waves and delivered his prophecies. While under a spell the priest could ask for whatever he wished and obtain it, even to the wife of the king, as it was a god that was supposed to speak. When thus possessed, the priest was said to be autihe. (Henry 1928:152-153)

Many instances could be cited of individuals who behaved most extraordinarily when so possessed-individuals who though having previously shown neither talent nor eloquence, spoke forth during their seizures with relevance and spontaneity and about the most crucial of matters. Moreover, the things they spoke about included topics of great delicacy and difficulty, such as one would suppose to be totally strange to them; and their manner of speaking on such occasions was not only often fluent, but was also usually couched in the kind of figurative and hyperbolic syle normally used only by chiefs and orators who had practiced it since infancy.

But then, immediately upon their release from the seizures which occasioned these extraordinary displays of eloquence, etc., the latter also ceased. Thus, if we may believe several eye-witnesses of such episodes, those individuals who while "possessed" and in battle had carried out great feats of bravery or wisdom or eloquence seemed to lose such abilities quite suddenly upon coming out of their seizures, and thereafter gave no evidence of possessing them until "possessed" again. I leave it to the physiologists to try to explain this strange anomoly-although I very much doubt that the state of their science is advanced enough to permit them to give a satisfactory explanation. (Moerenhout 1837:I, 483-484)

However Moerenhout's "physiologists" might have explained this phenomenon, it seems quite clear, from an abundance of evidence, that the messages of many taura were accorded the credibility appropriate to the pronouncements of the spirits themselves-varying of course with the status of the spirit:

... some [taura] pretend to belong to the particular deity, others to many: such as claim acquaintance with the three superior eatooos [atua] are the most conse- 
quential, and procure high reverence from the part they presume to act; indeed they do it with so much cunning and address, that the Swedes whom we found on the island, as well as the mariners who preceded them, really believed the appearances supernatural, and that the devil actually was the agent. (Wilson 1799:337)

When the spirit was a powerful one, then:

Whatever order was given, it was obeyed almost always in the field, without anyone, even the chiefs, daring to oppose it. At the request of the gods the people were seen running spontaneoulsy to arms, setting the pace for the rulers in spite of them, waging war against some district without the slightest provocation, and committing on the enemy territory excesses which could not be justified by the rules of war, believing in all good faith, to be obeying the Divinity, which quite probably was only a blind instrument of the animosity and the vengeance of the priests or the inspired one. (Moerenhout 1837:I, 483)

With all its powers and privileges, however, the professional practice of a taura was not without its risks-especially those deriving from repeated failure of prophecy, or from oracular statements unfavorable to more powerful individuals. It appears however that the more durable taura were able to rationalize their occasional failures in one of two ways: by subsequently "discovering" that the god in question had changed his mind, or by expressing the message in terms ambiguous enough to permit a variety of interpretations. ${ }^{34}$

In all the foregoing, emphasis has been on how spirits communicated with humans. Some indication has also been given concerning what was communicated, for example, information concerning future events and indication that certain past actions had been wrong. This raises still other questions concerning the relationship between spirits and humans: for example, To what degree were spirits omniscient? To what extent were events, including human actions, controlled by spirits?

The evidence on these large questions is fragmentary and inconsistent. It can be said at the outset that the above questions cannot be answered on the basis of available data; for one thing, they are greatly complicated by the issue of magic, which will be discussed later on. Somewhat more manageable are the corollary questions: What behavior did spirits require of humans and how were such norms made known? By what means did spirits enforce behavior desired by them? Some of the situations and procedures just listed provide evidence bearing on these questions, and more will be presented in the pages to follow; but next will be described the procedures whereby humans communicated their thoughts and wishes to spirits.

\section{Prayer and Offering}

Communications from humans to spirits consisted mainly of asking for something. Even rites of thanksgiving were conducted in a spirit of payment for past services, and of insurance for future ones. Having asserted that, 
however, the question should again be raised concerning the mechanism of such communications - that is, what proportion, if any, of these acts were conceived of as coercing spirits to react in desired ways, in contrast to requesting them to do so. Requesting seems to have been inherent in most of these acts, as evidenced by their constituent offerings, words of praise, signs of deference, etcetera; in these cases such labels as prayer and offering are clearly appropriate. But, when, for example, a man at sea holds up his tuft of red feathers and asks an approaching storm to retire, his action might be interpreted either as a request (a prayer) to the spirit behind the wind, backed up by a gratifying glimpse of feathers (an offering), or it could be interpreted as a magically coercive action made effective by some inherent powers of the word and feathers, in which case labels such as spell and charm would be more appropriate. Unfortunately (at least, for the sake of analytical tidiness), such ambiguity applies to descriptions of most of the ritual actions of the Maohis, but lacking neutral words to label these I propose, caveat lector, to describe the ritual as if all such acts were requests directed to spirits. This is not to say, however, that "magic" per se did not exist in these Islands-as witness the following passage from Henry:

In the pit of the ancestral marae families of all ranks were careful to bury all personal effects, which were regarded as the iho (essence) of the body, for safe keeping in charge of the gods. Following are injunctions given by priests:

Eiaha te rouru paoti hia e tahu hia i te auahi, a pahure te upo'o o te ta'ata no'na te rouru. Eiaha te mai-u'u ta'ata i 'o'oti hia ra, eiaha te a'ahu ri'i piro, te fenu ri'i peue e te ma'a tapa no te ro'i ia tahu hia i te auahi; e iho ia no te tino ta'ata, e humehume hia te iri e e po te mata o te ta'ata no'na tana mau mea ra ia tutui hia i te auahi; e tanu ra i taua mau mea ra i roto i te apo'o, i te tiria-pera, e 'aore ia e ha'amo'e roa i te tai hohonu.
Let not the cuttings of the human hair be burned with fire, lest the owner of the hair become bald. Let not the nail prunings of a person, or the worn out clothes, or shredded mats or tapa from the bedding be burned with fire; these are the essence of the person, and there would follow moles upon the skin and blindness to the owner if they burned them; but bury those things in the hole, tiri-a-pera, or drop them into the deep sea.

$(1928: 143)$

Communications from humans to spirits ranged all the way from perfunctory wordless offerings of tiny morsels of food before a meal, to week-long ceremonies involving numerous officiants and vast offerings, including human sacrifice. ${ }^{35}$ According to Ellis there was a "religious" rite connected with almost every act of life: "An $u b u[u p u]$ or prayer was offered before they ate their food, when they tilled their ground, planted their gardens, built their houses, launched their canoes, cast their nets, and commenced or concluded a journey" (1829:II, 216).

Prayers were uttered under all kinds of conditions and in all types of places, but the sources provide detailed descriptions only of those uttered with strict formality in marae. ${ }^{36}$ Under such conditions, the petitioner, sitting 
cross-legged or crouching on his heels or, more typically, kneeling on the right knee addressed the spirits. He did so on a broad flat stone near the center of a marae court, and often while leaning against an upright basaltic column (fao'a tu marae). Usually he faced the marae's stone platform $(a h u)$, in front of which the tutelar spirits' to' $o$ were customarily placed during services. According to one observer a petitioner bowed his head while praying, purportedly to avoid distracting his memory, but most other reports indicate that petitioners usually looked upward while praying. In any case, most petitioners bared their bodies to the waist while praying - a conventional mark of respect. Also, it was reported that a petitioner usually threw a branch of miro onto the ground before beginning his prayers; miro, it will be recalled, was one of the trees usually found growing within or near marae precincts, and spirits spoke through the sound of its rustling leaves. The miro was an ata of the god Ro'o, who served among other things to inspire priests at their devotions.

According to Henry, priestly apparel “... retained no warmth but conveyed cold to the body during night vigils in prayer upon the marae, producing a sensation called iri-anu (chilled-skin) or hau-mariri (dewy-chills) which was considered most pleasing to the gods" (1928:152).

Some prayers to minor spirits are said to have been uttered in hisses, but usually prayers were delivered verbally in shrill tones, described as having been "chantlike," "tremulous," and "unpleasant" (Ellis 1829:II, 209). When they were very lengthy, which was often the case, the petitioner bolstered his memory by means of a tally consisting of a bundle of sticks or a frond of coconut, although, it should be added, the repetitious nature of many prayers served to reduce the difficulties of memorization. As Bligh noted on one occasion, "Hammennemanne [a priest] now began another Prayer, it was very long, but had many repititions in it, so that it is not so extraordinary, as Strangers imagine, the retentiveness of the Mans Memory" (1792:137a).

See also the following passage from Davies' journal describing a ceremony consecrating a new god house:

... the drums continued beating incessantly \& the people in the house priests, chiefs \&c then joined in chanting a number of Ubus or prayers repeating the same form of words hundreds of times over, thus it continued all night without interruption, except for 2 or 3 minutes when they gave over the repetition of one Ubu in order to begin another. Many of these Ubus were nonsensical sentences not in the form of addresses to their gods, but a repetition of their names \& having sometimes some obscure allusions to some ancient transactions or traditions concerning the ancestors of the islanders, others had something of the form of prayers containing invocations to the gods, a declaration of their power \&c. (14 January 1809, in Newbury 1961:127n2)

Several European visitors attested to the solemnity and the profundity of feeling with which formal prayers were sometimes delivered. (This was 
in contrast, I should add, to the mood of frivolity that sometimes prevailed among those less directly participant in such ceremonies.) Thus, Ellis described a visit to an abandoned marae in the company of a Christian convert who had once been a priest:

After examining its ruins, we requested him to recite, simply for our information relative to the nature of the former worship, one of the prayers he had been accustomed to offer there. After great persuasion, he consented, and, assuming the crouching position, or sitting as it were on his heels, he commenced, in a shrill, tremulous tone, to repeat the names of the gods, \&c, but he was soon seized with a violent trembling and evident alarm, and declared he durst not, he could not proceed. (Ellis 1829:II, 210)

European observers also attested to the requirement that prayer utterance be letter perfect\& the slightest mistake or hesitation necessitated recommencement of the prayer or even abandonment of the whole ceremony. (In connection with the question of the mechanism of prayer, this requirement could of course be interpreted either as evidence of spirits' demands that they be addressed correctly or as confirmation that magical words must be uttered exactly, in order to be effective.) Errors in prayer delivery were, according to Henry, considered a "mortal sin" (1928:198). For example, a disturbance of a marae ceremony occasioned by the intrusion of a child was described in the following terms: "... ua fifi te aha atua," literally, is entangled the cord of the gods, or freely, "the thread of the prayers to the gods is entangled" (Henry 1928:169).

Some impression of the form and content of prayers may be gained from two short examples: the first an invocation (upu tarotaro) preliminary to a long marae ceremony, and the second a benediction (upu fa'atonu) terminating the same ceremony:

E te atua e! e aroha mai i to taura tahu'a nei. E fare nohora'a to te 'opu-nui, e to te mau uru, e pure 'iri anu ra matou, e 'ore e ta'oto, i teie 'aru'i, e rari i te hau, eiaha rà ia rari i te ua e te atua e!

Tahiti’a mai e te atua e! Tena tini atua, tena mano atua, a fariu mai, a fan'i i ta matou nei upu! I ora te fa'ao ta'ata o teie nei fenua, ia ora te huia, ia ora i te atua. Ia ora te mua fare ta'ata. E ara i te ta'ata papari‘a taratara, i te ta'ata papari'a hoai, i te hufapapai, i te maro ta'iri i te hauroa mua. E tu'u ana'e ia na vaho roa. Ia ora matou, te ta'ata nei, e te nu'u atua e!
O gods! Have mercy upon your body of priests here (present). The 'opu-nui and the possessed images have a house, but we shall be praying chilly, without sleep, this night; we shall be wet with dew, but let us not be wet with rain, O gods!

Hearken unto us, O gods!

Those numerous gods, those thousands of gods, turn unto us, accept of our petitions!

Preserve the population of this land; preserve the generation; may they live in the gods. Preserve the frontiers of the people's habitations. Watch against the man with rough cheeks, the man with angry looks, against the incendiary, against him who lets fly the ends of his loin girdle. Put all those things entirely away. Preserve us human beings, $\mathrm{O}$ host of gods! 
Some accounts state that the language of prayer was esoteric, incomprehensible to all but the priests. It did indeed contain many archaisms and vague metaphors, understood only by specialists (and perhaps not even by them), but the principal source of its obscurity probably lay in its manner of delivery.

Within some marae there were certain low stone uprights against which were kept human effigies of 'braided coconut leaves' (tapa'u), representing priests in continuous prayer. According to Henry these uprights, with their effigies, were called the 'life of the marae' (aho), and the stone columns themselves were called 'holder-of-the-tapa'au' (vaira'a tapa'au) (1928:134). The uprights symbolized the marae's main function, providing a place for humans to pray to spirits.

Davies observed a ceremony in which tapa'u were placed on top of a god's house which was being consecrated (Journal, 14 January 1809, LMS Archives).

Formal prayers, delivered in connection with protracted marae rites, were customarily accompanied by or alternated with the beating of marae drums, of which there were several varieties. These served both to provide breathing spells for petitioners and to intensify the awesome solemnity of the occasion.

Few if any prayers were directed to spirits unless attended by offerings of tangible objects. ${ }^{37}$ Fine mats, tapa, and other manufactures were occasionally proffered, but food of all kinds-plantains, coconuts, root vegetables, kava roots, fish, fowl, dog, pig-was the usual offering (fig. 3-4). Sometimes it was presented raw, sometimes it was cooked beforehand; the significance of the difference will be explored later on. In informal situations, such as an ordinary meal on land or sea, a sacrificial morsel of food was simply thrown onto the ground or into the water. According to Corney, if there was no marae nearby, some individuals placed their daily food offerings on their house roof (1915:259). Offerings made at domestic or "public" marae were usually placed on an altar. ${ }^{38}$

The altars of smaller, usually "domestic," marae were small square wicker structures, while those at the larger, more "public" marae were high platforms supported by carved and polished wooden posts and on occasion ornamented with tasseled leaves or plant fibers (Ellis 1829:II, 211). (See figs. 3-5, 3-6, 3-7.) In other instances offerings were hung from trees (Beaglehole 1961:797-798).

Uncooked pigs were offered up in one of two ways. They were sometimes strangled during the offering prayer by means of two sticks pressed together against the throat, thereby avoiding any disfigurement of the animal. At other times they were bled to death and their blood smeared over their bodies. Davies recorded in his journal that on one occasion witnessed by him the sacrificial pigs were made to squeal loudly "that the attention 


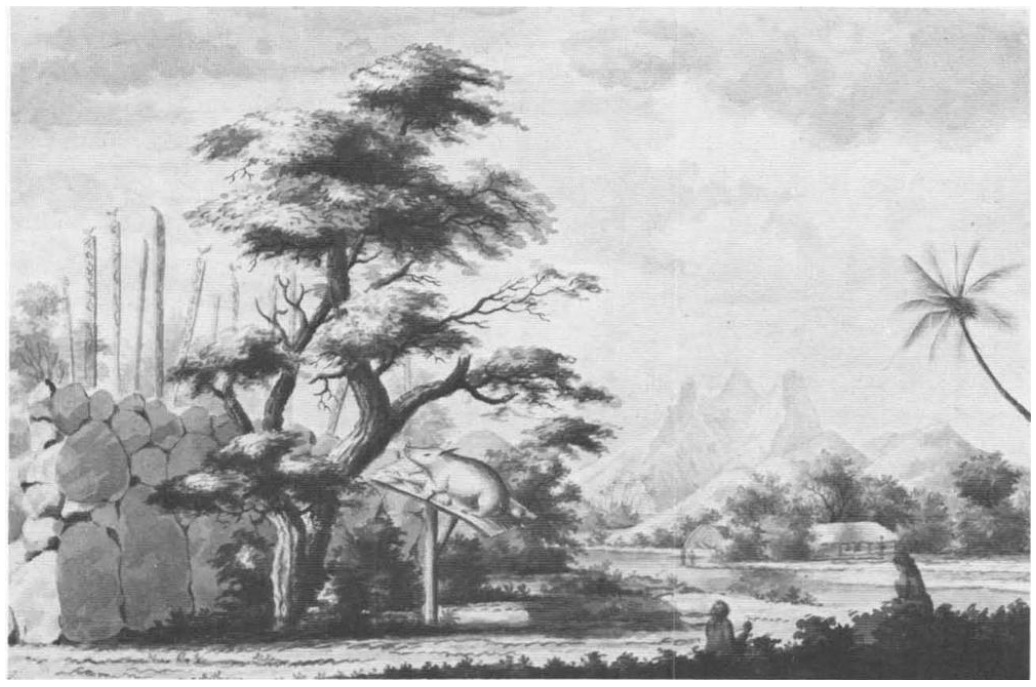

FiguRE 3-4. "A Morai (marae) with an offering to the Dead." Drawing by S. Parkinson. British Museum.

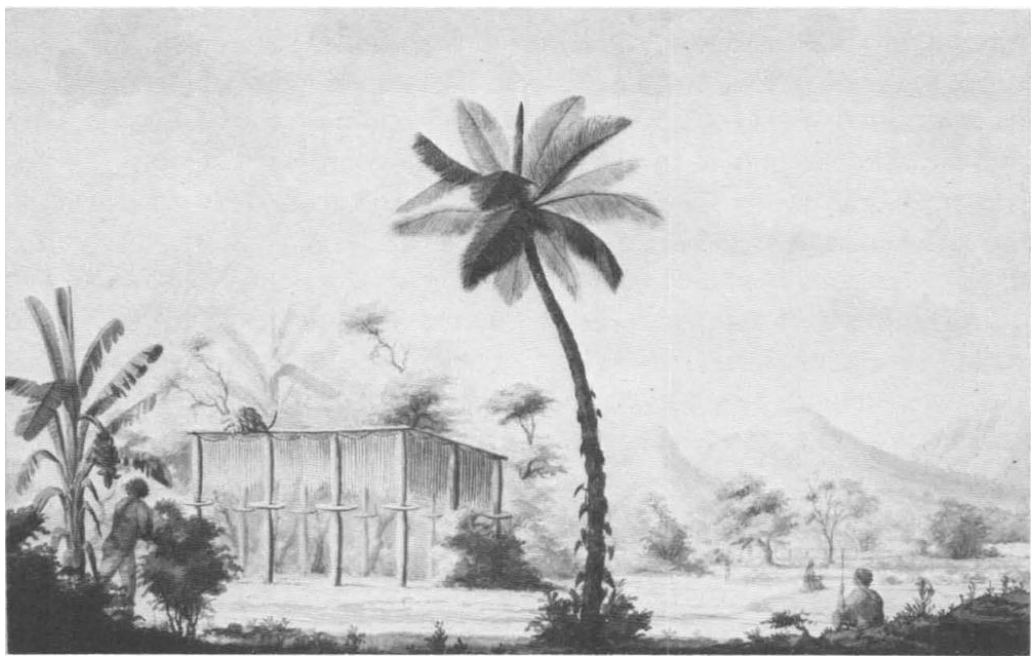

FIGURE 3-5. "A platform for supporting the offerings made to the Dead." Unsigned drawing. British Museum. 


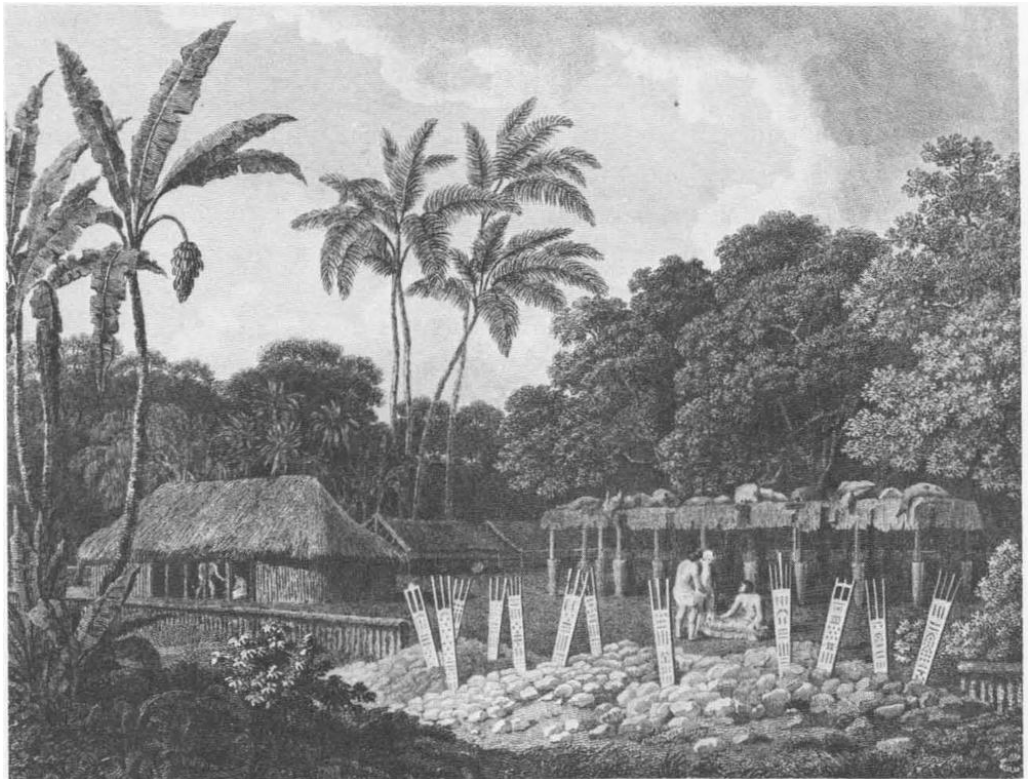

FIGURE 3-6. Marae Te Ara o Tahiti. Engraving based on a drawing by William Wilson.

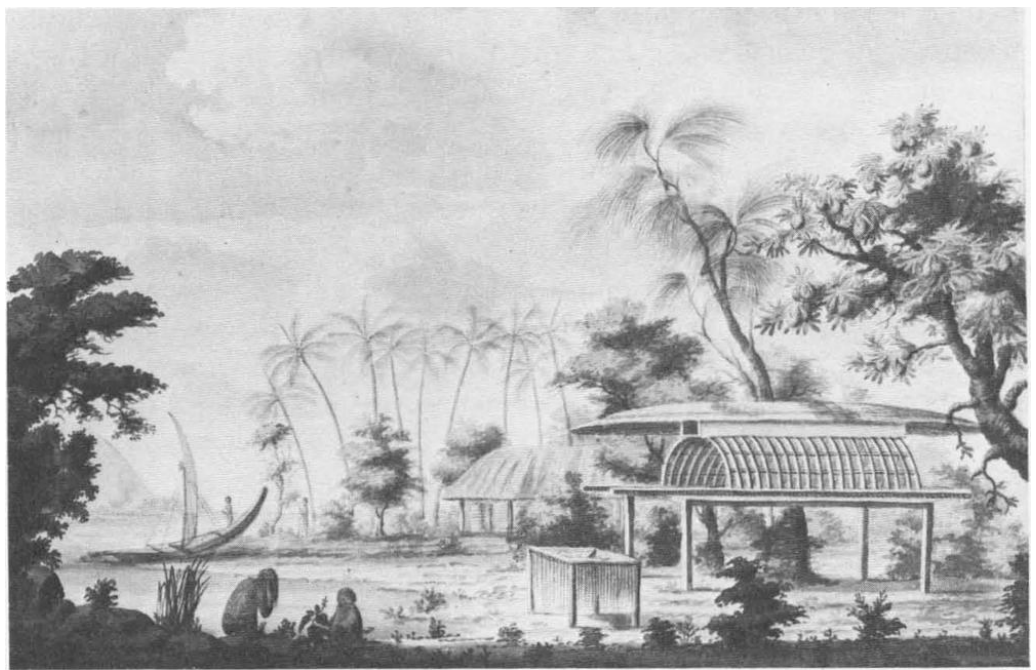

FIGURE 3-7. A Huahine marae, showing altar and god's house. Drawing by S. Parkinson. British Museum. 
of the gods if possible might be attracted" (Davies, Journal, 13 January 1809, LMS Archives). (The same procedures may also have applied to dogs, although the sources do not specify so.) If animals were presented to a marae's tutelar spirits in excess of current needs they were branded with a tapu mark and allowed to run free until required, and the same fate awaited all animals that happened to stray into marae precincts.

Henry provided an example of a prayer used in connection with an offering - this one a pig put to death by strangling:

Tahiti‘a, mai, te atua e, i ta matou nei fei'ai! Teie te pua'a taraehara ${ }^{[39]}$ na 'oe, e pua'a tapena, e pua'a porao ore.
Hearken O god, to our petition with food! Here is the sacrificial pig for thee, a sacred pig, a pig without a blemish.

(1928:168)

Offerings placed upon an altar remained there until they decomposed or were eaten by birds, the assumption having been that the spirit recipient, present either in the form of the birds, or invisible, consumed or otherwise used up the essence (iho) of the objects (Cook 1784:43; Bligh 1789:II, 25). This serves to account for the fetid air often reported of marae which may indeed have represented one component of the complex attribute of sacredness. In this connection it is also suggestive that officiants at formal marae services were not allowed to wear flowers or anoint themselves with aromatic oil. After decomposition-but usually not until the altar had to be emptied and refurbished for another service-the remains of most offerings were thrown into the marae's refuse heap (turuma) or pit (tiriapera), along with all other used items left over from the activities in the marae, including priests' vestments, decayed wood and thatch from marae buildings, moss scraped from marae stones, grass collected from weeding, and so forth ${ }^{40}$-all things having been too saturated with sacredness for disposal outside the marae grounds.

On occasions, some of which will be described later on, part of the food contributed for "religious" uses was eaten by officiants at the marae, or even taken home to be eaten (Henry 1928:177). One rationale for this practice was undoubtedly recompense for services performed on behalf of the marae's congregation. There may have been other reasons or imagined effects as well; but, as pointed out by Handy, there is no evidence to support a theory to the effect that this practice represented a conscious performance of "communal sacrament" (1927:189-190).

A human being was the most acceptable offering to the gods-principally to 'Oro in his various manifestations. ${ }^{41}$ (Figs. 3-8, 3-9.) The rationale for this preference was probably complex. In the first place, the god 'Oro delighted in warfare, so it is reasonable to assume that the Maohis conceived of him as delighting also in human death. Second, although the sources are not explicit on this point, it may well have been believed that the god in question nourished himself by actually eating the 


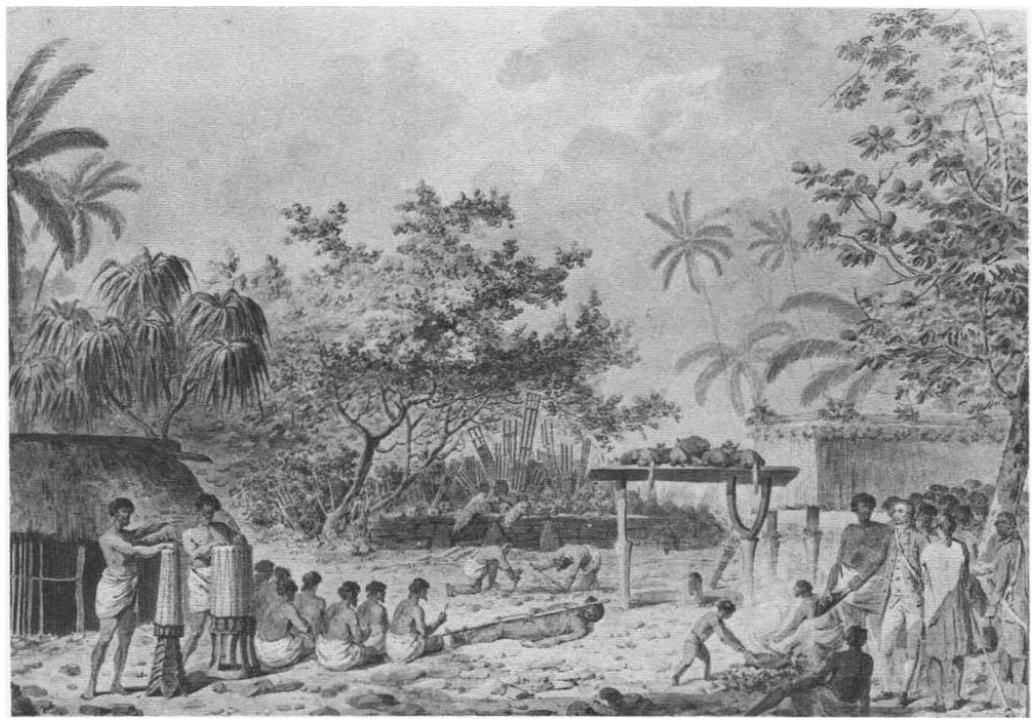

FIGURE 3-8. "A human sacrifice at Tahiti." Drawing by J. Webber. British Museum.

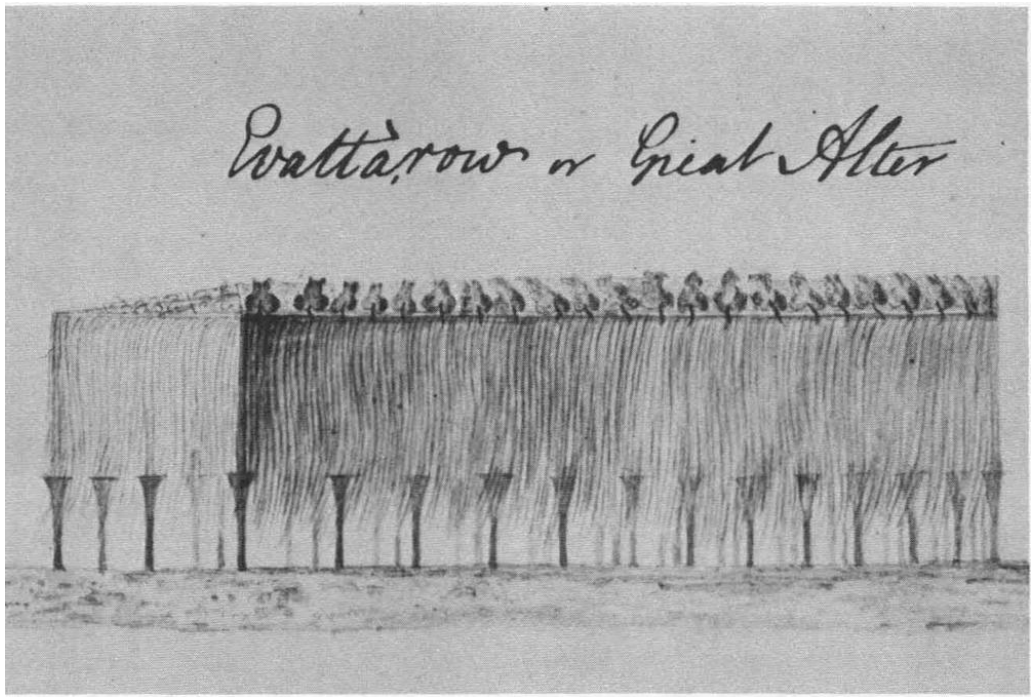

FIGURE 3-9. The great altar at marae Utuhaihai, Pare, Tahiti. Drawing by W. Bligh. Mitchell Library, Sydney. 
essence of the human offering; such was the case with other edible offerings, and in one widely current version of the fate of souls, gods are imagined as eating them. Third, it would be consistent with other manifestations of Maohi beliefs to infer that the victim's spirit or ghost, released by his sacrifice, would be imagined as hovering around the marae in question thereby augmenting the sacredness of the place (and of course awe of its tutelar god and human proprietor); but this takes us out of the realm of theology and into that of politics.

Actual selection of a human victim involved both punitive and political considerations, which will be described in other chapters. In terms of ritual, the victim in most instances had to be a male and was preferably an old one. In times of war captured and often badly maimed victims were offered, but in times of peace the victim was required to be physically unblemished, without crippled limbs or disfiguring scars-particularly scars produced by a woman. Because of this the victim was customarily killed by striking his head with a stone.

After having been killed, the victim, conventionally referred to as a "fish" or "man-long banana," was encased in a plait coconut-leaf basket and carried to a marae for formal presentation to the god. Sacrifices to 'Oro, at least, were smeared with their own blood to render them more acceptable. Except for the skull, which was sometimes displayed above ground at the marae, the corpse was eventually buried under a special pavement stone. On certain occasions an eye was removed and presented to the incumbent of the marae's highest-ranking kin-Title, who pretended to eat it. ${ }^{42}$ This was the usual procedure, but there were several variations to fit special circumstances. For example, when a god's house was to be consecrated human victims were sometimes deposited at the base of its principal supporting posts; or, when the canoe of a powerful god was launched or beached, human victims were occasionally used for rollers.

Only at the most venerated of marae were human offerings made to the spirits; these were mainly marae dedicated to 'Oro, although the god Tane was also occasionally honored in this way (de Bovis 1909:55).

Special behavior was required of officiants, spectators, and the community as a whole while major religious rituals were in progress. Primary officiants were obliged to withdraw from secular activities before and during the ceremonies at the marae and then to undergo specific deconsecration rites at their conclusion and before resuming everyday life. Henry's description of their preparations, the fullest available, will be reproduced later. Other officiants, including otherwise important spectators, also had to undergo some restrictions, at least during the ceremonies; but these were of less severity.

The garments worn by officiants during a marae ceremony became so infused with sacredness that they could not be used outside; consequently 
they were generally stored in the fare ia manaha when not in use (Morrison 1935:179).

In some instances deconsecration consisted of a verbal prayer; on other occasions, bathing in water served the same end.

During major marae ceremonies restrictions were imposed upon the community at large. In their most severe form no ordinary work could be performed; no fires could be lighted (hence no food cooked), and no noise of any kind made. Women and children remained at home, and no traveling on land or sea was permitted. All this served, of course, to heighten the sounds coming from the marae-especially the dread tones of the to'ere drum announcing a human sacrifice.

\section{Dancing and Prodigious Acts}

There remain to be considered certain other forms of action which might be viewed as special means of communication between spirits and humans. First are the kind of public performances which took place in connection with major religious ceremonies, although not within marae precincts. Notable among these were the public spectacles-pantomime, choral antiphonal chanting, and dancing-performed in connection with the annual first-fruit festivals, and those performed at other times to dramatize myths. (Detailed descriptions of these performances will be presented in later chapters.) All these performances seemed to entertain the populace and might also have had the purpose of entertaining the assembled spirits as well. The question, however, is whether the actions performed had the additional purpose of influencing, magically, either the spirits themselves or the "forces of nature," if there were any independent of spirit control (which I believe not to have been the case), to ensure a continuation of the growth of plants and animals and the replenishment of human society. The dancing, whose "erotic" qualities will be described in another place, had been claimed especially to influence the procreative forces of nature:

The erotic dancing of the tropical islands of Polynesia, which was in its origin a form of worship, was designed to stimulate and bring into action the mana of the gods who were believed to be animated by the same emotions as men and on whose procreative activities the fecundity of human beings, the earth, and sea depended. These rites have been characterized as "mysteries" but I see no reason to call them such. The gods, man-like in their nature, were present at the feasts. The dancing roused their passions, and they sought the satisfaction of their desire with their female mates. The nature father-Tane in New Zealand, Taaroa in Tahiti, Atea in the Marquesas-would enjoy with the mothers of fruits, as men enjoyed with the mothers of men, the orgy of sexual indulgence in which such feasts always culminated. There would be many children of the nature father-many breadfruit, taro, bananas, potatoes, many fish-and there would be many human children, both because the procreative power seated in the human fathers was released and freely spent, and because 
the nature father, from whom or through whom this power came to men, was aroused to impregnate the mothers in nature. (E.S.C. Handy 1927:210-211)

This is an intriguing theory, and one which might be pertinent as well, but like other aspects of the prayer-versus-spell problem of Maohi ritual, it can neither be confirmed nor denied by the Maohi evidence available.

A second form of action implicating communication between spirits and humans involved certain prodigious feats performed by the latter when purportedly possessed, or otherwise influenced, by the former. One of the most spectacular of these was rock climbing. According to an account given to de Bovis, individuals adept in this practice were able to climb high, perpendicular, smooth-faced cliffs by means of "invocations" and small wands of ironwood held against the face of the rock (1909:52). Another kind of spectacle was the well-known 'fire-walking ceremony' (umu ti), in which several devotees walked over a pit of white-hot stones without apparent injury; it so happens, however, that I can find no references to such ceremonies in eighteenth-or early nineteenth-century accounts, and if the early European visitors had seen or heard about such prodigies they would assuredly have mentioned them. In fact the only detailed descriptions of fire-walking ceremonies that I know about referred to some witnessed on Ra'iatea in 1885 and thereafter. ${ }^{43}$ Although these latter-day ceremonies seem to have been thoroughly "pagan" in inspiration and performance, and specifically Tahitian (or actually, Ra'iatean) in cosmographic reference, this does not necessarily prove that the custom prevailed in the Society Islands in pre-European times. Fire walking is attested to in other Polynesian archipelagoes and might well have been introduced (or reintroduced) into the Society Islands from elsewhere during the nineteenth century.

\section{Priests}

Every Maohi man (and probably also every Maohi woman) communicated with spirits from time to time, and most Maohis probably served occasionally as vehicles for spirits' communications with others. But, in addition, there were certain individuals who specialized in such practices, even to the point of making a full-time profession of them. I have already mentioned two such specialties, those of human oracle (taura 'shaman') and sorcerer. I now turn to the specialty of priest (tahu'a pure 'one-skilled-in-praying').

The distinction between shaman and priest is quite clear-cut; the former served as a medium through which a spirit addressed humans, while the latter addressed spirits as a representative of humans. (In terms of this distinction, the sorcerer was a kind of priest who exercised a relatively strong control over the particular spirit who served as his fetcher-familiar.) It should be noted, however, that the distinction just made refers primarily to roles. That is to say, while it is not unlikely that some religious prac- 
titioners (part- or full-time) may have been shamans exclusively, it is also likely that all professional priests (i.e., not just individuals such as household patriarchs who now and then carried out priestly functions) served occasionally as professional shamans as well. Here, however, we are concerned with the priestly role of the religious professional.

The main activity of priests was to receive and interpret spirits' messages to humans and to persuade spirits to comply with humans' wishes. As we have seen, this usually required inducing the spirits in question to embody themselves nearby (in some image or other "seat") and listen to verbal supplications backed up with offerings of objects or services considered pleasing to the spirits. In many-perhaps most-marae all the various jobs comprising this activity were probably carried out by one all-around priest, either part-or full-time; but in marae associated with the more socially important congregations, such as whole tribes or supratribal cults, the jobs were distributed among several specialist priests, including an officiating "high priest," marae attendants (ōpū nui 'big bellies'), image-bearers, novices, and so on.

The offices of the high priest and of some other prayer specialists were usually hereditary, but most incumbents underwent arduous training. After their formal consecration such officeholders were usually subject to punishment by spirits and fellow priests for committing errors in the technical procedures of priestcraft.

In brief, priesthood was a popular profession whose members were well compensated, materially and socially, in return for their onerous duties and dangerous risks.

\section{Marae}

Marae were the sanctity and glory of the land; they were the pride of the people of these islands. The ornaments of the land were the marae, they were the palaces presented to the gods. (Henry 1928:150)

In the myths of creation epitomized earlier in this chapter, it will be recalled that even after Ta'aroa had brought the universe into being, and even after it had begun to be populated with gods, humans, and demigods, disorder and chaos continued to reign. Darkness $(p \overline{)})$ prevailed everywhere and entities were not fixed in their proper places. A number of actions contributed to bringing order out of chaos, including the raising of the sky off the earth and the slowing down of the sun in his daily sweep across the heavens; but order was not fully established until relations between spirits and humans became regularized, and for this it was necessary to establish marae, where humans could "receive the gods in a befitting manner" (Henry 1928:429), with prayers and offerings presented through properly qualified intermediaries, mainly priests.

As we have seen, mortal humans' souls sometimes entered the sphere 
of spirits while asleep or entranced, and spirits visited mortals in many guises and in many kinds of settings; but the marae were the edifices where most of the interaction between spirits and humans took place. There are some grounds for concluding that Maohis considered marae to be outposts of $p \bar{o}$ (spirits' sphere, or "room," of the universe) within the ao (mortals' sphere), but this contrast cannot be pushed too far, because of lack of explicit native verbalizations on this matter. Also, in most cases about which such information is available, each marae was primarily devoted to interaction between a specific group or category of humans and a particular set of spirits (Henry 1928:132, 453). That is to say, no marae known to me served as an all-inclusive meeting place between humans and spirits in general-or rather, no edifice that I propose to call a marae served as such.

In the absence of the kind of linguistic evidence essential for authentic semantics, I can only guess at what the Maohis themselves felt to be the primary, as distinct from derivative, references of their very common word marae. For example, the miniature houses in which the images of some of the more powerful atua were kept, called fare atua by the Maohis, and "arks" by some of the European visitors, were also referred to as marae, as were the parts of the boats on which such images and their houses were transported (Morrison 1935:179). Marae seems also to have referred to some places set aside for burial-including one for dogs (Beaglehole 1961:419). In certain circumstances, as set forth in a chant reproduced in Henry, the sea itself was called a marae:

E pure tei te nu'u tai mimiha;

(There was prayer in the moving rolling ocean;)

o te moana te marae nui o te ao nei.

(the sea was the great temple of the [human] world.) (1928:356)

And not just metaphorically for, as Henry explained elsewhere: "On the seaside the wanderer or exile who owned no land [i.e., had access to no specific place of worship] worshipped his god. There he presented his son or daughter in marriage, there he offered his newborn child to his tutelar god, and there he presented himself or members of his family when sick or dying to the healing gods, and to Ta'aroa" (1928:144).

In any case, for my present purposes I shall use the word marae to refer primarily to any man-made structure consisting minimally of a discrete area of ground containing fixed places for interaction between humans and spirits. Specifically, the fixed places included at least some locus for one or more spirits and for one or more humans. Many marae also contained one or more of the following fixed elements: altars, graves, et cetera, for offerings to spirits; shelters used for storing paraphernalia not in actual use; pits or piles for disposing of ritual objects no longer subject to use; graves for temporary burial of certain deceased members of the 
marae's congregation; and loci for investing humans in certain marae-associated offices. Finally, in some locations several more or less discrete marae (each containing one or more of the above fixed elements) were spatially and ritually combined into marae complexes. (Figs. 3-10 through 3-12.)

Perhaps the most succinct contemporary description of marae functions and architecture is that of the missionary Jefferson:

Morai, in the language of the country, signifies a place appropriated to the worship of Eatooa, or deity. As the Otaheiteans have a plurality of deities, so they have many morais. They are temporary or permanent. Temporary morais are erected before the corpse of the dead agreeable to the fancy of the erector, and (from what I have hitherto seen) are commonly small altars, variously decorated, with leaves and the fruit of palm tree, that grows in abundance, and upon which are placed divers offerings of food. Permanent morais are numerous and divers: they are usually enclosed spots of ground surrounded with trees of different kinds, and having in them sundry small pavements of stone: at the head of each stands a stone of larger size, and at the back of the stone is generally fixed a board five or six feet long, with a little rude carving on it; the top divided into five parts, or slits, to represent the fingers of a hand: sometimes the board has the figure of a man or bird carved on its top. At the foot of this pavement the priest worships, with his face directed towards the headstone and plank, and throws his offering, consisting of a young plantain-tree root, green leaves, or the leaf of a cocoa-nut twisted in a peculiar form, upon the pavement. Besides these kinds of oratories within the enclosure, there are altars, on which meat offerings are placed, and before which prayers are made. Altars for the like purpose are scattered up and down the country where there is no morai. At one permanent place of worship, there are frequently a plurality of morais dedicated to different deities: thus the one I now visited, had in it two others dedicated to as many false gods. (LMS Transactions:I, 98)

This much is known, or can be credibly inferred, about the major functional components of marae. In addition, it is possible in some instances to identify certain functional components with specific architectural elements, to which I now turn. ${ }^{44}$

The "discrete areas of ground," which I propose were a feature of every structure I call a marae, varied greatly in area; some were no larger than a few square meters, while others comprised areas of several thousand meters. Most of these areas were floored with flagstones, river boulders, or pebbles, in whole or in part. Usually marae were laid out on naturally level ground, with pavements flush with ground level or raised somewhat to form a low platform. In uneven locations attempts appear to have been made to level their floors by means of excavations and terracing (sometimes built out into the lagoon), occasionally resulting in floors at two or more levels. The larger marae were roughly rectangular in outline and usually bounded by continuous stone walls of heights ranging from less than a meter to two or more.

A prominent feature of most of the larger marae was the $a h u$, a more or less rectangular platform built of stones and located adjacent to one of 


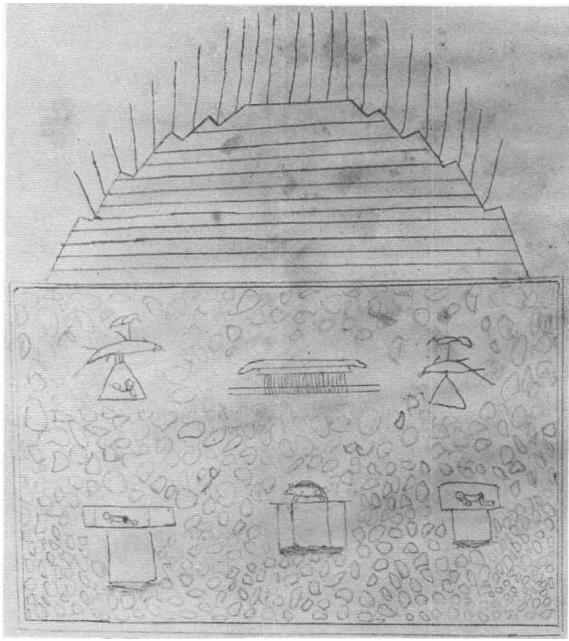

FIGURE 3-10. Marae plan. Unsigned drawing. Cook's first voyage. British Museum.

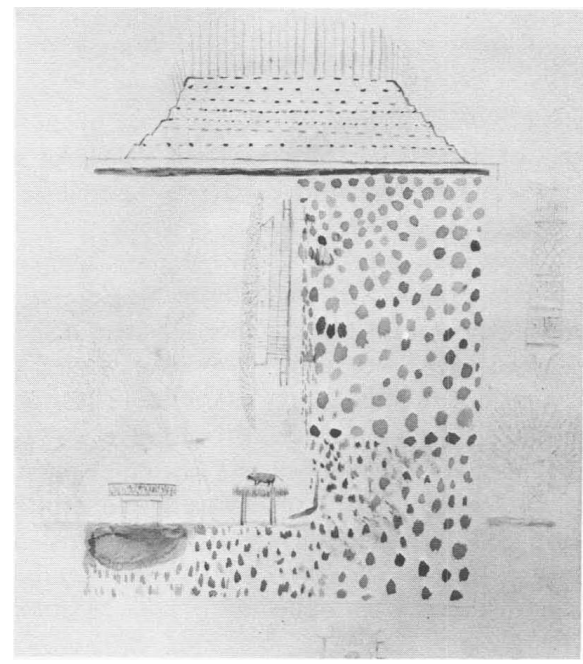

FIGURE 3-11. Marae plan. Unsigned drawing. Cook's first voyage. British Museum. 


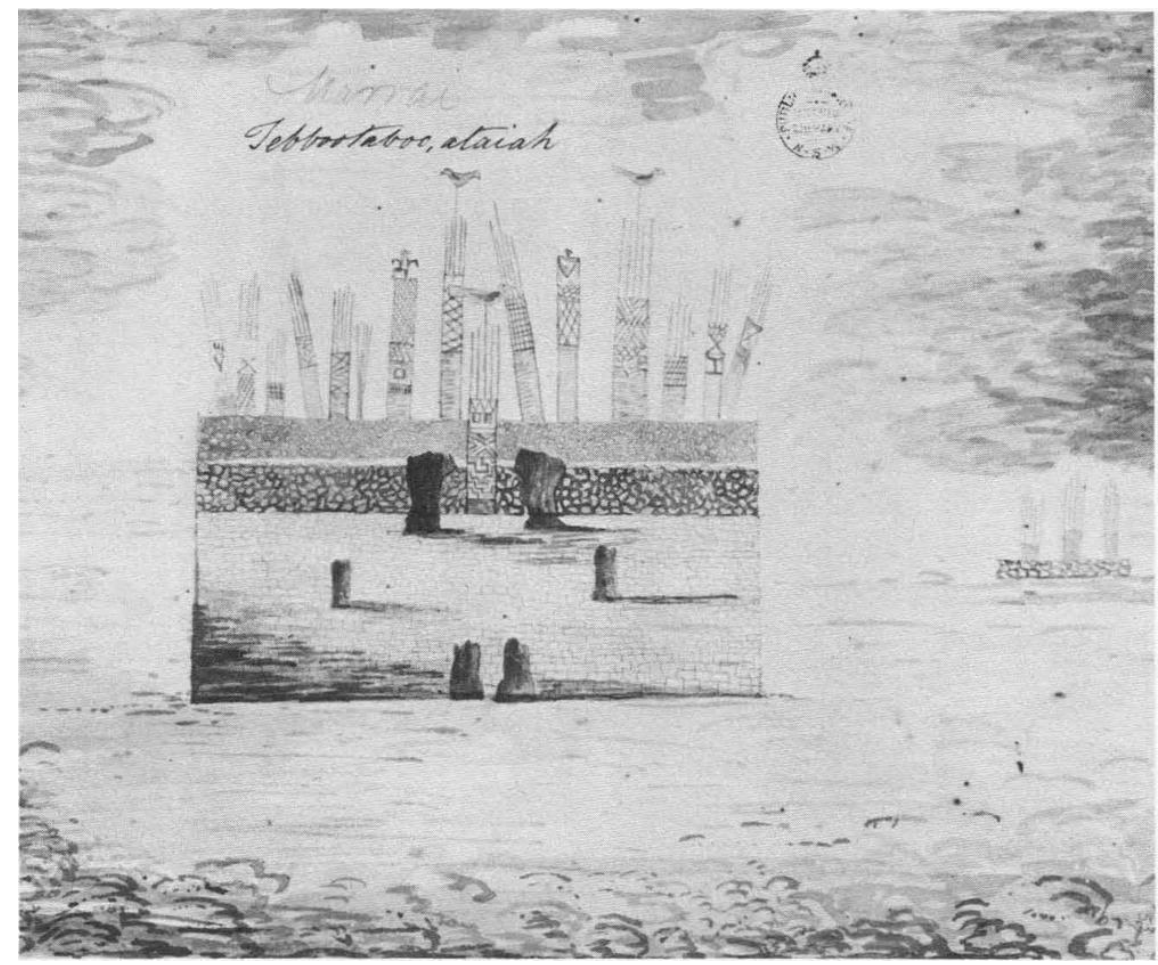

FiguRE 3-12. Marae Taputapuatea, Tahiti. Drawing by W. Bligh. Mitchell Library, Sydney. (Top right, library identification stamp.)

the marae's shorter boundaries-either separated from or continuous with the marae walls. Many $a h u$ consisted of only a rough pile of boulders three to four meters long and one or more meters wide. Others were constructed of carefully worked stone put together to form a single or multilevel platform. ${ }^{45}$ The largest was the ten-step pyramid of Mahaitea marae (Papara, Tahiti), which was about 81 by 24 meters broad at the base and 14 meters high. ${ }^{46}$

An $a h u$ was the place on or near which the congregation's tutelar spirits mainly stayed when they visited the marae. Having few reliable firsthand accounts of actual marae rituals, ${ }^{47} \mathrm{I}$ am not able to describe specifically and comprehensively what uses were made of $a h u$, but I can state in a general way what these elements were not. For one thing, they did not serve primarily as altars for offerings to spirits. One eyewitness drawing shows human skulls resting on an ahu (Beaglehole 1967:224-225); these were the remains presumably either of human sacrifices or of enemies slain in battle, but the food offerings to spirits that formed a regular part of marae rituals were placed elsewhere. Also, although marae functionaries may occasionally have climbed onto $a h u$ for some purpose or other, 
when rituals were in progress and spirits were actually present, they and not humans usually occupied these platforms.

As indicated above, not every structure I label marae contained an $a h u$, but every marae did contain a fixed element, usually one or more stone uprights that served as a principal locus for visiting spirits; and like $a h u$ these were invariably located near one end of the marae. In addition, in many cases stone uprights, usually consisting of worked slabs of limestone or of columns of basalt, were fixed into the tops of $a h u$ or set into the ground against the side of the $a h u$ facing the marae court. In some instances there was only one such upright, but the usual number was three.

Another architectural element reserved mainly for spirits was the $a v a^{\prime} a$, 'gods' bed', found in some marae. It consisted of a small stone platform immediately adjacent to the $a h u$. It served principally as a place for resting the images of the marae's tutelars during the rituals, and as such was considered to be the 'most sacred place' (te vahi mo'a roa) in the marae; but in some cases it served also as the place on which an individual stood when being invested with the highest-ranking Title associated with the marae in question. ${ }^{48}$ Some $a v a^{\prime} a$ are said to have covered a cist in which were deposited the images' discarded coverings.

Most marae contained stone uprights in addition to those mentioned above. Some of these were broad limestone slabs, others were basalt columns; their height above ground ranged from thirty or forty $\mathrm{cm}$ to two or more meters. The numbers of these uprights varied considerably, as did their arrangements. In many cases there was a group of three of them set close to and in front of the $a h u$, and another one or two set near the center of the marae court. In some marae these were the only uprights present, in others there were additional ones facing either the $a h u$ or the center of the courtyard. And in some marae there were no such uprights at all.

Interpretations differ concerning the function of these courtyard uprights. According to various reports they were leaning posts for officiating priests, backrests for the highest-ranking Titleholders of the congregation, resting places for visiting spirits, memorial stones for departed chiefs, and presumably resting places for the latters' visiting ghosts (Emory 1933:16-17). The possibility, or even probability, is that in some marae there were uprights for all these purposes (with considerable variation as to which was which), while in others some uprights served more than one purpose, according to circumstances.

In this connection, one will recall that tapa'u, priests' effigies fashioned out of braided coconut leaves, were sometimes attached to certain stone uprights to represent-and presumably to substantiate-continuous prayer, even when rites were not being conducted.

Some drawings of marae made by visiting Europeans show numbers 
of unu set up in the courtyard and on top of the $a h u$. These were wooden boards a meter or more high, variously carved and painted (usually with red ocher), and sometimes hung with feathers and strips of tapa and matting. Some unu were crudely anthropomorphic, others zoomorphic, but most were in the shapes shown in figures 3-8, 3-9, and 3-12. The sources differ concerning their function. One claims that they were erected to commemorate a human sacrifice, but as Emory pointed out they were also found at marae where human sacrifice did not take place (1933:15). Another account identifies them as memorial posts for local chiefs whose bones had been deposited in the marae, but in Henry's view they served mainly as racks for the objects that were presented to the gods (1928:134). As pointed out by Emory, the fact that they were characteristically set up on $a h u$ whose tops lacked stone uprights suggests that some may have been substitutes for the latter (1933:16).

In describing 'gods' beds' (ava'a) I noted that under some of them were cists said to have contained the discarded trappings of to'o (god-images)that is, items that were too dangerously "sacred" for disposal elsewhere. Stone cists have been found by archaeologists in several marae-in walls, courtyards, and even in $a h u$. Some of them were found to contain human bones, but others were found to contain nothing but soil and rubble. What purpose, or purposes, such cists served is not entirely clear, but there are suggestions in the sources that some of them were used as temporary burial chambers for a marae congregation's most distinguished members, prior to final deposit of the skeleton-or at least the skull-in more secret and secure places elsewhere.

In some of the few marae courtyards that have been excavated were found ordinary noncist burials containing complete or incomplete human skeletons. Some of these may be the remains of members of the marae's own congregation, but there are good grounds for concluding that most are remains of offerings, either victims that were deliberately sacrificed to the marae's tutelars, or enemies slain in battle and brought home as trophies.

As noted above, some offerings to a marae's tutelars may occasionally have been placed upon its ahu or walls, or buried in its courtyard; but most offerings, and particularly foodstuffs and tapa, were placed on the specially constructed altars (fata) already described.

Many marae contained special houses (fare ia manaha 'house of treasure') where images, drums, priests' vestments, and so forth, were stored, and where priests and attendants sometimes slept. These were in addition to the "moveable marae," or "arks" or gods' houses (fare atua, fig. 3-13) described earlier, which were seen on some marae by visitors. Also associated with some marae were special sheds (va'a ti'i, fareva'a a te atua) that served to shelter the canoes used to transport the tutelar images when it was necessary for them to travel. Because the "sacredness" of objects used 
in marae rituals made them too "dangerous" to dispose of elsewhere, special refuse pits and heaps (tiriapera, turuma) were an architectural feature of most marae.

Finally, a requisite feature of most marae was the "sacred" trees, already listed, which grew either within marae boundaries or nearby. Ellis provided a vivid word image of these trees and of the general atmosphere of marae precincts:

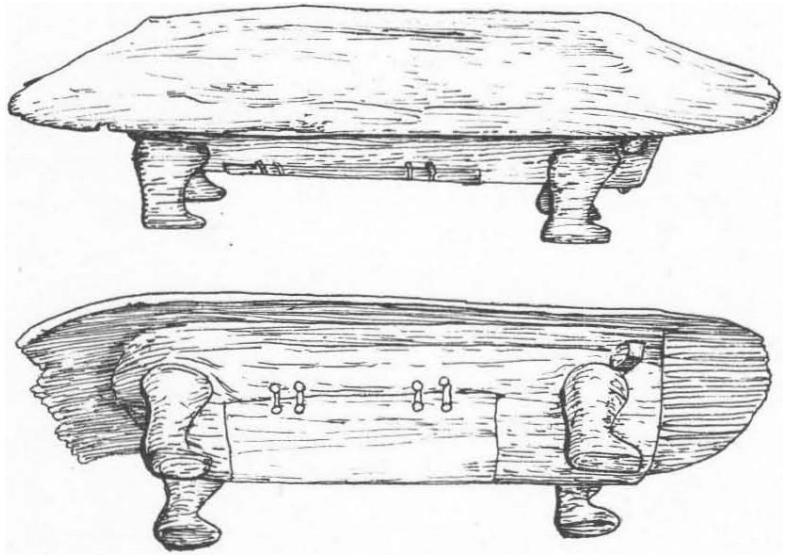

FIGURE 3-13. Wood god's house, length $87 \mathrm{~cm}$. British Museum.

These were, excepting the casuarina-trees, of large foliage and exuberant growth, their interwoven and dark umbrageous branches frequently excluded the rays of the sun; and the contrast between the bright glare of a tropical day, and the sombre gloom in the depths of these groves, was peculiarly striking. The fantastic contortions in the trunks and tortuous branches of the aged trees, the plaintive and moaning sound of the wind passing through the leaves of the casuarina, often resembling the wild notes of the Eolian harp-and the dark walls of the temple, with the grotesque and horrific appearance of the idols-combined to inspire extraordinary emotions of superstitious terror, and to nurture that deep feeling of dread which characterized the worshippers of Tahiti's sanguinary deities. (1829:II, 208)

How "sacred" these marae trees were can be inferred from a passage from Bligh's journal:

In the Morning one of my Officers on shore having plucked a branch of a Tree called Tu tuee [tutu'i] or Tee ighree [ti'a'iri] that bears the Oil Nut, which was growing at a Morai, and accidentally bringing it into the dwelling where my people are at, all the Natives both Men and Women suddenly left it. When I came on shore I found a branch of this Tree tyed to one of the Posts, altho they saw the effect it had of keeping the Natives from the House, and notwithstanding I ordered it away no one would come near the place. They said the House was tabbooed and that no one could come there untill the Taboo was taken off and that must be done by Tynan; he therefore from my Application promised to take it 
away in the After Noon. Any thing taken away from a Morai is said to give great Offence to the Eatua, no one will therefore come near the place where such an Article has been deposited untill they are satisfied that through prayer their God is no longer displeased. (1789:II, 13-14)

Until now I have discussed the structures I call marae as if they had all served the same general purposes, although noting that some were more elaborate architecturally than others. This of course is an oversimplification, and later chapters will reveal that in some instances differences in marae architecture were reflections of specialization in marae functions; (I believe that this and not the reverse was the causal sequence). Nevertheless, all the marae heretofore discussed were alike in being what might be called primary religious edifices-in contrast to those that might be labeled subsidiary ones. The latter were usually located close to, or in some instances directly adjacent to, primary marae; but they seem to have been so physically separated from the latter and so functionally highly specialized as to warrant separate treatment. There may have been several types of such subsidiary marae, but the only type that can be archaeologically identified is the one archaeologists call "shrine" (Green et al. 1967:141).

In most cases shrines were, literally, adjacent to the walls of primary marae. Nearly every edifice so far identified as a shrine contained the same features: three columnar stone uprights near one end with a stone slab backrest in front of and facing them. In addition, in many shrines have been found small anthropomorphic stone images set into the ground between backrest and uprights. It is reasonable to suppose that such images, before they were removed by latter-day curio hunters, were a characteristic feature of many shrines.

The sources are virtually silent concerning the specific functions, distinct from conventional primary-marae ritual, served by these shrines. From their small size and limited architectural elements, however, it is tempting to identify them as places where individual priests-or individuals acting as priests-addressed prayers and queries to spirits concerning matters of less public importance than those transacted in the primary marae itself. In this respect, shrines were practically identical with some of the smaller, discrete primary marae located in large marae complexes. On the other hand, the presence of a stone image on many shrines suggests a somewhat more specialized function-that of protecting the primary marae from hostile spirits by means of a fetcher-type spirit familiar ( $t i^{\prime} i$ ) embodied in the $t i^{\prime} i$-like image (Beaglehole 1962:I, 303). The sources refer to sorcerers (tahutahu), attached to some of the larger primary marae, whose office was “... to avenge the king and chiefs on their enemies, to annihilate offending tahutahu of an inferior order, to destroy a national foe, and to aid the warrior by performing deadly rites upon slain or captured chiefs in time of war" (Henry 1928:206). 
Maohi marae were located in a variety of settings: on the shore itself (sometimes even built out into the lagoon), on the flat coastal plains or on valley floors, and on the sides or summits of hills. According to Emory the builders seem to have followed no consistent rules of orientation either with regard to loci on the horizon or to the slope of the land (1933:26, 31).

Some marae were unitary, others were parts of complexes which included one or more principal "primary" edifices, a number of small lesser ones, shrines, an open courtyard for "secular" meetings, and occasionally an archery platform (figs. 10-1, 10-2, 10-3). A few of the smaller edifices were located near what appear to have been dwelling sites; these were probably what Henry called "family" or "ancestral" marae (1928:119). The ones associated with larger social units and more widely venerated gods probably were well isolated from dwellings, because-among other factors-of the mutual necessity of separating them from the usual haunts of females.

The basic function of marae was everywhere the same-to provide humans with fixed places and appropriate appurtenances for communicating with the gods “... in a befitting manner" (Henry 1928:429). Also, each marae had its own more or less exclusive congregation; but the character of such congregations greatly differed, as did the particular purposes which each marae served. These matters, which concern in large measure the very structure of Maohi society, will be discussed in later chapters; but I will list here the types of social units which comprised congregations: kin groups of various sizes and spans, occupational "guilds," tribes, and supratribal cults.

In the foregoing it has been made evident that females were generally excluded from most marae. Some sources imply, however, that they were admitted to services at their own family's domestic place of worship. There were occasions, such as the inauguration of a chiefess or the marriage of an upper-class couple, when the female principals were admitted within the precincts of larger and more public marae, but at such times elaborate steps were taken to insulate the marae from the women's ritual-nullifying "secularity" and to protect the women in question from the marae's dangerous "sacredness." This, however, does not mean that females did not "belong" to marae congregations or that they remained in social and religious limbo in this regard. All it does mean is that they were not active participants in marae rituals; in this respect males were their representatives and acted on their behalf.

The concept of "congregation" also requires broadening in another respect. While it is true that each marae was associated more or less exclusively with a single social unit, whatever its nature or scale, there may have been occasions when exclusiveness did not prevail, for example: 
Their morais are a kind of refuge for criminals of every kind; they fly to them when in any imminent danger, and, according to the custom of the country, must not be taken from thence (Turnbull 1813:366).

The sacred ground around the morais affords a sanctuary for criminals. Thither, on any apprehension of danger, they flee, especially when numerous sacrifices are expected, and cannot thence be taken by force, though they are sometimes seduced to quit their asylum. (Wilson 1799:339)

Interpreted broadly this could indicate that fugitives in general, (but not, evidently, intended victims for sacrifice) might find refuge in any marae (and not just those with which they were somehow affiliated). A text in Henry about these intended victims notes: “... fugitives that were chased by warriors, conspirators and captives who were chased to be slain, would run to the front of the marae and were saved. But persons destined to be sacrificed, found no place of refuge in all the land. When they ran before the marae, they were slain there, that was their proper place" (1928:150). Unfortunately, the evidence available permits me neither to confirm nor deny the possible generality of this statement, with its potentially far-reaching social implications. In this connection I note a passage from Henry regarding the extension of the notion of marae sanctity: "The house of a great man [ta'ata mana] became his marae; persons escaped being slain when they ran into his home, except those appointed for sacrifices" (1928:150-151).

I reproduce a chant, published in Henry and collected by Orsmond from the high priests Tamera and Pati'i. Some of its passages and references will already be familiar to the reader; others will become clearer as this description proceeds. It indicates, better than any other native text I have discovered, the central importance possessed by these edifices in the thoughts and activities of the Maohi:

O te marae nei te mo'a e te hana-hana o te fenua; 'o te teoteora'a ia o te ta'ata no teie mau fenua. $\mathrm{O}^{\prime}$ to te fenua ia unuana te marae; a aora'i ia i pupu hia na te atua.

'A'ore e ta'ata i ta'ahi noa i to te tahi e ra marae, i ha'apao ra $i$ to ratou iho. No te marae tupuna nei i tao hia ai e e ai‘a fenua to te ta'ata.

$E$ vahi hahano rahi e te hau rahi te marae; ei tere pure to te ta'ata i tae atu ai i reira 'a'ore atu e tere ê, A'ore te atua i vare. Ia tae te ta'ata i te vahi marae ra, e nao e atu ia te haere, e tu'u i te ahu i raro mai te tapono e tae atu i te papa, e mau raro hia te hopoia i te rima, e ia moe atu taua marae ra.
Marae were the sanctity and glory of the land; they were the pride of the people of these islands. The ornaments of the land were the marae, they were the palaces presented to the gods.

People did not intrude upon others' marae, but they adhered to their own. It was owing to the ancestral marae that people could say they had an inheritance.

A place of dread and of great silence was the marae; a person's errand must be to pray in going there, but for no other purpose. The gods could not be deceived. When persons approached a place where stood a marae, they gave it wide berth, they lowered their clothes from their shoulders down to their waists, and carried low their burdens in their hands, until they got out of sight of it. 
Ei te otue toro i tai ra te marae ari'i; ei te ooa ra ta marae o te ra'atira; 'o uta ra na te mau poti'i ia, oia te manahune.

E vahi ra'a te marae, e vahi hahano; e fa'atupura'a manava hirahira, e vahi iriha te marae.

E mea ri‘ari‘a roa te marae o te hui ari'i; te marae tupuna e te marae o te fenua! E vahi turuma ta'a e roa, e vahi amiami e te hauriria; e vahi mamae no te tahu'a e te fatu, e na te mau ta'ata ato'a. E mea mamae te patu marae; ia hape noa te pua'a i te patu marua ra, e'ore roa te fatu pua'a e'ite fa'ahou atu, mo'a ihora ia na te atua. Te va'a e hoe na tahatai ra e fa'a'ateatea roa ia tae i te otue marae ari'i ra, e tu'u te ahu o te ta'ata i raro, e hoe maru noa e ia ta'a e atu taua vahi ra.

E mana to te tihi marae; te ta'ata e a'ua'u hia e te 'aito ra, te orure hau e te titi, ia a'ua'u hia e tupai ra, e horo i mua i te marae e ora ia. Area ra te ta'ata i ha'apaohia ei tapu ra, 'a'ore a'na e vahi oraora i te fenua nei. Ia horo oia i mua i te marae ra, o te ha'apohe ra'a 'tu ia, o te vaira'a mau ia.

I riro te fare o te ta'ata mana ei marae no'na; e ora te ta'ata ia horo iroto i taua fare ra, eiaha te feia i ha'apaohia ei tapu. No reira te parau i nao hia nei e: "E are 'oe i te iriaputa mua o to' $u$ fare; o ta'u marae hoi to'u fare, o te āhu mua tei to'u iriaputa mua."

E mea poiri rumaruma i te ra'au nui o taua mau marae ra; e o te hau roa i te ra'a o te miro ia, oia te amara; $\mathrm{E}$ ta'ere tera no te 'oro'a; E ta'ere tera no te Ari'i; E fa'a'ara i te atua; E ha'amau i te maro o te Ari'i.
Upon the prominent points were the royal marae; in the bays were the gentlemen's marae; and behind them were the marae of the girls, that is, the common people.

A holy place was the marae, an awe-inspiring place; it was a place that awakened conscience, a dreaded place.

Terrible were the marae of the royal line; their ancestral and national marae! They were places of stupendous silence, terrifying and awe-inspiring; places of pain to the priests, to the owners, and to all the people. The walls of these marae were repelling; when a pig chanced to stray upon a wall fallen down, its owners never saw it again, it became sacred to the gods. When a canoe passed along the shore, it withdrew far off as it approached the point where stood the royal marae, the people lowered their clothes, and paddled lightly until they passed the place.

Potent were the horns of the marae; fugitives that were chased by warriors, conspirators and captives who were chased to be slain, would run to the front of the marae and were saved. But persons destined to be sacrificed, found no place of refuge in all the land. When they ran before the marae, they were slain there, that was their proper place.

The house of a great man became his marae; persons escaped being slain when they ran into his home, except those appointed for sacrifices. From this circumstance arose these words: "Beware of the front door of my house; my house is my marae, the front door has the front step."

It was dark and shadowy among the great trees of those marae; and the most sacred of them all was the miro which was the sanctifier. That was the basis of the ordinances;

It was the basis of royalty;

It awakened the gods;

It fixed the 'uru girdle of sovereigns.

(Henry 1928:150-151)

\section{Religious Ritual}

Nothing is so fruitless as academic argument over how terms ought to be defined, and this applies especially to religion and ritual. But rather than introduce new terms as means of avoiding such argument, I am going to use the familiar ones in their following meanings:

Ritual: behavior that is normatively defined and precisely conventionalized. 
Religious: objects and actions (including mental actions) that have to do with relations between spirits and humans.

Putting these terms together provides us with a definition of religious ritual, Maohi manifestations of which I will now summarize.

In line with a currently fashionable urge for analytic elegance, it may be possible to view Maohi religious ritual as a distinct language; this parallel cannot be pushed too far, but religious rites did indeed consist of a finite number of objects and actions which had explicit meanings and which were put together in different ways for different objectives.

First of all, included in the repertory of Maohi religious ritual was a number of natural objects; the most frequently used were feathers, blood, plantain shoots, rosewood leaves and branches, the ti plant, and sea water.

Feathers. A description and at least partial explanation of these most effective of all ritual objects were given earlier.

Blood. Human blood figured in religious ritual in a number of ways. It was smeared over the bodies of human sacrifices in offerings to 'Oro, presumably to make them more acceptable to that sanguinary god. It was shed by individuals through self-inflicted wounds to express both sorrow and joy; and when the blood of two persons was mixed, it served as a solemn pledge of social alliance. One seeks in vain for distinctively Maohi rationales for these meanings; perhaps they are nothing more than local variations of obvious and near-universal ones. However, it is tempting to link the redness of blood with that of certain feathers, although these two things were not apparently substituted for one another in ritual and there are no clues as to which derived its ritual importance from the other.

Plantain (met'a). Young shoots of this valued food plant are described in the sources as possessing three ritual "meanings"-having served as tokens of peace, as marks of deference, and as substitutes for humans in ritual situations. ${ }^{49}$ Cook described the first two:

The Plantain tree so often mentioned is always the first thing interduced, not only in all thier Ceremonies but in all their debates, whether of a publick or private nature, it is also used on other occasions, perhaps many more than we know of. While Towha was at Eimeo one or more Messengers came from him to Otoo every day, the Messenger always came with a young Plantain tree in his hand which he laid down at Otoos feet before he spoke one word, then sat himself down before him and related what he was charged with. I have seen two men in such high dispute that I have expected they would come to blows yet on one laying a plantain tree before the other they have become cool and carried on the argument with calmness. In short it is upon all Occasions the Olive branch of these people. (Beaglehole 1967:218)

Cook's examples were taken from nonreligious situations, but the plantain was used with similar meanings in religious ritual as well. As examples 
of the third kind of usage, such shoots, called 'man-long plantains' (ta'ata met'a roa), were used to represent or substitute for a human in connection with offerings, divination, sorcery, and scapegoating. The first two usages could be seen as linked; so might indeed the third as well, but that must remain speculative.

A cylindric piece from the heart of a plantain-tree stem was rolled over the skin of certain infants, to "purify" them, but it is not clear what the plant's properties were that led to this use of it other than the fact that it was in this context called "plantain of the gods" (Henry 1928:183).

Tahitian Rosewood (Thespesia populnea: miro, amae). This was a favored tree of the god Ro'oteroro'o, and presumably of other gods as well, inasmuch as some of them commonly communicated with humans by means of the rustling of its leaves. It was found growing within the precincts of many marae. Out of its durable and strikingly colored wood were carved some spirit images and ceremonial thrones (Henry 1928:190n), and twigs of it formed part of the shelter set up in marae to celebrate natal rites of offspring of high-ranking kin-Titleholders. Its leaves were offered to the gods as a substitute for kava (Henry 1928:161), and sprigs of it were held by priests as they prayed.

The various religious uses of rosewood are comprehensible in view of its association with Ro'o the Prayer Chanter, Tane's messenger and patron god of the priestly occupation of praying. But how this association came about in the first place is not explained in any myth known to me; nor is it clear historically whether this tree derived its religious associations from a natural proliferation at sites favored for marae, from the sculptural properties of its wood, or from some simile of name or of attribute.

Ti (Cordyline terminalis). The long glossy leaves and stem of this characteristically Polynesian plant served a variety of purposes, religious and otherwise. According to Henry, of the thirteen varieties of the plant distinguished by the Maohi, ti'uti was most favored for religious uses, and it was cultivated at marae (1928:37). In connection with religious ritual the ti plant was used to validate a marital agreement (Henry 1928:281); to inspire war orators (who were in fact called rau-ti 'ti leaf'); to protect ritual firewalkers from burns; and so forth. Some beliefs served to interlink and validate ritual uses of ti-for example, the patron goddess of firewalking wore ti-leaf skirts (Henry 1928:214); but I can discover no Maohi myths that "explain" such uses. Nor can I perceive how any natural attributes of the plant, except possibly its convenience in carrying, might have led to its ritual uses in the first place.

Water. Seawater, especially, had a number of ritual uses-serving mainly as a means (through sprinkling, bathing, or immersion) of investing some 
person or thing with sacredness, or of removing both sacredness and ritual contamination. Beyond the obvious everyday Maohi uses of water for cleansing purposes, I can discover no specific rationale-mythical or otherwise-for this Maohi version of a near-universal type of ritual practice. In this connection, I should mention the occasional ritual use of coral or sea moss as substitutes for seawater.

Several other plants were used in connection with religious ritual, but with less generality and frequency. Among these were ironwood, sugarcane and its juice, sandlewood oil, turmeric, maire fern fronds, coconut-palm flowers, cream of the coconut itself, and breadfruit. However, aside from certain valued physical attributes of these plants and plant products (e.g., hardness, sweetness, aroma, color, consistency, taste), I can find no specific mythical charters for their ritual employment.

To the list of ritual objects must be added human skulls, which served as "vehicles" for spirits. Also should be added the plants and animals regularly used as offerings to the spirits: kava, vegetable foods of several kinds, pigs, dogs, chickens, fish, turtles, and of course humans.

Besides the natural objects just listed there were several fabricated ones used regularly in ritual. Chief among these were the images ( $\left.\operatorname{to}^{\prime} O, t i^{\prime} i\right)$, prayer surrogates (tapa'u), and prayer tallies (viriviri) already mentioned, and also sennit (rope made out of coconut husk fiber), bark cloth (tapa), mats, and spears.

All the above-mentioned natural and fabricated ritual objects figured in more than one kind of rite, but most of them retained more or less the same "meaning" in all or nearly all the rites. Again, the "messages" of some of the ritual objects, such as plantain shoots and rosewood branches, were expressed simply by placing the objects in view, but in other cases it was necessary to handle the object with some conventional ritual action. I have already described some kinds of ritual actions: petitioning with words, offering objects, shoulder baring, drum beating, and (possibly) dancing. Some other of the more frequently employed ones are as follows:

Prostration. Ordinarily, respect for most manifestations of powerful spirits (and for humans holding very high-ranking kin-Titles) was expressed by shoulder baring or crouching, but in the immediate presence of such a god as 'Oro, men (women were not usually permitted so close) wholly prostrated themselves.

Self-offering. As a final appeal to a god on behalf of some ailing kinsman or superior, individuals sometimes tied cords around their necks and had themselves presented to the god as one would offer a pig for sacrifice-an expression of humility, it would seem, but not one to be accepted literally. 
Self-bleeding. Few customs of the Maohi so amazed and puzzled their European visitors as self-bleeding.

When a woman takes a husband, she immediately provides herself with a shark's tooth, which is fixed with the bread-fruit gum on an instrument that leaves about a quarter of an inch of the tooth bare, for the purpose of wounding the head, like a lancet. Some of these have two or three teeth, and struck forcibly they bring blood in copious streams; according to the love they bear the party, and the violence of their grief, the strokes are repeated on the head; and this has been known to bring on fever, and terminate in madness. If any accident happens to the husband, his relations or friends, or their child, the shark's tooth goes to work; and even if the child only fall down and hurt itself, the blood and tears mingle together. (Wilson 1799:340)

Women also used this means to express (or at least display) great joy, as upon the occasion of the return of a close relative after a long or dangerous absence. The custom was practiced more often to express "grief" resulting from bereavement, and as such it had both social and religious rationales. In connection with the latter, which is our present concern, it will be recalled that blood constituted a highly acceptable offering to 'Oro; and while a similar appetite need not be imputed to all spirits, it is not unreasonable to suppose that the ghosts of individuals being grieved for found satisfaction in this painful sacrifice of their survivors' precious blood. There were other highly conventionalized ways of displaying bereavement, including both wet-and dry-eyed weeping, but none apparently so telling as self-wounding and the copious flow of blood.

Conjoining. Blood also served ritually to symbolize marriage, but a more common way of ritualizing alliance-marital or political, or rather maritalpolitical-consisted of placing together two pieces of tapa. Conversely, disjoining was ritualized by tearing apart some token of unity. While both of these ritual actions directly involved relations between human social units, they presumably involved the spirit members of these social units as well.

Burying. Burying an object had the effect of confining its associated spirit to the immediate area. One manifestation of this was the practice of interring human sacrifices within marae precincts; another was the practice of burying the image of an unwanted tutelar spirit in some remote spot. Still another was the custom of filling in the hole containing a corpse's "sins."

Scapegoating. This also was employed as a special means of removing an unwanted spirit-associated object, often by sending it off to sea in an unmanned canoe.

Burning. In this connection it is noteworthy that burying and scapegoating were practiced far more frequently than burning as a means of dissociating unwanted spirits from humans. The assumption perhaps was that total 
destruction of an object-medium merely released its associated spirit, and nearby, at that.

From an observer's perspective the rationale for most Maohi ritual actions lies in metaphor, but whether the Maohi themselves regarded their actions in this light is a question that cannot be answered because of lack of myths or other evidence concerning their invention.

While all ritual objects and ritual acts had fairly explicit "meanings," they were employed to achieve various kinds of objectives by putting them together in various permutations. Self-bleeding, for example, could be employed either to turn aside the recriminations of a kinsman's ghost or to enlist a spirit's aid in revenging a political humiliation depending upon what other kinds of prayers and offerings went with it. Some of these combinations will be listed when I describe particular rites, but first it will be useful to list the more common, explicit and public, general objectives for which rites were performed. (I shall also leave for later discussion the "implicit" or "esoteric" or "underlying" objectives which some writers believe they can perceive in some Maohi rites. It was as true of the Maohis as of all other humans that they often performed rites for private, individual reasons which were in addition to or even contradictory to the rites' conventional purposes.) Some of these objectives were:

a. to invest with a spirit's presence a place, an object, or a person, in order to communicate with that spirit;

b. to dispossess a place, object, or person of a spirit's constraining presence;

c. to secure spirit validation for some social relationship: a marriage, a friendship, a political alliance, et cetera;

d. to enlist a spirit's aid in some specific, stated enterprise, such as causing crops to grow, fish to bite, tools to work, weapons to strike; or injuring or destroying an enemy, through sorcery; or protecting oneself, one's possessions, or one's enterprises;

e. to insure spirits' continued assistance in maintaining success and well-being;

f. to persuade a spirit to nullify the consequences of past errors; and, more rarely,

g. to render thanks to a spirit for past assistance.

In some cases a rite (oro' $a$, either a single integral ritual action or a whole series of partial constituent ones) had only one such "public" objective, but most Maohi rites had two or even more.

Most Maohi religious rites were so inextricably implanted in what Westerners would call the secular activities of life that they will be described in those contexts in chapters to follow. Here, however, I will 
describe two kinds of rites which had to do with ritual itself-the first with maintaining the prerequisites for it, the second with saving humans from the consequences of having performed it incorrectly, or too infrequently.

Paiatua. This grandest of all the Maohi religious rites was performed only at the so-called national (i.e., tribal) marae. ${ }^{50}$ According to Moerenhout, it took place every three months, at the beginning of each "season": beginning of "spring," in early October; beginning of "summer," late December or early January; beginning of "autumn," March or April; beginning of "winter," in June ("the season of mourning [for] the departure of the gods") (1837:I, 515).

In Henry's view, on the other hand, paiatua was performed as a part of or a prelude to other important rites marking, for example, the inauguration of a chieftain, or his prolonged illness, the cornerstone laying of a new marae, or the rehabilitation of a district after some great calamity. I prefer Henry's point of view over Moerenhout's because the latter appears to have confused paiatua with certain other rites, and to have exaggerated the importance, or indeed fabricated the very existence, of a Maohi four-season calendar. Another basic reason I prefer Henry's view to that of Moerenhout is that the former, working mainly from Orsmond's notes, was in a position to be far better informed about Maohi customs in general, and about Maohi religious ritual in particular.

Paiatua required three days to perform, preceded by a considerable period of preparation and followed by a day or more of feasting and other diversions. All members of a marae's congregation took part in the rite, although women and children were as usual only remotely and indirectly involved.

Three things had to be done in preparation for a paiatua, as well as for any other important public marae rite: a large supply of foodstuffs had to be collected and made ready for offering and feasting; the principal ritual officiants had to prepare themselves "spiritually" for their duties; and the marae appurtenances had to be put in order. Specific information about the first of these activities would be invaluable for an understanding of Maohi social relations and economics, but such information is unfortunately scant. A general account of priestly self-preparation was given earlier in this chapter. The activity of putting in order the marae's appurtenances (and ritual objects) must have preceded the rite itself by many days and even weeks, since it included painting or replacing the tutelar god's official canoe, and the manufacture of a large supply of fine white tapa by the marae's staff of big-bellies.

After everything was ready, and during the two days before the main program of the rite, messengers of the marae's principal proprietor went through his realm bearing the following proclamation: 
E fati 'ava, e fati 'ava!

Auanei e fati ai!

Te ara i te tai e taimara hia,

No te va'a hoehoe a te atua,

Eiaha te va'a ta'ata ia fa'afarerei.

Eara i te 'e'a i uta, na te ari'i,

E ara, aua'a e haerea

Te ara nui e te ara ri'i!

Aua'a ana'e ia!

Ei ahi tapo'i;

Eiaha ei turama, a mahuta te atua;

Te ra'a no te atua e purara.

E vaere'a marae apopo;

Ei a'ahiata apopo atu,

E fa'aarara'a,

E fa'aaraara'a i te atua.

A ara o taura tahu'a,

A ara mai apopo!

E hopu i te vai,

Mirimiri i te mata,

E hume i te maro 'uo,

E noho i ni'a i te mahora

E noho e upu i te ahoa

No te vaere'a marae.

O te ara o te ari'i,

Te ara o te ta'ata,

To ara o na hui tapairu,

E e'e i te papa.

E ra'a apopo,

E vaere'a marae.

Ei te a'ahiata nui atu

E fa'arara'a atua.

O te atua i ni'a, te atua i raro;

Te atua i tae, te atua i uta;

Te atua i roto, te atua i vaho:

$\mathrm{E}$ tae ana'e mai i teienei oroa.

E ra‘a, mo‘a!
The ava breaking, the ava breaking!

It is soon to break!

Avoid the sea restricted,

For the god's canoe for errands,

The people's canoes must not meet it.

Avoid the roads on shore, for the king,

Take heed and pass not

The highway and bypaths! Avoid them all!

The fires must be extinguished;

Burn no light, lest the gods take flight;

Sacredness of the gods will pervade.

Weeding of the marae tomorrow;

The following morning early,

The awakening,

The awakening of the gods.

Awake, O body of priests,

Awake and come tomorrow!

Bathe yourselves,

Feel your faces,

Draw on the white girdle,

And sit upon the lawn

To recite the ahoa (life giving)

For weeding the marae.

'Tis the awakening of the king,

The awakening of the people,

The awakening of the waiting maids

(lay worshippers),

Who will alight upon the stones

(marae).

Sacredness tomorrow,

Weeding of the marae.

And in the early morning following Awakening of the gods.

The gods above, the gods below;

The gods of the ocean, the gods of the land;

The gods within, the gods without;

They will all come to the ordinance.

'Tis sacredness, holiness!

(Henry 1928:158-159)

The rite itself was ushered in at nightfall by the beating of the marae's great drum, thereby announcing the prohibition of all ordinary activities, such as burning lights, cooking food, farming, traveling, and fishing. "No living being must roam about, no dog must bark, no cock must crow, and no pig must grunt or squeal; only the occasional sound of the marae drum should break the silence" (Henry 1928:159).

Early the next morning the principal men of the realm repaired to the marae and proceeded with the formal work of cleaning it; this vaere'a marae consisted of scraping accumulated moss from marae stones and of weeding and sweeping the courtyard. The principal laymen worked at their job 
from west to east and deposited in the marae's refuse pit all the trash they collected- "... blindness or death from the gods being the supposed sure consequence if they scattered it to the winds" (Henry 1928:159).

While this work was taking place the marae's priests sat to one side and chanted an ahoa (breath-giving chant), with repetitions and permutations of the following kinds of phrases:

It is marae weeding!

The scraping of moss for [the god] Ro'o-te-roro'o

And for the host of gods.

The moss will be scraped.

The grass will be pulled up

And swept will be the ground

To render the marae attractive

To Ro'o-te-roro'o and to all the host of gods.

(Adapted from Henry 1928:159-160)

Meanwhile the marae's attendants, the big-bellies, made new coconutleaf prayer surrogates and prayer tallies, hung new strips of tapa and matting on unu boards, and erected posts to serve as perches for visiting gods in their bird incarnations. They also cleared and refurbished the altars, laying out miro leaves for the gods as substitute for kava-a leaf for each principal god invited to the rite, with some extra leaves for whole classes of gods, collectively, in order to avoid slighting any of them and thereby incurring their displeasure and attendant penalties.

As night approached the priests proceeded to the marae to summon the gods by means of the messenger gods ('arere), whose images they set up and bathed, symbolically but not actually, in a basin of water formed out of a large leaf of bitter taro ('ape: Alocasia macrorrhiza), after first having consecrated the leaf and water to the purpose, and after repeating in unison two prayer-chants. The first chant was 'Maui's marae and altar blessing':

Ia ora te fenua! Ua ora te ma'i o te marae, ua vaere hia, ua ioio. Ua ora te ma'i o te unu.

Ua ora te ma'i o te fata rau.

Ua ora te ma'i o te 'utuafare o te atua. E haere ana'e mai te atua, e û ma te uri.
May the land live! The marae is restored, it is weeded and become handsome. The carved ornaments are renewed. The altars are renewed. The home of the gods is renewed. The gods will come, and gather in the darkness.

(Henry 1928:162)

Then it was followed by the 'preliminary invocation' (tarotaro):

E te atua e! e aroha mai i to taura tahu'a nei. E fare nohora'a to te 'opu-nui, e to te mau uru, e pure 'iri anu ra matou, e 'ore e ta'oto, i teie 'aru'i, e rari i te hau, eiaha rà ia rari i te ua e te atua $e$ !
O gods! Have mercy upon your body of priests here (present). The 'opu-nui and the possessed images have a house, but we shall be praying chilly, without sleep, this night; we shall be wet with dew, but let us not be wet with rain, $\mathrm{O}$ gods!

(Henry 1928:162) 
This second chant refers to the ritual requirement that priests say their prayers in some physical discomfort-for example, wearing thin and coldconducting garments in the chill night air. But, they plead, "do not add to our misery by causing rain to fall as well!"

Then the spirit messengers were sent forth by the priests with an injunction called 'sending-off-of-messengers' (tu'utu'ura'a 'arere), which in the case, for example, of 'Oro's marae of Opoa, (Ra'iatea) began as follows:

O Ti'a-o-atea, messenger of the gods, arise and feel thy face, bathe in the water, draw on thy loin-girdle, put on thine official clothing, take a great walking stick, and run to Red-Mountain in Tana'a, for Tane and his host of gods to come to Opoa, as gods for this rite.

There is prayer in this world, in the home of Warrior 'Oro.

O Rei-tu, messenger of the gods, arise, and feel thy face, bathe in the water ...

and so on, thus sending off each messenger by name to invite some specific god, and ending with a general invitation:

Arise and run, O messengers here present, to those gods, and they will bid the numerous gods, the thousands of gods, the gods above, the gods below, the gods of the sea, the gods of the land, the gods without, the gods within, the gods of darkness, the gods of light, to come as gods for this rite.

There is prayer in this world, the messengers are dispatched! (Adapted from Henry 1928:162-163)

Continuing in this vein, the high priest "reported" the arrival and favorable reception of each messenger at his destination and then "announced" his return with the god thus summoned-a lengthy repetitious exercise which took many hours to perform and ended with a dawn-greeting chant whose poetry even the purported "translation" cannot entirely spoil:

Ua taha te ata i te ra'i,

Ua ara te ata!

Enà te ata e hiti

E hiti i te po'ipo'i;

E ata i puia-

Puia ia ata poiri,

I oti matietie,

E mara'ara'a mai 'Oro-pa'à,

Te fatu moana, mai.

O maru i te pô

A taha te ata e hiti,

O te ata e taupape,

E fana 'tu i te râ.

I puia ia ata,

Aua'a i oti matietie,

E mara'ara'a mai 'Oro-pa'à,

Te fatu moana mai.

O maru i te pô

A taha, a ohiti te ata

E tautape, e tatapa

E fana 'tu ia ata 'ura'ura,
The clouds are bordering the sky,

The clouds are awake!

There are the rising clouds

That ascend in the morning,

Clouds that are wafted-

Wafted are those dark clouds,

Made perfect,

And lifted from 'Oro-pa'à,

Lord of the ocean.

In the shades of night

The clouds that rise embank,

The clouds condense, and

Form an archway for the sun.

The clouds are wafted,

Perfected betimes,

And lifted from 'Oro-pa'à,

The lord of the ocean.

In the shades of night

The clouds do rise, and part,

Condense, and reunite

Into an arch of red clouds, 
No te râ e hiti mai

Mai ‘Oro-pa'à o te moana mai.

Ua ao, e ti'i ra tatou i te atua, ia oti te pai atua, o te ro'o noa hia mai ho'i e te ta'ata e pohe atu i tona aro.
For the sun as it rises

From 'Oro-pa'à of the ocean.

It is daytime, let us now fetch the gods, that we may get through the assembling of them before people come and die in their presence.

(Henry 1928:165)

The third and climactic day of paiatua began with a procession to the $a h u$ of the marae led by the presiding priest. First in line were four "nurses" carrying the ark containing the image of the marae's tutelar god and shouting the god-calling "ho, ho, ho." Behind them walked priests bearing images of the marae's subordinate gods, and priestly representatives of all other marae in the district-familial, guild, and so forth-each carrying his congregation's god-image wrapped in its usual coverings. Last of all were the district's sorcerers with their fetcher-images. Only these and the marae's own clerical staff and official pray-ers (opure) were present at the marae on this awesome occasion; all others had to wait outside.

When the ark containing the tutelar image was deposited on the ava'a before the $a h u$ the climax of the rite began to unfold. With everyone seated the presiding priest took out the tutelar god's image from the ark and removed its wrappings. Then, while the wrappings were being removed from all the other assembled images, he intoned a prayer-chant, calling upon the god to restrain his devastating power while the image was thus exposed to public view. Thereupon, all present prostrated themselves and greeted the god, who replied (through the presiding priest) with a warning against thwarting him in any way.

Next came the taritoara'a atua (the god's exchange). ${ }^{51}$ Each imagebearer presented his exposed image before that of the uncovered tutelar god. In doing so he handed the tutelar's priestly guardian some new red feathers, and he received in exchange some of those that had formed the covering or had been stored inside the tutelar's own image. This action was, according to Henry, "... supposed to add new power from the greater god to the lesser ones" (1928:167). In other words, it was an act of central importance in Maohi religion and, as we will see, in Maohi politics as well.

Occasionally, reported Henry, an exchange was made on behalf of an old and desecrated image, one whose feathers had been stripped by an enemy in time of war-a predicament described as ludicrous to the gods and mirthprovoking to humans. Newly made images were also presented before the tutelar's image, whose priest provided them with consecrated feathers to the accompaniment of these words to his god: "Here is the image, here are the feathers; the image with feathers represent thee, O god: My invocation will enter over there; it will hold over there." (Henry 1928:168) 
Last in turn were the sorcerers with their fetcher-images, and after this a 'sacred male pig' (pua'a tapena) was offered to the tutelar god, along with a prayer of atonement ("to set free sinful man"). Then, all the images were covered in new wrappings, drums announced to the populace the completion of the episode made so dangerous by concentration and exposure of much sacredness. Outside the marae, restrictions on ordinary activities ended with this announcement, but inside the rite proceeded, with 'praise of the people' (umere a te ta'ata), in which the chief and other notables joined with the clergy in shouting "ho ho ho," in hand clapping, and in chants of praise and of petition, ending with a 'saving invocation' (upu fa'atonu), which went as follows:

Hearken unto us, O gods!

Those numerous gods, those thousands of gods, turn unto us, accept our petitions!

Preserve the population of this land; preserve the generation; may they live in the gods. Preserve the frontiers of the people's habitations. Watch against the man with rough cheeks, the man with angry looks, against the incendiary, against him who lets fly the ends of his loin-girdle [one so fleet of foot-intent on evil-that the ends of his girdle flew as he ran]. Put all those things entirely away. Preserve us human beings, O host of gods! (Henry 1928:171)

While this was going on more offerings were presented to the gods: pigs, dogs, and a long plantain shoot, in lieu of a human sacrifice.

Then the 'grand dismissal' (parima nui), quoted on p. 67, was chanted; the prayer called upon the gods to release the lay participants from the restrictions of sacredness. This was followed by a prayer from the presiding priest:

Ua ora te ma'i o te marae, ua vaere‘a ua ahoa hia! Ua ora te mai o te ari'i e o te va'amata-eina'a; ua tui roto hia, ua pe'e te hara; ua pure hopu hia, e ua mâ. Teie te 'ura, teie te hauniu, teie to ta'ata o mei'a roa; te omi'i ma te avae, te avae ma te omi'i, ei utu i to riri hotua nui, e te Atua; no te hara nui, no te tu'utu'u, no te tae reo, no te atua i ma'au hia, no te rimu o te marae $\mathrm{i}$ va'u hia i hara hia, no te mimiro 'oau, no te mata mataêa, no te tuhi, no te ahua, no te fa'atomo i te varua ino ia vetahi e. Tei reira te hara e uri mai ai 'oe, e te Atua?

E tara mai, e homai ia meia roa nei, e huri i tai nui atea, ia ora to maru. E te Atua e a parima mai i to pu'e 'opure nei, ua mo'a.
The evil of the marae is repaired, it has been weeded, accompanied with the chant! The evil of the sovereign and of the clans is ended; the inner service has wiped out sin, the closing prayer is finished, and all is clean. Here are the 'ura feathers, here is the peace token of coconut flowers, here is thy man, long banana, from his head down to his feet, his feet to his head, to arrest thine anger of great growth, O god; for great crimes, for family discord, for hasty words, for irreverence to the gods, for imperfectly scraping off the moss of the marae, for rankling rage concealed, for mutual estrangement (of friends), for cursing, for annihilating by sorcery, for sending evil spirits into others. They are the sins which displease thee, O god?

Undo them, place them upon long banana here present, cast them into the trackless ocean, that thy devotees may be saved. O god, dismiss these thy worshipers for they are holy.

(Henry 1928:172-173) 
After the lay participants had departed, the clerical staff of the marae terminated the main body of the rite with a special 'leave-taking' (ripoa, turue) prayer, while placing their prayer surrogates against the uprights before the $a h u$ :

E Ta'aroa-nui tahi Tumu, e tena ati tama aitu e! Ei onei 'oe ei roto i te reva o teie nei vahi a oa ia te ta'ata nei. Ua api roa ia 'oe. Ei raro matou te ta'ata nei, e taahi noa $\mathrm{i}$ i te repo fenua o te ao nei. E te ati matua manua mai te Pô mai, ei ona 'oe i roto i te reva o te vahi moa ia te ta'ata nei; ei raro matou e ta'ahi noa i i te repo fenua o te ao nei. E te matua maitatai o te Pô, ei ona 'oe ei roto i te marama o te ao i teie nei vahi moa ia te ta'ata nei, ei raro matou e ta'ahi noa i i te repo fenua o te ao nei.

Tapu atua na, noa mai nei! Tera te aho o te marae, to tapa'au ra'a mata, to pu'e tahu'a, o Anà-ni'a, o Anà-mua, o Anà-roto, o Anà-muri, o Anà-tipu, o Anà-heuheu, o Anàtahu'a-ta'ata-metua, o Anà-tahu'a-vahine, e o Anà-iva: Te maro tahu'a ia'na, to tuturi ia'na, te pure ia'na, te aro tahua ia'na. Parima mai i to pue tahua nei!

O hi'i rà ma tau epa,

Tau epa e toro e!

Tau epa rima, rima,

Tau epa rima hi'i!

E tû, tû a o tai tua,

Tau a 'ie,

O tai tovarovaro.

Tara papa,

Tara tava;

O hahu ma te maru,

O ha'apa'a tauai a maro

Oi re, oi re, oi re

I roo e,

A taviri ai ai i taha ruru e!

Ua hi'i ma epa, epa!
O, great Ta'aroa, the unique Tumu, and thy great family of gods! Remain here, in the air of this place sacred to man. It is filled with your presence. We mortals shall remain below, treading the soil of this earth. O hosts of malignant spirits from Pô, remain there in the air of this place sacred to man; we mortals shall remain below, treading the soil of this earth.

O host of good spirits from Pô remain there in the height of the world, in this place sacred to man; we mortals shall remain below treading the soil of this earth.

Let sacredness remain here, and let us become ordinary! There is the life of the marae [pointing to the tapa'au upon the slabs], thy sacred tapa'au with masks, the body of priests, Polaris, Antares, Regulus, Zubeneschamali, Dubhe, Alphard, Arcturus, Procyon, and Betelguese. [Then speaking of the tapa'au in the singular number]: Thy sacerdotal loin girdle is with him, thy leaning slab is with him, his are the prayers, he has the face of the priest. Dismiss thy priests here present!

Now, this is nursing thee to rest, Thine outstretched resting place! Thy resting place of arms, arms, Thy resting place of nursing arms! The ocean will ever exist, exist,

Sails will ever alight,

Upon the vibrating seas.

Enchantment on the [cloth] board,

Enchantment on the bark [cloth];

Made smooth and soft.

The sweet-scented cloth put out to dry.

Well nigh defeat, defeat, defeat,

Overtook [me], O,

As I rolled up the cloth outspread!

Nursed and rest, rest [thou]!

(Henry 1928:173-174)

Meanwhile the populace had brought to the marae quantities of baked hogs, fish, turtles, and vegetables, from which the priests selected some to place on the altars and some for their own use. In addition to the food, the populace brought mats, tapa, and feathers, for use in marae services. Presumably these offerings were supplied 
through means of a general levy on the marae's entire congregation; Henry stated only that it came "from all classes." Presentation was made by an individual described as "the people's orator":

E utu o ari Po ari ao. Pana hiti pana toa, e na Atua e; afa'i e atu i te 'ino, ia 'ore i te ao nei! A fariu mai i to aro ma te aroha ia matou, te ta'ata hara nei! E tapena pua'a, e tapena 'uri, e tapena moa, e tapena roroi; teie te meia, teie te mau maa ato'a o te fenua, a fari'i mai, e te Atua e. Euru pani hia te uru o te mai; e rau hihi; e rau avari. Fa'aaroha mai to maru, e te Atua, tahiti‘a mai.
Here are peace offerings to the depth of Hades, to the extremities of the world. Push from the east and from the west, O gods; remove all evil from this world. [Behold these peace offerings to ward off your anger, $\mathrm{O}$ gods], turn your faces with favor upon us sinful people. Here are hogs consecrated, dogs consecrated, fowls consecrated, coconuts consecrated; here are bananas, here are all the fruits of the land; turn to us, O gods. Effective prayer will be offered for the sick possessed; many spirits will flee away; many people will recover. Have pity in mercy on us, $\mathrm{O}$ gods, hearken unto us.

(Henry 1928:175)

\section{The presiding priest responded as follows:}

Na ho'i te ma, e ma no te aia'ai; a ma i uta, a ma i tai, a ma i ni‘a a ma i raro: a ma te Pô, a ma te ao, a ma te marae, a ma te opure, a ma te feia noa, a ma te huia ato'a. Homai i te 'ai o te fenua, homai i te 'ai o tai, homai i te hua'ai o te ta'ata ia rahi e te Atua e. Te haere ana'e nei ra te va'a mataeina'a i te 'utuafare, e ai mai te ai haere e ai 'ino, e 'ai i te atea; eiaha e hi'o atu, e te atua e! Area matou, e 'ai'ai mai te horuhoru i mua i to aro. E te atua e, aroha mai ia 'ore ia tupu te 'ino. Tahiti'a mai, e te atua e!
Behold the cleansing, cleansing from sin; clean inland, clean seaward, clean above, clean below, Po is clean, the world is clean, the marae is clean [and then he enumerated everything upon it as clean]. The worshipers are clean, the people ordinary are clean, the families are clean. Give us food in the land, give us food in the sea, give us numerous offspring, O gods, Now all the clans are going home, to eat moving about, to eat without order, to eat abroad; look not at them, O gods! But as for us, thy body of priests, we shall eat here in awe in your presence. O gods, have pity upon us that no evil befall us. O gods, hearken unto us!

(Henry 1928:175)

With this, the assembly again separated-the laymen to enjoy their feasting away from the marae precincts, and the clerical staff to remain at the marae to eat, with prescribed constraint and dignity, their portions of food near the place the gods were believed to be partaking of theirs.

\section{Paiatua was then concluded with a final prayer:}

Tapu atu na noa mai nei, e tena nu'u atua tena mano atua, te ho'i ne matou i to matou mau 'utu'afare, e tomo i te anu mo'a, e tauteute, e hani-hani, e fa'aapu e fa'anoa noa. Eiaha e mata roa mai, eiaha e taria roa mai ia matou. Fariu i to mata i te po e fariu i to tau i te ao. Te vaiho atu nei matou i te ra'a ei ona te mo‘a, e te Atua e!
Let sacredness remain here that we may become ordinary, O host of gods, those thousands of gods! We are returning to our homes to put on unconsecrated clothes, to do domestic work, caress, farm and become ordinary. Be not farsighted, be not farhearing to us. Turn your faces to darkness and turn your back to the light. We are leaving sacredness, let holiness be there [with you], O gods!

(Henry 1928:176-177) 
After this prayer the priests and their assistants returned to their homes and ordinary lives, but they left little prayer surrogates behind in the marae to continue their dialogues with the gods.

Taraehara. A large proportion of the religious rites performed by the Maohis had as one of its purposes-or even its main purpose-the "untying" of hara, or taraehara. To begin with, there were certain kinds of actions which, when committed by priests during religious solemnities, were regarded as 'mortal sins' (pāhara aiaai) and required taraehara: e.g., taute, doing domestic work; hara faiaia, irreverence in offering human victims; hara i te fa-'ahaere' $a$, clumsiness in processions or failures in recitations; paoa, hurrying over prayers to serve the food; ai haruma i te omu pu'ua (or honu), greediness in eating the head of a pig (or turtle). "For any of these offenses, sure judgement upon the [guilty] priest, people, and the land was supposed to follow, and if confession and atonement were not quickly made the priest, it is said, would die in great agony by a curse from the gods" (Henry 1928:198-199). In such cases, it was reported, the "people" (the whole congregation) atoned for the "sin" by offerings to the offended gods, while the offending priest was suspended from all clerical duties and privileges until he had personally atoned with an offering of his own.

Elsewhere, Henry reported that there were two kinds of offerings made to the spirits as taraehara: ta'ata o mei'a roa (man-long plantain), offered as a substitute for a man; and fei 'ai (petition with food), a pig or dog besmeared in its own blood, offered as a "national" [i.e., tribal] atonement (1928:198).

From these fragments it would appear that hara were (or included) certain errors made in the performances of religious ritual, and as such they required atonement in the form of another religious ritual, namely, taraehara. However, two other usages of taraehara serve to complicate its meaning or, at least, our comprehension of its meaning. One is the kind of hara that required, or could be nullified by, "untying"; the other is the mechanics of "untying."

The LMS Dictionary defines hara as sin, transgression, crime, guilt; unequal, not hitting the mark; to be unequal, to be deviating from a line or rule; to be in a transgression. As just noted, from the examples given above the kind of hara requiring religious atonement would appear to include errors committed by humans with respect to their relations with the spirits, but Henry implied the recognition of other kinds of hara, in her listing of the following additional types of taraehara: tai fenua (crying for homeland, homesickness), food and other objects presented to a chief by persons wishing to regain his favor in order to return home after banishment; and faitera'a tau'a (reconciliation of tau'a), objects exchanged between friends 
in order to resume friendship. Thus it would appear that acts of disobedience to one's chief and unfriendly acts between friends were also classed as hara, and as such were susceptible to "untying" by means of an exchange between the interested (human) parties.

Hara, then, would appear to signify errors committed by humans with respect to both spirits and other humans-which should not be surprising inasmuch as the Maohis believed, or at least acted as if they believed, that the boundaries of their society included both humans and spirits. On the other hand I have found no instance in which hara applied to error of a non-social-relational kind, such as a mistake made in making a mat or in casting a net. More crucial, however, is the question of what kinds of humanto-human hara were considered of sufficient interest to spirits to require "untying" not only by human-to-human exchanges but also by human-tospirit petitions and offerings. In other words, how far did spirits concern themselves with relations between humans? I must postpone consideration of this question, so relevant and important for an understanding of social relations, but I note in passing that it is often complicated by those not unusual instances in which humans came to be identified with spirits in one way or another-for example, when a district's highest-ranking Titleholder "became" its tutelar god.

The second obscurity in the concept and action of taraehara derives from the question of what was "untied," and how the "untying" was brought about. The Maohi language was rich in metaphoric usages, but certain mortuary practices, which will be described later, imply that at least some kinds of hara committed by an individual produced in his body a dangerously infectious deposit which had to be drained off and buried after his death lest it infect others as well. Added to this was the example of a type of scapegoating ritual, called ahuātai, defined by the LMS Dictionary as a certain prayer and ceremony formerly used when war and sickness prevailed; a model of a canoe was made, fitted up, and sent to sea with the supposed sins and sickness on board. Putting together these and other fragments (some of which will be listed in following chapters), one gains an impression that the Maohis placed credence in an actual guilt-substance, also called hara, which attached itself to people, and through them to objects and places, as a result of their having done or not done certain acts. Moreover, such guiltsubstance was dangerous to the health and well-being of the infected individual; but ordinarily it could be removed by performance of certain ritual action (taraehara), thereby rendering the person and thing and place clean $(m \bar{a})$ and healthy (ora). It is not entirely clear whether this type of guilt-substance owed its efficacy to an intrinsic power of destruction or to the attraction it offered to destructive spirits. In conformance with the general shape of Maohi thinking it was more likely the latter. 
Nor is it clear whether all "errors" classed as hara, or only those connected with human-spirit relations, resulted in deposit of guilt-substance.

Thus, many uncertainties cloud our understanding of Maohi suppositions concerning their universe, especially those regarding relations between humans and spirits. The sources contain a wealth of detail about religious belief and ritual, but they are not complete enough to provide answers to some of the more basic questions. Whether this is due to inadequate reporting or to my own failure in comprehension is not clear. It could even be that the Maohis did not address themselves to the basic questions or, if they did, that they were unable to formulate any consistent and universally accepted answers. I hope, however, enough of their ideas have been presented to provide more understanding of the descriptions that follow than would have resulted from presentation of a mere catalog of activities. 


\section{CHAPTER 4 THE DAILY CYCLE}

\section{DAILY ROUTINE}

To some of the early European visitors the life of the Maohis appeared to consist mainly, and by preference, of long periods of idleness and repose: "The usual times for eating are the morning, and before sunset in the evening. They devote all the rest of the day to lying stretched in the shade like beasts of the field, with the exception of a few who, being obliged by their lords to do so, go out to fish or attend to other jobs" (Corney 1915:28). If this was not true of everyone, it was said to be so at least of those who were free to do as they wished: “... the better sort [of middle-aged people] seem to spend most of their time in eating and sleeping" (Beaglehole 1955: 126). Another observer put it somewhat differently: "It is not that they are indolent; they are in fact never still, always moving about. What distinguishes them, however, is that their comings and goings are pointless, unimportant, often childish, and are engaged in in a spirit of light-hearted play." (Freely translated and abridged from Moerenhout 1837:II, 74, 77)

Sleep and play the Maohis of course did, and often at times that were considered to be unconventional by their routine-bound, toil-hardened visitors. They appear also to have derived amusement from some otherwise laborious occupations. The fact remains, however, that they did manage to survive and multiply, and even to fashion for themselves a way of life far more refined and a society considerably larger and more complex than was achieved by many other peoples constrained by a neolithic technology and a formidable insularity. But I leave to others the more theoretically rewarding task of evaluation by comparison, and I limit myself to description.

Most Maohis awoke and arose shortly after dawn, proceeded directly to a nearby stream or beach for ablutions, and to some naturally screened area for elimination. Returning to their homes they then rolled up their sleeping mats, partook of a light breakfast of leftovers, and set about their main tasks of the day-fishing, farming, collecting food, making bark cloth, constructing buildings, conferring, performing rites-or simply amusing themselves. The principal meal of the day was eaten in the early or late afternoon, de- 
pending upon the circumstance, and was generally followed by an hour or two of repose. After that there was more work for some persons, but most spent the remaining daylight hours chatting, playing, visiting, or preparing implements for the following day's work. Then, they had another bath and sometimes a light supper. By nightfall, which arrives fairly suddenly in this latitude, most people were usually inside their houses for more talk, work, and eventually sleep.

Such was the average sequence of events, day after day and year after year, but it was subject to a wide range of variations. Periodically, for example, the occupations of many individuals varied with day of lunar month and season of year; in addition, some changes in weather served to influence the activities of many people. Daily routine also varied with an individual's age, sex, special occupation, and inclination. And finally, contingent situations, such as wars and illness in the household, served to disrupt everyday life to a radical degree.

Unless some special enterprise required a particularly early start, the Maohis appear not to have bestirred themselves before daylight, regardless of seasonal and locational differences in daylight's arrival. That is to say, at the latitude of these Islands the length of the astronomical day is more than two hours longer in December than in June (Papy 1954:I, 70); and daylight appears considerably earlier at exposed settlements on the eastern sides of islands than it does elsewhere. The Maohis were evidently aware of annual variation in lengths of daylight and darkness, but there is no evidence that they adjusted their time of arising accordingly.

When certain rites were in progress at a marae the arrival of day was sometimes heralded with special prayers, but that does not seem to have been the case in most households.

A morning bath appears to have been regular and universal, not just a perfunctory, sleep-chasing douse, but an all-over affair in the ocean or preferably in a stream, with vigorous rubbing and splashing, and rinsing out of the mouth. Even the youngest infants were subjected to this treatment, which must have been very painful indeed in some fresh mountain streams. Nor did invalids spare themselves from the shock (and probably unfavorable consequences) if they were at all able to move about.

All this, according to Moerenhout, took place in an atmosphere of friendly sociability. People trooped off together to the morning bath, and although carefully keeping their genitals covered through skillful manipulation of clothing, they bathed near one another and kept up a steady flow of generally cheerful talk. (1837:II, 75)

At some point in these proceedings individuals managed to void their bladder and bowels, but aside from the European visitors' approving statements to the effect that elimination was invariably carried out in privacy and 
with nice modesty, there are few indications how that was managed. From common modern practice and from a passage in Rodriguez' diary (Corney 1919:180), his editor inferred that one preferred method was to betake oneself to a foliage-screened spot on the beach at low tide; scavenging fish then moved in with the tide to keep the spot clean.

Early morning domestic chores involved little more than rolling up mats, sometimes after sunning them, and storing them in the house rafters. Some individuals used separate bedcovers of tapa, which had also to be stored away; but for many others this tapa cover became the ordinary garment for everyday wear.

Breakfast was seldom a substantial meal in Maohi households. It usually consisted of leftovers from the previous day; to my knowledge no firsthand account contains a reference to the cooking of food for breakfast. The fact that morning was usually the period of hardest physical labor for most Maohis did not lead them to eat heartily beforehand, despite what may have been either actual hunger or anticipation of it. ${ }^{1}$

If an individual wanted to work, or had to do so, the usual time for it was between breakfast and what Westerners would call early afternoon. However, there was not to my knowledge any stated norm to the effect that this was the more appropriate time for work. ${ }^{2}$ Fishing activities, particularly, could not be confined to morningtime; indeed some fishing could only be pursued at night. Nor could the mountain-plantain collector always be home by early afternoon. On the other hand, the morning and early afternoon was the period during which, for example, most buildings were constructed, canoes worked on, textiles manufactured, crops cultivated, and food collected. It was the normal practice to collect most of the food on the day it was to be eaten; this meant collecting during the morning, since the main meal was usually early-or mid-afternoon. Exceptions to this same-day food collecting included: fish, caught the previous night; mountain plantains, which did not have to be cooked the day of picking; coconuts; and baked or fermented breadfruit. Several visitors commented upon the numerous signs of industry, which distinguished morning from other times of day, including the almost continuous sounds of mallets beating out tapa on wooden boards.

According to Moerenhout, if a household included any "prisoners" (i.e., titi 'war captives') ${ }^{3}$ among its members, it was these who did the harder work of collecting firewood and foods and preparing meals, while the "free" men of such households spent their time manufacturing weapons, fishnets and canoes, building houses, practicing martial exercises, or performing rites at the marae (1837:II, 77-78).

But Maohis did not "work" because of any notion that it was in itself a good thing. Many individuals able to command the services of others did little or no work of a materially productive kind; and many others-perhaps 
all others-often chose to spend their mornings unashamedly in what their visitors would undoubtedly have called idle chatter:

If they had nothing pressing to do, including any essential work activity (a circumstance that now and then occurred), everyone would lounge around in the open in front of the houses or under some trees, males and females together. On some such occasions they amused themselves at some game or other, but more often they did nothing but talk-for, conversation was their forte, and everyone, without exception, loved to chatter. And among these folk, who in this respect were perhaps unique, such chatter among women contained not a trace of slander, of biting criticism, or of malice. ${ }^{[4]}$ (Moerenhout 1837:II, 76)

The main meal of the day usually consisted of food freshly baked in an earth oven. The technological and social-relational details of this prosaic but pivotal event will be set forth in a later chapter, but it should be noted in passing that baking was a slow process. Some member of the household had to begin preparations for it hours in advance, which in turn necessitated an even earlier beginning to collect and prepare the food for cooking, since most of the items that went into an oven were-either by necessity or convention-picked, cleaned, scraped, and so forth, just prior to baking.

The early European visitors to these Islands differed widely in their estimates of this or that trait of the inhabitants' behavior, but no one to my knowledge characterized them as insomniacs. Nights, as we shall see, were sometimes enlivened with work, and with talk and other diversions long after dark, ${ }^{5}$ but the hour or two after the day's main meal was nearly always devoted to sleep. For one thing, this was usually the warmest period of the day; in addition, the impressive quantities of food ingested by most Maohis at this meal was undoubtedly immobilizing. In any case, while the digestive juices proceeded with their formidable task the people slept, sometimes in houses but more typically outside in some shady, breeze-cooled spot; another characteristic of these hearty eaters was their ability to sleep in almost any position, however hard or uneven the surface upon which they reposed.

After a lengthy siesta some adults may have resumed "work," or at least some productive activity that could be engaged in near home; but for most people the late afternoons appear to have been devoted to diversions of one kind or another, including visiting and lovemaking. Expressed in the lilting prose of the romantic younger Forster, "After their meals they resume their domestic amusements, during which the flame of mutual affection spreads in every heart, and unites the rising generation with new and tender ties." (G. Forster 1777:II, 111). Before nightfall the Maohis had another bath and perhaps a light supper of leftovers, and by dark everything was again quiet outside, except perhaps on the lagoon or reefs where fishermen might have been active, or at some marae where priests occupied themselves with preparations for rites or novices strolled about memorizing chants. 
Bright moonlight sometimes encouraged people to sit outside, but otherwise they usually sat or stretched out inside their houses, preferably in company, as a result of what seems to have been a sincere fear of the spirits believed to be more active during darkness, as was audibly manifest in the squeaks of rats and cries of night birds. The belief that some of these spirits were ghosts of relatives seems not to have been wholly reassuring. While some individuals slept, others talked or told stories or made music, in light provided by candlenut tapers. Some observers characterized the Maohis as having been livelier at night than during the day: "... and thus they continue [chatting and singing] nearly the whole of the night, making so much noise that no one can sleep among them. ${ }^{[6]}$ It may here be observed that in day time they frequently lay down and sleep. They appear throughout the day to be exceedingly troubled with Enui." (Threlkeld to Burder, 29 September 1818, LMS Archives)

According to Moerenhout, a prayer was usually said (presumably by the household's male head) before the household settled down for the night:

Save me! Save me! It is the night of the gods. Watch close to me, my God! Close to me, O my Lord! Protect me from enchantments, sudden death, evil conduct, from slandering or being slandered, from intrigue, and from quarrels concerning the limits of land. Let peace reign about us, O my god! Protect me from the furrious warrior, who spreads terror, whose hair bristles! May I and my spirit live and rest in peace this night, O my god. (E.S.C. Handy's translation [1927:201] of Moerenhout [1837:II, 81-82])

Perhaps such a ritual did in fact take place in some households, although none of the earlier visitors mentioned it. Moerenhout's stay in Tahiti took place during the 1830s, long after the missionaries had introduced the custom of Christian household prayer services, morning and night; and although the above prayer is pre-Christian in content it is quite Christian in tone, and it might possibly represent some informant's imaginary reconstruction.

In general, the daily routines of most Maohis followed the sequence of activities just set forth, with the following exceptions and qualifications. Warfare, natural and social calamities, and large festivities changed routine living radically, as will in due course be described. In addition, certain regular changes in the physical environment were conventionally adjusted to in ways that influenced daily routines. One such change was connected with the phasing of the moon, which affected-or at least was believed to influence-the habits of marine life, and hence of nighttime fishing. Marine life was also subject to longer, annual cycles of variation, which were reflected importantly in the daily activities of the master fishermen.

Inclement weather appears to have discouraged outside activity of all sorts; people tended to remain inside their houses, lolling about and sleeping, and subsisting on foods near at hand: "This [visiting the Spanish ships in inclement weather] was quite opposed to their usual habit, as they them- 
selves told us, of not going outside their houses on wet or misty days, even to look for food" (Corney 1915:141). ${ }^{7}$

Finally, the daily lives of the Maohis were adjusted to the annual natural cycle insofar as this affected the growth of their staple plants, particularly breadfruit. Details of these regular monthly and seasonal changes in food supply, along with their associated activities and systems of reckoning time, will be given in later chapters, but now I return to the daily cycle itself, to inquire how, if at all, it was conceptualized by the Maohis themselves.

\section{DIURNAL TIME RECKONING}

The Maohis had no distinctive word for the time unit called by Westerners a day (or, technically, a solar day) - that period defined by one complete revolution of the earth on its axis. They did, it is true, enumerate complete diurnal cycles in terms of ru'i (an alternative for pō 'night'), but ru'i appears not to have had the double usage that day has in English-that is, applicability both to a part of the diurnal cycle and to the whole cycle as well. Hence, when referring to a diurnal cycle in the description that follows, solar day will have to serve in default of a native term for this period of time. ${ }^{8}$

The Maohis had two ways of specifying solar-day time: by designating events which marked its course, and by defining its component periods. The principal event-markers were sun, stars, tides, and clouds; and the periods were defined mainly by sunlight or the absence of it.

Following are the expressions used for indicating sun-time points. Though sequence is implied in the listing (adapted from Henry 1928:327-330), some of the expressions clearly represent alternative ways of describing the same event:

Bordering sun rays.

The sun is inflated.

The sun is mostly revealed.

The sun is revealed just above the horizon.

The sun's rays are spreading.

The whole of the sun is visible.

The sun's rays are shooting forth.

The sun's reflection is glaring upon the sea.

The sun's rays sparkle upon the sea.

The sun has quite risen.

The sun is quite suspended.

The sun's warmth is spreading (about half an hour high).

The sun is reflected on the sea (about 7 A.M.). 
The sun's rays come from its disk (about 8 A.M.).

The sun is spreading its rays everywhere (about 9 A.M.).

The sun is producing waves.

The sun has waxed strong (about 10 A.M.).

The sun sits at an angle (about 11 A.M.).

The sun is over the crown of the head.

The sun points its rays evenly.

The sun shines with no shadows.

The sun has passed the meridian.

The sun is slanting.

The declining of the sun.

The sun is shortening its course.

The sun is taking its departure.

The sun is descending.

The sun's rays are as the fara roots [i.e., pandanus roots, which are very slanting].

The sun is speedily going down.

The setting of the sun.

The sun's course is shortened.

The sun has burst the surface of the sea.

The sun is going majestically to the rocks of the deep.

The sun has sunk below the surface of the sea.

The sun darts its rays upwards.

The sun has dropped.

Twilight (te vai mārerehu rā).

Indistinctness (te vai aroaroa rā).

Clouds were used for time-marking as they relate to the sun-that is, just before sunrise: The clouds are parting asunder; The red clouds have risen; The masses of dense clouds precede the sun; The dispersion of the clouds; Drifting off of red clouds; and just after sunset: The great disk of the sun has deserted the fleecy clouds.

Light, and specifically sunlight, also figured in two other time-marker expressions, referring in these instances to the beginnings of visibility before sunrise: The Great Star has risen; it is morning, Ta'urua has risen. ${ }^{9}$ 
It will be noted that several expressions in the Henry list of diurnal events refer to the tides-for example, "ua nano te tai, the tide has reached its highest" and "te pahe'era'a o te tat, the sea is receding." If the tides of these Islands had indeed occurred with the fixed regularity that some older writers claimed, then we would have to recognize these expressions as having been correspondingly precise. As it is, however, their sequence in this particular list of diurnal events must be regarded as accurate for only certain phases of the tidal cycle, and hence not a fixed element in a standard diurnal schedule of events. This does not mean of course that tides, meager as they were, played no part in Maohi life; they probably played their part, for example, in connection with the collection of molluscs on reefs, but not with the fixed regularity they were earlier supposed to have had.

The only other natural events which served as timemarkers (according to Henry) were the opening of the tiare blossoms, which occurred regularly about noon (i.e., "the Gardenia tahitensis flowers are fully open"); the singing of the thrush (oma'oma'o) shortly before sunrise; and the crowing of cocks, also before sunrise, in this sequence: It is the first cockcrow; It is the middle cockcrow; It is the last cockcrow; Cockcrowing is general.

Turning next to the ways in which the Maohis verbalized component periods of the solar day, the major division was between ao and $p \bar{o},{ }^{10}$ which in this context can be translated as 'day' and 'night', or 'day-lightness' and 'night-darkness'.

In Henry's sequence, ao "began" as soon as there was sunlight enough to distinguish a man's face (or to see flies flying) and lasted until all such light had disappeared (i.e., poiri roa 'very dark'), which approximately

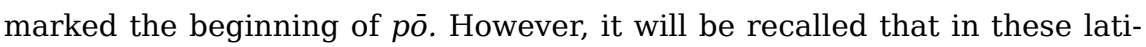
tudes sunrise was an hour and five minutes earlier (and sunset an hour and five minutes later) in late December than in late June.

Other divisions of the solar day were po'ipo'i 'morning', avatea 'midday', ahiahi 'evening', and $p \bar{o}$ 'night'. According to the sequential arrangement of Henry's list, po'ipo' $i$ began with the rising of the "great star," just before daylight, and it ended with avatea, at some imprecisely identified time before midday. In turn, avatea passed into ahiahi around midafternoon, and ahiahi lasted until darkness (poiri, pō). The periods of dim light immediately before po'ipo'i and after ahiahi were labeled rehurehu. Banks wrote that "every [solar day] has its respective name and is again subdivided into 12 parts containing about 2 hours each, 6 for the day and 6 for the night, each of which has likewise its respective name; in the day time they guess the divisions of these parts very well, but in the night tho they have the same number of divisions as in the day seem very little able to tell at any time which of them it then is, except the cleverer among them who know the stars" (Beaglehole 1962:I, 369). 
Clearly, the sun was by far the most decisive factor in Maohi solarday time reckoning. Not only did it provide a regularly recurrent reference point, but it was the source of the kind of light considered indispensable for most Maohi materially productive activities. Some things could be done and were done by moonlight or starlight or candlelight, or even in total darkness, but sunlight was the conventional illumination for gardening, collecting plant-food, preparing meals, manufacturing objects, constructing buildings, setting out on journeys, waging warfare, and for conducting most religious rites. The strength of this convention was conceptualized and reinforced in myth-specifically in myths dealing with the raising of the Sky and the snaring of the Sun.

For a while after their creation, humans lived in total darkness and confusion in the narrowly confined space between Earth and Sky. Then, the myths relate, Tane and his spirit helpers succeeded in raising the Sky off the Earth, thus admitting Sun, Moon, and Stars into the space between. But, even after these gods had been set in their proper courses;

There was but one drawback to this world, no work could be properly accomplished because the sun rose and set too soon. When an oven was heated in the morning and the food was placed in it, the victuals were not cooked when nightfall came; when the food was cooked and the oven was opened, people had not properly partaken of their meal when it was night again! So they ate rare food from the oven, in those short days, and their lips became swollen from irritation in eating ape (Alocasia macrorrhiza [bitter taro]) only half cooked.

The sun was just rising when Mâ-û-i set out on his journey to visit all lands, to build temples upon new lands, and to establish there the priesthood which he had trained. It was during the period of Antares (in Scorpio) and he had a fleet ... pressing on behind. They had no sooner got out to sea when they were benighted. When daylight came, Mâ-û-i fished up land that was jambed beneath the sea, and they were again benighted!

At length they reached an island named Fa'ana (Pacify), and they were erecting a temple-Apo'o-'ao (Heron-pit) was the name of that temple-and only one stone, the chief cornerstone, was laid that day when night came. The following morning they resumed their work, and they were making the wall of the temple when the sun began to decline.

When Mâ-û-i saw that, he counted the rays of the sun and there were ten. Then he took ten ropes with which he firmly secured the rays of the sun, and he tied them to a rock so that they could not be shaken. The sun was thus fixed, and the people built the walls of the temple and completed it that day. And when all was finished, Mâ-û-i let go the rays, and the sun continued its course in the same manner as before.

But Mâ-û-i ended his work there; he left priests with the new temple named 'Apoo-'ao, and returned to Havai'i [Ra'iatea] with his fleets to consult with the gods and people what to do to prolong the day. (Henry 1928:429-430) ${ }^{11}$

Finally, this expediency of detaining the Sun long enough to complete particular enterprises was replaced by permanent measures: Maui's 
younger brother, Maui i upo'o varu, became angered with his father the sun because his mother had to eat half-cooked food and his older brother could not complete his projects, so he set about to capture the Sun once and for all, using-among other kinds of cordage-a braid of hair of his sister Hina. He succeeded finally in noosing his father the Sun (chiefly with the braid of his sister's hair), and when his father demanded to be let free, he replied:

"You will not escape! Had you gone slowly, my mother's food would have got cooked, and my brother would not have had to hold you in doing his work. But you have been going fast."

The sun said: "If I die, you cannot find food, there will be no light by which to build temples, all will be in darkness. But let me go, and I will cause your work to prosper well."

Then Mâ-û-i said: "Will you not deceive me?"

"I will not deceive you," replied the sun, "but unfasten this very painful rope!"

Then Mâ-û-i stamped upon the disk of the sun so that it got cracked and weakened, and he unfastened the rope of hair. The sun then went slowly, and never again hastened its course in the sky.

So the world became perfect, two ovens of food were cooked in a day, and people were satisfied with properly prepared victuals. Work was then done with system. Mâ-û-i was pleased with his father, the sun, and all the world was also pleased with him. (Henry 1928: 432)

In summary, ao, the period of sunlight, was the time for doing the things that were done outside, while $p \bar{o}$, the period of darkness, was the time usually for being inside. During $a o$ the world outside was peopled with humans moving about and doing things; during pō humans remained inside and spirits haunted the world outside: "Ei te nu'u atua te pō, ei te ta'ata te ao. The night was for the gods, and the day was for man" (Henry 1928:412). ${ }^{12}$ It should be recalled that $a o$ was the term used for the room (piha) of the universe occupied by living humans in contrast to $p \bar{o}$, the room where spirits usually resided.

However, beyond this broad concurrence of pō-ao with inside-outside and spirits-humans, there was only the most general kind of coincidence between periods of $a o$ and types of daytime activity. The brief transition intervals between darkness and light were denoted with much more detail than was the long day itself. On the one hand, the boundaries between the day periods-po'ipo'i, avatea, ahiahi-were anything but sharp; and on the other hand the schedules of people's activities during the day differed considerably, from individual to individual and from day to day. Which circumstance was prior, the Maohis' imprecision in marking time or the variations in their daily routine, can only be guessed at, but during the era under study these circumstances probably interacted so as to foster even further the Maohis' inattention to punctuality or, for that matter, what Europeans would judge to be their relative unconcern with the whole dimension of time in human affairs. 


\section{CHAPTER 5 PRIMARY TOOLS AND CRAFTS}

\section{PRIMARY TOOLS}

Having described in general terms some of the basic ideas whereby the Maohis adjusted themselves to their physical surroundings, I turn to the more tangible implements with which they managed to survive and indeed prosper-that is, to the nature of their primary "tools" and the ways they used them.

First of all, something needs to be noted in a preliminary way about how the Maohis employed their own bodies as implements-not as machines for driving other tools, but as tools themselves.

\section{Human Body as a Tool}

The Maohis used their hands and arms, directly, for a wide variety of purposes, including eating, measuring, boxing, catching fish, drumming, et cetera. They were depicted as having been strong in hand and arm and generally unconstrained in their use of them. (Except for certain temporary ritual constraints upon self-feeding, there is little evidence suggestive of a possible devaluation of manual labor.) Judging by the visible products of much of their handwork, however, they appear to have devoted less attention to delicate, fine-grained, detailed execution than did, say, the New Zealand Maori or the Mangaians.

To Westerners the facility with which Maohis used their toes, to grasp and pick up objects, would have been unusual, as would the whole variety of objects on which they used their teeth, for tearing, softening, and cutting. For example, “... their teeth were always sufficient to clear a Cocoa Nutt of its Rind to give them food and drink" (Bligh 1789:II, 63).

For carrying heavy objects, males used their shoulders extensively, over which carrying sticks were balanced fore and aft, but heads were never used for this purpose, because of the ritual attitudes toward the head.

Some impression of the Maohis' abilities as walkers and climbers may be gained from G. Forster's description of an excursion inland:

From hence we proceeded up the valley, which having no rivulet in its middle, began to rise in proportion as we advanced. We resolved therefore to go upon the 
steep hill on our left, and with much difficulty accomplished our plan. Our Taheitian friend laughed at us, when he saw us faint with fatigue, and sitting down every moment to recover our breath. We heard him blow or breathe slowly but very hard, with open mouth, as he walked behind us; we therefore tried the same experiment, which nature had probably taught him, and found it answered much better than our short panting, which always deprived us of breath. (1777:I, 348-349)

Forster noted also that the Maohis customarily exercised the precaution of drinking only sparingly when overheated after great physical exertion (1777:I, 351).

Other Europeans recorded their impressions of Maohi body-use habits in more general terms, for example: "It is common with the Otaheiteans to begin their labours with a great deal of alacrity and earnestness, but as sloth and fickleness are predominant passions in their characters, they soon tire and grow indifferent, unless their activity is kept alive with constant feasting" (LMS Transactions:I, 204).

The following chapters will provide detailed examples of the Maohis' use of their own bodies-for traveling overland, for swimming, carrying, and performing other tasks-and of the constraints imposed upon body-use as a consequence of sex, age, religious belief, notions of personal beauty, and so on. But enough has been said to indicate that their conventional uses of their bodies differed in some respects significantly from those customarily employed by Westerners.

\section{"Natural" Objects as Tools}

The Maohis utilized numerous kinds of "natural" objects as tools without first modifying them essentially. They used "naturally" shaped stones for much of their hammering and pecking (fig. 5-1), and flakes of basalt rock for cutting shell, for drilling holes and for scraping. In fighting they used uniformly sized but unmodified stones for slinging, and heavy boulders for rolling down mountain slopes.

Unworked wood was used in numerous ways: as levers for moving heavy objects; as rollers for pulling boats overland; as carrying sticks, hammers, spears, and so forth.

Coral, both block and branch, served as an abrasive, as did sea urchin spines and the skin of stingrays and sharks (figs. 5-2, 5-3). Unworked shell was used for scraping, and both shell and splits of bamboo were used for cutting. For piercing holes some bone and teeth were probably used in their natural states, but others were first modified by sharpening (fig. 5-4). Smoothing and polishing were accomplished with sand and coconut husks or pumice. "All their [wood] work however acquires a certain neatness in the finishing for they polish every thing, even the side of a canoe or a Post of a house, with Coral sand rubbd on in the outer husk of a Cocoa nut and rays skin, which makes them very smooth and neat" (Beaglehole 1962:I, 364). 

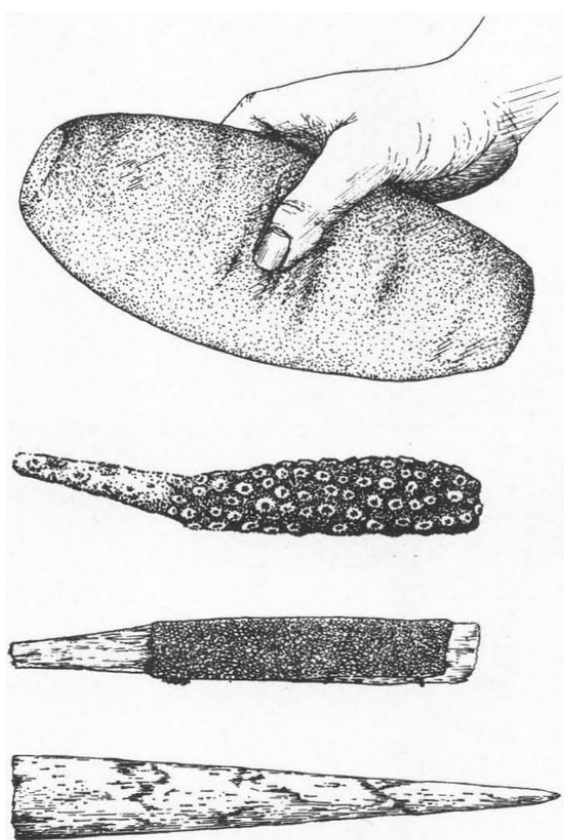

Figure 5-1. Stone hammer, length 19.6 $\mathrm{cm}$. Bishop Museum.

Figure 5-2. Coral file, length $6.9 \mathrm{~cm}$. Bishop Museum.

FIGURE 5-3. Rasp, wood covered with sharkskin, length $27 \mathrm{~cm}$. National Museum of Ireland.

Figure 5-4. Bone awl, length $14.2 \mathrm{~cm}$. Bishop Museum.

These are only a few examples, but they will indicate how the Maohis made very direct use of their physical resources in some respects.

\section{Fabricated Primary Tools}

In their carpenters, joiners and stone cutters work \&c. they are almost as little obligd to the use of tools as in making these [fish] hooks: an axe of Stone in the shape of an adze, a chisel or gouge made of a human bone, a file or rasp of Coral, skin of Sting rays, and coral sand to polish with, are a sufficient set of tools for building a house and furnishing it with boats, as well as for quarrying and squaring stones for the pavement of any thing which may require it in the neighbourhood. (Beaglehole 1962: I, 363)

One of the most noteworthy characteristics of the Maohis' primary fabricated tools was the limited variety of types coupled with their wide variety of uses. ${ }^{1}$ A long hardwood stick, sharpened or flattened at one end, served as an all-purpose hole digger and soil loosener. A shorter stick, stuck into the ground, served to husk coconuts.

As noted above, strips of bamboo and unmodified shells were used to cut some substances, but the Maohi's principal woodcutting tool was an adze blade hafted to a wooden handle by means of gum adhesives and cordage. (Figs. 5-5 through 5-7) Most adze blades were of basalt, shaped by flaking, pecking, and grinding, but some were fashioned out of Tridacna shell. According to Banks, their stone adzes were "not very hard but tolera- 


$$
\frac{T t}{D Q}
$$


bly tough," and they varied in weight and size from a few ounces to three or four pounds. Concerning their use, Banks added:

Whatever these tools want in goodness is made up by the industry of the people who use them. Felling a tree is their greatest labour, a large one requires many hands to assist and some days before it can be finishd, but when once it is down they manage it with far greater dexterity than is credible to an Europaean. (Beaglehole 1962:I, 363)

Banks and Wallis, also provided us with good descriptions of Maohi plank making:

If [a log] is to be made into boards they put wedges into it and drive them with such dexterity (as they have told me-for I never saw it) that they divide it into slabs of 3 or 4 inches in thickness, seldom meeting with an accident if the tree is good. These slabs they very soon dubb down with their axes to any given thinness; in this work they certainly excell; indeed their tools are better adaptd for it than any other performance; I have seen them dubb of the first rough coat of a plank at least as fast as one of our carpenters could have done it; and in hollowing, where they have liberty to raise large floors of the wood, they certainly work quicker, owing to the weight of their tools: those who are masters of this business, will take of a surprizing thin coat from a whole plank, without missing a stroke; they can also work upon a peice of wood of any shape as well as they can upon a flat one, for in making their canoes every peice is formd first into its proper shape, bilging or flat: for as they never bend a Plank all the bilging peices must be shap'd by hand which is done intirely with axes. (Beaglehole 1962:I, 363-364)

They cut the tree down with large Hatchetts, and afterwards into Junks of such Sizes as they have occasion for, then they beat the end of it, 'till it begins to crack and split-after which they make use of Wedges made of hard Wood \& soon split them into pieces the breadth of the tree, so that some of their plank is near two feet broad, but the generality about one foot .... (Wallis 1767:55)

Concerning Maohi use of adzes for carving, Banks had the following to say: "They have small axes for carving also but all their carved work was so bad and in so very mean a taste that it scarce deserved that name." Workmanship which Banks implied to have been crude was more likely, of course, to have been a matter of conventional "art" style. Other fabricated cutting tools used in woodworking were chisels made from basalt, and gouges made from shell (Green et al. 1967:198-199).

Many scraping and grating processes were carried out with unmodified shells, but in other instances deliberately sharpened shells were used. Similarly, while hole piercing was in many instances done with whatever bits of unworked bone or wood or stone there happened to be around, some holes were carved with awls or needles shaped deliberately out of these materials. Bone, particularly human bone, was also a favored material for splitting, chiseling, and gouging objects softer than wood. (Figs. 5-8 through 5-12.) Joining was accomplished mainly by tying, either with "natural" 

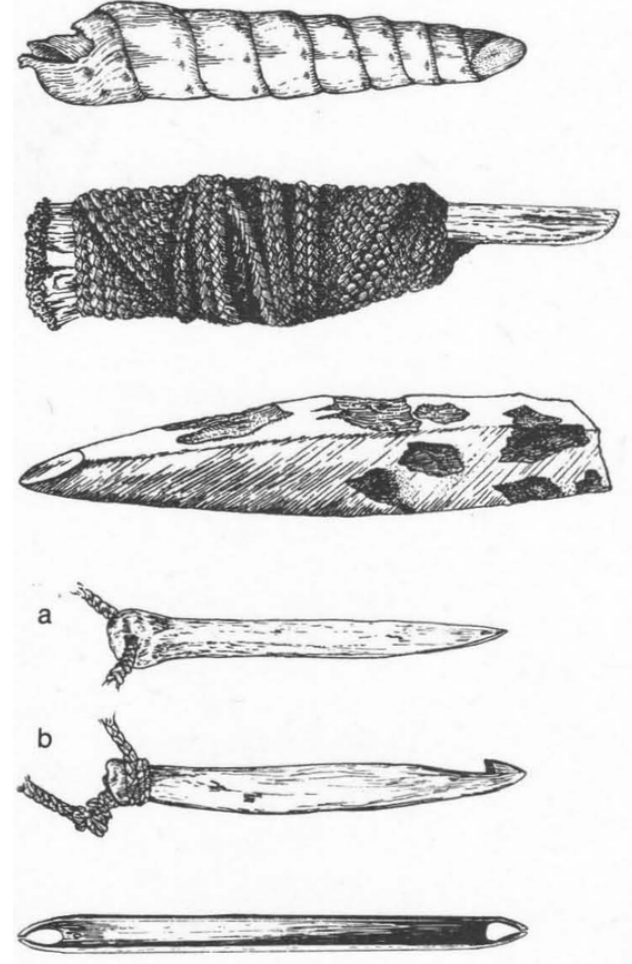

Figure 5-8. Shell chisel, length 10.8 $\mathrm{cm}$. Bishop Museum.

Figure 5-9. Bone chisel, length 13.9 $\mathrm{cm}$. Bishop Museum.

Figure 5-10. Stone gouge, length 11.7 $\mathrm{cm}$. Bishop Museum.

FIGURE 5-11. Bone thatching needles: $a$, length $20.4 \mathrm{~cm} ; b$, length $20.2 \mathrm{~cm}$. American Museum of Natural History.

Figure 5-12. Wood netting needle, length $26.5 \mathrm{~cm}$. National Museum of Ireland.

unmodified fibers (as mentioned above) or with sennit. In the case of some objects (for example, adze blades and boat planks) the elements to be joined were rendered more adhesive with resinous gum.

Fire must also be listed as one of the Maohis' primary tools; it was used not only for cooking, heating, illumination, lime making, and land clearing, but also for hollowing out logs for boats.

Of the raw materials comprising the fabricated and "natural" tools just listed, perhaps only basalt and pearl shell were "scarce," in the sense of having had geographically limited supply sources. According to some writers, the best basalt for making adzes and chisels was at Maupiti; I do not know however the extent to which Maupiti basalt figured in adzes used elsewhere-either as raw material or as products finished at Maupiti. More archaeology should be able to provide some evidence concerning the location, at least, of manufacturing centers. Pearl shell is believed to have been rare in the waters around the Society Islands (Green et al. 1967:185); and it is reported to have been traded from the Tuamotus.

One is probably safe in assuming that there was some specialization, both local and individual, in the fabrication of stone adzes, although there is little evidence for such now available; ${ }^{2}$ but most of the kinds of primary 
tools listed above were simple enough and consisted of materials common enough to have been fabricated nearly everywhere and by nearly everyone past childhood.

Another noteworthy aspect of the Maohis' inventory of fabricated "primary" tools is the apparent scantiness of nonutilitarian embellishment. Except for the lashings used in adze hafting, ${ }^{3}$ the manufacturers of these primary tools seem to have been unconcerned with making their products aesthetically pleasing - at least not in terms of any ordinary Western criteria of "aesthetic." This is not to say that the Maohis themselves did not derive some nonutilitarian satisfactions from the shapes and appearance of such tools.

I again touch upon the concept of mana as it referred to certain properties of tools; the inference has been drawn by some writers on the Maohis that their tools tended to acquire mana (effectiveness of a more or less supernatural kind) the longer they were used successfully, or, alternatively, that certain tools were mana (through spirit association) and hence of more than ordinary effectiveness. ${ }^{4}$ As I noted earlier, this is a complex question of interpretation which I am unable to answer on the basis of available evidence. Neither am I able to offer a full and documentable rationale for the practice, followed on occasion, of using bone from a former enemy in fabricating primary tools and fishhooks. (Does this imply, among other things, a view of tool-using activity as having been somehow disvalued?)

\section{CORDAGE}

The simplest kind of cordage made by the Maohis consisted of strips of bark, most commonly hibiscus, peeled off a tree trunk or branch and used as is. Otherwise cordage was made by twisting or plaiting various kinds of fibers, the principal of which were coconut husk, hibiscus bark, the inner bark of the flaxlike piripiri (Cenchrus echinatus), roa stalk (Urtica argentea), and human hair.

The sources contain such scant information concerning cord making by the ancient Maohis that we must depend upon more recent accounts of this craft, justified, perhaps, by the assumption that technical habits so "basic" as these are less likely to have changed than are most others. (I fully realize the vulnerability of such a sweeping statement, and cannot support it with anything stronger than personal opinion. In any case, the issue is not crucial to the main subject matter of this book.) Accordingly, in presenting the following accounts of cord making and plaiting I draw mainly from the excellent study of W.C. Handy which was based on field observations carried out in the 1920s.

According to W.C. Handy, "No material used for cords has such a grand old tradition as coconut fiber .... Its strength and durability have 
impressed visitors from the time of Wallace [Wallis] to the present day." It was used for a wide variety of cordage, including ropes of different dimensions, lacings, and thin decorative threads. Handy's description of the way fibers are (and presumably used to be) prepared for making cord follows:

Both the preparation and the manufacture of this material has always been the work of men. They select coconuts known as omoto, a term referring to that stage of growth where the meat of the nut is about half an inch thick. They split $(e \tilde{o})$ the husks from the hard inner shells of the nuts, dextrously jambing them down upon the pointed end of a stick planted solidly in the ground, and rip off the outer covering in segments. Tying these sections of husk in bunches and fastening them conveniently to the shore, they leave them to soak in the sea for two months. Thus softened, the worker undertakes to beat them into shreds. Holding a piece of husk in his left hand and swinging the heavy stone pounder known as a penu in his right, he beats the soaking mass until it is dry and the tough fibers separate. He then picks up a bunch of loose fibers in his left hand and combs the tangled mass with his fingers. The small combings he saves for making the twisted cord known as anave; the long strong fibers he ties in bundles to be plaited into nape. (1927:105)

I next reproduce Handy's graphic account of the manufacture of coconut-fiber cordage, both twisted and plaited. The episode she described was a twentieth-century one, but the techniques employed are implied to have been of ancient origin:

The honor of making cords, ropes and nets, still belongs to the men folk of the Society Islands, whenever they care to avail themselves of the privilege. The manufacture of some cord still involves the use of several materials-coconut fiber, and the barks of the purau, piripiri, and mulberry trees-but inasmuch as an "odor of sanctity" hangs about the use of the coconut fiber, more of the traditional method of manufacture persists in its use. The chief of Maupiti gave me a very complete demonstration of this time honored industry.

He sorted out the soft combings from the fibers beaten from the coconut husks, with the intention of making first a twisted two-ply cord, an anave of two ave (strands). He used the method common throughout Polynesia, twisting the fibers together by rubbing them between his hand and his thigh. This process included the continual lengthening of each strand by rubbing together short overlapping fibers, and the twisting together of the two ply. Laying the fibers across his naked right thigh in two parallel strands he held them apart with his left hand, while he pressed the palm of his right hand down and rubbed first the near ply, then the far ply, across his thigh in the following way. He drew the near ply towards him and pushed it away with a smooth, flowing movement. He rubbed the far ply towards him, then away from him, and then, without interruption of the smooth stroke, rubbed it again towards him, carrying it this time over the near ply and rubbing the two towards him together. Just as a loose twist was beginning to form in the two ply, he reversed his movement and rubbed the two together away from him down his thigh all the way to the knee.

Lifting up the section thus manipulated, he exhibited a firmly twisted twoply cord, the common form of anave puru haari. A three-ply cord of coconut fiber is now uncommonly made.

Having used up the pile of combings in twisted cord, the chief turned 
with satisfaction to the longer, stronger fibers, of which plaited cord is made. It was clear that he followed a method prescribed from generation to generation, as he gathered up a thick bundle of fibers, which had been tied in the middle for orderly keeping, and placed one end of it under his left thigh as he sat on a stool. His weight kept the bunch in place, so that he could pull out two or three fibers at a time without disturbing the others. In such small installments he pulled them out with his right hand and placed them crosswise in his mouth, the ends hanging from either side. It seemed to be the sense of bulk between his lips which advised him when he had selected enough fibers for the plait.

Holding the ends, then, in his mouth, he started a three-ply plait of the ordinary style, adding fibers as they were needed, always transferring them from the bunch under his leg to his mouth before working them in. When the plait was long enough, he tied one end to the end of a three-foot stick, indicating, however, that it was also permissible to tie it to his big toe. The stick method he preferred, for, shoving the free end under his right thigh to hold it firmly, he used it both as a stationary anchor for his work and, soon, as a spool on which to wind it as he finished the plait. This he accomplished by plaiting towards him for the length of the stick, then by pulling the finished plait tightly over the near end of the stick and turning it about so as to plait it again towards him along its length. Thus he wound length after length from end to end about his stick. When he had manufactured as much nape as he desired, he withdrew the stick very carefully, so as not to disturb the wound plait, and secured it by wrapping the bundle from end to end with the loose end of the plaited cord.

The tight, cigar-shaped bundle, in which form nape is usually kept, was thus secured. (W.C. Handy 1927:108-109)

The following description of sennit making comes from Orsmond's definition of aha firi tuatua, described by him as "Senet made from the stoutest fibres of cocoa nut husks."

In making [this kind of] Cenet, [the artisan] sits, ties the end to his great toe, while he plaits, and at about ever eighteen inches he has occasion to fasten it a new to his toe. He holds in his mouth several of the large fibres, which are from 8 to 10 inches long. The twisting is done by the thumbs and forefingers, and a dextrous hand will make 10 fathoms in a day. Every time he adds to the strands he lets the extreme ends stick up as bristles, so that on looking on it, the Senet seems to be lost in its bristles and is as unsightly as a web of new cloth before it is sheared. This extreme roughness is the tuatua of it and is removed either by a muscle shell, or a sharp knife.

Those fibres are obtained first, by burrying the whole of the husks mud and water, or in the sea, until greatly decomposed; they are then taken, and on a block either of wood or stone so beaten by a iron wood cudgel that the large strong fibres separate from the mass and are easily drawn out and tied in bundles as are coblers bristles. (Orsmond: Dictionary Notes)

My main reason for devoting so much space to this essentially technological matter in a book concerned mainly with social relations stems from my impression that this type of cordage making constituted a major activity for many Maohi males, and an almost constant preoccupation for some. Also, such cordage was evidently produced in huge quantities to sat- 
isfy numerous kinds of socially relevant needs. ${ }^{5}$ Moreover, cordage in general, and sennit in particular, is noteworthy in having served as metaphor for numerous socially relevant phenomena, for example, aha mata rau ("senet that has scarcely two parts in it alike. Thick here, thin there, smooth here, rough there, dyed of various hues") was applied figuratively to an individual who was "a breeder of disturbances; a refractory fellow"; aha vai (sennit made from barks steeped in water, i.e., very stringy) was applied frequently to a champion boxer, a man of tireless industry. (Orsmond: Dictionary Notes)

After coconut-husk fiber, the bark of the hibiscus tree was perhaps the next most common material used for cordage. For many purposes of ordinary tying, strips of the cut bark, unmodified, evidently sufficed; but for a more lasting cordage the inner-bark fibers (more) of the tree were used. According to W.C. Handy, "March, April, and May are still the months when the young shoots of the purau tree are cut for the making of more" (1927:9), and it is reasonable to suppose that seasonally in the processing of more was also the case long ago.

The first stage in preparing more consisted of soaking the young shoots of hibiscus in water for several days, after which the outer bark was removed and the white inner bark flattened out and left to dry. An even finer cordage than more was made from the inner bark of piripiri 'flax', following the same methods and quite likely, the same seasonal timing. (W.C. Handy 1927:8-9, 107)

According to Banks, the strongest of all Maohi cordage was made from the fibers of the roa shrub:

But of all the strings that they make none are so excellent as the fishing lines \&c. which are made of the bark of a kind of frutescent nettle calld by them Erowa (Urtica argentea) which grows in the mountains and is consequently rather scarce\& of this they make the lines which are employd to take the briskest and most active fish as bonetos, Albecores \&c. As I never made experiments with it I can only ascertain its strengh by saying that it was infinitely stronger than silk lines which I had on board made by the best fishing shops in London, tho not so thick by almost half. (Beaglehole 1962:I, 361)

Here is W.C. Handy's description of the manufacture of roa cordage:

In the old days, the preparation for the making of anave roa (twisted roa cord) was begun in October, cutting down the roa bushes at that time, so that new shoots might spring up and be ready for the cutting the following July. In July then, might have been seen the young, green sticks or roa heaped under a purau tree on the beach perhaps, ready for the stripping which was to leave them clean and greenish after the removal of the outer skin. For several nights they were spread upon the grass in the dew, soaking and bleaching to snowy whiteness. And finally came the combing of the fibers into fine threads with the aid of a thorn from an orange tree, a painstaking but sociable occupation. Such were the roa fibers which were twisted by the process known as nino into cords for fish lines and nets. (1927:107) 
How far back Handy's "old days" refer to is not specified, but they may possibly have extended to pre-European times.

Cordage made of braided human hair was highly valued, mainly for ornamental attire. According to various accounts, such braids were six to nine hairs thick, and some were scores of fathoms long. Banks reported having seen some specimens that were “... platted, scarce thicker than common thread, of this I may easily affirm that I have peices above a mile in lenght worked upon an end without a single Knot" (Beaglehole 1962:I, 339).

I shall not list the many other kinds of cordage materials and products used by Maohis, but it should not be forgotten how important such cordage was among these Islanders, who did not know of nails. Cordage was important in ways not only practical but social-relational as well, as later chapters will indicate.

\section{BARK CLOTH}

The textile used for most garments, turbans, and bed covers was made of the inner bark of several kinds of trees, principally of the Chinese mulberry (Broussonetia papyrifera: 'aute), a variety of breadfruit called pu'upu'u (Artocarpus altilis), and a figlike tree (Ficus prolaxa: àoa). The first of these, the most widely used, was cultivated mainly on plantations near residences; one of these plantations was seen and described by G. Forster:

The next day we took a walk up one of the hills, which is every where planted with bread-trees, pepper and mulberry-trees, yams and eddoes. The mulberry or cloth-trees were cultivated with particular attention; the ground between them was carefully weeded, and manured with broken decayed shells and coral, and the whole plantation surrounded with a deep furrow or channel, in order to drain it. In many places they had burnt away ferns and various shrubs, in order to prepare the ground for future plantations. (G. Forster 1777:I, 118-119)

Cloth made from these trees differed in strength, texture, and color, but the method of manufacture was about the same. Only young saplings were utilized, and the stems of the young plants had to be kept free of branches to insure that the bark would not be punctured. After the bark was peeled off the straight and unmarred young saplings or limbs, it was soaked in water, the rough outer layer was scraped off, and the inner bark was placed on a flat board and beaten thin with a wooden mallet (figs. 5-13 through 5-16. The width of the strips was increased several times by beating; to make them longer and still wider numbers of strips were felted together by further beating, helped by the resinous substance in the bark. Or, to thicken or repair the cloth separate layers were pasted and beaten together. Morrison gave the best account of the manufacturing process: 


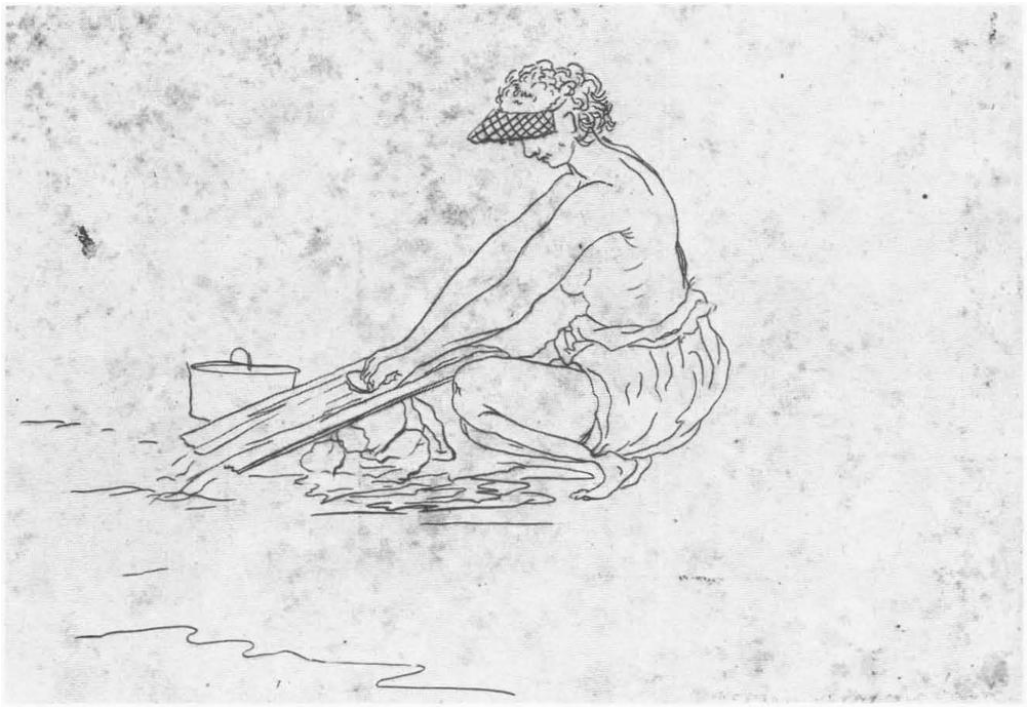

FiguRE 5-13. "A Girl Scraping the Bark to Make Cloth." Sketch by S. Parkinson. British Museum.

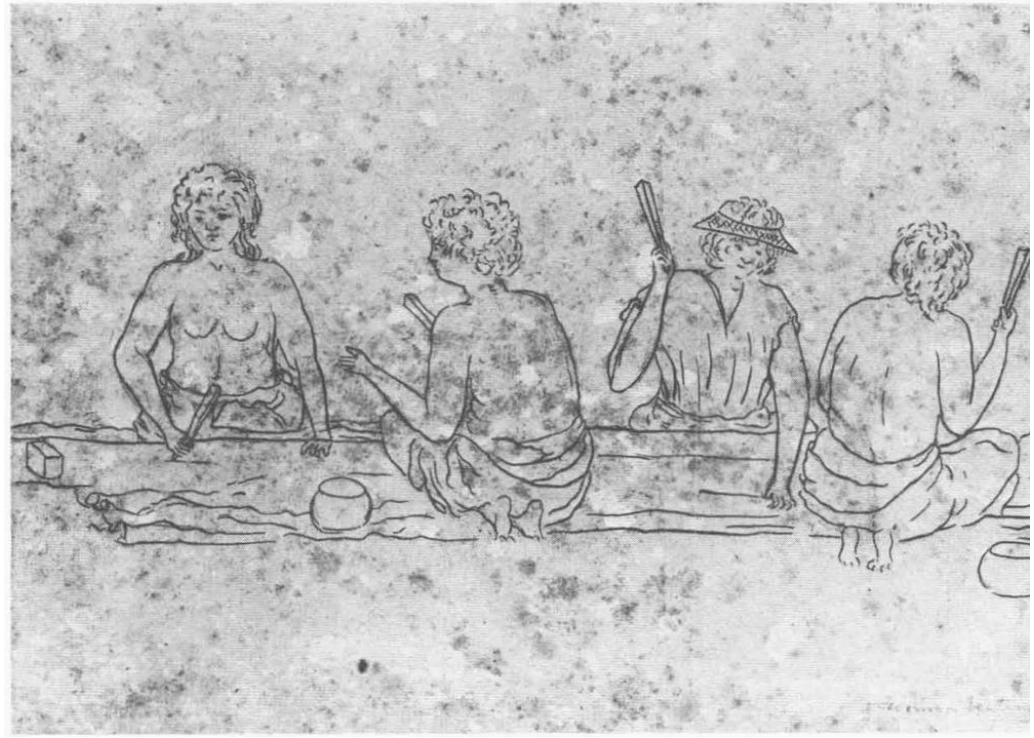

FIGURE 5-14. "Girls beating out the Bark with their Cloth beaters." Sketch by S. Parkinson. British Museum. 


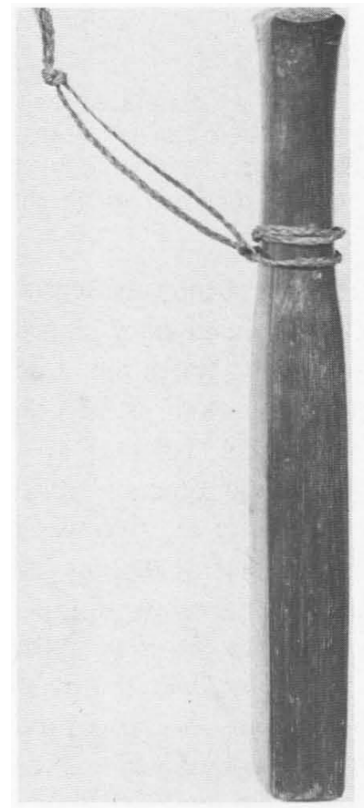

FigURE 5-15. Bark-cloth beater. Etnografiska Museet, Stockholm.

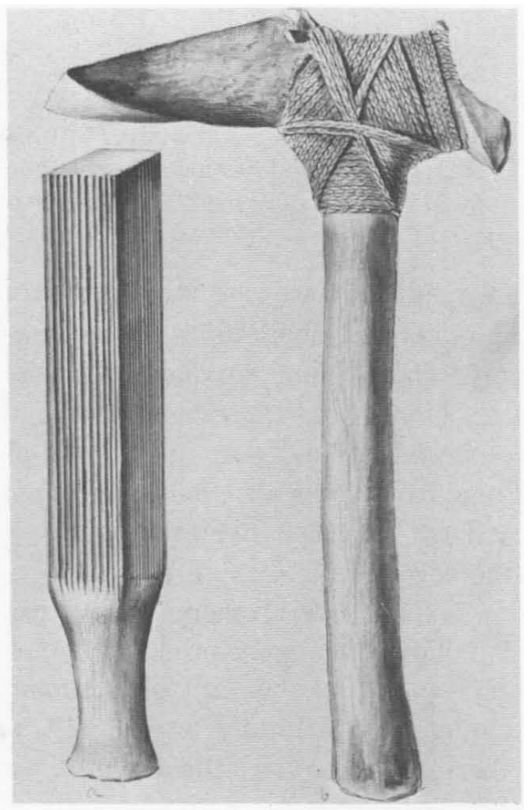

FIGURE 5-16. Bark-cloth beater and adze. Drawing by J. F. Miller, British Museum.

Their Cloth, of which the General Names is Ahhoo, is of Different sorts and and made from the Bark of different trees but the process of all is the Same.

The Best and finest white Cloth Calld Hoboo or Parrawye is made from the Yowte or Cloth Plant and is made thus-The plants having to their proper length (10 or 12 feet) are cut by the Men and brought in by them which is their part of the work, the Weomen then Strip off the bark by entring a pointed Stick between the bark and the Plant and ripping it the whole length on one Side, \& the Bark peels off. After they have Stripd all the Plants they take the Bark to the Water where they wash it, [and] spreading it on a board for the Purpose Scrape it Clean, taking off the Outside rind with a large Cockle shell and having freed it from the Sap and Slime it is wrapd in plantain leaves and covered with Grass, where it remains for two three or four days when it becomes Clammy and glutinous, \& is then fit for working, it is then spread of a regular thickness of several strips forming a band of 7 or 8 inches broad and of what length the piece is intended to be and the Ground where they intend to work is spread with plantain leaves to keep it from the dirt-the Beans are then placed at equal distances about 6 feet asunder $\&$ at each of them two weomen work, having the Piece between them, beating it with square beetles to its proper breadth; this they perform by a Song given by one \& Chorous'd by the rest and keep regular time and Shifting the Piece backwards and forwards till it is all beat out to a regular Breadth and thickness-it is then spread in the sun to Dry for one Day, after which it is bleachd in the Morning Dew till it is perfectly white, being kept from the sun till it is sufficiently bleachd, and then it is spread one or two days in the Sun to dry it and put up for Store or Use. 
They make another sort of several Thicknesses which are not placed regular or above half beaten, this is Calld Marro; of this they make their Upper Garments by Striping from one part and pasting on to another till they bring it to a rgular breadth \& thickness and trim the Fragments off with a piece of split bamboo which answers the purpose of a knife-(Morrison 1935:160-161).

The only indications I can find that there might have been any seasonality in the production of bark cloth occurs in a freely translated story reproduced in Henry. The reference in question reads as follows: "When the child was about six months old, the season for beating out tapa cloth arrived and all the women of the land were busy in the pleasant work" (1928:604).

Some bark cloths were only sun bleached before use, others were soaked in or painted with dyes. (Figs. 5-17, 5-18.) A favorite red dye was made from the berry of the mati (Ficus tinctoria) and the leaf of the tou (Cordia subcordata), but several other plants were also used for decorating this popular cloth. ${ }^{6}$ Yellow dyes were produced from the root bark of nono (Morinda citrifolia) and from the fruit of the tamanu (Calophyllum). Some of the bark cloths were naturally brown, but a brown color was also produced from the root of the tou. Black cloths were achieved by soaking the cloth in certain swampy spots, or by using the sap of the mountain plantain.

Most observers pointed out that the dyes applied to bark cloth were not fast, and indeed that bark cloth itself was short-lived. For example, Ellis wrote:

The ahu, or cloth made with the bark of a tree, although exceedingly perishable when compared with European woven cloth, yet furnished, while it lasted, a light and loose dress, adapted to the climate, and the habits of the people. The duration of a Tahitian dress depended upon the materials with which it was made, the aoa being considered the strongest. Only the highly varnished kinds were proof against wet. The beauty of the various kinds of painted cloth was soon marred, and the texture destroyed, by the rain, as they were kept together simply by the adhesion of the interwoven fibres of the bark. Notwithstanding this, a tiputa, or a good strong pareu, when preserved from wet, would last several months. (1829:II, 178-179)

'Ahu was the name for garments in general, as well as the general name for bark cloth; the different varieties of bark cloth also had more specific names.

Bark cloth not intended for immediate use was rolled up and kept suspended from house rafters. Some strips were dozens of yards long; one observer reported there having been some that measured four yards in width and two hundred yards long, and he added that "the wealth of a chief is sometimes estimated by the number of these covered bales which he possesses." (Ellis 1829:II, 174)

Every household evidently produced some bark cloth-probably enough for the immediate consumption needs of its members-but when additional amounts were needed, say, for taxation or gift-exchange, they were either secured from elsewhere (in ways that I will describe in later chapters) or manufactured in situ by means such as those described by Morrison: 


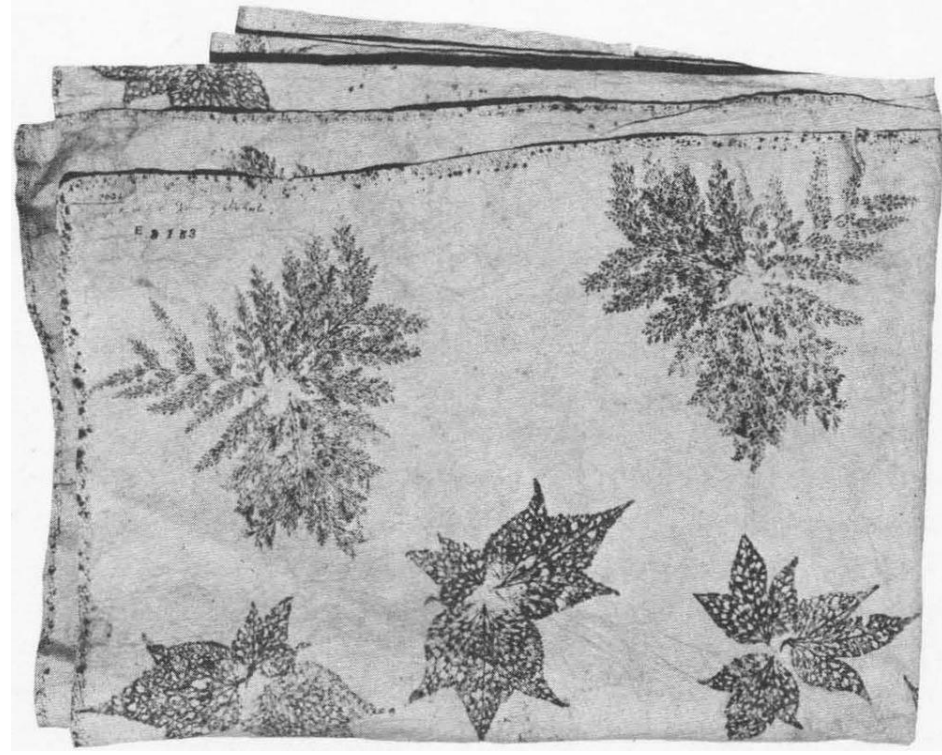

FIGURE 5-17. Bark cloth showing designs. Peabody Museum. Salem.

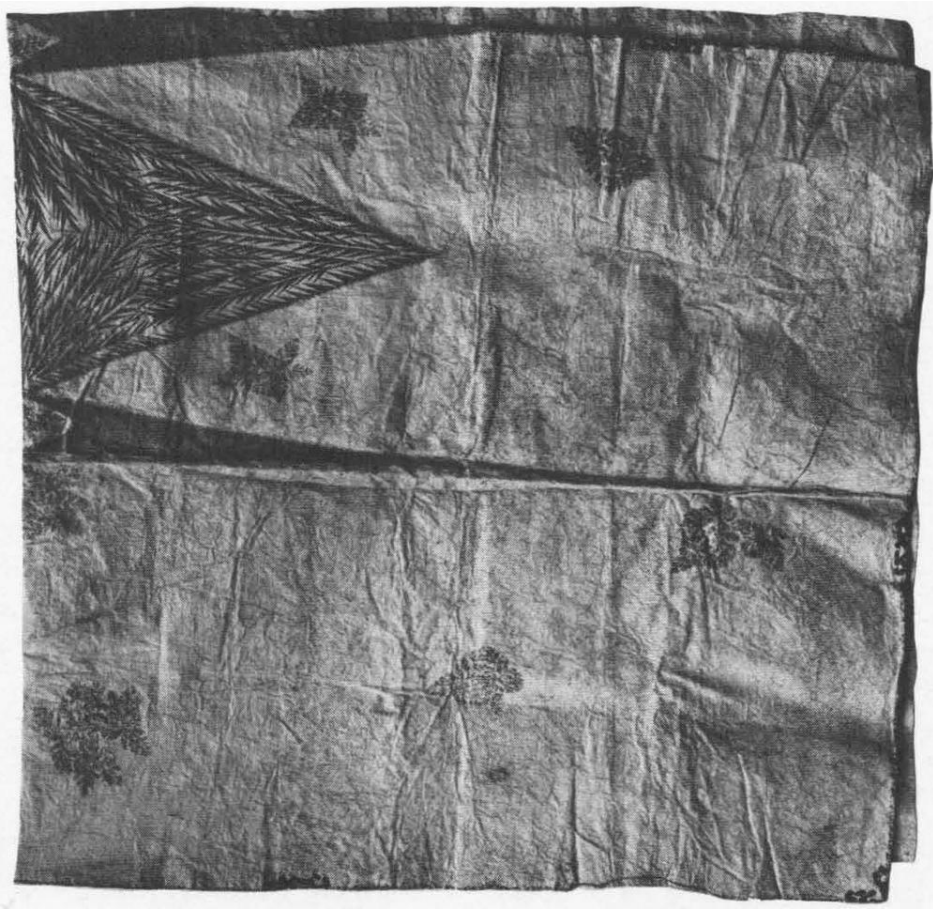

FIGURE 5-18. Bark cloth showing designs. British Museum. 
If a landed Man wants a large quantity of Cloth made at once, he informs his Tennants when he means to Cut his plants and on the Day appointed all the Weomen attend with each their Beam \& Beetle and a proportion of Breadfruit being prepared they bring the Work together and some times to the Number of 200 strike off together, making as much noise as so many Coopers. The piece is finishd in one Day and is sometimes 40 or 50 fathoms long and 4 fathoms wide. (1935:161)

In view of the many uses of bark cloth, and of the constant need to replace or mend the rather flimsy everyday garments made out of it, its manufacture and repair must have consumed a large part of the Maohis' working time. In fact, one of the characteristic features of residential settlements was the continual sound of beating mallets. According to Ellis most of this work was done by women, but men occasionally lent a hand, especially in the preparation of the large quantities needed for ceremonious visits. "There were some kinds [of bark cloth] used in the temples, in the service of the idols, which were made by men, and which it was necessary, according to the declarations of the priest, should be beaten during the night." (1829:II, 179). ${ }^{7}$ According to Banks, it was "... the business of the mistress of the family and principal women of it," to keep the householders' bark cloth garments in good repair, and in doing so "... seem to amuse themselves as our English women do in making Caps, ruffles, \&c; and in this they spend the greatest part of their time" (Beaglehole 1962:I, 355-356). Evidently, social value was attached to well-made bark cloth:

As the wives or daughters of the chiefs take a pride in manufacturing superior cloth, the queen would often have felt it derogatory to her rank, if any other females in the island could have finished a piece of cloth better than herself. I remember in the island of Huahine, when a native once passed by, wearing a beautiful ahu-fara, hearing one native woman remark to another-What a finely printed shawl that is! The figures on it are like the work, or the marking, of the queen! This desire, among persons in high stations, to excel in departments of labour, is what we have always admired. (Ellis 1829:II, 178)

The sources also report that bark cloth manufacture was usually a sociable affair. One such event described by Ellis, though written of a time decades after Wallis' visit, seems also typical of the earlier era:

In the manufacture of cloth, the females of all ranks were employed; and the queen, and wives of the chiefs of the highest rank, strove to excel in some department-in the elegance of the pattern, or the brilliancy of the colour. They are fond of society, and worked in large parties, in open and temporary houses erected for the purpose. Visiting one of these house at Eimeo, I saw sixteen or twenty females all employed. The queen sat in the midst, surrounded by several chief women, each with a mallet in her hand, beating the bark that was spread before her. The queen worked as diligently and cheerfully as any present. (1829:II, 177)

Thus, Maohi bark cloth was a product of great social importance. Its manufacture consumed large proportions of the Maohis' time; it constituted a major item in their social transactions and was thus looked upon as a principal repository of social affluence. 


\section{PlaitWARE AND NETTING}

After bark cloth, the Maohis' next most common textile was plaitware, of numerous kinds of raw materials, plaitwork patterns, element thickness, overall shape and size, form of decoration, and of course use. (Figs. 5-19, 5-20) The principal raw materials used for plaitware were the inner bark of purau (i.e., more); stalks of bamboo, arrowroot, and à'eho grass (Erianthus floridulus); midribs or stems of certain ferns; and leaves of coconut and pandanus. Although some plants used in plaitware may not have grown everywhere, most of the principal ones were probably widespread enough to permit nearly archipelago-wide collection.

A passage from Ellis states that "some kinds [of pandanus] grow spontaneously, others are cultivated for their leaves" (1829:II, 180). I have come across no references in other sources that some pandanus was in fact planted and tended for this purpose, but the circumstance that certain plants were cultivated for bark cloth provides reasonable evidence that such was the case with pandanus as well.

Plaitwork patterns, diameter of plaiting elements, and, of course, raw materials varied with the type of product. For example, for the fine plaitwork constituting the wraparounds (vane) and ponchos (tiputa) worn by certain of the "Principal People," thin bleached strips of hibiscus inner bark were used; Ellis described them as having been "light ... elegant and ... remarkably durable" (1829:II, 180). Some of the articles must have taken weeks or even months of daily work to complete, ${ }^{8}$ and they undoubtedly required a specialist's skill. In contrast, a serviceable basket could have been plaited out of coconut leaves in a few minutes time, and probably by almost any Maohi past early childhood.

In addition to the objects just specified, plaitware constituted certain other articles of attire, floor and bed matting, "room" partitions, boat sails, and numerous shapes and sizes of containers. Much less has been written about its manufacture and utilization than was the case with bark cloth, but the more specialized phases of its fabrication (for example, the making of fine hibiscus-bark garments) were evidently the work of women. (Ellis 1829:II, 179)

According to Ellis, ordinary (floor) mats were not more than six feet wide by nine to twelve feet long, but occasionally a very much larger one was made, some twelve feet wide by sixty to one hundred yards long. "Mats of this size," he noted, "are only made for high chiefs, and in the preparation, perhaps, the females of several districts have been employed." Such mats were usually kept rolled up and suspended from the rafters of the owner's house-“more for the purpose of displaying his wealth, and the number of his dependents [or, perhaps, subjects], than for actual use." (1829:II, 181) ${ }^{9}$ 


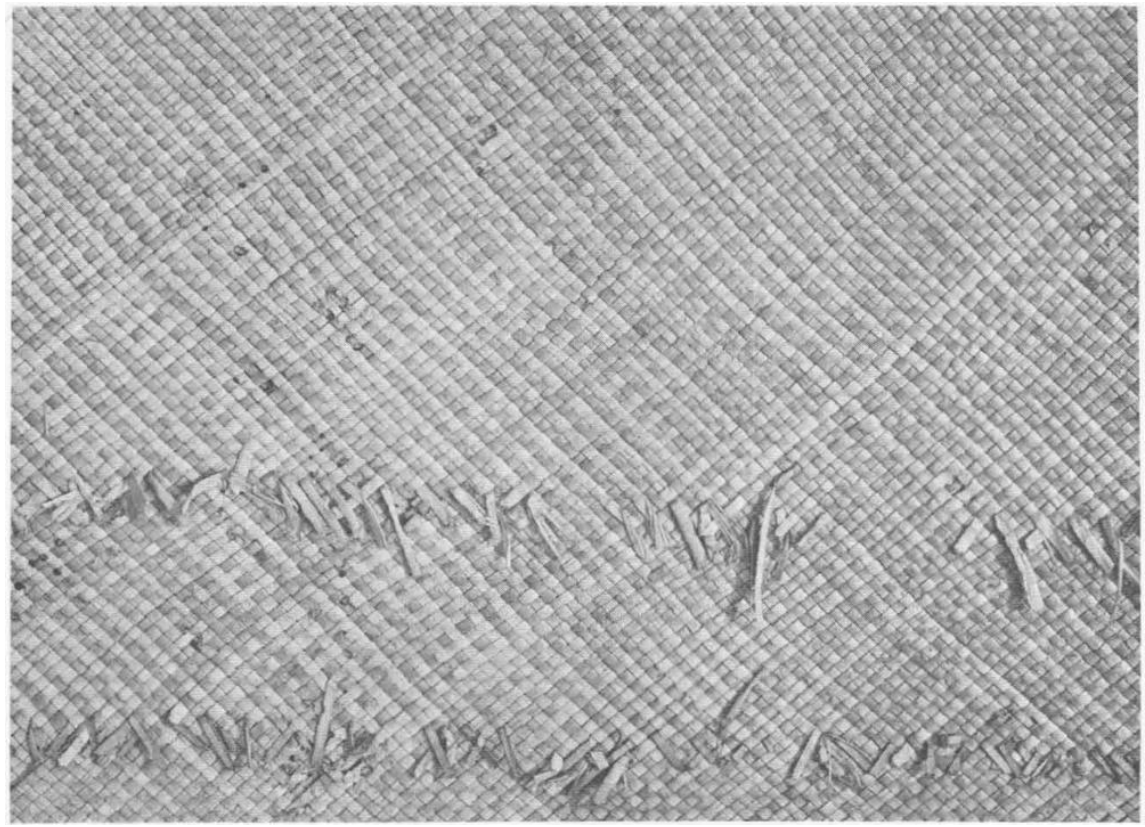

FIGURE 5-19. Plaitwork. Etnografiska Museet, Stockholm.

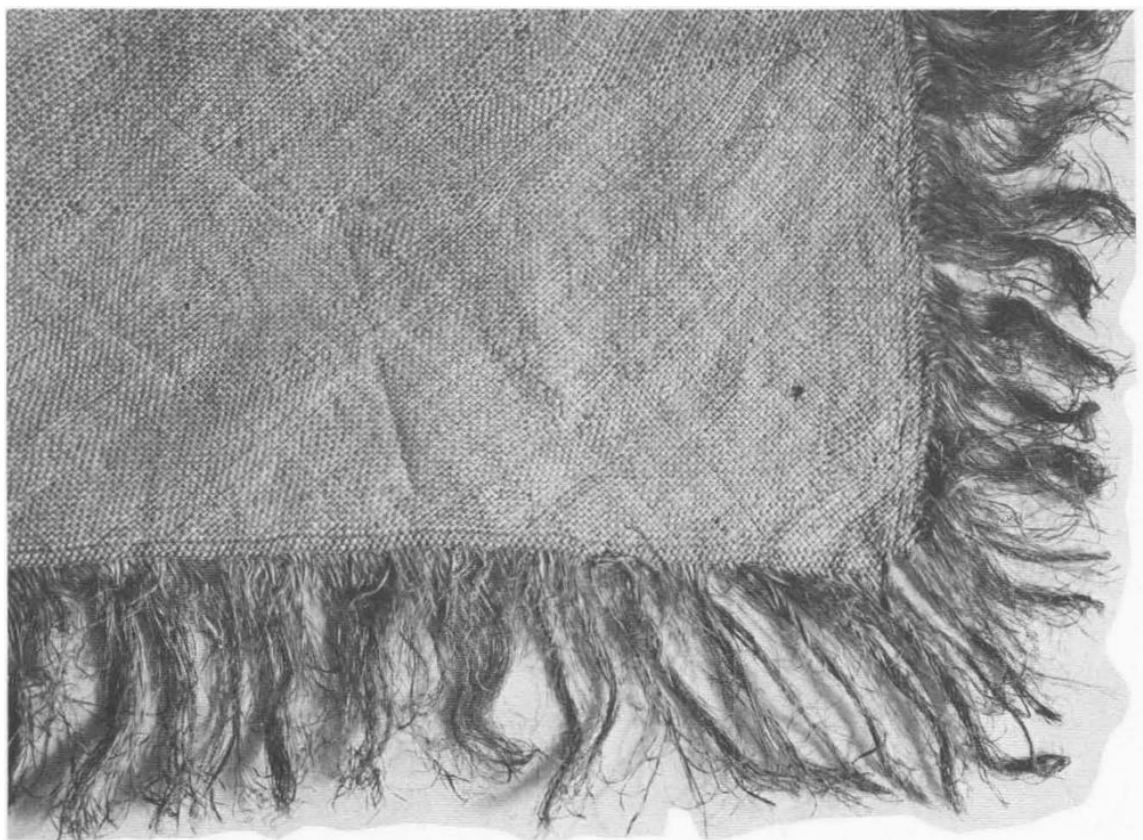

FiguRE 5-20. Plaitwork. Bernisches Historisches Museum, Bern. 
Like bark cloth, fine mats figured frequently in gift-exchange and possibly in taxation as well. There is, however, no evidence that I know of that it also figured in more "commercial" transactions, such as direct barter or manufacture on paid commission. Ellis described a trade link with the Tuamotus which involved plaitware from the latter, but I cannot say whether or not this was a pre-European occurrence:

The inhabitants of the Palliser Islands, to the eastward of Tahiti, exceed the Society Islanders in the quality of their mats, which are made of a tough white rush or grass, exceedingly fine and beautiful. They frequently manufacture a sort of girdle, called Tiheri, six inches in width, and sometimes twenty yards in length, but remarkably fine and even, being woven by the hand, but with a degree of regularity rivalling the productions of the loom. They are highly valued by the Tahitians, and are a principal article of commerce between the inhabitants of the different islands. (Ellis 1829:II, 180)

Plaitware decoration-mainly of certain garments-consisted of interwoven fibers, free-hanging fringes, brightly colored seeds, shells, and feathers. The latter, especially, added great social value to the article of wear.

I know from several sources that the Maohis made fishnets with some of their cordage, and I may safely assume that netting techniques were employed in fabricating some carrying bags; but in neither case can I reconstruct how such articles were made. ${ }^{10}$ 


\section{CHAPTER 6 GROOMING}

The Maohis can be characterized as having shown a significantly strong interest in the external condition and appearance of their bodies, as attested in the amount of time and scrupulous attention they devoted to their clothing and toilette.

\section{EVERYDAY CLOTHING}

Maohi children went naked until they were about five or six years of age-by European reckoning (see Morrison 1935:220); we are not informed how the Maohis judged when a child should don clothes. Thereafter, both males and females were accustomed to wearing clothes at all times except when asleep or on a few ceremonious occasions, which will be specified in later chapters.

The basic garment for males was a breech clout (maro), for females a short underskirt (pareu). Over these, both sexes wore a wraparound (also called pareu) which extended from waist to knee on males and from above the breast to below the knee on females. In addition both sexes sometimes wore a long, open-sided poncholike garment (tiputo) belted around the waist with a long girdle (tatua), and on top of these garments women occasionally donned a loose cloak ('āhu). (Fig. 6-1.) The garments themselves were made of bark cloth or plaited leaves, and the girdle occasionally was made of plaited hair. According to Banks, plaitwork clothing was favored in rainy weather because of its greater durability (Beaglehole 1962:I, 338).

Once bark cloth or mats had been fabricated, fashioning them into garments appears to have been a simple and extemporary job, as is seen for example in Robertson's account of his visit to a "royal" household:

I went to take my Leave of the Queen and the old Lady but they oblidged me to sit doun again and the Queen cut me out a Sute of the country cloath, and wanted me to throw of my own, but I declined that and put them on over my own, She wanted me to put on a Secant pece, but I refused that and pointed to the Youn Gentn [one of the ship's junior officers], and she put that on him, their was no great trouble in making this Sute. She only cut of about ten foot of the pece of Cloath, which was about five foot wide-and cut a hole in the Middle, throw which hole I put my head, and she then tyed it round my west with a Sash of 
mutch finer cloath, then made a Short Speech to her people who all seemd very happy And gave me a pece of very fine cloath made up snug it was about sixteen yards long and three Broad. (1948:214)

When engaged in strenuous physical activity-say, in fishing-men dressed only in the breech clout, and women in an underskirt.

Once having started to wear clothes, except on certain ritual occasions, both males and females were careful about keeping their genitals covered, ${ }^{1}$ and they were reported to have been skillful in changing their garments without uncovering:
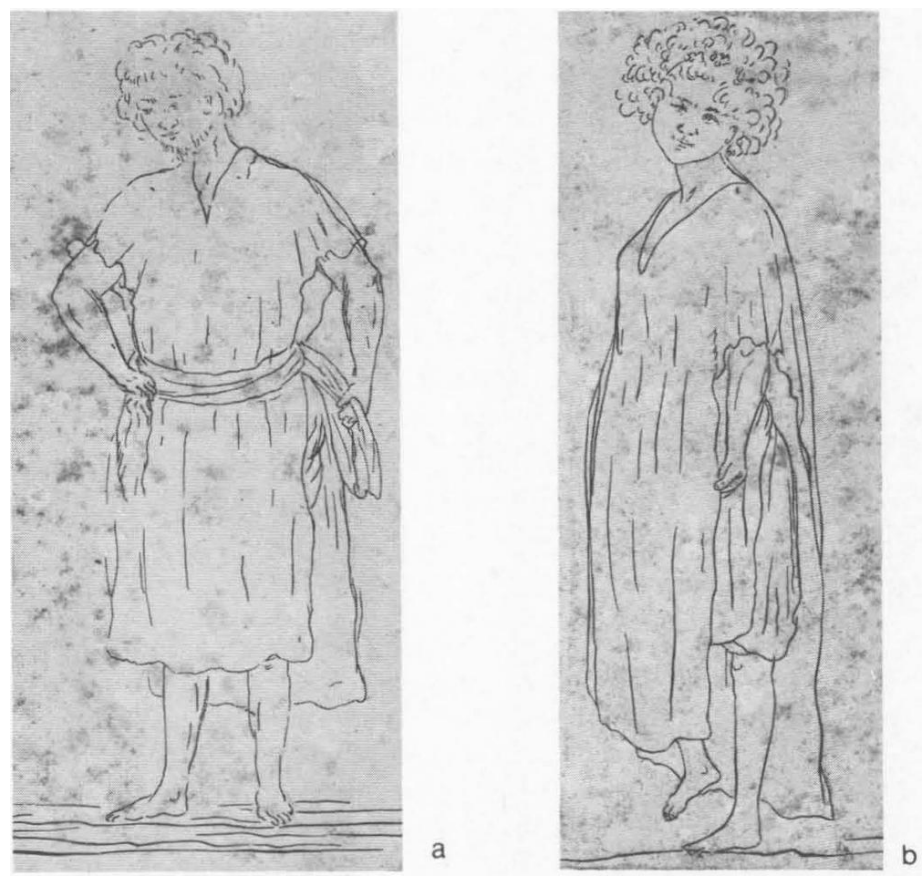

FIGURE 6-1. Outer garments: $a$, male's; $b$, female's. Sketches by S. Parkinson. British Museum.

The Single Young Men have also dances wherein they shew many indecent Gestures which would be reproachable among themselves at any other time but at the dance, it being deemd shameful for either Sex to expose themselves Naked even to each other and they are more remarkable for hiding their Nakedness in Bathing then many Europeans, always supplying the place of Cloaths with leaves at going in and coming out of the Water.... (Morrison 1935:225)

Morrison also stated that "... Weomen Never uncover their Breasts ..." except when bathing, but this was contradicted in part by Banks: "The 
women at sun set always bard their bodys down to the navel, which seemd to be a kind of easy undress to them as to our ladyes to pull off any finery that has been usd during the course of the day, and change it for a loose gown and capachin" (Beaglehole 1962:I, 338).

One of the sources states outright, and most of them at least imply, that the "principal people" tended to wear more clothes than the "common sort." "... the rich seem to shew their greatest pride in wearing a large quantity of cloth.... The poorer sort have only a small allowance of cloth given them from the tribes or families to which they belong, and must use that to the best advantage.... it was no uncommon thing for the richest of the men to come to see us with a large quantity of cloth rolld round their loins, ... sufficient to have clothed a dozn people." (Beaglehole 1962: I, 338) The bases of this difference will be examined in another context, but it should occasion no surprise in view of the labor required in the manufacture of bark cloth and fine matting. Moreover, we know from many reports that bark cloth, especially, was a regular item in gift-exchange and tribute.

Four kinds of headwear were worn by the Maohis: bark cloth turbans (tāumi upo'o), caps (taupo'o), braided head bands (tamou), and wreaths (hei) of many shapes. Warriors wore simple head wrappers of heavier cloth to protect their heads in battle, but lighter turbans were also worn for protection against the sun, and for show. Some of these latter, worn by men of social importance, were elaborate things built on a wicker frame and decorated with feathers, and so forth:

The most showy headdress worn officially by the king and princes and high chiefs was the taumi, a superb helmet made of clusters of crimson feathers of the moora 'ura (red-feathered duck), set upon a light framework and covering the head like a bird, with a glossy terminal behind of outspreading red, black, and white feathers tastily mixed together. This helmet, standing out from a closely fitting band round the head and towering high above, seeming to yield or bend with every movement, presented a formidable appearance. On public occasions, when meeting a man held in high esteem by his countrymen for valuable services, a king wearing a taumi would pass it on to his head as a mark of appreciation. After courteously receiving it the hero would return it to the king amid admiring acclamations. (Henry 1928:286)

In the sources there are many hints and a few explicit assertions that specific kinds of headwear served as insignia for certain high offices, but I am unable to go beyond that general statement.

The Maohis' only kind of footwear consisted of sandals made of bark cordage and worn usually for protection against the sharp coral and shell of reefs. Another protective device, occasionally worn by both males and females, were sunshades for eyes and face; usually these were plaited from coconut leaves each time they were needed and then thrown away. (Beaglehole 1962:I, 338) 
Other special items of dress, worn at times of mourning, fighting, dancing, and playacting, will be described later on.

\section{TOILETTE}

Children's hair was usually cropped close, with a shark's tooth, according to Ellis, who added that "this operation was frequently repeated during their juvenile years" (1829:II, 115). Most women wore their hair fairly closecropped also, although one reads of some females having had long flowing manes (e.g., see G. Forster 1777:I, 402). Men cut and wore their hair in various ways, for example:

The men wore theirs in every diversity of form-sometimes half the head almost shaved, the hair being cut short, and the other half covered with long hair-sometimes the crown cut, and the edges left the original length. Frequently, it was plaited in a broad kind of tail behind, or wound up in a knot on the crown of the head, or in two smaller ones above each ear. (Ellis 1829:II, 115)

According to Cook, differences in class and occupation were reflected in men's hair styles:

... the better sort [of man] let it grow long and sometimes tying it up on the top of their heads or leting it hang loose over their shoulders but many of the inferiors and such w(h)o in the excersi(se) of their profession fishing \&ca are obliged to be much upon or in the water wear it cropt short like the women. (Beaglehole 1955: 123-124)

Individuals of both sexes used implements of bamboo for combing their hair $^{2}$ and perfumed coconut oil (mono'i) as a pomade. Sandalwood was the chief source of perfumery, but G. Forster reported that some thirteen other plants were so used, “... which shews how remarkably fond these people are of fine smells" (1777:II, 83). Morrison provided the following description of the manufacture of mono' $i$ :

Their method of making Oil is this-The Cocoa Nuts being full grown, are Gatherd in and freed from the Husk. They are then Broke in halves and the Milk which is then sour is thrown away and the Inside of the Nut grated into a Trough made for the Purpose-a piece of Coral tyed on a kind of Horse on which they sit to steady it serves for a Grater. The Nuts being all grated, the trough is hung up, or fixd on a stand and the stuff left to disolve, and in a few days the Oil begins to run, then [they] Grate into it Sandal wood and mix into it the Dust from the palm blossoms and other sweet flowers herbs \&c-and when all is disolvd they strain it off, and put into Bamboos for Use, the Oil retaining the Scent while it is kept Close stoppd-this Process of making it takes up near three Weeks, during which time they mostly turn it over and Mix it evry day-Another Method is by placing the Nuts in the sun to melt, which is done in a few days, but the Oil thus made is always rank-The Cocoa Nut is the only oil they make and the Chief use of it is for Dressing their Hair or Anointing their Bodys where they Chance to be sunburnt-it is Calld Monnoe. (1935:164) 
They decked their coiffures with flowers, shells, feathers, leaves, and colored seeds. Women, especially, spent hours at this pastime, usually in company with others.

Many men kept their faces fairly free of hair by means of razors or tweezers of shell, fish scales, or shark's teeth; but certain men- "chiefs" in particular, according to G. Forster (1777:II, 111)-allowed some facial hair to grow, leaving, according to Bligh, a long tuft of chin whiskers, a narrow jaw bone rim, and a thin mustache (1789:I, 404), and producing an effect such that "... a painter might take an excellent copy of a Hector or an Achilles" (Morrison 1935:170).

In addition, most adults, of both sexes, made a practice of trimming their eyelashes and eyebrows and of plucking out all other body hair-mainly, it is reported, for reasons of hygiene. "They adjust their brows and eyelashes, clipping them if too long, and forming the eyebrows into regular arches." Even hair growing in the nostrils was plucked out ... "to prevent its harbouring any dust or foulness." (Wilson 1799:343.) According to this same source a black coconut shell filled with water served as a looking glass before Europeans introduced mirrors; "nor are the men less attentive [than the women] to their persons, and will sit at the glass dressing with the greatest complacence."

Available descriptions of the ancient Maohis all agree on their body cleanliness. As noted earlier, the morning usually began with a bath-an occasion for socializing, according to Moerenhout (1837:II, 75); and this was followed by other baths during the day. Fresh water was greatly preferred for bathing, and fishermen, after day-long immersion in salt water, customarily bathed in a freshwater stream. So addicted were these Islanders to bathing that it sometimes led to their undoing; no matter what the kind or stage of their infirmities the sick or wounded made every effort to bathe in fresh flowing water, which in many instances undoubtedly exacerbated their maladies (see Corney 1915:141). The Maohis were also scrupulous about keeping their garments as clean as their activities would permit. In fact, in comparing the odors of European and Maohi crowds, Banks and others commented favorably on the inoffensiveness of the latter. In this respect the only thing found offensive by the Europeans was the rancid odor of the Maohis hair after applications of their coconut-oil pomade.

Yet, despite all this attentiveness to their toilette, the Maohis were not able to keep themselves entirely free of lice.

Another custom they have that is disagreable to Europeans which is eating lice a pretty good stock of which they generaly carry about them; however this Custom is not universal for I seldom saw it done but among children and common people and I am persuaded that had they the means they would keep themselves as free from lice as we do, but the want of Combs in a hot climate makes this hardly possible. (Beaglehole 1955:124; see also Beaglehole 1962:I, 337) 
Many persons carried fly flaps and used them continually to keep off the myriads of flies and other insects that swarmed around, particularly at mealtime (figs. 6-2 through 6-5).

According to one visitor long fingernails were highly regarded as a mark of social distinction "... since only such persons, as had no occasion to work, could suffer them to grow to that length" (G. Forster 1777:II, 283). But this opinion was apparently based on a single reported observation, and the rationale given for it may have been influenced by the Chinese practice, offered as an analogy.

Turning now to the materials used by the Maohis to embellish their attire, there is no more succinct way to describe it than to reproduce Bank's observation:

Ornaments they have very few, they are very fond of earings but wear them only in one ear. ${ }^{[3]}$ When we came they had them of their own, made of Shell, stone, berries, red pease, and some small pearls which they wore 3 tied together; but our beads very quickly supplyd their place; they also are very fond of flowers, especialy of the Cape Jasmine [Gardenia taitensis; tiare] of which they have great plenty planted near their houses; these they stick into the holes of their ears, and into their hair, if they have enough of them which is but seldom. ${ }^{[4]}$ The men wear feathers often the tails of tropick birds stuck upright in their hair, they have also a kind of wiggs made upon one string of the hair of men, dogs, or Cocoa nut strings, which they tie under their hair upon the back of their heads; I have seen them also wear whimsical garlands made of a variety of flowers stuck into a peice of the rind of plantain, or of scarlet pease stuck upon a peice of wood with gum, but these are not common. Their great pride of Dress seems to be centerd almost in what they call Tamou, which is human hair platted, scarce thicker than common thread, of this I may easily affirm that I have peices above a mile in lenght worked upon an end without a single Knot, and I have seen 5 or 6 of such peices wound round the head of one woman, the effect of which if done with taste was most becoming. (Beaglehole 1962:I, 338-339)

To this can be added some interesting details reported in the Duff chronicle:

The tamōu is made from the hair of their departed relatives, and held in the highest estimation; ... They sometimes dress with a garland of cocoa-nut fibres, ornamented with bits of pearl-shell, and the nails of the thumb and fingers of their deceased relations: these they use as mourning, and consider as very precious relics. (Wilson 1799:329)

\section{FATTENING AND SKIN BLEACHING}

Further evidence of the attention devoted by the Maohis to "beautifying" their bodies may be found in their practices of head molding, "forced" fattening, and skin bleaching. I mentioned earlier the care taken to shape the head and facial features of infants into the desired form, and I shall provide more details on this matter in my discussion of child care. Also, I postpone until later, because of its wider significances, a fuller discussion of the Maohis' remarkable custom of ha'apori (to make fat and delicate, 


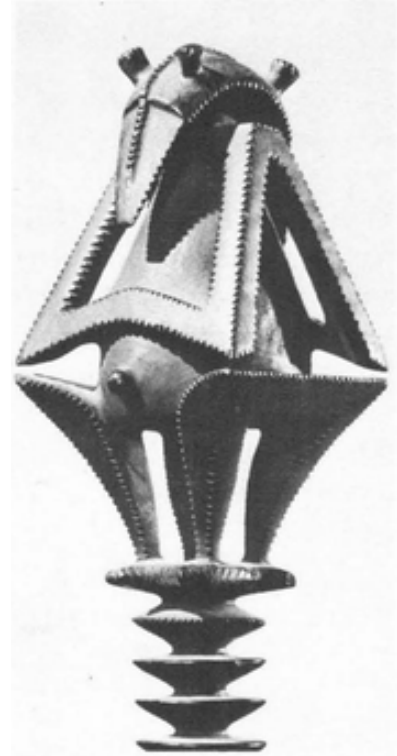

Figure 6-2. Detail of wood fly whisk, overall length $81.2 \mathrm{~cm}$. The Museum of Primitive Art, New York.

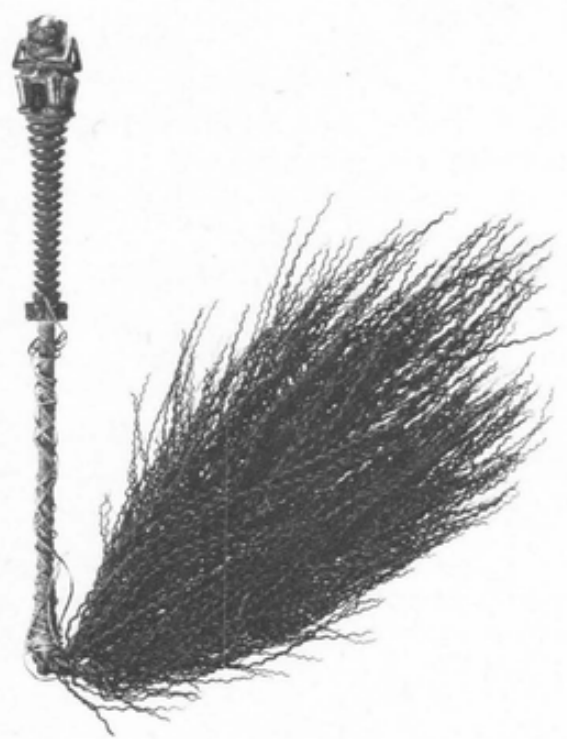

FIgURE 6-3. Wood fly whisk. The University Museum, Philadelphia.

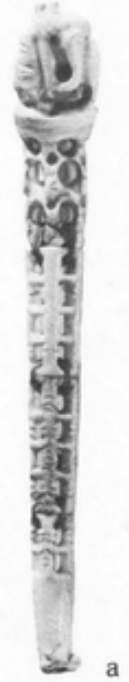

FIGURE $6-4$. Ivory fly whisk handles: $a$, length $29.8 \mathrm{~cm}$. The Museum of Primitive Art, New York; $b$, length $31.3 \mathrm{~cm}$. The Art Institute of Chicago.

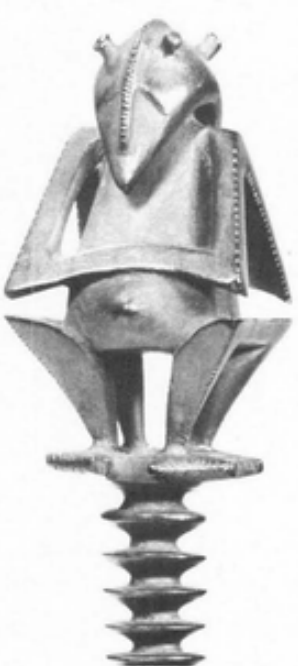

Figure 6-5. Wood fly whisk handle. The Art Institute of Chicago. 
by eating and keeping out of the sun [LMS Dictionary]), which also had the effect-evidently intended-of rendering skins whiter. ${ }^{5}$ I should, however, indicate now that many Maohis spent extended periods of their lives more or less immobile, shielded from sunlight, and gorging themselves with fattening foods. While the purposes of such acts were not entirely self-beautification, this reason was a strong one. The Maohi custom of body massage, which will be described later on, also indicates the attentiveness devoted to the body's well-being, but it had to do more with physical therapy than with beautification.

\section{TATTOO AND SUPERCISION}

Most if not all Maohis past childhood underwent tattooing; and while selfbeautification was not the only reason for doing this, and perhaps not even the most important one (as later chapters will describe), it did play some part, as is revealed for example in the following: “... for this Custom they give no reason but that they were taught it by their forefathers the doing it is attended with considerable pain yet so Essential is it esteemd to beauty and so disgraceful is the want of it that every one submits to it ..." (Beaglehole 1962:II, 332). And according to Moerenhout, young girls submitted to tattooing "solely in order to enhance their beauty" (1837:II, 122). ${ }^{6}$

The technique employed in Maohi tattoo was described by Banks:

Their method of doing it I will now describe. The colour they use is lamp black wich they prepare from the smoak [i.e., ash] of a kind of oily nutts usd by them instead of candles [i.e., candlenut, Aleurites moluccana]; this is kept in cocoa nut shells and mixt with water occasionaly for use. Their instruments for pricking this under the skin are made of Bone or shell, flat, the lower part of this is cut into sharp teeth from 3 to 20 according to the purposes it is to be usd for and the upper fastned to a handle [fig. 6-6]. These teeth are dippd into the black liquor and then drove by quick sharp blows struck upon the handle with a stick for that purpose into the skin so deep that every stroke is followd by a

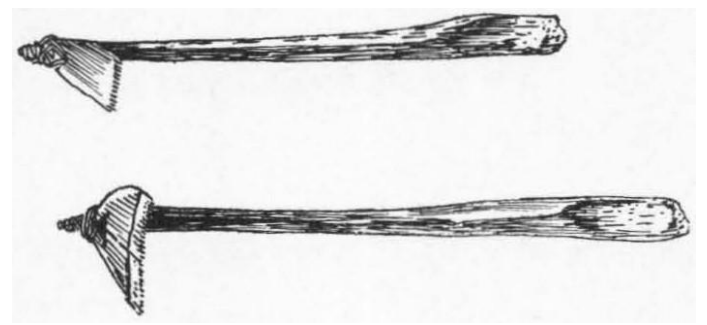

FIGURE 6-6. Two tattoo needles, bone blade lashed to wood hafts with coir fibers. Cambridge University Museum. 
small quantity of Blood, or serum at least, and the part so markd remains sore for many days before it heals. (Beaglehole 1962:I, 336)

Usually the perforations healed in a month or so, but infection sometimes developed, culminating occasionally in death. ${ }^{7}$

We are indebted to Banks for the earliest detailed description of the Maohis' tattoo designs also:

... every one is markd thus in different parts of his body according may be to his humour or different circumstances of his life. Some have ill designd figures of men, birds or dogs, but they more generaly have this figure $\mathrm{Z}$ either simply, as the women are generaly markd with it, on every Joint of their fingers and toes and often round the outside of their feet, or in different figures of it as square, circles, crescents \&c. which both sexes have on their arms and leggs; in short they have an infinite diversity of figures in which they place this mark and some of them we were told had significations but this we never learnt to our satisfaction. Their faces are in general left without any marks, I did not see more than one instance to the contrary. ${ }^{[8]}$

Tho they are so various in the application of the figures I have mentiond that both the quantity and situation of them seems to depend intirely upon the humour of each individual, yet all the Islanders I have seen (except those of Ohiteroa [Rurutu]) agree in having all their buttocks coverd with a deep black; over this most have arches drawn one over another as high as their short ribbs, which are often $1 / 4$ of an inch broad and neatly workd on their edges with indentations \&c. These arches are their great pride [fig. 6-7]: both men and women shew them with great pleasure whether as a beauty or a proof of their perseverance and resolution in bearing pain I can not tell, as the pain of doing this is almost intolerable especialy the arches upon the loins which are so much more susceptible of pain than the fleshy buttocks. (Beaglehole 1962:I, 335-336)

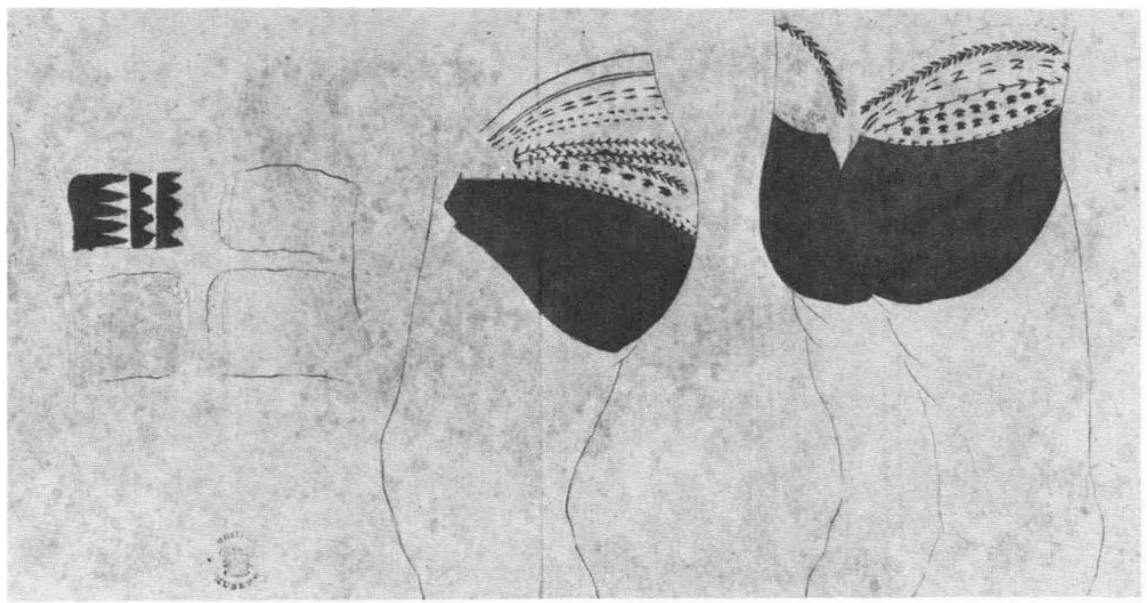

FIGURE 6-7. Tattoo designs. From a manuscript in the British Museum. 
As we shall see, the nature and distribution of tattoo marks did not depend altogether on "the humour of each individual" $\&$ nevertheless there appears to have been wide latitude for individual choice in the matter, and this circumstance was later exemplified in the practice of the many individuals who covered their bodies with European-inspired designs ranging from ship's anchors to muskets.

In addition to becoming tattooed, most Maohi boys were circumcised, or, rather, supercised, since the operation was limited to slitting rather than removing the foreskin. The slit was made in the upper part of the foreskin by means of a shark-tooth knife, and ashes were applied to the wound to stop the flow of blood. Although the operation is said to have made the male more "attractive," the rationale for it was more than aesthetic, as will be described in chapter 13.

Finally, in listing the attributes which the Maohis appear to have included in their notions about "physical perfection," I must specify unblemished skins and undeformed bodies. Except, of course, for tattoo marks and probably for battle scars, skins disfigured by the ravages of disease or by ordinary vicissitudes of living were in some measure socially devalued. The same was most emphatically true of deformed bodies, including albinoism. In these respects, at least, the Maohis wasted no sympathy on the physically (and, I believe, "aesthetically") handicapped. 


\section{CHAPTER $7 \quad B U I L D I N G S$}

\section{DWELLINGS}

The Maohis built numerous kinds of structures: dwellings, work sheds, canoe sheds, marae, theaters, forts, and so on. In this chapter I will describe how they built them and where they built them in relation to other structures and to the natural setting; details concerning their uses will be presented in later chapters.

Some legendary stories tell of individuals now and then residing in caves, but I have come across no actual instance of this in accounts describing life during the eras under study. A typical residential unit consisted of one or more dwellings (fare ta'oto 'house sleep') and one or more cookhouses (fare $t u \overline{t u}$ ), and was surrounded by a low fence or by clearings or gardens. Nearby was usually a small "domestic" marae either identified exclusively with members of the residential unit or shared by them with members of neighboring residential units. The residential units of some persons also included a large separate house that was used mainly for accommodating visitors (fare manihini, fare manuhiri, fare arioi). (Figs. 7-1 through 7-5.)

Dwellings varied considerably in size and shape. According to some estimates they averaged about twenty-four feet long by ten feet wide, but there were some that were much smaller and others that were very much larger. A flat-ended and generally smaller type (fare haupape) was somewhat more characteristic of the eastern islands, while an arch-ended type (fare taupe'e) was more common in the west; but these distributions were not exclusive. In addition, a generally larger, apse-ended type (fare pote $e$ ) was to be found sporadically but widely distributed.

All dwellings were built directly on the ground or, in the case of those located on slopes, on terraces just high enough to provide even floors. Some of them were enclosed by low curbings of logs, stones, or coral, and a few had "front-porch" terraces usually paved with stones. ${ }^{1}$ Floors were of bare earth, stone, or coral rubble over which aretu grass (Andropogon) was spread, creating a softer but in time damp and vermin-infested carpeting.

The sides of dwellings were open, or enclosed with wide-spaced latticed walls; low-hanging eaves and plaited screens provided additional shelter 


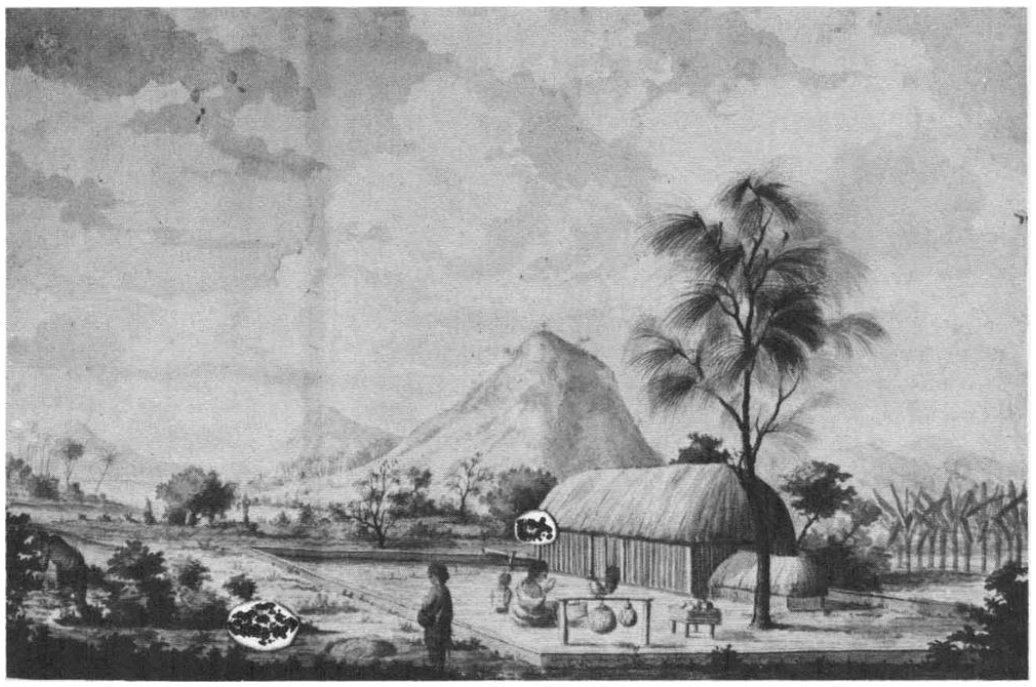

FIgURE 7-1. "House and Plantation of a Chief of the Island of Otaheite." Drawing by S. Parkinson. British Museum.

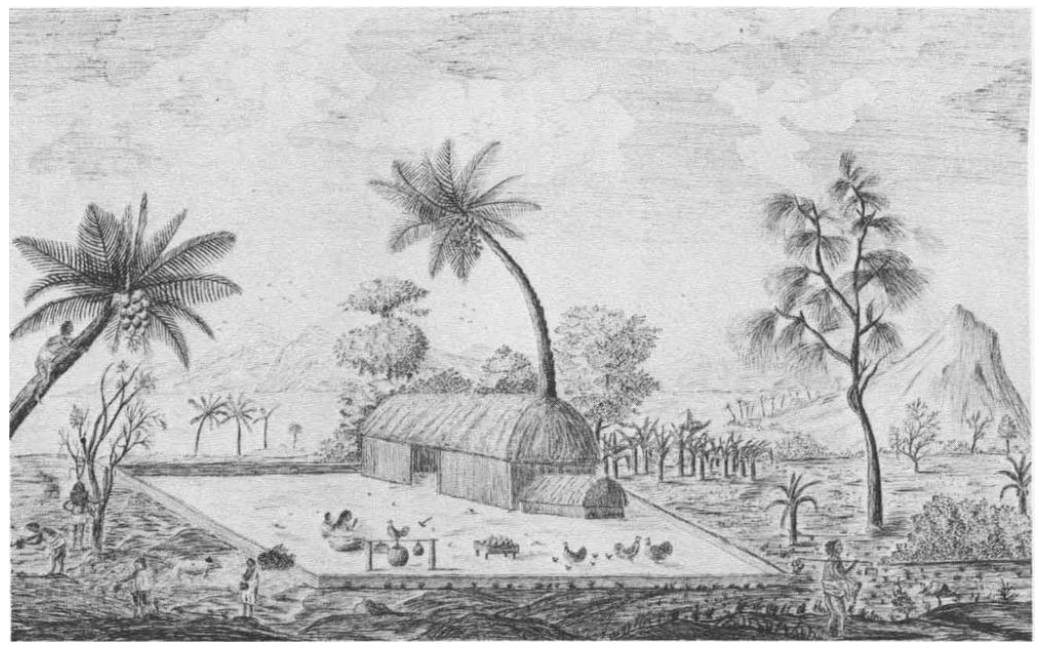

FIGURE 7-2. "A View near Ohamaneno Harbour in Ulietea [Ra'iatea]." Unsigned pencil drawing attributed to J. Cook, first voyage. British Museum. 


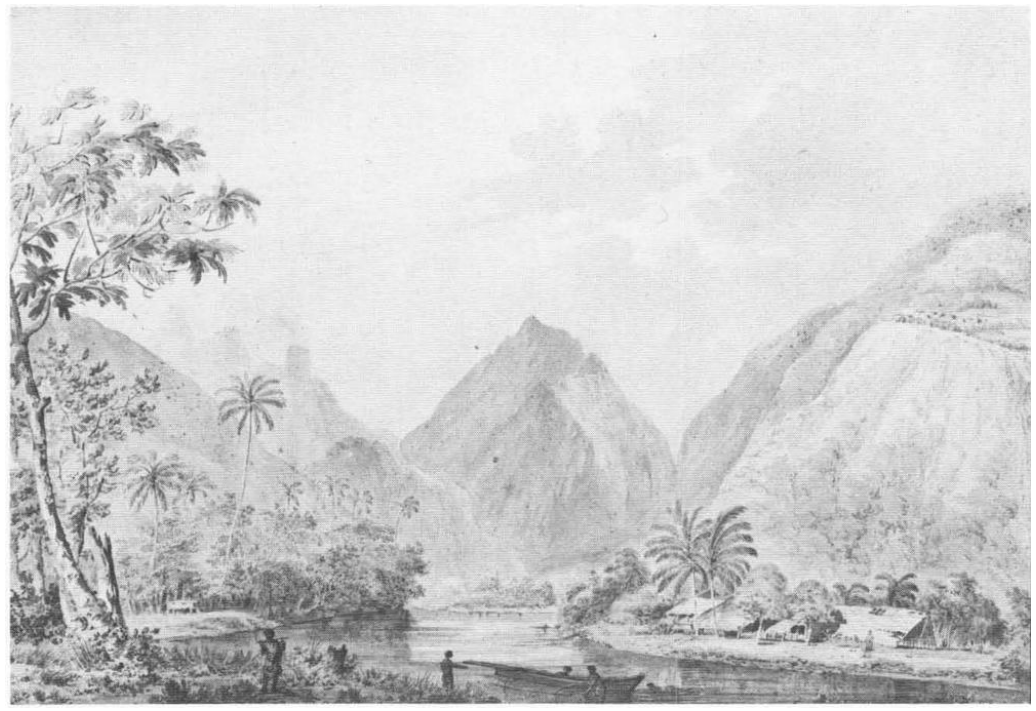

Figure 7-3. Vaitepiha Bay, Tahiti. Drawing by J. Webber. British Museum.

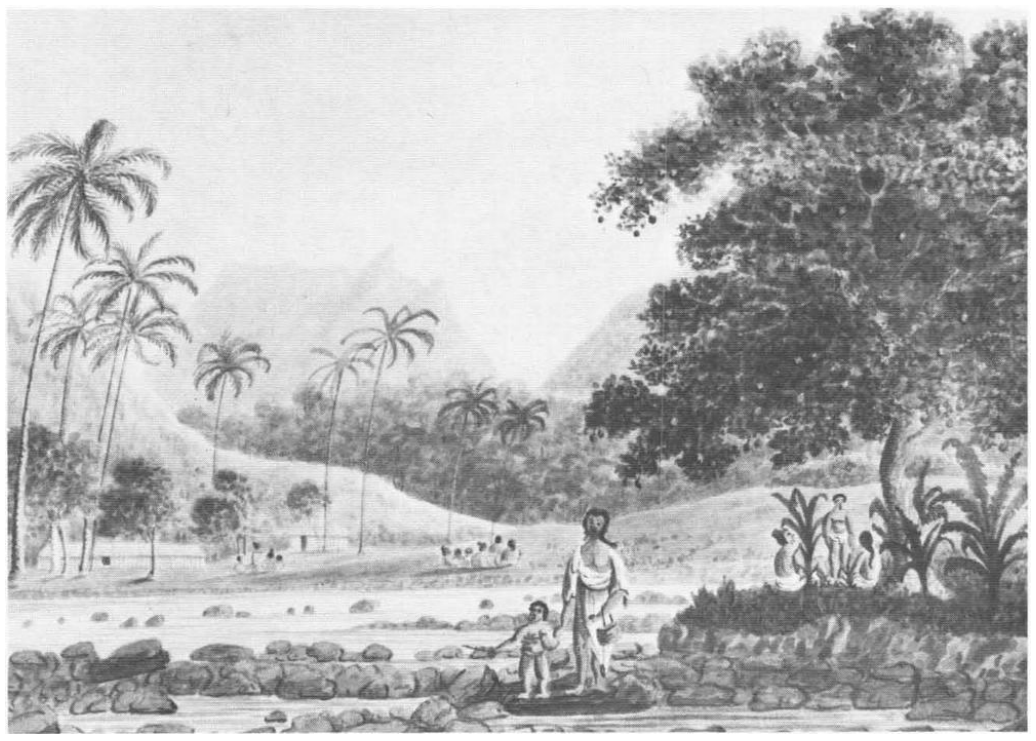

FIgURE 7-4. Scene on Tahiti. Watercolor by G. Tobin. Mitchell Library, Sydney. 


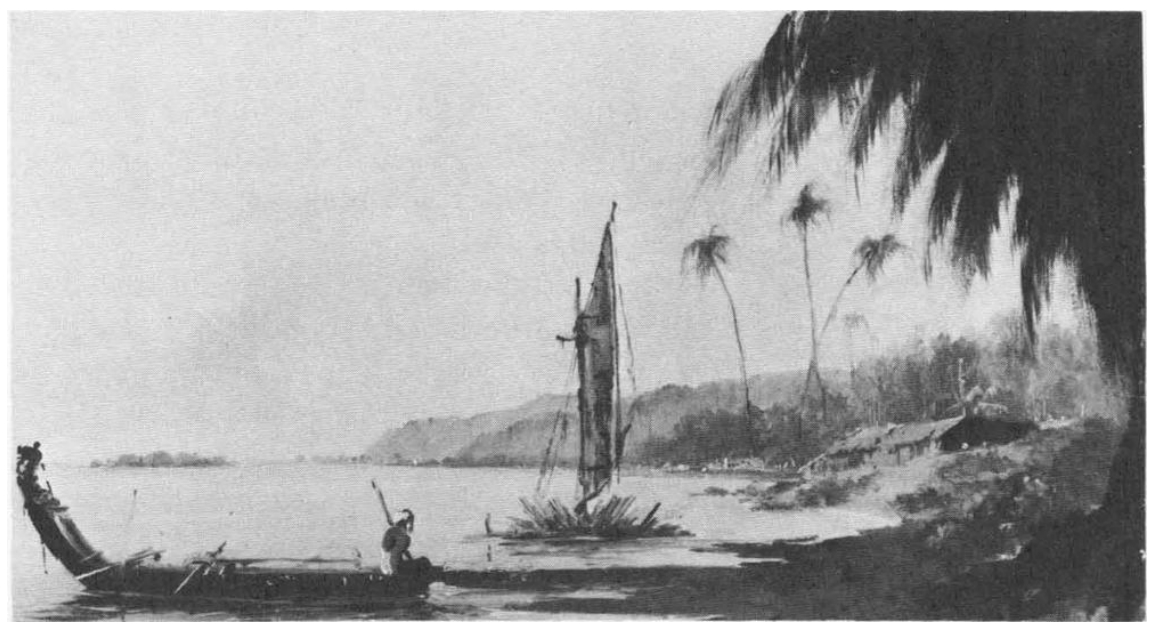

FIGURE 7-5. Tahiti, from Point Venus. Oil by W. Hodges. National Maritime Museum, Greenwich.

from the elements. Walled-in houses probably had at least two doorways (amuna), and even open-sided houses probably had two or more regular places of entry. The sources do not describe this feature of dwellings, but a paragraph in Wilson permits such an inference: "If a woman has a child, the provisions for it must not come in at the same door with the mother's; ..." (1799:351). Instead of permanent partitions, bark-cloth and mat hangings were occasionally used to screen off some parts of a house.

The trees which provided the principal timbers for houses were the coconut, breadfruit, rosewood (miro), tou (Cordia subcordata), mountain apple ('ahi'a: Eugenia malaccensis), mara (Nuclea Fosteri), and ironwood. Hibiscus wood and bamboo served for plates, rafters, struts, and rods, and for walling where that occurred. Roofs were thatched with coconut or pandanus leaves or, occasionally, with aretu grass, and the whole was lashed together with cordage made out of hibiscus bark and bast, and sennit. A pandanus roof took more time to make but lasted seven to eight years, about twice as long as one of coconut leaves. In this connection, it was by no means unusual for houses to be dismantled, in whole or in part, and moved to other sites, or for still sound parts of old houses to be salvaged and used in the construction of new ones.

Structural ornamentation was not very common and was limited mainly to elaborate lashings and well-joined thatching; in addition some houses were decorated with bark cloth, frayed-end cords, or finely fringed mats.

Dwelling-house furniture was exceedingly scant. People usually sat cross-legged on mats, but some houses contained one or more wooden stools. Mats also served as beds, and sheets of bark cloth served as covers. For pillows people used either bundles of bark cloth or blocks of wood, some 
of the latter having been small replicas of stools. When not in use most bedding, along with tools, weapons, clothing, and fishing gear, were kept inside the house, either hung from the rafters and beams or from a special rack (fata) inside, or just outside, the house.

There is a description in one account of wooden images kept in a dwelling, (Bougainville 1772:221-222) and hints in several others that skulls and other relics of deceased relatives were so kept, but it appears more usual for "religious" objects to have been kept in separate marae.

I will reproduce some eyewitness accounts of actual dwellings and their utilization. A lengthy quotation from Ellis provides both a detailed description of a house and the method of its construction. The house in question was one destined for the missionary, but according to him was built in the same way as other good-quality Maohi dwellings:

The timber being prepared, they planted the square posts which support the ridgepole about three feet deep. The piece forming the ridge was nearly triangular, flat underneath, but raised along the centre on the upper side, and about nine inches wide; the joints were accurately fitted, and square mortises were made, to receive the tenons formed on the top of the posts. As soon as these were firmly secured, it was raised by ropes, and fixed in its proper place. The side-posts were next planted, about three or four feet apart; these were square, and nearly nine inches wide. In the top of each post, a groove, about six inches deep and an inch and a half wide, was cut; in this was fixed a strong board, eight or nine inches broad, bevelled on the upper edge, forming a kind of wall-plate along the side of the house. The rafters, which they call aho, were put on next; they are usually straight branches of the purau, hibiscus tileaceus, an exceedingly useful tree, growing luxuriantly in every part of the islands. The poles used for rafters are about four inches in diameter at the largest end. As soon as they are cut, the bark is stripped off, and used in the manufacture of cordage, lines, \&c. The rafters are then deposited in a stream of water for a number of days, in order to extract the juices with which they are impregnated, and which, the natives suppose, attract a number of insects, that soon destroy them. When taken out, the poles are dried, and considered fit for use. The wood is remarkably light, its growth is rapid, and though the old parts of the tree are exceedingly tough, the young branches or poles, used for rafters and other purposes, are soft and brittle, resembling the texture and strength of branches of the English willow. The foot of the rafter is partially sharpened, and about eighteen inches from the end a deep notch is cut, which receives the bevelled edge of the ra-pe, or wall-plate, while the upper extremity rests upon the ridge. The rafters are generally ranged along on one side, three feet apart, with parallel rafters on the opposite side, which cross each other at the top of the ridge, where they are firmly tied together with cinet, or the strong fibres of the ieie, a remarkably tough mountain plant. A pole is then fixed along, above the junction of the opposite rafters, and the whole tied down to pegs fastened in the piece of timber forming the ridge. The large wood used in building is of a fine yellow colour, the rafters are beautifully white\& and as the house is often left some days in frame, its appearance is at once novel and agreeable.

The buildings are thatched with rau fara, (the leaves of the pandanus,) which are prepared with great care. When first gathered from the trees, they are soaked three or four days in the sea, or a stream of water. The sound leaves are then selected, and each leaf, after having been stretched singly on a stiff stick 
fixed in the ground, is coiled up with the concave side outwards. In this state they remain till they are perfectly flat, when each leaf is doubled about one-third of the way from the stalk, over a strong reed or cane six feet long, and the folded leaf laced together with the stiff stalks of the cocoa-nut leaflets. The thatch, thus prepared, is taken to the building, and a number of lines of cinet are extended above the rafters, and in each of the spaces between, from the lower edge to the ridge. The thatchers now take a reed of leaves, and fasten it to the lower ends of the rafters at the left extremity of the roof, and, placing another reed about an inch above it, pierce the leaves with a long wooden needle, and sew it to the lines fixed on the outer side of the rafters and in the space between them: when six or eight reeds are thus fixed, they pass the cord with which they are sewn two or three times round each of the three rafters over which the reed extends. Placing every successive reed about an inch above the last, they proceed until they reach the ridge. The workmen now descend, and carry up another course of thatch, in the same way inserting the ends of the reeds of the fresh course into the bent part of the leaves on the former, it is singular to see a number of men working underneath the rafters, in thatching a house.

When the roof is finished, the points only of the long palm-leaves are seen hanging on the outside; and the appearance within, from the shining brown colour of the leaves bent over the reeds, and the whiteness of the rafters, is exceedingly neat and ingenious. The inside of the rafters of the chiefs' houses, or public buildings, is frequently ornamented with braided cords of various colours, or finely-fringed white or chequered matting. These are bound or wrapped round the rafters, and the extremities sometimes hanging down twelve or thirteen inches, give to their roof or ceiling a light and elegant appearance. Most of the natives are able to thatch a house, but covering in the ridge is more difficult, and is only understood by those who have been regularly trained for the work. A quantity of large cocoa-nut, or fern leaves, is first laid on the upper part of the thatch, and afterwards a species of long grass, called aretu, is curiously fixed or woven from one end to the other, so as to remain attached to the thatch, and yet cover the ridge of the house.

The roof being finished, they generally level the ground within, and enclose the sides. In the erection of my house, this part was allotted to the king's servants. About thirty of them came one morning with a number of bundles of large white purau poles, from two to three inches in diameter. After levelling the floor, they dug a trench a foot deep round the outside, and then, cutting the poles to a proper length, planted them an inch and a half or two inches apart, until the building was completely enclosed, excepting the space left for a door in the front and opposite sides. In order to keep the poles in their proper place, two or three light sticks, called tea, were tied horizontally along the outside. Partitions were then erected in the same manner, as we were desirous, contrary to the native practice, to have more than one room. The house was now finished, and in structure resembled a large birdcage.

The houses of the natives, although varying in size and shape, were all built with the same kind of materials, and in a similar manner. (Ellis 1829:I, 384-388)

The durability of a house depended upon the thatching: "If there is much space between the reeds, it soon decays; but if they are placed close together, it will last five or seven years without admitting the rain" (Ellis 1829:I, 388).

Ellis, writing in the 1820s, also described doors: "Their door was 
an ingenious contrivance, being usually a light trellis-frame of bamboocane, suspended by a number of braided thongs, and attached to a long cane in the upper part of the inside of the wall-plate-the thongs sliding backwards and forwards like the rings of a curtain, whenever it was open or closed" (1829:I, 389). It is however possible that doors-as contrasted with openings-were a European-inspired trait.

Finally, Ellis took pains to point out that not all native dwellings were of the quality of the one just described:

... although all were capable of building good native houses, and many erected comfortable dwellings, yet great numbers, from indolence or want of tools, reared only temporary and wretched huts, as unsightly in the midst of the beautiful landscape, as they were unwholesome and comfortless to their abject inhabitants. (1829:I, 390)

Some observers commented upon the floor covering of dwellings. The Spaniard Varela wrote:

They cover the ground inside their houses with dry grass; and they are so particular that they even part this grass aside when they want to spit, and cover over the expectoration with it afterwards. They do not allow any one to come in with dirty feet, lest the mats they sit upon, and even the grass itself, be soiled: consequently they make no use of brooms, for with all this nicety they have no need for them. (Corney 1915:278)

This enthusiasm for the natives' "nicety" was not shared by Morrison or Ellis, who must have had to spend many a night trying to sleep inside their acquaintances' houses:

... but in fine weather they prefer the Open Air, as the Grass with which the floors are Covered, if not frequently removed, produced abundance of Fleas for which reason they sleep out of Doors to avoid these disagreeable companions .... (Morrison 1935:198)

The floor of their dwellings was covered with long dried grass, which, although comfortable when first laid down, was not often changed, and, from the moisture occasioned by the water spilled at meals and other times, was frequently much worse than the naked sand or soil would have been. (Ellis 1829:I, 389)

We are indebted to Ellis for detailed descriptions of house furnishings also:

Next to a sleeping mat, a pillow was considered essential. This was of hard wood, and often exceedingly rude, though sometimes ingeniously wrought, resembling a short low stool, nine inches or a foot in length, and four or five inches high. The upper side was curved, to admit the head; the whole pillow, which they call tuaurua, is cut out of a single piece. Upon the bare wood they reclined their heads at night, and slept as soundly as the inhabitants of more civilized parts would do on the softest down. [Fig. 7-6.]

In general, they sat cross-legged on mats spread on the floor; but occasionally used a stool, which they called iri or nohoraa [fig. 7-7]. This resembled the pillow in shape, and, though much larger, was made out of a single piece of wood. 


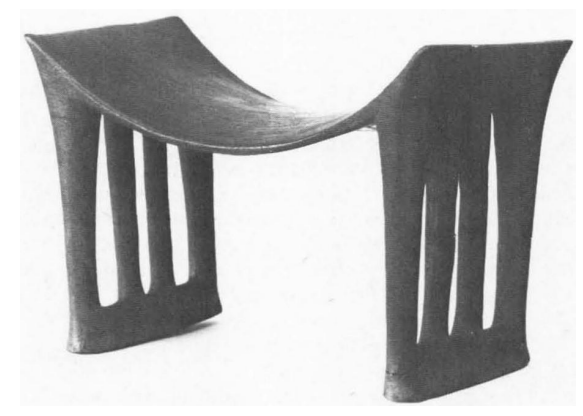

FIGURE 7-6. Wood headrest, length $235 \mathrm{~mm}$. Field Museum of Natural History, Chicago (from photo in British Museum).

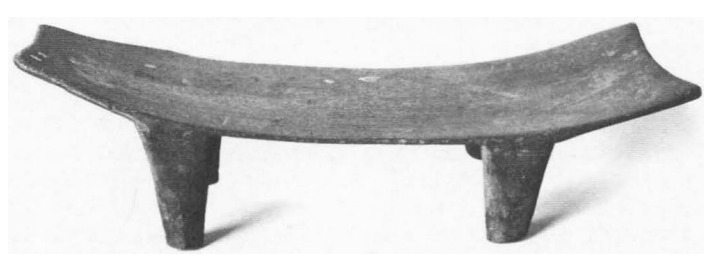

FIGURE 7-7. Wood seat, length $570 \mathrm{~mm}$. Etnografiska Museet, Stockholm.

The tamanu, or callophyllum, was usually selected, and immense trees must have been cut down for this purpose. I have seen iris four or five feet long, three feet wide, and at each end three feet six inches high; yet the whole cut out of one solid piece of timber. The upper part was curved, and the extremes being highest, the seat resembled the concave side of a crescent, so that, however large it might be, only one sat on it at a time. The iri was finely polished, and the wood, in its grain and colour resembling the best kinds of mahogony, rendered it, although destitute of carving or other ornament, a handsome piece of furniture in a chieftain's dwelling. The rank of the host was often indicated by the size of this seat, which was used on public occasions, or for the accommodation of a distinguished guest. Those in more ordinary use were low, and less curved, but always made out of a single piece of wood.

Next to these, their weapons, drums, and other musical instruments, were their most important furniture; a great portion, however, of what might be called their household furniture, was appropriated to the preparation or preservation of their food.

The umete, or dish, was the principal. Sometimes it was exceedingly large, resembling a canoe or boat more than a dish for food. It was frequently made with the wood of the tamanu, exceedingly well polished; some were six or eight feet long, a foot and a half wide, and twelve inches deep, these belonged only to the chiefs, and were used for the preparation of arrow-root, cocoa-nut milk, \&c. on occasions of public festivity. The umetes in ordinary use were oval, about two or three feet long, eighteen inches wide, and of varied depth. They were supported by four feet, cut out of the same piece of wood, and serve not only for the preparation of their food, but as dishes, upon which it is placed when taken from the oven. 
The papahia is extensively used. It is a low solid block or stool, supported by four short legs, and smoothly polished on the top. It is cut out of one piece of wood, and is used instead of a mortar for pounding breadfruit, plantains, or bruising taro; which is done by placing these upon the papahia, and beating them with a short stone pestle called a penu. This is usually made with a black sort of basalt, found chiefly in the island of Maurua, the most western of the group. The penu is sometimes constructed from a species of porous coral.

The water used for washing their feet is kept in bottles called aano, made from the shells of large and full-grown cocoa-nuts. That which they drink is contained in calabashes, which are much larger than any I ever saw used for the same purpose in the Sandwich Islands, but destitute of ornament. They are kept in nets of cinet, and suspended from some part of the dwelling.

The drinking cups are made with the cocoa-nut shell after it is full grown, but before it is perfectly ripe. The shell is then soft, and is scraped until much thinner than a saucer, and frequently transparent. They are of a yellow colour, and plain, though the cups formerly used for drinking ava were carved. These are the principal utensils in the preparation of their food; they are kept remarkably clean, and, when not in use, suspended from some part of the dwelling, or hung upon a stand.

The fata, or stand, is a single light post planted in the floor, with one or two projections, and a notch on the top, from which the calabashes of water, baskets of food, umetes, \&c. are suspended. Great labour was formerly bestowed on this piece of furniture, and the fata pua was considered an ornament to the house in which it was erected. About a foot from the ground, a projection extended six or eight inches wide, completely round, flat on the top, but concave on the under side, in order to prevent rats or mice from ascending and gaining access to the food. Their only knife was a piece of bamboo-cane, with which they would cut up a pig, dog, or fish, with great facility. (1829:II, 181-184)

In addition to the furnishings just described, most houses would have contained a special place for standing the wooden sticks on which candlenuts were skewered and lighted for illumination. ${ }^{2}$

The early observers agreed that the dwellings of "chiefs" were usually larger and in general better constructed than those of the rest of the populace, ${ }^{3}$ but it is not clear from some descriptions of very large houses-some of which were from one hundred to three hundred feet long-whether their owners regularly slept in them or used them mainly to house retainers and visitors. Some, at least, of the very large houses seen by Europeans resembled hostels in function. G. Forster described a house seen on Apotopoto Bay (Taha'a) as "One of the largest houses in all the Society [i.e., Leeward] Isles.... It was full of inhabitants, many of whom lodged with their families in different parts of it; the whole appearing to be rather a public building, erected for the casual shelter of travellers, like the carvansaras of the East, than a private dwelling-house." (1777:I, 416.) Cook also remarked upon the presence of large houses:

Besides these common houses [i.e., "private" dwellings] there are others much larger 200 feet long and upwards 30 broad and 20 in height. There are 
generaly two or three of these in every district and seem'd not only built for the accommodation of the principal people but common to all the inhabitants of that district and raised and kept up by their joint labour; these are always without walls and have generaly a large area on one side neatly inclosed with low pallisades \& ca. (Beaglehole 1955:129. See also Beaglehole 1962:I, 341)

The missionaries identified one such house as having belonged to a chiefess, but described it as having served as a kind of hostel: "We stopped at Pappara for the night in the house of my tayo [taio, 'friend'] Wyreede.... Here were a number of [visitors whose] great numbers made the house, wich was one hundred and forty feet long, appear like a little village, where each claimed the place on which his mat was spread." (Wilson 1799:206)

Ellis described the larger houses as having been erected "only for the leading chiefs":

The chiefs seem always to have been attended by a numerous retinue of dependants, or Areois, and other idlers. The unemployed inhabitants of the districts where they might be staying, were also accustomed to attend the entertainments given for the amusement of the chiefs, and this probably induced the people to erect such capacious buildings for their accommodation. (1829:I, 388)

What in fact were the purposes served by these large buildings? Were they free hostels for travelers in general, public centers for district gatherings, private dormitories and guesthouses of prominent individuals, or special lodgings for visiting Ariois? Actually, most of the very large houses which so impressed the Europeans probably served two or more of these purposes. In keeping with other aspects of Maohi society, it is logical to conclude that the leader of each political unit would have possessed a larger-than-average dwelling for the accommodation of visitors, including especially the Ariois-those most habitual and privileged travelers. Moreover, in the general scheme of things, such houses would have been built by corvée labor, who in addition to doing the actual construction work would have furnished the materials used.

Ellis was one of the few writers who described Maohi sleeping arrangements:

In the drier parts of the house, along each side, the inmates slept at night. However large the building might be, there were no partitions or skreens. Some of their houses were two hundred feet long, and on the floor, hundreds have, at times, lain down promiscuously to sleep. They slept on mats manufactured with palm-leaves, spread on the ground. These mats were generally rolled up like a sailor's hammock in the morning, and spread out at night. The chief and his wife usually slept at one end of the house, without the least partition between them and the other inmates of their dwelling. Instead of a single mat, three or four, or even ten, were sometimes spread one upon the other, to give elevation and softness; and this, with the finer texture of the mats, was the only difference be- 
tween the bed of the chief, and that on which the meanest of his dependents slept. Instead of being spread on the floor, the mats were sometimes spread on a low bedstead, raised nine or twelves inches above the floor. The sides and bottom of this bedstead were made with the boards of the breadfruit-tree. Next to the chief, the members of his own family spread their mats on the floor, and then the friends and attendants-the females nearest the chief, the men towards the opposite end of the building.

I have sometimes entered the large houses in Huahine, soon after our arrival there, and have seen, I think, forty, fifty, or sixty sleeping places of this kind, in one house, consisting of a mat spread on the ground, a wooden pillow or bolster, in the shape of a low stool, next the side or wall; and a large thick piece of cloth, like a counterpane or shawl, which they call ahu taoto, sleeping-cloth, and which is their only covering, lying in the middle of each mat. There was no division or skreen between the sleeping places, but the whole ranged along in parallel lines from one end of the house to the other. What the state of morals must necessarily be among such a community, it is unnecessary to shew; yet such were the modes of life that prevailed among many, even after they had renounced idolatry. Such we found society in Huahine, and such our friends in Raiatea found it there. One of the reasons which they gave why so many slept in a house, was, their constant apprehensions of evil spirits, which were supposed to wander about at night, and grasp or strangle those who were objects of their displeasure, and whom they might find alone. Great numbers passing the night under the same roof, removed this fear, and inspired a confidence of security from the attacks their idolatrous absurdities led them to expect. (Ellis 1829:II 66-68)

But so few specific examples of actual sleeping arrangements are to be found in the sources that I include the following observation made by Mortimer in 1789 while visiting Mo'orea: "The house in which we slept was full of people, men and women, who all laid upon the ground on mats, except the mistress of the house, who had an elevated bed-place" (Mortimer 1791:39).

When the weather was fair the main meal of the day was usually eaten outside in some shady spot; otherwise the Maohis ate inside their dwellings, where, however, strict segregation along sexual lines was customarily preserved. In the smaller households of socially unimportant people it appears that both males and females usually ate under the same roof, although spatially separate. But for larger households, and particularly those of upperclass persons, it seems to have been customary to have two dwellings, thus making it possible for men and women to eat separately; and in such cases, according to Morrison, "The unmarried Weomen generally Sleep Near the Parents [in one house] and the Unmarried Men and Servants generally sleep in the Weomens eating house..." (1935:198) Eating arrangements were even further complicated in the case of individuals holding very high-ranking kin-Titles, as will be described later on.

In a cosmogonic myth, "Birth of Heavenly Bodies," Henry indicated that the principal pillars of some houses were designated by functional labels, such as "the pillar to elocute by," "the pillar to tattoo by," "the pillar 
to stand by," and "cave interior (ana roto) pillar," which Henry identified as having been "where young maidens were held sacred from molestation" (1928:361). This is the only reference I have found to a custom of allocating house parts for special purposes; it is a credible enough phenomenon, and I am surprised to find no references to it in other sources.

As one might expect of these seasoned travelers, many of the more influential and affluent ones possessed small portable houses (fare $o^{\prime} a$ ), which could be set up on canoes or on shore. Afloat they served both as sleeping cabins and as protection from the sun; ashore they provided couples with privacy and with retreats from the noise and heat of crowded dwellings. (Beaglehole 1955:129; 1962:I, 341)

Cookhouses usually consisted of mere sheds, protecting the household's earth ovens and its attendants from inclement weather. They varied greatly in size and in quality of construction.

Larger, finer canoes were protected from sun and rain by being kept in special canoe sheds (fare $v a^{\prime} a$ ) built near the shore and constructed quite differently from most other buildings (fig. 7-8):

For the convenience of keeping these Paheis [pahi 'plank boat'] dry we saw in the Islands where they usd a peculiar sort of houses which were built on purpose for their reception, and put to no use but that; they are built of Poles stuck upright

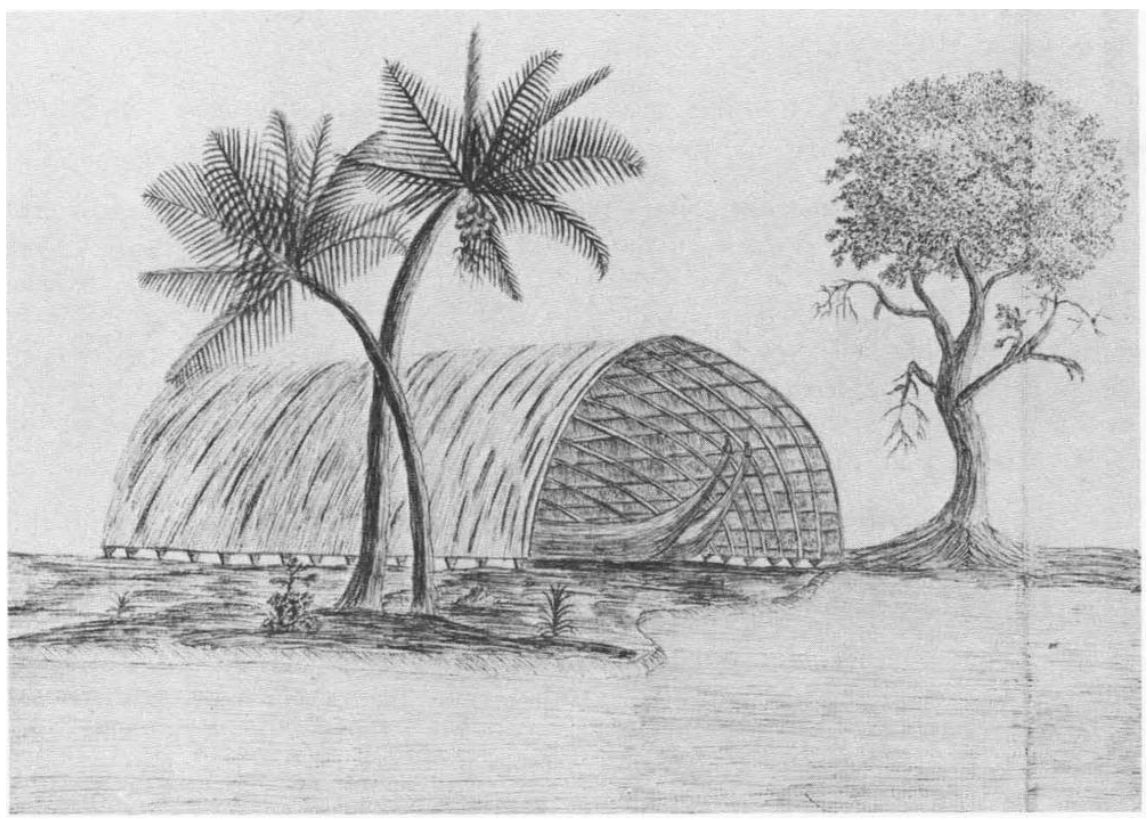

FIGURE 7-8. Canoe shed, Leeward Islands. Unsigned drawing attributed to J. Cook, after similar drawing by S. Parkinson. British Museum. 
in the ground and tied together at the top so that they make a kind of Gothick arch; the sides of these are compleatly coverd with Thatch down to the ground but the ends are left open. One of these I measurd, 50 paces in lengh, 10 in breadth and 24 feet high, and this was of the midling size. (Beaglehole 1962:I, 368)

In addition to all these more or less durable buildings, the Maohis were accustomed to erect temporary sheds (fare rau) for encampments ( $p \bar{f}$ fara, pūhapa) during warfare or journeys (Ellis 1829:I, 389).

One would be safe in assuming that many of the more or less "permanent" buildings, and especially the larger residences and "public" houses of important individuals, were built to the accompaniment of religious ritual and probably of some feasting as well; unfortunately the sources provide scant information on this score.

As previously noted, "public" buildings were usually erected by corvée labor, as was probably the case with the private buildings of chiefs. It is also likely that kinsmen and neighbors assisted one another with house building, but Morrison provided evidence of paid construction work as well:

If a man wants a house or a Canoe built, he employs one or more Carpenters, paying them before hand one half of what shall be Judged the Value of the Work they are to perform in Hogs, Cloth, Oil, Matting \&c-and finds them in provisions all the time they are at work and when the Work is Compleat he pays the remainder according to Agreement, but should he refuse or neglect and the Neighbours think the labour worth the stipulated agreement then they may plunder him of all that he is worth. (1935:165)

European visitors to the Islands recorded varying impressions concerning household precincts. Bligh, for example, was not favorably impressed:

They have as little neatness about their Dwellings [as about their gardens and groves]-an Otaheite Village, if their mixt Dwellings may be so called, is the dirtyest place immaginable, every thing is thrown before and around the House, even if they fix their Sheds upon the Sea side they will not take the trouble to throw the filth into the Sea, if they have ten yards to carry it-yet no People in the World are cleaner in their Persons. So much sloth and indolence may be attributed to the vast support that all bountifull nature has given to them in the use of the most valuable of all Fruits of the Earth, the Bread Fruit and Cocoa Nutt. (1792:157)

Vancouver, on the other hand, was very favorably impressed with the household complex of the chiefly Whytooa [Vaetua]:

They found [Vaetua's habitation] situated on the verge of the sea shore. In the front of it was an ava plantation, interspersed with sugar cane, and bananas; near the house was a small shrubbery, of native ornamental plants. The whole surrounded by a well constructed fence of bamboo, neatly intersected with clean paths, that led in different directions, produced an effect that was extremely pleasing, and redounded much to the credit and ingenuity of the proprietor. Whytooa had taken very effectual means to provide for their entertainment; for a large hog had been committed to the oven, and was nearly ready for the table, with an abundance of other refreshments. The mansion was large and airy. By lines stretched across, 
they had quiet possession of one half of the building; and this partition prevented the idle curiosity of the assembled natives from interrupting the comfort of their repast. (1801:283-284)

I turn now to the location of Maohi residence units-first in relation to the natural physical setting and then in relation to each other.

As previously noted, most Maohi dwellings were located in what has been defined, in European terms, as the adlittoral portions of the coastal zone and in the lower reaches of the valleys in the wet-tropical zone. Continuing our reconnaissance from this European-oriented perspective, several things about these locations appear relevant. To begin with most of them were within reasonable walking distance of the sea. Second, they were within easy reach of fresh water. Third, they were so placed as to be near groves and gardens of principal food crops. ${ }^{4}$ And fourth, they were located so as to be protected from harsher moods of the weather-out of the direct path of high winds and waves, and at a safe distance above ground subject to flooding. With a few possible exceptions residence sites do not appear to have been selected in order to provide commanding views; nor does defensibility from armed attack seem to have been a decisive criterion, except perhaps in the case of some isolated valley settlement, such as Papeno'o and Tautira, whose residents, it has been suggested, were in the main refugees from elsewhere.

In addition to these more general factors of location there appear to have been some others, such as the adjacency of a broad stretch of sheltered lagoon and proximity to a navigable reef-opening, which offered special encouragement to settlement. Houses were so concentrated around Huahine's saltwater lake, Fahune Nui (Maeva district), with its unusual tidal inflow of fish, that it came to resemble the European notion of a "village." G. Forster reported that he observed few houses on the banks of the lagoon (1777:II, 117), but he must have been referring to the shorelines themselves, since other visitors and numerous archaeological remains of marae, and so forth, attest to there having been a larger than average population concentration nearby.

As for the location of Maohi residences in relation to each other, eyewitness reports agree that they were, with some exceptions (e.g., Maeva), usually widely spaced:

They do not observe any regularity or method of alignment with their houses, for they are dotted about as if at haphazard all through the habitable tract of the Island, and they remove them with ease from one site to another. (Corney 1913:337)

The houses or rather dwellings of these people are admirably calculated for the continual warmth of their climate. They do not build them in villages or towns but seperate each from the other according to the size of the estate the owner of the house possesses; they are always in the woods and no more ground is cleard away for each house than is Just sufficient to hinder the Dropping of the branches 
from rotting the thatch with which they are coverd, so that you step from the house immediately under shade and that the most beautifull imaginable. (Beaglehole 1962:I, 339-340)

Even in such populous places as Matavai and lake-side Maeva, individual residential units were relatively far apart.

But what about residential location from the Maohi point of view? In the absence of contrary evidence it is not unreasonable to assume that the geographic criteria listed earlier were in fact consciously and deliberately applied by the Maohis themselves when locating their dwellings, although it is most unlikely that they perceived of their environment, by botanically defined "zones" and "subzones," in the systematic way that Western scientists have done.

As is to be expected, the Maohis had labels for numerous aspects of the geographic environment-for example, for a large and small mountain, cliff, pass, valley, stream, beach, cape, lagoon, reef, et cetera. The only verbalizations I can find expressing how they "thought about" that environment in more general taxonomic terms are those used by orators on public occasions to identify tribes or subtribes, that is, in terms of the specific place name of its associated territory's highest mountain (mou'a i ni'a), "floor" (tahua $i$ rare), principal cape ('outu i tai), and largest freshwater stream (vai). The sources contain no further explication of this formula, but a present-day expert in modern Tahitian has provided the following commentary (which, though of course speculative insofar as it refers to the pre-European Maohis, is as credible as we are ever likely to find):

These [the four place terms just listed] are [were] the keypoints of the mata'eina'a [tribal district], primarily from the 'aito's [champion warrior, Arioi lodge leader] point of view-and, more or less artistically, from the point of view of the general populace. However, they are also key points to the livelihood of the community. As such, the terms mou'a and tahua should be taken in their broadest senses: mou' $a$ would thus include valleys ( $f a^{\prime} a$ and peho), and tahua would cover the whole area which was level and had been cleared of major obstructions to movement (that is, habitation, cultivation, meeting grounds, etc.). Of course, the 'outu is the center of fishing activities; and vai, I suppose, essential for drinking and bathing and carrying on certain minor domestic industries such as felting, cleaning fibrous materials, bathing, preparing food, etc., and of course for drinking. (R.G. White: personal communication)

Turning now to the social aspects of residence location, the question arises, How did it happen that a people reportedly so gregarious as these came to locate their residences so far apart? The distribution of natural resources certainly did not dictate the kind of residential dispersion that actually obtained, so that other factors must have been involved. But this is a complex matter, and consideration of it will be postponed to volume 2 . Here I merely raise the question to indicate that it is crucial and anything but simple to answer. 


\section{MARAE}

I have already described the key importance of marae in Maohi religious activity, and the functionally specific architectural features that comprised them. In a later chapter attention will be devoted to their relevance to social relations, but now my concern will be with how they were built and maintained.

Although all Maohi marae shared certain basic functional features (a tautology, of course, since I have defined marae in these very terms), they varied greatly in overall size, in the way these features were combined and, indeed, in size and shape of the features themselves. Above all, they involved stones, and in all but the simplest and smallest of them, stone masonry as well.

Stonework figured in several kinds of complex construction: walls and fish weirs, house and terrace platforms. For such work basalt, tuff, coral limestone, and pumice stone were used for facings; and the same materials, plus earth, were used for fill. Emory distinguished several kinds of facings:

Rough. Walls and terraces carelessly faced with rough stones of all types.

Simple flat. More or less carefully fitted basalt stones of varied sizes with smooth flat faces showing in the wall. Courses were not parallel. Sometimes finished off at the top with a coping of horizontal slabs or of flat, water-worn, oval stones.

Horizontal slab. Slabs (mainly of limestone) laid horizontally on a first vertical course with a flat side exposed in the wall.

Vertical slab. A first (and only, in some cases,) course consisting of large slabs, sometimes of basalt but more usually limestone, planted on edge or on end, flat side out. The largest of these slabs, which formed the facings of certain Leeward Island marae platforms $(a h u)$, were of limestone and ranged from eight to thirteen feet in height above ground, up to eleven feet in width, and two and a half feet in thickness.

Curb. A one-course curb made by laying on edge (not on end) unworked roundstones of uniform size.

Unworked curb and roundstone. A first course of unworked curbstones under upper courses of unworked roundstones of uniform size.

Curb and block. Squared coral blocks only, or a combination of squared slab curb and upper courses of squared blocks (red tuff, white coral limestone, black pumice stone).

Worked curb and roundstone. A first course of coral tuff and basalt, and upper courses of round tuff and basalt stones of even size arranged in even rows. In most of these the stones were dressed top, bottom, and sides, in wedgelike shapes, for closer fitting, with the front face left smoothly convex. 
Coral veneer. An outer veneer of thin coral slabs placed against basic basalt facing. ${ }^{5}$

Coral, tuff, and pumice stones were probably squared with blunt stone adzes, while the harder roundstones were probably shaped by hammering and pecking techniques.

Little or nothing is known about the quarrying of the huge slabs of coral limestone used in some constructions, but they were very probably transported from quarry to building site by canoe or raft, and overland on log rollers. Emory (1933:6-7) suggested that quarrying methods probably resembled those of Tonga, which were described by McKern as follows:

Living informants give the following account, remembered from the testimony of the preceding generation, of how stones were taken from one island to another:

The boats, at first the tungiaki and later the kalia, were large double-hulled sailing vessels, bridged with spacious decks, quite capable of carrying heavy loads. The vessel was brought as near to the shore as possible without running the risk of grounding, and there anchored to stakes set up on the shore. The anchoring place was usually at the very edge of a coral shelf, extending outward from the main shoreline, which was submerged at high tide and comparatively dry at low tide. The stone was dragged over skids to the edge of this coral shelf. Heavy wooden poles were then placed each with one end on the deck of the vessel and the other end crossing the abrupt edge of the coral shelf. These served as skids over which the stone was dragged onto the deck, where it was carefully adjusted and balanced, then tied by many ropes radiating from the stone to various parts of the vessel. In removing the stone from the vessel the reverse order was used. Some of the smaller stones were carried by groups of men, selected for their great strength, who placed the stones on the decks of the vessels without the aid of skids. [McKern 1929:6]

Common to all structures thus far identified by archaeologists as marae was a rectangular courtyard, usually paved with flagstones or stream boulders. Some effort seems to have been made in most cases to build marae on level ground or to obtain level courtyards by terracing. Also common to most marae were stone uprights set in the courtyards. (Figs. 7-9 through 7-21) In other architectural respects the marae so far discovered have been classified by archaeologists into a number of types according to such criteria as presence or absence of wall and type of wall construction; presence or absence of $a h u$ and type of $a h u$ construction; position of $a h u$ in relation to wall; size of $a h u$ and of overall structure; and so forth. ${ }^{6}$ Some of the architecturally simpler types were common to all the Society Islands and thus presumed to be "ancestral" to the larger and more elaborate ones. In connection with these latter, certain regional differences tended to develop and become very marked in time; for example, whereas the natives of Tahiti and Mo'orea built larger and larger multistepped platform ahu out of numerous courses of smaller matched stones, natives of the Leeward Islands built one- or two-level $a h u$ of huge coral slabs set vertically and on 


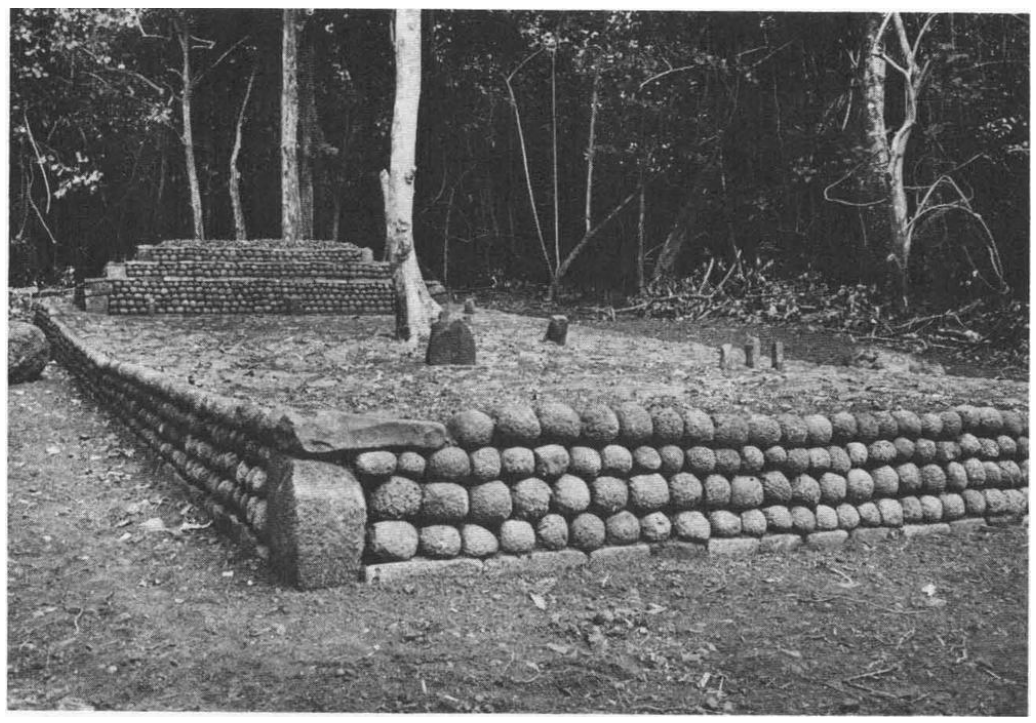

FIGURE 7-9. Marae at Opunohu, Mo'orea. Reconstruction and photo by Y. Sinoto, Bishop Museum.

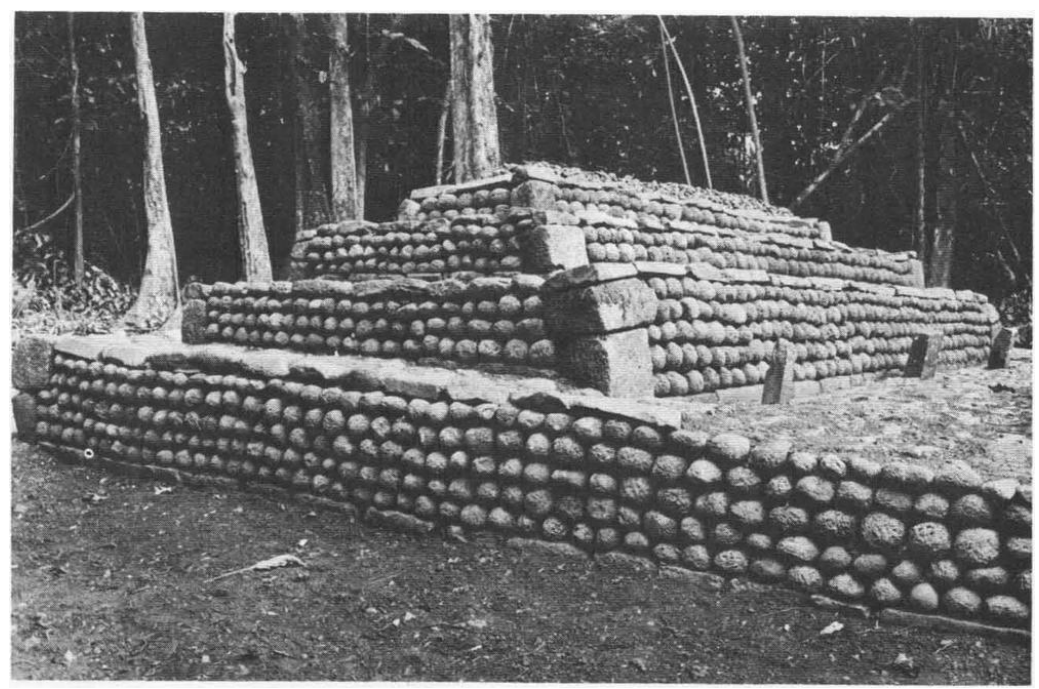

FIGURE 7-10. Marae at Opunohu, Mo'orea, detail of $a h u$. Reconstruction and photo by Y. Sinoto, Bishop Museum. 


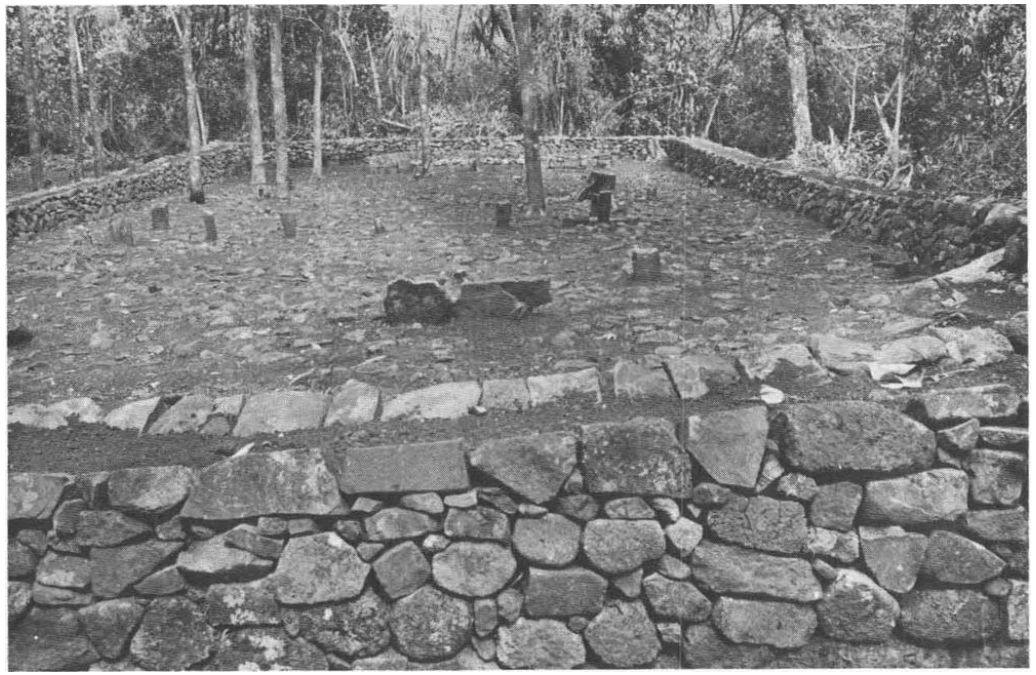

FIGURE 7-11. Marae at Opunohu, Mo'orea. Reconstruction and photo by Y. Sinoto, Bishop Museum.

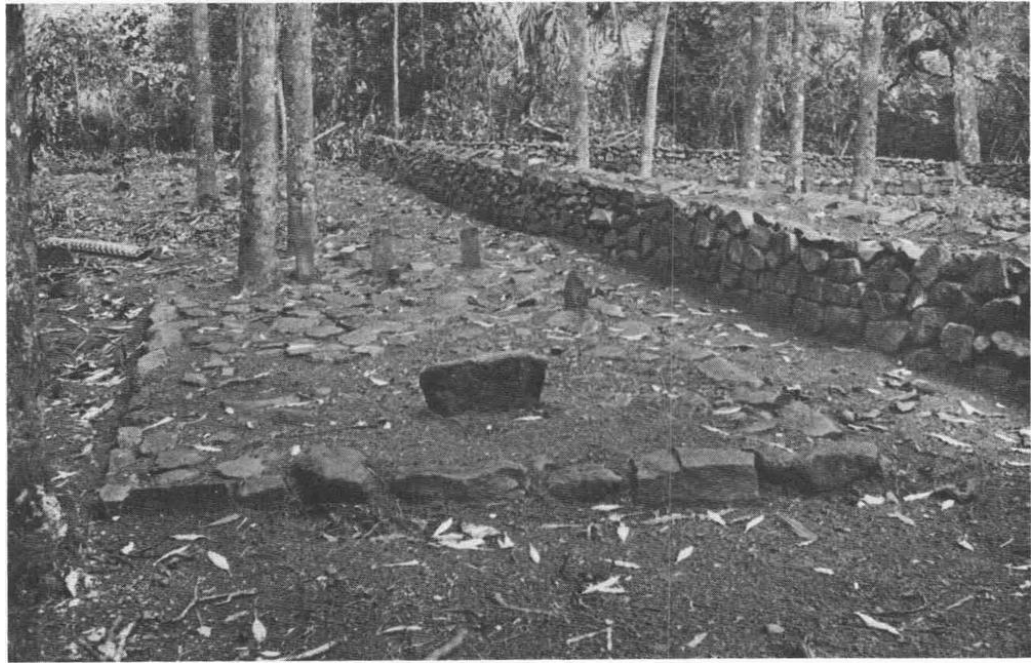

FIGURE 7-12. Shrine attached to marae at Opunohu, Mo'orea. Reconstruction and photo by Y. Sinoto, Bishop Museum. 


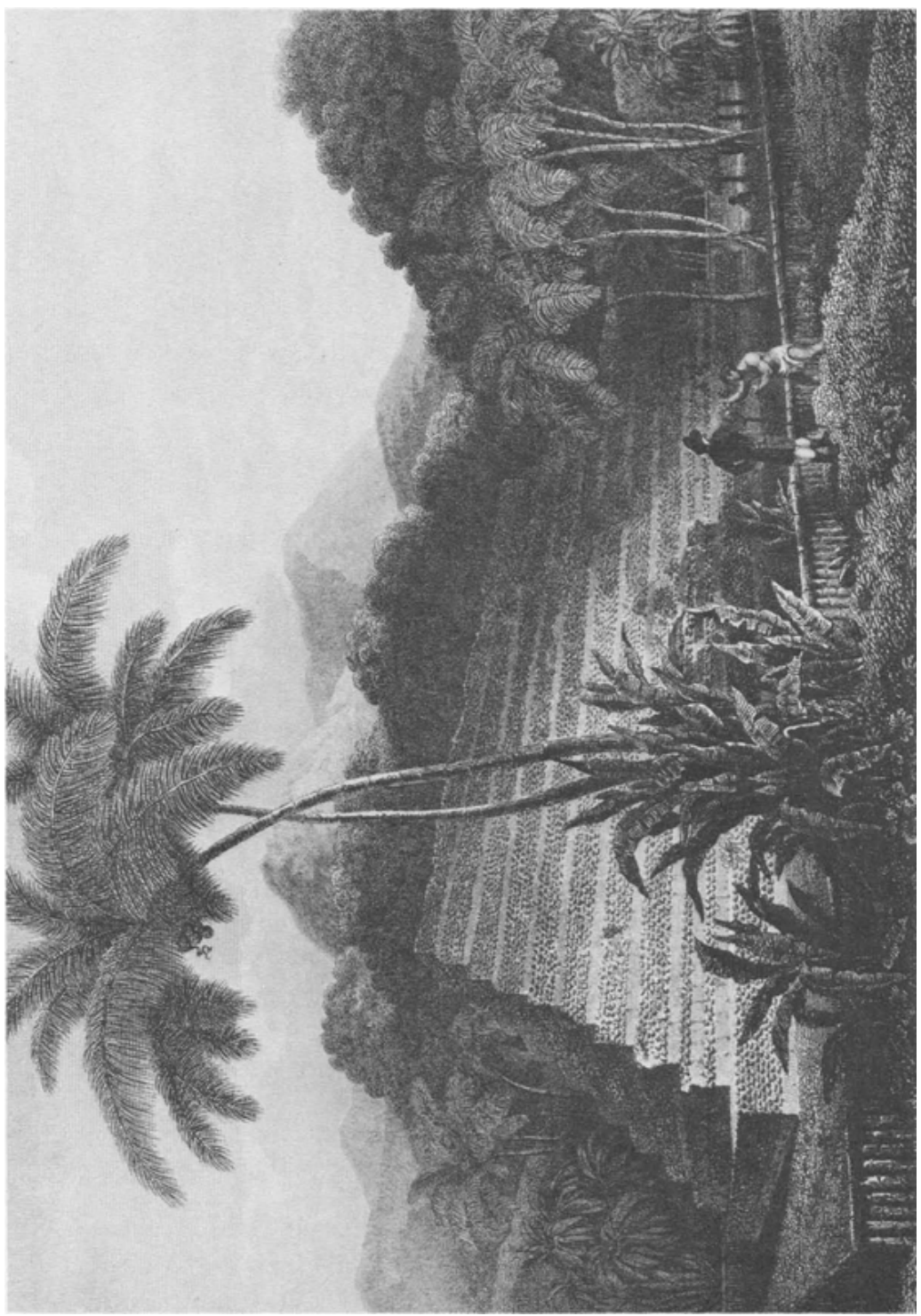

FiguRE 7-13. Marae Mahaiatea, Tahiti. Engraving based on drawing by William Wilson. From Archives of London Missionary Society Corporation. 


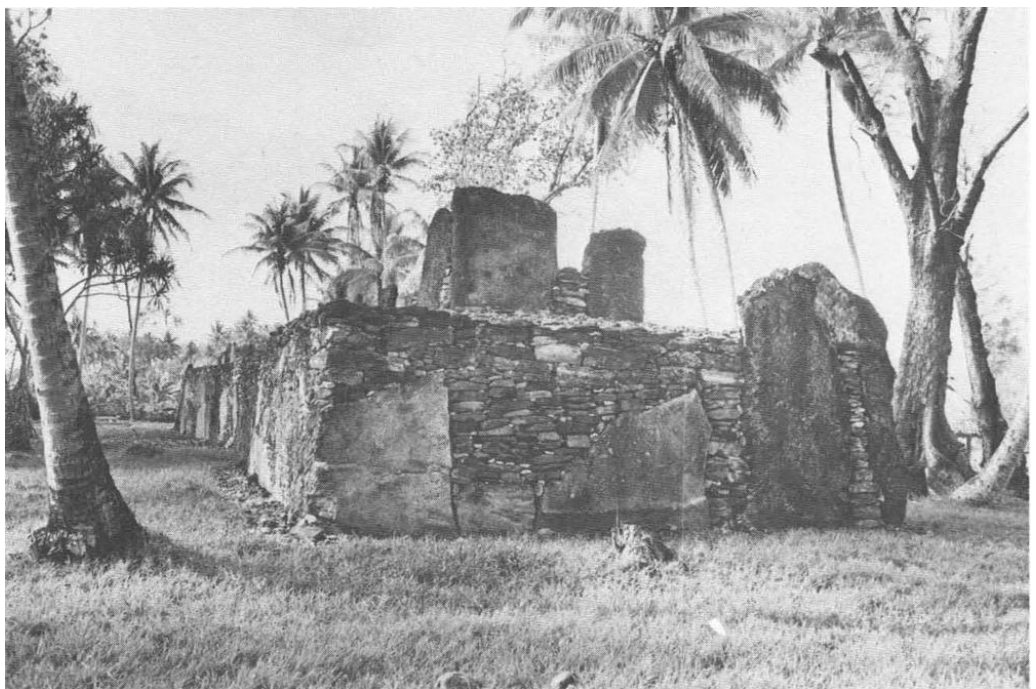

FIGURE 7-14. Marae Manunu at Maeva, Huahine. Reconstruction and photo by Y. Sinoto, Bishop Museum.

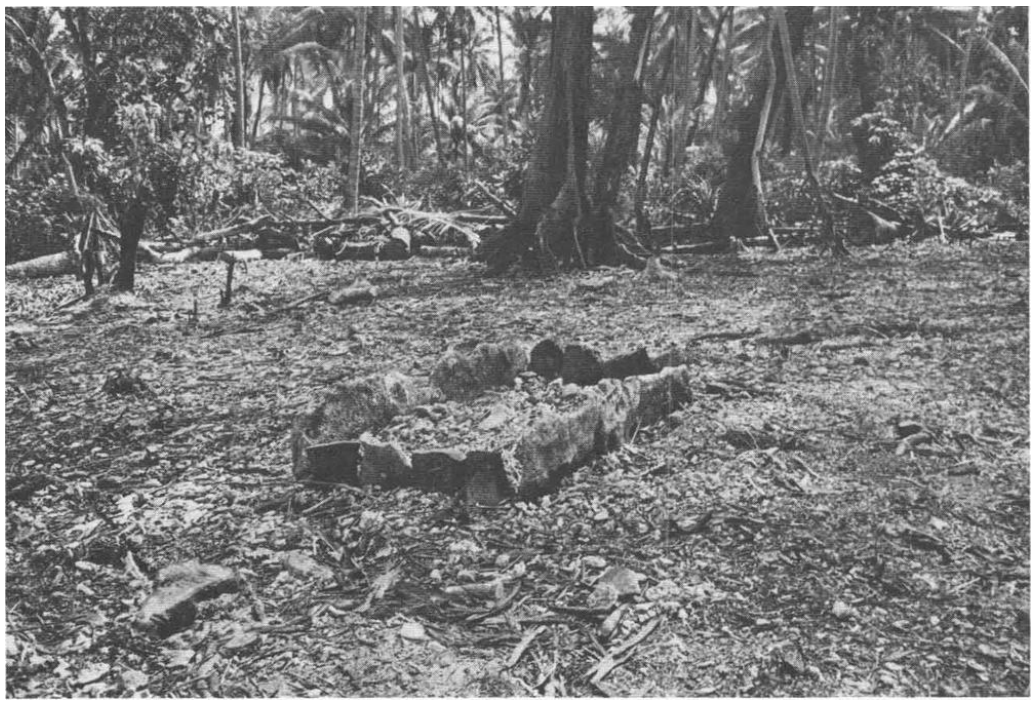

FIGURE 7-15. Grave in the court of marae Manunu at Maeva, Huahine. Reconstruction and photo by Y. Sinoto, Bishop Museum. 


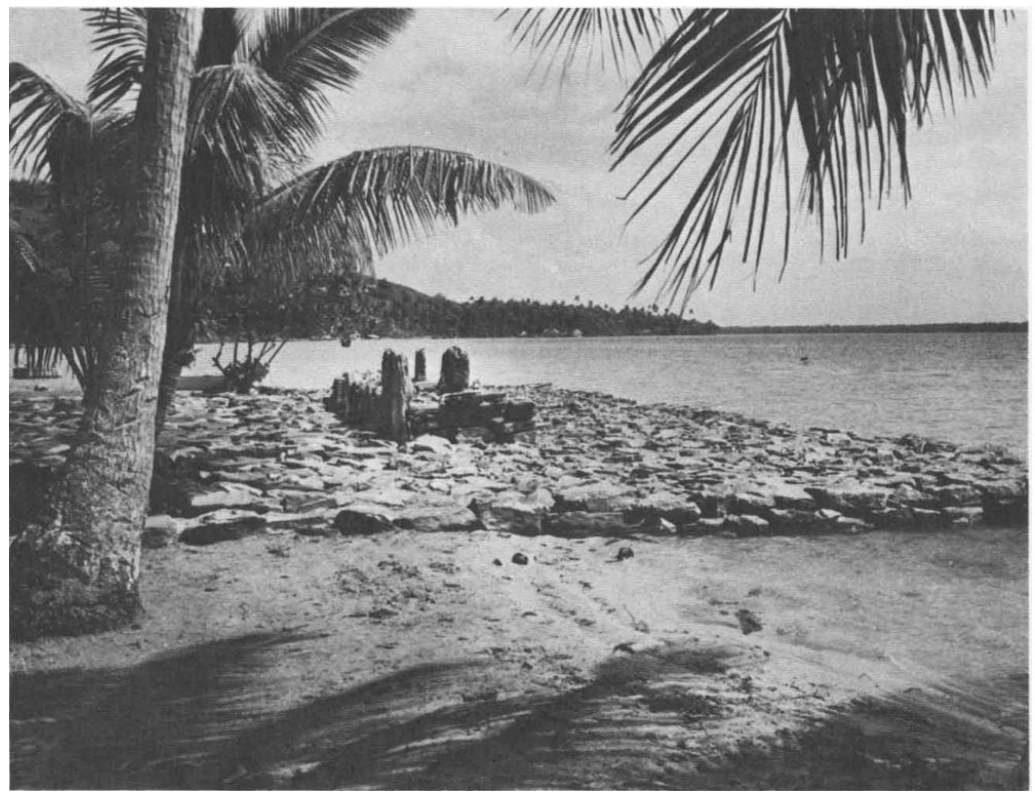

FIGURE 7-16. Marae Fareroi at Maeva, Huahine. Reconstruction and photo by Y. Sinoto, Bishop Museum.

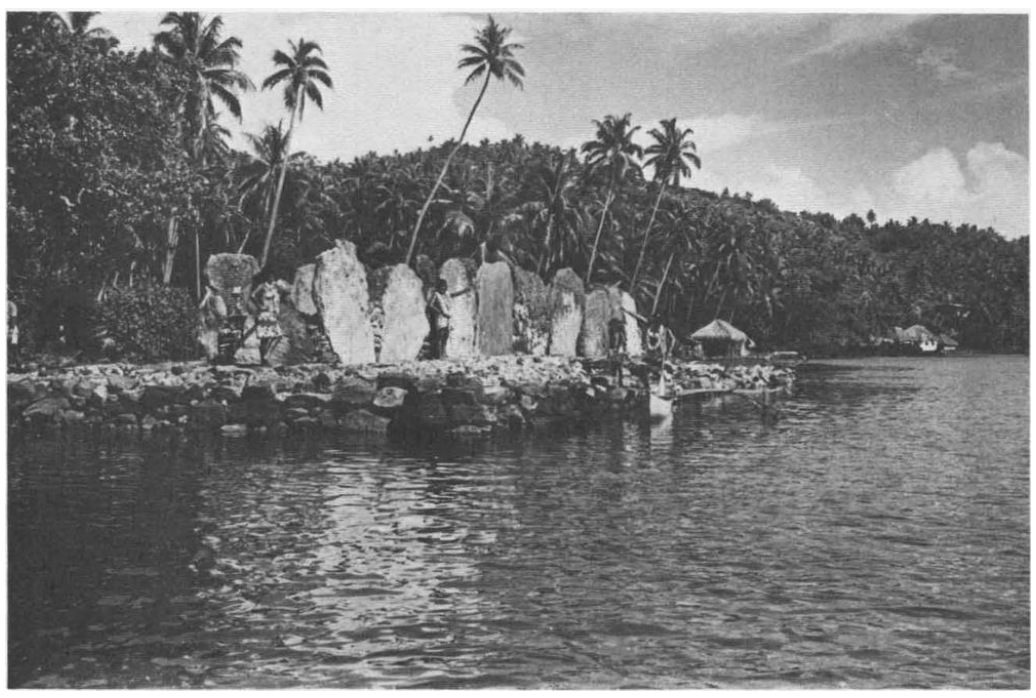

FIgURE 7-17. Marae Faremiro at Maeva, Huahine. Reconstruction and photo by Y. Sinoto, Bishop Museum. 


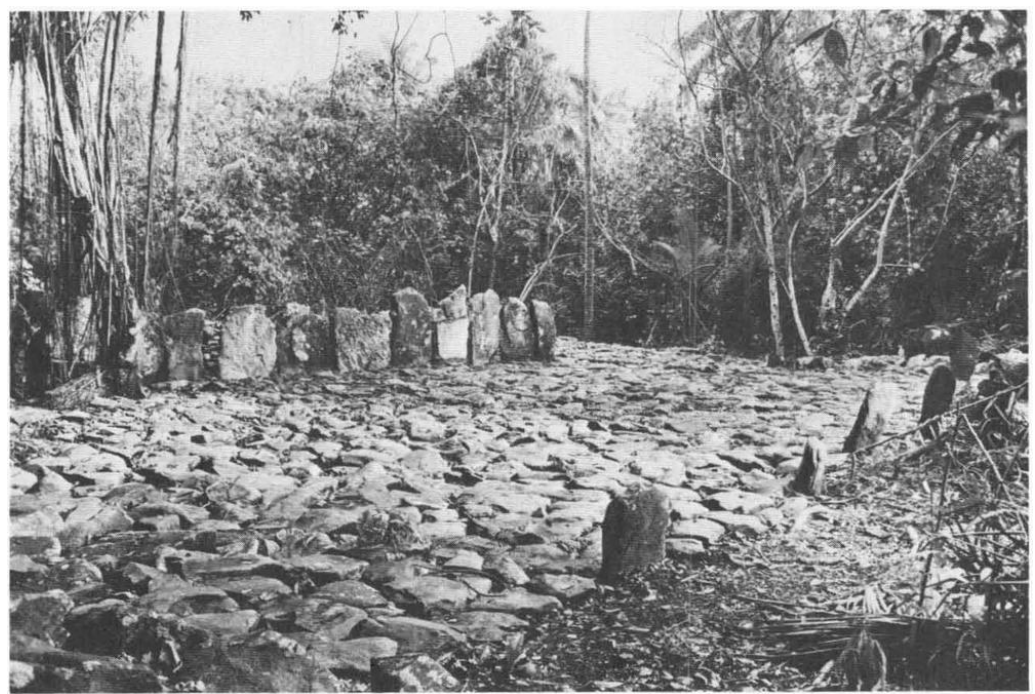

FIGURE 7-18. Marae Tefano at Maeva, Huahine. Reconstruction and photo by Y. Sinoto, Bishop Museum.

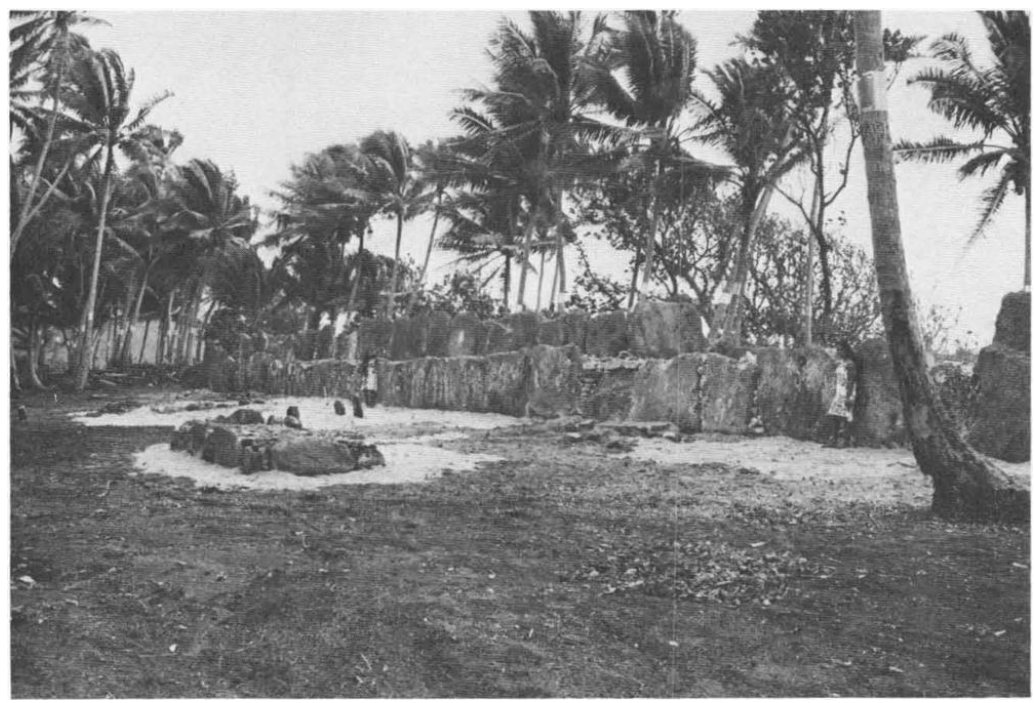

FiguRe 7-19. Marae Anini at Parea, Huahine. Reconstruction and photo by Y. Sinoto, Bishop Museum. 


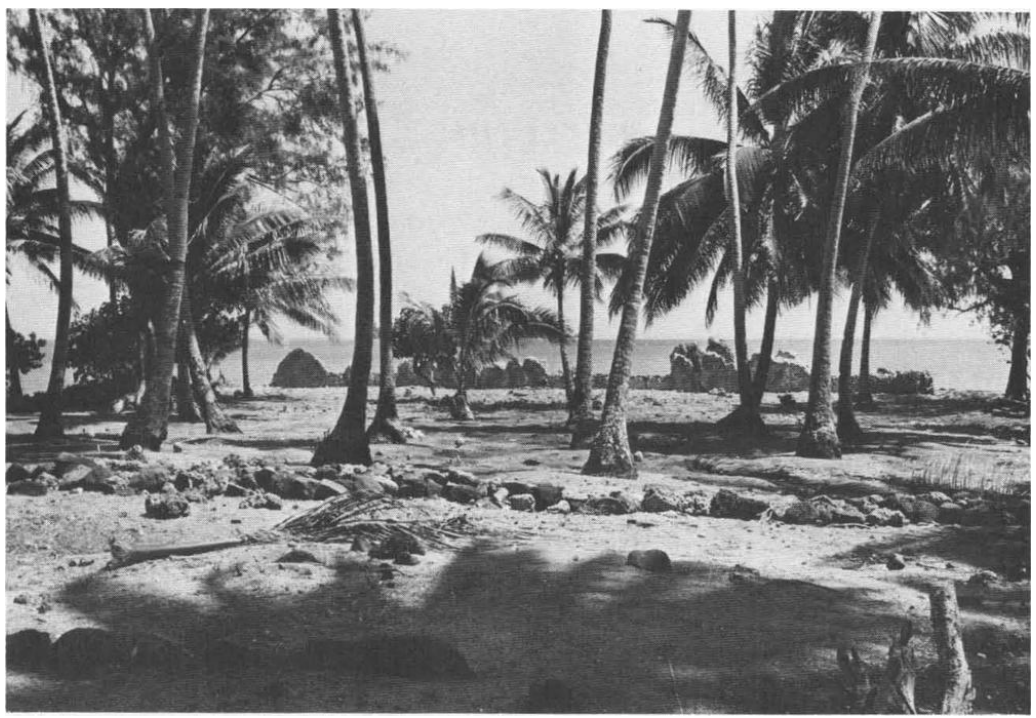

FIGURE 7-20. Marae Maratetini (or Fareura) at Farepiti, Porapora. Reconstruction and photo by Y. Sinoto, Bishop Museum.

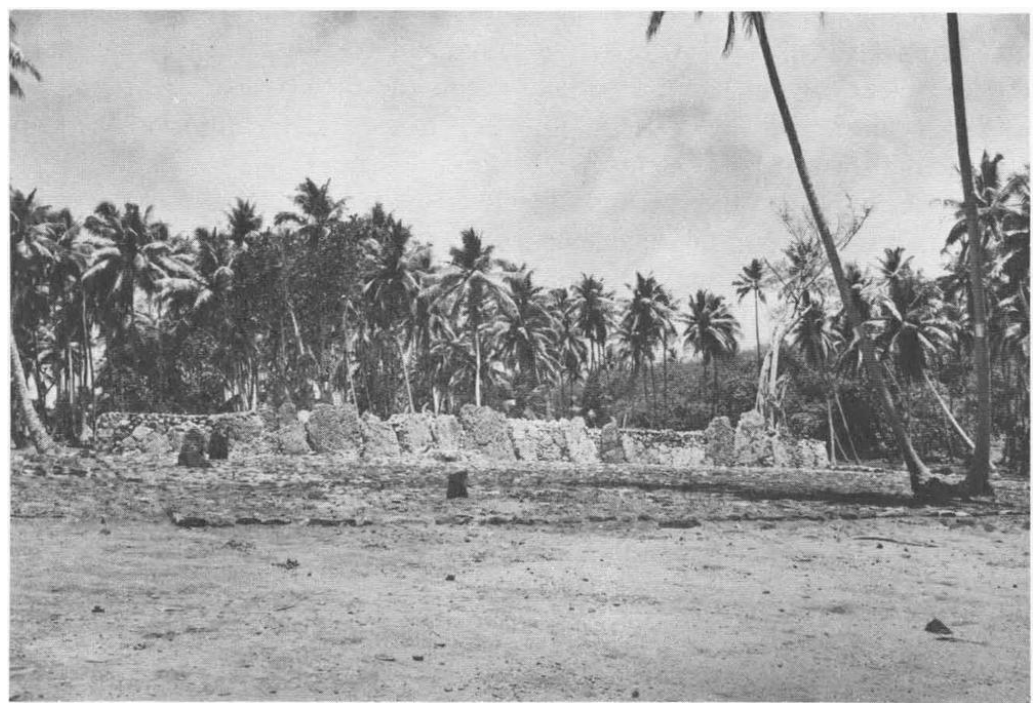

FIGURE 7-21. Part of marae Taputapuatea at Opoa, Ra'iatea. Reconstruction and photo by Y. Sinoto, Bishop Museum. 
end. With few exceptions (e.g., an intermediate-size Windward Islands-type marae found on Huahine), these regional differences were sharp and exclusive-interesting testimony to the strength of local tradition, in view of the frequent coming and going between leeward and windward groups-but whether due solely to architectural and ritual influences, is not at all clear. In both island groups the largest and best-built marae were located near the coast, and this led Emory to label them "coastal," as distinguished from small and relatively simple "inland," or from "intermediate," types. There may be some grounds for Emory's arrangement of these "types" in simpleto-complex developmental sequences. ${ }^{7}$ But the labels given them are not altogether apposite, inasmuch as "coastal-type" marae have in fact been found considerably inland, and small "inland" types have been found near the coast as well (Green 1961). The development of larger and more complex "coastal" types did not end the building of simpler "inland" ones, for one finds them existing side by side, with evidence, even, that some of them were actually constructed more or less contemporaneously.

The general stated reason for building marae was, as previously noted, to provide places where humans could "... receive the gods in a befitting manner" (Henry 1928:429). But within this general intent several special kinds of more or less overt religious purposes operated, for example: to ensure success in some enterprise (e.g., in the productivity of a new fishing site); to celebrate a successful outcome (e.g., of a battle, a hazardous voyage, a bout of illness, or of affairs in general); to mark the birth or inauguration of a chief (Adams 1901:42), or the joining of two dynasties by marriage (Henry 1928:122); to honor a particular god and thereby extend his earthly influence (e.g., see Henry 1928:128-129); to establish a kin-unit's title to a particular tract of land (Henry 1928:141).

Along with and reinforcing these overt purposes several more private, covert motives for building marae operated, such as: to enhance the prestige, and hence the political influence, of a particular individual or dynasty (e.g., "The greatest pride of an inhabitant of Otahite is to have a grand Marai...." [Beaglehole 1962:I, 304]); to extend political control by means of religious proselytization; to legitimatize political separation of a branch kinunit from its parent unit.

These various reasons, public and private, religious and political, will be exemplified in the chapters that follow. From the great number of marae found in every part of the archipelago it is obvious that such reasons were impelling enough to move the Maohis to expend large amounts of time and energy in the building and maintenance of marae.

At this remove in time from the people who actually built the marae we cannot discover directly the factors that entered into the placement of them, but it is possible to make some plausible inferences. 
To begin with, a text from Henry has been used by some scholars to imply in a general way a relation between location and type of marae:

The long capes were the inheritance of royalty and the nobility; there stood the great temples of the land which could not be hidden. Deep bays were the inheritance of the gentry [ra'atira]. As the land got thickly populated, the people spread everywhere. On the seashore and inland were the lands of the plebeians ( $a^{\prime}$ 'ata ri' $^{\prime}$ ) bordering on the lands of the great (feia mana). (1928:403)

The inference that has been drawn from this text is that, for social reasons, the size and elaboration of a marae increased with its proximity to the shore (Emory 1933:28). This correlation was indeed borne out in a general way by Emory's admirably energetic but admittedly partial pioneer survey of stone remains; but more recent and intensive surveys have demonstrated, in two populous regions at least, that large and elaborate "coastal-type" marae were also built miles inland (Green et al. 1967), and Emory himself pointed out that some small "inland-type" marae were built near the shore. As will be pointed out in a later chapter, size and elaboration of marae may in fact be correlated with the kin-Titular rank and political power of the proprietors.

Turning now to more particular locational factors, it does indeed appear that one of the places most favored for building large marae (or such as were built by people powerful enough to gain control of these favored places) was on capes extending into lagoon waters and opposite navigable passes in the barrier reef. The strategic advantages of such locations are obvious, but whether they were also favored on account of their conspicuousness is not quite certain. In this connection, although some of the marae at water's edge could be seen from far at sea, those farther inland seem not to have been located in order to command wide views.

Other locational factors that seem to have been considered favorable for such sites were standing groves of characteristic marae trees (e.g., ironwoods, rosewoods), good drainage, and proximity to fresh water. In the case of the larger slab-faced $a h u$ of the Leeward Islands, proximity to a suitable source of limestone may also have been a factor: transporting some of these enormous slabs on rafts or canoes may have been relatively easy, but moving them overland could not have been so.

In the case of certain smaller marae dedicated to specific activities-for example, to fishing in a particular lagoon deep, or to growing taro in a particular valley-the marae in question was of course located near the site of the activity. Also, the so-called "family" or "ancestral" marae, which was usually small and narrowly exclusive, seems to have been located near the residences of its congregation members. As stated earlier, the larger "public" marae were probably located at some distance from ordinary living areas. 
Next, in the case of marae built to establish a social unit's title to a particular tract of land, some of them appear to have been located near the tract's most important social boundary, as a kind of "guardian of the threshold." For example, in describing marae locations in the populous inland valley of Tautira district, Tahiti, an archaeologist declared: "It also appears that marae played somewhat the role of 'guardian of the threshold', inasmuch as they were built at the boundaries of each settled area, at the confluence of the valley's main stream and its tributaries" (Garanger 1964:10).

The locations of some marae were influenced by considerations of religious belief and practice. For one example among many, the venerable Vaearau marae of Ra'iatea is said to have been built to consecrate the spot where Ta'aroa first "... broke through the sky" and placed his foot on the island: however, there is a strong possibility in such cases that the myth was "invented" subsequently to "explain" the location of the marae (Handy 1930:84). Also it is consistent with other and better documented aspects of Maohi life to suppose that augury may sometimes have been consulted when seeking locations for marae, at least for locating some of the larger ones.

Finally, it is abundantly clear from archaeology that the Maohis were given to building new marae near and sometimes directly adjacent to existing ones. In some cases, in fact, there is evidence that a new marae was built on the very site occupied by an older one, even to the extent of cannibalizing the older structure for building stones for the new.

The building of smaller marae would have required little or no craftsmanship and energy beyond that of any ordinary man or small group of men. On the other hand, the building of the larger, carefully-faced walls and ahu called for considerable architectural and supervisory skills, as well as large levies of labor. There were, in fact, certain men (tahu'a marae) who made a specialty (presumably part time) of planning and supervising marae construction.

In planning new marae the tahu'a marae were probably constrained by their clients' wishes as to overall size; and they were obviously influenced by local architectural tradition- "obvious" inasmuch as such regional styles did in fact develop. But in view of the wide variation (in size and placement of $a h u$, etc.) a tahu'a marae may also have exercised considerable individual choice in planning the work for which he was commissioned. In all likelihood, the same specialists planned the marae and supervised its actual construction. We are not informed how they were compensated for their skills and labors, but it is reasonable to assume that they were compensated fairly generously.

A brief general account of the building of a marae appears in Morrison's journal:

When a Morai is to be Built the Chief Gives Notice thereof by sending a piece of Cocoa Nut leaf to evry Man under him, with orders that at the time and place appointed he shall appear with a Stone of the dimentions that he shall find described 
by the Priests and they accordingly attend. If the Stones are not Judged sufficient the order is renewd. These leaves are Generally made up by the Priests with knots, tied in a Manner peculiar to themselves, and Contain the Dimentions of the Stones that each man may work without the assistance of another. When the stones are all collected, the Priests give notice that they are ready and a part of each day is set aside for the Work-a sacrafice is then made, and they proceed in their work during which time no fire must be lighted in the District till they leave off Work each Day-after the work is finished and the Alter errected, they expend two or three days in the Consecration of it, which is done by making many Sacrafices, Human \& Common, with prayers $\&$ feasts and during the time the religious part of the rites are performing no fire must be lighted, and this is observed in all rites wherein the Generality of the People are Conserned. (1935:180)

Henry provided some additional generalities regarding both the actual construction and its accompanying ritual:

When a national or royal marae was to be built in a district, a branch of ti was taken and planted upon the assembly ground of the royal house, ti patia (ti stuck in), to show that religious restrictions were put upon pigs and fowls and all the produce of the land and upon the fishing grounds. The best of everything was to be cultivated and mature for the time of building, and the restriction lasted for two or three years. When the time to work arrived, the people entered a most solemn period. A puhapara'a, or encampment, was made in the woods for the laborers, who withdrew from their families to consecrate themselves to their work; and other encampments, called fare-hua, were made far inland for the old and infirm, for the women and children, and for domestic animals, so that their voices could not reach the appointed place, and that they might enjoy freedom. No living creature was allowed to approach the new site, no fires were kindled along the neighboring shores, where people even spoke in hushed voices.

No able-bodied man of the realm was idle on such an occasion, for the chief and all classes deemed it an honor to aid in so sacred a work. Some were food providers and cooks for the respective encampments, which were well looked after. Others collected stones from land and sea according to the directions of an artisan, who was called the tahu'a-marae, and they shaped the irregular stones into blocks and slabs with hard stone implements, leaving the round stones in their natural state to fit in between the others. This work took many months, and relatives or friends of the sovereign from other little kingdoms sometimes lent their aid. Marae dedicated to the god 'Oro were distinguished from all others by stones that were shaped like turtles' heads and set at regular distances along the sides of the construction.

When all the stones were collected, the ground for the marae was cleared and then sprinkled well by the priests with sea water to make it holy. A long stone was taken from some other grand marae, as the 'ofa' $i$-faoa (chief-corner-stone), a man was slain and placed in the hole dug to receive the stone-his spirit supposedly remaining to guard the marae-and the erect stone was planted firmly upon the corpse, while the priest prayed to the tutelar god in the following manner:

Tahi t'ia mai e te atua e, i ta matou nei pure!

Inaha, te pûpû hia 'tu nei e matou, na va'a mataeina'a o teie nei hau, i teie fenua, ei vahi mo'a na 'oe, ei ti‘ara'a marae e ei ti'ara'a fare no 'oe.
Hearken unto us O god, in this our prayer!

Behold we the clans of this kingdom ${ }^{[8]}$ present to thee this land, to become sacred to thee, upon which to build a temple and houses for thee. 
Teie te 'ta'ata ei tapu ha'amo'a na matou i mua i to'oe ei aro, e te Atua e, teie te 'Ofa'i-faoa mo'a no te 'utuafare ta matou e ha'a no 'oe e no te nu'u atua e haere mai ia 'oe nei ei manihini na 'oe, e te atua e! 'O ta matou teie pure, a tahiti'a mai e te Atua e!
Here is a man as a pledge of consecration from us in thy presence, O god, here is the sacred 'Ofa' $\mathrm{i}$-faoa (chief-corner-stone) of the home we shall make for thee and the host of gods who will come to visit thee as thy guests, O god! This is our prayer, hearken unto us, O god!

Another corresponding stone, which was called the $t i^{\prime} a-v a$ (stand-towering) was placed at the opposite corner, and these two stones were called the tihimarae (horns of the marae), which answered the same purpose as the horns of the Jewish temple [sic].

After the performance of the terrible consecration ceremony by moonlight, the people silently carried out the stones collected and reverently placed them in heaps around the place prepared, according to the directions of the presiding artisan. Some immense pieces of stratified rock, twelve to eighteen inches thick, about twelve feet long, and nine feet broad were used, as well as large rocks of other kinds, which the priests and workmen declared were made light in their hands by the gods, so great was their enthusiasm in the work. (1928:131-132)

Any attempt on my part to calculate precisely the amount of labor required for constructing one of the larger marae would be complicated by so many unknown factors-for example, time required to find and work a stream boulder or to quarry and transport a limestone slab-that my estimations would be largely factitious, but it is my guess that such an enterprise would not have unduly strained the manpower resources readily available to most "district" chiefs. The Maohis may have found their religion sometimes burdensome, as the following lament implies: marae!

Bowed down, forsooth! Crushed will be Tahiti before the marae!

(Henry 1928:131)

But this burden was more likely occasioned by the many restrictions on normal activities which accompanied marae ritual and by the large levies of goods required for marae offerings, rather than by the actual work of building a marae.

Of direct social-relational relevance is Henry's reference to the 'ofa' $i$ fao' $a$, the so-called 'chief cornerstone' or, better, 'marae founding stone', which according to Henry was "... a long stone taken from some other marae" (1928:132). There are many references in the sources to this custom. For example, marae Vaiotaha of Tautira district (Tahiti) is said to have been founded with a stone brought from a marae of the same name on Porapora (Corney 1915:127), and marae Fare Hau on Porapora was founded with a stone from marae Vaerai of Ra'iatea. In fact it would appear that the custom was general and universal, that is, nearly every marae was an offshoot of some earlier one,${ }^{9}$ forming a continuity which was substantialized in the founding stone. This important concept will be considered in 
later chapters, but it will be useful at this point to quote from Henry regarding the role of the founding stone in the establishment of a "family" or "ancestral" marae-a pattern which might conceivably be the mode for all founding-stone customs:

Whenever it was necessary for the land of a household to be divided into shares, each portion was nicely measured off by the etaeta (fathom), and the boundaries were marked with stones. Then the people who were leaving the old home took a stone from their marae, suitable for a chief cornerstone ('ofa'i haoa) for a new marae upon their respective shares. When this was laid, they collected stones unconsecrated, to complete the structure. In their turn and in due form these stones were also consecrated. The sacred stone obtained from the original marae was replaced by a new stone taken and consecrated to the tutelar god or goddess with prayers and sprinkling with sea water. With the stone taken from the old marae were also taken the hereditary names, which had been bestowed upon the new proprietor, and from that time forward the other marae holders were disentitled to them. The new temple was dedicated to the same tutelar deity as the old one, who was considered the great friend of the family. The opening was celebrated with an inauguration feast called the faato'moraa (entering). (1928:142)

In this connection it can be shown by archaeology that many marae were constructed largely with stones taken from older marae. ${ }^{10}$ In fact, archaeologists have come across the remains of several marae that have obviously been depleted this way, not in terms of a few symbolically significant "cornerstones," but of ordinary building material. The implications of this kind of measure, as evidence of changes in social relations and religious commitment, are as intriguing as they are obscure, and what little information there is available about them will be considered later.

According to Henry's general account (1928:137-138), the dedication of a "national" marae consisted of three ritual episodes:

Rao-marae (setting of the marae). All members of the marae congregation, including females, assembled at the marae, where young women threw tiare blossoms upon $a h u$ and pavement, and priests called upon the gods to fill the place with their presence.

Hao-marae (establishing the marae). The principal priest sprinkled sea water over all parts of the marae and called upon its tutelar god "... to take possession of his new home, and to make welcome his guests, the hosts of gods."

Eera' $a$ o te ari' $i$ (the mounting of the ari'i). The principal proprietor of the marae walked across the middle of it, whereupon the priest pronounced the marae to be mo'a roa (superlatively holy).

Upon the conclusion of these rites all the food levied for the occasion was divided-part going to the priests for the gods (and for themselves), 
part to the ari'i proprietor, and the remainder to other members of the congregation and guests, who ate it forthwith, but preserved great propriety in doing so:

The greatest propriety was observed by all parties concerned in the sacred marae inauguration feast, as it was believed that eating greedily or indulging in any excess of rioting would bring upon the offenders immediate calamity from the gods, such as choking while eating, strangulation, blindness, and many other troubles (Henry 1928:138).

This appears to have been the general pattern for marae dedication rites, although the scale of such events must have varied considerably. As was noted earlier, individuals and families sometimes vied with one another in having larger and more impressive marae. Such rivalry also appeared in connection with dedication ceremonies:

Many of the wealthy gentry of the land built their ancestral marae in pyramidal form [i.e., $a h u$ ] and inaugurated them with great pomp. They aspired to the honor of having their king or high chief perform the eera' $a$ ceremony, feeling this the highest temporal dignity that could be bestowed by man. But the chief never again returned to it. (Henry 1928:139)

Rites also accompanied the construction and consecration of marae appurtenances, as exemplified in the following account of the consecration of a new "house-of-treasures" on Huahine. This account from Davies journal is quoted at length mainly because it represents one of the few eyewitness reports of an actual Maohi rite; most rituals described in the sources are generalized versions and hence removed one step at least from actual events.

The god's house being finished yesterday its consecration began in the evening \& was as follows; a number of Priests \& old men assembled at the house, also all the chiefs, men \& women, Arepaea who is sick \& Edea excepted, then the sacred drums began to beat \& prayers commenced in the marae where the house stands, the priests then entered the house \& sat down in different parts of it, the chiefs also, men $\&$ women sat by them, a great number of people gathered about the house $\&$ a number of the men entered but no women of the common people, it was then beginning to be very dark, the drums continued beating incessantly $\&$ the people in the house priests, chiefs \&c then joined in chanting a number of Ubus (upu) or prayers repeating the same form of words hundreds of times over, thus it continued all night without interruption, except for 2 or 3 minutes when they gave over the repetition of one Ubu in order to begin another. Many of these Ubus were nonsensical sentences not in the form of addresses to their gods, but a repetition of their names \& having sometimes some obscure allusions to some ancient transactions or traditions concerning the ancestors of the islanders, others had something of the form of prayers containing invocation to the gods, a declaration of their power \&c. When daylight came everybody went out of the house, the drums ceased beating, 2 or 3 prayers were said by the Priests sitting by the side of the house, these were not chanted like the others. After this the gods were brought out from an old adjoining house \& laid down by the 
Priests seated on little stools, the gods were 5 in number viz Hoata the largest and for whom the house is more particularly built, Oro, Tane, Teare \& Manutahe, one of the Priests gave orders for a cocoanut branch to be brought, this being done a number of the leaves were platted into small bunches, these are called Tapau \& were in number 5 according to the number of the gods, a Priest then gave orders to a young man to climb to the top of the house \& put the tapaus on the ridge outside where the end \& middle posts were standing. This being done a boy \& a young man were ordered to take up the gods with their stools in their hands \& to walk round the house \& two other men to follow them carrying the sacred drums, this procession went round 3 times, $\&$ then stood by a Priest that was saying a prayer, the prayer being ended the drums were laid down \& the gods were taken into the house \& laid down by the 2 posts over which the tapaus were placed outside on the house top, one of the gods viz Manutahe who was very small was taken back into the old house \& so the ceremonies ended \& the people departed to their several houses. One man was ordered to sail for Raiatea immediately taking with him some palm leaves to put in a Marae there \& to acquaint the Priests \&c that the house of the gods in this island had been finished \& also its consecration. The things called after the names of their gods \& (which) were placed in the house are only little bits of wood wrapt up in cloth \& a number of feathers of various colours chiefly red fastened to them. The house of the gods is according to the fashion of the country an elegant and costly one, it is what is called a Fare pota having round ends, the length is about $56 \mathrm{ft}$. \& width about 28 it is supported by 32 strong pillars or posts well wrought two or three of the middle ones which support the Tahuhu or main beam that has the upper end of the rafters resting upon (it) are curiously wrapt round with matting $\&$ sinnet of various colours, also most of the rafters are wrapt round nearly to the top with the same, the making of this matting \& sinnet has been chiefly the work of the women \& it has cost them much time. Journal, 1 January 1808-24 February 1810. (Newbury 1961:127-128)

Once built and consecrated, marae had to be maintained, physically preserved against weather and encroaching vegetation, and thereby spiritually sustained as suitable visiting places for the gods. In fact, before any great rite could be performed at a public marae the place had to undergo formal "weeding" (vaerea marae). It is reasonable to suppose that some ritual also accompanied the tidying up of smaller domestic and occupational marae, but the sources do not report it.

Marae weeding was thus a solemn affair, but it would appear that it was only performed preparatory to other solemn rites at the marae and not as a regular, periodic act in itself. This is a significant example of Maohi "economics": labor was rarely expended for purposes of simple "maintenance" but, usually, only for the purpose of securing an increment or making up a loss. Marae reconstruction, on the other hand, constituted the principal episode in rites designed to "purify the land," to make it habitable again after it had been ravaged in war and its gods and marae defamed. A description of these rites is given in chapter 12 . 


\section{CHAPTER 8 BOATS AND TRAVEL}

As we have seen, the population of these rugged and widely separated islands resided in small scattered settlements, and it was socially divided into numerous political divisions as well. Comparable conditions in many other parts of the Pacific (for example, in Melanesia) were allied with cultural, social, and genetic distinctiveness; the fact that such fragmentation did not develop in the Society archipelago was made possible by the means the Maohis had for communicating with one another and by the use they made of such means.

Maohis traveled by both land and sea. Except for short stretches of some windward shorelines, the coastal belts afforded fairly easy walking, either through the parklike littoral zones or along the sandy beaches. In places where valleys cut deep into the islands' interiors people crossed from one side to another over well-traveled passes-except during rainy spells, when passage was rendered more difficult than even these sure-footed walkers were able to negotiate. ${ }^{1}$ At such times and at other times as well, the Maohis usually took to their canoes in order to reach distant destinations.

\section{BOATS}

The Polynesians traditions ... prove that voyages were made from the Society Islands to the very limits of Polynesia: to Hawaii, Rapa, and New Zealand. (Handy 1932:64)

At this time [after being regaled by a European about the latter's wide travels around the world] Pomārre and his retinue particularly regretted their want of ships, and knowledge to conduct them to foreign countries; and, addressing himself to me, said, in a tone of concern, that they were able to go no further than Ulietea [Ra'iatea] or Huaheine; and that at the risk of being driven they knew not whither, to perish ...." (Wilson 1799:200)

However maritime a people the Maohis may have been previously, at the point in their history when they were first sighted by Europeans they undertook deliberate round-trip voyages little farther than the limits of their archipelago, except for occasional voyages to and from the nearer Tuamotu atolls. But this did not diminish the immense influence of boats and boat travel upon the internal structure of their society. (Fig. 8-1.) 
The Maohis constructed three types of boats: small dugouts ( $p u$ ho'e), larger dugouts with built-up sides $\left(v a^{\prime} a\right)$, and composite-plank keeled craft (pahi). In addition to these specific labels, however, all three types were called $v a^{\prime} a .^{2}$

A pu ho'e consisted of a single hollowed-out log hull capped occasionally with thin gunwale strips. Such boats were round on the bottom, with a convex cutwater and slightly raised bow, and with a slightly raised and pointed stern. No visitor troubled to measure these small canoes, which were used mainly for inshore fishing, but it is unlikely that they were over fifteen to twenty feet in length.

The hull of a va'a was much like that of the pu ho'e in shape, but the larger ones-Banks measured one seventy-two feet long (Beaglehole 1962:I, 365) - were built on two or more dugout bottoms fitted together; and their afterpart was somewhat wider than the forward. They had long flat bowpieces and high upward-curving sterns.

Pahi differed from $v a^{\prime} a$ and $p u$ ho'e in shape and in construction. They had definite keels and rounded sides, and were elevated at both bow and stern. The keel was fashioned out of one or more hollowed-out logs, and the sides out of several planks. According to various accounts, pahi ranged in length from thirty to a hundred or more feet. One of average size measured

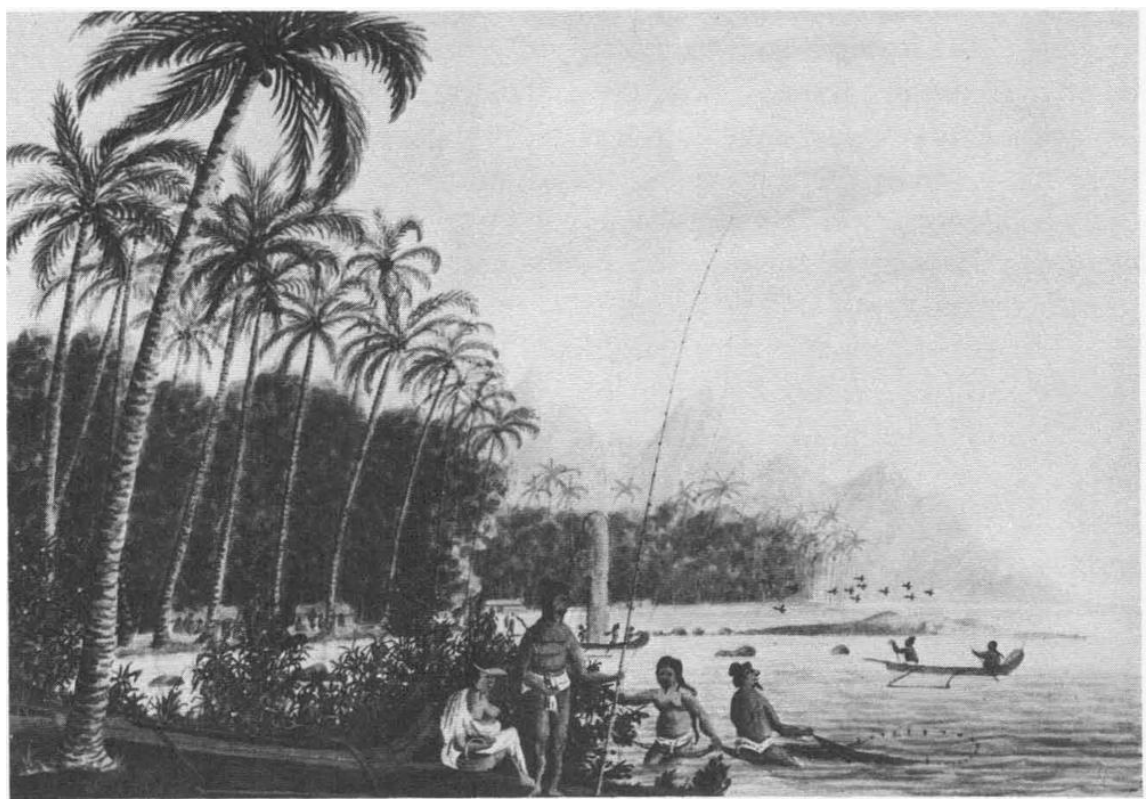

FIGURE 8-1. "In the district of Tetaha, Island of O'tahytey." Watercolor by G. Tobin. Mitchell Library, Sydney. 
by Banks was fifty-one feet long, gunwale breadth varied from fourteen to eighteen feet, bilge width from thirty-two to thirty-five inches, and depth amidships was three feet four inches. Like the $v a^{\prime} a$, the pahi stern consisted of a high curved piece topped with a carved figure, but the pahi also carried a figure on its raised bow piece (fig. 8-2 through 8-6).

The $p u$ ho'e was always stabilized by means of an outrigger float, whereas the pahi usually consisted of a pair of hulls joined together to form a "double canoe." Va'a were sometimes stabilized by outriggers or by means of double hulls.

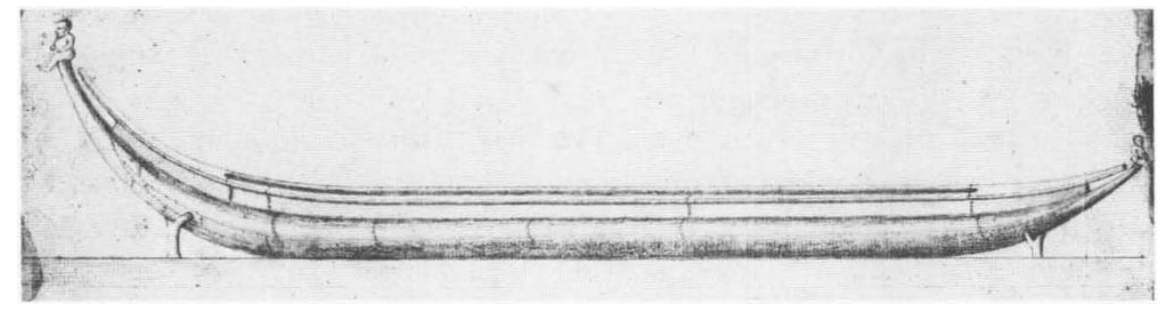

FIGURE 8-2. Hull of Ra'iatean pahi. Drawing by S. Parkinson. British Museum.

All these types of boats were propelled by pole, paddle, or sail-or by two sails, one stepped in each hull of double canoes. Steering was by means of paddles or larger paddle-shaped rudders. For sailing, a balancing board was usually lashed across the gunwales so as to extend several feet beyond the hull opposite the outrigger; by moving along this board crewmen were thus able to keep the vessel on a more even keel. Washboards were often added for travel in rough waters, and wooden bailing-scoops (fig. 8-7) were necessary at all times because of invariable leakage and water taken in over the sides.

The larger canoes were usually fitted with additional structural features for special uses. When traveling long distances it was customary to lash boards across the gunwales to form a wide platform upon which to sit and sleep, or even cook. For additional protection against sun and weather some boats carried mat-work canopies or portable cuddies, which also served as shelter for the travelers ashore. In the case of $v a^{\prime} a$ outfitted for war, raised platforms were built over the bows to accommodate the fighting men.

In fact hulls of the larger boats, $v a^{\prime} a$ and pahi, were put together and supplemented in various ways to suit various purposes. A favorite adaptation for traveling near shore, with or without sails, was made of twin hulls of medium size; larger double canoes were also used for fighting and for stately travel. For deep-sea fishing and interisland travel the single hull, with outrigger, was probably faster and safer. It was a simple matter to right 


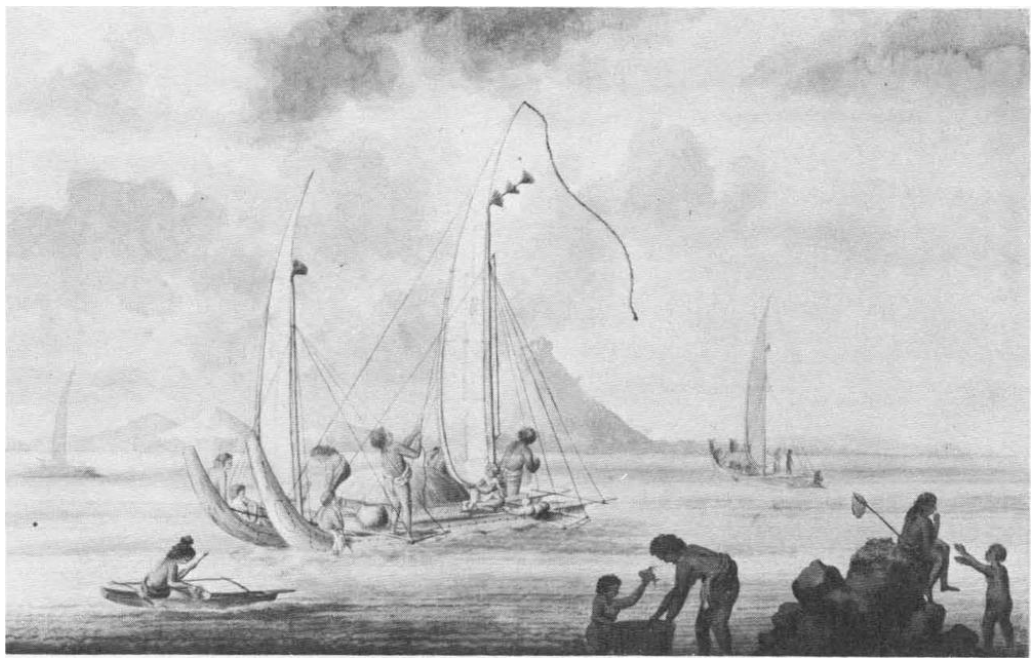

FIGURE 8-3. Double canoes. Drawing by S. Parkinson. British Museum.

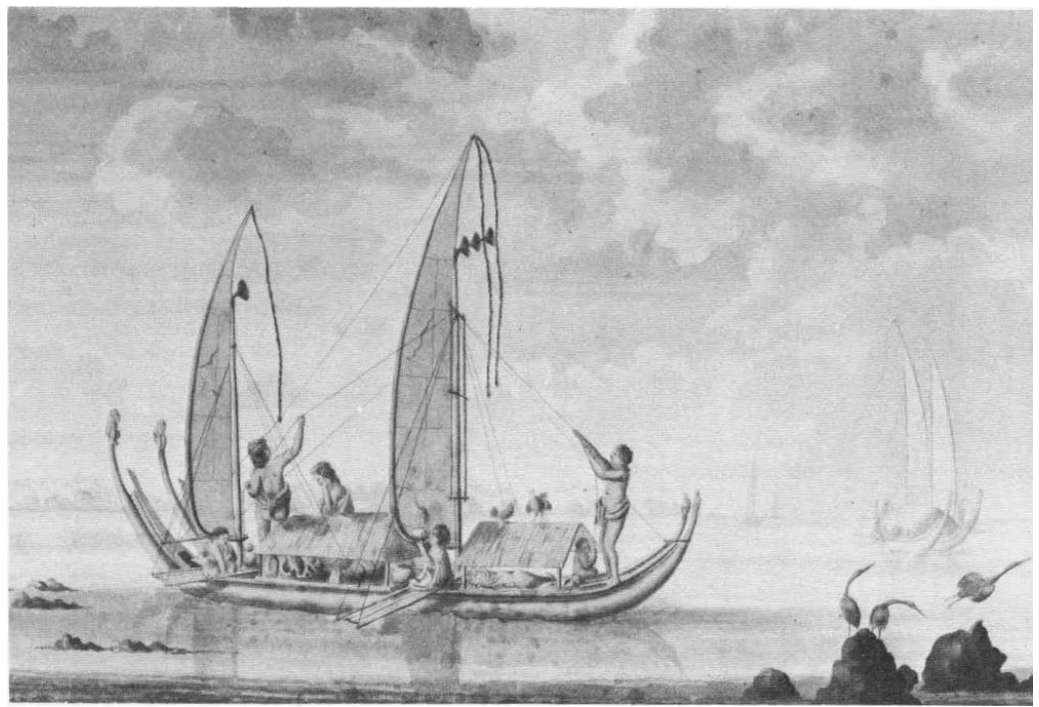

FIGURE 8-4. Double canoes. Drawing by S. Parkinson. British Museum. 


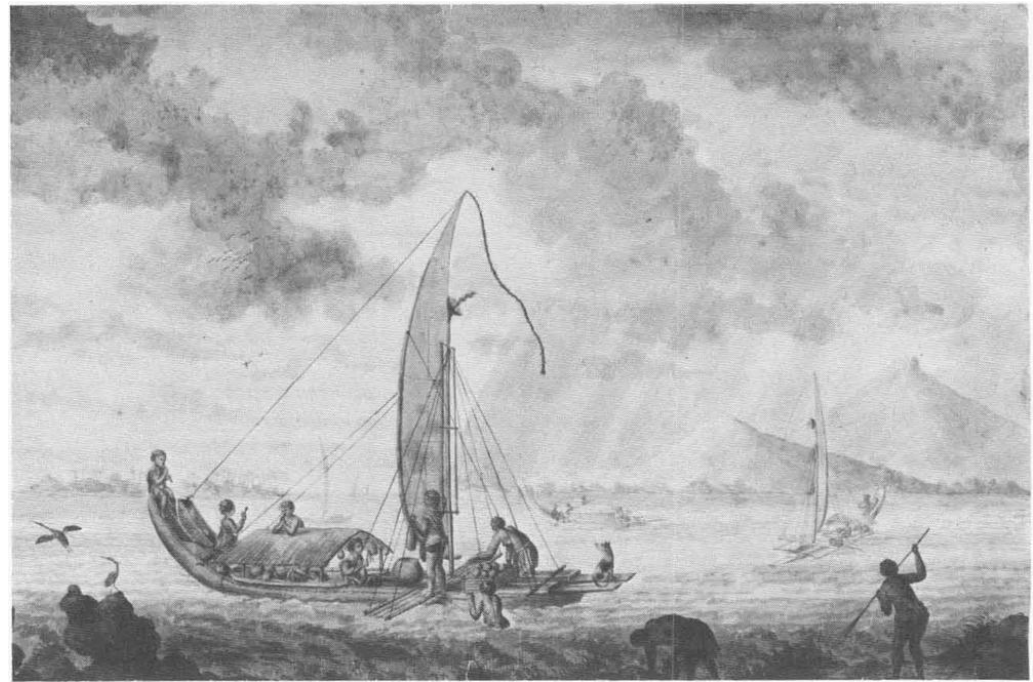

FiguRE 8-5. Double canoes. Drawing by S. Parkinson. British Museum.

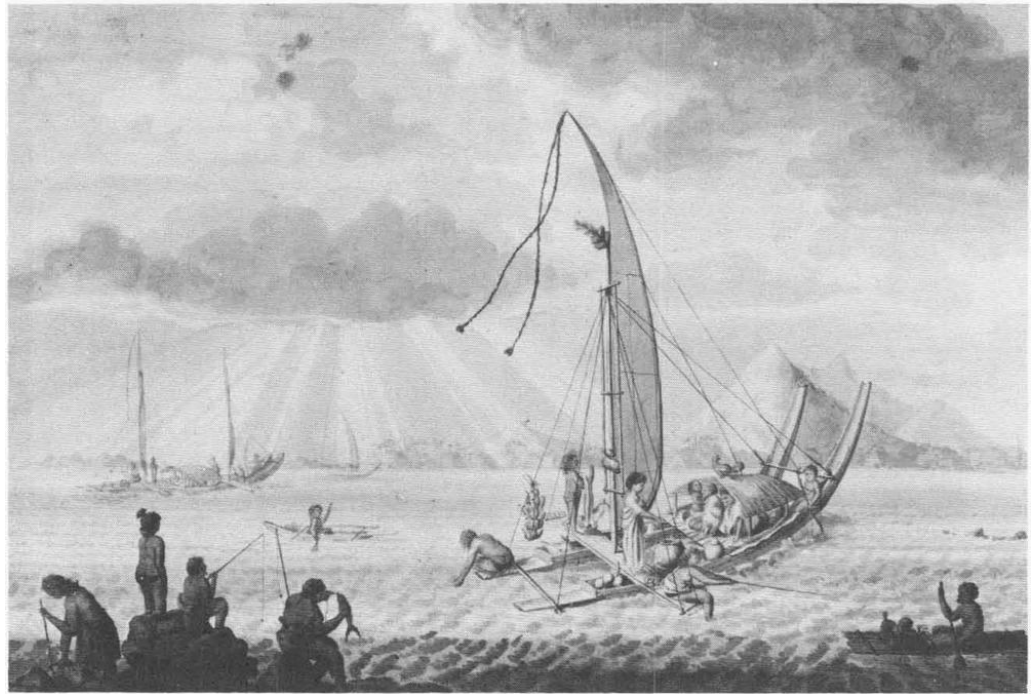

FIGURE 8-6. Double canoes and small dug-outs. Drawing by S. Parkinson. British Museum. 


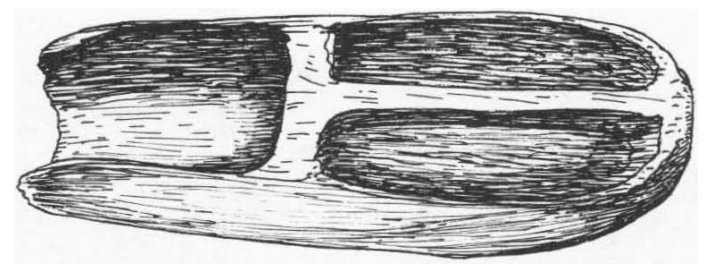

FIGURE 8-7. Wood bailer, length $40 \mathrm{~cm}$. Pitt-Rivers Museum, Oxford.

an overturned outrigger canoe, but if a twin-hulled one ever broke apart at sea there was nothing to do but hold onto one of its parts and drift.

The hulls themselves were not decorated, but upturned bows and sterns were in many cases carved and ornamented, and topped with figures of birds and humanlike beings. Also, long streamers trailed from the tops of some masts; and on special occasions canoes were ornamented in very colorful ways.

The preferred woods for hulls were 'ati, or tamanu (Calophyllum inophyllum), and mara (Nauclea forsteriana). Other more easily worked and often used trees included the breadfruit, tou (Cordia subcordata), mango, coconut palm, hutu (Barringtonia), and purau (Hibiscus tiliaceus). All these trees, be it noted, flourished in zones on or near the coasts, although the flawless great hardwoods preferred for the hulls of the largest boats were in time to be found only in more remote inland areas, in rain forests and on the lower slopes. When the latter were felled the timbers were trimmed and roughed out before they were dragged to places near the shore where they were customarily finished.

The boards of the hull were fitted edge-to-edge and then sewn together with sennit passed through holes drilled near the edges. ${ }^{3}$ Joints and holes were caulked with coconut-husk fiber and breadfruit-gum pitch; these had to be frequently renewed and, even so, did not render the vessels entirely watertight.

Fire was sometimes resorted to for hollowing out boat hulls, but most dubbing and thinning was accomplished with stone adzes of various sizes. Planks were obtained by splitting straight-grained timbers by means of heat and wedges. Chiseling, gouging, and drilling were done with bone tools; finishing, with coral rock and sand. No guidelines were used in boat construction save the practiced eye of the builder: "They have no rule for Building but the Eye, and have no Idea of working by a line; yet nevertheless some of them are built with as much exactness, as if they had been pland by able builders and according to the oppinion of some good Workmen they are well finishd" (Morrison 1935:205).

There is no recorded evidence concerning the number of man-hours required in the construction of Maohi boats and no reliable method for estimating such time. Nowadays it takes about forty hours for an expert 
to hollow out and finish a sixteen-foot hull, but the job is done with metal tools, which are of course more efficient in use and require far less frequent sharpening. A large va'a hull must have required many more man-hours, and a pahi still more-even without the additional time which had to be devoted to the ritual practices accompanying the construction of such boats.

Woods used for other parts of the boats-masts, outrigger attachments and floats, decking, paddles, bailers, et cetera-were easily obtainable, mainly from the coastal belt. Sennit and hibiscus bark were used for lines and lashings, and sails consisted of pandanus matting.

The smaller dugouts ( $p u h^{\prime} e$ ) were made and used throughout the archipelago, but, for reasons not entirely clear, the more seaworthy boats, the pahi, were constructed mainly in the Leeward Islands, particularly on Ra'iatea. Handy argued that this was due in part to the unavailability there of trees large enough for $v a^{\prime} a$ hulls and in part to the superior boat building skills of the Leeward Islanders. ${ }^{4}$ The second point seems valid enough, but the first is questionable in view of Ra'iatea's extensive forests.

According to Ellis:

Most of the natives can hollow out a buhoe [pu ho'e], but it is only those who have been regularly trained to the work, that can build a large canoe, and in this there is a considerable division of labour,-some laying down the keel and building the hull, some making and fixing the sails, and others fastening the outriggers, or adding the ornaments. The principal chiefs usually kept canoe-builders attached to their establishments, but the inferior chiefs generally hired workmen, paying them a given number of pigs, or fathoms of cloth, for a canoe, and finding them in provision while they are employed. (1829:I, 175; see also Morrison 1935:165)

It is not clear whether Ellis was writing about conditions obtaining during his visit (1818-1824) or about the pre-European era, but in any case his remarks about specialization would apply even more pointedly and restrictedly to the earlier era, before iron tools had simplified the craft of boatbuilding.

Another point of uncertainty about Ellis' statement is his references to the division of labor: that is, was there an institutionalized division of specialization among the expert boatbuilders into hull makers, outrigger attachers, and so forth, or were actual work assignments made on an ad hoc basis, with all workers more or less competent in all branches of the craft?

Specialist boatbuilders were called tahu'a tarai va'a (or pahi). Handy described such craftsmen in these words: "The canoe-building craft in the old days was in the hands of a class of highly respected and well-todo professional builders-who constituted a sort of guild having its own regulations, rites, and places of worship. The chiefs had tahu'a attached to their establishments, and there were other artizans who worked for hire." (1932:59.) This statement deserves closer attention, because of its direct relevance to our concern with social relations. 
In the first place, there is no evidence to indicate where a line might be drawn between Everyman's boatbuilding capability and the tahua's skill, or what proportion of the population was recognized as so skilled. Just as crucial, no records that I am aware of provide estimates of the time such specialists devoted to boatbuilding in comparison with time devoted to other kinds of productive work. That such craftsmen were "highly respected" may well have been true-at least, there is no evidence that they were not-but precisely which level they occupied in the hierarchy of "respected" professions we are not informed. Neither Handy nor any other writer provides evidence concerning the relative affluence of boatbuilders.

The question of boatbuilders "guilds" is also relevant. According to Henry there were special "canoe builders' marae" (1928:146), and it may well have been that the expert boatbuilders of various tribal districts had their cooperative work relationships so institutionalized, but nothing is recorded concerning the organization of any such groups, nor is there any evidence to indicate that such ties extended beyond a district's boundaries.

Morrison's account of the procedures followed by an individual in commissioning carpenters to build a boat (or a house) for his private uses was quoted above; the carpenters' services, commissioned by means of a verbal contract which involved coercive sanctions for nonfulfillment, were exchanged for such items as pigs, mats, bark cloth, and oil. We are also indebted to Morrison for a condensed account of the organization, work procedures, and religious ritual attending the construction of a large "official" boat.

The War Canoes (and those Made presents to the Deity which are occasionally Used for that purpose, and are in fact built for it only by the Contrivance of the Priests who are in the intrest of the King and tells the other Chiefs that the Deity wants Such a Number of Canoes of Such a Size \& they set about building them Immediately) are Built by levying Contributions and are done thus-Each Chief who has one to build Calls the Towhas \& Ratirras together to a Feast and informs them of the Request of the Deity and desires them to Collect Hogs, Cloth, Oil \&ca. to pay the Carpenters, to which they readily agree and the Carpenters are Employd who go into the Mountains and Mark their Trees, the Ratirra on whose land the Trees happen to be sends hands to assist in Cutting them down, and hewing out the peices in the rough according to the Carpenters directions, that it may be the easier brought down, as they form each part out of a Solid Tree, and often at some Miles distance in the Hills.

When they have Sufficient Collected to Make a beginning they fix a day to fetch them down and a house is erected to build the Canoe in. When the timber is brought down a Feast is made and an Offering of a Hog to the Deity to prosper the Work, a Feast is also made for the Workmen. At evry Piece they make Fast and when the Bottom is Compleated a Grand Feast and Offering is Made, which is repeated at the Finishing of evry Streak till the Whole is Compleat, when a greater Feast is Made, and the Canoes being Dressd with Cloth, Breast plates, Red and Black Feathers, Fine Matting \&c.--they are Brought to the Grand Morai, and a Man is killd and put on board and Offered as a Sacrafice, when the Ca- 
noes are hauld up near the Morai where she is Covered with Thatch till Wanted, the Priests securing the Feathers for the Deity and the other Decorations for the King, to whom they are presented in Form, as before, the Eye of each Sacrafice being presented before him and the Body interd in the Morai. The War Canoes are Offered in like Manner but Hogs serve instead of Men. (1935:205-206) ${ }^{5}$

The organization and economics of this boatbuilding project resembled other "public works" enterprises in that it was financed by means of a general levy of objects and services, while the carpenters themselves, that is, the individuals who devoted more skill and effort to the project than anyone else, appear to have received extra compensation for their extra work (Henry 1928:481). Another noteworthy aspect of this particular kind of project is the collusive religious support provided by priests on behalf of their rulers' social and political objectives.

As far as one can infer from eyewitness reports, all specialist boatbuilders were male, and presumably only males had any direct hand in the construction of boats intended for service to gods. On the other hand, women were observed assisting in the building of some small, ordinary-purpose boats, at least to the extent of helping a male in lacing together the boards with sennit. (Handy 1932:50; Montgomery 1832:I, 53-54)

The elaborate religious ritual involved in the building and launching of large, publicly important boats is described in detail in the following excerpts:

In the evening of the last night of the moon, a canoe builder of either of the two classes would take his axe and place it for the night in a recess of the marae, an act called ha'amoe ra'a to'i (putting the hatchet to sleep), at the same time invoking the presiding gods, Tane, Ta'ere, Te-fatu, and Ta'aroa, in chanting the following song:

A ti'i a naonao i te to'i,

I te rua to'i i Havai'i;

E naoa, e iritia uruuru hia,

E pepee hia, ia hoa hia

I te ha'a tua mea.

I fa'aina hia i te one mata huahua;

I tavai hia i te one mata ri'i;

I tapiri hia i te miro moa ma fau tu,

E faua i te aha mata tini a Tane.

E raa te to'i

I te aha mata ioio a te tahua,

E u e mau

Ei maro no te to'i,

Ei fafau no te to'i,

Te tua no te to'i,

Ei 'o'iri no te to'i;

Ei mama no te to'i,

Ei taputapu no te to'i,

Ei tuitui no te to'i,

Ei fa'aoti no te to'i,

Ei ta mana no te to'i.
Go and take hold of the axe,

In the aperture in Havai'i;

Hold, that it be taken out enchanted,

Made light; that it may produce sparks

In doing varied work.

It is whetted with fine sand;

Made smooth with loose-grained sand;

It is set in a firm handle of sacred miro,

United with many-stranded sennit of Tane.

The axe will become sacred

In the brilliant sennit of the artisan,

Which touches and holds

As a girdle for the axe,

For the handle of the axe,

The back of the axe,

To make one the axe and the handle,

To make light the axe,

To consecrate the axe,

To impel the axe,

To complete the axe,

To give power to the axe. 
Upon the marae ground, they prepared a feast called the 'aira'a tahua ohipa (artisans' feast), which was sacred to themselves. They killed a fatted pig, and as they wet it with water and steamed it over the fire to loosen the scarfskin, they took off handfuls of the hair and placed them on one side for Tane, saying: "Ei mata ora te ha'a, ei to'i horo" (Work with wakeful eyes, and with expeditious axes), which was the motto for all who worked for the god Tane. When the pig was cooked, they cut off the tail, which they took with the hair they had saved to their shrine and dedicated them specially to the god Tane, while they presented 'ura feathers to all the gods of the marae collectively.

They then partook of their feast, and feeling strong from it, retired to rest until the early dawn of day, when each man took his respective axe to awaken it in the sea with the following invocation:
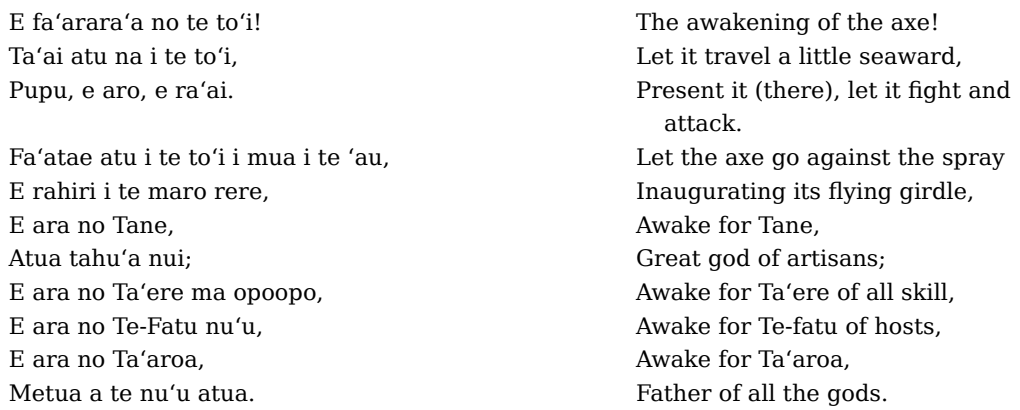

After this ceremony, before the sun had risen, the artisans put on their working maro (loin-girdles) and went, axe in hand, to cut and trim off suitable wood for their canoe, which they brought to their shed to make. They labored assiduously throughout the work, closely observing every sign of an omen. (Henry 1928:146-147)

When the canoe or ship was finished, great importance was placed in the setting of the rollers over which it was to be drawn into the sea, the builders chanting in the following manner as they set them:

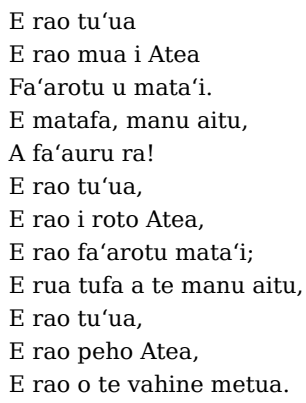

Nau te tu'i, e tu'i no te aha?

E tu'i mai mua.

Ei mahu no te aha?

E uru hia e Tane;

E Tane, a fa'auru ra!

E rao tu'ua na Ro'o te ro'oro'o.

E rao na Ta'aroa-Metua,
A roller is laid

A front roller for Atea

To cause commotion against the wind.

Far-seeing god bird,

Now enchant it!

A roller is laid,

An inner roller for Atea,

A roller to contend with the wind;

Twice served is the god bird.

A roller is laid,

A roller for the valley of Atea,

A roller for the motherly woman [Hina].

Mine it is to strike, to strike what?

To strike before.

To make spray for what?

For the enchantment of Tane;

O Tane, now enchant it!

A roller is placed for Ro'o the famous.

A roller for Father Ta'aroa, 
E rao na Te-Fatu nu'u,

E rao na Ta'ere ma opoopo,

E rao na Toa-hiti mata nui;

E Tane fa'auru ra!

Tu'ua te rao muri

Te rao na Tu pa nui

I fa'atu i te ra'i;

E Tane, fa'auru ra;

Toro ra, fa'auru,

E Tane aitu!

Nau te tu'i, e tu'i no te aha?

E tu'i no te taruarua nui,

$\mathrm{Na}$ Tane te 'opiri napenapea,

E tu'i mai roto,

E tu'i mai muri,

E tu'i tana aha mua.

E Tane e, fa'auru ra

Tane turu rao,

Fa'auru ra!
A roller for Te-fatu of hosts,

A roller for Ta'ere of all skill,

A roller for Toa-hiti (Bordering-rock)

of great eyes;

O Tane, now enchant them!

The hindermost roller is laid,

The roller for Tû, the great father

Who made stable the sky;

O Tane, now enchant it;

Now extend enchantment,

O god Tane!

Mine it is to strike, to strike what?

To strike the great rolling waves,

Tane will quickly turn them,

When they strike the midships,

When they strike behind,

When they strike his sennit in the bows.

O Tane, now enchant,

Tane, supporter of the rollers,

Now enchant them!

As they continued to place the rollers and until they reached the border of the shore, the artisans repeated this song, the burden of it implying that the canoe would be enchanted by the rollers. The day before launching, the canoe was drawn out of the shed onto the rollers and there propped up and rigged and decorated with pennants and garlands; and close by it the builders gave a feast at which great hogs were baked whole. They invited as guests men of the same profession as themselves, to whom they made liberal presents of baked pigs and cloth to take home. In the evenings, the hatchets were again "put to sleep" in the marae for the night. A piece of sennit about a foot long was taken and passed under the foremost end of the outrigger of the canoe and laid down to sleep also; it was placed flat upon the marae ground beneath a flagstone to obtain an augury from the gods. Early in the morning, the axe was "awakened" as before, and the flagstone was carefully lifted off the piece of sennit, which the artisans examined with great interest. If it was quite straight it indicated that the canoe had fine prospects before it, if tortuous, the canoe would be beset with dangers, but escape safely, and if the sennit had become twisted or turned over, the canoe would be in danger of being lost at sea. Then to ensure safety for the canoe at all hazards, a piece of the hull of an old marae canoe was "put to sleep" in the marae, there to remain untouched as long as the canoe lasted.

Soon the people assembled to see the launching and baptism of the canoe, which was performed with great solemnity, superintended by their sovereign, or the representative (always a man), who laid his hand upon one side of the canoe, saying: "A to! A to! A to!" (Draw! Draw! Draw!) Then it was launched into the sea gracefully, with little labor, amid the admiration and loud applause of the spectators, which was called umere. After this it was immersed, bows first and up again, which was called fa'ainuraa i te va'a (making the canoe drink), as the chief artisan said:

\footnotetext{
Fano ta'u va'a nei,

I te 'are miti fati,

Ei na raro mai,

Ei na ni'a 'tu ta'u va'a,

E Tane aitû e!

Fano ta'u va'a nei,
}

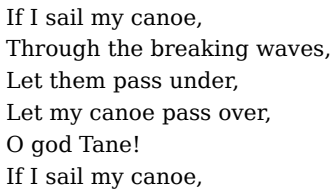


Na te tai vave‘a,

Ei na raro mai,

Ei na ni'a 'tu ta'u va'a,

E Tane aitu e!
Through the towering waves,

Let them pass under,

Let my canoe pass over,

O god Tane!

And so the artisan continued, improvising his words to suit the occasion, until the baptism was finished. The ahi-tu were also called te-varu (scrapers) because they did much scraping in polishing their work to a superfine degree. Their marae and working shed were consecrated entirely to the building of sacred canoes, which were those made for the national marae and for war. During the period of their work, their persons being regarded as sacred to the gods, they were fed on the fat of the land, and restrictions upon food were disregarded with impunity by those who required it in preparing their meals.

After a war canoe was launched, the ahi-tû and priests inaugurated it by paddling about the harbor, chanting prayers, finally ending by suspending their paddles in the passage abreast of the harbor. While the high priest broke open an opa' $a$ (matured coconut) and carefully sank the two halves in the sea with the hollow side turned upwards. If they went down steadily, maintaining their position, it indicated that the land would be prosperous under long peace. If one-half turned over in going down, it foretold war in the indefinite future. If both halves turned over, imminent war was anticipated. Then they returned to the shore and drew the canoe up on to the place allotted to war canoes, apart from all others. (Henry 1928:180-182)

\section{According to Ellis every boat, of any size, was given a distinct name}

[which was] ... always arbitrary, but frequently descriptive of some real or imaginary excellence in the canoe, or in memory of some event connected with it. Neither the names of any of their gods, or chiefs, were ever given to their vessels; such an act, instead of being considered an honour, would have been deemed the greatest insult that could have been offered. The names of canoes, in some instances, appear to have been perpetuated, as the king's state canoe was always called Anuanua, or the rainbow. (Ellis 1829:I, 169-170)

No evidence known to me can provide reliable estimates concerning the useful life of Maohi boats, although efforts were undoubtedly made to insure longevity: through choice of durable woods; through constant repair, periodic overhaul, and protection against undue sun drying (Beaglehole 1962:I, 368); and, of course, through seeking supernatural aid. Ordinary wear and tear of everyday use probably accounted for most deterioration, but in times of war an enemy's boats (along with his houses) were favorite targets of destruction.

There is no reliable method for estimating with any precision the number of boats in commission during the eras under study. It would probably be safe to conclude that nearly every household possessed at least one seaworthy $p u$ ho'e during periods of social tranquility, but the numbers of larger craft must have varied greatly from time to time, according to political events. The threat of war undoubtedly brought about an increase in construction, and war itself resulted in much destruction. Attention has been drawn to the immense fleet of fighting boats and smaller supply vessels seen 
by Cook on the eve of a planned attack by some Tahitians against Mo'orea: 160 large war canoes and 170 smaller supporting vessels on one occasion. But, as I noted in my discussion of this fleet, we cannot be certain what proportion of the total number of such boats was on hand-perhaps nearly all. Although boats built specifically for travel are said to have differed somewhat in construction from those designed for naval warfare (Morrison 1935:202), I believe it is safe to assume that the invasion fleet seen by Cook would have included nearly all seagoing vessels available, including "traveling" boats adapted to fighting or supply purposes for this occasion.

In any case, boating and boatbuilding soon declined from their peaks of that period and probably never again reached such levels. Morrison had this to say about the fighting boats available to one of the principal chiefs of Tahiti in 1788 to 1791:

Their Chief Strength consisted formerly in their Naval force, which at present is but triffling, their Navy being put on a very indifferent footing, oToo [the "king"] thinking it better to keep peace then make war. At present his whole Naval force does not exceed 20 sail of War Canoes \& for the most part of these he is beholden to his Sister Areepaeoa Waheine who brought them from Ryeataya-but he stands in no need at present of large Canoes as Morea [Mo'orea] is now under him, Mottooarro having adopted His Son to be Heir to Morea. (1935:171)

And Wilson, writing about the period 1797 to 1798, declared that there were only five large war canoes at Tahiti (1799:376). However, he did not explain how he arrived at this figure, and his statement did not pertain to travel canoes, which were probably far more numerous.

Turning now to the actual distribution of Maohi boats, individual and regional, I have already recorded my own opinion that, except for periods of social upheaval, nearly every household had its own pu ho'e; on the other hand the distribution of larger boats was probably quite uneven, in view of the resources required to build and maintain them and of the uses made of them. Precise inventories are of course not available but passages such as the following one from Ellis provide a general picture of the situation:

The most general and useful kind of canoe is the tipairua, or common double canoe, usually from twenty to thirty feet long, strong and capacious, with a projection from the stem, and a low shield-shaped stern. These are very valuable, and usually form the mode of conveyance for every chief of respectability or influence, in the island. They are also used to transport provisions, or other goods, from one place to another. (1829:I, 170)

Unfortunately we are left in the dark regarding the hierarchical positions or the relative numbers of Ellis' "chiefs of respectability or influence," but it seems clear from his statement that possession of a tipaerua was essential to such individuals for the purpose both of conducting their practical affairs and asserting their dignity. With respect to the former, while chiefly status was not, ideally, an outgrowth of commercial activity, a chief's ability 
to transport goods and people undoubtedly affected his status, particularly when it came to warfare. In the second sense, Ellis added the following: "The rank or dignity of a chief was supposed, in some degree, to be indicated by the size of his canoe, the carving and ornaments with which it was embellished, and the number of his rowers." (1829:I, 167) Confirmation of this generalization is provided by numerous passages in the earlier writings, giving eyewitness reports of stately processions in boats, whose large dimensions and elaborate decorations must have served mainly to show off their owners' titular rank, affluence, or political authority.

There were, then, individual differences in the kinds and numbers of boats owned, and these differences served both to influence and to symbolize individual differences in social status. But what about regional differences in boat ownership?

Mention was made above of the Ra'iateans' superiority in constructing composite plank-built boats (pahi); it is quite probable that there were more of these boats in Ra'iatea too. Whether this was due more to regional differences in technological tradition and skill or to local differences in availability of suitable woods is not altogether clear. It is evident that the huge trees required in the construction of large $v a^{\prime} a$-type boats were found in greater abundance on Tahiti than elsewhere and that less forested islands, such as Porapora and Mai'ao, were considerably handicapped in this regard. This circumstance does not, however, appear to have discouraged the Poraporans, particularly, from active seafaring; indeed it may have supplied a powerful motive for their forays against other islands.

\section{BOAT TRAVEL}

Performance quality of Maohi boats has been a subject of much discussion. The small pu ho'e appear to have been wonderfully adapted to movement in relatively quiet waters and easily righted after swamping or capsizing. Without question, nearly every Maohi male past early childhood, and probably many females as well, handled these tricky but versatile little craft with finesse. The paddling qualities, and the quality of paddling, of the larger boats were also admired by European observers, most of whom, it should be recalled, were themselves seasoned mariners. Also, the high sterns of some of the larger boats were well adapted to heavy seas. For example, Cook described them as "... the best calculated for landing in a Surf of any Vessels I ever saw, their high round sterns recives the force of the Sea in Such a manner that none ever enters the Vessel" (Beaglehole 1961:408). It was the performance of Maohi boats under sail that led many competent observers to less enthusiastic evaluations:

In fine weather, and with a fair wind, they are tolerably safe and comfortable; but when the weather is rough, and the wind contrary, they are miserable sea-boats, and are tossed about completely at the mercy of the winds. Many of the natives 
that have set out on voyages from one island to another have been carried from the group altogether, and have either perished at sea, or drifted to some distant island. (Ellis 1829:I, 176)

Under sail, boats with outriggers were probably somewhat faster and more maneuverable than those with twin hulls, and they were more easily righted after capsizing:

They have No Method of reducing their Sails but by Casting off the lower part and rolling it up and should that not answer, as it frequently will not, they must take their Chance and as they Cannot reduce the sail at Head but by Casting it off entirely, for which purpose a man must go to the Mast head, and it would be next to impossible to get them up again from the quick Motion of the Canoe, for which reason they let them stand at all events and had rather Overset, or loose the Mast, then Strike the Sail, and in Squally weather both these Accidents often happen, but they are so accustomed to them that they think nothing of either, tho by being dismasted they are frequently blown off and heard of no more-When they are taken in a Squall they luff Head to it and shake it out, but should the squall Continue too long \& the Vessel is like to fall off they all hands Jump overboard \& hang her head to windward till the Squall is over, when they get in \& steer their Course, but should they not be able to hold her on and she gets overset their First Care is to secure evry thing, and Make their Fish Cloth, Paddles \&c. fast and when the squall is past they tow the Canoe round with the Mast head to Windward and making a line fast to the upper part of the Spreet all hands get on the Out rigger, and hauling the head of the Spreet out of the Water and the Wind getting under the Sail lifts it, when they all swing off with their whole weight together [and] right her. Some hands then keep her head to windward till the others free her of the Water and then get in and proceed on their Voyage-this frequently happens on their return from Fishing, when they endeavour to out carry each other till they are overpowerd by the Wind \& get overset-of this they think the danger so little that they never require any Assistance except to take in their Cloth, or such things as may receive damage by being long wet, but they frequently loose so much ground as to be forced to run for Morea and somtimes for Hooaheine and Ryeatea and We have known some of them who being dismasted have been 9, 12 and 15 days at sea with scarce a Mouthful of Provisions and No Water, as they seldom Carry more then a Few Cocoanuts and a bread fruit or two Sufficient to Serve as long as they intend to Stay out, and trust to providence for a Fish-(Morrison 1935:204-205)

In comparison, double-hulled boats were steadier in the water and could carry relatively more passengers and cargo.

Both types sailed fast and steady before the wind. ${ }^{6}$ As just noted the outriggered boat was subject to capsizing, and the double-hulled one to excessive drag and dangerous-sometimes fatal-structural strain. Two passages by eyewitnesses will provide some flavor of the hazards of Maohi sailing:

An instance of this kind occurred a few years ago, when a number of chiefs and people, all together thirty two, were passing from one island to another, in a large double canoe. They were overtaken by a severe tempest, the violence of which tore their canoes asunder, and separated them from the hor- 
izontal spars by which they were united. It was in vain for them to endeavour to place them upright, or empty out the water, for they could not keep them in an erect position, nor prevent their incessant overturning. As their only resource, they collected the scattered spars and boards, and constructed a raft, on which they hoped they might drift to land. The weight of the whole number, who were now collected on the raft, was so great as to sink it so far below the surface, that they sometimes stood above their knees in water. They made very little progress, and soon became exhausted by fatigue and hunger. In this condition they were attacked by a number of sharks. Destitute of a knife, or any other weapon of defence, they fell an easy prey to these rapacious monsters. One after another was seized and devoured, or carried away by them; and the survivors, who with dreadful anguish beheld their companions thus destroyed, saw the number of assailants apparently increasing, as each body was carried away, until only two or three remained. The raft, thus lightened of its load, rose to the surface of the water, and placed them beyond the reach of the voracious jaws of their relentless destroyers. The voyage on which they had set out, was only from one of the Society Islands to another, consequently they were not very far from land. The tide and the current now carried them to the shore, where they landed, to tell the meloncholy fate of their fellow-voyagers. (Ellis 1829:I, 177-178)

Several Cannoes and Men and Women have been lost since we have been here in their excursions to Tetturaoh [Tetiaroa]. Their being overset in their Cannoes is not the least risk they have to run, as the Sharks frequently make a meal of them, and indeed were I to credit the accounts they are much more plenty than on the Coast of Africa. I am told likewise there are a kind of Sword fish that as they vault along on the Water the(y) peirce many people through the Body and kill them. They speak also of a kind of Fish like Bavia coota [barracuda] and attribute to them the same propensity, that of seizing the privacies of Men, as they are said to have in the West Indies. (Bligh 1789:II, 44)

Despite their weaknesses of design and construction, and their lack of deep keels, Maohi boats were believed to have been able to sail within sixty to eighty degrees of the direction of the wind, which, as one modern expert has pointed out, compares not unfavorably with America's famous clipper ships (Bechtol 1962).

Every large boat had paddlers, one or more steersmen and bailers, and a captain (who might also serve as steersman) overall. When sailing a large boat with outrigger, one or two men were usually assigned the task of moving along the balancing spar to maintain an even keel. Morrison reported that some canoes occasionally employed more than a hundred paddlers and up to six bailers. J. Forster reported having seen one double war canoe, "which required 144 paddles, and eight or ten steersmen to move it forward" (1778:457). The records are silent on this point, but it seems reasonable to assume that the jobs of paddling, steering, balancing, bailing, and sail handling were assigned according to strength and skill; demonstrated skill was probably required of boat captains as well, but factors of titular rank or political authority may also have figured in assignment of this job.

The method of paddling Maohi boats, which was described by Ellis 
for the period 1816 through 1822, probably did not differ markedly from the way it had been conducted fifty years previously:

The rowers appeared to labour hard. Their paddles, being made of the tough wood of the hibiscus, were not heavy; yet, having no pins in the sides of the canoe, against which the handles of the paddles could bear, but leaning the whole body over the canoe, first on one side, and then on the other, and working the paddle with one hand near the blade, and the other at the upper end of the handle, and shovelling as it were the water, appeared a great waste of strength. They often, however, paddle for a time with remarkable swiftness, keeping time with the greatest regularity. The steersman stands or sits in the stern, with a large paddle; the rowers sit in each canoe two or three feet apart, the leader sits next, the steersman gives the signal to start, by striking his paddle violently against the side of the canoe, every paddle is then put in and taken out of the water with every stroke at the same moment; and after they have thus continued on one side for five or six minutes, the leader strikes his paddle, and the rowers instantly and simultaneously turn to the other side, and thus alternately working on each side of the canoe, they go along at a considerable rate. There is generally a good deal of striking the paddle when a chief leaves or approaches the shore, and the effect pretty much resembles that of the smacking of the whip, or sounding of the horn, at the starting or arrival of a coach. (1829:I, 166)

From this it may be surmised that the propulsion of a large war canoe with its hundred and more paddlers represented a noteworthy example of precisely coordinated effort, containing important implications for one's understanding of Maohi social relations and social control. Even more impressive in this connection was the conduct of fleet maneuvers observed by Cook on the occasion of the naval assembly noted in chapter 2:

... we saw a Number of War Canoes coming round the point of Oparre [Pare], being desirous to have a nearer view of them I hastned down to Oparre (accompanied by some of the officers \&ca) which we reached before the Canoes were all landed and had an opportunity to see in what manner they approached the shore which was in divisions consisting of three or four or more [boats] lashed close a long side each other, such a division one would think must be very unwieldy, yet it was a pleasure to see how well they were conducted, they Paddled in for the Shore with all their might conducted in so judicious a manner that they closed the line a Shore to an inch.... (Beaglehole 1961:401)

The rowers were incouraged to exert their strength by their leaders on the stages, and directed by a man who stood with a wand in his hand in the fore part of the middlemost Vessel, this man by words and actions directed the paddlers when all should paddle when either the one side or the other should cease \&ca for the steering paddles alone were not sufficient to direct them: all these motions they observed with such quickness as clearly shewed that they were expert in their business. (401n)

In connection with travel by boat, mention should be made of the portage track across the narrowest part of the Isthmus of Taravao, where the main mass of Tahiti is joined to its southern peninsula. Canoes traveling between the island's southwestern and eastern coasts were regularly trans- 
ported across the isthmus to save time and effort, and particularly to avoid the hazardous passage around the peninsula's southernmost point, Te Pari, where the Pacific swells crash directly against the steep cliffs and rocky shores.

At day break we got up and while the boat was getting ready, I took a walk into the Country which I found here to be a low neck of land with a chain of morasses over which they track their canoes across the (Island) which may be about 2 Miles or more (Beaglehole 1955:107).

Clues to the length of the track and to the method and organization of portage are to be found in a statement from Rodriguez:

The arii of the district of Afaaiti, who was near there with a lot of his people, came to haul the canoe across by land\& and in a short time they launched her from the beach (at the opposite side of the isthmus), more than thirty men having lent a hand in the job. On my wishing to reward them with some glass beads for ear-drops, they would not accept them; but said they had done no more than their duty. (Corney 1919: 113)

After another such portage Rodriguez described the porters as having shown "... great zeal over the manoeuvre," and having been "highly pleased" and "happy" to carry it out (Corney 1919:124).

... we soon reached the place where canoes are hauled overland for a little more than half a league from the one side of the island to the other in order to shorten the journey, which is where the people were to be called up to transport ours. I landed, together with the henchman whom Vehiatua had given me for this purpose, and on notifying the head men of the locality they cheerfully complied, and collected all their people, so that by the time the sun was setting we were already on the opposite coast.... (Corney 1919:127)

They make use of skids for this job, both that the canoes may run the more easily and to save them from damage, although the track is a good one. (Corney 1919:54)

Wilson stated that canoes were hauled across the isthmus "... on rollers and by ropes." (1799:316)

It appears from these excerpts that local natives, particularly the residents of the district of Afa'ahiti, were somehow obligated to assist with the portage without direct compensation-at least if the canoe were engaged on a trip sanctioned by the peninsula's paramount chief (in this case, Vehiatua). How other travelers may have fared can only be surmised; presumably they either carried their canoes themselves or compensated the local porters in some way.

Comparative research has established beyond any reasonable doubt that the Maohis of the Society Islands bore very close biological and cultural resemblances to populations as far flung as those of Hawaii and New Zealand; it is even supposed by some scholars that two-way communication, infrequent perhaps but nonetheless deliberate, was kept up between the 
Maohis and those distant cousins of theirs long after dispersion from common homelands. ${ }^{7}$ It is also confidently claimed by some writers-and just as positively disputed, in whole or in part, by others-that individual Maohis known to Cook and other early European visitors were aware of the existence and the general location of such distant places as the Marquesas, Samoa, Tonga, Fiji, and Tubuai. ${ }^{8}$

Upon close examination, much of the allegedly pre-European knowledge may be found to be based on inaccurate etymologizing or false identification on the part of Europeans; Polynesians, like the rest of mankind, tended to carry along and perpetuate some of their stock place names wherever they colonized. Also, some of the places thus listed were doubtlessly added to their store of information as a result of early post-European accretions: for example, a lengthy list of "Islands known to the Tahitians," collected by the Spaniards in 1775, was recorded some months after the return home of a Maohi taken by Cook on one leg of the voyage of the Resolution. But even granting that the Maohis possessed a fairly extensive knowledge of the existence and general direction of islands many hundreds of miles away, ${ }^{9}$ such knowledge need not have been acquired by means of deliberate voyages to these islands and back, for, as Cook (or Anderson) came to recognize, much of it could and did derive, directly or indirectly, from natives of those islands more or less accidentally cast up on the Society Islands or on intervening islands:

The knowledge they have of other distant islands [i.e., other than the western Tuamotus] is, no doubt, traditional; and has been communicated to them by the natives of those islands, driven accidentally upon their coasts, who, besides giving them the names, could easily inform them of the direction in which the places lie from whence they came, and of the number of days they had been upon the sea.... We may thus account for that extensive knowledge attributed ... to Tupia [Tupaea, see note 8 , above], in such matters. And, with all due deference to his veracity, I presume that it was, by the same means of information, that he was able to direct the ship to Oheteroa [Rurutu], without having ever been there himself, as he pretended; which, on many accounts, is very improbable. (Cook 1784:177-178) ${ }^{10}$

Be that as it may, by Cook's time the Maohis themselves were engaged in more or less deliberate voyaging only within their own archipelago or to the nearest of the nearby Tuamotus-that is, over open-sea distances of no more than 280 to $330 \mathrm{~km}$. Within these limits deliberate travel between Tahiti and Mo'orea, between Maupiti, Porapora and Motu Iti, between Ra'iatea and Tana'a, and between Huahine and Mai'ao was commonplace and year round, weather permitting. Banks' strictures on the possibilities of very long overseas voyages would not, of course, apply to any of these relatively short trips: "They cannot however remain at sea above a fortnight or 20 days tho they live as sparingly as possible, for want of proper provisions 
and places to put them in safe, as well as water of which however they carry a tolerable stock in hollow Bamboes" (Beaglehole 1962:I, 366).

The other standard tracks, more or less frequently traveled were as follows:

Between Tahiti and Tetiaroa. The ten islands comprising Tetiaroa Atoll are located about $50 \mathrm{~km}$ north of Tahiti's northwestern point.

They are all low and for the Most part Covered with Cocoa nut trees which is all they Produce; they are the Property of o Toos [Tu] Family who keeps the Inhabitants in subjection by keeping them from Planting the Breadfruit or other Trees and suffers nothing to grow there except a few Tarro for His own use under the Charge of one of His favourites-and as these Islands cannot be Approachd by large Canoes He makes them His Magazine for all His riches; a Number of Canoes are kept there for Fishery and Near 40 Sail of small sailing Canoes which they Haul over the reef are kept constantly plying between them \& Taheite; they bring Fish for the Kings houshold, and return loaded with provisions-and besides these the Dolphin Canoes trade there when the Dolphin Fishery is over, Carrying Provisions and Returning With Oil which they Make in large quantitys, a Variety of Fine Fish and a Sauce Made of Ripe Cocoa Nuts Calld Tyeyro [taioro], the Nuts being gathered before they are too old and Grated in the same Manner as for Oil, which being Mixed with Shri(m)ps and left a day or two to ripen becomes like Curds and is excellent sause for Fish, Pork or Fowle. (Morrison 1935:201-202)

In addition, relatives and retainers of the Pare dynasty used to repair to Tetiaroa for "vacations" to rest, amuse, and fatten themselves, and to recover health after heavy bouts of kava drinking.

As indicated, traffic between Tahiti and Tetiaroa was frequent. Bligh, writing in June 1792, stated that fleets of ten to fifteen canoes used to ply the route at intervals of ten to fourteen days (Bligh 1792:163b). Under normal wind conditions this travel presented few difficulties; but, even so, canoes were occasionally lost at sea.

Between Tahiti and Me'etia. Me'etia was under the suzerainty of chiefs of Tahiti's peninsula, and the open-sea distance between these two points - some $110 \mathrm{~km}$-was traveled two or three or more times a year, subject to winds (i.e., the trip to Me'etia having been made during the occasional, and mainly summer, westerlies, and the trip westward having been made with the help of the tradewinds:

The Chief of Tyarrabboo [Taiarapu] keeps one of [his large sailing canoes] constantly plying between Taheite and Myetoo or Myetea, Calld by us Osnaburgh Island, 27 leages S.E. of Taheite, which is Subject to Him, and in her, he sends Iron Work and What European Commoditys he Can raise as presents to the Chiefs, who in return send back Pearls, Pearl Shells, Stools for Seats, Pillows $\&$ Pudding Stools Made of Tommanoo [tamanu: Calophyllum inophyllum], with Dishes \& Trays of the same wood, Matting, Cloth, Oil, Hogs \&c. \&c.-and she seldom returns without a Cargo. (Morrison 1935:201) 
What the Tahiti end of this trade contributed to the exchange before Europeans introduced iron is not specified. Perhaps there was a basic inequality in the exchange, because of Me'etia's political subordination, and hence obligation to render "tribute."

The occasional travel between Tahiti-Mo'orea and the nearest of the Tuamotuan atolls followed three routes: via Me'etia, via Makatea, or direct. Of the first of these connections, Morrison reported the following: "By means of [Me'etia] they have Communication with several others to the N.E. of Taheite and taking advantage of the Northerly Wind reach Myetoo [Me'etia] where they watch Wind shifting to stretch to the Northward to a Group of small Islands, the Capital of which is Calld Tapoohoe [Tapuhoe, or Ana'a] (1935:201). ${ }^{11}$

Most of the pearls and pearl shell reaching Tahiti from Me'etia presumably originated in the Tuamotus. The sources contain several legendary stories of voyages to the Tuamotus by Maohis in search of red feathers, but no authentic account of any such expedition was recorded by European visitors. On the other hand, Cook provided a report, from hearsay, about an expedition of some forty Poraporans who "... incited by curiousity, had roamed as far as Mataeeva [i.e., Matahiva, $250 \mathrm{~km}$ northeast of Porapora] ..." (Cook 1784:176-177). Actually, most of the travel between the Society Islands and the Tuamotus was carried out by the Tuamotuans, in their very seaworthy pahi. Some of this was deliberate voyaging, for trade or for political asylum; but the sources contain several references to the presence of Tuamotuans on Tahiti who drifted there as a result of mishaps at sea. ${ }^{12}$

Between Tahiti-Mo'orea and Huahine-Ra'iatea-Taha'a. Boats covered the 140 to $170 \mathrm{~km}$ of this stretch of open water in two, three, or four days of easy sailing, when the winds were right. People deliberately traveled this route for trade, pleasure, and affairs of kinship and state. There is no record of large-scale military-attack expeditions as such between the two groups of islands, but boatloads of warriors often made the trip to join warring allies. As an example of the close communications between Windwards and Leewards, it is recorded that an official delegation from Ra'iatea arrived at Tahiti to present condolences within nine days of the death of a Tahitian chief (Corney 1919:188).

Less frequently, Maohis visited isolated Mopelia Atoll, some $200 \mathrm{~km}$ west of Maupiti. In the list of islands reported by Don Thomas Gayangos as being known to the Maohis-information said to have been obtained at Tahiti, from "... the most trustworthy Indians of eminence in the Island" -Mopelia (Mopiha) was described, from this hearsay evidence, as follows: 
Of middling size and low, with a reef. Produces coco-nuts and pearls, but is not inhabited. They say there are birds of large size there in great plenty, which do not fly [i.e., boobies and noddies]; and they visit the island to catch them for eating, as they are very fine-flavoured. Canoes from Maurua [Maupiti] take two days to reach it. (Corney 1915:193)

On the other hand, Cook reported that "... it is reckoned a sort of prodigy, that a canoe, once driven by a storm from Otaheite, should have fallen in with Mopeeha [Mopelia], or Howe's Island, though so near, and directly to leeward"-and had managed to return (Cook 1784:177).

\section{NAVIGATION}

It may be noted that such voyages as those described were well within the navigational competence of the Maohis of the era under study-even according to the most unflattering estimates of their abilities in this field. To begin with, it should be recalled that most of the Maohis' common destinations were islands of considerable altitude and hence usually visible (by light from sun, moon, or stars) from long distances at sea. Thus, during clear-weather voyages between Windward and Leeward islands, perhaps only one-third of the distance would have to be covered completely out of sight of land. It has been reported for other archipelagoes in the Pacific that embarking travelers set their initial courses to known destinations by lining up standard landmarks behind them (e.g., see Hilder 1962). There are no specific reports in the sources that the Maohis followed this procedure, but it is reasonable to assume that they did so. In sailing to low islands, if the voyagers had managed to steer within a few miles of them by dead reckoning, they were probably assisted in locating them by such phenomena as the flight of homing birds, the scent of vegetation, and the color of clouds (e.g., the greenish tint of shallow lagoon waters is sometimes reflected against the undersurface of clouds).

It may be assumed that voyagers to nonvisible destinations knew the directions in which they lay-at least, from fixed points of reference. According to Varela the horizon was divided into sixteen parts, based on cardinal points at which the sun rose and set (Corney 1915:284-285). ${ }^{13}$ Of the sixteen allegedly "directional" terms given Varela and recorded by him, only about half are recognizable. J. Forster recorded terms for only the cardinal points (i.e., east, te hiti o te rā [border, extremity of the sun]; west, topa te rā [it falls the sun]; north, to'erau; south, toa) but surmised that there were twelve horizon divisions in all (1778:503). By comparing the so-called directional terms listed by these and other writers with the names for winds recorded in several other sources (e.g., Henry 1928:459; Cook 1784:143), it appears that many terms for directions serve also as terms for winds; but the coincidence is not complete. By comparing all the lists, one with 
another, it is unmistakably clear that some wide divergences exist: for example, to'erau was defined by Varela as "the west," by J. Forster as "the north," by Marau as "northerly wind," and by the LMS Dictionary as "westerly, or northwesterly wind." Some of these discrepancies may be based on differences in ethnographic skill among the observers. But it is also possible, indeed likely, that there were some local variations in the meanings given to some of the terms; one factor behind such differences may have come about through local differences in the wind patterns themselves.

In any event, the Maohis did divide the horizon into several directional or wind-direction sections, which they used-along with other phenomena-for navigational purposes (and possibly other purposes as well).

The most detailed account left us concerning the Maohis' methods of navigation is Andía y Varela's:

When setting out from port the helmsman reckons with the horizon thus partitioned counting from E, or the point where the sun rises; he knows the direction in which his destination bears: he sees, also, whether he has the wind aft, or on one or other beam, or on the quarter, or is close-hauled: he knows, further, whether there is a following sea, a head sea, a beam sea, or if it is on the bow or the quarter. He proceeds out of port with a knowledge of these (conditions), heads his vessel according to his calculation, and aided by the signs the sea and wind afford him, does his best to keep steadily on his course. (Corney 1915:285-286)

So far, so good-at least on the relatively short voyages to prominent destinations, which constituted most Maohi overseas travel. That is to say, the factor of unrecognizable displacement and slippage through current and changes in wind, which rendered instrumentless long distance navigation next to impossible, would not have been so critical on the usual Maohi short trips, although countless vessels must have been lost even in these familiar seas. But to continue with Varela: "This task becomes more difficult if the day be cloudy, because of having no mark to count from for dividing out the horizon." One can only assume that in such a situation no one set out on a long overseas voyage to a difficult destination unless compelled to do so. Even more difficult would have been the attempt to navigate on cloudy nights, but Varela's description of their procedure for doing so raises more questions than it answers:

Should the night be cloudy as well, they regulate their course by the same signs; and, since the wind is apt to vary in direction more than the swell does, they have their pennants, (made) of feathers and palmetto bark, to watch its changes by and trim sail, always taking their cue for a knowledge of the course from the indication the sea affords them.

Finally, Varela had the following to say about astral navigation:

When the night is a clear one they steer by the stars; and this is the easiest navigation for them because, these being many (in number), not only do they note by them the bearings on which the several islands with which they are in touch lie, but 
also the harbours in them, so that they make straight for the entrance by following the rhumb of the particular star that rises or sets over it; and they hit it off with as much precision as the most expert navigator of civilized nation could achieve.

They distinguish the planets from the fixed stars, by their movements; and give them separate names. To the stars they make use of in going from one island to another they attach the name of the island, so that the one which serves for sailing from Otahiti to Oriayatea [Ra'iatea] has those same names, and the same occurs with those that serve them for making the harbours in those islands.

Were this the case of course natives of, say, Mo'orea, Huahine, and Porapora would have applied the name Ra'iatea to different stars. None of the sources specifically recognizes or documents this point.

As critics of the theory of long-distance, deliberate, Polynesian voyaging have pointed out, the problems encountered in astral navigation are considerably more difficult than Varela's terse statement would indicate; but these would not have been so insurmountable in the Maohi case, since most of their long overseas voyages were generally to east or west, and were short enough to require something less than pinpoint navigation.

As often noted throughout this book, many aspects of the Maohis' lives were crucially affected by direction and velocity of wind, and this was especially true of their comings and goings by sea. Their vocabulary contained numerous words for patterns of the sea's surface shaped by the wind. It is no wonder, then, that this population of sailors and fishermen associated winds with spirits, as the following excerpts from Henry indicate:

Winds were potent agents of the gods, murmuring mysteries and warnings to men.

The Mauriuri-pe'e-va'a (Cry-that-detached-canoes [authorities]) was a wind full of the sound of the cricket's cry. That wind was the soul of the land, and when the sound of it was heard, evil was approaching the place, war was soon to rage.

Moe-rehu-turituri-roroa-no-Perete' $i$ (Lost-in-haze-of-distant-distractingsounds-of-the-cricket) was also a great wind of Tû-o-te-to'i-'oi (Stability-of-thesharp-axe). Its cry was deafening in the land, it was the upholder of kingly power. That wind drove away invading armies, who, when they heard it, would decide not to fight and would precipitate themselves into the sea to evade contact with the enemy. The sea and wind had ears to obey the cricket, Tû-o-te-to'i-'oi.

The Tui-hana (Soul-reposing-prayer) wind, from the rocks of Fenua-iti of the leeward islands, was a messenger of the gods; they brought it. It was a soothing wind, and the land was hallowed by it.

The Atoatoa (Contrary-wind), which blows very hard, was brought by the gods at times to destroy the land because of the sins of the people. That wind represented the gods themselves. As it approaches the seashore it resounds; it dashes upon the shore. The sky darkens until the sun cannot penetrate it. This wind has great force, and with it the gods destroyed the land, which could not escape it.

The Moana-roa-no-Tane (Distant-depths-of-Tane [god of beauty]) was a good wind indicating peace. When it was blowing, the sky was deep-blue and cloudless, and canoes sailed without harm to and fro at sea and among the islands.

The Paetahi (One-sided), a wind of the coast, was the wind of Punua-pae-vai (Side-pool-of-the-river-bank). It came from one side only, along the coast. 
The Huatau (North-wind) was from Ta'aroa, the Great-foundation.

The Mara'amu-moana (Trade-wind) came from the gods as a messenger of peace in the land; people dwelt in safety at those times.

The Mara'ai-pupua (Southerly-gale) was 'Oro's; it brought forth war.

The Rapati'a (Westerly-wind), from Vai'otaha, Porapora, was of the god Ra'a (Sacredness), and it produced destruction; it indicated the anger of Sacredness.

The Mata'i-fe'etietie (Cooling-wind), from the south, which caused the fleets to be frequently mended, came from the god Heima (Winter). ${ }^{[14]}$ It was a peaceful wind that came in gusts.

The Fa'arua, or Tumurua (Two-blendings, or Two-sources), joint-workers from the north, a stormy wind in its season, came from Te-fatu-tiri (The-lord-of-thunder). Coming from two directions it meets with heavy clouds producing thunder and breaks down the trees of the shores and the masts of the ships at sea. It prevents people at sea from coming to land, sending them far out of their course.

The To'erau (North-westerly) wind brought rain from the god Tumu-ruperupe (Cause-of-verdure); it was for times of peace.

The Hinu-taia (Smoothed-calmness), a stifled wind, caused excessive calmness; the shoals receded; there were no waves, no breakers upon the reef, and no ripples along the shore. It was ominous of death to the land. (Henry 1928:392-394)

\section{METEOROLOGY}

For sailors and fishermen, livelihood and even survival sometimes depended upon ability to predict the weather, a skill which, some observers such as Banks claimed, the Maohis had in considerable measure:

The people excell much in predicting the weather, a circumstance of great use to them in their short voyages from Island to Island. They have many various ways of doing this but one only that I know of which I never heard of being practisd by Europaeans, that is foretelling the quarter of the heavens from whence the wind shall blow by observing the Milky Way, which is generaly bent in an arch either one way or the other: this arch they conceive as already acted upon by the wind, which is the cause of its curving, and say that if the same curve continues a whole night the wind predicted by it seldom fails to come some time in the next day; and in this as well as their other predictions we found them indeed not infallible but far more clever than Europaeans. (Beaglehole 1962:I, 368)

Banks' high opinion of Maohi weather prediction was not however shared by Cook, who, after describing the more common local changes in wind direction and velocity, wrote, "The natives seem not to have a very accurate knowledge of these changes..." (Cook 1784:143).

\section{TRAVEL RITUAL}

Notwithstanding all their meteorological knowledge and their skills in building, sailing, and navigating their boats, the Maohis took measures to insure that the spirits would help them reach their destinations in safety and speed. These measures were not only against the usual hazards of wind and wave but also against the many malevolent spirits that inhabited the ocean in the form of large sharks, mantas, and the like. 
On setting out on any journey, travelers usually invoked their tutelar spirits to grant them a safe voyage and return, but the rites for an overseas journey were of a particular kind. Most of the following is based on Henry (1928:178-180); in all likelihood the ritual that accompanied so important an activity as overseas voyaging was more elaborate and varied than this version indicates, but Henry is the only source that provides much detail.

Before setting out the travelers and their kinfolk visited their marae and presented to the priest a length of sennit which had first been placed under their canoe's outrigger.

The priest placed it [a piece of sennit] straight and flat beneath a sacred slab, committing those who were about to depart to the care of Tane, god of beauty and fine weather, and also invoking all the sea gods to watch over them and guide the canoe safely away and back again.

This sennit, called 'aha moa (sleeping sennit), was left at the marae until it was time for the voyagers to arrive at their destination. Then those at home went to the priest requesting him to uncover it to see how it lay. If they found it lying quite straight, it was a sign that the canoe had arrived safely before a fine wind. If a little crooked, the canoe had met with contrary winds, yet was still safe. But if the sennit was twisted over, it was a sign that the canoe had upset and probably all those on board were lost. Then there was weeping and great anxiety until they received tidings of their absent ones or saw them again. If the omen proved to be a false alarm, the priest claimed that a lying spirit had deceived them. (Henry 1928:179)

If threatened by dangers at sea-say, by becalming or storm or following sharks-it may be assumed that someone aboard requested spirit aid by means of prayer, red feathers, and even object sacrifice. The spirits thus invoked probably varied with circumstances: sometimes it may have been the voyagers' tutelar deities; at other times the spirits inhabiting that particular area of ocean; and on occasion even Temariotu'u, god of navigation, himself.

Upon reaching their destination the voyagers presented thank-offerings to their kin-group's tutelar spirits, if there happened to be a marae dedicated to such spirits at that place, or if not to the sea gods themselves. The offerings so presented consisted of feather amulets and chunks of coral.

One can turn to myth and legend for further evidence of the important place overseas voyaging occupied in Maohi beliefs and aspirations. I cannot reproduce in this summary description the many long, drawn-out Odysseys of such gods and demigods as Tane, Maui, Hina, Rata, Honoura, and so forth, but I can at least point to them as indicating how deeply intrigued the Maohis were by overseas voyaging. Sea voyaging was undoubtedly a means to other ends for the Maohis, and there is some reason to believe that it was considered by many as an end in itself.

But whatever the motives and the means behind the Maohis' comings and goings by sea, the interactions resulting from that movement knit together all the islands of the archipelago into a single discrete and distinctive society. 


\section{chapter 9 FOOD}

\section{EATING AND COOKING}

There is no better way to introduce the topic of Maohi food than with a description written by Banks, himself a gourmet:

I will describe the manner in which one of their principal people is servd; they commonly eat alone unlesss some stranger makes a second in their mess.

He setts commonly under the shade of the next tree or on the shady side of the house; a large quantity of leaves either of Bread fruit or Banana are neatly spread before him which serves instead of a table cloth, a basket is then set by him which contains his provisions and two cocoa nut shells, one full of fresh water the other of salt. He begins by washing his hands and mouth thoroughly with the fresh water which he repeats almost continualy throughout the whole meal. He then takes part of his provision from the basket. Supose (as it often did) it consisted of 2 or 3 bread fruits 1 or 2 small fish about as big as a perch in England, 14 or 15 ripe bananas or half as many apples: ${ }^{[1]}$ he takes half a breadfruit, peels of the rind and takes out the core with his nails; he then cramms his mouth as full with it as it can possibly hold, and while he chews that unlapps the fish from the leaves in which they remain tied up since they were dressd and breaks one of them into the salt water; the rest as well as the remains of the bread fruit lay before him upon the leaves. He generaly gives a fish or part of one to some one of his dependants, many of whoom set round him, and then takes up a very small peice of that that he has broke into the salt water in the ends of all the fingers of one hand and sucks it into his mouth to get with it as much salt water as possible, every now and then taking a small sup of it either out of the palm of his hand or the cocoa nut shell. In the mean time one of the Standers by has prepard a young cocoa nut by peeling of the outer rind with his teeth (an operation which at first appears very surprizing to Europeans but depends so much upon a sl[e]ight that before we left the Islands many of us were ourselves able to do it, even myself who can scarce crack a nut) which when he chuses to drink he takes from him and boring a hole through the shell with his finger or breaking the nut with a stone drinks or sucks out the water. When he has eat his bread fruit and fish he begins with his plantains, one of which makes no more than a mouthful if they are as big as black puddings; if he has apples a shell is nescessary to peel them, one is pickd of the ground where they are always plenty and tossd to him, with this he scrapes or cutts off the skin rather awkwardly as he wastes almost half the apple in doing it. If he has any tough kind of meat instead of fish he must have a knife, for which purpose a peice of Bamboo is tossd him of which he in a moment makes one by splitting it transversly with his nail, with which he can cut 
tough meat or tendons at least as readily as we can with a common knife. All this time one of his people has been employd with a stone pestle and a block of wood beating breadfruit which by much beating and sprinkling with water he Reduces to the consistence of soft paste; he then takes a vessel made like a butchers tray and in it he lays his paste mixing it with either bananas sour paste or making it up alone according to the taste of his master; to this he adds water pouring it on by degrees and squeezing it often through his hand till it comes to the consistence of thick custard; a large cocoa nut shell full of this he then sets before his master who supps it down as we would do a custard if we had not a spoon to eat it with; and his dinner is then finishd by washing his hands and mouth, cleaning the cocoa nut shells and putting any thing that may be left into the basket again.

It may be thought that I have given rather too large a quantity of provision to my eater when I say he has eat 3 bread fruits each bigger than two fists, 2 or 3 fish and 14 or 15 plantains or Bananas, each if they are large 6 or 7 inches long and 4 or 5 round, and conclude his dinner with about a quart of a food as substantial as the thickest unbaked custard; but this I do affirm that it is but few of the many of them I was acquainted with that eat less and many a great deal more. But I shall not insist that any man who may read this should beleive it as an article of faith; I shall be content if politeness makes him think as Joe Millers freind said, "Well Sir as you say so I beleive it but by $\mathrm{g}-\mathrm{d}$ had I seen it myself I should have doubted it excedingly". (Beaglehole 1962:I, 346-347)

As Banks wrote there were many among the Maohis who were accustomed to eating “... a great deal more"-such was a man described by G. Forster:

Our walk continued along the shore beyond another marai, much like the first, to a neat house, where a very fat man, who seemed to be a chief of the district, was lolling on his wooden pillow. Before him two servants were preparing his desert, by beating up with water some bread-fruit and bananas, in a large wooden bowl, and mixing with it a quantity of the fermented sour paste of bread-fruit, (called maheî). The consistence of this mixture was such, that it could properly be called a drink, and the instrument with which they made it, was a pestle of a black polished stone, which appeared to be a kind of basaltes. While this was doing, a woman who sat down near him, crammed down his throat by handfuls the remains of a large baked fish, and several bread-fruits, which he swallowed with a voracious appetite. His countenance was the picture of phlegmatic insensibility, and seemed to witness that all his thoughts centred in the care of his paunch. He scarce deigned to look at us, and a few monosyllables which he uttered, were only directed to remind his feeders of their duty, when we attracted their attention. (1777:I, 295-296)

In fact, there were times when the whole populace ate gluttonously, as in connection with the mass-bakings ( $\bar{o} p i^{\prime} o$ ) of breadfruit when that staple was most plentiful. During these affairs, people “... seldom quit the house, and continue wrapped up in cloth: and it is surprising to see them in a month or so become so fair and fat, that they can scarcely breathe: the children afterwards grow amazingly" (Wilson 1779:358). Ellis reported the following about mass-bakings:

... they were usually attended with debauchery and excess, highly injurious to 
the health, and debasing to the morals of the people, who generally relinquished their ordinary employment, and devoted their nights and days to mere animal existence, of the lowest kind-rioting, feasting, and sleeping, until the opio was consumed. (1829:I, 356)

Jefferson commented also on this point:

Some of the great epicures of the country (and they abound) will at those seasons of the year when the breadfruit is in perfection (as it has been now for many weeks past) bake large quantities in a lot, sufficient to last some scores of men for many days and then they will sit and eat from morning to night without much interval of rest. This the Otaheiteans esteem as delicate living. This binds them to think well of this world \& to hear our message with great indifferency. (Journal, 13 March 1803, LMS Archives)

At other times individuals or groups retired from normal occupations for weeks or months to undergo deliberate fattening (ha'apori).

Another practice which led European visitors to charge the Maohis with gluttony was the manner and speed with which they could on occasion consume large quantities of food.

The following excerpt from the adventures of the demigod Honoura indicates the admiration expressed by the Maohis for trenchermen; the episode relates one of a series of trials he was forced to undergo:

All Tahiti was filling the affluents, Vai-te-piha-rahi and Vai-te-piha-iti, with food to present to the young man Honoura, and challenge him to eat it.

And they went for Honoura to come and eat the food, and the young man came.

He prostrated himself in the river, lowered one jaw down in the water, raised the other jaw up towards the sky, then all the food glided in. All Tahiti applauded him. The contents of Vai-te-piha-iti were consumed, and he turned his head to Vai-te-piha-rahi, and opened his mouth for the food there; all that was therein flowed into the great man until everything was quite gone-the food, the water, and the little stones even had disappeared! The young man was again applauded, and he laid himself down in the river-bed satisfied with the food. (Henry 1895:271)

Some of these practices can be "explained" in one way or another. For example, the gorging in times of plenty is a reasonable adjustment to seasonal variation in food supply. Also, the gormandizing that went on at some feasts becomes more comprehensible when it is pointed out that many such feasts were preceded by days or weeks of "officially" curtailed consumption.

... when they are from home, and Numbers are Met in one District, Provisions grow scarce from the Rahooe [rahui 'restrictions on consumption'] before describd and (they) are somtimes whole days without any and when they Get any they Eat so large a quantity as would readily give a Stranger an Idea that they were mere Gluttons and it would Certainly Appear more so to those who were perhaps Sated with the abundance of Good Provisions around them .... (Morrison 1935:209) 
Even their manner of eating may be somewhat absolved, as Morrison sought to do: "In general they Cannot be Calld ... immoderate eaters tho their Method of Stuffing their Mouths as full as they Can hold, has the appearance of it" (1935:210). As will be seen, eating greedily and with unseemly haste was particularly reprehensible during religious ceremonies. ${ }^{2}$

Nevertheless, the fact remains that the Maohis considered eating to be a great pleasure, and a great appetite a feat; and they ate, when they could, in a manner that many Europeans labeled gormandizing. It is unlikely, however, that "the poorer set" fared as well as the "principal people" pictured by Banks and Forster. Note, for example, the following passage from Bligh:

... Animal Food is so rarely made use of by the general run of the People here, that it may be said it is not eat by them at all, and I firmly beleive that the greatest Cheifs do not touch it one day out of ten through out the Year. Fish however falls generally to the lot of the Cheifs every day, but it is here in very Small quantities, and among the inferior order very small indeed, so much so that I have many times seen a peice divided into a dozen parts, each of which was not more than a Square Inch, and with these Morsels they would with a quantity of Breadfruit make their meal with the greatest chearfulness and content. (Bligh 1789:II, 31)

But there are indications that Morrison's description of eating habits applied equally well to households at all levels of society:

They sit Cross leggd and having a place spread with leaves (often under the shade of a Tree in fine Weather) for a Table Cloth and sit at a distance to prevent offending each other by Flapping the Flies away which are often troublesome, always swarming where any provisions are, especially Fish, which draws whole swarms about them, and having some Clean leaves laid for Plater \& dishes the Provisions are set before them \& They Cut their Meat or Fish with a piece of Bamboo or knife, and put it into a Cocoa Nut Shell with Salt water, and the Sause before Discribed and having washd their Hands in another shell they proceed, sucking the flesh or fish \& repeatedly dipping it in the sause, eating large quantitys of Bread fruit or Tarrow, drinking Clean water or Cocoa Nut Milk and after their Pork or Fish is done they have a sort of Pudding made of Bread fruit Calld Popoe of which each has a Shell which when they have eaten finishes this and they then Wash their hands and Mouths, Using a Piece of the Husk of the Young Cocoa Nut to Clean their teeth, of which they are particularly Careful. (1935:210)

From this and other accounts of eating, it appears that certain practices were followed, or at least held to be desirable, in all households. In connection with the menu, a full and balanced meal required a vegetable staple, a morsel of flesh or fish, a piquant sauce, a beverage of water or coconut liquid, and a more or less liquid vegetable or fruit "pudding." There were, however, numerous and varying restrictions concerning who could eat which of these foods. In connection with the act of eating, the Maohis were at pains to insure that the food that went into their bellies had not previously been in physical contact with certain "harmful" objects. And in connection 
with the social relations involved in eating, there were several evidently effective norms concerning who could eat with whom.

Now let us examine some of these considerations in more detail. Maohi eating habits were shaped by several considerations: by standards regarding food "hygiene"; by preferences concerning quantity of food and make-up of menu; by differing restrictions concerning who could eat what; by beliefs concerning sorcery; by conventions concerning where individuals ate in relation to each other; and by differences in productivity and in command over food resources.

From a Western point of view Maohi notions concerning food "hygiene" involved both "natural" and "supernatural" elements; it may be that a similar distinction was perceived by the Maohis themselves, although such a conclusion could not be readily proved:

They always wash themselves before, and after they eat, and should a Dead lizard, Mouse or rat toutch them they would wash before they handled any Food and should they happen to find one in or near their oven or toutch any of their Culinary Utensils they would use them No More. ${ }^{[3]}$ Notwithstanding which the(y) will eat a Hog which has died if they know of No disorder which might be the Occasion of his Death.

If any person toutches a dead body except of those killd by War, or for Sacrafice, is rendered unclean and can toutch no provisions with their hands for one Month, during which time they must be fed by another. (Morrison 1935:184)

Food preferences and eating-habit norms appear to have been fairly uniform. The LMS Dictionary contains words indicating that selfish eating, at the expense of other rightful claimants, was conventionally condemned, and "voracious" eating was under certain conditions regarded as unseemly, but, as noted above large appetites, as such, were admired.

Access to various foods did however vary-by virtue of sex, "ritual status," and kin-Title rank or chiefly authority. For example, females were permitted pork only if the animal in question were their own personal possession and had been raised by them from produce of their own land. (Dog flesh may have been in the same category, but evidence for such is lacking.) According to Morrison:

It has been supposed by Most Former Voyagers that they were also forbidden to eat Pork but in this they were most certainly Mistaken, for if any Woman has an Inclination to keep her Hogs Pennd up and prevent them from feeding on any other ground then their own they may eat pork, but as this is troublesom (and should the hogs get loose, and run on the land of their Male relations they become unfit for them to eat, or should any of their Male relations or the Chiefs toutch the Hogs it is the same) and attended with difficulty, they seldom attempt it as they have the Greatest Variety and abundance of fine Fish yet nevertheless they often kill and eat pork under that denomination, taking Care to keep such Men as are not of their retinue out of the Secret, their Servants always agreeing on this score are sure not to want for part of what the Mistress posesses. (1935:208) 
It is also suggested in some sources that women could eat only that fish caught by females or by certain males who were disqualified from the ritual status of full maleness, but there is uncertainty on this point. Nor, report some visitors, could women eat fermented breadfruit (mahi) except that taken from females' trees and prepared in females' pits.

In fact, it is implied that women were not permitted to eat any food touched directly or indirectly by males other than the ritually "unmale" ones just specified, but how far this distinction was carried in actuality is impossible to discover. It is recorded that "unmale" retainers were attached to the households of certain "principal" women, but does this mean that all other women could eat only that food produced, collected, cooked, and served by themselves? If this were the case most women would have been denied such staples as mountain plantains, because normally only men collected this fruit. Also, thoroughgoing food segregation on sexual lines would have imposed great hardships on small, "commoner" households with meager resources. Of course, "hardship" is a relative term, and there is little evidence on which to define its limits from the Maohi point of view. On the whole, however, I have an impression-from long-time immersion in the sources-that the ancient Maohis were not inclined to push ritual considerations to the point of continually painful deprivation. There is the possibility that this particular ritual consideration-the denial of male-touched food to women-was linked to, and directly correlated with, considerations of class and political power. And, as will become abundantly clear, most of the Europeans' informants were upper-class members and chiefs.

As for the reverse, males were not in general denied food touched by women:

The Men may partake of any of the Weomens Food but must not toutch any but what is given them and tho they enter the eating house of their Wives they must not toutch any of Her Culinary Utensils, otherwise she must not use them again but He may apply them to his own Use and she must provide herself with a New set or as many as he has toutchd. (Morrison 1935:208-209)

In addition to the food denied to women by virtue of its having been in physical contact with males, certain foods were denied them on principle, namely, the flesh of turtle, shark, porpoise, albacore, and dolphin. According to Morrison, these were regarded as "sacred," and even if caught by "unmale" fishermen they could not be eaten by women. A statement from Wilson implies that these prohibitions did not apply to certain women-that is, "The women who are not of the blood royal, or married to such, are forbidden to eat turtle, whale, porpoise, shark, albicore, and dolphin" (Wilson 1799:368). Bonito, the other pelagic fish most commonly caught, was not included in this list, whether by the writer's oversight or intent is not known.

Turtle flesh was ordinarily denied not only to females but to all but 
the holders of highest-ranking kin-Titles, and the most politically powerful chiefs. In this connection, it should be pointed out that turtle flesh was also considered a most appropriate food for the gods.

The rule prohibiting women from eating male-touched food was, however, strongly reinforced when that food was also butchered or cooked within marae precincts-that is, when it was "touched" by spirits as well. Yet, if we can credit information provided by Henry, even this double-sanctioned rule was on occasion relaxed:

Pork and turtle and the flesh of great white fish were publicly withheld from women and children as too sacred for them to eat, but by special dispensation the priests allowed their wives and children to partake at home with them of such meats, barring the heads, even when they had been offered to the gods. On favorable opportunities other men also secretly indulged their wives and children in these forbidden meats. (1928:177)

Ellis gave this description of a particular kind of Arioi ceremony:

The greatest peculiarity, however, connected with this entertainment was, that the restrictions of tabu, which prohibited females, on pain of death, from eating the flesh of the animals offered in sacrifice to the gods, were removed, and they partook, with the men, of the pigs, and other kinds of food considered sacred, which had been provided for the occasion. (1829:I, 324)

G. Forster described a meal served him and his companions by a "chief" as follows:

Our host now desired us to help ourselves, and in a short time we had cut the two hogs in pieces. All the women, and the common sort of people, applied to us with a begging tone for portions, and what we distributed was handed from our neighbours, to the remotest persons in the croud. The men consumed their share with every mark of a good appetite, but the women carefully wrapped theirs up, and preserved it till they should be alone. (G. Forster 1777:I, 405)

In addition to these general food prohibitions based overtly on sex, titular rank, and political authority, there were some special ones applicable to certain kinfolk of young Maohis during the latters' ritual status of "infancy" and "childhood" - an obscure set of conventions which will be described in a later chapter. Finally, certain food restrictions were laid upon individuals in mourning, when spirit-possessed, or under general economic or ritual prohibitions.

Another consideration which influenced Maohi eating habits was a belief in the efficacy of sorcery, specifically, in that technique whereby an individual's food exuviae, including food leavings, were used as a vehicle for attacking him. Thus, persons knowingly subject to the malice of others tended to be careful that leftovers of their meal (along with other kinds of their exuviae) did not fall into unfriendly hands. For example, “... the custom of the Tahitians in scrupulously burning or burying the hair when 
cut off, and also furnishing to each individual his distinct basket for food, originated in their dread of sorcery by any of these means." (Ellis 1829:II, 229)

Segregated eating was another common feature of Maohi life. Segregation based on sex has already been noted: "The Men and Weomen eat seperate, and for this reason each Family has two houses except a Man Chooses to reside in his Wifes house and then each take one end ..." (Morrison 1935:208). Particularly stringent was this rule in the case of men who held high-ranking kin-Titles:

No Woman Can eat in a house where a Chief has been, unless she is of the same rank and authority with Him and then she may Eat in his presence and if any Woman of Inferior rank should trespass in eating in any House, Canoe or Ship where a Chief Had been they would not only be severely striped but loose their possessions, for which reason they are Careful how they (infringe) these laws, as they know that few are given to keep a secret for which reason they always refused to eat when invited before Men, but would take the Food offered them and give to their relations; this may also account for a Number of the Chief Weomen who refuse to Dine at Table yet eat Hearty with the Servants. (Morrison 1935:209)

But mealtime separation went even further:

I have said that they seldom eat together the better sort hardly ever, even two brothers or sisters have each their respective baskets one of which contains victuals the other cocoa nut shells \&c. for furniture of their seperate tables. These were brought every day to our tents to those of our freinds who having come from a distance chose to spend the whole day or sometimes 2 or 3 in our company\& these two relations would go out and setting down upon the ground within a few yards of each other turn their faces different ways and make their meals without saying a word to each other. (Beaglehole 1962:I, 347-348)

Nor may sons eat in the presence of their fathers, nor even of their uncles and kinsmen senior to them in age; for they regard it as irreverence. (Corney 1915:258)

All these conventions greatly puzzled most observers, especially the sociable Banks: "What can be the motive for so unsocial a custom I cannot in any shape guess, especialy as they are a people in every other instance fond of society and very much so of their women" (Beaglehole 1962:I, 348).

One observer suggested that the habit of each individual sitting physically separated from all others was due, in part, to the presence of the cloud of flies which swarmed around the food, especially fish, or more specifically to the desire to avoid hitting others with the fly-flap continually at use during meals. Such may indeed have been a factor, but there were other factors as well, which later chapters will attempt to explain.

Finally, Maohi eating habits were shaped in part by individuals' differing capacities to produce food, or to dispose of the food produced by others. With respect to the first, the means of production-rights to land, to fishing grounds, to food-bearing trees, large seine nets, and so forth-were distrib- 
uted quite unevenly, as, apparently, were the skills and incentives to use them. With respect to disposal of food in this hierarchically organized society, one of the main prerogatives attached to superior status was choice food in the form either of volunteered "gift" or levied "tax." I shall summarize the various ways that food items circulated, between producer and final consumer-but first, I provide a listing of the Maohis' ways of processing their food.

The Maohis ate mangoes and custard apples raw, and they chewed raw sugarcane for its juice. They also ate uncooked meat of young and mature coconuts, often as a between-meals snack. Otherwise, however, most of the plant-food* eaten by them was cooked. The flesh of pigs, dogs, domestic fowls, and wild birds was always cooked before eating. Fish too was usually cooked or marinated before eating, although small fry and cockles and the like were sometimes eaten raw. Roasting, over an open fire or in hot ashes, was resorted to when circumstances demanded, but the most common method of cooking was by means of the earth oven (umu).

The Maohi oven (for the average size household) was a simple but highly effective affair, which consisted of a pit about one to two feet deep and five to six feet across. To prepare an oven, layers of firewood and stones were stacked in the pit and the wood burned to ash. One layer of hot stones was then left on the bottom of the pit and covered with leaves. On this was placed the food to be cooked, another layer of leaves, and the whole thing covered with ash, dirt, and sometimes more leaves. Such was the most common practice; in some instances, however, the food was placed directly on the hot stones. Unprocessed breadfruit, tubers, and roots were usually placed in the oven without additional wrappings, as were large cuts of pork and dog flesh, but fish, fowl, and vegetable puddings were usually baked in leaf wrappings, and other more liquid foods were baked in halves of coconut shell. Some oven pits were dug to dimensions required for the occasion, but in addition every household had one or more permanent ovens.

Different baking times were required for different items, and the Europeans who shared Maohi meals did not often complain, in writing at least, about overdone or underdone food; but it is not recorded how Maohi cooks actually "timed" their ordinary, everyday baking. However, it is reported that on occasion pig was deliberately undercooked: "... when they dress a large Hog for a Small Company they never dress it thoroughly that the Visitors may not have it spoild for a second dressing, as they always take away whatever has been provided for them" (Morrison 1935:213).

The stones used in native ovens were in ample supply, but whether such

* Plant-foods are the products of food plants. 
was the case with fuel is not entirely clear. According to Bligh: "... anything that will take fire and give a proper degree of heat to their Ovens is sufficient for all their culinary purposes, they are therefore abundantly supplied by the Cocoa nut shells and branches, underwood and Herbaceous plants" (1789:I, 408).

Some sources contain direct and indirect references to laborious firewood collecting trips into the hills and valleys, and Morrison stated that firewood was in short supply: "Water is plenty all over the Island but Wood for Fuel is not, as there are few other trees in the lowland except the Breadfruit \& Cocoa Nut, with which it is Covered; but evry tree has its owner, \& must be either purchased or leave obtained to Cut of the Natives" (1935:141).

Besides roasting or baking their comestibles the Maohis also occasionally cooked some of their puddings by "stone boiling" - that is, by dropping heated stones into a wooden trough containing the raw pudding mixture.

The so-called puddings of the Maohis varied both in terms of ingredients and consistency. The most common of them contained coconut cream mixed either with grated taro, mashed breadfruit, or grated arrowroot. Some puddings remained edible for days or even weeks. Softer puddings were made by mixing water or coconut juice with baked plantain or breadfruit (either plain or fermented); the whole was then drunk as a kind of gruel.

Greens were cooked either separately in coconut cream or as ingredients of puddings.

Both coconut juice and water were drunk at meals, the latter having served also as a sauce. Another common sauce, mitiero, was made by dissolving soft immature coconut meat in salt water; additional pungency was achieved by adding raw, and even nearly rotten, crustaceans to the mixture.

\section{CiRCUlation OF FOOD}

Some food went directly from the producer's hands, so to speak, into his mouth; but most of it was involved in intermediate transactions, some of which have already been described. Without attempting to be exhaustive let us list some of the many ways in which food "changed hands." 4

Most food was consumed by members of a producer's own household. The little direct evidence we have on this subject, plus a large measure of inference, seems to indicate that the food economy of most Maohi households operated on the principle of pooling and sharing: "from each according to his (productive) ability to each according to his (consumption) rights and needs"-bearing in mind, of course, that "abilities" and "needs" were defined according to Maohi cultural standards and not in terms of "objective" criteria of relative physical strength or nutritional requirements. Some of these standards will be discussed in chapters that follow; only a few of them will be indicated here, for reasons of emphasis. 
First, there was the common practice of sharing a token part of a household meal with its members' tutelar spirits. How widespread and invariable a practice this was is by no means clear; nor is it clear just who performed this perfunctory rite, whether the head of the household alone, or all individual members acting for themselves. But it was undoubtedly performed, and on a regular daily basis in some households; in addition it was institutionalized in an elaborate annual ceremony, a 'ghosts' night feast' ( later. Although listed here in connection with ordinary intrahousehold food-sharing, this ritual offering might alternatively be defined as an exchange-that is, a payment for services rendered, rather than a share of common resources regardless of past or expected contribution. Unfortunately, too little is known of Maohi motivation, either public or private, to interpret such acts with confidence.

The second intrahousehold food-sharing convention deserving emphasis has to do with the sex-linked segregation of food. Attention has already been drawn to the complexities resulting from this set of norms and to the unanswered questions concerning their application. The only other point about it that I wish to make here is that despite their very considerable freedoms in other phases of life, from a Western point of view Maohi females were distinctly underprivileged with respect to their consumption of household food.

Another practice bearing directly upon household food transactions was fosterage, which, significantly, was termed 'feeding'. The LMS Dictionary distinguishes fosterage ( $f a^{\prime} a^{\prime} a i$, to feed, nurse) $)^{5}$ from adoption (fa'atāvai, to adopt another's child); it is not clear whether these distinctive terms were in fact applied to comparably distinctive practices, but in any case it appears to have been quite common for households to take in "outsiders" for extended periods of time and to treat them as full-fledged members, at least with regard to food economy.

Visitors, ${ }^{6}$ on the other hand, were on principle accorded different treatment: “... nothing can give them more satisfaction then to see a Stranger ... [eat heartily] when they invite them to eat, which they are ever ready to do, always parting what they have Cheerfully, be it little or much ..." (Morrison 1935:209). In fact, Morrison went on to say that the Maohis were accustomed to stinting themselves in order to supply visitors with the best. A common practice was to supply the visitor not only with all he could eat at the time, but to send him on his way with the food left over from the meal cooked on his behalf.

Maohi hospitality ('aroa, kind, hospitable to visitors [LMS Dictionary]) varied in elaboration, from the spontaneous offer of a meal to a passing stranger to the lavish and ceremonial reception attending an official visit of an influential ally or rival. The underlying motives of individuals 
providing the hospitality varied-for example, expectations of reciprocal hospitality, desire to gain prestige, and even the wish to embarrass the guest with unreciprocable largess-but the practice was usually the same, namely, that visitors must be fed with the best the household could provide, without implying the expectation of return, except perhaps in the form of a token "guest's present," or $\bar{o}$ : "It has always been a custom to give presents and a feast called a fa' $a^{\prime} a m u^{\prime} a$ (feeding) to guests from another place on their first arrival among their friends; and the guests requite the presents with another, called an ō (welcomer)" (Henry 1928:177).

There is evidence even that hospitality was the law of the land; at least one finds the following decrees incorporated in the ture (rules, precepts) allegedly formulated by Tetunae, a legendary chief said to have ruled in southwestern Tahiti centuries before European contact: ${ }^{7}$

Do not just glance at the people going by your house, not calling out to them stop by and dine. In the matter of food, do not slight your near neighbors. Do not ill regard the stranger passing by the house, call out to him to stop by, butcher your pig, that the mortar may be rich with food filled for him. Everyone who does not respect these orders is to be taken to an open place and put to shame so that such offense be not removed from notice. It will be quite correct for the ari'i to absorb his land in punishment.

Tetunae's ture also contained words of advice to ari'i about hospitality:

Your household must not be accused of food hiding. Let not your name be associated with hidden food or hidden goods. The hands of the Arii must be always open; on these two things rest your prestige.

Long-term visiting, between relatives and friends, was also a common feature of Maohi household life. Such visitors were supplied with food as were other members of the household, but the extent to which they were expected to contribute to the hosts' food supply must have varied widely. As we shall see, one implicit assumption underlying much of this kind of visiting was the expectation, or at least possibility, of eventual return visits, but this did not always operate to the host's satisfaction as witnessed by the currency of such words as 'aihāmumu ['ai hamu mā'à], a person who continually imposes upon another by eating his food, et cetera (LMS Dictionary).

Other words, as translated by Davies for the LMS Dictionary, also reveal the prevalence of the practice by some individuals of sponging off other households for food: for example, anavenave ['ànavenave], addicted to getting food at another person's house; tutaraai [probably, tūtā va'a 'ai], a person who goes from place to place to eat what he can get; and, although not directly related to household economy, hamu, to go to a feast whenever one occurs. Thus, although the Maohis publicly professed hospitality-giving food to visitors without expectation of return-the actual 
transactions were ofttimes hedged about with many qualifications, or were undertaken with other purposes in mind.

The principle of food generosity was apparently so widely prevalent-ideologically, at least, if not in actual practice-that there may have been occasions on which food circulated in this manner outside the contexts of hospitality, that is, to persons from elsewhere not physically present in the donor's own household (or home district, or whatever larger place of reference happened to be relevant). On the other hand, most acts of food generosity described in the sources seem to have involved a more or less explicit expectation of return, whether in the form of a conventionally defined and immediately presented countergift or of some unspecified present to be made in the indefinite future. How the Maohis themselves distinguished between hospitality and this other form of food "generosity" is admirably illustrated in a passage from the journal of the perspicacious Banks:

The wrestling over the gentlemen informd me that they understood that 2 hoggs and a large quantity of Bread fruit \&c. was cooking for our dinners, news which pleasd me very well as my stomach was by this time sufficiently prepard for the repast. I went out and saw the ovens in which they were now buried, these the Indians readily shewd me telling me at the same time that they would soon be ready and how good a dinner we should have. In about half an hour all was taken up but now Dootahah began to repent of his intended generosity $\&^{[8]}$ he thought I suppose that a hog would be lookd upon as no more than a dinner and consequently no present made in return, he therefore changd his mind and ordering one of the pigs into the boat sent for us who soon collected together and getting our Knives prepard to fall too, saying that it was civil of the old gentleman to bring the provisions into the boat where we could with ease keep the people at a proper distance, who in the house would have crouded us almost to death. His intention was however very different from ours for instead of asking us to eat he ask'd to go on board of the ship, a measure we were forcd to comply with and row 4 miles with the pig growing cold under our noses before he would give it to us. Aboard however we dind upon this same pig and his majesty eat very heartily with us. After dinner we went ashore, the sight of Dootahah reconcild to us acted like a charm upon the people and before night bread fruit and cocoa nuts were brought to sell in tolerable plenty. (Beaglehole 1962:I, 273)

Up to a point, the Maohis also distinguished between the two kinds of food transactions just described and those we may label commercial. As far as I can discover the Maohis had no localized marketplaces, where food was exchanged regularly for food or other objects. ${ }^{9}$ There is evidence, however, that food was occasionally used in barter transactions, as for example in payment for bark cloth manufactured on commission, and in Wilson's description of a man "... by trade a fisherman, who supplied his neighbors with fish, and received from them canoes, hogs, fruit, roots and cloth" (1799:190). Morrison provides a fine account of a regularized barter arrangement, of pigs for fish: 
If a Man wants to be Constantly Supplied with Fish He takes a Hog to a Fisherman and according to the size He agrees with the Fisherman to supply Him with Fish for one or more months, which they seldom fail to perform, Weather permitting for the stated time. What they look upon as fulfiling the Agreement is bringing as much Fish evry day as the Family can Eat, and for Failure of Promise they may be Plundered as before. ${ }^{[10]}$ Sometimes they agree for a supply evry other day and when the Fisherman fulfils His promise well they make Him a Feast-and the Fish they bring are sometimes equal to ten times the price at a Fair exchange. (1935:165)

The last sentence in this excerpt raises the interesting possibility that there were two kinds of barter arrangements in operation: one a strictly "commercial," impersonal one, involving more or less fixed exchange rates (or possibly even "pure" market-price situations influenced by supply and demand); and a second, less impersonal kind of arrangement, such as the one just described, involving contractual relationships wherein values were influenced also by some of the considerations characteristic of gift exchange. In his reference to "price at a Fair exchange," Morrison may of course have been referring to the somewhat alien aspect of barter occasioned by trade with Europeans, but coexistence of the two kinds of native barter arrangements would not be inconsistent with other aspects of preEuropean Maohi life. Or rather, what probably existed was a continuum-or part of one, at least-with "pure" market barter at one end grading into gift exchange at the other, the point on the continuum exemplified by any particular exchange transaction having depended on such factors as kinship, friendship, Title rank, and residential proximity. ${ }^{11}$ In fact, it is reasonable to suppose that factors of relative rank of kin-Title or type of kinship tie may not have been wholly determinative and that individuals may have been left with a degree of freedom in choosing the kind of transaction to engage in, according to the kind of advantage desired at the time. So a passage from Cook seems to suggest:

I have occasionally mentioned receiving considerable presents from Otoo and the rest of the family, without saying what return I made. It is customary for these people, when they make a present to let us know what they expect in return and we find it necessary to gratify them; so that whatever we get as presents comes dearer than by barter, but in times of occasional scarcity which will sometimes happen, we can have recourse to our friends for a present, or supply, when we cannot get any by any other method, so that upon the whole this way of traffick is full as advantagous to us as them. (Beaglehole 1967:221)

There is very little information available concerning exchange values of food items among the Maohis themselves, and in view of the situational variables just mentioned it is not possible in any case to speak with confidence about the exchange value of any food item. Morrison reported that natives were accustomed to barter a one-hundred-pound pig for one frigate 
bird whose feathers they valued, but that is about the only data available concerning specific values in native "commercial" trade. ${ }^{12}$

Evidence will be cited later on for some exchange of breadfruit from areas of plenty to areas of scarcity; but whether this exchange was of the nature of barter, or constituted some kind of gift exchange between kinsmen or friends, cannot be learned.

There are numerous references to the use of food as payment for services: to "carpenters" for help in building houses, to specialists in diagnosing and curing ailments, to priests in conducting rites, et cetera. In fact, it is likely that most of the food and other offerings made to spirits were explicitly on the basis of quid pro quo. This raises questions concerning the rationale underlying the several kinds of food transactions between "inferiors" and "superiors," and between humans and spirits. Several of these transactions have already been mentioned, and many others will be listed in later chapters, for food figured very prominently in most such transactions.

Now I turn to accounts of the ways employed by the Maohis to produce the foods whose consumption and circulation I have just described.

\section{FOOD PlantS}

\section{Breadfruit}

The staple food of the Maohis was undoubtedly breadfruit (Artocarpus incisa: 'uru; fig. 9-1). It was either baked whole in an earth oven and eaten in chunks or mashed and mixed with other vegetables into puddings. The productive breadfruit tree with its large foliage and spherical fruit was undoubtedly introduced into these Islands by the Maohis and in time came to occupy, along with coconut palms, very extensive portions of the coastal plains and adjacent lower hill slopes, that is mainly the adlittoral and lowerslope parts of the mesotropical zone. The high, shady canopy and parklike settlement clearings provided by these picturesque trees charmed even the more hardbitten of the European visitors, and the quantity and richness of their fruit became proverbial:

In the article of food these happy people may almost be said to be exempt from the curse of our forefather; scarcely can it be said that they earn their bread with the sweat of their brow when their cheifest sustenance Bread fruit is procurd with no more trouble than that of climbing a tree and pulling it down. Not that the trees grow here spontaneously but if a man should in the course of his life time plant 10 such trees, which if well done might take the labour of an hour or thereabouts, he would as compleatly fulfill his duty to his own as well as future generations as we natives of less temperate climates can do by toiling in the cold of winter to sew and in the heat of summer to reap the annual produce of our soil .... (Beaglehole 1962:I, 341)

In addition to supplying the Maohis with their most important food 
the breadfruit tree had many other uses. Its trunk and larger branches provided the heavier timbers used in house construction; and, while not the best for the purpose, the trunk was used also for canoe hulls. The inner bark of its smaller branches was made into bark cloth, and its highly viscid resin served to close canoe seams and to trap small birds. Even its broad leaves were utilized, to wrap foods and to cover ovens.

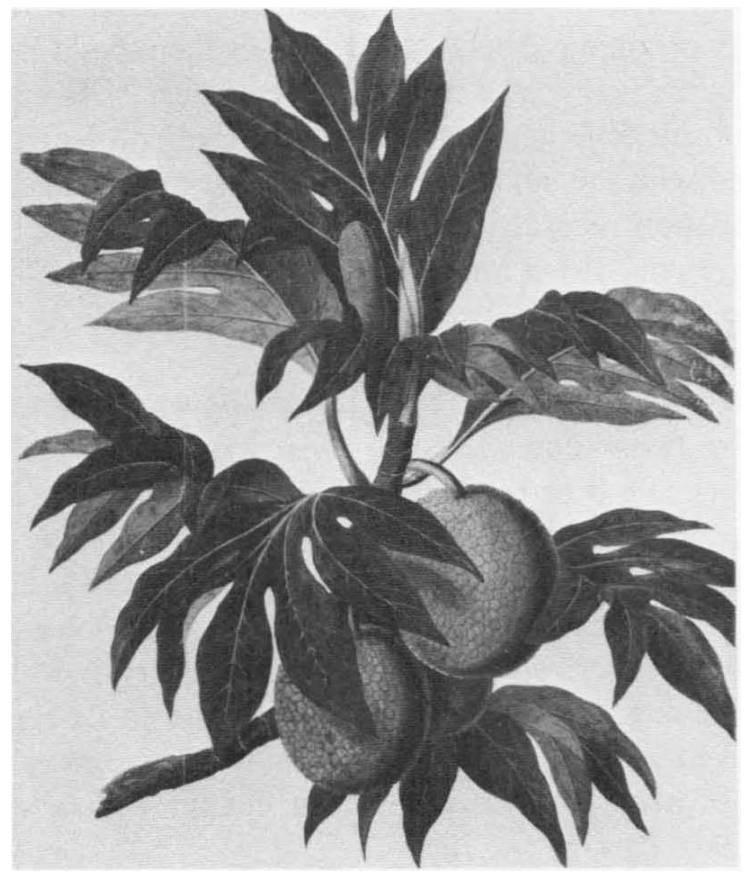

FIGURE 9-1. Breadfruit. Drawing by S. Parkinson. British Museum of Natural History.

There was a time, according to one legend, when the Mahois had no breadfruit. $^{13}$

A long time ago the land was smitten by famine, and the populace had nothing to eat but pandanus flour, teve [an acrid-tasting plant root] bitter-backed land crabs-and red clay. At that time a couple took their four starving children into the mountains to collect edible ferns. There, out of pity for his wife and children the husband transformed himself into a breadfruit tree loaded with fruit-and this was the origin of the tree. When some of the fruit was sent as a firstfruit offering to the local chief, the latter liked it so well that he confiscated the tree itself. In time however, shoots from it were propogated elsewhere, so that breadfruit became widely distributed among humans. (Adapted from Henry 1928:423-426)

A fully grown breadfruit weighs from two to five or ten pounds and 
consists of a core of fibrous, starchy, white pulp and a thin, rough-surfaced rind. The pulp contains some 17 percent starch, and although it serves to satisfy hunger it is not nourishing by modern nutritional standards. The Maohis picked the fruit at two different stages of growth: first, when its rind was yellow-green and the pulp firm, and when cooked it had the slightly sweet flavor and consistency of a baked yam; and later, when its rind was completely yellow and the pulp softer and sweeter.

To augment their supply of breadfruit the Maohis had only to plant cuttings-roots or young shoots-and protect them from destruction until they reached bearing age, some five or six years later. ${ }^{14}$ Even so, there must have been a considerable amount of technical lore and technical procedural detail connected with the cultivation of this most important food staple, but the only information recorded on this score concerns varieties recognized by the Maohis. Henry listed forty varieties (1928:40-41); Ellis asserted that he and his fellow missionaries were acquainted with "nearly fifty varieties" (1829:I, 357), but he did not list them.

Harvesting was an easy job, even for one person, but it was done more expeditiously by two-one person to twist loose the fruit by hand or by stick, another to catch it or break its fall to keep it from bursting.

The fruit was prepared for eating in several different ways. The simplest method, resorted to when traveling, was to roast it whole and then scrape off the charred rind. Usually, however, the fruit was baked in an earth oven, as has been described. Most commonly the fruit was picked at its first stage of ripening and baked, either whole and in its rind or with rind and core removed and cut in large chunks. The rind was removed with a sharp-edged bivalve, and the pulpy fruit cut up with a special wooden splitter. (Figs. 9-2 through 9-6.)

When breadfruit was in plentiful supply it was baked or rebaked every day: "For the chiefs, it is usually dressed two or three times a day; but the peasantry, \&c. seldom prepare more than one oven during the same period\& and frequently tihana, or bake it again, on the second day." (Ellis 1829:I, 355)

The mass-bakings (opi'o) already referred to were undertaken at the height of the breadfruit season. Large pits, ten or so feet in diameter, were made and scores of whole ripe fruit were baked in them. After three or four days of baking, the fruit was taken out as needed, scraped, and eaten until consumed. According to Ellis, fruit baked in this manner will remain edible for "several weeks" (1829:I, 355). It "... has a very agreeable tast and the Collour is Changed to brown throughout" (Morrison 1935:214).

I have already described the consumption of breadfruit prepared by mass baking; some aspects of its preparation are no less interesting and are directly relevant to our purposes: 


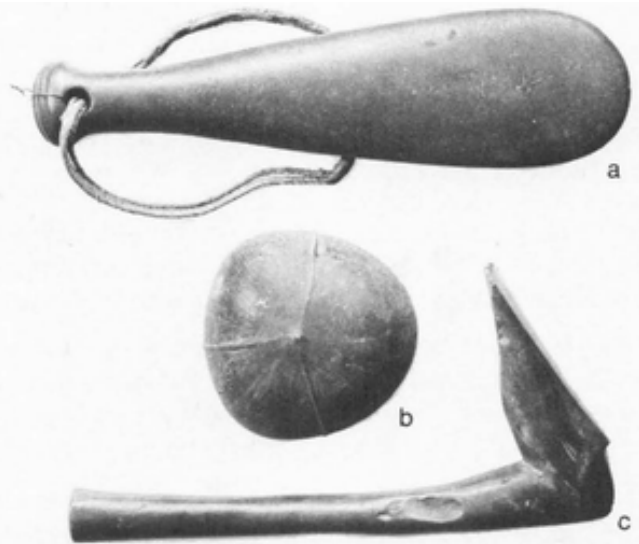

FIGURE 9-2. $a$, stone breadfruit splitter, $b$, coconut shell cup; $c$, wood breadfruit or coconut splitter. Bernisches Historisches Museum, Berne.

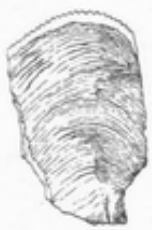

Figure 9-3. Shell grater, length 8.6 $\mathrm{cm}$. Bishop $\mathrm{Mu}$ seum.

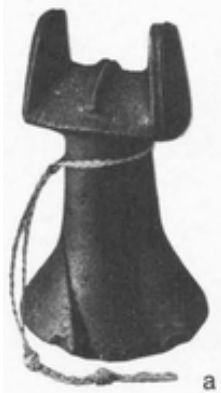

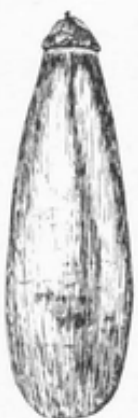

FIgURE 9-4. Wood breadfruit splitter, length $33.6 \mathrm{~cm}$. Bernisches Historisches Museum, Berne.

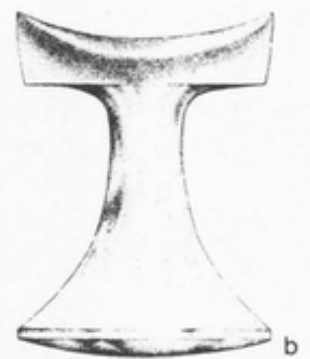

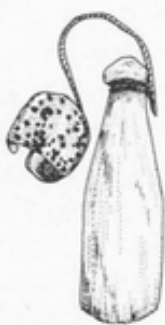

Figure 9-5. Breadfruit peeler and splitter.

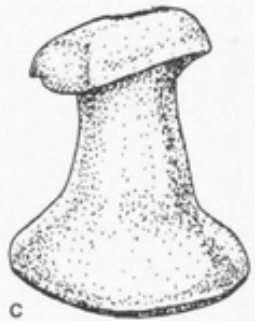

Figure 9-6. Stone pounders: $a$, height $17.5 \mathrm{~cm}$. Etnografiska Museet, Stockholm; $b$, height $15.9 \mathrm{~cm}$. Bishop Museum; $c$, height $136 \mathrm{~mm}$. Field Museum of Natural History, Chicago. 
When a Chief or Ratirra [ra'atira] wants one of these Ovens of Bread made, they inform their Tennants who go in a Body and bring Wood from the Mountains, while others Collect the Stones and while the fire is Burning evry Man brings his load of Bread which is put into the Oven whole and without further preparation and being Covered with leaves thatchd over with Grass \& the Earth thrown up over it an do not open it for three or four days, when they take it out for use evry day as it is wanted, keeping it covered till the Whole is expended, and this they repeat evry harvest.

The poorer people are not excluded from the Method of Feasting their Children tho they have not sufficient Bread for the Purpose, having nothing more to do but signify their intention to their Neighbours, who bring their proportions of Bread and Assist them to Collect Wood and Make their Oven; somtimes they Join two familys making one oven between them. (Morrison 1935:214)

Another method of preserving the fruit was to remove the rind, throw the pulp into a heap and allow it to ferment for three or four days, then store it in a leaf-lined, earth-and stone-covered pit, where it continued to soften and ferment for some months. Fermentation was hastened by adding a few overripe fruit to the heap, or by leaving in the cores. The paste (mahi) was taken out as needed and baked, either by itself or mixed with other ingredients.

Large quantities of breadfruit of precisely the right stage of ripeness were required in the making of mahi. Since few households possessed so much at any one time measures were taken to make up the difference:

If the Crop on any individuals land should run short of His expectation and He has not sufficient to make as much Mahee as he wants or thinks will serve He makes a Number of Garlands of a shrubb Calld Pirrepirre and takes One to evry House or as Many as he thinks proper and throws them in without saying any thing except to tell the day he intends to send for it or have it brought home, evry one knowing what is Meant by the Garland. If He has hands sufficient to Scrape the whole at once it is brought home to the House, each Man bringing the Garland left at his house as full of Bread as it Can be Made fast and laying it down at the Door returns without any further Ceremony then bidding God bless his Work; if He has not sufficient help to take the whole in hand at once he makes it known and either goes himself for it when he wants it or has it brought at the time he nominates to those who supply him, who are ever ready to assist evry Man according to his Abilitys. If he goes for it himself he always finds the Garlands ready filld at the appointed time-By this Method of assisting each other they never feel the least Inconvenience from having a Scanty Crop and if a Chief wants a Supply for the purpose of Making Mahee he sends a Bit of Cocoa Nut leaf to all, or as Many of the Inhabitants of his district as he shall think proper, and on the appointed day they Bring each a load, which is generally accompanied with a hog by some and fish by others according to their several abilitys, but this they have seldom occasion to do as they are always well supplyd and when supplys are raised this Way the people bring it in such a Manner as bespeaks at once their regard for their Chiefs \& fear of displeasing them, always testifying their sorrow that he should be so far neglected as to have the trouble of sending for bread. (Morrison 1935:215-216) 
Two wholly different kinds of transactions are indicated: the first is a "gift" between households of more or less equivalent social position, with implicit expectations of reciprocation; and the second is a levy of "tribute" by a chief upon his subordinates. In connection with the second, one is impressed, particularly, with Morrison's acuity in noting how the principals' manner of presenting their goods to their chief "bespeaks at once their regard for Chiefs \& fear of displeasing them...."

In my preliminary statement about eating, I noted that there were many restrictions concerning who could eat what and who could eat with whom. The making of mahi is a case in point:

... the men and Weomen having each their own trees have also their own Mahee and should a Man who is not the Servant of a Woman toutch even the Covering of the Womans Mahee it is rendered unfit for Her Use, which at once accounts for Sir Joseph Banks's having spoild a quantity which belongd to a Woman by his being desirous to see the nature of the Process of making it and examining the Contents of the pit-which was not only rendered of no use to the Woman but the place in which it was underwent the same fate and no woman Could ever use it afterwards. (Morrison 1935:215)

The reference to Banks concerns this episode reported in the latter's journal:

As the whole making of this Mahai as they call it depends upon fermentation I suppose it does not always succeed. It is done at least always by the old women who make a kind of superstitious mystery of it. No one except the people employed by them is allowd to come even into that part of the house where it is; I myself spoild a large heap of it only by inadvertently touching some leaves that lay upon it as I walkd by the outside of the house where it was. The old directress of it told me that from the circumstance it most certainly would fail and immediately pulld it down before my face.... (Beaglehole 1962:I, 345)

There is no question that men and women ate separately, but the reference in the above to men and women "... having each their own trees" is difficult to assess. It may well have been so with respect to fruit used for mahi, although one wonders in this connection how women managed to assemble enough female-owned fruit to prepare their own mahi. The reverse of the problem apparently did not occur, since men were not ordinarily restricted from eating food supplied or cooked by women. Also, it was everyday practice in some households to cook men's and women's food in separate ovens; but whether this was the case in all households, and how thoroughgoing a physical separation was made between men's and women's food at all stages of production, processing, and consumption will be evident later on.

As noted earlier, some breadfruit grew on the lower slopes of the mesotropical zone, but it flourished mainly in adlittoral portions of the coastal zone; consequently, places with wide adlittorals tended to be more 
abundantly supplied-a circumstance which was reflected somewhat in the distribution of population. Even with this fitting of population to environment some parts of islands appear to have produced more breadfruit per capita than did others, which raises the important question as to whether there was any regular trade in this vital food based on local differences in overall annual supply.

There certainly was circulation of breadfruit, for example, as "tribute" within political units, but the only documented instance that it moved long distances as a result of local differences in overall annual supply was traffic between Tahiti's Pare district and the Tetiaroa Atoll. As previously reported, Tetiaroa was part of the personal domain of Pare's principal chiefs, who, in order to "prevent the inhabitants from casting off [their] authority," are said not to have permitted breadfruit or other vegetables to grow there; an exception was coconuts and possibly taro, "for the convenience of the chiefs who go there on a visit" (Wilson 1799:380).

Somewhat better documented is the trade in breadfruit resulting from local differences, not in overall annual supply but rather in times of fruiting. Breadfruit ripens seasonally, but times of ripening are not the same everywhere in these Islands. Two of the three modern botanists writing on this subject asserted that there are three crops a year, during March, July, and November, the best and largest being in March, and on into April (Wilder 1928:9; Chabouis 1954:I, 71). The third botanist speaks of “... an abundant crop from November to April, and a smaller one in July-August" (Papy 1954:II, 262), but this might be taken to mean that the long November-toApril season consists of two peak fruitings with a slackening off, but not a completely barren, period in between. (It is likely that these writers were referring mainly to conditions on Tahiti itself, and possibly to those obtaining near its northern and western shores.)

Earlier observers, writing in general terms, also noted three, or even four, fruitings a year, ${ }^{15}$ and some of them specified local differences in times of fruiting, for example:

The seasons differ much on the opposite sides of this Island, partly owing to the Island of Morea or Eymayo lying in a N. \& S. diriction a cross the west part of it and while the Trade wind blows on the North side the West wind blows fresh on the South, but when the Wind gets to the Southward of S.E. it prevails against the West wind and then the south side is deluged with rain from the Clouds which settle on the Mountains of Tyarrabboo while the $\mathrm{N}$ side enjoys fine pleasant weather with scarce a shower of rain for 6 Months-this makes a material difference in the Bread-fruit Harvest, which generaly begins on the $\mathrm{N}$ side about November and is over by January; but on the S. side it is sometimes over by November at one Season and does not begin till January at another. (Morrison 1935:142)

When the trade wind gets far to the south, and blows fresh, it generally rains on the south side of the island [of Tahiti], bringing the clouds from the moun- 
tains of Tiaraboo, and emptying their contents at Papparā and the adjacent districts [on the south side of Greater Tahiti]. This occasions a great difference in the bread-fruit season between the north and south sides of the island; as on the north the rain is less frequent and less violent, and the trade wind constantly blows, except when the sun in vertical. Hence the great bread-fruit harvest commences on the northern side about November, and continues till the end of January; whilst on the south side, in some parts, it begins in January, and continues in different districts till November. But though this is the case with the general harvest on both sides the island, there are some kinds of bread-fruit, though scarce, in season all the year, especially in the district of Attahooroo [west coast]. (Wilson 1799:316) ${ }^{16}$

Apart from these general statements there are fifty-three observations contained in the LMS records-spanning forty-five years-concerning breadfruit seasonality, mainly for the island of Tahiti. In Matavai subdistrict, to which half of the observations appertained, the season of greatest plenty usually lasted from about the end of December to about the beginning or middle of May, with a smaller crop in August and September. These observations were not systematic, however; they consisted mainly of statements to the effect that, for example, "all the breadfruit is gone from the trees," or "the fruit is not yet ripe," or "there is a rich harvest this year." At Atehuru, on the other hand, about $15 \mathrm{~km}$ south and west of Matavai, the principal season began (during the year of recording, at least) in mid-February and lasted until June. Data from other districts of Tahiti, and from the other islands, are very fragmentary, but taken all together they confirm in general my impression that there was a considerable amount of variability in breadfruit ripening throughout the archipelago due mainly to the following factors:

Location, with respect to normal climate. On the exposed, dryer northern parts of Tahiti the main fruiting season began earlier than it did in the rainier south; within this general pattern there were even more localized variations associated with the island's many smaller pockets of "micro-climates." As for the other islands, in consequence of their smaller sizes and more uniform climatic patterns there was probably less local variability than on Tahiti, but there is no positive evidence available on this score.

Varietal differences. Several writers ${ }^{17}$ claimed that there were some varietal differences in fruiting times, but they provided no substantiation.

Altitude. A passage from Banks indicates that, in some places at least, breadfruit growing on the lower slopes had somewhat different fruiting times from those growing on the flat, but whether this was the direct result of differences in location, or of differences in variety, or of both, is not clear:

This morn [3 July 1769] Mr Monkhouse and myself set out, resolving to follow the cour(s)e of the valley down which our river comes in order to see how far up it was inhabited \&c. \&c. When we had got about 2 miles up it we 
met several of our neighbours coming down with loads of breadfruit upon their backs. We had often wonderd from whence the small supplys of breadfruit we had came, as there was none to be seen upon the flats, but they soon explaind the mystery, shewing us breadfruit trees planted on the sides of the hills and telling us at the same time that when the fruit in the flats faild this became ready for use, which had been by them planted upon the hills to preserve the succession. The quantity was they informd us much less than was in the low land and not sufficient by any means to supply all the interval of scarcity\& when this was exhausted they must live upon ahee (ahi) nuts, Plantains, and Vae (fe'i), a wild plantain which grows very high up in the mountains. (Beaglehole 1962:I, 306)

Weather. Some observations in the LMS Archives provide proof that the droughts which occurred in some years, especially in northern Tahiti, had the effect of slowing up breadfruit ripening and in reducing the size of the crop-sometimes to near-famine proportions (see Jefferson, Journal, 19 July, 19 August 1799). Of course, hurricanes and tidal waves are known on occasion to have destroyed growing or ripe fruit, or even whole groves of trees. But natural disaster was, perhaps, not as destructive as warfare, during which the opposing sides sometimes cut down or ring-barked each other's breadfruit and other fruit-and nut-bearing trees.

As Banks was helpful enough to observe, some households were able to bridge parts of the time gaps between main fruiting seasons by recourse to trees of their own deliberately planted in areas of later fruiting. There is also evidence, from journals in the LMS Archives, that the different fruiting times led to interdistrict exchange and to seasonal changes of residence, for example:

The King sent the [Missionary] Society a quantity of good Uru-it was brought from Atahuru at which place the Uru is in season, while here [in Matavai] and most of the other parts of the Island it is scarce (Davies, Youl et al., Journal, Tahiti, 3 June 1806).

Great scarcity of uru in Matavae and Pare, some has been fetched from Faa and Atahuru several times the past fortnight (Davies, Journal, Tahiti, 18 May 1808).

... most of the men were at Mape after Uru ... in the [Avea, Parea \& Mahoute] districts they have no Uru, but what is fetched from some other place ... (Elder \& Wilson, Journal round Huahine, 27 April 1809).

The uru begins to be scarce in Matavae. In Atahuru it is still in great abundance, and for that reason several of our neighbours are gone to reside there for the present (Davies, Journal, Tahiti, 24 March 1807).

There is a great scarcity at present of breadfruit, Taro \&c. and many of the people are scattered over the island for the purpose of procuring food (Davies, Journal, 4 September 1818).

The possible implications of these movements, of breadfruit itself and of people to breadfruit, will be examined in another place, but first some other ramifications of the seasonality of this important staple. 
In the first place, there is ample evidence that the Maohis made deliberate efforts to extend the supply of breadfruit by planting trees on hillsides (see Beaglehole 1962:I, 306) and by preserving fruit in the form of mahi. "A great quantity of bread-fruit was brought today to make mahie, as the time approaches when the ripe fruit will be scarce in the district for two months" (Wilson 1799:175). Also, the Maohis were able to retard for a few days the rotting of ripe uncooked fruit by keeping it buried in sand.

Our boys went to Tapaearue about 8 Miles distant for Breadfruit, there being none in this district. In order to keep it, they bury it in the sand, by which means it will continue good four or five days. If it is not buried or put in water as soon as plucked it gets soft and sweet, in less than 36 hours, and only fit to make Mahhe of. (Youl, Bicknell et al., Journal, 5 September 1806, LMS Archives)

However, it appears that none of these measures, including importing from places with different fruiting cycles, succeeded in providing a constant, year-round supply-not for ordinary individuals nor even for the "Principal People." ${ }^{18}$ In a word, the supply of this principal staple remained seasonal. The LMS Archives record numerous references to periods of general food scarcity, which occurred mainly in breadfruit off-seasons. ${ }^{19}$ Some accounts link such food shortages with epidemics, for example:

Several of the natives have been afflicted with a bad swelling (which in the general, is a little below the groin) as also with very bad Boils in other parts of the leg. The swelling is attended with excruciating pain, and in general after a time breaks into a running sore. It is thought to originate from the much wet weather $\ldots$ and it is observed that many more of the natives are sick and die in the scarce season, than at other times, owing much perhaps for the want of proper food. (Davies, Youl et al., Journal, 28 May 1806)

However, the only "eyewitness" statement that I can find which attributes death to seasonal scarcity is the missionary Bicknell's, written in January 1800: "The Natives have died with hunger in the scarce season which lasted 4 months this last year" (Bicknell to Callard, 14 January). While I acknowledge that seasonal food scarcities may have contributed to illness which terminated in death, I am inclined not to accept this statement literally-that is, I very much doubt that any significant number of Maohis past infancy ever died directly of seasonally-induced starvation. Anderson, also, asserted that "a famine frequently happens in which, it is said, many perish" (Cook 1784:153-154), but provided nothing more solid to document this broad statement than the usual "it is said." For famines resulting from the deliberate destruction of warfare, see p. 256.

One adjustment made by the Maohis to this fairly regular natural cycle was to consume as much of the fruit as possible as soon as it ripened-and

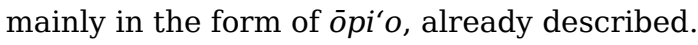

Another way the Maohis adjusted to the periodic scarcity of their prin- 
cipal food was to utilize other foods nearer at hand, such as sweet potatoes, pandanus, and 'ape, or to betake themselves to the mountains and valley fastnesses in search of plantains and other wild fruits and vegetables.

Finally, the seasonality of breadfruit helped to provide them with a schedule for activities not directly or physically connected with subsistence-religious ritual, social life in general, and concepts concerning the rhythms of the spirit side of their universe.

\section{Coconuts}

No plant of the Maohis had a wider variety of uses than the coconut (Cocos nucifera: niu, tumu ha'ari). To name the more important uses: the trunk was used for house and fence posts and for spears; the leaves for thatch, screens, baskets, and ornaments; the dried husk of the coconut for cordage, calking, sandals, and tinder; the shell for bottles and bowls, and for surgical trepanning; the liquid inside the green nut for a beverage; the meat of the nut or its extracted cream for food; and the oil derived from the cream for liniments and aromatic ointments. (Henry 1928:43-45)

The palm begins to produce nuts about five years after taking root and continues to produce for fifty to sixty years. Under favorable conditions the fallen nut will propagate unaided, but its survival and growth are better assured by planting. Palms were probably already growing in these Islands when the first Maohis arrived; nuts remain viable even after long immersion in salt water, but humans undoubtedly fostered their increase. When Europeans first arrived, palms were flourishing in large numbers on the atolls and off-island motus, as well as throughout the adlittoral zone. Small stands of isolated palms also were growing in altitudes up to 300 meters. (Papy 1954:II, 248)

No thorough scientific study has been published on palm varieties in these Islands, but the Maohis are said to have named about sixteen types, distinguished according to peculiarities of husk, nut, palm height, and so forth (Henry 1928:41).

To obtain an immature nut, for drinking, it had to be cut or twisted loose from the palm; this was done by hand, usually by a boy or youth who climbed the palm with the help of a coil of cordage stretched between his feet to aid in gripping the trunk. Such nuts were then husked and pierced, and the liquid drunk directly from the shell. The usual method of husking was to pry off the fibrous husk with the help of a pointed stick stuck in the ground, but people also used their teeth to tear away the fiber.

Needless to say, the Maohis were accustomed to recognizing and labeling several stages in the maturation of the coconut, and it is likely that most Maohis past early childhood could tell when a growing nut was at the best stage for drinking. 
As the coconut matures, its liquid is absorbed in an oily white solid, or "meat," that lines the inner surface of the shell. This meat was sometimes eaten when it was not yet entirely firm and dry. Perhaps more often, however, the meat was used only after it had become fully firm and dry, at which time it was scraped out of its shell by means of a shredding tool ('ana) - a serrated blade of shell or coral, usually attached to a wooden stand. The shredded meat was then placed in a skein of plant fibers which when twisted squeezed out the coconut cream. When nuts reach this stage of maturity they ordinarily fall from the palm, so that they need only to be collected from the ground. Banks reported having seen many such nuts tied onto the trunks of palms "that they might dry a little and be prepared for making poe" (Beaglehole 1962:I, 319).

Beyond the convention (but not, perhaps, the norm) that boys and young men were usually the ones to climb palms for immature nuts, there is no evidence of any customary division of labor connected with use of the palm or its products, except of course for such general practices as heavy construction, which was a male's job regardless of type of wood, or fine plait work, which was customarily allocated to females regardless of type of fiber.

Nut ripening was continuous and fairly even throughout the year. This, added to the circumstance that every household appears to have had access to enough palms for its own subsistence, indicates-what the early descriptions confirm - that there was no regular exchange involving products of the palm. Nuts, thatch, and other products did indeed circulate, but for purposes other than daily food needs.

\section{Wild Food Plants}

The mature Tahitian chestnut (Inocarpus edulis: māpē, rātā) is flat, kidneyshaped, about three inches long, and similar in consistency and in flavor to the common European chestnut. When roasted or baked it was much esteemed as a food by the Maohis; since, however, it ripened only once a year, in October through November, and evidently was not long preserved, it could not have been an important food staple. Yet, although unreported, there may have been some small-scale extrahousehold circulation of ripe nuts, since groves of the self-propagating trees were found only along certain streambeds and in other wet soils. There is no record of these trees having been purposely planted nor of any socially relevant practices concerning harvesting or preparation of the nuts.

Another self-propagating tree bearing fruit much eaten by the Maohis was the native mango (Spondias dulcis: vī; fig. 9-7), which grew at altitudes up to 600 meters in valleys, themselves fairly wet but located within the drier mesotropical zone. During its annual (summertime) ripening, the fruit, about the size of an orange and similar to a plum in flavor, was eaten raw 
in large quantities, but only as a supplement to ordinary cooked foods. On the smaller islands mango trees were within easy access of anyone; and although on the larger islands their locations were more unevenly distributed there is no evidence, direct or indirect, that this circumstance led to any regular extrahousehold circulation of the fruit.

Numerous other wild plants were collected by the Maohis for food; the more important of these having been the following:

The Malay apple (Eugenia malaccensis: 'ahi'a) flourished within the mesotropical zone and fruited but once a year, in summer. "The fine Apple called the Vee are now just in season, there must be however other seasons for this fruit, either from situation or habit, for when I first arrived we had great numbers of them. This is not the Case with the other Apple called the Ay-yah, the season for it being only once a Year" (Bligh 1789:II, 59). Because of its similarity to the common apple the European visitors appreciated its flavor, more so, apparently than the Maohis did.

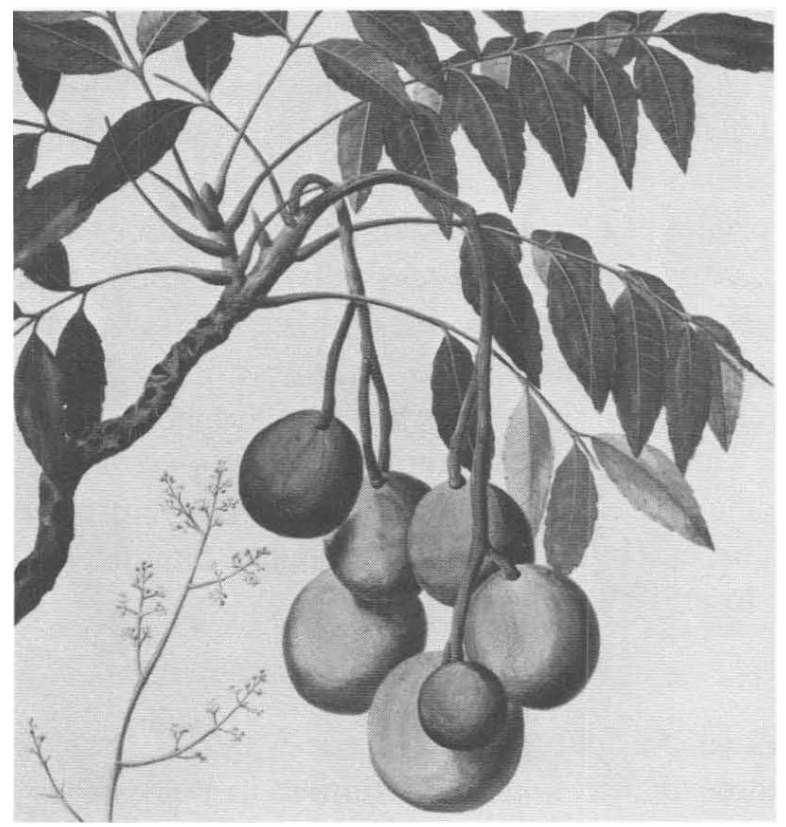

FIGURE 9-7. Tahitian mango (Spondias dulcis). Drawing by S. Parkinson. British Museum of Natural History.

The root of the ti plant (Taetsia fruticosa; also known as Cordyline terminalis, or Dracaena) was prepared by baking; favorite varieties grew mainly in wet valley pockets within the mesotropical zone. Henry has provided us with a description of a large-scale ti-root baking based evidently on late 
nineteenth-century observations, but presumably similar enough to earlier procedures to warrant quoting here:

The ti-leaf in the Society Group, was supposed to possess great magical power, and was much used for wands, or as garlands, by warriors or priests, and was also said to have enabled fugitives-by waving the branches before them-to fly over precipices and ravines away from their pursuers in troublous times. The yellow leaves are very much used in decorations, and have a sweet smell. It is stated that the ti-plant has been held in high esteem also by the Hawaiians, and is still supposed to possess great virtue.

The ti-root is frequently two feet long, and varies from six to ten inches in diameter. It has something of the texture of sugar-cane and its thick juice is very sweet and nourishing, but it requires to be well baked before eating.

The $t i$-ovens are frequently thirty feet in diameter, and the large stones, heaped upon small logs of wood, take about twenty-four hours to get properly heated. They are flattened down, by means of long green poles, and the trunks of a few banana trees are stripped up and strewn over them to cause steam. The $t i$-roots are then thrown in whole, accompanied by short pieces of ape-root(Arum costatum) that are not quite so thick as the ti, but grow to the length of six feet and more. The oven is then covered over with large leaves and soil, and left so for about three days, when the ti and ape are taken out well cooked, and of a rich, light brown colour. The ape prevents the ti from getting too dry in the oven. (Henry 1893:105-106)

Such ovens were also the sites of the "fire-walking" ceremonies, mentioned in chapter 3 , partly perhaps because of their suitably large diameters but also because of the direct availability of the ritually necessary ti leaves.

Of the many varieties of pandanus (fara) which grew wild in these Islands only those along the coast were occasionally used for food. The parts mainly eaten by the Maohis were the endosperms attached to the large strobile heads.

The small tree fern (Angiopteris evecta: nahe) supplied a root which was occasionally eaten, particularly by Maohis on hunting or fishing expeditions inland.

The "custard apple" tree (Morinda citrifolia: nono), which flourished especially in the adlittoral zone, near the sea, provided a small edible fruit, but was valued more for its leaves, which were used to wrap fish for cooking.

A variety of morning glory (Convolvulus brasiliensis: pohue) had stalks which were occasionally eaten.

According to Ellis, nahe, nono, and pohue served as famine foods, when more favored foods were not available (1829:I, 363-364). As Banks put it, these foods (plus the root of the teve [Amorphophallum campanulatus], which had to be treated like arrowroot) "... are eat only by the poorer sort of people in times of scarcity" (Beaglehole 1962:I, 343).

Another plant, the mountain plantain (Musa fehi: fe'i) far surpassed the others in alimentary importance. Ellis asserted that on several islands, "... the fei is the principal support of the inhabitants" (1829:I, 373-374); 
but he did not develop this potentially significant statement. (He elsewhere referred to breadfruit as "... the principal article of diet ..." [1829:355]); so one cannot be sure of the literalness of his reference to $f e^{\prime} i$.) These plantains grew mainly on high ridges and in valley recesses, often at altitudes of 600 to 900 meters; collecting them was a hazardous chore which taxed a man's skill and strength. Banks has left a description of the kind of terrain that had to be traversed to bring down the heavy bunches of $f e^{\prime} i$ :

At lengh we arrivd at a place where the river was bankd on each side with steep rocks, and a caskade which fell from them made a pool so deep that the Indians said we could not go beyond it, they never did, their business lay upon the rocks on each side of the plains above which grew plenty of Vae [fe'i]. The avenues to these were truly dreadfull, the rocks were nearly perpendicular, one near 100 feet in hight, the face of it constantly wet and slippery with the water of numberless springs; directly up the face even of this was a road, or rather a succession of long peices of the bark of Hibiscus tiliaceus which servd them as a rope to take hold of and scramble up from ledge to ledge, tho upon those very ledges none but a goat or an Indian [i.e., Maohi] could have stood. One of these ropes was near 30 feet in lengh. (Beaglehole 1962:I, 307)

Turnbull wrote, at the beginning of the nineteenth century, that "the Otaheiteans, indeed, have the mountain plantain at all seasons of the year; but they have a great dislike to climb the mountains after it, being much afraid of the wild hogs, which are very fierce. It is moreover a two-days journey, and therefore is an object of terror to the indolent inhabitants." (1813:351-352) But so highly favored was baked $f e^{\prime} i$ that large quantities were collected and consumed. ${ }^{20}$ This fact, together with the circumstance that some settlements were nearer than others to the sources of supply, may have resulted in some local variation in quantities collected and hence in some exchange with less favored locales, although there is no direct evidence on this point. According to missionary reports there was relatively little $f e^{\prime} i$ on either Huahine or Mo'orea. ${ }^{21}$ It was reported that in some settlements people were successful in cultivating $f e^{\prime} i-$ a measure that may have served to obviate the necessity for exchange; although Corney asserted that $f e^{\prime} i$ did not thrive in the lowlands even when cultivated (1915:271n).

\section{Cultivated Food Plants}

Their Cultivation does not extend to any great degree; the Chief Articles of it are the Cloth Plant, Yava, Tarro \& Sweet potatoes and some times they plant Cocoa Nuts \& Plantains but these plantations are generally the labour of the Chiefs and if they make one in their lifetimes they sufficiently do their duty-they seldom plant any Breadfruit trees as they grow up wherever the root is Seperated, by the Hogs or otherwise and they have often to root the young ones out, to Clear the ground of them, but the Plantains want Planting sometimes after the Westerly winds which if they are not secured are often blown down and these are the only things they take any pains with, nor can this be said to Cost them either Labour or 
Toil and as evry part of the Island produces food without the help of Man, it may of this Country be said that the Curse of Eden has not reachd it, no man having his bread to get by the Sweat of his Brow nor has he Thorns in his path. (Morrison 1935:152)

Morrison was a perceptive observer, and although his statement requires some correction and amplification it is in some respects confirmed by the reports of other early visitors to these Islands.

Certainly, taro (Colocasia antiquorum, C. esculenta) was the principal cultivated food plant of the Maohis, and it was in all likelihood introduced to the Islands by them. It must be grown in well-watered soil; some early observers noted the existence of extensive irrigated patches: "From thence we descended into a fertile valley, where a fine rivulet, which we were obliged to cross several times, ran towards the sea. The natives had placed several stone weirs across this rivulet, in order to raise the water, which might by that means be introduced into their plantations of the tarro, or eddy-root (arum esculentum) that requires a very marshy, and sometimes an inundated soil." (G. Forster 1777:I, 341-342; see also Pickersgill's Journal, reproduced in Beaglehole 1961:773.) The use of irrigation is confirmed in part by archaeological remains of terracing along the sides of stream beds. ${ }^{22}$ When mature, the tuberous root is ten to twelve inches long and contains about 50 percent starch; baked, it was a highly favored food, eaten by itself or mixed into puddings. Tender young leaves and stems of the plant, having a flavor like spinach, were also eaten. After the larger part of the tuber had been cut off the leaf stem for eating, the latter was replanted. In some cases, new plantings were started with small shoots growing around the main tuber. I cannot discover any early accounts of significant fluctuations in ripening, although the plant presumably did grow faster during the hotter and wetter "summer" months.

Gardening in general was the work of males; for lack of contrary evidence I assume that this generality applied also to cultivation and harvesting of taro. The early accounts do not refer specifically to the work of taro gardening - to the amount of time it consumed, to its organization, its ritual, and so on-except for such statements as "... its culture receives a considerable share of their attention" (Ellis 1829:I, 357).

Botanically related to taro and also utilized by the Maohis were taru'a and 'ape. The root of taru'a (probably Xanthosoma atrovirens [Papy 1951: 368]), resembling taro in flavor and consistency but smaller in size, was also extensively cultivated. 'Ape (Alocasia macrorrhiza) produces a much larger root which remains edible for months after reaching maturity, but it is coarser fibered and requires longer baking to render it edible. It was occasionally cultivated, in a drier soil, but grew also in a wild state and was eaten by the Maohis mainly in times when more favored foods were in short supply. 
Ellis and Davies added the following details concerning taro and tarolike plants:

Next to the bread-fruit, the taro, or arum, is the most serviceable article of food the natives possess, and its culture receives a considerable share of their attention. It has a large, solid, tuberous root, of an oblong shape, sometimes nine or twelve inches in length, and five or six in diameter. The plant has no stalk; the broad heart-shaped leaves rise from the upper end of the root, and the flower is contained in a sheath or spathe. There are several varieties; for thirty-three of which the natives have distinct names; and it is cultivated in low marshy parts, as the plant is found to thrive best in moist situations. A large kind, called ape, arum costatum, which is frequently planted in the dry grounds, is also used in some seasons, but is considered inferior to the taro.

All the varieties are so exceedingly acid and pungent in their raw state, as to cause the greatest pain, if not excoriation, should they be applied to the tongue or palate. They are always baked in the same manner as bread-fruit is dressed; the rind, or skin, being first scraped off with a shell. The roots are solid, and generally of a mottled green or gray colour; and when baked, are palatable, farinaceous, and nutritive, resembling the Irish potato more than any other root in the islands.

The different varieties of arum are propagated either by transplanting the small tubers, which they call pohiri, that grow round the principal root, or setting the top or crown of those roots used for food. When destitute of foreign supplies, we have attempted to make flour with both the bread-fruit and the taro, by employing the natives to scrape the root and fruit into a kind of pulpy paste, then drying it in the sun, and grinding it in a hand-mill. The taro in this state was sometimes rather improved, but the bread-fruit seldom is so good as when dressed immediately after it has been gathered. (Ellis 1829:I, 357-358)

The Ape is a specie of the Taro it grows in the mountains in most places and is sometimes planted in the low marshy ground, there are several sorts, three or four of which if well baked have a good taste and are not disagreeable in the eating, but will, if a considerable quantity be taken, cause a heat in the bowels and a very disagreeable itching of the anus. There are two or three other sorts, that baking will not qualify for use, for let it be ever so well baked, and tho' the taste be ever so agreeable in a minute or two after it is tasted and swallowed it will cause a burning and intolerable itching in the tongue and throat. This plant has very large leaves, and the root when in good ground near running water and sheltered from the sun, will grow very large frequently near two feet long and a foot in circumference and sometimes much larger, but will take considerable time to come to that size. (Davies, Journal, 19 December 1807, LMS Archives)

The sweet potato (Ipomoea batatas: 'umara) was cultivated by the Maohis, ${ }^{23}$ but, according to Ellis:

In the Sandwich Islands, the sweet potato is one of the principal means of subsistence; here [in the Society Islands] it is only partially cultivated, and is greatly inferior to those grown in the northern islands, probably from the difference of soil and climate.... The umara is very sweet, seldom mealy, and sometimes quite soft, and altogether less palatable than the taro or the yam. It is dressed by the natives in their stone ovens, and is only used when the bread-fruit is scarce. (1829:I, 360) 
Perhaps its method of cultivation may have contributed to its relative unpopularity; considerable labor must have been involved in building up the three-foot-high mounds of humus-rich earth in which these tubers were planted.

Yams (Dioscorea alata: uhi) were also cultivated by the Maohis. Somewhat puzzling is Morrison's statement that yams-he did not identify them further-were not cultivated: "Yams, Calld here Oowhi-these Grow wild in the Mountains, and are from one to six feet in length but not more then five or Six inches round, they are very good but as they take Much trouble to dig them out they are seldom sought after, except when the Bread fruit is Scarce, they never take the Pains to Cultivate them" (1935:143). But, according to Ellis, yams were cultivated "... to no great extent, on account of the labour and attention required," and perhaps also on account of food preferences. Papy noted that yams are eaten in modern times only when other foods are scarce (1951:99). Ellis continued:

The yam is one of the best flavoured and most nutritive roots which the islands produce. The natives usually bake them; they are, however, equally good when boiled; and, as they may be preserved longer out of the ground than any other, they are the most valuable seastock to be procured; and it is to be regretted that they are not more generally cultivated. Few are reared in the Georgian Islands [i.e., Tahiti and Mo'orea]; more perhaps in the Society cluster [Leeward Islands]; but Sir Charles Sander's Island [Mai'ao] is more celebrated for its yams than any other of the group. (1829:I, 360)

In this connection, however, there is no evidence that yams from Mai'ao circulated to other islands.

Early accounts list "wild yams"-hoi, pätara, and pā'auara-as having been occasionally collected by the Maohis in times of scarcity. ${ }^{24}$ Henry described pātara as "... a wild species of yam producing a mealy tuber not so sweet as the "umara; it is a native of the valleys" (1928:38). But it appears not to have been highly favored: “... I never saw one, for it is not cultivated, and but seldom sought, as the tuberous root is small, and more than two are seldom found attached to the same vine or stalk" (Ellis 1829:I, 361).

Ellis had this to say about hoi:

But though they have not rice, they have a plant which they call hoi, the shape and growth of which resembles the Patara; but in taste and appearance it is so much like rice, that the natives call the latter by the native designation of the former. It is very insipid, and only sought in seasons of scarcity. (1829:I, 361)

Pá'auara is described in the LMS Dictionary as an excellent root like a potato, but has a vine like the yam.

Most writers described these plants as having grown in the valleys-in 
the lower valleys of the wet-tropical zone, according to Papy (1951:99)—although the LMS Dictionary describes pātara as "... a good edible root, which grows in the mountains." 25

In my discussion of $f e^{\prime} i$ I noted that, although this highly favored plantain was occasionally cultivated, it was mainly collected from wild-growing stands located high in the mountains. In contrast, from among the many varieties of bananas and lowland plantains (Musa paradisiaca: mei'a) that grew in these Islands most of those consumed by the Maohis were cultivated by them in groves near their houses; but not in the orderly manner that Bligh had witnessed elsewhere: "I never saw a regular Plantain Walk in Otaheite-a few Trees are stuck in about their Houses, and others are dispersed arround the Hills in the same manner-this is all the trouble taken with them ..." (Bligh 1792:157). According to modern observations the cultivated varieties produce fruit year-round, although something of a peak is reached during the "summer" months.

Ellis provided some details concerning the "forced-ripening" of bananas:

The fruit is not often allowed to ripen on the trees, but it is generally cut down as soon as it has reached its full size, and while yet green; the bunch is then hung up in the native houses to ripen, and eaten as each turns yellow. When they wish to accelerate their ripeness for a public entertainment, they cut them down green, wrap them in leaves, and bury them thirty-six or forty-eight hours in the earth, and on taking them out they are quite soft, and apparently ripe, but much more insipid than those which had gradually ripened on the tree, or even in the house. (1829:I, 373)

Arrowroot (Tacca pinnatifida: pia; fig. 9-8) was probably introduced into these Islands by the Maohis. And the starch made from its root, by grating, water-settling, and drying, served as an ingredient in some of their finer puddings. According to Ellis the plant was sometimes cultivated, but it also grew spontaneously in sandy soils near the sea or on dry slopes. Though evidently - to Ellis at least-a food of superior quality “... and capable of being procured in any quantity, it requires some labour to render it fit for food, and on this account was not extensively used by the natives, but formed rather a variety in their dishes at public feastings, than an article of general consumption." (1829:II, 361)

Sugarcane (Saccharum officinarum: tō) grew wild in the coastal belt but some small patches were cultivated by the Maohis near their houses. The stalk was chewed between meals, and it was particularly favored as sustenance on journeys.

Although Wales described the Maohis' gardens as having been "their chief care" (Beaglehole 1961:798)—a judgment, by the way, not shared by many other European visitors-the layout of their cultivations did not correspond to the notions about gardening held, for example, by Bligh, who 
wrote that "cleaning and keeping their Grounds neat and free from Weeds is beneath the care of an Otaheitean." The reason therefore being, according to Bligh: "So much sloth and indolence may be attributed to the vast support that all bountifull nature has given to them in the use of the most valuable of all Fruits of the Earth, the Bread Fruit and Cocoa Nutt." $(1792: 157)^{26}$

All this, of course, is not meant to imply that Maohi horticulture was in fact slipshod. While the layout of their gardens may not have conformed to the Europeans' tastes in such matters, that in itself cannot be used as evidence that Maohi horticultural practices were inefficient. The truth of the matter is that what little information I can discover about those practices is not sufficient for making a judgment.

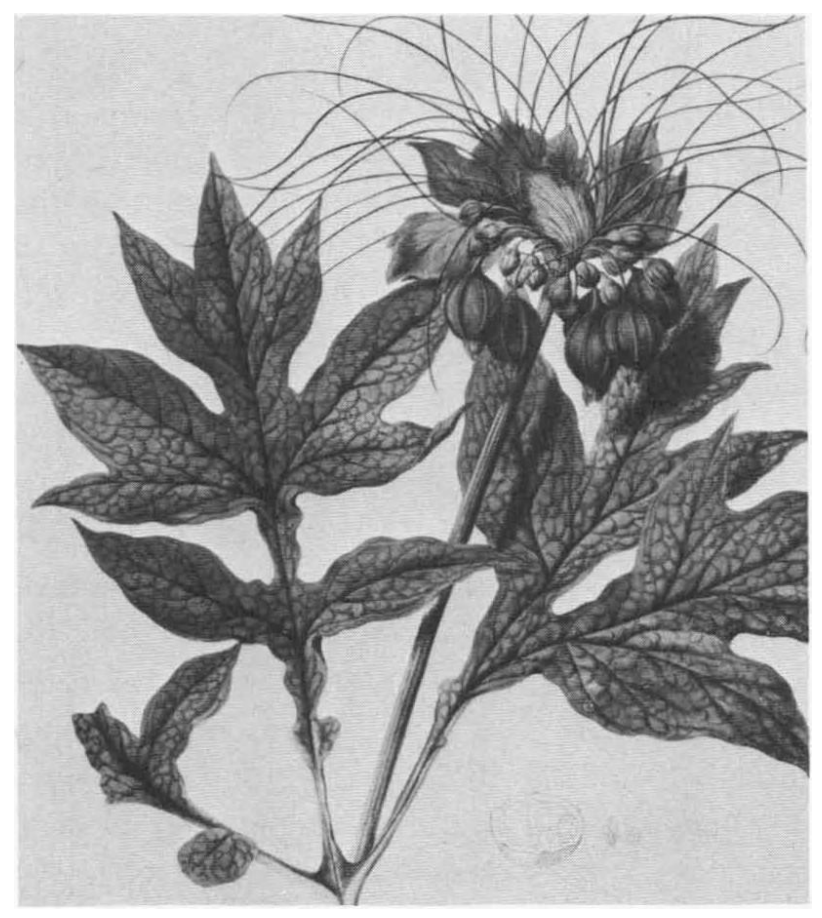

FIGURE 9-8. Arrowroot (Tacca pinnatifida). Drawing by S. Parkinson. British Museum of Natural History.

\section{PLANT-FOOD DISTRIBUTION}

From the foregoing it appears that these Islands were large enough, and fruitful enough most of the time, to provide adequate plant-food for their populations. ${ }^{27}$ There were certain geographically conditioned regional differences in overall productivity and in type of product, as, for example, on Mo'orea, where missionaries made the following kinds of observations: 
"Oteha is a small place \& has but few bread fruit trees but some good ground for tarro, of which they have a large quantity growing" (Elder \& Wilson, Journal, 10 February 1804, LMS Archives). "Farrearee is a large district, contains a considerable number of breadfruit trees: the land is tolerably good" (16 February 1804). "Teavaroo is a small district \& not many breadfruit trees ... Puppeare is a small district but little good land \& few breadfruit $\&$ coconut trees. The soil of the Island is not so good as Otaheite $\&$ the breadfruit trees are smaller." (20 February 1804)

These differences were reflected in population densities, in everyday activities, and even in social relations. There were also occasional natural disasters-principally hurricanes and droughts-which brought hunger in their train, but recovery from them was usually rapid. Thus, in terms of Maohi technology and food habits the physical environment of these Islands imposed no serious restraints on Maohi subsistence. But what about the social distribution of horticultural resources-land, trees, tools, and labor?

Treatment of the complex subject of Maohi land tenure will be discussed in several following chapters and summarized in chapter 24, but here are some generalizations about it that have to do directly with horticulture.

Residual title to or realistic control over most land, including that capable of food production, rested ultimately in the hands of a district's sovereign chief. Nevertheless, with a few possible exceptions (particularly on Tetiaroa, where few food plants would grow), every household had, through exercise of some sort of claim, use of as much food-producing land as it required-not always of the types suited to growing all plants in the proportions desired, but probably enough to satisfy biological needs. In this respect at least, there was not only enough horticultural land to support the whole population, but also social-relational norms varied and flexible enough to ensure practically everyone an adequate access to that land.

As for food-producing trees, on many Pacific islands it was not uncommon for valued trees to be owned separately from the land on which they grew. Similar usages probably obtained among the Maohis, although there is only one indirect evidence that such was the case. In any event, there was considerable freedom-among kin and neighbors, at least, except in periods of general shortage-to take fruit from one another's trees, as witnessed by missionary reports:

Since the islands became Christian, neither the Missionaries, nor the Natives in general can do now as formerly they did; with respect to pulling the bread fruit, cocoa nuts or mountain Plantains. Neither we nor they are at liberty to pull for our use but such as grow within our Gardens, or near our dwellings, without permission from the owner or proprietor of the land whereon these fruits grow. This is an entirely new regulation among them since they became Christian, and they conceive it to be equitable, and no way inconsistent with their profession. They 
are aware that this is the law of Britain and other civilized parts of the world. (Hayward to LMS, London 1819 or 1820, LMS Archives)

There is nothing in the sources to suggest that anyone went hungry during normal times for lack of planting stock or agricultural tools-adzes, digging sticks, and so forth. But what about labor?

The early observers may have exaggerated somewhat the physical ease with which most Maohis obtained what they considered to be an adequate supply of plant-food, but my impression is that arboriculture and tillage were certainly less time-consuming here than in many other Oceanic societies; there is no precise evidence concerning actual amounts of time spent in such work. Neither is there evidence that such work required a high degree of specialized knowledge and skill. Whereas there were specialists (tahu'a) in fishing, canoe building, religious ritual, and fighting, there is no specific mention of any specialists in connection with horticulture.

Men, in general, did most of the work of producing and collecting plantfoods, but women seem not to have been excluded from such kinds of work by any inviolable restrictions, nor were there any limits placed on such labor due to age or class. In fact, in connection with the latter the sources contain several references to upper-class men who joined energetically with their subjects in setting out new plantings of breadfruit and coconuts.

In summary, none of the factors just listed-proscriptive labor norms, lack of tools or planting stock, or availability of land-exercised any serious restraints upon plant-food production. In fact, what restraints there were derived mainly from other considerations.

Demand for tribute undoubtedly operated as an incentive for "surplus" agricultural production; but it also served to restrain production, as the missionaries discovered when they sought to induce their converts to grow more food:

When we exhort them to labour, and shew them the advantages of civilization; they acknowledge it is all very good, very delightful. They confess their inferiority \& say it be well for them to do so. But they immediately ask us Of what use is it? Soon as we have got these things about us the King's people will come \& say, give us this for the King, give me the other for the King...." (Platt to Burder, 12 November 1818, LMS Archives)

In other cases such demands had the effect of increasing the amount of labor spent in meeting the farmers' own subsistence needs:

From the centre hills towards the sea, for a little distance up, the hills abounded with cocoa-nuts and bread-fruit, and the more interior parts with mountain plantain, tarro, and a variety of other things, which they have recourse to when the low land cannot supply all their wants. Asking Peter what reasons they gave for not cultivating more of those articles on the low ground, as it was evident they would grow as well, or better, there, he said it was on account of the havoc made 
by the arreoies, and those who accompany Otoo (Tu) in his feastings round the island; at which times, though they only stay two or three days in a district, they consume and wantonly destroy all the produce, and often the young plants, leaving nothing for the settled inhabitants of the place to subsist on, but what they derive from the mountains: on this account they submit to the trouble of climbing almost inaccessible places, rather than expose much of the produce of their labour to their privileged robbers. (Wilson 1799:194-195)

Warfare was another activity that served to restrain agricultural production. Not only did invading forces destroy gardens and cut down or ring-bark food-bearing trees, ${ }^{28}$ but consequently during unsettled times people were reluctant to plant new gardens or set out new trees, as will be described in chapter 12 .

\section{KAVA}

The only intoxicant or narcotic imbibed by the Maohis was an infusion made from the root of the pepper shrub (Piper methysticum: 'ava), a plant which was found occasionally growing wild but which came mainly from gardens that, in their tidiness and layout, were quite uncharacteristic of the Maohis.

Here [near a dwelling] I thought I got a sight of an European garden; the plats of ava-ground were laid out in such nice order: each bed formed regular parallelograms, trenched two feet deep, and disposed with a great degree of taste; the whole enclosed with a fence of bamboo. (Wilson 1799:193)

The cloth plant, which is raised by seeds brought from the mountains, and the $a v a$, or intoxicating pepper, which they defend from the sun when very young, by covering them with leaves of the bread-fruit-tree, are almost the only things to which they seem to pay any attention; and these they keep very clean. (Anderson, in Cook 1784:145)

The beverage appears to have been made in two different ways. According to some accounts pieces of the root were chewed (by "servants" say some reports; by "young women" says another) and spit into a wooden bowl. To this was added some water or coconut juice, along with some crushed leaves of the pepper plant. After mixing the concoction the root fibers and leaves were removed with a strainer and the drink was ready. When the first brew was nearly consumed more liquid was poured over the masticated roots again and again, until the brew had no more efficacy. For example, Bligh's report begins: "It is drank four or five times a day, and the operation of making it, is as filthy as the Use of it is punicious." He continued: "This Ava is made from a Strong pungent Root which few Cheifs ever go without, it is chewed by their Servants in large mouthfulls at a time, which when it has collected a sufficiency of Saliva is taken and put into a Cocoa Nut Shell. This is repeated untill there is enough 
chewed, it is then squeezed and given to the principall Men...." (Bligh 1789:I, 382; see also G. Forster 1777:I, 406)

Anderson, however, described a very different kind of process: "But this beverage is prepared somewhat differently, from that which we saw so much of at the Friendly Islands. For they pour a very small quantity of water upon the root here; and sometimes roast or bake, and bruise the stalks, without chewing it previously to its infusion" (Cook 1784:155). ${ }^{29}$ Anderson's statement appears to have had reference to the Society Islands in general, or at least to Tahiti, but a passage quoted by Beaglehole and attributed to Williamson, who was also on Cook's final visit to these Islands, implies that nonmastication of kava was distinctive of Ra'iatea:

The Yava which I have before mention'd is drank at all these islands, but at Ulietea only clean and decent, in stead of that filthy manner of making their slaves first chew it, it is put into plantain leaves \& baked, the moisture of the leaves softening it, as if it was boil'd, it is then braised in a wooden bowl mix'd with water, strain'd, \& then served out to the guests. (Williamson, in Beaglehole 1967:252n)

The effect, all observers reported, was befuddlement leading usually to sleep. According to some accounts the drink immobilized the limbs, especially the legs, but heightened mental activity for a while, before sleep or stupefaction set in. The capacity to arouse oneself to action quickly out of a kava-induced stupor was regarded as an attribute of "heroes" (Adams 1901:19-20).

For maximum effect kava had to be drunk before and with meals. One such effect was observed by Cook: "The next morning the yava was in great plenty. One man drank so much that he lost his sences, I should have supposed him in a fit from the convulsions he was in; two men held him and kept plucking off his hair by the roots" (Beaglehole 1967:215-216). Drunk on a full stomach it produced only mild stupefaction. All observers agreed that excessive imbibing - that is, four to five times a day for weeks at a time-so reduced the appetite for food that the person became thin and drawn, and his skin scurfy: “... the skin begins to be covered with a whitish scurf, like the leprosy...: the eyes grow red and inflamed; and the soles of the feet parched and cracked into deep chaps, as some lips in winter." But upon discontinuance of the practice, we are informed, "... the skin soon becomes smooth and clean, and they grow fat...." (Wilson 1799:375). In fact, one visitor reported that if imbibed with regularity, though not to excess, it had the effect of warding off other bodily afflictions and thus lengthening one's life.

After about a fortnights Constant use the Skin comes all over with a white scurf like the land scurvy and the Eyes grow red \& firey and the Body lean and Meagre but on being left off for a few days the Scales fall off the Skin then be- 
comes clear \& smooth and they soon grow fat \& wholsom to view-this gives me reason to think that this nausious draught must be very wholesom as those who use it are Seldom afflicted with disorders of any kind and those who use it regularly are some of the oldest men in the Country (Morrison 1935:151). ${ }^{30}$

In contrast with Tonga, where the making and drinking of kava provided the activity whereby a large-scale assembly was ceremonialized, the making and drinking of it by the Maohis was done-according to one European visitor, who knew both archipelagoes-“... in an unsocial manner, by one, two, or three at a time" (Wilson 1799:191). "Large companies do not assemble to drink it, in that sociable way which is practiced at Tongataboo" (Anderson, in Cook 1784:155). I should point out also that I have come across no mention of the occurrence of kava drinking as part of religious ritual. Indeed, a passage from Henry seems to imply that kava imbibing was a specifically secular (noa) activity, to be kept apart from things and events that were sacred $\left(r a^{\prime} a\right)$. The passage in question is part of a chant uttered by the laity when taking leave of the marae at the conclusion of a large-scale and longlasting religious ceremony:

We are now retiring to use our hands and become vile [ha'a ha'a]: we shall do domestic work, wear flowers, paint ourselves yellow with mati [a dye made from berries of Ficus tinctoria], blow [make] fire, curse, give each other blows, practise black art [sorcery], caress, put on unconsecrated [noa] clothes, eat pork, cavalla fish, shark, bananas; and drink 'ava; look not upon us in anger for this, $\mathrm{O}$ god! (1928:172)

Some observers reported that in the Society Islands only the "principal people" imbibed kava with any regularity, so that the physical signs of excessive imbibing served somewhat as "... a badge of nobility" (Wilson 1799:375). Or, as one missionary observed: "This extremely odious appearance of the skin is looked upon as a badge of honour by the Taheitians, when a man from his circumstances can afford, or from strength of constitution can bear to drink sufficient quantities as to affect him in this manner." (Warner, Medical \& Surgical Journal, Tahiti, 9 May 1808, LMS Archives)

Scarcity of the pepper plants rather than any general explicit social prohibition was probably responsible for the sporadic consumption of the beverage (Corney 1915:472). "It [kava imbibing] is Common to all but is more used by the Chiefs \& their Familys, Servants \&c than by the common people. They prefer the method of Chewing it to any Other-it is in much request among people of rank but even some of them never tast it." (Morrison 1935:151) $)^{31}$

For some reasons difficult to fathom, pepper plants appear to have grown better in certain districts than in others, and in some not at all (Corney 1919: 52; Wilson 1799:192); hence, it served as a greatly appreciated gift when people visited each other. It also seems to have flourished more 
on some islands than on others: for example, when a Spanish vessel made a trip from Tahiti to Ra'iatea two Maohis were sent along by their chiefs for the purpose of bringing back a supply of the roots. But aside from occasional transactions of opportunity like these, it is not known whether kava, in the form of gift exchange, tribute, or barter, circulated with any regularity.

\section{FOOD-PLANT RITUAL}

For a people so dependent upon spirits for their personal welfare and for the success of such enterprises as boatbuilding, fishing, and warfare, it might be assumed with some justification that the Maohis took parallel ritual measures to ensure good harvests of food plants. But the only records we possess concerning these measures have to do with large-scale public ceremonies; to the best of my knowledge the sources contain no mention of specifically horticultural rites-consecrating planting stock, encouraging tree growth, et cetera-so prevalent in many other societies of the Pacific islands. What evidence we have on this score is indirect and concerns $t i^{\prime} i$, those images that fetcher spirits occupied while serving the interests of their human associates. The archaeological recovery of some of these images from spots that appear to have been sites of gardens suggests that they were placed there for purposes of stimulating crop growth, or of protecting the growing crop from destruction, or both.

The large-scale public festivals associated with food-plant production were of two types: one celebrating the beginnings of the season of greatest plant-food abundance (tau 'auhune) and the other, some months later, signalling its climax and approaching end.

The festival of the ripening-of-the-year (parara'a [or maoara'a] matahiti) took place at the beginning of the year's most plentiful breadfruit harvest, which usually occurred within a few weeks after the summer solstice (although it appears that the festival itself was scheduled according to the time of fruit ripening and not according to any recognized point in the solar, or sidereal, cycle). According to Ellis, the ceremony of ripening-of-the-year was, on Huahine at least, "... regulated by the blossoming of reeds"; but he does not specify exactly when that took place or what the reeds in question were (1829:218). Though certain other food plants, notably taro and bananas (mei'a), fruited more or less year-round they also ripened most abundantly during the summer months; in any case breadfruit was in most places the prime staple and its ripening was the event that mattered most. This meant of course that the ceremony itself took place at different times from one place to another, in line with regular climatic differences, and possibly also at somewhat different times of the year in any one place, because of rainfall irregularities.

Ripening-of-the-year consisted primarily of a public offering of food 
and other valuables to the communities' tutelar spirits and sovereign chiefs, followed by days of feasting, sports, and other diversions. Several writers mentioned this festival, but only fragmentarily or in the most general terms. ${ }^{32}$

The first question that arises concerning this festival has to do with the nature of the social units involved.

On such an occasion, the chiefs and people of the districts brought to the capital contributions of food, which they placed upon the assembly ground in an immense heap, called a poropa, and systematically divided a liberal part into shares. With appropriate speeches by the official orators they presented these to the gods and keepers of the royal marae, to the royal family, and to the clergy, reserving the rest for themselves. (Henry 1928:177)

Moerenhout was similarly vague, in speaking about an assembly of "... the whole population of the districts," under the general command of the "ari' $i$ rahi", or "superior chief" (1837:I, 519). For a small and more or less politically unified island such as Huahine this question is not difficult to answer: presumably the whole populace assembled at one place for the festival. On most other islands the social composition of such festive-making units must have varied greatly from place to place and from time to time, sometimes comprising a small compact and more or less autonomous tribal district, at other times and places a whole loose confederation of large districts. In this connection it would be interesting to know-but it is impossible to discover-what occurred in a political unit large enough to incorporate places with somewhat different fruit-ripening times. In any event, the accounts are in agreement that whole populations turned out for these occasions, and while women could not of course have witnessed the religious rites in the marae precincts, they presumably did partake of the feasts and join in the general revelry outside. It is also reported that while such festivities were in progress all hostilities ceased-at least among those social units joining in any one festival (Moerenhout 1837:I, 518). E.S.C. Handy implied that warfare was taboo during the entire "season of abundance"-from December through January to March through April (1927:301); if such were the case, however, it was a frequently dishonored truce.

A second question concerns the nature of the "offerings" involved in ripening-of-the-year. The breadfruit and bananas brought to the assembly were indeed "first fruits": supposedly they were the first fruits to ripen of each seasonal crop-te mau mä'a hou ote fenua the new fruits of the land' (E. Salmon 1937:30), and prior to the ceremony it was forbidden to anyone to eat any part of the new crops. In addition, people brought to the assembly coconuts and other food plants which ripen year-round, along with pigs, dogs, tapa, mats, and even canoes built especially for the occasion. In fact, according to Moerenhout, the several social units joining together in one of these festivals attempted to outdo one another in the value of their contributions, "... in order to win most favor with the gods." 
(1837:I, 518) In describing food brought as "gifts" or "tribute" to large public ceremonies the missionaries remarked that "... These presents of Fish, Plantains, Uru, Coconuts, \&c are generally more for shew than anything else. The Uru is commonly fit [only] for Hogs, and the Fish, Taiero \&c kept so long before ..." [page missing] (Davies, Youl et al., Journal, 29 March 1806, LMS Archives).

The ceremony itself has been described in some detail by Moerenhout. He could not himself have witnessed any such events and did not indicate the source of his information, but since his is the only reasonably full account of the proceedings I reproduce it in full, for whatever it may be worth:

This kind of festival always took place near an island's principal marae. ${ }^{[33]}$ Those from a distance made sure of arriving on time for it, but not before the day the ceremony was to begin.

It must have been a magnificent sight: with so many canoes arriving from far and wide, all in full sail and fully laden with the people and their chiefs robed in rich and impressive attire. Each [tribal] district sent four newly made canoes as an offering \& these preceded the main fleets and carried in them many objects destined for the gods. On landing, these canoes were ceremonially received by the [hosts'] priests, who performed several preliminary ceremonies, following which the chiefs and his subjects were permitted to disembark. Thereupon, the new canoes along with their cargoes were presented to the host, the Ari'i Rahi, who assumed custody over them but left them [for the moment] untouched.

After all the guests had arrived they and the host and his subjects assembled, by tribal contingents, and the local High Priest stepped forth and gave the command for all to proceed with the offerings to the marae, the High Priest then led the parade, accompanied closely by the priests of the visiting tribes, all garbed in their clerical garments-that is to say, enclosed in fine mats that reached up to their waists. Thus clothed they marched in line, blowing their bamboo-lipped conch-shell trumpets, with the kinds of sounds, more loud than musical, that accompanied all such processions associated with religious festivals or war ceremonials.

Upon arrival at the marae all the objects brought along were placed inside its enclosing walls and the priests began the services, which consisted of thanksgivings and of other long prayers, Then, the tâu pure [invocation pray-er], the local sacrificer, placed upon the altar a small amount of the received fruits and other comestibles, as offerings to the gods, and designated the remainder for the host chief.

On hearing this announcement the throngs crowded around the marae shouted out a demand for the food thus specified and a deputation from them presented their request to the host-chief, who, as was usual, made them a present of all the things not specifically reserved for the gods and the clerical personnel, or not required by the chief himself and his companions. When the chiefs' messages made this known to the crowds outside they rushed into the enclosure and set upon the vegetables, pigs, chickens, and so forth, so designated-fighting and grabbing and pulling them in a howling and savage melée, which, notwithstanding, usually ended up without any fatalities or serious casualties.

This mode of distribution was without doubt inequitable, but it may well have been a survival of [former, more barbarous days]. And in any case, when the [ritualistic] snatching melée was over, the goods themselves were then distributed quite equitably among all the participants.

The ceremonies just described were always followed by a general feast, and 
in view of the large quantities of provisions usually assembled on such occasions, the feasting ordinarily continued for several days. All this might seem quite alien to a so-called religious event, for with the exception of the "religious" chants that always preceded the Ariois' performances [which usually accompanied these affairs], the whole time was spent in feasting, dancing, racing, mock-fighting, boxing and wrestling, and so on; and such activities did not terminate until the food ran out. (Moerenhout 1837:I, 518-521)

According to Henry, the principal spirit honored at ripening-of-the-year rites was the god Romatane, who was special patron of the Arioi paradise; this god was invited "... to come with the spirits of [the offerers'] deceased friends to share their pleasures." Henry added that "... some families, especially in Huahine, spread out upon lines in their houses tapa, which they placed at the disposal of those spiritual guests" (1928:177).

Ellis characterized these rites as follows:

When the prayers were finished at the marae, and the banquet ended, a usage prevailed much resembling the popish custom of mass for souls in purgatory. Each individual returned to his home, or to his family marae, there to offer special prayers for the spirits of departed relatives, that they might be liberated from the po, or state of night, and ascend to rohutunoanoa, the mount Meru of Polynesia, or return to this world, by entering into the body of some inhabitant of earth.

They did not suppose, according to the generally received doctrine of transmigration, that the spirits who entered the body of some dweller upon earth, would permanently remain there, but only come and inspire the person to declare future events, or execute any other commission from the supernatural beings on whom they imagined they were constantly dependent." (1829:II, 218)

Morrison described two kinds of first-fruits offerings-one principally to spirits, the other principally to "chiefs":

The first Fruits of all kinds are offered to the Deity, next to the Chief and to the Lord of the Mannor before they eat any themselves, and the Fish in like Manner; if a Man has a Fishing Seine to Wet or a New Canoe to launch he makes a Feast on the Morai for the Priests, who offer up Plantain trees and prayers for their success, and the First fish always goes to the Morai where the priest offers it with prayers, The Next to the Priests, the 3rd to the Chief and the 4th to the Lord of the Mannor or landlord; and till all these are served they never taste the Fruits of their labour.

The first pig is always offered at 8 or ten Days old and a Chicken of the Brood is also offered, and for their Children they always make an offering according to their ability and is either a Pig or a Fowle. (Morrison 1935:183)

They Make an Offering of their First fruits to the Chiefs besides those Made to the Deity. This Ceremony is Calld Eehee Aree and is thus performd-the Fruits being ripe the Towha or Lord of the Mannor informs the Ratirra or Squires that on such a Day the Offering is to be made \& it is Proclaimed through the District by a Cryer to inform their respective Tennants, the Mattaeynas or Mannahoune's, who on the day appointed each gather some of evry species and having put them into a Basket, which is hung round with a piece of Cloth, [it] is tied to a pole, which is ballanced on their Shoulder by a sucking pig hung by 
one foot to the other end, and repair to the House of their respective Ratirra who then heads his own people and proceeds to the House of The Towha, who with His priest and Orator heads the Whole and the procession proceeds to [the] House of the Chief, somtimes four or five Hundred in a body, where being arrived the Towha by Means of His Priest and Orator (who always attend on such occasions) makes a Peace offering of [a] Young Pig, a Plantain tree \& a small tuft of red Feathers; these the Priest offers as usual and the Orator makes a long speech in behalf of the Towha \& Ratirras expressing their loyalty and the love they have for their Chief. The Ratirras having by Means of their Priests (each Family having One or More in or depending on it) made their Peace Offering, the Fruits are deposited before the Chief and they retire and return home. When this Ceremony is performd to the King the Chiefs of the District always head the procession.

This Ceremony is then performd by the Ratirras to their respective Towha and afterwards by the Tennants to their Ratirras, after which they Carry in as Much Bread as they think will be sufficient, putting it in large Baskets made of Cocoa Nut leaves which when filld are as Much as two Men Can Carry-with each of which they send a small Fish, intimating that they do not offer bread alone, with this a Baked hog and several small baskets of Bread, Tarro, Cocoa Nuts With the Husks peeld off, Plantains \&c. are Carried to the House of the Chief, Towha or Ratirra each in their due proportion. (Morrison 1935:216)

The second of these offerings will be described in chapters 16 and 23 . Meanwhile, it is noteworthy that neither of Morrison's accounts mentions redistribution\& whether this betokens an oversight on his part, or an actual difference in custom, is not clear. The same uncertainty holds for Morrison's omission of reference to spirits' shares of the contribution to the chiefs, but I very much doubt that any large-scale transactions of this kind ever took place without some part going to spirits.

The second great festival associated with plant-food seasonality took place at the time when such foods were most abundant-usually during March and April by Western reckoning, but varying in keeping with local differences in times of fruiting. It was in this sense, therefore, a harvest ceremony, and was accordingly a festive occasion. But while celebrating the height of the season of abundance, it was also (in these Islands where plantfoods were only partially preservable) the prelude to the season of greatest plant-food scarcity, and hence, according to one interpretation, was celebrated with dolorous overtones.

Little else has been written about these harvest festivals themselves except that they were "brillant" affairs, attended by multitudes of people dressed in their best attire, and consisting of some marae rites, dancing, games, competitive sports, and general revelry; a last grand fling, it is implied, before months of privation to come (Moerenhout 1837:I, 502). Immediately thereafter, each priestly representative returned to his own marae, public or domestic, and besought whatever spirit to which he prayed to return in due time from the realm of darkness $(p \overline{)})$, where spirits were believed to remain during the season of scarcity. Thereafter, and until the 
next season of plenty, according to Moerenhout's account, rites continued to be held at marae throughout the land, to encourage the spirits to cause plant-foods to ripen again. ${ }^{34}$

The ceremonies at the marae had no other object but to secure fertility and abundance from the gods during the seasons of slow growth and scarcity. Dealing with their gods as they had so often to deal with one another, they sought to gain their favor by appealing to their personal interests. "Oh Gods!" they would say from time to time, when delivering at the marae such offerings as unripe plant-foods and other comestibles of inferior quality, "Gods! This is all we have to offer you at present. But if you will hasten the ripening of our plant foods, and provide us with an abundant harvest, we shall bring to you the first fruits and all that is best thereof. (1837:I, 523)

\section{ANNUAL-CYCLE TIME RECKONING}

The relation between the great festivals and the seasonal ripening of staple plant-foods directs our attention again to Maohi time reckoning.

The Maohis perceived several of what Westerners would call natural cycles:

1. a diurnal rising and sinking of the sun (which has already been described);

2. a lunar month (marama) of twenty-nine days, or rather "nights";

3. an annual (matahiti) cycle of twelve to thirteen lunar months;

4. an annual cycle mainly in terms of the ripening of different breadfruit varieties;

5. a seasonal (tau) cycle based on visibility or nonvisibility of the Pleiades;

6. an annual cycle based on weather conditions at sea and on other conditions having to do with fishing.

The succession of nights making up the lunar month will be discussed in connection with fishing, with which it was mainly concerned. The earliest detailed statement concerning the annual cycle made up of the lunar months themselves came from Banks:

For their Method of dividing time I was not able to get a compleat Idea of it, I shall however set down what little I know. In speaking of Time either past or to come they never use any term but Moons, of which they count 13 and then begin again: this of itself sufficiently shews that they have an Idea of the Solar year but how they manage to make their 13 months agree with it I never could find out: that they do however I beleive because in mentioning the names of months they very frequently told us the fruits that would be in season in each of them, the sort of weather that was usual in them \&c. They have also a name for the 13 months collectively but they never use it in speaking of time, they use it only in explaining the mysteries of their religion: in their metaphorical way they say that the Year Tettowmatatayo was the daughter of their cheif Divinity Taroataihetoomoo ${ }^{[35]}$ and that she in process of time brought forth the months, who in 
their turn produc'd the days, of which they count 29 in every month including one on which the moon is invisible. (Beaglehole 1962:I, 368-369)

Thereafter, lists of lunar months were recorded by J. Forster, Bligh, and several of the London missionaries. All these lists contain many of the same names, which follow one another in about the same order. Yet, according to the English calendar with which each of them has been brought into correspondence, some of the same months occur on different lists as much as three or four months apart. Also, some lists contain twelve and others thirteen month-names\& according to Bligh the twelve-month calendar was most current on Tahiti, the thirteen-month one on Ra'iatea (1789:II, 45-46). The sources differ somewhat concerning where to place the beginning of each yearly cycle of lunar months. ${ }^{36}$ However, I am inclined to agree with Bligh that the Maohis probably had no conception of a beginning of the lunarmonth cycle before Europeans began to inquire about the matter.

The second of these discrepancies is not easily explained. In the face of it, neither a twelve-lunar-month cycle (i.e., 348 days) nor one of thirteen months (i.e., 377 days) can be harmonized with the 365-day solar cycle, with which it was evidently geared, without recourse to some system of intercalation. Bligh suggested that there was a special intercalary "month" called Tawa which somehow served the purpose, but the uncertainty remains to this very day.

As for the first of the discrepancies, a readier explanation is at hand. As we shall see, the names of most of the lunar months listed refer directly or indirectly to seasonal fluctuations in the supply of plant-foods, mainly breadfruit. In view of the local variations in the time of breadfruit ripening, it seems clear that the Maohis adjusted their month-names to their food supply. As examples of two of these calendars I reproduce below two lists reported in Henry-a thirteen-month one said to have been supplied by Pomare II in 1818, and a twelve-month one based on information from the Papara (Tahiti) chiefess Ari'i Ta'imai in 1891. References to English names of months clearly identify these texts as post-European, but there is no reason to suppose that these Maohi names, or their order of occurrence, had been adapted to European ideas:

Teie te piti o te tai'o i te tau; e na ni'a i te ava'e:

Here is the second way of counting the seasons; it is by the moons:

YEAR OF THIRTEEN MOONS

1. O Rehu (Varehu, Arehu), te haere mai nei te 'ahune; ia Titema e Tenuare ia tau. I te tua o Rehu, o

2. Fa'ahu-nui, te tamoe no te 'ahune; ia Tenuare e Fepuare. I te tua o Fa'ahu, o
Rehu (Levelling) is when harvest is coming in; this period arrives between December and January. On the back of Rehu comes

Fa'ahu-nui (Great-repose), the sound sleep of plenty; between January and February. On the back of Fa'ahu comes 
3. Pipiri, te 'ore ra te ma'a; ia Fepuare e Mâti. I te tua o Pipiri, o

4. Ta'a-'oa, te 'ore ra te 'uru; ia Mâti e Epereera. O te tua o Ta'a-oa, o

5. Au-unuunu, ua unuunu ia te hóe o te rava'ai, e anotau vero; ia Eperera e Mê. I te tua o Au-unuunu, o

6. 'Apa'apa, te pou no te tau o'e, te parara'a o te ra'o'ere ra'au e ma'iri atu ai; ia Mê e Tiunu. I te tua o 'Apa'apa, o

7. Paroro-mua, pohera'a o te re'a ia Tiunu e Tiurai. I te tua o Paroromua, o

8. Paroro-muri, e tau o'e; ia Tiurai e Atete. I te tua o Paroro-muri, o

9. Muri-'aha; ia Atete e Tetepa. I te tua o Muri-aha, o

10. Hia'ia, te pou ra'a 'tu i raro roa i te o'e; ia Tetepa e Atopa. I te tua o Hia'ia, o

11. Te-mâ, o te mâ rea 'tu ia o te ma'a tahito, e tupura'a o te ma'a api, o te tau ia e tanu ai i te ma'a; ei Atopa e Novema. I te tua o Te-mâ, o

12. Te-'eri, ia Novema. Ei reira e 'oteo mai ai te 'uru apî. I te tua o Te-'eri, o

13. Te-ta'i, Te-ta-ai-nui-ia-tuma, ia Titema. Te tupu ra te uru; te ta ai ra ia i te hui ma'a o te taevao i tai.
Pipiri (Parsimony), the time when scarcity begins; between February and March. On the back of Pipiri comes

Ta'a-'oa (Departing-joy); breadfruit is scarce. On the back of Ta'a-'oa comes

Au-unuunu (Suspension); the fisherman's paddles are then put away, it is a stormy period; between April and May. On the back of Au-unuunu comes

'Apa'apa (Severed-in-twain), descent into the time of scarcity of food; the leaves of plants then yellow and fall off; between May and June. On the back of 'Apa'apa comes

Paroro-mua (First-fall). Turmeric and wild ginger then die out; between June and July. On the back of Paroro-mua comes

Paroro-muri (After-fall), the last of the fruit season; between July and August. On the back of Paroro-muri comes

Muri-`aha (Prayer-behind); between August and September. On the back of Muri'aha comes

Hia'ia (Cravings), descent into the greatest scarcity of food; between September and October. On the back of Hia'ia comes

Te-ma (The-clearing), when the old crops are clean gone and new crops are developing, which is the season for planting food; between October and November. On the back of Te-ma comes

Te-'eri (Scarcity), most of November. Then the infloresence of the breadfruit begins. On the back of Te'eri comes

Te-ta'i (The-cry), Te-ta-ai-nui-ia-tuma (The epicure's-great-forage for food), in December. The breadfruit is developing; then wild foods of all kinds are brought out to eat.

On different islands and in different districts, the seasons vary in their time of coming, according to the wet and dry weather, and in this way the people had an irregular method of reckoning the year, each little kingdom following its own course. But they were all agreed in the length of time that the year lasted, being guided by the lunar month. Sometimes when there were only twelve complete developments of the moon's phases in the rotation of the seasons, whatever month did not agree in the conjuncture would be skipped:

\section{YEAR OF TWELVE MOONS}

Teie te i'oa o te mau ava'e o te matahiti e ta ratou mau vahine:

1. Paroro-mua, ei Eperera; o Mara'amu te vahine.

2. Paroro-muri, o Mê; o To'erau te va-
These are the names of the months of the year and of their wives:

Paroro-mua (First-fall), in April; Mara'amu (Trade-wind) is the wife.

Paroro-muri (After-fall), in May; To'erau (North-wind) is the wife. 
3. Muri-‘aha, ia Tiunu; e parara'a no te ra'au, o Te-'ura te vahine.

4. Hia'ia, ia Tiura'i; ua pohe te re`a; o Tura'i-re'a te vahine.

5. Ta'a-'oa, ia Atete, o Te-rere-'oa'oa te vahine. Ofaara'a o te honu e te upoa.

6. Huri-ama, ia Tetepa, o Te-mata-tauroroa te vahine. Ua vehe te tau, o te roroara'a ia o te mahana.

7. Te'eri, ia Atopa, o Te-ha'amoe'apa'apa te vahine. Ava'e ua.

8. Te-ta'i, ia Novema, o Te-hei-fa-'ataha te vahine. Te uaara'a ia o te pua, o te rave hia ma te ha'apae i te hei 'i'ino.

9. Varehu, ia Titema, o Oteatea te vahine.

10. Faahu, ia Tenuare, o Pahunui-atoitere-i-te-ta-moe te vahine. E ava'e 'ahune ia.

11. Pipiri, ia Fepuare o Pipirima'a-ifenua te vahine. "E 'ai atu te hoa i te tara fare, e 'ore e 'ite mai e, o te hoa here 'oe", e parau tahito ia. Utautara'a o honu ri'i e te upoa i tua.

12. A-unuunu, ia Mati, Ua-unuunu-mate-tai te vahine. E anotau vero.
Muri-'aha (Prayer-behind), in June; leaves turn yellow; Te-'ura (Gorgeousness) is the wife.

Hia'ia (Longings), in July; wild ginger and Turmeric die out; Tura'i-re'a (Batteringdown-of-re'a) is the wife.

Ta'a-'oa (Departed-joy), in August; Terere-'oa'oa (Flight-of-joy) is the wife. The turtle and the upoa bird then lay their eggs.

Huri-ama (Turned-outrigger), in September; Te-mata-tau-roroa (Face-longstanding) is the wife. Time is balancing, the days are lengthening.

Te'eri (Development of spring) in October; Te-ha'amoe-'apa'apa (Persistence) is the wife. It is a rainy month.

Te-ta'i (The-cry) in November; Te-heifa'ataha (Wreaths-worn-jauntily) is the wife. It is the season for the Besleria laurifolia flower, which is preferred to common wreaths.

Varehu (Spring-advanced), in December; Oteatea (Infloresence-of-bananas) is the wife.

Faahu (Restfulness), in January; Pahunui-atoi-tere-i-te-ta-moe (Great-drumextending-ripeness-with-sound-sleep) is the wife.

Pipiri (Parsimony), in February; Pipirima'a-i-fenua (Stinginess-of-food-in-the-land) is the wife. "The friend will eat then in the house corner, and ignore thee as a dear friend," is an old saying. The turtle and the upoa bird take their young out to sea at that time.

A-unuunu (Withdrawal), in March; Uaunuunu-ma-te-tai (Withdrawal-from-the-sea) is the wife. It is a stormy period.

(Henry 1928:332-334)

Several features of these lists are noteworthy, particularly the aforementioned associations with plant-foods and related human activities, and the reference to weather in conjugal metaphor; but they also raise some interesting questions. When persons from different calendar areas were faced with the necessity of referring to a date of mutual interest-say, for a proposed rendezvous-how did they do so? Or, when a chief of one calendar area extended his power over areas with different seasonal cycles, did his own home-area calendar become official in the latter? (In other words, did the facts of politics take precedence over those of ecology even in this technologically simple society?) In this connection, the so-called Pomare II thirteen-month version corresponds fairly closely to the one recorded in 1789 by Bligh and identified by him as Ra'iatean, whereas the Ta'imai or 
Papara (Tahiti) twelve-month list was nearer to Bligh's so-called Tahiti version. Pomare II certainly cherished his social ties with Ra'iatea, just as he considered Papara leaders among his (intermittent) rivals, but from this it cannot be assumed that the unsuitable Ra'iatean calendar was foisted upon Pomare's home districts.

Such questions as these are unanswerable, but perhaps they are trivial as well, for as Bligh suggested in the following prelude to the lunar-month lists collected by him, such calendrical reckoning may have been more of a specialty of savants than a common usage of ordinary men:

To get a certain Knowledge of their division of time has given me much trouble, for altho many people pretend to know it, Yet I have found them so contradictory in their Accounts as convinced me they were not acquainted with the particulars of it. Tynah assured me only a few Old People could give me any information and that he knew it but very imperfectly himself, he however has always referred me to Toota-ah or his Uncle Mowworroah. (Bligh 1789:II, 45)

In addition to the indrect implication of breadfruit seasonality in names of months of the lunar calendar, this staple also figured as a direct timemarker on its own: "They have ... criterions to judge of the particular times of the Year by the different kinds of Breadfruit coming into Season, and according to Toota-ah they have it divided under six General heads governed by the Name of that Fruit which is then fit for eating...." Bligh then went on to list the breadfruit varieties in question, and to indicate how the times of their ripening corresponded with the Ra'iatean lunar-month calendar referred to above:

$\begin{array}{cl}\begin{array}{c}\text { Ooroo-aowne } \\ \text { Do. }\end{array} & \text { To the Month of Sept. or Weeree-areearee } \\ \text { Tappeppee } & \text { of Oct. or Weereeamah } \\ \text { Do. } & \text { of Nov. or Tearee } \\ \text { Aieiotah } & \text { of Dec. or Tetta-igh } \\ \text { Do. } & \text { of Jan. or Worraihoo } \\ \text { Evynooah } & \text { of Feb. or Wahahoo Tawa } \\ \text { Do. } & \text { of March or Peepeeree } \\ \text { Tee-evveerah } & \text { of April or Ahoonoonu } \\ \text { Do. } & \text { of May or Parroromoah } \\ \text { Rowrow-we } & \text { of June or Parroromure } \\ \text { Do. } & \text { of July or Mooree-yaah } \\ & \text { of August or Ee-aheeya }\end{array}$

Now in this division Toota-ah placed Tawa between Feb. and March, which was interval, he said, where no Breadfruit were to be had, that as they were never used by them for the Trees were never bare all the Year round: but just at this time they were not in such perfection. (1789:II, 46) 
Stars figured in Maohi calendrical reckoning in the following way:

Teie te tau ari'i ma te tai'o na to Tahiti nei, 'oia o Matari'i-i-ni'a e o Matari'i-i-raro. O Mata-ri'i e pura na i te ata i te pae ra'i o na Hui-tarava ia Mere ra i te arehurehura'a o te ahiahi, i te Ava'e o Temâ ra, 'oia ia Novema 20, o te avei'a ia o te tau 'ahune O Matari'i-i-ni'a ia tau, e topa noa 'tu ia fetu ri'i raro a'e i te pae ra'i i te arehurehura'a o te ahiahi, i te ava'e o Au-unuunu ra, 'oia ia te 20 no Mê. O te upo'o ia o te tau 'ahune.

O Matari'i-i-raro te tau i ha'amata i te ava'e o Au-unuunu ra (ia Mê) ia mo‘e ae ia fetu ri'i i raro i te pae ra'i i te arehurehura'a o te ahiahi ra, e tae noa 'tu i te pura fa'ahou ra'a mai ini'a i te pae ra'i i te arehurehura'a i te ava'e o Tema ra (ia Novema). O te tau ia o te o'e.

A tahi matahiti, e rua tau i teie tai'o.
These are the kingly periods observed by Tahitians. They are Matari'i-i-ni'a (Pleiades-above) and Matari'i-i-raro (Pleiades-below). When the Pleiades first sparkles in the horizon towards the constellation of Orion's belt in the twilight of the evening, in the month of Temâ (Theclearing), on November 20th, they are the forerunners of the season for plenty. Matari'i-i-ni'a is then the season, until these little stars descend below the horizon in the twilight of the evening, in the month of Auunuunu (Suspension), on the 20th of May. That is the ending of the season of plenty.

Matari'i-i-raro is the season beginning in the month of Au-unuunu (Suspension) in May, when those little stars disappear below the horizon in the twilight of evening, until they sparkle again above the horizon, in the twilight of the month of Temâ in November. This is the season of scarcity.

One year has two seasons according to this reckoning.

(Henry 1928:332)

According to Henry, this account was provided by Pomare II in 1818, five decades after first European contact. Quite apart from its inclusion of the English words Mē (May) and Novema (November), it is clear, from other evidence, that the precise calendrical dates given in this text for the appearance and disappearance of the Pleiades either derived from European influence or were privileged information held only by certain leaders and sages. The evidence in question is contained in a passage from a journal in the LMS Archives:

Last evening, hearing much noise and shouting amoung the King's people towards the sea side, and enquiring of the cause, were informed that it was on account of the Mata-ree which is the Taheitean name for the constellation of Pleiades-for some months back they had had much disputing when the Mata-ree would set before dark, or, to use their phrase, when it would fall, and go to bathe in the sea-one party would have it to be before the death of the last moon, others not, and now knowing that the moon had changed and seen the Mata-ree still above the horizon-they shouted and triumphed over the other party ... though the Taheiteans are no great astronomers-and will not scarcely ever give themselves the trouble of thinking, how the revolutions of the heavenly bodies are performed ... and tho' they have no word in their language to signify a year or compleate revolution of the earth or sun; yet the periodical return of seasons, appearance of the planets, and other remarkable stars is noticed, and pretty exactly known by some few. (Davies, Youl et al., 19 April 1806) 
The remaining two kinds of time reckoning followed by the Maohis (a lunar month of twenty-nine nights and an annual cycle based on weather conditions and other conditions affecting fishing) will be described later on; for the moment I return to a question about solar time reckoning that has important implications for ritual.

The Maohis undoubtedly perceived the annual movement of the sun between summer and winter solstices, and they probably noted the associated differences in length of daylight; but how far they went in institutionalizing such observations is open to question. In Moerenhout's view they went quite far.

Evidently impressed with Hellenic parallels, and with alleged parallels in the Marquesas, Moerenhout identified the harvest festival mentioned earlier as year-end or year-closing rite, a farewell to the spirits, or more specifically a farewell to the sun as it began its solstitial descent into the $p \bar{o}$ (1837:I, 518, 523). I noted above that, according to Moerenhout, priests returned to their own marae after the harvest festival and addressed offerings and prayers to spirits, for their eventual fructifying return. ${ }^{37}$ In addition, he asserted in the same passage that the members of the Arioi cult-considered by Moerenhout to be worshippers of the sun-actually went into mourning during this period, "... suspending all their cult activities and returning to their own places to grieve for the absence of the gods."

One may not be able to go all the way in accepting Moerenhout's specific identification of these events, but the fact remains that the harvest festival as described was followed by a season of relative scarcity, which in many places did correspond by solar reckoning to winter.

On the other hand, and despite many instances of plant-food scarcities during the wintertime in these Islands, public activities by no means came to a halt, as witnessed by accounts of large-scale food-using assemblies during winter, breadfruit-scarce months. ${ }^{38}$ It is true that the Maohis were farmers and plant-food collectors heavily influenced by seasonal fluctuations in the supply of their staple plant-foods; but it should not be forgotten that they were also animal raisers and, above all, highly skilled fishermen.

\section{DOMESTIC ANIMALS}

\section{Pigs}

The high value placed by the Maohis upon their pigs is revealed in part in the following legend, recorded by Orsmond in 1825:

Havai'i (Ra'iatea) was really a land for strange things! It was people of that land who produced turtles, fowls, and pigs, all in one family. Those people, a man and his wife, were named Tü-moana-urifa (Dweller-in-sea-of-rank odor) and Rifarifa (Scarred)....

Tû-moana-urifa and Rifarifa had one child who was born a human being, a 
son whom they prophetically named Metua-puaa (Pig-parent), and when he had grown up they took him to Porapora, where he married a girl to whom he had long been affianced.

The young couple were very happy together for some time, when one day the young wife teased her husband on having no property in Porapora. So he went to his mother and told her of his grievance, and she replied: "Is that all that troubles you, my son? Do not grieve, but go early in the morning into the woods, and there open wide your mouth, and out of it will rush a multitude of small animals which will be called pua'a maohi (pigs; literally, native beasts). Secure them with cord, and proceed at once to make a large pen and a large shed for them. Before nightfall, your work will be done and your pigs will have grown to their full size. Place them in the pen, then go and fetch your wife to see them, and present them to her.

So the son obeyed his mother the following day, and to his great joy he realized all his expectations, and his wife and all her family were delighted with the new animals, never suspecting whence they had sprung. From that litter were propogated all other pigs upon this earth, and they became good food for gods and men. (Henry 1928:380-382)

The Maohis made tools out of pig bones, but their principal use of pigs was for food. The native (pre-European) pig ( $p u a^{\prime} a$ ) of these Islands was described by one early European visitor as being, “... a chaines [Chinese] breed, non of them above Eighty or a hundred pound weight" (Robertson 1948:179). In the opinion of Andia y Varela it was “... a very small breed [but] plump and well flavored" (Corney 1915:272).

Breeding stock introduced by the early European visitors appears to have become quickly dominant, for by 1797 the missionaries were able to obtain a dressed hog weighing 340 pounds exclusive of head and entrails (Wilson 1799:60). By Ellis' time (1817-1823) the native pig had been almost entirely displaced by, or interbred with, European breeds, but, from hearsay evidence, he described the native breed in these terms:

Those originally found there differed considerably from the present breed, which is a mixture of English and Spanish. They are described as having been smaller than the generality of hogs now are, with long legs, long noses, curly or almost wooly hair, and short erect ears. An animal of this kind is now and then seen, and the people say such were the only hogs formerly in Tahiti. It was also said, that they, unlike all other swine, were wholly averse to the mire.... (1829:I, 349)

The native pigs lived entirely on a vegetable and fruit diet; some of their food was obtained through foraging for roots and fallen fruit and nuts, but they were also regularly fed by their keepers. Beyond these few indications there is little known of their regime. Ellis described the habits of the mixed breed hogs of his time in these words: "The hogs now reared are large, and often well fed; they are never confined in sties, but range about in search of food. Those that feed in the heads of the valleys live chiefly upon fruit, while those kept about the houses of the natives are fed occasionally with bread-fruit or cocoa-nuts." (1829:I, 350.) The missionary 
Crook recorded in March of 1821 that "King" Pomare had ordered some of his subjects to round up all pigs "that run in the mountain \& whose owners are unknown" (Journal, 15 March 1821, LMS Archives)-and hence it would appear possible to distinguish three kinds of pigs: domesticated ones with known owners, semidomesticated ones of unknown ownership, and wild, feral ones. G. Forster provided some additional details:

On this walk we saw great numbers of hogs, dogs, and fowls. The last roamed about at pleasure through the woods, and roosted on fruit-trees; the hogs were likewise allowed to run about, but received regular portions of food, which were commonly distributed by old women. We observed one of them in particular, feeding a little pig with the sour fermented bread-fruit paste, called mahei (mahi); she held the pig with one hand, and offered it a tough pork's skin, but as soon as it opened the mouth to snap at it, she contrived to throw a handful of the sour paste in, which the little animal would not take without this stratagem. (1777:I, 377)

On this same excursion G. Forster witnessed a puppy being suckled by a woman:

We were witnesses of a remarkable instance of kindness, when we saw a middle aged woman, whose breasts were full of milk, offering them to a little puppy which had been trained up to suck them. We were so much surprised at this sight, that we could not help expressing our dislike of it; but she smiled at our observation, and added, that she suffered little pigs to do the same service. Upon enquiry however, we found that she had lost her child, and did her the justice amongst ourselves to acknowledge that this expedient was very innocent and formerly practiced in Europe. (1777:I, 378)

According to Ellis, unless the pigs of his era were well fed they could be very destructive to native gardens. Sometimes owners broke their pigs' teeth to keep them from biting through fences; another method for keeping them out of fenced-in areas was to yoke them:

... sometimes the natives ... put a kind of yoke upon them; which, in some of the islands of the Pacific, is rather a singular one. A circular piece, as large as a shilling or a half-crown, is cut out of each ear, and when the wound has healed, a single stick, eighteen inches or two feet long, is passed through the apertures. This wooden bar lies horizontally across the upper part of the pig's head, and, coming in contact with the upright sticks of a fence, arrests his progress, even when he has succeeded in forcing his head through. (1829:I, 350)

It is not wholly clear from this passage whether the custom here described was actually practiced by the Maohis. For that matter, neither can one be certain whether the conditions described by Ellis obtained in pre-European times as well.

There is some evidence for supposing that as elsewhere in Oceania the native domestic pig was a more docile, stay-at-home breed, and that its tendency and ability to roam widely and break into fenced gardens was increased only through the addition of larger European strains. The 
following text suggests that the Maohi pig was not always docile, but it also indicates that recalcitrance was an unusual occurrence, requiring special explanation:

The boar was a shadow of 'Oro-tauà (Warrior-at-war) as the man-slaying god;; ${ }^{[39]}$ it was 'Oro-pua'a-mahui ('Oro-the pig-revealing-secrets). When a gentle, domesticated boar got possessed, it was known that 'Oro was dwelling in him; that pig could devour a man. Pointing upwards to the sky was one jaw, and pointing downwards to the earth was the other jaw, which was the sign that the mouth of 'Oro was open ready to consume the king and his clans. That pig became very fierce, a great power in itself in the land. (Henry 1928:383)

I cannot imagine that even a most tractable animal would pass up an opportunity to root in an accessible planting of taro or potatoes or yams, and this raises a question that is familiar to students of Pacific island societies: Why do some peoples fence in their gardens, others fence in their pigs, and still others do neither? An answer to this question with respect to the Maohis would provide some valuable clues concerning their "economics" in a very broadly defined sense. Unfortunately, such an answer is not forthcoming, for we have very little data on either Maohi fencing or on the habits or management of their pigs, except that on occasion they treated them as pets.

In any case, despite a report of “... multitudes of hogs, which breed rapidly ...," ${ }^{\prime 40}$ the demand for pigs usually far exceeded the supply-a fact all too evident to the European captains, who were at pains to obtain pork for their meat-starved crews:

Tho they seem to esteem flesh very highly yet in all the Islands I have seen the quantity they have of it is very unequal to the number of their people, it is therefore seldom usd among them. Even their most principal people have it not every day or even week...." (Beaglehole 1962:I, 343)

They kill their hogs very seldom, perhaps only on certain solemn occasions; but at those times the chiefs eat pork with the same unbounded greediness, with which certain sets of men are reproached at the turtle-feasts in England; while the common sort rarely, if ever taste a little bit, which is always held as a great dainty among them. (G. Forster 1777:I, 315)

In view of the Islands' year-round abundance of the kinds of food eaten by pigs, this degree of scarcity is somewhat puzzling. One factor may have been the wars and forays so particularly prevalent during the Early European Era, for fighting was nearly always accompanied by destruction and looting. On the other hand there are suggestions of remarkably speedy recovery, in terms of numbers of pigs as well as of other necessities and luxuries of life. ${ }^{41}$

The methods of owning and rearing pigs reported by G. Forster and by Banks are particularly relevant to our concerns, although such reports are undoubtedly oversimplified and somewhat ambiguous: 
Notwithstanding this [the fact that only "chiefs" enjoy the privilege of eating pork with any frequency], all the trouble of breeding, bringing up, and fattening the hogs is allotted to the lowest class of people. (G. Forster 1777:I, 315)

... some of them [their "most principal people"] had piggs that we saw quarterd upon different Estates as we send Cocks to walk's in England; when any of these kill a hog it seems to be divided almost equaly among all his dependands himself taking little more than the rest. (Beaglehole 1962:I, 343-344)

I hope to render these fragmentary passages more intelligible in the course of presenting generalizations about Maohi society.

Cook's account of the butchering and baking of a pig is the best available:

One of the Hogs I order'd to be immidiately Kill'd and dress'd for dinner, and attended my self to the whole opperation which I shall discribe; the first thing was to Strangle the Hog which was the work of 3 men, the Hog being placed upon his back two of them laid a pretty strong Stick a cross his throat and press'd on each end with their whole weight, the third Man held his hind legs kept him on his back and plug'd up his backside with grass, in this Manner they held him for at least 10 minutes before he was quite dead and in the mean time some hands were Employ'd makeing a fire to heat the oven, which was close by; as soon as the Hog was quite dead they laid it on the fire and Burnt or singed the hair so that it came off with allmost the same ease as if it had been scalded, as they got the hair off one part a nother was applied to the fire $\& c$ till the whole was done, but not so clean but that another operation was necessary, which was to carry it to the Water side and scrub it well [with] Sand and Sandy stones, this took off the Scurf \&c which this Operation at the fire wou'd not\& as soon as this was done and all the Sand and dirt wash'd clean off in the Water it was brought again to the first place and their laid on Clean green leaves in order to be opened; they first riped up the skin of the belly only and seperated the skin from the fatt which lies between it and the inside flesh which they took out, that is that fatt which covers the belly and is in general as soft as the lard, this was laid on a clean leafe, they than riped open the belly and took out the Entrails which were put into a basket and carried away so that I know not what became of them, but am certain they were not thrown away. The Blood was now all taken out and put into a large leafe, then the Lard which was put to the other fat, the Hog was now washed clean both inside and out with fresh Water, Several Hot stones were put into his belly which was afterwards cram'd full with clean green leaves; by this time, or perhaps before, the Oven was sufficiently heated, what fire remain'd was taken away, together with some of the Hot stones, the rest were left in the bottom of the hole or Oven which was now covered with green leaves on which the hog was laid on his belly, the lard and fatt, after undergoing some washings with fresh Water was put in a Vessel made just then of the bark of Plantain tree, two or three hot stones being put in along with the fat, it was tied up and put in the Oven by the hog as was the blood also prepared in the same manner, round the whole were laid to Bake Plantains, Bread fruit \&c then the whole covered with green leaves on which were placed the remainder of the Hot stones and over them more leaves and then any sort of rubbage they could lay their hands upon and lastly finishd the operation by well covering the whole with earth, here it laid two hours and Ten Minutes, then the Oven was opened, the Hog as well as all the other victuals were taken out and laid on green leaves already spread for the purpose on the floor at the one end of a large boat house, such of the $\mathrm{Na}$ - 
tives who dined with us set down by themselves and we by our selves, that is they were at the one end of the Table and we at the other\& the Hog was plac'd before us and the fat and blood before them, which they chiefly if not wholy dined off and said it was Mona-mona ta, that is very good and we not only said but realy thought the same by the Pork. The Hog wieghed about fifty pound, some parts about the Ribs I thought rather over done, but the more thicker parts were excellent, and the Skin which by our way of drissing is generally either hard or tough had by this method a flavour superior to any thing I ever tasted. I have now only to add that during the whole process nothing could be done with more cleanlyness. (Beaglehole 1961:422-423)

As noted earlier, pork was in chronically short supply and consequently eaten with some regularity only by certain individuals-that is, by those privileged enough to receive it as "gifts" or tax, or powerful enough to require subordinates to raise pigs for them. But pork consumption was limited also by considerations less directly "economic"-namely, it was eaten mainly by males.

Some writers asserted that pork was forbidden to females in principle, but Morrison's explanation probably comes nearer the truth (1935:208; quoted earlier in this chapter.) In other words, the point here is an elaboration of the theme mentioned earlier, that women ought not to eat certain foods that have been in physical contact with males-that is, with males who are not members of the females' own retinue. Morrison's statement, if interpreted literally, might also be taken to mean that the males whose contact with the pork was to be avoided included only the women's "male relatives or the Chiefs"; but evidence elsewhere in the sources suggests that the interdiction was broader than that. But even this restriction was on occasion set aside: "Some share of the pork was given to Orea's wife and daughter, who carefully wrapped it up, in order to eat it apart. Thus it seems, that though the hog was wholly dressed, prepared, and distributed by men, yet this did not make it improper for the women to partake of it." (G. Forster 1777:II, 145) In this case, moreover, there was no suggestion of the hog having been prepared by men belonging to Orea's wife's "retinue."

Also, many of the women who visited the ships of the Europeans were anything but reluctant to eat the pork offered them, taking care only to insure that their actions were not widely publicized (for example, see Bligh 1789:II, 8). In fact, from such relaxations and "exceptions" as these, the possibility arises that rules restricting women from eating pork may have derived mainly from overall scarcities, with the addition of religiously colored ideas concerning maleness versus femaleness, or sacredness versus secularity, added mainly for purposes of sanction. There is, of course, no conceivable way to prove an historical hypothesis like this, but the fact remains that the most highly esteemed kinds of food generally forbidden to women-pigs, dogs, turtles, albacore, shark, dolphin, whale, porpoise-were among those shortest in supply, either seasonally or year round. 


\section{Dogs}

Dogs were kept and fattened by the Maohis mainly as a luxury food, for themselves and their gods. In G. Forster's words, the local breed were "... short, and their sizes vary from that of a lap-dog to the largest spaniel. Their head is broad, the snout pointed, the eyes very small, the ears upright, and their hair rather long, lank, hard, and of different colors, but most commonly white and brown. They seldom if ever barked, but howled sometimes, and were shy of strangers to a degree of aversion." (1777:I, 378; see also Corney 1915:287) Maohi dogs are described elsewhere as having been "... the ugliest \& most stupid of all the Canine tribe, ..." (Beaglehole 1962:I, 108), and Ellis added that they were "... by no means ferocious; and excepting their shape and habits, they have few characteristics of the English dog: this probably arises from their different food ..." that is, vegetables, coconuts, and fruits (Ellis 1829:I, 351).

The more experimental European visitors found baked dog flesh excellent fare, something like lamb; it was apparently greatly esteemed by the Maohis also, but so scarce as to be reserved for privileged individuals (males, of course) and special occasions. According to the passage from Ellis cited above, “... dogs do not appear to have been reared for food so generally as among the Sandwich Islanders; here they were fed rather as an article of luxury, and principally eaten by the chiefs."

Banks' journal provides the fullest available description of the Maohi manner of cooking dog flesh, which differed in no important respect from the baking of pork (Beaglehole 1962:I, 292-293).

The tail hair of dogs was used in making wigs and ceremonial breastplates (taūmi 'gorget'). Dog bones were made into tools, and dog teeth into fishhooks.

There is no evidence that dogs were used in hunting, and there is only one reference to their "service" to men: The dog was the shadow (ata) of the spirit, To'a-hiti. The sound ('aoa) made by the dog was helpful; it provided [warning] protection to man (adapted from Henry 1928:383). ${ }^{42}$

The dog-loving Englishmen were greatly puzzled by what they considered the Maohis' ambivalent treatment of their dogs. On the one hand the natives ate them, apparently without regret, and kept them hobbled in what certainly must have been a most painful fashion, with one front leg tied over the back of the neck. (Wallis, in Hawkesworth 1773:I, 231). On the other hand they treated them as beloved pets, as the following fragments indicate:

The dogs in spite of their stupidity, were in high favour with all the women, who could not have nursed them with a more ridiculous affection, if they had really been ladies of fashion in Europe. (G. Forster 1777:I, 377-378) ${ }^{43}$

We are at present surrounded with a great number of useless mischievous dogs, which the natives kiss and hug as much as they do their children, and call them good property and good food. (Jefferson, Journal, 4 March 1800, LMS Archives) 
Lost a young kid last night by a neighboring dog that has done much mischief in destroying the goats ... This morning he [Br. Nott] \& br. Eyre went to the house and spoke to the woman that the dog belonged to, informing her (as she had been informed before) the mischief it kept doing, and insisting it be killed. It was a long time before she consented to it, and wept, bewailed, hugged \& kissed it as if it had been an only child. However, at last she agreed to its death, and some of the family killed it, but in a very strange \& singular manner, the brethen believe, for they would not let them see how it was done, tho' they saw it dead. The woman talked of placing it upon a bier close by the corpse of her husband, after the country manner of burying those they love. (Jefferson, Journal, 6 February 1801)

In connection with the last kind of incident, Forster reported having seen a marae for dogs, which he took to be a special burial place for those animals (Beaglehole 1961:419).

\section{Chickens}

The Maohis reared fowls in what Ellis called "great numbers" (1829:I, 351) - the hens mainly for eating, the cocks for sport-fighting. Some Europeans found the former tougher and inferior in flavor to English fowl, but there is little information about the practices of rearing or about the actual numbers and distribution of such fowl. Henry provided a detailed statement about the rearing of fighting cocks which I quote in chapter 10 .

Of direct relevance to our interest is the following legendary episode collected by Orsmond in 1825 from a priest of Porapora; the part of the legend concerning pigs was quoted earlier, so I give here only the part dealing with chickens and turtles:

While they [the legendary couple Tumoanaurifa and Rifarifa] were on a visit at the Island of Pupua (Honden Island, Tuamotus), turtles were born to them and went out to sea; and in due time those turtles propagated their young throughout the groups, frequenting sandy, low islands, in preference to others for laying their eggs. When Tû-moana-urifa and his wife returned home to Havai'i, they produced a family of chickens, which prospered and were let to go into the woods, and from them the wild fowls of all the islands are descended.

It happened when the world was new, that a turtle and a fowl had a dispute, one contending for the prestige above the other, when the turtle said to the fowl: "You are common, you will be eaten by women and children, but I shall be sacred to the gods, I shall leap into the god's house." The fowl answered scornfully, "How can you leap into the god's dwelling? You will yourself be eaten by women and children, but I shall dive into the depths of the sea and escape from their hands."

Just then the turtle was picked up by a strong man and taken to the king, who was so pleased with it that he sent it to the marae for the gods, and thus the turtle was ever afterwards held sacred for the gods and was only eaten by kings, priests, and marae keepers. But as the fowl tried to dive into the sea for safety, it only succeeded in getting its head under water, when a party of women and children passing by went and seized it and took it home. So the fowl became a domestic animal and was eaten by women and children. Only white fowls were 
offered to the gods at the marae, because all white birds were regarded as sacred. (Henry 1928:380-381)

\section{Rats}

The native rat ('iore mā'ohi: Rattus exulans) was a small brown animal that lived mainly on fruits and vegetables. By all accounts these animals, quite tame and imperturbable, infested the Maohis' settlements in swarms. The Maohis, just as imperturbably, protected their edibles from rats by means of baffles but seemingly made no effort to destroy the rats or drive them away. Unlike some Polynesians, Maohis are said to have abhorred the very idea of eating rats. ${ }^{44}$

No specific reason has been offered for the Maohis' abstention from eating rats, or for Maohi tolerance of the evidently troublesome presence of rats; perhaps it derived in part from their belief that the animals were "shadows" (ata) of ghosts:

When it visited people at night and uttered strange sounds with its tongue or scratched the thatch inside the roof of the house until daybreak, it was communicating mysteries and reminiscences of war and times of peace from dead warriors to living men. But when it approached a sick bed articulating strange sounds, it was the shadow of a devouring ghost announcing the near approach of death to the patient. (Henry 1928:383)

\section{HUNTING}

Ellis said of the Maohis that "Their country was little adapted for hunting, and the only quadrupeds they ever pursued were the wild hogs in the mountains ..." (1829:II, 291).

After Europeans arrived on the scene some Maohi chiefs sent their subjects into the mountains to kill or capture wild pigs for barter with the visitors. Prior to that pigs were hunted, but perhaps as much for sport as for food, plus, of course, the occasional killing of marauding semi-wild pigs by irate gardeners. An example of hunting pig for sport, or as a feat of strength and courage and skill, is seen in the legend of Rata, whose chiefess mother hit upon a boar hunt as a way of selecting men to take part in a dangerous mission overseas:

Now this is what I have to say: because our land is replenished with people, let us have a boar chase, dividing the clans, having Hiti-uta and Hiti-tai on one side and Pe'eai and Papa-honu on the other. Then you will chase the boars, and we shall thus test the courage of the men of the different clans, so as to choose those who will be capable of action in going to the islands of Pu'a-tû-tahi, Hiti-tautaumai, Hiti-poto, Hiti-tautau-atu, and Hiti-au-revareva that rises to the sky. Such men can lay hold of the foes in the ocean, and even on the demons of the island of Hiti-marama. But if there be no capable men, we shall remain in this land and abandon the project of going. (Henry 1928:477) 
Birds were hunted both for feathers and, occasionally, for food. Morrison provided a vivid description of one kind of situation in which they were deliberately hunted for food:

When they Go into the Mountains, which they often do in Companys to Cut Timber, Gather Herbs \& sandal wood for their Oil, Cut rafters for their Houses, Paddles for Canoes, \&c. and for the Purpose of dying Cloth which takes them up several days, they subsist themselves on Birds, fish \&c. Using the Mountain Plantain and Wild Roots for Bread, the land producing plenty of Birds and the Springs plenty of Fish\& they catch the birds by fixing the Gum of the bread fruit on long Bamboos, and setting them up, take the Birds which perch on them as we do with Birdlime; others who are used to this Method of living can with much exactness knock them down with a stone which they throw by hand, pointing at the Bird with the fore finger of the left hand, as it were to take Aim while the Stone is prepared in Right and if the Birds are sitting they seldom fail to bring it down but cannot bring one off the Wing - and when a party go into the Mountains on any of the aforesaid occasions their first Care is to send a party in Search of Provisions (as they never Carry any with them) while others erect huts for their lodgings made of reeds and Covered with the leaves of the Tee and others procure fire and fuel-as they seldom take the trouble to Make an Oven they roast their roots $\&$ Plantains and dress their fish or Birds in Peices of Green Bamboos. The provisions, being put into the Bamboo and stopd up with leaves, is laid on the fire and kept turning round like a spit till the Contents are sufficiently dressd, the Moisture inside keeping the bamboo Wet it keeps its form tho burnt nearly to peices-In this Manner they live when on these excurtions and tho they have hard labour in hand they turn the work into pleasure, and taking no thought for tomorrow they leave off \& return when they think Proper. (Morrison 1935:217)

In another account, by the Spaniard Gayangos, some inhabitants of Maupiti are said to have traveled occasionally to uninhabited Mopelia Atoll-a two-day trip-to capture (flightless) boobies and noddies for food (Corney 1915:193). Another fragment of evidence that the Maohis occasionally hunted birds for food is found in the following passage:

Beneath [the shelter of a fern called fare-rupe 'mountain-pigeon-house'] the hunters of the rupe (mountain-pigeon) used to conceal themselves, holding to view a tame rupe and imitating its cry, like a man shouting, "Ho! ho!" Then the wild bird would gradually approach the tame one, until it came into the range of the man's hand and was caught. (Henry 1928:64-65)

Inasmuch as the feathers of the bird in question are not reported to have been especially valued, one is perhaps justified in assuming that the bird was hunted mainly for food. Thus the Maohis did indubitably eat wild birds on occasion, but most of their bird hunting was for feathers.

The tail feathers of the tropic bird, so highly valued for decoration, were sometimes found in the mountains on the ground under trees, where these birds rested at night (G. Forster 1777:II, 91-92), but most of these feathers were obtained by capturing the birds themselves: 
As they are very fond of the Tail feathers of the Tropic Birds which they esteem for dressing their Parais or Mourning dress they go two together to Hunt for them and as the birds build in the Face of the highest Cliffs they are at Much trouble to get them. Their Method is this-the Bird catchers are provided each with 10 or 12 fathoms of Rope of sufficient strength to bear His own Weight, \& having fixd their place of abode near the Clift, where provisions are in the greatest plenty they proceed together to the top of the Cliff, where bending their ropes together they make fast a stick of 18 or 20 inches long by the Middle and lower it over the face of the Cliff having a Stake fixd to Make it fast to on the top; if a Tree is Not Convenient, one hand then stays by the rope to haul up or lower down as the other shall order who goes down \& seating himself on the Cross stick, swings from hole to hole in search of the Birds, holding on by the points of the stones which project or the shrubbs which grow among the fisures of the Cliff-when he catches a Bird, he hauls out the Tail feathers which he secures in a Bamboo which he carrys for the purpose, and lets the Bird fly-having examined all the holes within his reach or is tired in the search he goes up and either shifts the rope to another part or attends it for his partner who takes a spell.

This tho it may appear Dangerous to us is no more to them then Amusement, and seldom attended with any Accident tho they hang some hours in this manner, sometimes 20, 30 or 40 fathoms from the top \& often four times that from the Bottom and perhaps do not get a single feather in a whole days search. (Morrison 1935:217-218)

We are also indebted to Morrison for a vivid description of the Maohis' method of obtaining the prized feathers of the man-o'-war bird:

The Shining Black feathers of the Men of War Birds they also hold in high Esteem, for which reason they always watch their Coming as they Seldom Visit this Island except when the Westerly Winds and thick Weather prevail-they afford diversion for Numbers as they are only to be caught at the Beach, or When it happens to fall Calm when they perch on the Cocoa Nut trees, and are Caugh[t] by a snare fixd to the end of a long stick with which a man goes up and puts the Noose over the Birds Neck while it is asleep, which is in a few Minutes after it lights, and letting the stick go, it brings the Bird to the ground-While they keep on the Wing they entice them down by a Fish into which they thrust a piece of Poorow to float it, and throw it into the Water keeping it within reach of their Wands, of which each Man has one of 14 or 16 feet long; as soon as the Birds observe the Fish they instantly make towards it, somtimes 8 or 10 together, and the Men stand by and knock them down as they attempt to seize the fish, which they all attempt to do. If they do not receive a Blow before they get near enough, these Birds always seize their prey in their Claws, which are long and sharp and Webbd only to the first Joint-they are Inhabitants of the low Uninhabited Islands in the Neighbourhood of the Society Islands, and never come from home but in thick weather, their Feathers are held in Such Esteem that the Natives will give a hog of 100 Weight for one of them for Making their War $\&$ Heiva dresses \&c. tho they never eat the bird-during our time we shot several which were deemd grand presents, but We thought the Powder of More Value and therefore made but little Waste of it for that use and seldom took that expencive diversion-the Cock Birds are the Most Valuable and the Back feathers are those they prize highest for their Beautiful shining Black. (1935:218-219) 
Still another method of catching birds (either for feathers or for food) was by smearing a viscid gum onto the limbs of trees where they ordinarily perched. ${ }^{45}$ Also, as noted above, some individuals were capable of bringing birds down from their perches with a well-aimed stone. In addition, there is a single report, by Friar Joseph Amisch, that birds were shot with bow and arrow: “... when in pursuit of birds they use very slender little arrows fashioned of reeds and tipped with hard-wood points (Corney 1915:81)."

Finally, the Maohis obtained some of the rarer and most highly valued feathers used in their religious rituals either by trade from the atolls to the northeast or by actual expeditions to these islands. I can find no historically validated account of any such expedition, but legendary accounts of them are numerous.

In closing this section on bird hunting, I wish to draw attention again to a matter mentioned before, namely, to the widespread intellectual interest in their natural environment shown by the Maohis, quite apart from any tangible utilitarian element present in that environment. Despite the fact that they utilized only a few of the available species of birds for food or feathers (or for navigation and, as we shall see, for aid in fishing), their acquaintance with the kinds and habits of their Islands' bird populations was exhaustive and extraordinarily detailed.

\section{FISHING}

Anyone reading the early descriptions of these Islands almost inevitably acquires the impression that the Maohis were rather indifferent farmers and swineherds but ardent and skillful fishermen. Some of this impression may derive from the bias of the European observers-most of them sailors-or from the greater excitement inherent in some types of fishing or from the exotic techniques often employed. (See figs. 9-9, 8-1 and 8-6.) But even discounting these and other extraneous factors, and recognizing that most Maohis may have spent more time cultivating and collecting plant-foods, the probability yet remains that fishing was the most technically developed of their subsistence activities.

In all likelihood it was also one in which they took most pleasure. Indeed, fishing was for them nearer to our Western category of "sport" than to our "toil"-even with all its seeming "drudgery" and strain, and even with, or perhaps because of, its physical hazards:

This kind of fishing was followed not only as a means of procuring food, but as an amusement. The chiefs were exceedingly fond of it, and often strove to excel. Hautea was celebrated for his skill and strength in taking some kinds of fish. Their country was little adapted for hunting, and the only quadrupeds they ever pursued were the wild hogs in the mountains; but the smoothness and transparency of the sea within the reefs, favoured their aquatic sports; and a chief and his men, 


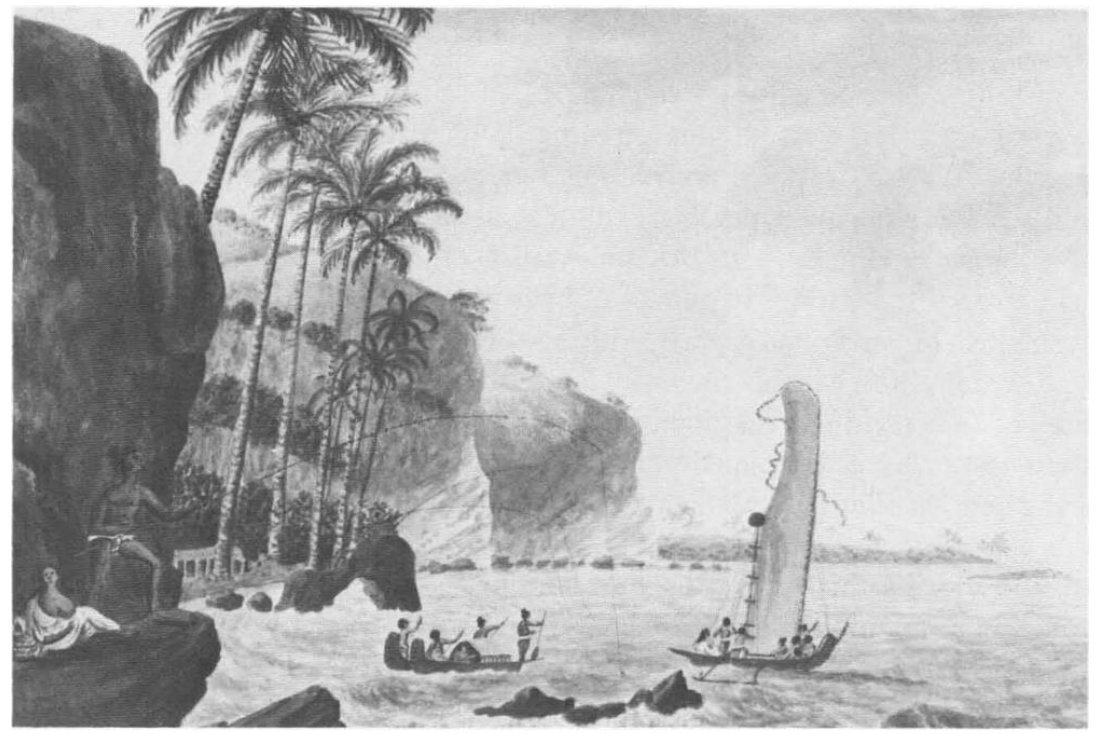

FIGURE 9-9. "In the district of Whapiāno (Ha'apaino‘o), Island of O`tahytey-Looking toward Matāvai.” Watercolor by G. Tobin. Mitchell Library, Sydney.

furnished with their spears, \&c. often set out on their fishing excursions with an exhilaration of spirits equal to that with which a European nobleman pursues the adventures of the chase. The more daring of the young chiefs were generally among the foremost in pursuing the shark, or other dauntless fish\& while others, more advanced in years, remained in their canoes at a distance, gratified to behold the sport, and share in some degree the excitement it produced. (Ellis 1829:II, 290-291)

Fishing, in general, was also a kind of amusement or recreation for them, whether they fished with a line at high tide, with a net in the lakes or bays, or with spear on the reefs. Nothing was more animated than the departure for one of these excursions by a chief armed with spears and harpoons, accompanied by a number of his subjects, all of which took place amidst a din of noise from the crowd. The chiefs hardly ever went except when fishing was plentiful; likewise, upon their return, each one sought his equal share, and these fishing days were just as much feast days. (Moerenhout 1837:II, 108)

The food resources sought after by Maohi fishermen were extraordinarily varied, and in some instances as plentiful as the seas are broad.

Edible tortoise (Chelonia mydas: honu) ${ }^{46}$ frequented the beaches of the motus and atolls. Crustaceans of dietary importance included freshwater shrimps (malacostracan decapod, 'oura pape), large reef langoustes (Panulirus penicillatus: 'oura miti); sand langoustes (Parribacus antarticus: ti'ane'e), marine hermit crabs ( $\left.u^{\prime} a\right)$; numerous other species of crabs; sea centipedes (Pseudosquilla ciliata: varo); and sand "beetles" (Hippa: popoti). As for the multitudes of echinoderms inhabiting the reefs and lagoons, the Maohis used only urchins for food. Much more widely eaten were the 
Islands' molluscs: mussels ('u'u), oysters (tio), cockles ('ahi), and the giant tridacna clam (pahua). The reefs and lagoons abounded in gastropods, whose shells were used by the Maohis for numerous other purposes, but of these only turbos ( $\left.\mathrm{mao}^{\prime} a\right)$ and vermets $\left(\mathrm{ua}^{\prime} \mathrm{o}\right)$ were regularly eaten. The most noteworthy of the cephalopods found in these waters were octopuses, which were highly esteemed as food.

Among the mammals frequenting these waters, porpoises ('ou'a) were a prized food, as was meat from reef-stranded whales.

But of all the marine animals which the Maohis ate, fish were by far the most important-in quantitites eaten and in number of species utilized. In Maohi practice the type of fishing-lake, stream, reef-lagoon, open sea-provided a more relevant classification, but needless to say it is not possible at this late date to subject the surviving data to the kind of investigation that could lead to an "ethnoscientific" analysis of this important realm of Maohi cognition. The saltwater fish most generally used were as follows (arranged according to Western taxonomy):

Elasmobranchii: sharks ( $\left.m a^{\prime} \mathrm{o}\right)$ and rays (fai)

Dipneustii: not represented, or at least not extensively utilized

Actinopterygii: of this large subclass only the teleosts (i.e., fish with bony skeletons) were important. The several orders which figured prominently in Maohi diet were:

Apodes: eels (puhi, āti'i)

Percesoces: mullets (aua, āha, nape); beloniforms: needlefish (āāvere) and flying fish (mārara, manana, pai ata'i)

Catosteomes: "flute-snout" (aupapa)

Heterosomes: flatfish (pati'i)

Percomorphs: Serranidae (rock cod, tarāo; Lutianus: to'au, ta'ape); Mullidae (āti'ati'a, ouma); Scaridae ("parrot-fish," pa'ati); Holocentridae ('̄'ihi, araoe, apa'i); Chaetodontidae ("flat-fish," paraha, paraha pe'ue, panapana); Acanthuridae ("surgeon-fish," maito, ume); Thunnidae (red tuna, 'a'ahi; bonito, atu; small barracuda, ti'atao); Carangidae (pai here, orare/ature, ore/ihe rahe); Scorpaenidae (nohu tarao, nohu pu'a, tatareihau)

Plectognaths ("spring fish"): "hedgehog" fish (oiri); 'checker fish' (momoa); "globe-fish" (huehue); "porcupine fish" (totara).

The freshwater fish that figured most importantly in Maohi diet were perch (nato), eleotrid (o'opu), and eel (puhi pape).

Factors of wind, rainfall, moonphase, and so forth, along with the reproductive cycles of the marine fauna, influenced the time, place, technique, and size of catch of Maohi fishing; but before discussing these let us itemize the more commonly used fishing techniques. 


\section{Fishing Techniques}

It is an everlasting pity that there did not happen to be a perceptive and literate fisherman among the early European visitors to these Islands, one able to do full justice to the extraordinary technology and skills developed by the Maohis in exploiting their rich marine resources. Such a man, Charles Nordhoff, appeared on the scene very late, and the description he left of one branch of modern Tahitian fishing is a minor masterpiece, ethnographically and artistically; compared with his account those written about fishing during the era now under study are for the most part superficial and flat. But even from these latter accounts one is struck by the multiplicity of Maohi fishing techniques and by the way many techniques had been adapted to highly particular, localized conditions. ${ }^{47}$

Small nets, sticks, or bare hands were used for collecting crustaceans, urchins, molluscs, and gastropods; and both males and females, walking along the reefs or in the shallow waters of the lagoons, joined in this occupation. Crustaceans, both the small-clawed South Seas lobster and freshwater prawns, were also caught by spearing and trapping. According to Ellis, the Maohis avoided oyster beds in order to prevent cutting their feet on the sharp shells; and they did not eat oysters; but whether due to the hazards of collecting them is not explained (1829:II, 284). The only report that I can find that the Maohis collected and ate sea slugs (bêche de mer) is contained in the journal of Tyerman and Bennet, who wrote that it was "... regarded as a great delicacy by the natives" (Montgomery 1832:II, 135). This was recorded in 1822 , so it may conceivably have been a recently acquired taste.

Poisoning fish was sometimes resorted to in quiet waters. The bruised leaves of several plants-for example Tephrosia piscatoria, Daphne foetida, Lepidium piscidium - when mixed with bait and scattered over the surface so stunned the fish that they could be collected by hand. Another effective fish poison was the fruit of the Barringtonia.

Some men were skillful enough to catch free-swimming fish by hand, particularly the porcupine fish:

They ... are excellent hands at diving after [rock fish] and I have seen a Diver in Clear Water and Calm weather pursue a Fish from one hole in the rocks to another without coming up to breath; but in rough weather they cannot see to follow them, the bottom being darken'd by the ripple on the Surface-the most curious part of this fishery is that of taking the Hedge hog fish and Sea Cat-the one being so full of prickles that they can take hold no where but by the Eyes, which is the Method by which they get them as very few are caught any other way-and the others adhere so close to the rocks, that it is as much as two men can do at times to haul them off and I have seen them in 3 or 4 fathom forced to quit them and come up several times before they could accomplish their end; if a Stone lies handy below they kill the fish there, \& then they get it off easy. This may seem an odd Method of Fishing but I have seen it attended with good 
Success and the Divers return in a few hours with large Strings of fine Fish. (Morrison 1935:155)

Ellis provided an account of the Maohi version of the widespread South Seas method of capturing octopus by means of lures:

They have a curious contrivance for taking several kinds of ray and cuttlefish, which resort to the holes of the coral rocks, and protrude the arms or feet for the bait, but remain themselves firm within the retreat. The instrument they employ, consists of a straight piece of hard wood, a foot long, round and polished, and not half an inch in diameter. Near one end of this, a number of the most beautiful pieces of the cowrie or tiger-shell are fastened one over another, like the scales of a fish or the plates of a piece of armour, until it is about the size of a turkey's egg, and resembles the cowrie. It is suspended in an horizontal position, by a strong line, and lowered by the fisherman from a small canoe, until it nearly reaches the bottom. The fisherman then gently jerks the line, causing the shell to move as if inhabited by a fish. This jerking motion is called tootoofe [to'oto'o fe'e], the name of the singular contrivance.

The cuttle-fish, attracted, it is supposed, by the appearance of the cowrie, (for no bait is used,) darts out one of its arms or rays, which it winds around the shell, and fastens among the openings between the plates. The fisherman continues jerking the line, and the fish puts forth another and another arm or ray, till it has quite fastened itself to the shells, when it is drawn up into the canoe, and secured. (1829:II, 292-293) ${ }^{48}$

Eels inhabited streams, lakes, and sea, and figured prominently in Maohi folklore and myth. Some at least were taken at night, by torchlight and spear; other specific techniques, if any, for taking them were not reported, but Morrison did provide an interesting example of the way in which people allowed their appetite for this delicacy to overcome the hazard involved in eating it:

Among the Fish there Is a kind of Conger Eel of a Brownish Collour with a Green border round the Fins from Head to tail. They are Caught about the reefs and are of different sizes from one to Six feet long; these Fish are of a Poisonus Nature to some and if eaten gives the most excrutiating pain while others who eat of it feel no effects nor do the Natives know who will be affected by it, till they have eaten it. As they have a remedy for it they take no account of the matter and eat them at a venture. I partook of one of these Fish without feeling the smallest effects from its poison, while another who eat of the same Fish was almost raving mad, His Body and limbs swelld to a very extraordinary degree and Covered with red blotches and at the same time the Hands \& feet itching in Such a Manner as to be unsufferable and burning as if on fire, the Eyes swelld and firey and to appearance fit to start from the Sockets, this Continued with short intermissions for Eight Days but in the Course of a Week more by the assistance of some of the Priests who procured Medicines he got quite well, but often found a great itching in the Palms of the Hands \& hollow of the feet-These Fish are Calld by the Natives Puhhe Pirrerowtee [puhi ai roto] and as they dont know the Good from the Bad they are loth to throw them away and therefore eat them to make sure of them-(1935:159) 
In this connection, Ellis described a curious custom of eel "domestication":

Eels are great favourites, and are tamed, and fed till they attain an enormous size. Taaroarii had several in different parts of the island. These pets were kept in large holes, two or three feet deep, partially filled with water. On the sides of these pits, the eels formed or found an aperture in a horizontal direction, in which they generally remained, excepting when called by the person who fed them. I have been several times with the young chief, when he has sat down by the side of the hole, and by giving a shrill sort of whistle has brought out an enormous eel, which has moved about the surface of the water, and eaten with confidence out of his master's hand. (pp. 285-286)

No explanation was offered concerning whether the ultimate end of such eels was as food, as pets, or as creatures in which to embody a spirit-familiar.

Turtles were occasionally found in the lagoons of the high islands but inhabited mainly the waters around the isolated western atolls. According to Nordhoff, they were "formerly" taken on a hook with a bait of seaweed (1930b:223); how else they might have been caught we cannot say. Turtle shell was used for making fishhooks and ornaments, and turtle flesh was considered a great delicacy. Ellis stated that turtles were considered "sacred" and that their flesh was cooked only within marae precincts (p. 285). Such flesh was reserved for certain "principal people" as was indicated in the legend of the turtle and the fowl, reproduced earlier in this chapter.

Whales were not hunted at sea, but when one became stranded in shoal waters or on a reef men went out in canoes and killed it-a dangerous adventure inasmuch as "... they sometimes get their Canoes dashd to pieces" in doing so (Morrison 1935:159).

Before proceeding to describe the more conventional fishing methods employed by the Maohis, I reproduce Ellis' account of catching needlefish on Huahine's large saltwater lake-another example of a highly specialized technique based on local conditions and on sound knowledge of the prey's characteristic behavior:

They have a singular mode of taking a remarkably timorous fish, which is called $a u$ or needle, on account of its long sharp head. The fishermen build a number of rafts, which they call motoi;each raft is about fifteen or twenty feet long, by six or eight wide, and it is made with the light branches of the hibiscus or purau. At one edge a kind of fence or skreen is raised four or five feet, by fixing the hibiscus poles horizontally, one above the other, and fastening them to upright sticks, placed at short distances along the raft. Twenty or thirty of these rafts are often employed at the same time, the men on the raft go out at a distance from each other, enclosing a large space of water, having the raised part or frame on the outside. They gradually approach each other till the rafts join, and form a connected circle in some shallow part of the lake. One or two persons then go in a small canoe towards the centre of the enclosed space, with long white sticks, which they strike in the water with a great noise, and by this means 
drive the fish towards the rafts. On approaching these, the fish dart out of the water, and in attempting to spring over the raft, strike against the raised fence on the outer side, and fall on the surface of the horizontal part, when they are gathered into baskets, or canoes, on the outside. In this manner, great numbers of these and other kinds of fish, that are accustomed to spring out of the water when alarmed or pursued, are taken with great facility. (pp. 287-288)

The Maohis were expert in the manufacture and use of nets of many sizes, shapes, and uses. Their small hand scoop nets have already been mentioned. Ellis provided a brief account of the use of cast nets: "Their light casting-nets were neatly made, and used with great dexterity, generally as they walked along the beach. When a shoal of small fish appeared, they would throw the net with the right-hand, and enclose sometimes the greater part of them." (p. 288) Such nets were either square or round, and were usually made of line, having meshes of various dimensions. The small fry thus netted was sometimes eaten, but it more usually served as bait.

In his study of modern Tahitian fishing, Handy reported having seen deep two-man bag nets used for fishing along the reefs, and small shallow landing nets of various sizes, shapes, and purposes (1932:84ff); and, while the older accounts provide no details about such implements, it is highly likely that similar forms of nets (but not similar materials) were made and used in pre-European times.

To European observers the most impressive of Maohi nets were the large seines, some of them thirty to forty fathoms long and twelve fathoms deep. The cord of the best of these was made of Ficus prolixa bark and had meshes about four inches square. The bottom edges of such nets were weighted with stones wrapped in coconut fibers, while the top edges were held afloat with short pieces of dry hibiscus wood. (Ellis: pp 289-290) Ellis also provided an account of the manufacture of such a net. While the event witnessed by him took place after the "official" capitulation of "paganism," and hence was devoid of the more public incidents of native religious ritual, the rest of the episode has the marks of pre-Christian authenticity:

Upea ['upea] is the common name for net. The upea ava, or salmon net, is the longest and most important, and is seldom possessed by any but the principal chiefs; it is sometimes forty fathoms long, and twelve or more feet deep. One of this kind was made by Hautea, the governor of Huahine, soon after our arrival. Although the former pagan ceremonies, and the offerings at the marae, were discontinued, some of the ancient usages were observed, one of which appeared rather singular. As is customary on all occasions of public work, the proprietor of the net required the other chiefs to assist in its preparation. Before he began, two large pigs were killed and baked. When taken from the oven, they were cut up, and the governor's messenger sent with a piece to every chief; on delivery, the quantity was stated which each was desired to prepare towards the projected net. If the piece of pig was received, it was considered as an agreement to furnish it; but to return it, was, in effect, to refuse compliance with the requisition. At this time, however, no 
one returned the tarahu, or price, but all agreed to furnish one or two fathoms of the net. When any other chief wanted a net, he took the same course. (p. 289)

Seining was carried out mainly in the shallow waters of lagoons. In some instances men working from canoes enveloped the prey by dragging together the wings of the net. In other instances the seine nets were fixed in a wide $\mathrm{V}$-with or without a bag left in the inner angle-and the fish were driven into the narrow end by swimmers or by men in canoes who beat the waters with long sticks or with heavy stones. (See Bouge 1928; Beaglehole 1955:133)

Once trapped within the closed nets the fish were taken either by hand or by hand net or by spear. Here is Morrison's description of such events:

These large ones [seines] have a bag or Cod in the Middle and when they haul them in Deep Bays they never land them till they are done fishing, but cast off the Cod on the outside of the surf, and bring the Fish on Shore in their Canoes when they haul the Sein into a Canoe and having laced on the Cod Shoot it afresh; in this Manner they Catch a great Number of fine fish and some turtle. While they are fishing in this manner the Net is always surrounded by Swimmers who dive down and secure such fish as are like to escape and tho the Sharks often attend them yet they seldom interrupt their work and if they Catch the Sharks in the Surf they Surround them and force them on shore, which is so far from being deemd dangerous that it is Counted fine Sport-the Sharks here are not very large seldom exceeding five or Six feet in length-with their Small Seines they Catch the Flying fish having Small Canoes for that purpose which will Carry two men; the seines for this purpose are 15 or 20 fathom long, and 9 feet deep; these they Shoot amongst the Fish and Splashing the water about with their paddles frighten the Fish till they dart into the Net and Mash themselves, they then haul in their net and take out the fish, and following the School shoot it afresh; as they fish for them for Bait for the Dolphin they frequently take the Night for it and Choose the Dark in preference to the Moon light when the fish cannot see to avoid the Nets-in Calm Weather they follow the School with a number of Canoes and Surround them with their Nets in a Circle and having drawn them into a small Compass make the Canoes fast to the Nets and Jump overboard, diving under the Nets and Seizing what fish they Can by hand and frequently bring up one in each hand besides what get Mash'd in the Nets, the fish being prevented from rising by the Sight of the Canoes, and keeping Close together never attempt to escape till the men come among them. (1935:154-155)

Some indication of the size of catch obtained by use of nets was given by Rodriguez:

In the afternoon I went out in quest of fish, and they gave me more than an arroba weight of scad, which is the most plentiful kind of fish in the harbour without going outside the reef; for, in three casts of the net, which is a very large one, they got more than sixteen arrobas of scad, insomuch that ten men did not suffice, between them, to haul in the purse. (Corney 1919:101) ${ }^{49}$

Morrison described a kind of drag fishing carried out in the shallower waters of lagoons: 
.... when the Fish comes into the Shoal water to spawn they get a quantity of Cocoa nut leaves from which they take the Stems and tying them together, twist them the inside forming a kind of rope with the leaves all round it this they Call Row [rau, leaf] and with this they Sweep the reefs \& Shoal Water and bring whole Schools of Fish to the Beach where they apply their small Seins and lade Nets to land them. (1935:155)

Handy (1932:106-107) provided a detailed description of modern drag fishing (rau ere) which appears to be identical to the type described by Morrison. Morrison also provided a description of drag fishing in streams:

In the rainy season they Catch large quantitys of Small Fry at the Mouths of the rivers by means of a large bag made of the Membranous Stratums of the Cocoa Nut tree sewed together, the Mouth of the bag being made with two Wings to Spread the river; they place it and lay stones on the lower part to keep it down, they then sweep the river with a Row and bring all the Fry into the Bag; and in this Manner get several Bushells at a haul, in the Mean time the Weomen have their part of the Fishery and each being equipt with a bag \& a Basket, form themselves into three or four lines across the river up to their Middle, and keeping the lower part down with their feet hold the upper part in their hands alternately searching it and putting the Fish into their Baskets till they are either tired or Satisfied, when they leave off and go home to Dress them. It is No disgrace for any woman to be thus Employd and if the Queen is present she generally makes one and they are Generaly paid for their labour with Good Sport and plenty of Fish. (pp. 155-156)

Some nets represented immense amounts of work and, with patching, lasted for years. Others were put together quickly for a season's use, such as the net roughly made out of hibiscus bark, designed to catch 'operu (Decapterus pinnulatus) during their seasonal visits inshore. The meshes were wide enough for these small fish to swim through, and served mainly to herd them together until they could be taken by net or spear.

Weirs were constructed with stones, coral, wood, leaves, nets, or combinations of these. Some of them were permanent structures erected at strategic positions in the lagoons; others were put up for seasonal use at stream mouths or in stream beds. The most notable weir of the Islands was at Maeva, in northern Huahine, where a shallow salt lake is joined to the sea by a long and narrow lagoon entrance (fig. 9-10). There the Maohis built a series of stone and coral weir traps so arranged as to trap the fish carried in or out of the lake by tides and winds. It was undoubtedly this circumstance-of a nearly automatic, regular, and abundant food supply-that served to make this place the largest population aggregation and major political center of all Huahine.

According to Handy, the only structures that might be called "fish ponds" (àva $\left.i^{\prime} a\right)$ were a few temporary enclosures, made mainly of wooden stakes and used for containing 'operu when they were caught in large numbers, and the small stone rectangular enclosures built along the lake shore at Maeva to hold fish taken from the stone weirs there (1932:93-94). 


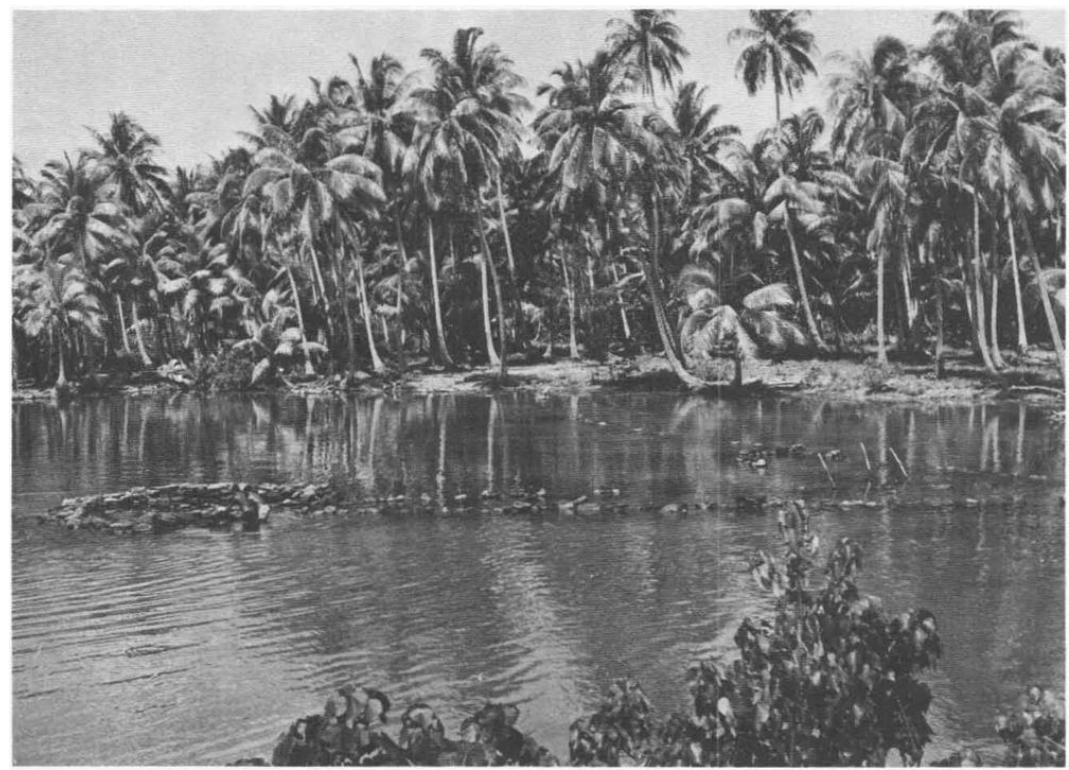

FIgURE 9-10. Stone fish trap at Maeva, Huahine. Photo by Y. Sinoto, Bishop Museum.

A wide variety of spears, varying in length, weight, and type of point, was used by the Maohis for catching fish. Some points consisted only of the sharpened end of the shaft itself; in other cases separate wooden (or bone) spearheads-from two to twelve or so, the number varying with intended use-were attached to the shaft.

Some spears were designed for jabbing while swimming, others were thrown from canoes, or hurled while the spearmen were standing in the water or on the reef or on shore. One very difficult but occasionally very rewarding technique was for the spearman to stand on the outer edge of a barrier reef and aim for the large fish brought in by the breaking waves. As there was no cord attachment, spearmen had to retrieve their spears by swimming after them. Moerenhout related that the Maohis took great delight in spearfishing and were continually practicing to improve their skills in order to surpass each other (1837:II, 105).

According to Ellis, some spearmen threw with great accuracy while others were very awkward at it (a useful observation to counter widespread beliefs that all Polynesians were by nature adept in all their arts). We are also indebted to Ellis for a vivid description of fishing by torchlight:

... a variety of ... methods of fishing, are pursued by day-light; but many kinds of fish are taken by night: sometimes the fishery is carried on by moon-light, occasionally in the dark, but fishing by torch-light is the most picturesque. The torches are bunches of dried reeds firmly tied together. Sometimes they pursue their nocturnal sport on the reef, and hunt the totara, or hedge-hog fish. Large parties often go 
out to the reef; and it is a beautiful sight to behold a long line of rocks illuminated by the flaring torches. These the fishermen hold in one hand, and stand with the poised spear in the other, ready to strike as soon as the fish appears.

In the rivers they also fish by torch-light, especially for eels; and though the scene is different, its impression is not inferior. I have often been struck with the effect of a band of natives walking along the shallow parts of the rocky sides of a river, elevating a torch with one hand, and perhaps a spear in the other; while the glare of their torches was thrown upon the overhanging boughs, and reflected from the agitated surface of the stream. Their own bronze-coloured and lightly clothed forms, partially illuminated, standing like figures in relief; while the whole scene has appeared in bright contrast with the dark and almost midnight gloom that enveloped every other subject (1829:II, 297-298)

Hook-and-line fishing was carried on both inside the lagoons and in the open sea. (Figs. 9-11 through 9-16) One procedure involved a long bamboo rod and a hook (of unspecified nature) baited with breadfruit; the fisherman stood in the water up to his neck to cast. Lagoon fishing was sometimes done with rod and line from the inner margins of the barrier reefs, or with handlines from stationary or moving canoes. But of all their methods of fishing the Maohis were at their best, at least with respect to individual skill, in the vigorous and often dangerous art of offshore fishing. In their quest for albacore, bonito, dolphin, shark, swordfish, and other pelagic fish they worked singly or in groups, sometimes staying out for days at a time.

The offshore fishing of latter-day Tahitians found a worthy reporter in the person of Charles Nordhoff, one of the fictionalizers of the Bounty mutiny and himself a knowledgeable and enthusiastic fisherman. The events described by Nordhoff occurred in the 1920s, but in many respects resemble so closely those recorded a century and more earlier that one may perhaps be forgiven for referring to them, to enliven the accounts of the earlier chroniclers. The durability of so many of these fishing practices through a century and a half of radical change in so many other areas of Maohi life might move one to marvel, until the thought occurs that the Maohi methods may indeed have reached perfection and the fishing techniques worked out over centuries of experimentation with the complexities and local particularities involved in these fisheries had demonstrated that they could not be improved upon. ${ }^{50}$

The pelagic fish most pursued by the Maohis were dolphin, albacore, and bonito. Others, such as cavally, swordfish, and shark, were also caught and gladly eaten; but one gets the impression that catching the latter was somewhat incidental to fishing for the former-possibly because bonito, dolphin, and albacore swam in larger schools and thus when located offered the opportunity for bigger catches.

The dolphin of these waters are of two kinds, Coryphaena equisetus (mahimahi tari'a) and Coryphaena hippurus (mahimahi). The latter runs 


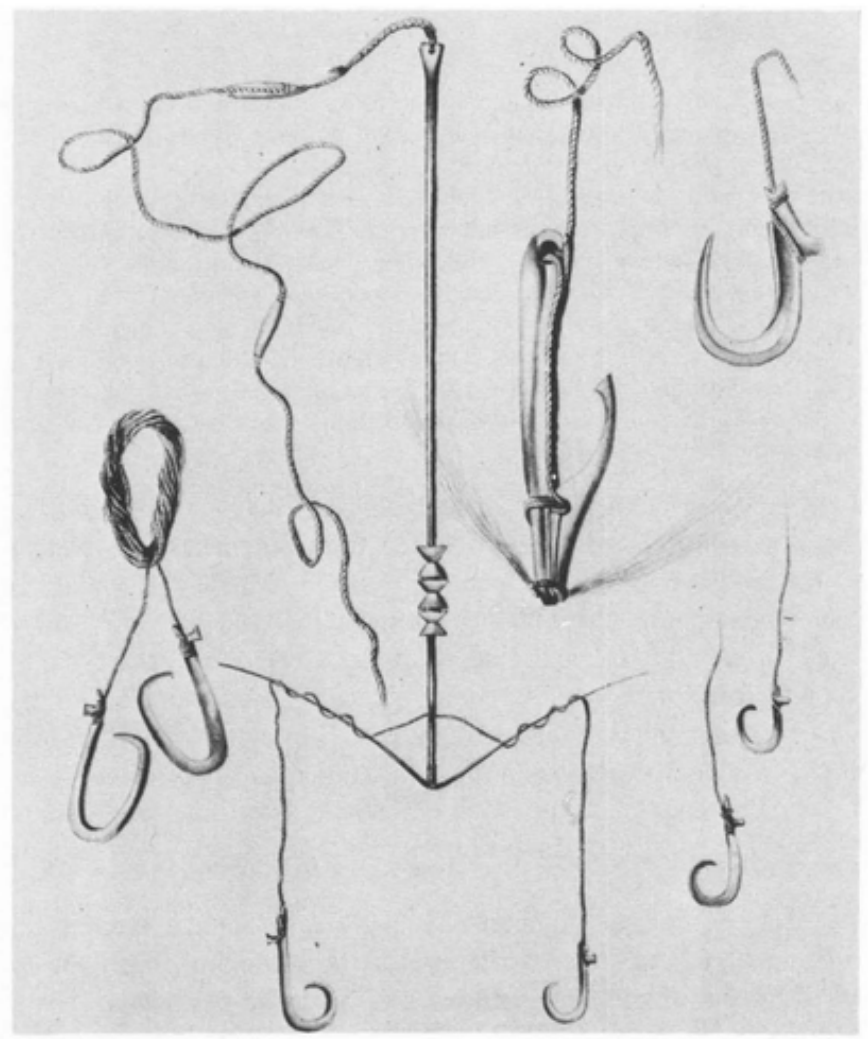

FIGURE 9-11. "Different sorts of fish hooks from Otaheite." Drawing by J.F. Miller. British Museum.
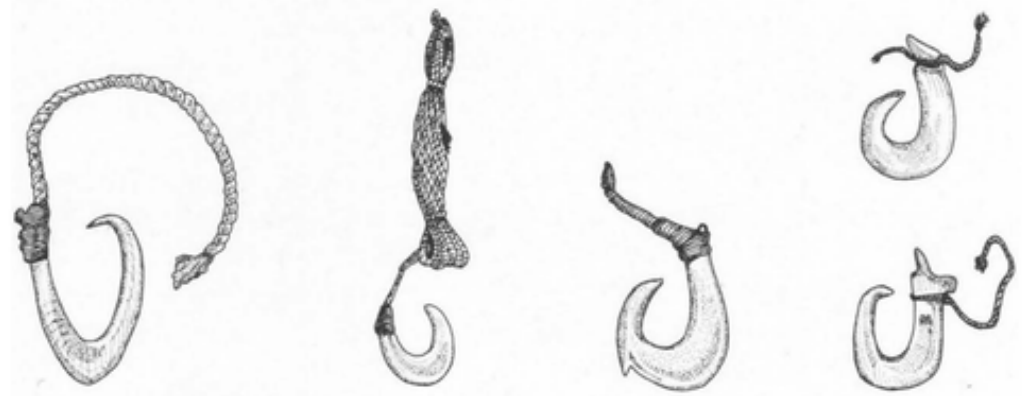

Figure 9-12. Fish hooks. 


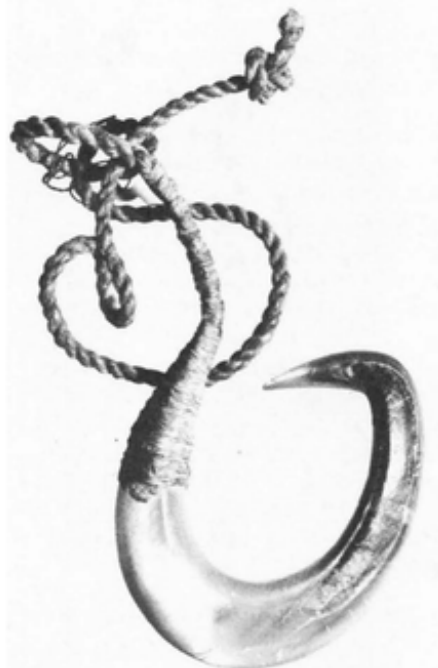

Figure 9-13. Fish hook. Peabody Museum, Salem.

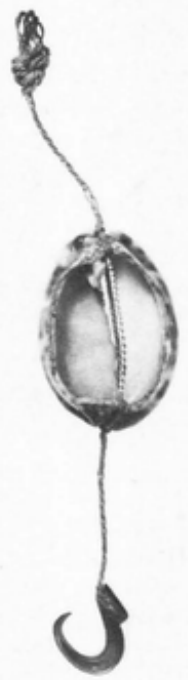

Figure 9-15. Fish hook with cowrie shell lure. British Museum.

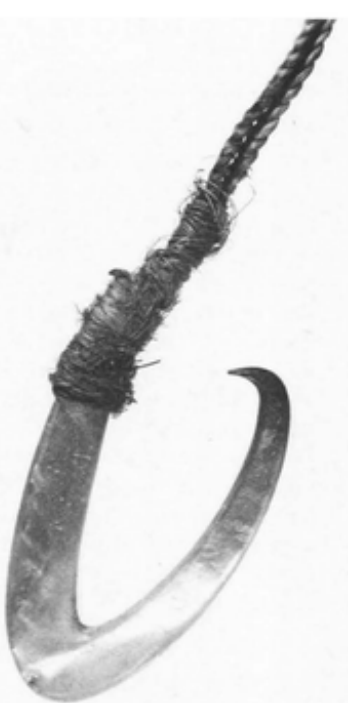

Figure 9-14. Fish hook. British Museum.

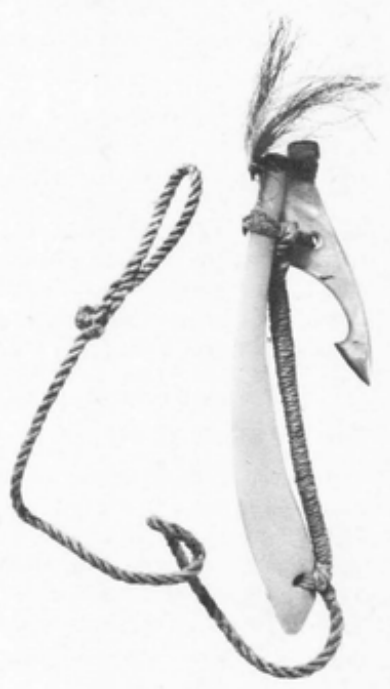

Figure 9-16. Bonito fish hook with lure. British Museum. 
much larger-one hundred pounds or more-and was the kind systematically fished for. Morrison described this fishery as follows:

They always fish for Dolphins four or five leagues from the land in sailing Canoes plying to windward-when they reach their distance they Bait with Flying Fish, and are very fond of Iron hooks; ${ }^{[51]}$ their lines for these Fish are generally two strands and of a Good length, some of them Measure 100 fathoms. They Choose the two Strand lines as they are less apt to get foul by Twisting then those of three and as the Dolphin Jumps and twists about when hookd they are not so ready to breake and easyer Cleard after running out; they never wet their lines till they see a Fish and then they make sure of it, tho they are often deceived; as the Fish will sometimes leave part of their Jaws behind them if too Suddenly Stopd in their Carreer, they are forced to play them some time before they haul them alongside to get them in, which they always do by laying hold of the tail part with one hand \& the line in the Other; the Canoe being low for that Purpose-These fish Follow the Sun and are therefore most plenty when the Sun is to the Southward of the Equator, during which season there are Not less than Sixty sail of Canoes from Maatavye only, employed in the Fishery-the Fish Spawn about March after which they seldom look for them.... (Morrison 1935:157-158)

I will expand somewhat upon this terse statement, with information taken mainly from Nordhoff and Ellis. The canoes used in this fishery were of medium size and outfitted with sail. Fishing was by handline baited with crayfish or flying fish. The line most preferred for this and all other fishing where strength was required was made of swordgrass cordage. Some of the native dolphin hooks were made of wood, about which Ellis wrote as follows:

The wooden hooks were never barbed, but simply pointed, usually curved inwards at the point, but sometimes standing out very wide, occasionally armed at the point with a piece of bone. The best were hooks ingeniously made with the small roots of the aito tree, casuarina, or iron wood. In selecting a root for this purpose, they chose one partially exposed, and growing by the side of a bank, preferring such as were free from knots and other excresscences. The root was twisted into the shape they wished the future hook to assume, and allowed to grow till it had reached a size large enough to allow of the outside or soft parts being removed, and a sufficiency remaining to make the hook (1829:II, 294)

Of hooks in general, and their method of employment, Nordhoff provided this confirmatory note:

In one respect the use of all these in-curved or angular native hooks differs from that of ours. When the fisherman using a European hook "gets a bite," he strikes to set the point and barb in the fish's mouth. With the native hook, on the other hand, one must never strike; a steady gentle tension is kept on the line and the fish allowed to hook itself. The pull of the line, leading from the inner head of the shank and causing the hook to revolve, sets the point deeper and deeper in the fish's jaw. (1930a:156)

According to Nordhoff, dolphin fishing was more prevalent off the windward coasts of the islands, some miles offshore. Morrison's report that 
dolphins were fished for only during the summer months is to be qualified somewhat by Nordhoff's statement that "Only a score of years ago, I am told, half-a-dozen dolphin-canoes were to be seen on any favourable day, tacking back and forth a few miles off Papeete (1930a:167).

As for the actual fishing, I can do no better than to reproduce Nordhoff's reconstruction of what it must have been like in the early years of the nineteenth century. Any attempt on my part to summarize this account would sacrifice much about Maohi fishing that is most valuable to know:

I have had many a yarn with former dolphin-fishermen, and in order to make clear how the fishing was carried on, I shall try to reconstruct in imagination a morning in a Tahitian dolphin-canoe, twenty-five years ago:

The bait of flying-fish has been obtained, probably at the morning market in Papeete, and the little vessel is headed offshore, close-hauled on the starboard tack. The maoa' $e$ is blowing, the fresh northeasterly breeze fishermen love, and the outrigger, on the lee side, is buried in foam. The old man, who handles the heavy steering paddle aft, gazes ahead from time to time, shading his eyes with his hand. He and the two younger men with him wear taumata, little bonnets of plaited coconut-leaflet. The others are busily arranging their fishing-gear and baiting several hooks, each of which is fast to a short trace of line, ending in a loop. This is essential in dolphin-fishing, for clubbing will not kill the fish at once, and a single slap of its tail is often enough to send it leaping back into the sea. When a dolphin is hauled aboard, the hook is left in its mouth, the bowline with which the line is made fast to the loop in the trace cast off, a hitch taken about the "small" of the fish's tail, head and tail pulled close together, and the trace made fast in that position, which ends the dolphin's struggles at once. The old man glances back toward the land, now five or six miles astern; the white line of breakers on the reef is no longer visible-ua moe te $a^{\prime} a u$, as they say. At this distance from land dolphin may be met at any time.

Aft in the canoe, propped against the flexible after-crossboom where it crosses the gunwales, are three fishingrods, equipped with lines and pearl-shell hooks. Two of them, about fifteen feet long, are for bonito-catching in case of sighting the fish; the other, six feet shorter and of enormous strength, is of a woody, short-jointed bamboo introduced to the islands in recent times; it carries a heavy line of native manufacture and a single huge pearl-shell hook for toheveri-the full-grown bonito of forty or fifty pounds weight. The dolphin-canoes never put out without bonito-tackle.

A word from the old man makes the others glance up from their work of arranging an entire flying-fish on each hook. Nearly a mile off and dead to windward a cloud of birds is hovering over the sea. The keen eyes of the fishermen appraise the situation at a glance. "E ere te auhopu" ("Not bonito") says one of the young men, and at the words a series of golden flashes in the sunlight prove that the fish are albacore. The old man shrugs his shoulders and does not alter the course of the canoe; the actions of the birds have long since told him that the fish will not bite, and the leaping of the albacore has confirmed an opinion already formed. When albacore and bonito leap freely from the sea, exposing their whole bodies, they rarely take the hook.

An hour passes; the island of Moorea is abeam, eight or ten miles to leeward, when one of the young men, stationed at the bow, sings out: "Mahimahi, paha!" ("Dolphin perhaps!"). His eye has caught the glint of a white wing in the sunlight to leeward; the canoe bears off while the sheet is slacked away. Before long 
two of the small white terns called itata'e (Leucanous albus pacificus) are clearly visible. They fly together low and erratically over the sea, stopping to circle at times and very obviously watching and following fish. These are the birds which indicate the presence of dolphin; one, two, or three of them flying as above described, are an indication of either dolphin or large solitary albacore. The natives believe that if the birds in their excitement as they circle give their little grating cry, it is a sure sign of dolphin below; if there are more than three of the terns together, it is doubtful if dolphin are about. The helmsman's ears are dulled by age, but as the canoe sweeps down on the birds, one of his companions shouts: "Ua ta'i te manu!" ("The birds are crying!"). The dolphin, unlike bonito and albacore, practically never surfaces.

Close-hauled once more, the canoe is now footing it just to windward, keeping the weather-gauge on the birds. They are very close and the three fishermen spring into action at last. The old man is flinging bits of cut flying-fish into the sea, and suddenly his eye catches a flash of blue and gold. "A $t u^{\prime} u$ !" he orders sharply, and a baited hook goes overboard at the word, at the end of twenty yards of line. The other young man stands with set lips and gleaming eyes, his own line ready in his hand. The canoe luffs more and more, slackening speed as the sail begins to shiver.

A shout goes up: "Mau! Mau!" (“Fast! Fast!”). The trolled line has straightened with a snap and is now running through the young man's fingers, while the sea blazes with the colours of the big struggling fish. It fights on the surface, unlike the albacore, in showy runs and leaps, but it is soon worn out by the steady tension and struggles weakly close alongside the canoe. " $A t u^{\prime} u$ " orders the old man once more. The canoe is now hove-to, and held so with powerful sweeps of the steering-paddle; the second flying-fish is whirled about the young man's head and flung well away, while his companion snubs the hooked fish not ten yards down. To take the hooked dolphin aboard before another one was fast would probably spoil the morning's sport, for at the disappearance of their companion, the other members of the little band would leave the canoe. But the natives believe, and I think with reason, that as long as one of these fish is held captive in the sea, its "friends" will stand by.

A moment later there is another shout of "Mau!" The old man nods to the holder of the first fish and ceases to paru (scatter chum) while he helps to secure the living rainbow now hauled aboard. In half a minute the fish is triced up and helpless; doubled in a circle it lies in the bilges, showing only by movements of the gills and a shuddering blaze of colour that it is still alive. The second fish is now alongside and another baited hook is cast out while the old man flings overboard a double handful of chum. The dolphin come aboard-fairae and $a^{\prime} o$ (male and female, only applied to dolphin)-until eight of them lie in the canoe and none are left in the sea. (1930a:170-172)

The albacore of these waters were of several varieties (and probably several species as well), the most commonplace having been Germo germo and Thynnus macropterus. The Maohis' generic name for these fish was ' $a$ 'ahi, but there were also distinctive names given to different varieties, based, among other things, on color and behavior, and on stages in growth. Nordhoff's account of these distinctions provides further evidence of the Tahitians' (and inferentially, the ancient Maohis') intimate knowledge of this domain of their natural environment: 
The small ones, which appear in large schools at the first of the season, and average six to eight pounds in weight, are called aahi tau, or aahi perepererau. The next size, believed at that stage to have a particularly white belly, is called aahi 'opu tea; and the next, thought to have dark-coloured pectoral fins, is known as aahi tari'a uri. The aahi mapepe, which comes next, will average about forty pounds, and aahi tatumu is the name of the fish when considered full grown. At this stage the albacore weighs from eighty to one hundred and fifty pounds. Aahi araroa is the name of the enormous two, three, or four-hundred-pound fish which roams the sea alone, or with one companion at most. The word araroa, by the way, means also: "The first hog taken to the king on removing a restriction," and "the first fish caught by a new fishing-canoe." This first fish was always given to the chief....

There are other names for the albacore, based on character. The vere may not be of the largest size, but it is particularly strong. Of the vere it was said: [native text omitted] "An albacore stronger (than usual is) the vere; the purau snaps; the line quickly breaks." The hae is the fierce, hungry fish which seizes the bait without hesitation; the tau maueue is the wary albacore which tries the fisherman's patience by refusing the bait. The teaamu is the fish that feeds freely on the live bait thrown out of the canoe, but will not seize the hook. The tia matau is the albacore which, having felt the hook and escaped, has learned to avoid the bait.... (1930a:141-142)

A peculiar characteristic of albacore is that they congregate in certain fairly sharply defined areas of the sea, called "holes"-although such holes have little to do with the conformation of the sea bottom:

Though fairly close to the reefs, all the holes are "off soundings," and the presence of the fish probably has nothing to do with the bottom, far below. The most reasonable explanation I have heard was offered by an old fisherman. "An albacore-hole," he said, "is a place in the sea where conflicting currents set up a condition like the nini (the "cowlick") on the back of your head. The small fry, moving with the currents, are swept into such places from all sides, and the albacore wait there for their food." Whatever the cause, it is a fact that albacore frequent these places, and strange as it may seem, I can vouch for the truth of the native belief that schools of albacore, after a day of roaming the open sea, return to their holes to "sleep" at night. (Nordhoff 1930a:143)

Such "holes" were found mainly in relatively calm waters off the leeward coasts of islands. Nordhoff estimated that there were only about a dozen off Tahiti; they all had names and they were probably included within the adjoining land and lagoon estates-obviously a valuable asset to their owners.

Three methods were used to catch albacore. Smaller ones were often caught with pearl-shell hooks in connection with bonito fishing. A second method, usually employed by a single fisherman in a small canoe, involved deep-line fishing in an albacore "hole," using stones to sink the long lines, baited hooks, and chum. The third was by means of a tira, which Ellis described as follows:

The most ingenious methods, however, of taking these large fish is by means of what is termed a tira, or mast. A pair of ordinarily sized canoes is usually selected, 
with a kind of basket-work fixed between them, to contain the fish. To the forepart of the canoes a long curved pole is fastened, branching in opposite directions at the outer end; the foot of this is fixed in a kind of socket, between the two canoes. From each of the projecting branches, lines with pearl-shell hooks are attached, so adjusted as to be kept near the surface of the water. To that part of the pole which is divided into two branches, strong ropes are attached; these extend to the stern of the canoe, where they are held by persons watching the seizure of the hook. The tira, or mast, projects a considerable distance beyond the stem of the canoe, and bunches of feathers are fastened to its extremities. This is done to resemble the aquatic birds which follow the course of the small fish, and often pounce down and divide the prey which the large ones pursue. As it is supposed that the bonitos follow the course of the birds, as much as that of the fishes, when the fishermen perceive the birds, they proceed to the place, and usually find the fish. The undulation of the waves occasions the canoe to rise and sink as they proceed, and this produces a corresponding motion in the hook suspended from the mast; and so complete is the deception, that if the fish once perceives the pearl-shell hook, it seldom fails to dart after it; and if it misses the first time, is almost sure to be caught the second. As soon as the fish is fast, the men in the canoe, by drawing the cord, hoist up the tira, and drag in the fish, suspended as it were from a kind of crane. When the fish is removed, the crane is lowered; and as it projects over the stem of the canoe, the rowers hasten after the shoal with all possible celerity. (1829:II, 295-296)

Tira fishing was highly productive and much more efficient, apparently, than ordinary rod or hand-line trolling, for the large fish were landed more easily and more quickly by means of the tira device. On occasion an individual deep-line fisherman might get a large catch for himself, but on the average the cooperative tira-fishing crew probably brought in better shares all around. Also, deep-line fishing in the albacore "holes" was believed to have diminished opportunities for tira surface fishing, since it accustomed the fish to bait at various depths below the surface. In any case, Nordhoff considered-with plausible reasoning-that deep-line fishing for albacore was, in his day, held in public disrepute. He cited linguistic evidence to support his opinion: the word puaro, which was applied to this method of fishing, was applied also to "an underhand blow among boxers." Similarly, he pointed out that the word mafera had two usages: "to take advantage of a person of the other sex when asleep" and "to fish for the aahi at night"-presumably the time chosen by a lone deep-line fisherman to avoid public exposure. (Nordhoff 1930a:155)

In pursuing the bonito (atu, auhopu) ${ }^{52}$ the Maohi fisherman reached an acme in craft refinement and individual skill. The problem facing him was described by Nordhoff in the following words:

The schools of bonito, under their clouds of birds, move rapidly here and there as they seek their food, chasing the small fry at a pace often times too fast for a canoe, or gobbling up entire schools and rushing off at even greater speed to seek new victims. The result is that the fishermen, after sighting the fish, often paddle at top speed for hours before they are able to drive their canoe into the midst of the school. When that time comes, they know that it will be only a mat- 
ter of minutes before they are left behind. Half the battle is won when the fish are breaking water about the canoe; the second half consists of landing in the shortest possible time the greatest possible number of fish. (1930b:235)

The requirements set by these conditions include knowledge enough to spot schools of the fish from the particular behavior of the birds that regularly feed on them, stamina enough to reach a school before it moves to another feeding ground, gear devised to lure and loose the fish easily, and skill enough to land them quickly.

First, let us examine the nature lore required in this demanding occupation. The following account, by Nordhoff, is based on observations made by him, but there is good reason to suppose that his description would have applied just as well to catching bonito two centuries earlier:

Boobies, when in large flocks and unaccompanied by other birds, are apt to be over a school of albacore or porpoise; or ordinary bonito travelling too fast for a canoe to come up with them. When the birds of such a flock dive repeatedly, but level off just before touching the water, they are following a school of flying-fish. When boobies are feeding close to a flock of feeding terns, but separate from them, the former are probably accompaning albacore, the latter bonito. Boobies and terns mixed and feeding eagerly, with cries of excitement, mean bonito which will take the hook and not travel too fast. A cloud of small white terns (itata'e) moving high and slowly above the sea, is an indication of albacore too big to take on bonitotackle. One, two, or three white terns, circling rapidly, indicate dolphin (mahimahi). A cloud of small dark terns with white caps ('oio) unaccompanied by other birds, means very small bonito, not apt to take the hook. The presence of frigate-birds above the boobies is a sign of good fishing, but an indication of bad weather on the way. When tropic-birds are diving among other kinds, it is a sign that the small fry are too small to resemble a bonito-hook. And so on ad infinitum.

In addition to the bird-lore suggested above, the old fishermen have a truly profound knowledge of weather and winds. Though I have never been able to learn how they go about it, it is a fact that such men can predict the weather with an accuracy the meteorological department of any government might envy. The winds unfavourable for off-shore fishing are the boisterous southerlies called maraamu (mara'ai), and the variable easterlies which come with heavy clouds, rainbows, and alternate calms and furious squalls. These variable winds, which blow from east to almost northeast, are called haapiti (faarua). The favourite wind of the bonitofisherman is the maoa' $e$-the light northerly to north-easterly breeze which blows warm and steady all day long. The to'erau-the northwest wind which raises a great swell and comes with blackened skies and heavy rain-squalls-is considered good by the hardier and younger men. (Nordhoff 1930b:249-250)

Bonito fishing was a seasonal occupation, beginning in November or December, with the appearance of the fry on which the bonito mainly fed, ${ }^{53}$ until early June, when these fry either disappeared or grew past favored sizes. As the appearance of this bonito fare regularly coincided with the flowering of swordgrass, this latter event also served to alert bonito fishermen to prepare their canoes and gear.

In Nordhoff's day bonito-fishing gear consisted of a rod of strong bam- 
boo, fourteen to eighteen or more feet long, a line of tough Pipturus argentens fiber slightly longer than the rod, and a two-piece baitless hook of what might appear to be simple but is in fact a most ingeniously complex design. In the first place, such a hook had to be so shaped and colored that bonito, chasing furiously after elusive small fry, would take it as bait. And second, the hook's point had to be so constructed that it could hold the fish during landing and then be freed without unhooking:

If the shanks of the hooks are not of the precise shade suited to the conditions, the fish will not strike. If the fish strike freely and the points are not cunningly designed for their work, bonito will be lost, or required to be unhooked when landed. When the man whose pearl-shell is of the proper colour, whose points are set at just the right angle and are of just the proper degree of bluntness, and who possesses the skill (comparable to that of an expert tennis player) necessary to handle a bonito-rod, will slam the fish in horizontally like slingstones, almost as fast as the eye can follow the operation. It is said of a good man that he will sometimes have two fish in the air at once, and the feat may be possible. True adepts are rare and probably always have been. (Nordhoff 1930b:235)

Figure 9-16 illustrates one of these wonderful implements. The shank, which is at the same time the lure, is ground out of pearl shell; the barbless point is of bone. ${ }^{54}$ The hackle, formerly made of fiber or pig bristle, was added to help attract the fish and to keep the point upright. And finally, the line was attached in such a manner that it spared the rather fragile shaft lure from the full pull of a hooked fish, for the shaft was the most crucial component of this ingenious apparatus.

The bonito hook shafts seen by Nordhoff were made from the blacklipped pearl-oyster shell, of which there are many local varieties differing from one another in color, luster, and so forth. Every expert bonito fisherman owned a number of such hooks of several different kinds. It was the general belief that a fisherman's success in attracting a fish depended upon his using a shank whose lustrous under-surface closely resembled-from the vantage point of the bonito, that is-the small fry on which the fish were feeding. Thus, choice of a shank depended not only upon the kind of small fry on which the bonito was feeding, but also upon such color-affecting variables as time of day, degree of cloudiness, and type of wave. To be successful a fisherman had to have the knowledge to size up conditions quickly, for slow experimentation meant loss of catch in this fast-moving fishery. Also, of course, he had to own a wide variety of hook shanks.

Such shanks were among the most prized possessions of fishermen known to Nordhoff; and their value appears to have increased with success. Each stretch of coast on each island produced a characteristic and distinctively named variety of shell; Nordhoff listed fifteen for Tahiti alone, and he stated that an expert bonito fisherman could recognize and name nearly all 
of them at a glance. In addition, each successful shank was given an individual name by its proud owner:

To illustrate the use of shell-names, let us suppose that two canoes are in the midst of a school of fish, and that one fisherman is taking bonito rapidly, while the other is getting no strikes. "What shell are you using?" the unlucky man might sing out. If the lucky fisherman felt well-disposed toward the other, the reply might be: "O Patiri" (Thunderbolt). Then if the other man came from a distant village and his blank expression showed that the specific name of the hook meant nothing to him, the lucky fisherman might enlighten him by continuing: "E rauoro, iri ahi'a" (A pink rauoro). These words inform the inquirer that the successful hook was a shank of shell from Maupiti, in the Leeward Islands, of a peculiar satin-like texture, and tinged with a rosy flush. (1930b:241)

Regarding the point of the fishhook, Nordhoff had the following to say:

The point of a bonito-hook is designed with considerable science for its special use. In fishing, the tip of the rod is held just high enough to give a little support to the forward end of the shank, so that it skips over the surface of the water like a tiny hydroplane. The bonito seizes it from behind and below, and it is obvious that out of a hundred fish, ninety-nine will be hooked in the upper jaw. As the upper jaw of the bonito is shorter than the lower one, the sharpened point of the hook (mata) must be higher than anything aft of it, for if the pafao bends to run parallel with the shank, or has the slightest incurve, its point may scratch the fish's upper jaw, but is apt to slip forward and out, without taking hold. Many of the bonito-hooks to be seen in museums would be worthless, for this reason, in actual fishing; and the shanks I have seen in the hands of collectors were equally worthless. A first-class bonito-hook is neither given away nor sold; in my experience such a hook can only be acquired by theft.

The skill of a bonito-fisherman may be judged from an inspection of his hooks. A green hand uses long points, very sharp, to insure landing every fish that strikes. The expert uses short, blunt points, just sharp enough to lift the fish out of the water before they drop out of the jaw. While the beginner is landing a dozen bonito, many of which must be disengaged from the hook by hand, the adept will have pulled out of the water fifty fish and landed forty-five of them without touching a hook. $(1930 b: 245)^{55}$

Finally, we turn again to Nordhoff for a vivid reconstruction of a bonito expedition; the time setting was that of the 1920s but in most essentials it would probably pertain just as faithfully to two centuries before:

Let us suppose that the maoa'e is blowing and that our man is preparing to go out. His canoe lies in the shallows before his house, and the hour is about two in the afternoon, for fish caught in the evening will be good for to-morrow morning's market. (Morning fishing is usually of a different kind, which I shall mention later on.)

A sturdy young man of twenty is arranging the gear in the canoe; the fishermen always go out in couples, and the forward paddler is usually an apprentice who does no fishing unless the canoe is loaded and the adept in a good humour, when he may suggest an exchange of seats. 
Resting on the cross-booms of the outrigger are three or four bonito-rods, completely rigged, with hibiscus-leaves ( $r a u$ fau) carefully tied over the hooks, which lose their lustre when over-exposed to the sun. (A parau pohe is a shank which has "died" in this way.) The men wear cotton undervests and dungaree trousers cut off at the knee; under their hats of pandanus they have placed fresh green leaves to protect their heads from the sun. In addition to paddles and fishing-tackle, they carry a bottle of water and a short club of 'aito wood (casuarina) to kill the fish.

A few women from neighbouring houses stand about, enjoying an exchange of banter, some of it rather broad to European ears.

"And if we hook a fish in the lower jaw," shouts the apprentice, as the canoe glides away from the beach, "I shall know what I have suspected for some time!"

A girl on the beach looks up with a malicious smile. "Paoa!" (Jonah) she sings out. "You'll never hook a fish at all! And if you did hook one in the lower jaw! What of it-eh?" A titter goes up.

In former times the sweethearts, wives, and daughters of bonito-fishermen were enjoined to strict chastity during the absence of the canoes at sea. A breach of this rule was believed to bring bad luck and even disaster to the fishermen. And when a bonito was hooked in the lower jaw-an unusual occurrence, as noted above-it was a sign that someone ashore was not playing the game. This belief is fully alive to-day, and it is also thought that if a man disputes with his wife before putting out to sea, he will catch no fish. And if an enemy, jealous of a fisherman's success, spits on his canoe as it lies hauled up on the beach, making some contemptuous remark as he does so, it is thought that the canoe's mana is seriously impaired.

As the canoe puts out through the passage in the reef, the old fisherman steers without hesitation toward a certain region, about six miles off-shore and to the north, where he knows fish are apt to be found at this time of year. A knowledge of such places, determined by cross bearings, and of the seasons when they are frequented by bonito, is part of the fisherman's stock-in-trade. It seems to be a fact, as the natives believe, that these "crossroads of the sea" exist, and that schools of fish, approaching from various directions, meet and linger there.

The two paddlers sit close together amidships, which leaves the ends of the canoe light, as they should be to ride the waves off-shore. Pipes are lighted when they reach their fishing-grounds, toward half past three; the old man takes it easy astern, while his apprentice, standing and shading his eyes, keeps a ceaseless watch on the horizon. He sights birds from time to time, and at a word from him the old fisherman rises for a look. A shake of the head indicates that the kinds of birds and their behaviour are unfavourable. Out of six or eight flocks sighted, there may be only one worth following; to recognize this flock, thus avoiding miles of useless paddling, is half the secret of success. Finally the old man gives the signal; a few boobies have been circling and diving about a mile away; terns and more boobies have joined them, and as the canoe approaches at top speed, the apprentice shouts "Ua apu!" Apu means the dart and plunge of fish feeding at the surface. A quarter of an acre of sea, under the birds, is whitened by spray as the school of bonito "surfaces."

The word for a school of bonito or albacore is iri, and when the school halts to feed, the natives say "Ua ea te iri." At such times they try to fish on the edges so as not to split the school; it is believed that the fish on the rear edge will strike more eagerly than those ahead. If the bonito begin to jump clean out of the water, showing their tails, it is thought that they will not take the hook freely. Such 
jumping fish, when caught and examined, nearly always have empty stomachs, and are called auhopu ma'i (sick bonito). If in the midst of a halted school, the fishermen perceive a large shark or a collection of floating rubbish, it is a sign that the canoes will soon be loaded.

Twenty yards from the feeding school the old man drops his paddle, swings about to face the stern, takes up a rod from the cross-booms and tears away the leaves covering the hooks. The apprentice, now paddling alone, is putting all his strength into the work. The fisherman unhooks a choice lure and flips it overboard, holding the rod-at an angle of about thirty degrees with the horizon-with his right hand, a yard above the butt. The butt itself is socketed in the muscles of his right groin, and his left hand is free. As the hook skitters on the surface in the wake of the canoe, he moves the tip of his rod back and forth laterally, causing the hook to follow a zigzag course. This increases its speed through the water and is believed to be tempting to the fish. A bonito makes the water boil a foot behind the shell, but refuses to take hold. Up comes the rod, the hook is made fast to the netting, and another one goes overboard. A moment, in the midst of the fish, suffices to try each shell, and no time must be lost. Sometimes when only an occasional bonito will strike, the expert hastily opens the fish he has caught, in search of roe. If roe is found, he compares its colour with his hooks until he finds one of precisely the same shade. Such a bit of shell, it is thought, will be seized without hesitation.

Finally, after three or four minutes of hasty trials, the right hook goes overboard, and a fish seizes it with a headlong rush. "Mau!" (fast) shouts the old man, as the line snaps taut and the stiff rod bends. He is a master of what is called ue-the violent, semi-circular wrench on the rod, which pulls the fish from the water and brings it flying aboard as though shot from a catapult. It is the fastest way of taking bonito, and as the tip of the rod is not brought up to a vertical position, the fishermen in other canoes, unless very close, cannot tell whether or not a man fishing in the ue manner is catching fish. This enables him to enjoy his sport undisturbed.

The first fish of the day leaves the water and flies in to strike the fisherman's chest or to be knocked into the bilges by his free left hand. But the hook has dropped out of its mouth halfway to the canoe, and an instant later another fish is on the way. They are striking freely now, and the old man is enjoying the oaoia-the unabated pleasure of a fisherman. The apprentice glances back with a grin, shaking the sweat from his eyes; as the fish continue to come thumping in to drum with their companions in the bilges, the old man shoults exultantly: "E au i te ueueraa mape!" (Like the shaking of the chestnut tree). This is a common exclamation at such a time, and means that the fish are dropping like Pacific chestnuts from the shaken tree. Twenty, thirty, and even fifty or more bonito are often taken in an afternoon.

To fish successfully in the ue manner requires powerful muscles, and a training of hand and eye comparable to that of a real expert at tennis or golf. There are only two men in Tahiti and one in Moorea (so far as I know) who are acknowledged masters of the game; such virtuosos were probably equally rare in the past. (Nordhoff 1930b:250-254)

\section{Seasonal Factors in Fishing}

It is evident from the foregoing section that there are (and were) both temporal and regional differences in the supply of marine products, and it is reasonable to propose that such differences were reflected in social relations. 
First of all, there was the annual cycle of seasons. Seasonal variations in temperature, rainfall, and wind affected the supply of fish in several ways. During the so-called rainy season, from November to March or April, the flooded streams disgorged increased quantities of food-plant-foods, insects, tiny molluscs, and fish-into the sea; this served to attract into the lagoons or around the passes in the reefs larger fish, which were either caught and eaten or used as bait for still larger, pelagic species. Certain winds also tended to increase this congregation of small fry near shore, and with it the larger varieties which fed on them:

Winds and currents not only directly affect the runs of certain fish, but occasionally appear entirely to control their movements. At Papara the following signs predict the appearance of the tiny ina (ina'a, "white bait"). From March to July, when a red cloud is seen in the south, it is known that the maramu (southeast trade) wind, which bears obliquely on the coast here, will shortly blow. Then there will be no inaa. On the other hand, from September to January a red cloud seen in the northwest is the forerunner of the toerau (north or northwest) wind. With this wind will come the run of the inaa. It is not the run of the inaa in itself that interests the fishermen, but the fact that when the inaa swarm near the mouth of the streams certain other fish which are among the best for eating (the aehaere, paehaere, omuri, uruati or urupiti, anciently urua), and others follow them and can be caught in the lagoon. Thus the effect, direct and indirect, of winds; and also the way in which a run of small fish attract the larger varieties that feed on them, are indications or signs. (Handy $1932: 79)^{56}$

Seasonal variations also affected the Maohis' ability to fish. No offshore fishing was possible during storms, and even lagoon fishing was difficult at such times. And while it was true that summer was the season of most storms, it was also the time of the lengthy calms, which many kinds of fishing required. Storms were infrequent during the winter season, but the trades which blew continuously during these months built up ocean swells of a magnitude unfavorable to fishing except in the more protected waters. Thus, the summer months were known as the season of te tai 'the (open) sea', when seafood was not only more abundant but also more easily procured.

In discussing dolphin, Morrison asserted that they “... Spawn about March after which [the Maohis] seldom look for them, but get ready for the Albicore \& Bonnetta fishery that then Commences and the Sailing Canoes ply between Taheite \& Tettooroa [Tetiaroa] for them Fish which are caught in great quantitys about the reefs of Teetooroa." (1935:158) It may be that there was some trolling for albacore and bonito during the winter months, but the main season for catching these pelagic fish, by tira and open-sea trolling, seems to have been summer, for reasons given above.

In addition, the spawning of certain fish had direct bearing on fishing activities-not only as a result of the presence near shore of the small fry, 
which in turn attracted the larger fish and was used to bait them, but also in connection with the spawning habits of some larger fish themselves:

The tarao (rock cod) come from their holes three times a year to spawn. When they make their appearance they are speared in great numbers. At other times they are caught only occasionally in the lagoon with the hook and line, or net. Another fish whose habits are closely watched is the small fao that lives in the lagoon. Every three months, on the night "when the moon and morning star rise together," the fao go over the barrier reef into deep water to spawn, and three days later they return in the same way. It is said that they make their way over the reef even if there is only a film of water over it. When such a condition prevails, natives stand on the reef with sticks and kill them as they scramble over the coral. (Handy 1932:79)

As revealed in the excerpt just quoted, the Maohis believed that the habits of certain fish were associated with the phases of the moon-directly, or as a result of association between moon phase and wind direction.

I reproduce below Stimson's version of the names and prevailing conditions of the Maohi "Nights of the Moon": ${ }^{57}$

This is a record for fishermen, recounting the ni for fishermen, recounting the nights when the fish run, this kind and that kind, and the seasons when these fish run, this month and that month, and the days which are favourable for planting food-plants.

1. Tireo

The radiations of the moon have become visible, it (is) a new moon, and the moon rests upon the horizon; the fish have risen, all species of fish; the iihi have commenced to run on this night; the method of fishing is with a net, but the opening of the trap-pocket should face the shallows; this (is) a night of very many fish.

2. Hiro-hiti

The moon has risen, she has revealed her form; the fish have also come in from the sea, and all species have risen and are moving about; the manini run on this night; the method of fishing is with hook and line. This is the night when Hiro was born.

3. Hōata

The moon has appeared, thereafter she is visible, and she has shed her light; creatures of the sea propelled by their tails, those having hard shells, and also those that crawl, move about on this night; the method of fishing is with hook and line, and also by torchlight on the deep sea for the paoe, the orare, the maunauna, the vau, and the omuri.

4. Hamiamu-mua

The fish make their appearance in wide curves, they swim in separate schools, this (is) a most favourable night for finding fish; the method of fishing is by torchlight, moving along from within the reef outward (and) fishing by torchlight from the canoe; the torch is then a cocoanut leaf.

5. Hamiama-roto

Again the fish make their appearance in wide curves, they swim in separate schools, this (is) another most favourable night for finding fish; the method of fishing is by torchlight, but one should wait until the moon has set, that is to say, until it becomes dark, and then one should commence to fish by torchlight (walking) upon the reef; the sea creatures found are the rock lob- 
ster and (a species of) the sea-eel; the $u h u$ and the tarao are also fished for on this night.

6. Hamiama-muri

Again the fish make their appearance in wide curves, and they swim in separate schools; this (is) another most favourable night for finding fish; the method of fishing is by torchlight, but again one should wait until the moon has set (then) fishing by torchlight from the canoe; the fish found on this night are the $m u$, the vete, the ume, and some others; one should seek in the crevices of the little channel-like openings of the reef.

7. 'Ore'ore-mua

This is a night when the fish disappear, they will seldom be found; from Oreore-mua to Tama-tea are the nights of which it is said that (these) are the nights when the fish copulate; nevertheless, the $m u$ run on this night when October has come; a net (is) then the fishing method; the opening of the trap-pocket should face the shallows, and when the sun has nearly set the net should be set low down in the sea while waiting for the flow of the tide.

8. 'Ore'ore-muri

This is also a night when the fish disappear; they will then seldom be found; it (is) a night of northerly gales in the months when they blow, and therefore it (is) a fishless night, however, the mu run again on this night; a net (is) again the fishing method.

9. Tamatea

The moon has begun to shine brightly, the great fish have come in from the deep sea upon the sand shallows; the toau, the taea, the maene, the auhopu, and also all species of fish have come in from the sea on this night; a net is still again the fishing method; the opening of the trap-pocket should face the shallows, and again, when the sun has nearly set, the net should be set low down.

10. Huna

The eyes of the fish are hidden (closed), they are asleep; this (is) a very fishless night, do not go fishing on this night lest you meet with disaster from fatigue.

11. Rapu

The roe of the fishes has become fully mature; this (is) a fishless night, however, it (is) a very good night for the maene; also, a net is the fishing method; when the sun commences to decline go and set down the net (and) turn the opening of the trap-pocket toward the shallows.

12. Maharu

The fish are seeking some place to deposit their spawn; this (is) a very fishless night; do not go fishing on this night lest you meet disaster from fatigue; this is the time when the spawn of all fish here mentioned is deposited in abundance.

13. Hu'a

All species of fish are found, the fish swim in schools in the months when they run; this (is) a night of very many fish in those months; the mu and the tuhara run on this night; a net (is) the fishing method, the opening of the trap-pocket of the net should still face the shallows; the mu (appear) in the evening, the tuhara at break of day.

14. Māitu

The maito, the oturi, the parai, and all kinds of red fish run at break of day when the months have come when (they) run; a net (is) then the method of fishing for these fish; the following morning is a (good) time for planting food-plants. 
15. Hotu

The moon has increased and reached her full development; before the sun has set the moon has risen; this is the (most) favourable night for planting all kinds of food-plants on the morning after, and it (is) also (a time) when large-eyed children are born; all kinds of fish run on this night; a net is the fishing method, but the opening of the trap-pocket should face toward the deep sea. This is the night when sea-crabs become soft-shelled.

16. Māra'i

This is the third (consecutive) night when food-plants should be planted on the forenoon following; this is the night of which it is said, "Through the shadow's treading upon the moon therefore she wanes;" as the sun sets the moon rises; this (is) a night of very many fish, a net (is) still the fishing method on this night, the opening of the trap-pocket should still face downward toward the deep sea, or else (as the case may be) should face the shallows. This is another night when sea-crabs become soft-shelled.

17. Turu

Beautiful children are conceived on this night; all the sea-creatures having hard shells, the sea-crabs, the spiny sea-shells, the one-sided sea shells, the maoa, and the land-crabs as well, have come together in the act of fecundation; do not any under circumstances go fishing on this night lest you meet disaster from fatigue.

18. Arä'āu-mua

From Araau-mua till the third Araau are the (three) nights when the fish run through the passageways of the reef, the great fish, the turtles, the urua, and the rest. When northerly gales blow the uhu come into the passageways of the reef, the paauara in advance. This is the night of which it is said that (it was) a (time of) roaming about of ghosts and of the risen dead in ancient days; (it is the night when we sanctified the altars of the temples which were worshipped in ancient times to protect us [from evil powers]); furthermore, do not go fishing on this night, for those dead will trouble the fishing; this (is) a rather short and fishless night.

19. Arä'àu-roto

This (is) also a night of the dead (in the days when they were propitiated); those dead bodies would indeed return that they might be lamented by the living; this night is also entirely without fish; do not under any circumstances whatsoever go fishing on this night.

20. Arä'āu-muri

This (is) a fishless night, nevertheless iihi run in great numbers on this night when the months have come when they deposit their spawn; a net (is) the fishing method of this night, the opening of the trap-pocket should still face the shallows.

21. 'Ore'ore-mua

From Oreore-mua till Oreore-muri are the nights when the great fish have disappeared, (they) have returned to the deep sea. This is the night (when) fish scales are shed; this (is) indeed a fishless night, (for) no fish whatsoever are found on this night, and verily what fishing method could be proper to it?

22. 'Ore'ore-roto This (is) a very fishless night.

23. 'Ore'ore-muri

This (is) a fishless night, it is the night of which they say that the fish merely follow along behind the hook, but will never bite. 
24. Ta'äroa-mua

From Taaroa-mua till the third Taaroa are the nights when long-snouted fish run, the ono, the haura, the aavere, and all similar fishes; this (is) a night when Taaroa remains awake, it (is) a night of very many fish, the net will be encumbered with araoe, a net (is) the fishing method on this night, the opening of the trap-pocket should again face the shallows.

25. Ta'äroa-roto

This (is) again a night of fish in the seasons when they run; a net is still the fishing method; the aahi and auhopu copulate on this night.

26. Ta'äroa-muri

This (is) still again a night of fish in the seasons when the fish run; a net (is) still the fishing method, the opening of the trap-pocket should again face the shallows.

27. Täne

Tane is the night; it is a time when man embraces woman. It (is) also a favourable night for planting sweet potatoes and all other kinds of foodplants which fructuate in the soil; it (is) a night of fish.

28. Ro'ō-nui

Roo-nui is the night; a great run of all fish of all species then occurs. This is also a favourable night for planting sweet potatoes and all kinds of foodplants which fructuate in the soil.

29. Ro'ō-māuri

The fish have disappeared, the moon has nearly set, nevertheless the tehu and the nape run in the months when (they) run; a net is still the fishing method, the opening of the trap-pocket of the net should still face the shallows, and when the sun has nearly set (the net) should be set low down; this (is) indeed a night of many fish in those months when they surely run.

30. Māuri-matě

Daylight has trodden upon the moon, the moon has set; the fish, too, have gone to sleep; this (is) a very fishless night; this is the night said to be the extinction of the moon's light.

Mutu is the night, Mãuri-mater is the day, Tireo is the evening (following); concluded also is (this) account (of the nights of the moon) from the rising of the new moon until the setting. (Stimson 1928:326-337)

Nordhoff had the following to add concerning a tie-in between moon phase and bonito fishing:

The Society Islanders believe that the moon has a great influence on the habits and behaviour of fish, and that bonito are no exception to the rule. The week of the new moon is believed to be a particularly favourable time for bonitofishing, and two of the "nights of the moon"-Tamatea and Ta'aroa tahi, or Mua Ta'aroa-are recommended as well. Of Tamatea, the ninth night (and day, of course) of the lunar month, it was said: "Bonito are the fish at sea," and of Mua Ta'aroa, the twenty-fourth: "An auspicious night for love-making; women give birth to red-haired children on this night; crabs and cray-fish shed their shells; albacore and bonito are the fish at sea. (1930b:254)

\section{Locational Factors in Fishing}

In addition to these temporal changes affecting the supply and pursuit of fish, there was a host of locational factors-some of them exaggerating, 
some neutralizing the seasonal variations. It goes without saying that calm leeward waters are better than rough seas for, say, underwater spearing and pelagic trolling. In fact, judging by today's conditions, there must have been a considerable amount of local specialization in fishing, based directly on difference in supply and on fishing conditions. For example, the sheltered shallow lagoons off Tahiti's southern shore are far richer in crustaceans than are the wind-tossed waters off the east coast.

Even excepting such obvious cases as Maeva (see p. 289), it is reasonable to suppose that access to good fishing, like availability of productive land, was a determining element in population distribution; compare, for example, Tahiti's thinly populated windward side with the populous leeward western districts. But local differences in the kind and quantity of fish supply apparently did not lead to any regular far-away movement of people and goods. With respect to people, fishermen undoubtedly roved widely offshore in their canoes in search of deep-water fish, but there is no evidence that they made a regular practice of fishing in foreign streams, lagoons, or "holes." With respect to goods, there are indications of a fair amount of circulation of fish, in the form of gift, tax, and even barter, but mainly within narrow territorial limits. Spoilage may have been a factor here, although the availability of live-fish containers would have served to keep smaller fish alive almost indefinitely.

\section{Social Factors in Fishing}

Within the limits set by seasonal and local variation, access to fishing was of course conditioned by ownership of equipment and fishing grounds. Regarding the former, most items-including canoes used in fishing, hooks and lines, and small nets-were probably within every Maohi man's reach (most men having made their own, in fact); it was only with respect to the large nets and the right to command the services required to man these and other large-scale fishing enterprises that individual differences became important. Consideration of this complex matter of "ownership" must await the more general discussion in later chapters, but it may be useful to anticipate that discussion and to record my opinion that the particulars of fishing-ground ownership were not of a kind to necessitate or encourage regular exchange of fishing products between "shore-dwellers" and "inlanders." Within any one political unit-and every one of these included fishing grounds-every resident probably enjoyed some fishing rights. This is not to deny that some individuals, and not necessarily those living on the shore, fished more often than others. It merely means that within any one political unit differences in proximity to fishing resources cannot have had a very decisive influence upon social relations-though the reverse may well have occurred.

The same general considerations apply to the raw materials used in fishing. Fibers used for making lines and nets; shell, bone, and wood used 
for hooks; bamboo for poles and containers; plants for poison-all of these were widely enough distributed about the Islands to render them accessible, physically and presumably also optionally, to all individuals. Wood for the larger fishing canoes was scarcer, but here the factor of labor was perhaps more crucial than the tree; and in any case most fishing canoes were probably made of plentifully and universally available trees. In other words, local differences in raw materials supply could not have been crucial enough to stimulate an active trade in such materials.

Within society at large the major division of labor in fishing was along sexual lines, but the evidence in the matter is unclear. According to Moerenhout, "fishing was an occupation carried out almost entirely by males ..." (1837:II, 108). But exactly what is implied by this is rather obscure: just what types of fishing were carried out by women, permissively or exclusively, and was the sexual division of labor based mainly on relative strength, or on extrinsic rules, or both? Handy's statement is somewhat more specific:

Consecration of canoes, nets, spears, lines, and hooks was an essential element in the success of fishing, for fish and fishermen, like all else, were under the control of tapu and mana atua [the mana of deities]. This explains why women in former days never, and now rarely, went out in the fishing canoes. The women being common (noa) would have neutralized the tapu of the craft, gear, and fishermen. (1932:73-74)

But this cannot mean that all of the items of fishing equipment were so consecrated and hence forbidden to female use. Handy himself mentioned some fishing by women-for example, by use of bag nets, and in drag fishing with rau $(1932: 91,106)$. It is not clear whether a canoe once consecrated for fishing was forever after forbidden to women, or forbidden only on the occasion following the consecration.

It is quite certain that most or all deep-sea fishing was carried out by men, but beyond that the facts and the rationale of the sexual division of labor in fishing are unclear. Complicating the matter are the circumstances that Maohi women were a robust lot and that, compared with some other Polynesians, the Maohis appear-to me at least-to have been quite pragmatic in their conduct of subsistence activities.

Aside from these differences in engagement in fishing based on sex, the activity was followed as a specialized occupation by some individuals, as a later chapter will describe.

\section{Fishing Ritual}

Religious belief and ritual figured prominently in fishing-in the making of fishing equipment, in efforts to control and conserve supplies, in the catching of fish, and in reinforcing differences in consumption rights.

Only the vaguest of references have been recorded concerning religious aspects of the manufacturing of fishing equipment. For example, it will be recalled that in the excerpt about net making taken from Ellis and repro- 
duced above, reference was made to "former pagan ceremonies, and the offerings at the marae" which accompanied the manufacture of a large upe'a ava, or salmon seine net. Also, Ellis recorded that "The first wetting of a new net was formerly attended with a number of prayers, offerings, \&c. at the temple, and on the beach" (1829:II, 290). And according to this same source there was a special patron deity of net makers, Matatine by name (p. 288). The manufacture of canoes, including those used in fishing, was attended with much ritual, as was described earlier\& but the only other reference I can discover concerning the ritualization of the manufacture of fishing implements is Nordhoff's suggestion: "It is probable that in the Society Islands in former times, the assembly of a bonito-hook was performed with the ceremonial which still persists in the Samoan and Ellice Groups, though no traces of such ceremonial are to be found to-day." (1930b:240)

Limitations were placed on fishing activities in two respects. First, it was the prerogative of the principal proprietor of any specific fishing place-say, an albacore "hole," or a rock-cod "deep," or even a whole stretch of reef or lagoon-to impose a rahui, or restriction, on fishing activities there for as long as he wished. This was done (among possibly other ways) by planting a pole on the reef or shore with a bunch of bamboo leaves fastened to it. (Ellis 1829:II, 286.) Details are lacking concerning the application of such a rahui and the sanctions behind it, but it is likely that there were some local differences in both respects. In some cases the rahui was probably general, including even the principal proprietor himself; while in some cases it excluded only outsiders, or it might be ignored by individuals upon receipt of permission from the proprietor. As for sanctions, in some instances the personal influence or coercive physical power of the proprietor may have sufficed to insure compliance, but it is highly likely, though not specifically so recorded, that the aid of the proprietor's spirit-familiar or tutelar was ritually invoked as well.

A second respect in which limitations were placed upon fishing had to do with the more general rahui imposed throughout whole districts on certain contingent occasions or during certain periodic times of the year. An example of the former was the general restriction placed on practically all subsistence activity, including fishing, during mourning ceremonies for persons of high status. The most notable specimen of the latter was the prohibition placed on general bonito and albacore fishing, at the beginning of the open-sea season, until certain ceremonies had been performed. Sanctions behind both these general restrictions were of a political and religious nature.

Another kind of control over fishing involved use of a punai' $a,{ }^{58}$ a $t i^{\prime} i$-image inhabited by a spirit capable of controlling the movements of fish. Such $t i$ ' $i$ were usually made of stone, and shaped like fish. Puna were still in use in Tahiti as recently as the 1920s: 
It is not easy to get information about puna, for the natives speak of them with reluctance and put one off by feigning ignorance. The following is what I have been able to learn; it may be inaccurate and is certainly incomplete. At one time there were puna for almost every kind of fish-sharks, parrot-fish, scad, bonito, albacore, etc. Nowadays the albacore puna are the only ones in use in Tahiti. Each district once had its puna for every kind of fish. Every puna had its owner, who had acquired it from his ancestors. It would be useless to make a puna now, for there would be no mana in it. When the fishermen return with their catch they must not neglect to give the owner of the puna a generous share. If he is well treated and feels friendly toward the fishermen, the owner of the albacore puna keeps the head of his image turned toward the mountain ( $i$ uta), which causes the albacore to stay in their "hole" close to the reef. If the owner's share is skimped or forgotten, he retaliates by turning the head of the image toward the sea (i tai), and the fishermen are soon brought to their senses by finding that there are no more albacore in the hole-like the image, they have turned their heads away from the land. The owner of the puna may still be placated with gifts, and cozened into turning the image's head $i$ uta (inland), when the albacore will be found in their hole once more; but if the man be deeply incensed, he will go secretly at night to where he keeps his puna, make sure that its head points out to sea, and cover it with a thick black cloth. Not even a stray albacore will then take the hook. Once or twice in the past puna have been stolen by foolish men, but in each case the thief fell ill or was pursued by bad luck, and the hiding-place of the image was revealed to its true owner by an appearance of blue fire, seen at night. Nothing is stranger about puna (the natives say) than the way they are well known to grow-increasing slowly and steadily in size as the years pass. (Handy 1930a:159)

Handy also wrote about puna, but those he knew about on Tahiti operated directly opposite to the procedure described by Nordhoff: that is, "When the figure was placed so that it faced the sea, aahi would be caught in large numbers; but if its face were turned inland, then no aahi would be caught" (Handy 1932:71). Handy also described from hearsay a Ra'iatean puna which brought about a plentiful catch of ' $a$ 'ahi only if stood upright on its small stone platform. Certain puna on Maupiti were placed in stone cists which flooded regularly at high tides (Handy 1932:72), but most of those written about were kept on dry land adjoining the fishing places under their supposed influence.

In addition to the several measures taken to insure the availability of fish, there were others of a religious nature designed to aid in catching fish. Among these were the rituals, already mentioned, whereby new fishing implements were consecrated to their tasks, and the use of red feathers to calm stormy waters. Of the same general nature was a small marae described by Bligh as having been built to insure success for a newly built fish weir:

I passed in my Walk to day a Morai which was called Rooahadoo-it consisted of a few Stones about three feet square, pieces of plaited Cocoa Nutt leaves (called Tepaou) placed before it with some small pieces of Tarro and Cocoa Nutts. The Evàtah or Alter of Offerings, was a Palm Stump with a small Stage on it, on which was a Cocoa Nutt grater, and some Cocoa Nutt, Mahie and an empty 
Basket. The whole was fenced in, and I found it was just errected to ensure success to a kind of Ware or Dam which Tynah has made with Stones without Point Venus to catch Fish. Prayers have been performed, and the Deity supplicated by Persons of the Priesthood. (Bligh 1792:159b)

It is reasonable to suppose that all fishing structures built with an eye to permanence would have had attached to them some marae, however small and simple.

There were many other little rites performed before, during, and after any fishing expedition-rites to preserve lines from breaking, to keep away sharks, to guide spears, to lure octopus, and so forth-but the sources are almost silent on this score. Instead, we are provided with a general statement by Ellis to the effect that "the favour of the gods was formerly considered essential to success in fishing" (1829:II, 288) and with Bligh's following observation:

Whenever there is a Show of Fish a large Fleet of Cannoes proceed to Sea. Sometimes they pray to the Eatua for their success, but at all times they carry in each Cannoe a Basket with some Cocoa Nutts, Breadfruit and Plantains as an offering to him. The Basket is Square, made of Reeds and has a place Sacred to it in the Cannoe. (1789:II, 26)

Henry furnished a more specific statement concerning the religious practices of fishermen's guilds:

The fishermen formed companies and built themselves marae (marae o-tefeia-tai'a) and dedicated them to the gods, the chief of which were: Rua-hatu-tinirau (Source-of-fruitful-myriads), the Neptune of the sea called in the story of the Deluge Rua-hatu-o-te-tai-euea (Source-of-fruitfulness-of-the-thrown-up-ocean), and Tino-rua (Body-of-two-natures) lord of the ocean, the merman who had the tail of a swordfish. The fisherman placed in their secret depositaries stone or wooden images of the fish gods and other sacred relics with birds' feathers. $(1928: 148)^{59}$

It is possible that the special gods of fishing named in the above passages from Henry were peculiar to only certain districts of the islands, since Ellis reported that "The gods of fishermen were numerous, though Tahuura and Teraimateti were the principal" (Ellis 1829:II, 288). ${ }^{60}$

The following excerpt from the journal of Tyerman and Bennet was recorded in 1821, based on hearsay, and deserves neither more nor less credibility than many of the other "facts" reported in these mission-inspectors' journal:

Sharks are numerous about this coast [Huahine], and they were formerly worshipped from fear; undeed, the fear that hath torment was the mother of devotion here, as it is in every other heathen land. Large oblations were frequently offered to them by the priests who served at their altars. We are assured that numbers of these ravenous animals were so far tamed in this bay, that they came regularly to the beach to be fed with fish and pork, which were provided for them in large quantities. This marae being situated very near the lagoon, a shark once 
worked his way through the sand, and took personal possession of his temple, the water flowing in with him; whereupon, the reservoir thus formed being properly dammed up, and from time to time replenished, he luxuriated in his sanctuary, and daily received his food from the devotees who flocked thither. Whenever the natives, in their canoes encountered a shark at sea, they endeavored to propitiate him by throwing out some of the fish which they might have caught; and such offerings were so acceptable to these divinities, that the latter would follow the boats to the shore, and gradually became familiar enough to wait till their portion was dealt forth to them. Nevertheless, the ungrateful sharks, having a god of their own- "their belly"-never failed to sacrifice even their worshippers to that idol, when they could catch a stray man, woman or child, in the water, or on the beach, near enough to be seized and carried into the deep. (Montgomery 1832:I, 180-181)

Finally, there were rituals, having both religious and political aspects, associated with the consumption of fish. The most notable of these was the "first-fruit" rites at the beginning of the albacore and bonito season:

When in the months of November and December, which were called te tai (season of the outside or of the sea), the bonito or scomber fishery opened, but a single canoe was allowed to go out to fish, and its entire catch was dedicated to the gods. This day was also tapu, that is to say, sacred. No one was allowed to approach the seashore, to make fire, to cook food, nor to partake of food before sunset. Nor could canoes or houses be built, or cloth manufactured, or mats or nets woven. In a word, all work was prohibited, and it was a day of silence and devotion.

While the fishers were away, the preists applied themselves to praying at the temples; and their assistants were busy, in the principal marae, in cleaning it up, decorating it with green branches, in dressing an altar to receive the first fish caught. When the canoe returned in the evening, it lay in the water near the beach, awaiting the arrival of the priests. After some prayers and other ceremonial these allowed the fishermen to land and to bring them the days catch, which, whatever it was, had to be carried in toto to the marae. There, after more prayers, two or three of the largest fish were placed on the altar, and the others were entirely consumed (burned?) on a fire that burned before the altar.

This first day's catch was for the gods; that of the second day was for the Arii, or chief; and it was only on the third day that the fishing was open to everyone, and anyone who desired could go fishing. (Moerenhout 1837:I, 516-517, as translated by Handy 1932:78)

Such rites were probably held at several places throughout the Islands, and the deities thus honored are unlikely to have been everywhere the same.

In addition to these large-scale ceremonies, it is reasonable to suppose that every catch of any consequence was shared, at least in token degree, with one or more of the fisherman's tutelar spirits and, in many cases, with his immediate social (or political) superior as well. ${ }^{61}$ 


\section{CHAPTER 10 DIVERSIONS}

I have already painted these islanders as being great conversationalists, lively, animated, and fond of company. They sought after and found distractions and occasions for merrymaking even in those of their tasks which seemed most laborious; therefore one can almost say, in its ordinary course, their (day to day) life was nothing but a holiday. (Moerenhout 1837:II, 125)

Granted that lightheartedness and playfulness colored much of Maohi life, including even moments devoted to backbreaking labors and perilous missions, one may nevertheless single out certain of their activities as having been undertaken primarily for what Westerners call "amusement"-leaving aside the question of the additional special motives of individuals taking part in those activities. ${ }^{1}$

\section{GAMES AND SPORTS}

Children spent much if not most of their time at play. Some of their more specific activities were cats' cradle, jumping rope, blind-man's buff, hideand-seek, a kind of jackstones, swinging, sliding, stilt walking, and kite flying. ${ }^{2}$ Other children's pastimes were imitative of adults-for example, sailing toy boats and "sacrificing" make-believe victims in small replicas of marae. We are not informed about sex lines, if any, that obtained in such play, or about the stage of life when children ordinarily abandoned such pastimes for more adult pleasures.

Children began at a very early age to swim and dive, and they soon developed skills that were the wonder of the European visitors. There is no record of how fast or how far they could swim, but their endurance and versatility in the water were quite remarkable. Swimming, or at least surfing, continued to be a favorite pastime with adults. For surfing they used a canoe paddle or more commonly a board; some experts were able to stand erect on a board while surging before a large wave. Both sexes engaged in this sport; in fact, some of its more skillful devotees were women. (For a full account of Maohi surfing see Finney 1959.) Here is Bligh's description of the activity:

The heavy surf which has run on the shore for a few days past has given 
great amusement to many of the Natives, but is such as one would suppose would drown any European. The general plan of this diversion is for a number of them to advance with their paddles to where the Sea begins to break and placing the broad part under the Belly holding the other end with their Arms extended at full length, they turn themselves to the surge and balancing themselves on the Paddles are carried to the shore with the greatest rapidity. As several seas follow each other they have those to encounter on their return, which they do by diving under them with great ease and cleverness.

The delight they take in this amusement is beyond anything, and is of the most essential good for them, for even in their largest and best Cannoes they are so subject to accidents of being overturned that their lives depend on their swimming and habituing themselves to remain long in the Water. (Bligh 1789:I, 408-409)

Surf-riding in boats was also a favorite sport, and it had the additional, though possibly unintentional, value of providing practice for the serious and often dangerous action of landing boats through heavy seas.

Competitive athletic sports included footracing, boat racing, boxing, and wrestling - the last having been the most popular and highly elaborated of the four. Wrestling was based more on brute strength than on skill. After witnessing some matches Bligh wrote:

Upon the Whole this performance gave me a poor opinion of these people. They have strength enough but they are very deficient in skill and equally so in courage. (1789:I, 391)

A fair fall like as it is in England is to be thrown on the back, but if they fall to the ground any way the trial for that time is over. They grapple by the Hair, Legs or any part they can lay hold of, however they have the art of the Cross buttock as in Cornwall, but the Man who takes that method is generally thrown or Obliged to quit it, if the opponent is stronger than himself. (Bligh 1789:I, 412)

Bligh's description and opinion were confirmed by most of the Europeans who left eyewitness reports of Maohi wrestling matches (e.g., Beaglehole 1955:91). Ellis, writing decades later, also described the unorthodoxy (in Western eyes) of Maohi wrestling tactics:

They grasped each other by the shoulders, and exerted all their strength and art, each to throw his rival; this was all that was requisite; and although they generally grappled with each other, this was not necessary according to the rules of the game. Mape, a stout, and rather active, though not a large man, who was often in my house at Eimeo, was a famous wrestler. He was seen in the ring once, with a remarkably tall heavy man, who was his antagonist; they had grappled and separated, when Mape walked carelessly towards his rival, and on approaching him, instead of stretching out his arms as was expected, he ran the crown of his head with all his might against the temple of his antagonist, and laid him flat on the earth. (1829:I, 289-290)

While the actual wrestling may have lacked finesse, its social-ceremonial setting was highly elaborated. Matches were held during nearly every large peaceful gathering of people, whatever the primary occasion. Informal matches often took place among residents of the same neighborhood or 
district, but climaxes of public interest occurred during matches between the champions of different districts; such bouts were witnessed by hundreds and even thousands of people.

Despite its ambiguities a statement by Ellis indicates that wrestling involved more than individual skill and strength:

In this, as in most of their public procedings, the gods presided. Before wrestling commenced, each party repaired to the marae of the idols of which they were the devotees. Here they presented a young plantain-tree, which was frequently a substitute for a more valuable offering, and having invoked aid of the tutelar deity of the game, they repaired to the spot where the multitude had assembled (1829:I, 288). ${ }^{3}$

Matches took place in a ring formed by the onlookers. In some cases challenges were issued in advance and the principal rivals began their bouts without further ado. Otherwise a champion from each side initiated the proceedings with a challenge, by walking around the ring, the left arm bent and hand on breast, while striking the right hand loudly against the left arm. According to Ellis, "The strokes on the arm were sometimes so violent, as not only to bruise the flesh, but to cause the blood to gush out" (1829:I, 289).

As soon as the challenge was accepted the rivals closed and kept at it until one of them was thrown. The victor had the choice then of retiring, with honor, or issuing another challenge. Sometimes several pairs wrestled simultaneously, and serious injuries were not uncommon. It was customary for some chiefly person to act as referee, to terminate stalemates or to award a decision when an outcome was not clearly decisive. The crowds remained silent during a match, but broke out in partisan furor when it ended decisively:

The most unbroken silence and attention was manifested during the struggle; but as soon as one was thrown, the scene was instantly changed; the vanquished was scarcely stretched on the sand, when a shout of exultation burst from the victor's friends. Their drums struck up; the women rose, and danced in triumph over the fallen wrestler, and sung in defiance to the opposite party. These were neither silent nor unmoved spectators, but immediately commenced a most deafening noise, partly in honour of their own clan or tribe, but principally to mar and neutralize the triumph of the victors. It is not easy to imagine the scenes that must often have been presented at one of their taupitis, or great wrestling matches, when not less than four or five thousand persons, dressed in their best apparel, and exhibiting every variety of costume and brilliancy of colour, were under the influence of excitement. One party was drumming, dancing, and singing, in the pride of victory, and the menace of defiance; while, to increase the din and confusion, the other party were equally vociferous in reciting the achievements of the vanquished, or predicting the shortness of his rival's triumph. (Ellis 1829:I, 290-291)

Controlled and good-natured rivalry seems to have characterized most matches, for the principals as well as for their supporters. "The greatest good humour is carried through the whole, and the Man that is thrown 
laughs at his overthrow as much as the other does at his success" (Bligh 1789:I, 412). "The conqueror never exulted over the Conquer'd, neither did the Conquer'd ever repine at his ill luck, but the whole was carried on with great good humour. Notwithstanding during the Combat their countenances appear'd to express as much fury as if they had been realy in earnest." (Beaglehole 1955:91.) Matches occasionally, however, did end in general brawls and even open warfare. ${ }^{4}$ A passage from Moerenhout indicates that a series of reversals had the effect of fanning tempers to a dangerous heat: "If it should happen that one side is beaten in match after match it usually ends up in real warfare" (1837:II, 141-142).

Champion wrestlers were loudly applauded and highly esteemed, but it is not reported whether they received any other rewards for their prowess. Some of them were individuals of upper-class status, but the sport was open to all-including women, some of whom wrestled publicly not only among themselves but also with men. "Persons in the highest rank sometimes engaged in the sport; and the sister of the queen has been seen wearing nearly the same clothing as the wrestlers wore, covered all over with sand, and wrestling with a young chief, in the midst of a ring, around which thousands of the people were assembled" (Ellis 1829:I, 292). According to Bligh (1789:II, 39), women's wrestling was if anything more savage than men's and included such tactics as gouging eyes (see also Morrison 1935:222). Turnbull witnessed one such melée:

Nor were these sports confined solely to the men; the women were equally emulous to signalize themselves, and their feats of pugilism were equally honourable to their courage. They fought with equal resolution and dexterity, hanging on each other's necks like bull-dogs, tearing their hair, bumping the stomach of each other, both with their heads and feet; in a word, neglecting no means of victory. Their husbands and relations were spectators of their efforts, and encouraged them to continue them; upon one or the other of them receiving a fall, the affair was terminated, and the parties, after adjusting their hair, would tenderly embrace, and be as good friends as ever. (1813:286)

Boxing matches were conducted similarly to wrestling matches:

The challenge was given in the same way as in wrestling; but when the combatants engaged, the combat was much sooner ended, and no time was spent in sparring or parrying the blows. These were generally straight forward, severe, and heavy; usually aimed at the head. They fought with the naked fist, and the whole skin of the forehead has been at times torn or driven off at a blow. No one interfered with the combatants while engaged; but as soon as either of them fell, or stooped, or shunned his antagonist, he was considered vanquished, the battle closed, and was instantly succeeded by the shouts and dances of triumph. (Ellis 1829:I, 292)

On the other hand, when one of the boxers was badly injured or killed, the spectators "... wildly dispersed, while friends uncomplainingly bore away the unfortunate champion." In Henry's opinion boxing was the most 
"barbarous" of all Maohi sports, and its champions "... were proud to boast of the number of men they had maimed or killed." (Henry 1928:277)

Boxing seems to have been more favored in the Leeward Islands than in Tahiti, and according to Ellis it was practiced mainly by "... the lower classes." But he added: "These barabarous sports [wrestling and boxing], though generally followed by the common people, were not confined to them; other classes sometimes engaged; chiefs and priests were often among the most famous boxers and wrestlers." (1829:I, 292-293)

Footracing was mainly a contest among young men (Ellis 1829:I, 293); Henry stated that a winner was awarded a prize, but she gave no further details (1928:278). Boat-paddling races were usually held in the protected waters of lagoons; they were described as affording "... a high degree of satisfaction" (Ellis 1829:I, 294), but no further information was recorded about their organization or ceremonial contexts.

In addition to these competitive athletic sports the Maohis played several varieties of ball games, all consisting of propelling a ball past a goal mark at the rivals' end of the playing field. 'Football' (tu'era'a pōpō) was played by men or women and involved kicking a ball made of the dried fibers of plantain stalks. 'Seizing-the-ball' (harura'a pu'u) was mainly a game for women, who ran with the ball or threw it towards the goal; it was played on the beach, in and out of the water, and usually resulted in some rough bruising scrambles. 'Hockey' (äpai, paipai) was played by men, ${ }^{5}$ who used sticks to drive a small ball made of tightly wound strips of bark cloth.

Sportive combat with weapons was another favored Maohi pastime, and seems to have been practiced specifically with martial purposes in view. Such combat, with spears and clubs, is described in chapter 12 .

The Maohis also held contests of skill in sling shooting, javelin throwing, and archery.

Sling shooting was used in warfare but also served as a favorite amusement in times of peace. An account from Wilson describes this activity:

They practise the sling for amusement, as well as to employ it in battle, and throw a stone with great force and tolerable exactness. Their slings are made from the plaited fibres of the cocoa-nut husk, having a broader part to receive the stone: at one end is a loop for the hand, in order to keep the sling fast when they discharge the stone. In charging the sling they hold it round their shoulders, keeping the stone fast in it with their left thumb, and jumping, swing the sling three times round their heads, holding the left hand grasped on the wrist of the right, and thus discharge the stone with a force sufficient to enter the bark of a tree at two hundred yards distance; the stone flying at an equal distance from the ground, like a bullet, all the way. (1799:354)

The light javelins used for sporting contests-but not, reportedly, for war (Bligh 1789:I, 412)-were thrown at fixed marks, usually stems of plantain trees, some thirty to forty yards distant. Both males and females 
engaged in this sport, and some were expert at hitting the mark; but not those witnessed on one occasion by Banks: "In coming down again we saw the game that the Indians call Erowhaw, which is no more than pitching a kind of light lances headed with hard wood at a mark: of this amusement they seem to be very fond but none that we saw now excelld in doing it, not above one in 12 striking the mark which was the bole of a plantain tree about 20 yards distant" (Beaglehole 1962:I, 326-327). In view of the expert marksmanship of many individuals, it is curious that such weapons and tactics were not used more commonly in fighting.

Archery, as practiced by the Maohis, is even more puzzling in this regard: it was a favorite pastime with many individuals and was surrounded with elaborate ritual, but, although occasionally used in hunting, bows and arrows were not employed in war-at least not during the eras now under study.

Bows were made of pūrau wood; they were about five feet long, strung with fiber of the Pipturus argenteus, and occasionally decorated with sennet or strings of human hair. Arrows were of bamboo, about two and a half to three feet long, unfeathered, and tipped with hard ironwood points; they were kept in decorated bamboo quivers. In shooting, the archer knelt on one knee, drew back the arrow to its point, and let go the bow as soon as the arrow was fired. Distance rather than marksmanship was the objective, and our sources reported shots of three hundred yards. The shooting was done from special stone platforms, three or four feet high and triangular in shape with one side of the angle convex (figs. 10-1, 10-2, 10-3). Arrow spotters were posted in the general area aimed at, and they signaled back to the contestants whether a shot went farther or fell short of the preceding best mark.

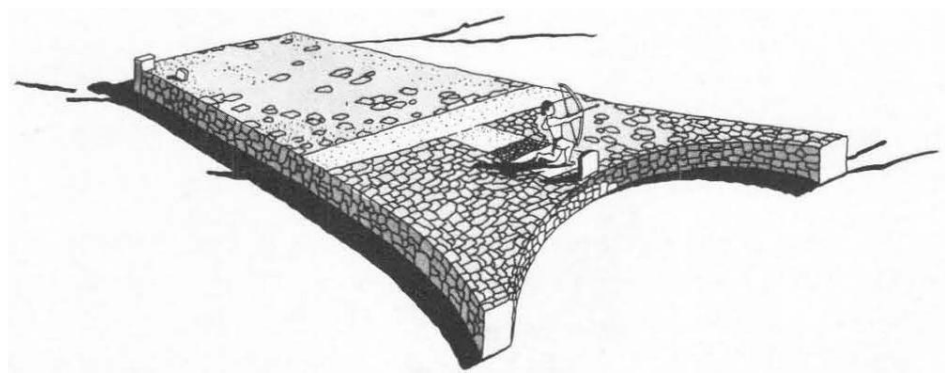

FIGURE 10-1. Archery platform.

According to Henry, archery was "... the most refined of the native athletic sports, and was a favorite amusement of the upper classes" (1928:276). The special garments of the archers, along with the bows and arrows, were 


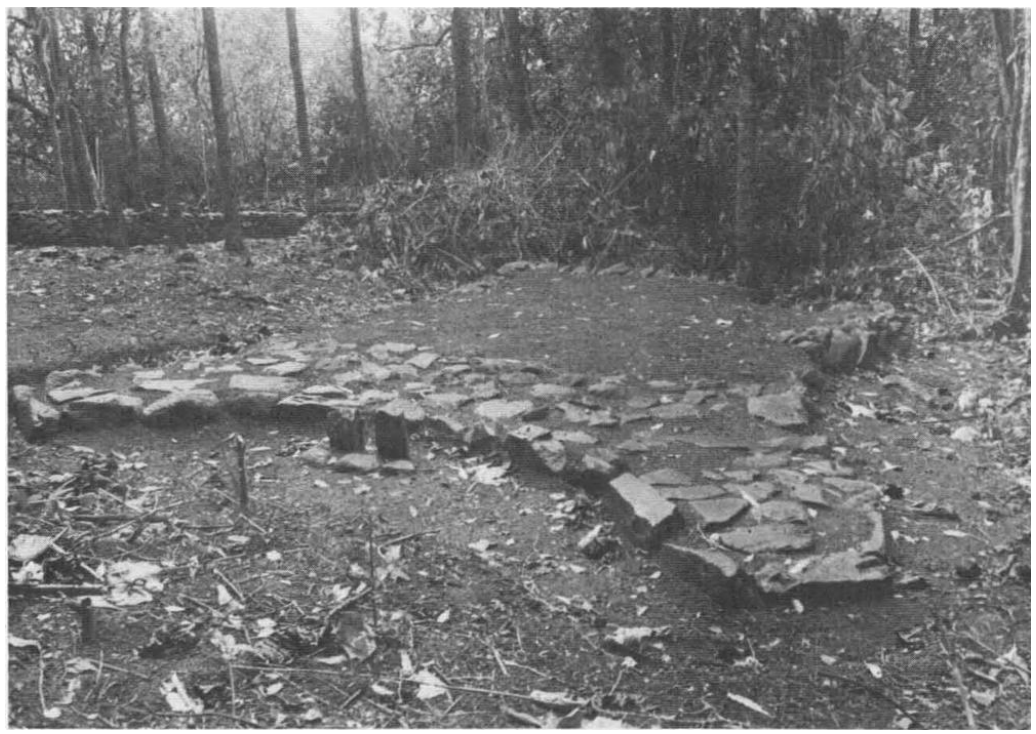

FIGURE 10-2. Remnants of archery platform near marae Afaveaito at Opunoho, Mo'orea. Reconstruction and photo by Y. Sinoto, Bishop Museum.

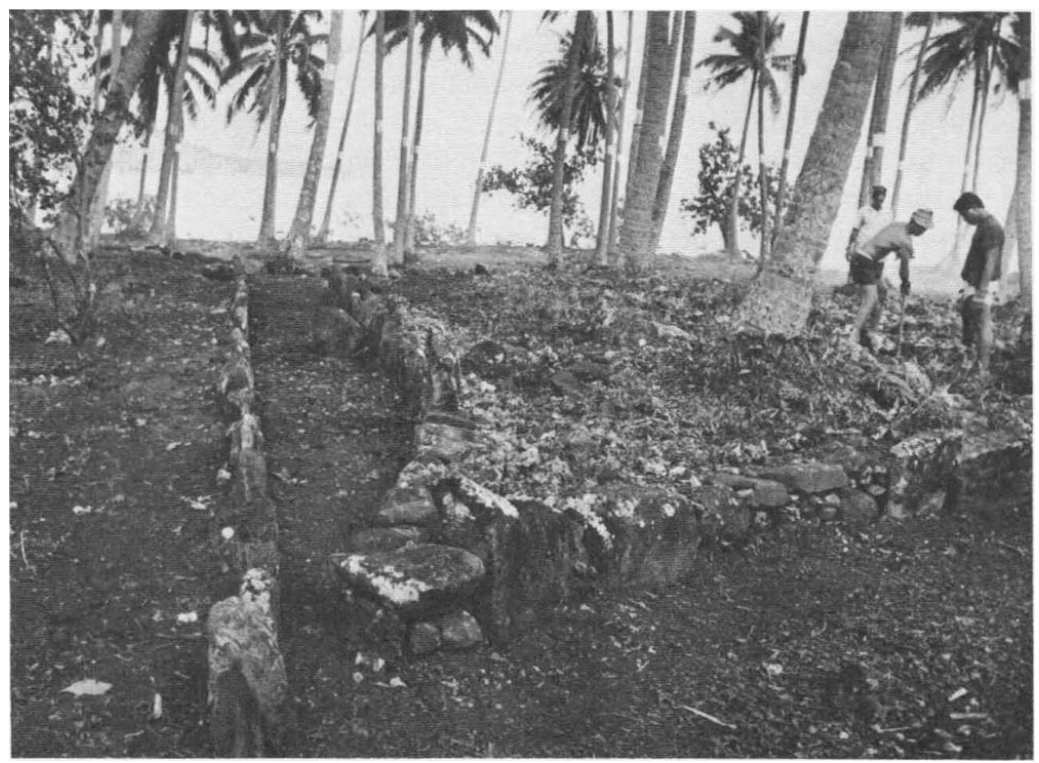

FIGURE 10-3. Remnants of archery platform at Hititai, Opoa, Ra'iatea. Reconstruction and photo by Y. Sinoto, Bishop Museum. 
kept in a separate house in the local marae of Paruatetava'e, the tutelar deity of the sport. There the archers dressed and prayed before a match, and there they had to bathe away the aura of sacredness after a match, and before returning to normal pursuits. ${ }^{6}$

Morrison asserted that women also engaged in archery (1935:223)-but presumably wholly separately from men and with less religious implication or ritual elaboration.

To the wonderment of Europeans, in none of the competitive sports I have been describing, except possibly in footracing, were the victors directly rewarded with anything more tangible than public acclaim, and such was also the case with the owners of victorious fighting cocks.

Cockfighting, according to Ellis, was a universally followed sport (1829:I, 303), but it was mainly pursued by younger men. Henry added:

In every district were young men who trained fowls for this purpose. They made house pets of them, fed them well, and taught them to open their mouths to receive food and water from their master's hand; in warm weather they were sprinkled with water to refresh them. The plumage of these fowls was never trimmed, the young men preferring to see them in all their natural beauty, and no artificial spurs were applied. (1928:277-278)

Fighting usually took place in the cool of the early morning, before the birds could be slowed down by the sun's heat. As soon as one bird tried to avoid the other he was considered beaten and the two were separated (Ellis 1829:I, 303; Henry 1928:278). Occasionally the cock fanciers of one district would join to challenge those of another, and the ensuing bouts would go on for days at a time, with the hosts-the challengers-providing hospitality in the form of food. As stated above, no wagering accompanied the cockfighting; the rewards were presumably in the form of praise for the victorious side, and in the case of the victorious birds' owners, of "... the gratification they derived from beholding [their birds] destroy each other" (Ellis 1829:I, 302).

It is astonishing how great is their pleasure in this diversion, which appears to be unconnected with any other considerations of personal interest; but there is little in their lives for which they have such passionate concern. No warrior takes such fierce pride in his acts of bravery as do the owners of fighting cocks in theirs. (Moerenhout 1837:II, 146-147).

Although Moerenhout seems to have been describing more specifically the situation that obtained in his day (i.e., in the 1830s), his remarks could well have applied to earlier days. In practically every house, he continued, there was at least one fighting cock, and their owners used to spend hours in stroking them, feeding them, and even just gazing at them. In fact, according to him, the owners of such cocks displayed toward them "... an affection seldom manifested for any other being, even including their own children." 


\section{STORIES, RIDDLES, AND JESTS}

What Westerners would call "idle chatter" was evidently one of the Maohis' most pleasurable pastimes:

If, as sometimes happened, there were no jobs that had to be done and nothing else of a pressing nature to occupy them, everyone-both males and females-would lounge about in the open, in front of their houses or under the trees, and amuse themselves with some game or other or, more usually, simply conversing. Indeed, conversation was their strong point and chatter was everyone's pleasure-something which they never let up with. (Moerenhout 1837:II, 76)

As for more formal (or more "structured") utterance, not only was "good speech" a prerequisite for some kinds of social distinction, but it was a highly developed art.

Eloquence was as much esteemed by these islanders as by any other people in the world. They had their masters of rhetoric and their schools where the art of speaking was taught; and it seemed eloquence was so necessary to the chiefs that to lack it was to lack the ability to rule; even today, when they speak of certain ancient chiefs, it is rarely that you hear: "That was a powerful man, a great warrior"; but, putting aside all he had done and only seeing in him the renowned orator, they say emphatically: "Ta'ata paraparau maitai! There was a man who spoke well!" (Moerenhout 1837:I, 411)

By Western criteria, Maohi formal utterances may be assigned to several distinct types, such as prayers, elegiac ballads, panegyrics, greetings and dismissals, public "debates," battle harangues, maxims, proverbs, love lyrics, genealogy, "true" stories-both "mythical" and historical-deliberate fiction, riddles and other enigmas, and jokes. ${ }^{7}$ Some types of utterances have already been touched upon (e.g., prayers and myths) and others will be described in their appropriate contexts. Here I wish to single out some types that were engaged in by people mainly for amusement-namely, fiction, enigmas, and jokes.

One gains the impression that riddles and other enigmas (parau piri) were a favorite diversion of the Maohis, but the only recorded examples of pre-European riddles that I could find are the following:

E fenua tu'u piri o Hitia'a; teie te vetahi tau piri: -

A tahi, a rua te marama i ha'aputuputu; a toru, a maha marama i ha'aputuputu; a pae a ono marama i ha'aputuputu; a hitu, a varu te marama i ha'aputuputu; a iva e ahuru te marama i ha'aputuputu; a tû mai, a fa'ati'ati'a, a vaiiho i vaho!

(1) 'O vai ia?

E te Tumu-nui e, o te tamari'i o te vahine matamua 'o te Tumu e to'na hua'ai, i fanau mai i te ao nei.
Hitia'a was a land of riddles; here are some of the riddles: -

One, two moons have supervened; three, four moons have supervened; five, six moons have supervened; seven, eight moons have supervened; nine and ten moons have supervened; come forth, be propped, remain outside!

(1) Who are they?

O Tumu-nui, they are the children of Tumu's first woman and her posterity, born into the world. 
(2) Eaha te faofao ata?

'O te repo fenua ia 'aore i $\hat{1}$; e o te moana atea ia.

(3) Eaha te ra'au e peha te tumu e peha te 'ama'a, e peha te ohiu, e peha te rau, e peha te 'iri, e peha te maea?

O te vahine ia fanautama.

(4) 'Eaha te tahu'a 'e tàtà i te riu o Ha'apaiano'o?

'O te Maoa'e e o te Papaite ia.
(2) What are the clouds' reservoirs?

They are the ground which is never full; and the vast ocean.

(3) What tree is it that duplicates its trunk, duplicates its branches, duplicates its shoots, duplicates its leaves, duplicates its outer bark and inner bark?

It is a woman bearing children.

(4) Who are the workers that bail up the waters of Ha'apaiano'o (Confluent-water)?

They are Maoa'e (northeast wind) and Papaite (northwest wind).

(Henry 1928:71)

Without raising the highly complicated (and, in my view, unanswerable) question of the Maohis' belief in the "truth" of other kinds of stories about the past, there were some stories told by them, evidently for amusement alone, that appear to have been quite deliberately fictional. Among such fiction was the tall tale reported by G. Forster:

The chief Orea had dined on board with captain Cook during our absence, and had drank about a bottle of wine, without appearing in the least intoxicated. He had however, as usual, been extremely facetious, and had conversed chiefly of the countries which we had lately visited, and of which he had received an account from his countryman Mahine. After being satisfied in regard to many particulars, he said, that though we had seen a great deal, he would tell us of an island which we had not met with in our voyages. "It lies," said he, "but a few days sail from hence, but it is inhabited by a monstrous race of giants, as tall as the main-mast, and as thick about the middle as the drum-head of the capstan. They are very good-natured people, but if they are ever incensed against any body, they take him up, and throw him as far into the sea as I would throw a stone. If you should happen to come there with your ship, they would perhaps wade up to it, and carry it ashore on their backs." He added several other ludicrous circumstances, and concluded with telling us the name of the island, Mirro-mirro, in order to give greater weight to his assertion. It appeared evidently to us, that his whole story was a fine piece of irony, directed against those parts of our narrative which he did not believe, and of which he could have no conception. We admired the witty humour which was so conspicuous in this little flight of fancy, and with $\mathrm{M}$. de Bougainville looked up to its great source, the affluence of the country, which produces contentment and pleasure. (1777:II, 139-140)

Some fictional stories invented by the Maohis were evidently meant to horrify, to scandalize, to arouse tears of compassion, and so forth, but many others were probably told to evoke mirth, which leads us to what I have labeled "jesting."

Jesting (hiro, hō'ata), a much favored mode of Maohi speech, was in the form of word labels applied to individuals or places, of informal gossip and badinage, or of dramatic travesty. Ellis provided post-European, but probably characteristically indigenous, examples of the first: 
The inhabitants of one of the Leeward Islands, Tahaa, I believe, even to the present time furnish matter for mirthful jest to the natives of the other islands of the group, from the circumstance of one of their people, the first time she saw a foreigner who wore boots, exclaiming, with astonishment, that the individual had iron legs. It is also said, that among the first scissors possessed by the Huahineans, one pair became exceedingly dull, and the simple-hearted people, not knowing how to remedy this defect, tried several experiments, and at length baked the scissors in a native oven, for the purpose of sharpening them. Hence the people of Huahine are often spoken of in jest by the Tahitians, as the feia eu paoti, or people that baked the scissors. (1829:II, 24-25)

Ellis remarked that "They do not appear to delight in provoking one another, but are far more accustomed to jesting, mirth, and humour, than irritating or reproachful language." In this evaluation Ellis was joined by Moerenhout:

They liked to banter words about to provoke laughter, even at the expense of others, whether their targets were present or not. On the other hand they were unaccustomed to satire, never using this means to injure one another. Epigrams, and often quite sharp ones, were commonly on their lips-but only for the purpose of producing good humor, and innocent, nonmalicious good humor at that. (1837:II, 76)

I cannot agree with this last assertion of Moerenhout's, but malicious or not, most evidence that we have on Maohi jesting is that it was delivered as if in joke. But however amiable some Europeans may have judged Maohi joking to be, they did not always approve of the style of that humor:

Their humour and their jests were, however, but rarely what might be termed innocent sallies of wit, and were in general low and immoral to a disgusting degree. Their common conversation, when engaged in their ordinary avocations, was often such as the ear could not listen to without pollution, presenting images, and conveying sentiments, whose most fleeting passage through the mind left contamination. Awfully dark, indeed, was their moral character, and notwithstanding the apparent mildness of their disposition, and the cheerful vivacity of their conversation, no portion of the human race was ever perhaps sunk lower in brutal licentiousness and moral degradation, than this isolated people. (Ellis 1829:II, 25) ${ }^{8}$

I must leave to others the specialized task of analyzing Maohi oral literature and formalized utterances. A few starts have already been made in that direction, ${ }^{9}$ but a major work on the subject remains to be done. I can, however, call attention to two stylistic (as opposed to thematic) features of the kinds of utterances just described that seem to me to be particularly relevant to social relations. First of all, in lengthy stories, about both humans and spirits, incidents tended to be strung together genealogically rather than by any development of converging themes perceptible to me. The protagonist first to appear in the narrative lives out his life of adventures and dies (or otherwise disappears from the scene), and then his son does likewise, and so on-with no discernible master plot or final resolution comprehending any time span longer than each protagonist's life. ${ }^{10}$ 
In connection with the more "public," formalized examples of jesting, the directness and pithiness that seem to have been so typical of informal conversation were not replaced by the kind of circuitous euphemism that characterized so many other types of Maohi public utterance. In other words, jesting, as a genre, appears to have been widely recognized as a licensed kind of free speech. Even men of great power and irritability, as we shall see, were required by convention to submit to such jesting now and then.

\section{MUSiC}

If one may say that eloquence was honored by [certain Pacific islanders], then one should add that poetry was a passion with them, and especially was this true of the Society Islanders, who were the least barbaric of all of them and the most inclined towards all forms of amusement. These latter made use of [poetry] in all their festivals and religious ceremonies, mainly in the persons of bards and traveling minstrels who enlivened such occasions with their [poetic] performances, their music, and their dancing. For the subject matter of their chants these latter dealt not only with the adventures of the gods and heroes, with the wars and great deeds of their reigning chief, and with the physical perfections or other virtues of other persons present, but even more often they concerned themselves with the delights of lovemaking, a subject about which they were able to produce improvisations with outstanding facility. (Moerenhout 1837:I, 411-412)

Many of the more stylized utterances listed in the preceding section-prayers, genealogies, ceremonial salutes, harangues, laments, love lyrics-approached singing in their delivery; but in addition there were others that the European visitors unequivocally called "songs" or "ditties." Both pehe and ütē are given as the Maohi terms for such songs, but it is not clear whether they both refer to songs in general or to distinctive types of songs. ${ }^{11}$ Banks described the pehe as consisting of "... two lines affecting a coarse metre and generaly in Rhime” (Beaglehole 1962:I, 349); such was a popular style of song, rendered either with or without accompaniment, and either in ceremonial chorus or by an individual idling away his time in solitary contentedness. Banks added: "At any time of the day when they are lazy they amuse themselves by singing these couplets but especialy after dark" (p. 350). Ellis translated pehe as song, but used the word upu for what he called their "historical ballads," although it is not clear whether he meant to imply that all their songs were "historical ballads," or that such ballads comprise only one type of song (1829:I, 285). In this connection, the LMS Dictionary translates upu as prayer.

Some observers described much Maohi singing as having been in the form of recitative: pehepupite, to sing alternately, as two persons, or parties (LMS Dictionary). But further details on song lyrics are lacking, except for a description of a kind of choral accompaniment, by males, to certain forms of dancing: 
Dancing [is sometimes accompanied by] a choir of males arranged in one or more rows and usually seated. The part played by such a group is to provide a choral background, consisting of guttural and inarticulate sounds uttered in unison, to a soloist who sings in a clear falsetto voice. Usually, the latter also serves as choir leader, and the members of the choir respond to his leads in howling and powerfully sounded cadence accompanied by bizarre gestures, and all carried out in remarkably precise unison. (de Bovis 1909:34)

The following passage, from a missionary journal of 1801, concerns performances put on by groups of "traveling players"-quite possibly members of the Arioi sect:

Arrived at Edea's house a company of travelling players, who go from one district to another to exhibit their truly savage performances. They generally travel in large companies, with a manager at their head. Their manner of performing is thus:-The actors place themselves in a ring on the ground, the manager stands in the middle, and begins with a prologue, which he delivers with much vehemency, and wild gesticulation of his arms, fingers and feet; then a signal is given to the actors, who all break out into a most singular and barbarous noise, which can be compared to nothing better than a herd of swine, grunting in concert, at the same time they keep working their hands and thighs as they sit cross-legged, like so many lunaticks, and thus they continue till they are obliged to stop for breath; a repetition of this continues about three quarters of an hour. During the whole of the performance the manager keeps his place, and plays his anticks; a drum is also kept beating, to which they grunt in tune. This abominable pastime is much delighted in by all ranks, though the higher class profess to despise the actors, and speak of them and their performances in a contemptuous manner. Upon what is termed grand occasions, the spectators who come from far and near, appear in their best apparel. (LMS Transactions:I, 216-217)

The subject matter of Maohi song lyrics varied widely. Many of them had to do with events that were either legendary or more credibly historical: the exploits of gods and heroes, the tribulations of all manner of individuals, the occurrence of noteworthy happenings, and so forth.

They were often, when recited on public occasions, accompanied with gestures and actions corresponding to the events, or scenes described, and assumed in this respect a histrionic character. In some cases, and on public occasions, the action presented a kind of pantomime. They had one song for the fisherman, another for the canoe-builder, a song for cutting down the tree, a song for launching the canoe. But they were, with few exceptions, either idolatrous or impure; and were, consequently, abandoned when the people renounced their pagan worship. (Ellis 1829:I, 285-286)

Some songs may have been of considerable antiquity, other songs were quite obviously of recent vintage or were observed to have been improvised on the spot and either forgotten immediately after delivery or stored up in the popular repertory. In any case, once widely known and firmly established, a song had what Ellis called “... a kind of standard, or classical authority, to which they referred, for the purpose of determining any disputed fact in their history." 
The fidelity of public recitals referring to former events, was sometimes questioned by the orators or chroniclers of the party opposed to that by whom the recital had been made. The disputes which followed, were often carried on with great pertinacity and determination. As they had no records to which they could at such times refer, they could only oppose one oral tradition to another, which unavoidably involved the parties in protracted, and often obstinate debates. At such times, a reference to some distich, in any of their popular and historic songs, often set the matter in dispute at rest. On a recent occasion, two parties were disputing in reference to an event which occurred in the bay of Papara during the time Captain Bligh remained there in the Bounty, in 1788 or 1789. The fact questioned was the loss of the buoy of his anchor: after disputing it for some time without convincing his opponent, the individual who had stated the fact referred to the following line in one of their ballads, relating to that event.

'O mea ei'a e Tareu ei'a

Ei'a te poito a Bligh.

Such an one a thief, and Tareu a thief,

Thieved (or stole) the buoy of Bligh.

The song was one well known to most, and the existence of this fact, among the others that had taken place, and the remembrance of which the ballad was designed to preserve, was conclusive, and appeared to satisfy the parties by whom it had been questioned. Most of their historical events were thus preserved. These songs were exceedingly popular for a time. The facts on which they were grounded became thus generally known; and they were, undoubtedly, one of the most effectual means they had of preserving the knowledge of the leading events of former times. (Ellis 1829:I, 286-287)

Singing, especially on public occasions, ${ }^{12}$ was nearly always accompanied by a kind of male chorus, already described; or by musical instruments or gestures or dancing; or by combinations of these.

The Maohis' musical instruments were drums (figs. 10-4, 10-5), shell trumpets (fig. 10-6), gongs, flutes (fig. 10-7), castanets, and dance rattles. Their drums (pahu) were made of a sharkskin head fastened over the hollowed-out end of a section of tree trunk. Pu'a (Fragraea berteriana) and reva (Cerbera manghas) were the favorite woods used, because of their durability and close grains (Ellis 1829:I, 282). The sharkskin head was stretched tightly over the opening by means of sennit cords attached to the solid foot of the drum. Drums varied in length from one to several feet and in diameter from one to two feet.

The Music was performed on three Drums of different Tones, arrising from their different magnitudes \& form. The Base, or deepest toned one, was about 12 or 14 Inches high, and perhaps as much in diameter: The Middle one was about $2 \frac{1}{2}$ feet high and about 10 Inches diameter; and that which had the highest tone, might be near $3^{1 / 2}$ feet high and about 7 or 8 Inches Diameter. Their Heads were made of Shark's Skin and braced much in the same Manner as ours are, only without the slides which ours have for bracing and unbracing.... (Beaglehole 1961:804)

The larger ones were usually beaten with sticks, two in number; the smaller 


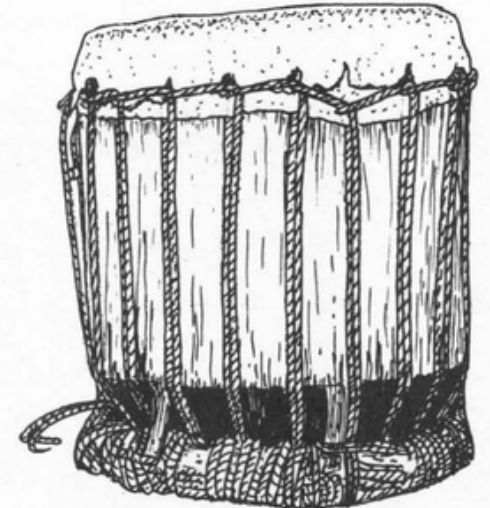

FIGURE 10-4. Wood drum with sharkskin head and sennit lashing, height $32 \mathrm{~cm}$. Institut für Völkerkunde, Göttingen.

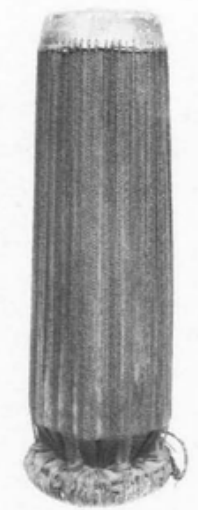

Figure 10-5. Drum, height $635 \mathrm{~mm}$. British Museum.

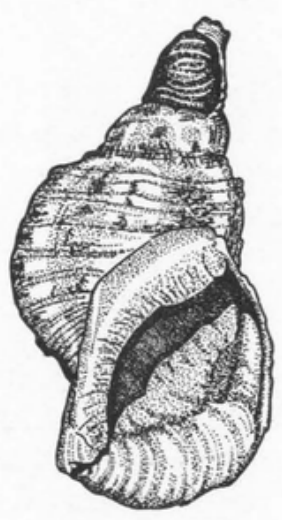

FIGURE 10-6. Shell trumpet.

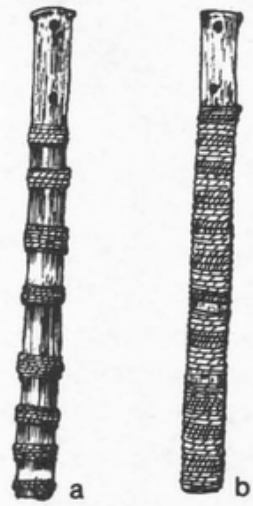

FIGURE 10-7. Nose flutes: $a$, length $42 \mathrm{~cm}$. Cambridge University Museum; $b$, length $45.2 \mathrm{~cm}$. Museum für Völkerkunde, Vienna.

ones by hand. When beaten they were fixed upright upon the ground and consequently, according to one report, "... produced no very musical effect" (Ellis 1829:I, 283). According to Banks, the Maohi drums were beaten so as to "... accompany the flute but not disagreably"; and, he added, "... they know also how to tune two drums of Different notes into concord which they do nicely enough" (Beaglehole 1962:I, 350).

There is little useful information available concerning the Maohis' repertory of drum rhythms, except for Banks' suggestive-but likely underestimating-assertion that their drums could make out only " 5 or 6 tunes." 
In general, the larger drums were kept in the marae and were sounded on such solemn occasions as sacrifices or the illness or death of an important person.

Ellis described the shell trumpet $(p \bar{u})$ in the following terms:

The sound of the trumpet, or shell, a species of murex used by the priests in the temple, and also by the herald, and others on board their fleets, was more horrific than that of the drum. The largest shells were usually selected for this purpose, and were sometimes above a foot in length, and seven or eight inches in diameter at the mouth. In order to facilitate the blowing of this trumpet, they made a perforation, about an inch in diameter, near the apex of the shell. Into this they inserted a bamboo cane, about three feet in length, which was secured by binding it to the shell with finely-braided cinet [sennit]; the aperture was rendered air-tight by cementing the outsides of it with a resinous gum from the bread-fruit tree. These shells were blown when any procession marched to the temple, at the inauguration of the king, during the worship at the temple, or when a tabu, or restriction [i.e., a rahui], was imposed in the name of the gods. We have sometimes heard them blown. The sound is extremely loud, but the most monotonous and dismal that it is possible to imagine. (1829:I, 283-284)

The same author described the gong (ihara) as follows: “... formed from the single joint of a large bamboo cane, cut off a short distance beyond the two ends or joints. In the centre, a long aperture was made from one joint towards the other. The ihara, when used, was placed horizontally on the ground, and beaten with sticks." (p. 284) According to Henry the aperture was kept open by inserting a stick under the strips of bamboo (1928:275).

The nose flute (vivo) was described by Henry as producing "... a soft, sensitive, and plaintive sound" (1928:276). It consisted of a joint of bamboo a foot or so long and up to an inch in diameter. It had four or five holes on one side and one on the other, and it was sometimes ornamented by burnt-in designs or with wound-about strings of hair and sennit. Ellis described the method for playing it: "It was not blown from the mouth, but the nostril. The performer usually placed the thumb of the right hand upon the right nostril, applied the aperture of the flute, which he held with the fingers of his right hand, to the other nostril, and, moving his fingers on the holes, produced his music." (p. 285)

According to Banks: "They also tune their flutes if two play upon flutes which are not in unison, the short one is leng(t)hned by adding a small roll of leaf which is tied round the end of it and movd up and down till their ears (which are certainly very nice) are satisfied" (Beaglehole 1962: I, 350).

Flutes were sometimes played alone but were more frequently played to accompany singing, at least on public occasions. The sound of flute and voice drew the following commentary from one eyewitness:

One of the young men had a flute made of a bamboo, which had but three holes; 
he blew it with his nostrils, whilst another accompanied him with the voice. The whole music, both vocal and instrumental, consisted of three or four notes, which were between half and quarter notes, being neither whole tones nor semi-tones. The effect of these notes, without variety or order, was only a kind of drowsy hum, which could not indeed hurt the ear by its discordant sounds, but made no pleasing impression on our minds. It is surprising that the taste for music should be so general all over the world, when the ideas of harmony among different nations are so distinct! (G. Forster 1777:291-292)

In practice, drums, gongs, and flutes-singly or in combination-served usually to accompany both singing and dancing.

Bligh provided the following description of castanets:

This Hevah [heiva] was different from any we have yet seen. The performers were eleven Men habited in that singular dress called Parry. They were placed in three files, and each Man had two Mother of Pearl shells in his hand, which by the Manner they were Strung on a peice of cord, and about an Inch asunder, with a small notion of the fingers made a clinking kind of Noise. (Bligh 1789:I, 422)

Anderson believed that the Maohis' fondness for music was related to their feelings, "which, though lively, seem in no case permanent":

Such a disposition, leads them to direct all their aims only to what can give them pleasure and ease. Their amusements all tend to excite and continue their amorous passions; and their songs, of which they are immoderately fond, answer the same purpose. But as a constant succession of sensual enjoyments must cloy, we found, that they frequently varied them to more refined subjects, and had much pleasure in chanting their triumphs in war, and their occupations in peace; their travels to other islands, and adventures there; and the peculiar beauties, and superior advantages of their own island over the rest, or of different parts of it over other less favourite districts. This marks, that they receive great delight from music; and though they rather expressed a dislike to our complicated compositions, yet were they always delighted with the more melodious sounds produced singly on our instruments, as approaching nearer to the simplicity of their own. (Cook 1784:149-150)

Finally, I quote some passages describing the companies of "traveling musicians" that made at least a part-time profession of these arts:

The drums are chiefly used at their Heivas which are a set of musicians 2 or 3 drums for instance as many fluits and singers, which go about from house to house and play and are always received and rewarded by the Master of the family who gives them a peice of Cloth or what ever he can spare, for which they will stay three or four hours during which time his house will be crowded full for the people are extravagently fond of this diversion. (Beaglehole 1955:127)

In my mornings walk today I met a company of traveling musicians; they told me where they should be at night so after supper we all repaird to the place. There was a large concourse of people round this band, which consisted of 2 flutes and three drums, the drummers acompanying their musick with their voices; they sung many songs generaly in praise of us, for these gentlemen like Homer of old must be poets as well as musicians. The Indians seeing us entertaind with their musick, askd us to sing them an English song, which we most 
readily agreed to and receivd much applause, so much so that one of the musicians became desirous of going to England to learn to sing. These people by what we can learn go about from house to house, the master of the house and the audience paying them for their musick in cloth, meat, beads or any thing else which the one wants and the other can spare. (Beaglehole 1962:I, 290)

\section{DANCE}

Any little melody played on their nose flutes, or even the muted sounds from their drums, was enough to set them in movement; and as soon as one of their favorite tunes was heard to the accompaniment of these instruments, their faces and bodies became animated, moving in rhythm and showing the pleasure given them. This type of dance involved two or four individuals who were usually clothed from the waist down. In some other types however some spectators, unable to contain their excitement and imitating the movements of the principals, leapt one after the other into the dance. And on such occasions all clothing became superfluous, and everyone performed entirely nude. At this point performers and spectators alike seemed to lose themselves in a mad frenzy, and not infrequently (as in the case of the Arioi) would perform actions of such depravity as to prohibit our description of them. Their dance movements alternated with gestures of hands and arms. The rhythmic beat of the men's voices formed a background to the women's singing, and all to the accompaniment of flute and drum. (Moerenhout 1837:II, 127)

Not all Maohi dancing began or ended in just this way, but the above passage does provide some sense of the mood, the social communion, and the deep absorption of these Islanders when circumstances moved them to dance.

Countless words have been written about ancient Maohi dancing, and from such descriptions one can glean many different impressions of their dance movements: for example, that they were sometimes slow and regular, sometimes rapid and wild; that at times they involved all the body, at times only the arms and shoulders. (Figs. 10-8, 10-9.) Furthermore, although many of the Europeans found some Maohi dance movements so "lascivious" or "obscene" as to elude description or demand reticence, others of their dances were innocent enough to please all but the most straitlaced prude. But for all this spate of words there has not survived any passage detailed enough to provide us with a precise account of the eurythmics of any of what must have been several different forms of Maohi dance. Perhaps the clearest account available is that of J. Forster:

... they by no means think the excellence of the performance to consist in the graceful motion of the feet, as they carefully cover them; but in the motion of their hands and fingers, they shew in my opinion, the greatest dexterity and elegance. They have generally long well shaped fingers, which are wonderfully pliant, so that they can with ease bend them so far back as to form with the rest of the hand a segment of a circle, and in this attitude they move them with an astonishing agility. This dance is called Heèva he-oòra, and the motion of the fingers Eòree. But beside this, they shake their hips in a rotatory motion, both 
when they are standing and when they are leaning prostrate on their knees and elbows, with a velocity which excited our astonishment, and this is named òneòne. There are other dances wherein they use measured steps, hold another by the hands and clap with them; which is called pa-àta. During the various kinds of dances, they never fail to make wry mouths, which, in our opinion, were the most extravagant and disgracing distortions, instead of being capable of giving the spectator ideas of gracefulness and harmony: habit has taught them to screw the mouth into an obliquely slanting direction by a kind of sudden convulsive mo-

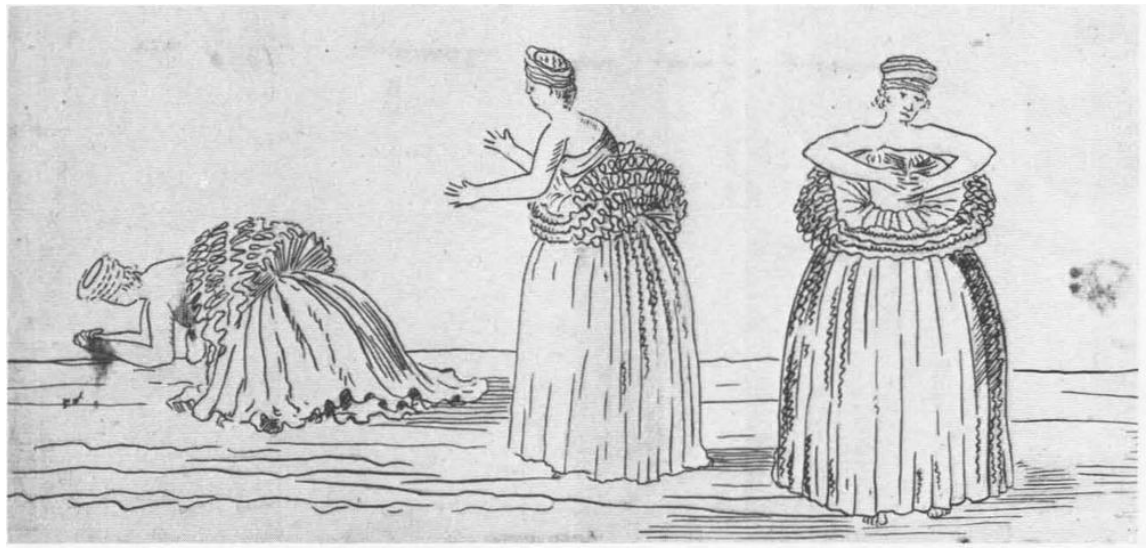

10-8. Dancing girls. Sketch by S. Parkinson. British Museum.

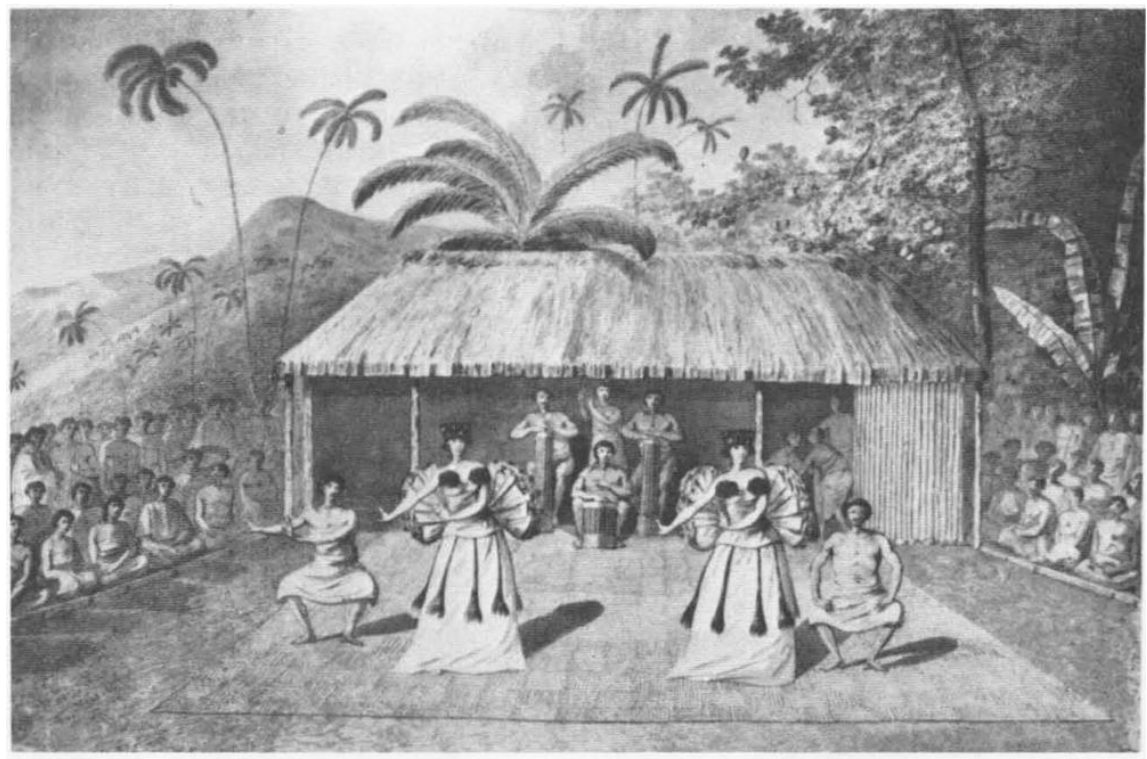

FIGURE 10-9. Tahitian dancing. Drawing by J. Webber. British Museum. 
tion of the lips, and custom only has made the sight of so unnatural and offensive a grimace a performance which pleases and merits applause. This distortion is called ootoo-ròa (large lips). [Fig. 10-10.] There are other dances usual in their nocturnal festivals with the Arreeoys, which, none of our ships company had an opportunity of seeing, and are according to the accounts of the natives extremely indecent and lascivious; these are called t'eài-mordèe, and the women exhibiting them Too-àha. The exercise of the common dramatic dances is very violent, the motion of the hands elegant, that of the feet not to be seen, that of the hips somewhat strange, and according to our notions indelicate; and lastly, that of the mouth horrid and disagreeable. The women when performing were always attended by a man, who accompanied the drums with a kind of song; and by some loud spoken words or the clapping of hands, directed their motions; which, in my opinion seems to intimate that they have a kind of plan in their dances, and that the transitions from the oblique steps, to the motion of the fingers and agitation of the hips, is in some measure connected with the words spoken by the master of the ballet. (1778:466-467)
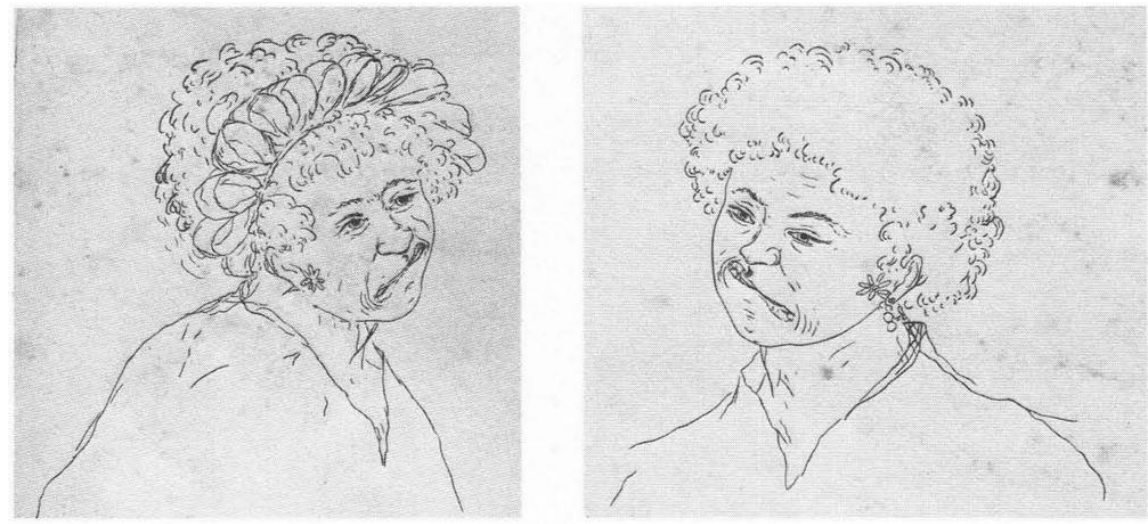

FIGURE 10-10. "Distortions of the Mouth used in Dancing." Sketches by S. Parkinson. British Museum.

The general terms for dancing were 'ori and 'upa. Some writers gave terms for different forms of dance, but none of these accounts is exhaustive or unambiguous, and no two of them are identical. ${ }^{13}$

The hura was described by Henry as having been danced "... only by women of [high] rank, the queen often taking the lead" (1928:275). Moerenhout described it in these terms:

The ehoura [hura] is a form of production in which the actors perform behind a railing. The actors open the scene by repeated summons to the actresses, who soon thereafter arrive elegantly dressed and with their tresses oiled, perfumed, and decorated with flowers. The actresses enter and leave the stage continually, to the incessant invitations of the actors, whose gestures, movements, and words express their impatient longings, and who appear to shudder with delight at the very sight of their ladyloves. (1837:II, 128) 
Morrison, on the other hand, identified the "hewra" [hura] as "... the Dance performd by the relations of Warriors Slain in Battle when they make friends with the Man who killd Him or them" (1935:224-225; see also Henry 1928:319). Morrison did not actually describe the dance itself, but his identification hardly accords with the one given by Moerenhout.

The descriptions given of the ponara are in better agreement:

Another Dance is the Ponnara which is performed almost evry evening in evry district through the Island. To this Dance the Weomen of evry age and discription resort to dance; young \& old, Rich and Poor mix promiscuously, but no Men Join with them-when they attend the Ponnara they are always Neat and dressd in their best, their Heads decorated with Garlands of sweet scented Flowers. Having fixd on the Ground they devide themselves in two partys and seperate at 30 or 40 Yards from each other, when one of the Best players having provided a small green Bread fruit for a Ball with which she runs out about half way between the two kicks the Ball with as Much force as she is able, striking it with the upper part of the foot near the instep; if she sends the Ball through the other party or past them so none can stop it till it stops itself then the Opposite or Her party strike up a Song \& Dance, beating time to it with hands \& feet with much exactness and regularity-after they have finnishd their dance, which lasts about 5 or 6 Minutes, the Other Party kick the Ball which if it Passes they who kick it Dance, but if it is stopt by them who Danced first then they dance again, Mean time the Others Stand still-after they have Playd at this for some Hours they Kick the Ball to one side and both Partys strike up together, when each, to draw the Spectators to their exibition, produce two or three Young Wantons, who stripping of their lower Garments Cover them selves with a loose piece of Cloth and at particular parts of the Song they throw Open their Cloth and dance with their fore part Naked to the Company making many lewd gestures-however these are not merely the effects of Wantoness but Custom, and those who perform thus in Publick are Shy and Bashful in private, and seldom suffer any freedom to be taken by the Men on that account. (Morrison 1935:225)

The Women divide into parties about 30 or 40 Yards apart and perform a kind of recitative accompanied with a Stamping of the feet and claping the hands with many wanton odd motions. A Breadfruit is then taken by a person of one party, and being placed on the foot is thrown over to the others. If it is caught, that party performs the dance and the others look on, but if it is not caught, the Party who threw it has the dance in token of the Victory, and the ball is thrown by turns from side to side. (Bligh 1789:I, 412)

Some other forms of dance identified in the sources include: ōte' $a$, "men's dance with spurt" (Henry 1928:275); oupépéhe ('upa-pehe?), "a dance accompanied by drums and the singing of a male and a female. The dancers themselves, all females and all completely nude, make a hissing sound as they dance"; and mamaha, "A dance by men and women together, all completely nude and accompanied by drums" (Moerenhout 1837:II, 127-128).

In addition, a number of other dances were described simply as being "indecent" or "obscene": for example, the mamua, the maupepe, and the 
po'opa'otati. Cook described one such dance, called by him the "timorodee"-a rendering which Beaglehole transcribed (not altogether persuasively) as te ai moro iti, pseudo-copulation:

The young girls when ever they can collect 8 or 10 together dance a very indecent dance which they call Timorodee singing most indecent songs and useing most indecent actions in the practice of which they are brought up from their earlyest Childhood, in doing this they keep time to a great nicety; this exercise is however generaly left of as soon as they arrive at years of maturity for as soon as they have form'd a connection with man they are expected to leave of dancing Timorodee. (Beaglehole 1955:127)

Anderson provided an even more detailed description of a "lascivious," woman's dance:

... in the evening a great many of them [women] having collected together stood upon the side of a small river near the middle of the Bay and exhibited a sort of dance that rather bespoke an excess of joy and licentiousness, though perhaps it might be their usual custom. Most of these were young women, who put themselves into several lascivious postures, clapp'd their hands and repeated a kind of Stanzas which every now and then began afresh. At certain parts they put their garments aside and exposd with seemingly very little sense of shame those parts which most nations have thought it modest to conceal, but in particular a woman more advanc'd in years who stood in front \& might properly be calld the tutoress or prompter of the rest, held her cloaths continually up with one hand and dancd with uncommon vigour and effrontery, as if to raise in the spectators the most libidinous desires and incite her pupils to emulation in such a wanton excercise. The men flockd eagerly round them in great numbers to see their performance and express'd the most anxious curiosity to see that part just mentioned, at which they seem'd to feel a sort of rapture that could only be express'd by the extreme joy that appear'd in their countenances. (Beaglehole 1967:977-978)

Rather than pursue further the complicated and probably fruitless exercise of trying to reconstruct Maohi categories for their dance forms, ${ }^{14}$ let us turn to more Western ways of classifying them.

First, the Maohis danced on all occasions, from carefree informal gatherings of a handful of people to solemn assemblies of thousands. They danced at welcomings and departings; at births and deaths; before, during, and after battles; as preludes, interludes, and postludes to contests, theatricals, and religious services.

Second, their manifest purposes in dancing were exceedingly varied. They danced for sheer pleasure or to give vent to rage, to express happiness or display grief, to invite or to defy, to entertain or to terrify. Dancing was an essential ingredient of many kinds of religious worship. It was also, occasionally, used as an instrument of politics: districts challenged one another to dancing contests, with victory, and praise, going to the side that displayed more agility and grace.

Districts contested with each other even in the form of dance and drama 
competitions. These [like athletic matches] involved formal challenges, and they took place in the presence of chiefs and numerous other spectators. And while their dancing in general may be characterized as having been more or less lascivious, those performed on the occasion of these competitions tended to be less so, the outcome having been decided more on the basis of agility and grace. (Moerenhout 1837:II, 129)

Third, the personnel of dancing varied from occasion to occasion from single performers dancing to the accompaniment of a single instrument-or with no accompaniment at all-to large troupes of males or females, or both males and females, with full accompaniment of flutes, drums, gongs, and chorus under the direction of expert prompters (pāta'u). For example, one writer witnessed a combination of three males and two females, and so on. As noted earlier, some of the dances may by name have been identified with one or both sexes and with a small or large number of dancers-as, for example, the ponara; but the sources are not explicit enough for more precise specification-or, what was more likely, Maohi conventions were not very specific in this regard. Andia y Varela witnessed on one occasion a dance performed by boys dressed as girls (Corney 1915:289).

Age was undoubtedly an indirect factor in dancing, that is, most dances required a suppleness and endurance which ruled out people past a certain stage of physical development or decline. There are numerous reports about very young dancers (especially females), but no eyewitness report that I know of concerning public dancing by elderly people. ${ }^{15}$ In fact, as will be noted in my description of the Arioi sect (chapter 22), in the public performances put on by these bands of cultist-entertainers, most accounts assert that only the novices and members of the lower hierarchic grades-that is, usually the younger members-actually danced or acted. In this connection, as noted earlier, certain of the more obviously copulatory dance movements of females-for example, Banks' and Cook's "Timorodee"-appear to have been danced exclusively by young women before marriage.

On the other hand, there was no restrictive connection between dancing and social (i.e., marriage) class, at least with respect to women:

The professors of these arts [dance, music, poetry] are so far from being degraded by them, that even the Princesses of the blood Royal think it not derogatory to their rank to exhibit their skill in dancing before a crouded audience of their father's or brother's subjects; and the actors were some of the Hoas or attendants upon the King (J. Forster 1778:475-476). ${ }^{16}$

There may have existed some relation between social class and specific form of dance, as recorded for example in Henry's statement that the hura was danced "... only by women of rank" (1928:275), but there is a good possibility that some such relation, if any, may have come about indirectly. The cost of certain dance costumes or of the expert instruction and the leisure needed for perfecting certain dance movements could normally have been 
better borne by people of affluence, ${ }^{17}$ as shown, for example, by the statement in Wilson regarding participation in a heiva: "Any number of women may perform at once; but as the dress is very expensive, seldom more than two or four dance; and when this is done before the chief, the dresses are presented to him after the heiva is finished; and these contain thirty or forty yards of cloth, from one to four yards wide" (1799:355).

Next-and a matter already touched upon-one should, technically be able to classify Maohi dances according to the actual movements of the dancers: the parts of the body moved and the nature of the movements, the rhythms, the spatial patterns traced by their movements over the ground, the vocal sounds of the dancers, the symbols expressed by the movements, and so forth. We do, it is true, possess such statements as the following:

Their movements were generally slow, but remarkably regular and exact; the arms, during their dances, were exercised as much as their feet. (Ellis 1829:I, 298)

... they advancd sideways keeping excellent time to the drums which beat brisk and loud; they soon began to shake their hips giving the folds of cloth that lay upon them a very quick motion which was continued during the whole dance, they sometimes standing, sometimes sitting and sometimes resting on their knees and elbows and generaly moving their fingers with a quickness scarce to be imagind. The chief entertainment of the spectators seemd however to arise from the Lascivious motions they often made use of which were highly so, more indeed than I shall atempt to describe. (Beaglehole 1962:I, 325-326)

These passages, as well as the excerpts from J. Forster and from Wales quoted earlier, provide useful general impressions of Maohi dancing, but they do not add up to a systematic classification of Maohi eurythmics.

Several writers reported that complete or partial nudity went with sexually expressive dance movements. Also, we are given fairly detailed descriptions of the elaborate garments worn by women during the hura, as, for example, in a statement by Banks:

The women had on their heads a quantity of tamou or plaited hair which was rolled and between the interstices of it flowers of Gardenia were stuck making a head dress truly Elegant. Their shoulders arms and breasts as low as their arms were bare, below this they were coverd with black cloth and under each shoulder was placd a bunch of black feathers much as our ladies nosegays or Bouquets. On their hips rested a quantity of cloth pleated very full which reachd almost up to their arms and fell down below into long peticoats reaching below their feet, which they managd with as much dexterity as our opera dancers could have done; these pleats were brown and white alternately but the peticoats were all white. (Beaglehole 1962:I, 325)

Otherwise the sources tell us little about the connections between costume and dance form-if indeed there were any beyond the few examples just listed.

Before proceeding we should take note of a spectacle witnessed by 
Bligh, and described by him as being "... of all things that was ever beheld ... the most uncommon and detestable."

They suddenly took off what cloathing they had about their Hips and appeared quite Naked. One of the Men was prepared for his part, for the whole business now became the power and capability of distorting the Penis and Testicles, making at the same time wanton and lascivious motions. The Person who was ready to begin had his Penis swelled and distorted out into an erection by having a severe twine ligature close up to the Os Pubis applied so tight that the Penis was apparently almost cut through. The Second brought his Stones to the head of his Penis and with a small cloth bandage he wrapt them round and round, up to-wards the Belly, stretching them at the same time very violently untill they were near a foot in length, which the bandage kept them erect at, the two stones and the head of the Penis being like three small Balls at the extremity. The Third person was more horrible than the other two, for with both hand seizing the extremity of the Scrotum he pulled it out with such force, that the penis went in totally out of sight and the Scrotum became Shockingly distended. In this Manner they danced about the Ring for a few minutes when I desired them to desist and the Heivah ended, it however afforded much laughter among the Spectators. (Bligh 1789:II, 35)

The best of the dancers presumably had their natural talents and basic training refined and elaborated by older experts in the art; and there are scattered references to such teachers, who attached themselves to socially prominent households or who traveled about the islands giving lessons. On the other hand, knowledge of ordinary movements was so widespread that most dancers probably learned the basics of the art through imitation and through instruction from relatives and friends.

Finally, before turning to other diversions of the Maohis it should be added that for dancing, as for all other socially important activities of these Islanders, there were believed to be special tutelary deities, who presided over the art and its more expert performers. ${ }^{18}$ Indeed, as noted earlier, some writers considered Maohi dancing to have had some deliberate, specifically religio-magical purposes.

\section{DRAMA}

On Tahiti, and on the neighboring islands, what the natives are most fond of doing in all the world is to dance and sing and playact (Moerenhout 1837:II, 126-127).

Maohis' playacting was in some particulars hardly to be distinguished from their dancing; or, rather, much of what Westerners would classify as dancing was pantomimic storytelling, and much of their playacting included dancing, and singing as well. These points should be kept firmly in mind as I describe the more specifically storytelling parts of their entertainments.

Maohi dramas were given at different times and in different settings. Sometimes they took place on a temporary stage of mats outside some house where a troupe of players happened to call on their tour around an 
island. If the residents so desired, the troupe would entertain for an hour or two before resuming their tour; these tours took place at any hour of the night or day. Other times, a host would arrange an impromptu performance for an unexpected guest, using what local talent he could summon. At the other extreme were those ceremonious performances which took place at large public festivals and state visits; these were usually staged in specially constructed theaters and involved more elaborate costuming. On such occasions the actual dramas served either as featured events or as minor interludes between exhibitions of dancing or singing. (Beaglehole 1962:I, 328)

One Maohi drama setting was described by G. Forster, who witnessed a performance:

The place where it was performed was an area, about twenty-five yards long and ten wide, enclosed between two houses which stood parallel to each other. The one was a spacious building, capable of containing a great multitude of spectators; but the other was only a narrow hut, which was supported on a row of posts, and open towards the area, but perfectly closed up with reeds and mats on the opposite sides; one corner of it was matted on all sides, and this was the dressing-room of the performers. The whole area was spread with three large mats of the best workmanship, striped with black on the edges. In the open part of the smaller hut we saw three drums.... (G. Forster 1777:I, 398-399)

The themes of Maohi dramas varied widely, but most of those actually described by European witnesses appear to have been carried out in tones of satire (in contrast to the alleged absence of satire in jesting) and buffoonery-although it must be reported that the sense of some of the performances so witnessed wholly escaped their European audiences. ${ }^{19}$

Some writers implied that the Maohis" productions included "mythological" as well as "historical" themes; ${ }^{20}$ this may indeed have been so, although the plays of this general type that were actually reported in the sources were more strictly "historical" (in the European sense) than "mythical." In fact, a large proportion of them were pointedly concerned with contemporary local situations-namely, with the deeds, and misdeeds, of their fellows, including their most feared and respected superiors:

When the Weomen [dancers, at certain performances] retire to take breath their place is supplyd by the Music and singers which is no way disagreeable when understood being soft and pleasing-at other times a set of Actors supplys their place-the principal part of which the(y) perform is Satyr, which is often directed at their Chiefs, and they never fail to expose such Charracters as draw their attention and tho they treat thier Chiefs with great freedom they incur no displeasure so long as they keep to the truth-by this Method they rebuke them for their faults in Publick, having first diverted them to draw their attention-this is done in a kind of Pantomime at which they are so good that any person who knows the Man they mean to represent may easily perceive who they are making the subject of their sport. (Morrison 1935:224)

After Dinner Tynah desired I would attend at a Heivah that was to be per- 
formed on account of a Warrior of Oporeeonnee that had been at Morea and was used ill, and which caused a battle between the parties concerned.

This Heivah was performed in honor of the Warrior, by Tynahs direction, by which it appears he is of such high power as to distribute publick marks of honor as a reward for publick or meritorious Services. (Bligh 1789:II, 61)

The timeliness of some of their plays is further indicated by the frequent references in them to the European visitors, as for example those witnessed by Cook and his companions on Ra'iatea: “... we well know they can add to or diminish their plays at pleasure; we, our Ship and our Country they have frequently brought on the Stage ..." (Beaglehole 1961:421).

Another play, witnessed on Huahine, indicates not only timeliness of theme, but also the social uses to which such presentations were now and then put; I reproduce the whole account of it, including the observerwriter's detailed, if rather sententious, analysis of it:

“... the little extempore farce seen by some of our friends at Huaheine, ... seemed to be levelled at a girl, a native of $O$-Raiedea, who came with us from Taheitee in order to return to her parents, from whom she had eloped some months before with a young Arreoy. Though the piece was but rudely performed, it however put the girl to shame, and drew tears from her eyes, which naturally must have a good tendency, especially with such persons of her sex as might be tempted to follow her example. Upon the whole, this circumstance gives us a very good idea of the nation in every respect: If we consider the poor girl, who was thus exposed, her bashful behaviour and her tears are certainly irrefragable proofs of her modesty and repentance. In a genial climate, with a warm constitution, a feeling heart, and an education which made her acquainted with all the mysterious parts of love, even though she should not chuse to put them in practice, it was no wonder she yielded to the tender solicitations of a youthful and vigorous lover, when her own age and the natural levity of the whole nation, contributed to lessen the crime of her inconsiderate step, and still more so, the possibility of obtaining a husband without hurting her character. On the other hand, there is something so generous in her behaviour that I cannot help taking notice of it. She became the object of indelicate, but sharp and salutary satire, and gave by her tears ample testimony of the immorality of her behaviour, and that she felt herself aggrieved under self-condemnation, and was not unwilling to become a fair warning to a whole croud of young persons of her own sex. If again we consider the actors who took the opportunity of exposing immorality for the instruction of the rising generation; they must be thought highly commendable for having dared to lay aside for so salutary a purpose, the respect due to a lady and a stranger. She was under the protection of a set of foreigners, whose fire-arms indeed commanded respect; but these censors were not to be browbeaten by power, or awed to silence by wealth, as is too often the case in Europe; they failed not to point the shafts of their satire at an object deserving censure, without regarding the consequences which might accrue to themselves from thence, being fully convinced of the rectitude of their action, and the salutary effects that might be derived for the benefit of the rising generation. Lastly the whole audience deserved in my opinion, likewise to be commended; for when the witty sarcasms were falling from the lips of their theatrical heroes, they laughed at their jokes; but when they observed that these shafts of satire were not discharged at ran- 
dom, but made the person smart who was the object of their instructive irony, when they saw the marks of returning modesty, of repentance and self-condemnation, in the attempts to hide her shame, and in the copious tears of the poor girl; many an eye was moistened, and many a heart sympathized with her; lastly, when the dramatic performance was over, every one was eager to give her the most unfeigned and unsolicited marks of his esteem and friendship, to comfort her in her distress and affliction, to countenance her modesty and return to her duty; and in a manner to thank her for having contributed to the innocent mirth, as well as to the instruction and the warning of her country women. If we reflect upon the want of feeling in the frequenters of our theatres, their indolence and inattention, and I may add their shameless effrontery, we must give the palm to to the O-Taheiteans, who, like the true children of nature, have a sympathizing tear, and unrestrained feelings, the tribute and glory of humanity, in readiness on all proper occasions.

\section{- - - Mollissima corda \\ Humano generi dare se natura fatetur, \\ Quae lacrymas dedit: haec nostri pars optima sensus.}

JUVENALIS.

(J. Forster 1778:472-457)

Other plays staged by the Maohis had more timeless, more general themes: what J. Forster called "simple representations of the common occurences of life." For example, one play witnessed by him had the following plot: "A man entrusts his servants with the care of his goods, they fall asleep, and though they are lying on their masters property, the thieves are subtle enough to steal them away from under the persons who were appointed to watch them; sometimes the thieves are detected and severely beaten, and sometimes they return the blows" (1778:471).

The most fully reported play seen by the early European visitors was one which took place on Ra'iatea and, although it may have contained a moral of sorts, seems to have been staged mainly for amusement:

In another farce, a man has a daughter, who has a lover; the father dislikes him and refuses his daughter, and being afraid of being deceived he watches her closely, but in the dead of the night, the lover meets the fair one and persuades her to run away with him; the consequence of this affair is the birth of a fine boy; the lady is in labour on the theatre and at last a large boy is exhibited, who immediately runs about the stage with the placenta and long funis umbilicalis; which is here not considered as indelicate, because every body is acquainted with the incident, the children of four or five years not excepted; and the oddity that the new-born child runs about and escapes the midwife, whose business it is to catch him, causes an universal and loud peal of laughter. The girls father upon seeing the cleverness of his grand-son, is at last reconciled to his son-in-law. (J. Forster 1778:471-472) ${ }^{21}$

The generalizations made above about Maohi dancers can be extended to actors; indeed, they were in many cases probably the same individuals. They included both males and females, and they tended to be young. On the other hand, the more featured roles in dancing appear to have been 
performed by females, while most of the dramatic roles were performed by males. It was not however true, as asserted by J. Forster, that females were not permitted to act. Although there are reports of males having played the parts of females, there are no reports that I know of where females played the parts of males. What was said of the connection between dancing and social status probably also applies to playacting: that is, women of even the uppermost class performed as dancers, although such was not evident in the case of men.

Expert actors and actresses, like many expert dancers and musicians, seem to have been compensated for their services, not only with praise but with more tangible goods as well.

Finally, I draw attention to one other feature of Maohi playacting: the fact that such drama provides additional evidence of these people's fine perceptiveness about social behavior in general and social role playing in particular. Accounts of their dramatic performances strongly confirm the evidence from more everyday situations that the Maohis were keenly interested in both the norms and the actualities of social interaction and that they demonstrated considerable skill, and took a certain waggish delight, in acting out (and thereby publicizing) the foibles of their fellows. Some of their dramas were evidently stiltedly formal affairs of a religious nature, but most of the others appear to have been concerned with various aspects of the Maohis' views of the "human comedy."

\section{TOURING AND VISITING}

It should now be clear that the Maohis possessed the means for traveling about their archipelago; and all the sources indicate that they made extensive use of those means. It is, of course, impossible to construct a credible flow map of all these movements in terms of numbers of individuals and of the frequencies of their comings and goings, but the impression is inescapable that traveling about and visiting was a main feature of Maohi life. One has only to peruse the journals of Rodriguez and Morrison to confirm this; in the course of their own travels about Tahiti, when they themselves were no longer the focus of the natives' curiosity, they visited places which were surging with crowds on some occasions and almost deserted on others.

Among the many motives which induced the Maohis to move about so extensively must be emphasized the pleasure they obviously derived from touring and visiting, including their desire to visit relatives and friends, and their curiosity to see new places and people and to witness unusual events. Sometimes pleasure-bent individuals moved about on individual and personal missions, as was the case with Cook's friend, Hitihiti: "Heete-heete, who is a native of Bolabola, had arrived in Otaheite, about three months before, with no other intention, that we could learn, than to gratify his cu- 
riosity, or, perhaps, some other favourite passion; which are, very often, the only objects of the pursuit of other travelling gentlemen" (Cook 1784:26).

More typically, travelers' missions were shared, as in Banks' amusing description of a visiting expedition:

... their visits are made with the utmost familiarity a family for instance when the weather is fine set out together to visit their neighbour and after staying a day tis ten to one but they join together and go to a third who with them goes on to a fourth who now gets notices of the number of Guests he is to expect and provides accordingly in this manner I have been in Company with above 30 Canoes whose crews were receivd with as much readiness and Ease as one could have been in these excursions they give loose to all kinds of Jollity Dancing singing publick wrestling and plenty of musick which as the professers of it get their livelihood by traveling from place to place never fail to attend on these occasions. (Beaglehole 1962:II, 333-334)

\section{Turnbull provided some observations about large-scale touring:}

When any of the greater chiefs return [to Tahiti] from the Mottos [motu, i.e., probably Tetiaroa], as they are called, they never fail to make the circuit of the whole island. Their retinue is numerous, for, though simple their life, they are not without a taste for pomp. Their followers consist of all the strangers from the Mottos, and the same merriment and diversion continue wherever they stop: add to this, they are every-where loaded with presents; so that by the time they have made the circuit of the island, a peregrination which usually occupies them three months, their canoes return as rich as a fleet of galeons. Their connection with the royal family renders the people more than ordinarily liberal; it is moreover the custom of the country, on such occasions, to hold no bounds to their generosity.

These excursions to the Mottos, or royal progresses, have doubtless no other purpose, than of extorting from the liberality of the people these voluntary taxes. Nothing indeed can exceed the prodigality of the people, except it be the avidity of the chiefs. (1813:289)

They are better at the projection than in the execution of any enterprise, and with them a very trifling excursion is thus denominated. A journey to the Mottos, about twenty miles distance, is a grand undertaking, a tour of vast magnitude, and occupies their thoughts and conversation for many months. Edeah had been upwards of a year in preparation for a tour to the leeward islands .... (p. 346)

I am indebted to Morrison for a lengthy and detailed description of the treatment of visitors. The references to such social-status categories as "rank," "class," et cetera, is explicated in following chapters, my main concern here being with the technicalities of "visiting."

People of Note always travel by Water about their own Island, and as there is a number of Houses Built by the Chiefs of each district for the reception of strangers, they are never at a loss for an Inn; some of these Houses are 150 feet long 50 or 60 wide, and 30 or 35 high. As soon as they land they Haul up their Canoes, Near their Inn and send Notice to the Nearest of the same Rank, who repair to the place Immediately with provisions for them-and if they stay long enough evry one of the same Class in the District supplys them with one days 
provisions for all their Company-In fine Weather they put up any where, and erect temporary sheds in the Most convenient place.

If any person of whatever Class he may be should be travelling by land and Meets None who Invite him or should happen to be unacquainted in the District he is passing through and has occasion for provisions, he enquires the Name of the first Ratirra ${ }^{[22]}$ and repairs to his house-on his entring he receives the usual Compliments and having made known his business, the Master of the House Immediately orders provisions to be got ready for him, and the Mistress entertains his Wife in the same Manner \& they enjoy a secret pleasure at having had the good fortune to have the Strangers come to their House and they are for ever after deemd friends tho they had never seen each other.

When a Chief or Stranger of rank from other Islands Visits them they perform a Ceremony Calld Ootdoo which is a Peace offering, which is done thus-the Chief or Stranger having taken up his residence in One of the Houses built for the reception of Strangers (of which there are several at convenient places in evry district) the Chiefs and people of the District Assemble near the spot with their presents, each Chief being attended by a Priest with Young Plantain trees $\&$ Pigs, they then take their places opposite the Stranger about 30 or 40 yards from Him, and the Priest of the First Chief begins by tying a Young Pig and a small bunch of Red Feathers to a young Plantain Tree, makes a long speech, welcomes the Stranger in the Name of His Master and the People, and then lays the Plantain \& Pig down at the Strangers feet who takes the red feathers and sticks them in his Ear or hair. A Number of Hogs Cloth \&c. are then brought in and presented to Him by the Chiefs Men-and the inferior Chiefs and landed Men go through the same Ceremony, each presenting him with a pig or Fowle with a Plantain tree, which is the Emblem of Peace on all occasions, and used in all civil and religeous Ceremonies and their present of Hogs \& Cloth and when the Whole have made their offering and presents the Stranger is invited to a Feast prepared for Him of Baked Hogs Breadfruit \&c. \&c.- of which none but himself and his retinue partakes. I have seen at one of these Feasts 50 Hogs Baked and as much provisions as one Hundred Men could Carry prepared for a Stranger of Quality for one Day; and repeated for several days in the same District, each Person of the same rank providing one Days food.

But nevertheless it is better to visit in quality of a private Gentleman then of a Chief; tho both fare sumptuously yet the gentlemen are the Most Numerous and they may expend more time in One District in a Continual feast somtimes they make a Months stay in one District but seldom Hurry when they are on a Visit.

The lower Classes always entertain those of their Class or Society in the same Manner, according to their Abilitys but they Mostly prefer the Method of Visiting in the retinue of Cheifs and Gentlemen and this Method of living draws many Young People into the roving Society of the Areeuoy, which shall be discribed in turn, and as they always find plenty of Food, and raiment without Much trouble they Never think of Settling till they Arrive at Mans estate, if they do then.

When People of equal rank visit each other in their own or other Districts they are always made welcome by Greetings as soon as they enter the House as before discribed ${ }^{[23]}$ and as soon as they are Seated, the Master of the House orders a feast to be prepared for them, and enquires the Cause of their Visit, What they want \&c. to all which they Answer without hesitation or Preface and their Wants being made known they are instantly promised to be supplyd if the other has it in His power and in the Meantime they are presented with a piece or two of Cloth and one or more live Hogs by way [of] earnest of their being supply'd; and 
if the Man of the House has not what his Visitors Want, He begs them to stay at His House till He can procure sufficient to supply their Wants among his Neighbours.

All the Provisions dressd for the Visitors they Must take with them, it being accounted no treat if any of the Family partake with them. Nor do they Call any thing a present which Nature produces, except accompanied by somthing which is procured by the Assistance of labour or the Art of Man; for which reason they always give Cloth or some thing else with their Gifts, Provisions being held of No value being produced by Nature, and they think it not proper to make store of them.

They never return thanks, but by deed, having no Word in their language expressive of it and when they part they always use Compliments-they always beg their Visitors to remain with them till they are perfectly well satisfied with their treatment for should any depart unsatisfied they would get a bad Name, those who are not Well treated never failing to declare how they have been used and in this Manner they frequently make a Visit of several Months getting a little from one, and a little from another till they get what they want before they return Home. (Morrison 1935:189-192)

Several points in this passage require emphasis and elaboration: first of all, who visits whom? In general it seems quite clear (and consistent with other aspects of Maohi life) that visits took place largely within "class" boundaries, or at least the principal member of any party of visitors was received "officially" by a host of approximately equal class status. The major exception to this norm concerned travelers without local connections; whatever their class, Morrison said, complete strangers sought out the nearest ra'atira for refreshment. This is shown in a statement by a missionary on tour: "We got in again and proceeded to Maraa the southern extremity of Atehuru and here we were met with a Southerly wind with cold driving rain so that we were obliged to put ashore \& pulled up our boat. We entered the first house according to the custom of the country...." (Crook, Journal, 23 July 1820, LMS Archives.) This general practice (if indeed it were as general as Morrison indicated) does not, however, necessarily imply that a traveler of lower-class status received the full honors of hospitality from the first ra'atira household he visited; it could have been merely a matter of an alien registering his presence in a foreign district and, upon doing so, being fed. In the journal of his Bounty visit Bligh wrote of Tina (i.e., Pomare I, chief of Pare-Arue) as follows:

I have before mentioned that all principal strangers come under Tynahs hospitality. I have now many instances of it, and scarce a day passes but he tells me he is obliged to quit me for a little to send provisions to some Friend or other. It is however all done without any ostentation, like a man actuated solely with a desire to do good, and altho he has no pomp, yet his good nature and manners rise him above the level of all the Cheifs I have yet seen. (Bligh 1789: II, 38)

"Tynah had a Visit today from some of Tiarraboo People. They were of no consequence with respect to Rank, as is common, however, he 
found himself engaged for the day to direct proper supplies, and to amuse them." (Bligh 1792:161). (This Tina was either an abnormally generous, hospitable chief, ruled by motives of pure altruism (which is unlikely), or one who availed himself of such opportunities to forward his political ambitions.)

Individual travelers, or small parties, seem to have sojourned in the ordinary sleeping-houses of their hosts-men with men, and women (and children) with women; but larger parties of visitors were more likely accommodated in the large guesthouses (fare manihini) which were to be found in most districts associated with the residential establishments of chiefly persons. Also, it will be recalled that some travelers, of authority or influence or affluence, took along their own sleeping quarters, in the form of the small shelters that were mounted on canoes or set up ashore, as occasion demanded.

Another feature of Maohi visiting that needs clarification is the convention regarding length of stay. Some statements by Morrison, which are confirmed by Ellis, lead one to the conclusion that norms for hospitality obligated a host to entertain a guest for no longer than one day. ${ }^{24}$ On the other hand, the sources contain many accounts of actual visits having lasted much longer; and Morrison himself, in the last paragraph of the passage reproduced previously, implied that such was the case. It is safe to assume that there was considerable variation in this regard, depending upon the visitors' missions and their relationships to their hosts.

Turning now to the heart of the matter-the nature of the "hospitality" purveyed-I have already described the central importance of food in these transactions-including that meant to be eaten by the guests on the spot and that meant to be carried away by them. Many other accounts could be added to Morrison's to indicate how open-handed and lavish the hosts usually were on such occasions-so much so that missionaries condemned visiting in general as a sin:

I have requested the people to do away with the silly, sinful, gluttonous practice of feeding visitors \& they have Kings, Chiefs \& all agreed to it in a public way. When persons visit, ten, fourteen $\&$ twenty hogs are roasted all at once; Rolls of cloth, and a variety of other things collected and taken at one time to the visitors, Who eat more like ferocious lions than men. (Orsmond, Journal, 5 February, 1821, LMS Archives)

The worthy Orsmond was, of course, fighting a losing battle with Maohi custom despite the people's "public agreement" to end the practice.

Particular interest attaches to Morrison's statement concerning the necessity to accompany food ("which Nature produces") with gifts of objects ("procured by the Assistance of labour or the Art of Man").

Of all these products of "the Art of Man" bark cloth was perhaps the most usual one given to visitors, and it was presented either in sin- 
gle pieces or long rolls. The most ceremonious method of presentation was that whereby a long roll was presented wound round one of the donor's people (usually a young woman): after placing the free end in the guest's hands the bark-cloth-laden agent of the donor then turned round and round until the strip was completely unrolled, leaving her completely nude. It may easily be imagined how charmed were the European visitors-at least the nonclerical ones-by this display of liberality and finesse. ${ }^{25}$

The ritual aspect of hospitality was also exemplified in the "peace-offering" act of 'utu, described by Morrison. 'Utu, a present to visitors as a token of peace (LMS Dictionary), is the ceremonial presentation of pigs, plantain shoots, and red feathers to important visitors from other (and, presumably, potentially hostile) districts. ${ }^{26}$

Services, as well as food and manufactured objects, formed part of a visitor's due. At the least these included the "compliments" paid him upon arrival and departure. In many cases they included a massage as well, if the visitor had traveled overland. Judging by some legends and the personal experiences of some Europeans, bed companions were on occasion provided; but in the case of this kind of service perhaps more commercial motives were also involved.

The question that now arises is what moved hosts to expend so many objects and attentions upon guests, many of whom were strangers and even potentially hostile?

It is undoubtedly true that liberal hospitality was a widely avowed norm..$^{27}$ No matter what the individual motives behind particular acts of hospitality, the norm itself was publicly affirmed and in some cases perhaps even privately cherished. The plaint of a missionary that "... we could find but little disinterested hospitality among them ..." could, I suppose, indicate that some was in fact found. In any event, sanctions existed to ensure performance, that is, public censure ("a bad Name"), according to Morrison; or (in the case of lower-class individuals) enforced public shaming and land confiscation, according to the "Maxims of Tetunae" quoted in chapter 9.

The Maohi norm regarding hospitality was undoubtedly selective, as witness the reported treatment of Tuamotuan castaways and of Europeans. Regarding the former, in some cases they received humane, even supererogatory treatment; in other cases they were tolerated and subsisted, but barely so; and in still other cases they were looted and driven away. ${ }^{28}$ Aside from personality differences among Maohi hosts-an "explanatory" principle of doubtful value in a book devoted to social relations-the only factor I can discern that influenced such wide differences in behavior on the part of the hosts was their relative social statuses: that is, persons holding high-rank- 
ing kin-Titles or political positions of considerable authority were more given to disinterested hospitality than were others.

I refer the reader to volume 3 for discussion of the complex question of Maohi treatment of Europeans.

In addition, many individuals were probably motivated to provide generally for certain of their guests in payment for past, or in anticipation of future, hospitality from these same individuals. "In connexion with this [matter of hospitality], it should be recollected, that for every such entertainment, the individual expects to be reimbursed in kind, whenever he may visit the abode of his guest" (Ellis 1829:II, 23). Some individuals-either ambitious or politically insecure, or both-undoubtedly purveyed liberal hospitality for political purposes: to win loyal supporters (or at least political debtors), or to enhance their public reputation for generosity.

But, whatever the motives behind individual acts of hospitality, travel in general and visiting in particular were more often than not welcome and frequently undertaken diversions from the routines of everyday life.

No description of major Maohi "diversions" would be complete without some account of their sexual activities; but so important a part did such activities play in their lives that I had best devote a separate chapter to them. 


\section{CHAPTER 11}

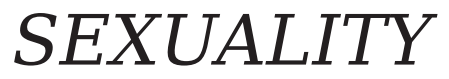

The great plenty of good and nourishing food, together with the fine climate, the beauty and unreserved behaviour of their females, invite them powerfully to the enjoyments and pleasures of love. They begin very early to abandon themselves to the most libidinous scenes. (J. Forster 1778:231)

For deception, lasciviousness, fawning eulogy, shameless familiarity with men, and artful concealment of adulterers, I suppose no country can surpass Tahiti. She is the filthy Sodom of the South Seas. On her shores chastity, and virtue find no place. The predominant theme of conversation from youth to old age is the filthy coition of the sexes. From the King and Queen to the lowest grade, all are alike guilty, and if secrecy can be obtained, a very small reward will seduce any female. (From "The Old Orsmond Manuscript", p. 2, LMS Archives) ${ }^{1}$

It will come as no surprise to readers familiar with accounts of Polynesia to be informed that the Maohis apparently looked upon coitus not as a necessary evil nor as a spouse's solemn obligation, but rather as one of the most pleasurable of all their activities, as "natural" and perhaps almost as essential to well-being as eating and sleeping. Moreover, the Maohis evidently did not deem it necessary to hide or disguise their interest in sexual intercourse; indeed, it appeared prominently and unequivocally in their everyday talk, their dance, their graphic art, their secular oral "literature," and in their religious beliefs and rituals.

\section{CoITUS}

In the light of the above, it is particularly regrettable that we have been left so little explicit information about the sexual act itself-about the physical techniques employed, about the Maohis' "understanding" of that act, and so forth. In fact, the European chroniclers on Maohi life have left us with fuller accounts on, say, the manufacture of bark cloth than on the conventional modes of coitus. We are informed again and again, with amusement or repugnance, about the tender ages at which such practices began, but the authors invariably drew the well-known veil of reticent respectability around the practices themselves. Under these circumstances, and mindful of the symbolic importance of coitus in Maohi life, one might be tempted by plausibility to pull in data from other histor- 
ically related societies of the South Seas; but there are obvious dangers in such a procedure, so that in the reconstruction that now follows I shall draw on the comparative materials only to aid in formulating queries and in indicating gaps in the records on the Maohis. ${ }^{2}$

In view of the Maohis' deep and wide-ranging interest in sexuality and of the apparent absence of any reluctance on their part to talk about it, the paucity of specific words for the genital organs and for coitus may seem somewhat surprising. Specific words have been recorded for such undifferentiated major referents as human penis (as distinct from an animal's), semen, testicles, vulva, and human copulation, but records of unassailable pre-European authenticity contain little linguistic evidence that the Maohis possessed a technical vocabulary to match the fine distinctions they appear to have drawn, in actual behavior, in this domain. One explanation for this is that the early European visitors were not sufficiently fluent in the local language to grasp such distinctions. Another is that the visitors' scruples were such that they did not record what they learned. Or, of course, the explanation might be that the Maohis themselves made no such fine distinctions, verbally, despite the interest and activity they devoted to the subject.

In any case, the relative paucity of this list of specific words for genital anatomy and coital action, even if real and not just apparent, cannot be taken to demonstrate that Maohi thoughts were vague about such matters, and the list could be lengthened considerably if one were to add the many words and phrases commonly used as metaphors for genitalia and coitus. For example, the penis (ure) is also referred to as 'aero (the tail of quadrupeds, or of the sting-ray and some other fishes; the after part of some business or conversation); patia (a spear); tara (a thorn or sharp point; a cock's spur); taharahara (to befoul, daub, or smear). ${ }^{3}$ However, it is probably safe to say that these Islanders' extensive use of metaphor was in this context influenced more by canons of rhetoric than by any standards of pudency.

I have been unable to find any accounts concerning the actual physical techniques of the act of coitus employed among the Maohis, although there are bases for drawing a few plausible inferences. Many of the early European visitors had sexual intercourse with native females, and some undoubtedly witnessed sexual intercourse between natives. The fact that no details were recorded about any such event indicates, in a negative way, at least, that the techniques experienced or witnessed were not markedly different from those to which the Europeans were accustomed. Some weight is lent to this conclusion through the circumstance that these same Europeans were quick to notice and faithful to record examples of other "curious" native customs, including sexual ones.

In view of the direct, unequivocally expressive connection between certain dance movements and coitus, it is not unlikely that intercourse was 
characteristically accompanied by the same kinds of movement, that is, by rapid, vigorous "rotatory" motions on the part of both male and female. It is also safe to emphasize the strenuousness of such movements inasmuch as the average Maohi female was not much less robust than the average Maohi male.

The reference cited in chapter 3 to a man's body having been unacceptable as a sacrificial offering if it were disfigured with scars produced by a woman, pertains mainly to the scratch marks made by a woman during sexual intercourse, suggesting that a woman's emotions on such occasions were sometimes aroused to the height of frenzy. But coitus cannot always have taken place with such active and presumably noisy movement; otherwise it could not have been accomplished (as it undoubtedly was) with any measure of secrecy in populous and unpartitioned Maohi houses.

The absence of contrary evidence also at least suggests that coitus was not preceded by any appreciable amount of foreplay, or by any lingering contact after the act; in a sense, of course, the kind of dancing which often preceded copulation probably had some of the same stimulating effects as physical foreplay, but this is a very obscure matter.

On the basis of many kinds of data about the brusque attitudes and behavior of Maohi males, it is reasonable to assume that they at least usually achieved orgasm in their sexual encounters. As for women, the evidence is less clear; their vigorous participation could indicate simultaneous release; on the other hand inconsiderate brusqueness on the part of their partners may have frustrated release now and then.

Adding all these inferences together we are still left with a very sketchy image of how the Maohis actually carried out the act which was so much a focus of their lives. It may be that I should admit evidence from later epochs, ${ }^{4}$ on a common "scientific" assumption that anything as basic as sex practices are less subject to change. But opposing this assumption is the assertion by well-informed scholars in this field to the effect that Polynesian sexual practices have indeed greatly changed. ${ }^{5}$

In view of the Maohis' elaborated interest in coitus one might perhaps expect them to have held some fairly specific ideas about the mechanics of the act and beliefs about the nature and effects of semen. Unfortunately, I can find no record in the sources of any ideas about the "chemical" properties of semen-nothing to indicate that it was thought to be, for example, like salty water, or like the soft "meat" of an immature coconut (which it resembles in appearance). Furthermore, I have discovered no references to certain foods (e.g., oysters or soft coconut meat) having been eaten in order to replenish one's supply of semen.

Regarding other properties of semen, I shall later reproduce one European's commentary on the Maohi homosexual practice of fellatio, 
wherein the commentator proposes (within the safe respectability of Latin) that the active partner acted so (partly) in order to obtain some of the other's "robur et vim" (vigor and force). I can find no Maohi's commentary on the practice, so we must rest content with this one. Nor can I find an explicitly Maohi explanation for another, equally suggestive, practice involving semen-namely, the practice by some women, usually upper-class ones, of copulating with tall and well-built males to help ensure that the offspring they subsequently bore (and not necessarily those sired by the males in question) would also be tall and well built. This idea is closely akin to the concept of telegony formerly followed by many European stock breeders in improving their herds:

Les femmes différent entre'elles par les charmes de la figure, comme dans les autres contrées; la taille, souvent au-dessous de la médiocre dans les femmes d'une classe commune, semble se relever avec avantage dans celle d'un rang supérieur. L'élévation de la taille est ce que les Dames Otahitiennes cherchent à conserver dans leur famille avec le plus grand soin. Ce n'est pas une chose rare parmi les dames les plus qualifiées de l'île, de faire partager quelquefois leur couche à celui de leurs valets qui est le plus grand et le mieux proportionné, tant il est à craindre que les enfan[t]s ne dégenerent de la taille noble et majestueuse qui faisoit la gloire de la famille. Autrement elles sont très-scrupuleuses sur le choix de leurs amants. (Mühlmann 1955:41) ${ }^{6}$

Maohi views of the reproductive aspect of semen will be discussed in other chapters, but I will anticipate this discussion by noting that semen was evidently believed to play an important part in reproduction, although not inevitably so and not always necessarily so (e.g., spirits occasionally sired offspring of mortal women by, say, merely hovering over them).

The sources provide even fewer insights into the beliefs held by the Maohis concerning the nature and effects of a female's substances emitted during sexual intercourse. As will be documented in another context, the ghost of a man was believed to escape certain indignities in afterlife if he had abstained from sexual intercourse for a certain period prior to his death, but there is no indication that this "state of grace" derived from lack of contact with the woman herself, her genitalia, her sexual "fluids," or from the man's full reservoir of semen, or whatever. The larger question of the connection, if any, between a woman's sexual organs or emissions or menstrual blood and her generic "psychic" condition of noa, which disqualified her from certain religious ritual activity, will be considered in another chapter.

Nor can I uncover any information relating to tangible-as distinct from magical-aphrodisiacs, for either sex. I am inclined to believe that there were some in use, because of the great pleasure and pride evidently derived from frequent sexual intercourse, but recorded evidence is unknown.

Information on the social aspects of coitus is somewhat fuller. Nearly 
every source contains assertions about how early in life many Maohi girls began the practice-not just in the form of simulative play but of actual intercourse with virile males. Bligh, for example, stated that "lower class" girls in particular began the practice at an early age, some starting "... even at the Age of 7 Years" (1789:II, 78). Since the Maohis themselves did not reckon age in years, such statements as Bligh's can be considered only estimates. Other witnesses put the age for girls' initiation to intercourse a year or two later, but even the sedate elder Forster was moved to state that "The young females of O-Taheitee and its neighborhood are not over scrupulous in admitting some lovers to their embrace before marriage" (J. Forster 1778:432).

This aspect of Maohi life understandably attracted the attention and disapprobation of the missionaries, and while the following statements of Osmond's concern a later era they could probably apply to the era under study: "Little girls about 11 to 13 . One boasts of having had 11 men, another nine, two five each ..." (Journal, 22 November 1826, LMS Archives); "Little children hardly ever live to the age of seven ere they are deflowered." (Journal, 24 October 1827). As for young boys, while they could not have achieved orgasm until the age of eleven of twelve it is quite certain that they too began to attempt coitus at younger ages.

In the absence of contrary information it is reasonable to assume that the Maohis, both males and females, continued to practice sexual intercourse as long as opportunities offered and their physical powers lasted. At least I can discover no kinds of shared norms which specifically restricted coitus because of increasing age.

\section{"PROMISCUITY"}

The evidence is somewhat misleading regarding the restrictive effects of marriage and class status on females' sexual activities; the only social restriction on extramarital sexuality seems to have been a jealous spouse.

What is misleading about the evidence is that most of it derives from the Europeans' own experiences with Maohi women, and not from observations on the relations of Maohi to Maohi. The situation created by the presence of shiploads of Europeans can by no definition be regarded as normal.

There was the added incentive provided by European goods-nails, cloth, mirrors, scissors, hatchets, and all the other wondrous things which by their novelty or superior utility delighted the Maohis. It is probably safe to say that most of the sexual encounters experienced by the European visitors had to be purchased at what came to be standard market prices, which, however, were subject to considerable fluctuation. This is not to say that sexual services circulated among Moahis themselves without regard to "price"; what is implied is that the commercial aspect became more 
explicit when Europeans were involved. The most sought after item in this commerce was not European at all, but red feathers obtained by the astute Europeans from other South Seas islands. To acquire these, we are told, even the most powerful Maohi chiefs were willing to offer their own wives:

So very solicitous \& zealously desirous are our good friends here for the attaining of these red Feathers and so thoroughly convinc'd of their efficacy with their Sovereign Deities that they will very chearfully oblige us in good natur'd but rather unhallow'd rites for the possession of them to render back religious Ceremonies by way of Propitiation to their Jolly Gods. (Clerke, in Beaglehole 1961:383n2)

On one occasion, for example, a very important chief appeared with his wife before Cook and tendered her sexual services to him in return for some red feathers:

Besides [another] instance of the immorality and selfishness of the great, I can add another; Wainee-òu and Potatou her husband, were so greedy after the possession of red parrots feathers, that having sold all the hogs, which they possibly could spare, together with a fine helmet, several breast-plates, and a mourning dress, they agreed to prostitute Wainee-òu, and she in consequence offered herself to Captain Cook, and appeared as a ready victim.

\section{- - - Tunica velata recincta.}

I must confess, having received a favourable and great idea of Potatou's character, this transaction made me ashamed of him; and being before elated with the thought of having found a nation, where one might at least find to the honour of humanity, less degeneracy joined to an aimiable innocence and primitive simplicity, my spirits were damped by this unexpected scene of immorality and selfishness, in a family where I least expected to hear of it. (J. Forster 1778: $391-392)^{7}$

In extenuation of such events Morrison added the following philosophical note:

Their Actions might possibly be for the sake of Gain-brought to a stile of what we call indecency, but where are the Countrys that do not produce Weomen of the Same discription-Iron is to them More Valuable then Gold to us, for the possession of which some of our own Country weomen would not stick at acts of indecency nor even horrid Crimes which these People would tremble to think of. Nay, they Challenge us with the Verry Crime and say we are ashamed of Nothing, using these things which we knew they were fond of to perswade them to commit such acts as their innocence had taught them to be ashamed of. If they can purchase Iron at the expence of their Beauty, or are able to get it by theft, they will. Neither of which Methods I hold to be a Crime in them. They know its Value and think no price to(o) great for it.

Gold is preferd in Other Countrys and some, as fine Weomen as any in Europe, are said to prefer it to Virtue yet we upbraid these untaught and uncontrould people with such actions as we ourselves help them to Commit. (1935:236)

Be it noted, however, that in the opinion of, and to the approval of, the fastidious younger Forster, not even these rare inducements were sufficient to buy every woman's favors-not immediately, that is. He described an occasion of a visit to the ship of three young women: 
They seemed never to have been aboard of a ship before, so much were they struck with admiration on beholding its variety of objects. They did not content themselves with looking around the deck, but descended into the officers cabins, whither a gentleman conducted them, and curiously examined every part. Marorai took a particular fancy to a pair of sheets which she saw spread upon one of the beds, and made a number of fruitless attempts to obtain them from her conductor. He proposed a special favour as the condition; she hesitated some time, and at last with seeming reluctance consented; but when the victim was just led to the altar of Hymen, the ship struck violently on the reef, and interrupted the solemnity. The affrighted lover, more sensible of the danger than his fair mistress, flew in haste upon deck, whither all the rest of our people crowded from their several occupations. (G. Forster 1777:II, 260)

A third basis for inferences regarding the local sexual habits was the European visitors' direct encounter with an institution resembling Europe's prostitution. It is probably safe to conclude that Maohi women were, by and large, easier marks than any other females the visitors had met with at home or on their travels. In addition to the majority of females, for whom sexual intercourse was an avocation, there were a few for whom it approached a profession even prior to the arrival of the Europeans. There is little on record about this profession, and while prostitutes were probably not numerous, there were, nevertheless, companies of young women attached to the households of some chiefly persons for the pleasure of the court members and distinguished guests. When Europeans arrived, the services of these young ladies of pleasure were not infrequently exchanged by their masters (or mistresses) for hard goods or diplomatic advantage. For example:

The Famous Queen Pbooraya being herself an Areeuoy [Arioi], it is not to be wondered at that evry licentious practice was carried on by her followers and Attendants, her Court being filld with such as preferd the Rites of Venus to those of Mars and as she saw that they were also more agreeable to her Visitors (the general Case with Sailors after a long Voyage) they were no doubt practised and carried to the utmost verge of their lattitude, it being in all Countrys the Case that those in power always lead the fashions, let them be good or evil. (Morrison 1935:237)

Also, with the appearance of Europeans, in addition to the numerous females who utilized such opportunities as were presented to satisfy their curiosities and acquire a nail or a shirt, there were some who made it a regular trade-sometimes on their own initiative but usually at the instigation of a male (including, we are informed, even fathers and husbands):

They tendered their women to us quite freely, and showed much surprise at our non-acceptance of such offers. The latter were also wont to make advances themselves, but with some show of coyness. (Corney 1913:333)

Those who Make a Trade of Beauty know how to value it, and when they come on board bring with them their Pimps or Procurers under the denomination of relations to receive and secure the Price and these ladys are as well qualified to Act their part as any of their profession in other Countrys and are no ways bashful in making their Demands-(Morrison 1935:237) 
Their general idleness is never interrupted but on the arrival of a ship. Every thing then is bustle and activity; they are then as busy as pedlars in fair time; every one has something to exchange in traffic; the husband not unfrequently brings his wife to market. Pomarre himself was as great a factor as any of them in the article of Otaheitean beauty. In one of my evening walks, I found him accompanying ten or twelve young women to the beach, commanding them to go on board a certain ship at that time lying in the bay, and not to fail in bringing him plenty of powder in the morning. They all willingly obeyed his orders, for the thing is so common, that it has become a constant and familiar practice. (Turnbull 1813:374)

But about such practices, the sympathetic Morrison added: "However the ladys who act these parts are not to be taken as a standard for the Whole no more then the Nymphs of the Thames or Syrens of Spithead are to be taken as Samples of our own fair Country Weomen" (1935:237).

As a result of their individually differing experiences and their generally distorted and out-of-focus views of Maohi sexuality, it is not surprising that the Europeans did not agree about the social boundaries of promiscuity. There is fairly close agreement that married women were less available to Europeans, and presumably to Maohi males as well, than were the unmarried ones. ${ }^{8}$ However, opinions differed markedly concerning which social class of women was more sexually unrestrained. At one extreme was Cook, who wrote that "... none but common women would yeild to the embraces of our people; not one of the gentlemen were able to obtain such favours from any women of distinction, though several attempts were made, but they were always jilted in the end" (Beaglehole 1961:236). Cook apparently chose to pass over the attempt of Potatau's wife to seduce him. Also, one might infer from a statement in Henry's account of a large ceremony that some upper-class girls remained chaste until marriage, namely: "The firstborn young virgins of the royal family of the kingdom represented their respective districts. They were arrayed in flowing white tapa and decked with wreaths and garlands of tiare (single Gardenia) blossoms, their emblem of purity." (1928:137)

At the other extreme was the opinion of Morrison:

The Weomen of rank are Most remarkable for their licentious practices and Many of them have a Number of Favourites, in which they pride themselves, tho many of the lower Class are what may honestly be Calld Virtuous, never admitting a Second to share in their favours. (1935:237)

\section{J. Forster concluded:}

... we are now certain, that there is hardly a country to be found, where the young unmarried females are allowed such a latitude as at O-Taheitee and its neighbourhood in admitting a variety of young males, and abandoning themselves to various embraces without derogating from their character. Women of all ranks follow these practices from the earliest time, and after having passed through the embraces of hundreds, are married to the first people of the isle. (1778:491-492) 
My own view of the matter, based on an assessment of all the above authorities and taking into account the many actual cases of sexual relationships reported throughout the sources, is that both marriage and upper-class status tended to restrict, up to a point, a woman's sexual liberty.

The Maohis of old (like those of today) took huge delight in reports of husbands ingeniously cuckolded-until such affairs reached too near home-but public opinion tended to censure the wife who adventured without her husband's consent. As for social class, the parents of unmarried upper-class girls evidently restricted their daughters' sexual activities more so than did parents of lower-class girls. Also, I suspect that most married women of upper-class status were less promiscuous than lower-class women. On the other hand, incumbency of kin-Titles of very high rank entitled women to such freedom of action in all spheres of social life that some of them lived separate from their husbands and openly consorted with one or more lovers.

But all these inferences concern averages and do not take into account other variables which probably operated to encourage some females to live more libertine lives than did others; such influences were size of family, order of birth, occupation of father, and perhaps even place of residence. The early observers may have made mental notes of such factors, but unfortunately they did not bother to record them.

\section{ChOOSING A PARTNeR}

I turn next to a consideration of what characteristics of an individual the Maohis found to be particularly attractive when selecting a partner for sexual intercourse. According to legend, when the emissaries of the god 'Oro descended to Earth to seek a sexual partner for him, they searched far and wide before finding a suitable candidate. Upon discovering on Porapora a maid of surpassing beauty they informed her of their mission and asked her consent. "'Is he handsome?' enquired the girl.

'Yes! He is handsomer than all the sons of men and is ever youthful,' they replied." (Henry 1928:231) Whereupon the maid readily consented and the intercourse was initiated.

This about sums up the quality most Maohis seem to have considered of prime importance when choosing a partner for sexual intercourse-not, perhaps, the only quality but certainly the most decisive. But, throughout the world's societies "beautiful" and "handsome" are of course defined in widely differing ways.

According to Henry, “... stoutness was a mark of beauty and characteristic of royal personages ... thin people were thought to be sick" (1928:274). There is no question that the Maohis admired corpulence in both males and females, and it is a well-established fact that they went 
to considerable pains to become corpulent. Presumably this general predilection carried over to choosing a sexual partner, but just how corpulent it was considered desirable for a lover or mistress to be is nowhere reported.

In the legend of Honoura is an episode concerning two women who travel in search of husbands. Upon arrival at Tahiti they are seen and welcomed by a friend and aide of the local chief who, upon learning of their mission, made the following proposal to his superior: "The well-favored (puroto) one will be for you; the thin (rairai noa) one for me." (Henry 1894:258-259)

One may infer from the efforts some Maohi females made to bleach their skins and protect their bodies from strong sunlight that lightness of skin was also considered a desirable trait in a lover or mistress. ${ }^{10}$

Other physical features esteemed by the Maohis were a flat broad nose (in females) and a flat-backed head (in males); it was noted above that adults sought to mold infants into these desired shapes. As for size and shape of a woman's breasts, I can find no evidence of what was considered most attractive, except for the general preference for corpulence.

It is well known that some Polynesian peoples considered a large clitoris an aid to heightened sexual pleasure and hence a desirable trait in a mistress, and in some societies attempts were made to enlarge the organ by regular manipulation during childhood (cf. Marshall 1961). Such is said to have been the case, for example, in the Marquesas, but I can discover no credible evidence of any such practices among the Maohis. There is however one piece of evidence which suggests that some importance was attached to a man's having a plastic, versatile penis; that evidence is the exhibition of genital acrobatics, described in chapter 10, this volume.

Crippled limbs, bald-headedness, disfiguring scars (with the possible exception of battle scars) - these were considered to be serious physical defects; persons so afflicted aroused more contempt than sympathy and were undoubtedly handicapped in competition for sexual partners.

Strength in a man may also have helped his cause with women, but since physical weaklings were a rare exception among Maohi men, it is not clear whether physical strength itself constituted an attraction distinct from, and in addition to, other criteria of male physical beauty.

It is not clear just how much added attraction accrued to the expert dancer or the expert lover or, for that matter, the expert in anything. The only direct evidence I have found on this matter are some lines in a text on "How to Seduce" (which are quoted on pp. 364-365, below), but this is hardly enough data on which to conclude whether behavioral traits were considered important enough in the diversion of sexual activity to augment or override physical traits?

Somewhat the same question arises with respect to age as a criterion of sexual attractiveness; it is not clear to us whether most Mahois' preference 
for young lovers or mistresses was because of the latters' chronological age or because of their possession of physical traits generally associated with people young in years.

The missionary Orsmond, writing in 1832, noted that some young women preferred much older men at that time, but whether that was the case in pre- and early-Europe an times is not indicated:

A native who belongs to this part of Taiarabu is just come from Raiatea He went down to amuse himself in the late war, is said to have shot six men \& has come with a little girl almost as high as his navel for his wife. He is a man of about 48 his former wives are dead \& he has a family of children. In all Tahitians as well as officers who come in ships there is a cry for little girls, those on the contrary generally to appear womanish crave full grown men. (Journal, 1 September 1832, LMS Archives)

Social class was a factor of overriding importance in choice of spouse, and it may also have figured in choice of a sexual partner for even the most casual of encounters. As we shall see in a later chapter, in selecting a spouse it was essential that he or she be of the same class-among other reasons, to avoid having offspring of mixed-class heritage. Since contraception was not practiced, the possibility that a casual sexual encounter could result in conception might well have induced some Maohis to remain within class bounds. Nevertheless, a sexual adventure with a person of higher social class must have had its attractions. In other words, although it is manifoldly clear from the sources that sexual encounters crossed class lines, it is not clear whether social class had more positive or negative influence in the pairing of lovers.

Unlike class, kinship exercised decidedly restrictive influence on choice of sexual partners, but I shall postpone discussion of this topic until a fuller description has been given of the subject of Maohi consanguinity.

A passage from Moerenhout indicates yet another factor which influenced Maohi females in their choice of a sexual partner:

As soon as an Indian [i.e., Maohi] found himself in that state (inspired by 'Oro, God of War), he usually wrapped his arm in cloth, in an unusual and recognizable way, a sign that gave him the right to women's favors. He could have up to twelve [women], the same number granted to the priests [sic] .... These women stayed with him as long as he remained in this frenzied state and gave themselves with ardor to his embraces, accepting them as being from the inspiring god himself. Also this kind of feminine cicisbeism was sought after even by upper-class women; but all left him as soon as he became himself again, and the spirit of the god was supposed to have left him. (1837:II, 48)

Finally, among the traits which appear to have rendered Maohi males and females sexually attractive to one another, body grooming must be rated very high: a clean and sweet-smelling body, a shiny, flower-decked head of hair, unsoiled garments, and all the other refinements mentioned 
in the description of grooming in chapter 6. It is not unlikely that extensive designs of tattoo were among the traits considered sexually attractive, but this was not the sole reason for submitting to such painful operations.

Supercision was so universal that it is unlikely to have figured very importantly as a trait of sexual attraction; although an unsupercised man, if there were any, would probably have been thereby handicapped.

\section{TIMES AND PLACES}

From some of the opinions set down by the early European visitors to these Islands one could gain the impression that the inhabitants spent most of their time arranging, preparing for, and engaging in copulation. There was, of course, no Kinsey among the visitors, no one who recorded when and how often the Islanders engaged in sexual intercourse, but from many kinds of evidence it is abundantly clear that the Maohis generally made use of opportunities for amours whenever they occurred.

There were, nevertheless, certain times when copulation was proscribed, either through individual decision or universal rule; generally speaking, these times for a man were when he was in more or less direct communication with major spirits (i.e., 'atua 'gods'). ${ }^{11}$ Such is the general impression, although I would be hard put to provide detailed documentation. The matter is complicated by the circumstance that many of the festivals that accompanied large-scale marae ceremonies-that is, those that seem also to have contained religiously-colored ritual-included a considerable amount of actual or symbolic copulation. Nevertheless, men actively engaged in rites at a marae do appear to have been constrained from sexual intercourse throughout the entire duration of those rites, as witnessed by a phrase in the formula terminating such rites, which said, in effect, that now that these rites are finished we can return to our everyday, secular (noa) pursuits, including domestic labor and caressing (hanihani) (Henry 1928:172). Also, a passage from Anderson could be interpreted as implying an incompatibility between copulation and becoming a spirit (or at least a ghost):

They have no idea of any permanent punishment after death, for crimes that they have committed on earth; for the souls of good and of bad men are eat indiscriminately by God. But they certainly consider this coalition with the Deity as a kind of purification necessary to be undergone before they enter a state of bliss. For, according to their doctrine, if a man refrain from all connection with women some months before death, he passes immediately into his eternal mansion, without such a previous union; as if already, by this abstinence, he were pure enough to be exempted from the general lot. (Cook 1784:164)

Between some husbands and wives sexual intercourse appears to have been interrupted during the latters' menstrual periods:

The separation of the women from their husbands on a particular occasion, Dr. Gillham had once the opportunity of remarking. Going into the hut of his tayo, 
named Poppo, very early, he observed him laid alone on the bedstead, and his wife lying on the floor. Inquiring the reason, Poppo informed him, it was because she was at present under the Otaheitean feminine infirmity. (Wilson 1799:340-341)

But whether such abnegation was a matter of mere individual preference or of society-wide proscription, and whether it was based on notions of aesthetics and hygiene alone or on fundamental religious ideas of, say, sacredness versus secularity, we are unable to learn.

As stated earlier, the Maohis tended to make use of opportunities for their amours whenever and wherever such opportunities occurred. Beach, grove, forest, dry stream bed-no kind of physical terrain seems to have been discountenanced as site for a sex tryst. In addition, the Maohis made frequent use of their dwellings for this purpose, in spite of the presence of others. Even the elder Forster, who was usually at pains to present a sympathetic picture of the Maohis, recognized that their standards of privacy and delicacy in sexual matters were different from those of Europeans:

... it is necessary to observe that a nation still enjoying that just and noble simplicity of manners, living in large houses with several families together, in the midst of their children, cannot conceal certain actions, which none of our Europeans, who have feelings and breeding, wished to commit in so great companies; this naturally makes all their children acquainted with transactions of which some European matrons perhaps may have no ideas, nor has love, and all its concomitant, and most mysterious endearments, enjoyments, and consequences, ever been stamped in these happy isles with a notion of turpitude. (J. Forster 1778:392)

Some writers even implied that Maohis preferred an audience for their sexual activities:

Our people were daily walking in the isle without arms, either quite alone, or in little companies. They were invited to enter the houses, where the people gave them to eat; nor did the civility of their landlords stop at a slight collation, they offered them young girls; the hut was immediately filled with a curious croud of men and women, who made a circle round the guest, and the young victim of hospitality. The ground was spread with leaves and flowers, and their musicians sung an hymeneal song to the tune of their flutes. Here Venus is the goddess of hospitality, her worship does not admit of any mysteries, and every tribute paid to her is a feast for the whole nation. They were surprised at the confusion which our people appeared to be in, as our customs do not admit of these public proceedings. However, I would not answer for it, that every one of our men had found it impossible to conquer his repugnance, and conform to the customs of the country. (Bougainville 1772:230)

A similar incident, but with native principals, was witnessed by Cook and his companions:

... this day closed with an odd Scene at the Gate of the Fort where a young fellow above 6 feet high lay with a little Girl about 10 or 12 years of age publickly before several of our people and a number of the Natives. What makes me mention this, is because, it appear'd to be done more from Custom than Lewdness, for there were several women present particularly Obarea and several others of the 
better sort and these were so far from showing the least disaprobation that they instructed the girl how she should act her part, who young as she was, did not seem to want it. (Beaglehole 1955:93-94)

According to Wales, who accompanied Cook on his second voyage, this incident involved factors not suspected by Cook:

... I have been informed from the authority of a gentleman who was in the Endeavour, and saw the transaction here alluded to, that it is very imperfectly, and in some measure erroneously, related ...[by Cook]. Oberea [whom Wales describes as "an old demirep of quality"] obliged the two persons to attempt what is there said to have been done, but they were exceedingly terrified, and by no means able to perform it. The same authority adds, that most of the natives reprobated Oberea in very severe terms for the part which she had in it. (Wales quoted in Beaglehole 1955:94n1)

Danielsson's judgment about these and similar acts of public copulation probably was most accurate:

Bougainville's and many other explorers' narratives certainly contain reports of unembarrassed sexual intercourse between native women and European sailors, but these cases were doubtless due to the Polynesians' curiosity and, like all instances of sexual intercourse in public, must be regarded as a special form of entertainment. (Danielsson 1956:64)

Although there is some justice in Wilson's charge about Europeans' connivance, in the following he undoubtedly overstated the case for Maohi "delicacy":

They have no partitions in their houses; but, it may be affirmed, they have in many instances more refined ideas of decency than ourselves; and one, long a resident, scruples not to declare, that he never saw any appetite, hunger and thirst excepted, gratified in public. It is too true, that for the sake of gaining our extraordinary curiosities, and to please our brutes, they have appeared immodest in the extreme. Yet they lay the charge wholly at our door, and say that Englishmen are ashamed of nothing, and that we have led them to public acts of indecency never before practised among themselves. Iron here, more precious than gold, bears down every barrier of restraint: honesty and modesty yield to the force of temptation. (Wilson 1799:332)

There were occasions such as Arioi meetings and other large public festivals when sexual intercourse did assume something of a crowd activity; some of these occasions have already been or will be described, but we should also inquire whether the Maohis practiced on a recurrent basis anything reminiscent of the mass "rapes," or the periods of general sexual license, met with in some societies.

So-called mass rapes were reported as having taken place in some Polynesian societies, and it is my belief, based on field investigations, that they occur among present-day Tahitians-with either "willing," "semi-willing," 12 or unwilling victims. I cannot of course urge that such evidence is sufficient to establish that the practice existed among the pre-European 
Maohis, but these considerations, along with other known aspects of Maohi sexuality, do persuade me that it did.

As for periods of special sexual license, in addition to the festivals mentioned, I do not know of any institutionalized occasions when the usual constraints were lifted, certainly not during, say, periods of mourning, or in connection with wars. The practice described by surgeon Ellis in the following passage about Arioi meetings should not perhaps be classed as "general sexual license" because of the limited category of persons participating: "Their amusements during these meetings consist of boxing, wrestling, dancing, and making feasts and entertainments, at which crowds of female spectators attend, the fairest of whom are always made choice of the conquerors" (1782:I, 160). Some of the most solemn (and inevitably "religious") rites of chiefly investiture and the like, were accompanied by dances, and so forth, described by Europeans as "lascivious," but these are not to be identified with actual sexual license.

\section{"SEDUCTION"}

In a statement delicately titled "Moyens de Séduction" (How to Seduce), ${ }^{13}$ attributed to a chief of Porapora, is the following sage advice:

Woman must be sought after like a prize before she accedes to man's desire. A man must overlook nothing in his hunt for little ways by which he can succeed in his conquest.

The libertine, the man whose every thought is about Women, searches carefully for ways to gain her good graces.

Woman is a fish without bones; Woman is a banana tree planted so [shallow] it will fall if a lizard pushes it.

Here are the little ruses by which a woman may easily be conquered: with gentle proposals, with little jokes. Awaken her and call her outside during the night; slip close to her while she is sound asleep; a murmur, a little stone or fruit thrown at her when she goes by or is bathing. These are the baits to catch the fish.

There are still others; a leaf-wrapped packet of well-roasted fish; a basketful of half-opened tiare flowers; a packet of very sweet poi; a piece of raw tuna; some ripe breadfruit; a piece of pork cooked in leaves and a cluster of coconuts to drink; a half-coconut full of pudding made with mountain plantain and perfumed oil; an oven-cooked breadfruit or a cake of mahi; a gourd of sweet coconut cream. ${ }^{[14]}$

A pair of scissors, ${ }^{[15]}$ a knife, some earrings, a ring, a piece of foreign cloth, a large mat, some bits of shiny money.

Here (lies) Life's Happiness for the Tahitian; there is nothing else; afterwards it is night. And the libertine cries to himself, "Come, let's enjoy life as long as life lasts!"

Tobacco and pipe are very effective methods of seduction.

Here are the kinds of men who are successful in their pursuit of women:

Note: I am not certain how to title this section. By dictionary definition the activities I wish to describe conform entirely neither to seduction, "the action of inducing [a woman] to surrender her chastity," nor to courtship, "the paying of court to a woman with a view to marriage" (Shorter Oxford English Dictionary). 
The man who beats the drum well (women will pursue him);

The one who plays the nose-flute well (they will take him forcibly);

He who leads the dance well;

He who energetically intones the chant to launch the canoe or to beach it;

He who composes pretty love songs and utters them with a tender voice, tender as the taro leaf softened by the evening breeze;

The handsome-faced Arioi who bathes early in the morning;

The renowned wrestler who has eaten the pork which will make him always win;

The warrior who has fought in many battles and whose head has never been struck by his enemy's club;

The artisan who builds a beautiful canoe;

The man who makes a fine orator's cap; and

He who builds a handsome house.

Mai's mention of taking advantage of a woman when she sleeps refers to the custom of mafera. We are not told what refinements the Maohis practiced in connection with this delicate and sometimes hazardous undertaking; elsewhere in Polynesia the male visitor sometimes greased his body with oil so as to elude capture if he had the bad fortune to be discovered by his mistress' relatives. One should add that women as well as men engaged in mafera, as attested by the sad, sad tale of an unnamed pillar of the missionary church:

On Monday night last a vile plot was executed for the seduction of a steady \& long since well behaved man. Two women of the basest sort came about midnight nearly or quite nakd into a small house where the man was contentedly asleep. They awoke him \& by fairness of speech persuaded him he sinned \& was judged yesterday for his crime. He has paid property equal to five fathoms of English print to the man whose wife the woman is. Beside that he has 30 fathoms of the most laborious fencing to do for the King. (Orsmond, Journal, 31 October 1827, LMS Archives) ${ }^{16}$

Many conventional signs were in use by the Maohis to proposition the opposite sex. The startled, and delighted, European seamen were extended invitations in the form of "wanton and lascivious motions." Similarly unequivocal signs were also issued by native women to native men, sometimes as an invitation, sometimes perhaps as direct challenges; in fact, some forms of dancing undoubtedly had this rationale. But there were other more subtle ways of making known one's intentions: "In the shaking of hands, in presenting one thing to another, especially by the eyes, and the toes, are signs ceaselessly given indicative of a desire for copulation" (Old Orsmond Manuscript: p. 2, LMS Archives).

Robertson reported receiving a proposition in the following form: “... she heald up her right hand and first finger of the right hand streight, then laid hould of her right wrist with the left hand, and heald the Right hand and first finger up streight and smiled then crooked all her fingers and kept playing with them and Laughed very hearty...." 
(1948:184). The puzzled Englishmen concluded that she was asking for an especially long nail in return for the services she undoubtedly was offering.

In 1822 a missionary deputation had this to report about lovers' signs:

Flowers and scents, indeed, in their days of profligacy, were much used among them to attract favor; the latter are now regarded with aversion, and the former have lost their hieroglyphic meanings. When presented by persons of different sexes, according as they were accepted, rejected, or interchanged, the parties understood each others' minds. When the blossom was torn in two by a lover and his mistress, and each retained one half, it was a pledge of reciprocal fidelity till these parts should unite again-an impossible conjunction of the petals, signifying an impossible separation of their hearts. (Montgomery 1832:II, 135-136)

As time was to show, the reverend gentlemen were overoptimistic in their diagnosis of this particular facet of culture change. In fact a little further along they reported how a missionary introduction, the art of writing, came to replace old Maohi techniques but not old Maohi activities:

Marriage [sic] compacts are easily arranged, and the overture may be made by either party, the woman as well as the man, and, according to ancient usage, as often by the former as the latter. A message of affection, with the request of a return in kind, is sent by a friend, or a note is written on a plantain-leaf with the point of a stick. The answer is generally as prompt as the proposal is direct-either aita, no, or ua tia, it is agreed.... (Montgomery 1832:II, 157)

Another method used by lovers to communicate their sentiments was reported by a merchant, Lucett, who resided in these Islands during the 1840s. The custom he described might be a later invention or borrowing, but I shall record it here on the chance that it could also have derived from the era of this study:

The unmarried girls have a custom of conversing with flowers not unlike the Orientals. If a coolness has sprung up between a young pair, the female will separate a flower partially down the centre. One half of the split flower is intended to represent the man, and the other half the woman; and it is meant typically to imply that, though separate bodies, they are joined together at the heart. If the lover puts the flower in his hair, it is a sign that he wishes to preserve her favour; but if he tears it asunder, it is a token that he has lost his regard for her, and wishes to be entirely separated. (Lucett 1851:I, 230)

A very direct technique used by women to indicate their choice of lovers was described by de Bovis:

Here and there around the Islands are to be seen many colorful things. For example, while watching a band of youths disporting themselves in one of the shaded and enchanting river pools to be found hereabouts, one now and then sees something thrown at them from a nearby thicket-something which will turn out to be a fruit called a nono, which makes a swift and quite harmless missle. When this occurs the youths raise a shout, for it is a stroke of good 
luck for the one hit by the nono. The lucky youth quickly scrambles out of the water and runs towards the place whence the nono was thrown, in pursuit of the Galatea who threw it, and who, by custom, will not seek too hard to avoid capture. Sometimes, however, the youth so singled out will pursue his quest obediently but with considerable reluctance, when it is known to him that the nono-thrower in question is [not a desirable young maiden] but some middleaged woman of chiefly status. In such instances, it is not passion that impells him, but obedience to a more or less "official" summons. But even in such instances, the youth will be repaid somewhat in the form of the honor thus bestowed upon him of having been favored by a woman of social importance; and such episodes lead to more of the same.

It is from this customary method [of initiating nonformalized sexual relationships] that illegitimate children (and especially those conceived in adultery) are labeled Taora nono (to throw the nono). (de Bovis 1909:33)

The following commentary by Moerenhout referred to the 1830s but describes what may well have been a continuation of earlier practices:

There is a practice still generally observed at O-taiti that the women go into the water completely nude, and that, often, in the places where there is scarcely a half-foot, there, if they don't uncover themselves completely, at least they take great care to show that they wash all parts of their bodies. They are always seen chosing, to perform their ablutions, the spots where many strangers pass by. I lived for a long time in a place where I could see this maneuver; and I am convinced that there is not at $\mathrm{O}^{\prime}$ taiti, a young girl so modest, so religious, that she would not use this sort of coquetry. (Moerenhout 1837:I, 219)

Earlier in this chapter, I recorded my opinion that "mass rapes" did in fact occur among the Maohis; I now raise the related question as to whether or not "rape" constituted a "customary" (even though perhaps unusual) technique used occasionally by an individual in satisfying his sexual desires. I raise the question but must confess my inability to answer it. By some European standards, the Maohi techniques of copulation were undoubtedly rather aggressive and violent, but unless it can be demonstrated that the woman in question was unambivalently unwilling, I fail to see how such an episode can be labeled rape. ${ }^{17}$ In this sense, the only occurrences of actual rape that we have come across in our sources are those perpetrated in warfare by the more frenzied victors upon the defeated side's women.

Finally, I call attention to what little information I have found concerning the use of "magic" for purposes of winning, or rewinning, sexual acquiescence:

Among the several types of "sorcerers" was one consisting of practioners who were benevolent in intent and innocent of fraud. Among these latter were included those whose specialty was to renew lost affections and discourage fickleness. Such specialists, who were called orou [oru?] were a busy lot. Their procedure resembled ordinary sorcery in that they worked through some object associated with the [person whose affection was to be captured or retrieved]. (Moerenhout 1837:I, 541n) 


\section{SEX TRAINING}

As we have seen, preparation for an active career of sexual engagements began at an early age; and it was encouraged by many features of Maohi life. To begin with, children cannot have missed witnessing some of the acts of copulation which took place in their populous and unpartitioned houses. While the sources make no specific mention of this, it is reasonable to assume from present-day circumstances, that the Maohi children of old were also encouraged by the example of their adults to take ribald delight in watching animals copulate. Also, children lived with older people who conversed openly, unashamedly, and noneuphemistically about sexual matters. The evidence on this point is unmistakable, for example:

Both sexes express the most indecent ideas in conversation without the least emotion and they delight in such conversation behond any other. (Beaglehole 1955:128)

Virtuous women hear a joke without emotion, wich amongst us might perhaps put some men to the blush. (J. Forster 1777:I, 393)

One thing that especially struck me ... was the shameless, uninhibited nature of their conversation, on any and all occasions, and with women as well as men. For, these people give everything its right name and have none of the polite circumlocutions which exist in our civilized communities, where people employ allusions, obscure phrases or accepted terms when talking of matters which, if frankly discussed, would be offensive and cause scandal. (Moerenhout 1837:I, 229; this translation taken partly from Danielsson 1956:59)

Nor, as pointed out earlier, was any mystery made of the human body. Children went mostly naked until they were six or seven years old, and after that they had ample opportunity to acquaint themselves with the genital anatomy of both sexes.

Another feature of Maohi life which served to encourage children toward early sexual engagement was the general attitude described by the Spaniard Blas de Barreda: "They think meanly of being virgins, and resent being twitted with it" (Corney 1915:471).

As for specific measures taken to predispose and prepare children for love making, I can discover nothing analogous to certain practices reported from some other Polynesian societies: namely, no direct evidence of stimulation of their genitals by older relatives, of regular sexual initiation of youths and girls by older persons, et cetera. (See Danielsson 1956.) Such practices may well have existed, but the early European observers were either unaware of them or unwilling to write about them.

Much of the general cultural setting of Maohi heterosexuality should now be clear; its place in everyday conversation and play, its simulation in drama and dance, its metaphoric application and its thematic occurrence in "oral literature", 18 and its symbolic representation in both religious and secular ceremony. And one has only to glance at examples of Maohi 
anthropomorphic sculpture to perceive how prominently genital anatomy figures in this form of "art." If there were any utility and validity to characterizing whole ways of life in terms of "themes" or "focuses" or "basic orientations," one would have to feature sexuality when describing that of the Maohi.

\section{HOMOSEXUALITY}

In the light of the foregoing one might expect that Maohi society, least of all, would harbor homosexuality. The fact that it did so greatly aroused the interest, and the distaste, of the early European visitors. Bligh was the first to inquire into the matter, and his account is as good an introduction as any:

On my Visit this Morning to Tynah and his Wife, I found with her a person, who altho I was certain was a Man, had great marks of effeminacy about him and created in me certain notions which I wished to find out if there were any foundations for. On asking Iddeeah who he was, she without any hesitation told me he was a friend of hers, and of a class of people common in Otaheite called Mahoo. That the Men had frequent connections with him and that he lived, observed the same ceremonies, and eat as the Women did. The Effeminacy of this persons speech induced me to think he had suffered castration, and that other unnatural and shocking things were done by him, and particularly as I had myself some Idea that it was common in this sea. I was however mistaken in all my conjectures except that things equally disgusting were committed. Determined as I was either to clear these people of such crimes being committed among them, or to prove that they were so, I requested Tynah to inform me, which as soon as I had requested it, a dozen people and even the Person himself answered all my questions without reserve, and gave me this Account of the Mahoos.

These people, says Tynah, are particularly selected when Boys and kept with the Women solely for the caresses of the men, here the Young Man took his Hahow or Mantle off which he had about him to show me the connection. He had the appearance of a Woman, his Yard \& Testicles being so drawn in under him, having the Art from custom of keeping them in this position; those who are connected with him have their beastly pleasures gratified between his thighs, but are no farther Sodomites as they all positively deny the Crime. On examining his privacies I found them both very small and the Testicles remarkably so, being not larger than a boys of 5 or 6 Years old, and very soft as if in a State of decay or a total incapacity of being larger, so that in either case he appeared to me [as] effectually a Eunuch as if his stones were away. The Women treat him as one of their Sex, and he observed evry restriction that they do, and is equally respected and esteemed.

It is strange that in so prolific a country as this, Men should be led into such sensual and beastly acts of gratification, but perhaps no place in the World are they so common or so extraordinary as in this Island. Even the mouths of Women are not exempt from the polution, and many other as uncommon ways have they of gratifying their beastly inclinations. (Bligh 1789:II, 16-17)

Many other European visitors touched on this subject in their journals. Mortimer had the following to report: 
Now I am upon the subject of these kind of entertainments, I cannot help relating a very droll ocurrence that happened in consequence of one of their nocturnal Heivas. Attracted by the sound of drums, and a great quantity of lights, I went on shore one night with two of our mates to one of these exhibitions. We seated ourselves among some of our friends, whom we found there; when one of the gentlemen who accompanied me on shore took it into his head to be very much smitten with a dancing girl, as he thought her; went up to her, made her a present of some beads and other trifles, and rather interrupted the performance by his attentions; but what was his surprize when the performance ended, and after he had been endeavouring to persuade her to go with him on board our ship, which she assented to, to find this supposed damsel, when stripped of her theatrical paraphernalia, a smart dapper lad. The Otaheiteans on their part enjoyed this mistake so much, that they followed us to the beach with shouts and repeated peals of laughter; and I dare say this event has served as a fine subject for one of their comedies. (Mortimer 1791:47)

In view of the mystery and contradictions now obscuring this unusual feature of Maohi society it will be useful to reproduce the more informative journal passages in full.

Besides the different Classes \& Societys already discribed they have a Set of Men Calld Mahoo. These Men are in some respects like the Eunuchs in India but are Not Casterated. They Never Cohabit with weomen but live as they do; they pick their Beards out $\&$ dress as weomen, dance and sing with them $\&$ and are as effeminate in their Voice; they are generally excellent hands at Making and painting of Cloth, Making Matts and evry other Womans employment. They are esteemed Valuable friends in that way and it is said, tho I never saw an instance of it, that they Converse with Men as familiar as weomen do-this however I do not aver as a fact as I never found any who did not detest the thought. (Morrison 1935:238)

To this island ... [Tetiaroa] they also send boys for the same reason [i.e., to "become fair by living on fish, and low diet"] whom they keep for abominable purposes. (Edwards and Hamilton 1915:113)

Something that was seen among the people today shews us these heathens, like the heathens of old, are given up to vile affections; the men leaving the natural use of the woman, burn in their lusts one towards another, men with men working that which is unseemly. Indeed it is said that Otoo [Tu] never cohabits with his wife but has a number of boys with whom he satiates his passion. (Jefferson, Journal, 8 June 1799, LMS Archives)

In various districts of the island there are men who dress as women; work with them at the cloth; are confined to the same provisions and rule of eating and dressing; may not eat with the men, or of their food, but have separate plantations for their peculiar use. (Wilson 1799:156)

As I fixed my eyes upon the fellow [the mahu], he hid his face: this I at first construed into shame, but found it afterwards to be a womanish trick.

These mawhoos chuse this vile way of life when young: putting on the dress of a woman, they follow the same employments, are under the same prohibitions with respect to food, \&c. and seek the courtship of men the same as women do, nay, are more jealous of the men who cohabit with them, and always refuse to sleep with women. We are obliged here to draw a veil over other practices too 
horrible to mention. These mawhoos, being only six or eight in number, are kept by the principal chiefs. So depraved are these poor heathens, that even their women do not despise those fellows, but form friendships with them. This one was tayo to Iddeah. (Wilson 1799:198)

Still more details, including a statement contradictory to Bligh's, appear in the following excerpt from the journal of the missionary Jefferson (his entry for 22 August 1800, LMS Archives):

Several women from Oriatteea arrived in the district. Some of them gained admittance into br. Henry's apartment, to see it; among them Was a man, no otherwise to be distinguished from the women but by a little coarser features \& rougher voice: this man keeps himself for the abominable sin of sodomy. We have lately learnt it is usual for some persons from their youth to set themselves apart for this base purpose. They go among the women, observe all their customs, eat \& drink \& sleep with them \& do all the offices of females in making cloth \&c. and prostitute their bodies to men for the above sin. They never cohabit with women, but only with men. They are not paid by men, but pay men for sinning with them. Some of them are so effeminated as not to be distinguished by their countenances, voices or manners from the women. They are, when spoken to, called by the same name of endearment that men use to women, \& women to women, Pattaa ... as also for the sin of bestiality (which the Otahieteans are guilty of with dogs), ${ }^{[19]}$ they seem surprised. Besides these sodomites, who are common in the land, the society of areeoies, have generally when they travel about in companies, one woman for the whole company.

A few months later the same Jefferson recorded in his journal another homosexual episode:

February 12, 1801: The chief of Hapyano was detected committing an act of bestiality with another man, which perhaps had not existence even in Sodom and Gomorrha. While the brethen were engaged at an exercise of the language in one of br. Henry's apartments the chief and two or three others were present. For a little time the chief laid himself down in the room upon one of his attendant's cloth as if to sleep. After we had concluded our exercise we went out, and br. Henry unwilling to disturb Paeete [the chief of Hapyano] left him and his man in his room by themselves. Not long after having the occasion to go back for something and entering suddenly, he saw sufficient to assure him a most singular and horrible species of bestiality was committing; the chief having in his mouth the other's _. The most unnatural lusts are indulged by the Otaheiteans perhaps to as great an excess as in any nation under the sun.

Additional information on fellatio is contained in a postscript commentary to Turnbull's account, in which he described mahu as "... a set of men ... whose open profession is of such abomination, that the laudable delicacy of our language will not admit it to be mentioned" (1813:382). Subsequently Turnbull was prevailed upon to overcome his scruples, with the result that the "abomination" in question was briefly described in print: "They put the penis into the unfortunate's mouth, and go on to emit the semin, which the wretch eagerly swallows down as if (it) were the 
vigor and the force of the other; thinking no doubt thus to restore himself greater strength (or manhood)."20

In discussing this practice, Bouge offered the suggestion that it was something more than a simple act of sexual inversion, and, by extension, that the mahu was not a mere invert. In brief, he argues that the participants in fellatio were perhaps accustomed to reversing their roles, to mutual advantage. Further, he likened the practice to the kind of cannibalism that follows wars in some societies, the kind whereby the victors acquire some of the qualities of strength of their enemies by actually eating parts of them. In the case of Maohi fellatio, Bouge went on to say, the thing so ingested, the semen, was particularly important inasmuch as semen was the very source of life. And as for the mahu, who were the "specialists" most accustomed to this practice, they were well suited to their calling, on two grounds. They were themselves well-built and robust fellows; and behaving, as they did, like women they emphasized the roles they played in maintaining the continuity of human kind. (Bouge 1955:148)

As some polite but skeptical critic might put it, Bouge perhaps stretches credulity to the boundaries of disbelief, but his ingenious interpretation does nevertheless deserve recording.

The prominent chief Pomare II was much addicted to homosexual practices, his favorite having been an individual (perhaps a mahu) named Toetoe, with whom, according to the Reverend Crook, he once "lived in a horrid manner at Matavai” (Journal, 2 March 1821, LMS Archives). During that period the missionaries were obliged to pursue their objectives under circumstances that truly outraged their notions of decency. For example:

At dinner ... [Pomare's] detestable pander sat along side of him on a low seat. The King cut some meat put it in a plate $\&$ gave it him $\&$ he took it back \& eat it. [Presumably, back to the eating place reserved for women.] Afterwards he came to the table again, the King poured him out spirits which he drank at the table. Br Nott reports that when he has gone to the King to translate the Scripture, this vile fellow has lain asleep \& when the King awoke him at one time he was offended and cried like a child. The King then coaxed him and made it up with him. Br Nott also informed the brethren Bourne Darling \& myself this day that he is very near to the Kings person who cannot bear him out of his sight for a minute and that when he is translating the Scriptures with the King, he $(\mathrm{Br} \mathrm{N})$ on one couch \& the King on another this detestible wretch is frequently between them, and he is obliged to turn his head from them to his book to avoid seeing what passes and still gets his ears shocked with what he hears. The King as we may expect pays no attention to his wife $\&$ seems to have no concern at all about his infant son, who was at our house most of the day, but the king made no inquiry after him. It is not to be wondered at therefore that he catches at every thing that seems to favour Antinomian principles. (Crook, Journal, 6 February 1821, LMS Archives)

I will now attempt to summarize, or to reconcile, all these accounts: first of all, the types of practices engaged in. 
According to Bligh's account, the mahu played what was a woman's usual role in coitus-that is, "... those who are connected with him have their beastly pleasures gratified between his thighs...." But, he adds, they all deny the "Crime of Sodomy" (i.e., probably anal coitus). The missionary Jefferson, writing a decade later, does however describe the practice as "sodomy." If "sodomy" did in fact mean anal coitus to both Bligh and Jefferson, its practice at the later date, as averred by Jefferson, could of course have been learned from some of the European visitors. In addition, the episode of male fellatio witnessed by Jefferson may well have been a general practice (cf. Bouge 1955).

As for other kinds of "aberrant" sexual practices, we have Bligh's statement that there were "... many other as uncommon ways they have of gratifying their beastly inclinations"; but the sources specify no types involving homosexuality other than those described above.

Turning now to the personnel involved in homosexual practices, most of the evidence indicates that they were mainly males. Bligh's remark that "even the mouths of women are not exempt from this pollution," could signify of course cunnilingus between females, but could also refer to a heterosexual mode. In any event, if female homosexuality was actually practiced, it was probably less common, or at least considerably less institutionalized, than that of males.

As for the types and numbers of males involved in homosexual practices, the evidence is somewhat unclear. There is no uncertainty about the existence of an out-and-out transvestite, mahu, although the sources differ concerning their number. Apparently, such "unmales" cohabited only with males and, it would seem, mainly with non-mahu males of upper-class status. Turnbull wrote: "I add, with some satisfaction, that the encouragement of this abomination is almost solely confined to the chiefs" (1813:382). In addition, however, one can infer from some sources that there were numbers of males-mainly youths-who were used as catamites, to "satiate the passions" of older and usually upper-class males, but who were not fully transvestite. ${ }^{21}$ Also, there is evidence that males in general indulged occasionally in homosexual practices including mutual masturbation and other unspecified acts, in response to needs that cannot all be attributed to a chronic shortage of females.

"In these Islands all persons seem to think of scarcely anything but adultery and fornication. Little children hardly ever live to the age of seven ere they are deflowered. Children with children, often boys with boys. They are often on the mountains playing in wickeness together all the day long" (Orsmond, Journal, 24 October 1827, LMS Archives). Though written in 1827, I suspect that such practices were current in earlier times as well. Save for Morrison's opinion, cited earlier, that most 
Maohis "detested the thought" of homosexuality, the sources indicate that such practices were not socially disapproved of by the populace in general, although those males who regularly lived or cohabited as females were identified with females in connection with religious ritual, eating, and other sex-linked customs. In fact, the true transvestite mahu were, we are told, "esteemd Valuable friends" especially by the women with whom they resided and worked. ${ }^{22}$

Some transvestites appear to have formed long-lasting sexual and domestic relationships with their male partners, but there is no evidence that any such relationships achieved the institutional status of "marriage," for example, with respect to exchanges of goods. Nor is there any record of child adoption by such a "couple" as occurs occasionally in modern-day Tahiti.

In some cases the male-acting partner in a homosexual relationship rewarded his female-acting mate with objects of value, but according to Jefferson, in a passage cited earlier, the reverse also took place. 


\section{CHAPTER 12 WARFARE}

Among the Society Islanders, in consequence of the influence of the climate, luxurious mode of living, and effeminacy of character, induced thereby, the obstinacy and the continuance of actual combat were not equal to that which obtained in other tribes; yet we learn from the frequency of its occurrence, and the deadly hatred which was cherished, that the passion for war was not less powerful with them than with the New Zealander or the Marquesian; and its consequent cruelties and demoralization were perhaps unequalled in any other part of the world. Their wars were most merciless and destructive. Invention itself was tortured to find out new or varied modes of inflicting suffering; and the total extermination of their enemies, with the desolation of a country, was often the avowed object of the war. This design, horrid as it is, has been [on occasion] literally accomplished: every inhabitant of an island, excepting the few that may have escaped by flight in their canoes, has been slaughtered; the bread-fruit trees have been cut down, and left to rot; the cocoa-nut trees have been killed by cutting off their tops or crown, and leaving the stems in desolate leafless ranks, as if they had been shivered by the lightning. (Ellis 1829:II, 494)

Warfare $^{1}$ does indeed appear to have been a major preoccupation of the Maohis, involving social interactions of a most crucial nature and bringing about extensive changes in social relations. There may have been periods in Maohi prehistory when warfare served to maintain existing social relations, but during the era immediately before and after first European contact it was revolutionary in its social consequences and, quite possibly, in its conduct.

Full explication of the various causes of warfare must be postponed to later chapters, but it may be useful to list a few of the more immediate ones here.

Some writers, such as Moerenhout (1837:II, 31) and Andía y Varela (Corney 1915:271), included "economic" factors among the several causes of war: the desire, for example, for better land or for certain food when local resources were in short supply. In connection with the latter, Moerenhout asserted that when their own supplies gave out people living high up the valleys often attempted, sometimes by force, to obtain breadfruit from the longer-producing plains areas, and reciprocally that plainsmen would raid inland areas for plantains and other wild foods. Such forays, Moerenhout added, were generally on a small scale, usually having involved only 
"chefs subalternes" of the same tribal district, and thus were of no real concern to the districts' sovereign chiefs. Some subsistence inequities may have occurred and have resulted in instances of localized raiding, but such conflict cannot have been very general or frequent, for, as noted in chapter 7 , most Maohis resided in or had easy access to the same type of resource zone. Moreover, there is no record of any specific conflict of this nature developing into one large enough to figure in Maohi verbal traditions or European written records. Similarly, with respect to warfare resulting directly from desires for territory with richer economic resources, instances of such may indeed have taken place, but they were neither frequent enough nor large-scale enough to have been chronicled. Numerous boundary disputes are recorded as having developed into major armed conflicts, and, although "economic" factors may have underlain many of these, their more immediate causes were usually of a different nature.

Andía y Varela listed the capture of women as having been one of the main causes of warfare (Corney 1915:271), and oral tradition contains episodes of this kind. It is probably true that males outnumbered females somewhat, but in view of Maohi women's relatively unfettered existences, except in certain dietary and ritual matters, it is unlikely that there was much widespread "capture" of them. Women undoubtedly figured among the causes of warfare, but not as mere pawns.

As already mentioned, disputes over boundaries are recorded as having developed into large-scale armed conflict (e.g., see Morrison 1935:173 ff.), and some of these were probably based on contention over economic resources. More often, however, boundary warfare resulted when one of the parties disregarded another's frontiers as a gesture of political affront. As later chapters will describe, ambitions to extend or efforts to curb political power probably accounted for most of the larger, more devastating armed conflicts of the eras under study. Even gratuitous acts of cruelty and predation did not usually lead to large-scale warfare unless the political interests of socially important individuals became involved; and this was also true of instances of sacrilege, whether committed purposefully or otherwise.

But it will be more sensible to discuss these matters after some basis has been provided for an understanding of Maohi social relations, so I proceed now with a description of the more technical aspects of Maohi warfare.

\section{WEAPONS AND UNIFORMS}

The principal weapons of the Maohis were spears, clubs, rasps, and stones. In addition, warriors sometimes carried "battleaxes" of pearl shell, but these were used more for dismembering fallen foe than for actual fighting. The Maohis also made bows and arrows, as noted above, but these were, inexplicably, used only for sport and hunting. ${ }^{2}$ (Figs. 12-1 through 12-6.) 


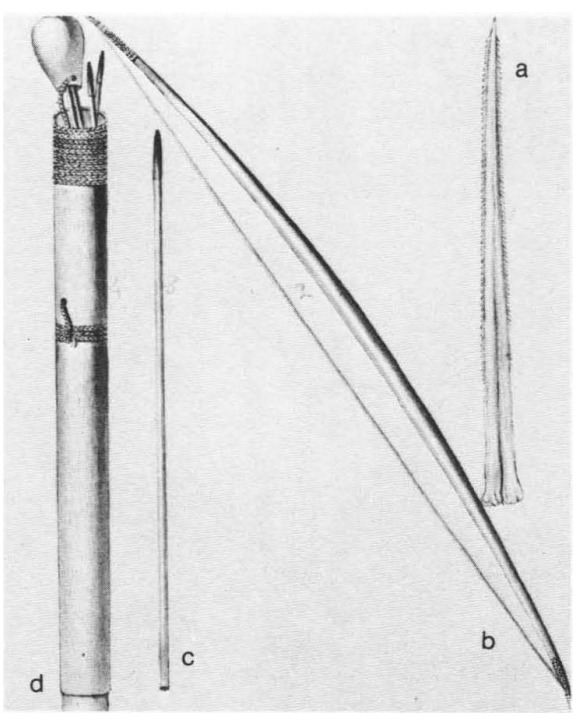

FIGURE 12-1. Weapons: $a$, stingray rasp; $b$, bow; $c$, arrow; $d$, quiver and arrows.

Drawing by J. F. Miller. British Museum.

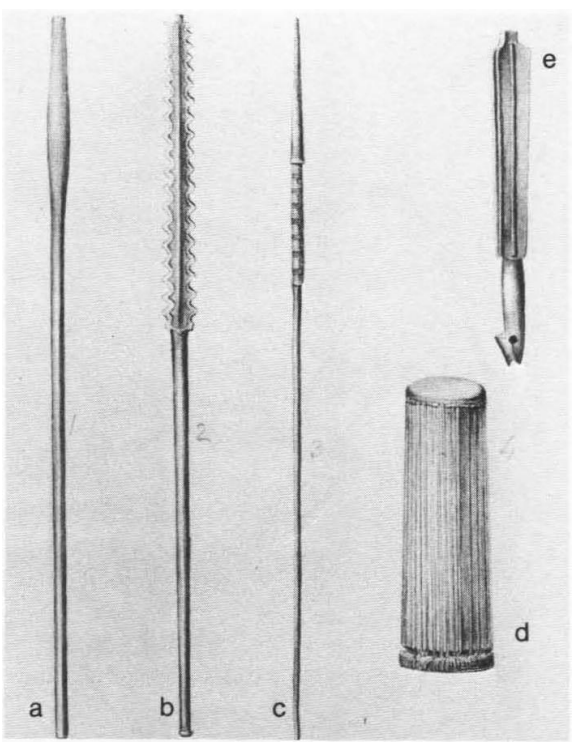

FIGURE 12-2. Weapons and drum: $a$, club; $b$, club; $c$, spear; $d$, drum; $e$, club. Drawings by J. F. Miller. British Museum. 


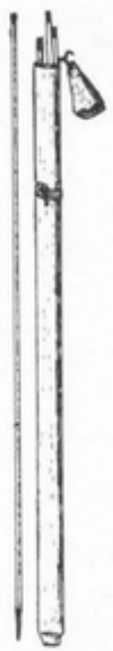

Figure 12-3. Arrows and quiver. Quiver length $85 \mathrm{~cm}$. Etnografiska Museet, Stockholm.

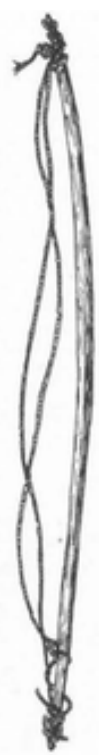

FIGURE 12-4. Unstrung bow, length $152.5 \mathrm{~cm}$. Etnografiska Museet, Stockholm.

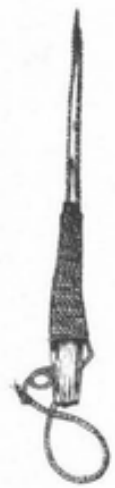

Figure 12-5. Dagger of hafted stingray tail, length $26 \mathrm{~cm}$. National Museum, Washington,

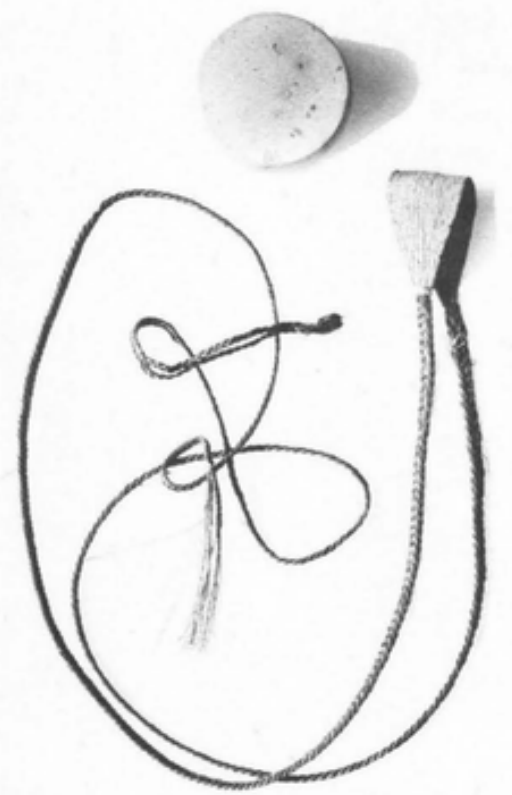

FIGURE 12-6. Sling and stone. Bernisches Historisches Museum, Berne. 
What most observers called "spears" were used for throwing, thrusting, and even clubbing and parrying. One type (pātia, tao), made of such hardwoods as ironwood, Alphitonia (toi), or coconut, was from twelve to eighteen feet long, about one and one-half to two inches in thickest diameter, and tapered to a pointed end. As was the case with other Maohi wooden weapons it was polished smooth but was not carved. Another type of spear differed from the pätia in being generally shorter and more slender, and in having a flat-bladed, lozenge-shaped fighting end. In some of these the butt end was rounded, in others pointed. A third type of spear (hoto ihe, maehae) was even shorter and had barbs of fishbones. Some flat-bladed spears were used also as clubs, but there were true clubs ('omore), varying from long flatbladed types to short bludgeons. Ellis reported that the handles of spears and clubs were covered, for surer gripping, with the resinous gum of the breadfruit tree (1829:II, 479).

Some fighting was done with the natural rasp provided by the serrated backbone of the stingray ('aero fai) drawn across a foe's body. Another fighting rasp consisted of a single or forked stick edged with sharks' teeth (paeho).

Stones were hurled in battle, both by hand and by sling, with what has been described as great force and deadly accuracy (Ellis 1829:II, 490; Wilson 1799:364).

In addition to all these fighting implements the Maohis fashioned long spears out of hibiscus wood ( $p \bar{r} r a u$ ), but these were used only for sport.

Ellis gave the following account of the offensive employment of spears and clubs:

The combatants did not use much science in the action, nor scarcely aim to parry their enemy's weapons; they used no shield or target, and, believing the gods directed and sped their weapons with more than human force upon their assailants, they depended on strength more than art for success. Their clubs were invariably aimed at the head, and often, with the lozengeshaped weapon, they would tapai, or cleave, the skulls of their opponents. Their spears they directed against the body, and the maui was often a deadly thrust, piercing through the heart. (1829:II, 489)

Cook, in describing a sham battle, praised the Maohis' defensive skills especially:

Otou [Tu] who was present caused some of the Troops to go through with their exercize on Shore, Two parties first began with Clubs, but this was so soon over that I had no time to make observations upon it, they then went to Single Combat and went thro' the Various Mithods of fighting with great allertness and parried off the blows, pushed $\& c^{a}$ each combatant intended the other with great dexterity; their Arms were Clubs and Spears which they also used as darts. In fighting with the Clubs, I observed all side-blows were parried with the Club except those intended the legs which were evaded by leaping over them, a downright blow on the head they evaded by couching a little and leaping on one side, thus the blow 
would fall to the ground: they parried off the Spear or dart by fixing the point of their spear in the ground and holding of it before them in an inclined posission more or less elivated, according to the part of the boddy they saw their antagonist intended to make a push or throw his dart, and by turning their hand a little to the right or left turn off either the one or the other. (Beaglehole 1961:401-402)

Cook however was less impressed than Ellis was with the Maohis' offensive tactics:

I thought that when one combatant had parried the blows $\& c^{a}$ of the other, he did not take all the advantages which seem'd to me to accrue, as for instance, after he had parried of a dart he still stood on the defensive and suffered his Antagonist to take up another, when I thought their was time enough to have run him thro' the boddy, but by such a step they might have exposed themselves to more danger than I could see or be aware of. (Beaglehole 1961:401-402)

According to Varela they handled their "cudgels" with "astonishing dexterity," having been able to "... defend themselves against a sword without their opponent being able to get a cut in, skilful fencer though he be. I speak from the experience of a friendly trial which took place between Titorea ... and a member of the storeship's crew-a smart enough adept in fencing with the Spanish sword." (Corney 1915:267)

A slingsman went to battle dressed only in loincloth (maro) and, sometimes, poncho (tiputa), but most other fighters wore one or more other items of body covering or headwear. Maohi "armor" consisted of a network of sennit cords wound around body and limbs “... so tight, as merely to allow of the unencumbered exercise of the legs and arms, and not to impede the circulation of the blood" (Ellis 1829:II, 500). This covering may have served somewhat to lessen blows of clubs and stones but did not defend much against a spear. Fine mats or sheets of bark cloth in place of armor were often worn in battle. Some men were so thickly girded with the latter that they were perceptibly impeded in their movements. "The very best things they possessed they always put on to go to war" (Orsmond, Notes on War). A most singular item of battle dress, and one having great exchange value, was the taūmi, or demi-gorget, a wickerwork breast covering decorated with shell, sharks' teeth, and feathers (fig. 12-7).

Some fighters wore only a strip of bark cloth around their temples, others protected their heads with huge turbans of the same material, still others decorated their heads with showy feather headgear, and a few made themselves conspicuous to both friend and foe by wearing an imposing fau, described by Ellis as

... a cap fitted closely to the head, surrounded by a cylindrical structure of canework, ornamented with the dark glossy feathers of aquatic birds. The hollow crown frequently towered two or three feet above the head, and, being curved at the top, appeared to nod or bend with every movement of the wearer. 

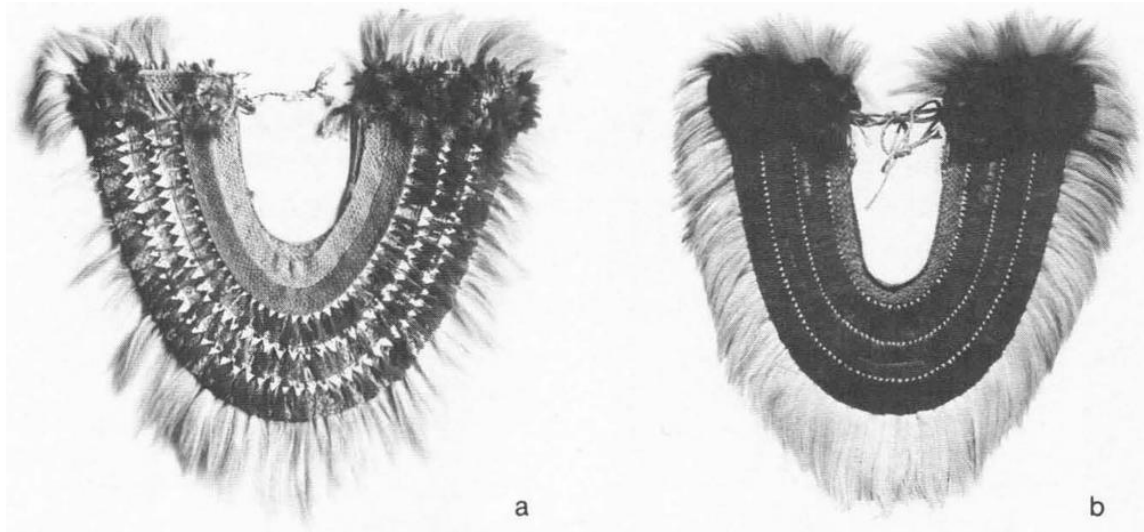

FIGURE 12-7. Gorgets: $a$, Bernisches Historisches Museum, Berne; $b$, British Museum.

This was a head-dress in high esteem, and worn only by distinguished men, who were generally sought out by the warriors in the opposing army. To subdue or kill a man who wore a fau, was one of the greatest feats. I have been often told, by a gigantic man who resided some time in my house, and was one of the warriors of Eimeo, that when the army of the enemy has come in sight, they used to look out for the fau rising above the rest of the army, and when they have seen one, pointing to it, animate each other by the exclamation, "The man with the fau; ha! whosoever shall obtain him, it will be enough." But, however imposing in appearance these high helmets may have been, they afforded no defence; and although formed only of cane-work and feathers, must have been cumbersome. (1829:II, 499-500).

The relevance of the foregoing to social relations lies mainly in the relationship of weapons and battle attire to class status, a matter that will be discussed later on; but one may draw attention here to the unsuitability of some aspects of battle attire to the business of fighting. Armor and thick turbans undoubtedly served to reduce the effects of blows. Thick layers of body wrapping had the same effect but must have encumbered offensive fighting considerably. And as for the elaborate ornamental headgear, it could only have been a hindrance to fighting and surviving.

\section{TRAINING}

The normal everyday activities of most Maohi males served to keep them in excellent physical trim for fighting, on land or on sea. Also, many of them engaged in sports which had the effect-and evidently even the avowed purpose-of preparing them for battle:

Their martial games were numerous; and to those preparatory sports, the youth paid great attention. The moto, or boxing, and the maona, or wrestling, were regarded as a sort of military drilling; but the vero patia, throwing the spear or javelin, and the practice of throwing stones from a sling, were the principal military games. (Ellis 1829:I, 294) ${ }^{3}$ 
But in addition, larger groups of males also occasionally engaged in practice maneuvers and sham fighting, probably more in preparation for specific engagements than as part of a peacetime policy of readiness.

Drilling was a standardized activity, as detailed in the following:

Standing upon an open field the drilling master said:

Toto'o i te tahua ia mata tahua roa.

Toto'o i te tahua ia mata tahua poto.

Tahi pae ia rupe-a-nu'u.

Tahi pae i tai ia rupe-i-tai.

E 'ori tatavi e ha'a ta te va.

E mataitai ta pua i te fau.

E 'ori te heiva ia orea.

Na atua i uta e, a haere mai!

$\mathrm{Na}$ atua i tai e, a haere mai!

$\mathrm{Na}$ atua i ni'a e a haere mai!

$\mathrm{Na}$ atua i raro e, a haere mai!

A haere mai ei atua a'e i ta tatou

Ei ha'api'i i teienei mau pipi

I te tia raau.

E moe i te Fatu,

E moe i te Fatu, Ta'aroa,

E tata te tapua ra'au,

$\mathrm{E}$ ta i te vai o $\mathrm{Tu}^{\prime}$

I noaa tana i’a,

E vaevae roroa

Tana tiea e 'ura!
March out upon the long course.

March out upon the short course.

One side for mountain-pigeon inland.

One side for mountain-pigeon coastwise.

Emotion will dance, the waves [people] will work.

Fau flower will look on.

Drilling will be the lively game.

O gods inland, come forth!

O gods coastwise, come forth!

O gods above, come forth!

O gods below, come forth!

Come as gods in our amusement,

To teach these pupils

The use of wood weapons.

Rest in the lord,

Rest in the lord, Ta'aroa,

The user of the wood must strike,

Must strike the waters of stability (war).

That he may obtain his fish,

Long legs (slain men).

This club is red!

Then they would drill first with the club in six movements.

(1) E 'ura teo; (2) e 'ura teni;

(3) E 'ura teo; (4) e 'ura teni;

(5) E 'ura pitara; (6) e 'ura faau.

E fa'a'a, e hoa ia Tane

Atua o te mau mea purotu,

Ia riro te hui ra'atira

Ei papa rahi,

Ei tahe vai pue i te 'ite;

Ei ueue a vi

Ei manuu a horo;

Ia poiri i vaho,

Ia marama i roto.
(1) Exaltation red; (2) boastful red;

(3) Exaltation red; (4) boastful red;

(5) Raising red; (6) striking red.

Suit it, O friends, to Tane,

God of beauty,

That the people may

Become a great rock,

A freshet in dexterity,

Become subduers,

Become fast runners;

That darkness be [thrown] out,

That the light be let in.

They went through all their drilling thoroughly on land and sea. (Henry 1928:300) ${ }^{4}$

Cook described one episode of sham naval fighting, this one specifically arranged on his account:

I looked upon this to be a good oppertunity to get some insight into their Manner of fighting and desired Otoo to order some of them to go through the necessary manouvres. Two were accordingly ordered off, in one of them Otoo Mr King and my self went and Omai in the other. After we were out in the bay, we faced, and advanced upon each other and retreated by turns, as quick as the paddlers could 
move them; during this the wariors on the Stages flourished their weapons and played a hundred Antick tricks which could answer no other end that I could see than to work up their passions for fighting. Otoo stood by the side of the Stage and gave the necessary orders when to advance and when to retreat, in this great judgement and a quick eye combined together seemed necessary to seize every advantage that might offer and to avoide giving advantage. At last after advancing and retreating, to and from each other at least a dozen times, the two canoes closed, head to head, or stage to stage and after a short conflict, the troops on our Stage were supposed to be killed and we were board[ed] by Omai and his associates, and that very instant Otoo and all the paddlers leaped over board to save their lives by swiming. (Beaglehole 1967:I, 212-213)

The Spaniard Andía y Varela also described a sham naval fight which took place on the occasion of the visit of one chiefly personage to another. Because of a food scarcity in the host's district, the guest of honor ordered supplies to be sent from his home district. When provisions arrived, carried by over two hundred canoes, some of them were left in the canoes to serve as a prize in a mock battle between local people and visitors-presumably a conventional kind of sportive encounter. In the foray which followed, "... many blows and hard knocks were dealt on either side." The winner in this game was the side that ended up with the most booty. (Corney 1915:269)

\section{MOBILIZATION}

Some large-scale armed conflicts commenced with stealthily executed attacks against unsuspecting enemies, but most Maohi warfare which the early Europeans chronicled began only after what amounted to public declaration and lengthy prologue, with the foe well warned if not well prepared. Mobilization involved both political and religious acts; in most instances the principal adversary on each side had to take steps to secure both human and supernatural assistance. Few leaders commanded enough wholly reliable manpower to be able to engage in large-scale battles without first taking steps to rally local support and secure allies. It seems to have been generally believed that no amount of human effort could achieve a victory without supernatural concurrence and assistance. Although it is impossible to learn, from available evidence, the relative decisiveness of these two factors in the thinking of most Maohis, some suggestive passages relating to this question will be quoted below. As a matter of fact, the political and religious steps toward mobilization were simultaneously pursued.

Even the most powerful tribal chiefs apparently felt it necessary to consult their principal supporters before committing themselves to full-scale war. This was usually done by convening a council of war, ${ }^{5}$ to decide whether to go to war and, if so, to apportion contributions in manpower and materials. Here is Henry's account of the physical arrangements of such a meeting: 
When at last the council met, the speakers sat in a central group, the sovereign and counselors sitting in a row at one end facing them and the chiefs and priests in a row to the right and to the left of the orators. The lower end of the two lines remained open for ingress and egress; but no one dared to cross the space between the sovereign and the orators, on pain of death. Outside of this official assembly sat an audience of the people, who had no voice in the meeting but felt a lively interest in what the orators said and were generally greatly impressed with their eloquence-the deliberations sometimes lasting over a day. (Henry 1928:297)

A passage from Moerenhout indicates that such meetings were no mere formalities:

These assemblies usually took place out of doors. The participating chiefs wore a special council-meeting garment (auhaana), a mat of fine quality which extended to the knees. The ra'atira, those proprietors of large estates, whom I have already mentioned, were seated there with their superiors; and knowing full well that the latter depended upon their assistance they did not hesitate to express their own opinions. Usually both the pros and the cons were discussed in such meetings with clarity, emotion and eloquence. And, however bellicose the general populace may have been, the counsel of the majority of inferior chiefs sometimes forced the arii to give up his martial enterprises. (Moerenhout 1837:II, 32-33)

According to Ellis, the harangues of the orators, presumably both for and against war, were specimens of "... the most impassioned natural eloquence, bold and varied in its figures, and impressive in its effects." Ellis continued:

I never had an opportunity of attending one of their national councils when the question of war was debated, under all the imposing influence imparted by their mythology, whereby they imagined the contention between the gods of the rivals was as great as that sustained by the parties themselves. A number of the figures and expressions used on these occasions are familiar, but, detached and translated, they lose their force. From what I have beheld in their public speeches, in force of sentiment, beauty of metaphor, and effect of action, I can imagine that the impression of an eloquent harangue, delivered by an ardent warrior, armed perhaps for combat, and aided by the influence of highly excited feeling, could produce no ordinary effect; and I have repeatedly heard Mr. Nott [another missionary] declare (and no one can better appreciate native eloquence), he would at any time go thirty miles to listen to an address impassioned as those he has sometimes heard on these occasions. (1829:II, 479-480)

As noted above, while the question of war and peace was being argued among political personages, priests sought signs from the spirits:

If in starting out to seek omens, the priests met with derision from a thoughtless group, it was regarded as a sign that defeat awaited the warriors, and that sufficed to cause abandonment of the project. If in seeking omens at night a priest chanced to touch something soft and pleasant with his toes, he said that the army would be victorious; but if his whole foot went in he said that the army would lose. If his face got covered with a spider's web in the bushes he returned home feeling that he was not inspired and advised the sovereign not to venture in the 
project. If he paddled out in a canoe at night and a school of fishes jumped into his canoe, he said the enemy would thus fall into their hands. (Henry 1928:297)

In addition to such informal actions as these, more organized measures were undertaken to prognosticate and to secure the active assistance of friendly spirits by scrupulous performance of certain rituals and by gifts.

There may have been times in Maohi prehistory when each warring unit enjoyed the more or less exclusive support of this or that tutelar spirit, whose goodwill had to be continually courted, and perhaps, but not usually, competed for. Some of the armed conflicts of the eras under study may also have taken place under that kind of fixed supernatural auspices, but by then many other of the large-scale conflicts appear to have involved adversaries seeking approval and assistance from the same spirit, or set of spirits, and this of course required the offering of competitively attractive gifts. ${ }^{6}$ In fact, during the second half of the eighteenth century, the god 'Oro appears to have achieved the status of a universal war god, whose favors were everywhere courted in connection with warfare. While most other spirits may have once been satisfied to receive offerings of pigs, dogs, fish, fine mats, and the like, 'Oro preferred human beings; and his preference appears to have begun to be shared by several other spirits courted specifically for war. In any case, in the fullest descriptions that have survived concerning the ceremonial aspect of warfare, human sacrifice was a recurrent theme.

In one version (Ellis 1829:II, 478-479) a full-scale program of prebattle religious ceremonies lasted several days. The first three episodes of these events took place in conjunction with political meetings: (1) matea (awaken): a human sacrifice was offered to 'Oro to "awaken" this deity and invite his presence and assistance; (2) maui fa'atere (the throwing, or darting): another human sacrifice was offered (to 'Oro also?), which served as a public declaration of war; (3) haea mati (tearing the peace-treaty emblem): still another human sacrifice was offered, figuratively representing the breaking off of any treaty relations that might have formerly bound the adversaries in a peace pact.

During these ceremonies priests continued to look for signs of the spirits' attitudes toward the proposed war, as indicated, for example, by movements of the victims' muscles. In the views of some writers these signs of a spirit's attitude were regarded by the general populace as completely reliable and utterly decisive, when in fact they were not infrequently mere "juggling and contrivance" designed only to "... deceive the people into a persuasion that the god sanctioned the views of the king and government" (Ellis 1829:II, 503). As Moerenhout observed:

These oracles, however, almost always conformed to the politics of the chief; and it was especially on these occasions that the latter needed (the) priests. Though some, in fact, oppossed the ra'atiras' making war, it was rare that they resisted 
the gods' will and no one would have refused to march when the sacrificers had promised victory. (1837:II, 33)

In this sense it was asserted by Moerenhout that the priests were masters of equivocation, having been cautious, for one reason or another, to interpret the signs in terms broad enough to accommodate to the shifting of political winds and even to the possibility of unfavorable military outcome.

Not so the shamans. When some spirit declared itself for war or peace through the instrument of a credible taura, its words were positive and usually decisive-which does not, of course, rule out the possibility that the behavior of some taura was, like that of the priests, influenced by politics. In any case, during the era under study the rise to influence of the war god 'Oro was accompanied by a proliferation of shamans serving more or less exclusively as that god's vehicle, and some of these achieved institutionalized positions of considerable influence over secular affairs. There is evidence for believing that when one of these shamans spoke out for peace or war even the most powerful secular leaders were swayed.

However the decision was arrived at, when war was decreed, there was set in motion another series of events, practical and ceremonial. Messengers were sent about the countryside announcing the decision to fight and calling upon the loyal leaders to mobilize their forces. In many cases mobilization required no longer than was necessary for the warriors to pick up their weapons and proceed to the assembly place; accounts speak of the continual state of readiness in which many men kept their weapons and battle dress. In other cases, however, there must have occurred long periods of preparation, especially when boats had to be built or converted to martial use. And during these proceedings steps were sometimes taken to remove the noncombatants-women, children, and the aged-to safer places.

Upon reaching the assembly place each leader and his immediate adherents encamped together and apparently retained their separateness as long as possible thereafter. If the force included the units of allies and not just members of a single tribe-and this was the case with most large-scale armed conflicts-the principal leaders of the separate units took the precaution of meeting together, in advance of their armies, to exchange compliments and each to assure the other of his intent. (Moerenhout 1837:II, 36)

Meanwhile another set of ceremonies took place, consisting of presentation by the secular leaders of valued objects-bark cloth, fine mats, pigs-to the priests, to compensate them for their unremitting efforts in securing the active assistance of spirits, including even winning over to their side the tutelars of the enemies (Ellis 1829:II, 481-482).

Following this was another set of ceremonies, often involving human sacrifice, in which the images of the supporting spirits were installed in temporary abodes as near to the actual fighting as possible, mainly in small 
marae erected on special canoes accompanying the fleet into battle. This was a most practical measure, since much large-scale combat usually took place at sea or near the shore. Also during some of these final prebattle ceremonies large quantities of food were consumed by the warriors, to sustain them during the ensuing fighting. ${ }^{7}$ These preliminaries completed, the forces then marched or paddled off to battle.

Before describing Maohi battle there remains the question of who actually took part in the battles and how often they occurred.

\section{Fighting PERSONNEL}

Most sources agree that every able-bodied male capable of bearing arms was expected to join in the fighting; ${ }^{8}$ this presumably excluded the decrepitly aged and the very young (see Corney 1915:267), although there is no information available concerning the stage of development-in terms of physical aging or instrumental skills-considered minimal for joining in organized fighting. Cook and others held the opinion that roughly one-third of the total population of any community served as fighters in time of war, but this figure cannot throw much light on the question of the age limits of soldiering, because of uncertainties regarding the age and sex composition of the Maohi population as a whole. As noted in chapter 2, it was the impression of some writers that males outnumbered females in the total population, but none of the early observers troubled to make an exact count. In this connection, however, it is important to recall Ellis' statement that the marked preponderance of males over females came about as a result of deliberate selection-that is, when parents were deciding which of their infants to allow to live they favored boys over girls mainly because of the former's potential in warfare (1829:II, 495-496). ${ }^{9}$

But women were not necessarily prohibited from organized fighting:

When the men went to battle, the women generally remained; but some of them fearlessly attended their husbands to the field, and either followed in the rear, or fought in the midst of the ranks. They carried the same kind of weapons as the men, but frequently used only their nails and their hands. Many were slain in the field, or during the retreat. (Ellis 1829:II, 485)

Instances were also recorded of upper-class women actually leading troops into battle.

\section{FREQUENCY OF WARFARE}

Turning now to the question of how often wars occurred, one finds in the sources such generalizations as, for example, that of Ellis, who stated that during the period 1797 to 1825 there were ten wars on Tahiti alone (1829:II, 477). By combining various chronicles of the period 1767 to 1814 (when Christianity itself became a major factor in inciting warfare), it is possible 
to distinguish for Tahiti and Mo'orea some 15 large-scale battles involving at least hundreds of warriors and having clearly discernible beginnings and more or less decisive outcomes-admittedly not a very precise method for defining the phenomena under study, but the best I can do with the data available. And lest this estimate be accorded more accuracy than it deserves, it should be added that during the period encompassing these so-called battles a far greater number of smaller engagements-skirmishes, raids, and so forth-took place. In fact throughout this whole period, states of war, if not actual combat, prevailed more persistently than states of peace.

But it should also be recalled that the state of affairs existing on Tahiti after at least Cook's first visit (1768) cannot be held typical of the preceding era, before the presence of European persons and implements began to influence Maohi polity and martial practice. And about that earlier era there has come down to us little information save ambiguous legend and biased chronicle.

One would like to learn whether there was some rhythm in Maohi warfare and some relation between climaxes of armed conflict and, say, the occurrence of seasons or the maturing of new generations. It seems obvious-and correspondingly tautological-that no political unit would have been in a position to wage Maohi-style warfare without certain minimum quantities of personnel and provisions, including goods for sacrifice. There are recorded instances of destitute and undermanned units striking out in desperation against more powerful adversaries, but most instances of the kind of deliberate warfare I have been describing seem not to have been undertaken without practical assurances of success. In view of the devastating nature of most Maohi warfare-a generalization that will be documented below-one might be led to conclude that a political unit decisively defeated in one battle would have to wait years before recovering enough strength to engage in another. This may indeed have been true in some cases, but there are other recorded instances of remarkably speedy comebacks, accomplished through industrious husbandry and shrewd diplomacy, as Cook remarked, after one eight-month absence from Tahiti:

I have already mentioned the improvements we found in the Plains of Oparre and Matavai: the same was observed in every other part into which we came, it seem'd to us allmost incredable that so many large Canoes and Houses could be built in so short a space of time as Eight Months, the tools which they got from the English and other Nations who have touched here have no doubt greatly accelerated the work and according to the old Proverb many hands make light work, for I shall soon make it appear there are no want of these; the Number of Hoggs too was a nother thing which struck our attention, but this is more easy accounted for, they might and certainly had a good many when we were here before but not chusing to part with any had conve(ye)d them out of our Sight, be this as it will, we now got (not only) as many as we could consume during our Stay, but some to take to Sea with us. (Beaglehole 1961:404) 
And there are well-attested instances of chiefs, after having been soundly defeated in one devastating battle, being able to assemble a new and victorious alliance within a matter of months.

In other words, from this limited sample of history, Maohi material resources seem to have been abundant enough, and Maohi society populous and complex enough, to preclude any simple direct relation between largescale armed conflicts and the passage of time-except in relation to the celebration of the annual first-fruit and harvest festivals, during which active hostilities are said to have ceased.

\section{FIGHTING ON LAND}

Most wars of any duration involved both land and sea engagements, although it now and then happened that an invasion from another island was entirely defeated and turned back at sea. I will begin with a description of fighting on land.

When preparations were going on for the kind of fighting on land that I have been describing, neither side appears to have been able to preserve much secrecy about its plans and arrangements. There was inevitably some movement across the frontiers, and a continual spreading of alarms. (For one thing, kinship ties invariably crossed and reduced the sharpness of political boundaries.) Also, there was posting of sentries-human and supernatural. In connection with the latter Henry reported the following:

When an invasion was expected, the priests went forth to the boundaries of their frontiers where the enemy would enter, and there dug little holes in which they placed 'ura [feather] amulets as mariua (breakers), or merely prayed, which was called maunu (entrancing), considering these acts potent means of weakening the power of the enemy, who on their side were on the lookout for disturbed-looking ground, guarding against such hui marei (hosts of entangling demons). (1928:304)

Most large-scale land battles took place near the shore and in more or less open country, although ambuscade was sometimes practiced (e.g., see Ellis 1829:II, 486). The two armies usually approached each other to the accompaniment of beating drums and trumpeting conch shells. If the force was composed of allied units it was customary for their respective leaders to march toward the battleground arm-in-arm (pito), as a sign of their union. Similarly, the leader of each army subunit marched in pito with his principal supporters, who also remained with him in battle; and the same was the case with sets of close relatives and friends. (Henry 1928:304; Ellis 1829:II, 492)

According to Henry, each army was grouped into three segments-front ranks (viri aro), second ranks (āpo'a viri, or hotuoa) and rear guards (tapono viri)-but it is not clear how this division related to an army made up of allied forces: that is, did each principal ally's force keep together in the 
same viri, or was each force broken up into separate viri and thus combined with analogous segments of the other allied forces? (Though this question may seem to involve a mere technicality, its answer-unfortunately lacking-would provide useful data concerning the evolution of Maohi political relations.) Similar uncertainties obscure the reconstruction one is able to piece together concerning other aspects of army organization.

Men going into battle were differentiated according to function and social class. Certain men served as 'battle shapers' (tārai-aro), others as 'priests' (tahu'a), still others as official 'exhorters' (rauti), and among the fighters there were specialist slingsmen as well as recognized 'champions' of close combat fighting (āito). Individuals from all classes of society-from highest to lowest-took an active part in fighting.

Battle shapers (tārai-aro), termed by Henry as "leaders" and "chiefs of the body of warriors," were said by Ellis to marshall the forces for fighting (1829:II, 486). The battle attire and weapons of such "leaders" were described in detail:

The tarai-aro wore over an armor (haana-tama'i) of closely braided coconut husk his best clothes, girded round the waist with sennit, the arms bare, and around the neck an elegant gorget of pearl shell mixed with various colored feathers and fringed with dog's hair, upon his head he wore the towering black feathered fau (helmet) and upon his broad shoulder he proudly carried the tao [long spear]. (Henry 1928:299)

Their precise roles in combat-other than "marshalling the forces"-is nowhere described; nor is it clear whether only tärai-aro were attired with armor, gorget, and fau.

Priests were indispensable participants in battle. Some of them worked at soliciting supernatural assistance (tahu'a-pure, haere pō), others prepared victims for sacrifice ('upo'o 'aha), still others ministered to the wounded (tahu'a ra'au). They went to battle dressed in their official garb, but in addition to carrying out their specialized jobs they also bore weapons and fought like the others.

The job of exhorters (rauti) was described in some detail by Ellis:

The din and clamour of the deadly fury were greatly augmented by the efforts of the Rauti. These were the orators of battle. They were usually men of commanding person and military prowess, arrayed only in a girdle of the leaves of the ti-plant round their waist; sometimes carrying a light spear in the left, but always a small bunch of green ti-leaves in the right hand. In this bunch of leaves the principal weapon, a small, sharp, serrated, and barbed airo fai (bone of the sting-ray), was concealed, which they were reported to use dexterously when in contact with the enemy. The principal object of these Rautis was, to animate the troops by recounting the deeds of their forefathers, the fame of their tribe or island, and the interests involved in the contest. In the discharge of their duties they were indefatigable, and by night and day went through the camp rousing the ardour of the warriors. On the day of battle they marched with the army to the onset, mingled in the 
fury, and hurried to and fro among the combatants, cheering them with the recital of heroic deeds, or stimulating them to achievements of daring and valour.

Any attempt at translating their expressions would convey so inadequate an idea of their original force, as to destroy their effect. "Roll onward like the billows-break on them with te haruru o te tai, the ocean's foam and roar when bursting on the reefs-hang on them as te uira mau tai, the forked lightning plays above the frothing surf-give out the vigilance, give out the strength, give out the anger, the anger of the devouring wild dog,-till their line is broken, till they flow back like the receding tide." These were the expressions sometimes used, and the recollection of their spirit-stirring harangues is still vivid in the recollection of many who, when any thing is forcibly urged upon them, often involuntarily exclaim, "Tini Rauti teia," this is equal to a Rauti.

If the battle continued for several successive days, the labours of the Rautis were so incessant by night through the camp, and by day amid the ranks in the field, that they have been known to expire from exhaustion and fatigue. (Ellis 1829:II, 487-489) ${ }^{10}$

I reproduce here a specimen of rauti chants, this one transcribed originally by Orsmond and possibly also translated by him, but evidently put in more polished (if less than faithful) form by Henry.

E ari'i tei nia o te ueue a nu'u,

O tapota a ra'i.

A fanoi te tere, e te toa, e te auta'ata.

A ha'apu i te tere,

E te toa, i ni'a ia Mou'a-raha

A Ta'aroa, tuhi mate!

Auanei e huri ai

I te vero moana.

Auanei to paepae, e tau ari'i,

$\mathrm{E}$ hi hee ai i te toto o te a'e.

Ei tao mato te nu'u,

E mo'o puapua tini tei roto;

Ei ava afa te nu'u

E mao avai ava tei roto.

Horo i mua na te riri.

Te fetoitoi maira te au.

Taua e oua i roto

I te ripo o te au.

Auanei e potu mai ai

Te mata'i ia Raa-mau-riri,

E tiu ma te toa,

E parapu huri fenua.

E uira tutui ra'i,

E uira rapa ni'a,

Te tua o te uira

E vero tei muri,

E vero 'ino, e mata'i ho'i ri'a.

A puta na te mata, a iriti;

A puta na te 'ouma, a ha'amahu;

A pee atu te ofai a ha'amahu;
There is a king above, who is the speaker of armies,

The roller of the skies.

Set about your errand, O warriors, O brave men.

Accomplish your errand,

O warriors, upon the flat mountain battlefield

Of Ta'aroa, whose curse is death!

From the will send out

An ocean storm battle.

Soon thy paving, O my king,

Will flow with the blood of the slain.

Let the army be as a cleft in the rock

Issuing out innumerable lizards;

Let the army be an open passage

Within which is a furious shark.

Rush forwards enraged.

The current rage begins to swell.

Let us leap into

The vortex of the current (heat of warfare).

Soon will burst forth

The wind waging war of Raa-mau-riri (Sacredness-holding-anger),

A descriptive south wind,

Which ravages and devastates countries.

Lightning anger setting fire to the skies,

With lightning flashes above,

Upon the back of the lightning

Will come the storm battle,

An evil storm, an angry storm.

If the eye get pricked, relieve it;

If the breast get wounded, wear it;

If a stone strike you, bear it; 
A motu na te 'iri, e tihi tau tana;

E 'ava ia na te taure'are'a;

E 'ava pua; e 'ava re‘a;

$\mathrm{E}$ 'ava te aninia;

E 'ava te tuiaroha;

$\mathrm{E}$ 'ava matapoiri;

E 'ava mau, te riri aitu;

E vahi iti e puta a'e ai te ao,

E ta maa 'ai te niu i

E hopoi ia taua i te Po,

E fa'aea i raro i te tumu o te niu.
If the skin get cut, it is a professional ornament;

These are opiates for the valiant;

Opiates fizzing and gay;

Opiates that make dizzy;

Opiates that make faint;

Opiates that obscure the eyes;

Opiates indeed, the anger of the gods;

A little more and day (victory) will dawn,

When we shall dine on coconuts

Take war to Hades,

And dwell beneath the coconut trees.

(Henry 1928:306-307) $^{11}$

Turning now to slingsmen, I noted earlier that these specialists wore only a breechclout and, perhaps, a poncho when fighting. Ellis has this to say about their employment in battle:

During the engagement, the parties often retreated, so that there was a considerable space between the ranks in these seasons, as when advancing to the onset. The slingers were then employed, and they often advanced in front of the ranks to which they belonged, and with boasting threats warned their enemies to fly or fall....

The most expert slingers were celebrated through the islands, as well as the most renowned among the warriors; and when one of these presented himself, a cry ran through the opposite ranks. Beware, or be vigilant, e ofai mau $o$ mea-an adhering stone is such a one; or e ofai tano e ofai buai-a sure or a powerful stone is such an one.... The slingers were powerful and expert marksmen. (1829:II, 490-491)

According to Ellis every male capable of bearing arms did so, but there were among these

... a number of men celebrated for their valour, strength, or address in war, who were called aito, fighting-men or warriors. This title was the result of achievements in battle; it was highly respected, and proportionably sought by the courageous and ambitious. It was not, like the chieftainship and other prevailing distinctions, confined to any class, but open to all; and many from the lower ranks have risen, as warriors, to a high station in the community. (1829:II, 496)

Although the sources are not very explicit on this point, 'aito appear to have been specialists in hand-to-hand combat, probably with spear and club. ${ }^{12}$

As noted above, persons from every social class engaged in fighting, but except for statements quoted above concerning the unimportance of social class in determining aito status, there are no data directly relating social class with combat specialty, battle priestcraft, or "exhorting." The following statement by Henry is ambiguous, to say the least: "The warriors next in grade [to that of tärai-aro] wore their best clothes in the same manner, with or without armor, and the immense turban, which the terrible 'omore [club] sometimes penetrated to the skull of the wearer; and they carried tiora and other spears according to their ranks" (1928:299). 
Even more puzzling is the relation between combat specialty, social class, and command hierarchy. While the battle shapers acted to "marshall the forces" before battle, we are not informed about the number of them in relation to the entire force, nor about their actual roles, if any, once fighting had begun. Also, although it is plausible to infer from numerous observations that mobilization was accomplished under the direct supervision of each territorial unit's "chief," no such inferences can be drawn concerning the maintenance of that hierarchy in actual battle.

Several accounts also speak of armies having had a "general"-sometimes in the person of the unit's tribal chief, or highest-ranking kin-Titleholder, but in some instances a noted warrior was assigned to that position by the latter. Presumably it was such men who "shaped the battle" (târai aro) and gave the signals for the commencement of hostilities. But whether and how they continued to direct operations during actual fighting is not reported.

As a matter of fact, the whole question of "command" becomes rather pointless in view of the Maohis' methods of fighting. According to Ellis, "The modes of attack and defence were various, and regulated by circumstances: there was either the aro [battle] viri, skirmishing of advanced portions of each army, or an arota, close engagement, when they fought hand to hand." Ellis added that "Sometimes their attacks were made by night, but then they generally bore a rama, or torch. To ambuscades they seldom had recourse, though they occasionally adopted what was called the aro nee, or attack by stealth." (1829:II, 486.) Henry and Moerenhout provided fuller descriptions; that of the former is, however, somewhat ambiguous in parts:

The chief modes of attack were: the fa'atia, in which two armies advanced for action face to face; the tu'umata, in which all aimed one way; the marua in which picked men united and forced their way into the fiercest of the enemy's ranks, to throw them into confusion and rout them; the aro nee, in which only a small portion of the army was open to view and the greater part stooped low or crept along in the bushes; the moohono (jointless backbone), in which the different ranks held fast together; the aro-ro (ant-fight), in which a line behind relieved the one before as it was getting worsted by the enemy; the pu-toa, in which the army stood in a body as a rock to resist the foe; the rapa-tahi, in which they aimed singly at the chiefs (1928:305-306).

As soon as the enemy armies met each other the troops took position and everyone, except the chiefs and commanders, sat on the ground. It should be noted that they knew how to form columns, keeping battle lines and maintaining reserve corps. Harangues were used by all these islanders. Each head chief, before giving the signal for battle, usually addressed to his warriors eloquent discourse appropriate to the circumstances, and almost always dwelling on the harm that the enemy had done previously, be it to them or to their relatives, as the best means of awakening in them the spirit of vengeance, so violent in all these savages. They did not fail either 
to arouse their courage, by reminding them of their lofty deeds in previous battles. (Moerenhout 1837:II, 37)

Actual accounts of battles do not confirm an impression of precise military tactics and disciplined command control which one might infer from these texts. Consider, for example, the manner in which a general engagement usually developed. Ellis' description is as good as any:

When their modes of attack were deliberate, the celebrated warriors of each army marched forward beyond the first line of the body to which they belonged, and, on approaching the ranks of the enemy, sat down on the sand or the grass. Two or three from one of these parties would then rise, and advancing a few yards towards their opponents, boastfully challenge them to the combat. When the challenge was accepted, which was often with the utmost promptitude, the combatants advanced with intimidating menaces.

These often addressed each other by recounting their names, the names and deeds of their ancestors, their own achievements in combat, the prowess of their arms, and the augmented fame they should acquire by the addition of their present foes to the number of those they had already slain; in conclusion, inviting them to advance, that they might be devoted to their god, who was hovering by to receive the sacrifice. With taunting scorn the antagonist would reply much in the same strain, sometimes mingling affected pity with his denunciations. When they had finished their harangue, the omoreaa, club of insult, or insulting spear, was raised, and the onset commenced. Sometimes it was a single combat, fought in the space between two armies, and in sight of both.

At other times, several men engaged on both sides, when those not engaged, though fully armed and equipped, kept their seat on the ground. If a single combat, when one was disabled or slain, the victor would challenge another; and seldom thought of retreating, so long as one remained. When a number were engaged, and one fell, a warrior from his own party rose, and maintained the struggle; when either party retreated, the ranks of the army to which it belonged rushed forward to sustain it; this brought the opposing army on, and from a single combat or a skirmish, it became a general engagement. The conflict was carried on with the most savage fury, such as barbarous warriors might be expected to evince-who imagined the gods, on whom their destinies depended, had actually entered into their weapons, giving precision and force to their blows, direction to their missiles, and imparting to the whole a supernatural fatality. (Ellis 1829:II, 486-487)

There appear to have been episodes in such battles when several men banded together for concerted action, as in the following:

When a distinguished chief or warrior fell, the party, to which he belonged, retired a short distance, collected some of their bravest men, and then, in a body, with fury and revenge rushed upon their antagonists, to vare toto, clear away the blood. The shock was terrific when they met the opposing ranks, and numbers frequently fell on both sides. (Ellis 1829:II, 490)

In addition, there were quite common reactions (if not concerted actions) as, for example, when whole armies broke and ran when one of their leading champions or chiefs was killed, or rallied when such a casualty was 
on the other side. Also, it appears that exhorters sometimes managed to revive the flagging spirits of whole armies, and the same may have been occasionally true of priests when they reported omens favorable to victory. In general, however, it was a matter of man-to-man, everyone for himself (or perhaps also for his companion or chief)-a fierce, surging, mass of individuals advancing or retreating in very small segments of the army as a whole, and quite out of touch with any overall tactical commanders, if such there were.

When the battle was fully joined, ${ }^{13}$ ferocity and savagery were the order of the day. A sample of conventional behavior may indicate the spirit in which the fighting was conducted. Sometimes when a warrior felled his opponent he would beat the body to a flat pulp, cut a slit through it large enough for his own head to pass through, and then wear it, poncho fashion, as a triumphant taunt (albeit a rather cumbersome trophy); or, not content with merely putting enemies out of commission, their subjugators would disembowel them, hack them to pieces, and collect their skulls or lower jaws as trophies.

Sometimes a disabled man succeeded in having his life spared, by supplicating his captor in remembrance of some previous relationship or by invoking the name of the captor's chief; but usually no quarter was given and no captives taken alive. In fact, the harangues of the exhorters urged explicitly against sparing any member of the enemy force just because he was a kinsmen or friend. For example, one war song urged: "Let the warrior's weapons clash together; Be courageous, brave men. Let the warrior take hold unsparingly; Let him take hold with closed eyes; That he perceive not a friend" (Henry 1928:308).

Often, if the victim happened to be an 'aito or influential chief he was delivered to priests for divination and sacrifice. In some cases the corpse was treated to the dread fate of sennit-binding: the entire body, contracted, was wound about with sennit and placed in the victors' marae as an offering to their deity.

A man thus bound was called an 'aha-ta'ata (man-sennit). It is affirmed that if he had children they had no issue after this and that all his family soon became extinct under the curse, a survivor merely existing as one doomed soon to die and if he endeavored to assert himself was exposed to taunts from his enemies as a remnant of the house of the 'aha-ta'ata.... [This fate] was regarded as far-reaching, as it was supposed to affect the man even when he was borne away by his own party.... (Henry 1928:310)

From these and other indications one may conclude that the "religious" part of fighting was carried out in a more concerted manner than was the tactical military part. Priests did engage in fighting, but their main job was to keep watch for signs of victory or defeat and to do all in their power, through sacrifice and prayer, to maintain or win over supernatural 
assistance for their side. In this connection, the Maohis' conception of the relation between themselves and their tutelar spirits in time of war is suggestively indicated by the following passage from Henry:

When one army felt that it was losing, the priest and one or two chosen men took valuable presents, called hiamoea (forget not), as near to the camp of the enemy as possible, and addressing their host of gods, who they supposed were forsaking them for that side, would lay the offerings upon the ground, enumerating each object and saying pathetically:

\section{O gods, forsake us not, go not away! \\ Behold, here we are also, take us to be your servants, $O$ host of gods!}

Sometimes they would find presents already spread out for their gods by the enemy, and if they were more valuable than their own they would return to camp dispirited, feeling that their gods were favoring the richer side. (1928:311-312)

Before proceeding to a discussion of the ways hostilities were terminated, I must mention how frequently and ingeniously the Maohis made use of guile in warfare. Later chapters will provide examples of such episodes from both "history" and legend; I wish now only to note that, while such measures as sneak attacks and the like were sometimes perpetrated with extraordinary treachery, they were nevertheless conventional strategies. They may have aroused the most violent anger among the victims, but I find no evidence of any general attitude to the effect that such measures were beyond the limits of admissible social activities.

\section{PEACEMAKING}

Sometimes a battle ended in a draw. If this occurred the two sides either withdrew to regroup and begin again-days, weeks, or months later-or their leaders agreed to make peace. In view of the crucial relevance of such actions to an understanding of Maohi social relations I quote in full Ellis' account of peacemaking:

If the conquered party surrendered at discretion, their land and property were divided by the conquerors, and the captives either murdered, reduced to slavery, or reserved for sacrifices when the gods required human victims. The bodies of such as were killed in their forts, were treated with the same indignity as those slain in the field; part of the bodies was eaten by the priests, the rest piled up in heaps on the sea-coast, where the effects of decomposition have been so offensive, that the people have forborne to fish in the adjacent parts of the sea. On the contrary, when neither party had been subdued, and, by intimation from the gods or any other cause, one party desired peace, an ambassador was sent with a flag of truce, which was usually of native cloth, a bunch of the sacred mero, \&c. and proposals of peace. If the other party were favourable, an interview followed between the leaders, attended by the priests and national orators.

They usually sat in council on the ground, either under a shady grove, or on the sandy beach. The orators of those who had sent the proposals made the 
first harangue\& this was followed by a reply from the orator of the other party, who was sitting on the ground opposite, and ten or twenty yards distant. Each held in his hand a bunch of the sacred mero. The king or chiefs sat beside them, while the people stood around, at some distance. When the terms were agreed upon, the wreath of peace was woven with two or three green boughs, furnished by each, as the manufaiti, the bond of reconciliation. Two young dogs were then exchanged by the respective parties, and the apa pia brought; it was a long strip of apa, or cloth, white on one side, and red on the other; the materials were furnished, and the cloth was joined together, by both parties, in token of their union, and imprecations were invoked on those who should hae, or rend, the apa pia, or band of peace. The apa pia and the green boughs were then offered to the gods, and they were called upon to avenge the treachery of those who should rend the band, or break the wreath. Divinations were also sometimes used, to know whether it would be of a long or a short continuance.

Feasting followed the ceremony, together with the usual native games; besides which, religious rites were performed. The first was the maioi, when vast quantities of food were taken to the king, and large offerings to the gods, together with prayers for the establishment and prosperity of the reign. Another was called the oburoa na te arii, and consisted also in offerings to the gods, with prayers for their support, and a large present of food to the principal warrior chief, under the king, as an acknowledgment of his important service in the recent struggles, and his influence in establishing the king in his government.

But the most important ceremony, in connexion with the ratification of peace, was the upoofaataa, \&c. It was commemorative of the establishment of the new government, and designed to secure its perpetuity, and the happiness of the community. A leading raatira was usually the chief proprietor of the entertainment, and master of the ceremonies. The festival was convivial and religious. Food and fruits, in the greatest profusion, were furnished for the altars of the gods, and the banquet of the king.

A heiva, or grand dance, formed a part of this ceremony. It was called the dance of peace, and was performed in the presence of the king, who, surrounded by a number of chiefs and warriors, sat at one end of the large house in which it took place. A number of men, and sometimes women, fantastically dressed, danced to the beating of the drum and the warbling of the vivo, or flute\& and though the king was surrounded by a number of attendants as body-guards, towards the close of the exhibition the men sought to approach the king's person, and kiss his hand, or the females to salute his face; when one or the other succeeded in this, the heiva, or dance, was complete, and the performance discontinued.

This, however, was only part of the ceremony, for while they were thus employed, the priests were engaged in supplicating the gods that these amusements might be continued, and their enjoyments in feasting, dancing, and the pursuits connected with them, might not be again suspended or disturbed by war. Peace was now considered as established, the club and the spear were cleaned, varnished, and hung up in their dwellings; and the festive entertainments, pagan rites, and ordinary avocations of life, resumed, till some fresh quarrel required an appeal to their weapons, and led them to the field of plunder and of death. (1829:II, 514-517)

There were other times when overtures for peace were turned down, resulting usually in resumption of hostilities; or, there may have been occasions when the winning side agreed to call off the battle in return for limited 
indemnities, although the sources are not very explicit on this point. On the other hand, most fully engaged battles involving large forces seem to have ended in total victory (however temporary) for one of the sides.

After such a victory-after the "breaking" and the "flying" of one of the armies-the victors pursued the vanquished and slaughtered every one whom they could overtake. The few captives who were taken were usually reserved for eventual sacrifice. Sometimes some of the defeated succeeded in reaching fortresses previously set up in the interior; others escaped to neutral or friendly districts or to other islands. Meanwhile the victors swept through the communities of the defeated-burning, pillaging, destroying gardens and groves, and slaughtering everyone they could find. To illustrate the mood of the conquerors, infants were sometimes transfixed to their mothers, or pierced through the head and strung on cords; or, women were treated with various "indignities" after which they were disemboweled and derisively displayed. And men were sometimes beaten flat with clubs and left to dogs and pigs, or lined up to serve as rollers for beaching or launching the victors' canoes. Efforts were made to retain as trophies the whole bodies or skulls or jawbones of the more prominent of the foe, and these were often deposited in the victors' marae; but most of the slain were left near where they fell. Observers commented on the intolerable stench which pervaded defeated districts for long periods after battle. ${ }^{14}$

The religious instruments of the vanquished did not escape destruction either: marae were sometimes dismantled and their stones used for ovens, priests were slain as were all other enemies, and god-images were confiscated or robbed of their feathers (Henry 1928:313).

Typical celebrations following a major victory included one or more of the following aspects and episodes: ${ }^{15}$

1. Ceremonial contempt for the vanquished foe by means of indignities inflicted on the corpses of their most influential people;

2. Honorable burial of the victors' battle casualties;

3. Dismissal of the spirts of war to $p \bar{o}$ (world of darkness) and recall of peace to ao (world of light);

4. Restoration of the victors' god-images to their marae, and thanksgiving services for victory;

5. Hailing of the secured or expanded power of the victorious chiefs;

6. Dismemberment and distribution, among the victorious chiefs, of the corpse of the most distinguished captive for deposit on the chiefs' marae;

7. Collection and redistribution of food and other valuables-to the tutelar spirits (as sacrifices) and leading chiefs of the victors, to the successful battle shapers, and to the general populace-for daylong feasting and revelry;

8. Distribution of the newly won land among the victorious chiefs. (Adapted from Henry 1928:314-315) 
Wholly different kinds of ceremony had to be performed by the survivors on the defeated side. Before setting out to reoccupy their devastated territory-if they were permitted to do so by the victors-the survivors' religious practitioners had to remove the sickness ( $\left.m a^{\prime} i\right)$ believed to infect a place devastated by war. Corpses were buried, marae were rebuilt and resanctified, god-images were restored to their places, sacrifices (including human) were rendered to the tutelar spirits, and a canoe loaded with supplies and manned by an effigy crew was sent into the sea bearing the "sins" (hara) of the place. (Henry 1928:320-321)

Another version of such ceremonies was provided by Ellis:

In addition to the rites connected with actual war there were two that followed its termination. The principal of these, Rau ma ta vehi raa, was designed to purify the land from the defilement occasioned by the incursions or devastations of an enemy, who had perhaps ravaged the country, demolished the temples, destroyed or mutilated the idols, broken down the altars, and used as fuel the unus, or curiously carved pieces of wood, marking the sacred places of interment, and emblematical of their tii's or spirits. Preparatory to this ceremony, the temples were rebuilt, new altars reared, new images, inspired or inhabited by the gods, placed in the maraes, and fresh unus erected.

At the close of the rites in the new temples, the parties repaired to the seabeach, where the chief priest offered a short prayer, and the people dragged a small net of cocoa-nut leaves through a shallow part of the sea, and usually detached small fragments of coral from the bottom, which were brought to the shore. These were denominated fish, and were delivered to the priest, who conveyed them to the temple, and deposited them on the altar, offering at the same time an $u b u$ or prayer, to induce the gods to cleanse the land from pollution, that it might be pure as the coral fresh from the sea. It was now supposed safe to abide on the soil, and appropriate its produce to the purposes of support; but had not this ceremony been performed, death would have been anticipated.

The maui fata, altar-raising, was connected with the preceding rites. No human victim was slain, but numbers of pigs, with abundance of plantains, \&c. were placed upon the altars, which were newly ornamented with branches of the sacred mero, and yellow leaves of the cocoa-nut tree. These rites extended to every marae in the island, and were designed to secure rain and fertility for the country gained by conquest, or recovered from invasion. (Ellis 1829:II, 214-215)

Mention was made above of "fortresses" to which survivors of a defeated army sometimes managed to escape. Such places have been described as “... rocky fortresses improved by art-narrow defiles or valleys sheltered by projecting eminences-passes among the mountains, difficult of access, yet allowing their inmates a secure and extensive range, and an unobstructed passage to some spring or stream." (Ellis 1829:II, 511)

Improvements to these natural refuges consisted of walled-up entrances and built-up platforms which overlooked the approaches and from which the defenders hurled down stones. If well provisioned, some of the more secure of these fortresses-for example, the famous Pare of the Atehuru district of Tahiti and Maeva on Huahine-held out against 
the longest of sieges, which were never of very long duration, in view of the characteristic impatience of most besieging forces. Various strategies, military and religious, were employed to breach the defenses\& when these succeeded the victors simply repeated the carnage already described. On the other hand, some sieges ended in truce or in withdrawal of the besiegers. In the latter event it is likely that the survivors sometimes drifted back to their old homes, after the fever of war had subsided. But there are other instances of people, freed of besiegers but not of the fear of destruction, remaining in hiding far in the interior for years.

The LMS Transactions contain an account of one method utilized for maintaining peace between neighboring tribes that had formerly been at war:

On the top of a hill, that separates Matava and Hapyano, [Messrs. Jefferson and Nott] saw a pole set up in the ground, upon which were fastened a dead dog, and a young plantain tree. On enquiring the cause of this, of the chief Vitua, they were given to understand it was the king's standard, by which the people of Hapyano were to take notice there is peace between him and them; and that they should not pass that pole, \&c. to make war on Matavai, and that he would not pass into Hapyano to injure them. If any was to break down the pole, \&c. it would be looked upon as a declaration of war. If it should fall by any casualty, the king must be made acquainted with the same, and a declaration made of its not being intentionally done. (LMS Transactions I, 87)

\section{FIGHTING AT SEA}

According to Moerenhout, before the arrival of Europeans naval battles were more frequent, more politically decisive, and on a larger scale than those on land (1837:II, 40). Perhaps they were. There are certain logical reasons for that having been the case-for example, except for enemies with common land frontiers, one side's movements must on many occasions have been at least partly by sea. Actually, most extended wars, and many battles, were fought on land and sea, as later chapters of this book confirm.

A fleet prepared for a war expedition contained fighting boats, supply boats, and a few "floating marae" (boats outfitted with a small shelter under which the force's tutelar god-images were installed). The supply boats were small-to medium-sized ordinary transport canoes, usually with sails\& they did not normally engage in fighting.

Descriptions of Maohi fighting boats vary somewhat, as did the boats themselves; but essentially they were twin-hulled vessels with up-curved sterns. Upon the fore part of each of them was built a raised stage or fighting platform. According to Samwell, "the Canoe which has the highest stage has greatly the advantage over the other as they always come to close Quarters where the hardest blows carry the day" (Beaglehole 1967:1064). Canoes were propelled by paddlers who sat behind and underneath the platforms. They varied widely in length, one of them measured by Cook was 108 
feet long. Some writers called them pahi, indicating that they were of plankbuilt construction, but it is likely that some of them were put together with $v a^{\prime} a$ (built-up dugout) hulls. In fact it is reasonable to assume that every sizable fleet contained an assortment of fighting boats, of many shapes and sizes, including some built specifically for fighting and others temporarily converted from ordinary transport and travel.

The manning of these naval vessels also varied, certainly in numbers and probably also in detail. Morrison, an eyewitness, asserted that some of them were capable of carrying as many as 300 men each (1935:175); while Cook, from his observations of the prebattle naval review, noted in chapter 2, estimated that they averaged about 40 men each, including fighters and paddlers. Writing much later and on hearsay evidence, Moerenhout described them as capable of carrying 150 to 300 "fighters" each (1837:II, 40).

Every boat had its complement of "paddlers" and "fighters" - including specialists in hand-to-hand combat and, perhaps, slingsmen. The proportions between these types may have varied considerably from boat to boat, although the question probably became academic at the height of battle. Every fighting boat also carried a commander or battle shaper (tārai-aro), along with one or two exhorters (rauti) (Henry 1928:316). ${ }^{16}$

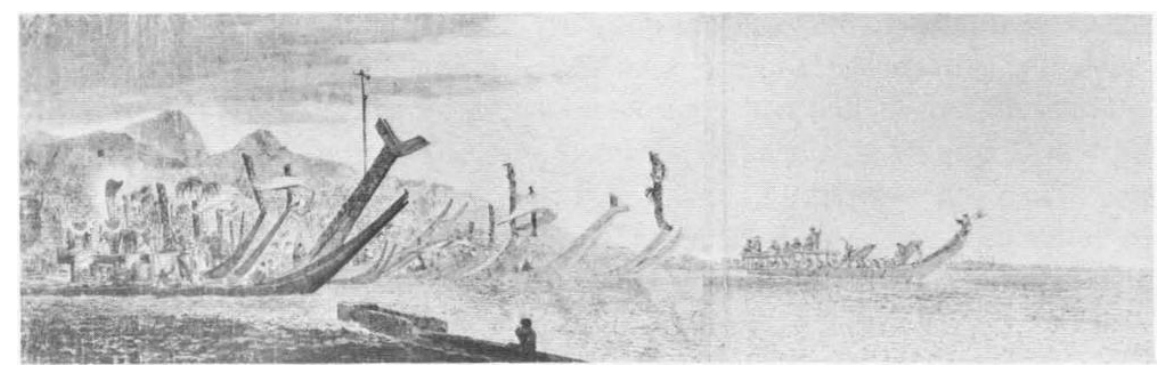

FIgURE 12-8. War Canoes, Tahiti. Drawing by W. Hodges. British Museum.

The largest fleet actually encountered by Europeans was the one assembled for a naval review at northwestern Tahiti on the eve of an expedition to Mo'orea (fig. 12-8). As noted above, Cook estimated this fleet to consist of 160 large double war canoes, carrying an average of 40 men each, and 170 smaller supply craft, carrying about 8 men each. (But of this large assembly, be it noted, many of the vessels did not actually participate in the expedition which followed.) Ellis wrote, from hearsay, about another large fleet consisting of 90 "war-canoes, each about one hundred feet long, filled with men" (1829:II, 484). This assembly of boats was involved in a war between Huahine and Ra'iatea and their respective allies, but it is not entirely clear from Ellis' statement whether he meant the number for the Huahine 
contingent alone or for all the boats engaged. In support of the latter inference is the consideration that a force of 9000 men (90 boats $\times 100$ men each) would imply a total Huahine population of some 27,000-a figure far in excess of any sensible estimate for that era. At the other extreme, Cook mentioned one naval campaign in the Leeward Islands which was won by a fleet consisting of only 10 boats (1784:132); and the secretly executed sea raids which helped establish a Porapora chief's suzerainty over most of the Leeward Islands were carried out with fleets probably not much larger than that.

In addition to each fighting boat having its own commander, fleets were also under the general command of so-called admirals (Cook's term; I cannot discover a Tahitian term for this office). According to Ellis, the whole Huahine force mentioned above was under the command of one man, who was at the time "king" of that island. But the fleet intended for the Mo'orean expedition seems to have consisted of five separate contingents, each under its own commander (Beaglehole 1961:405).

According to Henry (1928:316), the same kinds of ceremonies preceded both sea and land campaigns, with the exception, of course, of the customary naval review which, in Cook's view, was a commendable device for acquainting the commanders with the state of the whole fleet (Beaglehole 1961:408).

Most naval battles seem to have taken place near shore and even inside the barrier reefs. Since the defending side was nearly always forewarned of large-scale attacks through ordinary comings-and-goings and the posting of sentinels, their own vessels were usually prepared for the ensuing action. Rather inexplicably, they did not normally attempt to dispute the invaders' fleet in the narrow reef openings, where the advantage would have been on their side, but waited with their boats drawn up along the shore.

Naval fighting was usually preceded by verbal battles, to work up passions. Then the warriors "... fastened their canoes end to end, tied their two contending lines side by side, and completed the battle in terrible hand-tohand fighting resulting in great slaughter on both sides until one became victorious (Henry 1928:317). Ellis gave a fuller description of this tactic:

When the engagement took place within the reefs, the canoes were often lashed together in a line, the stem of one being fastened to the stern of the other before it. This they called $a p i$, and adopted it to prevent the breaking of their line, or retreat from the combat. The opposing fleet was, perhaps, lashed or fastened in the same way; and thus the two fleets, presenting one continued line of canoes, with the revas or streamers flying, were paddled out to sea, the warriors occupying the platform raised for their defence, and enabling them to command each part of the canoe.

At a distance, stones were slung; on a nearer approach, light spears or javelins were hurled, until they came close alongside of each other, when, under the influence of rage, infatuation, ambition, or despair, they fought with the most obstinate and desperate fury.

It is not easy to imagine a conflict more sanguinary and horrid than theirs 
must have been. Although the victors, when faatini'd or supplicated, sometimes spared the fallen, it was rarely they gave any quarter. Retreat there was none-and, knowing that death or conquest must end the fray, they fought under the power of desperation.

At times, both fleets retired, ... but when victory was evidently in favour of one, the warriors in that fleet sometimes swept through the other, slaughtering all who did not leap into the sea, and swim toward the canoe of some friend in the opposing fleet. I have been informed by some of the chiefs of Huahine, who have been in their battles, that they have seen a fleet towed to the shore by the victors, filled with the wounded and the dead-the few that survived being inadequate to its management.

When the canoes of a fleet were not fastened together, as soon as the combatants perceived they were overpowered, they sought safety in flight, and, if pursued, abandoned their canoes on reaching the shore, and hastened to their fortress in the mountains. (1829:II, 509-510)

Moerenhout's version differs somewhat from that of Ellis:

In naval combat, which usually took place in the large bays, inside the reefs, it was customary for the defenders to line up their boats in three lines. In the bow of each frontline canoe there stood a warrior armed with rope, while those armed with slingshots, spears, and clubs were positioned in the hull and on the fighting platform.

The attacking fleet (organized, equipped, and armed in exactly the same way) would then enter the pass-usually without contest, although it would have been easy enough in most instances for the defenders to have done so. Once inside the reef the attackers would then form three lines of their own, and the front lines of each would move together, boat against boat. As soon as the prows of two opposing boats touched, the individuals in the bows lashed them together with their ropes in such a way that they could be separated only with the greatest difficulty. This done, the warriors hurled themselves at each other with do or die spirit.

The courage needed for combat like this may best be imagined if one recalls that retreat from this kind of engagement was quite out of the question. That is to say, the only recourse for the defeated crew was to jump into the sea, where, however, they were totally defenseless against the enemy's spears. But even for the victors this kind of conflict proved very costly; it was unusual for more than a quarter of them to survive the battle or the wounds received in it. (Adapted from Moerenhout 1837:II, 41-42)

Moerenhout went on to say that the outcome of the encounter between the opposing frontline boats was usually accepted by the reserves as the signal for victory or defeat. Thus, if the attackers' first line was overcome, their comrades-in-arms usually retreated toward the open sea-a dangerous maneuver because of the narrowness of the passage through which their boats had to go. Sometimes the attackers were able to effect their retreat in good order and safety, but more often they rushed out in panic and disorder and then became easy marks for their pursuers, who compounded their victory by massacring those they caught.

If on the other hand, the first success went to the attackers, the rest 
of the defenders were in a better position to survive, by landing and either fighting on shore or escaping into the hinterland.

It sometimes occurred that the reserves did not break and run, but went to the rescue of their distressed comrades. When this happened-that is, when all of the opposing forces became engaged-the battle would occasionally last for several hours, with only a fourth or so of the warriors coming out alive. It was understood that no prisoners were to be taken. Moerenhout noted also that the champion warriors ('aito) were invariably placed in the frontline boats, thereby lending some rationale to the significance which the initial encounter had for the reserves.

In some wars the tactics involved a mixture of fragmented land encounters and sea combat, instead of mass frontal encounters either at sea or on land. In such wars the fighting would go on for several days and would end in victory for neither side, creating a state of continuing hostility (Moerenhout 1837:II, 42-45).

One should recall that all of these accounts were secondhand, having been written after the cessation of large-scale, purely indigenous, naval warfare. Actually, the nearest thing we have to a contemporary description of naval battles is by Cook, who did not witness an actual battle but did observe naval reviews and practice maneuvers:

I took some pains to inform my Self in what manner they joined Battle and fought at Sea, but knowing but little of their Language and they none of ours, the account I got must be very imperfect, it however gave me a tolerable Idea of it, which I shall endeavour to convey to the reader. I have before said that all their Vesels of War have a raised platform or Stage at the very fore part of them which will contain Eight or Ten Men, these are the Tata otai's or fighting Men. In forming the line of battle they draw up a breast of each other with their heads to the Enimy and as I understood in divisions as when they land, for the more readier closeing the line when the action begins: ${ }^{a}$ the enimies fleet being drawn up in like manner, they rush with all their might upon each other, the Attack is first begun with Stones, but as soon as they Close they take to their other weapons for the stages of the one fleet will be as it were joind to those of the other; it seems that general Ship is here very necessary, ${ }^{\mathrm{b}}$ to take the advantages of winds, currents and various other circumstances which may accrue, and may make it necessary to put in practise other Manoeuvres besides these just mentioned, but their Manner of fighting must however be the same. ${ }^{\mathrm{C}}$ I have said that each fighting stage will contain Eight or ten Men but we cannot suppose this to be the Number of Troops in each Cannoe, but even this number cannot act on the stage at once, ${ }^{\mathrm{d}}$ on the Contrary I think we understood clearly from Tupia who made a drawing of one of these Vessels ${ }^{\mathrm{e}}$ that no more than one or at the Most two Fought at the same time and as they were Kill'd or wounded were relieved by others. ${ }^{\mathrm{f}}$ (Beaglehole 1961:406-407)*

* Beaglehole added these footnotes: (a) ... and to add greater weight to the whole; (b) very necessary: as necessary, as in the conducting of one of our large fleets; (c) and may ... same: I know not if the whole fleet joins battle at once, I rather think not and that a part lies out of the line in order to be ready to assist and support such as may be in danger of being over powered, for as they have niether Masts nor Sails but are Navigated by paddles 
Cook's account also provided a description of a combat-landing operation:

Their Manner of landing in An Enimies Country must be in divisions in the same Manner as we saw them land at Oparre, these divisions must be formed with out the reach of the Enimies Stones, from what I have seen a division consists of no fixed number, if the shore is straight the divisions may be large, if Crooked they must be Small, otherways all cannot get close to the Shore; when the divisions and a resolution taken begin the attack they pull in for the shore, not directly in a line a breast, but each division upon the quarter of the other, in order the more readier to Close or form a line a Shore, at least it was something in this Manner they did it at Oparre; at this time the Padles exerted all their strength being incouraged by thier leaders on the Stage and directed by a Man who stood with a wand in his hand at the fore part of the divisions, this Man by words and actions directed the Paddlers when all should paddle, when either the one side or the other should cease $\& c^{a}$, for the Steering Paddles a lone are not sufficient, all these Motions they observe'd with such quickness as shewed they were very expert in their business; the very Instant the division touches the ground all the rowers jump out and drag it on the Shore till it is fast grounded, thus they form a line abreast all along the Shore not only of Vessels but arm'd men also, for the troops being mounted on the Stages are ready to land in an Instant, if the enimy give them so much time, if not they are ready to force a landing. We have been told that the Enimy some times meet them up to the Middle in Water but they must be a Strong boddy of Men that can support themselves against the weight of one of these heavy divisions. I never thought to ask how the Paddlers were imploy'd after the Troops were landed or in an Engagement at Sea when the fleet had graple'd each other, but I believe they do nothing but attend their paddles. This is the best account I can give of the Management and use of these Vessels of War on which the Strength and Power of these isles in a great measure depends: it was by these Opoone the King of Bolabola was inabled to conquor most of the neighbouring isles. (Beaglehole 1961: 407-408)

Not all naval battles were as sanguinary as the above excerpts may imply; even the huge expedition to Mo'orea alluded to above ended in truce, when after a few skirmishes neither side appeared willing to risk a general engagement.

In any case, by the turn of the century naval warfare had been superseded almost entirely by large-scale combat on land (see Vancouver 1801:334). As already mentioned in chapter 8, the Duff chronicler, writing about the years 1796 through 1798, knew of the existence of only five war canoes in all Tahiti.

\section{VEHIATUA'S WAR}

Until now I have limited my description to the more deliberate, twosided type of Maohi warfare. Pages could be written about other types

only, this may easily be done; this may however in some measure depend on the conduct and judgement of the leaders and the Nature and situation of the place; (d) ... for want of room; (e) ... with the warriors in her ...; (f) ... how far this may be true I will not pretend to say, but it seems to me to be too deliberate a way of fighting for people whose passions are Violent and are said to fight with great obstinancy; certain it is that the contest is never long and that a single battle desides the fate of the Nation for that time. 
of armed conflict: of boundary disputes developing directly and without ceremonial preliminaries into large-scale battles, of stealthily conceived and highly destructive forays, and many others. In fact, a very large volume could be compiled just describing the many conventional aspects of Maohi armed conflict, for no other concerted activity seems to have so preoccuped the thoughts and the physical actions of the Maohis during the eras under study. But enough has been presented to provide a background for our main concern with social relations, so I shall proceed to a description of other kinds of Maohi activity. But before doing so I reproduce here in its entirety a lengthy account of a war alleged to have taken place just prior to the arrival of Europeans. The account is quoted from Robert Thomson's unpublished "History of Tahiti." The document, in the LMS Archives, was compiled by the missionary Thomson after 1835, and is perhaps to be considered part "legend" and part "fact." I reproduce it here because it exemplifies so well many of the aspects of Maohi warfare just described.

Vehiatua chief of Taiarabu, [Tahiti's southern peninsula] and a renowned warrior, having taken offence at something done by the people of Moorea declared war against that island and prepared his fleet for immediate attack. The fleet of Taiarabu consisted of about 150 large double war canoes, each carrying from 40 to 50 warriors, and accompanied by a host of smaller canoes carrying food and other necessaries. A messenger having been despatched to their enemies to inform them of their intentions, and to dare them to put to sea, the Tairabu fleet set sail and with a fair wind bore down on the coast of Moorea; abreast of Paopao bay, better known among foreigners as Cook's harbour, they encountered the Moorea fleet as numerous and well manned as their own. The Moorea canoes having formed in a long unbroken line, each canoe was firmly fastened by ropes to the one adjoining, that the warriors might better sustain each other in the hours of conflict, and also to prevent any who might become faint hearted from deserting their post. The Tairabuans formed their canoes in several divisions each canoe being well secured to the division to which it belonged. All arrangements being complete the spear men took their position in lines along the front of the platform which was laid over the double canoes, the slingers behind them each with his heap of stones and bore down before the wind upon the enemies line; as they approached the slingers began the action on both sides and stones of considerable weight were hurled with great power upon the canoes of the warriors. The Tairabuans having the advantage of a good breeze soon broke the line of the Moorea fleet, killed numbers in the violence of the first furious attack, and soon compelled the Mooreans to cut the lashings of their canoes and retreat towards their own land. The retreat, soon became a confused rout, the Tairabuans chased them into the harbour of Papetoai, destroyed many canoes and drove others on the reef where many perished in the heavy breakers. No mercy was shown by the conquerors and hundreds were slain. The captured canoes were taken to the beach, all on board were detained as prisoners, others who had swam ashore were captured as they landed, and many of the aged, and infirm who had remained on their houses, being unable to flee to the mountains fell into the hands of the conquerors. These unhappy victims, with all the prisoners and the wounded, amounting to several hundred, were destined for the triumphal procession of the conquerors to the great marae of Moorea. Tied hand and foot these poor wretches spent the night on the sea shore, while those 
who had escaped, with all the women and children, and those who had not been engaged in the war fled to the mountains and sought a refuge in the most inaccessable steeps. Next day the warriors prepared for the procession. All the canoes were dressed with white and yellow streamers, the captives with cords round their necks were threwn into the sea, and towed at the stern of the canoes to the great marae called Tiahura a distance of 4 or 5 miles; and there before the altar which their own hands had reared these miserable creatures were offered up in sacrifice to their own idol god! The distinguishing feature connected with this battle was the treatment of the captives; and from the circumstances of their being towed by the necks at the sterns of the war canoes, the battle is chronicled in Tahitian history, as Te taoro ta-ata i Tiahura [the strung-together people at Tiahura].

This last triumph over their enemies, satiated the rage of their conquerors, who returned to Papetoai to feast on the good things of the land the fruits of their victory. Vehiatua sent a messenger to the mountains where the mass of the people had fled with offers of reconciliation, inviting them to return in peace to their homes; after the interchange of several messages the proposal was accepted and the fugitives returned to their homes. The victors in the meantime pillaged the land, and consumed whatever produce came within their reach, when they had destroyed all in the vicinity and were in want of provisions, the Moorea chiefs convened a meeting of all the people, and Paepae one of their number who had been most obsequious to their conquerors, and thus allayed every thing like suspicion; as the friend of the Tairabuans, addressed his countrymen, Friends, slaves of the mighty conquerors, the great Vehiatua and his renowned warriors have beaten us in battle, they drove us to the hills, but they did not leave us there; they had compassion upon us, and our wives, and children, they brought us again to our homes, and now, see! they are living in the land without food while plenty is in the country. Friends let your legs be firm, and your backs and arms strong, that we may go and seize all the pigs and kill them, strip the breadfruits of all fruits, and the vallies of all plantains, and bring plenty of food, to feast those generous warriors; and let those who stay at home prepare the ovens and collect the leaves. This speech delivered in presence of the Tairabuans was received by both parties as the speaker intended, the one anticipated a grand feast, while the other heard only of a conspiracy for the destruction of their enemies!

The Mooreans immediately went off and soon returned with plenty of provisions, in the meanwhile, the ovens had been prepared and plenty of leaves collected, and that the vicinity of the houses might be neat and clean all the dead leaves and rubbish had been collected and piled in little heaps. Early next morning all was activity in Papetoai, the Tairabu sentinels and others who happened to be awake, saw the Mooreans lighting their fires, congratulated themselves on the expected feast, and again lay down till sunrise. The wily Mooreans instead of kindling fires in the ovens which they had prepared, put the fires underneath the heaps of dead leaves and rubbish, these piles soon sent up volumes of thick smoke and filled the whole neighborhood, when all was ready at a preconcerted signal they rushed upon their sleeping enemies, and massacred numbers, the alarm was given the rest seized thir arms, but enveloped in smoke they knew not where to move unable to combine or resolve upon any plan of defence they fell an easy prey into the hands of their late captives. Guided by the roaring of the surf upon the reef, those who could rushed to the beach, reached their canoes and put to sea, numbers less fortunate perished, and during the few days which had passed since Vehiatua sailed from Tairabu upwards of a thousand lives had been destroyed. O te turai uru [the cut-down breadfruit] is the name under which this event has been handed down to present times. 
Vehiatua's canoe was among the last to push off from the beach, in their passage across to Tahiti they encountered a strong head wind, which drove their canoe down the passage between the two islands, and ultimately compelled them to put in at Afareaitu. Not knowing of the tragedy which had just taken place at the other side of the island, the people received Vehiatua and party as warriors returning from a victory, and hailed his approach with the flattering title of "The rising sun!" A chief of Tahiti called Auri, then on a visit at Afareaitu, gave the warrior chief a less cordial welcome. Observing that the Chief's canoe was alone, he suggested this as a favourable opportunity of putting to death this scourge of his country, he urged the subject warmly on the chief of Afareaitu, and that too even in the hearing of Vehiatua himself. The chief was unwilling to comply, and the Tairabuans seeing their danger, thought it prudent to depart and were allowed quietly to proceed on their journey; as Vehiatua stepped into his canoe, his eye fell upon Auri, he gave him a glance which told more than the words he uttered, and exclaiming "Auri we two shall meet again", he pushed off and pursued his voyage to Tahiti. 


\section{CHAPTER 13 THE INDIVIDUAL: FROM CONCEPTION TO AFTERLIFE}

In this chapter, I will describe the various kinds of Maohi activities that had to do more or less directly with each individual's (qua individual) membership in Maohi society-his "birth" (biological and social), nurturance, education, "head freeing," marriage, aging, biological death, and afterlife. I know of no word or phrase, in the Maohi language or in English, that precisely summarizes how the Maohis viewed-or implied that they viewed-an individual's passage through life. No notion of "cycling" or "progress" seems to have been involved. Perhaps "trajectory" would more closely approximate the native view, but that I shall leave to the reader to decide.

\section{CONCEPTION}

It will be recalled that a human being (ta'ata) was believed to consist of a corporeal body (tino) that ultimately disintegrates at biological 'death' (pohe), along with a soul (vārua) that is present in the body even before parturition and that usually survives death of the tino-for a while at least. In addition, some sources state or imply that every human was believed to be endowed with something called an iho, which may have been present in the fetus but which became a significant entity only after the neonate began visibly to draw breath, to cry, and to open its eyes; for want of anything better I shall translate iho as 'essence'.

The Maohis recognized that sexual intercourse was the usual prerequisite for reproduction, but precise details of their theories of conception are lacking. Several Maohi myths contain episodes wherein a male spirit caused some human female to conceive by means of actions described as, say, "passing over" her, but judging from the general reaction to Bligh's description of the virgin birth of Jesus, most Maohis evidently considered that human reproduction required something approximating sexual intercourse, however indirect it might be. Bligh reported as follows:

This brought on a religious conversation, and having told me their Great God was called Oro and that they had many others of less consequence, they asked me if I had any God. Having replied of course in the Affirmative, I was asked if he had 
a Son and who his Wife was. I told them he had a Son but no Wife. Who was his Father and Mother then? was the next question. I said he never had either Father or Mother. At this they laughed exceedingly. You have a God then who never had a Father or Mother and has a Child without a Wife, Aymah timoradei huheine arrami no Mydiddee. i.e. did he not lie with a Woman to get him? I said no. Who was then before Your God and where is he? Is he in the Winds or in the Sun? (Bligh 1789:I, 390)

Among precise details lacking are, for example, how many male ejaculations were believed necessary to initiate reproduction or whether it was believed possible for reproduction to be initiated, or contributed to, by more than one genitor. In connection with the latter, however, there are some bits of evidence that suggest that, while perhaps only one male served to initiate reproduction and to contribute the principal male-derived entities or attributes that went into the composition of the child, it was possible for other male sex-partners of a woman to contribute something to her child's makeup-as witnessed, for example, in the notion of telegony referred to in chapter 11.

We are indebted to George Hamilton, surgeon of H.M.S. Pandora, for another bit of evidence that might bear on this subject. After telling that he had enjoyed the sexual favors of a chief's wife, upon invitation of her husband, Hamilton added that the latter "... was a domesticated man, and passionately fond of his wife and children; but now became pensive and melancholy, dreading the child should be Piebald; though the lady was six months advanced in her pregnancy before we came to the island" (Edwards and Hamilton 1915:110).

Another very important question concerning Maohi theories of conception has to do with the nature of the entities or attributes passed on to the child by its mother and its principal genitor. As for the mother, she was acknowledged to provide at least the necessary receptacle for the child, as expressed in the following portion of a "creation chant" quoted from Henry:

To te tane nei ' $a p u$, o te vahine ia, no te mea na rei ra mai 'oia i te ao nei; e to te vahine nei 'apu, o te vahine ia, no te mea na te vahine 'oia i fanau.
Man's shell is woman because it is by her that he comes into the world [i.e., ao]; and woman's shell is woman because she is born of woman.

(1928:340, italics added)

In view of efforts made to fatten some young women prior to their marriage (and hence childbearing), it is probably safe to assume the existence of a belief that some of a mother's physical attributes were transmitted to her offspring, ${ }^{1}$ but I can find no further data regarding the supposed mechanics of that process. ${ }^{2}$

As for a child's principal genitor, I have already referred to the belief that some of a genitor's or, in this case, the cogenitors' physical attributes were transmitted to an offspring. A similar conclusion may be deduced from the stated belief that a child generally "resembled" his genitor in physical 
appearance. ${ }^{3}$ In neither case, however, are we apprised of the supposed mechanics of this transmission process.

On linguistic grounds one might conclude that both mother and genitor contributed some of their own blood to their offspring; I refer to the verbal distinction between 'blood relatives' (toto féti'i) and 'relatives by adoption' (fēti'i fa'atāvai hia). But, as I shall explain later on, I cannot be certain whether this was only metaphor or expressed a belief that blood was in fact transmitted from both parents to their offspring.

Turning now to Maohi beliefs concerning the more intangible entities, I can say without hesitation that something was transmitted from both parents in the reproductive process-something "psychic" or "spiritual" or the like. I base my conclusion on the whole panoply of beliefs and practices centering on the immense social-relational importance of descent, including the high value attached to "purity of line." Also, in view of the social weight accorded primogeniture, it is necessary to assume that whatever the "psychic something" that was transmitted by reproduction it must have diminished somewhat in efficacy with each new conception. There are certain clues as to the nature of this particular entity, but I must postpone consideration of them for a while. Meanwhile, I should point out that there may have been still other kinds of "psychic" entities that were thought to be transmitted from parent to child-for example, the one referred to in the belief that the fate suffered by a father was transmitted in some measure to his offspring. ${ }^{4}$

In a negative sense, however, I can point to instances in which important personal attributes were believed explicitly not to have been transmitted by sexual reproduction. I refer to the qualities thought essential for the practice of certain types of priestcraft and punditry-qualities in addition to training, experience, and good memory; qualities which, according to Moerenhout, were bestowed by the gods (1837:I, 507). The qualities in question could only be transmitted by the skilled practitioner through his last breath, which was infused in his successor.

The social-relational implications of Maohi theories, and lack of theories, about conception will be considered later on. Now let us turn for a moment to measures taken by the Maohis either to supplement coitus in order to insure conception, or to counteract coitus in order to prevent conception.

The Duff chronicler stated that Maohi priests "affect to possess extraordinary powers, to promote conception or abortion ..." (Wilson 1799:336), but he did not explain how either practice was carried out. In fact the only other reference I can find to any supplementary measures aimed at promoting conception or, at least, reproduction is a portion of a prayer uttered by a priest during the closing rites of a large-scale religious ceremony. Between requests to the gods for continuing supplies of food, and so forth, is the phrase: "homai i te hua'ai o te ta'ata ia rahi ..." "give us numerous offspring" (Henry 1928:175). 
The only analogous measure used to prevent conception that I can find is identified (but not further described) in the LMS Dictionary, namely, pāva, a ceremony and prayer to prevent further childbearing. Except for this, as far as I can discover, the Maohis took no practical measures-nor indeed did they entertain thoughts about any such measures, practical or otherwise-to prevent coitus from resulting in conception. This total absence of contraceptive devices is quite surprising in a people who were so evidently casual about coitus but who subscribed to such stringent class-based eugenical norms; but none of the sources describes or even alludes to such near-universal human practices as coitus interruptus or prophylaxis-mechanical, chemical, or magical. Instead, the Maohis appear to have depended upon abortion and infanticide to avoid raising unwanted offspring.

Thyes Natives have a Most Dreadfull Costom, of which they are often guilty, Viz. the killing the Infant in the whomb, which they do by taking a grass stalk having a hard white stem which they cause to pass to the embryo, which kills it; this they say, they can do if the woman is not gon above 4 months, if she excedes 4 months it is partty shure to kill her, some have expired through it. (Hassall to LMS, 11 November 1797, LMS Archives) ${ }^{5}$

It could be affirmed that of three young women pregnant for the first time, at least one made herself abort. There were women who were very adept at this kind of medical practice and the pressed sap of certain combined herbs quickly brought about the sought-for accident. (de Bovis 1909:33) ${ }^{6}$

As is to be expected, the Maohi practice of abortion was much less apparent to the chroniclers than was infanticide. In fact, the above excerpts summarize about all that I have found concerning the techniques, prevalence, and consequences of abortion in Maohi society.

Regarding the technique employed in abortion, there is however a somewhat ambiguous statement from another missionary, who reported having been told by one woman that she had "... strangled in [her] womb 5 children" (Orsmond, Journal, 10 January 1821, LMS Archives). What was meant by "strangled" is not clear.

There are legendary accounts of living beings who began life as aborted or miscarried fetuses, that is, as "shapeless clods." Inasmuch as some of these "clods" lived to become heroic demigods (e.g., Honoura, Maui), the social-relational implications thereof are important and will be discussed later on.

Even discounting the greater notoriety accorded infanticide in the sources, the likelihood is that it was in fact practiced more frequently than abortion, quitely possibly because of women's well-founded fears for their own health.

The only specific reference to pregnancy taboos I have discovered is a passage from Henry relative to spirits' ata (shadows): "The $u^{\prime} a$-miti (hermit crab of the sea) was a god to some persons. It was supposed that to 
eat it under such circumstances would cause swollen glands, sometimes ending in death, and that a child born of a mother so afflicted came into the world with swollen glands" (1928:392).

\section{BIRTH}

No where are children brought into the world with less pain or danger: the women submit to little or no confinement within doors, but rise and go about as usual. (Wilson 1799:330)

The sources contain several references to women going about their everyday activities up to the very beginning of labor, and being up and around again within a day or two of parturition. ${ }^{7}$ There are also reports of difficult and protracted births, of still births, and of mothers dying in childbirth. ${ }^{8}$ However, it is probably accurate to say that for most Maohi women childbirth was expeditious, safe, and relatively painless.

I can, however, find no references in the sources to Maohi reactions to caul or breech births, or to prenatal manipulation of the fetus to insure against breech birth.

We are indebted to Bligh for the earliest account of the physical techniques of childbirth:

Ideeah, Tynah's Wife began a Strange conversation, which was how the Women of England were delivered of their Children, and as I complied readily with the knowledge I had of the matter, I was led to the same curiosity with respect to the Otaheite Women. In this particular I was fully satisfied, and Iddeeah represented the Woman in Labour. One of her attendants seated himself in the Tent where we were and Opening his knees took her between them in a sitting posture with her legs under so as to rest upon her heels. His arms were brought round under hers, and his hands spread over the Upper part of the Belly, which they described were occasionally as the pains came on pressed downwards, and in this Manner the Mother was held untill the efforts of nature delivered her. I asked if no person came to assist in delivery. She said no, that was not proper, or indeed from her representation is it at all necessary for after a few distortions of the Countenance and trifling complaints the Infant was represented to be born. From her enquiries she found our English Women suffered much and had Assistance in the moment of labour, at which she laughed heartily. "Here," she said (placing herself in the posture already described) "let them do this \& not fear and the Child will be safe." I was now asked if our Women had more than one Child at a birth, I told her frequently two, and sometimes three; three she said was eeno or bad, that some Otaheite Women had three Children, but that the Woman generally died and some of the infants. (1789:II, 387-388)

Decades later the missionary Crook witnessed and described an actual childbirth episode wherein the techniques were not unlike those simulated for Bligh. The woman had been two days in labor when he first saw her:

She was seated on a flat stone two or three inches thick placed on the ground. A woman sat behind her crosslegged between the woman in labour \& the wall to 
support her back and loins. A woman also sat before her one at each foot which they well supported in the time of a pang. This is the general posture of women in time of parturition. As the case was lingering the women were changed several times and sometimes men took their place the husband brother \&c. During several hours they kept pouring water upon her head \& body without ceasing five minutes at one time. The poor creature seemed to enjoy this \& would frequently call for it. As night advanced, they lighted a string of tiaire nuts, the King having prohibited oil. Finding the case matured \& progressive I ventured out to prognosticate that she would be delivered before the string was burnt out. This was accordingly the case. After prayer \& supper I lay down on one of the besteads. The young woman lay on the ground very faint $\&$ feverish, her mother sat at her head for some hours applying a little cold water to her head \& breast very frequently. She took nothing but a little cocoanut liquor once. Toward morning they all fell asleep with their clothes drawn over their heads as well as bodies. When it was day I found the young woman entirely free from fever and cheerful. (Crook, Journal, 24 April 1821, LMS Archives)

This episode occurred in 1821, six years after the "official" capitulation of paganism and its attendant taboos, so that the fact of its having taken place inside an ordinary family dwelling may have exemplified a change in Maohi customs, since the older, pre-Christian accounts indicate that childbirth usually took place outside, or at least in a shelter constructed specially for the purpose. ${ }^{9}$ But at this point in our consideration of Maohi childbirth practices it becomes necessary to specify the social (i.e., marriage) class of the principals, for although a common thread runs through all such practices-in cases where the child is allowed to live, that is-there were some marked differences in procedure according to the child's social class.

The most elaborate birth practices attended those of the successor to a politically important district's highest-ranking kin-Title. Here is Henry's description of such practices:

When a queen was about to be delivered of her first child, ${ }^{[10]}$ called the matahiapo, a restriction proclamation was immediately issued similar to that of the pa'i-atua. All on land and sea along the coast throughout the realm must be silenced so that sacredness might reign until the fifth or sixth day after the birth of the child. Except the members of the royal family and their attendants, all the inhabitants retired into the mountain recesses, where they built huts and were at liberty to make fires and live comfortably until the restrictions were over, ${ }^{[11]}$ but not without anxiety for some. For an offering of a human sacrifice must close the sacred spell, and the crafty manslayer, unsuspected, already lurked among them.

A fence was erected and shaped upon sacred ground behind the ancestral marae, the two angles being turned outwards. In the outer space between the angles was erected the fare-rau-maire (maire-fern house), in which the queen was to be delivered of her child; in the inner space on one side was the fare-hua (house-of-the-weak), into which mother and child were to be taken; and in the space on the other side was the fare-noa (ordinary house), where the attendants, a chosen few of near relatives and retainers, were to stay.

While awaiting the birth of the child, the paia (royal family doctor) and many others chanted upu (prayers) for the queen's safe delivery, improvising cheering 
words, according to the circumstances of the case, and appropriating parts of the chant of Ro'o, the famous messenger of the god Tane. When the child was born, the paia said, "Ua muhuta mai nei te atua" (The god has flown hither) and all present extended happy greetings.

The infant was allowed to cry long and breathe freely so as to receive full life (iho) from its mother, after which it was severed with the razor-like outside edge of a piece of bamboo that had grown upon the premises. On such occasions the plant used was said to leap with joy out of the mound to meet the paia as he approached to take it. In the following chant the paia suited his actions to his words:

E ha'apa i te pito o te tama,

Te pito tapu

O te aitu o mahuta mai nei.

Ia roa, ei pito aho roa;

E taaai i te taura ia mau;

Tapu ai i te pito o te tama aitu

I te tipi moa o te ofe rare,

Hui i te pito, te pito rearea,

Ia mama te pito aitu.
Lay hold of the cord of the child,

The sacred cord

Of the god that has flown hither.

Let it be long a cord of life;

Tie it firmly with thread;

Then sever the cord of the child god With the sacred knife of the flying bamboo, Perforate the cord, the vigorous cord That the godly cord be light.

The paia then took a cylindric piece from the heart of the stem of a banana tree from the sacred ground and rolled it over the skin of the child, whom he then anointed well with sandalwood oil. Again he suited his actions to his chant:

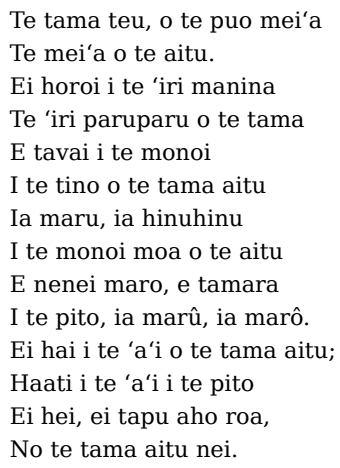

\author{
This is the purifier, the heart of the banana, \\ Banana [tree] of the gods. \\ To pass over the smooth skin, \\ The tender skin of the child. \\ Anoint with oil or sweet odor \\ The body of this child god \\ That it be soft, that it be glossy \\ With the sacred oil of the gods. \\ Squeeze dry, and saturate with oil \\ The cord that is flexible, be dry, \\ For a garland for the neck of the child \\ Encircle the neck with the cord \\ As a garland a pledge of long life, \\ For the child god here present.
}

Soon the babe was wrapped in soft tapa, and after short preparations mother and child were moved into the fare-hua, there to remain for five or six days, during which time oil was frequently used on the child. Everything that they left in the fern house was at once carefully buried close by, with appropriate invocations to render new sacredness to the ancestral center of royalty.

While in the fare-hua the queen's attendants conveyed her food and coconut water to her mourn. The attendants and the nurses of the day wore special clothes in which they never ate or drank for fear of bringing upon themselves king's evil. ${ }^{[12]}$ When off duty they changed clothes in the fare-noa (ordinary house), and they washed or bathed themselves before taking their meals. The father of the child was not admitted into the fare-hua until the last day of its stay there.

When the day arrived for the child to be bathed, the detached cord was carefully wrapped in scented cloth and placed by the paia in a little box formed of one end of a bamboo joint fitted into another, serving as a cover, and hidden away 
in the little chamber for that purpose in the ancestral marae. Such a relic was regarded as the essence of the child.

In the middle of this marae were stacked cratelike for the occasion the family war weapons as emblems of greatness, and in the hollow center of the pile was placed a great leaf of the ape (Alocasia macrorrhiza), forming the basin, which was filled with holy water. Thither the child was taken accompanied by the parents and other elder members of the family, called the hui metua (parental clan), and placed in the arms of the paia, who washed it with the water (uhi-airi), while chanting in the following manner:

Te uhi-a-'iri o te tama o te aitu,

Te uhi-a-'iri i te vai ora o Tane.

Fa'aro'oro'o o te mata'i moa o te aitu

Te mata'i maru o hiti

E ouhia mai nei

Ia manihinihi te 'iri o te tama.

A ti'a Ta'aroa, a ti'a Atea, a ti'a Tane

A ti'a e tena mano atua!

E ha'apa te tama nei i te meho tua

E ha'apa i te meho aro

O pa i ni'a ma te ho-ra'i,

E aitu e, e toa riro!
Bathing the skin of the child of the gods, Bathing it in the living water of Tane. Listen to the wind hallowed of the gods, The gentle zephyr from the east Which is blown this way,

To render sensitive the skin of the child Arise Ta'aroa, arise Atea, arise Tane! Arise, O host of gods!

This child will lay hold of fugitives behind And lay hold of fugitives before

The fort above, mid heavenly shouts,

O gods, a warrior accomplished (is this)!

As a sign of affection the hui metua then punctured their foreheads, and each mingled the purple drops that fell with a mixture of the juice of sugar-cane and milk expressed from grated coconut upon a miro leaf, which they held over their heads, and with a parent leading, they approached in turn the babe, still in the arms of the paia, and touched its cheek with the leaf, but not the mixture, signifying the union of blood. The father then received his child thus initiated into the family circle and embraced it tenderly, conferring upon it a royal name which had been duly and appropriately chosen beforehand, after which he was the first to pay it homage by embracing its feet and saluting it as a member of the royal house and heir to the throne.

This was, strictly speaking, a familial ceremony. Following it the principals congregated at the tribal marae (called, by Henry, "national" marae) to validate the new successor's tribal status:

After the hui-a-'iri ceremony the royal party proceeded to the national marae, where they were received by the high priest and his assistants in full array, who for the occasion were called ti'a-ra'i (stand-by-sovereign). The family assembled in the courtyard, and the babe was passed into the arms of the high priest, who followed by the father and other priests carried it to the avaa of the marae, within which was erected for the concluding religious rite a little awning called a fare'ura ('ura feather house), made of apaa (sweet-scented cloth) from the fare-ia-manaha. The awning was spread over a dome formed of miro sprigs against the stones of the wall and was bestrewn with 'ura feathers attached to it with paste. Upon the paving were spread fine mats, in the same manner as for receiving the image of the tutelar god, and upon the mats the high priest appropriately chanting a prayer placed the child and finally said "Ura epaepa! 'Ura huhu! 'Ura moemoe!” ('Ura unapproachable! 'Ura nurturing! 'Ura reposing!) This simple ceremony was to assert the rank of the child god above all there. 
From the national marae the babe was taken to a comfortable home, called the fare aua teni (house with exalted walls), which was enclosed within high fences or stone walls one within another, accessible only by stiles, and which was guarded by stalwart men armed with clubs and spears, who were ready to slay any daring intruder. There the royal mother and infant remained for about fourteen months or until the child could run about and was ready to be presented to the public. During that time the mother was free to stroll out of the aua teni, leaving the child in charge of some near and trusted relative.

On the same day that the marae ceremonies were performed, messengers, called arere or $t^{\prime}$ ati'a-vea, were dispatched in opposite directions to officially announce the birth and well-being of the child. Each messenger bore high above his head a flag, generally torn off from red marae cloth, called reva hahae (flags torn), in honor of which when they were leaving, a human sacrifice called $e$ ia no te turu i te reva o te ari'i (a fish to prop the flags of the prince or princess), was offered and buried at the national marae.

The flag was set upon the assembly ground of each district of the kingdom as the messenger passed, and there the people were summoned from their retreat by the blowing of a trumpet or the beating of a drum, by persons appointed for the purpose, to hear the message.

When the news was well received by the people they allowed the flag to stand until taken by the messenger, to whom they showed hospitality; but when the news was displeasing, the flag was torn down by order of the chief and gentry, the pole to which it was attached was broken, and the messenger was returned to his master with a challenge to settle the matter in war-a circumstance that sometimes happened in newly conquered possessions, when the people still hoped to recover their liberty.

After the messengers had passed the districts, the restrictions were removed, and it was a time of general rejoicing. Within a few days, great offerings of food, called ma'a-faiere (maternity-food) were brought in and presented to the royal family by representatives from all the districts of the realm, headed by chiefs and chosen orators. Etiquette in regard to precedence was strictly observed, those of most anciently established dignity coming first and those of newly acquired territory coming last. Besides food were presents of 'ura feather wreaths and capes, called 'ura-moemoe ('ura-reposing), specially made by the women of distinction of the realm for the queen and child. Such demonstrations showed loyalty to the royal family and created kindly feelings throughout the land, and the exchange of courteous speeches between the orators of the people and the royal spokesman would have done honor to any people. This pretty custom lasted throughout the Society Islands until annexation to France took place.

When the royal child was taken from the aua teni, a ceremony was performed called vahi apa (breaking the barrier). To give this sacredness, a human victim was offered at the marae. The royal parents and child borne upon men's shoulders then went forth with an imposing pageantry to meet a great throng of loyal subjects, foremost among whom were the chiefs and other dignitaries of the land, who gathered on the assembly ground to pay them homage and who as the royal herald cried "Te Ari'i, te Ari' $i$ " (The Sovereigns! the Sovereigns!), bared their bodies down to the waist and cried "Maeva to Ari' $i$ " (Hail Sovereigns). With courteous greetings and exchange of speeches between the two parties, were presented to the young heir gifts of all the produce of the land and sea. After this introduction the child was taken to the royal abode, called the Ao-ra'i (Skyhouse, or place), to dwell. (Henry 1928:182-188) 
At this point it may be useful to recapitulate the main stages in the events just described:

1. Prebirth imposition of restrictions.

2. Delivery, including first cutting of the umbilical cord, at the fare-raumaire.

3. Uhi-a-iri ceremony at the family marae.

4. Status validation ceremony at the principal tribal marae, accompanied by loyalty ceremonies throughout the successor's tribal realm.

5. Occupancy of fare aua teni for about fourteen months by mother and child heir.

6. Vahi apa ceremony, marking transfer of child heir to its "royal" abode.

In the case of a successor to a very high-ranking kin-Title there followed, in due course, a number of other ceremonies which marked his (or her) coming-of-age, assumption of political authority, marriage, and so forth; these will be described later on, but for the moment let us consider how other children were received into Maohi society.

According to Henry the birth of subsequent offspring of a district's couple of highest-ranking kin-Titles was treated like that of the firstborn, except for the absence of a human sacrificial victim. "But if the first-born child died, the same honors were bestowed upon the next one to make it the heir, and so on with every heir apparent" (Henry 1928:187). As for all others:

The under chiefs, gentry, and people rendered also for their firstborn, all the dignity and honors they could muster without restrictions at their respective marae, all performing the uhi-a-'iri ceremony. The firstborn children of the under chiefs were also entitled to the chieftain honors at the hands of the priests in their own local marae, where they erected an awning covered with sacred apaa, without feathers, called the fare apaa, where the priest invoked upon the children the blessing of the tutelar god. They were also entitled to the use of the sacred flag within their own districts and without human sacrifices. Their subjects brought presents of food, mats, and feather ornaments; but they had no aua teni house.

Exiles in the land performed their ceremonies as they chose along the seashore, erecting upon some rock within the shoal a fare apaa and planting in the sand their banners, if they were people of rank. (Henry 1928:187)

There are many versions of the ritual events marking the receiving of neonates ('aru'aru) into Maohi society. Henry's is the longest and most detailed available, but it omits some features described in other versions, and it is concerned preponderately with individuals of upper-class status. Believing as I do that this set of events constitutes a highly significant aspect of Maohi social relations, I now propose to reproduce as many primary-source 
versions as I have been able to discover-not only to fill gaps in Henry's version but to support my supposition that there may well have been variations in procedure based not only on differences in class but also on differences in locale. Complicating this matter is that the observers themselves differed widely in what they saw and felt worth recording, as is shown in a statement by the otherwise observant J. Forster: "After the birth of a child, they do not observe any ceremonies whatever, excepting that of depressing in some degree its nose, and giving it a name from some object or other which is nearest at hand, or which from some circumstance becomes remarkable" (1778:556).

A greatly simplified procedure marked the birth episode witnessed by the missionary Hassall in 1798:

About 7 o'clock this morning ... there came an old man up to me and I enquired where he was going. He told me for the priest ... his Master's granddaughter was now in labour, and that he was going for him to offer this Child to his god. I Requested the Old Man to call for me when the p. was come, accordingly in about half an Hour he came, and we went together toward the house. When we came within 100 yards of the house I saw the woman under a large BreadFruit tree in the midst of the long grass in greate pains without help, and in the open air, you must needs think, that I was Much affected at the sight. I requested that she might be taken into the house, to which they repleyed that their costoms would not admit it, the house being sacred and if the woman was to go in before the expiration of ten days the House must be Burnt down. After the Child was Born I went towards her and found the Child lieing in the grass, with a cut all across the Cheek, But a fine boy. I asked them to take him into the house and wash him \&c. But they answered, the Child is unclain and will be till it be given to the god twice, after it might go in the house and not till then, upon which they brought the child to the P. [at the marae]. (Hassall to LMS, 28 January 1798, LMS Archives)

While recognizing that many aspects of this event may have escaped the missionary's attention or sense of relevance, his account does establish the fact that some women gave birth out-of-doors (which is also confirmed in other eyewitness accounts). It also suggests that in some instances the ceremony at the family marae took place very soon after birth, which is likewise confirmed in other accounts. (See, e.g., Morrison 1935:186.)

Morrison added the following observation concerning the employment of specialists during a woman's labor:

... such is ... [a Maohi's belief in the efficacy of tahu'a], that they think if one of them is present, and not applied to, that the Mother would never be delivered-but instead of one they have somtimes half a Dozen who facilitate the Birth of the Child by their prayers and offerings, and in return Strip [the expectant parents] of Half they posess without giving them any other Assistance. (1935:182)

In Henry's account no mention was made of the mother's post-parturient bathing; according to Ellis (and others) mothers were induced to sweat 
shortly after giving birth, followed by bathing in the sea. ${ }^{13}$ The process was described by the missionary Crook:

When a woman has born a child it is usual for her to walk or to be led into the sea, here she presses or as it were kneads the abdomen and washes herself clean, after which she retires to her house. [To which has been added the note: "I find it is more common for her husband or some man of her acquaintance to take her by the hands when in the sea and press one foot repeatedly against the abdomen of the woman."] About the second day a temporary house or tent is made into which a number of hot stones are rolled. A quantity of leaves are put on the stones upon [which] the woman is seated and the entrance closed. After some time the woman comes out streaming with perspiration and bathes in the fresh water or has it poured or sprinkled upon her after which she bathes in the sea. This is intended to strengthen her or to remove any pains she may have in her limbs. (Crook, Journal, 4 March 1817, LMS Archives; see also Wilson 1799:341)

According to Ellis, “... the infant was taken to the water almost as soon as it entered the world" (1829:I, 342), whereas Henry implied that this occurred several days after birth. This seeming contradiction may derive from differences in the class status of the principals; otherwise, its significance escapes me.

Much more significant than any of these variations, at least in terms of social relations, were differences in the natal ceremonies performed at the "family" marae. In Henry's account of such rites, reproduced above, four episodes stand out:

1. Deposit of the child's unbilical cord at the marae. ${ }^{14}$

2. Bathing of the child in "holy water."

3. Touching of the child with the mingled blood drawn from both paternal and maternal relatives.

4. Acknowledgement of the child's titular legitimacy by its father.

In another detailed description of natal ceremonies recorded in the sources, the author impled that the uhi-a-iri episode usually took place some six to eight weeks after birth. In view of this and other differences between this account and Henry's, it will be useful to present it in its entirety:

There was, at the birth of a child, first of all a kind of taboo or restriction on the parents. A small shelter was built a short distance from the house. The mother withdrew there with her child, and no one but she and her husband could enter; if some close [female] relative wanted to see the child, she could only come into the hut if she completely disrobed at the door. During the time that the mother nursed her baby in this hut, she herself wore nursing clothing, which she had to leave if she went out and put on again when she reentered. She could neither touch anything nor use her hands except to give her child the necessary care. Other women came regularly to feed her, putting the food into her mouth just as they did with small children. This restriction lasted from six weeks to two months, until the performance of another ceremony, called aroa, which took place in the following manner for all [social] classes: 
The parents in advance laid in a supply of a quantity of tapa (the cloth of the country) and a good number of pigs. With this done, they set the day for the ceremony and invited the Arioi, the chiefs of the district, and the latters' close relatives. When the day arrived, the pigs were killed, a meal was served and the cloth was laid out in two equal parts in the house.... On their arrival the guests found everything prepared for the intended fête.

The Arioi were always most impressive. They came with their faces painted red and white, feathers atop their heads, covered with flowers and ornaments, and chose one of the two lots of cloth; after the Arioi came the chiefs, who took the remaining cloth. Then the roast pigs were brought and a good meal began the ceremony.

As soon as the mother and father saw the Arioi and other guests arrive, they took a large piece of cloth, some leaves of miro (Thespesia populnea), and a shark's tooth and they left with their child for the marae.

Coming near to the enclosure, the husband placed the piece of cloth inside so that his wife could walk on it, lest she should taint the ground of this sacred place. They came together, walking on the cloth, approaching the inner altar, where a priest awaited them; and, as soon as they were seated with their child, the priest began in a loud voice to invoke the gods. In the midst of these prayers, at a given signal, the mother, holding up her son in one hand, struck her head with the shark's tooth held in the other hand, until blood ran copiously from her wounds onto the miro leaves. Then handing the child and the murderous tooth to her husband, he did as she had. The priest then came to take the bloody leaves and deposited them on the altar before the god-images, and the ceremony ended with this offering and some short prayers. Returning to their home with the child, the parents left at the marae the piece of cloth, and this was burned or destroyed in fear that some woman might touch the side which had been in contact with the sacred ground. (Moerenhout 1837:I, 535-537)

In comparing the two accounts it will be noted that Moerenhout made no mention of disposal of the umbilical cord (probably a lacuna in Moerenhout's information rather than a variation in the events themselves); omitted any reference to ceremonial bathing of the child at the marae ${ }^{15}$ (again, this may have been due to a lacuna in his information); specified only the child's father and mother (in addition to the priest) as having taken part in the marae ceremonies, including the symbolically charged rite with blood, omitted Henry's episode of paternal recognition (it is unlikely that this part of Moerenhout's version involves merely a difference in symbolic reference); and emphasized the role of the Arioi in connection with the ceremony. (In explanation, one might suggest that in the case of such upper-class principals as those involved in Henry's account there would have been no need to issue special invitations or commissions to people, including the Arioi, to attend and participate.)

Morrison's version of natal ceremonies is brief, ambiguous, and in many respects incomplete, ${ }^{16}$ but it also adds some interesting details concerning treatment of the neonate's umbilical cord, and, more important, it places natal ceremonies within the wider context of āmo'a, which -it will be recalled (see chapter 3)-was a connected series of rites 
performed at certain times in an individual's life to remove, by degrees, the special kind of ritual constraints imposed upon him and some of his close associates at the time of his birth.

When a Child is born whether Male or Female it is taken to the Family Morai (of Which evry Family have one) by a Person who is employd to attend it while the Mother Goes into a Warm Bath-and the Father and Priests repair to the Morai and offer a Young Pig or a Fowle or two to the Deity, and a Priest, who is well paid for His trouble, Cuts off the Childs Navel String within Six or eight inches of the Belly with (a) piece of split Bamboo and while the others are praying buries it in the Morai. ${ }^{[17]}$ A Temporary hut is then prepared Near the Morai to which the Mother repairs, and the Child is brought to her by the servant appointed to attend it and who must remain there with the Mother \& Child till the rest of the Navel string drops off, which may be either kept in a house Sacred to the Child, or buried in the Morai. If the Child is Male, they May bury the Navel string as soon as it Comes off, which may be Six or Eight days but if Female it is sometimes kept a Fortnight or Three Weeks, during which time the Mother toutches no kind of Provisions herself, but is fed by another person, and whosoever else toutches the Child must undergo the Same restriction till an Amoa is performed to take it off, previous to which an offering Must be Made of a Plantain tree and a Young Pig, or a Fowle or two for the Mother, which is done as soon as the Navel string is buried or the time fulfild for the removal of the Child from the Morai nearer the Fathers House which is built for and sacred to the Childs use, but still they Can not enter that House nor toutch the Child with the same Cloths on which they wear when they (eat) their own provisions - to take off which from the Father \& Uncles, a Second Amoa must be performed and from the Mother \& Aunts, a Third before the Child may Come into a House where its Father and Uncles Eat, a Fourth and for the Mother \& Aunts a Fifth.

If the Child is Male there is one More which is performd when He adopts a Friend, which is the whole required to make his head Free, evry thing he toutches being in his Minority or Sacred State is made Sacred by his toutch and rendered useless to any other. If the Child is Female there are two others, one when she gets a husband that Her Male relations may Eat of the Provisions which he has toutchd, and another that they may eat out of the same Dish and then her Head becomes Free also but she is generally free before these two except her head should toutch any thing.

These Ceremonies when performed for the Males are Calld Amoa only, but for the Females they add Fwhatoe [fa'atoa], signifying something more, as they have one more than the Males-for the Males Hogs or Fowles and Cloth are always (presented) but for the Females if they can not raise them, a Fish will do-but however this is seldom the Case, and they are No way sparing in the performance of these rights and much Feasting then takes place.

Evry thing the Children happen to toutch before these rites are all performd is rendered sacred and thrown in a place adjoining to the House in which they live, and raild in for that purpose; they are always Careful how they go about and should a Childs Head toutch a Tree by the Carelessness of the attendant, the Tree tho ever so valuable is Cut down and destroyed root and branch, and if it should break a limb of another or bruise the Bark in its fall that tree Must be destroyed also; nor must they use the timber for fuel. Some of the Weomen are 16 or seventeen Years old before all their rites are performd, which makes them 
very cautious what house they go into or what things they toutch-but the Men are Generally Made free as fast as the father can get it done which is sometimes by Six Years old and sometimes not till twelve; the Children of People of rank are generally longer before they have all their rites performed, then the lower sort as it has a Grander appearance by being long about \& they always make large Feasts on these Occasions. (Morrison 1935:186-187)

Bligh provided us with another version of birth practices, and with it a clear account of certain of their ramifications:

Tynah as usual dined with me, and this is always a convenient Opportunity to make enquiries; it was particularly apropos to the subject I was on, and have long been endeavoring to get a certain knowledge of, the reason of his not feeding himself.

This circumstance is not confined to the Erree rahigh [ari'i rahi, the holder of a very high-ranking kin-Title, or the sovereign chief of an important district], but is common among all Cheifs who are married and have Children. When the Mother is delivered, the Father, who is always present, has the New born infant given to him before any other person but the Midwife touches it. As soon as he is satisfied with viewing the Child he returns it to the Mother, and from that moment untill the Child is grown up and considered a Man, he never tastes any food or nourishment but what is put into his Mouth by another person.

It is the same with Iddeeah, Tynahs Wife, for about ten Months, when she performs a ceremony Aammo-Aammo [amo'a], which is presenting some Cocoa Nutt, Sugar Cane and a Small bough of a Shrub called Errow-woah in each hand held to her forehead to the Child; this being done she is at liberty to feed herself.

It is the same with the Cheifs of Districts, but the Aammo is performed in a shorter space of time; some people tell me that both the Father and Mother are at liberty to feed themselves in ten Months after the Child is born.

I have mentioned in a former part of the Log that the Son of Marrémarré Cheif of Itteeah [Hitia'a], called Poohaitaiah Otee, was fed at my table the same as Tynah, and I now find without a doubt that it was from the same Cause.

No Common people are suffered to be present at the delivery of the Child [presumably, of an upper-class couple], or rather at the receiving it, for Nature itself is allowed to do all, as I have before Shown. Sometimes a Man and sometimes a Woman receives the Child, but they are always near of Kin or particular friends. They are however not brought under the penance of being fed.

If a Cheif has a Child by a Mana-howne [manahune] or Common Woman it is always killed as soon as Born.

I imagine that the reason of Cheifs not feeding themselves at the Friendly Islands [Tonga] is from the same cause.

This never happens with the Mana-howhes [manahune] or Towtows [toutou]." (1789:II, 43)

More about the rituals referred to in these excerpts will be presented presently, but one further food restriction should be mentioned in this context:

If a woman has a child, the provisions for it must not come in at the same door with the mother's; but there is an opening like a window, through which they are received; and it would be reckoned beastly in the highest degree for her to eat 
whilst she is suckling her child. When they travel, their provisions must be carried in separate canoes. (Wilson 1799:351)

Finally, I call attention to the fact that every child was given a personal name at birth, and in addition some children were appointed to kin-Titles. In view of the complexities attached to these practices, I reserve discussion of them for later chapters.

\section{INFANTICIDE}

Before describing the practical ways whereby the Maohis nurtured their offspring and prepared them for life in their society, I will describe how they destroyed those they did not wish to have survive; which ones they chose for destruction, and why, will be reported in other contexts.

Needless to say, no behavior of the Maohis so horrified the early European visitors as the frequent, systematic, and socially sanctioned practice of infanticide. Ellis summarized these reactions to what he termed, "... the most revolting and unnatural crime that prevails...."

When the Missionaries arrived in the Duff, this was one of the first and most affecting appendages of idolatry that awakened their sympathies, and called forth their expostulation and interference. Adult murder sometimes occurred; many were slain in war; and during the first years of their residence in Tahiti, human victims were frequently immolated. Yet the amount of all these and other murders did not equal that of infanticide alone. No sense of irresolution or horror appeared to exist in the bosoms of those parents who deliberately resolved on the deed before the child was born. They often visited the dwellings of the foreigners, and spoke with perfect complacency of their cruel purpose. On these occasions, the Missionaries employed every inducement to dissuade them from executing their intention, warning them, in the name of the living God, urging them also by every consideration of maternal tenderness, and always offering to provide the little stranger with a home, and the means of education. The only answer they generally received was, that it was the custom of the country; and the only result of their efforts, was the distressing conviction of the inefficacy of their humane endeavours. The murderous parents often came to their houses almost before their hands were cleansed from their children's blood, and spoke of the deed with worse than brutal insensibility, or with vaunting satisfaction at the triumph of their customs over the persuasions of their teachers. (1829:I, 332-334)

Recorded estimates of the numbers of infants destroyed range from three-fourths to two-thirds of all those born. The higher estimate was reported by the mission inspectors Tyerman and Bennet:

While going to Mr. Wilson's, in the morning, we conversed with Mr. Nott, who has resided here from the commencement of the mission, on the subject of infanticide, and learned, with horror, that it had been practised to an extent incredible except on such testimony and evidence as he, and the brethren on other stations, have had the means of accumulating. He assured us, that three fourths of the children were wont to be murdered as soon as they were born, by 
one or other of the unnatural parents, or by some person employed for that purpose-wretches being found who might be called infant-assassins by trade. He mentioned having met a woman, soon after the abolition of the diabolical practice, to whom he said, "How many children have you?" "This one, in my arms," was her answer, "And how many did you kill?" She replied, "Eight!" Another woman, to whom the same questions were put, confessed that she had destroyed seventeen! Nor were these solitary cases. (Montgomery 1832:I, 53)

Ellis' lower estimate is probably more credible, based as it was on a wider sampling of opinions:

In point of number, the disproportion between the infants spared and those destroyed, was truly distressing. It was not easy to learn exactly what this disproportion was; but the first Missionaries published it as their opinion, that not less than two-thirds of the children were murdered by their own parents. Subsequent intercourse with the people, and the affecting details many have given since their reception of Christianity, authorize the adoption of the opinion as correct. (1829:I, 334)

The numbers of infants slain varied widely from parent to parent, such differences having resulted from factors of social class, sect membership, personal predeliction, and so forth-all of which will in due course be discussed; but I have the impression that there was hardly a "married" woman alive who had not lost at least one offspring in this manner. ${ }^{18}$ In addition to the cases described above in an excerpt from Montgomery, there are instances recorded of some women having lost all the children borne by them-including a woman who was reported to have lost sixteen (J. Williams 1837:560).

Even allowing for some exaggeration on the part of observers desirous of emphasizing the magnitude of the pagan immoralities they had to contend with, and hence the glorious dimensions of their conversions, there can be no doubt that a very large percentage of Maohi infants were deliberately slain. The methods of slaying were many. Of these, suffocation, strangulation, and neck breaking were perhaps most frequently employed.

"When an Erreoe [Arioi] woman is delivered of a child, a piece of cloth, dipped in water, is applied to the mouth and nose, which suffocates it" (Anderson, in Cook 1784:158-159). Although Anderson specified this method as applying to infants of Arioi women, it was also used for others. A native's statement recorded in a missionary journal may be taken to imply that some infants had once been suffocated in placental material; Orsmond was told in 1827 by one of his congregation that "We do not [i.e., no longer] strangle our infants as soon as born by putting the placenta on the face" (Orsmond, Journal, 21 September 1827, LMS Archives).

"... they pinched their little throats until they expired" (J. Williams 1837:565). "The infant is strangled by the person who receives it the moment it is born, and from their representing the Act, it appears to me they 
break its Neck by a twist as is the Common Way of Killing a Fowl" (Bligh 1789:II, 79).

Other methods used included stabbing the infant with a sharp-pointed piece of bamboo or bone, treading or stamping out its life, breaking its bones, or dashing it to the ground. ${ }^{19}$ J.Williams' description of one of these (if true!) is as appalling to imagine as it is difficult to interpret:

The moment the child was born, they broke the first joints of its fingers and toes, and then the second. If the infant survived this agonizing process, they dislocated its ankles and the wrists; and if the powers of endurance still continued, the knee and elbow joints were then broken. This would generally terminate the tortures of the little sufferer; but if not, they would resort to the ... method of strangulation. (1837:565-566)

All the sources agree that when infants were killed the act took place within minutes of delivery. The exact timing of the deed is nowhere specified, nor is the rationale for the timing; possibly it took place before the infant had been "... allowed to cry long and breathe freely so as to receive full life (iho) from its mother ..." (Henry 1928:183), but that is mere conjecture on my part. In any case, once the infant was considered to have entered fully into living - by some criteria I have been unable to discover-its life was invariably spared, however strongly some persons may have desired its death:

The horrid act, if not committed at the time the infant entered the world, was not perpetrated at any subsequent period. Whether this was a kind of law among the people, or whether it was the power of paternal affection, by which they were influenced, it is not necessary now to inquire; but the fact is consolatory. If the little stranger was, from irresolution, the mingled emotions that struggled for mastery in its mother's bosom, or any other cause, suffered to live ten minutes or half an hour, it was safe; instead of a monster's grasp, it received a mother's caresses, and a mother's smile, and was afterwards treated with the greatest tenderness. (Ellis 1829:I, 337-338)

As to who perpetrated infanticide, though some evidence exists of there having been persons (male and female) who specialized in the act, there is also ample proof of its having been carried out by the infant's own mother or father-sometimes in common agreement, but perhaps not infrequently against the will of one of them. ${ }^{20}$

When all the principals were agreed upon the desirability of killing an infant, the deed was carried out privately and quietly. The Maohi native Mai reportedly told Georg Forster that infanticide took place in secret "... so that it would not lead to obligatory vengeance" (Mühlmann 1955:116). I am inclined to agree with Mühlmann's view regarding the credibility of this statement of Maj's, namely, that it is a schwindel! But disagreement did occasionally occur, as will later on be described. 


\section{NURTURANCE AND SOCIALIZATION}

It must be noted that there is little evidence of Maohi methods of nurturing and socializing children-certainly nothing approaching the detailed observations essential for valid generalization. Nevertheless, the few scraps of information and inference found scattered throughout the sources will be recorded here on the chance that they may prove suggestive.

I have discovered no general native beliefs about the process of physical nurturance analogous to those underlying the āmo'a rituals mentioned earlier, that is, no verbal formulations concerning the relation between nutrition, growth, and physical development during early childhood. On the other hand it is manifoldly evident that fatness in a child (as contrasted, for example, with physical mobility) was highly valued and actively nurtured. Babies were of course breast-fed, but for how long is not reported. I can find neither references to the presence or absence of wet nurses (although my supposition is that there were some) nor to the practices adopted in weaning. In this connection, it may be recalled that some women who had lost children made it a practice to drain their breasts by suckling small dogs and pigs. Very early in life babies were started on poipoi, a soft puddinglike mixture of mashed breadfruit and coconut cream, which was evidently very fattening. This was not so much as preparation for early weaning as encouragement of corpulence; and later in childhood Maohis were deliberately fattened.

Most accounts of Maohi nurturance practices have to do with the physical shaping of the child's body:

Great care has always been bestowed by the natives upon the development of an infant. It soon becomes hardy, being lightly clad, and being cleansed generally by lightly washing at first, and soon by bathing in cold water. For the first three or four months, when in bed, ${ }^{[21]}$ the child is kept lying on its back with a very low pillow slightly pushed up on either side, not only to flatten the back of the head and keep it from becoming lopsided but also to keep the back straight and allow freedom of motion for the limbs. Prominent bumps on the head are gradually leveled down by frequent rubbing with the finger tips; and a prominent forehead is also ameliorated by gentle pressure with the palm of the hand. Sweet-scented oil, generally of sandal-wood or tiare, keeps the scalp in a healthy condition. It is also applied to the body and limbs when massage is required to rectify defect. For girls, the eye-lashes are bitten short to make them grow long, and the finger tips are rolled between the thumb and finger to make them taper.

The nurses are careful not to strain the spine of the infant. After three or four months, as it gets strong, it is kept much of the time upon a mat on the floor instead of the bed, and then it soon turns and learns to crawl. When the child is first carried in a sitting posture the nurse carefully props its back with one hand, called fa'ati'ati'a (raising), and continues to do so until the child can sit up alone. When it can crawl and walk it is carried sitting astride upon the hip of the nurse, who passes one arm under the child's arm and around its waist to hold it in position, a mode called tuta. (Henry 1928:274) 
An excerpt from Ellis adds further details:

... [infants] were never confined in bandages, or wrapped in tight clothing, but though remarkably plump and healthy in appearance, they were generally very weak until nearly twelve months old.

The Tahitian parents and nurses were careful in observing the features of the countenance, and the shape of the child's head, during the period of infancy, and often pressed or spread out the nostrils of the females, as a flat nose was considered by them a mark of beauty. The forehead and the back of the head, of the boys, were pressed upwards, so that the upper part of the skull appeared in the shape of a wedge. This, they said, was done, to add to the terror of their aspect, when they should become warriors. They were very careful to haune, or shave, the child's head with a shark's tooth. This must have been a tedious, and sometimes a painful operation, yet it was frequently repeated.... (1829:I, 343)

According to Moerenhout: "In the case of the son of a chief, the top of his head was pressed in an effort to give him a prominent forehead, narrow at the top; but in all other instances, regardless of its sex or rank, they flattened the back of the head and the nose, for a flat nose was considered a trait of perfection and beauty on a female" (1837:II, 59).

Even from these scant reports some tentative inferences may be drawn: the Maohis appear to have considered the early months of a child's life crucial for its physical development; physical perfection in an "aesthetic" sense was an important, if not the most important, goal of the adults in tending their infants; little or no effort was made to hasten the infant's behavioral development. Although may persons may have shared in nurturing a young child, it is said to have been primarily the responsibility of its mother (Wilson 1799:328).

Moerenhout characterized the task of nurturing children as follows:

There [in the Society Islands] as in all countries (mothers' main job was to take care of their children) but in that felicitous climate, lying naked and uncovered on the grass or on mats, children are less trouble to their mothers than elsewhere, where constantly changing temperatures and harsh winters require that closest attention be paid to insure good health. We saw above ... the troublesome restrictions imposed upon a mother during the weeks immediately after birthgiving, but that was only a temporary ordeal. An abundance of good milk and of fruits and vegetables (which when made into soft, almost liquid pastes provide a most convenient and healthful food suitable even for the youngest infants) greatly facilitates the task of raising children, in comparison with the time and effort that has to be expended elsewhere under the regime of different customs. (1837:II, 58-59)

Another detail of child-feeding practices was described by Mortimer:

I could not help remarking a custom among the Otaheitean matrons in feeding their children, that seemed to be very extraordinary: this was, after they had given them a certain portion of bread-fruit or other food, they would scoop up two or three handfuls of salt water and pour down their throats, which they would repeat several times in the course of a meal; and however nauseous and 
disgusting such a beverage might seem to us, the little infants used to swallow it with great relish: perhaps this may account for the Otaheiteans being so fond of dipping their meat in salt water, when grown up to maturity; for I observed they preferred it to our dry salt. (1791:48-49)

We turn again to Moerenhout for a general description of the further socialization and training of Maohi children:

Children of both sexes begin at a very early age to [learn] the various occupations inside and outside the household which constitute their "industrial" life.

Without ever being forced to do so, girls nevertheless take pleasure in [accompanying] their mothers in order to learn how to process the bark ... from which fabrics and mats are made. Some girls are reared with great care and with strictest [chaperonage] by their relatives, who do everything possible to improve upon the advantages bestowed by nature. Such girls are kept out of the sun, even when bathing. They leave their fathers and mothers only upon marriage-which, in such cases, rarely takes place at an early age, and then only with someone chosen by their relatives-from which circumstances we might be led to believe the islanders were motivated by some sense of [sexual] propriety; but they themselves attach no importance to this [motive], being moved only by the desire to improve or conserve the beauty of their daughters. (1837:II, 59-61)

Some of the customs described by Moerenhout call for comment and elaboration. His statement about the careful solicitude and surveillance afforded "some" young girls is confirmed in other accounts, but he does not inform us who those "some" were. It would be plausible to assume that treatment of this kind would apply mainly to girls of upper-class status-the "better sort," as some writers liked to put it. As was noted in our discussion of sexual behavior, there were large numbers of girls, of unspecified class, who were anything but chaperoned or protected in the manner described by Moerenhout.

Class status also played a part in the training of boys, at least in formal instruction concerning what Moerenhout termed "religious ceremonies at marae." According to Henry's account, in certain districts there were schools (fare'aira'a upu 'houses for assimilating prayers and chants') presided over by teachers ('orometua) and attended by upper-class boys from near and far. ${ }^{22}$ One of these schools was at Opoa (Ra'iatea) and another was at Ha'apape (Tahiti) (Henry 1928:74-75). Henry provided some insights about the latter in the recorded legend of Hiro the Trickster, who was the giant-sized son of a Ra'iatean chief, and who subsequently became a devotee of Hiro, god of thieves:

While yet a young lad, Hiro went to Tahiti and lived at 'Uporu (Ha'apape) with his maternal grandfather, named Ana (Cave), the senior teacher in the school called Tapu-ata-i-te-ra'i (sacred-cloud-in-the-sky). There Hiro's four brothers had been placed as students, and while he was still too young to join them, he acquired a greater knowledge than they of the chants that he heard by lis- 
tening from outside. Hiro grew so fast that he was soon the biggest youth in all 'Uporu, and one night he stole up on to the ridgepole of the schoolhouse where his grandfather, who was blind, was teaching, and this he continued to do during six consecutive nights, at the end of which he had absorbed into his person all that was taught in the school. When he was admitted as a student he recited all the chants so well that the teachers were amazed, and his grandfather said that there was nothing more in the school for him to learn. It is said that Hiro's pastime at 'Uporu was to play with sand, which he easily heaped up into hillocks which are still standing along the shore. (Henry 1928:537)

I have already devoted some pages to children's games and to the ways in which boys and girls learned to sing and dance and play their roles in sexual relations; and I have given some observations about boys' training for war. As for technical training in subsistence activities, J. Forster had the following to say-based perhaps as much on a Rousseauean ideal as on actual observation, but probably not far from the truth, except for the last assertion:

The first notions necessary for the way of life now in use in these islands, are instilled into the tender minds of the children by their parents: these notions may be divided into various branches, as varied as the objects are to which they relate; the more universally necessary objects of all nations, are food, raiment, and shelter against the inclemencies of the weather; the operations therefore relative to food, dress, and habitation are the first, which are taught the children by their parents. As these nations have not yet a multiplicity of artificial wants, and as their time is not yet taken up with any business more material than the three enumerated articles, their manufactures are in consequence very simple, and undivided in many branches; nay, they are all thought necessary for every individual in these isles, and for that reason every child is instructed in the best methods of cultivating the bread-fruit tree, the plantane-stalks, the roots of yams, and other eatable roots; the most expeditious ways for catching fish, the proper season and bait for each kind, and the places which they haunt and resort to, are told to their children; nay, all the fishes, shells, and blubbers, which in any ways may with safety be eaten, are named and shewed to them, together with their nature, food, haunts, and qualities; the devices for catching birds, for rearing dogs, swine, and fowls, and all the names of spontaneous eatable plants are communicated to their youths, together with their seasons and qualities; so that there is hardly a boy of 10 or 12 years old, who is not perfectly well acquainted with these articles. But as the bark of the mulberry tree, requisite for raiment, must be cultivated with a great deal of care and application, their youths are well instructed in the methods necessary for that purpose: and every young woman is early instructed in all the operations requisite for manufacturing and dying their cloth, and likewise in those of making mats, and other parts of their dress. The wood which is best calculated for building a house, a canoe, or other utensils, together with every operation for erecting a habitation, for making the various parts of a boat, and for navigating it by paddles or sails, are understood by every person, from the last toutou to the first chief of the land. In short, there is not one mechanical operation, which they do not teach to every youth, and which, after some time, he is not capable of executing with as much adroitness and skill as the best and oldest man in the nation. (1778:439-441) 
This same writer also commented on a kind of "technical" training undergone by girls:

In O-Taheitee, and its neighbourhood, the women are possessed of a delicate organization, a sprightly turn of mind, a lively, fanciful imagination, a wonderful quickness of parts and sensibility, a sweetness of temper, and a desire to please; all which, when found connected with primitive simplicity of manners, when accompanied with a charming frankness, a beautifully proportioned shape, an irresistible smile, and eyes full of sweetness and sparkling with fire, contribute to captivate the hearts of their men, and to secure to them a just and moderate influence in domestic and even public affairs. We find the women esteemed at O-Taheitee, and its neighbourhood; they mix in all societies, and are allowed to converse freely with every body without restriction, which enables them to cultivate their minds, and to acquire the polish, which afterwards contributes to improve the manners of their young men; for, as it is one of the chief points of female education, in these happy isles, to learn the great art to please, they are instructed in all the means of gaining the affection of the males, of studying every winning art, and of habituating themselves to that sweetness of temper which never fails to merit the return of attachment, of friendship and love. (J. Forster 1778:422)

Turning now to the family setting in which Maohi children acquired their attitudes and skills, a statement by Ellis typifies the opinion of most observers that "In general, they are too tender towards their children, and do not exercise that discipline and control over them which the well-being of the child, and the happiness of the parent, requires" (1829:I, 341).

In contrast with this view, however, is one described by J. Forster:

... before [children] attain [the] age of discretion and maturity, the fond parents take peculiar care of their education: they frequently check the wild flights of their unruly passions, and instill order, moderate industry, and the principles of benevolence and gratitude into their tender minds. I have seen mothers punishing obstinacy and disobedience, and though extremely fond of their children, they nevertheless are sensible enough thus far to do violence to their own feelings, that their children may not acquire a habit of ingratitude, obstinacy, and immorality; I have likewise heard them expostulating with their unruly little ones, and expressing their displeasure at their conduct; all which proves that they have ideas of moral rectitude, of order and filial subordination, and of the necessity of instilling these principles early into the minds of their children. (1778:351)

I shall reconsider this topic of parent-child relations in other chapters, but now I shall discuss the less mundane, more ritualized events undergone by individual Maohis during their early years of life.

\section{MATURATION RITES}

\section{Tattoo}

All, or nearly all, young Maohis submitted to the tattoo (tatau) needle during the early years of their lives. Boys began being tattooed at age thirteen to fourteen, as judged by most of the Europeans, although Ellis said it was 
much earlier in some, unspecified cases: "They usually began to impress these unfading marks upon their persons at an early age, frequently before they had reached the seventh or eighth year" (1829:II, 464). On the average, tattooing of girls began somewhat earlier than did tattooing of boys. According to Moerenhout girls began being tattoed at 8 to 10 years of age, at which time they also began to wear clothes (1837:II, 122). Robertson stated that boys began being tattoed at sixteen, girls before they were twelve or thirteen, after which, "I suppose they look upon themselves as men and Women" (Robertson 1948:211). J. Forster added the interesting (but nowhere else confirmed) statement: "As soon as they [marks of puberty] appear, the young women are obliged to [be tattoed]" (J. Forster 1778:434).

I quoted in chapter 6 a passage from Banks describing the technique. Here is Morrison's general description of the operation:

The Tattowing is performd at the pleasure of the Partys who have it done and will not suffer the performer to leave off while they can bear a stroke, tho they make such a lamentation while they endure the pain that a stranger would suppose it was doing against their will and that they were forced to suffer it contrary to their Inclination. The young females are more remarkable for bearing it then the Males tho they cannot suffer more than one side to be done at a time and the other may remain perhaps for a Twelvemonth after before it is finishd, till which time they never Conceive themselves Company for Weoman-being only Counted as Children till they have their Tattowing done-While the Girls are having it done they are always attended by some of their female relations who hold them while they struggle with the Pain and keep their Cloaths from being kikd off and should they from their tears draw pity on themselves and the person who holds them should perswade them to leave of(f) they are often in such a passion as to strike even their Mother if she should happen to be performing that office, which she must not return on pain of Death-they often suffer so much to be done at once (through their Pride it being a disgrace to give out till one side is finishd) as throws them into a fever. (1935:221-222)

Banks' account of a tattooing episode he witnessed gives a somewhat different picture of who constrains whom in order to complete the operation. (Neither Banks' nor any other account throws light on Morrison's intriguing statement about a mother being prohibited from striking back at her daughter "... on pain of Death").

This morn I saw the operation of Tattowing the buttocks performd upon a girl of about 12 years old, it provd as I have always suspected a most painfull one. It was done with a large instrument about 2 inches long containing about 30 teeth, every stroke of this hundreds of which were made in a minnute drew blood. The patient bore this for about $1 / 4$ of an hour with most stoical resolution; by that time however the pain began to operate too stron $(\mathrm{g}) \mathrm{ly}$ to be peacably endurd, she began to complain and soon burst out into loud lamentations and would fain have persuaded the operator to cease; she was however held down by two women who sometimes scolded, sometimes beat, and at others coaxd her. I was setting in the adjacent house with Tomio for an hour, all which time it lasted and was not finishd when I went away tho very near. This was one side only of 
her buttocks for the other had been done some time before. The arches upon the loins upon which they value themselves much were not yet done, the doing of which they told causd more pain than what I had seen. (Beaglehole 1962:I, 309)

Tattooing required special skill and was practiced by specialists (tahu'a tatau), who were paid well for their services-precisely how much we are not told, but enough so that some were able to "... make it a Trade and subsist partly by it" (Morrison 1935:220). The operation was carried out at shrines dedicated to the supernatural inventors of the practice, whose aid was thereby invoked. Henry offered two versions of the origins of the practice:

In the genealogy of the gods, Tohu was named as the god of tattooing. He was supposed to have painted the fishes in beautiful colors and patterns, which human beings imitated upon themselves, and so men who made tattooing their profession invoked Tohu to aid them in their work. They were called ta-tatau [tātatau] (tattoo-adepts). (1928:234)

According to Tahitian folklore, tattooing originated among the gods, in the pô (dark period), and was considered highly ornamental and pleasing to themselves and to man. It was invented by Matamata-arahu (Printer-in-charcoal), who was aided by Tu-ra'i-po (Stander-in-dark-sky) or Ti'iti'i-po (Fetcher-in-darkness) - two gods who were of the body of artisans of Ta'ere, god of all skill,-and Hina-'ere'ere-manu'a (Gray-the-hasty-tempered), eldest daughter of the first man and woman, Ti'i and Hina, whom they succeeded in abducting from an enclosure where she had been closely kept by her parents by exhibiting the patterns upon themselves to her great admiration and selfforgetfulness.

At the shrine of Matamata-arahu and Tu-rai-po the tatatau or tahu'atatau (tattoo artist) always performed his work, invoking their aid in its execution and the healing of the perforations. His art was most remunerative, as people in days of yore thought such marks set off their beauty and dress. (1928:287)

There are no reported instances of collective tattooing, although Ellis stated that tattooing was accompanied by "idolatrous ceremonies" which included "the practice of abominable vices"; he did not specify what these latter were. (They were "abominable" enough, however, to incur the strong opposition of the missionaries, who placed the whole practice of tattooing high on the list of prohibited heathen customs.) One indication of the ritual aspect of tattooing lies in the fact that "the tools used for the first time on a Chief or the heir of a large family must be destroyd as soon as they are done with, and deposited in the Morai ..." (Morrison 1935:221).

Part of the rationale for tattooing was undoubtedly aesthetic, as some statements in the above excerpts plainly reveal; but the tattoo evidently served also to signal an important change in the individual's "social maturation"-for example, see Morrison's statement just quoted regarding the necessity for girls to be marked in order to be considered "Company for Weomen."

Finally, in addition to this general relation between tattooing and social maturation, one particular kind of tattoo sign served to mark progress in 
completion of the head-freeing rites, mentioned earlier, at least in the case of "Chiefs or the heir of a large family":

... when all the Amoas (except those of Marriage or freindship) are performd they receive a small spot [i.e., tattoo mark] on inside of each Arm Just above the bend of the Elbow which signifies that they are free to eat and drink of their parents food \& that Contrary their parents may eat of theirs; this Mark they Never receive till these rites are performd, nor is it always done, at the time of the last being performd. (Morrison 1935:221)

\section{Supercision}

In addition to being tattooed, boys were subjected to circumcision, or rather supercision (tehe), the operation having been limited to slitting rather than removing the foreskin. The slit was made in the upper part of the foreskin by means of a shark's-tooth knife, and ashes were applied to the wound to stop the flow of blood.

Morrison reported that the operation was performed on boys of about thirteen to fourteen years of age (Henry said fifteen to sixteen), and that, like tattooing, it was "... at their own option" - with the qualification that "... a person who is deficient of either is reproachd and told of it in Public and it is as bad to want these marks [tattoo and supercision] as it would be among us not to be Christened or to go Naked, tho some want both" (1935:220). ${ }^{23}$

As were tattooing experts, those who specialized in supercision (tahu'a tehe) were remunerated for their services. ${ }^{24}$ Morrison asserted that both tattooing and supercision were carried out by the same specialists, and that the latter was performed "... not from any religious Custom but from a Notion of Cleanlyness." Banks evidently held the same view, but neither he nor Morrison offered evidence that this explanation was a native one.

Whether or not supercision was a "religious Custom," it undoubtedly took place in a ritual setting:

... it was formerly a religious rite accompanied with prayer at the ancestral marae, at which the father and other male relatives of the lad assisted, sympathetically puncturing themselves freely with weapons of shark's teeth and causing the blood to flow.

For an heir apparent to the throne, one or more human sacrifices were offered by the priests at the national marae, while this rite was being performed at the ancestral marae. Several human victims were suspended with sennit strings strung through the ears, as "Oro's fish," as they were hung upon the toa tree around Tarahoi for Pomare II, under the direction of the high priest Tua-roa. (Henry 1928:188)

\section{Fattening}

Mention has already been made of the Maohi practice of fattening (ha'apori). The process of forced fattening here described was usually accompanied by skin bleaching, both deliberate and coincidental; except, however, for the aesthetic value associated with light pigmentation, the 
fattening aspect of this activity seems to have been more important. Individuals went through these regimens at various times of life, according to inclination and material means; not everyone, perhaps, could have afforded the luxury of weeks of unproductive leisure and continuous gluttony. For example, in discussing the atoll, Tetiaroa, Ellis described it as

a kind of watering-place for the royal family [i.e., the chiefly dynasty of Tahiti's northwestern districts], and a frequent resort for what might be called the fashionable and gay of Tahiti.-Hither the areois, dancers, and singers, were accustomed to repair, together with those whose lives were professedly devoted to indolent pleasures. It was also frequented by the females of the higher class, for the purposes of ha'apori, increasing the corpulency of their persons, and removing, by luxurious ease under the embowering shade of the cocoa-nut groves, the dark tinge which the vertical sun of Tahiti might have burnt upon the complexions. (1829:I, 173; see also Henry 1928:76)

The period of their teens (according to the European system of age reckoning) seems to have been the one especially devoted to fattening-indeed it is possible that such forced fattening constituted a more or less universal and ritualized episode in the maturation process. As I will describe later, it is also possible that such forced fattening constituted, more specifically, a step in a member's advance through the grades of the Arioi sect, but I refer now to the possibility of the activity having had more general, society-wide applicability. Both young men and girls were systematically fattened, presumably separately, but the best available account of such activities involved only young men:

In the morning there came a large number of youths, of good parts, to present themselves before their arii Vehiatua in accordance with a certain usage and custom they have. This custom is that at certain times, or Moons, the youths of each district meet together and repair to one of the large sheds they have for keeping their big canoes under, such as they employ when they go to war with another island. On being ensconced therein, and provided with their eatables, they lay themselves down in the dry grass spread for the purpose, and a wrap that each one brings serves him for pillow and covering.... They do not get up except for their bodily necessities; they eat and sleep as much as they can. An old man serves them with meals: they go on in this way for the space and time of one moon in order to grow fat and lusty and high-spirited.

When the period of fattening is completed they get up and anoint their bodies all over with coco-nut oil; and fix plaits of palm leaves on to their heads which, when placed above the forehead, keeps their faces shaded from the sun when it shines on them. They furthermore gird themselves about with a long strip of native cloth of various colours, over the breech-clout. Got up in this guise they march to the arii's house, on nearing which, but before reaching it, one of them who acts as their leader takes up a position in front of the fattened ones and gives utterance to loud yells until they all arrive opposite to the doorway of the house. The leader enters alone, to report to the arii and render an account of all the fattened ones, whom at the same time he announces as having come to make their obeisance before him, naming each one separately by his name and the district 
he comes from. He then immediately delivers to the arii the wraps of bark-cloth that the fattened ones present to him; while the bystanders rush forward with a lot of clatter and yelling and rip off the parti-coloured girdles, leaving the fattened ones with only their breech-clouts on. (Corney 1915:329-330)

Some additional details regarding this episode are contained in the journal of Rodriguez, who also witnessed it:

They lie there enveloped in wraps of native cloth, their waists unconfined by any girdle, until called up by their arii, when they put it on and say this word Ehuapipi, which is the day for this function ... (Corney 1919:135).

There was a great gathering of people in connection with the function of presenting the fattened up youths before him [the ari'i Vehiatua], which they call Ehuapipi, as was said before (pp. 155-156).

Huapipi, according to the LMS Dictionary, is the term applied to "the youth called pori [fat], who were fed for some time to make them fair and delicate," and not to the presentation occasion itself. The same dictionary offers as one meaning of pipi, "a disciple, a learner, or pupil," which is suggestive, but this possible and very interesting indication of the role of the youths during their fattening is not augmented by any other information that I know of. ${ }^{25}$

While references to the forced fattening of females occur in several of the older sources, the most detailed account of the practice was written by Moerenhout, in 1832:

Today going by the house which [Queen Pomare IV] occupies with her women and servants, I saw several large poles erected and festooned with plantains. On inquiry about their use, I was told that they were intended for fattening up the queen and her companions.

According to an old custom in these isles, plumpness was considered a mark of aristocratic beauty. To accomplish this women were fed popoi: fruits, bananas, and mashed breadfruit mixed with water and made into a semiliquid. During this time, all exercise was interdicted; they were allowed only to walk to bathe themselves in the river. Before appearing again in public it was customary for them to undress and be inspected by men; after which they became the object of admiration by young men, and were sought after more than ever. I cannot say whether nowadays their movements are subject to such strict control as formerly ...; but as regards the other aspects of the custom, I believe everything is carried on just about as in olden times. (1837:I, 286-287)

The Maohi custom of ha'apori provides a fertile field for speculation, and one that has been well sown. Perhaps the most ingenious explanation for the custom is that of Mühlmann, who suggested that with respect to young males it represents a ritual simulation of "femaleness." Another possible, but less imaginative, explanation of the forced fattening of young individuals, both males and females, is that it embodied the Maohis' Lamarckian theories of reproduction and served to implement their eu- 
genic ideals. Still another possibility (but in my opinion, not a probability) is that it constituted a manifestation of material affluence, a characteristically Maohi expression of conspicuous consumption. But whatever other purpose-sectarian, eugenic, social-the custom may have served, it was also quite directly and overtly cosmetic; plumpness of body (and lightness of complexion) was aesthetically valued and, in the young, at least, sexually relished.

\section{Coming-of-Age}

In addition to the foregoing "maturation" rites (which probably all or most young Maohis underwent), Henry described another one evidently performed only for the successors to high-ranking kin-Titles or to other heritable statuses of social importance:

When the young heir apparent became of age a feast, called the fa'atoira'a (becoming-of-age), was given at which he or she for the first time appeared officially among the dignitaries of the land. On this occasion was offered a human sacrifice called an amo'a-tapu (putting aside of restriction). For the firstborn of under chiefs there was also a fa'atoira' $a$, and their amo'a-tapu consisted of a fine hog offered at the local marae of their district.

As the Tahitians had no method for recording the years, coming of age depended upon the maturing of the child. (1928:188)

Here again in this passage is reference to the custom of $\bar{a} m o^{\prime} a$, which was mentioned earlier but which I will now discuss more fully.

\section{$\bar{A} m o^{\prime} a$}

In my account of the rituals accompanying birth and early childhood, I included some descriptions of āmo' $a$, which I identified as "a connected series of rites performed at certain times in an individual's life to remove, by degrees, the special kind of ritual constraints imposed upon him and some of his close associates at the time of his birth." I will review and supplement those descriptions, and attempt to explain them.

The most explicit reference to àmo' $a$ is contained in Morrison's journal, where, it will be recalled, several such rites were listed: six for males and seven for females, the first five of these being about the same both for males and females.

The first āmo'a was performed upon disposal (by burial or deposit in a "sacred house") of the umbilical cord that was left attached to the child after its original severance. In the case of boys this remnant was disposed of as soon as it dropped off, i.e., about six to eight days after birth; but in the case of girls it was disposed of seven to fourteen days after it dropped off. After performance of this āmo' $a$ the child and its mother moved from the temporary shelter erected for them near the marae (Henry's fare hua) 
into the more permanent house built for them-"nearer the Father's House" (Henry's fare aua teni).

Prior to performance of this first (according to Morrison's listing) àmo' $a$, the child's mother "toutches no kind of Provisions herself, but is fed by another person and whoseoever else toutches the Child must undergo the Same restriction ..." (Morrison 1935:186). From this account one might conclude that after this āmo' $a$ had been performed the child's mother, at least, was not required to be fed by others, but Bligh reported that in the case of one woman, herself the transmitter of a very high-ranking kin-Title, this self-feeding restriction was lifted by an ämo' $a$ performed some ten months after the birth of her child.

Henry's description supplements this one of Morrison's with the information that the attendants serving the mother and child on such occasions had to bathe and change into other clothes before they themselves could eat or drink, in order to avoid contracting the scrofulous disease, called o'ovi ari'i. Also, the child's father was not admitted into the fare hua "until the last day of its stay there" (1928:184)—until he formally "received" the child in the course of the ceremony terminating this stay in the fare hua.

Moerenhout's account has the child's mother and father attending it during this period, but he may have been referring to families of less social eminence, with whom the ritual constraints were customarily less severe. Also, it should be recognized that Moerenhout's account of the rituals under discussion is less detailed, and probably more indirectly transmitted, than the others drawn upon here.

By Morrison's account the second, third, fourth, and fifth àmo' $a$ rites, for both males and females, were performed during the infant's occupancy of the house built for it near its father's household (the one we believe to be Henry's fare aua teni); an occupancy that Henry said lasted about fourteen months.

Throughout this period, it appears that certain of the child's kinfolk (mother, father, "uncles," and "aunts") were allowed access to the house but were constrained from entering it (and from touching the child) while wearing clothes in which they were accustomed to eat. Thus, to remove this constraint two other āmo'a were performed: the first to free the child's father and "uncles," the second to free its mother and "aunts." Meanwhile, "... the mother was free to stroll out of the aua teni, leaving the child in charge of some near and trusted relative" (Henry 1928:185).

The child was not permitted access to other sleeping (and eating) houseunits of the familial household until two other àmo' $a$ had been performed: one to permit it to enter the house reserved mainly for the males, and the second to permit it access to the house reserved mainly for females. 
Henry reported that a ceremony called vahi apa ('breaking the barrier') was performed at the time a "royal" child was moved-permanently, we assume-from the fare aua teni into the regular family household (1928:187). I am not sure whether this ceremony may be considered identical with, or in addition to, the "house-entering" āmo' $a$ rites just listed. In any case, the latter two rites do seem to be the ones referred to by the missionary Hassall, quoted earlier, who was told that a newborn infant was "unclain" and hence unable to be taken into its parents' house "till it had been given to the god twice."

Before discussing the next āmo'a rites listed by Morrison I wish to examine another aspect of āmo' $a$ customs, namely, the self-feeding prohibition that was imposed upon the fathers of certain children during the latters' early lives. Among the several sources that refer to this prohibition Bligh's is most explicit, but even his account concerns only "cheifs," so that we do not know whether they alone, or all fathers, were thus constrained. ${ }^{26}$ Neither do we know for certain whether the prohibition was imposed with respect to all of a man's recognized offspring, or only to the first (or first male). In any case, however universal in applicability the prohibition may have been, its application evidently varied widely, both in terms of the relative rank of the principals' kinTitles and of the fathers' ambitions to enhance their successors' social positions. According to Bligh, ari'i rahi ('great chiefs') observed the prohibition "untill the Child is grown up and considered a Man," whereas mere "Cheifs of Districts" ended the prohibition by performing an ämo' $a$ about ten months after the child was born. I cannot discover what constituted the prohibition-lifting rite in the case of the $\operatorname{ari}^{\prime} i$ rahi, but I assume that one of the $\bar{a} m o^{\prime} a$ listed by Morrison (possibly the second) served the purpose in the case of other fathers.

Continuing now with Morrison's description of the àmo'a series of rites, it will be recalled that the sixth (and last) one said to have been performed for a male was "when He adopts a Friend, which is the whole required to make his head Free, evry thing he toutches [prior thereto] being in his Minority or Sacred State is made Sacred by his toutch and rendered useless to any other" (1935:186).

The terminal ämo'a rites for a young girl were performed on the occasion of her marriage. This àmo'a served specifically to enable her male kinsmen to eat food touched by her husband and "that they may eat out of the same Dish...." While recognizing its ambiguity, I take "they" to mean the young woman and her husband.

In addition to these àmo'a rites specified by Morrison there appear to have been others performed on behalf of individuals holding certain very high-ranking kin-Titles-including the one carried out during the comingof-age ceremony described earlier and one (if it was in fact separate) 
performed to relieve certain incumbents of the necessity of having to be carried over land not exclusively their own. But enough has been presented to permit us to proceed with a general discussion of these puzzling rites.

Three crucial questions arise from what appears to be this interconnected series of rites:

1. What attribute was attached to the child at birth that served to place the child in a special condition and that could be neutralized, by degrees, by certain rites?

2. What effects did this special condition of the child have on his own and others' behavior?

3. What was the nature of the rites that served to neutralize or remove the attributes in question?

Let us take up the second question first, inasmuch as the sources provide more specific answers to it. Morrison, in the last paragraph of his description of natal and other rites (reproduced on p. 422, above), provided a clue that is both succinct and comprehensive.

Ignoring for the moment the last portion of this informative statement, we are left with the information that while in this condition the child's body in general, and its head in particular, contained something that was somewhat dangerous to other people with whom it happened to have direct or indirect contact. Moreover, while the something produced its harmful effects over any and all parts of the contacted person's body, the victim's digestive organs were particularly vulnerable, as witnessed by the emphasis on food and feeding in the prohibitions associated with this condition. Perhaps the relevant factor here was not the stomach and intestines in their function in digestion but rather their proximity or identity with the seat of the soul.

How indirect the contact could be and still be effectively dangerous seems to be exemplified in one of the final rites for a girl which, it will be recalled, made it safely possible for her male relatives to eat food touched by her new husband, who, because of his intimate sexual contact with her might otherwise have conducted some of her dangerous something to them. This is the most plausible explanation I can offer for this curious custom. Her female relatives would not have been concerned, since ordinarily they would not have partaken of the same lot of food as did her husband.

By the same line of reasoning, I suggest that the performance of an àmo' $a$ rite upon the occasion of a boy entering into a formal "friendship pact" was necessitated by the circumstance that the two would thereafter share food and other possessions in ways that involved direct and frequent physical contact.

Two other problems raised by the foregoing are less amenable to explanation. One has to do with the consequences of bringing into contact 
two individuals in the same danger-laden condition-say, two lads of comparable social position and ritual experience: Would contact of such a pair have produced any mutual effects? The only evidence I can discern on this point has to do with the separate common households that were set up for the exclusive rearing of certain sets of siblings who were the progeny of socially prominent couples. While still in the ritual condition under review, such sets of siblings evidently played together and may have eaten together as well.

The second problem has to do with the possible two-way effects of contact between two persons, only one of whose "head was free." Having established that the one whose "head was free" suffered some ill effects from such an encounter, is there any evidence that the reverse also took place? Something of the sort probably was thought to occur in somewhat analogous ritual situations (see chap. 3, section on sacredness), but I can find no evidence of such in the kind of encounter now being described.

I turn now to the first of the three crucial questions posed earlier: What was the nature of the attribute that served to place the child (or some children, at least) in the ritual condition we have been describing?

It seems clear to me that we have here an entity that was, in Western terms, more "mystical" than "physical." (As I understand Maohi "thought" categories to have been, these too included such a distinction, although the boundary was not so sharply drawn.) Moreover, in reviewing the whole range of Maohi "mystical" beliefs and practices, I suggest that there were two kinds of attributes that might have been involved in the condition now being discussed; a something that was polluting, derived mainly from the mother, and a something that was sanctifying (but equally dangerous to others), derived from either or both parents, or from some other source.

The possibility that beliefs about mother-derived pollution may have figured in some àmo'a rites is suggested by other Maohi beliefs and practices (and by analogies from other Oceanic societies which I shall not document here). I refer to all females' generic ritual condition of "secularity" (noa) discussed in chapter 3 and to certain specific ritual acts discussed above, such as the mother's bathing after parturition and the neonate's "purification" with the heart of the "sacred" banana tree, both of which seem to have been aimed at removing menstrual and allied matter. ${ }^{27}$ The ceremonial bathing of the skin (uhi-a-iri) also could be viewed as a "purificatory" rite, although the ritual formula describes it as "rendering sensitive (manihinihi) the skin of the child" (Henry 1928:184). ${ }^{28}$

The other kind of entity or attribute that might have been involved was that of $\mathrm{ra}^{\prime} a$ or $\mathrm{mo}^{\prime} a$, which I gloss as 'sacredness' (in opposition to 'secularity', or noa). In this sense, the àmo'a rites could be viewed as measures for reducing by degrees the amount (or intensity, it is not clear 
how the Maohis conceived of this process) of sacredness present in the neonate at birth, so as to render the young person free to engage in the ordinary, everyday-secular-activities of life, without thereby endangering other persons. How such sacredness became attached to the child is suggested in the following passage from Morrison:

The reason for all these Ceremonies are that as soon as a Child is born it being the Fruit of the Father and Mother is superior to either, as Much as the Fruit is to the Tree for food, for which reason the Child is as soon as born the Head of the Family and the Honor and Dignity of the Father is transferd to the first born Child whether Male or Female, and before all these rites are performd the Parents are not thought worthy to partake of its Food, but as they have always a sufficient provision for themselves and have the ruling for their Children those of High Rank defer the performance under Collour of its being Grand to have their Children longer in a Sacred State, tho in fact it is that they may Continue longer in Power, but those of low degree have no intrest in it and therefore get it done sooner, and as soon as the Childs head is free it then becomes perfectly its own Master and May act for it self-Where this uncommon Custom, so contrary to Nature, took its rise we could never learn, it having been with them from time immemorial.... (1935:187) ${ }^{29}$

Thus, the something in the child that rendered it "sacred" and socially "superior" to both its parents was in fact derived from them and in a combinational way.

Moreover, there are clues as to what that something was-at least, in the offspring of parents holding high-ranking kin-Titles. I refer in part to phrases used in certain of the birth rituals in which the child is addressed or referred to as "child god" (tama aitu) or as "child of the god" (te tama $o$ te aitu). This usage of course could be merely eulogistically metaphoric, but there is a good possibility that it is more than that. There is evidence of a belief that certain children-namely, the firstborn offspring of parents holding very high-ranking kin-Titles-were in fact sired by some god. Bligh reported:

I have had many conversations with Tynah and many of the principal people but it requires a length of time before one can take up a thing with clearness and precision. A Strange circumstance however has long been my enquiry, and I have now no reason to doubt of the Peoples beleif of the Assertion, and that is, that the Queen, whoever she is, has her first Born Son, or the one that becomes the Heir to the Crown, through the inspiration of the Eatua. Nay more than that, they assert that while the Woman is asleep and the Husband by her, the Eatua hovers over her, and literally explaining their expression, says he has connection with her \& she conceives, but that all the other children are begot by the Husband. Yet they imply nothing more than that it was their God that gave them a King, without whose assistance they would have been without one. (1789:II, 24)

If $a m o^{\prime} a$ rites were performed only for such god-sired offspring as these, one would need to search no further for the rationale behind them; but the 
fact is that they were carried out for many other offspring who were viewed as having been sired specifically by the mother's human mate. From these considerations (and from certain cosmogonic and sociogenetic beliefs) I am led to the conclusion that the something, which was transmitted to offspring by their parents, that necessitated the performance of àmo' $a$ rites was not just a quality of sacredness $\left(r a^{\prime} a\right)$ derived from association with a spirit (in this case, a god), but a portion of some god himself. Thus, the āmo' $a$ rites, strictly speaking, may be viewed as either neutralizing or reducing the divinity in the child.

I wrote àmo'a rites "strictly speaking" because I believe that some of the rites I have been discussing-in particular, some parts of the earlier ones-had to do also with purification (specifically, with the ridding of entities associated with menses); but the other components of the ritual condition of the child (and the constraints upon others resulting from it) I believe to have derived, ideologically, from the divinity incorporated in the child at conception.

As we have seen, the offspring of parents holding high-ranking kin-Titles remained in the condition under discussion longer than did children of parents holding Titles of lower rank, partly through the common logic of kin-Title ranking (see chap. 16), and (according to Morrison) partly by "voluntary" design, but by design that sometimes sought its charter in "selfappraised" rank. I cannot discover how far down the social scale àmo' $a$ rites were deemed necessary, but according to Bligh, the associated prohibition on a father's self-feeding obtained only at the top level. It should be recalled that however male-biased Maohi social relations may have been in some respects, in the case of amo' $a$ some girls remained thus distinguished from the rest of the population as long as or longer than boys of otherwise comparable social position.

I will now consider the mechanics of the ämo'a rites, to try to learn how their various objects and actions were supposed to neutralize (or to reduce) the divinity present in the child whose "head was not yet free." But my efforts are frustrated at the outset by uncertainty concerning what those rites actually were.

Morrison, who designated the head-freeing rites as àmo' $a$, for males, and "Fwhatoe" (fa'atoi), for females, actually described only two of them: one performed at a marriage ceremony, and one performed "When a Man adopts a Friend for his Son":

The Amoa we saw thus performd at a Marriage Ceremony, and differs very little from that performd through the different degrees of Childhood-The Friends of Both parties being assembled at the Morai the Young Man and his Wife were placed on a large quantity of Cloth spread for the Purpose Near the 
Morai alongside of each other, the Man on the right of His Wife-opposite them at the Distance of 30 or 40 Yards and at the other end of the Cloth sat the Father, Mother, Uncles \& Aunts of the Bride, a Priest then having Furnishd the Mother with several pieces of Sugar Cane and some leaves from the Rowavva (or Sacred Tree $)^{[30]}$ she takes a sharks tooth and Cutting Her head on the Fore part, lets a Drop of Blood fall on each piece of the Sugar Cane and placing a peice on a leaf give(s) two to the Father and each of the Uncles \& Aunts and keeps two for herself, these they place on the Palms of their hands and holding them up to their Foreheads rise up and proceed slowly along the Cloth till they arrive where the Young Couple sit, keeping their bodys half bent all the way; and having deposited the leaves and Sugar Cane at the feet of the Young Pair they retire without speaking in the same Manner to their Seats. The Priest then advances with a Branch of the Rowavva in his hand and Makes a long Prayer; which having finishd, $\mathrm{He}$ goes to the Young Couple and biding "God bless them in their Union" (or as they express it in their Sleeping together) he takes up the leaves and pieces of Sugar Cane and proceeds to the Morai, where he burys them with prayers and makes an Offering to the Deity of a Hog \&c. and in the Meantime the Couple rise and go to their Parents and they Embrace them and bestow their blessings on them. The Cloth is then gathered up, and Presented to the Son in law, who generally throws part of it out for the Young People present to scramble for, and they are proud that can get a Narrow Strip of it to put on in Honor to the rite and wear it till it is expended telling all they know how they obtaind it-the Company then return to the Bridgrooms house and he sends three or Four Hogs to his Father in law, who has them immediately killd, and a Feast Made of which all the Males of both Familys partake\& a Feast is also prepared for the Weomen and all partake of the Festivity.

The Father of the Bride then delivers her portion to Her Husband as before discribed and an exchange of Names takes place.

When a Man adopts a Friend for his Son the Ceremonie is the same, only placing the Boy in the place of the Woman, the Ceremonie is ratified, and the boy $\&$ his friends exchange Names and are ever after lookd as one of the Family, the New Friend becoming the adopted son of the Boys Father-(1935:188-189)

The first question we might ask is: What features of the rites performed at a marriage ceremony pertained to head freeing, and what features were related specifically to marriage? A similar question arises with respect to the adoption ceremony, which Morrison characterized as being "the same" (as the marriage ceremony). Moreover, the obscurity is further deepened by Morrison's statement that the ämo' $a$ rites performed on these two occasions "differ(s) very little from that performd through the different degrees of Childhood." However, he did not describe the latter, except to list the objects that served as offering on such occasions: “... for the Males Hogs or Fowles and Cloth are always (presented) but for the Females if they can not raise them, a Fish will do-but however this is seldom the Case, and they are No way sparing in the performance of these rights and much Feasting then takes place" (1935:187).

Perhaps the best clue to an answer to the question posed above is provided by Bligh, who, it will be recalled, described the "Aammo-Aammo" ceremony performed by the chiefess 'Itia, in order that she be "at liberty to 
feed herself" (that is, the āmo'a rite listed by Morrison as "first"). This involved "presenting some Cocoa Nutt, Sugar Cane and a Small bough of a Shrub called Errow-woah [rauava] in each hand held to her forehead to the Child" (Bligh 1789:II, 43).

A similar complex of ritual objects and actions is evident in Henry's description of an episode of the uhi-a-iri ceremony, quoted on page 416, above. And finally, we have Moerenhout's description (see p. 421, above) of a ceremony approximating Morrison's "first āmo'a," Bligh's "Aammo-Aammo," and the episode just described from Henry's uhi-a-iri.

Thus, the elements common to all these ritual episodes (or, at least, to the available descriptions of them-which may or may not be equally exhaustive) are the presentation by a "parent" to the subject child or young person of a token amount of the former's self-induced blood deposited on a leaf of miro. In the earlier rites, the "parent" in question was the child's own mother, or mother and father, whereas in the later ones (according to Morrison) "uncles" and "aunts" were also involved. An understanding of the implications of this aspect of the rites depends upon the exploration of this wider categorization of "parenthood" (see chap. 17); but we can now at least recall that miro (Tahitian rosewood: Thespesia populnea) was of all the plants the one most highly favored as a vehicle for communications between humans and spirits ${ }^{31}$ and that self-bleeding (whatever else it may have signified) served on many different kinds of occasions to express intensity of feeling, either "joy" or "grief" (see chap. 3).

I suggested earlier the possible connection between 'sugarcane' (tō) and conception $(t \overline{)})$; and I now call attention to the regularity with which these rites focus on the principals' heads. But I am not prepared to go beyond pointing out these other glosses of the various objects and actions combined in this intriguing ritual. A number of obvious alternative interpretations suggest themselves to me-as they undoubtedly have to some readers of this study; but in view of my own misgivings about the value of such speculation, I shall leave this game for others to play.

\section{CONNUBIALITY}

\section{"Marriage"}

The Europeans who visited Tahiti came onto the scene with predetermined and highly specific ideas about "kingship," "individual rights," "sexual decency," and also about "marriage." Their notions about "marriage" undoubtedly varied in some respects: those of, say, the urbane Sir Joseph Banks did not entirely agree with those of the Reverend John Muggridge Orsmond; but common to all of them was a core of ideas-norms, memories, expectations-which shaped their observations and their generalizations about Maohi behavior. The fact that Maohis did enter into 
relationships resembling some features of European "marriage" served to complicate matters (at least for those like myself who attempt to reconstruct the actual lineaments of Maohi society), inasmuch as the European observers, in blandly assuming the local existence of "marriage," either did not perceive or did not trouble to record enough case histories to provide us with an adequate understanding of these relationships. What we are informed of is this: At some point or points in their lives nearly every Maohi (except for transvestites [mahu] and for some lifelong Ariois [see chap. 22]) entered into a relationship with one of the opposite sex. According to the Duff chronicler, the alleged paucity of women (the result, it was claimed, of a higher rate of female infanticide) deprived some men of an opportunity to marry: "... for the men that are not wealthy in cloth, hogs, or English articles, wherewith to purchase a wife, must go without one ..." (Wilson 1799:192). As we have seen, most of the sources agree that the population contained more males than females, but I am not convinced of the reliability of the extreme disproportions put forth in some of these accounts. And, quite apart from my objections to the flat statement about wife "purchase," I cannot believe that a large proportion of Maohis went through life without entering, even for a relatively short period, a relationship which involved the following: coitus, with open (in contrast to clandestine) coresidence, for a period of at least several weeks or months; tacit agreement to regard as "legitimate" (i.e., for purposes of inheritance) any surviving offspring of their intercourse; tacit agreement to exchange certain other services and objects; and some degree of public recognition of and sanction for the relationship, usually but not necessarily validated in a "wedding" ceremony.

For purposes of convenience I propose tentatively to call this kind of relationship marriage, but I caution the reader from reading into this label more than I here specify. ${ }^{32}$ In this section I will describe the practices which led up to and validated this relationship; other aspects of it will be described in following chapters.

It is, of course, impossible to discover the full range or the mode of the reasons which led individual Maohis to marry. To say that they did so because it was customary is not entirely adequate; no less a personage than the legendary Hiro rejected this reason.

When he [Hiro] became a man, he inquired of his grandfather what were the requirements of man. His grandfather replied:

"Provide yourself with a home, and marry a wife."

"If I do so," said Hiro, "what must I do with the wife?"

"Cherish and feed and clothe her," was the reply.

"That would be unprofitable," said Hiro, and so he went on disapproving of everything that Ana told him a man should do. Then he inquired what tricks man was capable of doing, and when Ana enumerated: lying, deceiving, and thieving, Hiro exclaimed: 
"Yes, stealing is good; that is a profitable thing; it will be satisfying to a man." So Hiro decided to become a thief.... (Henry 1928:537)

Some Maohis may have sought out and formally married a person in order to enjoy more or less unrestricted sexual intercourse with that person, but the review of sexual behavior given earlier makes it clear that marriage was certainly not the sole avenue to sexual enjoyment.

"Economic" reasons were undoubtedly influential in some cases, but not in all or even most. In the light of the traditional division of labor, anyone's comfortable subsistence normally required contributions from the opposite sex, and there may have been cases of individuals reduced to dependence upon the contributions of a spouse. On the other hand, most households included enough males and females to provide a balanced standard of living without the need for every adult to marry.

Immediate "political" reasons also operated in some instances, but usually where the gains mutually realized by a marriage pact were substantial-that is, only when they involved high-ranking kin-Titles or politically powerful authority. ${ }^{33}$

The desire for "legitimate" offspring undoubtedly was also influential. This reason operated potently in cases where succession to high-ranking kin-Titles was at stake, and it probably prevailed in other instances as well, where one or both parents were interested in passing on their heritage to their own offspring.

\section{Nuptials}

In any event, it is my conclusion that most Maohis did "marry," at least once and in many cases several times; so I will now examine the procedures followed in marrying. Perhaps the most illustrative beginning will be to reproduce some detailed descriptions of the marriage ceremonies for couples of upper-class status:

As the time for a marriage (fa'aipoipora'a) of importance approached, great preparations were made for the event by the families of the father and of the mother of both parties. Food in abundance was cultivated, fatted pigs and fowls were collected for the feast, and cloth and wearing apparel and feather ornaments were manufactured and kept in readiness for the occasion.

On the eve of the wedding ceremonies, all the relatives and friends of each party assembled at the respective homes of the young people, and members of the arioi society also came to them with music, singing, and dancing. On the morrow representatives of the household of the bridegroom, who was then called the papai-ni'a (upper rock), came to escort the bride, called the papa-i raro (lower rock), to his home for the first wedding ceremonies, called oro' $\bar{a}$-'ai-huno' $a$ (ceremony of feasting the son-in-law). With them they brought appropriate presents called the $o$.

Then the bride's party, including all those just mentioned, set out in a grand parade by land if not far to walk, and in new canoes made for the occasion if they had a long way to go, no old canoes being used for weddings. 
Following them in canoes were their presents, or $o$ (welcome insurer), which consisted of everything that had been prepared for the wedding, in two equal divisions, one from the side of the father and the other from the side of the mother. On arriving at the bridegroom's home, they were welcomed by a great party assembled in the same order as their own and the food and livestock they brought were presented and received in due form by the family. In the house a large mat was laid out, and upon it the father and mother of the bridegroom each spread a new sheet of white tapa, one overlapping the other, as an emblem of their two families, and there the young pair were seated. To the right and left of them were placed the rolls of cloth, mats, capes, and feather wreaths, those on one side being presented by the father and the others by the mother of the bride to the bridegroom in the name of their daughter. At the end of the performance the mothers and aunts of the young couple, called the hui-metua-vahine, class of mothers, punctured their heads and faces causing the blood to flow, as a manifestation of love and union of blood.

Then was given a great feast in honor of the bride, at which the bridegroom and other men sat apart from the women, as at all ordinary feasts, and the arioi danced and made merry. When night came, the bride, still in charge of her parents, remained with the other guests at the house of the bridegroom to await further ceremonies on the morrow. In the morning, the bride and bridegroom, dressed in beautiful fresh white tapa, which was prettily relieved with patterns of delicate fern fronds, and accompanied by all the relatives, went to perform the religious rites at the ancestral marae of the papa-i-ni'a, where were exposed for the occasion the skulls of ancestors with other fetiches.

A priest attired in the habiliments of his office met them upon the pavement at the closure of the marae, where sometimes an awning covered with green coconut leaves or green fei (wild plantain) leaves was erected for the wedding. The bridegroom took his station at one corner and the bride at the other, and before each of them assembled their respective relatives. The priest, approaching the young couple, then said, first to the bridegroom, "E'ita anei 'oe a fa'arue i te 'oe vahine?" (Wilt thou not forsake thy wife?), to which the bridegroom replied, "E'ita!" (No!). The same question was put to the wife respecting her husband, and she also responded in the negative. Then the priest answered, "E maitai ia mai te nua ra e e na reira 'orua" (It will be well if thus it be with you), and he admonished them after the manner of the sages of old and concluded with prayer to the gods to bless their union and keep them in the bonds of affection one to the other.

The father and mother of the bridegroom then came forward, each with a white sheet, called a vauvau (underspread), and placed them upon the closure of the marae in the same way and for the same reasons as on the previous day. There the young couple were seated, one holding the other's hand, and by them, keeping on their own sides, sat the relatives, both sexes puncturing themselves and causing the blood to drop on to the sheet, thus further blending family ties. The groom's parents then placed the juice of a young coconut leaf and of sugar-cane mixed in a coconut shell, upon a miro leaf, and held it first on their son's head then on the head of their daughter-in-law, after which they placed it beside the one as a pledge of unity, which they sealed with blood by puncturing themselves in the presence of all the company, each one causing some drops to fall upon a miro leaf which was placed upon the back stones of the marae. Then the bridegroom's parents joined their family and all the company on both sides arose. Another sheet, called the tapoi, was spread over the young couple who were still sitting, and under it they remained a few seconds and received the first wedding greetings. When it was taken off they also arose. Then the sheets of the vauvau were torn in halves, and the two 
sides that were stained with the blood of the relatives were folded together, enveloping the mixture on the leaf, and buried near the marae; the other two pieces of cloth were also folded together and were given with the oversheet and the wedding clothes and change for others to the arioi for their religious pantomimes. Thus ended the first part of the marriage.

The double party then proceeded to the house of the bride, the parents of the bridegroom taking presents as their $o$ equal to those that had been brought by the bride's parents, and also another great supply of things in readiness for the wedding feast. On arriving at their destination, the same reception and presentations as before were repeated on behalf of the papa-i-ni'a; and on the following day the bride and bridegroom, attired in new wedding clothes, went through the same religious ceremonies at the marae of the papa-i-raro and with the same termination as on the previous occasion. Handsome presents were always given to the priests who performed the marriage rites. Sojourners used the seashore in place of a marae.

Any differences of rank that may have existed between the two families were forever annulled by these ceremonies.

At the wedding feast, which lasted several days at the house of the bride, both families vied with each other in making a grand display of goods and food. Eloquent speeches were exchanged. To the young couple they gave a name which it had been previously agreed that they should bear, a custom still existing among the native people of the present time. If one side gave less than the other, it was at once noticed and recorded in song by the merrymaking arioi.

As royal marriages were national celebrations they were performed at the national maraes of the contracting parties; they were free from human sacrifices. (Henry 1928:282-284)

Several features of this version of Maohi nuptial ceremonies invite comment. First, there is what might be called the principle of kin bilaterality, which influenced the organization of the events. With reference to the bride and the groom, separately, this was expressed in the separate but more or less equal roles played by each one's relatives acting as a unit. (It might perhaps be argued that the groom's party enjoyed an added prerogative inasmuch as the ceremonies-according to this version, at least-began on their home ground; but against this it could equally well be argued that the ceremonies culminated on the bridal party's ground.) Bilaterality also shows up in the deliberate reciprocity involved in the $o$ gift exchange between the two parties; although it should be noted that the parties tried to outgive one another in connection with the final feast.

Second, although it would be inappropriate to distinguish "secular" from "religious" aspects of these ceremonies, or of any other Maohi ceremonies for that matter, the events can be characterized as having more or less distinctive "domestic" and "churchly" settings, emphasizing, respectively but not exclusively, relations with living and deceased kinfolk. And in this connection it is noteworthy that the ceremonies (aside from the suspiciously apocryphal priest-led "vows" of mutual affection) tended more to validate the union there and then rather than insure its permanence.

Finally, the symbolic acts combined in these ceremonies "said" not 
only that the union would be effectively important and socially valid (for example, some of the episodes involving bleeding and the blending of blood), and that sexual intercourse would figure centrally in its constitution (for example, the episode of "covering" the couple), but also (for example, the blood on miro leaf episode) marked another stage in the individual's head-freeing progression. ${ }^{34}$

Ellis' description of the more ceremonious weddings, those presumably of persons of upper-class status (1829:II, 568-570), is less detailed than, but generally, resembles, Henry's-as indeed might be expected, since much of Ellis' information came from the same source. However, they differ in important respects. In Ellis' version the domestic rites took place only at the bride's home; "... when the parties were connected with the reigning family," the "churchly" episodes of the ceremony usually took place at the "national" marae of "Oro or Tane; and certain "ancestral relics" (skulls, bones, etc.) were brought out for the occasion, to witness and sanction the union.

Ellis' description of the head-freeing episode also differs somewhat from Henry's, but the significance, if any, of this difference is not clear:

The relatives of the bride then took a piece of sugar-cane, and, wrapping it in a branch of the sacred mero, placed it on the head of the bridegroom, while the newmarried pair stood holding each other's hands. Having placed the sacred branch on the bridegroom's head, they laid it down between them. The husband's relatives then performed the same ceremony towards the bride. (1829:II, 569)

One cannot be certain whether the differences between these versions-and among these and other versions that will be described-are to be ascribed to differences in reporting or differences in the events reported; and with reference to the latter, whether the differences in the actual events were based on factors of locality or social class or particular circumstance. But let us consider another version.

Concerning weddings in general, Morrison said that unless the woman is a virgin [by which he perhaps meant that she had not previously been married $^{35}$ ] their nuptials consist of only an exchange of names-the groom with his father-in-law, the bride with her mother-in-law-and of presents. If on the other hand the woman is a virgin her friends must perform an àmo' $a$. (1935:185)

Bligh's account of nuptial rites closely parallels that of Morrison:

I have endeavored by every means to get a knowledge whether Marriage has any common and general ceremony attending it, to give legallity to the Man and Woman living together, and I find from the best collected accounts among those People who are capable of giving me information, that any ceremony attending Marriage is not general. The Women are sollicited for their consent, and untill they give it the Man dares not to take the Woman away. When the Parents approve of the Match, there is a ceremony of Prayer at a Morai, and The Parents 
perform Oamo to the married Couple. (This Oammo or Oammoah [ämo'a], as it is called, is a Ceremony performed by Parents to their Children when they are supposed to be able to look out, and take care of themselves.)

It is remarkable that the ceremony of Prayer is only performed to the first Woman, and might reason from thence that the others were Concubines and not Wives. (1792:152)

Ignoring the ambiguities in Morrison's version, and comparing it with those of Henry and Ellis, one is struck mainly by its omissions. For example, only the marae is specified as setting for the rituals, and while "... The Friends of Both parties" are said to assemble for the occasion, the featured ritual social interaction takes place between groom and relatives of the bride, and not bilaterally. But even more puzzling in Morrison's version is what it tells, or omits, about the transactions in tangibles accompanying the rites. We are informed, for example, that the couple's "Friends" present them with “... Hogs, Cloth and Sundry Necessary Articles," but we are not told which party supplied the items offered to the spirit by the officiating priest. Then there is the implication that the groom alone supplied the meat consumed at the wedding feast. But most puzzling of all is Morrison's assertion that the handing over of a dowry constituted an essential episode of the wedding ceremony, accompanying the exchange of names: "The Father of the Bride then delivers her portion to Her Husband ..." or, as he stated elsewhere, "The Husband then Claims his Wife's Possessions, which are delivered to him without reserve...." We shall return to this important question of dowry, but first let us turn to still another version of a Maohi wedding.

The most detailed account of the actual wedding of an upper-class couple was supplied by the missionary Jefferson:

March 6, 1799: A great concourse of natives about us who are passing their time in eating, drinking, wrestling, drumbeating, singing, hallooing, throwing their arms \& legs about in a frantic manner and such like revellings, the most part acting as if they were demoniacs. This assembly is owing to a marriage ceremony that is about to be performed, between a chief of Oryateea named Matteah and a young woman the daughter of the deceased chief of this district named Maheiannoo. She and Matteah are both branches of Pomerre's family, and chiefs by birth; so that if there should be any offspring it is probable it may live. Matteah has been living some months in connection with Maheiannoo who it is said has conceived seed by him. When the Spanish prize arrived here the Oryateean chief went early on board and offered his wife for prostitution.

March 7. Early this morning began the marriage ceremony between Matteah and Maheiannoo. As the habitation of the parties is but a few yards from our dwellings, some of the brethren went down to be spectators. The mother \& uncles of Maheiannoo were employed in giving cloth to various of their friends, who were met upon the occasion. Under one of the houses was a kind of altar erected, covered with a piece of white cloth. On it was placed some old cloth, which had lately en- 
closed the tomb of the deceased father of the bride. After they had distributed their various gifts of cloth, the parties went to the family's merrai, where the ceremony commenced with spreading a largepiece of white cloth across the pavement; this done the bride and bridegroom each changed their dress, after which the mother of Maheiannoo with two or three female relations, having taken a sugar cane and broken it into small pieces, laid the same upon the leaves of a tree called Amai; ${ }^{[36]}$ the mother \& female assistants then perforated their heads with shark's teeth, and caught the blood upon the leaves on which were placed the broken sugar cane, and afterwards male \& female relatives presented the leaves, sugar cane and blood to Matteah and Maheiannoo who were seated, the man on one side of the morai \& the woman on the other, about 6 yards apart. The whole was then offered up to the supposed god of the family, and laid upon the family altar.

These strange proceedings were conducted with that levity and thoughtlessness, which characterize in a peculiar manner the Otaheiteans. The mother of the bride appeared a little more thoughtful, being a woman advanced in years, and increased the superstition \& wickedness of the ceremony, by producing the skulls of her deceased husband and elder brother, which, according to the custom of the country, she had preserved and anointed with cocoa-nut oil. These skulls were held before the leaves, sugar cane and blood, at the time of presentation to the parties. These things being finished, the cloth spread upon the morrai, are deemed sacred, and not to be worn in common. Notwithstanding all this abominable idolatry, the marriage tie is no more binding than if it had never been performed; so that if the man thinks proper, he may put away his new wife tomorrow, and be united to another in the like manner on the next day. (Journal, 6 and 7 March 1799, LMS Archives)

This account is interesting mainly because, like Morrison's, it suggests that the near-perfect duplication of rites described in the Henry version, first at the groom's and then at the bride's, was more of an ideal than an invariable happening. Morrison did not tell us why the wedding he witnessed had the bride's home for its domestic setting, but in the case of the wedding witnessed by Jefferson its setting at the bride's home can be explained by the circumstance that the groom had come from distant Ra'iatea. ${ }^{37}$ Perhaps the duplication of events described by Henry occurred only when bride and groom resided within the same or in neighboring districts. In 1822 the politically important wedding between Aimata, only daughter of Tahiti's King Pomare II, and the high chief of Taha'a took place on middle ground, at Huahine (Ellis 1829:II, 559).

All or most of the nuptial ceremonies so far described involved principals of upper-class status. It is a reasonable inference that ceremonies as elaborate as these were reserved especially for such a couple's, or at least for the bride's, first marriage. The other extreme was represented by the kind of situation described by Anderson:

If a young man and woman, from mutual choice, cohabit, the man gives the father of the girl such things as are necessary in common life; as hogs, cloth, or canoes, in proportion to the time they are together; and if he thinks that he has not been sufficiently paid for his daughter, he makes no scruple of forcing her to leave her friend, and to cohabit with another person who may be more liberal. The man, on his part, is always at liberty to make a new choice; but, should his 
consort become pregnant, he may kill the child; and, after that, either continue his connection with the mother, or leave her. But if he should adopt the child, and suffer it to live, the parties are then considered as in the married state, and they commonly live together ever after. However, it is thought no crime in the man to join a more youthful partner to his first wife, and to live with both. The custom of changing their connections is, however, much more general than this last; and it is a thing so common, that they speak of it with great indifference. (Cook 1784:157) ${ }^{38}$

In between these extremes there must have been many gradations in ceremonial elaboration, but the sources offer little information concerning this subject, other than such generalities as those of Bligh, quoted earlier, or of Tyerman and Bennet: "The marriages of the common people, in former days, were simple compacts between the parties to live together as long as it suited their convenience or their caprice. But the feia maua [probably mana], the order of kings and head chiefs, celebrated their nuptials with extraordinary rites" (Montgomery 1832:II, 147).

Moerenhout's account of "weddings" provides more details, but he erred by implying that the pattern described by him typified all Maohi weddings:

Both sexes were married young, that is, generally between 12 and 16 years of age. It was a noticeable peculiarity, in this country where every action however slight in importance was ritualized, that only marriage was devoid of religious sanction. It was only a convention between the intended mother and father. When a young man appeared to ask for a young girl in marriage, he brought several gifts, hogs, cloth, etc. If he was pleasing and his courtship agreed on, a bed was then made up and he spent that very night with his would-be bride. Early the next day the hogs were killed and some friends and neighbors were invited to a small family celebration. The young couple usually stayed in the girl's parents' house for two or three days; then the husband led his wife from her father's (house) where another feast or meal took place; and that was all. (1837:II, 62-63)

\section{Arranging Marriages}

Having reproduced the principal available accounts of the practices which served to validate a couple's marriage, I turn now to a consideration of the kinds of events which led up to them. To begin with, it will be useful to distinguish between marriages by choice and marriages by arrangement. ${ }^{39}$

Scattered bits of evidence suggest that many marriages were instituted solely by choice of the spouses themselves, and with little or no regard for the wishes (if any) of their parents. This is to be expected, from the widespread freedom which prevailed in choosing partners for sexual affairs and from the circumstance that "marriage" developed quite commonly out of such affairs. With respect to such unions, Ellis stated: "It is only among the middle and lower ranks of society, that the contract is made by the parties themselves" (1829:II, 567). It is also evident that many other marriages were instituted solely by arrangement between parents, with little or no regard for the wishes of the couple. The LMS Dictionary gives the 
term fa'atina, to propose or appoint marriage connections, as parents often do. Ellis' statement continues: "Among the higher ranks, the individuals themselves were usually passive, and the arrangements were made by their respective friends." With respect, however, to their validation most marriages probably fell between these extremes, having involved varying degrees of both personal choice and parental arrangement, or at least parental consent.

Reports like Cook's, cited above, indicate that some men married off their daughters or sisters in exchange for objects-a kind of pimping for immediate material returns. On the other hand, two-sided parental ${ }^{40}$ arrangement of marriages most typically occurred when socially important kin-Titles were at stake and when the advantages thereby realized were in the form of more intangible goods such as ceremonial prerogatives and political support. In this connection it would probably be safe to conclude that the higher the class-status the more decisive the parental voice tended to be.

The distinction between personal choice and parental arrangement becomes especially evident when inquiring about the Maohis' criteria for selecting a spouse. To begin with, however, there was one criterion that influenced nearly everyone's decision concerning whom to marry, and that, briefly stated, was that one's spouse should not be a "close" consanguineal relative. An exception to this proscription prevailed in the case of certain upper-class individuals who, for reasons that will be discussed later, married consanguines as close as first cousins. But having said this there is not much more of a positive nature that one can say beyond recalling that ties of consanguinity were bilaterally reckoned, with about equal weight on the mother's and father's sides. The question is how far most Maohis considered it necessary to extend, bilaterally, the boundaries of prohibited marriage.

Unfortunately, none of the primary sources contains a comprehensive native statement regarding the prohibited degree of consanguinity, although several writers expressed what they interpreted the native view to be. Bligh, for example, wrote that "... it would be doing these People great injustice to say, that Sister and Brother had ever connection together in Marriage, and I declare it as an absolute fact that they would abhor an intercourse of this kind equal to a Briton" (1789:II, 63). And from Moerenhout came the statement that "... marriages between brother and sister or other close [proches] relatives were uncommon, having been considered repugnant by the Islanders, and undertaken only when political considerations absolutely demanded such" (1837:II, 67). ${ }^{41}$ De Bovis, writing around 1855, was somewhat more explicit; according to him the prohibited degree of consanguinity extended "even beyond" that established by the French Civil Code. ${ }^{42}$ And, he added, "One cannot imagine with what horror they regard marriage between close relatives" (de Bovis 1909:32). Unfortunately, de Bovis did not document his statement, nor is it clear what was intended by his phrase "even beyond." 
Another approach to answering the question concerning kin proscriptions in marriage lies in case studies of kin marriages that actually occurred and of marriage attempts that were forestalled on grounds of incest prohibitions. But again, the sources are not very useful. With respect to the first, the only relevant genealogical records are those of certain upper-class kin-Titleholding "lines." After combing through all those known to me, I succeeded in turning up only half a dozen or so instances of marriage between consanguines reputed to have been linked by ties of tertiary or closer degree. ${ }^{43}$

With respect to the second type of case-of forestalled attempts to marry kin-I have discovered only the following cases:

The Spaniard Rodriguez noted in his journal that after having lived with a mistress for some time, the Ari'i Vehiatua, holder of the highest ranking kin-Titles on Tahiti's peninsula, was induced to separate from her, because “... they were first cousins, and neither Vehiatua's mother nor her own relations approved of the alliance" (Corney 1919:111).

The missionary Crook reported in his journal for March 1826, that relatives tried to block the marriage between a chief's widowed sister and a young man who happened to be the bond-friendship "brother" (taiō) of the chief's foster son-that is, the woman was considered to be the young man's "aunt." (10 April 1826, LMS Archives)

About all one can conclude from these small scraps of evidence is that the Maohis disapproved of marriages between "close" consanguineous kin ${ }^{44}$ but that the boundaries of prohibitive proximity remained fairly open and verbally undefined, at least in terms of explicit and universally accepted norms. Moreover, even after an assiduous search I have been unable to turn up any information explictly formulating a "biological" or "mystical" rationale for this proscription; neither have I discovered any sanctions, other than here-and-now social ones, that served to maintain this proscription.

In contrast to the negative effect of consanguinty upon choice of mate, the influence of affinity was directly positive:

When they Marry they Never Join with their Blood relations but a Man May take two Sisters, and a Woman two Brothers at the same time if they are all agreeable, and it is looked upon (as) a piece of Great friendship for a Man to Cohabit with the Wife of His Adopted freind if She is agreeable: the Adopted friend being always accounted as a brother.

If a woman has (a) husband and he dies without Issue the Husbands Brother takes her; if He has no wife and should he have Issue by Her the Children are Calld by the Former Brothers Name, \& take his estate; but should he have a Wife he keeps her at his house till she gets a husband and she is still acknowledged as one of the Family. (Morrison 1935:184-185)

Other evidence supports Morrison's assertion that a man sometimes took as an additional spouse, or at least lived openly with, a sister of his 
own wife (e.g., Jefferson, Journal, 13 April 1800, LMS Archives). And, although not stated by Morrison, it is highly likely that widowers sometimes married a deceased wife's sister. We are not informed how the Maohis themselves justified such marriages, but one can see that they contained certain advantages to both parties in terms of co-wife harmony, established familiarity, mother-stepchild affection, and so forth. ${ }^{45}$ There is also evidence to confirm Morrison's identification of the levirate; indeed it was probably the basis for a number of marriages.

A second major criterion for selecting a spouse was social class. There was a universally applicable norm-dogmatically insisted upon by members of the upper classes and apparently accepted by all others-that marriages should take place only between members of the same class. ${ }^{46}$ This is a most complex matter, including such basic questions as where class boundaries were drawn, which will be discussed in later chapters. Having already indicated the effects of social class upon nuptial ceremonies and upon the extent to which marriages were arranged, I am concerned here only with those aspects of social class that bear directly on choice of spouse.

It should be recalled that the universal norm against interclass marriage did not presuppose an identical one against interclass sexual affairs. There were, it is true, rules and sanctions aimed at guarding upper-class unmarried girls from sexual contact with men of lower-class status (and with all other men, in the case of girls already betrothed); but older women of the upper class were restricted, practically, in their extramarital affairs only by rules against adultery, if that. And as for males, although fears of reprisals may have made them cautious about affairs with girls of a higher class than themselves, they were in no social ways constrained in their sexual relations with women of lower social class. Thus, it would appear that the principal consideration against interclass marriage (in contrast to interclass casual sexual liaisons) was to insure that no offspring would survive to degrade, by virtue of his own hybrid status, the lineal descendants of the higher-class spouse. There were undoubtedly other factors involved, such as politics, property, and family pride, but considerations regarding lineal continuity were probably the most weighty in maintaining this norm. In fact, it could be argued that the central purpose of nuptial ceremonies, and the symbolic message of much of their ritual, was neither to validate the couple's cohabitation nor the union of their families, but to legitimatize the class status of their offspring, and thereby maintain or improve the hierarchic position of family kin-Titles.

But effective as this norm was, it did not always prevail. The sources contain many bits of evidence, direct and indirect, mythical, legendary, and historical, of marriage across class lines. Although impossible to document, I have the impression that men married down more often than did women.

In addition, there are reported instances of the killing, on class grounds, 
of the offspring of a "married" couple upon the insistence of the relatives of one of its parents. This is, to be sure, not clear evidence of interclass "marriage" in the fullest sense, since by my definition the action by the higher-class relatives would imply that they had not validated the union to begin with. In fact, situations like these-and there were probably many of them-might justify setting up another relational category, ${ }^{47}$ semi-marriage, about which more anon.

But there is another kind of evidence for interclass marriage which demonstrates not only that it occasionally occurred but that its occurrence was widely recognized and institutionally provided for. I allude to two kinds of generalization recorded in the sources. First, the statement by Henry that "Any differences of rank [i.e., social class] that may have existed between the two families [of bride and groom] were forever annulled by these [marriage] ceremonies" (1928:284). This refers, of course, to ceremonies in which both the bride's and groom's families took active parts; and in the absence of contrary evidence one can only assume that the "annulment of rank differences" applied only to the offspring of the unions, which were thereby placed in the social class of their higher-class parent. In this connection, Henry has the following to report about unions that were not validated by both sides-an instance of "semi-marriage":

When a child of the royal family formed a misalliance which the parents did not wish to equalize, they refused to solemnize the marriage rites on their side, which lowered the erring one to the level of the inferior party, at whose home alone the marriage was performed. Such a person and the children of such a union, were called tamari'i ta'ahi hia (children trodden down or degraded). In such cases, when they could gain popularity among the people, they sometimes asserted themselves and regained prestige as rival members of the family that had disowned them. (Henry 1928:284)

The second way in which interclass marriage may possibly have been legitimatized is recorded in legends. For example, in the legend of Punaauia an upper-class maiden, who plans to elope with her lower-class lover, confides in her elderly, lower-class nurse that she hoped eventually to "legitimatize" the union in the eyes of his parents by "ennobling" the young man. To which the nurse replied:

Oh, my child! Why did you not confide in me sooner? I, a plebeian, can feel for Te-muri [the lover] as only a plebeian can, and I entreat you to release him of this intrigue. Your plan to ennoble him later might never be possible, and meanwhile he would be a fugitive, pursued and watched by some accomplice of your royal house, and eventually slain and sacrificed to the gods, and then you would be brought home to mourn your loss, a reproach to your own people. It is only for deeds of valor and heroism, when royal personages have been rescued from outrage or death in some extra-ordinary way that kings and queens consent to raise people of our standing to their rank. This is what Te-muri's parents would 
undoubtedly say also to you and him were they consulted in the matter, for no plebeians could ever wish to bring down wrath upon themselves and even their district by forming such a union. (Henry 1928:600)

Other legendary instances that suggest the possibility of "ennoblement" for marriage purposes will be given in other chapters.

When left to their own choice in selecting a spouse, the Maohis appear to have looked for the same attributes valued in selecting a mistress or lover, sometimes to the extent of overriding the proscriptive factors of kinship and social class. Indeed, for most young people not entirely constrained by parental authority the two roles-lover and spouse-were not sharply distinguished. For older persons considerations of subsistence skill and industriousness may also have been crucial, although the sources are singularly silent on this point. We are not specifically informed one way or another about the influence of place of residence as a conscious factor in selecting a mate, although on the basis of many reported cases there does not seem to have been any effective opposition to marrying an individual from another tribal district or even another island.

The factor of relative age is more complicated. On the one hand it cannot be separated from the factor of "good looks"-and in this respect older men showed a preference for younger girls, and older women (when they were in a position to exercise choice) were evidently attracted to younger men. On the other hand, although it may be assumed that young girls were attracted to young men, they were also reported at times to have favored much older men as well. Some cases involving young girls and older men were not entirely of the girls' choosing, as exemplified in the following excerpt from Orsmond's journal. (The date of this entry is 1827, but the attitudes expressed were probably not greatly different from those of an earlier time.)

At our meeting this afternoon (March 1827) I undertook to combat a vile practice that exists among the people almost without exception till the present time. Three days ago I married very much against my inclination and Judgment two persons the man was about 5'6". The little girl about up to his 3 rib. The parents were urgent $\&$ all the Governors Judges \&c commanded that the couple should be married. It has ever been a custom in these Islands for the man who has a Daughter to look out for some young, able young man \& who has property. To him the father usually and without ceremony would say There is a good little wife for you, my daughter. The brutal feelings of the human creature would of course be roused to momentary pleasure. He would be profuse in his presents to his newly acquired father in law. As soon however as all his pigs had been roasted, and all other property obtained by the father through the medium of the daughter, the father would tell the husband to go about his business but he must of course leave his daughter behind. For whom in the same way the father would soon find another husband, so that some have had $3-4-6$ or 12 husbands in three or four years. This I believed to be the case in the present instance. The poor old man who is unable now to climb a coaconut tree, but who nevertheless has sucking babes about him!!! (1827, LMS Archives) 
Another excerpt from Osmond's journal, for 1832, indicates that age discrepancy may also have been a matter of personal choice:

A native who belongs to this part of Taiarabu is just come from Raiatea He went down to amuse himself in the late war, is said to have shot six men \& has come with a little girl almost as high as his navel for his wife. He is a man of about 48 his former wives are dead $\&$ he has a family of children. In all Tahitians as well as officers who come in ships there is a cry for little girls, those on the contrary generally to appear womanish crave full grown men. (1 September 1832)

The missionaries, who were most scandalized by such situations, have provided us with enough data on age-discrepant marriages to indicate that there were no effective norms respecting the proper relative ages of spouses-that is, none in addition to the aesthetic ones influencing otherwise unconstrained choice.

In Maohi society the routes leading to marriage were many and varied. I have already noted how typical it was for sexual affairs to develop into "marriage," gradually and perhaps imperceptibly. "Courtship," in such cases, was no different from that involved in initiating sexual affairs in general. In somewhat similar circumstances of mutual choice the developments occasionally took place more rapidly, as for example in the instance reported by Tyerman and Bennet: "A wedding was solemnized here this afternoon. The parties had met, been mutually pleased, and agreed to live with one another, after a few hours of well-spent acquaintance" (Montgomery 1832:II, 156). Although this particular event occurred in 1823 and involved a regular Christian wedding, the situation exemplified may have been typical of earlier eras as well. In fact, the "love-at-first-sight" theme is a frequent one in Maohi narratives.

The most detailed reports of courtship available to us concerned episodes occurring in the early 1820s, and although by this time the missionaries had partly succeeded in replacing indigenous forms of weddings with "proper" Christian ones, the events leading up to many such marriages probably remained unchanged; and hence it will not be inappropriate to reproduce two such episodes here. The first concerned a canoe load of men, en route from Tahiti to Porapora, who stopped off on Huahine for a while as the guests of a local man named Taraimano. Ellis continued with this story:

During this period, a young woman, one of the belles of the island, belonging to the household of their hostess, became exceedingly fond of the society of one of the young men, and it was soon intimated to him that she wished to become his companion for life. The intimation, however, was disregarded by the young man, who expressed his intention to prosecute his voyage. The young woman became unhappy, and made no secret of the cause of her distress. She was assiduous in redoubling her efforts to please the individual whose affection she was desirous to obtain. At this period I never saw him either in the house of his friend, or walking abroad, without the young woman by his side.

Finding the object of her attachment, who was probably about eighteen 
years of age, unmoved by her attentions, she not only became exceedingly unhappy, but declared, that if she continued to receive the same indifference and neglect, she would either strangle or drown herself. Her friends endeavoured to dissuade her from her purpose; but, as she expressed her determination to be unaltered, they used their endeavours with the stranger who afterwards returned the attentions he had received, and the parties were married at Huahine.

And so ends the story, or so it might have ended in some societies, but with the Maohis there was little approaching finality about weddings:

His companions pursued their voyage to Borabora, and afterwards returned to Tahiti, while the new-married couple continued to reside with Taraimano. Their happiness was of short duration; not that death dissolved their union, but that attachment, which had been so ardent in the bosom of the young woman before marriage, was superseded by a dislike as powerful; and although I never heard the slightest charge of unkindness preferred against the husband, his wife not only treated him with insult, but finally left him. Instances of such unhappy marriages, though not unusual formerly, are now of rare occurrence. (1829:II, 567)

We are indebted to Ellis for another detailed eyewitness account of a courtship-this one involving individuals of relatively high class status:

The period of courtship was seldom protracted among any class of the people; yet all the incident and romantic adventure that was to be expected in a community in which a high degree of sentimentality prevailed, was occasionally exhibited, and the disappointed, perhaps, led to the commission of suicide, under the influence of revenge and despair. Unaccustomed to disguise either their motives or their wishes, they generally spoke and acted without hesitation; hence, whatever barriers might oppose the union of the parties, whether it was the reluctance of either of the individuals, or of their respective families, the means used for their removal were adopted with much less ceremony than is usually observed in more civilized society. Several instances of this kind occurred during our residence in Huahine: one regarded a chief of Eimeo, attached to Taaroarii the king's son. His figure was tall and gigantic, his countenance and manners not unpleasing, and his disposition mild and humane. He was upwards of twenty years of age. Some time after our arrival in Huahine, he became attached to the niece of the principal raatira in the island, and tendered proposals of marriage. Her family admitted his visits, and favoured his design, but the object of his choice declined every proposal he made. No means to gain her consent were left untried, but all proved unavailing. He discontinued his ordinary occupations, left the establishment of the young chief who had selected him for his friend, and repaired to the habitation of the individual whose favour he was so anxious to obtain. Here he appeared the subject of deepest melancholy, and, leaving the other members of the family to follow their regular pursuits, from morning to night, day after day he attended his mistress, performing, with apparent satisfaction, offices of humiliating servitude, and constantly following in her train whenever she appeared abroad. (1829:II, 565-566)

His friends interested themselves in his behalf, and the disappointment, of which he was the subject, became for a time the topic of general conversation in the settlement. At length she was induced to accept his offer; they were publicly married, and lived very comfortably together. Their happiness, however, was but 
of short duration, for his wife, for whom he appeared to cherish the most ardent affection, died a very few months afterwards. (Ellis 1829: II, 566)

The melancholy of the young chief reported above was not so deep, however, as that to which some hopelessly enamoured swains are reported to have sunk:

A Towtow [toutou]-Slave or Servant-in this Country can never get permition to be connected with a Woman who is above him in situation, \& to live publickly as Man \& Wife. There are many however who fall in love desperately where they can never expect any return to their affections, not even the inclination of the Woman bears the least in his favor, yet he will wander about and meet her at every turning in a disconsalate manner. At last comfortless he is left without any resource except an unnatural one which suggests itself-the beastly Swain follows the Lady and deprives the earth of that which she meant to be deposited in it. Of this strange and unnatural liking I never heard before. (Bligh 1792:151b)

Mention has already been made of the kind of "arranged" marriage negotiated by parents for immediate, material gains. A somewhat different practice, described by Tyerman and Bennet but based on hearsay, may have been similarly motivated, however for future rather than for more immediate gains. I present this report in full, because in addition to its description of a type of betrothal practice it also provides an account of a form of wedding ceremony which has not been described in any other source:

Marriages among the higher orders were often contracted in the following manner. A person who had a beautiful daughter brought her, while yet a child, to a chief, saying, with the utmost frankness, "Here is a wife for you!" If the great man liked the girl's appearance, he took her off her father's hands, and placed her with some trusty dependant, to be trained and fattened, like a calf for the slaughter, till she had attained a suitable age. When her master chose to take her for his wife, the betrothed and their friends met at the marae. The girl appeared there with a cord about her neck, supported by one of her nearest kin, and accompanied by a man holding some leaves of sweet-smelling fern in each of his hands, which he pressed on either side of his head, above the ears. When the procession reached the altar, these leaves were cast upon the ground. The priest, having muttered his prayers, took up one of the sprigs of fern, and, while each of the dead ancestors of the bride (so far back as they were remembered) was named, he doubled down or tore off one of the side leaflets. Then, while the names of her living relatives were mentioned in due order, one of the remaining leaflets was successively pointed out as the number of each. When that which represented the nearest in blood of those who were at hand occurred, that kinsman stepped forth, loosed the rope from the bride's neck, and delivered her to her husband. The friends on both sides then presented the couple with hogs, bundles of cloth, wooden dishes, canoes, \&c., \&c., according to their rank and ability. In less time than the honeymoon requires to fill and empty her horn, the chief probably grew weary of his spouse, and said to her, Atira (it is enough), haere $e$ jo (go away). The woman was then abandoned, and what often became of her may be easily guessed. In this manner the great people took and put away as many wives as they pleased, or could get. (Montgomery 1832:I, 243-244) 
If this version of a wedding ceremony is indeed credible-and I am not entirely convinced that it is-the use of a cord about the bride's neck suggests (and the account also implies) that the class of the bride was inferior to that of the groom. As for the other unfamiliar aspects of the wedding ceremony, I can offer no explanation.

We must turn again to Ellis for an account of childhood betrothal. Prefacing his description with, "It is only among the middle and lower ranks [i.e., social classes] of society, that the contract [to marry] is made by the parties themselves," Ellis stated:

Among the higher ranks, the individuals themselves were usually passive, and the arrangements were made by their respective friends. They were usually betrothed to each other during their childhood, and the female thus betrothed was called a vahine pahio. As she grew up, a small platform, of considerable elevation, was erected for her abode, within the dwelling of her parents. Here she slept, and spent the whole of the time she passed within doors. Her parents, or some member of the family, attended her by night and by day, supplied her with every necessary, and accompanied her whenever she left the house. (1829:II, 567-568)

Occasionally young people took matters into their own hands and married against the wishes of their parents. In chapter 10 I described one such episode-the case of the young Ra'iatean woman who eloped with an Arioi to Tahiti and the public reprimand meted out to her through means of a satirical drama. That such elopement was not entirely unusual is also indicated by the nature of a farce staged on that same occasion-the story of a couple who married against the wishes of the girl's father and how the latter finally became reconciled to the marriage. ${ }^{48}$

Besides instances of women having been taken as booty in time of war and incorporated into the households of their captors, there is no evidence of "marriage by capture"-either as an expediency or as a standardized ritual. ${ }^{49}$ I have not come across any instances of the kind of situation reported from some other Polynesian societies, wherein a young swain deliberately sought consent for his marriage to his mistress by permitting himself to be caught in the act of fornicating with her in her family's home.

The preceding pages contain ample evidence that Maohi marriages were often brief and were easily dissolved. As Ellis wrote:

Notwithstanding all this ceremony and form in entering into the engagement, the marriage tie was probably one of the weakest and most brittle that existed among them; neither party felt themselves bound to abide by it any longer than it suited their inclinations and their convenience. The slightest cause was often sufficient to occasion or to justify their separation, though among the higher classes the relation was nominally continued long after it had actually ceased. (1829:II, 570-571)

But I postpone to later chapters further discussion of this subject. 


\section{Polygamy}

Comparison of the many reports about polygamy in these Islands might persuade the reader that the authors could not all have been writing about the same place. At one pole is J. Forster's statement that polygamy did not exist (1778:424); at the other is Tyerman's statement which alleged not only that it was fairly general but, for example, that one man (a prominent priest) had "... upwards of thirty" wives (Montgomery 1832:II, 148). Among the other writers, some described the practice as "common," others as "rare." 50 Some of these seeming contradictions may be assigned to errors of observation, but others probably arose out of confusions in terms (a point previously made by Williamson [1939:181]). The clearest statement, and perhaps the best informed, came from Ellis:

Polygamy was practised more extensively by the Tahitians than by the inhabitants of the Sandwich Islands, and probably prevailed to as great an extent among them as among any of the Polynesian tribes. Many of the raatiras, or inferior chiefs, had two or three wives, who appeared to receive an equal degree of respect and support. With the higher chiefs, however, it was different; although they might ... keep a number of females, it was rather a system of concubinage, than a plurality of wives, that prevailed among them. The individual to whom the chief was first united in marriage, or whose rank was nearest his own, was generally considered as his wife, and, so long as she lived with her husband, the other females were considered as inferior. When the rank of the parties was equal, they often separated; the husband took other wives, and the wife other husbands; and if the rank of the wife was in any degree superior to that of her husband, she was at liberty to take as many husbands as she pleased, although still nominally regarded as the wife of the individual to whom she had been first married. (1829:II, 571)

Elaborating, and drawing on other evidence, direct and indirect, my interpretation of the fragmentary available data regarding polygyny is as follows (the converse situation, polyandry, will be mentioned later). There was no general, universal norm prescribing how many wives a man could have (and by "wife" I continue to refer to the woman a man has "married," in the sense explained above), although there were undoubtedly many wives who for personal reasons felt that their own husbands should have only one wife.

On the other hand, the incumbents and other stewards of a highranking kin-Title (by "stewards" I mean those consanguines interested in maintaining the rank of that Title) were at pains to insure, first, that the heir to the Title be mothered by a woman with an equivalent or even higher-ranking Title, and second (but less crucial) that there be no conflict about succession to the Title. The operation of this set of "special-interest" norms resulted in the situation, reported by Ellis, that the holders of high-ranking kin-Titles had only one "wife" at a time-that is, only one of 
the women such a man consorted with was at any one time regarded as the actual or prospective mother of his principal heir.

But many such men consorted openly with other women of titular status nearly as high as that of the wife just described-women who might take over the latter's special position in the event that she produced no heir. Following Williamson, I propose to call these potential heir-mothers secondary mates, to distinguish them not only from the actual heir-mother, or primary mate, but from concubines as well (for, there is evidence that the households of some men included all three).

In the case of those Ellis called "inferior chiefs" the kin-Titles were not important enough to require grading of their several consorts, who were presumably all of about equal status, and hence they all "... appeared to receive an equal degree of respect and support."

As for persons of lower-class status, in cases of men materially affluent enough to consort with more than one woman, the question of succession assumed little or no importance, and co-wives were probably socially graded (if at all) in terms of individual attributes and special circumstances.

One answer to the question of why some Maohi men had more than one mate at a time, might well be, "Why not?" (There is nothing more "natural" about monogamy than about polygyny, for the human species at least.) In some societies the ratio of women to men might serve as a partial constraint, but this could not be said of Maohi society, where men outnumbered women to some degree. ${ }^{51}$ Nor can one be satisfied with an answer framed in broad functional terms, such as, polygyny tends to be prevalent in societies, like that of the Maohis, having class stratification. This level of generalizing is a valid exercise, but it still does not provide specific enough explanations for particular societal cases. In Maohi society there were a number of factors that resulted in some families having been polygynous and others monogamous.

Sexual appetite undoubtedly moved some men more powerfully than others. And although extramarital sexual enjoyment was usually easy to secure, and a change of wives not difficult to accomplish, to have at one's continuous disposal an extra female or two was undoubtedly an attractive convenience. And as one grew older, and one's wife "older" still, the incentive to acquire a younger alternate probably increased-particularly in these Islands, where sexual activity was not considered to be unrespectable or ludicrous for older men. (There is no evidence that a woman was prohibited from having sexual intercourse during her pregnancy; hence this rationale cannot be adduced as an additional incentive for having more than one wife.)

But, economic factors would not have permitted all men desiring extra wives to realize their ambitions. The cost of supporting a wife was probably 
no barrier (indeed, perhaps in most cases a woman carried at least her own weight in domestic subsistence), but the cost of acquiring an extra, younger wife and of insuring that she and her guardians remained content with the arrangement, must have proved unobtainable for many, many men-especially in view of the reported scarcity of women.

Another general factor which must have operated differentially, in some instances encouraging polygyny, in other instances discouraging it, was the attitude of a man's established wife. There is not a great deal of evidence to draw on, but enough to indicate that not all women were equally enthusiastic or tolerant or submissive about sharing a husband.

"Social status" and "political" incentives for polygyny were influential in only a few special kinds of situations: when it became necessary to supercede an infertile wife with a fertile one in order to obtain an heir to an important heritage, or when it became expedient to acquire political and military allies in the guise of new affines. Other special incentives for polygyny were inherent in the characteristics attributed to certain religious specialists: to some so-called "high priests" who, for reasons unspecified, are described as having been "allowed" five wives apiece, and to some shamans believed possessed by the god 'Oro.

Finally, the institution of the levirate, already described, provided readymade polygyny in the case of men already married.

There is no question but that many Maohi women changed spouses frequently and that some women cohabited openly with one or more men in addition to, and even with the tacit consent of, a duly married husband. But I will postpone for a while investigation of the complex subject of Maohi polyandry.

\section{FORMAL FRIENDSHIP}

In discussing childhood head-freeing rites I quoted a statement by Morrison, which began: "If the Child is Male there is one More [ämo'a rite] which is performd when He adopts a Friend, which is the whole [i.e., the final rite] required to make his head Free, ..." (1935:186).

The sources contain numerous references to more or less formal parts of "friendship" among the Maohis, incorporating a variety of rights and obligations. The term taiō was used most frequently to label the partners in such a relationship, but taua and hoa were used as well. I postpone to chapter 20 the full discussion of this relationship; here it will suffice to record that during the course of their lives many Maohis (probably more males than females) entered such pacts, which had the effect of assimilating their social identity with that of some other individual in many socially significant respects. 


\section{OLD AGE AND INFIRMITY}

They always Venerate the Grey heads... (Morrison 1935:184).

Old age was seldom treated with respect, often with contempt and cruelty (Ellis 1829:II, 281).

Except for the fact that most other available evidence tends to confirm Ellis' opinion, one might be inclined to accept Morrison's direct eyewitness judgment about the treatment of the aged more readily than Ellis' somewhat secondhand reconstruction. ${ }^{52}$

We have already seen how parents' kin-Titles devolved upon children early in life-at least with respect to the ceremonial prerogatives. Moreover, we saw above how the type of sacredness associated with children at birth made them the object of still another set of ritual attentions, until removed through a series of head-freeing rites. In certain ritual respects, then, early infancy was the climax of some individuals' lives; no comparable climax of a ritual nature took place in later years, with the possible exception of the "inauguration" rites for the incumbent of a politically important kin-Title. However, in the practical world of earning a living and of exerting influence over others, the climax of a Maohi's life occurred much later. Exactly when (in terms of the European way of reckoning age) men and women reached their "prime" in these respects is not clear. Actually, I here refer to different kinds of "primes": men may have achieved reknown, say, as warriors at one point in their lives, as skilled craftsmen or influential leaders and counselors at another. As for women, they appear to have attained one kind of social advantage during those years when they were in greatest sexual demand and another kind later on, but before their offspring shook off parental control.

In any case, whenever such primes may have been reached-and individuals probably varied widely in this respect-by the time most Maohis had reached the stage of life that the Europeans characterized as "old age" they were past all socially recognized primes; and from the best available evidence such people were in general treated with neither respect nor compassion. What the European observers meant by "old age" is of course not entirely clear, but it is likely that physical decrepitude was the principal criterion. In Tahitian there were also words (such as ruau) that have been translated as aged, but one cannot now learn what precise meanings, in terms of physical condition or behaviors, were attached to them. ${ }^{53}$ It would not be appropriate to rely on meanings now attached to those terms, in view of the extensive changes that the Maohi language has undergone since the days of first European contact. Nevertheless, the dictionary glosses, crude as they may be, do indicate that physical decrepitude was also regarded as the central component of old age. ${ }^{54}$ In this connection, the LMS Dictionary definition of āhina, "a grey head; a contemptuous name for a greyheaded 
person," provides not only another criterion for old age but also indicates something about the popular attitude concerning this stage of life.

But we do not have to depend upon dictionaries for clues concerning the popular attitude toward the aged:

Among the most uncommon customs, we may add the dishonour and disrespect paid to old age. The advanced in years are thrust aside, and receive little or no attention. Even ... [the former high chief, and now grandfather of the reigning high chief, Pomare] was scarcely noticed by them: they would hardly permit him to enter the cabin when on board [the Duff]; and unless the captain expressly called to him, they kept him alongside in his canoe. One of our old seamen was often the object of their ridicule. In discourse, when any thing refuse was mentioned, they called it "old man." At Tongataboo we noticed the very reverse: in the presence of the aged the younger persons observed a most respectful silence. (Wilson 1799:348)

Another example was provided by Pickersgill. When he and some other members of Cook's expedition went in pursuit of the culprits who had made off with some of their trade goods, their move quickly frightened all other Maohis nearby.

... the Peple all fled as fast as they could with their Effects to the Mountains-we divided our forces and leaveing one half with one of the Mates to take care of the Boats, with the other we persued the Inhabitants who by this time had tolerably well cleard the Houses of their Effects and there was hardly a man to be seen, in this manner we follow'd for about 2 Miles where we over took a fat Chief whose Body was so unweildy that he could not move off fast enough, him we took who promise'd to bring back the things stolen from us, provided we would let him go which we did after taking most part of his Effects as a security for his return with which we march'd down to the Boats. Two Objects here struck me much, they were an extream old Man and Woman who thro' age and infirmities could scarce move and not being able to get away with the rest were left in the Woods, and with their utmost exersion crawled to wards us, each with a Dog in their Arms as an offering at the same time with the utmost dejection imploreing their forgiveness-in so pityable a manner, as was truely affecting; we received their Dogs; afterwards letting them loose and gave the Old People each a large Nail with the utmost assurances of their Safty, telling them we did not come to hurt the good people, but to punish the Theivs who had Stole our property, with this they seem'd tolerably satisfied and retired to their Hut. (Beaglehole 1961:773)

In some respects, the attitude toward old age was similar to the one generally shown toward the physically handicapped and invalids:

The condition of the blind, when suffered to live, must, under the reign of idolatry, have been truly lamentable-they were generally objects of derision and neglect, if not of wanton cruelty. (Ellis 1829:II, 274)

In seasons of illness, especially if protracted, the common people, and the aged, received but little attention. If the malady was not soon relieved by the prayers of the priest, and the remedies he administered, the sufferer was abandoned. Sometimes he was allowed to remain in the house of those with whom he was connected.-But, in general, a small temporary hut was erected with a few 
cocoa-nut leaves, either near a stream, or at a short distance from the dwelling. Into this, as to the condemned cell, the sick person was removed. For a time, the children or friends would supply a scanty portion of food, but they often grew weary of sending this small alleviation; and it is believed that many have died, as much from hunger, as from disease.

This process was sometimes too slow for those who were connected with the sick, and who desired to share any property they might possess. If they thought there was but little prospect of recovery, they would determine to destroy them at once. Murder was at times perpetrated under these circumstances, with the most heartless and wanton barbarity. The spear or the club was employed, to effect what disease had been too tardy in accomplishing. All the persons in the house when these deeds of horror were performed, were called out; and the friends or companions of the sufferer, armed with spears, prepared for their savage work. It was in vain that the helpless man cried for mercy; instead of attending to his cry, they "would amuse themselves in trying which could take best aim" with the spear they threw; or, rushing upon him with spear in hand, they would exclaim, Tui $i$ vaho, pierce through, and thus transfix him to the couch on which he was lying.

Sometimes they buried the sick alive. When this was designed, they dug a pit, and then, perhaps, proposed to the invalid to bathe, offering to carry him to the water, either in their arms, or placed on a board; but, instead of conveying him to the place of bathing, they would carry him to the pit, and throw him in. Here if any cries were made, they threw down large stones in order to stifle his voice, filled up the grave with earth, and then returned to their dwellings. (Ellis 1829:II, 281-282; see also LMS Transactions III, 168)

We could reasonably object that such general accounts as these might have been fabricated by urbane informants for the pleasure of horrifying the good Reverend Ellis-Maohis were (and still are) quite capable of such tall tales, in the interests of a good joke-but Ellis recorded cases which, for him at least, had the ring of reliability. ${ }^{55}$

The natives once gave me an account of an unhappy sufferer, whom they were conveying to the grave; he perceived it at a short distance before they approached, and, influenced by fear, sprang from the board, and endeavoured to escape. He was pursued, and crippled by a large stone, and thus secured by the murderers. I was acquainted with two persons, who were sawyers, and resided some time in the island of Huahine, who had both been engaged in burying one of their companions, merely because they felt the few attentions required, a burden. One of them, whose name was Papehara, is dead; the other is still living. (Ellis 1829:II, 282-283)

Important chiefs were usually accorded the most elaborate of services when they were ill, except if they happened also to be of advanced age, when they were treated with something amounting to disinterest and neglect. For example: "The interest manifested in the recovery of their chief would depend much upon his age. If advanced in years, comparatively little concern would be felt for his restoration" (p. 281).

Finally, we draw attention to a reported attitude that could be interpreted as evidence of a very important phenomenon: we refer to some scattered reports on the embarrassment experienced by certain high chiefs on being ill and their efforts to hide their infirmities from the general pop- 
ulace. For example, when the missionaries Bicknell and Henry asked about the health of Pomare II, the latter replied that he was well "(which according to the report of the natives was false) but did not shew us the part diseased, \& seemed desirous to wave the conversation about it; perhaps being ashamed, there being several persons present, $\&$ it being here a reproach to be afflicted with any disorder." (Bicknell \& Henry, Journal, 24 January 1805, LMS Archives) If this could have been a general occurrence, and not just concern on the part of one or two chiefs to put up a strong front in time of peril, the attitude could (as I am proposing) betoken a general belief linking the physical well-being of a chief with the physical and spiritual well-being of his tribe.

Unlike the attitude shown toward the physically handicapped was the treatment of the insane:

Insanity prevailed in a slight degree, but individuals under its influence met with a very different kind of treatment. They were supposed to be inspired or possessed by some god, whom the natives imagined had entered every one suffering under mental aberrations. On this account no control was exercised, but the highest respect was shewn them. They were, however, generally avoided, and their actions were considered as the deeds of the god, rather than the man. Under these circumstances, when the poor wretch became his own destroyer, it was not regarded as an event to be deplored. (Ellis 1829:II, 274)

\section{SICKNESS AND DEATH}

After the god Ruatupuanui (Source-of-great-growth) had conjured to final death the Great Octopus that was holding sky close to earth, and thereby confining all other spirits within the narrow-spaced darkness between, the goddess Hina commanded Rua: "Do not insist upon conjuring man to death but only cause him to fade, and I will resuscitate him" (Henry 1928:405).

So it was that unless some spirit intervened to shorten it, a human's life as such ended at a predestined time by simply withering away. At least this is the best summary interpretation I can put together from the innumerable bits of evidence for Maohi beliefs about what Europeans call "death."

It goes without saying that what evidence there remains in native statements about such beliefs is no better than the translations of a century and a half ago-and that is hardly a satisfactory basis for understanding such an exotic set of ideas about so deep a subject. Consider, for example, the LMS Dictionary definitions of the following most relevant words:

ora, life, salvation, health; a Saviour, deliverer; to live, to be healed; to be saved, or delivered; live, or alive, in opposition to pohe, dead.

pohe, death; also hurt, injury, sickness, see mate; to die, to be ill, or diseased, to be hurt; to be foiled in an argument, see mate; to perish, or to be punished for ever; to be affected with jealousy. 
mate, death, illness, hurt, injury; to die, to be ill, sick, or hurt $m a^{\prime} i$, disease, sickness; any bodily disorder.

In addition, each of these words had a number of "metaphoric" usages; and this raises a problem in semantics. For example, the most authoritative dictionary definitions of ora and $m a^{\prime} i$ are those just given, but one also comes across these words in such texts as the following prayer, chanted after a marae had been repaired and weeded for an important ceremony:

Ia ora te fenua! [May live the land.] Ua ora te ma'i o te marae, ua vaere hia, ua ioio. [Is cured the sickness of the marae, is weeded, is made handsome.]
May the land live! The marae is restored, it is weeded and become handsome.

(Henry 1928:162)

The question here seems to be, Is one justified in distinguishing between "basic" and "metaphoric" usages of these words, or were their "basic" meanings broad enough to include both the conditions of humans and of places and objects? And, of course, with this is the even more fundamental question concerning the connection of language with "thought." In other words, if for example ma'i was in fact used by the Maohis literally and nonmetaphorically with respect to disorders of both places and humans, does this mean that they "thought" of places and humans as subject to the same kind of disorder? Intriguing as these questions are, they cannot be answered at this great remove in time from the events in question.

Leaving aside, then, these broader problems and focusing again on man alone, several fundamental cognitive propositions seem to have underlain Maohi behavior regarding what we call injury, sickness, and death:

1. An individual remains alive (ora) so long as his soul (värua) resides more or less permanently inside his body (tino). The soul may wander sometimes outside the body (e.g., dreaming), or it may be forced outside for a while by a malevolent agent; but if its absence is not too prolonged-how long is not clear-the individual will remain alive.

2. When the soul's absence is too prolonged the soft parts of the body begin to rot away, and once this decay begins the process cannot be reversed-although it may be temporarily arrested in exceptional circumstances if the soul returns to the body. ${ }^{56}$ As long as there is any body remaining, however, there continues to be a link between it and the soul; for example, the skull may become an abode for the soul when it returns to its earthly haunts, and if an enemy obtains any portion of the bodily remains he can use it to secure control over the departed soul, just as the sorcerer uses exuviae to destroy a living victim.

3. As noted before, unless some outside agent intervenes, the soul will usually continue to reside mainly in the body until a predestined time (poi), presumably set by some spirit and marked by the body's general, progres- 
sive decrepitude (ōriorio). Whether the soul, also, weakens or fades through aging is not clear.

4. The outside agents which intervene to hasten a soul's permanent departure from the body are usually spirits-but spirits of many kinds, which either capture the soul or damage the body so badly that it is no longer fit for harboring the soul. ${ }^{57}$ (The kind and extent of such damage is not, however, specified.)

In terms of these general propositions the translations of the various words listed above appear less ambiguous: like the ideas assumed to underlie them, they express degrees of living or dying rather than polarized extremes.

But now let us return to beliefs about the various ways in which spirits acted to destroy a human's well-being. These may be categorized as follows (i.e., according to European logic-Maohi categories, if any, were not reported):

By capturing the soul itself, either directly from the body or during one of its normal absences from the body (e.g., during dreaming).

By damaging or destroying the body (and soul?), which could be accomplished by: causing an accident to occur (e.g., a limb to break while climbing, a tree to fall on one, a shark to bite one, or a centipede to sting); guiding an enemy's weapon to a vulnerable spot (e.g., during battle); legitimatizing the execution of an individual believed to have violated a spirit-sanctioned rule of conduct (e.g., the killing by a priest of an unauthorized onlooker at a restricted marae ceremony, or "execution" of a victim required for sacrifice) ${ }^{58}$ destroying the vitals through sorcery (i.e., through spirit agents acting under instruction of a human sorcerer); afflicting the body (or soul?) directly with a sickness, without a human agent as intermediary.

Some of the sources contain blanket statements to the effect that all human injuries and ailments were believed to have come about through spirit intervention, one way or another; ${ }^{59}$ but judging from the reported treatment accorded some cases this factor must have been considerably minor in them. In any event, whether or not there was a place for true accident (i.e., in the European sense) in Maohi reasoning-and this I cannot verify-there was probably a considerable range of differences among individuals as to estimates of where to draw the line between spirit intervention and "pure accident" as cause for injury and sickness. ${ }^{60}$

Warfare was, as we saw, the principal occasion for enlisting spirit aid in damaging one's enemies, and the practices through which this was accomplished have already been described in chapter $12 .{ }^{61}$ Nor does any more need to be written here about killing or injuring being carried out in execution of "official" orders. Instead, I turn now to a discussion of sorcery, which, 
according to some writers, was believed to be one of the major causes of sickness and death before European-introduced ailments became predominant.

\section{Harming}

One of the most common techniques employed by Maohis to harm one another was through the agency of fetchers $\left(t i^{\prime} i\right)$. Certain people (possibly men only) specialized in this practice, usually for hire; they were designated feia tahutahu (persons-kindlers; from tahu, to kindle a fire); but they were also known as nanati aha (to bind with sennit), ta'ata ōpū tara (incantation-stomach), and so forth (Henry 1928:203-204). Some persons may have practiced this technique rarely, surreptitiously, and for their own purposes, but there were others whose identities and reputations were well known; in fact, kindlers were present among the official staffs of some marae.

Fetchers $\left(t i^{\prime} i\right)$, which acted as agents of the kindlers, consisted in the main of small anthropomorphic images of wood or stone invested with the presence (mehoi) of malevolent spirits-either 'oromatua-ai-aru (devouring ghosts of darkness), 'oromātua-niho-roroa (ghosts of long teeth), vārua 'ino (evil spirits) (Henry 1928:203). According to Henry, in some instances the skulls of certain famous rulers and warriors served as fetcher-receptacles for their own ghosts (1928:206). The kindler is described as "invoking" a spirit to enter into his service, although exactly why particular spirits came to serve any particular human in the first place is not explained. One account has it that when the children of a kindler died their ghosts regularly served as fetchers (Elder \& Wilson, Journal, 19 June 1804, LMS Archives); and it is logical to assume that among any kindler's fetchers would have been some of his own ancestral ghosts.

According to Henry (1928:203-204), kindlers used to "adopt" their fetchers as sons and daughters and thus became known as their "parent-kindlers" (metua tahutahu). Parent-kindlers installed their fetchers in a special little house built high off the ground. There, on occasion, the kindler used to sleep, to feed his fetcher-children, bathe and anoint them, and hold "mysterious night festivities" with them. Fetchers communicated with their parent-kindler through the murmuring sounds of certain seashells, also kept in these houses. (See also, chap. 3, section on humans.)

If for any reason a kindler wished to disassociate himself from one of his fetchers he secretly buried its receptacle (image or skull) in a deep hole dug in unfrequented ground (Henry 1928:208).

A kindler usually carried out his work in the following manner: In the presence of his fetchers, he placed some object which had been in contact with the intended victim-some of his saliva, a hair from his head, a nail paring, food leavings, a bit of clothing or sleeping mat-into a tight container and conjured the fetchers to enter and destroy the victim's body through the link provided by the exuvial object (tupu), which contained 
some of the victim's iho. This part of the performance was called the tara; containers [fari'i tupu] were either stone bowls or baskets, with tight covers. ${ }^{62}$

Fetchers approached their victims by walking either on or through the ground. Once inside the body, they attacked the vitals in numerous ways-piercing them, crushing them, and so forth, with such devastating effects that the victim became feverish, writhed in agony, and foamed at the mouth; ${ }^{63}$ he soon expired unless the process was checked. Pifau (subtlehooker) was the word applied to this set of symptoms, as well as to this whole kind of sorcery.

The usual purpose of pifau was to destroy the victim's body and force his soul to vacate-and, according to one account, even to harass the soul into the $p \bar{o}$ (Ellis 1829:II, 231). On occasion, however, the kindler sought mainly to hypnotize the victim in order to force him to divulge secrets or betray relatives and friends (Henry 1928:205).

In addition to practicing pifau, some kindlers used a technique known as tuno'o, whereby they introduced their fetchers into the victim's body by means of his food or drink. Following this principle it was possible to destroy a whole household by implanting fetchers in its earth oven (Henry 1928:208; Davies Journal, 27 March 1809, LMS Archives).

Kindlers were usually paid handsomely for their services, some of them even collecting their payments before, during, and after their operations (Moerenhout 1837:I, 540-541). Moreover, some of them were universally feared and respected, depending mainly upon the proven efficiency of their fetchers, but occasionally upon their wild looks and manners. On the other hand it is reported that they sometimes went too far in their actions and pretensions and provoked their victims' relatives and friends to kill them or drive them away.

There is ample evidence that some Maohis actually practiced the arts of sorcery just described, and unquestionable indications that innumerable natives died of what they and others considered to be the effects of sorcery. ${ }^{64}$ Whether individual kindlers believed in their own personal powers is of course impossible to discover, but there are indications that some of them were just dubious enough of their own powers to supplement their magical acts by hiding genuine poisons in the food of intended victims. ${ }^{65}$

Somewhat similar to sorcery in its instigation was a request uttered by a human asking some spirit to harm another human. Some of these requests were in the form of more or less ad hoc prayers to specific spirits (and accompanied with sacrificial gifts)-for example, a chief's prayer to 'Oro which resulted in the death of a potential political rival (Jefferson, Journal, 18 August 1799, LMS Archives); others, however, appear to have been standard imprecations-tuhi, ahua, rorai-the latter being specifically aimed by parents at their children!

In still other instances direct attacks by spirits against humans were 
thought to have come about through the sheer malignancy of some of the former-especially of long-toothed ghosts and devouring ghosts, the spirits that also served as fetchers for sorcerers. Of course, even these spirits may have acted only against individuals considered by them to have broken some rule, but what may have distinguished such situations was the circumstance that the rules in question were unusually arbitrary, and perhaps esoteric as well, at least as far as the particular victim was concerned.

Much more common were injuries and ailments visited upon humans by spirits as punishment for the infraction of some widely recognized and generally unchallenged rule ranging from deliberate and massive acts of sacrilege to unwitting omissions of ritual detail. Many types of spirits participated in these transactions, from mighty 'Oro to the ghosts of infants just slain. In this connection, the majority of all cases of sickness suffered by the Maohis were, according to one writer, those instigated by ghosts upon their descendants, as punishment for family strife (Moerenhout 1837:I, 543).

The sources contain symptomatic descriptions of many native-defined maladies, including the punitive ones now under consideration, and these will be listed later on. But, in contrast to the highly specific methods ascribed to sorcerers, there are few indications of the actual techniques utilized by spirits in causing such maladies-except for statements like "so and so was seized (or strangled) by the spirit." (Ellis 1829:II, 275)

Maladies deriving from contact with sacredness $\left(r a^{\prime} a, m o^{\prime} a\right)$ are especially intriguing, and correspondingly puzzling. The sources abound with descriptions of behavior constrained by considerations of sacredness. As noted above, certain persons, places, objects, even words, were regarded as "sacred" (e.g., the heads of certain chiefs, and of certain children not yet desanctified by àmo'a rites) to an extent that anyone else touching them, nearing them, or even calling their names was stricken with illness, or worse. Finally, it should be recalled that the concept of hara, infectious guiltsubstance, was applied to people as well as to places and things (see pp. 120-122, this work).

\section{Curing}

The Maohis took many measures to avoid the bodily afflictions we have just discussed. For example, to guard against "accidents" they were accustomed to offer prayers and sacrifices to appropriate spirits before setting out on some hazardous enterprise. Before battle, priests led the forces in mass petitions to their tribal deities for protection against the enemy weapons. Against the possibility of sorcery, vulnerable people, especially influential ones, took care to see that their nail parings, hair cuttings, food leavings, cast-off clothing, and so forth, were placed out of the reach of enemies, and they were cautious about the source of their food. In a 
more general way, it may be stated with fair justification that most of the Maohis' regular, periodic prayers and sacrifices were carried out more in the spirit of prophylaxis than of gratitude; and this included maintaining fetchers and other spirits not only to assist in carrying out various enterprises but also as defense against potentially hostile spirits.

It appears in some cases that the alleged cause of an ailment was so obvious from its symptoms that no further action was necessary before proceeding to its treatment; all that was required was to call in the appropriate specialist. According to Ellis, when sorcery was suspected, a specialist known as a fa'atere (causing to move or glide) was brought in (1829:II, 233); in other instances people called in either a regular marae priest or a physician (tahu'a ra'au, ta'ata rapa'au), whichever was indicated. Ellis did not say how the Maohis decided which of these two professionals to summon, but in case it was the latter it was usual to call in someone whose medicines ( $\mathrm{ra}^{\prime} \mathrm{au}$ ) were known to be efficacious in treating the ailment in question (1829:II, 272).

A tahu'a tutera, as described by Moerenhout, was both diagnostician and adviser. Upon arriving at the home of the stricken person he acted as if possessed, presumably by his spirit-familiar, and proceeded to announce the cause of the ailment and the identity of the individuals responsible for it:

In this state, he often accused the father, the mother, or other members of the family of having caused the malady through their dissensions or by their negligence toward the gods. He ordered them to pray and to make offerings at the marae; sometimes he prescribed remedies; he had great power over the spirit of those ill; but, in grave cases, as for example a case of a dangerous illness or of a death attributed to some enemy, gifts were given to the tehoua toutera [tahu'a tutera] in order to discover who was guilty. The tehoua toutera then set about reciting prayers and walking about near the house, where the spirit of the deceased appeared to him; and after his appeal, judged whether it was the gods or some enemy who had made him die. In the latter case, there were other ceremonies, after which, claiming to be inspired, he named, in the midst of delirium and excitement, the real or pretended author of the death .... (1837:I, 542-543)

In contrast to Moerenhout's shamanistic tahu'a tutera, the specialist described by Henry functioned more as a priest:

People that were supposed to be under a curse of the gods of the feiatahutahu, both men and women were taken to a prayer-healing priest of the regular clergy, called the apa (disenchanter), ha'a-tupu (growth-combater), or tao-ti'i (rebukerof-fetchers), whose marae was dedicated to the god Ro'o-teroro'o, and who was at all times a defier of magicians and evil spirits, being in favor with all the gods of the higher classes. (1928:209)

The diagnostic procedure of an āpa was simplicity itself; he merely questioned the patient or his relatives about the cause of the ailment: "What 
complaint is ailing thee? Is it a curse, an error, or pride? ... What then is it? A parent's curse? ... An imprecation? Sacredness violated? ... A sacred wall pushed down? ... Is it a burdened soul, estranged, accused, that afflicts thee? ... Art thou possessed with witchcraft?" (Henry 1928:210) Having thus learned the cause of the malady he proceeded to apply the appropriate cure.

The seeming contradictions in these accounts (and they could be multiplied by excerpting from other sources) may derive in part from misinterpretations by the different writers or from gaps in their information; but they may just as well be a true reflection of the complexities of the situations they purport to describe. For, as nonliterate societies go, that of the Maohis was large and complex, with many types and degrees of occupational specialization. And among those who dealt with human ailments there was wide variation both in fundamental approach and in procedural detail. Some specialists acted primarily as priests, others as shamans, others as magicians, and still others as physicians or surgeons or bone setters, with only slight dependence upon spirit aid. Moreover, within each of these "specialties" there had developed individualized techniques and skills, and there were probably many practitioners who combined, in varying proportions, the elements of several specialties. It is more than likely that in addition to the presence of such specialists in this society, every man and woman was something of a practitioner himself, with his own little stock of remedies and skills.

Hence, rather than attempt to discuss Maohi therapy in terms of the practices of an àpa or a tahu'a tutera or a fa'atere, it will be less confusing and more realistic to describe the techniques themselves, disregarding the identities of the practitioners who used them.

One possible method of classifying Maohi methods for dealing with sickness and injury would be to rank them according to their dependence upon spirit agencies. In this sense the splinting of a broken arm or the attempted draining of a victim of drowning would lie at one extreme, while the exorcising of a victim of sorcery would lie at the other. Supporting this method is the fact that the sources do contain accounts of therapies that make no mention of spirit involvement: that is, direct, common-sensical physical procedures for treating obvious physical disorders such as insect bites, dislocations, and open wounds. While there may have been a tacit assumption that spirits "caused" many accidents and would in the course of events be petitioned to prevent recurrence, spirits were not reported as having been significantly involved in treating the disorder. And yet, if we place reliance upon reports that all injuries and ailments that befell Maohis were believed by them to result from spirit intervention, then, granting the Maohis' rationality, we are led to conclude that all their therapies must have included some effort to actuate spirits. The absence of reference to spirits in the ther- 
apies just mentioned may be ascribed to incomplete reporting rather than to the realities of Maohi life.

In view of these uncertainties about the data, and being unable to discover any comprehensive native classification of therapies, I can offer only a random listing of them. Ellis had the following to say about their methods for dealing with breaks and dislocations:

A fractured limb they set without much trouble: applying splinters of bamboo-cane to the sides, and binding it up till it was healed. A dislocation they usually succeeded in reducing; but the other parts of their surgical practice were marked by a rude promptness, temerity, and barbarism, almost incredible. A man one day fell from a tree, and dislocated some part of his neck. His companions, on perceiving it, instantly took him up: one of them placed his head between his own knees, and held it firmly; while the others, taking hold of his body, twisted the joint into its proper place.

On another occasion, a number of young men, in the district of Fare, were carrying large stones, suspended from each end of a pole across their shoulders, their usual mode of carrying a burden: one of them so injured the vertebrae, as to be almost unable to move; he had, as they expressed it, fati te tua, broken the back. His fellow-workmen laid him flat on his face on the grass; one grasped and pulled his shoulders, and the other his legs, while a third actually pressed with both knees his whole weight upon the back, where the bones appeared displaced. It was not far from Mr. Barff's house [a missionary] where the accident occurred, and, observing the people assembled, he went to inquire the cause, and saw them thus engaged. On his asking what they were doing, they coolly replied, that they were only straightening the man's back, which had been broken in with carrying stones. The vertebrae appeared to be replaced; they bound a long girdle repeatedly round his body, led him home, and, without any other treatment, he was in a short time able to resume his employment. (1829:II, 276-277)

Other writers reported the Maohi's surgical methods and skills:

... in surgery they are excellent and make surprizing Cures-We have been Eye witness to some-one of which was from a Musquet ball which a Man received in his Breast and passd through the Shoulder blade, another with his arm broke by a ball, a third having a Ball through his thigh \& a fourth received one through His Thigh while stooping, which passd under his ribbs and out by the Collar bone, with several others Wounded with Stones, all of which were perfectly cured within two Months-among those wounded with Stones was one who had all his Upper Jaw stove in and 6 or 7 teeth knockt out; several splinters of the bone were extracted and the Juice of herbs with Clean water was the only remedy ever we saw used. They cannot bear their wounds bound up and are Constantly Washing them to keep them from smelling; for this reason should they get a leg broke it is certain Death as they Cannot be kept from the Water tho they know the Consequence, always flying to the water as soon as the smell becomes disagreeable, and often grate sandal wood on the part to take away the Smell. For Splints they use bamboo and often repair broken Arms whether gotten by War on Accident. (Morrison 1935:228)

That they have skillfull Chirurgeons among them we easily gatherd from the dreadfull scars of wounds which we frequently saw that had been cur'd, some of which were far greater than any I have seen any where else, and these were made by stones which these people know how to throw with slings with great 
dexterity and force. One man I particularly recolect whose face was almost intirely destroyd, his nose one cheek and one eye being beat in and all the bones there flatted down so that the hollow would receive a mans fist, yet this dreadfull wound was heald clean without any ulcer remaining, Tupia who has had several wound(s) has had one made by a spear of his countrey headed with the bone of a stingrays tail which had peircd quite through his body, entering at his back and coming out just under his breast, yet this has been so well curd that the remain(in)g scar is as smooth and as small as any I have seen from the cures of our best European surgeons.

Vulnerary herbs they have many, nor do they seem at all nice in the choice of them so they have plenty of such herbaceous plants as yeild mild juices devoid of all acridity, such as chickweed groundsell \&c. in England. With these they make fomentations which they frquently apply to the wound, taking care to cleanse it as often as possible, the patient all the time observing great abstinence\& by this method if they have told us true their wounds are curd in a very short time. (Beaglehole 1962:I, 375-376)

The operation of trepanning they sometimes attempted, and say they have practised with success. It is reported that there are persons living in the island of Borabora on whom it has been performed, or at least an operation very much resembling it: the bones of the skull having been fractured in battle, they have cleared away the skin and coverings, and, having removed the fractured piece of bone, have carefully fitted in a piece of cocoa-nut shell, and replaced the covering and skin; on the healing of which, the man has recovered. I never saw any individual who had undergone this operation, but, from the concurrent testimony of the people, I have no doubt they have performed it. (Ellis 1829:II, 277)

This afternoon a few Young Men were wrestling when one of them having an untoward fall his Arm was put out of joint at the Elbow. As instantly as the accident happened three Stout Men took hold of the Man by the wrist and placing their feet against his Ribs they put it in again. My Boat being waiting I sent her off for the Surgeon but before he returned all was well, except a Swelling of the muscles from the Strain which he prevented from getting to a greater height. I was alarmed lest the Arm might be broke for they were wrestling to entertain me, but they all laughed heartily at it, and told me [that if it] was they could mend it again, and got a number of Sticks and placed round the arm and bound it with Cord to show me how it would be done. Many accidents of the kind they said happened at their Wrestling Heivahs, and I have no doubt of it as I have seen many deformed arms; that they have a skill in Surgery is therefore no longer a doubt, and I have already given an instance of seeing an amputated Arm perfectly healed and apparently performed with a great degree of skill. (Bligh 1789:II, 30)

Anderson was more skeptical and qualified in his judgments of their surgical skills:

Their arts are few and simple; yet, if we may credit them, they perform cures in surgery, which our extensive knowledge in that branch has not, as yet, enabled us to imitate. In simple fractures, they bind them up with splints; but if part of the substance of the bone be lost, they insert a piece of wood, between the fractured ends, made hollow like the deficient part. In five or six days, the rapaoo, or surgeon, inspects the would, and finds the wood partly covered with the growing flesh. In as many more days, it is generally entirely covered; after which, when the patient has acquired some strength, he bathes in the water, and recovers. We 
know that wounds will heal over leaden bullets; and sometimes, though rarely, over other extraneous bodies. But what makes me entertain some doubt of the truth of so extraordinary skill, as in the above instance is, that in other cases which fell under my own observation, they are far from being so dexterous. I have seen the stump of an arm, which was taken off, after being shattered by a fall from a tree, that bore no marks of skilful operation, though some allowance be made for their defective instruments. And I met with a man going about with a dislocated shoulder, some months after the accident, from their being ignorant of a method to reduce it; though this be considered as one of the simplest operations of our surgery. (Cook 1784:152-153)

The "vulnerary herbs" mentioned in Banks' account may indeed have been many in kind, but only a few have so far been identified. For example, pain from centipede stings, we are told, was quickly relieved with applications of chewed kava leaf in coconut oil (Crook, Journal, 3 July 1817, LMS Archives); cuts were closed by drawing together the edges and applying the caustic juice of the Arum costatum (Ellis 1829:II, 276); and sore limbs were rubbed down with "the juice of an herb" (Wilson 1799:165). Another account of external application of plant remedies is given in the following missionary journal entry, which referred to a "curious epidemic" that had recently killed several people:

It did not appear contagious, yet nine or ten were seized in a day. They were almost immediately seized with a locked jaw and the fists clenched. The people were confounded at its first appearance, but they hit upon a good expedient. As soon as they had collected their roots \&c they beat it up ready and always kept it ready at hand. Their method was, as soon as ever a person was seized, they immediately heated stones to warm the medicine. In the meantime several strong men were treading the arms and opening the hands rubbing and chafing them with all their might as soon as the medicines were heated they poured upon the patient. In many cases it succeeded effectually the arms became supple and the jaw unlocked, the patient was [cured]. (Platt to Burder, 28 February 1827, LMS Archives)

Plants were also given externally, for a variety of aches and pains. For example, "The chief of [Ha'apaiano'o] district is ill\& his complaint is violent pains in the temples of his head, thighs, and legs; by which he is disabled from walking alone. His remedy is drinking plenty of yavva, and sacrificing, with much prayer to his god. The [dis]order is prevalent ..." (Jefferson, Journal, 10 February 1800, LMS Archives).

According to Ellis, no animal or mineral substances were included in their pharmacopoeia: “... vegetable substances alone were used, and these simply pulverized, infused, heated on the fire, or with red-hot stones, and often fermented (1829:II, 271).

There may have been some medicines whose ingredients were widely known, but the identities of many others were professional secrets. Sometimes the specialist sent his patient's relatives to collect the various roots, leaves, and so on, used in his remedies; in other instances he collected them himself:

... the priest usually went himself to compound the raau [ra'au] or medicine: a 
considerable degree of mystery was attached to their proceedings, and the physicians appeared unwilling that others should know of what their preparations consisted. They pretended to be instructed by their god, as to the herbs they should select, and the manner of combining them. Different raaus, or medicines, were used for different diseases; and although they kept the composition of their nostrums a secret, they were not unwilling that the report of their efficacy might be known, in order to their being employed by others. Hence, when a person was afflicted with any particular disease, and the inquiry made as to who should be sent for, it was not unusual to hear it said-" $O$ ta mea te raau maitai no ia mai," - such a one has a good medicine for this disease. (Ellis 1829:II, 271-272)

There may well have been some general theories, both "magical" and "scientific," underlying the Maohi pharmacopoeia-something more than just an assortment of unconnected experiences and ideas-but they are not spelled out in the sources. However, there are such fragments as the following:

The Indian who had undertaken to finish the fence came to us wounded and slashed about by his father-in-law, as he told us, begging us very earnestly to treat him; and, on our desiring him to show us two wounds that he had bound up, we saw that they were dressed with herbs. He declared, however, that those herbs would be very good and would heal him quickly if the wounds had been (caused) by a stone or stick of Otahiti, but that, having been (inflicted) by a knife from Lima, it was necessary, for their speedy cure, to employ dressings from Lima in treating them. (Corney 1919:94-95)

We do learn from the sources that experiment was continual, but as the following excerpt indicates, the intrinsic qualities of the medicine may not have been the only thing tested:

Frequently, when some medicines were about to be administered, the friends and relatives of the patient were sent for, that they might be at hand, should the effect be unfavourable. They often expected it would either save or destroy the patient. A number of ceremonies were connected with every remedy applied; and much greater dependence was placed on the efficacy of the prayers, than on the effect of the medicine. (Ellis 1829:II, 271)

We shall return to the implications of this last point in a moment, but let us first consider a few other aspects of Maohi therapeutics.

As attested by grateful Europeans, many Maohis were expert at massage (rumirumi), which was successfully applied not only to relax tired legs but to reduce more general muscular pains as well. ${ }^{66}$

Forced sweating was occasionally resorted to, especially after a difficult childbirth, but the usual physical method of dealing with a fever in a patient was to help him to cool himself by lying in breezy locations or immersing in running water.

For this reason, and for other reasons as well, some importance was attached to geographic setting as a factor in the treatment of lingering illness. In fact there are several accounts of stricken individuals, mainly important chiefs, being moved from one spot to another in search of a more salubrious 
clime-salubrious, that is, as much or more in terms of spirit benevolence than of healthful air (Corney 1919:175).

Turning now to Maohi techniques for engaging spirits to help mend their injuries and cure their ills, it should be recalled that these were not merely supplementary to the more "physical" measures just noted but that they complemented them, activated them, or in some cases superseded them.

It sometimes happened that spirits intervened without having been petitioned to do so; this was particularly true of the spirit Tama. Writing in his journal about a captured warrior, the missionary Davies reported:

... the man from Teauru was taken away today, and will probably be put to death when he arrives in the Camp. He had been shot through the body in two different places, at the time of taking the fortress of Atahuru, and was now completely recovered, his recovery from such dangerous wounds, makes the people suppose him to be a peculiar favourite of the god Tama, whether this will have any significance with the king to spare his life is not yet known. The god Tama like Aesculapius the son of Apollo, in all probability was a man, famous in his day for his skill in curing wounds and diseases ... Whenever any of the Taheeteans escapes imminent danger of falling from a tree or a precipice, or when an unexpected recovery takes place from bruises, wounds, or any dangerous diseas, they commonly ascribe it to the good will and power of the god Tama. (27 August 1807, LMS Archives)

When it was determined, through questioning or through diagnosis from the symptoms, that an individual's illness was due to sorcery, prayers and sacrifices were sometimes offered to the god Ro'oteroro'o to turn away the fetchers destroying the victim. According to Henry, the specialist who brought this about was an àpa, a priestly devotee of Ro'o. The exorcism took place in the patient's house, where gifts were laid out for Ro'o, in the person of the apa. The latter, holding in his hand a banana shoot to represent the sorcerer, addressed a prayer to Ro'o asking him to spare the victim ("who faithfully provides the God with pigs and red feathers") and transfer the "evil" to the sorcerer, represented by the banana shoot, so that the latter will himself be destroyed (i.e., his soul will be grated for food for the gods in the $p \bar{o}$ ). It is not clear from the prayer itself what is meant by the "evil" (te 'ino), but, from further statements in Henry, it could be interpreted as implying that the action taken by Ro'o consisted in forcing the attacking fetchers to leave the victim and turn on their own keeper, their parent-kindler, destroying him and his family, and then disappearing from the world of light (ao). (1928:210-212)

In other instances it was necessary to learn the identity of the sorcerer or his client or both, before attempting to save the victim. A specialist was needed to perform this service-usually the same specialist who exorcised the attacking fetchers. The sources do not describe how this was accomplished, but presumably the specialist's own spirit-familiar was involved in the denouement. ${ }^{67}$ 
One method of counterattack involved engaging a specialist to employ his own spirit-familiars to attack the sorcerer (and possibly his client), “... and if the demon employed by [the patient and his relatives] was equally powerful with that employed by the first, and their presents more valuable, it was generally supposed that they were successful" (Ellis 1829:II, 233). But, according to Moerenhout, any such counterattack had to be aimed at the sorcerer's client, the sorcerer himself having been protected by his fetchers (1837:I, 541-542). Still another method of saving the life of a victim of sorcery consisted of bribing the sorcerer: an arrangement, according to Moerenhout, which was eminently satisfactory to the latter, not only because of the additional fee but because it provided him with a dignified excuse should the original sorcery have failed.

When it was suspected that an illness was due to spirits acting on their own initiative, or in response to a curse, the procedure was to induce them to desist by means of expiatory prayers and sacrifices. In some cases this had to be preceded by open confession on the part of the individual whose curse had activated the offending spirit, or whose acts of familial dissent or of sacrilege or of impious neglect had aroused some spirit's anger. (However, it should be emphasized that individuals were often thought to have been stricken because of the actions of others.) The prayers and sacrifices offered under these circumstances varied according to the social status of the stricken person and the duration of the illness. In simplest form they consisted of a brief rite at the family marae, with a perfunctory prayer and a small offering of food. A slight variation on this basic pattern was described by Banks:

I never hapned to be present when their preists performd their ceremonies for the cure of sick people, but one of our gentlemen who was informed me that it consisted in nothing but the preist repeating certain fixd sentences during which time he platted the leaves of the Cocoa nut tree into different figures, neat enough, some of which he fas(t)ned to the fingers and toes of the sick man, who (was during) the time uncoverd as in respect to the prayers, the whole ceremony almost exactly resembling their method of praying at the Marai's ... (Beaglehole: 1962:I, 374)

At the other extreme, for the critical, obstinate illness of a chiefly personage, many of the resources of his realm were applied to his cure. Priests kept up continual prayer services at his ancestral and district marae, which were often refurbished for the occasion. Much of his subjects' wealth in pigs and fine textiles were sacrificed; and if this had no apparent effect humans as well were sometimes sacrificed. If the vengeful spirits paid no heed to all this, priests ran about the countryside summoning them in frenzied cries, and the patient was vigorously fanned, on the supposition that spirits characteristically rode on whirlwinds. Meanwhile music described by Europeans as "doleful" was played on flutes and drums-whether to attract the spirits or simply to advertise the occasion's solemnity is not entirely clear. ${ }^{68}$ 
The propitiatory prayers were sometimes uttered in a most dramatic fashion. If, for example, it was determined that some other individual-say, the patient's father-was responsible for the illness, the culprit would announce his confession by proceeding to the marae with a cord tied around his neck. A priest would then hold the cord and address the spirits: "Here is the father to atone for the patient." And the father would add: "Yes, here is your human pig; cease to be angry." ${ }^{69}$ Moerenhout's description of such an episode is fuller:

When it was discovered that an action by some member of the patient's family was responsible for the latter's illness ... the lamentations of the culprit were intense: he wept and prayed night and day, offering to sacrifice all that he possessed; and it was not unusual for him to betake himself to the marae, with a cord around his neck, throw himself to the ground before the images of the gods, and cry out: "O gods! Take me as a token of my repentance; and restore the health and happiness of my family." If the culprit was a female, then she made her prayers outside the marae. (1837:I, 543-544)

If the patient happened to be an important personage, then in place of his relatives a band of strong men presented themselves as atonements, but, according to Henry, none of these was actually sacrificed (1928:290).

Another kind of action which accompanied some illnesses was in the form of ceremonial weeping beside the patient; but it is not clear whether the participants did so to reassure the patient of their sympathy (and loyalty) or to dramatize the occasion and thereby help induce the spirits to intervene. In either event (and perhaps both motives were present), the weepers crowded around the patient and stained pieces of bark cloth brought for the occasion ('ahu 'oto 'weeping cloth') with their tears or with blood produced by gashing themselves. ${ }^{70}$ For example, when Pomare II was ill

Many companies of people from various parts have come to testify their concern for the King. They come in procession bearing a very long piece of cloth which they call ahu oto or weeping cloth. This is received of them by the King's attendants, when they assemble themselves around the Kings bed and weep, the tears gushing from their eyes, and being wrung from their noses, but without much noise. After about 10 minutes they cease weeping and the King desires them to withdraw. (Crook, Journal, 3 December 1821, LMS Archives)

Moerenhout offered the opinion that these dolorous ceremonies, far from comforting most patients, served mainly to increase their anxieties and thereby aggravate their illnesses. (1837:I, 544-545)

Finally, if all else failed to move a spirit to overcome or withdraw the cause of an illness, the patient and his supporters occasionally went so far as to repudiate it ( $f a^{\prime}$ arue atua 'cast away the god') and induce another one to take its place. Conversely, when a patient recovered from a bad illness it was customary to offer thanks in prayers and sacrifices and, in the case of important personages, to serenade the convalescent with music and dancing (Corney 1915:329). 
Having discussed Maohi maladies in terms of general considerations of cause, diagnosis, and treatment, it may be useful to provide a list of the more common maladies. ${ }^{71}$ First are those believed to have been of pre-European incidence or prevalence:

Muteness: several cases, but no reported instances of deafness.

Blindness: also several cases. In addition, there are reports of sties and what appears to have been ophthalmia.

Rupture: said to have been "Very common, frequently Swelling to a Prodigious size, these are perhaps occasioned by too great an exertion of Strength when Wrestling, which however we were not able to perswade them to believe ..." (Morrison 1935:230).

Broken bones: frequent.

Rheumatism: said to be a common complaint, possibly seasonal. Bligh described some people as being "old and rheumatic."

Gout: several reports of a disorder similar to gout.

Humpback:

Among the most prevalent and obstinate diseases to which, as a nation, they are exposed, is one which terminates in a permanent affection of the spine; it usually appears in early life, commencing in the form of an intermittent and remittent. The body is reduced almost to a skeleton; and the disease terminates in death, or a large curvature of the spine, so as considerably to diminish the height of the individual, and cause a very unsightly protrusion of the spine between the shoulders, or a curvature inwards, causing the breast-bones to appear unusually prominent. Multitudes in every one of the Society Islands are to be seen deformed by this disease, which the natives call tuapu, literally, projecting; or as we should say, humped-back. (Ellis 1829:II, 272-273)

Insanity: several forms of behavioral abnormality are specified in the sources, including violent fits, temporary insanity, and conditions of more or less permanent fixation. I wrote briefly in an earlier chapter of the last-named state. Concerning temporary insanity Morrison wrote:

The Insanity is only temporary, and perhaps may proceed from too great a flow of Blood \& spirits and a Want of Exercise, as it generally Commences when the Bread begins to be ripe-at which Season others are troubled with Boils on their legs and thighs, this being the Wet Season and the Sun over head when they are More Confined to their houses by the rain; this generally leaves them when the Sun returns to the Northward, and it is Not Common for a Man or Woman to have it return, tho during its stay with them they are very Mischevious and go quite Naked. With some it stays longer than others \& they have it in different degrees from a heavy dull Melancholy to raving Mad. They never bind them but let them run and some travel all round the Island Naked in the time of their Madness and none interrupts them unless they do some Mischief as they suppose them posessd with some evil spirit. This is Common to Weomen as well as Men, who are not restrained but sufferd to take their own Course till the spirit leaves them when they return home and wear their Cloaths as usual. (1935:228-229) 
Other ailments described as having been seasonally epidemic are stomachache and fish poisoning. Rodriguez mentioned a case of what might have been ptomaine poisoning, and the LMS Archives record instances of lockjaw. Rodriguez also reported the case of "A Chief lady" who was "seized with an oppression or pain at the heart." Coughs and colds were evidently quite common. $^{72}$

There are additional diseases mentioned in the sources. ${ }^{73}$ Bligh described two persons as having died of "comsumption." The LMS Dictionary lists a native term, tūto'o, lasting cough, asthma, which later became identified with tuberculosis. There was also the term hotate, a fever or ague attended with wasting.

Dropsy: reported by J. Forster.

Elephantiasis $\left(f e^{\prime} e f e^{\prime} e\right.$ ): reported for both limbs and testicles.

I have already described some of the observed effects of excessive imbibing of kava. What may have been a form of ringworm was also reported. But the most problematic disease suffered by the Maohis, other than coral sores, which must have been widely prevalent, was body ulcers. Many observers were uncertain as to whether they were seeing a native form of yaws or the European-introduced venereal diseases. ${ }^{74}$

Another somewhat problematic pair of diseases that confused early writers on the Maohis was "Chief's leprosy" ( $\bar{o}^{\prime}$ ovi ari'i) and true leprosy. The former was defined as a certain scrofulous disorder (LMS Dictionary); (scrofula is described in the Shorter Oxford English Dictionary as a constitutional disease characterized ... by chronic enlargement and degeneration of the lymphatic glands. Also called King's Evil and Strumma.)

The earlier European visitors disagreed in their appraisals of the general health situation. Against Morrison's statement that the Maohis were "vigorous and healthy" (1935:230), one finds Bligh's statement:

... I do not beleive that they have superior blessings with respect to health; we already see them with dreadful Cancers, Consumptions, Fevers, Fits and the Scropula in a Shocking degree, and we may infer many incidental diseases besides. The fertile Country and delightfull Climate of the Society Islands does not therefore exempt its Inhabitants from the attendant miseries of ill health. (1789:II, 31)

But none of their bodily afflictions prepared them for the diseases-including gonorrhea, syphilis, influenza, true leprosy, dysentery-unwittingly introduced by Europeans. The cumulative effects of these served nearly to decimate the native population within four decades after the first Europeans stepped ashore.

\section{Death}

It is astonishing with what indifference these People speak of Death-it has even appeared to me that they cared little how short their existence was, they are 
nevertheless affraid of the final stroke, when by War or accident they have reason to expect it; while in disease they are patient and not alarmed. (Bligh 1792:169b)

The only crimes for which one was punished, in this world or the other, were for not observing sacred rites, negligence and disrespect for the gods and altars. Men who felt they were guilty of these faults, rarely neglected to try to appease the gods during their lifetimes, otherwise, if they unexpectedly became ill, they attributed it to the wrath of the gods. They almost always succombed to their fears and agonies, persuaded that the gods awaited them, just as we believe the devil does, impatient to ounouhi te varoua ('tear the soul from the body'), they lamented, prayed, sought refuge at the foot of the altar, sending offerings, and dying, generally presented to their family and their friends the horrible spectacle of the last moments of those unhappy ones to whom an overexcited imagination, or true remorse fortold eternal torment after their death. These circumstances were rare, but horrifying, the dying calling the priests with great shrieks, since these were, as everywhere, the only ones who could save the guilty, by pacifying the gods; and they, as everywhere, received, most often, from the hands of the sufferer, all his goods and those of his family, for the mere promise of pardon for his sins and exemption from terrible punishment. (Moerenhout 1837:I, 433-434)

Insofar as one can reconstruct Maohi beliefs at this remove in time, the transition between ora and pohe (or mate) was considerably less abrupt than that formulated by modern-day science. Except, perhaps, for cases of unexpected death: "Sudden death was also attributed to ... [direct power of the god]-and an attack so terminating, was called rima atua: "hand of god." Those who died thus were also said to be haruhia e te atua, or uumehia e te atua: "seized by the god, or strangled by the god" (Ellis 1829:II, 274-275). Even as late as 1827 people still clung to the belief that under certain circumstances a corpse could be revivified, by inducing its departed soul to reoccupy it:

Last evening the people were crowding past my door. On enquiry I found that they were going to be present while a certain person was to return the departing soul into the body [of a dead child] and cause it to reoccupy its habitation. The person to whose house they were going belongs to our church. I immediately wrote to him \& requested that he would make himself so foolish as to suffer the wicked man to try to keep back the soul of the child but send them all home directly. This he did, \& the circumstance died away. (Orsmond, Journal, 15 October 1827, LMS Archives)

A favorite legend that seems to have been widely believed concerned an upper-class young woman of Huahine, named Ariipaeavahine, whom the gods brought back to "life" by revivifying her decaying body by reuniting it with her wandering soul. That she had truly "died," in terms of the usual criteria, was attested by the fact that her revived body continued to bear the mottled markings of fleshly decay (Henry 1928:220-223; also Ahnne 1925). Grounds for such beliefs can be seen in the following episode reported in the missionary journal for 1805 : 
We have still to lament that the natives continue to show as much backwardness to hear the gospel, and as little inclination to obey it, as they did three years ago. They are deeply rooted in their prejudices against the truth, and in their love for their own delusions. They eagerly grasp at every occurring incident that tends to harden them in their infidelity, and with great greediness, embrace any lie that is proposed to them. A few days back the wife of a priest in Opeimanno was given out to be dead, and so continued two days; when, to the surprise of her husband and neighbours, she unexpectedly revived again. She has given a long and nonsensical account of the Po, or other world; which, notwithstanding its absurdity, her deluded countrymen seem to receive with a strong persuasion of its reality. Many, from all parts of the district, have gone to gaze on this supposed wonderful personage, and to hear her story. About eight months back a similar matter was transacted in Fwhaa, by the wife of a great priest there. Stupid old women pretend to be inspired by their gods, and utter their oracles with all the fantastical foolery a besotted heathen is capable of. One of this description has lately been running up and down Taue-Valley, in Oparre. (LMS Transactions:III, 51)

Notwithstanding these ambiguities, the state of "dying" was usually recognizable, and the social recognition accorded it seemed to legitimatize the transfer of tangibles: "If a man bequeaths his property to another on his death-bed, no person disputes the bequest, as there are always witnesses abundant to the gift, if the heir is not present" (Wilson 1799:325-326). In addition, the process of dying was invested with special significance for the transfer of knowledge as well, as was exemplified in a passage quoted earlier concerning the "inheritance" of a sage's knowledge by his heir (Henry 1928:290).

During recognizable states of dying, measures were taken to facilitate the exit of the soul and to protect it from hostile spirits. Someone, usually a priest, formed a little container out of leaves and placed it near the invalid's head, into which the soul might enter when leaving the body through the head, as it always did. A passage from Bligh describes this practice, as well as the continuing efforts that were made to maintain "life" even after most signs indicated "death":

This afternoon a Youth who lived near our Post died of a Consumption. As the Surgeon visited him from time to time, we knew of his death as soon as it took place. I therefore went to the House where were collected a few friends of the deceased. The Father was seated on the ground by his son with his legs across his thighs squeezing and pressing them, called Roomee [rumirumi]. Frequently he prest the eyelids over the Eyes and at times fanning away the flies, the Mother was seated on the opposite side driving a Sharks tooth into her head by which the blood run in Streams to the ground. No greif could appear more affecting than it did in these poor unhappy Parents, its violence however, or perhaps from some other cause, created intermissions which were more lasting than I expected. The Corps was stretched on the ground upon a Matt, and at the head was placed some twisted Cocoa Nutt leaves and some others with a few peices of Breadfruit. A bunch of the Cocoa Nut leaves were tyed up as a Nosegay is, and this they called the Morai of the deceased. (1789:II, 50) 
According to Henry the maire fern was sometimes used in place of coconut leaves (1928:291).

It is likely that several different kinds of measures were undertaken to protect the departing soul from hostile spirits. One of these was to provide food offerings for them, to deflect them from consuming the soul itself. The only other measure specifically reported consisted of attaching red or yellow feathers to the dying person's little fingers (Henry 1928:291; Corney 1919:93)

The missionaries encountered particularly stormy opposition to the Christian doctrines of Resurrection:

They offered only two reasons why the dead will not be raised again. 1. Many have been dead several thousands of years, \& still are not raised. Hence they infer, that there be no resurrection. 2. They are rotten $\&$ become dirt; therefore they affirm it is impossible ... They strengthen their unbelief in the resurrection by their own traditions. They say, that it was through the first woman, whom they call Hyena, that the moon, apples, turmeric \&c. was put into that state, to die $\&$ live again in their season\& and if she had got her will, man would have been so too, but the first man, whose name was Tee, wd. not agree to her proposal, \& therefore man will never live again. (Elder \& Wilson, Journal, 5 July 1803, LMS Archives)

If, finally, all measures failed to retain or bring back the soul to the body, before it suffered too much decay, the end was conventionally pronounced with the statement: "The spirit is drawn out by the gods" (Henry 1928:291), and with this began a series of events which will now be recounted. $^{75}$

For the following few days the corpse was kept at home, usually inside the house, and laid out on a sleeping mat. (In the case of Vehiatua, high chief of Tahiti's peninsula, his body was taken outside his house on occasion to enable the throngs of his mourning subjects to see him [Corney 1915:344].) During this period one or more of several kinds of events took place: the corpse was bathed, oiled, and dressed; the cause of death was sought; soul-reposing prayers were uttered; and the survivors indulged in conventionalized expressions of grief.

In addition to being bathed the corpse was rubbed over with scented oil to overcome the fast-developing odor of decay, and sweet-scented leaves and flowers were spread around the body and throughout the house for the same reason. Henry reported that it was "relatives and friends" who prepared the body (1928:291), but neither hers nor any other account specifies which relatives or friends these were. Exactly who performed this most intimate of services may of course have been of little or no significance, but in some Oceanic societies the allocation of this duty-also regarded as a rare privilege-had important social implications.

Divining the cause of death (which was not done invariably) was usually 
left to a specialist, who was remunerated for his services. According to Henry this was a tahu'a tutera, some of whose functions were described earlier in connection with divining the cause of sickness-which, after all, differed from "death" only in degree of finality. Henry's account of this specialist's procedure follows:

... a tahu'a tutera went out in a canoe, paddling slowly along the coast facing the house of the deceased, to find out the cause of the death by watching the flight of the spirit, which it was believed, would approach him with an emblem revealing the cause. If the spirit appeared to him in a flame of fire, it was a sign that the deceased had been a victim of the black art, fire being used by sorcerers in their incantations. If the spirit came out with a feather amulet in his hand, it showed that some one had used it to bring down the displeasure of the gods upon the deceased. If it looked dejected, some personal matter had been the trouble; but if it looked happy, all concluded that it had been the proper time for the deceased to go. (1928:291)

Henry's version differs from that of Ellis: "If he had been cursed by the gods, the spirit would appear with a flame, fire being the agent employed in the incantation of the sorcerers; if pifaod, or killed, by the bribe of some enemy, given to the gods, the spirit would appear with a red feather, the emblem or sign of evil spirits having entered his food" (Ellis 1829:I, 518). Henry's version is somewhat more consistent with other known facts, although, as has been previously pointed out, Maohi society incorporated many procedural variations. On the other hand, Henry did not explain what a "personal matter" might have been, nor how it could have resulted in death; and the notion of a "happy"-looking spirit pleased to pass on because of its "proper time" smacks of an eschatology not wholly Maohi.

Next, according to Henry, if the death was discovered to have come about through "illness"76 - whether from sorcery or curse or hara is not specified-it was necessary to calm or dispel the deceased's ghost by means of a soul-reposing prayer (tui fa'arairai or tui hana), usually performed by the presiding priest (tahu'a fa'atere). Ellis placed the soul-reposing episode after embalming (1829:I, 522). While this was in progress

... a straight branch of the ti, which has broad, spreading leaves and was supposed to be full of magical power, was stood erect by the corpse to conduct the soul to the spirit world. Breadfruit flower spikes and the tips of the stems of banana leaves, each one representing a member of the household of the deceased, were placed under the arms of the corpse while an address suited to the circumstances was made in the following manner:

Here is thy father; here is thy mother; here is thy wife (or husband); here is thy son; here is thy daughter; here are thy relatives (and so on). Turn thy face to Hades; look not back to this world. Let sickness end with thee.

If after this tui the family had no more sickness and saw no signs of a ghost hovering around them, they said, "E tui hana maitai roa teia" (This is a very good soul-reposing prayer). But if the illness followed, they called the prayer a tui pee (prayer that missed) and sought the aid of another priest to obtain the desired 
effect. All the household and relatives contributed towards paying the priests well, so as to secure their good will; their displeasure was carefully avoided by the people, who believed that their curse could bring sickness and death. (Henry 1928:291-292)

At a wake witnessed by Rodriguez the body was taken to a marae for prayers and then returned home (Corney 1919:34). Banks, on the other hand, stated that the priest presiding on this occasion carried out part of his ritual at the seaside:

The preists office now begins; he prays over the body, repeating his sentences, and orders it to be carried down to the sea side; here his prayers are renewd, the Corps is brought down near the waters edge and he sprinkles water towards but not upon it, it is then removd 40 or 50 yards from the sea and soon after brought back and this ceremony repeated which is done several times. (Beaglehole 1962:I, 376; see also J. Forster 1778:559)

Aside from the circumstance that seawater served in general as a purifying agent, I can suggest no explanation for this ritual episode.

Meanwhile the house was the scene of mourning ('otoha'a, taiha'a) in which grief, real or simulated, was expressed in several customary ways. Real or forced tears mingled with repeated interjections of aue! aue! flowed from nearly everyone present (Corney 1915:338; Jefferson, Journal, 3 July 1799, LMS Archives). Some mourners (only women, reported Henry and Morrison; both sexes, according to Ellis) gashed their heads and breasts with a shark's tooth instrument and caught the blood on pieces of bark cloth, which they left with the family of the deceased. This was in order to "strengthen the psychic bond with the deceased relative's soul" (E.S.C. Handy 1927:292).

Visitors to the wake brought condolence gifts of mats and bark cloth, along with red feathers if the deceased were socially important.

When any great personage such as a member of the $\mathrm{R}^{1}$ family, or a high Chief among subjects, dies, the King and all the great folk comprised in that family, and the District head Chiefs and deputies, assemble together. Each one carries a piece of new cloth to the deceased, and a small plantain shoot. They all form into two lines and walk in a procession towards the deceased's house, preceded by two of his female relatives distinguished from the rest by wearing small mat vestments of very fine quality which they call ahuaras [ahu fara pandanus mats], without any protection of cloth at all, excepting a strip they carry in the hand to receive the blood that they draw from their heads by means of a shark's tooth with which they scarify themselves in token of grief; which action they accompany by various lamentations. As each mourner arrives in rotation before the deceased he places the piece of cloth he is carrying at the feet (of the corpse), and lays down the plantain sucker in front of the widow, who occupies a seat near the deceased; and each one offers her at the same time some words of condolence. (Corney 1915:261-262)

While it is certain that such visits did not always follow a procedure as formal and well regulated as this, this description is indicative not only 
of the solemnity which imbued the wakes of great personages but also of the importance of the gift of bark cloth and mats, which is confirmed in an excerpt from the journal of a missionary: "July 3, 1799. Brs. Nott \& Jefferson went to Oparre with a design of seeing how the natives treated the corpse of Vareede, but they were debarred from having their design fulfilled, as the place where the body was lodged was prohibited to all, except they brought a gift of a peculiar kind of cloth" (Jefferson, Journal, LMS Archives). The relatives of the deceased took considerable pride in the quantity of cloth brought to a funeral and preserved it as a tangible sign of the deceased's acknowledged position and prestige. ${ }^{77}$

The crying and the wailing were periodically interrupted with eulogistic speeches and elegies, of which Ellis provided a sample:

Thickly falls the small rain on the face of the sea,

Not rain, but the weeping it is of 'Oro.

[recited on behalf of an only son]

The pride of Atiapii [Huahine] sleeps in the cavern;

Departed has its glory, or its brightness.

[recited on behalf of the heir to the chieftainship of Huahine] (1829:I, 531)

Longer dirges were composed for some occasions, as for example the one in honor of Moehonu, a Ra'iatean chief who had fallen in battle:

A row of stars, a mountain that stands

apart inland, leading to Aihi.

The chief from the rising of the sun,

The dear warrior, handsome in death,

has become like a bird!

Kingly body of Ahuroa, thou art overthrown!

My sky is darkened to me now!

True ancestor of Tapoa,

The warrior who made Borabora great,

Glide down thither dead, O my chief,

By the slippery mountain.

Blow (wind) around the Mehani.

The god of the darkness (Hades) will

praise (him),

The overthrown one who is dead.

What can quiet (Grief for the) dear face so pallid!

At the altar stone 'tis done!

A strange kind of wind is this, O woman of peace,

Moehonu is separated to the cold bed

(of death), alas!

His axe sleeps at Borabora,

It lies at Vaiotaha.

What art thou lamenting, O Tefaaroa? 
Dead is Tepeete.

He was the man who held the helm of state (lit. weights of

the fish-net),

So that Faanui is saved.

A person beloved at the fort Patahi.

Yonder is Moehonu, far away,

Inside of the turning place (Tioi)

(While) Remembered by the widowed one!

(Alexander 1893:58) ${ }^{78}$

Relatives of the deceased also cut their hair as a sign of mourning:

When any person dies the relations flock to the House in numbers making much lamentation and the Weomen cut their heads with sharks teeth; both sexes cut their hair off different parts of their heads, somtimes Cutting all of but a lock over one Ear, somtimes over both \& the rest Close cut or shaven.

For the loss of a relation they Cut a square place bare on the fore part of their head which they keep bare for 6 Moons or longer, according to the love they bear the deceased; but for a favourite Child they wear it so for two or 3 Years and all the hair they Cut off is either thrown into the Sacred Ground or Carried to the Morai. (Morrison 1935:231)

As could be expected, the initial mourning for socially important persons was extended beyond the bounds of kinship. For several days after the death of such a person a general mourning restriction (ta'imara, mo'e) was enforced, prohibiting the kindling of fires, the use of canoes for fishing, and even the taking of food during daylight hours. ${ }^{79}$

Questions concerning the fervor and "sincerity" of Maohi mourning behavior are directly relevant to our concern with social relations. Here are several reports on this matter indicating the range of variations that obtained (both in the events themselves and in interpretations of them). First, I quote a general statement made by Ellis:

Almost every native custom connected with the death of relations or friends, was singular, and none perhaps more so than the otohaa, which, though not confined to instances of death, was then most violent. It consisted in the most frantic expressions of grief, under which individuals acted as if bereft of reason. It commenced when the sick person appeared to be dying; the wailing then was often most distressing, but as soon as the spirit had departed, the individuals became quite ungovernable.

They not only wailed in the loudest and most affecting tone, but tore their hair, rent their garments, and cut themselves with shark's teeth or knives in a most shocking manner....

... they cut themselves unmercifully, striking the head, temples, cheek, and breast, till the blood flowed profusely from the wounds. At the same time they uttered the most deafening and agonizing cries; and the distortion of their countenances, their torn and dishevelled hair, the mingled tears and blood that covered their bodies, their wild gestures and unruly conduct, often gave them a frightful and almost inhuman appearance. This cruelty was principally performed by the females, but not by them only; the men committed on these occasions the same enormities, and not only cut themselves, but came armed with clubs and other deadly weapons. (1829:I, 526-527) 
The observant Banks questioned the depth of all this display of feeling:

As soon as any one is dead the House is immediately filld with their relations who bewail their Loss with Loud lamentations, especialy those who are the farthest removd in blood from or who profess the least greif for the deceasd; the nearer relations and those who are realy affected spend their time in more silent sorrow, while the rest join in Chorus's of Greif at certain intervals between which they laugh, talk and gossip as if totaly unconcernd.... (Beaglehole 1962:I, 376)

To this can be added the observations of Rodriguez and of Vancouver:

From the neighbouring settlements and valleys an immense concourse of people collected to bemourn the death of the arii, the Chiefly ladies bleeding themselves more as a matter of form than from grief or real sentiment, inasmuch as they drifted after a little while into busy conversations about their private affairs. (Corney 1919:186)

The grief of these good people is of two descriptions, natural and artificial; it is excessive on the first impulse, but soon moderates and wears away. (Vancouver 1801:296)

Much evidence suggests that the grief felt by a woman upon the death of her children was most profound. For example: "The Weomen often Cut themselves on these occasions till they bring on a fever and I have known a Woman Cut herself for the loss of a Child till a delirium was brought on which ended in the total loss of her reason" (Morrison 1935:231) ${ }^{80}$ Yet, note Bligh's experience:

In my way back I was suddenly surprized at a violent degree of distress by some one at a little distance off, where I saw a Toopapow [ghosthouse]. As I expressed a desire to see the distressed person, Tynah took me to the place, but we no sooner came in sight than the Mourner burst into a fit of laughter at seeing me. This person was the Mother of a Young female Child that lay dead. Several Young Women were with her, but they all resumed a degree of chearfullness, and the tears were immediately dryed up. I told Tynah the Woman had no sorrow for her Child, as her greif could not so easily have subsided if it was the case that she regretted the loss of it. When with some humour, he told her to cry again; however we left her without any visible marks of its return. These are nevertheless funeral rites which are paid to the deceased at certain times after his death, but it is extraordinary that the great degree of sorrow and distress that these people are susceptible of can be changed in an instant to an opposite extreme, and unless it can be proved, that as impressions are most violent they are the least lasting, I see no way of accounting for it, as they are fond Parents and in general affectionate and friendly to one another in the highest degree. (1789:II, 18)

To this can be added an observation of the missionaries: "July 4, 1803: There was a young woman in the house abt. 13 years of age just in the agonies of death ... None of the people present, not her father, mother, nor sisters, seemed at all affected with the solemn sight of a soul departing into eternity ..." (Elder \& Wilson, Journal, LMS Archives)

In this connection, a statement by Bougainville is interesting, if not altogether credible: "The mourning for the fathers is very long. The women 
mourn for their husbands; but the latter do not do the same for them" (1772:270). The first part of this statement is probably correct, the second part is demonstrably incorrect-although it is probably true that men did not engage in public display of their grief as violently as did women.

As could be expected, the greatest public outpourings of grief were reserved for tribal chiefs and for the incumbents of high-ranking kin-Titles:

I am not prepared to say that the same enormities were practised here as in the Sandwich Islands at these times, but on the death of a king or principal chief the scenes exhibited in and around the house were in appearance demoniacal. The relatives and members of the household began; the other chiefs of the island and their relatives came to sympathize with the survivors, and, on reaching the place, joined in the infuriated conduct of the bereaved; the tenantry of the chiefs also came, and, giving themselves up to all the savage infatuation which the conduct of their associates or the influence of their superstitions inspired, they not only tore their hair, and lacerated their bodies till they were covered with blood, but often fought with clubs and stones till murder followed.

... I cannot conceive of a spectacle more appalling, than that which the infuriated rabble, smeared with their own blood, presenting every frightful distortion in feature, and frantic madness in action, must often have exhibited. This scene was sometimes continued for two or three successive days, or longer, on the death of a person of distinction. (Ellis 1829:I, 528)

Ellis, writing several years after this form of mourning had been outlawed, asked his informants for the reasons behind such violent displays:

I have often conversed with the people on their reasons for this strange procedure, and have asked them if it was not exceedingly painful to them to cut themselves as they were accustomed to do. They have always answered that it was very painful in some parts of the face-that the upper-lip, or the space between the upper-lip and the nostril, was the most tender, and a stroke there was always attended with the greatest pain-that it was their custom, and therefore considred indispensable, as it was designed to express the depth of their sorrow - that any one who should not do so, would be considered deficient in respect for the deceased, and also as insulting to his family. The acts of violence committed, they added, were the effects of the paroxysms of their sorrow, which made them neneva, or insensible. They continued till their grief was ua maha, or satisfied, which often was not the case till they had received several severe blows upon the tender part above mentioned. (1829:I, 528-529)

After the events just described, the corpse was removed from the dwelling and either buried immediately or placed inside a ghosthouse (fare tupapa'u) for several weeks or months (figs. 13-1, 13-2). But in either case, everything, such as bedding, mats, clothing, that had been in physical contact with the deceased during illness and after death had to be burned. This was done in purifying fire (auahi tutae'e), after which the presiding priest pronounced a closed-by-burning (pani tutui) benediction, which stated that the pollution (māhuruhuru) was thereby disposed of. Following this it was 


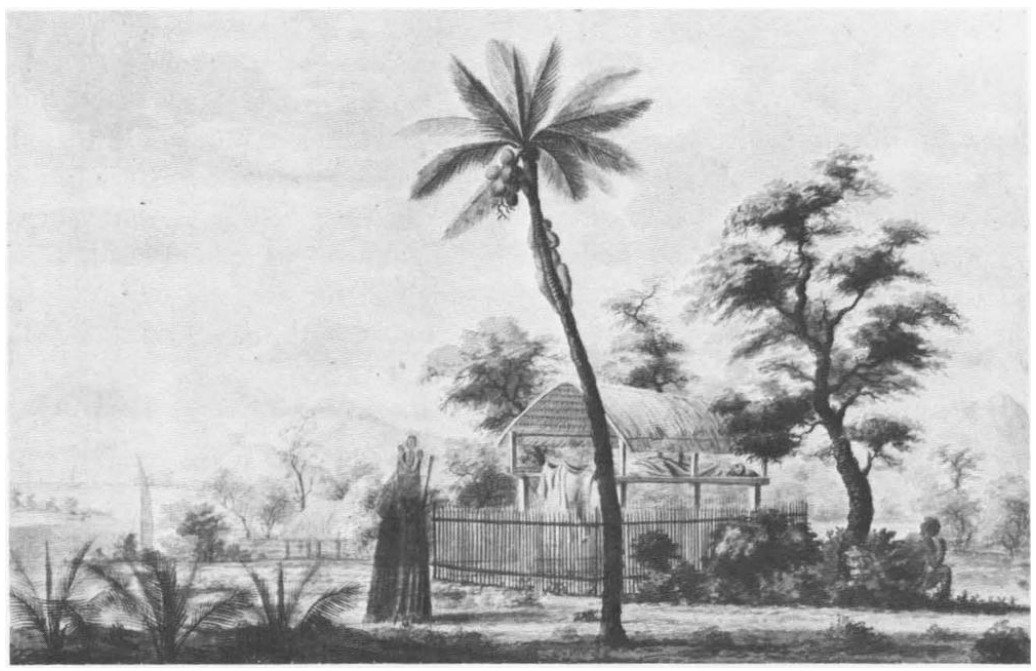

FIGURE 13-1. A ghosthouse (fare tupapa' $u$ ), with costumed chief mourner in foreground. Unsigned drawing. British Museum.

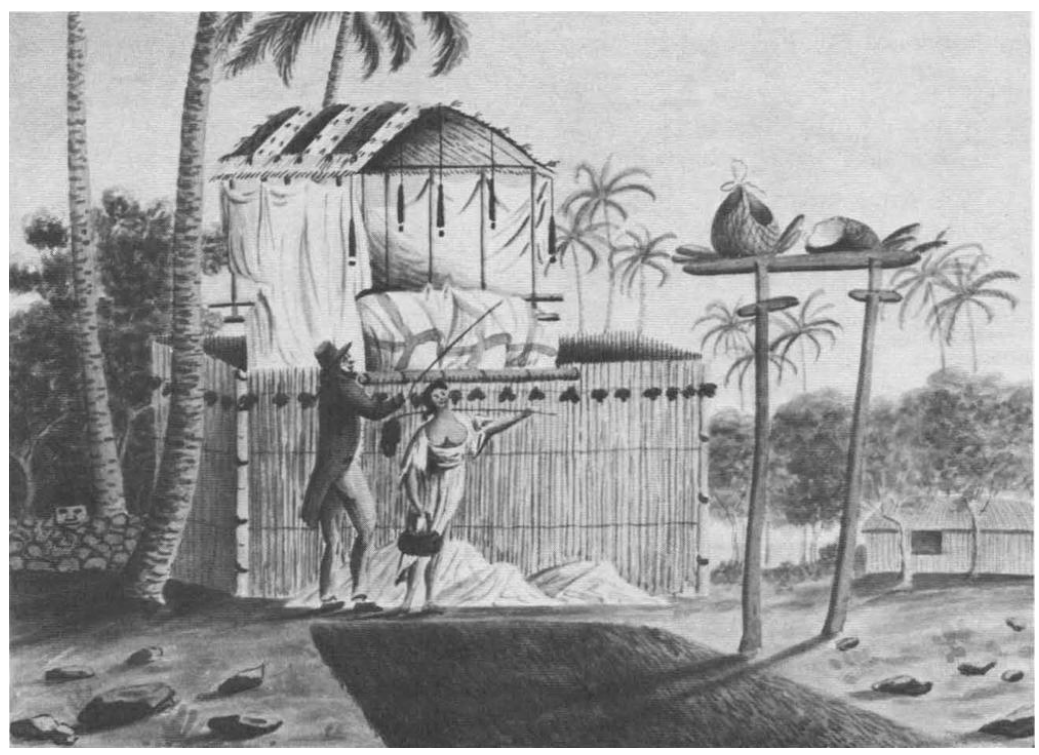

FIGURE 13-2. A ghosthouse, with corpse enshrouded. Watercolor by G. Tobin. Mitchell Libray, Sydney. 
safe to reoccupy the dwelling (Henry 1928:293; Morrison 1935:231). The exact nature, or cause, of this particular species of "contamination" is not clear. Morrison referred to it as the "disorder" which brought about the death, Ellis as "the guilt of the crime for which the deceased had died." According to the latter, all persons who had touched the body or the garments of the deceased were also required to purify themselves by bathing in the sea and casting into the sea their own garments worn while in contact with the corpse (1829:I, 523).

Fear of contamination was probably not the only motive for destroying, or safeguarding, the deceased's personal effects:

All the articles that the queen used and supposed to have had a particular regard too, which was not otherwise disposed of during her life, have been put in the Marae where she is put up-and to prevent them being taken away and used, they are broken to peices or otherwise spoiled, such as her cups she ate out of, Umette ['umete 'wooden bowl'], combs, and a Tommahawk-Baskets also all her cloth was put about the body ... (Davies, Youl et al., 1 August 1806, LMS Archives)

It is plausible to suppose that among the reasons for destroying or safeguarding a deceased's personal effects was also the desire to insure that such things could not be used as tupu, exuviae, by some hostile person waiting to gain control of the deceased's ghost through sorcery.

It is not altogether clear why some bodies were buried directly after the household wake, and some exposed in a ghosthouse for a further period of mourning. The nature and cause of the fatal illness or injury was relevant, according to Morrison, who wrote, "... those who die without disease are either laid on a beir or embalmed" (1935:231). But, Morrison did not explain what he meant by "disease," and there are reported instances of preservation in ghosthouses, including embalming, of persons who have died after lengthy illnesses. It is logical to assume, and probably accurate, that most important personages were thus exposed for an additional period of mourning, but there is evidence of relatively unimportant persons as well having been accorded this treatment (Bligh 1789:II, 44). Neither sex nor age appears to have been an absolute criterion in this respect, although there were proportionately fewer females or very young persons among the preserved bodies actually seen and reported on by the early Euorpeans. During troubled times, when deaths were numerous, it would have been physically difficult to handle many corpses in this way. Certainly during the almost continuously troubled final quarter of the century, when more devastating warfare and many introduced diseases took an increasingly large toll, the practice of exposing corpses in ghosthouses simply became a practical impossibility in most instances. Under normal circumstances, therefore, practical considerations must also have been influential: if the deceased's relatives and friends were able to do so, and strongly enough motivated, then they arranged for the body to remain in view to receive further expressions of grief. 
Banks provided a good description of the complex of structures which included the ghosthouse:

During our absence at Imao [Eimeo] an old woman of some consequence, a relation of Tamio, was dead and was plac'd not far from the fort to rot above ground as is the custom of the Island. I went this morn to see her. A small square was neatly raild in with Bamboe and in the midst of it a Canoe awning set up upon two posts, in this the body was laid coverd with fine cloth. Near this was laid fish \&c. meat for the gods not for the deceasd, but to satisfie the hunger of the deitys least they shoud eat the body, which Tubourae told us they would certainly do if this ceremony was neglected. In the front of the square was a kind of stile or place lower than the rest, where the relations of the deceasd stood when they cry'd or bled themselves, and under the awning were numberless rags containing the blood and tears they had shed. Within a few yards were two occasional houses $\&$ in one of them some of the relations constantly remaind generaly a good many; in the other the cheif male mourner resided and kept a very remarkable Dress in which he performd a ceremony, [i.e., a heiva] ... (Beaglehole 1962:I, 286)

The first detailed description of a ghosthouse appeared in the Endeavour journal of Captain Cook:

April 21, 1769: Yesterday as Mr Green and Dr Munkhouse were taking a Walk they happen'd to meet with the Body of the Man we had Shot, as the Natives by signs made them fully understand, the manner in which the body was enterr'd being a little extraordinary I went to day with some others to see it. Close by the House wherein he resided when living was built a small Shade [shed], but whether for the purpose or no I cannot say for it was in all respects like some of the Shades or house's they live in. This Shade was about 14 or 16 feet long, 10 or 12 broad and of a proportional height, one end was wholy open the other end [and] the two sides were partly inclosed with a kind of wicker'd work. In this shade lay the Corps upon a Bier or frame of wood with a Matted bottom like a Cot frame use'd at sea, and supported by 4 posts about 5 feet from the Ground, the Body was cover'd with a Mat and over that a white Cloth, along side of the Body lay a wooden Club, one of their weaphons of warr. The head of the Corps lay next the close end of the Shad[e], and at this end lay 2 Cocoa-nut Shells such as they some times use to carry water in. At the other end of the Shade was a bunch of Green leaves with some dry'd twigs tied all together and stuck in the ground and a stone lying by them about as big as a Cocoa-nut, near to these lay a young Plantain tree, such as they use as Emblems of Peace, and by it lay a stone Axe; at the open end of the Shade was hung in several Strings a great number of Palm nuts. Without the Shad[e] was Stuck upright in the ground the Stem of a Plantain tree about 5 feet high on the Top of which stud a Cocoa-nut shell full of fresh water, and on the side of the Post hung a small Bag wherein were a few peices of Bread fruit roasted ready for eating some of the peices were fresh and others stale. The Natives did not seem to like that we should go near the Body and stud at a little distance themselves while we examine'd these matters and appear'd to be please'd when we came away. It certainly was no very agreeable place for it Stunk intollerably and yet it was not above 10 yards from the Huts wherein several of the Living resided. (Beaglehole 1955:83)

Some of the leaves noted by Cook probably served as deodorants (see Morrison 1935:232); the plantain tree, here as in most other ritual contexts, 
served as an emblem of peace. The presence of food, including water and coconuts, in this context has been given two interpretations. According to Banks, it was designed to appease other spirits (Beaglehole 1962:I, 286, 377). Wilson, on the other hand, provided an indication that at least some of the food offerings were meant for the ghost of the deceased: "On the way we visited the tupapow of Orapiah; he is in a sitting posture, clothed in red cloth, under a shed; a native attending day and night, and offering provisions to the mouth of the dead corpse, which not being received, he eats them himself" (Wilson 1799:161; see also Ellis 1829:I, 524).

Ghosthouses were usually built at or near the deceased's family marae, which meant that in such cases they were not prohibited to close female relatives. According to Ellis ghosthouses and more permanent sepulchers were invested with a fearsome type of contagious influence, called aumiha, which caused them to be generally avoided (1829:I, 524). It is undoubtedly true that the Maohis believed such places to be spirit-ridden, and hence fearsome, but whether the aumiha of Ellis' report was in addition to the influence of heightened activity by the spirits that normally hovered around such places is not clear, as no other source contains any reference to aumiha. The LMS Dictionary defines 'aumihi, grief, pity, compassion, but does not list aumiha.

Bodies were left to repose on the bier in the ghosthouse for varying lengths of time, after which they were buried or otherwise disposed of. There is no information regarding the lower limits of this interval, but some bodies are reported to have been left for over four months. While a body rested in the ghosthouse one or more things were done in relation to it: efforts were made to postpone its physical decay; measures were undertaken to dispose of the "sins" that in some cases were thought to have hastened its demise; objects and prayers were offered to insure the departed spirit's vitality and benignancy; and conventionalized practices were carried out to honor the deceased and to demonstrate high regard for his survivors.

It appears that all bodies kept for any length of time in a ghosthouse were subject to some preservative treatment. At the very least they were cleaned, their skin rubbed with oil, and their body fluids allowed to drain. In some cases they were actually "embalmed," a difficult operation which required the services of an expensive specialist, a tapua miri, ${ }^{81}$ and which consequently was reserved for the socially important. As Bligh pointed out, if every deceased person had been so preserved, "... the whole country would become covered with Dead bodies which is not the case" (1789:I, 404).

The embalmer first disembowelled the corpse, using two fingers of one hand to pull the viscera out through the anus; then he is described as having "sucked" out the decaying brain through the nostrils-how this was done 
was not explained. Brain and viscera were then buried in a marae. The disembowelment was carried out in great secrecy and with all due solemnity, because, suggested Vancouver, of their conception of the bowels as the seat of what Europeans call thinking and feeling (1801:293). The body fluids were made to drain into a pit dug underneath the bier, and after the body cavity was emptied it was filled with bark cloth soaked in scented oil. Then the limbs were kept pliant by moving them, the skin was toughened by rubbing with oil and frequent sunning, and falling hair was glued back on-altogether a laborious process requiring considerable skill and what must have been considered onerous and spiritually dangerous work. And while it was a far cry from the effective embalming performed say in Egypt, it succeeded, despite these Islands' tropical humidity, in preserving the external form of some cadavers for many months. For example, after viewing one embalmed corpse, Cook reported:

When we first went the body was under cover and wraped up in cloth in the Tupapow, but at my desire the Man who had the care of it, brought it out and laid it upon a kind of beir or bed place, in such a manner that we had as full a view of it as we could wish, but we were not allowed to go within the railing that inclosed the Tupapow. After he had placed the Corse, he hung the place with Mats and cloth in such order as to have a very good effect. This Man had been dead above four months, and the body was so effectually preserved from putrefaction that there was not the least disagreeable smell about it. How this was perfirmed I could not learn any more than what Omai told me, he said they mad(e) use of the juice of a plant which grows in the Mountains, Cocoanut Oile and frequent washing in the Sea. I was told that they preserve the bodies of all the great men who die a natural death in this manner, and expose them to public view for a very considerable time after. At first they are laid out every day when it does not rain, afterwards the intervals become greater and greater and at last are seldom to be seen. (Beaglehole 1967:208-209)

Earlier in this journal Cook reported having visited the ghosthouse in which the remains of the great chief Vehiatua were still being kept, some twenty months after the latter's decease; but Cook did not comment on the state of the body. ${ }^{82}$

As far as one can reasonably infer, while a corpse reposed in a ghosthouse it was constantly attended by an adult or two, whose job it was to keep the corpse clean, supple, and dry; to offer it food and drink; to alleviate the odor of decay with fragrant plants; to keep out unwelcome intruders; and to dress the corpse, usually in a sitting posture, when mourners arrive to view it. Henry reported that the attendants were either an elder member of the family or a priest; in the case of embalmed corpses the embalmer himself may have continued to attend the body (Henry 1928:296). G. Forster reported having seen a woman in attendance at a female corpse's ghosthouse (1777:I, 294).

Because of an attendant's physical contact with a corpse one might 
suppose that his hands would be so "contaminated" that he would have been unable to convey food to his own mouth (see, e.g., Ellis 1829:I, $521 \mathrm{ff}$.). Yet one visitor observed an attendant at a ghosthouse who offered "... provisions to the mouth of the dead corpse, which not being received, he eats them himself" (Wilson 1799:160). Perhaps this feeding episode took place after the corpse's contaminating features had been disposed of.

Mention was made in chapter 3 of the Tahitian word hara, a term which appears to have been used both for a person's wrongful acts and for the substance deposited in the person's body as result of such acts-an infectious substance made dangerous either through its own intrinsic malignancy or through its attraction to malign spirits.

Again, the tentativeness of this interpretation requires underlining-a tentativeness that will have to remain until some more plausible interpretation is offered, since it is unlikely that any additional Maohi data will turn up to throw more light on the matter. This, of course, is regrettable because if my interpretation is near correct the concept would have considerable importance for an understanding of Maohi social behavior, including behavior vis à vis spirits.

However the Maohis may have conceived the hara substance to look or to operate, from some accounts it appears to have been present in the substance that was drained from the body during embalming or, in other cases, to have left the body while it underwent natural decomposition on the ghosthouse bier. As previously noted, this substance was made to drain into a pit dug for the purpose under the bier. When it was all collected there, a small pillar or post of wood, said to represent the corpse, was placed in the hole, which was then filled with dirt, to the accompaniment of the following words: "With you let the hara now remain," "Ei ia oe na te hara e vai ai" (Ellis 1829:I, 522). According to Ellis the hara would thereafter remain attached to the buried pillar personifying the corpse, and hence would be less contagious. Perhaps this was the source of the aumiha, or fearsome "contagious influence" noted by Ellis and reported above.

Ellis also stated that the general decontamination practices mentioned above took place after the hara-burying episode just described, but his account is somewhat inconsistent, in relating that the decontaminated persons returned to the house where the deceased had died and there addressed the dead body, saying, "With you may the mahuruhuru, or pollution, be" (1829:I, 523). Since the hara-burying episode took place at the ghosthouse, the corpse would have been there and not at the house where the person had died. Elsewhere I have noted the variation that there was in Maohi ritual practice, but I believe that here we have an example of uncertainties in the minds of the observers.

I noted above the offerings of food and drink made to a corpse reposing 
in its ghosthouse. According to Henry it was a daily chore for the deceased's family to keep the corpse supplied with "... flowers, food dry and crisp, and fresh fruit, from which it was supposed to absorb the essence" (1928:296). De Barreda wrote of one high-chief's ghosthouse: "He had a table on which they place his food every day, in the belief that his spirit comes down to partake of it. On the opposite side was an ... [altar], whereon those who come to visit him deposit sundry fruits and fish" (Corney 1915:470; see also Ellis 1829:I, 524). In the case of this high chief (Vehiatua of Taiarapu), a human sacrifice was offered to the gods (at a marae, not at his ghosthouse) on his behalf after his death, in addition to those offered before he died (Corney 1915:347; 1919:178). Similar mortuary sacrifices were reported on behalf of chiefs of Pare-Arue, and presumably were standard practice after the deaths of most great chiefs.

Actions carried on at the ghosthouse to honor the deceased and to express high regard for his survivors included one or more of several practices: repetitions of the conventionalized weeping ('otoha'a) carried out earlier at the house of death, mock combat, and "mourners' masque"; in addition, when a reigning high-chief died it was in some instances customary to carry his corpse around his whole realm before final interment.

In discussing the public outpourings of grief which usually followed the death of an important chief, I presented an excerpt from Ellis describing how many people flocked to the scene and "... joined in infuriated conduct," including fighting among themselves "... with clubs and stones till murder followed." In addition to displays like these, on such occasions a more formalized type of mock combat sometimes took place:

The same day as the body [of a "chief"] was placed on the fata, the enclosure was surrounded by people from his house or the district where he had lived, all well armed. A little later, the people of the closest neighboring district came (these were allies and friends), likewise armed, and those designated as eotahaas ['otoha'a] or weepers. Upon coming within hearing distance of the corpse's guardians they requested to be permitted to mourn their chief, a favor which was always refused them. Thereupon a battle ensued in which several warriors were usually wounded or killed. If the eotahaas won, (as they always seemed to do in this battle, although it often cost the life of a certain number of individuals, despite its being only a sham), the sides reunited and by agreement recommenced the bloody scenes already described. (Moerenhout 1837:I, 551)

E.S.C. Handy interpreted this practice as having been undertaken "... to free the environs of a house or community of lingering evil" (1927:252). This may indeed have been one "magical" dimension of the custom, although its symbolism is not altogether clear or demonstrable; but it is also possible to view such events as imbued with political meaning as well, as is indicated in the following eyewitness account of an episode during mourning for the great chief Vehiatua: 
About midday the heathen from the district of Ahuy [Ahui] arrived, armed with sticks, and proclaiming war against those of Ohatutira [Tautira], with loud shouts: while they rushed at a great rate towards the awning under which the body of the deceased arii was lying. The people who composed the circle and were watching over the deceased heard the other's yells, and seeing that they came armed, forsook their station and dashed over to the other side of the river to fetch their own weapons. But the Chief of the others, who happened to be present, did not move, and seeing that his people were coming armed to make war on those of Ohatutira, he walked forward to meet them with a plantain sucker in his hand (which is their sign that they do not want war, but are asking for peace); and with that they halted awhile to listen to their Chief who told them that those of Ohatutira were not for fighting. Thereupon they resumed their route, shouting and running until they reached the spot where the deceased was, and after having proceeded three times round it at a run they stopped still and all uttered together one single word at the top of their voices. We did not catch the meaning of the word, but we at once concluded that it was to proclaim peace, because the Ohatutira people, and the rest (assembled) from other districts, immediately recrossed the stream and joined the party from Ahuy. We were unable to make out the reason these latter had for declaring war against the others. [The diary then goes on to describe a similar encounter on the following day, between the men from Tautira and an armed contingent from Taiarapu.] (Corney 1915:345-346)

A "political" interpretation of this custom will be offered later on, but now I will describe a "mourners' masque" ${ }^{83}$-another conventional way in which the Maohis occasionally marked the demise of persons of social importance. Few native practices so intrigued early European visitors to these Islands as did the antics of masked mourners. Morrison's version of this custom can serve as a basis for discussing it:

Besides the Weeping and Cutting their Heads they have another Mourning Ceremony wherin they wear the Pari or Mourning Dress described by Captain Cook.-This is Mostly worn by two or three of the Nearest Male relations each of which are Armd with a Weapon Calld Paaeho, edged with a row of sharks teeth for three feet or four of its length, the Upper part forming a blade like that of a Gardners knife. They are attended by forty or fifty Young Men \& Weomen who disguise themselves by blacking their bodys and faces with Charcoal, and spotting them with pipe Clay; these seldom wear any other Cloths but a Marro and each is armd with a Spear or Club and parade about the district like Madmen and will beat Cut or even kill any person who offers to stand in their Way-therefore when any one sees them Coming they fly to the Morai, it being the only place where they can be safe, or Get refuge from the rage of the Mourners who persue all that they see. The Morai alone they must [not] enter, and while this Ceremony lasts, which is sometimes 3 weeks or a month, they pay no respect to persons nor are the Chiefs safe from their fury unless they take sanctuary in the Morai; the Weomen and Children are forced to quit the place as they Cannot take refuge in the Morai.

Should any person be stubborn or foolish enough to stop one of the Mourners or Not get out of their way and they should be killd no law can be obtaind nor any blamed but himself, as the Mourners are look'd on as lunaticks, driven Mad through Grief for the Death of their relations therefore none attempt to obstruct them but fly at their approach. This Ceremony is also Calld Tyehaa or 
Mourning, the Performers are Calld Naynevva [neneva], Madmen Hevva [heva] tyehaa-Mourning Spirits, Gosts, or Spectres. (1935:233)

Nearly all the principal sources contain descriptions of this institution but the various versions differ somewhat in details, due in part no doubt to the probable circumstance that the events themselves involved a fairly wide range of variation. To begin with, the several versions do not all agree about the identity of the participants. In the version just quoted, the principals (the wearers of the elaborate masks) were described as "two or three of the Nearest Male relations," and their attendants as "forty or fifty Young men and Weomen," whose relationships to the deceased are not specified. Other writers gave somewhat different versions:

principal mourner: "nearest relations," who take turns, and "priests" (J. Forster 1778:560-561, 563);

principal mourner: a man for a deceased woman, a woman for a deceased man (G. Forster 1777:II, 75);

principal mourner: usually a man; attendants: three or four, males and females, including close relatives of the deceased (Banks, in Beaglehole 1962:I, 286-289);

principal mourner: "priest" or "relative," male; attendants: "men and boys" (Ellis 1829:I, 532-533);

principal mourner: "a professional mourner"; attendants: "a crowd of small boys" (Moerenhout 1837:I, 547-549);

principal mourner: "a priest of the gods of mourning"; attendants: "young men and lads of the [deceased's] collateral lines and [of his] retainers" (Henry 1928:293).

The probability was that among those surviving families who were sufficiently motivated to sponsor this special form of mourning ceremony, some could only rely on the services of "nearest relatives"-for it was a costly exercise, as we shall see. But for those who could afford it, priests who specialized in mourning were probably called in.

A major item in the staging of a mourners' masque was the costume worn by the principal mourner (fig. 13-3). Henry described it as having consisted of the following:

... a petticoat of purau [pandanus leaf] fringe, called tihi-parau, a waist girdle, called a moeho, and a head gear, or fa'aupo'o. The fa'aupo'o consisted of a close turban of cloth, above which diverged like rays beautiful, snowy red-tipped tail feathers of the tropic bird, and a parae, or mask, of bright pearl shell. From the mask was suspended over the chest with the corners turned upwards a bright crescent-shaped board about a foot deep covered with a brilliant network of thin chips of mother-of-pearl about one inch long and a quarter of an inch wide. These were threaded together through little perforations at each end and bordered with a fringe of rich black feathers of the man-of-war-bird, terminating at each corner 
with a bunch and a tassel exquisitely made of the same feathers. This ornament, called ahu-parau (pearl-cloth) was considered very sacred. From it hung a drapery of pieces of yellow and black cloth, called a pautu (mourning cloth), attached behind and meeting the spreading fronds of the fare-rupe fern (Pteris milneana) set in the girdle against the back. But when the deceased was not of the highest rank the priest wore the fringy petticoat, girdle, and the fern frond, without the headdress and other paraphernalia. (1928:293-294)

(The last sentence is only partially correct, for the wearing of headdresses was not limited to mourning for "sovereigns or heir apparents.") From all accounts these headdresses and gorgets were rare and among the most highly valued possessions of the Maohis; it is unfortunate that so little is known about their ownership, or the conditions under which they were acquired, transferred, or "rented" for use by nonowners (if such were the case). (See Plischke 1931, and Mühlmann 1939.)
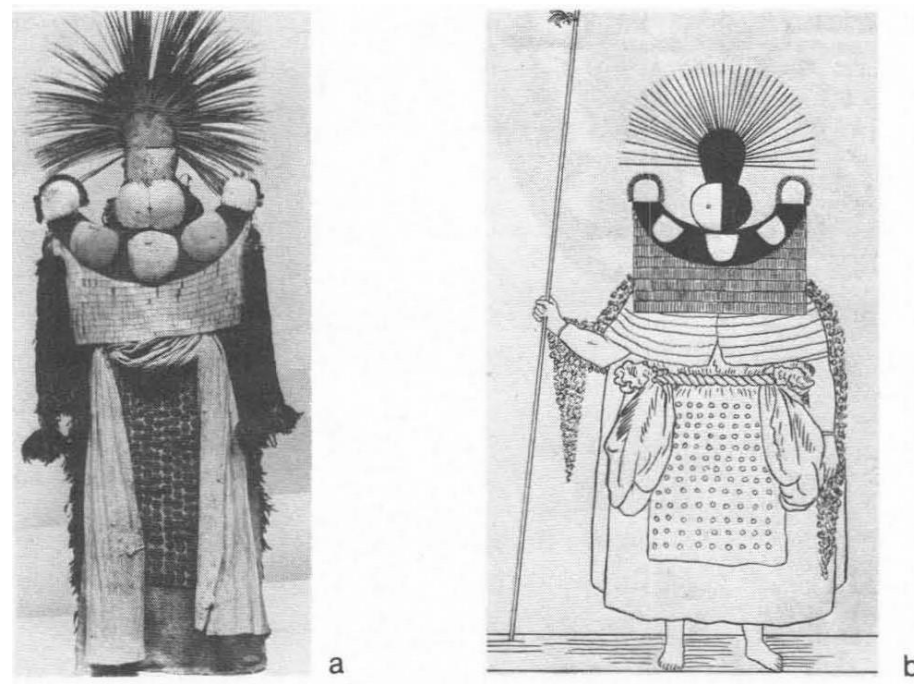

FIGURE 13-3. Mourners' costumes. $a$, British Museum; $b$, “Dress of Chief Mourner." Drawing attributed to H. D. Spöring, Cook's first voyage. British Museum.

The material value of a parae is indicated by the following episode reported by Rodriguez: "I went out with the arii and his house-party in quest of mother-of-pearl shells for making up a parae, or very intricate shell mask; a chattel much valued among them, for they are fain to ask a hog (in exchange) for each shell" (Corney 1919:205).

The principal mourner also carried with him a shark's-tooth weapon (paeho) and a pearl-shell clapper, which he used as a warning signal as he and his attendants made their rounds. 
Otoo and Tatooa-noce, and many of their attendants paraded about our dwelling, according to their custom. Sometimes the king and three of his principal attendants carried in their right hands a sort of clapper, made of two pearl oyster shells, so fastened, back to back, as that they could strike them one against another, by a gentle movement of their thumbs; these they kept clapping as they walked, keeping time together. This childish noise is a ceremony in honour of Orepiah, whose remains are at the Nānu. (LMS Transactions:I, 86)

The attendants, both male and female, wore only loincloths and improvised headdresses; they were blackened all over with candlenut soot, over which were painted red and white stripes and circles. They carried clubs and spears with which to threaten or actually wound hapless persons not quick enough to keep out of their way-except for Arioi, who, according to Orsmond, were not molested.

At the beginning the band of masked mourners probably made their rounds every day, starting and ending with obsequies at the ghosthouse, and scoured the countryside for about an hour or so. In time, the ceremony was repeated less and less frequently until, after a few weeks or months, it was abandoned. In some cases it was terminated at the behest of the deceased's family, for reasons of economy. But in instances involving very important persons, "political" factors were probably more involved:

This reign of terror lasted an indefinite period, the moon coming in, waxing, waning, and passing on some occasions when great love for their lost ruler was being expressed. When people of other districts thought it had lasted long enough, they would come to calm their zest by overpowering them. This was called fa'atihaehae i te heva (aggravating the mourners). A hand to hand fight followed, which became serious when allied parties joined in. Sometimes whole districts were involved, many being killed before the chiefs interposed. When the priest changed his dress it was the sign that the heva was marau (faded or ended) and then tranquility was re-established in the land. (Henry 1928:294)

This same writer also provided a vivid description of the antics of the masked mourners and hinted of an additional function served by the ceremony:

The sound of the tete [the pearlshell clapper] and the appearance of these persons as they approached terrified the community. The priest sometimes struck the side of a house menacingly with his scythe, while the inmates remained in breathless silence. Some of the people out-of-doors had time to flee to the local marae where they were secure from molestation; but others, particularly if they were not in favor with the terrible party, were either caught and mercilessly beaten with a club, or in fleeing were liable to be hit by scythe, spear, or stone. (p. 294)

While engaged in masked mourning the participants are reported as having been amply fed by the sponsors of the ceremony. ${ }^{84}$ This need not have been a burden when the mummers were close relatives, and hence themselves sponsors; but to feed a large troupe for several months, along with the additional remuneration probably paid to the specialists among 
them, would have required material resources available only to a few of the society's highest-placed families. What then was the meaning attached to this bizarrerie? And what were its sponsors' purposes?

According to Moerenhout the principal mourner was thought of as "representing" the spirit of the deceased, but he was not believed to have been "inspired" (inspiré) by the latter. Moerenhout implied that the whole troupe acted as if maddened by grief. Ellis, on the other hand, wrote of the mummers that "... they appeared and acted as if they were deranged, and were supposed to be inspired by the spirit of the deceased, to revenge any injury he might have received, or to punish those who had not shewn due respect to his remains" (1829:I, 534).

Moerenhout also offered an explanataion of the purpose of the masque: "The ceremony, whose only object was to honor the dead, lasted as long as the relatives wanted to pay and feed the official (mourner) and his retinue. They believed or pretended to believe that the longer the thing lasted, the more pleased with them the deceased would be." (1837:I, 550)

These two sets of interpretations and explanations are perhaps more complementary than contradictory; in any case, neither is inconsistent with other known facts about Maohi society.

The perceptive (or imaginative) Bougainville suggested one other possible motivation, if not for sponsoring, then at least for engaging in a mourners' masque:

When the people in mourning go out of their house, they are preceded by several slaves [sic], who beat the castanets in a certain cadence; their doleful sound gives every body notice to clear the way, whether out of respect for the grief of the persons in mourning, or because meeting them is feared as an unlucky and ominous accident. However at Taiti, as in every other part of the world, the most respectable customs are abused; Aotourou told me, that this practice of mourning was favourable to the private meetings; doubtless, as I believe, of lovers with wives, whose husbands are not very complaisant. The instrument, whose sound disperses every body, and the veil which covers the face, secure to the lovers both secrecy and impunity. (1772:270-271)

During the extended mourning period for the great chief Vehiatua, one observer reported witnessing dancing in his honor:

Before going on board again they let us see a very doleful dance, which they were perfroming out of sorrow for the death of their arii. They wore garments interwoven with feathers of very gloomy shades, with head-dresses to match, and masks of mother-of-pearl shell; and they held castanets of the same with which they clacked a mournful measure to the accompaniment of a drum, executing, as they danced, many gestures and weird grimaces. (Corney 1915:471)

One other mortuary practice reserved for important chiefs had an obvious political significance: 
When Chiefs or People of rank die their bodys are Embalmed and they are Carried round the Island to evry part where they have any Posessions, in each of which the Tyehaa or Weeping Ceremony is renewd; and after a Journey of 6 or 8 Months returns to their own estate where they are kept till the Body decays when the bones are interd. (Morrison 1935:232) ${ }^{85}$

\section{Body Disposal}

As reported earlier, some bodies were disposed of immediately following a two-or three-day wake, others only after a more or less extended stay in a ghosthouse. With respect to the latter, the length of time a corpse was maintained in the ghosthouse undoubtedly depended largely upon the deceased's kinship and political status; for example, the corpse of Vehiatua, the reigning chief of Tahiti's peninsula, was still being tended twenty-two months after death. But the moist tropical climate eventually took its toll, no matter how carefully a body was tended, and the bones were then put away. The most detailed (but not necessarily the most accurate) statement on interment was made by Henry:

In the upper classes, when the time for burial of the dead (hunara'a tu$p a p a^{\prime} u$ ) [literally "the hiding of the corpse"] arrived, the body was wrapped in sweet-scented tapa, placed in a coffin hewn from the trunk of a tree, and secretly placed in a marae vault, later being removed to a mountain cave by the family priest and a chosen few. People of low degree also made coffins or simply wrapped their dead in tapa, scented or otherwise, and then in a mat, placing the corpse in a cave or burying it in their marae with or without a priest officiating. Some of the bodies were interred in a sitting posture, three or four feet deep, and at the present time skeletons are occasionally unearthed in that position. The skull of a parent or other revered relative was sometimes retained by the family, by whom it was cleaned, saturated with sweet-scented oil, and aired many days in the sun. Then after invoking to it the spirit of the departed one, it became enshrined among the household fetiches. The finger nails were plucked from corpses, polished, threaded together, and worn in the hair by young girls as charms. (1928:295)

The likelihood is great that the use of wooden coffins reported by Henry was a custom borrowed from Europeans. Bligh wrote that "Iddeeah and several others say they took the Idea of making a Coffin from us, but many others say it is customary in Otaheite. I am nevertheless enclined to beleive Iddeeahs account, as in former Voyages no such thing was ever seen or heard of." (1789:II, 44)

Most eyewitness accounts agree that skulls were usually separated from trunk and limbs, the latter having been buried underground or hidden away in a cave and the skull kept either in house or marae. Morrison asserted that no bodies were buried in marae except “... those Killd in War, or for Sacrafice or the Children of Chiefs who have been Strangled at their birth" (1935:232). Ellis, however, reported otherwise: "The family, district, or royal maraes were the general depositories of the bones of the departed, 
whose bodies had been embalmed, and whose skulls were sometimes preserved in the dwelling of the survivors" (1829:I, 524; see also Moerenhout 1837:I, 554). J. Forster stated that "chiefs" only were buried within marae enclosures (1778:561); and Banks' statement implies the same: "The body is then taken down from the ewhatta [fata], the bones washd and scrapd very clean, and buried according to the rank of the person either within or without some one of their Marais or places of publick worship" (Beaglehole 1962:I, 378).

Many, but not all, bodies were buried with the bones bound together in a sitting posture; the reason for this was not reported. ${ }^{86}$ The only writer to report on the matter wrote that graves were oriented east and west (Bligh 1789:I, 418). It is quite likely that most bodies were, as Henry stated, wrapped in bark cloth or mats or both, for burial, and that the ground on top was left loose; at least this is an inference that may be drawn from a statement in the journal of Don Thomas Gayanjos: [After observing how the Spaniards buried one of their own number] "The Indians found much matter for remark in the interment; and they viewed our method of burying the dead very unfavourably, observing that to shovel earth in atop of the body, and then stamp it down (with the feet), was an act of disrespect to the departed" (Corney 1915:136).

As reported by Henry, some skulls were kept at home by the family of the deceased; others were deposited in marae (Bligh 1792:153), while still others were hidden away in caves. According to J. Forster, the skull of a chief was wrapped in bark cloth and kept in a wooden box, an 'ancestral ghost's house' (fare no te 'oromātua) (1778:561). Hair was also sometimes preserved by the family survivors:

A very Old Man paid me a Visit to day who is an Uncle to Tubai, the person Captn. Cook carried with him in the Endeavor to Batavia, where he died. He was first said to be Tubai's Father, because they called him Medooah, but it signifies an Uncle as well as a parent, and happend to be so in this instance. He is about 65 Years Old, and a person much esteemed. At this moment he seemed to mourn for the loss of his Nephew, and requested when I came here again that I would bring him his Hair. This perhaps is the greatest satisfaction these people can have after the death of a Friend, and is kept as a most sacred relic. When Tynah talked of going with me to England, about which he is still very anxious, I stated the chance of his dying, and in such a case I told him perhaps his friends would never wish to see me again, but he assured me that if he did die, I only had to cut his Hair off and bring it to Otaheite, and they would all be perfectly satisfied. It is a common custom among themselves, for after a certain time that the body has been carried to the Toopa-how, the Hair is cut off and hung up in their house made into the Mountains if they should be in War ... (1935:232-233)

The evidence from archaeology can serve to confirm all of these reports. Partial and whole skeletons have been uncovered within marae enclosures (in vaults, underneath pavements, in simple graves) and outside in various kinds of locations. In addition, many caves, some nearly inaccessible, have 
been discovered to contain skulls and other human bones, and, on Mo'orea, Green and his associates found in a coastal midden a canoe that had evidently served as a coffin (Green et al. 1967:183).

The main reason for burying bodies in marae was given by Ellis:

The marae or temple being sacred, and the bodies being under the guardianship of the gods, were in general considered secure when deposited there. This was not, however, always the case; and in times of war, the victors sometimes, not only despoiled the temples of the vanquished, and bore away their idol, but robbed the sacred enclosure of the bones of celebrated individuals. These spoils were appropriated to what the nation considered the lowest degradation, by being converted into chisels or borers, for the builders of canoes and houses, or transformed into fishing-hooks. In order to avoid this, they carried the bones of their chiefs, and even the recently deceased corpse, and deposited them in the caverns of some of the most inaccessible rocks in the lofty and fearful precipices of the mountain defiles. (1829:I, 524-525)

To this should be added Morrison's report:

... these bodys, while they are whole, are liable to be taken in War and the Man who takes one of them gets the Name and honors as if He had killd a Warrior, and should the body of a Chief be Carried off in this Manner before an other was Named the District would fall to the Conqueror as if he had killd him; for this reason they are always removed, having each a Steady Man to Carry them away into the Mountains if they should be in war ... (1935:232-233)

Moerenhout described the role of an "ancestor-guard," not found in detail in other accounts:

Usually only the trunk and limbs were interred at the marae. After a period of time, when, in spite of all the precautions taken, the body began to decay, the head was separated from it; and after new prayers and new ceremonies, ${ }^{[87]}$ (the head) was carried into secret, inaccessible caves, called anaa, high up in the mountains; then the body was buried in the marae. Sometimes, however (and this took place especially in the case of chiefs and principal families), the rest of the body, well wrapped in bark cloth, was carried whole into these sepulchers, where they were sheltered from every affront, the situation of the family anaa being only known to the head of the family and to its ancestor-guard. The ancestor-guard fulfilled for each principal family a very important hereditary function. He was charged with watching out for the preservation of the remains interred at the marae; and, furthermore, since he alone knew the location of the funerary cave which held the heads of all the family dead, he was as guardian and protector of the shades of the gods feared by all this family and the chiefs. The least insult made to him or to his children, by some member of the family he served, could bring upon (the family) illness or other evils. Thus, superstition itself often prevented the great from doing wrong, or at least made them fearful lest they should be exposed to divine prosecution or to the secret intrigues of their enemies. It is true, on the other hand, that they had, proportionate to their rank, resources and means denied to the common people, to avert human vengeance or to exorcise the anger of gods. (1837:I, 554-555)

There is little information available concerning the disposal of the bodies of persons who died while away from home-except in the case of 
warriors slain and left on foreign soil. There are reports of the bodies of certain socially important persons having been returned to their own domains for burial, and presumably this was also done for others whenever possible. On the other hand, when some castaways from the Tuamotus died on Tahiti their bodies were either "... thrown into the sea, on the sandbanks or on an old marae, where they have been soon devoured by dogs and pigs" (Davies, Journal, 28 December 1807, LMS Archives).

Finally, I present de Bovis' account of the way in which the bodies of courageous warriors were sometimes disposed of:

There was also another singular practice concerning cadavers consacrated to the divinity. When a celebrated man of proven valor died, he was not interred like others. The great marae which was the closest claimed his mortal remains, this being a great honor for his family. The body was hoisted to the top of an ironwood tree which shaded the enclosure or its vacinity;-the body was attached as high and as solidly as possible. It stayed there indefinitely until through decomposition, it disappeared in shreds. But this process was sometimes very slow if the body had been exposed to a strong sun in the dry season, and it was not rare for the grove surrounding the great maraes to display a dozen or even more of these singular ornaments. (1909:56)

In a general sociological sense, ${ }^{88}$ aside from the question of their "function," several more or less conscious motives have been proposed to account for conventionalized Maohi mourning behavior: the survivors' sincere desire to express grief, honest regard for the welfare of the deceased's departed soul (now a ghost) tinged with fear of its anger if not adequately mourned, feigned or unfeigned exigency for demonstrating maintenance of relationship with the survivors, and so on. Some or all of these motives continued to operate after the principal mourning period had ended-that is, after the bones had been disposed of in one way or another. A kind of climax to "post-burial" mourning occurred about a year after death, on the occasion of 'ghost's night' (ро tupapa'u); this event will be described presently, but, before doing so and before listing the various standard beliefs regarding the final or interim fate of the released soul, I will indicate the ways in which some of the deceased's close relatives continued to express their real or feigned grief. According to Banks:

The ceremonies however are far from Ceasing ... [with burial]. Frequent prayers are to be said by the preist and frequent offerings made for the benefit of the deceasd, or more properly for that of the Preists who are well paid for their prayers by the surviving relations. During this ceremony Emblematical devices are made use of: a young plantain tree signifies the Deceasd and a bunch of feathers the Deity invokd; opposite to this the preist places himself often attended by relations of the deceasd and always furnish'd with a small offering of some kind of Eatables intended for the God; he begins by adressing the God by a set form of sentences and during the time he repeats them employs himself in weaving Cocoa nut leaves into different forms, all which he disposes upon the Grave where 
the bones have been deposited; the Deity is then adressed by a shrill scritch usd only on that occasion and the offering presented to his representative, the little tuft of feathers, which after this is removd and every thing else left in statu quo, to the no small Emolument of the Rats who quickly devour the offering. (Beaglehole 1962:I, 378-379; see also J. Forster 1778:562-563)

A more common practice, perhaps, was bloodletting: "The mourning then ceases [i.e., after disposal of the bones] unless some of the women who find themselves more than commonly afflicted by the Loss repeat the ceremony of Poopooing $\left[\mathrm{pupu}^{89}\right.$ ] or bleeding themselves in the head, which they do at any time or in any place where they happen to be when the whim takes them" (Beaglehole 1962:I, 378). Two actual instances of this practice are reported in the sources:

On the 27th, we saw a very odd ceremony performed; Tiropoa, one of Tubora Tumaida's wives, after weeping, and expressing some emotions of sorrow, took a shark's tooth from under her cloaths, and struck it against her head several times, which produced a copious discharge of blood; then, lamenting most bitterly, she articulated some words in a mournful tone, and covered the blood with some pieces of cloth; and, having bled about a pint, she gathered up as much of it as she could, threw it into the sea, and then assumed a chearful countenance, as if nothing had happened. This, it seems, is a ceremony generally performed by widowers after the decease of their husbands. (Parkinson 1773:21)

This morning [9 March 1797] also Inna Madūa, the widow of Oreepiah (brother to Pomārre), lately deceased, paid us a visit, accompanied by two chief women. Oreepiah was much attached to the English; and his widow, supposing us sorry for his loss, on entering the cabin burst into tears, and continued this expression of grief till we all sympathized with her. However, this did not last long; for they soon became cheerful, breakfasted, and dined on board.... (Wilson 1799:67)

It should be recalled that people continued to show respect, or at least fear, for the deceased long after burial, in the form of the circumspection with which they approached burial places, evidently in the belief that the ghost of the deceased-along with other spirits, perhaps-continued to haunt such places.

\section{Case Studies: The Deaths of Vehiatua II and of Mahau}

To add substance to the generalizations about death presented above, I will reproduce extracts from the sources concerning the deaths and funerals of two socially important individuals: Vehiatua II, sovereign chief of Tahiti's Taiarapu peninsula, and "Mahow" [Mahau], a prominent Mo'orean chief linked by affinal ties to the Pomare dynasty of Tahiti. The former died in his own realm in 1775 and his demise was recorded in almost reportorial detail by the Spanish visitors. The latter died in 1791, while on a visit to Tahiti, where Vancouver witnessed his last days and the succeeding mortuary activities. The account of Vehiatua's illness, death, and the 
events following it is taken from the diary of Maximo Rodriguez (Corney 1919) with footnote additions from the diaries of the padres who were with him. The reports of this episode began in April 1775:

April 5: I ... begged Padre Geronimo to give me leave to go to the district of Guayari [Vaiari], in order to visit Vehiatua who was lying sick unto death there, with all the Chiefs of the island about him. (p. 107)

April 6: I found Vehiatua reclining in the laps of his relations, with a great display before him of the objects he had acquired from ships that had visited his, as well as other, territories in the island, looking like a stock-in-trade of shop wares; and on my asking what the idea of that was they answered me that Vehiatua had made an offering of all that he possessed to his God named Eatua. I endeavoured to console him, and he was much affected as soon as he saw me. Meanwhile, I noticed that one of the Indians within the house was dealing himself lusty thwacks, and in some alarm I enquired what it meant. They told me that what he was doing, and giving utterance to, signified that their God Eatua had descended, and that this man's body was possessed, thereby causing him to behave in this manner; and that the words he uttered were inspired by the said Eatua. Presently he quietened down somewhat and began to strip the cloth wraps that appeared to him the best ones from the people who were in the house, but those that he got from Vehiatua were only the poorer sort; and then, keeping for his own profit the wraps he fancied most, he directed the others to be distributed to whomsoever he pleased. The people gratified him in all that he did or desired, because, they said, he was under the influence of their Divinity.

I quitted the house, bewildered by the throng of people and the hubbub. I went over to where the other Chiefs at present staying in this district had their quarters; but the day was too short to allow of my being greeted by them all, for each one wanted to claim me as his guest. This being got through, I returned in the evening to Vehiatua and found him somewhat easier, and I tried to persuade him to come back with me, telling him he should be supplied with everything there was for his recovery; but he said he feared to come to Ohatutira for love of us, because he was aware of the sacrilege we had wrought in the cemetery or marae by taking stones from it to pave our house with, and he also cited the squabbles that had arisen with his followers when he was at Ohatutira. It was therefore his intention not to return to where we were until the frigate should arrive. (pp. 108-109)

[Vehiatua recovered somewhat from this spell of illness, but by May 10 was critically ill again.]

May 10: When we reached Ayautea the people greeted Vehiatua with much weeping at seeing him so prostrated, for he could not stand up. Then the tahua or priests of the place came to offer their opure or prayer in the marae where they worship, and the day and night were consequently passed without any fire being lit to cook with, as is the custom until the ceremony in the marae is concluded.

The rest of our people arrived in the evening from Mataoae, and the night was passed without incident, though there was much noise of drums in the marae, which is their way of invoking their God Eatua.

May 11: ... Vehiatua was in rather a bad way, wherefore their tahua offered up a prayer in the sea, for his recovery, and deposited a number of plantain shoots all round his hut. He felt somewhat relieved later, as I succeeded in inducing a 
perspiration, though not without some opposition on the part of his attendants, because they say that in order to procure a descent of their God named Eatua, it is imperative that the fanning should go on in the house.

May 12: ... I proposed to Vehiatua that he should set out with me for Ohatutira, as it was already noonday. He seemed troubled at my coming, and told me that his tahuas or priests would not let him go, because his God Eatua had not appeared, in spite of some of their number having gone forth into other districts to invoke him until they should find him; and I was unable to gain him round from his error however much I tried to undeceive him. (pp. 136-137)

June 1: ... it was not permitted to kindle fire while ... [prayers for Vehiatua] were going on in the marae or cemetery that exists in this islet, devoted to his God called Eatua.

Not one woman was met with in the precincts, for they have no place in these functions nor is their presence tolerated at them; but all the Chiefs of the provinces pertaining to Vehiatua were there.

... I, meanwhile, had remaind with Vehiatua discussing the continual opures or prayers that were being offered up in his several districts; and when I pointed out that the only result of it all was that the tahua or priests were using up his pigs, yet that no improvement in his condition was observable, he seemed to ponder over this and said he would presently come to Ohatutira. Just then the inspired person came on the scene in a passionately excited state and they immediately provided a seat for him, that he might blurt out the tomfooleries that came into his head, before Vehiatua; for to the natives these were as an oracle. Vehiatua told me that this man became very terrible while the God continued in his body, and that no matter what he asked for, or did, it was all good, because inspired; and that therefore if any one opposed him such a person would die of some serious illness by the will of his God. I told Vehiatua he should soon see how much power he had, and on my calling out in a loud voice to them to bring me the musket, the inspired one made signs to me not to kill him: and on that I asked him where his power lay! But the others then begged me not to say anything more to him, lest it should cause Vehiatua's ills to become aggravated; and rather than displease them I desisted.

We then took our departure, not desiring to witness any more barbarisms, and passed over to the mainland.... (pp. 148-149)

June 5: ... In the evening Vehiatua arrived with his people, from the district of Ayautea, though we had not expected him for three days yet, according to information supplied to us by some of those who were in attendance on him. We went down to the beach to welcome him, where we found him in a considerable fever, on account of which we at once arranged for him to be carried in his own canoecuddy to a spacious and sheltered hut he owned close to our house, pending a further arrangement of things on the morrow. He let himself be accommodated thus, and we saw that the cough he had was severe, for it gave him no rest, so that the natives proved somewhat undesirable neighbours. I turned out in the middle of the night to go and see him, and I found him with two coconut shells full of a food they call popoy, which is very indigestible stuff. They tried to hide it from me, but in the end I undeceived them as to the harm they were doing, and they agreed to act in whatever way I might advise them. I called their attention to the many hogs that had been relegated to the tahua or priests, and the absence of any visible improvement in Vehiatua's condition; but they contented themselves with saying that their God Eatua was not relieving him. (p. 151) 
[Shortly thereafter, the chief experienced a slight recovery and the assembled subchiefs, and so forth, returned to their respective homes.]

June 20: ... When I got there I was welcomed by the two arii of the districts of Guayuriri and Atimaono, who had come with a number of canoes in their convoy to visit Vehiatua, and to do honour to his recovery, of which they had heard, with a dancing festival.

June 22: ... A large number of people from the Guayuriri district arrived to entertain Vehiatua with sports, as a consequence of which there was a great riot and turmoil, and we were obliged to keep in-doors on our guard against anything that might happen. Vehiatua's mother came to us in tears begging me to get her son away out of the uproar, which I succeeded in doing. (pp. 160-161)

[Shortly thereafter, Rodriguez embarked upon a tour circuit of Tahiti; upon his return to Tautira he found Vehiatua in a worsened condition.]

July 18: ... Here [in Toutira] I heard the noise of drums in the marae that is Vehiatua's, meaning that prayers were being offered up to their God Eatua for the alleviation of the Chief's illness.

July 21:... They came from the Ohitia district to wail and scarify themselves, on account of Vehiatua's illness.

July 22: ... In the afternoon I stepped over to see Vehiatua and found him very ill. At night a flute concert and also opure or prayers were conducted in his house, while Teatua at the same time inspired them with his frenzied ranting ....

July 23: Vehiatua was alarmingly ill, so that they collected many pigs and plantain shoots to take to the marae as offerings to their God Eatua, everything being in confusion through the general weeping they were all giving way to. I stepped over to see him and found him in a critical condition; his mother came to us in tears, begging that we would once more take his case in hand, and promising us everything her son possessed, to which we replied that we valued nothing so much as a pure friendship.

July 24: ... Vehiatua felt somewhat better; but in the afternoon he relapsed again, and their God Teatua having entered into him at a moment of yawning this gave rise to a great stir among the natives, for they declared it was the God of an uncle of his who had died some time ago, and had now come to visit him, whereby the Chief would be on his feet again in ten days' time and able to walk without any infirmity whatever: which falsehood we looked to to disabuse them of their error.

July 25: ... Vehiatua's folk have found a key to the origin of his illness, but will soon discover their mistake, for they have assured him that he will be able to walk within five days from now.

July 27: ... The mother came in tears and saying her son was going to die. I went over to see him, and found him stretched on a platform of boards outside his house, and I told those who were present to take him inside again. We got word by one of the natives that five of Vehiatua's partisans had gone forth during the past night to kill three men to be offered up to their God Eatua, as a shrift by virtue of which Vehiatua might recover from his illness. So as soon as we learnt this we counselled them to desist from doing it, although they had not been able to get hold of anybody. Vehiatua's mother afterwards came beseeching us to take 
the treatment of her son in hand; but although Padre Narciso was willing to oblige her Padre Geronimo was of the contrary mind, being afraid that the Chief would die, because he had lost so much flesh. At mid-day we heard that two of Vehiatua's lieges had gone out into the gorge, with some people accompanying them in quest of three men to be killed as a sacrifice, and on this account we got our arms in readiness for whatever might happen.

July 28: ... I got word from the natives that one of the people of the gorge had been killed during the night, and that he had at once been carried off, with two hogs, to be offered up to their God Teatua in the Atehuru district; and that some other leading men, of the district of Ohitia, had afterwards sallied forth in that territory, to kill four men who were still wanted, as they had not been able to furnish the required offering in our parts because all the people had fled into the hills.

August 1: ... A little before sundown, learning for certain that two persons belonging to the neighbouring district of Ohitia had been slain as a sacrifice to Eatua and brought here, I went out, with Padre Narciso for greater safety, and, guided by a secret path on account of the marked aversion I betokened when it came to my knowledge, we saw the bodies in actual being. They were father and son; and the former had suffered this misfortune through trying to save his son at the moment when all the people fled in a general scatter. The bodies had been laid in baskets of plaited palm-leaf slung on a pole and hitched across from one tree to the next. The son was about twelve years of age. As soon as the tahua perceived us in this marae "Guayotaha" they insisted on our withdrawing immediately.

August 2: ... I was informed that the bodies had been conveyed to the district of ... [Atehuru or Punaauia], a part of the arii Otu's dominions, where the principal temple of all is, named Tuputupuatea: there was now only one victim wanting to complete the offering as ordained by the tahuas.

August 6: ... At midnight we heard unmeasured cries and wailing, and as they caused us alarm, we put sleep aside and kept within our enclosure in some fear; but towards daybreak one of the Chiefs came to call me, on the side where my bedroom faces, to hasten across to his arii, who was wishing to see me for the last time. Despite this request, which appealed to our compassion, we first held a brief consultation, being filled with apprehension. I resolved to go, and the Padres hastily shut the door. Once outside, I was more scared than ever, for the darkness seemed to me intense, and the natives were all in confusion, some in the temples beating their prayer drums, (which are different from those used for merry-making), others grabbing any odd pigs they met to offer them up to their Gods, with everywhere turmoil and wailing. They had a canoe in waiting to ferry me across the stream that flows between his dwelling and our own. When I arrived they broke out into still louder cries, and hung about my neck, hustling me along to the no small discomposure of the women, who were seated almost on top of one another. I approached the arii and, taking hold of his pulse, I recognised that he was at his last breath, so that in a little less than a quarter of an hour he expired. The mother and the most important personages were supporting him in their laps, not omitting any part of his frame. In front of him lay displayed all his most cherished treasures, those emanating from the country itself as well as those that he had acquired from our own monarchy and from the English and French.

Unspeakable were the mother's moans in the abandonment of grief: she who was so wrapped with affection for her son, whom she had brought up in all the pride and luxury his sovereign rank made possible. (pp. 175-183) 
[At this point Rodriguez wrote: "I omit the many mourning ceremonies of these natives, which I will relate in a separate description." That description has never been found.]

August 7: ... I went across to find the deceased arii's mother, and those in her company begged me to try and retrieve her from the grimy condition she had got herself into in the middle of the night, for they, seeing her in so unbridled a mood, could not make up their minds to attempt it, because they were afraid of her anger.

I approached this task during the time they were preparing a position in the form of a small open space for the accommodation of the persons appointed to remain in attendance by the corpse, as will be explained in due course. Accompanied by a few others I found the mourner so changed in countenance from the loss of blood that she was continually letting from her head and body that I was quite alarmed. Notwithstanding the petulance she evinced on seeing us, by abusing those who came to show me the way, I set about soothing her and at the same time tendering excuses for them. My counsel to her to be patient and resigned met with much resistance on her part. In her utter despair she wished only for death. To this moment she had not tasted one drop of water, It was a great consolation to those around us to see her softening down towards me, and they made signs to me not to leave her by herself, for they feared she would collapse altogether. I stayed with her as long as I could. From the neighbouring settlements and valleys an immense concourse of people collected to bemourn the death of the arii, the Chiefly ladies bleeding themselves more as a matter of form than from grief or real sentiment, inasmuch as they drifted after a little while into busy conversations about their private affairs.

In the afternoon the corpse was carried to the marae, that it might sleep amidst the continual prayers of the tehuas. The prohibition against fishing and kindling fire was observed; and the entire population hereabouts still bore itself in the deepest silence.

August 8: ... I noticed that no fire was yet lit, nor did anyone go a-fishing except to supply some very urgent requirement; and then only in the most secret manner, in order not to be observed. The beating of drums continued in the maraes.

August 9: ... The same mourning ceremonies continued to be observed as before.

August 10: ... There was a great gathering of the clansmen from Oayautea, the most gainful of all these Islanders and in their wars the foremost in renown, so that they stand high in the good opinion of their Chiefs. They brought a very handsome contribution of their produce and food-stuffs to the deceased arii's brother. This is the successor to the late one, and they call him Tetuaunouna, or Guatupua, a boy who looks to be six years of age, of good mien, and a fair liking towards us, according to the measure of our conduct.

August 11: ... the Papara people were proposing to offer a human sacrifice in the principal temple Tuputupuatea in memory of their Chief, Vehiatua.

August 13: ... They [natives from Mataoae district] presented a contribution of food-stuffs to the boy arii elect. The Ohitia people came to offer their condolements to the mother arii.

August 14: ... In the afternoon the clansmen of Guayari arrived to bemourn the death of their deceased arii, and the Chiefs' ladies presented their wraps of native cloth to the corpse with a very liberal hand. 
August 15: ... The Chiefs from most of the districts belonging to this Government made a great noise, continuing the wailing and blood-letting.

August 19: ... Information reached us that one of the natives of the district of Guayari had been killed as a victim for sacrifice.

August 21: ... A Chief of the people of the Atehuru district came with many others to bemourn the death of Vehiatua, wearing a shell affair of mother-of-pearl, that they call parae. Some ladies came in his company and besmeared themselves with blood: the gathering was very numerous.

August 30: ... There was a great gathering of the Guayautea people, who had recently come to bemourn the death of their arii, and they presented their rolls of drapery.

September 5: ... The people of Matabay [Matavai], ... in the dominions of Otu, came to offer their condolences to the arii Opo.

September 7: ... I went to visit the invalid lady Oviriau, and found her as it were dazed, and her body much knocked about. This and similar sudden attacks of illness are attributed by the natives to the spirit or evarua (as they call it) of deceased persons whom they may be bewailing having taken possession of the mourners by entering into their bodies; and they were persuaded that this was the case now in regard to the spirit of the deceased arii, who was Oviriau's first cousin. It was not possible to disabuse them of this error, set afloat and upheld by their tahuas, to whose fables they yield implicit belief. (pp. 183-193)

October 17: ... To-day a number of people came from the neighbouring district called Ahui to present hogs and rolls of cloth to the arii Tetuaounoona, the morrow being the day for his public acclamation or induction to official power by the Chiefs of the Tayarapu province.

October 18: ... There was a further gathering (of the clans) for the induction already announced, which commenced with opure or prayers offered up by the tahua or priests in a cemetery or marae named Guayotaha to Teatua their God, called Opunua. The length of time these natives allot for mourning the death of the predecessor of the arii, before celebrating the new one's instalment is remarkable. (pp. 204-205)

Here ends Rodriguez' account of the episode. The embalmed corpse of Vehiatua II reposed on the ghosthouse bier, where Cook was to view it some twenty months after Vehiatua's death (fig. 13-4).

Vancouver's first mention of Mahau's decline is recorded in his journal for January 1792:

January 2: ... Towards noon Mr. Mudge returned with my old friend Pomurrey, who was saluted, previously to his coming on board, with four guns from each vessel, which gratified him extremely. With him came Matooara Mahow, commonly called Mahow; the reigning prince, under Otoo, of Morea. There was however little probability of his long enjoying this honorable station, as he appeared to be in the last stage of a deep and rapid decline; his person was reduced to a mere skeleton, which he was not able to raise without great assistance. He was hoisted on board in a chair, and supported by six people down to the cabin, where, unable to sit up, or to stand, a bed was prepared for him on the lockers. The 


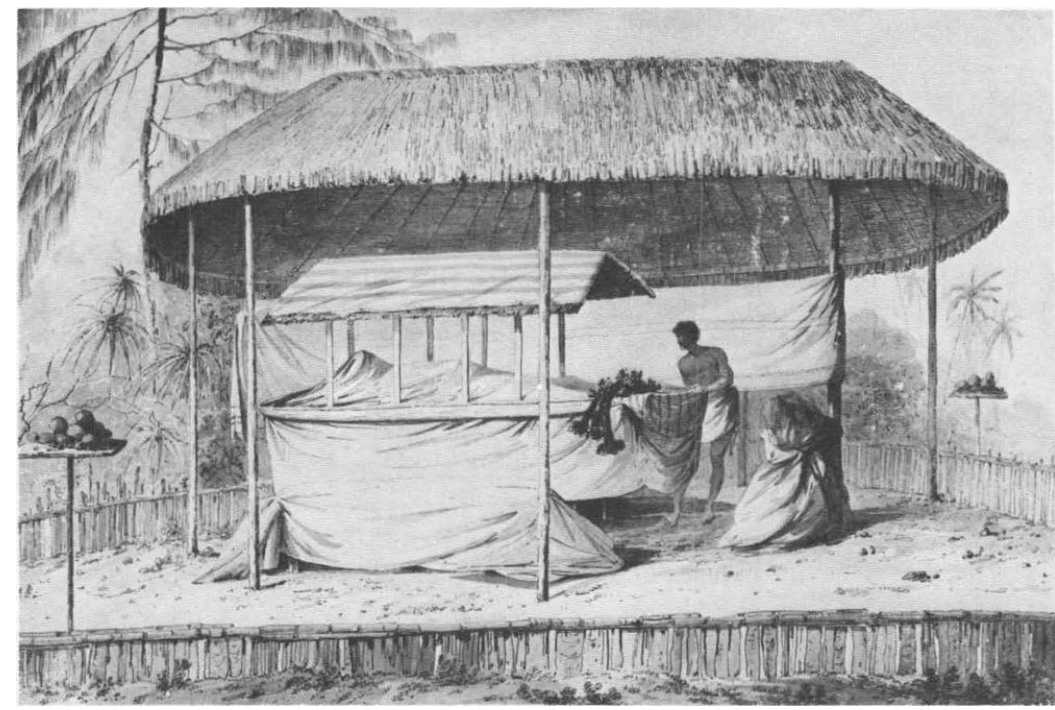

FIGURE 13-4. The corpse of Vehiatua installed in a ghosthouse. Drawing by J. Webber. British Museum.

reasons that could induce a man in his deplorable condition to undertake such a visit, must, without doubt, be not less curious than extraordinary! (1801:260-261)

January 4: ... Mahow, though extremely feeble, paid us a visit on shore; being unable to walk, he was carried about in a kind of litter. (p. 267)

[The ailing Mahau expired on January 13.]

January 14: Little concern could possibly be felt on this occasion. Mahow's relief from the wretched condition in which he existed, was directed by humanity to be esteemed a most happy event; particularly when the very singular treatment is considered, which this poor being endured whilst in our neighbourhood. Almost every evening, and sometimes twice in the night, he was brought in the litter from the royal habitation near the point, and placed in some one of our tents for a short time, and then carried back again. In the day-time he was either visiting the encampment, or, in the heat of the sun, or in the midst of rain was rowed round the ships, and insisted one evening on sleeping on board the Chatham. He was very fond of tea, and extremely desirous that whatever nourishment he took, should be dressed in the English fashion. The conduct observed towards this dying man, seemed calculated, if not intended, to hasten his dissolution. This however, was not to be reconciled with the general deportment of the whole royal party, and especially with that of Pomurrey, who appeared to regard him with great tenderness and affection. I was particularly inquisitive why he was so harrassed about; and they all agreed it was in consequence of his own desire, which, so far as could be learned, seemed dictated by superstitious notions.

January 15: I desired the messenger to inform Pomurrey, that I would attend the funeral solemnities of the deceased the next day. On sunday morning he again returned with a request from Pomurrey, that I would not visit Oparre until tuesday, when the religious interdiction under which that district had been laid would be at 
an end, no communication at present being permitted between the inhabitants of Oparre and those of the other parts of the island. This was made generally known by the display of flags in the several path-ways; not a canoe was suffered to move along the shores; nor was a fire allowed to be made; which produced a degree of solemnity, that was very expressive of the concern felt for the death of this chief, and of his consequence and respectability. Numerous fires had been observed the preceding day all over the district of Oparre. These, we were given to understand, were ceremonies of a religious nature consequent on the demise of Mahow; and it is reasonable to suppose that the mourners took advantage of this ordinance to cook sufficient provisions for the time of the interdiction. (pp. 280-282)

January 16: The next morning, they [some members of Vancouver's crew] were ... honored by a visit from Otoo and several of the chiefs, in their way to the morai. Soon after, a canoe covered with an awning was seen coming from the westward, paddling in a slow and solemn manner towards the morai, in which was the corpse of the deceased chief. On their expressing great anxiety to see Pomurrey for the purpose of obtaining permission to attend the burial ceremony, they were informed that he was gone to the morai, but would have no objection to their being present. They proceeded; and, near the rivulet that flows by Urripiah's house, they saw the queen-mother, Fier re te, and the widow of the deceased Mahow, sitting all in tears; and in the paroxysms of their affliction, wounding their heads with the shark's teeth they had prepared the preceding evening. The widow had a small spot shaved on the crown of her head, which was bloody, and bore other evident marks of having frequently undergone the cruel effect of her despair. Being apprehensive that the presence of strangers might be unwelcome, they took leave, and repaired to the morai, where the priests had already begun their funeral solemnities. Pomurrey, Urripiah, and others, silently assenting, they moved quietly through the assembly, and were seated with as little interruption to the duties, as on entering a church in England after the service is commenced. Five priests were seated before Pomurrey, chanting a prayer, with their faces towards Otoo, who sat on a man's lap. About ten yards from him was held a bundle of cloth, which contained emblematically the Eatooa; a general name for their deities. The body of Mahow, wrapped in English red cloth, was deposited under an awning in a canoe, whose bow was drawn up a little way on the beach near the morai, and was attended by one man only at her stern up to his middle in water, to prevent her driving from the spot. The priests continued chanting their prayers, frequently exalting their voices, until they ended in a very shrill tone. He who, on this occasion, performed the office of chief priest, was discovered to be our friend Mowree, whose prayer was equally fervent, and continued nearly half an hour longer than the rest; during which he was occasionally joined by another priest in a very shrill tone of voice. This prayer of Mowree's seemed at intervals, like an expostulation with the Divinity, by adverting to the different productions of the island remaining, and still flourishing in the greatest plenty, and yet $M a-$ tooara Mahow was suffered to die.

The address being ended they all rose up, and proceeded westward along the shore, followed by the canoe in which was the corpse, to the mouth of the rivulet, where the three royal ladies still continued to indulge their excessive grief; and who, on perceiving the canoe, burst forth into a loud yell of lamentation, which was accompanied by an accelerated application of the shark's teeth, until the blood very freely following, mingled with their tears. The canoe entered the brook, and proceeded towards another morai at the foot of the mountains, where the ceremonies to be performed on the body of the deceased required such secrecy, that, on no ac- 
count, could our gentlemen by permitted to attend, although it was most earnestly requested. As some alleviation to this disappointment, Pomurrey promised they should see the manner in which the remains would be deposited the next day, and earnestly intreated they would desist from following the procession any further on the present occasion. As it was generally suspected that the body was now to undergo the process of embalming, the party much lamented Pomurrey's interdiction, as it deprived them of the only opportunity that possibly might ever occur of becoming acquainted with the nature of this operation; whence might be derived not only curious, but useful anatomical information. This prompted Mr. Menzies to renew his solicitations to Pomurrey to be admitted alone; but as these were attended with no better success they determined to abandon these melancholy solemnities, ... (pp. 286-289)

[Returning to their ship after their excursion the aforesaid members of Vancouver's crew passed near the path leading to the marae where Mahau's corpse was being embalmed.]

January 15: They had not proceeded far when a general solitary gloom prevailed; all the houses were deserted, and not a living creature, excepting two or three dogs, were to be seen until they arrived near the morai; where, in a small house, three men were observed, who, most probably, were the centinels of the sacred place. These questioned the guide in a very particular manner, and then acquainted him, that the body of Mahow had been removed to the morai, where it had stopped the day before; and that Pomurrey was there also. They now took a cursory view of the holy spot, which afforded little worthy of notice. It was terminated by high perpendicular rocks, whence issued several streams of water, whose continued murmurs, assisted by the wild and gloomy situation of the morai, gave an awful solemnity to the place, and fitted it to the mournful, sacred purpose, for which it is designed. (pp. 291-292)

January 17: A message was received from Pomurrey, requesting my attendance at Oparre, to "tiehah," that is, to mourn for the death of Mahow. It was understood to be much wished, that we should be provided to fire some vollies; and that I should present, on this occasion, a piece of red cloth as an offering to the deceased. I was informed also that most of the neighbouring chiefs were to pay their last tribute of respect to the remains of Mahow, and that the ceremony would consequently be attended with many formalities; but on our arrival at Oparre there did not appear the least foundation for any such report. Mr. Broughton and Mr. Whidbey accompanied me. On our landing, we were conducted to a temporary habitation of Pomurrey, where we found him, his wives, and sisters, in readiness to receive us. Some little concern was certainly apparent for the loss of their friend and relation; though very unequal to the affliction I expected to have witnessed, from the great care, and tender regard, manifested to Mahow by the whole party when alive. The grief of these people is of two descriptions, natural and artificial; it is excessive on the first impulse, but soon moderates and wears away.

The corpse was laid on the tapapaoo, which seemed to have been erected for the express purpose about a quarter of a mile to the eastward of the grand morai; (or as it is called, "tapootapootatea") and appeared to be then undergoing the latter part of the embalming process, in the same manner as described by Captain Cook in the instance of Tee. The body was exposed to the sun; and, on our approach, the covering was taken off, which exhibited the corpse in a very advanced state of putrefaction. The skin shone very bright with the cocoa-nut oil, with which it had been anointed, and which, we understood, was highly impregnated with "aehigh," 
or sweet-scented wood. One of the arms and a leg being moved, the joints appeared perfectly flexible. The extremely offensive exhalations that were emitted, rendered it natural to conclude, that the whole mass would soon be completely decomposed; but, if credit may be given to their assertions, which were indubitably confirmed by the remains of Tee, and to which I could myself bear testimony, this will not be the case. Pomurrey informed us, the corpse was to remain a month in this place; then a month was to be employed in its visiting some of the western districts; after which it was to be removed to Tiaraboo for another month; whence it was to be carried to Morea, and there finally deposited with his forefathers in the morai of the family. In the course of a few months after its arrival there, it would gradually begin to moulder away, but by such very slow degrees, that several months would elapse before the body would be entirely consumed.

This method of embalming, or rather of preserving human bodies, is certainly an object of great curiosity; particularly, when it is considered that it is performed under the influence of a vertical sun; sometimes in the rainy season; and that the operators are totally ignorant of the properties of spices, salts, \&c. \&c. as antiseptics. Whether their preparations be simple or compounded, or what may be the peculiarities observed in the process, remains, I believe, intirely unknown to Europeans\& and it is much to be regretted, that their religious interdictions precluded our attending the whole of these mysterious obsequies, as many vessels may visit this country without meeting so favorable an opportunity, with persons on board qualified and inclined to direct such enquires into effect.

The boat's crew were ranged before the paling that encompassed the tapapaoo; the piece of red cloth was given to the widow, who spread it over the dead body; some vollies were then fired, and I was directed to pronounce "Tera no oea Mahow," that is, For you Mahow. On some rain falling, the body was taken under cover, and carefully wrapped up. We had but a few yards to retire to Pomurrey's habitation, where himself and family had taken up a temporary abode for this occasion; but the exceedingly offensive smell of the corpse obliged us to .... [move away]. (pp. 295-298)

Shortly thereafter the corpse of Mahau was sent forth on the tour described above, and life evidently returned to normal in the neighborhood where the events just reported took place. (Fig. 13-5)

\section{JOURNEY OF THE SOUL}

No domain of Maohi beliefs contained so many variations, and contradictions, as that concerned with the fate of a human's soul after the final and irreversible "death" of his body. ${ }^{90}$ Even granting the unreliability of some of the reports on this subject, and the invalidity of some of the reporters' interpretations, ${ }^{91}$ there remains a large number of inconsistencies which cannot be resolved-and indeed will not be attempted here. Along with persistent variations of a localized nature, the corpus of Maohi beliefs on this subject was being continually augmented and diversified through dreaming and trance, either sincere or feigned. One should not lose sight of the absence in this society of any comprehensive social relationships requiring or even encouraging universal conformance to any "official" doctrine, except possibly the dogmas which members of the Arioi sects and other 'Oro 


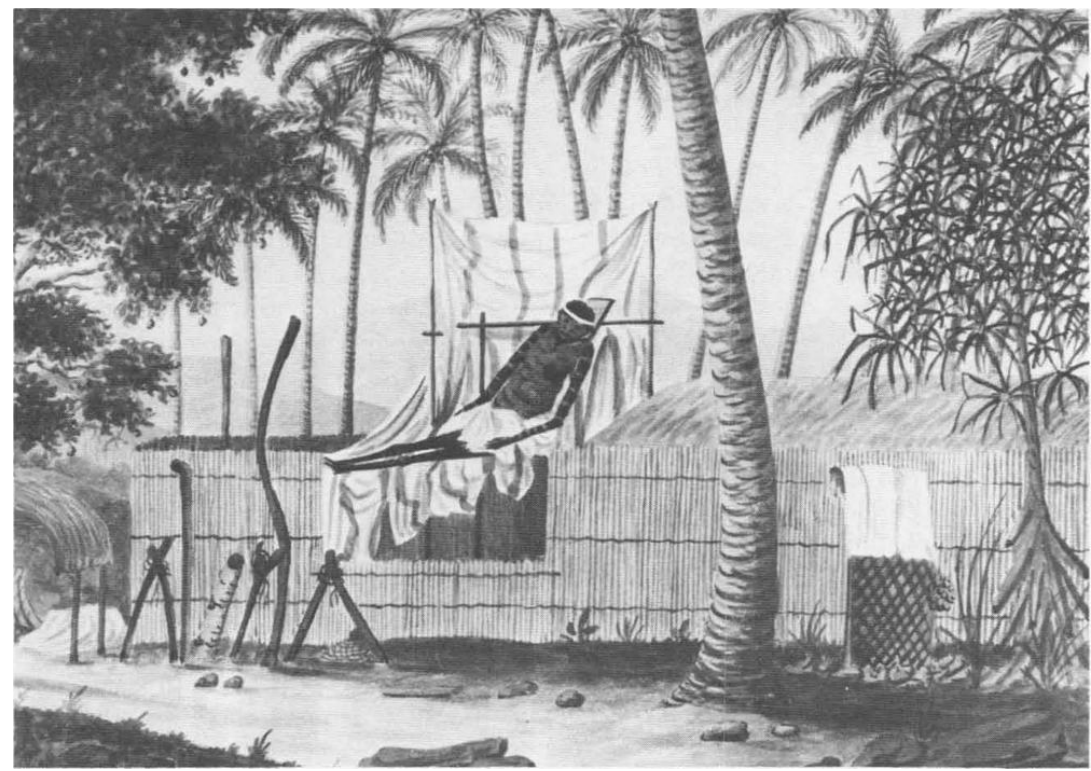

FIGURE 13-5. A ghosthouse with the exposed body of the ari'i Mahau. Watercolor by G. Tobin, painted more than four months after Mahau's death. Mitchell Library, Sydney.

worshippers were engaged in disseminating. In addition to variation of beliefs between localities, and among individuals in the same locality, it is not unlikely that often an individual held comfortably to beliefs that a Western observer would find quite contradictory.

Notwithstanding this, it is possible to single out a number of beliefs and to group them around a central set of themes, which I shall call "the journey of the soul." The only evidence we have concerning conformity to this doctrine lies in the circumstance that it is reported in many of the sources. The thread of this thematic complex runs as follows: when the soul leaves the body it is escorted by spirits, whose special function that is, to a place in or west of Ra'iatea and along an established and hazardous route. Near the end of its journey-if it has managed to survive that far-it undergoes a judgment to determine which of two (or three) places it will then proceed to. Borrowing Western analogies, one of these is a paradise, one a purgatory, and one a kind of limbo for purged sinners and for others not qualified to enter paradise. In due course many souls are released from limbo and allowed to revisit their earthly homes, while a fortunate few, presumably those mainly in paradise, become apotheosized. ${ }^{92}$

Souls originating on Tahiti assembled at Tata'a Hill (Puna'auia district) before starting out in convoy on the overseas journey. The takeoff place on Mo'orea was Mt. Rotui, and presumably for every other inhabited island there was such a place. ${ }^{93}$ Many souls eventually arrived at Mt. Temehani on Ra'iatea, but not all souls survived to reach that point. 
At Tata'a Hill (Tahiti) there were two stones, one of life and one of death; if the soul happened to touch the former it was able to continue its journey, if the latter it was annihilated (de Bovis 1909:39). In Henry's version, "If it alighted ... upon the ... stone-of-life it could return by powerful attraction to its body; but if it went on to the ... stone-of-death it was forever severed from its mortal remains" (1928:200). The utter fortuitousness and the seeming triviality of the event behind this fateful outcome is emphasized by the fact that the unknowing soul was also blind. De Bovis recorded another episode of fortuituous fatefulness in the belief that souls en route amused themselves along the way by picking tiare flowers, some of which were fatal; and if a soul happened by chance to pick any of these latter it was thereupon annihilated, or so these reports imply. It could well be that deeper enquiry would have turned up a belief that even consequences as seemingly accidental as these were decided by higher spirits on one basis or another. But like the question concerning Maohi beliefs in the possibility of free will, this one is now beyond answering.

Another kind of hazard along the soul's route was in the form of malicious spirits which sought to destroy it; measures taken to protect the soul from this danger were noted above.

According to Henry's version, the most detailed available, at Mt. Temehani on Ra'iatea the route branched:

At the point of deviation stood the god, Tu-ta-horoa (Stand-to-permit), and when the spirit coming from the stone of life at Tataa hill met him he would under certain conditions tell it to return to its body to remain a while longer in this life. But generally he merely pointed to one of the two roads, which the spirit silently took. When allowed to go to the right, it flew on to Pu-o-roo-i-te-ao and there met Roma-tane (Voluptuous-man) who received the 'ura feather amulets as peace offerings, whereupon the spirit was safely ushered into the desired Paradise, called Rohutu-noanoa (Rohutu-of-sweet-odor). But when directed to the left by Tu-tahoroa the spirit had no alternative but to obey and fly up on to Pu-o-roo-i-te-Pô, whence it flew down into the crater of Temehani and was soon ushered into the presence of Ta'aroa-nui-tuhi-mate (Great-Ta'aroa-whose-curse-was-death). In this region the rank of mortal beings was not respected, but all were treated alike. Kings, noblemen, and plebeians, according to their capabilities, were foodgathers, fishermen, planters, and menial servants to the gods; queens and all classes of women served the goddesses, for, as the legends of old Tafai and the goddess Pere show, regions like those above ground and the same kind of life were supposed to exist below. When their work was done these captive spirits had to sit about in the region of utter darkness-which to the gods was not obscure-by the ever-rushing river where Ta'aroa and his coadjutor Rua-tupua-nui liked to dwell; and when it pleased Ta'aroa, his cooks scraped the spirits into a pulp with the shell of the tupere (cockle) as sweetening for his pota (taro-leaf spinach). But this process did not annihilate them, and they came again to be at Ta'aroa's disposal.

After remaining about a year in this purgatory, the spirits looking miserable, would be sitting with recent arrivals around Ta'aroa, who at last moved to pity would ask if they were not happy, and on being answered in the negative, he 
would ask what they desired. The would say they were homesick and would like to be released to visit the upper world. Then Ta'aroa, after enquiring about their homes and relatives, showing great interest in all their answers, would tell them they were free to go for a visit. (1928:201)

Purification through being eaten-by a spirit bird, a spirit sea slug, the ghosts of relatives, or by one of the major deities-is an episode found in several versions of this thematic complex. One account, for example, reports that the souls of premature infants went to Ta'aroa's pools in the $p \bar{o}$, where they entered into periwinkles (hihi) and gobies (Electrisfusca, o'opu), and whenever one of these was eaten by a god it slipped into another periwinkle or goby. "Babes that had not seen the light from other causes were permitted to enter into the same kind of fishes in rivers on the earth." (Henry 1928:200) Another version asserts that a son's soul was eaten by his father's ghost-or vice versa, depending upon which one had died first. Henry in a more general statement said that "Children in the dependent state went to their ancestors" (1928:200). Still another account states that certain souls eaten by gods became assimilated into the latters' being (de Bovis 1909:40). According to Anderson, social relations in the afterlife were about the same as before death:

They are ... far from entertaining those sublime conceptions of happiness, which our religion, and, indeed, reason, gives us room to expect hereafter. The only great privilege they seem to think they shall acquire by death, is immortality; for they speak of spirits being, in some measure, not totally divested of those passions which actuated them when combined with material vehicles. Thus, if souls, who were formerly enemies, should meet, they have many conflicts; though, it should seem, to no purpose, as they are accounted invulnerable in this invisible state. There is a similar reasoning with regard to the meeting of man and wife. If the husband dies first, the soul of his wife is known to him on its arrival in the land of spirits. They resume their former acquaintance, in a spacious house, called Tourooa, where the souls of the deceased assemble to recreate themselves with the Gods. She then retires with him to his separate habitation, where they remain for ever, and have an offspring; which, however, is entirely spiritual; as they are neither married, nor are their embraces supposed to be the same as with corporeal beings. (Cook 1784:164-165) ${ }^{94}$

Anderson added the following somewhat puzzling statement, which is confirmed in no other source that I know of:

... they consider [being eaten by a deity] a kind of purification necessary to be undergone, before they enter a state of bliss. For, according to their doctrine, if a man refrain from all connection with women some months before death, he passes immediately into his eternal mansion, without such a previous union, as if already, by this abstinence, he were pure enough to be exempted from the general lot.

A different version of the soul's journey, reported by de Bovis, specified Tupai as the purgatory for souls not admitted to paradise. Tupai, an atoll about ten miles north of Porapora, had no permanent settlement but was vis- 
ited occasionally by fishermen-but only in parties, because natives feared the ghosts too much to visit alone or to reside there (de Bovis 1909:40). ${ }^{95}$

In Moerenhout's version the fateful branching of the route occurred at the soul's takeoff place on an island. On arriving there, if the soul perched on the right-hand stone, that in itself was proof of its innocence of punishable misdeeds and it was ushered into the limbolike $p \bar{o}$; but if it perched on the left-hand stone, that was a sign of guilt, and it was taken to a purgatory where it was punished and purged and then admitted into pō. ${ }^{96}$ But, continued Moerenhout, the actual numbers of those dying in fear of such punishment were few because, in the first place, most Maohis were careful not to commit punishable misdeeds(!), and secondly, those who did so usually took pains to expiate, with prayer and sacrifice.

Paradise, that is "Fragrant Rohutu," was according to some accounts conceived of as being on the north side of Ra'iatea, an elysium of a place, “... where the air was remarkably salubrious, flowers abundant, highly odoriferous, and in perpetual blossom. Here the Areois, and others raised to this [privileged situation], followed all the amusements and pursuits to which they had been accustomed in the world, without intermission or end. Here was food in abundance, and every indulgence." (Ellis 1829:I, 517.) And here there was no sickness and no aging, and all women remained eternally beautiful (Moerenhout 1837:I, 434). Altogether, a highly suggestive commentary on Maohis' life goals.

But even more significant are their beliefs about the manner of person admitted to that eternity of sensual bliss. First and foremost, the Maohi paradise was reserved for the souls of members of the Arioi sect. When one of these latter died his body was eventually interred within the precincts of a marae dedicated to the god 'Oro, where a priest invoked the god to "... bestow on the disembodied spirit all the mystic powers with which it had been supposed he had invested the arioi in life ... [and] to receive the arioi soul into the full enjoyment of their paradise, where it was believed that no children existed to mar their pleasure" (Henry 1928:241).

In addition, entry into paradise could be attained by the souls of all persons who, in de Bovis' words, "... had lived in an appropriate manner vis à vis priests and marae" (1909:41).

Moerenhout put the matter somewhat differently. In his version, in addition to the Ariois, paradise was accessible also

... to the friends of chiefs and to other such individuals affluent enough to provide the gods with enough sacrifices, and the priests with enough gifts, to induce the latter to pray so as to bring about, eventually, the transfer of the donors' souls from Po, the dwelling-place of shadows, to Rohutu noanoa, abode of light and pleasure. However, this required so much wealth that most people entertained no hope of 
ever tasting the delights of the heavenly abode. In the case of individuals who had left accumulations of wealth [but who had evidently not given enough to gods and priests while alive] their ghosts sometimes returned to their relatives and heirs and ordered them to donate that wealth to the priests and gods, so that they could gain admission to heaven. The prospect of this heaven, and the fear of the painful alternative, served to bring in immense revenues to the priests; hence, a large part of some people's wealth passed into or through the priests' hands. (1837:I, 435)

Combining these several versions of the soul's journey-which may well be a factitious exercise on my part ${ }^{97}$-there appear to have been three kinds of fates in store for souls: a paradise for all those who had lived lives of lavish supererogation vis à vis the deities and their priestly representatives, or whose resources were so used after their deaths; a purgatory for those who still bore the guilt of unexpiated sins; and a limbo for those whose sins had either been expiated before dying, or who had been purged in purgatory. ${ }^{98}$ And in addition to these, there was, of course, the fate of annihilation which some souls suffered before reaching purgatory or limbo; presumably, no soul bound directly for paradise met such a fate, since they were conducted thither by the god Uretaetae (de Bovis 1909:41). ${ }^{99}$

It would appear therefore that, in terms of the themes expressed in the journey of the soul, one's fate after death depended almost entirely upon conduct vis à vis spirits, rather than upon one's relations with humans. But that is perhaps too narrow a view, for it will be recalled (from Moerenhout's version) that the surviving kinsmen and friends of the deceased could insure the soul's avoidance of or release from purgatory by making large offerings to the gods through their priestly intermediaries, thereby favoring persons of social importance and affluence, but implying also that social morality and ethics may after all influence the soul's fate. Unless fear of a vengeful ghost were the only motive behind such mortuary offerings, the unloved and unlamented person would presumably have inspired less generosity among the survivors than would the more considerate and better loved. Also relevant is Henry's statement regarding the annual feast to departed souls, designed, according to other accounts, to obtain their goodwill through facilitating their release from purgatory:

During the year when the soul was supposed to be safe with Ta'aroa in the Pō, all the family and near and distant relatives planted food and fattened live stock. When all their plans were matured, at about the anniversary of the death, they made a feast in the home of the deceased, of which they partook in the night, pō-tupapa'u called (ghosts's night), when they invoked the presence of their lost relative, bidding him or her welcome home. This practice, they said, insured the continued good-will of the deceased, who then never haunted them.

After this [release from purgatory] they became inferior gods, called 'oromatua, that were composed of three classes: 'oromatua maitatai (good 'oromatua) who entered into their own skulls as family gods or guardian spirits; 'oromatua 'ori'ori noa (rambling 'oromatua), who sometimes appeared to members of their family 
to direct them in their worldly affairs or warn them of coming dangers; and 'oromatua nihoniho-roroa or 'oromatua-ia-aru ('ormatua with long teeth or people in the woods). The first class were always benevolent; the second class were kind when well treated, but abandoned those whom they would befriend; and the third class, when vexed, strangled and devoured people, even their relatives and friends and were invoked to do so by the sorcerers in their black art. (1928:201-202)

None of the sources provides a general comprehensive statement explaining why any particular soul assumed, or was made to assume, one or the other type of ghost role, but there are fragmentary bits scattered throughout the literature on the Maohis to indicate that an individual's preoccupations and temperament while living were in some degree maintained in the ghostly state; for example: Arioi remained devotees of pleasure, the most innocent of babes were transformed into the most harmless of animals, the souls of people committing suicide for reasons of unrequited love continued to hover near the loved one (Henry 1928:200), and warriors slain in battle became even more ferocious-wounds gaping, these latter were a deadly threat to any mortal brash or unwitting enough to go near the fatal battlefield (de Bovis 1909:40). In this connection, the view that many ghosts, presumably the more benevolent ones, materialized in the form of the type of animal or bird that had previously served to embody its spiritfamiliar, is also a "reasonable" conclusion (e.g., Moerenhout 1837:I, 457). But it does not thereby warrant describing the Maohis as "totemistic." On the other hand, Henry's statement about victims of infanticide does seem rather paradoxical: "Little babies murdered at birth (puaru) become house guardians of their parents, who sometimes fancied they heard their cries at night" (1928:200); but the paradox might perhaps derive from Henry's neglect to specify the kind of guardian meant.

In any case, the fate of a victim of infanticide does not present the only paradox or inconsistency in Maohi eschatology. There are other themes more or less in conflict with the journey-of-the-soul complex. "It was supposed that when people died violent deaths their spirits did not go the same way as those of people who died from natural causes, but that they remained at the places where the fatal accidents occurred, rendering these places sacred or dreaded" (Henry 1928:200); that is, such souls did not pass through purgatory or limbo. But what is meant here by "violent" death: death in battle? death from sorcery?

All souls whose bodies were not accorded a proper funeral remained near the place of death. All souls whose drowned bodies remained unrecovered from the sea lived forever after in a kind of paradise in the depth of the sea (e.g., see Cook 1784:165). “... if a man ate the head of a hog at the marae instead of giving it to the gods on such an occasion, his soul would enter into a hog after death; or into a fish if he ate the head of a fish" (Henry 1928:176). 
But far more important than any of these is the theme of apotheosis, which has a direct bearing upon our understanding of Maohis' valuation of mankind (i.e., is man a potential major god?) and of their kinship ideology. I shall take up the latter matter in other chapters, and here only present some evidence regarding the presence, or absence, of the belief. ${ }^{100}$

Moerenhout, speaking of major atua (dieux du premier ordre) gave as his own judgment that "apotheosis, if it took place at all, was very rare" (1837:I, 445). He noted that none of the most celebrated (historical) chieftains of the previous four or five generations was included in any list of gods (dieux). Presumably he was referring to an active belief in the process of apotheosis and not to the historicity of the process itself.

I have found no evidence of a doctrine of reincarnation and no belief that the soul of one deceased human ever reentered the sphere of humanity as permanent soul of another. ${ }^{101}$ In this respect, at least, every Maohi was unique. 


\section{NOTES}

\section{CHAPTER 1}

1 See, for example, Gautier 1947; Jacquier 1944; Volk 1934; B. Smith 1960.

\section{CHAPTER 2}

1 West of Maupiti, 180 and more km, lie the atolls Mopilia, Scilly, and Bellinghausen, which the geographers now include in the Society archipelago. The ancient Maohi knew of these atolls, but there were no permanent settlements on them.

2 Gougenheim 1956:40. According to several older accounts these Islands have also been represented as evidencing little or no variation in tide time, highs having been alleged to occur regularly near noonday and midnight, and lows near 6:00 A.M. and 6:00 P.M. As Gougenheim demonstrated, careful measurements have shown these other accounts to be inaccurate; the actual amplitudes of high tides are seen as varying between 10:00 A.M. and 3:00 P.M., and between 10:00 P.M. and 3:00 A.M.

3 Taxonomies given in this chapter are of course modern "scientific" ones; some parallel Maohi taxonomies will be presented in later chapters.

4 Mesotropical and hygrotropical correspond, respectively, to the zerotropical and pluviotropical zones distinguished in the Hawaiian Islands (Egler 1941); but in this connection Papy points out that the climatic differences are less clear-cut on Tahiti than on Oahu (1954:II, 176).

5 Based mainly on Papy 1954, supplemented by Henry 1928. In this and other lists of plants given in this chapter only the generic name is listed in the text (except when it is necessary to distinguish species of the same genus).

6 Papy characterized this zone as having a climate of B1 A' a' w according to Thornthwaites formula, i.e., a humidity index of 22.3; a very high evaporation potential (over $114 \mathrm{~cm}$ ), less than half of which occurs during the summer months; and a slight deficiency of precipitation during the winter months (1954:I, 120; and Thornthwaite 1948).

7 This chapter was first written prior to publication of Norma McArthur's book on Island Populations of the Pacific (1968), which includes a lengthy section on the population of the Society Islands during the eras now under study. Dr. McArthur's treatment of the few eyewitness estimates of these Islands' population in most respects is so detailed and authoritative that I am left 
with little more to do than echo her findings. In this connection I wish also to acknowledge Beaglehole's useful study of the same subject (Beaglehole 1955:clxxiv-clxxvii), and to thank R.G. Schmitt for his most helpful critique of an earlier draft of this chapter.

8 See Davies to Orme, 9 December 1830, LMS Archives. But see Schmitt's strictures concerning the reliability of all the early missionary censuses, as well as some of those conducted later. (Schmitt 1967).

9 The identification of Banks' O'whaa with Mahaena is rendered more credible by the circumstance that this district's principal river is named Fa'a (Henry 1928:72). Oapora is inscribed on Cook's map of 1769 between Oparre and Tettahah.

10 In this connection, shortly after Cook's return to Tahiti in 1793 one of his officers, Lt. Pickersgill, reported having landed at Hitia'a "amidst the acclamations of at least 5000 People" (Beaglehole 1961:768).

11 Father Joseph Amich, who remained on board the frigate during the party's reconnaissance ashore, wrote of having learned from the shore party that the island "was peopled by some 150 persons of all ages and sexes" (Corney 1915:73). This is further confirmation of Don Amat's reservations about the padre's reporting and of Schmitt's despair over the garbling of population estimates, both cited previously.

12 Cook, Banks, and other early visitors made no mention of throngs comparable to those experienced on Tahiti. And the paramount tribal chieftain of Ra'iatea, for all his social preeminence, apparently could not muster enough power to escape conquest by Poraporans.

13 During his second voyage Cook reported having seen a young man 6 feet 4.6 inches tall, who was accompanied by his "sister" who was herself 5 feet 10.5 inches in height (Beaglehole 1961:424).

14 Recent anthropological description of Tahitians is more precise by far than the impressions recorded by the earlier visitors, but it is in some respects less "authentic," in view of the increments of alien genes that are almost certainly contained in many of the individuals measured. See Shapiro 1930 and 1943; Marshall and Snow 1956.

15 See also Beaglehole 1961:769; Corney 1913:329-330; Corney 1915:80; Bligh 1789:I, 409.

16 Papy 1954:II, 266-267. Other plants that moved into these clearings were Urena lobata (piripiri), Triumfetta procumbens (urio), Adenostemma viscosum (vaianu), Gossypium tahitense (vavai), Ocimum gratissimum (miri) - in other words, indigenous species and not introduced by the Maohis.

\section{CHAPTER 3}

1 "We have heard other traditions on the same subject; little dependence can be placed on any as being universal; one was believed here, and another there, and they had only one common quality-that of being equally preposterous in mass and abominable in detail" (Montgomery, quoted by Mühlmann 1955:168). I am concerned here of course with the fact of vari- 
ability, and not with the so-called infrastructures revealed by comparing different versions of the same myth, as defined in Lévi-Strauss, 1960.

2 I am not able to document or explain the several factors that contributed to change in this sphere of Maohi life, but certainly one of the most important of them must have been dreams.

3 See, for example, de Bovis 1909:45.

4 According to E.S.C. Handy, "The ancient esoteric teaching in [Polynesian] cosmology postulated the preexistence of a self-created World Soul which evolved the world and the universe out of itself, and called manifest existence out of nothingness by the power of the Word" (1927:9). Handy went on to state that the only direct evidence we have of such a belief is from New Zealand and the Society Islands. The reasons why other Polynesian creation accounts make no mention of this World Soul are that the informants either did not know them or dared not reveal such esoteric knowledge.

I leave to others an analysis of the New Zealand evidence cited by Handy. As for his Society Island evidence, I fail to discover any credible basis for his postulation of a "World Soul." Neither of the brief and almost identical native texts he paraphrases-nor even the much expanded versions recorded in Henry-contains words or phrases which would permit any such interpretation. If, in defense, the emphasis is placed on "postulation" rather than "translation" then I must retire from this fascinating but fruitless pastime.

5 If admirers of Polynesian verbal arts object to the liberties I take with what in many instances are gems of sonorous and metaphor-studded expression, I offer as my excuse that I am interested in such matters only as they have a more or less direct bearing on the main subjects of interest.

6 Ellis 1829:II, 192; see also Moerenhout 1837:I, 442ff. Ellis added that one of the missionaries was told of the existence of still another god “... superior to them all, whose name was Rumia; he did not however, meet with any of their priests or bards who knew anything about him." According to the LMS Dictionary, Rumia was "... something like an egg floating in the abyss, or expanse, out of which came the materials of heaven and earth." See also Henry 1928:339ff.

7 For example, Emory 1928, Jacolliot 1954, Lavaud 1928, Roussier 1928.

8 In one passage Ellis asserted that "... Ta'aroa oriori, or created, the gods" (Ellis 1829:II, 193), but he did not specify the precise meaning of this term. In fact, the LMS Dictionary defines oriori, to shake, or dance repeatedly, to gad about.

9 The popularity of recent works such as La Pensée Sauvage, by Claude LéviStrauss, suggests that many persons still need to be convinced that all human beings, everywhere, display evidence of intellectual curiosity and skills going beyond the bare necessities of living.

10 Specific status names are referred to as Titles.

11 Recorded by Orsmond at Ra'iatea in 1817 (Henry 1928:399ff).

12 I emphasize that there were individual differences in this regard among the Maohis, as are to be found in all human societies. For example, individuals could be found capable of explaining a moon eclipse: "they suppose ... 
that an eclipse [of the moon] is a prodigy that portends war, the death of a Chief or some such thing... They say the moon in the time of Eclipse is pressed out and squeezed by some god and in danger of being devoured" (Davies, Journal, 10 May 1808, LMS Archives). Others among them appeared to be wholly disinterested in the phenomenon: "We do not find that the natives took any particular notice of the eclipse last night, which, considering the superstition of the islanders, is somewhat remarkable" (LMS Transactions:I, 218).

13 Throughout this and succeeding chapters I shall make extensive use of Maohi linguistic data for labeling and classifying such things as roles, activities, and the like. Unfortunately, however, no competent linguist has yet published the type of descriptive grammar of Maohi speech which would provide us with the kind of comprehensive "ethnotaxonomy" which only language can provide.

14 Throughout this book, "god," "ghost," and "demigod" will be used when the reference is clearly so intended, but otherwise the English term "spirit," for which, however, there is no exact Maohi equivalent, will be used-i.e., when the meaning is not sufficiently specific or when more than one type is intended.

15 Data on such "levels" are scant, imprecise, and conflicting, suggesting either that the concept may have been unimportant or that the European chroniclers were unobservant. The numbers of such levels vary in the accounts from seven to ten and more.

16 Moerenhout wrote that some of the Maohis' own deified chiefs were ranked among these principal gods (1837:I, 444).

17 The classification given here (i.e., into major and minor spirits) is largely my own, although supported in part by the taxonomic attempts of such writers as Ellis (1829:II, 191ff), Henry (1928:221), and Moerenhout (1837:I, 442ff). The Maohis did label some of their atua as ri'i (lesser, minor), and described some as having been more exalted than others, but I very much doubt that there was any consistent, comprehensive classification subscribed to on a universal society-wide basis. Individuals probably differed considerably in their rank-ordering of spirits according to personal, local, or cult ties with particular ones. Also, such rank-ordering was undoubtedly subject to change-as witness the rise in popularity of 'Oro during the second half of the eighteenth century (see chap. 12, this work).

18 "Like the Ancient Greeks, the Tahitians had their Oréades, their Maiades, their Dryades, their Sylvains, and their Faunes; but the Tahitians even outdid the Greeks in this regard" (Moerenhout 1837:I, 451).

19 See, for example, G. Forster 1777:I, 379, 394; Beaglehole 1961:424.

20 The LMS Dictionary implies that 'oromätua applied only to malevolent ghosts; but this is contrary to Henry's more general usage. The LMS Dictionary likewise states that tupapa'u, the term used for "corpse" (and for the bier on which a corpse was laid out), was used also for "ghost."

21 See quotation from Henry, page 54 above; also Moerenhout 1837:I, 507.

22 The LMS Dictionary gives the following definitions of these terms: mana'o, 
thought, idea, meaning, conception; to think, muse, reflect; horuhoru, to be agitated, troubled in mind; manava, stomach, belly, interior man. See also Henry 1928:367. A passage from one of the Forsters, who accompanied Cook, provides a highly specific account of all these matters, asserting that feeling and thinking were the function of a separate being, a tee or teehee (i.e., $t i^{\prime} i$ ), inside an individual; but in my judgment this version is less acceptable than those of better informed and less pretentious observers.

23 See, for example, Luomala 1940.

24 "Holy usually implies some quality or some attribute in the thing itself which makes it either suitable for use in worship or an object of veneration.... Sacred ... differs chiefly from holy in implying a character given to a thing by blessing, dedication, consecration to religion or worship or to the uses of religion or worship, or by its being devoted wholly to such ends or uses; the term therefore usually suggests an opposition to that which is profane or which exists for profane uses;" Webster's Dictionary of Synonyms, 1951.

In some unpublished notes of Orsmond there seems to be a suggestion that $m o^{\prime} a$ was simply a substitute for $r a^{\prime} a$, brought about by operation of the Maohi custom of pi (word replacement), but this has not been substantiated (White 1967:326). Also, there is a god named Ra'a but none, as far as I can discover, named Mo'a.

25 See, for example, Morrison: "If any thing toutches the Alter, or even the Sacred Ground about the Morai, let the Value be ever so great it is deemd Sacred, and for that reason can never be brought into unhallow'd ground, or toutchd but by the Priests \& should a Hog or Dog \&c. run into any of the Sacred Grounds they are killd for sacrifice" (1935:183).

26 See, for example, E.S.C. Handy 1927:28-29.

27 The LMS Dictionary gives the following meanings for tapu: (1) a restriction\& the word is obsolete in Tahiti, though much used in some islands. (2) sacred, devoted, but this sense is nearly obsolete in Tahiti, although retained in other dialects. (3) an oath or a certain solemn engagement to perform, or not to perform certain things. This is called parau mate tapu. (4) to bind one's self, or another person, with an oath to do, or not to do a thing; to adjure. (5) a sacrifice to the god Oro, commonly a man killed for the purpose, but this tapu, or taputapu, was generally called ia or fish.

28 See also Henry 1928:182. Sennit was used in certain kinds of divination, as will be described in due course.

29 Peter Buck put forward the idea that in the Society Islands the more anthropomorphic $t^{\prime} i$ were the older form of god-image, having been superseded by the less anthropomorphic to'o forms as god-images though surviving as repositories for sorcerers' familiars (Buck 1944:469). It is difficult to see how this interesting theory could be tested, archaeologically or otherwise.

30 E.S.C. Handy drew attention to the interesting parallel provided by the toko (probably equaling Maohi to'o), the sticks of wood which in New Zealand and the Marquesas represented the major deities, “... as supporters of the heavenly realm in its relationship to the earth" (1927:121). 
31 Clerke's reference here is to the offer by a chief and his spouse of the latter's sexual services. Cook, be it known, did not accept the proffered exchange! See also G. Forster 1777:II, 70-71.

32 Henry 1928:136. The LMS Dictionary, however, restricts the meaning of manaha to the name of a house sacred to 'Oro.

33 Although phrased in general terms, Ellis was writing here mainly of 'Oro-possessed "priests," i.e., oracles.

34 See, for example, Davies, Journal, 17 September 1807, LMS Archives.

35 The LMS Dictionary defines ha'a mori, to worship a Deity, to perform religious services; and pure, prayer, to pray, worship, to worship. The general term for a religious ceremony was oro' $a$, and for prayer $u p u$.

36 See, for example, Moerenhout 1837:I, 504ff; Ellis 1829:II, 209ff; Henry 1928:157ff.

37 See Ellis 1829:II, 211ff; Morrison 1935:182ff. The term fei'ai specifically signified "prayer accompanying a sacrifice," but in fact nearly all prayers delivered at a marae, or elsewhere, were accompanied by offerings in some form.

38 There appears to have been no word for altar other than fata, which also referred to bier, or any kind of detached platform, scaffold, or rack.

39 The use of taraehara (guilt-untying) indicates that this referred to an expiatory sacrifice. See p. 120, this volume.

40 Except for used wrappings of the marae's tutelar gods, which were buried under the $a v a^{\prime} a$, having been too sacred even for disposal with other used items.

41 Morrison 1935:206-207; Moerenhout 1837:I, 508ff; Henry 1928:196-198; de Bovis 1909:55-56.

42 Some writers accept this as evidence of a holdover from cannibalism. Although cannibalism did prevail in some Polynesian-speaking societies, this symbolic simulated eye-eating of the Maohis need not be so explained.

43 Henry 1893:105ff; Henry 1928:214; Huguenin 1902:141ff; Young 1925:214ff; Sasportas 1926:269ff.

44 Contemporary data about Maohi marae are anything but satisfactory: a few pictures showing parts of some larger ones; partial word descriptions of some of them-either largely impressionistic or emphasizing only their most dramatic features; some general accounts of ceremonies, which however seldom refer action to particular settings; etc. In fact, the best information available about marae comes from archaeology, which of course is limited to those stone remains that have withstood the ravages of flood, silt, destructive vegetation, and human depredation. All less durable marae features have long since disappeared; and even many of the surviving stone structures are now unidentifiable with respect to name and function. For archaeological studies of marae see Emory 1933, Garanger 1964, Green et al. 1967, and Green and Green 1968. The best data available on specific marae have been brought together by Green and Green, drawing on eyewitness descriptions, drawings, and analogous archaeological remains; the marae in question are located in Pare and Atehuru districts of Tahiti.

45 Cook and Banks reported having seen a "pyramid," about five feet high, 
"covered" with (or "adorned" with) pandanus and crataeva nuts (Beaglehole 1955:111; Beaglehole 1962:I, 302-303); but from their statements it is not clear whether the pyramid itself was constructed of such nuts.

46 I give only approximate dimensions, in view of the fact that observers differed in their estimates. See Emory 1933:72.

47 The best accounts are those of Cook and Bligh, which have been brought together by Green and Green (1968) and carefully related to architectural features of specific marae.

48 In marae Taputapuatea of Opoa (Ra'iatea) there was a separate stone column, the 2.8 meter high "Column of Investiture," which served this function (Emory 1933:146). Special columns or platforms may have served this function in other marae but are no longer identifiable as such.

49 For these and other ritual uses of plants see Rey-Lescure 1951.

50 Principal sources on this rite are Henry (1928:157-177), Ellis (1829:II, 217), and Moerenhout (1837:I, 514ff). Henry translated paiatua as "an assembling and uncovering of the gods"; Moerenhout (who incorrectly wrote it paa atua) as "the renewal of the shell or body covering of gods." The LMS Dictionary describes it as an idolatrous ceremony on the new decoration of the too or image of a god. Atua, of course, can be translated " $\operatorname{god}(\mathrm{s})$," but pai has a variety of meanings, none of which appears relevant; in any event, etymologizing Maohi words of that far-gone era is in most instances a fruitless task.

51 So Henry translated it; in the LMS Dictionary taritoa is defined as family, or personal gods; a certain amulet to protect a person from witchcraft, etc.

\section{CHAPTER 4}

1 A present-day long-time resident of Tahiti commented: "I suspect that [the Maohis] ate food with high sugar content for breakfast. When the [modern Tahitians] couldn't get sugar during the war they substituted mangoes and ti [i.e., roots] for highly sugared coffee." (R.G. White: personal communication)

2 It is not at all certain that the Maohis distinguished between "work" and "play" (in the Western sense). The LMS Dictionary does define the word ohipa as "work, employment; to work, labour, toil," but one cannot be sure that the missionary lexicographers were not influenced by their own conceptions when seeking equivalences for Maohi words.

3 See section on social stratification, chap. 18 this work.

4 If this appraisal of Moerenhout's is indeed correct (which I very much doubt) things have certainly changed from his day to ours!

5 See Wilson 1799:206.

6 "No Europeans" was probably meant; present-day Tahitians, and probably their ancestors as well, seem to be able to drop off to sleep despite any amount of din.

7 See also Corney 1919:57. In this connection, during my sojourns in present-day Tahitian villages I was struck with the degree to which this habit had survived. "We are morose on dreary days," I was told. "We think about all our relatives who have died." 
8 The LMS Dictionary translates mahana as the sun, also a day; but I am not certain how it was used in Maohi speech.

9 Ta'urua, without an attribute, was the name given to both Venus and Mars, but in this context it referred probably to Venus (R.G. White: personal communication).

10 In some texts ru'i is substituted for pō (in contrast to ao), but this was probably a late and local development-i.e., a case of pi, or word tapu. See chap. 23, section on symbols of chieftainship.

11 On the basis of his comparative study of Maui mythology, the linguist R.G. White has suggested that this particular version is more Tuamotuan than Maohi, and that it reflects some tinkering on the part of latter-day European "experts" (personal communication).

12 The Maohi rationale was perhaps that humans moved inside largely because spirits took over outside; although what the actual historical sequence may have been will, of course, never be discovered.

\section{CHAPTER 5}

1 Special-purpose tools, such as tattoo hammers and tapa mallets, will be discussed elsewhere, along with their relevant activities.

2 More archaeological investigations such as those described in Green et al. 1967 (see especially pp. $124 \mathrm{ff}$.), coupled with petrological studies, could provide at least a partial answer to this question.

3 Orsmond defined aha-mata-ioio as "pretily prepared Senet [which was] used by the artizans to bind the Stone adzes to the helve. It is singularly beautiful to see how many shapes the Senet is made to assume in binding the helve and adze together. Therefore called aha mata ioio, Senet of handsome faces." (Orsmond: Dictionary Notes)

4 Bearing on this point is a continuation of the Orsmond note on aha mata ioio quoted in note 3 "[Such an adze] will be sacred $\left[\mathrm{ra}^{\prime} \mathrm{a}\right]$ by the Senet of the artizan so pretily prepared; it will be secured by the devious coloured Senet of Tane the god of beauty, It sounds as it is drawn it is firm. It is a head dress for the adze, a back support for the adze, To give it lightness, to give it the keenness, the glossy polish of oiri (a fish renowned) and to finish the adze." This text raises again the question of magic: What was it that rendered such an adze sacred? Was it the very fact of its having been securely and "beautifully" hafted and thus metaphorically associated with Tane, god of "beauty"; or was it directly consecrated to Tane, and thereby personally "empowered" by that god, through having been fabricated, deliberately, as it were? Or both?

5 There were many varieties of sennit, differing according to grade of raw fiber, number of strands, diameter, etc. For example, there was aha pahu, sennit for drums, i.e., cordage for binding the sharkskin head to the drum; aha pāpā, "a very fine, flatly mate senet, of the finest cocoa nut fibres ... used ... to ornament the end, of the bow-of the club and of the lance." (Orsmond: Dictionary Notes)

6 For example, red fig (tahinu: Tournefortia argentea), strand-creeper vine 
(pohue: Ipomoea pes-caprae), and a shrub (pua: Solanum repandum). Beaglehole 1962:I, 358-359)

7 See also Henry 1928:151. In addition, G. Forster reported having seen a man preparing a red dye, which was then used by women on bark cloth (1777:I, 354).

8 Estimate is based on known parallels from places such as Samoa. According to Turnbull some mats required nine months of a woman's time (1813:345), but he did not specify what proportion of the plaiter's time would have been thus spent, nor did he explain how he arrived at this figure.

9 In this passage Ellis appears to have been writing specifically about the period of his stay in the Islands, i.e., from 1817 to 1824, but I am inclined to believe that the customs described by him were survivals of earlier decades.

10 For a description of more recent techniques see W.C. Handy 1927:110-115.

\section{CHAPTER 6}

1 In the legend of Honoura the demigod of that name refused to stand up and reveal himself to the populace until he had been given a loincloth (Henry 1895:263). And in the legend of Pai the young hero's entry into the company of his divine foster parents was signaled by his donning a loincloth, before which he wept unconsolably at his nudeness and lack of a name (Henry 1928:581).

2 Cook and Banks, however, implied that the Maohis had no combs of their own (Beaglehole 1955:124; Beaglehole 1962:337).

3 It was customary to pierce the earlobes of both sexes, presumably in childhood.

4 According to Henry, the tiare "... only decked the maiden's brow" (1928:287); from this it is not clear whether the "maiden" refers to virginity or to momentary unattachment, but probably the latter.

5 According to a visitor to Tahiti in 1832, many native women at that time "whiten their skin with the juice of the papa, an indigenous plant, and avoid the sun to improve their complexions" (Foltz 1835:543). If the "papa" referred to was papai (Carica papaya), this plant was a new one for the Maohis, having been introduced by Europeans. I cannot discover whether any native plants were used for skin bleaching in pre-European times.

6 See also Henry 1928:628. Ellis wrote of "the fondness of the Tahitians for these ornaments, as they considered the marks thus impressed" (1829:II, 463).

7 Henry 1928:287; Moerenhout 1837:II, 123; Ellis 1829:II, 466; Morrison 1935: 221. For technical details on Maohi tattooing see Roth 1905; Moschner 1955; Söderstrom 1939; Plischke 1931; P. Ahnne 1930; Rey-Lescure 1946.

8 See also Beaglehole 1955:125.

\section{CHAPTER 7}

1 For architectural differences based on resident's occupation or hierarchical position, see below.

2 See, for example, Beaglehole 1955:127. I can find no evidence of pre-European use of wick-in-oil lamps. 
3 See Corney 1913:337; Morrison 1935:198.

4 See, for example, G. Forster 1777:I, 341-342.

5 Emory 1933:6-12. Roger Green (personal communication) has drawn attention to another feature of some Maohi masonry, namely, the incorporation of single courses of horizontally laid dike-stone in walls and $a h u$ facings.

6 See especially Emory 1933; Green 1961; Green et al. 1967.

7 Emory went a step further in proposing that "The council platforms of the Leeward Islands are perhaps the original 'maraes' of the Society Islands, for as meeting and council places they fulfil the function of the New Zealand marae. The shrines today called 'maraes' were probably anciently called ' $a h u$ ', for numerous maraes in the Society Islands have 'ahu' in their names...." (1933:41)

8 “... na va'a mataeina'a o teie nei hau": for explication see chap. 23, section on hau.

9 A word in the LMS Dictionary, ahutapae, is defined as one who is a newcomer, not belonging to the place; one who joins in a work after it is partly done; a new marae derived from an old one.

10 Roger Green: personal communication.

\section{CHAPTER 8}

1 Morrison 1935:141; Wilson 1799:316.

2 G. Forster reported having seen an outriggerless boat: "After a short stay [ashore, near Matavai] ... I returned to our trading place, but finding all our [ship's] boats gone off, ventured to embark in a single canoe, without an outrigger, and was safely brought on board the Resolution for a single bead ..." (1777:I, 284-285). This is the only reference I have found to this type of boat, and I cannot explain it further.

Earlier I mentioned the possibility that rafts were used in transporting large stones for marae construction. In a missionary journal for 1806 is the following reference to use of rafts for transport: "Several more people arrived ... with large Pafata's or rafts loaded with food for the king" (Youl, Bicknell et al., Journal, 16 September 1806, LMS Archives). I cannot, however, find any description of the size or method of construction of such rafts. In an undocumented footnote commentary to the journal of Don Domingo Boenechea, the editor stated, "Kites have even been used for towing rafts of timber and bamboos at this part of the [Tahitian] coast-Mataiea and Papeari" (Corney 1913:324). It is not clear from this whether Corney was referring to ancient or recent times.

Nor is there agreement among the sources concerning the Maohi name for "raft"; for example, Handy identified it as reho (1932:39), which the LMS Dictionary translates as "a tiger shell, cut for the purpose of scraping the rind of the breadfruit." Jaussen (1898) listed three terms for radeau: afata [box], pafata [cage], and paepae [platform].

3 The term for this operation was ahatātā'i, which Orsmond defined: "Literally drawing tight the senet as in lacing a canoe, or on the outside of rafters at the time of thatching, or in lacing on the drum head. 
"Morally. A mutual agreement, or combination of a party, or engagement for a journey or for work. (1) The work they are performing in their ahatatai. (2) The party of which he is one is his ahatatai. (3) The journey he intends from Island to Island is his ahatai. (4) A pending ceremony of which he has to take a part is his ahatai." (Dictionary Notes)

4 "The pahi was a wholly different style of boat, and was, I am convinced, introduced by an experienced boat-building and seafaring group of immigrants" (Handy 1932:45). This statement refers to Handy's well-known thesis regarding earlier and later waves of Maohi immigrants.

5 See also Henry 1928:481ff for the detailed legendary account of the building of a boat for the hero Rata.

6 Wilson reported a speed of "seldom-above five or six knots an hour' (1799:379), but he did not specify how such speed was measured.

7 The arguments in this controversy are set forth-but I suspect, by no means disposed of-by Andrew Sharp (1963) and in Golson (1962). I find Sharp's arguments against deliberate, two-way, long-distance (i.e., over 300 to 400 miles by open sea) voyaging very persuasive. In any event, Sharp's skeptical approach to the question has cleared away a great deal of romantic legend about the Polynesians' own romantic legends on this subject of two-way voyaging, and has served to emphasize that in future any positive advance in knowledge about Polynesian culture history is more likely to come from professional archaeological and linguistic research than from amateur etymologizing or from armchair navigation.

8 The principal source for most claims about the Maohis' very extensive geographical knowledge was the Ra'iatean, Tupaia. See G.M. Dening 1962.

9 See, for example, G. Forster 1777:I, 397; see also Morrison 1935:72-74 for an account of a Maohi canoe accidentally swept to Tubuai.

10 As regards Henry's native text, "Tahitian Circuit of Navigation" (1928:464), which listed Samoa, Hawaii, and New Zealand among the places alleged to have been visited by a legendary flotilla of Maohi canoes, it is enough to add that the "information" was first reported in 1854 !

11 According to this same report by Morrison, the first iron ever to reach Tahiti came from African Galley, one of Roggeveen's West India Company squadron which was wrecked at Ana'a in 1722.

12 For a description of nondeliberate "voyaging" within the Society archipelago, see pp. 208-209. Also, early European voyagers found on islands to the west-i.e., leeward-of the Societies several Maohis who had landed there after having been driven off course during voyages in home waters; indeed, such episodes probably account for many of the similarities between the Maohis and populations to the west of them.

13 Neither this source nor any other notes whether any adjustment was made to what was commonly recognized as the seasonal north-south shift in position along the horizon of points of sunrise and sunset.

14 The god Heima, Winter, is obviously a European contribution: eheima, Greek 'winter'. Like many other texts in Henry this one was recorded many decades after first European contact. 


\section{CHAPTER 9}

1 Probably the native mango (Spondias dulcis).

2 Note such words as 'ai'aiha' $a$, to be of an ungovernable appetite; to covet everything; to eat voraciously (LMS Dictionary).

3 "Close by their dwellings they stick up certain straight posts terminating in four forks or branchlets from which they suspend their eatables in baskets or small frails, to be safe from rats, for which they employ the artifice of a shield or guard fixed below round the middle of the post" (Corney 1913:337).

4 This listing does not correspond strictly to either Maohi verbal categories or to analytic, anthropological ones, but will serve our purposes for the present.

5 Also, a fosterer, a nurse, a feeder. See also $f a^{\prime} a^{\prime} a m u$, to feed, supply with food (LMS Dictionary).

6 Tuhau, a visitor from another place; tuihau, a visitor or guest (LMS Dictionary).

7 “Les Maximes de Tetunae," by Ernest Salmon, 1937. This article contains the Maohi text of these ture along with Salmon's translation into French. The first paragraph herein was translated into English by Ralph White, working directly with the Maohi text. The second paragraph was translated in E.S.C. Handy (1930:41). According to White (personal communication) the original Maohi text of this particular ture has features that are suspiciously biblical in inspiration.

8 Dootahah refers to Tutaha, a very powerful and influential tribal chief of northwestern Tahiti. It may be objected that this episode is not strictly relevant, since it does not concern relations among the natives themselves, but I cannot believe that Tutaha behaved toward Europeans in ways that did not have some basis in his behavior toward his Maohi peers.

9 When such marketplaces were established by the European visitors, the Maohis fell into the practice easily. Also, it was noted by Banks that “... we have always found the people readyer to part with at their houses and selling cheaper than at the market" (Beaglehole 1962:I, 325).

10 That is "... should the Undertaker not fulfil His agreement, ... the other may if $\mathrm{He}$ is able plunder his house as for a theft" (Morrison 1935:165).

11 For a more analytical treatment of such transactions see chap. 24.

12 The logs and journals of the European sailors and missionaries contain rich information concerning prices paid by them for native produce, and a study of these transactions and of their changing social contexts will be published elsewhere.

13 The legend, which is summarized here, was recorded by a Tahitian schoolmaster at Ra'iatea in 1887, and thus it is not demonstrably pre-European in wording, or even in conception. For another and even more palpably post-European version see Malardé 1930.

14 Although all but one of the present varieties appear to be seedless, Papy suggested that the varieties introduced to these Islands may have had seeds, it being unlikely, he reasoned, that such indifferent gardeners as the Maohis would have been capable or provident enough to have preserved viable cuttings during their long canoe voyages en route (1954:II, 248).

15 Ellis 1829:I, 356; Henry 1928:40; Beaglehole 1962:I, 344. 
16 See also Ellis 1829:I, 357; Beaglehole 1955:114.

17 Henry 1928:40; Ellis 1829:I, 357; Wilson 1799:316.

18 Wilson wrote otherwise: "It is truly wonderful to see how Providence has furnished this place [Matavai]: as soon as the breadfruit fails in this district it is ripe in another, so that we never want" (1799:175). But this buoyant generalization is not confirmed by the journal entries of individual missionaries, on which it was presumably based.

19 LMS Archives: Elder \& Youl, Journal, 29 October 1805; Bicknell \& Wilson, Journal, 20 November 1805.

20 See Cuzent 1860. Corney stated that fe' $i$ will keep fifty to sixty days (1915:271).

21 LMS Archives: Davies, Journal, 23 February 1809; Gyles to Burder, 21 November 1818.

22 According to R. Green (personal communication), archaeological investigation in the Opunohu Valley of Mo'orea revealed lands of "agricultural terrain": irrigated, run-off, and dry.

23 According to Henry, the sweet potato “... does not produce tubers when left to run wild" (1928:38n).

24 Papy identified hoi and pa'auara as Dioscorea bulbifera (1954:II, 366). The Andrews dictionary also identifies hoi as $D$. bulbifera, but it identifies pätara as $D$. pentaphylla; it contains no entry for pä'auara.

25 In 1960 the author witnessed what was evidently an annual event in the village of Ha'apu, Huahine, namely a public exhibition of the largest yams harvested at that time, with prizes going to the gardeners producing the heaviest and largest ones. I can find no evidence of such competition in reports on the ancient Maohis, and the custom might well be a recent one, introduced, perhaps, by some enterprising agricultural officer.

26 Contact with Europeans did not serve to change their habits in this respect-e.g., "They are slovenly gardeners however and regard no order in laying out their ground" (Crook to Burder, 4 December 1824, LMS Archives).

27 "Adequate" in terms of the Maohis' own ideas about diet, which appear to have been the principal incentive for the work that they engaged in. There were of course other incentives created by demands for hospitality, for feast-giving, for sacrifice, and for "tribute," but with the available data it is not possible to measure the quantities of food so required.

28 Bligh provided evidence that efforts were made to save some trees damaged in this manner: “... a great deal of injury is done to the finest of the Trees-numbers of them are barked all round and are in a dying state, but others have been considered of such Value, the Natives have endeavored to save them by laying on a bandage or plaster of clayish kind of soil round the Wound, and wraping it carefully over with leaves" (1792:146).

29 According to some opinions, the technique of premastication produced a more potent beverage, pharmacologically, than the one described by Cook.

30 See also Beaglehole 1967:1384; G. Forster 1777:II, 118, 407; J. Forster 1778: 481, 485; Bligh 1789:I, 373, 382.

31 There are few reports of women drinking kava, but whether this sex-linked difference was based on any explicit prohibition is not known. 
32 Ellis 1829:II, 217-218; Henry 1928:177; Moerenhout 1837:I, 517ff.

33 This statement of Moerenhout's should be amended to read "near some very important marae," since on some islands no one marae was "principal" for all the inhabitants over any extended period of time.

34 As some readers will note, there is an inconsistency between spirits remaining in $p \bar{o}$ and being prayed to at the same time; as I pointed out earlier, it is my interpretation of Maohi prayer and offering that the recipient spirits had to be close at hand. I cannot resolve this inconsistency, which of course may only appear to be such in terms of Western logic.

35 Beaglehole's rendering of the names of these two gods is Te tau mata a Te a-Io (the time of the first origin of things) and Ta'aroa tahi tumu (Ta'aroa the unique source), respectively; of these the second rendering is probably correct and appropriate, but the first is open to question.

36 Cf. Beaglehole 1955:259.

37 See also Ellis' characterization (p. 262, this vol.) of religious rites following the ripening-of-the-year festival as intended to liberate spirits from the $p \bar{o}$, where they had supposedly remained during the season of scarcity.

38 A few examples from the LMS Archives are: a large collection of foodstuffs in midJune 1799, to celebrate the return home of the district's tribal sovereign (Jefferson, Journal, 17 June 1799); a great Tavao festival held during August-September 1806 (Youl, Bicknell et al., Journal, 21 August 1806); a large-scale collection of foodstuffs held in October 1806 in honor of a visiting delegation of Arioi (Youl, Bicknell et al., Journal, 16 October 1806).

39 For the concept of "shadow," or ata, see chap. 3, this volume.

40 This statement, contained in the missionary chronicles of 1797 (Wilson 1799:356) does not necessarily apply to the pre-European era, for by the time it was written, the new European breeds may have served to increase the numbers as well as the size of local pigs.

41 See chap. 12; and Beaglehole 1961:404.

42 See also Titcomb 1969:30. The LMS Dictionary translates 'aoa, to bark or howl, as a dog; the howling of dogs.

43 See also G. Forster's description, quoted above, of a dog being suckled; and see Turnbull 1813:281-282. In this connection, I can discover no parallel with the Hawaiian practice, reported in Titcomb 1969, of breast-fed dogs having been ruled out as food for humans.

44 Ellis 1829:I, 351; Corney 1913:328; Corney 1915:85; Beaglehole 1955:559; G. Forster 1777:I, 280. The native rat was replaced in time by European breeds, but even as early as 1788 most of them appear to have been exterminated by cats introduced by European ships (Bligh 1789:I, 413).

45 The gums most commonly used were from the pua rata (Metrosideros) and the puruhi (Pisonia grandis). With respect to the latter, puruhi was also the label applied to a cowardly [fighting] cock, or faint hearted warrior (LMS Dictionary)-i.e., a warrior "glued to the spot."

46 Zoological identifications are based on L. and F. Chabouis 1954, vol. II.

47 The main references used in compiling this summary are Ellis 1829:II, 284-298 and Morrison 1935:153-160, with a few fragments taken from J. Forster 
1778:461-463, G. Forster 1777:I, 347, Beaglehole 1955:133, and Beaglehole 1962:I, 361-363.

48 See also Rey-Lescure 1936.

49 An arroba is a Spanish weight equal to about twenty-five pounds. Although the translation reads "casts of the net" the reference is obviously not to "casting" in the sense of throwing a cast net, but rather to the operation of closing a large seine net-three separate times, in this instance.

50 See Anderson 1963.

51 Obtained, of course, from Europeans, and supplanting hooks of native materials.

52 Technically speaking, auhopu is the name now applied to this fish only when it is at the growth stage of from four to eight pounds in weight; for names at other growth stages see Nordhoff 1930a:236.

53 The bonito's favorite food seems to be 'ouma and ature, names applied to Mulloides auriflamma and Trachurops crumenophthalma, respectively, at certain stages of their growth. 'Ouma, particularly, was the fisherman's favorite “... because of their abundance, their slow swimming, and the fact that bonito feeding on them will seize the hook without hesitation" (Nordhoff 1930b:237).

54 Including human bone. In former times, according to Nordhoff, the victors used to search among the dead for men with particularly dark skins and curly hair, in the belief that their bones were more than ordinarily hard and thus ideal for fish hooks. (1930b:244)

55 For a description of some pre-European Maohi hooks, see Green et al. 1967, especially p. $184 \mathrm{ff}$.

56 Handy was writing of conditions as they were in the 1920s, but many of his statements probably apply to the eighteenth century as well.

57 I reproduce here only Stimson's translation. The Maohi text, along with information concerning its source, can be found in Stimson 1928. See also Henry 1928:331, and Handy's commentary thereon (1932:81).

58 This interesting term applied also to the places where fish tended to congregate-e.g., the so-called albacore "holes." According to the LMS Dictionary, another meaning of puna was prolific, as a female.

59 In his commentary on this statement of Henry's, Handy drew attention to the fact that tinirau finds its counterpart in Tini-rau, the New Zealand tutelary deity of fishes, and son of Tangaroa, Lord of Ocean. And further, that Tino-rua occurs in the name of the third night of the new moon: "The inference would appear justified that the name of the deity Tino rua has reference to the appearance of the moon in this phase; and this leads to the suggestion that the moon itself was venerated at some former time as a fishing deity. In these islands where the run of the fish is so obviously influenced by the phase of the moon, of which fact the natives were fully conscious, it would seem almost inevitable that the moon should be associated with the deity venerated as patron of fishing." (Handy 1932:72-73)

60 As Handy pointed out (1932:73), Ellis probably referred here to Huahine, where he spent the most time.

61 See, for example, Morrison 1935:183; Henry 1928:241. 


\section{CHAPTER 10}

1 When presenting data under such headings as farming or fishing or eating, the student of the ancient Maohis is on fairly safe ground. These English labels and their respective referents correspond closely enough to Maohi usage to render translation feasible. Such, however, is not the case with the data brought together in this chapter. The Maohis did, it is true, have the word heiva, which writers have variously translated as diversion, hobby, avocation, etc., and which included some (but only some) of the activities described in this chapter, although the sources are not in close accord on this point. For example, the LMS Dictionary defines heiva as "a dance, an assembly for dancing," and assigns to upaupa the fuller meaning, "a play, diversion, music and dancing; any game or amusement." According to Bligh, however, heiva was the older form, which was changed to upaupa after utterance of the word heiva became tabooed (1792:142). See below, chapter 23, section on symbols of chieftainship.

The Maohis might indeed have mentally lumped dancing with, say, cockfighting and archery, in contrast to fighting, or to fishing; but reliable evidence for this is now lacking, as indeed it is for reconstruction of practically every ancient Maohi cognitive domain. Extant dictionaries and translations provide nothing approaching the detailed contrastive and contextual matter now recognized as essential for credible cognitive mapping. So, in paging through this chapter the reader should keep in mind that the uniformities implied among its several topics reflect the author's mode of classification, and not necessarily that of the ancient Maohis themselves.

2 Also engaged in by men, according to Henry, who provided a good description of this and other children's pastimes (1928:279). See also Rey-Lescure 1955.

3 But did each district contingent have its own wrestling deity, or was there one such divine patron for all Maohi wrestlers? To what extent was victory due to divine intervention? These and other questions remain unanswerable.

4 See Bligh 1789:II, 37; Jefferson, Journal, 22 April 1801, LMS Archives.

5 Ellis 1829:I, 296-298; Moerenhout 1837:II, 152-153. The latter would seem to have disagreed with other writers in implying that all three varieties of ball play were strictly female games. Henry (1928:278) described apai, or paipai, as a game much resembling cricket, while the LMS Dictionary defines apai, to play with bat and ball.

6 Several writers on ancient Polynesia have sought to explain why the Maohis were not utilizing bows and arrows in warfare during the eras immediately before and after first European contact. (I have been unable to find reference to their use as weapons in stories about earlier eras.) Fascinating as such a guessing game may be, I see no reason for joining it.

7 For a description of elegiac ballads and other forms of "lyrical" utterances see Chadourne, 1922. See also E. Salmon 1937; Ahnne 1932b; Alexander 1893.

8 See also LMS Transactions:I, 174.

9 See for example Rey-Lescure 1944:431-441; Draper 1959; Beckwith 1944.

10 Except perhaps for the story of Rata (Henry 1928:468ff.), which includes an episode bridging two generations. 
11 Chadourne characterized the üte as intermediate in mood between the melancholy anau, or lament, and the lively dance-song, pā $\operatorname{ta}^{\prime} u t a^{\prime} u$ : “... [a] little song more hummed than sung, improvised more than composed; with the ūtē the tender bud fostered in each Tahitian heart blossoms forth. Furtive desires, the petty joys of daily life, feelings of pity, fleeting sadness, anxiety for one's hopes, meaningless pleasures, fondness for the familiar path or for the land of birth, customary objects, and the gaiety occasioned by a new face-it is of limitless range; a fragrance is wafted [on the breeze], an animal frolics, a cloud breaks off, an ūtē is born." (1922:67)

12 Cook distinguished between "private" and "public" performances, but the basis for his distinction was, as far as I can discover, Cook's and not a native one; on one occasion Cook seems to have called the performance he witnessed "private" because it was held in a private dwelling and was viewed by relatively few persons (1784:48).

13 Cf., for example, Rey-Lescure 1946:192-193.

14 The LMS Dictionary contains several other entries translated in such general terms as "a kind of dance," but with no specifying details.

15 Not even as burlesque, which one occasionally sees in present-day Tahiti.

16 See also Cook 1784:48, and the case of the special performances commanded for Cook and his associates on Ra'iatea in which the star performer was the accomplished little daughter of the local chief (Beaglehole 1961:421).

17 This did not, of course, apply to members of the Arioi sect.

18 Rey-Lescure (1946:193) asserted that Urataetae was the god who presided over dancing, but I suspect that numbers of others were also so engaged.

19 For example, see Beaglehole 1961:421.

20 For example, Moerenhout 1837:II, 131. However, it is not entirely clear whether Moerenhout was referring here to dramatic productions in particular or to productions (i.e., "representations") including dancing and singing.

21 See also G. Forster 1777:138; Beaglehole 1961:420, 842.

22 "Ratirra" (ra'atira): see chap. 18 for a full discussion of this term. For present purposes it may be glossed as 'member of middle class', 'principal proprietor of a sizable land estate', or 'petty chief'.

23 "They are ever Courteous to the Stranger and Hospitable to the Wayfaring Man and what they have is always at the service of their Visitors-and when a Stranger enters a House he is Saluted by the Master and perhaps all the Family With Mannowa (Welcome) Yowrye t'Eatooa te' Narria mye (God save you in your Coming) \& Yowrrana te Tirre raa (God save you in Your Journey) and the like Compliments at parting." (Morrison 1935:189)

24 See, for example, the account of Pomare's visit to Tautira during which he and his retinue were supplied mainly with food brought by special supply expeditions from his home district of Pare (Corney 1919:44).

25 Henry 1928:239; Beaglehole 1962:I, 275-276.

26 The ritual aspect of "hospitality" varied considerably in terms of the avowed purpose of the visit, the status of the principal visitors, etc.; details will be provided in later chapters. See also G. Forster 1777:I, 375-376.

27 The "laws" of hospitality are said (on one occasion, at least) to have provided a continuing sanctuary for the guest in question. I refer to an episode in the 
legend of the trance of Ari'i paea Vahine, wherein the sisters of a male spirit were constrained from doing away with the latter's mortal mistress, whom they disliked, because "she had become sacred to the household by the treatment of her by their brother" (Henry 1928:221). On the other hand, the annals of Maohi history-pre- and post-1767-are liberally sprinkled with accounts of hosts turning on their guests (and vice versa), sometimes in the most treacherous manner imaginable.

28 See Corney 1919:134; Bligh 1789:II, 45.

\section{CHAPTER 11}

1 Although missionary Orsmond's angry denunciation was written decades after Forster's bland appraisal, there is reason to believe that the Maohis had not in the interim appreciably changed in their preoccupation with sex.

2 See, for example, E. and P. Beaglehole 1938; Danielsson 1956; Firth 1936; D.S. Marshall 1961; Mead 1928.

3 These translations are from the LMS Dictionary. I am well aware of the difficulty-given the limitations of the data-of determining which of several synonyms was primary and which metaphoric, and I do not contend that I have succeeded in doing so here.

4 As for example, the statement of Paul Gauguin writing in the 1890s that "... all the women want to be taken in the Maori [Maohi] manner ( $\mathrm{mau}$, to seize), silently and brutally; they all more or less want to be raped." (NoaNoa [Paris: Les Editions G. Cres et Cie.], 1929). In another statement, Bengt Danielsson wrote that the ideal male partner is one who is "... able to achieve and evoke several orgasms at short intervals" (1956:78).

5 Cf., for example, Marshall 1961 and B. Danielsson, 1956. In this connection the latter writes: "As far as can be judged skill and refinement [in the techniques of sexual intercourse] were infinitely greater in former times; this was due principally to the thorough instruction in sexual technique and the regular demonstrations of intercourse. On their conversion to Christianity the Polynesians were naturally compelled to abandon such heathenish practices, and since then they have gradually become more and more awkward and incompetent in sex matters as well as in other things, without, fortunately, having yet sunk to our own low level." (1956:78-79)

6 This passage, quoted by Mühlmann, was taken from an anonymous publication (Journal du second voyage du Captaine Cook sur les vaisseaux La Résolution et L'Aventure, enterpris dans les années 1774, 1775. Amsterdam and Paris: 1777) to which I have not been able to refer. I have left this excerpt in the original French, because of its importance, but offer my own translation: "Women differ from each other by their charms and face, as in other countries; their stature, often less than mediocre in the women of the ordinary class, seems to be greater among the upper class. Tallness is what the Otaheitean ladies seek to conserve in their family with the greatest care. It is not unusual among the most distinguished ladies of the island to share their couch sometimes with whichever of their servants is the tallest and best proportioned, as they fear lest the children should lose the 
noble and majestic build which is the glory of the family. Otherwise they are very scrupulous in the choice of their lovers."

7 The famed navigator did not accept the offer!

8 See Corney 1915:263; Beaglehole 1961:236; Wales, in Beaglehole 1961:796, 839; and J. Forster 1778:392.

9 For further references to such practices see chap. 13, this volume, and Ellis 1829:II, 567-568.

10 All these physical criteria of beauty were shared by the Maohis with certain other Polynesian peoples. For an admirable summary of the subject, see Danielsson 1956.

11 Since females rarely communicated with gods, for them the proscription did not arise.

12 Including, nowadays, some who are either too intoxicated to be aware or to resist successfully.

13 The Tahitian original was aeari'i fa'aturi, literally, 'object-of-pursuit', 'fornication'. This instructive little piece appears in Bulletin de la Société des Études Océaniennes, vol. 4 no. 37, 1930 and is identified as having been uttered in 1824 by Mai, principal chief of Porapora, recorded in Tahitian by J.M. Orsmond, and translated by him into English. The original Tahitian text and Orsmond's translation is not available to me, so in composing my free translation I have had to make use of the French version, thereby doubling the possibility of semantic error, which is however reduced somewhat by the circumstance that the published translation does contain some explanatory notes that give the Tahitian originals of some of the words.

14 The flow of tangible inducements was of course not only from male to female. G. Forster, for example recorded an instance of the reverse, of a man having received several pieces of fine bark cloth from his sometime mistress (1777:II, 103). The man in question was young and of lower-class status, and the woman an older and evidently unbeauteous member of the upper class which would seem to account for the transaction, but it is highly likely that such exchanges also took place between partners more evenly matched in social class, age, and physical charms.

15 As this bit of advice was voiced as late as 1824 , the informant was compelled to add some European goods to the list of enticements.

16 This event occurred in 1827, but it is likely that the two seductresses were following ancient practice.

17 See also Danielsson 1956:153-154 for a sensible commentary on this matter.

18 Moerenhout's generalization on this score is, of course, overstated but probably contains a modicum of validity: "Relationships exist between the language and customs of the inhabitants of the different Pacific islands, as exemplified in the character of their poetry and their songs. Thus the cannibals of New Zealand only chant of war and vengeance; their music, always set in a mode of terror, expresses only carnage and battles, while the voluptuous inhabitants of O'taiti and other Society Islands chant only of pleasure and love. There is a gentleness, a touching simplicity in the delicate poetry of the latter." (Moerenhout 1837:I, 412) 
19 The only other reference I can find to bestiality is an entry in Jefferson's journal of 1803: "In the womb of a sow purchased and killed yesterday ... was found the embryo of a monster ... Some of the natives who saw it supposed that a man had had carnal connections with the beast. This crime, horrible as it is, it is to be believed that Otaheiteans are addicted to." (24 March, LMS Archives)

20 Bouge rescued this excerpt and its accompanying correspondence from ancient English literary periodicals, which are identified in the article cited (1955).

The original, Latin version read as follows: "Injicunt penem in orem infausti, atque emittunt semen, quod sceleratus avide deglutit tanquam robur et vim alterius; putans scilicet se ita fortiorem reddi." This translation was done by Brendan O. Hehir for Robert Levy, who kindly provided me with a copy.

21 See Gunson 1964:58.

22 As far as I can determine the term mahu referred specifically to transvestites, and only coincidentally to homosexuals.

As Gunson has pointed out (1964:58) it is quite possible that some mahu were "deliberately emasculated or 'degraded' to the position of women" not primarily for homosexual purposes but in order to serve as domestics, etc., for upper-class women, who, it will be recalled, were particularly constrained in their eating habits-i.e., they were proscribed any food prepared by "true" males. In this connection, however, there appears to have been some males who entered into the domestic service of certain upper-class women without having become truly transvestite in the process. While so employed these were of course rendered ritually noa (and thus unqualified to participate in marae services with other males), but upon termination of employment-I suggest, but cannot prove-such men were probably able to resume the full ritual prerogatives of other males.

\section{CHAPTER 12}

1 Warfare is used here to mean armed conflict, including feud, involving more than a handful of participants and having purposes more deadly than sport. Maohi warfare was on certain occasions conducted like a sporting event, with mutually acceptable, self-restrictive conventions, but the parallels cease there.

2 The only reference I have found to the use of bows and arrows for human combat occurs in the legend of Pai, wherein the hero had to prove himself in a deadly contest with rivals (Henry 1928:587-588).

3 The Pape'ete Museum contains a large stone, called ānave (breath; a line, cord, thread; perseverance; longevity [LMS Dictionary], said to have been found in Tahiti's Papeno'o Valley, where it formerly served as a test of strength for "warriors," who attempted to raise its 87.5 kilograms to their shoulders on certain public and ceremonious occasions. The ability to lift this stone to one's shoulders was considered to be a great feat, an important way of testing a warrior's strength. (Leverd 1918:146-147)

4 I reproduce this somewhat obscure text, without pretending wholly to understand it, mainly because it is the only native text I can find on the subject. 
5 Such a council of war should probably be distinguished from the kind of festive gathering described by Rodriguez, at which martial events provided the major topic of conversation, but not, it seems, the main purpose for the meeting (Corney 1919:43).

6 According to a missionary source, if side A presented to its tutelar an offering that was subsequently stolen or destroyed by side B, the tutelar in question would engage even more energetically in bringing about the defeat of side B (Hayward et al., Journal, 8 December 1808, LMS Archives).

7 In a footnote commentary to the legend of Honoura it was stated that "pork, with very little vegetable food, was eaten by warriors engaging in battle" (Henry 1895:293).

8 For exceptions see chap. 23.

9 For a contrary view concerning the reasons for the alleged favoring of males over females at birth, see chap. 11, this volume; and Gunson 1964:58.

10 See also Moerenhout 1837:II, 40.

11 The Mitchell Library collection of Orsmond manuscript notes contains several other rauti texts, most of them untranslated and probably now untranslatable. Along with them is a commentary, evidently by Orsmond, which calls attention to the rich and powerful metaphors used in these and in other Maohi poems and chants connected with warfare. Introducing the subject is the following statement: "There is nothing more difficult than to make a foreigner see the force and beauty of the Tahitian war language. The Battles themselves considered apart were contemptible, but the power of imagination and the fire of speech were amazing." And, "To understand the war speech of Tahiti, it is essential to possess a very general and a particular knowledge of everything that relates to Tahiti."

12 Toa appears to have been the more general term for 'warrior', with 'aito being reserved specifically for 'champion warriors'; but the two were in many contexts used quite synonymously. Toa (or 'aito), it will be recalled, was also the native name for the ironwood tree (Casuarina), from whose hard and heavy wood many weapons were fabricated. According to one tradition, these trees were originally fashioned out of the bodies of warriors: their sap from warriors' blood and their leaves from the latters' hair (Henry 1928:420).

13 Which, however, according to Bligh, was not always the case: "There [their] Men when heaped together in such numbers armed with Spears 12 or 14 feet long or more, have a tremenduous appearance, they nevertheless do very little mischief to each other, for I believe they seldom come to a serious charge, but content themselves with the execution they are able to effect by Slinging Stones, by which means some Men are Maimed and sometimes killed" (1792:127).

14 This lent some material basis for subsequent ceremonies aimed at cleansing-purifying such places.

15 Discussion of the varied implications of some of these episodes will have to be postponed to later chapters, my present purpose being merely to provide a summary description of warfare in terms of its having been an elaborate, complex, time-consuming set of activities of the Maohis. 
16 Henry implied that a much larger number of battle shapers and exhorters took part in naval warfare than was the case with land warfare, but this discrepancy is probably due to incorrect or incomplete reporting and not to the actual circumstances of Maohi warfare.

\section{CHAPTER 13}

1 This is not meant to imply that ideas about reproduction were the only ones involved in such premarital fattening; for one thing, aesthetic considerations were evidently also involved.

2 The LMS Dictionary word for conceive (applied only to females) is $t \bar{o}$, which incidentally is also the word for wrestle and sugarcane.

3 See, e.g., the legend of Mo'o Tua Raha (Henry 1928:622-623), which is reproduced in chap. 16 , this work.

4 See, for example, chap. 12 and Henry 1928:310, on the fate of sennit-bound war captives.

5 Presumably the writer was alluding to lunar months, but he did not describe how women determined the onset of pregnancy.

6 According to Nordmann the following plants were used to induce abortion: $\mathrm{Hi}$ biscus tiliaceus, Gossypium religiosum, Polygonum imberbe, Gardenia prenna, and unripe pineapple-the last named being a post-European introduction (1943:343).

7 See, e.g., Hassall to LMS, 31 January 1797, LMS Archives; Crook, Journal, 3-4 March 1817, LMS Archives; Wilson 1799:155.

8 See, e.g., from the LMS Archives, Crook, Journal, 3-4 March 1817; 24 April 1821; 24 May 1823; Davies et al., Journal, 22 May 1817. The following, though written in 1825, gives some indication of the problem: "No small portion of my time is taken up in administrating medicine \&c. and also in attending native females in difficult and bad cases of labour" (Henry to Burder, 3 February 1825).

9 See, e.g., Hassall to LMS, 28 January 1798, LMS Archives\& Threlkeld to Burder, 29 September 1818, LMS Archives.

10 Presumably her first child actually born, and not necessarily the first in utero.

11 According to one account these restrictions continued in force until the umbilical cord, still attached to the child, dried up and dropped off (Jefferson, Journal, 29 July 1799, LMS Archives).

12 "King's evil" ('o'ovi ari'i, scrofula): a disease characterized mainly by enlargement of lymphatic glands.

13 See Ellis 1829:I, 342; Moerenhout 1837:II, 59; Morrison 1935:186.

14 I am unable to explain the significance of the coconut cream used in this rite, but the use of the juice of the sugarcane $(t \bar{o})$ might possibly have been based on its metaphoric connection with conception $(t \overline{)})$. In this connection, none of the sources mentions the significance or treatment or ultimate disposal of the afterbirth in general or of the placenta in particular.

15 Elsewhere, however, Moerenhout did assert that infants were bathed in cold water soon after birth (1837:II, 59); but this may have been more for hygienic than for ritual purposes. 
16 Wilson's account of natal ceremonies (1799:341-342) merely paraphrases that of Morrison.

17 But see the following: "Pito roa (Navel-string long) ... refers to a custom of cutting the navel string down to the placenta that the child may be long winded and live to an old age. When it was cut the native doctor used to pierce it I believe the thumb and fingers press the liquid substance out of it and hang it over the infant's neck. After it fell from the belly it was preserved with sacred care." (Orsmond to Hankey, 20 September 1827, LMS Archives)

18 See, e.g., J. Williams 1837:560; Ellis 1829:I, 336.

19 Ellis 1829:I, 337; Nordmann 1943:342; Lesson provided a gruesome, and not altogether credible, account of the slaying of children, but more in the nature of human offerings to the gods than as instances of the kind of infanticide I am discussing (1839:I, 403-404).

20 Montgomery 1832:I, 53; Ellis 1829:I, 338; Williams 1837:563-564, 566.

21 The reference to a bed indicates, of course, that this account was compiled many decades after first European contact, when some natives had begun to acquire articles of European furniture for their houses. Nevertheless, there is a strong possibility that the rest of this description was also applicable to pre-European methods of caring for infants' bodies.

22 See also J. Forster 1778:529. A statement by Bligh tends to discount somewhat the educational privileges alleged by Henry to be enjoyed only by upper-class youths: "The School is common to all in this Country. There is no knowledge to be gained in the History of the Country but by tradition, and the only education being the Company of the Chiefs and old People of distinction; wherever nature has planted good sense and a quick conception, the Individual whether Chief or Towtow, becomes informed and well educated." (Bligh 1792:172)

23 This statement raises the question whether there were in fact any unsupercised adult males, or some individuals who went through life untattooed? Neither Morrison nor any other writer provided a categorical answer to this question, although J. Forster's statement quoted in the preceding section implies a negative answer, at least with respect to females.

24 See Morrison 1935:220; Beaglehole 1962:I, 382.

25 But see also chap. 22, for reference to huapipi in connection with Ariois.

26 Bligh's statement that "This never happens with the Mana-howhes [manahune 'commoner', member of lower social (marriage) class] or Towtows [toutou 'servants']" (1789:II, 43) could be taken to mean that fathers belonging to these categories did not undergo the self-feeding prohibition, even to a perfunctory degree.

27 "Purify, to rid of impurity or polluting matter" (Webster's New World Dictionary, College Edition). The first line of the formula for "purification" of a neonate is: "Te tama teu, o te puo mei'a." Henry translated this as "This is the purifier, the heart of the banana" (1928:183). Although te puo mei'a can indeed be glossed 'heart [of] banana', te tama teu could be either te tāmā teu, to cleanse of menses (LMS Dictionary), or te tama teu, the child (of) menses. See also one missionary's use of the word "unclain" to de- 
scribe the infant's condition, "... till it be given to the god twice" (p. 419, this volume). In this connection, the part played by semen in certain religious rituals argues against its having been considered a polluting entity.

28 Puzzlement over the obscurity of the word manihinihi is deepened even further by the LMS Dictionary definition: manihinihi, uneasiness; to be heavy, to feel lassitude, as in the commencement of a disease; to feel uneasiness of mind; to sympathize with the distress of others.

The Duff chronicler describes the earlier àmo'a rites as measures for ending the mother's segregation on account of her "uncleanness" (Wilson 1799:341), but since this description is evidently a paraphrase of Morrison's, which does not mention "uncleanness," I conclude that this, like so much of the descriptive portion of First Missionary Voyage, was incorrectly paraphrased.

29 This astute observer also saw in these customs the explanation for the alleged differences in physique between upper and lower classes: "[This custom] ... may in some measure account for the difference in stature between the Higher and lower Classes of People-the latter Class having sooner their liberty have earlyer Connections with each other than the Higher and the Chiefs in particular are Mostly arrived at years of Maturity and Manhood before they Cohabit with their Weomen" (Morrison 1935:187-188).

30 "Rowavva (or Sacred Tree)" is undoubtedly rauava, the miro or 'amae leaves used in the marae for various sacred purposes (LMS Dictionary).

31 I should point out that mo'a, in addition to being a synonym for $\mathrm{ra}^{\prime} a$ (sacred), was also the name for a branch of miro leaves used in the marae (LMS Dictionary). And while speculating (fruitlessly, I concede!) about Maohi etymologies, I draw attention to the fact that momo' $a$ is translated in the LMS Dictionary in two ways: to espouse [i.e., to become betrothed], or contract marriage; and, to make sacred, put under a restriction. There is a possibility that the first syllable of this word-which receives two listings in the LMS Dictionary-was of different vowel lengths for each meaning; such at least is indicated in the copy annotated by Louis Drollet now in possession of the Tahiti Mission of the Church of Jesus Christ of Latter Day Saints. But that aside, it is tempting to propose (without however any further linguistic rationale) that àmo' $a$ may be directly contrasted with momo'a (viz., mo'a, sacred; momo'a, to make sacred); and thus āmo'a, to make unsacred (de-sacrify). Fortunately, my interpretation of the significance of the rite does not have to derive its validity from my excursion into etymology!

32 The LMS Dictionary supplies the native terms, fa'aipoipo, to marry and fa'aipoipo ra'a, marriage, from ipo, a darling, one made much of; but that is no guarantee of exact semantic equivalence. The same dictionary translates ta'oto, to sleep, see moe; to lie down; to be cohabiting as man and wife; a dream. Moreover, the words ta'oto and moe occur most often in myth and other native texts as terms for sexual and even longer residential cohabitation, thus raising the suspicion that the missionaries themselves may have encouraged use of the more respectably romantic fa'aipoipo. (See also Henry 1895:282.) I wish to emphasize the tentative nature of this operational definition-for reasons that will be set forth in chap. 19 . 
33 But see also the following editorial comment upon an episode in the legend of Honoura, wherein the chief of a victorious tribe married the widow of the chief of the vanquished, who was slain in the battle; "A marriage of that kind was considered a most honourable way of ending strife, as it made allies and not slaves of the conquered" (Henry 1895:293).

34 In the legend of Honoura, āmo'ara'a ("ämo'a-ing") appears as the term for nuptial ceremony (Henry 1895:260).

35 There were however certain young women, presumably upper-class ones, who were, in Moerenhout's words, "reared with great care and with the strictest chaperonage" (1837:II, 60; see also Henry 1928:236 and Ellis 1829:II, 567-568), which included not only some systematic forced fattening, but also, in some cases, the narrow confinement of the girl in her parents' house, and hence enforced chastity. The native term for virginity was pirimomano, to be in a virgin state, but it is interesting to note that the label usually applied to such carefully chaperoned girls was vahine paheo, a lazy, lounging [female] who spends [her] time uselessly; indulged, as a spoiled child" (LMS Dictionary).

36 "Amai" ['amae] is another name for miro, thereby identifying this episode as an àmo'a.

37 The legend of Honoura provides a somewhat similar example of a wedding having taken place at the bride's home, where the groom happened to be on a visit. Later, however, the groom returned with his bride to his home district, where the marriage ceremony was carried out again. (Henry 1895:261)

38 A similar arrangement was described by the Reverend Orsmond, writing in his journal on 9 March 1827 (LMS Archives).

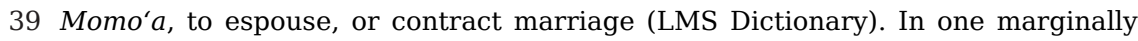
annotated copy of the dictionary, someone (probably the Tahitian expert Louis Drollet) added "to be engaged to marry before marriage."

40 In this context I use "parental" in a broad sense, including all relatives and counselors of an individual who had a voice in the choosing of his or her spouse. See for example Moerenhout: "We have already seen how the son, even as a child, succeeded to the father's authority; also it was the brothers who arranged matters for their sisters, and it was they rather than their father and mother to whom one looked to gain a girl's hand in marriage" (1837:II, 69).

41 The sentence immediately preceding this is the curiously contradictory statement that "It happened quite frequently that marriages took place between a brother and sister, just to avoid misalliances [in terms of social class]." It is not clear, however, whether Moerenhout was specifically referring to the Maohis, or to Polynesians in general (including Hawaiians, who were known by Moerenhout to practice brother-sister marriage on occasion). In any case, neither Moerenhout nor any other of the sources provides evidence of any actual, historical instances of brother-sister marriage among the Maohis.

42 “Art. 161. En ligne directe, le mariage est prohibé entre tous les ascendants et decendants légitimes ou naturels, et les alliés dans la même ligne.

“Art. 162. En ligne collaterale, le mariage est prohibé entre le frère et la soeur légitimes ou naturels et les alliés au même degré. 
“Art. 163. Le Mariage est encore prohibé, entre l'oncle et la nièce, la tante et le neveu." (Code Civil 1816)

43 Ego's primary consanguines comprise his father, mother, siblings, sons, daughters; his secondary consanguines comprise those other relatives who are the primary consanguines of his own primary consanguines-e.g., mother's brother, son's daughter. See Murdock 1949:94-95.

44 For information on the effects produced upon these norms by adoption, see chap. 20.

45 Granting that we do not possess a very clear picture of the more tangible aspects of the marital exchange, it is probably correct to say that such considerations did not enter importantly into the marriage of a man to his deceased wife's sister-i.e., as far as I can discover, a woman's family was not obligated to provide a substitute for her in the event of her death. But this is a domain of Maohi life about which little has been recorded, and about which little more can be safely inferred.

46 My statement that marriages took place, ideally, only within classes is in some respects tautological, since, as will be seen, I define "class" chiefly by the criterion of marriage. However, the statement is informative enough for present purposes.

47 Even at the risk of being accused of taxonomic "butterfly-collecting"! See Leach 1961:2.

48 For further examples of "elopement" see Crook, Journal, 10 April 1826, LMS Archives.

49 As, for example, on Tikopia (see Firth 1936). The legendary instances of woman-stealing, such as the one recounted in the Memoirs of Ari'i Taimai $E$ (Adams 1901:19), did not usually eventuate in "marriage," as I here use the term.

50 Cf. Henry 1928:285; Ellis 1829:II, 571; Bougainville 1772:256; Moerenhout 1837:II, 67; Corney 1913:357; Corney 1915:57, 85, 263, 271; de Bovis 1909:32.

51 See section on population, in chapter 2. This preponderance of males over females may have been offset somewhat by the earlier marriage age of females-but not much, since Maohi males tended to marry almost as young as females.

52 Also, in view of Morrison's statement elsewhere extolling the "virtue" of Maohi women, one may justifiably conclude that Morrison sometimes tempered his objectivity with a desire to defend his Maohi hosts from the unsympathetic criticism of other Europeans. For other evidence supporting Ellis' view see Wilson 1799:348, and Turnbull 1813:335.

53 Menopause seems to have been recognized, as witness the LMS Dictionary definition of aua, ceased to bear offspring; a woman or an animal that has ceased to bear offspring. But there is no evidence that this physical state was regarded as the principal, or even an important, criterion of ruau-hood.

54 For example: ruau, old, stricken in years; rauhurupe, an old banana; an old decrepit person, a grandfather; ôriorio, to fade, wither, or shrivel, as a plant; to wither, as a person by old age. (LMS Dictionary)

55 See, from the LMS Archives, Bicknell \& Henry, Journal, 2 February 1805, 
5 December 1805; Bicknell \& Tessier, Journal, 6 June 1820; also Edwards \& Hamilton 1915:117.

56 See pp. 486-487, this work.

57 I wrote usually, in paragraphs 3 and 4, because of an uncertainty on my part-i.e., in most cases of sickness and death on which the sources expatiate, the reported cause of sickness and "premature" death is laid to spirits, but there remain some accounts of instances of injury and death which seem to leave the question open.

58 I can find no positive statements in the sources to this effect, but it could be reasonably argued that infanticide also came under this heading, i.e., it was executed under standing instructions of ancestral spirits. Or, in another sense, inasmuch as those killed had not yet fully received their iho, they were not truly "human."

59 See Morrison 1935:230; Wilson 1799:333; Ellis 1829:I, 515, II, 280.

60 Moerenhout appears to have recognized the possibility of pure "accident," but I may be misinterpreting his intent: "There were no natural deaths except those resulting from true accident or warfare-and even those were often attributed to spirits" (1837:I, 539).

61 See also Ellis 1829:I, 515-516: "Those who were killed in battle were also supposed to die from the influence of the gods, who, they fancied, had actually entered the weapons of their murderers."

62 Moerenhout stated that the kindler placed both exuviae and fetchers into a pit, where they remained while the latter worked on their victim (1837:I, 540).

63 Other symptoms included a swollen scrotum or crippled limbs (Corney 1919:33).

64 According to Moerenhout (1837:I, 541) some victims may actually have died of fright upon learning that they were being sorcerized. Be that as it may-and such statements cannot be tested-sorcery symptoms in any individual could undoubtedly have been accounted for, to the satisfaction of all concerned, as resulting from some action on the part of the victim. In this connection, even the missionaries believed to some extent in the actuality of sorcery.

65 For example, in 1822, the missionary Darling reported about one native convert: "He is one of those that used to deceive the people by pretending that the Gods used to inspire him so that he used to kill many pretending that it was the evil spirit that had done it. He yesterday confessed and told that the truth was that he used to get a poison out of certain fish, \& mix it in food or (drink) \& so affect the individuals that he was offended with, this he says \& in no other way had he power over many that he had killed." (Darling to Directors, 25 July 1822, LMS Archives.) According to Ellis, however, "The natives acknowledged that they possessed articles of poison, which, when taken in the food, would produce convulsions and death, but those effects they considered more the result of the god's displeasure, operating by means of these substances, than the effects of the poisons themselves." (1829:I, 515; see also vol. II, 231-232)

66 Corney 1919:61; Beaglehole 1967:214-215; J. Forster 1778:417; Vancouver 1801:368.

67 According to Moerenhout if a victim of sorcery actually succumbed, the diviner 
became entranced and called upon the victim's ghost to reveal the identity of the individual who commissioned the sorcery (1837:I, 542-543). In the somewhat analogous situation of discovering the author of a theft, the thief's spirit was brought to the diviner by the latter's fetchers and caused to appear reflected in a spirit-reflector, a water-filled hole or bowl (Henry 1928:206-207).

68 See, e.g., Corney 1915:334, 339; 1919:176.

69 Adapted from Henry 1928:289; see also Davies, Journal, 8 September 1807, LMS Archives.

70 E.g., see Moerenhout 1837:I, 544; Orsmond, Journal, 24 January 1827.

71 Maladies were described by Morrison 1935:228-230; Bligh 1789:I, 409 and II, 41, 51, 54; J. Forster 1778:493, 484; G. Forster 1777:I, 373 and II, 102; Beaglehole 1967:113n, 926.

72 See Bligh 1789:II, 62; G. Forster 1777:II, 89; Corney 1919:92, 192; Gregory Warner, Medical \& Surgical Journal, 14 March 1808; Platt to Burder, 28 February 1827, LMS Archives; Morrison 1935:228-230.

73 See, from LMS Archives, Elder \& Wilson, Journal, 21 February 1804; Davies, Journal, 15 September 1807; Youl, Bicknell et al., Journal, 13 November 1806. See also, Morrison 1935: 228-230; Bligh 1789:II, 43, 50; J. Forster 1778:484, 487, 493; Beaglehole 1967:927-928; G. Forster 1777:I, 370-371.

74 See Beaglehole 1955:98-100; 1962:I, 374; Bligh 1789:I, 388-389, 398, 421:II, 10, 24, 30-31, 60; G. Forster 1777:I, 370-371; Morrison 1935:228-230; Vancouver 1801:337.

75 When describing this and other Maohi ritual procedures Henry wrote as if her version were the only one, the standard practice for everyone, everywhere. This we know was not the case; and wherever alternative versions are known I have reported them; but this is the only version of this particular episode that I can discover.

76 Wilson wrote "infectious disorder" (1799:349).

77 See, e.g., Orsmond, Journal, 24 January 1827.

78 See also Chadourne 1922.

79 Henry 1928:292; Moerenhout 1837:I, 550; Corney 1919:185; Vancouver 1801:290; Davies, Youl et al., Journal, 23 July 1806, LMS Archives.

80 For the moving account of the behavior of Vehiatua's mother on the occasion of his sickness and decease see Corney 1919:184.

81 Tahu'a miri or, according to Bligh, "meereeteeàppàpow" [miri tupapa'u] (1792:153b).

82 For other references to embalming, see Henry 1928:295-296; Vancouver 1801:293; Bligh 1789:I, 404; 1792:153b.

83 Also known as 'ghosts' masque' (heva-tupapa'u) (Henry 1928:293).

84 Moerenhout 1837:I, 550; Henry 1928:293. Parkinson stated that the principal mourner also served full time as attendant at the ghosthouse, setting out sacrifices and strewing the body and the environs with fragrant plants (1773:70-71).

85 Such bodies were usually transported in specially rigged canoes. See also Wilson 1799:349; Vancouver 1801:287-288.

86 "April 9th [1804] - the native that died on Friday night, was to-day buried not far from our dwelling. The corpse was wrapt up in cloth and laid in 
the grave dug for it, with the face downwards: over it was placed, on pillars, a small house, such as those in which they usually lay their dead. The reason of his being buried, and with the face downwards, was because of some superstitious notions that his friends have among themselves." (LMS Transactions:II, 302)

87 The details of such ceremonies are nowhere reported.

88 Reference here is to generalizations regarding, say, the extent to which mourning practices serve to restore equilibrium in interaction systems disturbed by the absence of a key member, etc.

89 The action referred to, i.e., self-bleeding, is elsewhere labeled pao; I can find no reference in the LMS Dictionary to pupu being used in this sense.

90 For a more detailed study see Williamson 1933, vol. 1, where the older published sources have been reproduced and summarized.

91 See, for example, "They have no Idea of a future State, but fall into a degree of nothingness without reward or punishment after Life" (Bligh 1792:169b).

92 This composite summary has been assembled from accounts of Henry 1928; de Bovis 1909:39-41; Moerenhout 1837:429-436; and Ellis 1829:I, 516-518.

93 In Henry's and de Bovis' versions the route from Tahiti also went via Rotui.

94 In evaluating the reliability of Anderson's statements about this elusively profound subject it should be recalled that he could not have been very proficient in the native language.

95 See also Ellis 1829:I, 516 and Moerenhout 1837:I, 432-434. In an excerpt from Cook, quoted in chap. 2 (Beaglehole 1955:146), is the statement that three families lived at the time on Tupai, but most other accounts describe this atoll as having been usually uninhabited.

96 See p. 486 for Moerenhout's definition of "punishable misdeeds."

97 There is no way of knowing whether any one individual held any such combination of beliefs. In fact, it is likely that even any priest's store of eschatological doctrines was less comprehensive than the synthesis put together here. For additional versions, which however express only slight differences from the ones recorded above, see Beaglehole 1962:I, 381; J. Forster 1778:554; Ellis 1829:I, 327.

98 Moerenhout explicitly distinguished between a purgatory and a limbo, and his version has some souls going directly to limbo and others first to purgatory before proceeding to limbo. Henry's version, in contrast, appears to imply that all souls not destined for paradise pass through a purgatorial stage. If I am not reading too much into these constructions the differences between these two versions reflect important native disagreements with respect to man's relation to his gods.

99 Uretaetae, i.e., ure, penis; taetae, sharp thorns or prickles on the tail of fishes (LMS Dictionary)!

100 Henry referred to a certain "deified family hero" (1928:144), but the spirit in question was only of local importance.

101 The only possible exception I have found is in the myth about Fa'ahoutu, referred to in chapter 3, in which the iho of that deity's deceased infants reentered her womb in order to be reborn (Henry 1928:373). 


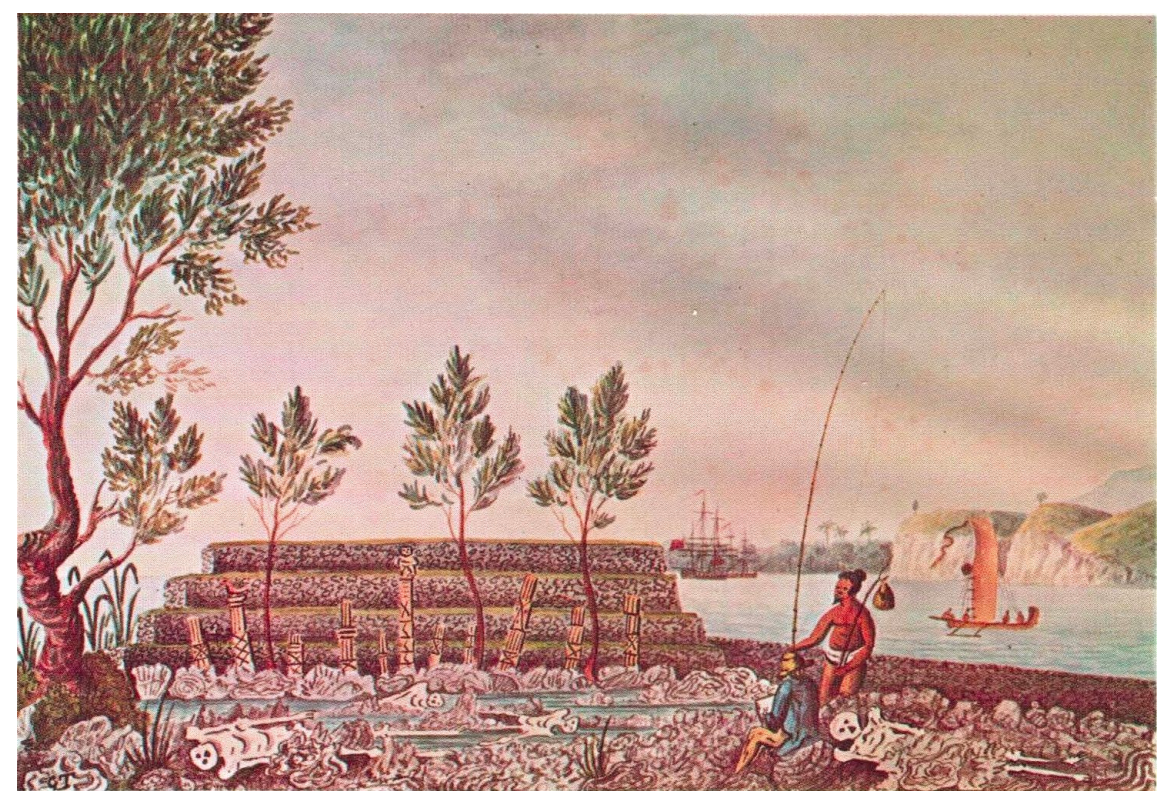

“Morāi Point at Oparrey, Island of O'tahytey, 1792." Watercolor by G. Tobin. Mitchell Library, Sydney. 
VOLUME 2
SOCIAL RELATIONS 



\section{CHAPTER 14 INTRODUCTION TO SOCIAL RELATIONS}

Many of the actions and beliefs that determined the social relationships that prevailed among the Maohis just before alien influences brought about radical changes in them have been noted in my descriptions of food production, recreation, warfare, weddings, and so forth. Now, however, these and other data on social relationships will be presented in more explicitly interactional terms.

As I interpret the evidence, the most important attributes recognized by the Maohis in their interactions with other Maohis were sex, relative age, consanguinity, affinity, class stratum, formalized "friendship," occupation, Arioihood, residential proximity, and a combination of the latter with the common, coercively backed submissiveness to some particular leader that I label "tribalism." Lexical distinctions indicate that people living in the more thickly populated areas nearer the coast were somewhat contemptuous of more rustic inland types, ${ }^{1}$ but this contrast was not further institutionalized as far as I have been able to discover. In addition, as in all human societies individual attributes of one kind or another (in terms of local definitions of "beauty," "strength," "temperament,") served to differentiate people in their everyday interactions, but among the Maohis such attributes were less important as social-relational criteria than were the ones listed above, which, accordingly, form the basis for the several chapters that follow.

Before plunging into this lengthy exercise I must digress to explain what I choose to convey by such overworked terms as social relationship, social groups, and certain other words that I propose to use in the interest of greater precision and more valid comparison. But let the reader be warned: the meanings I attach to these words are not exactly like those of any other writer that I know of-a regrettable but hopefully not obfuscating circumstance. It should be noted that the "persons" referred to in the following definitions can be either humans or humanlike beings, for reasons that will become clear.

Social relationship is my term for the kind of connection existing between persons who engage in social interaction-that is, in mutually 
adjustive behavior. If two or more persons live on the same island, or are of about the same age or height, or enjoy membership in the same class stratum-all these may be said to constitute connections of common categoryness between them; but they are not the type of connections I call a social relationship, which is a type that is constituted by social interaction. (It would make my task tidier in some respects if I were to declare how much social interaction should take place between specified persons in order to qualify their connection as a social relationship; but, for several reasons, to determine that would be both impossible and undesirable. I leave the definition as it stands, my primary purpose being to assemble and interpret data on Maohi society and not to refine a set of analytical terms.)

Another term I propose to use in a technical sense is group, a general label to designate specific persons who on occasion interact with one another more or less exclusively. In this sense a group differs from a category of persons, such as males, females, fishermen, or priests. But if, say, all the priests of Huahine interacted with one another on occasion, and more or less exclusively, they would of course also constitute a group. In this sense, a group also differs from an adventitious gathering, such as a meeting together of a person's assorted kinfolk and neighbors at his funeral. (The distinction I draw between group and gathering is less precise than that between group and category, but it is adequate for present purposes. $)^{2}$

Maohi groups ranged in size from two persons (e.g., a two-member household, a pair of lovers, a sorcerer and his spirit-familiar) to many thousands of persons (e.g., a tribe's whole fighting force assembled). In this sense, a married couple, or married couple with their children, living together and interacting in a household also containing other persons constituted a subgroup-provided, of course, they themselves on occasion interacted with one another more or less exclusively of those other members of the household. Here again, I acknowledge the ambiguity in my technical terms but believe that they are discriminative enough for the uses I shall make of them. It is hoped that the definitions will become clearer as the account unfolds.

\section{DIMENSIONS OF INTERACTION}

Returning now to the type of interpersonal connection that I label a social relationship, I find it useful for purposes of comparison to describe such relationships in terms of several aspects, or dimensions, namely:

terminology: the names or other kinds of labels the interactors call or use to refer to each other or that others use to refer to them, within the context of the particular interaction episode;

time: when and for how long the persons interact; 
space: the locations of the interacting persons, relative to one another and to the spatial setting;

governance: which person controls the responses of the others;

transaction: what "goods" (objects and services-or disservices) circulate between the interactors; and finally

emotion: utterances or other discernible bodily behaviors which accompany interaction and which the observer infers to be expressive of internal states.

Before examining specific social relationships among Maohis it may be useful to record, in these dimensional terms, some more-general impressions about Maohi social relationships.

\section{Terminology}

In analyzing Maohi social relationships from a Western point of view, I have found it useful to distinguish personal names (e.g., John, Mary), general status names (e.g., father, prince), and specific status names (e.g., Mary Smith's father, the Prince of Wales). Throughout this account personal names will be referred to as such, general status names as statuses or offices, and specific status names at Titles (thus reserving the uncapitalized form, title, to refer to anyone's claim on some object, service, or prerogative-which may or may not be labeled with a distinctive office name or Title).

The Maohi word i'oa undoubtedly stood for 'personal name', but whether it stood for 'Title' as well is not entirely clear. ' (I have not discovered any general Maohi word for the English status or office, although the word toro' $a$, business, office, occupation [LMS Dictionary], covered at least some of that meaning.)

Each child was given a personal name at birth. Some individuals were undoubtedly named after living or deceased relatives, presumably from either parent's kin; I can discover no fixed patterning in this regard, except for Moerenhout's curious and ambiguous statement: "A child is given a personal name at birth deriving from either maternal or paternal family. Later, if its parents separate the child goes with the parent whose family name it bears." (1837:II, 63-64.) Whether or not such a custom did prevail, it seems likely that a higher than average association may have developed between certain personal names and certain descent lines; but, except as will be noted below, there is no evidence of any exclusive ownership of such names. Some personal names were bestowed as is; others were specifically adapted to the recipient, as for example in the case of the Spaniard Maximo Rodriguez, who was named 'Oro Iti Mahe'ahe'a (Little 'Oro, after a friend's ancestor, fair skin): Little-'Oro-of-fair-skin (Corney 1919:183).

In other instances infants were given personal names "invented" for 
the occasion as a result of some peculiar circumstance attending birth: "After the birth of a child, they ... [give] it a name from some object or other which is nearest at hand, or which from some circumstance becomes remarkable" (J. Forster 1778:556). In such instances one is justified in searching for the meaning of the name, but in the case of most "inherited" names it is my opinion that the Maohis did not "translate" them any more than English speakers nowadays imagine a worker in metals when they think of Smith. A statement in Davies' journal for 1818 might be interpreted either way: "It was also inquired whether it was not wrong to retain the names of things indecent as the proper names of men and women, this was answered in the affirmative, and it appears that many such names, had been lately put aside, tho' some are still retained." (4 May 1818, LMS Archives.) Either the "indecent" personal names had been adopted because of their connections, or wholly independent of them. (The persons referred to were evidently new converts to Christianity.)

A possible exception to this situation occurred in the case of office labels used as personal names, such as Te Fatu, in the legendary story given by Henry: "Some time after ... there came to Porapora (Vavau) ... a prince named Te-fatu (The-lord), a god's name, which only the highest of Polynesians ever dared assume, and which brought this prince great authority upon land from the god Te-fatu, lord of the ocean" (1928:122).

It is conceivable that some families holding high-ranking kin-congregation Titles also entertained exclusive proprietary sentiments toward certain of their ancestors' personal names, thereby constituting an exception to the tendency described earlier; but I can find no specific evidence bearing on this point. Some personal names were invariably sex-linked, many others were not. Among the former were the names of major gods, all of whom were either male or female.

There were no beliefs attesting to a direct mystical connection between an individual's personal name and his soul. For one thing, individuals changed their personal names or added new ones almost at will, ordinarily to commemorate an unusual event.

The People here as well as in England have several Names, and being differently used, it is frequently perplexing when the same person is spoke of, to know who is meant. Every Cheif has perhaps a dozen Names in the course of 30 Years, so the Man or Woman that has been spoken of by one Navigator under a particular name, will not be known by another, unless other causes lead to a Discovery. (Bligh 1789:I, 384)

One prominent man known to the early English visitors changed his personal name to Winker ('Amo) because of his infant son's habit of winking. Another individual became Convulsion after a kinsman had died during a convulsive seizure (Baessler 1900:126). According to Bligh this was in fact 
a general practice: "Whenever a Child dies the Parents or relation take the Name of the disease; if a dozen Children die of different diseases, the Parents have as many different Names, (or give them to their Relations) and may be called by either, but commonly by the last" (1792:131b).

Another kind of circumstance was reported by Wilson:

Ahēine Eno [Vahine 'Ino], the name this man at present went by, means a bad woman; it seems that his mistress Inna Madūa [Vahine Metua] was a character of this kind, and had got this name from the natives; but not liking it, transferred the name (through not the odium) to her servant [who, incidentally, was also her paramour]. (1799:185)

The custom of pi is defined in the LMS Dictionary as the custom of prohibiting the use of a word, or syllable, which had become sacred by its having been adopted as the whole or part of the name of some chief, when another word or syllable was substituted in its place. Since this custom had to do mainly with the personal names of chiefs (and possibly with some highranking Titles) I shall postpone discussion of it to chapter 22 .

General status names, statuses or offices, included some terms used exclusively for address (e.g., $p a$, a term of reverence answering to father, and commonly used by children in addressing their father, and common people their chief [LMS Dictionary]); some used exclusively for reference (e.g., metua tane, male parent); and some used both for address and reference (e.g., ari'i, a person holding a high-ranking kin-congregation Title or exercising authority as a tribal chief). Statuses and offices will be listed in due course in connection with descriptions of their relevant social relationships.

\section{Time}

Few European observers bothered to record how often specific Maohis interacted, or how long such interaction lasted; but even if such information were available in numerous precisely recorded instances, generalizations drawn from it would not necessarily be significant in native terms. Consideration has already been given to Maohi ways of marking the passage of time or, rather, their ways of identifying and responding to the cyclical occurrence of certain natural events. It is quite unlikely that they conceived of time as something that "passed."

Time (in the Western sense) also entered Maohi consciousness in the form of verb tense, but with a noteworthy peculiarity. By the use of qualifying particles added to action words it was possible to distinguish present (or ongoing) action from completed action and from action in the future, but the particles for present and past also carried meanings of spatial proximity and distantness, respectively (Burbidge 1930:168-170).

In addition to these more or less conventionalized indicators, I offer-for whatever they may be worth-other impressions gleaned from 
the sources about Maohi behavior with respect to what Europeans call "time." Although precise timing was the hallmark of such skilled activities as angling and weapons play and group dancing, there seems to have been a universal unconcern with precision in the appointing of times for events; or, if times were appointed for events to take place they were set within very broad margins, and punctuality was usually neither striven for nor expected.

In yet another sense a rather low valuation seems to have been placed on the durational aspect of time in terms of services, as contrasted with objects. To the extent that exchange equivalences can be calculated, labor time entered into "price" to a lesser extent than did materials. Also, judging by the general absence of hurry in connection with most activities, and by the great amount of relaxed waiting that seems to have prevailed-waiting for events to begin, for weather to change, for crises to pass-individual Maohis did not, it seems, respond to the acknowledged limits of their own life spans with any sense of urgency. In this connection, however, they should be characterized as a-temporal rather than patient.

The relevance that all these highly impressionistic statements have to our present concern is that duration of interaction is less important in considering Maohi social relations than the Western observer might expect, at least with respect to Maohi thinking about interaction. Of course, the fact that any two persons interacted for several hours daily, rather than for a few minutes monthly, is to anthropologists a matter of considerable significance. But it would signify much more were we dealing with the kind of society whose members consciously "spend time" with one another.

Temporal sequence was expressed in the contrast mua-muri (beforeafter, earlier-later) and in such ordinals as i matamua (first). Compared with temporal duration, sequence received much more emphasis in Maohi interaction: for example, precedence was usually quite sharply defined.

\section{Space}

This dimension figured in Maohi interaction in terms of both arrangement and distance. The prime referents of arrangement were tai-uta, i ni'a-i raro, mua-muri, 'atau-maui or 'atau-aui, and mai-atu.

The tai-uta (seaward-landward) contrast was a fundamental one to these land-dwelling but sea-going Islanders, and it served to locate objects and other people wherever they were: one thing was nearly always recognizably closer to the sea or to land than another ("You there seaward, hand me that adze lying on your landward side"). I ni'a-i raro signified both abovebelow (or on top of-underneath) and upwind-downwind (i.e., toward or away from the prevailing easterly trades). And in connection with the latter, since these islands were located along a (roughly) east-west axis, i ni'a-i raro were also associated with sunrise-sunset, respectively. ${ }^{4}$ 
As I pointed out above, mua-muri referred in some contexts to the temporal sequence before-after (or earlier-later); in other contexts, however, this contrast signified what may be translated as in front of-in back of (or before-behind). 'Atau-maui (or 'atau-aui) seems to have signified quite unambiguously the body-oriented spatial-arrangement contrast right-left.

Finally, spatial arrangement was expressed by means of the contrasting particles mai (direction toward the speaker) and atu (direction away from the speaker) (Burbidge 1930:164, 167-168).

Turning now to measurement of spatial distance, the conventional length of a span (etaeta) served to indicate the length of canoes, of house beams, of dimensions, and so forth, but not, apparently, to describe absolute distances between persons or places or objects. Bligh wrote: "I now have no cause to doubt but that these people have no knowledge of the System of the Habitable Globe. Comparative distances must be explained to them by certain spaces of time which either would take up to perform according to their rate of travelling, and when this happens to be many Months, they are lost in a Maze." (1789:II, 38) Instead of terms of absolute distance, there were in use several terms to describe relative distances: fatata (near), atea (distant or extensive), roa and maoro (long), poto and mure (short)-all of which can apply to time as well as space. Words also existed for 'close to' in a temporal sense (piha iho), 'near together' with respect to several entities (piri), and 'far apart' (aehai). The tolerance for "crowding" that most Maohis sometimes manifested was balanced by an evident preference for keeping their residences fairly far apart. Also, in some instances spatial distance between persons was complicated by considerations of sacredness ( $\left.\mathrm{ra}^{\prime} a, \mathrm{mo}^{\prime} a\right)$; persons not possessing such attributes had in general to keep somewhat apart from those, both humans and spirits, who did.

Finally, one will recall that the oppositions expressed by pō (night, spirits' world) and ao (daytime, humans' world) also contain some implications of time-that is, primeval versus present era.

\section{Governance}

With apologies, but for lack of something better, I apply this awkward label to that dimension of a social relationship having to do with which of its parties controls the responses of the other, or others, and with the ways in which this is done. In more expansive terms, governance concerns the making and executing of decisions, chains of command, power and authority, dominance and submission, and the like. As befits its importance relative to other social-relational dimensions I shall feature governance in characterizations of specific types of relationships in the chapters that follow, but first I offer a few general impressions about the conditions in which governance was exercised. 
To begin with, Maohis sometimes met together in fairly large numbers-in scores, hundreds, and even thousands of persons; but most instances of coordinated interaction involved fairly small numbers. Agriculture, for example, was mainly carried out by groups of only household size, and the same was probably true of most subsistence activities, except for the infrequent occurrences of tira angling and sweep-net fishing. Large numbers of persons occasionally worked together to build a chief's house or a marae, but most building and manufacturing appears to have been carried out by groups of usually no more than five or ten persons.

Some ceremonies did indeed include multitudes of persons, but usually the active participants in such events-those whose actions required a certain amount of coordination-were few in number; most other persons simply looked on. Again, although certain large-scale festivals involved the bringing together of vast quantities of foodstuffs, contributed by scores of households, the assembling of such objects was performed as numerous small-group actions, and not as an overall coordinated and finely timed mass enterprise.

Even land warfare, which occasionally involved thousands of combatants, was characteristically an every-man-for-himself affair-or at most a matter of very small groups clinging together and fighting around a personal leader.

I recognize the data to be woefully inadequate on these matters, but I have the impression that the only kinds of collective activities engaged in by the Maohis in large groupings and with fine coordination were dancing and canoe handling. Of these, dancing undoubtedly involved a great deal of training, but dance leaders were more signalers than anything else. Good canoe handling also required much practice and probably some specific training as well, but it also required leadership able to size up unusual situations, devise plans of action, and see that these were carried out. And not only did such leadership operate effectively over canoe crews numbering up to a hundred or more men, but occasionally it embraced whole fleets of canoes.

Outside their canoes, however, the Maohis do not appear to have been comfortable or very effective as members of large, closely coordinated groups. Illustrations of this general attribute will show up particularly when I discuss territorial groupings.

\section{Transaction}

Transaction is that dimension of interaction having to do with the circulation of goods. The goods to which I allude include both objects and services: not only objects themselves but various kinds of use-rights and disposal-rights over objects; and not only services themselves, and rights to services, but disservices as well-for example, diminishing others' capacities to act by killing, wounding, exiling, bespelling, or defaming them. 
It would not be practicable to draw up an exhaustive list of the innumerable types of goods that circulated among the Maohis. Even formulating a list of the principal categories of such goods raises methodological problems that I am unable to solve. For example, there is no native verbal classification of objects into categories comparable to the tonga-oloa classification of Samoa (Mead 1930:62ff); neither does the Maohi language contain all-inclusive grammatical noun classes such as occur in some Oceanic languages. The language does, however, contain the widespread Polynesian $o$ - $a$ contrast, the so-called markers of alienability which occur as parts of most possessives. ${ }^{5}$ Briefly stated, $o$ is used for possession which is intimate, innate or permanent, while $a$ is used for possession which is incidental or transient.

In addition there appears to have been a general distinction drawn between manufactured objects (e.g., bark cloth) and provisions (e.g., plantfoods, fish)-at least for purposes of gift giving (i.e., reciprocity, either explicit or implicit).

Nor do they Call any thing a present which Nature produces, except accompanied by something which is procured by the Assistance of labour or the Art of Man; for which reason they always give Cloth or some thing else with their Gifts, Provisions being held of No value being produced by Nature, and they think it not proper to make store of them. (Morrison 1935:191)

In the absence of any explicit overall indigenous scheme of classifying circulating goods, I could perhaps attempt to introduce one of my own devising, in which case a number of possibilities come to mind. I might, for example, categorize them in terms of relative scarcity or relative value (not necessarily synonymous), or of relative tangibility, or of substitutability, or of "ends" versus "means." Some information bearing on these criteria has already been presented, but much more will be given in due course, so rather than prematurely attempt a brief summary, I shall treat the goods as they appear contextually in my descriptions of social relationships.

Turning now to the ways goods circulated among the Maohis, I can begin by noting how profuse their language was with respect to words relating to transactions. Here are some examples taken from the first few pages of the LMS Dictionary:

'aihu'ara'au, to possess land taken by conquest.

'ainanu, displeasure caused by not receiving proper share, etc.

'aita' $a$, a man of another district or country, who by marriage becomes an inheritor of land.

'aitaha, to eat fish without paying the usual tribute.

'aitārahu, a debtor [nonpayer of compensation, wages].

ānavenave, addicted to get[ting] food at another person's house. ani, to ask, beg; beggar.

This dictionary contains hundreds of words for transactions (e.g., con- 
fiscate, steal, feed, give, bribe, assist) and for individuals' predispositions regarding transactions (e.g., hospitable, covetous, niggardly), but the language itself does not provide any comprehensive lexical classification of transactions.

Before leaving this subject for the moment, I call attention to two general features of Maohi transactions. The first is the preponderance of terms having to do with generosity and stinginess, with sponging on others, with begging, and so forth, in contrast with the paucity of terms having to do with buying-selling, wages, rent, and other forms of barter or "commercial" exchange. And second, it should be pointed out that I have found no evidence of any Maohi aphorisms expressing generalizations about how all social units-individuals, both human and spirit; groups-transact or ought to transact. Aside from some general precepts in favor of food hospitality, there is nothing comparable in universal applicability to such Western ones as it is more blessed to give than to receive, or competition is the rule of life, or share and share alike.

Finally, I should point out the widespread practice of validating agreements by means of an exchange of objects, usually bark cloth. (Fig.

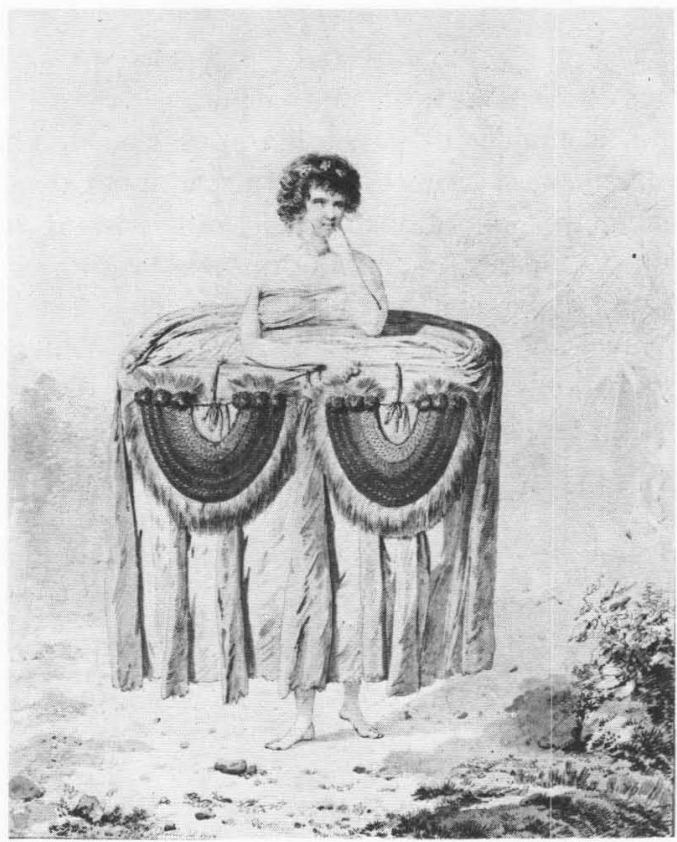

FIGURE 14-1. Tahitian girl bringing a gift of bark cloth and two gorgets. Drawing by J. Webber. British Museum. 
14-1.) That is to say, although the rites used in such agreements varied widely, according to the nature of the thing agreed upon, they were nearly always reinforced by an exchange transaction. Thus, one may infer a general Maohi proposition to the effect that while words were undoubtedly potent bearers of one's intentions they required the addition of valued objects to render them fully effective.

\section{Emotion}

My usage of the term emotion corresponds in part to what some writers call affect or expressive behavior; but I also use this term as a label for those utterances, gestures, and other bodily signs meant, for example, to express the interactor's feelings of inferiority to his betters, equality with his peers, affection toward friends, distance from mere acquaintances, anger toward enemies, and so on. (Ritual by very definition involves deliberate statement, even overstatement, of this dimension of interaction.) To avoid misunderstanding, I emphasize that emotion, as I use the term, does not purport to describe the internal states themselves but only label those observable, conventional, learned, and socially shared bodily behaviors tacitly understood to express internal states.

The Maohi language contains numerous interjections presumably meant to express internal states. The following examples are from the LMS Dictionary:

$a^{\prime} a^{\prime} a^{\prime} a$, laughter or ridicule.

'ae, surprise or disappointment; alas!

'aeo, contempt or disgust; ah!

' $a h a^{\prime} a$, fondness on meeting a friend.

$a u \bar{e}$, grief, ... sometimes an exclamation of wonder or surprise.

The language also contains scores of words labeling expressive behavior patterns. Some of these were of more or less "direct" reference, for example:

$a i$, to copulate, applied to both sexes.

'avau, to scold, reprove; use ill language.

fa'anonoa, to spurn with disgust ....

There were numerous conventional nonverbal behaviors, including some which struck the European visitors as highly bizarre, such as the custom of pao (striking and lacerating the head with sharks teeth, as evidence of strong feelings of either grief or joy) and that of tiapou (striking one's posterior and exposing it as evidence of contempt for someone). Wilson noted: "Their mode of salutation is very different from ours: they touch noses; and wonder that we can express affection by wetting one another's faces with our lips" (1799:348; see also Bligh 1789:I, 373). 
Ancient Maohi contained many words for the internal states themselves, for example the following from the LMS Dictionary:

' $a$ 'aia, pleasurable sensations of the heart.

'a'ataina, the strong desire or longing of the heart.

$a n a u$, grief of parents for their children, or of children for their parents.

atatu, the state of being agitated.

àtohatoha, a pleasing or satisfactory feeling of the mind.

faaeo, to be so affected with grief or love as to lose the appetite.

fe'ume, envy, malice, settled hatred between persons.

hae, jealousy; wildness of beasts.

hōioio, diffidence, fear of a superior.

mata' $^{\prime}$, fear, dread; to fear; to be in terror, or dread. ${ }^{6}$

mateono, a strong affectionate desire.

In view of the well-documented fact that the Maohis considered the more important internal states-thinking, feeling, and so on-to be centered in the 'a' $a u$, or bowels, references to "heart" and "mind" in the above definitions are plainly figurative. ${ }^{7}$ Aside from their acknowledgment that even the most impelling feelings of anger lost force with the passage of time, I can discover no detailed evidence of Maohi beliefs concerning the physiology of emotions. ${ }^{8}$ Nor can I discover any linguistic or other clues concerning how the Maohis themselves categorized these numerous "internal states" and the even more numerous conventionalized behavioral expressions concerning them; I do not know, for example, which of their terms for emotions were regarded as contrastive, which were entirely synonymous, or which were identical save for differences in intensity.

With respect to emotion in general, many European visitors were struck with two aspects of it which appeared to them to be contradictory. On the one hand the Maohis' ways of expressing joy or grief or anger seemed ridiculously overdramatic to the more stolid of the Europeans; to others, like the Forsters, such behavior was indicative of "excellence of heart" and of "generous and exalted sentiments" (G. Forster 1777:I, 386). Yet on the other hand the Maohis submitted to physically painful situations with remarkable stoicism (see, for example, Bligh 1792:148). One pattern of expression which struck the more forthright English visitors not only as overacting but as a case of barefaced hypocrisy was the violent but evidently simulated display of grief on occasions such as deaths, illnesses, or even mere partings. An example is the following observation by Mortimer: "The king's mother cried much at parting with us, but in such an affected manner that it was almost impossible to refrain from laughing" (Mortimer 1791:48).

The Maohi lexicon contained numerous words connoting (and implicitly censuring) the dissimulation of emotion. These were words such as the following from the LMS Dictionary: 
'arufa'ahema, deception by fair words, while a plot of destruction has been planned.

'arufa 'aīpaea, words of conciliation, without sincerity.

aureva, to impose upon a person under the appearance of friendship.

But certain highly dramatic expressions of emotion, such as those just mentioned, were evidently regarded by the Maohis themselves as admissable or even unimpeachable.

As was the case with transactions, I have found no aphorisms of general, society-wide application, such as love thy neighbor as thyself.

\section{KINDS OF INTERACTION}

The preceding sections regarding dimensions of interaction apply to three kinds of interaction: normative, historical, and suppositional. (Tedious as such technicalities may be to most readers, I regard it as essential to concern ourselves with such distinctions.)

I apply the label normative to subjects' opinions, expressed or implied, about how persons ought to act when interacting. I call interaction historical when there is reliable evidence that it actually took place, and in the manner observed or reported. And I call interaction suppositional if its historicity is presumably believed in by the persons under study, without, however, sufficiently reliable evidence that such interaction actually did or does take place.

Some historical interactions may in fact conform to most of our subjects' opinions about what they ought to be and to their beliefs about what they are, but such conformance is a matter for investigation. Whether conformance does or does not occur, data about all three kinds of interaction are relevant to a formulation of any society's social structure.

Having said so much, however, I must acknowledge the difficulty of applying this three-way distinction to the data available about ancient Maohi society. When the eminently reliable Captain Cook reported in his journal that he observed two men butchering a pig, we are probably justified in accepting that as history. And when a native 'Oro-worshipper related that his cult's founder was begotten by Ta'aroa's overshadowing of Hinatuauta in the form of a breadfruit branch (Henry 1928:375), we are equally justified in regarding that as a supposition (assuming, for the sake of argument, that the fellow actually believed the story). But there are countless other recorded instances of social interaction wherein such distinctions are by no means so clear-cut. Particularly, is it difficult to discern the normative bias in many native narratives: for example, does the recurrent theme of the cuckolded husband indicate general approval for such goings-on or merely acceptance that such things, regrettably, did (and do) occur? And, of course, in connection with a great deal of native "tradition" it is next to impossible 
to discover where myth (i.e., supposition) ends and history begins. For some purposes such a distinction may be unimportant; if a myth has currency as a charter for some contemporary situation it may not matter whether its events did or did not actually take place. Yet there is usefulness to be gained from reliable information that such and such did or did not take place.

In this connection, Maohis' accounts of past events are not easily classifiable into such conventional Western categories as myth, legend, folklore, and so on; I could not discover any evidence of an analogous vernacular classification. Furthermore, while one may use Western criteria with some validity to arrange most Maohis' accounts in terms of a kind of chronological sequence-say, a cosmogonic era, a middle era of dynastic origins and of demigod adventures, and a more uniformly recent era of quasi-historical events-these different eras are not altogether mutually exclusive. That is to say, "creation" continued into the middle era, and even into recent times; and the origins of some dynasties may well have taken place much later than their genealogical charters imply. In view of these uncertainties it may appear unreasonable to attempt to separate the actual history of Maohi social relationships from natives' rules and unverifiable suppositions about them, but an attempt will nevertheless be made.

Throughout the following chapters, to build up characterizations about social relationships I draw also on fictional material-that is, on stories told by Maohis mainly for entertainment, and not necessarily believed by them as having actually occurred. Thus, fictions are to be distinguished from suppositions and are relevant in at least two respects. First of all, the Maohi fictional stories that have managed to survive long enough to have been recorded are a prominent part of Maohi arts, and are thus intrinsically important (see chapter 10, on diversions). Second, although they do not constitute direct evidence of Maohi beliefs about the actual nature of social relationships, they do at least provide testimony concerning what features of social relationships the Maohis found interesting enough to tell about and to listen to.

\section{SANCTIONS}

The subject of sanctions is of course vast and diffuse, and I will not even attempt to trace its many ramifications in any systematic, analytical manner. However, I will indicate what mechanisms there were for assuring, or at least encouraging, compliance with social-relational norms. I have no data on Maohi generalizations indicating how they categorized or ordered according to strength what Westerners call sanctions. Instead, I shall give here a few impressions of the wide range of sanctions (in terms of common English usage), and place in the contexts of specific sets of social relationships other examples that the sources provide. 
Turning first to those negative sanctions that reinforced conformity to social-relational norms, one of the most direct of these was the implicit threat that the dissatisfied party could sever active relations. This obtained not only between more or less equals-between siblings or friends or partners-in-trade-but may have served somewhat to curb a husband's power over his wife, a father's over his children, or a chief's over his subjects; divorce by wives, change of residence by offspring, and transfer of allegiance by subjects could and did occur. Also, occasionally individuals resorted to suicide when frustrated, in one way or another, or in response to social embarrassment. A few examples of actual and threatened suicide will be found throughout the descriptive portion of the present work; however, there are too few cases to warrant further discussion.

As we shall see, certain kinds of contractual agreements involving long-term exchanges of objects appear to have contained (implicit) clauses regarding penalties for nonperformance; these clauses usually recognized the right of the aggrieved party to destroy some of the other's property in the event of nonperformance.

Superior physical force may not have been the most effective sanction in the minds of the Maohis themselves, but it was certainly one of the most widely exercised, both to enforce general rules of conduct and to settle interpersonal conflicts. Moreover, once physical force was brought into play against a particular individual in such situations, the tendency was to apply it to the limit-that is, not simply to maim the victim or to cause him pain, but to kill him; or, in some cases, to kill not only the victim himself but his parents, spouse, and offspring as well. There were however some alternative outcomes: in some instances transgressors were allowed to live but were exiled, or their goods either appropriated or destroyed. Physical force was also utilized in a more extensive way, but with what seems to have been rather indifferent effects. Some officials wielded clubs to clear paths through crowds for their superiors. In this connection I reproduce a statement from Turnbull which, however, I cannot further document: "Their morais are a kind of refuge for criminals of every kind; they fly to them when in any imminent danger, and according to the custom of the country, must not be taken from thence" (1813:366).

For a Maohi, to whom a spirit may have been just as physical (tangible, palpable) and in some respects a great deal more forceful than the ruleenforcers of his chief, our distinction between supernatural sanction and physical force would not perhaps have been very meaningful, but for Westerners it remains a useful one. Indeed, using present-day semantics, it is possible to distinguish two, or perhaps three, kinds of negative supernatural sanctions that served to ensure compliance, more or less, with many socialrelational norms. 
One of these was direct, purposeful, explicit action by a spirit to punish someone who had broken a rule sanctioned by that spirit or to punish noncompliance with a spirit-sanctioned oath. In connection with the latter is G. Forster's account of one such occasion:

The next morning at parting Potatow promised to accompany Mr. Pickersgill to Matavai, in order to visit captain Cook, provided he might be sure of good treatment. Mr. Pickersgill assured him of the best reception; but the chief, for greater safety, produced a few small yellow feathers, tied together into a little tuft, which he desired Mr. Pickersgill to hold, whilst he repeated his promise, "that Toòte (captain Cook) would be the friend of Potatow." This done, he carefully wrapped the feathers into a bit of Indian cloth, and put it in his turban. We knew, from former accounts, that red and yellow feathers were employed by the inhabitants of this island to fix their attention while they prayed to the Deity; but this ceremony conveyed an idea of a solemn affirmation or oath, which was quite new to us. Potatow was so well satisfied of the integrity of his friends, after this ceremony, that he and his wives, and several of their attendants, carrying with them two hogs and abundance of cloth, marched towards the boat, amidst an immense croud of people. (G. Forster 1777:I, 359-360)

Another kind of supernatural sanction was sorcery, through which humans manipulated spirits to punish other humans for private or public wrongs. As I indicated earlier, there may have been still another distinctive kind of supernatural sanction in operation, namely, an "automatic," "magical" process more or less independent of individual spirits and one which damaged the breakers of certain types of rules; but the evidence on this belief among the Maohis is not entirely clear. In any case, whatever the mechanism, most punishments involving negative supernatural sanctions consisted of some form of bodily ailment, including death, although infertility, property destruction, or enterprise failure were sometimes employed.

Compliance with social-relational norms was also sanctioned by various expressions of censure. The Maohis appear to have been especially sensitive to verbal censure, but individuals' reactions to it ranged from suicide to violent counterattack (including warfare), depending on many complex factors.

In discussing the difficulties experienced by Europeans in communicating with Maohis, Vancouver added the following:

These perplexities and disadvantages were also materially increased, by the difficulty of obtaining the truth from a race who have a constant desire to avoid, in the slightest degree, giving offence; insomuch, that, on the least appearance of displeasure, even in conversation; to disengage themselves from any such inconvenience, they would often, by that extensive and specious comprehension, which their language admits of, seemingly so qualify, what they before had asserted, as to contradict, according to our acceptation, a positive matter of fact; or, what amounted to nearly the same thing, a completely different construction was by us a very frequently put on a second conversation, from that which we had conceived from, or had attributed to, the first. (1801:317-318) 
Censure, it will be recalled, was also expressed in the form of dramatic skits. In one of the few episodes actually recorded, the reproof seems to have been most effective. But as for the "Satyrs" [satires] described by Morrison as having been "... directed at their Chiefs," although such criticism may have been licensed by the latter ("so long as they keep to the truth"), we are not informed how efficacious it was (1935:224).

We must face the question concerning the nature and potency of internalized sanctions, in addition to those reinforced by dislike of censure and anxiety about damage to self, to relatives, or to property. In this connection I believe it fairly safe to assume that even in the face of some conflict of ideologies, which I shall attempt to delineate, and even in the situational differences in child-rearing, which I am convinced did obtain, socialization was uniform enough and efficacious enough to ensure that most social-relational norms required no additional external reinforcements. For example, an individual's respect for his kin-congregation chief was in many instances spontaneous enough not to necessitate a fear of the latter's clubs or guardian spirits. It might be suggested, of course, that hara (error, defilement, guilt-substance) constituted an internalized sanction, a kind of substantialized metaphor for feelings of guilt; but such an interpretation cannot be soundly documented.

Finally, is the question of what meaning to attach to the intriguing word, ha'amā. The LMS Dictionary provides these glosses for the word: shame, remorse, to be ashamed, shameful, indecent; and for its factitive compound, fa'aha'amā, to put to shame, or make ashamed, to put on shame, to act as one abashed or shamed, the person or circumstance that makes another ashamed. Except for the gloss 'indecent', which in missionary terms may have referred to sexual misbehavior, the definition itself provides no clue as to the kinds of situations which brought on such ha'amā. The sources do not contain enough examples to permit insight into the word's interesting, and probably quite important, social-relational implications. ${ }^{9}$

Positive sanctions supporting social-relational norms are even harder to identify, since they reach even further into the terra incognita of Maohi psychology. I do, however, have a few impressionistic notions about the employment and efficacy of some of the more obvious ones. Verbal praise was frequently utilized, but I have the impression that in the situations in which it was most often uttered-that is, in extolling chiefs-it had reached a point of such stylized adulation that only the omission of it was seriously heeded. Such a word as tavaimanino, flattery (literally, smooth speech [LMS Dictionary]) indicates a general awareness of this circumstance, and this is confirmed by one of the "Precepts of Tetunae": "E ara i te reo aeae o te faaahaua ia oe, o te matamehai te reira o te fa'ahemara'a ia oe. Beware of the soft-voiced flatterer. Flattery is the commencement of deception." (Handy 1930:41) 
Ordinarily, it appears, in conforming to social-relational norms the Maohis were encouraged by anticipation of rewards more tangible than verbal praise-rewards in the form of objects, or of more substantial services such as labor and martial support. Yet, verbal praise and not tangible prizes were the more usual rewards for victory in competitive sports. Most positions in Maohi society (and the rewards for behaving properly in them) were ascribed by birth or age or sex, or a combination of these; but there were, as we shall see, many that could be achieved through effort and skills-physical, mental, and social-relational. Achieved positions of social influence-that is control over people's services-were usually attained by making objects and services available to them; and maintenance of that control depended, ultimately, on continuation of such outlays. In other words, while some individuals were able to maintain desired relations with others by use of negative sanctions, including physical force and publicly applied censure, others had to depend upon positive sanctions, in the form of objects and services, to maintain relations desired by themselves.

It is my impression that supernatural sanctions operated mainly in the negative sense noted above. I can find little evidence of belief that if one behaved properly one would be rewarded by some spirit or other. Rather, the common assumption seems to have been that if one behaved improperly (and this mainly with respect to relations with spirits) one would be punished by spirits.

As for internalized sanctions of a positive kind, I have come across no evidence, aphoristic or otherwise, embodying such sentiments as a job worth doing at all is worth doing well, or satisfaction in a job well done, or satisfaction from service is its own reward. I do not suggest that the Maohis did not experience such satisfactions from conformance to social-relational norms, but they apparently did not find it necessary to announce such satisfactions in verbal form. 


\section{Chapter 15 SEX AND AGE}

\section{MALENESS AND FEMALENESS}

In general the Maohis conceived of te huru tane ('human maleness') and te huru vahine ('human femaleness') in terms of sharply contrasting characteristics, both anatomical-physiological and behavioral. Social rewards in the form of approbation, as well as more tangible benefits, accrued to persons heavily endowed with certain aspects of this maleness or femaleness. Yet, a high degree of institutionalized tolerance was accorded anatomical males who for one reason or another opted for female behavioral roles-that is, the previously described mahu.

However, we are faced with a problem in interpretation: in reconstructing Maohi concepts of maleness and femaleness, whose opinions are to be invoked? In all likelihood, for example, young maidens' criteria for perfect maleness differed in some respects from those of mature men, and perhaps from those of mature women as well. In fact, differences of this kind were displayed in high relief in stories of former times: for example, equally praiseworthy, it seems, were heroic demigods of huge size and harsh insensitive manners, and diffident youths of moderate size and gentle, considerate conduct. Here we have not only the intrinsic difficulty of "role separation" but also the circumstance that Maohi society was complex and heterogeneous in this as in other respects. Nevertheless, an attempt will be made to present some evidence about human maleness and femaleness, as distinct from other Maohi social roles.

In terms of body anatomy the typical as well as the ideal male adult was taller and larger-limbed than the female. He was also more muscular, or at least physically stronger; large, prominent musculature was of itself not especially valued in males, particularly if it tended to knottiness. Females were praised for their soft, regular features, but for males also it was deemed appropriate to be smooth and rounded in body contours. And as already reported, the attribute of portliness was esteemed in both sexes.

A full head of hair was deemed desirable for both males and females. Other anatomical features favored in females were tapering fingers and a flat, wide nose. I described how nurses of infant girls encouraged these 
developments by manipulation; but whether this served to enhance the subjects' basic femaleness, or should be regarded merely as supplementary cosmetic conditioning, is, for reasons stated earlier, impossible to decide. This can be said also for the practice of flattening an infant male's occiput and molding his cranium into a peak.

The sources provide little information about how the Maohis conceived of sex differences in terms of the more common body attitudes or motor habits. It seems likely from present-day Tahitian custom, that females were conditioned to sit and squat with knees together, in a manner different from males, and the sleeping posture may have differed too. But there is nothing to indicate that females were expected, or taught, distinctive ways of walking, running, swimming, and so forth-except that males were probably expected to exercise more speed and endurance in such movements. There is no evidence of sex differences in the manner of chopping, cutting, throwing, and paddling, although males were undoubtedly expected to be better in such actions, both through greater basic strength and through practice. In connection with carrying, however, the distinction was quite clear-cut. There was perhaps no clearer mark of a male's maleness than his ability to carry huge bunches of wild plantains down long and steep descents from their mountain groves. These and other heavy burdens males characteristically balanced on their shoulders, while females carried their typically lighter loads by arm and hand.

As with the rest of humanity, Maohi males' voices were undoubtedly pitched lower than females', but there is nothing to suggest that the Maohis considered this attribute to be a significant mark of sexual dichotomy.

By inference, from sex-linked differences in the conventionalized expressive behavior patterns I label "emotions," it would appear that females were attributed with stronger and more sensitive "internal" reactions to felicity and tragedy than were males. Maohi males were much freer with their tears and raptures than were the stolid European visitors, but they rarely were so demonstrative as Maohi females. Men, for example, sometimes gashed themselves in a show of overpowering "grief" (Henry 1928:579-580), but with women the shark's-tooth immolation tool was a common accessory. In Maohi tales, fainting-usually in reaction to tragedy-is also more typical of women than of men; and in such stories it is more often women than men who display forgiveness, compassion, and similar signs of "tender-heartedness."

However, Maohi males were provided with more violent and picturesque conventions for expressing "anger" and "rage" than were the females-particularly in the form of challenges and insults hurled in connection with warfare; and one cannot ignore the fact that most of the killing of other humans, along with other ravages accompanying hostilities or reli- 
gious ceremonies, was conventionally carried out by males. If, however, the rivalry was in the form of a sporting event, male combatants were described as having been good-natured whatever the outcome-except for wrestling matches between members of separate tribes, which often ended in pitched battles. Female rivals characteristically, and presumably conventionally, lost with what Europeans would call very bad grace. ${ }^{2}$

It is next to impossible to generalize about Maohi courage. Some European observers found the Maohis sorely wanting in what Westerners usually signify by the term, but the matter is not quite so simple as might appear. The kinds of situations provoking fear cannot have been altogether like those producing what Europeans understand as fear. To a European, running away from battle-which Maohis often did-appeared timorous and "unmanly," to say the least. On the other hand, perhaps few Europeans would have had the courage to scale cliffs or swim in murky depths or brave high seas in fragile canoes or converse with spirits-all as everyday matters. This is not to say that European-style battlefield courage was not esteemed by the Maohis; it not only was, but it won high rewards for those who displayed it. Yet a man without such courage appears not to have been considered less of a male.

As for Maohi women, they were not expected to scale cliffs, or fish in the deeper waters, or fight battles (although some of them did, with great ferocity $^{3}$ ); but they did accompany their men on difficult treks overland or on perilous ocean voyages, and there is no indication that they were permitted conventionally any more display of fear than were males. ${ }^{4}$

Sexual differences in stoicism are only slightly less difficult to assess. From one account (Morrison 1935:221), previously quoted, girls reacted to tattooing with more fortitude than did boys, but suggestive as this is it does not warrant a general statement to the effect that stoicism regarding physical pain was considered by the Maohis to be more characteristic of females than of males. And as regards Maohi stoicism in the face of life's more psychic hardships, this is a question I cannot even adequately formulate, much less answer.

I am on surer ground when attempting to generalize about malenessfemaleness in regard to sexual passion itself. As the reader will recall, Maohis in general appear to have considered it true and appropriate that both males and females be endowed with strong sexual appetites. It was considered somewhat more fitting that males exercise the initiative in sexual encounters, but during the encounters themselves it was neither anticipated nor preferred that the female be any less active than the male.

With respect to male or female superiority in "intelligence," the following should be recalled. Perhaps the most highly valued kind of knowledge consisted of prayers, chants, and socially important genealogies; such know- 
ledge was usually acquired by rote memory training, although some Maohis were believed to have acquired it by "infusion"-by breathing in the expiring breath of a dying savant. In any case, most such training and transfusing involved males; in fact, some of the more esoteric bits of knowledge were probably deliberately concealed from females.

The most highly valued kind of information was believed to have come not from humans themselves but from spirits communicating through humans. Some mediums for this information were females, but most were males. And so it was with most other kinds of highly valued knowledge and information-including craft specialties, therapeutics, seamanship, and statecraft-most of which were the concern mainly of men. This is not to imply that women were not knowledgeable or well informed about a variety of things (including political relations), but what they usually knew counted for less, explicitly, in Maohi terms.

But what about those other elements of the European-defined attribute of intelligence, such as general analytical ability and problem solving? Did such aptitudes count for much among the Maohis; and if so how were they considered to be distributed between the sexes?

The most suggestive Maohi words I can find with direct bearing on these elements are the following from the LMS Dictionary:

mana'o, thought, idea, meaning, conception; to think, muse, reflect.

feruri, to ponder, reason, muse, consult.

pa'ari, wisdom, knowledge, skill, cunning; mature, old, ripe, hard.

'atama, wisdom, intelligence; an intelligent person.

hōhonu, deep, profound.

Compare these with their opposites:

matapō, blind, also ignorant.

$m a^{\prime} a m a^{\prime} a$, a fool, an idiot; also a vain thoughtless person.

The dual meanings of $p a^{\prime} a r i-d u a l$, that is, in the European sense-indicate that this attribute increased with age and experience. Other words suggest some acknowledgment by Maohis of the fact that individuals differed considerably in their capacities for everyday problem solving, quite apart from their age and perhaps apart from their sex as well. In any case, there is only scattered evidence that such aptitudes were highly regarded, so we are left with the proposition that no matter how intelligent Maohi females may have been vis à vis males, the uses they conventionally made of their intelligence counted for less. In this connection, in the legend of the discovery of fire this great invention was credited to the joint ingenuity of a man and his wife (Henry 1928:427ff).

The attribute-or contrasting pair of attributes-defined by $r a^{\prime} a / m o ' a-$ 
noa, which I have translated (inadequately perhaps, but conventionally) as sacred/secular, was of far greater importance in differentiating males from females than was intelligence. Recapitulating briefly, $r a^{\prime} a / m o^{\prime} a$ applied to spirits and everything in association with spirits, that is, images, marae, priests formally engaging in worship; noa applied to entities lacking $r a^{\prime} a / m o^{\prime} a$. Ra'a/mo'a was dangerous to persons in a state of noa; conversely, persons in a state of noa impaired $r a^{\prime} a / m o^{\prime} a$. Generally speaking, in everyday life humans were normally noa, but most males could by ritual means become $r a^{\prime} a / m o^{\prime} a$, temporarily, in order to associate with spirits safely and effectively. Most females on the other hand (and male domestics of females) were always noa, never permitted direct association with beings or things or places that were $r a^{\prime} a / m o^{\prime} a$.

By what reasoning did the Maohis come to ascribe, or to rationalize, this kind of difference between male and female? The primary sources do not provide explicit and direct answers to this question. It is tempting to refer to parallels in other Polynesian societies, where some at least of the ritual restrictions imposed upon women were explained as due to the magically contaminating effects of their menstrual flows. That may indeed have been an original "cause" for the Maohi attitude as well, but there is no direct evidence that such an explanation persisted into the eras under study. Also, the Maohis of those eras seem to have been quite casual about the process of menstruation.

One might also seek functional explanations in other Maohi beliefs and practices-for example, the belief that most deities were males, the fact that most Titles devolved upon males-but the causal sequence might well be reversed; and hence we must content ourselves with noting the contrast and with describing, if not its cause, then its ramifications.

Directly connected with, although not necessarily derived from, females' attribute of noa was the general restriction on their ritual activities: as previously noted, except for very rare circumstances they were not permitted entry into public marae nor contact with the paraphernalia of worship. Presumably, they had access to their so-called family marae, and they joined in worshipping family tutelars. Scattered throughout the sources are references to women having their own marae, but no details about the location or constitution of women's cults. Insofar as religious activities were public and large-scale, Maohi females were excluded from them. ${ }^{5}$

The ra'a/mo'a-noa contrast may also have been responsible for the Maohis' rules of sex segregation in activities relating to food-although again the causal sequence may have been the other way around. It will be recalled that men and women usually ate separately. The only women excepted from this rule-and that only occasionally-were those holding very high-ranking kin-congregation Titles (Turnbull 1813:338). ${ }^{6}$ 
Men could eat food prepared by women, but women were denied food prepared by males-except by women's own male domestics, who were themselves ineligible for sacred activities. These restrictions could be interpreted as having been in the interests of women, as devices to protect them from the dangerous contagion of males' potential sacredness; but the specific food restrictions-pork, dog flesh, certain choice fish-imposed on females look suspiciously like male oppressiveness, however they may have been rationalized. In this connection, I have come across no assertion that females were explicitly forbidden to partake of kava, but it was evidently drunk mainly by males-to such an extent, moreover, that later English visitors were led to surprised comment when they observed women imbibing it (Morrison 1935:210).

The male-female distinction shows up very clearly, for obviously more practical reasons, in many productive activities. As previously noted, some activities were carried out only by males; these included pelagic fishing, the collection of mountain plantain, ${ }^{7}$ house building (and, of course, temple construction), canoe making, and pig hunting. Warfare also was the domain of males, but occasionally some females took part. The sources are vague about the division of labor in gardening, but it seems reasonable to assume that most heavy clearing was the work of males. Fishing by females was confined mainly to collecting molluscs, crustaceans, and fry in shallow waters, but there is nothing to indicate that a woman could not fish from a canoe, or that a man was prohibited from picking up molluscs in the shallows. Making sennit was conventionally the work of males, and making mats and bark cloth that of females-although men (and even very important men) occasionally joined in the manufacture of bark cloth when large quantities were required.

In other words, the Maohis appear to have been pragmatists with regard to most of their productive activities, adjusting their work conventions to the physical capabilities of the workers rather than to any arbitrary and inflexible notions of what individuals should do in terms of their sex.

"Natural capability" (if that is the right term) shows up in distinctions between some male and female diversions-for example, in the mock combat and foot races of males. In connection with dancing, many of the distinctive movements assigned respectively to males and to females were imitative of each sex's conventionalized body movements in copulation. But in diversions, such as traveling, swimming, and surfing, in which physical differences were not crucial, both males and females took part. The goddess Hina, for example, was a great traveler, sometimes going alone and sometimes accompanying her brother, Ru (Henry 1928:463, 459).

As elsewhere in the world, the male-female contrast was conventionally expressed by differences in attire, in coiffure, in body ornamentation, and in tattoo. 
Having described how the Maohis conceived of the contrasting attributes of maleness-femaleness, I will summarize how they conceptualized the social relations between persons thus contrasted. Much interaction among Maohis took place only (or mainly) between members of the same sex, as for example eating, pelagic fishing, house building, fighting, public worship, and mat and tapa manufacturing. In addition there were some other kinds of activity, including certain forms of singing and dancing, which conventionally required interaction between males and females. Females appear to have been more skilled in the practice of rumirumi (body massage), and for the most part their willing patients seem to have been males. Courtship and sexual intercourse was, of course, mainly heterosexual, but, as I have pointed out in chapter 11, some homosexuality did take place between males, and with little or no show of furtiveness.

Beyond these kinds of interaction involving one sex exclusively, or both sexes preferably, there were many others wherein sexual roles were less crucial. Undoubtedly, most Maohis spent much of their lives in company which included members of the opposite sex: working, resting, traveling, conversing, celebrating, mourning, and so forth. Unfortunately for our purposes, however, there is very little information available about these commonplace, everyday events of Maohi life. What can be gleaned may be summarized in a "dimensional" paradigm as follows:

Terminology. Tane-vahine served both for address and reference: generally, as terms for human (and spirit) maleness and femaleness, and also specifically, for husband and wife. (But, as we shall see, there were some other terms also used for "spouse.") As for personal names, I have already noted that some were applied only to males, others only to females (usually these included names identified with gods, which were either male or female). In this connection, I can discover no instance of the custom of $p i$ having operated with respect to any woman's name.

Time. Data on this aspect of any social relationship, at least for purposes of Western-oriented description, should ideally be expressed in quantitative terms, with respect to the frequency and the duration of interaction episodes. (That such quantities were not necessarily significant criteria for the Maohis themselves, has already been indicated.) Needless to say the worthy sailor and missioner observers engaged no more in clocking or counting interactions than did the Maohi moralists or storytellers, and hence with regard to this dimension of male-female relations I can deal only in impressionistic generalities. One generality is that conventions regarding individual's interactions with members of the opposite sex varied, quantitatively, with "age."

Space. It is probably safe to say that in most interaction contexts it was conventional for persons of opposite sex, whatever their age, to remain at 
greater distances from each other than was the case between persons of the same sex. Another pertinent Maohi spatial convention was the mua-muri (front-behind) contrast mentioned earlier; in many regularized situations involving male and female participants the former usually occupied places "in front" and the latter "behind." I ni'a-i raro (on top-underneath) was another figurative convention for contrasting male and female, with respect to married couples at least. In Henry's account of nuptial rites the groom's party was called papa-i-ni'a (upper rock), and that of the bride papa-i raro (lower rock) (Henry 1928:282). This was a reference perhaps to a couple's positions in sexual intercourse, and to the cosmogonic identification of the original "husband" and "wife" created by Ta'aroa, who were known as Great Foundation Rock and Stratum Rock, respectively. (See chap. 3, this work; and Roussier 1928:191)

Governance. Maohi norms undoubtedly placed authority-that is, effective decision making - mainly in the hands of males, but a careful reading of the sources leaves one with the impression that many Maohi women were in actuality ("historically," in Western terms) anything but a passive, deferential, submissive lot: certainly not in domestic matters and often not in larger "public" affairs either. Backing up males' decisions were the sanctions of ideology, precedent, and (usually) greater coercive strength, but women also possessed sanctions, including sharp tongues, considerable freedom of movement, and, often, the physical strength and will to strike back.

According to one observer, "We noted many strange customs during the time of our stay which must make their [Maohis'] lives pretty uncomfortable; especially for the women, whom they treat with disdain" (Corney 1915:471). But the only documentation supplied by Corney was the eating segregation, which probably had little or nothing to do with "disdain."

One practice that may have led some observers to infer that females were generally disdained was the control some fathers (or other male guardians) exercised over their daughters' sexual services (or husbands over those of their wives), proffering them to the Western visitors in return for tangible goods. Episodes of this nature undoubtedly occurred, but one cannot rule out the possibility that the females in question were themselves eager parties to the exchange. (A similar interpretation is possible in the conventional wife-lending exchange that constituted one aspect of "hospitality," or one component of the taiō, bond-friendship, relationship between men.) Another factor in such episodes was the circumstance that sexual services were not themselves accorded less value, relative to other goods, as they are in most Western societies.

Again, as in most other social-relational matters, the fact of rank served to color interactions between males and females. Some women holding or transmitting high-ranking kin-congregation Titles, entered ag- 
gressively into political maneuvers and were laws unto themselves, as I shall describe in other contexts. Some of these women kept their own courts and were more active influences than were their husbands (or brothers or sons or nephews) in keeping alive the society's pervasive dynastic rivalries-although they themselves rarely occupied the Titles of highest social rank.

Transaction. In most transactions between males and females the principals were acting in more specific roles as lovers, spouses, parent-child, or other kin relationship, so that the general male or female component of the interchange eludes identification. However, it is my impression that in most such transactions the goods derived from males were likely to be in the form of objects while those from females were services of one kind or another. Needless to say, no such general proposition is to be found among the Maohis' own explicit norms or suppositions.

Emotion. Although in relation to males, females may have eaten and worshipped separately, sat "behind," been overruled or even not consulted in many decisions, and been forced to yield on occasion to males' superior physical strength, there is little to indicate, differences in titular rank aside, that females conducted themselves with any marked show of respect toward males as males; nor can I discover any evidence of norms requiring females to behave deferentially to males qua males. Moreover, although some degree of modesty obtained between the sexes with respect to exposure of genitalia, few or no constraints were imposed on male-female verbal interchange. There is not any evidence for believing that either sex was expected to curb "anger," or was licensed to any one-sided display of it, in interaction with the other.

The relations in general between Maohi males and females, both in conceptualization and in historical actuality, may not have been so idyllic as J. Forster eulogized them in the statement reproduced below, but he was probably closer to the mark than the previously quoted Corney, who saw women's lot as being held only in disdain:

In O-Taheitee, and its neighbourhood, the women are possessed of a delicate organization, a sprightly turn of mind, a lively, fanciful imagination, a wonderful quickness of parts and sensibility, a sweetness of temper, and a desire to please; all which, when found connected with primitive simplicity of manners, when accompanied with a charming frankness, a beautifully proportioned shape, and irresistible smile, and eyes full of sweetness and sparkling with fire, contribute to captivate the hearts of their men, and to secure to them a just and moderate influence in domestic and even public affairs. We find the women esteemed at O-Taheitee, and its neighbourhood; they mix in all societies, and are allowed to converse freely with every body without restriction, which enables them to cultivate their minds, and to acquire that polish, which afterwards contributes to improve the manners of their young men; for, as it is one of the chief points of female education, in these happy isles, to learn the great art to please, they are instructed in all the means of gaining 
the affection of the males, of studying every winning art, and of habituating themselves to that sweetness of temper which never fails to merit the return of attachment, of friendship and love. Their frequent songs, their dances, their innocent laughter, and humorous mirth, all conspire to make the most lasting impressions upon the youths of the other sex, and to cement an union which is dissolved only by death. (1778:422)

From all the foregoing we may conclude that the Maohis, like most of mankind, valued males more highly than females: for example, males enjoyed more intimate relations with deities, engaged in more prestigious activities, were subject to fewer food restrictions, occupied higher-ranking Titles, and were allowed to survive at birth more frequently than females.

Several of the sources attest to this sex disparity in infanticide.

It appears, that a far greater number of females than males fall a victim to this national depravity. This may be imputed to two causes: in the first place, it has been invariably so practised by their ancestors; and secondly, the greater difficulty and restrictions which are required in bringing up a female than a male. (Turnbull 1813:363)

In the perpetration of the unnatural crime of infanticide, boys were more frequently spared than female children, solely with a view to their becoming warriors. In all our schools, we were surprised at the disproportion between the boys and the girls that attended, and at the small number of women in the adult population; and on inquiring the cause, were invariably told that more girls than boys were destroyed, because they would, if spared, be comparatively useless in war. (Ellis 1829:II, 495-496)

Turnbull's assertion about the greater difficulties required in bringing up a female, referred mainly to those derived from food taboos, which, it will be recalled, involved not only separate eating but in some cases even separate production and preparation. As implied earlier, we do not know how far down the class scale these taboos obtained, but they were undoubtedly applicable at the top. Gunson proposed that they were more or less minimal: "in the Tahitian family, only the mother could gather food for the daughters and this labour could not commence until after midday" (1964:58). The Reverend James Elder, who was the missionary surgeon at Tahiti, stated that the rearing of a female child often put an end to the mother's social life because of the "inexpressible burden" placed upon her. This, he believed, explained the high rate of female infanticide.

There was not any temptation to destroy a Male Child, as the father could provide him with food. There was an exception to this, rigid, and inhuman Custom, Some few Men, consented or were compelled, to be degraded, to provide food for such females as were of the Royal Family, but this was the only exception. (Elder to Waugh, Australian Letters 10 March 1824, LMS Archives)

The statement about "degraded" men referred to the males who served as domestics for ari' $i$ women and who were thereby rendered noa in terms of religious ritual. 
In spite of the above, however, females were in no sense of the word regarded as "chattels"; in many instances they, or their sexual, reproductive, and domestic services, were deliberately "circulated" more often than males, but one has the impression that most Maohi women enjoyed a large amount of freedom, both in choice of mate and in license to disengage from an onerous marriage. In this connection, the LMS Dictionary contains words which may be glossed as 'rape', but I can find no evidence of its widespread practice: 'u'umi, to strangle; to force a woman against her will, stopping her mouth; mäfera, to take advantage of a person of the other sex when asleep.

This summary of Maohi beliefs and rules regarding male-female attributes, and relations between males and females, would be incomplete without recalling the ambiguous role categories of mahu and of females' male domestics. The former were outright and presumably permanent transvestites in nearly all behavioral respects. The latter may have included some true mahu, as well as some individuals only temporarily in the domestic employ of highly placed women, and as such too noa for religious activities but otherwise dressing and acting like ordinary males; the sources are somewhat unclear on this point. In any case, the very existence in Maohi society of these sexually ambiguous roles, and of the seeming tolerance and even respect for individuals occupying them, is a structural feature to be noted and to be looked for in other sets of social relationships.

\section{AGE}

In attempting to reconstruct Maohi concepts regarding the attributes associated with aging, I face the same difficulty met when generalizing about maleness-femaleness: namely, whose opinions are to be invoked? Presumably not all old people looked upon themselves as doddering nuisances, and not all youths considered themselves to be foolhardy irresponsibles; but widely voiced stereotypes of this kind did undoubtedly color many self-views.

As previously noted, the Maohis did not measure the human life span in terms of years or other cyclic periods. They undoubtedly gauged an individual's aging by means of innumerable maturational changes, both anatomical and behavioral, most of which seem to have occurred quite gradually. For females, even so delicate a sign of maturation as the onset of menstruation does not appear to have elicited special social recognition, although the appearance of pubic hair was accepted as readiness for reproduction:

When we were the second time at $O$-Raiedea, the chief of $O$-Tahà, called Bobà, came frequently to visit us; one day being on board, he saw his sisters coming towards the ship in a canoe, and pointing to his younger sister, desired me as soon as she came on deck, to say to her, Veheina-poowa [vahine pua ${ }^{8}$; I did so, not knowing what would be the consequence, and her elder sister immediately 
lifted up the garments of the younger, shewing that she had the marks of puberty. When she had done this two or three times, she refused to go through the same ceremony again. I then enquired more carefully into the meaning of this transaction, and learnt, that in these isles, it is a kind of reproach, or want of dignity not to be of age and to be destitute of the marks of puberty. As soon as they appear, the young women are obliged to undergo a very painful operation, viz. to have large arched stripes punctured on their buttocks: these curious marks are reputed honourable, and it is thought a mark of pre-eminence to be capable of bearing children. If therefore a man should reproach the person with the deficiency of these marks, she cannot in honour avoid refuting it by ocular demonstration. The origin of these strange customs, it was not in my power to investigate. I contented myself therefore with collecting and recording the fact. (J. Forster 1778:433-434)

In the case of males, supercision and most tattooing did take place after the early years of childhood and before full attainment of physical maturity, but neither set of operations was precisely timed to coincide with any visible or conceptualized point in physical maturation. As for the rites of āmo'a, head freeing, these began during infancy but were not completed until marriage in some instances; and in any case, the various episodes of progressive head freeing were not timed to coincide with, or to mark off, socially recognized stages of the physical life cycle, although they did of course constitute steps in a ritual progression, whose meaning we may not have fully penetrated.

One obvious source of information about Maohi age classification consists of the following definitions recorded in the LMS Dictionary:

'aīu, ['ai, to eat, and $\bar{u}$, milk] a sucking child; an affectionate term for a young person.

tama, a child, male or female.

taure'are' $a$, the young, healthy, and vigorous of the people.

pa'ari, mature, old, ripe, hard; wise, knowing, skillful, cunning.

ru'au, old, stricken in years; an old man or woman.

'Aiū appears to be the fairly unambiguous term for a definitely recognized stage of life, as does ru'au. In present-day Tahitian usage tamari'ira'a, taure'are'a, and pa'arira'a can be translated 'childhood', 'youth', and 'maturity', respectively, and it is tempting to assume that these words carried those same successive life-stage meanings two centuries ago, but the sources contain no positive evidence that they did so. The only concrete verbal evidence I can find bearing on this question is a textual passage concerning a physical struggle between the God Atea and his son Tane; when Tane challenged Atea the latter replied: E Tane e, e hia Atea ia 'oe? (O Tane, can Atea fall by thee?) E tama'iti Tane, e matuatua ovau. (Thou [Tane] art but a lad, but I, Atea, am a vigorous elder.) (Henry 1928:455, italics added)

With or without lexical confirmation, it is my impression that the Maohis 
did divide the life span, conceptually, into five stages, which we can call infancy, childhood, youth, maturity, and old age.

\section{Infancy}

The prevalence of infanticide among the Maohis is well established, but, as I have shown, those infants permitted to live were objects of careful nurturance and physical conditioning, warm familial affection, and ritual attention. Even the hypercritical missionaries recorded few instances of outright neglect.

I have already described the pains taken by parents or nurses to mold an infant's head, nose, and fingers into desirable shapes-for reasons of cosmetics and general physical welfare. Whatever may have been their indifference to human life in general, and however superficial may have been the "emotions" so expressed, most Maohis appear to have taken delight in fondling babies. And the ritual attention accorded infants has been noted in connection with restraints surrounding some young Maohis prior to completion of their head-freeing rites. In this connection, as will be described later, kin-congregation Titles devolved upon successors shortly after their birth, and even though the actual authority inherent in such Titles remained for some time with the former incumbents, the ritual prerogatives associated with them were transferred on that occasion to the new Titleholder.

\section{Childhood}

By literal definition Maohi infancy (breast-feeding) would have ended when the child was weaned, but we have no way of knowing when weaning took place or how it was brought about. In any case, once they had become independent of the breast and able to move about, Maohi children appear to have been left much to their own devices. Perhaps this occurred in many instances because of parental preoccupation with a new baby, but whatever the reason, children past infancy were by some accounts wide-ranging little creatures with minds, wills, and diversions of their own. Exceptions were successors to high-ranking kin-congregation Titles (and in some known instances their siblings); such children were subject to many restraints on their physical movements.

As I noted earlier, some writers described Maohi children as having been utterly undisciplined-the latter due mainly to the circumstance of early kin-Title transfer; but such an explanation could apply only to bearers of kin-Titles of relatively great social consequence. As for Maohi children having been unconstrained, there is ample evidence that much of the time most of them were left free to roam about and play (including sexual play), but some places (such as marae) and some occasions (such as council meetings) were clearly out-of-bounds to most of them. Also, though none of the 
sources specifically described such practices, I am quite sure that some of the energies of most children must have gone into acquiring, through imitation and practice if not through specific instruction, the fundamentals of many work skills. (That is to say, I simply cannot accept the proposition that in a subsistence economy like this one, children took no part in subsistence activities. And it is reasonably certain that older siblings were required to look after younger ones, especially when new babies arrived to engross their mothers' attentions.)

In terms of their movements, it will be recalled that many Maohi children were transferred from their natal families and attached to other families, for varying periods of time and degrees of jural finality; but this does not mean that life in the new setting was necessarily any different for the child.

With no explicit Maohi statements to draw upon concerning the attributes of childhood, one can only make inferences from the kinds of evidence summarized above, and that is not easy to do. From the degree of freedom allowed children one might infer that their elders regarded them not as helpless little pathetics wholly dependent upon others for welfare and guidance, but as competent though incomplete humans who would in due course, and by one means or another, manage to become complete. On the other hand, the fact that children were generally classed with females in matters concerning religious ritual might imply a social appraisal not only of "incompleteness" but of a more basic inconsequentially as well-against which, however, is the conceptualization of their greater sacredness as implied in the necessity for head freeing.

\section{Youth $^{9}$}

For girls the transition from childhood to young womanhood was fairly sharply defined. To recall a statement of Morrison's,

The young females are more remarkable for bearing [tattooing] than the Males tho they cannot suffer more then one side to be done at a time and the other may remain perhaps for a Twelvemonth after before it is finishd, till which time they never Conceive themselves Company for Weomen-being only Counted as Children till they have their Tattowing done (Morrison 1935:221).

As I recorded earlier, estimates varied concerning the age at which a girl's tattooing was begun, but J. Forster was likely correct in his statement already quoted, that the operation was started "... as soon as they [i.e., "the marks of puberty"-presumably the appearance of pubic hair] appear." In this connection one also recalls Morrison's observation that "in these isles, it is a kind of reproach, or want of dignity not to be of age, and to be destitute of the marks of puberty" (1935:433-34).

For boys the transition from childhood to youth also coincided with tattooing and with supercision, but the tattooing process was typically spread 
over a considerable period, and neither operation seems to have been synchronized directly with the appearance of any physical "marks of puberty." (It should be recalled that Maohi norms did not require young people to postpone sexual activity until after tattooing or tattooing and supercision. Exceptions occurred in the case of girls of certain Title-holding families, whose sexual activity was proscribed until marriage, which presumably occurred some time after tattooing in most instances.)

The "public reproach" reported by Morrison to have been leveled at the untattooed or unsupercised male presumably referred to males who were otherwise considered to be past childhood-however "otherwise" may have been defined.

The process of fattening (ha'apori), and of the usually attendant skin bleaching, was as already noted a regimen practiced by persons of all ages, but it was particularly characteristic of youth, when it served, among other things, to enhance the subjects' sexual attractiveness. ${ }^{10}$

In fact, all three of these practices-tattooing, supercision, fattening-suggest that the Maohis considered heightened sexual activity to be prime attributes of youth: qualities not only inevitable but appropriate and desirable.

Youth was also considered to be the ideal time for participating in other diversions as well-singing, dancing, athletic contests, touring, adventuring; in fact the literal meaning of taure'are'a (which the LMS Dictionary defines as the young, healthy, and vigorous of the people) seems to be tau, season; re'are' $a$, joy, gayety, mirth.

On the other hand there are numerous indications that young people were expected to work, and to work hard, although many of the tasks they engaged in, such as collecting wild plantains or bird feathers, group seining, and bark-cloth making, were conducted more in the mood of adventure and congenial sociability than of onerous toil. The legend of Punaauia contains an episode bearing directly on the segregation of work groups made up of young unmarried women and married matrons. ${ }^{11}$ The story concerns the tribulations of a beautiful young Tahitian "princess," Pereitai, who was sent to Ra'iatea to forget an unhappy love affair-that is, one with a commoner, who was slain for his presumptiveness in courting an ari'i maiden. At Ra'iatea, Pereitai was consoled somewhat by marriage to a young "high chief" and by giving birth to a daughter. Miss Henry's romantic and perhaps somewhat too free translation continues the story:

When the child was about six months old, the season for beating out tapa cloth arrived and all the women of the land were busy in the pleasant work. It was the custom for matrons to form groups for such work apart from the young maids, and the song of the tapa [bark cloth] mallet was everywhere heard in the cool morning hours. The Tahitian princess had not yet joined any of these parties, but one day seeing some young women, who had newly come from a neighboring island, hap- 
pily working in a shady nook by a rippling stream, she decided to get some cloth bark and join them. They were all unmarried girls, and seeing her young like themselves approaching them, they very readily made room for her, and she united with them in work and song; and so moments flew, until they beat out long sheets of beautiful tapa from their tapa boards and spread them out in the sun to dry.

The following morning, leaving her child with her nurse as she had done the day before, Pere-i-tai again went to work with her new and congenial friends. But meanwhile, the child, who had been sleeping, awoke and cried inconsolably, so that the faithful Rohi-vahine, sent Pere-i-tai's brother, Mata'irua-puna to fetch her home, which he did promptly. Pere-i-tai had been informed that her companions were all single girls, but not wishing to break the circle in the morning's work she chose to remain and finish her part with them, intending to retire from their midst gracefully and not return again. During an interval when the mallets ceased to beat and the song had also ended, Pere-i-tai distinctly heard the voice of her brother shouting:

'Pere-i-tai, ua ara o aiu!' (O Pere-i-tai, the child is awake!) Hoping that he might not find her, she kept quiet and soon resumed her work, which would shortly have been finished.

The brother passed different groups of tapa beaters but not seeing his sister, he went on his way, continuing to call, until at last he perceived her in the distance and ran up to her quite unconscious of being indiscreet. As he did so, all the young maidens looked up in astonishment, first at the lad and then at their beautiful companion, who in her confusion was speechless. Mortified in the extreme, Pere-i-tai abandoned her work and the group with whom she had been so happy and went her way shedding tears from chagrin at being thus exposed to the ridicule of strangers, her brother following her astonished at her emotion, and not understanding it.

She went home, quieted her child, and leaving her once more to the care of her nurse she went to Fa'aroa (Long-valley), not far off, and sat weeping upon a great stone at the point called Te-'ora'a-otaha (Digging-of-the-man-of-war-bird), and numerous white spots upon that stone are known to this day as Pere-i-tai's tears. Thither also her brother followed her, and avoiding him she arose and is said to have plunged into a dark hole at the side of the river, which led down to the netherland, where some of her ancestors dwelt. (Henry 1928:604-605)

After a year in the netherland, she and her brother returned to their original home in Tahiti, where her husband and child subsequently joined her to live "happily ever after" (in the inevitable happy-ending style of such Maohi stories), for under no consideration could she be persuaded to return to Ra'iatea, “... where she had met with such humiliation.” (Henry 1928:607, italics added)

This episode provides interesting documentation of the existence of age(or, rather, life-stage) segregated work groups, but it is the only indication that I can find that such segregation was so strict as to move an individual to near-suicidal humiliation at having been discovered working with an inappropriate group; in fact, this aspect of the episode raises intriguing questions for which I can supply no satisfactory answers.

Training in specialized skills may in many instances have begun during childhood, but was probably more characteristic of youth; this might be 
taken to imply that in Maohi ideology educability was a distinguishing attribute of this stage of life.

\section{Maturity}

Marriage undoubtedly constituted some kind of change in most individuals' activities, but it was probably only the first step in a very gradual transition from youth to the next stage of life, which I have labeled maturity. More likely, individuals did not complete the transition until after the birth (and survival) of a child or two, when the undertaking of marriage and the responsibilities of parenthood must have discouraged youthful ways. ${ }^{12}$ Eventually, of course, the inevitable decrease in physical exuberance and in sexual attractiveness would of itself have brought about a retirement from "youthing," but dependent offspring probably hastened the transition.

Females reached a high point in their lives during their youth, when their favors were courted by many males; but most males probably reached their prime only after youth and before old age. I refer here to climaxes in technical skills and social influence, not to focus of ritual attention. The several but related meanings expressed in the word pa'ari testify to the belief that wisdom and knowledge and cunning were in part a function of age-at least until offset by senility.

\section{Old Age}

To Maohis, physical decrepitude was the principal mark of old age; associated with it was the disappearance of most of the more valued attributes, including those entailing respect, authority, and even physical care. Some old people managed to maintain a degree of social influence through continuing success in some profession-priestly, shamanistic, craftwork-or by sheer force of personality; but for most the final stage of life was, by all the evidence I can piece together, a painful anticlimax.

From these and other data I can draw several inferences about how the Maohis conceptualized and actualized social relations between persons in terms of their equivalent or disparate ages.

Terminology. In addition to the terms for life-stage already given, the only Maohi words I know of referring directly to the contrast older-younger were those applied in the case of siblings of the same sex. (See chapter 16.)

Time. Disregarding infancy, when babies of both sexes necessarily spent most of their time with females (i.e., female relatives), during the period of childhood (tamari'ira'a) boys and girls spent many of their waking hours playing in each others' company, and this was presumably regarded by their elders as normal and appropriate. Later, however, during youth 
(taure'are'a), there was a much greater degree of sex segregation. Young men spent most of the daylight hours in the company of each other or of other men; and young women did likewise. Young males and females met together on occasion to dally and dance (work habits did not ordinarily combine both sexes at this stage of life), but it was generally assumed that deliberate encounters between a young man and a young woman could only be for purposes of fornication (I exclude of course encounters between siblings or other "close" relatives on domestic business). Still later in life,

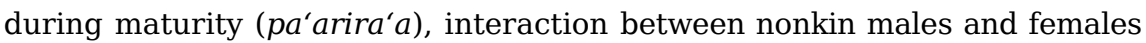
was perhaps even less frequent: daily occupations did not ordinarily bring them together and opportunities for joint, public diversions were exceptional. Finally however, there were apparently no public restraints upon old men and old women spending their declining years gossiping and reminiscing in each others' company, but whether they actually did so is not reported.

Space. Aside from the examples just noted, indicating that coevals tended to congregate more closely than persons of different life stages, I can find little evidence of any general supposition or norm about specific age-determined spatial positioning among interactors. Infants and children were classed with women as muri (behind) in relation to older males as mua (in front), so that this form of positioning had to do with age and sex.

Governance. Rules regarding succession-order to Titles exemplify the general notion that older should take precedence over younger in terms of ritual acts and of the exercise of authority, and this general proposition prevailed not only regarding authority among siblings but probably extended to older members of most groups of coevals. In fact, until senility claimed a person, and made age become more of a liability than an asset, the principle of seniority shaped most social relationships unless overruled by considerations of Titleholding.

Transactions. Within particular social units-families, households, neighborhoods of kinfolk-opinions undoubtedly prevailed to the effect that all members ought to succor the infants and helpless children, and perhaps to some extent even the aged members as well. Otherwise, one can infer from numerous kinds of evidence that transactions between younger persons and those considerably older conformed to a general formula of relatively unskilled services in exchange for objects or more skilled services. I suspect, but have no basis for asserting, that in any such exchange the younger party had the conventional expectation of receiving less than he contributed.

Emotion. Factors of kinship, Title rank, and so forth, served to complicate this matter intricately, but there appear to have been widespread expectations that the very young were to be tolerated affectionately, and the very 
old to be dismissed with disrespect bordering on contempt. I suspect also that children and young persons were expected to behave with some deference to their nonsenile elders, as inferiors to superiors, but I cannot find explicit evidence, linguistic or otherwise, on this point. In fact what impressed (and scandalized) most observers was the unruliness of children, including many instances of disrespect for their parents, but perhaps such behavior did not actually extend to elders in general.

I have already noted several instances of the sanctions that served to reinforce norms for age-linked behavior; these ranged from the "public reproach" leveled at untattooed or unsupercised youths to the death meted out to the lad who interrupted a marae ceremony. And conversely, I will draw attention to the preoccupation of many older persons with "youthfulness," as exemplified among the Arioi, and to the disesteem shown toward the aged because of their decrepitude. Yet, I have found no evidence that individuals were either rewarded or penalized for acquiring and practicing skills normally associated with persons older than themselves. And, in the few stories describing such encounters, there was no action taken one way or the other on the basis of age differences alone to requite youths challenging elders, or vice versa. 


\section{CHAPTER 16 CONSANGUINITY: COMMON-DESCENT UNITS}

\section{COMMON DESCENT}

No constituents of Maohi social structure are more preponderant, and certainly none more baffling, than the kinds of relationships approximating Western concepts of "kinship." The sources contain some data about specific dyadic relationships-for example, "brothers," "sisters," "brother and sister," "parent and child"-but information about relationships of more remote "kinfolk," and about larger aggregates of "kinfolk," remains largely inferential and obscured in the sources by undefined or inconsistent use of such terms as "relation," "family," and "clan." Presumably authoritative (LMS Dictionary) definitions of native terminology do not help to clarify kin relationships. For example:

'abu [apu], the shell of a nut, gourd, or fish; a concave or hollow, as abu rima, hollow of the hand, abu roro or abu upoo, the skull; a fraternity or family, as abu arii, the royal family, abu atua, the race of gods.

fèti' $i$, a family; the relations of a person; to tie or bind; a binding or knot. hiva, a clan, the company in a canoe.

natimo'e, a family or kindred. (Cf. nati, a class, or distinction of men, as nati arii, the class of superior chiefs; moe, sleep; to sleep, also to lie down.

[Hence, people who sleep together(?).]

pirita' $^{\prime}$, a relation by consanguinity, or by affinity.

hui metua, [literally, a set of parents] elder members of the family, parental clan (Henry 1928:184).

Of course, these terms may have had more specific referents which the missioner lexicographers simply did not understand, but these referents now remain beyond discovery. We cannot confidently rely on modern usage in a search for pre-European meanings-particularly with respect to kin relationships, which have been under such powerful alien pressures to 
change. One thing does, however, emerge from the available data, and that is the crucial importance of descent.

The Maohis in general may have been quite casual about sexual intercourse, and unable (or unwilling) to guard against conception during coition, but reproduction was to them a matter of great consequence, and the social ties resulting from it, or modeled upon it, surpassed all others in jural weight. Moreover, the Maohis understood enough about the physiology of reproduction to realize that it required both female and male to produce a child; and parallel with this knowledge was the practice (whenever possible) of according social recognition to ties with and through both a female parent and a male parent, although not necessarily with the child's own (supposed) genitor. In other words, the bilaterality of descent was socially recognized; descent itself, however, was subject in part to social definition.

In the first place, if a child's genetrix did not want it to survive and be a descendant (huä'ai), ${ }^{1}$ she either aborted it or killed it immediately after birth, with or without the consent of its supposed genitor. If the child's supposed genitor did not want it, it was usually within his rights and power to kill it at birth. In some instances the killing of a child was decided upon by kinfolk of either or both parents, and against the wishes of the latter, but the result was the same. Interested third parties occasionally made efforts to prohibit coitus between individuals in order to guard against progeny unwanted for some reason or other; as previously noted, however, during coitus itself the principals appear not to have taken measures to avoid conception. Underlying infanticide, which was a common occurrence among the Maohis, there appears to have been both a proposition regarding descent and a norm regarding parental duty. The proposition which seems to me implicit in these customs is a belief in the "reality" of biological reproduction-that is, something of each parent was believed to have gone into the composition of a child, something of each of what Westerners would call "physical" and "spiritual" (or "mental," or "psychic"). (See chap. 13, section on conception.) The norm associated with this proposition is equally inexplicit, but putting together a number of observations and inferences, particularly with regard to the rationale of infanticide, I think we can discern a moral imperative to the effect that any and every child allowed to survive had some claim, in terms of objects and services, upon its biological parents. The weight accorded these claims varied widely-with respect to the offspring's sex, birth order, class-and occasionally some fathers may have explicitly disavowed such claims; but even the disavowal in a sense constituted acknowledgment of the general validity of the norm. I have come across no instance of a woman refusing to "acknowledge" one of her progeny, although there are legendary accounts of a mother (and a father) discarding an offspring born in the form of a "shapeless 
clod"-which, significantly, survives and becomes a heroic figure (see the legend of Honoura and Maui). I do not of course suggest that all Maohis were conscientious about fulfilling their parental duties, the nature of which will be described later on, but I am now discussing not performance but a norm.

In stating that some fathers may have disavowed their progeny's claims, I refer mainly to the possibility of this having occurred. Acually the only recorded example that I know of is legendary, as set forth in the story of Mo'otuaraha:

There was once a bachelor chief in Papeno'o whose name was Pai-ti'a (Correctjudgment). He went with some of his people into the valley for timber for a canoe. They chopped down a fine tree and prepared it for further work, when evening came and the men dispersed to return to it on the morrow.

It happened that in descending into a ravine on his way home, the chief lost sight of his men, and suddenly he saw across his path a great lizard, of which he had never heard, named Mo'o-tua-raha (Lizard-with-broad-back). It was a monster of the feminine gender, begotten of human beings, and becoming enamored with the chief she charmed him so that he became spellbound and seemed to live long in bliss with a beautiful being, although in reality it was only for an hour before nightfall. When he came to himself, Mo'o-tua-raha was gone. Pai-ti'a went his way bewildered, not remembering his first encounter with the strange creature.

The canoe was completed, and the lizard, living in strict seclusion, gave birth to a son, who became the exact image of Pai-ti'a, whose name she gave him and whom she taught to call father, for she could act and speak like a human being. When he was about fifteen years of age there was a great feast in the land, and the different clans went in procession to present themselves before their chief, mentioning their pedigree. Being taught by his mother what to say, the lad went also, elegantly dressed, wearing a girdle of the smooth, glossy skin from off the under side of his mother, and presented himself, saying,

"I am Pai-ti'a, your son." This caused the chief and all the assembly to look amazed, and the chief replied:

"I have no son. Whence do you come?" The boy said:

"Do you not remember what happened in the valley when you were making a canoe?"

"No," replied the chief. "I have no wife and you are not my son." Then the people exclaimed:

"He must be your son, O our chief; for see how he resembles you!" And what was the man's humiliation when the boy added:

"I am your son by Mo'o-tua-raha, whom you met in the ravine when you were returning home from your work at the canoe."

Light then flashed across the chief's mind, and he almost sank to the ground with mortification at this revelation before all his people, especially the nobility, who prided themselves in their unbroken aristocratic lineage. This blighted the festivity; the chief could not give the son of a lizard a place in his family, nor would his subjects have recognized such as a chief to rule over them. So the poor lad, dejected, returned to his mother and told her all that had happened.

Very soon after this commotion, Pai-ti'a, feeling his humiliation, went away to Tetiaroa, the favorite watering place of the royal family and the poor lizard, hearing of it and still wishing to obtain favor for her son, swam across the ocean to go and plead his cause. But when the chief saw her approaching the reef-bound 
coast of the atoll, horrified, he sent his attendants to kill her where she was; and just as she was grappling the rocks to get up, she received a death blow upon her head with a stone. There she lay, her skeleton remaining long afterwards close against the shore of Tetiaroa.

It is said that descendants of the despised son of Mo'o-tua-raha are still living, although now they cannot well be traced. (Henry 1928:622-623)

There are of course many recorded instances of men denying paternity, but that is a different matter altogether. I cite Morrison to support my own conclusion that a child of unspecified paternity would have been socially disadvantaged in this bilaterally oriented society, no matter how well he was treated by maternal or foster relatives:

... as it is deemd highly reproachful for a Child not to know who his Father is ... when they are Pregnant with a Child of which they know not the true Father, to prevent its being treated with Indignity in its passage through Life (and as it could have no inheritance without a Father) it is no sooner born then some one strangles the little innocent and burys it. (Morrison 1935:234)

Morrison was referring specifically to Ariois, but his conclusion regarding the disability of being "fatherless" was probably applicable generally. In case it may be objected that this conclusion does not accord with the following statement by de Bovis, I point out that the latter was describing performance and not jural principles. Also, de Bovis' statement seems to refer more specifically to the 1830s, by which time the indigenous social structure embodying the jural principles I speak of had greatly changed:

Illegitimate children or those of adulterous unions were never the objects of baneful prejudice, having been welcomed as fully as all others. A husband may have been so jealously enraged by his wife's infidelity as to kill her; nevertheless, once children were born most husbands tended to treat them with care and affection even if they knew them to be not their own. And while one can find exceptions to this tendency, one can also cite cases in which the offspring of notoriously adulterous unions have been treated [by the mother's husband?] with lavish attention. It is fortunate that such was the case; for if a child's "legitimacy" had been viewed as we in our civilization view it, the unbridled sexual license which prevailed among these people would have resulted in an incalculable amount of misfortune and bad feelings. (de Bovis 1909:32)

As we shall see, adoption ( $f a^{\prime} a t a \overline{v a i}$ ) served to invest the adoptee with most of the rights and duties normally accruing to known (in the case of the mother, supposed and acknowledged in the case of the father) biological offspring, but it is clear that the Maohis distinguished between the two, as is expressed in the following: "Eiaha roa 'ia 'mo'e iā 'oe te toto fēti'i ho'e, e tō fēti'i fa'atāvai hia. Do not lose from view your blood relatives, nor your relatives by adoption." (E. Salmon 1937:29)

The gaps in our information about Maohi notions of conception make it impossible to decide whether this reference to "blood relatives" was merely metaphoric or based on an explicit idea that the blood of a fetus was actu- 
ally derived, in whole or in part, from its parents. In any case, the reference to "blood" just cited-whether or not it is metaphoric-prompts me to label such relatives consanguines (in contrast to adopted kin, and to affines). The parallel usage in common, nontechnical English also contains elements of metaphor and of folk-science.)

As we shall see, in general more social weight was accorded patrilateral ties than matrilateral ones, but the Maohis were less extreme than many other peoples in weighting one parental link over the other. In fact, there is evidence for a very widespread belief that all persons related to someone by ties of descent-lineal or collateral-that is, all consanguines, constituted with respect to that person a kind of social category for which the expression te mau féti' $i$ '[the (plural) relations] of such-and-such a person or set of full siblings' may have applied. (Henceforth, descent, son, daughter, and so forth, will stand for socially recognized relations unless specifically qualified by the adjective biological.) But probably never did all or even most of the members of any such category interact as a separate group, or enjoy joint ownership in any particular property, or function in any other way as a unit. Events such as births, marriages, or deaths mobilized numbers of the principals' consanguines (along with affines and nonkin neighbors), and at marriages some consanguines of the bride and some of the groom functioned ad hoc as distinct social units; but there is no information concerning the social boundaries of such units.

The phrase, firifiri'aufau, to trace [aufau] a person's ancestry (LMS Dictionary), ${ }^{2}$ implies a concept of "lines" of consanguines, and this is amply exemplified in genealogies, which constituted such important verbal documents to the Maohis. A passage from the "Precepts of Tetunae" suggests that the verbal root firi may have had a somewhat broader meaning: "Eiaha ho'i tō'oe mata 'ia fāriu 'ē ite 'ati o tō'oe firi'a feti'i. Let not your eyes turn away from the troubles of your 'line of relatives.'" (E. Salmon 1937:29)

Other manifestations of the conceptualization of lineal descent are exemplified in the words

te iho ari'i, which Emory translated "the chiefly line" (Emory, Marae Traditions).

ta'ahiaufau, to treat with contempt any one's ancestry, or fraternity (LMS Dictionary).

titoropa'ahoi, to heap upon a man the various crimes of his ancestors (LMS Dictionary).

Also, the "lines" comprising the incumbents of certain high-ranking kinTitles were symbolized in the form of feather girdles (maro ura and maro tea) - that is, a new lappet was added to the girdle upon the investiture of each new incumbent (Henry 1928:189).

There is also lexical evidence (LMS Dictionary) for conceptualization 
of a kind of social category made up of all persons descended from some particular ancestor (i.e., a cognatic stock):

huia, the suckers of the pia plant [arrowroot]; a parent with his descendants. 'ati, a patronymic prefix pointing out the name of the parent or ancestor with the descendants, as Ati Iuda, the descendants of (their father) Judah.

Other words listed in the LMS Dictionary suggest the conceptualization of segmentary units of consanguines. For example:

aveaveféti' $i$, the several branches of a family.

aveave, the long feelers of the fee[fe'e] or cuttle fish; a tassel or ornament appended to a bow; the tail or train of a gown.

aveaverau, a speech that has many bearings.

pao'aora, applied to a family when the different branches of it are all alive. pao'apohe, a family that becomes extinct in its several branches.

(Assuming these to be compound words, ora [life, health; to live, to be healed] is quite clear, as is pohe [death; to die], but pao'a is puzzling.)

pirifetau, a stranger or alien; an outer branch, not rising out of the proper trunk.

Unfortunately I have not come across any evidence, textual or otherwise, that indicates precisely the kinds of units these terms may have referred to-if indeed they had precise referents, which may not have been the case.

A statement by Handy, based on information received by him from "Queen" Marau, implies that the Maohis distinguished between senior (matahiapo) and cadet (teina) branches of any common-descent unit: "Matahiapo: first born, male or female. Also applied to all representatives of a family stock descended in the line of first-borns. Thus, if I belong to a matahiapo family it means that at least one parent was a first born right back to Taaroa. My first born will carry on the matahiapo. All others are teina." (1930:23.) Handy did not, however, explain what he meant by "family" or "stock," and the ambiguity is increased by his definition of teina: "Teina: younger brother for male, younger sister for female. First cousins of younger rank. I am a matahiapo; all cousins not matahiapo are my teina." (1930:23)

Some confirmation of this kind of segmentation is provided by a traditional account of the structure of Huahine society, which will be reproduced later on, but from these sparse references the distinction seems to have been only between the senior-line segment and all other segments, and not between any two of the latter relative to the birth order of their respective sibling eponyms.

In addition to these meanings of "firstborn" and "younger" (or "later- 
born"), respectively, matahiapo and teina undoubtedly had other referents, and it is reasonable to assume that they may have served to distinguish between senior and cadet segments of any common-descent unit; but it is not at all clear what the composition of such segments was conceived to be. Did a matahiapo segment, for example, consist only of the sons and daughters of a parent who himself (or herself) was the eldest offspring of a line of eldest offspring leading "right back to Ta'aroa?" Or did the term include all offspring of all the offspring of an eponymous eldest sibling, and so on? The first case concerns in part the concept of "lines" noted above; the second case concerns a far more inclusive kind of segment, that is, a cognatic stock.

As with analysis of any society's structure, one can discuss boundaried social units in terms of membership and structure, or one can take a hypothetical individual as a starting point and attempt to describe how he (or she) relates to all other individuals in his social universe. One strategy may be better than the other for particular purposes, but neither is necessarily "truer" to Maohi thought. In connection with consanguinity I believe that the Maohis thought about their relationships in both ways.

I do not know what part (strictly) genealogically defined units or subunits were conceived as playing in Maohi life. Were they groups, whose members interacted periodically and exclusively? Or property-owning units? Or both? Or were they mere conceptual categories of consanguines without further attributions? From the evidence available it is not possible to answer these questions. On the other hand there is ample evidence that the Maohis not only conceptualized but also actually banded together in social units of co-worshippers, consisting of a core of consanguines and their spouses, along with individuals adopted into the units.

\section{KIN-CONGREGATIONS}

When "thinking" in terms of consanguinity most Maohis undoubtedly "related" themselves to numerous specific individuals, to own or distant "father," to some "mother's" own father or some "father's" own mother, and so forth. In addition, many Maohis appear to have conceptualized this aspect of their society in terms of numerous categories of consanguines-including narrow descent "lines" reaching back many generations into the mythical past, and segmented common-descent networks varying widely in span, in genealogical depth, and in size. ${ }^{3}$ Genealogy, remembered or fabricated, provided the framework for these categories, but the thing that did most to make cohesive groups out of any of them was common association with some "family" marae.

As I noted earlier, marae were structures set up "... to receive the gods in a befitting manner" (Henry 1928:429): they were places set 
aside for more or less periodic and formal interaction between humans and spirits. As such it is possible to classify them according to their size, architecture, and spirit affiliation; in line with our present interest it is also possible to classify them according to the kinds of social units that comprised their regular congregations. It was a characteristic feature of Maohi society that nearly every social group of any permanence was at the same time a congregation, with its own tutelar and marae. But the only "social-unit" classification of marae I can discover is that of Henry, who typed them as follows:

Domestic: family, or ancestral [marae tupuna]; social [marae o te va'a mataeina'a]; doctors' [marae tahu'a ra'au]; canoe-builders' [marae tarai va'a?]; fishermen's [marae o te feia tai'a].

Those of public importance: local [marae mataeina'a]; national; international. (1928:119)

I am not at all convinced that this is an exhaustive or accurate classification in terms of Maohi thinking, nor is it entirely intelligible in terms of my analytical notions about Maohi society. That occupational specialists often had marae of their own is fairly certain and wholly comprehensible, but why Henry should label these "domestic" is unclear. Also, it is undoubtedly true that some marae were more "public" or more generally "important" than others, but Henry's sharply drawn distinction between "family or ancestral" and "social" marae is less understandable, as is her distinction between "local" and "national." The case for her "international" type of marae is clearer, as I shall later indicate.

To leave unstated a number of assumptions, to anticipate subject matter that will be discussed later on, and (an ethnographic heresy!) to ignore for the moment Henry's alleged native labels-I find it analytically useful to classify marae according to whether membership in their congregations was based primarily on kinship, or on tribal affiliation, or on cult commitment, or on occupational specialization. (Note the qualifying word primarily, since none of these categories is entirely exclusive.)

I classify under the label of kinship those congregations made up primarily of individuals interrelated by close ties of consanguinity or of affinity. Such congregations ranged in size from nuclear or small composite families occupying single households to populous units comprising several households (along with some close consanguines who for one reason or another resided elsewhere). In this chapter I will be concerned mainly with kinship congregations, but to sharpen the distinctiveness of this category I will characterize the other three.

A tribal marae had for its congregation all the residents of a particular territory, or better, all the subjects of a territorial (i.e., tribal) chief. Usually such a congregation was formed around some one kinship unit, but it con- 
tained some members who had no recognized kinship ties with it or whose membership was based more on their place of residence than on the nature of their kinship tie.

An occupational marae had for its congregation one or more craftsmen who conducted activities there for the specific purpose of achieving success in their particular occupations-fishing, canoe building, healing, and so on. The members of such a congregation were usually neighbors, and in many cases were probably kinsmen, but most of their activities at their marae had to do with pursuit of their occupations.

A cult marae had for its congregation devotees of some god not exclusively associated with any particular kin or tribal unit or with any specific occupation.

\section{Composition}

Focusing on kinship congregations, we see a continuous series of units, exemplifying the continuous developmental process whereby families formed, proliferated, and segmented. During the earlier-that is, developmentally prior-stages of this process the relationship between the kin-congregation and its marae was probably like that described by Henry in connection with the "family, or ancestral" marae (marae tupuna).

In such a marae, the head of the household offered family prayers at sunrise and sunset; there, confession of sins was made, and private petitions to the gods were offered by any member of the family; there, marriage ceremonies were performed; there, prayers were offered for the safe delivery of a woman in childbirth, and the child dedicated to the gods when it came into the world; there, also invocations for the sick and the dying were made. A man went into the front part to offer his prayers and gifts, but a woman offered hers at the back part; she was considered insane if she ventured forward.

When a woman was about to be delivered of her child, a small house was erected for her behind the marae, which was thatched with the maire. (1928:143)

I also quote some other remarks by Henry concerning this type of marae and its congregations (including some puzzling statements about "hereditary names," which I will discuss in the next section):

The family or ancestral temple, called marae tupuna, the god of which was always a family secret, was erected upon every portion of land that a person owned [?]. To the marae were attached the hereditary names of the family, without which they could give no proof of their ownership of the land, so that to this day the memory of this class of marae does not cease to be of importance to the heirs of those families, for it is necessary when dealing with land to state their title name is from the marae named so-and-so, from most of which a few uneven heaps of stones still remain. They have transmitted to memory and to writing, in these later times, their genealogies on both parents' sides, which they carefully conceal from others who might wish to dispute their rights to lands, and wouldbe claimants are put to confusion and shame when they cannot promptly answer these assertions with equally good records. 
Every foot of ground in these islands was owned by some one, and if a person encroached upon a neighbor's land by moving a boundary stone or erecting a marae upon its borders, it was considered a disgraceful way of claiming it. Such an act was called ai-fenua (eating land), and it was seldom attempted because of the odium it would produce.

Children of adoption in a family were made legitimate heirs to land by receiving a name from the marae, which was called the vauvau i'oa (name container), and it was considered an injustice to such children not to have them so admitted into the family. Hence it is that so much stress is laid upon a name in land controversies, and although the natives often give themselves other names, they lay them aside at pleasure, but jealously claim and guard their hereditary names from encroachers. (1928:141-142)

The kind of congregation implied by these remarks would appear to be a "family," ranging in size from a narrowly nuclear one (husband, wife, offspring) to a fairly large composite one consisting of a set of consanguines and their spouses. ${ }^{4}$ In view of the Maohis' rather flexible marriage proscriptions, and in the absence of rigid rules of marital residence (see below), the composition of such units must have been both varied and variable; but I suppose that a pattern made up mainly of an elder man and his wife, their married sons, and the latters' wives and children was a fairly common occurrence. In any case, the distinctive features of such congregations were twofold: membership in them was based mainly on kinship, that is, close ties of consanguinity and adoption, or direct ties of affinity; and they were of a size small enough so that every member could be personally involved in marae activities. Even women and small children took part directly or through direct representation.

Their Weomen bear no part in their relegious rites, and neither them nor their Male servants ever partake of these Ceremonies; they have no place of worship for themselves, nor do they ever enter one but at their Birth, but any priest may Officiate for them when any thing ails them, and they are no less in the Eyes of the Deity then those who are admitted to be partakers of relegious rites. (Morrison 1935:178)

While true of the marae of larger kin-congregations (and of tribes, etc.), I believe, based on other evidence, that women were not categorically excluded from marae of small kin-congregations.

Henry's remarks about land tenure suggest still another characteristic of these congregations. Although the members may have become too numerous and too segmented to engage in joint subsistence activity, they were still cohesive enough to hold joint, corporate ownership in the lands comprising their residences, gardens, groves, and common collecting and fishing areas. And, according to Henry, such rights were manifested by possession of one of the marae's "hereditary names."

In the characterizations that follow I shall be referring to the whole range of sizes of kin-congregations, but my remarks will apply most directly 
to those near the larger end of the range, for it is these that most of the information seems to concern.

But before proceeding, it will be necessary to inquire what name, if any, Maohis applied to the social unit that I have labeled "kin-congregation." The most likely terms that come to mind are 'ai' $a$, a country or place where one makes his abode; an inheritance or portion of land; mataeina' $a$, the subjects of a chief; a certain tribe, clan, or sub-division of the inhabitants (LMS Dictionary).

In support of ' $a i^{\prime} a$ is its denotation of land ownership, a basic feature of kin-congregation membership. Also, when combined with tupuna (i.e., 'ai'a tupuna, ancestral home), as appears several times in texts, the term denotes another feature of kin-congregation membership: land acquired by inheritance from grandparents and other ancestors, and/or the abode of one's ancestors. ${ }^{5}$ On the other hand, the term obviously refers more to territory than to people.

In contrast, the primary reference of mataeina' $a$ is people; but one complication in the way of accepting it as a label for "kin-congregation" is the wider connotations contained in the above definition. Another is the meaning attached to it in a passage from Wilson (1799:184) quoted in chapter 2 in connection with the report of the London missionaries' first census of Tahiti.

In view of these uncertainties I shall continue to refer to the units under consideration with the English label of "kin-congregation."

\section{Marae-Names and Offices}

One of the passages from Henry quoted above indicates that every member of a kin-congregation received at birth or adoption a "hereditary name" which served thenceforth as proof of entitlement to land identified with the congregation's marae. The same passage also distinguishes between these "hereditary names," which the incumbents "jealously claim and guard ... from encroachers," and "other names," which they may "lay ... aside at pleasure" (1928:142). In other words there is a distinction between personal names and a certain kind of specific-status name, or, as I label the latter, Marae-names.

The literature on the ancient Maohis abounds with references to what the various writers call "Titles"; usually the reference is to a small number of highly privileged offices associated with the most prestigious marae. Assuming Henry's statement to be true, a question immediately arises as to the relationship between Marae-names and such "Titles": do these labels refer to distinct types of statuses, or merely to graded differences in rights (and in duties)? And if distinct types, was a Titleholder the incumbent also of a Marae-name? 
Most regrettably the evidence provides no answers to these questions. Neither can we answer related questions, such as how many Marae-names were "contained" in each marae: Enough for each member to have one of his own? Or did some members share a Marae-name? As stated above, I assume that every member of a kin-congregation occupied a Marae-name, which gave him (or her) certain demand-rights over territory associated with the marae in question. And in due course I shall have much to say about certain Titles identified with certain socially important marae. But we cannot assume, on available evidence, that every kin-congregation marae had such a Title identified with it.

On the other hand, we can assume that every kin-congregation was for certain purposes hierarchically organized-that is, that its offices were graded in terms of differences in rights and obligations vis-à-vis the congregation's spirit tutelars, its living members, and its associated resources.

Kin-congregations differed widely with respect to numbers and kinds of offices, and not necessarily in correlation with numbers of members. Some of the larger ones may have contained only a single office, combining all sacerdotal, executive, judicial, and similar functions; while some of the smaller (and probably older) ones are known to have contained several. Again, although succession to most kin-congregation offices was probably by descent, some may have been occupied by either long-term or short-term appointees or electees. And finally, although there may have been generalstatus names for all kin-congregation offices-for example, priest (tahu'a pure) and messenger (ve'a)-only a few offices in only a few congregations appear to have been designated with specific-status names, or kin-Titles.

But however many offices a kin-congregation may have contained, and whether or not any of these was designated by a Title, one office always stood far above the rest, in terms of rights and responsibilities; and succession to this highest-grade office was usually by descent. There being no native label inclusive enough for this office, I have chosen to call it kin-congregation chief.

\section{Chiefs and Tutelars}

The chief of any kin-congregation was no mere primus inter pares; he was, among other things, that crucially important kind of Maohi official, the principal link between a congregation's living members and its tutelar spirits. I use the term tutelar for a spirit associated with a whole social unit larger than a single individual, and reserve the term familiar for any spirit associated more or less exclusively with an individual. I make this distinction only for the sake of convenience; as far as I can discover the Maohis themselves made no such distinction, verbally or otherwise. In terms of my classification of Maohi spirits (see chap. 3) there were 
three types that served as kin-congregation tutelars: major nonancestral gods (atua), who either created a congregation's human progenitor (by invocation or fabrication, but not by sexual reproduction) or who became associated with a kin-congregation already in existence; minor nonancestral spirits, both atua and 'oromätua, identified with kin-congregations through having served as familiars of deceased human members; and ghost-spirits of former members, either atua or 'oromātua. In addition, the spirit-familiars of individuals and the spirit-tutelars of individual families also were to be found in the vicinity of their human associates' kin-congregation marae, even though they may not have been associated with the congregation as a whole.

According to Henry, the members of a kin-congregation kept secret the identity of their "god" or "goddess" "... for fear of being betrayed by enemies or supplanted by them in the good graces of the deity" (Henry 1928:142). ${ }^{6}$ This may indeed have been the case with some units of recent establishment and uncertain reputation, but it was certainly not so with most of the older ones containing widely renowned Titles. Indeed, the identity of the tutelars of these latter was publicly proclaimed and, probably, universally known; in such cases, perhaps, any effort to alienate the tutelar would have led to countermeasures, including warfare. ${ }^{7}$ There is no explicit information about this matter, but we can guess that the conventional way for one kin-congregation to possess itself of another's tutelar was through prevailing upon it to change affiliation by means of larger offerings of objects and services.

A kin-congregation could also disaffiliate a tutelar spirit (po'ara'a tu $i$ te atua) and install another one in its place if the spirit continually ignored requests; whether this could be done with all types of tutelars, or only with minor nonancestral ones, is not recorded. Nor is there recorded any instance of a tutelar voluntarily dissociating itself from its kin-congregation, although such a move would not be inconsistent with the way Maohis conceptualized spirits' behavior.

Like all other social interactions, relations between kin-congregation members and their tutelars can be characterized in dimensional terms.

Time. Interaction between a kin-congregation and its tutelars took place on numerous occasions, both in connection with events in the lives of individual members and with circumstances affecting the membership as a whole-that is, with events such as birth, marriage, illness, and death; with regular offerings of first fruits as well as with occasional offerings of thanksgiving or expiation; and with the kin ceremony par excellence, the $p \bar{o}$ tupapa'u, or annual night of returning ghosts.

Space. Interaction between humans and their tutelars usually required the actual presence of the latter near the human communicant; prayers did not 
usually travel long distances, and the essence of food offerings was ordinarily consumed on the spot. Sometimes the tutelar remained more or less continually in the vicinity of the marae, in other cases it had to be sent for by spirit messengers. Moreover, mutually satisfactory relations required rather frequent or at least regularly periodic interaction-from short prayers and token offerings made daily, to elaborate and costly ceremonies carried out annually.

Governance. Humans nearly always had to take the first step in establishing interaction with tutelars, but the latter reserved the privilege of intervening in human affairs whenever and however they liked, and unless restrained by stronger spirits they almost invariably were able to impose their wills on humans.

Transaction. Some kinds of events, such as first-fruit offerings, imply a notion of pooling and sharing between kin-congregation members and their tutelars. The periodic fruiting of nature could be viewed as a communal enterprise, requiring both the services of humans and of spirits, and hence it was only proper that spirits should receive their share of the produce. (The same interpretation may be applied to many other kinds of offerings made by humans to tutelars.) There was also an element of exchange of objects (from humans) for services (from tutelars), and this became increasingly evident in situations involving occasional (in contrast with regularly periodic) enterprises and the welfare and success of individual members. In these cases the offering was presented either before the event, as a more or less coercive inducement, or after the event, as a kind of payment; and in these and other instances the presentation of the offering admitted of varying degrees of ceremonial elaboration.

Expiatory sacrifice requires a somewhat different interpretation, being in the nature of a penalty for objects not offered or services not rendered as due. There is even a suggestion of exploitation in some of the transactions between humans and their kin-congregation tutelars, but ideas of altruism-of selfless anonymous giving without expectation of return-are scarcely if at all discernible in any of the data of which I know.

From tutelars to humans the flow of goods was mainly in the form of services: helping plants to grow, fish to multiply, women to conceive, human and spirit enemies to weaken, tools to be effective, hands to be skillful, memories to be retentive, winds and waves to quieten, and so forth. From humans to tutelars flowed objects (food, fine mats, rare ornaments) and services of a more tangible kind (the construction and maintenance of marae, the performance of pleasing ceremonies and entertainments, frequent assertion in word and in gesture of the superiority of the spirit).

It is not entirely clear why tutelars needed or wanted such objects and 
services, but there is some indication that their very survival in the $p \bar{o}$, and not only their status among other spirits, was dependent in large measure upon objects and services rendered by their human associates in the ao. This was certainly the case with the ghosts of recently deceased members, and it may have been the case even with major gods. The nature of the sins (hara) which most displeased the tutelars and brought about reprisals from them is not inconsistent with this interpretation, for in the main these had to do with lapses on the part of humans in carrying out their obligations to the spirits, and only rarely with relations among humans themselves. The major exception to this is one described by Moerenhout:

These people had, in general, a great fear of spirits, and they greatly dreaded vengeance from the Dead, who, they were convinced, could do much harm. Those who were feared the most were children who died after the ceremony which I have just described. ${ }^{[8]}$ It was feared above all that angered with their mother they would seek vengeance against the whole family; and women, cleverly applying such presumptions in their own defense as soon as they felt themselves mistreated either by their husband or by their other children, threatened them with insulting the spirit of the dead child which spared them much bad treatment; because the effect of those threats could endanger the whole family, usually all its members interceded to reestablish peace in the household. The same procedure brought about the same results in the quarrels of all the other relations; at the least dispute, the slightest word [could] be enough to make a person fall out of the Oromatouas' or domestic gods' good graces and to bring down on him and on all his relations illnesses and other misfortunes. Consequently there were only a few quarrels among them, and generally they treated each other with kindness and courtesy, so that this useful belief in the Oromatouas, which was nothing else but worship of the Dead, made up for, in some way, among these people otherwise so barbaric, their absolute lack of feeling and affectionate sentiments. (Moerenhout 1837:I, 538-539)

In this connection it is, however, interesting to recall that humans were not entirely at the mercy of all spirits, at least not of their kin-congregation tutelars. They were vulnerable to attack by the latter, but only up to a point, for, by casting off their tutelar, humans could terminate the contract implicit in the relationship and seek protection from the vindictiveness of the castoff spirit by attaching some other spirit to their cause. At least this was the case with some tutelars; whether it was possible to become dissociated from an ancestral ghost is not known. A parallel to this freedom of action existed in the political sphere, as we shall see. As was the case with other supernatural sanctions, the threat posed by a displeased kin-congregation tutelar was usually in the form of bodily harm, although there is some evidence that a vengeful tutelar also punished by means of destruction of property, or infertility, or failure of enterprise.

In all the foregoing description of relations between humans and their kin-congregation tutelars I have written in collective terms, but it is important to specify that in events involving the congregation as a whole 
it was a unit's chief, or someone acting on this official's behalf, who directed or even played the principal role in the interaction. Along with much other evidence for this role assignment Henry stated: "Taruia was also taught the oral traditions of his country and all the mysteries of priestcraft by his father, whose double office of priest and chieftain he was to inherit" (1928:624).

One possible rationale for this assignment is not difficult to deduce: in conformity with the emphasis upon lineality and primogeniture, which served to structure consanguineal relations in general, and succession to kin-congregation chieftainship in particular, the kin-congregation chief was the closest human consanguine of his unit's founders, and thus of its ancestral tutelar spirits or of the tutelars' chosen human associates. Unquestionably, the Maohis attributed a large degree of sacredness to certain of their chiefs: "Everyone is to treat with respect the ari'i, his descendants and his feti'i; let the ari'i be sacred $\left(m o^{\prime} a\right)$ : he is a descendant of the gods" (E. Salmon 1937:29). Some writers on the Maohis go even further and impute "divinity" to certain kin-congregation chiefs-as manifested in their mana, an attribute which (according to such interpretations) varied in its degree of "divinity" in proportion to the "purity" of the incumbent's descent lines, reaching back to their founding deities. In the case of those kin-congregation chiefs entitled to the designation ari'i, Handy wrote: "... the divine first-born (matahiapo), who was the [congregation's] Arii, was regarded by the population over which he presided, as the embodiment of the mana of the people and land as a whole" (Handy 1930:46).

Such interpretative statements as the above are attractive in their simplicity and coherence. They may even be true; some of the Maohi data could be made to fit quite nicely into a general belief system of this kind. On the other hand, many of the pieces necessary for constructing such a system are missing, and I am unwilling, for reasons previously stated, to supply those pieces by so-called logical deduction or by borrowings from Polynesian belief systems elsewhere.

In any case, whatever may have been the rationale behind the kin-congregation chief's priestly role, in numbers of cases the priestly job of a kin-congregation was delegated to some other member (conventionally to a younger brother); this occurred so frequently that the priestly function, sometimes symbolized in a separate Title, became identified with a separate (and usually collateral) "line." Ideally, however, the function remained a delegated one.

Finally, there is the important question of the locus of punishment (and hence, presumably, the locus of responsibility) for acts or omissions displeasing to a kin-congregation's tutelars. Inasmuch as most acts or omissions involved interaction between congregation and tutelar-for example, 
sacrifices or prayers-and inasmuch as such interaction was conducted by the congregation's chief, or by priests deputized by him, these officials were, one might suppose, most vulnerable to supernatural ire; yet the sources are ambiguous on this point. On the one hand there are recorded instances of a tutelar concentrating punishment on the individual malefactor; on the other hand there are accounts of a wrathful spirit destroying everybody and everything around, regardless of whom Westerners would identify as technically culpable.

Emotion. There is more evidence of respect (tura) and fear (mehameha) than of aroha (affection, compassion) in the behavior of humans toward their tutelars; on their part the tutelars were either inimical, indifferent, or sympathetic-usually according to value received.

\section{Chiefs and Other Members}

The main element in the office of a kin-congregation's chief was his relationship with the unit's tutelar spirits, and this was manifested in his responsibility for the priestly function of officiating between living members and tutelars. But he also carried out more secular functions as chief steward and administrator of the congregation's resources and as principal link with other congregations, especially "genealogically" related ones.

Among the most important of the secular functions of a congregation's chief was that of rahui. Rahui was mentioned previously, where it was shown to be the term for the placing of restrictions on fishing activities. Actually, rahui was the general term applied to the placing of restrictions of several kinds: upon productive activity in general or, in terms of specific products, upon consumption of specified foods, upon construction work, upon engaging in diversions, and so forth. The LMS Dictionary gives the following definitions:

rahu, a certain prayer, or incantation used in laying a restriction on fruit, etc.

rahuii, a prohibition or restriction laid on hogs, fruit, etc. by the king, or chief.

rahui, to lay on such a rahui; in some of the islands it is called tapu. rahuipotuara' $a$, the great or universal restriction by the chiefs.

Rahui was imposed by means of a prayer, which presumably invoked supernatural sanctions upon anyone violating the restriction; but it was backed by more tangible sanctions as well, since the right to impose such restrictions over a particular area of land or sea rested ideally only with the persons capable of enforcing them, physically, and such a person was, in the ideology of consanguinity, the kin-congregation's chief. 
They have a Ceremony Calld Rahooe which is a Kind of Jubilee but have No fixd time allotted for keeping it-It is a Prohibition or Embargo laid on the Provisions, \& Stock, in Whole or in Part; in any one or More Districts to prevent a Decrease by consuming the Provisions or Stock in or transporting them out of the Districts so Raahooe'd, which they are forced to observe under pain of being driven from their land. (Morrison 1935:194)

Along with his proscriptive right of rahui, a kin-congregation's chief also owned the positive right to allocate use of his congregation's natural resources-soil, wild foods, fishing grounds-among fellow members, although ideally that right was exercised only when rival claims were disputed, and it was in any case constrained by the weighty convention that any member's long-term use of some portion of the common territory constituted a preemptive claim. As for the chief's right to reserve choice use-rights to himself, that of course was possible, but normatively such a right was at least partially limited by his obligation to behave generously toward fellow members, like the consanguine that he was.

As for the chief's right to expel members from kin-congregation territory, I noted this possibility in a previous section but ventured my opinion that such expulsions, though quite within the bounds of the ideology of consanguinity, applied only to the expellee himself and not to his descendants. In any case, as I conceive consanguineal ideology to have been, it did not justify a kin-congregation's chief confiscating for personal use the land formerly occupied by an expelled member. (Whether this norm was actually effective I cannot say.)

The foregoing statements concerning rights to territory (land and lagoon) apply specifically to territory identified with kin-congregations as corporate units. In addition, some Maohis appear to have held more or less exclusive and undivided rights to territorial "estates" of their own. (This is a highly important aspect of Maohi social relations, about which, unfortunately, very little has been recorded, and hence very little of a factual nature can be reported; but the matter is of such importance that I am prompted to supply some deductions about it.)

In the sense that any kin-congregation member's long-term use of some portion of the common territory constituted a preemptive claim, all "owned" territory in these Islands (by which I mean all territory) would have approached the status of an inviolable personal estate to the extent to which its owner was independent of governance by others and its produce not subject to taxation. In other words, the only territories that were estates in the fullest sense were those individual-or family-owned ones whose owners were sovereign tribal chiefs. There were, evidently, many other portions of territory whose long-term association with tribal subchiefs or with close relatives of sovereign chiefs, served to place them in the same category 
for most purposes, but in Maohi society (unlike in some Western ones) the hierarchial principles manifested in interpersonal relations applied to command over objects and territory as well.

And now let us summarize the various rights and obligations between a kin-congregation's chief and its other members. The distinction between "rights" and "obligations" is, of course, my own. I can discover no Maohi words corresponding closely to this distinction in English, but I presume that some such distinction was in fact conceptualized. It would be valuable indeed to know just how the Maohis distinguished between "rights" and "obligations," but that information is beyond our reach. Most of what follows is mainly about norms inasmuch as data on actual performance, on credibly validated historical happenings, are very sparse in this domain.

Terminology. In addition to the Title borne by chiefs of some kin-congregations, many also bore such general-status names as $p a$, ari'i, 'iatoa' $i$, or ra'atira-all of which will be discussed below.

Time. I cannot discover any evidence bearing directly on this dimension of interaction between a kin-congregation's chief and its other members, but the inference seems warranted that, in at least the ideology of consanguinity, a chief was expected to be easily and continually accessible to his people-even though that interaction may on occasion have been constrained by other considerations.

Space. I noted earlier the general rules regarding positioning of individuals: certain ones were conventionally in front of (versus in back of), and upper (versus lower) in ritual contexts. These rules applied particularly to interaction among kin-congregation members; indeed, the more general practice was possibly modeled upon the applicability of such rules among consanguines. It may also be that in some kin-congregations the chiefs' residences were in locations nearest the sea, but this does not appear to have resulted in any convention regarding such positioning of kin-congregation members during interaction.

Governance. During the era under study many kin-congregation chiefs were also leaders of tribal units which encompassed other kin-congregations not genealogically related to their own, and it is not a simple matter to discover which aspects of their roles derived from considerations of "consanguinity," as opposed to those of "tribal" authority-an uncertainty which applies especially to the dimension at issue. As I remarked earlier, this whole attempt to sort out separate "ideologies" referable to different role networks (e.g., relative age, maleness versus femaleness, consanguinity, class) is highly subjective when studying a living society, and when working with the kinds of documents at our disposal the element of subjectivity is increased manifold.

In any case, it is my impression-it would be inaccurate to call 
these inferences anything else-that a double standard of behavior was expected of a kin-congregation's chief with respect to governance. In everyday interaction with congregation mates, including ordinary work activities, the chief was expected to participate on a par with other members, initiating and responding as the work technique required, and leaving direction, if required, in the hands of the technically best qualified person (who was not necessarily himself). On more formal occasions, such as those requiring the making of important decisions affecting the whole congregation, the chief was required to be final arbitor, the sole initiator. Others could debate issues but he decided them.

Another facet of the chief's hierarchical position is revealed in the term haumäteata, defined in the LMS Dictionary as a government in the hand of a chief by blood, or hereditary descent. The interesting word hau is defined in the LMS Dictionary as peace, government, reign. This and textual occurrences of hau indicate that the term referred as much to the presence of social order as to the active exercise of authority; and while I would be among the first to urge the futility of speculation about the etymology of Polynesian words, it might be held that the harmony-maintaining function of a kin-congregation's chief was considered to be among the most important of his duties. ${ }^{9}$

More will be said about chiefly authority when I discuss relations based on tribalism, and some of the attributions to be made in that context undoubtedly apply to the authority of kin-congregation chiefs; but as noted above, with the data available, it is next to impossible to identify behavior patterns distinctively attributable to the latter.

Transaction. Following is a list of the kinds of contributions the members of a kin-congregation were expected to make to their unit's chief:

1. Periodic contributions of the first fruits of collecting, gardening, and fishing.

2. Solicited contributions of food, textiles, building materials, and other objects for the chief's own use.

3. Unsolicited contributions of token amounts of food, from the members' own celebrations.

4. Unsolicited but "on order" contributions of such special objects as fine mats and turtles ${ }^{10}$ (and of course European goods).

5. Specified fines for wrongdoing, in the form of food, mats, and other goods.

6. Solicited contributions of labor services for communal enterprises-construction, transportation, entertainment, perhaps even fighting.

7. Solicited contributions of services for the chief's own uses.

It is possible that a kin-congregation's chief also enjoyed a recognized 
right to exact of any member the supreme form of service, that is, to use him as a sacrifice to the unit's tutelar spirit; but for reasons stated earlier such a right would have been somewhat inconsistent with other components of what I propose was a consistent "ideology of consanguinity."

Following are the kinds of goods that a kin-congregation's chief was expected to supply to his fellow members: Objects, especially food, solicited by members in dire need; Objects derived from members' contributions but surplus to the chief's own "official" and domestic needs, that is, redistribution; and Services of various types: priestly, administrative, adjudicative, defensive. In connection with the last, the priestly obligations of a congregation's chief were clearcut and comprehensive: he (or someone deputized by him) was the most "direct" link between congregation members and their common tutelars and thus was the most appropriate person to maintain ritual relationships with them. Also, his responsibilities were undivided insofar as they concerned the administration of communal secular enterprises and the allocation or security of commonly owned goods (and presumably this included the defense of other members' persons against outsiders). Finally, his adjudicative responsibility was suggested in his role as controller of hau.

How may we categorize these normative transactions in more general terms? They certainly do not constitute self-seeking actions on the part of the chief or his fellow members to deprive one another of goods. Neither do they seem to have been conducted in the spirit of voluntary gift giving, devoid of any wish or expectation of return. Indeed, they appear to constitute various sorts of "exchange." We are concerned here of course with the public, overt conception of these transactions. In many actual historical instances of transactions among kin-congregation members, the parties, while conforming publicly to the ethos of exchange, may have been privately motivated by more selfish, or more selfless, objectives.

But "exchange" is a very comprehensive category, including transactions ranging all the way from barter, with hard bargaining, to the kind of pooling and sharing, with little or no explicit "bookkeeping," which, ideally at least, characterizes interaction among family members in many Western societies. It is not altogether clear just where in this continuum to place the transactions under consideration, except to state that they cluster around pooling and sharing, with more conscious "bookkeeping" than occurs, ideally, in Western families but with less punitive sanctions than those usually accompanying institutionalized reciprocity. Three general principles seem to have governed such exchange between a kincongregation's chief and all other members: the former should retain for his personal use only a modest proportion of the goods contributed to him-for example, "When any of the Chiefs kill a Hog it seems to 
be almost equaly divided among all his dependands and as these are generaly very numerous it is but a little that comes to each persons share ..." (Beaglehole 1955:122); the latter need not deprive themselves unduly in order to contribute to the former's personal well-being; and the former should be impartial when distributing, or redistributing, his goods among other members. Unfortunately, I cannot define "modest" or "unduly" in any quantitative way, but this need not render the formulation useless-especially when one contrasts it with certain other kinds of principles which seem to have governed interclass relations. Impartiality seems to have been expected of chiefs in general (Henry 1928:478), but it is logical to assume that it was particularly enjoined upon a kin-congregation's chief in his dealings with the congregation's members.

Under the general subject of pooling and sharing I cannot resist the temptation of reproducing, for the reader's delectation, J. Forster's Rousseauean appraisal of the Maohis in this regard:

The happiness resulting from the fertile climate, and from a profusion of fine vegetable productions, raised by the industry of the Manahounes and Toutous in Taheitee, and its neighbourhood; the very moderate and mild servitude of their Toutous, the order and regulation in their domestic societies, the benevolent and paternal affection of their chiefs, their association for the security of property and liberty, their commerce, wealth, and enjoyments, give us the best idea of the more refined and exalted situation of the inhabitants of Taheitee, and the Societyislands, above all the rest of the nations we visited in the course of our voyage. Convinced of the rectitude of order, and justice, as far as they relate to human societies; sensible of the pleasure arising from each common act of benevolence, and fired with the generous spirit of communicating happiness to as many as are willing to form with them the same society; they are likewise capable of that noble and disinterested desire to work for the common weal as much as lies in their power, which we call public spirit or true patriotism, and what is still better, they actually shew it on many occasions. I have seen a man eating a small proportion of bread-fruit, or other food, and nevertheless sharing this trifle out amongst several of his brethren, whilst it would admit of division. The solicitude of their chiefs, to strike a good bargain for their subjects, when they brought fruit, fish, or hogs to market, is likewise another proof of this assertion; nor can I omit the assistance they generally gave to one another; the detestation in which the better sort of people held all the thieves and robbers; the striking increase of happiness we observed in O-Taheitee, were, at our second arrival, after an absence of eight months, owing to the encouragement and minute inspection of the situation of every individual family under $O-T u$, the resignation of the command of the fleet to T-Owha, made by O-Tu, and the readiness of T-Owha to undertake that expedition, though ill of the gout; the wisdom and public spirit with which they politely declined the assistance offered them by Capt. Cook for conquering the revolted island of Imeo. All these particulars give me the highest opinion of their true patriotism, and noble attachment to the weal of their country. This great maxim is the first germ of all noble social feelings and sentiments: it assigns to the various relations of man their true valour, and bids him act in consequence of each of them; it prescribes the simplicity and unity of principles, and the harmony of means for acting upon these principles. It teaches individ- 
uals to scorn to enjoy advantages which cannot become universal, or must be purchased at the expense of the happiness of the community, and makes of every individual a hero; who, if he lived in countries, where poets, orators, and authors, for gold lavish their incense, would have such monuments of eloquence raised to his memory, as are but too common in our adulatory age; and had he been born with those noble sentiments at Athens or Rome, he would have deserved to rank with Aristides, Agesilaus, Leonidas, Fabius, Africanus, Cato, and the sacred bands, who fill the temples of Grecian and Roman patriotism. (1778:376-378)

Emotion. One can characterize the normative interaction between a kincongregation's chief and his fellow members, or between any members of a kin-congregation, with labels like "amity" or "affection." This is not, of course, meant to imply that such individuals usually "felt" amicably or affectionately disposed toward one another, nor even that they usually acted as if they so felt. I mean to assert only that between kin-congregation mates in general, and between the chief and other members in particular, interaction was ideally expected to consist of those vocal or gestural conventions that I have labeled "amity" and "affection." Historically, as we shall see, in many situations interaction among kin-congregation mates was anything but amicable.

In terms of those emotion-expressing conventions we may label "sexual," interaction among kin-congregation mates was normatively defined only in certain special instances. There may have been general proscriptions against marriage-including copulation-between "close" consanguines, but the span of collaterality was broad enough in many kin-congregations to permit some members to intermarry. Moreover, in the interest of status consolidation, even those general proscriptions were overruled in the case of some closely related congregation mates of superior social position, including the units' chiefs. On the other hand, considerations to be discussed in chapter 18 proscribed marriage between a kin-congregation's chief and a person of inferior social class whatever her kin-congregation affiliations or degree of consanguinity may have been.

Turning now to behaviors expressing differences in precedence, I can summarize my inferences by stating that as a minimum a kin-congregation's chief was normatively accorded respectful deference by his fellow members, especially on ceremonious occasions, while he in turn treated them with somewhat lofty benevolence. In this regard acknowledgment of the chief's "dominance superiority" was tempered by the circumstance of his consanguinity. But that was "as a minimum," applicable mainly to the smaller, less class-stratified kin-congregations. Even normatively the chiefs of certain venerable congregations were accorded a degree of respect approaching reverential obeisance, not only by their fellow members but by the populace at large. Respect for such exalted personages was expressed most visibly by keeping one's head lower than theirs and by baring one's 
shoulders when in their presence. Here are some eyewitness accounts of the operation of these rules:

When a Chief is present in any Company the Men strip their Bodys to the Waist not suffering any Covering on their Head or Shoulders in His Presence-and all the Weomen present uncover their Shoulders tucking their Cloth under their armpits, to Cover their Breasts in token of obedience and respect, to his presence; the Men are not always particular in this point except Upon the Chiefs Heredetary land or that of His adopted friend, where any neglect would be deemd an Insult and punishd accordingly-but in presence of the King the Chiefs themselves must strip-Nor do they stop to see him first if they Have Notice of His approach either by land or in a Canoe, Nor must any person pass his land by walking over it or Sailing by it without paying the Compliment. (Morrison 1935:168)

They Have Carved Wooden Images of Men which they call Etee [ti'i] set up as boundaries of their Estates, not to pay devotion to but to remind passengers below \& of equal rank to the Posessor and owner of that land, to strip the Cloths off their shoulders \& heads, as they pass by in Compliment to the Owner-All ranks of People must pay this Homage as they Pass the land belonging to the Earee da hye [Ari'i rahi] or King-The Etee or Image denoting the Kings land is remarkably larger then the Common size, and the Towhas or Ratirras [ra'atira] land is known by a Number of little White Flags being fixed in different parts beside the Etee-(Morrison 1935:192-193)

His subjects not only uncover to him, when present, down to the waist; but if he be at any particular place, a pole, having a piece of cloth tied to it, is set up somewhere near, to which they pay the same honours. (Cook 1784:170)

A question that must be raised is, What sanctions were in force to back up all these norms for interactions between a kin-congregation's chief and its other members? But here again we face the difficulty of distinguishing between this and other forms of "chieftainship." The sources are replete with observations about the relations between "chiefs" and other Maohis, for no other subject was so crucial to the European visitors' purposes and welfare. So far, however, in my inferences about kin-congregation "chieftainship" I have dealt only sparingly with the subject-not because richer details are lacking but because I have gone about as far as one conscionably can go in selecting data about this particular aspect of differential privilege and power-further, perhaps, than some readers feel is warranted. In fact, despite my best efforts, there remain some fundamental weaknesses in these attempts to separate various role behaviors and assign them to distinct ideological systems.

The negative sanctions behind chiefly authority took many forms; in fact "chiefs" were effective beyond other humans in employing or directing all forms of negative sanction: social isolation, physical coercion, public censure, and supernatural punishment. However, according to my inferences about Maohi consanguinity, which involve certain assumptions about ideological con- 
sistency, I believe that the chief of a kin-congregation would, or at least should, have tended to refrain from physical coercion and imposition of exile, and would have reinforced his authority when necessary by use of publicly aired censure and of supernatural punishment.

Inasmuch as the status of a kin-congregation's chief was an ascribed one, presumably reinforced by weighty and deeply internalized norms regarding consanguinity and birth order, these officials may not have had to resort to other kinds of positive sanction to maintain proper relations with congregation mates-provided of course such chiefs carried out their end of the exchanges which helped to define these relations.

\section{Kin-Congregation Titles and Marae Stones}

As noted previously, the herditary and highly privileged offices associated with certain socially important kin-congregations bore individual identifying labels, which I call kin-congregation Titles. Such Titles were in the form of proper names. Some were quite short (e.g., Te Fatu, Teri'i), others were long and studded with metaphors (e.g., Aromaitera'i, War-from-the-sky; Tunuia'eiteatua, Stability-greater-than-the-gods [?]). The principal (i.e., highest-graded) Title of any kin-congregation marae often consisted of a name, like the above, combined with the name of the marae itself (e.g., Teri'irere i To'oara'i, Flying [or Leaping]-ari'i-of-To'oara'i [marae]), or the Titleholder in question was simply referred to by the name of the marae itself. $^{11}$

Unlike the Marae-names mentioned by Henry, kin-congregation Titles were not "carefully concealed"; in fact, they were often publicly proclaimed and presumably universally known. In the "official" genealogies that figured so importantly in Maohi ceremony, some of the constituent labels for individuals were kin-Titles, but most of them were personal names-as indeed they would have had to be in order to render them informative.

Traditional accounts of the genesis of particular kin-congregation Titles, or simply kin-Titles as I shall henceforth refer to them, usually involve incumbents already holding one or more of them. For example, when for some reason or other a kin-Titleholder moved away from his home marae he could, without necessarily vacating his former kin-Title, create a new marae for his family and a new kin-Title for himself and his successors in the new home. Or, it was not unusual for particularly solicitous kin-Titleholding parents to build a new marae and create a new kin-Title for their successor, in addition to passing on to him their own respective kin-Titles. But I can discover no traditions relating how non-Titled offices first evolved into Titled ones. I can, however, suggest how some such developments may have taken place.

If, say, in the course of time a family became numerous and affluent, while remaining spatially united and socially cohesive, several things seem to have occurred: 
1. The various collective-action functions-policy-making, administrative, sacerdotal, and so on-would have become embodied in a number of explicitly defined offices.

2. In time one or more of these offices would have become labeled with the personal name of the current incumbent or with some descriptive or panegyrical name invented for the occasion, and the office in question would thenceforth devolve with its distinctive new label, or Title.

3. Thereafter, if the congregation continued to prosper and become widely known, the kin-Title held by the congregation's chief member would have become more specifically identified by addition of the local marae's name.

4. Meanwhile, all such Titles (like kin-congregation offices in general) were graded within each kin-congregation and between interrelated congregations, in terms of rights and obligations vis-à-vis the congregations' tutelars, its living members, and its associated resources.

In any case, whether or not kin-Titles actually evolved in the manner just suggested, they devolved, normatively, from parent to (socially recognized) child. What I say here about succession to kin-Titles may well have applied to other hereditary offices as well, although the sources have little to say about the latter. (Note that the present discussion of succession concerns kin-Title, and not chiefly authority, which in many instances were separate attributes not only in actual practice but perhaps even in conceptualization as well.)

All writers who concerned themselves with this subject seem to have accepted the general proposition that "primogeniture" governed which child ought to inherit the parent's Title, although there is some uncertainty about what type of "primogeniture" was held to be most desirable in terms of the ideology of consanguinity I am now describing: the firstborn child regardless of sex, or the firstborn male child. Some sources state or imply that the first rule prevailed. ${ }^{12}$ Others vouch for the second. On this matter, Moerenhout wrote:

Despite the disrespect generally shown for females, the nobility was so infatuated with its superiority that if it happened that a daughter was the sole scion of a noble family that daughter would inherit the sovereignty, for the purpose of keeping it going. In due course she would marry, but without her husband taking the Title of Ari'i or any of the authority thereof, at least if he himself were not the son of a principal chief. If and when a son issued from such a marriage, he would take the Title of Ari'i. If the father was only an inferior chief, and the mother a member of the high aristocracy, then she would reign (or be regent). (1837:II, 11n)

It is my conclusion that the second rule was the one more often followed in practice, although in many instances considerations other than sex or birth-order entered into choice of successor. After having made a painstak- 
ing study of all available genealogies, published and in manuscript, Emory found that "the genealogies frequently show a succession [to important kinTitles] through children other than the first-born" (Marae Traditions).

These alternatives also obtained in the event of a kin-Titleholder without offspring-that is, the kin-Title could and usually did pass to the male child next in birth-order, but it also could and sometimes did pass to a female child if she were eldest among her surviving siblings. ${ }^{13}$ In any case, I can find little evidence for the rule of succession having been formulated exclusively on sexual lines, that is, all males in birth-order before any females.

In my discussion of "consanguinity" I noted the Maohi belief that "something" of each parent went into the composition of a child. Maohi norms about succession-order suggest a corollary belief that whatever that "something" was it diminished with order of birth (in addition to whatever difference may have resulted from the sex of the child)-but it is only a suggestion. I have searched in vain for explicit formulations which might throw some light on this matter, so I am unable to join with some other specialists on Polynesia who write with such assurance and plausibility about "primogeniture" and mana and such.

Much about consanguinity-based succession-order appears reasonably certain, but some amplification is called for. First, it can be noted that by norms of consanguinity a kin-Title passed only to an incumbent's own (socially recognized) child; that is to say, in polygynous families, regardless of birth-order, a wife's own kin-Title (if she had one) was passed only to her own offspring and not to the offspring of some other wife of her husband. As for the polygynous husband's own kin-Title, it was usually (and probably normatively) passed to an offspring borne by the first woman to whom he became officially "married"-who, as we shall see, was required to be of the same "class" as himself.

But I reiterate that these statements about succession-order apply to only one set of Maohi norms-that is, "ideology of consanguinity." In some situations this set of norms was overruled by sets appertaining to different and in some respects conflicting ideologies, such as that relating to membership in a tribe, so that considerations of sex and birth-order gave way to those of, say, competence or dynastic rivalry, as later chapters will indicate. In fact, in connection with some of the highest kin-Titles, a claimant's eligibility, based on birth-order, seems normatively to have required validation in the form of some sign of supernatural approval, as manifested, for example, in a test in which the claimant entered the sea; if the family's shark-god tutelar approached the candidate in a friendly manner, then that was proof of acceptability (Henry 1928:192).

The timing of succession to a kin-Title occasioned much surprised comment among the early European visitors, principally because most of them 
tended to identify Title with authority. The correct interpretation would appear to be contained in the detailed account of natal ceremonies described by Henry and quoted earlier:

[On the occasion of the uhi-a-iri ceremony, which took place a short time after birth of the successor to a high-grade kin-Title] ... The father ... received his child thus initiated into the family circle and embraced it tenderly, conferring upon it a royal name which had been duly and appropriately chosen beforehand, after which he was the first to pay it homage by embracing its feet and saluting it as a member of the royal house and heir to the throne. But the reigning father or mother did not abdicate their power and proclaim the young heir sovereign of the realm, as some writers have stated, for inauguration ceremonies must be performed before the people recognized a new ruler. (1928:185)

As Wilson wrote: "A chief is always a chief; and though expelled from his command, losing his district, or having his honours transferred to his child, he continues noble and respected" (1799:325). ${ }^{14}$

Assuming the "royal name" to be a kin-Title, it appears that although the label of such a Title, along with certain "honours" associated with it, passed to the successor in a ceremony shortly after his birth, most of the more secular rights and obligations represented by that label were transferred piecemeal, over a long period of time, and culminating with the fa'atoira'a feast, celebrating the final removal of childhood restrictions, which was held-according to Henry's imprecise phrasing-“... upon the maturing of the child" (1928:188). ${ }^{15}$ In fact, in the case of very highgrade $\operatorname{ari}^{\prime} i$ Titles the transfer of all the duties and privileges pertaining to them was not completed until a still later ceremony, that of inauguration $\left(\right.$ fa'aari'ira'a) $^{16}$

Most generalizations in the sources about the timing of succession to hereditary kin-congregation offices refer to kin-Titles, but it is not unlikely that much the same kind of arrangement was applied to other offices as well-although the less consequential the office the less formal would have been the ritual actions signaling its transfer.

Another general description of this matter was supplied by Ellis:

The most singular usage, however, connected with the established law of primogeniture, which obtained in the islands, was the father's abdication of the throne on the birth of his son. This was an invariable, and appears to have been an ancient practice. If the rank of the mother was inferior to that of the father, the children, whether male or female, were destroyed; but if the mother originally belonged to the hui arii, or had been raised to that elevation on her marriage with the king, she was regarded as the queen of the nation. Whatever might be the age of the king, his influence in the state, or the political aspect of affairs in reference to other tribes, as soon as a son was born, the monarch became a subject-and the infant was at once proclaimed the sovereign of the people. The royal name was conferred upon him, and his father was the first to do him homage, by saluting his feet, and declaring him king. The herald of the nation was then despatched round 
the island with the flag of the infant king. The banner was unfurled, and the young sovereign's name proclaimed in every district. If respected, and allowed to pass, it was considered an acknowledgment by the raatiras and chiefs, of his succession to the government; but if broken, it was regarded as an act of rebellion, or an open declaration of war. Numerous ceremonies were performed at the marae, a splendid establishment was forthwith formed for the young king, and a large train of attendants accompanied him to whatever place he was conveyed.

Every affair important to the internal welfare of the nation, or its foreign relations, continued to be transacted by the father, and those whom he had formerly associated as his counsellors; but every edict was issued in the name and on the behalf of the young ruler; and though the whole of the executive government might remain in the hands of the father, he only acted as regent for his son, and was regarded as such by the nation. The insignia of regal authority, and the homage which the father had been accustomed to receive from the people, were at once transferred to his successor. The lands, and other sources of the king's support, were appropriated to the maintenance of the household establishment of the infant ruler; and the father rendered him those demonstrations of inferiority, which he himself had heretofore required from the people. (1829:II, 346-347)

Ellis was writing at a time when Tahiti-Mo'orea were united under the sovereignty of a single tribal chieftain- "King" (and later, "Queen") Pomare-but his description evidently refers to earlier times. Also, he noted specifically that the custom of early succession to office was not limited to tribal chieftainship: "This remarkable custom was not confined to the family of the sovereign, but prevailed among the hui arii and the raatiras. In both these classes, the eldest son immediately at his birth received the honours and titles which his father had hitherto borne" (p. 347). This statement of Ellis' would also appear to support the notion expressed earlier that kin-Titles were fairly numerous and widespread.

The early and fairly automatic designation of a kin-Title successor undoubtedly served to reduce somewhat the element of sibling rivalry so characteristic of succession in many other societies, but the piecemeal transfer of powers seems to have introduced other opportunities for contention, as will be described in later chapters. Nevertheless, enough powers were transferred to persons of tender age, including whatever ceremonial deference was due the Titleholder, to produce a general effect on social relations between persons of different age, as indicated in chapters 13 and 15 . What I am suggesting here is that the ideology of consanguinity, with its emphasis on the kind of "purity of line" concept crystallized in primogenitural and early succession, was in a causal sense prior to Maohi children's reported freedom of action, rather than the reverse. However, I have no means of proving this point.

As I have already indicated, the ideology of consanguinity probably favored male succession to kin-Titles, but it was flexible enough to permit females to hold them-not only in the absence of male offspring but occa- 
sionally even in preference to males. Actual instances of this kind will be described later; I introduce the subject here to indicate how such occurrences affected kinship-Titleholding in general.

First of all, the fact of kin-Titleholding by females resulted in certain individuals holding more than one Title-that is, a Title of the father and of the mother, and even in some cases including separate Titles inherited by the father from his mother, the mother from her mother, and so on. Inasmuch as choice of spouse was not limited by kin-congregation membership per se (i.e., marriage was generally proscribed only between "close" consanguines), it was normatively possible either for all one's Titles to be identified with one congregation, or alternatively distributed among several. In the first case if an individual happened to hold more than one kin-Title associated with a single congregation, this undoubtedly served to enhance his privileges locally and his reputation abroad; although, cumulatively, two or more middle-grade kin-Titles probably did not raise their incumbent's status to the level of the congregation's highest-graded Titleholder. In the second case an individual holding kin-Titles in more than one congregation usually made his (or her) permanent residence in one place, but now and then visited his other congregation, where he was accorded the privileges appropriate to his local kin-Title, which in some instances may have been higher-graded than all other local Titles. Some narratives indicate that a stranger sometimes turned up to claim possession of a long-vacant kin-Title and ended up either winning acceptance, by authenticating his claims genealogically, or endangering his life by inability to do so.

A further complication is introduced by the circumstance that some kinTitles could be and were transferred from one kin-congregation to another (see p. 660).

A particularly puzzling aspect of kin-Titleholding is presented in the case of the immediate families of individuals holding very high-graded Titles in certain of the more venerable kin-congregations. In such families, in addition to the privileged status enjoyed by the official successor to the parent's (or parents') most imposing kin-Title (or Titles), it seems quite clear that all other recognized offspring of the parents enjoyed positions of some privilege. Among the records kept by the Spaniards, there is an intriguing and suggestive observation concerning the younger brother and successor of a recently deceased incumbent of the very high-graded (and high-ranking) kin-Title, Vehiatua:

After having paid this visit [to view the corpse] we went back to his mother's house, where we met his brother; and we noticed that he had his lower lip blue [i.e., tattooed] (the same was the case with the deceased, and they told us it was the caste mark of the Vehiatuas). (Corney 1915:471. See also Bligh 1789:II, 56; Vancouver 1801:273) 
The problem is, Were the favored positions of recognized offspring merely the result of their "close" links with the principal Titleholder? Or were their privileges derived from distinct but unreported kin-Titles separately inherited?

I can find no evidence indicating that all of a parent's kin-Titles necessarily devolved upon a single successor; on the other hand, in the scant documentation available I have not come across any actual case of splitting of a parent's kin-Titles among two or more offspring-nor a case of one spouse's Title devolving upon one of their common offspring and the other's upon another offspring. But recall Moerenhout's curious and ambiguous statement reported earlier: "A child is given a personal name, at birth, deriving from either maternal or paternal family. Later, if its parents separate, the child goes with the parent whose family name it bears" (1837:II, 63-64). Even if such processes did take place, this cannot account for all or even most of the privileged positions enjoyed by the siblings and other "close" relatives of certain Titleholders. For example, the "Precepts of Tetunae" exhorted everyone to "... treat with respect the ari'i, his descendants [huä'ai], and his 'relatives' [fēti'i]." Evidently, this is an implicit Maohi proposition to the effect that all offspring of any individual, and not just his (or her) "successor"-firstborn or otherwise-share some rights accruing to that individual's status in relation to other consanguines.

Now the question to be faced is, How many Titles were there in existence throughout Maohi society? Assuming Henry to be correct, every Maohi was given a Marae-name, which entitled him to use some of the territory associated with his kin-congregation marae and, presumably, also entitled him to be represented to the marae's tutelars. On the other hand we have no sure way of knowing, even approximately, how many kin-Titles were in existence at any point in time. It is my guess that not everyone had one-at least as I construe such statuses to have been. And it is also my guess that there were more of them in existence than the few score that have been recorded, either in European accounts or in the handful of native traditions that have managed to escape oblivion. But guesses are shaky foundations for building theories about a society's structure. In the matter of kin-Titles, as in many other aspects of Maohi social relations, we are provided with some fairly rich data about the uppermost levels of society, and next to nothing about the rest. Moreover, we cannot even assume with any confidence that propositions worked out for the upper levels may be applicable for the rest; Maohi society was far too complex to permit that comfortable step to be taken.

As described in chapter 7, one of the characteristic features of most Maohi marae, including especially kin-congregation marae, was one or more stone 
slabs or columns set upright in the court. They have been identified variously: as leaning posts for priests engaged in prayer or perches for priestmanikins (aho tapa'u), as backrests for principal worshippers, as resting places for visiting tutelars, and as memorial stones for deceased "chiefs" (and hence resting places for their visting ghosts). Some marae contained only one such stone; most had several. In the larger marae each stone may have had a special function, but in the smaller marae it is more likely that one stone served several purposes; and archaeology cannot, and contemporary accounts do not, inform us about which stones served which purposes in specific marae. In any case, our present interest in such stones is limited to the more or less permanent associations some of them are known to have had with particular members, or with particular hereditary offices, of kincongregations.

A feature typical of many marae was a row of three uprights located in front of the ahu; Emory's inference is that these were "seats of honor" for the highest-"ranking" members of the congregation: a central upright (ha'ai) flanked by a tarahu (or terahu) on both sides (1933:17-18). According to Emory the ha'ai was for the "first-born," the right-hand tarahu (facing the $a h u$ ) was for the "second-born," and the left-hand one for the "thirdborn." In a marae of five such uprights the same birth-order pattern is said to have prevailed. ${ }^{17}$

Whether or not these particular uprights had precisely those associations, it appears fairly certain that some uprights on some kin-congregation marae were associated with individuals holding important congregation offices, including Titled ones, that were not exclusively sacerdotal in function. Moreover, some of these uprights are known to have had individual, "proper" names in addition to their generic ones, but as far as I can ascertain a distinction was drawn between the name of an individual's upright and that of his kin-Title (if he had one).

Other evidence concerning the kinds of uprights under discussion comes from numerous accounts, both general and specific, relating how some individual removed his upright from his "ancestral" marae and planted it in another one, usually in a new and distant marae established by himself, but occasionally in an already established one to which he had acquired membership by marriage or by some form of "adoption."

Putting these indications together provides some general conclusions about congregation colonizing and about individual members' peregrinations, and these will be discussed in another section; but they raise some puzzling questions about the matter at hand.

If an upright were in fact identified with a particular congregation office, whether Titled or non-Titled, it is incomprehensible how it could be moved from one marae to another without transferring the office as well. ${ }^{18}$ 
And if the office in question consisted of functions specific to its "ancestral" congregation, it is difficult to see how those functions could continue to be exercised in the "ancestral" congregation, or become applicable to the new one.

The answer probably is that the only uprights that were moved from one marae to another were those associated with offices having only general functions, such as assisting in worship or work or warfare. In this sense, I would be greatly surprised to come across evidence that a congregation's chief removed his upright to some new marae unless accompanied by most or all of his fellow members.

Indeed, most of the kind of uprights under consideration remained in situ, even though the individuals associated with them moved about or resided elsewhere. This was particularly the case when the individual in question held an important kin-Title (and an associated upright) in two or more congregations, as was described above. It also transpired that an upright's associate sometimes moved elsewhere, leaving his stone in place and no successor to claim it-until one of his descendants would someday return "home" and do so. Some uprights (i.e., the so-called memorial stones) were apparently left vacant for all time through lack of all possible successors, although they continued to serve as resting places for the visiting ghosts of previous associates.

\section{Changes in Kin-Congregation StRUCTURE}

At several points in the foregoing, reference has been made to locational changes-of whole kin-congregation marae or parts thereof, and of the stone uprights, "hereditary names" (Marae-names), offices (both Titled and non-Titled), and living associates of those marae. This is one of the most crucial aspects of Maohi social structure, and one of the least understood. First let us consider the marae themselves.

I have already recorded how the Maohis conceived of the beginnings of the first marae to be established in these islands: as founded either by the first priest-god, Maui, in many different places and for the use of mankind in general, or by certain other gods or demigods for the use of their own descendants and worshippers. In both instances these "original" marae seem to correspond to what later generations called marae tupuna (ancestral kin-congregation marae). In any case in whatever manner such marae may have been "created" or "invented" or introduced in these islands, they were-according to a variety of native traditions, pieced together with other kinds of evidence-subject thereafter to several kinds of change.

In some instances whole kin-congregations appear to have died or been wiped out or scattered and their marae abandoned-as witnessed by the LMS Dictionary definition of $m o^{\prime} o p \bar{o}$, to be lost, or be extinct, as a family; to 
be erased, or lost, ${ }^{19}$ and by the presence of numerous nameless marae ruins for which no traditions whatsoever have been uncovered. The causes, mythical and historical, were various. Native traditions charge some of these extinctions to warfare or extirpative chastisement, and recorded history confirms that such catastrophies did now and then occur. The practice some chiefs had of selecting human sacrificial victims from certain families would, if carried far enough, have had the same consequences. ${ }^{20}$ Sickness may also have extinguished entire congregations, in historical fact as well as in native beliefs-that is, the beliefs that some sorcerers cast their nets over whole families and that vengeful spirits sometimes did the same.

In other cases the only transformation experienced by an autonomous kin-congregation and its marae was to grow older and perhaps to change tutelars from time to time. Individual members of such congregations may have gone elsewhere to reside, but without carrying along stones or Titles wherewith to maintain more ineffaceable connections with the ancestral home. One would expect to find more communities of this kind in regions of small isolated settlements, as along much of Tahiti's eastern coast.

Another kind of change undergone by some kin-congregations consisted of a wholesale move to another location. According to one tradition this occurred in the case of an illustrious kin-unit living a mile or so inland in Opoa Valley on Ra'iatea. When this family increased and prospered (the account implies), it abandoned its original tutelar-established marae of Vaearai and moved to a more favorable spot near the coast. Native traditions mention a few other moves of this kind, and I suspect that many more of them occurred, not only to accommodate an increasing membership but perhaps in some cases to flee form an actual epidemic or an imagined scourge, or to escape from an area subject to constant warfare or to the rapacity of a neighboring chief.

Much more complex, structurally, were the consequences of the kind of change involved in the partition of a congregation, as set forth in the passage from Henry I have several times referred to (1928:142). Probably behind most such changes were overall population increase and a general tendency toward autonomy on the part of the congregation's constituent families, although the precipitating reasons were undoubtedly varied (e.g., cumbersome organization, interfamily tension, and unpopular leadership). As Henry stated, the change consisted of a formal partition of the congregation's territory indicated by construction of a new marae to which was transferred the separatists' Marae-names (their "deeds" to the plots thus detached) and presumably any Titles and marae uprights they may have possessed. Also the connection of the new marae with the old one was visibly expressed by incorporating a stone from the latter into the former; this not only conduced continuity with the ancestral 
marae itself but served more specifically to maintain ties with the congregation's common tutelars. According to Moerenhout (1837:II, 12 ), there was strong sentiment against fractionating land, but I can find no tangible evidence elsewhere for such a sentiment.

The location of the new marae may have had considerable significance. In some cases it was constructed at a distance from the old one, in the midst of the detached plots of land. In other cases it was built directly adjacent to the old one: a more or less private family "chapel" attached to the larger "church" it came to be more and more autonomous in terms of its associates' property rights and joint activities, including direct interaction with tutelars. ${ }^{21}$

Using Western logic one might be inclined to see in these differences in spatial separation of offshoot from ancestral marae a corresponding difference in social separation in terms of the latters' tribal and religious autonomy; but we cannot be sure that Maohi logic operated in this way. Henry's account implies that the inauguration feast ( $\mathrm{fa}^{\prime}$ atomora' $a$, entering) which "opened" the offshoot marae served also to signalize the offshoot congregation's tribal and religious autonomy, but I suspect that the process of fission was in general a more gradual one, especially in cases of partition. Moreover, some adjacent offshoots may have been more autonomous than were spatially distant ones, which brings us to the important question concerning the kinds of social relations that prevailed, normatively, between kin-congregations arising out of the type of fission under discussion.

In order to broaden the discussion, I base it on the schema represented in the following diagram-a fictitious but not unrealistic set of "genealogical" connections between marae.

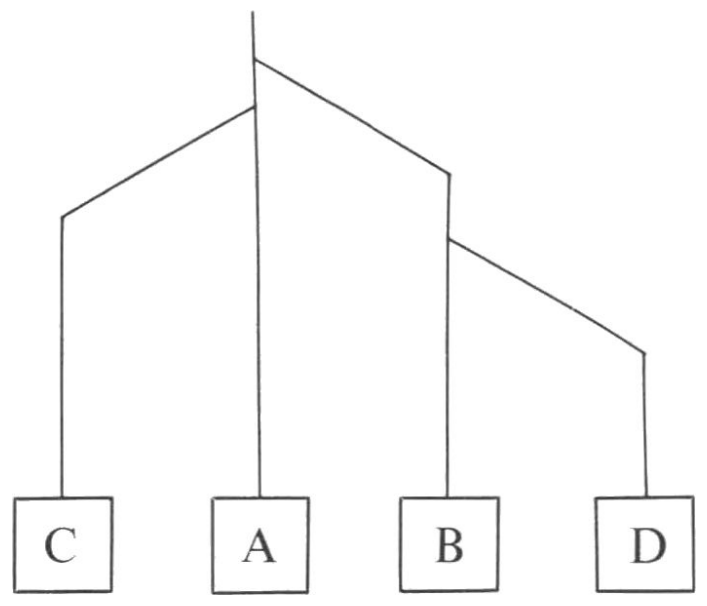

Let us suppose that all four units are subdivisions of what was formerly a single kin-congregation, whose ancestral "temple" was marae A. In the 
course of time one part of the congregation-say, a set of siblings and their spouses and offspring-separated from the rest and set up their own marae, B. Somewhat later, another group did the same and set up C. And finally a part of the congregation at B did likewise and set up D. (Events considerably more complex than this probably occurred, but this schema is intricate enough for present purposes.) I wish to inquire how the Maohis conceptualized relationships deriving from these events: with respect to the marae themselves, to the separate congregations as whole units, and to the more important officeholders of the separate congregations (especially the chiefs). Since this is a "descent" type schema, we are particularly interested in learning whether the resulting relationships were conceptualized in terms of consanguineal relations among individuals, thereby exemplifying the well-known phenomenon of "pattern replication," which anthropologists nowadays are acknowledging to be so widespread.

In many instances Maohi traditions do explicitly relate how certain marae were founded by members of, and with founding stones from, older marae; and in several such instances the older, source marae does indeed seem to have been regarded with more "reverence" than the younger offshoot. $^{22}$

Although all marae of common derivation may have been recognized as such, there is no evidence that such connections were conceptualized in a broader "consanguineal" sense: that is, B and C were indeed regarded as direct offshoots of A (as was D of B); but there is nothing to indicate, say, that C was regarded as "brother" to B or as "father" (i.e., father's brother) to D. Nor so far as I can discover were all such interrelated marae ordered in a more comprehensive sense: for example, $\mathrm{C}$ marae was not entitled to more reverence than D. In this connection Vaearai, on Ra'iatea, the marae traditionally held to have been the one from which all the most widely reverenced marae of the Leeward Islands ultimately derived, appears to have been abandoned and allowed to disintegrate when its congregation moved to the coast.

Turning now to whole kin-congregations attached to marae of common derivation (i.e., to the groups of members themselves, rather than to their marae), the only suggestion that their interrelations were conceptualized in consanguineal terms is in Handy's reference to matahiapo (firstborn) and teina (younger sibling of same sex) "family stocks" (1930:23). Whether the members as a whole of a matahiapo congregation were privileged in any way vis-à-vis the whole memberships of congregations teina to themselves is a question I shall have to postpone for later discussion.

Finally, I turn to relations among the various offices attached to marae of common derivation. To begin with, I have found no evidence that such relations were conceptualized in consanguineal terms-that is, the chief himself of congregation A was not labeled, or otherwise implied to be, "fa- 
ther" or "elder brother" to the chiefs or other officials of congregations B, $\mathrm{C}$, and D. On the other hand, the chief of A did enjoy a measure of authority and precedence over the chiefs of B, C, and D in connection with matters, mainly religious, involving all of them. This probably held also for the chief of $\mathrm{B}$ in his relations with the chief of $\mathrm{D}$-but not, evidently, for relations between C and B, or C and D. In other words, relations between the chiefs of kin-congregations of commonly derived marae were graded, but not comprehensively, and not in explicitly consanguineal terms.

I wrote earlier of rahui, the custom of placing restrictions upon specified kinds of activities in specific places, and I described it as having been one of the rights owned and exercised by any kin-congregation's chief over all the territory identified with its marae. The next question is, To what extent did the normative right to rahui enter into the relations between congregations connected as were those under discussion? This question is of prime importance; unfortunately the answers I am able to provide are incomplete and not very conclusive.

In the first place, I believe that the chief of kin-congregation A would have had the right of rahui over B, C, and D as well. Also, I am inclined to believe, but am by no means certain, that in terms of the ideology of consanguinity this right of rahui was normatively executed through "channels," that is, when imposing a general rahui the chief of A included B by asking the latter's chief to impose it, and not by direct order to B's whole congregation. In addition, although it might be consistent to assume that a rahui command by A's chief to D's should have been channeled through the chief of $\mathrm{B}$, I can discover little evidence concerning this possibility.

In the second place, I believe that while rahui rights may have extended to offshoot territories they did not parallel consanguineal relationships in any broader sense: that is, the chief of B could rahui its offshoot D but not C, even though B's own eponymous ancestor may have been an "elder brother" of C's-a status which among individual consanguines would have embodied some authority over a "younger brother."

Turning from rahui to tax, from an imposing of restrictions to a levying of goods, I believe that the chief of any kin-congregation would indeed have had the right to receive objects and services from its offshoot congregations, either by explicit levy or by regular periodic flow. ${ }^{23}$ Evidence is firmer than was the case with rahui that such objects were normatively required to flow through channels-for example, from the chief of D to the chief of B and thence to the chief of A. But as with rahui, there is no evidence that such levies of goods were required to be passed between units linked by what I have diagramed to look like sibling or collateral ties.

The same kinds of stricture applied to goods moving downwards; the 
chief of a "source" congregation was required to provide some services and objects to offshoot units but not, I believe, to "sibling" or "collateral" ones. The services in question were probably in the form of priestly representation and martial support, while the objects consisted mainly of contributions originally from those offshoot units but in excess of the source unit's needs, that is, redistribution. Passages from Henry and Handy-Marau raise the possibility that one of the services performed by the chief of a source kin-congregation for offshoot congregations was to consecrate the marae of the latter:

Many of the wealthy gentry of the land built their ancestral marae in pyramidal form and inaugurated them with great pomp. They aspired to the honor of having their king or high chief perform the eera'a ceremony, feeling this the highest temporal dignity that could be bestowed by man. But the chief never again returned to it. (Henry 1928:139)

According to Marau these [ra'atira, family] marae were consecrated by the Arii under whose rule the family lived. (Handy 1930:43)

The question raised by these passages is whether they were referring to relationships based on kinship or on kinship and common tribe.

Finally, the several offices associated with any set of marae of common derivation do not appear to have been arranged in any conventional sequence in terms of succession; if the chiefly office of A became vacant, with no direct descendants or siblings of the previous incumbent to fill it, the office did not devolve automatically upon the chief of $B$, then of $C$, and so on.

Yet, despite all the negative conclusions proposed in the foregoing, another statement from Henry suggests that in some places the various neighboring offshoots of a source kin-congregation did maintain active ties in addition to their common involvement in rahui and taxation:

The social temple (marae-o-te-va'a-mataeina'a) of the clan was of considerable importance to the people, as it distinguished them as a community. It was made after the manner of the family marae, presided over by a priest in patriarchal form, and dedicated to a god of the first class. There the men of the clan assembled to present petitions and oblations for their little community in times of rejoicing or sickness; and there the priest received offerings to the gods from persons going away or upon their return home, and offered appropriate prayers on their behalf. There also in like manner he bid the stranger welcome. (1928:144)

When this passage was written, or edited, the word "clan" undoubtedly carried some meaning of "kinship," as it does today; with this in mind, it is entirely possible that where a number of kin-congregations of common derivation were located contiguously they were united into a larger unity, which was also localized in its own special marae. Henry's statement that it was "the men of the clan" who assembled for services at this kind of marae suggests that the wives and children of most of these 
men had no direct access to it, as they had to their respective kin marae, where matters of importance to particular families continued to be conducted. On the other hand, we are not informed whether the marae of the larger unit was one set up separately from the marae of its constituent kin-congregations, including its source marae, or whether it was in fact the source marae. In the latter case, which seems to me to be the more likely possibility, there is a further unanswerable question: Did the source (now "supra-kin") marae continue to serve the more personal, "domestic" needs of all the individuals whose kin marae it originally was?

Equally puzzling is the native label said by Henry to be attached to the unit she describes, that is, $v a^{\prime} a$ mataeina'a. Va'a was the general term for canoe, as well as for a special kind of canoe, (see chap. 8). As for mataeina'a, the LMS Dictionary defines it as the subjects of a chief; a certain tribe, clan, or subdivision of the inhabitants. This is not much more helpful to our present inquiry than is the same source's definition of the composite word, va'amataeina'a, a division of the land owners. I shall consider this puzzling term later on in other contexts, but I must acknowledge that it does not help one way or another to throw light on the questions now concerning us.

Far more important than what label was attached to such suprakin-congregations is the question of the social relations among their constituent branches-or perhaps more precisely, among the representatives of those branches. We are informed by Henry that they "assembled" on certain occasions; but we are not specifically told about the order of precedence that prevailed among them on such occasions. In fact, the only direct clue to the religious aspect of social relations among members of this supra-kin-congregation is Henry's statement that its marae was "presided over by a priest in patriarchal form" (1928:144 [italics added]). I take this to mean that this office was none other than chief of the source unit of the several kin-congregations represented, whose rights and duties I have previously discussed.

More light is cast on this supra-kin-unit by a passage from de Bovis, which I reproduce in full:

Religious neutrality [le culte neutre] was a peculiar custom which serves to demonstrate that the natives of this archipelago were at a level of civilization far superior to that met with among any of the savage peoples one meets with, from the western part of the Americas to New South Wales.

We have already pointed out that the marae was a type of family property, and that its king [roi] ofttimes bore the title of tribal chief [chef de race]. When he was absent his brother or his son or some other close relative substituted for him, and even the most remote [éloignés, space or kinship?] members of the family were accustomed to speaking of it as "our marae." Now if it transpired that the brother of a reigning prince married someone far away and became chief or 
king in a different district or even in another island, he would nevertheless continue thereafter to call it "our marae," when referring to the marae where his father ruled, and he never failed to return there to worship whenever circumstances so permitted and when certain ceremonies took place. He would have grieved not to have been able to do so. When he died his son inherited the right of sitting in the marae side by side with the reigning king, and on a basis of near equality with the latter.

Thus it came about that two or three familes, scattered about in districts as far apart as the outer limits of the archipelago but more typically living on neighboring islands or on the same island, were in possession of equal rights in one and the same marae, where they convened to worship on certain occasions. This circumstance did not stop such princes of common origin from making war on one another; it merely resulted in hostilities being suspended at certain times. And when such enemies met together in this common marae, neither party attempted to take advantage of the temporary armistice. Many maraes occupied positions like the one just described. (1909:57-58)

Without subscribing to de Bovis' use of labels like "king" and "prince," or to his flattering evaluation of Maohi "civilization," his generalization otherwise strikes me as being highly plausible, even in its emphasis on the offices he labels "kings" and "princes." For it is my opinion that an individual Maohi's view of his membership in kin-congregations differed, probably, according to his status in his own local kin-congregation-that is, it was only those individuals who held higher-grade offices (and perhaps other members of their immediate families) who remained aware of and occasionally made use of the wider ramifications of their kin-congregational ties. In other words, for most members of any kin-congregation their local unit was their whole church; only a few saw or treated their local unit as a branch of a larger unity.

Finally, at this point one might be led to inquire about the connection between kin-congregations and the cognatic stocks I discussed earlier. At first appraisal these two kinds of social units and their various subunits would seem to be merely two different ways of looking at the same thing, and perhaps some Maohis also viewed them in this way. But what I wish to make clear is that we cannot be certain that this was the view of all or even most Maohis, and our concern at present is with the way the Maohis themselves viewed their society. Even most of the individuals holding kin-congregation offices-who were as a rule well informed about their ancestral "lines," both in terms of individual ascendants, historical and mythical, and of source marae-even these were not likely to have looked upon remote, "collaterally" related congregations as being populated by relatives of such and such degrees of consanguinity.

Still another kind of locational change undergone by kin marae and their human associates may be labeled colonization, to distinguish it from the process of partition just considered. In what I call colonization, 
one or more members moved entirely beyond the congregation's territorial boundaries and staked off territory elsewhere, formalized by establishment of a new marae whose derivation from the source one was substantiated by incorporating within the former a stone from the latter. But the accounts are somewhat ambiguous. Some of them state or imply that these "founding stones" were taken from the walls of the source marae and were embodied in the offshoots as "cornerstones." According to other accounts the new marae were usually "founded" with colonizers' uprights (i.e., backrests) taken from the old marae and presumably used as uprights, and not as "cornerstones," in the new one. The ambiguity derives from the fact that in some accounts no distinction is made between construction stones, which symbolized a whole marae, and uprights, which usually symbolized kin-Titles or other marae offices. In some cases the two may have been synonymous, but not in all.

I shall not even attempt to reconstruct the myriad private motives which led individuals to leave their home kin-congregations, eventually to establish new homes (and new kin-congregations) elsewhere; for present purposes it is sufficient to distinguish between deliberate and accidental colonization.

Deliberate colonization was not unusual even during the Late Indigenous Era, and it must have been a common solution to overcrowding during the eras before most parts of the Islands became inhabited and staked out. In the later era, after all areas had been claimed by some unit or another, members of some kin-congregations continued to try to carve out new domains elsewhere-to escape troubles at home, to better themselves socially or materially, to extend the home congregation's political influence, or even in a spirit of adventure and discovery. In some of the less politically motivated instances it may be that the new colony made no effort at all to maintain connections with the home congregation, but such episodes are of course unrecorded. In any case, our present concern is with colonies that deliberately maintained a symbolic link with the home congregation, by incorporating a stone from the source marae into their new one.

It is likely that some colonization also resulted from accidents-say, by a canoe load of congregation mates being stranded on a foreign shore and then deciding to stay; or, probably now and then, a canoe load made up of members of two or more different, and even "unrelated," kin-congregations combined forces on some foreign shore to establish a common marae which thereafter served as the temple of the "kin"-congregation made up of their immediate descendants. Although unable in such cases to embody a stone from the source marae in their new edifice, it would have been possible to maintain continuity with the home congregation by other means, including commitment to the same tutelar, active genealogical recall, and deliberate social interaction-which raises the question of the kinds of social 
interaction that took place between a source congregation and its colonial offshoots. I shall summarize below some traditional evidence dealing specifically with some ramifications of the famous Opoa source congregation. The only general statements I have found that might possibly concern relations between far-flung colonial offshoots of common derivation are from de Bovis just given, and from Henry which I quote below.

It will be recalled that the LMS Dictionary definition of 'ati clearly referred to a category made up of members of common descent: a patronymic prefix pointing out the name of the parent or ancestor with the descendants, as Ati Iuda, the descendants of (their father) Judah. In contrast, Henry's 'ati (which she translates both as tribe and as denomination) seems to refer more to the devotees of a particular deity, and not just those descended from him:

The clans were thus classified into denominations which never displayed bigotry toward each other, as the gods belonged to one common category. The clans whose god was Ta'aroa were called 'Ati Ta'aroa, meaning "tribes of Ta'aroa"; those of Tane were called 'Ati Tane; of Ra'a, 'Ati Ra'a; of 'Oro, 'Ati 'Oro; of Hau, 'Ati Hau; of Tû, 'Ati Tû; and so on. Many gods were thus enshrined.

Strangers from other lands were cordially received at the social [i.e., "clan" or supra-kin] marae if they were of the same denomination as the people of the clan. So when they came and wished to offer gifts and thanks to their god for their safe arrival, they would enquire of the clan, " $E$ 'ati ha 'outou?" (Of what tribe are you?) If the answer was favorable, they would say, "Oia 'toa matou" (That is the same as ourselves), and they were at once received with open arms; the priest officiated for them, and they were no longer considered strangers. (Henry 1928:144-145)

In other words, although it is possible that the Maohis recognized a larger unit, an 'ati, composed of dispersed kin-and supra-kin-congregations of common derivation, it is also possible that membership in an 'ati had to do more with common worship than with common derivation.

Then, of course, there is a third possibility-namely, that by Maohi reasoning the two kinds of unit were necessarily, or at least very probably, the same. With no system of writing available to help freeze tradition and inhibit invention, it would have been natural enough to broaden the assumption that "most kin-congregation tutelars were ancestors," into "all worshippers of the same deity were that deity's descendants."

Until now in this discussion of partition and colonization I have sought evidence of continuing connections between source units and their offshoots. It must also be noted that in some instances a deliberate severing of connections may have taken place. Despite Henry's statement that, "clans" of the same denomination "... never displayed bigotry toward each other," there is clear evidence that quarreling and open warfare among consanguines were deemed wrongful only in the most utopian of ideological terms. 
In volume 3 I shall reproduce native traditions regarding such strife; at the moment I draw attention only to some slender but picturesque evidence of the act of severance. A passage from Henry (1928:122) relates how a famous Porapora "Prince," Te Fatu, traveled to neighboring islands dispersing valuable objects and customs of many kinds (e.g., sea urchins, athletes, lasting luxuriance). To Porapora itself he gave the sea snail, the sea cucumber, and "the mussel to cut off the end of the house of Havai'i" ("...e $u^{\prime} u$ $e$ 'oti'oti i te tara fare o Havai'i"), which signified severing connections between Porapora's principal kin-congregation and its source congregation of Opoa (Ra'iatea).

Finally, another kind of locational change involving all or parts of the associates of kin marae was fusion whereby two previously distinct units were joined together. In some instances this may have been accomplished by adding one unit's marae onto the other's; more typically it appears to have been effected by construction of a new and separate marae. Also, while it is conceivable that fusion may have been brought about by an alliance between friends, and while there is a tradition of its having been forced upon a defeated dynasty by the victors (T. Salmon n.d.), it was more typically effected by marriage-in which case a new marae was usually constructed either to substantiate the alliance of two important kin-Titles or to provide a more impressive structure for the heir in whom the two Titles were combined.

I write of fusion as if it involved a combination of entire kin-congregations. Actually the little evidence we have on this matter does not indicate whether whole congregations were so combined, or only some of the principal people from each. Nor do the sources indicate what happened with the old units upon establishment of a new, combined, marae: Were the old marae abandoned altogether or did they continue to serve some distinctive purposes of the allied but still partly separate congregations? The state of disrepair of some marae seems to indicate that most of their stones had been taken by the Maohis themselves to build new marae nearby. (As with other aspects of Maohi consanguinity, the data at our disposal provide more questions than answers.)

I turn now to consideration of locational changes of stone uprights, those slabs or columns set up in a kin-marae court and associated with congregational offices, either Titled or non-Titled. There are several references in the sources to such stones having been moved from one marae to another; I wish to inquire what this signified in terms of social-relational changes. But first, a few words concerning the beginnings and the ends of such stones, as objects of social interest.

I have come across no references to the initial establishment of a new stone upright, but suppose that there was nothing particularly intricate 
or esoteric about the process. In my opinion, during the formative stage of a kin-congregation, stones were set up as needed, to accommodate the separation of offices, especially those assigned to new sons of the congregation chief. As noted earlier, the total number of uprights ranged from one to many. We have no way of knowing, however, which ones of these were associated with particular congregational offices. Sets of three or five seem to have been particularly common-for what social, aesthetic, or metaphysical reasons I do not know.

We are somewhat better informed concerning the ultimate fate of stone uprights. When the particular office associated with an upright became vacant-typically through death of an incumbent without successors-the upright seems to have become a 'memorial stone' (ofa'i manava) and served thenceforth as the resting place for the visiting ghost of some former incumbent (whether of the last incumbent, or the most famous one, or even of the ghosts of all past incumbents is not clear). In this connection, it is possible that some uprights may have been deliberately left vacant, as permanent memorials to especially revered officeholders, with new uprights having been set up to accommodate their successors in office.

There are also some clues concerning the uprights left vacant through the peregrinations of the human associates of the stones. The sources indicate that the officeholder in question was entitled to resume his association however long he remained away-or in the event of his death, that a lineal descendant of his could do so upon satisfactory demonstration of his pedigree. There may also have been situations in which an office, and its upright, was subject to conflicting claims, by a local incumbent and by a claimant from abroad; but I have no information about this or about the principles or processes by which such issues were decided. It is even conceivable that "memorial-stone" uprights may accordingly have been "reclassified" to accommodate a claimant from abroad, or even to serve a new office; but no accounts of such happenings are known to me.

When whole marae were moved from one location to another the uprights were probably moved with them, but that situation has already been discussed. Our present concern is with the upright moved to a different marae. Except in cases of fusion it is likely that the only uprights that were so moved were those associated with offices having only general functions. Such moving usually took place when a kin-congregation was subdivided, or when a colony was established elsewhere-situations which have already been discussed and which entail no particular incomprehensibility, except the ambiguity, noted above, regarding the type of stone that constituted the "foundation stone" of new marae. What is puzzling, however, is the situation resulting from transfer of an upright from one kin-congregation marae to another, already-established one.

I have already recorded my notions concerning the creation of kin-Ti- 
tles, that special kind of kin-congregation office embodied in a proper name. I suppose also that many Titles must have passed into limbo for lack of qualified successors, although the possibility of reincumbency by claimants from elsewhere appears to have been generally recognized and sometimes realized. I have described situations in which the kin-Title itself remained in its own marae while its incumbent resided elsewhere. This occurred mainly with individuals holding two or more kin-Titles in as many different kin-congregations. In such cases as these it was customary for the incumbent to be invested in each Title, separately, in its own marae. The sources are not explicit on this point, but it is quite possible that an incumbent was expected to validate each Titleholding by means of occasional visits to each Title-containing marae.

But what about special moves, not of Titleholders but of Titles themselves? In moves involving whole kin-congregations the Titles, of course, also moved. In the process of partition some kin-Titles probably accompanied the separatist group; and with colonization this was demonstrably the case. As for fusion, although kin-Titles themselves could not have become merged so long as they remained associated with separate marae, there is a distinct possibility that in some instances of marae fusion some kin-Titles of each constituent were combined-not in the sense of being held by the same individual but of becoming actually merged into a new unitary marae. This may also have occurred in the case of non-Titled kin-congregation offices, although I have found no specific evidence on this point.

The kind of kin-Title transfer that appears to have taken place occasionally, and that is most difficult to comprehend, is the one wherein a kin-Title was installed in an established marae having no apparent "genealogical" connection with its former "container." One possible explanation for this "anomaly" lies in the versatility of the Maohi custom of "adoption," and in the frequency of its occurrence. Adoption of individuals into family congregations appears to have been a common practice, as a passage from Henry attests; if such an adoptee happened to have a kin-Title it is possible that the Title may also have moved. Another possible explanation for such a move lies in the importance which some Titlebearing descent lines seem to have achieved, almost to the point of being semi-autonomous social entities, enhanced more by the individuals holding them than by their association with specific marae.

\section{The Opoa Cognatic Stock}

\section{Leeward Islands}

Traditions regarding the founding of specific kin-congregation marae are almost wholly limited to those identified with a few families who enjoyed highly privileged social positions during the eras under study. 
By the time Europeans came onto the scene most of these marae had become "tribal" in character (or, in Henry's terms, "national"). As for most other kin marae (and there must have been hundreds), accounts of their origins and derivations have been lost forever-either through political eclipse of their associated Titles, or extinction or dispersal of their congregations, or lack of European interest. For example, virtually nothing is known about the marae traditions, or anything else, of the Maohis living on Greater Tahiti's eastern coast. Except for a brief stay by Bougainville's ships and an occasional visit by reconnoitering ships' officers and missionaries, few facts were collected about this extensive area. And while it was undoubtedly less densely populated than some other parts of the island, the role in island affairs played by its principal kin-congregations cannot have been so inconsequential throughout history as the blank record might imply.

By the middle of the eighteenth century there had crystallized a body of tradition which attributed social preeminence and highest antiquity to an interrelated set of marae established on Ra'iatea but with offshoots on nearly every other island in the archipelago. Indeed, according to Emory, "The whole of [traditional] Leeward Island history is built on [these marae]" (Marae Traditions). Accounts of this set of marae and of its associated Titles and Titleholders were set forth in numerous myths, genealogies, and "family chronicles." Nowadays, most anthropologists have given up trying to read "real history" into such data (not only as a hopeless task but as an inappropriate kind of exercise), and the accounts I am discussing are characterized by so many inconsistencies that it is difficult to distill from them even a common thread of fiction. Such efforts have been made, however, and I present in figure 16-1 and table 5 information based on the most ambitious synthesis attempted to date, that of K. P. Emory (Marae Traditions).

In presenting this version I do not imply that it is the "correct" one, historically, but it does have the virtue of a certain amount of chronological consistency. In any case, to avoid the appearance of dogma, I intersperse a few versions markedly different from the ones accepted in Emory's synthesis.

I devote considerable space to these traditions because they are virtually the only data we have bearing on how the Maohis conceptualized connections between marae and kin-congregations of allegedly common derivation. As the reader will see, some of the passages quoted throughout the rest of this chapter contain references to subjects not yet touched upon in this work, and hence somewhat incomprehensible at this stage of my exposition. But rather than pause to explain such matters at this time, I shall return to them in later chapters, and I request that the rest of this chapter be read only for what light it can throw on the topic now under consid- 


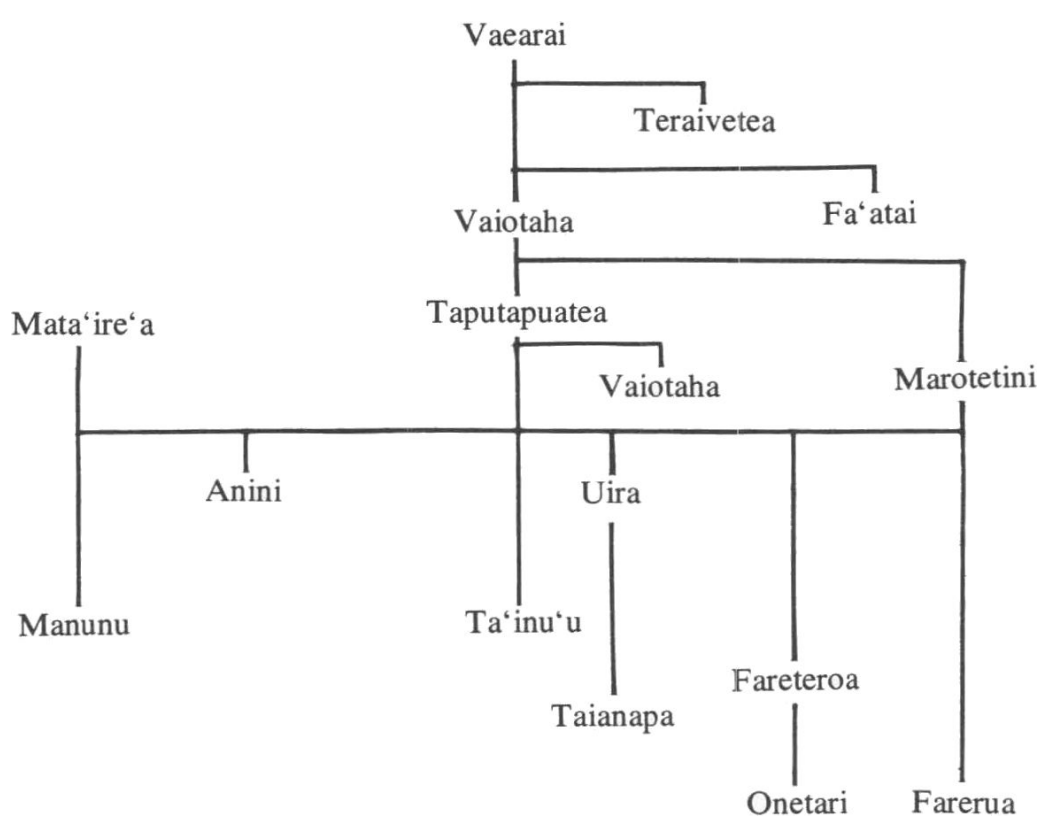

FIGURE 16-1. Traditional relationships of certain Leeward Island marae (according to Emory).

eration-namely, on the "mythical charters" that had been formulated to "explain," and doubtless lend weight to, the society-wide prestige enjoyed by a set of kin-Titles allegedly derived from Opoa.

\section{VAEARAI (RA'IATEA)}

Different traditions attribute the founding of marae Vaearai to 'Oro (a son of the god Ta'aroa), or to Ta'aroa himself: Ta'aroa first broke through the sky here and placed his foot upon Vaearai (Handy 1930:84).

Vaearai was situated in Opoa Valley, Ra'iatea, about a mile inland. According to Emory's calculations it was founded about forty, twenty-five-year generations, or one thousand years, before 1900. Some eleven generations later its kin-congregation abandoned this site and moved nearer the coast and constructed new marae with stones from Vaearai. ${ }^{24}$ One of these, Fa'atai (called also Afa'atai), does not figure importantly in recorded tradition; the other, Vaiotaha, built on Matahira Point, achieved far-reaching fame.

\section{VAIOTAHA (RA'IATEA)}

This marae is said by some accounts to have been founded by a grandfather of Hiro of the Vaearai family (see below), and it had for its major 
TABLE 5. Traditional chronology of certain Leeward Island marae (according to Emory).

\begin{tabular}{|c|c|c|c|}
\hline Marae & Location & $\begin{array}{l}\text { Generations } \\
\text { before } \\
\text { A.D. } 1900^{*}\end{array}$ & Comments \\
\hline Vaearai & Ra'iatea & 40 & \\
\hline Teraivetea & Ra'iatea & - & \\
\hline Vaiotaha & Ra'iatea & 29 & Founded in the time of Hiro's father. \\
\hline Fa'atai & Ra'iatea & - & $\begin{array}{l}\text { Founded about the same time as Vaiotaha at } \\
\text { Opoa. }\end{array}$ \\
\hline Taputapuatea & Ra'iatea & 26 & $\begin{array}{l}\text { The name was in existence at least two gener- } \\
\text { ations after Hiro, for, according to } \\
\text { Rarotongan genealogies, one of his grandsons } \\
\text { bears the name. Taputapuatea is a name } \\
\text { taken on by Vaiotaha marae when it became } \\
\text { the center of an international alliance. It may } \\
\text { have been rebuilt at the time, by Hiro. }\end{array}$ \\
\hline Mata'ire‘a & Huahine & - & $\begin{array}{l}\text { An ancient marae, which was probably con- } \\
\text { verted into a marae of the Hui Arii when they } \\
\text { first succeeded in establishing themselves on } \\
\text { Huahine Nui. }\end{array}$ \\
\hline Vaiotaha & Porapora & 25 & $\begin{array}{l}\text { Founded or created a royal marae by } \\
\text { Hoataatama, great-grandson of Hiro. }\end{array}$ \\
\hline Marotetini & Porapora & $20+$ & $\begin{array}{l}\text { Founded by a chief from Vaearai marae. Was } \\
\text { in existence in the time of Unutea. }\end{array}$ \\
\hline Anini & Huahine & - & $\begin{array}{l}\text { Established after the time of Hiro and by one } \\
\text { of his descendants. Hiro was venerated at this } \\
\text { marae. }\end{array}$ \\
\hline Uira & Taha‘a & - & \\
\hline Ta'inu'u & Ra'iatea & 20 & Erected after the time of Hiro. \\
\hline Manunu & Huahine & 15 & $\begin{array}{l}\text { Seems to have been built in honor of Hoto- } \\
\text { hiva, daugher of a Ra'iatean high chief. }\end{array}$ \\
\hline Taianapa & Taha’a & 20 & Founded by Unutea. \\
\hline Fareteroa & Taha'a & - & \\
\hline Onetari & Taha'a & 13 & Its ancient name was $\mathrm{O}^{\prime} \mathrm{omo}^{\prime} \mathrm{o}$. \\
\hline Farerua & Porapora & 13 & $\begin{array}{l}\text { Was erected by Tefatuiarua, and seems to } \\
\text { have become the representative of Marotetini } \\
\text { marae, which it is sometimes called. }\end{array}$ \\
\hline
\end{tabular}

*Dates are reckoned on the basis of twenty-five years to a generation. 
tutelar the sanguinary god 'Oro. By this time the principal people of Vaiotaha had begun the practice of wearing girdles decorated mainly with red feathers, the famous maro 'ura, as distinctive emblems of their kin-Titles. Also, according to the accounts on which Emory's synthesis was based, the entire kin-congregation of Vaearai-Vaiotaha, or at least its principal families, were known as ari'i-te féti'i ari'i, 'the ari'i kinfolk', one of three meanings imputed to this term by some students of Maohi society.

After about three generations, according to Emory's reconstruction, Vaiotaha was enlarged and its name changed to Taputapuatea, in line with its change of character from a narrowly "family"-associated marae to one of "tribal" or even "supratribal" affiliation. (The semantic logic of this name change is not explained.)

Henry provided an entirely different version of the antecedents of Vaiotaha:

At a very remote period, before 'Oro was born at Opoa, it [Vaiotaha] was the national marae of Hava'i (Ra'iatea), named in full, Tini-rau-hui-mata-te-papa-o-Feoro (Fruitful-myriads-who-engraved-the-rocks-of-Feoro), but it was briefly called Feoro, and to it were attached eight memorial stones which represented eight kings who had reigned over the land, and which became eight symbols of the royal insignia of the kings and queens in long succession afterwards. The stones were named, Te-'iva (Somberness), Feufeu (Reserve), Nuna'a-e-hau (Peacefulmultitude), Te-ata-o-Tu (The-cloud-of-Stability), Manava-taia (Conscience), Huiai-te-ra'i (Piercer-of-the-sky), Paie-o-te-fau-rua (Supporter-of-twice-chief), and Tera'i-pua-tata (The-sky-with aurora).

When 'Oro, god of war, was born of Ta'aroa and Hina-tu-a-uta, at Opoa, his father gave him Opoa with the marae, Feoro, as his home. So he soon waxed very great, and the people of all the land and beyond the shores of Havai'i acknowledged him as the supreme god of the earth and air. The name Feoro was changed to Vai-'otaha (Water-of-the-man-of-war-bird) which, in addition to their local names, became the clerical name of all marae dedicated to 'Oro, because the man-of-war bird was 'Oro's shadow [ata], and the water meant human blood. 'Oro's high priest at Opoa was named Tiri (Throw-out), meaning extension of power and also nurse of the god.

The image of 'Oro in this marae was woven with fine sennit into the shape of a man, two or three feet long, and covered with red and yellow plumage. It wore a girdle of red feathers. The title 'Oro-maro-'ura (Warriorof-the-red-girdle) was given to it, associating 'Oro in his earthly capacity with the highest royalty. (1928:120-121)

\section{TAPUTAPUATEA (RA'IATEA)}

According to de Bovis, this great complex of temples was founded by Hiro, who came in time to be one of its major tutelars. (This same Hiro was honored elsewhere as the special tutelar of thieves.) Emory reconstructed its lay-out as shown in figure 16-2. 


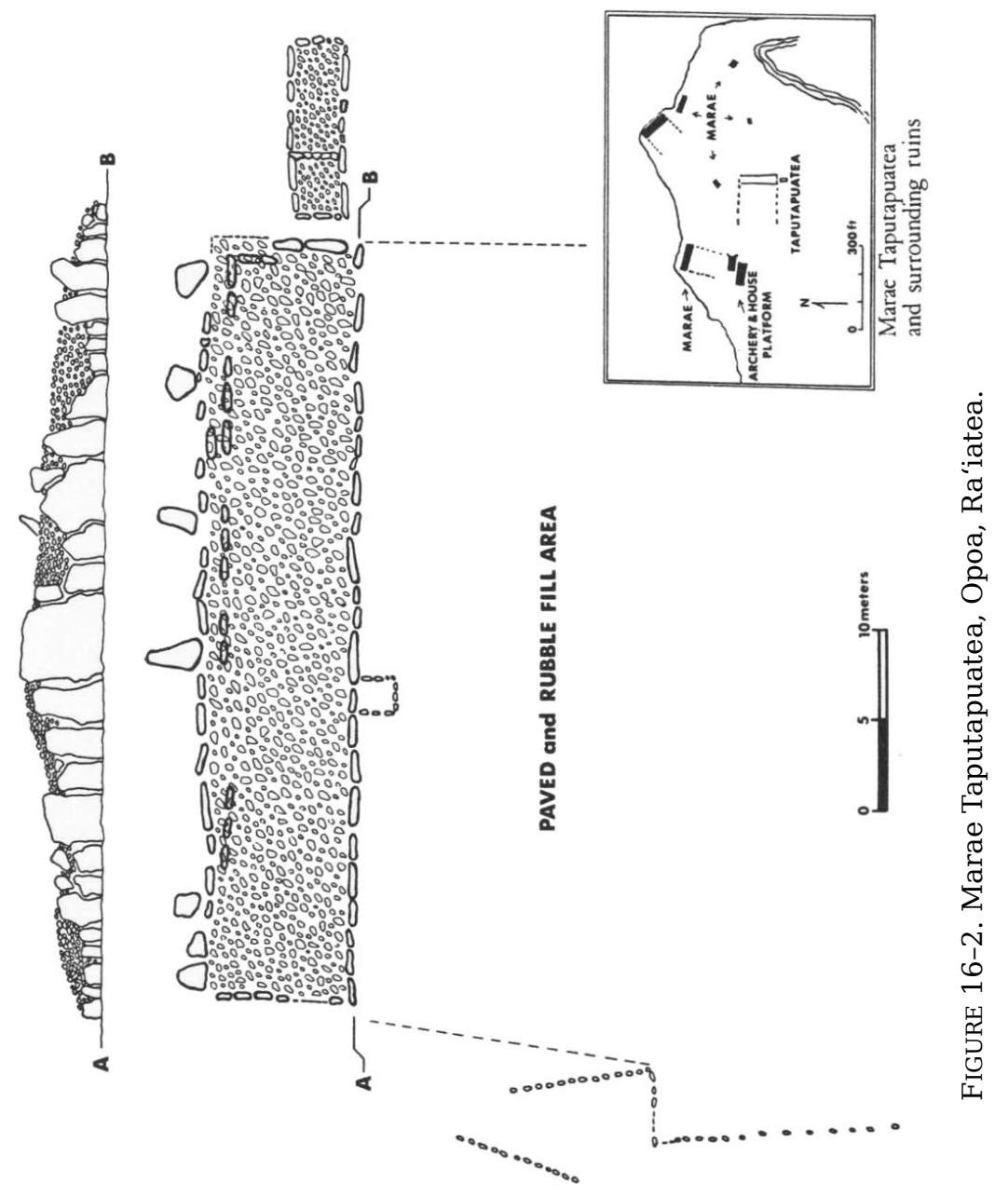


Here is how an early visitor described this awesome place:

We have just returned from a visit to Opoa, the metropolis of idolatry, not in Raiatea only, but throughout all the South Pacific Islands, within a compass of five hundred miles. Hither, from every shore, human victims, ready slain, were sent to be offered on the altar of Oro, the god of war, whose principal image was worshipped here, with the most bloody and detestable rites. To describe the various maraes and their appurtenances, the priests and their sorceries, the sacrifices, feastings, and fightings of the votaries, at this hideous rendezvous, would only be to exhibit, in aggravated language, scenes of disgusting horror, similar to those which have, too frequently perhaps, already occupied our pages. Opoa was also the residence of the kings of this island, who, beside the prerogatives of royalty, enjoyed divine honors, and were in fact living idols among the dead ones, being deified at the time of their accession to political supremacy here. In the latter character, we presume, it was, that these sovereigns (who always took the name of Tamatoa) were wont to receive presents from the kings and chiefs of adjacent and distant islands, whose gods were all considered tributary to the Oro of Raiatea, and their princes owing homage to its monarch, who was Oro's hereditary high-priest, as well as an independent divinity himself. Happily nothing but the ruins of maraes remain, and Opoa, flourishing in all the unpruned luxuriance of tropical vegetation, is one of the loveliest and most peaceful spots in all these regions of beauty and fertility. (Montgomery 1832:II, 126-127)

As indicated in this passage, Taputapuatea came in time to have several separate but interrelated functions:

1. It, or at least some parts of it, remained the kin-congregation marae of one of the Vaearai-Vaiotaha descent "lines" whose principal Title eventually became Tamatoa.

2. It became the principal marae of the whole tribe ruled over by chiefs in the Tamatoa line; that is, its congregation probably came in time to include many individuals not descended from Vaearai-Vaiotaha families.

3. It served as source marae for descendants of the Vaearai-Vaiotaha people who had left Opoa and settled elsewhere. Presumably some of these latter returned there occasionally, to worship together, but not, as far as I can discover from recorded traditions, to render obeisance and tribute to the current Tamatoa.

4. According to certain traditions, it also served as an assembly place for the periodic meetings of an intertribal alliance devoted, among other things, to the worship of 'Oro.

5. It became the principal cult center of the Arioi sect.

Even before Vaiotaha grew into Taputapuatea, some members of the Vaearai-Vaiotaha families-“junior chiefs" said Emory-moved to other islands and established offshoot marae: Marotetini and another Vaiotaha on Porapora, and Mata'ire'a on Huahine. Thereafter these three, with Taputapuatea, “... became the head Maraes [of the Leeward 
Islands; see fig. 16-3] ... chiefs whose genealogies started from these taking always first rank" (T. Salmon n.d.: 4).

\section{VAIOTAHA (PORAPORA)}

This marae was, according to Emory, founded with a stone from Vaearai and by a man named Hoataatama, who instituted the wearing of a yellow, instead of a red, feather girdle as emblem of his line, to show his independence of Opoa. ${ }^{25}$ Still another account of the founding of the Porapora Vaiotaha describes the event as having taken place, during the time of the gods, to honor the birth of the first $a$ ri' $^{\prime} i$ on that island, one Tiria mata o Vavau, who was the offspring of a stone and a cliff (T. Salmon n.d.).

\section{MAROTETINI, OR FARERUA (MAUTAU POINT, PORAPORA)}

According to one tradition reported in Emory, Marotetini was founded with a stone from the Opoa Vaiotaha-its founder, one Mara'a-ari'i, having left Ra'iatea after a quarrel over use, or misuse, of "royal" insignia. The derivation of Marotetini from the Ra'iatean marae was believed by Emory to be
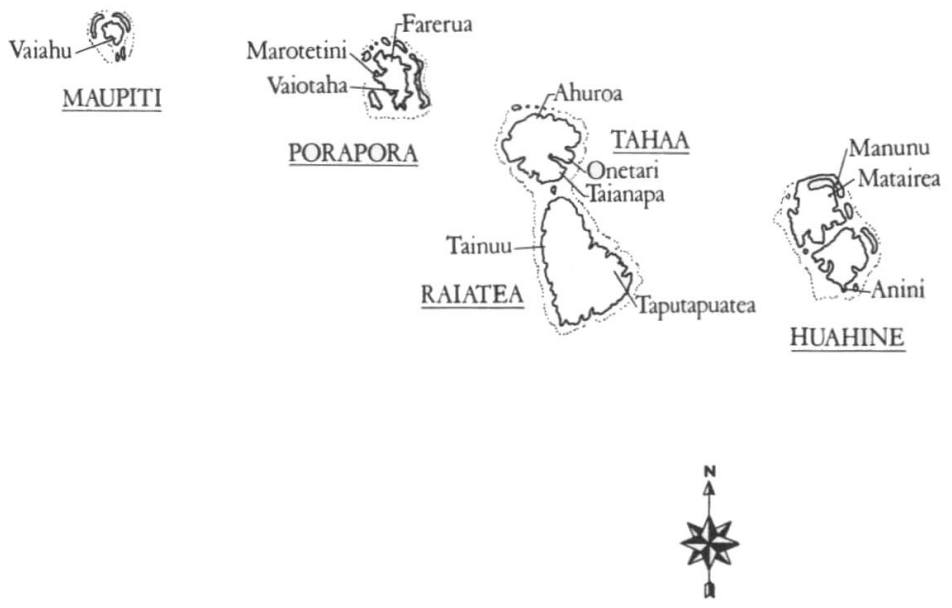

FIGURE 16-3. Principal marae of Leeward Islands. 
confirmed by the fact that both of them have an $a h u$ of exactly the same length and lie in the same north-south axis "... in a region where orientation of maraes is not a practice" (Emory, Marae Traditions). Emory believed that Marotetini was the principal marae on Mautau Point and Farerua was its offshoot, but in time the two structures were combined into a single marae complex.

Differing stories about the founding of Farerua itself provide a good example of the variability of Maohi traditions: (1) Two brothers worshiped at Marotetini. The elder stayed at Marotetini while the younger pulled up his stone, went to the point, built Farerua, and there started a new kin-congregation, called Pa, whose special tutelar was the god Ra'a; (2) It was founded by Te Pevaari'i of Marotetini marae who gave it the name Farerua because of the two houses (fare rua) built nearby for his two wives; (3) It was founded to celebrate a new family alliance (and a new descent "line") established through the marriage of a Poraporan "princess" and a "prince" from Rotuma (not, said Emory, the Rotuma west of Fiji but a forgotten name of one of the Cook or Austral islands). The marae was called Two-houses because of the two families thus united.

The subsequent "history" of these important Porapora marae reveals something of the interplay between "consanguineal" and "tribal" ideologies. I reproduce below an excerpt from T. Salmon's "The History of the Island of Borabora, and Genealogy of our Family from Marae Vaiotaha," but postpone discussion of this matter until later. The hero of the piece, Teihotu, was the highest-graded Titleholder of Marae Vaiotaha (Porapora), and the events set down are calculated to have taken place during the early years of the eighteenth century:

In Teihotu's reign happened one of the greatest events in the Government of Borabora, he having been obliged to absent himself from his island to fight and keep his possessions in peace; his people were jealous, and those who represented him at home created a new state of affairs, the principal ones being to cut down the austereness of everything concerned with Marae Vaiotaha. The Talmas [obviously a typographical error, for tahu'a] of Marae Farerua claimed to be of the same rank as those of Vaiotaha. They waited for Teihotu's departure, and at once started the revolt. The precincts of Vaiotahu could not protect any one. [Its nature as a sanctuary was violated.] Before the messengers could reach Teihotu, who was fighting at Teraitoa at the time, the rebels had gained the victory. $\mathrm{He}$, however, returned, and on arrival found an army ready to give him battle at Faanui, the principal stronghold of the insurgents. He arrived at home at night, bringing only a few of his warriors; the enemy next morning marched against him. Teihotu made his preparations on his arrival and arranged at early morn he would make his attack. He said, "The sunrise on Mount Para must not hide the heads of my spears from my enemies." Before starting he took his son from his mother's arms, and held him to his men, saying, "My men of Vaitape and Vaiotaha, here is your chief; look at him well, for you will have occasion to remember, I go to fight for the glory of Vaitoha." His warriors requested him to fight in the 
rear ranks. "No," he replied, "Teihotu has only one place in battle, and that leading." He gave the word to march and kissed his son. He led his men so fast that but few could keep up; over the hill he went just as the sun was rising over Mount Para. His enemies were ready for him; knowing his recklessness they had laid an ambush, only one chief showing himself; he taunted him to come on and fight a single combat; this chief's name was Taeaetua. Teihotu accepted at once and ordered his men not to advance any further and follow him. He came on, Taeaetua backing all the time till he got him well amongst the ambushed warriors; these surrounded him. Teihotu fought as no other chief of that time, and killed several before he received his death wound. His men were doing their best, but their enemies were so superior in numbers that all were killed. They called the dead chief Teihotu matanevaneva, glancing eyes. They took his body to the beach, where it was exposed. His boy and girl were sent to Fahaa. The revolt was then complete, and the Marae Farerua became first Marae of the Tevaitapu Government. To do this, however, they took the principal stones from Vaiotaha and reconstructed Marae Farerua. These stones were, the one representing the head or eldest family; it is a stone of 6 feet by 4 feet, standing (for these stones still exist) on the right and left, two stones each, in all five. There are five families from which head chiefs sprung and directed the Government. The rebels, when they elected the head chiefs, could not find a single member of these families amongst them, for all of age had gone with Teihotu to fight at Rarateam [sic], some having stopped behind fighting when he returned.

Taeaetua, the usurping chief, proposed himself, saying, "I killed Teihotu; mine is the place." The Tahu'as disputed this, and by underhand means ordered his death. The men of Faanui then made a proposal that if Teihotu's son would come back they would accept him, only he must take the name of Puni-and this name was the head name for Marae Farerua-and govern under Teraitapu rule. After long discussions, and to prevent civil war, the young chief was counselled to accept. The Taiateans were at the bottom of the whole affair. The young chief returned and was crowned, not at Vaiotaha as of old, but at Farerua.

Teihotu mataroa, or Puni, took to wife Tetuanui, Borabora; born of them, Tetuanui marua ite rai. The name of the island was changed from this time, as well as the Government and name of governing chief. It became [respectively] Borabora, Puni, and Teraitapu Government. For the birth of the first chief under the Teraitapu Government they built the Marae Marotitini, and declared that only the first-born of the eldest branch could be crowned in it; the second branch taking the place of the first in case of no representative, and so on through the five branches. (T. Salmon n.d.: 25-29)

Two other Porapora marae listed in Emory's "Marae Traditions" are Nonohaura and Faretai. There exists a genealogy for the former going back nineteen generations (before 1900), but it does not appear to be connected, genealogically, with the Vaearai-Vaiotaha set. Faretai marae has completely disappeared, and no genealogies have been discovered to connect it with known marae or family lines, but one account claims for it an antiquity as great as that of Vaiotaha (Porapora).

Of the thirty-five or so marae on Maupiti (Emory 1933:167) only two are the subject of recorded traditions which might possibly link them with the Vaearai-Vaiotaha set. One of these, Teparoa, was said to be the oldest, and appears to have been the kin-congregation marae identified with the 
Title Tu-Nui-Paia-i-Teparoa, whose incumbent is characterized by Handy as an ari'i (1930:108). According to information collected by Handy from informants in 1923, Marae Teparoa was founded sixty-two generations previously by the god $\mathrm{Te}$ Tumu $\mathrm{O}$ Te Papa (The-foundation-of-the-rock) (1930:108).

The other such marae on Maupiti was Vaiahu, the island's only "national" one, where "tribal" ceremonies took place (Handy 1930:108). (Actually, Teparoa and Vaiahu were only about one hundred yards apart, and probably parts of the same complex.) I can discover no specific traditions concerning Vaiahu's founding, but it, along with Teparoa, was regarded as having had connections with Vaearai-Vaiotaha, or so a legend collected by Ropiteau would appear to imply. I quote only the most immediately relevant part of this "Story of the Rock Called Tatuapuha":

A king [roi] of Maupiti happened to wed a woman not of "royal" blood [i.e., not

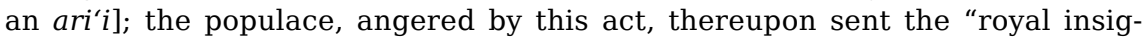
nia"-what these were is not specified-to Opoa (Ra'iatea). Later on, tiring of being without a king, the populace sent a delegation to Opoa to retrieve the royal insignia. Arriving there, one of its members, Hataiau, was interrogated in the following way by Tu, the King of Ra'iatea: "Where do you come from?" "From Maupiti," responded Hataiau. "But are you really from Maupiti?" Tu asked. "Yes," said Hataiau. "Then what is the name of your marae?" Tu inquired. "It is Vaiahu," Hataiau replied; whereupon Tu realized that he was indeed of "royal blood," so helped him to procure the royal insignia for Vaiahu marae, thereby saving it from being captured by members of the delegation who wanted it for other Maupiti marae. (Ropiteau 1932:128-129)

By European times Maupiti had become politically subordinate to chiefs of Porapora, but there is no recorded tradition of which I know that bases this relationship on consanguineal ties.

To return to Ra'iatea, Emory also placed marae Ta'inu'u on his chart, indicating it to be linked with the Vaearai-Vaiotaha set. Ta'inu'u, the largest recorded marae on Ra'iatea, is at Tevaitoa, on the island's west coast. Handy asserted that this was the only district on Ra'iatea besides Opoa that was "ruled by an Ari'i family. I have never been able to find out," Handy continued, "just what was the relationship between the family here and that at Opoa, beyond the fact that Tevaitoa was autonomous. The Tevaitoa family was related in some way to Rarotonga." (1930:91)

Henry was more explicit about Ta'inu'u-perhaps too explicit to be entirely credible:

Rarotonga is an offshoot of Tahiti, and intercourse between the two peoples has always existed. When the royal family of Rarotonga became numerous, they decided to strengthen their ties with the royal house of Opoa. So a prince named Poiriri (Shades-of-night) took a marae stone and accompanied by two princesses, Te-unu-tai-ahu (The-image-on-walled-sea), and Te-unu-taimarae (The-image-on-marae-sea), and a retinue becoming their rank, sailed 
to the southwestern coast of Hava'i [Ra'iatea]. They landed at a point named Tai-nu'u (Moving-sea), where they were kindly received and allowed to establish themselves and build their marae. These high personages intermarried with the royal family of Opoa and thus consolidated forever the relationship between the royal houses of Rarotonga and the Society Islands. Since then other matrimonial ties have been formed. (1928:121-122)

During the eighteenth century the three most important marae on Taha'a were Taianapa, Onetari, and Ahuroa. According to Handy, Onetari was the "original" marae of this island, having been founded as an offshoot of Vaearai (1930:93). In Emory's reconstruction, however, Onetari was established only some thirteen generations before 1900, but was a continuation of an older marae named Fareteroa, or O'omo'o, whose connections, if any, with Vaearai-Vaiotaha are not recorded. Taianapa was also linked to Vaearai-Vaiotaha, having been founded by Unutea, a famous "princess," some seven generations after Hiro, that is, after the traditional date of the transformation of Vaiotaha to Taputapuatea. Notwithstanding the asserted Vaearai-Vaiotaha links of Onetari and Taianapa, it was Ahuroa that was the "national" (i.e., principal "tribal") marae of Taha'a. According to Henry, Ahuroa was consecrated to the god Tane, but Emory and de Bovis stated that 'Oro worship was subsequently established there. ${ }^{26}$

Extensive traditions have been recorded for only two of the numerous marae on Greater Huahine: ${ }^{27}$ Mata'ire'a, located on a hill overlooking the central part of Maeva settlement, and Manunu, located on the narrow peninsula north of the lagoon around which Maeva settlement was built. By the eighteenth century both had become "tribal" in character, but are traditionally associated with families whose genealogies lead back to Vaearai. According to one account Manunu was built in the eighteenth century, and Mata'ire'a shortly thereafter (Chesneau 1928), but all other accounts accord them much greater antiquity and give priority to Mata'ire'a. According to Salmon, Mata'ire'a was one of the original offshoots of Vaearai-Vaiotaha (along with Vaiotaha and Marotetini on Porapora), and, as stated above, hence one of the four most venerable marae of the Leeward Islands, ... "Chiefs whose genealogies start from there taking always first rank." Emory, on the other hand, concluded that it was founded even before Vaearai-Vaiotaha people had reached Huahine, and that these latter took it over upon arrival.

The founding of Manunu provides another useful example of the variability of Maohis' suppositions about their own past. The first version I quote appears in the introduction to the LMS Dictionary:

The Rohu Atua [history of gods] gives the following account of the titular god and royal family of Huahine.

Tutapu and his wife dwelt on a land called Puatiriura. They had an only daughter, Hotuhiva. No husband was to be found for her on her own land. Her 
parents, however, were very anxious she should obtain one, and therefore put her in a drum, called Taihi, under the care of Tane and the god or idol Taputura, and sent her to sea. After sailing about for some time, they landed at Manunu on Huahine; which name signifies "cramped."

The spot was formerly called "Toerauroa."

Tane became the titular god of Huahine. The young lady, Hotuhiva, was married to a chief named Teaonuimaruia. They had two sons, Tina, and Hena, and they are considered to be the ancestors of the present chiefs." (p. iv)

The next version is taken from Henry:

Tû-tapu (Stand-to-pledge), a king of Ra'iatea at a very remote period, had a daughter named Hutu-hiva (Splash-of-clans [!]), who as a result of inspirational revelation was sent on a voyage in a great sacred drum to meet her future husband at Huahine. She traveled safely, coiled up uncomfortably in this way, and was borne upon the crest of a wave on to the shore of To'erau-roa (Distant-north), where stands the warriors' marae of that name. As she emerged from the drum she found herself crippled with numbness in all her limbs, for which reason the point was afterwards called Manunu (Benumbed).

It was not long before two warrior princes, named Tû (Stability) and Teao-nui-maruia (The-great-world-overshadowed), approached her from the marae and bore her kindly across the lagoon to their home at Maeva; and in due time, she became the wife of Te-ao-nui-maruia, of the first dynasty that reigned in Huahine, called Te-pà'u-i-hau-roa (The-excellent-waist-cloth).

She bore him ten sons, after whom the ten districts of Huahine-nui are named .... (1928:100)

Emory's version came from one of his own informants:

A chiefess, Hotuhiva, set out for Papenoo, Tahiti. Being badly received, called a manahune [commoner], she returned, landing upon Manunu Point. She then ordered her company to beat their drums. This attracted the chief and people of Maeva Village. When the chief saw her he had presents of food sent for her. Subsequently he built Manunu marae in her honor. (Marae Traditions)

The next version is a summary made by Emory from notes of Tati Salmon:

The wife of Tutapu was Tehaamahea, and their children were Hotuhiva, the older, and Roo and Tane. Hotuhiva was carried off and made to sleep with Manuarii i Vaiotaha. She was put into the drum Ipuipu-i-te-rai, with her brothers and set adrift to return to Matairea. When far out to sea, they were blown on to their land. The servants of Teaonuimaruia informed him of the arrival of Hotuhiva. He deserted his wife, Hotuaito, for her.... The two brothers who were put to sea became the gods Tane and Roo. (Marae Traditions)

According to a version collected by Ropiteau, the heroine of this tradition, Hotuhiva, was a native of Maupiti. She voyaged to Mata'ire'a, Huahine, riding on her drum, Taimoana. As she was arriving there the actual spot where she landed was Paorie), Teaonuimaruia, the "king" of Maeva, who lived at Aiatupuna [ancestral source] with his pregnant wife, Hotuaitu, dreamed that someone was being carried by sea to Maeva. Un- 
able to sleep after that, the "king" went to Paorie early in the morning and saw Hotuhiva sitting in the shade and somewhat wearied by her sea voyage. He took her and carried her inland and ordered his people to make a marae there for her. When it was completed he placed her on the marae, which he named Manunu. Upon hearing of this the "king's" first wife became angry and left him, and he kept Hotuhiva as his principal wife. (This Ropiteauan version of the Hotuhiva legend will be taken up again in another context.)

Finally, there is a wholly different version recorded in Chesneau. During the years of the eighteenth century, after all Huahine had been brought under control of a single chiefly line there lived at Maeva a famous woman of that name who was sovereign of the whole island. From her marriage with Tuaroanuihau she bore four sons: Horohaehaa, Maruahitu, Matatoerau, and Tiriarai. After the disappearance of Tuaroanuihau the four children built a marae on Point Mata Toerau and consecrated it to the god Ta'aroa and his subordinates, Tane and Hiro. Since her "widowhood" weighed heavily upon their mother, Maeva, her sons named the marae Weariness (Manunu). Later on Maeva came across a large drum washed ashore near Manunu and a man who had arrived with it. This man was Terorohiti, a warrior chief of Matahiva (Tuamotu). Much taken with the new arrival, Maeva settled down with him and bore four more sons. (Chesneau 1928:60ff)

The most imposing marae of Huahine Iti (i.e., southern Huahine) was Anini, located at Tiva Point, the southern extremity of the island. Its principal tutelars were 'Oro and Hiro. Handy stated that Anini served for the worship of 'Oro and Hiro, and that it was an offshoot of Opoa. Handy also asserted that Little Huahine was "independent" (politically) until brought under the sway of the chiefs at Maeva. (1930:98)

Mai'ao island is described as having been a "dependency" of Huahine (de Bovis 1909:61), and one of its marae, Nu'utapu, has been labeled a marae ari'i (Verin 1962a:43); but I can discover no recorded traditions regarding its founding.

Traditions about events on Huahine subsequent to the founding of its principal marae will be summarized in a later chapter, but I reproduce here one recorded episode because of its reference to connections between Huahine and Opoa's Taputapuatea.

According to some accounts (traditional, historical, and anecdotal, recorded by Chesneau from 1907 to 1914 and based largely on information from Marcantoni), all Huahine was, during the seventeenth century, under the sovereignty of the "Queen" Maeva (Maeva Vahine) noted above. After her death her eight sons-the four from her first husband, Tuaroanuihau, and the four from her second husband, the warrior-chief from Matahiva-claimed the right to succeed. They held innumerable 
meetings but were still unable to decide upon a successor, so they agreed to go together to Opoa "... to request the maro'ura (red-feather girdle) of the High Priest of 'Oro." After building a canoe for the journey they obtained eight human victims, one from each of their districts, and traveled to Taputapuatea. On their arrival they presented the victims to the High Priest as an offering to 'Oro, who acceded to their request for some red feathers. (This account describes these feathers, synonymously, as mana ura, red power.)

Had the tokens been entrusted to one of the sons, as a way of selecting the one to be sovereign, the whole episode would be somewhat more comprehensible; but that was not the outcome at all. Instead, the eight claimants returned to Huahine, taking with them two newly acquired friends (tau'a)-presumably junior members of Taputapuatea gentry-who were of the "Oro family," and they tried again to agree among themselves upon a successor. After months of stalemate they reached the compromise of offering the sovereignty to one of their new friends, but still they could not agree upon which one to offer the office. Finally, the more enterprising of the Ra'iatean visitors took matters in his own hands and seized power, through a combination of trickery and fighting. Thus, the token of connection with Opoa was arranged by "treaty" (actually, "bought" with human sacrifice), but social links themselves between Huahine and Opoa were established (or reestablished) by "friendship" pact and a combination of election and physical seizure of power. How such a connection was subsequently manifested is, however, not described.

\section{Tahiti-Mo'orea}

Emory revealed his interpretation of marae traditions on Tahiti-Mo'orea in the following straightforward statement:

The building of maraes of cut stone in contrast to selected water-shaped boulders on the points and along the shores of the Bays of Tahiti and Mo'orea, was the work of the ruling families of chiefs who styled themselves Hui Arii (the chiefly class), or Opu Arii (chiefs from the royal womb). Traditions point out and genealogies prove that these Hui Arii of the Windward Islands are the descendants of invaders who married with the local people and set up the dynasties ruling when the Europeans came upon the scene. (Marae Traditions)

According to this interpretation there were numerous "pre-ari'i"marae on these islands, some of them of considerable antiquity and associated with families of great strength and influence, but in the course of time the more important of these acquired Opoa connections through marriage of one of their members to an Opoan. Other Tahitian and Mo'orean marae labeled by Emory as having been "most important" were founded directly by "colonists" from Opoa itself. (The list of "most important" Tahitian marae given by Adams and Baessler agrees closely with Emory's; this should not 
occasion surprise, since the ultimate source of information of all three of them was the same Papara family of Ari'i Ta'ima'i, Marau, and Tati.) ${ }^{28}$

I reproduce in figure 16-4 Emory's diagram illustrating his reconstruction of connections between these "most important" marae, the locations of which are shown in figure 16-5.

Other marae, apparently belonging in the formative period of the Hui Ari'i, were Ahurai (Fa'a'a), Hitia'a (Hitia'a), Fareroi (Ha'apape), Utuai (Pa'ea), and Umarea and marae Tefano (Mo'orea).

Most accounts agree in calling Farepua, of Vaiari district, the oldest, most revered marae of Tahiti-Mo'orea. With its principal Title, Te ari'i nui o Tahiti, went the privilege of wearing the maro 'ura. According to information supplied by Marau to Handy, the founder of the line of Vaiari chiefs (and presumably of their marae, Farepua and closely connected marae Tahiti) was Tetunae, who was a great-grandson of the (star) god Venus (Taurua horo po'ipo'i) and his mate, a daughter of Ta'aroa. (Tetu-
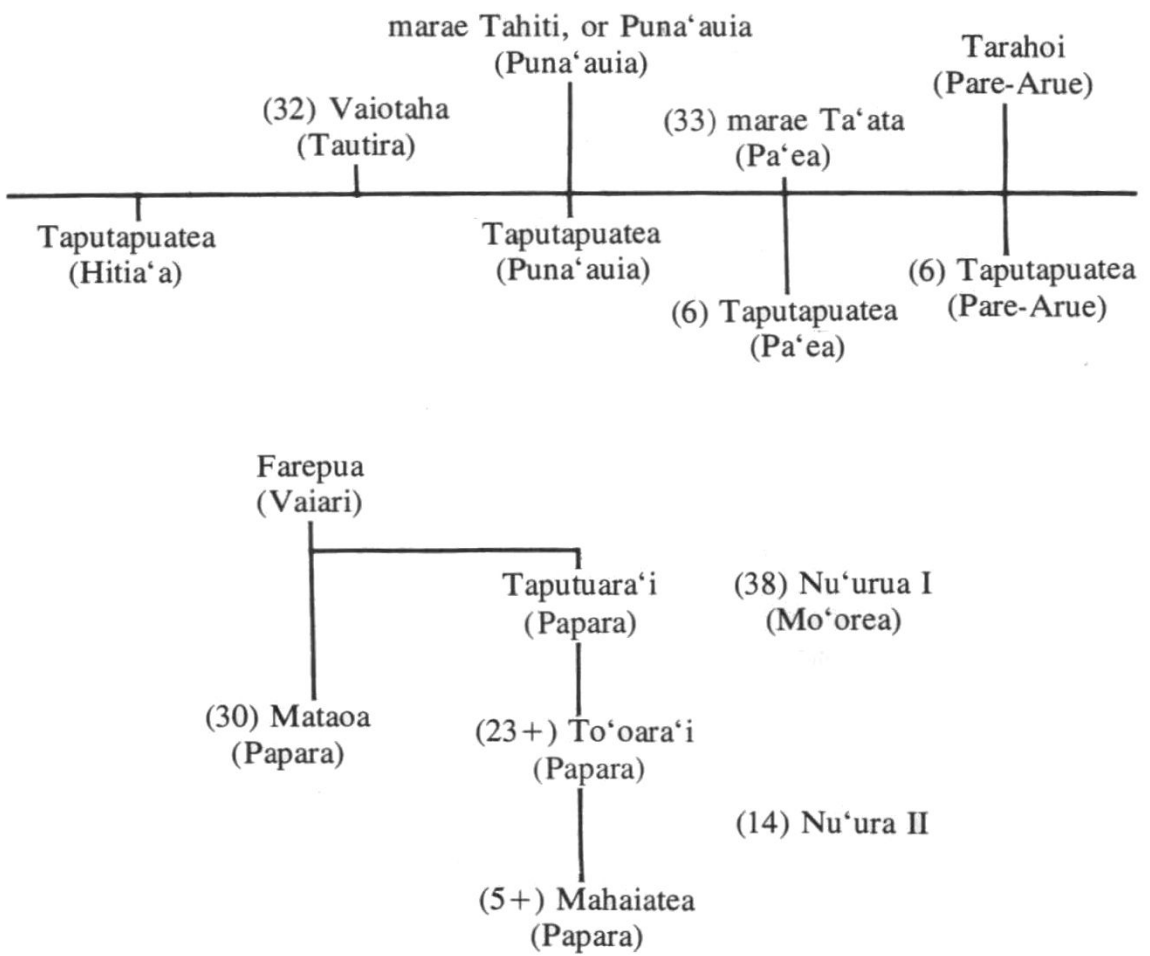

Note: Figures enclosed in brackets represent number of generations before A.D. 1900 .

FIGURE 16-4. Traditional relationships of some important marae of Tahiti and Mo`orea 
676

Ethnography

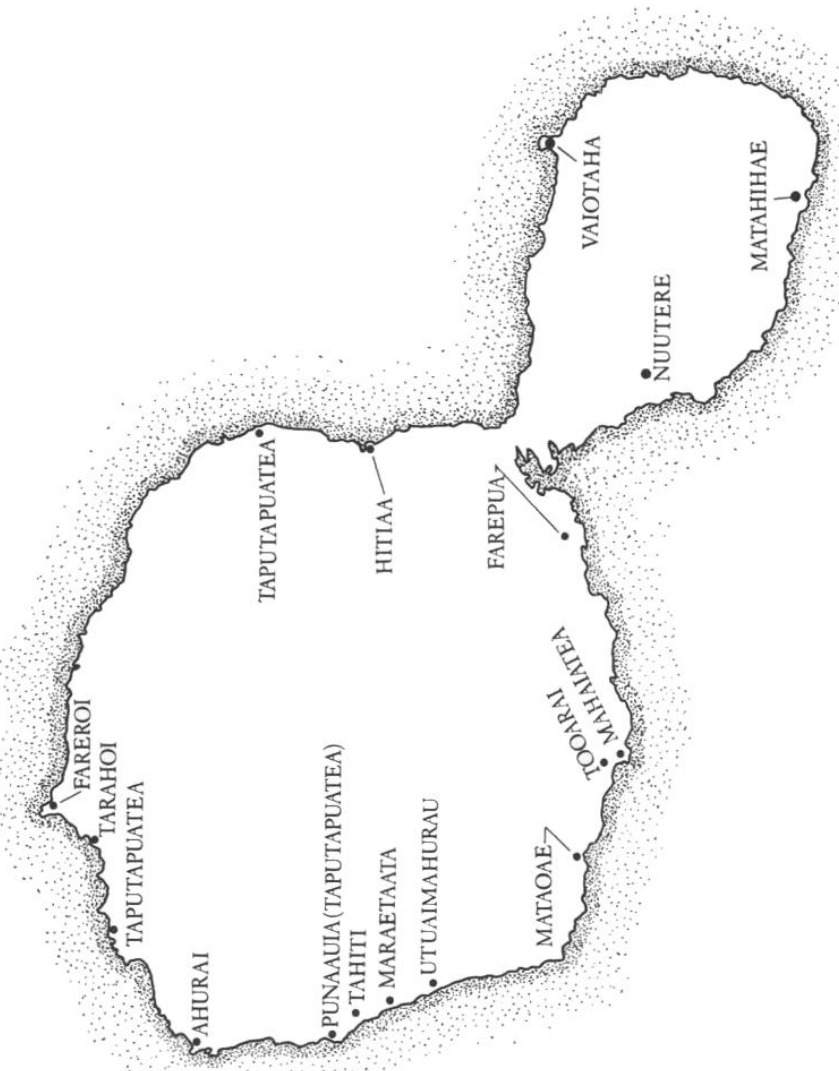

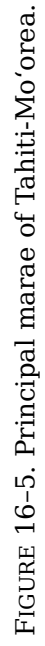

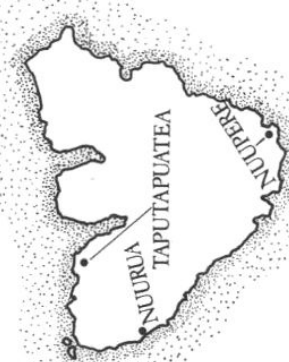


nae's connections with Opoa are not explicitly mentioned but are strongly implied.) During the next five or six generations after Tetunae, other individuals-ari'i-with Opoan antecedents are said to have spread through Tahiti and set up several other "royal" [ari'i] marae. (Emory, Marae Traditions)

Adams pointed out that the Title Te ari'i nui o Tahiti (The Great Ari'i of Tahiti) did not proclaim its holder to be the sovereign of all the island (1901:16). Handy appeared to imply in one place that Tetunae, or rather his descendants, acting in council, were in a position to govern all Tahiti (1930:70); but even the possibility that the island was ever subject to unified control in pre-European times is not recognized in any other "traditions" of which I know.

The only other Tahitian marae of that earlier era having a maro 'ura Title (Te atua nui e maru ae i te ra'i) was Tahiti-Puna'auia, in the Punaru'u valley on Tahiti's western coast. Traditionally this was a populous and politically strong area prior to the alleged "ari'i invasion." The presence of a maro 'ura kin-Title here, before the legendary spread of Opoan ari'i just mentioned, suggests either an earlier connection with Opoa, or the possibility that this emblem of exalted prestige was not the exclusive prerogative of the Opoa line of chiefs. Or, since the marae itself is said to have been founded by Te Manutunu, a Puna'auian chief, and his wife, Hotutu, a member of the Farepua (Vaiari) family, one might explain the marae's maro 'ura prerogative by this connection. Handy gave a different account of the founding of marae Tahiti-Puna'auia: "I understand from Marau that the first marae arii of Punaauia was that named 'Tahiti', founded by Tetunae sixty generations ago in honor of his granddaughter, Nuutea, who married the chief Nuu of Punaauia" (1930:72). It is not surprising to discover two entirely different versions of the same legendary episode, but it is curious that they derive from the same source, the omniscient Marau. Also, one should note in this version another example of the tendency to build the legendary Tetunae into larger and larger culture-hero proportions. In any case, this marriage served to connect (or reconnect) the Vaiari and Puna'auia congregations; meanwhile a new family connection with the prestigious Leeward Islands was being made. Henry Adams paraphrased the story he was told by Ari'i Ta'ima'i-Marau:

Many generations ago a chief of Punaauia, named Te manutunuu, married a chiefess of Vaiari, named Hototu, and had a son, Terii te moanarau. At the birth of the child, the father, Te manutunuu, set out in his boat for the Paumotu islands to obtain red feathers (Ura) to make the royal Maro for the young prince.

So the story begins by taking for granted that before the first Teva existed, Punaauia and Vaiari had already their own chiefs and Maraes. The legend is clear in adding that the Marae of Punaauia was founded for this same young prince, Terii to moanarau, by his father, Te manutunuu, in order that he might wear in his own Marae the Maro-ura which was made of the 
feathers collected in this voyage to the Paumotus. The name Punaauia is said to have come from the killing of a relation whose body had been rolled up as fish were rolled. The legend starts by assuming that Vaiari was the oldest family, with its Maraes, and that Punaauia was later in seniority and rank.

While Te manutunuu was absent on his long voyage to the Paumotus, which required several months, a visitor appeared at Vaiari and of course had to be entertained by the chiefess. This visitor, our first ancestor, was what Europeans call a demi-god; he was only half human; the other half was fish, or shark-god; and he swam from the ocean, through the reef, into the Vaihiria river, where he came ashore, and introduced himself as Vari mataauhoe. The chiefess received him with the hospitality which was common to the legends of most oriental races, and Vari mataauhoe took up his residence with Hototu; but after their intimacy had lasted some time, one day, when they were together, Hototu's dog came into the house and showed his affection for his mistress by licking her face, or, as we should now say, kissing her, although in those days the word was unknown, for Polynesians never kissed each other, but only touched noses as an affectionate greeting. At this, the man-shark fell into a mood of reflection, and, after turning the subject in his mind, decided that the fault was so grave as to require him, as a person of refinement, to abandon Hototu: "You have been untrue to your husband with me," he told her; "you may be untrue to me with the dog."

Men have in all times been ingenious in their reasons for deserting women when tired of them, but, even in the South Seas and at that early day, this pretext must have been thought at least unusual, since it was preserved in legend. Unusual or not, it was enough for the man-shark, who walked off to the river, and turning into a fish again, swam out to sea. As he went on his way, or wherever he belonged, he met the canoe of the husband, Te manutunuu, returning from the Paumotus, and stopped for a conversation with him. Te manutunuu, regretting to have lost the pleasure of a visit from so distinguished a guest, and obeying the rules of the somewhat excessive generosity which marked the island manners, invited Vari mataauhoe to return, but the man-shark civilly declined, giving as his excuse the reason that Hototu was too fond of dogs.

Perhaps this legend is as old as India and belongs to the common stock of world-myths; but, whatever its origin, its form seems to show that the natives looked on Vaiari as the source of their aristocracy. Not only did the Marae and Maro-ura of Punaauia claim descent from Vaiari, but Papara also followed closely, for when Vari mataauhoe was about leaving Hototu, he said to her: "You will bear me a child; if a girl, she will belong to you and take your name; but if a boy, you are to call him Teva; rain and wind will accompany his birth, and to whatever spot he goes, rain and wind will always foretell his coming. He is of the race of Arii rahi, and you are to build him a Marae which you are to call Mataoa (the two eyes of Tahiti), and there he is to wear the Marotea, and he must be known as the child of Ahurei (the wind that blows from Taiarapu)."

A boy was born, and, as foretold, in rain and wind. The name of Teva was given to him; and Mataoa was built; and there Teva wore the Marotea. The Teva name came from this boy; but when or how it was given to the clan is unknown. Only we know that it must have been given by the Arii of Papara or Vaiari. To this day the Tevas seldom travel without rain and wind, so that they use the term Teva rarirari-Teva wet always and everywhere.

Apart from these facts in regard to Teva's father and mother, little is known about him, but he must have been a very distinguished person, if the Vaiari peo- 
ple are to be believed, for they still point out the place where he lived as a child, his first bathing-place, and the different waters he fished as he came on his way toward Papara, and would feel insulted if any one should express a doubt of Teva's being a Vaiarian. In our family, we all admit not only that Teva was a branch of the Vaiari family, but that he wore the Maro-tea by right of that descent, and set up his Marae at Mataoa by transferring his stone seat or throne from the Marae of Farepua. (1901:12-14)

The maro te' $\bar{a}$, it will be recalled, was traditionally associated with an Opoan branch on Porapora; unless the "shark god" Vari Mataauhoe was also a Poraporan, the appearance of the maro te' $\bar{a}$, at Vaiari is not otherwise explained. However, as I shall later on propose, there may be a more explicitly "structural" explanation for adoption of this maro te' $\bar{a}$.

The above accounts of marae Farepua and marae Tahiti-Puna'auia are based mostly on information from Papara informants but "interpreted" so as to emphasize Opoan sources of Tahiti's so-called ari'i kin-Titles. Another version, also provided by a Paparan-Tati Salmon, who was head chief of the district in the late 1800s and brother of Marau-did not deny ultimate Opoan connections but emphasized local origin of Tahiti's so-called family of ari'i:

The meaning of the word "Arii" in Tahiti and the islands of the Society Group is "chief," and of "Arii nui," "great" or "head chief." In Tahiti, all those who trace the origin of their family to the "Maraes" (temples) of Farepua at Vaiari, now Papeari District, or Puanaauia at Punaauia District, of the West and Southwest Coast of Tahiti, belong to the Opu-huiarii or family of Ari'is. The eldest representative was known as "matahiapo." This person, whether male or female, was called the "paarae," meaning "frontal part of the head," that is the "Great Chief."

The institution of the Opu-huiarii was of divine origin, and the distinction of the Arii-rahi was made by Taaroa, the god creator. Socially and politically the Arii-rahi was head of the family. The prerogatives of the title were unlimited. Socially, the paarae, as head of the Opu-huiarii, remained as such till death, ${ }^{[29]}$ but as political head he could be superceded by a member of his family.

The laws that governed the acts of the Ariis, both socially and politically, are too many to enumerate in this paper. I will, however, quote from traditions and attempt to give some proofs of the foregoing statements.

The District of Vaiari, or Papeari, as it is now commonly called, has the honour of being the "tumu," or foundation, of Tahiti. There exists to this day the "foundation stone," if I may call it so, "Hiti," from which the name of Tahiti was taken. Whether it meant "east" and "ta" "the lesser," or if we take the whole word "Tahiti," in its meaning as "transplanted," no one can tell now. One thing, however, seems clear. The god creator, Taaroa, decided that Nuutea Tepurotu, "fairest of the fair," chiefess of Vaiari, was to be the first possessor of the first temple.

The place chosen by the god creator for the building of this temple was on a piece of flat land facing the sea as well as the valley. The builders were the "Fanaupo." The word means "born of darkness," understood by us as the creatures of the gods, therefore priests. The orders they received for the building of this temple were that it should be beautiful and all decorated with "uras," "decorative feath- 
ers," and that it should be called "Farepua," meaning "house of whiteness." The old words concerning this temple are still remembered and sung by our natives.

Farepua ua raaraahia i te ura

E ura te tuturi e ura te paepae

E ura te fata e ura anae a

Tena Marae o Farepua

Farepua, raised on pillars of ura,

The kneeling stones of uras,

The paving stones of uras,

All of that temple of uras.

When the temple was finished the ordination of the first head chief-chiefess Nuutea-was ordered and the name "Te rii nui o Tahiti" was given to her, and to this day her descendants are the only ones who can take the name and be the social head of the family Huiariis. After the naming of the chief, the creator ordered that the ordination of the high priest should take place and that he should always bear the name "Teao" - the "light of day" or "the wise." The temple, therefore, was to possess a head chief and a head high priest....

The chiefess Nuutea then took for her husband the chief of Punaauia, named Nuu, and thus the family of the Opu-arii or Huiariis was constituted.

For the two following generations, the chief of Vaiari remained both socially and politically the head of Tahiti. In the third generation, however, was born a second child of the Vaiari-a boy-under very peculiar circumstances, for the legend declares his father to have been a shark god. This boy was named Teva. The meaning of this word has altogether been lost in Tahiti, but it is hoped that from elsewhere some knowledge of its history may be acquired.

Teva was a restless boy and declared that the little district of Vaiari was too small for himself and his elder brother, Terii Temoanarii, who naturally was the high chief. So he travelled down the coast lazily, fishing for a pastime, and on arriving at Paparia, about eleven miles distant, chose a place which he called Mataoa, to have built for himself a temple, which had for its foundation his stone from the temple of Vaiari to commemorate his ancestry.

Ua hume ihora Teva

I tana Maro i nia i Mataoa

E ua tao ihora e

Ei marotea, tau e hume

I nia, i tau na vaa mataeinaa

Ia Faina, te horo ia paepae uriri

Oropaa toa, i fenua ura.

Then Teva said:

"I will use on Mataoa, my temple,

My girdle of yellow feathers,

And over my people of Faina,

And the warriors of Oropaa."

From that day the clan took the name of 'Teva', and their gathering (clan) call was:- 
Teva te ua, Teva te matai,

Teva te mamari, E mamari iti,

Au na Ahurei!

Teva is the rain, Teva is the wind,

Teva is as the roe of fish,

The roe loved by Ahurei!

(T. Salmon 1910:39-40, 41-42)

In any case Mataoa was not the first "important" marae in Papara; it was preceded by Taputara'i, which, wrote Adams, "was the original marae in the territory now known as Papara [located in] the small subdistrict called Amo, a mile from the sea and close under the mountains." Subsequently a stone was taken from this marae to found marae To'ora'i, nearer the shore. Still later (1767-1768) To'ora'i's chief and his wife, Purea, of historic fame, combined their ambitions and built the impressive marae of Mahaiatea nearby, as a place in which their son could parade his Titles, including the one from Taputuara'i (Tui te ra'i i Taputuara'i), the one from To'ora'i (Aromaitera'i i outa rau ma To'ora'i), and the one presumably created for the occasion (Teri'irere i Mahaiatea). (Adams 1901:16)

During these pre-European eras the whole southern part of Greater Tahiti, from present-day Pa'ea to Hitia'a, is said to have consisted of an entity labeled Inner Teva (Teva i uta) - a single "clan," said Adams; but what is meant by that is not clear, except that Farepua-Tahiti marae were at one time considered by all the populace of this area as the center of spiritual and political authority. In time the center of political power of Inner Teva shifted to Papara, ${ }^{30}$ but Farepua remained the religious center to such an extent that "it was always necessary, that the chief of Papara, as [political] head of Teva, should be consecrated on that marae in Vaiari" (Handy 1930:69).

Some writers maintained, that the whole of Tahiti's peninsula (that is, Seaward, or Outer Teva: Teva i tai) was also a part of the Teva "clan." The basis for this "clanship" is not explained, but according to Adams it was manifested on certain occasions in the form of meetings (at least when the parties were not at war with one another):

The distinguishing mark of the Tevas was their clanship. They alone in the islands looked on themselves as a clan, and had a sort of union, weak at all times, but still real enough to make them unpopular outside their own limits. The eight Teva districts recognized Teriirere or Temarii of Papara as their political head, although Teriinui o Tahiti, the Vaiari chief, was socially the superior, and Vehiatua of Taiarapu was sometimes politically the stronger. Whenever Teriirere i Tooarai, the chief of Papara, sent his messengers to call the Teva districts together, the districts came; but the summons was so peculiar that it needs a whole volume of explanation.

The messengers whom Teriirere i Tooarai sent to summon the Tevas were Iatoais or under-chiefs of Papara, and of three kinds: one messenger for the home district, 
one for the inner Tevas, and one for the outer Tevas. They bore an official name while on service; they inherited the position, and the office might be filled by any member of the family to represent the actual head.

The messenger that summoned the inner Tevas went to Vaiari, or, as it is commonly called, Papeari (Vai and Pape both mean water), to the head-chief Teriinui o Tahiti, who wore the Maro-ura, the girdle of red feathers, and was the older and socially superior branch of the Tevas. The messenger delivered his message not to Teriinui o Tahiti, but to Maheanuu i Farepua, the same man or woman under another title. Maheanuu then came to Papara with Teihotua of Mataiea and Teriifaatau of Atimaono, and these three chiefs, with Teriirere, made the four heads of the inner Tevas.

The third messenger went to Vehiatua i te Matai of Hui and Taiarapu, and Vehiatua called for the chiefs of the outer Tevas. In calling out the clans the names of the districts were rarely used; the official names of the head-chiefs alone were enough, but these names were really titles of rank, and sound quite unpronounceable to any but a native. In Taiarapu, for example, the head-chiefs of the district first called (Vairao and Toahotu, next the isthmus) were Teahahurifenua and Moeterauri; the head-chief of Tautira was Tetuanui haamarurai; of Pueu, the title was Tetuanui Maraetata; of Afaahiti, it was Tetuanui Moearu. These chiefs or chiefesses represented the four outer Tevas, and came to Papara when summoned by Teriirere i Tooarai. (Adams 1901:8-9)

As this and other accounts indicate, at the time of these (relatively recent) happenings the sovereign chief of Outer Teva bore the Title Vehiatua i te mata'i, which was "originally" associated with marae Matahihae $^{31}$ in the district of Teahupo'o but also established at marae Vaiotaha, Tautira, by force of arms - the Vaiotaha family having been defeated in battle by a Vehiatua, and either killed or driven off the island (see Adams 1901:27-29).

According to Henry this important Tautira marae was "originally" consecrated to Ta'aroa and was called Pureora, but its name was changed to Vaiotaha (or Taputapuatea) when a high priest of 'Oro, named Tupui mataroa, installed in it a stone from Opoa's Taputapuatea, thereby consecrating it to 'Oro. Or it may be that the new marae dedicated to 'Oro was set up apart from the original one, and came in time to supersede it-but I shall not pursue any further this puzzle lest I succumb to the intriguing but fruitless pastime of attempting to "make sense," historically, out of Maohi legend. Later on, still another connection with the Leeward Islands was formed when a stone from Porapora was brought to the Tautiran Vaiotaha by the famed navigator Ra'amauriri (Corney 1915:127; Emory, Marae Traditions). This may have been more religious proselytization, or political aggrandizement, or both, than family colonization (if such distinctions are indeed appropriate), but the consequences for "consanguinity" were probably much the same.

Some episodes in these legendary epics will be referred to again in other contexts, but let me now continue with Emory's synthesis, to see what 
light it and other accounts of marae on Tahiti-Mo'orea can shed on how the Maohis conceived of the nature of relationships that prevailed between kincongregations connected by "consanguineal" ties.

$\mathrm{Nu}$ 'utere was the principal marae of Tahiti's Vairoa district, and its principal Title was Te aha huri fenua. Adams asserted that its Title was Tetuau meretini (1901:17), but I can find no confirmation of this. Geographically, it was included in Outer Teva, hence its chiefs were "politically" subordinate to Vehiatua-Titled chiefs (for some periods at least); but whether this relationship was based on consanguineal ties, or on physical force, or both, is not revealed.

The two "important" marae of Hitia'a district were Hitia'a and Taputapuatea. Te ari'i atua (Teri'itua) was the principal Title associated with the former; if there was a separate Title attached to the latter we do not know it. From its name it is assumed that Taputapuatea was consecrated to the god 'Oro, and derived either from Vaiotaha-Taputapuatea in Tautira, or perhaps directly from Opoa itself; but no tradition of which I know reveals anything further of its nature or relationships. And traditions do not account for the beginning of Hitia'a marae. It may originally have been pre-ari'i (adopting the idiom of the ari' $i$ invasion proponents); and it seems not to have been included in the Teva domain, although a puzzling passage from Handy might appear to suggest otherwise:

According to Marau, three generations after the death of Teva a council of the descendants of Tetunae was held at Vaiari at which it was decided that Punaauia and Hitiaa had a right, the former by reason of the marae Tahiti, the latter by reason of the fact that its chief was a matahiapo [firstborn] of Vaiari, to rank their marae and titles with those of Papara, the head of Teva. At this time the chief of Hitiaa was made Arii Nui of Mahaena, Tiarei, Papenoo, Matavai [Ha'apape], and Porionuu [districts]; these, with Hitiaa, were termed "Te Ono" (The Six), or "Te Aha-roa" (The Long-cord). (1930:70-71)

Nothing is known about the connections and congregations of marae in the districts of Mahaena and Ti'arei. If the small and isolated kin-congregations of this rugged area had consanguineal links with any elsewhere (which seems likely), they have not been recorded.

The northern district of Ha'apaiano'o (called also Papeno'o, and formerly Vavau), with its great bowl-like valley, Te piha ia teta (Room of Refuge), contains the ruins of many marae, but none that I know of is traditionally linked with any elsewhere. Henry stated that the principal Title of Ha'apaiano'o was Tupua'i o te rai, one of the most prestigious on Tahiti, according to some accounts; but I have uncovered no traditions regarding its origin or connections.

The district of Ha'apape, or Mahina (formerly also Uporu), is again in the more populous part of Tahiti, and the part better known to Europeans 
and hence better memorialized. Emory listed one of its principal marae, Fareroi, as belonging to the "formative period of hui arii," thereby implying a connection with Opoa. Ha'apape was the site at which an 'Oro zealot is said to have "established a school for the aristocracy of Tahiti and taught them the folklore of the mother land, Raiatea" (Emory, Marae Traditions; Henry 1928:130).

Arue and Pare, the two districts on Tahiti's northwestern side, were separate in pre-ari'i times. Arue's principal marae was Tarahoi, Pare's, Raiamanu. In due course the two districts were united (possibly by conquest) into a single tribe called Te Porionu'u, with Tarahoi its principal marae, and its chiefly kin-Title Tu nui ae i te atua. By European times the family in possession of this Title had managed to increase very substantially its influence over districts to the east through marriages with women of Title-holding families elsewhere-including one whose mother was a Vehiatua of Seaward Teva and whose father was a sovereign chief of Opoa. In fact, the principal Titleholders of Tarahoi marae even succeeded in convincing the monarchy-minded Europeans whose ships anchored nearby that they were Tahiti's "kings." The realities of this situation will be described in volume 3 .

The principal marae of the small district of Fa'a'a (or Te fana i Ahurai, Tetaha), comprising part of modern Pape'ete, was Ahurai, and its chiefly ari' $i$ Title was Te ari'i Vaetua. The earlier connections of Fa'a'a chiefs are not recorded but during the eighteenth century one of them married a member of the Vaiari family, marae Farepua, and the issue of this marriage played fateful roles in the last chapter of "native" Tahitian history.

The large and populous western side of Tahiti, between Fa'a'a on the north and the Papara district of Landward Teva on the south is a section of broad central plains and deep valleys. It was called Atehuru and its inhabitants Te Oropa'a; but it was divided into several separate and occasionally mutually hostile units.

In the north was Manotahi district, whose "original" marae was at one time great Tahiti-Puna'auia; it will be recalled that with its chiefly Title, Te atua nui e maru ae i te rai, went the privilege of wearing the maro 'ura. Marae Taputapuatea, on Puna'auia point, was founded much later than marae Tahiti-Puna'auia, reportedly to commemorate a marriage between an Opoan chief, Titihauri, and a chiefess of Puna'auia. By European times this marae, along with the Taputapuatea of Tautira and of Manorua, had become main centers of 'Oro worship on the island, but the nature of its connection with the older Tahiti-Puna'auia marae is not known.

Finally in the southern part of Atehuru is the district of Manorua (Pa'ea). One of the two principal marae of this district was Maraeta'ata, said to have been founded some thirty-three generations before 1900 (Emory, Marae Traditions). Acually, the marae consisted of separate "chapels"32 indicating 
to Emory that it was associated with three separate branches of the kincongregation associated with it. The principal Title of Maraeta'ata was $\mathrm{Te}$ Vahitua i Patea, and was of ari'i grade. Its connections, if any, with Opoa or Vaiari are not specified.

The other principal marae of Pa'ea during the eighteenth century was Utuaimahurao, which according to one tradition was established by proselytizing priests of 'Oro from Opoa and Tautira (see chapter 22). It came eventually to be associated with principal Titleholders of Pa'ea.

Three of Mo'orea's many marae were listed by Emory among those of the "formative period" of Hui Ari'i colonization in the Windward Islands-namely, Nu'urua of Varari; Umarea of Afareaitu; and Marae te Fano of Pape'are (anciently a district between Afareaitu and Teavaro). According to Handy's information (from Marau) the Hui Ari'i arrived on Mo'orea at about the same time as they reached Tahiti, the principal colonizer having been the bearer of the Opoan-derived kin-Title, Terii o Marama i te tauo o te ra. ${ }^{33}$ This Marama is said to have "placed on the land of Eimeo, one foot resting on the marae of Tefano, the other on the marae, Nuurua" (Handy 1930:81). Thereafter, and until European times, Maramas continued to be important personages in the southern parts of the island. ${ }^{34}$

Another far-famed marae of Mo'orea was the Taputapuatea at Papeto'ai, the island's main center of 'Oro worship. In a passage already quoted Henry stated that the former name of this marae was Te Puatea, and it was changed to Taputapuatea on the occasion of marriage between a local chief and a "princess" of Opoa, who installed there her stone from Opoa's Taputapuatea and thereby "raised the marae from a social [i.e., supra-kincongregation] to a national grade, so that it became the Taputapu-atea of all Mo‘orea” (Henry 1928:130-131).

A fuller interpretation, along with some explanation, of the mass of traditional lore discussed above will be attempted later. This lore serves to provide a charter for the social preeminence enjoyed by a number of Maohi kin-Titleholding families by reference to their consanguineal connections, ultimately, with principal members of a kin-congregation originally situated in Opoa (Ra'iatea), and in part secondarily situated in Vaiari (Tahiti). We are concerned here not with whole kin-congregations-not with the kind of "supra-kin" units made up of whole kin-congregations, which Henry labeled "clans"-but rather with disparate "lines" of consanguines all tracing descent from certain principal members of the Opoan and Vaiarian kincongregations. In this connection, it should be especially noted that these "lines" contained female links as well as male, and that collaterality, in this wider context, appears to have carried with it no prescriptions enjoining "amity," and so forth, among the individuals thus connected. 
RANK

Before leaving the subject of kin-congregation offices and turning to explicitly "consanguineal" aspects of Maohi relationships, it will be useful to indicate how office-holding in any particular kin-congregation influenced an incumbent's social position in society at large, a positioning that I characterize with the general label rank (to distinguish it from the previously introduced positioning label grade).

Earlier in this chapter, on the basis of a few fragments of explicit information, along with some plausible inferences, I suggested the possibility that in addition to their differences of function, all the offices of each (localized) kin-congregation were comprehensively graded, in terms of authority and precedence in religious events, and perhaps in secular events involving the kin-congregation members as well. But whereas I suggest this as a possibility, I propose with near certainty that in every kin-congregation one office, that of the "chief," stood out from all the others, in terms of authority, and so on. I also propose as a strong probability that in many kin-congregations one or more of the nonchiefly offices were also thus graded higher than the rest.

I use the word grading also to characterize the social positioning among offices attached to kin-congregation marae linked together by imputed ties of common descent. As we saw, in terms of formalized procedures, in both religious and secular contexts, the evidence indicates that the only offices explicitly subject to such grading were those of the chiefs of the component congregations. On the other hand, I have no doubt whatsoever that the holder of a higher-than-average grade of office in one kin-congregation would have been accorded higher-than-average respect, on informal occasions at least, by members of kin-connected congregations; and this leads into the positioning phenomenon I label rank.

The highest-graded offices of certain Maohi kin-congregations tended to be ranked with respect to each other on a comprehensive, society-wide basis. These offices were invariably Titled ones; and during the eras under study there were probably fewer than a hundred such offices of sufficient society-wide significance to become involved in such ranking.

This over-all society-wide ranking of kin-Titles undoubtedly changed from time to time, and there were evidently some differences of opinion regarding the rank-order of particular Titles, at any one time. Historically, the ranking was probably based on the respective kin-congregations' relative sizes or political power, or on their order of settlement on a particular island, or perhaps on the extent to which any one's own tutelar deity became the focus of worship by persons belonging to kin-congregations having other tutelars. It appears, however, that there was some time lag in this connection-that is a Title seems to have retained its society- 
wide rank-order for some time after the situation responsible for its rank no longer prevailed-a circumstance that appears to apply to titled aristocracies nearly everywhere. During the era under study, such criteria continued to influence the ranking, but those Titles generally conceded to be highest in rank were the ones involving the following connections and special functions: current association with or recent "descent" from the kin-congregation at Opoa; frequent interaction with and receptive reaction by the god 'Oro; the right to don a feather girdle, primarily red and secondarily yellow; the right to receive human offerings on behalf of some deity.

Finally, I wish to introduce still another technical term to accommodate to the circumstance that some individuals held two or more kin-Titles from as many different kin-congregations. To compare the social positions of such individuals I shall use the term rank-status. As later chapters will reveal, if the several kin-Titles of two individuals were about the same rank, it appears that the one who held the larger number of such Titles was generally esteemed to be of higher rank-status.

In later chapters we shall see how the various criteria for Titleranking entered specifically into the ranking of certain kin-Titles and individual statuses on Tahiti and Mo'orea, and how such rank-orders were manifested in political offices. But it is important to emphasize that rank, as I here define it, is to be distinguished from political authority and political influence. The full meaning of this distinction will require several chapters to elucidate, but I can explain at the outset that an individual may have held one or more very high-ranking kin-Titles, and thus have enjoyed a relatively high rank-status, while exercising little political authority or influence. Conversely, some of the society's most powerful and influential tribal leaders held single kin-Titles of only medium rank, and on a few critical occasions great political power and influence were wielded by individuals holding no kin-Titles at all. 


\section{CHAPTER 17 CONSANGUINEAL ROLES}

To round out our understanding of the ways in which the Maohis conceptualized and engaged in relationships based on common descent I now shift my view away from relationships between officials and other members of kin-congregations and look at our subjects as "fathers," "cousins," and so forth.

This is not an easy thing to do, for at least two reasons. In the first place, the early explorers and missionaries were more interested in relations between "chiefs" and "commoners," or "husbands" and "wives," than between, say, "cousins" or between "uncles" and "nephews," so that data about the latter are scanty, to say the least. And second, in their descriptions or translations the early visitors to these Islands used English kin terms for Maohi relationships which were at very best only partly analogous. But they should not be blamed for such errors (many trained anthropologists are still making them!); this aspect of Maohi society is difficult to comprehend despite its paucity of native "kin" terms-or perhaps partly because of it. The Tahitian language contains among the smallest number of referentially used "kin" terms of any language known.

Why, then, concern ourselves at all with the terms for consanguines? Social scientists have long since discarded the notion that humans in general, and "natives" in particular, always suit their actions (including their "mental actions") to their words, or vice versa, in the domain of kinship relations: an anthropologist working anywhere would be more surprised than otherwise to discover that all X's treated or thought about all their Y's exactly alike. On the other hand, data from all over the world support the assumption that there is some correspondence between relationship term and the interpersonal behavior normatively associated with it. Moreover, any society's system of "kinship" terms constitutes in itself a noteworthy ethnographic datum. It may not reveal too accurately how the native speakers themselves consciously "think about" that system, analytically, but it is nevertheless a product of historical processes that have some connection with native "thought" about social relations.

The principal sources of information on Maohi kin terms are lexicons 
of one sort or another, which, however, leave much to be desired in precision and comprehensiveness. All sources agree on the English (or French) equivalences of certain terms; but there is some difference about the range of equivalences of other ones, and flat disagreement about the meanings of still others. Moreover, there is not enough textual material to make up for these deficiencies or to indicate the extent to which terms were used mainly for address, or mainly for reference, or for both.

It is not entirely safe to rely on modern usage, on the comfortable assumption that habits as "basic" as kin-term usage tend to change very slowly. ${ }^{1}$

With all these lacunae it would be inappropriate to attempt a rigorous formal analysis of ancient Maohi kin terms; nevertheless, certain more obvious components of these terms do warrant listing: consanguinity (versus affinity); generation; sex (of person referred to with respect to sex of speaker, or of person referred to regardless of sex of speaker, or of person constituting the link between referent and speaker); relative age. ${ }^{2}$ Relative age is a component, terminologically, only of terms for consanguines of the same sex and generation (but of which degree of genealogical proximity is not certain), while male-female and consanguinity-affinity are components of most kin terms. But generation-or better, genealogical level ${ }^{3}$-is implicit in all the terms insofar as I have been able to identify their denotata, so I shall follow this kind of classification in presenting descriptions of Maohi consanguineal relationships.

There is fairly good evidence that the Maohis themselves conceptualized the notion of genealogical levels; for example, according to the LMS Dictionary the word $u^{\prime} i$ may have had as some of its meanings an age, season, generation. A similar inference could be drawn from the following passage from Henry: "A tū maoro te fenua; a fanau te u'i apï i te fenua.... The land had been long standing; new generations were born in the land ..." (1928:440). The word $a^{\prime} a$ is similarly translated in another passage from Henry: "O tahi nei $a^{\prime} a$ a fanau, o papa tau'a ti'a ia. The first generation of growth was born, it was affinity rocks" (p. 340). But a third passage from Henry provides a somewhat different translation: "'A'ore $a^{\prime} a$ ri'i i itea noa iho.... There were no roots to be found" (p. 447). (Italics added.) And this is also one meaning given the term in the LMS Dictionary: the root or roots of any tree or plant; hold, right, support; footing or settlement in a country.

In any case, lacking contrary evidence, I shall proceed on the assumption that the Maohis did in fact conceptualize "genealogical level"; but just how they determined the genealogical level of distant collateral kin is not clear. It may be that they "placed" such relatives by counting back to (or from) a known common ancestor. It is also possible that they manipulated 
genealogy to adjust to the facts of biological age, or in order to establish a level of relationship appropriate to some desired pattern of behavior. But all these remain only possibilities; I cannot discover how often any of these devices were actually employed.

Before presenting what I have found about dyadic relations among consanguines, let us inquire whether the Maohis formulated any norms embracing consanguines in general, regardless of any more specific statuses they occupied vis-à-vis one another. It is perhaps significant that I have succeeded in turning up only two formulations which may have been of this kind, and these have already been noted. One of these is the precept which declared: "Let not your eyes turn away from the troubles of your firia feeti'i ..." [consanguines in general? "line" of consanguines?]. The other was recorded in connection with my discussion of marriage proscriptions in chapter 13: "Close' consanguines ought not to marry one another."

Except for such general precepts as these, relations among consanguines were more typically described or conceptualized either in terms of comembership in the same kin-congregations or in dyadic terms.

\section{AdJACENT GENEALOGICAL LEVELS}

What can be said about the terminological dimension of relations between consanguines of adjacent genealogical levels?

A familiar, commonsensical way to begin would be to state that Maohis referred to an individual's father (or him whom an English-speaker would call "father") as metua tane (parent-male), and to an individual's mother as metua vahine (parent-female), and that these same terms were extended to all consanguines of the same genealogical level as the referent (as well as to the latter's same-genealogical-level affines).

The above statement might appear straightforward, adequate, and unexceptionable-yet it is anything but that. For one thing it incorporates some wholly unwarranted assumptions about word meanings; in addition it implies a course of etymological evolution, or a pattern of language learning, that cannot possibly be documented in the case of the Maohis. And finally, it goes beyond available evidence in defining the boundaries for this category of denotata.

Another way to approach the matter would be to state that the Maohis referred to an individual's consanguines (and to the latters' samegenealogical-level affines) in the genealogical level immediately ascendent to his (or hers)-including those whom English-speakers would call "father" or "mother"-as metua tane (if male) or metua vahine (if female).

This statement is somewhat less exceptionable than the first one in that it involves no assumptions about "original" meanings of the terms. On the other hand it involves some unwarranted assumptions about the boundaries of the category metua. 
The fact is that we have no reliable way of knowing how inclusive the category of metua actually was, or was normatively intended to be. That it was widely inclusive is attested by such statements from Henry as the following: "The word metua is applied to real and adoptive parents, to uncles and aunts, to first cousins in relation to their cousins first removed, to bosom friends of parents, and even to children's nurses" (1928:494n). "A parent's friend is regarded as a relative also of a child" (p. 521n). (It should be noted, however, that these statements appear in footnotes to Ancient Tahiti, and seem to refer to the era in which the volume was edited, between about 1890 and 1915.)

On the other hand, it is well to state at the outset of our discussion of kin terminology that as far as I can discern the Maohis did not follow the practice of some societies of extending a particular kin term to all members of some group containing a distant but crucial kinsman. For example, a man having a genealogically distant but socially intimate metua in some faraway community did not call the latter's community-mates metua.

Moreover, my second statement uses "genealogical level" with an appearance of certainty which the scant information does not wholly justify. For example, one might reasonably assume that one way in which a Maohi contrasted the female who gave birth to him (his natal mother) with a female borne by her, was that they were, obviously and demonstrably, of separate (and adjacent) genealogical levels. But even if this were so, we have no sure way of knowing what criteria led to classifying other females with the former. Because of "same genealogical level?" If so, how was this determined, practically, in the case of distant collaterals? Because of their coevality? If so, in the absence of chronological age-reckoning, how was coevality determined? Or, if both these criteria were applicable, how were discrepancies between genealogical level and biological age reconciled? For such discrepancies are inevitable in every society.

But one is not even warranted, from available Maohi data, in assuming that an individual's natal mother, or socially acknowledged father, served as the main points of reference for the classification of other metua. ${ }^{4}$

Had some observer lived among the ancient Maohis and recorded their conversations with and about their consanguines and kept records of their use of metua in the course of their chatting, working, quarreling, praying, and especially in their meetings with thitherto unacquainted and "unplaced" consanguines, then we might today be able to answer some of these questions. ${ }^{5}$ Failing that however, my generalizations must remain limited by the gaps and ambiguities in the sources. If the resulting exposition seems more European than Maohi, that is because our view of Maohi "kinship" relations comes to us through uncompromisingly European eyes.

Here are some other LMS Dictionary definitions of metua which will give some impression of the wide range of references of the word: ${ }^{6}$ 
metuahoovai [metua ho'ovai], a parent-in-law.

metuatavai [metua tavai], a parent that adopts a child.

metuafaai [metua fa'a'ai, parent to feed or nurse], a nursing parent.

metuafaaamu [metua fa' $a^{\prime} a m u$, parent to feed or supply with food], the same

as metuafaai. [According to Rey-Lescure (1947:284) the former is a more recent variant.]

metuapuru, a parent that caresses his children.

In addition, the LMS Dictionary lists the following terms, mainly of address:

$p \bar{a}$, a term of reverence answering to father, and commonly used by children in addressing their father, and common people their chief.

pa'ino, a familiar term of endearment used by a child in addressing his father.

patea, a term of respect addressed to a mother or a woman of rank.

pateaino, a term of respect addressed by children to their mother as pa'ino is to their father. ${ }^{7}$

titae [ti'itae], a parent, a term of endearment used by a child for his father or mother.

The imputed meanings of these terms have obvious implications for interaction norms; at the same time they indicate some conceptual parallels between "parenthood" and "higher grade." (Indeed, it is possible to extend this parallel even further to include the normative relationship between "younger" and "older" consanguines-but more of this anon.)

Turning now to the other role in the dyad, I list the various glosses found in the LMS Dictionary approximating the English word "child" (including kin of first descending genealogical level):

tama, a child, male or female.

tamāhine, a daughter, or female tama.

tamaiti, a son; a little tama.

tamaitiiti, a little son.

tamarii, children.

tamāroa, a boy, a male.

poti'i, a girl.

hunō'a, a son- or daughter-in-law.

Lacking textual material I cannot be certain about the precise meanings of these terms (although the definitions give by Jaussen are practically identical), but on the basis of these glosses they appear to be classifiable as follows:

a category referring to young people in general: tama (singular), tamari'i (plural); tamāroa (male); poti'i, tamāhine (female); 
a category referring contrastively to certain kin of the speaker's first descending genealogical level: tamaiti (son), tamāhine (daughter, but also means girl), hunō'a, spouse of son or daughter.

What these glosses do not indicate is whether or not all the terms in the first category (and not just tamāhine) referred also to denotata of the second category. And, much more important, neither these particular glosses nor any other lexical or textual sources that I know of indicate the limits of applicability of the terms of the second category.

With respect to tamaiti and tamāhine, modern usage (e.g., Panoff 1965) and implied ancient usage (e.g., Handy 1930) list both "nephew" and "son" as denotata for the first, and both "niece" and "daughter" for the second. It seems to be the assumption underlying these and most other writings about the Society Islands, ancient and modern, that these terms refer to all consanguines of a speaker's first descending genealogical level. It is the assumption I also make-but for negative, not positive reasons: I do not know what degrees of collaterality were actually referred to by these terms, but at the same time I know of no other terms in the language that might have served to limit their degree of collaterality. ${ }^{8}$ (Similar questions arise concerning the meaning of $\operatorname{huno}^{\prime} a$, but these will be discussed in chapter 19.)

Despite the many intimations these linguistic fragments may contain concerning the Maohis' broad conceptualization of "parenthood" and "progenyhood," the solid information we can retrieve having to do with their interactions concerns almost entirely an individual and his parents-natal, feeding, or foster. ${ }^{9}$ The only direct statements I can find about action involving whole sets of "parents" occurred during ceremonies described by Henry and reported earlier. The first concerned a nuptial ceremony:

At the end of the performance [i.e., a presentation of valuables to the groom by the bride's natal parents] the mothers and aunts of the young couple, called the hui-metua-vahine, class of mothers, punctured their heads and faces causing the blood to flow, as a manifestation of love and union of blood. (1928:282)

The second concerned a natal ceremony:

Thither [an "ancestral" marae] the child was taken accompanied by the parents and other elder members of the family, called the hui metua (parental clan) [sic]...."

As a sign of affection the hui metua then punctured their foreheads, and each mingled the purple drops that fell with a mixture of the juice of sugar-cane and milk expressed from grated coconut upon a miro leaf, which they held over their heads, and with a parent leading, they approached in turn the babe, still in the arms of the paia [royal family doctor], and touched its cheek with the leaf, but not the mixture, signifying the union of blood. (1928:184-185)

Before considering how the Maohis conceptualized and engaged in "parent-child" relations in dimensions other than terminological, I will list 
some situational factors that might be expected to have influenced these relationships:

The size, composition, and location of households: typically they were large and comprised more than one nuclear family, and although more often scattered than grouped together, they were distantly isolated from one another in only a few regions.

The frequency and extended duration of visiting.

The impermanence of many marital unions, and the existence of some polygyny.

The bilaterality of descent-reckoning: although more recognition was accorded patrilateral ties, those through the mother were frequently and heavily weighted.

The varied nature of marital residence: virilocality may have been preponderant, but not markedly so; and there was a goodly amount of ambilocality.

The weightiness of hierarchic ordering, by sex and birth order, with respect to authority and privilege. These considerations were especially influential in families of superior social position, but were probably also operative in some degree throughout the society.

Beliefs and practices associated with the above and having to do with "purity of line"-that is, "class endogamy," the slaying or nonrecognition of "mixed-class" infants.

The timing of succession to Titles: early in the successor's life.

The governance evident in families' "congregational" activities (and presumably in many ordinary "domestic" activities as well), wherein authority was often vested in a male other than a child's natal father.

The prevalence of fosterage.

The separation of females from (at least older) males, in connection with eating and with most subsistence activities, including the learning of technical skills.

The delegation of some infant and child care to older siblings.

Norms defining "incest": with some notable exceptions, sexual relations with "close" consanguines were proscribed.

Beliefs concerning the "psychic" state of individuals prior to complete head freeing $\left(\bar{a} m o^{\prime} a\right)$.

Beliefs concerning the prevalence and characteristics of ghosts. ${ }^{10}$

On the basis of what has already been reported about these several factors one could arrive at some fairly plausible-sounding inferences about parent-child relations in Maohi society; and the paucity of data having to do directly with parent-child interaction prompts me to do so, but the reader is now in a position to do the same (and hopefully with simi- 
lar results). Instead of spelling out the obvious or speculating about the probable, I present what little direct information there is.

I turn first to the famous "Precepts of Tetunae" where, if anywhere, one might expect to find Maohi canons about parents' relations with their children.

Actually, the only precepts conceivably related to the tie under consideration are the following:

'Ia tura ite ta'atoa te toto o te metua, e ara 'a hara 'otou ite reira. [May the blood of the parents be respected by you one and all, beware lest you offend in this matter.]

"E fa'atura tu i tō matahiapo ta'ata, 'o tō 'oe ia pa'arae." [Respect your firstborn, he is the bone of your foreheads.] (E. Salmon 1937:29)

I present the first because of its allusion to metua, but I confess that I cannot divine the intended meaning of the statement. Is one exhorted to act with "respect" toward the parents themselves? (And exactly which parents?) Or is this a metaphoric reference to the rule of incest? Or does it refer to rules regarding purity of line?

The second statement could be an exhortation to parents to "respect" their own firstborn offspring, but it was more likely addressed to people in general, exhorting them to respect the "firstborn" chief of their kin-congregation-or so I interpret it.

Acts of infanticide provide some indications of parents' attitudes toward children; these were certainly not uniform. ${ }^{11}$ As we saw earlier the deed was carried out privately-sometimes by the mother herself-when all parties agreed upon its desirability; but cases of disagreement did occur, as exemplified in the following episode witnessed by the missionary Davies in 1808:

As one of the brethren was going to bathe in the River, he observed among the bushes at some distance from the pathway, a number of people apparently watching something ... the woman above mentioned was there, either delivered or about being delivered of a child, and that the husband's father and mother, and some others were waiting in order to kill the infant as soon as it should be taken from the mother. Seeing things in this state he resolved to see the end and do all he could to save the infant, he spoke to the husband's father and mother, upon the horrid cruelty of their intended action, and then proceeded to the woman tho' opposed by several who wanted to keep him at a distance till the affair was over, he found the child had been just born, a fine boy and that a young man a brother to the woman was intent to do all he could to save the infant, the mother was also desirous to have it saved. The husband kept out of the way, and also the old man his father who notwithstanding was fully determined to have the infant murdered and for this purpose had sent a man there to bring it to him, either dead or alive. By this time people were crowding there from all parts, but not one either male or female offered to do the smallest thing to save the infant, the mother's brother excepted who with our brother did all he could to keep off the man 
who was in the greatest fury and rage fully bent upon murdering the infant, the man was kept from approaching the woman and her infant for sometime partly by perswasion and partly by force, our brother dispatched a messenger for some of the brethren to come to his assistance, but the people kept back the messenger so that he could not go, he then sent another who proceeded on, in the mean while he and the young man above mentioned struggled with the murderer keeping him off from the infant, but notwithstanding he once got so near that he snatched the head of the infant, intending to turn his neck, which he could not affect, being dragged back again, and the woman also doing what she could to defend her infant, however he gave some scratches about the head. Soon after this came a message from the father saying, let the infant alone if it is a boy let it be saved, the man that came there to murder it then made off as fast as he could, and a little while after Sister Henry came there and by the consent of the mother and also the father who then came to the place, she took the infant home with her, the mother also sometime after followed that she might sleep at brother Henry's.

The woman and her infant mentioned on Saturday were till this morning in brother Henry's apartment. Today she went home with her babe, it is probable that all danger is now over, at least it is so according to the usual custom of the country, the husband appears to be fond of his child as well as the mother and it is reported that the king has threatened the old people for their attempt to kill the child and told the husbands father that if he had been in England he should have been hanged. This we know is only a sham, the natives understood one another well enough, had they thought the king would have been really displeased, they would not have acted as they did. (Journal, 18 June 1808, LMS Archives)

Analogy with Western attitudes leads one to expect that in these situations the mother was usually in favor of sparing the child. That in fact is my expectation, but there is no direct evidence to support it, while there is a good deal of indirect evidence that many young women were as eager to avoid parenthood, as were many young men. Moreover, Maohi motives to avoid parenthood were undoubtedly different in some respects from those prevailing in Western society.

Birth rites are also informative in that they indicate some jural expression of parental attitudes. When they did take place (which was probably not always, and certainly not always in the same manner, that is, they differed in ceremonial elaboration with respect to the social position of the infant's family and with respect to the sex and birth order of the infant) no act was deemed necessary or, at least, none was performed to express the mother's own relation with the infant, as occurred in the case of the father, but members of the mother's family joined with those of the father, thereby symbolizing the bilateral nature of the ties.

Another whole set of beliefs and interaction patterns involving parentchild relations is included in the ritual acts and abstentions of head freeing, àmo'a. These, it will be recalled, placed constraints upon parents' interaction with their offspring-constraints which in some cases lasted until after an offspring's marriage, and which reportedly involved "aunts" and "uncles" as well as parents (see chap. 13). Particularly noteworthy in this connection 
was the distance maintained between a Titleholding father and his successor during the latter's early years. In fact, although highly born infants remained with their mothers during the first year or so of life, some of them were thereafter secluded from both parents for many years in entirely separate court-households of their own. Indeed, the constraints laid upon interaction between some parents and their successors were so formidable that one can hardly speak of interaction at all. These, and the restrictions against parental self-feeding during the offspring's pre-"head-free" years must have colored attitudes, mutually, even after some of the constraints had been removed. And one does not have to resort entirely to speculation concerning some possible sequels to these constraints, as my account of the Pomare family conflicts will exemplify (see vol. 3).

It is happily different with the lower order of the People-The Father and Mother have mostly their flock of little Children about them, they nurse them with great care and tenderness, and receive returns of Affection and respect-In short no Parents can regard or attend on their Children more than they do, and but few more engaging and pretty Children are to met with, could we divest ourselves of the dislike to the Colour. (Bligh 1792:155b)

So let us see what evidence there is for everyday interactions between parents and children not subject to the extreme forms of such constraints. To begin with, although there is no explicit verbal evidence concerning how long such children were expected to stay at home with parents, and how dependent they were upon the latter, there is a word in the LMS Dictionary that appears to imply some disparagement of too long and too close a dependency: 'aimāmā, to eat food chewed by the mother; a person who always remains at home and lived with his or her parents to adult age. Other kinds of evidence on this point are more ambiguous. On the one hand fosterage, dispersed kinfolk, and early marriage (with residential change) provided young people with ample opportunity for reducing everyday contacts with their natal parents. On the other hand, I know of no ideological factors that encouraged young people, single or married, to "be on their own." And if they happened to leave the household of their natal parents it is likely that they usually moved into households where other "mothers" or "fathers" were to be found. In this connection, a statement by Varela is ambiguous and, in the extent to which it implies neolocality of residence pattern, probably overdrawn: "As a rule, children only live with their parents while they are quite young; but, when they grow up, those of either sex part company and withdraw to live by themselves" (Corney 1915:258).

Two other conventions served to reduce interaction between parents and their children: the delegation of child care to older siblings, and the ganging together of children in play worlds of their own. But in most cases interaction between children and their natal parents did take place over a 
long period of time. In the early years interaction was more with the mother than with the father, not only in connection with the child's feeding but also with its general welfare, as is indicated in the following:

As wives, in private life, they are affectionate, tender, and obedient to their husbands, and uncommonly fond of their children: they nurse them with the utmost care, and are particularly attentive to keep the infant's limbs supple and straight. A cripple is hardly ever seen among them in early life. A ricketty child is never known; any thing resembling it would reflect the highest disgrace on the mother. If an utter stranger discovers the least defect in a child, he makes no scruple to blame the mother, and imputes it to her want of sense and experience in nursing: so that if the child is not born radically defective, which is seldom the case, they will mould it into a proper shape. (Wilson 1799:328)

At an age not specifically indicated, but probably in most cases not later than six or seven, boys tended to spend more time with their father and other older male relatives, when not sporting about with other boys, and this tendency increased with youth and early adulthood, as we saw above. The parallel tendency prevailed with most girls, who seem to have spent less and less time in the company of their fathers and older male relatives as they grew older. In this connection, one should recall the exceptional circumstances surrounding those girls of superior family position who were betrothed very early in life. These pahio, as they were called, were kept secluded at home until marriage, and presumably in closer than usual contact with their parents.

Within these temporal limits of parent-child interaction what do the sources report concerning the actual nature of that interaction? Moerenhout's assertion, quoted earlier, that children were in general self-willed and subject to few parental restraints (except for the strictly supervised daughters of high-ranking Titleholding parents), is confirmed by statements of other writers:

They lay no restraint on their Children because they are the Head of the Family and therefore do as they please; having no law nor Custom to prevent them they have a Number of Amusements which would not suit the Idea of Europeans, which however are dropd as they Grow up, when they become ashamed of these Childish sports but are not Compelld unless they think proper themselves.... (Morrison 1935:236)

The first sentence in the above excerpt refers to the early transfer of kin-Titles discussed earlier, but the statement is somewhat puzzling in its intimation that all children became "Head of the Family." It may be that the pattern set by Title transfer to the appropriate successor, including the accompanying behavioral manifestations, was extended to other children in families with Titles, but I very much doubt that the latter also became "Head of the Family" in any jural sense.

This excerpt again raises the structurally important question concerning 
family offices. That is to say, one might assume that, normatively, in every family there was one person who in some measure occupied a recognized position of authority over other members. As we have seen, in cases where these socially recognized positions-offices-were embodied in kin-Titles, the Titles themselves and some of their accompanying prerogatives, were transferred to the appropriate successors very early in the latters' lives. The question now is, did the same thing take place when no kin-Title, as such, was involved? Surely, this is one of the most crucial questions facing anyone concerned with understanding Maohi society, but unfortunately no decisive answer is possible. The above excerpt from Morrison, as well as other eyewitness reports, attest to the light-handedness of parental authority in general. Yet, I cannot believe, based on "common sense" and on much other evidence about Maohi life, that all or even most Maohi parents abdicated all their powers of decision-making and enforcement, in favor of one or more of their puerile offspring. A certain amount of indulgence, yes, but crucial authority, no. A society could not operate even moderately successfully under such circumstances. The practice of early kinTitle-succession, which prevailed at the "top" of society, may have influenced parent-child relations generally (or it may have been the other way round), but I cannot believe it to have been much more than that. But let us leave speculation and return to some other firsthand observations-remembering that the observers in question were men inculcated in the norms of a Western society where parental authority was close to absolute:

The natives are sinfully \& very injuriously indulgent to their offspring now. I have often seen a child cast stones at his parents while they only laughed at it. (Orsmond, Journal, 22 November 1826)

In general, they are too tender towards their children, and do not exercise that discipline and control over them which the well-being of the child, and the happiness of the parent, requires. (Ellis 1829:I, 341)

Their children [are] under no restraint from their parents: and are allowed to gratify every appetite without leave of any person. (Gyles to Sleigh, 23 November 1818, LMS Archives)

$\mathrm{Br}$ [other] Broomhall's attempt to instruct the young chief of Tearay to read, does not succeed. Savage ignorance and brutal freedom are their delights. The children cannot bear to have their desires crossed, their actions prohibited \& their wild ramblings controuled. Learning requires application, to which they are not only strangers but averse. (Jefferson, Journal, 23 April 1799, LMS Archives)

The parents have not energy to back our instructions. We appoint constables to collect \& bring the children to school but some will slip way to the mountains or to their canoes, and they are all their own masters at a very early age. We may reprove the parents and punish the children, the parents being called to witness $\&$ approve, but they have not the energy to do these things themselves.... (Crook to Burder, 4 December 1824, LMS Archives) 
They [Maohi boys] are more mannish here at 14 than boys in England at 17 or $19 \&$ therefore the less docile, the more impatient of restraint ... I think I can say that there is not a little native creature who has reached his seventh year, but who knows more of human nature than I did at 28 years. (Orsmond to LMS, 8 March 1829, LMS Archives)

For a contrary appraisal I offer the following statement by J. Forster, whose romantic, rosy-tinted perception of Maohi social relations was matched only by the floridity of his prose:

This refinement of mutual love and matrimonial complacency, produces those tender regards with which this happy passion inspires its votaries for the beloved object; and it creates that mutual happiness, which is the result of all the more refined manners, and of their more polished behaviour towards one another. The offspring of such a happy couple early imbibe by the example of their parents, that kindness and benevolence, and those refined sentiments of love and happiness which contribute so much to confirm the felicity of their parents, and wish to reduce them to practice, as soon as they feel the call of nature and find a partner whose sentiments are in unison with their own; so that these simple, but more exalted ideas of matrimonial union, are thus propagated and perpetuated in the progeny of a virtuous and tender couple. But before they attain that age of discretion and maturity, the fond parents take peculiar care of their education: they frequently check the wild flights of their unruly passions, and instill order, moderate industry, and the principles of benevolence and gratitude into their tender minds. I have seen mothers punishing obstinacy and disobedience, and though extremely fond of their children, they nevertheless are sensible enough thus far to do violence to their own feelings, that their children may not acquire a habit of ingratitude, obstinacy, and immorality; I have likewise heard them expostulating with their unruly little ones, and expressing their displeasure at their conduct; all which proves that they have ideas of moral rectitude, of order and filial subordination, and of the necessity of instilling these principles early into the minds of their children. Nor is this careful education without the good effects, which ought to be the consequence of it: for we saw many a family, where every individual belonging to it, gave strong marks of an attachment to the rest of the family, and evident proofs of those ties of benevolence which united them all. The younger part of them shewed reverence and respect to the older individuals, and at the least and most distant danger were alarmed and anxious for the welfare and safety of their parents. The injunctions of the parents were executed, with a readiness and truly exemplary affection. The father seemed to be the soul which animated the whole body of the family by his superior wisdom, benevolence and experience; in a word, they all assist one another, and contribute their share of offices and labour, towards the support, security and happiness of the whole family. (1778:350-352)

Many theories may be offered to account for the state of affairs described in these excerpts. The early transfer of parental Titles, just mentioned, was perhaps one influential factor; the availability to a child of several "fathers" and "mothers," symbolized in terminology and probably reinforced in normative statements was another. This however is just an assumption; I have not come across any statements explicitly exhorting children, say, to act alike to all parents, except for the statement by Armitage quoted below. Ofttimes these coparents lived in the child's own house- 
hold, or at least nearby, and played very active, daily roles in bringing him up-sometimes reinforcing but presumably also occasionally counteracting his natal parents' authority. In other cases the child's coparents lived just far enough away to provide him with a convenient escape from natal parental discipline, if the need for such an escape arose.

In this connection, the alternatives open to a child were not limited to his "fathers" and "mothers"; another characteristic of Maohi society was the ease and the apparent frequency with which children moved into kinfolks' households, to be fed and generally cared for, for long or short periods of time. In addition, the parents of a child sometimes formally engaged other persons to act as coparents:

One heathenish custom still exists which in my opinion lies in the way lik[e] an impenitrable barrier to benifiting the young persons among the natives it is this When a child is born \& some times before the birth of the Child persons are applied to to act as Parents to there children two or three Fathers \& as many Mothers are fixed on they very seldom refuse $\&$ the engagement is a sacred one the Child is taught to regard them equal to his own parents shoud the first parents offend this child (of whatever sex) he or she leave there home \& if not satisfied there they try another \&c untill they meet with one that comes nearest there vews of Good by this means all parental restraint is frustrated entirly. (Armitage to LMS, 25 March 1836, LMS Archives)

This brings us again to the set of practices usually labeled "adoption" or "fosterage," of which the custom just described was one variety. I indicated earlier the distinction made in the LMS Dictionary between tavai, adoption of another's child, and $f a^{\prime} a^{\prime} a m u$, to feed, supply with food, (or $\mathrm{fa}^{\prime} \mathrm{a}^{\prime} \mathrm{ai}$, to feed, nurse). ${ }^{12}$ On this evidence it might seem warranted to distinguish rather sharply between "adoption" and "feeding," the former involving a decisive, jural, change in the child's consanguineal status, the latter merely a temporary or occasional dependency. Indeed, we were provided an example of the former in the passage from Henry regarding the giving of a "marae name," with accompanying land-use rights, to an individual "adopted" into a family congregation (Henry 1928:141-142). However, other references indicate a wide range of practices rather than a sharply distinguishable dichotomy. At one extreme was the action taken by a childless Titleholder designating some young person-usually a consanguine-to be his "son" or "daughter," and hence his successor. At the other extreme was the mutual but casual arrangement whereby a child lived for varying periods of time with some relative, without, however, being invested with any new demand rights in its "feeding parents' "descent-derived goods. ${ }^{13}$ Inasmuch as the two variables, degree of everyday dependency and formal transfer of property rights, appear not to have been related-that is, some designated "sons" did not reside with their new "parents," and vice versa-it is tempting to take this as addi- 
tional evidence for a native lexically formulated distinction between tavai (adoption) and $f a^{\prime} a^{\prime} a i-f a^{\prime} a^{\prime} a m u$ (feeding). Unfortunately I cannot assume that to have been the case. For one thing, although the LMS Dictionary makes a (suspiciously!) clear-cut distinction between adoption and feeding, such writers as Henry (and presumably Orsmond) used adoption for the whole range of practices under consideration. To avoid such ambiguity I prefer to label all such arrangements "fosterage," except when a native text explicitly labels it either tavai or fa' $a^{\prime} a i$ (or fa' $a^{\prime} a m u$ ).

In any case, in terms of patterns of interaction, our present concern, the practices under consideration served to provide children with "parents" (and adults with "sons" and "daughters") beyond those provided by descent; but, as I noted above, the range of situations embraced by such practices was very wide indeed. ${ }^{14}$ Even the high gods occasionally fostered humans, as for example, Ta'aroa did with the youth Pai, whose mother entrusted him to the spirits in order to save him from sharing the sacrificial victim's fate to which other members of his family had been doomed (Henry 1928:584). ${ }^{15}$

Probably the most common form of fosterage was that described by Henry:

Tahitians have always been fond of children, those having none adopting some, and parents with large families adopting others while giving away some of their own, adoption being a bond of love and union between relatives and dear friends. Such children frequently divide their time happily between their two homes. Offspring is well received under any circumstances. (1928:274)

I have already spoken of the action taken by some individuals to acquire successors for their Titles. The following represents a variation on that practice-but with a grim twist. In the legend of Pai, referred to above, the events which led to his family's downfall was his father, Rehia's, lese majesty of acquiring for a beloved wife (wherein lies another story) a shipment of food intended for the tribal chief. Upon learning this some of the chief's subjects, "some warriors of an inland clan," took it upon themselves to revenge the crime, and an opportunity presented itself soon thereafter, when Rehia's wife, Huauri, gave birth to a daughter:

... when the hostile warriors heard of [the birth] one of their number ... said to the orator ...:

"Go and ask for the little babe, and giver her the name Hina-ari'i (Gray-queen), and tell them we wish to adopt her as our chiefess, as we are only plebeians here."

So the man went and was welcomed by Rehia and his wife, who were much pleased with the message brought to them, and they agreed to let the inland clan thus adopt their little daughter, who would be given into their hands when old enough to be separated from her mother. Accordingly, after a year had elapsed the orator returned with nurses to claim the child, and she was given over in a regal manner, with clothes and feather ornaments befitting a child of high rank, 
the parents feeling the parting much and comforting themselves that it was for the benefit of their daughter, whom they could visit frequently. With affectionate leave-taking they parted. But when the party with the child arrived midway between sea and mountain regions the orator dashed out her brains against the trunk of a fei tree, which became blood stained-ever since then the sap of the fei plant has remained purple-and then they went and buried her body in their marae. (Henry 1928:579)

Fosterage was used also as a means of cementing peaceful relations after a war:

The amusements [accompanying the peace pact] ended with the hura danced by young girls, in which a daughter of a slain chief or warrior would take up a wand and verge out from the floor towards the slayer of her father, if he was known, and touch him with it, after which he assumed the role of father to her in place of the deceased, an adoption which was regarded as a most touching and sacred tie between them. (Henry 1928:319)

Morrison provided a fuller and somewhat different version:

... after the Peace is made [following warfare] the relations of the Deceased Warriors soon find out the Men who killd them and each Family send a present to the Man by Who their Freind or Relation was killd \& hire a Set of Urre Heiva or a Sort of People somthing similar to our Morris Dancers and a Principal part is acted by the Daughter or Nearest Female relation of the Deceased Warrior in a Dance at the House of the Man who killd him. The Dance being Finished the Cloth, Matting \& Dresses are all presented to Him and He Now entertains all the Deceaseds Relations, sumptuosly for Several days and they Declare that they (do not) Owe him any Grudge or animosity for killing their Relation and their Sorrow is now turnd to Joy and evry thing is most amicably Settled and the Conqueror, to Make the Friendship more Firm on his part, adopts the Nearest relation of the Deceased as his Friend, and by bearing his Name becomes one of the Family and is ever after Treated as such and is as much beloved in the Family as if he had been born in it. (1935:175-176)

These two practices, the one described by Henry and the one described by Morrison, had the same rationale, that is, to make "consanguines" out of former enemies and thereby, ideally, create a basis for amicable relations. (It is highly significant, I believe, that with all the alternative models which might have been utilized for establishing such relations-affinity, neighborliness, tribal or cult comembership, etc.-consanguinity remained for the Maohis the most appropriate one.) The fact that the Henry version concerns "fosterage" and the Morrison one "siblinghood," is an unimportant consideration under the circumstances.

Ideologically, the parent-child relations consequent upon fosterage probably differed little if at all from those based on descent; actually (i.e., historically) the range of degree of intimacy was probably just as wide. Adams' statement (1901:123) that "adoption was rather stronger in the South Seas [i.e., Tahiti] than the tie of natural parentage" is suggestive but 
undocumented except in a few highly special cases, where political rivalry with a parent was involved.

A comprehensive study of Maohi fosterage would include many questions that we cannot hope to answer-questions concerning the prior relationships of the principals, the individual and professed motives involved, the extent to which the fosteree's new ties were extended to the fosterer's kin and vice versa. ${ }^{16}$ For example, I suspect that in some cases the foster child served mainly and deliberately as a means of strengthening relations between families, but I have found no cases to support such speculations. And one of only a few bits of evidence of the extension of fosterage ties concerns the rather ambiguous case of the Spaniard Rodriguez. Having been "given an ancestral name" identified with the Vehiatua line of chiefs, he was required to show appropriate expressions of grief when a member of the family died, “... because I was related to the deceased arii, inasmuch as he was related to all the Chiefs" (Corney 1919:31). ${ }^{17}$

Let us return to the sources and search out evidence of a suppositional nature bearing on relations between "parents" and "children." Appropriately, I begin with an account, which was probably chanted, telling how Ta'aroa exalted Tane over Great Tumu, the Foundation; the latter was, like other gods, created by Ta'aroa, but Tane was Ta'aroa's biological son (te fanau'a o Ta'aroa). ${ }^{18}$

This is what Ta'aroa did for the god Tane, the handsome offspring of Ta'aroa:

Tumu had little temples; Tane had great ones. Tumu had a few priests; Tane had many priests. Tumu had small drums; Tane had big drums. Tumu had a few altars for his temple; Tane had many altars. Tumu had gods in sennit with a few red feathers; Tane had gods in sennit with many red feathers. The enclosure of the temple of Tumu had a small rear entrance; the enclosure of Tane's temple had a broad rear entrance. The temple of Tumu had a small sacred enclosure within; that of Tane had a spacious one.

Tumu had a few stone slabs to lean against for prayers; Tane had many leaning slabs. Tumu had a few stone pillars, upon which the coconut-leaf images to represent the priests were placed, in his temple; Tane had many pillars. Tumu had a few coconut-leaf images to represent his priests in his temple; Tane had many in his. Tumu had a few coconut-leaf rosaries in his temple; but Tane had many in his. Tumu had a few paddles (poles) erected (by which the sacred birds descended into the temple); Tane had many paddles. Tumu had a few masts upon which the sacred birds alighted in the temple; Tane had many masts in his temple. Tumu had a low sacred wall to his temple; Tane had a high wall to his temple.

If a small sea bird alighted upon the temple of Tumu, a surf-duck settled upon Tane's temple. If a surf-duck alighted upon the temple of Tumu, an albatross descended upon Tane's temple.

When Tumu had a little religious ceremony; Tane had a great one.

This then was Tane; he was a very great god. Ta'aroa made him great, and all his greatness emanated from Ta'aroa. All Tane's work was beautiful. He did not slay men in former times; it was only very recently, long after the 
Deluge, that he received the homage of human sacrifices, but they were not numerous. (Henry 398-399)

Ta'aroa, it will be recalled, also worked with and for his daughters when between them they constructed out of Ta'aroa's own body the first god house for mankind's use (Henry 1928:426). But affection and altruism did not always prevail between divine parents and their children; see, for example, the account of how Maui noosed his "father," the sun (Henry 1928:431-432). ${ }^{19}$ A parallel case is found in the story of Tane's struggle with Atea, the god-dome of the sky, whose enveloping presence placed limits on Tane's peregrinations. Frustrated and angry, Tane demanded passage, threatening Atea with the force of the winds. To this Atea replied:

O Tane, can Atea fall by thee? Thou art but a lad, but I, Atea, am a vigorous elder; it was I who begat thee, Tane! [na'u 'oe i fanau e Tane!] But by what force can Atea fall by thee?

Unable to move Atea, Tane travelled to Ta'ere-of-all-skill, learned from him all his wisdom (pa'ari), then returned to Atea to slay him and take all his possessions for himself. And again Atea chided Tane:

Atea will not die by thee, O Tane! Thou art but a child, Atea is a parent [ $e$ tamaiti $e$ 'oe, e ta'ata metua Atea]; it was he [Atea] who begat thee!

Note that Atea refers to himself not as thy parent, but as a parent-that is, a member of the parental genealogical level.

To make a long and rich story short, none of Tane's efforts prevailed, and finally, his anger appeased, he went away and sent back a peace offering and token of deference to the invincible Atea. And the encounter ended with this conciliatory speech by Tane to Atea:

When strife arises in the morning, let it be peace in the evening; when contention arises in the evening let it be reconciliation in the morning between kinsfolk [taea'e]. (Henry 1928:455-458)

Tane's speech is interesting enough as an exhortation for kinfolk-taea'e, in this passage-to keep their (inevitable) conflicts short lived. However, is one also justified in seeing in this whole story a more specific theme?-an allegorical expression of youth's inevitable striving to break through constraints imposed by, or at least represented by, their elders, their "parents," and of their equally inevitable inability to do so? Such an interpretation is of course possible, but I leave to others the task of discovering deeper messages in Maohi myths, and content myself with some of the more obvious meanings to be inferred from them.

Turning to stories involving humans, albeit legendary ones, we recall the story summarized earlier on the origin of breadfruit, in which Ruata'ata so pitied his starving wife and children that he transformed himself into a 
breadfruit tree, to provide them with food (Henry 1928:423-424). A reversal of this theme is found in the following story about the origin of coconuts:

A very long time ago, there was such a famine in Tahiti that people stripped the land of all that was eatable and were reduced to eating red clay. Children wept with hunger which could not be satisfied, their parents wept in despair for them, and many families died of starvation.

At that time there was a man named Piti-iri (Husky-chestnut), and his wife, whose name was Pito-ura (Red-umbilicus), who had three small children, Pa-rapu (Fort-in-perplexity) and Toerau-roa (Continual-north-wind), two sons, and the third a daughter, named Ha-muri (Final-prayer). The mother died in her efforts to provide for her children, not taking nourishment herself, and the sorrow-stricken father took his motherless children into the interior of the island to a table-land called Oro-fero (Tied-oro-fern), where he made a comfortable hut to reside in. Then bidding the eldest son take care of the two younger children he left them and went in search of food.

He went up into the recesses of the valleys, only to find that others had been there before him and taken all available food. Then he was benighted, and on the following day he climbed the great mountain sides in search of fei (plantain). He continued his search for two days to no purpose, but on the third day his eyes, which had become dim with tears and hunger, were gladdened by the sight of a cluster of the desired trees laden with ripe fruit growing at the base of a towering peak. He soon possessed himself of a load of fei, ate some not cooked, and hastened to return to his children, whom he could not reach until the following day, the fourth since he had left them. When he arrived, he found them dead, where they had huddled together outside of the hut awaiting him. On approaching them, he found that their heads were growing, and soon he perceived they were producing plants that he had never seen before. As he buried each child, he carefully placed the heads so as to allow the plants to continue growing. They matured into three coconut trees and yielded fruit in a few days, and they were the first trees of their kind that ever grew in these islands. (Henry 1928:422-423)

In the legend of Tafa' $i$ this young hero's father became so aggrieved at the unkind treatment accorded Tafa'i by his envious cousins that he "... took leave of this world and went down to the pō (darkness), to live." (Suicide or withdrawal was not an uncommon reaction to aggrievement.)

Reversing the roles, the young prodigy Pai (who it will be recalled was fostered by Ta'aroa himself, to save him from death at the hands of his father's slayers) so longed for his natal mother that he returned to the $a o$, to comfort her and restore the family's good name (Henry 1928:585-586).

Examples of fatherly affection are provided in Henry and in Adams.

... a man named Rahute (Abundant), of the household of Chief Moe, once left his district in a quarrel and went to Mataiea. He soon longed to see his little son whom he had left at home; and one day as he was fishing he met the family shark, told it his trouble, and asked it to go and bring him his dear child. The shark went its way. It hovered around the shores of Mata'oae, until one day as the boy was playing near the seaside upon the bank of the river, Vavî (Rashness), it decoyed him into the sea, caught him in its jaws, and bore him away to Mataiea. The father was awaiting him at a passage on the reef, and when he saw the shark 
approach he swam onto a great wave and received his son, who was placed unharmed in his arms. (Henry 1928:389-390)

... Niuhi [a chief of Pare] ... was the subject of another tragedy caused by his killing the two sons of a man named Tetohu of Faaa, and placing their bodies on the Marae of Raianaunau. When the father heard of their death he called his daughter Terero and said to her: "I have just heard that my sons are put to death by Niuhi, and I am going to Raianaunau to mourn for them." She remonstrated: "Do not go! You will be killed." "I will go!" he replied; "but I wish you to wait three days, and if I do not return I shall be dead." ... After giving these instructions to his daughter [concerning how he was to be avenged], Tetohu bade her farewell and started for Marae Raianaunau, where he arrived the same evening, and found the bodies of his sons on the Marae, tied together and covered with a cloth of tapa. He uncovered and separated them, and then lay down between them, with their heads on his arms, and there he lay till, in the morning, the Tahua or priest, coming to the Marae to prepare the sacrifice, was surprised to see six legs instead of four under the tapa covering. Lifting it, he saw Tetohu, and was so deeply touched by his mournful face, with the dead sons lying in his arms, that he had not the heart to call the alarm, which must be the signal for the death of the father. "Get up and fly while there is yet time," he said to Tetohu. "Do you not know that it is death to interfere with Niuhi's vengeance and mount his Marae of Raianaunau?" Tetohu answered: "I have come to follow the fate of my sons, sure that my revenge is close at hand." The Tahua had then no choice for his own life but to report the event to Niuhi, who instantly ordered Tetohu to be killed. (Adams 1901:81-82)

There are also legendary accounts of services performed by parents for their children, as in the legend of Tumoanaurifa and Rifarifa reproduced in chapter 9.

Another extract from Henry touches on a father's affection-but one which had to give way to religious duty:

So sacred was the pa'i-atua regarded that were a stray man to appear upon the scene, whatever his rank or station, he was immediately seized and slain as a sacrifice to the gods and buried near the marae to add to its sacredness. And even if a little boy chanced to break away from home and go to his father at the marae, the father would say resignedly to the high-priest:

"Take this child and slay him for the gods! Behold the order of the marae is disturbed by him, the thread of the prayers to the gods is entangled. He is my son, I begat him, but I must not regret (losing him), because he has erred in coming here to the assembly of the gods."

Then the high priest approvingly would have the child sacrificed in the manner just described-as he would his own child. (1928:169)

But all was not affection and altruism in these stories about parent and child. For example, in the story of Mo'o-tua-raha reproduced earlier the factor of class overrode a father's expectable pleasure in having a son. In one of the numerous Maui legends, a maiden was so pressed by her parents into an unwelcome marriage with an eel-demon that she fled from home and never returned. 
There was once a beautiful young princess of Papeuriri, Tahiti, of the highest lineage, whose celestial patrons, the sun and moon, had named her Hina (Gray). When this young girl had reached the stature of womanhood and was becoming much admired for her beauty-flashes of light emanating from her person restricted her to a very select circle-the sun and moon espoused her to the king of Lake Vaihiria, before she had any personal acquaintance with him or her even seen him. The king's name was Fa'arava'ai-anu (Cause-to-fish-in-the-cold), and as her parents agreed to the marriage Hina felt no doubt of the suitableness of the match and entered happily into all the preparations for her wedding. Hina chose for her maids of honor, two childhood companions, named Varua (Spirit) and Teroro (Brain), and when at last the marriage day arrived they were attractively dressed in white tapa gracefully wound around their persons, with garlands of maire fern interwoven with red fara strobile tips and snow-white tiare, and in their flowing raven hair they entwined similar wreaths. The bride also wore, in token of her rank, a necklet and girdle of rich red and yellow 'ura (parrakeet feathers).

At length the bridal party set out to meet the bridegroom, accompanied with the measured beat of the drum and the soft notes of the bamboo flute and other primitive musical instruments, and they had gone half way up the valley to Lake Vaihiria, when, lo, the bridegroom was seen descending the declivity to meet them. And there in the distance Hina saw to her great horror, an immense eel, as great and long as the trunk of a tall coconut tree; this was Fa'arava'aianu, king of Lake Vaihiria, the intended bridegroom for the beautiful Hina!

Terror-stricken, she turned to her parents and exclaimed: "It is indeed this, O my parents? Do you wish me to be wedded to a monster and not a person? O how cruel of you! And now I shall seek my own salvation!" And she fled out of the valley to her home.

On arriving there, the people were surprised to see her and enquired what had happened. On knowing her grief and disappointment, sorrow and sympathy filled their hearts towards her.

"And now," she said, "farewell. I must seek my salvation quickly away from here. If all be well, I shall return again; but meanwhile, my dear friends, I entrust all my treasures to your care. If I live, I shall return to my own district, to be with you, my dearly loved ones."

Willing hands quickly prepared a swift canoe, and just as the moon was rising in its full glory, Hina, with trusted retainers, set off for Vaiaro, Taiarapu, to seek the aid and protection of the great Mâ-û-i who had noosed and controlled the sun, and there they arrived just before daybreak.

On entering his cave, Hina found Mâ-û-i was out, but she was kindly received by his wife. Shortly afterwards he came in and enquired of his wife what caused the brilliant flashes of light in their dark abode, and she replied:

"This is Hina of the 'ura girdle, Hina of lightning flashes in the east, Hina, child of the sun and moon; her wind is the northeast trade wind."

Then Mâ-û-i welcomed Hina, and kindly addressed her saying, "O Hina, beloved daughter of Mataiea, what is your errand, my Princess?"

"O Mâ-û-i," she exclaimed, "save me from the hideous monster, the king of Vaihiria, who will be coming here to claim me as his wife! Have pity on me, behold now outside, and what is the wind? It is possessed, darkness is overshadowing the land, and the sea is foaming so that the ocean beyond cannot be seen?" And then, while Hina told her sad story, they saw the eel king breaking an entrance passage in the reef. 
Mâ-û-i was horrified, and he hastened to place his two stone gods upon the cliffs and to sharpen his axe and make ready his fishhook for action. Then, as the eel was approaching the shore, Mâ-û-i placed some tempting bait upon the fishhook and secured it with Hina's hair.

As soon as the eel saw him, he roared out in a thundering voice, "Mâ-û-i, deliver me my bride!"

And Mâ-û-i cast his fishhook into the sea, saying, "This is I, Mâ-û-i the brave! No king can escape me here in my heritage; he will become food for my images."

Then the eel perceiving the food, opened wide his mouth and swallowed the fishhook and bait, and soon Mâ-û-i drew him up on to the shore. He chopped off his great head, which he wrapped in tapa, and presented it to Hina, saying:

"Hold this, and put it not down an instant until you arrive home; then take and plant it in the center of your marae ground. This eel's head contains for you great treasures; from it you will have material to build and complete your house, besides food to eat and water to drink. But remember my warning, that you lose not your valuable property by putting it down before you reach home. Then you will ever be remembered as Hina-vahine-e-anapa-te-uira-i-te-Hiti`a-o-te-ra (Hinaof-lightning-flashes-in-the-east)."

So Hina took the great bundle, which became light by magic, and sending on her canoe along the coast, she and an attendant maid preferred walking a few miles. So they went on their way rejoicing, and arrived at a place called Pani (To-close), where they saw a nice deep stream of water, at which they stopped to drink. In doing this, Hina thoughtlessly put down her bundle. Soon the two girls made up their minds to take a bath. So in they plunged and dove first upwards in the stream and then downwards, when Hina all at once remembered her eel's head and left the water quickly to go and take it up again. But lo, as she approached it, she found the tapa removed, and there the head stood erect, rooted to the ground and sprouting! It had become a young coconut tree. Then Hina saw and understood why Mâ-û-i had told her only to put it down at her own marae, and she wept bitterly.

Just then a woman of the people, but of good standing in the land, came along and enquired of the girl her trouble, and when Hina told her, the woman whose name was Rû-roa (Great-haste), said comfortingly:

"Be not troubled for this land is ours; come and sojourn with me so as to watch the growth of your new tree, which shall always be yours."

Hina, comforted, accepted the woman's kind invitation, and after sending her companion on to the canoe with word for her people to return home, she committed herself to the care of her new friend, who soon made her very comfortable in her home not far off.

After partaking of a hearty breakfast, Hina threw herself down upon a mat, and fell asleep, which rest she needed, and towards evening as she awoke, she heard voices outside not far from the house. Looking out she perceived two handsome young men, sons of Rû-roa, who had been out fishing; and she heard them enquire of their mother as to the cause of flashes of lightning that they saw coming out of their dwelling, to which she replied:

"It is Hina, princess of Papeuriri, and child of the sun and moon. She has a young coconut tree growing yonder, which she is staying here to watch until it matures."

Awe-struck, the young men would not enter the house but remained outside. The younger brother went to see the new tree, and found it loaded with coconuts. So he picked one and husked it and took it to his mother and brother, and while 
they were examining and admiring it, Hina, wishing to place them all at ease in her presence, called to them to come in. She said to the elder brother:

"Your name must be Mahana-e-anapa-i-te-po'ipo'i”" (Sun-that-flashes-in-themorning). And to the younger brother she said: "You must be called Ava'e-e-hitii-te-ahiahi" (Moon-that-rises-in-the-evening).

By giving them these names, which plebeians never dared to adopt in times of yore, she created them nobles, an act which also gave rank to their mother. Thus united in bonds of friendship, they all lived happily together, the family being charmed with the beautiful and affable Hina, and they enjoyed eating the coconuts, which had become the admiration of all Tai'arapu.

Hina and Mahana-e-anapa-i-te-po'ipo'i became much attached to each other and they were married, and in due time she had a daughter whom they named Te-ipo-o-te-marama (Pet-of-the moon). But to her great sorrow Hina's husband soon died. She afterwards married the younger brother, who reminded her much of her deceased husband, and by him she had another daughter, whom they named Te-ipo-o-te-here (Pet-who-loved).

One day, as each child held a matured coconut in her hand, they were caught up by the gods on to a rainbow, by which they were conducted to Taka-horo, in the atoll of Ana (Chain Island), in the Tuamotus. The younger sister, finding that her coconut was without water, changed it for that of her elder sister, unbeknown to her, which displeased the gods; and causing her to drop the coconut, which was sprouting, they carried her away in the clouds, and she was never seen again. So Te-ipo-o-te-marama became the sole owner of this, the first coconut tree that grew at Ana, from which were produced all the coconut trees that have spread throughout the group and have developed into many varieties. The tree stood, towering high above all other trees of the group, until the cyclone of February 8, 1906, broke it off in three pieces, which were washed away by the sea.

Hina lived long and happily with her husband, sometimes in Tai'arapu, sometimes in Pape'uriri, and she had numerous issue. (Henry 1928:615-619)

An episode in the story of Rata tells much about the expected behavior of a chief, and this will be referred to in another chapter, but it also provides some insights into Maohi norms for relations between mother and son. The main theme of this lengthy epic concerns the efforts of relatives to avenge the death and recover the bodies of a chief and his followers who had been slain by a giant tridacna clam. For a time the chief's widow acted as regent on behalf of her son, Rata, but when the latter had matured and acquired prodigious strength he was made chief, and his mother began preparations for an expedition of vengeance. To select the hardiest companions she decreed a contest in the form of a wild boar chase:

The giant king, Rata, entered enthusiastically into his mother's plans, wishing also to accompany her on her voyage. Wild boars with long tusks were caught and kept in readiness, and the day was fixed for the sport, after which a prolonged feast was to be held in honor of the king's coming into power. The regent decided to go herself as umpire, and she told her son that as king he should not take part in the chase but that he should preside over it with her, and this he agreed to do. But she was careful in cautioning him to exercise self control, as she feared he would become excited and side with one party against the other. 
This might end tragically, for, she said, he would thus be drawn to interfere with the hunters, and as he was so strong, one blow of his hand would fell a man to the ground and disable him, and he would thus lose caste as king in the land. But Rata assured his mother that he loved his people impartially and would control his feelings as umpire with her. So her mind was set at rest.

The day arrived, and in the cool of the morning the young men of Hiti-uta and Hiti-tai coasts ranged themselves along on one side of the assembly ground and those of Pe'eai and Papahonu on the other side. The king and his mother, as umpires, took their seats in the rear, and one of the boars was let loose in the center of the assembly ground. At first the boar stood bewildered in his strange position, but soon endeavored to make its escape by running inland.

The rival parties kept their respective sides as they chased the pig and closed in the road he was taking. The Hiti-uta and Hiti-tai side almost caught him, but he slipped out of their hands and was escaping into the woods, when the king, growing interested in the chase and forgetting his place as umpire, shouted:

"A rohi, e Hiti-uta e Hiti-tai!" (Be sharp, Hiti-uta and Hiti-tai). This fired them with new zeal. The king's mother reminded him that he should keep calm and be silent; yet he could not contain himself.

Soon the hunters, each party keeping its own side, had overtaken the pig inland and turned his course out of the woods into the scrub upon the sands of the coast, and just as the people of Pe'eai and Papahonu were about to catch him, he disappeared in the sea; but he was again nearly in their hands as he emerged and was swimming away.

Now Rata lost all control of himself, and shouted to the other side to push into the rival ranks and outdo them, saying:

"Na onei mai, na onei mai!" (Come this way, come this way!). The mother in vain exclaiming:

"E Rata, eiaha 'oe e parau atu i ta vera haru ra'a pua'a! E ari'i 'oe, parahi noa oe i to parahira'a mataeina'a e a vai iho noa 'tu ia vera!" (Rata, do not interfere with their pig catching! You are the king, sit still in your official place, and leave them alone!)

But all system and order were now forgotten by the king in his excitement. He heeded not his mother's words and joined the party, felling to the ground those he sided against, as they laid their hands upon the pig, now slippery from being wet and endeavoring to run out through the crowd. Some of those Rata struck with his heavy fist died instantaneously; others were stunned and carried away. Thus tragically was the people's sport ended, while the persecuted pig slipped away unobserved to its home in the woods.

All attention was then directed to the injured and dead. The king stood aghast, overwhelmed with shame and remorse, as the people of Pe'eai and Papahonu turned to his mother and said with bitter sarcasm:

E te Ari'i Maemae-a-rohi vahine e, tera iho te ta'ata o Peeai e o Papahonu, i ha'apori hia ei ta'ata no te tere, ei fa'a'ite ra'a ui i te tere o te Ari-i-vahine o Maemaea-rohi!

Stung with poignant sorrow, her tears mingled freely with those of the people, who bewailed the day's adventures, and she retired to her home much mortified with her son's conduct. For two days and two nights she upbraided him in the following scathing manner:
O Princess Maemae-a-rohi, these are the people of Pe'eai and Papahonu, fattened for their journey, as an illustration to generations of the travels of the Princess Maemae-a-rohi! 
Eaha 'oe i taparahi ai i te ta'ata? Ta 'oe ia i na o mai e, 'e'ita 'oe e rave noa a'e i ta vera harura'a pua'a? E ari'i maitai 'oe? Inaha, to pue metua o tei pohe i te toa o te moana, te mau ari'i ia i ha'apao hia ei ari'i no te fenua, 'a'ita i taparahi i te ta'ata; e tae mai nei ia 'oe, o'oe atura e taparahi i te ta'ata i fa'aea noa i ni'a te fenua nei! Eaha 'oe i rave nunui ai i te ta'ata? E ho'ona ho'i te taua ia 'oe, e tena ta'ata ino? Ahiri ho'i 'oe e ta'ata maitai, e 'ai 'oe i te pua'a o to 'oe na'u metua, ta'ata ino pai 'oe. Haere pai 'oe e'ai i te huehue ia pohe vave atu i tena na mahana. 'Aore 'oe a pohe i reira, a haere a amu i te tutae. Eiaha 'oe e amu i te ma'a maumau, te ma'a o te fenua nei a pau i te manumanu ia 'oe, tena na ta'ata 'ino!
Why did you murder the people? Was that keeping your promise not to interfere with their boar seizing? Are you a good king? Behold, your father and uncles, who were slain by their foes of the ocean, were worthy princes of the land; they did not slay men; and now you have arisen, you have killed inoffensive people of the land! Why did you lay a heavy hand upon them? Can you recover friendship, O man of evil? Were you a worthy person, you might eat pork as did you fathers, but you are unworthy. Go then and eat globe-fish, that you may die today. And if you do not die of that, go and eat dung. Eat not the food of the brave, lest the aliments of the land become blighted by you, unworthy man!

Rata's heart, already heavy, was sorely pricked with his mother's reproaches, his head was bowed down with true contrition, and his loud wailing was heard far away, so that all the people pitied him. At length he said:

E ta'u metua vahine, e te Ari'i Maemaea-rohi vahine e, mea ra te toetoe o to'u 'a'au ê! Ahiri 'oe i tu mai e taparahi ia'u, mahana-hana ai to'u 'a'au. Eiaha e atu ia, ahiri 'oe i fa'aue i te ta'ata o te va'-amataeina'a e tu mai e tata ia'u i te ra'au, 'e'ita roa vau e mamae i tereira! 'A'ita 'tu e ra'au mamae rahi, maori ra o te reo i avau mai nei, e te amuamu; toetoe maite atura to'u 'a'au! Na vai teie, mai te po'ipo'i mai a e a pô maite, e ao a'era e a pô ho'i teie ra, te avau noa mai nei a 'oe! Ta 'oe e parau mai nei e ta'u metua vahine, e Maemae-arohi, taria-pu tena parau no'u.

Teie ra ta'u parau, e ta'u metua vahine, $\mathrm{E}$ hoe atu taua i to 'oe tere. E roa'a ia'u te mata taua; pohe ana'e ia mau toa ia'u. Ahiri e mai te fenua tuati ra e tae noa ia haere, teienei ia mahana e pau ai ia mau toa ia 'u. Napehea rà, inaha e tai tua. E'ita atura e noa'a i teienei!

A rave ra vau e tarai i ta'u pahi, e ia oti, taua 'toa te haere i to tere taua. Fa'aho'i ra i to va'a a'era i roto i te farau, e hoe a'e o taua tere, 'e'ita ia 'oe e pohe.
O my mother, Princess Maemae-a-rohi, how chilled now is my heart! Oh, that you would come and beat me so as to warm my heart. And if not this, were you to order the people of the clans to come and smite me with rods, I should not feel pain from them! There is no rod that hurts so badly as the voice of reproach and derision that reaches me; it has chilled my heart! What manner of doing is this, from morning till night from day until now it is night again, you are still upbraiding me! What you say to me, O my mother, Maemae-a-rohi, your words my ears retain.

And now here is what I wish to say, O my mother. Let me go with you on your voyage. I am capable of waging war; all those foes I can slay. Were it land joining this, upon which I could go, this day would I consume all those foes. But what can be done when there is the open sea? They cannot now be reached!

Then let me make my ship, and when it is finished allow me to accompany you on your long journey. Have your canoe now replaced in its shed, and let us both go together, so that you may not die.

But the mother was so sorely displeased that she refused to wait for her son to build his ship and made preparations to go on her long journey without him. In vain Rata entreated her to let him accompany her; his waywardness, which had brought death and sorrow to his people, had broken her confidence in him. She 
refused to accept his services but chose rather to entrust herself to the care of her older tried friends and retainers. (Henry 1928:478-480)

The prodigious Honoura also enjoyed less than felicitous relations with his parents, but he can hardly be blamed for his pique, for when born, in the form of a shapeless clod, that is, an abortion, his parents abandoned him in a cave. In time Honoura grew to enormous size, and was rediscovered by his family. Once when his mother and brothers went to visit him he was at first considerate of his mother's comfort; then for reasons not given

... the anger of Honoura was kindled against his mother, and he took her and wrestled with her. The night was far advanced as they did so, and the sea was ebbing while they continued so, and the early dawn came, they still continuing, daybreak came, and they wrestled on, the sun arose they the while continuing, the sun was high in the heavens, and still they wrestled on!

When the brothers saw (the wrestling) they said (to Honoura): "Friend, you are an unkind man to our dear mother!" They tried to throw him down, but did not succeed. And when the wrestling was over the son let himself down, and the mother stood up like a little fowl that had been dipped in water. (Henry 1895:269)

After that Honoura's family attempted to kill him, without avail, and eventually peace was made.

Another episode, in the meandering legend of Tafa'i, indicates that favoritism was a recognized circumstance in Maohi ideas about parent-child relations:

In course of time, Hina who married her protector and deliverer, gave birth to a son, who was named Pū-a'a-ri'i-tahi (Cluster-of-first-small-roots). Another son, named Hema (Deceived), followed and she had no more children. The two boys became fine young men, and they were adepts in Surfriding. One day as they were preparing to go out for their sport, the mother asked the elder son, Pu-a'a-ri'i tahi, to dress her hair. But he did not comply, and she said,

"Ah, your wife will not be a woman of distinction." Then, as Hema came by, she asked him to dress her hair, which he readily did. As he combed out her long glossy locks and braided them, he discovered a louse and taking it out he showed it to her. She said:

"Your wife will be a notable woman." (Henry 1928:555)

In due course Hina helped her favored son to obtain a goddess for a wife, who in turn gave birth to the heroic Tafa'i.

Earlier in the legend of Tafa'i his grandmother, Hina, was less fortunate in her family relations. Hina's own mother, Nona, was “... an elegantly formed woman of high rank," but these attractions were offset by her appetite for human flesh. The story is worth reproducing in full, since it involves a family triangle of a most unusual kind.

[Forsaken by her husband, Nona] lived alone in her home shaded with coconut trees on her own hereditary land near the sea. There she gave birth to a beautiful little girl, whom she named Hina (Gray) and whom she brought up 
tenderly, as befitted her rank, concealing from the child the human prey which she procured for herself.

At the foot of the great projecting cliff of Tahara'a (Barrenness), conspicuous for its red clay, is a great cave bordering on the sea, forming a tunnel open at each end, through which pedestrians can pass at low tide so as to save going round the hill, and it is famed to this day as No-na's hiding place, where she waylaid passers-by and slew them to eat, sometimes cooking and sometimes devouring them still warm and sanglant.

In the days of No-na, people gradually became very scarce in that region, and homes lay mysteriously desolate. But a handsome young man, named Mono'i-here (Favorite-perfumed-oil), had escaped the wily woman, and he had become much attached to her daughter Hina, whose affections he won as she verged to beautiful womanhood. They clandestinely met at a cool sequestered spot, called Oro-fara (Fara-fern), where there is a spring, called Rati (Splash), which watered Hina's bathing pool-still called Te-hopura'a-vai-o-Hina (The bathing pool of Hina) - and close by a cave, which in their time it is said, was not known to exist, as at their bidding it opened and closed in the solid rock.

Protecting the Bay of Matavai (Face-of-water) is a broken line of reefs, called the Chain-of-to'a-tea (Light-rocks), and thither No-na, who was an expert fisherwoman, frequently went to obtain fish for herself and her child. While she was thus employed the two young people, Mono'i-here and Hina, met, feeling safe and free. Hina had the habit of carrying a basket of food to her lover when he was concealed in the cave, and in approaching him they would exchange the following passwords:

Hina. Mono'i-here te tane, Hina te vahine!

Mono'i-here. Teihea to metua vahine niho roroa, o No-na?

Hina. Tei te a'au roroa, tei te a'au potopoto, te ravaa'i ra i te i'a na taua, ta'u hoa tane. Te tumu o te papa e vahia!
Hina. Mono'i-here is the man, Hina is the woman!

Mono'i-here. Where is thy mother, Nona, with long teeth?

Hina. She is on the long reef, on the short reef, catching fish for us, my lover. Oh foundation of rock, break open!

Then the rock would burst open and out would come the lover, and they would pleasantly while the hours away until the time approached for No-na to return home, when Mono'i-here would either return to the cave or go to his home in the distance, as circumstances guided, always cautiously avoiding an encounter with her.

But there came a time when the mother began to miss the food and so wondered how her daughter could consume so much in her absence, and she determined to solve the mystery. So one day, after cooking their usual supply of food, she feigned indisposition and went to bed, then she snored deeply and appeared to be in the soundest sleep. Finally No-na saw her daughter stealthily approach the food, take out choice morsels, place them in a basket, and go noiselessly out. When No-na saw the course the girl was taking she took a short cut, halting here and there to keep sight of her, until she turned up into the shady nook; then No-na, arriving before her, ascended into a pua tree, where she could see and hear unobserved. As No-na had never known of the existence of the closed-in-cave, she was soon astonished at what she witnessed, and she repeated to herself the passwords, so as to remember them, as she kept motionless until the lovers had held their interview and parted, when she quickly descended from the tree and returned to her bed at home, while her unsuspecting daughter leisurely followed and found things there just as she had left them.

The following day, after partaking of food and putting some by, No-na took 
leave of her child, saying she was going to prepare torches for night fishing. But she quickly went to the lovers' haunt, and standing by the cave she spoke, imitating Hina's tone as nearly as she could. But Mono'i-here, detecting the fraud, replied:

"E'ere oe o Hina, o te vahine nihoniho roroa ra 'oe, o No-na!" (You are not Hina, but you are No-na the woman with long teeth!) But she had learned the magical words, and fiendishly said:

"Te tumu o te papa e, vahia!" (Oh foundation of rock, break open!)

Then the cave opened. She entered quickly, seized the hapless young man, and killed and feasted on him. She looked for his heart but could not find it, and leaving his bones and vitals thrown together she left the cave, which closed after her, and returned to prepare her torches as she had planned.

Meanwhile, Hina went with her basket to the cave and was surprised when no response came to her from within, and as the rock opened at her bidding she encountered the ghastly spectacle in the cave. What remained of Mono'i-here was still warm, and Hina at once sought for and found the heart, which was still pulsating. This she placed next to her own heart and guided by it went home to act. In the absence of her mother she got the trunk of a banana tree and laid it in her bed to counterfeit her body, and to simulate a head upon her pillow at one end of it she placed an 'a'ano (coconut-water-bottle). Then she covered all up in her tapa sheet and fled in fear from the home of her childhood, until she arrived at the adjoining district of 'Uporu (Ha'apape or Point Venus). Still guided by the pulsating heart of her lost lover she stopped at the house of a fine young chief, named No'a (Sweet-ordor), who was famed for his hairy though handsome person and who with all his household received her cordially, and she was at rest.

When No-na returned home with her torches she prepared supper, and thinking Hina was having a nap in her bed she called her; but no voice came. After calling several times, No-na became enraged and threatened to eat her daughter. But as there was still no response she furiously exclaimed:

"Tera mai au, e Hina, ua pau oe ia 'u!" (There I come, O Hina; you will be devoured by me!) So saying, she rushed to the bed, laid hold of the banana effigy of her daughter, and bit into it through the sheet, when, to her great surprise, she found that the girl had outwitted her, and she exclaimed:

"A ua ora 'oe!" (Ah, you have escaped!)

Early on the following day, No-na set out to recover her daughter, and ascertaining the course she had taken she went on and on enquiring for Hina until she also arrived at the house of the hairy chief, No'a. When she saw Hina, she made a rush to seize her, but the chief seeing how terror stricken the girl was, and hearing her say that No-na was a savage woman and would kill her he intercepted her grasp. Then with muscular strength, No-na grappled to strangle him; but he overpowered and strangled her and so ended the life of the famous No-na of the cave of Tahara'a. (Henry 1928:552-555)

The fabulous Hiro figures in many legendary episodes, only one of which concerns us here. This has to do with his strained relations with his son, occasioned by his slaying of his wife, the latter's mother (out of anger for her having jokingly alluded to his strong odor).

[After he had brutally kicked her to death,] ... he dug a shallow grave in the sand beneath the chips of his canoe and there buried her, thinking that no one had witnessed the scene; but a man who was passing by heard her cries and, com- 
passionating her, saw all by peeping into the shed from the outside, at the risk of losing his own life and quite powerless to save hers.

While this tragedy was taking place, their son Marama was out surf riding, which was his favorite diversion. When he returned home, not finding his mother and seeing a mat that she had been making lying with the strands scattered around as if left for a short time, he went to the canoe shed and inquired of his father where she was. But Hiro, fearing his son, replied:

"A'ita vau i 'ite" (I do not know).

Then feeling impelled by an invisible power, Marama went towards the spot where his mother lay, and moving the sand away he found her calm and beautiful in death. He bore her body away and buried it in sacred ground in her marae, and then he went to a distant point and sat alone on the seaside, mourning deeply for her and refusing to take nourishment or receive comfort from anybody. His father did not dare approach him. As days thus passed, and Marama neither ate nor drank, feeling anxious for him Hiro sent his daughter Pî'ho, to try to console her brother and bring him home, which after great difficulty she at last succeeded in doing. Hiro felt himself condemned in the eyes of his son and avoided falling into his hands by taking frequent long voyages, fearing that he might avenge the death of his mother upon him. But, not being of the fierce nature of his father, Marama sought not his life. (Henry 1928:544-545)

Thereafter they continued to reside together for a while, but Hiro seemed intent upon rousing his son's ire, for reasons that are not explained:

Hiro prided himself on doing things that other men could not do. At the request of his son, he made fire by friction, using toa for the upper attrition and a stone for the under attrition, instead of pliant wood for both. Then Hiro told his son to wield on a hillside, without missing, an immense heap of stones of all shapes and sizes, instead of pebbles, in a game of timo, which Hiro was accustomed to doing with his great hands without difficulty. His son complied with the request and succeeded well until he came to the last stone, which as he was about to take it up Hiro kicked away and caused Marama to stumble. This enraged Marama; he struck the hill with his fist and caused a landslide, which left steep, bare rocks. Hence the ever-standing epithet relating to the hill, "Te mou'a ta Marama i po'ara" (The mountain which Marama boxed). (Henry 1928:545)

A final legendary example concerns relations between Hiro and the husband of his mother, Faimano. Hiro himself was sired by a chiefly visitor, who enjoyed the lady's favors while her husband, Tepouaru, was away on a lengthy expedition (a recurrent situation in Maohi stories). This part of the Hiro cycle concerns other kinship relations, which will be discussed later on.

At his departure he said to her, "I know you are pregnant from me, and I wish to tell you if the child is a boy you will name him Aru mearau; he will be a great warrior. Your husband will be jealous and will endeavour to do his best for the death of the child; be fonder of bonitas and Aahi, and I will work on the Tahuas of Marae Vaiotaha to bring him contrary winds and keep him at sea longer. He will not dare use open means to hurt the child, so be prepared. It will be better for you to go and live at old Ana's, he can protect the child better 
than you." He wished her good-bye, and left. As he was being rowed out in his war canoe, Tepuatere ia Hotu, he met Tepouaru, coming in from his fishing. This chief was much troubled in seeing this war canoe coming out from his landingplace, and asked of his men whom it could be; coming closer these saw who it was; why, it is Moeterauri on his canoe Tepuatere ia Hotu; Tepouaru saluted, as is usual, his speaker, and invited him to return to Faaha and accept the hospitality of Tepouaru. The reply came, "Many thanks, I have been enjoying it for three days." Tepouaru was very jealous and hastened his men to get in as quickly as possible.

Faaha is a bay on the Island of Upolu of Tahaa, about two miles in depth and a mile wide; the valley is large and fertile; it is said that it was well cultivated with umaras, yams, taro and kava, the usual cultivation of those days. This was done by old blind Ana, Tepouaru's father; although old and blind he was a wise man and famed for his good government, so that in his valley was always plenty; at times of scarcity of food many went there to get food. The old fellow had arranged for the yam and umara plantations to be protected from thieves by two warriors, Tanihaa and Tanivaere by name, and the kava, the most precious, by the man-eater pig Moiri, so no one went into these without authority. Tepouaru had deprived his father of all government authority and he lived away from him.

On Tepouaru's arrival, he at once made enquiries of the doings during his absence, and of the reception given to the departed guest; he was told that they had been different to the usual feasts given to high placed chiefs, who often came to Faaha. He suspected the infidelity of his wife, and watched her closely, intending all the time to kill her if a child was born. He made his plans early to prevent failure. Faimano saw all this and kept her own people closer around her for protection if necessary.

The time of birth arrived, and happened on the second night of the new moon, a night known as Hirohiti. Tepouaru had left for fishing the day before, and Faimano had gone to old blind Ana's house; there she gave birth to a fine boy; the old man hearing it was a boy, asked if anything strange about it could be observed. The midwife reported that the child had a strange red eye and the navel stood straight up. The old man then predicted that he would be a fearless boy and would become noted; and gave him the name of Hiro. On Tepouaru's return he looked at the boy, and said, "As my father has given him a name, he can keep and take care of him."

As he grew up the old man taught him the art of club-fighting and wrestling; so strong was he that no one of his age could match him. He returned the love of the old man. He was also taught the movements of the stars and navigation; he excelled in all of the sports of those days. Faumana had three boys by Tepouaru and these became very jealous of their younger brother. Whilst canoe-racing they became so furious when Hiro had beaten theirs that they suddenly fell upon him to kill him; they got him down stunned, and put a large flat stone on his body and left him for dead. Hiro, however, got up from under the stone and went up the valley to old Ana. (The stone still exists at Faaha; I saw it in 1901, as also the lands where yams, \&c., \&c., were planted. Moiri's cave exists still, and so also the paepae or platform where Tanihaa and Tanivaere lived.) When Hiro arrived at manhood he began asking his mother about his father, "for," he said, "you cannot make me believe that I am the son of Tepouaru, for he shows his hate plainly. Tell me the name of my father"; his mother always replied to this, "When you have done some warrior's deed I will do so." For this Hiro learned the art of fighting.

One day there arrived a chief, Raatapu, from Havai (Raiatea) with his canoes 
and men. Tepouaru made preparations to receive such a noble guest, food was collected and pigs roasted. At the morning meal of the second day this chief asked for Kava, the famous umaras and yams. Tepouaru could not refuse, and thinking of this chance to get rid of Hiro sent for him, and before his guest told him of what was wanted. He said, "Hiro, our guest wants to see the umaras and yams of Faarahi, and after that, get the Kava of Puroa." "All right," Hiro replied, and started. As he passed by old Ana, the old man called, "Where are you going?" Hiro told him. The old man then explained about Tanihaa and Tanivaere and warned him to strike from left to right, and call Tanihaa first, that the other was a sleepy head, and he could have time to kill Tanihaa before the other could come up. Hiro was on no account to go at once for the Kava, but to return with the umaras and yams. Hiro went, followed the old man's instructions, and returned victorious. Having killed the two warriors, he brought the umaras and yams to old Ana, who told him to take them to Tepouaru and return to him, and not to tell that he had killed the two keepers. Hiro did this. Tepouaru, being furious, said, "Where is the Kava?" Hiro replied, "I go now to get it." He went, and again called to see old Ana, who told him that when he arrived at the place to be sure and make as much noise as possible, and to throw branches of Kava plant in the cave to enrage the man-eater out of his hole, and if Moiri did not come out, he must not attempt to go in to drive him out for there was no room inside for fighting. Hiro followed again the instructions of the old man. When he arrived at the place, and after making as much noise as possible, he heard the great pig grunt, but he would not come out. Hiro then threw in branches of the Kava; this enraged the pig so much he made a rush outside, then Hiro sent his spear through the pig, giving a death wound. He picked up the pig still sticking on his spear, rooted up the Kava, tied it on the other side to balance the weight, and started for the feasting-place. Old Ana was anxiously waiting; when he heard Hiro arriving he called out, "Welcome, for I was afraid Moiri would get you."

On leaving Hiro left the Kava roots behind him and told the old man to take care of them till his return. Ana asked, "Why do you do that?" "Oh, they can get some from up there now Moiri is slain; mine is for us two only."

When Tepouaru and people saw Hiro arriving with the pig dead, they became afraid, and wondered at the success of Hiro. He came up to where Tepouaru and his guest Raatapu were. Turning to the former, he said, "Here is your famous pig, Moiri; the Kava I have left at home for my own use; if you want any send your sons for it, for no one will hurt them up there." This was an insult to Tepouaru and sons. Hiro then left for his home. The feast ended at once, and Raatapu left, knowing that some trouble was soon to take place. On Hiro's arrival home he started to munch the Kava; this took him a long time to do, and by the time it was ready to drink it was evening. He gave old Ana the first cup, and began drinking himself. The old man kept saying, "Hiro, don't drink too much, for I am blind, and cannot watch for your enemies, for it is certain that my son Tepouaru will attempt your life." But the Kava could not make any effect on Hiro, whereas the old fellow got quite drunk. During the night men were sent to see how these two were getting on; these saw Ana drunk and took it for granted that Hiro was also in the same state; they quickly went back to report. Tepouaru's three sons left at once, saying, "Now is the time to kill our enemy." Arriving, Hiro pretended he was drunk, and these three men quarrelled as to who should give the blow to kill him. Hiro then got up and fought them, killing two; the third seeing this, ran down to his father's and Hiro after him. Tepouaru, hearing the voice of his son calling for 
help, ran out to help; just as Hiro was dispatching him he aimed a blow at Hiro which wounded him. Hiro, however, turned and speared Tepouaru, and killed him. Faimano ran out, followed by her people, and when they saw Tepouaru dead and Hiro standing over him, she called to her warriors to protect him if Tepouaru's men should try to revenge their chief. These, however, thought that Hiro was Tepouaru's son, and the deeds performed by him during the day were such that they were proud of him, and proclaimed him as chief of Faaha. The place was called Vaitoto, bloody waters (and is shown to you to this day). Old Ana heard of these deaths and declared the act was done in self-defence. So Hiro commenced his rule with full approval of everyone. He ordered a new Marae to be built and called the Tau i Upolu (Time of Upolu). He could rest in peace, and called his mother to fulfil her promise and tell him who his father was. She told him. (T. Salmon n.d.: 8-16)

The corpus of recorded Maohi legends contains a few other episodes concerning parent-child relations, but those given above are fairly representative in terms of the dimensions herein discussed. These narrative fragments are far too few for statistical analysis but they do permit some general impressions about parent-child relations as represented in stories the Maohis found interesting enough-possibly even credible enough-to listen to and retell.

Both sons and daughters appear in the stories, although the former figure more frequently and more prominently. With respect to dyads, episodes involving sons and mothers are about as common as those involving sons and fathers, the least featured being relations between a father and his daughter.

Affection and altruism are the mode in most episodes, but conflict is highlighted in some, ranging from mild pique to deadly enmity, and resulting from many kinds of situations. In this connection, mothers are depicted in conflict with sons and with daughters, and fathers with sons but not with daughters-an interesting but not necessarily significant omission in this small sample.

Another noteworthy aspect of these fragments is that most of them concern natal parents. Moreover, in the one episode in which choice is made, the protagonist, Pai, rejects his divine foster parents in order to return to his natal mother. And finally, the alleged tolerance of Maohi husbands for their wives' bastard offspring is emphatically controverted, at least in the instance of Tepouaru and Hiro.

Evidence concerning parent-child relations is provided also by certain words such as the following from the LMS Dictionary: àtama, affection for a child; anau, grief of parents for their children, or of children for their parents; mere, the affectionate grief of a parent. These appear to apply distinctively to the relations under consideration, indicating verbal recognition of their special nature. ${ }^{20}$ This is true also of rorai, a curse or imprecation of evil on children; more specifically, according to Henry, rorai means "a parent's curse," this being a common cause of illness (1928:210). 
One finds in Morrison the puzzling statement that "A Child may Curse its Father, Mother, Uncle or Aunt but it would be Blasphemy for them to Curse it" (1935:184). Two factors may have been involved here: a belief that an adult's curse was more effective than a child's, and hence the necessity of avoiding unintended harm brought on by momentary anger; and a concern for family "honor" as embodied in the parental kin-Titles now held by the child in question. Concerning the second factor is a statement by Wilson about the causes of interfamily strife:

Such broils, indeed, are sometimes produced by what appears to us a very trifling matter; such as scurrilous words spoken against the heir of a large estate, or even of a small one; neglect of proper respect to a child, and other things as trivial; for instance, as the child from the moment of its birth becomes the head of the family, the boundaries of his land are new marked with rude images; and if this new-born infant be a tōwha, of ratìrra, a number of little flags are set up in different parts of the boundary; to these all persons of inferior rank must uncover themselves as they pass, whether by day or by night; and should this mark of homage be contemptuously neglected, the mother flies to the shark's teeth and cuts herself, and the party must make his peace-offering with the plantain: should this be refused, the father and mother would tear off the clothes from his back, and well drub him into the bargain. The friends and relations on both sides sometimes arm, and fatal consequences follow. Even a chief has been known to be driven from his district on account of a dispute originating about a poor man's child supposed to be affronted by one of the same rank with himself. (1799:326)

This statement is confirmed by one of Morrison's, of which, indeed, it seems to be a paraphrase:

-any neglect or refusal of these Honors [i.e., paying respect to an estate's boundary markers] are the occasion of Disputes and often are the occasion of Wars or Houshold Broils between the partys-if the owner is a Minor, the affront is the greater, the Mother instantly applys the Sharks tooth to Her head in Grief that Her Child should be insulted, \& the Father flys to strip by force those who have offended. If the offender makes a Concession by offering a Plantation leaf and declaring their Ignorance, the Matter is settled but if they continue obstinate Blows ensue which increase as the Friends of each party become acquainted with the affair, who repair Armd to the place and the Battle becomes general and often ends with the loss of some lives, and often involvs whole Districts in a War With each other, and a Chief and his people may be driven from the land through the means of a quarrel arising from the neglect or refusing to pay the proper Compliment to a poor Mans Child, tho the Father might have been beaten with impunity by one who might quarrel with Him, but no Man must presume to treat the Heirs of large estates with such contempt or neglect on pain of Death and such insults often end in the total extripation of one of the Familys concernd, it being deemd Blasphemy to Call them by a Wrong Name. (1935:193)

Somewhat connected with these beliefs and practices was the procedure followed by some men in denying guilt; they called not only upon their tutelar spirit to witness their innocence, but upon their firstborn son as well 
(Henry 1928:207). A son was also associated with higher authorities in connection with the distribution of food, or so is implied by the definition of hi'irima, the first fruit for the king, principal chief, or favorite son (LMS Dictionary). Recall the eating proscriptions noted earlier: "Nor may sons eat in the presence of their fathers, nor even of their uncles and kinsmen senior to them in age; for they regard it as [an act of] irreverance" (Corney 1915:258). In view of the timing of Title succession one cannot be certain whether the "irreverance" applied to son or father.

Eating restrictions also obtained between a mother and her children, although the timing and rationale were evidently different:

The Children eat with the Mother till their restrictions are taken off, tho she Cannot eat of the Food which is the Childs nor that it has toutchd nor must the Childs provisions enter the House by the same entrance at which the Mothers come in at and in travelling they Must have seperate Canoes for the Men \& Weomens food, of which the Children may partake. (Morrison 1935:208)

The tie between father and son (and possibly also between mother and daughter) was in many instances reinforced through the latter's "inheritance" of the former's specialized occupation, usually through mundane on-the-job training but in some cases through more esoteric means as well, as in the situation described earlier in which a sage transmitted his "knowledge" to his heir through his dying breath.

Additional evidence for the bilaterality of Maohi conceptualization of consanguinity is contained in the word $\bar{a}^{\prime}$ aupiti, which the LMS Dictionary defines as a double mind (from $\bar{a}^{\prime} a u$, the bowels or intestines-fig. the heart or mind; the affections; the conscience; courage or spirit; and from piti, two); double minded, undecided; having two stems, as a plant or tree-fig. a person whose father belongs to one country and his mother to another is called ta'ata à'aupiti.

The conventional disposal of children in the event of divorce might also be expected to provide some clues to Maohi conceptualization of parentchild relations, but the evidence is not altogether clear. As I noted earlier, Morrison wrote that when a couple separated boys remained with their father and girls with their mother (1935:185); but according to Moerenhout the disposition was made by name-that is, every child was at birth given a name either from the father's family or the mother's and was disposed of accordingly at the time of divorce (1837:II, 63-64). The two accounts are in agreement only if it turns out that boys received a paternal family name and girls a maternal one, which none of the sources states. In any case, however the disposition was determined, the accounts agree that both parents had rights (or obligations?) in their offspring.

I remind the reader of the parts played by parents in choosing marital 
mates for their children: in families holding high-ranking Titles parental consent and even parental selection was the rule. ${ }^{21}$ In other cases parental consent was usually required mainly for legitimatizing offspring, which was desirable only if some consequential inheritance was at stake. Of course, even if Titles or inheritance were not involved, this did not stop some parents-particularly fathers-from selecting mates for their daughters.

Parental decision, however, did not always prevail, as witnessed in the following episode of a version of the legend of Honoura. The legend relates that a young $\operatorname{ari}^{\prime} i$ from a small district met a princess in populous and powerful Puna'auia and decided to marry her. Returning home, he announced to his parents what he planned to do. His mother was distressed, and urged him:

"Oh! do not go, or your little dominion will be taken from you." But the son replied, "Am I a son that you have begotten that you should have authority over me? My parent is the god Raa-mau-riri, I shall not give heed to your words; I shall persist in going to take myself a wife." "Go then!" rejoined the man Teena to his son, whilst the mother wept. (Henry 1895:259)

The same kind of arrangements prevailed in connection with nuptial rites; when important inheritances were involved the families, especially the parents, of both principals played active roles.

Parent-child relations were also manifested on the occasion of death, but beyond a few generalities, such as "close relatives surrounded the corpse" or "female relatives bled themselves more copiously than males" or "relics of the deceased were worn by relatives," we are not informed about the specific parts played by parent or child, if indeed such parts were specifically prescribed.

Bougainville's statement that "the mourning for the fathers is very long..." (1772:270) only confirms what is already obvious, that men in general were more important, socially, than women or children (except in situations of early Title transfer). There is also an implication in a passage from Bligh that parents, in this case a father, were expected to manifest some "grief" upon the death of an offspring, even if the latter were an infant and not a firstborn. In this instance the child's mother, 'Itia, "attended" the corpse, but its father, Tina, appeared to Bligh to be "... not at all concerned at the loss of his child." But, Bligh added, "he would not however return with me to the Ship, for he seemed to consider it but decent to remain with Iddeah [his wife, 'Itia]." (1792:153-153b)

The greater concern toward a deceased child on the part of the mother is also shown in an episode reported by Rodriguez. In searching for medicinal plants for himself and his companions he discovered some purslane (aturi: Portulaca lutea) growing near a boy's grave. When he sought to obtain it, the boy's mother objected strenuously to the sacrilege, but was overruled by the boy's father. (Corney 1919:100) 
One of the very few references to relations with collateral "parents" is found in Rodriguez' journal and concerns the ari'i Vehiatua: "News reached Vehiatua that the ari'i Pahairiro [brother of Vehiatua's father] had died, which he lamented, but not very much" (Corney 1919:31). Another episode concerning a collateral "parent" occurred upon Mai's [i.e., Omai] return to the Islands after his sojourn in England. Soon after landing his "... attention was drawn to an old Woman, the Sister of his Mother. She was already at his feet, and had bedewed them plentifully with tears of joy." (Beaglehole 1967:188)

I described in chapter 13 the ceremony of "ghosts night" (pō tupapa'u), when the ghosts of relatives were welcomed back home a year after their death and thereby prevailed upon to remain benevolent. Assuming that such ghosts would also include those of parents and children, we may conclude that some of the affection or respect toward a parent or child became translated into fear after its death. This view is confirmed by another belief, described by Moerenhout, who stated that the Maohis feared most of all the ghosts of children deceased after the natal ceremony. These ghosts, although mainly angered at their mother (because of neglect?) would also take revenge upon all members of the family. Hence a woman used this belief to protect herself from ill treatment by her husband and others-threatening to curse the ghost and thereby bring venegeance upon all family members. In fact this fear of corporate punishment acted as chief sanction to enforce harmonious relations of all sorts. (Moerenhout 1837:I, 538)

I will summarize in more analytical terms the parent-child interactions revealed in the evidence just surveyed. I have already generalized about the terminological and temporal aspects of these relationships, but the other aspects merit some discussion.

It will be recalled that parents' interaction with their matahiapo (usually but not invariably their firstborn son) differed somewhat, normatively, from interaction with their other children-in terms of locational intimacy, authority, inheritance, and deferential behavior. This difference prevailed especially in families of superior social position, but echoes of it probably occurred throughout the society. In the generalizations that follow I shall not specify this distinction, but it should nevertheless be kept in mind. Some observations by Bligh and Vancouver indicated that relations between a kinTitleholder and his parents became less aloof and disdainful after the Title had devolved upon his successor. The relevant episodes concerned Hāpai, Pomare I (Hāpai's son), and Tu (or Pomare II, the son of Pomare I):

Pomurrey's father, who was formerly known by the name of Happi, now called Taow, had arrived from Morea, on Saturday the 7th [January 1792], and was on board the Discovery, where he desired to see me; on which, Pomurrey with Urripiah and Whytooa, his two next brothers, accompanied me to pay our 
respects to their old sire, who had just arrived in a large canoe, laden with the productions of the country as a present. This interview was excessively affecting. It was with great satisfaction that I beheld the affectionate regard with which the three sons embraced their aged and venerable father; who, in acknowledging a grateful sense of their dutiful congratulations, exhibited feelings which drew tears from the whole party. When these filial effusions, which would have done credit to the sensibility of the most polished nations, had subsided, I presented Taow with a suitable return.... (Vancouver 1801:I, 270-271).

These "filial effusions" were also remarked upon by Bligh a few months later: "these old People [Hāpai and wife] are now infirm.... They are happy in their Children ... [whose] filial attention is such a blessing to the Old Pair as delights me on every occasion" (1792:171). No such effusions were forthcoming, however, when Hāpai's grandson, the Titleholding Tu, appeared on the scene.

In terms of spatial arrangement, except possibly for high-ranking Titleholders, young children were (along with their mother) usually required to be muri (in back of) their father, but as boys grew older they joined their father mua (in front of). Beyond this, however, I can discover no evidence of other positional norms.

Turning to governance, evidence concerning parental authority over sons is somewhat ambiguous, but not enough to obscure the circumstance that the latter were permitted much freedom of action. With daughters, however, this was emphatically not the case.

Several types of transactions characterized the interactions described above. Unqualified altruism was apparent in some of the actions-for example, the father who transformed himself into a breadfruit tree can have expected no return save self-satisfaction (in Maohi ideology selfless acts toward other humans were not rewarded by spirits, either in the pō or in the $a o$ ). Some of the things done by parents for children (and by children for parents) might come under the heading of "long-term loans" (and deferred repayments), although I have not come across verbal formulation of such a norm. (Also, much of the evidence concerning treatment of the aged-including, presumably, aged parents-indicates that if such a norm did exist, it was not very persuasive!) In historical terms the variety of exchange I label "pooling-and-sharing" was probably the principal type of transaction in most households containing older children, but this preponderance is not reflected in ideology (perhaps because it was taken for granted). Nor is explicitly quid pro quo exchange between parent and child featured in the evidence I have assembled, but the reason for that is more likely to be that such exchange was in fact rare.

I come now to competition (non-reciprocated "taking") as exemplified in Tane's confrontation with Atea, when the former hurled this threat: "I have obtained the means to overcome you and to take over everything that 
you possess" (adapted from Henry 1928:457). No other ideological evidence that I know of is so dramatically explicit on this aspect of father-son relations, but historical data show that such situations did in fact occur, as the mode of Title devolution would almost inevitably bring about.

The "emotion" dimension of parent-child interaction is rendered quite explicit, at least in some respects in the evidence bearing on ideology. Aside from the ceremonial deference which even parents accorded their successors in the case of high-ranking kin-Titles, words like $p \bar{a}$ and patea indicate that respect toward parents was at least prescribed, although in the stories reproduced above such prescriptions are sometimes ignored, especially with respect to the mother. See, for example, the following excerpt from Wilson:

When we had got within a short mile of the isthmus, in passing a few houses, an aged woman, mother to the young man who carried my linen, met us, and, to express her joy at seeing her son, struck herself several times on the head with a shark's tooth, till the blood flowed plentifully down her breast and shoulders, whilst the son beheld it with entire insensibility. I was not aware of this action to prevent it, but as she continued it without mercy on herself, I spoke to them angrily, and obliged her to desist. The son seeing that I was not pleased with what was done, observed coolly, that it was the custom of Otaheite. (1799:194)

Affection between parent and child is even more heavily featured in word and in story than is deference (toward the former), but some stories contain instances of repudiation and even murderous dislike as well. (One may recall the ambivalence toward deceased relatives, including parents and children; energetic mourning and touching memorializing were often blended with fearful avoidance.) Bligh provided an interesting example of what might be called "ritual ambivalence" in his report on a meeting between Pomare II and his mother, 'Itia, after a long absence. The boy was at the time about ten or eleven years old and had long since succeeded to his father's high-ranking kin-Titles. "I bantered Iddeeah with the indifference her Son shewed her after a long absence, which gave me a Novel sight, her taking him in her Arms (or rather on her Hip as they carry their Children) She was however obliged to be uncovered as they always are in the Boys presence." (1792:172b)

Finally, aside from general proscriptions upon sexual relations between "close" consanguines, I have not come across proscriptions specifically directed to parent and child. ${ }^{22}$ Nor does any story that I know of present this form of incest as a featured episode or an explicit moral. I feel sure that sexual relations did occasionally take place between some "fathers" and "daughters" and some "mothers" and "sons," including some very closely related ones. But that such predictably disturbing situations were not mythically chronicled or explicitly proscribed is a curious omission; or could it be that they simply did not survive censorship by the missionaries whom we have to thank for saving from oblivion so much other data? 


\section{SAME GENEALOGICAL LEVEL}

The Maohi term having the widest set of "sibling" referents was taea'e, presumably used both for address and reference; yet, consider some "authoritative" definitions and translations of it:

a brother, cousin, any near relation; see also vaitaea'e, cousins, distant relations (LMS Dictionary).

frère, cousin, proche parent d'une même lignée (Jaussen 1898:145).

all brothers, sisters, and first cousins (Handy 1930:23, from a list given by Marau).

brother (of a brother), sister (of a sister), cousin (of same sex) (Burbidge 1930:267).

"O taua tama'i no tatou nei, i te taeae..." "As for conflict between us who are kinsfolk ..." [the speaker's listeners included his "father," Te Tumu, other deities, a friend, and mankind in general] (Henry 1928:354).

"Ua ti'a roa ia ia'u e ta'u taeae." "I am quite willing, my brother" [said by Tane to fellow deity, Ta'ere-of-all-skill] (Henry 1928:456).

"... ia faite a'e i te poipoi, i te taeae nei." “... let it be reconciliation in the morning between kinsfolk" (Henry 1928:458).

"Fa'atura atu i to utuafare ito mau taeae e ito mau tuahine" (E. Salmon 1937:23). "To your home and your brothers and your sisters you owe respect." This is presumably addressed to a male. Note the contrast between taea'e (for "brother") and tuahine (for "sister"). This translation is by Handy and is to be compared with his definition of taea'e given above.

It is no longer possible to decide which of these translations was the "correct" one; indeed consensus may have been lacking concerning "primary" and metaphoric usages. ${ }^{23}$

Other Maohi same-genealogical-level terms are, as we shall see, somewhat more precise in their referents as regards, say, relative age or sex of speaker; but they all resemble taea'e in their imprecision regarding propinquity-that is, in their non-specificity concerning type of siblinghood (e.g., full, uterine, agnatic) or degree of collaterality. ${ }^{24}$ This is not to imply, however, that the Maohis did not make such distinctions, or that they lacked other verbal ways for doing so. ${ }^{25}$ If a direct question had been put to the more philosophical-minded Maohis about such matters it may have elicited generalizations to the effect that one taea'e is as close as another, or that one should behave with generosity and affection toward all taea'e. But aside from an occasional voicing of expressions such as these, when the situation demanded, most Maohis probably had the linguistic tools to indicate very precisely whether a taea'e was, say, a "full sibling" or a "fourth cousin." Most Maohis probably also subscribed to behavioral standards which cut fine distinctions between such relatives, differentiated according to col- 
lateral distance and sex of linking parent. I have come across no native aphorisms or explicitly formulated rules bearing directly on these kinds of distinctions, but what I have learned about common descent in general, and kin-Titles in particular, makes it highly likely that full brotherhood (or sisterhood) was regarded differently from, say, uterine brotherhood, or cousinhood. Perhaps such reported factors as the relatively large size of some Maohi households, the impermanence of many marriages, and the prevalence of fosterage did indeed serve to blur the boundaries of familial ties, including "siblinghood"; nevertheless, such factors as differences in descent-unit affiliation of half-siblings (or step-siblings or cousins) undoubtedly exercised their influence on people's expectations about interpersonal relations as well. For example, as we shall see, one of the more recurrent legendary themes concerns strife between half brothers or stepbrothers or male cousins-usually in competition for property in which they have common but differential claims. Strife among full brothers is also thematic, particularly in legends involving elder brothers' jealousy of a youngest brother's superior natural abilities; but much more often the stories about full brothers which have been preserved for us (and hence those perhaps most congenial to their listeners' preferences in human relations) are concerned with cooperation and with boundless loyalty. ${ }^{26}$

Other maohi terms pertaining mainly to same-genealogical-level consanguines were tua'ane, tuahine, tua'ana, and teina. As I am unable to divine what the "correct" definitions of these terms were, I am obliged to list the more authoritative glosses. Generally speaking these terms comprise two contrasting sets:

tua 'ane-tuahine

tuaane, a brother in relation to a sister; tuahine, a sister (LMS Dictionary).

tuane, frère (pour la soeur); tuahine, soeur (pour le frère) (Jaussen 1898:161).

tua'ane, brother (of a sister), male cousin (of a female); tuahine, sister (of a brother), female cousin (of a male) (Burbidge 1930:267).

tu'ane, brother, female speaking, or male first cousins belonging to branch of family of equal rank (if both matahiapo ${ }^{27}$ or both teina);

tuehine, sister, male speaking. Or female first cousin belonging to branch of family of equal rank (see tu'ane) (Handy 1930:23, after Marau).

tua'ana - teina

tuaana, an elder brother, also a senior relation; teina, a younger brother or sister (LMS Dictionary).

tuaana, frère ainé pour les frères et soeur ainée pour les soeurs, cousin, ami; teina, frère cadet, soeur cadette (Jaussen 1898:160, 154). 
tua'ana, elder brother of a brother, elder sister of a sister, cousin of same sex or of the same senior parent, both male, or both female (Burbidge 1930:267-268).

tua'ana, reverse of teina; teina, younger brother for male, younger sister for female. First cousins of younger rank. I am a matahiapo; all cousins not matahiapo are my teina. (See matahiapo) (Handy 1930:23, after Marau).

Overlooking some small omissions, all the authorities agree in attributing at least the following meanings to these terms: tua'ane, female speaking: brother; tuahine, male speaking: sister; tua'ana, female speaking: older sister; male speaking: older brother; teina, female speaking: younger sister; male speaking: younger brother. The sources differ markedly, however, with respect to range of meanings of these terms, and I am unable to decide with any sense of certainty which (if any) of the reported meanings were the correct ones. Because of what we know about other Maohi practices I feel fairly confident that, say, tua'ane and tuahine applied not only to siblings (full, uterine, agnatic, foster), but I am at a loss to decide what their full ranges of application were: "cousin," reports the Burbidge Dictionary, but "first cousin belonging to branch of family of equal rank," reports Handy. ${ }^{28}$ Uncertainty is increased by the additional meanings attributed to tua'ana, a senior relation (LMS Dictionary); cousins of ... the same senior parent, both male, or both female (Burbidge Dictionary). And as for Handy's ambiguous comments about family "stocks" and "branches," and about equal and younger "ranks," I must confess utter perplexity and considerable frustration. As I noted earlier these carelessly introduced words raise some intriguing and crucial questions, for which however there are no reliable answers; and these questions have to do not only with the kinship terms under consideration but, more importantly, with behavior prescriptions associated with these terms.

For example, did a man address a cousin (say, a same-genealogical-level consanguine related through a common grandparent) on the basis of relative age (as with siblings) or of relative age of their linking parents? (And if the latter, how were the inevitable discrepancies between relative chronological age and, say, grade of kin-congregation offices resolved?)

With a little plausible coaxing and a few ethnographic analogies I could construct out of these "definitions" a compendious, logically consistent ramage-type model of a consanguineal terminology system. Alas, my aesthetic taste must bow to my historian's conscience.

Before considering some data about interaction among samegenealogical-level consanguines, I reproduce Bligh's contribution to this discussion of sibling terminology:

Tuanah Tuanee [tu'ana tu'ane], eldest Brother. Tuanah Tuheine [tu'ana tuahine], 
Eldest Sister, but in general Tuanah [tu'ana] is only used unless it is not understood which is spoken of. Tinah Tuanee [teina tu'ane] is Brother. Tinah Tuheine [teina tuahine] is Sister. The Youngest children always called the eldest Brother and the eldest Sister Tuanah [tu'ana].

All the Younger Brothers call one another Tinah [teina] and their Younger Sisters Tuheine [tuahine]; but the Younger Sisters call one another Tinah [teina] as well as all their Brothers. What is remarkable [is] that the sisters should not call one another Tuheine [tuahine] (or Sister) as the Brothers call them.

First Cousins call one another as Brothers and Sisters do. (1789:II, 11)

The only new possibility to emerge out of this ambiguous statement is that relative age also figures, when necessary, in terms for siblings (and for first cousins) of opposite sex.

The sole general native precept that I can discover about relations among same-genealogical-level consanguines is the one previously quoted: "Fa'atura atu i to utuafare ito mau taeae e ito mau tuahine." "To your home and your brothers and your sisters you owe respect." (E. Salmon 1937:23.) In addition to the linguistic peculiarity of this prescription, already noted, the remarkable thing about it is its usage of fa'atura; it is puzzling to find applied so indiscriminately this word which is defined by the LMS Dictionary as to honor, exalt, show respect, and is used consistently in this sense throughout the textual sources. If the LMS definition is "correct," this precept exhorts one to behave toward siblings and cousins, regardless of sex or relative age, with the same "respect" ordinarily reserved for persons holding high-ranking Titles, or for close relatives of Titleholders. An alternative interpretation, and probably the sounder one, is that the LMS Dictionary definition is perhaps "correct" as far as it goes, but that it does not go far enough.

Morrison's statement that “... The Child may not Curse its ... Brothers or Sisters ..." (1935:184) has already been commented upon, as has Banks' observation that "... they [the Maohis] seldom eat together the better sort hardly ever, even two brothers or sisters have each their respective baskets one of which contains victuals the other cocoa nut shells \&c. for furniture of their seperate tables" (Beaglehole 1962:I, 347).

I have come across no references to prescriptions or rituals involving joint actions on the part of same-genealogical-level consanguines in general. A statement from Morrison does, however, indicate belief in a very close "identity" of some kind between "brothers": "If a woman has (a) husband and he dies without Issue the Husbands Brother takes her; if He has no wife and should he have Issue by Her the Children are Calld by the Former Brothers Name, \& take his estate ..." (1935:184-185). Legends constitute about the only evidence available concerning the way Maohis conceptualized the relations under consideration. Some legends provide accounts of interaction among brothers and male cousins.

Six "demigods," all named Maui, were born to Hihira (Sun-ray) and 
his spouse Uahea (Bereavement). The youngest, it will be recalled, was a "clod" (i.e., an abortion) with eight heads, who was abandoned by his parents but subsequently rejoined his family and assisted them in their work of perfecting the universe. This Maui's most important accomplishment was the slowing down of his father, Sun-ray, in the latter's race through the heavens. The thing to be noted about this adventure is that it was the youngest Maui who undertook it, and expressly for the benefit of an elder brother: "He [the youngest Maui] was enraged also [at his father, Sun-ray] in finding that the work of his elder brother could not progress properly because of the shortness of the days" (Henry 1928:431). The elder brother in question was Maui the Priest, who even with all his powers and his status as firstborn was unable to accomplish what the youngest brother could and did do with, it should be added, the indispensable help of a noose made from his sister's hair.

The legendary trickster Hiro (a protegé of Hiro, god of thieves) was also a younger son more prodigiously endowed than were his older siblings, or, specifically, his agnatic half siblings. When all of them undertook a voyage overseas it was Hiro who captained the vessel. For a time he was able to ward off dangers from the deep by virtue of his superior strength and wisdom, but even he was unable to save them from supernatural vengeance when they committed a foolish sacrilege. (Henry 1928:539ff.) In a different version of the adventures of trickster Hiro, he is pitted against half brothers rather than united with them in a common enterprise; in this version Hiro not only kills them all, but their father (his stepfather) as well (T. Salmon n.d.: History).

The legend-or legends, there being many versions—of Tafa'i provides a more complex illustration. Tafa'i was an only son of a human, Hema, ${ }^{29}$ and the latter's spirit wife. Hema's older brother had five offspring, all older than Tafa'i-that is, all were his tua'ana; but Tafa'i was superior in all respects among his cousins. The cousins played together constantly but Tafa'i always won at their competitive games. All but Arihi, the eldest among them, became so enraged by this that they tried many times to destroy Tafa'i, but to no avail. Despite this Tafa'i accompanied them, unasked, on an adventure and managed to restore them to life after they had been magically slain. Apparently convinced of the injustice (or lack of wisdom) in their jealous efforts to destroy Tafa'i, his cousins invited him to become their leader; but to this Tafa'i properly replied (and this is the second moral to the tale): "No mua ra, ei mua ra, ei mua ia, e no muri ra e na muri iho ia. Those born before must stand in-front-of; those born later must stand behind." (Leverd 1912:21.) This noble sentiment did not, however, dissuade Tafa'i from getting his revenge eventually, for with the exception of Arihi, who had all along befriended him, he finally caused all his cousins to be transformed into porpoises. 
Another tale of fraternal strife was reported by Tati Salmon. However, I am not sure whether the legend came originally from Tahiti or Rarotonga.

From Tahiti went forth Taihia, the favourite of the people, followed by his elder brother-Chief Tutapu-with the pick of his warriors. Although the cause of his pursuit was but paltry jealousy, yet days, weeks, and even months passed without his relaxing his intention of killing Taihia. Even at the request of his men to give up the chase he refused. At last, when they met at sea, hundreds of miles from their home, Taihia ordered his war-canoe to be rowed near to his brother, and respectfully, according to the teaching of his youth, called to him:

"E tau arii, e tau arii, teie taua

Tei, teie uriuri, ua moe eana

Te mata o to taua aia here e

Aita ea, to riri, i maha?"

"My chief, my chief!

We are now on this briny sea

Out of sight of our dear home,

Your anger, is it not yet appeased?"

"No," roughly answered the brother, "the battle must commence at once!" In spite of the fact that Taihia had only one war-canoe to the two against him, he was victorious and his brother was killed. The warriors of Tutapu then joined the victorious band and they all continued on to the next island, which is now Rarotonga, and Taihia made a history for himself. (1910:43-44)

I reproduce below the full text of the legend of Huriitemonoi, as presented in Henry. Miss Henry's rendition of this delightful tale is filled with many romantic, un-Maohi, embellishments, but any resumé of it would sacrifice social-relational data of too great a rarity to be spared:

Mahu-tu-rua (Twin-cloud) was the king, Toae-hau (Oration-of-peace) was his queen, and there was born to them a princess, whom they prophetically named Huri-i-te-mono'i-a-'are-vahine (Pour-perfumed-oil-upon-the-woman's-billow). Hiti-poto (Short-border, or Mangareva) was the land.

Hiti-roa (Long-border, or Tahiti) was the land, Manua (Hasty) was the king in the north, Ma-tu-tere (While-standing-to-sail) was his queen, and there was born to them Pua (Flower), a daughter, Me-to (Towed), a daughter, and Mua-va'a (Front-canoe), Roto-va'a (Inner-canoe), Oti-va'a (Last-canoe), and Tui-hani-potii (Invocation-of-girl-caressed), who were sons.

The fame of the beauty of the princess, Huri-i-te-mono'i (Pour-perfumed-oil), of Hiti-poto extended to all lands, and many high-born suitors set out to find that land and marry the princess; but they were lost in mid-ocean and were never heard of any more. At last the two Tahitian princesses, Pua and Me-to, said to their brothers:

"Prepare a ship and go to Hiti-poto for the beautiful princess and bring her here that she may become the spouse of whichever one of you may prove deserving of her."

This proposal, approved of by the parents, pleased well the young men; but they feared to go, for, said they, "Many valiant suitors have gone forth to woo this beautiful maid, but they have perished at sea, been devoured probably by the guardian shark of her land or by other monsters around her shores." The sisters 
urged, and the brothers objected that storms would overtake them and high seas would engulf them; but the sisters continuing to press them at length prevailed upon them to make the attempt.

So a ship was built with four little thatched houses upon its deck for the princes and was laden with provisions and presents. They named the ship Uru-ehau (Forest-of-food-and-peace), manned it with experienced navigators, and set out to sea with all the usual religious rites for the occasion and the good wishes and encouraging predictions of those they left behind. They sailed away with a fair wind, which soon wafted them without adventure towards the shores of the land they wished to visit. On the day they hove in sight, the princess was enjoying the gentle summer breezes at a pretty seaside residence facing the harbor on the leeward side of a promontory that obscured her parental home, attended only by a fair daughter of a retainer, Hina-te-pipiro (Gray-of-rank-odor). Having the gift of clairvoyance the princess foresaw that a ship was approaching with young suitors for her hand, and so she said to her maid:

"Remain here and watch for a ship that will soon arrive with princes from Hiti-roa, while I go into the woods over yonder for sweet-scented ferns and flowers with which to deck myself, and when you see the sail in the horizon come and notify me that I may be prepared to receive them."

So Huri-i-te-mono'i went her way, and shortly afterwards the looked-for sail appeared. But Hina-te-pipiro suddenly became ambitious to be herself the heroine of the romance that was to follow, and so she reflected:

"I must go and plunge in the royal bathing pool close by and then come and put on the royal apparel of my mistress, of which she has a supply in this house, and I'll wear her royal wreath of red and yellow and purple feathers and seat myself upon the royal mat for the reception of those princes, that they may believe me to be the princess." And immediately she began to put her plans into execution.

She bathed in the limpid cool waters of the pool sacred to royalty, but finding on coming out that her plebeian odor still remained with her, she again bathed, anointed herself with sweet-scented oil from an aroro (small gourd) of her mistress, and arrayed herself as a princess. Then she hastened to complete her preparations, and by the time all was ready the vessel had entered the spacious lagoon, unnoticed by the people, who were enjoying their noonday nap in their huts on the windward side of the headland.

It was decided that the three elder brothers should bear the message to the princess, while the youngest brother staid on board to mind the ship. So they landed, and as they approached the door of the house, the scheming girl seated upon the royal mat welcomed and greeted them in the usual way and bid them enter the dwelling. They greeted her as the princess and yet wondered to see her entirely unattended. But having no misgivings, they told her that their errand was to invite her in the name of their parents and sisters to go with them to Hitiroa and make it her home. They then spread before her the presents of choice mats and tapa and feather ornaments they had brought for her and her parents, to whom they also wished to be presented.

According to the custom of those times, the visitors should have been escorted to the dwelling-place of the family and there made to feel at home. Then as soon as possible a feast should have been spread before them with an exchange of presents. Moreover, a princess should have been provided with presents and a chaperone and retainers to go to a strange land. But Hina-te-pipiro replied that she was highly gratified to go to Hiti-roa and cordially accepted the 
presents on behalf of her parents as well as herself, and she added that she regretted much that she could not take them to her home or offer them hospitalities, as they must make all speed and bear her away before her numerous gods came to molest them and prevent her from leaving her land, which she said the princes would not mind as their errand was to fetch her. This answer sounded feasible, and feeling charmed with her readiness to accept their proposal they decided to do as she advised. So they quickly took in a new supply of water and coconuts, and one man carried her in regal style upon his shoulders to the ship. Then they sailed out of the harbor as quickly as they had come in and were out of sight of land just as the sun was setting.

While the real princess was gathering her flowers and weaving them with sweet-scented fronds and leaves into a wreath and garland, she heard spirit rappings and a low cry that was communicated to her from the seaside house through the ground to tell her all that was happening, and as soon as she completed her work and realized the import of the strange warnings she emerged from the woods and returned to the house just in time to see the strange vessel in full sail passing outside of the reef. She looked around in the house, and saw that her oil gourd, her choice apparel, her feather wreath and girdle, her mat, and other royal insignia were all gone, and then she knew that her plebeian maid had really usurped her place and fled. Impelled by her guardian spirits, she took a surf-board and prepared to launch out upon it in pursuit of the voyagers, singing as she did so in the following strain:

Hini riaria te tai o te atua,

Terrific are the waves of the ocean of the gods,

E hoho mai i ni'a.

Tei po ta'u vana'a tue rire, Hini, hini e! Roaring as they rise.

Benighted is my oration,

Impelled by the applauding terrific, terrific waves.

Then she launched out into the sea singing:

Tau 'aura'a tei tua; tei Hiti-roa e To ro'i ai'a e ri e,

To ro'i ai'a e taa au ra Tei tua tei Hiti-roa e!

\author{
Thy swimming extends out to sea; to \\ Hiti-roa far off \\ Will thy bed of refuge lodge, \\ Thy bed of refuge upon which I depart \\ Away to sea, to Hiti-roa!
}

The wind lulled, and as Huri-i-te-mono'i swam out upon her surf-board she lost sight of the sail in the horizon, and when she reached the open ocean darkness surrounded her. But with one steady purpose she continued her course, guided by her ocean gods. All night and all day she swam, and after the second night, as day dawned, she saw the ship appear behind her and awaited its approach. Soon the navigators were gazing with amazement upon the beautiful woman, so much more beautiful than the one under their care, poised upon the swelling sea. The princess accosted them in a melodious voice, and said to the eldest prince, whose deck-house was foremost:

"O Mua-vaa, take me up into your ship!" But just as he was about to do so, the faithless maid on board, now desperately bold, warned him not to come in contact with her, saying that she was a fiendish phantom from the rocks beneath the ocean, intent on doing them harm, and so he pushed her away with a long pole.

Then Huri-i-te-mono'i turned to the second brother, Roto-va'a, whose house was in the center of the ship, and implored him to receive her; but his actions 
were also overruled by Hina-te-pipiro. So also she appealed to the third brother, Oti-va'a, with the same result, and finally she implored the fourth and youngest brother, Tui-hani-potii, who was yet but a young lad, to receive her, and he heeded not the artful adventuress, but filled with pity he asked:

"Who are you?"

"I am Huri-i-te-mono'i-a-aru-vahine, the true princess whom you came to seek. That woman you have with you is my servant maid," she replied.

In spite of all demonstrations from the other woman, the young man lowered a rope, which Huri-i-te-mono'i firmly grasped, and he soon aided her up into his house in the mizzen of the ship, which he placed at her disposal. She was exhausted, cold and hungry and thirsty, and he gave her dry clothes to wear, but when he went for food and water for her, Hina-te-pipiro induced his brothers to oppose him in doing so, saying that such a phantom of the deep did not require food but would shortly bring a dire calamity upon the ship, and they told him he must not allow her to come out of the house on pain of death and that she should not be cast overboard. But Tui-hani-potii stood firm in his deep sympathies for Huri-i-te-mono'i in whom he recognized the refinement of a princess, and he contrived later to procure her food and water, which she so much needed.

A great calm, caused by the gods in honor of the princess, ensued. Supposing the pretended princess was possessed of magical charms the brothers asked her to invoke the winds to blow, and as she bethought herself of the waistcloth of her mistress she consented to do so. Telling them to draw up the sails and tighten the ropes for the breeze, she went forwards to the bows of the vessel and waved the cloth vigorously in the air. But instead of a breeze, the ship was soon filled with a rank odor, so that all the men exclaimed:

"Oh, what can this odor be?" She replied:

"You see I came away from my land in haste and have taken away the waistcloth of my servant maid instead of my own." But as no breeze followed, the elder brother told the youngest brother to go and ask his guest to come and try her powers of bringing it, and so Huri-te-mono'i, after much persuasion from them all, went forward, and taking the same waistcloth waved it in the air as her maid had done, and soon a sweet odor pervaded the ship and the steady-blowing maoa'e (northeast trade wind), the royal wind of her land, came in obedience to her bidding.

The three elder brothers were amazed and began to suspect Hina-te-pipiro to be an imposter and Huri-i-te-mono'i to be the real princess, as the very elements obeyed her, while the youngest brother was delighted and upheld his protégèe in whom his confidence had not been shaken. But the artful imposter, still equal to the emergency, exclaimed:

"That phantom woman is the demon Fe'e-matotiti (Octopus-of-the-rocks) of our reef, intent upon destroying us. Witness my sweet odor and my royal breeze that she has stolen from me! Let her not live."

Then were her adherents about to slay the princess, who besought them not to kill her, but to wait until they reached a confluent current in the sea, which they soon would pass, into which they could cast her. This to them was proof enough that she was the demoness, and they thought it would be prudent to allow her thus to disappear. Knowing that her hour soon must come, the princess, full of emotion, in the following strain invoked her ancestral fish gods to receive her:

Maoa'e maoa'e hia e,

Maoa'e ri'i mata ioio ra.

Te maoa'e hia e!
The trade wind has come

Trade wind with brilliant sea caps. The trade wind has come! 
Ia riro atu vau i ta'u tupuna, O tonu ma vaha, te maoa'e Ia Tonu-ma-vaha, nui ra.

Te maoa'e, maoa'e, maoa'e hia e!

Ia riro atu vau i ta'u tupuna, Ia Roi, ia Roi matao matao ra; Ia riro vau i ta'u tupuna ma'o,

Ia Tama-'opu-rua, te maoa'e e!
Let me go to my ancestor,

To Tonu-ma-vaha, O trade wind,

To Tonu-ma-vaha with great mouth.

The trade wind, trade wind, trade wind has come!

Let me go to my ancestor,

To Roi (Black-fish), Roi so dark;

Let me go to my shark ancestor

To Tama-'opu-rua (Child-of-two-stomachs),

O trade wind!

A strong attachment had grown between the maiden and her young benefactor, and they felt that it would be hard thus to part forever, but as her antagonists were relentless they sorrowfully awaited her fate for two days and two nights, when they came to the confluent current. Then the wind suddenly ceased, and there approached the ship the great shark, Tama-'opu-rua, with the tiger fish (Tonu-ma-vaha) on one side and the black fish (Roi) on the other. Rising upon the crest of a towering wave the shark opened his great jaws and received the girl as she was thrown overboard by cruel hands, and she safely entered into an inner receptacle, where she was kept alive, and her fish ancestors bore her away as queen of the sea.

The trade wind sprang up again, and the following day the ship hove in sight of Tahiti. So preparations were made for the reception of the famous beauty of Hiti-poto. A royal mat was laid for her in a place of honor in the house, and little banners that were insignia of royalty were stood around the mat. But the banners would not remain stationary; they fell down in spite of care, which was an omen of something unusually wrong. Mats were laid from the royal dwelling down to the sea shore for her to walk upon, and the two sisters of the princes went forth to await her disembarkation. Forebodings came to those young women, and they exchanged thoughts concerning their guest just arriving and sang as they went:

Tau tapaau ua hara;

E ta'ata paha tei tai i hiti e.

A ti’a mai, a haere mai i uta nei e!
Thy banners are deviating;

Perhaps some person is at sea in the horizon.

Arise and come to this land!

They said: "We shall soon see if this is a princess by her actions: she will walk unhesitatingly upon the mats laid before her if she be royal; but she will not tread upon them if she be a plebeian."

Soon the vessel anchored, and arrayed in her mistress's clothes the pretended princess was borne on a man's shoulders to the shore. On arriving at the line of mats, where she was set down, she clumsily stepped aside and walked upon the ground on one side of them to the house, despite the demonstrations of the princesses, who walked alone upon the mats. On arriving at the entrance to the house and seeing the king and queen surrounded by other royal personages ready to receive her, she became completely disconcerted and shrank away outside of the house to conceal herself. In vain they bade her welcome and tried to reassure her in her supposed maidenly diffidences; but she would not accept the proffered honors.

On their arrival on the scene, the three admirers of Hina-te-pipiro were surprised to meet the family without the guest and went also to beg her to enter the house; but she persisted in remaining isolated in a shed outside, where she proposed holding her court with them. When they returned and told this to the family, the sisters asked all particulars concerning their meeting and bringing her away unattended from her home, in answer to which they related the circumstances of their 
meeting at Hiti-poto and their hasty departure, omitting to record their adventures with the beautiful maid they had encountered at sea. But Tui-hani-potii, had a different story to tell, and his account as above described convinced his sisters that their forebodings were right and that the real princess had been cruelly wronged. Then the eldest sister, Pua, said to this brother:

"You and I must immediately go in search of Huri-i-te-mono'i of Hiti-poto." Notwithstanding his conviction that the attempt would be futile, she persisted, and excluding all others from the ship they two set sail, he at the helm guiding the ship and she seated in the center, amid a terrific trade-wind wafting them to the confluent current.

"E ta'u Tuahine e ua pohe taua!" (O Sister, we are lost!) exclaimed the brother. But she replied:

E utue, e parare ia.

Te ora iti a'e a te ora

Tereira ia.

'Aore paha ia'u nei, tei ia'na ra paha,

Mai to'na ui, mai to 'na ua,

Mai to'na patu tere i te moana,

E tere au i te moana.
The pledge of peace will disperse it. A narrow escape of life Will it be.

Not perhaps with me, it is perhaps with her, In her season, in her rain.

As she propelled her course in the ocean, So shall I move on in the ocean.

Soon they encountered a tempest and were surrounded with darkness so thick that they could not see each other; this indicated the presence of the god ancestor of Huri-i-te-mono'i, Roi, and the brother exclaimed:

"O Sister, we are lost!" She made the same reply and they sailed steadily on. The storm dispersed and light appeared, and a great wave came that raised them to the sky.

"O Sister, we are lost!" said the brother again; but she bravely replied:

"Eiaha e meta'u!" (Do not fear!) And on they went upon the billow until it passed and divided itself on either side of the ship. Then the sea became smooth, without a ripple, and they perceived red rocks in the depths below. This the sister said was the desired spot, and she directed her brother to spread a mat out upon the water and give her the princess's gourd of oil, which he soon did. She invoked the shark god to come forth and yield up the princess, while she poured the oil upon the mirror-like sea, and as its sweet odor descended into the depths they heard a rumbling sound and soon saw the shark come out of his cavern in the rocks and ascend towards them. When he arrived by the ship they presented acceptable presents to him, and Pua told him that she had brought her brother to recover the princess whom he so much loved and to take her as queen to his heart and home. The shark replied approvingly, opened his spacious mouth, and soon yielded up the beautiful maid, who had been cared for and fed in her strange fishy chamber and who was safely received in the mat and cleansed of the fishy slime with the oil upon the surface of the sea. Then the strong arms of her lover lifted her up into the vessel, and they returned triumphantly to Hiti-roa.

When the same preparations that had been made in Hiti-roa for the reception of the expected guest in the first place were made again, the princess Me-to noticed that everything was harmoniously accomplished, the royal insignia falling naturally into their places. As the guest was escorted to the house by her lover and Pua, she walked with a regal step upon the mats from the seashore and into the house and saluted with dignity the members of the royal family, accepting with grace their tokens of respect. A murmur of applause and admiration at last ran through the house with the exclamation: 
"E ari'i mau teie vahine, e hau roa to'na nehenehe i to te ao nei!" (This is indeed a princess, whose beauty exceeds all other in this land!)

The three brothers who had cast away Huri-i-te-mono'i were now dismayed, and each in his turn afterwards strove to win over the beautiful girl. But she was firm in her attachment to her benefactor and became affianced to him, awaiting for their marriage the arrival of her parents, who were to be sent for in a befitting manner.

Although Hina-te-pipiro, for whom a separate house and a few attendants had been set apart, still exercised some influence with the three princes she had deceived, yet they envied their more fortunate brother and planned his destruction. They proposed a game at archery, hoping to pierce him through, and in order to facilitate their design they proposed to him to stand foremost in the game. But he deferentially declined, saying that as he was the youngest he must be last. His spear alone reached the target, and so he won the applause of the spectators. They took him fishing out to sea and there smote and threw him off the canoe as dead; but the waves bore him to the shore, and his sisters, who waylaid him by inspiration, restored him to life by massage and the application of sweet herbs, singing:

Tuia e, tuia hani potii nei!

E te va'a fau rua e, te ravaai nei!

Tuia e, tuia!

Touched, touched by caressing girls!

Oh, the double canoe is fishing!

Touched, touched!

Gradually life returned to the young man, and he opened his eyes and exclaimed:

"Oh, what delightful sleep I have had!" And he arose and returned home with his sisters. There they rejoined Huri-i-te-mono'i, and shortly afterwards the elder brothers arrived and were astonished and conscience-smitten to see the younger brother, whom they thought they had left dead in the open ocean, safe and well. Yet they still sought by various contrivances to get rid of their rival. But they utterly failed, and at last their sisters advised them to remain content as servants to their younger brother, who had won the fair princess and who would be appointed king over North Tahiti by their parents. To this they agreed, and domestic harmony in the family soon followed. Amid auspicious circumstance and in due time the marriage of the happy young pair took place.

Hina-te-pipiro, the heartless maid, became a prey to shame and chagrin, and at last, after a painful interview with her mistress, she died uttering her own dirge:

Te 'are o te tai, 'ore, 'ore tei po moe, moe,

The waves of the sea do not, do not at night sleep, sleep,

Patua vau nei. E vaiiho

I te tane ari'i ei tapu,

Ua mate au!

Which propelled me. I must leave

My princely suitors in retribution, I am dead!

And this was the last of Hina-te-pipiro, whom they quietly buried beneath the drooping boughs of a toa tree in North Tahiti. (Henry 1928:607-615)

It might appear from the foregoing that Maohi storytelling embodied more interest in undermining birth-order precedence than in reinforcing it, ${ }^{30}$ but that was not always the case. With Honoura, for example, the storytellers were provided with a protagonist who was both firstborn and heroic. His brothers proudly honored his great strengths and willingly followed him on his adventures abroad. (Henry 1895:256 ff.)

Legends about sisters, or female cousins, are as rare as they are 
uninformative. Only one, which I know of, features them in anything but the blandest of situations. The story, which was reproduced earlier in this chapter, concerns the two daughters of Hina. In it, the younger one was punished by gods when she deceitfully appropriated a coconut belonging to the elder.

Many legendary accounts feature relations between brothers and sisters. (I need not resort to the more general, and egregiously awkward, phrase "relations between opposite-sex consanguines of same-genealogicallevel"; the legends about which I know concern only the narrower range of such relations.)

$\mathrm{Ru}$ and his sister, Hina, are the subject of two legends reproduced in Henry. One of these, "Ru and Hina Explore the Earth," was collected by Miss Henry in 1884. The noteworthy thing about these accounts is the companionship they depict between this sibling pair during their long voyages: "Ru sat astern with his great paddle for steering in sailing and a smaller paddle to use in calms or for plying against the tide in meeting with head winds; Hina sat in the bows of the canoe to watch for land, and thus they sailed away" (1928:459-460). To the question, Why a sister and not a wife? one might reply that a wife, having a role complementary to that of her husband (sexually and otherwise), would have been less able to play a male's role in this essentially male enterprise. Moreover, since the object of the journey seems to have been more for curiosity than for colonization, the sexual inaccessibility of a sister would have been no liability. However, lacking better data, such "explanations" as these deserve little credibility.

Another famous brother-sister voyage was depicted in the legend of Huriitemonoi, reproduced in full above. It will be recalled that it was the youngest brother's eldest sister, Pau, who moved him to go in search of the authentic "princess." Not only did she accompany him on the search but it was she who actually directed the search and urged him on when his own courage failed.

In the Henry version of the origin of the Arioi (see chap. 22, this work), it was 'Oro's sisters who sought out a human male for him and thus set in motion the event which culminated in the founding of this famous cult. They performed this task for him out of compassion for his loneliness, after he had ungraciously ousted his former wife and reduced her to a heap of sand (Henry 1928:231).

Another sister-brother pair was featured in an incident of the legend of Puna'auia, the main episode of which was the tragic love affair between the high-born Pereitai and her low-born lover. After the lover had been slain for his presumptiveness, the girl was taken by her family on a visit to the Leeward Islands, where she found consolation in the person of a young chief. In due course they were married and her parents re- 
turned home, leaving with her her young brother, “... as a binding link between her and her own family circle in Tahiti" (Henry 1928:604). It will be recalled that subsequently this brother unwittingly subjected Pereitai to such painful embarrassment, by revealing her matronly status to the young unmarried girls whose company she had sought out, that she ran away to the $p \overline{\text { in }}$ order to hide her shame. The faithful young brother followed her and remained with her until their spirit ancestors conducted them back to the $a o$.

Finally, I present a legend explaining the building of marae Nu'urua (Varari, Mo'orea), which was perhaps the largest one in existence in TahitiMo'orea up to the time of the building of Mahaiatea (Papara, Tahiti) in the 1760s. This legend was recorded by Marau and is reproduced in Emory's unpublished manuscript of Marae Traditions. The builder was a woman, Tefeao, who was evidently the firstborn offspring of a high-ranking Varari Titleholder. When Tefeao herself bore a son, he succeeded to the Title in question, thereby ruling out the heirs of Tefeao's younger and much loved brother, Punua:

The birth of Tefeao's son meant the exclusion of her brother's (Punuate-rai-tua's) heirs; for according to the decree of the first Marama, only an elder could have a seat on the marae of Nuurua and Tefano. But Tefeao's love for her brother was great. She obtained special permission from her husband to build him a marae, another Nuurua, higher than the old-by order of Marama-in order to raise it to the distinction the other derived from its priority. Thereon he was consecrated and given a right to a seat on a Nuurua, which he had lost through the birth of his sister's child. These two maraes are still there near each other. One is Nuurua the elder, the other is Nuurua the younger. On the day of the consecration, Tefeao spoke words that did her honor:

"By order of the gods, my brother, I had to be born your elder;

But you will ever be to me a bright star above my head.

Nuurua, O my little brother, will be to the ages

The temple of the love of a sister for her brother."

The one legendary allusion to sexual relations between brother and sister that I have found is a very general statement in an account of the Deluge. The only humans to survive were a married couple, but on the morning after the storm the woman gave birth to twins, a boy and a girl. Then other offspring followed:

The woman was again delivered of children; one night would pass, and as the day came a child was born; the food had not yet grown when the children got matured. The shores became thickly populated with people not dressed! The elder child married the younger, and the younger child married the elder [O te matahiapo ra, ua taoto ia i to'na muri a'e, e tei muri a'e, taoto atura ia $i$ to'na mua]. (Henry 1928:447)

To a methodological purist it might not seem appropriate to infer norms from actual interaction, but there is so little information concerning Maohi 
brother-sister relations that I am disposed to present whatever I can find, whether explicitly normative or not. The sources contain many accounts of sisters' emotional reactions to a brother's return-for example, Rodriguez' description of the return home of his native companion, Pautu: "Pautu himself, who had gone ashore alone, having seen the weeping-match his sisters were putting up for him, felt some qualms about returning to the boat when we called him ..." (Corney 1919:10-11).

The next account is from Morrison's pen; it concerns an incident created by one of the Bounty mutineers, Thompson:

We had hitherto gone on with our Work without any thing to obstruct us except Rainy Weather but now an accident happend which put a Stop to it for some time-

The affair was this, Thompson who resided with Coleman at Point Venus had ill used a young Girl, for which her brother in revenge knock'd Him down, and Fled. (1935:87)

(The drubbing so angered Thompson that he subsequently shot and killed the first Maohis who did not jump to his commands.)

When Mai returned to Tahiti with Cook he was warmly greeted by some of his relatives, including (presumably) his sister, but the latter soon joined with her husband and a few others and "... ingross'd him intirely to themselves with no other view than to strip him of every thing he had got ..."-or such at least was Captain Cook's view of the situation (Beaglehole 1967:220).

Vancouver also witnessed an episode revealing this less accommodating side of a sister's relations with her brother:

Poatatou [Pohuetea], who was now called Hidiea [Hitiea], with his wife and sister, accompanied me on board. Amongst the valuables with which I presented my old acquaintance and friend, was an axe, of which his sister became so enamoured, claiming to herself a part of the present I had received, that Hidiea was under the necessity of using some force to prevent her wrenching it out of his hand; but, on my making a small addition to the articles she had received, the lady became reconciled. (1801:276)

A tantalizingly brief statement by Bligh indicates not only that brothers were sometimes at odds, which we have already seen in legends, but that such troubles sometimes were due to quarrels between their wives:

The two Cheifs told me that Tynah [Tina, i.e., Pomare I] and his Brother Oreepyah [Ari'ipaea] were on bad terms and that they would quarrel and fight as soon as I sailed. I have observed some coolness between them and knew they did not heartily like one the other, on every opportunity therefore I have endeavored to make them friends, but it has had no effect. This dislike has arisen from the disagreement of the Two Wives. (1789:I, 407)

The requirements of office affected relations between siblings no less than it affected those between a Titleholder and his ascendants, as shown 
in this observation by Vancouver of the deferential behavior accorded young Pomare:

This mode of behaviour is, however, rather to be attributed to the force of education, than to a want of the proper sentiments of affection; as I perfectly recollect that, when I was here with Captain Cook, Pomurrey treated his brothers with the most cool indifference, although, on the present occasion, there are few examples of three brothers living in greater harmony, or regarding each other with more fraternal affection: it should therefore seem, that this sort of distant deportment is a necessary appendage to the high office of sovereign. (1801:272)

Finally, a very special form of sibling relationship is revealed in the following passage from Rodriguez:

It dawned clear and with the wind at S., fresh. I went to visit the invalid lady Oviriau, and found her as it were dazed, and her body much knocked about. This and similar sudden attacks of illness are attributed by the natives to the spirit or evarua (as they call it) of deceased persons whom they may be bewailing having taken possession of the mourners by entering into their bodies; and they were persuaded that this was the case now in regard to the spirit of the deceased arii, who was Oviriau's first cousin. It was not possible to disabuse them of this error, set afloat and upheld by their tahuas, to whose fables they yield implicit belief. (Corney 1919:193)

In view of the fragmentary, and in some respects contradictory, nature of these data, they hardly justify generalizations about the relationships under consideration, but a few points can be made.

Time. Congruent with the absence of explicit rules of marital residence there seems to have been a wide variety of interaction situations among siblings with respect to the frequency and duration of their interaction. I can discover no tendency, say, for all brothers to remain in close proximity and in frequent contact with one another throughout life, while their sisters dispersed-or vice versa-nor for patrilateral cousins to be together more frequently than matrilateral ones.

Fosterage had the effect of widening an individual's contacts with relatives outside his family of orientation and, of course, of limiting his contacts with his own brothers and sisters. But because of what appears to have been its rather haphazard nature, fosterage did not result in systematically increased contact with any particular sets of cousins, matrilateral or patrilateral. (There is a possibility, of course, that this appearance of haphazardness may be due mainly to a paucity of data.)

In some families of superior social position, interaction among siblings may have been inhibited, at least during the early years of life, by the practice of insulating young children in separate households of their own.

Space. The mua-muri (front-behind) opposition which characterized male-female relationships generally applied to brother-sister relations as well; but 
it appears also to have been applied metaphorically among male siblings to distinguish the firstborn from the rest. It may also have had this usage among female siblings, but I can discover no evidence for this.

The most explicitly locational expression of sibling relations occurred in connection with marae stone uprights. In certain sets of marae stones the central upright facing the $a h u$ was reserved for the firstborn, with the second-born to its right (facing the $a h u$ ), and third-born to its left (see chap. 16).

Spatial distance may also have been preserved to a greater degree around a firstborn than around his siblings, inasmuch as Titles, which tended to require some insulation for their incumbents, devolved more usually upon firstborns.

Governance. In Tafai's words, quoted earlier: "No mua ra, ei mua ra, ei mua ia, e no muri ra e na muri iho ia. Those born before must stand in-front-of; those born later must stand behind" (Leverd 1912:21). But, as was amply indicated, some legends that the Maohis found apposite enough to perpetuate identified initiative, decision making, and precedent as attributes of younger or even youngest siblings or cousins.

Transaction. Objects and services continually flowed between siblings in connection with ordinary household pooling-and-sharing. Moreover, older siblings, especially girls, provided services for younger ones, as nursemaids; and among boys, at least, younger ones did chores for older ones. On the other hand I can discover no evidence of any systematic, explicitly prescribed flow of goods among siblings or cousins as such, in addition to the goods owed to those who were at the same time heads of their common social groups. Ellis wrote: "It is reported that brothers, or members of the same family, sometimes exchanged their wives ..." (1829:II, 369), but his is the only statement to this effect that I have found.

Emotion. Affection may have been prescribed among siblings, and I have presented evidence that such sentiments were indeed expressed: in legendary accounts, in ritual self-bleeding, and in historical episodes. But evidence of enmity has also been provided, not only between cousins, and stepsiblings, but between full siblings as well. (I have come across no historical cases of such enmity having resulted in family-congregation fission, but I imagine that it was a fairly common occurrence. Indeed, I suspect that hostility between stepsiblings, especially, was one of the society's most divisive factors.)

Sexual avoidance was of course the most commonly stated norm between brothers and sisters, and between "close" cousins; but how far the norm was extended collaterally, we do not know. Conversely, the genealogies of some socially superior families contain instances of first-cousin marriage. 
Aside from the precept exhorting siblings to behave with respect (tura) toward one another, and specifically not to curse one another, I have found no evidence of norms prescribing any systematic expression of "superiority" or "inferiority" among siblings-except, of course, when one of them held an office requiring such expression, as Vancouver perceptively recognized.

\section{NONADJACENT GENEALOGICAL LEVELS}

The terms listed for these relationships in our principal lexical sources were the following:

\section{tupuna}

an ancestor, a grandfather (LMS Dictionary).

ancêtre, grand-père (Jaussen 1898:163).

grandparents (t. tane, [grandfather], $t$. vahine, [grandmother]) (Handy 1930:23, after Marau).

Modern usage corresponds to Handy's; tupuna refers to grandparent (or ancestor) regardless of sex, sex specification being supplied by the qualifying tane or vahine, respectively. On the other hand, the LMS and Jaussen entries indicate that tupuna, used without qualifier, referred specifically to male grandparent, and they imply that female grandparent required the qualifier vahine. In any case, whichever practice actually prevailed, in the absence of contrary evidence and in keeping with other Maohi terminological usage, it may be assumed that tupuna referred not only to lineal ascendants but to collaterals as well. ${ }^{31}$

mo'otua

a grandchild (LMS Dictionary).

petit-fils, petit-neveu, petite-fille (Jaussen 1898:120).

the children of first, second, or third cousins (Handy 1930:23, after Marau).

The Handy-Marau definition is puzzling, to say the least-especially since their own list does not include a term for a lineal descendant of nonadjacent genealogical level. The Jaussen definition is also puzzling, since it specifies "grandson" but not "granddaughter." As for the LMS definition, its omission of collaterals was probably due more to oversight than to design, for, as in the case of tupuna, I am of the opinion that mo'otua applied to all consanguines of this genealogical level.

I do not know what to make of the separate LMS listing for mootua, which appears in the dictionary immediately after mo'otua, but is defined as a great-grandchild. This is the only one of the sources to draw this particular distinction.

Mo'otua was also used, in compound, for descendants of more widely separate genealogical levels for example: 
mo'otuatini, a great-great-grandchild (LMS Dictionary).

mootuatinitini, a very distant progeny indefinitely known (LMS Dictionary); arrière-petit-fils (Jaussen).

mootuatuarau, same as mootuatini (LMS Dictionary).

mootuarau, same as mootuatinitini (Jaussen).

(If a choice had to be made between these somewhat conflicting definitions I would favor the LMS version.)

Finally, we find different versions of meanings attached to hina and its compounds:

hina

seed, posterity (see hua'ai) (LMS Dictionary).

posterité (Jaussen).

great-great-grandchildren (Handy 1930:23, after Marau). hinarere ${ }^{32}$

progeny, offspring, descendants; beginning with great-or greatgreat-grandchildren (see hua'ai) (LMS Dictionary).

descendants, arrière-petit-fils (Jaussen).

great-great-great-grandchildren (Handy 1930:23, after Marau). hinatini

great-great-great-great-grandchildren (Handy 1930:23, after Marau).

The more recently compiled Burbidge grammar-dictionary adds hina $p a^{\prime}$ arae, great-great-great-grandchild; but this is the only instance of such usage that I have found (1930:269).

With such an irreconcilable array of "evidence" it is not possible to be dogmatic about specific terminological usages referring to widely separate genealogical levels of consanguines, but certain generalities do emerge.

Beginning with the second ascending genealogical level, all ascendants (lineal and collateral) are lumped together under the single term tupuna, ancestor. Descendants are considerably more differentiated according to genealogical level. ${ }^{33}$

With the possible exception of tupuna (which may have specified males when used without a sex qualifier), the terms under consideration were used for both males and females. Despite contrary indications, which were likely due to oversight, these terms did not ordinarily distinguish lineal from collateral consanguines. Maohis had relatively short life spans, yet it seems likely that the early age at which couples produced offspring resulted in numerous instances of coexistence between individuals and their (lineal) grandparents, and even some cases of coexistence with lineal greatgrandparents. Moreover, the inclusion of collaterals in these paired kin categories increased these instances manifold. In other words, such relationships deserve close study. But inasmuch as the sources devote so 
little direct attention to them, I must resort to indirect evidence. Several contextual factors were likely to have influenced interaction between consanguines of nonadjacent genealogical levels:

The generally contemptuous attitude, already described, toward agebased decrepitude.

The timing of succession to kin-Titles-that is, during an individual's Title incumbency his grandparent had long since been superseded in his incumbency, thereby reducing causes for rivalry between them and also minimizing the bases for the older relative's authority over the younger.

The individual's relationship with his parents. Certainly, for some individuals, the freedom from harsh parental authority allegedly enjoyed by most Maohis may have obviated the kind of compensatory, affectionate, freeand-easy interaction with grandparents that has been reported from many societies; but instances of the reverse can also be found.

The extended-family composition of many households. Despite the paucity of information on household size and composition, it appears likely that many if not most households contained at least one "grandparent," and for most children some tupuna probably lived nearby.

The belief in the existence of ancestral ghosts, and, in many cases, the belief in their active intervention in descendants' affairs.

Direct testimony concerning the relationship under consideration is sparse indeed. The only general prescription I can find which bears directly on grandparent-grandchild relations is the statement by Morrison that "a Child may Curse its Father, Mother, Uncle or Aunt but it would be Blasphemy for them to Curse it. The Child may not Curse its Grand Father, Grandmother, Brothers or Sisters but the Grand Father or Grandmother may Curse their Grand Children with Impunity." (1935:184.) As I confessed earlier, I do not know what to make of this alleged rule, which seems at odds with other inferences about the relationships between grandparents and grandchildren.

Wilson stated that the reason the Maohis believed themselves unable to use sorcery against Europeans was that "... they knew not the names of our God and our grandfather, which is necessary" (1799:336).

The story told about the youthful Hiro's relationship with his mother's father was quoted in part above, but bears reproduction in full in the present context:

While yet a young lad, Hiro went to Tahiti and lived at 'Uporu (Ha'apape) with his maternal grandfather, named Ana (Cave), the senior teacher in the school called Tapu-ata-i-te-ra'i (Sacred-cloud-in-the-sky). There Hiro's four brothers had been placed as students, and while he was still too young to join them, he acquired a greater knowledge than they of the chants that he heard by listening from outside. Hiro grew so fast that he was soon the biggest youth in all 'Uporu, and one night 
he stole up on to the ridgepole of the schoolhouse where his grandfather, who was blind, was teaching, and this he continued to do during six consecutive nights, at the end of which he had absorbed into his person all that was taught in the school. When he was admitted as a student he recited all the chants so well that the teachers were amazed, and his grandfather said that there was nothing more in the school for him to learn. It is said that Hiro's pastime at 'Uporu was to play with sand, which he easily heaped up into hillocks which are still standing along the shore.

When he became a man, he inquired of his grandfather what were the requirements of man. His grandfather replied:

"Provide yourself with a home, and marry a wife."

"If I do so," said Hiro, "what must I do with the wife?"

"Cherish and feed and clothe her," was the reply.

"That would be unprofitable," said Hiro, and so he went on disapproving of everything that Ana told him a man should do. Then he inquired what tricks man was capable of doing, and when Ana enumerated: lying, deceiving, and thieving, Hiro exclaimed:

"Yes, stealing is good; that is a profitable thing; it will be satisfying to a man."

So Hiro decided to become a thief under the protection of Hiro, god of thieves; and he commenced by stealing young breadfruit and coconut trees, taking the precaution not to do so from lands close by, and planting them upon his own grounds. He also acquired a great passion for navigation and visiting lands far away. He became skilled in hewing canoes out of solid logs and was the first builder of large canoes with planks sewn together, which he called pahi (ship). He was a great pig hunter. Early one morning Hiro told his grandfather that he was going far up inland to a sacred place called Ou-tupuna (Ancestor's-stronghold) for a branch of an ava tree named 'Ava-tupu-tahi (Solitary-ava), famed for its age and immense size, and his grandfather cautioned him to be careful not to desecrate the sacred grounds. So Hiro went, and on arriving there was greeted by two men who were keepers of the premises, named Taru'i-hau (Exceeding-darkness) and Te-rima-'aere (The-hand-in-space). They inquired of him his errand, for, said they, "No man dares enter here," and when Hiro told them what he wanted, they refused to allow him to break a branch or to approach the sacred ava. They yielded not to his entreaties and finally threatened to take his life if he would not depart.

Much vexed, Hiro struck off some branches from the ava tree with his spear but by enchantment the two keepers caused them to reunite and grow again in their places. Hiro also used enchantment, made the tree grow very high, again broke off its branches, which remained upon the ground unaffected by the further invocations of the keepers, and pulled the tree up by the roots. The keepers then called to their aid a boar named Mo'iri (Swallow-whole), of prodigious size and possessed by a man-devouring demon, so that it terrorized men who chanced to pass near the place. Soon it came and was rushing towards Hiro, when he met it with his spear, which he thrust through its open mouth, and killed it, consigning the evil spirit to the pô (darkness). Then the two men stepped forwards with their spears to fall upon Hiro, but warding off the spears he caught his assailants by the hair, beat their heads together, and killed them.

Finding himself master of the situation, Hiro tied the two men together by the hair of their heads and placed them thus across his spear with the great ava tree at one end and the pig, Mo'iri, tied by its four legs, at the other. Then he raised his spear upon his shoulders and carried home his burden as though it were nothing. On arriving home late in the afternoon, Hiro found his grandfather 
sitting beneath a spreading breadfruit tree, and before him he threw down his load upon the ground with three tremendous thuds and a crash.

"What have you there, Hiro?" asked the old man.

"The pig, Mo'iri," was the answer.

"What is it that crashed?" he asked.

"The famous solitary ava," said Hiro.

"And what produced the other two heavy sounds?" asked the old man.

"The two men, Tauri-hau and Te-rima-'aere, whom I have slain."

"Aue aue! (Alas, alas!)" said Ana, sorely mortified. "You have committed a great crime!" But when Hiro explained everything to him his anger ceased.

Hiro buried the two men in his marae, after which he purified himself for domestic work by bathing in the sea. He made an oven in which he baked the great pig and some taro, and then he prepared the ava drink by chewing up the roots, according to custom, and in a few moments his work was done; he had filled forty 'umete (wooden trough) with pulp and poured on water and strained out the ava juice ready to drink. The old man was astonished when, on inquiring, he was told that forty 'umete of ava had been prepared so quickly and he asked to feel his grandson that he might form an idea of his size. So Hiro sat down while his grandfather stood up, and although Ana was a man of fine stature he found that his hands could reach up only below Hiro's shoulder blades, which caused him to exclaim:

"You are indeed an immense man, and your mouth must hold a great deal more than that of an ordinary person. It is not surprising then that you have masticated all the ava so soon."

They feasted on the famous pig and drank freely of the ava, which they found very good. Hiro ate three-fourths of the pig and drank thirty 'umete of the ava and was only moderately filled; his grandfather was amply satisfied with a hind leg of the pig and two 'umete of ava. From this event arose the saying, formerly common in Tahiti and the Tuamotus: "Te pua'a o Mo'iri, e te 'Ava-tupu-tahi" (The pig Mo'iri and the Ava-tupu-tahi).

A day came when Hiro conceived a strong desire to go and visit his parents in Ra'iatea, and his grandfather agreed to let him go. (Henry 1928:537-539)

In another version of the Hiro cycle, given earlier, Hiro was reared and protected by Ana, who was the father of his stepfather; the latter jealously resented Hiro's conception (by a visiting stranger) and begrudged him his strength and talents. Hiro's mother went to Ana's home to be delivered, and the old man named the child and predicted for him a notable career. In reaction to this, Hiro's stepfather left him with Ana: "As my father has given him a name, he can keep and take care of him." In due course Hiro was assisted by Ana in his contests with his stepbrothers (who were Ana's own son's son) and even in the final duel which ended in Hiro's slaying of his stepfather and stepbrothers.

Another mythical episode involving the relationships under discussion occurred in connection with the separation of Tahiti from Ra'iatea:

There was once a time of sacred restriction at Opoa, the home of the gods; there was hallowedness in Great-Havai'i, when no cock must crow, no dog must bark, no pig, no man must walk abroad. The wind blew not, and the sea was very still. 
At last, one day during that time, a comely maid, named Tere-he (Wrongerrand), transgressed by stealing away to swim in the river near her home. This displeased the gods, so that they caused numbness to overcome Tere-he and she was drowned. Then there swam up an eel of wonderous size. Such as was never seen before or afterwards, from a great hole in the bed of the river, which swallowed her whole.

There was one person powerless to save, who saw all this; it was the aged grandmother of the girl, named Mou'aha'a (Low-hill), who, missing her at home, ventured out with fear of the god to find her; and she traced her to the river, where she arrived only to see her sink beneath the water and shortly afterwards taken by the great eel and swallowed whole. For this reason was the grandmother named Mavete-'ai-tune (Expanding-eel-devourer). (Henry 1928:438)

Such fragments as these are slender evidence for generalizing how the Maohis conceptualized the relationships under consideration. The historical testimony is not any fuller; about the only accounts of this nature that can be found concern interaction between young Pomare II and his father's parents. The following report by Vancouver is typical:

Soon after our arrival at the encampment I witnessed a scene, very different from that which had been exhibited on board on the meeting of three sons with their venerable parent. It was shortly announced that Otoo was approaching. On this occasion, it became necessary that the grandfather should pay homage to his grandson. A pig and a plantain leaf were instantly procured, the good old man stripped to the waist, and when Otoo appeared in the front of the marquee, the aged parent, whose limbs were tottering with the decline of life, met his grandson, and on his knees acknowledged his own inferiority, by presenting this token of submission; which, so far as could be discovered, seemed offered with a mixture of profound respect, and parental regard. The ceremony seemed to have little effect on the young monarch, who appeared to notice the humiliating situation of his grandsire with the most perfect indifference and unconcern. This mode of behaviour is, however, rather to be attributed to the force of education, than to a want of the proper sentiments of affection; as I perfectly recollect that, when I was here with Captain Cook, Pomurrey treated his brothers with the most cool indifference, although, on the present occasion, there are few examples of three brothers living in greater harmony, or regarding each other with more fraternal affection: it should therefore seem, that this sort of distant deportment is a necessary appendage to the high office of sovereign. (1801:271-272)

Actual reports, or legendary accounts, about relationships with collateral mo'otua, or with lineal or collateral hina, and so forth, are entirely absent. In fact, the only inference I am able to draw about the latter is the one already noted, namely that social considerations, about which one can speculate but cannot document, led to a more minute concern with descendants than with ascendants, in terms of what genealogical level they occupied. ${ }^{34}$ 


\section{chapter 18 CLASS}

\section{SOCIAL STRATIFICATION}

One matter that all writers on the Maohis agree upon is that the society was stratified in terms of privileges and valued attributes of various kinds. Terms such as "the better sort," "propertied class," "nobility," "servant class," "commoners," "upper level," and "slaves" pervade the visitors' descriptions; and these are paralleled by many Maohi labels of similar connotation. Unless indicated otherwise, the following definitions are from the LMS Dictionary:

hutehute, mean in rank, of low birth.

hotehote, small in quantity; also men of low birth, or diminutive in stature. $h \bar{u}^{\prime} a r i$, a person of a despicable birth.

papauri, a title given to inferiors.

te fanau'a oura ri'i, progeny of little shrimps; figuratively, people of little power. (Henry 1928:80)

ta'ata ri'i, little people; figuratively, people of little consequence. (Henry 1928:451)

tarihau, the populace, or lower rank of the people.

feiā mana, people [of] power, might, influence.

In the (unpublished) texts on the Arioi sect collected by Orsmond, a status opposition of similar kind is expressed by iti (little, "low" status) versus rahi (large, great, "upper" status). The text in question concerns a Ra'iatean man named Mahi who was engaged in trying to secure a foothold for the sect on Tahiti. Upon landing there he was at first befriended by a man of no particular importance; Mahi was pleased at his reception but in the interests of proselytization saw the need for a more influential sponsor: "Ua tupu atura te mana'o ia Mahi e taua iti noinoi tono, e imi atu ai oia i te ravea e rahi ai." "A thought occurred to Mahi that his friend was very low, therefore he sought means to obtain a high one."

In addition to recognizing the existence of the kinds of status inequalities implied by these labels, most writers on the ancient Maohi attempted to specify the society's strata in terms of "ranks," "classes," "castes," and 
so forth, and to apply native labels to these; but a perusal of figure 18-1 will indicate the wide disparity in the interpretations.

Some labels listed on the chart can be set aside, as being only indirectly connected with social stratification:

ta'ata'ino [Bougainville's tataeinou], literally, a person bad, evil, wicked, base, vile, sinful (LMS Dictionary); was, with tapu, the label applied to persons designated for human sacrifice. Such persons were described as having been "despised by all classes" (Handy 1930:44).

tìtī, a captive in war, a slave, a refugee (LMS Dictionary). According to Ellis, tìtī were included among the manahune, or those who had "lost their liberty in battle, or who, in consequence of the defeat of the chieftains to whom they were attached, had become the property of the conquerors" (1829:II, 342).

teu/teuau (plural, teuteu) ["teou," "toutou," "towtow"], an attendant on the chief, or principal man (LMS Dictionary). According to Handy, teuteu referred to "hereditary servitors of the ari'i," and the label "designated a function and not a class" (1930:44). Ellis stated that teuteu were included among the manahune (1829:II, 343), but this was contradicted in part by Morrison, who wrote "servants are calld Tewtew [teuteu] in General but those who wait on Weomen are Calld Tewty [tītī by way of derision-tho it is not uncommon to find Young Men of the first Familys and the Younger Brothers of Chiefs in the Service of the Fair Sex" (1935:167).

tatatoo-ow. This rendition of Bligh's is uncertain. Possibly intended was ta'atatufa' $a$, an heir; one that has an inheritance or a portion (LMS Dictionary). More likely the word intended was 'iatoai (see below).

tatama-auree. This listing of Bligh's is inexplicable.

tavana. This was, of course, derived from English "governor," and it referred to the officers, either hereditary or appointed, who administered district affairs after institution of the Pomare monarchy in 1815.

mattaeyna [mataeina'a]. Morrison's and Handy's use of this term as an alternative for manahune represents simply another application of this broadly used label, which (it will be recalled) was defined in the LMS Dictionary as the subjects of a chief; a certain tribe, clan, or subdivision of the inhabitants.

It will also be noted that there is some disagreement among the sources concerning the numbers of distinct categories, but all writers after Cook's last visit, in 1777, agreed upon a hierarchy of major categories consisting of ari'i, ra'atira, manahune; most writers also agreed upon a division of the first into ari'i rahi (or nui) and ari'i ri'i (usually including 'iatoai or to'ofa). These later writers also agreed on including teuteu 
and tìtī among the manahune. What the sources do not agree upon, however, are the meanings attached to all three major category terms; more broadly, they did not agree upon the distinctive features of all three categories of persons, or upon the relations between them. Some writers emphasized governance as the criterion distinguishing these categories (e.g., the use of such words as "king," "vassal," "servant"); others indicated property (e.g., "landed proprietors," "tenants"); others occupation (e.g., "yeoman," "villain"); still others birth (e.g., "nobles," "gentry")—and some used two or more kinds of criteria in the same series.

Some of these attributes were evidently based on European visitors' notions of how all proper societies were stratified (the feudal model having been especially favored), with only minimum attention given to the opinions of the Maohis or the facts of Maohi life. In other instances some observation and interviewing obviously went into the formulations-but with the imprecise and inconsistent interpretations we have just seen. Actually, although the Maohis undoubtedly viewed their society as being "stratified," and although authority, property, occupation, and birth-separately and in combination-undoubtedly entered into their conceptions of social stratification, I suspect that the Maohis themselves were neither altogether clear nor of one mind as to where the boundaries between strata were or ought to be. (I imagine that not all Maohis would have agreed in all cases on whom to label ari'i or ra'atira or manahune.)

The following note from Cook's journal of 1774 indicates how the Maohis sought to present themselves to the naïve European visitors:

We hardly ever met with a man of the least Note who did not call himself an Aree, nay even the very common fellows would now and then interduce themselves to us with this title. It gave them an air of importance, they could not have assum'd without, and was usefull to them in many other respects. Our very best friends, would suffer us to be impos'd upon by any fellow who had address enough to do it-nay whatever the fellow said they would confirm. (Beaglehole 1961:394 n3)

In characterizing the "women of the lowest rank" who consorted with the European sailors, G. Forster wrote: "It was remarkable that they were not without some degree of vanity, as they never gave themselves any other name than that of tedùa [tetua], (lady), which is the title of their female nobility, and which, by way of eminence, is particularly applied to the princesses of these islands" (G. Forster 1777:I, 403).

There is, however, one criterion on which a large degree of consensus would likely have prevailed, and that was marriageability; who could marry whom (consanguinity aside) seems to have been the most crucial factor in most Maohis' definition of the boundaries separating the various strata of their society. Even in this respect consensus appears not to have been universal-neither about the weightiness of the criterion nor about the pre- 


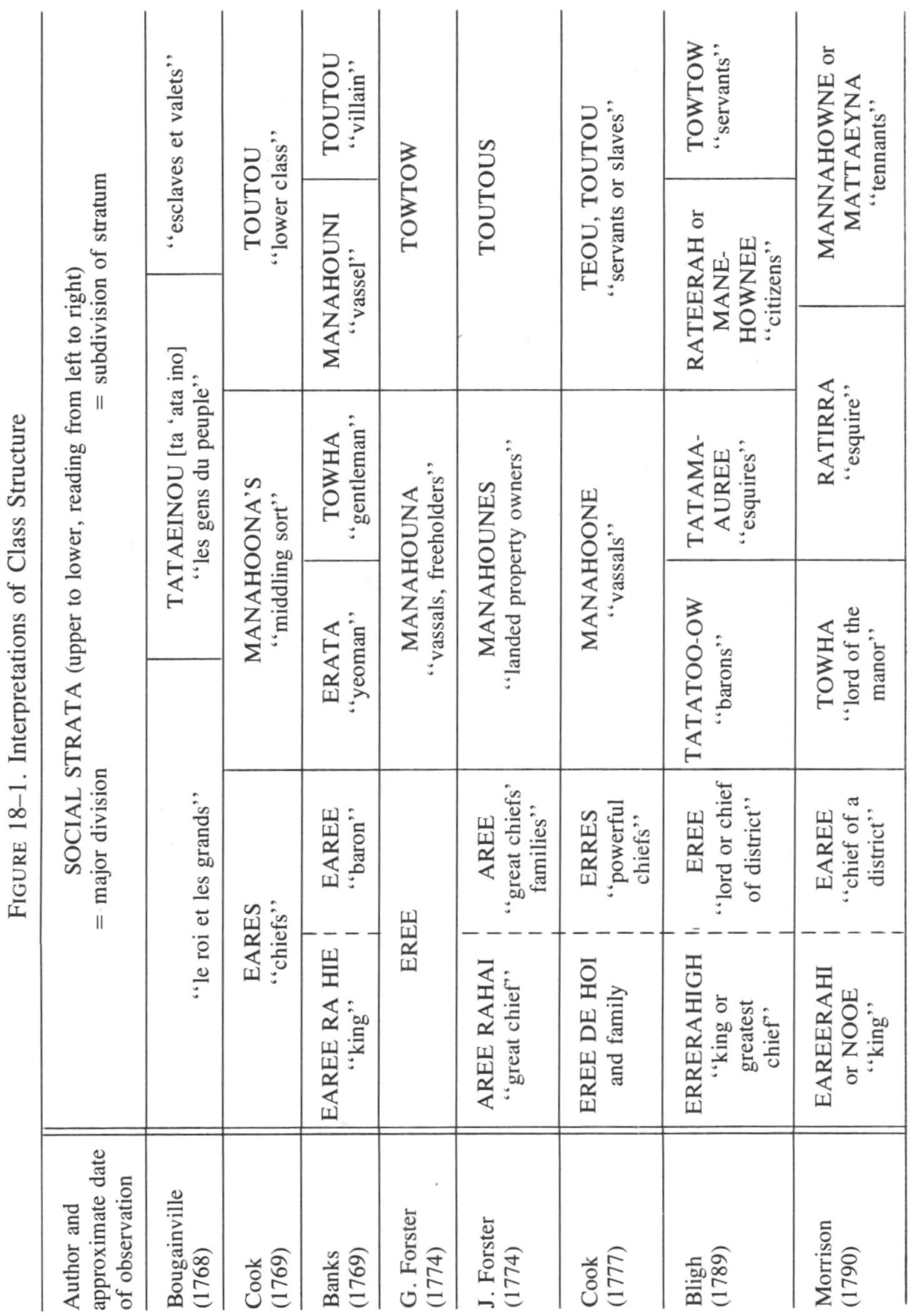




\begin{tabular}{|c|c|c|c|c|c|}
\hline \multirow{2}{*}{ 总: } & $E \quad \sum_{\vdots}^{\infty}$ & \multirow{2}{*}{$\underbrace{\stackrel{5}{E}}_{\text {四 }}$} & \multirow{3}{*}{ 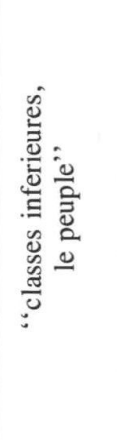 } & \multirow{3}{*}{ 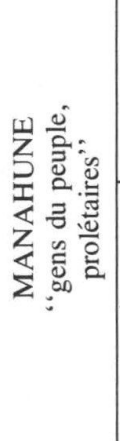 } & \multirow{3}{*}{ 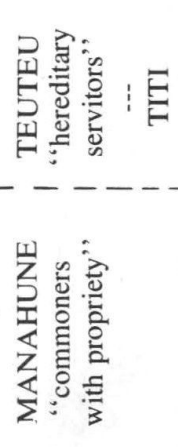 } \\
\hline & \multirow{2}{*}{ 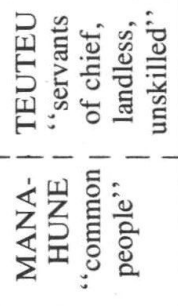 } & & & & \\
\hline 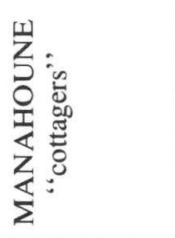 & & 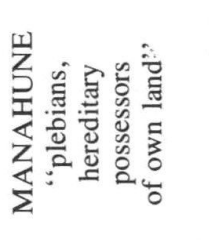 & & & \\
\hline 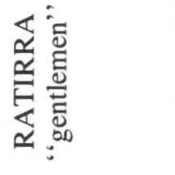 & \multirow{2}{*}{ 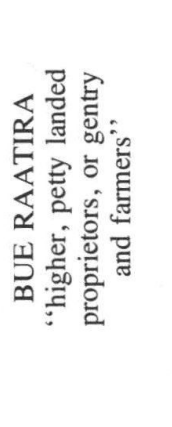 } & \multirow{2}{*}{ 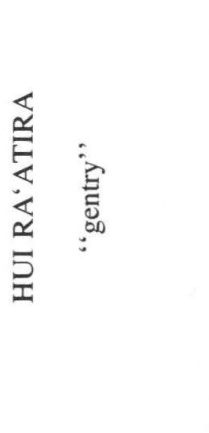 } & \multirow{2}{*}{ 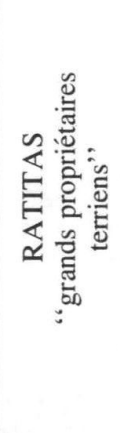 } & \multirow{2}{*}{ 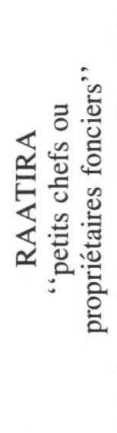 } & \multirow{2}{*}{ 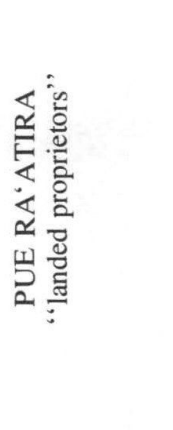 } \\
\hline 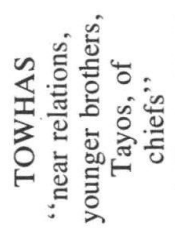 & & & & & \\
\hline 穿: & 尝总 & 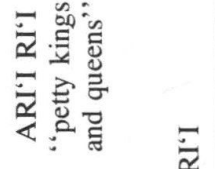 & in & 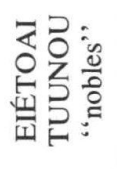 & 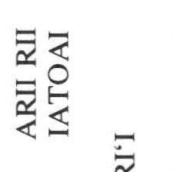 \\
\hline 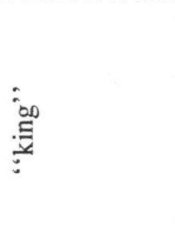 & 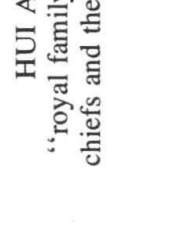 & 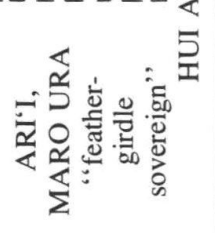 & 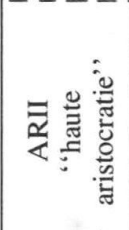 & 离 & 至 \\
\hline 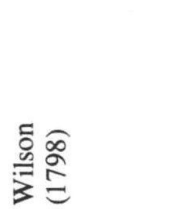 & 竞 & 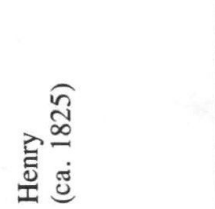 & 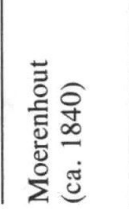 & 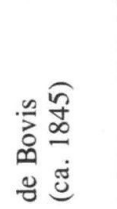 & 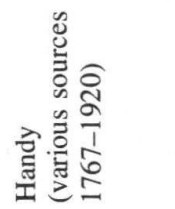 \\
\hline
\end{tabular}


cise placing of all individuals in the strata, but it is the nearest thing I know of to a native operational procedure for defining the boundaries in question. It is for this reason that I label such strata marriage classes, or simply classes.

For the reader's convenience I repeat the components of Maohi "marriage": (1) it was a heterosexual relationship which, ideally, involved coitus, with open (in contrast to clandestine) coresidence, for a period of at least several weeks or months; (2) tacit agreement to regard as "legitimate," for purposes of inheritance, any surviving offspring of their intercourse; (3) tacit agreement to transfer to one another rights to certain other of one's services and objects; (4) and some degree of public recognition of and sanction for the relationship, usually (but not necessarily) validated in a "wedding" ceremony.

Of all these elements the second was perhaps the most crucial; at least it was certainly the most definitive with respect to membership in a class, as may be exemplified in a number of ways. First, the existence of certain highly explicit rules addressed mainly to the ari'i class and forbidding them to have progeny by a lower-class mate:

Whosoever resisted it [this rule] was condemned to social death and the loss of all hereditary rights, as stated in the family law, ture feti'i $i:^{[1]}$

Go down to the depths of Toareva,

Thy bones shall be scattered over the long road of exile;

Forever shall thy face be covered with clouds of darkness;

Thine eyes shall nevermore look upon the light of day;

For you have tainted the blood of the gods. ${ }^{[2]}$

Go! We know you no more. The mountains and the sea are now your legacy.

(Handy 1930:40, after Marau)

Second, there is the evidence derived from numerous acts of infanticide, several of which have already been described; the following excerpt from Wilson will serve as a reminder:

Pomārre intimating a wish to sleep on board, it was granted; he then asked leave for his wife and servant, which was also complied with. It may be proper to remark here, that Iddeah, though still considered as the wife of Pomārre, has not for a considerable time cohabited with him, but with one of her touttous (or servants), by whom she has had one child, and is again pregnant; her younger sister, Why 'reēde, next cohabited with the chief, but left him through dislike for one of far inferior rank; and his present wife is a very stout young woman, but of what condition we could not learn. However, it is evidently clear, that they hesitate little about mixing with the lower orders of the people; but if issue should be the consequence of these connexions, it is rarely the pride of rank suffers the poor infants to live an hour after they are born. (1799:73-74)

Other episodes taken from missionary journals exemplified the not uncommon circumstance that however "married" a cohabiting couple might have 
wished themselves to be, they were discouraged from having progeny if they happened to be of different marriage classes. For example:

The people persist in infanticide in spite of all the missionaries' teaching. The people almost universally blame the king and principal chiefs for imposing such things upon them, [i.e., heathen practices generally] but in respect to infanticide they have not that pretence, the king and chiefs very seldom interfere at all in the business, it rests with the common people themselves. There is at present a woman, the wife of one of our nearest neighbours, (who is a petty ratera) big with child, and very near her time, she says, and also all the neighbours say the child is to be killed as soon as born, she has had one before who was killed in the same manner. She and also her husband say they want the child to be saved but the husband's father and mother are determined to have it killed, because the woman is reckoned of lower rank than their family. (Davies, Journal, 9 June 1808, LMS Archives)

A few days back a young woman was delivered of a child, which was immediately strangled by the relatives of the woman's husband. It is said that the cause of this barbarous act, (common in Tahaete), was, her being a common woman, that is, one of no rank, and inferior to her husband, who is the son of a neighbouring ratera. (LMS Transactions:IV, 188-189)

Third, it may be assumed that in many instances potential misalliances of this kind were blocked before cohabitation could begin. This was shown in the legend of Pereitai, whose infatuation with a lower-class youth, Temuri, was ended by the latter's murder. Henry told the story as follows, beginning with the point where the young lovers were about to elope, despite the urgings of both of their families to break off the affair:

... as the night advanced Pere-i-tai became so restless that she sent for her old nurse and second mother to come and sit by her. The good woman promptly obeyed the summons, and seeing her beloved young mistress toss uneasily upon her bed she stroked and rubbed her down, as she had often done in former times when she was a little infant entrusted to her care-a form of massage much practised among the Polynesians everywhere under like circumstances. At length Pere-i-tai could bear it no longer, and she unburdened her heart to the sympathizing Rohi-vahine, who replied:

"Oh, my child! Why did you not confide in me sooner? I, a plebeian, can feel for Te-muri as only a plebeian can, and I entreat you to release him of this intrigue. Your plan to ennoble him later might never be possible, and meanwhile he would be a fugitive, pursued and watched by some accomplice of your royal house and eventually slain and sacrificed to the gods, and then you would be brought home to mourn your loss, a reproach to your own people. It is only for deeds of valor and heroism, when royal personages have been rescued from outrage or death in some extraordinary way that kings and queens consent to raise people of our standing to their rank. This is what Te-muri's parents would undoubtedly say also to you and him were they consulted in the matter, for no plebeians could ever wish to bring down wrath upon themselves and even their district by forming such a union."

This matured reasoning caused the royal maiden to see for the first time the disadvantage of a misalliance and the serious evil to which it inevitably would have led; but not yet quite willing to be convinced of its utter folly she answered: 
"Oh! Why indeed did I not confide in you before! It is too late now for me to retract, Te-muri must not be disappointed, and we will trust to the gods for future developments to save us from the evils you portray."

"No, my child, it is not too late! Now, while Te-muri finds his life in jeopardy is the best moment to break off this engagement. Let me go and reason with the poor misguided though brave young man, for his parents' and your sakes." A dead silence ensued, and Pere-i-tai wept with regret and relief combined, and at length she said:

"Yes, I agree to what you say, my dear second mother. Te-muri is probably waiting anxiously now for my return. Bear him my deep 'aroha (affectionate regards) and tell him that I pray the gods to give him a handsome wife worthy of him and whom he must regard as my second self." As the nurse quietly glided away from the dwelling, the girl drew a long deep sigh, exclaiming, "Aue!" which, throughout Central Polynesia, from Hawaii to New Zealand, is a word used to express deep or undefined feelings. And now she grew calm and fell into a peaceful slumber, which she so much needed. All was quiet and peaceful in the king's premises, and Pere-i-tai's secret was safe in her plebeian friends' keeping.

The following day, as final preparations were being made for the trip to Tautira, Pere-i-tai entered into them with a light heart. The evening approached, and the final meal was made ready before parents and child were to part for a season. They were just about to partake of it when the king, seeing the high priest enter the courtyard, went out to meet him and speak on private matters. At the same moment, the boy, Vaiiho, who had been sent out on an errand, approached looking much agitated, and as soon as he was able to speak, in a hoarse whisper he said:

"Have you heard the news?"

"What news?" asked the girls much surprised.

"Do you know where Te-muri is?"

"Has he not gone home to his parents?" asked the princess.

"Alas, alas, no!" replied the young man.

"Then where is Te-muri?" she gasped.

"Our good friend, Te-muri, whom you met last night, is with the gods in the marae."

"What is he doing with the gods there?"

"Ta'aroa in Hades only knows that!"

Not realizing what had happened, Pere-i-tai turned to her nurse, Rohivahine, who had also just come in, and asked her if she had met him to deliver her message. Her reply was in the negative, and she added that she had remained out by the canoe all night and had been on the alert to meet him all day, but had seen no signs of him. Now light began to dawn upon their minds, and just as Pere-i-tai was about to enquire again of Vaiiho what had really befallen TeMuri, her father returned from his interview with the priest, looking very grave, and he called her to him.

"Pere-i-tai," he said, "you have brought sorrow upon us and upon the house of your plebeian lover! We did not expect this of you. Te-muri is no more!"

Fully realizing the evil she had unwillingly caused and overwhelmed with sorrow and regret, she fell senseless upon the mat where she had stood with her father and was soon borne away in the arms of ready attendants to her bed, where she was gradually restored to consciousness; and she became a prey to deep and bitter remorse.

The cause of Te-muri's doom was that a priest who was out on duty for the night, seeking for omens and revelations from the gods, was led by the cry of the 
cricket to the point where the young people were, and seeing them in earnest conversation on royal premises he felt it his duty to know who they were and ascertain the purport of their conversation. So he stealthily approached them in the thicket behind where they sat, the sound of the wind off the sea preventing them from noticing any rustle while it carried their voices distinctly to his ears in his place of concealment. He overheard all their plans and abided his time to frustrate their purposes. As the young girls disappeared, he saw the unsuspecting Te-muri kneel down upon the sand and address an invocation in a low tone to the gods of the sea to be by him and his ladylove in their hour of need and then lay himself out with his face down and chin resting upon the back of his hands (a favorite posture of repose among Polynesians), and now the decisive moment had come.

Noiselessly approaching him from behind, the priest raised a club, which he carried in his bosom when on duty, and with steady aim administered a heavy blow upon the nape of the young man's neck, which caused instantaneous death while it averted the spilling of blood and breaking of bones, circumstances that were carefully avoided by Tahitians in slaying victims for their gods. Filled with religious zeal, he picked up the corpse and threw it over his shoulders as though it were nothing-so strong were the heathen priests of Tahiti when executing the functions of their office. He then bore the body away over sandy, shaded shores and around bleak, woody bluffs, avoiding meeting stray wanderers, and at last he arrived at the grand marae. Here he presented his offering to the high priest, telling him all that had happened, who accepted it in the name of the god Cricket, to whom they offered invocations to secure the departed spirit as a new guard to the sacred grounds, rendered superlatively sacred by many human victims that from time to time were buried there. A grave was dug beneath a great tree, supposed to be inhabited by numerous spirits that were ever there to watch over the dreaded premises, and this was the end of Te-muri's young life.

Thus the evening so long looked for with conflicting hopes and fears, ended sadly for the royal house of Fa'a'a. Te-muri's parents watched expectantly for the arrival of their only son to his home, and as night advanced went to rest, supposing that he was safe with some of his friends on the seaside, yet with some misgiving, and they were troubled in their dreams about him. It was a sleepless night for Pere-i-tai and her parents. The child's sorrow was poignant and heartrending, and the parents were truly sorry for the sad termination of their friendship for Te-muri and his good parents, while the murder of the young gallant was a natural course of events under the circumstances in those times-regretted but not censured by the great, and mourned but not murmured at by the common people. The news broke the hearts of Te-muri's parents, who soon followed him to the other world. (1928:600-603)

The most noteworthy thing about this tale is not that the youth was slain-that, as the text put it, "was a natural course of events under the circumstances in those times"-but rather that the slaying was "mourned but not murmured at by the common people." ${ }^{3}$

Adams described a similar situation (though with a less dramatic outcome), but one in which the class affiliations of the lovers were reversed:

Now that I am on the subject of family poetry, I must give here another song which was made by Taura atua $\mathrm{i}$ amo, and is still a favorite with the Tevas, the more because it is a love-song. The name of Tauraatua belongs to the little district of Amo, in Papara, and has been one of the family names for so many centuries that I cannot say which of the Tauras was the poet; but the motive of the 
poem was probably common to all of them, for it was common enough throughout the world. The young chief was in love with a girl of lower rank, who lived at the Ruaroa, a cluster of houses near the beach, by the Marae of Mataoa at the western end of Papara. The paepae, as I have said, was the paved terrace before the house. He calls his mistress Marae-ura in the song. Illegitimate connections were common enough in all societies, but in one way Europe was less rigid than Tahiti in its rules, not of morals, but of marriage. Unequal marriages were not merely unusual; they were impossible. The family would not permit them even in the case of the most powerful chief that ever lived. Illegitimacy was common, but if there was danger that a low-born child should ever take inheritance in the family, the child was put to death. Even if the connection threatened to be inconvenient, the family or the Hiva would interpose and insist on the chief's return to his own place. This is the subject of Tauraatua's song. The messenger, called the bird Uriri, had come to the Ruaroa, where Taura was living with his mistress, and brought the order for him to return to Papara. The song begins by repeating the message, and closes by a verse in which the lover, who is obliged to leave his mistress, pushes aside the leaves to catch sight of her bathing on the beach.

\section{LAMENT OF TAURAATUA.}

Taura atua te noho maira i tona ra paepae i te paepaeroa

E uriri iti au e rere i te Ruaroa

E fenua Papara ite rai rumaruma

E haere a i Teva tena teaia tei Papara to fenua ura e

Moua tei nia Moua Tamaiti

E Outu tei tai Outu manomano te faarii raa ia Teriirere i outu rau ma Tooarai

E tii na vau e turai e atu i teniau para o te Ruaroa e

Ia vai noa mai nau i puu rii o Maraeura tei tai e

"Taura atua lives at the Paepae of the Paepaeroa

The little Uriri flies to the Ruaroa, for him the loved:

'Come back to Papara, the heavy-leaved;

Come back to Teva, your home, your Papara, the golden land;

Your Moua, the Moua Tamaiti above;

Your Outu, the Outu Manomano on the shore,

The throne of Teriirere of Tooarai.'

Then let me go and bend aside the golden leaves of the Ruaroa

That I may see those two buds of Marae-ura on the shore."

(1901:36-37)

Misalliances did however occur, and resulted in progeny which occasionally were allowed to survive.

If a Man takes a Wife of inferior rank to himself and has a Child by her it is strangled immediately it is born to prevent its bringing disgrace on the Blood of His Family and tho he wishd to preserve its life himself his relations would oblige him to kill it or declare himself no longer of their Family-and it is the same if the Wife be superior in rank to the Husband both of which frequently happens. If the Child should chance to cry out in Coming into the World, or should the Mother Chance to see it before it is killd, Nature takes place of Custom and the Child is Saved. (Morrison 1935:235)

Later I shall consider the class status of such progeny; meanwhile enough has been reported to substantiate the existence of a castelike 
boundary between the category of people labeled ari'i (chiefs) and all other persons. Some evidence for such a boundary between so-called ra'atira and manahune is also available, though not nearly so abundant; but whether this paucity reflects actual situations.... or the chroniclers' notorious inattention to the affairs of "commoners" and the "midling sort," is not possible to say.

We may next inquire whether the Maohis possessed a generic name for what I label a "marriage class." From its ubiquitous association with ari'i, one might suppose that the word hui had the meaning of "class," but in fact it was simply one form of what the LMS Dictionary describes as a plural or collective particle prefixed to various nouns, as hui ari'i, the royal party or family; hui ra'atira, the inferior chiefs collectively; hui tupuna, ancestors; hui metua, parents; hui hoa, friends; and so forth. ${ }^{4}$

A more plausible candidate is the word nati, defined in the LMS Dictionary as "a class, or distinction of men; nati ari'i, the class of superior chiefs; nati ra'atira, the class of inferior chiefs." (See also natimo'e, a family or kindred.) However, the only textual use I can find of anything resembling this word occurs in one of the "Precepts of Tetunae": "Let not your eyes turn away from the troubles of your own family line (firi'a féti'i); may each help the other in order of the rules of rank-distinction (i te 'ohipa natia)" (E. Salmon 1937:29). On the other hand, this reference could be also to the grading or ranking of kin-Titles ${ }^{5}$ or to the grades of sibling seniority, rather than to level of marriage class.

Still another possibility is nāna'i (or āna'i), which the LMS Dictionary defines as a row, a number of things ranged in a line. The basis for this possible identification is an aphorism:

Na ana'i o te ta'ata e toru.

The types of men are three.

Faauhia nei i te uru. Paihi te iri, na ke [te] ta'ata.

Take a breadfruit. When it is cooked, take off the skin-that is for the people [middle class?].

$\mathrm{E}$ amu to io na te arii.

The meat, that is eaten by the ari'i.

E tuu te hune na te manahune.

The core is given to the manahune.

(Handy 1930:42)

In any case, whether or not there was a standard generic term for what we call "class," there did exist various verbal means for generalizing about it. I will examine the class labels themselves.

\section{ARI'I}

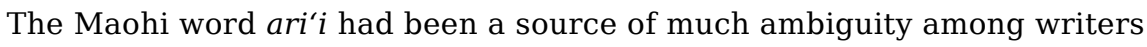
attempting to describe and analyze Maohi social relations. The commonest translation in the literature is "chief," but one finds other renditions, such as "principal chief," "head chief," "prince," "king," "feudal lord."6 
Ari' $i$ is the Maohi variant of the Polynesia-wide word ariki, aliki, ali' $i$; but one would be injudicious to assume that all these cognates were precisely the same in meaning. The various local forms of the word did undoubtedly refer throughout much of Polynesia to statuses of command and privilege, but even hasty comparisons indicate important local differences. In the Society Islands the word seems to have been used in at least two somewhat different senses.

First, it was used as a term of address and reference for the sovereign ruler of each tribal unit, as for example: "O Maha'ena ia fenua.... O Ro'ure te ari'i." [Maha'ena is (the name of) the tribal-district. Ro'ura is its sovereign.] (Based on Henry 1928:72.) "E Pomare Ari'i i Taraho"i .... Teie mai nei to pu'e ta'ata o Te'aharoa, e ono...." "O King Pomare of Taraho' ${ }^{[7]}{ }^{7}$.... Here are thy people of the six districts in Te'aharoa...." (Henry 1928:114)

Second, as we have seen, ari'i was used in a general way to identify persons holding high-grade offices (usually Titled) in certain kin-congregations.

During the eras under study, the kinds of units I call tribes were invariably larger than single kin-congregations, and while some tribes contained one or more kin-congregations with ari'i-type kin-Titles, there were other tribes containing no such kin-Titles at all. Hence, there were instances of tribal ari' $i$ who also held ari'i-type kin-Titles, of tribal ari'i who did not hold ari'i-type kin-Titles, and of ari'i-type kin-Titleholders who were not also tribal ari'i.

The question, Who was an ari'i? is also complicated by the circumstance that the label designated not only incumbents of certain kin-Titles, but some members of their families as well; exactly which members, I am unable to discover. Some evidence from genealogies and legends implies that all recognized offspring of a duly married, kin-Title-type-ari'i couple were called ari $^{\prime} i .^{8}$ Moreover, the sources are entirely silent concerning any explicit rule or tacit practice whereby this kind of ari'i-hood diminished with collateral distance from a senior, ari'i kin-Titleholding line. I suspect that unless other factors served to keep ari'i reproductivity at a rate similar to or lower than that prevailing in the rest of Maohi society there were such rules and practices. Otherwise, Maohi society would have become more top-heavy with privileged consumers than even its considerable resources could have catered to. (The reader will undoubtedly have noted that I have offered no estimates regarding the numbers of people belonging to each class; the reason is that I simply do not know.)

The question of which kin-congregations-or, put in the idiom of consanguinity, which descent "lines"-contained ari'i-type kin-Titles, is partly answered, in mythical form, in the set of traditions about the ramifications 
of the families originating in Opoa and Vaiari (summarized in chap. 16). These do not account for all such ari'i-type kin-Titles, but they include enough of them either to lend some historical credibility to the myths or to suggest that the mythical advocacy of Opoa and Vaiari was so influential that members of other family lines reshaped their "traditions" to show links with them. ${ }^{9}$

Returning for a moment to that other type of ari'i, the sovereign ruler of a tribe, I pose the question, Were members of his family also labeled $\operatorname{ari}^{\prime} i$ if he (or they) did not hold ari'i-type kin-Titles? That is to say, was an achieved tribal ari'i-hood extended to the achiever's family mates or inherited by his descendants-thereby constituting a process, or perhaps even the process, by which all ari'i-hood had its inception? This important question will be discussed at greater length later on, but, to anticipate my findings, I can state that an unequivocal answer is not to be found in the sources.

In other words, in the case of both types of ari'i-hood, I can specify the prototypes of these statuses but am unable to discover the "lower" boundaries of the class they belong to, and this obscurity is darkened by some of the meanings attributed to 'iatoai and tooha, or to'ofa.

'Iatoai is defined in the LMS Dictionary as the second class of the inferior chiefs, and it undoubtedly derives from 'iato, the transverse beams which connect the outrigger to a canoe; that is, they were "supporters" or "stabilizers," in line with the Maohi metaphor identifying a district with a canoe ( $\left.v a^{\prime} a\right)$, and its chief as a mast (tira). Thus, 'iatoai would appear to have been an office, and most plausibly one connected with a tribe. It was so described by Adams:

... the messengers [sent by the ruler of the Papara tribe] were political personages .... They were under-chiefs-Iatoai. How many Iatoai formerly belonged to Papara I do not know; but in our day there are two subdistricts of Papara, Faina and Oropaa, and Faina has eight Iatoai; Oropaa has six. The whole body of Iatoai in each district are known as Hiva, and to any one who cares for the beginnings of things they are the most interesting part of our old society, for the Hiva of Papara might have been the source of all modern notions-Parliament, Civil Service, Army, Law Courts, Police, Aristocracy, Democracy, and Commune. The Iatoai were the chosen fighting chiefs or warriors, and they had, as a part of their functions, the duty of punishing or revenging insults offered to the head-chief; but they could also, and sometimes did, depose and exile a head-chief and name another or recall the old one. Their interference in this way makes one of the most dramatic motives in island history (1901:8)

Although none of the sources specifically so states, the office of 'iatoai was probably a hereditary one; and it seems also to have occupied a place in the class hierarchy, but whether among the ari'i, or below them, is uncertain. Handy described 'iatoai as "... the nobles, or younger branches or the Hui Ari'i" (1930:42); but de Bovis identified them as "un echelon inter- 
mediare," which sprang from unions between ari'i and ra'atira and which consisted of persons "... qui n'etaient point egaux aux Arii, mais supérieurs aux petits chefs [i.e., ra'atira]." And, de Bovis went on to state, "... les grands Arii leur ['iatoai] donnaient volontiers une suprématie heréditaire ou temporaire sur certaines parties du pays où ils avaient de l'influence." (1909:18.) He also stated that the 'iatoai did not, in his opinion, constitute a separate "caste"; but he did not indicate whether they (or their families) married "up" or "down."

Similar questions are raised by to'oha, or to'ofa, which is defined in the LMS Dictionary as a chief next in rank to ari'i. Banks identified "towha" as "Gentleman" and placed them between "Erata" [probably ra'atira] and "Manahouni"; but he explained: "as I was not acquainted with the existence of these classes [Erata and Towha] during our stay on the Island I know little of their real situation" (Beaglehole 1962:I, 385). Morrison identified "Towha" as "Lord of the Mannor," and placed them in a separate "class" between ari'i and ra'atira (1935:167). According to Wilson, "towhas" were "... the near relatives, or younger brothers, or tayos, of the chiefs"; they were of higher "rank" than ra'atira, but whether they were also called ari'i he did not state (1799:322-323).

Are we discussing two distinct statuses, or one only-with 'iatoai being a metaphor for to'ofa? In support of the first possibility is the LMS Dictionary distinction; but in support of the second is the fact that no other source that I know of uses both terms in any sense that can be read as contrastive. ${ }^{10}$

Another kind of uncertainty is raised by distinctions made in the sources between "great $\operatorname{ari}^{\prime} i$ " (ari'i rahi, or ari'i nui) and "petty ari'i" (ari'i ri'i), or between "great ari' $i$ " and mere "ari'i." Figure 18-1 indicates the various meanings assigned to these labels, representing earnest but misguided efforts to supply European parallels for Maohi statuses that were at best only partly understood.

The label "great" (rahi, nui) appears to have been used to qualify both types of ari' $i$-hood; it applied to the highest-graded Titles of certain prestigious kin-congregation marae (regardless of the current "tribal" authority of its incumbent) and to certain tribal sovereigns ruling large or influential tribes (regardless of the grade or rank of their kin-Titles). It is even possible that some tribal chiefs, designated ari'i rahi, did not even hold an ari'i-type kin-Title, but we cannot be certain of this. On Tahiti itself there were at the time of "discovery" by Europeans some ten to fifteen individuals called ari'i rahi, including both types. The principal kin-Title of Farepua Marae (Vaiari District), Te ari'i nui o Tahiti, once stood above all the rest in terms of rank, despite the limited political influence of its incumbent at the time of early European contact. Politically, however, the three ari'i rahi of greatest, island-wide influence were the possessors of 
kin-Titles which ranked not only below Farepua's, but below Puna'auia's and probably below Hitia'a's as well. On all the other islands there was at least one ari'i rahi, and in some places more.

While great ari'i-hood based mainly on tribal authority and influence undoubtedly waxed and waned with the fortunes of war, when identified with the principal kin-Titles of Opoa and Vaiari it seems to have remained ceremonially preeminent over a long period of time; but the relation between the two types of ari'i-hood was a very complex one, as later chapters will show.

An even more limited category of ari'i-hood was constituted by those entitled to don feather girdles at their investiture and on other occasions of religious import. In some instances feathered eyeshades were also donned in association with the feathered girdles (Morrison 1935:116), but the latter were always the principal objects in this ritual context. As we have seen, there were two kinds of such girdles (maro), one decorated mainly with red feathers (maro 'ura) and one with yellow (maro te'a). ${ }^{11}$ Legend has it that the first such girdle was red-it having been the insignia of Title-holders of the kin-congregation of Vaearae marae (later Vaiotaha) in Opoa District, Ra'iatea. Yellow girdles were more closely identified with Porapora ari'i; one tradition states that this form of insignia was introduced by a Vaearae man who immigrated to Porapora, founded a new marae (Vaiotaha) and a new descent "line," and instituted the wearing of a yellow girdle to mark his "line's" (political) independence of the Opoan homeland. (See chap. 16.)

I have already described the association between feathers, especially red feathers, and spirits, including their connection with Ta'aroa ${ }^{12}$ and 'Oro. I cannot account for their special identification with the Opoan kin-congregation, except through the latter's traditionally close connection with Ta'aroa and 'Oro: it was at Vaearae that Ta'aroa "first broke through the sky,"13 and according to some myths 'Oro not only became tutelar of Opoa but at one time actually made it his home. It should be recalled that the girdles used in investing a new incumbent with these highest-ranking kin-Titles contained some feathers taken from 'Oro's image, and that they were usually stored either inside the god's image or close by.

As for the girdle (maro) itself as an insignia of ari' $i$-hood, there may have been not only a "symbolic" association but a direct magical conjunction between it and the generative powers of the male loins and genitals, which it encloses, thereby featuring the wearer's function as perpetuator of a descent "line."14

While both red and yellow girdles served as insignia for this category of $\operatorname{ari} i$, the former appears to have been more prestigious. For example, in a "boasting contest" between inhabitants of Tahiti and Ra'iatea, the latter 
flung at the former: "Yellow feathers may abound with you, But red feathers have we in abundance" (Henry 1928:436). Also, although individuals entitled to wear the maro 'ura were referred to as ari'i maro 'ura, I have come across no reference to ari'i maro te' $a$. (It is possible, however, that those entitled to wear the yellow girdle were also called ari'i maro 'ura.)

The most puzzling aspect of feather-girdle wearing is the basis on which the right was exercised. Right to don such insignia was acquired by inheritance, mainly primogenitural but evidently not exclusively so, and through females about as often as through males. On the other hand, it would appear that not everyone inheriting such a right actually exercised it. For example, in certain myths having the legitimacy of "official" charters, the principal kin-Titles of Farepua and of Puna'auia marae carried maro 'ura rights, but during the Early European Era none of the incumbents of these Titles is reported as having exercised that right. Conversely, the insignia was donned by certain individuals whose ascriptive rights to do so seem somewhat attenuated in terms of the usual primogenitural criteria. Indeed, this is a very complicated matter, and an explanation of it will have to await my description of tribal organization and intertribal politics.

Let us return to the castelike aspect of the phenomena under consideration. I have already described the rules and sanctions restricting an ari'i's marriage to a non-ari'i. It is also clear from numerous kinds of evidence that efforts were made to mate great ari'i and members of their immediate families with individuals of comparable status, and this was especially true of feather-girdle ari'i. For example, after the untimely death in 1806 of the wife of Pomare II, the missionaries concluded that his line was nearly extinct-his deceased wife having had no offspring by him. (All her other offspring had been sired by her commoner courtiers, and killed at birth.) "There is but one woman on the Island that the king can take to wife-so as to preserve issue-her name is vahaene [Vahine] Moe ea belonging to Tehohu's family of Hedea [Hitia'a] - she it is said is bad-and it is likely that the king will not take her." (Davies, Youl et al., Journal, 21 July 1806, LMS Archives)

As we shall see, political considerations were very influential in many such matches. Maohi society had not proceeded nearly as far as Hawaiian society toward increasingly restricted endogamy at the summit, but a start had been made in that direction. Whatever else they were, the persons whom most Maohis labeled ari'i were set off from all others by explicit rules of marriage. As for the rest of the population, most of the sources divide it into two major categories: ra'atira and manahune, which, among other things, are described-or at least implied-to have been marriage castes. That is to say, we have found no rules that state explicitly that ra'atira should marry ra'atira, or that manahune marry only manahune, but norms prohibiting ari'i from marrying ra'atira (or manahune), and discouraging 
ra'atira from marrying manahune, apparently exercised the same kind (if not the same degree) of constraint that explicit rules might have accomplished. So let us consider what other characteristics distinguished ra'atira and manahune from one another and from ari'i. I begin with manahune, since the data on ra'atira are more limited and more ambiguous.

\section{MANAHUNE}

Manahune is not even listed in the LMS Dictionary, but it is defined in Jaussen as "plébéien." Elsewhere in the sources the word is translated as "midling sort" (Cook), "vassel" (Banks and Cook), "vassels and freeholders" (G. Forster), "landed property owners" (J. Forster), "citizen" (Bligh, who includes them with ra'atira), "tennants" (Morrison), "cottagers" (Wilson), "common people" (Ellis), "gens du peuple, proletariens" (de Bovis), "classes inferieurs de peuple" (Moerenhout), "plebians, hereditary possessors of own land" (Henry), and "commoners without property" (Handy). In addition to characterizing manahune in terms like these, some writers have gone a step further and distinguished them from ari'i in terms of ethnic and even racial differences. As for the Maohis themselves, while there is evidence for believing that ari'i used the term manahune as a label for individuals, I have come across no reference to anyone speaking of a manahune class, parallel to such collective expressions as hui ari'i and hui (or pu'e) ra'atira. Neither do I know whether a person called manahune by an ari'i (or ra'atira) classified himself as such, or was so classified by other manahune. In other words, whereas there is considerable positive evidence that some Maohis-perhaps all Maohis- "thought" about ari'i as constituting a collectivity of a special kind, manahune, on the other hand, may not have been viewed in the same light; but my uncertainty in this regard may be due more to the preoccupation of the sources with the "better sort" than with actual events. ${ }^{15}$

Emory asserted that manahune was the label applied distinctively to the populace of Tahiti and Mo'orea: "But manahune, unlike raatira and arii, is not a class name in Polynesian dialects outside of the Society Islands; the term, as a class name, seems to have been coined from the name of the people who supplied that class" (Marae Traditions). Against this interpretation, however, is the fact that by European times, manahune constituted an element of the population of all the Society Islands, and it is difficult to see how a purely local label could have become thus generalized.

Perhaps the most crucial question concerning the place of manahune in Maohi society has to do with their rights in territory. Handy epitomized manahune as "commoners without property" (in contrast to ra'atira, who were "landed proprietors"); this was also the expressed view of de Bovis (1909:22), and was implied by Morrison (1935:167). Directly contrary to this view was the one expressed by Henry, who said of manahune that 
"they served as retainers and workers for the upper classes, but also enjoyed their own hereditary possessions" (1928:230). Views similar to Henry's were expressed by the Forsters, who called manahune "freeholders" and owners of "landed property" (G. Forster 1777:II, 258-259; J. Forster 1778:355); but even if these characterizations happen to be more accurate than those of de Bovis they can hardly be accepted as good evidence, in view of their authors' notoriously imperfect understanding of Maohi social relations.

How can one reconcile such contrary opinions? I believe the answer lies in the nature of Maohi land tenure, which differed so markedly from European concepts of "ownership" that these contrasting labels are not so much "right" or "wrong," as inappropriate. I postpone until later the detailed consideration of this matter, but my views about the property rights of the manahune can be summarized here.

I believe that all Maohis had rights-including what might even be called "demand rights"-in some piece of territory, but that all such rights save those of the highest-grade kin-Titleholders were subject to occasional limitations exercised quite "legitimately" by other persons. (This was in addition to limitations sometimes imposed by means of coercive force.) In other words, undivided ownership was a very rare phenomenon in Maohi society. Most territory (terrestrial and marine) was held in divided ownership; and the demand rights of provisional ownership varied greatly in weightiness and in effectiveness. Indeed, some persons' claims to specific territories appear to have been at times so outweighed by claims of others that they were, so to speak, relegated to a "waiting list"; but to call such persons "landless" is, I believe, a misnomer.

In this connection, I suspect that in some places many manahune may have been on "waiting lists," but that this was not the case everywhere. In fact, Handy, while calling them "commoners without property" in one passage (1930:42), intimated (perhaps unwittingly) that they did own effective land rights in the islands' interiors: "They had no individual land rights but were tenants or serfs of the land-owners [i.e., ari'i and ra'atira], or else they lived in the inner valleys or on the plateaus" (1930:7). Then, continuing with an excerpt from Marau, he wrote:

They were allowed to have a road to the seashore, so that they might fish; but they had to go direct to the reefs and back by the road allowed them. They were called "the dwellers in the far-away mountains and the vao, or depths of the valleys," the noho-vao, an epithet still applied to their descendants. They were the wood-cutters for the royal family, the high-priest, and the warriors; they were the pickers of taro leaves, the fishers of eels and fresh-water fish. Their condition is referred to in the insult:

Go to the mountains where you belong,

Far, far away up there;

Far away where the red skies lie, 
Away to the road of separation,

Far away to the clustering yellow bamboos,

Torch-fisher of the nato of Motutu,

Picker of eels,

Thou art the grandchild of the mountain,

Thou slave of the arii!

(Marau, in Handy 1930:7-8)

Apart from the question of the credibility of this passage there is some ambiguity in it-that is, were all manahune "slaves" of the ari'i or "tenants or serfs of the land-owners," or only those manahune living near the latter?

The location of lands on which manahune resided and subsisted is described in a chant: "On the seashore and inland were the lands of the plebeians bordering on the lands of the great" (Henry 1928:403). Aside from the question of its historical validity, this statement implies a recognition of manahune property righs in land, both near and away from the shore-rights that may of course have been subject to others' overriding claims, and parcels that were not situated in the most favored places, but rights that were nevertheless proprietary and locations that were not invariably noho-vao.

Marau's description of the manahune as "woodcutters," "pickers of taro leaves," and "fishers of eels and fresh-water fish," implies that they worked mainly for their superiors and in relatively unskilled capacities. This opinion was voiced also by Handy, who wrote: "The crude labor in all work was, however, performed by manahune. They were the paddlers (rao) in the Arii's canoes, and they rendered military service in war time." (1930:43.) Wilson also wrote of them that they "cultivate the land, and most resemble our cottagers .... These hold under the tōwhas [to'ofa] and ratirras, answer all their demands to the best of their ability, make cloth for them, build their houses, or assist in any laborious work required of them." But then Wilson added: "yet their vassalage compels no constant service or residence: they may change chiefs, and go to another district." (1799:324)

Undoubtedly, many manahune served their superiors either regularly, as domestics (teuteu), or occasionally, in response to special levies of labor or to general corvées. Also, they contributed food and other objects to their superiors, regularly and on special occasions, as members of kin-congregations and of tribes. But to depict all or even most of them as full-time servants, or to imply that they were severely restricted in the kinds of work they were allowed to do-and largely unskilled in the work they did do-is certainly not warranted.

Like the ari' $i$ themselves, some manahune were occasionally " $r a$ ' $a$, or hallowed; and others common or unclean" (Wilson 1799:324). One would not expect to learn of a manahune playing a high-priest's role in a tribal 
or "international" marae, but many of them undoubtedly served priestly functions in such temples. Also, the head of a manahune kin-congregation was no less priest than the head of one composed mainly of ari'i-that is, the tutelar of the latter was undoubtedly more powerful and the ritual of communication more exacting and fateful, but the function of priesthood was the same in both cases. ${ }^{16}$ Moreover, as we shall see, manahune were not excluded from the prestigious Arioi sect, although they did not rise very high in its hierarchy. And finally, there is no evidence to suggest that manahune were discouraged from becoming shamans; on the contrary, there are indications that they were among the most successful practitioners of this occupation.

As mentioned previously, teuteu designated not a class but an occupation: the job, in many cases hereditary, of serving persons of high kin-Title grade or extensive tribal authority. The services thus rendered are implied to have been "domestic," but that probably covers a range of activities: counselor, wet nurse, entertainer, bearer, steward, cook, gardener, swineherd, and so forth. More will be said about this occupational category in chapter 21. Although many or most teuteu were probably classed as manahune in terms of their marriageability, as noted earlier "... it is not uncommon to find Young Men of the first Familys and the Younger Brothers of Chiefs" working as servants, indeed, even "in the Service of the Fair Sex"; but, as Morrison pointed out regarding the latter, "by debasing themselves thus, they are rendered Incapable of assisting at any religeous Ceremony" (1935:167).

Anderson wrote that "if a Teou [teu] be caught in an intrigue with a woman of the blood-royal, he is put to death" (Cook 1784:171). Presumably a teu of less than "first Family" position was implied; on the other hand, it was a well-reported fact that many ari'i women cohabited openly with what appear to have been teuteu of lower if not manahune class.

The class status of tìtī is somewhat more difficult to assign. Such individuals, it will be recalled, were "those who had lost their liberty in battle, or who, in consequence of the defeat of the chieftains to whom they were attached, had become the property of the conquerors" (Ellis 1829:II, 342). Handy identified tìtī as "certain of the manahune families whose members were for some reason condemned to furnish the victims for the human sacrifices on the chief's marae" (1930:44). A statement by Henry, on the other hand, could be interpreted as distinguishing the two: "The victims for human sacrifices were always taken unawares, and were men chosen from among war captives, called titi, men of the lowest rank [sic], called manahune, and men of the middle classes who made themselves obnoxious to those in power" (1928:196).

Putting these and other references together, we seem to be discussing 
three different statuses: war captives and their immediate descendants ( $t \bar{t} t \bar{i})$, potential sacrificial victims (ta'ata tapu, ta'ata 'ino), and members of the lowest marriage-class (manahune). Ta'ata tapu were not all chosen from manahune, and all manahune were not automatically relegated to the status of ta'ata tapu. Moreover, ta'ata tapu were not exclusively taken from among tìtī. However, it is not at all clear whether all tìtī were relegated to ta'ata tapu status. Neither is it clear whether only manahune became tìt $\bar{l}$, or whether, in terms of marriageability, all war captives (or refugees), regardless of previous class, became manahune. In any case, although manahune served as an epithet under certain circumstances, and persons called manahune were, as we shall see, treated usually with something short of respect, the tīti were the object of universal contempt.

\section{RA'ATIRA}

The hui (or pu'e) ra'atira were identified variously as: "yeomen" (Banks), "esquires" (Morrison), "gentlemen" (Wilson), "landed proprietors, or gentry and farmers" (Ellis), "a chief; the general title of the inferior chiefs" (LMS Dictionary), ${ }^{17}$ "petits chefs ou proprietaires foncieres" (de Bovis), "grandes proprietaires terrains" (Moerenhout), "gentry" (Henry), and "landed proprietors" (Handy). Nearly all identifications of ra'atira focus on their roles as landowners. For example:

... under them [the chiefs] are The Towha [to'ofa] \& Ratirra each holding his land independant of the Other, any Ratirra can put a Raahooe [rahui] on his own division... (Morrison 1935:167).

The next rank [below to'ofa] is the ratirra, or gentlemen, who has one portion [of land] to the tōwha's three. These smaller estates are called rāhoe [rahui], from the power the ratirra has to lay a prohibition on his own land, or on any particular sort of provision. (Wilson 1799:323)

They [ra'atira] were generally the proprietors and cultivators of the soil, and held their land, not from the gift of the king, but from their ancestors. The petty raatiras frequently possessed from 20 to 100 acres, and generally had more than their necessities required. They resided on their own lands, and enclosed so much as was necessary for their own support.

The higher class among the raatiras were those who possessed large tracts of land in one place, or a number of smaller sections in different parts. Some of them owned perhaps many hundred acres, parts of which were cultivated by those who lived in a state of dependence upon them, or by those petty raatiras who occupied their plantations on condition of rendering military service to the proprietors, and a portion of the produce. (Ellis 1829:II, 343-344) ${ }^{18}$

These persons [ra'atira] are the possessors of landed estates in capitie. (Montgomery 1832:I, 152) ${ }^{19}$

The land and goods which the barons [sic] and inferior nobles owned were not considered as benefices granted by the prince [ari'i] and did not revert to him in case of disinheritance or during the minority of their holder; and he could not, 
on some pretext, confiscate them to add them to his own lands. These properties were considered to be private and inviolate, even though a large proportion of their produce was always demanded or seized arbitrarily for the ari'i, whose incomes were not set and consisted of what they received from their subjects or what was gotten through seizure. (Moerenhout 1837:II, 11-12)

... they [hui ra'atira] were farmers on their own lands and trusted keepers of the lands of their sovereigns and chiefs. (Henry 1928:229)

Except for Ellis' category of "petty ra'atira" (who are described as resembling tenants), all these characterizations depict ra'atira as holding their lands in something approximating undivided ownership, subject only to confiscation by their superiors as result of lese majesty or default of taxes (and, of course, subject to capture in war). I suspect, however, that there were several degrees of such "ownership," parallel to the "owner's" position in kin-congregations and tribal hierarchies, so that the question of who was a ra'atira is not easily decided-at least at its lower hierarchical boundary. It is true that, except for Montgomery, early writers emphasized the hereditary derivation of the land rights which distinguish ra'atira-hood; but then heredity was the source of most land rights held by all Maohis. Also, much is made of the right of a ra'atira to impose a rahui upon the land "owned" by him; but again, just as that right was subject to preemption and overriding by the superiors of ra'atira, I imagine that even manahune were privileged to place restrictions over some of their goods, including perhaps modest portions of land.

In other words, neither the hereditary nature of a right in land, nor the privilege of rahui (which was nearly always limited) was in itself a criterion sharp enough to permit us to define the lower boundaries of ra'atira- hood. Indeed, I suspect that the Maohis differed not only among themselves in bestowing the ra'atira label, but, more crucially, that persons universally labeled ra'atira were not always in full agreement concerning the eligibility of some particular individual as a spouse for one of them.

This raises a question of identification of another kind: to what extent was the label, and associated marriage proscriptions, applied to persons other than the principal label-bearing ra'atira? Did it apply to all his (or her) progeny or only to his principal heir; to the progeny of parents both of whom were ra'atira or to those having only one ra'atira parent? Unfortunately, I am even more unsure of answers to these questions than I was to analogous questions about ari'i. The explorers and missionaries were more concerned with $\operatorname{ari}^{\prime} i$, and also the label $\operatorname{ari}{ }^{\prime} i$ was undoubtedly subject to much sharper definition by the Maohis themselves. The sources do indeed refer to hui (or pu'e) ra'atira, but it is not always clear whether such references are to a category consisting only of the "petty chiefs" themselves, or to a whole class consisting of "petty chiefs" and their families. 
Most uses of the label ra'atira by Europeans appear to apply to the former, but I have no certain way of knowing whether that corresponded to native usage. ${ }^{20}$

In any case, when the explorer and missionary writers characterized those whom they labeled ra'atira, they extolled their virtues. Compared with the ari'i (who were "overbearing," "indolent," "licentious," etc.) ra'atira were described as possessing many of the virtues considered atractive by the essentially middle-class missionary chroniclers:

These individuals were a valuable class in the community, and constituted the aristocracy of the country. They were in general more regular, temperate, and industrious in their habits, than the higher ranks, and, in all the measures of government, imposed a considerable restraint upon the extravagance or precipitancy of the king, who, without their co-operation, could carry but few of his measures. In their public national assemblies, the speakers often compared the nation to a ship, of which the king was the mast; and whenever this figure was used, the raatiras were always termed the shrouds, or ropes by which the mast is kept upright. Possessing at all times the most ample stores of native provisions, the number of their dependents, or retainers, was great. The destitute and thoughtless readily attached themselves to their establishments, for the purpose of securing the means of subsistence without care or apprehension of want.

The bue raatira were the middle class in society; forming the most important body in times of peace, and furnishing the strength of their armies in periods of war. Warriors were sometimes found among the attendants on the king or chief; but the principal dependence was upon the raatiras. These, influenced by the noble spirit of independence, accustomed to habits of personal labour, and capable of enduring the fatigues of war, were, probably from interest in the soil, moved by sentiments of patriotism more powerfully than any other portion of the people. (Ellis 1829:II, 344-345)

\section{According to Morrison:}

The Weomen of rank are Most remarkable for their licentious practices and Many of them have a Number of Favourites, in which they pride themselves, tho many of the lower Class are what may honestly be Calld Virtuous, never admitting a Second to share in their favours. (Morrison 1935:237)

It is not certain, however, whether Morrison was referring to ra'atira or manahune.

\section{RECRUITMENT}

"Membership in a marriage class was established mainly by descent." When I composed this statement it seemed to be accurate, adequate, and intelligible. Now, hundreds of study-hours later, its accuracy-such as it is-remains unchallengeable, but the statement is so inadequate as to be virtually unintelligible.

I have come to realize how complex a matter "descent" was among the Maohis. To be the "offspring" of a person in the fullest sense required not only parental recognition-tacit, in the case of the "mother," mani- 
fest in the case of the "father"-but validation of that recognition by the parents' families as well. Some of the force in this requirement was seen in the case of the cohabiting couple who wished to preserve (and presumably recognize) their offspring, but whose wish was opposed by the man's family (to the point of attempted infanticide) on the grounds of the woman's lower-class status. Presumably, such issues did not arise when both parents were of the same class; but I suspect that there were cases in which the class status of one of the parents was equivocal enough, or the intraclass distance between them wide enough, to give rise to disagreement. Indeed, I suspect that the actual marriage preferences and proscriptions were narrower and more specific than my proposed threeclass schema indicates. This was certainly the case in the upper reaches of the ari'i class, and it may well have been so among the ra'atira and even the manahune. That is to say, a ra'atira of considerable affluence and influence and of respectable pedigree would have raised objections to his principal heir's marriage into a ra'atira family of relatively small account. I cannot, however, document this opinion very persuasively, so I leave the three-class formulation as it stands.

As we have seen, the offspring of different-class parents often were slain at birth; but there is also substantial evidence that many such offspring were allowed to survive. The question then is, To which marriage class were such offspring assigned?

Handy, writing of ari'i misalliances, stated that parents and child were driven into exile, but other writers described less drastic outcomes. T. Salmon, for example, recorded the following episode in the pedigree of one of his ari'i "lines": "Mehae takes to wife Tuteraipuni from Taipoto district, Marae Mataifare, born of them Terupe, boy; (2) Vaeruatua; (3) Vaeraauri; these two marry beneath them, and tutehia (set aside), meaning their heirs can never become chiefs" (n.d.:23). Henry described the outcome of such misalliances in more detail:

When a child of the royal family formed a misalliance which the parents did not wish to equalize, they refused to solemnize the marriage rites on their side, which lowered the erring one to the level of the inferior party, at whose home alone the marriage was performed. Such a person and the children of such a union, were called tamari'i taahi hia (children trodden down or degraded). In such cases, when they could gain popularity among the people, they sometimes asserted themselves and regained prestige as rival members of the family that had disowned them. (1928:284)

De Bovis was even more explicit, differentiating outcomes according to the sex of the erring upper-class mate:

If she [an $\operatorname{ari}^{\prime} i$ woman] had a child by an unknown father, that child was considered just as royal as if it had counted a long line of kings in its pedigree. If the 
father were known to have been a lower-class man, that affected somewhat the status of the child, but the latter remained nevertheless a prince.... But, it was not thus when an arii male had a misalliance. The offspring of such a union had neither rights nor privileges [in their father's family], nor had they the status of their father [in society at large] .... (1909:23)

These statements by de Bovis are puzzling on two counts. First, they constitute the only direct statement I can find that the offspring of an ari'i woman by an unknown genitor, or by a genitor known to be of a lower-class, were allowed to survive. Such situations probably did occur, but I have not come across any legendary or historical references to specific occurrences of this kind. (In this connection, the likelihood of a higher-class male siring offspring by a lower-class female was probably far greater than the reverse, as was the possibility of that kind of offspring's survival.)

But assuming the validity of both parts of de Bovis' statement, I must then try to explain the differences in outcomes of these contrasting kinds of misalliances-that is, why should the higher-class mother's offspring be assigned a class status higher than that assigned offspring of the higher-class father? Is this evidence of a concept that uterine descent was in general weightier than agnatic descent? Or were more practical considerations involved?

With respect to the former explanation, Gunson stated: "It would seem reasonable to assume that a royal chief of senior patrilineal descent would be forced to yield pre-eminence to a junior chief of the same lineage who was of superior status through his mother" (1964:55). If by this is meant that a "junior chief" whose mother was member of a maro 'ura kin-Titleholding family took precedence over a cousin whose father's Title was graded higher than the former's but whose mother was not of maro 'ura status, then this may well have been so-provided of course the higher-graded Title of the father was not itself of maro 'ura status. But such precedence was probably due to the preeminence of the maro 'ura factor, and not to the uterine link. It so happens that several preeminent Maohis, legendary and historical, owed the high rank of their Titles largely to uterine ties; but it does not follow from this that agnatic ties were not of equally, or even greater, weight.

With respect to the practical considerations contributing to the situations alleged by de Bovis, the very fact that kin-Titles did devolve more often through males than through females would have served to make the relatives of an ari'i male more circumspect about assigning upper-class statuses to the latter's half-caste offspring.

Elsewhere, de Bovis wrote that his so-called échelon intermédiare consisting of 'iatoai and tuuhou derived from "alliances" between ari'i and ra'atira-his wording seems to imply that the "alliances" in question were 
actual "marriages": "These alliances gave birth to people who were not at all equal to the Arii, but superior to the small chiefs. And the Great Arii gladly gave them an hereditary or temporary supremacy in certain parts of the country where they had influence." (1909:18)

Henry wrote that ari'i ri'i (nobility, petty kings and queens) were "of part royal and part plebeian descent" (1928:229), but this disagrees with a passage cited elsewhere in Henry from the chant "Creation of Man":

When Ti'i and Hina-maha'i-tua-mea (Hina-mitigator-of-many-things) begat children they became the high royal family of the 'ura girdle; they were descendents of the gods from darkness. When people stood forth conjured into being by Ti'i and Hina-maha'i-tua-mea, they became the common people, the plebians of the world. When the royal family espoused common people, they begat the gentry of the world. When the royal family espoused the gentry, they begat the nobility of the world. (1928:403)

What can be concluded from these various passages is that interclass matings did occur, even some "marriages," and that any surviving offspring of such matings were assigned class statuses somewhere between those of their parents. That is not a very precise conclusion, but it is about as much as the differences in testimony will justify, ranging as it does from allegations about "exile" to assertions about "petty kings and queens." Probably, there was an even greater variety of outcomes than the sources describe, depending not only upon distance separating the classes of the offsprings' parents, but upon numerous other familial and political factors, and upon the offsprings' birth order, sex, and personality. But concrete instances of such outcomes are not recorded.

The foregoing refers to the offspring of humans only. Occasionally, it was believed, a god cohabited with a human female and sired offspring by her; mention was made earlier, for example, of the eagerness of women to become impregnated by the god 'Oro, acting through one of his mediums. ${ }^{21}$ The best known "historical" case of an allegedly spirit-conceived individual was that of Pomare II. Morrison described the episode as follows:

The present Earee Nooi [ari'i nui] (or King) is the Son of Matte or O’Too [Tu, or Pomare I], his name is Toonooeayeteatooa [Tunuia'eiteatua] which may be thus translated, "Too, the Great begotten of God," and his title Eatoa Raa [e Atua Ra'a] or Sacred God-which Sacraligous Name and title He obtained by His Mother declaring that the Deity (Taane) Cohabited with her in her Sleep and, proving Pregnant soon after, the Child was declared to be the Offspring of the Deity and is rever'd as something supernatural. (1935:166)

To those placing credence in this explanation of Pomare II's conception, the circumstance may have served somewhat to enhance the already very high rank of his Titles. The alternative explanation accepted by many was that the child was sired by one of the manahune gallants with whom his mother notoriously consorted-a circumstance which was used on one occa- 
sion by his political rivals to deny him sovereignty over Taiarapu. (Morrison 1935:96)

Another question left unanswered by our inadequate generalization about class status and "descent" has to do with ramification. The only specific reference in the sources to this aspect of the process is by Handy, who wrote: "There was a subdivision of the Hui Arii called by Marau the iatoai, consisting of the families derived from the younger branches of the arii stock" (1930:42). The question is much more crucial than this meager reference intimates.

The occasional indistinctness of class boundary lines, combined with the operation of the seniority principle among siblings, lead me to believe that reduction in class-status level was a general and inevitable process in all but the lowest class. Unless other considerations intervened, the class-status distance between a matahiapo-line firstborn and the last-born offspring of a long line of last-born offspring must in many cases have become so great that the latter could no longer qualify as a member of the same class. There is no evidence concerning how wide that distance had to (or happened to) be and no reference to formal procedures serving to recognize or institutionalize such reductions; but, tacitly or otherwise, at some stage in their descent many lines must have become transformed from ari'i to ra'atira, and from ra'atira to manahune.

Further reading of the sources also raises the possibility that membership in a higher class was attainable by marriage. Principal evidence for this is found in statements by Ellis and Henry. The former wrote:

Whenever a matrimonial connexion took place between any one of the hui arii with an individual of an inferior order, unless a variety of ceremonies was performed at the temple, by which the inferiority was supposed to be removed, and the parties made equal in dignity, all the offspring of such a union was invariably destroyed, to preserve the distinction of the hui arii, or reigning families. (1829:II, 345-346)

In his comment on this statement, Handy wrote:

Ellis, doubtless basing his observations on the none too strict conformity of the Pomare family to the regulations of the Hui Arii to which it only half belonged, speaks of adjusting of differences in rank by ritual. Doubtless this was done with younger branches of the arii families, but I doubt if it was permitted with the matahiapo of a ranking Arii, for the prestige of a ruling family depended wholly upon descent. (1930:27)

Whether Handy was correct in his stricture is impossible to discover. Emphasis upon "purity of line" undoubtedly increased in the upper ranks of ari'i-hood, but Handy-as a result of his reliance upon Marau, whose aristocratic (and anti-Pomare) biases were all too evident-may have been overengaged with this aspect of Maohi society.

According to Henry, the ceremonies in question consisted of the nuptial 
rites themselves-provided, of course, that the family of the higher-class principal also took part in the ceremony. Henry stated that "Any differences of rank [i.e., marriage-class level] ... between the two families were forever annulled by these [wedding] ceremonies" (1928:284). Despite the ambiguities of this statement, I believe that the class elevation brought about by these ceremonies referred only to the spouse (and mainly for the purpose of assigning the higher-class status to his or her offspring); it is quite unlikely that the elevation included other relatives of the lower-class spouse-except perhaps in legend (see below, the Tuna of Vaihiria).

Another statement from Henry, quoted earlier, asserts that a partner to a union with a lower-class mate was "lowered ... to the level of the inferior party" if his or her family "refused to solemnize the marriage rites on their side" (1928:284). As reported earlier, Handy asserted that any ari'i who formed such a union was driven into exile, but Henry's statement is the only one of which I know to allege an actual lowering of an individual's class level (as opposed to the assigning of a lower level to his offspring) through a definite act.

A number of statements in the sources indicate that there were ways to elevate an individual's marriage-class status by procedures other than nuptial rites. The missionaries Tyerman and Bennet reported having been shown a small marae on Huahine which they were told had been built "on the occasion of making an arii, that is adopting into the royal family a person of inferior birth." However, besides noting that the ceremonies observed on such occasions were of a nature "which the worst words in our language would be abused in describing," they offered no further explanation for these unusual events. (Montgomery 1832:I, 177.) ${ }^{22}$

One means of elevation is described in the legend concerning the tragic love affair of "Princess" Pereitai, and the commoner, Temuri. In an effort to induce the maiden to break off the affair, her old nurse warned that the princess' plan to ennoble her lover might never succeed, and he might always be a fugitive sought by her royal family and slain as a sacrifice to the gods. "It is only for deeds of valor and heroism, when royal personages have been rescued from outrage or death in some extraordinary way that kings and queens consent to raise people of our standing [plebeians] to their rank." (Henry 1928:600) I have come across no legendary or historical incidents of an ari'i-hood having been conferred upon anyone for such "deeds of valor and heroism," but I suppose that the possibility did exist.

Another reference to ennoblement is contained in the legend of the Tuna of Lake Vaihiria, in which, it may be recalled, another young "princess" ran away from home to avoid marriage with a giant eel. She finally found refuge with a widowed "woman of the people" and her two handsome sons, and to show her gratitude bestowed upon them "noble" names. 
Perhaps the young woman had more than gratitude in mind, for she eventually married first one brother, and then (after the death of the first) the other.

De Bovis asserted that it was impossible for a ra'atira to become elevated to ari'i-hood, or for an ari'i to become a simple ra'atira:

He [a ra'atira] could, it is true, become Arioi and priest, but he maintained a position proportionately inferior, even though it elevated him substantially, at certain times, not only above his own [class], but even above the class immediately superior. He could also become teuteu ari'i, that is servant of an ari'i, and thus acquire great importance, but he was never more than a reflection of the power he served: he was able to command some respect and obedience only by acting on behalf of the revered Titleholder [he served]; there lay the limit of his nobleness, and it never went beyond this. (1909:22)

It was however possible, according to de Bovis, for a manahune to become a ra'atira, ".... par un don définitif"; but he did not specify the circumstances in which this took place nor the way in which it was done. A hint of the procedure is found in a missionary journal entry. In 1808, after Pomare II had vanquished the Atehuruans and taken over control of their lands, he made a grant of one portion of it-or rather of this portion's produce-to King George III (as represented by the latter's subjects, the English missionaries, who lost no time in attempting to substantiate the arrangement:

Missionaries resolve to ask Pomare to give them a written statement of the grant of Outu Maro land to K. George, and to ask him whom they should place on the land as tenants, and whether they should make one man a ratera or head over the rest.

He [Pomare] advised that we should put in the land some of the poor people that formerly resided there and approved of making one a ratera over the rest, but did not name any person, only he intimated it should be some man from among the lower class. (Davies, Journal, 19-20 October 1807, LMS Archives)

Evidently, this usage of ra'atira referred to an administrative office, but the episode is nevertheless suggestive of the wider meaning which ought to be attached to the label.

\section{ORIGINS OF CLASS STRATIFICATION}

Some theories, including various explanations by the Maohis themselves, have already been touched upon concerning the origin of class differences in ancient Maohi society. (See chap. 16.) The most succinct of these is the one contained in the cosmogonic chant quoted on page 774 .

The earliest European to record his own theory about the origin of Maohi classes was J. Forster, whose ponderous prose combined both "evolutionary" and "conquest" explanations:

If several families find the wisdom, experience, valour, and benevolence of one head of a family to be superior to those of the rest, they all look upon him as their common father, they submit to his advice as to injunctions, and 
his councils become as sacred and inviolable as laws. This voluntary union into one great family, diffuses through them all that attachment, and benevolence, that spirit of order and regularity, which are the true promoters of morality, and universal happiness. If the son of this chief has skill, address and benevolence enough to tread in his fathers footsteps, he succeeds his father in authority, and thus a society gradually accustom themselves to look upon their chiefs with reverence, and accept the posterity of an equitable, benevolent leader, for their hereditary chief. As all the regulations for the weal of the society are chiefly issued by this ruler, as he is foremost in defending their liberty and property against any daring invader of their common right, as he decides between man and man in private disagreements, and punishes the wanton disturbers of public peace, all the authority of the whole community, centers in him; and as many advantages accrue to him on different occasions and opportunities offer of making acquisitions of property, either by the voluntary, general contributions, of all the inferior members of the community, or by the administration and distribution of the public property and wealth, it may be expected that he will become possessed of a greater share of wealth than any of the rest, which must gradually give him more influence and greater power: his family no doubt participate of this power, influence and wealth, and consequently form a class of people distinct from the commons.

If the society is attacked or injured by another society, and all unite to avert the injuries, to repel violence, and to retaliate upon the invaders and disturbers of the peace, the same wrongs which they intended to inflict; it is natural to suppose, that upon a very great provocation, and a consequently greater exertion of power, they may become victorious, which must, of course, make the condition of the vanquished tribe, inferior to that of the lowest of the victorious community, and create a new rank of people in their society. These seem to be the consequences of matrimonial union, of paternal authority, and the more general authority of a chief of a society, and the origin of ranks in O-Taheitee, the Society, and Friendly Isles. (1778:352-353)

The "conquest" theory was carried even further by de Bovis, who postulated three separate migrations to these Islands. First came the manahune, these were later overwhelmed by a wave of ra'atira, who in turn were overcome by invading ari'i. (1909:20-21)

The most comprehensive "conquest" theory is that of E.S.C. Handy, who epitomized his findings as follows: "... the native civilization of Tahiti at the time of its discovery was the product of the blending of an early tribal culture with that of an invading dynasty whose customs and traditions were of a wholly different order" (1930:7). According to Handy's interpretation the Hui Ari'i were a "maritime dynasty" who descended upon these Islands from the west in the late sixth or early seventh century A.D. They settled first upon Ra'iatea; then, after consolidating their power over the aboriginal, Maohi, population, spread to the other islands and imposed their rule everywhere. ${ }^{23}$

I infer that this intermediate class, with land rights of its own, arose through a fusion of followers of the ari'i with the earlier population. Followers of the conquering ari'i would naturally have intermarried most with members of the families of the superior element of the old population-the fatu toa (war lords), 
and others; and in the allotting of lands after the conquest, it is fair to assume that the followers of the ari'i were rewarded with estates. Thus, I infer, arose these "landed gentry" (ra'atira; Marquesan, 'anati'a, Maori, rangatira, Hawaiian, lanakila). The ra'atira owned large and small estates, both by the sea and inland, by right of inheritance. Such right could not be alienated even by the Arii except as a penalty for disregard of certain of the laws of the land, such as the rahui, for failure to render tribute or service to the Arii, rebellion, and inhospitality. Even then, according to Ellis ([1831] vol. 3, p. 120), the Arii could not confiscate land but only banish a man and name his successor. At times ra'atira would band together to defend the rights of one of their fellows whom they felt to have suffered injustice at the hands of the Arii, and on such occasions they were capable even of resorting to arms. Obviously this class had the power to check their overlord in any move, for the chief could undertake no large enterprise in peace or war without their support. It appears that even conquest of a district by an enemy Arii did not deprive the landed families of their title to land and other hereditary rights, though their members were slaughtered, their plantations destroyed, their pigs stolen, and their buildings and maraes razed. The ra'atira had in their service manahune who assisted them in planting and other labor. Over their own lands they had the right of rahui, a right, however, which the Arii had over them also. The ra'atira had their own family marae, for which a member of the family acted as priest, where remains of the dead and other sacred objects were left, and where the family ancestors were worshipped. According to Marau these marae were consecrated by the Arii under whose rule the family lived.

The third great class were the manahune, the subjugated and unassimilated bulk of the pre-arii population of "plebeian Tahiti." The arii appear to have had little to do with them directly, for to the arii service was rendered either by ra'atira with manahune as assistants, by their hereditary servitors (teuteu), or by their craftsmen (tahu'a). The crude labor in all work was, however, performed by manahune. They were the paddlers ( $r a o$ ) in the Arii's canoes, and they rendered military service in war time. It must certainly have been the inferior element in the early population that became the servile manahune, or serfs, of historic Tahiti, for it is quite beyond the range of possibility that the stock whose virile and independent descendants were the warlike 'enata of the Marquesas and tangata of New Zealand, could have been reduced to a condition of servitude. For the "war lords" of old Tahiti it is certain that there were open, when the Arii conquered their country, three alternatives: annihilation, emigration, and assimilation. Undoubtedly large numbers suffered annihilation; others, escaping this and preferring the dangers and hardships of exploration and pioneering, must have taken to the sea in vaka-often carrying their women and children with them-becoming the founders of warlike clans in the Marquesas, New Zealand, and elsewhere; while still others, perhaps less independent or more favored by circumstances, remained in Tahiti to play an honorable role under the new regime. (Handy 1930:43-44)

Handy's 1923 enquiries on Maupiti persuaded him that only two classes emerged on this small and isolated island as a result of the imposition

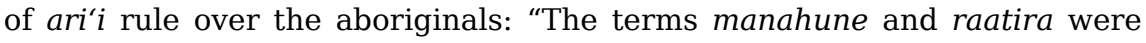
practically synonymous, signifying land-owning commoners. The class of manahune are spoken of collectively as the hui raatira or taata rii (little fellows)" (1930:103). Also there were, according to Handy, some distinctive local, Maupitian, usages regarding other class-connected labels: 
On this island the term iatoai was applied not only to the children of the chief after the first-born (matahiapo), and to the first-born before he was consecrated (faa tahinu, annointed), but also to the prominent men (taata rarahi) of the island, including the war leaders (aito), the district subchiefs, and other "folk with mana" (fei'a mana), which presumably signifies the tahua, or masters of priestcraft and handcraft. In other words, iatoai, which was apparently not employed in Raiatea, was used in Maupiti but with a meaning quite different from that given in Tahiti." (1930:102-103)

Hui Ari'i tradition, as interpreted by Handy, Henry, Salmon, and Emory, represents Tahiti and Mo'orea as the last islands to have been occupied by the newcomers. ${ }^{24}$ Handy's version is as follows:

Through most of Polynesia, war captives, dedicated as sacrifices to the gods, were figuratively referred to as fish. The phrase, "Tahiti, a fish," may therefore originally have meant, "Tahiti, a war prize." Henry gave a record of the conquest of Tahiti by those who in historic times were its overlords, the Hui Arii (group of chiefs). The reference to the separation of Tahiti from Raiatea and Tahaa, in this legend I interpret as a reminiscence, recounting in the figurative fashion typical of the native lore, the separation and departure for Tahiti of a branch of the Hui Arii then already established in control of Raiatea and Tahaa. The mythical "cutting of the sinews" of Tahiti I take to refer to its conquest.

According to the legend:

There was no hui arii family upon Tahiti, land of warriors. The warrior lords (fatu toa) who owned it and their clans controlled (tiai) the land. Because of this it was called Tahiti Manahune (Tahiti of the Plebeians).

This pre-arii Tahiti is also referred to as "Great Tahiti of Tu, Tahiti of Oropaa."

The legend under discussion, and the information given by Marau, both indicate that the penetration of the island was through the south and southeast, the most favorable region in which to gain a first foothold. According to Marau the first seat of the Hui Arii was at "Vaiari" (Papeari), the district immediately north of Taravao; while in the legend of "Tahiti the fish" the island is described as being "cut asunder" at Taravao by Tafai. Thus, according to the legend, were formed the inner Teva and the outer Teva, the two great divisions of southeast and south Tahiti. (The Teva originated six generations after the first arii of Tahiti according to Marau.) "So the cutting of the sinews of the fish was completed, and the land of Great Tahiti became stable."

It is noteworthy that in the chant no other section of Tahiti except that of the Teva is mentioned at this time.

The chant goes on to draw the picture of the penetration of the island by the new dynasty:

After the separation of Tahiti from Havaii (Raiatea) came the gods of this land to godless Tahiti-nui.... Swept over the bluffs of Taiarapu, the gods descended upon the left cheek of the fish. Then the people were terror stricken and fled from their presence.

Upon the winds did the gods fly to Tahiti.

The people fled away with terror

Into caves and ravines

Of the mountainous land, 
And upon the mountain peaks ...

A dreaded rule was that of the gods with no interpreter!

The gods said:

'Give us

The heads of warrior men.'

And the people answered:

'We shall not go thither,

We are in dread of the reign of the gods!'

It is interesting to note that the gods were calling for heads, but not human sacrifices. These, I believe, belong to the later Taputapuatean phase.

The chant describes the penetration through the south.

Little Tahiti (Tahiti-iti, the southern peninsula), first alighted on by the gods, Land upon which settled the arii Raapoto,

While Great Tahiti (North Tahiti) had no gods.

Aimeo (Moorea), the bed of peace for the warriors when closely pursued in Great Tahiti.

The gods descended into the great valley and upon the plains of Tautira, but the people approached them not; then they gradually dispersed and settled throughout the land of Great Tahiti, and the people of Tautira returned to their valley, having no more fear.

Soon the people of the long upper border (Tahiti and Moorea) erected temples and dedicated them to the gods....

Taaroa, with his artizan, Tu, and Tane, god of beauty, reigned supreme over all the earth at that time; they were above all the hosts of gods throughout the islands. Taaroa gave Tane his great power.

In other words, after the conquest of the country, Tu and Tane, gods of the ancient Tahitians, were recognized by the conquerors in the new regime established by the Hui Arii, as has ever been the case with the gods of conquered peoples. By recognizing him, Taaroa "gave Tane his great power." If, as seems certain, the Hui Arii contingent intermarried with the local chiefery, this acceptance of the gods of the land would have been inevitable. (Handy 1930:15-17)

According to this reconstruction, in due course many of the indigenous chieftains of Tahiti and Mo'orea married into ari'i families and thereby established local ari'i dynasties, which become "enriched" from time to time by new marriages with ari'i from Opoa itself.

The "conquest" theory of Maohi class formation has been widely influential among ethnologists, but it has also elicited some sharp opposition. Piddington, for example, stated:

There seems no reason to split up the culture of the Society Islands into that of the original inhabitants (surviving as the manahune) and a subsequent band of arii conquerors. Probably the "conquests" of Polynesian history usually occurred mainly between Islands of the same group, or within the individual islands, that is, conquerors and conquered possessed very much the same type of cultural organization. Of course, the fortunes of war produced a re-arrangement of groups 
within this organization, for example in regard to land tenure and social status, but it seems probable that the forms of organization themselves were the product of the operation of internal factors.... (Williamson 1939:226) ${ }^{25}$

Both Sahlins (1958) and Goldman (1960) also rejected the ari'i-conquest theory and explained Maohi class stratification as resulting from the operation of "internal" factors: Sahlins in terms of ecology as manifested in surplus food production, and Goldman in terms of "status rivalry." Because of the wide ramifications of these two important studies, I postpone a consideration of them to chapter 24, where I shall also give my own views concerning the origins of Maohi marriage classes.

\section{ATTRIBUTES OF CLASS}

I turn now to consideration of the attributes which were regarded as distinctive, more or less, of persons belonging to each marriage class; such attributes include characteristics of physique, of "psyche," occupations and preoccupations, privileges and restrictions, the special labels attached to each, and their actions. ${ }^{26}$

Several observers were struck by the relatively larger size of most $\operatorname{ari}^{\prime} i$, both male and female, ${ }^{27}$ although exceptions were noted in both highest and lowest classes. Some observers attributed this to differences in race (e.g., J. Forster 1778:229, 263-264, 358-359), but most concluded that these dissimilarities were due to the better diets and less trying occupations of the ari'i. In addition, Morrison (in a passage previously quoted) attributed some of the dissimilarity specifically to the greater length of time that upper-class children were subject to restrictions preceding the performance of their head freeing rites: "... [this custom] may in some measure account for the difference in stature between the Higher and lower Classes of People-the latter Class having sooner their liberty have earlyer Connections with each other then the Higher and the Chiefs in particular are Mostly arrived at years of Maturity and Manhood before they Cohabit with their Weomen." (1935:187-188)

The most comprehensive explanation for the observed class differences in physique was offered by Ellis:

It is a singular fact in the physiology of the inhabitants of this part of the world, that the chiefs, and persons of hereditary rank and influence in the islands, are, almost without exception, as much superior to the peasantry or common people, in stateliness, dignified deportment, and physical strength, as they are in rank and circumstances; although they are not elected to their station on account of their personal endowments, but derive their rank and elevation from their ancestry. This is the case with most of the groups of the Pacific, but peculiarly so in Tahiti and the adjacent isles. The father of the late king was six feet four inches high; Pomare was six feet two. The present king of Raiatea is equally tall. Mahine, the king of Huahine, but for the effects of age, would appear little inferior. Their limbs are generally well formed, and the whole figure proportioned 
to their height; which renders the difference between the rulers and their subjects so striking, that some have supposed they were a distinct race, the descendants of a superior people, who at a remote period had conquered the aborigines, and perpetuated their supremacy. It does not, however, appear necessary, in accounting for the fact, to resort to such a supposition; different treatment in infancy, superior food, and distinct habits of life, are quite sufficient. (1829 II:16-17)

Ari' $i$ women were also noted as having been lighter than others in skin color, but this was attributed to their greater freedom from work requiring long exposure in the sun, and to deliberate efforts made to bleach their skins. With males, however, this difference seems not to have prevailed, or, at least, it was not deliberately striven for-except on certain occasions (see chap. 13).

Darkness of colour was generally considered an indication of strength; and fairness of complexion, the contrary. Hence, the men were not solicitous either to cover their persons, or avoid the sun's rays, from any apprehension of the effect it would produce on the skin. When they searched the field of battle for the bones of the slain, to use them in the manufacture of chisels, gimlets, or fishhooks, they always selected those whose skins were dark, as they supposed their bones were strongest. When I have seen the natives looking at a very dark man, I have sometimes heard them say, "Taata ra e, te ereere! ivi maitai tona:" The man, how dark! good bones are his. A fair complexion was not an object of admiration or desire. They never considered the fairest European countenance seen among them, handsomer than their own; and sometimes, when a fine, tall, wellformed, and personable man has landed from a ship, they have remarked as he passed along, "A fine man that, if he were but a native." They formerly supposed the white colour of the European's skin to be the effect of illness, and hence beheld it with pity. (Ellis 1829:II, 18-19)

In the legend of Huriitemonoi, reproduced earlier, more fragrant body odor was attributed to ari'i females. It will be recalled, the princess' faithless maidservant had to bathe in a "royal" pool and anoint herself with her mistress' sweet-scented oil to dispel her "plebian odor," and even then it returned to bear witness to her imposture (Henry 1928:608-611). ${ }^{28}$

Reference has been made in previous chapters to the relatively greater mana (power, influence) allegedly attributed to holders of high-ranking kinTitles, especially those designated as ari'i. If one accepts the view of some writers that mana figured in (or derived from) the "purity of line" rationale for class-defining marriage proscriptions, it then follows that all members of the ari'i class had more mana than ra'atira had, and the latter had more than manahune had-although, as noted earlier, I am not certain just what this signifies over and beyond the obvious attribution of political power and influence, which seems to have been one, but not the only, ingredient of the Maohi concept of mana. Another point of uncertainty has to do with the locus of mana of Titleholding ari'i: Does it attach to the kin-Title itself or to ari'i-class members (as such), or to both? But again, it is of course quite possible that the distinction I draw had no parallel in Maohi thought. 
Reference has also been made to the sacredness ( $\left.r a^{\prime} a / m o^{\prime} a\right)$ of some ari'i: presumably those holding kin-Titles deriving from divine forebears, and possibly some others as well. For example: "Everyone is to treat with respect the $\operatorname{ari}^{\prime} i$, his descendants and his family; let the ari' $i$ be divinely sacred [mo'a]: he is of divine descent [e hua'ai 'oia nā te atua]" (E. Salmon 1937:29). But sacredness as such was of course not limited to such officials; even some manahune were (or could become) sacred in some respects. The question is, Were $\operatorname{ari}^{\prime} i$-class men, as such, eligible for more sacredness than lower-class men? I suppose that the answer is yes; but I have come across no Maohi formulation to that effect. As noted earlier, the disease o'ovi ari' $i$ (chiefs' leprosy) was believed to have resulted when an individual desecrated certain marae-persumably those associated with "chiefs," but the mechanics of this effect are not specified (Henry 1928:149).

Most of the cosmogonic myths, genealogies, dynastic traditions, and lengthy legends that have been conserved for us were recorded from the lips of persons mainly of ari'i-class affiliation. Moreover, the only record that exists of organized schooling in such matters involved children of ari' $i$, tamari' $i$ a te hui ari'i (Henry 1928:75)—which should occasion no surprise, inasmuch as such persons were the principal ones to benefit from the preservation of these kinds of lore.

On the other hand the priestly profession was not monopolized by the ari'i:

The Priests are of two Classes and are formed out of all ranks of People according to the Ability they Posess. They are the only People who have any knowledge and it is their business to keep the lower Classes in Ignorance; tho some are of the lowest Class themselves yet they gain Esteem according to their knowledge, or rather from their being lucky in the business they profess.

The first of These are Calld Tahowwa Morai and their business is to make the offerings at the Morai and have the Charge of the Holy place; their prayers or Hymns they Chant out in an unknown tongue which the Natives or at least such as are not of their profession do not understand nor do many of the Chiefs, tho they are all considered as Priests and they seldom Officiate but on particular occasions when they are forced to assist for want of others, but as they are Plenty they are seldom under such Necessity.

The others are Calld Tawra tooa and pretend to Devine Inspiration, and are Consulted on all Occasions, whether in War, Sickness or otherwise and through them the Will and Pleasure of the Deity is known; few of them pretend to be inspired by the same Deity and those who claim the Superior ones are Men of Great Art and address, and from their Skill in their Art make themselves of great Consequence. They never attempt to apply to their Deity, but when a Chief is taken sick, or to know the event of any War which they may have in hand and as they are well acquainted with most of the Circumstances before they begin they Can tell events of this kind to a Certainty. If their skill proves ineffectual in sickness they never fail to accuse the Friends and relations of the sick for their want of Relegion and Neglect of their Duty in the performance of it, but should he recover while under their care their 
Charracter is firmly establishd, and tho' of the lowest Class become the Bosom friends of the Chief or Party in whose behalf they used their skill, and are sent for on all Occasions and Carress'd, even tho their skill should afterwards fail. (Morrison 1935:180-181)

In addition, there were several other vocations and avocations, requiring what Westerners would label "intelligence," that lower-class persons could and did make their marks in. Indeed, there is no evidence that the Maohis themselves considered wisdom and knowledge ('atama, pa'ari) to be limited by boundaries of class. When Bligh agreed to take one of his ari'i friend's servants back to England, he justified his choice as follows: "He is a Servant, and therefore a more elligible person for the purpose of learning than if he had been a Chief .... Such a towtow [teuteu] is more likely to benefit his Country than a Chief who would be only led into Idleness and Dissipation as soon as he arrived in Europe...." (1792:172) J. Forster accused "those in power" of utter laziness (1778:231), and Mühlmann asserted that the ari'i devalued manual work in gardens (1955:137). Forster, however, based his charge mainly on the observation that some upper-class persons were fed by others-which, as we have seen, was done for reasons of ritual restriction and not from indolence. As for Mühlmann, it may well have been that much of the manual labor for ari'i households was done by servants and other lower-class persons; on the other hand, there are accounts of ari'i men, including an ari'i rahi, joining with others in tasks involving vigorous manual labor. And ari'i women, like all other women, not only engaged in making bark cloth, but they took pains to excel in this laborious occupation:

They [ari'i] have in General a more serious and thoughtful turn and are more accomplished, they are always superior to them at all things either Labour or diversion, and the Earee weomen are by far the Best Clothmakers; in labour they are always first, it being no disgrace to know how, but a great one not to know how-and they always bear a part in the Cooking Provisions for their Guests. (Morrison 1935:169)

But there can be little doubt that members of the ari'i class devoted less time to subsistence activities than did their class inferiors, and this gave them more time for idle and play, at which they excelled: "The Chiefs are in general best at [surfing] as well as all other Diversions, nor are their Weomen behind hand at it. Eddea ['Itia, wife of Pomare I] is one of the Best among the Society Islands \& able to hold it with the Best of the Men Swimmers." (Morrison 1935:227.) This same wife of Pomare I also excelled at wrestling: "At this Sport Eddea and her Sister are always first [among women wrestlers], and often come off with Victory and Eddia always directs the Ceremony \& fixes the Number of falls that must be Wrestled" (Morrison 1935:222).

One sport, archery, was reserved mainly for the upper classes. ${ }^{29}$ As 
described earlier, it was carried out with elaborate ceremony and solemn consecration. Morrison interpreted its restriction to "those of rank" as due to the costliness of the sport's paraphernalia; that may have been a contributing factor to the restriction at one time but was not likely to have been the main reason for its continuance.

Mühlmann proposed an association between dance style and class:

Dances of an erotic character were engaged in by commoners and by members of the lower grades of the Arioi sect, whereas the more refined costume dances (and dramatic performances) were traditionally engaged in by members of the nobility (Fürstenfamilien), from which the members of the upper Arioi grades originated" (1955:189).

While it is true that upper-class maidens did take part in "the more refined" costume dances and dramas, and perhaps even to a more than proportionate degree (they probably had more opportunities for learning and practicing, and could better afford the costly costumes), they were not the only ones to do so. Moreover, some of these "refined" costume dances were not without eroticism. Banks, after describing the elaborate costumes of one such performance, wrote as follows:

In this dress they advancd sideways keeping excellent time to the drums which beat brisk and loud; they soon began to shake their hips giving the folds of cloth that lay upon them a very quick motion which was continued during the whole dance, they sometimes standing, sometimes sitting and sometimes resting on their knees and elbows and generaly moving their fingers with a quickness scarce to be imagind. The chief entertainment of the spectators seemd however to arise from the Lascivious motions they often made use of which were highly so, more indeed than I shall attempt to describe. (Beaglehole 1962:I, 325-326)

Traits of personality and character valued generally throughout the society were said to have been especially evident among ari'i. Morrison said of them that "their only pride is Cleanlyness and Generosity for which they are remarkable, and I may say they have no equals in these points" (1935:169). In the legend of Huriitemonoi, already cited, the true "princess" manifested her superior status, against the pretensions of her plebiansmelling, socially awkward maidservant, through her poise, beauty, and courtliness. "This one is a true arii," her hosts said of her, after comparing her appearance and behavior with her rival's (Henry 1928:614). Again, in the legend of Tuihiti and Hauvana'a, the young ari' $i$ bride, who elected to follow her husband back to his distant homeland against the entreaties of her parents, was finally told by her father (in what can be taken as a mixture of pride and regret): "Go. You have a royal will [mārō ari'i]; you cannot be persuaded to stay." (Henry 1928:470)

Against these native assessments of ari'i character, one will recall the opinions of explorers and missionaries, including Ellis' approval of the 
ra'atira, whom he described as being, "more regular, temporate, and industrious in their habits" (1829:II, 344).

The division of society into classes was also manifested in certain other labels and verbal expressions: for example, tetua, a girl or young woman; a title given to those of the chief families (LMS Dictionary). Ari'i were said to glide (he'e) or fly (fana), whereas others only walk (haere). Similar differences were expressed in greetings, and in references to death:

Maeva te arii: hail to the chief!

Ho mai, e haere mai: give way, come hither (to ra'atira, landowners).

A pae a'e i o: just to one side, just this way (to manahune).

Ua mate te arii: the chief is dead.

Ua mairi roa te tavana: the administrator is dead.

Ua pohe roa te manahune, e te puaa: the commoner, or pig, is dead.

(Handy 1930:38)

In addition to these general class-associated expressions there were many other euphemisms applied specifically to ari'i tribal chieftains (see chap. 23).

Class differences in clothing, in ornamentation, and in tattooing were referred to in chapter 6 , however, I have found no evidence of any special sanctions serving to enforce such distinctions. I have also described in other contexts the greater degree of elaboration which characterized life crises rites of high-ranking kin-Titleholders, and I suppose that such differences accompanied class stratification in general. ${ }^{30}$ In this connection, I recall a particularly suggestive observation of Morrison's referring to head-freeing rites:

Some of the Weomen are 16 or seventeen Years old before all their rites are performd, which makes them very cautious what house they go into or what things they toutch-but the Men are Generally Made free as fast as the father can get it done which is sometimes by Six Years old and somtimes not till twelve; the Children of People of rank are generally longer before they have all their rites performed, then the lower sort as it has a Grander appearance by being long about \& they always make large Feasts on these Occasions. (1935:187)

Class distinctions showed up most explicitly in connection with consumption rights. Most of the information on this subject relates only to ari'i privileges, so I cannot say whether in some instances the distinction was between $a r i$ ' $i$ and all other persons or was graded still further between ra'atira and manahune. Marau's "breadfruit" aphorism, quoted earlier, indicates a more comprehensive differentiation of consumption rights, but most of the sources tell only what "the principal people" could lay claim to.

In terms of food, the following observations are found in the sources; the first is probably an overstatement:

Those who fare best are the Caciques and headmen, for they possess pigs of 
fair size, and also fowls; because (although we saw none) those who went round the island in the launch heard hens and cocks crow on two mornings, and they (the Chiefs) told us so too. Thus it is that the arii or Caciques are all stout, some of them to ungainliness, so that they have two Indians constantly kneading their legs and even then are scarcely able to stand upright.

The common people frequently suffer a dearth of food, and most of them support themselves on cockles, and some fish which they eat raw. The good and finer fish, of which there is great plenty in the sea, are (reserved) for the arii and principal persons. (Corney 1915:55)

Of animal food, a very small portion falls, at any time, to the share of the lower class of people; and then it is either fish, sea-eggs, or other marine productions; for they seldom or ever eat pork, The Eree de hoi alone, is able to furnish pork every day; and inferior Chiefs, according to their riches, once a week, fortnight, or month. Sometimes, they are not even allowed that; for, when the island is impoverished by war, or other causes, the Chief prohibits his subjects to kill any hogs; and this prohibition, we were told, is in force, sometimes, for several months, or even for a year or two. (Cook 1784:154)

The following precept is also relevant here, but is somewhat puzzling: "Let not one single thing which has been restricted for the ari'i alone be eaten. Like the Tortoise, the Cavally, and the larger fish of the sea and the lagoon, breast of pork and the (popo'uru?) of pork, and the new fruits of the land, these are all reserved foods, foods set aside. (E. Salmon 1937:31)

The question is, Were these food items restricted to each tribe's sovereign chieftain alone (as the precept appears to imply) or to all (male) ari' $i$ class members (as certain other evidence seems to suggest)? The evidence is ambiguous in another respect on the matter of who ate turtle meat. The precept just quoted indicates that this delicacy was restricted to ari'i-either the Ari'i of a tribe, or all male members of the ari'i class. On the other hand, Ellis wrote that "This fish was formerly considered sacred, and was cooked within the precincts of the temple, part being offered to the gods, and the remainder eaten only by sacred persons." To this statement about pre-Christian times Ellis added, "It [turtle meat] is now [the 1820s] eaten indifferently by any one, though most of those caught by the people are taken as presents to the chiefs" (1829:II, 285).

G. Forster, in describing a meal provided for himself and his shipmates, related that when he and his companions passed out pork to the crowd of begging commoners who surrounded the dining Europeans and "Chiefs," the latter evidently disapproved of this generosity: "The eagerness with which [the commoners] repeated their importunities, as well as the envious looks of the chiefs, whenever we granted the request, convinced us, that the commonalty were in this island deprived of all sorts of luxuries and dainties" (1777:I, 405).

Ari'i undoubtedly had access to more food delicacies than other persons, and the excessively corpulent people noted in some of the sources 
were in the main members of the ari'i class. For example, "The great profusion, and variety of choice fruit, delicious fish, and fine pork and dogs flesh, has likewise occasioned in the idle men belonging to the race of arees, a propensity to indulge themselves in the pleasures of the table beyond what is usual" (J. Forster 1778:414). But there were no restrictions that I know of which limited vegetable food consumption to them. In fact, in describing the seasonal custom of "breadfruit gluttony" Morrison commented:

The poorer people are not excluded from this Method of Feasting their Children tho they have not sufficient Bread for the Purpose, having nothing more to do but signify their intention to their Neighbours, who bring their proportions of Bread and Assist them to Collect Wood and Make their Oven; somtimes they Join two familys making one oven between them. (1935:214)

Kava was not proscribed for lower-class persons, but its relative scarcity probably had the practical effect of restricting heavy use of it to the more affluent ra'atira and ari'i. According to Morrison: "It [kava] is Common to all but is more used by the Chiefs \& their Familys, Servants \&c then by the common people. They prefer the method of Chewing it to any Other-it is in much request among people of rank but even some of them never tast it." (1935:151) Moreover, even in connection with general imbibing those of the superior class appear to have gotten the best of the brew:

This Ava is made from a Strong pungent Root which few Cheifs ever go without, it is chewed by their Servants in large mouthfulls at a time, which when it has collected a sufficiency of Saliva is taken and put into a Cocoa Nut Shell. This is repeated untill there is enough chewed, it is then squeezed and given to the principall Men, each of them taking nearly a pint wine measure. What remains is mixt with water and again squeezed and Strained, it is then delivered to the inferior Cheifs, or those of the highest class if they prefer it diluted, and it frequently undergoes a second and third mixture if there is not enough to supply every one. (Bligh 1789:382) ${ }^{31}$

In this connection, the Reverend Orsmond, writing in 1826, complained that religion in Tahiti "is too much an instrument of state and I had great opposition because I receive a few people of common rank [sic] to the Lord's Supper before the Royal Family" (Orsmond, Journal, 20 December 1826, LMS Archives).

Among those few European visitors who commented on the matter of shelter there was agreement that the dwellings of the "principal people" were somewhat larger and perhaps better constructed than those of other folk-but not outstandingly so. That is to say, these differences were of smaller magnitude than the observers might have expected, given the wide differences between "chiefs" and others that prevailed in terms, say, of ceremonial precedence or of food consumption rights. These domiciliary differences were also apparent in architectural style, according to Turnbull, who wrote that "The houses of the royal family and great chief 
bear a near resemblance to an English cart-shed; they are usually of an oval shape, ..." (1813:355; also chap. 7, this work). However I suspect that such style differences are to be correlated more with size of building than with any normative connection with class.

As for class differences in the location of dwellings, I have, in the section on manahune, offered my opinion of the meaning to be assigned to the wellknown cosmogonic formula regarding each class' domain.

A sharper class distinction appears to have been expressed in connection with boats:

The Chiefs and better sort of people generaly go from one place of the Island to a nother in small double Canoes which carry a little moveable house.... (Beaglehole 1955:I, 131)

On the top of [the stern of traveling canoes] are placed pieces of rude Carved Work of a Cilindrical form of two or three feet high; they are hollow and the Open work represents rude figures of Men Supporting each other on their hands forming several Teirs and have some resemblance of an old round tower; the size of these denote the quality of the Owners. (Morrison 1935:202)

I cannot be certain whom Morrison intended to include among his “Owners of quality," although I suppose he was referring at least to ari'i.

Class distinctions per se seem not to have been the most telling criteria for access to esoteric information, but when missionaries began to propound their new doctrines to mixed-class audiences they recorded that some of those present: “... put very pertinent questions; among others, doubting whether we would bestow aught that could be esteemed a benefit equally on all. They asked, whether the message of the British God was to the toutous as well as to the king and chiefs?" (Wilson 1799:70; see also William Henry, Journal, 12 March 1797, LMS Archives)

The only evidence I have discovered that might be interpreted as constituting class differences in objects of worship is a tantalizingly brief and somewhat ambiguous passage in one of Cook's journals:

Soon after we had dined [ashore, on Ra'iatea] we set out for the Ship with the other Pig and a few races of Plantans which proved the sum total of our great expectations. Poor Odiddy had drank a little too freely either of the juice of peper or our Grog or both and was brought into the boat dead drunk. In our return to the Ship we put a Shore at a place where in a House we Saw four wooden Images standing upon a shelf each about 2 feet in length, they had Turbands about their heads in which were stuck some long feathers. A person in the house told us they were Fatua's no te Tou tou, that is the gods of the Common people, but this is by no means Sufficient to conclude that they worship them as such or that the Servants or Slaves are not allow'd the same Gods as those of a more elevated rank. I never heard that Tupia made any such distinction, besides these were the first wooden gods we had seen in any of the isles and all the authority we had of their being such was the bare word of, perhaps, a Superstitious person. ${ }^{\text {[32] }}$ (Beaglehole 1961:423-424) 
Finally, in regard to privileges after death, it will be recalled that the sources are not in entire agreement concerning the kinds of persons and the kinds of behavior rewarded in afterlife, but by almost any criterion ari'i fared better than others.

They believe in a heaven and a hell, the first they call Tairua l'orai the other Tiahoboo. Heaven they describe as a place of Great happines and hell is only a place enjoying less of the luxuries of life; to this they say that the souls of the inferior people go after death and those of the cheifs and rich men to the other. This is one of the strongest instances to shew that their religion is totaly independent of Morality: no actions regarding their neighbours are supposd to come at all under the Cognizance of the Deity, a humble regard only is to be shewn him and his assistance askd on all occasions with much Ceremony and some sacrafice, from whence are derivd the Perquisites of the Preists. (Beaglehole 1962:I, 381)

These honours and gratifications were only for the privileged orders, the Areois, and the chiefs, who could afford to pay the priests for the passport thither: the charges were so great, that the common people seldom or never thought of attempting to procure it for their relatives; besides, it is probable that the high distinction kept up between the chiefs and people here, would be expected to exist in a future state, and to exclude every individual of the lower ranks, from the society of his superiors.

Those who had been kings or Areois in this world, were the same there for ever. They were supposed to be employed in a succession of amusements and indulgences similar to those to which they had been addicted on earth, often perpetrating the most unnatural crimes, which their tutelar gods were represented as sanctioning by their own example. (Ellis 1829:I, 327-328) ${ }^{33}$

\section{Class-BASEd PATTERnS OF INTERACTION}

I will now consider evidence bearing on interaction between persons as members of different marriage classes, with the observation, however, that it is largely impracticable to separate behavior referable to this kind of role from that of other role sets-from, say, interaction between a kin-congregation chief and a very junior consanguine, or between mistress and servant.

Terminology. Terms of reference for class membership have already been discussed. The extent to which ari'i, ra'atira, and manahune were also used for direct address is not reported, except for indications that manahune figured sometimes as an insult. For example, the political enemies of the Pomares used to point out that one of the line's ancestors was named Ta'aroa-Manahune, in reference to his Tuamotuan, non-ari'i paternal forebears (Handy 1930:76). Also, when occasion demanded, Ra'iateans had a stock phrase for natives of Tahiti (and Mo'orea), calling them, "our fish, Tahiti torn-away; Tahiti-Manahune” (Henry 1928:436). ${ }^{34}$

Time. According to Handy, ari'i had little to do directly with manahune (except servants): "for to the ari'i service was rendered either by ra'atira 
with manahune as assistants, by their hereditary servitors (teuteu), or by their craftsmen (tahu'a)" (Handy 1930:43). On the other hand, Handy added that manahune did serve ari'i as paddlers (rao) in their canoes. Such may indeed have been the case, although the generalization is obviously based on inference and not on reports of direct observation or on any explicitly formulated norms. But see the following observation by Bligh: "Tynah [Tina-i.e., Pomare I, Ari'i Rahi of Pare-Arue] had a Visit to day from some of Tiarraboo People-they were of no consequence with respect to Rank, as is common, however, he found himself engaged for the day to direct proper supplies, and to amuse them" (1792:161).

Morrison reported that dancing was a leveler of "wealth," and perhaps, inferentially, of class as well: "Another Dance is the Ponnara which is performed almost evry evening in evry district through the Island. To this Dance the Weomen of evry age and discription resort to dance; young \& old, Rich and Poor mix promiscuously, but no Men Join with them." $(1935: 225)$

Space. The sources contain many statements regarding restrictions on direct or indirect physical contact between "chiefs" and other persons-for example, a low-class female's house was forever after interdicted to her after a "chief" had once entered it (Morrison 1935:168); a male commoner was prohibited from storing the fishnet of an ari'i in his own dwelling, which was a fare noa (Corney 1919:115); the commoner maid who attempted to usurp her ari'i mistress' role (in the legend of Huriitemonoi) was so thoroughly conditioned to her real class status that she was unable to walk upon the "royal" mats laid out for her (Henry 1928:612) ${ }^{35}$ However, most of these incidents appear to refer to $a r^{\prime} i$ who were at the time tribal sovereigns rather than to members of the ari'i class in general. Notwithstanding, I suppose that some of the insulation surrounding the former was applicable to the latter as well.

In addition to such restrictions regarding spatial distance, it may be assumed that there prevailed some interclass norms relating to spatial arrangement, such as the rule against stepping over an ari'i, or passing something over his head. My favorite passage dealing with such matters comes from the journal of Tyerman and Bennet (which, incidentally, reveals as much about these worthies as it does about the Maohis themselves):

We also observe, with great satisfaction, that Christianity, so far from destroying those distinctions in social life, which a wise Providence has made so necessary to human happiness, that no barbarians are entirely without them, has both sanctioned and sanctified them here. The kings and chiefs were never held in higher esteem by their subjects and dependants than they are now; nor are the gradations of rank in any part of Europe more easily recognized than in these uttermost parts of the sea. High birth is observable, not only in the countenances, speech, and personal carriage of the magnates, but even in the manner, 
or rather the order, in which they walk. Though a causeway has been made from the houses of the missionaries to the chapel, protected by cocoa-nut trees, laid along the sides, the middle part being covered with pebbles, and wide enough for several persons to walk abreast; yet the people continue one to follow another in line, as formerly, in the narrow tracks. If both be of the same rank, the wife comes after the husband; but if the wife be a woman of rank, and the husband of an inferior class, she goes first, and he, without ever imagining himself degraded, treads in her steps. (Montgomery 1832:I, 149)

Located as these islands were, along a roughly east-west axis, upwinddownwind were associated with sunrise-sunset, respectively; and a passage from Henry indicates that (for the residents of Tahiti, at least) these direction markers were metaphorically linked with differences in social status. Henry's text consists of a formal verbal exchange between Ra'iateans and Tahitians; after the former belittle the latter as being "commoners" (manahune) and people of generally unpleasant manners, the latter retorted as follows:

\footnotetext{
“Eaha ho'i to Tahiti e 'ino ai ai Ra'i atea? E topara'a mahana ho'i e te avae na matou o Ra'iatea. E fari'i pehu ho'i na matou o Ra'iatea. E hiti mai te mahana i Tahiti nei, e ma'iri atu i Ra'iatea na; e pai'uma te avae i Tahiti nei e ma'iri atu i raro na. $\mathrm{Na}$ te hiti'a-o-te-râ nei te 'otaha te ma'ue i te po'ipo'i, e ei Ra'iatea na i te ahiahi fa'atopa 'tu ai i to ratou huruhuru, e ho'i noa mai ai i Tahiti nei. O Tahiti o Hiti-ni’a, o Ra'iatea o Hiti-raro.

O raro ho'i outou i tô‘o‘a na, o ni‘a matou i te hiti'a o te râ nei. Ia tae mai to Ra'iatea i Tahiti nei, te parau ra e te fa'atere nei i ni‘a, e o ni’a mau à ia. Ia ho'i atu rà ratou i Ra'iatea, e na'o ia e, te fa'atere nei i raro, e o raro iho à ho'i o Ra'iatea no Tahiti.”
}

\begin{abstract}
"How can Tahiti be underrated by Ra'iatea? The setting place of our sun and moon is Ra'iatea. The recipient of our rubbish is Ra'iatea. The sun rises over Tahiti, and sets over Ra'iatea; the moon ascends over Tahiti and sets down there. The man-of-war-bird flies from the east here in the morning, and arrives at Ra'iatea to drop its feathers in the evening, and return free to Tahiti. Tahiti is Hiti-ni'a (Upper-border), Ra'iatea is Hiti-raro (Lower-border).

You are indeed below in the west, and we are above in the east here. When Ra'iateans come to Tahiti, they say they are sailing up, and it is really up. But when they return to Ra'iatea, they say they are sailing down, and Ra'iatea is really down from Tahiti." And so the dispute ended.
\end{abstract}

(1928:436)

Ideologically the seaward-landward contrast also had implications for class stratification, as expressed in the following excerpt, which though quoted previously is important enough to repeat:

The long capes were the inheritance of royalty and the nobility [hui ari'i]; there stood the great temples of the land which could not be hidden. Deep bays were the inheritance of the gentry [hui ra'atira]. As the land got thickly populated, the people spread everywhere. On the seashore and inland were the lands of the plebeians [ta'ata ri'i] bordering on the lands of the great. (Henry 1928:403) ${ }^{36}$

Front-back (mua-muri) also contained implications of social status-for example in any aggregation involving men and women, men were positioned mua and women muri; and in formal assemblies of men those holding higher-ranking kin-Titles or those otherwise playing more important roles 
sat mua. It is probably no mere coincidence that mua-muri also refers to temporal sequence of events in this society, where greater privilege attaches to firstborns, and where greater antiquity means closer identity with ancestral or creator deities.

There seems also to have been a general rule to the effect that persons

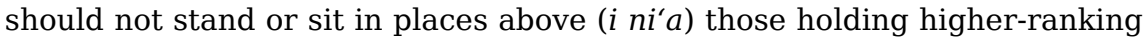
kin-Titles, but this did not result in the extreme forms of obeisance which prevailed in some other Polynesian societies (for example, Tonga and Hawaii). In addition, there is some suggestion that the various "levels" of the sky were ranked in ascending order, through identification with hierarchically "higher" deities. It might also be argued that the very high headgear worn by some leaders in warfare was, among other things, directly emblematic of social height; such headgear certainly was not very well adapted to the business of fighting.

Governance. Especially with respect to this interaction dimension is it difficult to decide whether the sources refer to ari'i tribal sovereigns or to ari'i-class members in general when they refer to "chiefs," or to the "principal people." Undoubtedly, other things being equal, more weight was accorded decisions or commands made by ari'i-class members than those coming from ra'atira or manahune classes, but that ponderous banality is based on inference rather than direct report. It is only in regard to courtship that the sources are explicit on this point: "In those unsophisticated times," said the narrator of the legend of Pereitai, "the lady felt as free to make advances in love matters as the lover, and the princess could command in wooing a man of inferior rank to herself" (Henry 1928:597).

Transaction. Ari' $i$ tribal sovereigns had the coercive power to levy taxes of their subjects, and to confiscate the latters' goods with or without cause. Also, it is safe to infer that most ari'i-class members were more privileged than were lower-class persons to call on a neighbor for services or objects.

Reversing the direction, several writers characterized ari'i as generous and hospitable (Morrison 1935:169; Handy 1930:41), but it is not clear whether this referred to $\operatorname{ari}^{\prime} i$ in general, or only to $\operatorname{ari}^{\prime} i$ tribal sovereigns. Nor is it clear whether such generosity was extended to members of all classes, or only to other ari'i. In support of the second interpretation, Morrison indicated that it was customary for travelers to be entertained by members of their own class. But he added:

If any person of whatever Class he may be should be travelling by land and Meets None who Invite him or should happen to be unacquainted in the District he is passing through and has occasion for provisions, he enquires the Name of the first Ratirra and repairs to his house-on his entring he receives the usual Compliments and having made known his business, the Master of the House Im- 
mediately orders provisions to be got ready for him, and the Mistress entertains his Wife in the same Manner \& they enjoy a secret pleasure at having had the good fortune to have the Strangers come to their House and they are for ever after deemd friends tho they had never seen each other. (1935:190)

Balancing these two flows of goods, from and to ari' $i$, we are left with the impression that members of the ari'i class fared better than their class inferiors, both in terms of expressed norms and in fact; but I must emphasize that I am dealing here mainly with inference.

Emotion. Again, I infer that lower-class persons behaved "respectfully" toward their class superiors, but my inference rests mainly on reports of behavior toward ari'i kin-congregation chiefs or tribal sovereigns and not on prescriptions or observations about class members in general. We are informed that on occasion "chiefs" mixed with commoners, but formal friendship appears to have been kept mainly within class bounds. ${ }^{37}$ Missionary Elder reported: "Otu [Tu, or Pomare II] asked for the welfare of his Majesty King George, and if he is an old man. He also asked our names and occupations, and said that all of us should be his friends [possibly taio], but that we must not be friends with any of the Common People." (Elder to Waugh, Tahiti, 23 July 1801, LMS Archives) Morrison also reported that "If any Person speaks disrespectfully of a Chief he is sure to suffer death." But disrespect was not easily tolerated by class equals either: "... should one Chief speak ill of another it would instantly bring on a War and this has been the occasion of several bloody battles" (1935:169).

On the other hand, there prevailed among "chiefs" a code of chivalry which went even further than the most magnanimous medieval specimen of which we know. The episode in question is a legendary account contained in Adams. It is long and involved, but since it refers to customs that I shall speak of in the next chapter I reproduce it in full, with all the noted historian's asides, and despite the liberties obviously taken by him with his informant's narrative:

About the year 1650, Tavi was chief of Tautira, and prided himself on being as generous as he was strong. All chiefs were obliged to be generous, or they lost the respect and regard of their people; but Tavi was the most generous of all the chiefs of Tahiti. He had a wife, Taurua of Hitiaa, the most beautiful woman of her time, and a son, Tavihauroa.

The chief of Papara and head of the Tevas at that time was Tuiterai or Teuraiterai. Like Hurimaavehi of Papeari, Tuiterai could not hear of a handsome woman without wanting her; but Tavi's wife was a person of too much consequence to be approached except in the forms of courtesy required between chiefs, and therefore Tuiterai sent his messenger to Tavi to request the loan of his wife, with a formal pledge that she should be returned in seven days. In the Polynesian code of manners, such a request could not be refused without a quarrel. It could not even be evaded without creating ill-feeling that might end in 
trouble. Had Tuiterai asked for Tavi's child or anything else that he regarded as most precious, the gift would have to be made, subject of course to reciprocity, for every chief was bound to return as good a gift as he received. Tavi did not want to lend his wife, but his pride and perhaps his interest required the sacrifice, and with the best grace in the world, like the grand seigneur that he was, he sent her to Papara. Apparently she made no objection; if the husband was satisfied, the island code had nothing to say to the wife.

Taurua came to Papara, like a Polynesian queen of Sheba, and made her visit to Tuiterai, who immediately fell madly in love with her, showing it by some acts that were amusing, and by others that were too serious for us to laugh at quite heartily even after eight generations. One of his amusing acts was to take the name Arorua (Aro, breast; rua, two) as a compliment to Taurua's charms, and Tuiterai arorua he is called to this day. The more serious act was that, at the end of the week's visit, he broke his pledge to Tavi, and refused to return Tauroa to her husband. This was an outrage of the most grievous kind, such as he might perhaps have inflicted on a very low man-a man fit only for a human sacrifice-but not on a chief; least of all on a chief of equal rank with himself. It was a challenge of force; an act of war. Tuiterai did not attempt to excuse it except on the plea of his infatuation. The Tevas still sing the song of Tuiterai arorua replying to Tavi's messenger who came to demand Tauroa:

"Why should I give up Tauroa? I will not give her up-I, Tuiterai of the six skies-her, who has become to me like the Ura to my eyes, brought from Raratoa-my dear treasure. I have treasured her, and I treasure her yet as the Uras of Faau, and I will not give her up now. No, I will not give her up. Why should I give her up?-I, Tuiterai of the six skies-her, who has become like the Uras of Raratoa."

This song is a famous bit of Teva history and literature, and yet I am not sure either of its text or its exact translation. I have given it as it is often sung, but nothing is more difficult than to render the exact meaning of such a language. The song, as the Tevas sing it, is made up of two separate parts; the first is Teuraiterai's refusal to surrender Taurua. The native text, with an attempt at literal translation, runs thus:

\section{TEURAITERAI AND TAURUA.}

E ore e pa iau. no fea e pa iau.

I will not give her up! Why should I give her up!

Teuraiterai ono rai ono. e ura piria mai tau orio.

I, Teuraiterai of the six skies! the Ura that clings to my eyes!

E ura ahuahu mai Raratoa mai e te ipo iti e.

The Ura, sunshine from Raratoa, my dear treasure.

E tahi arii haamoe ite ura here.

One king lulled to sleep his dear Ura.

Mai piti e mai faau. tau mate ono i aia.

Like two united. I should die without her.

Ruruu te rai ma fau hia

Tie up the heavens like a net.

Fau hia te rai mai ata. e ata pua e ata rai.

Tangle the clouds of the sky, the clouds of Pua. 
Mahiti te pea ma te paora

Open the net, make me dry.

Paora te pa ma tuatini tuatini te pito i haafifi

Dry the thousand thousand bonds that unite us.

Anapea anapea ia mau maitai.

The net, the net holds well.

Poetry is not supposed in any language to have an exact equivalent in prose, and I do not pretend to give an English equivalent for anything Tahitian. Whatever these verses mean in prose, at all events they show that our great-ancestor Tuiterai arorua was regarded as an uncommonly arbitrary chief even by his own people, much as they may have admired an act which appealed to the sympathy of every true South Sea islander. Fortunately this story, at least, is too modern to be suspected of being a myth. Taurua of Tautira and Helen of Troy belonged to the same society; Tavi and Menelaus were relatives; the coincidence runs through every island in the South Seas, where no traveler has been able to keep the Odyssey out of his mind whenever he has approached a native village; but the truth of the Trojan story might be proved by that of Papara; for no sooner did Tuiterai's refusal reach Tautira than Tavi-Menelaus, acting up to his high reputation, summoned his warriors and sent them against Papara, with orders to destroy it and to kill its chief. Papara had no walls like those of Troy to stand a siege; its forces were beaten in battle. Tuiterai was taken, and Taurua recovered.

Among the score of wars fought in early societies about women, and then made the subjects of poetry or legend, the Tahitian variety has a charm of its own because its interest does not end as most of such stories end, with the revenge of the injured party. It should have ended in the usual way, and Tavi had intended to do what any Greek or Norse chief would have done: kill his rival and sack his villages; but the affair took another turn. Tuiterai was wounded, captured, and bound; but when his captors were about to kill him he remonstrated, not with any feeble appeal for mercy, but with the objection, much more forcible to a Polynesian, that a great chief like himself could not be put to death by an inferior. None but an equal could raise his hand against him. None but Tavi must kill Tuiterai.

Tavi's warriors, in spite of their orders, felt the force of the objection, which was, no doubt, in reality an appeal to religious fears, for Tuiterai, as head-chief of the Tevas, was a person of the most sacred character. They carried him, bound and blindfolded, along the shore, some thirty miles, to Tavi. The journey was long, and the wounded chief, feeling his strength fail, urged them on, and as they passed each stream he managed to dip his hand in the water to mark his progress, for he knew the touch of the water in every stream.

When Tavi learned that his warriors had brought Tuiterai alive, he reproached them for disobeying his orders. Even he found it hard to live up to his reputation. The pride of generosity had cost him his wife and a war; and still he must forfeit his character if he put Tuiterai to death with his own hand in his own house. The wars of Tahiti were as cruel and ferocious as the wars of any other early race, but such an act as this would have shocked Tahitian morality and decency. Tavi felt himself obliged to spare his rival's life, but between complete vengeance and complete mercy the law knew no interval. A chief spared was a guest and an equal. Tavi gave Tuiterai his life and his freedom and Taurua besides. The legend repeats his words in a song which is still sung, like the answer of Tuiterai to the demand for Taurua, as one of the best-known Teva ballads: 


\section{TAVI AND TEURAITERAI}

A mau ra i te vahine ia Taurua.

Tou hoa ite ee. e matatarai maua e.

Taurua horo poipoi oe iau nei.

To aiai na pohe mai nei au ite ono.

Nau hoi oe i teie nei ra.

A mau ra ia Taurua tou hoa ite ee.

Matatarai mauai maua e.

"Take, then, your wife! Taurua! my friend! we are separated, she and I! Taurua, the morning star to me. For her beauty I would die. You were mine, but now-take, then, Taurua! my friend! we are separated, she and I!" (1901:23-27)

Another example of an ari'i code of chivalry was reported by Adams in his account of the defeat and capture of the chieftain Niuhi:

Another curious custom of war was shown in this affair of Niuhi, who seems to have been the object of rather unusual hatred. Temana, having led the attack, was perhaps required by courtesy to share his victim with his allies. He invited them to exercise the right of offering the worst insult that could be inflicted on an Arii, of beating the back of the victim with their spears, as he lay bound. Namiro, who figured as the head of the cuttle-fish, was the first to strike. "I am a prisoner," said Niuhi, who could not see, and did not know his captors; "I am dishonored by any one who strikes me on the back; but still I have the right to ask who strikes me." "I am Namiro, the warrior of Ahurai," was the answer; "I beat you with my lance Tuahinearamarama." Niuhi was silent. Teruru of Pereaitu stepped forward next and struck. Niuhi repeated his question, and was told: "I am Teruru of Pereaitu. I strike you with my lance Teaho." Again Niuhi was silent. Tevavahiiteraa struck next. "Who is that?" asked Niuhi; "what wood is your lance made of?" "It is the apiri of Tamahue," replied Tevava, with another insult, for the apiri is only a weed. "No!" said Niuhi; "the apiri would sting, and would make a singing in the air as it struck, while this falls on my back with a dull thud." "Know, then!" said Vavahiiteraa, "that it is the Teae of Mouoe!" The teae was a hard wood growing only on the hills of Mahaena. "I know now that I am lost," said Niuhi, "for I am surrounded." (1901:83)

Notwithstanding the respect ${ }^{38}$ normally shown ari' $i$ - "chiefs"-by their class inferiors and by other ari'i, there were occasions on which even they were not privileged. For example, while the berserk-like mourning ceremony, the taiha' $a$, was in progress, the masked participants recognized no class rules. They roamed about, wounding or even killing:

... when any one sees them Coming they fly to the Morai, it being the only place where they can be safe, or Get refuge from the rage of the Mourners who persue all that they see. The Morai alone they must (not) enter, and while this Ceremony lasts, which is somtimes 3 weeks or a month, they pay no respect to persons nor are the Chiefs safe from their fury unless they take sanctuary in the Morai; the Weomen and Children are forced to quit the place as they Cannot take refuge in the Morai. (Morrison 1935:233, italics added) 


\section{CHAPTER 19 AFFINITY}

Any attempt to comprehend the kind (or kinds) of Maohi relationship I have dubbed "marriage" is immediately confronted with problems of definition, and not much clarification is obtainable from native terminology. As noted previously the following words occur textually to label situations which specify, or include, the relationship in question (definitions are from the LMS Dictionary):

ta'oto, to sleep, see moe; to lie down; to be cohabiting as man and wife; a dream; see moemoe.

moe, sleep; see ta'oto; to sleep, also to lie down; lost. (moepo, the first embrace; to keep close together, as a new married couple. natimoe, a family or kindred.)

momoa, to espouse, or contract marriage; to make sacred, put under a restriction.

fa'aipoipo, to marry. (fa'aipoipo ra'a, marriage. ipo, a darling, one made much of.)

To focus on the relationships under consideration we may recall that they invariably involved coition, or the intent (or appearance of intent) of coition. (In other words, although the rite establishing some friendship pacts between males may have in some respects closely resembled the one instituting a "marriage," the resulting relationship differed in intent and in interaction. Although many males carried on homosexual practices, such partnerships were in other important respects unlike the relationship under consideration. $)^{1}$

It is also useful to distinguish, as the Maohis themselves probably did, between "marriage" and casual heterosexual affairs-but here we begin to encounter some taxonomic difficulties. In the first place, the Maohis undoubtedly distinguished between two modes of life which correspond, more or less, to the distinction made by them between taure'are'a (youth) and pa'ari (maturity). This correspondence, which though not exact but suggestively close, is epitomized in the organization and ethos of the libertinistic Arioi society-that is, any member who settled down into a long-lasting 
heterosexual, domestic partnership was retired from full participation in the society's activities (see chap. 22). Another exemplification of this kind of distinction was seen in the legend of Pereitai, which revealed a deeply felt Maohi antithesis between married and unmarried females. Notwithstanding all this contrast between youthful or youthlike unattachment and more sober social attachment, the transition between the two modes was in many instances a gradual one, marked by no definable event, ritual or otherwise. In other words, in the absence of a wedding ceremony or of some other definite evidence of "in-law" recognition, it is difficult for us, as it may also have been for other Maohis, to perceive when a casual affair settled down into a "marriage."

Another circumstance which obscures the distinction (for us, at least) between Maohi "marriages" and their casual affairs was the occurrence of "casual" sexual encounters undertaken with what appears to have been entire willingness on the part of the male to sire acknowledgeable heirs. (It will be recalled that one of the most important diagnostics of what I chose to label "marriage" was the "agreement to regard as legitimate, for purposes of inheritance, any surviving offspring of [a couple's] intercourse." All casual encounters of this kind that I know about were legendary, and they involved visiting deities or heroes, but one cannot rule out the possibility of there having been similar episodes involving human sires; and in any case the very existence of this story theme suggests that the Maohi distinction between "casual" affair and "marriage" was a more complicated matter than I have been able to fathom.

In any event, if we could turn back the clock and revisit these islands during the latter half of the eighteenth century we would find large numbers of male-female couples residing together openly and for months or years at a time-sleeping together and cooperating in subsistence activities. Also, most such couples would be sharing in the nurturance of children-either their own or others'-and committed to passing on some or all of their own goods to those children at the appropriate time. And finally, these relationships and commitments would have been recognized with more or less approval by most relatives of the couple. In the course of our retrospective visit we would also find other couples, probably not so numerous, but numerous enough, whose relationships resembled those just described in some respects, though not in all; these also require discussion, but first I focus on the numerically preponderant kind of relationships that I, at least, label "marriage."

\section{MARITAL RESIDENCE}

There does not seem to be any explicit statement of Maohi opinion concerning where a married couple ought to reside, and a tally of residential situ- 
ations, from legend and from real life, indicates that nearly every possible alternative occurred. However, it is possible to infer from these situations an implicit and fairly decisive preference for virilocality. Moerenhout wrote: "We have seen that the bridegroom used always to install his wife in his own father's household" (1837:II, 69). While this arrangement may have been the most usual one, to characterize it as invariable (i.e., toujours) is clearly inaccurate. The choice of virilocality is dramatically exemplified in the legend of Tuihiti and Hauvana'a:

Matamata-taua, a taua ia Tumu-nui i Tahiti-To'erau, e ei tamahine a'e o Hauvana'a.

Taoto a'era te Ari'i Tû-i-hiti ia Hau-vana'a 'a'ore ra i piri. Toina atu ai te hana i te metua, fa'aora hia mai ai i rapae e te metua.

Ua puta atura te hani i roto i te 'a'au o te tamahine, ta'i atura ta'i atura i te Ari'i Tûi-hiti.

Ua parau atura te metua;

"Ua piri to vahine." Haere atura oia i te vahine ra. Ua parau mai ra te vahine:

"I hea 'oe, e te Ari'i Tû-i-hiti? i oto noa na vau ia 'oe!" Ua parau atura te tane:

"No te aha 'oe i oto mai ai ia'u? Parahi ra'a roa to'u io 'oe nei, e 'a'ita 'oe i parau maitai mai ia'u, e inaha ua mauru te pae o to'u 'upo'o i to'u oto. Teie ra ta'u parau ia 'oe, e ta'u vahine, e poroi atu na vau ia 'oe, e haere au i to'u ra utu'afare i to'u ra fenua.” Ua parau atura te vahine,

“Eiaha ‘oe e fa'arue ia'u!” Ua parau te tane.

“A, tei ia 'oe iho, e ta'u vahine. Ua hina'aro 'oe i te haere 'atoa taua io'u ra e parahi ai?” Oto noa 'tura te vahine, nao atura:

“E, e poroi na ra vau i ta'u na metua.”

Haere atura i te metua ra ma te oto, manao 'ino atura te metua tane e e mea taparahi hia oia e tana tane, ua ui mai ra; “E Hau-vana'a, na vai 'oe i taparahi? E ari'i 'oe io'u nei, 'e'ita 'oe e aa hia e te ta'ata." $\mathrm{Na}$ o atura te tamahine:
Matamata-taua (Endless-strife) became the bosom friend (wife) of Tumu-nui (Great-foundation) of North-Tahiti, and Hau-vana'a (Government-of-orators) was their daughter.

King Tû-i-hiti (Stability-of-the-border) took as his wife Hau-vana'a, but she cared not for him. She turned away pining for her parents, and so the parents withdrew her from him.

Then love pierced the heart of the daughter, and she fretted for King Tû-i-hiti.

And the parents said to him:

"Your wife has become attached to you." And so he went to his wife. She enquired:

"Where have you been, King Tû-i-hiti? I have been weeping for you!" The husband replied:

"Why have you been weeping for me? I remained a long time with you, and you did not speak kindly to me, so that you see the hair of my head has partly fallen out from grief. Now this is what I wish to say to you, my wife, I am taking leave of you, and am returning to my home in my country." The wife replied:

“Do not forsake me!” The husband said:

"Ah, it rests with yourself, my wife. Do you wish to go with me to my home to dwell?" The wife wept freely, and she said:

"Yes, but I must first bid farewell to my parents."

So she went to her parents still in tears, and her father suspecting that her husband had beaten her, said:

“Hau-vana'a, who has been beating you? You have been a princess with me, no one daring to assault you." The daughter replied: 
“'E'ere au i te mea taparahi hia." Fa'ai'te roa 'tura i te parau. Ma te nao e, e reva raua e te tane i to'na ra fenua i Hiti-aurereva. Ua parau mai ra Tumu-nui:

“Te parau atu na vau ia 'oe e ta'u tamahine, eiaha 'oe e nonoa i to tane, e ari'i tena no Hiti e e fa'aho'i 'oe i tereira huru. E i teienei, e pau to va'a-mataeina'a i tena; e rave rahi te toa i te moana. Oia o Pu'a-tu-tahi, o Ahifa-tu-moana, o 'Aremata-roroa, o Are-mata-popoto, o Pahuanui-api-taa-i-te-ra'i, o Anae-moe-oho, o Tupe-io-ahu, e o 'Otu'u-ha'a-mana-aTa'aroa! E i teienei e ta'u tamahine, eiaha 'oe e haere; e fa'aea mai 'oe i onei, i to na metua nei." Nao atura te tamahine:

“E 'ore roa vau e parahi." Nao atura te metua tane:

"'E'ita 'oe e oto ia'u e i to metua vahine?"

"E oto ho'i au, e hau ra to'u u oto I ta'u tane."

"A haere, E màrô ari'i to oe; 'e'ita e fati ia tapea." Haere atura te tamahine i te tane ra, e ua parau mai ra taua ari'i ra:

“Ua ta'a maitai to manao e Hau-vana'a e e haere 'atoa 'oe i to'u ra fenua? tane

“E haere ‘atoa vau!” Nao atura rá te

“Teie ra ta'u parau ia 'oe, e ta'u vahine. E parahi i te fenua nei, e hi'o i te metua e to 'oe va'a-mataeina'a, e to 'oe mou'a, e to ‘oe umere.” Ua parau mai ra te vahine:

“"E'ita roa vau e parahi.” Ua parau atura te tane: "Eiaha ra, e ta'u tuahine, e taoa ta'i te metua e te fenua ia moina a'e taua i te ahinavaira. Eiaha, e ta'u tuahine, 'e'ita ia e 'itea fa'ahou hia mai e te mata te fenua nei!"

"E haere atoa taua!"

Ua fa'ati'a mai ra te tane, ua parau mai ra:

"A rave mai i to taua a'ahu, e to taua ma'a moe'a."
"I have not been beaten." And she told them everything, stating that she and her husband were going away to his land, to Hitiau-revareva (Border-of-passing clouds, Pitcairn Island). Tumu-nui replied:

"I told you, my daughter, not to spurn your husband, that he was a king from the Border and you might thus send him back there. Now, your countrymen would be lost in this voyage; many are the foes of the deep. There are, Pu'a-tû-tahi (Coral-rockstanding-alone), Ahifa-tu-moana (the Seaserpent), 'Are-mata-roroa (Long-wave), Aremata-popoto (Short-wave), Pahua-nui-apitaa-i-te-ra'i, (Great-Tridacna-that-opensagainst-the-sky), Anae-moe-oho (Shoal-ofmonsters), Tupe-io-ahu (Beast-of-heatedflesh), and 'Otu'u-ha'a-mana-a-Ta'aroa (Stork-exalted-by-Ta'aroa)! And now, my daughter, do not go; stay here with us, your parents." The daughter answered:

"I shall by no means stay." The father said:

"Will you not weep for me and your mother?"

"I shall weep [she said], but I should weep more for my husband."

"Go" [said he]. "You have a royal will; you cannot be persuaded to stay." So the daughter went to her husband, and the king said [to her]:

"Have you properly considered the matter, Hau-vana'a, to go with me to my country?"

"I will go with you" [she said]. But the husband said:

"Here is what I would say to you, my wife. Stay here in your country, and behold your parents, your clan, your mountain, and hear your praises [in the chants]." The wife answered:

"I shall by no means stay." The husband continued:

"But no, my sister, parents and country would cause regret as soon as they became lost to you and me in the distant haze. No, my sister, your eyes then would not again see this land!"

"I will go with you!" [she said]. And so the husband consented, and he said [to her]:

"Put together our clothes and our bedding." 
And King Tû-i-hiti went to prepare his canoe, which was a great double one, and to take in provisions for the voyage, while his wife made preparations at home to accompany him, amid the deep regrets of her parents and all their kin and people.

The canoe was named Are-mata-roroa (Long-Waves), and when everything was made ready, one morning King Tû-i-hiti and his queen, accompanied by their respective personal attendants, bade farewell to all in Tahiti and set sail for the far-off land. They sailed to the southeast, bearing up against a stiff breeze, and were soon out of sight of Tahiti. (Henry 1928:468-471)

After surviving many perils of the sea, the couple reached the husband's homeland, where "they lived long and happily together and had numerous issue. But they never returned to Tahiti." Meanwhile, Hauvana'a's father, regretting her absence, set out to visit the couple and try to persuade them to return to Tahiti, but en route he was swallowed by a Giant Tridacna. The efforts to recover his body form the basis of the epic of Rata, episodes from which are given elsewhere.

Distance ruled out the possibility of Hauvana'a's returning home to visit her own people, but in many other legendary and historical instances of virilocal residence, wives are described as visiting their natal families quite often and for long periods of time-and not only wives but in some cases their husbands as well. In fact, the extended duration of many such visits raises the question of whether these residential situations should not be labeled bilocal.

Although virilocality was probably the preferred and most common pattern of marital residence, there exist many references to couples residing in or near the household of the wife. (In several other instances a newlywed couple is described as dwelling with the bride's family for a while after marriage before moving to the groom's to stay; I refer here not to visiting but to more domiciliary-like residence at the wife's.) Some instances of uxorilocality involved husbands from places distant enough to discourage return home, but others involved men from nearby. (I have the impression that a man residing more or less permanently at or near his wife's family tended less frequently to visit his own home community, with or without his wife, than was the reverse case.)

No Maohi statements that I know of give reasons why virilocality was preferrable to and more common than uxorilocality, but a plausible explanation is not difficult to deduce. Generally speaking, a male's choices were more decisive than a female's in Maohi society, and this was especially true of husbands vis-à-vis their wives. In other words, a couple usually resided where the husband chose to reside, which usually meant where his own interests were best served. (I recognize the ineptitude of "explaining" a particular case by means of a generalization consisting in part of that case, but I trust that the reader will tolerate this broad usage 
of "explanation.") Occasionally such interests may have been dominated by a wish to please a wife-uxoriousness was common enough among the Maohis to generate a distinctive word, tite'amatahani, and wives were commonly represented as preferring the familiarities of their childhood home. Also, in many instances a husband's more self-centered interests were best served by residing at or near his wife's home. In most instances, however, a husband stood to gain or maintain more by residing at his own family home; this was emphatically the case with kin-Titleholders, but true also of most other males, inasmuch as inheritance in general favored males over females.

A male's self-centered interests would have been better served by residing at his wife's family home in the case of a younger ari'i- or ra'atira-class son, whose family heritage was outweighed by that of a wife who was, say, the principal inheritor of her parents' estates, or in the case of a drifting commoner whose paltry resources were fewer even than those of his mate's.

But male self-interest was not conceived wholly in terms of material resources. In all likelihood some husbands settled down in their wives' communities because of opportunities for more pleasurable employment, such as proximity to a tribal chieftain's residence and its livelier diversions. We cannot discount the likelihood that some wives were forceful enough or sexually desirable enough to overrule their husbands' inclinations to return home. Also, the frequent home-visiting indulged in by virilocally resident wives is testimony to women's persuasiveness or freedom of action.

In the foregoing I have dealt with marital residence in the broad alternatives of husband's versus wife's "place," without specifying what the residential units consisted of. I can say, however, with near certitude, that most newly married couples resided in the already established household of either spouse's relatives. The basis for this statement is the well-authenticated observation that most Maohi households were populous, to which must be added the circumstance that no reference can be found to the setting up of independent households by or for newlyweds. We can also deduce that the relatives constituting the households in which the newlyweds resided usually included one spouse's "parents" - natal, collateral, or foster. But this is about as far as the evidence will permit us to go.

Maohi households, like domestic establishments elsewhere, must have undergone "developmental cycles" of certain characteristic kinds, but we know more about what those patterns were not than what they specifically were. We can deduce for example, that wholly new households were not established lightly-their buildings and appurtenances having been laborious productions intended, evidently, for perpetual occupancy by one family-generation after another. Maohi household buildings were apparently not as large or elaborate as those of, say, Samoa, but most of them described in the sources, or revealed archaeologically, were of a size or degree of durability that bespeaks more than nuclear-family occupancy or one-generation 
span. And, as stated above, there is no evidence that newly weds, as a matter of course, sought to begin life in households of their own. It goes without saying that new households were now and then established, including some for newly wedded couples, but it is my surmise that new ones were set up mainly for successors to high-ranking kin-Titles (including those newly wed), or by later-born, nonsuccessor sons of ari'i or ra'atira families, and after these had produced offspring of their own.

Residential separation of husband and wife was not unknown among the Maohis, but it occurred intentionally in only two highly special kinds of situations. One was that of certain female conveyors of very high-ranking kinTitles. Some of these women, after bearing successors to their husband's kin-Titles (and possibly to their own), resided apart from their spouse, amicably or otherwise, and lived courtly lives of their own. The other such situation represented a step toward divorce, and will be described later on.

A final word on marital residence concerns locational factors influencing choice of mate. As pointed out earlier I have come across no explicitly formulated native statement about this matter, and there is no indication of any implicit preferences or prohibitions regarding where to find a mate. On the other hand, there is considerable evidence of marriage between ari'i of widely separate homelands, including different islands-a consequence of both class and political considerations. By the same token, in the absence of considerations encouraging choice of a mate from faraway, it is reasonable to conclude that commoners, and perhaps ra'atira, found mates much nearer home.

\section{Nuptial Rites}

To many Maohis, perhaps the most important aspects of marriage were a spouse's sexual accessibility and contribution to subsistence-public recognition and sanction of such unions having been taken for granted, and questions concerning legitimacy of offspring having been largely irrelevant, or resolved tacitly, in the absence of socially valuable heritages. At the other extreme, among people holding or controlling socially valuable heritages, legitimacy of offspring was the paramount aspect of a marital union and this was conventionally acknowledged by means of a bilaterally sponsored ceremony, which also served the purpose of securing supernatural approval for the covenant and widespread public attention to it-a most desirable objective in view of the political implications of such heritages.

I do not propose that nuptial ceremonies were usually dispensed with for unions involving no socially valuable heritage, ${ }^{2}$ but only that they did not, or did not need to, perform the function of legitimizing the couple's offspring. (In many such cases, I suppose, the nuptial ceremony was looked upon as an opportunity for conspicuous consumption and a good time.) All the above functions of Maohi nuptial ceremonies seem straightforward 
and self-evident, but the transactional dimension of a marriage's inception requires some additional examination, since the sources refer to three different types. ${ }^{3}$

First there were the "balanced" contributions made in connection with the more elaborate kind of ceremony in which the parties of both principals provided approximately equal amounts of food and other objects for the wedding feasts and for the couple's use. According to Henry there was an element of competition in some of these contributions, but the basic equation of them appears to have been symmetrical. "At the wedding feast, which lasted several days at the house of the bride, both families vied with each other in making a grand display of goods and food" (1928:284). ${ }^{4}$

The second type of transaction accompanying a wedding was described by Morrison, who wrote that in addition to the "Hogs, Cloth and Sundry Necessary Articles" presented to the couple by their "Freinds," the husband also "Claims his Wifes Posessions, which are delivered to him without reserve" (1935:185). Elsewhere Morrison said of this transaction, "The Father of the Bride then delivers her portion to Her husband" (p. 189). But, added Morrison, "Should they [subsequently] part, then the Wifes property returns to herself" (p. 185). The nature of this dowry-if such it was-is nowhere specified.

The third type of transaction, referred to by Anderson, implies that goods moved the other way also:

If a young man and woman, from mutual choice, cohabit, the man gives the father of the girl such things as are necessary in common life; as hogs, cloth, or canoes, in proportion to the time they are together; and if he thinks he has not been sufficiently paid for his daughter, he makes no scruple of forcing her to leave her friend, and to cohabit with another person who may be more liberal" (Cook 1784:157).

A similar kind of arrangement was described by Orsmond in his journal entry on March 9, 1827 (LMS Archives).

At first glance, it may appear that we have here not only three different types of transactions, but three distinctive types of "weddings" paralleling three equally distinctive kinds of "marriage." Actually, such an interpretation is probably not warranted; the three so-called types do indeed represent three distinctive kinds of circulation of goods in terms of direction of flow, but the end-uses of the goods seem not to have been the same. Type one appears to have consisted of things meant to be consumed by all participants in the wedding, or by the married couple. Type two on the other hand seems to have consisted of more durable objects, and possibly of use-rights in some kinds of estates, inasmuch as they were "returned to the wife" in the event of divorce. Type three is to be characterized less as a "dowry" than as a "gift" by a man to a girl's father (and consumed at least partly by the latter) to persuade him to agree to the marriage. 
There is a possibility that some weddings involved all three types of transactions: suitor's gift, dowry, and bilaterally provided wedding feast and housekeeping donation; or that others involved only one such transaction, or two. The fact is that the sources may not be so much in contradiction on this matter as they are incomplete. Indeed it is possible that there were wedding transactions of types that I have not even listed-for example, one of Morrison's observations could imply that at certain weddings only the bridegroom's party supplied pork for the wedding feast: after the rites at the marae "The Company then return to the Bridgrooms house and he sends three or Four Hogs to his Father in law, who has them immediately killd, and a Feast Made of which all the Males of both Familys partake" (1935:188).

Yet, even granting the obvious shortcomings of the sources it seems quite possible that Maohi weddings were indeed of three distinct types in terms of social accounting: some consisted of a more or less balanced exchange of similar objects and use-rights; others can be interpreted as an exchange of a wife's sexual and reproductive services in return for a husband's objects; and still others may be viewed as exchange of a wife's objects (and possibly certain other estate use-rights) for a husband's superior social status. The first type is straightforward and fairly well documented; I surmise that it occurred principally in connection with intraclass marriages and was hence the most common mode. I suggest that the second occurred mainly in intraclass marriages between young wives and much older husbands, and the third in instances of husbands having somewhat higher class statuses than their wives. I cannot specifically document these suggestions, but I present them as informed impressions nevertheless.

Finally, I remind the reader that it is possible to distinguish several conventional and more or less explicitly avowed motives Maohis had for marrying (in addition to what were probably numerous private, situational ones too complex to discover). Sexual attraction (one-sided or mutual), material gain, status improvement, social obligation, desire for offspring, political advance-all these, singly or in combination, were probably recognized as good and sufficient reasons for marrying; and each of these reasons probably influenced in some degree the character of the resulting relationships, which I now undertake to describe.

\section{HusBand-WifE RELATIONS}

"Domestic happiness," wrote Ellis, was "formerly unknown even in name," and "men were often cruel in their treatment of the women, and considered them as their slaves" (Ellis 1829:II, 572-573). But J. Forster saw the relationship in a somewhat different light:

The Taheiteans as individuals, not only have the several good qualities above 
mentioned, of a domestic kind, but they are likewise sensible of the great advantages of a social or civil union: and as far as our imperfect knowledge of their language; our short stay amongst them, and the desultory instruction of Maheine and $O-M a i$ would permit, I have reasons to think, that the beginning of their civil society is founded on paternal authority, and is of the patriarchal kind. The husband and the wife of his bosom, whom love unites by the silken ties of matrimony, form the first society. This union is, in these happy regions, first founded on the call of nature, in mutual assistance, and the sweet hopes of seeing themselves reproduced in a numerous offspring. In more degenerated nations, matrimonial union takes place from brutal appetite, is grounded upon the satisfaction of sensuality, the expectation of assistance from persons, whom oppression and custom has condemned to become drudges, and lastly the idea of gaining more strength and power from a numerous family of children. On the contrary, the mildness of the climate, the happiness of organization, and the kind and benevolent temper of this people, together with their more enlightened intellects, contribute very much to refine and to ennoble that soft passion which is the first beginning of this congenial harmony; and hence the brutish instincts, which were wants of the same low rank with hunger and thirst, are raised to a lasting, virtuous passion. This refinement of mutual love and matrimonial complacency, produces those tender regards with which this happy passion inspires its votaries for the beloved object; and it creates that mutual happiness, which is the result of all the more refined manners, and of their more polished behaviour towards one another. The offspring of such a happy couple early imbibe by the example of their parents, that kindness and benevolence, and those refined sentiments of love and happiness which contribute so much to confirm the felicity of their parents, and wish to reduce them to practice, as soon as they feel the call of nature and find a partner whose sentiments are in unison with their own; so that these simple, but more exalted ideas of matrimonial union, are thus propagated and perpetuated in the progeny of a virtuous and tender couple. (1778:349-351)

How either of these authorities formed his opinion I cannot divine, but I shall proceed as heretofore and assemble all the bits and pieces I have found about husband and wife interaction, whatever their source. The resulting miscellany is not likely to add up to any impressive generalizations, but it should indicate the wide range of behaviors comprising this relationship-or of the perceptions and prejudices of the Europeans who authored them!

Most of the source passages concern monogamous marriages, but there were many families that were polygynous, especially among the middle and lower classes, where the importance of one's heritage was less crucial. (See chap. 13, section on polygamy; and Ellis 1829:II, 571.)

Terminology. Tane, used both for reference and address, was the most common word for "husband," as vahine was for "wife," and both these words also had the more general meanings of (human) "male" and "female," respectively. Hoa is translated in the LMS Dictionary as "friend" but is elsewhere defined also as "wife." ${ }^{5}$ In addition to these terms for "wife" I have also come across tau' $a$, which more usually meant "friend" and "companion," and tuahine, which usually meant (male-speaking) "sister" or "female cousin" (Henry 1928:468, 470). 
In this connection, in a legend regarding the Deluge, there is a verbal distinction made between féti'i and wives (vahine) in a query put to two humans by a demon:

Na ui maira taua tuputupua ra: "E fetii anei ta 'orua i uta na?"

Then the monster asked: "Have you relatives inland?"

[Upon being answered in the affirmative, the monster then asked]

"E vahine anei ta 'orua i uta na?"

"Have you wives inland [as well]?” (Henry 1928:449)

Time. Maohi married couples were accustomed to two forms of interruption to their interaction: to long periods of absence occasioned by either one's visits to relatives elsewhere or by the husband's wide-ranging travels; and to the shorter separations occasioned by their respective roles in domestic and community affairs.

With respect to the first, such absences were probably longer and more characteristic with upper-class couples: the parental homes of such spouses tended to be farther apart, and ari'i husbands were perhaps more given to traveling than were others.

The shorter separations referred to were occasioned by many kinds of rules and practices. Leaving aside the interruptions to domestic routine accompanying such special situations as births and deaths, a couple's interaction was regularly interrupted when they went about their subsistence jobs, most of which were spatially apart from one another. Even when both were at home they ate separately, and in larger households, at least, they appear to have spent most of their waking hours in the company of others of their own sex-the males conventionally mua, the females muri.

From the scanty evidence available it appears that a wife slept slightly apart from her husband during her menstrual periods, but unlike women in many societies elsewhere Maohi women seem not to have been strictly isolated at such times. On the other hand, when Maohi men were actually engaged in religious activities their segregation from all women was strictly prescribed.

Space. It will be recalled that at weddings the husband's party was figuratively referred to as the "upper rock" (papa i ni'a) in contrast to the "rock underneath" (papa i raro) consisting of the wife's party. Also, according to Morrison, during the wedding àmo' $a$ rites at the marae, the groom sat to the right of the bride (1935:188). I imagine that when Maohi couples were actually together on more mundane occasions and able to conform to such standards certain other locational conventions were observed in addition to the mua-muri placement noted above; but the only specific references I can find to such matters concern the position of man and wife when walking together. In the legend of Tafai, mentioned previously, after the youth Hema had captured a beautiful fairy to be his bride, he followed his mother's 
instructions by carrying her homeward over his shoulder. In an effort to escape, the fairy appealed to Hema's sense of propriety by urging, "O Hema, leave me, the man should go first and the woman follow after so that it be said that the young Hema has a wife." (Hema succumbed to this appeal the first time and his bride escaped, but after capturing her the second time he ignored her plea and carried her home.) (Leverd 1912:5-6)

But, as we saw in the previous chapter, considerations of class may on occasion have outweighed those of marriage: that is, "If both be of the same rank, the wife comes after the husband; but if the wife be a woman of rank, and the husband of an inferior class, she goes first, and he, without ever imagining himself degraded, treads in her steps" (Montgomery 1832:I, 149).

Finally, for whatever it may signify, the word piri meant both "narrow, confined, close together" and "to care for" or "have affection for," as appears in the legend of Tuihiti and Hauvana'a, wherein the bride Hauvana'a is described as at first "not caring for" her husband, "'a'ore ra i piri" (Henry 1928:468).

Transaction. "The men," wrote Ellis in a passage previously quoted, "were often cruel in their treatment of the women, and considered them as their slaves." If such had been the case it could mean that wives were usually the helpless drudges of household work. In actual fact, many wives may indeed have contributed more time than did their husbands to their joint subsistence and family concerns, but there is no evidence of which I know that women's work per se was characterized as "drudgery," and there are few indications that wives were helpless. ${ }^{6}$

In any case it is useful to particularize husband-wife transactions under four headings: exploitation, altruism, exchange, and pooling-and-sharing; but first I present a statement by Bligh: "The Woman who bears Children has greater priviledges than those who do not-they always abide by the property of the Husband, while the others have little or no share" (1792:152).

Exploitation. Some husbands probably did "exploit" their wives, in the sense of coercing them to do more than the conventionally accepted amount of household work expected of a wife; but the sources describe no specific instances of this sort, and Maohi oral literature contains no stereotype of the victimized wifely drudge. Of course, it could be argued that conventional Maohi expectations of wifely work constitute "exploitation" in the Western sense (this, at least, seems to have been Ellis' view), but that argument would be as difficult to define as it would be to document.

I cannot find any evidence of husbands expropriating objects from their wives against the latter's wishes and expectations, although of course there may have been such instances. As for a man coercing his wife into sexual 
intercourse with his bond-friend or others, we have no way of knowing the extent to which such women may have been willing or even eager parties to those transactions; in any case, I refer to my opinion, expressed earlier, that sexual services were not valued very highly.

Though there were undoubtedly some exceptions in practice, the norm for marital transactions appears to have exemplified mutuality rather than exploitation-except possibly in terms of the more general prohibitions on females' consumption of certain food delicacies. ${ }^{7}$

Altruism. It is not possible to know whether Maohi norms recommended nonreciprocal giving between husband and wife, but there are some scattered indications that this kind of transaction did occasionally take place, or that it was regarded as a possibility. I have already mentioned the case of the selfless man who gave his life in order to provide food for his starving wife and children. A more trivial, but perhaps more revealing kind of story theme concerns husbands' actions in satisfying their wives' whims. One such action was referred to in the synopsis of the legend of Pai; the episode that now concerns us is as follows:

A long time ago, when King Ta'ihia (Wept-for) reigned in Tautira, there lived at Ata'aroa, adjoining his realm in the west, a chief named Rehia (Prize-won) and his wife named Huauri (Dark-fruit). They had goodly possessions and were distantly connected with the reigning family. Their house, named Fare-ti'a-tahi (House-standing-apart), stood on a point of land.

It happened one day that the wife, Huauri, heard the sound of a conch trumpet blast over the sea, and upon going out to see what it meant she saw a great canoe close by laden with food of all kinds going towards the settlement. So she told her husband, who according to the laws of Tahitian hospitality invited the people of the canoe to land and rest themselves, which they did.

"Whither are you bound with that food?" Rehia enquired.

"We are taking it for King Ta'ihia and for his father Ta'i-te-ari'i (Wept-for-theking) and for Tû-tapu (Sacred-standing), the king's friend," was the reply.

Huauri saw fish and pigs, ripe bananas, and many things that tempted her appetite, and seeing that she was longing for them her fond husband proposed to buy all the food of the men.

"What goods have you to buy with?" said they.

"We have feather cloaks and ornaments, mats, and rolls of cloth," was the reply.

The bargain was struck, the food was placed in a great heap on shore and sold to Rehia, and the canoe returned whence it came to collect more food for the royal family. (Henry 1928:578-579)

The magnitude of this indulgence is seen in the reaction to it: some of King Ta'ihia's subjects were so outraged by this action of lese majesty that they eventually slew both Rehia and his baby daughter. (One cannot escape the conclusion that the inventors of this story must have assumed Rehia's knowledge of the risk he took to satisfy his wife's wishes.) The opportunity to kill Rehia occurred when he went in search of yams which his 
pregnant wife longed for but which were not then in season. It was because of his digging for such yams that he met his death; but did he voice any recriminations against the fateful appetite of his spouse? Not at all; the faithful husband's last words were, "Ah, I shall not see my dear wife again, and she will not have the yams she longs for!" (Henry 1928:580)

Occasionally, even otherwise wicked husbands were imagined by the Maohis to indulge their wives. Such a man was a legendary "king" of Arue (North Tahiti), who used as a matter of course to kill persons whom he disliked. Among others, he did away with his wife's grandparents, but his wife traded on her husband's regard for her to obtain her revenge.

The king had a fine pet eel, which was bewitched by his evil genius and which he kept in Pû-'o'oro (Gurgling-pool), unapproachable to all the people. The queen, feigning sickness, assumed great fastidiousness, refusing to eat fish of all kinds, until at last she persuaded her husband to give her his pet eel, assuring him that she would enjoy it if he would allow it to be cooked for her.

This grieved the king sorely, and he went out for the day fishing so as not to see the eel killed. (Henry 1928:619)

Oddly enough the only evidence I have found of a wife's sacrifice on behalf of her husband is contained in the following passage:

When a man was knocked down for a sacrifice in the presence of his wife, which was not unfrequently the case, the assassins used to take great care to prevent the wife from touching the body, as in that case it would be of no use for sacrifice, as it would lose all its sacredness if touched by a woman. The wife used generally in such a case to make a sudden dash toward the body to fall upon or touch it to prevent its being carried away, that she might have the melancholy pleasure of burying it. (Henry to Burder, 21 May 1822, LMS Archives) ${ }^{8}$

The paucity of such evidence could signify perhaps that such transactions did not often take place, but it might also indicate that such sacrifices were so commonplace that they were not the subject of stories.

Exchange. The clearest manifestation of direct exchange between husband and wife involved one another's sexual services. This comes out clearly in instances of "jealousy," some of which will be described below, and which indicate not only some mutual attitude of proprietorship over the spouse's sexual resources (no matter how low a valuation such services may have had, per se) but a concern for reciprocity. Perhaps many other of the objects and services that passed between spouses were viewed by them as constituting direct exchange: "My $\mathrm{X}$ in return for your Y"; and this may have been especially true of childless couples living more or less alone. ${ }^{9}$

But probably most transactions involving spouses constituted poolingand-sharing - that is, separate contributions of objects and services into a common pool for common consumption. I have described elsewhere the contributions to household subsistence made by individuals as "parents" or as "males" or "females," and the consumption rights of persons in 
these various roles. Also I have discussed the parts played by parents in nurturing and socializing children, in representing family members to spirits, in celebrating marriages, in tending the sick, in mourning the dead, and so forth. In other words, I have already detailed the respective contributions by husband and wife to their joint family enterprise, and their respective withdrawals therefrom. Of course, the kinds and amounts of contributions and withdrawals must have varied widely indeed-in terms of size and composition of household, class of principals, and occupation of husband; but enough has been said to suggest what the influence of such parameters might have been.

Governance. In keeping with the more general norm which placed precedence and effective decision-making mainly in the hands of males, Maohi husbands were undoubtedly assigned such primacy over their wives. Moreover, most husbands probably exercised these privileges in some measure, even to the point, in some cases, of backing up their authority with blows, as Anderson recorded:

As in such a life, their women must contribute a very large share of its happiness, it is rather surprizing, besides the humiliating restraints they are laid under with regard to food, to find them often treated with a degree of harshness, or rather brutality, which one would scarcely suppose a man would bestow, on an object for whom he had the least affection. Nothing, however, is more common, than to see the men beat them without mercy.... (Cook 1784:160-161)

But as I remarked earlier, although subjected to occasional beatings, many Maohi wives were normally anything but a passive, deferential, submissive lot. A perusal even of Cook's journals will turn up many instances of wives asserting themselves most effectively in their relations with their husbands. Some examples of wifely assertiveness were given in my discussion of marital transactions; a few others are to be found in eyewitness accounts, as will be described in volume 3 . There are also stories that describe husbands who placed great confidence in their wives' judgment (Henry 1928:625), or who followed their wives advice in moments of crisis (Henry 1928:445).

Most such accounts, both legendary and eyewitness, concern ari'i wives, and many ari'i women are known to have been laws unto themselves; but from this one should not conclude that wifely authority and assertiveness were limited to that social class.

Emotion. As revealed in legend, history, and vocabulary, the "feelings" expressed by husbands and wives ran the gamut, from self-sacrificing affection to murderous hate. At one extreme were such crystallized (but not wholly intelligible) expressions as hina'aro (love, desire, affection, choose) and aroha (compassion, pity, sympathy, love, affection); at the other were such expressions as $f a^{\prime} a n o n o ' a$ (to spurn with disgust, applied to husbands and wives who have an aversion to each other) and fe'ume (envy, 
malice, settled hatred between persons). As heretofore, I shall exemplify this range of behavior by presenting synopses of situations or full accounts of episodes taken from both legend and history, in the belief that generalization without documentation would rob this work of its most useful asset.

Happily-ever-after marriage based on mutual love-at-first-sight romance is the theme of several stories, some of them enlivened by the overcoming of obstacles of one kind or another. An example is the legend of Taruia, evidently collected by Miss Henry herself and bearing her rhapsodical style: ${ }^{10}$

On the eastern side of the town of Pape'ete, the capital of Tahiti, is the beautiful valley of Fautau'a (Confederation), famous in Tahitian history and romance, with its rapid, winding stream, for miles along the banks of which are scattered elegant and humble dwellings of rich and poor. Far in back, at the head of the valley, stands in bold relief the circle of basaltic peaks called La Diadème, nature's royal insignia gracefully worn by the "Queen of the Pacific," peaks that form a background, perfect in its outlines, for other beautiful valleys that rise to this central point.

At the base of La Diadème is a tableland called Rupe (Mountain-pigeon), where in former times stood a little hamlet that was the birthplace of Taruia (Benighted), the hero of this story. He was the son of Hihi-mai-vao (Sun-rays-ofthe-recess), the chieftain and priest of the clan of that region, and his mother's name was Ra'i (Sky). He also had a younger brother whose name was Vini (Whistling-parrakeet). They lived at a time when the districts for Tahiti formed little independent kingdoms, over which reigned high chiefs and chiefesses, called ari'i (kings or queens).

With the youths of their clan the two lads grew up, accomplished in the use of bow and arrow, in hunting and in fishing, and in all the arts and sports of their time. Taruia was also taught the oral traditions of his country and all the mysteries of priestcraft by his father, whose double office of priest and chieftain he was to inherit. Light of foot, the young mountaineers scaled the heights up to their lofty peaks after pretty feather birds, which were used for ornaments in those times, and in their rambles they descended into the valleys, where they plunged or slid down over smooth slippery rocks of slanting cascades into deep pools of water, in which they rivalled the fishes in swimming and diving. They sometimes went down on to the plains and out into the sea to swim and ride upon the surf and to fish, where, it is said, Taruia and his brother were carefully guarded from harm by their great blue shark god, which was possessed with the spirit of one of their ancestors and made itself known to them by caressing movements against their persons, to the great dismay of their playmates.

The story opens in the beginning of the reign of Teri'i-tau-mata-tini (Kingof-the-period-of-thousands), an ancestor of Paraita (Tattoo-marking), a chief who became regent under Queen Pomare and was a prominent figure in the history of his island.

It was at harvest time, the height of the breadfruit season and most other fruits, and, according to custom, after the people had offered the first fruits to their god at the national marae, a public festivity, called the feast of the umu-'opi'o (ovenlong-cooking), was proclaimed. In an immense oven of heated stones were placed in a great heap hundreds of breadfruit in all stages of ripeness, whole and unpared. These were covered with banana, breadfruit, and purau leaves, hilled over with earth, and left thus for a couple of days, after which they were thoroughly cooked and most enjoyable to the taste. For the feast of the $u n u^{-}$'opi' $^{\prime} o$, food in various other 
ways was prepared also, and great hogs were baked whole in ordinary ovens covered before daybreak and opened at noon.

On native festive occasions long sheds are erected upon a lawn, generally near the chief's house, covered with braided coconut fronds, and tastily decorated with green and yellow ti leaves, stripped into fringes, and garlands of flowers interwoven with sweet-scented fern fronds and herbs. Previous to the modern use of tables, chairs, and hardware, banana or other broad leaves were laid in a row upon the ground along the center of each shed and upon them were spread large purau leaves for tablecloths and plates, on either side of which the people sat. For each person was set a coconut-shell cup, containing sauce served from gourds, and within everybody's reach were bowls of gourd or coconut shell and wooden dishes, containing the steaming meats and various delicacies with an abundance of fresh coconut water, the natural wine of the country, and cool fresh water to drink. In olden times the people took their seats according to rank and clan, and the men and women had their feasts apart from each other, boys and girls uniting with fathers and mothers, respectively; but modern civilization has changed those restrictions.

On this special occasion, the strangers and sojourners in the land were to be the guests of the day, besides whom the young King Teri-'i-tau-mata-tini who dwelt at Taunoa (Alighting), a place on the sea side of the plains facing Fautau'a Valley, wished to have as his guest the handsomest man in his dominion, irrespective of nationality or rank. Accordingly, two days before the feast was to take place, messengers went forth to invite the guests. Two men who were considered good judges were sent to find the handsomest man, and after their search over the plains the first day they returned and told the king that they had only met ordinary-looking men. He bade them not be discouraged but to go again and search on the morrow, as it was then nightfall.

That night the king had a dream; he heard the voice of his great god Tipa (Healer) address him, and he answered promptly:

"E, teie au!" (Yes, here am I!) the god said:

"You will find a young man of perfect beauty in the clan of Rupe. Send for him to-morrow; his name is Taruia." But the king answered:

"I have never heard of Taruia and have never been to Rupe." After giving him the information concerning the young man that is mentioned above, the god said no more and left him sleeping soundly.

Very early in the morning, the king awoke, and thinking of his dream he told it to his wife, for whom he had a great regard and in whose judgment he always felt great confidence, asking her what she thought of it.

"You must be in favor with our great god," she replied. "You and the people have borne away the sins of our kingdom by offering him and his spirit guests the first fruits of our harvest, and now it is evident that he approves of the feast you are preparing for us mortals. Your dream can be no deception." The husband answered: "I believe you are right, my dear Miriama!" And he arose and went and sent the two messengers of the day before in search of Taruia in Fautau'a Valley.

The two men passed different hamlets, inquiring where the place called Rupe was, and were directed farther and farther, until at last they came to the rising ground. After reaching a considerable height above the level of the sea and the plains below had disappeared behind the towering mountains forming ravines and dales, they saw before them a stronghold enclosed in an amphitheatric range of mountains united away inland by La Diadème. At their feet lay a formidable precipice extending from one side of the valley to the other, down the center of which falls the sparkling water of a magnificent cascade 426 feet high. The water 
descends into a great gorge, where it forms a pool and issuing thence in roaring and musical sounds among the boulders, it meets rivulets, great and small, on the way downward to the plains, where it forms rapids and pools-nature's bathing places, much frequented by the people-and thence flows onwards to the sea.

Following a footpath across a precipitous pass to the left, the messengers enter the amphitheater. Here they found some habitations, and inquiring of the people if that was the place they were seeking they were told it was not but that it was the settlement that they could see at the farthest end of the valley, beneath La Diadème. They went on their way rejoicing that they so soon would reach their goal.

As they were approaching Rupe, the priest, Hihi-mai-vao, received a communication from the god of the local marae, where he and his son, Taruia, were working, telling him of the arrival of the two men and of their errand and that he must conceal his son from them in the marae, which stood on a terrace on the side of the mountain. So the father immediately turned to the son and directed him what to do. They moved away a great slab that concealed a vault on the inner side, in which he entered and was closed in.

When the messengers arrived, they found the priest and his wife and younger son Vini sitting beneath a spreading tree in front of their house, and they were cordially greeted with:

"Manava, haere mai!" (Welcome, come hither!) The young men respectfully answered: "E! Ia ora na 'outou i te atua" (Aye, may you live in the gods).

A fara leaf mat was placed for the visitors under the tree, and when they were seated comfortably upon it the dignified host sat them at ease by opening the conversation, and saying:

"A great errand must have brought you to our inland clan." They answered:

"Yes, indeed, we have come on a great errand."

"Tell it!" expectantly replied the former.

"You know," said they, "that our harvest feast is to be tomorrow?"

"Yes."

"The king wishes to have as his special guest on that occasion the handsomest man in the land, and he has sent us here to invite your son, Taruia, to be that guest." The parents replied:

"Here is our son, but that is not his name, we called him Vini." But the messengers, prompted by their god said:

"We know that you have another son, and that you had hidden him away. Permit us to go and search for him."

Permission was granted, while the parents still denied having any other son. So the messengers went searching in likely and unlikely places until they arrived at the marae, and thinking he might be hidden somewhere within the structure they removed a slab or two on the outer side and at the ends, but finding no vault they replaced them and continued their search on the inner side, when lo! as they moved away a great central slab, they found the handsome young man, who met all their expectations, sitting within. Being inspired what to do, he welcomed his discoverers and went out with them after they had closed the vault as before.

The parents were much chagrined on seeing that their son, Taruia, was found by the strangers, but the father, recovering himself, said:

"It is well! I am persuaded that it is the will of the gods that my son should obey the summons of the king and go as his guest tomorrow. But the matter now rests with himself, ask him if he is willing to do so. Representatives of our clan will be there also." 
Turning to Taruia, the messengers delivered the royal invitation and explained that it was by revelation that they had been directed to come to him. He answered that he accepted the invitation, highly gratified at such an honor. Elated at their success, the messengers wished to take him away at once to Taunoa; but he preferred going early in the morning, inviting them to tarry at his home with him until then. This they declined doing, and not even waiting to partake of food hospitably offered them, they took their leave and hurried home to inform the king of their happy success.

As the sun was declining towards the west, the two men arrived at Taunoa and found the young king and queen awaiting them with much interest to know the result of their errand. When they were told all the circumstances of their search and that the young man was coming early on the morrow, they were highly pleased and patiently waited for the time to come to see their handsome guest. Early in the morning, before the eastern sky was gilded with the rays of the rising sun, the drums of the various clans announced that the final preparations for the feast were being made. Men and women, old and young, were setting to work to accomplish their respective parts, while the children, in high glee, were everywhere rejoicing.

Faithful to his promise, Taruia left Fautau'a early on his way to Taunoa. As the heir to a chieftainship, he attired himself becomingly in a gay waist cloth of fine tapa and a richly fringed poncho of the same material, ornamented with rosettes studded with small red pipitio seeds, his clothing arranged so as to reveal elegant tattooing upon his bare limbs. Upon his head he wore a soft tapa turban, entwined with a garland of sweet-scented mountain ferns and flowers, and in his hand he carried, as an insignia of rank, his ancestral wooden spear, which was about six feet long and which served as a weapon of defense in cases of emergency and as a staff in going on a journey. Taking an early breakfast prepared by a retainer, Taruia took a lingering leave of his fond parents and set out on his journey, all feeling strange presentiments of something coming that the gods did not reveal to them.

On arrving half way down the valley at a picturesque little vale called Pureora (Prayer-for-life), where stood the home of the king's sister, Tui-hana-taha-te-ra (Evening prayer), enclosed in a high stone wall, where she lived with her adopted parents, he was invited in, his fame having preceded him, and the young girl's guardians proposed that they should all go to the king's house together in a little while, which Taruia agreed to do and sat down upon a proffered mat. The young princess was tall, fair, and comely, about sixteen years of age, with gentle manners, soft regular features, and a profusion of flowing raven hair, loosely looped up and interwoven with a wreath of white, starlike Tahitian gardenias. She was gracefully draped in soft, lightly printed white tapa, which was passed around her body and secured upon one shoulder with her arms exposed. Upon her tapering fingers, wrists, and ankles were beautifully tattooed circles resembling finger rings, bracelets, and anklets, and upon her feet were tattooings that much resembled elegant sandals. Other high-born ladies of the house were attired and tattooed in much the same fashion, the matrons wearing bright-colored flowers in their wreaths and garlands, only the maidens having the right in those days to wear the simple gardenia.

The princess was soon to marry a young prince who was heir to one of the neighboring kingdoms, and though she had no deep-seated affection for him she had been brought up to feel that such a union would be most suitable and proper. But now when the eyes of the fair young damsel and the elegant mountaineer met for the first time and they bashfully exchanged the friendly 
greeting, "Ia ora na" (May you live), they at once felt a kindred attachment for each other, which they could not shake off.

In a little while, the sound of the drum summoned the clan to meet together on the assembly ground, which was some distance away and out of sight of the house, where they were to form in procession ready to proceed to Taunoa. Taruia was requested to remain on the road until the procession approached, when he was to join it also. The strictest etiquette was always observed by the natives in falling into line and presenting themselves before their chiefs; and every clan claimed a certain place in prestige that was always maintained and recognized by their rulers.

Just at the lower end of the stone wall at Pure-ora (Prayer-for-life) a little rivulet made its escape across the public pathway towards Fautau'a River, and upon the bank of this little stream, near the wall, was a spot saturated with gore, where hogs for the feast had lately been slaughtered. Not far from this spot was the road where Taruia stood, holding his spear by his side, nothing doubting, in readiness to join the procession.

Meanwhile, four of the royal retainers carried the news to the king that on this festive day a fierce young stranger was intent upon doing mischief wherever he could find opportunity, and that they last saw him close by the young princess's premises with his spear in his hand, after killing her and her chaperone while they were out alone, the evidences of which they had themselves seen. This story was corroborated by others who followed, each new party stating that they had seen the man at the place mentioned. Enraged, the king sent the four retainers armed with spears to seize him, whoever he might be, and carry him to the grand marae, there to be slain and offered to the gods and buried at once before the opening of the feast, as executions were not performed during such an occasion or just afterwards. So they sped up to Pure-ora and there saw the spot mentioned and Taruia not far off sitting upon a log, his spear held erect in his right hand, ready to rise as the procession approached.

In the minds of the men, this attitude confirmed the story they had told, and not giving him time to move, supposing that he was ready to spear them, they surrounded him and taking his staff said:

"Where is the king's sister?"

"Over there," he replied, pointing in the direction where the family had gone.

"What is that from?" they asked, looking at the stain.

"I do not know," he said, "I only arrived here this morning." Then they said:

"The king has heard that you have killed his sister and has sent us to arrest you and take you to the marae, where your doom awaits you." Inspired by the spirit of his ancestor of the shark god. Taruia replied: "If you slay me and bury me in the ground, I shall live again; but if you bind me and sink me in the sea, I shall surely die."

So saying, he feigned to fall in a swoon, from which they could not recover him, and binding him hand and foot, attached him to a pole, which was placed upon the shoulder of a man at each end, and they carried him to the marae, whence they sent to enquire of the king what should be done, after what Taruia had told them. The king answered:

"Take him far out into the sea, and invoke the great god, Rua-hatu (Sourceof-fruitfulness), to keep his spirit from troubling us."

The men then fastened stone weights to Taruia's feet, as he lay motionless, placed him in a canoe, and took him through the passage of Pape'ete 
Harbor. Outside of the reef, opposite the islet, they dropped him deep down among the wide, spreading branches of coral, one of the haunts of great, deep-ocean fishes, and while they were still committing his spirit to the ocean god, they saw the long, blue shark that Taruia knew, approaching him, as they thought to devour him. Thus leaving the young man in his watery bed, they hastened to return home to continue their festive duties.

On arriving at Taunoa they found that the king's sister and her clan had arrived at her brother's house safe and sound, and soon afterwards Taruia's clan arrived, expecting to be met and headed by their young chief in presenting themselves before the king and queen, who did not yet know that the supposed foe lying at the bottom of the sea was their intended guest whom they were expecting soon to see. When the king saw his sister, he enquired:

"Mai hea mai 'oe?" (Whence do you come?) Feeling surprised at his question, she replied:

"Mai Pure-ora mai nei au" (I have come from Pure-ora). But he told her he had been assured that she was dead and recounted all that had happened that morning. Soon all the people heard the sad story. There was a general wailing, and their gladness in coming together ended in bitter sorrow.

It was almost sunset when the young princess, recovering from the first terrible shock, begged to be taken out to see the place where the young victim had been dropped. As she was fixed in her determination to go, the men who had done the deed quickly bore her across the smooth, ebbing current to the spot, and looking down in the glimmering light, they saw the body of the young man lying upon his coral bed, his limbs unfastened and appearing as if asleep, with his guardian shark at his side. Sitting in the stern of the canoe, in the seat of honor, the young woman bade the men return home, and as they turned the canoe round to do so she suddenly plunged beneath the waves, out of their reach, and with the darkening waters separating them, she too soon lay beside her late acquaintance and the shark, leaving her attendants no alternative but to go and tell her brother of the sad event.

But the tragedy did not end there! The king had the men who had been the cause of Taruia's downfall slain and buried at the marae in his stead, as an example to all his subjects never again to circulate false reports. Thus the day of rejoicing was turned to one of mourning; and what became of the Umu-'opi'o no one ever sought to know.

But the two bodies left with the shark as dead were preserved alive by the ocean gods, and that night while the king's heart was sorest their faithful guardian bore them in his great jaws on to the sandy shore of Taunoa, where he resuscitated them, and knowing their affection for each other he told them that now was their opportunity to go and obtain permission from their king to be united in marriage. When they were seen approaching the royal dwelling early in the morning, they were regarded as specters from the sea, and the news spread everywhere that the ghosts of the two young people had returned among them. But their dripping, briny clothes gradually convinced the king and queen that they really saw their sister and her companion in the flesh. Moreover, they found also that their voices and actions were not supernatural, and soon they were received with open arms by the royal couple and people, and the glad tiding was carried to Taruia's parents, who joyfully went forth to meet and reclaim their son for whom they had mourned as dead.

Permission was obtained from all parties concerned for the marriage of the young people, the former lover of the princess magnanimously consenting to relinquish his rights to her hand in favor of the hero of the day. A marriage feast 
was made ready, and escorted by their respective nearest relatives, the happy young pair met the high priest before the great altar of the royal marae and stood apart on either side of him. In solemn tones he addressed the bridegroom with the following question:

"Do you consent to take this woman as your wife, to remain with her until you die?" Taruia answered:

"Yes, I do." Then turning to the bride, he answered:

"Are you willing to be the wife of this man until you die?" She also answered in the affirmative. Then taking their left hands in his, the priest placed that of the bride in the bridegroom's, saying:

"It will be well with you if you thus keep your vows," and he dedicated them in wedlock to their god.

The royal nuptial feast lasted three days, and then the wedding party proceeded to the bridegroom's home, where in becoming pomp the marriage ceremony was repeated in the same manner by Taruia's father, the priest of Rupe. Here also the feast lasted three days, and there was great rejoicing among the mountain clans of Fautau'a.

This is how they say Taruia, a petty chieftain, became the husband of a princess of Pare. They lived long and happily together, dividing their time among their people in the highlands and lowlands, and were much beloved by them. It is well known that they became the ancestors of some of Tahiti's illustrious personages.

Vini, the younger brother, also grew up a handsome young man and married a fine young chiefess of his own rank in another clan, where they dwelt in harmony and also begat sons and daughters who became a credit to their race. (1928:623-632)

Another theme is exemplified in the legend of Tuihiti and Hauvana'a, reproduced earlier. In this account the young bride entered dutifully into marriage caring little for the groom, but after a while "love pierced her heart" (ua puta atura te hani i roto i te a'au, literally, was pierced then the affection inside the intestines) and, as we saw, the couple lived "happily ever after."

In the legend of Tafai, "death" itself was overcome by the young hero disconsolate at the loss of his wife (a noteworthy variant on the Orpheus theme):

Tafa'i married a fine young chiefess of North Tahiti, named Hina (Gray), famed for her beautiful raven hair, which when let loose flowed down in waves to her feet and covered her graceful, majestic form; and their attachment for each other was strong and lasting.

Tafa'i was prompt to go wherever duty called him in his own land and also in other lands and, as old records everywhere show, was beloved for his goodness and kind, generous deeds. On one occasion when he returned home from a long voyage he found to his great grief, that his wife was dead. She had just suddenly died, and her body, still warm, was lying in state upon an altar in the ancestral marae, guarded by the priest and elders of the family. Soon, in his sorrow, he determined to contend for her even with the gods! So he inquired of the priest whither her spirit had fled, and he told Tafa'i that it had left their sacred precincts and was now with the spirits of other departed ones at Tataa about twenty miles west of Uporu, which was their place of rendezvous in Tahiti before taking flight for Paradise or Hades in Ra'iatea. 
Tafa'i lost no time in seizing his great paddle and launching out into the sea his single canoe (Niu); and then he swiftly darted over the smooth water within the friendly reef and arrived at Pa'ea just at dusk, the right time to meet the souls departing. There he found that his wife's spirit had left some time before for Mount Rotui (Soul-despatching) on Mo'orea, whither the spirits went to take their final departure for Te-mehani (The-heat) in Ra'iatea, which was the last place whence they could return to this world. Onwards he sped across the channel to Mount Rotui, towering steep and high up into the clouds, and soon he was upon its summit. But there too he found that his lost Hina had gone on some time before! With unshaken purpose, Tafa'i descended the mountain and again took to his canoe, and in the dim light of the waning moon, aided by a favorable breeze, he made his canoe almost fly across the wide channel that separates the windward islands from the leeward group. Then he took the shortest route up to Te-mehani, and he did not stop until he arrived at the spot on the mountain plateau where the roads radiated, one to the cliff on the right, called the "Stone of Life," from which spirits ascended to Rohutu-no'ano'a (Paradise-of-sweetodor), somewhere up in cloudland above the highest mountains of Ra'iatea, and the other to the cone on the left, from which they descended down into the yawning crater of Te-mehani, which led to the Pô.

The moon was almost setting and the morning star was heralding the day when Tafa'i arrived at that place and was met by the god Tû-ta-horoa (Stand-topermit), who guarded the roads. Tafa'i inquired if Hina, his wife, had passed by, and to his great relief the god replied that she had not yet come. But he told Tafa' $i$ to be quick and conceal himself in the bushes in a precipitous nook close by and that he must rest to gain strength for his undertaking to capture her in her flight, as that was the last place whence spirits could be recalled to this world. Breathlessly Tafa'i seated himself in his hiding place, and just as he recovered breath from his late exertions he heard leaves rustling a little way off, and the god told him to be ready, as Hina had just arrived.

Soon Tafa'i perceived the tall, familiar form of his wife with her hair streaming down her back, and as she arrived upon the ridge of the rock by which he stood she drew back as she scented a human being. Just as she was about to ascend into the air to fly to the Stone of Life, where she would have escaped him, he made a desperate leap up onto the ledge and into the air and caught her by her flowing hair with his long fingernails. Hina struggled to be released, as she was intent on going to the happy spirit world, but her husband held her fast, and when Tû-ta-hora told her that her time had not yet come to leave this world she was prevailed upon to remain longer with her husband. So they returned to 'Uporu, and as soon as Hina reentered her body, which was still well preserved, and opened her mortal eyes, there was great rejoicing in their home and in all the district over the safe return of Tafa'i and his wife from the borders of the spirit world.

It is not recorded in Tahiti that Tafa'i ever again went away from his native land, but it is stated that he and his wife lived long and happy together and that of them was born a son whom they named Vahi-ê-roa (Place-entirelystrange), probably in commemoration of the long voyages of Tafa'i to strange lands. (Henry 1928:563-565)

But not all story marriages were happily-ever-after affairs. In some of them it was the husband whose ardor first cooled, in others the wife's, and in still others the coolness developed mutually. An example of the first theme is found in one episode in the interminable cycle of legends about Hiro: 
At last Hiro went to his parents' abode and there dwelt a long time. Hitherto he had lived a bachelor life, indifferent to the fair sex; but in Ra'iatea he at last conceived a strong attachment for a most beautiful woman named Vai-tû-marie (Clear-still-water), who was the wife of a noted warrior named Tutae (Dung), and he determined to possess her himself. So he made advances to the man, sometimes feigning friendship and again aggravating him to hostility, until one day the warrior raised his spear to strike him, when Hiro caught him by the head and broke his neck. Thus freed of the husband, Hiro took possession of the wife, of whom he became very fond, and by her he had two children, a son, named Marama (Moon), and a daughter, named Pî-ho (Splash-and-shout), and everything went on harmoniously between them until the children had grown up.

It happened one day as Hiro and two artisans, named Topa (Fall) and Tovana'a (Thy-herald), were building a canoe and the wife, Vai-tû-marie, and two companions were talking in a house close by, that the two artisans overheard them discussing the qualities of their husbands, and in an unguarded moment, Vai-tû-marie laughed concerning Hiro's strong odor while the other two women were boasting that it was not so with their husbands. This little episode the men repeated to Hiro, who had not heard it, and he became very angry and bided his time for revenge upon his wife. One day while he was alone, sewing on the planks of his canoe, his wife was passing by, and calling her to him he bade her aid him by getting into the canoe and drawing the sennit in while he drew it out. This the wife willingly did, but as she was not accustomed to such work Hiro contrived by jerking the sennit to make it hard for her to guide it, and in a little while she cried:

"O Hiro, my finger is pinched!"

"Which finger?" said he.

"My little finger," she replied. So he released her, and in a little while another finger got pinched and was freed, then another, and another in the same way, until at last her whole hand was caught. Then Hiro tightened the cord around her wrist and would not release his wife in spite of all her cries and entreaties, but taunted her by repeating what she had said and asking her if it was customary for women to depreciate their husbands in the eyes of others.

"O Hiro," exclaimed the poor woman writhing in agony, "I have not depreciated you, I have praised you to all my friends; regard not this passing remark as evil speaking, and let me go."

"No," said Hiro, "I will not let you go; you are tied with sennit, and you will be inclosed in a wall of shifting sand." Knowing then that he meant to kill her, she said:

"O Hiro, remember how you have loved me, witness my agony in this painful position, and consider yourself avenged for all my thoughtlessness. If I die, I shall belong to the gods, but spare my life now, O Hiro, and let me go." But Hiro got into the canoe and brutally kicked his poor victim to death. Then he dug a shallow grave in the sand beneath the chips of his canoe and there buried her.... (Henry 1928:543-544)

The adventurous Hiro was turned against his wife specifically because of injured pride, but as Adams wrote of another such disaffection "Men have in all times been ingenious in their reasons for deserting women when tired of them" (1901:13).

Reversing the situation, below is a lament credited to Moanarai, a man 
of Ra'iatea, as he watched his faithless wife Aitofa sail away in a canoe toward Porapora:

Come back from Toa, O Aitofa, O my beautiful erring spouse!

As the rapid flow of the current at Onoiau, And as the swollen torrent from the valley,

So flows my yearning heart after thee.

O Aitofa, have compassion on thy lover lest he die!

The promontory of Tainuu has become beautified (by thee).

The husband will fear, will shrink, will faint at the re-appearance,

At the return of the love of the cherished wife,

Of that face so bright and beautiful.

Look whichever way he will, she seems to be still down there.

The moon sinking into the western shades is the image of the husband,

The image of Moanarai at this moment.

As a great cloud obscuring the sky is his grief,

The grief of the husband mourning for his estranged wife,

And like the sky darkened by its rising is my distress for her.

Alas for me! Alas for me! my little wife,

My darling has gone astray!

My little beautiful wayward spouse,

My friend who made my heart brave,

My friend in the storm has been stolen away.

A wreath of the fara tree, a garland of Pandanus blossoms I have gathered for thee,

O Aitofa, and lo! thou art flown.

$\mathrm{Ah}$, woe is me! Is it thus that thou shouldst treat me?

Lo, thou art drifting away over the ripples in the Aoa shallows,

Thou art passing the fragrant vale of Vavaara,

And leaving Mt. Rotui, the upper jaw of Hades, behind thee.

Thou hast forsaken thy favourite bathing place with its clear water,

And thy Tiare (Gardenia) bush that blossoms without ceasing.

Alas for thee, Aitofa! Thou art a little toy canoe that the wind carries away.

Alas for my anguish and the rage of my heart!

Ah me! I despair and think of suicide.

I am possessed with frenzy. Alas for us both!

The mind of the husband gives up the effort to win back thy love.

Alas for my darling! Thy fair face is lost from sight.

There is no benefit from the home.

A piercing thorn to me, a pretty thorn to me (art thou).

What is my fault for which thou art vexed,

For which thou hast disdained me?

Why hast thou cut the cord of love, and deserted me?

An evil-working woman.

As a long continued storm is my anger,

At the throbbing within, within me,

My bowels yearn, my heart flows out after thee.

I am chilled with lingering affection for thee, O Aitofa, return! 
Here is a bunch of red feathers for thee,

Here is a wreath of scarlet feathers for thee,

Here is a necklace of beautiful pearls for thee,

Here is thy home.

I am Moanarai, thy husband.

(Alexander 1893:55-57)

Turning now to what purports to be a real-life episode, I remind the reader of the case of the Huahine maiden who obtained the marriage consent of a reluctant youth only after threatening suicide. But this marriage was of short duration. According to Ellis, "That attachment, which had been so ardent in the bosom of the young woman before marriage, was superseded by a dislike as powerful; and although I never heard the slightest charge of unkindness proferred against the husband, his wife not only treated him with insult, but finally left him" (1829:II, 567). And Ellis added, "Instances of such unhappy marriages ... were not unusual."

As was reported by Montgomery, and reproduced earlier, men also tired of their spouses, in real life as well as in story. Speaking of liaisons among "the higher orders"-or more specifically between a "chief" and what I take to be a young girl of lower class-it is stated that "In less time than the honeymoon requires to fill and empty her horn, the chief probably grew weary of his spouse"-and forthwith abandoned her (Montgomery 1832:I, 244).

Marital jealousy is the theme of many legends and real-life accounts. One such is the story of Tepua:

In the valley of Pape'iha, Hitia'a (East Tahiti), there once lived a beautiful maiden, named Te-pua-iti-i-te-rau-'onini (The-little-flower-in-budding-leaves), whom we shall call simply Tepua. She had many suitors, and at last she accepted as her husband a young man from Ra'iatea, named Ta'arei (Fallon-nape-of-neck), who became greatly enamored by her. They lived happily together for some time, when finally Tepua met a new admirer from Papeari in South Tahiti, named Ma'irûrû (Trembling-sickness), who became their guest and completely won her affections from her husband. Soon being awakened to the fact, the husband became jealous and determined to have his revenge, contrary to the usage of hospitality of that time.

So he invited several friends to join him in fishing for 'o'opu, which have always been plentiful in the beautiful river of Pape'iha, and his wife and guest, quite naturally joined the party, having no suspicion of evil designs. They went out in the morning with line and hook and were soon busy ascending the valley along the river bank, drawing up 'o'opu from the pools. By noontime there was an abundance of the desired fish, and then the woman set out to gather wild taro pota (spinach) while the men went higher up the valley for $f e^{\prime} i$ (wild plantains). In a most natural way the two rivals found themselves alone together in a ravine, where there were many fine $f e^{\prime} i$. Then the hour had come. While Ma'rûrû was intent on disentangling a fine bunch from vines overhead, Ta'arei stole up behind and slew him with a heavy pole, so that he fell backwards to the ground. Then Ta'arei mutilated his body with a bamboo knife and cut off a piece of his flesh, 
which he wrapped in leaves and placed among his $f e^{\prime} i$; and he took the body into a family marae, where he left it covered over with maire fronds, after which he returned home coolly with his load of $f e^{\prime} i$ and the secreted flesh.

All the company had returned to the house and were preparing the food to eat when Ta'arei arrived. The men had made an oven, and the women were wrapping the fish in the taro leaves, which in turn were enveloped in banana leaves to steam in the oven, when Tepua seeing her husband arrive enquired after their guest, he merely replied evasively, inferring that he thought he had already returned home. Then Ta'arei sat down and helped make up the bundles of fish and spinach, into one of which he slipped the piece of human flesh, taking care to mark the bundle apart from the rest. At length the food was all cooked, and as the shades of evening were falling it was brought out and served under a spreading tree. According to custom, they formed little groups of members of different families, uniting together at short distances from one another, and soon all were happily feasting.

Ta'arei opened the special bundle and placed it before his wife with $f e^{\prime} i$, and he opened one of the other bundles for himself. Soon she was struck with the firmness of her supposed fish and enquired into the cause, as she commenced to bite it. After a few evasive remarks, he answered:

"That is a portion of thy heart's desire, is it not according to thy taste?" Then light began to dawn upon her mind, and she enquired where he had left Ma'irûrû. "In the presence of thy god," he said, "under fronds of the sacred maire fern."

Thus Tepua realized the painful fact of the tragedy commmitted by her spouse, and leaving her food uneaten she went away in bitter grief, girded on her tapa, braced herself with strong cords, and set out into the dark woods, improvising plaintive dirges for the lost Ma'irûrû.

All night long she wandered in the valley, and the following day she arrived at the marae, where she found the mutilated body, and with wonderful strength she raised it and strapped it to her back. Then she bore it out into the village, mourning for her dead, and adhering thus to her burden, refusing to give it up or to be comforted, for two days and two nights, as she bewailed him. (Henry 1928:589-591)

Shortly afterwards the unhappy Tepua gave way to melancholy and died. As for her husband, he returned to his home in Ra'iatea, finding life untenable in Tahiti, because-and this interests us as much as the slaying itself- "the sympathies of all the people of that time were turned in favor of Tepua" (not, perhaps, because of their acquiescence in the adultery or their disapproval of the slaying, but because Tepua was one of their own).

As noted earlier, there were several kinds of occasions when a husband tendered his wife's sexual services, mainly in connection with friendship pacts; but this tolerance seems not to have been extended to unauthorized affairs, for, "while their conduct with respect to the taio, \&c. exhibits an insensibility to every feeling essential to conjugal happiness, the least familiarity with the wife, unauthorized by the husband, even a word or a look, from a stranger, if the husband was suspicious, or attributed it to improper motives, was followed by instant and deadly revenge" (Ellis 1829:II, 370).

What was true in Ellis' time was evidently also true during Morrison's a generation earlier:

If a Man finds his Neighbour, or one who is not his adopted Friend in 
the Act of Adultry with his Wife he has the Law in His own Hands and may if He thinks proper put One or both of them to Death with impunity or punnish His wife with Stripes, and Plunder the House of the Offender; the latter is the Most Common but I have known two Men killd, who were taken in the Fact, and no further enquirey made then the Acknowledgement of the partys present to Certify the Fact. (1935:185)

As we shall see, even an authorized relationship with a bond-friend caused some husbands distress, but the existence of a formal pact evidently denied public approval or tolerance of acts of jealous vengeance.

Records of instances of wifely jealousy exist, but are neither numerous nor detailed. For example, in one version of the legend of the founding of Marae Manunu (Huahine), it will be recalled, when the chief Hotuaitu paid court to the newly arrived Hotuhiva, his own wife left him in jealous anger. But in few of these legendary accounts of wifely jealousy, or in the fragmentary records of real-life parallels, did the wife attack her erring husband or his mistress with anything more injurious than words ${ }^{11}$-one additional bit of evidence, perhaps, of males' greater authority and privilege in Maohi society.

But what, one may ask, was this "jealousy" that we have been discussing? And what occasioned it? These questions are especially relevant in a description of this society, where sexual interaction went on unconcernedly among the unmarried, and where marital sex exclusively was breachable by customs like friendship pacts.

The LMS dictionary contains several entries translated (among other things) as "jealousy"-mi'imi'i, nanu, tapariri; but the nearest one, semantically, to the expressive act now under consideration is hae, jealousy; wildness of beasts; to be jealous, as men and women; jealous; wild, as beasts; enraged; and pohehae, jealousy (evidently from pohe, to die; to be ill, hurt, or diseased; to be foiled in an argument, or affected with jealousy, and from hae). The inference possible to draw from these definitions is that we are discussing an emotion as wild and uncontrolled as that of an enraged animal, occasioned by being deprived of a sexual partner's services (and affection?). When applied to a married couple, however, the deprivation is still more serious in that it violates socially sanctioned rights-not necessarily to the spouse's "affection" perhaps, but at least to control over the spouse's sexual services. Moerenhout put the matter as follows:

The jealousy of a [husband] had more to do with his sense of violated authority than with any regard for virtue or honor. The thing that [husbands] insisted on was that they and not their wives exercised full control over the latters' sexual services, and they did not scruple to bestow those services upon a friend or a stranger, even to forcing [a wife] to accept the caresses of anyone at all in return for money, or some gift or hope of future gain. Exceptions to this practice did exist but were few in number. After tiring of their wives, sexually, they were interested only in maintaining authority over them. To share out their possession 
was not the least bit repugnant to them and the ways in which they did so carried no implication for them of shamefulness or baseness. ${ }^{[12]}$

And on their side, wives were far from being free from jealousy. Some of them tagged along with their husbands everywhere, never for a moment leaving them alone, and at any hint [of infidelity] they did weep and engage in such demonstrations as almost to convince one that they were based on a love and attachment most sincere. But the fact remains that very few of such wives apparently so deeply affected remained wholly faithful with the husband whose least deviation seemed to drive them to despair-even in some instances to the point of causing them to do themselves bodily harm if unable to discover the rival on whom to vent their wrath. Here, as in some other lands, injured vanity accounted for much jealousy of women. It was not their attachment to lover or husband, but the idea of there being a preferred rival, which led to their despair. I do not wish to imply that there were no exceptions, that there were not some women capable of sincere affection and attachments, but what I fear to be true is that no woman remained faithful of her own inclination. (1837:II, 64-65)

Thus both spouses were vested with rights in the sexual services of the other, but, as is evident in other aspects of the marital relationship, the husband's rights were not only more exclusive, he also had more coercive powers, physical and otherwise, to enforce them-as the rest of Moerenhout's discussion of this subject plainly indicates:

Actual marital separations scarcely ever took place as a result of mutual consent; on principle, the husband alone having the right of repudiation, he was entitled to bring back his wife by force if she left home without his consent. In fact it happened frequently that a wife would run away from her conjugal home and would then he brought back by force. Almost as often, spouses would resume living together after having been separated for some time, for until one of them contracted a new marriage they remained husband and wife. Deviations in [wifely] conduct only rarely led to separations; husbands usually meted out punishment by beating their wives over whom they had right of life and death, even to the point of actually killing them in some cases. There were few young wives who did not have their moments of infidelity, and though some of them may have been somewhat constrained before marriage, generally speaking they made up for lost time afterwards, and especially when their husbands were away, giving themselves over to licentious living the more willingly in the knowledge that such would not prejudice [their chances of remarriage], in as much as the most shameless of women succeeded no less than others in getting husbands.

All the above seems to demonstrate that in connection with their love making and other pleasures, excepting for a husband's right [over his wife's services] Tahitians in general recognized no distinction between good and bad conduct. $(1837: I I, 65-66)^{13}$

The above discussion of marital jealousy should not be taken to imply that all married couples reacted to trespass in this way. Most of the exceptions involved certain ari'i who appear to have been quite indifferent to their spouses' affairs. Typically, the unfaithful wife in question was one who herself held or conveyed a very high-ranking kin-Title; several such women, 
after having borne a successor to their husbands' kin-Titles and their own, openly carried on affairs with no apparent objection from their spouses. And conversely, their husbands' affairs seem to have aroused no objection from them. Similar situations may have occurred at middle-or lower-class levels of society, but reports about them are largely lacking.

Symptoms of murderous hate did not usually appear between spouses unless incited by relations with in-laws, which we will examine after a word about co-wives.

The clearest general statement regarding the relationship between a polygynous man and his wives is the one by Ellis quoted earlier: "Many of the raatiras, or inferior chiefs, had two or three wives, who appeared to receive an equal degree of respect and support" (1829:II, 571). Ellis, like this author, distinguished between situations such as these, which constituted mutual marriage, and those involving men holding high-ranking kin-Titles, who were obliged to restrict their "official" siring to one wife of an appropriately superior social position:

With the higher chiefs, however, it was different; although they might ... keep a number of females, it was rather a system of concubinage, than a plurality of wives, that prevailed among them. The individual to whom the chief was first united in marriage, or whose rank was nearest his own, was generally considered as his wife, and, so long as she lived with her husband, the other females were considered as inferior. (1829:II, 571)

Henry concurred in this distinction:

Polygamy was much practised by these people, especially those of the ra'atira class, their plural wives standing on equality with each other. But a king had but one queen whose children could by right inherit the throne-his children by other women of high rank did not always enjoy the same privilege as those of the members of the legitimate circle. (1928:285)

Whether this statement should, however, be considered an independent observation by Orsmond, or merely Miss Henry's paraphrase of Ellis, is not clear.

Since the only specific case material recorded concerns higher chiefs, we have no way of knowing whether the actual co-wives described by Ellis as having "an equal amount of respect and support" were in fact treated in this way by their husbands. Nor do we know what their relations were among themselves, once they became established as co-wives. I suspect, however, that some such relations were anything but harmonious, judging by the prevalence of other manifestations of wifely jealousy described above. ${ }^{14}$

IN-LAWS

The Maohi lexicon contained only four relationship terms applied exclusively to in-laws: ho'ovai, aupurua, tao'ete, and hunō'a. 
Ho'ovai was used with metua to specify "parent-in-law"-with the addition of tane and vahine to indicate male or female, respectively. It was undoubtedly used as a term of reference and may also have been used for address, although I can find no textual evidence for such usage. Also, I have come across no instances of ho'ovai used alone.

I confess to some puzzlement over the set of parent-in-law terms variously listed as purua, apurua, and aupuru'a. The LMS Dictionary lists purua only (a father- or mother-in-law). Jaussen listed purua (beau-père, bellemère) as well as apurua (a[djectif] parent par mariage), and aupurua (s[ubstantif] les parents de deux mariés). And Handy listed only aupuru'a (term applied to each other by married man or woman's mother and motherin-law [1930:23]). ${ }^{15}$ Faced with this array of variants I am tempted to take part in this intriguing game of etymology by pointing out that apu has among other meanings that of 'family', and rua means 'two'.

Tao'ete appears in Jaussen but not in the LMS Dictionary. ${ }^{16}$ In the former it was entered as "s[ubstantif] beau-frère, belle-soeur," but usages in subsequent compilations indicate with near certainty that for the Maohis of the eras under study this word had the more specific meanings of "wife's brother" and "husband's sister." I can find no textual evidence to indicate whether tao'ete was used for address or reference or both, or whether it was used with the sexual qualifiers, tane or vahine.

As noted earlier, among their other meanings tane or vahine were terms of address and reference for "husband" and "wife," respectively. In addition, a female's husband's brother and her sister's husband were her tane, and a male's wife's sister and his brother's wife were his vahine. ${ }^{17}$

Hunō'a appears in the LMS Dictionary as "a son- or daughter-in-law"; whether it was formerly used for address or reference or both is not indicated. Presumably, in the event of its use for reference, tane or vahine were used when required. I have come across no information to indicate how far these terms were extended in a classificatory sense.

In view of the many things about Maohi life that conspired to bring about links of one kind or another between in-laws, it is surprising that so few generalizations have been recorded about such relationships. I list below the few such generalizations, or episodes, I have found that refer specifically to them.

Several references have been made to the parts played by many young couples' parents in arranging their marriages and in carrying out the nuptial rites. I called attention especially to the symmetry of events in such marriages, the principal exception thereto having been the competitive giftgiving engaged in by the respective families on some occasions. It is not unreasonable to assume that family units linked in this way continued to maintain the relationship in some more or less formalized manner, especially on occasions marking the life crises of offspring of the linking marriage. (The 
existence of a special relationship term, aupurua, adds weight to this belief.) However, no references to such a continuing relationship are known to me.

In my description of the custom of āmo' $a$, I reproduced Morrison's statement that such rites had to be performed with reference to a girl after her marriage, in order to permit her husband to eat with her other male relatives (see chap. 13).

Passages have also been recorded concerning marriages arranged by a suitor and the family (mainly the father) of a young woman-it being stated or implied that the suitor's family had little or nothing to do with either arranging or celebrating the marriage. Also noted has been a typical sequel to many such arrangements, mainly, the tendency by the wife's family to repudiate the contract in time, in favor of a more profitable match.

In some cases similar to these the intervention of the wife's family had more tragic consequences, as shown in the following excerpt from the journal of the missionary Jefferson:

We have also been lately informed that the Otaheiteans are guilty of self-murder, generally on the following account. A man is upbraided by his wife and her family, because he does not make them presents, \& is bid to be gone, \& come no more near them. This sometimes makes so deep an impression upon the despised husband, that he is resolved to destroy himself, which he effects by casting himself from some rocky precipice or lofty cocoa nut tree. (18 October 1799, LMS Archives)

The legend of Tuihiti and his bride Hauvana'a, reproduced in the section of this chapter on marital residence, exemplifies not only the competing pulls of family and husband experienced by a young wife, but her father's protective attitude toward her-and perhaps also his injured pride.

The motive of the father-in-law in the following report by a Spanish padre seems to have been based less on protectiveness for his daughter than on outraged propriety. (I cannot even guess what the woman's motives may have been!)

Now I want to relate an affair that happened to this headman in the last days of February, before this. He was a married man; but did not live with his wife, as he had turned her out of his house. The woman was staying at her father's house, quite close to our Hospice, although the latter did not want her there, and was not giving her food. Notwithstanding this he (the husband) came after her to use her as his wife, when the father was absent; and the latter learnt from his daughter what I have just said. So, resenting this conduct on the part of his son-in-law, the father kept watch over his house to catch him inside having commerce with the daughter, and to take his life. He succeeded at last in catching him and attacked his son-in-law with a Flemish knife in hand to kill him, while the daughter helped him also with the same intent. But they were not able to finish with him; for, although badly wounded, he escaped from them and fled to our hospice. (Corney 1915:325)

One wife's reaction to "divided loyalty" is seen in Cook's account, quoted in chapter 17, of the treatment accorded Mai by his sister and 
brother-in-law. The latter, it will be recalled, combined forces to relieve the unsuspecting Mai of his precious store of red feathers by feigning affection for him. (Beaglehole 1967:220)

In contrast, the following account by Marau (to Adams) indicates not only that brothers-in-law were capable of enmity, but it shows where one wife's loyalty lay when having to choose between husband and brother:

Taua-i-taata, or Tau, for short, Arii of Pare, married Taia, sister of Vanaamai-terai, chief or Arii of Papenoo, the district beyond Haapape, some fourteen or fifteen miles to the east of Pare. They had two children, whose descendants, by the way, remain Arii of Papenoo down to the present day. That they are Arii of Papenoo and not of Pare was due to the feud told in the following legend.

Vanaa of Papenoo had two jesters, a class of men much petted and allowed many liberties by all Arii. Among other privileges, they were always in the habit of receiving some of the best shares in distributions of food by the Arii. Vanaa's two jesters were or thought themselves slighted in some such distribution and swore revenge. They asked permission to visit Tau at Pare, and on their arrival were received by Tau with the usual feast, for which fatted pigs were killed as an offering (Faaamua). When it was brought before them they turned to Tau and thanked him, remarking, with a laugh, that Vanaa had compared him with a pig. Of all the stock insults that are most resented throughout Polynesia, one of the worst is to call a man a pig. Such a man is, like a pig, fit only for sacrifice. Many a death and not a few wars have sprung from this word puaa. Naturally Tau felt himself mortally insulted by his brother-in-law, and lost no time in preparing his revenge.

Ordering a great feast to be made ready at the Marae of Raianaunau, Tau immediately bade his men bring out his canoes, while the two jesters, fearing the consequences of their act, especially to themselves, escaped to Papenoo. Tau's wife, Taia, noticing the preparations, asked her husband where he was going, and he merely replied, "I go to visit your brother." Very little time was needed for expeditions of this sort in the South Seas, unless some ceremony was to be performed or resistance was expected. A few hours would be enough for the insult, the passion, and the revenge. Tau started immediately, and his men soon paddled his canoes round the point at Matavai and abreast of the village of Papenoo, where they stopped and hailed, with the cry that it was Tauaitaata of Pare. The people of Papenoo gathered on the beach to receive him, but were surprised to find that no one came ashore. The Arii himself, Vanaamaiterai, then hailed the canoes and asked, "Why does not Tauaitaata land?" The reply came that the sea was, for the moment, too rough. Then Vanaa, in the courtesy of the chiefly relation, did what Tau intended him to do, he swam out, and on swimming alongside Tau's canoe he was quietly and instantly clubbed on the head and his body drawn into the canoe without betraying to the people on the shore a sign of what was happening. They were only somewhat surprised to see that after their chief had got aboard, alone, the canoes turned and paddled back toward Pare with Vanaa, but without a single attendant.

On arriving at Pare, Tau had the body of Vanaa carried to the Marae of Raianaunau, and without going to his house, followed the body to the Marae where the feast was already prepared. Of course Tau meant that the murder should be kept a secret from his wife until he should be ready to deal with her; but when the drums of the feast began beating for the dead, Taia, hearing them and not hearing of her husband's return, asked: "Why are the drums of Raianaunau beaten?" Her women answered that the Arii must have arrived; but she knew the 
tones of the pahu too well to be deceived. She listened again, and cried: "That is not for an Arii's arrival; it is for an Arii dead! Who is dead? Not Tau, for I should have been told! Why am I not told?" She sent one of her women to ask, but the woman came back without an answer. Then Taia sent for her husband, Tau, who sent back word that he could not see her for three days, as his duties or ceremonies required.

This was enough to waken Taia's suspicions. She knew that Tau had abruptly started to visit her brother, and had returned without coming near her, and was making a feast over a dead Arii. She ordered one of her women to go out and look for the first person coming from Papenoo, to ask about Vanaa. Two days passed before the woman reported that she had just seen a man from Papenoo who told her that Vanaa had gone away with Tau, on his return to Pare. "I know now," she cried, "that my brother is dead"; and she ordered the man to be brought to her, to tell her all he could. Then she sent him back instantly to tell the people of Papenoo that their Arii was murdered, and they must send canoes immediately to rescue her. The same evening the boats arrived and she set out in them, taking with her, after much hesitation, her two children.

Then began the part of her activity which was most characteristic of the island society. Custom prescribed a regular course for women who sought justice or revenge. In the murder of Vanaa, Tau had outraged not only the district of Papenoo, of which Vanaa was Arii, but all the districts and Arii connected by political or social ties with Papenoo. The whole eastern coast of Tahiti beyond Pare Arue (Haapape, Papenoo, Tiarei, Mahaena, Hitiaa) formed one connected group known as Teaharoa. When united, the Aharoa were much stronger than the Purionuu, or Pare Arue, where Tau was Arii. To revenge her brother, Taia had to visit each of the Aharoa Arii in turn, and claim his assistance, which, in such cases, was seldom refused.

Accordingly Taia stopped first at Haapape and made her complaint. Then, continuing on her way eastward, she stopped abreast of her landing-place at Papenoo, where the beach was already crowded with people awaiting her; but she cried out: "I will not land! My orders are: Let no one pass through Papenoo! Bind the two jesters! Prepare for war! Wait my return! I go to tie our alliance of the six Teaharoas!" Going directly on to Tiarei and Mahaena, she ended her journey at Hitiaa, received everywhere with open arms and pledges of support. Returning to Papenoo, she put the two jesters to death and their bodies were taken to the Marae. This done, she waited the arrival of the other districts to make the attack on Pare.

Against such an attack the chief of Pare seems to have felt himself helpless, for when his feast was over, and he learned that his wife and children had fled, he knew what she would do to revenge her brother, and, without waiting for the invasion from Teaharoa, he escaped to Moorea.

With his departure, his line ceased to be Arii of Pare. He never appeared there again. His wife, afterward married Tevahitua i Patea, and from this marriage our Papara family is descended. (1901:78-81)

It would be unwarrantable to generalize about Maohi in-law relationships on the basis of these few episodes, but certain features of Maohi life cannot have helped but influence those relationships in many cases:

1. Extended family households inevitably brought some in-laws together into close, everyday interaction, resulting in situations of divided loyalty, split authority, diffuse affection, multiple sexual standards, sharpened aversions, and so on. 
2. The potentiality for sexual relations between a man and his wife's sisters, as institutionalized occasionally in sororal polygyny, seems likely to have colored their relations even without their actual marriage; and in view of the institution of leviratic marriage, the same may be said of the relations between a woman and her husband's brothers. In other words, it is my surmise that many such relationships included casual sexual encounters, for example:

The Women have too great an intercourse with different Men. An Elder Brother has connection with another Brothers Wife, and the Younger Brothers with their different Brothers Wives whenever Opportunities offer without giving Offence, it is considered no infidelity, for I have known a Man to have done the Act in the presence of his own Wife, and it is a common thing for the Wife to assist the Husband in these Amours. But what is remarkable, it is not so among those who are not related to one another; it is then a violation if a married Couple err on either side, for if a Man finds another with his Wife he'll kill him if he can, and if the Woman discovers the infedelity of the Husband she will certainly take revenge on the Woman. (Bligh 1789:II, 78)

3. The timing of kin-Title transfer had well-recorded consequences upon parent-child (successor) relations, which probably extended to the latter's spouses.

4. In the case of a couple's respective families, one may suppose that their interests converged, when their kin-Titles or other properties devolved upon a single successor, as was often the case. On the other hand, instances of divorce, which were all too evident, probably led to conflict between the respective families as well.

I cannot spell out how these several features may have influenced relations between various pairs of in-laws-say, between a man and his wife's brother, a woman and her husband's mother-but it may be useful to remind the reader of the greater frequency of interaction between some of these pairings, brought about by the preponderance of virilocal residence. In other words a man was less likely to interact with, say, his sister's husband than he was with his brother's wife. I think it possible that such tendencies may have had institutionalized consequences of one kind or another, but I cannot discover what these were.

\section{SEMI-MARRIAGE}

I believe it possible and useful to distinguish four other kinds of regularized heterosexual union that occurred among the Maohis in addition to the one I call "marriage." 18 These were unvalidated unions; unions of a man and a secondary wife; unions of a woman and a secondary husband; and unions with concubines or gallants (as distinguished from casual sexual encounters). 
"Unvalidated unions" designates those characterized by all features of "marriage" except for the circumstance that one or both of the principals' families deliberately withheld its recognition of the full family status of the union's progeny. Many persons living far from their relatives undoubtedly entered into marriages without the latter's knowledge, or concern, but at present I refer to unions toward which one or both of the principals' families deliberately and openly withheld recognition. That such unions were not unusual has already been indicated. Most typically they involved couples of different class status from whom recognition was withheld by the family of the higher-class spouse. There may also have been cases of recognition withheld for other reasons-say, because of interfamily enmity-but records of such situations are lacking. Also, instances of two-sided family disapproval undoubtedly occurred, for example the story of the tragic love affair of "Princess" Pereitai and her lower-class lover, Te Muri, wherein it was naturally assumed that the latter's parents would have disapproved of the match, "... for no plebeians could ever wish to bring down wrath upon themselves and even their district by forming such a union" (Henry 1928:600). However most of the information on the subject implies positive disavowal by only one side.

Some "unvalidated" couples were "driven into exile," or "lived in disgrace," according to some accounts, but many others probably lived fairly normal lives, incapacitated, if at all, only by the ambiguous status of their offspring.

Unions with "secondary wives" were probably numerous, especially among ari $^{\prime} i^{19}{ }^{19}$ As pointed out earlier, men with high-ranking kin-Titles usually had one "primary" wife, by whom succession was appropriately assured; in addition, some of them appear to have had a secondary wife or two, as well as regular concubines (and of course any number of casual sexual affairs). In some recorded instances the social position of the secondary wife was as high as that of the primary wife, the only difference having been the latter's antecedence-indeed, in some instances such women were sisters, and the offspring of the secondary wives were likely to have been allowed to survive (Jefferson, Journal, 13 April 1800, LMS Archives). The offspring enjoyed all the prerogatives of their superior positions, including in some instances eligibility to their fathers' kin-Title. (It also happened sometimes that a secondary wife superseded a primary one if the latter failed to produce a successor.)

Evidence regarding the relationship between a man's primary and secondary wives is as scant as it is inconsistent. When the legendary maiden Hotuhiva landed on Huahine and moved directly into the affection (and presumably into the bed) of the reigning chief, the latter's wife left him in anger (Ropiteau 1932:124-125). In contrast, relations between Po- 
mare I's first (and principal) wife, 'Itia, and his third wife (or "semi-wife"), Pipiri, were evidently entirely congenial.

Like much else about Maohi social relations, generalizations on this subject are either rendered impracticable through flimsiness of data or overly complicated through differences of personnel and of context.

Many Maohi married women had more or less recognized lovers, as the following paragraphs will show; but the only specific cases of "polyandry" that I have come across occurred in legends, as for example in the one about Honoura. When this giant-hero arrived at Ra'iatea in the course of his adventurous travels, his brothers are described as having gone inland "to pay their addresses to the famous handsome woman Teura-tau-e-pa. And they obtained her as their wife" (Riro atura taua vahine ra ia raua). To this the translator, Miss Henry, added this prim note: "In olden times partnership in wives or husbands was not ill regarded." (Henry 1895:277, 293)

But to accept as an instance of "marriage" such a case as this may be reading too much into the story. (For example, the phrase taua vahine, which Henry translated "their wife," could also be translated "their mistress.") And the same holds for Ellis' general statement on the subject:

When the rank of the parties was equal, they often separated; the husband took other wives, and the wife other husbands; and if the rank of the wife was in any degree superior to that of her husband, she was at liberty to take as many husbands as she pleased, although still nominally regarded as the wife of the individual to whom she had been first married. (1829:II, 571, italics added)

Indeed the strength, persistence, and in some respects exclusiveness of a validated marital tie once established is revealed in Morrison's description of the levirate:

"If a woman has (a) husband and he dies without Issue the Husbands Brother takes her; if He has no wife and should be have Issue by Her the Children are Calld by the Former Brothers Name, \& take his estate" (1935:184-185). (The rationale for this intriguing custom would be more apparent if the deceased had been the elder of the two brothers, but such is not specified in Morrison's passage.)

It is my belief that most if not all that has been labeled polyandry in ancient Maohi society was not "multiple marriage" at all but instances of husband surrogation or of overt and more or less regularized unions of married women with their lovers. As Ellis indicated in the passage quoted above, and as documented in several well-known cases, the latter kind of situation was a fairly common occurrence, mainly (if not entirely) with ari'i-class women. The best-known relationships of this kind were those of "Itia, the "primary" wife of Pomare I. Bligh provided the following report 
of her situation. (In 1788 when this observation was made 'Itia was about thirty years old and had eight years previously borne a successor to the high-ranking Title of her husband, and the latter had been relegated to the regency, which was shared in some measure by 'Itia.)

Tynah [Tina, i.e., Pomare I] as usual gave me his constant Company, and put me in mind that when I came here again I was not to forget the different things I had promised should be brought out to him. He left the Table soon after dinner, when Oreepyah (his Brother) and Odiddee told me a peice of Scandal I had never heard of with certainty before. This was that Iddeah, Tynahs Wife, kept a Gallant called Taerree, and that he was a towtow and the very person who had fed Tynah at dinner. They said also that Tynah knew it, and it was so far agreeable to both parties that both men cohabited with the Wife in the same hour, and in the presence of one another. As I appeared to doubt of the fact, they took several Opportunities to convince me in the course of the day by mentioning it to some others who all declared it was true, and I have no longer any doubt of it, not but I believe it is more or less the case as far as I can find throughout the whole Island. The Virtue and chastity of the cheif Women is by no means equal to what it has been represented, and it certainly is not a fact that they will not grant favors if opportunity and convenience offers. (1789:I, 399)

And Bligh further added:

The Peice of history of this Woman, Tynahs Wife, which I have already related concerning her having a Gallant, was to day most effectually confirmed to me by Odiddee, for her Husband leaving us after dinner, Odiddee opened the discourse to the Lady herself, and told her he had mentioned to me that Taerree was a particular friend of hers, and of the intimacy that subsisted between them, at which she laughed, but said he behaved ill for telling me of it. He seemed however not to have spoken any thing that was illiberal, for it was a matter that diverted them both for some time, and I beleive is very common in this country, without any disgrace to either party. (1789:I, 404)

Some fourteen years later the conduct of this same 'Itia, this time with a much more distinguished bedmate, was chronicled in Turnbull's journal:

About this time the king's mother, Edeah, appeared alongside, in a canoe, attended by her favourite, a chief of the island Huaheine, a man of a most savage figure and manners. This lady had been for some years separated from her husband Pomarre; but had not on this account suffered any diminution of power or respect in the country. These two personages came on board our ship with their characteristic frankness, and were treated by us with all possible attention, having learned from the gentlemen of the mission, that Edeah still enjoyed such influence in the state, that her favour might be essentially useful to us, as we had every thing to fear from her resentment. No pains, therefore, were spared to gain her good will; she and her favourite chief were conducted to the cabin, and there entertained with grog, tobacco, \&c. \&c. Several presents were offered her, on which she seemed to set very little value; but expressed great eagerness to possess a poo puey, or musket. This, however, we thought most prudent to withhold at present, as we were not as yet sufficiently acquainted with our company, 
nor with the state of matters on shore. This queen dowager and her paramour, however, continued to drink, and interchange tobacco, till they were nearly incapable of leaving the ship, each appearing to be equally delighted with their entertainment. The attendant was so well pleased, that on taking leave, he urged the writer of this narrative to accept him as a tayo, or intimate friend, a civility he declined in the way least likely to give umbrage. (1813:134-135)

A few days later Turnbull received a return visit from the pair, and the episode that followed is revealing both of their relationship and of Tina's ('Itia's husband's) attitude toward her:

One day we had Edeah and her favourite chief to dine on board; not that they cared for our food dressed after our own manner, but because they knew that unless they ate with us, they could hope for none of our ava and tobacco, for which they both ardently longed. That we might not appear to be perre perre, niggardly and stingy, qualities they very artfully affect to abhor, they were suffered to indulge to their fullest wishes. After a very short interval, they renewed their calls for more; this was set before them, but the division of it had nearly occasioned a very serious quarrel between the lady and her attendant, who started up from table, and with the most savage fury swore in the language of the country, he would put an end to her existence for having, as he said, taken to herself a little more than her due share.

The effect of the liquor on the two guests was very different; for while the man became mad and furious, the poor queen dowager appeared silly and childish. She burst into tears and trembled with fear, as her companion grew outrageous and desperate. Just at this time Pomarre came on board to have some work done at our forge, and hearing the noise below, was touched with compassion for Edeah, his former consort; but unwilling personally to interfere, he beckoned to me to go down, and endeavour to arrange matters, without his appearing to know any thing of the business. This was done; but it was only by a promise of a little more spirits that peace could be restored, and the fury of the savage restrained from breaking out into some desperate act. Poor Edeah, however, still affirmed that he would take some other opportunity to reproach her for the imaginery offence. The glass again went round to the great satisfaction of our company, and we at length succeeded in getting the lady and her companion out of the ship; for which Pomarre afterwards repeatedly expressed his gratitude. (145-146)

In comparison with her son's wife's affairs, 'Itia's sexual behavior was restraint itself. According to Wilson, "The queen has had as yet no child, nor is it likely she should produce any, as, if the reports our missionaries have received are true, she is a perfect Messalina, and lives in a promiscuous intercourse with all her porters" (1799:322). As noted previously, the wife of a very high-ranking Titleholder, such as Pomare II's was, did not normally engage in extramarital affairs openly until after bearing a successor for her husband, but this wife's behavior may perhaps be accounted for by the notorious circumstance that her husband seems to have preferred the embraces of men.

Georg Forster witnessed a situation which could be interpreted as multiple marriage, or divorce and remarriage, but probably should be 
viewed as the kind of arrangement under discussion. On one excursion this fastidious naturalist had occasion to stay overnight at Atehuru with a man named "Potatow [Pohuetea, tribal chief of Puna'auia], who had "parted with his wife Polatehèra, and taken a younger to his bed, while the lady had provided herself with a lover or a husband, and they all continued to live very peaceably in the same family." (1777:I, 359)

Perhaps not entirely peaceably, for elsewhere Forster indicated that Polatehèra seemed to have had some troubles with her gallant: "The young man had an affection for a Taheitian girl, and our ship was the place of their rendezvous. They did not however contrive their amours so well, as to remain undiscovered. The masculine Polatehera caught them one morning, gave her rival many hearty boxes on the ear, and humbled the guilty lover with a severe reprimand." (1777:II, 94)

Enough instances of concubinage have already been listed to indicate the range of the occurrences of this kind of relationship. It was probably more common than cicisbeism and less limited to the upper class, but, beyond that, generalization is scarcely feasible. For one thing, from the scant information recorded, it is often impossible to know whether certain heterosexual relationships involved concubines or secondary wives; indeed some of these relationships probably were borderline cases. (But I persist in maintaining that the distinction is a genuine one, both by modern analytical standards and by Maohi classification.)

\section{SEPARATION AND DIVORCE}

As we have seen, separations between spouses were fairly common, but according to the definition of some writers-a definition I favor-divorce was not final until one of the couple remarried. ${ }^{20}$

Several writers have expressed general opinions about the frequency, procedure, causes, and consequences of Maohis' separation/divorce. A passage from Ellis describes the marriage tie as one of the "most brittle" of Maohi relationships, and as having been terminated easily and on slightest cause (1829:II, 571). According to Moerenhout, "These marriages, so easily entered into, are terminated with what seems to be equal facility; for couples remain united only as long as it suits their mutual inclinations se quittant dès qu'il leur en prenait envie [lit., leaving each other whenever they feel so inclined]." (1837:II, 63; see also J. Forster 1778:424)

Moerenhout also voiced the opinion that divorce occurred most frequently during the period just after marriage. This may have been the case with lower-or middle-class couples, but I have the impression that when a high-ranking kin-Title was involved, separation (divorce itself having been rare) was most common after birth of a successor. Needless to say it is not possible to provide statistics to support either of these opinions. (In this 
connection general statements about the prevalence of divorce have to be weighed with the possibility in mind that the observers' attentions were probably directed more to the wrecks of marriages than to instances of marital stability.)

Statements about the ease with which separation and divorce were effected are somewhat at variance with other observations, sometimes by the same writers, about the control many husbands exercised over their wives, including their ability in many instances to retrieve runaway wives by force. There must have been wide situational differences in this respect-depending upon the social position of the wife, the support given her by her own family, the personality and relative strengths of the spouses, and so forth-but in general the statement about ease of divorce probably ought to be qualified by "the husband permitting." This does not mean, however, that I subscribe fully to the following statement by Morrison that "If a Man has a reason to part with his Wife he informs her of it to which she mostly agrees, deeming it reproachful to remain after such notice" (1935:185); for the first step toward separation or divorce was sometimes initiated by the wife.

As for the final step, while my belief about divorce being effected only by remarriage of one of the spouses may in general be valid, it is not unlikely that some instances were less clear-cut. What, for example, would the situation have been if a woman quit her husband, returned home, and then remarried-all with the support and approval of her own family, but against the wishes of her first husband and his family? Or, if a husband had cast off a wife to marry another, against the wishes of the former's influential family? Uncertainties and ambiguities like these serve to reinforce the conclusion that Maohi society, for all its size and interconnections, still lacked central institutions for interpreting and enforcing widely recognized but vaguely formulated norms.

In the same sense, in the absence of any central authority for legislating valid grounds for separation or divorce, the numerous admissible causes differed greatly in applicability and weight. In some instances, it appears, a husband chastised but held on to his wife despite her continued indolence or her habitual adulteries; while in others, he dismissed her on nothing more tangible than boredom with her presence. And on their side some women remained with their husbands despite hideous provocation, ${ }^{21}$ while others left them for no discernible reason at all. In other words the potential grounds for separation or divorce included anything that displeased one spouse about the other; what use was made of such grounds depended upon the choice of the defecting spouse and his or her-mainly his-ability to enforce that choice.

Turning now to the consequences of separation and divorce, I continue quoting Morrison's summary of arrangements: 
“... he then Devides all His Goods and Chattles with her, and she leaves him and takes the Female Children with her leaving him the Males. If she lives single she always Claims the rights of a Wife, and tho they do not Cohabit, always look on each other as Friends and Apply to each other for any little property which at any Future period of their seperation they may stand in need of and each enjoys their own estate but should they Choose to live together after such seperation it lies at their own option and they may return to each other at any time. If the Woman takes an other husband she relinquishes all claim to her rights in her first Husband, and Can demand No More of Him but Her own estate and her part of the Goods as before discribed. (1935:185)

Morrison's distinction between separation and final divorce has already been included in my definitons, although his notion about the amiable relations between separated spouses is doubtless too inclusive and too cheery by far. His description of the property settlement is, moreover, far from clear.

The property transactions accompanying the inception of marriage were, it will be recalled, of several different kinds, depending upon the type of wedding, the spouses' social statuses-absolute and relative-their relative ages, the bride's previous marital history, and so forth. If by "Her own estate" Morrison referred to the divorced wife's rights in her own family lands, then it seems altogether plausible that her former husband's use-rights in that estate would have terminated with the divorce. But I cannot divine what Morrison intended by the husband's "Goods and Chattles," which were said to have been divided with the separated and divorced woman. Were these the durable objects constituting her former dowry? Objects produced by herself, or by their joint labor? Or even those objects produced or owned entirely by him? Lacking, as we do, any clear and full picture of the property aspects of the marriage contract itself, I am not in a position to describe what took place at the termination of the contract.

Finally, I am not at all disposed to accept, literally, Morrison's statement about disposal of a couple's offspring in the event of their divorce. Compare, for example, Moerenhout's account of such happenings:

If they separated, after having had children, as rarely happened, it was always arranged in such a way that there would be no argument [dispute]; for, from the moment of his birth, a child belonged, by virtue of a general covenant, either to his father or to his mother; and, in keeping with this covenant, followed one or the other, when they [happened to] separate. This covenant was based on the fact that at birth a child took the name of some member of his family, either on his father's or his mother's side, and belonged to the family from which he had received his name. (1837:II, 63-64)

If it were customary to bestow upon a male child some name derived from the father's relatives, and a name from the mother's relatives upon a female, then Morrison's statement might be brought into line with Moerenhout's; but I can find no other evidence that such a custom prevailed. 
As for Moerenhout's other generalization, that a child was at birth assigned to only one parent's family, be it mother's or father's, this is so fundamentally at odds with all we know about Maohi consanguinity that I cannot understand how Moerenhout came to accept it. The physical location of children of divorced parents was probably determined by a number of factors-Title incumbency, age, even sex-but a newborn's consanguineal ties were based on descent, which in most instances was inclusively bilateral. Perhaps what Moerenhout had in mind was the popular (but not invariable) custom of assigning newborns to foster parents, including relatives of either father or mother. 


\section{CHAPTER 20 FRIENDSHIP}

In a society so diffusely consanguineal and so pervasively hierarchical as that of the Maohis, most of an individual's day-to-day interactions probably took place with persons explicitly identified as consanguines (or affines) or as having more (or less) authority or privilege of some kind or another. But interaction did take place between persons not thus categorized, or between persons whose ties of kinship, superiority, or subordination were tenuous enough to ignore or override in favor of a more positive relationship of friendship.

The Dictionary of the London Missionary Society lists three Maohi words as having had the meaning of "friend": hoa, taua [tau'a] and taio. In the absence of adequate textual materials it is impossible to specify how these words overlapped or contrasted in meaning, but taio is certainly the one most frequently encountered in the sources, and it is the form used most often to refer to the more formalized friendship relationship founded on a definite contract, that is, on a friendship pact. ${ }^{1}$

Friendship pacts varied rather widely in reference and overlapped with the relationship I label "fosterage." At one extreme such a pact seems to have been a formalized but rather casual way for two individuals to indicate peaceable intent toward one another-say a traveling chief with a dignitary met en route (Corney 1913:317). ${ }^{2}$ In many cases the "contract" was probably short-lived and was concluded with nothing more than a temporary interchange of names and an exchange of presents. Some such encounters may in fact have dispensed with name interchange, as witness the following report:

We now took our leave of our freindly cheif and proceeded along shore for about a mile when we were met by a throng of people at the head of whoom appeard another cheif. We had learn'd the ceremony we were to go through which was to receive the green bough which was always brough(t) to us at every fresh meeting and to ratifie the peace of which that was the emblem by laying our hands on our

The bulk of this chapter appeared originally in Polynesian Culture History: Essays in Honor of Kenneth P. Emory. Bernice P. Bishop Museum Special Publication 56, edited by G. A. Highland et al. (Honolulu: Bishop Museum Press, 1967). 
breasts and saying Taio, which I imagine signifies freind. The bough was here offerd and accepted and in return every one of us said Taio. (Beaglehole 1962:I, 254-255)

The visitors having been European may have colored somewhat the Maohis' view of the situation, but probably did not alter radically the ritual procedure. At the other extreme was the kind of "friend-adoption" described by Morrison (I reproduced the passage in chapter 13, in connection with my discussion of āmo'a but now do so again for the reader's convenience):

When a Man adopts a Friend for his Son the Ceremonie is the same [as a nuptial rite], only placing the Boy in the place of the Woman, the Ceremonie is ratified, and the boy \& his friends exchange Names and are ever after lookd as one of the Family, the New Friend becoming the adopted son of the Boys Father-this Frindship is most religiously kept, and never disolves till Death, tho they may seperate, and make temporary Friends while absent, but when they meet they always acknowledge each other.

And should a Brother or one who is an adopted friend become poor or loose his land in War, he has nothing more to do but go to his Brother, or Friend, and live with him partaking of all he posesses as long as he lives \& his wife and Family with him if he has any-or if any relation or Friend, tho not in immediate want, comes to the House of his Friend, he is always fed while he Stays and is Not only welcome to take away what he pleases but is loaded with presents. (1935:189) ${ }^{3}$

Motivations for this kind of contract must have differed rather widely, both in terms of public avowal and private design. One motive was described by Morrison:

If any Person wishes to have his son or Daughter instituted into the [Arioi] Society he procures an Areeuoy to be His Son or Daughters Friend and Adopts him for His Son by performing the Amoa ... towards Him and His Son or Daughter at the Morai and the Child is acknowledged an Areeuoy immediately the Ceremony is over, and May Continue to follow their Methods while $\mathrm{He}$ or she thinks Proper. (1935:235)

It goes without saying that friendly acquaintances developed among females as well as among males. If evidence were needed on this score there comes to mind a story about a young woman who gave her own life to save a female friend from the former's cannibal mother. They are described as "... loving one another like sisters with the same father and mother" (Ropiteau 1929:289). On the other hand, I have found no specific references to friendship pacts between Maohi females. Yet Turnbull did record that offers of taio-ship were made by many Maohis, including some females, to the Hawaiian mistress of an officer of a visiting ship (1813:267).

Friendship, quite apart from consanguinity, affinity, and casual sexual liaison, also occurred between females and males. When Europeans arrived on the scene some women actively made taio pacts with their visitors, evidently for political advantage or for a more dependable source of European objects; but whether such pacts had been entered into previously is not 
certain. In this connection, Wilson wrote: "Lieutenant Corner also added, that a tayoship formed between different sexes put a most solemn barrier against all personal liberties. Our brethren [the London Missionaries] who are returned, however, think this not to be the case; or that they have, since his visit, degenerated." (1799:346) ${ }^{4}$ This "backsliding," if such it was, must, however, have begun much earlier, for in his journal of 1769 Molyneux wrote that "Individuals form Freindships with Individuals \& every ... [European] has his Tayo (or Friend) this might be productive of good Consequences but the women begin to have a share in our Freindship which is by no means Platonick" (Beaglehole 1955:553).

Another passage from Wilson raises the possibility that women occasionally became taio of mahu (male transvestites): "These mawhoos, being only six or eight in number [on Tahiti?], are kept by the principal chiefs. So depraved are these poor heathens, that even their women do not despise those fellows, but form friendships with them. This one was tayo to Iddeah ['Itia, wife of Pomare I]." (1799:198)

Mahu, who spent much of their lives living and working as females, undoubtedly formed "friendships" with some women, but whether they entered into formal taio pacts with them is not altogether sure. It is quite possible that Wilson's use of the word "tayo" to describe 'Itia's relationship with a mahu may have been based on his own incomplete understanding of the taio institution, and not as a result of hearing Maohis refer to the relationship as such.

Most of the friendship pacts reported in the sources were, however, between males, and usually, but not invariably, between those of approximately the same age and class; in these and other respects such relationships somewhat resembled brotherhood, but came even closer to approximating actual interchange of identity. Finney made the interesting but undocumentable suggestion that "... all chiefly youths ordinarily took a bond-friend in the course of growing up" (1964a:435n).

In attempting to reconstruct the taio institution, we face the problem of deciding what aspects of it were pre-European. Most recorded instances of it had to do with pacts between native and European; and while much of the native institution probably carried over into the new manifestations, it may be assumed that some changes were thereby introduced-in motivation as well as in degree of commitment and pattern of interaction. For example, the case of Mai excepted (see below), it is unlikely that cynical self-interest was so prominent in pacts between Maohis as it was in some pacts initiated by Maohis with their unsuspecting European visitors.

Name exchange was a fundamental part of a friendship pact between Maohis, but I am uncertain about the details of the arrangement. ${ }^{5}$ It may occasionally have involved Titles, but perhaps more commonly it involved personal names. Also, although some name exchanges may have become 
complete and "permanent," others appear to have prevailed only when the principals were in each other's presence or proximity. There is, however, a legendary account of a friendship pact between an island's tribal chief and highest-ranking kin-Titleholder and one of his subjects which involved an exchange of names and which (for certain purposes at least) is described as having invested the latter with "regal authority." This account concerns the spread of the Arioi sect from Ra'iatea to Tahiti and will be presented in chapter 22 .

The extent of "identity interchange" involved in some friendship pacts is revealed in the following excerpt from a statement reproduced earlier:

When a Chief is present in any Company the Men strip their Bodys to the Waist not suffering any Covering on their Head or Shoulders in His Presence-and all the Weomen present uncover their Shoulders tucking their Cloth under armpits, to Cover their Breasts in token of obedience and respect, to his presence; the Men are not always particular in this point except Upon the Chiefs Heredetary land or that of His adopted friend, where any neglect would be deemd an Insult and punishd accordingly-(Morrison 1935:168, italics added)

The sources generally agree that a friendship pact had the effect of prohibiting sexual relations between a man and his taio's sisters or daughters, ${ }^{6}$ (and presumably mothers): “... if a Man Makes a friend that Friend can never have any Connection with any female of the Family except His friends Wife, evry other becoming His relations which they hold an abomination to have any Conexion with, nor can they be perswaded to alter that Custom on any Consideration, detesting as much as we do to have their own relations as wives" (Morrison 1935:237). I have discovered no evidence of the extension of this prohibition to other consanguines of each taio. In fact, the question of how far a friendship pact involved relatives of the principals is unanswerable. Statements, such as the following, imply a rather wide extension of the pact's undertakings-at least in terms of norms: "Otu [Tu] show such a friendly attachment towards me [Rodriguez] that in a little while he adopted me as his brother, and as a son to his own parents and other kinspeople; and he exchanged his name for mine, an act which, among these people, is the bond of highest favour" (Corney 1919:6). But we are provided with little evidence concerning the actual implementation of such promises. An episode recorded by the missionary Crook provides an example of the consequences of friendship combined with fosterage (presumably, the "friendship" in question was of the pact variety): ${ }^{7}$

Some unpleasant things happened today which evinced the ignorance, pride and duplicity of our judges. A widow woman has been excommunicated for crim. con. with a young man who is unbaptized. Her brother a chief of a district prevented their being married and therefore they ran into the mountains together. On Saturday last they were caught tied with ropes and used very cruelly by some of the inferior judges. Today the judges informed me that they were going to 
bring them to trial. I told them to do so and then allow them to be married to prevent future mischief. They seemed to consent but took every indirect method to counteract my design. They sentenced the man to be banished and the woman to work altho three months gone with child. As the man was forcibly led away the woman followed him, but was dragged from him with many struggles. I remonstrated against their proceedings.

The chief judge a member of the church accused me with opposing the king and the laws and with opening a door for the commission of crime. After such an insult the people expected that we would leave them and were much alarmed. The chief of the district and a multitude of people thronged our house entreating that we would not leave them. The cause of the marriage being so much opposed is that the chief has adopted a boy who is a friend of the young man, and therefore the young man is his friend or son as well as the boy according to their old customs and therefore must not marry his aunt. (Crook, Journal, 10 April 1826, LMS Archives)

In striking contrast with these proscriptions, a friendship pact appears to have licensed and even encouraged sexual relations with a partner's wife, she having been considered "... a common property for the tayo" (Wilson 1799:346). ${ }^{8}$ According to Morrison, however, the woman herself had a choice in the matter: “... it is lookd upon (as) a piece of Great friendship for a Man to Cohabit with the Wife of His adopted freind if She is agreeable: the Adopted friend being always accounted as a brother" (1935:184).

In one version of the legend of Honoura, warrior-heroes ('aito), as an occupational category, are also described as licensed to "take liberties" with one another's wives. In the episode in question, while traveling to his home, a young $\operatorname{ari}^{\prime} i$ and his bride met two other warriors, who said to him: "Give us charge of our little lady for a short while, since you and we are warriors all." The husband consented and the warriors had their pleasure with the woman. (As the translator added in an editorial note, "Women in those days were very passive.") However, these privileges evidently had their limits. Not content with such temporary entertainment the two warriors made off with the woman, but they were overtaken by the irate husband and killed. (Henry 1928:519)

Several legendary accounts indicate that "hospitality" sometimes included access to the host's wife (e.g., Adams 1901; T. Salmon n.d.). Indeed, one may conclude from all such accounts that there prevailed a very general norm to the effect that whatever the intended degree of intimacy, the goods exchanged between males in the name of formal amicability quite often included access to one another's wife-but with varying degrees of access, ranging from tolerance of a one-time embrace to acquiescence in a continuing liaison, such as the taio pact is alleged to have entailed. ${ }^{9}$ Yet, in contrast to this norm, there is evidence that many husbands did not care for the arrangements when their own wives were involved; and this applied not only to absentee hosts but even to the case of close friends, as exemplified in the legend of Turi and Mahu: ${ }^{10}$ 
Turi was a [demi] god. He originated at Fa'aroa, Ra'iatea. Raure'a was his wife; ${ }^{[11]}$ Mahu was his friend. One day Mahu and Raure'a went inland in search of some bark of the breadfruit tree for making bark cloth. Turi remained at the shore and watched them go. When the couple arrived at a place called Puarairai, Mahu seduced Raure'a. Turi found out about this and was displeased. He dove into the sea and swam until be reached Papetaitai, which was a spring on Taha'a near which dwelt a beautiful virgin. She refused all Turi's advances [so] he took to the sea again and swam to the west coast of Taha'a where dwelt a woman named Farafara-ura. This one was receptive to him sexually, but when he ordered her to climb a palm and get some coconuts for him she refused him and went away.

Meanwhile Mahu left Turi's wife and went in search of his friend. He discovered the latter swimming through the reef towards Ra'iatea and followed after him so energetically that he caught up with him between Taha'a and Ra'iatea. When Turi spotted him he shouted out, "So, it's you, the wicked friend who has treated me so disloyally. Go on back to your woman." "No," said Mahu, "I won't return [to her]. I shall go with you wherever you go, for the rest of my days."

So the pair of them swam together out to sea [and thenceforth remained friends], but Turi retained his bitter feelings toward the wife whom he had lost. (Ahnne 1931b:168-169)

Hamilton, surgeon on the Pandora, gave this account of the practice of "wife-lending":

In becoming the Tyo, or friend of a man, it is expected you pay him a compliment, by cherishing his wife; but, being ignorant of that ceremony, I very innocently gave high offence to Matuara, the king of York Island [Mo'orea], to whom I was introduced as his friend: a shyness took place on the side of his Majesty, from my neglect to his wife; but, through the medium of Brown the interpreter, he put me in mind of my duty, and on my promising my endeavours, matters were for that time made up. It was to me, however, a very serious inauguration: I was, in the first place, not a young man, and had been on shore a whole week; the lady was a woman of rank, being sister to Ottoo $[\mathrm{Tu}]$, the king of Otaheitee, and had in her youth been beautiful, and named Peggy Ottoo. She is the right hand dancing figure so elegantly delineated in Cook's Voyages. But Peggy had seen much service, and bore away many honourable scars in the fields of Venus. However, his Majesty's service must be done, and Matuara and I were again friends. He was a domesticated man, and passionately fond of his wife and children, but now became pensive and melancholy, dreading the child should be Piebald; though the lady was six months advanced in her pregnancy before we came to the island. (Edwards and Hamilton 1915:109-110)

The passage from Morrison quoted near the beginning of this chapter provides some notion of the range and amounts of objects and services exchanged between the principals of a friendship pact. Morrison added the following important detail: "No Man ever Claims a right to any land but his own, ${ }^{[12]}$ or His adopted Freinds, which he may Use during his Friends life, and should his Friend die without any other Heir the Adopted friend is always considered as the right owner and no man disputes his right" (1935:194). 
An example of this aspect of pact-friendship is provided in a traditional account of the establishment of the Pomare "line" on Tahiti:

Tu of Faarava, having undertaken a visit to the distant land of Tahiti, came in by the Taunoa opening, which is the eastern channel into what is now the harbor of Papeete. Landing at Taunoa a stranger, he was invited to be the guest of Mauaihiti, who seems to have been a chief of Pare. Tu made himself so agreeable, or so useful to his host, that Mauaihiti adopted him as hoa, or brother, with the formal ceremonies attached to this custom, which consist in a grand feast, and union of all the families, and offering of all the rights and honors which belong to the host. $\mathrm{Tu}$ accepted them, and at the death of Mauaihiti he became heir and successor in the chief's line. He gave up all idea of returning to the Paumotus, and devoted his energy to extending his connections in Tahiti. (Adams 1901:85)

According to one account, an individual's "title" also could devolve upon his taio, but exactly what this "title" consisted of is not clear:

The force of friendship amongst those good creatures, will be more fully understood from the following circumstance: Churchill, the principal ringleader of the [Bounty] mutineers, on his landing, became the Tyo, or friend, of a great chief in the upper districts [i.e., Vehiatua III of Seaward Teva]. Some time after the chief happening to die without issue, his title and estate, agreeable to their law from Tyoship, devolved on Churchill, who having some dispute with one Thomson of the Bounty, was shot by him. The natives immediately rose, and revenged the death of Churchill their chief, by killing Thomson, whose skull was afterwards shown to us, which bore evident marks of fracture. (Edwards and Hamilton 1915:110)

Needless to say, this was an exceptional case, probably influenced by Churchill's domineering personality and his possession of firearms. No other European that I know of was awarded a high-ranking kin-Title through this mechanism. (See, for example, Turnbull 1813:321)

Another statement by the missionary Crook indicates that six decades of European contact had altered only the sexual aspect of taio practices among the Maohis themselves:

... none of them know what it is to possess property in our sense of the word. If a native possess many articles of property, he must distribute and cannot withhold; all his friends have a kind of positive claim, and to refuse to give would be shocking. He would be a taata hamani ino [ta'ata ha'amani ino], literally a man that works evil. It is to be observed that friendship, from whatever mercenary cause it was entered into is inviolate and is a kind of real relation in Tahiti. The friend was a representative of the person, and partner in everything, the wife not excepted. Our people have of course done away with the sinful part of it, but they are shackled by what remains, and will be many years before they can advance much in civilized life. (Crook to Burder, 4 December 1824, LMS Archives)

Undoubtedly, underlying all such transactions was a tacit expectation of reciprocity - that is, the fundamental conception of the relationship was one of direct and equivalent exchange, even though each contribution may have been phrased as an act of altruism, a nonreciprocable "gift." Indeed, 
so seemingly sincere were many such "gifts" that Bligh took them to be gifts. (Although the pacts in question involved Maohis and Europeans, it is reasonable to assume that the transactions, in this respect at least, resembled those between Maohi pact-friends.)

As it is the custom among these people whenever a Ship comes here, to have their separate Friend or Tyo as he is called so it has been the case among my people and Officers. Great friendship and disinterestedness from the Natives have been the result of this connection, for those who could not get a Cannoe to come off in, swam to the Ship with bunches of Cocoanutts without any view of reward. (Bligh 1789:II, 415)

Against this attribution of "disinterestedness" was Cook's appraisal of the reception accorded Mai, when the latter returned to Tahiti after his visit to England:

When we first drew near the island, several Canoes came off to the Ships each conducted by two or three men, but as they were only common fellows Omai took no notice of them nor they of him, they did not even seem to perceive he was one of their Countrymen although they conversed with him for some time. At length a Chief whom I had known before named Ootie and Omai's Brother in law, who chanced to be here, came on board, and three or four more, all of whom knew Omai before he imbarked with Captain Furneaux; yet there was nothing either tender or striking in their meeting. On the contrary there seemed to be a perfect indifferency on both sides, till Omai asked his Brother down into the Cabbin, opened the drawer where he kept his red feathers and gave him a few. This being presently known to those on deck, the face of affairs were intirely turned and Ootie who would hardly speak to Omai before, now beged they might be Tyo's and change names. Omai axcepted of the honour and confirm'd it with a present of red feathers, and Ootie by way of return sent a shore for a hog but it was evident to every one that it was not the Man but his property they were in love with, for had he not shewed them his red feathers, which is the most Valuable thing that can be carried to the island, I question if they had given him a Cocoanut. Such was Omai's first reception amongst his Countrymen and such as I always expected, but I expected, that with the property he was master of he would (have) had prudence enough to (have) made himself respected and even courted by the first persons in the island, but in stead of that he rejected the advice of those who wished him well and suffered himself to be duped by every designing knave. (Beaglehole 1967:I, 186)

A special kind of service exchanged between pact-friends was described by Morrison: "They take No Captives nor give any quarter, unless a man falls in with one who has formerly been His adopted friend, a breach of which they were never known to make ..." (1935:174). In contrast, however, is the following passage excerpted from a battle-exhortation of a rauti: "Let the warrior take hold [of his weapons] unsparingly/ let him take hold with closed eyes, that he perceive not a friend [tau'a]" (Henry 1928: 308).

There is a somewhat puzzling statement by Bligh in which he distinguished an individual's taiō (friend) from his ari'i (champion, protector): 
Every Person who comes among these people has or may have his Tyo or Friend, but the Commander or Erreerahigh (as he is called) has also his Erree [ari'i] (in this sense signifies a Champion). Now the Erreerahigh is beyond being an Erree to any one, and is only nominated a Tyo; it is therefore with me that Tynah is my Friend and Moannah my Erree, who is supposed to be determined to revenge any insult that may be given to me.

When Captain Cook was here he was in the same situation. Tynah was his Friend and Poeeno his Erree, and it is from that circumstance that his Picture, which he gave to Otoo, now Tynah, is kept by Poeeno, which I have been long in discovering the Cause of. Poeeno is also my Tyo and in his own district by his people bears my Name and I his, but everywhere else I have the name of Tynah or Matte which are the two Names he has. (1789:II, 6)

The implications of this alleged distinction will be discussed in a later chapter.

The historian Gunson raised the possibility of homosexuality having been a factor in friendship pacts:

To what extent the sexual element was present [in friendship contracts] is not clear, but there is reason to believe that it was. High ranking chiefs very often married much later than was usual amongst the people. The concept of continence was unknown, and pederasty (as in Hawaii) and other forms of sexual irregularity was regarded as chiefly prerogatives. Friendship rites with such implications are known in other cultures, and the suggestion is made to emphasize the commitment of the two parties to the contract. (1964:66)

I doubt very much that friendship pacts were deliberately entered into for homosexual purposes, although some contract-friends may very well have engaged in such practices, as indeed did many other pairs of males. ${ }^{13}$

Finally, I draw attention to that unusual and unelucidated manifestation of the friendship pact described by Morrison, in which a warrior not only assumed the name of the individual killed by him in war, but "... adopts the Nearest relation of the Deceased as his Friend, and by bearing his Name [presumably in addition to the name of the slain] becomes one of the Family and is ever after Treated as such and is as much beloved in the Family as if he had been born in it." (1935:175)

The account of friendship pacts given in this chapter leaves unanswered many important questions such as, What proportion of the population entered into such pacts, and were the pacts ever terminated by a specific ritual act? It would be of particular interest to know whether they were ever concluded between consanguines, or between same-genealogical-level affines. (This latter situation would appear however to result in a status conflict vis-à-vis one another's sisters.) Unfortunately, as with so many other aspects of Maohi social structure, the available data cease to provide answers when the questions begin to become interesting. 


\section{CHAPTER 21 OCCUPATION}

As we have seen, such factors as sex, age, consanguinity, affinity, and marriage class greatly influenced what activities Maohis engaged in or how they interacted; and the next chapters will describe the effects on individual behavior resulting mainly from three other factors: sect membership, residential contiguity, and coercive force. Special occupation must also be counted among such factors- "special" in the sense of not having been ascribed solely or mainly by one's age, class, and so on, and "occupation" in the sense of its having engaged significant amounts of the individual's time and energies. For example, every Maohi past infancy must have communicated from time to time with spirits; and for heads of households and larger kin-congregations such communication on behalf of their units was a regular part of their duties of office. Some men, however, made a special practice of priestcraft over and beyond the requirements of household headship, and it is these kinds of actions and interactions that concern us now. Most of the information relating to special occupations has already been presented, so that my task in this chapter will be to chronicle what social relationships arose from occupational specialization. The Maohi word most nearly equivalent to "occupation" was tōro'a, which is translated in the LMS Dictionary as business, office, occupation. But I cannot discover whether this word had a wider or a narrower meaning than the category of roles I now delimit.

It may be useful to point out a few more generalizations. First of all, I cannot ascertain fully which occupations the Maohis looked upon as involving evaluated and socially consequential differences in performance. For some activities-fighting, wrestling, making bark cloth-there are clear indications that such differences were recognized and appropriately rewarded (or penalized); but for such activities as cooking, swimming, or weather predicting, I do not know.

Second, I cannot discover how "specialized" an individual had to be, in terms of skill or amount of application, for him to be considered an "occupational specialist" by the Maohis themselves.

And third, unlike some students of Polynesia, I am far from certain that I comprehend Maohi views concerning the underlying bases of "skill." 
Regarding the first of these points, I reproduce here an intriguing text collected by Orsmond concerning what some Maohi informants considered to be the principal "occupational" specializations-or at least those providing training in the skills required to carry out their respective functions:

E maha rehua [probably te hui] o te Tahiti.

There were four "kinds" of persons in Tahiti.

Na te arii, na te opunui, na te arioi, e na te ravaai.

The $\operatorname{ari}^{\prime} i$, the big-bellies [marae functionaries], the Arioi, and the fishermen.

E fa'a ui anae ìa.

They were all trainers of youths.

E fa 'a'amu te arii i te ui, e riro atura ei teuteu arii.

The ari'i supported [trained] youths to become their servitors.

Fa'a'amu atura te opunui i te ui, e riro atura ei opunui, ei poro, ei hoho ei amo atua.

The big-bellies supported youths to become big-bellies; heralds, god-wakers, god [image]-bearers.

Fa 'a'amu i te Arioi i te reira ui, e pa 'ari atu, riro atura ìa ei Arioi.

The Arioi supported youths, and when these were grown up they became Arioi.

Fa 'a'amu te Ravaai i te reira ui, e pa 'ari aera, riro atura ìa ei ravaai.

The fishermen supported youths, and when these were grown up they became fishermen.

Tira ra ìa rehui[te hui].

These were the [only? principal] "kinds" of persons. (Orsmond: Arioi)

\section{FOOD PRODUCERS}

For a society that subsisted mainly on plant-food it is curious how little has been recorded about the work and geography of plant-food production. Perhaps because most of the early European reporters were sailors or townsmen, but whatever the reasons, next to nothing was recorded about the practice or the practitioners of growing or collecting fruits and vegetables. It is quite clear that some adults, including some male adults, had little to do with this kind of work; at the other extreme it is likely that for some adults in most areas, and for most adults in other areas, such activity was the principal employment. When considered against a background of nearly universal similarity in consumption habits, these differences in productivity undoubtedly led to some plant-food circulation within regions; it may have resulted in some interregional circulation as well. The question then becomes, What were the social-relational aspects of these differences in the production and circulation of plant-food?

Turning first to the social status of the individual plant-food producer, I find it difficult to accept the inference that outstanding skill and productivity were not in some way recognized and praised; but the evidence of such 
is lacking. There must have been master farmers, but either their social significance was wholly noninstitutionalized, which is unlikely, or, what seems more probable, their roles were so basic and mundane as to have escaped the Europeans' notice.

I suspect also that high productivity was an important factor in social influence. The individual capable of providing larger-than-average amounts of food-in the form of hospitality, "gifts," tax, et cetera-was undoubtedly compensated in social currency of one kind or another; but our information about such situations has to do with individuals exercising control over the circulation of such plant-food, and not with the individual producers themselves. In fact about the only concrete evidence available concerning the direct advantages accruing to the individual who produced plant-food in excess of ordinary domestic needs concerns the contracts some such individuals entered into with fishermen, for regular exchange of plant-food for fish.

Instances of regional specialization in plant-food production may have been more numerous than the records indicate, but not markedly so. (I refer here to the kind of specialization that produced a net annual surplus, and not to that resulting from regional seasonal differences in plant-food ripening, which was discussed in chapter 9.) This is not to deny the fact of regional differences in plant-food productivity, which was clearly in evidence, but these differences were more typically manifested in corresponding population densities than in interregional movement of goods.

The one well-documented exception to this generality was on Tetiaroa, the atoll whose small permanent population had to depend on Tahiti for most of its plant-food, which it received in exchange for fish-an arrangement characterized by one writer as having been deliberately fostered by Tetiaroa's Tahitian proprietors in order to keep these atoll dwellers dependent and loyal. (Morrison 1935:202; see also Bligh 1792:163b, and Wilson 1799:89.)

Kava was undoubtedly more bountiful in some areas than in others, and circulated widely in the form of gifts and tax. We are not certain which areas were most productive, or why they were so, but there is no indication of individual occupational specialization in such production, or of regularized interregional channels whereby it circulated.

What applied to food plants applied also to pigs. One writer asserted that only commoners raised them, ${ }^{1}$ but this is difficult to accept. It may be that the actual job of tending the animals was turned over to the servants, but I would be surprised if middle-and upper-class families did not themselves raise pigs (in addition to the ones farmed out to their subordinates). Indeed, as was the case with food plants, it is my surmise that the actual raising of pigs was a standard practice employed by some individu- 
als for gaining social influence, acquired through distributing the animals in the form of gifts and feasts. Specific evidence for this kind of specialized occupation is not recorded and the Maohi version of the familiar Oceanic "pig politics" institution pales in comparison with its Melanesian parallels, but I am confident that it was practiced.

Maohi fishing, however, is quite a different matter. The sources indicate not only that differences in skill were recognized and evaluated by the Maohis, but that fishing was a specialized employment for some individuals which eventuated in at least two distinctive types of social relationships: guilds and exchange contracts. These were in addition to the kind of relationship, described earlier, that prevailed between Tetiaroa and Tahiti, in which the inhabitants of the atoll supplied fish to their Tahitian superiors in return for plant-food.

As will be recalled, the Orsmond text reproduced above identified fishermen as one of the four categories of occupational specialists providing training in their required skills. Another text ascribed to Orsmond tells of local fishermen's guilds, each having its own meeting house, called in the text a ruahatu, and characterized by courtyard fences made of "little sticks driven into the earth." Bligh reported having seen a ruahatu, but he identified it as a marae dedicated to the successful operation of a fish weir (whether it was also associated with a fishermen's guild is not stated):

I passed in my Walk to day a Morai which was called Rooahaddoo-it consisted of a few Stones about three feet square, pieces of plaited Cocoa Nutt leaves (called Tepaow) placed before it with some small pieces of Tarro and Cocoa Nutts.-the Evatah [fata] or Alter of offerings, was a Palm Stump with a small Stage on it, on which was a Cocoa Nutt Grater, and some Cocoa Nutts, Mahie and an empty Basket.-the whole was fenced in, and I found it was just errected to ensure success to a kind of Ware or Dam which Tynah [Pomare I] has made with Stones without Point Venus to catch Fish. Prayers have been performed, and the Deity supplicated by Persons of the Priesthood. (1792:159b)

Henry supplied more details about marae associated with fishermen's guilds and provided an explanation for the label ruahatu:

The fishermen formed companies and built themselves marae (marae $o$-te-feia-tai'a) and dedicated them to the gods, the chief of which were: Ruahatu-tini-rau (Source-of-fruitful-myriads), the Neptune of the sea called in the story of the Deluge Rua-hatu-o-te-tai-euea (Source-of-fruitfulness-of-thethrown-up-ocean), and Tino-rua (Body-of-two-natures) lord of the ocean, the merman who had the tail of a swordfish. The fisherman placed in their secret depositaries stone or wooden images of the fish gods and other sacred relics with birds' feathers. (1928:148)

We are, however, not informed about the number, sizes, or composition of such units, nor about their internal or their external social relations. Handy asserted that Maohi fishermen (feia taia) were not regarded as a "distinct 
professional class." According to Handy, "Different localities had their sacred places dedicated to the fishing gods, but these would appear to have been community shrines rather than sanctuaries belonging to a professional class, as in the case of the sacred precincts of Marquesan fishermen" (1932:69). It is undoubtedly correct to state that Maohi fishermen differed from Marquesan ones, insofar as the latter were "accorded an inferior position in the social scale" (Handy 1932:69), but we have it on the authority of Orsmond that Maohis who specialized in fishing were indeed considered to be a distinctive social category (Orsmond:Arioi). It would be extremely revealing of Maohi society's whole "evolutionary" direction to know, for example, whether such guilds cut across kin-congregation or tribal boundaries; or whether their officials were "elected" on the basis of kin seniority, or class status, or technical-managerial ability; or whether such guilds acted as units in tribal levies and councils.

The exchange contracts between fishermen and farmers, described earlier, are the only ones of this kind to be recorded. While the principals in any such exchange may in some cases have been consanguines-or affines, or "friends," or subject and chief-the transactions appear to have been motivated by complementary desires for the objects themselves. And although some such transactions may have been phrased in the idiom of consanguinity or friendship, the relationship so established appears to have been of less importance than the goods exchanged. Also such transactions differed from other exchange contracts in that they involved only objects, and not objects for services or services for services. And finally they differed from ordinary object-for-object barter, which was probably much more widespread than the sources report, in that the exchange included many transactions spanning a relatively long and evidently fixed period of time.

It appears that such contractual relationships had not become institutionalized into "permanent" trade partnerships, like those found in many other parts of Oceania (especially Melanesia), but they probably contributed to the development of occupational specialism, at least in the sphere of fishing.

Again, concerning the geographical aspect of such exchanges, while it is reasonable to assume that men specializing in saltwater fishing would not have resided miles inland, there is no evidence that the farming parties to the exchange were inlanders; and in any case, "inland" residence was rarely more than a mile or two distant from some shore.

\section{CRAFT SPECIALISTS}

Evidence for local specialization in the manufacture of objects is fragmentary, the following being the only passages I could find:

These happy isles have almost every article necessary for the supply of their 
wants; nevertheless their manners are already so far polished, that they like to be possessed of some articles chiefly of ornaments and luxury, which they cannot meet with in their own isle, or at least, not in such plenty as in others situated in the neighbourhood. Bora-bora, and O-Tahaw, are both well provided with coco-nut-palms, from which they manufacture an oil, well known in the East Indies; the inhabitants of Taheitee and its neighbourhood, use this oil perfumed, by means of various odoriferous plants, and aromatic woods, as an article of luxury to stain and to perfume their cloth, and even their hair, and sometimes their bodies. As the coco-nut-trees are not so plentiful in O-Taheitee as to enable the inhabitants to prepare a quantity of oil, to satisfy the great demand for it, and as on the contrary, the natives of Bora-bora, and O-Tahaw, cannot manufacture such a profusion and variety of cloth as they do at O-Taheitee, where the paper-mulberrytree is much cultivated; there are persons who every year undertake a voyage from Taheitee to Tahaw and Bora-bora, in order to barter great quantities of cloth, for joints of thick bamboo-reeds filled with coco-nut oil. (J. Forster 1778:365-366)

Maupiti is said to have been the source of a gray-black, very hard dolorite from which were made some particularly fine adzes, pestles, bowls, and seats, all of which were used widely throughout the Society Islands. Corney was probably right in supposing that many of these objects were made in situ-thereby implying a local craft specialization of some extent, but of what extent we do not know (1919:xxxiv, 156).

I have the impression that turtles were more plentiful at isolated Tupai and Mopelia where their visits ashore were subject to fewer interruptions by humans. Inasmuch as Leeward Islanders were the most frequent visitors to these places, it is reasonable to suppose that they more than others tended to specialize in the fashioning of turtle-shell objects. (LMS Transactions: vol. III, narrative 6)

As reported earlier, easternmost Me'etia Island engaged in a regular exchange with Tahiti's peninsula, sending pearls and pearl shells (probably from the Tuamotus), mats, bark cloth, oil, dog's hair, ${ }^{2}$ pigs, and carved wooden objects in return (in later days) for objects of European make. We are not informed what went from Tahiti to Me'etia prior to 1767, but if the pre-European objects from Me'etia to Tahiti were about the same as reported by Morrison (1935:201) this would argue for some craft specialization in woodworking on Me'etia.

Expeditions went occasionally to Scilly Atoll (Fenua Ura) in search of red feathers:

The red feathers of parrots are employed in ornaments for their warriors, being fixed at the end of the tassels, which they wear like queues, and likewise in small bundles tied together with coco-nut-core, which they make use of in order to fix their attention during their prayers. The O-Taheitee parrot has but few and very dirty red feathers, but more to the West are islands, which have fine parroquets remarkable for beautiful red feathers. One of these isles is low, and destitute of inhabitants, at about ten days sail from O-Taheitee and is called WHENNUAOORA the Land of red feathers, to which the people from the Society-Isles sometimes re- 
sort, in order to procure some of these red feathers, for they are the most valuable article of commerce, and there is nothing which a Taheitean would not give or grant in order to acquire some of these precious feathers. (J. Forster 1778:366-367)

As I reported in chapter 8, most of the composite plank boats (pahi) found in these islands were constructed on Ra'iatea, or by Ra'iatean-trained artisans working elsewhere. Such boats were evidently highly prized and in great demand, so that it is conceivable that whole communities on Ra'iatea may have specialized in this craft.

Bark cloth was manufactured everywhere, but a passage from Morrison already quoted suggests that there was some local specialization in terms of the quantities produced, in addition to the interisland differences noted above: "If a Man has occasion for more Cloth then he can procure from his neighbours, he takes a large hog or two, to the House of some of the People who Inhabit the Valleys and whose Chief Employment it is" (1935:165).

It is likely that there were other instances of localized craft specialization around these islands, but if so it was evidently on a scale small enough to have escaped notice. Also, the products of such enterprises probably circulated by means of numerous ad hoc transactions between kinsmen, neighbors, and friends, rather than through regular institutionalized channels such as formal exchange contracts or deliberate trade expeditions.

Evidence for the existence of individual artisan specialists is very specific, but probably incomplete. The sources refer explicitly to experts in boatbuilding (tahu'a tarai va'a, expert-shape-canoe) and marae building (tahu'a marae); some men, called simply "carpenters" in the sources, were also employed as expert housebuilders, but whether this represented a separate occupation, or was identical with the canoe experts' trade, is not clear (Morrison 1935:165). A more serious omission is the lack of information about the makers of such objects as stone tools and containers, high-relief images in wood and stone (tahu'a tarai to'o), ornamental headgear, gorgets, and the like. Anyone who has seen and handled such objects would agree that their manufacture required a considerable amount of skill, gained only through special training and long practice. Their manufacture probably did not occupy all the working hours of their makers, but these were not Everyman's avocations. Also, perhaps many such items circulated as contributions to kinfolk or gifts to friends or taxes to superiors; but it is my surmise that they were also involved in more commercialized exchange, and hence served to satisfy their makers' wants for other tangible goods.

With regard to bark-cloth making there were recognized individual differences in skill and in productivity, but probably all females past childhood (and many males) engaged in this craft, and for some women it appears to have been a nearly full-time occupation. In terms of social relations bark- 
cloth making was relevant in at least two important respects: as a focus for group interaction and as a means of acquiring both intangible social "capital" and a variety of other tangible goods.

I noted earlier the presence of women's bark-cloth-making groups, composed exclusively in some cases of either the married or the unmarried. We are not informed how common these groups were, but my surmise is that they were numerous and widespread. Neither have we any description of the organization of such groups; it is safe to assume that techniques of production shaped much of the members' interactions, but considerations of consanguinity, class, age, and skill probably also intervened. Further, although there is no record of bark-cloth-makers' marae, it may be taken for granted that well-established groups worked in places reserved for themselves. And, although I can find no mention of a specific deity of bark-cloth making, it is reasonable to suppose that many such groups had tutelars of their own.

Marae-building experts (tahu'a marae) were evidently highly specialized, but they cannot have spent much time in the actual practice of their profession. As noted in chapter 7, there is no record of their manner of compensation, but it may be assumed that they were at least well fed for their labors. There is no positive information concerning the social relations characteristic of such specialists. Morrison intimated that every occupation was organized into local chapters: “... evry profession or Calling [is] a distinct Society and all of the same profession are made Welcome by the rest all through these Islands" (1935:233). As we have seen, this was true of fishermen, in some places, and of boatbuilders; but I doubt very much that it was true of "every Calling"-for example, there is no evidence with respect to tahu'a marae. In fact, it seems unlikely that any one locality would have had more than one or two of these specialized but decidedly parttime craftsmen. Nor does it seem likely that even the most powerful and affluent chief would have had need for a staff tahu'a marae on a permanent basis. Though not mentioned in the sources, it seems reasonable to assume that in some instances individuals combined this profession with that of priestcraft.

Information is somewhat ambiguous about the role of "carpenters"-whether they constituted a distinct profession or were boatbuilders as well-but I imagine that all three types of specialists were to be found: boatbuilders, housebuilders, and combinations of the two.

Specialists were probably not required in the building of all houses; the following probably applied only to larger or more elaborate buildings: "Most of the natives are able to thatch a house, but covering in the ridge is more difficult, and is only understood by those who have been regularly trained for the work" (Ellis 1829:I, 386). However, individuals may have 
availed themselves of such specialists for reasons other than their own lack of the requisite skill. Morrison provided an informative statement on this matter:

If a Man wants a house or a Canoe built, he employs one or more Carpenters, paying them before hand one half of what shall be Judged the Value of the Work they are to perform in Hogs, Cloth, Oil, Matting, \&c-and finds them in provisions all the time they are at work and when the Work is Compleat he pays the remainder according to Agreement, but should he refuse or neglect and the Neighbours think the labour worth the stipulated agreement then they may plunder him of all that he is worth. (1935:165)

The principals in transactions like these would appear to have been of more or less identical class, and either ra'atira or manahune (otherwise the sanctions would have been either unnecessary or difficult to enforce).

When a house or public building for a chief was to be built, it was customary to employ labor corvée rather than commission the job to be done by some equal. For work like this the services of one or more specialists were probably essential for planning and supervision, and such services were probably compensated with extra portions of food and possibly also with bark cloth, mats, oil, and other goods. It is even possible that professionals of this type were more or less permanently attached to some chiefly households.

Specialists were also not needed in the construction of the most simple boats, but by now it should be abundantly clear that the construction of other types of boats called for high levels of skill and work organization. As we have seen, some of these "boat-shapers" worked on a contract basis, others probably worked for hire, and still others may have been attached to chiefly households on a more or less permanent basis. All boat-shapers probably had their spirit-familiars or tutelars, and the records state that in some localities they had their own marae, where, among other things, their tools were "empowered" (mana) before being used. Finally, although I can find no accounts of boat-shapers' guilds, inasmuch as there were marae and tutelars especially associated with this occupation it is reasonable to assume that the specialists of various locales made up groups, with more or less exclusive membership. Handy characterized boat-shapers as "highly respected and well to do," which was probably quite true; but there is to my knowledge no record of this or any other craft specialist being able to move into a higher marriage class, or into a position of tribal authority, by this route alone.

\section{SERVICE SPECIALISTS}

One of the larger social categories in Maohi society was that made up of teuteu, the servants attached to the households of persons of superior social 
position or extensive authority. Most teuteu evidently worked as domestics, but some became valued companions and counselors of their masters and mistresses. Their compensation was mainly in the form of subsistence, but that could have represented a relatively high standard of living for those attached to affluent households. In many cases the attachment of teuteu to a particular family was inherited, but some teuteu apparently took up such positions voluntarily. There are no specific accounts of teuteu having terminated their relationships with patron families; such a move may have been difficult for practical reasons, but I have come across no evidence that it was impossible. In other words teuteu were dependent family retainers, not physically constrained slaves.

A somewhat different position appears to have been occupied by tapairu, which the LMS Dictionary defines as a young woman that lives delicately; a young woman that is an attendant on a chief woman. The tapairu has also been characterized as a "queen's waiting woman, selected for her beauty" (Alexander 1893:57n3). No further specific information is available concerning the origin, duties, compensations, or ultimate fates of tapairu, but some fairly plausible assumptions about these matters may be proposed.

Concerning their origins, it seems unlikely that tapairu were of the lower class; not only were lower-class maidens generally unable to afford the luxury of "living delicately," but upbringing in a lower-class household could hardly have prepared a girl for the refinements demanded of a "chief woman's" attendant. ${ }^{3}$ (And a "chief woman" would have had a wide choice of attendants from both the middle and upper classes.) Indeed, it seems likely that a "chief woman" would have appointed some of her own kinswomen to serve as her tapairu. As for the fate of tapairu, it is reasonable to suppose that they married and returned to more routine existences when they were no longer "young."

The duties of tapairu are not specifically described, but I suppose that they consisted mainly in serving as companions to their mistresses, and not as ordinary domestics. That "chief women" had such companions is well attested in eyewitness accounts. As for their compensation, they would have shared in the high standard of living of their mistresses, and they would have enjoyed the entertainments associated with chiefly life, including probably a wider assortment of lovers than would have been otherwise possible.

But my concern here is with occupational specialists, not with the general master-servant relationship itself. The information about the many kinds of special services performed by some Maohis for others is more detailed than that about the service specialists themselves. Those kinds of services distinctive enough to have received labels, or to have been remarked upon by the European visitors, were tattooing and supercising, embalming, domestic service, ghost guarding, prostitution, entertaining, teaching, communicating with spirits, healing, sorcery, and waging war. 
There are a number of questions to be asked about the practitioners of each of the above-mentioned activities:

1. Were they recruited by descent, personal achievement, spirit selection, age or sex qualifications?

2. Were they distinguished by any special costume, insignia, or other visible signs?

3. Were they set off from others by any special behavioral prescriptions or proscriptions, including any associated with sacredness $\left(\mathrm{ra}^{\prime} \mathrm{a} / \mathrm{mo}^{\prime} \mathrm{a}\right)$ or secularity (noa)?

4. What proportions of their time were spent in the activities in question?

5. How many practitioners were there?

6. What was distinctive about their social relationships: did they form guilds, work on commission, occupy staff positions?

7. Were they reimbursed for their services by subsistence support, fixed lump-sum payments, "gifts," anticipated reciprocation with food, tapa, praise, a share of spoils?

8. Were there any occupational hazards?

9. What effects did their occupational activities have on their class status, or on the class status of their families?

10. Which occupational roles were combinable?

Needless to say, this set of queries represents a counsel of unattainable perfection; not one of the occupations I have listed is described well enough to provide answers to all the questions, and about some of them we are left almost totally uninformed.

\section{Tahu'a Tatau (Tatatau), Tahu'a Tehe}

Morrison stated that both tattooing and supercision were performed "by a particular set of men who make it a Trade and subsist partly by it always getting well paid for their Work" (1935:220). Banks stated that only "priests" were allowed to perform such operations, in return for which "they are paid by every one according to his abilities in the same manner as weddings Christnings \&c \&c. are paid for in Europe” (Beaglehole 1962:I, 382). Ellis called such practitioners "... professors of the art of tatauing, who were regularly employed to perform it, and received a regular remuneration" (1829:II, 463).

It is possible to infer from these and other statements that both tatau and tehe were performed by the same specialists. The little additional evidence we have concerning this occupation refers specifically only to tatau. There was a deity, Tohu, specially associated with this operation, and the operation was performed at the shrine of two other spirits, Matamataarahu and Turaipo, who invented the custom, and whose aid was solicited in performing the operation and in healing the punctures (Henry 1928:234, 287). 
If more than one tatau specialist used the same shrine, which was probably the case, then they probably formed a local guild. Also, if, as is reported, all tatau specialists revered the same tutelars, it is possible that they shared archipelago-wide social bonds of some kind, manifested perhaps in reciprocal hospitality. It is unlikely that ari'i or affluent ra'atira would have engaged in this or any other personal-service occupation. The amount of skill required, for tattooing at least, argues for a long period of training and apprenticeship, and hence the likelihood of the craft having been learned from a close relative.

\section{Tapua Miri}

Embalming required much skill and involved considerable risk, both "physically" and "psychically" (although the Maohis themselves would probably not have made this kind of distinction). According to Henry, "Incurable blood poisoning in consequence of following this vocation sometimes ended the lives of tapua miri" (1928:296). Since the bodies of only high-ranking kin-Titleholders or powerful and affluent tribal leaders received the full embalming treatment, there cannot have been a large number of practitioners. (In giving the names of "the embalmers who were living when the Missionaries came to Tahiti," Henry listed only three, suggesting that there may never have been many more.)

\section{Teuteu}

As stated previously, persons bearing this label, roughly classifying them as "domestic servitors," served families of superior social position or extensive authority and affluence in such roles as wet nurse, bearer, steward, cook, swineherd, gardener, entertainer, jester, ${ }^{4}$ and even counselor. Probably most, but not all, teuteu were manahune. ${ }^{5}$ For many teuteu the occupation was hereditary, but some probably entered this employment by other routes. Any male servants who worked directly for females were of course noa-that is, "rendered Incapable of assisting at any religious Ceremony." (Morrison 1935:167)

Compensation for all such servitors consisted of subsistence (probably more lavish than manahune could otherwise enjoy), and the various intangible benefits derived from living close to loci of power and entertainment. In some cases particularly clever or useful servitors may have received more tangible rewards, such as lucrative administrative posts or even grants of territory, leading eventually perhaps to higher class-status.

\section{Ghost Guardians}

Moerenhout's is the only reference to such a profession, but a variety of considerations argues for the reliability of his account, which characterizes ghost guardians as a hereditary function performed by some retainer 
attached to each socially superior family (1837:I, 554-555). The kind of material compensation that went with this job is not specified, but Moerenhout asserted credibly that the secret knowledge possessed by such guardians gave them influence considerably beyond that normally associated with individuals of their social position and degree of tribal authority.

\section{Prostitutes}

The presence of Europeans turned many Maohi females to prostitution, but prior to that some leading chiefs evidently attached a few young women to their households for purveyance to distinguished visitors. Nothing further is known about these females, save that their mode of employment seems not to have prejudiced to any significant degree their eventual marriage. As for compensation, they probably received a comfortable keep along with some respite from work ordinarily expected of females of their social class.

The services provided by eminent women's gallants were "special" in a social-relational sense, but hardly so otherwise. Such men were evidently of lower-or middle-class origin, and were remunerated with an abundance of good food, a steady flow of presents, perhaps a certain amount of political influence, and release from other kinds of "work."

Enough has already been said about mahu to characterize clearly their occupational roles. Many questions about these transvestites remain unanswered, but we can be sure that their special qualifications were not inherited.

\section{Entertainers}

At some time or other every Maohi danced; and most males, at least, probably made music and play-acted for the entertainment of their fellows. Indeed it is difficult to draw the line between "amateur" and "professional" in these activities; for example, some of the most habitual and expert dancers were upper-class maidens who performed mainly for their own and their families' entertainment (Beaglehole 1961:421). These and many other "amateurs" performed on many kinds of occasions, before large and small audiences, and were customarily rewarded with presents of food, tapa, and generous applause. In addition, however, there were those who engaged in such activity as an occupation. The excerpts from Banks and Jefferson, quoted in chapter 10, clearly indicate the commercial motives of companies of "traveling musicians" or "strolling players," who, when they ended their tours, used to "divide the spoil" of the hogs, bark cloth, and so forth, with which they had been paid. Some of these companies were small and consisted only of the performers themselves, while others evidently were large and included the players' spouses and children. A passage from Jefferson implies that such companies were made up of a lower-class people-which may or may not have been so: "This 
abominable pastime is much delighted in by all ranks, though the higher class profess to despise the actors and speak of them and their performing in a contemptuous manner" (Jefferson, Journal, 10 February 1801, LMS Archives). I shall have more to say about "strolling players" later on, in my discussion of the Arioi cult, whose members made of "entertaining" not just an occupation but a whole way of life, and whose membership included persons of the very highest class levels of society and who were anything but "contemptuous" of their own brand of histrionics.

Of traveling bards, Moerenhout said:

They had tales, just as they had all sorts of poetry, sad, horrifying or ludicrous. As for this last kind, strict decency was not always observed; but several (persons) knew how to tell tales charmingly, and make the audience, naturally gay by disposition, laugh until they cried. Men who were gifted with this talent were, like the poets, much sought-after. Such persons travelled frequently, and were not only welcomed but were invited to return again and again everywhere they went." (1837:II, 81; see also de Bovis 1909:34)

Athletes also served to entertain, those of various skills having practiced a great deal and competed publicly to the entertainment of large throngs. Champions' rewards came mainly in the form of praise. According to one account footracing champions received tangible prizes (Henry 1928:278), however, footracing could not have been an "occupation" without there having been some sort of subsidy, and I have found no evidence for that.

\section{Teachers}

The general term for "teaching" was 'orometua, an instructor of any sort, either of religion, or of any art, or trade (LMS Dictionary). All 'orometua may have received some tangible compensation for their labors, but only the two types to be discussed here seem to have made teaching their principal occupation.

A passage from Andía y Varela indicates that "The Kings and great personages each keep one of these dancing masters to teach their families, just as they keep e pure or master versed in law for their instruction in that" (Corney 1915:289). It seems likely that such "dancing masters" provided instruction in music and dramatics, although there may have been some who specialized in each form.

The $e$ pure mentioned by Varela probably referred to tahu'apure, a priest officiating at the marae (LMS Dictionary). Some such priests may indeed have been attached to the households of "great personages," where they dispensed knowledge and precepts, but there appears also to have been a category of persons-mainly male, but some females as well-whose primary occupation it was to instruct the young in genealogical and other traditional lore. This group was known as tahu'a parau 
tumu fenua, "experts in basic knowledge of the world." (The fragmentary evidence seems to imply that only boys received such instruction, but if this were so, Where would the female teachers referred to by Henry have received their instruction?)

One teacher was Hiro's maternal grandfather, Ana (Cave), who was "the senior teacher in the school called Tapu-ata-i-te-ra'i"at 'Uporu (Ha'apape), Tahiti (Henry 1928:537). Henry had the following to say about the school:

At Uporu is the school of savants [te ti'ara'a fare 'aira'a upu ana-vaha-rau, literally, the residence prayer cave-of-many-openings] of royal families [hui ari'i] named Tapu-ata-i-te-ra'i (Sacred-cloud-in-the-sky); there are the women teachers [orometua vahine], Toa-te-manava (Brave-hearted) of Ra'iatea, and Mu-reo (Murmur-of-voices), reciter of heraldry [firifiri 'aufau, literally ancestry tracer, genealogist], of Papeari in Tahiti; there was the boy teacher [orometua tamaiti], Hiro (Jester), who knew the recitations from listening to them from outside of the house before he was admitted into the class of pupils [pipi, a disciple, learner, or pupil] in the school, when he became a scholar of the highest merit.

That school is attended by the children of the royal families of Tahiti and Ra'iatea and other kindred people; and to the school [ha'api'ira'a] of Opoa in Ra'iatea also go forth pupils of Tahiti to learn. (Henry 1928:74-75)

Henry also listed schools in the "districts" of Hitia'a, Fa'a'a, Pare-Arue, Papara, Vairao, Mataoae, and Teahupo'o. She stated that students in such schools "paid their teachers with the best of food, with birds' feathers, images of wood and stone, rolls of tapa, choice mats, and every kind of wearing apparel and ornament of the time" (1928:154).

In addition to "schools" organized as was the one described by Henry, the passage from Andía y Varela quoted earlier indicates that one or more persons well versed in traditional knowledge and attached to ari' $i$ households also served as teachers when required. And, of course, some of the more or less full-time priests attached to important marae undoubtedly instructed the more eminent members of their congregations from time to time.

G. Forster provided a useful account of one teacher-sage:

Among the natives of the Society Islands there are a few men who preserve the national traditions, together with all their ideas of mythology and astronomy. Mahine, whilst we were at sea, had frequently spoken of them as the most learned of his countrymen, and named them Tata-o-Rerro, which we would express by teachers. After much enquiry, we found a chief, named Tootavaï, in the district of Hamaneno, who was distinguished by this epithet. As our departure was so near at hand, we regretted that we had not known him sooner; but my father determined to employ his remaining time in making enquiries on a subject so interesting as the history of religious opinions.

Tootavaï was pleased with an opportunity of displaying his knowledge; he was flattered with the attention which we paid to his words, and therefore continued to converse on the same subject with much greater patience and perseverence, than we could have expected from a lively inhabitant of these is- 
lands. (1777:II, 148-149) Besides the priests, there is also in every district one or two teachers, or tata-o-rerro like Tootavaï, who are skilled in theogony and cosmogony, and at certain times instruct the people in these things. The same persons likewise preserve the knowledge of geography, together with their ideas of astronomy and the division of time. (1777:II, 154-155)

Recruitment to the teaching profession was likely to have been mainly by inheritance, customarily from parent to child. Close association over a long period of time would have been required in order to commit to memory the large store of precisely worded information on which this profession was based. In this connection, it will also be recalled that some of this knowledge was supposedly transmitted from parent to child by more esoteric means.

The sources do not specify the class status of the 'orometua we have been discussing, but my surmise is that they were mainly from the upper levels of society, or, if not from the upper levels to begin with, they were able to move upward as a result of the highly valued character of their skills and of the status of their clients.

As pointed out earlier, all Maohis interacted with spirits at some time or other, but for many it was a principal activity, by which they earned their subsistence and, in some cases, many privileges and considerable influence. Having already described the techniques followed by these specialists, and the rationales for their actions, I focus now on the social relations of these professions.

\section{Taura, or Tahu'a Atua}

Human oracles, shamans, "prophets," "inspiré"-these were to be found in all marriage classes, from lowest to highest. Tamatoa, the highest-ranking kin-Titleholder of the Leeward Islands and sovereign chief of Ra'iatea was a Taura, as were some manahune and, according to Ellis, all "idiots" as well (1829:II, 193; see also Adams 1901:61).

The Maohis believed that spirits themselves selected the individuals they wished to possess. All taura mentioned specifically in the sources were adult males, but I have come across no statements to the effect that only males were eligible. (While it is true that females were usually noa, and generally prohibited from contact with sacred entities, were they also ineligible for possession by female spirits?) Ellis' statement about "idiots" suggests that factors of personality deviance entered into the selection-although it may be that this kind of deviance was regarded as a manifestation of possession. I cannot discover any specific instance of inheritance of the taura role, except in the very general sense that an eminent "descendant" of a deity sometimes became possessed by that deity. 
"It goes without saying that ... birth had nothing to do with spirit possession" (de Bovis 1909:51-52).

The sources describe taura as dressing themselves "in a fantastical form," decorated especially with red and black feathers, of which the spirits were "i[m]moderately fond" (Morrison 1935:181). The behavior of a "possessed" taura, described earlier, may be characterized as "frenzied trance." 6 While there is no reason for suspecting the authenticity of many such manifestations, a skeptical missionary proved to his own satisfaction that at least one "seizure" was faked:

They gave us a specimen of their conjurors in one of our visits to Temārre. A man presented himself in an old blue coat turned up with red, his head surrounded with numerous feathers, so as to hide his countenance entirely: he ran up to us with an unintelligible jargon, making a squeaking noise, and actions so wild, that we asked if the man was delirious. The natives not seeing us at all frightened, said it was Temarre's son, the Etōoa ete [atua iti], the little god, which killed Omiah and many others. Having with us a great dog, he fell upon the priest, who fled; at which the natives seemed terrified, and said he would kill us. After a while, the priest returned with a club in his hand, driving like a fury before him, the women and children shrieking, and the natives trembling. On this one of the brethren jumped up to protect the dog, against whom his rage was directed, and wresting the club from him, turned up the feathered cap, and discovered a well-known countenance, who had run away from Matavāi after robbing Pyetea. We immediately charged him with the theft; on this he changed countenance, and shewed the greatest terror. The natives interposing in his behalf, while we were telling them of the man and his imposture, he gave us the slip, and fled; so we saw no more of him. (Wilson 1799:336-337)

When possessed (uruhia), a taura was of course "sacred," being in one sense himself a spirit. According to Ellis, an individual was actually called atua when possessed, "though at other times only denominated taura, or priest" (1829:II, 237). On the other hand this manifestation of sacredness seems not to have been so unapproachably dangerous as some others, since females were not apparently prohibited in the vicinity of one possessed; indeed, it was reported that individuals possessed by 'Oro were sought after by women for procreative purposes.

In some cases the taura was more or less continuously possessed, to the point of being "permanently" identified with the spirit in possession; in most cases, however, the possession was intermittent, for hours or days at a time. We are not informed whether an individual, once possessed, ever lost the capacity to become so. Taura cannot have been very numerous-at least there are not many actual exemplars of them recorded, and their behavior was peculiar enough to have attracted the attention of the most casual observers. Davies reported four of them in the vicinity of Fare (Huahine): two in the service of the god Tane, one of 'Oro, and one of a shark-god Tohu. Elsewhere there were reports of one or two nearby, but 
seldom more. Of course, many individuals subject to only occasional possession, by minor spirits, may have escaped the visitors' notice, but by the same token such part-time activity was unlikely to have provided the individual with any sizeable amount of compensation, tangible or otherwise.

Regarding the social relations of taura, it should be noted first of all that a possessing spirit evidently did not limit its manifestations to a single human oracle; at least the major deities did not do so. (For example, two oracles of Tane were reported on Huahine by Davies.) Next, it appears that most taura, if not all, required an aide-usually a priest-to receive and interpret the messages transmitted by them; we are not informed, however, whether every taura had his own particular aide, or aides. As for relations between taura and other persons, taura were in general respected like the deity they sometimes embodied, at least when actually possessed. Some became the center of cultlike deference, and were able to pass between opposing armies without harm. One report states that they were obeyed immediately and without question, by chiefs and commoners alike, even to plunging a populace into unprovoked war; but this can only have been true of those who had demonstrated their bona fides by correct predictions or proven efficacy, or who had been eminent personages to begin with. Some appear to have acted independently and neutrally, while others were evidently leagued with tribal authorities. A passage from Ellis indicates how influential some taura were:

In the year 1808, during the civil war between the king and rebel chiefs, of whom Taute was the leader, the priest of Oro, who was known to be not only attached to the king's interests, but a personal friend of Pomare, left the royal camp, and went over to that of the enemy. Many of Pomare's friends endeavoured to persuade him to remain with them, but no one dared to use force, as it was supposed that he acted under the inspiration of the Oro. This circumstance greatly discouraged the king and his friends, and probably prepared the way for their discomfiture, and retreat from the island, as they supposed the god had forsaken them, and fought with their enemies. (1829:II, 236-237)

There are few references to tangible objects being handed over to taura specifically in return for their services, ${ }^{7}$ but it may be assumed that they consumed parts of the offerings made to the spirits at their behest. Also, it is most likely that a successful taura would have been abundantly supplied with whatever subsistence and comforts he demanded. In addition to these material things, an effective taura would have been rewarded with various kinds of privileges (including in some cases a choice of women's favors) and, as we have seen, a large amount of influence over community affairs; but whether success ever had the effect of raising the class status of a taura is not recorded.

The profession was not however without risks. A succession of prophecy failures, for example, not only reduced the credibility and in- 
come of a taura but also likely endangered his life at the hands of disillusioned patrons or a deceived public.

Some individuals functioned professionally only as taura, while others combined this role with that of priest.

\section{Priests}

There were probably hundreds of marae throughout the Society Islands. We are not specifically informed how many of these, or which kinds of marae congregations, supported specialists in priestcraft, but it is my surmise that it was mainly some tribal and cult marae that did so. Also, among the priest-supporting marae were some that supported numerous individuals distinguished according to specialized function, and others that supported only one general priestly practitioner. I listed earlier the various specialized functions of high priest, ordinary priest, orators ('orero), "night-walkers," big-bellies, image-bearers, et cetera.

De Bovis' and Moerenhout's accounts of the office of high priest (tahu'a rahi, tahu'a nui) are the fullest available:

It was the high priest who played the supreme role in religious ceremonies. It may be that the marae's "owner," the king [i.e., tribal chief], was more important overall, but his role in religious ceremonies was purely passive, while the high priest, who mediated between king and deity, played a very active part in all religious events. In fact the white maro, which was his official insignia, served to confer upon him a statue of "religious royalty" - but only those attached to the most noble of the royal [i.e., ari'i] maraes were entitled to wear it. It was the high priest who opened all ceremonies [in his marae], who directed them and uttered the most important prayers, and who invested the king in office.... But his activities were not confined within the marae precincts; in other [secular] affairs as well he exercised immense influence, depending more or less on the character of the king (as is usually the case in such circumstances). It was the high priest who decided when the gods required a human sacrifice, which the king then selected. It was the high priest who ordained solemn prayer services on the spur of the moment, and who summoned the people to the marae on extraordinary occasions.

In fact, the high priest's jurisdiction resembled that of a bishop. It [usually] extended over all the maraes located in the territory ruled by his sovereign chief; but there were exceptions to such parallel jurisdictions. ${ }^{[8]}$ In some cases, for example, a chief had two or more high priests in his domain; in other cases a high priest's jurisdiction extended over two [independent] tribal domains. And finally, there were certain "international" maraes served by the most renowned high priest thereabouts [regardless of tribal domain].

High priests almost without exception were members of the most superior arii families. (de Bovis 1909:49-50)

The priesthood exercised very great powers; and although priests did not [customarily] sit in on [tribal] council meetings, nor take part in political discussions, they were no less feared than chiefs. And in view of the populace's atitude toward priests, and of priests' ability, in their professional capacity, to harm chiefs politically, the latter would not have dared to treat them with harshness. The 
mere announcement of a baneful omen was enough to lead people to abandon some chiefly enterprise; in fact they had the power-acting willfully, covertly, and with no danger to themselves-to avenge themselves even against their tribal chiefs, including the power to destroy them. On the other hand, Oceanic history offers few examples of discord between high priesthood and tribal chiefs; more often than not the high priest was a brother or close kinsman of the chief, as a result of which the two worked together to maintain their mutual powers. In fact, it was not unusual for the same person to hold both priestly and administrative powers, thereby giving the government the character of a theocracy; such was usually the case when a deceased tribal chief was succeeded in office by a brother or some other close kinsman who already held the priestly office, and who continued to preside over the more important religious rites even after becoming tribal chief. (Moerenhout 1837:II, 10-11)

In view of the social importance of high priests one might expect to find their offices embodied in specific-status names, parallel to the kin-Titles of kin-congregation chiefs (indeed, some of the latter may have embodied the high-priestly office); however, I can find no explicit information to this effect. And, what is more surprising, in Henry's catalog of Tahiti's districts, in which she lists the names (or Titles?) of each district's chief and subchief, she also notes in many cases the names of each district's marae, school, school teacher, and Arioi leader, but not of its high priest as such.

Ordinary priests (tahu'a pure, specialists [in] praying) either officiated on their own, at less than "tribal" or "cult" marae, or served in these latter under a high priest. In the latter case, ordinary priests may have specialized somewhat in their jobs; otherwise their professional functions were the same as those of the high priests, except in scale. For example, only a high priest customarily officiated at the inauguration of a tribal chief (de Bovis 1909:50).

Priesthood is described in most sources as having been "hereditary," subject to certain limitations. Putting together information and inference, I surmise that the office was evolved and transmitted in the following way. When a kin-congregation reached the stage of growth at which it was no longer feasible for its chief to perform both secular and priestly roles, the job of priestcraft was delegated to a younger brother-conventionally to the one next in age and still in residence. Then, in the course of time the job became institutionalized into an office which was proudly and jealously "owned" by it separate "line" of incumbents. This (perhaps too tidy) explanation does not of course account for the proliferation of priests known to have taken place at some marae. It may be that all or most recruits were supplied by the established "priestly lines," but I imagine that in some cases candidates were selected for the offices on the basis of their interest, their physical attributes, and their technical competence. And, by the same token, some hereditary candidates were probably rejected because of deficiencies in these respects. 
The ideal prerequisites for priesthood were described by Henry: "The men set apart for the priesthood were able-bodied and most of them were tall. They were free from personal defects, as the gods were supposed to reject a man with a blemish, such as having a hump back, bald head, blind eye, or eyes that squinted. They must also be deft of hand and sure-footed, so as not to be awkward in the service of the gods." (1928:154.) A man was also disqualified if he bore any scars made by a female-not an unusual blemish in view of the deep scratches said to have been inflicted by some women on their lovers during the frenzy of sexual intercourse.

Training for the priesthood must have varied widely in duration and intensity. We do not know the amount of training required of novices destined to officiate in the less important marae, but for those assigned to the more important ones there were regular clerical schools, fare aira'a upu (houses in which to absorb invocation). Teaching was carried out by older priests and consisted mainly of rote-memorization of several types of rites:

upu marae, marae prayers

tahu tumu, religious and political speeches for the public

upu ti'a rau tī, or rau tī tama'i, war songs and enchantments, with the ti leaf

hopu, the formulae used in sueing for peace, or cutting short long prayers in emergencies

upu fa'auru i te mehoi o te atua, formulae to invoke a spirit to possess an image, and so forth

upu nanati 'aha, invocation for binding victims in sennit

upu auea, or upu 'ai-apa, formula for removal of sorcery

upu haere ru'i, night chants

upu rava'ai, fishing invocation and rules taught to fishermen

(Based on Henry 1928:155)

It is not clear whether all tahu'a pure were required to master all these types of rituals-I suppose not; but it is highly probable that every one of them known as such was in possession of a vast repertoire of verbal formulae.

According to Henry, "night invocations were taught in the dark or moonlight stillness upon the hills in the woods and upon the seashore, where the novice learned to observe omens and signs in the sky and upon the earth where he walked: the fall of meteors, the flight of clouds, the cry of birds and insects-all having forcible language to the scholars of those times, the study of which they never tired and frequently pursued until early morning" (1928:155).

The sound of these night-walkers (haere po, oripo) strolling within marae precincts and endlessly reciting their lessons was a familiar, and to 
European ears, eerie, aspect of Maohi life. De Bovis wrote the following about these clerics:

Generally speaking, the Oripo were young men in training for the priesthood, who would eventually occupy positions in the priestly hierarchy in keeping partly with their competence but mainly with their social class. In ordinary marae activities they served in subordinate roles, as assistants to full-fledged priests, and like the latter they were under the supervision of a high priest. But in addition, they carried out a special function aptly described by their official label: Nightwalkers, whose job it was to roam about at night as spies, through their own districts and through those of the enemy. Indeed, in time of war, the function just described was the principal one of these novices, and it was considered a most honorable profession, one that was held by individuals, some of whom eventually became great tribal chiefs (including Tapoa the Great). (1909:50-51)

A further statement by de Bovis reports that some individuals remained oripo throughout their lives.

As in the case of students in the less clerical schools mentioned earlier (i.e., fare ha'api'ira'a), they or their families compensated their teachers with food, bark cloth, mats, and feathers. The end of the training is described in another passage from Henry:

When the novice had acquired proficiency in his recitations, he was required to appear before the fraternity, called autahua, to display his eloquence, and if he broke down in any part of his speech he had to take up his lesson again and reappear later for examination. Upon graduating with honors, he was received by the body of priests as an utu-pa'â (lips-inured), and then he was ready for inauguration, called $a m o^{\prime} o$-upu (forerunner-of-prayers). This consisted of a good feast prepared by his family, for the priests exclusively, on the marae ground, and of it they solemnly partook after placing an appropriate share upon the altars for the gods. Then the new priest was established permanently as a member of the fraternity. If anyone questioned his right to his title he would proudly answer:

\footnotetext{
'E'ere au i te tipara, 'e'ere au i te aihamu! E upu Ta'ere au.

E purau ta'u i hopoi na te 'orometua; e i`a ta'u i tapupu na te 'orometua; e ahu vane ta'u i hopoi na te 'orometua; e pe'ue ta'u i hopoi na te 'orometua; e popoi ta'u i papahia na te 'orometua; e e pua'a feti'i ta'u i hopoi na te 'orometua.
}

I am no beggar; I am no eater of scraps! An invoker from Ta'ere am I.

Purau [bark] have I taken to the teachers; fish I have chopped for the teachers; finely braided clothes have I taken to the teachers; mats have I taken to the teachers; fruit batter have I pounded for the teachers; and family pigs have I taken to the teachers.

Then he would enumerate the schools he had attended, and the famous teachers and priests who had taught him, which always secured him his proper standing. His first official oration in public was called the tauira-ra'a-upu (opening-invocation), or vahi-a-piha (breaking-from-the-room). (1928:155-156)

Another lengthy passage from Henry describes the procedures followed in readmitting a priest to his profession after a fall from grace:

The sins that were held as mortal sins (pahara aiaai) against the priests during religious solemnities were: taute, violation of sanctity by doing domestic work; 
hara faiaia, irreverance in offering human victims; hara i te fa'ahaerea, clumsiness in processions or failing in religious recitals; paoa pure, hurrying over prayers to serve the food; ai haruma i te omu pua'a, greediness in eating the head of a pig; ai haruma i te omu honu, greediness in eating the head of a turtle.

For any of these offenses, sure judgment upon the priest, people, and the land was supposed to follow, and if confession and atonement were not quickly made the priest, it is said, would die in great agony by a curse from the gods. In that case the people made atonement with peace offerings at the marae. When a priest was seen committing such misdeeds during the sacred spell for which he had been purified, it behooved the witness of the act immediately to report him to the fraternity and all the community, who would hold a general meeting and suspend the offender from his sacred functions at that time. This was a great degradation, for he thus remained among the people divested of clerical honor. At length when the time for another festivity approached, one priest would propose to the others to pardon the offender and receive him again into favor. When all agreed to do so, they would make it known to the high priest and community, who after assembling and deliberating would agree also to the proposal. Then a priest of good standing was chosen to fetch the offender, who would come with a chicken and a sprig of miro (called ava) in his hand. If his offense had been domestic work, for example, he would say:

Teie au, teie te pinia moa, teie te rau 'ava, ei taraehara a'e i taua hara na'u ra, i taute ai au. Fa'aora ia'u i taua hapa ra.
Here am I, here is the chicken, here is the ava sprig to atone for my sin, when I did domestic work. Forgive me that transgression.

The offering was accepted for the marae, and all present would respond:

A haere mai. Ia ora 'oe! A haere mai i te 'oro'a. A haere na ra e horoi i taua mahuruhuru nau ra.
Come hither! May you live! Come to the ordinance. But go first and be cleansed of your debasement.

So the priest who had fetched him immersed him with the following prayer to accompanied him to the sea and there the tutelar god:

Tahiti‘a mai, e te Atua, tohiu maro e, i tohiu tahu'a nei! Fa'atiama'i i to tahu'a i hara nei, ia ma te taute i tai nui atea ia moe i tai mauriuri; ia ma te mahuru huru, te hara o to tahua nei. Fa'aho'i mai i te moa nona, ia tarai fa'ahou 'oia i te urua ia hi'i fa'ahou i te aitu, ia poro fa'ahou, ia ho, ho fa'ahou, ia rutu fa'ahou i te pahu, e ia naupa fa'ahou tana rau 'ava. Tahiti'a mai e te Atua e!
Hearken, O god, inspirer through the loin girdle, to thy body of priests! Cleanse thy priest who has offended, that his domestic defilement be cleansed in the trackless ocean, be lost in the murmuring sea; that the debasement, the sin of this thy priest be cleansed. Restore him to holiness, that he may again cut up cavalla fish, again nurse the gods, again herald them, shout for them, that he may again beat the drums and again obtain the ava leaf. Hearken to us, O gods!

(1928:198-199)

Priests were evidently well compensated, in tangible goods and services as well as in respect. "Everyone is to treat with respect the tahu'a [pure] and also his directions; such are sacred with sacredness of divine origin. It is you who are to make his humble abodes and provide him with food and gifts of clothing" (E. Salmon 1937:II, 2). A passage from Moerenhout (1837:I, 435), cited earlier, asserts that some priests received 
large revenues from individuals who sought intercession on their behalf with spirits in order to insure places in paradise for themselves or deceased relatives. According to Henry, "When a body of priests near of kin to each other lived in one district they were called pae-tau-aitu (sidedwelling-with-the-gods) or pae-mua-fare (front-part-of-the-house) of that district, which they were deemed to render most respectable" (1928:154).

Some priests were able to use their authority in religious affairs to political advantage as well. ${ }^{9}$ But with all this, their jobs were no sinecures:

In view of the circumstance that all questions having to do with war or peace, all those having to do with government or the commonweal, and even all those having to do with an individual's actions, large or small, had to be submitted to the gods for their consideration and prior approval, the ceremonies and other activities carried out at the maraes were of such burdensome frequency and length as to leave the officiants extremely fatigued. Consequently, the exercise of priestly offices came to be painfully onerous, despite the considerable privileges attached to such offices. Obligated as they were to serve everyone, without even being exempt from the perils of war, priests led lives of such hyperactivity, physically and mentally, as to cause them great discomfort in this enervating climate and easygoing society...." (Moerenhout 1837:I, 474-475)

Priests at the principal marae were assisted in their duties by lay marae attendants called big-bellies (ōpu nui, "august Stomachs" according to Henry's more elegant translation), who according to Henry were "... stalwart, hairy men of dark-brown complexion" (1928:151), probably meaning strong and unkempt commoners accustomed to work in the sun. The reason for calling these men big-bellies is unspecified, but it possibly reflected the circumstance that they lived well off the food levied for religious purposes. In fact, in many marae there was a special drum, a pahu rutu m'a na te ōpū nui, used for announcing general levies of food for marae attendants.

The regular duties of big-bellies included all the more menial tasks associated with priestcraft: keeping altars stocked with offerings and protecting the offerings from wandering dogs, manufacturing bark cloth and mats for covering images, and so forth. They were reported as having been "chosen by the priests from the laity" for these duties (Henry 1928:151)—on what basis is however not specified-and they served for limited periods, probably in shifts. While on duty they slept within the marae precincts and wore a special uniform. Presumably, although this is not reported, they had to undergo ritual deconsecration before returning to everyday life after completing their tours of duty. What compensation they received, in addition to the better-than-average food consumed while on duty, is not specified. ${ }^{10}$

It is likely that many priests were skilled also in the practice of sorcery-that is, in employing spirits linked to fetcher-images ( $\left.t i^{\prime} i\right)$ for generally destructive purposes. Attached to some marae, however, there were regular staff sorcerers, individuals whose main or only function was to protect their patrons or execute politically inspired attacks by means of their craft. 
In addition to the above there were some individuals whose principal duty was to carry the deities' images in ceremonious processions. Because of their direct physical contact with spirits embodied in these images they remained in a particularly sacred state, at least during any particular ceremony, to the point of not being able to feed themselves; the food touched by their own hands was too sacred for their stomachs to tolerate. According to de Bovis the men who performed this service were usually commoners (1909:51), but it is not clear whether such men took up their duties only on occasion, or were a part of the full-time clergy.

Some sorcerers (feiā tahutahu, nanati āha, orou, ta'ata ōpū tara) were attached to the priestly staff of certain marae, but most of them worked on their own, either on behalf of their own enmities or as commissioned agents of others. Marae sorcerers probably received a share of food and goods contributed to the marae staff as a whole, and a sorcerer's clients undoubtedly paid for his services in the form of food and objects. For the successful sorcerer compensation was also forthcoming in the form of public respect, based in part on fear; but such a practitioner also ran the risk of antagonizing people who commanded enough physical force to end his career. On the spirit side, however, they were better protected, since counterattacks were usually aimed at the sorcerer's clients, rather than at the sorcerer himself-a nice instance of professional immunity, of institutionalized adroitness in the exercise of a profession!

There is no way of knowing the number of practicing sorcerers during the eras under study, or the extent to which sorcery constituted a full-time profession. As to recruitment, an individual evidently took this step on his own, or perhaps in some cases at the suggestion of some spirit, in a vision or dream. In some instances a sorcery practice may have been built around exclusive possession of trade secrets-of materials and techniques-which were usually inherited and which were jealously guarded. But this applied more particularly to physicians, tahu'a ra'au (herbalists). In any case such specialists were found in all marriage classes, from lowest to highest. Even some of the society's highest-ranking kin-Titleholders and most powerful tribal chiefs occasionally engaged in the practice in order to advance their ambitions. And it is not unlikely that for a man of middle-or even lowerclass beginnings, a successful sorcery practice, exercised with political tact, would have brought material affluence, social influence, and possibly even a rise in class status.

I noted in chapter 13, section on curing, the proliferation of specialists connected with phases of curing: bone setters, surgeons, physicians, diagnosticians, dis-enchanters, et cetera. One or more of these specialties sometimes formed part of the repertory of priests or of shamans; in other instances the specialties were practiced by laypersons. In either case it is unlikely that any of these activities required, or permitted, full-time occupa- 
tion, even though the rewards for such practices appear to have been fairly lucrative-at least in tangible objects and at least for some practitioners.

Certain of the staff specialists attached permanently to important marae or to chiefly households undoubtedly received regular retainer fees, or salaries, for their services. Such fees were in the form of subsistence allotments of food and clothing, as well as in occasional bonuses. These bonuses were realized in two ways: in the form of direct gift-payments to a practitioner after a successful treatment, and in the form of "sacrificial" goods presented to his marae spirits but consumed by the marae staff itself.

Free-lance practitioners were paid by the job, usually in the form of food, bark cloth, or mats. In fact it appears that most of them were paid before the job was begun and that their response to a call depended somewhat upon the fee offered; and if they were successful it is likely that they were given bonus payments as well. In obstinate cases physicians were probably like sorcerers in that they demanded extra payments while treatment was still going on (Moerenhout 1837:I, 540-541). Another tactic was described by Ellis:

There were persons among them celebrated as oculists, but their skill principally consisted in removing foreign substances from the eye; and when applied to for this purpose, they, as well as others, received the payment or fee before they commenced their operations; and if the present did not satisfy them, if they took one splinter, \&c. out of the eye, to satisfy the employers, they left another in, that they might be sent for again. (1829:II, 275-276)

Confirmed by other statements to the effect that practitioners occasionally ate up a family's pigs (Corney 1915:327) or stripped it of its possessions (Morrison 1935:182), we can assume that medical care was a costly matter for the ancient Maohis.

\section{Fighters}

I turn now to a wholly different kind of activity, which was engaged in occasionally by all Maohi men (and by some women), and which appears to have been a profession for some. As described in chapter 12, there were three types of war specialists: exhorters (rauti, leaf of the ti plant\& a war song; to excite to courage and bravery, as in time of war; to cause a party to retire), battle-shapers (tarai aro; tarai, to shape [as a canoe]; aro, a battle), and warrior-champions ('aito, a warrior, hero, conqueror, military man; or toa, a warrior, a valiant man). (LMS Dictionary) ${ }^{11}$

As I noted above, the job of a rauti was to urge men to fight, before and during the battle. They were usually "men of commanding person and military prowess" (Ellis 1829:II, 487-488), who fought as they exhorted. There is no information concerning specifically how they were recruited, or how they were compensated, save the implication that they were highly 
praised and cherished for their declamatory skill and endurance. Two statements from Henry also suggest that rauti had a special "sacred" status:

Indefatigable among the ranks during the deadly conflict were the rauti (stimulators), clad in ti-leaf petticoat, necktie, and turban, and waving in the hand a bunch of ti leaves, in the center of which they held a deadly weapon of the barbed and serrated tail bone of the sting ray. These men, who because of their weapons were supposed to be possessed with supernatural power, were of commanding appearance and dauntless aspect. (1928:306)

When a battle had continued for several consecutive days, the rauti sometimes collapsed from exhaustion, in which case they were stealthily removed at night to the fare hua so that the enemy might not exult over the misfortune or, still worse, obtain the sacred persons to slay and desecrate them. (1928:309-310)

Battle-shapers, whom Henry labeled "chiefs" of warriors, and whom Ellis called "the principal leaders" of fighting forces, were described as "marshalling the forces" for fighting. I have already cited Henry's description of their sennit armor and elaborate gorgets and headdress-which served, among other things, to single them out for attack. A further statement from Henry leaves some ambiguity concerning the identity of these officials: "They [all members of a fighting force] were headed by the ari'i or chiefs of the districts from whence they came who were often themselves the taraiaro (warriors)" (1928:299). To'ofa, the so-called fleet "admiral" mentioned by Cook, was evidently both tribal chief and battle-shaper (Beaglehole 1961:405). This seems to suggest that the commander-in-chief of a force, its tribal ari'i, was usually-but not necessarily-its tactical field commander as well. If this were so then the question remains unanswered concerning recruitment of tactical commanders who were not also tribal sovereigns. It seems likely that some martial skill was required of all battle-

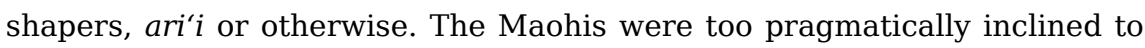
place their fates entirely in the hands of proven incompetents; and it seems just as likely that few if any commoners would have been appointed to such commanding statuses. However, a battle-shaper who was not also a tribal sovereign probably would have been at least a ra'atira, or more likely a near relative of the sovereign himself.

Some battle-shapers may also have been 'aito, but the latter achieved their position by individual valor and fighting skill alone. As I quoted earlier: "This title [status name] was the result of achievements in battle; it was highly respected, and proportionably sought by the courageous and ambitious. It was not, like the chieftainship and other prevailing distinctions, confined to any class, but open to all; and many from the lower ranks have risen, as warriors, to a high station in the community." (Ellis 1829:II, 496.) ${ }^{12}$ Henry described 'aito as having been "... very highly esteemed by these people as protectors of their land, the renowned ones standing high among the princes of the realm" (1928:298). 
We are not informed whether 'aito wore any distinctive costume or insignia, in or out of battle, except for Henry's puzzling statement that "warriors next in grade [to that of the tarai aro] wore their best clothes ... with or without armor, and the immense turban ..." (1928:299). ${ }^{13}$

There is no way of knowing the proportion of 'aito to men in general, or to what extent an 'aito's status required, or privileged, him to devote more or less full time to his specialty. Some of the principal tribal sovereigns had men attached to their households as a kind of bodyguard, a fighting cadre, and as teachers of martial skills; and among these there may have been some 'aito. There is some evidence to suggest that certain skilled fighters moved about as mercenaries. And finally, some of the most renowned 'aito appear to have spent most of their time in peaceful pursuits, including managing households, carrying out administrative duties, or even serving as Ariois or priests.

I presented in chapter 20 the textual passage in which 'aito were characterized as having constituted something of a "fraternity," resembling pact-friendship with respect to sexual access to each others' wives. Otherwise there is no evidence of unity among them-certainly not a universal one, and indeed not even any in terms of local or tribal "guilds" or congregations. On the other hand, those residing in the same community must have been together much of the time, perfecting their skills and competing in such sports as archery.

Compensation for 'aito came in the form of subsistence support from their patrons and large shares of spoils of war, including even conquered, annexed territory. They experienced the pleasure of basking in public esteem, with attendant tangible and intangible advantages. ${ }^{14}$ Also, their high standing "among the princes of the realm" undoubtedly meant some influence over public affairs. And finally, there is strong likelihood that an 'aito born as a commoner would have been able to marry into the ra'atira class without undue protest. As for a non-ari'i 'aito marrying an ari'i woman, a passage in the legend of Pereitai suggests that such a possibility did exist, but I have come across no specific instances of it ever having taken place.

Experts in stone-slinging were a specialized part of any fighting force, and, as one writer noted, the best of them were "celebrated through the islands, as well as the most renowned among the warriors" (Ellis 1829:II, 490). These specialists also wore a distinctive fighting uniform, consisting only of maro and, perhaps, tiputa. But whether the best among them were also called 'aito, or whether in native classification they constituted an entirely separate category of fighters, is not recorded. Neither do the sources distinguish between slingers and other warriors in discussions of the advantages accruing from successful practice of their skills. 
This does not exhaust the catalog of occupational specialists reported for Maohi society, but it probably lists the main types-except for those associated more exclusively with tribal government and the Arioi sect, which will be discussed in the following chapters. The sources contain many more names for certain activities which might possibly be construed to constitute occupations, such as the paddlers of war canoes, or men specializing in particular kinds of divination, but it is my belief that such jobs were either only occasional pursuits or represented only special aspects of one of the professions already listed.

\section{SKILL}

How did the Maohis conceive of the skills which distinguished the successful occupational specialist from other individuals not so qualified?

The term tahu'a mana is defined in the LMS Dictionary as one skilled in the art he professes. ${ }^{15}$ This raises again the puzzling problem of the Maohi meaning of mana-that is, in the present context did the word signify "skilled," in an adjectival sense, or something that brought about the skill? This distinction, so fundamental in English, may have been insignificant in the Maohi language, but I am attempting to explicate Maohi behavior in terms familiar to speakers of English, and hence will continue with an English-language approach and then attempt to translate my conclusions into Maohi concepts. (The limitations in the data rule out the converse approach.)

Skill in the occupations I have been describing consisted of one or more factors: social attributes that permitted the individual to engage in the occupation in question; motivation; a certain amount of "natural" talent: physical dexterity, coordination, quickness, strength, endurance, mental facility, memory, and adequate training. Taking these in order, it should be clear by now that most Maohi occupations were reserved for one sex or the other. A female could not have practiced priestcraft in an all-male marae regardless of her natural "talents"; nor would a male (unless a mahu) have regularly performed "female" dances. Again, it is extremely unlikely that a priest who began life as a manahune would ever have achieved the position of high priest in an important tribal marae. On the other hand, lower-class affiliation was not a bar to success and acclaim as, say, a shaman or boatbuilder or fighter.

"Motivation" was probably supplied (or indeed compelled) in many instances by family tradition, but there was ample leeway for individuals to specialize in occupations of their own choosing, either to gain tangible rewards or to acquire command over persons and affairs or perhaps just to sense the pleasure afforded by the activity itself. (What supplied these kinds of motives is a question too complex for me to attempt to answer here.) 
The third factor was as crucial in the Maohi conceptualization of "skill" as it was in the folklore of Western society, but the two modes of thought differ significantly with respect to the source of the specialist's talent. According to Maohi belief, the ultimate source of most specialists' skills, superseding in some cases-or even obviating-training, was spirit intervention of a direct or indirect kind. In the case of shamanism it was the spirit itself that performed the service, though embodied in a human vehicle of the spirit's own selecting. And for the priest and sorcerer, their very occupations consisted of maintaining cooperation with spirits. There is a possibility, even, that spirits may have been directly responsible for the mistakes made by some priests in carrying out the rites which helped to maintain that cooperation.

For the successful fisherman or artisan, spirits intervened in at least two ways: by "empowering" their tools; and by causing hands to be steady, fish to congregate, weather to be suitable, and so forth. In the case of 'aito, not only did spirits fill them with courage and guide their spears, but spirits also warded off enemies' blows.

Less is known about the source of the skills of famed dancers or actors or athletes, but probably all of these had their activity tutelars or individual spirit-familiars who helped guide their movements or who gave them added strength, or perhaps weakened their rivals.

For skills that required verbal "knowledge" some individuals acquired that knowledge by inhaling the last breath of the expiring possessor, whose ghost was thereby enabled to visit the successor and teach him what the possessor had known (Henry 1928:290).

Even the requisite of superior social position, which governed who should be high priests, is to be accounted for in this way. That is to say, only the more godlike humans were fit to interact with the high gods, and hence high priests had to be from among those humans who were "closest" to those gods, in terms of "descent."

This focus upon spirits is not meant to imply that the Maohis did not recognize training as a necessary ingredient of most skills; a review of previous chapters would show that they did recognize it. Nevertheless, as I have reconstructed their beliefs, they held that no amount of training would have led to successful performance without the direct or indirect intervention of spirits of some sort. 


\section{CHAPTER 22 CULTS}

As I noted earlier, it was a characteristic feature of Maohi society that nearly every social group of any temporal continuity-consanguineal, territorial, occupational-was at the same time a religious congregation. But there were some social units, both categories and groups, made up of persons whose only, or most notable, common attribute was their primary homage to a specific god; for want of any better term, I label these units cults. In such cases the god in question was usually also the tutelar of some smaller group within the larger cult unit; and, in the case of the cult dedicated to worship of the god 'Oro, there were a number of special cult subgroups, or sects, whose members, called Ariois, devoted major portions of their lives to 'Oro worship in general and to sect activities in particular.

The earliest recorded information available concerning Maohi cult units was supplied by the Forsters, writing about conditions as they were in 1774 . Both father and son recorded the names of the "principal" gods worshipped at each of the several islands, as follows: Tahiti and Mo'orea: Ruahata; Mai'ao: Ta'aroa; Hauhine: Tane; Ra'iatea: 'Oro; Taha'a: Ra; Porapora: Tautu; and Maupiti: Tu (G. Forster 1777:II, 150-151; J. Forster 1778:539). Anderson, writing three years later, described 'Oro as having been the principal deity of Tahiti Nui, Punua (?) and Fatutiri (?) of Tahiti Iti (Taiarapu), and Tane of Taha'a (Cook 1784:175); his list otherwise agrees with the Forsters'. Henry listed Tane (along with Ruahatu) for Tahiti-Mo'orea, Tane for Huahine, 'Oro and Ruahatu for Ra'iatea, 'Oro and Ra'a for Porapora, Ta'aroa for Mai’ao, and Tu and Ta'aroa for Maupiti (1928:128-129). De Bovis' list (1909:44) agrees in essentials with Henry's. ${ }^{1}$

Some of the discrepancies among these lists may derive from each having referred to a different locality on an island-for example, Tane and Ra may have been worshipped on different parts of Taha'a. Still other discrepancies almost certainly derive from different dates of recording-for example, the cult of 'Oro is known to have superseded those of Tane and Ruahatu in many parts of Tahiti-Mo'orea during the latter third of the eighteenth century.

Another uncertainty about these lists has to do with the social units 
with which some of the deities were associated. For example, in view of the fact that Mai'ao constituted a single group politically (actually, a subtribe, since the island was a dependency of Huahine), it is not possible to separate Mai'aoans' roles as fellow tribesmen from their roles as common devotees of Ta'aroa. In fact, most if not all of the deities listed above served as tutelars of political (i.e., tribal) groups, which in some instances comprised whole islands. However-and this is the important distinguishing feature of the units now under discussion-the cults of certain gods were supratribal in membership. Specifically, around the middle of the eighteenth century the deities most widely revered in these islands were Ta'aroa, Tane, and 'Oro.

\section{TA'AROA}

By the time Europeans arrived on the scene, Ta'aroa evidently was the principal focus of cult practice on the small and isolated island of Mai'ao only. On other islands this deity figured mainly as a kind of "grey eminence" in religious ritual, an awesome Being too indifferent to mortal's affairs to require or encourage interaction. At that same time, both Tane and 'Oro were worshipped directly and preeminently in many tribes, their respective devotees having been about equal in number.

Any number of explanations might be offered for this state of affairs depending upon the explanator's faith in this or that mythical tradition, or his espousal of this or that theory of Society Islands "history." Inasmuch as most of the cosmogonic myths that happened to be recorded portrayed Ta'aroa as the first god, the creator or ancestor of all others, including Tane and 'Oro, one might conclude that the cult of Ta'aroa had in fact been society-wide in the distant past, and that those of both Tane and 'Oro had sprung from it. (The conceptualization of Ta'aroa as otiose could then perhaps be seen as a projection of the fate of mortal progenitors after the birth of their successors.)

Or, if one entertains doubts about the representativeness of available cosmogonies, most of which feature the primacy of Ta'aroa, this raises the possibility that a wider sampling would have exposed rival claims on behalf of the primacy of Tane, thereby revealing the existence of rival cults of Tane and of Ta'aroa at some time in the past. This is a possibility suggested by Williamson, who proposed (on the basis of much positive evidence) that the cult of Ta'aroa was originally centered on Ra'iatea and Porapora, and (on the basis of ingenious but undocumentable speculation) that the cult of Tane was centered on Tahiti-Mo'orea (1924:218ff.). As a corollary to this reconstruction the cult of 'Oro is viewed as a recent successor (and not a rival) to that of Ta'aroa, and hence a rival to that of Tane.

Still other explanations might be offered, including the one that every 
separate community, or every separate "wave" of immigrants, had "in the beginning" its own distinctive tutelar, which after a while lost out to proselytizing devotees of Ta'aroa, or of Tane, or others, a development eventually "legitimatized" in myths. We shall never be able to reconstruct those more remote happenings; and, indeed, historical knowledge of them is not crucially important to our understanding of more recent events. On the other hand, credible information about certain aspects of more recent cult practices and history are indispensable to anyone attempting to understand political events in these Islands (and particularly in Tahiti-Mo'orea) during the second half of the eighteenth century.

Although Europeans identified Ta'aroa as having been "principal" deity only on tiny Mai'ao, nothing was reported concerning cult practices on that isolated island. During that period Ta'aroa was described as having been recipient of first fruits on Tahiti (LMS Dictionary, p. iii), and Ellis stated that Ta'aroa was invoked (along with 'Oro) in some inaugural rites. Ellis also named Ta'aroa as recipient of some human offerings, specifically of the first enemy warrior captured in war, but both Henry and Moerenhout asserted that humans were not offered to this deity. ${ }^{2}$ In fact, Moerenhout's view of Ta'aroa's position typified those of other writers as well:

... Ta'aroa was so far above the affairs of this world that he did not deign to concern himself with their governance, nor to interest himself in the fates of men. Moreover, since mortals expected nothing from Ta'aroa-neither benefits nor misfortune, neither punishment nor reward-they dedicated no temples to him and consecrated no altars. But even though few people actually worshipped this god, they all vied with one another in extolling his glory, his power, and his deeds. He was veritably the God of Epicures poetized by Lucretius. (1837:I, 439)

As noted earlier, Ta'aroa's role had been a much more active one in the remote past, this deity having been primarily the principal tutelar-some traditions say actual ancestor-of the socially and politically élite kin-congregation centered at Opoa and of its several offshoots elsewhere, including such notable ones as those of Porapora, Farepua (Vaiari, Tahiti), and Puna'auia. In the context of this body of tradition, kin-Titles derived ultimately from the Opoan kin-congregation would have been preeminent wherever Ta'aroa himself was considered supreme-or so one can reasonably infer. Moreover, the highest-graded kin-Titles associated with or derived from Opoa are said to have been emblematically distinguished by feather-decorated girdles (maro), primarily red and secondarily yellow. The ritual association between Ta'aroa and such girdles would have been close.

It is possible to view certain legends as euphemistic accounts of the waning of active Ta'aroa worship; I refer to the Porapora chief's "declaration of independence" of his source kin-congregation of Opoa and the supplantation of Farepua by Papara (see chap. 16), and to the "retirement" 
of Ta'aroa in favor of his son, 'Oro, at Opoa. In the first two instances the new arrangements may be viewed as symbolized by adoption of a yellow (in place of the usual red) feather girdle as Title insignia. There is no suggestion in either of these instances that Ta'aroa himself was wholly abandoned for some other tutelar; it was more in the nature of removing him from direct association with kin-congregation events and Titles in Porapora and Papara. As for Opoa (as we shall see), the transition simply constituted a conventional Maohi episode wherein an office-holding father was succeeded by his principal successor-or so the legends imply. Later on I shall raise the possibility that the Opoan shift from Ta'aroa to 'Oro may in fact have been connected with a major dynastic change.

\section{TANE}

The god Tane figured in beliefs and religious practices throughout the Society Islands and was the focus of worship on Greater Huahine and in parts of Tahiti, Mo'orea, and Taha'a. ${ }^{3}$ Particularly on Huahine was Tane the most active and preeminent deity. According to Henry, Tane's cult on Huahine was established by Ruahatu Tinirau, the Maohi Neptune who swam around these Islands after a deluge, repairing old marae or setting up new ones. After calling at Ra'iatea, "Ruahatu then swam to Huahine-nui and opened two passages in the reef, named Apo'o-uhu (Aperture-of-the-parrot-fish) and Peihi (Prayer-for-fishing). There he stood upon the point named Manunu (Benumbed), and placed the corner-stones of the marae called Mata'i-rea (Breeze-of-space), which he dedicated to the god Tane (god of beauty)." (1913:25)

A wholly different version was provided by Davies:

The Rohu Atua gives the following account of the titular god and royal family of Huahine.

Tutapu and his wife dwelt on a land called Puatiriura. They had an only daughter, Hotuhiva. No husband was to be found for her on her own land. Her parents, however, were very anxious she should obtain one, and therefore put her in a drum, called Taihi, under the care of Tane and the god or idol Taputura, and sent her to sea. After sailing about for some time, they landed at Manunu on Huahine; which name signifies "cramped."

The spot was formerly called "Toerauroa."

Tane became the titular god of Huahine. The young lady, Hotuhiva, was married to a chief named Teaonuimaruia. They had two sons, Tina and Hena, and they are considered to be the ancestors of the present chiefs. (LMS Dictionary, p. iv)

Whatever its beginning may have been, the cult of Tane became so firmly established in northern Huahine that even the proselytizing zealots of 'Oro were not able to supplant it. The fullest description we have of this cult comes from the missionaries Tyerman and Bennet, who visited Huahine in 1821 to 1822 , four years after the populace's "conversion" 
to Christianity but early enough to find many remains and memories of the cult still extant. (I reproduce extensive portions of these observations, both for the information they contain about the cult of Tane and for the insight they provide into the problems of compiling an ethnography from the kinds of writings available.)

Jan. 4. The weather not permitting us to resume our journey, we made an excursion to the neighboring motu, to visit the marae of Tani, the chief god of Huahine in the age of idolatry. It stands about a hundred yards from the shore, embosomed among trees of many kinds, which wholly obscure the edifice till the spectator arrives upon the spot. Like most erections of the kind, it consists of two stories, of oblong shape; the lower, a hundred and twenty-four feet by sixteen, and the upper diminished proportionately, with a small wing at the back. The basement is about ten feet in height, and fronted with coral blocks, placed on their edges, some of which are as high as the story itself; these form the walls of an enclosure, which is filled up with earth. The superior but smaller part is faced with coral, and filled with earth, in like manner, but not more than three feet high, having at each end an upright stone of twice that elevation. In the centre of the principal front stands the bed of Tani, a stone-framed pile, eighteen inches above ground, but twenty-four feet long by thirteen wide! Hard by is another and lesser inclosure, not more than half the dimensions of Tani's bed, yet large enough to hold all the gods beside that belonged to this celebrated grove and temple. All these various structures were exceedingly rude, but massy, in materials and masonry. Not a tool seems to have been lifted up upon any of the stones, the angles are ill-formed, nor are the walls in right lines; but the whole pandemonium is in rare preservation, scarcely a block having been dislodged from its place. Trees of centuries, judging from their venerable and magnificent appearance, overshadow this "dark place," with meeting arms, and foliage "star-proof." One of these ancients measured fifteen yards in girth above the root. There is a tradition worthy of the superstition attached to this shrine of folly. Tani often wanted to fly away-from his bed here, we presume-but having a very long tail, like a boy's kite, that unlucky appendage always caught in the boughs of this sacred tree; by which he was instantly dragged down to earth again. However, he has now escaped-escaped for ever-though not by flight, but by fire, having been burnt (in effigy, of course) in his own house, called Taumatai, in the year 1817, by those resolute image-destroyers, Hautia and Tiramano, in their zeal for the Lord of Hosts. The idol, a huge, mis-shapen block of wood, was about the height and bulk of a very tall and stout man; but, like many of his fraternity here ("the gods made with hands"), by the bungling of the artist, he was one of those "whose heads do grow beneath their shoulders," there being no separation of those parts above; whilst below, the uncouth body terminated in a point (without legs) like a cone inverted. It had likewise the usual mockeries to represent eyes, ears, nose, mouth, and arms; but these were "most lame and impotent conclusions" of such matters. The whole was covered with cinet, or platted twine, made from the fibres of the cocoa-nut husk.

At this marae, once a year, when the kings and priests thought proper, there was what might be called a national assembly and festival held. Hither all the idols of Huahine were brought from their various temples to be clothed with new dresses and ornaments. On this occasion, Tani was laid on the middle of his bed, having the gods of four districts placed on his right hand, and the gods of four other districts, into which the island was divided, on his left. The chiefs 
stood in rows opposite to their own divinities, and the priests round Tani, as lord over them all. Various antic ceremonies having been performed, and prayers offered, the images were stripped of their old vestments. Many of these wooden stocks, being hollow, were filled with beautiful feathers, and other precious trinkets, which were also brought out, and either renewed or replaced. None but men were allowed to attend this anniversary. One who had often been present assured us that, on these occasions, a quantity of $a v a$, for the purpose of making a detestable intoxicating liquor, nearly as large as the marae itself in bulk, used to be collected, besides provisions in an immense quantity; eighty or a hundred hogs, also, were slaughtered and roasted to entertain the multitudes that were attracted hither by their devotion to the gods and their love of good cheer. The feast lasted three days, and was a season of gluttony, drunkenness, and debauchery of every kind. The priests themselves were often so intoxicated as to be unable to repeat their devotional addresses in the required posture; they would then grovel upon the ground, like swine, muttering and hiccuping their incantations. While this carnival lasted, no fire was allowed to be lighted, nor labor to be performed, throughout the island. At the close of the ceremonies, a particular god, called Maavai, was brought forth, stripped and gutted like the rest, when immediately, they say, it began to rain tremendously. This was the signal for the removal of all the new-clad idols to their respective maraes. No female was permitted to approach one of these sacred edifices on pain of death, which was instantly inflicted by whoever witnessed the sacrilege. Nay, such was the cruel and remorseless proscription of the sex from religious rites or privileges, that if the wives or children of the priests themselves came within a certain distance, while they were engaged in some particular services, they were murdered on the spot, even by their husbands and fathers, with the most desperate ferocity. (Montgomery 1832:I, 194-196)

This was evidently marae Manunu, which I mentioned in chapter 16 and which was located on the flat strip of land closing off Lake Maeva from the sea.

Shortly after visiting Manunu, Messrs. Tyerman and Bennet visited the main settlements and marae complexes along the southern border of Lake Maeva:

The great marae itself was dedicated to Tani, the father of the gods here; but the whole ground adjacent was marked with the vestiges of smaller maraes-private places for worship and family interment-while this was the capital of the island, and the head-quarters of royalty and idolatry. On the limbs of the tree already described, there is reason to believe that thousands of human sacrifices have been hung. One low bough, of great length and bulk, was pointed out to us, as having been the principal gibbet for such victims, century after century. The tree itself was sacred to Tani... (Montgomery 1832:I, 198-199)

Near the chapel there is a stone, on which the idol Tani was wont to be set down, that he might rest himself after the fatigue of being carried in a man's arms (whose peculiar office it was) down the steep hill adjacent, from his grand marae above, when, on certain extraordinary public occasions, it was necessary that he should be removed. The stone is a rough flag, as it was separated from the rock, four feet long, one and a half broad, and nine inches thick. It is placed horizontally on the edge of the lake, about half a mile from the sacred tree. (pp. 202-203)

Jan. 8. We visited several maraes, accompanied by Mr. Ellis and a native, 
named Toumata, who formerly held the illustrious office of te ama atua, or bearer of the god Tani. He belonged to the order of priests, and was a personage of such superhuman sanctity that every thing which he touched became sacred; he was, therefore, not suffered to marry, as the honor of being his wife was too much for any mortal woman. But this was not all; he would himself be so defiled by such a connection that he would be disqualified for his office, and must immediately resign it; nay, if he did not repent, and return with a great peace-offering to Tani's house, he might expect to be first struck blind, and afterwards strangled in his sleep. He was not allowed to climb a cocoa tree, because, if he did, it would be so hallowed that nobody else durst afterwards ascend it. He was the only man living who had a right to handle the god Tani; and it was his special prerogative to carry the idol when it was annually removed to the neighboring motu to be stripped and new dressed, as already described; and though the latter ceremony was permitted to be performed by the priests, he alone could carry back the image to its marae on the mountain side. To do this, and re-instate it in its upper chamber, he had to climb a post of Tani's house, twenty-five feet high, with the unwieldy block on his shoulders. This office he voluntarily resigned, with all its privileges and emoluments, and embraced Christianity, on the day and at the place where Tani was burnt by Hautia and the zealous warriors who overthrew their country's idols with violence, but subdued their pagan adversaries with meekness, as stated in yesterday's journal. Toumata is a stout man, about thirty-five years of age, and very well versed in the traditions of his heathen forefathers, which enabled him to give us much information concerning the objects that attracted our curiosity in this day's excursion.

The first marae that we visited was the sepulchral one of the kings of Huahine, for many generations. It was an oblong inclosure, forty-five feet long by twenty broad, fenced with a strong stone wall. Here the bodies of the deceased, according to the manner of the country, being bound up, with the arms doubled to their shoulders, the legs bent under their thighs, and both forced upwards against the abdomen, were let down, without coffins, into a hole prepared for their reception, and just deep enough to allow the earth to cover their heads.

Close behind this was another inclosure, thrice the length and twice the width of this; the whole raised to the height of five feet above the ground; the walls of oblong, and the pavement of flat, stones, forming a pretty level platform. On this were held the national councils, when the kings, priests, chiefs, and land-owners assembled to determine questions respecting peace, war, or other great public concerns. On such occasions this stage was crowded with the great actors in those scenes of violence which used to convulse the island with civil strife; while thousands of the people, the sufferers in such tragedies, thronged around it, to hear the issue of consultations which were to relieve them from hostilities already raging, or to break tranquillity then reigning, by letting loose man against man, family against family, and district against district, till rapine, murder, and devastation had done all but their worst, by stopping short only of utter extermination in their progress. The political and priestly orators who were wont, at such times, to harangue the multitude, often displayed no mean powers of savage eloquence.

Close upon the margin of the lagoon, and under the shadow of the sacred tree, stands a marae, dedicated to the departed spirits of the kings whose bodies are interred in the adjacent one. This, like the rest, is composed of rough coral blocks for walls, and raised to a second story by small flags and stones. A third, belonging to a family of the Bue Raatera, built in like manner, is seen in the same vicinity. Others appear on the lower slope of the hill, which are respectively ded- 
icated to Tani, Raa, and Oro, the principal idols of Huahine. Above these there has been constructed, at some barbarous period, a vast wall ten feet high and six thick. This rampart consists of rough masses of stone from the crags above, or coral-reef from the sea, piled and attached without cement, with great labor and no small art. It was raised for the purpose of obstructing the course of a pursuing or invading enemy up the steep side of the mountain, which it engirdles to the length of two miles, and only breaks off at points of interruption where the precipice itself precludes all possibility of assault. The upper regions of this acclivity were considered almost impregnable; and they not only afforded security to fugitives who gained them, but the fertility of the soil, which was thick-planted with cocoanut and bread-fruit trees, nearly to the top, and the perpetual springs of fresh water abounding there, furnished provision for the occupants as long as they were likely to be besieged by a baffled army below. Behind this fortified eminence, and with a small valley only between, the moua tabu, or Sacred Mountain, already described, rises about three thousand feet; from the summit of which, as a last retreat, defiance might be hurled, not in words only, but in the enormous missiles of disrupted rocks, and the smaller ammunition of loose stones, with which the surface was abundantly strewn.-On the lower mountain are many maraes, of which particular notice is unnecessary. The whole hill and subjacent beach seem to have been holy ground, in the unhallowed sense in which men consecrate, upon the face of God's earth, temples and altars to idols and devils.-The great marae, so dedicated to Tani, stands superior among all these, being nearly a hundred feet by eighty in length and breadth, with walls in some parts nine feet thick. In the centre of this rude edifice, Tani's bed is seen, on which his idol was laid when prayers were offered to it, and near that another platform, which the dumb stock occupied on special occasions.

At the distance of thirty feet, in front of the marae, is the usual raised seat for the priest when he performed his devotions; and, near the same, what may be called the altar, consisting of a flat flag-stone and an upright one, on which the animals, offered in sacrifice, were formerly slaughtered; these were swine and fowls. But the altar on which the bodies of the victims, when slain, were presented, was a frame of wooden piles and planks, sixteen feet long, six wide, and ten high. On these occasions the fowls of the air had plenteous feasting. Near the spot were two large heaps of bones, principally the skulls of hogs. On the declivity, immediately below the marae, are two small terraces, raised to the height of twelve inches each from the ground, and on the lower side of these are stationed eight insulated stones, set up at some distance from one another, designating, by their position in reference to the temple, that part of it which particularly belonged to each of the eight districts of the island; and round which the inhabitants of the same, on public solemnities, congregated in tribes, as we were given to understand. On the north of the marae was Tani's house (now destroyed), a little wooden chamber, built on posts, twenty-five feet high, and to which there was no access except by climbing one of them. This was the sanctuary where the image was usually kept, and from and to which it was always carried by our companion, Toumata, till the day when the idol, the sanctuary, and the worship of Tani were destroyed. We are told that when the people saw the flames ascending from the pile on which Tani was laid, by Hautia and his Christian warriors, they were powerfully affected-some with joy, others with sorrow, and not a few with apprehension that the god would speedily arise and inflict summary vengeance on his enemies, if not destroy the whole island and its inhabitants, for the indignity offered to his wooden proxy. It ought to have been mentioned that on one side of Tani's house there is a remarkable stone, set on 
end, which (like the tree on the motu, formerly mentioned) is said to have caught his long tail, when, from the top of it, he attempted to mount into the air on a journey of mischief. This tail, it seems, was a grievous drawback to Tani, and various trees, in the boughs of which it had been entangled when he was taking his flight, have become sacred in consequence of being touched by it, though to his own bitter disappointment, when they caught him and prevented his aerial flight. The old people say that meteors were formerly much oftener seen from these islands than they are now. These, as well as comets, they imagined to be the tails of the gods, and, therefore, when they saw them streaming through the atmosphere, they immediately threw off their upper garments and exclaimed, "a god! a god!" Tani's unlucky appendage, probably, was of celestial origin, in this respect; and, instead of being translated to the skies, like Berenice's locks, was attached to the popular image of his person, in commemoration of some magnificent meteor, whose train, in its flight, measured ninety or a hundred degrees. (pp. 204-207)

When living animals were brought to be sacrificed to Tani, no blood was shed. They were laid upon the stone, and most cruelly, because most clumsily, strangled by the pressure of their necks between two pieces of wood. Not hogs and fowls only, but fishes, fruits, and intoxicating spirits were offered at this altar. Of these good things-though presented on the frame, before described, for Tani to feast upon, or rather to be consumed by the birds or perish by putrefaction-it was shrewdly suspected that few were consumed by so slow a process, the priests having found a much more convenient way of disposing of them. It is remarkable that among the contributions to Tani's service were first-fruits, according to the season of the year; a poor person was expected to bring two of the earliest gathered, of whatever kind, a raatira ten, and the chiefs and princes more, according to their rank and riches. These were thrown down upon the ground, at the marae, with the expression, "Here, Tani, I have brought you something to eat." In general, when hogs were presented, the heads only were laid upon his altar, the remainder being baked and devoured by the worshippers and the priests. Many kinds of fish, but neither sharks nor turtles, were thus offered. Human sacrifices were never slain or exposed here; these were all gibeted at the enormous aoa tree, on the beach below. For Tani's bearer (our friend Toumata) there was set apart, out of these gifts, a certain portion of food, which even the kings dared not to take away or touch. At a marae, on the beach, we were shown a precious relic. This was said to be a fragment of Tani's canoe, which, though a stone, could swim as well as if it had been timber. To prove this a man threw it into the water, and it actually floated! The fact and the solution of the puzzle were equally apparent; it was a large piece of pumice-stone. Whence this specimen came the people could not inform us, but they said that there were more pieces of the same substance at other places on the island, which, according to an old tradition, had been collected by some devout person, formed into a canoe, and presented to Tani. The priests, no doubt, knew well how to avail themselves of a natural circumstance to hold an ignorant and credulous people in delusion by the semblance of a miracle. (pp. 208-209)

As we shall see in volume 3, Huahine had eventually become a unified tribe, under chieftainship of dynasties residing mainly at Maeva, where were located the principal marae of Tane just described. Thus, latterly at least, the cult of Tane on Huahine was coterminous with the island's tribal 
unit (and congregation). On the other hand it is possible that many or most Huahineans were devotees of this god even before they became politically united. Moreover, as we saw earlier, Tane worship was also established on other islands which cannot be linked politically with Huahine and which appear not to have been interlinked by any evident kinship ties. Thus, I feel justified in describing Tane worship as an archipelago-wide, supratribal cult.

There is no evidence of special association between Tane and any particular unit of consanguines (as was the case with Ta'aroa, in spite of his "universality," and as was the case also with 'Oro). As might be expected, Huahine's principal chiefs played leading roles in Tane worship, but their connections with the deity were evidently not rationalized in terms of descent. Moreover, as far as I can discover, unlike Ta'aroa and 'Oro, Tane was not identified with any kin-congregation's Title-validating insignia, such as the feather girdles that linked Ta'aroa or 'Oro with Opoa and its offshoot kin-congregations. And in this connection, while images of Tane are well attested, I can find no evidence of "genealogical" connections among them, such as will be shown to have been the case with images of 'Oro.

\section{‘ORO}

'Oro worship may at one time have been identified exclusively, or principally, with one kin-congregation, and then later with a single tribe; but during the era under study its devotees were drawn from several kin-congregations and tribes. And, as we shall see, the cult thus constituted became an important factor in dynastic and intertribal rivalries.

\section{Myths of 'Oro}

One version of the origin of 'Oro is given in a sonorous chant dictated to Orsmond in 1840 by Tamara (of Tahiti) and Pati'i (of Mo'orea):

A hee mai te tua, e ia papama'ehe no te tai a tau te pô.

E pô fanaura'a atua, o te pô MuaTa'aroa; o 'Oro-taua te atua i fanau mai i tereira pô; 'Oro atua o te Reva e te Fenua nei; 'Oro haia; 'Oro atua o te Arioi.

O Hina-tû-a-uta te metua vahine o 'Oro, i ha'amaru hia e Ta'aroa i raro a'e i te 'ama'a uru i fanau mai ai o 'Oro, ei tamaiti na Ta'aroa. I Opoa i te ao nei o 'Oro te fanau raa hia; O Tai'au, te tane o Hina-tû-a-uta, te metua fa'a'amu a 'Oro.
The sea rolled, and the tides succeeded each other for a period of nights.

It was the birthnight of a god, it was the night Mua-Ta'aroa (First-severed); 'Orotaua (Warrior-at-war) was the god born that night; 'Oro (Warrior), god of the air and earth; 'Oro, the manslayer; 'Oro, god of the comedians.

Hina-tu-a-uta (Hina-of-the-land) was the mother of 'Oro; she was overshadowed by Ta'aroa beneath a breadfruit branch, which caused the birth of 'Oro, the son of Ta'aroa. Opoa of this earth was the birthplace of 'Oro; Tai-'au (Sea-for-swimming), the husband of Hina-tu-a-uta, was the adoptive father of 'Oro.

(Henry 1928:374-375) 
It should be noted that Henry subtitled this chant "Birth of More Gods" and placed it sequentially after several other chants describing Ta'aroa's acts of deity creation, by sexual reproduction and otherwise.

Ellis' version was evidently derived from sources similar to Orsmond's:

Oro was the first of the fourth class, and seems to have been the medium of connexion between celestial and terrestrial beings. Taaroa was his father. The shadow of a bread-fruit leaf, shaken by the power of the arm of Taaroa, passed over Hina, and she afterwards became the mother of Oro. Hina, it is said, abode in Opoa at the time of his birth; hence that was honoured as the place of his nativity, and became celebrated for his worship. Taaroa afterwards created the wife of Oro, and their children were also gods.

After the birth of Oro, Taaroa had other sons, who were called brothers of Oro, among whom were the gods of the Areois. (1829:II, 194)

With these two versions may be contrasted the one collected by Lavaud in 1849 from Mare. My translation is from Lavaud's French text (Roussier 1928:190-191), and hence two removes from the original native text, which is not available.

Ta'aroa then perceived that there were no inhabitants on earth. On looking down he saw Te-papa-raharaha, who turned her eyes toward him and smiled. Whereupon he said to her: "Here are Ta'aroa's genitals. Cast your eyes upon my Tumu. Stand up and gaze upon them. Insert them." And to his genitals, named Teapoirahi, Ta'aroa said: "Descend upon Te-papa-raharaha, who was created out of my own leg bone." The female thereupon was known as Te-faimai-i-raro, because she was underneath, and Ta'aroa was known as Te-faimai-i-ni'a, because he was on top. From the union of these two were born, first, Redearth and then Whitesand, who became the soils so colored. ${ }^{[4]}$ After them was born 'Oro, who became a god and lived in the sky. After 'Oro were born several other males, all of whom were sky-dwelling gods: Tane, Teiri, Te Fatu, Moe, Ruanu'u, Tu, Toahiti, Tanuta, Temeharo, Tunuatefatutiri. Then was born [of this union] a daughter named Hina-tutupo, whose job it was to make clothing for Ta'aroa and her divine brothers.

I do not know what significance, if any, to attach to the fact that the Mare and Henry-Ellis versions provide 'Oro with different mothers. Perhaps, in this instance paternity figured more importantly than maternity in 'Oro's antecedents.

Several points are worth noting about these versions of the origin of 'Oro:

1. The deity was unequivocally male.

2. He was created by sexual reproduction.

3. He was not the firstborn of his genitor, Ta'aroa, ${ }^{5}$ and, in the Mare version, not even his mother's firstborn. In the Henry-Ellis versions his creation took place some time after Ta'aroa had created certain other deities-a consideration which led Ellis to place 'Oro in the fourth and last category of "principal" divinities, after such gods as Ro'otane, Toahitu, Te Fatu, and others, including several gods of war (1829:II, 194). 
The principal divinities were distinct from "the gods of particular localities or professions" and from an "intermediate class" who were "not supposed to have existed from the beginning, or to have been born of Night, i.e., Pō." Ellis related that these "intermediate" divinities were often described as having been "renowned men, who after death were deified by their descendants" (pp. 194-195). Ellis seems also to have implied that the order in which a category of principal gods was created was reflected directly in their hierarchical positions, but this implication is not further documented. In any case, the eminence ultimately attained by 'Oro evidently did not lead his devotees to mythicize that position wholly in the conventional terms of birth order.

4. In the Henry version, 'Oro is represented as having been born out of wedlock: that is, his genitor, Ta'aroa, was not his mother's "tane"-the latter having been Tai'au, who became 'Oro's "feeding-parent" (metua fa'a'amu). (The similarities between this version and the New Testament account of the origin of Christ would arouse stronger suspicion of borrowing were it not for the fact that this thematic situation is a common one in myths of unquestionably native authenticity.)

5. The Henry-Ellis versions specify Opoa as having been the birthplace of 'Oro. Lavaud's summary of Mare's version does not specify 'Oro's birthplace, but does identify Opoa as the site of what one may infer to have been his first marae: "The marae of Oro, ... Taputapuatea, is located in Raiatea on land called Pupua. The southerly gales originating here are called 'The Winds of Pupua.'” (Roussier 1928:192)

As I noted in chapter 16, Taputapuatea was not always so called; the name of its earliest component was Feoro.

When 'Oro, god of war, was born of Ta'aroa and Hina-tu-a-uta, at Opoa, his father gave him Opoa with the marae, Feoro, as his home. So he soon waxed very great, and the people of all the land and beyond the shores of Havai'i acknowledged him as the supreme god of the earth and air. The name Feoro was changed to Vai-'otaha (Water-of-the-man-of-war-bird) which, in addition to their local names, became the clerical name of all marae dedicated to 'Oro, because the man-of-war bird was 'Oro's shadow, and the water meant human blood. 'Oro's high priest at Opoa was named Tiri (Throw-out), meaning extension of power and also nurse of the god.

The image of 'Oro in this marae was woven with fine sennit into the shape of a man, two or three feet long, and covered with red and yellow plumage. It wore a girdle of red feathers. The title 'Oro-maro-'ura (Warrior-of-the-red-girdle) was given to it, associating 'Oro in his earthly capacity with the highest royalty.

At the ancient royal marae of Fa'a-nui (Great-valley) in Porapora kings, called the arii marotea (royalty of the yellow girdle), received the maro-tea (yellow-girdle of parrakeet feathers) instead of the maro-ura (red-feather-girdle) of the kings of Opoa. Another name for this marae, Vai-'Otaha, indicates that the royal scions of the house of Porapora, from Opoa, took their chief corner stone 
from the parent marae while it was so named. Over it was placed Oro-marotea (Warrior-of-the-yellow-[or light colored]-girdle), his image being woven in the likeness of that at Opoa but covered with yellow feathers instead of red.

To Taputapu-atea, the national marae of Ra'iatea, were taken most of the heads of warriors, who were decapitated as they lay dead or wounded upon the battlefield. The heads were cleaned and closely stacked in rows in the crevices and nooks of the marae, where contrasted with the background of stones, they produced a terrifying sight. Bleached with age, these skulls lay sacred upon the marae. (Henry 1928:120-121)

In due course 'Oro-worship spread to other islands. Henry gave a version of its establishment upon Tahiti:

Since the legend of Tahiti being a fish from Ra'iatea was believed to be a historic fact (a belief that has not yet died out among the native people), the priests of Ra'iatea claimed Tahiti for 'Oro after he had been established at Opoa.

In the reign of Tamatoa I there came to Tahiti a high priest of 'Oro, named Tupua-nui-te-fa'aonoono (Persistent-great-growth), accompanied by his two brothers, Te-tupu-amiha (Steady-growth) and Te-haruru (The-noise), who were priests under him, and also a sister, Toa-te-manava (Brave-hearted), who was a learned scholar. They brought with them a stone from Taputapu'atea (Sacrificesfrom-abroad) at Opoa, to set up in a marae in Tahiti. Their great canoe, Pa-tarava (Extended-fort), was built for the occasion on the builders' marae, named Tahiria-manu (Fanned-by-birds). It was well laced and ornamented with sacred sennit, so that it was said to be possessed with great power or magnetism (mana). The visitors also brought becoming gifts to present to the Tahitian gods and chiefs, such as poe-mata-uiui (pearls), ahuara (soft, fine mats), 'oro'oro huruhuru 'otaha (bunches of man-of-war bird feathers), 'ura (parrakeet's feathers), and fau fringe.

While they were preparing to take their presents for the gods to the marae, Tûmarama (Stability-of-the-moon), of the god Tû, represented by the meho birds, or rails, the marae that faced the passage of Pape'ete by which they had entered, the warriors of Te-oropa'a perceived the canoe moored out in the shoal and were about to seize it when the sister of the priest loudly invoked the aid of 'Oro to deliver them out of the warriors' hands. In an instant the canoe, with its owners, was caught up into the clouds and borne speedily by a strong wind to Opoa, where they told their story to the king, who went with them to the great marae and presented the offerings from the canoe to 'Oro in gratitude for the god's act of deliverance.

Finally 'Oro's zealots set out for Tahiti, and they went to Tai'arapu, the head of the fish, and landed at the point called Ta'ata-tua (Man-of-the-sea) at the marae called Te-ahu-o-rua-tama (Wall-of-the-source-of-fair-child), chief of the fire gods, and there they presented their gifts and religious homage. They were well received with all due ceremonies, and allowed to set up their cornerstone, called Tupu-i-mata-roa (Growth-of-long-face), for a home in the east for 'Oro. As all Tahiti and Mo'orea regarded this as a natural sequence in the history of Tahiti, the fish, they peacefully united in building a great national marae for 'Oro, which they named Taputapu-atea. The incarnation of the god in it was a small log of toa or aito (also meaning warrior), about six feet long, which was decked in sennit and red, yellow, and black feathers to give it all the original attributes of the terrible god. Soon, during the usual solemnities of the occasion, came a strong southwesterly wind, on which 'Oro rode with flashes of lightning. He entered into the image, which was then called 'Oro-rahi-to'o-toa (Great-'Oro-of-the-toaimage), and thus his hold on Tahiti commenced. (1928:129-130) 
'Oro acquired spouses and reproduced offspring of his own. According to the Henry version the first of his spouses was Tufeufeumaitera'i, who was "conjured" ( $r a h u$ ) into being by Ta'aroa, and from this union came three goddesses: To'imata, 'Aitupuai, and Mahufaturau. "These goddesses, followed by a host of other goddesses, always accompanied 'Oro and his host of gods to battle, whither they never failed to go" (1928:375). Then followed the birth of Hoa-tapu Ho'ata-meamea Ho'ata-tino rau, "one god with three names, the last child and only son born of the wife Tu-feufeu-mai-te-ra' $i$ " (Henry 1928:376).

Mare's version differs from the above: “'Oro took Hotupapa to wife and by her produced two sons, Hoatapuiterai and Teriitapotu, and three daughters, Te toimata a tuanuio oro, Vaeaiteuruoro, and Muri hea te pairu" (Roussier 1928:192).

The only obvious correspondences between these two versions consist of Hoatapu, a son, and To'imata, a daughter-both of whom appeared elsewhere as deities in accounts of Maohi pantheons. To'imata, especially, figured in beliefs and rituals concerned with warfare, ${ }^{6}$ and she was described by Henry as having been the recipient of human offerings: "Only male sacrifices, human or otherwise, were supposed to be acceptable to the gods, the sole exceptions to the rule being a woman or girl who died from the black art or was slain in war time, when she was offered to Toi-mata, daughter of 'Oro”' (1928:198).

To 'Oro's second "marriage" was ascribed much greater cosmogonic importance, serving as it did to inaugurate the Ariois. The earliest printed version of this mythical episode appears in the first edition of Ellis' Polynesian Researches, published in 1829. Ellis characterized this version as "one of the most regular accounts of the origin of the Arioi institution," and attributed the information on which he based his rendition to the Reverend Barff, of Huahine, who received it from Auna and Mahine (the latter a chief of Huahine):

Oro, the son of Taaroa, desired a wife from the daughters of Taata, the first man; he sent two of his brothers, Tufarapainuu and Tufarapairai, to seek among the daughters of man a suitable companion for him; they searched through the whole of the islands, from Tahiti to Borabora, but saw no one that they supposed fit to become the wife of Oro, till they came to Borabora. Here, residing near the foot of Mouatahuhuura, red-ridged mountain, they saw Vairaumati. When they beheld her, they said one to the other, This is the excellent woman for our brother. Returning to the skies, they hastened to Oro, and informed him of their success; told him they had found among the daughters of man a wife for him, described the place of her abode, and represented her as a vahine purotu aiai, a female possessed of every charm. The god fixed the rainbow in the heavens, one end of it resting in the valley at the foot of the red-ridged mountain, the other penetrating the skies, and thus formed his pathway to the earth.

When he emerged from the vapour which, like a cloud, had encircled the 
rainbow, he discovered the dwelling of Vairaumati, the fair mistress of the cottage, who became his wife. Every evening he descended on the rainbow, and returned by the same pathway on the following morning to the heavenly regions. His wife bore a son, whom he called Hoa-tabu-i-te-rai, friend, sacred to the heavens. This son became a powerful ruler among men.

The absence of Oro from his celestial companions, during the frequent visits he made to the cottage of Vairaumati in the valley of Borabora, induced two of his younger brothers, Orotetefa and Urutetefa, to leave their abode in the skies, and commence a search after him. Descending by the rainbow in the position in which he had placed it, they alighted on the world near the base of the red-ridged mountain, and soon perceived their brother and his wife in their terrestrial habitation. Ashamed to offer their salutations to him and his bride without a present, one of them was transformed on the spot into a pig, and a bunch of uru, or red feathers. These acceptable presents the other offered to the inmates of the dwelling, as a gift of congratulation. Oro and his wife expressed their satisfaction at the present; the pig and the feathers remained the same, but the brother of the god assumed his original form.

Such a mark of attention, on such an occasion, was considered by Oro to require some expression of his commendation. He accordingly made them gods, and constituted them Areois, saying, Ei Areoi orua i ie ao nei, ia noaa ta orua tuhaa: Be you two Areois in this world, that you may love your portion (in the government, \&c.) In the commemoration of this ludicrous fable of the pig and the feathers, the Areois, in all the taupiti, and public festivals, carried a young pig to the temple\& strangled it, bound it in the ahu haio, (a loose open kind of cloth,) and placed it on the altar. They also offered the red feathers, which they called the uru maru no te Areoi; the shadowy uru of the Areoi, or the red feathers of the party of the Areoi.

It has been already stated that the brothers, who were made gods and kings of the Areois, lived in celibacy; consequently they had no descendants. On this account, although they did not enjoin celibacy upon their devotees, they prohibited their having any offspring. Hence, one of the standing regulations of this institution was, the murder of their children. The first company, the legend states, were nominated, according to Oro's direction, by Urutetefa and Orotetefa, and comprised the following individuals: Huatua, of Tahiti; Tauraatua, of Moorea, or Eimeo; Temaiatea, of Sir Charles Sander's Island; Tetoa and Atae, of Huahine; Taramanini and Airipa, of Raiatea; Mutahaa, of Tahaa; Bunaruu, of Borabora; and Marore, of Maurua. These individuals, selected from the different islands, constituted the first Areoi society. To them, also, the gods whom Oro had placed over them delegated authority, and gave permission to admit to their order all such as were desirous to unite with them, and consented to murder their infants.* These were always the names of the principal Areois in each of the islands; and were borne by them in the several islands at the time of their renouncing idolatry; when the Areois name, and Areois customs, were simultaneously discontinued.

*The above is one of the most regular accounts of the origin of the Areois institution, extant among the people. Mr. Barff, to whom I am indebted for it, received it from Auna, and Mahine the king of Huahine. (1829:I, 312-315)

Ellis has this to say about Orotetefa and his brother:

According to the traditions of the people, Taaroa created, and, by means of Hina, brought forth, when full-grown, Orotetefa and Urutetefa. They were not his sons; 
oriori is the term employed by the people, which seems to mean create. They were called the brothers of Oro, and were numbered among the inferior divinities. They remained in a state of celibacy; and hence the devotees were required to destroy their offspring. (p. 312)

The next extensive version of this episode to appear in print was Moerenhout's, in 1837; from other evidence it seems likely that it derived from informants living mainly on Tahiti:

'Oro, son of Ta'aroa the Creator, and next to the latter the most important of all gods, ${ }^{[7]}$ wishing to choose a mate from among mortals, descended from Te Ra'i tu i tai, the highest level of Heaven, onto Mount Paia of Porapora, where dwelt his sisters, Te Uri and Oaaoa. ${ }^{[8]}$ 'Oro explained his mission to his sisters and asked them to accompany him to aid in his search for a mate worthy of himself. They descended by way of a rainbow mist placed there by the god, with one end resting upon the mountain summit and the other upon the ground, and disguised as mortals-'Oro himself in the form of a young warrior, his two sisters as maidens. They went from one island to another, putting on the kind of festival called opera, in which all women customarily took part; but it was all in vain. Among all the daughters of Man not one was seen that pleased the God. Becoming weary of the fruitlessness of their search the divinities were on the point of returning to their celestial home when finally at Vaitape on Porapora they came upon a maiden of outstanding beauty bathing in the small lake of Ovai aia. So charmed was 'Oro by the sight of her that he sent his sisters to visit her, while he himself returned to the summit of Mount Paia.

On approaching her the goddesses greeted her and praised her beauty, telling her that they were come from Avanau district of Porapora, and that their brother was desirous of mating with her. Vairaumati-for such was her name-looked them over carefully and replied, "You are not of Avanau, but it doesn't matter. If your brother is an ari'i, and young and handsome, he may come here and Vairaumati will mate with him."

Te Uri and Ha'oa'oa ascended to the summit of Mount Paia and reported to their brother the results of their mission, on hearing which Oro replaced the rainbow and descended by way of it to Vaitape. There he was received by his loved one, who had prepared for the occasion a table loaded with fruits and a bed made of fine tapa and mats.

Thereafter, delighted with his new wife, 'Oro spent the nights with her and the days on his mountain-top, travelling between there and Vairaumati by means of the rainbow. When his absence from his celestial home lengthened, his brothers-Orotetefa and Uretetefa-started out in search of him, finally finding him on Porapora, seated in the shade of a sacred tree with his loved one. So struck were they by the beauty of the maiden that they were ashamed to approach the couple emptyhanded. Whereupon one of them transformed himself into a sow and the other into some red feathers. Then, separating their true selves from these objects and changing back into their own forms, they presented the objects to the couple. That very night the sow produced a litter of seven, which were distributed as follows:

pua'a te vaa pou

a pig to sacrifice to gods

pua'a maro ura te Arioi

a pig for maro ura Ariois 
pua'a te haere roa

a pig for visitors or companions [?]

pua'a fature no te vahine

a pig for festivals in honor of women [?]

te vai pua'a

two pigs for breeding

tei te fatu pua'a aa iho

a pig for the household, for eating.

In due time Vairaumati knew herself to be pregnant and so informed 'Oro. Upon learning this 'Oro immediately carried the maro ura pig to Ra'iatea, to the great marae of Vapoa [Opoa?]. There he found a man named Mahi, to whom he handed over the pig, saying: "Take over this pig and look out for it. It is a pig of the Arioi, a sacred (ra'a) pig, a pig for maro ura Arioi. I hereby make you an Arioi among mortals. I, having become a father, can no longer be an Arioi."

Mahi then called upon the chief of Ra'iatea and told him what had come to pass; and not being able to tend these sacred objects himself, unless he were a friend of a chief, he proposed to the other that they exchange names. The latter accepted, and they adopted in common the name Taramanini.

(At this point Moerenhout observed that there were several versions of this myth, but noted that all of them recognize Mahi as having been the founder of the Arioi sect, or the "mysteries of 'Oro.")

It is also said in this version of the myth that, upon returning to Vairaumati, 'Oro informed her that she would eventually give birth to a son, whose name would be Hoataputera'i (Sacred-friend-of-heaven), but that with respect to himself, 'Oro, the time had come for him to leave her. At this he transformed himself into an immense pillar of fire which rose majestically into the air over Pirepire, Porapora's highest mountain, and while his mate wept and the populace watched with amazement he disappeared from view. Finally, it is said that his son, Hoatapu, eventually became a great chief who did much good for his people and delivered them from many difficulties, with the help of his father and other gods; and also that after death he joined his father in Teraituitai, to which place 'Oro also elevated Vairaumati, who took her place among the goddesses. (Moerenhout 1837:I, 485-489)

The next published version of this mythical episode was Henry's; she described this version as having been received by Orsmond in 1840, from a Tahitian source:

'Oro and his wife, Tu-feufeu-mai-i-te-ra'i (Stand-to-unfold-the-sky), and their three daughters, To'i-mata (Axe-with-eyes), Ai-tupuai (Eater-of-summit), and Mahu-fatu-rau (Fog-of-many owners), and their only son, Hoa-tapu (Swornfriend), dwelt with many gods in the firmament, where 'Oro reigned as king and from whence he one day ungraciously pushed his wife down to the earth, where she became a great heap of sand and so remained ever afterwards. 
'Oro became lonely without his wife; and his sisters, Te-uri (Darkness) and Haoaoa (Grossness), compassionating him, said they would go down to the earth to find him a new spouse. So they descended to Tahiti clad in ti leaves, shredded into a fine plumelike fringe, each carrying in her hand a reed as a wand. Their lofty bearing instilled awe into the hearts of earthly beings, who soon obeyed their bidding to assemble all the beautiful women of the land before them that they might choose one as a wife for the god.

But all the women of Tahiti were too coarse and common for his divinity, and the sisters passed on to Huahine, then to Ra'iatea, Oro's native land, and on to Tahaa, only to meet with the same result as in Tahiti. At last, despairingly, they went to Porapora, and there were told of a royal maiden of surpassing beauty, named Vai-rau-mati (Water-of-Ficus-tinctoria). As she was too dainty to be brought out before them, they had to go to see her. They went to a princely house nearVai-otaha (Water-of-man-of-war-birds), 'Oro's marae, and found the maiden in her apartment, screened off with the richest vane (mats). Enchanted were they with her beauty! Her face was as the noontide light, and the luster of her dark eyes shone forth like stars from the deep-blue sky. She kindly welcomed them, and they greeted her as their taua (bosom friend), encompassing her with flashes of lightning, which made her divine like themselves, and she bade them be seated with her on her mat.

According to the usual custom, Vai-rau-mati, addressing her visitors said, "A great errand has brought you to me, O great goddesses?"

"Yes," was the answer, "we have indeed a great errand! We have come to ask you to become the wife of our brother 'Oro, god of the firmament."

"Is he handsome?" enquired the girl.

"Yes! He is handsomer than all the sons of men and is ever youthful," they replied.

So it was arranged that this lovely maid was to become the spouse of the great god 'Oro, and the sisters returned to the sky to tell of their success and to direct their brother where to find his bride. 'Oro was highly pleased at what his sisters told him, and early the following morning he descended in a cloud by a brilliant rainbow, which was his means of transit to the earth, and it conducted him to her home, where he found the princess all that even a god could wish.

Soon afterwards, their marriage took place, the bride having many valuable gifts for the occasion, while 'Oro, who had nothing terrestrial to present, was at a loss to know what to do to save himself from ridicule on such an occasion.

Then a new thought struck him, and he went up into the sky and said to his sisters, "Where are our two lads, Uru-te-tefa (Vain-head) and Oro-te-tefa (Vainwarrior)?"

"Over yonder, cooking our food," they replied. So he called them, and with willing steps they came running into his presence, when suddenly they were transformed into two fine hogs, a boar and a sow, such as had never been seen before. They were never to be killed, and he named them both 'Oro-i-te-pua'amahui (Oro-in-the-pig-revealing-secrets). "Now," said 'Oro triumphantly, "I have gifts worthy of presenting to my wife." And he led them down by the rainbow-while his sisters wept for their two attendants, whom they had regarded as brothers-and he presented them to his wife with a bunch of red feathers, which he called Uru-maru-no-te-arioi (Shady-grove-of-the arioi). These two pigs became gods of the arioi, retaining their names Uru-tetefa and Oro-tetefa.

The following night the sow produced a litter of five fine little male pigs. The first one was the first sacred pig of the arioi, yet to be organized, and it was 
named Oro-i-te-tea-moe (Warrior-of-the-laid-down-spear); the second was sent into the sea and became a porpoise; the third was a pet for 'Oro's wife; the fourth was for sending to different lands; and fifth was sacred to the marae, marked with a ring of sacred sennit through its nose.

King Tamatoa I, as 'Oro's incarnation, was the first arioi on this earth, and he organized the first arioi society at Te-pori-a-tai (The-fullness-of-the-sea), a place near his residence at Opoa. 'Oro gave the arioi pig to King Tamatoa, as his representative in this world, and the king set in its nose to insure its life a ring of sacred sennit terminating with a tassel, and let it loose at Opoa. But the pig would not remain there, and so the king gave it in charge of a friend named Mahi (Fermented-breadfruit) to take to Tahiti, and there find a place for it. Thither Mahi went with the pig, but as it was a time of solemn restriction in the land he found no footing there and returned to Ra'iatea for a short season. He made the trip to Tahiti three times before he was hospitably received and found a home for the pig. The third time they landed at Afa'ahiti, bordering upon the Isthmus of Taravao, and Mahi was compassionated by a young woman named Taurua (Venus), who, seeing he was a friendless stranger, called the attention of her father, Hua-tua (Ocean-sprays), to him, and he was soon cordially welcomed to their home. Mahi told his errand, and Hua-tua received the wonderful pig, dedicated to Oro-i-te-tea-moa, after whom it was named, and set it free in the thickets of Taravao.

The two men became taua, in honor of which a feast was prepared. Great hogs were baked whole and presented to Mahi, who was highly gratified at his reception. In the name of the god he was serving, he divided one pig into four equal parts; one quarter he sent to Maro-'ura (Red-girdle) of Hitia'a, one he sent to Mataa (Cheerfulness) of Papara, one to Taura'a-atua (Alighting-of-the-gods) of Papetoai in Mo'orea, and the fourth and last one he kept for Atea of Huahine, all of whom were great personages. Soon afterwards these men became chief comedians of the arioi society in their districts and aided Tamatoa in electing those of all the other islands in the group. The names of the chiefs descended to their successors in their respective districts until the arioi system ended.

According to the native custom, Mahi required presents to give as a requital of friendship to his new taua, and so he returned home to procure them. After arriving at Ra'iatea, and telling the king and Atea what he had done in Tahiti, he went to an islet off the coast of Taha'a, called Motu-torea (Islet-of-the-whistlingplover) and there raised pigs and made rolls of cloth and mats to take to his friend in Tahiti. But a thought occurred to him that he needed a more influential friend than Hua-tua to enable him to propagate the arioi society, and so he took the presents to his King Tamatoa and asked him to invest him with regal authority, that he might represent him worthily in Tahiti. To this the king readily agreed. He took him to Opoa, and there placed upon him a rich cape from the temple of Oro; he gave him a royal canoe named Hotu (Sea-swell), which they loaded with rolls of fine cloth and mats, sennit, coconut shell cups, and water bottles, clothbeating mallets, capes, waist cloths, girdles, and feather ornaments for the head and neck. And they exchanged names, Mahi being called Tamatoa and the king naming himself Mahi.

Thus equipped, King Tamatoa's proxy went to Tahiti, attended by an arioi chief named Te-ra-maniou (The-declining-sun), of Ra'iatea, and a staff of arioi. They landed at Afa'ahiti and presented the gifts to the good friend Hua-tua (Ocean-spray), whom they created chief arioi of Afaa'hiti and who joined them in their errand. Then they all went from district to district, around Tahiti 
and Mo'orea, their canoe gaily decorated with long pennants of many colors (matiti) and small circular mat sails (mou, meaning tops) attached to the tops of the masts, which were tipped with spreading bunches of cocktail feathers (tefatefa, this being the special rigging of the arioi canoe). The sound of their drums and flutes, accompanied with dancing, attracted much attention and curiosity among the crowds of people who went to meet them. They soon gained numerous adherents and thus made general their society over Tahiti and Mo'orea. Then every district in all the islands dedicated pigs to 'Oro, sacred to their society. The great body of arioi throughout the group was called "Te-papa nui arioi" (The great rock of arioi). Only well-developed persons of comely appearance, qualified as feia purotu (handsome people), were admitted into the society, and both sexes enjoyed the same ranks and privileges. $(1928: 231-234)^{9}$

Leaving aside for the moment the more noteworthy differences among these three versions, we have basically three mythical episodes in the establishment and spread of a "new," powerful, and eventually widespread sect. In keeping with the catholicity of Maohi religious beliefs it is likely that all Maohis acknowledged the existence of 'Oro as one of the more powerful gods in their pantheon. And for many, 'Oro came to be recognized as the principal "official" tutelar of their tribal congregations. But in addition, for some Maohis, namely the Ariois, 'Oro worship became a specialized occupation, a sectarian order.

The relationship between "official," tribal-wide 'Oro-worship and Arioihood is not altogether clear. Not all leaders of 'Oro-dedicated tribes were Ariois, and not all Ariois were members of 'Oro-dedicated tribes. And although the growth and spread of Arioihood undoubtedly served to disseminate 'Oro worship in general, it is not ascertainable what role Arioihood played in the earlier diffusion of 'Oro-cultism. Legendary evidence can be interpreted either way; on the one hand there is the statement that "there have always been Ariois" (Ellis 1829:I, 312), but on the other hand the myth reproduced earlier concerning the establishment of 'Oro-worship in Tahiti-Mo'orea makes no reference to Ariois. Some writers have attempted to specify actual dates for the origin and spread of one or both of these movements, and later on I shall present these writers' arguments, for whatever they may be worth; but, in the reconstruction that I now undertake, I shall treat the movements separately, first describing the tenets and practices of 'Oro-worship in general, before outlining those associated with Arioihood in particular.

\section{'Oro Worship}

As noted earlier, 'Oro was conceived of as having been male; and in his most important human guise he was youthful, handsome, and of the ari'i class. He is represented in myth as having been sexually active, moderately prolific, and even more undependable as a spouse than was the average human male. ${ }^{10}$ But what distinguished him from most other gods 
was not so much his eagerness for warfare, perhaps his most publicized attribute, as his avidity for human lives.

'Oro became manifest to mortals in a number of forms; for example, the yellow thrush ('omana 'o-pua-fau) was ata of the god in his yellowgirdle manifestation ('Oro-i-te-maro-tea), while the green and yellow parakeet (a'a-taevao) was his ata in his red-girdle manifestation ('Oro-ite-maro-ura) (Henry 1928:384-385). More important than these however was the man-of-war bird ('otaha), which was ata of 'Oro-the-dauntlesswarrior (Oro-pa'a). In addition, 'Oro-at-war occasionally manifested himself in boars:

The boar was a shadow of 'Oro-tauà (Warrior-at-war) as the man-slaying god; it was 'Oro-pua'a-mahui ('Oro-the-pig-revealing-secrets). When a gentle, domesticated boar got possessed, it was known that 'Oro was dwelling in him; that pig could devour a man. Pointing upwards to the sky was one jaw, and pointing downwards to the earth was the other jaw, which was the sign that the mouth of 'Oro was open ready to consume the king and his clans. That pig became very fierce, a great power in itself in the land. (Henry 1928:383)

Like other deities 'Oro sometimes entered into a human's body, usually for the purpose of communicating with other humans. As we have seen, in some instances the god possessed (uruhia) some individuals sporadically and unexpectedly. In other instances individuals served as regular oracles (taura) for him, even to the point of being capable of inducing his presence when needed. And, in rare instances, 'Oro possessed some individuals on a more or less permanent basis. ${ }^{11}$ When possessed by 'Oro a taura usually wore a strip of tapa wound around one hand. According to one missionary account however the practice was peculiar to the taura Metea:

When the god ['Oro] comes to [Metea] he has his left hand always wrapped up in cloth \& so continues till the spirit or inspiration is departed. The reason he assigns for covering his hand is that the gods hand is deformed. This custom appears to be peculiar to this prophet, we never observed it in any of the others, and now whenever the prophet is seen covering his hand the people are ready to tremble thinking there is some mischief coming. (Davies, Journal, 7 October 1807, LMS Archives)

It will also be recalled that individuals possessed by this god were sought after by women for procreative purposes.

Finally, 'Oro regularly inhabited certain images, to'o, partly as vehicles for issuing instructions and prophesies but mainly for the purpose of receiving worship and of validating certain events of great social importance. During the eras under study most of these 'Oro images consisted of club-shaped pieces of ironwood (Casuarina equisetifolia: 'aito, toa) wholly or partially covered with sennit to which were attached feathers (figs. 22-1 and 22-2).

One exception was noted in a missionary journal of January 1801 : 
A large fleet of double-canoes arrived from Hapyano. One of the canoes was decorated with various apparatus of idolatry; such as the image of a bird, nearly as large as a goose, rudely formed, and covered with feathers of different colours, into which the poor natives boldly assert their god Ooro delights to enter; a small canopy, fixed over a little stool under this also they believe their god at times rests himself; the canopy is covered with feathers; a hollow cylinder, about ten feet long, and three feet round, covered with feathers, set upright on the stern of the canoe, which was very lofty-its use we know not;-and various other things. (LMS Transactions:I, 214)

'Oro images varied in length from about two to five or six feet, and to some of them were appliquéd additional strips of sennit representing anthropomorphic features. ${ }^{12}$ It may be that some 'Oro images consisted, like some $t i$ ' $i$, of anthropomorphically carved wooden figures, with a hollowed repository for storing feathers (Kooijman 1964:115), but most known specimens were of the form just described.

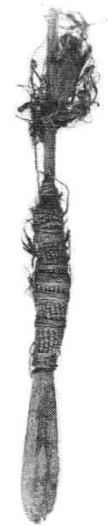

FIGURE 22-1. Sennit staff god, length $1520 \mathrm{~mm}$. British Museum.

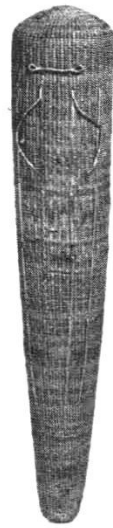

Figure 22-2. Sennit god (to $\mathrm{o} O$ ), length $640 \mathrm{~mm}$. British Museum.

To Europeans accustomed to the convention of idols and images shaped anthropomorphically, the apparent "shapelessness" of these objects of Maohi veneration occasioned some astonishment, but as frames for attaching feathers, which was perhaps their principal purpose, they served just as well as anthropomorphic figures, especially when covered with sennit, which was itself an object extensively used in religious ritual and thereby imbued with qualities of "sacredness." Also, they may not have been as "shapeless" as some writers alleged. So important were the feathers associated with 'Oro images that human sacrifices were occasionally consecrated to feathers taken from and representing the image itself: "These red feath- 
ers are as much honoured by the natives as if Oro's body-the shapeless log-was present” (Jefferson, Journal, 23 October 1804, LMS Archives).

Three reasons may be advanced for images having been made of ironwood. First, and most prosaically, objects made of this heavy and hard-grained wood were more indestructible. Second, although ironwood trees did not grow exclusively in marae precincts they were characteristic features of such places, and as such they possessed a special association with gods. And third, as I pointed out earlier, the native names for ironwood, toa and 'aito, were applied also to warriors, perhaps because the latters' better clubs and spears were made of the wood. 'Oro was above all else the most powerful god of war. This association with war has led to speculation that 'Oro images of the to' $o$ variety were in fact representations of weapons-clubs or spears.

In contrast to this last notion has been advanced the idea that 'Oro images were carved to represent a phallus-an interpretation strengthened by 'Oro's function as tutelar deity of the allegedly erotically inclined Ariois. (Kooijman 1964:122-123)

I know of no data capable of providing a wholly credible answer to questions concerning why 'Oro images were shaped as they were. Nor can I offer any documentable explanations for certain other aspects of 'Oro worship, such as the circumstance that certain kinds of bark cloth proffered to the god had to be manufactured at night (Jefferson, Journal, 24 December 1805, LMS Archives).

Museum and ethnohistorical research has turned up several images resembling those of 'Oro, including some described as "war gods," but actual images of "Oro himself seem to have been few in number. A suggestion that perhaps no more than one or two existed on each island during the eras under study is rendered plausible by accounts of the intertribal struggles which took place in Tahiti to possess one located there. An account of these struggles will be presented in volume 3 , but it will be useful to anticipate those episodes in order to list some facts and questions regarding the significance of these images.

According to the myths, Opoa was the birthplace of 'Oro and its marae complex the repository of an 'Oro image, presumably the first and principal one, which was named 'Oro-of-the-red-feather-girdle (Oro-maro-'ura) (Henry 1928:121). At the same time, the principal (or only?) 'Oro image on Porapora was "woven in the likeness of that at Opoa," but it was covered with yellow feathers instead of red (as was the girdle identified officially with Porapora's highest ranking kin-Title), and was therefore named Yellowgirdled-'Oro ('Oro-maro-te'a). One of the myths relates that after some 'Oro zealots from Opoa had gained a foothold and built a marae for their god at Tautira (on Tahiti's peninsula, and with a cornerstone from Ra'iatea's 
Taputapuatea marae) they placed in it an "incarnation" of their god, about six feet long and covered in red, yellow, and black feathers "to give it all the original attributes of the terrible god." Thereupon, "... during the usual solemnities of the occasion, came a strong southwesterly wind, on which 'Oro rode with flashes of lightning. He entered into the image, which was then called 'Oro-rahi-to'o-toa (Great-'Oro-of-the-toa-image), and thus his hold on Tahiti commenced."13

Later, this myth relates, some priests of 'Oro (inferentially, from the Tautira marae) set up in Atehuru a new marae called 'Utu-'ai-mahu-rau, and installed in it an image called 'Oro-hu'a-manu ('Oro-of-the-bird-featheredbody) which was "... woven the size of that at Opoa and covered with red, yellow, and black feathers from the image at Tautira." Then gradually "as the priests of the new order increased, new marae to 'Oro in the feather body were erected all around Tahiti, and finally [at] Pepeto'ai [Papeto'ai] in Mo'orea." (Henry 1928:130)

According to these traditions, then, there were two major offshoots of to' $o$ derived from the 'Oro image installed at Opoa: a somewhat separate yellow-feather-girdled one on Porapora, and a whole "line" of red-feathergirdled ones on Tahiti and Mo'orea. Not much is reported concerning the social functions of the Porapora one, but it is clear from historic evidence that on Tahiti-Mo'orea during the eras under study no successor to one of the higher-grade kin-Titles derived ultimately from Opoa could obtain universal recognition of his right to bear that Title until performance of an investiture ceremony involving ritual use of red feathers derived, directly or indirectly, from the 'Oro image of Opoa. The fact of there having been several 'Oro images, each with a different name, again raises the question concerning the unity versus multiplicity of 'Oro, but even this last-mentioned evidence of "lineal" continuity cannot provide a satisfactory explanation.

Turning now to marae dedicated principally to 'Oro worship, we have seen that most of them were called Taputapuatea, or Vaiotaha, or both; and that all of these incorporated stones derived from Opoa itself, or from Opoaderived marae. ${ }^{14}$ Most such marae seem at one time or another to have housed actual 'Oro images, but reliable accounts of actual events on Tahiti indicate that the island's principal image of 'Oro was moved about from one marae to another as a consequence of political change. There are also grounds for believing that any repository in which an 'Oro image happened to be (marae, ark, canoe platform) was called Taputapuatea. (Figs. 22-3 and 22-4.)

As noted elsewhere, most European observers characterized 'Oro as the most powerful god in the Maohi pantheon; this leads one to inquire into the Maohis' beliefs concerning 'Oro's relations with other gods.

Among 'Oro's close consanguines, his genitor, Ta'aroa, figured only 


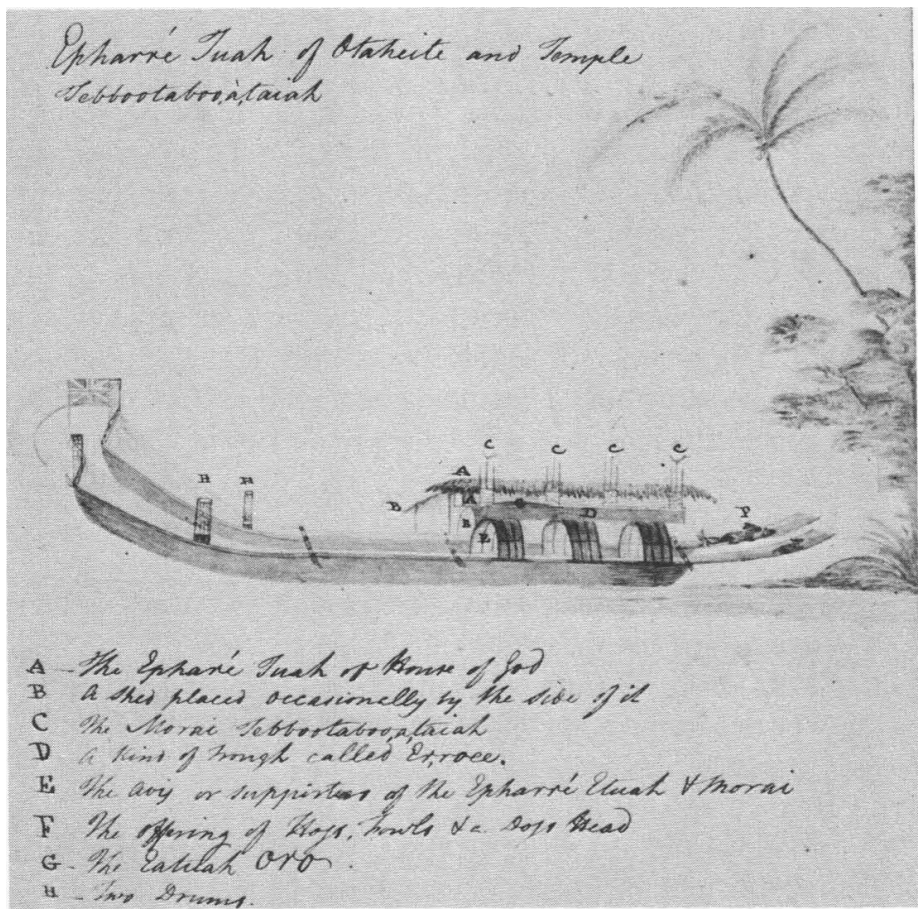

FIGURE 22-3. God house, Taputapuatea, mounted on double canoe. Sketch by W. Bligh. Mitchell Library, Sydney.

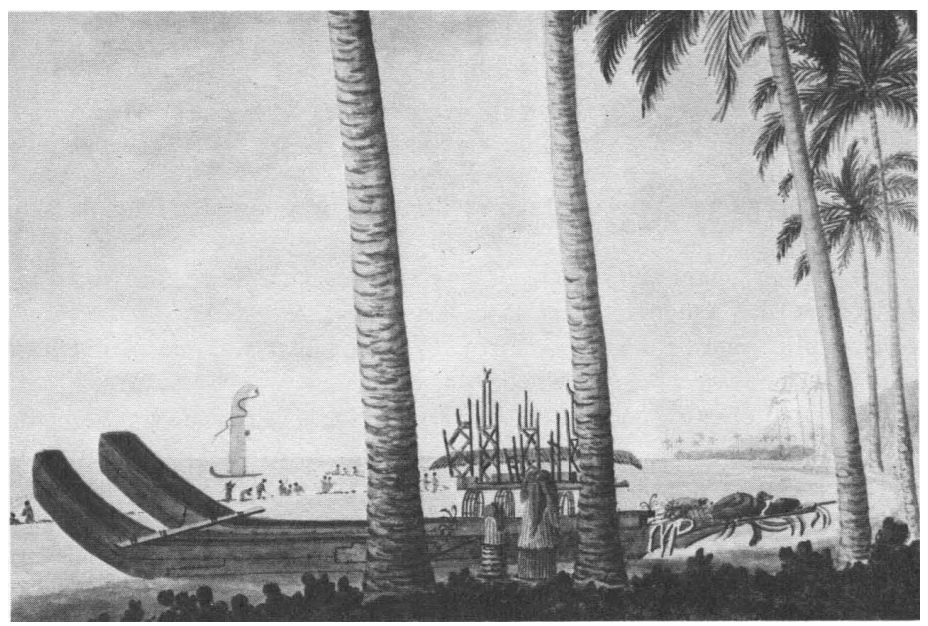

FIGURE 22-4. God house mounted on double canoe, with offerings. Watercolor by G. Tobin. Mitchell Library, Sydney. 
minimally in other myths concerning 'Oro. (As for other mythical associations between 'Oro and any of his "mothers," I know of none at all.) Of his many siblings, listed in the Roussier text, several figured in his subsequent career. For example, Tane was described as Oro's principal rival in his successful "conquest" of Tahiti and Mo'orea (Henry 1928:129); ${ }^{15}$ and on Taha'a 'Oro is said to have replaced Tane in services conducted at marae Ahuroa (see chap. 16, and de Bovis 1909:42). The principal marae on Lesser Huahine was from its beginning dedicated to 'Oro (or so one myth goes), but Greater Huahine was dedicated principally to Tane. Tu, another "brother," may also have been a rival to 'Oro, inasmuch as some tribes previously dedicated to the former seem to have changed their allegiance, but evidence is lacking on actual confrontations between the two.

Rivalry between 'Oro and Hiro, god of thieves, seems to have been almost as active as that between 'Oro and Tane. In some places, "he [Hiro] was revered even above 'Oro, to whom he proved himself superior by throwing him down and lying upon him" (Montgomery 1832:I, 187). But in the end, we are told, Hiro also lost out to 'Oro nearly everywhere. (See above and Henry 1928:131.)

'Oro's relations with his mythical sisters were of a more peaceful nature. One of these, Hinatutupo, made clothing for him; and two others, Te Uri and Ha'oa'oa, assisted him in his search for a mate. (In the Ellis version of this episode, however, these two are described as "brothers.")

In connection with the Arioi phase of 'Oro worship, the two associated spirits figuring most actively were Orotetefa and Urutetefa, variously described as 'Oro's "younger brothers," "young boys" (tamari'i), and "household servants." ${ }^{16}$ It was these who, according to most accounts, were transformed into the pigs, or pig and feathers, which served to validate, transactionally, 'Oro's marriage to Vairaumati, as consequence of which they became tutelars of the Arioi sect second in importance only to 'Oro himself.

'Oro's principal son, Toatapu, figured occasionally in 'Oro worship, and some of his daughters came to be associated, as was their father, with warfare; also, one of them, To'imata, like her father was the recipient of human offerings, but only of females, of course.

More interesting perhaps than most of these associations were the instances of syncretism, or even assimilation, that appear to have occurred. ${ }^{17}$ One such took place in 1806, after Pomare II had gained possession of the great 'Oro image held previously in Atehuru. In depositing this image in the Taputapuatea marae in Tautira he placed nearby it, but in subordinate positions, the images of five other deities, including one of Hiro, one of Tane, and one of Temeharo, who previously had been principal tutelar of the Pomare family. ${ }^{18}$ As Kooijman noted, this indicates that Temeharo had 
been able, "albeit in the shadow of Oro, to maintain his position as the tutelary god of one of the leading families of the country" (1964:116).

That 'Oro was "believed in" by all Maohis goes without saying, and for many he was the principal focus of fear and worship. ${ }^{19}$ In addition, this god had special relationships with a number of individuals, such as those "possessed" by him (from single occasions to more or less continuous durations); those serving him as his priests or other clerics; and those holding kin-Titles derived from Opoa (Ra'iatea) and Vaiotaha (Porapora) marae. It should be noted that in some instances individuals held more than one of these roles. One such was an incumbent of the Opoan kin-Title of Tamatoa, in whom were combined all three; more about this extraordinary office will be said later on. Another special category of 'Oro associates was occupied by members of the Arioi sect, which will presently be described.

Some human associations with 'Oro were inherited and others came about through "appointment" by the god himself, but other humans desiring special ties with 'Oro were required to make offerings to him, sometimes on a competitive basis, as the following excerpt from Davies' history nicely exemplifies (this particular episode occurred in 1808 during a "rebellion" by natives of Matavai against Pomare II):

Had Pomare's plan been adopted of falling upon the Matavaians immediately, it is probable the rebellion would have been soon crushed; but so infatuated were the king's people, and so bound by their superstitions that they would not stir a step beyond the usual routine of prayers, sacrifices, \&c. The priests went to their prayers, and sacrifices to engage Oro on their side, and a man was killed immediately to be a sacrifice to him, was put (in) a canoe in a haapora (basket) and sent by the way of Papara and the isthmus to Tautira. This delay afforded time for the disaffected to assemble together, and get the people of Hapaiano to join them, and also to send messengers to the Districts to the eastward. They also endeavoured to get Oro on their side, killed a man to be a sacrifice to him, and sent him to Tautira the eastern way. Each party appeared to be in earnest to get the god on their side. (Newbury 1961:117)

For the 'Oro congregation at Opoa (and possibly on Porapora as well) connections between the god and his devotees may have been so fundamental and stable that only perfunctory rites and offerings were required to maintain good relations, but elsewhere in the Society Islands 'Oro was a very jealous god, and relations with him were anything but stable. In fact, his favor (or absence of disfavor) could only be maintained through frequent offerings tendered with elaborate ritual procedure. From some accounts it would appear to have been believed that it was only, or mainly, those humans enjoying good relations with 'Oro who were guaranteed entry into paradise\& but just how widespread such a belief actually was, or indeed just how much value was placed on entering paradise, is difficult to tell. If the 
Maohis had in There may have been a time whenfact been deeply preoccupied with their fates after death, and if veneration of 'Oro were universally believed to have been a prerequisite for postmortal bliss, then one need search no further for explanations of the spread of this cult. It is my impression, however, that neither of these conditions prevailed, though I cannot document this to any satisfactory extent.

As already noted, one of the most notable features of 'Oro worship on Tahiti-Mo'orea was human sacrifice. Human offerings were proffered to Tane, To'imata, and perhaps other deities as well; but on Tahiti-Mo'orea during the eras under study, 'Oro was the recipient of most such offerings by far. ${ }^{20}$ Following is one mythical account of the origin of this custom:

Before the flood, when Maui the priest built marae and established priests in all regions, the world was luxuriant and the people were in favor with the gods, so that they had no need of human sacrifices. But there came a time when there was a great drought and excessive heat in Hava'i (Ra'iatea), so that the people exclaimed, "Ta'aroa, the Unique-foundation, whose curse is death, is angry; he is consuming us!" And the king, moved to pity for his people, told the priests to pray and present offerings to Ta'aroa that they might regain his favor and obtain rain from heaven to restore the land. The priests reflected and said, "We must have a pa'i-atua service," which was done with offerings of lean pigs, fish, and bird's feathers, having no fruit or other things to present with them. The bark of trees from which cloth was made and the leaves of Pandanus, from which mats were made, were dry and parched upon the trees. But that pa'i-atua did not produce any effect.

Then the king said, "We must humble ourselves before God; we must tremble with fear! Let us offer a man as a tapu (pledge or sacrifice) to atone for unintentional offenses and regain God's favor in this our great distress." So the priests slew a man and offered him at the shrine of Ta'aroa, and soon clouds gathered in the sky, and rain fell and restored the land to its former flourishing condition. Thus it was shown that the gods liked human flesh, which was called te avae roroa (Long-legged fish); and it remained the custom ever afterwards for the king or high priest to decide when such a sacrifice was required and for the priest to put his order into execution. But this happened very seldom until 'Oro, god of war, came into favor after the Flood, when he required many human sacrifices. (Henry 1928:196)

Later in this study I shall propose some explanations as to why gods in general, and 'Oro in particular, may have placed highest value on human offerings- "explanations," that is, in terms of other Maohi beliefs and associations. Also, I shall discuss the extent to which chiefs used human offerings-and especially offerings to 'Oro-to enforce their secular authority. In other words, here is a case par excellence wherein religious commitment and politics were mutually supportive, an ideal condition for aggrandizement by either one or both, which, as we shall see, did in fact take place. Myth aside, there is no way of reconstructing which factor was prior. By the time of the eras under study the former had become more the instrument of the latter, than vice versa. But let us return to our consideration of the cult itself. 
There may have been a time when 'Oro's part in religious ritual was in many places limited to his specific role as a god of war, or to roles shared with other deities. However, as a result of his ascendancy in Tahiti-Mo'orea during the era under study most religious rites of tribal scope witnessed by the Europeans there featured 'Oro to an almost exclusive extent, hence it is not feasible to certify any other features of ritual as having been distinctive of 'Oro worship per se.

In view of the "erotic" character of some Arioi activities (see below) a case might be made for characterizing 'Oro worship in general in such terms, and this is strengthened by such reports as the following:

This forenoon, a strange heathish ceremony was performed on the beach. Their great god Oro was laid upon a long stool, covered with cloth, and the king with several of the Priests were sitting by, praying or chanting something to Oro, which we could not understand. They seemed to keep time with their drums, and conch shells. The natives stood, so as to form a circle round the idol, to which several of them were exposing themselves in the most shameful manner, and every now and then calling out "Maeva arii." This continued for several hours, during which a native, who pretended to be inspired by Oro, was seen, with the most strained distortions of countenance, and limbs, giving them directions for their future proceedings. (Newbury 1961:45)

There is no way of knowing with any certainty whether such actions were distinctive of 'Oro worship in particular. Most of the larger ceremonies witnessed and described by Europeans were in fact focused upon 'Oro, and with few exceptions data recorded in interviews, usually conducted by missionaries using Christianized informants, were likely as not to have been bowdlerized in the process.

\section{Cult of 'Oro}

An account obtained by Henry and identified by her as having originated from an "old scholar," purports to describe, among other things, certain periodic meetings held at Opoa during pagan times, and attended by delegations from islands constituting a Friendly Alliance (Fa'atau Aroha), mainly for the purpose of rendering respect to 'Oro on his home soil. The assertion that delegations came not only from all islands in the Society Archipelago but from places as far away as Rotuma, the Australs, and New Zealand should stretch beyond breaking point the credibility of even the most uncritical romanticizer of Polynesian history. Nevertheless, I quote from part of it not as "history" but as evidence of the way some Maohis conceptualized the influence of the 'Oro cult and the mechanics of 'Oro worship. The so-called Friendly Alliance encompassed in these legendary events was described as having been formed by a Rotuman chief, Te Fatu, and his son (by a Poraporan wife), both of whom had traveled widely, "creating friendly feelings": 
These allied island kingdoms formed a convention for their priests, scholars, and warriors to meet periodically at Opoa for great religious observances and international deliberations. The appointed time was exactly reckoned by numbering the year and naming the season, the lunar month, and the day of the month. Te-ao-uri chose a primate, called $a^{\prime} o$ (counsellor) or $t i^{\prime} a$ (intercessor), whom they named Pa'oa-uri (Dark-Turbo); and Te-ao-tea (Light-land) chose their primate, whom they named Pa'oa-tea (Light-Turbo). They were appointed guardians of the alliance, called Tia'i-hau-atea (Keepers-of-expanded-govemment), at Opoa, where they dwelt as guests of the royal family. Then the name of the marae became Tapu-tapu-atea (Sacrifices-from-abroad).

So it became the custom from a remote time until about the year 1350 (according to the calculations of S. Percy Smith), for these groups to send representatives with offerings to 'Oro in great double canoes, distinguished as te-va'a-roa-o-te-mata'i (the-long-canoes-in-the-wind), from which streamed long pennants of their respective colors, dark and light. Each had one or two great deep-toned drums, called ta'i-moana (sounding-at-sea), and a great conch-shell trumpet, called pu-ta'i-i-te-aeha (trumpet sounding over the sea from horizon to horizon), with which they kept track of each other at sea and signalled, and when approaching the sacred goal triumphantly announced themselves.

The time of such a gathering was one of awful solemnity to those on land and sea. The old and infirm, and women and children, with their domestic animals, retired to places far inland prepared for them; all was still along the shore, even the sea and elements, which, tradition states, were hushed in unison for the festivity of the gods.

Upon approaching the sacred passage of Te-ava-moa, just at daybreak, the canoes united in procession, and out from the horizon, as if by magic, they came in double file, each representing a separate kingdom. To the north were those of Te-aotea, to the south those of Te-ao-uri, approaching side by side, the measured strokes of the paddles harmonizing with the sound of the drum and occasional blasts of the trumpet. In grand array appeared the numerous voyagers of high degree according to their different ranks, all unarmed and unaccompanied by women or children.

Across the bows connecting each double canoe was a floor, covering the chambers containing idols, drums, trumpet shells, and other treasures for the gods and people of Ra'iatea; and upon the floor were placed in a row sacrifices from abroad, which consisted of human victims brought for that purpose and just slain, and great fishes newly caught from fishing grounds of the neighboring islands. There were placed upon the floor, parallel with the canoe, alternately a man and a cavalli fish, a man and a shark, a man and a turtle, and finally a man closed in the line. Behind this grim spectacle stood two or three priests in sacerdotal attire, which consisted of a plain loin girdle, a shoulder cape reaching down to the waist and tipped with fringe, wide or narrow according to their grades, and a circular cap fitting closely to the head-all made of finely braided purau bark bleached white. Seated at the paddles were the navigators and warrior chiefs in gay girdles and capes of tapa and helmets of various shapes, and wise men in plain girdles, capes, and turbans of brown or white tapa.

As this terribly earnest procession arrived, the canoes were quietly drawn up along the shore, and the guests were met at the receiving marae by an imposing procession of the dignitaries and warriors of the land grandly attired, and also unarmed, headed by the king, the two primates, Paoa-uri and Paoa-tea, and the priests of the realm, who greeted them in low, solemn tones. Then everybody alike set to work silently disposing of the sacrifices just arrived, combined 
with others of the same mixed kind prepared by the inhabitants of the land. They strung them through the heads with sennit, an act called tu'i-aha, and then suspended them upon the boughs of the trees of the seaside and inwards, the fish diversifying the ghastly spectacle of the human bodies, a decoration called $\mathrm{ra}^{\prime} a$ nu'u a 'Oro-mata-'oa (sacredness of the host of Warrior-of-long-face).

After this the priests of 'Oro chanted:

A 'ai ra i te ia vavae roroa na 'oe, e ta'u ari'i, e 'Oro-mata-'oa! A 'ai i te i'a o te tai na 'oe, e ta'u ari'i, e 'Oro-tauà! Manava 'outou e te nu'u atua, i te tairurura'a mai ia 'Oronei i to'na 'utuafare, ei 'utuafare no te mau atua ato'a. Maeva te atua!
Now eat of thy long-legged fish, 'Oro-mata'oa! O my king. Eat of thy fish of the sea, my king, 'Oro-tauà (Fighting-warrior); Welcome to you, O host of gods, in coming here to 'Oro in his home; the home of all the gods. Hail to the gods!

Upon the road that led up to the inner marae were then laid as rollers, called $r a^{\prime} o$, the bodies of slain men, and over them were drawn the canoes still containing idols and precious things, all present deeming it an honor to aid in the arduous work. Soon the canoes were systematically drawn up beneath the spreading trees, extending from shore to shore of the two bays, those of Te-aotea keeping northwards, and the others southwards of the point.

While the mystic rites were being performed that day by the priests at the marae at Opoa, no fire was kindled and no food was eaten. When all those who were not of the clergy had retired to the fare-'opu-nui (house-of-august-stomachs) and to the fare-tara-'toa (house-of-all-wisdom), the priests from abroad carefully took their idols, closely covered in choice tapa and gay feathers, with offerings for 'Oro in his home, and accompanied the priests of the land, also carrying gifts, up into the marae. The presiding high priest, the primates, and other high priests entered the inner sanctum; the greater body of priests took places according to their respective ranks upon the walls and outer borders of the marae. Then was performed the most sacred of all their sacerdotal rites, the pai-atua (assembly-of-gods), when it would have meant death for any of the laity to have approached or looked on.

After this exchange of civilities of the gods, the idols were again carefully covered and replaced in their respective chambers, the image of 'Oro being returned to the fare-ia-manaha (house-of-sacred-treasures), and then mortal beings could breathe freely at Taputapu-atea.

The clergy finally went into the front courtyard of the marae, where before daylight had been laid out upon the numerous altars the best food that land and sea could produce, and invoking all the gods visiting to partake of 'Oro's hospitality, they partook of the sacred repast with the utmost reverence and retired to join the other devotees, who in the same way broke their fast on sumptuous fare with their hosts, the opu-nui, outside of the sacred grounds. Then nightfall came and shrouded in darkness the scene, still terrible with the suspended and prostrate bodies of the dead, which were intended to be pleasing to the gods.

Early the following day, the "long-legged fish" of 'Oro, but not the sea fishes, were taken down and buried with the mutilated bodies that had served as rollers for the canoes; they were placed in sitting postures in their graves, beneath the trees, and were supposed to render more sacred the home of 'Oro. This ceremony was called ha'apou (getting down). The relatives of such victims were not allowed to reclaim their dead for home burial or to indulge in grief for them, as it was believed that such demonstrations would incur the great displeasure of 'Oro and bring down consuming vengeance upon them and all theirs. Thus were painfully marked the periods of religious and social gathering between those widespread insulars. 
For some days the devotees remained upon the sacred grounds, acquiring and exchanging knowledge at the fare-tara-'to' $a$ (house-of-all-wisdom), while observing the utmost decorum and retiring outside the marae grounds to eat their meals. Then they withdrew to the settlement of Opoa to enjoy respite and public feasting, giving and receiving presents. The people who had fled to the woods also returned home; and the visitors were hospitably entertained until they wished to take their departure, when sometimes they took with them from Ra'iatea some of their kinsolk of either sex who wished to accompany them, there being no restrictions observed in going away. (Henry 1928:123-126)

(The Alliance broke up, according to the legend, as the result of a quarrel between chiefs.)

A particularly noteworthy aspect of this legendary account is not so much the focus upon 'Oro, but the absence of any explanation of that focus. One interpretation might be that personal commitment to 'Oro was strong and widespread enough to move his devotees to meet together for joint worship regardless of tribal boundaries. A second might be that 'Oro's ascendancy was so unchallenged and so nearly universal that any intertribal convocation, for whatever purpose, would quite naturally have taken place at this god's principal marae. And a third might be that the social eminence of Opoa's hui ari'i was such as to constitute them (and incidental thereto, their tutelar god) the hosts to intertribal assemblies of any kind. If it is not too implausible to impute motives to legendary (and probably fictitious) personages, I suggest that those behind the Friendly Alliance meetings would have been a combination of my second and third "interpretations." That is to say, powerful as was the hold over men's minds that 'Oro may have exercised, I cannot imagine that Maohi chiefs were so preoccupied with matters of religion per se as to ignore more practical political considerations.

We are dependent upon myth for clues concerning the motives and processes connected with earlier diffusion of 'Oro worship from Ra'iatea to Tahiti-Mo'orea, but we have many more or less reliable accounts, both eyewitness and hearsay, about the last, and perhaps greatest, efflorescence of this cult. (Details of these events will be given in volume 3, for they constitute a dominant aspect of political history throughout the period under study.)

I am struck, first of all, by the dominance gained by the cult of 'Oro in Tahiti-Mo'orea in what seems to have been a fairly short time. Other deities were still proffered offerings; yet in most eyewitness accounts of the period 'Oro was not just the "war god," or just "the most powerful god," but the God (Te Atua).

Second, this trend toward monolatry seems to have been paralleled by one toward mono-imagery; there may have been in existence several distinct to' $o$ of 'Oro, but, in Tahiti-Mo'orea, at least, one of these so outweighed the others in importance that wars were fought to obtain or maintain posses- 
sion of it. In this connection, while offerings appear to have been directed to 'Oro from several marae, including especially those dedicated principally to him, those made directly in the presence of his principal to' $o$ were apparently considered most efficacious by far.

Third, while I recognize the hazards of imputing motives to individuals for acting as they did so long ago, it nevertheless appears that their main reasons for attempting to obtain or maintain possession of 'Oro's principal image were political. On the one hand they wished to secure the god's exclusive patronage in fighting wars; on the other hand they required the physical presence of the image to validate certain Opoan-derived kin-congregation Titles-that is, those high-ranking enough to legitimatize and sanctify coercive power, however acquired. (This latter reason worked in two opposite ways: some individuals sought to possess the image in order to legitimatize their own authority, while others, without themselves having pretensions to high authority, sought to possess the image in order to frustrate their rivals' pretensions.)

Finally, the ascendancy of the cult in general, and its focus upon a single image, is further exemplified in sacrificial procedures. During the period of the cult's efflorescence, wherever human offerings to 'Oro may have originated they were forwarded to the marae then tenanted by the god's principal image for ritual oblation and ultimate disposal-and this despite any political coolness that may have obtained between the chiefly proprietors of the respective marae.

\section{ARIOI}

Arioi was the name applied by the Maohis to specially selected and ceremonially initiated individuals who devoted themselves in large measure to activities connected with 'Oro worship. Such individuals thus constituted a sect, or a number of associated sects, within the larger cult of 'Oro. ${ }^{21} \mathrm{Be}$ cause of the inadequacies of the sources, the relationships between roles in these two kinds of units cannot be made altogether clear, but some things about them will emerge in the description that follows.

Needless to say, recorded characterizations of this sect, or sects, vary with the understandings and biases of the observers. G. Forster described them as a society of warriors (1777:II, 128ff.); Cook and Anderson, as affluent young male libertines "of the better sort," and likened them to freemasons (Beaglehole 1961:415; Cook 1784:157); Morrison, as a "set of young Men of Wild, Amorous \& Volatile dispositions who from their Infancy devote the youthful part of their lives to Roving, Pleasure \& Debauchery" (1935:234); and Ellis, as "a sort of strolling players" (1829:I, 315). Later writers, drawing on hearsay rather than actual observation, also differed in their characterizations: Orsmond called them "Players 
... the most obsessed and wicked creatures conceivable" (Orsmond: Arioi); Henry, "a society of comedians" (1928:230); Tyerman and Bennet, "human harpies ... in whose character and habits all that is most loathsome-earthly, sensual, devilish-was combined" (Montgomery 1832:I, 186); de Bovis, "a non-political pépinière [nursery, training ground] of warriors" (1909:37); and Moerenhout, "a society concerned with propagation of the cult mysteries of 'Oro" (1837:I, 484). And finally, a century and more later, scholars continued to differ somewhat in their emphasis on the distinctive features of this institution: Williamson called it "an organization of professional entertainers" (1939:113); Handy, a sect of sacred dancers consecrated to the cult of fertility (1930:61); and Buck, an actors' guild organized to win converts to 'Oro (Mühlmann 1955:65). ${ }^{22} \mathrm{My}$ own interpretations of the activities of the Ariois will be given later on, but first I must describe the activities of the sect members themselves.

How many Ariois there were at any one time is of course impossible to reconstruct. Mühlmann asserted that they constituted about one-fifth of the total population (1955:28), but he cited no evidence for his estimate. About all that one can say is that they were a numerous band: their numbers during the early 1770 s probably reached into the thousands, according to statements by the Forsters and by Cook. Most Ariois were males, as the early observers recorded, but the sect also included some females; Tyerman and Bennet put the ratio at about five to one (Montgomery 1832:I, 239), which is not out of line with other evidence.

Most earlier writers identified the Ariois with the upper-class strata of society, and G. Forster, in describing an expedition of Ariois from Huahine to Ra'iatea, wrote that all of its members were "persons of some consequence, and of the race of chiefs" (1777:II, 128). Most later writers, however, agreed that among Ariois were persons from all classes; the reason for the earlier writers' opinions could perhaps have been that all Ariois received privileged treatment, on some occasions at least.

Some middle-aged and even elderly persons are reported as having belonged to the sect, but most of its members were handsome young men and comely young women.

As for the organization of this category of persons called Ariois, with some exceptions there appears to have been many local "lodges" of the sect, but these were all linked together, on some occasions and in certain respects, into a larger unity.

And finally, to complete this epitome, the overt activities of Ariois consisted mainly in traveling about from place to place (including island to island), performing ceremonies and entertainments in exchange for lavish hospitality and within the context, largely, of 'Oro worship. 


\section{Activities}

Persons who were Ariois functioned mainly as such on their organized tours. The fullest description we possess of such tours is Henry's, which consists largely of an embellished translation of texts collected by Orsmond:

It took many days for the arioi to prepare for their trips among the districts, as they required the best of cloth mats, ornaments, and food to maintain their prestige among the people. When all was ready, their leaders took strips of fa'aio cloth, or pure white cloth, and an arioi pig to the marae of 'Oro, and tying the strips upon the unu (carved ornaments) of the marae, and upon the ti plants before the marae, the chief arioi invoked the gods, saying:

Ei onei 'oe, e te atua, e 'ite mai ia matou. Teie te pua'a na 'oe; teie te 'ahu taviriviri na 'oe, te 'ahu no te oroa no te mareva, no te aha tatai; ta 'oe teie.

E aratai 'oe ia matou e i te fenua; homai te tahi mata'i na matou, ei ahi na muri, ia tere i te hinu ma te ro'i. Fano te aha tatai nei, e te atua, e i te ava o te fenua e haere hia nei. Eiaha matou ia pae e atu i te moana e i te fenua; e 'aroha mai i to maru.

Eiaha 'oe e fa'arue mai ia matou; eiaha to matou ia pee hia i te ro'o 'ino, e ua pohe ia mareva! E tatai tau aha ei te ava i te ho'i ra'a mai i te fenua nei.
Remain here, O god, who seest us. Here is a pig for thee; here are strips of cloth for thee; cloth for the ordinance of sailing away for prayer to secure safety at sea; these are for thee.

Lead thou us on to land; give us a breeze, to encompass us from behind, that we may sail as smoothly as upon a bed. Let this prayer safely take us, O god, even into the harbor of the land to which we are going. Let us not beat up to other seas or lands; have pity upon thy shadows.

Forsake us not; let us not be overtaken with evil tidings that those sailing are lost! Let this prayer to thee secure our safety to the harbor even in returning to land. ${ }^{[23]}$

Then they took a sacred marae stone and some 'ura feather amulets and placed them in the canoe of the chief arioi upon a small altar, which sufficed for the devotions of all the flotilla. In each canoe was placed a platform upon which the leaders sat or the dancers performed as they approached the shores in their travels. Their canoes were double or single, as they chose to have them. The arioi named their canoes mareva (flying) or au-ono (swimming-in-company).

They were frivolous people and did not commit the sacrilege of having a priest with them in their excursions of pleasure, but a member of their society, anointed with oil highly perfumed and decked in gay wreaths and garlands, represented the god of Paradise, Roma-tane, whose name he bore prefixed with the article te (the) Te-roma-tane. Near the arioi house he had a little marae about six feet long, made of stone, and complete in structure and appendages, in which was placed an image of the god. At this shrine he invoked the presence of Romatane, Hoa-tapu ('Oro's son), and Uru-tatefa and Oro-tetefa (the two lads that had been turned into arioi swine) to accompany the arioi in their expedition and to aid them in their performances. This completed their preparations, and then they took their departure. ${ }^{[24]}$

On arriving at their destination, amid merrymaking on their canoes and applauding from the people in crowds along the shore, they were received by the local arioi and made to feel at home in the arioi house of the district. Immediately the leaders resorted to the marae of 'Oro, if one was there, or to the local marae of the god of the district, carrying their maro-tai (sea-voyage-offerings), which the chief arioi presented saying: 
Tera te maro-tai na 'oe e te atua e! O te vane, te 'ura te fa'aio, te pua'a, te apaapa 'uru, e te rahiri; ta 'oe ia i to matou tae ra'a mai i te tenua nei ma te ora.

E ‘aroha mai i to maru e te atua e, eiaha te 'ino ia tupu ia matou i te fa'aea ra'a i teie nei fenua, e tae noa tu i to matou mareva ra'a tu. Tahi tia mai i ta matou aha e te atua e!
There is the sea-voyage-offering for thee, O god! A fine mat, 'ura feather arioi cloth, a pig, half a breadfruit, and a bunch of braided coconut leaves; they are for thee on our safe arrival in this land.

Have compassion on thy shadows, O god, let no harm behall any of us while we remain in this land, even to when we sail away. Harken to our petition, $\mathrm{O}$ god!

When companies were combined, one presentation to the god at the marae was sufficient, and one spokesman officiated. After their invocation, the leaders returned to their encampment, free to refresh themselves by bathing and eating, which for fear of incurring his displeasure and bringing sudden death upon themselves, they dared not do before presenting an offering to the god. Their next duty was to take to the high chief handsome gifts, consisting of choice handiwork and a fine pig-a presentation called an $o$ (fitter in); and an exchange of compliments beautifully worded followed. Then presents of all kinds and appropriate speeches between the visitors and the hosts were exchanged on a grand scale, those of the visitor being called an $o$ and those of the hosts a fa' $a^{\prime}$ amua (feeding), because they were accompanied with a feast prepared for them, immense quantities of cloth called ahu rao (voyagers cloth) were wound by the hosts around some of the women guests, from their waists up to their necks and down to their feet, as they stood upon the tavehea (open space) of the floor in the house, until they looked like great balls of various colors; the women sometimes fainted from such close confinement. After accepting the present, the chief arioi unwound the cloth and distributed it among the other guests, reserving for themselves and the gods a share that grew into great heaps upon the mats spread out for the purpose, and resulted for the recipients in profits exceeding what they had lost in what they gave.

The distinguishing feature of the feast was an arioi pig, baked and pierced through lengthwise with a long slender pole and planted in the midst of the other food. It was exclusively for the chief arioi. No one else dared eat any of it from fear of strangulation by the gods; no thief was ever so bold as to steal such a pig. On the occasion of so great a gathering of arioi, impostors dressed like them came from other districts, intermingled with the assembly, partook of the feast, stole some of the property, and made their escape without being detected. But afterwards they boasted of their cunning tricks.

The amusements generally took place at night, when the great arioi house was illuminated with fires and candlenut tapers, so that it was called rehu arui (night daylight). On a high platform called a raira'a-maro 'ura (exalting-red-girdles), erected at one end of the house were placed high stools as seats for the chief arioi of both sexes. In the center of the building were the comedians, over whom presided the arioi-hi'o-niao (master-of-ceremonies). The royal family had their seats of honor, and within the building and outside upon the grass were the spectators. Even the crickets, it is said, cried with joy on these occasions.

When all were ready for the entertainment, the chief arioi came in singly, with a step like a strutting peacock, and crossing the arms over the breast, said-if of Haapape, for instance:

Ha, ha, ho'i! O vau, ‘O Tiaau. E mou'a i ni'a 'o 'Orohena i hau roa i n'ia i Tahiti nei! E tahua i raro, 'o Fae-ria; e 'outu i tai, 'o
$\mathrm{Ha}, \mathrm{Ha}$, indeed! It is I, I stand. My mountain above is 'Orehena, which is above all in this Tahiti. The assembly 
te Fau-roa; e vai, ‘o Vai-popoo. 'O vau, ‘o Tia-au, 'arioi i te fenua, otuituia i te 'ofai pupuhi. ground below is Fae-ria; the cape seaward is Fau-roa; the river is the Vai-popoo. It is I, I stand comedian of the land that vibrates with the sound of the gun.*

*This last boastful attribute was added, of course, after the arrival of the early explorers, who generally anchored at Haapape near Cape Fau-roa, named Point Venus by Captain Cook.

After they had introduced themselves in this manner, Te-roma-tane opened the entertainment by taking a rahiri (bunch of braided coconut leaves) and casting it at the feet of the sovereign, saying as he did so:

Ena hoi te manava e manava o te ari'i! E manava mai ra oe, e te ari'i nui tua tinitini; e manava maira oe' e te ari'i manomano! I fano mai 'oe i te mahora o te ra'i; i fano mai 'oe i na va'a 'ura ma te heihei, ma te tarehu roto; i fano mai 'oe i na va'a muri; i fano mai 'oe i te va'a i te re‘a, i te va'a 'ura ma te heihei, ma te tarehu moana. Manava te ari'i nui, tau aea!
Here is indeed the welcome, the welcome of the sovereign! Thou art welcoming us, $\mathrm{O}$ great sovereign of thousands of thousands! Thou art welcoming us. O great sovereign appearing from the sky [royal abode]! Thou hast flown hither to the lawn of the sky; thou hast flown to the foremost canoes; thou hast flown to the after canoes; of gaiety, to the canoes of red garlands from across the hazy deep. Welcome, O great sovereign, this introduction to thee!

Then the amusements and more feasting were indulged in till early morn when the arioi were glad to take rest. They slept most of the time during the day. These entertainments lasted many days, when the farmers' gardens were stripped of their produce and the distrct became so impoverished that it took long for it to regain its former state of prosperity.

In their plays the actors flattered or ridiculed with impunity people and even priests, from the greatest to the least, and they often did much good in thus causing faults to be corrected. They cannot, however, be placed upon a moral pedestal. From the testimony of their own members, a curtain must forever be dropped before many of their deeds on such occasions-deeds, which combined with the crime of infanticide, ended the career of the arioi society. After its members became more enlightened, many of them became faithful and zealous workers in the Christian cause.

On returning home in the name of 'Oro the arioi first made a bonfire of the clothes in which they had been acting, and when they reached home they took new offerings to their marae, the chief arioi presenting them to 'Oro and saying:

Teie matou e te Atua i fa'ahoi fa'ahou hia mai e te fenua, i tana tere ta matou i poroi ia 'oe ra. Teie matou tei te fenua ma te ora. Teie ta 'oe e pua'a e 'ahu e te 'ura. Ta matou teie maro-tai na 'oe, e te Atua e.
Here we are, O god, returned from the land whither we were bound when we took leave of thee. Here we are safely landed. These are for thee-a pig, cloth, and 'ura feathers. These are our sea-voyage-offerings to thee, $\mathrm{O}$ god.

After this they disbanded and went to their own homes, until new organizations were required. (1928:237-241)

This account of the Ariois' most important activity requires some correction and amplification, which I shall now undertake, following as closely as possible the sequence of events set out in Henry's text. 
First, concerning the outfitting of an Arioi expedition, the Henry account seems to imply that the work and expense fell to the Ariois themselves, but the translation accompanying the original Orsmond text indicates that contributions were made by the non-Arioi populace as well: "All the body of chiefs. And all the land beside prepared those things. Not the arioi merely" (Orsmond: Arioi).

As we shall see, Ariois did indeed hold privileged positions in Maohi society and, as de Bovis wrote, used to "assemble in front of their chiefs' houses in order to beg for bark cloth" (1909:37), for uses which probably included outfitting for tours; but to imply as de Bovis did that they engaged in begging only because they manufactured no bark cloth themselves cannot be true. Perhaps they spent less time at such domestic chores than did other persons, or perhaps their personal and ritual needs for bark cloth were greater than average, but according to Morrison they were "very excellent hands in evry branch of the work but especially at Dyeing \& Painting" (1935:162). Morrison also wrote:

The Ora is a Grey strong Cloth made of the Bark of the Sloe tree-Large quantitys of these trees grow in the Mountains, particularly Near Vyeooredee, where there is a great lake which they Call Vye Heereea from a large kind of Eels which they say it produces as big round as a Man; to the Banks of this lake resort Numbers of the Areeuoy (Who are Generally good Cloth Makers tho it is Chiefly the Weomens employment) to make the Cloth, it being held in great esteem being the Strongest \& Best for wear. They Generally stay some months on the Banks of this lake where they have plenty of Provisions. (1935:162)

The size of these expeditions must have varied considerably; the largest one actually reported was one which sailed from Huahine to Ra'iatea in 1774 and consisted of some sixty to seventy boats carrying some seven hundred persons. ${ }^{25}$ According to surgeon Ellis, who accompanied Cook on his third and last South Seas voyage, such flotillas proceeded in squadrons of ten to twelve boats each (1782:I, 159), suggesting the likelihood that each "lodge" (the local chapter of each tribe or tribal subdivision) taking part in an expedition traveled as a unit.

The missionary Ellis' account of expedition preparation attests to more elaborate ceremony: "Great preparation was necessary before the mareva, or company, set out. Numbers of pigs were killed, and presented to Oro; large quantities of plantains and bananas, with other fruits, were also offered upon his altars" (1829:I, 316).

Turning now to the divine auspices under which these expeditions traveled, Henry's version implies a distinction between 'Oro, whose blessing for the travelers was requested but whose presence was meant to remain at the home marae, and certain other deities, whose presences were requested to accompany the travelers. (The only explanation I can suggest for this 
distinction is the possible belief that 'Oro was too important a god to be expected to attach himself exclusively to any one party-but this is pure speculation.) Among the latter was Romatane; I have not come across any myths associating Romatane with the origins of the Ariois, but he appears in descriptions of the fate of Ariois in afterlife. As for Hoatapu, he will be remembered as having been 'Oro's son in some mythical versions, but as such had had much less to do with the beginnings of the Ariois than had Orotetefa and Urutetefa, whose transformed selves served to validate 'Oro's marriage to Vairaumati and who were parents of prototypes of the sect's principal animal offerings.

Concerning an expedition's arrival at its destination, Ellis provided a vivid description:

Sometimes they performed in their canoes, as they approached the shore; especially if they had the king of the island, or any principal chief, on board their fleet. When one of these companies thus advanced towards the land, with their streamers floating in the wind, their drums and flutes sounding, and the Areois, attended by their chief, who acted as their prompter, appeared on a stage erected for the purpose, with their wild distortions of person, antic gestures, painted bodies, and vociferated songs, mingling with the sound of the drum and the flute, the dashing of the sea, and the rolling and breaking of the surf, on the adjacent reef; the whole must have presented a ludicrous imposing spectacle, accompanied with a confusion of sight and sound, of which it is not very easy to form an adequate idea. (1829:I, 318-319; see also Moerenhout 1837:II, 133)

The marotai, religious offering made upon arrival, seems to have been the standard procedure followed at the conclusion of most sea voyages and was not peculiar to Arioi expeditions, except that the Ariois' marotai seem always to have been directed to 'Oro. Similarly, the genre of the ceremonial exchanges from guests to hosts (o), and from hosts to guests ( $f a^{\prime} a^{\prime} a m u^{\prime} a$ ), accompanied all large-scale visiting, although the balance in this case was explicitly described as favoring the guest-recipients.

Turning now to Henry's reference to the "arioi pig," which was reserved exclusively for the chief Arioi and which constituted "the distinguishing feature of [this] feast" (1928:239), one will recall its prototype as having been one of the litter born on the occasion of 'Oro's mating with Vairaumati and having been designated "a pig for maro 'ura [i.e., a chief] Arioi." (Another of this litter was "a pig to sacrifice to gods"- that is, presumably the prototype of all pig offerings to 'Oro.) ${ }^{26}$ Orsmond's Arioi text about "the sacred pig" is as follows (with translation by White):

E Buaa raa. E pau te fenua i te buaa raa, o ta te arioi ia taoa here rahi, e taoa mana. Ia rave ra te hoe taata i te reira buaa e eu nana, e ore te buaa e vera, oia iho te pohe na. Na te atua ìa e uumi. E pinia iti taua buaa ra, e uumi noa hia, e e faahume hia i te maro ura. E ia pohe
The sacred Hog. The land suffered a scarcity of hogs because of this; it was one of the players' favourite possessions, an object of strong magic. Should someone take one of those hogs and roast it for himself, it would not cook, but he himself would sicken and maybe die, strangled by 
ra a faaite atu ai i te ioa o te avae parai nana te buaa e ia faaite raa hia ra e hopoi i mua ia Oro ra e [?] te mahana taupiti ra uumi ai. the god. If it were a newborn pig, it would simply be strangled and girded with a red girdle. And when it was dead, the name of the chief player, for whom the pig was intended, would be announced and when he had received the pig, would be born before 'Oro, and for the festival day to be strangled.

Henry's interesting reference to "imposters," who went uninvited to feasts to partake unbidden of the largesse, provides additional evidence that ordinary religious and other sanctions were not sufficient to enforce unremitting social conformity in all members of society. In this instance an explicit sanction backed by 'Oro's divine aides seems to have been required to protect this Arioi prerogative-which conceivably was one of the circumstances that led to the invention of this episode of the Arioi myth of origin.

What Henry called the Arioi "amusements" constituted one of the sect's major activities, whether they occurred during regular Arioi expeditions or during meetings of other kinds. Several aspects of these "amusements," beginning with the buildings in which they took place, deserve attention.

A text from Orsmond distinguishes two kinds of "large" buildings built by public corvée (as distinguished from each Arioi's own private dwelling, which he probably built by himself):

The largest houses on Tahiti belonged to the Players and were equal in size to those of the Kings in magnitude. The players were men of superior strength in the execution of their work. The whole of the class built those great houses because they were for public exhibitions. They were one, two, three, and four umis long (10 fathoms is a umi). In those houses the players slept, resided, and exhibited their plays, and waited for the times of sports. They performed by night and by day, at one end, at the opposite end, and in the middle at the same time. But it was in the large houses of the Kings that visitors were presented with national offerings of all eatable. The houses of smaller size for the private use of the players, they built them selves, but those for public sports the chiefs prepared. (Orsmond:Arioi)

Presumably the "arioi houses" alluded to included what some writers called "theatres," along with others described as "hostels" (see above, chaps. 7 and 10), but if so they must have varied considerably in form and in internal arrangements. Elsewhere in Orsmond's texts, Arioi dwelling houses are described as having been "superior" (maitatai), "large" (30 fathoms long), and "surrounded by fences of breadfruit planks." But I take these to have been the privately built dwellings alluded to earlier. In any case, "arioi houses" appear in some way or another to have contained at least four functionally distinct parts: a high platform on which sat the highest-grade Arioi present; a space reserved for $\operatorname{ari}^{\prime} i$ (including tribal chiefs); a place for performing $A r$ iois; and spaces for other spectators. 
Elevated seats were one of the Ariois' hallmarks, serving to distinguish them from the rest of the populace:

E iri noho raa no te arioi. E papa noho raa no te arioi.

Ta ratou taoa. E tarai maite te mau iri rahi ra, ei noho raa no te arioi. E arioi noho papa tona ioa. E ore oia e noho noa i raro i te repo. E taoa rahi ìa i te fare o te arioi.
The large stools seats for the players. That was the property they prized. They made them in great numbers for the arioi. A player that sits on the high stool was his name. He would not set down on the earth in the house of the Players the stools were numerous.

(Orsmond: Arioi)

Similarly, according to one source, Ariois also had a distinctive way of sitting:

The fraternity of Areois had some customs and practices which they affected to reserve to themselves, and which it would have been at the peril of others to adopt. These were either exceedingly gross or exceedingly puerile. Of the latter we are assured that the following was a favorite one, which it might have been death for an uninitiated person to imitate. When they sat on the ground, or on a low stool, they put one foot on the other thigh, and continued giving the toes a particular motion, while in the one hand they waved at arm's length a fan, made of the white hairs of a dog's tail, to drive away the mosquitoes; and in the other held a nasal flute, on which they occasionally made a flourish of notes, by blowing into it through one of the nostrils. It is remarkable that this little musical pipe is shaped like a German flute or fife, and is sounded as above, through a hole in the side, near the upper end, which is plugged. (Montgomery 1832:I, 187)

The Henry account implies that the highest grade of Ariois, the so-called Arioi maro 'ura, occupied the "exalting" platform as spectators, during Arioi performances, but in Moerenhout's account (1837:II, 136) all those who did not actually take part in the performances-that is, all the higher grades of Ariois-occupied the platform. Information is lacking on this point, but it would be of interest to know whether this platform was reserved for the visiting Ariois only, or if it was shared by higher-graded members of the local lodge as well. (In other words, was tribal status maintained, or outweighed, in such gatherings?)

In the place reserved for what Henry labeled "the royal family" must have sat the local tribal chief and his nearest relatives, and probably other spectators of upper-class status. Again, it would be interesting to learn which place was occupied by upper-class persons who were also Ariois but not of the principal visiting contingent-that is, Was class status outweighed by Arioi status on such occasions?-but such information was not recorded.

The place set aside for the performing Ariois-presumably both the "stage" itself and the seats of performers awaiting their turn-was dominated by the raised seat of the master of ceremonies:

Their captain, on public occasions, was placed cross-legged on a stool seven feet 
high, with a fan in his hand, in the midst of the circle of laughing or admiring auditors, whom he delighted with his drollery, or transported with his grimaces, being, in fact, the merry-andrew of the corps, who, like a wise fool, well knew how to turn his folly to the best account. (Montgomery 1832:I, 240)

According to Henry (1928:239) this individual was called arioi-hi'o-niao (Arioi Inspector). ${ }^{27}$ Elsewhere reference is made to a "master of diversions" (fatu no te upaupa), who is described as "a kind of master-of-ceremonies, who presided at these exhibitions" (Moerenhout 1837:II, 140). We cannot discover whether these were separate offices, or one office having somewhat different characteristics. Nor can we discover to what grade of Arioihood, or what marriage class, such officers belonged.

Concerning the rehu arui (night into twilight?), the name given to the taper-lighted performances of the Ariois, Orsmond wrote:

The Nighttime Ashes. That, too, was one of the players' festivals. When night fell, pigs would be roasted and apparel cut. It was a musical gathering. The fires made the night like day. For which reason it was called Nighttime Ashes (or Twilight). Thieves would sit around waiting patiently, clothed like players. From time to time a breadfruit would disappear or a pig, and they would call out as though they were members of the gathering, if they were not reprimanded.... (Orsmond:Arioi)

The prologue to an Arioi performance served to emphasize the tribal identity of the performers in question. According to Henry, quoted earlier, it was the member of the performing unit (presumably the lodge's leader) who made this opening speech. Orsmond provided a number of examples of such speeches, one, in fact, for nearly every district lodge on Tahiti-Mo'orea. The example reproduced by Henry, that of Ha'apape, is evidently based on the Orsmond text, but leaves out some noteworthy words, including the name of the lodge's Arioi house (in this case, Te Atita, "agitation"?), and an opening phrase, haha hoi (which Orsmond translated, "the strutting of the cock by the hen," which was evidently the metaphor for the man's manner of entry on stage). Also, Henry's own phrasing of this speech does not indicate clearly enough that "I Stand" is in fact the distinctive official Title of this premier Arioi of Ha'apape; the Orsmond text shows that every such Arioi prologue contained the Title of the lodge's premier official along with a listing of the home district's highest mountain, assembly ground, cape, and so forth. In other words, a district's premier Arioi was ceremonially identified by a formula like that of its tribal chief-except that the formula applied to the former seems not to have included the name of the tribal marae, whereas the formula of the tribal chief did include the name of his district's Arioi house.

Much has been written about the "amusements" and "entertainments" of the Ariois, both the performances presented by them for public 
consumption and the allegedly "sacred" activities engaged in by them exclusively. Concerning the first there is not much to be added to the general description of dancing, singing, play-acting, et cetera, given in chapter 10. It is undoubtedly true that such activities were a specialty, perhaps the main specialty, of Ariois. A text recorded by Orsmond, and translated by Ralph White, describes the penalties served upon inept Ariois: "[Concerning] the poor [inept] Arioi and the poor musical comedian and the poor acrobat: As for the inept Arioi who did not know how to dance and sing, he would be led outside, off grounds. No one would look at him. His rendering was slovenly and full of mistakes." But Ariois were not the only persons to engage in such activities, or even to specialize in them. In fact, some of the troupes of "strolling players" described in the sources may not have been Ariois at all. ${ }^{28}$ Nevertheless, the public performances put on by Ariois do appear to have represented in marked degree certain features of these activities, namely, their religious aspect, their employment of sexual and especially copulative imagery, and their uninhibited lampooning of prominent persons.

Concerning the religious emphasis of their performances, Moerenhout said: “... their exercises commence always with religious subjects. The description of the two principles, Taaroa and matter with which he joined himself, the creation of the universe, gods, the elements, spirits, plants and other productions of the earth ..." (Handy 1930:65, translated from Moerenhout 1837:II, 134).

The emphasis on sexuality in public performances of the Ariois is to be distinguished from the sexual promiscuity said to characterize their offstage lives. Like most writers on the ancient Maohis, Miss Henry "drops a curtain" before such goings-on. The missionaries Tyerman and Bennet imposed their own censorship:

The stories [performed by Ariois] were called Aamu, and were dramatic in form, so that several speakers might take their distinct parts, and not merely recite, but act them. These compositions, we are told, frequently did credit to the talents of the authors, while the accuracy and liveliness with which they were repeated, showed considerable powers of memory, as well as of imitation in the performances. But they were connected with unutterable abominations.... (Montgomery 1832:I, 69-70) On their lewdness we shall not dwell ... (Montgomery, p. 239).

Though not as descriptive as we would like, Moerenhout was more specific, and he posited a religious rationale for this on-stage aspect of Arioi sexuality:

Their performances were not limited to mythological and historical subjects. Some of them were even livelier and more bizarre. It was these in which their lower-class members presented without scruples the uninhibited representation of sensuality and love-making. And in connection with these latter performances 
it was not unusual to see young men and young women actually offering their sacrifices to the goddess of love in public. Such scenes as these also commenced with chanting and dancing, the former having revolved around the delights of sensual pleasures, which were depicted with utmost candor and ardor, and in the most unequivocal terms. As for the dancing, it was entirely distinctive to these particular occasions, and was everything in the way of lasciviousness that their voluptuary geniuses could invent. Yet, notwithstanding the fact that such scenes would appear so scandalous to our [European] eyes, when looked at from their point of view they were anything but reprehensible or shocking. In my judgment, what is entailed in these scenes, as in mythological and other solemn performances carried out in connection with the Arioi, is nothing more or less than the living portrayal (in lieu of inanimate symbols) of the natural principle of sexual generation-no different from that symbolized by the Ancient Egyptian's phallus or the East Indian's lingam. (1837:II, 131-132)

I have described in chapter 10 the satirical character of some Maohi theatre. It is likely that this characteristic was not limited to Arioi performances, but I suppose that it was more prevalent in such performances-probably because Ariois were in general a highly privileged category of persons, more immune than many others from the application of certain social sanctions. In some descriptions of satirical performances the performers are not identified, but Ellis referred specifically to Ariois: "Their public entertainments frequently consisted in delivering speeches, accompanied by every variety of gesture and action; and their representations, on these occasions, assumed something of the histrionic character. The priests, and others, were fearlessly ridiculed in these performances, in which allusion was ludicrously made to public events." (1829:I, 317)

One additional characteristic of the public performances put on by Ariois was their athletic exhibitions and contests. As we saw earlier most large-scale Maohi assemblies of any nature included athletic events of many kinds. But we are informed by Ellis that Ariois "sometimes engaged in wrestling, but never in boxing; that would have been considered too degrading for them" (1829:I, 317-318). Reasons for this attitude, if indeed it prevailed, ${ }^{29}$ were undoubtedly complex but may well have been based on the high valuation placed by Ariois on physical perfection; and the bare-fisted, do-or-die character of Maohi boxing must have been very disfiguring. The statement by some observers that boxing was a "lower-class" sport could also help explain its alleged proscription among the socially élite persons comprising the Ariois-were it not for other claims that some "chiefs" were champion boxers!

Finally, a text recorded by Orsmond helps to lift the "veil" that most other writers insisted upon drawing over the off-stage "abominations" indulged in by Ariois during their tours. I reproduce the text itself and a translation worked out by White. As the reader will perceive, even so expert a Tahitianist as White is unable to deliver a wholly lucid rendition of these largely obsolete fragments. In the matter of translation, this and other ex- 
amples of White's renditions do not always completely "make sense," but I greatly prefer his deliberate cautiousness to the more manufactured lucidity of some other translators.

\begin{abstract}
E vahine roi na te arioi. Oia te mau vahine e pee ia ratou ra i to ratou ra mau tere. Ei pia ahu ana īa, e e ope(re) taoa na te arioi. E vaiho noa ia mau vahine. E taata e te haere e haere mai e taoto, e afai i te taoa na te arioi.
\end{abstract}

E vahine tāiato. E roi tâiato. Te mau tapairu e haere roto i te na hoa i te arioi ra īa, e te ma hina a te hui raatira ra; o ratou te riro ei vahine taiata. Ei te arui ra, e vahine tamahanahana na te arioi, ei te ao ra, e vahine taiato ra īa. E mea ê ra te mareva. Ia obua ra te arioi, e e taamu i te fenua, e haere atoa i a mau vahine taiato. $\mathrm{E}$ ia tae $\mathrm{i}$ te hoe faaea raa ra, i te vahi e faamu hia 'i ra, e noho tu i te fare, o te arioi o te vahi e noho hia ra, e na te hui taiata ra o reira iho hoi e pii haere "Taiato, e ai o, e ai o, e ai o. E i roto roa i te fare. Tei hea te mau vahine taiato nei?

No te mau arioi ra. Teie matou. Mai haere i o ae ra. Eiaha ei o nei i, e haere mai e ai. E taau, e taau, e taau i te taata. Too-pae, too-ono, too-hitu vahine. Aore taoa. E ai noa. Te ai atu, te pohe atu, Te ai atu, te pohe atu. Ei te ao anae ra e haere mai ai. E ore e haapao, e ore e haama, Ei reira iho i mua i te aro o te tane e o te vahine. Teie ra te tau maamaa rahi roa. Ua rahi roa te taiato i teie nei. Aita ra te vaha e pii, te mata ra te parau. E ia oti ratou i te faa amu hia ua haere atura i tetahi vahi iho, e o te peu noa iho a ìa e ati noa ae Tahiti \% E haere mai i tera bubu, e i tera bubu maiite, piiaraa, oetei vaha, e ai o, e ai o, e ai o, mai no te rauti, e te monoi, e te mati. Teie te arioi mau, o te mau tutae auri nei e huru ê. Te mati anae te toe, e te mau inu raa ava ra, o te tâiato raa ìa, o te ai raa īa.
Bed-mates for the players. These were the women who followed along after them in their travels. They were clothe-starchers, one and all, and gift distributors for the arioi. Those women would just leave them. A different person would come and come and sleep, and bear gifts for the 'arioi.

Whores. The lecher bed. The beautiful hand-maidens would go in as friends for the arioi, daughters of the local adult population; it was they who acted as whores. During the nighttime, they warmed the players, and during the daytime they were prostitutes. But the fleet was strange and different. Should the 'arioi decide to circumscribe the land, the whores would go along too. And when they came to a stopping over place, a place where they would be fed, they would stay in the house, the 'arioi of the place whereat they stayed, and the honorable group of whores of that very place would call out "Fornication, our wares are copulation. And right into the homes. Where are the whores?

About the arioi. Here we are! Let's go off there. We had better not do our fornicating here. There were scores and scores and scores of men, and only five or six or seven women. No payment. Just copulation. Copulation to climax, one after another. But they would pursue their course only during the day. They were subject to neither restraint nor shame. Right there in front of husbands and wives. For this was the completely crazy age. Fornication had now increased tremendously. The mouth did not even have to call out, the eyes said all that was necessary. And when they had been fed, they would go on to a nearby place, and so on until they had made the circuit of Tahiti. They would come to this group and that group, their voices (mouths) calling out: Fornicating! Fornicating! Fornicating! with ti fronds and scented oil and crimson dye. These were the real players, the hardened reprobates ... a strange lot. Only the crimson dye remained, and drinking spirits, and dissipation, and fornication.

We now leave the "entertainments" provided by Ariois on their tours away from home to consider the more tangible goods that circulated in con- 
nection with their visits. Included among these were offerings made by the touring Ariois to their tutelar deities, mainly 'Oro, for safe passage; gifts formally exchanged between the touring Ariois and their hosts; and food supplied by the hosts for daily provisioning of their Arioi guests.

I have already indicated my uncertainty regarding the source of the objects handed over by the touring Ariois to their tutelars and to their hosts-that is, I cannot discover whether these objects were the product of the Ariois' own husbandry or manufacture, or were supplied in part by their non-Arioi neighbors at home. However, no such uncertainty prevails concerning the source of objects provided by the hosts: several passages establish incontestably that the entire populace of the host district was required to contribute to these occasions, and if the extra amount needed was not obtainable through general levies then the tribal chief would bestir even himself to produce it. For example, under the date of October 16, 1806 there is the following entry in the LMS records: "The people of Hapaeno passed on to Pare with a great quantity of food, cloth, ava and Hogs which are intended for an Oroa that is to be held in a few days on account of the Areoes belonging to Raeatea and the other Islands to Leeward" (Youl, Bicknell et al., Journal; see also, Jefferson, Journal, 22 October 1800).

As for the degree of balance maintained between guests and hosts in the formal exchanges of objects, Henry's opinion was that the former gained more than they gave up, and this difference was even further widened by means of the daily provisioning supplied them by their hosts throughout their visits. To the best of my knowledge, rationalization of this discrepancy is nowhere explicitly voiced in statements attributable to the Maohis themselves, but I believe that its basis was implicitly recognized in acceptance of the specific principle that the entertainments provided by the visitors were fair exchange for the surplus in objects they received, and in acknowledgement of the general premise underlying "hospitality"-that is, the roles of host and guest might someday be reversed.

Another aspect of these transactions that has provoked most writers' comment is the extent to which such visits used up the resources of the host district and the manner in which these "costs" were apportioned and borne. Henry wrote of farmers' gardens being "stripped" and whole districts "impoverished" (1928:240). Further evidence of such consequences comes from Ellis, Bennet, and Wilson.

... in the constant repetition of ... often obscene exhibitions, [the Ariois] passed their lives, strolling from the habitation of one chief to that of another, or sailing among the different islands of the group. The farmers did not in general much respect them; but the chiefs, and those addicted to pleasure, held them in high estimation, furnishing them with liberal entertainment, and sparing no property to detain them. This often proved the cause of most unjust and cruel oppres- 
sion to the poor cultivators. When a party of Areois arrived in a district, in order to provide a daily sumptuous entertainment for them, the chief would send his servants to the best plantations in the neighbourhood; and these grounds, without any ceremony, they plundered of whatever was fit for use. Such lawless acts of robbery were repeated every day, so long as the Areois continued in the district; and when they departed, the gardens often exhibited a scene of desolation and ruin, that, but for the influence of the chiefs, would have brought fearful vengeance upon those who had occasioned it. (Ellis 1829:I, 319)

Free from labour or care, they roved from island to island, supported by the chiefs and the priests; and were often feasted with provision plundered from the industrious husbandman, whose gardens were spoiled by the hands of lawless violence, to provide their entertainments, while his own family was not unfrequently deprived thereby, for a time, of the means of subsistence. (Ellis 1829:I, 325-326)

This rite, therefore, was followed by a feeding (as it was called), when fifty or sixty hogs, perhaps, and fruit in proportion, were presented to them, together with rolls of cloth, and every necessary for their personal accommodation. This "feeding" was not all consumed at once, nor upon the spot, but portions of it were set apart, and sent to their brethren in other islands by early canoes. Thus when they alighted, like a swarm of locusts, in a rich district, they were not, like locusts, contented with what they could devour themselves, but swept away from the miserable inhabitants whatever they could obtain, for the support of those of their order who were wallowing at their ease on dunghills of sloth, while these were laboring abroad in their vocation. (Montgomery 1832:I, 239; see also Wilson 1799:195)

I shall return to this topic in my general discussion of the position of Ariois vis-à-vis other members of Maohi society.

Henry's description, quoted earlier, of the concluding ritual of an Arioi tour requires no amplification, except to draw attention to the statement that the Ariois, upon reaching home, burned all clothes worn by them during their performances-an action presumably based on the same general premise underlying the disposition of the clothing of priests and others after ceremonies in a marae. The final sentence quoted from Henry does however require additional comment: I refer to her statement that "After this [i.e., the final offering to 'Oro upon the expedition's return home] they disbanded and went to their own homes, until new organizations were required" (1928:241). This assertion implies that Ariois did other things than engage in the kinds of activities just described. And it also raises questions concerning the frequency and timing of the tours themselves.

Some writers have characterized the Ariois as "eternally wandering, homeless vagabonds," thereby implying that they were continually on tour. The facts, as far as they can be gleaned, are that none of the Ariois were "homeless" and that their organized tours, at least, were rather infrequent. Although some Ariois were probably on hand at every large-scale gathering witnessed by European visitors, the only recorded instance we have of an actual large-scale Arioi tour in progress was the one witnessed by Cook and his crew in the Leeward Islands in 1774 and 
mentioned above. The tour just mentioned took place in May, and in addition there is the testimony of missionaries cited earlier concerning preparations being made on Tahiti, in October, to receive a large fleet of Ariois from the Leeward Islands; but there is no direct evidence that either of these was a preferred time of year. In comparing such activity in these Islands with similar but more seasonal kinds elsewhere, Moerenhout wrote that "on Tahiti as in the other Society Islands, where natural abundance was always to be found, the Arioi festivals were practically continuous"-by which I interpret his meaning as not that they went on all the time in any one place but rather that they knew no seasons (1837:I, 501).

Organized touring may have been the most spectacular part of Arioi activities but it was not the only one. For example, they put on their performances on other festive occasions-familial, tribal, and intertribal. At nearly every large-scale gathering of people described in the sources mention is made of "entertainments" having been provided by Ariois; the latter were perhaps not the sole "entertainers" on such occasions but they were usually the most prominent ones. Like most Arioi "entertainments" these performances probably involved religious overtones, and this was emphatically so of performances accompanying individuals' rites of passage.

I reproduce again Moerenhout's general account of natal ceremonies, in which the part played by Ariois was particularly noted:

The most active [participants in these occasions] were always the Ariois. On arriving, with their bodies painted red and white, with feathers in their hair and decorated all over with flowers and ornaments, they chose for themselves one of the two lots of tapa [provided by the hosts], the chiefs taking what was left. Then, after the roast pork had been distributed the ceremony began. (1837:I, 536)

Thereupon, while the parents and close relatives of the newborn child repaired with it to the marae for performance of the rituals already described, the rest of the company remained at the parents' household:

During the parents' absence, and often throughout the rest of the day, the Ariois kept up their chants and dramatic acts concerning the actions of the deities. All of these ceremonies, both the ones at the marae and at the household, had no other purpose than to assure divine protection for the newborn. And the reason why the parents went to such expense in accommodating the Ariois is that since these latter were regarded as such favorites of the deities it was believed that their very presence would secure divine favor for the newborn (Moerenhout 1837:I, 537)

I have not come across any description of the part played by Ariois at weddings, but a reference to them in Ellis' account of such occasions indicates that they were in attendance and implies that they participated to some extent: "The cloth used on these occasions [i.e., the nuptial rites at the marae], as well as the dress, was considered sacred, and was taken to the king, or appropriated to the use of the Areois" (1829:II, 570). 
Ariois also took part in ceremonies of inauguration. In the one ascribed to the inauguration of an Opoan sovereign chief, Henry noted that Ariois were a distinctive element in the processional review:

Soon upon the sea and along the shore a semibarbarous pageantry took place. A long flotilla bearing nude men and women of the arioi and hihomoa fast element, headed by the new anuanua (rainbow) or sacred canoe of 'Oro, which was distinguished from all the rest by tapaau (coconut-leaf images), viriviri (braided coconut-leaf) chaplets suspended around its borders, and by the presence of opunui who named it, dressed in their best marae costumes, each carrying a tapaau on his left arm and wearing wreaths of coconut leaves. The canoe had a platform towards the center for 'Oro and the coming sovereign. (1928:190)

Then, near the conclusion of the ceremony, "The nude party, some of whom were mounted upon trees, hailed him as monarch of their persons, suiting actions to words in language too primitive to be repeated" (Henry 1928:195). Henry added that a "queen was happily exempted from this undignified greeting."

Ariois had, as we shall see, distinctive ways of solemnizing the death of one of their own members, but I can discover no evidence that they played special parts in connection with the death of nonmembers-except, according to the Orsmond text, that they alone of all persons were immune to the dangerous antics of the "ghost-masquers": "An Arioi would not run from the ghost-masquers. The former went his way, and the latter his." (Orsmond: Arioi) ${ }^{30}$

The privileges accorded Ariois did not end with death, as the following description of their funerals and afterlife shows:

When an arioi died, the body lay in state for two or three days at the home of the deceased, where members of the society assembled to perform the funeral rites. Accompanied with loud lamentations, called an otoha'a or ta'iha'a, for the dead, they first brought presents to the family and made a feast, holding a wake at night time, when they called loudly to the spirit to return to its body. On the last day the corpse was taken to the marae of 'Oro, where the high priest met it and in a long prayer invoked 'Oro to bestow on the disembodied spirit all the mystic powers with which it had been supposed he had invested the arioi in life. Then the body was interred as that of an ordinary man within the precincts of the marae, after which, at the little shrine of Roma-tane, Te-roma-tane invoked the gods to receive the arioi soul into the full enjoyment of their paradise, where it was believed that no children existed to mar their pleasure. (Henry 1928:241)

Several accounts of the Ariois emphasize their roles as "warriors":

Wales described them as having had "a considerable share in the Management of their Military Affairs” (Beaglehole 1961:843).

"They were in general stout and well made, and all professed themselves warriors" (G. Forster 1777:II, 129).

"They were a chief's most faithful companions, and generally speaking 
the bravest. Indeed, the sect was a veritable "nursery" (pépiniere) of warriors...." (de Bovis 1909:37)

"They are generally distinguished for their prowess, valour, and activity in battle; and if any of them shew the least signs of cowardice, he is excluded the society; which is esteemed such a disgrace, that from that time he loses all his consequence, and nobody will associate with or speak to him" (Surgeon Ellis 1782:I, 160).

I suspect that the last statement, by the surgeon Ellis, is a somewhat exaggerated characterization of the military aspect of Arioi life, but it seems clear that ablebodied male Ariois did indeed number among any tribe's better fighting men (despite Morrison's cryptic statement that 'They are Never Calld upon in War" [1935:235]). But they were certainly not the only fighting men, and perhaps not invariably the best fighters or the most effective war leaders. ${ }^{31}$ Moreover, when engaged in the religiously colored "entertainments," which was perhaps the most distinctive side to their way of life, they put aside fighting altogether. In fact, warfare was delayed or interrupted in places where Arioi were engaged in their "entertainments." For example:

... let them direct their course to whatever island they please, they are always certain of being well received; nay if they have even been at war but a few days before the visit, all animosity is laid aside, and they are as perfect friends as if nothing had happened. (Surgeon Ellis 1782:I, 159-160)

In times of war or other trouble, the arioi were never molested, and they sometimes safely entertained warriors at intervals of respite on the battleground. (Henry 1928:241) $)^{32}$

During these [Arioi-featured] festivals all the populations [of these Islands], even the most savage ones, often suspended their almost constant warfare. (Moerenhout 1837:I, 502-503; see also Moerenhout:II, 402.)

(If this norm was in fact observed-regrettably we have no direct eyewitness evidence on this score-it would of course distinguish sharply between assemblies featuring Ariois and others, where, as we have seen, sport competitions quite typically ended in brawls. [See chap. 10.])

In this connection one will recall that 'Oro, the Ariois' principal tutelar, was above all else the God of War, who delighted in offerings consisting of warriors slain in battle. On the other hand, that capacity of 'Oro most distinctively associated with the Arioi sect was 'Oro i te tea [te'á?] moe, "'Oro-of-the-laid-down-spear." ${ }^{33}$ One explanation offered for this seeming paradox is that 'Oro as god of war was consequently master of $i^{34}$-which could be the logic involved in this usage but is not necessarily so; indeed, for the Maohi it may have constituted no paradox at all.

I turn now to the "secret rites" alleged to have taken place among the Ariois. ${ }^{35}$ Ariois were an exclusive category of persons-just how exclusive 
is indicated in the following text collected by Orsmond and translated by White:

E bubu taata tino maitatai te mau arioi ra, e te taa â. Aita ta ratou ra oroa i taahi hia i te avae taata, aita hoi ta ratou amu raa e haere noa $\mathrm{h}$ hia 'tu $\mathrm{r}$ te taata 'toa. Te taata ra e haere noa i ta ratou amu raa maa, e i ta ratou oroa, e repo ìa i ta ratou parau ra. Eiaha te taata e haere na roto, na vaho ê ra. E pohe, e tairi hia i te omore. E rohi i te oroa a te arioi, eiaha e repo. Tera te repo o te haru, e o te taata e haere na roto. Na te orõa, ua a, ua ama te buaa, ua motu te ahu, no te mea, aore i haere hia i te taata, e aore e haru. Ua ai ota teie nei buaa. Tera te ai ota o te taata, ua haere na roto te haru, ua tubu. Aore â te bubu arioi reporepo raa. Mai te Oro metua nei hoi te arioi. Te monoi, te tiare, te faio, ta ratou haa, e e ore tona tua ra e haere hia tu. E feia moa rahi.
The arioi were a company of fine bodied men, and separate (from them). Let not the foot of man tread their ceremonies. Not one of all went to their ceremony, and eating was filth in their estimation. Let not a person go in the midst, but outside. (If he went then he would be slain, stricken by the club.) Be on the alert, let not the ceremony of the arioi be defiled. A thing snatched away or a man going through was the defilement. Behold the feast it is consumate, the hog is done, the cloth is cut, because no man has snatched, no one has approached. Is raw (sodden) hog. That is the rawness, a man has gone through the ranges, a person has seized (his) past. The arioi have no filthy habits. Like the race of ministers were the arioi, scented oil, betties (flowers), scarlet dyed cloth was their work. His bed place must not be trodden on. They were sacred.

Thus, their separateness from the rest of the population is undeniable; the question, however, is whether they also engaged in activities that were kept hidden from non-Ariois and unrevealed to them. Evidence on this point is scarce and not very explicit:

They are amused with music and dances, which are said to be particularly lascivious at night, when no other spectators besides themselves are admitted. (G. Forster 1777:II, 130)

There are other dances usual in their nocturnal festivals with the Arreeoys, which, none of our ships company had an opportunity of seeing, and are according to the accounts of the natives extremely indecent and lascivious; these are called t'eaì-morodèe [te ai moro iti? tāmure?], and the women exhibiting them, Too-àha [? tu'a'a, lewd, shameless, indecent, profane (LMS Dictionary)]. (J. Forster 1778:467)

The two Forster accounts, by son and father, respectively, and probably based on the same source of information, seem, however, to be contradictory; the first asserts that the night revels were both secret and exclusive, whereas the second seems to imply that they were perhaps secret but not altogether exclusive. Moerenhout's account, like that of G. Forster, emphasizes the exclusiveness of the Ariois' night meetings. But it should be recalled that Moerenhout's version was based on information collected many years after the events:

Their various poetic, musical, choreographic or gymnastic exercises often took place in the evening by torchlight, and these night scenes, in places where puerile superstition and fears scarcely allowed other people to leave their houses, added substantially 
to the prestige of the [Ariois] and to the respect which they inspired; since, only they alone, under the gods' protection, would dare to face the spirits. (1837:II, 32)

Hawkesworth, drawing from the journals of various visitors to Tahiti, put together the following passage: “... the members have meetings, at which no other is present, where the men amuse themselves by wrestling, and the women, notwithstanding their occasional connection with different men, dance the Timorodee in all its latitude, as an incitement to desires which it is said are frequently gratified upon the spot." (1773:II, 207-208)

The only reference I have found to Arioi nuptial rites is the following: "Marriages of the arioi were always performed at a marae of 'Oro, the accredited founder of their society" (Henry 1928:284).

The funeral rites held for a deceased Arioi were, as we have seen, undoubtedly distinctive; they may have been somewhat exclusive as well.

The same characterization probably applies to the regular rites of worship which Ariois directed to 'Oro and to their other tutelars. Many such services may have been exclusive, and the rituals may in places have been replete with "unusual, symbolistic, and obscure language,"36 but the same may also be said of some of the religious services conducted by other types of congregations.

Before leaving the subject of Arioi activities which characterized, though not altogether distinctively, membership in this sect, I raise again the question, What proportion of their lives did Ariois devote to such activities? I have expounded my own opinion that they were not continuously "on tour" and I have implied that between tours-and when not engaged in performances for local birth ceremonies, and so forth-they lived much like their non-Arioi neighbors. Now, however, I must confess that certain passages from Wilson and Bligh raise the possibility that being an Arioi was more of a full-time occupation than I had earlier suggested:

We stopped at Pappara for the night in the house of my tayo Wyreede: as I had not seen her since my late arrival, she expressed much joy on the occasion, ordered a pig to be instantly dressed, and made me a present of several things; among others, a quantity of human hair made into fine sinnet. Here were a number of arreoies with their separate wives, who, by the attachment they shewed for their husbands, seemed to discountenance the assertion of promiscuous connexion, with which they are charged. Their great numbers made the house, which was one hundred and forty feet long, appear like a little village, where each claimed the place on which his mat was spread; and almost all were employed in making mats, sinnet, \&c. As soon as it was dark they brought lights, and danced and sung till near midnight, and perhaps would have continued all the night, had I not begged my tayo to cause them to desist\& for the drums appear not to disturb their sleep; but, when tired with dancing, they lie down, and a fresh party rises to the sport: and in this manner 
the arreoies usually spend their nights, and thus they train the youths to the same irregular living. (Wilson 1799:206)

It appears however that the Erreeoys from leading an Idle and gay life have among them the finest Women of the Island. They have luxuriant and fine situations where they have their Meetings and live with all the disipation imaginable, and they vary the enjoyments of their lives with the Seasons of the Year. As for Example the Island of Teturoah, which is a few leagues to the Northward of this, they resort to in Crouds in the Season when the Fish is plenty, and at other times to some Charming places in the Mountains to enjoy other peculiar dainties. They are always in large Parties. Always drest with the greatest profusion of the best Cloth and are generally fat and Saucy. (Bligh 1789:II, 78)

\section{Social Relations}

A distinction can be drawn between types and grades of Ariois. I find it useful to distinguish the following types of (male) Ariois: "active," parentaged, "retired," nontattooed, inspector, decorated-sennit and edge-of-the-dress. In native use the word arioi used without qualifiers seems to have had the meaning of active. Active members-the term is mine-were separated into several grade levels, from "highest" to "lowest," each with its distinctive tattoo pattern and uniform and other insignia. Perhaps each grade was characterized by distinctive forms of rights and duties as well, although the sources provide such details for only the highest and lowest of the grades. I paraphrase below the characterization of each grade from highest to lowest as set forth in the Orsmond text, with interpolations taken mainly from Henry:

1. Āvae Parai (blotted-legs or, as most sources label them, black-legs): Members of this grade had their legs completely covered with tattoo marks, from foot to groin. Such were the "parents" (metua) of all other Ariois; they were the ones in highest authority, and were appointed to their office by the tribal ari'i. Black-legs were easy to distinguish because of their oil-glistening skin and hair, their mati-besmeared faces, and their ample bellies. No Arioi was as eminent as a black-leg; here are some of the privileges of such a one: he was the head of any group (?); he was the one who had the (sole?) right of dividing the bark cloth; the altar on which pigs were placed was his; ${ }^{37}$ he alone wore a red loincloth, which led to his being also called arioi maro 'ura; he controlled the fleet of canoes (used in touring); he sat on the (highest) seat; it was he who stood on the high platform and called out the names of those receiving portions of the goods being distributed.

Note: Unless otherwise specified everything I say throughout this section refers to males, who constituted by far the largest and most important part of the membership of the sect, and to whom most of the data pertain.

2. Harotea (light-colored haro tattoo mark): According to Henry men 
of this grade bore a tattoo pattern of "filigree bars crosswise on both sides of the body from the armpits downwards towards the front." Henry also described their official insignia as consisting of skirt and shoulder garlands made of shredded ti leaves, and of wreaths over the brows. (1928:234)

3. Taputu, or Ha'aputu (gathered together): The tattoo pattern of this grade consisted of "diversified curves and lines radiating upwards towards the sides from the lower end of the dorsal column to the middle of the back" (Henry 1928:235). They wore skirt and shoulder garments like those of the Harotea, but made of shredded leaves of ginger (opuhi).

4. Ōti'ore (unfinished): Their tattoo pattern was light marks on knuckles and wrists and heavier ones on arms and shoulders. Their garments consisted of a yellow creeper plant (seaweed?).

5. Hu'a (small): Their tattoo pattern consisted of two or three small points on each shoulder; their overgarment was made of the fibrous covering of the young coconut leaf ( $a^{\prime} a$ ha'ari), and their headdress was of the young coconut leaves themselves.

6. Atoro (? a fragrant herb, Geniostemna rupestre): Members of this grade had a single small tattoo stripe down the left side, and they decked themselves in yellow mountain-plantain $\left(f e^{\prime} i\right)$ leaves.

7. Ohe mara (seasoned bamboo): Members of this grade were tattooed with a circle round the ankle, and they decorated themselves with clubmoss (mai'u'u tafai).

8. Tara tutu (pointed thorn?), Tara tihi (?): Their tattoo mark consisted of small marks in the hollow behind the knees, and they wore bright flowers and a headdress of red and yellow Barringtonia leaves.

As Henry pointed out: "It is evident that as the comedians [Ariois] received promotion and underwent the operations necessary to raise them the tattooing of one order [grade] did not obstruct that of another." In addition to these marks of grade membership, all Ariois put on other markings in connection with their performances: "Before acting, the chief comedians dyed their faces red with the sap of mati (Ficus tinctoria) and tou (Cordia subcordata) leaves. So also did all the other orders, in addition blackening themselves with soot from burnt tutui (candlenut), which some of the men, to create laughter in their plays, used for painting grotesque figures over their bare bodies and limbs." (1928:235)

One other grade of active Arioihood was that of novice-made up of young males selected as candidates for membership in the sect and who were undergoing a period of instruction and probation. Novices were called by several names: àvaeāvae (footing?), fa'a'are'are'a (diversion-

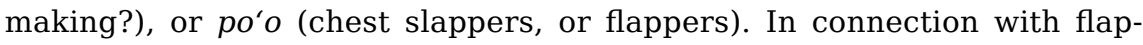
pers, it is explained that the principal activity of such individuals in public entertainments was to stand along the perimeter of the entertainers with 
left arm bent, striking the elbow with right hand and flapping the left arm, like a bird flapping its wing, while chanting about their identity-that is, the geography of their home district, the mythical history of the sect, and so forth (Henry 1928:236). This is the same movement, it will be recalled, used by athletes in their challenges. It probably was meant to represent the bravado expressed by a cock before a cockfight, or in the presence of a hen.

As Mühlmann pointed out, there is some discrepancy between the accounts of Ellis and Moerenhout, ${ }^{38}$ on the one hand, and Orsmond-Henry on the other, with respect to the number and names of the various grades (Mühlmann 1955:32). This could, of course, have come about through their having obtained their information from informants from different islands, which they probably did. I suspect, however, that the discrepancies are due mainly to Orsmond's better comprehension and reporting; in my judgment, cultural differences as fundamental as these are unlikely to have been maintained for long, in view of the constant interisland touring that went on.

But returning to the visible signs employed in distinguishing the various grades, the notion of progressive tattooing as a mark of advance through the grades strikes me as quite comprehensible; in view of the permanent nature of tattooing no other course would have been possible. On the other hand, I can offer no explanation for the types of patterns used, or for the order of their placement on the body.

As for the distinctions in other insignia, some of these are comprehensible but others are not. The most intelligible is, of course, the red-dyed barkcloth girdle worn by members of the highest grade, the black-legs-who were in fact also called "red-girdle Ariois." Henry's statement that this maro was deliberately made to resemble the red-feather girdles that went with highest-ranking kin-Titles is probably correct, but whether this was done in the spirit of "burlesque," which she proposed, is open to question. Certainly, some of the entertainments put on by Ariois were designed to ridicule eminent persons, but black-leg Ariois were themselves anything but clowns, and their wearing of red-colored girdles could have been designed to indicate that their eminence was parallel to and nearly equal to that of red feathergirdled $\operatorname{ari}^{\prime} i$.

In connection with the mono'i, or sweet-scented oil, with which Ariois in general, and black-legs in particular, used to anoint themselves so liberally, one will recall that this kind of cosmetic was a hallmark of the youthfulness and festivity which characterized Arioihood in general, but it was also a specific attribute of Romatane, one of the sect's principal tutelars. $^{39}$

Some parallel with ari'i-hood may also have occurred respecting quality of garments - that is, those of the upper grades seem to have been costlier in terms of manufacture. I shall have more to say about attire in connection 
with distinctions between types of Ariois, and between Ariois and non-Ariois, but with the few instances just noted I can discover no further symbolic parallels between insignia and grade level.

Distinctions between grade levels in terms of activity have also been noted, but only in general and somewhat ambiguous terms:

Their prostitution, dancing, and lewd performances were engaged in only by the lowest grade numbers. Upper grade Ariois were by contrast individuals of grave and reserved comportment. (Moerenhout 1837:I, 495)

All these dramatic performances and dances and sport contests were executed by the many subordinates [lower grades, or lowest grade?] Ariois, and by those who attach themselves to their company. [See below.] The principal persons, comprising the chiefs [chiefs of Arioi lodges? chiefs in general? or both?] and members of the six upper grades [including, or in addition to, the chief Arioi?] did nothing but preside over the festivals, dressed in their ceremonial costumes.... (Moerenhout 1837:II, 135)

On the appointed day they began their dramatic performances dances, over which presided the principal Ariois [les premiers Areois, i.e., chiefs of Arioi lodges? or members of the other higher grades as well?], who were grandly costumed but who merely occupied elevated seats, as spectators, not themselves taking part in the performances. (Moerenhout 1837:II, 133)

From these and other descriptive fragments it seems clear that certain higher-grade members took no active part in the sect's public performances (I shall return to the matter of prostitution later on), but as indicated by my interpolations I am not clear just where such lines were drawn. Particularly puzzling is Moerenhout's inclusion of all "six upper grades" among the spectators, since these constituted, according to his conception, all the fully initiated members of the sect, leaving only the "apprentices" ( $\mathrm{po}^{\prime} \mathrm{o}$, $f a^{\prime} a^{\prime}$ are'are' $a$, novices) as performers.

A similar question is raised by Mühlmann's assertion that "only the higher grades were in possession of the [sect's] deepest religious secrets" (1955:34). Also, Mühlmann cited no direct evidence for his implication that upward progress in the sect also involved the learning of "secrets." But before continuing with this survey of Arioi grade levels let us look further into the matter of membership itself.

Active Ariois constituted a privileged category of persons and a fairly limited one in size. In other words, not every Maohi could qualify for membership (nor, probably, wished to do so). The various motives for joining will be examined shortly, but first an account of the three recorded routes to membership.

The best described and probably most usual route to membership was by self-indicated candidacy. Mühlmann's survey of this procedure draws on all the principal sources and embraces several essential points: 
Whoever wished to become a member was required to demonstrate that he was possessed by the god Oro-such indeed served as prime proof of youthfulness. This qualification testing took place ideally during one of the Arioi public meetings. [On such occasions] an aspirant fastened about himself a girdle of yellow leaves, painted his face scarlet (with a sap from berries of ficus tinctoria), shaded his eyes with yellow leaves, and decorated his aromatically oiled coiffure with flowers: such was the traditional costume of members of the Sect's lower grade. By appearing thus costumed the candidate gave token of [his desire] for membership. And thus outfitted he assumed the behavor known as nevaneva-deranged, howling and raving about the house where Ariois were performing or dancing, and engaging furiously in their play-acting or dancing. In this way was an individual's desire for membership in the Sect clearly expressed. Thereupon, if [the active members] were convinced of the candidate's skills in dancing and play-acting, the highest grade one of them present called him by name in friendly fashion, tapped him on the shoulder, and said to him: "Manau, manau, haere mai (you are one of us, come hither). $(1955: 28-29)^{40}$

Self-candidacy, then, was proof of an individual's own desire for membership, but acceptance evidently depended upon other factors as well.

First was approval by the sect's tutelar deity, as manifested in the candidate's state of possession (nevaneva). It is, of course, possible that by Maohi reasoning the candidate's own desire for membership came about as a result of initiative on the part of the god, and not vice versa, but I have no evidence to support either of these explanations.

A second factor was evidence of the candidate's aptitude for dancing, pantomime, and other performing. The sources also assert, with uncommon unanimity, that only those who were physically handsome (feia purotu) could successfully qualify; and while age qualifications are not specified it seems obvious from several kinds of evidence that most candidates were in the tau re'are'a period of life-that is, past childhood (tamari'ira'a) but not yet fully settled down ( $p a^{\prime} a r i a^{\prime} a$ ). Finally, although some of the earlier observers were of the opinion that only persons of highest class origins were eligible for membership, the accounts of later but better informed writers indicate clearly that candidates were accepted from all class strata. ${ }^{41}$

Before proceeding to outline a novice's progress toward active Arioihood, I must draw attention to references to two other ways in which individuals were selected for membership. The first is an all too brief passage in de Bovis that says in effect that the chief of an Arioi lodge had the prerogative of bestowing membership upon anyone "who pleased him," simply by girding that individual with his maro (1909:38). Although de Bovis does not so specify, from the context in which this sentence occurs one may infer that such an individual was thereby excused from the long novitiate which most other candidates were required to undergo.

The second reference to Arioi recruitment was quoted earlier, in connection with àmo'a: 
If any Person wishes to have his son or Daughter instituted into the Society he procures an Areeuoy to be His Son or Daughters Friend and Adopts him for His Son by performing the Amoa (before described) towards Him and His Son or Daughter at the Morai and the Child is acknowledged an Areeuoy immediately the Ceremony is over, and May Continue to follow their Methods while He or she thinks Proper. (Morrison 1935:235)

This is the only reference that I can find to this intriguing mode of recruitment, and the only inference of general interest one can draw from it is that it provides still further evidence of the prevalence and versatility of "fosterage" as a technique for instituting social relationships of various kinds.

The next stage in the accepted candidates' progress to full active membership was recounted by Henry:

If approved [as indicated above] they went through the novices' initiation, which was to pledge themselves not to suffer their offspring to live if any came to them and to obey absolutely the orders of their arioi chief or chiefess, as the case for man or woman might be. They were then invested with the maro pipi (girdle of the native pea vine), which was their public uniform, being their insigne of attachment to the society, to which they became the humble servants, the men doing all the drudgery and the women lighter work required in their expeditions and at the princely homes of the chief arioi. Their novitiate lasted two or three years, or until they became accomplished in recitals of historic events, in music, dancing, and acting (chiefly in pantomime form)....

When the novices were considered accomplished enough to be admitted into the society, an assembly of arioi convened at the marae of 'Oro for the purpose of receiving them. The poo were first privately invested by the arioi maro 'ura with a loin girdle of white breadfuit tree bark, dyed lengthwise or crosswise with wide red bars, called a fa'aio, and with a fringed cape of the same material, called a titi, dyed to match the girdle, some capes having fantastic figures printed upon them. These insignia of their profession they wore only when performing in public, the women wearing their girdles as sashes over their wrappers.

The novices were then solemnly dedicated to 'Oro-i-te-tea-moe, to whom was presented a pua'a ra'a (sacred pig), wrapped in arioi cloth of bright colors, called a haio. If the pig were presented alive, its ear was marked with the 'oro'oro, and it was set free; but if baked, it was buried in the ground in front of the marae as a sweet offering to the god.

Finally, after being anointed with perfumed oil in honor of Roma-tane of their Paradise, upon whose stone image, which stood close by the marae, they placed garlands of flowers, they were led forth by their chiefs and chiefesses and introduced to the assembly by new names by which they were ever afterwards known to the society. After a cordial reception and kind greetings from the assembly, the ceremony ended in a feast provided by the relatives of the new members, then called tara-tutu, of the eighth or last order, and for them the tattoo printer soon afterwards made the marks of their order. (1928:236-237)

Several points in this account require elucidation: first, the novices' pledge regarding future offspring. I join with Mühlmann in rejecting surgeon Ellis' observation on this point: 
It will here be necessary to observe, what it is that first constitutes a member, and some of the rights and privileges annexed to this society. It is in consequence of a most cruel and unhuman action: a man must connect himself with a girl, and the first child he has by her, must be strangled the instant it is born. At the next meeting they must bring witnesses to prove this horrid deed, after which they are admitted as members. (1782:I, 159)

I know of no other support for this improbable statement, and the missionaries would undoubtedly have noted and castigated such a practice if it had in fact existed. This of course does not preclude some candidates having practiced abortion and infanticide before seeking membership; in fact it is highly likely that many did so. My point is that proof of infanticide is not likely to have been a prerequisite for Arioi candidacy.

As Mühlmann pointed out, sources are not in agreement concerning the extent of the pledge regarding offspring. Ellis (1844:108) asserted that all active Ariois were required to obey it, whereas Henry stated: "Offspring of the lowest orders was not permitted to live, in consequence of which infanticide was a common practice among them. If any saved their babes they were dismissed in disgrace from the society. But children born in the highest ranks were regarded as descendants of gods, and were spared to inherit their parents' titles." (1928:235) Moerenhout was even more specific: "In the case of a member who happened to be an ari'i, his first son was permitted to survive whereas all his other offspring were destroyed at birth. But in the case of a member who was chief of a lodge, all his female offspring were destroyed along with his firstborn male offspring, whereas all other male offspring were spared." (1837:I, 495)

I must confess my inability to resolve these contradictions and ambiguities. Moerenhout's statement, if it is even partially correct, leaves unexplained what occurred in the case of a lodge chief who was also a member of the ari'i class-a circumstance which indeed was usually the case. Moreover, his statement seems to refer only to male sect members, although it is well established that the sect included not only female ari'i but had female lodge chiefs as well.

These uncertainties aside, however, the sources are practically unanimous with respect to the fate of those active members who broke the sect's rules regarding offspring-whatever those rules actually were. Such violators were labeled fänaunau (parentaged) and were thenceforth prohibited from taking active part in any of the sect's organized activities. Here is White's literal and vivid translation of Orsmond's text on the subject:

E arioi fanaunau, te hoe bubu arioi. Taa atura ìa tiaa. Oia ra i fanaunau ra. Ua paari tana tamarii. Ua ino īa arioi-Eita e tuu hia i o i te arioi-avae parai ra, e o ra i te bubu fanaunau ra. E ore e tae faahou
Players who became parents was a distinct class of arioi. They were made distinct because they were parents and saved the lives of their progeny. Therefore they were diffranchisd. They entered no more into the com- 
i roto i te tavehea o te arioi ra. oia hoi te tabu raa ahu. Na te maitai mai nei oia i te haere, e naha ua ino! E ua matara tona maro ura e e tae faahou i te rai raa maro ura. E ia pa parau hia ra, eiaha e tae e oto ia, e tautau tona hupe, e haere i muri ma te haama, e hobu i te vai, e e notu noa i o te mau arioi fanaunau ra. Faaturi noa, e fanau noa, eiaha ra e faa-ora, e arioi a ia. pany of black legs, but associated with those other arioi who had also become parents. They went no more into the space-of-thehead-players-in-which-the-cloth-and-weredivided. He had been in the high rank but was now defamed. His red loin girdle was taken away, the sacred pig. He went no more on the high scaffold from which was pronounced the names of those to whom severally belonged the sacred hog and loin girdle. On being told go no more up. He wept, the excrements streamed from his nose, he fell behind, ashamed, washed off his cented oil and red dye and went to dwell with players of old who had also been put out for having families. The Player may be a whore monger at pleasure and have many children, so long as he does not have one alive.

Some points in this text will be elucidated later on, and others must remain obscure, ${ }^{42}$ but it is well to note that although violators of the rule were expelled from active membership, they retained some status in the sect, as Arioi fänaunau. Bligh commented on this point:

A man after being in the Society may marry and have Children, he therefore loses his priveleges, but having had the Honor of being of the Society, he retains the Name of Erreeoy affixing the name of married to it, so there are two set of Erreeoy, one called Erreeoy Nahnownow and another Erreeoyrahigh, the latter being the highest rank. Nahnownow signifies Married and [they] do not kill their Children." (1789:I, 420)

Having children was not the only grounds for "excommunication" from active Arioihood:

E arioi repo. Te arioi maua, e arioi api, e arioi ahi maa ore, Ua itea hoi tana hapa, ua repoaīa. E arioi ino horovaru, e te haere aru. E ore e rave hia i tona rima, a viivii. E tapu hia ra i rapae au. E ore ra te mau arioi atoa e o i mua i te marae. E tapara mati ìa. E ree hia te arioi ino.

Ia hamani ino ra te hoe arioi, a aore i oto atu, e aore i faa amu atu i te hoe tiaa arioi, ua haere ra i te aehere e pupuri haere ra. E arioi iino ìa e, e ree hia. E ore roa tu te hoe bubu arioi e ite ai iana, e ore e pa te maa nana. No te mea, e arioi ahi maa ore, E arioi utuafare ore, e te manava ore, mai i te mau arioi paari.
The filthy player. The awkward player, the inexperienced player, the player without cooking facilities. His mistakes found out, he was begrimed. An evil player-he was a bushwhacker. He would not be touched for fear of contamination. He would be excommunicated. There was not room for all the players before the temple-place. These poor players would be besmeared with scarlet dye and cast out.

Should a player do evil, be inhospitable and not feed a certain group of players, but instead went and hid in the bush, these were evil players and would be Not a single group of players would accept him, not would they share food with him, because he fired no oven of his own. He was a homeless player, with no amenities for entertaining established players. 
Te horoi raa repo ra. E ere ra te repo i parai hia i nia iho iana. No roto ra iana taua repo ra. O tona hamani ino i te tiaa arioi ra. Ia ree hia ra oia, e imi oia i te manao a pa ia arioi, ua taora maira i te manava, ua eu i te buaa e ua tuu maira te peue, te ahu, te poe, e te tuu atu ra îa manahini mai mauruuru, e ma īa manahini mai mauruuru, e ma ìa tona repo. Te horoi ra oia i te repo, E riro a oia ei arioi, e e horoa hia 'tu i tana tufaa.
Wiping off the dirt. But it was not the dirt which had been smeared on him; that dirt came from within the person in question-from doing evil to the whole player profession. When he was [excommunicated], he would seek an idea [to propitiate the arioi]-he would throw out greetings of welcome, he would roast pork and bring out mats, clothing, pudding [? pearls] and distribute them for the pleasure of the guests-thus his filth would be cleansed. If he took the trouble to wipe off the dirt, he would again become a player and given his share. (Orsmond: Arioi; translated by R. G. White)

And this leads me to introduce the interesting subject of Arioi fau fenua, which Henry unconvincingly translated as "Arioi-high-in-the-land." Her text describing this type of membership follows: "When arioi retired from active life they became farmers and artisans for the society, called arioi-fau-fenua (arioihigh-in-the-land), and were still regarded as regular members; the women made cloth and did all the handiwork required by their sex" (1928:237). Judging from the rest of her account of Arioihood Henry probably drew her information mainly from Orsmond; but Orsmond himself made no reference to "retirement" in the text collected and translated by him:

E arioi faufenua. E ore ia arioi e hahaere. E ore e faatia $i$ te tere. Ei te fenua nei e rave ai i tana peu. E tanu i te o, e faaai i te buaa, ato i te fare umi, e tarai i te vaa-E fatu i te taumi, e ia oti roa ra, e mareva taua, ei hoo i toua ra maro ura, e te monoi. E faatomo i te fare i te ruru. Ua oma te fare i te ruru, i te otaa, e i te monoi. Ei reira oia a haere ai.

\begin{abstract}
The player who was always abode at home and cultivated the land was another class. They did not travel they did not join with voyagers, on shore they did their pleasures, they planted gardens, fed stock and built canoes. Made celebrated caps and on finishing a large fleet (mareva) for the players as a restitution for the honours of his loin girdle, he then filled his house with rolls of cloth till their weight and that of the scented oil tied on the rafters made the house sway down with load. Then he would also take a voyage. (Orsmond: Arioi)
\end{abstract}

Henry was probably correct in her interpretation, but on the basis of Orsmond's text alone one could not know whether the Arioi fau fenua constituted retirees from active membership or an altogether separate auxiliary with a different method of recruitment. My reason for believing that Henry was correct is based on some recorded instances of individuals who had indeed "retired" from active membership to family domesticity (including having offspring) without suffering the kind of criticism leveled at "faithless" Arioi fänaunau. A statement from surgeon Ellis concerning such "normal" retirement might also be used to support this interpretation, but could refer just as well to Arioi fänaunau: "In general, they continue in this Society 
to the age of thirty or thirty-five, when by suffering one of their children to survive, they debar themselves of the privileges of an arreoi. Many remain members all their lives, and die in a most emaciated state, occasioned by their very debauched way of living." (1782:I, 160-161)

I now confront the complex question of why active members of this sect were required to dispense with some or all of their offspring-a question which since Cook's time has intrigued students of Maohi life. ${ }^{43}$ The answers that have been proposed to this question may be treated under two partly separate headings: first, the reasons which, consciously or unconsciously, led the sect's founders to establish the sect (including its fundamental rule regarding members' offspring); and second, its members' reasons for continuing to accept-indeed, enthusiastically embrace-this rule. A passage from G. Forster exemplifies how some of the earlier visitors sought to account for the sect and its rules and privileges:

Two reasons seem to favour the existence of arreoys, and both are in some measure connected together. The first appears to be the necessity of entertaining a body of warriors, to defend their fellow-citizens from the invasions and depredations of enemies. This is confirmed by the circumstance, that all the arreoys are warriors; but as love might be supposed to enervate them, they were restrained to that celibacy, which they have since found it too difficult to observe. The second reason for the association of the arreoys, seems to be to prevent the too rapid propagation of the race of chiefs. An intelligent man, who perhaps was once the law-giver of Taheitee, might foresee, that the common people would at length groan under the yoke of this numerous and ever-multiplying breed of petty-tyrants. To oblige a part of them to a single life, was the shortest means of obtaining this end; but certain glaring advantages were to be held out, to make them submit without reluctance to such a restraint. From hence we may derive that high esteem with which the whole nation honours the order of arreoy; and likewise account for their authority, and for their gluttony in eating, which has been the privilege of warriors in every country, before they became the tools of tyranny. When the arreoys had once so far departed from the laws of their first institution, as to admit the commerce with the sex, it is easy to conceive, that, by insensible degrees, they have almost wholly lost the original chaste and sober spirit of the order. (1777:II, 131-132)

Others have proposed that the sect was founded with some other major objectives in view, and the rule regarding offspring introduced as a means of insuring that members would not be distracted by domesticity from devoting their full energies to the main business of the sect. But let us list the separate kinds of "explanations" that have at one time or another been offered, and note hereto that most writers have acknowledged that a combination of such facts was probably involved:

1a. The sect was established in connection with 'Oro worship, and the offspring rule was deliberately imposed in order to disencumber members from time-consuming domesticity.

1b. It was established in connection with 'Oro worship, and its mem- 
bers' actions in killing their offspring constituted a form of sacrifice to that sanguinary god.

2a. The sect was established as a deliberate means of general population control.

$2 \mathrm{~b}$. It was established as a means of curbing the increase, specifically, of the upper-class stratum of the population, including especially the offspring of cadet siblings of kin-Titleholders.

3. The sect was in the first instance a company of warriors upon whom celibacy was enjoined in order to guard them against the enervating effects of sexuality. Later, however, when the "strong calls of nature" (J. Forster) proved to be undeniable, infanticide was introduced to spare members of the company from the encumbrances of parenthood.

(In connection with both the "population control" and "warrior celibacy" explanations it has been suggested that the various privileges accorded the sect's members were designed to compensate them for the celibacy that was originally enforced upon them.)

4. After the sect was established, for whatever reason, and in view of the sexual promiscuity that became in time a part of its way of life, abortion and infanticide were prescribed in order to avoid the survival of offspring of mixed-class descent-a strong possibility in view of the sect's multiclass composition.

It is evident that the writers proposing the various explanations set forth above do not all share the same assumptions regarding Maohi beliefs and values. In addition to the "original-cause" explanations just cited other reasons have been put forward for the willingness, indeed eagerness, with which individual members embraced this part of the sect's precepts. These reasons differ somewhat in expression but all are aspects of what is characterized as the high valuation placed by the Maohis on "youthfulness"-in body, in activities, and in prerogatives.

Youthfulness in body meant physical perfection as manifested in face and physique, in sexual energy, and in aesthetically perfected motion. In females, according to this line of reasoning, such youthfulness was marred by domesticity and the nursing of children, and in males by the kinds of manual labor required to support a family. By the same token, domesticity, including especially parenthood, left less time and opportunity for dancing, for unrestricted lovemaking, and for other forms of diversion. And finally, parenthood meant for many individuals the abdication of some of the privileges associated with kin-Titleholding.

In other words, the things about the sect that attracted and held members were not only the positive advantages of membership, which still have 
to be described, but the institutionalized opportunity it provided for perpetuating "youthfulness" in all its gratifying aspects. ${ }^{44}$

We shall later consider how these various explanations are reflected in the sect's myths of origin, but let us turn now to other aspects of becoming an Arioi.

According to Henry, candidates for Arioihood spent their time in learning to take part in Arioi entertainments and in doing all the work required "in their expeditions and at the princely homes of the chief arioi" (1928:236). They were under oath "to obey absolutely the orders of their arioi chief or chiefess, as the case for man or woman might be." They are also described as having been "humble servants" to "the society," but it is not made clear in this passage or in any other source known to me just who their masters or mistresses were: the master (or mistress) of their own lodge? all full active members of their own lodge? or all full and active Ariois anywhere?

In connection with the candidates' initiation into full membership, the offerings to 'Oro and Romatane are explicable in terms of the sect's cosmogonic and eschatological beliefs, the latter yet to be described. ${ }^{45}$ On the other hand it is not clear what social unit Henry was referring to when she wrote of the initiates' having been "introduced to the assembly." Did she mean to other Ariois only or to the populace at large? (This bears on the broader question of the place occupied by the sect in Maohi society in general.) Ellis described the ceremony as having taken place "at some taupiti, or other great meeting of the body," and he wrote that the new member was presented "to the members who were convened in full assembly" (1829:I, 322). From this and other statements it seems fairly certain that initiation ceremonies were attended by Ariois from not only the initiates' own lodge but from other lodges near and far.

Although acceptance of a postulant's candidacy seems to have been on an individual basis, and on no set occasion, the phrasing of accounts by Henry and others leads me to believe that ceremonies of initiation involved several candidates at a time.

Another noteworthy point about the passage of Henry's quoted above is the statement that the feast terminating the initiation ceremony was "provided by the relatives of the new members." This raises crucial questions concerning the costs, in material terms, of sect membership-including, as we shall see, advancement within the sect itself.

Henry's terse statement regarding advancement within the sect is little more than suggestive: "The various orders [i.e., grades] were gradually promoted according to their merits by the society, but for the king [presumably, a tribe's sovereign chief] was reserved the right to bestow the order of the red girdle and black leg, when such a dignitary was required in the community" (1928:237). 
Ellis' lengthier text will serve to elaborate the first part of Henry's statement:

The lowest members [i.e., members of the lowest grade] of the society were the principal actors in all their exhibitions, and on them chiefly devolved the labour and drudgery of dancing and performing, for the amusement of the spectators. The superior classes led a life of dissipation and luxurious indolence. On this account, those who were novices continued a long time in the lower class; and were only admitted to the higher order, at the discretion of the leaders or grand masters.

The advancement of an Areoi from the lower classes, took place also at some public festival, when all the members of the fraternity in the island were expected to be present. Each individual appointed to receive this high honour, attended in the full costume of the order. The ceremonies were commenced by the principal Areoi, who arose, and uttered an invocation to Te buaa ra, (which, I presume, must mean the sacred pig,) to the sacred company of Tabutabuatea, (the name of all the principal national temples,) belonging to Taramanini, the chief Areoi of Raiatea. He then paused, and another exclaimed, Give us such an individual, or individuals, mentioning the names of the party nominated for the intended elevation.

When the gods had been thus required to sanction their advancement, they were taken to the temple. Here, in the presence of the gods, they were solemnly anointed, the forehead of each person being sprinkled with fragrant oil. The sacred pig, clothed or wrapped in the haio or cloth of the order, was next put into his hand, and offered to the god. Each individual was then declared, by the person officiating on the occasion, to be an Areoi of the order to which he was thus raised. If the pig wrapped in the sacred cloth was killed, which was sometimes done, it was buried in the temple; but if alive, its ears were ornamented with the orooro, or sacred braid and tassel, of cocoa-nut fibre. It was then liberated, and being regarded as sacred, or considered as belonging to the god to whom it had been offered, it was allowed to range the district uncontrolled till it died.

The artist or priest of the tatau was now employed to imprint, in his unfading marks, the distinctive badges of the rank or class to which the individuals had been raised. As this operation was attended with considerable suffering to the parties invested with these insignia of rank, it was usually deferred till the termination of the festival which followed the ceremony. This was generally furnished with an extravagant profusion: every kind of food was prepared, and large bales of native cloth were also provided, as presents to the Areois, among whom it was divided. The greatest peculiarity, however, connected with this entertainment was, that the restrictions of tabu, which prohibited females, on pain of death, from eating the flesh of the animals offered in sacrifice to the gods, were removed, and they partook, with the men, of the pigs, and other kinds of food considered sacred, which had been provided for the occasion. Music, dancing, and pantomine exhibitions, followed, and were sometimes continued for several days. (1829:I, 323-324)

This account brings out clearly the society-wide unity of the sect, as manifested in attendance at the promotion ceremony (i.e., "all members of the fraternity in the island") and in the invocation (see also Moerenhout 1837:I, 493-494). However, it does not answer the important question of who supplied the food for the feast or the bark cloth given to the Ariois. And it does not offer any rationale, native or otherwise, for the puzzling respite in eating restrictions. Nor does it indicate the bases on which promotions were made; 
"according to [the members'] merits," wrote Henry, but such merits are not specified. Moerenhout had the following to say on this point:

All candidates having pretensions to [higher grades in the sect] were first tested in public by the masters of the art. The smallest mistake, the slightest hesitation, led to their being disdainfully rejected and hooted down by their examiners and the people at large. In addition, perfect knowledge of these poems and sacred chants not only served to elevate the fortunate adept to places of honor among humans, but provided him with sacredness and made him a favorite of the gods. (1837:I, 501)

(Moerenhout's reference to sacredness is too vague for us to pursue further, but the general meaning of this passage seems clear.)

Evidently the merits in question were ones which received divine approbation, and hence included expertise in the sect's religious rituals. However, I suggest that such expertise was not sufficient to insure promotion into the higher grades of the sect. As will be presently indicated, class status figured importantly in fixing one's grade level in the sect, but I suspect that such factors as personal forcefulness and political skill were also influential, as they were in the tribal hierarchies with which Arioi lodges were so closely intertwined.

As for each lodge's highest office, the sources are quite explicit. As Henry stated in the passage quoted above, "for the king [i.e., tribal sovereign] was reserved the right to bestow the order of the red girdle and black leg, when such a dignitary was required in the community" (1928:237). A text collected by Orsmond is even more explicit on this point: The Ari'i created the Arioi Rahi, otherwise the latter would not become so. Only when agreed to by the Ari'i and the [other] chiefs did a person become Arioi Rahi... (adapted from Orsmond: Arioi).

As for the sect's highest grade, that of black-legs, I must confess to some confusion despite the attention devoted to the subject by the sources. As I have indicated earlier I am uncertain concerning the distinction, if any, between a lodge's highest official-its 'aito, or red-girdled Arioi (or Arioi Rahi) - and the grade-level of black-legs. According to Henry the statuses were identical: that is, for each lodge there were only two active blacklegs, the male and female red-girdled leaders of its respective male and female units. According to de Bovis however the statuses were separable: "The Ariois [presumably, each lodge] had [its own] red-girdled Ari'i, who was selected for that office from among their high-ranking, or rather highest-ranking members (1909:38, italics added). ${ }^{46}$

In any case, from the evidence of both Henry and Orsmond it does seem quite clear that the appointment of a lodge's two principal officials-male and female-was done by its members' tribal chief, presumably in consultation with other tribal officials and with members of the lodge's higher grades. Also, from this and other evidence it seems clear 
that class status was an important, if not the most important, criterion taken into consideration in the selection of a lodge's principal officials, as well as for promotion into its higher grades generally. Regarding the latter, Moerenhout made the following comments:

The great principle of equality [i.e., the possibility that individuals of any class could become members] was however bent in favor of the leading chiefs or arii, who, upon wishing to join [the sect] were usually admitted and placed immediately in one of the higher grades (aux premiers grades), without ever being required to submit to the numerous trials through which other members were required to pass; but even though chiefs, here as elsewhere, did remain above rules and formulas, it was nevertheless possible for other individuals to achieve, in time, the same grades as they. (1837:I, 490-491)

I reserve some skepticism regarding the generality of Moerenhout's last phrase, but none of the sources deny that individuals of ability, regardless of class, could rise to some heights in an Arioi lodge.

Before attempting to summarize the relations among members of any lodge, we need to consider some bits of information concerning one other grade level of Arioihood, and a theory that has been propounded to explain it. I refer to the grade labeled $h u^{\prime} a$ (small), the one numbered 5 in the series recorded above, which was derived from Henry and, ultimately, Orsmond. Elsewhere in the Arioi texts collected by Orsmond, and translated by White, is the following:

$\begin{array}{ll}\text { To te feia pipi ra. } & \text { E hu'a pipi. }{ }^{[47]} \\ \text { Concerning the pupils. } & \text { They are fattened-youth pupils. }\end{array}$

E te he ${ }^{[48]}$ nei, tera mai, tera mai.

There they go [?], there they go.

E puroto, e te hee nei.

They [look] handsome in their going.

E umere te vivi, e umere te vava

Astonished [are] the locusts, astonished the grasshoppers

e puroto, te hee nei.

[at] the handsomes going by.

If Orsmond's description of the feia pipi (or hu'a pipi) is meant to refer to members of a specific grade level of active Ariois, then there is a possibility at least that at this stage in the members' advance from novice to black-leg they underwent systematic fattening-not just the kind of self-indulgent regime that many persons, especially Ariois, occasionally underwent, but fattening as a distinct step in the process of grade advancement. ${ }^{49}$ However, on the basis of the evidence just quoted-the only evidence I can discover referring directly to the matter in hand-this is as far as I feel justified in carrying the argument. ${ }^{50}$

There is not much that can be added to passages already quoted 
concerning the governance of an Arioi lodge. Each segment, male and female, had its leader, whose authority was presumably far-reaching, and included the sole or overriding right to nominate new candidates, to expel sect rule violators, to promote members, and to decide other lodge matters. All novices were placed directly, wholly, and absolutely in their service. Information about the extent of their authority over full members of the lodge is not as explicit; I surmise that it was final in matters relating to Arioihood but that it did not extend so absolutely to other aspects of members' lives; it is my assumption that not all members devoted all of their lives to being Ariois.

As for the more material aspects of relations among lodge members, the sources contain the following:

The members or Arioi befriend each other sometimes with rolls of native cloth, or it may be pigs, or canoes, so that whenever an Arioi lets it be known that he needs one of these things, it has to be given. (Corney 1915:377)

They [Ariois] are united by the ties of reciprocal friendship, and exercise hospitality towards each other in its greatest latitude. As soon as an arreoy visits another, though he were unknown to him, he is sure to have his wants supplied, and his desires gratified; he is introduced to other members of the order, and they vie with each other in loading him with caresses and presents. (G. Forster 1777:II, 129)

Beyond this "mutuality" among lodge members there probably prevailed a general hierarchy of privilege based on grade level, but what these transactions consisted of we are not told. When referring to higher-grade Ariois (and particularly to those of ari'i class) a text collected by Orsmond reads as follows:

$\mathrm{Na}$ te arioi rarahi ra e tii atu i te tamarii mana, i to te hui raatira ra tamarii ei arioi, ei taetaeae arioi. Ei tii raa buaa na te arioi. E feia taoa rahi $\overline{1}$, e te maa rahi, e ore te mau tataeae ra e patoi i te feia tii i te buaa e te ahu.
The first rate arioi used to go for the primes and children of chiefs to te arioi or fraternity of players. By which means as occasioned may be, they could obtain hogs and cloth for the body of the arioi. A people possessing great property, abundance of food were the arioi. None of the fraternity would resist their request either for hogs or for cloth.

I cannot decide from this whether the objects supplied in response to requests of the high-grade Ariois came from the populace in general, or from lower-grade members of lodges.

The sources are somewhat more explicit about another aspect of intralodge transactions; I refer to the distribution of objects turned over to a lodge, whatever the occasion, by nonmembers. The places regularly set aside for such distributions (and perhaps the distributions themselves) were called tavehea, and there is no doubt that this type of distribution was presided over by a lodge's leader and participated in exclusively by active 
Ariois-supposedly by active members of the lodge in question. One will recall in this connection that attribute of a black-leg quoted earlier: "It was he who stood on the high platform and called out the names of those receiving portions of the goods" (Orsmond: Arioi). Again, in describing the plight of an expelled member it was specified that he could "go no more into the tavehea" (Orsmond: Arioi).

Sex was another aspect of Arioi relations which has been referred to repeatedly in the sources; however, it is not always clear whether the references are to the sexual activities of Ariois in general, to sexual relations among Ariois generally, or to intercourse among members of particular lodges. Of course, recorded opinions about such matters have been widely disparate.

... more than half of the better sort of the inhabitants of the Island have like Comus in Milton enterd into a resolution of enjoying free liberty in love without a possibility of being troubled or disturbd by its consequences; these mix together with the utmost freedom seldom cohabiting together more than one or two days by which means they have fewer children than they would otherwise have, but those who are so unfortunate as to be thus begot are smotherd at the moment of their birth. Some of these people have been pointed out to me by name and on being askd have not denyd the fact, who have contracted intimacies and livd together for years and even now continue to do so, in the course of which 2, 3 or more children have been born and destroyd.

They are calld Arreoy and have meetings among themselves where the men amuse themselves with wrestling \&c. and the women with dancing the indecent dances before mentiond, in the course of which they give full liberty to their desires but I beleive keep strictly up to the appearances of decency. I never was admitted to see them, one of our gentlemen saw part of one but I believe very little of their real behavior tho he saw enough to make him give credit to what we had been told. (Beaglehole 1962:I, 351-352)

They are at present, without doubt, the most luxurious set of people in the island\& though I have not found the least reason to charge them with a refinement in voluptuousness, which is at once improbable, and inconsistent with the tenderness of the whole people. We have been told a wanton tale of promiscuous embraces, where every woman is common to every man: but when we enquired for a confirmation of this story from the natives, we were soon convinced that it must, like many others, be considered as the groundless invention of a traveller's gay fancy.

Some arreoys are married to a woman, in the same manner as Mahine was to the daughter of Toperree; but others keep a temporary mistress. Many may perhaps revel in the arms of several prostitutes, which are to be met with in all the islands. This dissolute pleasure is however much more frequent in every civilized country of Europe. (G. Forster 1777:II, 132)

It appears however that the Erreeoys from leading an Idle and gay life have among them the finest Women of the Island. They have luxuriant and fine situations where they have their Meetings and live with all the disipation imaginable. (Bligh 1789:II, 78)

Here [at Papara] were a number of arreoies with their separate wives, who, by 
the attachment they shewed for their husbands, seemed to discountenance the assertion of promiscuous connexion, with which they are charged. (Wilson 1799:206)

The Erreoes are only those of the better sort, who, from their fickleness, and their possessing the means of purchasing a succession of fresh connections, are constantly roaming about; and, from having no particular attachment, seldom adopt the more settled method mentioned above. And so agreeable is this licentious plan of life to their disposition, that the most beautiful of both sexes thus commonly spend their youthful days, habituated to the practice of enormities which would disgrace the most savage tribes; but are peculiarly shocking amongst a people whose general character, in other respects, has evident traces of the prevalence of humane and tender feelings. When an Erreoe woman is delivered of a child, a piece of cloth, dipped in water, is applied to the mouth and nose, which suffocates it. (Anderson, in Cook 1784:157-159)

One of their privileges is to keep two, three, or more women at once, who however must be members. They always wear the best cloth the islands produce, and eat many peculiar things, which others, even if arees, are not permitted to do. They are generally distinguished for their prowess, valour, and activity in battle; and if any of them shew the least signs of cowardice, he is excluded the society; which is esteemed such a disgrace, that from that time he loses all his consequence, and nobody will associate with or speak to him. Their amusements during these meetings consist of boxing, wrestling, dancing, and making feasts and entertainments, at which crowds of female spectators attend, the fairest of whom are always made choice of by the conquerors. (Surgeon Ellis 1782:I, 160)

Although they were libertines in the extreme, yet an arioi husband was exceedingly jealous of his own wife, and improper conduct of one of their number towards her sometimes cost him his life. (Henry 1928:235)

In support of this statement of Henry's is another from the same source: "Marriages of the arioi were always performed at a marae of 'Oro, the accredited founder of their society" (p. 284).

In the journals of some of the early European visitors are also to be found references to specific upper-class couples who were well and truly "married" (according to my usage of the term) and one or sometimes both of whom were active Ariois in the sense set forth above. In fact each lodge of the sect is likely to have included among its active membership married couples, unmarried individuals, and individuals who were married to nonmembers. In addition, except perhaps for some of the Arioi couples, the other members are likely to have enjoyed more publicly sanctioned opportunities for extramarital intercourse, both at home and on tour, than were available to the populace at large.

Several times throughout this account I have alluded to female Ariois. The status itself is well attested by nearly all the sources, but specific references to their activities, as distinct from those of male Ariois, are practically nonexistent. As noted earlier, one account put their numbers, in proportion to male Ariois, as having been about one to five (Montgomery 1832:I, 239), 
but this estimate was made long after the sect had largely disbanded and cannot be considered anything more than a responsible guess. A statement by Henry might appear to bear the stamp of authority: "Young girls who enlisted in the role, some of whom were the cherished daughters of the highest people of the land, were carefully guarded and chaperoned by the chief arioi woman, and their persons, being regarded as sacred, were respected by all the members of the society" (1928:236). But compare this with a text collected and translated by Orsmond (who, it will be recalled, was the source of most of Henry's information!):

E vahine avae parai. Ua parai atoa tona avae e, e tiaa rahi 'toa tana. Tei te mau vahi atoa ra, e noho ai te tane avae parai, e noho atoa tu ai te hoe avae parai vahine. $\mathrm{E}$ haere hoi te mau vahine arioi iana ra.
A female black leg. There were also females whose legs were blacked these were every place where the black legged gentlemen resided. They were a seperate body for the wife of the head places. To her all actresses applied as the mates to the avae parai.

The fact of the matter is that next to nothing can be said with any assurance about this aspect of Arioihood.

I began this section by lisiting the several types of Arioi, namely, "active," parentaged, "retired," nontattooed, inspector, decorated-sennit and edgeof-the-dress. I have focused attention on the first three types, for, in fact, information about the other types is exceedingly scant. Henry (evidently drawing on Orsmond) provided a brief account of one of these latter, but the only reference to the remaining three types is in short texts collected by Orsmond. Henry's account concerns the Papa te'a (clear-bodied) Arioi, whom I label "nontattooed":

There was also an independent order of men arioi, called papa-tea (clearbodies), who did not undergo the tattooing of the society. Neither did they bind themselves to any of its regulations, but rambled from district to district to meet the regular orders and aid in their performances and share their benefits. Without being reproached they settled in homes with families when they chose. (1928:237)

Orsmond's text, on which the Henry account may have been partially based, provides a less flattering view of these individuals, who appear to have indulged themselves in many of the pleasures of active Arioihood but were unwilling, or perhaps unable, to undergo the disciplines of the sect:

E arioi papatea. Te mau arioi nanao ore. E arioi fare ore, e te ori noa, o tona ia i ioa, e te ioa o tona tiaa o Papatea ia. Faarue ia tere, tei nia i tera tere, o tana a ia peu. Tei hea to tatou nei taata? Tera tei tiaa papatea i te oriori haere noa. E aha ra oe e ori papatea mau. E mea vahavaha ra na te vahine o Tahiti te papatea ra. Te tatau a te tatau, e tatau iti noinoi ra, aore
The white [clear] skinned players were a body that had no tatoo. They had no house, they were wanderers from place to place. Their name and the name of the party was white skins. They left this party and joined with that. That was their practice. Where is our man, he is there with the party of white skins, roving from place to place. Do not have [?] a white skin, it is contemptible 
rea. Oia ra i oriori maro i tao hia tu ai e, e papa tea. to the females of Tahiti to see a skin without tatoo. They had some very small marks, but very little, but because they wandered obstinately, therefore they were called white skins.

(Orsmond: Arioi)

The other three types, if such they were, are described in the following texts:

E arioi hio niao. Na rapae au e ia arioi $\mathrm{i}$ te hio haere raa mai. Aita oia i popore mai i roto nei. E feia hiô tere ïa. E hio ratou e ino taua tere ra, E riro a ïa ei arioi rahi, e ore ra e ru i te avae parai ra.

E arioi aha vai. Te tiaa i te ahavai, e mau arioi unauna rahi roa, e te fare rarahi roa, e aore roa o ratou reporepo raa, E mea anoano atoa e te arioi, e oia te taata e tae i to ratou fare. E rahi te avae parai, e rahi atoa hoi te ahavai. Eiaha te taata repoe eiaharteotaatae maimai e tae i to ratou fare. E avau hia ïa. E au ratou i te mau orometua papaa nei i te faaenaaaru.

E arioi taratihi. E taratihi tona tiaa. Aore rea tatau. Tei te apoa avae te nanaō
The players of inspecting skill. Those were content with passing around on the extremities. They did not crave to be in the midst. They were persons who inspected narrowly the new come company, that they might find out the defects. They were sure to become first rate players, but they were in no haste to have their legs made black.

The players called decorated senet was a very celebrated boy. They had very large houses and were removed from all filth. The arioi were grand, no persons entered their houses. The black legs were high but those were also high. Let not a filthy person nor a diseased person go to their house. He could be scolded away. Those called decorated senet were as the foreign Teachers for grandeur.

The players called the edge of the dress was a distinct body. They had but very little tatooing what they had was behind in the hollow of the leg under the knee.

(Orsmond: Arioi)

It is of course possible that Arioi hi'o niao referred mainly to the duties regularly performed by some active Ariois, and not to a category distinct from active, retired, or other types. It is also possible that the label ahavai referred to some special function performed by an otherwise active Arioi, or to some specially privileged office among active Ariois. But lacking evidence of either of these possibilities, less violence is done to such information as there is by classifying Ariois as I have.

I must, however, acknowledge that I am not fully convinced of the accuracy of my overall classifications of Arioi types or grades. For example, in some of the exceedingly terse texts on Arioihood recorded by Orsmond, there is occasionally discernible a distinction between Arioi Rahi (including and even solely comprising black-legs) and another category made up of novices, active members of all lower grades, "retirees," and so forth. And somewhat parallel to this twofold division is one expressed by Morrison, who distinguished simply between "Old" and "younger":

The Old Members of this Society are distinguishd by having a black Oval tattow'd under their left Breast, one on the right side of the back below the 
shoulder, their Legs \& thighs entirely blackd from the Ancle to the short ribbs and their arms from the finger ends to the Shoulder-They are always well dressd, with the best Cloth that can be made, their hair Scented and Adorn'd with Various kinds of odoriferous flowers. The Younger Members, and indeed all in general being fond of variety, seldom remain any length of time with one Woman but are Constantly Changing. (1935:234)

Aside from novices, among all the so-called types and grades of Arioi I have sought to distinguish, the clearest distinction is between those who have abided by the sect's injunctions regarding offspring, and those who have not. I have already reproduced the Orsmond text telling how the latter, the parentaged (fänaunau), were deprived of their privileges of wearing red girdles, and so forth. A passage from Morrison also emphasizes this distinction, although the reference implied in the last sentence in the passage is not entirely clear:

If an Areeuoy preserves any of His Children (which they seldom do till they advance in Years \& the Fire of their Youthful Passions is a little quench'd) they are not treated with so much respect as when Batchelors \& are then denominated Areeuoy fwhanownow or a Childbearing Areeuoy and are not entertaind at the feasts till after the Batchelors are served tho they are always lookd on as part of the Society and treated as such. They are Never Calld upon in War and May pass through the Countrys at war without Molestation, and be well received, tho part of them belong to the enemys District. (1935:234-235)

Another kind of evidence bearing on the distinction between these two categories of Arioi-the respected and privileged childless versus the discredited parentaged-is contained in G. Forster's journal:

The arreoys enjoy several privileges, and are greatly respected throughout the Society Islands and Taheitee; nay, they claim a great share of honour from the very circumstance of being childless. Tupaya, when he heard that the king of England had a numerous offspring, declared he thought himself much greater, because he belonged to the arreoys. In most other countries the name of a parent gives honour and respect; but when an arreoy, at Taheitee, emphatically bestows it, it is meant as a term of contempt and reproach." (1777:I, 130)

But perhaps most revealing of all is Bligh's account of his participation in a presentation to some (visiting?) Ariois.

After Dinner I ... walked with Otoo to see an offering of food to the Erreoys. In this ceremony he made me the principal person. As soon as we had got to the spot where this offering was to be made whither I was carried up the River in a Cannoe dragged by eight men, (round the Banks of which I had always walked before this time,) a large quantity of Bread fruit and some Hogs ready dressed were brought in baskets and some cloth. At about 40 Yards distant sat a Man who he said was an Erreeoy, and a lane being made by the Natives, he was addressed by one of Otoo's party in sight, (standing on a Cannoe) in short sentences for a quarter of an hour. In the mean time a peice of Cloth was got ready about 6 Yds. long, (one end of which I held) and a small sucking Pig. Four Men were ordered to take four different baskets, and being desired to Walk, we proceeded to the 
Erre-oy and laid the Offering on the ground. I now spoke several short sentences dictated to me by Otoo, which as I did not pronounce them very exact, created great mirth, and I retired.

The same ceremony was gone through three different times, and a fourth to another Man who had come from Ulietea.

Otoo had several times asked me how many children I had, and I told him four Girls, but not reccollecting he asked me again, and said You must go with these things in favor of them. There remained now only 3 baskets of Bread fruit and a small Pig, which with another peice of cloth, assisted as before, I made this offering in favor of my children to the Man who was first honoured. No reply was made by him, and Otoo returned with me to the tent.

All that I could make out of this strange ceremony was, that the Erree-oys were people highly respected that they had a claim to those marks of homage for their Valour or other causes, and that there was great trust and confidence reposed in them, but what my Children had to do with them I could not conceive, unless from a supposition that they might ever exist under their Government. (1789:I, 383)

On first reading this passage I, like Mühlmann, was deeply puzzled regarding its significance. In time, however, I have come to see it as a particular manifestation of relations between childless and childed Ariois. As Mühlmann pointed out (1955:102-104), because of Bligh's position it was perhaps inevitable that the Maohis would have identified him with their most privileged people, ari'i and Ariois. And Bligh, like other childed Ariois, was especially obligated to offer objects to the more highly respected childless members of the sect. Mühlmann may have been correct in characterizing Bligh's presentation as objects in lieu of services, ${ }^{51}$ but there is also a possibility that his donation was regarded by the Maohis as an expiatory offering as well.

Both myth and ritual served to link all Arioi lodges into a unified, hierarchically structured sect, and this unity was preserved-between lodges as such and between members acting individually-in times of relative peace. But as we shall see, in times of active intertribal hostilities, ties of tribe overrode those of sect.

All the mythical versions of Arioi origins place the institutional beginnings of the sect at Opoa, Ra'iatea, and accord priority and paramountcy to Opoa's Master Arioi, whose official sect-Title became Taramanini. (According to the Henry version it was this official who also established the local lodges elsewhere.) One will also recall that Taramanini's name was uttered in Arioi invocations generally, along with that of the sect's "sacred pig" and of the generic name of its principal 'Oro-dedicated marae, Taputapuatea. ${ }^{52}$ Presumably, Taramanini would have been shown a special degree of respect on encounters between his own lodge and others; on the other hand there is no evidence of any regular flow of objects parallel to this hierarchical flow of respect. Neither are there grounds 
for believing that those lodges associated locally with taputapuatea-type marae enjoyed any special ritual or other advantages in their relationship with lodges elsewhere.

Moerenhout stated that the sect was in the beginning organized into twelve lodges, whose respective "grand masters" were called ta'ata hoa arioi (Arioi companions) and who bore the following sect-Titles (which continued to be borne by the heads of these lodges until the introduction of Christianity): Taramanini (Ra'iatea), Pouna roun [Puna rua] (Porapora), Alae (Huahine, Tauraa toua [tua] (Eimeo, Temaiatea (Mai`ao), Moutahaa [Mutaha'a] (Taha'a), and the following on Tahiti: Nouatoua [Nuatua], Mauroura, Tera'a roa, Maouaroa [Maua roa], Nita and Paa. ${ }^{53}$ Moerenhout went on to state that "in addition to these twelve superior 'grades', associated respectively with the twelve principal lodges of the society, there were several other [grades] to which any member could aspire" (1837:I, 489-490).

Both Orsmond and Ellis provided lists of such lodge masters, which agree in some measure with Moerenhout's. According to Ellis these sect-Titles were originally the names of individuals who made up the first "company" of Ariois, and who "were nominated, according to 'Oro's direction, by Urutetefa and Orotetefa":

These individuals, selected from the different islands, constituted the first Areoi society. To them, also, the gods whom Oro had placed over them delegated authority, and gave permission to admit to their order all such as were desirous to unite with them, and consented to murder their infants. These were always the names of the principal Areois in each of the islands; and were borne by them in the several islands at the time of their renouncing idolatry; when the Areois name, and Areois customs, were simultaneously discontinued. (1829:I, 315)

Given the hierarchical nature of Maohi society generally, it would be surprising if the headships of certain local Arioi lodges were not differentially distinguished in terms of respect, but I can find no other kinds of evidence relating to this particular hierarchy.

According to de Bovis, when a new lodge master was appointed he visited the "principal" marae of all the islands, se faire reconnaitre ["to have himself recognized"] (1909:38). Unfortunately, this is the only reference I can discover to such a custom, so that I do not know what this recognition entailed.

The most direct evidence on interlodge relations is, of course, to be found in the accounts already given of organized Arioi tours. Another source of information is a journal entry by Bligh that seems to concern not an organized tour but a reception for local and other Ariois coming home from an extended "vacation" at Tetiaroa. To me the chief interest of this ceremony lies not so much in its details of procedure, some of which 
I am unable to explain, but in its composite nature-that is, in the manner in which Arioi ritual was combined with official considerations of tribe:

Several Cannoes arrived at Matavai from Tetturoah, in these were a large tribe [sic] of the Erreeoys, and among them Huheine Moyere, the Wife of Oreepyah, who remained there after her husband left it. It is customary on these occasions for a ceremony to be performed called Hooepippee [hu'a pipi] which seems to be chiefly designed as a publick visit to all their friends at once, who are collected on the occasion, and I beleive it is confined to the Erreeoys.

Huheine Moyere is an Erreeoy Woman, she had two Women to attend her, who with Six Men made the principal part of the Group. The Women were dressed in a kind of short petticoat and a large quantity of very fine Cloth rolled round the Waist up to the Arms. The Men had only Marros with long peices of Varigated cloth hanging from them which nearly reached the ground, and in their hands a plantain leaf; their faces and parts of their body were Smeared with the beautiful red colour called Matte, but it is so carelessly laid on, as would lead one at first to imagine they were wounded in many places, and that the blood was issuing fresh from them.

They proceeded by pairs [to] where I was by appointment with Iddeeah to receive them. Here, walking with great pride and ostentation a few times before the House, I was presented with two peices of white Cloth, and they proceeded on to Oreepyahs. On their return they again Stopt at my Post and the Women began to undress, which before they could cleverly accomplish the Erreeoys who were not of the procession, which were a great many, began to plunder according to their accustomed right, so that all the cloth was soon divided among them.

Three large peices of Cloth with a large baked Hog and much Breadfruit were now brought to me from Iddeeah, who told me I must give that as my present, the Cloth to Huheine Moyere and the Hog to the Erreeoys, and each of us carrying the Cloth and her Servants the Hog and Breadfruit, I presented them to the parties as she directed me, amidst a great croud shouting and bellowing applause.

As a Number of people were here belonging to different districts, Iddeeah gave me dressed Hogs, \&c. to present to them also, but this was done in honor of the principal Cheifs of the places they belonged to, none of them being here.

Soon after all these ceremonies had past, a Present from the Principal People was made to Otoo. It consisted of five Hogs and forty eight Baskets holding Cocoa Nutts, Breadfruit, Tarro and different kinds of Puddings. The Baskets were hung with Cloth Variously Stained with Red. Twenty four Men carried them on Poles across their Shoulders, so that each Man had two Baskets. It was first received by Iddeeah, Tynah being absent, and from thence it was sent to Otoo, the Erreerahigh, without any other ceremony. (Bligh 1789:II, 55-56)

Elsewhere in this chapter I have given evidence of the wide-ranging sentiment of mutuality that obtained among Ariois whatever their place of residence: between lodges on tour and among individual members wherever they happened to be. The very existence of such associations may indeed have served to mitigate somewhat the hostile rivalries among tribal chiefs, but when hostilities broke out sect membership was subordinated to the more impelling tie of tribal membership:

However, the idleness of the principal Areois did not continue beyond times of peace-otherwise it would be impossible to account for their privileges and their 
persistence as a society. They were in fact a tribal chief's bravest and most faithful companions. The society was a veritable nursery of warriors, who recruited one another but who did not reproduce their kind.

The thing that accounts for the persistence and growth of the Areois, the thing that provided them with their most solid foundation, was that they never became a single political unit. Members never put aside their subordination to their respective tribal chiefs \& they took part in the enterprises of the latter and [made no concessions] to fellow Areois who happened to be in the enemy camp. They were warriors who in times of peace retired to the delights of their way of life and shared them with one another without seeking any advantage other than pleasure and convenience. Theirs was an epicureanism pushed to its very limits.... (de Bovis 1909:37)

\section{Position of Ariois in Maohi Society}

In the discussion of occupational specialization, in chaper 21, I reproduced a text recorded by Orsmond concerning the four "principal kinds" (te hui) of persons-ari'i, big-bellies, Ariois, and fishermen. I would willingly exchange a whole volume of missionary homilies or ships captains' log-entries for some insight into the Maohi logic involved in this puzzling social classification; but lacking such data I must rest content with defining Ariois' position in Maohi society according to my self-devised role classification. But first some evidence, partly previously quoted, concerning Ariois' position in Maohi society at large.

I have already commented on the exclusiveness of the sect, as manifested in the insulation afforded some of its meetings, in the distinctiveness of its members' rites of passage, and so on. As Orsmond's anonymous informant asserted:

E pupu ta'ata tino maitatai te mau arioi ra, e te toa a.

A fine-bodied company of men were the Ariois, a company apart.

E ore tona tua ra e haere hia tu. E feia mo ' a rahi.

The bed of an Arioi must not be trodden upon. They are a holy [sacred] people.

(Orsmond: Arioi)

Ariois were also a highly privileged segment of the population: "Wherever they go they exercise power to seize what they want from the inhabitants. They smite their hand on their breast, and say, 'Hārre, give,' whenever they covet any thing, and none dares deny them. They never work; live by plunder; yet are highly respected, as none but persons of rank are admitted among them." (Wilson 1799:172)

Material collected by Lavaud indicates that there were standard formulae sometimes used by Ariois in soliciting objects. The following text is titled "Formula or chant of Ariois when they went to demand tapa from the powerful children of ra'atira, that is to say, from persons of eminence." ${ }^{54}$

Here is the way they begin:

"Lie down at nighttime; lie down in daytime.

Taiheritiriti is a god, Taiherarata is a god. 
You people to eastwards and to westwards, arise;

You are being awakened by the godly hosts.

Arise. There is the star Feinui rising;

There are the crickets chirping.

We [animals] are chilled through and through."

Then they commence to play on their noseflutes and drums.

Here is their first chant:

'Seat yourselves behind the house, or in front of it;

your little [animals] are very chilled."

It is amazing how successful they were in obtaining gifts by such means at places where they called. (Roussier 1928:197-198)

Another standard formula may be involved in the following episode, although what its "deeper meaning" may be I am unable to fathom:

The Areois were countenanced, not by the vulgar only, but by the kings and chiefs, who indulged them in all their licentious practices, and probably found them very convenient tools for the furtherance of their own purposes of fraud and oppression. Availing themselves of the influence which they thus possessed, these reprobates were guilty of the most cruel exactions wherever they went. One of them, for example, would enter the house of a poor man, and by certain ceremonies pretend to make his little boy, playing on the floor, a king; then, with mock homage, he would say, "I am come to the king's house; I want food, give me that pig; I want apparel, give me that piece of cloth." And the father of the new-made king seldom had the hardihood to refuse the boon so flatteringly demanded. If he did refuse, his visitor would threaten him with banishment or death; and such threats were not to be despised. (Montgomery 1832:I, 240) ${ }^{55}$

In these pastimes, in their accompanying abominations, and the often-repeated practices of the most unrelenting, murderous cruelty, these wandering Areois passed their lives, esteemed by the people as a superior order of beings, closely allied to the gods, and deriving from them direct sanction, not only for their abominations, but even for their heartless murders. Free from labour or care, they roved from island to island, supported by the chiefs and the priests; and were often feasted with provision plundered from the industrious hubandman, whose gardens were spoiled by the hands of lawless violence, to provide their entertainments, while his own family was not unfrequently deprived thereby, for a time, of the means of subsistence. Such was their life of luxurious and licentious indolence and crime. (Ellis 1829:I, 325-326)

Wherever they travel they are fed by the Cheif of the district with abundance, who calls them his Man-nee-innees or Erreeoy Friends. (Bligh 1789:II, 78)

... the Erree-oys were people [so] highly respected that they had a claim to those marks of homage for their Valour or other causes, and that there was great trust and confidence reposed in them.... (Bligh 1789:I, 383)

They are continually going from one Island to another and from one District to 
another in Companys of four or five Hundred together upon Partys of Pleasure, and as Nearly all the Chiefs are of this Society they ever Meet with the best entertainment from them all in their respective districts. So greatly are they indeed respected throughout all the Islands, that if any of the Members take a liking to the Cloaths which they see any person wearing they are never refused them or any thing else they may chuse to Demand, and are always sure to carry off the finest weomen in the Country. (Morrison 1935:234)

The reference to bark cloth in the last excerpt points to what appears to have been an especially characteristic, perhaps even a distinctive, privilege of Ariois: "The Erree-oys also began to play their part which was to rob every Woman of her Cloaths if it was worth taking. These people it seems have the Power and privilege whenever they are in want of Cloth to take it from any Woman they see." (Bligh 1789:I, 391.) Later on this occasion Bligh interceded to protect a young woman who evidently was not submitting willingly to being thus deprived. Mühlmann interpreted the woman's actions in this episode as being ritually feigned (1955:45-46), a part of an Arioi novice's initiation; to me the woman's struggle to retain her clothing is simply an indication that Ariois' "privileges," though widely enough recognized, were not invariably done so.

That the victims of Ariois' "bark-cloth snatching" were not always nonArioi is shown in another passage from Bligh's journal; it occurred during the welcoming ceremony quoted earlier, and the deed was perpetrated by male Ariois upon female members of the sect: “... the [Arioi] Women began to undress, which before they could cleverly accomplish, the Erreoys who were not of the procession, which were a great many, began to plunder according to their accustomed right, so that all the cloth was soon divided among them" (1789:II, 55).

The characterizations made of all these privileged transactions, between Ariois and the rest of the population, have varied widely-from "ruthless plunder" and "heartless extortion" to joyfully given "hospitality" or fair compensation for highly valued services. As a matter of fact, if a wide enough range of such transactions could be examined it would probably be found to include examples of all of these, along with the finding that the same transaction was regarded by some as "hospitality" or "fair compensation" and by others as oppressive confiscation. But of course no such range of information is available, least of all in terms of individuals' opinions about such acts, so we are left with institutional modes. And in connection with these latter there is probably no better way to judge Ariois' privileges in the population at large than by the order of procedure in which they received their share of objects at public distributions-not during Arioi festivals as such but during the celebration of general religious rites. According to Moerenhout such distributions proceeded as follows: "The gods or the priests received their portion before all others; 
then the Ariois; and then the chiefs, each of whom divided his portion among his subordinates" (1837:II, 140).

The privileges enjoyed by Ariois were also manifest in their immunity from the murderous attacks of ghost-masquers, and in their licensed, public lampooning of persons of eminence and authority. And finally, the privileges enjoyed by Ariois among their living contemporaries were conceived of as continuing after death:

And such was the character of their delusive system of superstition, that, for them, too, was reserved the Elysium which their fabulous mythology taught them to believe, was provided in a future state of existence, for those so preeminently favoured by the gods.

A number of singular ceremonies were, on this account, performed at the death of an Areoi. The otohaa, or general lamentation, was continued for two or three days. During this time the body remained at the place of its decease, surrounded by the relatives and friends of the departed. It was then taken by the Areois to the grand temple, where the bones of the kings were deposited. Soon after the body had been brought within the precincts of the marae, the priest of Oro came, and, standing over the corpse, offered a long prayer to his god. This prayer, and the ceremonies connected therewith, were designed to divest the body of all sacred and mysterious influence the individual was supposed to have received from the god, when, in the presence of the idol, the perfumed oil had been sprinkled upon him, and he had been raised to the order or rank in which he died. By this act it was imagined they were all returned to Oro, by whom they had been originally imparted. The body was then buried as the body of a common man, within the precincts of the temple, in which the bodies of chiefs were interred. This ceremony was not much unlike certain portions of the degrading rites performed on the person of a heretic, in connexion with an auto de fé, in the Romish church.

The resources of the Areois were ample. They were, therefore, always enabled to employ the priest of Romatane, who was supposed to have the keys of Rohutu noanoa, the Tahitian's paradise. This priest consequently succeeded the priest of Oro, in the funeral ceremonies: he stood by the dead body, and offered his petitions to Urutaetae, who was not altogether the Charon of their mythology, but the god whose office it was to conduct the spirits of Areois and others, for whom the priest of Romatane was employed, to the place of happiness.

This Rohutu noanoa, (literally, perfumed or fragrant Rohutu,) was altogether a Mahomedan paradise. It was supposed to be near a lofty and stupendous mountain in Raiatea, situated in the vicinity of Hamaniino harbour, and called Temehani unauna, splendid or glorious Temehani. It was, however, said to be invisible to mortal eyes, being in the reva, or aerial regions. The country was described as most lovely and enchanting in appearance, adorned with flowers of every form and hue, and perfumed with odours of every fragrance. The air was free from every noxious vapour, pure, and most salubrious. Every species of enjoyment, to which the Arois and other favoured classes had been accustomed on earth, was to be participated there. Rich viands and delicious fruits were supposed to be furnished in abundance, for the frequent and sumptuous festivals celebrated there. Handsome youths and women, purotu anae, all perfection, thronged the place. These honours and gratifications were only for the privileged orders, the Areois, and the chiefs, who could afford to pay the priests for the passport thither: the charges were so great, that the common people seldom or never thought of attempting to procure it for their rela- 
tives; besides, it is probable that the high distinction kept up between the chiefs and people here, would be expected to exist in a future state, and to exclude every individual of the lower ranks, from the society of his superiors.

Those who had been kings or Areois in this world, were the same there for ever. They were supposed to be employed in a succession of amusements and indulgences similar to those to which they had been addicted on earth, often perpetrating the most unnatural crimes, which their tutelar gods were represented as sanctioning by their own example. (Ellis 1829:I, 326-328)

I turn now to more specific indications of the Ariois' place in Maohi society-to their positions vis-à-vis statuses such as marriage class, occupation, and kin-congregation.

Several writers have asserted that Ariois were drawn entirely or mainly from the upper class. As stated earlier, I believe that not to have been the case, although in terms of the total number of persons in each class the proportion of hui ari'i joining the sect was perhaps greatest. Also, although the higher grades of the sect were not closed to members of lower-class origin, it seems to have been generally true that the higher grades were populated mainly by upper-class members.

As for relations between Ariois and other members of the major class strata of Maohi society, the opinions of some observers were that they were the pampered darlings of the hui ari'i, the admired models but ruthless exploiters of the commoners, and the privileged parasites of the ra'atira (Ellis 1829:I, 319). ${ }^{56}$ Of course, no such simplistic characterizations are admissible when applied to so heterogeneous an institution as Arioihood. (I do not have to emphasize that most of these attributions were colored by the social perceptions of the observers.) There was, nevertheless, some basis for these opinions in fact. To the least affluent and least privileged members of society, Ariois must have appeared an unfettered, high-living, diverting lot; and the realization that membership in the sect was achievable even by themselves must have mitigated somewhat any deprivations suffered by them on behalf of sect members. ${ }^{57}$ To the more affluent ra'atira on the other hand, the touring Ariois must have constituted an economic drain, since a large proportion of the food and goods provided the visitors probably came from this source. (I cannot, however, accept some missionary assertions that ra'atira "disapproved" of Arioi entertainments; certain of these observers were all too ready to impute sober, Calvinistic sentiments to what they considered the Maohi equivalent of England's middle class.) Of course there may also have been individuals of hui ari'i status to whom a touring swarm of Ariois was no more welcome than a plague, but such individuals were perhaps exceptional; and in any case the demands of hospitality, reinforced by sentiments of noblesse oblige, curtailed public expression of any such resentment (including the hosts' reactions to being lampooned by their visitors). On the positive side, we have the assurance of several writers that 
much congeniality prevailed between hui ari'i and Ariois (many individuals having had both statuses). Two questions of relevance and importance that the sources do not answer, however, are, What kind of interaction prevailed between ari'i and those Ariois whose origins were lower class? And, if an Arioi of lower-class origin managed to achieve promotion to one of the sect's higher grades did this also raise his class status: did it render him (or her) eligible to marry an individual of higher class?

Connections between Ariois and hui ari'i are discernible in the official attire of lodge masters, whose red-colored girdles have been described as being imitations of those donned by the highest-grade kin-Titleholders of the more venerable kin-congregations. According to this same source, "other clothing used [by Ariois] in acting was also in burlesque imitation of royal apparel" (Henry 1928:234), but what such clothes were is not specified. Of course, there are at least two possible explanations for this "imitation." It may represent a deliberate effort on the part of Ariois to identify, sympathetically and pretentiously, with feather-girdled kin-Titleholders because of the latters' high rank in society at large. Or it may as Henry implied represent another way of expressing criticism of ari'i shortcomings, as some of the dramatic skits are said to have done. Or, what is quite likely, it may have been some of both.

Some writers have described Ariois in occupational terms, calling them "entertainers," or "players," or "warriors," or the like. "Players" they indeed were (at least the lower grades of the membership), but not all entertainers, traveling or otherwise, were Ariois. Most Ariois, probably, were also "warriors," but there is no evidence that all "warriors" were Ariois.

The connection between Arioihood and the priestly profession is a complex one. Certainly, many priests were Ariois, and it would be logical to infer, but impossible to document, that most priests attached to 'Oro-dedicated marae were Ariois.

Some writers have characterized Ariois as full-time drones, living off the toil and produce of others. Drones some of them undoubtedly were (leaving aside their services as ritualists and entertainers), but it is yet to be proved that this was true of all or even most Ariois. While on tour they could not have farmed had they wished, and they may even not have fished; but between tours it is probably safe to assume that some of them were no less industrious than their neighbors.

It is also implied in some sources that female members of the sect were in fact professional prostitutes. Information on this aspect of Arioihood is too scant and contradictory to warrant agreement or denial to this claim, but we are informed that much of the so-called prostitution that accompanied Arioi entertainments was provided by eager young non-Arioi maidens.

Regarding the kinship status of Ariois, Mühlman proposed that the male upper-class ones were in many cases younger siblings-a fact that 
may be demonstrable in a few well-known instances, but cannot otherwise be proven; ${ }^{58}$ and certainly, no native statements that I know of indicate any such predilection. This proposal is of course tied with the theory that one of the original purposes of the institution founders was to discourage younger siblings among the hui $\operatorname{ari}^{\prime} i$ from procreation.

Another connection between kinship and Arioihood is implied in the mythical account of the sect's origin, specifically, in its link with the principal kin-congregation of Opoa; but by the time history had begun to emerge from the fogs of myth the Opoan lodge of Ariois was linked with the entire Ra'iatean tribe, and derivations from Opoa of the other lodges-if such had actually been the case-were acknowledged only in the invocation mentioned above. ${ }^{59}$ Of more immediate relevance is the nature of the links between Arioi lodges and tribes. I shall list the various lodges here, but will postpone discussion of this matter until chapter 24 .

The most authoritative list of Arioi "house" names (which in the absence of contrary evidence I equate with "lodges") is that contained in the Orsmond text. ${ }^{60}$ Here is the list for Tahiti, by district, along with the title of the lodge's master Arioi ('aito, maru 'ura):

\begin{tabular}{lll} 
Tribal District & Arioi Houses & Arioi Lodge \\
& & Masters \\
\hline Pare-Arue (Te Porionu'u) & Nanu'u & Moua roa \\
Ha'apape & Te Atita & Tiaau \\
Ha'apaino'o & Te Ao e reva & Va'a iti ni'a \\
Tiarei & Matahira & Upaparu \\
Mahaena & Faretai & Raupa'a \\
Hitia'a & Pereue & Maro ura \\
Afa'ahiti & Nanu'u & Hua atua \\
One uri (Pueu) & Taharoa & Tuturu ma'a \\
Tautira & Pararo & Te ra'a roa \\
Teahupo'o & (a) Te Pu'u maru & Te ra'a roa \\
& (b) Tahuna Aharu & \\
Mataoae & (a) Pou Omata & Heiva (upaupa) ino \\
& (b) Matiti & \\
Vaiuru-Vairao & Tava ni'a & Tu mata riri \\
Vaiari (Pape ari) & Fare ute & Mata'a \\
Vaiuriri & Araiteva & Tuturu rai \\
Atimaono & Te Hi ra'a rupo & Mata'a (Te rupo) \\
Papara & Te Rehe & Mata'a \\
Atehuru (Pa'ea) & Te Fare roa & Hita \\
Puna'auia & Te Tai tapu & Puahaha \\
Fa'a'a & Te Fare o Tau'a & Paa
\end{tabular}


The Orsmond text lists the lodge names and lodge masters titles for Mo'orea as follows:

Tribal District

Arioi Houses

Te Atae pua

Tau ma mata ura

Uramea
Arioi Lodge

Masters

Tohe ura

Omaomao

Taura'a atua

I do not know how to evaluate this Mo'orea list since it does not mention the important tribal-geographic units of Ha'apiti and Te Aha roa (to each of which Henry attributed a lodge).

Orsmond's list includes only Tahiti and Mo'orea; for all the other islands of the archipelago we must depend upon Henry and Ellis, whose attributions are as follows:

\begin{tabular}{lll} 
Island & Arioi Houses & $\begin{array}{c}\text { Arioi Lodge } \\
\text { Masters }\end{array}$ \\
\hline Ra'iatea & $\begin{array}{l}\text { Nanu'u } \\
\text { Fare Ohe } \\
\text { Fare Meia } \\
\text { Tairoiru }\end{array}$ & $\begin{array}{l}\text { Teramanini } \\
\text { Airiha }\end{array}$ \\
& Tapu temu & \\
Taha'a & Tuaoteuira & Mutaha'a \\
& Te rua o te mata'i & Atae \\
Huahine & Te Vau & \\
& Para ra'au & \\
Mai'ao & $?$ & Temaiatea (after Ellis) \\
Porapora & Fare Rua & Puna ru'u \\
Maupiti & $?$ & Marore (after Ellis)
\end{tabular}




\section{ChaPter $23 \quad$ PROXIMITY AND FORCE}

We have considered how the Maohis structured their relationships, conceptually and "historically," according to such factors as sex, age, consanguinity, affinity, friendship, marriage class, occupation, and cult. Two other factors that powerfully affected how individuals interacted were residential proximity and relative strength of coercive force. Both these factors influenced somewhat the relations among, say, consanguines and affines, but we are concerned now with the part they played in reinforcing or overriding these other factors, or in shaping interaction between persons who were not consanguines, or affines, and so forth.

\section{RESIDENTIAL PROXIMITY}

The fact of where people resided in relation to one another exercised strong influence, historically, over their interpersonal behavior, although this distinct aspect of social structure was only weakly conceptualized-distinct, that is, from considerations of consanguinity, affinity, et cetera. For example, I have come across no aphorisms regarding "neighborliness," and no explicitly stated preferences for spouses based on locale. There were several words serving to express the stereotyped contempt of the shore dweller for the inlander (see chap. 14), but these referred mainly to kind of locale, not relative distance. (However, the inlanders' actual distance from the shore dwellers in question may have been a factor in the latters' attitude of disdain. I can find no evidence that inlanders accepted this view of themselves.) Also, there were words contrasting a native with a nonnative of a place, and these expressions did convey something of an invidious attitude toward the latter (see chap. 20). But these few expressions are scant and pale compared with the wealth of normative assertions and legendary episodes concerning behavior between, say, father and son, or husband and wife, or ari'i and commoner.

Yet, as we shall see, where people resided in relation to one another evidently did strongly influence their mode of interaction. 


\section{TERRITORIAL UNITS}

\section{Households}

The Maohis spent most of their lives in or around the buildings and areas making up their households-working, resting, playing, eating, and sleeping. One name for such units was 'utuäfare, which appears to have labeled both the buildings and precincts making up the unit, and the people residing there. ${ }^{1}$

The labels attributed to households by the officers of the Duff were "matteyna" (mata'eina'a) and tee (ti'i). The former was said to be

... a principal house, distinguished either by a degree of rank in its ancient or present owner, or by a portion of land being attached to it; and sometimes on account of its central situation to a few other houses: that the matteyna sets up a tee (or image) at the morai [marae], which entitles it to the liberty of worshipping there; and the other houses in the department of the matteyna claim a part in the same privilege, and are thence called tees (Wilson 1799: 184).

I cannot entirely discount these specific usages of mata'eina'a and $t i^{\prime} i$, but should point out that they do not appear anywhere else in the sources that I know of.

The average size of households is given in a continuation of the Duff officers' statement:

... in some matteynas there are eight or nine persons in the family, in others but two or three; and ... it frequently happens, that a matteyna or a tee is totally deserted. Therefore, from this account, and what I afterwards saw of the thin population, I allow but six persons to each matteyna, and the same to a tee, as the latter is often occupied by a larger family than the former....

The observations (or estimates) on which this statement was based were made in 1797-that is, after three decades of European contact, during which time the population had been reduced, by conservative estimate, to about a quarter of its previous size. ${ }^{2}$ This decrease could of course have effected reduction both in size of household and in number of households; it probably did both.

Certainly, the general impression I glean from most of the earlier sources is that nearly all Maohi households were larger than nuclear-family size, and some of them, particularly those of the "principal people," were very populous indeed. Even two decades and more after the Duff officers made their estimates Ellis described some of the larger houses on Huahine; he appears not to have been referring to special guest houses but to regular dwellings as containing "... forty, fifty, or sixty sleeping places."

One of the reasons which they gave why so many slept in a house, was, their constant apprehensions of evil spirits, which were supposed to wander about at night, and grasp or strangle those who were objects of their displeasure, and 
whom they might find alone. Great numbers passing the night under the same roof, removed this fear, and inspired a confidence of security from the attacks their idolatrous absurdities led them to expect. (Ellis 1829:II, 67-68)

Generalizations about the composition of Maohi households, and about the social relations among members of most of them, can be inferred from earlier chapters, nevertheless I wish to emphasize some additional points. Although households were made up mainly of consanguines ("real" or foster), affines, and in some cases servants, some households did at times contain individuals not so categorized; and hence the social relations among members of households cannot be entirely inferred from generalizations about consanguines, and so on. Also, the fact of residing together must have shaped relations between individuals in ways not directly attributable to "consanguinity" or "affinity," as normatively defined. In other words, coresidence itself must be reckoned to have been a more or less independent factor in shaping Maohi social relations. For example, siblings residing together interacted in some ways different from siblings living apart; and an individual shared certain life experiences with coresidents, including siblings and even nonkin, which he did not share with persons living elsewhere no matter what their consanguineal or other ties may have been. The distinctive life experiences of coresidents included not only more interaction, but somewhat differently patterned kinds of interaction-transactional, emotional, and so forth-deriving from the innumerable accommodations, small and large, required for living together. I cannot document this inference with particulars, and hope that readers will agree that I need not do so.

\section{Neighborhoods}

Preceding chapters have also established the existence in these Islands of what may be called neighborhoods-that is, although individual households were usually rather widely spaced, ${ }^{3}$ they did tend to form clusters. This tendency was observed by the missionaries as late as 1821:

This morning in company with Br Williams \& Threkeld went to Tahaa to entreat the King \& people to leave the various little districts \& form a settlement on one side of the Island that [is] nearest Raiatea that they may be visited regularly \& have a Missionary among them. They are deaf to entreaty. Their pride will not suffer them to come \& settle on Raiatea \& they say till a Missionary is come among them they will not move. They all seemed to spurn at our visit \& solicitation. The people of the Islands are dispersed about 4 or 5 families in one place, 2 in another 1 only in another 6 or 7 perhaps just where the King resides. (Orsmond, Journal, 10 August 1820, LMS Archives)

Returning to the earlier observations and estimates of the Duff officers, in 1797, their statement, it will be recalled, included the following exchange between them and a native of the "district" of Whyripoo (de- 
scribed as a "small district" between Matavai and Ha'apaiano'o [Vavau, Papeno'o], about a mile along its northern, coastal border):

This man having a shrewd, intelligent countenance, I desired Peter [the Swedish beachcomber] to communicate to him the purpose of our journey, and to ask how many persons he thought usually resided in Whyripoo; assigning for our motive the wish of the earees of Prētane [ari'i of Britain] to render them service according to their numbers: when he instantly suggested a mode, which I afterwards adopted. He said that in Whyripoo there were four matteynas, and to each matteyna there were ten tees; and by these he estimated the number of men, women, and children, to be about two hundred and fifty. I desired him to explain what a matteyna was, and what was a tee. [Whereupon were given the definitions quoted above.] (Wilson 1799:184)

What appears to be involved here is a neighborhood cluster of households consisting of one "principal" household and a number of others-all interconnected by worship at a common marae. Ignoring for the moment questions concerning the validity of this terminology, the reliability of this method of calculation, and the nature of the ties uniting the households making up "the department of [a] matteyna," let us look at the numerical results of these officers' survey. To begin with, they list the "districts" of Tahiti as having been forty-one in number, including two uninhabited ones. A few of these contained only one neighborhood each (i.e., a principal household and its associated households), but most contained several-the range having been from two to forty-two. For all of Tahiti there were 314 "matteynas" and 2,362 "tees" giving a range of two to twenty-two households per neighborhood, an average of eight or nine, and modes of nine to ten and thirteen to fourteen. ${ }^{4}$ There is no way of checking the reliability of these estimates, and their method of calculation was hardly such as to instill confidence; on the other hand there is nothing in the sources directly contrary to them.

But even if one accepts these figures, as I am inclined to do, the fact remains that they refer to 1797 and not to 1767 , when the total population of Tahiti was possibly about four times as large. The question raised by this circumstance is, Was the decline manifested in a disappearance of some neighborhoods, a diminution in number of houses per neighborhood, a general decrease in household size, or some combination of all these? It is my surmise that all three processes took place, but that the sharpest decline was in household size and the next sharpest in neighborhood size. Except in cases where whole neighborhoods died out-a development which quite possibly took place-it seems to me unlikely that there would have been a general tendency on the part of diminishing neighborhoods to move and consolidate their remnants with other neighborhoods just to maintain some standard of what constituted an "appropriate" neighborhood size. (This was, of course, before the missionaries succeeded in persuading natives to move 
their regular residences to central locations near the mission stations, a development which became quite general after 1815.)

The validity of labeling these neighborhoods mata'eina' $a$ is impossible to confirm or deny. As I have noted in several places, the numerous referents in the sources to this word are so varied, and usually so obscure and ambiguous, that I feel obligated not to add to the confusion by proposing another "authoritative" one of my own. ${ }^{5}$ On the other hand, the alleged practice of referring to each household in a neighborhood as a $t i^{\prime} i$ is quite credible, as a metaphor for its representative membership in the neighborhood marae.

The question of nomenclature is further complicated by a passage from Morrison: "The Island of Taheite is devided into Seventeen Districts Calld Venooa [fenua] (or Lands) with the name of the Head Chief of each annex'd. These are again divided into Chiefs Shares (or Patdoo [patu] and these again into lesser Division calld Bahooe which are the Squires Shares and the Lord of the Mannor holds three Bahooe." (1935:165-166.)

Elsewhere Morrison equated the "Head Chief" with "earee" [ari'i], the "Lord of the Mannor" with "Towha" [to'ofa], and the "Squire" with "Ratirra" [ra'atira]. Morrison's "Venooa" [fenua] and "Patdoo" [patu] will be discussed below. His "Bahooe" is at first sight very puzzling, for none of the more obvious transcriptions-pahoe, pahui, paui, paue-seem to have any connection with the entity in question. The answer to the problem is probably supplied in Voyage of the Duff (i.e., Wilson 1799), whose compilers evidently depended upon Morrison's manuscript for much of their ethnographic generalities. After paraphrasing Morrison's statement about districts and patu, this source goes on to relate: "The next rank [after te to' $o f a$ ] is the ratirra, or gentlemen, who has one portion to the towha's three. These smaller estates are called rahoe [rahui], from the power the ratirra has to lay a prohibition on his own land, or on any particular sort of provision, as well as the towha on his portion, and the chief on the whole." (p. 323)

Morrison also lent credibility to this interpretation in a later passage which states: "... any Ratirra can put a Raahooe on his own division (which is so named from their power to prohibit the expenditure of any species of Provisions on his own land." (1935:167). From this and the passage from Wilson just quoted it seems clear to me that Morrison's "Bahooe" is an error due to faulty copying.

What then is the relationship between "neighborhoods" and Morrison's "Rahui"? On the basis of the accounts thus far cited, the former refers to a residential center of co-worshippers, the latter to a tract of land subject to some one individual's control. They might possibly represent two different labels for the same kind of unit, or different aspects of the same kind of unit. There is nothing in the sources to controvert this identification, and a good deal of analogy exists to confirm it, at least 
with respect to some neighborhoods and some "Rahui." On the other hand it seems quite possible that there were some tracts of land-rahui-containing no households, and some neighborhoods whose lands were not subject to unitary control. Because of these possibilities, and in the absence of positive identification, I believe it advisable to keep these categories distinct.

I take it for granted that members of most neighborhoods interacted in ways additional to co-worshipping, although the only explicit reference I can find to any such activity is Morrison's description of cooperative mahi making, which I quoted in chapter 9.

As far as I have been able to determine, there were in pre-European times no household clusters in these Islands larger or denser than the "neighborhoods" just described. On the other hand, the distances between neighborhoods were shorter in some areas than in others-as, for example, around the southern borders of Lake Maeva (Huahine), and elsewhere on wide coastal plains adjacent to navigable passages in the reef. In addition, and a general tendency throughout these Islands, valley ridges served to separate the population into distinct clusters of neighborhoods.

Spatial proximity beyond the neighborhood "level" does not necessarily conduce social relations, but it seems to have done so in Maohi society; and in all cases that I can document the spatial clusters of neighborhoods just mentioned did in fact constitute discrete social units of some kind. The question is, What was the nature of the social relations within and between such larger units?

\section{Larger Territorial Units}

Some of the territorially based units I have labeled neighborhoods may have been more or less unattached, socially isolated, and "politically" autonomous, although for the eras under study I know specifically of none that so qualifies. ${ }^{6}$ But when it comes to specifying the composition and nature of those larger territorial units, the clusters of neighborhoods, the sources are far from agreement. Most writers label such units "districts," but there is wide disagreement concerning the number and size of such "districts," their degree of autonomy, and even the native term applicable to them. The matter is of sufficient importance to warrant reproducing all the more "authoritative" generalizations about it. Some of the offices labeled in the following passages as ari'i rahi or "king" refer to preeminence in the rank hierarchy-that is, to incumbency of feather-girdle kin-Titles-and not to (coercive) authority over supratribal units, as later sections will serve to elucidate.

In his journal of his first visit Cook wrote:

... this Island [Tahiti] is divided into two districts or Kingdoms which are frequently at war with each other as happend about twelve Months ago, and each 
of these is again divided into smaller districts, Whennuas [fenua] as they Call them, over each of the Kingdoms is an Eare dehi [ari'i rahi] or head whome we call a King and in the Whannuas are Eares or Chiefs. The Kings power seems to be but very little, he may be reverenced as a father but he his [?] neither fear'd nor respected as a Monarch and the same may be said of the other Chiefs, however they have a preeminence over the rest of the people who pay them a kind of volantry obedience. (Beaglehole 1955:133-134)

Bank's account, written on the same visit, is more detailed:

The Earee re hie [ari'i rahi] is always the head of the Best family in the countrey; to him great respect is paid by all ranks but in Power he seemd to us inferior to several of the Principal Earees, nor indeed did he once appear in the transacting of any part of our business. Next to him in Rank are the Earees, each of whoom hold one or more of the Districts into which the Island is divided (in Otahite there may be about 100 such districts); which are by the Earees parceld out to the Manahounies [manahune], who cultivate each his part and for the use of it owe their Cheif service when calld upon and provisions, especialy when he travels, which he often does accompanied by many of his freinds and their families often amounting to near 100 principals besides their attendants....

The Earees or rather the districts which they Possess are obligd in time of a general attack to furnish each their Quota of soldiers for the service of the Publick. Those of the Principal districts which Tupia recolected when added together amounted to 6680 men to which army it is probable that the small Quotas of the rest would not make any great addition.

Besides these publick wars, which are to be headed by the Earee ra hie, any private difference between two Earees is decided by their own people without at all disturbing the tranquility of the Publick....

Otahite at the time of Our being there was divided into two Kingdoms, Oporenoo the larger and Tiarrebo the smaller. Each had its seperate king \&c. \&c. who were at Peace\& the king of Oporeonoo however Calld himself king of both in just the Same manner as most European Monarchs usurp the Title of king over kingdoms over which they have not the least influence. (Beaglehole 1962:I, 384-386)

The next impressions recorded about Tahiti's larger territorial units were those of the Spaniards. Boenechea described the Island as being divided into eight districts, each governed by an ari'i (Corney 1913:I, 337). Bonacorsi was more specific:

There were observed in the island eight principal arii, and some others of inferior degree; and one who is the chief one of all, whom the rest recognise as their superior. Nevertheless, I do not think they render him much obedience, as each one rules his respective district. Some of the latter are at cross purposes with one another, and I believe that they even fight, at times, as do the natives of the neighbouring island called Morea. (Corney 1915:58)

According to Friar Amich:

The dwellers in this island are not fewer than eight thousand souls of all ages and sexes: there are ten or twelve Caciques, whom they call Eries, and each one rules over the people of his own District; but they all look up to the arii 
Otu as the higher and paramount Chief, and acknowledge themselves his subjects. (Corney 1915:79)

Rodriguez' account contains many references to "districts" headed by ari' $i$, but it gives no actual count. The closest Rodriguez came to specifying territorial boundaries was his references to those between the respective realms of the two ari'i, Vehiatua and Tu. (Corney 1919:118, 126, 165)

During his second voyage Cook described Tahiti as being made up of two kingdoms, which he named Opoureonu [Poreonu'u] and Tiarabou [Tiarapu], ${ }^{7}$ and he added that the former contained twenty-four "districts," the latter nineteen. J. Forster's account, written during the same voyage, describes these Islands as having been organized on "a kind of feudal system":

The great chief or king, grants to the inferior chiefs, a district or province; under them, the rest of the Arees or chiefs have portions of land allotted to them; and the Manahounes, though not of the royal family, have likewise grants of land. The chiefs of the provinces, as well as the inferior Arees, have their demesnes cultivated by Toutous, who are obliged to raise fruits and roots, for the necessary food of their Aree; to fish, to build houses and canoes, to make cloth, to work their boats in war and peace, and to do every thing they bid them: and for this service they have the overplus of fruit and fish; which latter, the chief commonly distributes among all his vassals, very impartially, if they catch a considerable quantity at once. The Manahoune, his brethren, and offspring, cultivate the ground, which is granted to them; and I cannot say, that I ever observed Toutous attached to them. In war time, the great chief, with the advice of his relations, and of the chiefs of the provinces, who seem to have great influence in public affairs, orders an armament to be prepared; and as the shores only are inhabited, the attack commonly is made by sea: for that reason they have numbers of war-canoes, built and laid up under large sheds, which are immediately fitted out upon any such requisition, from the Lord Paramount; each inferior chief and Manahoune is again either master of such a war-canoe, or he does service on board of one of them, as a warrior, and the Toutous are employed in paddling and working them. The chiefs of provinces regulate every thing in their districts, and administer justice, their authority being as great as that of the king. On extraordinary occasions, however, the king interposes his authority: thus I heard Oree, king of Huaheine, order his Hoa (Hoa signifies a friend, or chief-attendant on the king, we should call him a lord in waiting, of which the king of Taheitee has a good number, doing duty in their turns) to go into a district of another chief, and bid him tell such were the words of the Aree-rahai; to apprehend the thieves, and seize the stolen goods, which he enumerated; the goods were in part restored the same day, and the next day he was ready to punish the thieves in our presence, had we not already been too far out at sea, and had we at first well understood his meaning. At O-Taheitee we saw the review of the naval armaments of two districts, which were destined to subdue a great revolted vassal, or feudal lord, on the isle of Imeo, in the district of Morea; and we were told, that every chief of a district must send his quota towards this expedition; and even the great chief of O-Taheitee-etee, or Tiarraboo, would join in it as his duty required. O-Too, perhaps, not being well enough skilled in the noble art of war, was not intended to command the fleet, and therefore gave the dignity of high-admiral to T-Owha, chief of Atahooroo; though he told us at the same time, that he would 
likewise be in the fleet, in the quality of a warrior, or we might call it, of a knight. These circumstances sufficiently prove, that their government is a kind of feudal system; but it has much of that original patriarchal form, blended with it, which rectifies the many defects of the feudal government, and for that very reason is infinitely superior to it, being founded on principles of kindness and benevolence, and on that primitive simplicity, which bears always the stamp of perfect undegenerated nature. (1778:355-358)

The next substantive account of Tahiti's territorial organization came from Bligh, writing in 1788 :

The Cheifs of all the districts have the common appellation of Erree, and one is independant of the other. Over these people the King has no power, they will either fight for, or against him, as their interest or inclination leads them, \& this they do with impunity with respect to punishment by the transgression of a law of the Land. (1789:I, 396)

I reproduced above Morrison's summary statement regarding territorial division: "districts" (fenua), subdistricts ("Chiefs Shares," patu), and "lesser Divisions" ("Squires Shares," "Bahooe"-probably rahui). According to Morrison (writing between 1789 and 1791) Tahiti itself had seventeen districts at the time; these were united into two mutually supporting alliances, Te Porionu'u and Teva i uta, against which were the "rebellious" districts of Atehuru and Tetaha, and six districts of the peninsula. (See figs. 23-1 and 23-2.)

Hamilton, writing in 1791, added nothing to his predecessors save the statement that Tamari'i, “... a great chief in Papara, ... was the proper king of Otaheitee, the present family of Ottoo [Tu] being usurpers" (Edwards and Hamilton 1915:102).

During his return visit to Tahiti in 1792 Bligh recorded that Tahiti was divided into four "grand divisions" (or "Princedoms") which were made up of a number of "counties" or "Governments" as follows: POREONU'U: Pare, Matavai, Ha'apaino, Tierei, Mahaena, Hitia'a; Atenuru: Tetaha, Pa'ea, Paterre; TEVA I UTA (or "Otaiwyotah"): Papara, Atimaono, Vaiuriri, Vaiari; TEVA I TAI: the whole of the Peninsula, or Taiarapoo ("counties" not specified). (Adapted from Bligh 1792:166.)

The "counties" or "Governments" were also subdivided, according to Bligh, into "districts" or "chiefdoms." Bligh shared Cook's opinion that the Island was once governed by one "king," but had subsequently been divided into the four divisions known to him, each division being "independent of the rest." To this observation Bligh added the following:

There are two Words which they attach to the different Subdivisions of the Island-one is Manno, and the other Matynah. Oparre \& Attahooroo have each two Mannos, but all the others, even Tiarraboo they say are not Mannos but Matynahs. The People of Oporeeonoo are Matynahs no Tynah-those of Tiarraboo are the People (Manno) of Whaeeahtuah. Those of Terryoyootah are the People of Tomarre and those of Attahooroo of Tettowah and Poohaita- 


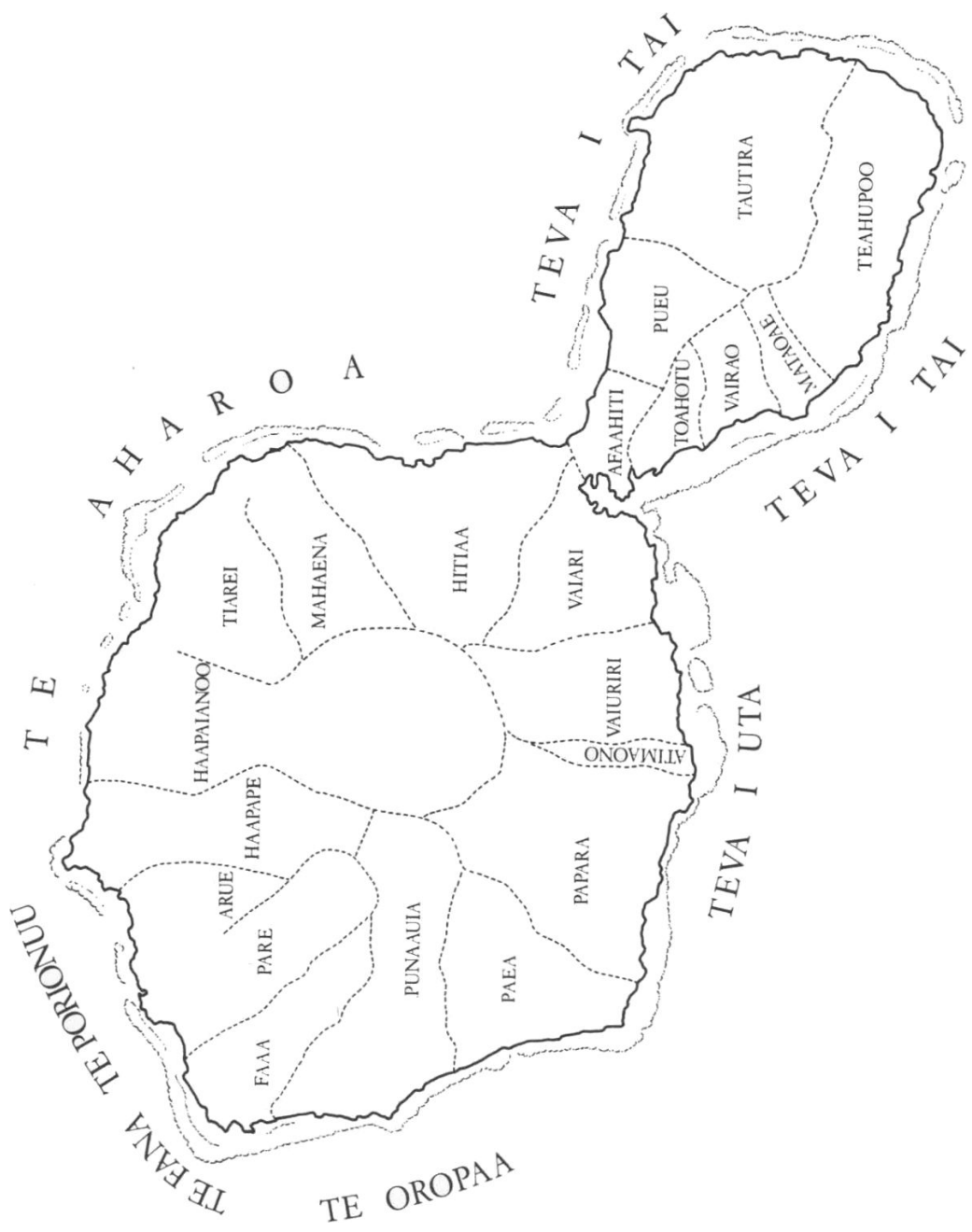

FIGURE 23-1. Principal tribal boundaries of Tahiti. 


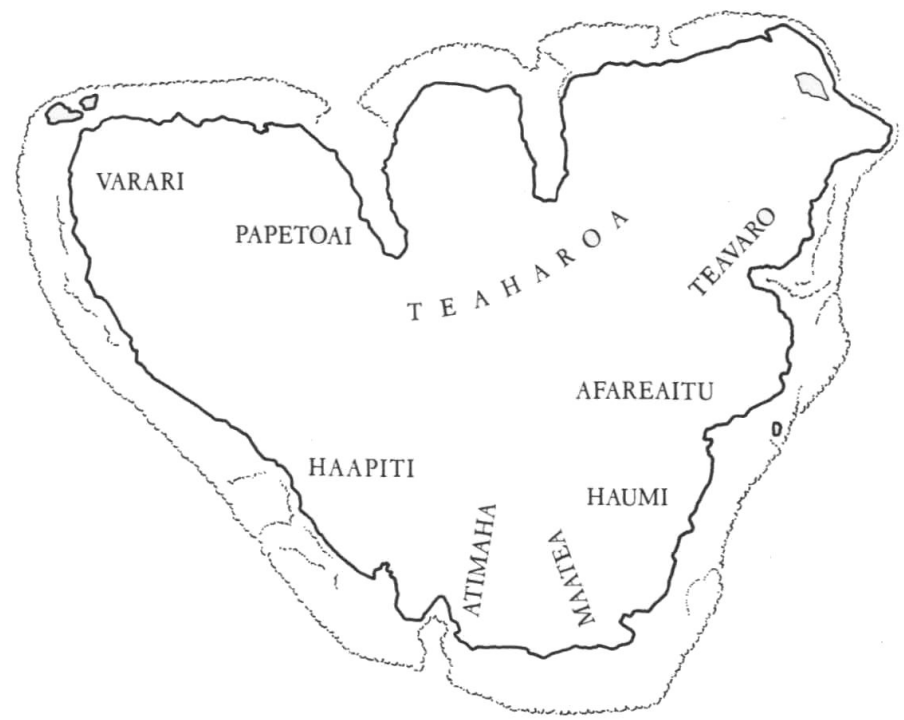

FIGURE 23-2. Principal tribal loci of Mo'orea.

iah. Yet they say that the whole of them are Matynahs no Otoo. This certainly implies he is their king.

Matynah signifies a set of People belonging and governed by a Chief, but I am at a loss to know what Manno means, unless it is the place of resort or Palace of the King. (1792:166b-167)

"Matynah" is mata'eina'a; and "manno" (mano) means many or numerous, ${ }^{8}$ and was also included in the names of the two major subdivisions of Atehuru (or Te Oropa'a): mano-tahi (one thousand [?], i.e., Puna'auia) and mano-rua (two thousand [?], i.e., Pa'ea). In this connection, the territorial unit commonly labeled Pare also consisted, as Bligh noted, of two major subdivisions, Pare and Arue; I cannot, however, find any other evidence of these subdivisions having been called mano.

The next visitor to record his impression about the larger territorial units of these Islands was Vancouver, in 1792, who wrote (evidently based on information from Tu [Pomare I] himself!): “Otoo's authority is acknowledged in Otaheite, Morea [Mo'orea], Mattea [Makatea?], Tetero [Tetiaroa], Tupea-mannoo [Tupae-mano, Mai'ao], and Huaheine [but not, he added, in Ra'iatea-Taha'a] (1801:328).

Thereafter, the London Missionaries arrived on the scene and were administered daily lessons in the realities of Maohi political geography; yet even their most literate chronicler, William Ellis, drawing on nearly thirty years of missionary experience, including six years of his own, persisted in describing the pre-Christian polity in terms of kingdoms, viceroys, barons, and other faintly analogous but mischievously inappropriate Euro- 
pean terms. Later writers or editors were either too far removed in time from the pre-European polity or too preoccupied with supposed European parallels, or both, so that their generalizations about the larger Maohi territorial units are of little use. Nevertheless, by reexamining the data contained in such sources as Henry, Montgomery, and the LMS Archives, along with opinions supplied by earlier writers, it is possible to put together a construct of Maohi territorial units that may be lacunary but at least is consistent.

\section{Orders of Territorial-Unit Complexity}

First-order tribes. Next to the household itself, the smallest territorial unit in these Islands was what I have called a neighborhood, consisting of one or more households. Evidence was presented earlier of Maohi beliefs relating to autonomous neighborhoods, ${ }^{9}$ and during the eras when these Islands were being populated there must have been many such. But as noted earlier, by the Late Indigenous Era there appear to have been no autonomous territorial units, or tribes, ${ }^{10}$ simpler than that of Tetaha, which consisted of several neighborhoods combined into at least two multineighborhood subunits. Most of the tribes of that era were more complex than that, and even Tetaha was able to preserve its autonomy only by means of shifting alliances with its more complex and populous neighbors.

Second-order tribes. The simplest tribe larger than a single neighborhood would have been one composed of two or more neighborhoods differentiated only to the extent that the chief ${ }^{11}$ of one of them exercised final authority over all of them in events involving all of them. (The events in question might have had to do with a whole range of activities, but were probably most definitively concerned with combined action against outsiders.) Most of the territories comprising such simple multineighborhood units were evidently contiguous, but there may have been some that were not so. For example, in their survey of Tahiti's peninsula, the Duff officers showed the "District" of "Ereemeoo," consisting of seven mata'eina'a, fifty-one $t i$ ' $i$, and under one chief, as divided into two geographic parts which were separated by the "District" of "Bobeourooh" (Wilson 1799:199). Although "Ereemeoo" may indeed have been autonomous in earlier eras, by the time of this survey it had long since become combined with others into larger units. Again, most such units acquired in time a common name, but that may not have always been the case. As for the source of the common name, in some instances the name of the principal neighborhood may have been extended to the whole unit, but I believe that in most instances a different name was invented, or borrowed, for the whole.

Third-order tribes. Next in order of complexity was a tribe composed of two or more multineighborhood units each with its own local chief but 
all subject to the ultimate authority of one among them. On Tahiti itself, during the eras under study, this multi-multi neighborhood order of complexity seems to have been exemplified only by Fa'a'a (Tetaha, Te Fana i Ahurai).

Fourth-order tribes. More complex still was a type of tribe composed of two or more multi-multineighborhood units. On Tahiti one such unit was known as Te Porionu'u, made up of the multi-multineighborhood units of Pare and Arue, before their overall chief Pomare I succeeded in extending his sway elsewhere.

The native label fenua seems to have been applied to tribes of both the third and fourth orders of complexity; and if one follows Morrison's usage, the major subdivisions of both would have been patu-although, according to Bligh, Pare and Arue were also known as the two mano of Porionu'u. But again, some writers apply the labels mata'eina' $a$ and va'a mata'eina' $a$ to these territorial units and their inhabitants, respectively.

Fifth-order tribes. A fifth order of complexity was the type of unit latterly exemplified on Tahiti by Teva i uta and Teva i tai. As we saw, Bligh called such units "grand divisions" or "Princedoms," and Morrison referred to them as "alliances." To the best of my knowledge there was no distinctive native lable for this type of unit.

The units I have included in this fifth order of complexity, on Tahiti and elsewhere, differed markedly in degree of integration. Teva i uta (Landward Teva), for example, was an old and fairly stable unit; for a long time before 1767 its three eastern subdivisions (fenua?), Atimaono, Vaiuriri, and Vaiari, had been firmly dominated by the chiefly dynasty of its western division, Papara. And Teva i tai (Seaward Teva), composed of the several second-, third-, and fourth-order units comprising Tahiti's peninsula, had for some time been a stable union dominated by a single line of chiefs.

During the five decades after 1767 these and other Tahitian territorial units were linked to one another in various shifting combinations, and in the end all Tahiti (along with Mo'orea) was united into a single, sixth-order unit. But that is the subject of volume 3 .

Throughout the foregoing I have written of distinct "orders of complexity," but now I feel it essential to issue a caveat. My classification may have a certain usefulness in calling attention to regional differences in Maohi territorial organization and to the general trend toward larger and more complex unities. On the other hand, that trend probably was a continuous process or a number of parallel continuous processes; and to describe the outcomes at any one point in history in terms of "orders of complexity," or some such metaphor, is to imply more of a notion of discontinuities than probably obtained. 


\section{The Nature of Territorial-Unit Interrelations}

As postulated earlier, the very circumstance of residing together was an influential factor in shaping the relations among members of any household, whatever other bases for interaction there might have been. Residential contiguity also must have been an influential factor in shaping relations among members of neighboring households-providing opportunities, as it doubtless did, for frequent face-to-face encounters. But in addition, within the units I call neighborhoods the residents' face-to-face encounters in the ordinary course of everyday life were supplemented, we are informed, by their co-worship at a common marae, and by their common association with a "principal house," which was "distinguished either by a degree of rank [grade of kin-congregation office?] in its ancient or present owner, or by a portion of land being attached to it; and sometimes on account of its central situation to a few other houses" (Wilson 1799:184).

The last named basis for neighborhood unity cited by the Duff observers is one of spatial position alone, but all the others strongly suggest that the Duff officers" "mateynah"-and, by extension, my "neighborhoods"-were none other than the territorial aspect of the local kin-congregation units, which I described in chapter 16. The parallels are not complete: for example, the Duff officers made no mention of household (i.e., "family") marae in addition to the common "mateynah" (i.e., neighborhood) one; and they omitted references to kinship ties among their "mateynah's" households-but this is not surprising in view of their survey procedures and of their superficial acquaintance with Maohi kinship relations. In any case, if the Duff officers' "mateynahs" (and my "neighborhoods") were not kin-congregations, I cannot conceive of what other kind of unit they could have been!

Turning now to more complex orders of territorial-unit organization, it may be recalled at the outset that at the time of first European contact most Maohi tribes consisted of contiguous subdivisions, or, if they were not actually contiguous, they were at least near one another. Proximity plainly was a factor in the development of such units; but the "proximity" I speak of is not to be measured in terms of "crow-fly" distance, but rather in terms of relative physical access.

The effectiveness of mountains as barriers to social interaction is clearly evident in the location of territorial-unit boundaries. Conversely, the social distance between settlements tended to be greatly shortened when they fronted on leeward, protected lagoons. Yet, such natural features were not invariably determinative. For example, Taiarapu's formidable mountains and dangerously exposed southwestern cape waters did not stop southern shoredwellers in Teahupo'o from seizing and maintaining control over people living on the transmontane, cape-separated side. Also, the settlements 
facing each other across the narrow, lake-like lagoon which separated northern from southern Huahine seems for a long time to have been more divided than joined by the water. On balance, however, proximity between territorial units, measured in terms of physical accessibility, was an influential factor in uniting such units; but it was by no means the only factor, or perhaps even the most important one.

Kinship, as we have seen, was perhaps the most influential factor in integrating single neighborhoods-assuming, as I do, that such units corresponded to kin-congregations. Kinship was also an influential factor in the formation of territorial units of more complex orders of composition.

One process accounting for the tribal or subtribal unity of neighborhoods was the familiar one of kin-congregation ramification, which was described so fully in chapter 16 that I need not describe it again. There must have been many units of the second order of complexity (i.e., multineighborhood units); in fact some tribes or subtribes of third- and fourth-order complexity appear to have been formed around a set of kincongregations connected in this way. In most such units the interrelated segments were probably spatially contiguous, but that was not always the case.

However, kin-congregation ramification did not invariably serve to extend tribal boundaries. As we have seen, spatially separate offshoots of the same "ancestral" marae (marae tupuna) were often integrated into distinct and even mutually hostile tribes; and the same may have been true of some segments that were spatially contiguous. Conversely, there were instances of alliances between distinct tribes based mainly on the presence within each of branches of a common kin-congregation.

Another kind of "kinship" process that served to bring about or to consolidate tribal accretions and intertribal alliances was marriage between members of the respective tribes' chiefly families. An example of the former appears in Adams' version of the union between Pare and 'Arue. The story concerns the family line that culminated in the so-called Pomare dynasty of the Porionu'u:

Tu of Faarava, having undertaken a visit to the distant land of Tahiti, came in by the Taunoa opening, which is the eastern channel into what is now the harbor of Papeete. Landing at Taunoa a stranger, he was invited to be the guest of Mauaihiti, who seems to have been a chief of Pare. Tu made himself so agreeable, or so useful to his host, that Mauaihiti adopted him as hoa, or brother, with the formal ceremonies attached to this custom, which consist in a grand feast, and union of all the families, and offering of all the rights and honors which belong to the host. Tu accepted them, and at the death of Mauaihiti he became heir and successor in the chief's line. He gave up all idea of returning to the Paumotus, and devoted his energy to extending his connections in Tahiti. He himself married into the Arue family, which gave his son a claim to the joint chiefery of Pare Arue.... (1901:85) 
Other examples of tribal accretion brought about by this means will be offered later on. ${ }^{12}$

There are also accounts of the consolidation of new tribal accretions by marriages, after the accretion itself had been effected by other means, mainly force. In fact, I suspect that some of the accounts of accretion-bymarriage were ex post facto rationalizations of forceful seizure.

The sources also contain legendary and semihistorical instances of intertribal alliances having followed from, or been consolidated by, marriage. Yet, many more instances could be cited wherein marriage between chiefly families did not result in fusion of the respective tribes, or even alliances between them. The individual offspring of such marriages may have been thereby entitled to places of honor in both tribes' marae, without any extension of such relationships to other members of the two tribes. Indeed, traditional instances can be cited of marriage, or at least of marriage failures, having led to open warfare between tribes. ${ }^{13}$

According to legend, some tribal chiefs acquired new adherents by voluntary action on the part of the latter. An example of this was provided by Adams in his legendary account of how a Marama, chief of Ha'apiti (Mo'orea), came to extend his domain over parts of Afareaitu:

Two under-chiefs of Afareaitu, called Tuhei and Matafaahira, built a Marae which was to bear the name Horora. They wished to dignify their Marae, and give it the rank of the Maraes of high chiefs, and they selected the chief of Nuurua as the one whose supremacy they preferred; for, whoever he might be, the chief who mounted their Marae made it and them sacred to himself,-became in fact the head of their family and the master of their power, much as a feudal lord became master of one who sought vassalage, except that the Tahitian head-chief was both spiritual, temporal and patriarchal head at once; and the chief of Nuurua seemed to be looked upon as the mildest and least aggressive of head-chiefs

Tuhei and Matafaahira went to Nuurua to see the chief, whose official name [was] Punua Teraitua.... Teraitua seems to have been the butt of Moorean satire, for the story says that when he heard that Tuhei and Matafaahira were coming, he hid himself that he might not be obliged to see them. The visitors were not to be got rid of in that manner, and as they insisted on seeing him, he had to receive them, which he did at last in the presence of the high-priest Te mooiapitia; but, instead of treating them with respect, he showed complete indifference to their request, declined to give a decided answer, and told them he would consider the matter.

The least civility he could offer was to give them the usual guest-pig, and the pig was ordered to be killed and cooked, but while the feast was preparing, the messengers arrived who had been sent by Tuhei and Matafaahira in advance, and had tarried on the road. To the astonishment of Temoo, the high priest, the messengers were received with more courtesy than had been shown to their masters, and to his still greater astonishment, at the feast the best part of the pig was given to the messengers while the intestines were passed to the masters. Temoo then said to the two under-chiefs: "You see how Teraitua has ridiculed your request and has shown his contempt by giving you the intestines of the pig. What more do you want? Return home, and mount your Marae of Horora yourselves". They said: "No! our people wait; all is ready; and our minds are made up, and declared to the peo- 
ple, that our Marae of Horora shall be mounted by one higher than ourselves". "Then why not ask Marama?" said the high-priest; "He will receive you with more courtesy and treat you with less contempt."

So Tuhei and Matafaahira went on from Nuurua to Amehiti, and arrived there after Marama had gone to sleep under the effects of his kava. The natives still show the cave where Marama drank kava and where no sound was permitted; not even the crowing of a cock, that his repose should not be disturbed. The chief's person was sacred when under the influence of kava, and the man who dared to disturb him did so at the risk of his life. The two under-chiefs, who were in haste to get their ceremony at the Marae performed, could not wait, and went to the priest for advice. He told them to take the sleeping Marama on their backs, and risk the consequences of carrying him off. They followed the advice, and each taking one of Marama's legs, were carrying him off, when Marama awoke and asked who they were and what they wanted.

"We are Tuhei and Matafaahira", they answered.

"Welcome, then, to Amehiti", said Marama.

"We need welcome, for we come to beg a favor. Come with us to Afareaitu, and mount our Marae of Horora."

"Your request must wait till I can call my districts. Atituhaui and Fanauaraa; Atitanei and Tefanaautaitahi; Rotu and Tefarerii; Porotonatoofa, Amehiti and Tupaururu. Marama cannot go alone without his two Vaa (canoes; i. e. districts.)"

"We will be your Vaa", they replied: "We pray you to be satisfied with Amehiti and Tupaururu who are at hand."

Marama at last consented, and was carried over the mountains to Afareaitu, where he mounted the Marae of Horora. The third chief of Afareaitu, Tepauarii, who had not taken part in the proceeding, heard the drums, and asked what they meant. When he was told, he said: "Be it so! Marama is worthy, and I too bow my head to him."

Thus Marama was chosen chief of Afareaitu, and became head of that district as well as of those he had inherited and those he had conquered. In the meanwhile Terai tua of Nuurua becoming conscious of his mistake, had called his people to carry him to Afareaitu, but on the way learned that his place had been taken, and he too bowed his head to the choice. (1901:168-171)

Another process that may account for the tribal or subtribal unity of some territorial units was common commitment to a distinctive religious cult. In this connection, I have referred many times in previous chapters to traditions regarding the spread of 'Oro worship from Opoa (Ra'iatea) to other islands, culminating in the establishment of several 'Oro-dedicated marae. Through such measures, Opoa's influence was undoubtedly widened; and tribes containing such cult centers may thereby have become more well disposed toward one another in some instances. But I can discover no evidence, legendary or historical, that this kind of cult commitment alone ever resulted directly in the actual integration of separate tribes. Several instances can be found of a distinctive and more or less "religious" ideology having served as motive (or at least as the announced reason) for conquest by force. ${ }^{14}$ And several more can be cited in which commitment to some cult followed upon success in warfare, but not the other way around.

This brings us to consideration of coercive force, which more than 
any other factor served to integrate and maintain the unity of tribes, at least of those beyond the second order of complexity-the so-called simple multi-neighborhood units.

\section{TRIBES}

\section{Force}

War is growth (extension) to the land,

Establishment of rock strata (great men),

Spreading out of land (population).

Take the spade (war weapon).

Dig the holes (drill the lines);

War is fertile soil;

Soil that will produce seeds (extension),

Soil that will be verdant (produce power),

Soil spread out,

Soil for leaning slabs (increase of priests),

Soil for pavings (for marae).

(Henry 1928:307)

Judging from many pieces of evidence in the sources, sentiments of kinship and common cult-commitment, even backed by awesome supernatural sanctions, were rarely sufficient to hold together indefinitely tribes of more than multineighborhood complexity; and only exceptionally were such sentiments directly effective enough to fuse such units into larger ones. At some point, coercive force, or the threat of such force, played a role both in forming the more complex tribes and in keeping them integrated. I shall describe the relation of force to maintaining tribal unity, but first let us consider it in relation to tribal expansion. As with other matters relating to the Maohi past, the evidence is a blend of legend and history-both being illuminating, although in somewhat different ways.

Whether or not it is "history," Handy's description of how Opoans came to rule all Ra'iatea reveals one Maohi version of this supposed chapter of their past:

The inmates of the marae dwelt in the great house, sleeping, eating, making their weapons and implements, and performing their rites there. Their women and children all lived i uta (inland or upland) for fear of being killed. The land on which the marae stood was called "Hiti Nia" (Upper Hiti), and the region about it was termed the "Po" (darkness, night). The rest of Raiatea was the "Ao" (light). Sacrifices brought to the marae were spoken of as being brought to Po, and its inmates were said to dwell in the Po. On the west the boundary of the Po was marked by a stone named "Tuia" (tu'ia). The point of land on which the marae stands is "Matahiraterai" (Mata-hira-te-ra'i). The Po extended on the east to the border of the land "Matarepeta" where dwelt the people of Hotopu.

The warriors of the chief would go out, sometimes by canoe, sometimes by land, going to this or that house through the length and breadth of Raiatea. Coming to a house they would inquire, "Aita te hue parari?" (Is the gourd not broken?) 
If an inmate replied, "No," the household was spared; but if the reply was, "Yes," the householder was thrust through with a spear and with all the members of his family, was taken back to the marae. Only adults were impaled; children had a spear thrust through one ear and were dragged in the water behind the canoe. Those that did not drown before they reached the Po were killed at the marae. The skulls of the sacrifices were thrown into the great box-like platform. The following was said to Oro when sacrifices were presented, and to the Arii when his food-never human flesh-was brought, or when he was called to come and eat:

Eat The-fish-with-long-legs (man)

And The-fish-with-angry-fin (urupiti, or cavalla fish),

And the fish-with-reddish-back (turtle).

"It is not to be inferred from this that human flesh was ever eaten by the inmates of Taputapuatea," said Roometua. The reference to long-legged fish was figurative, so far as the Arii was concerned.

It was at this time that Raiatea was divided into eight districts. The Arii at Opoa took his urupiti (cavalla fish, signifying Raiatea), cut it down the middle, and laid the two halves down side by side. Each side he divided into four mataeinaa. Hence the saying, "E vau Raiatea" (Raiatea the eight). Opoa was the head of the fish, the ninth part, hence "Opoa te iva" (Opoa the ninth). (1930:89-90)

Similar instances of one tribe's domination of a whole island were cited earlier, in reference to Huahine and Mo'orea, but without details (chap. 16).

When Europeans arrived on the scene all the "districts" of Tahiti's peninsula were united under the chieftainship of a holder of the Vehiatua Title, associated with Marae Matahihae of Teahupo'o "district" (see chap. 16).

The story of how part of this union came about is related by Ari'i Ta'ima'i, via Adams. After describing how Tavi the Tautira chief had vanquished Papara (but not seized it) in a dispute over his wife, Adams related that:

Tavi became by this triumph the most powerful chief in all Tahiti, and asserted his power by imposing a rahui for the benefit of his young son, Tavihauroa. A rahui was a great exercise of authority, and was more than royal in its claims. The rahui, which might last a year or more, was a sweeping order that everything produced during that time in the whole territory subject to the influence of the chief should be tabu or sacred to the young prince. Not a pig should be killed; not a tapa cloth or fine mat should be made; "not a cock should crow," except for the child; and at the end of the rahui, all was to belong to the infant.

Tavi's direct and full authority extended only over his own chiefery of Tautira, but by rank or courtesy, through his family connection or his influence, it extended over the whole island, and only Eimeo or Moorea was exempt. A rahui was a form of corveé to which other great chiefs seldom willingly submitted; but even if a chief were himself anxious to avoid a war, which was the penalty of breaking it, his wife or his sisters or his relations were always ready to urge him to conspire against it. Tavi's chief rival was Vehiatua, head-chief of Teahupoo, which backs against Tautira on the south. Vehiatua had a daughter who had mar- 
ried the head-chief of Pare Arue, the district in the extreme north where the city of Papeete stands; and this daughter, Tetuaehuri, was about to give birth to a child.

... Tetuaehuri was with child, and her midwives or attendants, or, as we now say, her medical advisers, told her that she must eat pig every day. If Vehiatua was consulted he gave his assent, for Tetuaehuri broke the rahui and eat [sic] the pig. Tavi acted at once as though this were a declaration of war by her father; he crossed with his warriors into Teahupoo and was totally defeated by Vehiatua.

The quarrel must have been unusually bitter, for this was one of the few instances where a great family was driven fairly out of the island. Vehiatua did not imitate Tavi in generosity, but seized his land. Some say that Tavi went to the Paumotus, but certainly after the war of the Rahui he was never seen again or heard of in Tahiti. His son, Tavihauroa, the cause of the disaster, came back and was protected by his old neighbors and relations, the chiefs of Hitiaa, Mataoae and Vaiari. By giving him land and servants they made up a small district for him, the modern Afaahiti, five or six miles of the coast beyond the isthmus of Taravao. He had also the names of Territua in Hitiaa and Terii oiterai in Vaiarai.

One day the unfortunate young chief was flying or racing his kite, a common amusement in ancient times when the men made kites as big as a house, and raced them against each other. The strong southeast trade wind which blows across the isthmus of Taravao carried the kite some miles to the westward, and he pursued it until it lodged in a tree within the Marae of Farepua in Vaiari. The high-priest happened to be conducting some sacred caremony in the Marae, and at such a time the intrusion of a stranger was death. Terii oiterai climbed the tree to recover his kite, and was then and there instantly killed.

The extinction of this line must have been a serious matter for the island, because it gave to Vehiatua so great an increase of power as to make it a mere matter of time when he should do to Papara what Papara had done to Vaiari, and become the political head of the Tevas, and therefore the most powerful chief of the island. The Papara chief could escape danger only by an alliance with Vehiatua, and accordingly in the next generation Vehiatua had for a wife Teeva Pirioi, an elder sister of the Papara chiefs Aromaiterai and Tuiterai. Papara managed to retain its supremacy for that generation, but the danger was always there.... (1901:27-30)

By genealogical reckoning these events took place only shortly before Wallis' arrival. Earlier, however, Teahupo'o had already seized a part of Tautira as the result of a boundary dispute. According to Henry, Teahupo'o district's former name was Matahihae:

The name Teahuupo'o was derived from a wall of heads taken from people slain in a battle between the districts of North and South Tai'arapu. One party contended that the other did not observe the proper boundary line between Tautira and Matahihae. So when the matter was settled by strife and bloodshed, the victorious southern side decapitated their slain foes and at Râpa'e made a wall of their heads for the boundary line. (1928:86)

According to this same source, the nine territorial subdivisions of Tautira seized in this war were thereafter called “... Fenua-ai-hua-ra'au (Landeating-small-wood), signifying that they were tributary to a conquering power ruling over them, a condition to which they were subjected after conquest by the chiefs of the South when they erected a wall of heads. Upon 
these subdivisions were placed chiefs and marae from the south, according to the custom of conquerors." (p. 87)

The last sentence above describes one method used by victors in integrating conquered territories with their own. Another and less radical procedure was to retain a defeated chief or subchief in his office, and require him to render tribute. This compromise was most likely resorted to when a victory was less than absolute, but it was a dangerous gamble for the victor in view of the Maohis' penchant for revenge. In still other instances the victor's reason for waging war appears to have been satisfied with devastation of the opposing tribe's settlements, and so forth, without any subsequent assertion of authority over the conquered territory-but there is ample evidence that during the eras under study physical force, successfully deployed, was a common and favored method for tribal expansion.

\section{Size}

An important question raised by the foregoing concerns the sizes (and, by implication, the orders of complexity) which Maohi tribes tended to reach and maintain before European times. I do not propose anything here quite so static as an equilibrium model, but there are certain parallels. For example, although we have no way of knowing whether the population was stable or on the increase, the techniques and goals of food production seem to have become fairly fixed, as were other activities-such as therapeutic practices, warfare, and the division of labor along sexual lines-having to do directly with size of population and application of human resources. Of even more direct relevance is the historical circumstance that during the Late Indigenous Era there were no stable tribes less complex than multi-multineighborhoods, and none encompassing complexities greater than those characteristic of Tahiti's Seaward Teva. ${ }^{15}$ By that era, simple multineighborhood units had become integrated into larger ones, and recorded efforts to consolidate units larger than, say, Seaward Teva, either met with successful opposition (internal or external) or resulted only in unstable alliances. ${ }^{16}$

We have already seen what happened in certain cases when some tribe's chief sought to extend his rahui authority beyond his tribal boundaries. The best reported instance of this will be reproduced in volume 3. Another kind of evidence relating to "maximum" tribal size is contained in accounts of secessionist intratribal strife (as distinguished from revolution aimed at supplanting a tribe's ruler, which will also be discussed later on).

The reasons are more elusive for there having been no tribes extant during the Late Indigenous Era smaller or less complex than multimultineighborhoods. Since most multineighborhood units were probably self-sufficient in the material necessities of life, the factor of "economic" interdependence cannot have figured very widely in tribal expansion or 
fusion. And I am unaware of any other functional reason for all tribes having reached or passed the reported minimum. Hence, I can suggest only the phenomenon of personal motivation, that is, the desires of certain tribal chiefs to expand their domains and increase the number of their subjects as far as practicable. In other words, under such circumstances as these, any unit smaller than multi-multineighborhoods was probably not strong enough, militarily, to resist absorption by larger units. Moreover, units as small as these were probably headed by chiefs insufficiently influential (for one reason or another) to form alliances protective enough to resist such absorption.

\section{Composition}

Having touched upon tribe composition in terms of numerical size and constituent territorial units, I next inquire about individuals' requisites for membership in a tribe.

By definition, it would seem that everyone residing within the physical boundaries of a tribe was a member of that unit; and if coresidence had been the only common feature serving to categorize such persons I could leave the matter there. But that was not the case. The units I am now concerned with were made up of persons who were at the same time coresidents and subject to the authority of the same chief. ${ }^{17}$ The statement of that generality, however, does not exhaust the matter.

I have noted repeatedly that the Maohis moved about a great deal, and much of this movement was across tribal boundaries. Although, as noted earlier, the language contained words and phrases complimenting the natives of a place and disparaging the newcomer ${ }^{18}$ there appear to have been no really potent norms, positive or negative, against changing tribal residence. We read of individual cases of homesickness (e.g., Adams 1901:35), and of a chief's complaint at having been forsaken by fickle subjects, but these were all individual grievances and not expressions of universal rules.

Again, there must have been many instances of individuals maintaining residences in two or more separate tribal territories, and I can discover no rules proscribing such behavior. Although the condition of "divided loyalty" ( $a^{\prime}$ aupiti) was clearly recognized and verbalized, I have come across no explicit statements condemning the condition, and no rules for resolving it.

It appears to have been a common procedure for an individual to transfer primary loyalty to a chief other than his own in return for more effective championing of his causes, and this behavior was explicitly recognized in (some) Maohis' image of how their society worked: "This habit, that any one with a grievance could appeal before another Arii, made public law in Tahiti. Ariis rarely refused to take up such a quarrel, and sometimes ... risked their whole fortune to do it." (Adams 1901:82)

Needless to say, Adams (i.e., Ari'i Ta'ima'i) provided no statistical 
documentation for this far-reaching assertion, and indeed would have been hard-pressed to do so. In fact, I would qualify the statement by adding that we are dealing here more with expediency than with an abstract principle of "justice," or of the conscious application of noblesse oblige. Moerenhout probably overstated the case in his reconstruction of such situations-both in terms of their generality and of chiefly restraint-but he did sound a more realistic note than did Adams:

It is noteworthy, that, despite their despotism, and perhaps even because of their despotism, the chiefs generally lost no opportunity to keep on friendly terms with their subjects, of whom they had such great need in their frequent wars. A native, unjustly treated by his chief could threaten to leave him, and it was rare that the latter did not seek to appease him and to retain him in his service. There is something almost touching in the threats of a simple Indian to his chief, which seems to prove that the latter was more father than despotic master of his subjects. "You are angry with me," said an Indian I know, an old man now, and from whom his chief had taken the little bit of land he owned. "Ah well! I will leave the land where my fathers died ... and I shall go away with my children to die among strangers, enemies of yours." His chief, moved, went away without answering; but the next day he returned to the Indian double the amount of land which he had taken, with other gifts. (1837:II, 19n)

In addition to these "voluntary" changes of residence or of loyalty, the sources provide numerous instances of refractory subjects having been expelled from a tribal territory by its chief, usually because of refusal to pay taxes, in objects or services. In this connection, however, I have not been able to establish whether the banishment applied only to the expellee himself or to his heirs as well.

Finally, statements specifying the members of any tribal unit must include the spirits associated more or less exclusively with it. Whatever their "original" association may have been, with particular kin-congregations or narrowly specific localities, certain deities came, in time, to be the tutelars of whole tribes and played all-important roles in the affairs of their tribal affiliates in both peacetime and war. In fact, their relevance to tribal fortunes was such as to lead one annalist to epitomize one stage in Island history in these terms: "Before 'Oro's forces in war, those of Tane and Hiro generally fell” (Henry 1928:131).

\section{TRIBAL ACTIVITIES}

\section{Warring}

The tribe was above all else a unit for waging war-not the only warwaging unit but certainly the most characteristic one. As we shall see, battles sometimes took place between subdivisions of a tribe, but unless these threatened the tribal chief's personal interests the latter did not usually intervene. Also there is a distinct possibility that some intertribal wars 
were fought by subtribes (comparable, say, to California waging war against Japan, or Kyushu!). I have no direct, positive evidence that this ever took place, but also no assurance that it did not take place or that it was explicitly proscribed. Indeed, the indifference with which certain tribal chiefs sometimes regarded strife between subdivisions of their tribe suggests that they would not have prohibited one of their subtribal chiefs from engaging in intertribal military adventures unless it affected their own personal interests. (This supposition is very hypothetical, but I put it forward to emphasize my notion that Maohi tribes, for all their similarities to modern national states, also differed from the latter in some significant respects.)

Having already described in some detail the conventional techniques of deciding, conducting, and terminating warfare (see chap. 12), I now focus attention on social-relational aspects of this activity.

First, regarding the decision to engage in warfare against another tribe (if, that is, the decision were not inescapably forced by foreign attack), the sources emphasize what might appear to be contradictory views. On one side, one reads that the decision rested entirely, or mainly, with the tribal chief; on the other, some sources assert that if the majority of subtribal chiefs were opposed to a war they could force the tribal chief to give up his martial enterprise "however bellicose the general populous may have been" (Moerenhout 1837:II, 32). In connection with the second view, it is pointed out that no tribal chief possessed a personal force large enough to wage large-scale warfare, and hence he was dependent upon the active support of his subtribal chiefs for mobilizing enough manpower. But in connection with the second view, one reads that a tribal chief could usually depend upon his official priests to read omens in such a way as to secure supernatural support for his policy (Moerenhout 1837:II, 33). One source states that "official" shamans, speaking directly for deities, sometimes supplanted the priesthood in times of war, but it is not suggested that they were any less politically influenced than the official priests themselves. As for "unofficial" shamans-that is, individuals subject to spur-of-the-moment spirit possession-Moerenhout reported that although they were sometimes able to move ordinary people to rush off to fight someone or other, their influence was rarely strong enough to bring about wars, "even between petty chiefs" (1837:II, 48). (But see vol. 3 of this work.)

The truth of the matter undoubtedly lies somewhere in between these views. As with most momentous real-life situations in complex societies like this one, decisions to make or not to make war were subject to various influences. Among these the voice of a tribal chief was probably most influential. But then again, that voice was usually no stronger than the support he was able to elicit from his subtribal chiefs, by one or more means: identity of goal, political maneuver, evidence of supernatural support, and so forth. 
Moerenhout implied that sometimes a tribal chief was confident enough of adequate support simply to announce his decision to his subtribal chiefs by means of a messenger ( $v e^{\prime} a$ ); in such cases those resolutely opposed were considered rebels and efforts were made to punish them accordingly. On other occasions the decision was "reached" in council made up of the tribal chief and his subtribal chiefs; but as I view the realities of Maohi society, this could not have been a straightforward matter of vote taking. In my opinion most chiefs would not have summoned war councils unless there were some assurance of favorable "decisions": that is, a sincere commitment to democratic procedure was neither a hallmark of tribal ideology nor of any other Maohi ideology for that matter.

The most noteworthy social-relational aspect of mobilization for warfare was the circumstance that each subtribal chief supplied not only a contingent of fighters but also their armament as well. In addition, subtribal chiefs were called upon to provide their tribal chief with the war canoes required by his personal fighting force, and with enough food, tapa, et cetera, to compensate the official tribal priests, shamans, and exhorters, for their services on behalf of the whole tribal cause.

Accounts concerning actual intertribal battles raise more questions than they answer regarding the social organization of fighting. First of all, reports suggest-but do not firmly establish-that the several subtribal contingents, except possibly slingmen, fought separately. Second, while implying that the officials known as battle shapers (äro tarai) were called upon to plan broad strategies and even some detailed tactics, and that exhorters served to maintain fighting morale, neither these nor any other officials exercised overall command once the fighting had been joined. Third, while some subtribal and tribal chiefs did undoubtedly act as battle shapers, sometimes even playing heroic roles in actual combat, others-including some very prominent tribal chiefs-left most of the planning to experts and took little part in the fighting itself. And fourth, there is again the question of who actually did the fighting in intertribal wars. Although most accounts state outright, or at least imply, that all able-bodied youths and men of a tribe took more or less active parts in such fighting, a passage from one missionary's letter suggests that in some wars only the "professional" warriors, the toa, actively engaged in combat:

Upon the whole this short campaign through the mercy of God has tended very much to destroy the strength of the prevailing commotion. The two chiefs above named (one of whom is dead) ... may be considered as the life of the rebellion. Their fighting men remaining are but few, as for the body of the people (on both sides) they are always spectators, and prepared to fly or plunder, and exercise cruelties on those wounded or slain. (Jefferson to LMS, 8 July 1802, LMS Archives)

One other aspect of battle having social-relational significance was 
the effect upon the combatants of injury suffered by a chief or warriorchampion. Sometimes when one such man was struck down it served to rally his companions or followers to furious aggressiveness, while on other occasions it demoralized them into general retreat; in either case the reaction was probably out of scale with the loss of the actual fighting contribution of the individual himself.

Still another social-relational aspect of Maohi battles was their ruthlessness. Unless stalemate forced a mutual withdrawal or a mutually acceptable truce, the killing went on without restraint, until abatement of the victor's "fury"-an emotional state considered by the Maohis to be natural to warfare and certain other expressions of anger, and one which subsided only with time. ${ }^{19}$

Finally, there is the particular application of the more general question concerning what parts spirits were believed to play in victory or defeat. Judging from the amount of religious activity that accompanied warfare, and the rewards earned by the victorious side's war-supporting priests and deities, one would be justified in believing that the latters' roles in warfare were important indeed. But whether that importance reached the degree of decisiveness, or was regarded merely as supplementary, is impossible for me to establish. I imagine that beliefs about these matters differed rather widely, both individually and situationally; however, I know of no instance of a tribal chief bent on making war having depended entirely on either human or superhuman support. (Although, as I shall describe in volume 3, some chiefs spent so much time in obtaining supernatural aid against their enemies that they lost the wars in question.)

Intertribal wars ended in one of three ways: by stalemate, followed by a pause for recovery and then resumed fighting; by draw, formalized in a mutually accepted peace treaty; or by total victory. ${ }^{20}$ Stalemate requires no further comment, and the contractual nature of such peace treaties has already been described in chapter 12; the social-relational aspects of total victory deserve, however, some additional attention.

I have already noted the ruthlessness and destructiveness displayed by the victors against the opposing populace and its goods. Presumably some useful goods were spared from destruction and eventually distributed among the victors. Also, some enemy captives were evidently spared as well, either to be offered as thank-offerings to the victorious tribe's tutelars, or to become titi, or even to be released without further restrictions of status. The place of titi in Maohi society was described earlier and need not be discussed here. Some clues have also been offered concerning the kinds of captives that were freed and the circumstances surrounding such acts. ${ }^{21}$ But there remains to be considered the fate of the defeated tribe's territory and of its members who managed to escape capture until after the victors' battle anger had run its course. 
In some cases, we are told, those defeated in intertribal warfare but still able to travel sought refuge with distant tribes or even on distant islands, and they lost all claims to their former lands. More typically, however, the survivors were eventually permitted to return to their homes-reportedly, only after performance of the ritual, described earlier, designed to restore the "health" of their territory, and presumably render it suitable for visits from their tutelars-and resume living much as before.

The various arrangements made by victors for dealing with conquered but still resident tribes differed widely in punishment and in the degree to which the conquered people and their territory were integrated into the victor's tribal domain. At one extreme, members of the conquered tribe were left untouched in their lives and their possessions, their government having become integrated only to the extent of requiring their own chiefs to render occasional tribute and labor or fighting services to the victorious chief. Moerenhout reported:

There are always 2 or 3 of these principal chiefs on an island; and even when they have all submitted to one of them, the government still preserves its aristocratic form, since [seeing that] it was invariably divided into [several] major districts each with its own chief, and only temporarily [intermittently?]-and at that not absolutely-subordinated to the chief of one of them. Moreover, it appears that each district's own chief had more authority locally than did the chief whose overlordship had been established by conquest.* The overall power of the latter was so limited by the jealousy and unity of the former that he was never able to annex their districts to his own domain, because even if he dismissed from office the more obstinate and seditious members of the high aristocracy, he dared do so only with the individuals in question, the latters' families having lost none of their power or rights, some other family member simply assumed the office. And even if it reached the point where all members of one of the "first families" were killed in warfare, their estates still did not pass to the king. There always turned up some distant relative, or some subordinate chief, to take over the title and office. Such was the state of affairs in the Society Islands, as well as in practically all other islands [of eastern Polynesia]. The "first families" were like so many sovereign "houses." Some of them, it is true, sometimes found themselves by force of circumstance reduced to submission and forced to a position tributary to someone more powerful, but one never saw them dispossessed of all their rights or did they ever renounce all their power-except in later times, when the influence of foreigners caused them to give up their ancient custom, either by force or voluntarily. (1837:II, 8-9)

*All these local chiefs bore the same official title of Ari'i as the conquering chief himself, which goes to prove that they regarded themselves as his equals.

At the other extreme, the victorious chief replaced the conquered chief and subchiefs with individuals of his own choice ${ }^{22}$ and confiscated some of the defeated territory for his own personal use, under custodianship of a supporter whose job it became to send most of the territory's produce to the chief's household. Confiscation of this kind was, how- 
ever, exceedingly rare. In some cases similar grants of personal estates were made by the victorious chiefs to their leading supporters, but such personal estates are to be distinguished from the territorial units associated with the administrative posts mentioned above. The residents of the latter supplied their administrative chief with objects and services from time to time; but the resources of an individual's personal estate were directly and entirely his own.

A victorious chief usually appointed only the most loyal of his supporters-typically, close consanguines-to administrative posts in the new domains. Loyal supporters were also rewarded with grants of personal estates, and in addition such grants were occasionally made for more obviously political and diplomatic purposes, for example to placate potential enemies and to line up influential allies for future enterprises.

I label this latter kind of arrangement an "extreme" one in the sense of its having been a logical extreme: on the basis of the Islands' political geography in 1767, one may postulate that such arrangements had been made in earlier eras, although we have no explicit accounts, legendary or semihistorical, of any such arrangement. In fact, the first documented report available concerning such an "extreme" had to do with the division of territories conquered by Pomare II in 1807, which will be described in the next volume.

Summarizing these findings on Maohi warfare-that most violent and final application of coercive force to achieve social ends-I can state that the "efficient" causes of intertribal warfare were almost as numerous as the varieties of interindividual conflict. Moreover, warfare represents a procedure for resolving social conflict that is entirely different, ideologically, from that associated normatively with relations among consanguines, and even affines. I am not suggesting that it was a relatively new procedure among the Maohis-a kind of social technique for resolving conflict invented after a "Golden Age of Kinship," that is, of patriarchally or consensually maintained harmony. And, although this does not argue for its historicity in their remote past, warfare is a prominent theme in the Maohis' myths about the very beginnings of their universe.

In any case, however warfare may have been related, chronologically, to other methods of resolving social conflict, at the time of the eras under study it was a very widely approved method; and those skilled in its performance were correspondingly valued. ("To the Aito you owe respect: they are the protectors of the honor of the land" [E. Salmon 1937].) The individual who was an 'aito and only an 'aito was still not shown the social esteem enjoyed by the one holding an important kin-congregation Title; but the individual who combined both statuses, or the high-ranking kin-Titleholder who also commanded the services of skillful and successful war-makers, was esteemed above all other humans. 


\section{Intertribal Visting}

Warfare was the principal activity engaged in by a tribe acting as a unit vis-à-vis other social units, but there were other intertribal activities, less sanguinary and at least ostensibly less competitive: namely, sports contests, hospitality exchanges, and reciprocal expressions of condolence or congratulation.

As described earlier, tribes sometimes engaged in sports contests with one another. More typically, these contests took place in connection with other intertribal events, but it is possible that such contests themselves were occasionally the principal purpose for intertribal meetings. Wrestling and boxing were the main sports in most such meetings, but archery and even cock fighting also figured. (See chap. 10.)

Intertribal wrestling matches resembled warfare in the fierce passions they sometimes aroused; indeed, they occasionally ended in open warfare.

It was today reported that a skirmish has lately taken place to the westward between the fleets of Attahooroo [Atehuru] \& Papparra and the people of a small district called Fah-ah [Fa'a'a]. The occasion of it is said to be as follows. The people of Attahooroo and Papparra triumphed in wrestling over the people of Fah-ah, \& from sporting went to slinging of stones and beating with sticks, which obliged the inhabitants of Fah-ah to fly towards Oparre while the others pursued them. The flying party in their flight were joined by the neighbours they past, and at last formed a body strong enough to beat back in return the people of Attahooroo and Papparra to their canoes. We hear not what mischief has been done on either side, or how it has ended; but as Otoo and his brother Tearee-nava-roa are at the head of the fleets, we suppose they will take care it does not go too far. (Jefferson, Journal, 22 April 1801, LMS Archives) $)^{23}$

Bligh provided an excellent account of the dangerous possibilities of intertribal wrestling. The events described took place in connection with a general assembly of natives from several of Tahiti's western tribes, to witness Bligh's investiture with an "honorary" Title. After the official ceremony,

The Men now divided, and there was a confused Wrestling Match, which soon after Old Otow, Tynahs Father, came and desired I would put a Stop to. The Sagacity of this Old Cheif did not counteract what I beleive he foresaw would happen in case they proceeded. There were many Strangers here, and not a particle of real friendship between them and [the] Oparre people. Otow was therefore Apprehensive they would quarrel, and it realy happened so, in an instant every Man was Armed and an Attack begun in a tumultuous manner. Tynah and Iddeah were absent, but as soon as they heard of it their first care was about me. Iddeeah came with much fear lest I might be absent from the Post; she had a double covering of Cloth over her and her waist was girded round with a large Rope. I desired her to Stay with me and I would defend her. No, she said, I am going to Tammy [tama'i, fight]; do you remain here and I will come to you as soon as all is over, and away she went.

As I was not certain how far I might be forced to have a hand in the business, I had all the party on shore, which were nine under Arms, and I had a Boat with 
seven men under Arms lying at a Grapnel fronting the Post. I also sent of[f] Word for the Ship to be ready to assist us, and in the mean time to fire two Guns without Shot in order to disperse the Mob.

It however happened very happily that no Cheif was concerned, their endeavors therefore were to quell the tumult among their own people, and mine to keep my Post clear, which I effectually did, so that all combined to produce peace, which was the case in an hour.

The Guns had a good effect and Tynah and Iddeeah returning to me with the News that all was Settled, we went to some old relations of his that belonged to Attahooroo, and having quieted their minds we came on board to dinner. I told Tynah and the Cheifs that for the future I would not admitt any Wrestling near my Post, and desired they would inform the People of it, which they did. (1789:II, 37)

As Bligh perceptively observed, the reason why this incident did not deteriorate into actual fighting was that "no Cheif was concerned."

In fact, wrestling was so widely recognized as a precipitant of fighting that visiting chiefs sometimes prohibited it in order to avoid unwanted warfare:

There seems to be much suspicion \& mistrust between the Raeatean Chiefs \& Arepaea, Edea \& Puru yet they strive to make things agreeable to one another. (Davies, Journal, 27 February 1809, LMS Archives)

The whole of Huaheine brought food \& presents for Tematoa \& Tapoa, we were apprehensive that so many people coming together wd. cause some mischief to happen especially if the Raiateans \& Huahineans went to wrestle together, however no wrestling took place, which was probably by orders of all the Chiefs \& the people departed peaceably to their several homes. (28 February 1809)

In another account, Davies indicated that sports contests-in this case archery-were arranged as a pretext for warfare:

Brother Nott went down to Pare to see whether anything more could be found out concerning the war. In the evening he returned accompanied by the king and most of his men ... from a variety of circumstances it appeared as if the king came to Matavae with hostile intentions, tho' under the pretence of having a meeting for archery ... (6 October 1806)

With all these indications one might reasonably expect that a tribe's champion athletes occupied positions of honor, and indeed they did. But killing an actual enemy remained a much more prestigious activity than winning a sports contest against a potential one.

I described earlier the importance of "hospitality" in Maohi life. I confess to much uncertainty in this matter, but I can detect nothing in Maohi hospitality exchanges so directly and transparently competitive as potlatch. For all their seeming open-handedness, the lavish hospitality exchanges between chiefs of different tribes did contain elements of social contest, but seem to have been designed more to enhance the host's reputation 
generally, than to defeat the guest specifically. ${ }^{24}$ (This distinction may appear to be trivial, but I believe that it is important.) In any case, while such exchanges may have lacked institutionalized rivalry, they appear to have often included actual hostility barely held in check. General descriptions of official intertribal visits emphasize the lavish interchanges of goods and entertainments, the impressively elaborate etiquette, and the sonorous expressions of mutual esteem. But particular accounts by the more perceptive observers demonstrate beyond doubt that some visits were very tense, weapon-bristling affairs.

In some instances, of course, intertribal visting was deliberately undertaken as a means of asserting one tribe's superiority over, or at least equality with, another. I refer here, for example, to the visits undertaken by representatives of the chiefly families of Fa'a'a and Pare to Papara for the express purpose of forcing Papara's chiefess Purea to break the rahui she had imposed in an effort to assert her son's supremacy over all Tahiti. (See vol. 3.)

Effusive demonstrations of sympathy among tribal chiefs seem to have occupied much of their time. Large and costly expeditions to remote points were carried out, ostensibly in order to mourn for a deceased dignitary or to help celebrate some tribal rite. Many such visits were made in the name of kinship, but many others were carried out as visits between tribal heads of state (even though some of these latter may have been phrased in terms of kinship). Here again, however, no matter how ceremoniously tragic or joyful the occasion, such events were very often imbued with scarcely veiled hostility.

In summary, relations between tribes were characteristically hostile. ${ }^{25}$ Intertribal alliances were occasionally entered into, but these were typically fragile and short-lived. A consequence of this state of affairs (or was it also a cause?) was to popularize a kind of social ethic and glorify a type of role quite different from those esteemed in the ideology of consanguinity.

The activities just described concerned the tribe's relations with other tribes. We turn now to activities within the tribe, to those things done among fellow tribesmen acting in their roles as such-to tribal work projects, to the sharing of objects and entertainment, to common worship of tribal deities, and to the celebration of chiefly rites.

\section{Work Projects}

The use of labor for coordinated tribal construction and production projects differed from its use for similar kin-congregation projects in method as well as scale. ${ }^{26}$ The projects in question had to do with the construction and renovation of marae and other public buildings, the building of canoes, and the manufacture of fish nets and bark cloth.

The best description of construction of a tribal (i.e., "national") marae 
appears in Henry, and was reproduced in chapter 7, this work. The aspects of that activity most salient to our present concern are:

1. The construction was preceded by a lengthy ("two or three years") rahui period for the purpose of accumulating supplies needed to feed the marae builders, to sustain the rest of the populace during their enforced idleness while construction was in progress, and to provide food for the marae consecration ceremony.

2. "No able-bodied man of the realm was idle on such an occasion, for the chief and all classes deemed it an honor to aid in so sacred a work" (Henry 1928:131).

3. A rahui was imposed during construction upon all ordinary activities, including the lighting of fires.

4. The marae builders lived in a separate encampment while work was in progress, and the rest of the populace-women, children, and men unable to work-lived in temporary camps inland and far away from the construction site.

5. The workmen were divided into two major contingents: one for commissary purposes and the other for construction. In addition, the priests were occupied with their usual jobs, since every phase of the construction-before during, and after-was accompanied by intensive ritual activity aimed at securing the tutelars' assistance and sanctification.

6. The actual work of construction was under the direct supervision of specialists, "marae shapers."

Morrison's description of marae construction differs from Henry's in one significant respect. ${ }^{27}$ While the labor of actual construction was reportedly carried out en masse, the stones used in the construction were collected beforehand, and by a kind of tax levy:

When a Morai is to be Built the Chief Gives Notice thereof by sending a piece of Cocoa Nut leaf to evry Man under him, with orders that at the time and place appointed he shall appear with a Stone of the dimentions that he shall find described by the Priests and they accordingly attend. If the Stones are not Judged sufficient the order is renewd. These leaves are Generally made up by the Priests with knots, tied in a Manner peculiar to themselves, and Contain the Dimentions of the Stones that each man may work without the assistance of another. When the stones are all collected, the Priests give notice that they are ready and a part of each day is set aside for the Work.... (Morrison 1935:180)

In all probability both of these types of work procedure were utilized, sometimes perhaps even on the same marae; but the difference between them contains important implications for our understanding of Maohi social relations, as will later on be discussed.

The sources contain numerous references to the building of "public" 
houses by labor corvée, but few details concerning the actual organization of such work. One description containing a little more information than usual is Davies' account of the thatching of a missionary's house:

Pomare is come up [to Matavae] from Pare, it appears that he has now given orders to the Rateras of Matavae to prepare thatch for our house, the work is divided between the several subdivisions of the District. (6 August 1808)

The people began early to thatch the house, and finished it in the evening. The Society fed them according to the custom of the country, several hogs were killed and dressed for them. (Journal, 6 September 1808, LMS Archives)

Davies' account is not entirely clear on this point, but it appears that the thatch plates were prepared in advance, on a quota system (which possibly involved women from every neighborhood in Matavae), while the actual job of tying the thatch plates onto the house rafters was carried out by a number of workers, undoubtedly males. The latter were evidently compensated for their labors with food, "according to the custom of the country"; what compensation, if any, was received by the thatchmakers was not reported.

The fullest description available concerning actual construction work on a large "public" house also came from Davies' pen. Writing about Huahine in July 1809, he stated:

The people from different parts are assembling in our neighbourhood in order to thatch the big house called Nanu which is built at the public expense.

The people of both Huaheines are gathered together in our neighbourhood to thatch the large house they have brought their several divisions of thatch \& also a great quantity of food for the Chiefs consisting of baked hogs, mahe, Yams, Taro, Cocoanuts, pia, plantains \&c. There are in all about $120 \mathrm{Ca}-$ noes come, each of which had with his division of food either a hog or baked fish, about 100 hogs of different sizes all baked were heaped up on the beach today with the baskets of Yams, Taro, Mahe \&c delivered up to the Chiefs with great ceremony. The Chiefs after receiving them gave orders for the whole to be divided again \& returned to the people particularly the workmen employed at the house reserving a part for themselves \& another for the gods \& priests $\&$ a small one for us consisting chiefly of Cocoanuts \& Mahe.

The people as usual on these occasions are feasting, drumming, dancing, wrestling \&c. Twice today they have been very near quarreling, they were divided into two parties, Huaheine rahe \& Huaheine ete. The wrestlers of Huaheine rahe beat those of Huaheine ete \& they in their turn got the better of Huaheine Rahe in kicking the foot ball but there was no fair play the Chiefs being in the party of Huaheine Rahe. The parties for a while were exasperated the one against the other, \& were very near coming to blows, but it seems the quarrel was soon dropped \& things were amicably settled.

Our neighbourhood, Puaoa \& Maeva, brought their divisions of food today ... there were at least 43 hogs baked, \& great quantity of Cocoanuts, Mahe, pea $\&$ c. this was divided among the people as before. Thus the profusion \& wastage of food has been great these few days past notwithstanding the great scarcity.

Many of the people in our neighbourhood have gone to their several 
homes having finished the thatching of the large house, but a good number remain to make a fence which will enclose the house \& a large court all round it, this court \& also the inside of the house is to [be] levelled \& overlaid with a sort of grass called Nonoha which will appear clean \& decent for a while. The house is about $180 \mathrm{ft}$. long \& 25 broad is supported on the sides \& ends by 89 strong pillars made of good Uru trees \& there are 11 in a row inside which make 100 in all, the rafters are of strong Purau having their lower ends to a good way up covered with matting \& Sinnet of various colours which make a pretty appearance. (Journal, 10 June 1809, LMS Archives)

The noteworthy aspects of this event are as follows:

1. The thatch plates were manufactured in advance on the basis of what seems to have been a tribe-wide quota system. (It would be most revealing to learn the basis on which the quotas were assigned to each subtribal chief, but we are not vouchsafed such information in connection with this or any other reported house thatching.)

2. Out of the very large crowd of people from all parts of the tribe that gathered for this occasion only a few were actually employed in the work.

3. In addition to thatch plates, those attending brought large quantities of food (probably also according to quotas), which were turned over to the "Chiefs" for redistribution, with special portions going to the workmen, the priests, and the chiefs themselves, and the remainder to the populace in general.

4. As with most large concourses, the main activity of the occasion was accompanied by sports and other festivities.

Individuals acquired boats in one of five ways: (1) by building them themselves (usually with the help of close relatives), (2) by commissioning expert boatbuilders to do the job in return for specified compensation, (3) by gift or barter, (4) by having one's own staff boatbuilders do the job, or (5) by ordering one's subjects to build them, as a form of tax. The first method was probably employed only by lower-class individuals, or by others with relatively few resources, or by individuals who were themselves especially skillful in boatbuilding. The second method was probably employed by individuals of all classes-that is, by anyone who possessed the resources for paying boatbuilders and who did not have staff boatbuilders of his own. Acquiring a boat by gift or barter was also open to anyone, but only those in positions of considerable authority or affluence were apt to receive large boats in this way. As for the fourth method, only persons of very high authority were able to maintain specialist boatbuilders on their domestic staffs, and the same was true of the ability to acquire boats in the form of tax.

For persons of high authority (and hence in a position to command 
considerable wealth), all of the above methods for obtaining boats were available so that the method followed in any particular instance must have depended upon the chief's judgment concerning the degree to which the boat in question was to serve a "tribal," as opposed to a purely "personal" purpose. (I am convinced that this factor was a conscious one.) At one extreme was the chief who was strong enough, and willful enough, to demand "gifts" of boats from his subjects or to require them to build boats, for the more "personal" kind of use. But at the other extreme was the chief who mobilized tribal manpower and resources only to acquire boats for warfare or for use in connection with tribal tutelars. It is about the latter that Morrison wrote in an excerpt (1935:205-206) quoted earlier. We are not informed how other tribal boatbuilding corvées were organized, but the account by Morrison reveals what we have come to expect of such tribal projects-namely, that the boats were actually built by a few specialists. Any heavy carrying was done by the ordinary tribal members, but their principal contributions were in the form of objects, for feeding and otherwise compensating the specialists (including, undoubtedly, the officiating priests). ${ }^{28}$

Some methods of fishing, such as lagoon fish-drives, required large numbers of persons, and it is reasonable to suppose that some of these activities would have been organized on a tribal basis, especially among smaller tribes such as Mai'ao and Maupiti. But the only evidence of an entire larger tribe's engagement in a fishing enterprise is to be found in Ellis' description of salmon fishing in Huahine; ${ }^{29}$ and the cooperation was not in the fishing itself but in manufacture of the net.

Upea is the common name for net. The upea ava, or salmon net, is the longest and most important, and is seldom possessed by any but the principal chiefs; it is sometimes forty fathoms long, and twelve or more feet deep. One of this kind was made by Hautea, the governor of Huahine, soon after our arrival. Although the former pagan ceremonies, and the offerings at the marae, were discontinued, some of the ancient usages were observed, one of which appeared rather singular. As is customary on all occasions of public work, the proprietor of the net required the other chiefs to assist in its preparation. Before he began, two large pigs were killed and baked. When taken from the oven, they were cut up, and the governor's messenger sent with a piece to every chief; on delivery, the quantity was stated which each was desired to prepare towards the projected net. If the piece of pig was received, it was considered as an agreement to furnish it; but to return it, was, in effect, to refuse compliance with the requisition. At this time, however, no one returned the tarahu, or price, but all agreed to furnish one or two fathoms of the net. When any other chief wanted a net, he took the same course.

The cord was about a quarter of an inch in diameter, and made with the tough white bark of the mate, ficus prolixa, which, next to the romaha, or flax, is considered more durable than any other indigenous vegetable substance. The cord was twisted with the hand across the knee, in two or three strands or threads, and was even and firm. The meshes were about four inches square. 
The servants of the chief furnished their quantity of netting, and the needle with which they wrought was not unlike that used by European workmen. As the other parties brought in their portions, the chief and his men joined them together. On entering the house of Hautea, I have found him in a profuse perspiration, toiling in the midst of his men at the manufacture of the net. (1829:II, 289-290)

The only other activity I know of which may have employed concerted labor on a tribe-wide scale was the making of bark cloth. Persons requiring bark cloth in large quantities, it will be recalled, could obtain it in the form of tax, by having their domestic servants or subjects manufacture it, or by contracting with others to make it in return, say, for pigs. The use of subjects to manufacture bark cloth is described in a passage from Morrison:

If a landed Man wants a large quantity of Cloth made at once, he informs his Tennants when he means to Cut his plants and on the Day appointed all the Weomen attend with each their Beam \& Beetle and a proportion of Breadfruit being prepared they bring the Work together and some times to the Number of 200 strike off together, making as much noise as so many Coopers. The piece is finishd in one Day and is sometimes 40 or 50 fathoms long and 4 fathoms wide. (1935:161)

A labor force of two hundred women would have been about as large as some tribes could muster, so we may have in this activity yet another example of tribe-wide corvée. On the other hand, when the chiefs of the larger tribes needed to replenish supplies of bark cloth, they usually had to resort to all three methods of procurement. Among other things, a technical obstacle lay in the way of mustering bark-cloth-making corvées significantly larger than those described by Morrison: the saplings from which such bark cloth was usually made were probably produced in the employer's own gardens, and, as far as we know, not even the most affluent chiefs personally owned enough trees to require bark-cloth-making corvées of a very large size.

Summarizing these findings on coordinated tribal work projects, one can discern differences in labor use corresponding to size of social unit (in this case the tribe). In the case of a small tribe all the unit's manpower (or woman power) was more or less directly employed in some phases of the work activity, in addition to providing the food consumed, by themselves, the specialists, chiefs, priests, and tutelars, during and after the work. In the case of a large unit, however, most of the actual work on such projects was performed by specialists, the rest of the populace having made their contributions in the form of such items as materials for the construction or processing, food for everyone's consumption while the work was in progress, and-a new factor-objects with which to compensate the specialists for their extra services. In other words, as the labor force increased in size, contributions to joint work projects tended to polarize in kind: the specialists (artisans, priests, managers) did more of the actual work of building 
and manufacturing, while the populace supplied more of the objects needed for the work.

There were at least two factors involved in this trend. The first was directly technological: Maohi techniques for building and manufacturing were suited mainly to work groups of small size, that is, only a limited number of persons could be directly engaged in making something simultaneously. The second factor was organizational: for some reason or other (possibly as a result of habituation to the techniques just mentioned) the Maohis were not accustomed to working together in large numbers in a precisely coordinated way (a combination, probably, of both managerial ineptness and worker inflexibility). With respect to large-scale activities in general the Maohis demonstrated their capacities for fine coordination in certain kinds of dancing and in their handling of boats, but, with the possible exception of making bark cloth, this seems not to have carried over into most construction or manufacturing activities (or for that matter into large-scale fighting).

Parallel with this trend in the organization of tribal work projects one can discern a correlative decrease in the number of such projects themselves, along with an increase of levies in the form of objects. In other words, as tribes grew larger and more complex in composition, objects tended to supplant direct services as means to support the cost of central government.

\section{Levy of Objects}

As just noted, in connection with some tribal work projects, many members made their contributions in the form of objects in lieu of services, the objects having been used to support the specialists actually engaged in the work at hand. In addition, there were many other occasions on which objects and not services were the intended objective of the contributions made by people as members of a tribe. Among such occasions were seasonal first-fruit rites, the ceremonious rendering of substantial or token "tribute" to tribal chiefs, contingent levies by the latter for specifically tribal or administrative purposes, and delivery-on "standing order" - to tribal chiefs of such luxuries as turtles, pearls, and most other objects considered by the Maohis to be of special interest and value. ${ }^{30}$

First-fruit offerings were described earlier in connection with agricultural ripening-of-the-year rites, and it was indicated that most such offerings included a share for the social unit's administrative leaders as well. ${ }^{31}$ In addition, I included an account by Morrison of first-fruit offerings made principally to "chiefs"; the importance of this account to our present concerns is such that I refer the reader to it pp. (262-263).

There are several noteworthy things about the set of events described by Morrison:

The contributions appear to have been of two kinds: (1) a more symbolic 
offering consisting of token amounts of objects purportedly designed to express the subjects' loyalty and affection for their chief; or (2) more substantial amounts of edibles designed for actual consumption by chiefs.

All contributions appear to have been upwards: that is, Morrison's account gives no indication of immediate redistribution.

The goods moved along regular tribal channels: "tenants" to ra'atira to subchief to chief, a procedure which was then repeated for each subtribal unit and sub-subunit.

Although identified by Morrison as an offering of first fruits, the instance described was more "secular" than were other levies identified by the sources as first-fruit offerings. In all probability most if not all tribe-wide collections of objects included portions both for tribal tutelars and for tribal chiefs (and, on some occasions, for Ariois), but in different proportions-or at least with differing ritual emphases-according to the avowed purpose of the occasion. The more "secular" of such levies were of three kinds: collections of comestibles and other objects delivered to a chief at his principal tribal marae by each subtribal unit and intended mainly for support of himself and his household; collections (mainly comestibles) delivered by subtribal units to their chief while he was on tour around his realm, for immediate consumption by himself and his retinue; and collections delivered to a chief for entertainment of dignitaries from other tribes.

On Tahiti and Mo'orea the first of these kinds of collections included one known as tavaru (usually contracted to tavau), which is defined in the LMS Dictionary as a fleet of canoes bringing food for the king or principal chief. The name is from varu meaning eight; a meeting of eight divisions of mataeina $a^{\prime} ;^{32}$ a meeting of different districts, for business and feasting.

The fullest description extant concerning an actual tavau is contained in a document allegedly written about 1845 by the Maohi genealogist Mare, and describing the tavau rendered the Pomares after this line of Pare-Arue chiefs had extended its rule over all of Tahiti and Mo'orea (after 1815) ${ }^{33}$ The document may contain elements of fiction, invented by Mare to authenticate the Pomares' political pretensions, but the general procedure described appears credible. And even though the specifics of individuals and Titles and places refer to a later era in the Islands' history, I reproduce this document because the forms of the transactions described in it seem indigenous enough to be applicable to the eras under study.

The first text concerns the tavau delivered, by the several tribes of Tahiti, to the ruling Pomare, at Tarahoi (his principal marae, which was in 'Arue and at which he bore the Title, Tu Nui eaa i te Atua): 
Here are the procedures followed in connection with the Great Tavau.

The people constructed boats, manufactured large bundles of tapa [bark cloth] and mats, and fabricated taurui [ornamented breastplates] and fau [headdresses]. They collected pigs, and prepared māpura [a prized variety of wild mountain-growing taro] and uhi parai [a variety of yam]. They carried all these things throughout the moonlit nights, which occur at the times appointed for a tavau. [The significance, if any, of this timing escapes me.]

There are eight districts in the Porionuu division itself, and these provide eight boats, eight bundles of tapa, along with breastplates, headdresses, and live pigs. Such are the objects loaded into the boats.

Together, the two major subdivisions of Te Oropaa, and the district of Taumata i te fana ia hurai [Fa'a'a] contribute three boats, three bundles of tapa, along with headdresses, breastplates, and live pigs.

The four districts comprising inland Teva [Papara, Atimaono, Papeare, Papeuriri] contribute four boats, four bundles of tapa, four breastplates, headdresses and live pigs; and when all these things are loaded onto the boats they set out for Tarahoi.

The various kinds of comestibles-mapua, poe, taioro, tuparu [coconut, bananas, etc., pudding], arrowroot poe, pēpē [sweet, ripe breadfruit], and mountain plantain-are carried in a separate canoe in which the passengers beat on drums and ihara and dance en route.

The boats intended for the king do not carry comestibles, but are canopied with tapa stretched out on poles. In presenting these [boats? all the above items?] to the king one addresses him by his Title, Tu Nui eaa ite Atua, in the following words: "You [who are] over Tarahoi, here are we eight districts of Porionuu; the two major subdivisions of Oropaa and district of Taumata i te fana ia hurai, the peoples living between the Vainiania and Vaiovau rivers [i.e., the inland Teva]. Here are the seaward Teva as well.... Here is the tavau collected for you: the boats, tapa, breastplates, headdresses, boat canopies, pigs, mapua, and all kinds of fruits-all constituting a symbol of royal power [mana ari'i?]. (Rey-Lescure 1946:196-197)

The next text concerns the tavau rendered Pomare on Mo'orea, at marae Nu'urua, where he bore the Title Punua te rai tua:

Mo'orea was composed of eight districts and correspondingly provided eight boats, eight bundles of tapa, breastplates, headdresses, live pigs and all the kinds of comestibles appropriate to a tavau, except for mapua and paroi yams, which do not grow on that island.

As with Tahiti, a special boat was reserved for transporting the comestibles, and on this the passengers danced and beat drums and ihara; but those boats making up part of the tavau itself were canopied with tapa, which constituted tihi [i.e., ceremonially given bark cloth].

In making the presentation the king is addressed thus: "Oh Punua te rai tua, [of Nuurua?], here is the tavau furnished you by Mo'orea, [several words missing] as a symbol of your authority over the island." (p. 198)

According to another text included in this document (reportedly originating with some "chiefs" of Porapora), the custom of tavau was also practiced in the Leeward Islands, but there it was known as mareva. 
For a tavau [mareva] in these islands all the population of an island comes together at the same place-men, women, and children.... When all the people were assembled for a tavau they readied all kinds of comestibles-pigs, bananas, breadfruit, taro, etcetera. They added to these some rolls of tapa, some mats, and some ponchos, and when everything was assembled in one place they presented these objects to the prince for whom the ceremony was arranged. (pp. 200-201)

In the Windward Islands, according to the document just quoted, tavau was rendered only to a sovereign chief by his subjects. The ceremony for honoring (and provisioning) a dignitary from another tribe differed in procedure and possibly also in tangible content: "When Tapoa ["King" of Porapora] and Tamatoa ["King" of Ra'iatea] visited Tahiti, they were not presented with tavau: instead, each district, one after the other, presented its presents of comestibles to the [visiting] king" (p. 200). If this report is accurate, then, such visitors received only, or mainly, comestibles, and the presentation lacked the explicit symbolic references to tribal unity and fealty implied in tavau.

Tavau differed also in procedure and in content from the presentation rendered a tribal chief on tour around his realm. The primary purpose of the latter was the immediate provisioning of the chief and his retinue. Most of this kind of provisioning was probably moderate and orderly, but, as I have indicated, some such tours were marked by impoverishing rapacity, mainly on the part of a chief's ruthless and insatiable servitors.

The sources have referred to many other kinds of occasions on which all or large parts of a tribe provided their chief with comestibles or other objects, in connection with an event either mainly religious or mainly secular, and with varying proportions of the total collections allotted to the chief's own use. I am unable to provide descriptive classifications for all such transactions, but it is possible to discern some interesting and perhaps highly significant differences among them-quite apart from differences in the degree of "secularity" of the occasion for the transaction.

\section{TYPES OF OBJECTS}

Certain varieties of plant-foods were reported to have been included in presentations only to "kings" (i.e., presumably to any tribe's sovereign ruler): māpura, a species of white taro that grows wild in the mountains; pēpe , a sweet, ripe breadfruit; and uhi parai, a species of yam. In contrast, it was said that certain other varieties were not good enough for "kings" but might be presented to other persons: for example, pae' $a$, an inferior species of breadfruit. (According to Rey-Lescure, however, although pae' $a$ was given to "strangers," it was not given to traveling entertainers.) The logic behind this use of māpura may perhaps be based on its scarcity and the difficulty of obtaining it; as for pae'a, it would seem to be a simple 
case of not giving an "inferior" food to a "superior" person. But how to explain uhi parai is not clear.

Certain other plant-food preparations-puddings (poe), baked plantains, taioro (a sauce made of scraped coconut, salt water, and shrimps)-were said not to have been included in presentations to "strangers"; but whether these were specifically reserved for presentations to "kings" is not clear. The explanation suggested by Rey-Lescure for these foods having been restricted is ingenious, and perhaps even correct: "Since these foods require prior preparation they ought not to be included among the presents offered spontaneously upon the [unexpected] arrival of a guest and given at the beginning of a meal."

Cooked pork (and probably cooked dog flesh) formed part of many tribal presentations, from which the tribal chief received portions, but those presentations, such as tavau, intended mainly as manifestations of tribal fealty and for revenue usually included live animals as well. (In fact, on some such occasions the animals were turned back to the donors to keep and fatten until they were actually required by the chief.)

I have already noted that tortoise flesh was restricted to ari'i (but not perhaps only to those who were tribal chiefs); the same limitations appear to have applied to i'a raararoa. Rey-Lescure interpreted this to be "a type of shark with a greatly developed fin, or a large-fin fish," but the closest LMS Dictionary form is i'a ara roa, a fish, a present of fish taken to a chief; used figuratively, it meant "a dead enemy carried to the marae for sacrificial offering" (Andrews and Andrews 1944: 69). Human beings intended for sacrifice were, of course, offered only on behalf of tribal chiefs-and only for a very limited number of these.

Turning now to noncomestibles, boats appear to have been included only or mainly in tavau-like presentations to tribal chiefs-for use by chiefs or in the service of their deities-and the same was probably true of red feathers. Gorgets and fau headdresses also constituted a kind of tribal revenue; they were worn mainly in warfare and by a tribe's leaders, and hence were required by a tribal chief for the proper uniforming of himself and his principal lieutenants. Mats and bark cloth figured in all kinds of transactions, but when presented to a tribal chief, on tavau-like occasions, they were usually given in the form of large bundles or long strips wrapped around some individual or the chief himself.

\section{AMOUNT AND CONDITION OF OBJECTS}

The amount of an object presented to a tribal chief varied widely. At one extreme were contributions of large amounts of things used by the chief to sustain himself and his retinue and to maintain or increase his power and influence. At the other extreme were contributions of token quantities, 
more symbolic than substantial. In fact, in some of these latter instances the items were worse than useless in a practical sense; I refer here to the ma'a opu roa, comestibles spoiled as a result of long periods in transit and hence inferentially symbolic of the extensiveness of the chief's domain (Rey-Lescure 1946:199, 204).

It seems to have been of crucial importance that the objects originally destined for some chief should in fact reach their destination-not equivalent substitutes for those objects but the very objects themselves. In other words, even when the avowed purpose of a contribution was revenue, its initial consignment to some chief served to identify it specifically and exclusively with him. The penalty for interference with such a consignment was revealed in the legend of Pai, reproduced earlier, wherein the petty chief Rehia was slain by "King" Ta'ihia's jealous supporters for daring to purchase a load of objects en route to the king. ${ }^{34}$

The procedure followed in the first-fruit offerings described by Morrison, and quoted above, constitutes a fine example of this convention and differs significantly from the procedure, followed in many societies elsewhere, whereby goods move up composite social hierarchies in one movement, with portions being removed en route to provide for the various subunit chiefs. (Among other things, the Maohi variant strikes me as an effective measure for reinforcing centralized control over a whole tribal unit, against the centrifugal forces exerted by strong subtribal chiefs.)

\section{PLACE AND MODE OF PRESENTATION}

A presentation made to a tribal chief at his own marae seems to have contained stronger implications for tribal unity and fealty than one made to him elsewhere in his tribal domain. (And, of course, presentations made to him when he was traveling abroad usually implied only "amity" or at most "alliance.")

It goes without saying that the procedures involved in members' presentations to their tribal chief varied in ritual symbolism and in ceremonial elaboration. For example, the sound of a conch-shell trumpet ( $p \bar{u})$ was an unmistakable sign of the donee's sovereign power, as was the feigned eating by him of a human offering's eye. But our concern here is with differences in the social mechanics of such presentations, which appear to have followed three different patterns. In one of these a presiding priest presented to the chief his share of a larger collection only after handing over shares to spirits, and in some instances to priests as well. In other situations, whole presentations were made directly to the chief, but in subtribal "installments": separate collections of objects were made by subtribal chiefs on separate occasions. The third pattern was the one followed in tavau, wherein all subtribal units brought together their respective, and equivalent, contributions and participated simultaneously in a joint presentation to their tribal chief. 
The second of these patterns provided a clear indication of a subtribe's fealty, but the third can be interpreted as indicating tribal unity as well.

\section{REDISTRIBUTION}

Some of what tribal chiefs received from their subjects was ultimately "redistributed," but there were some widely and probably highly significant differences-in the proportions of a presentation redistributed, in modes of redistribution, and in the kinds and ratios of tribal members included in the redistribution. (I am concerned here with the redistribution of objects first presented to the tribal chief, and not with those allotted for redistribution on spirit-focused occasions, at which separate portions were initially allotted to spirits, Ariois, priests, chiefs, and other participants. On the latter occasions, a tribal chief in whose domain such ceremonies took place undoubtedly exercised some control over the proceedings, including the redistribution, but normatively the division of goods rested in the hands of spirit-serving priests.)

In some instances, most of what was presented to a tribal chief was immediately redistributed, in an orderly and comprehensively proportional way. That is to say, most of the objects-mainly comestibles-were immediately returned to the subchiefs, who then distributed them among their followers for on-the-spot consumption. In such instances, it was likely that most if not all of the original contributors received some share of the food.

In other instances of immediate redistribution, a smaller part of the presentation was returned to the donors, not, however, by orderly division but by recourse to "scrambling." Excerpts from missionary journals describe this custom:

We met the people with the food \& cloth going to present it to Puru and were soon after informed that when the food was divided by Hitoti and a portion allotted to the Papas (Englishmen, ourselves) a number of people rushed in and scrambled for it (Crook, Journal, 25 October 1816, LMS Archives).

When the canoes were come to the place of landing, before they put on shore, a parley commenced, between Pomerre and certain of his orators, who were ranged in line on the sea beach, with the king's representative before them: and Teohu and his orators on board the canoes, in which were recapitulated certain articles of their superstitious belief-respecting the originality of their forefathers etc.-during the repetition of these things each party threw towards the other, some part of a cocoanut tree: perhaps as a token of the rectitude of their belief in the things related. After this ceremony was concluded, the canoes landed, and were hauled up on the strand then another ceremony commenced, of presenting cloth to the chief, very little of which came to his share, for as fast as bundles were brought to him, a band of persons laid hold of it and a furious struggle ensued in which the cloth was torn to pieces, and he thought himself highly favoured who could get a piece a foot or two in length. In this strange barbarous manner many fathoms of cloth that had cost some trouble in making were in a very short space 
of time totally destroyed. (Jefferson, Journal, 2 April 1801, LMS Archives; see also Robert Thomson, "History of Tahiti," part 2, pp. 87-88, LMS Archives.)

In still other instances, however, there is reason to believe that no redistribution took place at all-at least none outside the chief's own domestic and official establishment. Or if it did take place, the objects in question found their way into a very limited number of hands.

However abundant the supplies might be which the king received, he was in general more necessitous than many of the chiefs. Applications for food, cloth, canoes, and every other valuable article which he received from the people, were so frequent and importunate, that more than was barely sufficient for his own use seldom remained long in his possession. A present of food was usually accompanied with several hundred yards of native cloth, and a number of fine large double canoes; yet every article was often distributed among the chiefs and favourites on the very day it arrived; and so urgent were the applicants, that they did not wait till the articles were brought, but often extorted from the king a promise that he would give them the first bale of cloth, or double canoe, he might receive. At times they went beyond this; and when a chief, who considered the king under obligations to him, knew that the inhabitants of a district were preparing a present for their sovereign, which would include any articles he wished to possess, he would go to the king, and tapao, mark or bespeak it, even before it was finished. A promise given under these circumstances was usually regarded as binding, though it often involved the king in the greatest difficulties, and kept him necessitous.

In the estimation of the people, one of the greatest virtues and highest excellencies of a king, was generosity; and one of the most unpopular dispositions he could cherish, was illiberality. In describing a good chief, or governor, they always spoke of him as one who distributed among his chiefs whatever he received, and never refused any thing for which they asked. (Ellis 1829:II, 373-374)

From one point of view, several of these variations in object transactions between members of a tribe and their chief seem to suggest a range of types of relationship. At one extreme was a relatively small tribe, knit together by close ties of kinship and by firm loyalties to a chief who was kinsman of many members of the tribe. Tribal presentations to the chief were more in the nature of shared bounteousness; the symbolic aspect of the transaction was that of commensality, and the religious side of such occasions was usually present, whether explicitly manifest or not.

At the other extreme was a very large tribe composed of historically distinct units held together mainly by force. In these, at least some tribal presentations to the chief were mainly for purposes of revenue; and although some of the symbolism of commensality was retained in such customs as "scrambling," the principal messages these transactions were intended to convey were those of "fealty" (however tentative) and of tribal "unity" (however fragile).

\section{HOSPITALITY}

One of the greatest demands upon a Maohi's resources was for the purpose of "hospitality," the implications of which I have already described. When 
such outlays pertained to official visits by chiefs of other tribes, the inherent demands of hospitality were so amplified by considerations of intertribal politics that the whole tribe was usually involved in the transaction.

Throughout the archipelago the objects handed over to a visting dignitary appear to have been presented in three or four installments: a small token amount of food given to the guest of honor as soon as he (or she) set foot ashore: this was sometimes called a fa'ahopura'a vai, literally, "the action of bathing someone in water"; a more substantial amount of food, and so forth, given to the visitor shortly after his arrival and upon his departure, known as ma'a fa'a'amua, a term also applied to some first-fruit offerings to deities; ${ }^{35}$ the principal presentation, known variously as mareva, poropae, and so on. ${ }^{36}$

According to the BSEO document on tavau, a poropae was carried out as follows on Porapora: ${ }^{37}$

When a visitor calls upon the king [of Porapora], all Faanui [the king's home district] prepare comestibles and carry them along with tapa to the home of the king, and hand them over to him, for him to present to his visitor. This poropae is provided by all the districts of Faanui, and when the poropae and the fa'amua [ma'a fa'a'amua] have been completed, then one brings the maa tumu uru which is also given to the guest of the king.

But this [last item] is not provided by all Faanui; only the king and his own people [close relatives and retainers?] provide this, and this has been the case whenever comestibles have been provided the kings of other lands visiting here. Everyone assembled to present provisions to such a guest, but here such a practice is not labeled tivau [tavau] although it is the same thing. (Rey-Lescure 1946:201)

Elsewhere in the same document is a statement purportedly contrasting this mode of presentation with that practiced on Tahiti: "When, however, King Tapoa [of Porapora] and King Tamatoa [of Ra'iatea] betake themselves to Tahiti they are not [entertained in this way]. Each district [of Tahiti] simply presents its gift of comestibles to [the chiefly visitors] in succession" (p. 200).

Still another complication is added to this "explication" of poropae by the LMS Dictionary entry for poropa, a large and unsightly collection of food intended for visitors. ${ }^{38}$

Cutting through the tangle of these and other accounts, I believe it possible to distinguish three kinds of procedures followed in making principal presentations to visiting tribal chiefs. In one, all the tribe-wide contributions were put together and turned over to the local tribal chief, who himself made the presentation to the honored guest. In another, each subtribe made its own presentation to the guest, successively. The third presentation was also handed over to the guest by the local chief, but it consisted of objects contributed only by the chief himself and his near relatives-the ma'a tumu uru.

Considerations of social class may have been behind the distinctiveness 
of the third kind of presentation. As for the significance of the distinction between the first and second procedure, it might be argued that the unity of the host tribe (and the authority of its chief) would have been better expressed by the first procedure; but the data on which this inference is based are so slender, and ambiguous, that I attach little weight to them.

A question remaining to be answered about tribe-wide levies of objects is, How were they initiated and sustained? Presumably most first-fruit presentations took place periodically, upon ripening of the seasonal fruits, or upon the natural reappearance of certain schools of fish. But all other levies depended upon the plans and appetites of the tribal chief. Ellis described how a chief usually went about mobilizing his tribe's resources, in both services and objects:

Whenever a measure affecting the whole of the inhabitants was adopted, the king's vea, or messenger, was despatched with a bundle of niaus, or leaflets. On entering a district, he repaired to the habitation of the principal chiefs, and, presenting a cocoa-nut leaf, delivered the orders of the king. The acceptance of the leaf was a declaration of their compliance with the requisition, and to decline taking it was regarded as an intimation of their refusal to accede to the measure proposed. Hence the messenger or herald, when he had travelled round the island, reported to the king, who had received and who had refused the niau. When the chiefs approved of the message, they sent their own messengers to their respective tenants and dependants, with a cocoa-nut leaf for each, and the orders of the king.

The niau, or leaflets of the cocoa-nut tree, was the emblem of authority throughout the whole of the Georgian and Society Islands; and requisitions for property or labour, preparations for war, or the convocation of a national assembly, were formerly made by sending the cocoa-nut leaf to those whose services or attendance was required. To return or refuse the niau was to offer an insult to the king, and to resist his authority.

If the king felt himself strong enough, he would instantly banish such an individual, and send another to take possession of his lands, and occupy his station as chief of the district. Should the offender have been guilty of disobedience to the just demands of the king, though the lands might be his hereditary property, he must leave them, and become, as the people expressed it, a wanderer "upon the road;" but if the king's conduct was considered arbitrary, and the individual justified in his refusal by the other chiefs, they would tapea, or detain him, and protest to the king against his removal. The parties generally knew each other's strength and influence, and those who had little hopes of succeeding by an appeal to arms, usually conceded whatever was required. Personal security, and the rights of private property, were unknown; and the administration of justice by the chiefs in the several districts, and the king over the whole, was regulated more by the relative power and influence of the parties, than by the merits of their cause. (1829:II, 367-369)

This procedure was followed not only for such momentous objectives as mobilizing for war but also for such prosy purposes as the laying in of a supply of mahi:

“... if a Chief wants a Supply [of breadfruit] for the purpose of Making Mahee 
he sends a Bit of Cocoa Nut leaf to all, or as Many of the Inhabitants of his district as he shall think proper, and on the appointed day they Bring each a load, which is generally accompanied with a hog by some and fish by others according to their several abilitys, but this they have seldom occasion to do as they are always well supplyd and when supplys are raised this Way the people bring it in such a Manner as bespeaks at once their regard for their Chiefs \& fear of displeasing them, always testifying their sorrow that he should be so far neglected as to have the trouble of sending for bread. (Morrison 1935:215-216)

Rodriguez provided a description of the consequences of noncompliance with a chief's levy of food supplies:

Vehiatua banished the Indians of the gully, for not having contributed the food supplies due from them; the number of those banished was very large.

When I arrived on shore with the working party I found all the Indians in a state of excitement, some fixing the cuddies on to their canoes, others arming themselves for battle; and, going up to Hinoy, whom I found wearing a tunic that Señor Don Raymundo had given him, I asked him what it all meant. He answered that the Indians of the gully whom Vehiatua had banished the day before had risen in revolt against him, in consequence of which that arii and all his party had gone to punish them for their hardihood; and that Otù had also gone with his own people in pursuit of them, to assist Vehiatua if necessary and, in case of being worsted, to rescue him and carry him off to Opare, one of his [Otù's] districts.

On learning this I went on board and reported it to the Comandante, who ordered me to return to the shore and keep myself informed of everything and see what the upshot would be; and at the same time he detailed an officer, with a serjeant, a corporal and squad, to protect the house and cover our own party at work there in the event of an assault of any kind. I myself went forward, accompanied by some natives, to where the combat was going on, and after walking rather more than half a league I came to where Otù was encamped with over four hundred Indians who were wrecking all the huts they found and looting everything they could lay hands on, for they destroyed even the seedling beds that had been made. I passed on until I met Vehiatua, whom I found with quite two hundred Indians carrying clubs, long spears, and slings, over and above those who had gone still farther ahead in pursuit of the fugitives. Presently one of his captains arrived with a good number of people bringing in one of the rebels a prisoner, and on coming up to Vehiatua the captain presented a small plantain shoot to him, together with the offender. Presuming that he would be punished I asked what the man's end would be, and was told that a tree they call evizo was to be his punishment. But nothing was done to the prisoner after all, as they interceded in his behalf and he was pardoned. (Corney 1919:27-28)

\section{Worship}

Joint worship was one of the most important activites engaged in by persons as members of the autonomous territorial units I label tribes. Ordinarily, only males participated directly in such worship, but females also were indirectly involved-in helping to supply food offerings, ${ }^{39}$ in maintaining ritual restrictions, and in reaping the benefits or suffering the consequences of the worship. 
For many members of any tribe the tribal tutelars thus worshipped were different spirits from those worshipped in a member's own kin-congregation marae. (As suggested earlier, there may have been a time when many distinct kin-congregations constituted wholly autonomous territorial units, or tribes, but during the eras under study all the tribes about which I know were made up of two or more kin-congregations, presumably worshipping distinct tutelars.) In most cases perhaps, the tutelar spirit of a tribe was the tutelar of its sovereign chief's own kin-congregation marae; but the exceptions to this generality, both evidential and conceivable, require discussion.

One such exception is indicated in a passage from Henry describing the ceremonies attending supercision of a successor to a tribal chieftainship: "For an heir apparent to the throne, one or more human sacrifices were offered by the priests at the national [tribal] marae, while this rite [supercision] was being performed at the [heir's] ancestral marae" (1928:188). It is of course possible that the same tutelar was worshipped at both of these marae, thereby leading to the credible conclusion that some tribal chiefs maintained two kin-congregation marae: one for large and public tribal worship, and another for intimate, familial rites. (The archaeologically attested evidence of small "shrines" in the vicinity of large marae-in many cases actually abutting them-lends some plausibility to this suggestion.) On the other hand, we cannot rule out the possibility that some principal, ancestral marae tutelars were wholly distinct from those of their tribal, "national" marae. Indeed, from what is recorded about the Maohi past, this possibility becomes a probability. My evidence for this conclusion is as follows:

Several accounts, more or less "historical," indicate that certain tribal chiefs replaced their established tutelar with a new one, accomplished either by construction of a new tribal marae or by installation of a new tutelar in the old marae. (This process undoubtedly exemplifies much of the diffusion of 'Oro worship, as described in the previous chapter.)

There are several other accounts, both legendary and "historical," of dynastic changes in tribal leadership, without any accompanying changes in tribal marae or in tribal tutelars.

In any case, however such associations may have come about, during the eras under study all tribal members were expected to venerate the tribal tutelars in addition to their own kin-congregation tutelars, if these happened not to be identical.

Tribal marae were in general larger and more complex structures than were ordinary kin-congregation ones. As already described, the whole tribe was involved in their construction, in some role or other, and their consecration was also a tribal affair: 
The inauguration of the national marae was performed with great festivity; the clans of all the kingdom were represented, and a great feast was prepared on the assembly ground. On the appointed day all work was done in the morning, and in the afternoon amid impressive stillness the people in their best attire, followed the queen and chiefesses and other members of their families, gathered at the new marae, and took their stand at the place for the congregation in the rear. Then followed the ceremonies, which thrilled the hearts of all with joyous but silent religious enthusiasm. The first-born young virgins of the royal family of the kingdom represented their respective districts. They were arrayed in flowing white tapa and decked with wreaths and garlands of tiare (single Gardenia) blossoms, their emblem of purity. Carrying round green coconut-leaf baskets of these flowers in their hands, they led a procession formed by the clergy in sacerdotal array each of whom carried a miro branch in his hand. The king wore his royal feather clothes and the chiefs their regal raiment. The procession halted on reached one side of the marae, and then the young virgins walked around it, casting their flowers upon it as high as they could reach and upon the paving close by. The high priest followed calling upon the gods to fill the place with their presence.

This was called the rao-marae (setting of the marae). Then the young maidens returned to their post at the side, while the high priest, taking sea water in a gourd, went up into the marae and sprinkled it everywhere, as he called upon the tutelar god, whose name he repeated, to take possession of his new home, and to make welcome his guests, the hosts of gods. This was called the hao-marae (establishing the marae). After this part of the ceremony, the king ascended and crossed the middle of the structure, descended on the opposite side, and returned to his post. Following this act, called the eera'a o te ari' $i$ (the mounting of the king), the high priest pronounced the marae mo'a roa (superlatively holy), and the procession again resumed order and repaired to the assembly ground. All the people that had been present followed, and the commonalty and women returned no more to that marae.

The division of food next took place. A portion of the best was presented by the orator to the priests for the gods, then a goodly portion was presented to the sovereign, the remainder was distributed among the different clans. The greatest propriety was observed by all parties concerned in the sacred marae inauguration feast, as it was believed that eating greedily or indulging in any excess of rioting would bring upon the offenders immediate calamity from the gods, such as choking while eating, strangulation, blindness, and many other troubles. (Henry 1928:137-138)

The religious rituals held at tribal marae pertained mainly to war and peace (including resanctification after defeat), to first-fruit and tavau-like levies, to visits of important officials, to great seasonal festivals, to tribal rites of thanksgiving and atonement, to resanctification of the marae tutelars, and to critical life-cycle events of the chief and his successor. All these ceremonies have been or will be described elsewhere. Of more immediate interest at present are the social relations between tribal and other tutelars, and between tribal tutelars and tribal members, as manifested in these tribal rites.

That a tribal tutelar was regarded as more effective than other tutelars within his domain is undoubtedly true, although I know of only one specific instance wherein such powers were explicitly compared. ${ }^{40}$ Evidence for 
the tribal tutelar's superior sacredness is expressed in unmistakable terms in an episode of that most awesome rite of paiatua, "the assembling and uncovering of the gods," namely, its culminating taritoara'a atua, or "god's exchange." This episode, it will be recalled, consisted of a refurbishing of the images of lesser tutelars-presumably those of the tribe's constituent kin-and occupational-congregations-with feathers taken from the image of the tribal tutelar itself: surely, one of the most unequivocal symbolic messages concerning religico-political integration ever designed. ${ }^{41}$

I have no explicit evidence concerning the kind of relationship that existed between a tribe's tutelar spirit and a member whose kin-congregation tutelar he happened not to be; but from other kinds of evidence I am led to believe that the relationship was not a direct one. Generally speaking, except for shamanistic episodes, a Maohi approached his tutelar spirits-as distinct from his spirit-familiars-"through channels"; and if this were true with kin-congregation tutelars, it was doubly so with those awesome spirit eminences, the tutelars of a whole tribe. To a people conditioned to ideas of social hierarchy and spirit truculence, a direct approach to a tribal deity would probably have been considered both impudent and dangerous. On the other hand, the Maohis were not beyond switching allegiance from one tutelar to another, if the old one did not act his part. And at the same time, Maohis were capable of allegiance to any number of tutelars, provided the latter were not at odds.

\section{Fattening of Youths}

I described in chapter 13 the custom of ha'apori (fattening) and the practice followed in some places whereby large numbers of youths went through the process together. The culmination of these events, it will be recalled, consisted of a public exhibition of the fattened youths, and their presentation to their tribal chief. If this institution contains meaning and functions other than such obvious ones as enhancement of physical well-being, of beauty, and possibly of virility, I am unable to document them.

One possible line of speculation is that the institution was a practical measure designed to improve a tribe's manpower resources-whether actually "true" or not, corpulence does seem to have been regarded as associated with physical strength, both phenotypically and genotypically, and perhaps with "psychic" strength as well. In any case, whatever deeper meanings may have been attached to this institution, it does appear to have been, in some places at least, a tribal affair.

\section{Carnivals}

Festive moods prevailed at most kinds of tribal assemblies, but there were two kinds of tribal assemblies that appear to have been primarily devoted 
to entertainment-although religious rationales and religious rituals figured prominently in these as well. One of these, the so-called harvest festival celebrated at the height of the season of plant-food abundance, was described in chapter 9. Another, which sometimes accompanied other assemblies, but at times was celebrated alone, occurred during visits of large troupes of Ariois, and was described in the preceding chapter. These most brilliant of Maohi carnivals usually took place at the headquarters of tribal chiefs, and were usually joined in by all members of any tribe who could walk or be carried to the spot.

\section{Rites for the Chief}

A cursory reading of the sources might well create the impression that a very large proportion of the Maohis' actions were for the principal purpose of supporting and glorifying their chiefs. Much of this impression derives from bias in the sources themselves; as I noted earlier, the European chroniclers of Maohi life were habituated (and apparently not dissident) to aristocratic societies at home, and they saw nothing bizarre or repugnant in nonegalitarianism as an organizing principal of society. Moreover, for practical considerations, and probably by preference, they focused most of their attention upon events involving tribal chiefs.

But this impression cannot be attributed entirely to the chroniclers' biases. It is simply an undeniable fact of Maohi life that a very large proportion of social activity was indeed focused upon the persons and the actions of chiefs in general (whatever their social unit) and of tribal chiefs in particular. While this applies generally to nearly every aspect of a tribal chief's person and actions, it is especially applicable to his birth, head freeing, tattooing, supercision, marriage, office-taking, illness, and death. The only one of these events yet to be described is office-taking, which in many respects is the one most relevant to our present concern with tribal aspects of social relations. Accordingly, I shall reproduce the fullest available accounts of office-taking, before discussing some of the features of all such events which appear to bear on tribalism.

The fullest available accounts of tribal-chief office-taking, fa'aari'ira'a (literally, ari'i-making), are found in Henry, Ellis, Moerenhout, and Morrison. Unfortunately for our purposes, these relate only to the ceremonies attending the assumption of chieftainship over tribes of considerable complexity, and involving the incumbent of a feather-girdle kin-Title. While it is logical to suppose that chiefly investiture ceremonies of less complex tribes contained some of the same kinds of objects and actions, that must remain an undocumentable assumption.

Prior to any such investiture it was, of course, essential for the wouldbe chief to make certain of enough human and spirit support for his claims. 
Unless elected or confirmed to the office by some prior action, heralds were sent around the region over which he claimed authority in order to assure himself of human support. According to Moerenhout these heralds carried two chiefly standards, flags or banners-one representing the former chief and one the new. These were shown to each subtribal chief, who either acknowledged them, thereby giving consent to the new chief's claims, or ignored and destroyed them, thereby refuting such claims. Some claimants thus challenged tested their strength in warfare, but others appear to have let the matter stand, reducing their claims accordingly, at least for the time being.

Morrison provided a first-hand account of one such episode, which will be reproduced in volume 3. To that description he added: "If a Man of Property is found Guilty of a Crime which deserves death he is punishd as well as the Poorest in the Island. An Instance of this we saw at the time the Young King was invested with the Royal Marro-one of the first Men in Morea being sacraficed for attempting to stop the Flag from Passing through his land on that Island." (1935:207)

To secure spirit support for a claim to tribal chiefly authority it was sometimes essential for the claimant to obtain priestly backing, especially when chieftainship over a more complex tribe was in question:

... as this elevation to supreme power was ordained by the gods, any chief who wished to obtain this honor for himself and his family first found it necessary to apply to the priests [for recognition] no matter how powerful he might have been [in terms of military strength]; because, even though he might have overcome all his rivals by force of arms, he could not gain recognition of his authority from them as long as the grand priest had not proclaimed it as divine will. This proclamation was made by sending a herald carrying a flag into every district, and if the chief in question was indeed powerful and also had the support of the high clergy, it was rare that the other chiefs dared to refuse him their homage. (Moerenhout 1837:II, 28)

The most detailed account we possess of chiefly office-taking is Henry's, which purported to describe specifically the procedures followed at Opoa in installing the sovereign chief of all Ra'iatea, ${ }^{42}$ but which seems to resemble closely the procedures followed elsewhere for installing chiefs of tribes of comparable complexity. In reproducing Henry's account, I append some notes designed not only to clarify but to expand Henry's treatment of certain episodes.

The ceremony for the inauguration of a king or queen (fa'aari'ira'a) of Ra'iatea was the same as that for all sovereigns of the group. It was a time of the greatest moment to the nation, and extensive preparations were made for several months. Food was cultivated for a great feast, to which were to be invited guests, representatives from neighboring kingdoms; the choicest materials for vestments, which were ruru (rolls of cloth), tiputa, capes of purau bark and of cloth, ornamented or plain, and also of 'ura or black feathers were made; and greatest of all the work was the con- 
catenating of a new lappet to the maro 'ura ('ura feather girdle), the royal insignia in which the monarch of either sex was invested on the ascension day. The girdle derived superlative sacredness from some of the feathers, which were taken from the image of the tutelar god, who in later times in Ra'iatea, Tahiti, and Porapora was 'Oro, while Tane remained supreme in Huahine.

The royal girdle was an article of very skilful workmanship, which consisted of a close network of fine, strong threads of the ro' $a$ bark (a kind of flax), and a background of choice ora (banyan cloth), closely perforated. In each little hole was set the stem of an 'ura feather, which was caught in a lock stitch on the opposite side with a long polished needle of human bone, and set closely against the next one to imitate bird's plumage. Artistic patterns, mostly in squares, were thus formed by turning the feathers in different directions, answering nearest to hieroglyphics of anything in the handiwork of these islands. For they symbolize to the national chronicler the name, the character, and the acts of every monarch that reigned and the annals of the land which were faithfully recorded in chants and songs of those times. ${ }^{[a]}$

The sacred needle was never taken out of the work, which was intended to continue forever, a new lappet being added for each successive reign. A human victim was sacrificed for the mau raa titi (perforating the cloth), for the tuira' $a$ $o$ te $a u$ (first putting in of the needle), and for the piura'a o te maro (completing of the maro), and during the performance of these cruel rites it is said that the gods manifested their approbation by sending flashes of lightning upon the scene with loud peals of thunder, even when the sky was unclouded. The royal red maro of the Tamatoa family of Ra'iatea being the most ancient in the group was the longest, measuring twenty-one feet in length and six inches in width. ${ }^{[b]}$...

The canoe builders were busy choosing good timber and skillfully making a new canoe, called te-va'a-roa-i-te-mata'i (the-long-canoe-in-the-wind), for the god and paddles for it, called mehine-i-te-ata (moon-in-the-clouds), when using which the paddlers looked up into the sky. The discarded canoes were used for sacred fires at maraes.

The priests had a marae weeding and pa'i-atua ceremonies, and they fasted much and prayed at the marae, invoking the favor of all the hosts of gods for the new king, that his sins of omission and commission might be forgiven and that his reign might be prosperous. These devotions were called pure manava huihui na te tahu'a (prayers with throbbing vitals of the priests), for they felt the solemnity of the occasion.

On the eve of the great day, at Ra'iatea, for instance, the clergy of the royal marae held sacred vigils throughout the night at Taputapuatea marae in Opoa, inviting all the hosts of gods to be present on the morrow, as for the paiatua.... This was called pure toiaha, pure iri anu a te tahu'a (weighty prayers, prayers with chilly skin of the preists; ${ }^{[c]}$ and as the morning was ushered in, the gods were said to be heard flying and whistling around the marae and all over Opoa.

a. This is the only reference I know of which proposes that the "designs" worked into a maro were "symbolic"; in the absence of supporting evidence I suggest that Miss Henry's proposal is unwarranted.

b. A note accompanying this text states that this maro was subsequently sent by the king, "in the early days of his conversion," to the LMS Museum in England, from which it later disappeared.

c. So-called because the officiants were required to carry out their duties in the chill of the night and without extra clothing. (See chap. 3, section on religious ritual.) 
It was a most sacred spell, and another human victim was slain in honor of the gods before commencing the inauguration ceremonies for which all who were to take part had sanctified themselves. It was said that a root of the great banyan tree believed to have come from the moon, which struck out from a branch at the royal birth, on that morning reached the ground. ${ }^{[\mathrm{d}]}$

Soon upon the sea and along the shore a semibarbarous pageantry took place. A long flotilla bearing nude men and women of the arioi and hihimoa fast element, ${ }^{\text {[e] }}$ headed by the new anuanua (rainbow) or sacred canoe of 'Oro, which was distinguished from all the rest by tapaau (coconut-leaf images), viriviri (braided coconut-leaf) chaplets suspended around its borders, and by the presence of opunui ${ }^{[\mathrm{f}]}$ who named it, dressed in their best marae costumes, each carrying a tapaau on his left arm and wearing wreaths of coconut leaves. The canoe had a platform towards the center for 'Oro and the coming sovereign. Inauguration ceremonies for either sex were the same rank, waiving restrictions on state occasions. ${ }^{[\mathrm{g}]}$ The heralds, called tama horo fetu pao (sons running meteors), and people on shore contrasted favorably with those on the canoe, being arrayed in their gayest and best attire, decked in wreaths and garlands. Then came the solemn procession with shoulders bare heralded by blasts of 'Oro's trumpet, pu-o-roroi-tau (trumpet-of-ages), and his sacred marae drum, pahu-rutu-roa (long-beating-drum), from Taputapuatea inland to the great sacred white stone pillar, te-papa-o-ruea (the-rock-of- investment). The following order was observed: first the tiri moa (holy nurse of the god) bearing 'Oro's image exposed to view in all its brilliant 'ura feathers; next the new sovereign in a waist cloth of sacred marae tapa, accompanied by the chiefs of the realm, four of whom bore him upon their shoulders on a large wooden couch; ${ }^{[\mathrm{h}]}$ and closing in the rear the high priest followed by the clergy of his marae.

As the procession passed, the spectators on either side gave it wide berth. 'Oro's image was carried on to the god's canoe, followed by all the priests except the high priest, who remained with the king or queen; and the sovereign, surrounded by chiefs, seated himself upon the throne placed near the seaside. Thence, the high priest and the king went into the sea, facing Te-ava-moa (The-sacred-harbor), where the king, keeping on his waistcloth, simply immersed himself, while the high priest with a miro twig in his hand sprayed water upon him, pronouncing him clean and chanting the pure utuhi (invocation for dipping). ${ }^{[i]}$

Fa'aatea no te ari'i e tae i Motu Tapu;

PURE UTUHI

Make way for the king onwards to the acred Isle;

d. This refers to the 'aoa (banyan, Ficus prolixa?), which was believed to have set forth a new fibrous branch at the time of birth of a successor to a chiefly office; the branch finally reached the ground on the day of the successor's investiture in office. (Ellis 1829:II, 353-354.)

e. Hihimoa: I have come across no other references to such persons and am unable to clarify the etymology; hihimoa, "the feathers on the back of a fowl's neck," or hihi (rays of sun; whiskers of rat), mo'a (sacred)?

f. Ōpū nui, "big bellies"; marae attendants, (see chap. 21).

g. I take this somewhat obscure statement to mean that the ceremonies under consideration were performed in essentially the same manner whether the investee were male or female.

h. An accompanying footnote adds: "The couch was hewn out of solid miro wood. It had four legs, a raised piece forming a pillow, and carvings at each end. It was called the parahiraa or nohoraa aru (royal seat or throne)." (Henry 1928:190.)

i. According to Ellis, the purpose of this episode was "to purify the king from all mahuru huru, or defilement and guilt, which he might have contracted, according to their own expression, by his having seized any land, banished any people, committed murder \&c" (1829:II, 357). 
E papa e haruru te ra'i i ni'a e!

I te maro 'ura e!

Ua 'ura tini

I te ahu taa

I to maro 'ura na e tau ari'i e.

Tuia te ra'i i ni'a e,

E te ari'i nui ia 'Oro Toa,

Te tupuai fa'aari'i o Ra'iatea,

Rerea i te 'ura i Hauviri.

Horo te arere te haha i ni'a ia 'Oro

Ia hio mai ai ia Ra'iatea

I mua i to maro 'ura na e!

Tau ari'i o te ra'i e te maro 'ura e

Ua 'ura tini

I te ahu taa

I to maro 'ura na e ta'u ari'i e

Ei hea hume ai

To maro 'ura na e ta'u ari'i e?

Ei te tai tua mai o Taputapuatea.

A tiu ta ria roohia

Te pure ari'i i te utuhi

Ua puni a'enei te uru o 'Oro

I te rau o te 'ura

Manu na te ra'i e!

Manu tahi atua

Te 'ura amo a'e

I te pure i te rau roa

Ua oti te maro o te ari'i

Tatou e noho ai e

Tui te noroa o maeva rua

$\mathrm{Na}$ 'Oro te metua o 'oe.

E ti'i i te 'ura tei Tahuea

Raverave noa mai i te pua tiri

O 'ura i te ara o Tane

E noa'a i reira

O te 'ura rau nui

Ahiri ho'i e ora na o Tumaraa

Eo Tevaitoa i te Rapatia

Ei ono i to maro 'ura

E ta'u ari'i e

Te ra'i e te maro 'ura e!

Te'ura tini

O te ahu taa

I to maro 'ura na, e tau ari'i e

E ti'i i te 'ura ia tini

Ia mano i anapanapa

I te ahu taa ha'amana
Loud peals resound in the sky above, O!

For the red girdle, O!

Numerous are the 'ura feathers

From the wall of jawbones ${ }^{[j]}$

In thy red girdle, $\mathrm{O}$ my king.

The sky is reached above,

By the great Warrior Sovereign 'Oro,

The high investor of Ra'iatea's kings,

Flying in the feathers of Hauviri.

Let the herald run up fearlessly to 'Oro

As he looks down to Ra'iatea

Upon thy red girdle, ${ }^{[\mathrm{k}]} \mathrm{O}$ !

$\mathrm{O}$ my king of the skies and the red girdle,

Numerous are the 'ura feathers

From the wall of jawbones.

In thy red girdle, $\mathrm{O}$ my king,

Where shall the girding on

Of thy red girdle be, O my king?

Upon the seaside of Taputapuatea.

In a vision the king saw in

His royal prayer for the immersion

Enchantment of 'Oro secreted

In the body of the 'ura (feathers)

Of the heavenly birds, O!

The unique birds of the gods

The 'ura (feathers) carried.

To the service upon the long sides (of the marae)

Finished is the girdle of the king

Which is why we are here, O!

Strong are the prayers for the double greeting

To 'Oro, the father, and to thee.

Fetch 'ura (feathers) from Tahuea marae

Bring forth flowers in profusion,

'Ura (feathers) on the track of Tane

Obtained from there,

Great 'ura feathers.

Behold then, awake are Tumaraa

And Tevaitoa ${ }^{[l]}$ to brave vicissitudes,

To stand by thy red girdle,

O my king.

The sky and the red girdle,

Thousands be the 'ura feathers. ${ }^{[\mathrm{m}]}$

From the wall of jawbones

In thy red girdle, o my king,

Fetch 'ura (feathers) in abundance.

Let there be thousands resplendent

At the wall of jawbones, which gave power

j. An accompanying footnote explains this as having reference to the walls of the marae, where skulls and jawbones of defeated enemies were sometimes kept.

k. A footnote points out that the 'ura girdle was also an emblem of the aurora.

l. Tumara'a and Tevaitoa were two of the nine subdivisions of Ra'iatea. (See chap. 25.)

$\mathrm{m}$. Some of the feathers used in adding the lappet to the maro were from the reserve kept in the marae, and already charged with sacredness. 
'Ura i tau rere

Iriti a te papa ia hute.

Te tapa ia i to maro 'ura na

E ta'u ari'i e!

Te ra'i e te maro 'ura e

Ia 'ura tini

I te ahu taa

I to maro 'ura na, e ta'u ari'i'i e.

Ta'u Ari'i 'oe, a ti'a i ni'a

I te tua o Marama;

E ti‘a i ni’a

Ia Ra'iatea nui hau Marama

E to i te tini e to i te mano,

E to i te mata

O Ra'iatea nui e vau.

Tau Ari'i 'oe i te fa'anehenehe,

To roro una,

Hei atu a i Taputapuatea,

Te 'Oro matau tua, 'oe e ta'u ari'i e.
To the 'ura feathers that settled and flew

Were the rock ${ }^{[n]}$ taken up, glory would depart.

That is the strength $\left[\operatorname{tapa}^{0}\right]$ of thy red girdle,

O my king!

The sky and the red girdle, $\mathrm{O}$ !

Thousands be the 'ura feathers

From the wall of jawbones

In thy red girdle, O my king.

My king, thou arise

From the Sea of the Moon; ;p] $^{[p]}$

Arise

To great Ra'iatea of the peaceful Moon

And draw the tens, and draw the thousands,

And draw the whole

Of Ra'iatea of eight [districts].

My king thou, to be adorned,

Thy brain indeed shall be

Crowned by the god of Taputapuatea,

By 'Oro inured to the sea, $\mathrm{O}$ thou, my king.

Then the king stood up and faced the sacred passage, where it is said that he was approached by two deified sharks, Tuu-mao (Let-go-shark) and Ta-hui (By-the-clan), which were always the first to come and pay their respects to a legitimate heir to the throne, but kept out of sight of a usurper. They swam in joyously and rubbed caressingly against the royal person, who feared them not, and then returned to the open sea. ${ }^{\text {qq] }}$

After his chant, the high priest conducted the king back to his seat, upon which the chiefs bore him reclining to the great stone pillar, at the foot of which were placed in readiness the royal insignia: the famous red maro, tipped with black feathers; a waist girdle; a red 'ura toque; a tahiri (fan), which was a waving cluster of tail feathers of the man-of-war bird and the tropic bird, attached to a long pole like a great duster and resembling the royal kahili of Hawaii; a long toa spear; and a miro walking stick. By the pillar the high priest performed the inauguration ceremony, called the pure rahi o te atoreiau (great invocation of inauguration):

The king, clad in a small dry maro $\operatorname{cloth}^{[r]}$ (loin girdle), stood in front of the pillar with his chiefs in the rear and on either side of him, and the high priest, introducing the royal symbols to him, explained their signification and disposed of them in their proper places. ${ }^{[s]}$ Pointing to the pillar, the priest said, "To papa-ia-ruea" (Thy rock-of-investment); pointing to the wooden pillow upon

n. Refers to the stone column of investment.

o. An inference that might be drawn from this is that the feathers in question were also "empowered" as a result of their association with the human remains reposing in the marae-that is, that at least some of a chief's tapa was derived from the enemies slain in tribal wars. Henry translated tapa as "strength," whereas the LMS Dictionary defines it as "the groin." I am not sure about either of these translations, but there is much in Maohi metaphoric imagery to support a linkage between the two.

p. Native name for the waters between Ra'iatea and Tahiti-Mo'orea.

q. An occurrence which was, of course, attested by impeccably reliable witnesses-or so claims a footnote!

r. Or, if the investee were a female, a footnote hastens to point out, she would have been more modestly attired, in pareu and cape.

s. Moerenhout described this episode as having taken place in the "sacred" canoe rather than at the marae. 
the throne, he said, "To rurua, o Fefeu" (Thy pillow, Spread-out); presenting the tahiri, he said, "To tahiri, o Nunaa-e-hau" (Thy fan, Nation-of-peace), which the king passed into the hands of his senior chief, who held it upright upon the paving beside him, the plumes rising high above the King's head, "To taupo'o, te Ata-o-tu" (Thy toque, the Cloud-of-Tu), he said, placing the toque upon the king's head; "To tatua, o Manava-taia" (Thy waist girdle, Sensitive-conscience), adjusting it upon him; "A rave $i$ to omore ia Huia-i-te-Ra' $i$ " (Take thy spear, Family-of-the-sky), which the king received and passed on to the next high chief; "A rave i to to'oto'o ia Paia-i-te-faurua" (Take thy staff, Double-pure-descent), which he placed in the hands of a third chief; and finally the priest said, "A maro i to maro, ia Te-ra'i-pua-tata" (Gird on thy loin girdle, Sky-of-the aurora); and the most sacred of all the symbols was so placed upon the king as to have one end gracefully streaming before him, and the other behind. Then as he sat upon his throne bare-shouldered in that sacred locality, the chiefs raised him to view on top of the pillar by stepping upon stones placed to the right and left for that purpose, and there the people on land and sea held up their hands and greeted him deafeningly many times with "Maeva Ari'i! maeva Ari'i!" (Hail, King! hail, King!).

From the pillar the chiefs bore the king, still enthroned, to the sacred canoe and placed him side by side with the image of his spiritual father, 'Oro, the high priest standing beside them. Then the steerman gave the signal for the flotilla to set out by striking the paddle against the side of the canoe, and immediately the trumpets blew and the drums beat and they went forwards, up into the bay of Toa-hiva and out to the sacred passage, the high priest pronouncing the pure-faufenua (invocation-for-highest chieftainship), declaring the king lord of the land and sea and all upon and within them, and invoking the hosts of gods, still supposed to be around them, to aid the new king in wisely governing his people, to be with him in peace or in war, to extend sway to the east and west, to the north and south, and to bring all other monarchs under his feet [italics added].

On landing on the shore whence they had departed they returned to the inner marae at Taputapuatea in the same manner as they had come out. The procession formed as before, except that the king, borne upon the shoulders of the four high chiefs of the royal house, reclined in royal array upon his throne. Following the priest carrying 'Oro's image they went up into the marae, where all took their respective places, the image being placed upon a mat in the avaa, the king by his leaning slab, the trumpeters by the drummers, and the priests and chiefs in the rear. Then the high priest concluded the inauguration ceremony by plucking out the eye of one more human victim and proffering it to the sovereign, who made a semblance to receive and swallow it, but in reality did not touch it. This was intended to give keen perception and farsightedness to the recipient and was called pivai-ari'i (apart-with-sovereign). ${ }^{[\mathrm{t}]}$ The high priest then said:

\author{
A hi'o i to mou'a ia Te-a'e-tapu, \\ A horo i to tahua, O Mata-tu-tahua-roa. \\ A hopu i to vai, ia Via-tiare. \\ A 'au i to vai, ia Ra'i-to-moana.
}

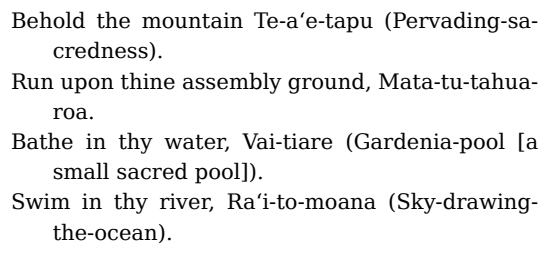
credness).

Run upon thine assembly ground, Mata-tu-tahuaroa.

Bathe in thy water, Vai-tiare (Gardenia-pool [a small sacred pool]).

Swim in thy river, Ra'i-to-moana (Sky-drawingthe-ocean).

t. According to Moerenhout, the officiating priest extracted both eyes of the victim, offering the right one to the tutelar's image and the left one to the investee (1837:II, 25). 
Pau i to vai ia Vai-tara-toa.

A hi'o i to 'outu, ia Mata-hira-i-te-ra'i.
Splash thy water, Vai-tara-toa (Water-of-sharprocks).

Behold thy cape, Mata-hiri-i-te-ra'i (Faceflinching-at-the-sky)

They then took leave of 'Oro and the marae, ... the image was put to bed and carried home to the fare-ia-manaha, and after announcing to the public that the solemnity was ended and the festivity and gaieties were to begin, the trumpets and drums were also put away.

The priests put on fine ordinary clothing, the chiefs their official feather vestments with the gorgeous taumi upon their heads; and over the shoulders of the king, in his girdles and toque, was thrown a tiputa (poncho) of glossy black, red, and yellow feathers, finished around the neck with 'oro'oro (clusters of feathers) of the man-of-war bird, and extending down to his throne. Again, amidst the assembled throng, the air was rent with "Maeva ari'i!" accompanied with the raising of hands. The nude party, some of whom were mounted upon trees, hailed him as monarch of their persons, suiting actions to words in language too primitive to be repeated. A queen was happily exempted from this undignified greeting. ${ }^{[\mathrm{u}]}$

All the dignitaries of the land were dressed in official garb, and the king on his throne was finally borne on to a stone platform covered with mats laid upon long 'aretu (grass) and sheltered with an awning of coconut leaves, which was beautifully decorated with green and yellow coconut and ti leaves and flowers. Here, with the queen and royal household and his counsellors, he reviewed and received the loyal greetings of his chiefs and chiefesses, who headed long processions of the people of their districts. The people were assembled in proper order for the great feast that was to take place in long coconut-leaf sheds upon the assembly ground.

After the inauguration festivity, the king's 'ura feather maro, the most sacred of all his royal insignia, was carefully wrapped in tapa and a mat by itself, and the cape and toque were in like manner wrapped by themselves and put away in the fare-ia-manaha. The only other occasions on which he appeared in state were: at the marriage of an heir apparent; at a reception of the sovereign of another realm as a great guest; and when concluding peace after war. Without the other two appendages the king wore his maro for the pa'i-atua service, and it was spread out to view for the pure ari'i or prayer for the king before commencing war, as was seen by Captain Cook. (Henry 1928: 188-195)

As I noted above, Henry's account of chiefly office-taking, the fullest available, refers specifically to Ra'iatea. Ellis' account is less detailed and appears to refer more particularly to Tahiti, and the same is true of Moerenhout's. ${ }^{43}$ Moreover, if one uses the Henry version as a base, those of Ellis and Moerenhout will be found to expand, omit, combine, or reverse the sequence of certain episodes. The expanded versions of episodes

u. Ellis wrote, "A veil must be thrown over the vices with which the ceremonies were concluded" (1829:II, 359). Moerenhout wrote, “... une scène qui devait en ravaler singulierement la solemnité, et dont le simple exposé ne pourra que blesser étrangement la delicatesse européenne." But, he went on to explain: "The chief or king, while reclining on a mat near the god's image, received what was termed the populace's ultimate mark of respect. This consisted of dances and gestures of shocking filthiness, of the grossest kind of obsenity, wherein stark naked men and women surrounded the king and attempted to touch him with various parts of their bodies-even including their urine and excrement." (1837:II, 27) 
have been reported in my notes to the Henry text; as for the omissions, combinations, reversals, and so forth, I believe these to be of no great weight in terms of this important ceremony's overall social significance and symbolic messages, which I shall now attempt to elucidate. ${ }^{44}$

First of all, with an exception to be noted below, there is nothing especially distinctive about the ritual idiom in which the ceremony was performed-at least not with respect to the symbolic referents of specific ritual objects and acts. (As will be pointed out, the ceremony's distinctiveness lies rather in the ways these ritual "phrases" were juxtaposed-i.e., in syntax rather than lexicon.) As with all Maohi ritual, spirits played indispensable roles; and the messages contained in the various objects-feathers, seawater, chiefly insignia, sacrificial victims; actions-spirit-validation, tribute rendering, commensual eating; and locations-land and sea settings-were fairly conventional and (hopefully, by now) not altogether obscure to the reader. (The symbolic referent of the number four is, however, not clear to me.)

Second, most of the secular, political, aspects of the ceremony are intelligible, and consistent with conventional expressions of social relations: I refer to the "tributary" contributions of subtribal chiefs, the tokens of recognition of chiefs of other tribes, the implication of universal tribal involvement contained in the redistribution and joint consumption of the collected foods, and so on. Also, the various acts of obeisance and acclamation are wholly consistent with conventional Maohi behavior toward persons in authority.

On the other hand, I must confess my perplexity concerning the "indignities" heaped upon the chief by the party of nude celebrants. If these gestures had only to do with sexuality, and if semen alone were applied to the chief's person, one could perhaps interpret this episode as a rite of fertility, a reference to beliefs in a chief's mystical association with tribal fertility, natural and human, which some writers on Polynesian chieftainship assert to have been widespread. However, the addition of urine and excrement to these "indignities" seems to me to imply another dimension. It is of course possible that urine and excrement had associations with sexuality; but I believe that not to be so, and that excrement, at least, was indeed associated with "indignity." 45 This being the case, the only explanation I can offer for subjecting the newly vested chief to so gross an indignity, in a context otherwise characterized by such heights of dignification, is to regard the behavior as a caveat: that is, "Eminent as you are, and powerful as you seem to be, you remain vulnerable to the moods of spirits and consequences of your actions with humans." Belief in the fickleness of spirits has already been documented, and later on I shall adduce evidence of the social constraints imposed upon even the most glorified of chiefs-so this interpretation is not altogether without basis. 
But far more noteworthy than this ritual juxtaposition of glorification and debasement is the extent to which the ceremony combined recognition of what appear in Western eyes to be two contrasting bases for chiefly legitimation, that is, descent versus coercive force. On the one hand, the chief's authority was represented by several symbolic means as his by right of birth, ultimately by descent from the tutelar himself, thus explaining as well as legitimizing his exalted status. On the other hand, certain other expressions, verbal and otherwise, substantiated his status in terms of his martial successes. And though in one ritual episode the victorious chief was required to be expurgated of the mystically dangerous consequences of his aggressive use of force, another episode expressed the wish and intent for more of the same.

Of course, for any individual to attain chieftainship over tribal units as large and complex as those involved in the office-taking ceremonies now under consideration, both descent and coercive force were required to a degree that may not have obtained with chieftainship over less complex tribes. But one must also consider the possibility that what we view as contrasting bases of legitimation were not so regarded by the Maohis themselves. It may have been that descent and coercive force were inseparable and valid bases for tribal chieftainship, not only in the realities of Maohi history but in Maohi ideology as well. Indeed, in terms of Maohi history, the route to chieftainship of a complex tribe involved not only descent and coercive force, but other factors as well.

\section{ROUTES TO TRIBAL CHIEFTAINSHIP}

Previous chapters should have made abundantly clear the importance of descent in allocating statuses of many kinds, including establishment of eligibility to positions of privilege and authority in kin-congregations. Within this same ideological frame I also noted the social weight that was attached to birth-order and maleness, and I drew attention to the rather distinctive timing practiced by the Maohis in transferring a kin-Title to a successor. At the same time I took pains to point out that kin-Title succession did not inevitably conform to priorities established by birth-order and sex, and that verbal transfer of Title did not usually betoken simultaneous transfer of the secular authority that went with it. If these constraints applied to chieftainship in a kin-congregation, they were even more applicable to chieftainship of a tribe.

There is no question but that chieftainship of a tribe devolved most customarily upon an incumbent's eldest son. But exceptions to the mode of succession were frequent enough to require discussion. Occasionally a chief himself named someone other than his eldest son to be his successor. On other occasions, the more influential persons of the realm (including 
powerful subtribal chiefs, priests, and other relatives of the former chief) intervened to elect some more desirable candidate-“desirability" having been defined to suit various interests, as we shall see. ${ }^{46}$

One such case of the latter was described by Adams and concerned the head chieftainship of Papara:

Aromaiterai and Tuiterai were the names of Teriitahia's two sons, and, if our genealogies are right, they must have been born, as I have said, between 1690 and 1700. Aromaiterai was the elder, and naturally claimed his father's position as head-chief. Tuiterai disputed the claim, and, if the family tradition is correct, his plea raised a question worth noticing in these days, when the study of primitive law has become a hobby.

Tuiterai's plea or defence seems to have turned on the idea that the eldest child, whether male or female, was the only heir who could set up an indefeasible right to the succession, and since the eldest child in this case, being a woman, had married and gone off to Raiatea, all the younger children had equal rights, and might with equal justice claim the position of head-chief.

This was one of the cases in which the sub-chiefs or Hiva must have been the judges, and although we know nothing about the reasons for their action or even the time when they acted, we do know that at one time or for a certain period they decided to send Aromaiterai away-banish him, in fact-and that they did it. (1901:33)

According to T. Salmon's legendary account of Porapora's dynastic struggles, when some of the sovereign chief's rebellious subjects ended his austere reign by killing him in battle, and were unable to agree upon one of themselves as a successor, they settled upon the dead sovereign's own son, though requiring him to dissociate himself from the past by assuming a new dynastic Title and occupying a new marae (n.d.:29).

Another case of "election" to tribal chieftainship concerned succession to Huahine's "Queen" Maeva, which I described in chapter 16. On that occasion, it will be remembered, the chief electors were the queen's own eight sons. Uable to agree upon one of themselves, they divided their votes between two Ra'iateans, one of whom finally won the office by a military ruse.

Moerenhout described still another situation involving election to chiefly office:

... after long periods of warfare, when all combatants have begun to be weary of the violence, it sometimes transpires that priests will initiate a proposal to designate a chief to rule over both sides, in order to make an end to the bloodshed. It was customary to name some young chief to this office, someone agreeable to all parties, and to provide him with dictatorial powers to resolve the severe strife. In such cases the investiture ceremony was the same as in ordinary situations of chiefly office-taking, and it was always the religious functionaries to whom such chiefs owed their position and the respects paid to them. (1837:II, 28)

No record is available concerning the civil procedures followed in such 
"elections." Some of the reasons behind some of the choices can be guessed at-for example, the logic of adhering as closely as feasible to normal criteria of kin-office succession, or, in situations of stalemate, of settling upon relatively nonpartisan candidates. In other instances the electors may have been influenced by statesmanlike concern for fair and effective leadership, but I suspect that concern for narrower self-interest also frequently prevailed.

The legend of Honoura tells us little about election procedures, but it does add something to our impressions about what the Maohis generally sought for in their chiefs. Honoura, it will be recalled, was born in the form of a shapeless abortion and was left in a cave to survive as best he could. Eventually, however, he grew up to be a giant of a man, whose prodigious strength and warrior skill were matched only by his valorous spirit and generous good will. After a series of successful adventures against his tribe's enemies, he and his shipmates finally returned home: "... and when the people of Tahiti knew of Honoura's valour [puai] they all came to the bluffs to present him with the kingdom [E pupu atura nona te hau], but he quietly remained under the government [hau] of [Chief] Ta'ihia, and he did not usurp the power [ai te hau; i.e., 'eat the hau'] over the land of Tahiti" (Henry 1895:276-277). ${ }^{47}$

The role of spirits in chiefly elections is easy to discern but difficult to weigh. We read in Henry's and other versions of the office-taking ceremony how shark deities were thought to express their view of the legitimacy of a new chief's claims, but there is no evidence that a rebuff from such deities would have put an end to the ceremony. We also read in Moerenhout's account that it was essential for a candidate to obtain priestly backing for his claims, but it is not explained on what basis the priests themselves made their choices: by divination? concern for their profession? broad public interest? or narrow self-seeking? Judging by the faith individuals were accustomed to repose in proven tutelars in connection with war and other enterprises, one can be sure that they depended upon such spirits to support them in their bids for chiefly authority, but it is not at all clear how spirits intervened in the election process itself.

In some instances individuals became tribal chiefs by the process of "self-selection," that is, they attained the office by forceful seizure of one kind or another: by assassination, by force of arms, by guile, or by political maneuver. ${ }^{48}$ Of course, no individual acting alone could attain tribal chieftainship. Some social support (with or without evidence of spirit support) was indispensable; however, it was possible for a determined man, with a loyal and equally determined following, to achieve this office even though his party was small in numbers. Well-documented instances of this form of succession are lacking, but inferences regarding its prevalence are contained in many passages of legend and "history"-at least with respect to the less complex tribes. 
Later on I shall describe some other attributes considered by the Maohis to be desirable in individuals holding tribal chieftainship, but the factors just discussed were the ones most influential in any individual's attainment of the office. ${ }^{49}$

\section{OTHER TRIBAL OFFICES}

There may have been a time in Maohi history when a tribe's chief was sole administrator, war leader, high priest, seer, principal orator, font of knowledge, and so on-with staff assistance, when needed, provided mainly by his close relatives. But by the time of the eras under study, tribal units had reached sizes and orders of complexity that permitted or required a number of officials to perform these various offices. We do not possess information on the numbers of such officials in any specific tribe: a regrettable omission, since such information would provide better bases for generalizing about social evolution, with regard to such matters as role differentiation, cost of government, et cetera. The sources do, however, provide some information concerning the kinds of such officials in general, along with accounts of certain individual office-holders in particular tribes.

In most tribes that we know anything about, the office of high officiating priest of the tribal marae was held by someone other than the tribal chief himself. Probably all tribal chiefs were regarded as being closely akin to their tribal tutelars, and most if not all of them may have been acknowledged as priests on occasion, but none that we know of officiated regularly at tribal services at the tribal marae. ${ }^{50}$

I indicated in chapter 21 the influence some individual tribal high priests exercised over tribal secular affairs, but we are now concerned with their office and its distinctiveness from that of tribal chief.

Owing to the official character of a tribal marae, one would be justified in classing other functionaries of such marae as tribal associate priests-sorcerers, big-bellies, image bearers-but having described these offices previously, I shall not do so again. A more difficult classification problem is raised by the offices of sage and teacher: it is not always clear whether some such offices were primarily associated with tribal marae or with the domestic establishments of individual tribal chiefs. In other words, are such specialists to be regarded as tribal functionaries or as members of personal retinues of high-ranking kin-Titleholders who happened also to be tribal chiefs? (A similar question arises with respect to certain other offices to be listed below.)

At first glance this question might appear to be trivial and hair-splitting; a closer look reveals it to be significant. I am examining here a crucial aspect of the process of social evolution-the cumulative changes in social relations which usually (perhaps even necessarily) accompany increase of a social unit's size. As set forth earlier in this chapter, the 
available data on Maohi society indicate an evolution in the size and in the nature of territorial units, from small units composed mainly of kinfolk to larger units composed of several of the smaller ones linked together in part by nonkinship ties. Accompanying this change there was a numerical increase in offices having to do with affairs involving, on occasion, all of the unit's expanding memberships: this I believe to have been not only historically but perhaps inevitably so. But there was much less inevitability about the ways such offices could have developed. At one logical extreme were offices concerned more or less impersonally and indiscriminately with the welfare, and so forth, of the whole tribal membership; at the other extreme were offices concerned primarily with the welfare of the tribal chief, and with the rest of the tribe only insofar as this concerned the chief's personal welfare. (For, as we shall see, the interest and welfare of the chief and of the tribe were not always identical, despite certain writers' imputation of mystical identity of the two.) Among the Maohis, as in perhaps all human societies undergoing increase in the size of their territorial units, both types of offices were to be found; but the important question is, Which type predominated during the eras now under study, and in which of these two possible directions did the society appear to be moving? In other words, was Maohi tribal government moving more in the direction of constitutionally based statuses administered and otherwise served by an impersonal, politically neutral bureaucracy, or in the direction of societies run principally for their rulers' own advantage by supporters committed to their rulers' personal causes? (There may be other possible directions open to societies like those of Polynesia prior to European contact, but these represent one pair of logical extremes.)

Returning now to the offices of sage and teacher, with which this excursus began, the information supplied concerning them is not sufficient to enable us to decide directly which type they exemplified. Moreover, the question is complicated by the possibility that a teacher, say, in one tribe fitted into the structure of his tribe in a way different from a teacher in another. It does appear, however, from the nature of most of the knowledge and skills which these officials professed, that they served principally the interests of the higher classes of society, including those of the tribal chiefs. But let us go on to other officials more or less tribal in scope.

Since coercive force was perhaps the principal factor in putting and holding together large and complex territorial units, the roles of military specialists may be regarded as mainly tribal in character. A tribe's sovereign was invariably commander-in-chief in wartime. Some tribal sovereigns also served as tactical field commanders, or battle shapers, but that was not always the case. The question is, Where did the loyalties of such nonsovereign field commanders mainly lie: with the tribal membership as a whole, or with the sovereign's own personal advantage? There is not much infor- 
mation bearing on this question, but what there is indicates that there were both tribal and situational differences in this regard. Some field commanders appear to have been unfalteringly loyal to their sovereigns whatever the military cost, while a few acted independently, or even insubordinately. In most of the latter instances the field commander in question was chief of a powerful subtribe, whose "loyalty" to the tribal sovereign was tenuous at best. (Such situations seem to have posed a chronic problem to the sovereigns of most complex tribes: that is, internal cohesion and success against other tribes required the support and leadership skills of subtribal chiefs who often had diverse ambitions of their own.)

The sources do not indicate what positions battle exhorters (rauti) occupied in a tribe's normal hierarchic structure. They were described as having been "of commanding person and military prowess" (Ellis 1829:II, 487-488), and presumably they were drawn from any and all tribal subdivisions. But whether they served the sovereign in particular or the tribal force as a whole, or whether they acted more narrowly to stimulate the fury of their own subdivisions, is not reported. A passage in one exhortation suggests the former role for some of them (Henry 1928:306):

"There is a king above, who is the speaker of armies,

The roller of the skies.

Set about your errand, O warriors, O brave men.

Accomplish your errand,

O warriors, upon the flat mountain battlefield

Of Ta'aroa, whose curse is death!

From the will send out

An ocean storm battle.

Soon thy paving, O my king,

Will flow with the blood of the slain.

Another passage suggests tribal patriotism (p. 308):

As for 'Uporu it is the home of the gods.

But as for Havai'i (Ra'iatea)

It is strong rock

Of the night from whence sprang Vavau (Porapora).

Rouse up friends! Ye sons here,

Ye sons here, rouse up!

Rouse up adhering to your land;

Rouse up, rouse up, adhering

To your land peopled inland and coastward.

Fly up? Ah yes!

Simultaneously? Ah yes!

O generation of red (sunburned) backs,

Be ready for action,

Be troops to stand against,

To save, to break the storm (war),

To let the hurricane spend itself. 
Still another passage indicates a concern for the population at large (p. 309):

Let them [the enemy] no longer persist

In this bad play, fighting,

Let their valiant men sue for peace,

For a bed for their carcasses,

That their children may live tranquilly upon the seashore.

On the other hand, most passages of war "exhortations" that have been translated (I find some of these to be quite "untranslatable") have little or nothing to do with "loyalty" to any social entity-tribe, subtribe, or chief-but only with the fury and glory of combat.

A passage from the "Precepts of Tetunae" charges people to "bear respect toward the 'aito; they all protect te tura o ta te fenua." Fenua refers literally to territory or to territorial social unit, and tura means "to be exalted, to be invested with power, to have honor," and hence the phrase could signify "the power, honor, and prestige of the tribe." On the other hand, in view of the Maohi penchant for this kind of metaphor, the phrase might well refer to the sovereign chief as embodiment of the tribe's power. In any case, except possibly for those constituting a chief's own bodyguard, on the evidence available I cannot justifiably identify the main loyalties of 'aito as either tribal (or subtribal) or personal. The probability is that there were some of each.

Turning now to those offices concerned with the administration of tribal affairs, it is necessary first of all to distinguish between line and staff offices: the former having been the chiefs of subdivisions of the tribe, the latter having been concerned with affairs of the tribe as a whole.

The relationship between a tribe's sovereign chief and its subtribal chiefs (i.e., the chiefs of its major territorial subdivisions) was one of the most important but unstable and ill-defined in Maohi society. I shall have more to say about these relationships later on.

In some tribes the principal administrative officer presumably was the chief himself; in some others that function was performed by another official (or officials). A passage in the "Precepts of Tetunae" refers to such officials as tauimihau: ${ }^{51}$ "The tauimihau are to be held in respect by you, they are to be treated with respect; they are the administrators of the government [te fa'atere i te hau]." In other sources administrators were called tu'aāu, ti'aāu, or ani (LMS Dictionary; Henry 1928:116ff.; Rey-Lescure 1946:201).

Very little was recorded concerning the specific functions of such officials, but the text quoted earlier in this chapter regarding the custom of tavau contains an account of how such an official was invested in office:

When the people of Faanui [Porapora] wished to elevate a man to be their tu'aāu, they did so by handing over to him the reigns of government, signified by present- 
ing to him a leg of pork [a portion usually reserved for ari'i]. In so doing the orator would say: "Here is the leg of pork we hand over to you [figuratively, with this you eat the hau-i.e., take over the government], along with the mootara [provisions carried on a shoulder stick], ma'aopuroa [provisions spoiled as the result of a long journey en route], some ahia leaves [a plant having medicinal properties, signifying that the new official must look out for the well-being of his people and improve the governing of them], a ta'avai [a stone worn smooth by rushing waters, signifying that the new official must wash wrongdoing from the land], and the water of maehai nui [?] to enable you to serve as tribal steersman. If after you have eaten the leg of pork [i.e., taken over the reigns of government], you then eat "leg of human" [promote warfare and the killing of men], and if you lead the tribe's canoe into the underworld [?], you will be banished." ... The method of investing a tu'aāu in office followed essentially the same procedures in all tribes, although the actual wording of the ceremony differed somewhat from place to place. (Rey-Lescure 1946:201) ${ }^{52}$

$T u^{\prime} a \bar{a} u, t i^{\prime} a \bar{a} u$, and ani appear to have been different local labels for the same office. It seems likely that tauimihau was another such label, although the precept refers to tauimihau in the plural, while the text just quoted implies that there was only one tu'aāu in a tribe. ${ }^{53}$

Some tribal chiefs presumably "spoke for themselves" but others had staff orators ('orero) to present their ceremonial greetings, public announcements, parliamentary exhortations, and so forth, for them. See for example the following excerpt from Jefferson's journal:

This afternoon the natives held a public meeting near the British house when the peace between Otoo, Pomerre, \& this district was again ratified \& confirmed. As all public business is transacted between persons called Taaoraro or orators, the speakers for Otoo \& Pomerre were seated on the ground, opposite to each other, about 15 yards asunder, each having a bunch of green leaves in his hand, (perhaps) as tokens of peace; and there harangued upon the subject of their meeting. The spectators kept at a proper distance. Otoo was present, but did not seem to take much notice of what was doing. (19 March 1799, LMS Archives)

An impressive presence, a sonorous and tireless voice, mental agility, a memory full of striking imagery, a knowledge of social etiquette and political realities-all of these were essential to effective oratory in the domain of tribal affairs. It is no wonder then that some tribal chiefs could not, or wished not, to do their own speaking. ${ }^{54}$ It is, however, far from clear just who such staff orators were. In view of their necessary qualifications it is not very likely that they were, like most ordinary servants, of lower-class origin. Perhaps they were recruited from the tribal chief's circle of close kinsmen or from among the petty chiefs of subdivisions of the tribal chief's own subtribal unit-but this is surmise. Nor is it clear how they were compensated for their labors, if indeed they were compensated directly in the form of deliberate payment for services.

A chief's messenger ( $v e^{\prime} a$ ) was sometimes much more than a mere bearer of messages. Within the tribal boundaries it was required that such 
officials be treated with some of the respect due the chief himself; and abroad they often served as ambassadors, with considerable scope for initiative and negotiation. A passage from Ellis describes one function of the $v e^{\prime} a$ :

Whenever a measure affecting the whole of the inhabitants was adopted, the king's vea, or messenger, was despatched with a bundle of niaus, or leaflets. On entering a district, he repaired to the habitation of the principal chiefs, and, presenting a cocoa-nut leaf, delivered the orders of the king. The acceptance of the leaf was a declaration of their compliance with the requisition, and to decline taking it was regarded as an intimation of their refusal to accede to the measure proposed. Hence the messenger or herald, when he had travelled round the island, reported to the king, who had received and who had refused the niau. When the chiefs approved of the message, they sent their own messengers to their respective tenants and dependants, with a cocoa-nut leaf for each, and the orders of the king. (1829:II, 367-368)

There were undoubtedly wide differences in social import in the messages carried by ve' $a$ and, accordingly, wide differences in the social positions of $v e^{\prime} a$. Ordinary commoners were probably used on ordinary errands, but such occasions as tribal assemblies required $v e^{\prime} a$ of higher-class status, as reported by Adams:

Whenever Teriirere i Tooarai, the chief of Papara, sent his messengers to call the Teva districts together, the districts came; but the summons was so peculiar that it needs a whole volume of explanation.

In the first place, the messengers were political personages, such as I never heard of elsewhere. They were under-chiefs-Iatoai. How many Iatoai formerly belonged to Papara I do not know; but in our day there are two subdistricts of Papara, Faina and Oropaa, and Faina has eight Iatoai; Oropaa has six. The whole body of Iatoai in each district are known as Hiva, and to any one who cares for the beginnings of things they are the most interesting part of our old society, for the Hiva of Papara might have been the source of all modern notions-Parliament, Civil Service, Army, Law Courts, Police, Aristocracy, Democracy, and Commune. The Iatoai were the chosen fighting chiefs or warriors, and they had, as a part of their functions, the duty of punishing or revenging insults offered to the head-chief; but they could also, and sometimes did, depose and exile a head-chief and name another or recall the old one. Their intereference in this way makes one of the most dramatic motives in island history.

The messengers whom Teriirere i Tooarai sent to summon the Tevas were Iatoais or under-chiefs of Papara, and of three kinds: one messenger for the home district, one for the inner Tevas, and one for the outer Tevas. They bore an official name while on service; they inherited the position, and the office might be filled by any member of the family to represent the actual head. (Adams 1901:8)

A passage from Cook refers to messengers as members of a chief's "Court":

The Eowa's [e houa] and Whanno's [fana?], we have sometimes seen covered before the King, but whether by courtesy or by Vertue of their office we never could learn; these men are the Principal persons about the King and form his Court and are generally, if not allways his relations. Tee whom I have so often mentioned was one of them; we have been told that the Eowas, who have the first rank at- 
tend in their turns, a certain number each day, which occasioned us to call them Lords in waiting, but whether this was realy so I cannot say, we seldom found Tee absent, indeed his attendance was necessary, as being the best able to negotiate matters between us and them, on which service he was allways imployed and which he executed, I have reason to think, to the satisfaction of both parties.... The Eowa's and Whanno's always eat with the king .... (Beaglehole 1961:410; see also G. Forster 1777:I, 346, and J. Forster 1778:357)

Houa is defined in the LMS Dictionary as to be in a state of perspiration; this is apparently a reference to such individuals' activities as messengers proceeding on their errands at great speed. Fana means an archer's bow, which could refer to these officials' speed in transmitting messages.

Handy listed the "guardians of the rahui" (arata'i rahui [arata'i, a leader, guide, conductor; to lead, guide, conduct-LMS Dictionary]) among those officials who were "attached to the Arii" and "concerned with particular duties" (1930:47). But this is the only reference I can find to this duty having been invested in a distinctive office.

It could be inferred from some sources that the duty of executing a human victim required for sacrifice constituted a distinct tribal office, and some individual members of chiefly retinues may indeed have specialized in this activity; but I can discover no evidence that such an office, if it existed, was institutionalized in terms of insignia, succession, or order. More likely, the job was simply handed over to someone of proven loyalty to the chief in question-someone who was also "a stern-willed warrior" (Henry 1928:197).

Several of the sources refer to chiefly "councils." For example:

There was a consultation between the three principal councillors [of Vehiatua, high chief of Peninsular Tahiti], named Tetumanua, Teyeye, and Otitoi, which last (cannot be) less than seventy years of age, as to what should be done with the vessel sent over by the arii of Orayetea [Ra'iatea], and it was decided she should remain here to do battle against the people of the neighboring island of Morea [Mo'orea] (Corney 1919:189).

A passage from Cook describes in some detail a meeting between himself and the said Vehiatua, suggesting the influence exercised over the latter by his "counselors"; the occasion was Cook's arrival at Tautira, where the Spaniards had previously landed and made their claim to the whole island:

Presently the young Cheif came attended by his Mother, and several person(s) of note, who all seated themselves facing us; then a man who sat by me made a speach part of which was dictated by those about him; he was answered by one near the Cheif; Etary spoke next, then Omai both of which were answered by the opposite party. These Oraisions were intirly about my arrival and connections with them, the last man that spoke told me a mongst other things, that the men of Rema, that is the Spaniards, had desired them not to suffer me to come into Oaitipeha bay, should I return any more to the island for that it belonged to 
them, but that they were so far from paying any regard to it that he now made me a formal surrender of the Province and every thing in it the meaning of which I perfectly well understood. At length the young chief was ordered to come and imbrace me and by way of confirming this treaty of Friendship we exchanged names. After the whole was over, the young cheif and his friends accompaned me on board to dinner. (Beaglehole 1967:190)

From many bits of evidence it is fairly clear that a tribal chief's staff counselors included several kinds of officials: his chief administrative officer (or officers), principal messengers, and perhaps his tribe's chief priest as well. We also have evidence that a chief's close relatives (including in some instances his wife [Vancouver 1801:322]) were among those upon whom he depended for counsel, in addition to those relatives who occupied specific staff offices, as was often the case. And this circumstance points up another feature of Maohi tribal organization, namely the overlap in offices and in officeholding. Probably in no two tribes were tribal functions distinguished into offices in exactly the same way; and one can be quite certain that tribal offices were not distributed among the same number or kind of officeholders-relatives, neighbors, friends, heads of small subdivisions of the chief's own subtribal division, and even some members of the chief's own domestic establishment, to which I now return briefly.

Mention has been made in other contexts of the kinds of retainers found attached to the households of individuals of eminence and authority, including tribal chiefs: for example, carriers, domestics, male and female attendants, teachers, entertainers, "ghost guardians," along with others who can only be described as hangers-on. Most of these differed from the "tribal" officials listed earlier in being concerned with the welfare of the chiefly master himself-insofar as this can be distinguished from tribal welfare as a whole. As indicated earlier, it is not always possible to draw such a distinction, but passages such as the following indicate the feasibility of occasionally doing so: "The king and queen were always attended by a number of men, as carriers, domestics, or favourites, who were rāa, or sacred, living without families, and attending only on the royal pair; and a worse set of men the whole island does not afford for thievery, plunder, and impurity" (Wilson 1799:321-322).

Ellis enlarged considerably on this theme:

Notwithstanding this generosity on the part of the king, the conduct of the government was often most rapacious and unjust. The stated and regular supplies furnished by the inhabitants, were often inadequate to the maintenance of the numbers, who, attaching themselves to the king's household, passed their time in idleness, and were fed at his table. Whenever there was a deficiency of food for his ordinary followers, or a large party that had arrived as his guests, a number of his servants went out to the settlements of the ratiras, or farmers, and, sometimes without even asking, tied up the pigs that were fed near the dwelling, and 
plundered the abode, ravaging, like a band of lawless robbers, the plantations or the gardens, and taking away every article of food the poor, oppressed people possessed. Sometimes they launched a fine canoe that might be lying near, and, loading it with their plunder, left the industrious proprietor destitute even of the means of subsistence; and, as they were the king's servants, he durst not complain.

When the king travelled, he was usually attended by a company of Areois, or a worthless train of idlers; and often when they entered a district that was perhaps well supplied with provisions for its inhabitants, if they remained any length of time, by their plundering and wanton destruction, it was often reduced to a state of desolation. Sometimes the king sent his servants to take what they wanted from the fields or gardens of the people; but often, unauthorized by him, they used his name to commit the most lawless and injurious depredations upon the property of the inhabitants; whose lives were endangered, if they offered the least resistance.

Mahamene, a native of Raiatea, gave, at a public meeting in that island, the following account of their lawless plunder. "These teuteu," (servants of the king,) said he, "would enter a house, and commit the greatest depredations. The master of the house would sit as a poor captive, and look on, without daring to say a word.-They would seize his bundle of cloth, kill his largest pigs, pluck the best bread-fruit, take the largest taro, (arum roots,) the finest sugar-cane, the ripest bananas, and even take the posts of his house for fuel to cook them with. Is there not a man present who actually buried his new canoe under the sand, to secure it from these desperate men?"

Nothing fostered tyranny and oppression in the rulers, and reduced the population to a state of wretchedness, so much as these unjust proceedings. Those who, by habits of industry, or desire of comfort for themselves and families, might be induced to cultivate more land than others, were, from this very circumstance, marked out for despoliation. They had no redress for these wrongs, and therefore, rather than expose themselves to the mortifying humiliation of seeing their fields plundered, and the fruits of their labour taken to feed a useless and insulting band that followed the movements of the king, they allowed their lands to remain untilled. They chose to procure a scanty means of subsistence from day to day, rather than suffer the insults to which even their industry exposed them. (1829:II, 374-376)

Again, it will be recalled that Ellis was referring to the later period when the authority of the "King" in question, Pomare II, was nearly absolute, and his subjects' recourse to self-defense was presumably more constrained; but there was apparently nothing new about the arrogance and predatory habits of chiefly retinues.

The stewards of chiefly family estates referred to earlier can also be counted among a chief's personal-as opposed to his tribal-government staff, although it is possible that some of the former also participated in tribal councils.

Many decisions respecting tribal affairs were undoubtedly made by the tribal chief, with or without advice. Others were made by him in consultation with members of his own staff: the counselors of one type or another discussed above. Still other decisions were made by the chief and his staff counselors in concert with other subtribal chiefs. ${ }^{55}$

Apo'o, or apo'ora'a, was the general term for "council" or "meeting 
for consultation" (LMS Dictionary), but there were no labels that I know of to refer to the kinds of councils distinguished here, although Handy inferred from the name of one such "staff" council, tahuna i ahuru (secret of ten) that its proceedings took place in private (1930:48). If such were the case, one would be justified in describing the other kind as "public"-for so did Ellis and other writers reveal them to be:

Their public measures were not distinguished by promptness or decision, excepting when they wreaked vengeance upon the poor and helpless victims of their displeasure. After a meeting of the chiefs had been summoned, it was a long time before all came together, and their meetings were often interrupted by adjournments.

Their councils were usually held in the open air, where the chiefs and others formed a circle, in which the orators of the different parties took their stations opposite to each other. These orators were the principal, but not the only speakers. The king often addressed the assembly. The warriors and the raatiras also delivered their sentiments with boldness and freedom. When a difference of opinion prevailed, and words ran high, the impetuosity of their passions broke through all restraint, and the council terminated in scenes of confusion and bloodshed; or if they ended without open hostility, the chieftains returned to their respective districts, to assemble their tenantry, and prepare for war. (Ellis 1829:II, 363-364)

The kinds of decisions made by each of these three bodies-the chief's staff council, the tribal council meeting in secret session, and the tribal public council-must have differed from tribe to tribe, and within any tribe from time to time, depending upon the will and personal style of the chief and upon the extent of his authority over tribal affairs.

The decision to make or not make war must occasionally have been decided, or at least confirmed, in public council, because only thereby could the tribal chief, in some cases, have assured himself of manpower enough to wage successful war. I quoted earlier some general descriptions of how such meetings were conducted; a further passage from Cook provides additional insight into the politics that often entered into such deliberations:

This being settled, we left Etary and his party to ruminate on their folly and attended Otoo to another place close by where we found the servants of a Chief whose name I forgot to ask, attending with a Hog, a Pig and a Dog as a present to Otoo; these were delivered with the usual ceremony and with a set speach in which the bearer in his Masters name, enquired after the health of Otoo and all the principal people about him. This compliment was echoed back in the name of Otoo by one of his Ministers and then the dispute with Eimeo was discussed with many arguments both for and against it. The Servants, or deputies of this Chief, were for procecuting the War with Vigour and advised Otoo to offer a human Sacrifice, on the other hand a chief who was continually about Otoo opposed it, seemingly with great strengh of argument, this confirmed me in the opinion that Otoo never entered heartily into the spirit of this war; he receiv'd daily messages from Towha importunating him to hasten to his assistance, who we were told was surrounded by Maheines fleet, but neither the one nor the other durst hazard an engagement. (Beaglehole 1967:211-212) 
Of course, it was not required in all cases that a tribe's subchiefs actually assemble to make decisions on weighty issues. In many instances an active tribal chief would have known fairly well the sentiments of his realm's subchiefs, and on such occasions an assembly mainly served the purpose of ceremonial ratification, including confirmation by spirits.

Assembled or otherwise, then, a tribe's chief, his staff counselors, and the chiefs of the tribe's major subdivisions constituted a decision-making body-in addition to the other functions they severally performed. ${ }^{56}$ There may even have been a label for this whole body, although the information on the subject is somewhat ambiguous. The label in question is hiva, about which the "Precepts of Tetunae" demand: "The Hiva ... are to be held in respect by you, they are a group in authority [e pupu mana ratou]; they have been engaged to uphold the dignity of the Homeland [te tura o te aia]." ${ }^{\text {"5 }}$ Adams identified the hiva as meaning, "the whole body of Iatoai [i.e., subchiefs] in each district" (1901:8).

But, however many other offices and officials a tribe may have comprised, and whatever actual situations may have constituted the realpolitik of a tribe, the office of sovereign chief was the symbolic focus of the tribe, to an almost exclusive degree.

\section{SyMBOLS OF CHIEFTAINSHIP}

In discussing the symbolic aspect of tribal chieftainship we again face the question of what was distinctively tribal about the office. The sources are replete with references to the innumerable kinds of privileges, insignia, metaphoric usages, et cetera, associated with "chiefs," ari'i, and "principal people," but it is not always clear as to the identity of the office referred to: chiefs of kin-congregations? members of the ari'i class in general? de facto leaders of complex territorial units? or territorial-unit leaders who also held kin-Titles of highest rank?

The question is also complicated by the changes in tribal organization that took place during the Early European Era, the one chronicled by most of the sources. During the period described in the earlier of these sources, Tahiti itself was divided into several separate tribes; but, by the time of Orsmond and Ellis, Tahiti and Mo'orea had a single "king," upon whom the entire symbolic apparatus was focused. ${ }^{58}$ Even during the Late Indigenous and Early European eras of Maohi history, tribal leadership had become so intimately linked with ari'i-type kin-Titleholding that it is next to impossible to separate the two kinds of roles. That they were up to a point separable, however, is suggested by legendary but fairly credible accounts of tribes governed by individuals who became sovereign chiefs but who were not ari'i by descent.

But perhaps the question is problematic only in a short-term sense-that 
is to say, it is raised only with respect to the individuals who reached tribal chieftainship via routes other than descent. Since such individuals tended to found dynasties, and since the Maohis were no less ingenious than the rest of mankind in adapting genealogy to politics, the successors to dynasty founders were probably ari'i, in both senses of the term.

With respect to the other face of the question, the one occasioned by differences in tribal size and order of complexity, I assume that there were some corresponding differences in the symbolism associated with the chiefs-for example, other things being equal, the ritual constraints surrounding the chief of a small tribe of third-order complexity were probably less stringent than those surrounding, say, the chief of Tahiti peninsula.

In any case, having called attention once again to these two aspects of the question, I shall proceed as if they did not exist. I begin by listing some of the tangible insignia of tribal chieftainship.

In Henry's version of the investiture of a tribal chief quoted above, the individual was presented with the following items: a wooden pillow (rurua), a feather fan or fly flap (tahiri), a helmet(tāupo'o), a waist band (tatua), a spear ('omore), a staff(to'oto'o), and a breechclout (maro). According to Handy a chief's "personal possessions and insignia, each of which had its own title," also included the following: residence (fare), throne (papa), dugout boat $\left(v a^{\prime} a\right)$, plank-built boat (pahi), paddle (hoe), bailer (tutua), rope (taura), fishing net ('upe'a), bow (pana), arrows (te'a)), wreath (hei), food dish ('umete), cup (ipu), carrying pole (amo), and tapa beater ('ie). (See also Handy 1930:35.) As examples of the proper names given such items, Handy listed the following that were applied to those of Vaiari: the "royal seat" was named papa o te toa o te tumu (the stratum of the basic foundation), the rope was firifiri tau (braided by the age), the boat was te anuanua (the rainbow), and the food dish was poria (fat). $(1930: 18)^{59}$

I noted earlier that each tribe, or large subtribe, was identified in formal speeches with certain specific features of the landscape: its most notable mountain (mou'a), its largest stream (vai), its most prominent cape ('outu), its place for tribal assemblies (tahua), and its tribal marae. Occasionally all of these features, or the marae alone, served as metaphors for the tribal chief as well. Another chiefly metaphor was ihoari' $i$, the dignity and office of a king or principal chief. Iho is described as having a variety of meanings: (1) self, an affix to pronouns, as vau iho, myself; (2) an affix to adverbs, to denote sameness or proximity; (3) the essence or nature of a thing or person; (4) applied to a person coming to himself, or recovering his intellectual faculties (LMS Dictionary).

Another metaphor for chief was tira, mast (of the tribal boat). Completing this metaphor, 'iatoai, the term sometimes applied to subchiefs and other principal supporters, probably derived from 'iato, outrigger; and it is 
possible that ra'atira also meant rigging (Handy 1930:42). This equating of tribe and boat was a favorite Maohi figure of speech; for example, in addition to the above the sources contain such statements as: (address to a chief) "Your seat is on the prow of the great canoe" (Handy 1930:40).

The chief was also referred to as "holder of the weights of the fish-net," i.e., holder of the helm of state (Alexander 1893:58); taurua, the morning star (Handy 1930:40); and ra'i, the sky.

Ellis summarized admirably this aspect of chiefly preeminence (at least insofar as it applied to Pomare II, who held an Opoan-derived maro 'ura kinTitle, in addition to his office as chief of Pare-Arue, and eventually of all Tahiti-Mo'orea):

The phraseology of the Tahitian court was in perfect accordance with the elevation, and sacred connexion with their divinities, which the binding on the red girdle was designed to recognize and ratify. The preposterous vanity and adulation in language, used in epithets bestowed upon the king of Tahiti and his establishment, fully equal those employed in the most gorgeous establishment of Eastern princes, or the seraglios of Turkish sultans.

It was not only declared that Oro was the father of the king, as was implied by the address of the priest when arraying him in the sacred girdle, and the station occupied by his throne, when placed in the temple by the side of the deities, but it pervaded the terms used in reference to his whole establishment. His houses were called the aorai, the clouds of heaven; anuanua, the rainbow, was the name of the canoe in which he voyaged; his voice was called thunder; the glare of the torches in his dwelling was denominated lightning; and when the people saw them in the evening, as they passed near his abode, instead of saying the torches were burning in the palace, they would observe that the lightning was flashing in the clouds of heavens. When he passed from one district to another on the shoulders of his bearers, instead of speaking of his travelling from one place to another, they always used the word mahuta, which signifies to fly; and hence described his journey by saying, that the king was flying from one district of the island to another. (1829:II, 359-360)

The preeminence of a tribal chief is attested not only through metaphor, but through numerous acts of adulation, deference, and interdiction:

Whenever the king appeared abroad, or the people approached his presence, this mark of reverence was required from all ranks; his own father and mother were not excepted, but were generally the first to uncover themselves when he approached. The people inhabiting the district through which he passed, uncovered as he approached; and those who sat in the houses by the road-side, as soon as they heard the cry of te arii, te arii, "the king, the king," stripped off their upper garments, and did not venture to replace them till he had passed. If by any accident he came upon them unexpectedly, the cloth they wore was instantly rent in pieces, and an atonement offered. Any individual whom he might pass on the road, should he hesitate to remove this part of his dress, would be in danger of losing his life on the spot, or of being marked as a victim of sacrifice to the gods. (Ellis 1829:II, 352)

In one known instance, at least, this particular sign of deference was accorded to siblings of the officeholder as well-that is, to siblings of 
Pomare I, who at the time was holder of a maro 'ura kin-Title and was tribal chief of Pare-'Arue:

His sister Tedua-Towrai was on board the Resolution in the mean while, and all the women paid her the same respect by uncovering the shoulders, which the whole nation owes to the king. The active youth $T^{\prime}$-Aree Watow, who was with the king his brother, had the same honours paid to him; and it appeared to us that the title Aree, though common to all the chiefs of districts, and the nobility in general, was yet applied by way of excellence to the persons of the royal family. (G. Forster 1777:I, 338; see also LMS Transactions:I, 101)

In this connection I call attention to the custom of pi, mentioned earlier, which was the prohibition of the use of some chiefs' names and of many words containing sound combinations more or less identical with such names.

The Maohi custom of $p i^{60}$ has long intrigued Westerners. The LMS Dictionary defines it as "the custom of prohibiting the use of a word, or syllable, which had become sacred by its having been adopted as the whole or part of the name of some chief, when another word or syllable was substituted in its place; as rui [ru'i] for pō and hota for mare, as these two words formed the name of the late King Pomare." The earliest detailed reference to this custom I can find is Anderson's, from 1777:

On some other occasions, they carry their veneration for his [a feather-girdled ari'i] very name, to an extravagant and very destructive pitch. For if, on his accession to the maro, any words in their language be found to have a resemblance to it in sound, they are changed for others; and if any man be bold enough not to comply, and continue to use those words, not only he, but all his relations, are immediately put to death. The same severity is exercised toward those who shall presume to apply this sacred name to any animal. And, agreeably to this custom of his countrymen, Omai used to express his indignation, that the English should give the names of prince or princess to their favourite horses or dogs. But while death is the punishment for making free with the name of their sovereign, if abuse be only levelled at his government, the offender escapes with the forfeiture of land and houses. (Cook 1784:170)

During his visit some fifteen years later Vancouver expanded upon Anderson's report:

The veneration these people entertain for the names of their sovereigns, has already been very justly related by Mr. Anderson. But no example, I believe, had then appeared to that judicious observer, of the extent to which this respect is carried. On Otoo's accession to the Maro, a very considerable alteration took place in their language, particularly in the proper names of all the chiefs, to which however it was not solely confined, but extended to no less than forty or fifty of the most common words which occur in conversation, and bearing not the least affinity whatever to the former expressions.

This new language every inhabitant is under the necessity of adopting; as any negligence or contempt of it is punished with the greatest severity. Their former expressions were, however, retained in their recollection; and for our better communication, were, I believe, permitted to be used in conversation with us, with- 
out incurring displeasure. Pomurrey however would frequently correct me on my accidentally using the former mode of expression, saying, I knew it was wrong, and ought not to practise it. Were such a pernicious innovation to take place, generally, at the arbitrary will of the sovereigns throughout the South-Sea Islands, it would be attended with insurmountable difficulties to strangers; but it appears to be a new regulation, and as yet, confined to these islands... $(1801: 316)^{61}$

Bligh also referred to the custom of pi in the journal of his visit in 1792:

I asked Iddeeah to day if her Name was to be changed on account of her late Child dying, she said no as the name was given to the Childs Aunt, Wattourau, who in my last Voyage was called Towry.-It is very extraordinary the shifting of Names in this Country.-Upon the permition of the Erreeràhigh a Chief may take any Name he likes, and if it happens to be the name of any particular Article-of day-night, or any other known thing, another is thought of for it to be called by. Example-Pomorre, (the Name of Tynah \& Iddeeah) is from Po, night, and morré the Name of the disease the Child died of-To make up for the loss of Po, in the language, Oo arroo, ee is substituted.-

Oreepyah has fancifully taken the name of Alolo-In the language it means To morrow, but it is very odd, that in supplying the want of this Word they have substituted ahnonnàhigh, which before, and does now mean yesterday.-

Since my last Voyage, Heivah, the common name for all their Dances, has been taken by Terrederrie, and it is now known by the term Oopeowpah.-

Tynah also took the name of Mattee, which signifies to kill, and Po, ee was ordered to be used instead of it, which was strictly attended to-I remember Iddeeah scolding at the People when they inadvertently made use of the word Mattee.-

I should imagine this mode of changing names must be attended with many disadvantages to the language.--the alteration in the course of a Century must be very great.-it makes it difficult to be understood.-(1792:157-157b)

Writing about the period between 1819 and 1821, the missionary Orsmond described the custom as follows: “... There is hateful pride among Barbarians, \& to have a distinguished name was a very predominant feeling among the Tahitians. The name must stand alone, the pii enabled a chief to alter his name at pleasure, \& to alter any word that contained a syllable like that which composed his name." (quoted by White 1967:326)

The discrepancy between Bligh's and Vancouver's accounts with respect to the enforcement of the pi taboo could probably be explained by the identity of the transgressors - that is, a person of consequence may have only been "scolded," whereas a nobody is likely to have been punished more severely. More puzzling is the discrepancy among the several accounts regarding which persons were entitled to exercise this form of privilege. Whereas Anderson and Vancouver seem to have implied that the privilege was restricted to feather-girdled ari'i, Bligh stated explicitly that it was extended to other "chiefs" as well. Bligh also stated that the latter had to obtain approval from the ari'i rahi (in this case, a Pomare) before exercising the privilege, but in the case of one of the examples cited by him-that is, 
the substitution of heiva for teri'irere-I consider it unlikely that the person in question, who was himself the sovereign chief of Papara, would have deferred to anyone else in this matter.

Another question suggested by these reports, but not touched upon by them, concerns the territorial extent of a pi prohibition. In my opinion an honor of this kind would have been accorded its principal mainly within the territory against whose population he was able to apply coercive sanctions-although on occasion persons elsewhere may also have practiced the courtesy in the interests of diplomacy. As for the duration of any particular name taboo, we have Wilson's report that the taboo lapsed, officially, upon the person's death (1799:351); but after a very long usage of a substitute word it is reasonable to suppose that it stood a good chance of remaining in common usage. ${ }^{62}$

The custom of pi has also attracted the attention of later students of ancient Maohi life, including Ahnne, Marau, Elbert, and White. Ahnne, for example, declared that the punishment meted out to anyone violating a name taboo was rectal impalement:

In those former times it was no trifling matter to violate a name taboo. Indeed, death was the invariable fate of anyone violating this taboo; as the saying went, "Te taata i hape i te reo ra. O ohure ura tona ioa. Tera te au raa o te ohure ura, e tabu ia." (Those who violate this taboo are called "red anus," which is to say that they became offerings to the gods.) (1926:6)

This statement by Ahnne drew forth a critical reply from M. T. Salmon:

This chastisement (impalement) was reserved especially for those vanquished in war .... The punishment inflicted for a lapsus linguae (slip of the tongue), as I understand the word, was the chastisement called the "hoi-pu" (ho'i-puu), which consisted of obliging him (the taboo breaker) to recite exactly a certain number of times, without making a mistake, a hundred or more times, the consecrated names. If he made a mistake in reciting the "hoi-pu," the transgressor was punished by having one eye removed, or both. The eyes of the victim were offered to the arii whose name had been harmed by the use of the forbidden syllables.

It is from this chastisement that the name "Aimata" ('ai-mata) comes, which means the right to eat the eye. (Salmon 1927, as translated by White 1967:324)

We are no longer in a postion to evaluate these markedly different retrospective versions, and leave them in the limbo they now find themselves in, and perhaps deserve. ${ }^{63}$

Turning now to other behaviors by or respecting tribal chiefs, I reproduce some excerpts from Ellis:

This distinguishing mark of respect was not only rendered at all times, and from every individual, to the person of the king, but even to his dwellings, wherever they might be. These houses were considered sacred, and were the only habitations, in any part of the island, where the king could alight, and take refreshment and repose. The ground, for a considerable space on both sides, was 
in their estimation sacred. A tii, or carved image, fixed on a high pedestal, was placed by the roadside, at a short distance from the dwelling, and marked the boundary of the sacred soil. [See fig. 23-3.] All travellers passing these houses, on approaching the first image, stripped off the upper part of their dress, and, whether the king was residing there or not, walked uncovered to the image at the opposite boundary. After passing this, they replaced their poncho, or kind of mantle, and pursued their journey.

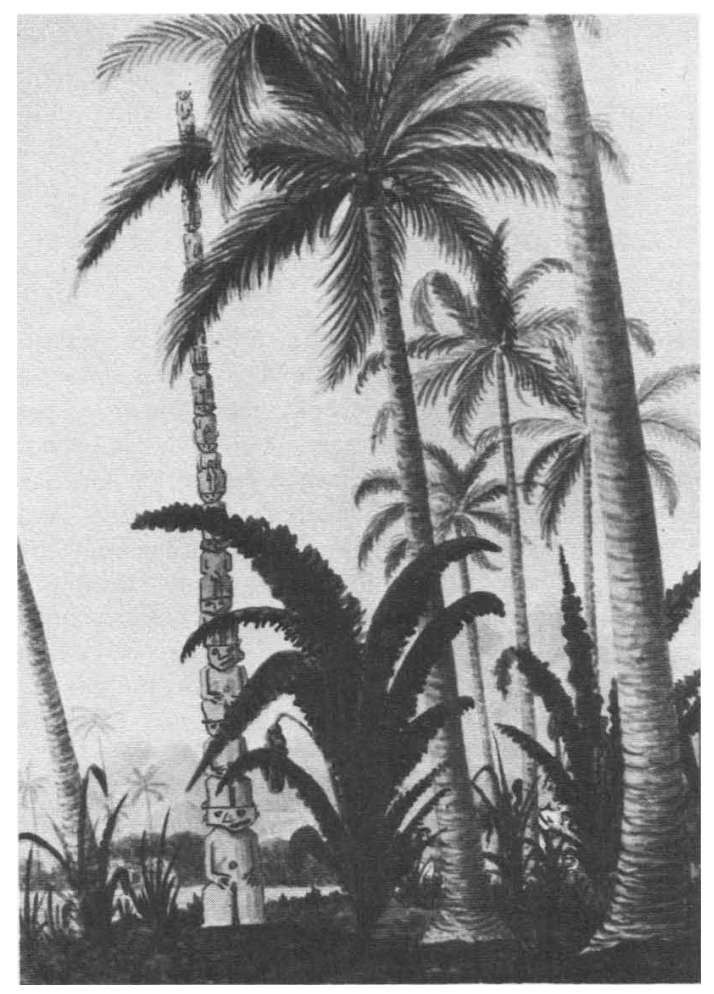

Figure 23-3. Ti'i image. Watercolor by G. Tobin. Mitchell Library, Sydney

To refuse this homage would have been considered not only as an indication of disaffection towards the king, but as rebellion against the government, and impiety towards the gods, exposing the individuals to the vengeance of the supreme powers in the visible and invisible worlds. Such was the unapproachable elevation to which the superstitions of the people raised the rulers in the South Sea Islands, and such the marked distinction that prevailed between the king and people, from his birth, until he was superseded in title and rank by his own son. (1829:II, 353)

Every thing in the least degree connected with the king or queen-the cloth they wore, the houses in which they dwelt, the canoes in which they voyaged, the men by whom they were borne when they journeyed by land, be- 
came sacred-and even the sounds in the language, composing their names, could no longer be appropriated to ordinary significations. Hence, the original names of most of the objects with which they were familiar, have from time to time undergone considerable alterations. The ground on which they trod, even accidentally, became sacred; and the dwelling under which they might enter, must for ever after be vacated by its proprietors, and could be appropriated only to the use of these sacred personages. No individual was allowed to touch the bodies of the king or queen; and every one who should stand over them, or pass the hand over their heads, would be liable to pay for the sacrilegious act with the forfeiture of his life. It was on account of this supposed sacredness of person that they could never enter any dwelling, excepting those that were specially dedicated to their use, and prohibited to all others; nor might they tread on the ground in any part of the island but their own hereditary districts. (1829:II, 348-349)

Morrison's account of the constraint on entering a house indicates less stringency:

If a Chief should enter or even toutch the House of any Female of a lower Class, it is rendered sacred by his presence and She Can never eat in it any more (but any man may) and she must provide herself with a new house and new furniture-for this reason if the Chief should be caught in the rain, he must not take shelter till he comes to a mans house, or one of His own (of which He has several for that and such like purposes) tho He should be a mile from one, and for this reason also No woman except of equal rank, can eat on board a Ship after the Chief has been on board, under pain of severe punishment, which accounts for the Women Calling the provisions on board Maa Raa (Sacred food) every thing on board being made sacred by his presence, yet nevertheless when they were right Hungry would eat in private, tho even then they will hardly ever eat in company with other Weomen except they are well acquainted. (1935:168-169)

The difference between these accounts may be due either to source of information or to time of observation. Morrison undoubtedly witnessed the events he reported, while Ellis was probably reporting mainly from hearsay. On the other hand, Ellis' information came from a time somewhat later than Morrison's, after Pomare II had become sovereign of Tahiti and Mo'orea, with resulting magnification of his official trappings.

The custom of amo, referred to above, aroused much interest among Europeans:

The sovereign and his consort always appeared in public on men's shoulders, and travelled in this manner wherever they journeyed by land. They were seated on the neck or shoulders of their bearers, who were generally stout athletic men. The persons of the men, in consequence of their office, were regarded as sacred. The individuals thus elevated appeared to sit with ease and security, holding slightly by the head, while their feet hung down on the breast, and were clasped in the arms of the bearer. When they travelled, they proceeded at a tolerably rapid pace, frequently six miles within the hour. A number of attendants ran by the side of the bearers, or followed in their train; and when the men who carried the royal personages grew weary, they were relieved by others.

The king and queen were always accompanied by several pair of sacred men, 
or bearers, and the transit from the shoulders of one to those of another, at the termination of an ordinary stage, was accompanied with much greater despatch than the horses of a mail-coach are changed, or an equestrian could alight and remount. On these occasions, their majesties never suffered their feet to touch the ground; but when they wished to change, what to them answered the purpose of horses, they called two of the men, who were running by their side; and while the man, on whose neck they were sitting, made little more than a momentary halt, the individuals who were to take them onward, fixed their hands upon their thighs, and bent their heads slightly forward: when they had assumed this position, the royal riders, with apparently but little effort, vaulted over the head of the man on whose neck they had been sitting, and alighting on the shoulders of his successor in office, proceeded on their journey with the shortest possible detention.

This mode of conveyance was called amo or vaha. It could not have been very comfortable even to the riders, while to the bearers it must have been exceedingly laborious. The men selected for this duty, which was considered the most honourable post next to that of bearers of the gods, were generally exempted from labour, and as they seldom did any thing else, were not perhaps much incommoded by their office; and although the seat occupied by those they bore was not perhaps the most easy, yet as it was a mark of the highest dignity in the nation, and as none but the king and queen, and occasionally their nearest relatives, were allowed the distinction it exhibited, they felt probably a corresponding satisfaction and complacency in thus appearing before their subjects, whenever they left their hereditary district. The effect must have been somewhat imposing, when, on public occasions, vast multitudes were assembled, and their sovereign, thus elevated above every individual appeared among them. (Ellis 1829:II, 349-350) ${ }^{64}$

The individuals thus carried may, as Ellis speculated, have derived some "satisfaction and complacency" from the circumstances of being carried, but the main objective appears to have been to avoid the consequences of the chief's touching an estate not his own, which would have interdicted its use by others. Lest I create the impression that I fully comprehend the rationale of this custom, I hasten to add that such is not the case. Among other things, we do not know whether the custom applied specifically to all tribal chiefs, whatever their mode of recruitment, or only to those holding high-ranking kin-Titles, or perhaps to high-ranking kin-Titleholders whether or not they were also tribal chiefs.

But with all this, there were times when it would have been difficult to single out a tribal chief from his fellows:

The establishment and habits of the king often exhibited the most striking contrast; at one time he was seen surrounded by the priests, and invested with the insignia of royalty, and divinity itself; or appeared in public on the shoulders of his bearers, while the people expressed every indication of superstitious reverence and fear. At other times, he might be seen on terms of the greatest familiarity with his attendants and domestics.

He never wore a crown, or any badge of dignity, and, in general, there was no difference between his dress and that of the chiefs by whom he was surrounded, excepting that the fine cloth and matting, called vane, with which he was often arrayed, were more rare and valuable than the dress worn by others. His raiment 
frequently consisted of the ordinary pareu, or ahu pu, in quality often inferior to that worn by some of the chiefs in attendance upon him. (Ellis 1829:II, 360-361)

The respect due a chief's houses and estates, noted by Ellis, extended, as I reported above, to other representatives of chiefly office: to a chief's messengers, to his boat (even when manned only by his servants (Bligh 1937:I, 419), and so forth; but the most conventional emblems of chiefly office were branches of the miro plant and of the coconut palm:

The other branches used in Ceremonies are the Rou avva and are Commissions borne by substitutes for Chiefs and evry person bearing one of them is treated in the same Manner as the Chief would be if he were present; these Commissions or Emblems of truth are Never Assumed by any unless on such occasions as they would suffer death for such fraud ... (Morrison 1935:237-238).

The niau, or leaflets of the cocoa-nut tree, was the emblem of authority throughout the whole of the Georgian and Society Islands; and requisitions for property or labour, preparations for war, or the convocation of a national assembly, were formerly made by sending the cocoa-nut leaf to those whose services or attendance was required. To return or refuse the niau was to offer an insult to the king, and to resist his authority. (Ellis 1829:II, 368)

Finally, the body of a chief continued to receive special ritual attention after death-not just in terms of respect for his former preeminence, but in view of the continuing connection believed to persist between him and his tribe. This belief was particularly manifest in the care taken to guard a chief's remains:

... these bodys, while they are whole, are liable to be taken in War and the Man who takes one of them gets the Name and honors as if $\mathrm{He}$ had killd a Warrior, and should the body of a Chief be Carried off in this Manner before an other was Named the District would fall to the conqueror as if he had killd him; for this reason they are always removed, having each a Steady Man to Carry them away into the Mountains if they should be in War ... (Morrison 1935:232-233)

"Blasphemy," that is, disrespect in almost any form, against a chief or his tutelar was subject to extreme sanctions, usually banishment or death. (In case of the latter the victim was usually sacrificed to the offended spirit or to the offended chief's tutelar.) According to Morrison, it was to escape this fate which led Mai to seek passage with Cook to England (1935:112). And known blasphemers, along with notorious thieves, constituted a reservoir which was tapped whenever a sacrificial victim was required for some ceremony (see below).

What was the rationale underlying the symbolic hyperbole associated with a tribal chief's office and person? Although the argument is circular, a certain amount of respectful deference is accountable in terms of what might be called the Maohis' traditional commitment to the principle of social hierarchy in general. And, in the case of tribal chiefs this commitment was 
probably reinforced by awareness of the physical coercive sanctions controlled by the latter. But more than these factors were involved. A statement by Handy epitomizes many "explanations" of Polynesian chieftainship:

In considering the unity of the social order under the arii it must never be forgotten that the divine first-born (mata-hiapo), who was the Arii, was regarded by the population over which he presided, as the sacred embodiment of the mana of the people and land as a whole. He was to them their iho, which means umbilicus, pith, core, and first-fruit, the medium through whom flowed fertility to the land, prosperity to the people in peace time, and power in war. Hence, the bond was one of the heart as well as of dependence and the rendering of service and tribute-which was paid all up the line, from manahune to small proprietors, to subchiefs, to chief-the people were not acting as mere puppets of an arbitrary system invented by despotic overlords, as has been frequently supposed by many uninformed writers; but they were obeying psychological, religious and social principles that were far older with the Polynesians than the Hui Arii, in fact certainly older than the earliest Polynesian settlement, for they prevail throughout the region of Malaysia and southern Asia whence the ancestors of both maoriTahitians and arii certainly came. (1930:46)

This statement probably underestimates the influence of coercive force and overestimates that of servile commitment to "age-old tradition"; and its characterization of the substance of that tradition, by reference to mana, is an example of "explanation by labeling." To summarize in the term mana all the native concepts that "explain" chieftainship may be valid for some Polynesian societies, but I am unable to locate a parallel usage in the sources on the Maohis. I do, however, discern two components of Handy's mana construct in Maohi thoughts about their chiefs. One is the belief that chiefs were in more intimate communication with spirits than were most other mortals. The other is the belief, or the hint of a belief, in some kind of mystical connection between a chief and the welfare of his tribe.

There are recorded instances of tribal chiefs having been treated like gods, not simply because that was the proper way to treat chiefs but because the chiefs in question were gods. However, not all gods in human bodies were treated like chiefs. (See chap. 3, section on human oracles.) The best reported example of a chief who was fully a god was Tamatoa, sovereign chief and high priest of Ra'iatea:

There were some circumstances in the life of this celebrated chieftain which, although a digression, may be introduced here with propriety. He was the patriarch of royalty in the Society Islands, his eldest daughter having the government of Huahine, and his grand-daughter being the present queen of Tahiti. He was a remarkably fine man, being six feet eleven inches in height. Respecting his Christian consistency different opinions have been expressed; but, for my own part, I confidently hope that he was a subject of Divine grace. I will, however, relate a few particulars of his history, and leave the reader to draw his own conclusion. In his heathen state he was worshipped as a god, and to him the eye of the human victim was presented before the body was carried to the marae. When 
visited by the Deputation, Mr. Bennet requested me to ask him, which, of all the crimes he had committed, lay heaviest upon his mind; and, after some hesitation, he replied-that of allowing himself to be worshipped as a god, when he knew that he was but a man. Before he was brought under the influence of the Gospel, he was much addicted to the use of the intoxicating juice of the kava root, which appears to produce a narcotic effect, so peculiar that the slightest noise is exceedingly distracting to persons under its influence. Immediately it was known that the king had been drinking, the women ceased to beat their cloth, and all sounds in the immediate vicinity were to be hushed. Children also were carefully removed from the premises, lest he should be annoyed in the slumbering fit which had been induced by the stupifying draught. It appears that he was exceedingly desperate while in a state of intoxication, and that on the slightest disturbance he would seize a club, spear, or any other weapon, rush out of the house, and wreak his vengeance of friend or foe, man, woman, or child, whom he might happen to meet. In this way several persons had fallen victims to his ferocity. On such occasions his look and manner must indeed have been terrible. The flashing fury of his eye, the curl of his thick lip, the lowering aspect of his brow, together with the growling tone of his voice, and the violent gestures of his herculean fame, were calculated to strike the stoutest heart with terror. Once, when thus aroused, he rushed out of his dwelling, and not being able to find a weapon, he struck an unoffending person such a violent blow with his fist that he knocked his eye out, and mutilated his own hand so much that he lost, in consequence, the first and second bones of his forefinger. (Williams 1837:373-374)

In other instances some of the adulation, interdictions, et cetera, associated with the chief might be accounted for by beliefs that he was part divine-either by ultimate descent from some ancestral divinity (the rationale for the preeminence of the Opoa and Vairi descent lines), or by immediate descent from a divine parent (the claim made for Pomare II by his mother) (Morrison 1935:166). Still another possible basis for the treatment accorded chiefs was their more or less direct association with spirits: not only direct "physical" contact with spirit presences (in the chiefs' roles as priests), but occasionally perhaps actual possession by some spirit (in roles like those of shamans).

Then there is the possibility of an even more general premise, that chiefs and gods, both having qualities that were exceptional when measured against other people and spirits, were simply different kinds of personification of the same type of being. (Nor were they so very different at that, as witnessed by the god-chief Tamatoa and by the concept of divine ancestry-including gods' well-known practice of cohabitating with mortal women.) A corollary of this general premise might then be that a chief was believed to be a god because of his exceptional attributes and powers; and circularly, that a chief was exceptional because he was a god. I hasten to add, however, that attractive as this notion might appear as an explanation for these and other Maohi beliefs and practices, it is purely speculative on my part; I can find no verbalization of it in any of the primary sources. 
Turning now to that other component of Handy's mana construct, to belief in a mystical connection between the chief and the welfare of his tribe, we find some elements of such a belief in at least two customs: in first-fruit offerings to a chief, and in the care exercised in safeguarding a chief's mortal remains from an enemy, particularly before a successor has been named to the office (see chaps. 13 and 21).

First-fruit offerings undoubtedly exemplified some other more mundane ideas about tribal hierarchy and revenue, but, as suggested earlier, it is also possible that they may have exemplified beliefs about connections between a tribal chief and the productivity of the tribe's natural resources. One may even contend that there was something in this connection, as suggested for example in the emphasis upon the breachclout as an insignia of chieftainship, and in the youthfulness of chiefly officeholders consequent upon (perhaps deliberately?) the timing of rites of succession. But this contention can be based on nothing firmer than possibilities; however closely Maohi customs may parallel those of other Polynesians in other regards, I can find no direct statements, verbal or ritual, attesting a sexually reproductive connection between a tribal chief's virility and the material welfare of the tribe's members. There is plenty of evidence for beliefs that spirits included a chief's mortal subjects when punishing him or rewarding him for something done or not done in his relations with themselves, but such may be explained as acts of redundance and do not require a more profound mystical rationale, and particularly not one with sexual overtones.

\section{$H A U$}

And now I return again to the more secular aspect of tribal chieftainship, which seems to have been summarized symbolically in the native word hau. The LMS Dictionary lists three separate entries for hau: the dew that falls at night; peace, government, reign; more, or beyond, in comparing adjectives, greater, larger, longer, et cetera.

Comparative material raises the possibility that there may have been still other homonyms, or that we are encountering here not so many separate words but rather a set of semantic continuities. However, the paucity of Maohi texts employing these words is such that I cannot explore these avenues very far, except to note a possible overlap in meaning between the second and third definitions. In any case my present interest is focused on the second of the entries listed-hau, peace, government, reign,-which, parenthetically, is not quite so palpable as the innocently straightforward dictionary definition suggests.

The "peace" meaning of hau seems to emerge fairly unequivocally in the following text from Henry, in which the word is directly contrasted 
with "war" (tama'i). (The passage is taken from a cosmogonic myth narrating Ta'aroa's fashioning of the universe and describes specifically how he provided Atea [Space] with stars for eyes.)

Then Ta'aroa placed as a right eye for Atea, Ta'urua (Venus), who runs in the evening, and he said: "It is to be a light bending before the earth, to lead it, to give great peace [i.e., hauhau], peace to the inhabited world [i.e., hau fenua noho]; thy right eye is Ta'urua, O Atea."

And Ta'aroa placed as left eye for Atea, Ta'ero (Mercury), and said: "Let anger be kindled, let war [tama'i $i$ rage upon the earth; thy left eye is Ta'ero, $\mathrm{O}$ Atea." (1928:417, italics added)

This referent of hau as "peace" also emerges in several other texts, adapted from Henry (1928, unless otherwise indicated). For example:

in a prayer accompanying resanctification of a community after its defeat and devastation in war:

Fano ei hau, e hau rahi. Ei hau hohonu, ei hau maoro, ei hau maitai roa.

Extend forth peace, great peace. Let it be deep peace, long peace, excellent peace. (p. 321)

in the speeches that accompanied truce negotiations (it will be recalled that a decision for peace was indicated by throwing a rock onto the ground):

Ter te toa o hau; e toa na te hui toa.

There is the rock for peace; the rocks of the body of warriors.

E toa fa'aroa i te ta'ata, ia ruperupe te fenua.

The rock for sparing men, that the land may flourish.

E ia maoro te aho ote arii i te fa'aeara'a mai i tana hau i te fenua nei.

And that long may be the life span and reigning of the arii in this land.

A tonoi te 'orero ia fa'aite i te hau.

Send forth the heralds to proclaim peace.

Ei hau, ei hau maoro pu'upu'u'ore.

Let there be peace, long unbroken peace.

Ia atua te atua, ia tahu'a te tahu'a pure i te marae.

That the gods be gods, and the priests be priests in the marae.

Ia ari'i te ari'i e ia ra'atira te ra'atira.

That the arii be arii, and the ra'atira be ra'atira.

Ei hau te nohora'a o te ta'ata i to ratou mau mataeina'a.

Let peace be in the dwellings of the people in their districts. (pp. 318-319)

in such metaphoric expressions as:

'Aimeo, the bed of peace (te tua ro'i i te hau) of warriors. (p. 436)

Great Taha'a of peaceful skies (ra'i hau). (p. 462)

It should be added that there was a spirit named Hau, identified as god of peace and characterized as a tutelar of medical specialists (tahu' $a$ 
ra'au, tahu'a mori) noted particularly for their healing powers by massage with coconut-oil ointment (p. 145). In addition, I note Henry's observation that the "shadow" (ata) of this tutelar was the surf duck (toroā) (p. 384), but I know of no basis for this association.

Hau meaning "government" and "reign" is considerably less intelligible than hau meaning "peace." Here are some examples; first, two phrases from a speech made by a visiting chief's orator in response to a welcoming speech by his hosts:

E te Tevahitua ari'i e, e To'ofa, te papa o teie nei hau ... O Ari'i Tevahitua, and you under-chief, who art supporter of this government ...

Behold, because of your liberal gifts [to us] of food and other goods of your land, we knew that what we had already heard was true, that your mode of governing (fa'aterera'a hau) was favorable for the prosperity of the land. (Henry 1928:244; fa'aterera' $a$, from fa'atere, to steer about, to guide or direct, to go on with a speech or oration [LMS Dictionary].)

The next examples are from the legend of Honoura. In one episode the people decided to reward the heroic Honoura by naming him their tribal chief:

They all came ... to present him with the kingdom (e pupu atura no'na te hau) [which offer he however declined, out of loyalty to the incumbent]. (Henry 1895:277)

In another episode, after conquering a legendary tribe of a far distant place called Hiva, Honoura presented the conquered domain to his own tribal chief, Ta'ihia, with these words:

There is your possession (tera mai to oe hau), O Ari'i Taihia; when you see it, take good care of your land. (1895:289)

Another example is taken from the prayer uttered by a priest when laying the foundation stone of a new tribal marae:

Harken unto us O God, in this prayer. Behold, we the subdivisions of this tribe (na va'a mata'eina'a o teie nei hau) present thee this land. (p. 132)

The next textual example is taken from a statement by the tribal chief Rata to two wood sprites who had built a fine boat for him:

Welcome to you both! May you live [fare well] in coming to my kingdom (i to'u nei hau). (p. 490)

We turn now to a similar usage of hau, as an element in names applied to forms of government. According to Chesneau's history of Huahine, during an earlier epoch, called the Hau morere, the island was divided into several independent, mutually hostile tribes each under the leadership of a warrior chief. Then, when the Maeva tribe conquered the rest of the island and united it under its own chiefly dynasty, this epoch was referred to as the 
Hau Ari'i (1928). I can find no translation for morere, but mo'o rere could mean "progeny-flying" (translated by Henry as "Flying Scion"). In this connection, Henry's account of Huahine history differs somewhat from that of Chesneau, but that is not the point now under consideration.

In connection with $\mathrm{Hau} \mathrm{Ari}^{\prime} i$, the LMS Dictionary contains the following entries: Hauari'i, a kingly government. Haumanahune, a government of the common people; a democracy. Haumāteata, a government in the hand of a chief by blood, or hereditary descent.

As noted above, there is textual corroboration for hauari'i, but haumanahune-democracy!-strikes me as suspiciously post-European. (See vol. 3.)

In Salmon's history of the Island of Borabora, quoted from earlier (chap. 16, section on Opoa cognatic stock), reference is made to a change of "government," which I interpret to be a translation of hau. (A Tahitian-language text of this piece may once have existed, but we know nothing of its present whereabouts.) The change was brought about by a successful rebellion against the island's sovereign chief, Teihotu, who was killed in the fighting. The victorious rebels, unable to find anyone among themselves of sufficiently high-ranking Title, selected Teihotu's own son as his successor, but instituted with him a new "government" called Tevaitapu, by investing him in office in a partly new tribal marae (built in part with stones from the former one) and by bestowing upon him a new Title.

According to Henry, during the first half of the nineteenth century an alliance was formed between the "kingdoms" of Tahiti, Huahine, Ra'iatea, and Maupiti, "... for aid in maintaining their independence when invaded by the warlike people of Porapora and other islands. On such occasions they adhered to this agreement. But in time of civil war [in any "kingdom"] no interference occurred, though sometimes help was received from personal relatives and friends among the allies. This alliance was called the Haupahu-nui (Government-of-the-great-drum), and it remained in full force until French rule was permanently established in Tahiti in 1847." (p. 128.) (Elsewhere in Henry [p. 122] a generic word for "alliance" is represented as faatua (from fa'ataua, to make a friend?).

In some of these usages hau appears to refer specifically to a tribe's (or tribal alliance's) government, in others to the tribe itself. It is of course quite possible that the word had both of these meanings, but it is also possible that neither of these two referents corresponds exactly to what the Maohis themselves meant by hau, and this possibility is increased when we add the referents which were tentatively translated above as "peace."

Even the adjectival entry of hau (more, or beyond, in comparing adjectives, greater, larger, longer, etc.) might be related to the substantival entries discussed. For example: 
O Havai'i, i ae hau te amaama.

O Raiatea, that towers exceedingly in glory. (Adapted from Henry 1928:462)

E manu, rere hau e.

A bird, far soaring. (p. 504)

E ari'i mau teie vahine, e hau roa to'na nehenehe i to te ao nei!

This is indeed a princess, whose beauty exceeds all other in this land. (p. 614)

And finally, there is the even more suggestive line (p. 406) from the cosmogonic myth concerning some lesser gods' efforts to raise Atea, the sky:

The artisan, Rima-roa, with Fa'atae, hastened up to Atea, to the confined sky. But they did not reach their hands to touch him, they feared the power of King Atea (i mata'ua'e i te hau o te ari'i o Atea.)

I have engaged in this lengthy search for native meanings of hau not merely as a linguistic exercise but impelled by the hope that it would reveal something about the way Maohis' thought of the tribal aspect of their lives. Obviously, the textual material alone does not carry us very far in that direction, except to indicate some connection between a chief's authority and "peace" or "social order." So I turn to other kinds of information for more evidence concerning these important connections. First, I return again to an assertion made earlier to the indifference with which tribal chiefs seem sometimes to have regarded intratribal strife.

\section{CHIEFS AND SOCIAL ORDER}

In chapter 12, I remarked upon the indifference with which tribal chiefs sometimes seem to have regarded strife between subdivisions of their tribes, provided it did not affect their own positions of authority. ${ }^{65}$ This raises the question, To what extent was a tribal chief concerned with maintaining orderly relations among his subjects, outside of enforcing compliance in matters affecting his own interests?

Throughout this and previous chapters I have presented whenever available descriptions of the kinds of reactions set in motion by people's breaches of more or less widely shared social-relational norms-of a spouse's unauthorized "adultery," of a couple's flouting of incest standards or class-based sexual prohibitions, of the failure of one party to live up to the terms of an exchange contract, of a subordinate's act of lese majesty, of a devotee's failure to fulfill obligations to his tutelar, and so on. The subject is a vast and complex one and does not permit facile generalization. One could, of course, attempt to classify breaches in terms of their appropriate sanctions-except that appropriateness varied rather widely with respect to a person's marriage class, and to elapsed time between the breach and punishment. Also there was considerable variation, situationally, with respect to "jurisdiction." ${ }^{\prime 66}$ In some instances, for example, a wife's seducer 
was killed on the spot by her husband, with no further repercussions, while at other times the wronged husband placed his complaint in the hands of his chief, who then imposed penalties varying from fines to banishment, depending upon factors of class, kinship, the chief's own concerns, et cetera. On one occasion, for example, a chief decided to banish not only the seducer himself but all the latter's near kin, including the mummifying remains of some of them!

At early dawn this morning the tahua or high-priest named Orae came to lay a complaint before Otù against an uncle of the latter who had been detected in adultery with his wife. Having listened to the complaint Otù promptly ordered that the uncle be notified of his sentence, which was banishment; the which, being taken with a bad grace by the parents and other relations of the said Otù, he got angry and extended the banishment to them all, without excepting his father and mother and even the dead (it being the custom among Chiefs to preserve their bodies dry, and keep them always near them at their homesteads or places belonging to each). (Corney 1919:201)

Indeed, with respect to relations among humans there seems to have been only two kinds of breaches that provided almost invariable and universally assentive sanctions, namely, theft from another Maohi, and offenses of almost any kind against the position, property, or person of a tribal chief.

\section{Theft}

I have frequent conversations with Tynah respecting the want of power or order in his government to prevent thieving. He has told me that only good people could be governed by advice, Townahs (or Rogues) he said would at all times when it was in their power, do mischief and commit Thefts, and could only be guarded against by strict Watch, and desired whenever we had it in our power to put them to death, that an example might be made to deter others. (Bligh 1792:150)

By conventional Western standards the Maohi attitude toward theft was somewhat ambivalent. On the one hand, a proven thief could usually be killed with impunity. Notwithstanding which, there appears to have existed a widely shared admiration for clever thievery, including some emulous veneration of Hiro, god of thievery. Although Hiro had devotees throughout these Islands, the principal center of his cult appears to have been in southern Huahine. Here are some passages from missionary accounts of this god:

Having frequent occasion to recur to the former state of society in these islands, we have just heard, that, among other idols, there was a god of thieves, held by his worshippers in the highest honor. He was called Hiro, and among his votaries were many of the cleverest men, not from the lower ranks only, but even some of the principal chiefs. The arts and contrivances which these resorted to, in order to obtain the property of their neighbors and strangers, proved that this strange representative of Satan was served with more than ordinary devotion. His rites were celebrated in darkness, at the change of the moon. While the husband prowled forth to rob, the wife went to the marae to pray for his success; 
yet, if success were not always found, it would be with an ill grace if they should charge Hiro with bad faith towards his followers; for, faithful as they were in making vows, they were knavish enough in performing them; thus, if a hog had been stolen, an inch or two of the end of the tail was deemed a sufficient thankoffering to him. With this in his hand, the thief went to the marae, and, laying it down on the ground, he would say, cantingly, "Here, good Hiro, is a piece of the pig that I stole last night for you,-but don't you tell." Then he would slink away, persuading himself that, if he had wronged his neighbor, he had not wronged his god; though, to do his ingenuity justice, he had tied such a triple knot of villany, that it would be a nice point for a casuist to determine, whether he had cheated his neighbor, his god, or himself, the most. (Montgomery 1832:I, 67)

Auna, who was formerly one of his most zealous and favored votaries, informs us that Hiro, the patron divinity of thieves, was devoutly worshipped here and throughout these islands, though he was a god of but recent creation. He is said to have been a native of Raiatea, and so far from being born an immortal that (if the ambiguity may be allowed) he did not even die one-his skull having been preserved at Opoa, in that island, and seen by persons now living there, though it has recently disappeared with the other relics of idolatry. This Hiro was so subtle and audacious a robber that even the altars and maraes of the gods were not safe from his sacrilegious fingers. To his skill in thieving were added all those other accomplishments for which heathen deities in all countries, from Greece and Rome to Tahiti and Raiatea, have been celebrated,-lying, murder, debauchery, \&c. \&.c. Nor was he less famous for managing a canoe, and playing the pirate by sea, than the burglar and bandit on shore. After his death, when enrolled among the gods for his atrocities, he was reverenced even above Oro, to whom he proved himself superior by throwing him down and lying upon him. His skull, as already mentioned, was deposited in a large marae, which he had himself erected, and his hair was put into the body of Oro's image and committed to the flames at Maeoa. The devotees of this idol were all persons of more than vulgar rank; our friend Auna, being of royal kindred, was admitted to that honor. Indeed, it was not to be expected, even in such a state of savage society as then existed, that any except the great should be permitted to seize their neighbors goods with impunity. (Montgomery 1832:I, 186-187)

Henry described how thieves made use of the services of Hiro:

The dragonfly was a shadow of Hiro, god of thieves. It was a god that flew and halted before and behind. It was carried by thieves in their clothes, so that when they entered the dwelling of those they wished to rob, they let the dragonfly go, and it dazed the inmates so that they did not notice that they were being robbed. (Henry 1928:391; see also Moerenhout 1837:I, 447-448)

Some of this ambivalence toward thievery might be resolved in terms of "localism" (or of ethnocentricity in the case of taking from Europeans-that is, the Maohis rarely passed up an opportunity to steal from Europeans and did so with an audacity and adroitness that moved their victims to grudging admiration).

I do not hesitate to say, that the whole island is but a den of thieves. European property they will possess by some means or other; and theft they consider 
as the cheapest and easiest method of purchase. They will not hesitate even to waylay and rob a traveller! for one mode of theft is as palatable to them as another. Old Pomarre was as dextrous a thief as any amongst them, if borrowing, without any intention of repayment, merit this name. He would often request me to lend him a hog, for which, when once received, he never again thought of making any return. This could proceed from nothing more but mere avarice, for he could have had any number at a very easy rate. But theft, as I have observed, is a cheaper method of acquisition than purchase. (Turnbull 1813:282-283)

The Natives cannot withstand thieving even from the King to the Towtow or servants, great Numbers of them constantly coming on board \& going about the Ship \& riging they frequently steal things, \& whenever catched or the thing lost found on them, we immediately sieze them up to the Shrouds \& give them a dozen or two according to the nature of the Theft, without any respect to rank or distinction, \& let them loose \& flock them out of the Ship \& make them swim on shore, as no Canoe takes in the Teeto or Thief-notwithstanding there is few of them can Avoid thieving when an opportunity offers (Clerke, in Beaglehole 1961:227).

But, whatever the full explanation of this seemingly double standard, the Maohi who stole from a fellow tribesman thereby placed himself in double jeopardy: in most cases his victim enjoyed the socially acknowledged right to kill him on the spot (see Moerenhout 1837:II, 18), or if he managed to escape that immediate execution he remained vulnerable to future execution in the form of human sacrifice on some occasion concerning his tribal chief or his tribe as a whole.

As just noted, the usual immediate punishment of a thief was death, ordinarily through drowning:

This offence [theft] is punishable among themselves by the death penalty: the victim's hands and feet being lashed up to his neck in a bunch, after which he is made fast to a large stone and thrown into the sea (Corney 1915:259).

Among themselves, if detected, the thief experienced no mercy, but was often murdered on the spot. If detected afterwards, he was sometimes dreadfully wounded or killed. Two very affecting instances of vengeance of this kind are recorded by the early Missionaries. I have also heard that they sometimes bound the thief hand and foot, and, putting him into an old rotten canoe, towed him out to sea, and there left him adrift, to sink in the ocean, or become a prey to the sharks. (Ellis 1829:II, 371)

Even the romantically sympathetic J. Forster confirmed this penalty to thieves: "... we were told that thieves were either hanged or drowned with a weight tied to their necks; in either kind of punishment are no vestiges of cruelty [!]" (1778:407).

The sources contain several other references to thieves having been punished with severe beatings or banishment, but as these concerned penalties imposed by chiefs upon individuals caught stealing from Europeans, one cannot confidently say that these penalties were typically Maohi.

Sometimes, however, the death penalty was commuted to some other form of punishment: 
If any Man is Caught in the act of Theft and is immediately put to Death, the Person who killd him is brought to No account for it. But if the Thief escapes \& the Property is afterwards found on Him the Person whose property it is, may plunder him of His Goods and Chattels which the Theif always submits to, the Owner leaving with Him the property which he stole and taking all the rest, but should he absent himself, and take His goods off His land, the Person Injured may oblige the Thiefs land lord to deliver to Him the House \& land which the Thief did posess till the damage is made good or ransom it with Hogs to the full satisfaction of the Party injured. This latter Mode is mostly practised: as if the land was once put into posession, the Party so holding it could never be removed except by War, or the Commission of some Crime against the Chief; after such ransom is paid the Squire may if He pleases compromise Matters, with the Thief, and let him return, on Condition that He pays the Ransom or gets Friends to do it for him, or give it to some other who has been distressd by War and the Theif must go and live on His Friends. (Morrison 1935:192)

The haru raa, or seizing all the property of delinquents, was the most frequent retaliation, among the lower class, for this and other crimes. The servants of the chiefs, or injured party, went to the house of the offenders, and took by force whatever they found, carrying away every article worth possessing, and destroying the rest. If the inhabitants of the house received previous intimation of their purpose, they generally removed or secreted their most valuable property, but seldom attempted to resist the seizure, even though every article of food and clothing, and the mats on which they slept, should be taken away.

This mode of retaliation for theft, or other injury, was so generally recognized as just, that, although the party thus plundered might be more powerful than those who plundered them, they would not attempt to prevent the seizure: had they done so, the population of the district would have assisted those, who, according to established custom, were thus punishing the aggressors. Such was the usual method resorted to for punishing the petty thefts committed among themselves. They were generally satisfied with seizing whatever they could find in the houses, yards, or gardens of the offenders; but when it was practised by order of the king or chiefs, the culprit was banished from his house or lands, and reduced to a state of complete destitution. (Ellis 1829:II, 371-372)

As noted earlier, if for some reason or other a known thief managed to avoid direct retaliatory punishment, that did not remove him entirely from peril, since such individuals, along with "blasphemers," were generally considered to be the most suitable candidates for human sacrifice:

When Men are Wanted for Such Occasions the Chief assembles the Ratirras, at the Morai and a Feast is Made at which none must be present but those who are by birth intituled to give their Oppinion, he then informs them of the Business, which they however know beforehand. They then agree among themselves about the Fittest Man and if any have been Guilty of Blasphemy or has been a Most Notorious thief and has escaped punnishment they fix on him and one of themselves undertakes to kill him and watches his Opportunity, the business being mostly kept a secret till he is killd, which is generally in the Night when the Man appointed to kill him, finding where he sleeps, knocks him in the Head with a Stone and gets his servants to make a large Basket of Cocoa Nut leaves into which they put the body and Convey it to the Canoe to be offered into which they 
put it-they are careful not to disfigure the Face as that would make them unfit for an offering and an other must be got in stead, for which reason they mostly strike them on the back of the Head or Neck.... (Morrison 1935:206-207)

Further along in this passage Morrison added an observation which seems to underline the judicial nature of this process: “... and should any Man be killd without sufficient Cause (tho they Never admit them to be present at their Tryal) His Friends instantly make War on the Offenders, but if $\mathrm{He}$ is known to be guilty of the Crimes laid to his Charge No Notice is taken of it as evry one deems it right and the Man who kills him is Justified as having been the Executor of Justice."

The severity of this sanction was increased by the circumstance that death by sacrifice resulted in placing the victim's relatives in similar jeopardy. $^{67}$

A statement by Anderson asserted that there were some generally accepted associations between severity of penalty and value of stolen object:

... if any one be caught stealing, which is commonly done in the night, the proprietor of the goods may put the thief instantly to death; and if any one should inquire of him after the deceased, it is sufficient to acquit him, if he only inform them of the provocation he had to kill him. But so severe a punishment is seldom inflicted, unless the articles that are stolen be reckoned very valuable; such as breastplates, and plaited hair. If only cloth, or even hogs be stolen, and the thief escape, upon his being afterward discovered, if he promise to return the same number of pieces of cloth, or of hogs, no farther punishment is inflicted. Sometimes, after keeping out of the way for a few days, he is forgiven, or, at most, gets a slight beating. (Cook 1784:172)

The severity of a penalty seems also to have been influenced by the status of the principals:

This morning a barbarous murder was committed by one native on the body of another in a house a few yards distant from us. The murdered man it appears had been guilty of a very petty theft, and for which he lost his life. He was struck a dreadful blow on the nape of his neck with a Tommahawk that almost severed his head from his body \& his right shoulder was horribly cut with repeated blows. The perpetrator of this savage act walked about afterward with the Tommahawk in his hand, with as much unconcern as if he had been splitting up fire wood, \& behaved very insolently when spoke to about it. The person killed belongs to Paheete's jurisdiction, who is now in Oparre; but it is apprehended that no notice will be taken of the matter whether by him or Pomarre (to whom the other man belongs) as he was accounted a person but of little worth, \& his murderer is a man of consequence. This same man who has so inhumanly destroyed his countryman for a mere trifle we have reason to suspect of having plundered us of various valuables. Towards evening Paheete arrived in the district. He made some inquiries concerning the above murder, and ordered the corpse which its murtherer had buried to be digged up \& to be placed within view of him in Edeea's house on the point where he is fled for refuge. It appears that this is held by the natives as a mark of abhorrence of the act, \& what is very unpleasant to the guilty person. There is some talk 
among our neighbours, that the inhabitants of this district \& Hapyano will revenge the murder \& even burn Edeea's dwelling in which the man has sheltered himself. If this shd. be done it will certainly produce a war. The servants of Edeea removed her property from the point into br. Nott's apartment for fear of the worst.

Nothing has this day been done towards avenging the murder. It is said that Pomarre has been made acquainted with it, and justified the deed, and has given directions that nothing be done to the man. (Jefferson, Journal, December 1802, LMS Archives)

But, however popular the approval may have been for punishment of known thieves, the matter was sometimes complicated if it touched upon the interests of a chief:

A native living near our four brethren's had stolen from him two bits of wood that he designed to make into combs. Having found the thief, a furious and long contest in words took place upon the occasion \& the person from whom the wood had been taken several times lifted up a felling axe he had in his hand, threatening to dash to pieces therewith the transgressor's head. Fear kept him back from the action as the thief was a native of Oryatteea and under the protection of the king. Some of the brethren who were spectators of part of the contention laboured for peace between them when one of the Standers by gave them to understand, that if it was not for fear of Otoo they should see an Otaheitean custom, intimating thereby they would certainly kill the man. (Jefferson, Journal, 14 July 1799, LMS Archives)

Finally, chiefs themselves were not exempt from the common proclivity to thievery:

It is not always in the power of the chiefs to prevent robberies, they are frequently robed themselves and complain of it as a great evil. Otoo left the most valuable thi(ng)s he had from me, in my possession till the day before we sailed and the reason he gave for it, was, that they were no where so safe. Sence the bringing in of new riches among them, the inducements to robberies must have increased, the cheifs seem sencible of this and are now extremely desirous of Chests, a few that the Spaniards had left a mong them, they seemed to set much Value upon and were continually asking us for some. I had one made for Otoo according to his own dimensions, it was eight feet long five broad about three deep; locks and bolts were not a sufficient security, but it must be large (e)nough for two people to sleep upon by way of guard(ing) it in the night. (Beaglehole 1967:222)

\section{Lese Majesty}

Offenses against the position, property, or person of a tribal chief also resulted invariably in severe penalties, from temporary exile to death. When carried out at the behest of a tribal chief, a punitive slaying was even more harsh a measure than was usually the case, since nearly all such victims were disposed of as offerings to some tribal tutelar. For example, according to one source, whereas a person caught thieving from nonchiefs was simply killed, anyone caught thieving from a chief was sacrificed to a god (Corney 
1919:155). This measure sometimes had the effect not only of placing the victim's near relations in peril of similar fates, but it reduced even further the inclination or the possibility of revenge: especially in cases where the offering was made to 'Oro, as it was deemed a sacrilege for anyone even to express grief for a victim offered to this god (Henry 1928:126). In fact, so powerful a sanction was human sacrifice, and so apparently necessary was it to chiefly authority, that some chiefs, upon being urged by Europeans to give up the practice, exclaimed, "If we do there will be no Chiefs" (Morrison 1935:207). ${ }^{68}$

At this point a distinction must be drawn between two "official" roles played by a tribal chief in meting out the death penalty. In some situations he acted more or less impersonally, as tribal administrator; either on his own initiative or in response to priestly requisition, he called for some victim to fulfill a ritual need. In other situations, he ordered the execution of some specific individual who had offended his own person, property, or office; it is this role with which I am presently concerned. There is evidence that some tribal chiefs utilized valid or even trumped-up requisitions for sacrificial victims to punish enemies whose gratuitious slaying would otherwise have proved too unpopular-but tribal chiefs were perhaps not alone in playing this cynical game.

The other kinds of sanctions regularly employed by tribal chiefs toward offenders against themselves were whipping, banishment, and destruction of the malefactor's goods. One method of whipping was described by de Herve: "... when [a chief] wants to punish any persons of his District for an offence against his person, or otherwise, he orders them to be tied by the hands and beaten across the pit of the stomach with a stick; the severity of the punishment varying with the nature of the fault" (Corney 1913:356-357).

Banishment sometimes consisted merely of causing the malefactor to be "turned off his land" (Morrison 1935:110), but more often involved driving him outside the tribal territory or making it impossible for him to survive except on charity, by forbidding him to subsist on any other part of the tribe's land (Corney 1919:99). Most references to banishment imply only that the exile had to leave his tribal territory, but one source indicated that those banished from Teva i Tai were sent to Me'etia Island, which was a dependency of the Teva i Tai chief (Corney 1915:264). Destruction of a malefactor's goods (house, furnishings, gardens, groves) was also accomplished on occasion, either as the sole form of punishment or accompanying other penalties. Sometimes the moveable items were plundered instead of being destroyed (but, as will be explained, not ordinarily for use by the tribal chief himself).

Another typical feature of the punishment meted out by a tribal chief 
was its occasional extension to members of the principal offender's family or neighborhood. The ari'i Vehiatua, for example, ordered the banishment of the principals responsible for robbing his friend Rodriguez, and in addition dispossessed the innocent relatives of the culprits of their land (Corney 1919:87) ${ }^{69}$ On other occasions whole neighborhoods were laid waste as the result of the offense of one resident.

A review of reported cases of chiefly punishments reveals some measure of association between types of offense and of punishment-for example, default of "taxes" was punished by banishment, and "blasphemy" by death-but as much or more determinative were the chief's personality and coercive powers, and the social identity of the culprit. For example, when Pomare II was relatively secure politically he angrily ordered the death of a commoner who unwittingly awakened him from a kava stupor (Jefferson, Journal, 16 May 1799, LMS Archives): an extremist action which more benign chiefs, or those less powerful, would probably have hesitated to take. And, as we have seen, few tribal chiefs, however powerful, were able to punish with complete impunity the well-connected or more influential of their subjects. In other words, whereas a tribal chief could mete out punishment directly upon a more humble offender, he was obliged to accept a substitute when the culprit was of superior status, as witnessed in the following:

I was sorry to hear again of a human Sacrifice.-Iddeeah informed me that the Chiefs of Wa'ennah (called Oha aine in C. Cooks Map) had sent one to Otoo-I found it wrapt up in a platted Cocoa Nutt branch and Slung to a Pole as usual-it stunk very much, and on that account was hung up among the Bushes a part from any dwelling.-The late disturbance and War between Matavai and Oparré People was the cause of this Sacrifice-the People of Wa'ennah took part with Matavai, and the offence was not to be forgiven but by this melancholy claim.-The absence of Otoo prevents any thing being done untill his return, when the Eye will be presented, and the Etuah supplicated to continue the friendship between the two Districts.

I am now perfectly satisfied that Human Sacrifices are common and very frequent.-If a Chief or Powerfull Man seriously offends the Eneerahigh he is obliged to obtain forgiveness by this means.-It is not to be refused, so sacred is it as a pledge of faith and good will.-It is evidently not confined to making Peace or declaring War, or supplicating the Etuah on an emergency, or any general calamity. (Bligh 1792:162)

The question of constraints, or lack of constraints, upon chiefly authority will be discussed later on, after we have considered what roles chiefs played in adjudicating and punishing breaches of social norms other than those concerned mainly with their own persons, offices, and goods.

\section{Social Justice}

I cannot discover that they have any custon or law which inflict punishment for particular Crimes by Trial-The Strongest Man, or the most powerfull Chief decides 
in his own cause, but there is an appeal from the inferior people of every District to their superior Chief who judges fairly of the matter in dispute. (Bligh 1792:150)

It appears that the chiefs, like the gods, were not concerned with protecting the innocent or with avenging crimes; in fact, it seems that the only advantage which people drew from their [tribal] government consisted in its actions of mobilizing and leading them to fight against common enemies. On all other occasions it was a case of might makes right.

There were, to be sure, some circumstances wherein complaints were taken to the chiefs; but it was rare that the latter championed justice to the extent of correcting wrongs or punishing wrongdoers, especially if it was a case of strong against weak-for, in this form of government the people at large were always oppressed. It can be stated as a general condition that the chiefs' judicial decisions were usually arbitrary; and, if they were indifferent [to the application of justice] among their subjects at large, they punished with fury and cruelty the least offense or mistake against themselves or their favorites.

In addition to their unconcern with dissension among [other] individuals, including even the most infamous actions and the most atrocious crimes, except when they were personally affected, the principal chiefs or ari'i intervened only rarely into the more serious quarrels of their tribal subchiefs, whom they allowed to war [against one another] for the most frivolous kinds of reasons. (Moerenhout 1837:II, 16-17)

As Bligh indicated, chiefs may have intevened occasionally in their subjects' disputes if asked to do so, but for all its bluntness, Moerenhout's statement seems to be essentially true in most other respects. A contrary view was expressed by Banks, whose statement, however, is in itself contradictory:

It is not to be expected that in a Government of this kind Justice can be strictly administerd, we saw indeed no signs of Punishments during our stay. Tupia however always insisted upon it that Theft was punishd with death and smaller crimes in proportion: in cases of Adultery the offenders were in the power of the offended party who if he takes them in the fact frequently kills them both. All punishments however were the business of the injurd party, who if superior to him who committs the crime easily executes them by means of his more numerous attendants; equals seldom chuse to molest each other unless countenancd by their superior who assists them to defend their unjust acquisitions. The cheifs however to whoom in reality all kinds of Property belong punish their dependants for crimes committed against each other, and the dependants of others if caught doing wrong within their districts. (Beaglehole 1962:I, 386)

The sources do not contain instances of, or general statements about, tribal chiefs intervening in the quarrels of their subjects, either unbidden or at the behest of one of the parties; ${ }^{70}$ but nearly all such instances can be shown to have touched upon the chiefs' own interests. A chief did occasionally champion a subject in the latter's quarrels with members of other tribes; in fact, that was a standard strategy for gaining or maintaining adherents when such measures became politically expedient; ${ }^{71}$ but the picture of a tribal chief holding court to protect the weak from the strong, to 
uphold justice for justice's sake, is quite alien to the Maohi scene as I have been able to reconstruct it. By this I do not mean to imply that the populace was universally and unceasingly "oppressed" (as Moerenhout would have us believe); under some tribal regimes this was undoubtedly the case, both by Western and Maohi standards, but it is unlikely that most Maohis would have characterized their normal situations in such terms. For, the behavior of tribal chiefs was of the nature of things.

According to Anderson, chiefs sometimes put a desire for goods above any feeling of responsibility for the welfare of their own immediate dependents:

If a Manahoone [vassel ${ }^{72}$ ] kill the Toutou, or slave of a Chief, the latter sends people to take possession of the lands and house of the former, who flies either to some other part of the island, or to some of the neighbouring islands. After some months he returns, and finding his stock of hogs much increased, he offers a large present of these, with some red feathers, and other valuable articles, to the Toutou's master, who generally accepts the compensation, and permits him to repossess his house and lands. This practice is the height of venality and injustice; and the slayer of the slave seems to be under no farther necessity of absconding, than to impose upon the lower class of people who are the sufferers. For it does not appear, that the Chief has the least power to punish this Manahoone; but the whole management marks a collusion between him and his superior, to gratify the revenge of the former, and the avarice of the latter. (Cook 1784:173)

Anderson also wrote that when parties to a land dispute took the case to their tribal chief, the latter "... terminates the difference amicably," but de Bovis indicated that such appeals were avoided when possible:

When two raatiras, of same or different families, engaged in a dispute-a situation which ordinarily arose only in connection with differences regarding partitioning or sole ownership of land-the contestant who believed himself wronged had the "right" [i.e., could take recourse] to deed to the king or some other member of the royal family the disputed object, to which three-fourths of the time he himself had no just claims. (1909:21)

According to Morrison there was a little need for disputes to be referred to higher authority:

If any dispute should happen about the boundarys of their land, as they have No Records nor any deeds of Gift they always refer to the Neighbours for a decision, who new Mark the bounds of each Mans land, and None disproves of such decision, as they are very superstitious in religious rites they would rather submit to let the whole be Common to both, then either would undertake to Mark his own bounds, fearing that he should be punishd with sickness or Disease if $\mathrm{He}$ incroachd on the property of His Neighbour.

This and all other Disputes is settled by the Neighbours and the party who is declared to be in the wrong, almost always submits at the first word and making a Peace offering to the Man offended, declares himself in fault, and desires he may think no more of it. (1935:193-194) 
But against this flattering characterization (a typically Morrisonian one) is de Bovis' view quoted above, along with much other evidence of the same kind. In other words, while it seems to have been generally true that a tribal chief seldom intervened to settle disputes or avenge misdeeds among his subjects, unless of course his own interests were at stake, this does not signify that all such disputes were amicably resolved, or that all such misdeeds were appropriately punished, among the subjects themselves. It signifies, rather, that Maohi social relations encompassed a great deal of unresolved conflict and unrequited wrongs: a situation which for one reason or another tribal chiefs were either unwilling or unable to reform. ${ }^{73}$

\section{Constraints on Chiefly Authority}

In an earlier section I listed the various kinds of officials who supported a chief's authority over his tribe: priests, administrators, warriors, subtribal chiefs, and so forth. Looked at from another point of view, some of these officials can also be seen as having limited such authority.

The most powerful constraints on a tribal chief's authority were exercised by the chiefs of the subtribes making up his realm. To begin with, most evidence tends to confirm Ellis' (1829:II, 366) and Moerenhout's (1837:II, 8) dicta that the chief of a subtribe nearly always exercised weightier authority over his own subtribe than did the tribal leader himself. (It will be recalled, however, that most tribal chiefs also exercised direct authority over a particular subtribe as well.) As indicated earlier it was very rare indeed that a tribal chief had direct relations, especially on official matters, with ordinary members of subtribes other than his own. Nearly all commands and requisitions went through the subchiefs; if the latter approved or were unable to offer successful resistance at the time when such orders were usually executed, but that was not always the case:

The parties generally knew each other's strength and influence, and those who had little hopes of succeeding by an appeal to arms, usually conceded whatever was required. Personal security, and the rights of private property, were unknown; and the administration of justice by the chiefs in the several districts, and the king over the whole, was regulated more by the relative power and influence of the parties, than by the merits of their cause. (Ellis 1829:II, 368-369)

In this and the following statement, Ellis was evidently referring mainly to the polity after Tahiti and Mo'orea had become "unified" under Pomare II, when all subtribal chiefs had become known simply as "chiefs" or ra'atira. Writing in more general terms, Ellis stated:

Notwithstanding the many acts of homage paid to the head and other branches of the reigning family, and their imagined connexion with the gods, the actual influence of the king over the haughty and despotic district chieftains, was neither powerful nor permanent, and he could seldom confide in their fidelity in any project which would not advance their interests as well as his own. Every 
measure was therefore planned with the most cautious deliberation, the approval and aid of a number of these nobility of the country being essential to carry it into effect; but when the interests of the reigning family and those of the chieftains were opposed, it produced no small embarrassment. (p. 367)

The sovereign was, therefore, more desirous to conciliate their esteem, and engage their co-operation, than to prejudice them against his person or measures. (p. 366) ${ }^{74}$

Recorded instances of the relative independence of particular subtribal chiefs are numerous, and range from petulant obstructionism to rebellious disobedience. There were also institutionalized expressions of this latitude, for example, in the degree to which debate characterized tribal council meetings, and in the license enjoyed by subtribal chiefs in expiating their own acts of lese majesty by means of substitutes - that is, by sending a human sacrifice to the tribal chief in lieu of being punished themselves (Bligh 1792:162). These indications of the nature of the relationship between tribal chief and subtribal chief are sharpened by evidence that a tribal chief rarely took over personal possession of estates whose owners he had banished: "For treason, rebellion, or withholding supplies, individuals were liable to banishment, and confiscation of property. The king had the prerogative of nominating his successor, but could not appropriate the lands of the exile to his own use." (Ellis 1829:II, 365) ${ }^{75}$

The ultimate constraint exercised by subtribal chiefs upon their superior was to kill him or to remove him forcibly from office. Both measures are attested to in legend and in history. A legendary account of the killing of a chief by his disgruntled subjects was provided by Henry:

On one occasion, it happened that a king named Tai-è (Odd-cry), who was much hated by his people for his tyranny, went up with a party of his subjects determined to explore the crater and ascertain what kind of creature dwelt there. He had a long strong rope, and being the bravest man in the party, attached himself to one end of it, telling his men to hold the other and to pull him up quickly when he gave the signal by jerking a small rope attached to the upper end of the big one and hanging by his side.

With this understanding, while the men held on, the king descended and disappeared in the labyrinth below. Soon he violently jerked the signal rope, but no heed was paid, and he continued doing so for some time, till gradually the pulling ceased. After waiting still longer the treacherous attendants drew up their king, whom they found with his flesh devoured from his bones. They carried home what remained of him, saying as they did so, "Ua ora râ te fenua i teie nei ari'i ino" (The land is now free of this bad king), which was ever afterwards regarded as a terrible warning to other kings against despotism. (1928:98)

Rebellion sometimes accomplished the same end, as exemplified in the traditional story of the Poraporan chief Teihotu reproduced in chapter 16, section on Leeward Islands. Dissatisfaction with Teihotu's rule derived partly from the "austerity"-probably the excessive prohibitions and demands for offerings-emanating from his "tribal" marae, Vaiotaha. In this 
case the rebellion ended in the killing of Teihotu in battle, and the installation of his infant son as head of a new tribal regime controlled by the successful rebels.

I have come across no specific instance, legendary or historical, of a tribal chief having been removed from office by peaceable persuasion or mere threat of force, but such actions may well have taken place, as attested in Morrison's general statement that “... if the Chiefs should not act up to the Dignity of their Office they may be devested of their Office, but they are still Chiefs [members of the ari'i class?], and tho the King may be stripd of his Government he still retains his royalty ..." $(1935: 167)^{76}$

According to Moerenhout:

Priestly power was extensive; and although priests did not sit in [tribal] councils, or take much part in political discussion, they were not therefore less respected than chiefs, because-regarded as priests were by the populace-chiefs would not have dared to mistreat them, since their offices provided them with a thousand ways to obstruct chiefly policies. Just their announcement of a direful omen usually had the effect of dissuading the populace from supporting the chief in some enterprise. Also they were in a position to punish or even destroy persons [in power], including the sovereign, without taking overt action and without thereby compromising themselves in any way. (1837:II, 10)

While most of the sources agree in general with Moerenhout's estimate of the reach of priestly influence, I have come across ample evidence that some priests did take part in tribal councils, either regularly or occasionally. Moreover, I suspect that some of them engaged regularly and heatedly in "political discussions." In other words, it is my conclusion that some priests exercised constraint upon a tribal chief's authority not only by doing priestly things, but also by means of secular, political tactics as well. For, it should not be forgotten that in some tribal congregations sacerdotal offices

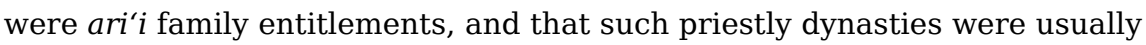
backed by extensive estates and numerous fighting forces of their own.

This conclusion is confirmed by a passage from de Bovis indicating that the high priest's activities were not confined within the marae precincts, but in secular affairs as well he exercised immense influence (1909:49-50). But, as de Bovis also pointed out, the extent of priestly influence upon secular affairs depended much upon the character of the tribal chief himself. In addition, it should not be forgotten that the interests of priests and chiefs probably more often than not ran parallel. In describing this situation Moerenhout noted that a tribe's high priest was usually a close relative of its chief (1837:II, 10). While this circumstance may sometimes have resulted in identity of interest between the two, it did not always or necessarily do so. In fact, what scattered evidence we have concerning actual-that is, "historical"-political events shows that although relatives did in some cases aid a chief in extending or 
maintaining his tribal authority, there were several other instances when they managed to curb his ambitions or reduce his authority. Some of these instances have already been discussed-they involved not only collateral family lines but siblings and parent-child rivalries as well. I shall not attempt to "explain" all such rivalries, but one type merits some additional remarks.

In the case of kin-Titles also identified with tribal chieftainships, the transfer of such a Title to the new incumbent early in the latter's life undoubtedly minimized chances of succession rivalry. On the other hand, the practice whereby effective tribal authority was transferred only piecemeal served to encourage conflict between old and new incumbents, who in most cases were father and son. And, since individual rivalries usually tended to involve other relatives and their adherents and allies, such situations typically culminated in civil or even intertribal wars, which occasionally may have served to increase the new incumbent's authority but in other cases accomplished the very opposite effect. ${ }^{77}$

Finally, we have to consider whether and how a tribe's populace at large exercised effective constraint upon their chief's authority: I raise this question because of the phrasing found in some of the sources that generalize about the limits to chiefly power. There is no reason for doubting the sources when they refer to "the people," or "the populace," or "the tribal members" as "grumbling about their tribal chief's oppressiveness," or "muttering thoughts of rebellion"; but I have come across no evidence that any such "popular" movement ever succeeded against a tribal sovereign without the leadership of some one or more subtribal chiefs. However, it was reported that individuals or whole families occasionally defected, that is, moved into some other tribal domain, when displeased with their own tribal chief (Moerenhout 1837:II, 19n2).

The knowledge, or anticipation, of a popular groundswell of discontent may in some cases have caused a tribe's chief to exercise self-constraint, but, as I understand Maohi tribal politics, interpersonal limits on tribal chiefly authority originated mainly with priests and with other chiefs.

\section{THE PRECEPTS OF TETUNAE}

The sources contain many references, explicit and implicit, to Maohi ideals and expectations concerning tribal chieftainship. These references range from statements in, say, the legend of Rata (Henry 1928:478), to legendary and historical evidence regarding popular discontent with tribal government. But the most explicit by far of these data are a list of precepts, ture, said to have been "orally transmitted since the time of Tetunae, and taught to each succeeding generation of ruling arii" (Handy 1930:39). ${ }^{78}$

1. You are like the Morning Star, Taurua. Your seat is at the prow of the great canoe. You will eat of the chest and filet of the boar. 
2. The life and death of men is yours. Let not one support of the canoe outrigger be broken, lest its weight bear you to the ground. It [each outrigger support-principal supporter] is held in respect by the Farepuans.

3. Let not the blood of your parents be tainted by you; better were it for you to hide your shame in Toareva, the afterworld.

4. To your household and brothers and sisters you owe respect. They must not be defiled by you. Misdeeds against them will leave an ever-open wound.

5. Let not the bilge water of your household be carried and spilt on the wayside. It turns to stirred-up mud, which the mamo fish likes to eat.

6. Let not your eyes be blind to the errors of your relatives (feti'i). It [the errors?] will be like a blazing fire inside your household.

7. Let your eyes, not your ears, be open to the reports of mischievous persons. You will be the first to be harmed if you believe such, or are blind to such as those.

8. Let not your head to be stroked by the hands of a woman [of low birth?]. Your head is not for the likes of them.

9. Take care in choosing the polisher of your spear case.

10. Guard yourself against courtesans, who anoint themselves with sweet-scented oils in your household. They will be the cause of the drowning of your soul with the boasting pride that is the mark of the lowborn (hunareho).

11. Let not folded legs and the love of soft couches be known in your household. Such could be the cause of your ruin.

12. When you reign (eat the hau) remember that the people are servants (titi) of many masters (fatu); that their eyes are ever open to mistakes and verbal abuses; and that, when the $a a u$ ['au' $a$, food bowl? or 'au' $a$, spirit?] is full, bundles [i.e., belongings] are quickly packed and faces turned to a new master.

13. Beware the woman who is footloose and fancy free, quick of tongue, prone to arguments. Arguments are not good; their tail end never fails to strike you.

14. Keep a ready ear open for the agitated cries of the torea [a night bird]. It is the herald of the warrior of death.

15. Let not your death sentences be too frequent, lest your own bones follow the road to death. It will be like having your own house torn down by the warrior at night, leaving you in total darkness, the enveloping darkness of your sin (hara).

16. Let not your breast be brushed by the butt (of the coconut frond) of the voice of contention, lest such weaken relationship bonds.

17. Let not your household be accused of hiding food. Let not your name be associated with hidden food or closely held belongings. The 
hands of the ari'i must ever be open; on this rests his "prestige" [hanahana: appears to be a biblically derived $\operatorname{word}^{79}$ ].

18. The populace is like a crying child: easily coaxed with gentle words, easily enraged by ill treatment.

19. The "heart" [ $a^{\prime} a u$, bowels, i.e., spirit, mind, etc.] of the $\operatorname{ari}^{\prime} i$ must be equal to do good, never too weary to listen to his people's complaints, his ears and eyes ever open to the demands of the law(?) (te ture ra mau faataa raa). ${ }^{80}$

20. Break the sudden rage that shakes your body, that beclouds your brow. Careful pondering is the wise way to proceed.

21 . Be strong to kill the roots of trouble, the breeders of war.

22. Guard yourself against the revenge of a woman; it will pursue your footsteps. Her laugh will be like the wind, the scattering rain on Pou-ma-riorio (official name of the chief's house).

23. Never undertake small enterprises, nor encourage the soul of the shrimp or of o'opu [a small black fish]; their brains are but mire.

24. Ants can hide under leaves-but there are not enough leaves about to cover up your name.

25. Beware of the soft-voiced flatterer. Flattery is the commencement of deception.

26. Wisdom and aau hau [gentle heart? peaceful spirit?] are the best

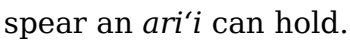

27. Your government (hau) must be stable. It must not be left to run itself, or allowed to be run in ignorance. It must be governed properly and honestly, and not be pushed aside. The ari'i who follows this rule displays great wisdom. Prosperity will follow him; his enterprises will be crowned with hanahana [prestige? glory?].

28. The head of the government (upo'o o te hau) should not be seen with grinding teeth, with lifted voice, with frowning brows, with emotion-shaken body, with a heart angrily beating like the liver of a tortoise-or like a commoner (manahune), from whom alone are such things expected.

29. What you have ejected from your mouth you cannot again swallow, for the wind has scattered it far and wide.

30. Never interrupt nor controvert the words of an orator while he is performing his proper function. Avoid impatience; be attentive [to his words] with open eyes and ready ears. His belly is full of pa'ari (wisdom, experience, sophistication).

31. Never give ear to the advice of a wanderer. He is but the semblance of a man; he is a fruit afloat, going on and on with no place to land and take root.

32. Let not your mouth breed food for the maggot. It must hold only vaianui [a medicinal plant]. 
33. See to it that your chiefly residence, Ao ra'i, does not become the habitation of useless mourning and regret. For you cannot stop the coming of the sun god, Ra'a.

34. An ari'i's anger must be like the mara'amu wind, not heard but felt. Let there be no lasting anger; it must be over quickly, like a gust of the west wind, Toerau.

35. Ponder your words before speaking. They are like flashes of lightning, as mighty as a clap of thunder; no amount of effort can recall them.

36. Be able to accept trouble of all kinds, as an ari'i nūi. Trouble must not find you fearful or shamefaced. You cannot stop the blowing of the boisterous ha'apiti wind, nor the call of Toareva (afterworld).

37. Let not unbecoming tears of irrational anger be seen with you. Night hides what cannot bear the light. The dew [tears?] falls, but the light of Ra'a, the sun god, dries it.

38. Watch your people. Arouse not that which will pain them-you might not be able to find the cure.

39. Your oath must be as respected as your person. Your word must be as dependable as the [daily] appearance of the Morning Star, as binding as the regulations emanating from Marae Farepua.

I need hardly point out that the principal message contained in this "Advice to Chiefs" (who are presumably of the hui ari'i) has to do with their own preservation. The desirability of their maintaining their class purity and family unity and welfare is phrased as moral absolutes; the admonitions concerning liberality, judiciousness, magnanimity, moderation, administrative attentiveness, and so forth, seem, however, to be directed more toward insuring a chief's authority and influence than his subjects' welfare. In some respects, of course, what was good for the former was good also for the latter. But, as I interpret these remarkable guidelines for tribal "good government," the "goodness" had to do mainly with benefits to the chief. This raises the question, What in fact were the benefits that accrued to ordinary people as members of one or another tribe?

\section{Advantages of Tribal Membership}

During the era under study, most tribes appear to have been governed primarily for the benefit of their governors, including principally the tribal chief and his close relatives and counselors. Basis for this proposition is the fact that most interaction between governors and governed related to providing the former with objects and services, and not vice versa. For example, ordinary tribesmen contributed their military services in wars that served principally to maintain or extend their governors' own authority, and only rarely to defend themselves or improve their own lots. The objects and labor provided on other tribal occasions served largely to maintain or 
enhance their governors' welfare-material, political, and spiritual. ${ }^{81}$ And most encounters between governors and governed were marked by the latters' expression of deference, without a balancing return of service on the part of governors, except perhaps in terms of priestly representation.

Support for this proposition is also provided by information concerning the measures which sometimes had to be taken to obtain a populace's contributions-that is, by means of physically coercive sanctions, or by threat of such sanctions, rather than by voluntary consent. The following passages from G. Forster indicate how subjects sometimes had to be "coerced" into behaving "respectfully" toward their chiefs:

The respect which was paid to the sovereign by all ranks of people, and which consisted in uncovering the shoulders in his presence, did not prevent them from thronging around us on all sides with the greatest eagerness of curiosity. The croud was beyond comparison more numerous than at our interview with Aheatua, and the king's attendants in different corners of the area were obliged to exert themselves in order to keep them within bounds. One in particular displayed his activity in a furious manner to clear the way for us, by beating them unmercifully, breaking several sticks on their heads, and no doubt breaking their heads too. (1777:325-326).

During this conference the croud, amounting at least to five hundred persons, was so excessively noisy, that it was impossible at times to distinguish a word; and on those occasions some of the king's attendants with a Stentor's voice called out mamoò! (be silent,) and enforced his command by dealing out hearty blows with a long stick. (p. 307)

But lest my evaluation seem too arbitrary let us examine some more approbative sterotypes about the functions of Polynesian chiefs. I refer generally to the "noble savage" view which pervades so many writings about Polynesians, with especial emphasis upon the "benevolent paternalism" of their chiefs. This attitude also colored some writers' general accounts about Maohi society-particularly accounts written by visitors already imbued with the virtues of monarchical and aristocratic ways of life, or by writers whose information derived mainly from aristocratic sources, either from the aristocrats themselves or from traditions concerned mainly with aristocrats and preserved mainly by aristocrats. Fortunately, some balance to such views are provided by a few visitors and long-term residents who, unwittingly or not, managed to reveal much concerning the ways Maohis actually behaved.

Because of the summary nature of what follows I hope readers will agree with me that it is not necessary to provide specific references for either the stereotypes or for my own qualifying views. I turn first to those notions about the economic advantages gained by subjects from membership in tribes.

One common notion about tribal economics is its preponderance of redistributive type transactions, which are viewed as accomplishing a more 
equitable distribution of goods-more equitable, that is, in the sense that more members of the tribe enjoyed larger portions of the tribe's total resources than would have otherwise been the case. As we have seen, some of the transactions between Maohi tribal chiefs and subjects can indeed be characterized as redistribution, but in most specific instances that I know about the goods that were left over from consumption by those at the top of the hierarchy were either appropriated by those near the top, or were further redistributed in only token amounts. Another common notion about redistribution, namely, that it served to make fuller use of "windfalls," by averting spoilage, cannot be applied to Maohi economics, except perhaps in connection with large hauls of fish.

Some writers characterized rahui or rahui-like prohibitions as conservation measures-deliberate acts on the part of wise administrators to permit the recovery of endangered sources of supply. ${ }^{82}$ Such indeed may have been the rationale, or the unwitting consequences, of some Maohi rahui, as for example in connection with seasonal fishing. Most rahui, however, were deliberately imposed for the benefit of the imposers-explicitly, perhaps, in preparation for some tribal event, but implicitly (in some instances) to assert their own political supremacy.

Another common notion about Polynesian societies is that the strongly authoritarian structure of their tribes resulted in a wider extension of social order than was achieved among peoples interrelated mainly by ties of kinship. Some social order, with attendant benefits, there indeed was among members of any Maohi tribe, and insofar as that order concerned relations between chief and subjects it was explicitly defined and effectively policed. In some respects social order was also well defined and effectively enforced among other members of any tribe, but not entirely or even principally due to the intercession of chiefs. ${ }^{83}$ What tribal "law" there was applied mainly to relations between subject and chief-and in some respects only to a particular chief. $^{84}$

As an example of benefits accruing from the social orderliness just mentioned, it can be assumed that effective popular enforcement of norms against theft contributed to nearly everyone's material advantage; but this was offset in many instances by the impunity with which a chief or his minions could plunder an innocent's goods.

But what about the psychological advantages, if any, acquired by subjects from their membership in tribes? Leaving aside the satisfactions which some members undoubtedly derived from identification with a successful, splendor-auraed chief, and the more tangible pleasures many of them probably enjoyed at his official celebrations, it might be asserted that a chief's subjects obtained intangible benefits from evidence that he was maintaining proper relations with tribal tutelars. These benefits included both decrease 
in anxieties about potential calamities and increase in convictions about possible successes. Some such benefits may indeed have come about now and then, but one will also recall the plaint raised against excessive, politically inspired religious demands: "Bowed down, forsooth! Crushed will be Tahiti before the marae!" (Henry 1928:131)

In proposing the above evaluation of Maohi tribal government I do not, of course, intend to imply that the Maohis themselves necessarily held such views. Some Maohis, especially subtribal chiefs, expressed desires for a return to an allegedly earlier situation of smaller (and presumably more kin-homogeneous) tribes. Ordinary tribal members may occasionally have viewed their own circumstances in the tribal system as inequitable, but it is unlikely that any ordinary (or rather extraordinary) Maohis viewed the whole chief-subject relationship in the objective (i.e., modern Western) light set forth above. Some "memory" - reliable or fictitious-of the kind of chiefsubject relationship associated with membership in a kin-congregation may have served to sharpen individual dissatisfaction with particular tribal situations, but except for that pattern, which was itself anything but democratic and egalitarian, the Maohis knew of no other kind of system. 


\section{CHAPTER 24 SUMMARY, SYNTHESIS, EVOLUTION}

In this final chapter of my attempted reconstruction of the Maohis' social relations as they were during the middle third of the eighteenth century, I propose to do four things:

to review what I conceive to have been these Islanders' principal goals in life and the resources and behavioral means they used to reach them; to summarize the more widespread types of social units and categories that crystallized out of that behavior;

to list the more evident kinds of connections that existed between different types of social units and categories, and between social units and socially valued goods; and

(as an exercise in self-indulgence) to record some of my own pet notions about how Maohi society came to be what it was during this era.

I leave to others, better qualified, the task of making generalizations about the modal types of Maohi personality. ${ }^{1}$ Much of the data I have adduced for my generalizations about "social relations" could also be utilized in generalizing about "personality," but with the use of somewhat different criteria of relevance and-I feel very strongly-of largely different techniques of analysis.

\section{ENDS AND MEANS}

\section{Life Goals}

There were probably times in the life of every Maohi when, say, desire to drink water, or to evacuate the bowels, or to assuage some particular pain dominated all other conscious goals, immediate or long-range; but in this section I shall be concerned with the Maohis' less minimally pan-human and less directly biological needs and drives-that is, with the wishes seemingly shared by some or most Maohis that served to distinguish them (in this respect at least, and in part) from, for example, the Murngin or the Siuai. ${ }^{2}$ I am acutely aware of the methodological weakness involved in an exercise based on the kinds of fragmentary and archaeological data at 
our disposal, but I believe that some statements on this important subject are called for, however unsystematic and impressionistic they may be. ${ }^{3}$

To begin with, it seems quite incontrovertible that eating was regarded by most or all Maohis as one of the supreme pleasures of life-and not just as a means of restoring energy or of warding off illness and assuaging the discomfort of hunger, but as a recurrent end in itself. Moreover, the consequences of what we would regard as dangerous overeating, as evidenced in obesity, were deliberately striven for through institutionalized means. Indeed, the high social value attributed to food and eating was made evident in numerous ways: in the connections between hierarchial status and consumption privilege, in the symbolic use of food in social ritual, and so on.

For some individuals, the drinking of kava, and its resulting state of mellow stupefaction, seem to have rivaled or even surpassed the pleasure experienced in eating, but these were but a small minority. (And although only the more affluent were able to indulge in heavy kava-drinking, the practice does not seem to have been a high-priority goal of the populace at large, or even of the affluent in general.)

Turning now to other aspects of physical well-being, I have the impression that "bodily comfort" was not very high on most Maohis' conscious list of desirable end-states-at least not the sort of "bodily comfort" that Westerners measure in terms of soft places to recline, of situations involving no hard physical exertion, of body conditions free from aches and pains, et cetera. The Maohis evidently enjoyed resting and they slept probably as much as most other peoples, but they do not appear to have invested much thought or physical energy into "making better beds" for themselves (figuratively speaking), or into avoiding situations and circumstances known by them to involve physical strain and predictably large amounts of physical pain. It is, of course, true that some of the objects and services devoted to religious activities were for the deliberate purpose of avoiding bodily discomfort, in the form of spiritinduced illness and accidents; but perhaps the larger part of such goods were intended to secure spirit aid for enterprises not directly connected with "bodily comfort" per se. And to select one more argument from a number of possible ones, the Maohis' apparent willingness to undergo tattooing suggests that certain other goals outweighed whatever general desire they may have had to avoid physical pain.

One such goal was self-beautification, which must be placed high in the Maohis' hierarchy of end-states. Some of their behavior involved in grooming was undoubtedly looked upon as a means for winning sexual favors, but it seems to me that these Islanders also valued good-looking bodies per se, and expended many of their resources, in energy and objects, in making themselves attractive.

Among the several activities engaged in by the Maohis, one that ranked 
near the top of their list of goals was sexual intercourse-not mainly as a necessary release of tension, but rather as an activity as highly pleasurable, in its way, as the eating of good food. Also, although the sexual services of most Maohi women may not have been valued very highly relative to certain other goods, the very frequency of their circulation stamped sexual intercourse as a most popular and recurrent social goal.

Other Maohi activities that ranked high in their hierarchy of ends were dancing, music, dramatics, and sports. Some writers asserted that fighting was also an important if not the most important goal of some Maohis, and so it may have been; I believe, however, that with respect to the majority, while fighting itself may have been an intoxicating experience at the time, and a memorable one in retrospect, it constituted mainly a means toward other ends rather than an end in itself.

It may be that some individuals considered their everyday labors to be pleasurable enough to list among primary goals for living, but the only such activities that seem to have thus qualified with large numbers of Maohis were certain types of fishing, for males, and perhaps group bark-cloth-making for females. Although most Maohis appear to have endowed much of their everyday work with jollity, and especially those jobs involving several persons, I do not find evidence of any widespread sentiment to the effect that work itself-or "a job well done"-constituted a high-priority goal.

Maohis' goals respecting peoples' relationships with information, with objects, and with other people may also be generalized. Some individuals may have valued information for its own sake: certainly many of the things they "knew" about their environment seem to have had little or no practical utility; but I have the impression that in most cases knowledge was regarded as a means toward other ends.

Moreover, I believe that a similar generalization may be made concerning the Maohis' relationships with objects, although the exceptions were probably more numerous than was the case with knowledge. Reports of the avidity with which Maohis sought after European goods might seem to controvert this assertion, until one inquires into the fate of most such objects: that is, instead of preserving them for the sheer joy of counting and looking at them, the owners used them to improve their work efficiency, to beautify themselves, to attract sex partners, to gain political allies, to maintain safe relations with spirits, et cetera. ${ }^{4}$ I would even go as far as to propose that ownership of territory (in so far as it was defined as an object) was valued by most Maohis as means to other ends-for example, as a source of subsistence and of political power. ${ }^{5}$

I suggest that among the many goals striven for by Maohis in the conduct of their relationships with other Maohis the three that ranked highest in the hierarchy of ends were "satisfactory" relations with offspring, mentally supportive relations with one or two "friends," and command over the 
services of as many other persons as feasible. Evidently not every adult Maohi consciously strove toward all three goals (in some cases, in fact, such goals were in conflict), and individuals differed in their priority ordering of them with respect to each other and to all other goals, but generally speaking these three objectives were the paramount social-relational ones in Maohi society during the era now being discussed.

What I term "satisfactory" relations with one's offspring was a complex mental attitude involving a number of sentiments of varying strengths: parental affection, pride of parenthood, desire for lineal continuity, expectations of material support and of politically useful aid, and perhaps even hope for some ultimate intervention with spirits that would help assure one's ghost a better fate. (As I warned at the outset, my generalizations in this section are both impressionistic and unsytematic, as this and the following paragraphs all too obviously indicate!)

Much of the motivation for making and holding "friends" was undoubtedly aimed at other ends as well, but I believe that one can discern in some instances of friendship a disinterested satisfaction in the relationship itself.

I am not prepared to decide how widespread among the Maohis was a strong desire to control others' services (or to precede others in ritual or everyday events, which was in some sense the symbolic indication of such control), but in those individuals for whom it was a goal, it was evidently attractive enough, given the nature of other aspects of Maohi society, to keep large domains of social relations in states of continual (though quite patterned) flux. Nor, of course, am I in a position to decide what part of this desire was "instinctive" and what part conditioned by Maohi customs in general or by particular familial, or other, circumstances. It would be most useful in explaining Maohi behavior if I could assume, as some writers have done, a more or less universal human drive for social power. This I cannot honestly do in the form of an assumption about all Maohis; I can, however, put it in the form of a finding about many of them.

Next, we have to consider again how a pleasant fate after death figured in the Maohis' hierarchy of favored ends. As I have indicated several times throughout this study, the sources do not agree in this matter, and there may have been wide individual differences. Probably, if questioned, all Maohis would have expressed a strong desire to end up in the "paradise" sphere of $p \bar{o}$; but I have the impression that this was not nearly so popular a preoccupation as, say, eating or having sexual relations or gaining social power in the here-and-now ao. Moreover, the social exclusiveness of "paradise" (according to some accounts) removed it from the expectations of many persons; and the very fortuity of getting there (according to other accounts) may have dissuaded some other persons from trying.

This brings us again to the question of why the Maohis devoted so 
much energy to religious activities. I have already proposed that most of that energy (in the form of both objects and services) was expended in order to insure exemption from spirit-induced ills or to secure spirit aid for enterprises of various kinds. But was there in addition a conscious desire held by some persons that led them to strive for good relations with certain spirits as an end in itself? I suppose there may have been, but if so it was, evidently, neither widely diffuse throughout the population nor strongly impelling to those few for whom it was a goal.

\section{Physical Resources}

Having indicated what Maohis appear to have wanted most out of life, I next review briefly the physical resources available to them for getting what they most wanted. From evidence presented earlier in this study it seems quite clear that the natural resources of these Islands as a whole were more than sufficient to satisfy the principal wants of the population. There were, of course, some local disparities in terms of relationships between population and natural resources, but institutional means were available for offsetting most of these.

I employ the word "sufficient," not from the vantage point of Western science (with its more comprehensive knowledge of the Islands' natural resources, including knowledge of materials neither used by nor familiar to the Maohis), but from a comparison with the ecologies of some other societies, ${ }^{6}$ and from the evidence that large parts of Tahiti, Ra'iatea, and other islands were almost wholly unexploited even in terms of resources elsewhere utilized by the Maohis.

\section{Labor}

Looking at the Maohi population as labor with which to exploit the physical resources just mentioned, I have found evidence of relatively few natural constraints upon the employment of that labor. The Maohis suffered some disabilities from endemic diseases but were on the whole a strong, hardy, and fairly healthy lot.

"Arbitrary" cultural constraints, regarding who could and could not do what jobs, were very light in terms of age and in terms of which sex did which kind of productive job. On the other hand, if the sexual segregation that prevailed in eating carried through to food production as well, as some sources suggest, this could have imposed some heavy constraints upon the "rational" employment of labor in this domain. Also, the society as a whole was undoubtedly handicapped as the result of restrictions imposed upon females in matters of religion. Religion itself also served to remove some persons from productive work from time to time, but over the long run this may have been more than offset by the impetus that religion sometimes added to productivity. 
In some societies customs associated with social stratification impose almost crippling constraints upon productivity, but that cannot be said of the Maohis, among whom even the very eminent would sometimes work at the most commonplace productive jobs.

Finally, it should be recalled that two other Maohi practices, infanticide and warfare, served (though possibly not deliberately) to maintain a favorable relation between population and natural resources-favorable, at least, with respect to the satisfaction of most high-priority Maohi goals that involved objects.

\section{Technology}

One can best epitomize Maohi primary tools as having been relatively simple in construction, versatile in employment, and made of materials readily available to almost anyone-that is, no large output of energy or goods was required to have in hand a "basic" kit of tools. Nearly the same may be said of the more complex tools required in productive activities, except perhaps in certain types of fishing.

Most productive techniques were also relatively simple, tradition bound, and within the capabilities of Everyman. And even those more specialized ones requiring long apprenticeships and, perhaps, nonuniversal talents were for the most part so constrained by tradition that they did not encourage improvements in productivity. (Technological innovation may not have been socially penalized, but neither does it appear to have been rewarded: for how could mere mortals improve on the inventions of gods and demigods?) Reinforcing the traditional basis of productive techniques was the tradition-based noninductive nature of most natural-historical knowledge-but not all; for within the limits set by the general conception of a spirit-dominated universe there was still room for some pragmatism, which served in time to provide Maohi technology with features not found elsewhere.

\section{Social-relational Techniques}

We turn now to the social-relational techniques utilized by Maohis in their attempts to achieve their goals-namely, to the conventional procedures followed by them in their interactions with one another, as sought-after ends and as means of reaching other ends. As I proposed earlier, one way of describing these interactional procedures consists of analyzing them in terms of what I label their various dimensions. Throughout the previous chapters I have sought to characterize various types of social relations in these dimensional terms; I now want to record some more general inferences about Maohi social interaction, as viewed in these same dimensional terms. But first, I wish to direct attention to some general features of Maohi social interaction by recalling the pleasure that many, perhaps most, of them derived from mimicry and play acting, and the skill with which they partic- 
ipated in such things. These Islanders evidently possessed acute awareness of one another's behavioral characteristics, including foibles, and they were not inclined-except under coercion or in ritualistic contexts-to evaluate one another on the basis of the other's self-estimate. In other words, these Islanders impress me as having been, social-relationally, a very knowing, sophisticated lot.

Terminology. As noted earlier, the Maohis distinguished in practice, and perhaps lexically as well, between personal names (i'oa pi'i noa?), generalstatus names (including offices), and specific-status names, or Titles (i'oa mau?). All three types of names served useful social purposes, for identifying individuals and categories of persons, and so forth, but in terms of the society's more durable social relationships the third type was most important by far. With a few exceptions, general-status names were used as labels for such populous categories of persons that the attributes and social positioning of their referents were thereby only vaguely defined. Except perhaps for ari' $i$-the name used to address and refer to tribal chiefs and high-ranking kin-Titleholders-general-status names seem not to have been used very extensively. As for personal names, they seem in many instances to have been both casual and transient, and thus it is not surprising that no evidence has been uncovered attesting to some kind of mystical link between an individual and his personal name. ${ }^{7}$

In other words, in Maohi society, the more precise, fixed, constant loci pertaining to individuals were their specific-status names (if they had such), and of these the most important were kin-Titles. Individuals moved in and out of these Titles, but the Titles remained the same. ${ }^{8}$

Explanation for the situation just described may be sought in many directions. In my opinion, the Maohi emphasis on kin-Titles as terminological loci in the social network was influenced both by the importance of consanguinity in defining social relationships, and by the relatively narrow scope provided in this society for socially consequential individual diversity. Among the Maohis, conformance to traditional patterns of role behavior counted for more than did innovation.

Time. I trust that intervening chapters have provided ample documentation for my introductory opinion that temporal sequence was more important than temporal duration in Maohis' interactions and in their relative valuation of serial events (chap. 14). Also, with respect to sequence, the higher valuation placed on acting or being mua (first, before), as opposed to muri (afterwards, later on) is well documented, as exemplified in the sharp definition of precedence in many types of interaction, in the privileges ascribed to firstborns, in the consignment of first fruits to gods and chiefs, and so on. Notwithstanding the prevalence of both these orientations in many other so- 
cieties, there is nothing "natural" about them; and hence one is led to ask why they prevailed in Maohi society.

Regarding the relative unimportance, socially, of temporal duration, there is not much explanation I can offer. Perhaps one factor was these Islanders' experience, and conceptualization, of the ways things change: more cyclically than cumulatively. (Possibly reinforcing, and being reinforced by, this was their relatively noninnovative technology, and the weight attached to birth in allocating social roles.) Also, it will be recalled that for most individuals the zenith of the good life was reached during the period of youthfulness; after that there were no comparable climaxes to look forward to, or status enhancements to achieve.

Regarding the higher valuation placed on mua, the rationale might be sought in the Maohis' preoccupation with pedigrees that led back to divine ancestors. Even if one accepted some writers' theories identifying manahune and ari'i with aborigines and more recent immigrants, respectively, this would not necessarily cancel out all advantages deriving from priority of settlement, or the Maohis' appreciation of such advantages.

Space. The several paired opposites used by the Maohis for verbalizing different aspects of spatial arrangement seem to have had quite different referents, denotatively, but they all carried an evaluational connotation: tai (seaward) was socially "better than" uta (landward), i ni'a (above, on top of, upwind) was better than $i$ raro (below, underneath, downwind), mua (in front of, before) better than muri (in back of, behind), and 'atau (righthand) better than maui/ani (lefthand). ${ }^{9}$

As we have seen, ideological identification of coastal areas with hui ari'i did not reflect residential facts in all cases, but there was some historical basis for the supposition. It is not difficult to see why seaward was associated with social advantages, in terms of valued natural resouces, ease of communication, and heightened social activity generally; one does not have to invoke a conquest by confirmed "seafarers" to explain this association.

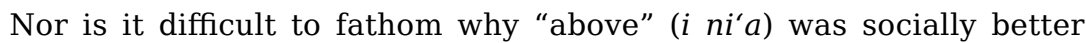
than "below," as was expressed in many, many ways (including prescriptions about posture relative to rank, the association of sky "levels" with the hierarchy of gods, etc. ${ }^{10}$ ) I suspect that a pan-human value is here involved, possibly deriving from the concentration of human beings' sense organs in the head. ${ }^{11}$ And in the case of the Maohis this value may have been reinforced by the male's upper position in the conventional posture of copulation, (although the sequence of reasoning may have been the reverse).

The extension of $i$ ni'a-i raro to upwind-downwind (which most of the time also corresponded with east-west and sunrise-sunset) might conceivably derive from the parallel between the natural movements of objects 
downwind and downward-and, of course, the rising and falling of the sun. A text previously quoted injects a value comparison into this opposition by associating downwind with rubbish-receiving. (This represented a Tahitian's jibe at Ra'iateans, and was opposed to a fairly widespread view of Ra'iatean superiority in matters of cult and kin-Title rank.)

The use of mua-muri for both temporal sequence and spatial arrangement has already been noted-although I cannot, of course, reconstruct which, if either, of these meanings developed first. Like mua's meaning of "first" and "prior," its meaning of "in front of" and "before" was better than its opposite, muri (in back of, behind). I suspect that mua or muri uttered in a spatial context referred (as it probably also does in English) primarily to location with respect to socially valued activity, and only secondarily to fixed features of buildings and landscape. I suggest, therefore, that a more appropriate translation of this pair of opposites would be center, or focus (of some interest) versus margin of the same, but I shall continue to use the more common glosses of "in front of" - "in back of."

The conventional Maohi opposition of 'atau-maui/ani (right-left) represents a local manifestation of a well-nigh pan-human way of conceptualizing the arrangement of entities in space. And like much of mankind the Maohis valued right over left, ${ }^{12}$ as shown for example in the positioning of the groom vis-à-vis his bride during nuptials (Morrison 1935:188); in the disposition of a sacrificial victim's eyes (the right one going to the god, the left one to the chief [Moerenhout 1837:II, 25]); in the path taken by a soul after death (i.e., the righthand one leading to the $a o$, the lefthand one to the pō [Henry 1928:201]); and in the identification of right with the planet Venus, and peace, and left with Mercury and war (Henry 1928:417). ${ }^{13}$

Finally, I invite attention once more to the complex and far from comprehensible synthesis represented in the paired opposites, pō-ao, which, besides serving to distinguish night and darkness from daytime and light, contains implications for (cumulative, rather than cyclical) temporal sequence (long ago versus now), as well as for planes of existence (the domain of spirits versus the domain of mortals).

Governance. Every Maohi social group may be characterized in terms of its governance-that is, in terms of which members control the actions of the others, and of how this was done. In the case of certain kinds of minimumsize groups-say, two men linked in a friendship pact-decision making and initiative may have been fairly evenly exercised, but most other Maohi groups, including many two-member ones, were hierarchically organized in this respect.

Two other features about this dimension of Maohi social relationships strike me as being noteworthy. One concerns the upper-size limits of effec- 
tively governed groups, the other the mode of governing that obtained in perhaps all but the smallest groups.

As I pointed out earlier, except in connection with large-scale dancing and the practice maneuvering of war fleets, where leadership was more in the nature of signaling to already practiced performers, the Maohis did not act together very coordinately in large groups. They turned out in huge gatherings to glimpse and deliver tribute or ceremonial respect to eminent personages, but their effectively governed units-those carrying out specific objectives in response to explicit exercise of leadership-were quite small. This does not mean that large-scale objectives were never pursued or accomplished, but rather that they were somewhat atypical and were characteristically carried out as delegated piecework. In other words, leadership tended to be direct and personal.

With respect to mode of governing, even within the characteristically small-scale limits in which leadership was most effectively exercised, giving orders tended to be curt and unmitigated, and compliance ungrudging but far from servile. In this socially stratified, aristocratically oriented society, subordination was not usually considered debasing: when the relationship between "governor" and "governed" was defined as such, there was evidently no necessity felt to maintain a polite fiction of "equality," such as obtains in some societies wedged between egalitarian ideals and hierarchic reality.

Transaction. As far as I can discover, the goods that circulated among the Maohis were not categorized by them, explicitly, in any comprehensive, all-inclusive way-except possibly the one derived from the linguistic $o-a$ contrasting device, which distinguished, respectively, between "inalienable" and "alienable" items. A classification of certain circulating objects into "natural" and "processed" categories is implied by a text from Morrison cited earlier (1935:191), but only a few kinds of objects are so identified, and in this case the list is only a partial one. I propose to inquire whether any more comprehensive, implicit, categorization of circulating goods may be inferred from their modes of circulation and from the identities of the parties to such circulation.

In the absence of any explicit, overall Maohi classification of modes of goods circulation, I propose one consisting of three broad types: nonreciprocable giving, nonreciprocated taking, and exchange; the last embraces two major subtypes, equivalent exchange and pool sharing.

By nonreciprocable giving ("pure" or altruistic gift giving) I refer to transactions wherein one party transfers some valued object, or performs some valued service, with no discernible expectation of or wish for a return.

By nonreciprocated taking I refer to transactions in which one party 
deprives another of some valued object or attribute, with no discernible intent of making a "satisfactory" return.

Exchange, on the other hand, refers to two-way transfers of goods that are conventionally regarded as being "satisfactory" to all parties to the transactions. More specifically, direct exchange occurs when the transfer is directly between the parties and when the exchanged goods are more or less the same in value, whereas pool sharing occurs when the parties pool and then share the goods according to conventional definitions of their respective resources (including abilities) and needs.

It should be emphasized that these are my categories; there are no Maohi words known to me that seem to correspond exactly to any of these semantic domains. They may, in fact, correspond roughly to some implicit Maohi conceptual categories, but the available evidence does not permit the kind of ethno-scientific analysis, now being undertaken among contemporary peoples, which could test such a possibility.

Nonreciprocable giving seems to have been a rare phenomenon among the Maohis. ${ }^{14}$ Indeed, about the only type of relationship unambiguously characterized by this kind of transaction was that of parent and child, with the goods in question going from the former to the latter. Actually the only specific references I have found to such disinterested giving were legendary-I refer to the tales of parents who gave their lives to save their children (and in one case, a spouse)-but it is reasonable to assume that such giving (of objects and services) was inherent in real life as well, in the relationships between most parents and their infants and young children.

It is perhaps possible that nonreciprocable giving was also inherent in the ethic of hospitality, which constituted such a popular Maohi ideal-perhaps not with regard to processed objects, but at least with regard to such "natural" ones as plant-foods. This, however, cannot be learned from available evidence, but it is my impression (which is equally undocumentable!) that most so-called hospitality was provided with the expectation of ultimate return.

In contrast to disinterested giving, nonreciprocated taking can be copiously documented in Maohi affairs. People diminished one another's resources not only with respect to objects (as witnessed by the prevalence of theft, plunder, expropriation, and damage), and not only with respect to their physical capabilities (as witnessed by the widespread occurrence of murder, assault and battery, and sorcery), but also with respect to their social positions (as witnessed by the popular addiction to slander, defamation, and such). ${ }^{15}$

But in terms of both frequency and variety, exchange-type transactions were more numerous by far. As specified above, I apply the label exchange to two-way transfers of goods that are regarded as being satisfactory to the 
parties concerned-satisfactory being defined according to conventional, society-wide standards, and not necessarily according to the personal wishes of the parties involved in any particular transaction.

Direct exchange, the kind of transfer that took place directly between two parties, involved goods regarded as equivalent in value-services and services, objects and objects, or objects and services. In some instances such exchanges were explicitly "commercial": objects were exchanged for objects, or services for objects, either simultaneously or within a contractually established period of time. However, most instances of direct exchange were conventionally phrased as gift giving, although implicitly embodying the obligation of eventual reciprocation. ${ }^{16}$

As the preceding chapters indicate, transactions that were unambiguously "commercial" in intent and method appear to have been very limited in kind and in frequency. ${ }^{17}$ There were the arrangements between farmers and fishermen for exchange of products over an agreed-upon time period, and there were canoe building and similar sorts of services performed by specialists for specified food and other objects; on the other hand there is little or no evidence for on-the-spot object bartering, or for commercial exchange of services for services. As we have seen, an important feature of these exchanges was the existence of certain sanctions against nonfulfillment; and while it was usually left to the injured party to apply the sanctions, his publicly acknowledged right to do so seems to have lent weight to such contracts and to have discouraged feuding.

For better comprehension of Maohi social relations it would be useful to learn more about the relationships of the parties to "commercial" exchange. In this respect, on the grounds of negative evidence and of inferences from evidence on other kinds of relationships, I conclude that such exchange occurred most commonly between persons who were otherwise not related-as close consanguines or affines, as subject and chief, as occupational guildmates, as fellow Ariois, as politically allied chiefs, or as formally linked "friends." (Indeed, it is possible that one of the most common personal motives for entering into a friendship pact was to establish a more convenient and congenial exchange relationship.) In other words, there may be a direct functional connection between the widespread ramification of those ties of kinship, and so forth, and the relative infrequency of commercial exchange. (Of course, we cannot know with certainty which of these situations was the causal one, but my guess is that the latter was a consequence of the former.)

In this connection, I suggest that the absence in Maohi society of a general-purpose kind of value repository and exchange token-that is, "money"-may also be connected with these circumstances. It is true that bark cloth did serve some of the purposes generally attributed to 
"money" in other societies, but to the best of my knowledge the Maohis used neither bark cloth nor any other kind of object for direct buying and selling of other objects or services.

Most descriptions available regarding "commercial" exchange involved Europeans, and I cannot be certain that the attitudes expressed in such exchanges were typical of commercial exchange between Maohi and Maohi. See, for example, the following from missionary records in the LMS Archives:

We have been endeavouring to bargain with some of the natives to put up a fence and enclose a little ground for us in consideration of receiving a few yards of India print. In our general intercourse with the natives we see little or nothing of the evil dispositions of the heart. They in a public way supply us with vegetable food, put up our buildings for us \& $\mathrm{c}$ and in a private way they come to us in all their troubles of body \& mind as Children to their parents. But when they sell us animal food or undertake any work in consideration of receiving European or Indian property then they show the evil dispositions of the heart, covetousness, envy discontent so that we need very great caution to deal with them. (Crook, Journal, 10 April 1817)

We are all in arrears with our servants \& it seems that nothing is come to relieve our wants. I must I suppose go to Tahiti among the brethren \& borrow Print, calico or any other species of cloth. It is our circulating medium. The Tahitian motto is "the price in the hand the work is done." (Orsmond, Journal, 27 August 1827)

A very large proportion of Maohi transactions may be categorized as gift exchange-that is, transfers conventionally phrased as nonreciprocable giving, but consensually embodying the obligation of an eventual return.

One possible basis for the preponderance of gift exchange over commercial exchange may have been the nature of a large proportion of the items exchanged-namely, food items, subject to rapid spoilage. Anyone acquiring an immediate surplus of, say, fish or breadfruit or taro would have had to consume or otherwise dispose of it rapidly to avoid total waste. And in the absence of an active marketplace, or of an adequate number of trade partnerships (which I believe was not the case), it would have been impracticable to search out buyers on all such occasions. Gift exchange, with its flexibility concerning time of "payment," coupled with the social obligation on the part of the donee to accept, was an ideal solution to this "ecological" problem. Of course, the same argument cannot be made with respect to such goods as bark cloth or mats, but perhaps these and other durable objects that entered into gift exchange were introduced into such transactions at a later time and accordingly were integrated into the pattern already established with respect to food. Such transactions varied widely, in terms of a number of features, for example: the degree of explicitness with which a return gift was specified; the lapse of time prescribed for the return; the amount of "interest" expected; the appropriate nature of the return "gift"; and, of course, the ceremonial techniques involved. 
Much of the information concerning gift exchange comes from Europeans, to whom the practice was baffling, frustrating, and occasionally infuriating. Many of them were moved to comment upon the "cool indifference" with which costly European gifts were received (e.g., Vancouver 1801:257), and upon the absence of any expression of gratitude (e.g., Morrison 1935:191). Conversely, some Europeans were piqued at what they considered to be the materialistic spirit in which "gifts" were presented to them by the Maohis. For example, "It is customary for these people, when they make a present to let us know what they expect in return and we find it necessary to gratify them ..." (Beaglehole 1967:221).

Cook, like some other Europeans (for example, see Wales, in Beaglehole 1961:799), found gift exchange to be on the whole more costly and time-consuming than barter, and more likely to engender ill feelings. On the other hand he came to recognize the advantages inherent in gift exchange: “... in times of occasional scarcity which will sometimes happen, we can have recourse to our friends for a present, or supply, when we cannot get any by any other method [i.e., barter], so that upon the whole this way of traffick is full as advantagous to us as them" (Beaglehole 1967:221).

I have come across no instance of gift exchange between Maohi and Maohi in which expectation of a return was so explicitly specified-unlike Europeans, Maohis undertood the rules of this transactional game-but the expectation was nonetheless impelling. As Morrison put it, "... they all prefer the having to give then being forced to receive" (1935:174-175). Also, one will recall in this connection, the example of coercive gift exchanging related in the story of Hiro's building of his canoe (Henry 1928:547).

As for the nature of an appropriate counter-gift, the common expectation seems to have been a return in kind; that is to say, I have found no instances in which objects were reciprocated mainly in the form of services, or vice versa. Also, a gift of a "processed" object-say, bark cloth or boats-would not have been satisfied by a return gift consisting entirely of food. Besides these, however, the paucity of explicit formulations about such matters and the unmistakable evidence of there having been a good deal of dissatisfaction about gift exchanges indicates that there was no universal consensus about what were and were not appropriate returns. (This situation is undoubtedly connected with the lack of a comprehensive pricing system, whereby most kinds of objects and services might have been compared. However, there is no way of discovering which of these circumstances came first.)

About the only generalization I can offer concerning the time factor in gift exchange is that in general it appears to have been only very loosely defined, and characterized by little or no sense of urgency-another exem- 
plification of the Maohis' unconcern with temporal duration. There were, of course, some conventional differences in this respect; for example, on certain kinds of intertribal visits, the exchanges between hosts and guests took place in regularly prescribed sequences. Yet, according to some stories, a generation or more seems not to have been considered excessive for the balancing of certain exchange accounts.

The question of gift-exchange "interest" is a refractory one. On the one hand, Maohis appear to have derived satisfaction from providing lavish hospitality-and without any evident contriving to embarrass the donees or to encourage a larger counter-gift. (As I suggested earlier, organized potlatching-competitive gift exchange for purposes of status enhancement-seems not to have prevailed on any large scale.) On the other hand, although coercive giving, or "baiting," appears not to have been engaged in to compel returns in the form of larger quantities of the goods first "given," it does seem to have served as a device for obtaining more highly valued kinds of goods. (See for example the Hiro legend referred to earlier.)

The last mentioned point brings us again to the purpose of gift exchange among the Maohis. Examples have been adduced of its deliberate use as a more convenient or more dependable or in some cases perhaps the only feasible means for obtaining desired goods; in other words, the relationship comprising the transaction was the means, and the goods thus obtained were the end. In many other instances, however, the purpose of the transaction was evidently the reverse-that is, the goods in question were exchanged to establish or maintain a relationship. And, of course, many such exchanges were probably engaged in with both purposes in mind.

In contrast to direct exchange, pool-sharing exchange occurred when the parties contributed goods to a common pool on the basis of their conventionally defined resources, and then took goods out of the pool on the basis of conventionally defined needs. The "resources" in question included services as well as objects, and the "needs" I refer to included not only such tangible items as food and other forms of nurturance but such intangible items as status-maintaining (or status-enhancing) praise.

As I conceptualize this type of transaction, it was best exemplified in the way most goods circulated among the members of a household, through the kinds of actions partly described under such labels as "division of labor" and "consumption rights." The notion of "equivalence" was implied here as in the case of direct exchange, but it was an equivalence in terms of the parties' respective resources and needs, rather than of the exchange values of the goods themselves. Pool sharing was also characteristic of many transactions among members of a kin-congregation, and indeed of any type of group, although in the larger types of groups, such as tribes, transactions between individual members were perhaps quite often also in the form of 
direct exchange-which raises the possibility of there having been still another type of exchange, in addition to those already mentioned.

The sources contain few explicitly defined examples of loans, the transfer of a good from one person to another for use and then eventual return, but we are probably safe in assuming that many such loans were in fact made, especially between members of any household, kin-congregation, occupational group, Arioi lodge, or pair of friends. What we cannot discover, however, is whether such loans required rents or interest, or whether there were any standards regarding limits of time, or any external sanctions to enforce repayment.

It may be, however, that land was lent out to nonowners on occasion, and that "rent" therefor was paid in the form of a portion of the produce. In fact, it could be that some of the "tax" levied by chiefs upon some of their subjects should be classified as "rent"; but I think that such transactions were quite rare and were probably phrased in other terms.

I reproduce here a passage from Turnbull, which raises the possibility of there having been an additional kind of transaction: "Old Pomare was as dexterous a thief as any amongst them, if borrowing, without any intention of repayment, merit this name. He would often request me to lend him a hog, for which, when once received, he never again thought of making any return. This could proceed from nothing but mere avarice, for he could have any number at a very easy rate. But theft, as I have before observed, is a cheaper method of acquisition than purchase." (1813:283.) Perhaps we have here two different "messages": one public and explicit (i.e., loan), the other private and implicit (i.e., taking). As I pointed out earlier, a double message was probably also involved in most instances of gift exchange, that is, an intended exchange of equivalences in the public guise of nonreciprocable gift.

Here, then, were the major types of Maohi transactions that I can distinguish:

I. Nonreciprocable giving: $\mathrm{A} \rightarrow \mathrm{B} 0$

II. Nonreciprocated taking: A

III. Exchange

1. direct exchange $\mathrm{A} \rightleftarrows \mathrm{B}$

a. gift exchange

b. loan

c. commercial exchange

2. pool sharing $A \leftrightarrows[A B] \rightleftarrows B$

Later on I shall summarize the associations between these different patterns and those of other dimensions of interaction; but before leaving for the 
moment the subject of circulation modes I return again to that of the circulating goods themselves.

As I indicated earlier, I am unable to discern any Maohi-formulated categorization of circulating goods that approaches all-inclusiveness. And although it would be possible (within limits) to derive a sort of categorization by listing all the myriad kinds of objects and services that circulated and assign them to their respective transaction circuits, such an exercise would be tedious-and I hope unnecessary. It may, however, be useful to recall one noteworthy point about such circuits, at least those comprising exchange-namely, their "openness" with respect to their goods, even in the absence of "money."

As is well known, in some human societies exchanges take place within several types of discrete, "closed" circuits, each with its own distinctive kind of good or goods. (In most Western societies, for example, sexual services may normatively circulate only within very narrow and wholly closed circuits. And in the Trobriands certain shell necklaces may be exchanged only for certain shell armbands. $)^{18}$ In many other societies are to be found numbers of exchange circuits that resemble those just mentioned in some respects but differ from them in being interconnectible by means of a multipurpose ${ }^{19}$ kind of exchange token, or "money." The only object approaching such a kind of token in Maohi society was bark cloth, and even that entered into relatively few types of exchange circuits; yet, Maohi exchange circuits were for the most part relatively "open": Maohi goods appear to have been interconvertible to a very marked degree. In fact, about the only wide-reaching example of nonconvertibility that I have discovered is the sentiment that in certain kinds of transactions perishable foodstuffs did not constitute appropriate equivalences for manufactured objects (chap. 14).

It may be that this quality of widespread interconvertibility characteristic of so many kinds of Maohi goods is one reason why a more multipurpose "money" did not evolve in this society; there was little need for it. Another reason, perhaps, was the relatively minor role played by large-scale accumulation of capital in the form of objects in determining one's social status. Most high statuses were acquired by ascription; and even with those acquired by achievement, and by means of objects, the objects assembled for such purposes were not usually kept in the form of "wealth" but were fairly speedily used for "buying" services, immediate or deferred. A third possible reason for the absence of "money" in Maohi society was the preponderance of gift exchange over commercial exchange, in general, and the wide prevalence of "hospitality" in particular; that is to say, for goods exchanged in this fashion there was less of a requirement for exact equivalence, and hence less necessity for more precise markers of relative value. 
Emotion. The conventionalized bodily behaviors of the Maohis that were tacitly meant to express their "emotions"-that is, to reflect their "internal states"-toward one another may be arranged along three major axes. (Again, as in the case of transactions I am left to devise my own commonsensical classification, as the Maohis themselves have provided us with none of their own making. The examples given in the following paragraphs include both particular behaviors and Maohi labels for whole sets of associated behaviors. I have not attempted to "morphemicize" these latter in any systematic way, but previous chapters do provide illustrations enough to enable the reader to visualize what is referred to, say, by the labels ätama or toro'irirō. [Definitions in this section are from the LMS Dictionary.])

Affection-hate. Along this continuum I place at one pole such Maohi expressions as àtama (affection for a child) and aroha (compassion, pity, sympathy, love, affection), at the other pole, tiapou (to strike one's posterior and expose it as evidence of contempt) and fe'ume (envy, malice, settled hatred between persons), with potaua (a friend who has ceased to show kindness) and airuma (to eat sullenly and unsocially) in between.

Sexual attraction-sexual aversion. There are grounds for concluding that Maohis considered this axis of emotion to be independent of affectionhate, although in the case of young lovers, especially, sexual attraction and affection were undoubtedly linked. At one pole of this continuum are to be placed copulation itself and such verbalized expressions as pupa (to be desiring the other sex), at the other, fa'anono' $a$ (to spurn with disgust, applied to husbands and wives who have an aversion to each other). These expressive behaviors apply mainly, of course, to relations between males and females, but may also have applied to relations between males and males, or females and females, quite apart from the institutionalized ones involving persons labeled mahu.

Dominance-subordination (or superiority-inferiority). At one end of this axis were behaviors verbalized by such expressions as fa'ahepō (to command, impel to action; to domineer, exert authority or power, to tyrannize others) and 'ahāhā (to boast or vaunt; to exalt oneself), at the other, fa'aatua (to acknowledge, serve, or act toward some person or thing as a god) and toro'irirō (to be humbled or abashed before a superior; to humble oneself before a great man).

The examples just cited provide only a very small sample of the large and varied repertory of Maohi emotion-expressive behaviors, which range from direct verbal address to such indirect messages as fashioning of an enemy's bones into fishhooks. Some such behaviors were evidently meant to express only one kind of emotion, while others seem to have expressed two: for example, while fetafetau (to quarrel, or combat in pairs) signi- 
fied mainly a locus on the affection-hate axis, fäiru (to befoul a person in contempt) appears to signify both that and a position on the dominancesubordination axis as well.

In addition to all these refinements, the Maohis possessed symbolic means for expressing distinctions in terms of intensity of emotion, as exemplified in the custom of pao-lacerating the head with shark's teeth as evidence of very intensive feelings of "grief" or "joy," and shoulder baring as a mark of intensified humility.

In chapter 14 I drew attention to two general characteristics of Maohi emotions which struck Europeans as particularly alien-one, an "unseemly" habit of overexpressing some of their presumed feelings, and, second, a tendency to show little or no emotion in other situations where feeling would "naturally" be intense. Aside from the value judgment expressed in such comparisons they have a certain descriptive usefulness and lead me to propose a more structurally relevant comparison of my own-namely, that in comparison with parallel emotion-axes in Western societies, those of the Maohis tended to stress the polar extremes. That is to say, in connection with the affection-hate axis, those behaviors expressing "affection" and "hate" were more highly elaborated than those expressing "feelings" in between, and the same was true with the other axes as well.

In summary, despite the absence of indigenous systematics about the matter, the emotion dimension of Maohi interaction patterns seems susceptible to systematization in fairly commonsensical ways. But, before ending this discussion, I must confess to an uneasiness about it all. The early European visitors to these Islands had trouble even with, say, the palpable transactions of gift exchange, so how much more alien and obscure must have been to them some of the expressions of emotion they sought to interpret by use of superficially similar cues, and to describe in English-language terms. Even such relatively unambiguous behaviors as shedding tears posed the same interpretative difficulties to the early European visitors as they continue to pose to us today. And, when it comes to behaviors labeled ha'amā (shame?) and mata'u (fear?), neither they nor we can provide reliable translations. In other words, were the information fuller, and were there opportunity to test for semantic oppositions, and so forth, we might very well discover that there were more than three so-called emotion axes to reckon with-including, perhaps, an axis of familiarity-fear (independent of the one I have labeled dominance-subordination). But such questions are regrettably unanswerable, and, because of my commitment to the analytic canon of economy, I leave the axes at three.

\section{SOCIAL UNITS AND ROLES}

Having summarized the ways in which the Maohis carried on social interaction, I now offer some generalizations about the types of relationships 
thereby constituted, including their more important extrapolatable roles. Insofar as possible my focus in this section will be on Maohi society as I think it was during the Late Indigenous Era. Discussion of the changes that took place in the society during the Early European Era will be the subject matter of volume 3 of this study.

\section{Consanguinity}

Since relationships based on common descent outweighed all others in influencing how the Maohis interacted, it is especially regrettable that so little is explicitly recorded about the rationale for this kind of connection. Nevertheless, I have attempted to reconstruct, from various kinds of evidence, what that rationale was.

Something from both biological parents was evidently believed to have gone into their offspring, and at least two kinds of elements were involved. One of these seems to have been mainly "physical": I refer, among other kinds of evidence, to the interpretation that may plausibly be made from the practice by some women of copulating with large, stalwart men in order, reportedly, to enhance their own capacities for bearing such offspring-a Maohi manifestation of the widespread "folk-scientific" notion of telegony. The Maohi practice of distinguishing between "blood" (toto) and "adoptive" (fa'atavae) relations suggests that there might have been belief in the physical continuity of blood, as well, from parents to offspring. But lacking any other reference to this matter, I think it more likely that this expression was intended as metaphor.

The other and more important element believed involved in the composition of offspring may for lack of a more specific label be called "spiritual."20 As previously stated, I propose that this "spiritual" element consisted in part, at least, of a portion of some god, and I also drew some inferences about the changes it underwent in transmission, namely, that its "efficacy" (or whatever) remained "strongest" in a directly lineal way. In other words, as I reconstruct the process, the most efficacious part of any person's "spiritual" inheritance was transmitted to his or her firstborn offspring (or firstborn male offspring?) at the time of conception; later-born offspring also received some of that element, but in attenuated measure, and possibly decreasing regularly with order of birth. Some grounds can also be found for concluding that this element decreased in efficacy with each generational remove from its divine ancestral procreator (or fabricator?).

Falling back on Western logic, one might also conclude that every individual embodied one such spiritual element for each of his ultimate ancestors; but whether the Maohis themselves so reasoned I do not know.

In any case, whatever that "spiritual element" was, and however many distinct units of it any individual may have embodied, certain instances of it were considered far superior to the rest (or more "efficacious"? or 
more "god-like"? etc.). During the era now under study those instances generally considered to be most "superior" were the ones embodied in the principal members of the kin-congregation of Opoa. But it is reasonable to conclude that such rank-ordering, for all its alleged perpetuity, was subject to revisions as reflections of familial vicissitudes. In this case, at least, I acknowledge a firm commitment to the proposition that the changes in ideology were a reflection of historical events, and not the reverse.

The conceptualization of descent just referred to was epitomized by the Maohis in genealogies and in such verbal expressions as consanguineal "lines" (firia) and segmented cognatic stocks ('ati). Moreover, the most "efficacious" embodiments of the most "superior" (or whatever) of these lines were identified in specific-status names, or kin-Titles. And, finally, the Maohi conceptualization of descent served as the major principle of recruitment and organization of the social groupings I have labeled kin-congregations.

The type of group I have labeled kin-congregation consisted mainly of a set of persons interconnected by acknowledged, and fairly close, ties of common descent, who resided near one another and engaged all together in worship of commonly acknowledged spirit tutelars (including in many instances their divine or once-human progenitors). Focal to each kin-congregation was a marae, or temple, where its qualified members (mainly males past childhood) convened on occasion to communicate with the tutelars. Also, there was associated with each kin-congregation a well-defined tract of territory, which, though subdivided and assigned provisionally to individual members for everyday use, yet remained residually identified with the group as a whole-as manifested especially in the tutelars' rights to the tract's first fruits, and as attested by each member's right to make use of some part of the tract for satisfaction of subsistence needs.

There is a possibility that the rights just mentioned were betokened in specific marae names-one for each member of the kin-congregation-but whether or not that was the case, it is practically certain that every such congregation disposed of certain offices having to do with the conduct of congregation activities, both religious and secular. It is not entirely clear whether all such offices of any kin-congregation were distinctly differentiated in terms of function, or whether they were all differentially graded in terms of rights, et cetera, but it is beyond doubt that for each kin-congregation one such office stood out from all the rest, in terms of rights and duties-this having been the one I label kin-congregation chief. In addition to the general-status names that appear to have been applied to the offices of some kin-congregations-for example "priest"-some offices of certain kin-congregations were also identified by specific kin-Titles which were not only graded within each congrega- 
tion, but were also ranked on a more or less society-wide basis. And finally, within the marae of most kin-congregations were one or more stone uprights which were identified with certain of its offices, and which served as back rests or leaning posts for the respective incumbents on religious occasions.

Interaction among kin-congregation members, qua members, was largely of a religious nature. Included on the one hand were prayers and offerings to the tutelars, and messages from them, all mediated by the congregation chief, or by his delegated assistants. And included on the other hand were interactions between the chief and other members having to do directly with the above, or with maintaining the chief in his roles as mediator with the tutelars and as steward of the congregation's tangible resources; these interactions can be summarized in so-called dimensional terms, as follows:

\begin{tabular}{|c|c|c|c|}
\hline Dimension & Chiefs & & Other Members \\
\hline Space & $\left\{\begin{array}{l}\text { mиa } \\
\text { ini'a }^{\prime}\end{array}\right.$ & & $\left\{\begin{array}{l}\text { muri } \\
\text { i raro }\end{array}\right.$ \\
\hline Governance & command & & obey \\
\hline $\begin{array}{l}\text { Transaction } \\
\quad \text { (pool sharing) }\end{array}$ & $\begin{array}{l}\text { special services } \\
\text { occasional objects }\end{array}$ & $\underset{\rightleftarrows}{\rightleftarrows}$ & $\begin{array}{l}\text { manual services } \\
\text { periodic services }\end{array}$ \\
\hline Emotion & $\begin{array}{l}\text { dominance } \\
\text { (softened by affectio }\end{array}$ & & $\begin{array}{l}\text { subordination/respect } \\
\text { (mitigated by affection) }\end{array}$ \\
\hline
\end{tabular}

Some kin-congregations were entirely unattached, but many others were linked together by alleged ties of common descent. Many of these multicongregation units occupied adjoining territories and presumably came about as the result of gradual proliferation and fission. Others were made up of related but widely separated congregations, the outcome presumably of deliberate or accidental "colonization." Evidence for such links was maintained symbolically in legends and genealogies, and by the practice of incorporating architectural elements from a source marae into its offshoot. In some cases offices in the source congregation, including Titled ones, accompanied the move to a new site, but the chiefly office of the older congregation usually remained at the source marae, and its incumbent continued to exercise some authority over the offshoot, through the latter's own chief, and mainly in connection with religious matters involving the units' common tutelars. Moreover, the religious matters in question often involved a levy of objects and services, for offerings to the common tutelar, for maintenance of the source marae, and occasionally for personal use of the source congregation's chief.

The process of kin-congregation fission just mentioned can be only 
partly reconstructed. General conditions, such as population pressure, were undoubtedly influential, but I have not been able to discover any widespread verbal sentiment either encouraging or discouraging fission on this or other general grounds; for example, I have come across no general norms about optimum household size or territorial intactness, and no explicitly voiced desire for either "individual independence" or "group solidarity." The dispersed nature of residential units may be taken as possible evidence of a universal desire for "independence," but that is about as far as I can go. In fact, the only factor I know of that may have encouraged fission generally was rivalry among brothers or male cousins, the widely prevalent situational outcome of clashes between norms favoring seniority on the one hand, and actual differences in individual capabilities on the other. Other situations, such as instances of uxorilocal marriages and accidental colonization, accounted for some fission, but must be labeled special cases.

During the Late Indigenous Era a highly distinctive position was occupied by the multi-kin-congregation unit whose source marae was at Opoa, Ra'iatea. As I noted earlier, the "spiritual" elements embodied in the most directly lineal descendants of that congregation's divine and semidivine founders were generally considered to be "superior" to all others in Maohi society, a comparison which was manifested in the relatively highest rank accorded the kin-Titles held by such persons. Stories concerned directly or indirectly with the Opoan kin-congregation imply that in the course of its long (legendary) history it became divided and subdivided, locally and colonially, into numerous offshoot congregations, just as did other kin-congregations elsewhere. But more so than with any other kin-congregations, the specific kin-Titles associated with the Opoan kin-congregation attained a degree of social importance greater than, and indeed somewhat independent of, their congregational group. Also more than others, persons holding Opoan kin-Titles contracted marriages in places far from home, thereby associating their Titles with marae and congregations of non-Opoan derivation. In other words, we see here the institutionalization of certain "lines" of consanguines, somewhat distinct from the consanguineal groups-the kincongregations themselves.

While growth and fission, or decrease and extinction, were the more common processes whereby kin-congregations underwent transformation, fusion of previously unrelated units also took place occasionally, usually to consolidate some new marital or political alliances.

Turning now from whole categories and actual groupings of consanguines to normatively and observationally defined consanguineal roles, I again invite attention to the three components which were most decisive in differentiating such roles: genealogical level (generation), sex, and birth-order among siblings. 
The most noteworthy way in which differences in genealogical level influenced behavior among consanguines may be summarized by saying that those of the youngest level were the most privileged, at least in terms of rights associated with the "spiritual" element involved in "descent." Members of the older levels continued to exercise decision-making authority in everyday matters until the younger level members were more or less competent to do so-the society could not otherwise have survived-but in matters of ritual precedence and the like, older-level members abdicated their rights to their progeny upon the latter's birth.

As has been described, within certain class limits a Maohi's sex served importantly to define his (or her) rights and obligations, vis-à-vis every other Maohi, with respect to such things as division of labor, access to spirits, food consumption, spatial positioning, and decision making; but for the bilaterally minded Maohis the component of sex was of relatively little influence with respect to the "spiritual" element of descent. Remembered or fabricated "lines" of descent, and particularly those in which kin-Titles were transmitted, included names of many females. In fact, during the era under study, the circumstances that incumbents of some of the society's highestranking kin-Titles had received them from or through their mothers appears to have dulled their luster not at all. Nevertheless, males were favored over females in terms of succession to consanguineal offices. And in all but the highest class of society, where such proscriptions were outweighed by other considerations, consanguinity placed constraints on sexual intercourse in general and on marriage in particular.

The third differentiating component was order of birth among siblings, but, as noted earlier, I am not altogether certain how comprehensive this ordering principle actually was. In some instances both succession-order to offices and general hierarchies of authority and respect seem to have run parallel to order of birth, but in others only the firstborn (or firstborn male) was singled out from his siblings for special treatment. Again, while acknowledging some validity to Handy's distinction between collateral matahiapo (eldest) and teina (younger) "lines" (though with some uncertainty about what exactly he meant), such a distinction does not appear to have been comprehensively extended. That is to say, while all other "lines" of a putative cognatic stock, including collateral sets of same-genealogical-level "cousins," may have been teina to their matahiapo "line," they seem not to have been so ordered among themselves relative to the birth-order of their own respective eponyms-or at least I can find no evidence that such was the case. This same absence of comprehensive ordering in consanguineal terms also pertained, as we have seen, to relationships among kin-congregations of purportedly common descent. In other words, although status inequalities based on birth-order may have been the 
basis of the inequalities which came to be institutionalized on the broader social stage, this "design" was not followed out in detail. ${ }^{21}$

\section{Class}

During the Late Indigenous Era the populations of every island (except possibly Maupiti [see Handy 1930:102-103]) seem to have been divided into three more or less endogamous categories, which were also differentiated with respect to a number of consumption rights and other attributes. Lacking an unambiguous native term for such categories I have called them marriage classes (or simply classes), because of what appears to have been their principal function; and by cutting through (perhaps too arbitrarily) the tangle of names applied by the sources to the society's numerous hierarchical statuses, I have labeled these three classes ari'i, ra'atira, and manahune. At the same time, I have taken pains to point out that within the ari'i class some further differentiation was evident in the direction of narrowed choices of spouse, and the same may have been true of the ra'atira class as well; and that the distinctions between "lower" ari' $i$ and "upper" ra'atira, and between "lower" ra'atira and manahune, seem to have been less than sharp, and subject to changes both situationally and over time.

I also pointed out that while marriage-class status was usually ascribed by descent, a few ra'atira seem to have become ari'i, and some manahune became ra'atira, through individual achievement of some kind. Similarly, it is not unlikely that some ari'i and ra'atira suffered down-classing as a result of defeat in warfare or economic disaster or, in the case of younger siblings, of attenuation of heritage. And finally, I reproduced, without valuation, the opinions of some of the sources about the existence of a "half-caste" category of persons intermediate between ari'i and ra'atira-allegedly the progeny of ari'i misalliances.

Subject to the vagueness and traversability of class boundaries, as described above, one can epitomize interclass relations as follows:

\begin{tabular}{lll} 
Dimension & Upper & Lower \\
\hline Space & $\left\{\begin{array}{l}\text { mua } \\
\text { i ni } a \\
\text { tai }\end{array}\right.$ & $\left\{\begin{array}{l}\text { muri } \\
\text { i raro } \\
\text { uta }\end{array}\right.$ \\
Governance & command & obey \\
Transaction & taking & $\cdot \cdot \cdot \cdot$ \\
Emotion & dominance & subordination/respect
\end{tabular}

Leaving aside for a while the larger question concerning the origin of social stratification in Maohi society, it may be useful here to inquire 
why rules regarding choice of spouse were such an important facet of that stratification. ${ }^{22}$ In my opinion these rules derived from Maohi notions about procreation, namely, that the all-important "spiritual" elements which linked each human with his divine or semidivine ancestors were transmitted through genitor and mother, and that each parent owed it to his forebears and his descendants to insure that the quality, or degree, of divinity contained in his (or her) self would not be passed on to an offspring in reproductive association with an element of less divine quality. As previously acknowledged, I have been unable to discover any deeper rationale for this eugenical norm-no explicitly worded belief, for example, that the elements transmitted by one parent would have suffered some kind of diminution if mated to ones of inferior "efficacy" or whatever. But to a people so committed to the social system of aristocracy perhaps no deeper cognative reinforcement was required.

\section{Affinity}

In addition to the ascriptive ties of consanguinity which served to link individuals of opposite sex, and in addition to their actual heterosexual encounters, most Maohis past childhood also entered into heterosexual unions which involved some duration and some fairly explicit mutual undertakings regarding matters other than copulation. Earlier in this study I attempted to describe the wide variations in such unions, under rubrics such as "marriage," "semimarriage," "concubinage," and so forth, but I now wish to summarize those data in somewhat more functional terms. That is to say, I suggest that all such relationships, which I call conjugal unions, served one or more of the following purposes:

1. to provide the partners with ready access and more or less exclusive rights to each other's sexual services;

2. to provide the partners, complementarity, with goods required for subsistence;

3. to reproduce offspring by which to transmit valued statuses; and overlapping this,

4. to gain allies for political ends.

Despite the many reports of Maohis' "free love," sexually desirable young women were relatively scarce. Males of suitable class seem to have had little difficulty obtaining sexual favors on a temporary basis, either through mutual attraction or in exchange for something more tangible, but longer and more exclusive enjoyment of such pleasures must have been highly competitive and costly. (Such roles may have been reversed in the case of a few outstandingly handsome or socially preeminent men, but by and large the greater scarcity was of women.) 
In connection with 2, Maohi conventions regarding the sexual division of labor required contributions from both male and female to provide for a fully satisfactory household economy, ${ }^{23}$ and a conjugal-type union was admirably suited to this complementarity. However, not all men or women had to enter such unions in order to enjoy the benefits of household living, for as already noted, during the Late Indigenous Era most households were probably populous enough to accommodate unattached adults of either sex.

Neither was it essential in all cases that a Maohi enter into a conjugal union in order to sire or bear offspring, but such was the case for individuals of superior ascriptive status-that is, for those (and the close consanguines of those) holding high-grade kin-congregation offices. ${ }^{24}$ For as we have seen, in keeping with the bilaterality of Maohi notions about descent, the procreation of suitable successors to either parent's kin-congregation status required that the other parent's status be of at least equivalent grade, a condition that required affirmation by consanguines (and tutelars) of both parties, conventionally expressed in ceremonious nuptials. In this connection, both the transactions accompanying these nuptials and the symbolic language of their ritual acts served to define such unions as contractual undertakings concerned mainly with reproduction (and, with respect to the àmo'a episodes of such rites, with physical intimacy in general). An exchange of some other services-sexual, domestic, protective-may also have been stipulated, or implied, in such contracts, but procreation of suitable successors was undoubtedly their principal concern.

Even the political purposes served by some Maohi conjugal unions seem to have been realized mainly through the spouses' reproductive success. Some mutual political advantages undoubtedly resulted from many such unions whether they were fruitful or not, but it was the uniting of thitherto separate entitlements in the persons of common consanguines that gave the most cohesion to marital alliances.

Such then were the several different purposes that conjugal union could serve, but as we have seen, unions differed in terms of the numbers of purposes they served. Some matches between highly placed young people served all four purposes, but other unions served only one or two, as exemplified by instances wherein an older man virtually purchased a young wife from her guardians mainly in order to enjoy her sexual favors, or wherein political alliances were cemented by nuptials which were followed by no further interaction between those so wed, or wherein older women were added to households mainly for their domestic services. In view of these variations one is not justified in generalizing about Maohi "marriage" in currently fashionable "communicational" terms; that is, while some unions may indeed have involved the "circulation of women" (or rather, the circulation of specific aspects of women), others were mutuality-marked alliances in a very literal sense. 
These differences were also apparent in the variations that obtained regarding choice of spouse. That is to say, whereas the union of close consanguines was stringently proscribed in other instances, it was permitted and perhaps even encouraged when the principals were the holders or transmitters of very high-ranking kin-Titles. As previously acknowledged, I have not been able to fathom the "mystical" reasoning that led to (or served to rationalize?) the general incest rules, but whatever it was, the belief that close in-mating was generally deleterious was outweighed in some instances by a conflicting commitment to eugenical values based on notions about the "spiritual" component of descent.

One cannot, of course, recover the actual historical sequence between belief and practice in this set of behaviors, but one possibility lies in a correlation between choice of spouse and political structure (and perhaps ecology as well); this reconstruction goes something like this. Earlier in Maohi history, when political units were much smaller (and the population less numerous and more thinly distributed as well), the mystical rationale for marrying out was congruent with (and perhaps consequent upon) the political (and economic) advantages felt to result from connections with non-consanguines. In the course of time, perhaps, as tribal units became larger, and political considerations weightier, marrying out came to have even more importance as a means of forming or cementing intertribal alliances. Eventually, however, a turning point was reached; as tribal units decreased in number (and increased in size), the politically inspired marital choices of their principal people were correspondingly narrowed, a trend further reinforced by the social and mystical rationale of class. And finally, the trend toward political consolidation proceeded so far that, among the principal people at least, the policy of out-marrying for building new alliances was replaced by one of in-marrying for maintenance of existing ones.

In view of the wide variations in purpose that served to differentiate Maohi conjugal unions, one should expect differences in husband-wife interaction patterns as well-an expectation that is borne out by the reports and stories reproduced in earlier chapters. Although such interaction seems to have corresponded to general male-female formulae in the more ritualized dimension of spatial positioning (except, for example, when outweighed by considerations of class status) and in the sphere of sex-linked work habits, it varied widely in terms of emotion and probably of governance as well. (I refer here mainly to actual behavior, but it may well be that the norms for such behavior also varied.)

\section{Friendship}

The formal friendship pacts entered into by Maohi males ${ }^{25}$ resembled conjugal unions in a very important respect: they provided an institutionalized means for acquiring durable and dependable extra-consanguineal sources 
of objects and services. Moreover, the resemblance between the more formalized versions of these two kinds of union was evidently recognized, as indicated in their having been instituted and accompanied by fairly similar rites. On the other hand, whereas most conjugal unions involved an exchange of complementary objects and services, those exchanged between pact-friends were not only equivalent in value but were more or less similar in kind. And, as noted earlier, although the transactions between pact-friends balanced out over time, they were phrased as nonreciprocable giving.

Friendship pacts, like conjugal unions, also varied in kind and degree of association from a perfunctory exchange of names and presents to virtual interchange of social identity with respect to each partner's social statuses and goods.

\section{Occupation}

Some members of Maohi society practiced highly specialized occupations which comprised a number of kinds of social relationships and from which they received various kinds of rewards. I find it analytically convenient to summarize these occupations under three headings: those consisting of the production of objects for exchange that was mainly "commercial"; those consisting of the performance of specialized services more or less explicitly in return for some tangible compensation; and the very distinctive one of serving as medium for some spirit. ${ }^{26}$

Under the first heading I place fishermen, gardeners, perhaps pig raisers, woodcarvers, bark-cloth makers, and workers in tortoise shell. Most of these specialists must also have produced their respective products for paying taxes, and so on, but what interests us at present is the circulation of those products in commercial exchange.

What led certain individuals to become such specialists is not directly reported. Family tradition probably played some part, particularly with respect to the crafts requiring extended apprenticeship; in the absence of organized training in, say, woodcarving, kinsmen would have been one's likeliest teachers. Also, place of residence may have been a factor in some cases; other things being equal, for example, the carving of stone bowls was probably more prevalent on Maupiti, where the best stone was found.

More important and less speculative a matter has to do with the kinds of social relationships involved in the production and circulation of such products.

I noted earlier the likelihood of there having been fishermen's guilds, with special marae dedicated to the tutelars of the occupation. No such guilds are reported for other kinds of specialists of this category, but one would be safe in assuming that most of these had their generic or specific tutelars, and quite possibly their distinctive shrines as well. 
With regard to circulation in commercial exchange, we do not know how craft objects were bartered, but the report on fish-for-plant-food transactions, which might well have been the pattern for other kinds of barter, reveals a standardized, long-term contractual arrangement which involved clearly understood equivalences and mutually accepted sanctions against nonfulfillment. I suppose that some products of this nature circulated between kinsmen, or between pact friends, and in less explicitly "commercial" ways (say, by gift exchange); but the very presence, not to say prevalence, of this commercial-type exchange indicates to me that the existing networks of kinship or pact-friendship connections were neither extensive, reticulated, nor potent enough to serve all individuals' wants for objects they themselves did not produce. ${ }^{27}$

Probably the principal advantage gained by the "commercial" -object specialists was the satisfaction of acquiring items they wanted but either could not or would not themselves produce. They may also have derived special pleasure from their activities, but there is no way of documenting that. Nor is there any evidence that their activities encouraged or allowed them to accumulate tangible, durable, socially useful objects-that is, "wealth." What does appear fairly clear is that however much "wealth" they may have thus accumulated, and however praised they may have been for their expertise, these considerations alone were not very influential in elevating their statuses in other social hierarchies.

The second category of specialists, those who exchanged their services for tangible compensation, included a wide variety: architects, carpenters and boatbuilders, experts in tattoo and supercision, entertainers, teachers, clerics, curers and sorcerers, warriors, domestics and retainers. As we have seen, some of these specialists owed their positions-or at least their eligibility for such positions-to their class status, and more specifically to family tradition; but for most of these occupations some training and some "natural" talent were also requisite. In connection with the latter, I reported how the Maohis sought to account for it in explicit spirit-associated terms (a fairly clear-cut explanation which some writers have tended to obscure by invoking the conveniently ambiguous concept of mana).

While we cannot discover how much of their time these specialists actively devoted to their occupations, or how many of them there were, their very existence provides another indication of the complexity of Maohi society, and is another measure of its affluence.

Morrison, it will be recalled, intimated that every specialized occupation was organized into local guilds (1935:233); this does indeed appear to have been the case with fishermen, and possibly also with carpenters and boatbuilders, but (as previously stated) I doubt that such was the case with the other occupations listed above. On the other hand, the camaraderie that 
evidently prevailed among most men of the warrior profession (except when at war with one another!) may also have occurred among members of some other professions.

In the case of most builders, tattooers, professional entertainers, curers, and the like, their relations with their employers or clients were determinate and brief; but some of these, and most of the other specialists listed earlier, remained engaged with their employers or clients on long-term or even "permanent" bases. An important question has to do with the identity of such employers: while some functionaries may have served the whole kincongregation or tribe to which they were attached, it is my impression that most such specialists were in the personal service of particular chiefs.

Another noteworthy thing about the social relations of specialists concerns the jurisdiction of certain high priests: while most of these were coterminous with tribal or subtribal boundaries, a few of them extended over two or more tribal domains (de Bovis 1909:49-50).

Rewards for proficiency in service occupations varied with the specialty. In most cases, perhaps, success was attended by occasional or continual consumption of luxury foods, and release from less desirable employments. Some specialists may also have earned tangible goods of more durable kinds, such as tools, ornaments, weapons, and bark cloth enough for social capital; but this aspect of Maohi economics was virtually unreported. Also, increased social influence undoubtedly attended the labors of some specialists such as teachers, great warriors, and successful physicians; and such influence was inherent in the positions of high priests, tribal functionaries, and chiefly retainers. In fact, certain of the latter, along with some warriors, succeeded in gaining not just influence but personal political power, and along with it, in some instances, an elevation in marriage-class status.

The third category of service specialists consisted of those very distinctive individuals, who served as mediums for spirits. As I reported, these taura included persons from all marriage-classes. There may have been some element of family tradition in their recruitment, but self-selection, involving variable proportions of psychological aberration and shrewd design, was probably most contributory (but phrased, of course, as selection by the spirit).

As we have seen, taura differed greatly in their periods of spirit-possession and length of tenure. Some appear to have served for one or two occasions only, while others remained in a continual state of "low intensity" possession over periods of years. Their relations with other taura were quite commonly competitive-consequent either upon their conflicting versions of the same spirit or upon their representations of rival spirits. And, as has been documented, the rewards they received varied widely. Some of them gained momentary success (as measured in affluence, in influence, and even in personal political power) followed by failures which led to so- 
cial oblivion or even physical peril; others enjoyed longer and more even careers which placed them in positions or near loci of tribal authority.

\section{Cult}

As we have seen, co-members of all kin and tribal units, and of at least some occupational units and categories of specialists, were co-worshippers of one spirit or another. But in addition, many Maohis worshipped deities not directly associated with their kin, tribal, or occupational groups or categories. It is the social-relational aspects of these cults in essentia that I now summarize.

During the Late Indigenous Era the most active and widespread of such cults were those of Tane and 'Oro, whose devotees belonged to many separate and otherwise unrelated kin-congregations and tribes. (Of these two, the cult of 'Oro was the more active and popular even during this era, but did not become overwhelmingly so until later on.) Formerly, perhaps, the cults of these deities had been limited to single kin units, and then single tribes, but by the middle of the eighteenth century, or perhaps a little earlier, their memberships had been expanded by means of proselytization and voluntary initiation. These, at least, were the more immediate processes involved in the spread of these two cults. In neither case was cult membership deliberately limited to particular kin groups, classes, tribes, or occupational categories; but as was customary in Maohi society, the more active members were males, and those usually having most direct access to these awesome deities were persons occupying leading kin-congregation or tribal statuses-the rare exceptions having been those persons of otherwise little consequence who claimed to be possessed (usually for brief periods) by one of these gods. (An additional commentary upon the Maohi commitment to social hierarchy: only persons in otherwise superior statuses appear to have served as long-term mediums for either of these gods.)

Notwithstanding the wide inclusiveness of both of these deities' congregations, a highly privileged connection obtained between the god 'Oro and members and associates of the Opoan kin-congregation (whose particular tutelar 'Oro was) - that is, those persons holding the highest-grade Titles of this congregation (the feather-girdle ones) were the most acceptable (and in due course, the only) ones to officiate at human offerings to the god. (In this connection, during the Late Indigenous Era the cult's most outstanding member was the Ra'iatean, Tamatoa, who held the highest-grade feathergirdle Title of the Opoan kin-congregation and who was also the more or less permanent medium of one of 'Oro's manifestations.)

The privilege (and duty) of officiating at the worship of either of these gods was understandably reflected in the relations between such officials and the other local members of each cult, as manifested in such be- 
haviors as deference, obedience, and donations of objects. And there is also evidence that certain of those officials were treated with more than usual ceremonial respect among cult members everywhere. Also, devotees everywhere were likely to have behaved respectfully, and perhaps even obediently, to any medium of either 'Oro or Tane in their midst. On the other hand, I can discover no other kinds of indications that the various local "chapters" of either of these two cults were linked together in any kind of coordinate activity or overall authority hierarchy. ${ }^{28}$

I wrote above that the membership of the cults of Tane and 'Oro had been expanded beyond their narrower beginning by means of "proselytism and voluntary initiation"-or so I surmise. Actually, the only (circumstantial) evidence we have on this matter concerns the spread of 'Oro-ism, which included political events to be summarized in volume 3. I can however suggest that, in a society so constantly imperiled by war, to court the favor of the principal god of warfare must have appeared to most Maohis to be a highly rational course of action. And in addition, for large numbers of Maohis, the attractions of being an Arioi must have led them, concurrently, to worship 'Oro, the founder and tutelar of the sect. I do not assign much motivating influence to the alleged belief that worship of 'Oro insured one's place in the Maohi paradise. In the first place, I am not convinced that the belief was as explicit or widespread as represented, and, perhaps more important, I do not consider that the Maohis were deeply enough concerned with an afterlife to lend much weight to such a belief.

\section{Arioi}

During the era now under consideration the numerically largest social group in Maohi society was the Arioi sect. Even if we do not accept some writers' estimates that Ariois constituted one-fifth of the population, there can be no doubt about the large size of this society-wide unit. Its membership was evidently drawn from all tribes and marriage classes, and included both males and females in the ratio of about five to one. Most of the active members were young unmarried adults, but a few individuals continued active membership into old age.

The principal sect activity of active Ariois consisted of large-scale tours, during which they entertained their hosts and themselves by performing as dancers, musicians, actors, and bards. While their performances contained much that was purposefully diverting, including some social satire, they were in some respects also religious, having been concerned, implicitly or explicitly, with the worship of 'Oro and other tutelars of the sect. Even when not on tour Ariois performed their religiously colored entertainments at fellow tribesmen's festivals and rites of passage, and probably also among themselves, for their own diversion and spiritual welfare. 
Some accounts emphasize the male Ariois' roles as warriors; in view of the youthful age and prime physical conditions of most of them it is not surprising that they were so characterized, but warfare was not their preoccupation, nor were they the only-or, in all cases, the principal-warriors of any tribe.

Another question concerning the activities of Ariois has to do with their lives at home between tours. Evidence on this matter is scanty, but my guess is that while some of them may have lived off the production of other persons, most of them engaged in at least some subsistence labors. Affluent as Maohi society undoubtably was, I cannot accept the implication that it was rich enough to maintain such a large proportion of its most work-capable members in luxurious indolence.

To an extent less true of all worshippers of 'Oro or of Tane the Ariois of the Society Islands constituted a unified social group, a sect. Not only did all Ariois everywhere look upon one another as co-worshippers and as fraternal (or sororal) colleagues (except when killing one another in war!), but they all acknowledged with some deference the ceremonial preeminence of one of their number-that is, the Taramanini of Ra'iatea, the official head of the Opoan branch of the sect. ${ }^{29}$ On the other hand, the more binding social ties among the Ariois were those uniting the members of each local lodge.

Generally speaking, each tribal district contained its own Arioi lodge (exceptions to this parallel will be discussed later, as they constitute very noteworthy social facts), and the active male members of each lodge were divided into a novitiate and seven or eight grades through which they could be promoted upon evidence of skill in performance of the sect's principal arts. Thus, in this otherwise prevasively ascriptive society, the Arioi sect provided a means for individuals to achieve valued statuses-up to a point: the highest grades tended to be reserved for upper-class persons, who in fact usually entered them upon initiation into the sect. And what is more, the head of each lodge, although presumably a highly experienced member as well, was appointed to his office by the local tribal chief.

We saw also that candidacy for active membership in the sect was based mainly on evidence of "seizure" by 'Oro, by the foreswearing of progeny, and then by proof of capability in mastering the sect's arts.

Whatever its origin may have been, the sect's rule regarding progeny served to maintain its active members' relative freedom from domestic concerns and their engagement in sect activities-in other words, to extend the attractive life-patterns of "youthfulness" into middle or even old age. And, as abundantly documented, the rule was applied by means of abortion and infanticide and not by celibacy, which, indeed, was emphatically contravened by the members' very active and unconstrained sexual habits. Breaking of the rule led in most instances to exclusion from most sect ac- 
tivities, but in some other instances older members seem to have retired more or less deliberately and honorably from active membership to take up ordinary family life.

As described earlier, there existed certain other statuses associated with Arioihood, but I am not entirely clear about the nature and function of these.

Special tattoo patterns and costumes served to distinguish one grade of Ariois from another, and from the rest of the populace. On the other hand, the red-dyed bark cloth maro worn by the heads of lodges served, perhaps deliberately, to equate them with the holders of feather-girdled kin-Titles, in terms of their preeminence in a hierarchy of almost comparable social value. Moreover, a similar construction may be put on the fact that lodge heads were called 'aito, which, it will be recalled, was the label reserved for preeminence in the practice of warfare. ${ }^{30}$

That the Ariois were an exclusive and privileged lot there can be no reasonable doubt (their ideology even provided them with a privileged fate in afterlife). But to balance the account, they served the rest of the populace as entertainers and as performers of ritual designed to court the favor of powerful 'Oro and his divine associates.

\section{Tribe}

The factor of residential proximity served to influence people's interactions in intangible but weighty ways, reinforcing or overriding such other factors as consanguinity, sect membership, and class. In this connection, the Maohis resided in rather populous households and the latter were clustered into neighborhoods, each constituting a unit with respect to common worship and some common subsistence activity; but during the Late Indigenous Era the least complex residential unit possessing a large degree of political autonomy-that is, the smallest and simplest kind of tribe-consisted of two or more contiguous clusters of neighborhoods. And most tribes were larger and more complex than that, the extreme having been the stable Seaward Teva tribe of Tahiti's peninsula and the temporarily put-together unit of Porapora (and Maupiti)-Ra'iatea-Taha'a.

One kind of cement that served to connect neighborhoods into larger units was kinship: that is, connections deriving from common descent or marriage. But in the case of larger and more complex tribes the factor most responsible for constructing and maintaining unity was the exercise or threat of coercive physical force.

The exercise of coercive force among the Maohis was institutionalized in several ways: by the glorification of warfare, by the worship of war gods, by the praise and respect shown to warrior champions, and by the legitimation (although not necessarily the universal acceptance) that was accorded to seizure of territory and other goods by force. Although subdivisions of 
the same tribe, and subdivisions of different tribes, sometimes fought one another, whole tribes were most usually the principal units for waging war. The dominance of coercive force over all other bases of hierarchy will be set forth in detail in volume 3. For the present it is perhaps sufficient to point out that the tribal chief of Porapora succeeded, by force of arms, in reducing to political impotence the tribal chief of Ra'iatea who was also the Islands' highest-ranking kin-Titleholder, highest-graded Arioi lodge master, and principal medium of 'Oro Himself!

In addition to cooperating in the waging of war, all or most members of any tribe-or their representatives-united occasionally to participate in intertribal visits, in large-scale work projects (usually on behalf of their tribal chief), in paying taxes in objects (also to the tribal chief), in worshipping the tribal tutelars (which were characteristically those of the chief's own kin-congregation), and in celebrating their chief's rites of passage. Various other sanctions helped to insure participation in all these activities-including well-enculturated attitudes toward social rank, fear of supernatural penalties, desire for largesse, and so on-but reinforcing all other sanctions was the chief's command over superior physical force.

Like succession to kin-congregation chieftainship (with which, indeed, the office was frequently identified), succession to tribal chieftainship was based most usually on descent, having passed from an incumbent to his eldest son. On the other hand, more so than with distinctively kin-congregational offices, the holders of tribal chieftainships were sometimes elected to office by the tribes' leading members-or some men even seized office by force. Also, compared with the chiefs of kin-congregations, the chiefs of tribes were less likely to have held office as the tribes' officiating high priests. And even though physical force was a tribal chief's principal resource, it sometimes happened that the chief himself was not a skillful warrior or combat leader, having relied instead on other measures to assemble a fighting force.

By the Late Indigenous Era, Maohi tribes were sufficiently large and complex as to require both staff and line offices to carry out tribal activities. Among the former were administrators, chief's spokesmen, and messengerambassadors (quite apart from the chief's own personal retinue); some such offices were held by the chief's close kinfolk, others were assigned on the basis of friendship or proven ability. Probably no two tribes were alike in the functional definition of all offices, or in the way such offices were allocated, or in the locus of its incumbent's loyalty-whether the tribe itself or the individual who was its chief.

The more important line offices in tribal organization were the chieftainships of a tribe's constituent subtribal units. In some cases the holders of these offices were appointed by the tribal chief from among 
his kinsmen and friends. But in most cases, probably, the chiefs of subtribes succeeded their own kinsmen into office, and displayed varying degrees of independence of the tribe's sovereign chief. With respect to this last point, the most effective and ubiquitous constraints upon a tribal chief's authority were these subtribal chiefs, some of whom wielded enough coercive force themselves to constitute a continual challenge to the authority of the former.

For these and other reasons, few tribal chiefs displayed much interest in maintaining social order or social justice throughout the whole of their tribes. Indeed, most appear to have concerned themselves only with furthering their own personal interests. In other words, the conclusion is inescapable that, whatever advantages people may have derived from tribal membership, most Maohi tribes were governed mainly and deliberately for the benefit of the governors.

The benefits of governing a tribe were both tangible and intangible. Among the former were better food and clothing (but not significantly better housing), freedom from onerous labor, more diversions (including wider choice of sexual partners), and, through copious offerings, better relations with spirits. Among the latter was the satisfaction derived from commanding others' services (a sentiment which cannot be documented, but must, in my opinion, be acknowledged), along with that of being the cynosure of elaborate deference.

\section{Sex and Age}

Having summarized Maohi society's more specifically identifiable social units, relationships, and roles, I turn now to the more general categories of maleness-femaleness and relative age. Much has already been said about these categories in connection with my summaries of consanguinity, occupations, and so forth-for example, most Maohi ideas and practices relating to relationships between males and females pertained to relationships between male and female consanguines or affines-so there remains little left to summarize. Nevertheless, certain behavioral regularities appear to be assignable to sexual roles in general, quite apart from (or rather, basically constituent of) kinship roles.

In matters of descent the Maohis were less male-based than most other Pacific Islanders, but maleness was unquestionably favored in a number of ways:

Males were generally considered to possess more of the attributes that appear to have been valued by the Maohis-for example, greater physical strength, more "sacredness," more decision-making intelligence.

To males were assigned the more highly valued positional loci in interactions-mua (versus muri), i ni'a (versus $i$ raro), and right-hand (versus left-hand). Also, decision-making and interactional initiation rested more 
usually with males than with females. And judging by accepted equivalences, in transactions of exchange, males' services, time for time, were considered more valuable than those of females.

To males were allocated the more favored food delicacies.

And to males were assigned more of the most valued statuses including high-ranking kin-Titles, tribal chieftainships, and priesthoods.

In addition, there were more all-male social units than all-female ones; but it should be kept in mind that the exclusive, highly privileged Arioi sect contained some female members.

Explanation of the Maohi penchant for valuing males more than females may be sought in a number of directions-but satisfactorily found in none. One might assert that males were so esteemed because of the relatively higher valuation accorded the activities they engaged in, or the objects they produced, or the knowledge they professed, or their greater intimacy with spirits. But of course, such explanations are entirely circular; and the only way for breaking out of such circularity would involve knowledge of events in Maohi prehistory far beyond our capacity to reconstruct.

A more feasible quest would be for explanations as to why Maohi females were valued as highly as they were, relative to their statuses in many other Pacific Island societies. But even that would involve comparisons that I am not prepared to undertake.

Finally, in this summary of sex roles, a word should be said about the institutionalized ambiguity represented in the status of the mahu. In my view, the most noteworthy features of this intriguing phenomenon are twofold. On the one hand, the very existence of the status underlines how sharply some Maohi behaviors had been normatively allocated in terms of sex. Notwithstanding this, however, the degree to which mahu were socially tolerated, and even respected, suggests that the male-female opposition was a more technical than a value-laden one.

At this point one might be inclined to join with Bligh in asking how the practices associated with mahu-the "sensual and beastly acts of gratification" and particularly the transvestite elaboration thereof-came to be so highly institutionalized "... in so prolific a country as this?" Or, to rephrase the inquiry, The question is not how did homosexuality come to be practiced among the Maohis-there are probably few societies in the world where it is wholly absent-but rather, how did homosexuality develop in the way it did, and to the extent that it did, in this heterosexual Eden?

Attempts to explain phenomena like this are at best difficult, and are usually unrewarding as well; and when the institution in question is long since gone, ${ }^{31}$ and information about it to be found only in ancient books written by prejudiced observers, it would be pretentious indeed to specify this or that cause. On the other hand, one may be permitted to 
suggest that there were certain other features of Maohi life which helped to shape that institution. First was the marked numerical preponderance of males. (This factor would not of course be relevant to the homosexual affairs of chiefly males, who usually had their choice of women.) Second, certain behavioral distinctions between male and female roles-that is, males unable or unwilling to play the physically demanding and often hazardous roles expected of Maohi men in climbing, canoeing, fighting, and so forth, were permitted and, perhaps, even encouraged or required to play female roles. ${ }^{32}$ Third, the wide degree of freedom permitted to individuals in connection with sexual behavior in general, coupled with frequent indulgence in sexual intercourse. (It is conceivable that some males became so sated with heterosexual affairs at an early age that they turned to homosexuality for novelty.) ${ }^{33}$

In addition to these general factors there are two of more special application. First, there is Hamilton's statement that certain boys were purposely groomed to serve the "abominable purposes" of upper-class men; it is reasonable to believe that such conditioning as this led some recruits into a lifetime of homosexuality. And second, it should be recognized that the role of male lover of an upper-class man carried with it many advantages, both tangible and intangible. In fact, it was one of the most rewarding of achievable careers in this society of largely ascribed statuses.

As a factor of social differentiation, age-both absolute and relative-was somewhat more ambiguous than sex, as the circumstances described below indicate.

Succession to kin-congregation offices took place shortly after the new incumbent's birth; and even though most of the powers of such offices were transferred only much later, the very fact of transfer of symbolic perquisites at so early an age implies an attitude sharply different from that held in many other societies, where the young are generally disesteemed. Also, parallel with this jural acknowledgment of the full humanness of the very young, many observers agree in stating that young children were an independent, undisciplined lot.

The period of youth (taure'are'a) was institutionally recognized as the most appropriate time for immersion in many activities valued highly by the society as a whole: in singing, dancing, touring, sporting, and in copulating without the aftermath of onerous parenthood. Also, for those holding highly graded (or highly ranked) kin-Titles, the period of their preconjugal youth was the prime one of their lives: by then they had acquired most of the authority that went with their offices, and being without recognized offspring they retained the symbolic perquisites of office as well. 
For many females, especially, youth was a prime period of life: their sexual services were in lively demand, and without the encumbrance of offspring many of them appear to have been relatively free to indulge their wishes for diversion and courtship. On the other hand, for high-ranking Titleholding women, and for the wives and mothers of highranking Titleholding men, their period of maturity (pa'arira'a) was the prime time of life, in terms of the respect shown to them, the authority they wielded, and the freedoms they enjoyed. And except for those whom parenthood had divested of kin-Titles of high grade or rank, the same was true of many men.

Thus, there is some equivocalness in Maohi attitudes and practices regarding the relative valuation of youth and maturity. But regarding old age the situation is crystal clear.

Old age (ruau-ra'a), or rather physically and behaviorally defined senility, was comprehensively disvalued. Except for a few individuals of forceful personality (such, apparently, as were Vehiatua I and the Poraporan chief Puni), old people tended to be ignored, neglected, and depreciated.

How can we explain these Maohi attitudes and social practices concerning individuals' ages?

Perhaps technology, and ultimately ecology, may have been factors in the relatively high valuation assigned to most men, and to some women, in their period of maturity: effective performance in the business of getting a living, in conducting social-relational affairs, and in maintaining good relations with spirits required knowledge and skills that could only have been acquired over time-something more than the years reached by taure'are' $a$, and considerably less than those reached by ruau.

As for the seemingly contradictory high valuation assigned to males in their period of youth, it should be recalled that the value was placed mainly on those holding kin-Titles of high rank or grade, and may have derived from notions about the "spiritual" element involved in descent-that is, whatever it was that lent preeminence to a kin-Titleholder remained with the individual only until he begat a legitimate successor. On the other hand, the relatively privileged statuses enjoyed by most young females requires a less cryptic rationale: competition for the sexual services of these proficient and accessible young sex artists could quite well account for that.

And finally, the factors just listed that served to enhance individuals' social value during "youth" and "maturity" seem to have served, per contra, to have impaired their value during "old age." Nor were the Maohi aged left with any mitigating attributes, such as occurs in societies where the philosophical perspective gained from long life counts for more than rotememory mental skills. 


\section{SYNTHESIS}

\section{Comparisons of Intrarelations of Social Groups}

Having summarized the kinds of major social groupings and categories of which Maohi society was composed during the Late Indigenous Era, I turn now to the task of synthesis-first, to a comparison of certain of those groupings in so-called dimensional terms.

\section{KIN-CONGREGATION AND TRIBE}

Although the tribes extant during this era had long since expanded beyond the boundaries of single kin-congregations, or even single ramages of kincongregations, the social intrarelations among fellow tribesmen continued to resemble those of kin-congregation mates in many essentials, at least in a normative sense. In fact, with some of the smaller, less complex and more stable tribes, the social-relational resemblances with unitary kin-congregations may have been nearly exact. With larger tribes, however, some important differences were evident, particularly in terms of transactions and governance, and perhaps emotions as well.

While pool sharing was for tribes, as for kin-congregations, the dominant transactional norm, its practice in the two contexts was markedly dissimilar. Whereas the objects and services contributed by members of kin-congregations at the behest of their chiefs appear to have been "redistributed" in wide-reaching and equivalent returns, those going to most tribal chiefs were redistributed, if at all, in only token terms. In other words, such contributions constituted tribute rather than tax.

Although we know next to nothing about how kin-congregations were governed, I cannot imagine that their chiefs ruled with the same partiality and self-interest-or disinterest-displayed by some chiefs in their governing of tribes. And I believe that physical coercion-and human sacrifice, particularly-was not employed so characteristically as a sanction in the governing of kin-congregations as was the case in the governing of tribes.

And as for the emotional dimension of interaction between subjects and chief, although the resemblance between kin-congregation and tribe may have been close in terms of formalized patterns of obeisance and the like, I suspect that fear was much more evident in tribal contexts than among the consanguines who made up kin-congregations-and for very good cause!

\section{KIN-CONGREGATION AND LODGE}

Arioi lodges resembled kin-congregations, social-relationally, more closely than they did tribes, although their compositional boundaries were typically conterminous with tribes. Terminologically, for example, the relations among lodge members were sometimes phrased in kinship idiom; and the 
pool sharing (and lending?) that characterized transactions among them were much nearer to kin-congregation patterns than to tribal ones. The parallel also extended, in respect to behavior at least, to a similarity between ramages of kin-congregations and the loose unity comprising the whole Arioi sect.

\section{ALLIANCES}

All the above-named social units were alike in having been structured hierarchically, and normatively, according to the principle of pool sharing. In contrast to them were various kinds of alliance units-friendship, barter, and reproductive (i.e., marital) - that were entered into by "contract" and structured in terms of equality and direct "equivalent" exchange. ${ }^{34}$

If one wished to emphasize this way of looking at social relationships one might separate those of the Maohis into three major categories: one containing those deriving from descent, a second made up of those established by mutual contract, and a third containing those imposed by force of one sort or another. A reexamination of the data might turn up some other features shared distinctively by the kinds of relationships in each of these categories, and some probing into Maohi history might uncover, say, that contractual relationships increased relative to numerical size of population, and so forth. These are intriguing, highflown ideas to experiment with, but I leave further experimentation to others, and proceed upon a more pedestrian course.

\section{Relative Positions of Boundaries of Social Groups}

\section{KIN-CONGREGATION AND TRIBE}

During the era now under study, every tribe about which we have such information contained more than one kin-congregation, single or ramified; it is, however, possible that there was a tribe here and there that encompassed all of some kin-congregation-either a single unconnected one or all the branches of a ramified one. Conversely, it is well documented that some ramified kin-congregations contained branches located in two or more tribal territories, including noncontiguous ones, thereby constituting certain supra- (but not necessarily inter-) tribal connections, which, however, consisted mainly of common worship. I refer here to connections between whole groups of consanguines. In addition, there were of course innumerable kin networks that extended across tribal boundaries.

\section{TRIBE AND LODGE}

During the era now under study the cults of both Tane and 'Oro were supratribal in distribution, but, aside from the mythical Friendly Alliance, and despite legendary assertions concerning "Oro's forces in war" (Henry 1928:131), tribes co-worshipping either of these gods seem not thereby to 
have become allied in any other respect. Common commitment to either of these gods did indeed occasionally bring together members of different tribes for religious services; but as often as not such common commitment led tribes to compete and even war with one another for their god's favor.

A much closer correspondence existed between the boundaries of sect lodges and tribes. As a basis for this discussion I refer the reader to the lists of Arioi "houses" and lodge masters given in chapter 22.

What is to be concluded from these lists? If they are indeed exhaustive, and fairly reliable, then by comparing them with the list of tribal unities one may conclude that for each relatively stable tribe or large subtribe there was a single lodge, except when tribal geography made it difficult for all local sect members to meet together regularly in the same place (as in Teahuupo'o, Mataovae, ${ }^{35}$ Ra'iatea, Taha'a, and Huahine). A second general conclusion to be drawn from these lists is that trends toward larger political unities were also mirrored in sect organization, as manifested in the multilodge jurisdiction exercised by some lodge masters. This trend had not moved as far with sect organization as it had with tribal organization, but such a lag is perhaps expectable; and in any case it is another indication of the primacy of politics over sect as factors in Maohi social change.

A more interesting and perhaps more significant aspect of the list is the lack of correspondence in some cases between lodge and 'aito. Mataovae's two lodges apparently came under the authority of a single 'aito, which is perhaps understandable inasmuch as these two noncontiguous geographic areas did come within the jurisdiction of a single tribal chief. More interesting is the case of the jurisdiction of Mata'a, who was 'aito of Papara, Atimaono, and Vaiari, but not of Vaiuriri-in other words, of all Landward Teva except the last-named subtribe. Finally, in the case of Teahuupo'o, both its lodges, along with that of Tautira, came under the jurisdiction of one 'aito, Te Ra'a Roa, thereby corresponding to the political connections between these units, while the other subdivisions of Seaward Teva (Pueu, Afa'ahiti, and Vairao) each had its own lodge and lodge 'aito.

Another line of inquiry regarding relations between sect and tribe involves instances of identity, of the offices of tribal chief and lodge master. Actually, the only such instance that I can discover is that of the office label Taura'a atua of Mo'orea's Papetoai; we are not so informed, but it seems to me more likely than not that one individual occupied both offices. (I can find no evidence to support Mühlmann's contention that a similar situation prevailed in Afa'ahiti [1955:48].) On the other hand, the sources are quite explicit in stating that it was each tribe's sovereign chief who appointed the district's lodge master to his office.

Concerning connections between Arioihood and tribalism, one will recall de Bovis' statement, which is confirmed by much other evidence, 
that, however friendly and hospitable may have been the relations between members of different lodges in times of peace, and despite their common acknowledgment of the primacy of the Taramanini (the office of the master of the Opoan lodge), when hostilities broke out between tribes the members of their respective lodges not only fought one another, but were typically the most fierce and loyal supporters of their respective tribal chiefs.

\section{Consanguinity and Class}

Since membership in a marriage class was mainly by descent, the question arises concerning the relationship between class and consanguinity-more specifically between membership in class and in kin-congregation or descent line.

While information about kin-congregation composition is quite unspecific, some plausible inferences may be drawn. The smaller "family"-size congregations would by definition have been class-homogeneous-all ari'i or all ra'atira or all manahune. Mahaetea marae (Papara), founded by ari'i parents for their kin-Titles successor, Teri'irere, seems to have been mainly for an all-ari'i congregation, and there were probably others of the same kind. It is also safe to infer that there were large numbers of all-manahune and all-ra'atira kin-congregations: "The ra'atira had their own family marae, for which a member of the family acted as priest, where remains of the dead and other sacred objects were left, and where the family ancestors were worshipped" (Handy 1930:43).

At the other extreme (in terms of consanguineal span) were the many networks of kin-congregations of common derivation-both territorially contiguous and widely dispersed ones. Suprakin units, as large and widely subdivided as some of these, were likely to have contained two or even all three classes within their memberships, thereby confronting the integrative ideology of consanguinity with the more differentiating one of class. It would be most instructive to learn whether such oppositions were recognized and how they were dealt with, although it is quite possible that actual confrontations did not often occur, inasmuch as the more active participants in joint, suprakin assemblies were likely to have been the "principal people" of the constituent subdivisions, and hence all more or less of one class. (See chap. 16.)

As for the descent "lines" important enough to have been memorialized in lengthy genealogies, most of these were probably made up of putatively ari'i members; inclusion of a non-ari'i link would have depreciated the genealogy's value as evidence of social superiority, which was one of its principal functions. In this connection, I again call attention to the special position occupied by persons claiming descent from kin-Titlebearing forebears of Opoa: not only were most (or all?) such persons acknowledged 
to be members of the ari'i class, but during the era now under discussion such persons appear to have constituted almost the entirety of that class.

\section{Tribe and Class}

Understanding of the connections between marriage class and tribe is obscured somewhat by the different explanations that have been offered concerning the origin of the upper (i.e., ari'i) class. If, as some writers proposed, this class was composed exclusively of persons claiming descent from kin-Titlebearing forebears of Opoa, then we have a very special and highly important exemplar of the supratribal kin ramages, mentioned earlier. Or if, as other writers held, Maohi class stratifications in general, and the "emergence" of the upper class in particular, came about everywhere as the result of such factors as kin-congregation ramification, differential distribution of resources, and so on, then we are seeing a quite different phenomenon-although during the Late Indigenous Era the marital connections among upper-class members were so encompassing as to render the differences between these two explanations of little social relevance. In any case, although the principal people of many tribes were able to assert kin ties with one another, this did not insure amicable relations among them-in fact, the contrary was often the case.

\section{Statuses}

Another measure of "social integration" may be exemplified, first, by the extent to which statuses in different kinds of social groupings and categories tended to correspond, and, second, by the frequency with which particular individuals held different statuses in any one group.

Considering the latter first, perhaps the most informative example of such in Maohi society was the dual status of secular ruler and officiating priest occupied by the chiefs of some kin-congregations. The office of kincongregation chief included by definition the role of principal communicant with the unit's tutelars, but I refer here to the status of priestly officiant, which in many instances came to be held by some other member of a kincongregation (typically, by a younger brother of the chief, or by the head of a collateral "younger brother" line).

Instances existed of an even more far-reaching example of coalescence of statuses-as occurred in the case of the Opoan Tamatoa IV, who was not only secular ruler of his kin-congregation, and its principal priestly officiant, but the frequent mediumistic vehicle for its major tutelar as well.

With respect to tribal groupings, although most typically a tribe's sovereign chief was at the same time the chief of its principal kin-congregation, that was not always the case. And although tribes were by character put and held together mainly by coercive physical force, the 
chiefs of some tribes were not themselves warrior champions ('aito), or even fighters.

Turning now to correspondences between statuses in different kinds of social units, I point to the central part played by Opoan-derived maro-'ura kin-Titleholders in the supratribal 'Oro cult. But a more widespread correspondence was that between Arioi grade and marriage class, in terms of both membership and insignia. As for the label 'aito, which was applied to the office of lodge chief, I suppose that this reflected the circumstance that most Ariois were active warriors when the time for fighting came.

As I noted earlier, it is also possible to discern some correspondences in the statuses of pact-friend, formally wedded spouse, and other contractual relationships, but I shall not attempt to itemize such correspondences here.

\section{Symbols}

The subject of the role played by Maohi words, gestures, objects, et cetera, in symbolizing social relationships is vast, complex, and largely obscure. It has been touched on at many points throughout this study-in connection with labels, emblems, interaction etiquette, and especially religious ritual. My concern here, however, is with only a small phase of the subject-namely, with the use made of verbal metaphors and ritual objects in symbolizing the interrelations of certain social units and statuses.

First of all, one recalls the popular Maohi metaphor that equated a tribe with a boat, its chief with the mast (tira), the latter's principal aides with the outrigger ('iato): a vivid expression of the way tribal officers were expected to relate to one another to make the "ship of state" go well.

Next, one may recall two especially expressive uses of ritual objects that served to symbolize resemblances between statuses in different kinds of social units: the red (bark-cloth) girdle of an Arioi lodge master and the red (feather) girdle of a high ranking kin-congregation Titleholder; and the use of ironwood (toa, 'aito), the wood of weapons of warriors (also called toa, 'aito), for the image ( $t o^{\prime} o$ ) of 'Oro, the principal god of war.

One will also recall the figurative use of the octopus to represent the several geographic divisions, and by implication the constituent subunits, of a unified tribe. But, of all such symbols of integration, among any social unit's constituent parts none approached the powerful expressiveness of the paiatua, the awesomely solemn ceremony in which the image of each subunit's tutelar was reconsecrated with feathers taken from that of the tutelar of the whole unit (or of the whole unit's chief). I am not certain, however, whether the units in question were kin-congregational, tribal, or cults per se-the ritual language having been general enough for all three.

Finally, I should point out again that metaphor and ritual objects were also designed to symbolize instances of social dis-integration. With respect 
to the former, one will recall the equating of Tahiti with a fish that detached itself from Ra'iatea and swam away-most probably a reference to legendary events of both political and religious character. With respect to the latter, the legend describing the "invention" of the maro te' $a$ explains explicitly that it was done to signal the severance of a Poraporan branch from its source kin-congregation of Opoa. And I propose that the legendary introduction of the maro te'a into Tahiti was similarly meant to symbolize Papara's breakaway from the maro ura dynasty at Vaiari.

I wish to conclude my epitome of Maohi social-relations with some general references about the kinds of symbolic connections that existed between social units and socially valued goods.

\section{Property}

I find it necessary to employ some technical terms in discussing the highly complex subject of property-to begin with, the term property itself: entities in which particular social units are considered to have "quasi-exclusive and limiting connections" vis-à-vis other social units. ${ }^{36}$ Title is shorthand for "quasi-exclusive and limiting connections vis-à-vis other social units"; and the full characterization of any particular title would include a description of the rights and duties of the titleholder(s) with respect to the property in question and in the context of the rights, and so forth, of others' titles to that property. Concerning the latter, a title may be either undivided or divided; and if divided, either provisional or residual.

With definitions as broad in scope as these one would need hundreds of pages to present a full and detailed description of this aspect of Maohi society-a task I shall not and need not undertake, since most if not all of the information required for such an undertaking has already been supplied. (A full treatment of just that part of the topic conventionally labeled "land tenure" would involve paraphrasing very large portions of volume 2.) In this brief "synthesis," instead of reviewing, redundantly, the kinds of property associated with particular social units, and the nature of the titles thereto, I wish to record a few inferences about the topic as a whole.

First of all, I can point to the very wide range of entities that constituted property in Maohi society: single words (e.g., certain personal names, kinTitles, etc.), verbal formulae (e.g., certain genealogies and verbal rites), material objects of innumerable kinds, territory (both terrestrial and marine), certain kinds of services of certain kinds of persons, and so on. Also, as the reader undoubtedly will have concluded, some of the comments made earlier about goods subject to transactions apply equally well to goods looked upon as property; but in addition, there were certain goods held as property which, normatively at least, did not circulate (e.g., marae associated with particular kin-congregations). 
Next, I can offer three very broad generalizations about Maohi propertyholding social units that differentiate them somewhat from those of, say, Western societies: Maohi society contained fewer one-person property-holding social units; specific entities of property tended to be "owned" by larger numbers of social units of different types; and in most multiperson social units the rights constituting their titles tended to be more widely differentiated. (In other words, the hierarchic principles which underlaid "governance" carried over, explicitly, to property rights as well.)

Finally, with respect to titles, perhaps the most noteworthy generalization to be made about them is the relative paucity of truly undivided ones. The titles to certain kin-congregation marae, and to the personal estates of certain politically powerful chiefs, seem to have been undivided, but titles to most other entities of Maohi property were either provisional or residual in nature, not only in terms of historical actualities but of norms and suppositions as well.

\section{EVOLUTION OF MAOHI SOCIETY TO 1767}

I now propose to set scholarly caution aside and for a few pages indulge in the popular pastime of speculating about the course and causes of changes in Maohi social relations until 1767. Some such speculation has crept into previous chapters of this work despite my emphasis on "fact"; some of it is stated here for the first time. I had best begin by recording my present conception of how and when these Islands were first settled, and of the structure of Maohi society "in the beginning."

The earliest datable evidence of human settlement in these Islands yet discovered consists of some burials uncovered on Maupiti. Along with sixteen skeletons the archaeologists uncovered some seventy artifacts (mainly fishhooks and ornaments), which have been dated between A.D. $860( \pm 85)$ and $1190( \pm 90)$ and which revealed close relationships with some of the earliest cultural remains found in New Zealand. Another site, at Afareaitu, Mo'orea, appears to have been occupied about A.D. 1000, but all other datable materials thus far discovered are considerably more recent. ${ }^{37}$ Much more archaeological work needs to be done in these Islands before a persuasive reconstruction can be formulated, but the archaeological evidence, here and elsewhere in Polynesia, suggests the following sequence of early relationships between the Society Islands and other Polynesian archipelagos: a settlement of the Marquesas from West Polynesia, before about A.D. 300; a settlement in the Society (and Hawaiian) Islands from the Marquesas, before about A.D. 600; and a settlement in New Zealand from the Society Islands, about A.D. 750.

Linguistic and other ethnological evidence tends to support these conclusions and also to suggest some more frequent connections between 
the Society Islands and certain of the Cook and Austral islands. And, of course, connections between the Society Islands and the Tuamotus were not only more frequent but more purposeful and institutionalized as well. ${ }^{38}$

The picture I perceive from the foregoing is of numerous landings on the Society Islands throughout a millennium or more, from other archipelagos near and far, and ranging in size from a lone and near-dead survivor in a drifting canoe to a modest-sized fleet. Most newcomers would have added some new ideas and objects to the local cultural inventory, and during the earlier centuries some of the larger-scale immigrations were probably nearrevolutionary in their influence. But as time passed and the local population made settlements on all islands of the archipelago, subsequent new arrivals, (say after about A.D. 1200), even large-scale ones, could not have been large enough, or culturally "superior" enough, to have effected radical changes in the technological and social patterns that had by then become fairly well consolidated. This raises the question, What were those patterns of about A.D. $1200 ?^{39}$

In the domain of technology, I suggest that the tools, productive techniques, and so forth, of circa 1200 were not markedly different from those of 1767 . Those of the later era were undoubtedly more refined in certain respects (say, in offshore fishing, and in stone masonry), but not comprehensively or significantly so.

As for social relations, I suggest that most of the differences between A.D. 1200 and 1767 are ultimately attributable to the latter era's larger population. I propose, for example, that tribes (i.e., politically autonomous territorially defined social units) were smaller and less complex in 1200 , having consisted mainly of single kin-congregations or sets of contiguous kin-congregations, which were interrelated by ties of common descent. In such tribes the chief would have been both administrator and high priest, and succession to that office would have adhered more closely to male primogenitural norms.

In that earlier era, I picture conjugal unions as having been more universally "domestic" and less deliberately "political" than they later became. That is to say, even chiefs were concerned less with a spouse's ancestral lines or tribal affiliation than with her physical charms and household and reproductive capabilities. Moreover, I imagine that even chiefs were careful not to marry "close" consanguines.

Even at that earlier era there probably prevailed some marks of social stratification, at least to the extent that each tribe's chiefly family enjoyed special consumption rights, and other privileges; but I suggest that only two such strata were discernable, and that they had not yet become sharply separated by powerfully sanctioned norms against intermarriage.

I suppose that even at that earlier date some occupational specialization 
had developed; but I doubt that the earlier population was large enough to support the degree of specialization that prevailed in 1767. I suppose also that some more or less "autonomous" cult activity sprang up and spread about from time to time-probably as a consequence of some individuals' mystical experiences. I cannot, however, believe that anything so large scale and full time as Arioihood would have been possible in a population of much smaller size.

As for the factor of age, I imagine that while a successor to chiefly office was, even during the earlier era, a focus of ritual attention, such attention was less hyperbolic by far, and that for all other persons maturity was the prime time of life, not only in mundane affairs but in ritual ones as well.

Finally, with respect to the social-relational aspect of sex dichotomy, I believe that norms were the same in the earlier eras as they were in 1767 in terms of technology, religious ritual, and interaction. Moreover, I suggest that women of chiefly families-that is "upper-stratum" women-were not yet such pawns or performers in intertribal politics as they later became.

How, then, did the (hypothetical) society of A.D. 1200 just epitomized become transformed into the one I have reconstructed for 1767? What "causes," exogenous and endogenous, set changes in motion, and how did such initial changes influence the other parts of the society's structure? (In the following paragraphs I shall touch only on those changes of major social-relational significance-that is, those which my biases lead me to emphasize.)

As stated earlier, I believe that the principal influence upon social change in these Islands was population increase, and not so much by immigration as by steady internal increase. Moreover, inasmuch as this increase was not accompanied by any major changes in subsistence technology or in preferences regarding settlement patterns, it led people to spread out over all the Islands and, eventually, in some places (but not everywhere), to exert pressure upon the land-to compete for favorable territory, terrestrial and marine.

I suggest that the spreading of the population took place initially and mainly in the ways postulated in my treatment of kin-congregation ramification. That is to say, the spread was by gradual filling up of contiguous empty tracts or by more or less peaceful colonization. Endemically "structural" factors, such as sibling rivalry and the occasional emergence of strong and restless personalities, ${ }^{40}$ undoubtedly initiated many such movements; there may also have been instances of warfare between unrelated kin-congregations, and even between branches of the same unit, but few if any cases of massive migration or preemptive conquest. 
However, sooner or later, some neighboring and thitherto unrelated kincongregations were united into larger tribes-either by force of arms, by marital alliances, or by both. In time these units came to be combined into still larger and more complex tribes, which served both to tie together unrelated kin-congregations and to separate consanguineally related ones.

I shall not endeavor to recapitulate here all the kinds of "causes" behind such developments; suffice it to say that they were many and varied. For example, although economic necessity may have helped to influence the inhabitants of small and relatively unfertile Porapora to invade richer Ra'iatea, such cannot have been a decisive factor in most of the tribal consolidation that took place on huge and sparsely populated Tahiti. And although calculated ambition to command the labor or ceremonial respect of more subjects may have led some individuals to undertake wars of conquest, many of the bloodiest encounters resulted from motives of pique or personal revenge.

Several features of Maohi multi-kin-congregation units serve to identify them with the ramages, said by Sahlins (1958) to be characteristic of Maohi society-but only insofar as concerns kinship ties. Unlike Sahlins' hypothetical ramages, the Maohi kin units did not constitute autonomous, political-that is, tribal-groupings during the Late Indigenous Era, so that Sahlins' theory about the ecological basis of their evolution is not entirely relevant to the Maohi case.

But even if the Maohi multi-kin-congregation units had been tribal, their internal structure cannot be accounted for in the way proposed. Very briefly stated, Sahlins holds that the several subunits of a ramage-the component kin-congregations of a multi-kin-congregation unit-owed the maintenance of their interconnections to the way in which subsistence resources were spatially distributed: that is, "... empirical evidence, (other factors being constant) should show ramified systems in islands in which there is a variety of scattered resource zones differentially exploited by families or small groups of families. Or, inversely, ramified systems would be expectable on those islands where a single patrilocal extended family could not efficiently exploit the total range of available resources on a high level." (1958:203)

As I have endeavored to show in earlier chapters, Maohi subsistence resources were indeed "scattered," but not to the degree suggested by Sahlins; except for the very special case of Tetiaroa, and possibly Mai'ao, on every island known to me, every major kind of "resource zone" used by the Maohis would have been well within the daily-use range of any household, both in terms of spatial distance and of right of access (see Finney 1966). Objects did circulate among interrelated kin-congregations, but such objects were of kinds commonly accessible to most or all households. In fact, a better argument could be made for the proposition that 
the objects in question circulated, more or less ritually, in order to maintain the interrelationships, and not the reverse.

This is not to deny the existence of exchanges involving objects needed for themselves-for example, the kind that took place between an occupationally specialized fisherman and a man specializing in gardening, either as commercial transactions or in the form of gift exchange. And while many such exchanges undoubtedly took place between individuals who were also kinsmen, they were probably of only marginal importance in maintaining kin-congregation connections. And, even more directly relevant to the present discussion, the complementarity exemplified in such exchanges was based mainly on individual occupational specialization which had very little to do with differential access to diverse resource zones.

However it was that such tribal consolidations took place, it is evident that two different bases for interpersonal relations were involved in the developments leading up to them and in the resulting social hierarchies comprising the tribes. One was the norm for grading siblings by birth order and sex; the other was the recognition that was accorded coercion by physical force. The former became institutionalized in the hierarchic grading and ranking of kin-congregation offices; the latter became exemplified in numerous individuals of political authority who owed their position mainly to martial, political, or diplomatic skills. In some instances the highest tribal offices exemplified both these principles; in others, highest grade (or rank) was personified in one individual, political authority in another. In any case, the interplay of these two contrasting principles of hierarchy served further to complicate Maohi social relations-not only "horizontally" as it were, in intensifying "status rivalry" (see Goldman 1960), but "vertically" as well.

In addition, there were two other characteristics of Maohi society that contributed to maintaining the viability of both of these contrasting, and what might otherwise have become irreconcilable, principles. One of these was the tolerance toward bilaterality combined with a considerable degree of flexibility in allocation of kin-Titles: although male primogeniture was probably the ideal, the basis for succession was not dogmatically adhered to in the face of all other considerations. ${ }^{41}$ The second was the device commonly used to legitimatize achieved political power, by reproductive alliance ("marriage") of the achiever with a high-rank kin-Titleholding (or Title-conveying) woman, upon whose offspring would devolve both political power and high rank. As we shall see in volume 3, however, this latter measure was not always resorted to. Nor did high rank always insure political power, as attested by the state of political impotence to which the holders of Farepua kin-Titles eventually declined.

Accompanying the political developments just mentioned, Maohi soci- 
ety was becoming more highly and more disjunctively stratified into three classes: ari'i, ra'atira, and manahune. Several different explanations have been offered for Maohi social stratification; some of them pertain to the increase in status "levels" in general, and others pertain to the three-level marriage-class system in particular. The most widely espoused explanation for the Maohi three-level class system has been the "conquest" theory, best epitomized by Handy. According to this writer a "maritime dynasty," possessing a markedly different and in many respects "superior" culture, descended upon these Islands from the west and established a beachhead settlement at Opoa, Ra'iatea, from which their descendents eventually spread out and overcame the Islands' original inhabitants. ${ }^{42}$ Needless to say, I reject this type of explanation as being overly simplistic, undocumented, and quite unnecessary.

Piddington also rejected the notion of outside conquests as a general explanation for social stratification in the Society Islands as a whole, but he did fall back on intra-and interisland conquests to account for the subordinate position occupied by the "vanquished" and "landless" manahune (Williamson 1939:225n). And although Piddington referred generally to other "internal factors" influencing social differentiation in Polynesian societies in general, he offered no explanation for the marital boundaries separating Maohi or other Polynesian social strata.

Among recent studies pertaining to the increase in Maohi status levels in general, perhaps the best known is the one advanced by Sahlins in his comparative study of the relationship between social structure and ecology throughout Polynesia, in which he concluded that social stratification varied "both in degree and form according to ecological conditions" (Sahlins 1958:ix). ${ }^{43}$ Our present concern is with "degree of stratification."

Sahlins divided the Polynesian societies examined by him into four major categories in terms of "degree of stratification":

1. Hawaii, Tonga, Samoa, Tahiti ("structurally complex ranking systems, usually with three status levels");

2. Mangareva, Mangaia, Easter Island, Uvea ("two basic status levels with tendency to form third");

3. Marquesas, Tikopia, Futuna ("two status levels");

4. Pukapuka, Ontong Java, Tokelau ("two status levels; upper containing very few members").

He then undertook to demonstrate that degree of stratification in these societies ("other factors being constant") varied directly with productivity of foodstuffs-and succeeded to his own satisfaction in doing so, by means of the following method for estimating productivity.

Since few of the sources about pre-and early-European Polynesia provide quantitative data on food production, Sahlins fell back on the familiar 
notion of surplus-“surplus increases as productivity increases." He proposed this statement to be valid for Polynesia because "first, as the cultures compared here are historically closely related and have more or less the same foods and types of distributional systems, it is unlikely that a serious discrepancy in producers' wants would arise from society to society; second, and more significant, the surpluses which are being considered are food surpluses, and any discrepancy in wants that might arise would a priori be small. Human beings can consume just so much or so little food; in contrast to many other goods, the potential range is relatively small." (1958:108)

Sahlins then distinguished two kinds of food surplus, immediate and cyclic: the former refers to "the ability of food producers to acquire, in a single exploitative activity, an amount of food beyond their immediate consumption needs, or an amount greater than would be needed before production is resumed again." Cyclic surplus, on the other hand, is "that food which the producer has left over after a full cycle, e.g., a year, of production." He considered immediate surplus to be particularly appropriate as a measure of productivity of Polynesian societies because, he claimed, "it is precisely those foods produced beyond the immediate needs of the producers which were collected by chiefs and then redistributed by the system operating in conjunction with religious feasts and other occasions ...." Therefore, other things being constant, "a fairly accurate indication of the ability to produce ... [immediate surplus] may be gained by considering the greatest number of people encompassed in a single [average] redistributive food network, and the frequency per annum of over-all redistribution in such a network." (1958:109.) For this proposition to be valid, Sahlins added, every consumer must receive a proportionate amount, or bit, of the food so distributed-a condition which he believed to be met throughout Polynesia. ${ }^{44}$

In terms of immediate-surplus productivity, Sahlins ranked the Maohis third in his list of fourteen societies-after Hawaii and Tonga and before Samoa-which corresponds closely with the Maohis' position in his "degree of stratification" rank-order list. He based this rank-ordering on his estimate that the largest average redistributive networks of Maohi society included about 8,250 persons at the "district" level and about 68,000 persons at the "division" level, with a "frequency of redistribution" factor of three per annum (at least, for each "district").

I suppose that no student of Oceania would disagree with the placement of Maohi society among the most highly stratified ones of Polynesia. And no one familiar with descriptions of Maohi life could justifiably deny the existence from time to time of "immediate surpluses" of foodstuffs in the Society Islands. Moreover, I am disposed to expect some positive correlation between degree of stratification and immediate surplus-not necessarily in all human societies, but in enough of them to warrant 
tests of the hypothesis. On the other hand, the particular test applied by Sahlins fails on two grounds with respect to the Maohis: first, on account of his misconceptions regarding Maohi "redistribution," and second, on account of the inaccuracy of the population estimates he utilized.

As I have abundantly indicated, Maohi tribal chiefs did collect foods from their subjects on occasion, and now and then some of this food was "redistributed" to some extent; but the only evidence bearing on how much of a producer's immediate surplus circulated in this way suggests that very little of it did so. ${ }^{45}$ (Unless, of course, one were to label every household head a "chief," which Sahlins plainly did not imply.) Thus, in this sense, Maohi "redistribution" does not provide a very informative, or necessarily accurate, measure of Maohi productivity.

Indeed, even when "redistribution" did take place among the Maohis, it did not typically conform to the mode proposed by Sahlins when the larger social units-that is, "tribes"-were concerned. For example, on many occasions the bulk of the food so collected was consumed at or near the top of the hierarchies, or arrived there in a deliberately decayed state, or was "redistributed" in token and unequal amounts by "scrambling." And while this does not rule out the possibility that the size of the social unit involved in contributing on such occasions may have borne some (indirect) relation to stratification, it has little to do with "redistribution" itself.

One will recall that the food contributed by subjects to their tribal chief may have served to support the diplomatic and other public intents of the latter, but it did not ordinarily supply his domestic subsistence needs, which were usually met from his own estates. Also, as tribal units increased in size, some "taxes" changed in kind. (See chap. 23.)

Turning now to the population estimates utilized by Sahlins in calculating the size of his so-called "redistributive networks," I trust that no further documentation is needed to demonstrate how extravagantly inflated those statistics are. Also, I am unable to find reliable evidence for his conclusion that "redistribution" encompassing "districts" took place at the average rate of three per annum.

Thus, although Sahlins' characterization of Maohi society as having been, comparatively, both highly productive and complexly stratified is undoubtedly accurate, the method and the data utilized by him to calculate that productivity are irrelevant and inaccurate. Moreover, even if Maohi redistributive networks were of the type, size, and frequency posited by Sahlins, and even if (as he assumes) all or most surplus production was distributed from "central agencies," I fail to see how such facts could serve to explain, except tautologically, Maohi society's three-level stratification. And finally this theory offers no specific explanation for the marital boundaries known to have separated the Maohi classes. 
In his comparative study of social evolution in Polynesia, Goldman placed the Maohis among his most "evolved," highly stratified societies, and characterized the three Maohi strata in the following terms: "Tahiti had a class of chiefs, arii, who were the ruling aristocracy and a raatira middle class that was made up of lower-ranking "nobles" and of upwardmoving plebians. Land ownership was prerequisite for raatira status. At the bottom of the social scale were the landless manahune, the commoners and the majority of the population." (1960:698) And in another place he characterized the manahune as "not only landless but to all intents and purposes a caste" (p. 699). I cannot agree with Goldman's characterization of manahune as "landless"; and although he acknowledged the marital barrier that separated them from ari'i and ra'atira, he did not attempt to explain it.

Goldman was concerned mainly with the interplay between hereditary rank and force-sanctioned authority, which I shall return to later on. Like myself, he looked upon sibling grading (by birth order and sex) and kin-congregation ("lineage") branching as having provided an important structural basis for stratification. "Seniority ... defines the rank of individuals, which follows a fine gradation from highest ranking chief, the descendant of a line of first born males (the ideal of highest rank), to the lowest ranking 'commoners,' a descendant of junior lines" (1960:689). Thus Goldman characterized the "prototype form" of Polynesian societies generally-including Maohi.

Also, like myself, while he acknowledged the possible relevance of ecology to "social complexity," in certain particular instances, he rejected it as an overall explanatory device. For example, "Among interactive factors must be included ecology. Polynesianists have always called attention to the fact that the more complex Polynesian societies were formed on the high volcanic islands and the simple ones on the low coral atolls. This generalization is, on the whole, valid. All the atolls were traditional societies [i.e., kinship dominated], while the high islands contained all three types [i.e., "traditional," "open," "stratified"], as one would expect from the common dictum that environment limits but does not create. We cannot accept blindly the time-honored assumption that "surplus" provides the necessary basis for continued political evolution.... In other words, it was the political incentive and the presence of a political organization that made public works possible rather than, as commonly believed, the other way around." (Pp. 709-710.)

It now remains for me to offer my own explanations for the degree and kind of social stratification found on these islands in 1767. First, a word about its degree. 
With the proliferation and ramification of kin-congregations an important change took place in their internal social relations, in addition to the complete fission which some of them doubtless underwent, and in addition to the changes accompanying their consolidation into more complex tribes. In other words, as kin-congregations ramified, the number of their offices-including Titled ones-also increased and became further differentiated, in the following ways. In keeping with the fundamental Maohi principle of grading siblings by birth-order and sex, the hierarchically differentiated statuses in each suprakin-congregation came to be extended over a greater vertical range, which, among other things, greatly widened the social distances (in terms of differential privileges) between the statuses of "senior" branches and of the "junior" ones. Then, at some point in this process of differentiation the continuities of consanguinity linking all these statuses, from most senior to most junior, came to be interrupted by barriers of class and caste.

The crucial question is, What events or lines of reasoning served to restrict an individual's choice of spouse (in addition to the restriction of marrying close consanguines) and thereby transformed status levels into castes? In my opinion a number of convergent developments may have been involved.

There is a strong likelihood that tendencies toward endogamy developed among the higher-graded members of suprakin units as these latter differentiated in the ways just proposed. In other words, as social distances (in terms of privileges) increased between "senior" and "junior" members in such units, the former sought more deliberately to maintain the distances by devoting more attention to the eugenics of reproduction-that is, to insuring that the "spiritual" elements passed on to an offspring were bilaterally equivalent. (This type of "social eugenics" was probably conceptualized at a very early time in Maohi-or indeed in Polynesian-history, but I suggest that it became a decisive influence in spouse-choosing only after kin-congregation statuses had reached a certain point of "vertical" differentiation-which point, however, I am unable to specify.)

My further suggestion is that under the influence of this "eugenical" thinking two kinds of events occurred with increasing frequency. On the one hand, more and more marriages took place among senior co-members of kin units, even at the cost of overriding general society-wide proscriptions against marriages between "close" consanguines. And on the other hand, more and more marriages were contracted between senior members of different kin units. Needless to say, both these kinds of occurrences served to increase the social distances between "senior" and "junior" members of the kin units in question, and the inter-kin-unit marriages served also to extend these conditions society-wide.

As for the inter-kin-unit marriages just mentioned, many of them undoubtedly had political consequences as well. Indeed, it is possible that 
marriages of this kind were occasionally contracted for mainly political purposes and before eugenics became such a decisive criterion. Or, what is even more likely, both eugenical and political motives entered into most such marriages during earlier eras of Maohi history, and with the passage of time they both became weightier through mutual reinforcement.

All the above happenings are of the nature of general societal developments. I look upon them as having taken place, potentially, anyand everywhere in these islands. But I also admit the possibility that certain particular happenings may have had weighty influence upon the development of stratification in general, and of class endogamy in particular. What I am suggesting is that at some point or points in Maohi history certain "autonomous" kin-congregations came to be widely regarded as socially "superior" to all the rest. Whether this came about as a result, initially, of military superiority, or cult proselytism, or political maneuver, or a combination of such measures, I of course cannot say, but it is reasonable to expect that such "superiority" would carry over to those units' higher-grade members, thereby creating or reinforcing a society-wide system for comparing kin-congregation statuses-of rank, as contrasted with intracongregation grade-which served to widen even further the social distances between status extremes.

During the Late Indigenous Era the kin-congregations holding the society's highest-ranking kin-Titles were those of Opoa and of Vaiari, but that need not always have been the case; like social units everywhere, Maohi kin-congregations undoubtedly had their rises and falls, and like genealogical myths everywhere those of the Maohis were inevitably tailored to social change. In any case, whatever circumstance it was that started it on its rise, somewhere along the way the Opoan kin-congregation became specially (though not exclusively) associated with the god 'Oro; and thenceforth the prestige, and legitimation, of the two-Opoan kin-Titles and cult of 'Oro (including its Arioi sect)-increased even further by mutual enhancement.

Returning again to the question of the influence exerted by ecological factors upon social stratification, I acknowledge now as I did previously that such influence prevailed (and in fact was two-way). On the other hand, no formulae that I know about or can conceive of would serve to measure or explain the highly complex connections between these two sets of events. For example, whereas the low productivity of Porapora seems to have predisposed its inhabitants to the foreign conquests which led to their chiefs' political superiority over nearby lands, that of Tahiti's northeastern districts helped to keep their chiefs subordinate to Pare-Arue and Hitia'a. And the society-wide preeminence enjoyed for so long by the principal people of Fa'a'a (Tahiti) derived not from the meager economic resources of their small domain, but from their political and diplomatic skills.

When postulating the kinds of conjugal unions that prevailed among 
the Maohis circa 1200, I pictured them as having been more "domestic" than "political" in their inception, and as having conformed more closely to the widespread Polynesian rule against marriage between "close" consanguines. Later on, the growing concern with social eugenics, coupled with political motives, led to marriages with closer consanguines (to first cousins, in some instances), and to marriages that were more in the nature of reproductive alliances than of sexual and domestic unions. I should point out, however, that these developments were probably restricted to the upper-class members of Maohi society; for most other persons, choice of mate and functions of union remained largely unchanged.

The only general explanation I can offer for the increase, during the period between 1200 and 1767, in total number of occupational specialists is the increase of the population as a whole. On the other hand, the relatively greater increases that characterized certain occupations may be accounted for in so-called "functional" terms, as may be exemplified in the case of more or less full-time warriors. That is to say, as coercive force came more and more to supersede high kin-Title rank as a basis for tribal authority and intertribal influence, so did warfare become a more specialized profession and warriors a more numerous and better rewarded lot. As another example, the rise in numbers of entertainers, and the polished refinements in the arts practiced by them, may be accounted for in large part by the growth of the cult of 'Oro and of its Arioi sect. (More such examples could be cited ${ }^{46}$ but since the reader now has enough data to engage in this "functional" pastime on his own, I turn to changes that seem to have taken place, between 1200 and 1767, in the social-relational aspects of age and sex.)

With regard to age, it is of course obvious that the extravagant ritual cynosure enjoyed by youthful kin-Titleholders could have come about only after kin-congregations had become large and structurally complex enough to have indulged in the luxury of a figurehead chief. To the extent that society at large followed the same practice of extolling and indulging the very young, I imagine that this also was a latter-day development; I cannot believe that a pioneer, colonizing people could or would have done so.

Finally, with regard to sex dichotomy, I suggest that the prominent political roles played by upper-class women during the Late Indigenous Era may in a general way have been made possible by the larger populations and increased productivity that freed some women from domestic chores, but that the roles were more directly a consequence of the rise in the concern over social eugenics. 


\section{NOTES}

\section{CHAPTER 14}

1 Some examples are the following LMS Dictionary entries: taetaevao, an inhabitant of the interior, a clown, one not accustomed to society (also, taevao); ara'ara'aivao, an inhabitant of the upper valleys; a wild or untamed animal; wild, untamed, unaccustomed to the seaside, as an inhabitant of the interior of the country.

2 The LMS Dictionary contains several terms for social units, such as $t i^{\prime} a^{\prime} a$, a company of people, a flock or herd of sheep, goats, etc.; and pupu, a company, party, or a class; however, I am unable to specify exact referents for them.

3 White (1967:328), drawing on textual material recorded by Orsmond, described personal names as "circumstantial" - "e i'oa pi'i noa: simply a name of address," as distinguished from "grand names" (i'oa mau, name-true), or what I call Titles.

4 As far as I can discover, the various wind-directional compass points described in chapter 8 did not serve as a general locational reference system for entities other than the winds themselves.

5 White and Terupe 1958:57. I have not examined the older textual material with enough attention to this aspect to be able to list which items were "alienable" (incidental or transient) and which items "inalienable" (intimate, innate, or permanent), but a statement concerning such distinctions in twentieth-century Tahitian is probably applicable enough for present purposes: Perhaps the most confusing of all Tahitian idioms are the several distinctions in the use of the vowels $a$ and $o$ in $a, n a, t a$, and $o$, no, to.

Rule: Use $o$, no, and to for: (1) All members of the body, and all that emanates from the bod[y] including one's thoughts expressed, but not one's words articulated, nor sins committed; (2) All that the body may enter; (3) An integral part or portion, or specific attribute, of anything, as one of several objects required to complete the whole; (4) The land of one's birth or origin, or permanent residence; (5) All attributes, qualities, and dispositions proper to the word modified; also all such in the abstract, as ideas; (6) All participial nouns used verbally where the thought dwells rather upon the action than upon the completed act; (7) And for one's own child, parent, or other relative, slave, servant, friend, etc., in a definite or specific form.

Rule: Use $a, n a$, and $t a$ in all cases not covered by the above. (Burbidge 
1930:223-224.) See also Pukui and Elbert 1957:xix; H. W. Williams 1957: $1,237$.

6 According to one observer, mata'u carried an additional meaning. On one of those frequent occasions when some native stole a valued object from Europeans at Matavai, the characteristic reaction of the local chief, Pomare I, was to hide away in fear of reprisals: "The next day there was no trade carried on; but Tee [Tii, a subtribal chief] came on board again, desiring the captain [Cook] to visit the king [sic] at Parré, who was matòw [mata'u], an ambiguous court-phrase, expressing not only that he was afraid, but that he wished to be put into good humour with presents" (G. Forster 1777:II, 99-100).

7 See LMS Dictionary: 'á'au, the bowels or intestines-fig. the heart or mind; the affections; the conscience; courage or spirit.

8 In a poem reproduced in Alexander (1893:55-59), the deserted lover (husband?) describes himself as being to'eto'e (chilled) with lingering affection for his fickle lady love; but whether this is meant to be literally descriptive of an internal sensation, or merely metaphoric, is not known.

9 See also the LMS Dictionary definition of tumaoaoa, "to be ashamed, as a person not taken notice of," which is a perfectly straightforward expression of chagrin pertinent to a whole range of emotions.

\section{CHAPTER 15}

1 See, for example, the wholly benevolent role played by Hina, the lunar goddess, and the host of "old women goddesses" who became "... guardians of the world." But note also that there were many malicious female spirits as well, including a goddess of "strife and cruelty." (Henry 1928:180, 416, $417,462-463)$

2 One of the "Precepts of Tetunae" reads in part: "Guard yourself against the revenge of a woman. It will pursue your footsteps." (Handy 1930:41)

3 For example, in the cosmogonic chant "Birth of More Gods," it is recorded of the God 'Oro's three daughters: "These goddesses, followed by a host of other goddesses, always accompanied 'Oro and his host of gods to battle, whither they never failed to go" (Henry 1928:375).

4 See, for example, the legend of Huri i te Monoi, about how a maiden who accompanied her brother on a long and dangerous voyage proved the more courageous and persistent of the two, sustaining him by her words and example in the face of numerous perils (Henry 1928:613-614).

5 Mühlmann (1955:190ff) proposed that the ritual restrictions on women came about as a consequence of the (alleged) history of the peopling of these islands, namely, as a result of the successful conquest of their aboriginal "Old Polynesian" inhabitants by a culturally superior wave of ari'i maritime adventurers. According to this explanation, ari'i women enjoyed favored positions in their own communities, but few of them accompanied the ari'i males on their journeys overseas, so that the latter had to mate with local "Old Polynesian" females in their overseas colonies in the Society Islands. And, inasmuch as they regarded "Old Polynesians" in general, 
and their women in particular, with some contempt, they imposed upon the latter all manner of constraints, domestic and ritual. This ingenious reconstruction has the virtue of "explaining" a number of other features of Maohi society, including class stratification in general, but, like most ethnic-wave theories about Polynesian culture history, it is lacking in proof. For further discussion of it see chap. 18, this volume.

6 See also the ritual restrictions associated with head freeing $\left(\bar{a} m o^{\prime} a\right)$, whether male or female (chap. 13).

7 Although in the legend of the Great Mo'o [lizard] of Fautaua a married couple went off together into the mountains in search of plantains during a period of famine (Henry 1928:621).

8 I have no way of knowing which of several different words found in the LMS Dictionary is intended here: $p u^{\prime} a$ (the coral rock; a disease accompanied with a swelling and an abcess; the name of a tree bearing fragrant yellow flowers, and the flowers thereof; to scour with coral; a person who scours), puā (the blossom of certain reeds etc.; to blossom), puāa a (to be enlarged as the abdomen, either in health or by disease), etc.

9 The LMS Dictionary contains the entry oeahōu, a young comer; a young person just come to age, but provides no further details concerning this stage.

10 For a discussion of Mühlmann's thesis regarding the "weibliche" symbolism implicit in the fattening of youths, see chap. 22, note 50 .

11 I can, however, discover nothing in the sources relating to the formalized kinds of young men's groups described for Samoa (Mead: 1930).

12 As will be discussed in chap. 22, one of the prime requisites for continued membership in the youth-oriented Arioi sect was submission to the rule of childlessness.

\section{CHAPTER 16}

1 Most usages of huä'ai seem to refer quite unambiguously to descendant, but fēti'i remains puzzling, especially when used in contrast with huä'ai, as for example in one of the "Precepts of Tetunae": "E fa'atura te ta'ata ato'a ite ari'i, i tāna huā'ai $e$ tona féti'i." Everyone is to treat with respect the ari' $i$, his descendants and his fëti'i [other relatives? collaterals? immediate family?] (E. Salmon 1937:29). It is noteworthy that huä'ai is qualified with the "impersonal," or $a$, form of the pronominal (i.e., something acquired) and féti'i with the "personal," or $o$, form (i.e., something ascribed).

2 See also firi, to plait, as sennit, human hair, etc. (LMS Dictionary).

3 Also, the Maohis evidently distinguished between "close" and "distant" relatives (consanguines only? or consanguines and affines?): viz., féti'i piri noa mai, close relatives (E. Salmon 1937:29); vaia'a, distant, applied to a relation (LMS Dictionary). However, I can find no clues as to where the line was drawn.

4 In his discussion of birth rites Morrison asserted that they took place at the "Family Morai (of Which evry Family have one)" (1935:186). However, he did not explain what he meant by "family." Further on he qualified this 
statement somewhat and added an interesting note about marae size: "Of these [marae] evry family of note have one of proportionable size to the Wealth of the Owner..." (p. 197).

5 'Ai' $a$ appears to be cognate with Tuamotuan käinga ("a homeland, inherited land; Lit. a place of eating. A heritage" [Stimson 1964:186]), and with Maori kainga ("place where fire has burnt, hence place of abode, etc; unfortified place of residence; country; home" [H.W. Williams 1957:81]).

6 See also T. Salmon 1910:39.

7 This does not mean that alienation in such cases was never attempted, or accomplished; actually something of this sort was successfully achieved by Pomare II (see volume 3), although the association in question went beyond kin-congregation ties.

8 Moerenhout was referring to the natal ceremonies which he described on pp. 535-538 (vol. I).

9 For fuller discussion of hau, see chap. 23.

10 In general, however, turtles were reserved only for chiefs who held high-ranking Titles.

11 According to Baessler (1897:252) the name of the marae's ahu was in some cases also added to the Title. This may have been so, but it does not necessitate acceptance of the rest of Baessler's view of the functional distinction between $a h u$ and marae. (See chap. 7, this work.)

12 See particularly Henry 1928:182-188; Handy 1930:22; Morrison 1935:101, 187; Panoff 1965:83; also see this volume, p. 739.

In this connection Handy voiced the following qualification: "The matahiapo, or male first-born, was honored as the scion of the sacred line. (In general matahiapo signified first born in any family. Here I am speaking of the matahiapo arii, the first-born of the reigning Arii.) A first-born female could not be the matahiapo; but if her first-born was a son, he would be matahiapo. Upon the birth of the matahiapo, he was immediately recognized as the head, spoken of as the pa'arae (frontal bone) of his family, and his parent or grandparent, head until then, fell into the position of regent." (1930:24)

13 See puita'ao, a relic; one that remains of a family, and becomes the heir (LMS Dictionary). Cf. Bligh 1789:II, 76.

14 See also Moerenhout 1837:II, 13-15; Henry 1928:480-481; Morrison 1935:169, 187.

15 As noted earlier, we do not know for certain what the connection was between this feast and "head freeing" (āmo' $a$ ), but I assume that an àmo' $a$ was held at this time.

16 Henry 1928:188-195; Davies, Youl et al., 24 May, 1806, LMS Archives.

17 Handy 1930:86; Emory, Marae Traditions. According to verbal accounts given to Handy on Maupiti in 1923, one of the flanking uprights in a local marae was called 'iato rather than tarahu (1930:105).

18 I assume that the "hereditary names" alluded to in Henry's account of congregation fission (1928:142) symbolized territory entitlement and not the functions of an office, as herein defined.

19 See also tamahaea, a person of roving disposition; a family that is disunited; 
$f a^{\prime}$ atupui, the remaining one of a family or race, who is to keep it from extinction by becoming the root of a future progeny (LMS Dictionary).

20 See the legend of Pai, Henry 1928:310, $578 \mathrm{ff}$.

21 For archaeological evidence bearing on these interpretations see Green et al. 1967.

22 I use "source" instead of "parental" or "ancestral" in order to avoid prejudging the question of whether or not the Maohis did in fact conceive of the relationship in terms of descent. The Maohi label, marae tupuna, which I call 'kin-congregation marae', did in fact have the literal meaning of 'ancestral temple', but more in the sense of it having been the very own kin-congregation marae of its members and their immediate forebears than of it being the one from which their own marae had derived.

23 'Aufau (a tribute or tax; a contribution; to pay a tax or tribute; to contribute property for any purpose) comes nearer to what I wish to express by "tax" than any other Maohi word listed and defined in the LMS Dictionary, but I have come across no textual uses of it bearing directly on the kind of transaction now under discussion. Moreover, the LMS Dictionary definition implies that an 'aufau included only objects, whereas I am referring to services as well.

24 For a discussion of the calculations on which this average generation length was based, see Emory, Marae Traditions, and S. P. Smith 1910. Regarding the Teraivetea marae listed on Emory's chart, the only thing he says is that it was established on the north shore of Opoa Bay with a stone from Vaearai.

25 De Bovis claimed that Hoataatama was a son of Hiro, and that another son remained at Opoa and carried on the sovereignty there (1909:9).

26 Henry 1928:99; Emory, Marae Traditions; de Bovis 1909:44.

27 In his meticulous survey of Greater Huahine, Emory discovered and charted remains of twenty-six other marae that he identified as marae tupuna (ancestral, family marae), for which, however, little or no traditional information has been recorded.

28 Another and more extensive list of marae ari'i is given in the Bulletin de la Société d'études océaniennes 1, no. 6 (September 1922):47-48. On it the marae are listed "in order of importance," evidently based on information received by the editor from Marau.

29 By Salmon's time-that is, the latter half of the nineteenth century-perhaps the Maohi custom of transferring a Title soon after birth of its new incumbent had given way to European ways; at least, this is the only explanation I can offer of this un-Maohi generalization.

30 For one account of events leading up to this shift, see Adams 1901:18-21; also, T. Salmon 1910:42-43.

31 Another Title closely linked with marae Matahihae was Te arii na Vahoroa (Henry 1928:86). In fact it is not clear whether it was another label for the same office, or a differently Titled office usually held by the same individual.

32 Four, actually, including another more recent addition which Emory believed was built to accommodate the Pare chief Pomare I.

33 "The name of Marama belongs to four arii families who are closely related 
to each other and their heirs alone have the right to be called by it. They are Terii-o-Marama-i-te-tauo-te-rai of Marae Tefano (Moorea); Te-ivinui-o-Marama of Anini, Huahine; Marama-toa-o-fenua-ura of Marotetini, Porapora; and Marama-o-moua-roa of Ahuroa, Mataiea, Tahiti." (Handy 1930:81)

34 I am at a loss to explain why the Title of this dynasty at Nu'urua is given as Punua i te rai atua, and not as Marama, in both Henry's survey (Henry 1928:70 ff.) and in Gunson's list of ari'i rahi Titles (personal communication).

\section{CHAPTER 17}

1 This is one of the reasons I am unable to utilize Panoff's definition of current kinterm usage given in his most interesting article, "La terminologie de la paranté en Polynesie: Essai d'analyse formelle," in L'homme, vol. 3 no. 4 (1965) pp. 60-87. Another reason is that my own observations in contemporary Tahitian communities differ in some respects from Panoff's; indeed, I found some local and even individual differences with respect to the usage of certain terms, e.g., tae'ae and hina.

2 In the article mentioned in note 1, Panoff also listed lineality-collaterality as a component of three currently used terms: tua'ana, teina, and tae'ae; but his analysis rests on a translation for tae'ae which I do not find substantiated in the sources on the ancient Maohi. Actually, about the only explicit reference I have found to "collaterals" as a distinct category of kin is in Henry's account of mortuary practices. According to her the heva tupapa'u for "a member of the royal family" was performed by "... the young men and lads of the collateral lines and of the retainers" (1928:293), which may simply have been Henry's way of specifying all young men in the vicinity save members of the deceased's immediate family.

3 "Genealogical level" is more appropriate than "generation" since the latter also connotes biological coevality (see Needham: 1962a). Behavioral norms associated with the Maohi terms do seem to be formulated on the assumption that persons occupying the same genealogical level will be approximately alike in biological age, but actual incongruencies were probably so numerous that the two attributes should be distinguished.

4 In other words, I cannot offer the Maohi data as evidence for either Lounsbury's or Leach's (and Needham's, etc.) opposing views concerning the "primary function of kinship terminologies." The function is in Lounsbury's words: "... to delineate the relation of ego to the members of his personal bilateral kindred in such a way as to express some socially and legally important aspect of each of these relationships. From the kindred, these terms can be extended and reextended till they reach the sky." (Floyd Lounsbury, "A formal account of the Crow-and Omaha-type kinship terminologies," in Explorations in Cultural Anthropology, New York: McGraw-Hill, 1964, p. 382.) For opposing views, see E. R. Leach, Rethinking Anthropology, London School of Economics Monographs on Social Anthropology, no. 22, 1961; and Needham $1962 b$.

5 A rare exception occurs in a missionary journal in the LMS Archives (Crook, 
for 27 June 1820) describing the care given to a high-born infant, the son of "King" Pomare II: "The infant was most of the day at our house with Pomare vahine [i.e., "Queen" Pomare], who is his nurse. Our daughter Mary is denominated his mother being the friend of the Queen.... The child is also called Mrs. C[rook]'s son, because she has the principal charge of it."

6 For a metaphoric usage, see the following Tetunae precept: "Ia tura ite ta'ata te 'Ai'a, te metua i fanau iā ōtou”' (E. Salmon 1937:29). May the Homeland ['ai'a], the parent which gave birth to you, be respected by the populace.

7 "Pattèa is properly a word of endearment, equivalent to our mamma. This last the Taheitians likewise make use of in the identical sense that we do." (G. Forster 1777:II, 91n.)

8 Except qualifiers like pitoho'e: persons of one fraternity (LMS Dictionary), literally, "navel-one," i.e., probably, "uterine siblings."

9 By natal parent I mean the female who gave birth to the individual, or the male who accepted social "paternity" of it shortly after birth-regardless of his known or suspected biological role in conceiving it. For "foster" and "feeding" parents, see pp. 701-702, this work.

10 With a little "functionalist"-inspired ingenuity one could, of course, enlarge this list almost indefinitely; but these appear to me to be the most influential general factors (leaving aside factors of individual idiosyncracies, which resist generalization but which cannot be ignored in many of the particular family situations about which we have information).

11 See also note on conception prayers in Wilson 1799, p. 336.

12 See also metuatavai, a parent that adopts a child; tamaiti tavai, an adopted son, metua fa' $a^{\prime} a i$, a nursing parent; metua fa'a'amu, the same as metua fa'a'ai (LMS Dictionary).

13 In the middle of this range of practices was one alluded to in a memoir of Tati Salmon describing the alleged last "ceremony of ordination" for an ari'i rahi to have been held in Tahiti: "As the time approached [for the Title successor to be born], representatives from the different members of the family began to arrive to adopt the expected child according to old custom." (1910:41)

14 For example, the young chief Tu (Pomare II) was described as having been "adopted" by his "cousin," Temari'i (Teri'irere), who was only some ten years older than he. In this connection we are told, "Between his natural father, Pomare [I], and his adopted father, Temarii, the young Tu preferred the latter, and sooner or later everyone knew that Temarii would help Tu to emancipate himself and drive Pomare from the island" (Adams 1901:122-123; see chap. 22, this work).

Maohi were also described as having "adopted" Europeans (see, for example, Corney 1919:183), a practice which will be described in another context.

15 It will also be recalled that Henry described sorcerers as "adopting" the spirits who served as their "fetchers": "The magicians adopted them as sons and daughters, carefully observing the prestige of their different ages and addressing them accordingly" (1928:203).

The sorcerers were known as their fetchers' metua-tahutahu, and addressed them as ta'u tamari'i (my children) (Henry 1928:204, 207).

16 One of the few indications I have found that fosterage involved special behavior 
is a passage in Orsmond's unpublished notes on the Arioi sect. The passage in question occurs in a section dealing with the special clothing worn by Ariois, and it describes one such costume worn by novices (in this case, hua pipi, fatted creatures) as the one having been given them by their metua pori i fa' $a^{\prime} a m u$, the parents who fed them to make them fat. (Orsmond: Arioi)

17 In his perceptive study of fosterage in a modern rural Tahitian community, the anthropologist-psychiatrist Levy has advanced beyond a suggestion originally made by Firth (1936), to the point of stating that "relationships between all parents and children are [seen by Tahitians to be] conditional," whether based on descent or fosterage (this is seen to be contrasted with the Western view that such relationships are "categorical"). In other words, it is the history of the relationship, and not an ideological generalization about the absolute rightness of the descent-based tie, that determines the quality of the specific "parent-child" relationship. (Levy 1970)

We have too little relevant data on the ancient Maohis to allow us to test this intriguing notion. My guess, however, is that if Levy's hypothesis were applicable, it would have been so among families of inferior social position. Among those of superior social position, where important goods were transmitted by "descent" and where much pride was manifested in pedigree, I suggest that "parent-child" relationships based on "descent" were viewed as being more "categorical." (This does not mean that such relationships were inevitably affectionate, but rather that they were not viewed indifferently.) In support of Levy's analysis of the modern Tahitian institution, it should be noted that the ancient Maohi preoccupation with Titles and pedigree has almost completely disappeared.

18 Again those readers who are skeptical of the relevance of myths to an understanding of how the Maohis conceptualized social relations should recall that, according to my formulation of "social structure," even if there were little or no congruence between myth and norm, or myth and current historical events, the very fact that myths were told and retold (the only way they were able to survive in this nonliterate society), and presumably believed in by some individuals, makes them a part of the society's concept of the possible. Actually, I suspect that the continuous retelling of a myth does usually indicate some congruence between it and actual practice, or between it and norm, either approbative or disapprobative-for example, a story about attempted patricide (of which there are several) may not by itself imply either approval or disapproval of the act, but it does at least imply an interest in the relationship so involved. In contrast, I know of no Maohi stories about attempts to kill, say, a mother's brother.

19 I shall not enter into a controversy concerning the precise nature of the relationship between Maui and the sun; suffice it to say that in this particular account the latter is referred to as "his parent" (tona metua).

$20 \mathrm{Ta}^{\prime} u$ tiare 'apetahi'oe, which is defined by Henry (1928:61) as a term of endearment for "... a darling child or loved one," would appear to have a broader application.

21 De Bovis' statement implying that all marriages required also the approval of "the local chief" is probably too far-reaching (1909:32). 
22 A historical exception was recorded in the case of the youth who was obliged to withdraw from his union with an "aunt"-i.e., a "mother."

23 Some of the obscurity enveloping the term taea'e undoubtedly derives from its literary enshrinement in earliest translations of the Bible by missionaries who required a native term for the biblical "brethren." After a generation or two of Bible reading it would have been surprising indeed to find any Maohis aware of all older meanings of the term. (See also Burbidge 1930:267)

24 See also a usage recorded by Orsmond (Arioi texts), taetaea'e arioi, which he or some subsequent editor translated as "the fraternity of Arioi." But see Marau's terms, under my discussion of tua'ana.

25 See, for example, pitoho'e (pito the navel; the navel string), persons of one fraternity, i.e., uterine siblings (LMS Dictionary).

26 See, for example, Henry 1928:474.

27 Handy's definition of matahiapo reads as follows: "first born, male or female. Also applied to all representatives of a family stock descended in the line of first-borns. Thus, if I belong to a matahiapo family it means that at least one parent was a first born right back to Taaroa. My first born will carry on the matahiapo. All others are teina." (1930:23)

28 A character in the legend of Rata addresses his wife, who was not recorded as having been a consanguine as well, as "... my tuahine" (Henry 1928:470), but I believe this usage to have been uncommon and probably derivative.

29 This was the Hema who was also favored over his elder brother as a consequence of having deloused their mother, a chore which the elder brother disdained.

30 One possible "functional" explanation for this featuring of a younger sibling's greater strength and skill might be put as follows: If Maohi descent-based kincongregations had branched off in a consistently seniority-based manner, and had been intra-and inter-structured entirely on a seniority basis, then one would be inclined to expect an oral literature consistent in its preoccupation with strong, talented, and so forth, firstborns. Since, however, kin-congregations did not consistently branch in this manner, and were not always so structured-that is, since younger siblings were often in fact more enterprising and more influential than their elders-the oral literature served not only to reflect such circumstances, but to help institutionalize them as well.

31 According to Handy (after Marau) there were two other terms used for "grandparents": hanahana, "the grandmother was hanahana of the child (used by Hui Arii only)," and ti'itae, "the grandfather was ti'itae of the child (Hui Arii)" (Handy 1930:23). The LMS Dictionary definitions of these words strongly indicate, however, that they were not kin terms as such: hanahana, splendour, glory, awfulness; titae, a parent, a term of endearment used by a child for his father or mother.

32 The LMS and Jaussen dictionaries have hinerere, which is incorrect.

33 See Panoff 1965. The LMS Dictionary entry, "ruahine'aimamau [literally, old woman-or goddess-food-abundance-of], a female ancestor of the third generation back, and who takes care of her posterity," is found in no other source and is perhaps too specific to have been a general kin term.

34 I refer to the timing of kin-Title succession, whereby the society's most honored 
statuses were held by individuals of the younger genealogical levels. Something of the same notion was expressed by Panoff, who, however, emphasized the more tangible side of the transactions involved: "Autrement dit, la langue situe le sujet parlant, d'une part, en face de 'vieux' et, d'autre part, en face de personnes qui sont distinguées selon qu'elles sont des conjoints possibles ou interdits et qu'elles sont ou non des héritiers. Tout se passe donc comme si les Polynésiens ne se préoccupaient des différents status que pour les transmettre à d'autres et non pour les acquérir eux-mêmes de ceux qui les détiennent. Ce n'est sans doute pas par hasard que ces sociétés ont un terme spécifique pour désigner ceux de leurs membres qui, bien que considérés comme adultes (soit à partir de l'âge de 15 ans environ), n'exercent pas encore de responsabilités: les mots tahitien taure'are' $a$ et futunien tauleleka s'appliquent aux hommes qui n'ont pas encore fondé de famille et ne sont donc des 'vieux' pour personne." (1965:84, italics in original)

\section{CHAPTER 18}

1 According to the LMS Dictionary ture was derived (presumably, under the influence of the missionaries) from Hebrew torah.

2 The expression "tainted the blood" is, of course, a translation, and evidently a very loose one. We are not given the words used in the original Maohi text, but suspect that 'taint' is less appropriate a gloss than, say, 'adulterate'. For "explanations" in physiological-or psychical, or mystical-terms of this proscription see chap .13, section on conception.

3 In the legend of Taruia of Tahiti, translated into even more sugary prose, the handsome young hero wins the maiden's affections and hand in marriage despite the seeming disparity in their family positions (she is the daughter of a "king," and he the son of a petty chieftain), and in the face of a rival of "royal" status (Henry 1928:623-632). Evidently the disparity was less than would appear-or perhaps some European romanticism has crept into the retelling of the story.

$4 P u^{\prime} e$ appears to have had the same usage as hui, although in modern Tahitian it is more conventional to speak of hui ari'i and pu'e ra'atira.

5 See chap. 16.

6 LMS Dictionary; Jaussen 1898:94; Handy 1930:7; Beaglehole 1955:134; etc. Adams, purportedly paraphrasing Ari'i Ta'ima'i, wrote: "We believe ourselves to belong to the great Aryan race-the race of Ari'i-and our chiefs were Ari'i, not kings" [!] (1901:7).

7 Taraho'i was the principal marae of Pomare's home district of Arue.

8 For an account of the offspring of misalliances, see section on recruitment, this chapter.

9 See T. Salmon 1910.

10 De Bovis identified 'iatoai with "tuuhou," stating that the former was the label used for these "nobles" in Tahiti and Mo'orea, and the latter in the Leewards (1909:18). If "tuuhou" was his rendition of to' ofa, then his explanation is made dubious by the circumstance that Morrison, whose ex- 
perience was on Tahiti, used only "towha." Moreover, de Bovis' "tuuhou" is suspiciously close to the LMS Dictionary entry, tuhou, a novice, a newcomer; young, inexperienced. See also Handy 1930:90.

$11 T e^{\prime} a$ (also teatea) is defined in the LMS Dictionary as "white." In modern Tahitian, te'a covers a wide spectrum of colors from white to light yellow, as it probably did in the past; but since most of the sources translate it as "yellow," I follow that convention here.

12 See chap. 3, and Henry 1928:338. Also, according to Henry, "The 'ura girdle was an emblem of the aurora in the sky" (1928:192).

13 Handy 1930:85. See also Henry 1928:403.

14 For example, the opening line of a prayer states: "Tahiti'a mai, e te Atua, tohiu maro e, i tohiu tahu'a nei. Hearken, O god, inspirer through the loin girdle, to thy body of priests!" (Henry 1928:199.) For parallels in other Polynesian societies, see E.S.C. Handy 1927:143ff.

15 For an excellent Polynesia-wide study of this topic, see Luomala 1951.

16 See Luomala 1951:55; de Bovis 1909:22.

17 According to the LMS Dictionary a second meaning of ra'atira was an officer on board a ship; but this may be a post-European accretion.

18 It is likely that Ellis' acreage figures referred to the missionary period-that is, after 1798-by which time most surviving units' landholdings had increased in size as a result of the radical depopulation that had taken place between 1767 and then.

19 "Capite ... occurring in tenere in capite to hold (of the king) in chief; whence tenant, tenure in capite, and capite in Law Dicts, as the name of a tenure by which land was held immediately of the king or of the crown" Shorter Oxford English Dictionary.

20 The problem of identifying the referents to this term is complicated by the fact that after 1815, when all of Tahiti and Mo'orea became subject to Pomare's rule, it became fairly common to apply the label ra'atira to all other (subtribal) chiefs, on the basis that the only Ari'i-that is, Te Ari'i, The Ari'i-was the monarch himself (or, herself). At the same time, hui ari'i continued for a while to be applied to members of that hereditary class.

21 Nothing is reported, however, of the class to which such 'Oro progeny were assigned.

22 In all specific evidence on formal "adoption" (tavai) that I have discovered, the foster parents and child were of the same class, and the same situation prevailed in most instances of bond-friendship.

23 E.S.C. Handy's comprehensive theory of Polynesian racial-cultural history was put forward in his Polynesian Religion (1927), which postulates an (Asiatic) Indian source for the first wave to populate these Islands, and a South China source for the Ta'aroa-worshiping, second-wave Hui Ari'i.

24 See, Henry 1911; T. Salmon 1910; Emory, Marae Traditions.

25 But, in a criticism of Handy's specific interpretation, Piddington (in Williamson 1939) appears to have accepted a modified "conquest" theory to account for Ra'iatea's so-called social superiority over Tahiti-Mo'orea. He stated that "There were, of course, recorded instances of successful invasion-for exam- 
ple, the conquest [?] of Tahiti by people from Ra'iatea" (p. 225). About the origin of the manahune he said, "It seems much more probable to the present writer that the Tahitian manahune were simply an accumulation of people vanquished in successive wars; flight to the mountainous interior was the obvious course for such unfortunates, while the vistors appropriated the more desirable land along the seashore" (p. 226n1).

26 I draw attention to a statement by Ellis quoted in chap. 16, this volume, that the custom of early succession to "titles and offices" was characteristic of members of both ari'i and ra'atira classes (Ellis 1829:II, 347).

27 For example: tupuari'i [tupu, to grow], a fine grown person (LMS Dictionary). "The Chiefs are in General taller, stouter and of a different appearance from the Common People and their Weomen are also larger and fairer then the lower Classes" (Morrison 1935:169). Cook, in writing of the Marquesans noted: "The men are in general tall, that is about 5 feet 10 inches or six feet, but I saw none that were fatt and lusty like the Arees of Otaheite" (Beaglehole 1961:374). And, with undoubted exaggeration, Bonocorsi wrote of ari'i, that they "are all stout, some to ungainliness, so that they have two Indians constantly kneading their legs and even then are scarcely able to stand upright" (Corney 1915:55).

28 There may indeed have been some basis to this alleged class difference in body odor-i.e., ari'i women were undoubtedly better able to avoid dirty and sweaty work and to indulge themselves in frequent bathing and fragrant cosmetics. See also the alleged social distinction attached to long fingernails: chap. 6; G. Forster 1777:I, 283; J. Forster 1778:271.

29 Moerenhout implied, and Rodriguez stated, that only ari'i practiced archery (Moerenhout 1837:II, 148-150; Corney 1919:45); but other reports imply that non-ari'i also participated (e.g., LMS Transactions).

30 See also Beaglehole 1962:I, 337, 338; Henry 1928:286-287; J. Forster 1778:415; Ellis 1829:II, 179-181; Bligh 1792:153.

31 See also Bligh 1792:156, 158, 159b, 160. Bligh's is the only description I have found concerning kava-drinking etiquette, which constituted important facets of social stratification in Samoa and Tonga.

32 A marginal supplement to this passage adds “... which we were likewise liable to misunderstand" (Beaglehole 1961:424n3).

33 Cf. Henry 1928:201: "Kings, noblemen, and plebeians, according to their capabilities, were food-gatherers, fishermen, planters, and menial servants to the gods."

34 The reference was to the legend which identified Tahiti-Mo'orea with a "fish," a part of Ra'iatea separated by an act of sacrilege, and on which no ari'i at first resided.

35 One of the preceptual admonitions addressed to an ari'i reads, "Eiaha te upoo ia taea i te horomiri ate vahine Puti, e oro to upoo e au i nia ia ratou" (E. Salmon 1937:23). Handy translated this, "Allow not your head to be touched [stroked] by the hands of the woman of low birth. Your head does not belong to them." (1930:41.) But I have found no other occurrence of Puti, for this or any other meaning. 
36 I emphasize the ideological-“suppositional" - nature of this statement; in actuality-i.e., "historically" - it was only partially valid.

37 But see the exception reported in chap. 20; also in Morrison on visiting (1935:190).

38 I do not know whether respectful deference had anything to do with the matter, but an account of a football match between Greater Huahine and Lesser Huahine, in 1809, does imply that class differences in behavior carried over even into games. "The people as usual on these occasions [i.e., a large public-house thatching party] are feasting, drumming, dancing wrestling \&c. Twice today they have been near quarreling, they were divided into two parties, Huaheine rahe \& Huaheine ete. The wrestlers of Huaheine rahe beat those of Huaheine ete \& they in their turn got the better of Huaheine Rahe in kicking the foot ball but there was no fair play the Chiefs being in the party of Huaheine Rahe." (Davies, Journal, 14 June 1809, LMS Archives)

\section{CHAPTER 19}

1 As far as I can discover, ancient Maohi society had not yet begun to harbor the kind of husband-"male wife" ( $m a h u$ ) domestic establishments to be found occasionally in modern Tahiti.

2 Although some of the sources do so imply (e.g., Morrison 1935:185\& Bligh 1792:II, 152).

3 Also, although I have presented a hypothesis concerning the meaning of the $\bar{a} m o^{\prime} a$ rite accompanying some (or all?) nuptials (see chap. 13), I cannot be certain that my hypotheses is the right one.

4 In this connection in Henry's version of the marriage of the god 'Oro to the Porapora maiden Vairaumati (an event that led to the founding of the Arioi sect, as will be discussed in chap. 22), the following passage appears: "Soon afterwards, their marriage took place, the bride having many valuable gifts for the occasion, while 'Oro, who had nothing terrestrial to present, was at a loss to know what to do to save himself from ridicule on such an occasion" (1928:232).

5 Rey-Lescure distinguished between hoa and vahine, the former being "wife" and the latter "concubine," or "woman, in general" (1947:286). This corresponds to "respectable" modern usage, but whether it prevailed among the ancient Maohis is not known to me.

6 See chap. 15. The only Maohi word or phrase I can find approaching English "drudgery" or "menial" was haupau, to toil, to work hard (LMS Dictionary), which does not appear to have carried the additional meaning of "ignoble." In terms of the ra'a-noa contrast, and of the generally higher social valuation accorded many exclusively male activities, it could be suggested, perhaps, that women's work was more "ignoble" than men's; but that kind of comparison requires a better knowledge of Maohi mental attitudes than I possess.

7 While de Bovis did not specifically characterize wives as "slaves" of their husbands, he did imply something of the same thing when describing their various jobs, eating arrangements, and ritual restrictions. By his own stan- 
dards such customs may have been considered to be "exploitation," but it is questionable whether the Maohis in general, or even Maohi wives, considered them to be such.

8 Whatever the immediate motive for such wifely actions, saving the corpse from sacrifice did have the practical effect of sparing other family members, including the wife, from the threat of future sacrifice.

9 The cases of so-called altruism described earlier may also be viewed as episodes in a chain of exchanges, although the narratives in question do not characterize them in these terms.

10 In several of the stories that appear only as "translations" in her Ancient Tahiti, I suspect Miss Henry of having taken some rather over-romantic, un-Maohi liberties with the original text; but I reproduce them just the same for want of the original texts themselves.

11 For example, Crook recorded in his journal of March 1824 that "The wife of our principal Chief has taken a fit of jealousy, causelessly as far as we can learn and has caused some disturbance. This we find has frequently been the case." (20 March 1824, LMS Archives)

12 See also the following observation by Bligh: "The infidelity of a Wife, any further than the husband permits or aproves, is considered whoredom and punishable by himself; but while he approves of the Man she is connected with, they may Sleep under the same roof, so that it is not uncommon for a Husband with his three Wives to sleep on the same floor, and they with their Gallants" (1792:152).

13 Moerenhout's visits to Tahiti extended over the years 1828 to 1846, and one cannot always discern whether his generalizations referred to that era or to former times, or both. His reference to husbands prostituting their wives for money applied mainly to the Early European Era, but I am inclined to accept his major thesis as applicable to both. Leaving aside the chaste romanticism of some of Henry's translations, Moerenhout's unvarnished appraisal is confirmed by most of the earlier observations as well.

14 See also Ropiteau (1932:124-125) concerning Hotuhiva, and the LMS Archives, Journal of Elder and Wilson for 10 July 1803 concerning a runaway wife.

15 Andrew's more recently compiled dictionary gives the following: 'aupurua, parents of a married couple ('au, plural; purua, parent); 'apuru'a, parent by marriage, father- or mother-in-law; purua, parent-in-law (cf. puru, protect).

16 Handy listed this as tauete, and ho'ovai as ho'oai, on the authority of Marau (1930:23).

17 The Burbidge grammar-vocabulary also lists the following:

Man speaking: elder brother's wife, tua'ana vahine.

Man speaking: younger brother's wife, teina vahine.

Man speaking: sister's husband, tuahine tane.

Woman speaking: brother's wife, tu'ane vahine.

Woman speaking: elder sister's husband, tua'ana tane.

Woman speaking: younger sister's husband, teina tane. (1930:269-270)

These are evidently modern usages; they may also have been current in 
ancient times, but I have not come across them in texts originating in earlier eras.

18 Included under my unfelicitous label semi-marriage are those types of heterosexual union lacking one or more of the features by which I-and to a certain extent the Maohis themselves-have identified "marriage." See definitions at beginning of this chapter.

19 The meaning assigned to tiupoorua (ti upo'o rua) is a ti root out of which grows two stems; fig. a person who has beside his wife, another secret one (LMS Dictionary). A union would not be a marriage (in the sense we use the term) if it were wholly secret, and hence this must refer either to a man with a secret mistress, or to one who had entered into two recognized marriages in places far enough apart to preclude such information from passing between them.

20 The LMS Dictionary translates ha'apae, to put off, lay aside; to divorce. Lacking textual examples I cannot, however, discover whether this meant mere separation, or final divorce, or both. More poetically, in his plaint at being deserted by his mistress (wife?) Moanarai refers to her as having "cut the umbilical cord" (Alexander 1893:56).

21 For example, the "queen" in the legend of the king's favorite eel remained married to her wicked husband even after he had gratuitously slain her grandparents (Henry 1928:619).

\section{CHAPTER 20}

1 Hoa may have had the general, informal meaning of "companion," inasmuch as it is used in modern Tahitian not only for friend, companion, even acquaintance, and (in church parlance) for spouse as well; but modern usage is no guarantee of pre-European meaning (Finney 1964a). G. Forster's characterization of "king" Pomare I's hoa evidently had reference to the latter's personal retinue and not to the kind of friendship pact now under consideration: "The only person exempted from the general custom of uncovering the shoulder was the king's hoa, one of his servants, whom we could not better compare than to the lord in waiting, and of whom we understood there were twelve who officiated by turns. Some of them were the same gentlemen who had displayed their dexterity before, by dealing out hearty blows to the crowd." (G. Forster 1777:I, 328)

In a passage regarding a woman who saves a slain warrior from being used as a sacrificial victim, Henry wrote: “... the good woman who [thus] interposed became a taua (bosom friend) of all his family ever afterwards" (1928:311).

2 The ceremony of "friendship" observed by Bligh and labeled by him "Errowwowah" (rauava-i.e., miro leaves; Bligh 1792:137b-138) seems to have been concerned more with intertribal alliances than with interpersonal friendship of the type now under consideration, although the two types of relationships did of course overlap. See chaps. 13 and 23.

3 Gunson (1964) distinguished dichotomously between taio pacts and what he 
labeled "friendship nuptials," but I believe we are concerned here with a more or less continuous series of contractual relationships, with or without āmo'a rites, rather than with two contrasting types.

4 The Lieutenant Corner referred to had visited Tahiti in 1791 on the Pandora, to capture the Bounty mutineers.

5 Parkinson 1773:68 and Corney 1919:6.

6 The case of Stewart, one of the Bounty mutineers, may have been an exception to this, but the matter is not altogether clear. Stewart was "married" to the daughter of a man described as being "... of great possession in landed property, near Matavy Bay" (Edwards and Hamilton 1915:106). At some point Stewart and the man interchanged names, but whether before or after the "marriage" is not specified. It may be of course that this relationship was conceived less in terms of "friendship" than of "fosterage," as was the case of Pomare II's fosterage of a prospective son-in-law.

7 The date of this incident was 1826-some eleven years after Tahiti's "Christianization"-but I include it on the assumption that this kind of social relationship had not been radically changed as a result of European contact.

8 See also Morrison 1935:237; Adams 1901:24; and Ellis 1829:II, 369.

9 Ellis emphasized the privileged nature of the friendship pact in a passage on conjugal "jealousy" quoted in chap. 19.

10 The original text of this version (which I cannot locate) was evidently recorded by Orsmond in 1830. My rendition is based on a French translation of Orsmond made by Ahnne.

11 In her survey of Tahiti's districts, Henry made the following reference to Raure'a: "Hina-rau-re'a was the most famous surf rider of [Mahaena]; she was the wife of Turi the demigod" (1928:72).

12 This assertion, like many others made by Morrison is so very categorical that it can be taken, I suspect, as reflecting Maohi norms rather than invariable practice.

13 This qualification was also expressed by Dr. Gunson in a personal communication to me.

\section{CHAPTER 21}

1 "All the trouble of breeding, bringing up, and fattening the hogs is allotted to the lowest class of people" (G. Forster 1777:I, 315).

2 "The Low-Islands have a race of dogs with long white hair, which the natives employ in fringing their breast-plates or war gorgets; and these low islanders cannot cultivate the mulberry-tree on their sandy, barren ledges of lands, which includes their salt lagoons; therefore these reciprocal wants, form a kind of commerce between the inhabitants of the high and low islands, and a mutual exchange of superfluities." (J. Forster 1778:366.)

3 Also it is suggestive, although of course not decisive, that in another nearby Polynesian society tapairu designated females of high birth (Barthel 1961). In this connection, the wicked maid-servant in the legend of Huriitemonoi-the one who attempted to usurp her young mistress's position-could not have been a tapairu, as I imagine the status to have been. 
4 Adams described jesters as "a class of men much petted and allowed many liberties by all Arii. Among other privileges, they were always in the habit of receiving some of the best shares in distributions of food by the Arii." (1901:78)

5 As noted earlier, it was not unusual to find young men of superior social position, even including "Young Brothers of Chiefs" (Morrison 1935:167) working as servants, but whether these also were labeled teuteu is not certain.

6 While too few manifestations of Maohi "trance" behavior have been recorded for comparison, there are nevertheless some suggestive similarities between it and certain other characteristic forms of dancing, anger and grief display, and even copulation-all of which contained elements of "frenzy."

7 One exception is a passage in Davies' journal, quoted earlier, in which the god Tane, speaking through a taura, admonished the chiefs "to leave this part of the Island [Huahine] with the Uru [breadfruit] \&c. for the gods and the Priests" (13 January 1808, LMS Archives).

8 According to the Spaniard de Hervé, "Each District [of Tahiti] has but one Pure [tahu'a pure], and one Eri [ari'i] or Cacique" (Corney 1913:357), but this is obviously an oversimplification, based on slim information.

9 Turnbull 1813:365; see also Morrison 1935:180.

10 I cannot account for the fact that the Orsmond text quoted earlier singles out $\bar{o} p \bar{u}$ nui (rather than, say, priests in general) as one of the four categories of "specialists," along with ari'i, Arioi, and fishermen.

11 In some contexts 'aito and toa appear to be synonymous-both, in fact, being metaphors for the 'aito (or toa) tree, the hardwood (casuarina) favored for weapons. In other contexts toa appears to refer to fighting men in general, and 'aito to warrior-champions. For example: "Tia maira te reira tau toa, mai tana raau, e haari ta te taata haere noa, e omore ta te taata aito ra. And each of those warriors stood with his weapon of wood, the simple followers had coconut clubs, the heroes had spears." (From the legend of Honoura, Henry 1895:283.) But against these alleged semantic differences are assertions, by Ahnne (1926:9) and M. Salmon (1927:264), that 'aito was simply a substitution for toa (an example of the custom of $p i$ ) following upon Pomare I's name change to Vaira'atoa.

12 A line in a rauti chant reproduced in Henry equates 'aito with ra'atira: " $E$ pu'u te 'upo'o o taua fare 'aito ra. Bumped will be the heads of the warriors of that [enemy] camp. I te 'omore nei e tahe te roi mata o te ra'atira ra. From these spears those gentlemen's tears will flow." (1928:309)

13 See also note 11, above, which reproduces the text describing common fighters as fighting only with coconut-wood weapons, and 'aito with 'omore.

14 Bligh reported having attended a heiva given at a chief's direction to honor one of his warriors "that had been at Morea and was used ill, and which caused a battle between the parties concerned" (1789:II, 61). See also the following excerpt from a rauti's battle chant extolling scars of battle: "A motu na te 'iri, e tihi tau tana. If the skin get cut, it is a professional ornament" (Henry 1928:307).

15 See also pä'aiea, mature, grown to perfection, as a plant; well informed or skilled, applied to a person. (LMS Dictionary) 


\section{CHAPTER 22}

1 For additional references to these ascriptions, and for a general discussion of the Society Islands' pantheon, see Williamson 1937.

2 Henry 1912:xxxi, 77; Moerenhout 1837:I, 257. See also Williamson 1937: 47-48.

3 See Williamson 1937:51-54, for a survey of beliefs and practices associated with Tane. Williamson proposed that Tane was tutelar of Tahiti's Teva (among other so-called clans), and his arguments are no more implausible than most such inferences drawn from Maohi myth (1924:218 ff.).

4 This is Lavaud's rendition; I do not know what the original was, but it is unlikely to have been a word meaning "color."

5 This is contrary to Mühlmann's curious conclusion (1955:169), which was based on the same versions cited here.

6 For example, see Henry 1928:304, 322.

7 It is interesting to note that Ta'aroa the Father is described in this and other cosmogonic myths as having continued to be "more important" than his offspring, contrary to Maohi notions about succession to human kin-Titles, wherein an heir to a Title superseded the parent-incumbent upon birth, at least in terms of ceremonial prerogatives.

8 Probably, Ha'oa'oa. These two also appear as 'Oro's sisters in the Orsmond-Henry version of 'Oro's birth, which may be explained by the fact that Tahiti was the source of both these accounts.

9 The original text from which Henry prepared this version has also been translated by Ralph White, who, characteristically, took fewer liberties with the text than was the practice of Miss Henry. If our interests here were mainly linguistic I would reproduce the White version, but since the narrative itself is what most concerns us now I choose Henry's. In any case, as White himself acknowledged (personal communication) so much of the original Orsmond-recorded text is in words long since forgotten, it is difficult to judge which of the alternative translations is more "accurate."

10 Attempts to etymologize 'Oro end up as indecisively as most such efforts involving unphonemicized and uncontextualized Polynesian words. See for example, Andrews and Andrews (1944), “'oro, a person, man; affection, desire; vibrate, shake; etc."; also Kooijman's proposal (based on Williams) of a correspondence between Maohi 'Oro and the Maori god, Koro, "who was the teacher of dancing and the god of desire" (1964:123). Handy identified 'Oro as "the god of fertility" - the Maohi equivalent of Rongo in New Zealand and Lono in Hawaii (1930:61) - while the missionary Davies identified him as a "deified man" (Newbury 1961:65).

11 Again, I call attention to the problem raised by Maohi beliefs regarding the phenomenon of a god's capability of being simultaneously in several places (e.g., in ata, in human oracles, in images). Are we dealing here with a single deity capable of omnipresence, or with a whole category of more or less identical deities or of the many attributes of a single god (as was the case, for example, with the Olympic pantheon)? Unfortunately, I know of no way of 
answering this question in terms of Western logic; as for Maohi logic, there is no evidence that this question ever arose!

$12 \mathrm{To}^{\prime} \mathrm{O}$ of this general form varied in length from six to eight inches to as many feet (Ellis 1829:II, 220-221), but all those believed to have been identified with 'Oro himself were among the longest known. For a useful study of such images, including photographs and descriptions of most surviving specimens, see Kooijman 1964.

13 Some writers have proposed that 'Oro's first foothold in Tahiti was at Atehuru, and that the attribution of priority to Tautira was a device to strengthen one dynasty's claims to preeminence.

14 According to Henry, all marae dedicated to 'Oro had stones shaped into the likeness of turtles incorporated in their walls. Also, Green and Green (1968) suggested that their type III M marae were identified particularly with 'Oro; if so this would represent a most significant development, and perhaps not a unique one-i.e., the association between a new religious movement and an innovation in architecture.

15 An interesting example of the imputed rivalry between these two gods is found in Davies history, under the date of June 11, 1802: "News having been brought from Moorea, that war had commenced there, some of the people (Teioinia [te i'o i ni'a] that is of Afareaitu and neighbourhood) had rebelled against the king's government. In consequence of this, as well as the state of things at Tahiti, eupootami [e upo'o tama'i] or council of war was held when two men pretended to be inspired, one by Oro and the other by Tane, they disputed for some time, at last it was agreed to send over a party to Moorea to assist the king's friends. This was done, and tho' several had been killed, peace was soon restored there." (Newbury 1961:52)

16 According to de Bovis, Orotetefa, who was considered "the founder of the Arioi sect," was member of a maro te'a family (i.e., an ari'i) associated with Porapora's Vaiotaha marae. "It is said that he was a varuaino (wicked spirit), which is to say that he was an individual possessed by some god." (1909:36)

17 It is, of course, not unlikely that some of the imputed kin-relationships among gods that I have been listing represent syncretisms, in kinship idiom, of previously "unrelated" mythical personages. And it is possible that some of the attributes, functions, and manifestations imputed to 'Oro represent assimilation of attributes, etc., once associated with other gods. (See for example, Handy's notion about Ro'o having become 'Oro [1927:109].) I am concerned here, however, with more recent, better circumstantiated instances.

18 Williamson 1924:208; Lesson 1839:400.

19 Some skepticism undoubtedly prevailed in this society, and there were probably wide differences of opinion concerning the relative powers, etc., of individual spirits; but I hold it to be highly unlikely that any eighteenth-century Maohi questioned the existence of 'Oro. Indeed, events indicate that this god inspired more fear than most.

20 But see de Bovis on this subject: "Close by [some of] the principal marae associated with 'Oro worship were to be found ones of secondary importance 
consecrated to the god Tane, and it was to these latter that they carried the bodies of human sacrificial victims after these had been offered to 'Oro. I am even led to believe that every marae's charnel-house was specifically consecrated to Tane, who seems to have thrived on corpses." (1909:44)

21 In Orsmond's Arioi text they are referred to as a "fraternity," taetaeae Arioi.

22 Many other visitors to the Society Islands, and several other ethnologists, have written descriptively or interpretatively about the Ariois-including Rivers, Bastien, Webster, Schurtz, von den Steinen, and Frazer. The monograph Arioi und Mamaia, by Mühlmann (1955) is by far the most comprehensive and detailed study to appear so far, and while I do not agree with all the author's interpretations I have leaned heavily on his work for many ideas and references. In this connection, however, Mühlmann's synthesis is disadvantaged somewhat by his lack of access to such works as Bligh's journal of his second "Breadfruit Voyage," Morrison's journal, and unpublished records of the London Missionary Society.

23 Compare Miss Henry's rendition of this text with the following, which accompanies Orsmond's text itself: "O Fare, o God-be propitious to us, here is a pig for you, here is cloth, cloth for our festival of the comedians party. This is your share. Conduct us to the shore to which we are going, Give us a fair wind, a true East Wind. An impelling fire astern that we may sail with the softness of oil and the ease of a bed, Drive far away oh God the whistling in our senet. In to the harbour Farerea of Huahine, direct us, let us not stray away in the deep, but go fare to the land we purpose; compassionate your free adherents, but abandon us not, let no ill fame follow us."

24 The text on which Henry based her account also contains a section which White (personal communication) has translated as follows: "And in the lands where there are no chief players, they [the offerings] are to be borne to the ari'i's marae. For every ten canoes there is to be one thank offering. The person to whom the fleet belongs is to bear the gift. The players accept gifts. Lone uninvited visitors who drop in must bear their own individual gifts to the marae. The person who came hither to that country was to be fed and food taken to him, and gifts too for the members of the fleet."

25 See G. Forster 1777:II, 128; and Beaglehole 1961:415. In addition, Moerenhout reported: "According to tradition some of the expeditions originating in Ra'iatea, Huahine, etc. included as many as 150 boats, each carrying rarely less than 30-40 persons, and sometimes up to 100. Natives still recall festivals where more than 1000-1200 pigs were butchered." (1837:II, 132-133.) In contrast, Bligh reported seeing a group consisting of only fifteen who had traveled from Ra'iatea to Tahiti in one canoe (1792:175b).

26 This derives from Moerenhout's version; in the Orsmond version of the myth these two were designated, respectively, "the sacred pig for the arioi" and "the pig brought from far distant places to 'Oro."

$27 \mathrm{Hi}^{\prime}$ o niao, to scrutinize to find defects (LMS Dictionary).

28 In taking this position I differ from Mühlmann, who stated or implied that public entertainment was an almost exclusive specialty of the Ariois.

29 An assertion by surgeon Ellis, quoted earlier, contradicts the missionary Ellis 
on this point: "Their [the Ariois'] amusements during these meetings consist of boxing, wrestling, dancing, and making feasts and entertainments ..." (1782:I, 160).

30 On the basis of a statement by Lesson, Mühlmann concluded that the "ghostmasquers" were themselves Ariois. The statement in question reads: "Dans les cérémonies funèbres, tous les habitants non initiés devaient se tenir cachés dans leurs maisons, ou du moins se tenir éloignés du lieu ou les prêtres faisaient leurs prières" (Lesson 1839:406). Mühlmann based his inference on Lesson's reference to "non initiés," evidently reasoning-incorrectly, I believe-that Lesson was referring to "initiation" into the Arioi sect.

31 In this connection, a generic name applied to a lodge's chief Arioi was 'aito, which, one will recall, was also the honorific label applied to champion fighters. Be that as it may, I do not subscribe to the idea that all such chief Ariois were also war heroes. Nor can I find any indication that each lodge fought together as a unit.

32 This means probably that they stepped out of their roles as fighters to become "entertainers," and not that they themselves never engaged in fighting. See Mühlmann (1955:142) on this point.

33 This is Henry's translation. Literally, te'ā means "arrow" (and not "spear"), but since arrows were not used in warfare (during the eras under study at least) "arrow" makes less sense than "spear" in this phrase, which appears to connote "truce" or "peace."

34 "Diese Tatsache verliert ihre Paradoxie, wenn man bedenkt, dass der Gott der kriegerischen Besessenheit eben auch Herr über die kriegerische Besessenheit" (Mühlmann 1955:168).

35 Some ethnologists have considered this aspect of Arioihood so characteristic that they have sought to link the sect, historically, with "secret societies" of Melanesia. See Rivers 1914, Webster 1908, and von den Steinen 1925-1928.

36 “... ungewöhnliche, symbolhafte und dunkle Sprache” (Mühlmann 1955:56). Reference has already been made to certain distinctive features of Ariois' worship-for example, the fact that their "sacred-pig" offering was wrapped in special "Arioi" bark cloth, the use of perfume in rites directed to Romatane, etc.

37 In connection with this somewhat puzzling statement are some found elsewhere asserting that one of the two pigs that figured in most Arioi ceremonies-namely, the pig-on-the-pole (pua'a fata)-was reserved for eating by the black-legs. (The second pig, wrapped in red bark cloth, was offered to 'Oro himself, and was never eaten by humans.)

38 Moerenhout 1837:I, 491-492; Ellis 1829:I, 320.

39 Thus, Ariois differed from (other?) priests, who were not permitted to anoint themselves with mono' $i$ when performing their services. See chap. 3, section on priests.

40 Based on G. Forster 1777:II, 100; Montgomery 1832:I, 238 ff.; de Bovis 1909: 406; Moerenhout 1837:I, 492ff.; Ellis 1829:I, 322; Henry 1928:235-236.

41 See G. Forster 1777:II, 128; Wilson 1799:172; Ellis 1829:I, 321; Williamson 1939:116; Mühlmann 1955:28. 
42 I refer mainly to the reference to red-girdled black-legs. It is possible to infer from the wording that the text concerns the fate of this highest grade of Ariois only.

43 For a comprehensive review of this subject see especially Mühlmann 1955.

44 Including (according to one report) freedom from offensive odors: Nordmann states that, among other reasons, Ariois did away with their offspring because they objected to the smell of the latter's urine in their lodge houses! (1943:342)

45 A detail of the initiation ceremony added by Ellis is also explicable in view of the use of this behavior ritual in all Arioi public performances; I refer to the requirement that the initiate go through the $p o^{\prime} o$, or "flapping" movement, while calling out his district's geographic features. However, another detail of the initiation ceremony added by Ellis is considerably less comprehensible: "[The initiate] was then commanded to seize the cloth worn by the chief woman present, and by this act he completed his initiation, and became a member" (1829:I, 323).

46 I believe de Bovis to be referring to holders of kin-Titles, and hence use "rank" in the technical sense defined in chap. 16.

47 One Orsmond text characterized nontattooed novices as "those who sit lazily covered with cloth," an obvious reference to fattening; but that is as far as it goes.

48 The LMS Dictionary gives these meanings of $h e^{\prime} e$ as a verb: to purge or evacuate the body; to be swimming in the surf; to be in a discharged or banished condition, as one turned out of his place.

49 In a passage from Bligh, to be quoted later, hu'a pipi ("Hooepippee") is described as the name for the ceremony carried out among Ariois when visiting one another or upon returning home. In this instance the arrivees were returning from Tetiaroa, where presumably everyone had indulged in fattening, and hence $h u^{\prime} a$ pipi may refer specifically to the fattened individuals themselves; but this is a possibility I cannot further substantiate.

Also see the following comment on skin-bleaching: "Personal endowments being in great esteem amongst them, they have recourse to several methods of improving them, according to their notions of beauty. In particular, it is a practice, especially amongst the Erreoes, or unmarried men of some consequence, to undergo a kind of physical operation to render them fair. This is done by remaining a month or two in the house; during which time they wear a great quantity of clothes, eat nothing but bread-fruit to which they ascribe a remarkable property in whitening them." (Anderson, in Cook 1784:147)

50 Not so Mühlmann, who, by analogy with some Melanesian societies, not only accepted the Arioi fattening period as fact, but saw it as evidence of a standard "weibliche" stage in the process of initiation into full active Arioi membership. Mühlmann's theory is one of the most ingeniously constructed ones I have encountered, but it is based on a whole set of unsupported assumptions-about fattening, the sexual division of labor, mahu, etc. (1955:36-46)

51 "Vornehm ist einer [Arioi] nur, solange er ohne Leibeserben ist. Hat er einen solchen oder gar mehrere Kinder, so ist er ein Abgedankter, ein alter Mann 
oder 'alter Herr.' Diese aber mussten ja für die aktiven Mitglieder den Boden bebauen und handwerkliche Arbeit leisten." (Mühlmann 1955:103-104)

52 See Moerenhout 1837:I, 494; and Ellis 1829:I, 323.

53 Henry stated that the chief Arioi of Porapora was Puna ru'u, whose Arioi house was on Farerua peninsula (1928:103); that the chief Arioi of Huahine was Atae (p. 101); Henry (p. 93) listed Taura'a atua as Arioi chief of Mo'orea's Papeto'ai district; Mutaha'a was attached to Taha'a's "national" marae, Apuroa (p. 99); "Nouatoua" (Nuatua), "Maouaroa" and Nita do not appear in Henry's list, but "Manoura (Mano'ura) is identified there as chief Arioi of Hitia'a, Tera'aroa as chief Arioi of Tautira and Teahupo'o, and Pa'a as chief Arioi of Fa'a'a. The other chief Ariois listed by Henry for Tahiti were Raupa'a (Mahaena), 'Upaparu (Tiarei), Va'a iti ma te toi i te piha ia teta (Papeno'o), Ti‘a au (Ha'apape), Puahaha (Punaauia), Hita and Uri (Paea), Mata'a (Papara), Terupo (Atimaouo), Tiatia (Pape'uriri), Tiapou (Papeari), Tumatariri (Vairao), Heiva ino and Upa upa ino (Mataoae and Toahotu), Tuturumaa (Pue), and Huaatua (Afa'ahiti). (pp. 70-88)

54 At the time this text was recorded, between 1846 and 1850, there was only one ari' $i$ in Tahiti, Queen Pomare herself; all other persons of eminence or power were labeled ra'atira.

55 Mühlmann's explanation for such procedures is as follows: "Auch hier ist die Logik vielleicht die: Wer jemanden zum 'König' macht, kann von dessen Vater als einem 'alten Herrn' eine Sonderabgabe verlangen. Vielleicht aber handelt es sich auch einfach um einen Heilssegen, den der Arioi einem Kinde spendet und der natürlich zu vergüten ist." (1955:105)

56 According to one missionary, "They are looked upon as gentlemen or noblemen are in England or Ireland, by the lower ranks of men there" (William Henry, Journal, "Early Days in Tahiti," 8 March 1797, LMS Archives).

57 For example: "The meeting of the arreoys gave rise to these frequent dramatic entertainments; their presence seemed to enliven the whole country, and to inspire all the people with extraordinary cheerfulness" (G. Forster 1777:II, 142).

58 Except for such general statements as that put forward by G. Forster (as reported in Mühlmann 1955:48): "From every distinguished family one or more persons became Ariois."

59 Most myths connect the sect's founding with an early Tamatoa, the kin-Title borne by the individuals who were for some generations also sovereigns of the Ra'iatea tribe, which by genealogical reckoning would locate the event between the fifteenth and eighteenth centuries A.D.; but I leave such problems to specialists who apparently have more faith in such reconstructions than do I. See, for example, Mühlmann 1955; Newbury 1961: xxxvi; Williamson 1939.

60 Henry's list of Arioi lodges and masters is unlike Orsmond's in several respects (a puzzling situation, inasmuch as her data derived mainly from Osmond). For example, she attributed three lodges each to Mahaena, Pa'ea, and Papara-but only one master for each district. Also, she and Orsmond disagree on the Title names of the masters for Atimaono, Vaiuriri, and Tautira. Despite the insistence of Henry and others that every district had both a male 
and female contingent of Ariois, headed up, respectively, by a lodge master and a lodge mistress, all the lists of such officials seem to pertain only to the former.

\section{CHAPTER 23}

1 The LMS Dictionary translates 'utuäfare as a person's own home or house; also the family or household of a person. I may be reading too much into the phrasing of this definition, but I find in it an ambiguity that other textual examples (e.g., Henry 1928:450) do not clarify. Was the word applied to such units in general or to them only in reference to particular individuals? Did the Maohis speak of, say, X number of 'utuäfare in such and such a place, or did they say that in such and such a place are the 'utuäfare of $\mathrm{A}$, of $\mathrm{B}$, of $\mathrm{C}$ ?

2 "Six is the largest Family of Children I have met with, and in common I have not found above three, but these Families are numerous" (Bligh 1789:II, 79).

3 See above, chap. 7; also, "They do not build them in villages or towns but seperate each from the other according to the size of the estate the owner of the house possesses ..." (Beaglehole 1962:I, 339).

4 To translate these figures into individuals one can multiply the number of households by six or seven, according to the estimate of the Duff officers. This would result in an average of about fifty individuals per neighborhood, and two modes of around sixty and eighty-seven, respectively.

5 It may be that mata'eina'a was used in the same manner as is the Nuer word cieng: "The variations in the meaning of the word cieng are not due to the inconsistencies of language, but to the relativity of the group-values to which it refers ... A man is a member of a political group of any kind in virtue of his non-membership of other groups of the same kind. He sees them as groups and their members see him as a member of a group, and his relations with them are controlled by the structural distance between the groups concerned. But a man does not see himself as a member of that same group in so far as he is a member of a segment of it which stands outside of and is opposed to other segments of it. Hence a man can be a member of a group and yet not a member of it. This is a fundamental principle of Nuer political structure. Thus a man is a member of his tribe in its relation to other tribes, but he is not a member of his tribe in the relation of his segment of it to other segments of the same kind. Likewise a man is a member of his tribal segment in its relation to other segments, but he is not a member of it in the relation of his village to other villages of the same segment. A characteristic of any political group is hence its invariable tendency towards fission and the opposition of its segments, and another characteristic is its tendency towards fusion with other groups of its own order in opposition to political segments larger than itself." (E. E. Evans-Pritchard, The Nuer: A Description of the Modes of Livelihood and Political Institutions of a Nilotic People [New York: Oxford University Press, 1940], pp. 136-137. 
6 In their list of Tahiti's "districts" the Duff officers recorded one, Wharoomy [Farumai?], as having contained only one mata'eina' $a$, and as having had its own "Presiding Chief"; all other sources, however, describe the territory (and population) corresponding to this "district" as having been part of a larger unit.

7 "This Island was formerly under one Kin[g]dom, how long sence it was formed into two I cannot say, but I believe not long" (Beaglehole 1961:409).

8 Mano also is defined as $10 \mathrm{rau}$, or hundreds, i.e., 1000.

9 See, for example, chap. 16, the Porapora colony.

10 I am most reluctant to utilize this overburdened term. As Fried said of it: “... If I had to select one word in the vocabulary of anthropology as the single most egregious case of meaninglessness, I would have to pass over "tribe" in favor of "race." I am sure, however, that "tribe" figures prominently on the list of putative technical terms ranked in order of degree of ambiguity as reflected in multifarious definitions." (1968:4-5.) On the other hand, I know of no better shorthand label for what I call an "autonomous territorial unit." I must regretfully concede that I am unable to formulate a concise definition of it at this stage-in fact, it will require the rest of this chapter to do so adequately.

11 Here and elsewhere in this book I use the word chief for that individual member of a social unit whose decisions about actions involving other members tended to be final.

12 Also, see chap. 19. I have searched the sources for instances of fusion of territorial units brought about by such quasikinship bonds as fosterage and bond-friendship, but without success.

13 In an editorial footnote about a martial episode in the legend of Honoura, in which the victor married the widow of his principal adversary, whom he had vanquished and slain, is the statement, "A marriage of that kind was considred a most honourable way of ending strife, as it made allies and not slaves of the conquered" (Henry 1895:293).

14 For example, the legendary conquest of Tahiti-the-Fish by priests from Opoa, Ra'iatea.

15 I would like, of course, to be able to write also in terms of numbers of persons; but, as the reader will recall, the available information concerning these Islands' pre-European populations is so inconsistent and unreliable that any estimate based thereon would be similarly suspect. In any case, if any reader cares to engage in this game he is referred to the figures presented in chapter 1, from which he can construct his own estimate.

16 The "unification" which Porapora's Puni imposed upon Ra'iatea and Taha'a in the 1760s probably comprised an even more complex organization, but it fell apart upon Puni's demise. See vol. 3 for further details.

17 As far as I can discover there was no general Maohi term for a social unit of this kind. Nuna'atini, for example, had the meaning of a concourse of people who follow a chief; and as for va'a mata'eina'a, I have already discussed its ambiguities.

18 For example: anoanomatie, a native of a place where his ancestors were before 
him; a wise person; àvaetutu'eè, a stranger from another country who is not interested in the welfare of the place of his residence (LMS Dictionary).

19 A specific instance of this kind of conventionalized "anger" was reported by Morrison in his account of the killing of the Bounty mutineer, Thompson. Patiri, one of the natives who killed him, did so to avenge Thompson's murder of another mutineer, Churchill, who was Patiri's friend. When Morrison later expostulated with Patiri "for taking justice into his own hands," and asked why he and his associates had not simply delivered Thompson to Matavai for judgment, he was told, "the distance is too great, and our anger would be gone before we could get there; and we should have let Him escape when we were coold \& our anger gone so that He would not have been punishd at all and the Blood of the Chief [i.e., Thompson] would have been on our heads." (1935:95)

20 As Henry pointed out, nothing was gained by a losing party by suing for peace, because even if the winners accepted, "the same barbarities as just described were shown the surrendering warriors in their camp; and if there were no more home forces to resist, their land became tributary to the conquerors. Hence the unwillingness of a side to submit and preference to retreat" (1928:315).

21 For example, see the gesture of noblesse oblige in the story related by Adams (1901:27).

22 However, it will be recalled that the supplanted officials did not thereby forfeit any kin-congregation Titles they may have held, insofar as their ceremonial prerogatives were concerned. (See chap. 16.)

23 See also Moerenhout 1837:II, 141-142.

24 See, for example, a missionary's account of food contributions assembled in one Tahiti district for presentation to some distinguished visitors from Mo'orea: "A day of much noise and confusion about us. The people of this District brought here what they had prepared for their guests-it consisted of two lots of Ava each laid on a Pafatu or a frame made of large sticks and carried by 30 or 40 men (to make it appear heavy), of about 60 baked Hogs and great quantities of baked Uru. (Jefferson, Journal, 11 February 1806, LMS Archives)

25 One of the few notable exceptions was the friendly relations that appear to have prevailed for several decades before and after 1767 between the Puna'auia and Pa'ea tribes of Tahiti. (See vol. 3).

26 In addition to the example of coordinated tribal work projects to be discussed in this section, there were of course the uncoordinated work activities required of a tribe's membership when its chief called for objects of one kind or another. Such work may have been concentrated within a few days of intensive effort, or spread out over a year or more; but by the extent to which it exceeded ordinary work activity it should be counted as tribal work. And in this connection one might view some tribe-wide rahui as coordinated inactivity.

27 Morrison's description also differs with respect to the intensity of the rahui, etc., but this may be more a reflection of differences in scale.

28 See also Henry 1928:481-482. 
29 Turnbull described a large-scale fish-seining episode on Tahiti which took place during festivities carried out to honor some members of the local chiefly family upon their return from a sojourn on Tetiaroa. How "tribal" the seining was we cannot discern, but Turnbull's comments upon the distribution of the catch are particularly relevant: "This [the seine] is a net made of the leaves of the cocoa-nut tree, and extending full a quarter of a mile in length; it will sweep round a rock without much injury, and whatever fish may be adhering to its side, it will force from their holds without difficulty. Some of the king's attendants are always in waiting upon these occasions, and seldom fail to seize upon two-thirds as the royal tribute. The king being thus served, the multitude are let loose upon what remains, a scene truly ludicrous: and a general scramble of men, women, and children, then ensues; the seine is torn to pieces in the contest, and every one decamps with what portion of the prize he can get." (1813:288)

30 These included, in the early days of contact, most items of European origin, however incomprehensible or useless. In fact, in some places the chief made a practice of demanding all European objects obtained by his subjects. (Wilson 1799:194; J. Forster 1778:369-370)

31 One legend relates that after the chiefs of Maeva had conquered the other tribes of Huahine, the latter became known as "Places where the left-overs are eaten," with reference to the fact that all the first food productions of such places went to Maeva (Chesneau 1928:60).

32 This definition indicates a metaphorical extension of the conventional eightfold division of every island-partly fictional and partly actual-to an assembly of all subunits of a tribe.

33 This interesting document was rescued from archival obscurity by the knowledgeable student of Maohi antiquities M. Rey-Lescure, and published in Bulletin de la Société d'études océaniennes (June 1946). In reproducing it I interpose several explanatory notes, including some provided by ReyLescure. The original text was partly in Maohi and partly in English, but the published version is in French. In retranslating it into English we may be losing some of the original sense of the document, but the original version is not available to me.

34 A similar rule was in force respecting objects consigned to spirits, as witnessed in the legend of the revenge of Mara'a (Henry 1928:241 ff.), wherein two fishermen were slain for consuming a portion of the first large fish caught by them and dedicated by them to their tutelar.

35 It may be that $f a^{\prime} a$ hopura'a vai and $f a^{\prime} a^{\prime} a m u a$ were simply local variants of the same transaction and not two separate transactions, but the sources are somewhat ambiguous on this point.

36 The LMS Dictionary defines mareva as a fleet of canoes with visitors, bringing presents from one island to another; but Rey-Lescure, in the document on tavau, assigned it the meaning given here.

37 Again I quote from the Mare document referred to earlier, which although having to do with events of a later era than the one now under study, 
seems to me to be indigenous enough to throw light on transactions of an earlier time.

38 That is, "unsightly" to the puritanical missionaries; in the eyes of the Maohis such a collection was presumably a highly gratifying sight!

39 Actually I am not sure about this point. It may be that pigs, etc., which females had had a hand in raising, were thereby rendered unsuitable for offerings to most spirits, but I cannot find any evidence on this.

40 I refer to the "rivalry" between 'Oro and Temeharo. See vol. 3.

41 It may be, however, that paiatua rites were occasionally carried out on a cult as distinct from a tribal basis. We know, for example, that the cults of 'Oro and Tane included devotees from several distinct tribes (including tribes whose tribal tutelar either god happened to be). And there is evidence for concluding that tribes thus connected (in common worship of 'Oro and Tane) sometimes met together to have their own tutelar's images refurbished with feathers from an 'Oro or Tane image in the keeping of the chief of one such tribe, and with no implications therefrom concerning political connections.

42 The sovereign chief of Ra'iatea, it will be recalled, was vested with a maro 'ura kin-Title of the Opoan kin-congregation. Unfortunately, we are provided with no description of the office-taking ceremony of a tribal chief of lower kin-Title rank, and hence I am not in a position to sort out those elements of the ceremony specifically referable to tribal chieftainship alone. Also, the central position occupied by 'Oro in Henry's account should not be seen as indicating that 'Oro played this role everywhere. For an eyewitness account of an inaugural ceremony, see Bligh 1792:138-138b.

43 Morrison's account is based on his own observations of the investiture of Pomare II at Pare, in 1791, and hence has the weight of authenticity. While it does not contradict the summary accounts of Henry, Ellis, and Moerenhout, it does not add anything new except in a quantitative sense. For example, Morrison recorded that the human sacrifices offered at this investiture were thirty in number, "some of which had been Killd near a Month," and that the feast after the former lasted "some weeks." (1935:117)

44 The only significant addition to be made to the accounts of chiefly office-taking recorded and described herein is a passage from a missionary's journal, which described how one tribal chief, Pomare II, underwent separate investment rites in each of the districts over which he had gained ascendancy (Youl et al. 24 May 1806, LMS Archives). Presumably such rites were carried out not only in connection with a chief's original investiture over a complex tribe, but also when a new territorial unit was added to his realm.

45 See, for example, the contempt gesture involved in bearing one's buttocks toward someone (chap. 14). See also the legend of Tafa'i, in which the hero's father, Hema, underwent an extreme form of degradation by having been made into a repository for the excrement of his spirit-adversaries (Leverd 1912:10-11).

46 I am concerned here with chieftainship of a tribe, not with the administrative office $t i^{\prime} a \bar{a} u$, for which see p. 1030.

47 In another legend the hero Tafa'i was elected by his warrior companions to be their leader because of his strength, bravery, and generosity; but this office 
was not the same as a tribal chieftainship (Henry 1928:557; Leverd 1912:21).

48 Turnbull reported, "The power or ambition of an enterprising chief will indeed often disturb the regularity of succession; but the principle of hereditary government seems to be fundamental" (1813:358).

49 According to Handy, "In considering the unity of the social order under the ari' $i$ it must never be forgotten that the divine first-born (matahiapo), who was the Arii, was regarded by the population over which he presided, as the sacred embodiment of the mana of the people and land as a whole" (1930:46). As noted previously, the available data on Maohi usages of this troublesome word mana are simply not adequate to confirm or refute statements such as the one just quoted.

50 Tamatoa, sovereign chief of Ra'iatea, is described in some sources as having been a "high priest" as well, but there is no indication that he was actively the principal officiant in tribal services. See also the case of Papara's chief Temari'i (Teri'irere), in vol. 3.

51 I can throw no light on the etymology of this word: possibly, tau, (?); imi, seek; hau, peace, order, etc.

52 In the interest of clarification, I have taken some liberties in translating this text, however, I am still uncertain about how this official was selected in the first place.

53 According to one source the label ti'aâu was also applied to the chief functionary of an Arioi lodge (Orsmond: Arioi).

54 See, for example, Vancouver 1801:256.

55 The writer of the following passage, written in 1927, was descended from the chiefly "line" of Papara, but one may legitimately question her reliability: "Some of the laws strike us as having been [unnecessarily] strict and quite arbitrary. They were in fact concerned mainly with the protection and preservation of private property and of titular prerogatives. One might think [for example] that nothing would have been easier than to change a name or modify a word. Yet, even such matters as these had to be brought up and discussed first of all in the royal family council in order to decide upon the appropriateness. Then such matters were passed on to a Supreme [tribal] Council composed of the tribal ari'i, the head of the tribal military force (who was usually an ari'i as well), and the High Priest (who [in one particular case] bore the official title of Teao [Light]). It was within the powers of the Council to either reject or confirm the proposal in question. If such a proposal were confirmed by it, the decision then had to be consecrated at the marae, with which it became binding upon the whole populace. Thus one sees that a strict formalism obtained with this institution and seemed to regulate it." (M. T. Salmon 1927:261)

56 See J. Forster 1778:362.

57 Handy (1930:42), however, referred to the Hiva of Hoomatavana as the "bodyguard" of the chief of Vaiari, which in one sense it probably was.

58 Also most of the writers, from Wallis to Handy, described the chieftainship of only the largest, most complex tribes, so that we know next to nothing about chieftainship in such relatively small and less complex tribes as, say, Mai'ao.

59 See also the following passage from Jefferson's journal, 27 May 1799 (LMS 
Archives): “... Notwithstanding in our opinion the king's habitation is a very humble one It appears that himself and countrymen have the most elevated ideas of it and of everything appertaining to the great chief, as the following speciman will show. The king's title is Otoo-nooey te Atooa-the meaning of which we do not clearly understand but as the word te Atooa is used to express the object of worship, it is doubtless as full of arrogancy and pride as is possible. His house is called yow-rye (clouds of heaven) his double canoe anooanooa (the rainbow) his manner of riding on the shoulders of an attendant mahowta (flying) his torch Ooweera (lightning) and a drum that is frequently beating for his amusement pateere (thunder)."

60 Not pi'i (as rendered by Ahnne 1926), which probably corresponds to forms of the LMS Dictionary entry pii, to call upon a person or a thing; to shout, to raise up the voice. See White 1967:328.

61 Unknown to Vancouver the particular prohibition relating to Pomare's name seems also to have been prevalent in some of the western Tuamotu Islands, where this chief's influence was strong (White 1967:332).

62 What might have turned out to be temporary word changes (in the normal course of events) became permanent ones as a result of the missionaries' introduction of writing, and their publication of scripture in the native language.

63 For an incisive critique of these and other latter-day accounts of the custom of $p i$, see White 1967.

64 Another "imposing effect" must have been created by the numerous tapers that were burnt to illuminate a road over which one chiefly family sometimes traveled at night: "In the beginning of the Night Tarrah Hill was beautifully illuminated with Flambeaus to light Tynah over, who had stayed late at Oparré, perhaps a prettier sight was never seen than the effect it had upon the smooth Water about the Shore, for the lights were brilliant and numerous-When any of the Royal Family pass over the Hill they have it lighted, as the Road is bad and a fall likely to be attended with bad consequences." (Bligh 1792:151b-152)

65 “... the Society Islanders [were] almost continuously at war, either the principal chiefs of any island were fighting each other for sovereignty over the whole, or petty chiefs were fighting among themselves for the most frivolous reasons and without the principal chiefs themselves deigning to become involved" (Moerenhout 1837:II, 30-31).

66 The following passage by Anderson, included by Cook in his journal for 1777, evidently contains as much fiction as fact: “... long custom seems to secure property here as effectually, as the most severe laws do in other countries. In conformity also to ancient practice established amongst them, crimes of a less general nature are left to be punished by the sufferer, without referring them to a superior. In this case, they seem to think, that the injured person will judge as equitably as those who are totally unconcerned; and as long custom has allotted certain punishments for crimes of different sorts, he is allowed to inflict them, without being amenable to any other person" (Cook 1784:172).

67 There are some indications that known sorcerers, or at least individuals 
widely believed to be such, could also be slain with impunity by their supposed victims (Elder \& Wilson, Journal, 19 June 1804, LMS Archives), but I can find no evidence that sorcerers were also considered suitable candidates for human sacrifice.

68 See also Moerenhout: "The cruel custom of human sacrifice ... provided both basis and support of chiefly power. The gods, who were the terror of the populace, were always favorable to the chiefs; and when some unfortunate individual happened to displease the latter, he was certain to fall victim [to human sacrifice]." (1837:II, 6)

69 These sentences were however commuted, on Rodriguez's petition. See also, earlier in this chapter, concerning a Pomare's banishment of a whole family, including the mummified bodies of deceased members.

70 In the passage from Bligh, quoted at the beginning of this section on social justice, he evidently expressed a contrary view, but provided no example.

71 For a legendary account of one such episode see Adams 1901:163-168; see also Bligh's definition of ari'i as one's champion or protector (Bligh 1789:II, $6)$.

72 I pointed out in figure 18-1 that Cook in his 1777 listing of social classes translated "Manahoone" as "vassal," and incorrectly placed this class between "Erres," "powerful chiefs", and "Teou" and "Toutou," "servants or slaves."

73 See vol. 3 for an example of the anarchy that could be generated by a small band of troublemakers in a community lacking a strong chief.

74 In this connection Bligh wrote: "In the Districts of Oparre or Matavai Tynah [Pomare I] can take any thing he wants or has a liking to, but in other Parts, altho he is called their Erreerahigh and is considered as such, he can have nothing but with consent of the resident Cheif" (1789:II, 63; see also Bligh 1789:I, 375, 396).

75 See also Moerenhout's statement that a chief seldom confiscated for personal use any conquered territory (1837:II, 12n).

76 The measures regarding election and impeachment discussed earlier in this chapter concerned tribal administrators ( $t u^{\prime} a \bar{a} u, t i$ ' $a \bar{a} u$, ani) rather than tribal chiefs. See also Moerenhout 1837:II, 9.

77 See especially Moerenhout 1837:II, 13-14.

78 These precepts were translated by Handy into English from an unpublished, and now unavailable, manuscript of the "Memoirs of Marau Ta'aroa." They subsequently appeared, in Tahitian and French, in Ernest Salmon, "Les Maximes de Tetunae," Revue de Folklore Français et de Folklore Colonial, No. 1, 1937. The English version reproduced here is based on the Maohi text published in Salmon, and is a combination of Handy's translation and one produced by R. G. White. The Farerua referred to in the text is the marae of that name in Vaiari, Porapora (see chap. 16). Most metaphors in these ture seem sufficiently transparent to obviate explanation. The word ture is probably a slightly transformed version of Hebrew torah; we do not know what the Maohi word for such precepts might have been.

79 R. G. White: personal communication. 
80 Note the gap between norm and practice in this respect; see earlier in this chapter, section on chiefs and social order.

81 Therein lies the irony contained in the speech quoted from Henry in which the spokesman for a visiting notable thanked their chiefly host for his gift of welcome, and accounted for its liberality as due to the latter's felicitous "mode of governing" (Henry 1928:244).

82 One of the few such episodes actually recorded had to do with pigs: "This afternoon I found a Stop was put to the Sale of Hogs in the district of Tettahah, we therefore can get no more Supplies from that quarter. Teppahoo told me there were now but few Hogs there, and that for a certain time, some Months, no person was allowed either to kill or sell, that they might have time to breed again." (Bligh 1789:II, 58-59)

83 Although, perhaps, the very presence of an active and firm-handed tribal chief served to inhibit disorder among tribal subjects-e.g., in describing the unruliness of Huahine natives G. Forster wrote: "This was the second time that our people were thus boldly attacked by the natives of Huahine, who seem, upon the whole, to be more licentious under the infirm government of old Oree, than those of Taheitee, and of the other Society Islands" (1777:II, 117; see also vol. 3, this work).

84 Some of the general disorder, both spontaneous and ritualized, which unsually followed upon the death of a chief could be interpreted as deriving from a common attitude that some rules regarding orderly social interaction were invalidated when the chief himself ceased to live. In this connection, Orsmond reported much later, after the death of Pomare III, "It is a prevalent feeling among the lawless race that as the King is dead the law ought to die and be burried also" (Journal, 1 February 1827, LMS Archives). The law in question was an official, missionary-inspired code, but the attitude so expressed may have been an ancient one.

\section{CHAPTER 24}

1 See, for example, Levy 1968.

2 W. L. Warner, A Black Civilization (New York: Harper Bros., 1937); D. L. Oliver, A Solomon Island Society (Cambridge: Harvard University Press, 1955).

3 In the generalizations that follow I refer mainly, of course, to the goals of those Maohis who were past childhood in "life stage," and not yet in senile decline. I suppose that the pleasure of, say, eating began earlier and continued past that span, but the same can hardly be said, for example, of sexual relations.

4 As a small but perhaps not insignificant piece of confirmation for this thesis, I point out that praise (i.e., status enhancing service) rather than any kind of object was the prize in most kinds of competitive sports.

5 The territory comprising the childhood "home" (which usually included one's own marae) would have been stoutly defended, or deeply longed for from afar, by some (or most?) Maohis. In such cases, however, I believe 
that the factor that made these territories so highly valued was the social relations mentally associated with them, and not the mere fact that they were of specific geographical extent. (Indeed, the very lack of any unit of land measure would seem to add some small weight to this conclusion.) I hold firmly to this belief despite such statements as the following: "Land constituted the principal-or better, the only real-form of wealth of these people." Moerenhout continued, "The amount of authority exercised by any chief depended upon the quantity and quality of his land, for the better able they were to provide food for people, the more certain they were of having [faithful] subjects." (1837:II, 12)

6 For example, on several atolls viable societies developed despite relatively much more unfavorable relationships between population and natural resources.

7 This of course does not eliminate the possibility of there having been sorcery procedures that utilized a victim's personal name as a means of attack, although I have come across no specific instances of such. And in this connection, although the custom of $p i$ seems to have been applied to personal names more typically, perhaps, than to Titles, the prohibition was evidently backed by other than supernatural sanctions.

8 Despite the subordination, in many instances, of kin-congregation to tribe, kin-Titles retained their preponderant structural significance.

A contrast to Titles remaining the same would be provided by a society in which an individual's personal name never changed, and in which new status-names were invented ad hoc to reflect his achievements, etc., at any particular time. Another contrast is provided by the popular practice in American society of continuing to label an individual by the office-name once held: for example, calling an individual by his military title long after he has left military service.

9 "Better than" is, of course, our way of generalizing about the differences between the terms in each of these paired opposites. I know of no comparable Maohi word or phrase for expressing the same generalization; indeed, it is possible that the Maohis themselves did not recognize any common characteristic among these four sets.

10 The absence of live volcanoes in the Society Islands may account in part for the conceptual unimportance of "below" as a domain for the major deities.

11 Despite the Maohis' identification of the bowels as the principal seat of emotion, they continued to treat the head with greatest respect, ritually.

12 See Hertz 1960.

13 In addition to, or instead of, interpreting this as a general devaluation of war (which our evidence would hardly support), the LMS Dictionary definition given for maui, "to be in a pet, or fit of anger, on account of disappointment in food, etc.," suggests another possible basis of this identification of left with war. This assumes, of course, the words "left" and "fit of anger" were in fact phonemically identical, a matter we cannot be certain about in view of the absence of vowellength markings in most of the early transcriptions.

14 Actually, it is probably a rare phenomenon in most human societies. Even in our own society, where altruism is asserted to be a popular ideal, the aphorism 
considered by most people to embody it-namely, "It is more blessed to give them to receive"-seems to imply that the givers will eventually receive their rewards in Heaven.

15 Including, for example, such vivid measures as fashioning the bones of one's vanquished enemy into fishhooks, or wearing his body poncho-like in battle. Also, evidence that Maohis recognized the injury-dealing power of words can be seen in thc following LMS Dictionary entries: $M a^{\prime} a u$, blemish, injury, damage, hurt; to be injured or damaged; vile, slandered by accusation. Tãora, to throw a stone or other thing; to reflect, or make censuring remarks, on a person.

16 It may be that the Maohi words ho'o/taui and höro'a served to distinguish what I label "commercial exchange" and "gift giving", respectively, but I cannot be certain of this: $H o^{\prime} O$, price, exchange, equivalent; to buy or sell, exchange property. (See also tapiho'o, to make an exchange.) Taui, a price, purchase, compensation; to exchange property, to buy. Horo' $a$, to give or bestow some good; the gift that is given; generous, liberal. (LMS Dictionary)

17 “.... the Ingenuity of these people is highly Conspicuous in evry article of their Manufacture, of which their Cloth Matting and oil are particular Articles of their Trafic, if it may be so Calld, but this is Generally carried on by making presents rather then by Exchange of Commoditys" (Morrison 1935: 160).

18 See Bronislaw Malinowski, Argonauts of the Western Pacific (London: George Routledge and Sons, 1932). See also Paul Bohannan, "Some Principles of Exchange and Investment among the Tiv," American Anthropologist 57 (1955):60-69, and R. F. Salisbury, From Stone to Steel (Victoria: Melbourne University Press, 1962).

19 Multipurpose, not all-purpose; cynics to the contrary, I know of no human society possessing a really all-purpose kind of exchange token-that is, "There are some things even money can't buy."

20 To identify it as mana, as some writers have done, is inappropriate on two grounds: first of all, there is no persuasive evidence that the Maohis themselves so labeled it; and second, in view of the impossibility of discovering the meaning of this word, our understanding of the "spiritual" element in question would not be advanced were we to assume that the Maohis labeled it mana.

21 It would simplify my synthesis considerably (and render it more aesthetically pleasing!) if I had found evidence at different "levels" of social relations for the kind of structural replication of consanguineal role-networks that allegedly prevailed in some other Polynesian societies, but the data on Maohi society do not so permit.

22 In many stratified societies, choice of spouse plays little part in maintaining the lines of stratification; while in many other nonstratified societies, choice of spouse is subject to very narrowing constraints.

23 By a "fully satisfactory" household economy, I mean one in which the members were provided with adequate food, etc., without having to work unduly hard or at uncongenial tasks. As we have seen, except for a very few jobs 
such as pelagic fishing or fine-plaiting, Maohi household tasks were not sex linked to an exclusive degree, so that a marked male-female disparity would not have resulted in intolerable hardship; but it would almost certainly have occasioned some discomfort and dissatisfaction.

24 Even in legend, the sexual encounters between deities and mortals (e.g., 'Oro and Vairamuti, Varimataauhoe and Hotutu) were more than one-night affairs, although it is true that some of these unions were "adulterous" by conventional Maohi standards.

25 As indicated in chap. 20, it is possible that formal friendship pacts were instituted between Maohi males and females, but most of them by far were between male and male.

26 As noted earlier, the only Maohi general classification I have uncovered of an "occupational" kind was the fourfold one of ari'i, Ariois, big-bellies, and fishermen (see chap. 21). Unfortunately, I do not comprehend the rationale for this intriguing classification.

27 This has some bearing on the thesis, referred to earlier, that complementary exchange was the factor most responsible for maintaining ties among consanguines scattered over varied "resource zones." Even granting some correlation between occupational specialization and resource accessibility-not a very high correlation but a positive one nevertheless-and even granting that some complementary exchange did flow along kinship channels, nevertheless, the prevalence of commercial-type arrangements reduces the explanatory power of that thesis.

28 Excepting of course the legendary Friendly Alliance, which may never have existed historically (as I pointed out in chap. 22, section on 'Oro cult), but whose mythical currency does indicate that the Maohi accepted the possibility of active intertribal relations based mainly on common religious commitment.

29 In addition, according to Moerenhout twelve of the branches (including the Opoan) were acknowledged as having been those originally and directly founded by the sect's tutelars, but there is no evidence that the heads of all these branches were accorded any special deference throughout the sect.

30 The fact that the focus in this summary statement is on male Ariois is a reflection of the circumstance that very little has been recorded about the female members of the sect.

31 Homosexuality, including transvestitism, is of course still to be found among modern Tahitians, and while it may resemble the older forms in many respects, it is also necessarily different in others, due to different social contexts and probably to new homosexual techniques as well.

32 Some women, notably high-ranking kin-Titleholders such as 'Itia, appear to have worked, fought, and played like men, and indeed to have looked very "masculine," but this did not seem to have led to their becoming mahu. The mahu transition was from "male" to "female," but not the reverse.

33 Danielsson offered the plausible suggestion that pair or group masturbation, which was practiced by young people in some parts of Polynesia, may have laid the foundation for homosexuality in such places (1956:151). Unfortu- 
nately, there is too little reported about masturbation in Maohi society to adduce it as a factor in homosexuality there.

34 Equality except in the case of a married couple, whose "equality" was somewhat qualified by the circumstance of their differences in sex.

Too little is known about the structure of occupational guilds for us to be able to characterize them; my guess, however, is that they were moderately hierarchic in governance but that reciprocity marked co-members' exchanges.

35 The case of Teahuupo'o is not readily explicable, except perhaps on the grounds of that district's poor communications; but it will be recalled that the Mataovae tribe (or subtribe?) was itself made up of two noncontiguous subdivisions.

36 This definition is adapted from that of Hoebel (1949:94). It is not as precise as some readers might wish-e.g., "considered" by whom?-but is sharp enough for present purposes.

37 Garanger 1967. See also Emory and Sinoto 1964; Emory 1962; and Green et al. 1967.

38 Garanger 1967; Emory 1963; Green 1967.

39 By A.D. 1200 I simply refer to the time by which settlements had become established on all the islands; the actual date might have been any time from about 900 to 1500 .

40 The presence of a few such individuals during the Early European Era (see vol. 3), and legendary accounts about earlier eras (including the evidently popular stories about heroes and demigods) lend support to this assumption.

41 This point was deservedly emphasized by Goldman for Polynesia in general. In this connection, even fosterage was resorted to in some instances, in order to insure suitable successors. And one will recall the story of the Maupiti delegation that went to Opoa to retrieve their marae's "royal insignia" (chap. 16), and one of the claimants, a political "achiever," was not required to prove his eligibility by reference to a particular pedigree, but merely by proof of membership in an Opoan-derived kin-congregation.

42 See chap. 16, this vol., and Handy 1930. For a fuller inventory of such theories see Williamson 1939:201ff.

43 “'Degree of stratification' refers to the complexity of the status system, i.e., the number of different kinds of ranks, and the extent to which they confer unequal privilege in economic, social and religious life. 'Form of stratification' refers to the social organization of the status system, that is, the sociological principles that determine rank differences." (Sahlins 1958:x)

44 As an indicator of cyclic surplus Sahlins utilized the well-known measure of occupational specialization-i.e., the proportion of people in the population divorced from food production. He also brought in such formal criteria as relative number of food crops and efficiency of production techniques as supplementary checks on relative food productivity, but he placed heaviest reliance on the "immediate surplus" measure, which thus deserves our closest attention.

45 This is a far cry from the assumption made by Sahlins (and which constituted the principal rationale for associating immediate surplus with redistribution), namely, that "in Polynesia, surplus production was distributed from a central agency" (1958:129). 
Although critical of Sahlin's treatment and interpretations of data on the Society Islands, I must add that I consider his larger effort (i.e., to offer another kind of theory to account for variations in Polynesian social structure) a noteworthy one-a refreshing and potentially more constructive approach than those based on hypothetical migrations. No one kind of theory will, however, suffice for such purposes. Nor are data on individual Polynesian societies likely ever to be sufficient or reliable enought to permit a comprehensive and wholly credible reconstruction.

46 See, for example, chap. 23, section on work projects, for a discussion of the relation between increasing size in tribal work force and occupational specialization. See also chap. 20 for a possible connection between population increase and contractual types of social bonds. 


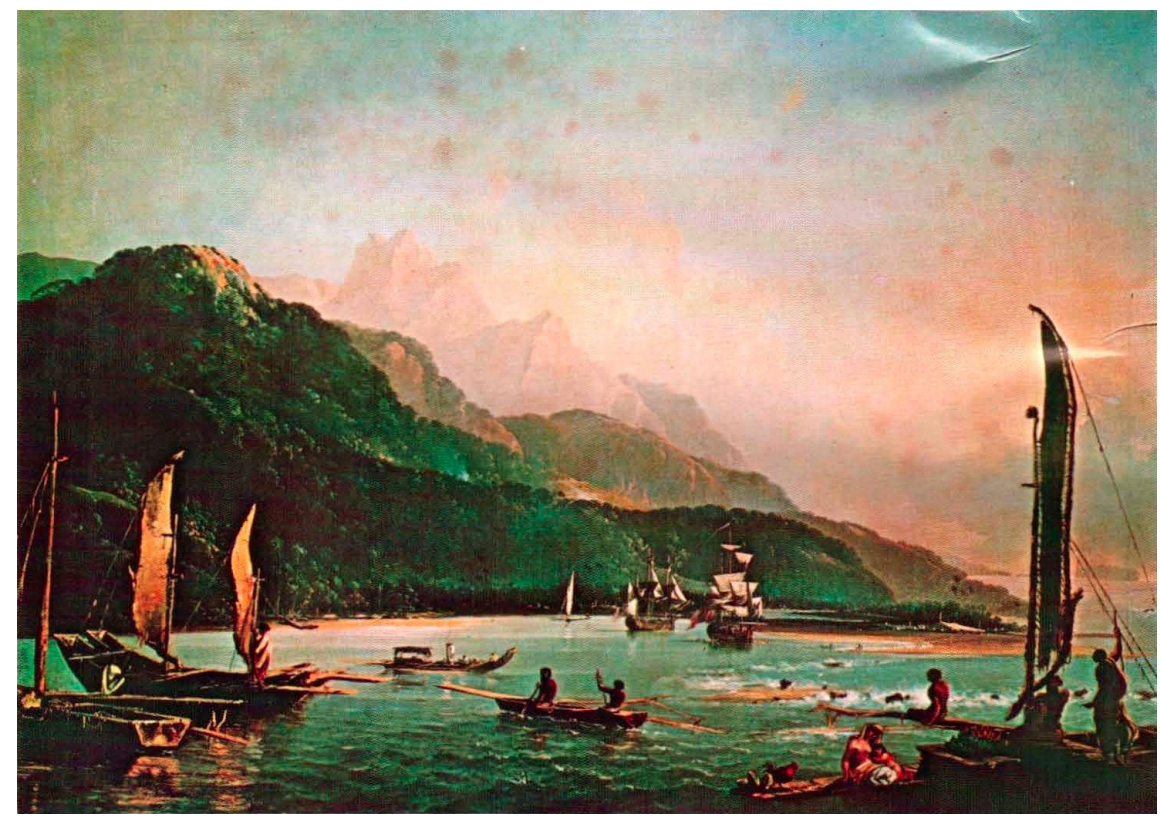

The Resolution and Adventure at Tahiti. Painting by W. Hodges, Cook's second voyage. National Maritime Museum, Greenwich, England. 


\section{VOLUME 3 \\ RISE OF THE POMARES}





\section{CHAPTER 25 TRIBAL POLITY AT BEGINNING OF EARLY EUROPEAN ERA}

[The] prime duty of the historian [is] a willingness to bestow infinite pains on discovering what actually happened. (Collingwood 1946:55)

Chapter 23 was concerned with Maohi social relations insofar as they were affected by considerations of residential proximity in combination with coercive force. The attempt was made to depict these kinds of social relations before they began to undergo radical change as a direct or indirect result of European influences. ${ }^{1}$ Moreover, events were dealt with largely in terms of modes, and persons in terms of statuses; this course was followed partly by design, but it was also necessitated by the nature of the available data.

The present chapter will be concerned with the same kinds of social relations, but will focus upon the changes they underwent during the first five decades after Europeans appeared on the scene. The focus will be upon specific individuals and events rather than upon generalized statuses and typical occurrences. Such a reconstruction may serve to provide some corrective, and an additional footnote or two, to current notions about this minor but intriguing chapter of colonial history. But my main object is to add some flesh and movement to the skeleton of pre-European Maohi politics hitherto assembled; for, it is my firm opinion that although Europeans wrought radical changes in some phases of Maohi life - via their steel tools, their diseases, et cetera - and although European influence also had the effect of encouraging and facilitating certain developments in Maohi polity, the motives and instrumentalities of such developments remained basically Maohi, and hence directly relevant to my reconstruction of pre-European Maohi society.

The developments I refer to comprised the consolidation of coercive authority over all Tahiti and Mo'orea into the hands of one individual or, in labels current to the era, the emergence of a "monarchy" out of what had been a number of more or less autonomous tribal chiefdoms. Besides the general ethnological and sociological interests attached to this topic, which I consider to be of major theoretical importance, it deserves 
attention for some special, local reasons. To begin with, of all the matters touched upon in the journals and other writings of the early European visitors to these Islands it is the one they were most crucially concerned with, and about which they wrote most fully. Second, these developments encompassed more aspects of Maohi life than perhaps any other configuration of events. And finally, they have occasioned more scholarly controversy, perhaps, than any other aspect of Maohi life (except, possibly, for the question concerning the origins of stratification).

The differences among scholars who have concerned themselves with these matters have tended to polarize. At one extreme is the implication that indigenous Maohi society was fundamentally and immutably multitribal, and that the monarchy which emerged resulted solely or mainly from European influences (e.g., Handy 1930:77ff.). At the other extreme is the conclusion set forth by other scholars that the trend toward consolidation of political authority was intrinsic to Maohi society - that monarchy was undoubtedly hastened by European intervention but would in time have culminated even without that intervention (e.g., Newbury 1967a). The general theoretical implications of this issue, which reach far beyond the confines of Tahiti, or even of Polynesia, have been largely overlooked in most writings on the subject, or obscured by parochial advocacy of this or that competing dynastic claim (Gunson 1963). For example, one question that arises in regard to societies like this one has to do with the inevitability of political consolidation: inasmuch as most types of Maohi groups were pervasively hierarchical, and because in most such hierarchies there was only one status endowed with final decision-making authority, was it inevitable that the top status-holders of the various tribes would vie for overall supremacy when population increase, aided by ease of communication, brought them into more frequent interaction with one another? And if so, what were the other factors that served, in the long run, to promote or frustrate such consolidation? Because of the "exogenous" factors represented by the European presence, the events I am about to describe do not constitute a "pure" case study of this kind of development, but they nevertheless provide some suggestive clues.

There are undoubtedly many ways of looking at changes in a society's administrative structure and politics. The present focus is on tribal chiefly authority, which I view mainly as command over certain kinds of services and certain material products of services. The nature of such services and objects will of course vary from society to society. I trust that the nature of services and objects comprising such authority in Maohi society has been described sufficiently in previous chapters, so that I now concentrate on the campaigns waged by certain chiefs to extend their domains of command. Assuming (justifiably, I believe) the absence of any significant regional dif- 
ferences with respect to cognitive inventory and social values, I will devote most attention to the resources and strategies of the principal campaigners themselves.

\section{TAHITI}

When H.M.S. Dolphin anchored in Matavai Bay in 1767 the island of Tahiti appears to have been divided into several tribes, or closely knit tribal coalitions, of various orders of complexity:

Teva i tai (Seaward Teva), a unit of fifth-order complexity (see chap. 23) that made up the whole of the Taiarapu Peninsula and numbered about 14,000 to 15,000 inhabitants. $^{2}$

Teva i uta (Landward Teva), a unit of fifth-order complexity occupying the southern quarter of Greater Tahiti and numbering about 7,000 inhabitants.

Mano rua (or Pa'ea), a unit of fourth-order complexity.

Mano tahi (or Puna'auia), a unit of fourth-order complexity.

Throughout the era under study, and possibly for some decades prior thereto, these last two tribes (which I shall henceforth call by their more familiar territorial labels of Pa'ea and Puna'auia) were on many occasions so closely allied that their inhabitants and territories came to be known collectively as Te Oropa'a and Atehuru, respectively. This union, which had a population of about 2,100 , was, however, an alliance of near-equals rather than one unified hierarchically to the degree that Seaward Teva was.

Te Fana, a unit of probable third-order complexity whose 1,000 or so inhabitants occupied an area known as Tetaha or Fa'a'a. ${ }^{3}$

Te Poreonu'u, a fourth-order unit of about 4,200 inhabitants that occupied the major territorial divisions of Pare and Arue as well as the atoll Tetiaroa (Wilson 1799:380).

Te Aharoa was the name applied collectively to the inhabitants of the five major territorial units of Tahiti's thinly populated northeastern side: Ha'apape (or Mahina), Ha'apaiano'o (or Papeno'o, or Vavau), Tiarei, Mahaena, and Hitia'a. Little, however, is known about their interrelations beyond the fact that Hitia'a's principal people figured more prominently in events elsewhere on the island than did the chiefs of the other units. This may signify that Hitia'a's chief also exercised some authority - or at least weightier influence - over other Te Aharoa chiefs. ${ }^{4}$ But lacking evidence of such authority I tentatively classify these populations into five separate tribes of third-or fourth-order complexity. They numbered about 6,300 people.

Something has already been said of the topography and natural re- 
sources of these various regions of Tahiti island, so I turn to the principal dramatis personae of the events about to be described.

\section{Seaward Teva}

By 1767 the Seaward Teva, comprising the population of Tahiti's Taiarapu Peninsula, had become a relatively stable tribal unit, of fifth-order complexity, under the firmly entrenched and only occasionally challenged chieftainship of the members of a dynastic line whose official incumbent bore the Title of Vehiatua i te Mata'i (see fig. 25-1, foldout), traditionally associated with marae Matahihae of Teahupo'o, but later established also at marae Vaiotaha of Tautira, by virtue of Teahupo'o's defeat of Tautira in the Rahui War described earlier. After Taiarapu was politically unified, Vaiotaha became its most important marae, and Tautira its main center of tribal activity, probably because of the localization there of the cult of 'Oro.

The first Vehiatua to "enter history" was the one seen by Cook during his circumnavigation of Tahiti in 1768. Cook met this Vehiatua briefly at Tautira; he labeled him "King," or "Ari'i Rahi of Taiarapu," and described him as "a very old man with a white beard, not at all attended by a crowd of people." At the same time Cook encountered Vehiatua's elder son, Ta'ata Uraura, who was about thirteen at the time and who, according to Cook, "seem'd to have much influence." (Beaglehole 1955:108-109.) We learn from other sources that the spouse of Vehiatua was Purahi (or Pura'i?) or Te Vahine Moeatua, ${ }^{5}$ a firstborn child of a couple combining high-ranking Titles from Papara, Hitia'a, Vairao, and Ha'apape (Adams 1901:32). Cook's "Old King" Vehiatua died about 1771 and does not figure prominently in the visitors' accounts of this era; but the fierce old chief's violent attack against Mo'orea (described in chap. 12), left a residue of ill will there and among Mo'orean partisans on Tahiti, particularly in Poreonu'u. And as for his spouse, it is claimed that she was one of the principal instigators of the War of the Ahu Ra'a Reva, which served to curb the political pretensions of Papara, of which more anon. After the death of her husband, Te Vahine Moeatua took as her consort Ti'itorea of Mo'orea, whose kin-Title evidently ranked below that of his mate's. He served as "prime minister" to his mate's sons (Corney 1919:270) and was identified by Morrison as "Chief of Towtirra [Tautira]" (1935:93). ${ }^{6}$ It is not clear whether their relationship was ever institutionalized by a contractual rite of "marriage."

When the curtain of written history rises over Taiarapu there is revealed an autonomous tribe, called the Seaward Teva, whose various subdivisions were more or less united under the political supremacy of the individuals named in figure 25-2. The numerals I, II, III are my notations for purposes of identification. The Maohis themselves did not use such notations as far as I know, and even the person designated as Vehiatua I was not the first to bear that Title. 
The relationships of these principals to others elsewhere will be described as the story unfolds; meanwhile it will be useful to reproduce some of what has been recorded about their personalities.

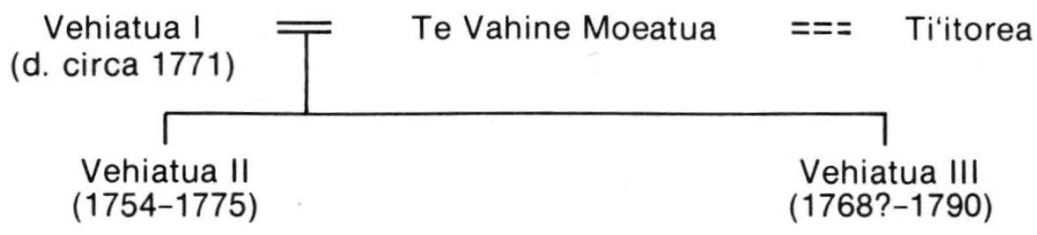

Figure 25-2. Kin relations among principals of Seaward Teva.

Vehiatua I, whom Cook and Banks met in 1769, had been in his prime a fierce and relentless warrior. An account of his war against Papetoai was reproduced in chapter 12; the same document provides an additional picture of his character in an account of his treatment of a "rebel" chief, Mae:

Vehiatua seeing Mae in the hands of a warrior and about to be slain, gave orders to spare, and secure him as a prisoner. According to usage a few captives were taken to be offered at the marae, these, with the captive chief, were marched to Taiarabu, the inferior prisoners were immediately offered in sacrifice to the gods. But Mae who was considered as a rebel was reserved for a more fearful end, as a warning to other chiefs on the peninsula. When this savage conqueror was surrounded by his warriors, he ordered the captive to be brought before him, pinioned his arms, ordered the scalp to be cut off, the eyes to be drawn from the head of the living victim and the body otherwise mutilated. During this diabolical process, the savage warriors ridiculed the agony and mimiced the contortion and dying struggles of the victim, and seemed to derive the greatest pleasure from the whole scene. To complete the disgusting tragedy the skull of the unhappy victim was carefully cut off, and made into a cup from which Vehiatua quaffed his frequent draughts of the inebriating ava, prepared by a process worthy of the cup from which he drank. (Thomson, History, pp. 24-25)

Vehiatua II, elder son and successor to Vehiatua I, was a wholly different kind of man; perhaps the clearest description of him is by G. Forster, who met him in 1773:

O-Aheatua, the king of O-Taheitee-eetee, (Little Taheitee) which is otherwise called Tiarraboo, was a youth of seventeen or eighteen years of age, well-made, about five feet six inches high, and likely to grow taller. His countenance was mild, but unmeaning; and rather expressed some signs of fear and distrust at our first meeting, which suited ill with the ideas of majesty, and yet are often the characteristics of lawless power. His colour was of the fairest of his people, and his lank hair of a light brown, turning into reddish at the tips, or being what is commonly called sandy. He wore at present no other dress than a white sash, (marro) round the waist to the knees, made of the best kind of cloth, and his head as well as all the rest of his body was uncovered. On both sides of him sat several chiefs and nobles, distinguishable by their superior stature, which is the natural effect of the immense quantity of food which they consume. One of them was punctured in a surprising 
manner, which we had never seen before, large black blotches of various shapes, almost covering his arms, legs, and sides. This man, whose name was E-Tee, was also remarkable for his enormous corpulence, and for the deference which the aree (king) paid to him, consulting him almost upon every occasion. The king, during the time he sat on the stool, which was his throne, preserved a grave or rather stiff deportment, scarce to be expected at his years, though it seemed to be studied and assumed, only to make our meeting more solemn. (1777:I, 305-306)

The young chief was to die in 1775, after a lingering illness, which was described in almost daily reportorial detail by the Spaniard Rodriguez (Corney 1919).

Vehiatua IIII (also, Tetuaunumaona), younger brother of Vehiatua II, succeeded the latter to the office of chieftainship of Seaward Teva at the tender age of about seven and continued in office until his death some fifteen years later. I have found no direct description of his personality and only indirect and marginal references to his actions. In any case, he appears, like his brother before him, to have been strongly influenced if not actually dominated by his strong-willed mother, the famous Vahine Moeatua, or Purahi.

\section{Hitia’a}

As noted in chapter 3 the most outstanding Maohi of Hitia'a at the opening of this era was its tribal chief, Reti, who bore the kin-Title Teri'itua associated with marae Hitia'a. Reti is introduced to us in Bougainville's account of his short visit to Tahiti, specifically to Hitia'a, in April 1768. At that time Reti seems to have been in authority, but his father was still alive and active. Reti and his principal people conducted themselves hospitably toward the Europeans and were evidently pleased to have them there, after an understanding had been reached that the visit would be brief. From this and other evidence the impression we gain from this encounter is of a Maohi chief whose authority was benevolent and firmly established - that is, one who, unlike some other chiefs we shall meet, had no need or wish for European aid in maintaining or increasing his authority. According to the Spaniards who met Reti in 1774 he was at that time between forty-five and fifty years old. Gayangos described him as being "of good presence, full of humour active in body," adding that "he made himself more easily understood by all of us than did any other" (Corney 1915:133). To this evaluation Rodriguez added that Reti was "brown in hue, tall, very active, and has a large and deepish scar on the forehead; he is a man of proved bravery, and quick understanding" (Corney 1919:10). Even the more laconic English subscribed to this favorable evaluation:

Could I have prevailed on my self to have again altered My Conduct, and make choice of a Tyo [taio] or Friend, as is the Custom here, it should have been Ereti the Friend of M. Bougainville; not that he was less importunate \& craving than 
others; but because he was much more sensible and inteligent ... than any others were. (Wales, in Beaglehole 1961:799)

\section{G. Forster wrote of him as follows:}

O-Rettee was a fine grey-headed man, but very healthy and vigorous, as the old people of Taheitee in general seem to be; his countenance was the picture of a lively, chearful, and generous man. He told us he had been in many battles, and shewed us several wounds he had received, particularly a blow with a stone on his temple, which had left a deep scar. (1777:II, 85)

Boenechea's journal describes a meeting in 1774 with Teinui, a young man of eighteen or twenty, who was said to be the son of Reti (Corney 1913:314). Teinui also asserted that he himself was chief of Hitia'a, and, according to normal rules of succession, he may indeed have succeeded his father to kin-Titles and their ceremonial prerogatives. But the descriptions of his relations with his father indicate that the latter was at that time still very much the wielder of tribal political authority. According to Rodriguez, Reti also had daughters (Corney 1919:10); however, I have sought in vain for clues to Reti's other kin relations. Nor can I find any references to Teinui in accounts of subsequent events, or identify Teinui with any other name that appears later on. Reti himself was still alive during Cook's last visit, in 1777 (Beaglehole 1967:1344), but how much longer he survived I cannot discover.

In any case, Reti was at one time an ally of Tutaha, tribal chief of PareArue, during the latter's war against the Seaward Teva in 1773. Earlier evidence of this relationship occurred during Bougainville's visit to Hitia'a, when Tutaha was afforded a friendly reception there (Bougainville 1772:229). And he seemed quite at home at Matavai at the time of Cook's last visit (G. Forster 1777:II, 85; Beaglehole 1967:1063). More puzzling is the connection between Reti and the Leeward Islands, for it was to the chief of Porapora (and conqueror of Ra'iatea) that Reti made a present of an anchor lost by one of Bougainville's ships off Hitia'a. ${ }^{7}$

Writing in 1769, Cook described Hitia'a ("Whidea") as having two chiefs, Reti ("Orrette") and "Teemehinnee" (Te Mahinau?) (Beaglehole 1955:105); but I can find no other reference to the latter, or to "Fanaue," whom Henry identified as "under chief" of Hitia'a (1928:71). Names of still other Hitia'a "chiefs" are introduced into the historical cast by later writers (e.g., "Marre marre" and his son, "Oeehaitaih Otee" by Bligh in 1789, and "Teehu" by missionaries in 1801 through 1808), ${ }^{8}$ but I am unable to connect these with Reti or with anyone else.

\section{Mahaena, Tiarei, Ha‘apaiano‘o, Ha‘apape}

No individuals from the tribal territories of Mahaena, Tiarei, and Ha'apaiano'o were prominent enough on Tahiti's political stage during the 
first part of the "historical" era to draw Europeans' attention; but some Ha'apape personages figured in the chronicles of that era. not only because European vessels made a practice of anchoring at Matavai Bay, but also because of the historical importance of certain individuals associated with Ha'apape's marae Fareroi.

In Emory's Ha'apape genealogy (reconstructed by him from notes of Brander ${ }^{9}$ ) the entries coming within the purview of this era are related, as shown in figure 25-3.
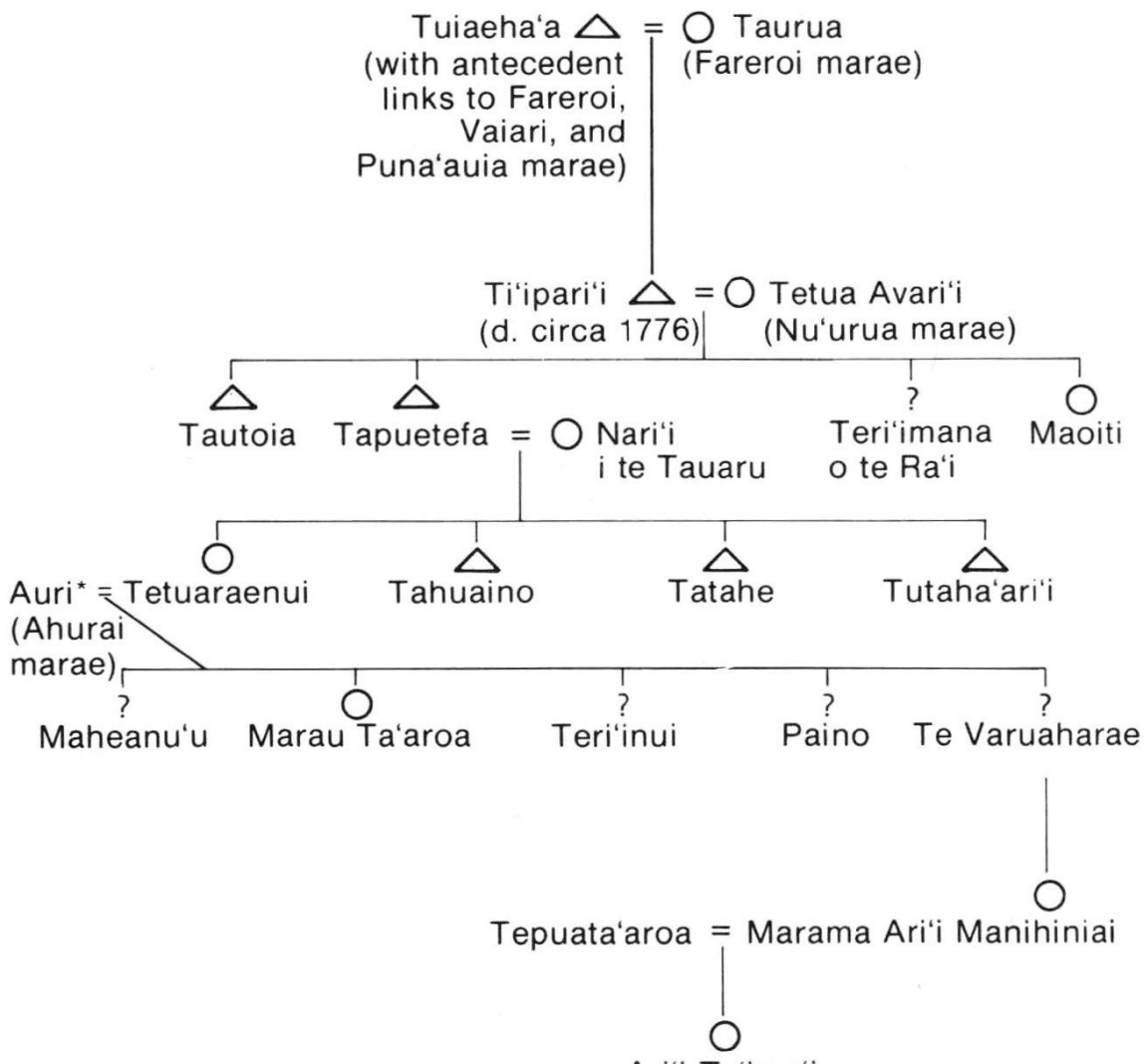

Ari'i Ta'ima'i

(b. circa 1824)

*Auri was brother of Purea and of Pomare I's wife's father.

FIGURE 25-3. Kin relations among principals of Fareroi.

Reckoning back from the approximately accurate birth date of Ari'i Ta'ima'i (the famous Papara dowager immortalized by Henry Adams), the Ti'ipari'i ("Little Ti'ipa") here listed would have been born between 1700 and 1715, and his eldest son, Tautoia, between 1720 and 1735. (According 
to Henry, Ti'ipa and Tuteia (Tautoia?) were names (or Titles?) of Ha'apape's high chief and underchief, respectively.) In 1774 Cook was met by a "chief" named "Tee," whom he described as an "Uncle to the King [i.e., Pomare I] and one of his prime ministers" (Beaglehole 1961:384). ${ }^{10}$ "Tee," who made himself helpful to Cook throughout this visit, was reportedly one of the "Principal People." Although "Tee" may have exercised some local influence he was clearly overshadowed by other notables from elsewhere who turned up at Matavai, and he seems not to have possessed the authority one might expect of the chief of an autonomous tribe, despite his distinguished connections. ${ }^{11}$ "Tee" died some months before Cook's last visit, in 1777, when his preserved corpse was still on view (Beaglehole 1967:208).

The middle-aged woman who was seen in Matavai and whom Wallis took to be "Queen" of Tahiti was Purea - who was not "queen" of any place, and whose main connections with Ha'apape derived from the marriage of her brother Auri to Tetuaraenui (see fig. 25-2), and from her husband Amo's mother, Teroro e Ora. Purea's ancestral home was Fa'a'a, and she resided at Papara, the home of her husband; the respectful consideration shown to her at Matavai was based on these other connections, and probably also upon her notoriously imperious bearing in whatever company she happened to be.

When H.M.S. Bounty was at Matavai in 1788 the local chief was one called "Poeno" ("Poenu," "Poe'eno"); such was also the case during Vancouver's visit (December 1791 to January 1792) and during Bligh's return visit some months later. ${ }^{12}$ The nearest name to "Poeno" I can find on the Ha'apape genealogy (fig. 25-2) is Paino, who would have been a greatgrandson of Ti'ipari'i - a not impossible identification, if the genealogy may be trusted. In any event, by this late date Matavai, and possibly all Ha'apape, had become at least intermittently subordinate to Pare, whose situation we will consider.

\section{Poreonu'u}

By 1767 the inhabitants of Pare-Arue constituted a unified and fairly stable tribe known as Te Porionu'u. Inasmuch as it was the principal personages of this tribe who succeeded eventually in consolidating political authority over all Tahiti and Mo'orea, we need to look very closely into the genealogical connections on which their political pretensions were founded. It goes without saying that it is unrealistic to hope for historical reliability; Maohi genealogies were no less subject to manipulation than were other forms of verbal "documentation." The extent to which the genealogies in question were thus manipulated is evident in statements attributed to the two most "authoritative" Maohi historians of post-European times: Mare and "Queen" Marau. The former mobilized genealogical evidence reaching back to the Maohis' most venerable ari'i marae in order to "prove" the supremacy 
in rank of the Poreonu'u chiefs' Titles over all others throughout the archipelago. In striking contrast, Marau (in the words of her amanuensis, Adams) characterized the Poreonu'u chiefs as having been "an inferior chiefdom" with their principal roots in the savage, "Manahune," Paumotus. (Handy 1930:79; Adams 1901:84. ${ }^{13}$ With respect to their genealogical evidence, and insofar as that evidence is "authentic" (in terms of Maohi admissibility, which is the criterion most relevant to our present concerns), both these authorities were of course "right," for like most Maohi notables the Poreonu'u chiefs had antecedents reaching in all directions and back to the gods themselves. But rather than reproduce any of these genealogies in full, my present purposes will be amply served, first, by summarizing some fairly consensual traditions regarding the beginnings of this chiefly line in Pare-Arue, and, second, by identifying in detail the eighteenth-century representatives of that line.

According to Adams, Arue and Pare formerly constituted separate tribes (1901:77ff). There may have been other eras during which they were allied with one another, or even joined together into a single tribe, but some traditions have it that the unity manifested during the era now under study was established in consequence of the settlement there of a chiefly personage from Fakarava (Paumotu) named Tu. Here is the Ari'i Ta'ima'i-Adams version of this episode:

Aimata's son, Pomare V, the last king, wanting to establish his title to lands in the Paumotus, had naturally to acknowledge the connection and to prove his descent. The genealogy adopted for the occasion made the first Tu, who came from the Paumotus, grandfather to Taaroa manahune, who married Tetuaehuri i Taiarapu, as I have told in Chapter III. Tu of Faarava, having undertaken a visit to the distant land of Tahiti, came in by the Taunoa opening, which is the eastern channel into what is now the harbor of Papeete. Landing at Taunoa a stranger, he was invited to be the guest of Mauaihiti, who seems to have been a chief of Pare. Tu made himself so agreeable, or so useful to his host, that Mauaihiti adopted him as hoa, or brother, with the formal ceremonies attached to this custom, which consist in a grand feast, and union of all families, and offering of all the rights and honors which belong to the host. Tu accepted them, and at the death of Mauaihiti he became heir and successor in the chief's line. He gave up all idea of returning to the Paumotus, and devoted his energy to extending his connections in Tahiti. He himself married into the Arue family, which gave his son a claim to the joint chiefery of Pare Arue; and at last his grandson, or some later generation, obtained in marriage no less a personage than Tetuaehuri, daughter of Vehiatua of Taiarapu. The received genealogy represents the son of Taaroa manahune and Tetuaehuri as Teu, who was known as Hapai or Whappai to the English, and lived into this century, but Tahitian genealogies have a perplexing way of dropping persons who do not amuse them, and there may well be a leap of one or two generations in that of Pomare. (Adams 1901:85)

Another version, derived from Ari'i Ta'ima'i's daughter, Marau, exemplifies the last sentence in the above passage and also reverses the positions of Pare and Arue: 
According to Marau, the Tu or Pomare family of Pare were descended from a Taumotuan chief name Tu who came from the atoll of Fakarava in the 17th century. Tu was adopted (fa'a taua) by an iatoai named Mauaihiti, in Arue. Later it is said, he married a daughter of the chief of Arue. Their son was Taaroa-Manahune, to whom this anomalous name, or nickname, came as a result of an insult sustained in reference to his Taumotuan derivation. Taaroa-Manahune married Tetua-e-huri, daughter of Vehiatua of Teahupoo. Their son was Teu, who was married in the middle of the eighteenth century to Te-tu-paia, chiefess of Opoa, Raiatea. The son of this marriage was Tu (Cook's "Otoo"), later known as Pomare I. (Handy 1930:76)

To further complicate matters, a reconstruction put together from various sources by Newbury and labeled "Origins and Genealogy of the Pomare Dynasty" derives the Paumotuan link from a marriage between a Pare chief and a Paumotuan woman in the latter part of the seventeenth century (1961: Appendix I). And the famous Puna'auia genealogy, the one publicly adopted by the Pomares themselves (Emory, Marae Traditions), traces the "official" Pomare line some forty generations back from Vaira'atoa, the first in the line to bear the name Pomare, showing links to the most venerable and highly respected marae of Tahiti and Mo'orea, and with no mention whatsoever of any Paumotuan forebear.

Without attempting to decide which, if any, of these accounts is the "true" one, we can rest assured that the enemies of this chieftainship selected the versions that imputed the most recent and socially inferior origins to it.

Be that as it may, the eighteenth-century representations of this chiefly line included some forebears of sufficiently high kin-titular rank to secure for them almost universal acknowledgment of their rights to certain preeminent ceremonial privileges. For purposes of this narrative I use the eighteenth-century phase of the "official" Puna'auia genealogy (Emory, Marae Traditions), beginning with a Tutaha (whom I shall designate "Old" Tutaha), who appears to have been born about 1680 and who is described as having resided both in Puna'auia and in Pare-Arue (near marae Tarahoi).

As several members of this set of kin played such key roles in the events we are concerned with, I should attempt to identify them; but this is easier said than done. Not only is identification obscured by Europeans' inconsistencies in transcribing Maohi names, and by individuals having had multiple names, but there are some significant differences among the various recorded family inventories with respect to numbers of offspring and (a crucially important factor) to order of birth.

"Old" Tutaha, who evidently died long before 1767, affects the story mainly in having provided his descendants with consanguineal links with Tarahoi, his primary ancestral marae in Pare-Arue, and also with important marae in Ha'apape, Fa'a'a, Afareitu (Mo'orea), Fa'ahiti, and so forth. To this array of potentially useful kin connections, his wife, Tera'iatua, added 
her own immediate connections with marae Tepotuarai of Papararau (Puna'auia).

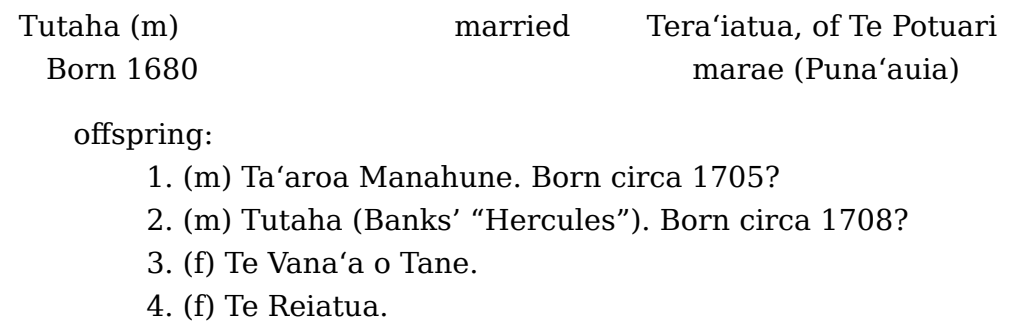

Ta'aroa Manahune, married (first wife) Tetuaehuri of marae (resided at Matahihae Matahihae (Teahupo'o) and Tarahoi)

offspring:

1. (m) Teihamoeroa i Matahihae (or Fa'atupuai i te Ra'i o Vehiatu i te Mata'i). Also called Teu and Hapai. Born circa 1728.

2. (m) Mauaroa (or Teri'i Hinoi Atua). Called "Mowroah" by Bligh, who viewed his corpse in 1792.

3. (f) Teri'i ae Atua.

\author{
(second wife) Tetua Umeretini \\ i Vairao (also called \\ Mataitatia) of marae Nu'utere.
}

offspring:

4. (m) Te Fana Mua i Tarahoi.

5. (f) Tetua Umeretini.

6. (f) Uratua.

7. (m) Te Aha Huri Fenua.

This couple's oldest child, Ta'aroa Manahune, who evidently also expired before 1767, extended the family connections to Teahupo'o and Vairao through his marriage to high-ranking women in these districts; but it is his younger brother, Tutaha, who engages our interest as a living participant in the events under study. Tutaha has also been identified as "brother" of Teu (see G. Forster 1777:II, 92 and Gunson 1964:68), but I am inclined to accept the Puna'auia genealogy in this particular, especially since it was confirmed by that punctilious investigator, Bligh (1789:II, 62). ${ }^{14}$

According to my calculations Tutaha ("Tootaha," "Tutuhah," "Tuteha," "Dootahah") was born about 1708; 'he died in battle in 1773. Banks dubbed him "Hercules," whom he seems to have resembled in physique (Beaglehole 1962:I, 258). Being only a second-born son, Tu- 
taha's kin-Title evidently ranked lower than that of his elder brother, Ta'aroa Manahune (and of the latter's eldest son, Teu); but there is no question whatsoever that it was Tutaha who exercised the chiefly authority over Pare-Arue during Cook's first visit to Tahiti.

Of all these Courts Dootahah's [in Pare] was the most splendid, indeed we were almost inclined to believe that he acted as Locum tenens for Otou [Tu, Pomare I] the Earee rahie [ari'i rahi], his [great] nephew, as he lived upon an estate belonging to him and we never could hear that he had any other publick place of residence. (Beaglehole 1962:I, 385)

Indeed his influence was so powerful in that part of the island that in neighboring Ha'apape, through a grandparent's connections there, he was able to interdict the local residents' trade with Cook:

Early this Morning the Master went to the Eastward in the Pinnace to try if he could not procure some Hogs and Fowls from that quarter, but he returnd in the evening without success, he saw but a very few and those the Inhabitants pretended belonged to Tootaha: so great is this mans influence or authority over them that they dare part with nothing without his consent, or other wise they only make use of his name to excuse themselves from parting with the few they have, for it is very certain these things are in no great plenty with them. (Beaglehole 1955:92; see also Beaglehole 1962:I, 274.)

And his connections and influence in Fa'a'a and Puna'auia were such as to entitle him to receive the Europeans there with all the formality of a visit of State. ${ }^{15}$ In fact, so evident was this man's authority and influence that Cook described him as "the Chief man of the Island" (Beaglehole 1955:85). ${ }^{16}$ In any case, whatever the extent of his personal influence, or of his kinship connections, Tutaha's tribal domain was Pare-Arue, and his principal marae was Tarahoi, on Pare's Cape Utuhaihai (Cook's Marae Point).

By my calculations Teu (Hapai) was born about 1728; he lived until 1803 , and although he was close to the events that shaped these Islands' political history, he seems to have played a relatively minor role in them. In fact, his most notable actions were his marriage to Tetupaia ("Oberroah"), the eldest offspring of Tamatoa III, Ra'iatea's highest-ranking kin-Titleholder and sovereign chief, and his siring of Tu, or Pomare I. Cook and Banks do not even mention Teu during H.M.S. Endeavour's visit in 1769. In the journal of his second voyage Cook mentions him briefly, as Tu's father, and as having interdicted local trade with the English on one occasion; but that is all. Here is G. Forster's description of an encounter with Teu, in 1773:

As this visit was merely a visit of ceremony, we soon got up to return to our boat, but were detained a little longer by the arrival of E-Happai the father of the sovereign. He was a tall, thin man, with a grey beard and hair, 
seemed to be of a great age, but was not yet entirely worn out. He received the presents which our captains made him, in a cold careless manner, which is natural to old people whose senses are considerably impaired. The accounts of former voyages had already apprised us of that strange constitution, by virtue of which the son assumes the sovereignty in his father's life time, but we could not without surprize, behold the aged Happai, naked to the waist in his son's presence, conform to the general custom. Thus the ideas universally annexed to consanguinity, are suppressed in order to give greater weight to the regal dignity, and I cannot help thinking that such a sacrifice to political authority, argues a greater degree of civilization than has been allowed to the Taheitians by our former navigators. However, though Happai was not invested with the supreme command, his birth and rank entitled him to deference from the common people, and to a proper support from the king. The province or district of O-Parre, was therefore under his immediate orders, and supplied not only his wants, but those also of his attendants. (1777:I, 330-331)

In 1788 Bligh described Teu as follows: "I found this Old Cheif, who I suppose is about 70 Years of Age, lying under a Small Shed ... He is a tall Man with weak Eyes and his Skin is much Shrivell'd and Dryed by drinking of that punicious [pernicious] Root the Ava" (1789:I, 382).

In 1803, when Teu died, the Davies History described him as "probably the oldest man on the Island," and as having been for some time "quite childish" (Newbury 1961:59).

Most of Teu's offspring played key roles in the events herein chronicled. To begin with, however, we must attempt to resolve some discrepancies in the sources concerning the number and birth-order of these offspring. Putting together information from various sources (including eyewitness accounts by G. Forster and Bligh), I propose the following list in order of birth: ${ }^{17}$

1. Te Ari'i na Vaho Roa, also Tetua Nihura'i; a girl born circa 1749.

2. "Tedua Towrai" (Tetua te Ahurai?), also Ari'ipaea Vahine and Fataua; a girl born circa 1750 .

3. Tu Nui e A'a i te Atua, also Vaira'atoa, Pomare I, and Tina; a boy born circa $1751 .^{18}$

4. "Tedua Tehamai" (Tetua te Ahamai?); a girl born after Tu, died young.

5. Te Ari'i Fa'atou, also Ari'ipaea; a boy born circa 1758.

6. Te Tupuai e te Ra'i, also Vaetua, Maioro, and Paiti; a boy born circa 1763.

7. Auo, also "Erreretua"; a girl born circa 1768.

8. Te Pau; a boy born circa 1770 .

Teu's eldest child, Te Ari'i na Vaho Roa, is something of a mystery. According to several sources she was married to Teri'irere, chief of Papara, who was some thirteen years younger than she; but she bore him no children. She died sometime prior to 1789 (according to Bligh) without having 
actually figured in any way in the stormy events of the time. The obscurity surrounding the existence of this eldest member of an otherwise politically active set of siblings is particularly puzzling in view of the status of her next younger sister, Tetua (te Ahurai?), "Towrai," also called Fataua and Ari'ipaea Vahine. ${ }^{19}$ The latter, whom G. Forster described as having "almost as great authority among the women, as the King her brother [i.e., Pomare I] had in the whole Island" (1777:II, 96), removed to Ra'iatea at what must have been an early age (probably because of her mother's connections there). She does not enter the story until 1789 , when she returned to Tahiti on a visit; on this occasion Morrison wrote of her as follows:

This woman being the first Born has the right of the Sovereignity of Taheite but having no Child she had Transferd the right to her Brother [i.e., Pomare I] during her Absence, and now Continues it to his son [Pomare II); tho she is not out of Power herself by it when she visits Taheite, being always honor'd and respected.... (1935:101)

I am at a loss to explain Morrison's identification of her as "first Born" in the face of Forster's and others' assertions that that position belonged to Te Ari'i na Vaho Roa. However, Ari'ipaea Vahine was more politically active and influential than her elder sister.

This Homage [i.e., of being uncovered to] is due to Otoo [Tu, Pomare I] as Earee dehie of the isle, to Tarevatou [Te Ari'i Fa'atou] his Brother and [blank] his second sister, to the one as heir and to the other as heir apparent [blank] his eldest Sister being married, is not intitled to this Homage. (Beaglehole 1961:409-410)

According to Morrison's report, which is contradicted by no other that I know of, Ari'ipaea Vahine was childless. G. Forster, writing in 1774, described her as unmarried; whether she remained so thereafter cannot be ascertained, but the circumstance of childlessness and postponed marriage (or no marriage at all), when considered in connection with her activities and influence, suggests that she may have been a leading member of the Arioi - a status that may have outweighed the social superiority ascribed to her elder sister by birth.

The first son of Teu and Tetupaia is our principal character. Tu Nui e A'a i te Atua ("Tu," “Otu," "Otoo"), also known as Vaira'atoa, later became Pomare I, and - after this newly assumed Title passed to his son - ended his days mainly as Tina ("Tynan"). This individual, whom I shall continue to call Pomare I (for the sake of clarity, even though the Title Pomare was not assumed until his adult years, and even though he retired from that Title upon his son's succession), must have been born between 1748 and 1752; he died in 1803. I shall have much to say later on about his character and actions, but can point out now that he was a very large man (according to G. Forster, he was the tallest man on Tahiti [1777:I, 326]; see fig. 25-4). He may also have been physically powerful, 
but his talents were better suited to political maneuver than to physical combat. He began his career as chief of the relatively small tribe of Poreonu'u (Pare-Arue), but possessed in addition the less tangible but immensely important asset represented by kin connections with several high-ranking and/or tribal chiefly persons elsewhere, including principally a link through his mother with Ra'iatea's highest-ranking dynasty.

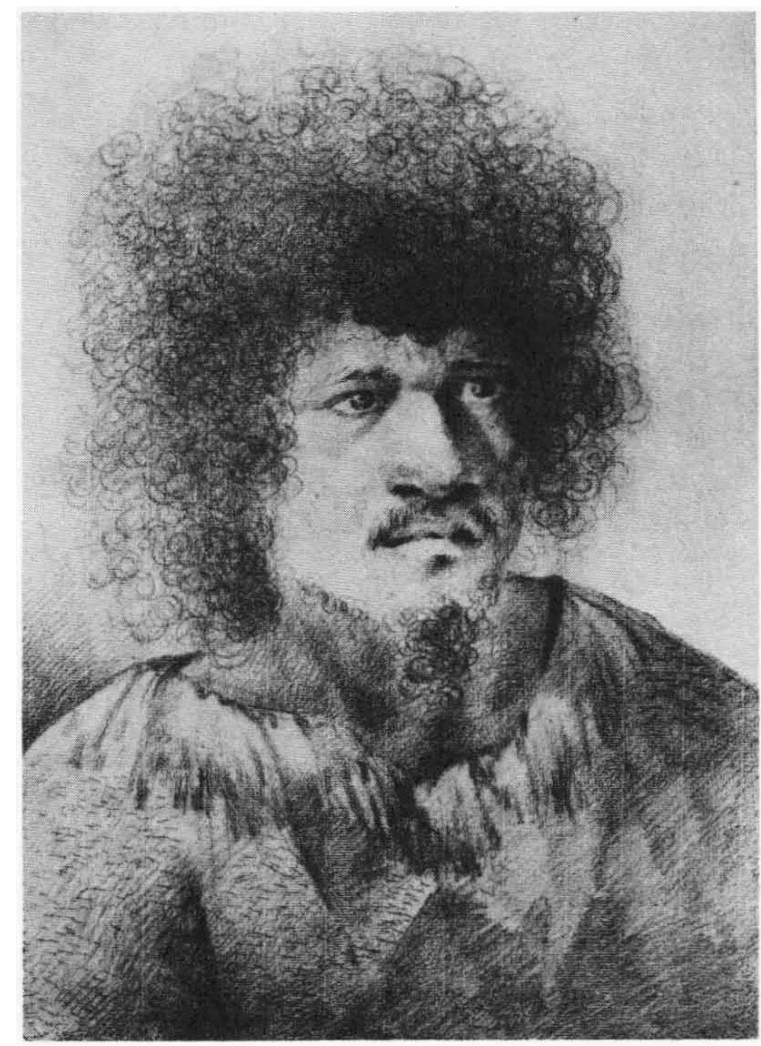

Figure 25-4. Pomare I. “O Tu-Nui-e-A'a-i-Te-Atua, Lord Paramount of Tahiti (1747-1803)." Drawn from life by W. Hodges in 1773. Greenwich Hospital, Greenwich, England.

Of the number of women who shared Pomare I's sleeping mat from time to time ${ }^{20}$ there were three whose relations with him had some degree of institutionalized "permanence." One of these was his official "wife." Although I can find no account of the performance of their nuptials, I conclude that there must have been such, inasmuch as the offspring this woman bore Pomare I were generally recognized as his successors and heirs. (While recognizing the fact of their "marriage," some Tahitian factions did, however, 
cast doubt upon the biological paternity of the principal successor, Pomare II.) Another of these women, who is generally acknowledged to have been a sister of the first one, seems to have been accorded as much "queenly" ceremonial deference as the first, and considerably more husbandly attention; but I can find no indications that her relations with Pomare I were ever institutionalized in terms of nuptial rites (a circumstance which turned out to be irrelevant, since - as I shall attempt to demonstrate - this woman bore no children to Pomare I). Finally, the third of these women was described by Turnbull as Pomare I's "supplementary wife."

The first of these consorts may have begun living with Pomare I as early as 1774; in any case the two were almost certainly "married" before 1780, when their successor-to-be was born. (According to Morrison the marriage itself took place shortly after Cook's departure, in 1773 [Morrison 1935:173].) Thereafter, this woman bore Pomare I four surviving children, and one who was strangled at birth - the parents being Ariois at the time. Until Pomare I's death in 1803 this woman was generally regarded to be his principal consort.

The name usually given to this first and most "official" of Pomare I's consorts was 'Itia ("Iddeah," “Edea," “Edeea," etc.), or Tetuanui Rei i te Ra'iatea, and her kinship connections were very distinguished indeed. Her father was Teihotu, whose closest consanguineal connections are shown in figure 25-5 (based on Emory, Marae Traditions).

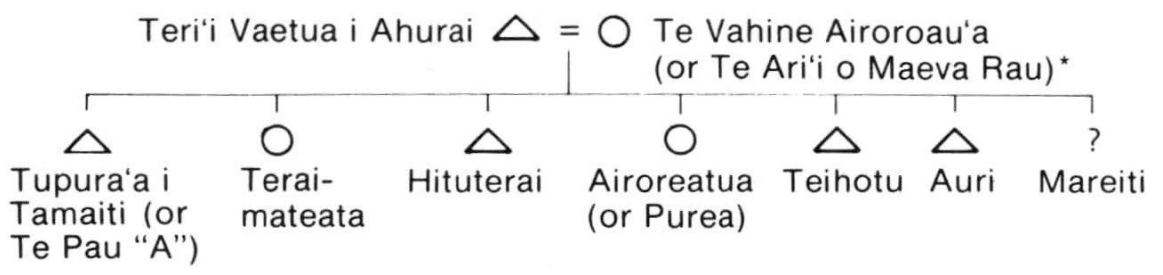

*According to Gunson's undocumented assertion (1964:61-62), Teri'i Vaetua was the wife and Airoroau'a the husband, but this is contrary to both Adams and Emory.

FIGURE 25-5. Some kin relations of 'Itia's father.

Ahurai was the principal marae of the Fa'a'a district, and Teihotu's eldest sibling, who held the Title Te Pau i Ahurai, was ari'i rahi of that tribal district. This important chief was named Tupura'a i Tamaiti. In addition, Teihotu's sister, the famous Purea, was the wife of the chief of Papara, and Teihotu's younger brother, Auri, married into the principal families of Puna'auia and Vaiari. 'Itia, through her mother, Vavea, ${ }^{21}$ had other connections no less distinguished (fig. 25-6). 


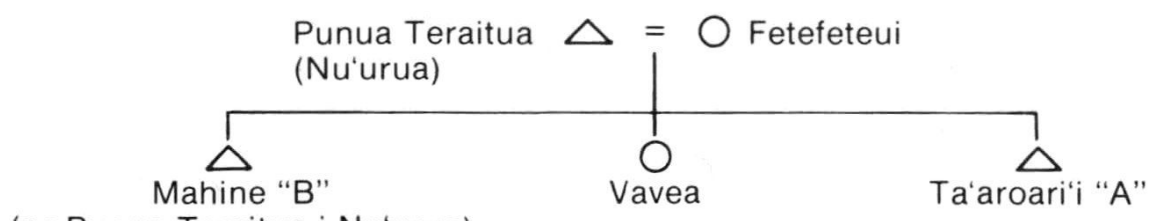

(or Punua Teraitua i Nu'urua)

FIGURE 25-6. Some kin relations of 'Itia's mother.

This family was associated with Mo'orea's preeminent marae, Nu'urua, and, as I shall show, 'Itia's uncle Mahine was Mo'orea's most powerful chief during the 1760s and 1770s. Through her maternal grandmother, Fetefeteui, 'Itia traced connections with high-ranking Titleholders of Pa'ea and elsewhere. Vancouver provided a description of her:

The queen-mother, although destitute of any pretensions to beauty, and having in her person a very masculine appearance, has yet, in her general deportment, something excessively pleasing and engaging; free from any austerity or pride, she is endued with a comparative elegance of manners, which plainly bespeaks her descent, and the high situation in which she is placed. Although her figure exhibited no external charms of feminine softness, yet great complacency and gentleness were always conspicuous; indicating, in the most unequivocal manner, a mind possessing, and alone actuated by those amiable qualities which most adorn the human race. All her actions seemed directed to those around her with an unalterable evenness of temper, and to be guided by a pure disinterested benevolence. Self, which on most occasions is the governing principle in the conduct of these islanders, with her was totally disregarded; and indeed, such was her very amiable disposition, that it counterbalanced any disadvantages she might labour under in a deficiency of personal attractions. (Vancouver 1801:320-321) ${ }^{22}$

The second consort of Pomare I was, as noted above, a younger sister of 'Itia. In referring to this woman the sources apply three different names to her: Pateamai (Emory, Adams), Vaiareti/Vaieriti (Bligh's "Whyerredee," Vancouver's "Fier re te"), and Teano (Morrison); but putting together the circumstantial evidence provided by these sources, I am fairly certain that they all refer to the same person. Vaiareti (for so I shall call her) was first married to the sovereign chief of Taiarapu, Tetua Ounumaona, the younger brother and successor of the Vehiatua who died in 1775, during the Spaniards' stay at Tautira. Tetua Ounumaona, who also bore the Title Vehiatua, died in 1790, without issue. Vaiareti, shortly after having been widowed, must have joined her elder sister, 'Itia, in Pomare I's household. This timing accords with Bligh's statement, in 1792, that he was "surprised ... to find Tynah [Pomare I] to have another Wife while Iddeah was living" (1792:130). In other words, when Bligh left Tahiti at the end of his previous visit, in 1789, the new "wife" was not yet in evidence. As we shall see, these connections provided additional rationale for the subsequent political union of Pare-Arue and Taiarapu. 
Apparently, the new arrangement was a congenial one all round. Bligh described Vaiareti as being "a Woman of Iddeah's Stature, but [having] a much handsomer Countenance," and he added that "the Women were on the best of terms with each other" (1792:130). Indeed, so close was their relationship that 'Itia expected Vaiareti to look after her ('Itia's) own offspring:

Tynah and his Wives as usual dined with me to day. He took an opportunity to sollicit the attendance of the Surgeon on his youngest Child Oro(a)oh, who he said was very ill. We found it under the care of an Old Man, for what is strange, Women are not permitted to be attendants on any of the Royal Family, so that Male or Female, the Children are unnaturally nursed by Men. The Complaints of the Child was said to be in his bowels, - the belly was much distended; but the Scorfula (?) seemed the most alarming symptom, for in one groin it had broke out, $\&$ in the other were swellings which convinced us of the deploreable state this poor infant was in. I told Iddeeah to take better care of her Child, and altho I disputed the propriety, she insisted that Whyerreddee's attention should be engaged towards it \& not particularly hers. (Bligh 1792:155b)

Vancouver, writing a few months earlier, provided a sharper contrast between the sisters, along with a description of their mutually shared position of privilege:

The portrait of Fier re te on canvas would most probably be generally thought intitled to a preference; yet she appeared by no means to possess either mental endowments, or other excellent qualities, in the same degree with the queen-mother; if she had them, they were latent, and required some particular exertion to bring them into action. Her softness and effeminacy afforded her some advantage over her sister; yet there was a shyness, want of confidence and manner in her general demeanor, that evinced her motives to be less disinterested. We were however led to believe, that she was not destitute of the amiable qualities, though to us they did not appear so conspicuous as in the character of the queen-mother. Of the two ladies, Fier re te was now the favorite of Pomurrey, at least we had every reason to think so by the general tenor of his conduct. ${ }^{[23]}$ Notwithstanding this preference, he was observed in several instances to abide implicitly by the advice and opinion of the queen-mother, and to treat her with great affection and regard; who in return never appeared jealous or dissatisfied at the marked attention, or evident partiality, with which her sister Fier re te was treated by Pomurrey. (1801:321-322)

The third woman to have had more than a casual connubial relationship with Pomare I was Pepiri ("Pepeere"), described by Turnbull in 1802 as one who "attended him [Pomare I] in the double capacity of mistress and servant" (1813:140). Pepiri was a daughter of Piha, a man of Vaiuriri, whose rank, or at least tribal authority, entitled him to a polite formal relationship with Pomare. In other words, Pepiri herself was of some social consequence; but there is no evidence that her connection with Pomare I was ever institutionalized by formal marriage rites. Nor does Pomare's connection with her appear to have had any political intent; Pepiri's father was a minor notable, at most, and he ended up among the enemies of Pomare I's successor 
and was slain and sacrificed by the latter's supporters in 1807 (Newbury 1961:99).

Vaiareti's incumbency seems to have been short lived; she was Pomare I's favorite during the early 1790s, but had dropped out of the picture by the time the missionaries arrived, in 1798. She was succeeded, it appears, by Pepiri. Of the three, 'Itia was most consequential by far. She bore all of Pomare I's acknowledged children, and she remained his ally and solicitous aide to the end of his days. Perhaps even before she bore him his last child she began to maintain her own separate establishment, which she shared with a succession of paramours, but this seems not to have affected her nonsexual relations with Pomare I.

The second son of Teu and Tetupaia was Ari'ipaea ("Oreepyah"), or Te Ari'i Fa'atou, who was born circa 1758 and who played a very active part in the events to be described. ${ }^{24}$ As noted earlier, Ari'ipaea's wife was the famous Vahine Metua ("Inomedua," "Inna Madua"), or Teri'itua i Hitia'a. (She is not to be confused, however, with the Teri'itua i Hitia'a, or Reti, who was chief of Hitia'a.) I am at a loss to describe this woman's antecedents. Adams listed her as a daughter of Aromaiterai (of Papara and Mataoa) and of Tetua Unurau (sister of Papara's chief, Amo), and hence a sister of Te Vahine Moeatua, the widow of Taiarapu's Vehiatua I (1901:32). This may be so, although as Gunson pointed out, it was unusual for uterine siblings to be so far apart in age - that is, Te Vahine Moeatua was born circa 1736 and Vahine Metua circa 1762 (1964:63). In any case, the younger woman's antecedents were superior enough to warrant her marriage to the highranking Ari'ipaea, and the position assured her by pedigree was reinforced by virtue of a strong personality.

The next offspring of Teu and Tetupaia was a son, Te Tupuai e te Rai, also known as Paiti (which I shall call him), Maioro, and Vaetua ("Whydooah," "Whytooa," "Wyetua," "Widouah"). Paiti, who was described by Mortimer in 1789 as "a very impudent, dissolute young man," much addicted to kava (1791:45), also acquired a reputation as a bold warrior. He wielded great influence in Ha'apaiano'o, where he resided most of the time - why, I do not know, but possibly because of marital connections there (Bligh 1789:I, 411; Vancouver 1801:300ff). He was also given to homosexual practices, as witnessed by a missionary. According to Wilson, Paiti was an Arioi "of the first rank" (1799:179).

After Paiti was a daughter, born about 1768, named Auo ("Wowwo"), also called "Terrerree" (by Cook), "Erreretua (by G. Forster), and "Whyerreddee" (by Bligh). The Puna'auia genealogy places Auo before Paiti in birth order, but Bligh (1792:141), G. Forster (1777:II, 96), and Henry (1928:249) placed her after him, with which I am inclined to agree; in any case, the question is not structurally crucial, as is the one regarding 
Ari'ipaea Vahine noted above. Auo's chief significance derived from her marriage to Metuaro Mahau (or Ta'aroari'i), a high-ranking kin-Titleholder and influential tribal chief of Mo'orea, of whom I shall say more later on.

The last-born child of Teu and Tetupaia was a son, Te Pau Ari'i i Tarahoi ("Teppahoo," "Tuppahoo," "Tepaow"), of whom Vancouver wrote the following in 1792, when this Te Pau (there were several of that name or Title) was about twenty-two years of age:

There is yet a fourth brother whose insignificance has hitherto precluded his name, which is Tapahoo, from appearing in any of our transactions with these worthy people. Although in the possession of a very considerable property, Tapahoo seems little regarded by his family, and less esteemed by his people. This want of respect is greatly, and possibly wholly, to be attributed to a natural imbecillity of mind; as, to all appearance, he is a young man of an exceedingly weak and trifling character. (1801:325)

Evidently, however, his shortcomings did not stand in the way of his political advance, for he succeeded to the chieftainship of Fa'a'a upon the death of that tribe's chief, also named Te Pau. Bligh's explanation for this succession was that the elder Te Pau (i.e., Te Pau "B" in fig. 25-1) had married a sister of the younger Te Pau's (Te Pau "C") mother, Tetupaia (Bligh 1792:135). It is in fact possible that Te Pau " $B$ " had no son of his own, and moreover that Te Pau " $\mathrm{C}$ " was his namesake, and perhaps even adopted son.

When the Dolphin anchored in Matavai Bay, Pomare I was between fifteen and nineteen years old, and his youngest sibling, Te Pau "C," was still unborn. Although Pomare I was accorded the deference due a successor to the de jure chieftainship of Pare-Arue, and the ceremonial respect to the incumbent (through his mother) of a maro ura kin-Title from Opoa, he was very decidedly under the de facto tribal authority of his great-uncle Tutaha. In fact he was so overshadowed by the latter that Wallis evidently did not even know about the young man's existence. Even Cook, writing in 1769, knew no more about him than that there was somewhere nearby a sovereign ar'i rahi"which was not Tootaha from what we could learn, but some other person we had not seen, or like to do, for they say that he is no friend of ours and therefore will not come near us" (Beaglehole 1955:104). According to Banks, "The Earee ra hie [ari'i rahi, i.e., Pomare I] is always the head of the Best family in the countrey; to him great respect is paid by all ranks but in Power he seemd to us inferior to several of the Principal Earees, nor indeed did he once appear in the transacting of any part of our business" (Beaglehole 1962:I, 384).

\section{Fa'a'a (Te Fana)}

The triangle-shaped area between Pare and Puna'auia known as Tetaha, or Fa'a'a, was occupied by a unified tribe known as Te Fana i 
Ahurai - Ahurai having been the marae of the tribe's highest-ranking kin-Titleholders and tribal chiefs. Handy included this population among the Oropa'a, along with Puna'auia and Pa'ea $(1930: 71)^{25}$ and such an alliance undoubtedly existed from time to time; but during parts of the Early European Era the chiefs of Te Fana acted independently, and entered into intertribal coalitions to suit their own purposes. Adams characterized this tribe's position in the following terms:

The district of Faaa, though it contained only about seven miles of seacoast, was for many reasons very important. It stood, as an independent little nation, between the great Teva alliance in the south, the Porionuu and te Aharoa in the east, and the large island of Eimeo or Moorea, some twelve miles to the west. As Tefana leaned toward Papara or against it, the chiefs of Papara were apt to be less anxious about their enemies or more anxious to win friends. (1901:41)

I listed, earlier in this chapter, the members of the leading family of Fa'a'a who were alive during the first years of the era now under study. Their various kin connections and ties of sentiment indicate how central was the part played by this small tribe in Tahitian-Mo'orean history. The senior member of the family, and its tribal chief, was Te Pau i Ahurai (also called Tupura'a i Tamaiti), who appears in the sources as "Toobouratomite," "Tipouro," "Teppahoo," and "Lycurgus." ${ }^{26}$ During Cook's first visit, this chief, who was most hospitable and helpful to the visitors, appeared to be as much at home in Pare-Arue as in his own home district, and he was evidently on the best of terms with the Pare-Arue chief Tutaha. His younger brother, Teihotu, does not figure in the recorded events of that era; but, as we have already seen, the latter's wife, Vavea, was a member of Mo'orea's leading family, and his daughters married the chiefs of Pare-Arue and Taiarapu, respectively. Still another brother of Te Pau's, Auri, acquired affinal connections with leading families of Puna'auia and Vaiari; and a sister, Purea, was principal consort of the chief of Papara. Te Pau himself (Te Pau "A" in fig. 25-1) was killed in 1773, along with his ally Tutaha, in their joint expedition against the Seaward Teva. Thus, it is his successors who are of more direct relevance to subsequent events, but the identity of these successors is puzzling.

During Cook's second and third voyages, of all the individuals met by the captain and his aides, the one whose presence was most commanding, and whose influence and authority was most extensive in Tahiti's northwest quadrant, was one whose name was first recorded as "Towha" ("T'tewha," "Tettewah," "Tetewha," "Tewha," etc.). It was he who was "Admiral" of the impressive assembly of war canoes reviewed by Cook in 1774, who orated so eloquently and commandingly when occasion demanded, and who was in fact so superior to Pomare I - in probity, in courage, in qualities of leadership, and so forth - that even the Pomare- 
serving English came in time to acknowledge the contrast. (Beaglehole 1961:389; Beaglehole 1967:219n)

"Towha" seems to have been equally at home in both Fa'a'a and Pa'ea. Adams identified him as having been leader of the "family" of Ahurai (1901:94), but his name does not appear on any Ahurai genealogy that I know of, and he was almost certainly not the titular successor to the Te Pau i Ahurai mentioned above, who died in 1773. Adams also stated that Towha's other name was "Tahua," but I can find no confirmation of this in any journal or genealogy. My own conclusion is that "Towha" is the Te To'ofa, whom Henry listed as having been an "underchief" of Pa'ea, the same Te To'ofa perhaps whose Title, Taura Atua i Patea, was associated with one of the three marae which made up that district's Maraeta'ata temple complex. This is confirmed by such statements as J. Forster's, naming him one of the two "joint-chiefs" of Atehuru (1778:354). Cook described "Tewha" as having been "Chief of the district of Tettaha" (Cook 1784:30), ${ }^{27}$ and he undoubtedly wielded authority over that tribe, but his Ahurai kin-Title (if indeed he held one) ranked inferior to that of the titular successor of the Te Pau i Ahurai named Tupura'a i Tamaiti (Tepau "A") who ruled in Fa'a'a until 1773.

According to J. Forster the successor to the Te Pau i Ahurai kin-Title was "Toomataroa" (Tu Mataroa?). This distinction between the titular offices of "Towha" and "Toomataroa" is sharpened by the passage from J. Forster that specifies the former as having been a joint chief of Atehuru and the latter, chief of Fa'a'a (1778:354). In other words, the situation in Fa'a'a paralleled for a time the one in Pare-Arue, where the highest-ranking local kin-congregation Title was held by Teu (and subsequently by Pomare I), while tribal authority actually rested in the hands of a lowerranking relative, Tutaha. "Toomataroa," who also held the Title Te Pau, was evidently so eclipsed by "Towha" that little is recorded about him save that he was married to "Terrano" (or "Tettoohow-deeah"), a sister of Teu's wife, Tetupaia; he was friendly toward Pomare I, and he died sometime between Bligh's visits of 1789 and $1792 .{ }^{28}$ Having died childless, he was, as noted earlier, succeeded by his wife's sister's son (Pomare I's youngest brother), who then himself assumed the Title Te Pau (i.e., Te $\mathrm{Pau}$ "C").

\section{Puna‘auia (Mano Tahi)}

Due to the proximity of Ha'apape, Pare-Arue, and Fa'a'a to the Europeans' ship anchorage in Matavai Bay we are relatively well informed about personalities and events of that region. And because of Paparan pride and its nineteenth-and twentieth-century historian champions, we have been provided with some fairly detailed - though not necessarily wholly accurate - accounts of leading personalities and important events in that 
region. But written chronicles about the region between these two, generally known as Atehuru, are scant and confusing - due in part to the region's distance from Matavai and in part to its leaders' hostility to the European-backed Pare-Arue regime. Nevertheless, a few essentials of its political landscape may be reconstructed, including the circumstance that it consisted of two autonomous but fairly consistently allied tribes, Mano Tahi (or Puna'auia) in the north, and Mano Rua (or Pa'ea) in the south.

During the Early European Era politically significant ceremonial activities in Puna'auia took place mainly at a large coastal marae called Taputapuatea. The marae ruins in Puna'auia now called by that name are located on Puna'auia Point; assuming the two to be the same - a likely but not absolutely certain identification - the marae was founded, according to tradition, by Titihauri, a high-ranking kin-Titleholder of Opoa, to commemorate his marriage to the daughter of a Puna'auian chief (Emory, Marae Traditions). During the era now under study it was a major center of 'Oro worship, although of course not the only one; and, according to Rodriguez, it was the marae "whereat they swear [Pomare I] in as arii" (Corney 1919:170). Like other Taputapuatea marae - that is, those serving as repositories of an 'Oro image - it was the locale for human sacrifices to that god. (Rodriguez and his editor, Corney, appear to have assumed that this Taputapuatea was the "senior" one of its kind on the island [Corney 1919:155n], but it had not always been so, and would not so remain.) On the other hand, the district's most venerable marae was marae Tahiti (or Te Ara e Tahiti, or Puna'auia), a small, unpretentious structure located in the Punaru'u Valley about a mile inland. This marae was second only to Vaiari's Farepua in social preeminence, having been established (according to one tradition) by the fabled Puna'auia chief Te Manutunu and his Vaiari wife, Hotutu (see chap. 16). In 1797 marae Tahiti was also a repository of an 'Oro image and hence was a "Taputapuatea" - which seems not to have been the case during the 1760s and 1770s (Wilson 1799:208). The principal kin-Title associated with this marae was Tetuanui e Mania i Te Rai, one of Tahiti's highest-ranking ones, whose incumbent during the first part of this era was Pohuetea ("Potatow," "Pottatea," "Poatateu"). ${ }^{29}$ Pohuetea's main Title is said to have bestowed upon its bearer the right to don a maro ura; as far as I can discover (and for reasons I cannot fathom) Pohuetea did not assert this privilege for himself, but he did exercise extensive authority and influence, as chief of a populous and warlike tribe.

The first mention of Pohuetea in any of the sources occurs in Gayango's account of his circumnavigation of the island, in 1772 (Corney 1913:322-323). Cook first referred to him in the Journal of 1773, but he had evidently known Pohuetea during his earlier visit to Tahiti, for he refers to him as "my old friend Potattou the chief of that district [Atehuru]" (Beaglehole 1961:210-211). Pohuetea was described by Pickersgill as having 
... carried great command over his teritories and had allways a number of men exerciseing and seemingly kept stricktly to military Duty; he is one of the stoutest men I ever saw, his thigh would measure more round in the Middle then any part of my Body he is very proportionablely made, and his natural Powers are so great that his vast bulk is no impediment to his agility. (Beaglehole 1961:769)

To this may be added G. Forster's comment:

... his features were so mild, comely, and at the same time majestic that Mr. Hodges immediately applied himself to copy from them, as from the noblest models of nature.... His ample garments, and his elegant white turban, set off his figure to the greatest advantage, and his noble deportment endeared him to us, as we naturally compared it with the diffidence of O-too. (1777:I, 360-361)

In 1773 Pohuetea was evidently one of Tahiti's most powerful tribal chiefs. He was also one of her most durable ones, politically, for Bligh was able to report, fifteen years later, that Pohuetea was one of the island's three greatest chiefs, along with Pomare I and Vehiatua III (1789:II, 77). Indeed, he was still alive and active in January 1792, when he visited Vancouver having meanwhile assumed the new name of "Hidiea" (Hitiea?) (Vancouver 1801:275-276), but he died shortly thereafter, or so Bligh reported in June of 1792 (1792:165b).

Pohuetea was unquestionably a man with noble consanguineal antecedents, but what those were I am unable to discover. Individuals bearing the name (or Title?) Tetuanui e Marua i Te Rai appear in the Puna'auia genealogy, the more recent having been the great-grandfather (father's father's father) of Ta'aroa Manahune and Tutaha (Emory, Marae Traditions), but what Pohuetea's kin relationship was to that individual, if any, is not known to us.

We are provided with descriptions of Pohuetea's first wife, and of his subsequent marital arrangements, but no information about the genealogical connections of these women. The first wife was Purutihara ("Polatehara," "Polotheara") about whom G. Forster wrote:

Polatehara ... was so like [Pohuetea] in stature and bulk, that we unanimously looked upon her as the most extraordinary woman we had ever seen. Her appearance and her conduct were masculine in the highest degree, and strongly conveyed the idea of superiority and command. When the Endeavour bark lay here, she had distinguished herself by the name of captain Cook's sister (tuaheine no Toote;) and one day, being denied admittance into the fort on Point Venus, had knocked down the sentry who opposed her, and complained to her adopted brother of the indignity which had been offered to her. (1777:I, 361)

In due course Pohuetea and Purutihara separated and took new mates - the amicability of which arrangement was reported on earlier (chap. 19, section on semi-marriage). ${ }^{30}$

According to Bligh, when Pohuetea died, in 1792, he left no child to succeed him, “... in consequence [of which] the present Minor Chief, some relation, is not firmly fixed in his Government” (1792:165b). 


\section{Pa'ea (Mano Rua)}

Mano Rua, or $\mathrm{Pa}^{\prime} \mathrm{ea}^{31}$ the district south of Puna'auia, was made up of three divisions, each with its own marae complex - namely 'A'ou'a (marae Maraeta'ata), Natu'oha (marae 'Utu'aimahurau), and Mara'a (marae Tuitui). These divisions were eventually under the same regime whose high chief and underchief bore the Titles Te Vahitua i Patea and Te To'ofa, respectively. (Henry 1928:78-79)

Only two of Pa'ea's marae complexes figure importantly in events of this era, but these two were very important indeed. One of these was Maraeta'ata, situated about 460 yards inland and consisting of four separate marae units, three enclosed and one detached rectangular platform. ${ }^{32}$ According to Adams (1901:75), Maraeta'ata had three "heads": "Pouira, the Tevahitua i Patea; Tetooha, the Taura Atua i Patea; and Punua'aitua." I interpret this to mean that each of the three enclosed units in this complex had its own proprietary kin-Title, as given. As noted above, Henry names only two chiefly Titles for this division of Pa'ea (and by direct implication, for the division marae); but her designations are otherwise the same as those of Adams.

Elsewhere Adams represented his informant, Ari'i Ta'ima'i, as asserting that Maraeta'ata "belonged to" Tutaha, the powerful Pare-Arue chief (1901:109); but I consider this wholly unlikely. Like most Maohis of his social status Tutaha could probably trace - or contrive - connections with any important marae, anywhere; and for someone of his great political authority such claims would probably have been acknowledged, willingly or under coercion, by all but his most active enemies. In fact, Tutaha could have made quite credible claims to Pa'ea connections, but to identify Maraeta'ata as "his own" marae, as Adams so stated, is an unwarranted assertion as far as I can tell - indeed, it stands in direct contradiction to another of Adams' statements, just quoted, naming "Tevahitua," "Tetooha," and "Punua'aitua" as "heads" of the marae. The importance of this point should become clear as I begin to chronicle the events of this era.

Marae 'Utu'aimahurau was situated directly on the lagoon shore and about five kilometers south of Maraeta'ata. After 150 years of neglect and dismemberment it is now no longer possible to identify its original form, but various descriptions of it during its heyday, including a sketch by Webber, indicate that it was a complex structure similar to Maraeta'ata, ${ }^{33}$ and even more important in terms of politically significant ceremonials.

According to Henry, Tevahitua and Te To'ofa, two of the proprietary kin-Titles connected with Maraeta'ata, were the same in the case of 'Utu'aimahurau, and partial confirmation for this is found in a Pa'ea genealogy reproduced by Emory, which is labeled "Genealogy of Te-To'ofa, chief of Teoropaa. Outuai was his marae." (Marae Traditions.) I am led to 
conclude that these two marae complexes were closely connected, ceremonially, by reason of common proprietorship. Under such circumstances, as loci for certain kin-specific ceremonies, they may well have been interchangeable, which may account in part for the confusion between them in some sources. ${ }^{34}$ On the other hand, it appears that 'Utu'aimahurau was the preferred location for performance of those rites involving the presence of 'Oro. According to Thomson one of the principal images of this god was installed at 'Utu'aimahurau about the middle of the eighteenth century; the incident is described in a tradition recorded in Henry and said to have been taken from the priests Tamera and Pati'i. After establishing a foothold of 'Oro at Tautira, in the form of a marae and an image for that god,

... the priests of 'Oro went to the body of Tahiti, the fish, with a sacred stone from the marae they had just made. They landed at 'Utu-'ai-mahu-rau (Cape-eatingmany-mists), at Pa'ea, then called Atahata or Ata-huru (Fleeing-clouds).

There they were allowed to take possession and were also aided in building their marae, which was called 'Utu-'ai-mahu-rau. 'Oro-hu'a-manu ('Oro-of-thebird-feathered-body) became master there; the image was woven the size of that at Opoa and covered with red, yellow, and black feathers from the image at Tautira. $(1928: 130)^{35}$

All three of the proprietors' names (or Titles?) listed by Adams (including the two chiefly Titles given by Henry) are to be found on a genealogy reproduced by Emory - that is, the one labeled "Genealogy of Te-To'ofa, chief of Teoropaa. Outuai was his marae."36

I cannot discover who specifically bore the name or Title Tevahitua, ${ }^{37}$ but, however senior that individual may have been in terms of kin-Title rank, he was clearly overshadowed in political authority and influence by the incumbent Te To'ofa. (It is, of course, possible that one individual held both Titles at some time or other, but based on a statement in Adams, which will be reproduced later on, I consider this to have been unlikely at this period.)

Te To'ofa, holder of the Title Taura Atua i Patea, is undoubtedly "Tewha," or Cook's "Admiral," et cetera, whom I have described above as having exercised chiefly authority, though holding a subordinate kin-Title, in Fa'a'a. As noted earlier, I have been unable to specify Te To'ofa's kin connections in Fa'a'a, and from the Paea genealogy he does not appear to have reached his position of tribal authority by primogenitary succession, but there can be no doubt whatsoever about the reality of that authority. Also, he seems to have been the close and consistent ally of Puna'auia's Pohuetea, and a relative of Papara's Teri'irere. ${ }^{38}$

In February 1789 Bligh reported that he received a visit from the widow of "Old Admiral Tet-towah" and recorded that the latter had died "many Months before I arrived" (1789:II, 35). Thus, Te To'ofa evidently died about 1787 or 1788, leaving his son as his successor, under 
the regency apparently of his widow, whom Bligh described as having been "considered a high personage." Bligh gave the latter's name as "Wanowoorah" (Fanau Ura?); I cannot identify this woman genealogically. Bligh had the opportunity of seeing this woman in company with Pomare I on two occasions. In 1789 he described their relationship as "affectionate"; in 1792 he wrote that "I found a shyness about our Friend Tynan [Pomare I] and his Wives to this Woman and her party" (Bligh 1792:166). Slender as this evidence is, it does suggest that Te To'ofa's widow was a woman with very high-ranking kin connections, including probably some with Pomare I. In 1789 she was described as having been "old and infirm," (Bligh 1789:II, 35) but this evidently had not discouraged her "remarriage," to a man of unrecorded origins, named "Tewryighne" (Tauriaine?) (Bligh 1792:166). In addition, Bligh recorded during his next visit, in 1792 , that she was assisted in her regency by "a very clever young fellow called Terraighterree - his official capacity is that of a Priest and had great weight among the People" (1792:165b).

As for Te To'ofa's son and successor, in 1790 Morrison estimated his age to have been about twenty-two. This tall young man, who also bore the Title $\mathrm{Te}$ To'ofa, evidently proved to be a vigorous and politically consistent successor to his famous father, but his reign was brief, for he died ("of an ague") even before Morrison's departure, in 1791, and was succeeded by the son of his sister - subject to the latter's "regency or Guardianship" - inasmuch as the successor was only four years old at the time. $(1935: 106,107)$

\section{Landward Teva}

The social unit called Landward Teva (Teva i Uta) consisted of four major subdivisions, which were (from east to west) Vaiari (or Papeari), Vaiuriri (or Papeuriri), Atimaono, and Papara. For several decades prior to this era the chiefs of Papara had dominated the whole unit in terms of coercive authority and persuasive influence - although their control over the three eastern divisions was largely indirect, and at times probably quite ineffectual. At one time in the traditional, far-distant past, ceremonial preeminence over all Landward Teva (based on kin-Title rank, and possibly also decisive coercive authority) rested with the high-ranking proprietors of marae Farepua, in Vaiari. Subsequently, however, that authority (such as it was) was seized by Paparan leaders; and by the opening of the Early European Era some of the ceremonial eminence attendant upon high rank had shifted to Paparans as well. Indeed, during the early years of this era, efforts were undertaken to assert the Paparan chiefs' rank supremacy over all other Tahitian kin-Titleholders.

When H.M.S. Dolphin anchored in Matavai Bay the tribal chief of 
Papara was Amo, or Tevahitua i Patea, a man of middle age. Few direct observations have been recorded about the personality of this man, even though he was at the center of the swirling political events of the 1760s and 1770s. The main reason for his historic obscurity probably lies in the distance of Papara from Matavai, but it may well be that Arno was in fact overshadowed, in terms of personal qualities, by such individuals as Tutaha, Te To'ofa, Pohuetea, "Old” Vehiatua, and Amo's own wife, Purea. It is also likely that Arno was deliberately discouraged from visiting the Europeans at Matavai, as was his son two decades later. Bligh wrote of the son: "I have sent a message to Tomārre, the Chief, that I shall be glad to see him. - he has hitherto been prevented from coming by a dread of my not treating him well, and I have not been able to do away his fear. I attribute it to some underhand Work of our Friends at this place, who would consider him as a Rival, and do not like him to partake of the benefits they derive from us." (1792:170b)

The fullest (though not necessarily the most accurate) genealogy I have found listing Amo's antecedents and collaterals is Emory's reconstruction (Marae Traditions) based on notes left by Tati Salmon; this takes us back only to Tavi Hau Roa of Tautira, whose estimated birth date is circa 1660. Tavi, it may be recalled, was the too-generous husband of beautiful Taurua, of Farepua marae, Vaiari. According to the traditional story, Tavi "lent" Taurua to a Paparan chief named Tuiterai ("A"), and then wholly relinquished her to the latter even after defeating him in a battle fought over her. ${ }^{39}$ The only issue of the mating of Tuiterai and Taurua so recorded was a male, Teri'itahi, who eventually married Tau Vahine (or Tetua Umeretini) of marae Nu'utere, Vairao; the latter bore him three offspring, Te'eva Pirioi, Aromaiterai, and Amo, whose lines thereafter separated but continued in some measure to influence each other's lives.

Te'eva Pirioi, the daughter and eldest child, is recorded as having married Ari'imao, a high-ranking kin-Titleholder of Opoa. This couple resided in Ra'iatea but their son and only child, Maua, is credited with the fateful act of having transferred to Papara, circa 1760, an image of 'Oro and the maro ura called Teraiputata, which embodied (among other things) symbolic connections between ari'i of Ra'iatea and Huahine. ${ }^{40}$ Other descendants of Te'eva Pirioi played roles, and possibly leading ones, in the stormy political events of the Leeward Islands, but do not directly concern us here.

Teri'itahi's second child and elder son was Aromaiterai ("A"), who, it will be recalled, was for reasons unstated denied the succession and exiled to Mataea. This occurred circa 1730, according to Adams (1901:37). He and his wife (a local woman named Terahi i Te Tua) had three offspring: Tetuanui (f), Vanu'u (m), and Mutuarea (m). ${ }^{41}$ Tetuanui married a Pa'ea man; their descendants were prominent in the affairs of Mo'orea and Tahiti, 
but not enough so to require further description here. ${ }^{42}$ The names Vanu'u and Mutuarea drop out of sight, but another Aromaiterai (Aromaiterai "B" in fig. 25-1), which seems to be an alternate name for one of them (Adams 1901:38), appears in another genealogy as the husband of a sister of Amo, to whose branch of the family we now turn.

After his sister's removal to Ra'iatea and his elder brother's exile to Mataoa, Tuiterai “B” (or Teri'i Tu A'a i te Ra'i, or Te Ura i te Ra'i) remained in undisturbed possession of the chieftainship of Papara, and he and his wife (Teroro e Ora of Fareroi marae, Ha'apape) are recorded as having had eleven offspring, only three of whom concern us here. The firstborn, a daughter, was Faretopa (also Teharetuanui), whose marriage to Tuva'a might have forged a useful link with Pa'ea had any offspring remained long enough alive. Tuiterai's second-born, also a daughter, was Tetua Unurau, whose marriage to her father's brother's son, Aromaiterai "B" served to join these collateral lines, genealogically - but not politically, as we shall see. The Papara genealogy reproduced by Emory credits Tetua Unurau and Aromaiterai "B" with seven offspring, the ones of immediate concern to us being Te Vahine Moeatua (or Purai, or Purahi), the wife of Seaward Teva's "Old" Vehiatua, and Vahine Metua ("Inomedua"), also Teri'itua i Hitia'a, who was the wife of Pomare I's brother, Ari'ipaea. ${ }^{43}$

Tuiterai's third child, and first son, was Amo, who must have been born circa 1725. As noted above, few direct observations have been recorded about this chief's personality, and inferentially the sources provide almost diametrically opposite views of him; in some accounts he is represented as having been a shrewd and active aggrandizer, in others as the timid and somewhat reluctant cat's-paw of his wife, Purea.

Purea, or Airoreatua i Ahurai i Farepua, was sister of the chief of Fa'a'a, named Te Pau i Ahurai ("A"), and could claim other kin connections reaching into some of Tahiti's and Moorea's highest-ranking and politically most powerful families. Along with these social-relational resources she possessed a forceful, imperious presence joined with great ambition. In introducing her to his readers Adams wrote, "If a family must be ruined by a woman, perhaps it may as well be ruined thoroughly and brilliantly by a woman who makes it famous" (1901:40).

Purea's entry into recorded history occurred in 1767, when she visited H.M.S. Dolphin: "At PM, the Gunner came off with a tall well looking Woman about forty five years old, she had a very Majestic Mein, \& he seeing her paid Great respect by the Inhabitants, she being just come there, he made her some presents" (Wallis, Journal, 13 July, LMS Archives). Thereafter, Wallis referred to her as "Queen"; her manner was undoubtedly "queenly" wherever she happened to be, but what respect she commanded in Matavai derived mainly from her husband's maternal connections there (that is, Amo's mother, Teroro e Ora, was associated with Ha'apape's marae 
Fareroi). Writing two years later, Banks described Purea as being “... about 40 , tall and very lusty, her skin white and her eyes full of meaning, she might have been hansome when young but now few or no traces of it were left" (Beaglehole 1962:I, 266). And G. Forster, writing in 1774, said of her: "She appeared to be between forty and fifty; her person was tall, large, and fat, and her features, which seemed once to have been more agreeable, were now rather masculine. However something of her former greatness remained; she had 'an eye to threaten or command', and a free and noble deportment." (1777:II, 100-101)

Like many such couples of high rank and extensive political authority, Amo and Purea came in time to have separate households and sexual partners, but there were offspring of their union - at least one and possibly as many as nine. ${ }^{44}$ In any case, all sources that I know of identify their firstborn, a son, as having been Teri'irere, said to have been born about 1762 . As successor to his father's kin-Titles, including two feather-girdled ones, and through his mother's family connections in Fa'a'a, Teri'irere's rank was among the highest in Tahiti-Mo'orea. And his parents' ambition to enhance his prestige even further was one of the principal motives behind events on Tahiti in the early years of this era. But before chronicling these events something more needs to be said about this notable, but as it turns out, hapless young man.

The first European to meet up with Teri'irere was Cook, in 1769:

This morning a Chief whose name is Oamo, and one we had not seen before, came to the Fort, there came with him a Boy about 7 years of Age and a young Woman about 18 or 20; at the time of their Coming Obarea and several others were in the Fort, they went out to meet them, having first uncover'd their heads and bodies as low as their waists and the same thing was done by all those that were on the out side of the Fort; as we looked upon this as a ceremonial Respect and had not seen it paid to any one before we thought that this Oamo must be some extraordinary person, and wonder'd to see so little notice taken of him after the Ceremony was over. The young Woman that came along with him Could not be prevaild upon to come into the Fort and the Boy was carried upon a Mans Back, altho he was as able to walk as the Man who carried him. This lead us to inquire who they were and we was inform'd that the Boy was Heir apparent to the Sovereignty of the Island and the young woman was his sister and as such the respect was paid them, which was due to no one else except the Arreedehi which was not Tootaha from what we could learn, but some other person who we had not seen, or like to do, for they say that he is no friend of ours and therefore will not come near us. The young Boy above mention'd is Son to Oamo by Obarea, but Oamo and Obarea did not at this time live together as man and wife he not being able to endure with her troublesome disposission. (Beaglehole 1955:103-104)

The "Boy" in this passage was successor not to the "Sovereignty of the Island" but to his father's kin-Titles and to his de facto chieftainship over Papara; and the "other person," still unseen by Cook, was Pomare I.

Several sources state that Teri'irere's wife was none other than Te Ari'i 
na Vaho Roa, the firstborn child of Teu and Tetupaia, and hence Pomare I's eldest sibling. If so, the age of the spouses was discrepant even by Maohi standards, for according to the most plausible estimates I can arrive at, the wife would have been some thirteen years older than the husband. In any case she bore him no children that we know of, and according to Bligh she had died before the latter's visit of 1789 (1789:II, 62).

Another question regarding identity concerns Teri'irere himself. According to Adams' version, Teri'irere died very young and was succeeded by a half-brother, Temari'i (or Ari'ifa'ataia), who was ten years younger than Teri'irere, and was the son of Amo by another wife (a niece of Purea's, and also from Fa'a'a). ${ }^{45}$ But according to another version, which I accept and which seems also to have been tacitly accepted by most primary sources, including the London missionaries, and Bligh (1792:157b, 166b), Temari'i was an alternative name for Teri'irere, and not a brother of the latter's (although the latter may well have had a brother, or half-brother as well). Morrison met "Temmaree" in 1791, and described him as "... a Handsom well made man of about 27 or 28 years old and about 6 feet high" (1935:114); in other words, the age of Temari'i would have been the same as Cook's Teri'irere, and not of the latter's half-brother, who by Adams' birth date estimate would have been less than twenty years old at the time of his meeting with Morrison.

In any case, Temari'i Ari'ifa'ataia (formerly Teri'irere, and eventually Ari'ipaea "B") lived on for another seven years after his encounter with Morrison, during which time he played a leading role in the island's political developments. ${ }^{46}$

Finally, in my list of principal Paparans figuring prominently in the political history of the era, I must not overlook Tupaia, the remarkable man who accompanied Cook's first expedition homeward but who died in the Indies en route. Tupaia was first met by Wallis. At that time he was with "Queen" Purea on her visit to Matavai; he appeared to be her principal aide and advisor, but may also have been her current bedfellow as well. He was still attached to Purea during Cook's visit two years later, but left her service to accompany Cook (and more specifically, Banks) to England.

Tupaia appears to have been born circa 1725, in the northwestern region of Ra'iatea. Banks described him as "well born" (Beaglehole 1962:I, 312); but nowhere is the claim made that he was of the Hui Ari' ${ }^{\prime}{ }^{47}{ }^{47} \mathrm{He}$ was, however, trained in the priestly craft and was knowledgeable in many other fields, including particularly geography and navigation. After arriving on Tahiti - circa 1760, if he accompanied Maua and Manea, as one account implies - he joined Purea's establishment and served as her principal political advisor (and possible abettor); what his relations with Amo were, we are not informed. 
Turning now to the other territorial divisions that, along with Papara, constituted Landward Teva, their populations were of course also caught up in the wars and other political maneuvers characteristic of Tahiti and Mo'orea. It is reasonable to suppose that some of their principal people were deeply and actively engaged in some of these events - but about this one can only speculate. For, either the roles of such personages were so secondary, or their distance from European observers so remote, that they figure hardly at all in the written accounts of the era. From the Europeans' vantage point of Matavai these Vaiarians, and others, were part of the Paparan hinterland, and to Europeans visiting at Tautira they were seen to be vaguely under the Vehiatuas' sway.

In fact, the political situation of these districts did probably correspond fairly closely to the Europeans' perspectives. That is to say, although their chiefs' traditional political loyalties were with Papara, the nearby presence of a strong and aggressive Vehiatua - or a display of overpretentiousness on the part of Papara's chiefs - probably encouraged a shift in alliance. One of the more notable aspects of this situation is of course the extent to which Vaiari itself seems to have become eclipsed. Not only had it become dispossessed of the political influence which it allegedly once exercised over all of Landward Teva, but even the ceremonial preeminence once accorded its highest-ranking Titles (of marae Farepua) seems to have shifted to kin-Titles elsewhere.

\section{MO'OREA}

If the political landscape of the island of Tahiti is in some places overclouded with uncertainty, that of Mo'orea is almost wholly fogbound. Except for a few forays, measured in hours or days, no noteworthy Europeans spent any time there during the first four decades after 1767. In fact, Cook himself did not learn until 1777 of the existence of its magnificent harbors: "It is a little extraordinary that I should have been thrice at Otaheite before and on(c)e sent a boat to this island and yet not know there was a harbour in it ..." (Beaglehole 1967:226). Except for traditional data collected decades after the era under study, most information we have about the island's territorial divisions and leadership was obtained by the Europeans from residents of Tahiti or political exiles from Mo'orea, who could hardly have been counted on for unbiased objectivity.

Handy (after Marau) asserted that the island "anciently" consisted of eight subdivisions, but Henry listed twelve so-called districts, ranging in complexity from one small single-neighborhood unit (i.e., 'Oi'o) to one comprising most of the island's populous northern half and itself subdivided into seven divisions of at least multi-neighborhood size and complexity. In choosing between these two authorities one should take into account the 
possibility that Handy's version was influenced by the eight-tentacled octopus metaphor, which was used so commonly to refer to this island and others; whereas Henry's version lists for many of her "districts" the names of the conventional "tribal" designata, such as mountain, cape, marae, assembly ground, Arioi house, chiefly Title, and so forth.

The fish-anatomy names applied metaphorically to Mo'orea's various parts - The Fin in the South, The Upper Flesh of the Fish, et cetera probably referred not to social divisions but to the island's outline and topography. Nor can I find any historical evidence of a persistent confederation of units corresponding to Handy's reported "The Four Above" (i.e., South) and "The Four Below" (i.e., North) (1930:79-80).

Traditions concerning the founding of Mo'orea's principal marae do not tell us much about tribal boundaries or political realities, nor do they indicate clearly where the island's highest-ranking kin-Titles were localized. According to these traditions, summarized in chapter 16, the four most famed marae were Nu'urua (at Varari), Te Fano (at Pape'are), Umarea (at Afareaitu), and Taputapuatea (at Papeto'ai).

During the eighteenth century the Titles (or were some of them personal names?) that figured most prominently in the accounts were Marama, Mahine, Punua Teraitua i Nu'urua, Teri'itapu nui, Tetuanuireia i te Ra'iatea, Pateamai, and Hamoa (or Ha'amo'a?). Henry listed numerous others (1928:89-94; but only the above, and certain personal names or subordinate Titles closely associated with them, play identifiable parts in the events we are considering. ${ }^{48}$ It is important for my purposes to be able to match names, Titles, and places (including marae), but the extent to which I have failed to do so will be woefully apparent.

The Title Marama appears preeminently in traditions of Mo'orea's beginnings; according to the Handy-Marau version reproduced earlier it was a Marama (from the Leeward Islands) who first established Hui Ari'i rule at Mo'orea, with bases at Nu'urua and Te Fano marae. Later on, according to traditional accounts recorded in Adams, members of this dynastic line extended their authority or rank superiority, or both (the traditions are somewhat ambiguous), over most or all of Mo'orea (1901:161-171). However, during the five decades now under study, the holders of the Marama Title - Marama Ari'ihau and his daughter, Marama Ari'i Manihinihi - do no figure prominently in the recorded chronicles. Although according to Adams, the rank of their Title was supreme in Mo'orea, the tribe over which they ruled was less powerful, and less actively engaged in the wars of the era, than others on the island.

The Mahine who played so active a part in this half century's political events held the Title - he may also have held others - of Punua Teraitua (Te ra'i atua?) i Nu'urua (Adams 1901:95), but he was identified by 
Adams as chief of Opunohu (p. 107), and not of Varari "district," where $\mathrm{Nu}$ 'urua was situated; and it was in the Opunohu area that Cook encountered him in 1777 and described him as "The Cheif" (Beaglehole 1967:226). Henry also listed a Mahine as having been high chief of Atimaha (1928:94). In any case Cook described this Mahine as being between forty and fifty years old, and bald-headed. ${ }^{49}$ Cook stated that Mahine's wife was the sister of Papara's Amo (Beaglehole 1967:226). ${ }^{50}$ We learn elsewhere (Vancouver 1801:323) that Mahine was an Arioi, and childless, but Morrison credited him with an adopted son, "Tayreehamoedooa" (Tairihamoetua?) (1935:173).

In 1777 and for some years thereafter this Mahine (i.e., Mahine "A") was the most powerful and perhaps the most influential tribal chief on Mo'orea, but nowhere is the actual source or domain of his authority made explicit. Cook first called him "a popular Cheif of that Island" (Beaglehole 1967:198), and "This Cheif who with a few people has made himself independant of Otaheite" (p. 227); but this opinion was based on the notion, undoubtedly mistaken, that Mo'orea had at one time been a dependency of Tahiti. Vancouver described Mahine as "the usurping chief of Morea" (1801:319), and Morrison reported him as having seized the "Government" in a revolt against his "nephew" Metuaro, the "proper king of that Island" so-called (1935:172).

The exact identity of this Metuaro (also called Motuaria and Mahau) is difficult to pin down. A genealogy of Nu'urua marae (constructed by Emory from notes of Tati Salmon and Brander) lists Mahine's closest relatives (see fig. 25-7).

Assuming that Mahine's brother had no issue (the sources mention

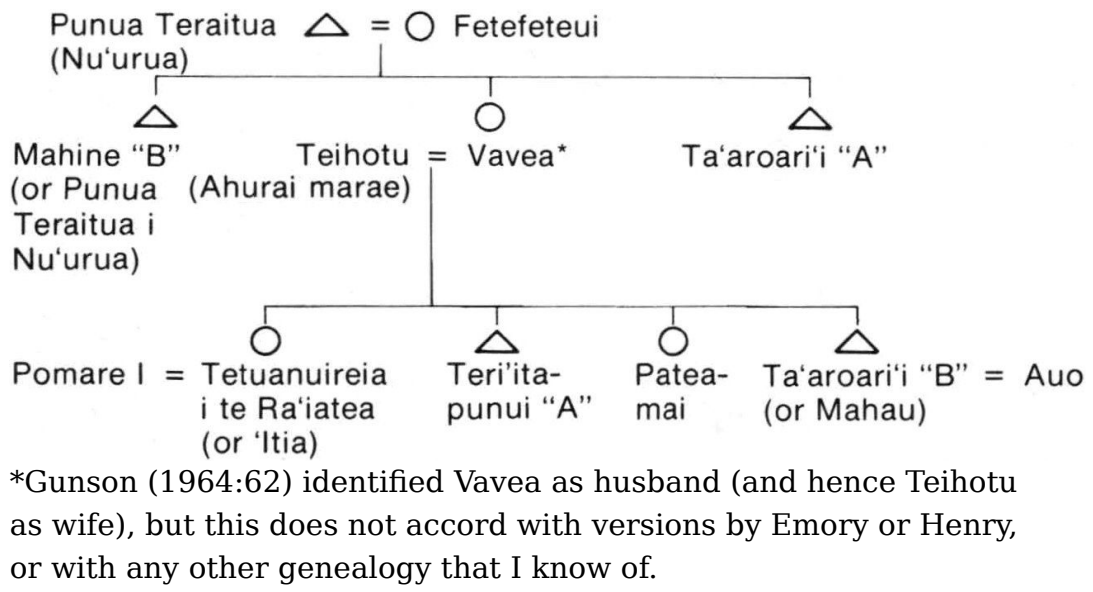

FIGURE 25-7. Some kin relations of Mahine. 
none), the nephew in question must have been a son of Vavea; but this creates another problem, since according to both Adams and Emory, Vavea had two sons, Teri'itapunui and Ta'aroari'i ("B"). Vancouver identified Metuaro with the former:

Mahow I considered to be the same person mentioned by Captain Cook, under the name of Tiareetaboonooa; as, on our first arrival, he was introduced to me by the name of Areetaboonooa, which appellation was almost immediately dropped, and he was afterwards called Mahow; occasioned most likely by the recent alteration in their language, which has been stated to have taken place on the accession of the young king Otoo." (1801:322-323)

Adams made this same identification, at least on one genealogy; on another one Adams identified Metuaro with Ta'aroari'i ("B"), and provided a clue to the puzzle in another passage.

Vancouver sent a boat to Eimeo for Pomare, who came over January 2, 1792, bringing with him his brother-in-law Motuaria, or Metuaro, who was supposed by Vancouver to be the same Terii tapunui that was known to Cook and Forster as chief of Varari in Eimeo. He was called commonly Metuaro Mahau. According to our records, he was Taaro-arii, a younger brother of Cook's Terii tapunui, who was dead without issue, and left his name and property to Taaro-arii, who also had no male children. (1901:106)

In any case, the importance of the problem of one Teri'itapunui-Metuaro or two is diminished somewhat, structurally, inasmuch as the second of the candidates (if there were two) was sibling and successor to the first. (I sympathize with any reader who may have become impatient at my concern with these tedious details but wish to remind him that correct identification and genealogical placement of the dramatis personae is essential for understanding the political events of this era.)

Cook mentions a Teri'itapunui, in 1777, as having been Mahine's sister's son, chief of Varari and the "lawful heir" to the kingship of Mo'orea (Beaglehole 1967:198, 231). In 1789, Mortimer visited Varari and there met "King" Teri'itapunui, whom he described as "a tall, stout, good-looking man, speaks but little, and seemed to be of a timid disposition." According to Mortimer, Teri'itapunui received him in company with his wife, who was "a very agreeable, insinuating woman, with a great deal of natural politeness about her." (1791:38) If my identification is correct this woman was none other than the youngest sister of Pomare I, one named variously Vai'io, Auo, "Wowo," "Tirrayraydooa," and so forth; and some of her poise may be accounted for by the circumstance of her earlier familiarity with Europeans at Matavai and Pare. Vancouver had much more to say about Teri'itapunui-Mahau during his 1791-1792 visit, but these events will be described later on.

Tetuanui Rei i te Ra'iatea was, of course, the famous 'Itia, Pomare I's principal consort, whom I have already identified. I have also described 
Pateamai (or Teano, or "Fier rete"), as having first married Vehiatua III and, after his death, as having for a time shared her sister's connubial relationship with Pomare I.

\section{LEEWARD ISLANDS}

Tahiti and Mo'orea were closely linked with the Leeward Islands by ties of trade, cult, and kinship, some of which were of crucial importance to political developments on Tahiti-Mo'orea during the era now under study. Events on Tahiti-Mo'orea also had consequences upon those in the Leeward Islands during this era, although perhaps relatively less so until the very end of the era. In any case, interest throughout the remainder of this book will focus on Tahiti-Mo'orea; among other reasons for doing so is the fact that until about 1809 the information on the Leewards is mythical, indirect, or based on observations made during Europeans' very brief visits there. I have elsewhere reproduced mythical evidence concerning some aspects of the "prehistory" of the Leeward Islands - evidence relating mainly to the origin and spread of Opoans and their institutions (including feather-girdled kinship Titles, the cult of 'Oro, and the Arioi sect). The first recorded European visit to these islands was Cook's; after leaving Tahiti in 1769 the Endeavour cruised and visited among them between July 16 and August 11 . Cook made brief return visits in 1773 and 1774, and again in 1777; and the Aguila visited Ra'iatea for about two days in January 1775. H.M.S. Pandora called briefly at Huahine (fig. 25-8), Ra'iatea, and Porapora in May 1791 searching for Bounty mutineers. The next visit was a short one by Turnbull in 1801, when the ship barely escaped seizure by Ra'iateans. Missionaries began visiting the Leeward Islands in 1807, but it was not until 1818 that a permanent mission station was established there.

Ra'iatea resembled Tahiti's fifth-order tribal units in territorial complexity. According to Henry it consisted of nine "districts" - Opoa (the district of the dynasty that traditionally supplied the island's sovereign chief) and eight others, said by Handy to have been delimited by an Opoan chief after his supporters had conquered the rest of the island's populations. ("The Arii at Opoa took his urupiti (cavalla fish, signifying Raiatea), cut it down the middle, and laid the two halves side by side. Each side he divided into four mataeinaa" [Handy 1930:90].) Nothing is reported in this or other accounts concerning the territorial organization of Ra'iatea prior to this legendary reorganization; nor can I discover any information about the orders of territorial complexity of the reorganized "districts."

The sources agree that the Opoan chiefs did in fact exercise some tribal authority over the whole island, but the western "district" of Tevaitoa, which I mentioned in another context, in chapter 16, appears to have been somewhat more independent of Opoa than were the seven others.

In addition to the tribal authority exercised by Opoans, the kin-Titles 
of its chiefly dynasties were, during the eras under study, ranked as high as or higher than those of any other kin-congregations in the Society Islands.

Henry designated Apu Roa as the "national marae" of Taha'a, thereby signifying that the island's four "districts" constituted a larger territorial unity of some kind, but indications are that this larger unit itself did not remain autonomous, having become a "dependency" first of Ra'iatea then of Porapora before Europeans first touched ashore there. According to the summaries of Henry, Porapora consisted of eight so-called districts, but I am unable to specify their respective orders of complexity. From time to time all or most of the island seems to have been dominated by the chiefly dynasties of one or another of these districts; this was certainly the case during the sixth and seventh decades of the eighteenth century, but otherwise, dynastic rivalries appear to have kept the island in a fairly constant state of political instability.

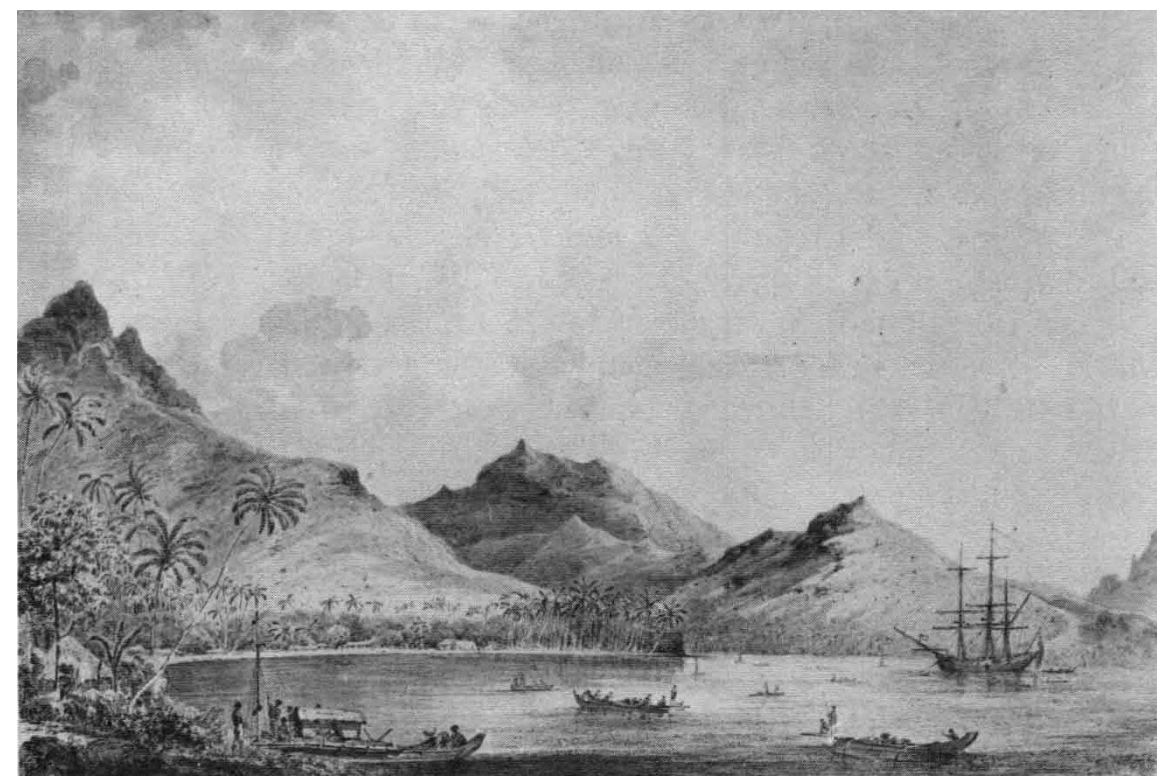

FIGURE 25-8. "The harbour at Huahine.” Drawing by J. Webber. British Museum.

Maupiti resembled Ra'iatea in being divided into nine so-called districts - eight subordinate ones and that of the island's "high chief." From Handy's account it appears that these "districts" became firmly united, but judging from the small size of the island and of its population, it seems unlikely that it had reached an order of complexity, in terms of territorial units, much beyond what for Tahiti I labeled multi multi-neighborhoods.

By European times the island of Maupiti is reported to have become 
subordinate to chiefs of Porapora, but the precise nature of the relationship is not recorded. ${ }^{51}$

The territorial organization of Huahine differed somewhat from that of the other islands. By European times the island's two geographic divisions had become wholly subordinate to a chiefly dynasty residing near Lake Maeva in the north. Southern, or Little, Huahine was composed of four contiguous "districts" of unspecified complexity; before becoming subordinate to the Maeva overlords these four were united under the authority of the chief of one of them, but whether this same arrangement prevailed after Maeva domination is not recorded. As for the northern geographic division, Greater Huahine, Henry stated that it was divided into ten "districts," without specifying their nature. Other writers however listed only eight, and according to Handy these were not "districts" in the ordinary sense:

Maeva had eight sons, four by Tuaroanuihau (the last high priest of Huahine) whose ancestral marae, Orohaehaa, at Maeva, was named Tua-roa-nui-i-ae-pau and then four by Teroro Hiti, a warrior chief from Matahiva in the Tuamotus. The land at Maeva, called aia tupuna o te ui was divided into the eight mataeinaa, one for each son, and each land they had conquered outside Maeva was also divided among these eight sons to be added to their mataeinaa and to be a possession of their families and descendants. Thus Huahine, in patchwork fashion became entirely apportioned among the eight mataeinaa. Each mataeinaa was, in turn, divided into two parts, one for the matahiapo (senior branch), and the other for the iato (junior branch) of the family. (1930:96)

This Huahinean method of subdividing conquered territory was of course much more inclusive, but resembled somewhat one practiced elsewhere. I refer to the practice followed by some head chiefs of complex territorial units in acquiring and maintaining personal family estates in each of the major territorial subdivisions under their authority. Usually such chiefs established their own stewards in separate estates, and these were directly responsible to their master and not to the local chiefs in the territorial subdivisions in which the estates were located.

Little is recorded about Mai'ao's political situation, save that it was a "dependency" of Huahine (Teissier 1956:518), and that it was a refuge for survivors of canoes swept off course between Tahiti-Mo'orea and the Leeward Islands.

According to mythic evidence already cited, the various Leeward Islands were closely interlinked by numerous ties of kinship, reinforced by easy and frequent visiting, and evidently also by much intra-and interisland warfare. Opoa appears to have retained over a long period of time its cult primacy and its preeminence in terms of ranked kin-congregation kin-Titles; and inasmuch as statuses in these hierarchies sometimes, and in some respects, were backed by coercive sanctions, the principal chief of Opoa (and 
hence of Ra'iatea) may be said to have exercised a kind of authority over all these islands from time to time. But, around 1750, under the leadership of a chief named Puni, Poraporans defeated most of their neighbors and imposed Puni's force-backed authority over them. Huahine evidently threw off the invaders after a while, but in 1769, the date of the first European visit, the other Leeward Islands were firmly under Puni's control. (Beaglehole 1955:153; 1962:I, 317-318)

Having heard much about this military conqueror, the English visitors were somewhat surprised at sight of the man himself:

In the evening we all went to see the great king and thank him for his civilities particularly of this morning. The King of the Tata toas or Club men who have conquerd this and are the terror of all other Islands we expected to see young lively hansome \&c \&c. but how were we disapointed when we were led to an old decrepid half blind man who seemd to have scarce reason enough left to send hogs, much less galantry enough to send ladies. ${ }^{[52]}$ (Beaglehole 1962:I, 327)

On this occasion Cook also referred to Puni as appearing to be "stupit" (Beaglehole 1955:150).

Four years later, on his second visit to Ra'iatea, Cook was able to report at greater length about the political situation in these islands:

Before I quit these isles it is necessary to mention all I know concerning the government of Ulietea and Otaha. Oreo, so often mentioned is a Native of Bola bola, but is possessed of Whenooa's or Lands at Ulietea, which I suppose he as well as many of his Country got at the conquest. He resides here as Opoonies Lieutenant, and seems to be vested with regal authority and to be the supreme Magistrate in the island, Oo-ooroo who is the Aree by hereditary right seems to have little more left him than the bare title and his own Whenooa or district in which I think he is sovereign. I have always seen Oreo pay him the respect due to his rank and was pleased when he saw me distinguish him from others. Otaha, so far as I can find is upon the very same footing, Boba and Ota are the two Chiefs, the latter I have not seen; Boba is a Stout well made young man and we are told is, after Opoone's death, to Marry his Daughter, by which Marriage he will become Vested with the same regal authority as Opoony has now, by which it should seem that tho a Woman may be vested with regal dignity she cannot have regal power. I cannot find that Opoony has got any thing to himself by the conquest of these isles any farther than providing for his Nobles who have siezed on best part of the lands; he seems to have no demand on them for any of the many articles they have had from us. Odiddy has several times enumerated to me all the Axes, Nails \&c Opoony is possessed of which hardly amounts to so many as he had from me when I saw him in 1769. Old as this famous man is he seems not to spend his last days in indolence, when we first arrived here he was at Mauraua, soon after he returned to Bolabola and we are now told he is gone to Tubi. (Beaglehole 1961:429-430)

Cook's "Oo-ooroo" [Uru], the ari'i of Ra'iatea "by hereditary right," was Vetea Uru, son of Tamatoa III by the latter's third wife, and thus halfbrother to Pomare I's mother, Tetupaia, who was daughter of Tamatoa III by his first wife. Evidently Vetea Uru retained the tribal (now subtribal) 
chieftainship of Opoa district, and continued to be recognized as Ra'iatea's highest-ranking resident Titleholder, but was subordinate to Puni's deputy, Oreo, in secular matters concerning Ra'iatea's other subtribal districts.

As for Popa and Ota, identified by Cook as Taha'a's two chiefs, I cannot further identify them, nor discover whether the former did subsequently marry Puni's daughter, as Cook was told would be the case. G. Forster described "Boba" as a relative of Puni's (1777:II, 391) - a likely but not very useful identification. Vancouver reported the presence of a man named Boba on Tahiti in 1792 (1801:307), but there is no evidence of his having been the same person.

The identity of Puni is certified by Emory as having been none other than the Teihotu Mataroa, son of Teihotu Matanevaneva, the Poraporan chief whose downfall and heroic but somewhat foolhardy death is described in a mythic account reproduced earlier. In that account, it will be recalled, after the latter had been killed by his rebellious subjects and political rivals, the victors elected his infant son to chieftainship of the new regime (Hau Teraitapu), therewith changing his name to Puni. (See chap. 16; and Emory, Marae Traditions.) According to Emory's calculation Puni was born circa 1700; in 1789 it was reported to Bligh that the great warrior had died some thirty months previously, that is, about 1786 . It speaks much for Puni's reputation that one of the anchors lost by Bougainville off Hitia'a was subsequently sent to Puni, presumably as a respectful gift (Beaglehole 1967:252; Lesson 1839:450).

As noted earlier, Huahine was at one time attacked and occupied by Puni's forces, but the invaders were shortly thereafter driven away. In any case, when the Endeavour called there in 1769 the "King" of the island was reported to be a man named "Oree" (Ori) and relations with Porapora were described as hostile:

... the People of this Isld are remarkably Civel and Expres'd a great Desire of our going to kill the Bollobollo Men who are their Enemies and come every month or six weeks taking away their Things and Killing all that Oppose them. (Pickersgill, in Beaglehole 1955:143n)

This view was repeated to Cook in 1773 , but was evidently not shared by Ori himself:

Oree probably heard of this [i.e., requests to Cook to attack Porapora] and took an oppertunity when he was left aboard to disire that I would not, teling me that Opoone their King was his Friend, the Common people in general seem to bear an implacable hatred against the Bolabola men nor is this to be much wondred at sence they have made a conquest of most of the neighbouring iles, the little Island of Huaheine under the brave and wise conduct of Oree still preserves its independancy, not a Bolabola man have yet been able to get a footing there tho' we have been told some attempts have been made but of this we have no absolute certainty, from the great plenty of everything on the Isle one might conclude that it had injoyed the b(l)esings of Peace for many years.... (Beaglehole 1961:221) 
As Cook subsequently learned, Ori may have possessed much authority in Huahine - or, at least, on the northern of the island's two parts - but the highest-ranking kin-Titleholder at the time of Cook's visits was a young lad named Teri'itaria, who had been born about 1763, the son of Mato and Fatuarai (Fatuarei?). In 1777 Cook found Ori to be no longer at Huahine, having removed to Ra'iatea. As for the current government of Huahine Cook wrote at the time:

Anarchy seemed to prevail more here than at any other place, the Earee rahie as I have before observed was but a Child and I did not find there was any one man or set of Men who managed the Government for him, so that when ever any missunderstanding happened between us I never knew whom to apply to to settle matters. The you(n)g Chiefs Mother would some times exert her self but I did not see she had greater authority than many others. (Beaglehole 1967:237)

As one example of this anarchy, Cook had some unhappy encounters with a Poraporan adventurer then on Huahine who had succeeded in collecting around him some other ruffians and who seemed to be a law unto himself (Beaglehole 1967:236-237).

Fatuarai, the young ari'i rahi's mother, who was known also as Teha'apapa, was descended from high-ranking kin-Titleholders of Tahiti, Mo'orea, and Huahine (Henry 1928:257). Her father is described in one account as having been Huahine's "principal warrior chief" and associated with marae Tiva (Chesneau 1928:81). Mato, the boy's father (also known as Terii te Po Arei), was identified by Henry as "high priest of Opoa" (1928:257). His kinship with some other principal personages of the era is shown in figure 25-9.

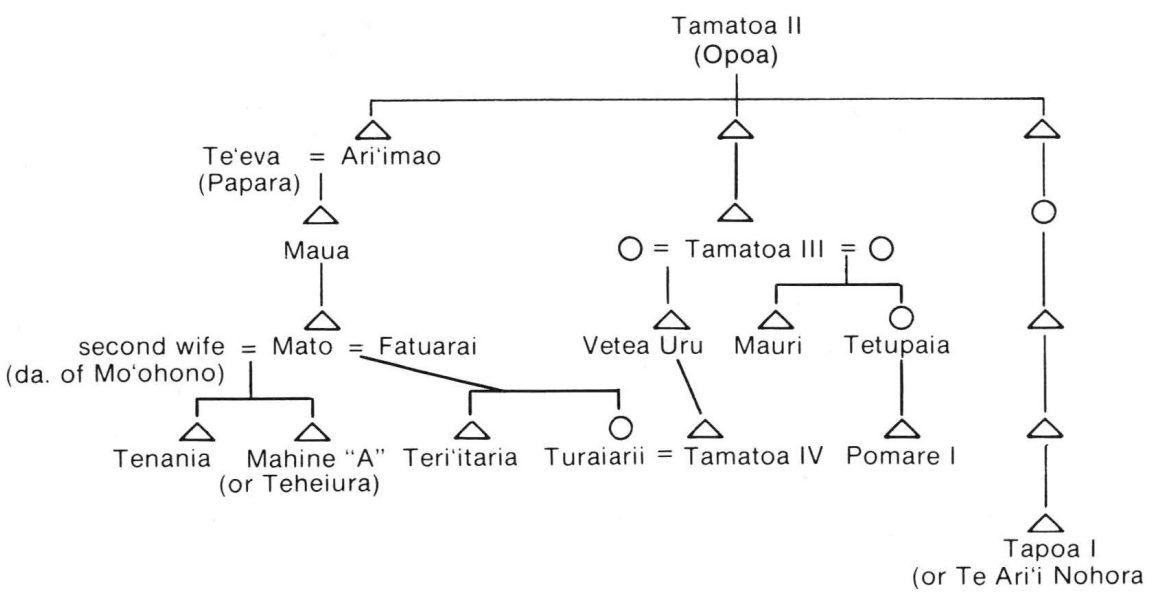

FIGURE 25-9. Some kin relations of Teri'itaria. 
After siring Teri'itaria (about 1763) and Turaiarii, Mato left Fatuarai and married the daughter of Mo'ohono, identified by Chesneau as "grandpriest of Huahine" (1928:81). By this wife he sired three children, two of whom figure prominently in political developments, namely, Tenania (who "married" 'Itia after the latter separated from Pomare I) and Mahine ("A") (known also as Teheiura and Puru, who later became "king," or, with Tenania, "coking," of Huahine). Mato was not in evidence during any of Cook's visits to Huahine; Chesneau reported that he was killed around 1775 in an interisland battle, but this date and the circumstances of this conflict are clouded with uncertainties. ${ }^{53}$ All of this is of course most intriguing, and probably important; and I relegate discussion of the matter to a footnote only because of the paucity of data concerning it.

I shall take up the threads of this Leeward Islands history as events in Tahiti-Mo'orea warrant. Meanwhile, let us consider what ideas and objects of Leeward Island origin were exercising palpable influence upon the course of political history of Tahiti and Mo'orea at the beginning of the European era.

\section{'ORO IMAGES AND FEATHER GIRDLES}

In my accounts of myths having to do with the diffusions of 'Oro worship I reproduced (in chap. 22) one of Henry's, which described how some of the god's zealots had established the cult on Tahiti by building a marae called Taputapuatea on Taiarapu and by installing in it an 'Oro image called 'Oro Rahi To'o Toa (Great-'Oro-of-toa-wood). The date of this event is not given, but the description of it implies that it was the first successful establishment of the cult on Tahiti. ${ }^{54}$ The account then continues:

Thus encouraged, the priests of 'Oro went to the body of Tahiti, the fish, with a sacred stone from the marae they had just made. They landed at 'Utu'ai-mahu-rau (Cape-eating-many-mists), at Pa'ea, then called Atahata or Ata-huru (Fleecy-clouds).

There they were allowed to take possession and were also aided in building their marae, which was called 'Utu-'ai-mahu-rau. 'Oro-hu'a-manu ('Oro-of-the-birdfeathered-body) became master there; the image was woven the size of that at Opoa and covered with red, yellow, and black feathers from the image at Tautira.

Gradually, as the priests of the new order increased, new marae to 'Oro in the feather body were erected all around Tahiti, and finally Pepeto'ai in Mo'orea had its Taputapu-atea, which was originally Te-pua-tea (Whiteflower). The change of the name was occasioned by a marriage which took place between a high chief of the Manea family in Papeto'ai and a princess of Opoa. The princess brought her marae stone from the original Taputapu-atea, and she and her husband named it Tura'a-ma-rafea (Kneeling [stone] of-twomeetings). This stone raised the marae from a social to a national grade, so that it became the Taputapu-atea of all Mo'orea. (1928:130-131)

This account does not indicate whether facsimile images of "'Oro in the feather body" were made and installed in the various marae erected 
for this manifestation of the god, nor does it imply that a separate 'Oro image had been installed in the Taputapuatea built on Mo'orea. In fact, the only other evidence, mythical or otherwise, for the presence of any other 'Oro image on Tahiti-Moorea during the era under study derives from Thomson's History.

Shortly after [1730-1740] a quarrel took place between the two districts of Te oropa and Teva uta. A battle called Ohure popoi hoa (a name of filthy meaning) was fought at Papara in which the latter were beaten and dispersed. A party fled to the island of Raiatea, among whom were Faanonou the grandfather of Tati and Teiva [Te'eva Pirioi] a female who was soon afterwards married to Ariimao ancestor of Tamatoa and king of Raiatea, by whom [Ari'imao] she had a son called Maua. Faanonou became the friend of Maua, and when he resolved to return to Tahiti, through the influence of his friends, and his mother he obtained an idol made at the great marae of Oro at Opoa, and which had been consecrated by the priests there, and became a duplicate of their god. This new idol was deposited in the sacred canoe of Oro called Te vaa roa i te matai and committed to the care of Faanonou to be conveyed to Tahiti. The priest of Oro giving strict injunctions that it should be conveyed to his paternal marae at Papara with as little pomp and ceremony as possible. Faanonou accordingly sailed for Tahiti accompanied by Tupaia a priest of Oro and one or two canoes, arrived in safety at Papara, where in the small family marae adjoining the dwelling of the chief the god Oro found his first resting place on Tahiti probably about the year 1760 . So quiet and unostentatious was the landing of Oro, that it was scarsely known for a considerable period, that such an arrival had taken place. When it at last became generally known throughout the island, he was at once adopted as the national god, the god of war, and the spirit of the new god seemed at once to have possessed the people. (Thomson, History, pp. 16-17)

Thus, we are provided with evidence - legendary but circumstantial - of the presence of three 'Oro images on Tahiti-Mo'orea during the eighteenth century: the Great-'Oro-of-toa-wood (at Taputapuatea, Taiarapu); the 'Oro-of-the-bird-feathered-body (at marae 'Utu'aimahurau, Pa'ea); and the one installed by Maua and Tupaia at Papara (which I shall call the "Papara image," in the absence of its name being given in the sources). There may have been more, but these alone are specified in the accounts about which I know.

Indeed, the only one of these three images that I can actually account for in historically authenticated reports is the so-called Papara one, which, as we shall see, became a most important element in the political strife of the era.

Of parallel and indeed interdependent importance in the political history of the Early European Era were the feather girdles, which served to symbolize and legitimatize certain of the very highest-ranking kin-Titles of Tahiti-Mo'orea. One of these was the red-feathered girdle (maro ura) reportedly introduced into Papara (along with the Papara image of 'Oro) as the result of Te'eva's marriage to Ari'imao. Another was the fabled yellow- 
feathered girdle (maro tea) allegedly bestowed upon the first Te'eva by his genitor, Hotutu's shark-god lover from overseas. Thenceforth, after Te'eva moved from Vaiari and settled down at Papara, entitlement to this girdle was identified with the dynastic line holding the chieftainship of Papara's principal kin-congregation, and it was the only such yellow-feathered girdle recorded for Tahiti-Mo'orea. ${ }^{55}$ Thus, during the era now under study, there were traditions extant concerning two distinct feather girdles associated with the chiefly kin-Titles of the principal Paparan kin-congregation (and derivatively, with chieftainship of the Papara tribe). Whether these traditions were substantialized in the existence of two actual girdles - a maro tea and a maro ura, or two maro ura - I cannot say.

The question is further complicated by references in the sources to what Adams called "a curious form of the Maro ura."

Besides the ura or red feathers, which were the exclusive signs of the Arii rahi, a curious form of the Maro ura had been made the symbol of supreme authority by Purea [the Fa'a'a woman married to Amo, chief of Papara]. This was the British pennant left flying at Matavai by Captain Wallis at his departure. Purea took it to her Marae of Mahiatea, and seems to have converted it into the Maro ura with which her son was to be invested. (1901:109)

This same girdle (which I shall call the "Wallis maro") was seen in 1777 by Cook, who described it as follows:

One of the bundles was now untied and it was found, as I have before observed, to contain the Maro with which they invest their Kings with Royalty. It was carefully taken out and spread out at full length on the ground before the Priests, it was about five yards long and fifteen inches broad, and composed of red and yellow feathers but mostly of the latter; the one end was bordered with eight pieces, each about the size and shape of [a] horse shoe, with their edges fringed with black pigeon feathers; the other end was forked and the ends not of the same length. The feathers were in square compartments ranged in two rows and otherways so desposed as to have a good effect being first paisted or fixed to their Country cloth and then the whole sewed to the upper end of the English Pendant, Captain Wallis desplayed, and left flying a shore the first time he landed at Matavai, so at least we were told and we had no reason to doubt it as it was part of an English pendt. About six or eight inches square of the Maro was not compleat, that is there were no feathers upon it except a few that were sent by Waheatua as before mentioned. The Priests made a long Prayer over the Maro in different forms which, if I misstake not, they called the prayer of the Maro. When it was finished, the Maro was carefully foulded up put into the Cloth and laid upon the Morai. (Beaglehole 1967:202; see also Bligh 1792:138)

It would be useful to discover whether the British pennant in question was in fact added to one of the traditional Paparan maro - the ancient maro tea or the more recent maro ura introduced by Maua and Tupaia - or whether the whole Wallis maro had been fabricated de novo by Amo and Purea. Unfortunately a positive answer to this question eludes 
me - although I strongly suspect the first alternative to be the correct one. My interest in this question goes deeper than idle ethnographic curiosity. Such a development would carry important implications if it turned out that an entirely new maro, and one deriving its significance from the European presence, had been created as the symbol for Teri'irere's incumbency.

Another maro - this undoubtedly an ancient one - which figured importantly was the one usually deposited at Pare's Tarahoi marae and allegedly introduced by Tetupaia from Opoa, when she became the wife of Pare-Arue's chief Teu, circa 1740. (Tetupaia was the eldest child of Ra'iatea's sovereign chief, Tamatoa III.) (Henry 1928:249.) In February 1791 Morrison witnessed the investiture of Pomare II at Tarahoi with a maro ura that may plausibly be identified, in whole or in part, with the one introduced by Tetupaia:

This day the Ceremony of Investing the Young King with the Marro Oora or Royal Sash took place; the Sash is of fine Network on which Red and Yellow Feathers are made fast, so as to cover the netting; the sash is about three yards long, and each end is devided into six tassels of Red Black \& Yellow feathers, for each of which they have a name of some Spirit or Guardian Angel, that watches over the Young Chief while the Marro is in his Posession and is never worn but one day by any one King; it is then put into the Sacred Box and with a Hat or Shade for the Eyes Made of Wicker \& Covered with feathe(r)s of the same kind and never used but on the Same occasion it is delivered to the priests, who put it Carefully by in the Sacred House on the Morai, where no person must toutch it. (Morrison 1935:116).

Two other maro ura figure in accounts of Tahiti-Mo'orea. One was the traditional entitlement to such associated with the principal kin-Title, $\mathrm{Te}$ Ari'i Nui o Tahiti, of Vaiari's Farepua marae, the other was the entitlement associated with the kin-Title, Te Atua Nui e Maru Ae i Te Rai, of Puna'auia's marae, Tahiti-Puna'auia. During this era both these kin-Titles were probably assigned: the former perhaps to a certain Maheanu'u (Henry 1928:83), and the latter quite possibly to Puna'auia's high chief, the genial giant, Pohuetea. However, there is no record that these individuals, or anyone else, ever asserted the right to wear a maro ura during this era, nor can I discover evidence that either of these legendary maro ura actually existed at the time. I shall try in due course to account for this circumstance, but with the stage thus peopled and provided with its most important props, I am now in a position to reconstruct and perhaps better illuminate the drama itself. 


\section{CHAPTER 26 THE EMERGENCE OF THE POMARES}

\section{THe PAPARA DEBACle}

While H.M.S. Dolphin (fig. 26-1) was anchored in Matavai Bay in June and July 1767 its personnel were totally unaware of the drama that was unfolding at Papara, 40 kilometers along the coast to the south. This drama reached a climax in December 1768, and by the time H.M.S. Endeavour arrived four months later, this particular act had ended, and the principals were contemplating, and perhaps even then preparing for, the denouement. ${ }^{1}$

The first recorded notice of these events appears in Bank's journal, on the date of 29 June 1769, during his and Cook's tour around the island. At Papara the visitors were much impressed both with the size of marae Mahaiatea and with the apparent decline of "Queen" Purea's fortunes, from the high point reported of them by Wallis two years previously. (See fig. 26-2)

The greatest pride of an inhabitant of Otahite is to have a grand Marai, in this particular our freinds far exceed any one in the Island, and in the Dolphins time the first of them exceeded every one else in riches and respect as much. The reason of the difference of her present apearance from that I found by an accident which I now relate: in going too and coming home from the Marai our road lay by the sea side, and every where under our feet were numberless human bones cheifly ribbs and vertebrae. So singular a sight suprized me much; I enquird the reason and was told that in the month calld by them Owiráhëw last, which answers to our December 1768, the people of Tiarreboo made a descent here and killd a large number of people whose bones we now saw; that upon this Occasion Oborea and Oamo were obligd to fly for shelter to the mountains, that the Conquerors burnt all the houses which were very large and took away all the hoggs \&c., that the turkey and goose which we had seen with Mathiabo were part of the spoils, as were the jaw bones which we saw hung up in his house; they had been carried away as trophies and are usd by the Indians here in exactly the same manner as the North Americans do scalps. (Beaglehole 1962:I, 304-305)

So much for the first recorded "facts" concerning this first major political upheaval of the European era. Subsequently recorded "facts" about this episode will agree with the bare statements set forth in Banks' report but add enough others to produce some wholly different versions of "what actually happened." 


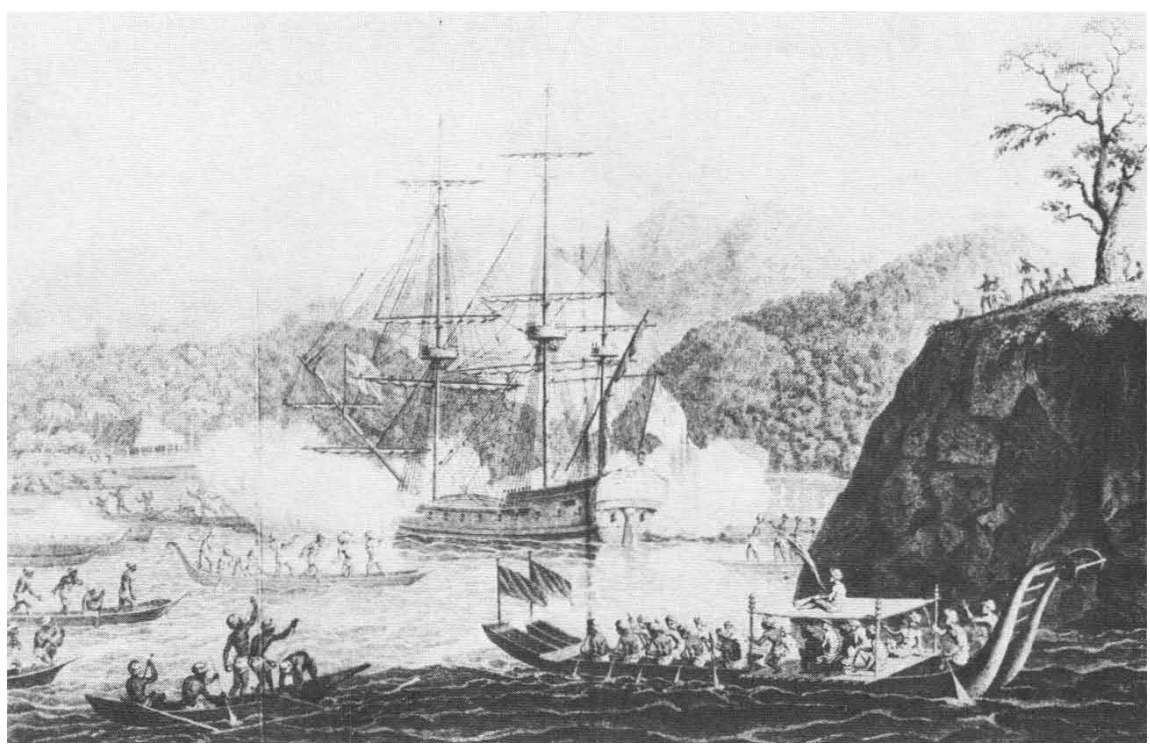

FIGURE 26-1. "A representation of the attack of Captain Wallis in the Dolphin by the natives of Otaheite." In Hawkesworth 1773, vol. 1.

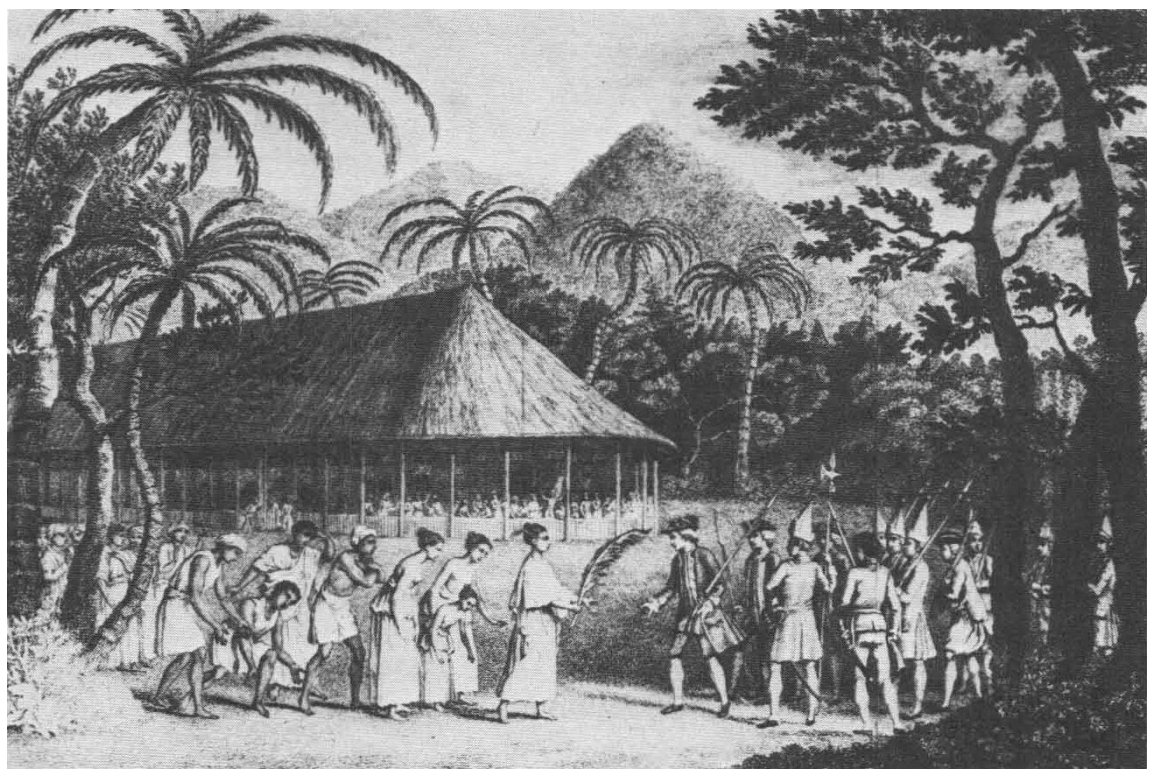

FIGURE 26-2. "A representation of the surrender of the island of Otaheite to Captain Wallis by the supposed Queen Oberea." In Hawkesworth 1773, vol. 1. 
The most detailed account is provided by Adams. ${ }^{2}$ The whole debacle, this version implies, came about as the result of Amo's and Purea's but mainly the latter's - obstinate desire to elevate even further their son, Teri'irere's, very high-ranking status (and derivatively, his political influence) over all Tahiti and Mo'orea. To accomplish this they undertook, according to Adams, "... what no other great chief had ever attempted":

They not only imposed a general Rahui for the child's benefit ... but they also began a new Marae for Teriirere, in which he was to wear the Maro, and they set their people to work on the enormous task of piling up the pyramid at Mahaiatea which was an exhibition of pride without a parallel in Polynesia. (1901:42)

The immediate consequence of these acts was a series of challenges. I reproduce the full account of this episode, however dubious or clearly inaccurate parts of it may be, because of its exemplification of what appears to have been a very characteristic tactic of social competition.

This was more than Purea's female relations could bear, and it set society in a ferment. The island custom provided more than one way of dealing with pride. Though Purea and Teriirere were admitted to be political superiors, they were socially no better than their cousins, and custom required that if during a Rahui any relative or guest of equal rank should come to visit the chief who had imposed it, the Rahui was broken, and the guest received by courtesy all that the Rahui had produced. Such an attempt to break the Rahui was of course an act which could not be ventured by any ordinary chief within the direct control of Papara; but Tefana i Ahurai was independent, and if Purea's own family chose to set up such a claim, Purea would resist it at her peril. Not even she could afford such a quarrel.

The first person who undertook to break the Rahui was probably Purea's sister-in-law, no doubt the wife or widow of Teihotu, on behalf of her son, Terii vaetua. ${ }^{[3]}$ She set out from Faaa in her double-canoe, with the house or tent, called fare-oa, in the prow, which only headchiefs could use; and a crew of fifty men or more paddled this barge of state, with all the show of a royal ceremony, along the coast to Papara, some twenty miles away, until, opposite to the Point of Mahaiatea, they turned in to an opening in the reef which had on some pretext become sacred, and was known as the sacred pass, through which only sacred chiefs might go. Purea was then living on the Point, and probably was superintending the work on her great Marae. She came out on the beach, and as the double canoe, with its royal tent, passed through the opening and drew towards the land she hailed it:

"Who dares venture through the sacred pass? Know they not that the Tevas are under the sacred Rahui for Teriirere i Tooarai? Not even the cocks may crow or the ocean storm."

"It is Terii vaetua, Arii of Ahurai."

"How many more royal heads can there be? I know none but Teriirere i Tooarai. Down with your tent!"

The Ahurai chiefess wept and cut her head with the shark's tooth till blood flowed down her face, which was the custom of women in sign of great emotion, and meant in this instance revenge as well as grief; but Purea was inexorable, and Terii vaetua was obliged to turn round and go home like any ordinary stranger.

The quarrel, once begun, was extended by another of the Ahurai family, a woman who proved to be more than Purea's equal in most forms of energy. She 
was Purea's niece, the daughter of Teihotu and sister of the insulted Terii vaetua. Her name was Tetuanui rea i te Raiatea, and she was or became the wife of Tunuieaiteatua i Tarahoi, Cook's friend Otoo, and the missionaries' friend Pomare. A very famous woman in Tahitian history, much talked about by Captain Bligh in 1788 and by the missionaries as Iddeah, Tetuanui i Nuurua was not even mentioned by Wallis or Cook, although the latter, in 1774, frequently mentions "Tarevatoo, the king's younger brother," whom I take to be Terii vaetua, the king's brother-in-law, who had begun the attempt to break the Rahui. ${ }^{[4]}$ Indeed, Cook never saw even Pomare until August, 1773, when Pomare was already thirty years old.

After the repulse of Terii vaetua, this sister undertook to pursue the quarrel. The matter had become uncommonly serious, for a feud between Papara and Ahurai might upset the whole island. Nothing more would then be needed to overthrow the Papara supremacy than the alliance of Ahurai and the Purionuu with Vehiatua, whose fortunes had been made a hundred years before by a similar combination to break a similar Rahui. Tradition has preserved the precise words used by the family to avert the peril into which Purea's pride and temper were pushing them.

Tetuanui in her turn made her appearance in the state canoe off the point of Mahaiatea, and as she approached the beach was received by Purea with the same order, "Down with your tent!" Tetuanui came ashore and sat on the beach and cut her head with the shark's tooth till the blood flowed down into a hole she dug to receive it. This was her protest in form; and appeal to blood. Unless it were wiped away it must be atoned by blood.

Then the high-priest Manea interposed. Manea was Amo's younger brother, from whom we are directly descended in the fourth generation, and probably we owe our existence in a double sense to him, for his act wiped out the blood-feud as far as his own descendants were concerned.

"Hush, Purea! Whence is the saying, 'The pahus (drums) of Matairea call Tetunai for a Maro-ura for Teriirere i Tooarai. Where wilt thou wear the Maroura? In Nuura and Ahurai. One end of the Maro holds the Purionuu; the other end the Tevas; the whole holds the Oropaa.'”[5]

Manea quoted the maxim of family statecraft in vain. Purea replied only that she was going to allow no rivalry to her son. "I recognize no head here but that of Teriirere." Then Manea dried the blood of Tetuanui with a cloth, wiping away the feud as far as he was concerned; and so long are these things remembered that forty years afterwards, when the Purionuu savagely raided Papara, Manea's great-grandchildren were supposed to have been spared in memory of Manea's act. (1901:42-46)

Continuing the Adams version, the parents of Teri'irere persisted in their undertaking and assembled a large gathering to witness his investiture in the maro (which maro is not directly specified) and to partake of the feast that followed. Those invited to the occasion (Adams wrote "summoned") included Pohuetea of Puna'auia; Tepau "A" of Ahurai; Pomare I of Pare-Arue, designated "Terii maro ura" (the maro-wearing ari' $i$ ) of Tarahoi (Pare-Arue's principal marae); along with "the Island of Eimeo" (probably Mahine); Puni, chief of Porapora; Ra'a, chief of Maupiti and Tupai; and Teae of Ra'iatea. This version does not indicate which ones of these notables attended or whether the investiture actually took place, but proceeds to explain that the whole occasion was interrupted and brought 
to a bloody conclusion by means of an armed attack of Seaward Tevans who (as Banks reported) killed a large number of people, burned houses, collected all moveable loot, and forced Amo, Purea, and Teri'irere to flee (Adams 1901:71; Beaglehole 1962:I, 305).

According to Adams' version, then, the immediate cause of this upheaval was Purea's overweening pride; but in the background certain other factors were involved - one of the weightiest having been the acts of Tutaha, great-uncle of Pomare I and tribal chieftain of Pare-Arue. (Tutaha himself was evidently content to wield the secular authority of the Pare-Arue chieftainship, leaving to his grandnephew the ceremonial honors attending high rank-status, to which indeed Tutaha himself was not even eligible.) Tutaha's part in the Papara affair was aimed immediately at elevating his grandnephew's rank-status even further, which could be done only by diminishing that of the latter's principal rank-status rival, Teri'irere. It is not stated what part Tutaha and his forces played in the actual fighting, if any, but his share of the spoils were described as follows:

While the Taiarapu people carried off the heads and the property of the victims, Tutaha and the northwestern districts carried away the symbol of supremacy, the standard and feathered girdle, from the Marae of Tooarai and Mahaiatea, and placed it in the Marae of Maraetaata in the district of Paea in the Oropaa, or, as it was usually called by the English, Attahuru. Amo and Purea were forced to make what terms they could with Tutaha, and to recognize Otoo, as having a right to the dignity of the Maro-ura at Maraetata. (Adams 1901:74)

(As I noted earlier, I believe that these "symbols of supremacy" were taken not to Maraeta'ata but to Pa'ea's other principal marae, 'Utu'aimahurau; but that need not immediately concern us here.)

It is not clear from this version just what Tutaha's long-range goals were in this affair. An historian accustomed only to Western man's motives would probably conclude that Tutaha sought additional power and influence for himself; but Tutaha was a Maohi, and this version alone does not throw enough light on the man's deeds to permit such a straightforward ascription.

According to the Adams version another major factor involved in the Papara affair was active enmity between Papara and Taiarapu. Some of this marked a continuation of the general, long-time antagonism between the respective leaders of the two tribal complexes. ${ }^{6}$ A more specific reason for this active enmity was the long-standing rivalry between the Aromaiterai and Tuiterai branches of Papara's leading family. This came about, it may be recalled, when Aromaiterai, the elder son of the Paparan chief, was passed over in the succession in favor of his younger brother, Tuiterai, and then sent into exile. Thus, when Purahi, the eldest grandchild of Aromaiterai, married Vehiatua I, the Taiarapuan chief, she was thereby provided with the means for striking against Tuiterai's successor, his grandson and lineal successor, Teri'irere. 
It is not clear from this version whether the Aromaiterais (in the person mainly of Purahi) had for a long time been eagerly awaiting a favorable opportunity for revenge, or whether Purahi was moved to reopen the rivalry as a result of Purea's pretensions. Nor is it clear whether she hoped to recapture Teri'irere's kin-Titles for her son, or merely to humble somewhat the Tuiterais. In any case, whatever her motives and expectations may have been, she was given full credit (or blame, depending upon the point of view) for the devastation wreaked upon the Paparans by her husband's forces. ${ }^{7}$ And although the Tuiterais were duly humbled by these measures, their losses, in terms of rank-status and political influence, accrued as gains not to the Aromaiterais in particular (or to the Taiarapuans) but to Tutaha and Pomare I.

A second version of the Papara affair, which was quoted by Adams but not wholly integrated into the "Adams' version" of the affair, was supplied by Tupaia. ${ }^{8}$ The latter is reported as having roused the enmity of Tutaha, as the result of his association with Purea, whom Tutaha wished to supercede as "regent."

The better to effect it [this purpose] he [Tutaha] began to create divisions between the inhabitants of Otahitee-eta (Taiarapu) [Lesser Tahiti] and of Otahiteenua [Greater Tahiti], which finally produced hostilities between them. At that time Tobia [Tupaia], who had great sagacity and judgment, having discovered Tutahaw's designs, advised the queen to procure his death privately, as the only expedient to restore peace and preserve her authority; but she, thinking his advice too cruel, refused, for the first time, to comply with it; and he, foreseeing the consequences, retired to the mountains, alleging that this retreat was necessary for the preservation of his life. Soon after, the inhabitants of Lesser Otahitee making frequent incursions into the greater division, and their numerous depredations having thrown the inhabitants of the latter into confusion, which Tutahaw artfully improving to his advantage, they at length offered him the regency, thinking their affairs too much embarrassed for the administration of a female; an agreement was therefore made between Oberea and Tutahaw, in which it was conditioned that she should preserve the title and state of queen, with a certain number of attendants, \&c., and that the regency should devolve to Tutahaw; who, respecting Tobia's understanding and sacerdotal character, afterward permitted him to return from the mountains in safety; but he was so much displeased with this revolution that he embraced the opportunity of our departure to leave the island. (pp. 72-73)

The most interesting aspect of this version is its singling out of Tutaha as the prime, indeed the only noteworthy, mover in the affair. As for this account's reference to "the regency," it presumably applies to regency for Teri'irere, although no other version that I know of includes this as one of Tutaha's own objectives, or as one of his spoils of war.

Certain other accounts of the Paparan debacle are simply rehashes of some or all parts of the ones just reproduced, ${ }^{9}$ but there are two that cast different lights over the whole affair. The first of these is the version 
recorded by the missionary Robert Thomson several decades after the events but based on information from Tahitians who were alive at the time or who had learned about the events from the participants. According to Thomson, the incident that initiated this chain of events was the introduction in Tahiti of the cult of 'Oro - specifically the establishment in Papara of an 'Oro image from Ra'iatea circa 1760. According to this unique reconstruction, which was quoted in chapter 25, after 'Oro's adoption as the god of all Tahiti the decision was reached to build a new marae to house his image, at Mahaiatea: "all the districts engaged to unite in forwarding this national work" (Thomson, History, pp. 26-27). Then, Thomson continued, after the marae was finished about eight years later, and after the god had begun to receive there the homage of all Tahiti, the chief of Papara developed pretensions of his own:

Amo feeling that his district had acquired a new and paramount importance in the island, began to think of dominion, and to devise the means by which he might accomplish this end; afraid to attempt it by war he had recourse to an expedient, probably suggested by Tupaea the priest of Oro who had accompanied the god from Raiatea, and who is reported by the people themselves, as well as by Cook to have been one of the cleverest men of the island. Amo suggested that the flag of Oro should be sent round the island, and each chief show his submission to the new god, by allowing the flag to pass in triumph through his district. The flag used on the occasion was not the one which Wallis had hoisted at Point Venus, but a flag or rather pendant made of some material and woven in the manner in which mats were made, and fringed with red feathers, this pendant was called a vane. It was accordingly sent round the island and each chief met it at his marae and allowed it a free passage thru his district. It passed thru all the districts on Tahiti without interruption, till it came to the territory of the haughty chief of Taiarabu, who when he saw it exclaimed, "who are the 'feia inro' degraded people here who will allow this flag to pass thru the district," and seizing it, he tore it in pieces, and sent it back to Amo; who, much mortified at the failure of his scheme, resolved to avenge it, and declared war against Taiarabu.

His active enemy more prompt at war exploits than himself, did not leave him long time for preparation, he mustered his warriors, sent the portion of his fleet which was on that side of the isthmus to attack Papara, while he and most of his warriors marched by land. Amo in the meantime prepared to meet him, so sudden was the attack that he had not time to obtain the assistance of many allies; when the intelligence reached Teoropa and Purionuu, the chiefs with a few of their people immediately joined Amo, but not until the battle was begun. The conflict was not of long duration but was obstinate and bloody, many hundred were slain on both sides. Amo and his allies were defeated, but brought away with them the priest of Oro, who had charge of the sacred and royal girdle, and various other relics brought with the idol from Raiatea. These were safely deposited in the marae at Atehuru. Amo accompanied Teu to Pare and resided there with him for some time, until he could return in peace to his district. In giving an account of this sanquinary battle the old people say that the beach for a long extent, from the sea side up to the base of the hills was covered with the slain. Numbers too were killed in the canoes which met and fought inside the reef, the whole coast in that neighbourhood 
was afterwards strewed with the bones and skulls of the killed, and numbers of the latter which were lying in the sea were taken possession of by the fishes, especially by the cuttle fish which lodged in the skull, projecting their long feelers thru the eyes and other holes in the skulls. And from this circumstance the engagement has derived the name of "The battle of mata toroa". Mai, the brother of Amo fell in this battle, and Vehiatua had the body cooked in an oven, but whether it was afterwards eaten, or not, never was known. After desolating the country, the Taiarabu warriors returned home, And Amo and his friends were soon after taken back to Papara by his allies.

The chiefs of the northern and western districts having assisted Amo great offense was taken by Vehiatua, who preparing to attack them, when another circumstance diverted their attention, and suspended hostilities for a time. This was the arrival of another foreign ship. (pp. 38-40)

Not a word was written about Teri'irere in this version; and the ambitions which led to the debacle are represented as having been Amo's, not Purea's. Also, far from joining to defeat Amo (as in the Adams and other versions), the Porionu'u (i.e., Tutaha) and the Oropa'a are shown in this version to have been his tardy but loyal allies.

The version put forward by Moerenhout, writing a few years earlier than Thomson, and like Adams heavily dependent upon Paparan sources for his information, began with the assumption that Amo was "King" of the whole island. Translated very freely, Moerenhout's reconstruction is as follows:

Soon after the departures of Wallis and Bougainville, Amo, who until then had been king of the whole island, perceived that his influence had diminished relative to that of the chiefs who lived nearer the Europeans' anchorages. The latter had been the principal recipients of valuable gifts from European officers and had had their reputations enhanced and their causes supported through friendship pacts with Europeans. In addition, these chiefs were the ultimate recipients of the countless objects collected by their subjects from Europeans. In contrast, Amo and Purea profited from the European visits only to the extent of a few personal gifts, which went mainly to Purea; and their subjects gained nothing at all. Thus, as a result of the European visits, Amo fell behind other chiefs, in affluence and in prestige, to whom he had previously been superior. Then, on top of this, Amo's power and influence were further diminished as the result of his disastrous defeat at the hands of Vehiatua I.

Moerenhout's version of this final act in the Paparan downfall contains some novel points:

Bougainville became particularly attached to the family that resided near his vessels' anchorage, which resulted in the enhancement of its social position, thereby threatening the position of the family that had been supreme for so long [i.e., Amo's]. Thus, upon the departure of Bougainville, Amo, fearing opposition from other chiefs, but wishing to have his son recognized as ari'i rahi or king, sent his standard around the island to receive the sign of submission from other ari' $i$ and from the nobility (la haute aristocratie). On the prompting of Tutaha (Bougainville's friend and protégé) Taiarapu's chief, Vehiatua, not only refused to 
honor the standard but went so far as to tear it up, an insult which could only be wiped out by war. Going even further, Vehiatua had the audacity to attack Amo near Papara itself, despite the fact that the people of Mo'orea fought on Amo's side. The resulting battle was a terrible one, lasting many hours. It is said that so many people were slain that Vehiatua was able to build a whole marae on Taiarapu entirely out of their skulls and named accordingly Tiahupo'o - certainly one of the most extraordinary temples ever raised to a god. (1837:II, 407-408) ${ }^{10}$

Several points in this reconstruction deserve comment. First of all, it should by now be clear that neither Amo nor any other chief was at that time the king of all Tahiti. Second, the prominence accorded Bougainville in this account looks suspiciously like an example of Moerenhout's Francophilia. Tutaha did visit Hitia'a briefly while Bougainville was there, but if Bougainville became "particularly attached" to anyone during his nineday stay it was to the local chief, Reti; and it is difficult to see how this brief encounter could have shaken established hierarchies as violently as Moerenhout implied. Again, this view that Tutaha was largely responsible for Vehiatua's attack on Papara is incomplete, to say the least. While there is evidence from other sources attesting to bad blood between Taiarapu and at least some Mo'oreans, Moerenhout's is the only account that I know of which identifies Mo'orea as an ally — and indeed the only ally — of Papara in this particular conflict.

To the extent that these different versions were credibly delivered Maohi accounts, and not just Europeans' constructions, they are all revelatory of the mainsprings of Maohis' political actions. In terms of "history," however, we have no way of knowing which version most closely fits the actual events. Nevertheless, I believe that as a consequence of certain events approximating those just described, intertribal relations on Tahiti entered a different and perhaps entirely unprecedented phase. In the island's hierarchy of rank-statuses, preeminence began thereafter to be ascribed not to two individuals but to one. It required several years for this process to be completed, and many more to accomplish a parallel development in the sphere of coercively sanctioned tribal authority.

\section{CONTEST BETWEEN NORTH AND SOUTH}

After Papara had been laid low in the war of 1768, intertribal strife on Tahiti became polarized between north and south - or, more specifically, between the island's two most forceful and contentious tribal chiefs, Tutaha of PareArue and Vehiatua I of Seaward Teva. It is difficult to say what led these two to their confrontations; to evoke some general psychological factor, like ambition for personal monopoly of power, may in fact be true, but cannot be specifically documented.

Cook and his Endeavour shipmates remained in the dark about the complex relationship between kin-Title rank-status and tribal authority, but 
they were emphatic in characterizing Tutaha as the most powerful and influential chief in northwest Tahiti. The Endeavour's personnel had less opportunity for appraising Vehiatua's position at the time, but it is clear from other evidence that he was the unchallenged master of Seaward Teva, in terms both of active, effective leadership and of ascriptive paramountcy that is, his incumbency of the region's highest-ranking kin-Title, Vehiatua (which, however, did not include the right to don a feather girdle). In the latter respect he possessed an advantage over Tutaha, whose kin-Title, if any, was that of a younger sibling; but perhaps Tutaha's regency over Pomare I's maro ura kin-Title served to lessen somewhat that advantage. Seaward Tevans seem not to have questioned the superiority of Pomare I's rank-status over that of their own chief, Vehiatua; this was revealed in their conversation with the Spaniards at Tautira in December 1772 (Corney 1913:307).

The most widely accepted account of the dual between Tutaha and Vehiatua I is G. Forster's, written in 1774:

Captain Cook found the government of Taheitee in the hands of Tootahah, when he arrived in the Endeavour. After his departure Tootahah, being greatly enriched by the presents he had obtained, persuaded the chiefs of O-Taheitee-nue, or the Great Peninsula, to go against Aheatua, whom he could not forgive on account of the insult shewn to his family. ${ }^{[11]}$ They equipped a fleet, and went to Tiarraboo where Aheatua was prepared to receive them. He was an old man, desirous to end his days in peace; and therefore sent to Tootahah, to assure him that he was his friend, and always intended to continue so; and that he desired him to return to his country, without attacking those who had an affection for him. Tootahah was not dissuaded from his purpose, but gave orders to engage. The loss on both sides was nearly equal, but Tootahah retired, in order to attack his enemy by land. Happai, with all his family, disapproved of this step, and remained at o-Parre; but Tootahah took o-Too with him, and marched to the isthmus between the two peninsulas. Here Aheatua met him, and a pitched battle ensued, which ended in the total dispersion of Tootahah's army. Tootahah himself was killed. Some told us he had been taken prisoner, and was put to death afterwards; but others, and among them oMai, asserted that he had been slain in the heat of the engagement. O-Too retired precipitately to the mountains with a few chosen friends, whilst Aheatua, with his victorious forces, immediately marched to Matavai and o-Parre. At his arrival Happai retired to the mountains, but Aheatua sent to assure him that he had no quarrel with him or his family, and that his wish had always been for peace. Those on the mountain enquired in their turn concerning the fate of Tootahah and o-Too; they heard that the former was killed, and that no body knew what was become of the other. Soon after o-Too arrived through many difficult passes, and over precipices, and coming down from the highest summits, joined his father, and all who were with him. A general peace was immediately concluded, after which O-Too assumed the reins of government himself, and the vast improvements in the country, which we noticed in eight months time, ${ }^{[12]}$ seem to prove that he is a very intelligent man, who promotes the general good of his subjects. Aheatua died soon after; and his son of the same name, whom we found at Aitepeha in August 1773, succeeded him. (1777:II, 94-96)

Some importance attaches to the dates of these alleged events. Forster's 
wording locates them no more exactly than between Cook's two visits of August 1769 and August 1773, and implies that the war had been won, and Tutaha slain, some months before Vehiatua I himself died. Cook's own brief notice of these events places Tutaha's death about March 1773, a date also accepted by Adams (1901:91). Writing at Tautira in August 1773 Cook reported: "These people informed us that Toutaha, King of the greater Kingdom of Otaheite was kill'd in a Battle which happen'd between the two Kingdoms about five months ago" (Beaglehole 1961:202). A difficulty in the way of accepting this dating appears in Boenechea's account of his expedition's visit to Tahiti during November and December 1772. At that time the "cacique" at Tautira, where the frigate anchored, was Ti'itorea, whose spouse at the time "... was formerly the arii Taitoa's" [probably Vehiatua I] (Corney 1913:335). ${ }^{13}$ In other words, Tutaha's principal antagonist had by this evidence died much earlier, possibly even in 1771. This means, of course, that Vehiatua I had not lived to see his Seaward Tevans defeat Tutaha and his forces. Consequently, if this dating of events is correct, then one must impute to this conflict motives broader than the long-standing personal animosities of two contentious chiefs. A further point, not specified in Forster's version, but attested elsewhere, is the circumstance that Te Pau i Ahurai died along with his ally, Tutaha, in the war's culminating battle (Beaglehole 1961:202).

More important than the precise date of Tutaha's death is the question of the disposal of his corpse, but consideration of that will be postponed until I have reproduced a somewhat different version of this calamitous north-south conflict. This is the account recorded, and doubtless elaborated, by Moerenhout, writing many decades after the events themselves.

The results of this battle [the Papara debacle] changed the political shape of the island. Amo was no longer ari'i rahi, and nearly every chief went his own way, each one regarding himself as independent and free in his own district. Only Tutaha held on to his visions for the future. The others continued to recognize the son of Amo and Purea as heir presumptive, but Tutaha dreamt of supplanting the latter with young $\mathrm{Tu}$, who was a member of his own family. In order to accomplish, this he set about organizing a campaign against the very individual who had contributed to his own rise [i.e., Vehiatua I]; with considerable shrewdness he even managed secretly to enlist Amo to lead the expedition. After extensive preparations their forces embarked in a fleet of several hundred canoes to attack Vehiatua, their most redoubtable rival. Despite the numerical inferiority of the latter's forces, this venerable chief, who was one of the island's most celebrated orators, managed so to inspire his followers that they defeated those of the allied chiefs in a battle in which Tutaha himself was slain, along with several members of his family, although young Tu managed to escape. After laying waste to part of the island, particularly Amo's own district, which was nearby, Vehiatua acceded to the pleas of friends of the vanquished and made peace with them. This chief, who after this great victory was in a position to rule the whole island, was however very old and preferred tranquility instead. Accordingly, he permitted the [chiefly] families he had conquered 
to retain their former authorities and privileges - except for the family of Amo, which had lost so much in the recent conflicts that they could no longer be counted members of the high aristocracy. Some time after this Vehiatua died; Tu recovered all his former influence, and remained the sole rival of Amo's son, who although still too young to act for himself nevertheless continued to be regarded by most of the island's chiefs and populace as heir presumptive to the crown. (1837:II, 408-409)

A markedly different version of the same conflict was composed by the missionary Robert Thomson, whose stay on Tahiti overlapped Moerenhout's but began a few years later:

After the departure of Cook, the hostile feelings which Vehiatua entertained towards the chief and people of Purionuu broke out in an open war. The latter party were assisted by the chiefs and people of the eastern district, the first collision took place at Hidiaa, and is termed the battle of "Vaihee," another engagement soon took place in the same district called the battle of bu wue (?) but with no more definite results - if advantage leaned to either side it would seem to have favoured Purionuu, as Vehiatua immediately afterwards sailed for Raiatea, although the object of his visit is not now known. He enjoined the chiefs of the peninsula to carry on the war, which, after the usual rest of a few months and plenty of feasting, they did more vigorously than ever. It may not be improbable that Vehiatua's sail to Raiatea was a visit to Oro to propitiate his favour, as the image of that god which had been sent to Tahiti was now in the hands of his enemies.

In the course of the year 1770 a severe naval battle was fought a considerable distance from land off the coast of Teaharoa, between these two parties. The Purionuu warriors having recoiled a little when the first shower of stones fell upon their canoes, the circumstance has been recorded to their disadvantage in the name given to the engagement "The battle of taora atahi." This, and the following, seem to be among the most furious and savage of their wars. Each party being resolved on victory, and determined not to give way, they agreed to take their fleets a long distance out to sea, that no hope might remain for the disabled and shattered canoes of the conquered party being able to reach the land. Each canoe was secured in its position in the fleet, and when the hostile fleets met at sea, there were men appointed with ropes in their hands all ready to tie the contending fleets firmly together, and on this platform of canoes hand to hand with club and spear the warriors fought with desperation and thousands must have perished in these dreadful conflicts. From the description which the natives give of these two fleets, it is probable that upwards of 10,000 men were engaged in this battle, the greater part of whom perished; as the warriors fought until the shattered fleets would no longer hold together, but broke asunder and drifted away. Both parties had suffered so severely that neither was in a position to chase the other, and each made the best of their way to their respective districts, (pp. 45-46)

(There follows a lengthy passage, including excerpts from Cook's description of the famous naval review of 1774, attesting to the vast scale that characterized some naval engagements.)

From these statements of Cook, it is evident that Tahiti at that period possessed a respectable navy and fully justified the accounts which the natives give of the magnitude of their fleets and the bloody character of their wars. After the 
great battle recorded above, the combatants rested some months, feasting with their friends, detailing their exploits, and repairing their shattered canoes; but both parties were mortified that they had not conquered, and resolved to continue the war. Several months afterwards or about 1771 the combatants having built several new canoes, renewed the war; many of Amo's people who had now forgotten their former defeat, joined the Taiarabuans; and many from Teoropa assisted Teu and Tutaha the principle chiefs of Purionuu, with whom Teaharoa was still leagued. Having completed all their arrangements for this, the most memorable naval battle recorded in Tahiti history, to enflame their passions, and irritate the minds of their opponents, messengers were sent by both parties, to taunt them with cowardice in the last battle, and dare them to the fight. A day having been fixed, the Taiarabu warrors came down to their enemies coast, and after some of the warriors had exerted all their powers of buffoonery in mockery of their enemies, they stood out two or three miles to sea. The Purionuu and Teaharoa fleet were soon in motion, and numbered two or three hundred sail. After the canoes had formed into divisions, and were secured to each other, the warrior, Paetia of Point Venus and ancestor of Taaiirii, who took the chief command mounted the platform on the front of his canoe which was placed in the center, and haranged the warriors. He recounted the deeds of their ancestors, mentioned in chronological order all the battles in which they had engaged, eulogized the chiefs who had shown the greatest bravery, and concluded with a tirade against the enemy, in which no epithet was spared which might expose them to the contempt of the warriors. Two or three other chiefs spoke in a similar strain, enciting them to deeds of bravery. Having thus stimulated their own courage, and worked up their hatred of their enemies, to the highest point, the fleet put out to sea. And as these two fleets were the largest which the people had ever seen they must have carried many thousands of warriors. They met at Toahiro, and from the place where they fought the engagement is termed "Te pau i Toahiro," the destruction at Toahiro! Having made their arrangements as on former occasions, and firmly secured the contending fleets, the work of destruction began, and was carried on with fearful ferocity on both sides. In the heat of the engagement the canoe of the chief Teu in which was his son Tu, afterwards Pomare I, was cut away from the assigned position in the rear of the fleet, and the Royal party believing discretion to be the better part of valour, set their sail, left the combatants behind, and stood away for the little island of Tetiaroa. Whether the flight of their chief affected the spirits of the Purionuu warriors is uncertain, as it is what they had seen performed before, but they began to waver and fought with less bravery afterwards. Towards evening another circumstance happened to damp their spirits, and cheer and encourage their enemies. Vehiatua's war canoe was recognized returning from Raiatea, but before he could join in the battle, night separated the combatants now thinned by many hundred from the fierce engagement of the day. The fleets retired for a little distance and spent the night on the bosom of the deep. Having eaten a little and rested in the night, they began at daybreak to renew the struggle. The day before they had gone out, a good distance to sea, in hopes of a decisive engagement, and cutting off the retreat of the vanquished. But now their feirce passions were aroused, like the tiger which has tasted blood, they could not be restrained, and attacked each other, in the position where the breeze and the current had carried them, in the harbour of Matavai and not far from the shore. The Purionuu warriors felt that they were fighting on their own coast, in sight of their own friends, and fought with renewed valour. But the Taiarabuans still more encouraged by the presence of their renowned chief fought with equal desperation. In close contact with club and 
spear, no mercy was asked or shown, and death rapidly thinned the ranks of the assailants. The engagement of the preceding day, and the blood which had been so lavishly spilt had drawn hundreds of sharks to the spot, and now when a shattered canoe drifted away from the fleet, the sharks were seen to join in the dreadful havoc, and drag the wretched natives to the deep, who were clinging to the fragments of their wreck or who, in the violence of the struggle had been driven, from their standing, into the sea. It is in vain we try to estimate the numbers who fell, the best idea perhaps may be formed from the circumstance which has given a name to the battle. The whole neighbouring sea even to the beach was tinged with blood, and the engagement is termed "Te tamai i tetai uteute," The battle of the red sea! During this bloody conflict the breeze had borne the fleets down upon the shores of Tetiaroa [?] where many of the warriors leaping on the shore the battle was continued for some time partially on land, but the Taiarabuans had still the best of the battle, and pressed hard on their enemies, who feeling themselves giving way on their own soil soon became dispirited, broke and fled in confusion to the hills. The slain now strewed along the beach, were collected near Taunoa and piled up into a long and high pyramid, as an offering to the gods. This pile soon becoming putrid was taken possession of by thousands of rats, and is to this day spoken of as "Te fare ione" the house of rats! This horrible structure was said to be about sixty feet long, and upwards of twenty feet high! In addition to this mighty pile, the sea beach from Point Venus to Papeete was for many days thickly strewn with the dead cast ashore by the sea. Numbers had been devoured by the sharks, and those who fell on the first day at Toahiro perished too far out at sea ever again to be heard of! Such is the fearful account which the natives give of this dreadful battle. After desolating the coast, and sending an invitation to the refugees to return to their lands, Vehiatua and the Taiarabu warriors went home laden with spoil. Some days after the battle Teu and Tu arrived at Moorea, and ascertaining that their people had come down from the mountains, they came across and again established themselves in Pare. Peace was not again broken for about two years, and during this period perhaps the most important event was the death of Vehiatua who died in peace at Tautira, but the remembrance of his cruelty to Mae was not permitted to rest in the same grave, Mae's son hearing the same name had vowed revenge, which was afterwards visited on the head of one of Vehiatua's descendants. Shortly after the death of this great warrior, Tutaha, uncle of Tu, and a more firey spirit than his brother Teu the ruling chief of Purionuu, resolved on avenging the former disastrous defeat. In opposition to the wishes of his brother he collected the Purionuu warriors and placing himself and $\mathrm{Tu}$ at their head he marched against the Taiarabuans, his old allies joining him as he passed through their districts. A battle was fought between these parties headed respectively by Tutaha, and Vehiatua son of the former chief of that name. The place where this battle was fought is variously stated some asserting that it was on Taiarabu and others that it occurred at Afaira near Papara. Whether it happened the event was again disastrous to the people of Purionuu, who were again beaten and driven to the mountains. Tutaha was killed in the battle by a man called Tehoaraau, and his body having been brought to the marae at Bunaania it was disemboweled, as an expression of great contempt, and hung upon the branch of a breadfruit tree which still stands, immediately adjoining the French fort. When the warriors returned to Taiarabu they carried the remains of Tutaha with them, to deposit on the marae at Tautira. This event was long remembered by the family and thirty years afterwards was avenged by Pomare II on a Taiarabu chief. So deeply is the feeling of revenge seated in the bosom of the savage. (Thomson, pp. 48-52) 
The naval engagements described in this version are mentioned in no other source that I know of, and I am at a loss regarding their credibility. Such episodes as Vehiatua's trip to Ra'iatea and Pomare's defection from battle give the account the ring of authenticity; but its details concerning the scale, tactics, and sanguinary nature of the encounters were probably characteristic narrative modes used to dramatize any such tale. What interests us more than these matters, however, is this account's different version of the immediate cause of the conflict, and of the line-up of its combatant tribes.

According to Thomson, the contest was initiated by Vehiatua I because of his "hostile feelings ... towards the chief and people of Porionuu" (p. 45). The basis of those hostile feelings is not specified, but in Thomson's version of the Papara debacle the Porionu'u were allied with Amo against Vehiatua. As for the tribal line-up, note should be taken of the report that Papara's Amo was allied with Vehiatua, his recent assailant, against chiefs listed elsewhere by Thomson as having been his loyal friends.

I alluded earlier to the importance of the question concerning how and where Tutaha's corpse was disposed of after he was slain in battle against the Seaward Tevans. The answer to that question should indicate in an unmistakable way not only who Tutaha's allies were, and how he was regarded by his enemies, but should also throw some light upon the remaining mystery about his kin ties outside Pare-Arue. ${ }^{14}$

As just quoted, Thomson's answer to the question was that the Seaward Tevans disemboweled Tutaha's body at the marae at Puna'auia (presumably the famed 'Oro-dedicated Taputapuatea on Puna'auia Point) - "an expression of great contempt" - and then deposited it on the marae at Tautira, evidently as a more permanent offering to 'Oro's presence at this latter marae. In connection with this version it should be noted that, while the Tautira marae was within Seaward Teva, the one at Puna'auia was in the territory of the Oropa'a, whom Thomson listed as allies of Tutaha!

In September 1773, when discussing the events that had transpired at Tahiti since his first voyage, Cook wrote that his old friend, Tutaha, lay "entar'd in the family Marai at Oparre" (Beaglehole 1961:213), that is, at Tarahoi. Four years later however, when Cook visited the "Great Morai at Atehuru," which has recently been identified as 'Utu'aimahurau, in Pa'ea, he wrote as follows:

We were told that the late King Tootaha, Tebourai Tamaida, and a nother Chief who fell with them were brought to this Morai, their bowels cut out by the Priests before the great alter, and the bodies afterwards buried in three different places, which were pointed out to us in the great pile of stones which compose the most conspicuous part of this Morai. And the Common Men who fell also in this battle were all buried in one hole at the foot of the pile. This Omai, who was present, 
told me was done the day after the Battle, with much Pomp and ceremony, and in the midst of a great Concourse of people, as a thanksgiving offering to the Eatua for the Victory they had obtained, while the vanquished had taken refuge in the Mountains, where they remaine'd about a week or ten days till the fury of the Victors was over and a treaty set on foot that concluded with Otoo being invested with the Maro and made King which was done with great ceremony at the same Morai in the presence of all the principal men in the island. (Beaglehole 1967:205)

We cannot of course determine which of these versions is the "correct one" but again - as in the case of the discrepant versions of other "historical" episodes - we may infer something useful, however seemingly contradictory, from each of them.

It is interesting to note that 'Oro was looked upon as generally nonpartisan, evidently content to receive offerings from either side in a conflict. Whether Tutaha was disemboweled at Puna'auia's Taputapuatea or at Pa'ea's 'Utu'aimahurau, both these marae were situated in territory belonging to his allies in the war just concluded - which might indicate either that losers' marae were not sacrosanct, or that 'Oro-dedicated marae were not tribally exclusive, or both (or perhaps even that Tutaha's former allies were not unhappy to have him slain). And finally, it was evidently regarded as appropriate for this famed chief to be buried in his own kin-congregation marae, or alternatively just as appropriate to inter him in the principal marae of his victor.

In any case, whatever may have been the causes of this costly northsouth conflict, and whatever may have been the actual battle line-ups or the fate of its casualties, Tahiti's political structure was markedly different at its end, both as a result of the conflict itself and of the natural processes of man's aging and dying.

\section{NEW ALIGNMENTS}

Seaward Teva held together after Vehiatua I's death, but his young successor, the elder of his two sons, did not seem actively inclined to war or other forms of intertribal politics. Indeed, he appeared to have been heavily dependent upon his mother and her new consort, Ti'itorea, for counsel and initiative.

After Tutaha's death whatever coalitions had been put together either fell apart or became inactive, so that by the time of Cook's visit in 1773 there were on Greater Tahiti several tribes of fairly equal political strength - namely, Hitia'a, Pare-Arue, Fa'a'a, Puna'auia, Pa'ea, and Papara - together with several others of secondary strength that were politically affiliated with their stronger neighbors.

Hitia'a's famed chief Reti sided with Tutaha in the war with Taiarapu, and, although he is reported to have escaped Tutaha's fate, we cannot discover how long he lived thereafter. In any case, Hitia'a played little or 
no part in the island's political maneuvers during the next three decades, either because of distance from the centers of European influence, or of disinterested leadership, or both.

After their defeat by Vehiatua's forces, Amo and Purea retired from active intertribal politics. Although their distance from Europeans based at Matavai might explain the obscurity surrounding their existence, that alone cannot wholly account for the lack of references to them. Their son, Teri'irere, apparently retained the ceremonial privileges associated with his high-ranking Teva kin-Title, including the maro - either ura or tea - linked with it, but the family's other maro - the one I have labeled "maro Wallis" - was, along with the so-called Paparan image of 'Oro, evidently removed by Tutaha during the Papara debacle and deposited in the 'Utu'aimahurau marae of Pa'ea.

It is not clear just what part the Oropa'a people played in the Papara or north-south conflicts just described, but whatever it was neither Pa'ea nor Puna'auia appears to have suffered any major losses from those events. Puna'auia's tribal chieftainship remained in the hands of the huge and genial Pohuatea. Pa'ea's most prominent chief, Te To'ofa, had not figured in Wallis' journal or in accounts of the Endeavour's 1769 visit, but on his subsequent voyages Cook came to regard him as the island's most impressive chief. Pohuatea and Te To'ofa were independent rulers of their respective tribes but were usually to be found in close alliance with each other in intertribal affairs.

Upon the death of Fa'a'a's chief, Te Pau " $\mathrm{A}$ ", in the 1773 battle against Seaward Teva, his son, Te Pau "B", succeeded to his Title; but the most influential individual in Fa'a'a was Pa'ea's chief, Te To'ofa, whose unspecified kinship to Fa'a'a's principal family provided scope for his chiefly talents in this district as well as in Pa'ea.

While Tutaha lived, his grandnephew, Tu (Pomare I), had to rest content with the prerogatives attending his high rank-status, but upon the death of the former Pomare I began to exercise authority as PareArue's tribal chief, de facto as well as de jure. As a tribe Pare-Arue was stronger in manpower than was Fa'a'a during the 1770s and 1780s. But even with the support of its semidependency, Ha'apape, Pare-Arue was inferior to Oropa'a both in numbers of warriors and in qualities of leadership - a circumstance that was undoubtedly well known to the whole populace of the island. Similar comparisons between Pare-Arue and Papara or Seaward Teva would probably reveal the same widely recognized disparities in tribal strength and leadership. In other words, in terms of both the tribe over which he ruled and of his qualities as a tribal ruler, other chiefs appear to have held Pomare I in rather low esteem during this part of the Early European Era. Nevertheless, despite his unimpressive reputation as a tribal leader, after the Papara debacle 
Pomare I was universally acknowledged to be higher in rank-status than all other persons of Tahiti and Mo'orea.

First of all, through his maternal connection he was privileged to wear a feather girdle - the so-called Tetupaia maro ura - in his family marae of Tarahoi (although it seems quite clear that he could not, or so far as I know did not, wear this particular feather girdle elsewhere in Tahiti-Mo'orea). But in this respect he was no more highly privileged than Teri'irere, who exercised a similar right, with at least the Teva maro, in Papara. The titular prerogative which made Pomare I preeminent in Tahiti-Mo'orea derived from another rank-associated object, namely, the so-called Wallis maro ura, removed by Tutaha from Papara during the upheaval there and deposited in a Pa'ea marae, probably 'Utu'aimahurau. Why this maro ura was deposited in Pa'ea and not in Pare-Arue is difficult to explain. To begin with, although Tutaha probably had kin connections in Pa'ea his closest kin connections, and those of his grandnephew-protégé Pomare I, were with Pare-Arue's marae Tarahoi. One possible explanation is that the Oropa'a chiefs overruled Tarahoi as a depository, the price of their efforts in overcoming (or salvaging?) Amo. ${ }^{15}$ Another possibility is that Tutaha deliberately preferred a Pa'ea depository, intending thereby to provide his grandnephew with a new base, in this stronghold of potential opposition, for exercising the extraordinary rights associated with this maro. Or finally, it may be that 'Utu'aimahurau's established position as a center of 'Oro worship (the most important one outside of Seaward Teva) was the decisive factor in depositing the maro there. (To the best of my knowledge there was at that time no image of 'Oro at Tarahoi.) The rationale for this last possibility requires some additional comments.

At the beginning of their respective careers as objects of social significance, feather maro and 'Oro images are implied to have been associated, if at all, in only indirect ways. For example, in traditions about the Farepua or Teva maro no mention whatsoever is made of 'Oro. And, more "historically," in statements concerning the maro ura brought by Tetupaia from Ra'iatea to Pare in the mid-eighteenth century, nothing is said of any 'Oro image or even of the god himself.

Conversely, traditions relating to the diffusion of 'Oro worship from Ra'iatea to Tautira, and then on to 'Utu'aimahurau, and so forth, specify 'Oro images but not maro. In fact, the only reported instance I know of wherein a maro ura and an 'Oro image diffused together from Ra'iatea prior to the European era, was that in which Manea and Maua introduced these objects into Papara, accompanied by Tupaia, the famed 'Oro priest. Since this occurred as recently as about 1760 , and since previous diffusions of feather maro and 'Oro images seem to have been separate events, I am inclined to believe that the close connection which these two kinds of objects 
came to have in Tahiti-Mo'orea during the Early European Era derived from fairly recent developments, which I reconstruct as follows.

It is safe to assume that any person's investiture with a kin-Title required the "presence" of the congregation's principal tutelar; and if an image of the tutelar were on hand - a typical but perhaps not unexceptionable circumstance - that image constituted an important element in the ritual of investiture. In the case of feather-girdle kin-Titles such investitures also required the actual use of the maro itself, along with the "presence" of the tutelar. This much about kin-Title investiture seems reasonably certain.

Turning now to Opoan kin-Titles, and especially to feather-girdled ones associated with (or derived from) that congregation, although earlier investitures may have been sanctioned by the god Ta'aroa, by late indigenous times the god 'Oro had been assigned that role. Now, as noted above, no actual image of 'Oro seems to have been involved when Pomare I was invested in the feather-girdled Opoan kin-Title passed on to him through his mother, Tetupaia. On the other hand, his subsequent investiture with the socalled Wallis maro (and its associated kin-Title) evidently required the actual presence of the Paparan image (which had been taken to Paṕara along with what was probably the original section of the Wallis maro).

In other words, what previously seems to have been a general connection between all Opoan feather-girdled kin-Titles and the god 'Oro (in whichever of his manifestations locally prevailed) came to be superceded in social importance on Tahiti-Mo'orea by a specific connection between one such kin-Title (the Wallis maro) and one particular 'Oro image (the Papara to'o).

Newbury's statement that an 'Oro image “... was ceremonially essential for the investiture of Titles of Ra'iatean origin ..." (1961:xxxvi) would seem to apply, by implication, to all prominent Opoan Titles; this may have been so, but the only specifically reported examples that I know of were investitures involving the Wallis maro and the Papara to'o. Indeed, it is possible that the requirement may have been "invented" on Tahiti - done, say, by Amo, Purea, and Tupaia in order to intensify respect for the wearer of the maro.

Having departed thus far from documentable generalizations, I am tempted to push my speculations a step or two further, this time concerning the reasons for the connections between feather girdles and 'Oro. These reasons, I suggest, are to be sought in 'Oro's attribute as principal god of war and in his congruous preference for human offerings. My theory is correspondingly twofold.

First of all, a god of war is a singularly appropriate tutelar for a tribe (in contrast, say, to a kin-congregation), and especially for a tribe that is held together by coercive force and is reduced or enlarged through armed conflict. If there is any truth in the conjecture put forward earlier, concern- 
ing the increasing role of warfare in the evolution of territorial units, then it is reasonable to assume a corresponding increase of attentiveness to the deities of war. In some instances the sequence may have been the reverse, with intertribal conflict incited by adoption of 'Oro worship; in fact, once started the two processes probably intensified each other - reinforced by 'Oro's reported desire for human offerings.

In my earlier discussions of human sacrifice I pointed out that 'Oro may not have been the only deity with this kind of preference, but during this era he was certainly the most demanding and insatiable one. Quite apart from any functional affinity between 'Oro's attributes as war god and as recipient of human offerings, for which a case could be made, I suggest that command over this explicitly ritual activity - in terms of when to sacrifice and whom - would have reinforced any chief's secular authority to a highly effective degree. (Since we do not know how a Maohi would have rated his own death by sacrifice as compared with other kinds of sanctions, I cannot of course characterize this sanction as the ultimate one in Maohi terms; but my hunch is that it was considered to be so.) Although many tribal chiefs probably had the power to execute fractious subjects from time to time, there were usually some implicit and fairly narrow restraints on the exercise of that power. How many fewer restraints there would have been, therefore, upon a chief who had not only the ideologically supported right to kill his own subjects, but the solemn duty to do so. Again, any tribal chief could and probably did on occasion rationalize an execution in these very terms, but all those phrased as offerings to 'Oro - that is, the majority of human offerings made during this era - required the ritual presidence of an individual invested in a maro consecrated by 'Oro. Moreover, the individual so invested was ipso facto a prime vicar to the god, a kind of ritual and secular double (as contrasted with an oracle [taura] or a cleric [tahu'a]). As I indicated above, I am not entirely certain which ones of the maro and 'Oro images in TahitiMo'orea bore the ritual human-offering function just described, but as time passed the Papara image (and in the beginning, its associated Wallis maro) came to be the only ones so endowed. This, then, may help to explain why Tutaha was at pains to obtain control over these "symbols of supremacy" during the Papara debacle, and why the image played such an important part in subsequent events. 


\section{CHAPTER 27 TAHITI AND MO'OREA}

From the position of Pare-Arue, Fa'a'a, Puna'auia, or Pa'ea (that is, Tahiti's west coast), Mo'orea is closer, more accessible, and a great deal more palpable than, say, Seaward Teva. The two islands had been for centuries closely linked through numerous kinship ties, with their usual train of alliances and feuds. It was inevitable then that the smaller island would have become embroiled in the political contests taking place on the larger one during this era, and especially those of the latter's western shores.

At the beginning of this era two kinship links between the islands turned out to be most significant, politically: the wife of Mo'orea's principal chief, Mahine, was sister of Papara's chief, Amo; and Teihotu, the husband of Mahine's sister Vavea, was brother of Fa'a'a's chief, Te Pau "A".

Another factor influencing political relations between the two islands was a long-standing state of hostility between Seaward Teva's chiefs and some, at least, of the chieftains of Mo'orea. Evidence of the latter is provided in a number of passages. For example, when Don Domingo Boenechea visited Pare in 1772 on his circuit of the island he met there a chief of Mo'orea, who with

... an eager assertion, backed by gestures of the most vehement and animated kind, [claimed] that ... Titorea [a Taiarapu chief] and all his pack were thieves and robbers who went over to raid his island, and that on that account a state of war existed between them. The arii Tomegeui [Tomaheui, a local Pare chief] bore out what the Morean Chief had said, protesting that he had right on his side. (Corney 1913:320)

Some women decked in quantities of native cloth presented themselves before the Chiefs in order to strip themselves and make an offering of the cloth to the said Chiefs, being left with only a maro on to cover their nakedness. They call this festival a taurua, and after it they prepare for a paraparau, which is like a tertulia or well ordered conversazione of which the main topic is the wars these natives engage in against those of Morea. The Chiefs called to me to know whether perchance I would assist them against the Morea people, if occasion should arise; and when I replied that I could not do so without superior orders, they seemed surprised. (Corney 1919:43-44)

There was a consultation between the three principal councillors [of Vehiatua II] ... as to what should be done with the vessel sent over by the arii of Orayetea 
[Ra'iatea], and it was decided she should remain here [at Tautira] to do battle against the people of the neighboring Island of Morea. (Corney 1919:189)

A person arrived from the island of Morea with orders from his arii to pick a quarrel, but he got no response whatever from the natives here [in Tautira]. (Corney 1919:155)

On the other hand, the hostility does not appear to have been entirely general, or continuous. For example:

Some people of the Island of Morea who were on a jaunt came [to Tautira], and some glass beads were given to them. (Corney 1919:116)

The liegemen of this arii set out for Guayotihi, an islet apart, to offer up prayers to Eatua, their God. They told us that the arii of the neighbouring island of Morea had caused certain persons to be killed who had treacherously murdered a native of this island of Otahiti, when it was not war time, and that he had sent the bodies over to Otu, in satisfaction, that he might offer them up in his principal marae. Let the truth bide its time. (Corney 1919:195-196)

Two versions exist concerning the immediate state of enmity between Mo'orea and Taiarapu. One is found in Thomson's History, and concerns a raid allegedly carried out by Vehiatua I sometime between 1761 and 1766 . I reproduced this account in chapter 12, because of the light it casts upon Maohi warfare in general; its present relevance is the information it provides concerning the enmity between Taiarapuans and some Mo'oreans in particular, and concerning the character of Vehiatua I. With respect to the end of this account it should be noted that only part of Mo'orea was involved in this conflict, and further that Vehiatua had his enemies on Tahiti as well.

The second version concerning the immediate cause of the quarrel between Seaward Teva and Mo'orea was given by King, writing in 1777:

... the ground of the present quarrel between the two Islands is this; that some years back the brother of Wa'heeatooa [Vehiatua III] named Tei-a'ree-tetooa a onnona, having some lands at Morea came to settle here, or as some say was sent as a chief in opposition to Maheine, which brought on a battle, where he, many chiefs of Otaheite \& relations of his were kill'd. The Otaheitians enrag'd at this, set up Teree tapooe nooe [Teri'itapunui] against Maheine, although his own sisters son by one of the Eiree de hoi's [ari'i rahi; probably Pomare I] family.... (Beaglehole 1967:1382)

Cook's own, less detailed summary of what was probably the same informant's explanation is as follows:

On our enquiring into the cause of the War, we were told that some years ago a Brother of Waheatua of Tierraboo, (a boy), was sent to Eimeo at the request of Maheine, a popular Cheif of that island, to be their King, but he had not been there a week before Maheine caused him to be killed and set up for himself, in opposition to Tieratabunue [Teri'itapunui] his sisters Son who became the lawfull heir or else was set up by Otaheite upon the death of the other. (Beaglehole 1967:198) 
Parts of this account appear also in other journals:

When they [the Seaward Teva] see a mist rising over against an island near-by, named Morea, they believe it means that Teatua [te atua, i.e., 'Oro] wishes them to go and make war on the people of it: they are their greatest enemies, through having killed an arii who had gone across to take possession of some lands in that island, that he had inherited.... (Written in 1775, by Don Blas de Barreda in a letter to the Duchess of Medina Sidonia. Corney 1915:472)

The sons [of Vehiatua I and Purahi] were Whaeeahtua [Vehiatua II], Tettuaooaowna [Tetua uaona?] and Warrooary [Varuari?]. The first died [in 1775], the 2nd was killed in Battle with Morea, and the 3rd became Erreerahigh and was no longer called Warrooary but Whaeeahtua [Vehiatua III] and is the present reigning King. (BLIGH 1789:II, 63) ${ }^{1}$

Despite these specific references, Seaward Teva's involvement in TahitiMo'orea conflict has been subordinated to western Tahiti's in most accounts of it. One reason for this was of course the Europeans' closer connections with the western districts of the island, from their vantage point in Matavai. Another was Fa'a'a's (and later, Pare's) direct entanglement in Mo'orea's succession controversy.

\section{THE MO`OREAN SUCCESSION WAR}

At the beginning of this era, Mahine, the principal tribal chief of northern Mo'orea, seems to have been the island's most powerful and influential individual - but one without any offspring of his own to succeed him. Mahine was also an Arioi, but whether this was the main reason for his childlessness is not known. Mahine evidently sought to keep control of his offices by fostering a boy, Tairihamoetua (?), and naming him successor. (I cannot discover what, if any, were this boy's kinship connections with Mahine.) But for unspecified though transparent reasons some of Mahine's kinfolk wished to name one of his sister's sons to succeed him. A glance at the Mo'orean genealogy (fig. 25-7, p. 1205) will reveal how seriously political this issue was likely to be.

As noted above, Mahine's sister, Vavea, was married to Teihotu, who was a brother of Fa'a'a's ruling chief (and subsequently uncle to the latter's successor). Thus the son of Vavea and Teihotu, Teri'itapunui, better known as Mahau, would have had strong claims, backed by strong supporters, to succeed his mother's childless brother. In addition, Mahau's elder sister, 'Itia, was married to Pare's Pomare I, and his younger sister, Pateamai, to Seaward Teva's Vehiatua III. ${ }^{2}$

The earliest record we have of any large-scale hostilities connected with this war of succession appears in Cook's journal for April and May 1774. I reproduce his comments in full, as they touch on many aspects of Tahiti's politics during this period. 
In the Morning I set out for Oparre accompaned by the two Mr Forsters and some of the officers to pay Otoo a formal Viset by appointment; as we approached Oparre we observed a number of large Canoes in Motion; but we were surprised when we got there to see upwards of three-hundred of them all rainged in good order for some distance along the Shore all Compleatly equip'd and Man'd, and a vast Crowd of Men on the Shore; So unexpected an Armament collected together in our Neighbourhood in the space of one night gave rise to various conjectures: we landed however and were received by a Vast Multitude some under Arms and some not, the cry of the latter was Tiyo no Otoo and the former Tiyo no Towha, this Cheif as we soon after learnt was General or Admiral of the fleet. I was met by him presently after we landed, he received me with great Courtsey and then took hold of my right hand. A Cheif whose name was Tee, Uncle to the King and one of his Prime Ministers, had hold of my left, thus I was draged along as it were between two parties, both declaring themselves our friends, the one wanted me to stay by the fleet and the other to go to the King, at last coming to the general place of Audience a Mat was spread on the ground for me to sit down upon and Tee went to bring the King, Towha was unwilling I should sit down but partly insisted on my going to the fleet but as I knew nothing of this Chief I did not comply; presently Tee return'd and wanted to conduct me to the King and took me by the hand for that purpose, this Towha opposed so that between the one party and the other I was like to have been torn to pieces and was obliged to disire Tee to desist, and to go with the Admiral and his party to the fleet. As soon as we came before the Admirals Vessel two lines of Arm'd Men were drawen up on the shore before her to keep of the Crowd and clear the way for me to go in, but as I was determined not to go (unless forced) I made the Water which was between me and the Canoe an excuse, this did not answer for a Man immidiately squated himself down at my feet and offered to carry me in and then I declar'd I would not go and that very moment Towha quited me without my seeing which way he went nor would any one inform me; I therefore turn'd back and inquired for the King, Tee who I beleive never lost sight of me, came and told me he was gone into the Country Mataou and advised me to go to my boat which we according did as soon as we got all together for Mr Edgcumb was the only gentleman that could keep with me, the others were jostled about in the crowd in the same Manner as we were. When we had got into our boat we took our time to view this fleet, the Vessels of War consisted of 160 large double Canoes, very well equip'd, Man'd and Arm'd, altho' I am not sure that they had on board either their full compliment of Fighting men or rowers, I rather think not. The Cheifs ie all those on the Fighting Stages were drist in their War habits, that is in a vast quantity of Cloth Turbands, breast Plates and Helmmets, some of the latter are of such a length as to greatly incumber the wearer, indeed their whole dress seem'd ill calculated for the day of Battle and seems to be design'd more for shew than use, be this as it may they certainly added grandure to the Propsect, as they were complesant enough to Shew themselves to the best advantage, their Vessels were decorated with Flags, Streamers \&ca so that the whole made a grand and Noble appearence such as was never seen before in this Sea, their implements of war were Clubs, pikes and Stones. These Canoes were rainged close along side each other with their heads a Shore and Sterns to the Sea, the Admirals Vesel was, as near as I could guess, in the center. Besides these Vesels of War there were 170 Sail of Smaller double Canoes, all with a little house upon them and rigg'd with Masts and sails which the others had not; These Canoes must be design'd for Transporte or Victulars or both and 
to receive the wounded Men \&ca; in the War Canoes were no sort of Provisions whatever. In these 330 Canoes I judged there were no less than 7760 Men a number which appears incredable, especially as we were told that they all belonged to the districts of Attahourou and Ahopatea. (Beaglehole 1961:383-386.) [See frontispiece vol. 1, this work.]

When we got on board the Ship, we were told that this fleet was a part of the armament intended to go against Eimeo whose Chief had revolted from Otou his Lawfull Sovereign, (p. 387)

The King seem'd not only to pay the Admiral much respect himself but was desireous I should do the same, he was nevertheless certainly jelous of him, but on what account we knew not for it was but the day before he frankly told us the Admiral was not his friend. Both these Chiefs when on board to day Solicited me to assist them against the people of Tiarabou altho at this time the two Kin[g]doms are at peace and we were told go with their joint force against Eimeo. To this request of theirs I made an evasive answer which I believe they understood was not favourable to their request. (p. 388)

We had no sooner dispatched our friends than we saw a Number of War Canoes coming round the point of Oparre.... This fleet consisted of Forty sail, were equiped in the same manner as those we had seen before and belonged to the little district of Tettaha and were come to Oparre to be reviewed before Otou as those we had seen before had done.... (pp. 400-401)

When I was last here I conceived but an inddifferent Opinion of Otou's Talents as a King, but the improvements he has sence made in the isles has convince'd me of my Mistake and that he must be a Man of good parts, he has indeed some judicious, sensible men about him who I beleive have a great share in the Government. I was sorry to see a jealousy subsisting between him and other great Men, he publickly told us one day that neither Towha the Admiral nor Poatatou, two leading Chiefs, were not his friends, this Shews that there are Divisions amongest the great people in this state as well as in Most others, probably this jealousy arose from their great power for Otou on all occasions seem'd to pay them much respect and so far as we knew they raised by far the greatest Number of Boats and Men to go against Eimeo and were two of the Commanders on the expedition which we were told was to take place five days after we sail'd. Oheatoua of Tiarrabou was also to send a Fleet to join those of Otous to assist him in reducing to Obedience the Chief of Eimeo. One would think so small an Island would hardly attempt to make head against the United force of the two Kingdoms but endeavour to settle Matters by Negotiation, but we heard of no such thing, on the Contrary every one spoke of nothing but fighting. Towha told us more than once that he should die there which in some Measure shew'd what he thought of it. Odiddy told me the Battle would be fought at Sea, in which case they must have a Fleet nearly if not quite equal to the one going against them and as this is not probable it is more likely they will remain on shore upon the defensive as we have been told they once did when attack'd by the People of Tiarrabou whom they repulce'd. Five general officers were to command in this expedition of which number Otou was one and if they named them according to the Post they held he was only the 3rd in Command, this seems probable enough as being but a young man could not have the experience necessary to command such an Expedition where the greatest Skill and judgement is required, (pp. 404-405) 
Cook's view of this whole episode was warped by two assumptions, both of them false and both probably deliberately implanted by Pomare I's partisans. One was the notion that the expedition was intended to put down Mahine's "rebellion” against Pomare I, "his Lawfull Sovereign." The other was the idea that navies of the several tribes had come to Pare to be "reviewed" by their "King" preparatory to battle. No additional remarks are needed to establish the fallacy of the first of these assumptions; as for the second, the main purpose behind the assembly seems to have been to rendezvous, at what was the most convenient port of disembarkation, and possibly also to use this show of strength in an effort to persuade the reluctant Pomare I to add his contingent to the expedition.

Fa'a'a's commitment to this cause is easy to account for: namely, its support for Mahau, whose father was a member of the district's principal family (see fig. 25-5, p. 1187). This same connection also probably explains Te To'ofa's part in the affair - another instance of the influence of ties of kinship upon intertribal relations - for I know of no other reason for Pa'ea's hostility toward Mahine. As for Pohuetea's commitment of Puna'auia's forces to the expedition, again I know of no direct reason for his enmity with Mahine, and am left to conclude that it was based on his friendship with Te To'ofa and Te Pau, reinforced perhaps by his eagerness for a good fight and the possibility of spoils. I am similarly perplexed about the reasons for Ha'apape's (or, at least, Matavai's) participation in the preparations, and can offer no specific explanation.

By ordinary Maohi standards, Pomare I had a very good reason for taking part in the assault against Mahine - that is, he was either betrothed to, or actually married to, Mahau's sister, 'Itia. (He may also have had the additional reason of his sister Auo's betrothal or marriage to Mahau; but we cannot be certain when this connection was actually established.) Yet, there are grounds for concluding that Pomare I played little part in the campaign. Cook, it is true, stated that Pomare I would be "the 3rd in Command" of the forthcoming expedition, but no mention is made of any Pare forces. In fact, Adams went so far as to assert that Pomare I played no part at all in the expedition (1901:94), but this opinion may have been just another expression of Adams' systematic detraction of the Pomares.

Two explanations may be offered for Pomare I's conduct thus far outlined and for his role in events still to be described. One was the man's well-attested cowardice in the face of physical danger; even his greatest champions described him as "timerous" (Beaglehole 1961:206), "of fearful disposition" (G. Forster 1777:I, 327), et cetera - all confirmed by subsequent accounts of his reactions to threats and of his outright craven behavior in battle. The other explanation for Pomare I's conduct in this affair may have been his desire, based on his equally well-attested political 
canniness, to avoid a situation in which he would inevitably have been dominated by the powerful figure of Te To'ofa, in terms both of his own tribe's indifferent military strength (despite its larger population!) and of his own personal shortcomings as a military leader. Attention should be drawn to the statement that "Oheatoua [Vehiatua II] of Tiarrabou was also to send a Fleet to join those of Otous to assist him in reducing to Obedience the Chief of Eimeo" (Beaglehole 1961:405). No specific mention is made of a Taiarapuan [Seaward Tevan] contingent in the naval "review" just described, and I can discover no direct evidence one way or another that such a contingent actually took part in the subsequent attack on Mahine; on the other hand, the Seaward Tevans in general, and their chief in particular, had ample grounds for joining in the campaign. However, it should be noted that the intended participation of Vehiatua II in the cause against Mahine evidently did not induce Pomare I or Te To'ofa to embrace the Seaward Tevans as friends.

The only contemporary report that I know of on the outcome of the Tahitians' descent upon Mahine came from Cook and his companions, writing in August 1777, after nearly three years' absence from the islands:

The difference which subsisted between the two islands in 1774 as mentioned in my last Voyage has partly subsisted ever sence; the Armoment I saw at that time actually went against the Malecontents of Eimeo but returned without effecting much. (Beaglehole 1967:197)

We can only speculate about what went on between Mahine and his Tahitian adversaries during Cook's absence from the islands - at least, an uneasy truce seems to have prevailed; but when Cook reappeared on the scene the conflict became heated again. Shortly after the English arrived in Matavai in August 1777,

... some messengers arrived from Eimeo with an acco $^{t}$ that the people in that island were in arms and that Otoos friends had been obliged to fly to the Mountains.... On the arrival of these messengers all the Chiefs that were at Matavai assembled at Otoo's house where I happened to be at the time. One of the messengers opened the assembly in a long and set speach, but little of which I understood any further than the general purport, he explained the situation of affairs in Eimeo and endevoured to excite the assembly to arm on this occasion. After this there was great debates on both sides which were carried on with great order, no more than one man speaking at a time but at last they became very noisy and I expected it would have ended like a Polish Diet, but I found they cooled as fast as they heated and soon returned to order, at length it was resolved to send a strong force to assist their friends at Eimeo: but this resolution was not obtained without some opposition. Otoo was silent all the time except now and then speaking a word or two to the speakers. Those who were for procecuting the War asked for my assistance and all of them wanted to know what part I would take. Omai was sent for to be my interpreter, but as he was not to be found I was obliged to speak for my self and told them as well as I could that as I was not throughly acquainted with 
the dispute and the people of Eimeo having never offended me I could take no part in it, with this declaration they either were or seemed satisfied. After this the assembly broke up, but before I left them Otoo desired I would come to him in the afternoon and bring Omai with me. Accordingly a party of us went, he carried us to his Father when the dispute with Eimeo was renewed. I wanted to have found out some method to have made up this breach and sounded the old gentleman on that head, but we found him deaf to any thing of that kind and fully determined to procecute the war and wanted very much to prevail on me to give them my assitance. (Beaglehole 1967:197-198)

T'towha [Te To'ofa] one of the Chiefs of Attahourou and a man of much weight in the island happened not to be at Matavai at this time consequently not present at any of these consultation, it however appeared that he was no stranger to what had happened and entered with more spirit into the affair than any other chief, for early in the Morning of the Ist of Sepr he sent to acquaint Otoo that he had killed a Man to be sacrificed to the Eatua, to implore the assistance of the God against Eimeo. This was to be done at the great Morai at Attahourou, where on this occasion Otoo's presence was absolutely necessary. (Beaglehole 1967:198-199) ${ }^{3}$

The line-up appears to have been much the same as in 1774, with Te To'ofa and Pohuetea spoiling for a fight, and Pomare I no more eager to involve himself or his Pare force than before (even though by this time his wife 'Itia probably added her forceful voice to the others' on behalf of intervention). Pomare I did lend his essential presence to a human-sacrificial service to 'Oro, imploring the god's help against Mahine, but he appeared less than eager to join in the atttack. In fact, as Cook perceived, sentiment was anything but unanimously in favor of war: “... I found there was three parties in the Island, one extremely Violent, one perfectly indifferent about the Matter and the third openly declaring themselves friends to Maheine and his party" (Beaglehole 1967:205-206).

Anderson's account provides a more connected summary of these events, including the differences of sentiment just noted:

We had enquird at Tiaraboo about the success of that expedition and were told that it prov'd fruitless, in so far that the inhabitants of Morea had retir'd to the mountains on the approach of the Ta'heiteans and the last returne'd without effecting what they intended. Since that time we were told they had been at peace, but to day some people arriv'd with an account of a disturbance that had happened there wherein some partizans of Otoo had been worsted and fled to the hills for security. Upon this several of the principal people met and consulted what should be done but did not seem unanimous, as the debates were carried on with some warmth, though it would seem they at last concluded on going over to fight them as they were urgent with Captn Cook to grant them some assistance or go there with the ships.

This news however seem'd only to affect the few chiefs whose business it was to prepare for war; for the populace paid so little attention to it that their usual mirth was not in the least interrupted. The women, who it might be suppos'd would feel most on the occasion, were if any thing less concern'd than the men; for in the evening a great many of them having collected together stood upon the side of a small river near the middle of the Bay and exhibited a sort of dance that 
rather bespoke an excess of joy and licentiousness, though perhaps it might be their usual custom. (Beaglehole 1967:977-978)

The element of "indifference" extended to other domains of social relations, as Cook noted in a retrospective comment written while at Kauai (Hawaii):

There is something in the Police [civil polity] of these People wholly unintelligible to us - by their manner of talking I should suppose that Tu'mutta'ah'ra and Ta'ma'ha'no could not well meet without proceeding in some measure to hostilities, as they are doubtlessly now at open War with each other, but here I was mistaken. A circumstance of somewhat a similar Nature occur'd during our stay at Matavai: whilst Otu and many of the Arees of that part of Otaheite were at war with Imaio (as recorded in the Account of those times) many of the Imaio People would come to us and trade, the Otaheiteans would observe sometimes that they were e' no (that is bad) but never offer'd to molest them in their business though at Imaio old To'haw the Otaheitean Admiral with his Fleet were making all the devastation they possibly could. (Beaglehole 1967:579) ${ }^{4}$

These fragments bring into focus an aspect of Maohi society that receives little or no illumination in most of the sources. As I pointed out earlier, and as must be clearly evident to the reader by now, the Europeans who first recorded their observations about the islands concerned themselves almost wholly with the doings of "the Principal People," "the Better Sort." And for the most part this concern is true of the Maohis' own myths that survived long enough to be recorded: stories about gods, demigods, chiefs, heroes, and the like - and very little about the rest of the population. All this restricts us to a one-sided view of Maohi society, a shallow perspective, of course, but less shallow perhaps than would be the case of some society structured along less hierarchic, aristocratic lines. For, here in these islands the doings of "the Principal People" affected to a very decisive degree the fate of the populace at large. While recognizing this we should not, however, lose sight of that other part of the population, whose members provided the principal people with the resources for their political contests but who were most of the time individually unconcerned with their leaders' motives and social maneuvers.

Returning to the narrative, the supplicatory offering to 'Oro was carried out at 'Utu'aimahurau at the beginning of September. After that Pomare I returned to Pare, where discussions continued concerning the advisability of an expedition against Mahine. While these were still going on "T'towha, Potattow and another Chief were already gone with the Fleet of Attahourou, for a messenger arrived in the evening with an account of their arrival and that their had been some skrimishing without either loss or advantage on either side" (Beaglehole 1967:210). After this, wrote Cook, Pomare, “... who never entered heartily into the spirit of this war ... receiv'd daily messages from Towha importunating him to hasten to his assistance, 
who we were told was surrounded by Maheines fleet, but neither the one nor the other durst hazard an engagement" (Beaglehole 1967:211-212).

But instead of joining his allies at Mo'orea, Pomare I led his forces in an impressive and colorful naval review at Pare. As one Englishman noted: "We have much parading with the war Canoes, and the Admiral (Toohaw) [Te To'ofa] is gone to Emio with 30 Sail of War Canoes, but Otoo does not seem disposed to fight nor does any of his brothers. - \& many of the Chiefs say he is a Coward" (J. T. Bayly, p. 13, quoted in Beaglehole 1967:211n).

The "Paradings" were interrupted on September 22 by news from Mo'orea that $\mathrm{Te}$ To'ofa and his companions had concluded a peace with Mahine and had returned home: "Soon after we got their [to Pare] a Messenger arrived from Eimeo and related the terms of the Peace or rather a Truce for it was for a limited time. The terms were disadvantagious and all the blame fell upon Otoo for not going to assist Towha in time" (Beaglehole 1967:214).

No record remains of the actual fighting in Mo'orea, but from subsequent observations it appears that the Tahitians had moored their vessels off Opunohu for several days and had destroyed some of the nearby settlements, without, however, engaging Mahine's forces in a decisive battle of any kind. Later, when Cook himself visited this part of Mo'orea, and inflicted similar damages in a punitive effort, one of his men referred to the destruction as "... these Losses together with those they suffered by Admiral Tohaw, are very heavy ..." (Beaglehole 1967:232n).

A passage from King's journal records the immediate reaction to the news of the Mo'orea truce:

... upon this intelligence all warlike preparations [at Pare] ceas'd \& the Canoes went away to the Etward. We however proceeded to Oparre, \& found Otoo \& the Royal family in Violent agitation on the late news; Otoo's Sister \& Mother told Capt that Towha was so inrag'd at his conduct that he \& the Tyarra'boo people ${ }^{[5]}$ were determine'd to wage war against him, \& they appeard much to dread this event, imploring our assistance. Otoo's father on the other side was as violent against the rash proceedings of Towha, foreseeing the advantages that woud have happen'd in their expeditions going seemingly under our protection; in the midst of these heats a Messenger came from Towha \& laid a plantan branch at Otoo's feet, \& repeat'd his message; which we understood was requiring Otoo to go \& perform some ceremony at Attahooroo, at the Royal Marea, they call'd it Heeva E'ree ... (Beaglehole 1967:1377)

It is impossible to say whether Te To'ofa's irritation with Pomare I was due to the latter's nonfulfillment of a prior agreement or refusal of an emergency plea for aid, but it must have been a chief-size dudgeon! "The old Admiral [Te To'ofa] was Irritated to a Degree of Madness, he Abused him [Pomare I] Every where and was very glad to get any of 
us to Listen to him He would Curse Ottou for an Hour to gether and Foam At the Mouth with rage" (Home, Ottihiti, quoted in Beaglehole 1967:211-212n).

The terms of the truce were regarded as unfavorable to the Tahitian principals' interests, but there is no specific record of what those terms actually were. ${ }^{6}$ From subsequent events, however, and from the nature of the quarrel itself, we may conclude that Mahine permitted Mahau to continue his rule over Mo'orea's Varari district, while retaining authority over most of the rest of the island for himself and his protégé, Tairihamoetua (?). Later, when Cook arrived at Mo'orea and expressed the wish to see Mahine, “... it was not till after much invit'ing that he quitd his Canoe \& ventur'd on board, \& then with evident mark's of fear; \& mentioned immediately to the Captn that Otoo was his Chief to whom he would submit" (King, in Beaglehole 1967:1382). Like most other Maohis, Mahine probably acknowledged Pomare I's ceremonial preeminence, but his talk of "submitting" to Pomare I as "his Chief" was undoubtedly based on his fear of Cook's guns and knowledge of the latter's championing of Pomare I. In his subsequent conduct toward Pomare I, this independent-minded chief expressed anything but submission to the Pare ari'i.

The ceremony held at 'Utu'aimahurau to formalize the truce with Mahine was attended by Te To'ofa, Pohuetea, an unnamed Seaward Teva chief, a representative of Mahine (reputedly his brother), and Pomare I. Despite the contempt and bitterness the other Tahitian principals may have had for Pomare I, his presence at the ceremony was indispensable, inasmuch as validation of the truce, by 'Oro, required a human offering, over which only Pomare I, as wearer of the distinctive Wallis maro, could officiate. (It was for this specific purpose, I believe, that Te To'ofa, at the crest of his rage, sent a plantain leaf to Pomare I, and not as a sign of general reconciliation.) The ceremony itself was witnessed by King, in Cook's stead; in view of the fact that it included most of the principals of the war under consideration, and that it is one of the few records left us of a specific, as opposed to a generalized account of such a ceremony, I reproduce Lieutenant King's description in detail.

It was Sunset when we embarked in a Canoe and left Oparre, about 9 oclock we landed at Tettaha at that extremety which joins to Attahourou; before we landed the people called to us from the shore, probably to tell us that Towha was there. The meeting of Otoo and this Chief I expected to be curious and worth seeing; Otoo and his attendants went and seated themselves on the Sand close to the Canoe in which Towha was. On the Servants of this cheif wakening their master and mentioning Otoo's name, immediately a plantain tree and a Dog were laid at Otoo's feet, and many of Towha's people came and talked with him, as I conceived about their expedition to Eimeo. After I had remained for some time, seated close to Otoo, and not perceiving Towha to stir from his Canoe, nor hold any conversa- 
tion with us, I went to him. He asked me if Tooti was angry with him, I told him no, that he was his Taio and that he ordered me to go to Attahourou to tell him so. Omai had a long conversation with this Chief, but I could gather no information of any kind from him. On my returning to Otoo, he seemed pressing that I should go to eat and then to sleep. Accordingly Omai and I left him. On questioning Omai, he said the reason of Towha's not stiring from his Canoe was his being lame, that presently Otoo and he would converse together in private, this seemed true, for in a little time those we left with Otoo came to us, and about ten minutes after Otoo himself came and we all went to sleep in his Canoe. The next morning the yava was in great plenty. One man drank so much that he lost his sences, I should have supposed him in a fit from the convulsions he was in; two men held him and kept plucking off his hair by the roots. I left this spectacle to see a nother more affecting, this was the meeting of Towha and his Wife and a young girl that I understood to be his Daughter; after the ceremony of cuting their heads and discharging a tolerable quantity of blood and teers, they washed, embraced the Chief and seemed unconcerned. But the young Maids punishment was not yet to an end, Terry Derry came and she went with great composure to perform the same ceremony to him she had to her Father. Towha had brought a large War Canoe from Eimeo, I enquired if he had killed the people belonging to her, and was told there was no men in her. We left Tettaha about ten or eleven and landed close to the Morai at Attahourou a little after noon. There were three Canoes hauled up opposite the Morai with three hogs exposed in each; the sheds had something under them which I could not discern. We expected the Ceremony to be performed the same afternoon but as neither Towha or Potattow came nothing was done.

A Chief from Eimeo came with a small pig and a Plantain tree and placed them at Otoo's feet, they talked some time together and the Eimeo chief often mentioning the words Warry warry ('false') I supposed that Otoo was relating to him what he had heard and that the other denied it. The next day (Wednesday) Towha Potatow and about eight large Canoes came and landed near the Morai, many plantain trees were brought on the part of different Chiefs to Otoo. Towha did not stir from his Canoe. The Ceremony began by the first Priest bringing out the Maro wrapt up, and a bundle shaped like a large fidd; these were placed at the head of what I understood to be a grave, then three Priests came and sat down opposite and at the other end of the grave, bringing with them a Plantain tree the branch of some other tree and the Sheath of the flower of the Cocoanut tree.

The Priests, with these things in their hands seperrately repeated some thing, and at times two and sometimes all three sung a Melancholy ditty little attended to by the people. This praying and Singing continued for an hour; then, after a short prayer, the high priest exposed the Maro and Otoo got up and wrapt it about him and held in his hand a Cap or Bonnet made of the red feathers of the Tail of the Tropic bird and other dark feathers. He stood in the Middle space facing the three Priests who continued their prayers for about ten minutes; when a man started from the Crowd, said something which ended with the word Heiva and was answered by the Crowd Earee three times, and this as I was told before, was the principal part of the ceremony. The Company now went to the opposite side of the great pile of stones, where is what they call the Kings Morai, which is not unlike a large grave. Here the same ceremony was performed over again and ended in three cheers, the Maro was now wrapt up and increased in richness by a small piece of red feathers which one of the priest(s) gave Otoo while he had it on and which he stuck into it. From this place the people went to a large hut close by the Morai, where they sat themselves down in much greater order than is usual among them. A Tierrabou man then made 
an Oration of about ten Minutes, he was followed by an Attahourou man, afterward Potattow spoke with much greater fluency and grace than any of them, for in general they spoke in short broken sentences with rather an awkward motion of the hand; Tuteo Otoo's orator spoke next and after him a Man from Eimeo. Two or three more speaches were made but not much attended to. Omai said that the Speaches declared that they should not fight but be all friends. As many were warm it might possibly be some recriminations and protestations of their good intentions. In the Middle of their speaking an Attahourou man got up with a Sling fastened to his waist and a large stone held on his shoulders, with this he marched in the open space repeating something in a singing tone. After parading near a quarter of an hour he threw the stone down. This Stone and a Plantain tree that lay at Otoo's feet were, after the debates ended, carried to the Morai and one of the priests and Otoo with him said something on the occasion. On our return to Oparre the Sea breeze set in which Obliged us to land and we had a pleasant walk through almost the whole extend of Tettaha to Opare, a tree with two bundles of dried leaves suspended from it was the boundary of the two districts. The Man who had performed the Ceremony of the stone and sling came with us, with him Otoo's Father had a long conversation, he seemed very angry, I understood he was enraged at the part Towha had taken in the Eimeo business.

From what I can judge of this ceremony it had not been wholy a thanksgiving as Omai at first told us, but rather a solemn confirmation of the Treaty or Truce, or perhaps both. (Beaglehole 1967:215-218)

Thus ended the Mo'orean Succession War - for the moment, at least. For, as King reported in his description of the battle's aftermath, Te To'ofa and his allies rankled at Pomare I's dereliction and vowed publicly to punish him. Cook's version of this threat, and of his reaction to it, are worth reproducing; his own warning proved to be a potent factor in political events of the next few years:

The terms [of the truce] were disadvantagious and all the blame fell upon Otoo for not going to assist Towha in time. The current report was now, that Towha assisted by the forces of Waheatua would, as soon as I was gone, come and fall upon Otoo; this called upon me to support my friend by threatening to retaliate it upon all who came against him when I returned again to the island, if there was any truth in the report at first this had the desired effect, for we heard no more of it. (Beaglehole 1967:214)

Thus was formulated a more or less "official" English policy which was to have a very material influence upon the political developments of the next four decades. For, just as Wallis had made a "Queen" of Purea, and Cook a "King" of Tutaha, with the latter now dead the principal personage in the vicinity of Matavai, namely Pomare I, was duly given that label, and was courted with official courtesies and innumerable valuable gifts. In the person of Tutaha the visitors had a man of unmistakable coercive authority and wide political influence - a real "king" in the civil, temporal sense of the word. In the person of Pomare I they at first recognized his shortcomings and limitations in civil affairs, but acknowledged, as did most Maohis, the preeminence of his rank-status. But Cook, through his warning, 
had managed to increase Pomare I's authority in civil affairs far beyond the point warranted by the latter's own resources. We cannot tell the extent to which Cook's promise of support, along with the other English attentions, served to enlarge Pomare's own ambitions, but these factors undoubtedly improved the chances of their ultimate realization. Some historians appear to imply that this "official" policy adopted by the English visitors came about unwittingly, almost wholly the result of the use of Matavai and Pare anchorages. This may indeed have been so in the beginning, but a case could be made that later voyagers (and even some of the earlier ones) fostered this policy deliberately and with eyes wide open.

To the ritual-minded Maohis the numerous courtesies extended to Pomare I by the English - including the daily associations, the meals on board, the royal salutes, et cetera - must have added some luster to his already preeminent rank-status. The large quantities of English gifts that passed through or ended up in Pomare I's hands, provided him with unmatchable resources for rewarding supporters and for courting the loyalty, or at least the neutrality, of other chiefs. And, with Cook's promise of armed support, Pomare I was provided with the means of complementing his rank-status and gift-bribed cooperation with coercion-sanctioned authority.

Needless to say, the peers of Pomare I were unhappy about these goods in the hands of an individual whose personal qualities some of them held in contempt; but they were compelled by Cook's unequivocal warning to bide their time.

Cook's party left Matavai shortly after the truce ceremony just described and made their way to Mo'orea. There they met Mahine, as earlier described, and experienced anew the frustrations of trying to recover stolen property - in this case some goats. Cook himself became so deeply involved in this matter, and his temper so enflamed, that he had his men destroy numerous houses and canoes in an area already damaged during Te To'ofa's campaign. Eventually Mahine was prudent enough to see that the stolen property be returned, and he even voiced his intention to continue "submission" to Cook's protégé, Pomare I; but he too was simply biding his time.

\section{TE TO`OFA’S REVENGE}

Cook, of course, never returned to Tahiti. In fact no European vessel put in there for about eleven years, ${ }^{7}$ at which time Bligh, Christian, and the others of that famous crew turned up on H.M.S. Bounty, intent on collecting a cargo of breadfruit plants for Jamaica, where it was hoped they would answer the planters' need for a cheap staple for their slave labor. H.M.S. Bounty remained at Matavai from October 26, 1788 to April 4, 1789; during this time Bligh faithfully kept a journal whose usefulness is enhanced by 
virtue of his prior experience on the island, gained in 1777 as master aboard Cook's Resolution.

The visitors found Pomare I in a sorry state. The ari'i was described as “... a Man only nominally possessed of power, or otherwise he has not abilities to govern, which may be the Case, as the Cheifs revile him upon all occasions" (Bligh 1789:I, 375). As for his formerly populous and prosperous district, Bligh reported:

The extensive Houses that we have seen before are no where to be found, and every habitation seems to have no more pains taken with it than to make it answer its use. They are nothing but small light sheds, the largest of which taken by the four corner supporters, might be taken away by four Men. Their large Cannoes also are gone except two or three, so that I imagine the injury these People have sustained is very great. (1789:I, 379)

What had happened was reported to Bligh by Pomare himself:

He said that after five Years and three Months, from the time of our sailing, counting 63 Months, the Imeo People joined with Tettowah, (the noted old Admiral called by Captain Cook Towah) and made a descent at Oparre ... that after some resistance by which many Men were killed, he and all his People fled to the Mountains. The People of Imeo and those of Atta-hooroo under Tettowah now being masters of all their property, destroyed every thing they could get hold of, among which were the Cattle, Sheep, Ducks, Geese, Turkeys and Peacocks left by Captain Cook in 1777. (p. 378)

Evidently Cook's warning had had its effect - for five years at least. Then Te To'ofa, probably concluding that Pomare I's friends would not return, descended upon Pare as he had threatened to do. Taiarapu seems also to have joined in the attack, and although Fa'a'a and the northeastern districts are not specified as having participated in the actual fighting indeed, their forces would have been superfluous - they certainly did not offer any comfort to Pomare I. (Bligh pp. 396-397)

We cannot be certain that Mahine's forces actually joined with Te To'ofa's in attacking Pomare I, but they played a major part in the latter's rout. Each of the chiefs had his own grievances against Pomare I, but it may seem surprising to see them as allies, in view of Te To'ofa's previous espousal of Mahau's claims against Mahine, and of his own earlier attack upon Mo'orea. Nevertheless, it appears that these two chiefs' shared antagonism against Pomare I overrode their differences regarding the Mo'orean succession. Te To'ofa's grievance is well documented: a general resolve to deflate Pomare I's unwarranted political pretensions, and a particular desire to punish the latter for his conduct during the earlier Mo'orean campaign. Through inaccurate but comprehensible reasoning Mahine probably blamed Pomare I for the destruction meted out by Cook on Mo'orea, in the episode of the stolen goats (Bligh 1789:I, 378). But in addition, Pomare I was doubly 
identified with Mahine's rival, Mahau, by virtue of Pomare I's marriage to the latter's sister, 'Itia, and of Mahau's own marriage to Pomare I's sister, Auo - for both of these unions were evidently established by 1782, the approximate time of the attack upon Pare.

Although Mahine's (and Te To'ofa's) forces lay waste to Pare and forced Pomare and his family to flee, the Mo'orean chief himself was slain, reportedly by Pomare I's younger brother, Vaetua (who as a consequence was "esteemed as a great Warrior") (Bligh p. 411). ${ }^{8}$

Mahine was succeeded in his tribal chieftainship by his adopted son, Tairihamoetua (?); Mahau retained his office as chief of Varari, in northwest Mo'orea, and an uneasy peace prevailed between the two. Meanwhile, Pomare I's relationship with Tairihamoetua (?) was hostile but fairly quiet; when Bligh asked the former about this he was told that they were still at variance and that "... if an Otaheite Man went to Imeo he would be killed, and the same would be done at Otaheite [read, Pare] by a Man from Imeo" (1789:I, 378-379). As an indication of this relationship, Bligh attended a heiva performed at Pomare I's direction as "publick mark(s) of honor as a reward for publick or meritorious Services" in honor of a Pare warrior who had happened to be "ill used" while on a visit to Mo'orea (1789:II, 61).

Te To'ofa, Pomare I's other principal antagonist, evidently died shortly before Bligh's arrival, but his son and successor appears to have sustained the father's hostility toward the Pare ari'i.

According to Bligh, "The inhabitants also of Tiarraboo had made some attack on this devoted place [i.e., Pare] ..." (1789:I, 397); and from what Bligh could learn at Matavai their hostility had not abated - a somewhat surprising state of affairs inasmuch as 'Itia's (and Mahau's) sister, Pateamai, ${ }^{9}$ was probably by then married to Seaward Teva's ari'i, Vehiatua III.

Pohuetea, whom Bligh also characterized as one of the island's "great Personages," invited the English to visit Puna'auia but would not travel to Matavai, "such is the Mutual jealousy of these People" (1789:II, 77). Indeed, about the only influential chief on Tahiti not hostile to Pomare I at this period was Te Pau"B", of F'a'a'a, and even this relationship appeared threatened:

Tynah [Pomare I] was uneasy on account of Teppahoo being ill at Tettahah, who he esteems above all other of his friends. He tells me that when Teppahoo dies the district will then join with Attahooroo and fight against him, as the Erree then will be a Brother of Teppahoos, (he having no Children) who is a great enemy to him. (Bligh 1789:II, 48-49). ${ }^{10}$

During the five-months' visit of H.M.S. Bounty, Pomare I's many enemies carried out no overt attack against him (perhaps because of the 
ship's presence at Matavai), and Pomare I did his best - or rather, Bligh's best - to conciliate them:

As I make it my study to do every thing for the good of our Friends here [i.e., Pomare I and his family], I have therefore to establish peace around them as I consider it their greatest blessing, given Tynah the power of making Friends if possible by presents. In consequence all his late powerful enemies have received presents, Saws, Shirts and many other things, this however I fear will but whet their inclinations for War as soon as I am gone; he is nevertheless apparently anxious to conciliate their regard, in which I am happy to assist. (Bligh 1789:II, 38)

There is no better way of summarizing Pomare I's political predicament than by quoting another statement of Bligh's, which, in addition, shows how faithfully the conscientious lieutenant continued to carry out the policy of "king making" so clearly enunciated by his former captain, James Cook:

There is a great deal due from England to this Man and his Family; by our connections with him and them we have brought him numberless Enemies. Their elligble situation for our Ships has brought us intimately connected with them, and by this perhaps we have not only sown the seeds of discord but of revolution. On one side he has Attahooroo disposed to attack him, and on the other Tiaraboo ready for a total extirpation of his Authority, while he has an Enemy equal to the other two in Imeo (or Morea) who will venture anything buoyed up by their former Successes. All those I am confident will on my leaving this Place make a joint Attack on this part of the Island, and these poor people will have no resource but to fly to the Mountains and defend themselves there. It will certainly be against them, my not taking vengeance on the Attahooroo and Morea people for taking the Cattle and destroying part of them, and was it not for the particular trust that is reposed in me to complete the Undertaking I am sent on, I would certainly adopt such means as to oblige those people to repent of their incursions.

I hope however, and have given Tynah and all the principal People reason to think, that they will never be forgot by us, because it will at any period or case be justifiable in England to support the Otow family, and they have shown that faith and Affection to the Erree no Pretanee, as their expression is, as demands all our Assistance and utmost efforts to defend them. If therefore these good and friendly people are to be destroyed from our intercourse with them, unless they have timely assistance, I think it is the business of any of his Majestys Ships that may come here to punish any such attempt. (1789:II, 28)

When H.M.S. Bounty arrived at Tahiti, Pomare I exercised secular authority over Pare-Arue, and at least western Ha'apape; but the label of ari'i rahi, and the prerogatives and duties associated with maro ura rank - presumably with both the Tetupaia and Wallis maro ${ }^{11}$ - had already been transferred to his eldest son and successor, whom I shall call Pomare II. $^{12}$

According to Bligh's account, 'Itia had borne five offspring to Pomare I. The first, a female, was slain at birth, Pomare I having been an active Arioi at the time (1789:II, 56; I, 387, 389). The second, a male born about 1783, was, as had been his father, generally called Tu (Pomare I having 
relinquished this name and become Tina). The third, a female born about 1784, was named Teri'i na Vaho Roa. The fourth, a male born about 1786, was named Teri'i Tapanoai (?), and the fifth, a female born about 1787, was named "Tahamydooah" (Tahamitua?). During Bligh's Bounty sojourn these "royal" progeny dwelt with their attendants in a set of households apart:

I do not often speak of Otoo [O Tu, Pomare II], for his being a Child and kept out of our way we have of course no intercourse with him. I however see him perhaps once a Week and the other Children, but we never come nearer each other than 30 or 50 yards. At those times I carry them some little presents and by this Means they are always rejoiced to see me. The River separates their dwelling from the part we are at, and it would be considered as a great violation were we to cross it near their dwelling. There are two Brothers and two Sisters but they do not eat or sleep under the same Roof. On that account the Girls have a House about $1 / 4$ of a Mile from their Brothers. Each of them are situated on the side of a pretty River which has its source out of a Rock on the side of the Hill near Otoo's House. The Parents sleep every night at the Girls House, but are mostly absent from them in the day. (1789:II, 56)

With these children also lived the two offspring of Pomare I's sister, Auo, and the latter's husband, Mahau; and, according to Bligh, these latter "... have similar marks of Attention \& respect paid to them" (p. 56).

Turning now to other members of what Bligh was pleased to call "the royal family," old Teu (Hapai) and his wife Tetupaia ("Oberreeroah") were still alive, but evidently wholly retired from engagement in political affairs. Of their three surviving daughters, the eldest, Te Ari'i na Vaho Roa (also called Tetua Nihura'i) still presents something of a mystery; I am fairly well convinced that she had married Teri'irere, ari'i rahi of Papara (now become Temari'i), but she evidently bore him no children and seems to have dropped out of sight by 1788, probably through death. The next eldest daughter, Ari'ipaea Vahine, resided in Ra'iatea and was not in evidence during Bligh's stay. The youngest daughter, Auo, who was married to Mahau of Mo'orea, seems to have divided her time between her husband's Varari district in Mo'orea, and Pare, where, as just noted, her children lived.

Of the four sons of Teu and Tetupaia, the condition of the eldest, Pomare I, is well documented. During Bligh's visit to Matavai, Pomare I's next younger brother, Ari'ipaea (Te Ari'i Fa'atou), was residing with his wife nearby; concerning the relations of these two brothers Bligh was informed that

... Tynah and his Brother Oreepyah were on bad terms and that they would quarrel and fight as soon as I sailed. I have observed some coolness between them and knew they did not heartily like one the other, on every opportunity therefore I had endeavored to make them friends, but it has had no effect. This dislike has arisen from the disagreement of the Two Wives. (1789:I, 407) 
That the two wives in question had disagreements should occasion no surprise - both having been strong-minded, ambitious personalities, from familes of divergent political interests.

Pomare I's next younger brother Vaetua (Te Tupai e te Ra'i, Maiore, Paiti), resided in Ha'apaino'o, but spent much time at Pare, where he seems to have distinguished himself to Bligh mainly through his steady consumption of kava. The youngest son, Te Pau "C", eventually succeeded to tribal chieftainship of Fa'a'a, but during Bounty's sojourn he remained little noticed by the English.

The newest person of note to appear on the Matavai scene during Bligh's visit was Ha'amanemane, also known as Tuteha. The first reference to this man, who was to play a very important role in Tahitian politics, appears in Bligh's journal under date of November 4, 1788: "A Cheif of much consequence and related to Tynah [i.e., Pomare I] has been here these two days from Ulietea [Ra'iatea]. He is called Toota-ah" (1789:I, 385). Ha'amanemane was also known as Mauri. About four months later Bligh described "Toota-ah" as being "... generally with Tynah, he is a Priest and considered to have great Knowledge" (1789:II, 45). Ha'amanemane was a brother of Pomare I's mother, Tetupaia, and was evidently forced to flee from Ra'iatea during that island's wars with Porapora. As we shall see he came to have a weighty influence over Tahitian affairs. 


\section{CHAPTER 28 WARS OF THE BOUNTY MUTINEERS}

What happened to Lieutenant Bligh and H.M.S. Bounty after leaving Tahiti is of course widely known, but, as Adams put it:

What Bligh said to Christian, and what Christian said to Bligh, and what Peter Heywood said to both, and how Thursday October Christian made his dramatic appearance at Pitcairn Island, and a thousand other details of the picturesque story, have been told a hundred times, and always to interested audiences; but no one has taken the trouble to tell how great an influence Bligh and his mutineers exercised over the destinies of Tahiti, and especially of its old chiefs. (1901:98)

After setting Bligh and his closest supporters adrift in the ship's launch off Tonga, on April 28, 1789, the mutineers returned for a brief visit to Tahiti in June, to collect livestock and some Maohi companions, and then sailed for Tubuai where they hoped to settle.

The next European vessel to call at Tahiti was the Swedish brig Mercury (Captain Cox commanding), which remained at Matavai from August 12 to September 2, 1789. One of the Mercury's officers, Lieutenant George Mortimer, compiled an account which, while recording no change in the island's political situation, does supply some useful confirmatory details. He wrote, concerning Pomare I and some members of his family:

We remarked that his [Pomare I's] subjects paid him very little respect, and seemed under no kind of restraint in his presence, every dirty fellow entering freely into conversation with him; indeed, were it not for the distinction of being fed, and that the women sometimes uncover their shoulders in his presence, it would be difficult to tell him from any of his people. (1791:30)

Otoo [Tu, Pomare I] happening to see a pair of scissars, with a long chain suspended to them, given by our second mate to his [Pomare I's] wife, had a great desire to possess them, and demanded them of her; but she positively refused to give them up: upon which he fell a-crying, and was not to be pacified till he obtained a pair like them. After this, he gave us another proof of the childishness of his disposition, by employing a man for two or three hours in sewing additional buttons down the back and on the flaps of a coat Mr. Cox had given him. His wife Etea is a clever sensible woman, and the only one of her sex permitted to eat in the presence of the men: she makes use of a knife and fork nearly as well as an European; and she is fond of tea. Her Majesty is likewise an excellent shot, and hit our buoy the first time she fired, with a single ball, though it lay at a consid- 
erable distance from the ship; she having first taken the musket from Otoo, who was afraid to discharge it. (pp. 31-32)

The men [of Mo'orea] made us a tender of their women, and seemed to think it a necessary proof of our friendship that we should accept their offer. The ladies on their part seemed to have no aversion to comply with the requests of their husbands and relations, not excepting her Majesty. This did not surprise us after what we had heard at Otaheite: for we were there informed that Otoo's wife made no scruple of granting her favours to some of the great chiefs; and that Otoo sometimes solaced himself with his brother Orepia's wife, which she acknowledged, and seemed to think an honour, (p. 44)

... we were frequently troubled with the company of a younger brother of the king's named Widouah [Vaetua], a very impudent, dissolute young man. (p. 45)

The principal matter of interest to us in this journal is an account of the officers' three-day excursion to Mo'orea. There they met Varan's chief, Te Ari'i Tapu Nui (i.e., Mahau) and his wife (presumably Auo, the younger sister of Pomare I), along with a boy identified as their son. Mahau himself was described as "... a tall, stout, good-looking man, speaks but little, and seemed to be of a timid disposition" (p. 38). Then, on the return trip they stopped at Opunohu Bay, where they witnessed a brief skirmish between some of Mahau's partisans and what I assume was a small force of Tairihamoetua's people. The whole incident attests to resumption, or continuation, on Mo'orea of the long-seated war of succession.

Later in September 1789, the Bounty mutineers returned to Tahiti after having met with a hostile reception at Tubuai, and then the ship sailed almost immediately again for what turned out to be Pitcairn Island; this time, however, sixteen of their number elected to remain at Tahiti. Until March 1791, when the survivors of those who remained on Tahiti were sent back to England on H.M.S. Pandora, the ship sent out to capture them, they played important, probably decisive roles in Tahiti's political affairs. Of great good fortune for the historian and student of Maohi society, one of the mutineers who survived was James Morrison, ${ }^{1}$ who compiled an account of his stay on the island, along with a most valuable description of many other aspects of Maohi culture, from which earlier chapters in the present work have abundantly drawn.

The sixteen mutineers met with a very hospitable reception in Matavai and Pare, and at the beginning most of them elected to settle there. Soon, however, two of them responded to a general invitation from Vehiatua III and went to live in Taiarapu, and another moved to Papara at the invitation of Temari'i (the then current name of Teri'irere). Of those remaining in Matavai-Pare some embarked upon the difficult undertaking of building a schooner in which they hoped to reach Batavia, and thence find passage to England.

Throughout their stay the mutineers saw much of Brown, the seaman 
left ashore by the Matilda, but most of them remained wary of him. Brown, however, proved far less troublesome to his compatriots, and to the Maohis, than did Churchill, the Bounty's master-at-arms, who, in fits of temper, killed or wounded several Maohis and who managed to become a "chief" for a brief period before he himself was murdered.

It is not possible to discover the whole range of relationships obtaining between this wide assortment of aliens and their Maohi hosts. Each of the former seems to have had close, taio-like, relations with one or more Maohis (usually with upper-class ones), and many of them also had Maohi mistresses. The fact that they were in general so hospitably and deferentially treated, despite their obvious weakness in numbers and armaments, is undoubtedly due to a number of reasons. Great value was evidently attached to their presumed knowledge and technical skills, particularly with respect to warfare. Moreover, the well-founded expectation that other European vessels would in time appear and revenge mistreatment of them probably exercised some constraint, but there seems also to have been other, less tangible factors at work. I have already pointed out how generally hospitable the Maohis were toward aliens who happened to land on their shores. Exceptions of course occurred, but by and large a stranger cast ashore on one of these islands stood a better chance to be fed and left unharmed than would have been the case in many other South Sea archipelagoes. And finally, in addition to the numerous instances of sincere friendships formed between individual Maohis and Europeans during this first quarter century of contacts, there seems to have developed a respect for certain Europeans, which in the case of James Cook reached the dimensions of cult veneration. ${ }^{2}$ Whatever the reasons behind individual cases, some Maohi chiefs competed to secure the friendship and services of the European castaways - and well they should have, in view of subsequent events.

The first of these events took place in early March 1790, when Mahau set out from Mo'orea with canoe loads of hogs and tapa for the youthful Pomare II. When rumors circulated that a force of Oropa'a was planning to waylay the expedition, Morrison and some of his compatriots were sent for to frustrate the attack. Their appearance under arms had the desired effect and the attack never materialized (Morrison 1935:89); and thus it was that part of the mutineers became actively identified with Pare, and the ambitions of the Pomares. ${ }^{3}$ Others of the Bounty people, however, became associated with the Pomares' rivals in Seaward Teva.

Early in their stay, two of the mutineers, Churchill and Thompson, moved to Seaward Teva, where the former became taio and principal aide to Vehiatua III. In fact, the relationship was so close that when Vehiatua III died shortly thereafter, in mid-March 1790 , and without issue, his supporters elected Churchill to succeed him; but this troublesome man did not live long to enjoy his position. Within a month he had quarrelled so vio- 
lently with Thompson that the latter killed him - and was himself killed by Churchill's supporters to avenge the death of their new "chief." After this unsuccessful experiment the Seaward Tevans reverted to their usual practice and named a nephew of Vehiatua III to succeed him (the exact nature of the kinship tie is not reported). As the successor was only about four years old at the time, his father was appointed regent for him.

Meanwhile, it is interesting and somewhat surprising to learn that during all these proceedings, and for some months previously, Pomare I was living on the peninsula, in the district of Afa'ahiti (Morrison 1935:76, 96). According to the latter's reports to Morrison he was treated "very uncivil" by the people of Seaward Teva, but evidently not to the extent of making his life intolerable. The land on which he resided, described as "some possessions given to himself," is not further specified, but may well have been some estate inherited from his father's mother, Tetuahuri, who was the daughter of an earlier Vehiatua. Pomare I's major object in remaining in this uncongenial situation was, as he expressed it, his "... hopes of gaining a party in his Sons favour" (p. 96). In view of Vehiatua III's lack of issue, and of Pomare I's descent from the Vehiatuan Tetuahuri, his own son was undoubtedly eligible for consideration as a successor to Vehiatua III. The Taiarapuans' general hostility toward Pare's principal family was probably responsible for their passing over Pomare II, but the reason they gave was that, in their belief, Pomare II was a bastard, having been sired by his mother's commoner paramour, and not by Pomare himself.

The next episode of political significance involving the mutineers occurred during the early part of April 1790:

In the Mean (time) the Morea People haiving rebell'd against Mottooarro, Chief of that Island \& Brother-in-law to Matte, he sent to us to know if He should send his arms over to quell them, to which We agreed, but told Him to send His own people to use them; and Heete-heete being present was appointed to the Command. The Arms being brought to us we Cleand them and put them in order when they set off and Arriving at Moria soon brought them to subjection, Heete-heete having himself killd the Inspired Priest of the Rebels and their Chief, (the adopted Son of the late Maheine) Tayreehamoedooa, forced to fly to Attahooroo, leaving the Island in posession of Mottooarro whose right it was, but from which he had been kept by Maheine his Uncle and His party, till the Bounty had Saild in April 89, when he having formed a strong party was Calld Home from Taheite where he then resided and having strengthend his party from Taheite was admitted as Joint Chief with Tayreehamoedooa who now became Jealous of His power, and had taken up arms to drive him out again, but the fire arms gave Mottooarro such strength that $\mathrm{He}$ was forced to relinquish all Claim \& fly to Taheite for refuge. From Attahooroo he went to Papaara where Tommaree gave him land and where he now resides private with His Mother \& Aunt (Wa Vaheine) who was the Wife of Maheine deceased. (Morrison 1935:92-93)

Thus in one brief action the seventeen-year-long Mo'orean Succession War was brought to a conclusion favorable to Mahau, and hence to the Pomares. 
The mutineers' firearms were probably decisive factors in the conflict, but the hero of the action was Hitihiti, the well-known man who had accompanied Captain Cook on his southern swing in 1773 and 1774, and had since become principal aide to Pomare I. Hitihiti was also Pomare I's uncle-by-marriage, but whether this relationship preceded or followed his occupational attachment to Pomare I is not recorded. The skills and knowledge Hitihiti acquired during his seven-months' service with Cook probably account for his prominent position in Pomare I's entourage, because he does not appear to have been otherwise gifted. ${ }^{4}$

Tairihamoetua's (?) right to refuge in Papara evidently derived from his "aunt," Mahine's widow, who was the sister of Papara's Amo. From these circumstances it would seem likely that the principal people of Papara were maintaining their posture of hostility - or at least coolness - toward the Pomares, but such apparently was not the case. For example, under the date of March 1790, Morrison recorded that two of the mutineers had gone to Papara to live, and that Pomare I raised no objections to the arrangement, inasmuch as he was "in alliance" with Temari'i (Teri'irere), the Chief of Papara (p. 91). Elsewhere, Morrison recorded that Pomare I's brother, Ari'ipaea, was visiting Papara. This introduces a set of events not specifically reported by any contemporary, on-the-spot observer, but presented in Adams' history as reliable oral traditions of Papara's chiefly family.

The gist of Adams' account, abstracted from intricacies too confused, ill founded, and irrelevant to concern us here ${ }^{5}$ is that the young Papara chief, Teri'irere-Tamari'i, became more sympathetic to the aspirations of the Pomares than his parents had been - more specifically, to those of the young Pomare II. Adams proposed that this change in sentiment was affected mainly by Pomare I's brother, Ari'ipaea, whose wife was Amo's niece. ${ }^{6}$ Ari'ipaea was undoubtedly friendly with Teri'irere-Temari'i, and may have contributed to the improved relations, but one will also recall that the latter's first wife was Pomare I's eldest sister, and his mother was 'Itia's father's sister. While ties of kinship were no warranty of amicable relationships, as must by now be clear, they cannot be dismissed as irrelevant.

However it came about, relations between Pare and Papara were such in mid-1790 that the warriors of these two districts fought more or less simultaneously to defeat a common enemy, even if they did not join together to fight as close allies. The next set of events in Tahiti's political history commenced in September 1790:

September 12th. this Day a Messenger arrived from the Young King desiring our Immediate Assistance to quell the People of the District of Tettahah who had rebelld, and made an inroad into Oparre, burning all before them; the Messenger also informd us that the Oparre people had repuls'd them forcing them to leave two of their Dead behind them which were brought to the Young Kings Morai, and that they were preparing for another attack, being set on by 
the People of Attahooroo. - he told us also that areepaeea-Waheine the Young Kings Aunt who had been at Ryeatea for some years, was arrived at Oparre with a Numerous Fleet which were all ready for War. (Morrison 1935:100)

The Ari'ipaea Vahine referred to in this passage was none other than Pomare I's elder sister. (Morrison elsewhere described her as Teu's and Tetupaia's eldest offspring.) I cannot discover what induced her to return to Tahiti perhaps only to pay a visit to her family - but the presence of her entourage could not have been better timed.

More inexplicable is the fact of Tetaha's (Fa'a'a's) "rebellion" against Pare. To begin with, this small district on Pare's southern border could not have "rebelled" against the Pomares because it had not been under their domain. On the other hand, since the death of Te To'ofa some years earlier, Fa'a'a's relations with the Pare chiefs appear to have been more friendly than otherwise. The matter is complicated by the question of the identity of Fa'a'a's chief (or chiefs) at the time of this "rebellion." In March 1789, it will be recalled, Pomare I revealed to Bligh his uneasiness over the ill health of Fa'a'a's chief, and Pomare I's friend, Te Pau "B", stating that if the latter died he would be succeeded by his (Te Pau "B's") brother, who was an enemy of Pomare I. When Bligh returned, some three years later, he found Te Pau " $B$ " to have died, and the chieftainship of Fa'a'a held by Pomare I's youngest brother, Te Pau "C" (1792:135). Another limiting date was provided by Morrison, who in a passage yet to be reproduced, reported that upon the defeat of the Fa'a'a "rebels," in September 1790, the Oropa'a victors appointed Mahau, then chief of Mo'orea, to the Fa'a'a chieftainship. In other words, unless Te $\mathrm{Pau}$ "B" had turned against his friend Pomare I, between March 1789 and September 1790, for which there is no evidence whatsoever, it appears likely that Te Pau "B" had died prior to the "rebellion," and that his place had been taken by someone hostile to the Pomares - probably the unnamed brother whose enmity Pomare I had earlier reported to Bligh.

Morrison's account of the next chapter in this conflict continued:

As we did not know that ever we should be able to effect our purpose, tho evry thing was getting forward, we found it necessary for our own sakes, to assist them, and therefore returnd for Answer that we should be at Oparre Next morning - and Armd Accordingly. On the 13th, leaving one to take Care of the Schooner, We marchd to Oparre, where Areepaeea-Waheine received us, and a Dressd Hog was presented to us. - Byrn \& Ellison being at Tetooroa and Musprat on a Visit to Papaara with his Friend Areepaeea, we were now only Eight in number, but were here Joind by Brown, who informd us that the Attahooroo people had made war on Tommaree; which was further Confirmd by a Letter from Burkett desiring our assistance. Having made our breakfast we proceeded to Tettahah Surrounded by a Multitude (with Poeno \& Pyeteea two Chiefs at their head) from Maatavye.

Before that we had proceeded half a Mile We found the Marro Eatooa or Signal for War (which is several Fathoms of Cloth in one piece passd round several 
Trees, crossing the path several times) and a Hog tied to each tree which the Marro passes round; this is generally Put up with some Ceremony, and the Enemy are defied to take it down.

On seeing this our party ran instantly and seized on the Marro \& hogs, when the Enemy who lay conceald till now, made their appearance, and a Fray instantly commenced and Several heavy blows exchanged before We were observed by them - on our approach they Fled, but this Confused Method of engageing prevented us from knowing our own people, who were so scattered that we were not able at a Distance to tell them from the Enemy and we were therefore of No use but to look on while the Enemy retreated to the Mountains $\&$ our party returned with a deal of Plunder, \& several Canoes which they had not been able to remove. We Now informd the Chiefs that they must alter their mode of Fighting, and bring their people under some Command, in Case they should have occasion to go to war again which they promised to do; and having Demanded Matts to make sails for the Schooner, we took our leave of Fatowwa, or Areepaeea Waheine, and returned to Maatavye. (1935:100-101)

\section{About a week later the conflict started up again:}

Mean while the Tettahah \& Attahooroo people had united their forces \& were began to Commit Hostilitys both on Papaara \& Oparre, and on the 20th we were demanded to assist again, which for our Credit we could not refuse, nor was the Sails any excuse, as we were wanted on Shore, and the Enemy looking on our peaceable inclination as the effects of Fear, sent us word that they would Come to Maatavye \& burn the Schooner and a Challenge sent to each Separately by their Warriors, who bid us defiance, telling us that each would have his man to Carry to the Morai, and much more such language. - they had also entered Oparre again burning and destroying all before them.

On the 21st early in the Morning, leaving one as before to take care of the Schooner, we got into our Canoes and paddled to the Lower end of Oparre. Here we were Met by Poeno, Tew, \& Fatowwa, and almost all the Men of Maatavye with Pyeteea, \& Mattaheyapo at their head who were both principal men \& their head Warriors. We were now but Eight in Number, and having given the Chiefs such directions as we thought necessary, they promised to observe them, and being willing to take the Cool of the Morning, we set forward in Good order, surrounded by Multitudes of all ages from both Districts, but the Maatavye men kept Close to us, claiming the preeminence, and keeping the others in the rear. - on our approach the Enemy retreated to a high steep eminence in the Mountains, which Commanded a narrow pass, which was the only one by which they could be approachd, and as this place had resisted all Former attacks, they had got all their property to the place in readiness, \& had formd an encampment of Huts ready to dispute the Pass; however we determined to proceed, as we could not hope for Peace without driving them from their strong hold: but it being some miles up in the Mountains, it was Noon before we got near enough to see the pass \& the situation of the enemy, who we found well posted. The heat became so intense that we should have been in a bad plight had not our friends brought with them plenty of Cocoa Nuts which we found very refreshing and tho we had Marchd at a slow pace, we now stood in great need of - having halted a few minutes we proceeded to the Pass, which was along a Narrow ridge where two men could scarcely pass in safety. - the Taheiteans made a full stop when they came to the place but seeing us proceed they followed, and Pyeteea \& Mattaheyapo came in the Van to be 
our guides over. - in crossing the pass we found ourselves open to their Stones with which they plyed us briskly from the Eminence above our heads, where our Musquets would not reach to do execution - tho we were forced to walk over at an easy rate for one Hundred yards or more, none of us except Coleman was hurt, and he only received a blow of a Stone in the leg which did not disable him - however his Taheite friend received a blow between the Mouth \& Nose that brought him down, \& having English Cloaths on was Mistaken for one of Us and they gave us a loud Shout \& redoubled their Vollies of Stones, by which upwards of twenty more we(re) wounded before we could fire a Shot. However we got over and with a warm fire advanced up the Hill; when they soon gave way. As soon as this was observed by our Party they rushd in, \& three of the Enemies Head warriors having fallen by our shot they fled; and our party persued them down the other side of the Mountains. Mean time the Plunder of their Camp was seized by the Oparre Men, the Maatavye people being more intent on driving their Enemies; the Chief part of their Houses being burnt, and distroyd, we returned in the evening to Maatavye. The Number of Hogs taken here were incredible; several of the largest died with the fatigue of coming down, their own weight \& fat being more then they Could support. (pp. 102-103)

I cannot identify the exact location of this battle, but infer from later events that it was in Fa'a'a, and that the defenders were largely Fa'a'a men. Also, it is reasonable to conclude that the Pare-Matavai forces would not have won the engagement without the firepower and leadership of the eight Englishmen. It remained to dispose of the larger forces of Puna'auia and Pa'ea:

... the Party in Attahooroo, being Yet in arms, the Young King was desirous that we should assist him to quell them, and force them to restore the Marro-Oora, or Royal sash, together with the Morai Tabbootaboatea, being the Movable place of sacrafice; - the Pehharaa or Sacred Chest wherin their Images are kept with the Valuables belonging to the Deitys; the Farre 'Atooa, or house of God, with several other things which belongd to them, which the Father of the Present T'towha Chief of Attahooroo had taken in war from oToo or Matte and which had been kept in Attahooroo ever since, but we found it so fatigueing that we Got the Sails ready in Order to Shorten our marches. - We had by this time between 6 and 7 hundred weight of fine Pork Salted, \& got it on board, and having bent the sails and Got our Amunition on board, on the 26th we saild for Oparre leaving the Houses in charge of the Natives with what things We did not want and leaving only Skinner in Maatavye who was bad with sore eyes which made our Number still but Eight. At Oparre we found Heete-heete who had come from Papaara where he had been with Burkett \& Sumner Who with the Assistance of Muspratt, Brown \& Himself had repulsed the Attahooroo \& Tettahah people with a great slaughter but as they would not submit to Tommaree, they Had Sent him to us to desire that We would keep them in play and appoint a day to let the Armies of Papaara \& Tippirreonoo meet in the Center of Attahooroo. We kept Heete-heete and armd him with one of Matte's Musquets. - we found at Oparre a large Fleet assembled under the Chiefs of Tippirreonoo, who inform'd us that they waited our Orders. the Canoes with provisions being arrived from the different districts and the Morning of the 27th being Calm the Canoes drew up in a line and took the Schooner in tow. The line consisted of 40 Canoes paddling 50, or 60 hands; they had pieces of Painted Cloth 
hoisted on the Sterns of each, \& Drums beating \& flutes playing made a very war like show the Warriors Cutting a Number of Capers on their Stages, being dressd with Featherd headdresses \& all in their best Apparal, the smaller Canoes being kept at a Distance on each side the line began to move forwards within the reef towards Attahooroo. Mean time Multitudes Went a head by land, and the beach appeard Covered all the Way as we passd. As we entered the enemys Country, they fled to the Mountains, and our party on shore persued them, Burning the Houses, and destroying the Country where ever they Came by rooting up the Plantains \& Tarro, and notching the bark round the Breadfruit Trees to stop their Growth, and laying all in ashes before them. About Noon we anchord at Taboona, part of Attahooroo, under Pohooataya, the Same known to Captain Cook by the Name of Potatow. The Canoes were here hauld up, and an encampment made with the roofs of the Houses, which had escaped the fire, or that had been spared for that purpose. We were now informd, that the Enemy had posted themselves in a Strong hold in the Mountains, and Could observe them with the glass going up in large bodys to the place where they intended to stand a Siege. - A Council of War was now held, and finding it would be difficult to approach them, it was agreed to send out several partys to burn the reeds on the Sides of the Hills to prevent them from approaching unseen, or laying in ambush for any Stragling party. Heete-heete was appointed to this business, and in the mean time Ambasodors were sent to demand a Surrender, and a White Flag was hung out on board the Schooner and an(other) sent to be stuck up at about 2 miles distant. During the time the Hills were burning several Skirmishes took place between our party \& theirs; but Heete-heete having the Musquet with him always repulsed them, and they were forced to retire to their Strong hold, as we did not approve of their destroying the Trees the partys were Calld in and placed to look out and Heete-heete always caused one or More of His party to Cry out 'alls Well' in the best Manner they Could pronounce it every half Hour on Notice being given on board the Schooner, for which purpose, we fixed one of the Hoops of the Ships Anchor stock to serve as a Bell, striking it with a hammer, and this was repeated by all who happened to be awake in the Camp, which together with Continual fires which were kept burning all night, served to shew the Enemy that we were always prepared for them.

In the Afternoon of the 29th we observed a White Flag coming down the Hill, and orders was given not to Molest any who came with it, and before Sunset the Chief Pohooataya with his Wife, attended by a Priest bearing the Flag, came to the Camp. A Council was now held of the Chiefs \& Principal Men; when it was determined that peace should be made, on Condition that evry thing should be restored to the Young King; and that the Chiefs of Attahooroo should acknowledge him as their Sovereign. To all which Pohooataya agreed, \& with His Wife Came on board the Schooner as hostages for the performance of his part. - but as several of the things were in posession of the other Chief T'towha, messengers were sent to Him to demand them, with orders to tell him if they were not produced in 24 Hours that He might expect no quarter. In the Night Came Burkett from Papaara, and told us what dispositions were made there, and We informd him how we intended to proceed if Tetowha was obstinate and having appointed the time for storming him on both sides Burkett return'd to Papaara. He inform'd us that Te'towha had, in their attack, been forced into the Mountains \& had several killd \& wounded.

31st. This Morning we were informd that Te'towha had pass'd by in the Night, and was gone to Oparre with the Royal Marro which he intended to present to the Young King in person, and hoped to get Peace by it alone without surrender- 
ing the Morai \&c. - as soon as we knew this, a Double Canoe was got ready, and Millward was sent to bring Him to the Schooner, which he did in the evening. - the same Day passd by Areepaeea and Muspratt, from Papaara, they Calld on board, and Areepaeea made each a present of a Hog \& a piece of Cloth, and set forward to Oparre to get ready for us. When T'towha came on board, he seemd apprehensive that we intended to kill him, and made his fears known to Pohooataya, who Cheerd him up, telling him that he knew the English better, and that for Captain Cooks sake they would not suffer either of them to be killd. When we knew his fears we told him He should not be Hurted, telling him that Englishmen never used those ill who the Chance of War made their Prisoners; at which he seem'd easy, and promissed that evry thing in his posession should be restored, and that He would submit to evry thing we demanded in favour of the Young King. T'towha's friends soon Came after him to the Schooner, and he gave them Orders to go and Bring evry thing that belongd to the Morai; which they Obeyd. (pp. 103-106)

Thus it was that the proud and fierce Oropa'a fell before the combined forces of the Porionu' $u$ and the Paparans, and their English supporters. On the basis of Morrison's description of the battles, the only one we possess, I am bound to conclude that they would have ended either in stalemate or in a victory for the Oropa'a had the English not been engaged. In view of the nature of Maohi politics the verbal promises of submission exacted from the Oropa'a chiefs would probably have been no more durable than the length of the Englishmen's stay on the island, but their obligation to transfer the Wallis maro and the Papara 'Oro image and associated objects from 'Utu'aimahurau to Pare constituted decisively tangible evidence of a shift in political strength. Thenceforth, the young Pomare II would have in his immediate possession two of Tahiti-Mo'orea's three most potent emblems of preeminent rank-status - the Tetupaia and Wallis maro, along with the principal receptacle of the god 'Oro, whose avatar was essential for validating the wearing of the Wallis maro and for transmitting the human offerings required to gain that god's fullest support. (In other words, whereas Pomare II had previously been required to travel to 'Utu'aimahurau to exercise his exclusive right, and duty, to officiate at offerings of human victims to 'Oro, he now was able to do so at Tarahoi. ${ }^{7}$ The transfer was carried out in short order, as were some other political dispositions resulting from the war:

On the 1st of October the Canoe bearing the Morai, Ark \&c. - was brought and deliverd into charge of the Priests of Maatavye and Oparre; who proceeded with her directly to Oparre, and Orders were now given for the Fleet and Army to return home, when they accompanied the Sacred Canoe escorting it Carefully to Oparre, and in the afternoon a breeze springing up we Weighd, having Poeno \& the Two Attahooroo Chiefs, and run up to Tettahah where we anchord for the Night, and weighd at 9 Next Morning the 2nd. here we were Joind by Burkett and Oammo ${ }^{[8]}$ who came to assist at the Peace and Worked up to Toa Roa harbour where we anchord in the afternoon where we landed the Chiefs and Went with them to the Morai, where the Peace was Concluded, and by our advice they 
were continued in posession of their Land; and Paa, and Old Chief who was out of Commission, was put into the District of Tettahah as a Substitute for Mottooarro to whom it was voted, the Attahooroo Chiefs promised on their parts that they would always honor the Young King as their Sovereign, and by way of strengthning the Peace each of them took one of us as his Friend. Great feasting now took place a Volly of Small arms was fired on the occasion and all the Chiefs of Taheite Nooe or Substitutes for them attended. Much feasting now took place, \& on the 4th we weighd and workd up to Maatavye, where we arrived by Noon. (Morrison 1935:106)

We learn from a later passage that a new temple was built adjacent to those already constituting the Tarahoi marae complex at Pare, for accommodating the 'Oro image, and so forth, brought from 'Utu'aimahurau (p. 116). ${ }^{9}$

The fact that the Oropa's chiefs, Te To'ofa "B" and Pohuetea, received such leniency, with respect to their lives and their lands, may have been due to the mutineers' counsel to the victors, but I suspect that it was also in tacit recognition of the likelihood that Pare and Papara would not have prevailed without the mutineers' assistance. Now and then in Maohi wars noblesse oblige may have served to temper a victor's treatment of his helpless adversary, but such niceties were not ordinarily observed when the stakes were as high as in the conflicts now under consideration. The likelihood of Pare and Papara maintaining their advantage over the Pa'ea part of the Oropa'a was improved shortly thereafter by the death of $\mathrm{Te}$ To'ofa "B"; as noted earlier, having no heirs of his own this young chief was succeeded by the four-year-old son of his sister, who was made regent for him (Morrison 1935:107).

Another item of considerable interest in the passage just reproduced is the one regarding the chieftainship of Fa'a'a - that is, the victors replaced the incumbent, whoever he was, with Mahau, now the unchallenged chief of most of Mo'orea, and named a "retired" minor chief, Pa'a, as Mahau's locum tenens. Mahau's appointment to this office was, of course, the result of his close ties of affinity and political alliance with the Pomares; his claims to the office derived from his consanguineal ties with Fa'a'a's chiefly family - his father having been a younger brother of $\mathrm{Te}$ $\mathrm{Pau}$ "A" and he himself thus first cousin to Te Pau "B", who had evidently succumbed by this time.

It should be noted that in the campaign just concluded, the victors had depended upon their handful of English friends not only for firepower but for tactics and combat leadership as well.

Now that the trappings of highest rank-status and the principal avatar of supernatural efficacy were concentrated at Pare, it remained to use them to consolidate and perhaps even extend the newly won political authority and influence. An opportunity for doing so was provided by the formal inaugural rites still to be held for the young Pomare II. As a pre- 
liminary to the main ceremony, the standard (vane) of the young ari'i was carried around the island, in order that each tribe's chief pay ritual obeisance to it, thereby expressing recognition of the young ari'i's supremacy. As I indicated earlier, I am not certain whether this type of formal recognition referred only to the vane owner's rank-status or to his political paramountcy as well. In the present instance it probably was intended to refer to both. Morrison was visiting in Papara when the flag reached there.

While I was here the Young Kings Flag arrived, and was received by Tommaree and Conducted to His Morai, but they kept by the Beach close down in the Surf till those who Carried it were abreast of the Morai, when they turnd short round and proceeded to the Morai - as the Flag passd, the Inhabitants hid themselves, and all Fires were put out - we attended them to the Morai, where Tommarees priests having set the Flag up, made the Usual peace Offering of a Hog and a Plantain tree, the Priests repeated it and several young Pigs \& Plantain Trees were Offered with long Harrangues and Tommaree made a long speech declaring Toonooeaiteatooa to be his Chief, and ordered a feast to be provided for those who bore the Flag - this Flag was the Union Jack which they had got from Captain Cox, and was Slung a Cross the Staff with a stick in the tabeling as we sling a Pendant, it was decorated with Feathers Breast Plates Tassels \&c. - as the Chief People of the District were present, we honord the Ceremony by firing our Musquets, - which was received as an honor, and some of those who were present interpreted this into a declaration on our part to support it in Circumventing the Island, as it was Composed of English Collours, and they made no scruple to say that War would be instantly made on those who should attempt to stop it.

It was kept one Night in the Morai, during which time prayers were Constantly saying by one or other of the Priests which attended it; and when it proceeded they returnd to the Water Side, where they had before been, \& proceeded along by the edge of the Surf towards Tyarrabboo. (1935:114-115)

The Captain Cox here referred to was skipper of the brig Mercury, which had called at Matavai some sixteen months previously. I do not know whether the Union Jack in question had been incorporated into young Pomare II's vane with the deliberate intent of symbolizing English support for the Pomares' pretensions, but it evidently was so interpreted.

From Papara Morrison went on to Taiarapu, where he visited Pomare I (now going under the name of Mate) at the latter's residence in Afa'ahiti:

He [Mate] now informd us that the people of Tyarrabboo had used him very uncivil, altho the Flag had been received, and passd with all the Ceremonies; which he said was only for fear of us and not their regard to His son. He told us that we had yet a right to Chastise them for Killing Thompson, and said that if we once made our appearance in Arms in Tyarrabboo they would never make any resistance and he would be at the Expence of the Amunition, that his Son might be Sole King, he also told us that he had conversed with Tommaree who was ready to furnish Men \& Canoes when ever we thought proper to take it in hand.

Having told him that we would Consider of the Matter we signified our intention to go homeward. (p. 115) 
Back at Pare Morrison found large numbers of people assembled to attend the approaching ceremony, including Mahau (of Mo'orea) and, in Morrison's words, "all the principal Men of the Island." The rites took place on February 13, 1791. (I reproduced this passage earlier but do so again because of its direct relevance to the events now under discussion.)

This day the Ceremony of Investing the Young King with the Marro Oora or Royal Sash took place; the Sash is of fine Network on which Red and Yellow Feathers are made fast, so as to cover the netting; the sash is about three yards long, and each end is devided into six tassels of Red Black \& Yellow feathers, for each of which they have a name of some Spirit or Guardian Angel, that watches over the Young Chief while the Marro is in his Posession and is never worn but one day by any one King; it is then put into the Sacred Box and with a Hat or Shade for the Eyes Made of Wicker \& Covered with feathe(r)s of the same kind and never used but on the Same occasion it is delivered to the priests, who put it Carefully by in the Sacred House on the Morai, where no person must toutch it. (p. 116)

This was evidently the maro whose original section, at least, was introduced into the Pomare family by Pomare I's Ra'iatean mother, Tetupaia. I cannot vouch for Morrison's interpretation of the significance of the tassels; nor is there any direct evidence that I know of to support Gunson's suggestion that each tassel stood for each district over which Pomare II exercised "spiritual hegemony" (1964:57). But, to return to the ceremony itself:

This Ceremony was performed at Oparre on the New Morai which was built for the reception of the Movable Morai \&c. which we had brought from Attahooroo and where these things were now kept. The Chiefs (or their Substitutes) of Tipperroonoo and Morea attended, and Toonooeaiteatooa the Young King being placed on the Morai, a Priest making a long Prayer put the Sash round his Waist and the Hat or Bonnet on his head \& haild him King of Taheite. Mottooarro then began by His Orator making a long Speech and acknowledging him his King, when three Human Victims were brought in and offered for Morea, the Priest of Mottooarro placing them with their head towards the Young King and with a long speech over each, he offered 3 Young Plantain trees. He then took an Eye out of each, with a Piece of split bamboo, and placing them on a leaf took a Young Plantain tree in one Hand, and the Eyes in the Other Made a long speech holding them up to the Young King, who sat above him with his mouth open: after he had ended his Speech \& laid the Plantain trees before the Young King the Bodys were removed \& buryed by his priests in the Morai, and the Eyes put up with the Plantain trees on the Altar - the rest of the Chiefs then brought in their Sacrafices in the Same Manner, going through the like Ceremony, some bringing one Victim \& Some two according to the bigness or extent of their districts, after which large Droves of Hogs and an immense quantity of other Provisions such as bread, Yams, Tarro, Plantains, Cocoa nuts \&ca. were brought and presented to the Young King. Several large Canoes were also hauld up near the Morai on the sacred ground; these were dressd with several hundred fathoms of Cloth, Red Feathers, Breast plates \&c. - all which were secured by the priests \& Young Kings attendants - the Marro being now removed and taken Care of by the Priests, they all repaird to feasts 
prepared for them, which lasted some weeks, the Number of Hogs destroyd on this occasion were beyond all conception, besides Turtle, Fish \&c. \&c. -

I enquired the Cause of the Eye being offered, and was thus informed. The King is the Head of the People for which reason the Head is sacred; the Eye being the most valuable part is the fittest to be offered, and the reason that the King sits with his Mouth open, is to let the Soul of the Sacrafice enter into his Soul, that he may be strengthend thereby, or that He may receive more strength of disernment from it, and they think that His Tutelar Deity or Guardian Angel presides to receive the Soul of the Sacrafice.

Several Large Hogs were placed upon the Altar and the Human sacrifices offered this day were 30, some of which had been Killd near a Month.

These were the First that had been offered since our coming to the Island. (pp. 116-117)

The question of attendance at the ceremony is important, but it is not one that can be conclusively answered. In one place Morrison recorded that "all the principal Men of the Island" were assembled, but a few passages later he reported that "None of the Chiefs of Tyarrabboo had assisted at the Ceremony of investing the Young King with the Royal Sash" (p. 117). In his description of the ceremony itself he mentioned as having attended only "The Chiefs (or their Substitutes) of Tipperroonoo [Te Porionu'u] and Morea." In other words, no specific mention is made one way or the other of representatives of Pa'ea, Puna'auia, Papara, Hitia'a, and so on, whose presence one would expect but cannot confirm.

In any case, the all too evident absence of representatives of Seaward Teva was received as additional grounds for waging war against that tribe, and plans were formulated accordingly, with the English now clearly taking the initiative in the whole affair:

Feb. 20, 1791: Arrived Mill ward and McIntosh who having settled the Matter relative to the War, we determined to put it into execution, as None of the Chiefs of Tyarrabboo had assisted at the Ceremony of investing the Young King with the Royal sash. Tommaree had proposed to Make a Grand Feast, under Cover of which he Could have his Men and Canoes collected before he told them what he wanted them for, and by that means would prevent it from being blazed about - the English were to be there as partakers of the Feast, and when we were ready to attack them we could be in their Country before they knew what we were at, and by this means make an easy conquest. This appearing to us a very good plan, we agreed to prepare for it as fast as possible, and began to get things in order for Launching the Schooner; but from the Number of Visitors which daily came to see us, owing to the Number collected together in the two districts, we were not able to make any Progress, and it was the 1st of March before we Got her Launched. We filld the Water for Ballast and Stowd the Casks with Stones and Wood, we also got the Pork on board, masted and rigg'd the Vessel, but still kept our intentions a secret. (Morrison 1935:117-118)

But this ambitious undertaking, which would probably have removed all effective opposition to the Pomares for a while, never took place. The day after most of the Englishmen arrived in Papara to put the plan into 
operation, a messenger appeared and announced the arrival in Matavai of H.M.S. Pandora, which had been sent to capture the mutineers and return them to England for trial.

Pandora remained at Tahiti until May 8, and then sailed homeward with the fourteen surviving mutineers, and Brown. Records of the stay are contained in reports of her commander, Captain Edward Edwards, and in a journal kept by the ship's surgeon, George Hamilton. The former account is terse and matter-of-fact; the latter is more detailed and entertaining, ${ }^{10}$ although much of it deserving of little credibility.

The passages from Edwards' reports most relevant to our present interests have to do with relations between Teri'irere-Temari'i and the Pomares. In Morrison's journal these relations were seen to be friendly and mutually supportive, with Teri'irere-Temari'i actually acknowledging Pomare II's supremacy, as exemplified in his reception of the latter's vane. But note Edwards' view of their relationship:

The next morning Lt. Hayward was sent with a party in the pinnace to join the party in the launch at Papara. I found the Otoo ready to furnish me with guides and to give me any other assistance in his power, but he had very little authority or influence in that part of the island where the pirates had taken refuge, and even his right to the sovereignty of the eastern part of the island had been recently disputed by Tamarie, one of the royal family. Under these circumstances I conceived the taking of the Otoo and the other chiefs attached to his interest into custody would alarm the faithful part of his subjects and operate to our disadvantage. I therefore satisfied myself with the assitance he offered and had in his power to give me, and I found means at different times to send presents to Tamarie (and invited him to come on board, which he promised to do, but never fulfilled his promise), and convinced him I had it in my power to lay his country in waste, which I imagined would be sufficient at least to make him withhold that support he hitherto, through policy, had occasionally given to the pirates in order to draw them to his interest and to strengthen his own party against the Otoo. (Edwards and Hamilton 1915:32)

Edwards' grasp of the political geography and structure of the island was superficial, to say the least, but there must have been some evidence for his view that Teri'irere-Temari'i was not in Pomare II's pocket at the time. Also, his suggestion that the hospitality of the former to the mutineers was based in part on a desire to separate them from Pomare II is characteristic enough of Maohi political tactics to be quite credible. Some Paparan partisanship seems also to have rubbed off onto surgeon Hamilton, who described Teri'irere-Temari'i as "the proper king of Otaheitee, the present family of Otoo being usurpers" (p. 102). Hamilton also picked up from some source a report that Teri'irere-Temari'i was with the help of the mutineers planning to attack the Pomares, when Pandora arrived and so brought an end to the enterprise. Many high-ranking Paparans of that era probably did indeed consider the Pomares to be "usurpers" (as Paparans continued to do 
for several generations thereafter); and the proposed attack against Seaward Teva may indeed have included some hidden objectives designed to strengthen Teri'irere-Temari'i's cause vis-à-vis that of Pomare II. But these considerations do not require me to revise my earlier estimate of the Pomares' political position in early 1791 - that is, they were primi inter pares of Mo'orea and of Tahiti's larger peninsula, the only serious challenge to their paramountcy having come from Seaward Teva. 


\section{CHAPTER 29 RANK VERSUS POWER}

\section{AGGRANDIZEMENT BY KINSHIP}

The next few years were to see an increase in the Pomares' political potential, mainly through the forming of new ties of kinship and the wider deployment of old ones. (I italicize potential since some of the individual, interpersonal relationships in question remained to be tested in terms of actual intertribal alignments.) During this period several European vessels visited Tahiti. H.M.S. Discovery and H.M.S. Chatham (Captain George Vancouver commanding) anchored at Matavai from the end of December 1791 to January 24, 1792. Vancouver himself had accompanied Cook during the latter's second and third voyages, and had some familiarity with the local scene; he devoted many pages in his journal to Tahiti and his stay there. ${ }^{1}$

During February 1792, a small British whaler, the Matilda (Captain Weatherhead commanding), called briefly at Matavai for refreshments; then, after the vessel was wrecked on a Tuamotuan reef, Weatherhead and his crew managed to make it back to Tahiti, where they were plundered of their possessions but otherwise hospitably received. As far as I know none of the Matilda's company left a written account of their adventures on Tahiti.

During March 1792 two other small vessels, Prince William Henry and Jenny spent a few days at the island and took off some of Matilda's men others choosing to remain. Again, no records of the visit are known to have been preserved. ${ }^{2}$

The next vessels to call at Tahiti were Providence and Assistant, under the command of Bligh, whose mission it was to obtain a new load of breadfruit as replacement for the one lost with H.M.S. Bounty. This expedition remained at the island from April 7 to mid-July 1792 (figs. 29-1 through 29-5) and left with the remaining members of Matilda's company, except six who chose to remain. Bligh's account of this stay is rendered more useful due to the knowledge he had gained on previous visits, but he persisted in viewing the island's politics with a "king" Pomare bias. ${ }^{3}$

Finally, in February 1793, the British storeship Daedalus (Captain New commanding) paid a short visit; she took off one of the Matilda survivors upon departure, but left behind a crew member, "Peter the Swede," 


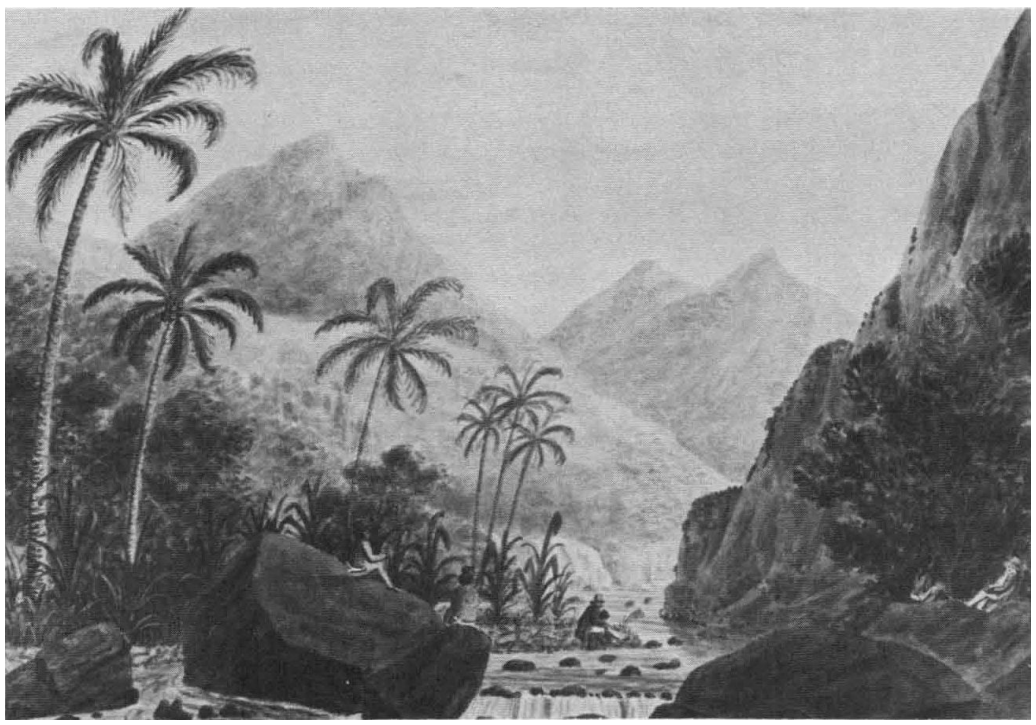

FIGURE 29-1. "On Matavai River, Island of Otahytey, 1792." Watercolor by G. Tobin. Mitchell Library, Sydney.

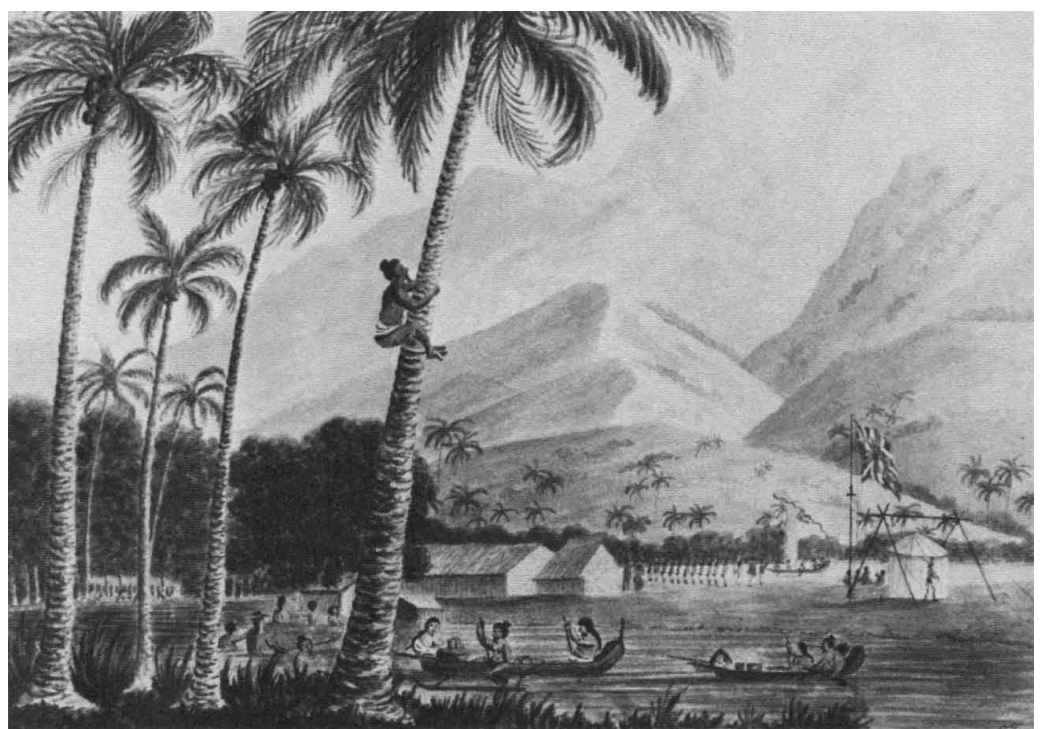

FIGURE 29-2. "The observatory ... Point Venus, Otahytey, 1792." Watercolor by G. Tobin. Mitchell Library, Sydney. 


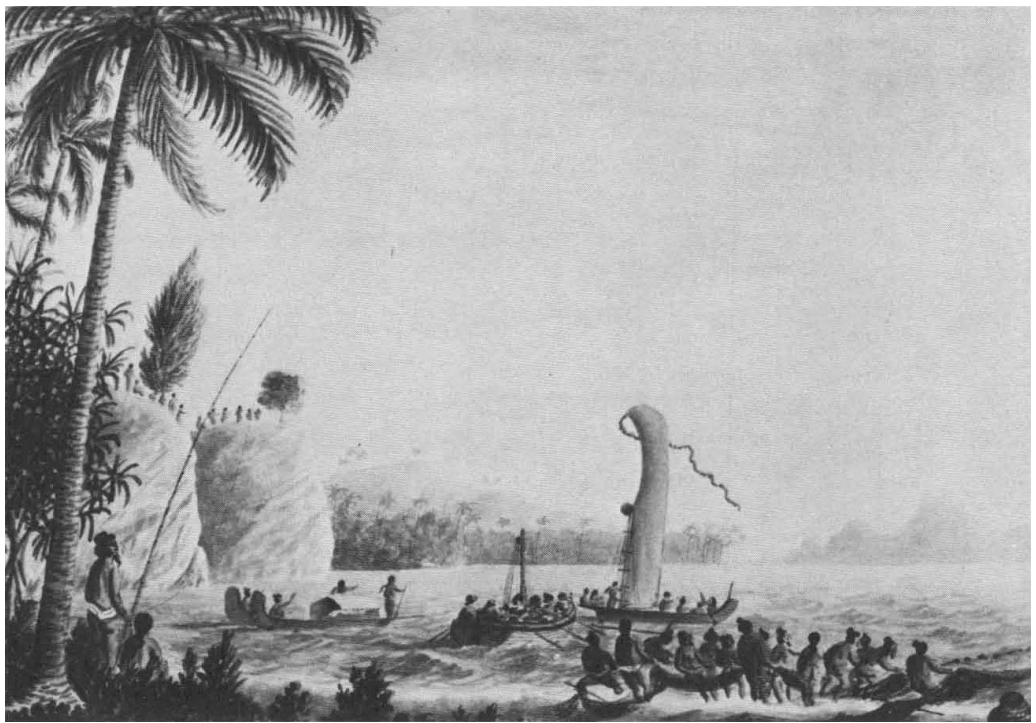

FiguRE 29-3. “Tanna Heads in Matavai bay ... Island of Otahytey, 1792.” Watercolor by G. Tobin. Mitchell Library, Sydney.

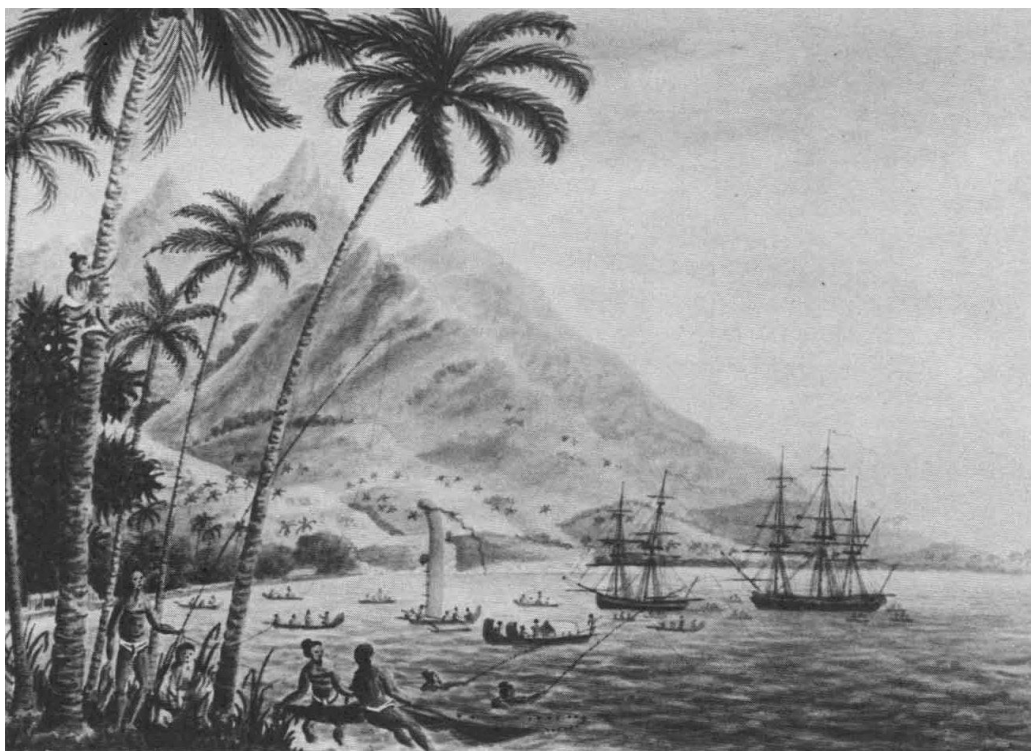

Figure 29-4. "Matavai Bay, Island of Otahytey ... Sunset, 1792." Admiral and Providence shown in background. Watercolor by G. Tobin. Mitchell Library, Sydney. 


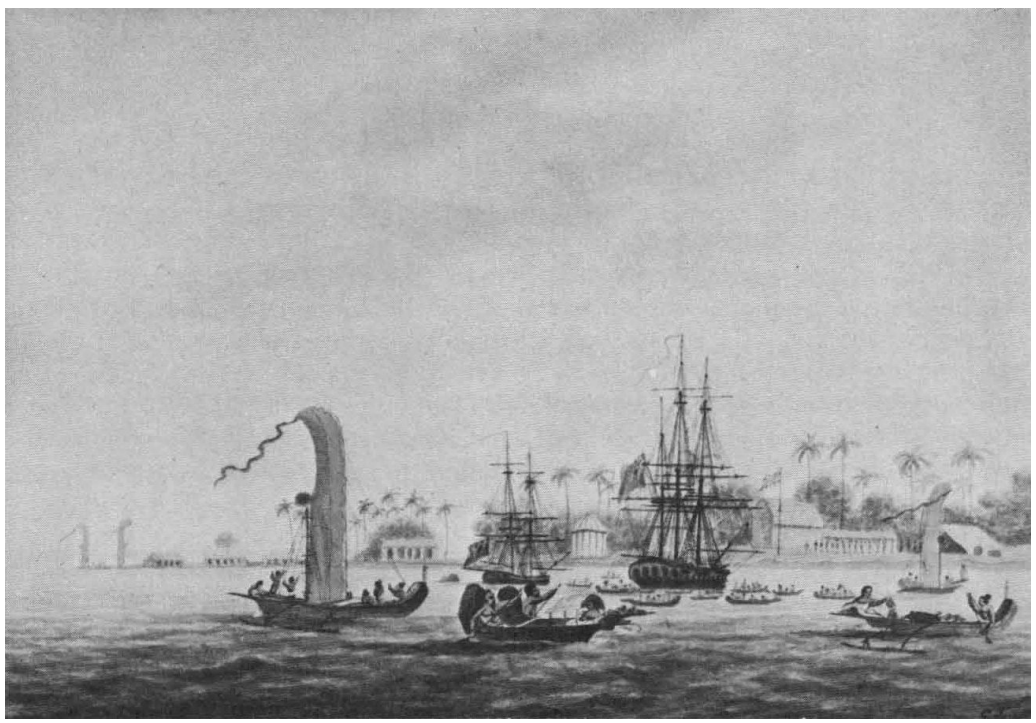

FIGURE 29-5. “Point Venus ... Island of Otahytey, 1792.” Watercolor by G. Tobin. Mitchell Library, Sydney.

who became a lifetime fixture of mixed influence on the island. No other European vessel was to arrive until March 1797, when the ship Duff put in with its company of hopeful but sadly misinformed missionaries - but that begins a new chapter in this era, and a new section of this history of it.

Up to the time of Bligh's departure, in July 1792, the most lasting instance of consolidation of the Pomares' influence outside Pare was their connections with Mo'orea. Although Pomare I had been disastrously dilatory about supporting Mahau against Mahine in terms of military action, the mutineers' arms and Hitihiti's leadership ultimately defeated Mahine's successor; $^{4}$ and Mahau remained attached to Pomare I by double affinal bonds. Moreover, Pomare I and his two wives, along with his father and mother, spent more time on Mo'orea than on Tahiti. Finally, the interests of the two familial domains - Parean and Mo'orean ${ }^{5}$ - became merged, literally, upon the death of Mahau, which occurred in January 1792 during Vancouver's visit. $^{6}$ Thereupon, the succession to tribal chieftainship passed to Mahau's four-year-old son, Tetuanui, whose mother was Pomare I's sister Auo. In addition, at about this time the young Pomare II became betrothed to Tetuanui's younger sister, who was thus his own first cousin Tarovahine. ${ }^{7}$

When the Pandora arrived in Tahiti on March 23, 1791 to capture the Bounty mutineers, she interrupted preparations for an attack against Seaward Teva designed to overcome that tribe's opposition to Pomare II. A few months later, in January 1792, Vancouver wrote the following about 
Pomare II's younger brother, Teri'itapunui (who was about four years old at the time): "The youth ... had taken the name of Whyeadooa [Vehiatua], in consequence of his being the acknowledged sovereign of Tiarabou, under his brother Otoo [Pomare II]" (1801:273). Elsewhere, Vancouver added:

At this time [i.e., the successful overthrow of the Mahine regime in Mo'orea] Whyeadooa the king of Tiarabou died, leaving only a very distant relation to assume his name and government; who was by Pomurrey and his adherents obliged to relinquish all pretensions to such honours, and with the people of Tiarabou to acknowledge Pomurrey's youngest son as their chief, under the supreme authority of his eldest son Otoo [Pomare II]; which on their assenting to, the youth assumed the name of Whyeadooa as a necessary appendage to the government....

Urripiah [Ari'ipaea], the next brother to Pomurrey, having acquired the reputation of a great warrior, has taken up his residence on the borders of Tiarabou, to watch the conduct of those people in their allegiance to his nephew Whyeadooa; and on the least appearance of disaffection or revolt, to be at hand for pursuing such measures as may be required to bring them back to their obedience. (pp. 324-325)

It should be noted that during Vancouver's visit the newest Vehiatua - the four-year-old Teri'itapunui - resided at Pare with his older brother, Pomare II, and their nurse-attendants.

Aside from his failure to mention Churchill's brief reign as successor to Vehiatua III, Vancouver's reference to the succession having gone to a "distant relation" agrees with Morrison's report. Bligh, writing on May 8, 1792, added some corroborative details, but neither his nor any other account that I know of describes how Pomare I's supporters persuaded the Taiarapuans to acknowledge young Pomare II's legitimacy, and hence his fairly weighty claims upon the office:

In my last Voyage I have given a particular account of the Principal Families of this Island ... From a connection in the female line, the present Otows Grandmother being Sister to the then King of Tiarraboo, his grand child is now become Erree of that place, the Heirs of Whaeeahtuah in the male line being extinct. The late Whaeeahtuah whose Wife Tynah is now connected with, died without any Children, and on his death (since my last Voyage) Terreetapanooai Tynahs second Son was sent to Tiarraboo to be elected, or more properly, acknowledged Erree of that part of the Island.

The Tiarraboo People always insisted that Whaeeahtuah was Errerahigh of that Country, \& Otoo Ereerahigh of the Western part of the Island, but all the Otoo family \& connections, say there is only one Erreerahigh - their power however has not marked any superiority over the Tiarraboo People since our time, and the present Terreetapanooai, has taken the Name of Whaeeahtuah. - We may date the birth of this Boy in the Year 1787 and his being acknowledged as Erree in 1790. (1792:144)

With reference to Bligh's assertion that the Taiarapuans had acknowledged Teri'itapunui to be their ari'i in 1790, it will be recalled that the principal people of the district had indeed "received" Pomare II's vane during January 
1791, when it made its circuit of the island, but that they had subsequently failed to "assist" at the investiture ceremony that followed, thereby providing the Pomares' supporters with a cause (or at least a pretext) for preparing an attack upon them.

Summarizing this phase of the Pomare expansion one can say, then, that sometime between March and December 1791, some of the leaders of Seaward Teva were persuaded to recognize the Pare family's claims to the Vehiatua kin-Title and its tribal perquisites. That this recognition was not universal, or wholehearted, is indicated by the circumstance that a constant watch had to be maintained, by Ari'ipaea, against too disruptive dissent.

Another direction in which the Pomare family appears to have extended its influence, and perhaps even coercive authority, was the large northern district of Ha'apaino'o. Like other tribal districts of northeastern Tahiti, Ha'apaino'o seems to have been linked with Pare-Arue by ties of alliance over a long period of time. But a passage in Vancouver indicates that something more solid than alliance now joined the two tribes; Vancouver referred to Ha'apaino'o as "... one of the districts belonging to Whytooa [Vaetua]" (1801:305), who was Pomare I's second brother - after Ari'ipaea, and before Te Pau. This attribution was later confirmed, in connection with Pomare I's efforts to recover the goods taken from the Matilda crew. No clue, however, is provided as to how Vaetua came to occupy the office of chief of this tribe - a largely absentee official, it should be noted, since Vaetua appears to have resided mostly in Pare, where he was charged with safeguarding the interests of his young nephew, Pomare II - Pomare I meanwhile having retired to Mo'orea.

But the Pomare pretensions did not stop at the boundaries of Tahiti and Mo'orea. While Vancouver was at Matavai, he was informed that young Pomare II was "supreme sovereign" of Huahine, and that he would eventually succeed to such offices in Ra'iatea and Taha'a as well. These pretensions involved two men who were at Pare at the time, the one visiting and the other evidently there to stay; the former was called by Vancouver "Matuarro," the latter "Mowree."

The appearance in the sources of another Matuaro (i.e., Vancouver's "Matuarro") constitutes one of those situations capable of reducing the ethnohistorian to utter despair. Vancouver distinguished between "Matooara Mahow," the Mo'orean chief whose funeral he witnessed, and "Matuarro," whom he described as ari'i rahi of Huahine:

In consequence of Pomurrey's [Pomare I] connexion with Mahow's family [i.e., Pomare I's wife 'Itia having been sister of this Mahau], his son Otoo [Pomare II] in right of his mother [i.e., 'Itia] was acknowledged as the supreme sovereign of Huaheine; and Matuarro the king of that island, had consented to the superiority of Otoo [Pomare II] over him, as 'Aree Maro Eoora' [ari'i maro ura]; but that he Matuarro was 'Aree de Hoi' [ar'i rahi]. (1801:326) 
I take this passage to mean that Pomare II was acknowledged in some quarters (notably by Huahine's tribal chief, Matuaro) as "supreme sovereign" of Huahine, but I am uncertain as to what Vancouver meant by the rest of the sentence, or what he meant by "sovereign." If Vancouver intended to convey that Pomare II's alleged "sovereignty" over Huahine came to him through his mother's connections there, then I must confess that I can find no specific genealogical evidence for such a connection. If on the other hand the writer was referring to Pomare I's mother (and Pomare II's grandmother), Tetupaia, then some such connection can of course be traced - for example, Tetupaia was second cousin to Mato, a former chief of Huahine; but even so I fail to see why this would have qualified Pomare II for "supreme sovereignty" over Huahine. Indeed, I suspect that this was another example of a European's confusion between rank-status and tribal chieftainship, and of the Pomares' efforts to trade on such confusion - or even to convert the former into the latter. As for the visiting Matuaro, described by Vancouver as an Arioi, and ari'i rahi of Huahine (p. 258), I suppose that his alleged acknowledgment of Pomare II's "supremacy" referred mainly if not solely to the latter's rank-status as a twice-over maro-ura-wearing kin-Titleholder. ${ }^{8}$

Vancouver's "Mowree" [Mauri] was probably none other than Ha'amanemane, whom we have met with before. About him Vancouver wrote:

Excepting the daughter of Opoone [Puni], who reigned over Bolabola, and its two neighbouring isles, we had now the presence of all the sovereigns of this group of islands. Opoone had formerly conquered and annexed the islands of Ulietea and Otaha to the government of Bolabola; but, on his death, the sovereignty of these islands had, in right of natural, or original succession, fallen to a chief whose name was Mowree. He was a shrewd sensible fellow, affected to be well acquainted with the English language, and certainly had acquired some words which be pronounced so as to be understood. He was a brother of Pomurrey's mother, was on a visit to the royal family here, and was by them treated with much respect and attention. (1801:278)

In Henry's reproduction of Mare's genealogy of the Pomares' Ra'iatean antecedents (1928:247ff.), the offspring of Tamatoa III are listed as follows:

by his first wife, Mai-he'a

1. Te-tu-paia (f), who married Teu and mothered Pomare I

2. Teri'i-na-vaho-roa $(\mathrm{m})$

3. Teri'i-tari'a (m)

4. Hapai-taha'a (f)

by his second wife, Te-hani

1. Te-moe-ha'a (m) 
2. Ara-po (m)

3. Te-ha'ame‘ame‘a (f)

4. Vetea-ra'i Uuru (m)

Elsewhere in the sources both Terano (wife of Te Pau "B") and Te Pau (wife of Hitihiti), have also been identified as siblings of Tetupaia; whether these are the same as or additional to either of the above females, I cannot say, and I am in a similar quandary respecting Mauri-Ha'amanemane. My guess is that the latter was the Teri'i na Vaho Roa in the Mare genealogy, as he is described by Vancouver as having succeeded to his office by right of "natural or original succession," and as Teri'i na Vaho Roa was the eldest of Tamatoa III's sons.

Otoo, in right of his grandmother by his father's side, on the death of Mowree will claim the sovereignty of Ulietea and Otaha. Mowree, who is brother to Pomurrey's mother, is an Ereeoe of an advanced age. He seemed extremely fond of Otoo, and proud of his succeeding him in the government of those islands; saying, that, at present, there were two sovereigns, that "Maw ta Tarta," but when he should die then there would be but one, meaning Otoo. This expression, in its literal signification, means "to eat the Man;" the idea, however, which in this sense it is intended to convey, is to point out those, whose rank and authority entitle them to preside at human sacrifices; a power which at present is possessed only by Mowree and Otoo. (Vancouver 1801:327)

Evidently, having been "an Ereeoe of an advanced age," Ha'amanemane had had no offspring of his own, so was in a position to foster or otherwise designate someone to succeed him in his office; in this instance that person appears to have been Pomare II. As for the nature of that office, Vancouver went on to say that “... it does not appear that even Mowree himself has much influence in those islands [Ra'iatea and Taha'a], notwithstanding that he is their acknowledged sovereign" (p. 328). In other words, Ha'amanemane's preeminence, which he shared with Pomare II, consisted mainly of "presiding at human sacrifices," - a function associated with the holding of an 'Oro-sanctioned, feather-girdled kin-Title, and being only indirectly related to tribal authority.

As I recorded earlier Ha'amanemane had arrived in Tahiti in 1788, during the Bounty's stay at Matavai, and Bligh remarked upon his social eminence, calling him Tutaha, which name he evidently went by at the time. By 1792 Tutaha (Ha'amanemane, Mauri) had made an important place for himself in Pare:

Tomorrow Morning I am to have a sight of it [the tabernacle of an 'Oro image], and to hear prayers performed by Tootaha the Priest - This Man is a great Orator among them, and highly respected for his abilities, as well as being a Chief of consequence - he has always been the Prime Minister of Tynah [Pomare I], is their Oracle, and Historian of this Country, and possesses a great fund of hu- 
mour - he is now called Hammenemanné, but was spoken of in my last Voyage by the Name of Tootaha - He is remarkable for speaking English, and could he write is capable of forming a vocabulary of near a thousand English Words. (Bligh 1792:135)

Ha'amanemane was also a distinguished Arioi, but his relevance to our present concern has to do with his alleged introduction of yet another set of insignia of 'Oro-sanctioned rank. According to Mare, Ha'amanemane brought with him to Tahiti the following: the maro ura named Teraipu Tata, the sunbonnet (taumata) named Te Ata o Tu, the fan (tairu) named Hotu, and some priests of 'Oro (Newbury 1967a:14). Later, in the proceedings that were conducted by French officials with the evident hope of establishing Pomare, and hence French, claims to the Leeward Islands, witnesses implied that Ha'amanemane bequeathed these items (which constituted his Ra'iatean inheritance) to the young Pomare II, who was probably his grandnephew and whom he also "adopted."

I do not know what to make of this statement. For example, was this maro ura in addition to the one already introduced by Tetupaia decades earlier and, if so, what ritual use was made of it thereafter? And, if Ha'amanemane did in fact introduce another 'Oro tabernacle (and 'Oro image), what was its relation to the Papara image removed to Tarahoi after the mutineers' war against Atehuru, in September 1790?

In any case, even though I cannot confirm from eyewitness accounts the introduction of these ritually important items, Ha'amanemane himself was indisputably there at the time, and through him the Pomares' social ambitions toward the Leeward Islands were undoubtedly nourished. In fact, through their combination of preeminent rank-status, other distinguished kinship connections, death of rivals, mutineer-achieved military successes, and English advocacy, the Pomares' political ambitions reached what in Maohi thinking was probably an entirely new scale, as witnessed in the following passage from Vancouver:

In consequence of the extensive dominion that has devolved upon this young monarch, he is not now distinguished by the title of Aree de Hoi, but by one which is considerably more eminent and comprehensive; since they say there may be many Arees de Hoi, but there can be but one Aree Maro Eoora; which means the chief of the red feathered Maro; and under which title, Otoo's authority is acknowledged in Otaheite, Morea, Mattea, Tetero, Tupea-mannoo, and Huaheine. But the people of Ulietea and Otaha, seem much averse to this submission; and it does not appear, that even Mowree himself has much influence in those islands, notwithstanding that he is their acknowledged sovereign. Since the death of Opoony, the government of the islands under his late authority appears to have been ill administered; the inhabitants having been very turbulent and much disposed to anarchy: and in consequence of the disinclination which the people of these islands have manifestd to subscribe to the supreme authority of Otoo, an expedition was in contemplation from Otaheite, to enforce the power of the Aree Maro Eoora over them, and little doubt was entertained of its success. Another favorite object was the annexing to Otoo's 
present dominions by conquest, (for no right was set up) the islands of Bolabola, Mowrooa, and Tapi, which, since the death of Opoony, had been governed by his daughter, and were said, in a great measure, to have lost their former high reputation as a martial and warlike nation.

Pomurrey and his brothers having procured from the vessels which had lately visited Otaheite, several muskets and pistols, they considered themselves invincible; and the acquiring of new possessions for Otoo, now seemed to occupy the whole of their study and attention. They were extremely solicitous that I should contribute to their success by augmenting their number of firearms, and adding to their stock of ammunition. Of the latter I gave Pomurrey a small quantity; but of the former I had none to dispose of, even if I had seen no impropriety in complying with his request. Finding there was no prospect of increasing their armory, they requested that I would have the goodness to conquer the territories on which they meditated a descent, and having so done, to deliver them up to Otoo; and as an excuse for their subjugation, insisted that it was highly essential to the comfort and happiness of the people at large, that over the whole group of these islands there should be only one sovereign. On satisfying them that the islands in question were quite out of my route, and that I had no leisure for such an enterprize, Pomurrey, in the most earnest manner requested, that on my return to England I would, in his name, solicit his Majesty to order a ship with proper force to be immediately sent out, with directions, that if all those islands were not subjected to his power before her arrival, she was to conquer them for Otoo; who, he observed, I well knew would ever be a steady friend to King George and the English. This request was frequently repeated, and he did not fail to urge it in the most pressing manner at our parting. (1801:327-330)

An opportunity to learn how the facts of everyday political life corresponded to those grandiose political pretensions is presented by the Matilda incident.

\section{THE Matilda INCIDENT}

In February 1792, the crew of the English whaler Matilda made it back to Tahiti after their ship was wrecked in the Tuamotus. The captain and part of the ship's company left Tahiti in March aboard the Jenny and Prince William Henry, but the rest of the survivors were still on the island when Bligh arrived on April 7. Bligh described the incident:

[After their wreck] They proceeded fortunately [in their boat] to Maitea [Me'etia], \& after a Nights rest and kind treatment, they Sailed for Otaheite on the 5 March. - On the next Night, by bad Weather, the Boats were separated, two arrived at Matavai, one at Oaitepeah, and the other round by Attahooroo. The People of Oaitepeah were too hostile to induce the Boat to remain with them, she therefore proceeded to Matavai and joined the Party that had got there before them. - Afterwards, in the course of eight Days, the Men who had landed at Attahooroo also came to join their Companions. - It however appeared so much the opinion of the Captain that they should not all remain at one place, that some resided at Matavai, some at Oparré, and some at Attahooroo. - They were all dispossessed of their Cloaths \& Articles they had with them; but the greatest prize fell in the hands of the Matavai People, under the command of Poeeno the Chief, and one Tabyroo a Person of some power. - The circumstances no sooner became 
known than Otoo demanded the Articles taken at Matavai, consisting of Money \& Arms, in behalf (as he asserts) of his Friends the English; but no restitution was made. - some deliberation immediately took place, result of which was, that on the 19th March, War was proclaimed, and the Oparré People came to Matavai destroying Houses, \& all the provision kind they could lay their Hands on. - The Matavians made very considerable resistance; still retain their Booty, and at this instant the Parties are violently at War with each other.

Notwithstanding our Countrymen were robbed of their Cloaths, they were treated afterwards with much kindness \& attention, it would however have been better, if the whole had gone to Oparré under the protection of Otoo, and as there were three, at this time absent with the Matavians; the first step I took was to order them to join their Ship Mates.

The War was interrupted by the arrival of a Schooner called the Jenny from Bristol burthen 90 Tons. - This Vessel remained here untill the 31st March, when she Sailed for the NW Coast of America and by this opportunity Capt. Weatherhead with Two Boys and One Man, had the means of returning home. - He had one passenger more than he expected, a Seaman secretted himself on board \& sailed with them as it is supposed, for he has not been heard of since.

While the Jenny remained here the Second Mate, - Campbell undertook to go away in one of the Whale Boats for Port Jackson. - It was fitted up in a miserable manner with Mat Sails, and himself with two Men, Phillip Christall \& Jn. Basster sailed the same day.

The Number of Men now remaining on the Island are 21 including the Convict who has absented himself. - Among them is the Chief Mate, Surgeon, Boatswain $\&$ Carpenter. - The whole of them I directed to stay at Oparré where they are well taken care of. (1792: 125-125b)

The next episode in this war between Matavai and the Pomares' supporters from Pare took place on April 11:

In our return to the Ship I saw a miltitude of Men on the low land of Matavai all Armed, preparing for an Attack on the Matavians who they had already driven from the Spot, and burnt all their Houses. The Afternoon produced the result of their determination. - The Oparré people drove the others to the Mountains, killed one Man, \& returned victorious. - I have been sollicited very much to join Otoo's Army, but I only promised to interfere should the Matavians attempt to go near Oparre, in which case I assured them I would land a Party of Men \& drive them back, which gave great pleasure to our Oparré Friends. - I also sent the Surgeon of the Matilda to Poeeno and Tabyroo, to order them to return the Captains effects, if they ever wished to be on good terms with us, \& he brought me back Word from them, that everything would be returned. - The Surgeon informed me that he was conducted through an immense number of Men armed with Spears, Clubs \& Slings, who appeared extremely anxious to know the Message he had brought, \& if I intended to act against them. - They behaved with much decorum and some attention to the Chief who went with him; for the front of each army was so near to each other as to use their Slings, - hostilities ceased during the parley. - There Men when heaped together in such numbers armed with Spears 12 or 14 feet long or more, have a tremenduous appearance, they nevertheless do very little mischief to each other, for I believe they seldom come to a serious charge, but content themselves with the execution they are able to effect by Slinging Stones, by which means some Men are Maimed and sometimes killed. (pp. 126b-127) 
In due course the Matavaians were driven into the mountains, and Bligh sent emissaries to their leaders:

At day dawn I sent away Mr. Norris Surgeon of the Matilda with a Message from me to Poeeno \& Tabyroo for Mr. Weatherheads Money, \& some other articles that were in their possession, particularly the Musquets. - After a troublesome Walk of Six Miles he found Poeeno \& Tabyroo at Wapyhanoo. - They received him in a very friendly manner and promised that the Money should be returned as soon as it could be got from Teturoah where they had sent it for security. - They refused to give up the Musquets, unless by mutual consent all those that were on the Island were to be given to me; - in that case they had no objection to comply; but in their present situation they could not think of it, as it was necessary for them to preserve some Means to regain their property, or to establish themselves in another situation. - They would do any thing to serve me, and hoped I would not be angry with them - it was the Mob, they said, had taken away the peoples Cloaths, and hauled the Boats on Shore - they endeavoured to restrain them, but could not. - If I came after them, they said, all that could be done, was for them to fly farther. - They called Matavai my Country, and described that the People of Oparré had destroyed all their Houses, Barked their Trees, destroyed what I had left among them, and done the Country irrepareble injury. (p. 128b)

Soon thereafter Pomare I returned to Pare from Mo'orea, where he was then residing, and attempted to persuade Bligh to intervene more actively against the Matavaians and others:

Poeeno \& the Matavai People seem to be objects of great dislike to Tynah and his Father, they requested I would undertake the War with them to destroy those People, as well as the Inhabitants of Paparrah \& Oaitepeeah, who had a number of musquets. - they knew it was an object worth their most strenuous endeavours to persuade me to, but they had the good sense not to be seriously offended at my refusal, when I told them it would interfere with the busyness I was sent on. - I however still threatened the adverse Party unless they brought in the Arms \& Money, (pp. 129b-130)

So much for the Pomares' "supreme sovereignty" over Papara and Taiarapu - not to speak of nearby Matavai!

On April 26 Bligh was able to report an end to hostilities, temporarily, at least:

Peace is established - Poeeno and Tynah have had a meeting, and it is agreed that Poeeno shall live again at Matavai. - They have promised to return C. Weatherhead's Money, but I am in doubt about their sincerity - I however dare not involve myself in any trouble with these People to get either one part of his property or the other, altho I will do my utmost to regain it by every fair Means I am capable of. (1792:136)

On May 4, however, the "peace" was disrupted again:

An account was brought me to day, that Poeeno and all his adherents had left Matavai and fled to Itteeah, the cause of this was owing to an attempt of Wydooah (the younger Bror. of Tynah) to seize on the Musquets, which Tabyroo had the charge of, and kept at a distance from Matavai. (p. 141b) 
Meanwhile, Tapiru and Poeno implemented the return of all the money they and their people still held, but refused to give up the arms - this, in view of their knowledge of the Pomares, one can put down to their realistic desire for self-survival. Further insight is derived from a passage of Bligh's regarding relations between Pare and Papara:

Oreepyah, with his Nephew Otoo, (the King) \& Hammennémanné came to take their leave of me on their going to Paparrah to see their Relation Tomaree the Chief of that place, who lies very Ill and is expected to die; But their principal object is to see what can be done, to take away some Musquets which the People of that District are in possession of from the Seamen of the Matilda's Boat who put in there. Nothing can equal the rage these people have after Arms - there is nothing they would not sacrifice to procure them, but the Parties who have them in possession I believe are too wise to part with them. Could the Otoo Family get Arms I have no doubt but they would govern the whole Country, - a Right which they say is inherent in themselves.

Before they sat out on their expedition it was necessary to consult me. - Tynah therefore came with the party to give his interest for them to be so equipped with presents of different kinds, as would insure them a welcome reception.

I indulged him in the most he asked for, and they left us with light hearts, dressed in European Clothes, and a large quantity of Iron Work and Trinkets in their bundles. (p. 145b)

Another event connected with the Pare-Matavai war occurred on June 19:

I was sorry to hear again of a human Sacrifice. - Iddeeah informed me that the Chiefs of Waennah (called Ohaaine in C. Cooks Map) had sent one to Otoo I found it wrapt up in a platted Cocoa Nutt branch and Slung to a Pole as usual - it stunk very much, and on that account was hung up among the Bushes a part form any dwelling. - The late disturbance and War between Matavai and Oparré People was the cause of this Sacrifice - the People of Waennah took part with Matavai, and the offence was not to be forgiven but by this melancholy claim. The absence of Otoo prevents any thing being done untill his return, when the Eye will be presented, and the Etuah supplicated to continue the friendship between the two Districts. (Bligh 1792:162)

Bligh sailed on July 18, with Tapiru and Poeno still beyond reach of the Pare forces and with the Matilda loot still unreturned. How the affair was finally settled - if it ever was - we shall never learn.

\section{Other Changes in MAOHI LifE}

My emphasis in the foregoing chapters of this volume has been on political developments; let us now look at some parallel (and in part interdependent) developments which occurred in other domains of Maohi life. I begin with a trivial but highly indicative example, that of personal attire:

The quantity of Old Cloaths that has been left among these People is considerable. Any article of Dress they set the highest Value on. - they wear such rags and dirty things as are truly disgusting, and deform themselves in a very great 
degree. - It is a rare thing to see a person dressed with a neat piece of Cloath, which formerly they had in abundance and wore with much ellegance. - Their general habiliments are now a dirty Shirt, and Old Coat, Jacket or an Old Waiscoat, so that they are no longer the clean Otaheiteans, but in appearance a set of Raggamuffins with whom it is necessary to have great caution in any intercourse with them. (Bligh 1792:134b)

According to Bligh and Vancouver these substitutions had extended to their basic tools and manufacturing processes:

So important are the various European implements, and other commodities, now become to the happiness and comfort of these islanders, that I cannot avoid reflecting with Captain Cook on the very deplorable condition to which these good people on a certainty must be reduced, should their communication with Europeans be ever at an end. The knowledge they have now acquired of the superiority and the supply with which they have been furnished of the more useful implements, have rendered these, and other European commodities, not only essentially necessary to their common comforts, but have made them regardless of their former tools and manufactures, which are now growing fast out of use, and, I may add, equally out of remembrance. Of this we had convincing proof in the few of their bone, or stone tools, or untensils, that were seen amongst them; those offered for sale were of rude workmanship, and of an inferior kind, solely intended for our market, to be purchased by way of curiosity. I am likewise well convinced, that, by a very small addition to their present stock of European cloth, the culture of their cloth plant, which now seems much neglected, will be intirely disregarded, and they will rely upon the precarious supply which may be obtained from accidental visitors, for this and many others of the most important requisites of social life.

Under these painful considerations, it manifestly appears that Europeans are bound by all the laws of humanity, regularly to furnish those wants which they alone have created; and to afford the inhabitants from time to time supplies of such important useful articles as have been already introduced, and which having excluded their own native manufactures, are, in most respects, become indispensably necessary to their whole œconomy of life: in return for which a valuable consideration would be received in provisions and refreshments, highly beneficial to the traders who may vist the Pacific Ocean.

The various manufactures in iron and in cloth have become so essentially requisite to their common concerns, that instead of these commodities being reduced in their value by the frequent visits of Europeans, or their supplies of food and refreshments being less plentiful in return, we were served with every article in the greatest profusion. Six hogsheads of very fine pork were cured; and had we been better provided with salt, we might have secured ten times that quantity; and sailed with a large supply for present use, which comprehended as many live hogs and vegetables, as we could find room to dispose of; the whole procured at least 200 per cent. cheaper than on any of Captain Cook's visits, notwithstanding the recent departure of the Pandora. (Vancouver 1801:332-334) ${ }^{10}$

I have forgot if I have taken notice of the loss of originality in the use, Among these People in a great measure, of their implements. It is now a rare thing to see them use any other than Iron Tools. In their natural State they used a peice of Bamboo for a Knife, a hard black Stone brought to a blunt edge for an hatchet, and a Splintered peice of the same for a Drill, and their teeth were always sufficient to clear a Cocoa Nutt of its Rind to give them food and drink. 
But now they will do nothing without a Knife and a Hatchet. It is however very extraordinary altho they see the valuable Use of a Saw that they do not take to the use of them. They prize Needles and Scissars and even Pins they make Hooks of to take small Fish. (Bligh 1789:II, 63-64)

Vancouver, a perceptive visitor, also noted a radical change in military tactics:

Great alteration has taken place in the military operations of these people. On our first discovery of these islands their wars were principally of a maritime nature; but at present it should seem they were conducted in a very different manner. For although some of our gentlemen extended their excursions to a considerable distance, not a single war canoe was seen belonging to Otaheite. I had much conversation with Urripiah on this subject; from whom I learned, that in their late contests they had found them so unmanageable, particularly when the wind blew at all strong, that they had intirely given them up, and now carried on their enterprizes by land, using the larger sort of their common canoes, when their wars were offensive, to convey them to the place of their destination, which was generally effected under cover of the night, or in dark rainy weather. (1801:334-335)

In this connection the radically new tactics that the mutineers introduced, and by which they were able to dislodge the Atehurans from their mountain fortress should be recalled. As for firearms, the consequences of their introduction should by now be crystal clear, as seen, for example, by the military advantage they bestowed upon their fortunate owners, and by the extremes to which individuals would resort in order to obtain them. With his usual attention to detail, Bligh endeavored to compile a list of all the firearms known to be on the island at the time:

From the most authentick account I can get, I find the Otaheiteans have got from different Ships, Musquets \&c as follows. -

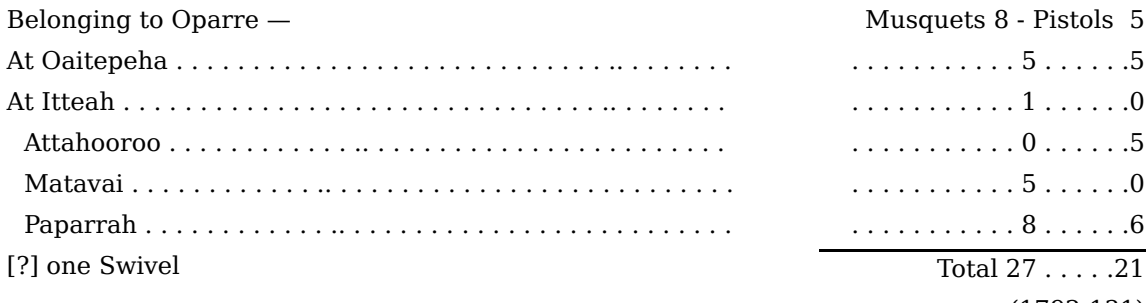

(1792:131)

Central, of course, was the change in the number of people involved in the political developments under study. As I indicated in chapter 2 the only eyewitness estimate we have relevant to the time span just considered is Morrison's guess, made between 1789 and 1791, of 30,000 (1935:171), which according to my own "calculations" (if so pretentious a label may be given to my method of inference) would represent a diminution of the island's population by about 5,000 from its size in 1767. If credence may be given to Maohi opinion expressed to Bligh, an even greater decline took 
place as the result of an epidemic introduced, presumably, by Vancouver's expedition in 1791-1792. We cannot identify the disease this visitation is believed to have introduced, but the extent of its fatal consequences evidently left a deep impression even upon these inured people. ${ }^{11}$

Before commencing with the next chronicled chapter in the Pomares' political career, I reproduce a passage from Vancouver characterizing some changes remarked by him in the personality of our principal character:

I cannot take leave of my friend, for to such an epithet from me Pomurrey's conduct justly entitles him, without adverting to the alteration which seemed to have taken place in his character, since my former visits to this country. At that time, he was not only considered as a timid, but a very weak prince; on this occasion, however, he did not appear deficient either in discernment, or intrepidity; although it must be acknowledged his fears were exceedingly awakened at the display of our fire-works, and that he always appeared to regard fire-arms with a considerable degree of terror; which possibly might arise from his knowledge of their destructive powers, whilst at the same time he remained ignorant of the extent to which they were capable of doing execution; but this description of weapons out of the question, we had reason to believe his courage was equal to that of his neighbours, of which he certainly gave an undeniable proof by joining our party alone and unarmed at the encampment; in direct opposition to the counsel and apprehensions of his surrounding countrymen. On former occasions, I had also considered his general character to be haughty, austere, and combined with much low cunning. When he condescended to speak, or converse, which was not frequent, little or no information could be derived; whilst the questions he asked in return, did not tend to the acquisition of useful knolwedge. His conduct and deportment on the present occasion, were extremely different; and, when compared with that of his associates, were marked with an evident superiority, expressive of the exalted situation he filled; and indicated that he possessed a just knowledge of himself, and an open generous, and feeling heart. In conversation, there were few from whom better information could be acquired; nor was he now deficient in directing his observations and enquiries to useful and important objects. For this purpose only, he would remain whole days in our working tents, observing with the strictest attention the different transactions going forward; and frequently interrupting the mechanics, to require explanations of their several operations. The whole tenor of his behaviour towards us was so uniformly correct and meritorious, that, on his taking leave, I could not resist making him, and his wives, such acknowledgments in useful articles, as he conceived they could have no possible claim to; and suspecting I was about to make some addition, he caught my arm, expressed how highly repaid and gratified they were with what they had received, and observed, as I was going to visit many other countries where such things would be equally valuable; I ought to be careful and œconomical. (1801:330-332) 


\section{CHAPTER 30 THE MISSIONARIES ARRIVE}

\section{The Political Situation IN 1797}

On March 4, 1797 the British ship Duff (Captain James Wilson commanding) arrived at Tahiti intent on landing eighteen Englishmen and the wives of five of them, for the purpose of establishing a Protestant mission. (In addition, the Duff carried eleven other missionaries to establish missions in the Marquesas and Tonga islands.) As one can imagine, this event marked a new and wholly different kind of relationship between Maohis and Europeans. These "visitors" were there to stay, and they cherished the hope of revolutionizing almost every aspect of Maohi life. (Figs. 30-1, 30-2.) In fact, so different was this new breed of visitors from their predecessors, and in so many respects, that - as their chroniclers put it - the Tahitians “... profess hardly to know what we are, and suspect we are not Englishmen, or like any others they have seen who have ever visited their island" (Wilson 1799:156). In the course of time the Maohis came to discover that some of this new breed did not differ from other, less Calvinistic Europeans in their reactions to nubile and half-naked young women; but the majority of the missionaries abided by their moral code. Cook and some other earlier visitors had declined personal invitations to sample the charms of Tahitian women, but no previous set of visitors had prescribed this and other tenets of Calvinism as official policy. ${ }^{1}$

The full story of the English missionary enterprise on Tahiti deserves a separate volume, which would look beyond the tragi-comedy of this preposterous confrontation and provide a deep and comprehensive analysis of its effects upon Maohi life. But I leave this task to others, and limit myself to indicating, as explicitly as possible, how the missionary presence influenced political developments. ${ }^{2}$ Needless to say, years passed before the missionaries began to comprehend those developments; as time went by they acquired, by bitter experience, a much deeper knowledge of Maohi political structure than Cook or Bligh ever achieved, but this did not lead them

Note: In this chapter, unless otherwise indicated, page number only refers to Wilson 1799 and volume and page number refer to the LMS Transactions. 


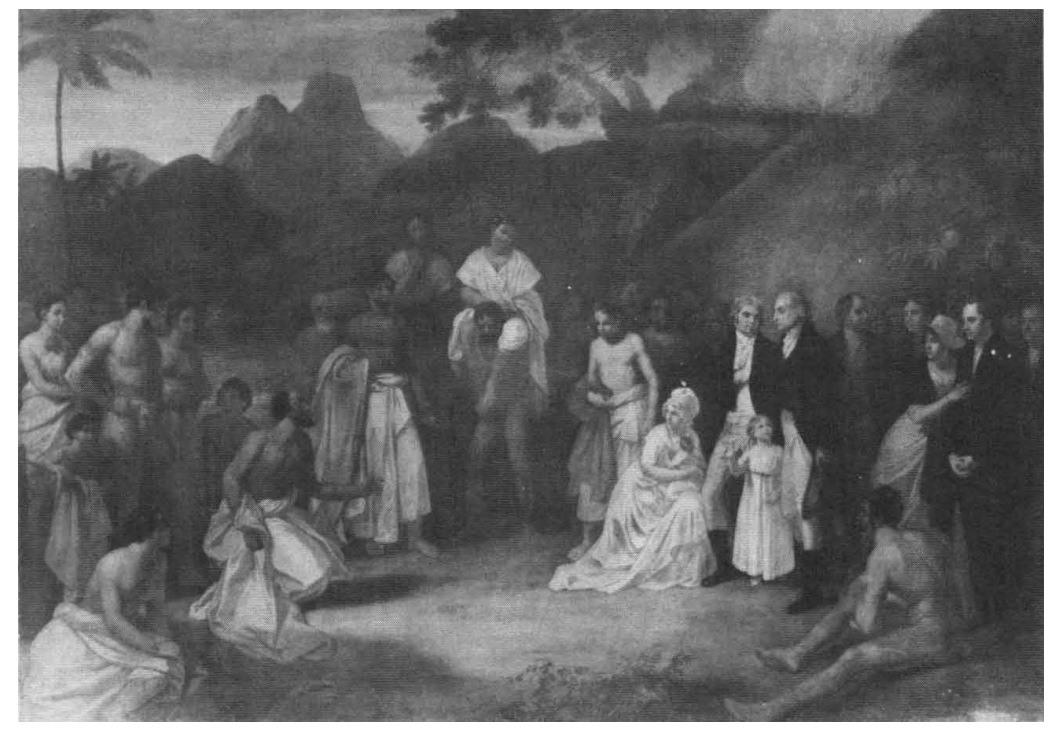

FiguRe 30-1. "The Cession of the District of Matavai to the Missionaries, 16 March 1797." Painting by R.A. Smirke. London Missionary Society.

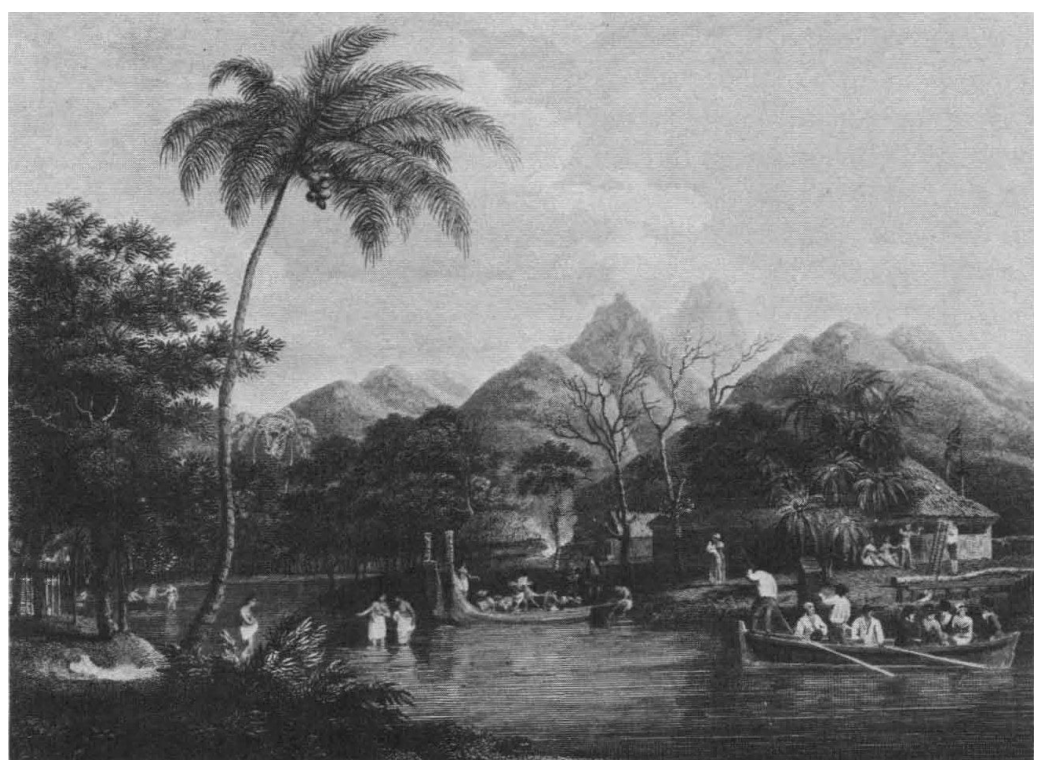

FIGURE 30-2. "Missionary House and Environs in the Island of Otaheite." Sketch by W. Wilson. In J. Wilson 1799. 
to revise their belief in the desirablity, the ultimate rightness, of a monarchical form of government.

Perhaps the most useful way to open this new chapter in Maohi political history is by summarizing the changes that had taken place since Bligh's last visit in the situations of the island's principal personages.

In 1797 the arrival of the Duff found Pomare I, now in his mid-forties, living with Pepiri, "a very stout young woman," the daughter of a Papeuriri subchief. His second connubial partner, Vaiariti, was no longer with him, having "left him through dislike[,] for one of far inferior rank." (p. 73.) Meanwhile, 'Itia had long since ceased to share Pomare I's sleeping mat, and was living openly with one of her lower-class paramours. And while she had her own domestic establishments and was in fact a chiefly person in her own right, she continued to ally herself faithfully and energetically with Pomare I against his many ill-wishers.

Pomare I's next younger brother, Ari'ipaea, died a year or so prior to arrival of the Duff; his widow, Vahine Metua, was described as "chief over all Hedeah [Hitia'a]" (p. 190), and she also held sway over a small subdistrict of Ha'apaino'o, called "Whyripoo," said to have been presented to her by Vaetua, her late husband's brother (p. 185).

Vaetua himself continued in active authority over Ha'apaino'o, and resided mainly there. As for Pomare I's youngest brother, Te Pau "C", earlier described as having succeeded to the chieftainship of Fa'a'a, I find no mention of him under any identifiable name in missionary accounts.

Pomare I had two surviving sisters. No mention of Ari'ipaea Vahine, whose timely home visit in 1790 had helped overcome the Oropa'a, appears in the first missionary chronicles, so she may be assumed to have returned to Ra'iatea, or to have died. The other sister, Auo, the widow of Mo'orea's chief, Mahau, was found to be married to Mauroa, a petty chief, characterized as "a man of good sense and great authority" (p. 151). Auo herself was described as "presiding over" Teahono'o, the eastern subdivision of Matavai (Ha'apape?), but she and her husband resided also in Pare (p. 183).

At the time of the Duff's arrival, Pomare II was about sixteen or seventeen years old and living at Pare with his wife, Tetuanui, daughter of Auo and Mahau (and hence his first còusin), of about the same age. Both Pomare II and his young wife traveled on the shoulders of bearers when away from their own estates. ${ }^{3}$ Wilson characterized the couple as follows:

Otoo, the present king, is about seventeen, and very large limbed, promising to be of a size like his father. Though he is absolute, he lives in the greatest familiarity with the lowest of his subjects. He is differently represented: some say he looks solid, and of a thoughtful aspect; whilst others call him stupid, and his countenance vacant. His queen, Tetua, daughter of Wyreede, relict of Motuāro, is about his own age, and rather the larger of the two. Her countenance is pleasing and open, but masculine, and widened by the usual method of pressure, called touroome. (p. 321) 
The king and queen were always attended by a number of men, as carriers, domestics, or favourites, who were rāa, or sacred, living without families, and attending only on the royal pair; and a worse set of men the whole island does not afford for thievery, plunder, and impurity, (pp. 321-322)

Although cohabiting, Pomare II and his wife were already seeking some of their sexual partners elsewhere, Pomare II being described as "given up to unnatural affections" (LMS Transactions: I, 122), and Tetuanui as being "a perfect Messalina," living in "a promiscuous intercourse with all her porters" (p. 322).

Though the dwelling of Pomare II in Pare was characterized as "a very humble one," the labels applied to everything about his situation reflected the preeminence of his rank-status:

The king's title is Otoo-noo-ey-te-Atooa; the meaning of which we do not clearly understand, but as the word Atooa is used to express the object of worship, it is doubtless as full of arrogancy and pride as is possible. His house is called Yowrye, (clouds of heaven); his double canoe Anooanooa, (the rainbow); his manner of riding on the shoulders of an attendant Mahowta, (flying); his torch Ooweera, (lightning); and a drum that is frequently beating for his amusement Pateere, (thunder). (LMS Transactions:I, 121)

Other aspects of the young chief's behavior will be discussed later on.

Teri'i na Vaho Roa, the younger son of Pomare I and 'Itia, was found by the missionaries to be residing in Seaward Teva, where he was called $a r^{\prime} i$ rahi, bearing the Title Vehiatua ("V"). His wife was Tupu, younger daughter of Auo and Mahau (and hence sister of Pomare II's wife, Tetuanui). Vehiatua V and Tupu resided in "Matowee," or "Mattahwey" (Mata'oae?); how much actual authority - as distinct from rank-status - he exercised over the rest of the Seaward Teva is hard to say. His parents, Pomare I and 'Itia, resided occasionally in nearby Teahupo'o.

Turning now to Temari'i-Teri'irere, ${ }^{4}$ chief of Papara, this individual, now approaching forty years of age, was generally conceded by the missionaries to be the island's second most important chief. His wife at this time was "Tayreede" (Tairiti?), daughter of the chief of Papeuriri. When Teri'irereTemari'i first visited the missionaries he was described as a "chief priest," and either an "atua" or "ta'ata no te atua" (a god, or a god's human - i.e., a shaman subject to long periods of possession by some god). Some time previously he had "adopted" Pomare II and, as we shall see, was the latter's close friend and ally. (pp. 161-162)

As we thus see, most of the individuals playing important roles in the political developments of this decade had undergone some changes in their situations since Bligh's departure in 1792, but none so much as Ha'amanemane, the ari'i priest, who had sought refuge on Tahiti in November 1788, after suffering political reversals on his home island of Ra'iatea. Even during Bligh's last visit this elderly man had become the 
island's high priest of 'Oro and Pomare I's principal political aide; in addition he is said to have "adopted" Pomare II, and bequeathed to him the various insignia, and so forth, symbolizing his Ra'iatean kin-Titles. Now, some five years later, Ha'amanemane was found to be identified more closely with Pomare II than with the latter's father, and to be embarked on a political career of his own. While he plotted to retrieve his authority in Ra'iatea, he seemed no less intent upon gaining some in Tahiti as well. The missionaries were informed that his influence rested on his effectiveness as priest (and sorcerer?).

His own power seems to depend on his priesthood: the poor natives say, "If we deny him any thing, he will pray to the Eatooa, and we shall die." We often, as far as our knowledge of the language will admit, enter into conversation with him respecting his notions of religion, and find him very bigoted in his opinions, concerning the gods of Otaheite, but from no other authority than, as he says, "my grandfather told my father, and my father told me." (LMS Transactions:I, 12)

Not the least of the old priest's characteristics was his physical vitality:

Nov. 23d. - Mannemanne, who, though nearly blind with age, is as libidinous now, as when thirty years younger; and, in order to gratify his lust, has frequently upwards of a dozen females with him, some of them apparently not above twelve or thirteen years of age; had to-day two of his concubines eloped from him; a great stir was made upon the occasion, and about three in the afternoon, near two hundred men and boys, armed with spears, clubs, and sticks, issued forth into the neighbourhood, to beat the bushes in search of the two women, but without finding them. (I, 88)

Although Ari'ipaea's widow, Vahine Metua, was characterized by Wilson as "chief over all Hedeah [Hitia'a]" (p. 190), the person who seems to have exercised that authority was one Teohu, whose relationship to Vahine Metua (or to anyone else) I have not succeeded in tracing.

From these and other fragments of information it is possible to essay some kind of political geography of Tahiti at the end of the eighteenth century. It will be found to be incomplete and in part less than credible - that is, since most of the information was obtained from the Pomares, or from individuals allied with them, some of it will be biased, if not actually wrong but worth the effort anyway. We can begin with Seaward Teva, which in the recent past, at least, constituted a fairly unified tribe under the chieftainship of its line of Vehiatuas. In 1797, as we have seen, the individual who bore that Title was Pomare I's youngest son, Teri'i na Vaho Roa, who resided on the peninsula, without reported opposition from any of his "subjects"; but this appraisal might of course reflect lack of information rather than lack of any such opposition. In any case, when Pomare I was engaged in collecting objects for a ceremony to be held at Papara, the missionaries reported having seen "most of the chiefs of Tiaraboo" assembled with their contributions. (pp. 198-199) 
In their survey of the peninsula's population, the missionaries listed twenty-one territorial subdivisions (including an uninhabited one) and the "cheif" of each; among the latter are included Pomare I, 'Itia, and Ha'amanemane; but the other names listed resist identification (p. 199).

According to the missionaries, the chief of Vaiari was "Maahehanoo" (Ma'ahehanu?), a girl of about fifteen, whom I cannot otherwise identify. The same account has her "betrothed" to a youth of the same age named "Towha" (Te To'ofa), identified as son of another "Towha," whose identity I am unsure of. ${ }^{5}$ This young couple was said to have been under guardianship of a man named "Tootahah" (Tutaha), described as "having descended from the earees," but he was not otherwise identified. ${ }^{6}$

The missionaries named "Tayredhy" (Tairiti?) as current chief of Vaiururi (Papeuriri, Mataiea) and Atimaono, succeeding her father. As she was at the time married to Teri'irere-Temari'i it may be assumed that the longstanding political connections between these districts and Papara were still extant. (The then current state of the similarly long-standing connection between Papara and Vaiari was not specifically reported, but in the absence of contrary evidence one may assume that it also was extant.)

Papara was, of course, under the chieftainship of Teri'irere-Temari'i. As for the Oropa'a, the missionaries stated that "Attahooroo is divided into two or three departments, over which chiefs subordinate to Temarre preside" (p. 207). While it is true that the warlike residents of this large region had been defeated by the mutineers and other forces aligned with Pomare I and Teri'irere-Temari'i, I very much doubt that they had remained "subordinate" to either of the latter in the sense that the missionaries attached to that term. Their lack of leaders such as the former Te To'ofa and Pohuetea undoubtedly served to weaken their independence, but much of the old spirit was still alive. By 1797 the famous "Papara" image of 'Oro, which had been taken to Pare after the mutineers' victory in 1790, was again housed at Pa'ea's marae 'Utu'aimahurau. ${ }^{7}$ When and how it came to be returned there from Pare we do not know; the only reference I find to the transfer occurs in the missionary Jefferson's journal under the date of April 20, 1801: "We also hear that the ground of the quarrel between Pomerre \&c. and the district of Attahooroo is, because some persons belonging to that district stole some time ago from Oparre the image of their great god O'oro and have secreted it..." (Jefferson, Journal, LMS Archives). As we shall see, the efforts by Pomare II to recover this immensely important object were a central element in island politics during the next few years.

At the time of the missionaries' survey in July 1797, Fa'a'a was listed as being under the chieftainship of Pomare I (p. 210). Previous reports had named Pomare I's youngest brother, Te Pau "C", as chief of this unit, but what his role was in 1797 - if indeed he were still alive - is not reported. 
Pare-Arue were of course still the headquarters and the principal base of the Pomares, father and son, and many of their nearest kin also resided there. Ha'apape was also under Pomare's overall authority, but had its local subtribal chiefs as well.

Ha'apaiano'o came under the chiefly authority of Pomare I's brother, Vaetua, and while the latter was not openly opposed to his elder brother's interests, neither was he obediently aligned with them at all times.

At this point in history Tiarei and Mahaena were as usual somewhat aloof from political developments elsewhere, probably the result of their inaccessible situations and their thin populations. On those few occasions when they were drawn into the island's larger political conflicts they seem to have followed the lead of their larger neighbor Hitia'a.

The identity of the tribal leadership of Hitia'a is a puzzle. In one context the missionaries attributed the office to Ari'ipaea's widow, Vahine Metua, whose father had previously held authority there. This forceful woman did indeed maintain a residence and a retinue there, but three years later, when a confrontation occurred between Pomare II and Hitia'a, the chief of the latter was a man named Teohu, whose antecedents I am unable to identify.

Turning now to Mo'orea, there is no indication of a change having taken place in the political geography or chieftainship of that Pomare refuge. The unity of the island is suggested by a brief passage in Wilson, describing a visit there by some of the ship's company. Upon arrival at Uponohu they found a rahui in effect:

This rahoo is laid on by the chiefs to repair the desolations their inordinate feastings make, and is always religiously observed by the people. It seems that the whole island of Eimeo was at this time under this injunction, but at Otaheite it is only imposed on a few districts at one time, during which none of the residents dare sell a pig, or kill one for their own use. However, they may take hogs from those districts that are free, and use them as they please. (p. 83)

From the fact that Pomare I and 'Itia spent much of their time there, one may assume that its chieftainship was still in the hands of Mahau's (and Auo's) son, and that the latter's uncle, Pomare I, continued to exert a large measure of authority, or at least influence, there. (Ha'amanemane seems also to have used Mo'orea as an occasional residence, but he, of course, was closely identified with both the Pomares at the time [pp. 58-59].)

Finally, any summary of these Islands' political geography in 1797 must mention the existence of its handful of beachcombers. The Swedish Andrew Lind, then about thirty years old and formerly a member of Matilda's crew, had been in Tahiti since 1792. A second Swede, Peter Haggerstein, then about forty years old, had been there since 1793, when he was left by Daedalus. A third Swede, "John," also from the Matilda, spent some of his time on Mo'orea, and was considered by his compatriots to be insane. 


\section{SON AGAINST FATHER}

In addition to its other lacunae, the résumé just given leaves unspecified the most fateful element of all in the political geography of Tahiti and Mo'orea - namely, the developing rivalry between Pomare I and his son and successor, Pomare II. It is impossible to discover when that rivalry overtly began. Perhaps it was just one more example of an inevitable, even habitual, consequence of the Maohi mode of kin-Title succession, wherein the trappings of the office devolved upon a Titleholder's successor at an early and fixed time, while the substance of any associated authority was transferred sometime later, and usually in steps that varied in magnitude and in timing according to factors of personality and situation. ${ }^{8}$ It may be that most or all such authority transfers involved a type of rivalry, and that the one between the Pomares, father and son, has attracted attention mainly because of the size of the stakes, and of course the illumination cast upon it by the European spectators.

The missionaries were in Tahiti for one year before they began to acknowledge how things stood between Pomare I and his son, but the signs were there all along. In a word, Pomare II's close friendship with Papara's chief, Teri'irere-Temari'i, stood in sharp contrast to the latter's avowed hostility toward Pomare I. And although the Ra'iatean Ha'amanemane maintained in public a friendly and more or less respectful relationship with Pomare I, he sought to undermine him in private - in contrast to his identity with the interests of Pomare II. (pp. 61, 206.)

The first time the missionaries saw most of these principal personages together was at Papara, in August 1797, after the Duff had departed for England. The occasion for this meeting was a taurua, a large-scale assembly held at Papara which included a human offering and presentations of food and other objects by the host to certain of the guests. The missionaries' description of this event is so sketchy that I cannot identify it specifically with any of the distinguishable types of large-scale assemblies characterized in previous chapters. The first reference to the event occurs in the Duff officers' account of their meeting with Pomare on Taiarapu during July 1797:

When I asked him [Pomare I] his reasons for not going to Matavai, he answered, that at present he could not possibly go, it being a very busy time with him, having to collect canoes, cloth, hogs, \&c. to give away among the different chiefs and arreoies, who would attend him to the great feast at Papparā, which was to take place in a few days, and for which all the island was looking up to him. This excuse I had reason to believe, for public care seemed engraven on his countenance. (p. 198)

A month later some missionaries saw Pomare I just prior to the assembly at Papara, where he was again preparing objects for distribution:

When we arrived at the habitation of Pomere, we found him busily employed in 
superintending his servants in dying of cloth, it being customary for him to make large presents to the chiefs and Areeoies at the annual feast, which is near at hand, for which he has been making provision some time past. (LMS Transactions:I, 6)

The description of the occasion as an "annual feast" is puzzling, inasmuch as its timing, in mid-August, seems to distinguish it from the great plant-food ceremonies, which usually took place at the beginning and climax of food ripening, in December through January and in April through May. Nor does this occasion correspond to the periodic "intertribal" assemblies at which the flow of goods was from subject to chief. Indeed, Pomare I, the host of this particular occasion, seems to have been the principal donor, and the political-diplomatic emphasis of the event was heightened by another aspect of it: "... at this feast it is also customary to offer human sacrifices, and distribute the limbs of the victims to the populace, in the same manner as they do the cloth, the heads being deposited on the Morai, and the eyes presented to the young king [Pomare II]" (I, 6).

Evidently, the affair was sponsored and largely provisioned by Pomare I, to maintain and revalidate the rank-status of his successor, Pomare II. Why it was held at Papara, and not at Pare (Pomare I's own marae) or at 'Utu'aimahurau (where the principal 'Oro image then was) is not explained, but I suggest that it may have been done deliberately as a means of demonstrating Pomare II's ascendancy in this rival center of rank-based preeminence and political influence. One of the passages quoted above seems to imply that all the island's principal chiefs assembled for this occasion, but the only ones specifically named were Pomare, father and son, Teri'i na Vaho Roa (Pomare I's youngest son, the current Vehiatua), Teri'irere-Temari'i, and Ha'amanemane (whose presence was required to help officiate at the human sacrifices).

The two missionaries who attended this occasion (mainly in order to protest the human offerings) did not see the religious ceremony or the distribution of objects, but, more relevant to our interests, they were witness to a clash between Pomare I and Teri'irere-Temari'i, which they described in the following words:

On our arrival [at Teri'irere-Temari'i's residence], we were informed of a very awful and affecting circumstance having taken place: viz, that the servants of Temaree had killed a man; on enquiry, they informed us, that the man was a thief, that they caught him robbing the plantations of Yavva, and stoned him to death. We were desirous of knowing, if they had offered the man as a sacrifice to their Eatooa; the replied, no: that they had buried him, and that thieves should be punished. To this we could make no reply, being unable to inform them (for want of knowing their language) how to proceed in such cases. In the afternoon, several men from Tiaraboo came to Temaree, and seemed much displeased, on account of the man's being killed. In the evening, the natives who came with us from Matavai, being alone with the writer, informed him that it was very bad of Temaree to kill the man, who was no thief, but only came to ask for (or demand) the Yavva, being 
a principal servant of Pomere, but that they were afraid to say much for fear of the images, or gods, which Temaree had in his house, who would come at night, when they were asleep, and kill them. I endeavoured to convince them their fears were groundless, but to no purpose, they told me, I might ask Peter, or John the Swede, if what they told me was not true. It growing dark we took some refreshment, and the writer engaged in prayer, after which he retired to rest, leaving brother Main in conversation with Temaree. In a short time we were alarmed with the cry of Tamai! Tamai! i.e., War! War! occasioned by a report that the people of Tiaraboo intended to attack Temaree in the night. (LMS Transactions:I, 6-7)

... the alarm of war having in some measure abated, the natives were quiet, and turned their attention to the Yavva, the juice of which is an antidote to all their cares and complaints. After breakfast I went to Pomere's house, where I was surrounded by many natives, who, thinking I was a friend to Temaree, looked very sternly at me; having their war weapons in their hands, and their turbans on their heads, their appearance was truly formidable. I remained at the house the whole of the night, but had but little rest, being often disturbed with the cry of war! Pomere slept with a spear by his side, and had a musqueteer to guard him. Having been preserved from danger through the night, the next morning I set off for Matavai, with orders from Pomere to inform the brethren there would be no war. Pomere advised me to go over the Isthmus, to avoid any ill-designing men among the opposite party, and make the best of my way home. (I, 7-8)

On August 22, Brother Main returned to Matavai and reported that the difference between Pomare I and Temari'i had been "amicably settled" - or so it appeared at the time.

At this early stage the missionaries were so preoccupied with their own personal and domestic problems, and so ignorant about the workings of Maohi society, that they have left us only brief glimpses of native political activity. For example, they recorded their participation in a ceremony held at the huge Pare assembly house, Nanu, but, besides describing a ritual episode suggestive of peacemaking and noting that it was attended by large numbers of persons, including Ariois, their account is uninformative. In their journal record for January 31, 1798, after describing the day's prayer service and the progress made on a new building is the following sentence: "We have, in some measure, been the happy means of preventing Pomere from going to war with the Teeahroa" (I, 25). And that is the only reference to what was probably a most critical episode!

On March 6, 1798, there began a series of incidents that was to bring to a climax, and a resolution, the rivalry between Pomare I and his son. As the missionaries themselves were directly involved, their reports, as preserved in the LMS Transactions, are somewhat fuller and more intelligible. On the date in question there arrived at Matavai a small vessel out of Macao; the Nautilus (Captain Bishop commanding) was headed toward South America to pick up sealskins. The ship was badly in need of food supplies, but as it had only muskets and powder to barter the missionaries provided food from their own stocks in exchange for the understanding that 
no guns or ammunition would be left with the Maohis - a hoped-for assist for peace and security, which however turned out to be quite the reverse.

Inevitably, knowledge of the missionaries' maneuver became public, and the chiefs who had hoped to replenish their arsenals were resentful. This appears to have been particularly so of Pomare II, whose feelings were probably intensified by his irritation at the favored treatment characteristically accorded his father by the missionaries. The resentment finally culminated in an attack made on some missionaries at the end of March 1798. One morning, as four of them were returning home from Pare, where they had sought the help of Pomare I, his son, and Teri'irereTemari'i in recovering some Nautilus seamen who had jumped ship, they were manhandled and relieved of their clothes by a gang of natives. The reaction of Pomare I (and 'Itia) to the affair seems to have been one of genuine surprise, regret, and annoyance. Pomare II also expressed his concern, but in a manner hollow enough to raise doubts even among the credulous missionaries.

The effect of this encounter upon the missionaries was electric. After putting themselves in a "posture of defense" they solemnly voted (after prayer) "that from the recent occurrence, and present appearance of things, a removal of the Society off the island seemed necessary" (I, 37). Four days later the Nautilus departed for Australia, carrying all but five of the unmarried missionaries, and all the married ones save Brother Nott and his wife (the latter having been considered either too infirm for the voyage, or too elderly to invite molestation). Those left on the island turned over most of their remaining goods to Pomare and 'Itia in order to be relieved of the risk of further injury to themselves by covetous natives. Pomare I's reactions to the attack were more forceful: "March 30th. Heard this morning that Pomere was avenging our cause, on some of the people of Opare, and that he had killed two, who either were the principals, or assisted in stripping the four misisonaries" (I, 42).

Two weeks later, word reached the remaining missionaries that the neighbors and relatives of the men killed by Pomare were determined to avenge their death and had declared war against both Pomare I and his son. Aroused by this challenge to their authority (the declared enemies were residents of Pare itself), the two chiefs descended upon their adversaries and drove them into the mountains, meanwhile burning forty to fifty of their houses and killing ten men and two women. According to the missionaries' tally, as reported in the LMS Transactions: "... with the two men killed before, and one that died of his wounds, make fifteen lives lost since the brethren were stripped of their clothes at Opare, and which was the foundation of this slaughter. We have not heard of any of Otoo's party being slain." (I, 49)

Much was to happen between the clothes stripping incident and the 
missionaries' retrospective comprehension of it; but this will be described later on.

In July the remaining missionaries recorded a rumor that Teri'irereTemari'i was about to make war against Matavai, but shortly thereafter a report reached them that the threatened attack had been called off as a result of Pomare I having made an atonement offering (tarae hara) to Teri'irere-Temari'i in the form of a live pig and a young plantain tree: "The cause of Temaree's anger, it is said, originated from some unbecoming jest that had been put upon one of his family. As we do not hear that the offence was given by Pomere, we cannot tell how he came to atone for it." (I, 54-55.) No further explanation is to be found for this puzzling episode, but it does serve to confirm that relations between Teri'irere-Temari'i and Pomare I were anything but friendly. However, the unfriendliness of the former was not to last very long.

On August 30, the missionaries were asked to hurry to Pare and minister medically to a person injured in a gunpowder explosion. On arriving there they found the patient to be none other than Teri'irere-Temari'i, who had burned himself critically while testing the effectiveness of some gunpowder acquired from a visiting vessel. Brother Broomhall, the "surgeon" among them, applied medicine to the wounded man's skin and returned to Matavai. On visiting the patient the next morning he found him in a worse condition, his body covered with a paste made of the scrapings of yams. Having suffered much pain from the missionary's previous medication, Teri'irere-Temari'i and his associates, including Pomare II, were ominously angry. After a threatening encounter with Pomare II the missionaries managed to reach home in Matavai, where Bromhall summed up their thoughts in the following words:

I thought the scene of March 26th [the stripping incident] was again about to be acted, only in a more tragic manner; inasmuch as the natives' suspicions then were small when compared with the present. At that time they suspected we had prevented captains Bishop and Simpson, of the Nautilus, from bartering with them for musquets; but now they believed we had cursed the medicine, that it might kill the patient, and that the greatest man on the island, he being closely allied with Otoo against his father and mother. (I, 77-78)

Pomare I appealed to the missionaries to treat Teri'irere-Temari'i with medicine that would cause no pain, but, as that was impossible, nothing further was done by the missionaries, who described the situation in a statement notable for its increased understanding of Maohi politics:

The king, queen, Pomere, Edea, Mannemanne, are to the westward, anxiously waiting the issue of the late calamitous visitation. We have reason to believe Orepiah's death would be the cause of great secret rejoicing to Pomere, Edea, and others, who seem to stand in much dread from the close union subsisting between 
Otoo and Orepiah: the latter being the uncle of the former, has acted as a kind of guardian to him during his youthful days. Though the wheels of political government are not so many in this as in our native island, yet they are more in number than any would conceive from the rude and barbarous state the nation is in. They have their plots and court intrigues, their parties and partisans, as well here as in England; and they are as important in their way as in the most refined court of Europe. (I, 78-79) ${ }^{9}$

Teri'irere-Temari'i finally expired. While embalming and funeral proceedings were in progress Pomare I found it convenient to withdraw to Tetiaroa, and it was announced (presumably by Pomare II) that the corpse would be sent on a tour of the island, to receive the expressions of respect traditionally accorded the remains of individuals of such high rank-status and political power. The response to this announcement from Matavai was admirably candid - but fatally foolhardy: according to the missionaries it consisted of “... some improper expressions said to be uttered by Pomere's [the father] orator and others, concerning the corpse of Orepiah [i.e., Temari'i]; namely, that the king [Pomare II] should not bring the corpse of Orepiah to Matavai, but throw it into the sea" (I, 84).

The reaction of Pomare II to this insult to his late friend (and undoubtedly to himself) was swift and deadly. His forces swept through Matavai, driving out most of its inhabitants and killing four of them. The missionaries were again spared of any molestation, but this encounter between Pomare II and his father's closest supporters opened missionary eyes still further to the real issues involved:

Pomere is at the Motoo [Motu, i.e., Tetiaroa], ignorant of the transactions of the day. We have more than once had occasion to notice a disunion between Otoo and his father, and a strong attachment between the former and the deceased chief Orepiah. The providential destruction of Orepiah, though it has deprived Otoo of a powerful ally, may have nothing lessened his disaffection to his father: indeed, the occurrences of this day seem to be a proof it has not, or we suppose he would never have treated his father's friends as he has done, for the imprudent speech of one or more persons. Edea is in Opare indisposed with the rheumatism: how far she approves of her son's conduct we know not. The chief of Tiaraboo (Otoo's younger brother) threatened some time ago to make war upon Otoo; and we have some reason to apprehend there is a league formed between him and his father Pomere, and his uncle Vitua, against Otoo. Thus we see men are the same in Otaheite as in Europe, and other parts of the world: "their feet are swift to shed blood: destruction and misery are in their ways, and the way of peace have they not known." The ties of consanguinity are no more binding here than any where else where men have not the fear of God before their eyes. (I, 84) ${ }^{10}$

Such then was the line-up. Pomare I, 'Itia, Vaetua, and Teri'i na Vaho Roa (now Vehiatua) ${ }^{11}$ against Pomare II and the latter's chief counselor, Ha'amanemane. With Pomare I absent and taking the "cure" on Tetiaroa, Pomare II and Ha'amanemane moved swiftly to exploit their advantages: 
A little after morning service we heard, that Otoo and Manemanne had usurped the power over all the larger peninsula, and turned Pomere out from exercising authority in any part of the same. The districts of Opare, Tataha, Attahooroo, Papara, \&c. (all the lands to the westward, and running round to the isthmus on the south) have declared for Otoo. The land of this district, from the river before us, to the eastern boundary, Otoo has given to Mannemanne, reserving the westernmost part for himself. If the districts on this side of the island, to the isthmus, shall refuse to acknowledge the sovereignty of Otoo, we are informed, war will be declared against them, and their submission extorted by force of arms. Something like this we expected, but did not imagine it would be put into execution so soon, since Temaree, who appeared to be at the head of the faction, was so suddenly cut off. Pomere's absence proved a favourable opportunity, and the indiscreet expressions of some of the inhabitants of this district, respecting the corpse of Temaree, the cause of embracing it. Not long after our settling on the island, we were told of there being two parties, that were meditating the destruction of each other; hence arose the great eagerness of the chiefs to get musquets and ammunition into their hands, from every vessel that has touched here; as also the desire of encouraging seamen to quit their ships, and reside among them: knowing, by former experience, one musqueteer is sufficient to terrify many natives armed with clubs and spears. The Swede and seamen are on Otoo and Mannemanne's side; so that, judging after the manner of men, and forming our conjectures from human reason and probability, we suppose the king and his party will carry all before them. (I, 85)

Vaetua remained in Ha'apaino'o in a state of siege, with too few forces to counter his nephew's moves:

The two brethren found Vitua encompassed with a few adherents, the greatest part of his people being fled beyond the reach of supposed danger. The chief behaved with his accustomed civility. Vitua appeared much incensed against Mannemanne (perhaps he considers him as the principal instigator of the king to the present disturbance) and was preparing to send off a canoe to Tatooroa, to inform Pomere of all particulars, and excite him to come and revenge his cause. But, it is probable, Pomere will not do this; it is said, he is personally a great coward; and as Otoo and Mannemanne have the three Europeans with musquets (the very sight of which strikes terror in every breast) on their side, it is likely he will quietly submit to what is done, till a more favourable opportunity occurs. (I, 87)

True to expectations, Pomare I sent word from Tetiaroa ceding authority over Matavai to Pomare II (including access to the goods which had been turned over to him by the missionaries), and even 'Itia appeared to reconcile herself with the new turn of events, and was "upon the whole ... sociable with her son" (I, 89). At the moment, then, peace seemed secured, with Pomare II and Ha'amanemane wholly successful.

But within the week rumors reached the missionaries that Taiarapu, Ha'apaiano'o, and rest of Aharoa were determined to war against Pomare II and Ha'amanemane - in the midst of which there came the news that Ha'amanemane himself had been slain. On the heels of this, 'Itia arrived at the missionary settlement to announce that the threatened war would not take place: 
Edea came to brother Eyre's door (she had a cartouch box buckled round her waist, a musquet, she had been seen with in her hand a little before, was now laid aside) with a settled air of triumph on her brow, she shook hands in a friendly manner with the Swede, saying unto him, "It is all over"; meaning the war, and retired immediately to the point. (I, 90)

Two days later, the missionaries learned what had transpired:

Heard Edea was gone to Opare, upon the horrible business of sacrificing a relation of Mannemanne's to her devil god. The prevailing account of Mannemanne's death is this: Pomere sent word in a private manner, to Edea, to have him killed. Edea went twice or thrice to Otoo, to draw him to consent to his death; at first he was unwilling, but at length yielded, and assented to the desire of his father and mother. Early yesterday morning Mannemanne set off for Opare, and was followed by Fareroa, the man Edea cohabits with, and one of the Sandwich islanders; they overtook the old priest at the bottom of One-tree-hill, on the west side, and after a little conversation with him, Fare-roa smote him on the head with a stone. (I, 91-92)

The end of Ha'amanemane called forth from the missionaries a résumé of the island's recent political history, which deserves quotation in full:

Mannemanne was a native of Oryateea, of which island he was once chief, but his subjects revolting expelled him the island. He then sought shelter on Otaheite, and obtained it, and has here exercised the office of chief priest for many years; under this character he has been guilty of much slaughter, shedding torrents of human blood in sacrifice to abominable idols and devils. He was esteemed, by all ranks, as a man of great knowledge, so that it was thought he had not his equal on the island. It appears, a jealousy has long subsisted between the deceased and Edea and Pomere, upon what account we know not. Pomere seemed to stand in fear of the priest (who was related to him) and had a kind of persuasion respecting him, similar to that the king of Moab had of Balaam, namely 'Whom he blessed was blessed, and whom he cursed was cursed.' Many were led away with the delusion that Mannemanne had great influence with their gods. It is evident to us, the casting out Pomere from having any power, driving out the inhabitants of the district, and dividing it between Otoo and himself, were projected and chiefly effected through the instrumentality of the priest; and for which, some of us thought, he would draw upon himself what he really has. Mannemanne, though far advanced in years, and almost blind, was, notwithstanding, very active and full of animal spirits; he was always attended with many females, as before observed, who only stayed with him while he could gratify them with gifts. Whether Mannemanne had any foresight of the gathering storm, that was to crush him, and wanted to avoid it, or whether he thought he was now near the time of putting a long devised plan into execution, (and for which purpose, the obtaining of musquets, and making friends with Europeans, for their assistance, were his constant arms) for regaining the chiefship of his native country, we cannot tell, but a small vessel, of about twenty tons, was to be equipped with all expedition, with which he, and the three Europeans, were going with haste off the island. And early on last Sabbath morning, Mannemanne went into brother Eyre's apartment, as soon as he was up, to beg an axe; brother Eyre informed him it was our Sabbath, and that we did not meddle with such things on that day. With this reply he was satisfied, and said no more. He then groped his way to the bed (sister Eyre being asleep) and began to feel the curtains, and to measure them with his arms, in their length and 
depth: brother Eyre observing him, conceived he wanted them for sails to his boat. Having satisfied his curiosity he retired from the room, and never entered it more. The old man's conduct toward us has always been friendly, and free from that deceit which others have practised, but he was a perpetual beggar. What may follow the late judgment we know not, every thing at present looks very dreary. (I, 92-93)

Their appraisal of Pomare II's role in the recent events was perhaps just as realistic:

The conduct of Otoo, in consenting to the death of Mannemanne, at the time he was in close alliance with him, opens the character of the man in a conspicuous manner, and confirms us in a suspicion we have long entertained, but knew not how to account for, concerning the stripping of brothers Broomhall, Jefferson, Main, and W. Puckey, at Opare. When that circumstance took place we seemed assured it was done by the king's authority, but when Otoo afterwards joined his father in punishing the poor people for the same, we could not readily reconcile his authorizing the action and then destroying those that did it. But we had seen so much of him since, that we believe he is capable of committing any wickedness the devil, his carnal mind, and blood-thirsty followers may excite him to, if God did not restrain him; we therefore think the true cause of that event was this, Temaree, the foster-father of Otoo, was in close connection with him, and clearly appeared to be meditating some great blow, by which they would exclude every other person from having authority on the island but themselves and followers. To effect this they were extremely desirous to get into their hands musquets and ammunition. When the bark Nautilus arrived, finding that she had a large quantity of these articles on board, but that they were deterred from obtaining them through our interference, they were offended, and determined to be revenged. Accordingly, when the Nautilus arrived the second time, and the two seamen escaped from her, and took refuge with Otoo, and the four brethren were dispatched with an endeavour to recover them, the king, thinking it a favourable opportunity to execute his revenge upon the society, secretly gave orders for their being plundered. Otoo and Temaree, though powerful, were not sufficiently strong at the time to oppose Pomere, who shewed displeasure at what was done; and though, no doubt, he was acquainted with the true authors of the action, yet from prudent motives, it may be, vented his anger upon the instruments rather than the movers of them; while Otoo and Temaree, to hide their crime, joined Pomere in so doing. What wicked policy! (I, 93)

The announcement of a peaceful settlement to this whole affair was, characteristically, quite premature. Pomare I and 'Itia appeared to remain reconciled to the new dispensation, and the inhabitants of Matavai returned home after due expression of subservience to Pomare II; but some local skirmishing continued between Taiarapuans and Teri'irere-Temari'i's former supporters in Vaiari. Meanwhile, the whole area from Ha'apape to the isthmus served as a refuge for enemies of Pomare II, and reports reached the missionaries that Atehuru and even Papara were "... in great confusion among themselves." In fact, the situation reached a point so unsettled that the missionaries were moved to report: "It appears upon the whole, the inhabitants of the island do not know what they are doing, or what they would be at." (I, 95.) 
Nothing however developed from these alarms - not immediately at least - and when Pomare I finally returned from Tetiaroa six months later the island was enjoying what the missionaries earlier called "a great degree of outward peace," and father and son met with mutual displays of amity (I, $115,123)$. Meanwhile Pomare II's everyday behavior reached heights of arbitrary arrogance, which even the long-suffering missionaries remarked to be extreme. ${ }^{12}$

\section{"DisAFFECTION OF THE COMMONALITY"}

The reconciliation between Pomare II and his father was followed almost immediately by signs of hostility toward both of them. As usual, the center of opposition was Atehuru, where someone had burned the house of Peter the Swede, and thereby issued a challenge to the latter's protectors, the Pomares, that they could not ignore. The cause of the impending war, as represented to the missionaries, was "... that the inhabitants of that district have resented the tyrannical and oppressive conduct of the chiefs [i.e., the Pomares], who exercise, with an high hand, their authority over those subject to their power." (LMS Transactions:I, 143)

As an indispensable move in preparing for war the Pomares stepped up their human offerings to 'Oro; the fact that the god's principal image was in Atehuru (i.e., at 'Utu'aimahurau, Pa'ea) seems to have induced the Pomares to offer an increased number of propitiating sacrifices to it:

Heard that five human sacrifices have, within a few days, been brought over from Eimeo, to this island - Also that many of the inhabitants of Opare (of the poorest sort), have fled to the mountains, to avoid being seized for human sacrifices ... It appears that these things are preparations for the proposed war, and that Pomere is doing what other blind heathens have done before him, labouring to bribe his idol-god to be propitious to him, and to forsake the district of Attahooroo. (I, 143)

Within a few days, the number of human offerings had exceeded ten, Pomare I having demanded some from each district believed to be loyal to him and his son (I, 145).

In the midst of these preparations the missionaries received assurances from Pomare I regarding their own safety; the direct bearing of this message on the subject of this chapter warrants quoting it:

Nov. 30th ... About noon, Michael Donald [a beached seaman in Pomare I's retinue] came to us from Pomere, the purport of whose message was, that we should be under no fear of danger to our persons, that we should consider him as our protector, and that he considered us, by the property we had put into his hands, as his protector (that is, we apprehend, Pomere considers his power and authority, and consequently his safety, greatly augmented and established, by the vast addition of wealth he has derived from us). (I, 153) ${ }^{13}$

Meanwhile European vessels began to call at Tahiti (usually Matavai) with increasing frequency: the Betsey (and a Spanish prize) in December 
1799 and the Eliza in January 1800. From these vessles the Pomares were able to add to their European manpower and to increase their arsenals, including an "eighteen pound carronade, ... several muskets, and a great deal of ammuniton" (I, 169).

But Atehuru, and now Papara, continued to threaten the Pomares, and Hitia'a served as a base for the latter's enemies. Even within their own home district of Pare, Pomare I and 'Itia were, according to the missionaries, “... so much afraid as to have a guard around them at night" (I, 201). In October 1800 , Pomare I summed up the current situation in a statement of remarkable candor:

To-day the chief, \&c. visited us. In a conversation a brother had with Pomere, the chief gave him to understand, that there is a probability of war upon the island, but not directly. He did not seem to know who were his friends, or who his foes, but acknowledged the general desire of the people is a suppression of a monarchical form of Government, and the re-establishment of independency in each district. It was observed to him, that the arbitrary proceedings of Otoo, were probably the cause of the present discontent. He did not deny it. Pomere wished much for a ship of war to arrive, which he supposed, by an interference in his favour, would restore tranquility, and confirm his and his son's authority. Or if a number of Englishmen like ourselves were to join us, and continue their residence among them in the manner we have done, he said, he was sure there would be no war. (I, 202-203)

Similar sentiments were expressed by Pomare at the beginning of 1801 in a letter to Philip King, Governor of New South Wales:

May it please your Excellency,

Your letter and present I kindly accept. I love king George and his subjects, and will, while I live, be a protector to those of them who put themselves under my care; but I must tell your excellency, I at this time stand in fear of the commonality, many of them being disaffected towards me, and their disaffection, I fear, is encouraged by some seamen who are on the island; and therefore I wish your excellency to present me with a few fire-arms, whereby my authority may be maintained, and the peace of my kingdom preserved. (I, 213-214)

Despite all these preparations for war, formal visiting continued between the chiefly adversaries, including some solemn (and obviously hollow) peacemaking ceremonies. One such meeting was held at Pare during 1801, attended by all the island's principal chiefs and probably most of its fighting men as well. I cannot discover the declared purpose of this meeting, nor can I fathom the Pomares' private reasons for holding it and thereby bringing so many of their enemies to their own district. In any case, the meeting appears to have gone well for the Pomares, as the result of two episodes. The first was the arrival in June of the Porpoise, an armed vessel from Port Jackson, with gifts and a letter to Pomare I, which were presented with an impressive show of military ceremony and force. ${ }^{14}$ In commenting on this event the missionaries wrote: 
By intelligence that we have received, it seems that the arrival of the Porpoise is a very providential interference, as the affairs of this country were brought to such a crisis, that a few days, if not hours, would have either dethroned Otoo, or established him in his authority; this could not have been done without much bloodshed, the effusion of which, we hope, is now stopped, and Otoo and family will be permitted to retain quiet possession of their dignity. The Lord does all things well. (I, 229n)

The second advantage secured to the Pomares during this lengthy meeting was the death, at Pare in August, of Teohu, chief of Hitia'a. Teohu had been the Pomares' most outspoken opponent, and his district had been a rallying place for dissidents from elsewhere. He had brought with him to the meeting a formidable force of his own, augmented by the fighting forces of Mahaena and Tiarei, who seem to have accepted his leadership. Teohu appears to have been sufficiently constrained by the show of English support for the Pomares to have concluded a peace settlement with the latter (the terms of which are, however, not clear), but he still constituted a threat. Recognizing this, the Pomares made plans to kill him immediately after the "peace" ceremony, but he saved them the trouble by dying of illness instead.

The Pomares' position received additional strengthening with the arrival, in July 1801, of another contingent of English missionaries together with another supply of goods which, in the nature of things, would eventually in large part find their way into the Pomares' hands (Newbury 1961:32ff.).

On December 12 of that year the climactic session of the greatly heralded meeting took place at Pare; unfortunately for the historian of that crucial period, the information about its proceedings is limited to the following terse entry in a missionary chronicle: "Decr 12th it was said the meeting was to commence five of the misss went down to Pare, to see how things were likely to turn out, and in the evening returned with the good news that the great meeting was likely to terminate peaceably" (Newbury 1961:41). ${ }^{15}$

Characteristically however, within a month a missionary historian had to report that war alarms had been renewed. The general cause of dissension continued to be the widespread hostility to the Pomares' arrogance and pretensions. And on their side, the Pomares - and particularly the son continued to press the Oropa'a to give up the "Papara" image of 'Oro, which the latter had held on to, perhaps viewing it as the one remaining check to Pomare II's ambition for absolute power.

This raises again the question concerning the advantages accruing from actual physical possession of this particular image of 'Oro. Because of the deep and widespread faith that seems to have been entertained about 'Oro's decisive effectiveness in warfare, this issue evidently had immensely important political implications. Over the course of time it seems to have become 
the principal, or perhaps even the sole, 'Oro image of Tahiti-Mo'orea into which the great god could be induced to enter - at least, for the purpose of receiving human offerings. Along with this, however, there appeared to be a generally accepted and widely honored agreement concerning the supratribal status of the god - that is, even in time of intertribal tensions the tribe within whose boundaries the image happened to be lodged usually permitted potential enemies access to it. On the other hand, in view of the efforts made to obtain, or maintain, physical possession of the image, one must infer that there were additional advantages in actually having it, either in terms of prestige, or easier physical access, or both. As we shall see, the Pomares were allowed access to it at 'Utu'aimahurau even during a period of extreme tension; perhaps their enemies suspected, with good grounds, that a similar right of access would not be extended to them if the image were in Pomare hands.

\section{THE IMAGE OF 'ORO}

In March 1802 the Pomares and a large force of their followers went to 'Utu'aimahurau, ostensibly to present human and other offerings to 'Oro, but evidently also to negotiate further concerning physical possession of the god's image. The missionaries who witnessed these events gave the following account of them:

Tuesday, March 30. Left Hafaena, and came on to Attāhooroo, near the place where the ceremony is held, which commenced this day. Passed the great Marrai: saw several large hogs upon the altar, and several human sacrifices hanging on the trees. When we arived at the meeting the ceremony for the day was over. Pomarre was offering as a present five or six large hogs to their great god Ooro on board a sacred canoe on which the ark or residence of Ooro is placed. Informed Pomarre that Jehovah is the true God; and there is none else; that hogs are not acceptable to him, that he is offended at them for killing men, and that Jesus Christ is the only atonement for sin. He was also told that Christ would come to raise the dead, judge the world, and turn the disobedient into the fire. At first the Chief seemed rather unwilling to hear, but those around him continued the conversation by asking questions, and at length Pomarre said, that he would attend to our religion.

Wednesday, March 31. This forenoon a strange heathenish ceremony was performed on the beach. Their great god Ooro was laid upon a long stool covered with cloth, and the king, with several of the priests were sitting by, praying or chanting something to Ooro which we could not understand. They seemed to keep time with their drums and conck-shells. The natives stood so as to form a circle round the idol, to which several of them were exposing themselves in the most shameful manner, and every now and then calling out "Māévā-aré." This continued several hours, during which time a native, who pretended to be inspired by Ooro, was seen, with the most strained distortions of countenance and limbs, giving them directions for their future proceedings.

Thursday, April 1. This morning the fleet moved down to the Great Marrai, where several large canoes were hauled on shore with great quantities of cloth upon them for a present to Ooro. The fleet kept about one hundred yards from the 
shore, while the priests were performing prayers in the Marrai, with the king and their god Ooro; the drums beating as yesterday. This continued some hours, and then orders being given, all the fleet shouted, saying, "Māévā-aré, Māévā-aré." After this, Ooro was carried upon mens' shoulders backwards and forwards along the beach, some of the natives running before the throng exposing themselves, and calling out as above, the fleet answering them in the same manner. After this a council was called, and Pomarre, with the king, and all the principal rātérā's met in the Marrai. The people of Attāhooroo sat on one side of the ring, and the king and Pomarre on the other, and the orators on each side spoke by turns. The purport of the meeting was to consult upon the manner how they should proceed in what they had to do. The king, after the people of Attāhooroo had refused to give up Ooro, who was in their possession, spoke himself, and demanded him. He was answered immediately by their orators in the negative. Pomarre then addressed himself to his son the king, in behalf of the Attāhooroo people, and requested him to yield to them, and suffer them to keep the god, as it seemed that they did not wish to keep him long, but only till a certain ceremony was performed. The king then directed his speech again to the Attāhooroo people and said, it should not be as his father had requested, and insisted upon their delivering up the god directly: But he was still refused. After asking a long time, he rose up in anger, and ordered all his party that were present to draw back. Immediately the cloth upon the canoes was plundered, and a number of the king's people took hold of Ooro and rescued him from the hands of the Attāhooroo people and ran to the sea side. It was then expected that the Attāhoorooans would pursue to take Ooro from them again, and so war thereby commence; the fleet, therefore, was commanded to advance towards the shore, and all the muskets were loaded. However, the Attahooroo people were afraid and made their retreat into the valley. Orders were then given not to pursue them, and Pomarre, Edeā, with several of the principal men stood on the beach, charging the people to go to their canoes: but notwithstanding all that they could say, many pursued them inland, and dared them to return and fight; but they refused. Pomarre continued to send messengers to order his people to come back, which at length, through fear of offending, they did. He then directed the fleet to return to their quarters, which was complied with. Numbers of the people returned by land, and plundered the deserted huts as they went: all arrived at the place of rendezvous about sun-set. We were informed that the king as soon as their god Ooro was taken from the people of Attahooroo, commanded a human sacrifice to be sought for, lest Ooro should be angry at such treatment. Accordingly one of his own servants was killed upon the beach soon after the fleet got on shore.

Friday, April 2. Quietness through the night. Early this morning the fleet sailed to Papparra on their route towards Towtérāin Tyarabboo, where the ceremony closes and where Ooro is to be deposited according (as they suppose) to his desire. Before the king's party sailed, they set fire to the temporary houses they had erected for their convenience during the continuance of the ceremony.

This day we came on to the west end of Oparre. Saw but few people they being gone with the fleet. (LMS Transactions:II, 63-65) ${ }^{16}$

The fleet's destination was Tautira's marae Taputapuatea, at which, according to one account recorded earlier, the cult of 'Oro had been first introduced to Tahiti. ${ }^{17}$ (I am not certain about Pomare II's reasons for depositing this image at Tautira, rather than at his own Tarahoi in Pare.) The passage just reproduced implies that the location was the god's 
own choice - and perhaps that was indeed the politically disinterested revelation of some 'Oro priest on the Pomares' staff. But if political considerations did enter into the choice, as I firmly believe, Pomare II's interest would probably have been considered better served by this strengthening of his base of influence in distant and still uncertain Taiarapu than by concentrating one more token of authority and influence in Pare itself. In other words (and I consider this to be a most important feature of Maohi politics in general), locational centralization had not yet become the dominant strategy for aggrandizement; the ambitious individual extended his authority and influence not solely by increasing the sanctions behind specific statuses, or by eliminating rival statuses, but also by occupying more statuses - including especially those having territorial bases elsewhere.

If any further evidence were needed on the degree to which the Maohis were influenced by their religious beliefs, as contrasted with an objective appraisal of physical strength and military skill, the Pomares' behavior during the ensuing weeks could provide it. While warning the missionaries that the Oropa'a would probably attack, to avenge their recent setback at 'Utu'aimahurau, the Pomares went on to Tautira and proceeded to install the 'Oro image there with ceremonies lasting several weeks, during which the Oropa'a were devastating Fa'a'a and Pare. (Even the force of several hundred Mo'oreans which the Pomares sent for could not withstand the Oropa'a attack.) After this the Oropa'a, joined by forces from Papara, Vaiari, and Vaiuriri, attacked Tautira itself, with such success that the Pomares and their supporters had to flee for their lives. ${ }^{18}$

At this juncture, the victors could probably have made an end to the Pomares with ease, but instead, quite characteristically, they tarried in Taiarapu killing and pillaging, and then returned home, their fury evidently spent. Needless to say, they recaptured the 'Oro image and reinstalled it at 'Utu'aimahurau. (Newbury 1961:47-51)

Meanwhile the Pomares remained at Pare repairing their losses and girding for another attack. They even revived enough resolution and support to help put down a threatened "revolt" on Mo'orea; the precise nature of the issues involved in this "rebellion" are not reported, but its center was in Afareaitu and neighboring districts. (Thomson, History, p. 54)

On June 26 there arrived from New South Wales the Nautilus (Captain Simpson commanding), with news that other vessels were also en route. This appeared to instill new life into the Pomares and their supporters, and Pomare I renewed his pleas for armed support from his English friends, who were by now a sizeable community - including a Captain Bishop, left there by the ship Venus to salt pork (for transport to New South Wales); the captain and crew of the Norfolk, engaged in the same mission; and now the personnel of the Nautilus. To begin with, Pomare I 
persuaded the captain of the Nautilus to send him with an armed escort to $\mathrm{Pa}$ 'ea in order to make some offerings to 'Oro. This mission was peacefully accomplished, although the Oropa'a obliged Pomare I to make his offering to the god on the beach some distance from the marae.

Thus encouraged, Pomare I again asked his European friends for assistance in putting down the "rebellion," and this time his pleas were sympathetically received. In fact, as a result of the alarms experienced during his six months residence on the island, Captain Bishop urged his compatriots to put an end, once and for all, to the "rebels'" threats. His primary purpose was the security of the English community, and of the Pomares only insofar as this helped the English. After the missionaries themselves agreed upon the desirability of an end to the "rebellion," the project was launched, and on July 2, 1802, the expeditionary force embarked: "The number of Europeans with Capt. B[ishop] was 19 men well armed, a Boat with the first mate and four men from the Nautilus, a four pounder cannon, and all Pomare's forces. Mr. Elder also went to attend as surgeon. The king [i.e., Pomare II], his brother and a few servants staid at Matavai." (Newbury 1961:53)

The missionaries' report of this encounter follows:

The fleet landed in Attahooroo on Saturday, July 3d, at eleven A.M. a small party of the rebels saw their approach, and retired. The enemy was withdrawn to their strong holds, which, on reconnoitering, were found to be almost impregnable, the storming of which, however, must be attended with great loss. Capt. B. and men would have made the attempt; but Pomarre and men could not be brought to venture on so desperate an action. Several shots were fired, which in general fell harmless. One of Pomarre's men was wounded in the chin and throat, by a ball from the enemy; though they fired but few musquets, owing perhaps to their scantiness of ammunition; stones they slung in abundance, and rolled down some from a great height, of several hundred pounds weight. On the following morning, a party of Papparra people, marching to join the rebels, was intercepted by a party of the royalists. The leader of the party and his wife were slain; the rest made their escape. The bodies of the man and his wife were treated in a most inhuman manner. The rest of the day passed without any particular occurrence, till evening, when Capt. B. wearied with the inactivity, irresolution, and want of subordination, that pervaded Pomarre's camp, had actually re-embarked his men, to return to Mattavai. Pomarre also, who thought it not safe to remain there without the Englishmen, was re-embarking his people with all possible speed. The embarkation was nearly completed, and most of the canoes were moving off, when an unexpected event took place, which gave a new turn to affairs.

A young man who has been with the Society some years, and who had taken to himself the name of To-morrow-Morning, had shewn a most active and courageous spirit, and performed such feats of bravery as astonished our countrymen, and excited the admiration of his own. This young man at the time of embarking, was up with one more, at the enemy's entrenchments, braving them to appear and fight, and firing at them, as he saw opportunity. At this season a heavy shower of rain came from the mountains. The rebels deeming this a favourable time, seized, 
as they thought, the golden moment, and, in great numbers rushed out, armed with musquets, spears, clubs, and slings, and chased To-morrow-Morning and the other down to the fleet; they at times firing upon him and he on them.

The noise of the musquets attracted the attention of the people embarked, and stopped their further proceedings. To-morrow-Morning came in sight, and gave notice that the enemy was come. In the twinkling of an eye, a few of Pomarre's musqueteers, not yet in their canoes, sprang forward to the combat. A successful discharge of their pieces obliged the rebels to turn their backs and fly. In the mean time the seamen and soldiers re-landed, and joined in the pursuit of the flying foe; who, in a very peculiar manner, after running some space, in a moment rallied, and faced their pursuers. Some of Capt. B.'s party were sufficiently near for the attack. The sight of the Europeans overpowered the rebels; their spirit failed them, and they now fled in different directions.

This circumstance proved highly advantageous for Pomarre, as God gave into his hands seventeen of the rebels, who were killed upon the spot; all fighting men, and among them one of the principal ringleaders of the rebellion. Many others were wounded, but escaped. Though we may be thankful to God for the subduing of those who delight in war, and are averse to peace, yet, we find much cause to lament the extreme depravity of man's nature, which admits no bounds to cruelty, when resentment is roused, and power obtained to execute it. Each of the seventeen bodies was treated in the most wantonly barbarous manner: - pierced with spears, beat with clubs, dashed with stones, derided, scoffed, and otherwise maltreated, as if now susceptible of pain, or affected by their taunts.

Pomarre thought the rebellion was crushed, and that he should have nothing more to do the next morning than to go and take possession of their strong holds, and wreak his unpitying anger on those who should fall into his hands. Captain Bishop seeing such a sudden change of circumstances determined to remain the night, and give the finishing blow to the war.

On Monday morning they marched up to the entrenchments, which are about four miles and a half from the beach; but how great was their surprize, when, instead of finding them abandoned, they saw every part as well manned as before. They could do no more than discharge several musquets upon them, and return to the fleet. A woman, an ambassadress, was permitted to pass between the parties. She carried an account to the rebels of those who had been killed, and how they were treated. They received the intelligence with seeming indifference; said that they did not know them; and as for the slain chief, they supposed that he had been carried away by the river, and not slain by the royalists. The surviving ringleader of the rebellion, a relation of Pomarre's, named Tahtahaee, bade the ambassadress acquaint Pomarre, that when they had done to him as they had done to Rooa (the name of the chief killed) then, and not till then, there would be peace in the land.

Capt. Bishop knowing that Capt. Simpson could not be detained longer from prosecuting his voyage, returned with the boat, leaving fifteen men with Pomarre. Brother Elder also returned. Pomarre has not lost in the expedition any man killed, and but four wounded: one of whom was by his own party, by mistake. On Tuesday Pomarre sent the Europeans home, and removed his fleet about twelve miles nearer Mattavai, and there encamped.

Upon the whole, this short campaign, through the mercy of God, has tended very much to destroy the strength of the prevailing commotion. The two chiefs above named (one of whom is dead) may be considered as the life of the rebellion. Their fighting men remaining are but few. As for the body of the people, on both 
sides, they are always spectators; and prepared to fly, or plunder, and exercise cruelties on the wounded or slain. (LMS Transactions:II, 115-118) ${ }^{19}$

Thus were repeated the events of twelve years earlier, when a handful of Europeans armed with muskets and conditioned to military order won a victory for the Pomares over their traditional enemies, the Oropa'a, and thereby rescued the Pomares from political mediocrity or even physical extinction.

This chapter of Tahitian history ended fourteen months later when Pomare I died, ${ }^{20}$ only a few months after the death of his aged father, Teu, and of his younger son, Teri'i na Vaho Roa, the Vehiatua of Seaward Teva. The character of this Pare ari'i was summarized in a passage written by the missionaries, who had every reason to know him well:

Sept. 10th. - It may perhaps be expected, that we give some account of Pomarre's character, so far as it came under our cognizance, which we shall do as follows: - Respecting his family, his father was an Otaheitean; but his mother a Ryatteean. He was born in the district of Oparre, where his corpse now is, and was by birth chief of that district, and none other. The notice of the English navigators laid the foundation for his future aggrandizement; and the runaway seamen, that from time to time quitted their vessels to sojourn in the island, especially that part of his Majesty's ship Bounty's crew, which resided here) were the instruments for gaining to Pomarre a greater extent of dominion and power, than any man ever had before in Otaheite.

We suppose the deceased chief to have been between fifty and sixty years of age. In person, he was the most respectable man we have seen since living here; tall, stout, well proportioned; grave in countenance, majestic in deportment, and affable in behaviour. As to his morals, he was a poor untaught heathen, under the dominion of a reprobate mind; and, according to his religion, nothing was sin with him but neglecting praying and sacrificing to his gods. In these things he was exemplary. Satan surely never had, (and we pray God he never again may have) another like him among these heathens who supported his interest with his whole power, and whose study, (from the servile fear of death) was to gain his favour, whatever it might cost. The marais built, and the altars reared at his command all over the island, are not a few, on which hogs and fish were profusely offered; and several hundreds of his subjects he has, in his time, caused to be murdered, and presented as costly sacrifices to the powers of darkness, besides the innumerable gifts of canoes, clothes, \&c. \&c.

As a governor, if we may judge by the complaints every where made, he was oppressive: but it is probable, that, with the Otaheiteans' present sentiments of right and wrong, those who have complained loudest of him, if in his situation, would not have been less oppressive. He was a peaceable man; and it is generally agreed, that the island has enjoyed a far greater degree of tranquillity, during his reign, than it had even while every district was an independent state. He was an active man. If every subordinate chief had followed his example in this respect, Otaheite would have exhibited a much more pleasing prospect than it now does. Erecting houses, building canoes, and cultivating ground, were employments in which Pomarre appeared to take great delight, and for which he deserves to be well spoken of. It is surprising, all things considered, how he was able to carry 
on such works as he did; works, that an inconsiderate Englishman, accustomed to behold the labours of art of his own country, would look upon with contempt; but which, notwithstanding, are such as bespeak the greatness and power of an Otaheitean chief, beyond any of his predecessors, and which will perpetuate his memory to long succeeding times.

Pomarre always shewed a fondness for foreigners, especially Englishmen; so that he was sure to give encouragement to any seaman that would elope from his vessel; and he often inveigled them himself: but this proceeded from policy. He supposed that every Englishman was expert in the use of fire-arms, the engine of destruction that carries terror with it all over the island; and he hoped so to engage them on his side, as to have them at his command, to come, and go, and do as he desired. The characters that he has had to deal with (since we have been on the island) have been, generally, the most abandoned, and they have disappointed his hopes and expectations. But had it been otherwise, the chief was not a grateful man: he could forget the services of those who had obliged him, and take no farther notice of them.

His behaviour towards us has always been friendly; which, without doubt, was regulated in a very great measure, if not solely, by the pecuniary advantages he has derived from our residence on the island. The vast acquistion of wealth that he gained at our first coming, and at different periods since, served to bind him to us. But latterly he did not, we think, behave so well to us as he did before the arrival of the Royal Admiral. Perhaps, the great and unexpected calls that he has had upon his attention, by the confused state of his own affairs, and the frequent arrival of vessels, may be some reasons for this change. We have also, for many months past, been enabled to open our commission, and have given him and his countrymen to know the true reason why we quitted our relatives and friends, to come and live with them: and, as the Gospel is so inimical to Satan's kingdom, we are certain that the chief could be no friend to us on account of our religion; and that he ridiculed our preaching (though he would sometimes hear, and use his power to collect his people about him to hear) and counted it foolishness, is not unlikely; and we have heard that he did so.

Upon the whole, as the Otaheiteans in general conceive Pomarre to be the greatest king they ever had, so we believe that he has not left his equal on the island. We have cause to be thankful to God, for the peace we have enjoyed under him, and that he has never debarred us the privilege of endeavouring to plant the Gospel in this island, or in any other, within his jurisdiction. (II, 295-297) 


\section{CHAPTER 31 FALL OF THE POMARES}

\section{FRAGILE VICTORY}

At the beginning of 1804, Pomare II was "King" of Tahiti-Mo'orea in fact as well as in name; ${ }^{1}$ no effective opposition to him was anywhere evident, and he was again in physical possession of the principal image of 'Oro (although the image itself was left at 'Utu'aimahurau - apparently as a token compromise with the deep feelings expressed by the Oropa'a). But, only five and a half years later, he was forced to flee for his life to Mo'orea, with only a handful of supporters; even his faithful European friends, the English missionaries, had left the island fearing for their lives. What happened to bring about such a radical change in the position of this man?

First, I list the more palpable occurrences of this period, without attempting to explain them. In September 1803 the missionaries reported that Pomare II was residing near the 'Utu'aimahurau marae, with an unidentified new "wife." He seemed at the time "but little affected with his father's decease," his principal preoccupation having been fear of the latter's ghost: "he was so terrified with the apprehension of his father's apparition, that he called for an attendant to sleep by him." (LMS Transactions:II, 294-295)

For a few months he remained mostly in Atehuru, carrying out unspecified rites involving use of the 'Oro image, then in May he moved to Mo'orea - evidently to Varari - with the image and a number of hangers-on; the reason for his move is not known.

The next time we hear of Pomare II was in July 1804, when the missionaries reported a rumor that

... the people of Atehuru were coming to make war on the Districts of Matavai, by orders of the king, who was angry because some man of the District had cursed him. The miss. were alarmed, and kept a watch thro' the night. Next day it was found the Raatiras had killed a man, as a sacrifice, to be conveyed to Eimeo to appease the anger of the king \&c. (Newbury 1961:72)

A curious turn of events, with Atehuru acting for Pomare II against Matavai - but I very much doubt that any large segment of the Oropa'a was so engaged. 
More interesting, politically, was another incident reported shortly thereafter:

There was a report of a war having been kindled in Moorea or Eimeo, on account of the people refusing to acknowledge the king's half-sister (daughter of Idia and Otihe [i.e., Tenania, the Huahine ari'i]) as their governor, several were killed and the muskets of the people in general were seized by the kings orders. Peace was however soon restored. (Newbury 1961:73)

The half-sister in question could not have been more than a young girl at the time, but that, of course, would not have disqualified her for a Title; and her parents or half-brother were entirely capable, and perhaps more than willing, to assume the "regency." But the affair does raise questions concerning the Mo'orean succession, and the relations between Tahiti-Mo'orea and Huahine at this time. ${ }^{2}$

Regarding the office of Mo'orean head chieftainship, I noted that upon the death of Mahau in 1792 the (tribal) office had devolved upon his son, Tetuanui (whose mother was Auo, sister of Pomare I). Twelve years later, assignment of the office to Pomare II's half-sister is reported, with no further information concerning the fate of Tetuanui. However, intriguing (and insoluble) as this question may be in terms of intrafamily arrangements, the events themselves had little apparent effect upon wider political developments; for, whoever may have occupied the de jure office of Mo'orean chieftainship, the Pomares firmly held onto de facto coercive authority over the island.

Of considerably more importance, politically, is the question this affair raises regarding relationships between Tahiti-Mo'orea and Huahine, as exemplified by the "marriage" between 'Itia and Tenania.

During Cook's last visit, in 1777, the person having the highest rankstatus on Huahine was a youth named Teri'itaria, the son of Mato and Fatuarai. A quarter of a century later that preeminence seems to have rested with Mahine (also known as Teheiura, or Puru) who was Tenania's younger brother (the two, it may be recalled, were Mato's sons by his second wife). The only explanation I have uncovered concerning the transfer of office from Teri'itaria to Tenania and Mahine is found in Chesneau-Marcantoni's circumstantial (but not necessarily accurate) reminiscences. After Mato had left Fatuarai, to marry the daughter of Mo'ohono ("high priest of Huahine"), and had by the latter sired Tenania and Mahine (and a daughter, Rereao), "Moohono asked Tehaapapa (i.e., Fatuarai) to transfer to his grandsons, Tenania and Mahine, the "royalty" of Maiao [a dependency of Huahine]; upon her refusal to do so he attacked and defeated her forces, dethroned her, and transferred her royal office to his two grandsons." After Mo'ohono's death, Fatuarai made five unsuccessful attempts to win back the office for her son. Finally, this account continues, when Tenania went to 
Tahiti and married 'Itia, he turned over to Mahine the office of tribal chieftainship of Huahine and Mai'ao. (Chesneau 1928:81-82)

No explanation is offered for the ultimate fate of the deposed Teri'itaria, but his sister, Turaiari' $i$, is recorded as having married the Ra'iatea-Porapora chieftain Tapoa.

Pomare II remained about nineteen months on Mo'orea, where two of the missionaries visited him and found him "... as much, if not more than ever given to the ava drinking \& we add, perhaps to those vile affections \& the commission of those things that are not seemly to mention." He also suffered from an unspecified disease which he would not discuss in public, "it being counted a reproach to be afflicted with any disorder." (Bicknell \& Henry, Journal, 24 January 1805, LMS Archives)

In January 1806 Pomare II accompanied the 'Oro image back to Tahiti. The movement was marked by ceremonies involving throngs of people (including a large number of Ra'iateans [Jefferson, Journal, 20 January 1806, LMS Archives]) and huge collections of offerings to the god, including several humans. During the passage, and for some time thereafter, the channel between Mo'orea and Tahiti was prohibited to all canoes not connected with the official procession (Jefferson, Journal, 25 November 1806, LMS Archives). Three months later the 'Oro image was carried to Tautira and reinstalled there; then, for some months thereafter, there took place an almost uninterrupted series of ceremonies which had the purpose of validating Pomare II's status as "King" of Tahiti ${ }^{3}$ - including the parallel supremacy of 'Oro, the god whose principal "seat" (nohora'a) - the to' $o$ - was once again in Pomare II's physical possession. Before the to' $o$ was transported to Tautira (in a canoe paddled mainly by Hawaiians left on the island by visiting ships) it was kept in Pomare II's own marae, Hetemahana, near Point Venus. ${ }^{4}$ At this new depository were enacted a "marae renewal" ceremony as well as the awesome paiatua, the refurbishing of 'Oro's image, and of other images with feathers from it - all accompanied by lavish expenditure of human offerings.

One of the more secular ceremonies enacted during this period was the presentation of tribute (i.e., food, bark cloth, human offerings) to Pomare II by various tribes and subtribes. ${ }^{5}$ Those from Aharoa traveled to Matavai to make their contributions, but Pomare II himself went to Pare and Atehuru for the presentations from those places. In connection with his visit to Atehuru he and his retinue went well armed, as acknowledgment of the hostility toward him still prevalent there. (Similar tribute-rendering ceremonies were later accorded Pomare II in Seaward Teva, but I can find no report of any such having been rendered by the Landward Teva - although their contributions may well have been made while Pomare II was receiving the tribute from Atehuru.) 
Of even greater importance, symbolically, was the series of kin-Title-investiture ceremonies that culminated during this period. (Such ceremonies had apparently been going on for some time, but had escaped the notice or comprehension of the missionaries.)

Today the people of this District presented the king with 20 Hogs, some English and Taheitean cloth, two Breastplates \&c. \&c. It is part of an Oroa or ceremony called Bure toto or Fa Eree te Eree, that is, making the king chief of this District, by investing him with the ancient chiefs name of Teepa by certain prayers \&c. - therefore it is said to be a confirming him king of Matavae. This Oroa is a part of the ceremony for the king, that has been performing for several years past, and is to be observed in most if not all the Districts in the Island - some have had it performed, in Pare he is called Tunue-ai-te-tua, in Faa he is called Te Eree vae-e-tua, in Attahuru he is called Te-vahe-atua, in Taearabu he is called T'Eree-navaho-roa, and in Eimeo he is called Punua-te-rae-e-tua. These names given to the King, signify his authority as being invested with that power, which in old times belonged to the several Chiefs who presided over the different Districts, and are used on particular occasions. (Davies, Youl et al., 24 May 1806, LMS Archives)

With the image of 'Oro were transported to Tautira the images of five other deities: Hiro, Tane, Temeharo, Ruahatu, and Huiima'o. (The last two were shark-gods, and Temeharo was the principal familial tutelar of the Pomares.) These other images evidently served as a kind of honor guard for 'Oro, as it was reported that they were to be returned to Mo'orea after 'Oro's image had been installed at Tautira (Jefferson, Journal, 28 January 1806, LMS Archives).

One should not conclude from my brief statements that the flow of goods between Pomare II and the populace was always in his direction. Some of the so-called tribute was evidently redistributed, either in the form of allotments to tribal chiefs and subchiefs or of free-for-all "scrambling." Also, on some occasions, Pomare II acknowledged, and thereby publicized the eminence of, the principal chiefs by making special gifts to them and calling out their names (or Titles?) (LMS Transactions:III, 172). And, following upon some human offerings he had small portions of the victims' bodies cut off and sent to the chiefs of some tribes as confirmation of friendship - a token which the missionaries described as having been received with much satisfaction (LMS Transactions:II, 322).

During September 1806, an especially large meeting, a tavau, was held in Pare which evidently included representatives from all the island's tribes. Food and other objects passed to and from Pomare II, and some ten days were spent in feasting and in making plans for a solemn ceremony scheduled to be held later on at Tautira. According to Davies' version the coming ceremony was to be a pure ari'i, or "worship for the king" (Newbury 1961:87), ${ }^{6}$ and it was to require five more human offerings: one each from Mo‘orea, Aharoa, Seaward Teva, Landward Teva, and Atehuru - a most 
telling indication of current political geography (Youl, Bicknell et al., Journal, 30 September 1806, LMS Archives). The absence of Porionu'u from this levy was probably due to its having been Pomare II's own tribal unit. ${ }^{7}$

At this same meeting a demand was voiced for a large tract of land to be set aside for the exclusive use of 'Oro:

One of their principal Prophets has for some time pretended at be inspired and says that Oro must have the land on the North and Eastern sides of Taearabu to himself, (which extends to the Isthmus from the Rocks, about 20 miles in length) and therefore all the people who reside in the several Districts within the said boundary, must leave their lands and houses, and go to the south side and dwell. The principal Chief of Taearabu asked the king leave for the people to continue on their land, but he gave no answer. And it is said that if they refuse to obey, they will incur the gods anger and may terminate in a war between them and the King. (Youl, Bicknell et al., Journal, 30 September 1806, LMS Archives) ${ }^{8}$

Before this meeting, Pomare II's wife died. Her written obituary is brief:

This morning about nine O Clock the Queen departed this life, she was (we suppose) about 23 or 24 years of age - her person was of the middle stature, of a delicate constitution - affable in her behaviour - She possessed little more than the name of queen, having no Authority. All the children she has had have been killed, as it is said, they were by common men, Owo her mother - Edea - Taepoto the chief of Aemeo and two other women according to the custom of Tahaite, cut their heads with sharks teeth, and lamented over the deceased; the King appeared affected, as also some of the people about him. (Davies, Youl et al., Journal, 21 July 1806, LMS Archives)

In late May 1807 the peace that had settled on Tahiti during several months past was suddenly broken by a fierce and unhearalded attack upon Atehuru by Pomare II and his warriors. Eight or so persons were slain in the first assault and the rest driven into the mountains, where many more were also slain, including the two most "disaffected" subchiefs. The immediate cause of the assault was described as follows: "The cause of the offence it seems was the conduct of the people of Teoropa, in taking the bones of Mateha, a chief killed by them in the last war, and making fish hooks of them. This had been done as an expression of contempt for the king who was related to the late chief." (Thomson, quoted in Newbury 1961:97n; see also Adams 1901:149-150.)

When the Paparans and other Landward Teva people sought to aid the Oropa'a they too were attacked, their warriors driven into the mountains, their settlements plundered and burned, and their crops destroyed. (The Seaward Tevans showed an inclination to join with their neighbors against Pomare II, but were so impressed with the speed and ferocity of Pomare II's forces that they joined with the latter instead - though evidently not in time to win ultimate exemption for themselves.) 
For several weeks thereafter Pomare II's forces ranged through the defeated areas searching for survivors to kill and property to seize or destroy. Some missionaries traveling through the area at this time on a mission of mercy found almost total desolation, and great numbers of corpses left to rot or destined for the Tautira marae. Throughout September the work of destruction was extended to Taiarapu and would probably have gone to the limits reached in Atehuru and Landward Teva but for an illness that overtook Pomare II.

Sometime during this war some prominent leaders, including Te To'ofa, ${ }^{9}$ surrendered to Pomare and were granted refuge by him, only to be eventually slain. Supposing his illness to be a supernatural visitation in consequence of this act of treachery, Pomare II ordered an end to the slaughter and declared a general amnesty. ${ }^{10}$

For the moment, then, all effective opposition to Pomare II was put down; but the "King" himself knew how temporary such victories tended to be and warned both his mother and the missionaries to be prepared to flee the island in case he should die.

In October another great meeting was held at Pare, reportedly “... for the purpose of dividing the lands of the conquered Districts viz. Atehuru \&c. and appointing their respective chiefs" (Newbury 1961:104). The missionaries have provided a colorful account of the ceremonial proceedings of this event and of the clothing worn by the principals. They also reported at length on the fact that one small portion of Puna'auia land was granted to themselves - a tract called Outumaoro near Tata'a Point. But concerning the politically important aspects of this extraordinary event - the specific units into which the conquered territories were divided, and the identity of their new proprietors - not one word was reported! (Newbury 1961:104; Davies, Journal, 12 October 1807, LMS Archives)

Ten months passed without the occurrence of any major political upheaval, but there did take place events that had some bearing on the political situation. In March 1808 Pomare II lost another loyal supporter with the death of Auo, the last survivor of his father's siblings, and the mother of his own first wife. As wife of Mahau, Auo had played a prominent part in the Mo'orean Succession War, and latterly had been Pomare II's appointive chief of Ha'apaino'o. Then, in May, 'Itia and her husband Tenania removed to Huahine; 'Itia seems to have had less influence upon her son than she had had upon his father, but her absence certainly did not serve to strengthen Pomare II's cause.

Meanwhile, Pomare II made a lengthy visit to Mo'orea; when he returned to Pare in early May he was very ill and evidently very anxious about his political fortunes, not to say about his life. When an explanation was sought for the cause of his illness, the principal 'Oro taura there- 
abouts, a man named Metea, could not (or would not) offer one. Instead, a taura inspired by Tepa, the healing god, declared that it was Tepa who had stricken Pomare II, in consequence of this god's having been ill-used some months previously. The report of that occurrence warrants reproduction on several counts:

Yesterday a man was killed in Pare for a sacrifice, and we find today that this was the real cause of Pomare's coming here, he had given orders for the man to be killed but did not like to be present at the time, at first we supposed it was a sacrifice to Oro on account of Pomare's late illness and recovery, but we were mistaken the cause of the sacrifice is said to be as follows; some years ago, when the people of Atahuru \&c. had rebelled and made war upon the king and his Father, every method was then used by Pomare's party to make the gods propitious, as is common in such cases, but one of the gods, called Tepa, did not display his power, nor do that for the protection of his votaries that was expected from him, this exasperated Paraha the late chief of Pare to such a degree, that he resolved to use the god in a similar manner to what some of the Negroes in Affrica are reported to do when their gods disappoint their expectations. Paraha took the Too or image representing Tepa, broke it to pieces and put it in a basket called Habora, the same as those human sacrifices are put in, and then he took the Habora, and the broken image in it, to the Marae and offered it a Sacrifice to the god Oro. Thus was Oro magnified at the expence of poor Tepa, however the despised god was (as the Taheeteans think) meditating a severe revenge for this spiteful way. Paraha was taken ill of the Dropsy, and died some months ago, and now Tepa has inspired one of his worshippers who declared in the name of the god that Tepa had already killed Paraha the chief of Pare and that he would also lay his hand upon the king, except his anger was quickly appeased by offering him a human sacrifice, and in consequence of this the man yesterday was killed and offered to Tepa ... and some say that he must have more human victims. (Davies, Journal, 23 October 1808, LMS Archives)

According to the taura, Tepa would withdraw Pomare II's illness only upon assurance of receiving some human offerings and a certain piece of land on which would be built a marae for him. Pomare II promised to do these things, so that his recovery, which occurred shortly thereafter, was attributed to these actions, thereby serving to rehabilitate the offended Tepa to a position of near-rivalry to 'Oro himself.

\section{QUALIFIED DEFEAT}

In August 1808 there began the series of events that culminated in the defeat and temporary eclipse of Pomare II. The facts, as reported by the missionaries, were as follows:

On Sunday last a number of people from the District of Hedea [Hita'a] arrived at Matavae, bringing with them some Cocoanut leaves, which they laid at Pomare's feet, these leaves were called Rahere, and the meaning of the Ceremony seems to be, an acknowledgement of Pomare's sovereignty over the Hedeans. This transaction gave a great offence to the people of Pare, they look upon it as an indignity to them to have the ceremony performed in Matavae instead of Pare 
the kings own District. Today brothers Eyre and Scott went down to Pare ... they found almost all the people of Pare gathered together at the big house at Papaoa, dressed and armed for war, and talking about falling upon Matavae but they were waiting for one or two of their principal chiefs who were absent. The brethren therefore returned without having an opportunity of speaking to them. The people of Matavae are much alarmed today, they took a large hog as an atonement to the king, but they say they are innocent and that all the fault is the kings. The king sent several messengers to the people of Pare, and there is a probability that the affair will be amicably settled. (Davies, Journal, 9 August 1808, LMS Archives)

And so it seemed to be - for the moment, at least. But there was evidently more to the affair than the missionaries were aware of, for their Matavai neighbors voiced the suspicion that "... the king has some evil design against them, and that the occurrence mentioned was a preconceived scheme of his" (Davies, Journal, 13 August 1808). And on his part, Pomare II warned the missionaries to be on guard against the Matavaians, because of their talk of war against the missionaries and himself (Davies, Journal, 3 October 1808).

Like most other inhabitants of Tahiti, the Mahinans had ample grounds for their hostile feelings toward Pomare II - feelings that he was undoubtedly aware of - so they were probably correct in suspecting him of contriving a casus belli. In any case, although the Hitia'a affair was settled with a prompt tarae hara, the mutual bad feelings simmered on. The Matavaians were further incensed by Pomare II's taking of another human offering from among them, and Pomare II's feelings were inflamed by the revelation received from 'Oro, through the taura Metea, urging war on the Mahinans. Matters came to a head in November:

Novr 6th. About 11 at night some of the king's people alarmed the miss. with a report that a great number of the people of Matavai, were armed and assembled by the sea side at Hitimahana (less than a mile from the miss, residence) apparently with some hostile intention.

The king was then on board the brig drinking, and unacquainted with the state of affairs. Messengers were dispatched to tell him, and bring him on shore. In the meantime, the king's people gathered together and armed themselves, and went towards Hitimahana, but soon returned without doing anything.

The king came on shore drunk, and assembled his people near the large house of the miss. where they were for some time deliberating upon the measures they should pursue. The king wanted to go and fall immediately upon the Matavaians, but his uncle Taipoto, the chief of Eimeo, dissuaded him from it, representing the necessity of prayers \&c first. But while they were thus deliberating, all the Matavaians fled over Tapahi to Paperipo, first the women and children, then the warriors. Not an individual was left behind, except the servants of the miss. and a few that lived by the sea side close to Pomare's people. Messengers were dispatched to bring up the people of Pare, and also those of Faaa \&c to the westward. The people came up just as it was daylight and then they, and Pomare's servants, scattered themselves thro' the District, plundering and destroying, some few houses were burnt, all the canoes seized, and also all the hogs they could catch. 
Had Pomare's plan been adopted of falling upon the Matavaians immediately, it is probable the rebellion would have been soon crushed; but so infatuated were the king's people, and so bound by their superstitions that they would not stir a step beyond the usual routine of prayers, sacrifices \&c. The priests went to their prayers, and sacrifices to engage Oro on their side, and a man was killed immediately to be a sacrifice to him, was put [in] a canoe in a haapora (basket) and sent by the way of Papara and the isthmus to Tautira. This delay afforded time for the disaffected to assemble together, and get the people of Hapaiano to join them, and also to send messengers to the Districts to the eastward. They also endeavoured to get Oro on their side, killed a man to be a sacrifice to him, and sent him to Tautira the eastern way. Each party appeared to be in earnest to get the god on their side.

In the evening the miss. heard there was little doubt of all the eastern side of the island joining the rebels, the king had sent messengers to the chiefs on that side but had received no answer. This was perhaps the most gloomy Sabbath day ever spent by the miss. tho' they had been in very trying circumstances often before. They could hardly meet for public worship for noise and confusion about them, tho' they attempted to meet together for prayer \&c.

Novr 7th. The miss. had had little sleep the past night most of them kept watch not knowing what might happen. They heard in the morning that the rebels were encamped in Hapaiano, waiting for those of the Districts to the eastward to come and join them.

Pomare sent a messenger to them to signify if they were for Peace, he was not for war, he also requested that two of the Raatiras, one belonging to Matavai, and the other to Hapaiano, would come to him.

By the time however that the king's messenger had reached the camp, Vaiturai, the young chief of Tiarei (the present Hitoti) with his party had arrived at the camp all talk of peace was therefore at an end. The two Raatiras sent for would not come to the king, and it was expected that in the afternoon, Taute the chief of Faena and all his people would come, as also Teohu the chief of Hitiaa. And it was expected Taute would head the whole party. The miss. dreaded this Taute more than any man on the island, as he was courageous and enterprizing, and many instances of his treachery and cruelty had occurred. He had been called Mr Pit by foreigners and had been Pomare's chief counsellor, had lands given to him after the conclusion of the late war, and was under many obligations to Pomare, and yet it now appeared that he was the very soul of the rebellion.

The king also and his people, on learning how Taute was likely to act, and that he was apparently at the head of the rebellion, were much discouraged. Pomare observed to the miss. that Taute was a warrior, and knew how to act, he advised therefore that the wives and children of the miss. should by all means be sent on board the ship then in the harbour. As it was not at all improbable that Taute and warriors would come to Matavai that night. This was also their own opinion, they thought the party now under the conduct of Taute would come and attack the king and in that case they knew not what to expect. (Newbury 1961:116-118)

One circumstance that happened on the passed day (the 7th) deserves to be mentioned, as it had a great effect on the minds of both parties. Meetia, the prophet of the god Oro, was said to be inspired, at which time he happened to have a dispute with a prophet of Tipa, as they were disputing he suddenly started, and ran away over the rocks and precipices of the hill Tapahi towards the rebel camp at Hapaiano. Some of the king's people attempted to detain him, but in vain. He pro- 
ceeded to the camp and joined the rebels. This discouraged Pomare's people very much, and as much elated the other party, for it was looked upon by both parties as the action of the god not of the man, who was well known as Pomare's friend. (Newbury 1961:118)

This threatening situation prompted the majority of the missionaries to leave the island, and they went aboard the brig in order to take passage to Huahine. ${ }^{11}$ Their version of the war continues:

In the afternoon, there was a report there should be peace, and the king in public talked as if peace had been made, but called some of the miss. aside, and said secretly there was no real peace, that he was afraid of his own people, that the Porionuu or people of Pare upon whom he depended most, had already shown themselves inclinable to betray him. Temaehuatea their principal chief had secretly sent several messages to the rebels, and evidently intended to espouse their cause. (Newbury 1961:119-120)

In the afternoon [Nov. 9] at the request of Pomare, two of the miss. Messrs Nott and Scott went to Hapaiano to the rebel camp to speak to the disaffected chiefs, and endeavour to persuade them to come to Matavai and have an interview with Pomare. The chiefs received them in a friendly manner, said they were sorry for the miss. and inquired if it was true they were going away? Being answered in the affirmative they were earnest in persuading them not to go. And there was no doubt some of them had a friendly regard for the miss. though not on account of their religion; yet in case they should prevail against Pomare, they had no power to protect them against the wild rabble that followed them.

The miss. endeavoured to persuade Taute and the other chiefs to come and have an interview with Pomare. But to this they made many objections, mentioning several instances of treachery that had occurred during the late war, and saying they had apprehensions of being served in the same manner as others had been. A(t) last they agreed to come to Matavai with their men, and that Pomare also might bring his men, and that the wariors on both sides should remain behind their leaders at a distance, then the chiefs to advance to the middle, and meet Pomare there with as many of the miss. as would come. Mr S(cott) then returned to acquaint Pomare with these terms, leaving $\mathrm{Mr} \mathrm{N}$ (ott) with the chiefs to conduct them to Pomare. The king being made acquainted with those agreed to them and advanced with his people to Hitimahana, thinking the others were coming. After the departure of Mr S(cott) the chiefs hesitated, and would not come that day, but sent to Pomare they would come the next. Mr N(ott) then returned to his brethren, and Pomare began now to hesitate about going in the ship, thinking if he left the island he would lose all at once, but by staying there might be a chance of recovering his affairs, but he said perhaps the people would cut off his head as the people of France had done with their king. (Newbury 1961:121)

Other sources provide somewhat different accounts of this episode:

The outrage of June, 1807, had exhausted the last remnants of patience in the islanders, and this time the whole island rose, determined to make clean work of Pomare and all his surroundings. For this purpose they needed a warrior, and as a warrior Opuhara had no superior. So Opuhara became chief of Papara, and soon afterward head chief of the island; for he and his army advanced to Papenoo in 1808, and there, on December 22, Pomare attacked them, and was totally defeated. Po- 
mare and his household, and the whole missionary establishment, without waiting for further notice, abandoned the island, and fled to Eimeo. (Adams 1901:153)

Success had made the conquerors insolent; they indulged in unspeakable atrocities and cruelties, but all the more unbearable was that these (conquerors) for the most part were strangers from Huahine, Ra'iatea, Taha'a, etc., who came to the aid of Pomare and who made up a large part of his army.

Their imprudent conduct produced discontent, which despite the conquered being downtrodded, soon resulted in another war, which failed to remove Pomare's power permanently. This (war) broke out for such an unusual reason in this country, that it is worth describing.

Metouave, a common man but very courageous, had a wife renowned for her beauty and whom one of the principle officers of the king wished to have. The husband and the wife both rejected him. A few days later, she was wrested from her home by force. The husband, furious, ran to announce everywhere the violence of which he was the victim; and so by these speeches he shared his indignation with the people and stirred them up to revolt.

In a few days a large number of discontents met at Hirahouraia or Tire, under the orders of Pafai, who was still living, and at Oahouio. They marched against Pomare, who was at Papara, coming from the North, while the inhabitants of Papara and the Aroopas, who lived in the southeast, came from the other side. All the island rose up. No one remained loyal to the king except strangers, who, attacked from everywhere at once, had many losses and could not hold up. He himself was forced to leave the island and to retire to Eimeo with what was left of his army. (Moerenhout 1837:II, 447-448)

In the end, Pomare II remained at Matavai with four bachelor missionaries and his more loyal followers, while his adversaries continued at Ha'apaino'o; and such was the state of affairs when the brig sailed for Huahine taking the other missionaries along.

The following April (1809) two of the missionaries who had remained at Matavai made their way to Huahine with information about the state of affairs on Tahiti:

They reported, that there had been a cessation of hostilities between Pomarre and the rebels, from the departure of the Missionaries, in the Perseverance, to the $22 \mathrm{~d}$ of December; on which day, Pomarre being infatuated by the predictions of the prophet Metea, rashly attacked the rebels in the district of Onowhea. The enemy had not only a superiority of numbers, but also greatly the advantage of ground. Pomarre's party was repulsed, and fled to Nanu, some of his principal men were killed, and many muskets fell into the hands of the rebels. The four Brethren, as soon as they heard of this defeat, sailed for Eimeo. In the meantime, the rebels overrun the district of Matavai, Pare, \&c. and committed great devastations. The picture of King George, which was sent from England to Pomarre, was also taken by them to the Marao, and offered to Oro. Pomarre, after staying three weeks at Nanu, followed the Brethren to Eimeo, where Messrs. Scott and Wilson left him, with the Brethren Nott and Hayward. (LMS Transactions:IV, 335-336)

In September 1809 there occurred another event which signaled the end of this chapter in Tahiti's history. The first European ship to an- 
chor at Matavai after departure of the Perseverance was the Venus, a twenty-ton schooner from Port Jackson. It was forthwith captured by some Tahitians, its mate killed, and its master and all the crew made prisoner. Forty years earlier the pioneer Dolphin had been attacked by Tahitians, and more recently the castaway company of the Matilda had been relieved of some of their property, but otherwise Europeans had suffered little more than thievery or ridicule from their Maohi hosts. And, to underscore the radical nature of this turn of political events, the hope and patience of the long-suffering missionaries finally ran out and most of them embarked for Port Jackson, believing their mission to have failed.

Some discussion is called for to review and try to explain the events that led to this radical change in the political fortunes of Pomare II, only a few years after he had reached the pinnacle of rank-status and of force-sanctioned authority. The measures used in reaching that pinnacle - mostly by Pomare II's father, by his great-great-uncle Tutaha, and only in small part by himself - were as follows:

winning and maintaining European military support, both in terms of an almost complete monopoly of firearms and of active military aid;

securing an almost monopolistic supply of other European objects and distributing them among other Maohis in return for political support;

adding luster to their established rank-status preeminence through prestige-enhancing associations with European leaders;

skillful use of established kinship connections, along with the formation of valuable new ones;

and, gaining most influence with, and most direct access to, the island's most powerful god, 'Oro.

As we have seen, Pomare II continued to utilize these strategies, along with some new ones; so why, one may ask, were they less successful than before?

During the five-and-a-half-year period now under consideration twenty European vessels visited Tahiti, some more than once, and Pomare II continued his forebears' policy of courting the visiting Europeans ${ }^{12}$ - but such efforts were nowhere near as rewarding as they had been in the past. For, by this time firearms were in the hands of nearly every one of the island's principal chiefs. Although many arms originally acquired by others eventually found their way into Pomare II's arsenal (LMS Transactions:III, 36), a large enough number was outstanding to render his advantage less overwhelming.

As for other objects of European origin, nearly everyone on the island now had some iron and some article of European dress, so that gifts of such items were no longer as productive of political advantage as they 
once had been. Moreover, it appears that Pomare II, unlike his father, kept for himself most things received from Europeans. Despite his requests, during this period, Pomare II was never once successful in influencing Europeans to fight his battles. Besides, by this time, many Tahitians were themselves skilled in the use of firearms, and most of them had lost their awe of an armed European.

Nor was there much advantage to be gained, in tangible ways, from close association with Europeans. Many if not most Tahitians had come to harbor hostile feelings toward Europeans in general (though not apparently toward all European individuals) on account of the sicknesses that were so widespread - sicknesses that they almost universally, and bitterly, attributed to Europeans. (LMS Transactions:II, 328-330)

In other words, the awesome wonder that was formerly associated with everything European was most definitely a thing of the past, and the earlier advantage enjoyed by the Pomares as a consequence of such association became in some measure a liability. ${ }^{13}$

Another measure utilized by Pomare II's forebears in support of their aspirations was the exploitation of old kinship connections, and the establishment of new ones. Pomare II also utilized such measures, but to far less extent and to considerably less advantage. In terms of politically profitable alliances, Pomare II (probably through no will of his own) was married to his own first cousin, and his younger brother to the latter's sister; thus, considerations of rank-status eugenics were allowed to overrule those of political alliance. Actually, these considerations appear to have been pushed so far that, according to one presumably "official" view, after the death of Pomare II's first wife there remained but one female on Tahiti-Mo'orea of sufficiently high rank-status for him to marry, and even that union did not take place (LMS Transactions:IV, 185). Moreover, Pomare II failed to sire any offspring by his first wife and thereby lost the opportunity for acquiring the means of forming politically useful alliances through an offspring's marriage.

Pomare II did, it is true, attempt to exploit his kinship connections on two different occasions: once, when he forced the Mo'oreans to accept his infant half-sister as their ruler, and again, when he appointed his female cousin to the chieftainship of Ha'apaino'o. In both cases, however, he did so over the strenuous objections of the appointees' new subjects. In the case of Mo'orea he had to put down an armed opposition to gain his point; and in the case of Ha'apaino'o his appointee died soon thereafter, before the political objectives of his action could be achieved. ${ }^{14}$

In fact, there remained very few close kinfolk for Pomare II to lean upon, even had he been so inclined. All siblings of his mother were dead, and the last remaining sibling of his father died during this period; even 
his mother, the once formidable 'Itia, left his side to go with her husband to Huahine.

So, instead of the kinfolk - who, despite temporary differences, had provided such political strength for his father's regime - Pomare II found himself surrounded and dependent upon a motley of parasites, including the mischief-making Metea (the principal 'Oro taura), and a crowd of Ra'iatean Ariois and bloodthirsty Hawaiian castaways, whose time (in the words of the missionaries) "... appeared to be taken up in feasting and merriment."15

As events were to demonstrate, support from persons like these tended to melt away in times of stress. And, although the preceding pages have made it abundantly clear that kinship among the Maohis was no warranty of loyalty, it did transcend ruthless self-interest more often than did other kinds of relationships known to them.

The most substantial, and eventually most effective, type of support courted by Pomare II was in the persons of chiefly Leeward Islanders. His mother's second husband, Tenania, was, as we have seen, a high-ranking Titleholder and co-chief of Huahine; and Pomare II was reported on one occasion to have organized an expedition to send presents to Ra'iatean chiefs (Youl, Bicknell et al., Journal, 20 August 1806, LMS Archives). ${ }^{16}$ His preference in that direction is also evident in his patronage of an immigrant Ra'iatean named Paraha, ${ }^{17}$ described in one report as "the most thriving man on the island"; "He [Paraha] has lately been made a rattera of Oparre \& his favour is much courted in tht. district. If anything should happen to the king, he is likely to be made of much consequence. He is a distant relation of Pomerre's \& is from Ryatteea." (Jefferson, Journal, 24 January 1805, LMS Archives)

Pomare II also adopted his forebears' strategy for gaining and maintaining political power by the process of eliminating the opposition - and if anything he was more uncompromising in that than they. I need not repeat the passages describing his many ruthless military campaigns, or the instances of unprovoked and even treacherous murder carried out at his behest. Many of the killings ordered by him were phrased as offerings to the insatiable 'Oro, but the bitterness and vengefulness engendered by them were evidently no less intense. Even Pomare II himself appears to have recognized that he had overreached the limit in this regard, as witnessed by his self-acknowledged guilt in the treacherous slaying of the defeated chiefs who had sought refuge in his camp (Davies, Journal, 7-16 September 1807, LMS Archives).

But Pomare II did not restrict himself to physical measures in eliminating opposition. It is reported, for example, that on one occasion he brought about the death of a Mo'orean by prayer: 
The story is thus told: Otoo was at his worship, and while employed, was disturbed by some one's beating a drum. He sent to order the person to desist; but his order was not obeyed, and the man continued beating; on which the king said, "Let him alone": and that same night the man expired. This is esteemed by the natives as an infallible proof of the power of their god Oro, and of their king Otoo. (LMS Transactions:II, 317-318)

Under Pomare II's regime some actions traditionally regarded as trivial errors, or no errors at all, came to be treated as crimes of lese majesty. For example, the chief of Tiarei was banished from his lands for eating part of a turtle, a delicacy which formerly had been accessible to any male tribal chief or high-ranking Titleholder (Jefferson, Journal, 28 February 1805, LMS Archives). Again, for garbling a message from Pomare II to some priests, an aged messenger was condemned to death (Davies, Journal, 29 July 1808, LMS Archives).

Indeed, so encompassing did the presence and will of Pomare II come to be that many reversals formerly put down to the vindictiveness of miscellaneous spirits came now to be attributed to acts (deliberate or otherwise) of lese majesty. For example:

Tuesday, 20. There have been for several weeks upwards of thirty sailing canoes, waiting for a favourable wind to go to Te-tea-roa; they have several times made the attempt, but have been compelled to return. The Taheiteans are easily made to believe that the cause of their miscarriages, in the general, is on account of the god' or the king's anger. The present disappointment, they say, is on account of the king being angry with them, and that while his anger remains, the wind will continue against them. They went to Edea for advice, which was, to take a tara-ae-hara to the king, to which they agreed, and yesterday they took a young pig for an atonement to the king, who is at Hapaeano. (LMS Transactions:IV, 183)

The severity with which Pomare II countered opposition, or even suspicion of opposition, may have served to secure immediate political objectives, but there is much evidence for concluding that it produced an almost universal residue of ill feeling toward him and his regime.

Like his father before him Pomare II also courted the favor and support of the god 'Oro for what appear to be political objectives. But unlike his father he went so far in this direction that his attentiveness to the god eventually worked against his political interests. Consider, for example, the numbers of persons slain to provide offerings to 'Oro. An exact count of such victims is impossible to make, but my estimate is that several scores met that fate during the period now under review - not including those slain in wars and afterward presented to the god. One does not have to fall back on "human nature" to explain attitudes of recrimination on the part of the victims' kin and friends. I give but two modest examples from the LMS Transactions:

May 1st. Hear that the inhabitants of Fwhaa were very near coming to blows with the king for the murder of the man for a sacrifice yesterday. They resented it because it was a young and useful man that was killed. (II, 304) 
When we have endeavoured to persuade the people, in public and private, to turn from their vanities, and worship the true God, they have frequently replied, by asking, Whether any of the rulers have believed, and turned unto the Lord? They frequently mention Pomarre's killing men for sacrifices, and tell us to go and preach to the king and him. The generality of the people are dissatisfied with his conduct in this particular: and, in some, we have seen a disposition to retaliate. One man was heard to say that Pomarre came to his house seeking a sacrifice, and had his friend, who was sitting by him been killed, he had his spear by him, and would, be said, have killed the man who killed his friend, or Pomarre. (II, 327)

Dispossession of land for 'Oro worship was probably only slightly less popular a measure than loss of a kinsman or friend. There is no report of people having been dispossessed to make way for the uninhabited district dedicated to 'Oro on Mo'orea, but opposition is recorded to the proposal to set aside a twenty-mile stretch in Taiarapu for that purpose (Youl, Bicknell et al., Journal, 30 September 1806, LMS Archives).

Pomare II's almost slavish dependency upon 'Oro was manifested in certain other ways that adversely affected his political fortunes. The extent of that dependency is attested in several passages in the missionaries' journals, such as the following:

Last night the Prophet that has been attending Pomare all the time since the commencement of the late war, came to him in a great fury, being inspired as he pretended by the god Oro, he declared in the name of the god that he had raised up Pomare from his late illness, blamed him for his remissness concerning certain prayers and sacrifices that he has not attended to as he ought to have done, as also his neglect of causing some houses to be built, he threatened to lay his hand upon Pomare again if he did not speedily observe those things. Pomare appeared alarmed, and it seems he has determined to comply, and for that reason will go down in a day or two to the District of Pare, and some say the god must have a human victim, perhaps more than one. (Davies, Journal, 7 October 1807, LMS Archives)

On some occasions Pomare II was persuaded by 'Oro taura to undertake irresponsible military adventures against recognized odds, and with disastrous consequences. (See for example the raid against the Oropa's in 1809.) And on other occasions military advantages derivable from prompt action were allowed to lapse while Pomare II was carrying out the ceremonial accompaniments of warfare dictated by 'Oro's clergy. (See for example the Oropa'a's devastation of Pare, while Pomare II and his forces were at Tautira.)

Finally, there is dramatic evidence that Pomare II and his associates had begun to recognize the disadvantages of their exclusive attentiveness to the one god, 'Oro. (I refer to the case of "Tepa's revenge” mentioned earlier.)

As we have seen, most measures undertaken by Pomare II to secure his political objectives were continuations, at intensified levels, of strategies followed by his father. In one respect, however, he went far enough beyond his father to give the appearance of innovation, and that was in his substitution of direct rule for indirect, in territories conquered by him. ${ }^{18}$ 
The principal action undertaken by Pomare II in this direction was the "division of lands" described earlier, and his appointment of new, and evidently nonlocal, individuals to preside over the conquered territories. As indicated earlier, except for the report that such land divisions and new appointments were made, we are provided with no further information about this momentous event, but it is probably safe to assume that the advantages gained by Pomare II in having his own appointees installed in these territories were more than likely offset by the local resentment engendered by such moves. Moreover, in at least one recorded instance, the appointee eventually turned on his patron and led a large-scale "rebellion" against him. (I refer to the famous Taute, Pomare II's former chief counselor [Newbury 1961:118]. Another action of Pomare II that may be regarded as a substitution of direct for indirect rule, was his personal assumption of several high-ranking kin-Titles traditionally associated with other tribal chieftainships. Multiple kin-Titleholding was of course not a new development in Maohi history, but in the past most such instances involved an individual's succession by purported descent, or by fosterage. It may be that Pomare II was able to justify some of the Title taking he engaged in by reference to legitimate or contrived kinship connections, but there is no evidence that that was attempted or even considered by him to have been necessary.

A question arising at this point has to do with the distinction to be drawn, in Maohi terms, between "ruling" and "governing." I referred to such a distinction when contrasting chieftainship of kin-congregations with that of tribes. As I indicated, I believe that popular expectations regarding such roles did in fact include some differences - although I acknowledged the methodological difficulty of deciding what those differences were. In any case, while I continue to recognize the difficulty in documenting such propositions, I believe that some of Pomare II's behavior did not conform to most Maohis' notions of what constituted a "good chief" or even a "great chief." In his disregard for the welfare of his ordinary subjects he certainly did not live up to what was expected of a chief by members of his own kin-congregation. And there is reason to believe that he exceeded even the broad limits of willfulness in a tribal chief tolerated by members of his tribal unit. I touched upon this matter in my discussion of human offerings, but there were other kinds of excesses as well - that is, actions which even this long-suffering populace considered to be "excessive" - for example:

Such is the rapaciousness of the king and chiefs, that the common people can keep nothing scarcely; for as soon as they know that they have any thing valuable, it is sent for; and if denied, taken by force: the consequence is, the people are discouraged, which would be prevented if a moderate share was left them, and be an additional comfort and reward for their labour. (LMS Transactions:IV, 184) 
As I attempted to show in an earlier chapter, the image of a benevolent leader who spends his time maintaining equities and redressing wrongs among his subjects is hardly applicable to Maohi tribal chieftainship even in a normative sense. Nevertheless, Pomare II appears to have maintained an aloofness from such concerns to a degree that even some Maohis may have found unwarranted. I reproduce below a rambling but revealing account by one of the missionaries:

This morning a barbarous murder was committed by one native on the body of another in a house a few yards distant from us. The murdered man it appears had been guilty of a very petty theft, and for which he lost his life. He was struck a dreadful blow on the nape of his neck with a Tommahawk that almost severed his head from his body \& his right shoulder was horribly cut with repeated blows. The perpetrator of this savage act walked about afterwards with the Tomahawk in his hand, with as much unconcern as if he had been splitting up fire wood, \& behaved very insolently when spoke to about it. The person killed belongs to Paheete's jurisdiction, who is now in Oparre; but it is apprehended that no notice will be taken of the matter whether by him or Pomarre (to whom the other man belongs) as he was accounted a person but of little worth, \& his murderer is a man of consequence. This same man who has so inhumanly destroyed his countryman for a mere trifle we have reason to suspect of having plundered us of various valuables. Towards evening Paheete arrived in the district. He made some enquiries concerning the above murder, and ordered the corpse which its murtherer had buried to be digged up \& to be placed within view of him in Edeea's house on the point where he is fled for refuge. It appears that this is held by the natives as a mark of abhorrence of the act, \& what is very unpleasant to the guilty person. There is some talk among our neighbours, that the inhabitants of this district \& Hapyano will revenge the murder \& even burn Edeea's dwelling in which the man has sheltered himself. If this shd. be done it will certainly produce a war. The servants of Edeea removed her property from the point into br. Nott's apartment for fear of the worst.

12.24: Nothing has this day been done towards avenging the murder. It is said that Pomarre has been made acquainted with it, and justifies the deed, and has given directions that nothing be done to the man.

12.25: Missionaries agree to ask Pomare to remove the murderer from the district, \& to inform him of the law of civilized nations regarding such crimes.

12.27: Brs. Eyre \& Elder ... found Pomarre in Nannoo bay and declared their message to him.... He directed them to Edeea, alledging that the man belonged to her, $\&$ therefore application shd. be made to her from his removal from Matavai. After some time the chief acknowledged that the man had been unjustly killed but either did not or would not understand that no one of his subjects had right to avenge himself after such a manner, \& that it belonged to him as governour of the Island to judge between man \& man \& punish the guilty. Nor did he seem to take any notice when told that the law of God had been violated by cruelly shedding blood. Some of his attendants were more candid than Pomarre on the occasion \& confessed that the crime was to insignificant for which the man had been killed $\&$ that the murderer deserved banishment \& advised the chief to banish him. He said at length that he shd. be removed out of the district, but he spoke this so cooly that there is reason to doubt his word \& also still recommended that appli- 
cation should be made to Edeea. As Edeea is in Attahooroo the brethren did not think it meet to proceed without knowing the Society's mind, \& the Society did not see it necessary to pursue the matter further at present. (Jefferson, Journal, 23-25, 27 December 1802, LMS Archives)

It might be argued that some of Pomare II's popularly adjudged excesses or shortcomings were offset by the attention he devoted to enhancing the trappings of high rank-status and great political power - for such he did to a surpassing degree, in the form of rituals and feasts and other assemblies of many kinds. In fact, an uninformed observer might have concluded that life in Tahiti consisted entirely of, and was about equally divided between, wars and ceremonies. Such of course was not the case, but under Pomare H's regime his activities (and inactivity) were ceremonialized considerably more than those of his father or other known forebears. The question becomes, Did this frequent and highly acclamatory symbolic acknowledgment of Pomare II's preeminence serve his more tangible political objectives?

The answer was eventually provided by events themselves, for when his enemies began to gather on Tahiti against Pomare II he was found to have no friends outside his home district of Pare. Evidently the dramatization of social rituals was no substitute for genuine personal loyalty, or even for effectively applied coercive force. The excitement and entertainment provided by festivals may have served momentarily to raise the spirits of these sick and generally dispirited people, but even that is likely to have been offset by the cost of the festivals, which as usual was borne mainly by the populace at large. 


\section{CHAPTER 32 AND RISE AGAIN}

\section{HAU MANAHUNE}

The next five years of Tahiti-Mo'orea history have been labeled, quite inappropriately, the period of the Hau Manahune - government of commoners; as we shall see, there was not much "government" in evidence, and what there was was exercised by people of commoner origin only episodically. During this period Pomare II divided his time between Mo'orea, where as "King" he continued to be respected and in general obeyed, and Tahiti, where his presence was tolerated, but only as tribal chief of the district of Pare. Meanwhile, politically significant events in the two islands developed in markedly different ways.

The period began with an unsuccessful attempt by Pomare II to reestablish himself as Tahiti's "King." The occasion was the expedition from Mo'orea to Tahiti, by the captain of the brig Hibernia, to recapture the schooner Venus; ${ }^{1}$ Pomare II joined forces with the Europeans, but whereas the latter succeeded in their mission, the former failed dismally. Here is the story of this enterprise, as it was reported by the missionaries still on Huahine:

... Pomare and party sailed from Aimeo for Taheete in company with Capt. C., [and] while the Capt. was endeavouring to retake the vessel, which they had towed to the isthmus in her way to Tearabu, Pomare and fleet made the District of Faena where the rebels had collected their forces and canoes, but being suddenly surprised by the unexpected arrival of Pomare they left their canoes by the sea side and fled up the valley. A party of Pomare's people, consisting chiefly of those from Huaheene, pursued them, the rebels rallied and faced the pursuers, trusting to a party that lay in ambush of which Pomare's people knew nothing till they were fired upon, the royalists were put in disorder and forced to retreat with the loss of 24 men, some of them noted warriors. The rebels pursued them in their turn to the sea side where P. and party saved themselves by getting on board their canoes. They, however, succeeded in seizing and taking away all the rebels' canoes. P. and fleet then sailed for the District of Pare, and Capt. C. having recovered the vessel and the men belonging to it sailed for Aemeo, and few days after for this harbour [i.e., Fare, Huahine]. From this account it is evident that the affairs of P. are as bad as ever; he is waiting with great anxiety the arrival of the chiefs from these islands [i.e., Huahine, Ra'iatea, Taha'a, Porapora], and apparently not able to act on 
the offensive till then, and from their long delay it appears very doubtful whether they will give him any assistance before it be too late. Pomare and his people are forced by the famine in Aemeo to endeavour to keep their station at Pare in Taheete where there is at present abundance of food. (Im Thurn 1925:122-3)

The wonder is, of course, that Pomare was permitted even a foothold on Tahiti, but this he managed to maintain, perhaps because Tahiti itself remained as divided as it had been decades previously; and added to this were certain other circumstances that may have militated against vigorous common action against the self-styled "King" (Newbury 1961:135-136; Moerenhout 1837:II, 449-50).

If one may place any confidence in missionary estimates, the population of Tahiti during this period probably numbered no more than 9,000, and possibly considerably less. ${ }^{2}$ In other words, the population as a whole was still subject to the same kinds of influences that had brought it to that nadir during the preceding decade, including especially sicknesses that reduced fertility and cut off lives before they reached reproductive age. While we cannot assume that such a situation was socially "demoralizing" in any way (a condition as difficult to define as it would be to assess), one is certainly justified in assuming that the manpower available to Pomare II's principal chiefly adversaries was not sufficient to encourage them to undertake hazardous military adventures.

Another factor that might have contributed to the Tahitians' disinterest, in general, in uniting to drive Pomare II off the island again was the widespread addiction to the new (for Tahiti) kind of alcoholic beverage mentioned earlier:

Intemperance at this time prevailed to an awful and unprecedented degree. By the Sandwich Islanders, who had arrived some years before, the natives had been taught to distil ardent spirits from the saccharine ti root, which they now practised to a great extent, and exhibited, in a proportionate degree, all the demoralizing and debasing influence of drunkenness.

Whole districts frequently united, to erect what might be termed a public still. It was a rude, unsightly machine, yet it answered but too well the purpose for which it was made. It generally consisted of a large fragment of rock, hollowed in a rough manner, and fixed firmly upon a solid pile of stones, leaving a space underneath for a fire-place. The but-end of a large tree was then hollowed out, and placed upon the rough stone boiler for a cap. The baked ti root, Dracanoe terminalis, macerated in water, and already in a state of fermentation, was then put into the hollow stone, and covered with the unwieldy cap. The fire was kindled underneath; a hole was made in the wooden cap of the still, into which a long, small, bamboo cane, placed in a trough of cold water, was inserted at one end, and, when the process of distillation was commenced, the spirit flowed from the other into a calabash, cocoa-nut shell, or other vessel, placed underneath to receive it.

When the materials were prepared, the men and boys of the district assembled in a kind of temporary house, erected over the still, in order to drink the $a v a$, as they called the spirit. The first that issued from the still being the 
strongest, they called the $a o$; it was carefully received, and given to the chief; that subsequently procured, was drunk by the people in general. In this employment they were sometimes engaged for several days together, drinking the spirit as it issued from the still, sinking into a state of indescribable wretchedness, and often practising the most ferocious barbarities.

Travellers among the natives experienced greater inconvenience from these district stills than from any other cause, for when the people were either preparing one, or engaged in drinking, it was impossible to obtain either their attention, or the common offices of hospitality. Under the unrestrained influence of their intoxicating draught, in their appearance and actions they resembled demons more than human beings.

Sometimes, in a deserted still-house might be seen the fragments of the rude boiler, and the other appendages of the still, scattered in confusion on the ground; and among them the dead and mangled bodies of those who had been murdered with axes or billets of wood in the quarrels that had terminated their dissipation. (Ellis 1829:I, 229-231)

While one need not subscribe fully to this missionary judgment concerning the prevalence and effects of ti drinking, the practice was, nevertheless, very widespread and undoubtedly quite deleterious in terms of the ordinary work of living and war making. A drunken mob might have been easily roused to rush into battle, but could hardly have sustained a lengthy campaign.

Still another factor - both symptom and cause - prevalent in the social disarray of this period had to do with peoples' relations with their gods. Although concrete evidence for this thesis is scattered and fragmentary, it seems quite clear that the more organized means of communicating with spirits, through "official" tribal or kin-congregation priests, was giving way increasingly to the revelations of taura. Moreover, there were signs in some quarters that belief in 'Oro was beginning to be complemented, or even superseded, by belief in Jehovah. (This last was firmly evident in Mo'orea, as we shall see; and it seems to have been occurring in Tahiti as well.)

Meanwhile, the political boundaries of Tahiti had been reconstituted to their locations of five decades earlier, that is, into the separate tribes or close tribal coalitions of Seaward Teva, Landward Teva, Oropa'a, Aharoa, Porionu'u, and possibly Fa'a'a. ${ }^{3}$ With the exception of Papara, where Tati and then his brother Opuhara ruled, there is little or no information available concerning the identity of the chiefs of these various tribes. ${ }^{4}$ In any case, none of them was of sufficiently high rank-status to exercise or even affect claims to maro ura associated rights. ${ }^{5}$ In other words, with the exception of Pomare II, there was during this period no other conspicuously eminent individual in terms of rank-status among Tahiti's several ari'i, and this seems to have been true of the political side of intertribal relations as well.

Indeed, according to one reconstruction of the history of this period, the actual tribal chiefs were partly eclipsed by certain taura: 
There was at this time at Tahiti an unusual man, the prophet Tino who was called Taramea, when he was in his natural state, and Oro, when he claimed to be inspired by this god. Since, during Pomare's exile, there was no ari'i rahi at Tahiti, it was really he who ruled the island, not exactly as chief or king, but as prophet or rather as god. He had begun to play his role even before that year and his power extended because of the calamities of the island, into recent times. He lived in Southwest Tahiti at a point called Mara, in a marae where he was brought offerings and provisions from everywhere. His authority was despotic; he did almost anything he wanted, having been feared in such a way that his slightest threat was tantamount to the most positive order. Should he have to go somewhere? Everything was prepared to receive him; women gave lavishly of their favors to him. Perhaps there has never on earth been an individual so highly honored, so powerful; his slightest wishes were irrevocable laws; the chiefs themselves did not dare to resist him; but he did not directly interfere with warfare, since his good graces were solicited insofar as his displeasure was feared. His moments of inspiration were moments of triumph. Everyone trembled then. Each side dreaded some fatal prescription; and if he had cried "War!" all would arm themselves without question. (Moerenhout 1837:II, 450-451) ${ }^{6}$

Eventually Tino was superseded by another "prophet" who came to exercise an even more fateful influence upon events - but more about this later on.

\section{REINFORCEMENTS}

On Mo'orea, where Pomare II again resumed residence in July 1810, two developments of major political importance began to take shape. One was his "conversion" to Christianity, which reached the point of public profession in July 1812; the other was the build-up of his military forces, mainly through reinforcements from the Leeward Islands.

Previous to this Pomare II's links with the Leeward Islands were traced mainly through his father's mother, Tetupaia (who was the daughter of Opoa's ari'i rahi, Tamatoa III), and through his mother's recent marriage to Tenania of Huahine. Tenuous as these connections may seem, they were substantial enough to induce the Leeward Islands' most powerful chiefs to lead large contingents of reinforcements to Mo'orea and Tahiti to help restore Pomare II to power, or perhaps to fish in Tahiti's troubled waters. ${ }^{7}$

Among the first of the Leeward Island chiefs to arrive was Tamatoa IV, of Opoa (Ra'iatea), along with his second daughter, Terito o Te Ra'i (later, Tere Moemoe).

The first wife of Pomare II, it will be recalled, was his father's sister's daughter, who died leaving no offspring. Shortly thereafter, 'Itia appears to have undertaken negotiations for a new wife for her son (this may in fact have been the principal reason for her move to Huahine). The woman selected for this important role was Tamatoa IV's daughter, Teri'itaria, whom Davies described as having been "the proper chief (of) the whole Island" (Newbury 1961: 126). This arrangement, however, did not work 
out. According to Davies, soon after Tamatoa IV and his second daughter, Terito, arrived on Mo'orea, the former proposed that Pomare II marry her instead; whereupon Pomare II "... ascertaining that she was both younger and more handsome than the sister who had been previously proposed at once consented, and she became his wife" (Newbury 1961:137). (Thus, Pomare II's personal, aesthetic preferences were permitted to overrule the usual requirement that a person of superior rank-status be mated with one as comparably high-ranking as possible.) Then, continued Davies, "to soften the disappointment of the elder sister, she was still allowed the name of Pomare vahine wh(ich) she retained for many years afterwards." (What rights, and so forth, this entailed I cannot say; but as will be seen, Pomare Vahine proved to be a most useful ally to the man whose name she bore but whose sleeping mat she evidently did not share.)

As a sign of further changes to come, the marriage between Pomare II and Terito evidently took place without any of the ceremony traditionally associated with the linking of kin-Titles as important as theirs.

Accompanying Tamatoa IV to Mo'orea-Tahiti was also a considerable force of fighting men, but, before discussing that aspect of the Leeward Island aid to the embattled Pomare II, let us examine the nature of the social reinforcement represented by his marriage to the daughter of Tamatoa IV. To begin with, who and what was Tamatoa IV in terms of Maohi social hierarchies?

In her versions of "Royal Tahitian Genealogies" Henry listed Tamatoa IV as the third offspring of Vete'a-Ra'i Uru by his second wife (his first wife having had seven offspring, and his third wife two); Vete'a-Ra'i Uru was identified by Cook as "Ooroo" [O Uru], who during Cook's visit to Ra'iatea was highest in rank-status, ${ }^{8}$ but who was politically subordinate to the Poraporan, Puni. Despite his birth-order position Tamatoa IV appears to have succeeded to his father's preeminent rank-status, but what that status carried in terms of coercive authority over all Ra'iatea is uncertain. Also, one will recall a statement by Vancouver reported earlier concerning Mauri (Ha'amanemane), the "high priest" expatriate from Opoa and brother to Tetupaia, who designated his grandnephew Pomare II as successor to his (Mauri's) Opoan Title, which was characterized as having been as high-ranking as Pomare's maro ura one (Vancouver 1801:327). Although Vancouver implied that Mauri himself enjoyed little influence at Ra'iatea, despite his high-ranking Title there, this does raise questions concerning the nature of that Title. In other words, according to one set of reports, the highest-ranking Opoan kin-Title passed from Tamatoa III to his son, Uru, and on to the latter's son, Tamatoa IV; while, according to another reconstruction, it passed from Tamatoa III to his son (and Uru's half-brother), Ha'amanemane, and then on to Pomare II. It may be, of course, that the 
reports are of two separate Titles, or that Ha'amanemane had forfeited his claims to the Opoan kin-Title upon leaving Ra'iatea, or even that it was in active dispute. In any case, the marriage of Pomare II to Terito (along with the ambiguous link between him and Terito's elder sister) served to reinforce any claim to the Title that Pomare II may have acquired from Ha'amanemane. By his marriage to Terito, Pomare II also reinforced his connections with Huahine's chiefly family, since Terito's mother was a daughter of Mato and his first wife, Fatuarai (and hence half-sister of Tenania and Mahine).

Other Leeward Island chiefs who traveled to Mo'orea during this period were Mai, Tefa'aora, Fenua Peho, Mahine and his son Ta'aroanui, Tenania (with 'Itia), and Tapoa. Mai and Tefa'aora were associated with Porapora's famed Marotetini marae, and are shown on an Emory genealogy as having been first cousins; their relationship to Pomare II, if any, is not known to us. Tefa'aora was described simply as chief of Tana'a. Mahine was Tenania's brother, and co-chief of Huahine.

Tapoa (also Teri'i Noho Rai), the most formidable of this company, is also the most difficult to place. ${ }^{9}$ Among his antecedents were both Tamatoa II of Ra'iatea and Puni of Porapora, and his sister was the wife of Huahine's Mahine. In some accounts he is identified as chief of Ra'iatea, in others as chief of Porapora; both attributions were probably correct as far as they concerned kin-Titles, but whether he also exercised coercive chiefly authority over both islands at any time I cannot discover. (His main tribal base seems pretty clearly to have been Porapora, where his most serious political rival was Mai.)

In any case, even though Tapoa's kinship connections with Pomare II were quite remote - Tamatoa II having been their common great-greatgreat-grandfather - his presence in Pomare II's camp was considered the sine qua non for the latter's political (i.e., military) comeback.

Along with these Leeward Island chiefs went hundreds of their male subjects, but some of the actions of this impressively large force are more suggestive of peaceful pilgrims than of battle-eager warriors. For example, Davies reported that Tapoa (or was it Tamatoa?) brought with him from Opoa the sacred canoe of the Opoa 'Oro image, along with a "deputy" image made from the 'Oro image's bark cloth and feathers, and with these a company of priests. Then, "after many ceremonies at the principal maraes on Mo'orea it [the Opoa 'Oro objects] was sent to Tautira, calling on their passage at several maraes and offering many prayers" (Newbury 1961:137). Indeed, the whole expedition turned into something of a festival:

In January 1811 Pomare and the leeward islanders went over to Tahiti. But peace having been established they were well received by all. The rebels came to Papeete to meet Tapoa and prepared a great feast for the stranger the food 
for wh(ich) was brought from every district on Tahiti. Previous to the arrival of this reinforcement the two hostile parties seem to have been of about equal strength and now that at least 700 more had joined Pomare it appears strange that no attempt was made to recover his lost kingdom. It was very generally supposed that Tapoa, although he had joined Pomare with many of his people, was yet not very hearty in the aid wh(ich) he had so tardily rendered, and this impression may have prevented Pomare from endangering a peace wh(ich) had secured to him one of the five districts of the island. Instead of fighting their time was spent in feasting and dissipation, and after a few months numbers returned to their own island. (Newbury 1961:138)

In fact, however, the very presence of this force probably served to discourage the enemies of Pomare II from attacking him again.

\section{CONVERSION}

The second development of major political importance to take place at this time was the "conversion" of Pomare II to Christianity. "In July 1812," Davies wrote, "King Pomare acquainted several of the brethren with his full determination to cast away his false gods, and former evil practices, and that it was his sincere desire henceforward to embrace the Christian Religion as the only true one; to receive Jehova as his God, and Jesus Christ as his only Saviour and atonement; and that if they thought proper, they might write down his name as a candidate for Baptism; he desired also they might pray for him" (Newbury 1961:153).

This was not the first intimation of the change in Pomare II's public attitude toward religious matters. I noted earlier the circumstance of his marriage to Terito having taken place without traditional religious practices. Somewhat later the death of the young daughter of 'Itia and Tenania brought forth an even more positive response. During the child's illness so many prayers and offerings were made to the native gods that her death moved some influential people to angry recriminations, and led Pomare II to announce his intent to forsake their "false and foolish" gods and thenceforth worship Jehova (Newbury 1961:138).

One could speculate endlessly, but still more or less fruitlessly, concerning the circumstances and motives behind this change in Pomare II's outward behavior. (I shall not even begin to conjecture about its sincerity and depth, mentally and affectively.) His bountiful train of human and other offerings to 'Oro may have accompanied some of his former successes, but had not saved him from disaster in the end. Also, one could not continue forever to ignore the reality and potency of a god (i.e., Jehovah) whose devotees were obviously so numerous, so knowledgeable, so affluent, and so militarily unconquerable. In any case, it is evident that when circumstances encouraged Pomare II to become more preoccupied with these misgivings and reasonings, the missionary Nott was there to reinforce them. (The missionaries began to arrive back in Mo'orea in 1811, but it was Nott who had 
remained more closely and continuously associated with Pomare II during the Mo'orea "exile," when the latter's profession of belief took place.)

As one would expect, Pomare II's public declaration of belief in Jehovah led many other persons to profess, including some of the visiting chiefs. In addition, the missionaries reported signs of "conversion" among people who cannot be viewed as emulators of Pomare II. I shall not attempt to chronicle or explain at any length the tide of public "professions" that began to rise with that of Pomare II, in 1812, and ended some three to four years later by engulfing the whole population. Frustration with the old gods played a part, as did "miracles," missionary exhortation, genuine emulation, and, of course, political expediency. One of the most dramatic, and probably influential, episodes in this movement occurred at Papetoai, Mo'orea, in February 1815, when Pati'i, the local high priest of 'Oro, committed all the images in his care to flames.

The sincerity of most of the "conversions" did not entirely satisfy the missionaries' Calvinistic standards in terms of personal behavior, ${ }^{10}$ but the pure-atua (the pray-to-God people), as the converts came to be called, had by 1813 increased so much in number, and were so widespread, that they became a factor in intra-and intertribal politics. In some areas on Tahiti the pure-atua were threatened and attacked by pagan tribesmen, and thus they constituted a divisive element, locally. On Mo'orea and Pare, on the other hand, they became the official party; so the process of conversion became more or less identified with the movement to restore Pomare II's political fortunes.

Soon after he made his public profession of belief at Mo'orea, an emissary arrived from Tahiti inviting Pomare II to resume his residence there. The only report on this noteworthy event is contained in Davies' History: "Soon after the above circumstance [i.e., the public "profession"], some of the chiefs of Tahiti came over to fetch the King, professing their desire of restoring him to his government, at least to a part of it, and promising to use their endeavours for that purpose" (Newbury 1961:154). No single clue as to the identity of these chiefs is provided, and no word written as to the circumstances that led them to extend this fateful invitation.

Moerenhout, too, found this development puzzling: “... a démarche for which no reliable explanation has yet been discovered" (1837:II, 455). After canvassing the opinions of Tahitians, many years after the event, he reported as follows:

Some, jealous of Oupoufora [Opuhara], said that those who came to make these propositions to him were sincere, others pretended that this was only a trap; while an opinion more generally shared is that they wished to maintain the old religion, by preventing Pomare from becoming Christian....

Needless to say, Pomare II accepted the invitation, and with him went 
to Tahiti his Leeward Island chiefly visitors and most of their men (whose numbers by this time had increased to almost a thousand). A little further along in Davies' History the report is amplified somewhat:

As to the natives, it has been already observed, that Pomare's government in Tahiti had not been restored. He had been invited over, by some of the chiefs, and the District of Matavai and some others were in a manner given up to him, but he had reason to suspect the sincerity of those concerned in the gift, and war was still agitated among the different chiefs. Pomare had been residing for some time on the little island at Papeete (or Wilks harbour) and was there by sufferance as it were for it does not appear the District of Pare was truly given to him. The strong party of the Leeward islanders that were with him, kept his enemies in awe and fear of attacking him; and on the other hand, he had some hope of regaining his authority without commencing hostilities. The former religious services, sacrifices to the gods \&c had been entirely abandoned on Pomare's side, and though Tapoa and others of the Raiateans would have had recourse to their former heathen customs, they dared not set about it in present circumstances. (Newbury 1961:158)

The year 1813 passed without any new major political developments. Pomare II remained at Pare with some of the Leeward Islanders, while the rest of the Leeward Islanders remained on Mo'orea. Conversions continued apace at both locations, so much so that when an 'Oro taura of Tahiti visited Mo'orea he was met, according to Davies' History, "with unexpected ridicule and contempt everywhere" (Newbury 1961:156). Even where the pure-atua were in a small minority, the History continues, although "several of those things [i.e., pagan practices] were still kept up in some measure, tho' the circumstances of the Island at that time had greatly deranged the system. Many of the people everywhere seemed to doubt about the efficacy of their prayers and sacrifices, ${ }^{[11]}$ and the various [Christian] truths which had been so often and so long promulgated among them seemed at times to come to remembrance." (p. 158)

In October 1813 a tavaru was held at Pare. Since participation in such tribute rendering was indicative, traditionally, of the shape of political or at least rank-based hierarchic structures, it would be illuminating indeed to learn who attended and how the objects were transacted; but the only information recorded is that it was attended by the co-chiefs of Huahine with their people, along with 'Itia, and by most of the people then residing at Mo'orea (Newbury 1961:168).

In January 1814 'Itia died, and shortly thereafter her husband too; earlier this would have represented a significant political setback for Pomare II, but with his connections with Huahine now firmly established, these deaths were for him more of a personal than a political loss.

In July, Tamatoa, Fenuapeho, and most of the Ra'iateans (and presumably most Taha'ans) left Tahiti and Mo'orea for home. ${ }^{12}$ Shortly thereafter Pomare II removed to Mo'orea, probably because of the insecurity of his position in Pare resulting from the departure of the main forces of Leeward 
Islanders. In fact, despite steady increments to the ranks of the pure-atua, on the surface at least it appeared for a time that Pomare II's political fortunes were again in decline. Then there occurred one of those series of "accidents," so characteristic of Maohi political history, that wholly reversed the trend of events.

\section{JEHOVAH VERSUS 'ORO}

In May 1814 a flotilla of canoes arrived at Mo'orea bearing Pomare Vahine and a retinue of Huahine people. As eldest child of Tamatoa IV and as onetime consort-designate of Pomare II (whatever that signified!), her visit was of extraordinary ceremonial consequence. She and her following remained for a year on Mo'orea, where most of them became "converted," and then continued to Tahiti to carry out a grand tour. Less than two months later, the party hastily returned to Mo'orea, accompanied by many Tahitian pureatua. The following weeks brought other canoe loads of refugee pure-atua from Tahiti, along with reports of conflict among the pagans themselves. The missionary version of these events was provided by Ellis. His account of the episode offsets reports of the glitter of Pomare Vahine's ceremonious tour of Tahiti:

When a present of food and cloth was brought to the visitors by some of the chiefs of Tahiti, the priests also attended, and, observing the party disinclined to acknowledge or render the customary homage to the gods, began to expatiate on the power of the gods, and, pointing to some bunches of ura, or red feathers, which were always considered emblematical of their deities, employed insulting language, and threatened with vengeance the queen's companions. One of Pomare-vahine's men, the individual who had offered their acknowledgments to God, on the presentation of food in Eimeo, hearing this, and pointing to the feathers, said, "Are those the mighty things you so extol, and with whose anger you threaten us? If so, I will soon convince you of their inability even to preserve themselves." Running at the same time to the spot where they were fixed, he seized the bunches of feathers, and cast them into a large fire close by, where they were instantly consumed. The people stood aghast, and uttered exclamations of horror at the sacrilegious deed; and it is probable that this act increased the hatred already rankling in the bosoms of the idolatrous party. (Ellis 1829:I, 237-238)

The man credited with this preposterous act (and with the unlikely phrases that accompanied it) was a recent convert of Poraporan origin. About him Ellis wrote (with an understatement that surely must constitute some kind of record): "He was a man of decision and daring enterprise; and though on the occasion in Tahiti above referred to, he may have acted with a degree of zeal somewhat imprudent, it was a zeal resulting, not from ignorant rashness, but enlightened principle, and holy indignation against the boasting threatenings and lying vanities of the priests of idolatry; to whose arts of deception he had formerly been no stranger" (1829:I, 239).

As Ellis would have put it, the idolatrous party continued to rankle, 
and the chiefs of Pare, Mahine, and Ha'apaino'o formed a project to exterminate every pure-atua among them. Ellis continued:

The influence of the Bure Atua in the nation, from the rank many of them held, and the confidence with which they maintained the superiority of their religion, together with the accessions that were daily made to their numbers from various parts of the island, not only increased the latent enmity against Christianity which the idolaters had always cherished, but awakened the first emotion of apprehension lest this new word should ultimately prevail, and the gods, their temples, and their worship, be altogether disregarded. To avoid this, they determined on the destruction, the total annihilation, of every one in Tahiti who was known to pray to Jehovah.

A project was formed by the pagan chiefs of Pare, Matavai, and Hapaiano, to assassinate, in one night, every individual of the Bure Atua. The persecuted party was already formidable in point of numbers and rank, and the idolaters, in order to ensure success in their murderous design, invited the chiefs of Atehuru and Papara to join them. The time was fixed for the perpetration of this bloody deed. At the hour of midnight they were to be attacked, their property plundered, their houses burnt, and every prisoner secured, to be slaughtered on the spot. The parties, who for a long time had been inveterate enemies to each other, readily agreeing to the proposal, were made friends on the occasion, and cordially assented to the plan of destroying the Christians. The intended victims of this treachery were unconscious of their danger, until the evening of the 7th of July; when, a few hours only before the horrid massacre was to have commenced, they received secret intelligence of the ruin that was ready to burst upon them.

Circumstances, unforeseen and uncontrollable by their enemies, had prevented the different parties from arriving punctually at their respective points of rendezvous; otherwise, even now escape would have been impracticable, and destruction inevitable, as the Porionu, inhabitants of Pare, Matavai, and Hapaiano, would have been on the one side, and in their rear, and the party from Atehuru and Papara on the other. The delay in the arrival of some of these, afforded the only hope of deliverance.

At this remarkably critical period, the whole of the party having to attend a meeting either for public worship, or for some other general purpose, assembled in the evening near the sea. No time was to be lost. Their canoes were lying on the beach. They were instantly launched; and, hurrying away what few things they could take, they embarked soon after sunset, and reached Eimeo in safety on the following morning, grateful for the happy and surprising deliverance they had experienced. The different parties, as they arrived towards midnight, learned, with no ordinary remorse and disappointment, that their prey had been alarmed, and had escaped beyond their power.

A large body of armed and lawless warriors, belonging to different and rival chieftains, thus brought together under irritated feelings, and perhaps mutually accusing each other as the cause of their disappointment, were not long without a pretext for commencing the work of death among themselves. Ancient animosities, restrained only for the purpose of crushing what they considered a common enemy, were soon revived, and led to an open declaration of war between the tribes assembled. The inhabitants of Atehuru and Papara, who had been invited by the Porionu to join them in destroying the Bure Atua, attacked the Porionu; and, in the battle that followed, obtained a complete victory over them, killing one of their principal chiefs, and obliging the vanquished to seek their safety in flight.

After this affair, the people of Taiarabu joined the victors. The whole island 
was again involved in war, and the conquering party scoured the coast from Atehuru to the eastern side of the isthmus, burning every house, destroying every plantation, plundering every article of property, and reducing the verdant and beautiful districts of Pare, Faaa, the romantic valleys of Hautaua, Matavai, and Hapaiano, and the whole of the north-eastern part of the island, to a state of barrenness and desolation.

Success did not bring peace or rest to the victorious party. Proud of their triumph, insolent in crime, and impatient of control, the Atehuruans and natives of Papara quarrelled with the Taiarabuans, who had joined them in destroying the Porionu. A battle followed. The natives of Taiarabu were defeated, and fled to their fortresses in the mountains of their craggy peninsula, leaving the Oropaa masters of the island.

Numbers of the vanquished fled to Eimeo, where they were received by the king, or protected by the chiefs, who had taken no part whatever in the wars that were now desolating Tahiti, and who determined to observe the strictest neutrality; or, if they acted at all, to do so only on the defensive, should invasion be attempted, (pp. 239-242)

Moerenhout, drawing his information from Paparan sources some two decades after the fact, provided a different perspective on these events. $\mathrm{He}$ began with an account of the tour of Pomare Vahine:

She disembarked at Pare (or Papaoa) with a large entourage. She was greeted most respectfully and, as was customary, was presented with bark cloth and other gifts; however, one of her followers, a convert to Christianity, audaciously aroused the anger of a priest (and of the gods) by his insulting gesture of ripping off some of the red feathers that covered the images and throwing them into a brazier that had just been lit. The populace was surprised and horror stricken, and the humiliated priest cried out for revenge; thereupon commenced a conflict which one can label the Religious War, on account of the circumstance that an attempt was made, at the priest's instigation, to slay all the visitors. The chiefs of Matavai and the rest of northwestern Tahiti made up their minds to attack the pure-atua - the Christians - but in view of the limited number of the former they prevailed upon the Paparan chief, Opuhara, to join with them in the enterprise. Opuhara immediately set out with the warriors of Papara, along with those of Atehuru as well. With him he also took the well-known taura named Taramea, who up to that time had been a center of superstitious awe and who was a deadly enemy of the new [Christian] religion, having seen in it a threat to his own position of power (which, however, was already in something of a decline even before Christianity's rise in influence).

En route to battle it was noticed [among the pagans] that one of their number, a hitherto unknown commoner named Maro, displayed the usual signs of being possessed by a spirit, namely, a solemn expression on his face and a strip of bark cloth wrapped around one arm. Taramea indignantly accused him of imposture, whereupon the latter, instead of replying in words, fixed the former with such a ferocious stare that the frightened onlookers cried out in chorus, "He is possessed! He is possessed!" Opuhara alone seemed not to be taken in by the skillfully acted grimaces, et cetera; he silenced Taramea's objections and walked on, but somewhat apart from the others, for the first time giving evidence of some indecisiveness and lack of energy.

The agreed upon time for attacking the Christian party was midnight. Meanwhile, wholly ignorant of the fate planned for them, the latter remained calm and secure up to the time, at sunset, when a secret message arrived to warn them of their danger. In order to escape they would have to move immediately and in a 
way calculated to arouse no alarm in the hostile Matavaians and Paparans, who were strong enough to destroy them and who were by then only a short distance away. This they succeeded in doing, having embarked in their canoes and stolen away without being discovered in the act. It is still not known for certain who it was who sent them the warning, but it is thought [by some] that Opuhara himself had done so; although this great, open-handed chief had been on occasion a rival of Pomare's, he would have been unwilling to take part in a conspiracy of this kind - especially one involving some chiefs whom he knew to be unfriendly toward him and whom he detested even more than he disliked Pomare himself.

In any case, it was Opuhara's tardiness in arriving that saved the Christian party. If he had led his men with his customary speed, he would have reached the environs of Papaoa before nightfall, and the Christians would not have been able to escape as they did, unseen. The new taura, Maro (or rather, Aretaminu - for so quickly had he taken on a new name), wished to join immediately in pursuit in order to attack Pomare Vahine and her party, promising victory and annihilation of all the Christians; but Opuhara refused to do so, as did the Chief of Puna'auia, thereby indicating that [even the pagan] Tahitians had begun to lose some of their superstitious awe for taura. Thus, the queen's canoes were able to make for Mo'orea that very night; in pointing this out, Maro accused the chief [Opuhara] of negligence and threatened him with the wrath of his gods. Opuhara, however, seems not to have been moved by this threat, stating that he had no ill will toward [Pomare Vahine] or her people, and that instead he would turn his attack against his ancient enemies, the Poreonu'u. This he did, having proceeded immediately to Papaoa, chasing after the enemy and killing one of their chiefs. The Poreonu'u retired to Matavai and sent forth an envoy to ask for peace. Maro agreed to their proposal on condition that they would send him a Christian for sacrifice to 'Oro (by whom Maro himself was possessed). The terrified Poreonu'u hastened to comply by killing a young convert and sending his trussed body to Maro at Papaoa. The latter, however, replaced the corpse in the canoe, ordered it to be returned to Matavai, and advised the envoy that if the chiefs of Matavai would set fire to their Arioi lodge house the sight of the blaze would serve as a signal for the Oropa'an army to return home. When the envoy reached Matavai with the sacrificial victim and informed the anxiously waiting chiefs of the wishes of the taura they hastened to comply. But then, when Maro saw the flames rising he immediately cried out, "Victory! Victory!" and, explaining the fire signal as a sign of triumph, he urged Opuhara to proceed to Matavai [to finish off the enemy]. Then, as Opuhara and his attacking force drew near them, the Poreonu' $u$ took flight and abandoned everything in their rush to reach their fort in Ha'apaiano'o. Thereupon, the victors laid waste to the district, burning all the houses and massacring all those whose age or infirmities hindered their escape. From there they proceeded to Ha'apaino'o where they remained for four days encamped on the coastal plain. On the fifth day Maro announced that it would be necessary to attack the fort itself, which was situated some distance in the interior. However, the besieged force was so panic stricken that they were almost incapable of resistance, and after a light skirmish they fled into the mountains upon the first attack of the Oropa'a. All told, only a dozen or so people were killed.

The Oropa'a took over the fort and were joined there by the Seaward Tevans, with whom they were then at peace. When the Tevans arrived, Maro was sitting on a high spot of ground close to Opuhara and the other chiefs. As usual he was in a somber mood, seemingly lost in deep thoughts, and appeared not to have seen the Tevans for a while; but then he raised his head and demanded to know who the newcomers were. When told that they were "friends, from Taiarapu," he 
cried out, "Friends nothing! They are our enemies, and we must attack them forthwith." The chiefs, however, refused to do so, but some of them sought to appease him. Meanwhile, after learning what the taura had urged, the Seaward Tevans desired to leave, and despite all Opuhara's reassurances they kept to themselves and on guard. Nothing happened, however, so that they all found courage again and rallied their forces in order to take after the unfortunates who had sought refuge in the mountains. Then, after two days, the victorious forces departed from Ha'apaino'o and went to Papetoare, where they carried the corpses of their slain enemies around the marae, and - on orders from Maro - returned to their homes in Papara and Puna'auia, lest their continued absence encourage the Mo'oreans to go there and attack their women and children.

Scarcely had they arrived at Afaina [?] when many of them, believing peace to have been restored, took off for the mountains in search of the friends and relatives who had sought refuge there during the absence of their chiefs and fighting men. Then, while persuading the refugees to return to their homes they received news that the taura Tino (or Taramea), the one who had played such an influential role in former years but who was now eclipsed by Maro, had joined with the Seaward Tevans and they were marching to attack Papara. The only force left [in Papara] to oppose this attack consisted of Opuhara and some thirty of his subjects, plus the taura Maro. The chief wanted to retreat before the enemy's superior 200-300 man force, but Maro, on hearing that his archrival was with the enemy, ordered the Paparans to stand fast, telling them that Taramea no longer had any power and that the god 'Oro would fight on their side. And so it happened that Maro, whether out of hatred toward his rival or out of pure enthusiasm, marched at the head of this little troop against the Tevans, even after having been abandoned by Opuhara, who was highly skeptical of his prediction. Whereupon the Paparans actually routed the Seaward Tevans, Maro having killed five or six by his own hands. The rest of the Seaward Tevans managed to escape, and many of them, fearful of further pursuit by the Paparans, went over to Mo'orea to join up with Pomare. (II, 458-464)

In December of 1814 Pomare returned to Tahiti accompanied by his supporters and most of the fugitives from the recent Tahitian wars. I reproduce two versions of the episode, not only because of the climacterical importance of the events themselves but because of the contrasting perspectives on them served up in these different versions. First, the missionary version, as set forth in the Davies' History, presents a touching picture of a peaceloving Pomare II returning home merely to carry out his official duties:

After this [the defeat of Taiarapu by Papara] there was a prospect of peace being established; and the people, who on account of religion, had fled to Eimeo to save their lives, were invited to return to Tahiti, and take repossession of their respective lands. This made it necessary for the King and his people, and most of the people about us to go over to Tahiti in company with the different parties of the refugees, and according to an ancient custom of the country, to reinstate them in a formal manner in their old possessions.

On the arrival of the king and those who followed him, at Tahiti, the idolatrous party appeared on the beach, in a hostile manner; seemed determined to oppose the king's landing and soon fired on his party; but by the king's strict order the fire was not returned, and at last apparently issued in peace and reconciliation. 
In consequence of this, several of the people returned peaceably to their different lands; but still fears and jealousies existed on both sides. This state of things continued till Sabbath day Novr 12th 1815 when the heathen party, taking advantage of the day, and of the time, when the king and all the people were assembled for worship, made a furious, sudden, and unexpected assault, thinking they could at such a time easily throw the whole into confusion. They approached with confidence, their Prophet having assured them of an easy victory. In this however they were mistaken. It happened that we had warned our people before they went to Tahiti, of the probability of such a stratagem being practiced should war take place; in consequence of which they attended worship under arms; and tho' at first they were thrown into some confusion, they soon formed for repelling the assailants; the engagement became (warm) and furious, and several fell on both sides.

In the king's party there were many of the refugees from the several parties who had not yet embraced Christianity; but our people not depending upon them took the lead in facing the enemy, and as they were not all engaged at once, being among bushes and trees, those who had a few minutes respite, fell on their knees, crying to Jehova for mercy and protection, and that he would be pleased to support His cause against the idolatry of the heathen. Soon after the commencement of the engagement, Upufara the chief of Papara was killed, this when known threw the whole of his party into confusion and Pomare's party quickly obtained complete victory. (Newbury 1961:191-192) ${ }^{13}$

\section{Moerenhout's version was written from the vantage point of Papara:}

Those last conflicts, which were more destructive to property than to life, resulted again in bringing all of Tahiti under Opuhara's sway. But in doing so they made a near-desert out of the island and left the conqueror with only a small force of warriors, most of the defeated ones having escaped to Mo'orea and joined forces with Pomare. As for the latter, when he saw his forces thus augmented day by day, he began to entertain the ambition of conquering Tahiti itself. Meanwhile Opuhara, with what remained of his forces from Papara and Atehuru, made ready the foodstuffs and bark cloth for a puriri ceremony (a rite of thanksgiving), or Te Deum ...; it was during these preparations at the Taiarapu marae [the Taputapuatea marae at Atutira?] that he learned of Pomare's arrival at Pape'ete, on the northeastern coast of Tahiti Nui. At this news the taura Maro became highly excited and mobilized the warriors; in a state of possession he predicted the wholesale destruction of the party of Christian converts. Opuhara, similarly aroused by his enmity for his old rival, set forth to battle with all his own warriors and with those recently united to his cause.

Despite their lack of intrinsic interest I have been at pains to record the details of all these petty wars because it was through them that was brought about such a total change in the life of these Islanders, namely, the successful introduction of a wholly new religion. In taking refuge with Pomare on Mo'orea, those defeated in these wars served not only to augment his fighting strength but also swelled the ranks of converts to the new religion - encouraged, as they were, by the example of their new chief and reinforced in their change by their belief that their former gods had forsaken them.

Thus, the army with which Pomare returned to Tahiti was in large measure one of Christians; that is to say, like Pomare himself this army placed its trust in a god said to be more potent than 'Oro or any other gods known to them (whose existences, by the way, the missionaries did not deny, but rather lumped them with their varua ino - evil spirits or demons - and in opposition to the True God). 
On a Sunday in December [sic] ... Pomare arrived from Mo'orea, accompanied by about a thousand people, and he betook himself to services in the chapel constructed at Nari'i, in WSW Tahiti. Scarcely had the services begun when gunshots were heard, announcing the approach of the enemy, who at the very same moment came into view as they rounded a point of land some distance away - all of which set forth cries of "War! War!" Fortunately, the Christians had armed themselves - although the enemy had planned the attack for that day [i.e., the Sabbath] in the belief that they would have found them to be without arms or other means of defense (or so Maro had predicted). As soon as the enemy came into view most of the Christians became eager to rush into battle but Pomare held them in check, telling them that the prayer services must first be completed for, the whole outcome would depend on the backing given their side by God. (In this respect, evidently, Pomare had not changed his views: as he had in the past done with 'Oro, he now put all hope and faith in the protective powers of Jehovah.) When their prayer service was finished the Christians drew up in battle formation: the more zealous ones in the front lines, the recent [Tahitian] refugees (whose loyalties were more uncertain) in the center, and the Mo'oreans in the rear.

The enemy advanced to attack in full cry, under the leadership of the courageous Opuhara and urged on by the taura Maro, who assured them a certain and easy victory. Some of the attackers wavered when shots from a cannon [of Pomare's], mounted on a small boat and fired by a European, killed a few of them, but their leader brought them back into order, saying: "Those of you who have been killed brought it onto themselves. Can't you see that the enemy's shots usually go either too high or too low? If they fire too high you must lower yourselves, and if too low simply leap into the air. Just look at me in front of you all; they will not hit me."

The heathens attacked recklessly, and for a time Pomare's forces seemed in danger of losing the fight. The latter fought with unusual bravery, but they lost large numbers of men and gave up much ground, so that it appeared [for a while] that the victory would go to Opuhara. This chief continued to stay out front and to lead the attack, thereby inspiring his troops by example and going to their assistance when needed - until, that is, he himself was felled by a bullet. Opuhara did not succumb immediately, and raised himself enough so that he continued to face the other side. On seeing him struck down several of his companions rallied round him to carry him to safety, but realizing that his wound was mortal he ordered them in a voice still firm with command: "Leave me here; instead, fight on and avenge my death. Over there is the one who has slain your chief," he added, pointing to one of Pomare's men. At this, his companions rushed into the attack a handful of men against a whole formation of Pomare's best fighters....

Despite the loss of Opuhara his troops continued to fight with great ardor - indeed, the condition of their chief seemed to inspire them to even greater efforts. Meanwhile, however, Pomare's forces were encouraged [by the felling of Opuhara] and held tenaciously to their ground. [From then on] the heathens lost more and more of their leaders on account of the Christians' greater number of firearms; particularly deadly was the firepower directed at them from several boats that were under Pomare's personal command and that struck them on their [seaward] flanks. Finally, the heathens had to give way; and with this their ranks broke in disorder and they turned and fled. Such was the sight that met the eyes of the fallen Opuhara as he breathed his last breath. (II, 464-468)

Considering their reinforcements (from Mo'orea and the Leeward 
Islands) and the greater number of firearms in their hands, it is not surprising that the Pomare forces finally prevailed. What is surprising, however - and not only to the student of Maohi society, but, evidently, to most Maohis of that period as well - is the fact that Pomare II held back his followers from completing their destruction:

Flushed with success, in the moment of victory, the king's warriors were, according to former usage, preparing to pursue the flying enemy. Pomare approached, and exclaimed, Atira! It is enough! - and strictly prohibited any one of his warriors from pursuing those who had fled from the field of battle; forbidding them also to repair to the villages of the vanquished, to plunder their property, or murder their helpless wives and children. (Ellis 1829:I, 252)

The final events in this fateful episode are described in the missionary History, under the date of November 17, 1815:

Many people returned these days from Tahiti, and brought news that the Teva $i$ uta and the Oropaa viz those of Atehuru, Papara \&c who had fled, were come to Pomare and had delivered up their muskets, and that it was said all these were resolved to embrace the new Religion. Pomare had sent people to destroy the maraes and altars and fetch Oro from Tautira, that he also might undergo the same fate. [Fig. 32-1]

Some days after this the king wrote to the miss, if they could make it convenient, it would be well if two could come over to Tahiti to instruct the people how to proceed in the present new state of things. (Newbury 1961:193-195)

\section{"NeW State of Things"}

With the battle of Fei Pi all effective political opposition to Pomare II was extinguished in Tahiti and Mo'orea. The monarchy therewith established

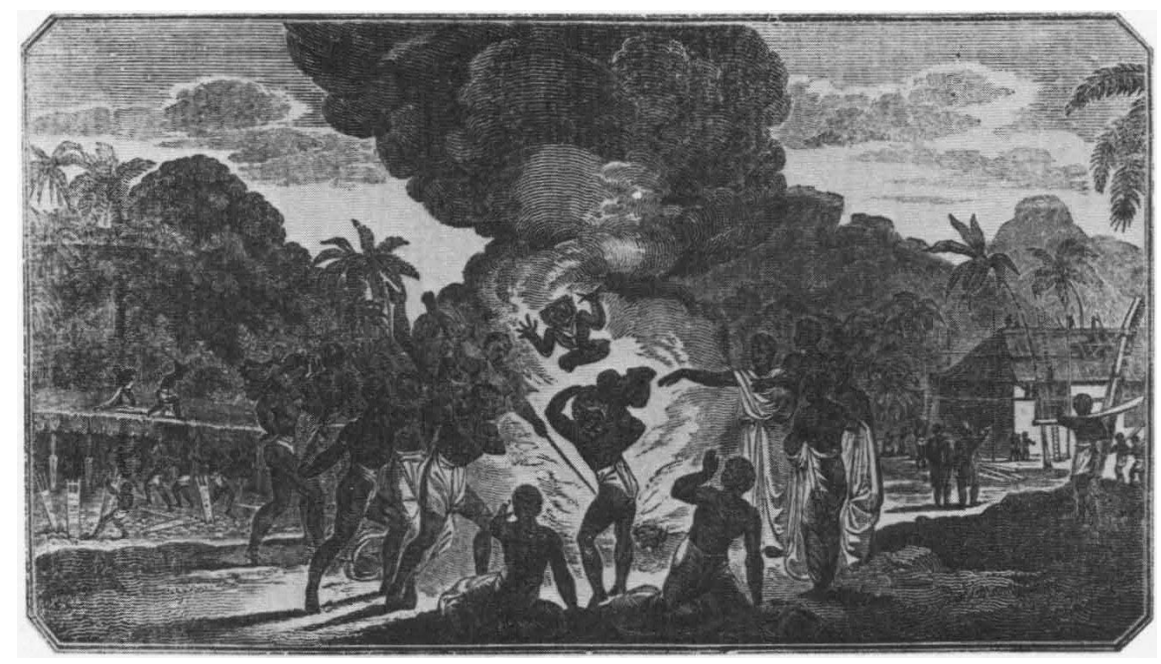

FIGURE 32-1. From Missionary Sketches, July 1819. London Missionary Society. 
was preeminent in terms of both coercive authority and rank-status, and in addition the monarch became head of the official Christian (Protestant) Church.

In 1843 French colonial rule superseded the monarchy's coercive, governmental authority, but the Pomare Dynasty was permitted to retain its ceremonial prerogatives for another four decades. - - But that is another story, better told elsewhere. 


\section{NOTES}

\section{CHAPTER 25}

1 As I acknowledged previously, I am conscious of the difficulties of such an undertaking and am not altogether confident that I have succeeded in carrying it out.

2 Population figures in this section are derived from the Tupaia-based estimates (see chap. 2), and thus are subject to innumerable qualifications.

3 "Tetahah" appears on Cook's map of 1769, and later it was used interchangeably with "Fa'a'a" to refer to the territory between Puna'auia and Pare. It may possibly represent a misreading of "Te Fana," as Newbury implied (1961:xxxv).

4 See chap. 16, section on Tahiti-Mo'orea. According to Rodriguez, Reti's domain extended only up to Mahaena on the north (Corney 1919:165).

5 Emory's Papara genealogy, however, equates Te Vahine Moeatua with Purai, and lists Purahi as a younger sister of the latter (Marae Traditions).

6 Morrison identified Ti'itorea as "uncle" of the younger Vehiatua, but the genealogical basis for this is unrecorded.

7 According to Corney's note Bougainville lost six anchors and kedges during his brief stay at Hitia'a: "The anchor recovered by the natives weighed 700 lbs., and was given to Puni, the noted Chief of Porapora who subjugated the greater part of Ra'iatea" (1919:136n).

8 See, for example, Jefferson, Journal, 24 January 1806, LMS Archives.

9 Captain Winnifred Brander, "Society Island Genealogies," manuscript, Bernice P. Bishop Museum, Honolulu, Hawaii.

10 This "Tee" (i.e., Ti'ipari'i) was probably the individual identified as Toppere by J. Forster, who described him as having "the direction of Matavai" (1778:354).

11 Another name prominent in the earliest accounts of Matavai and its vicinity was Robertson's and Cook's "Owhaa” (Robertson 1948:169-175; Beaglehole 1955:75n) and Thomson's "Ofa'a" (Thomson, History, p. 36). Henry transcribed this name as $\mathrm{O} \mathrm{Hau}$, which raises the possibility of its having been an official designation for Ti'ipari'i - i.e., as hau of this tribe. However, I consider this an unlikely transcription and settle for Thomson's identification of "Ofa'a" as a landed proprietor of Point Venus - in other words, a ra'atira of only local consequence.

12 Bligh 1789:I, 372; Vancouver 1801:262, 285; Bligh 1792:125a. It was Poeno 
who was custodian of Webber's portrait of Cook, the back of which served as a ship's register for a while.

13 The bases for these conflicting interpretations, which were touched upon earlier, are set forth in Gunson 1963 and Newbury 1961.

14 In his journal of his voyage of 1792, under the date of 29 April, Bligh identified Tutaha as "uncle" of Tu (Pomare I), but his journal of 1789 indicates that he probably intended "great uncle." See also Beaglehole 1955:clxxxii.

15 Beaglehole 1955:95-96; Beaglehole 1962:I, 280-282. It will also be recalled that Tutaha's relations with Hitia'a's chief, Reti, were such that he was able to visit Bougainville there.

16 Tutaha evidently had some proprietary rights in the important Pa'ea marae, Maraeta'ata, but I cannot discover the basis for these rights, except possibly from "Old" Tutaha's mother, who is given in Emory's Tarahoi genealogy as having been a To'ofa, the Title usually associated with that marae.

17 While this list is of Teu's offspring, there is some question as to whether the mother of all of them was in fact Tetupaia. For example, Adams stated that Ari'ipaea (Te Ari'i Fa'atou) was son of another of Teu's consorts (1901:100).

18 My bases for setting the birth years of these first three offspring of Teu and Tetupaia are as follows. Most writers (correctly, I think) identify Te Ari'i na Vaho Roa as the young woman seen by Cook et al. in 1769 in company with Papara's young ari'i, Teri'irere (and who was at the time either his wife or his wife-to-be). On that occasion Cook estimated her age at about 18 or 20, and Banks estimated it at 16 (Beaglehole 1955:103; Beaglehole 1962:293), which would put her birth between 1749 and 1753. In December 1772 Boenechea guessed Pomare I to be 20 to 22 years old (Corney 1913:319), and writing in August 1773 G. Forster put his age at 24 or 25 (1777:I, 326). These estimates would locate the young ari'i's birth date between 1748 and 1752. Adams put the date at about 1743 (1901:88) but on what evidence I cannot discover. I have found no observer's estimate of the age of Ari'ipaea Vahine, but, if she was in fact born after Te Ari'i na Vaho Roa and before Pomare I, her birth date must have been as given in my list.

19 Gunson - mistakenly, I believe - identified Morrison's Ari'ipaea Vahine with "Ine Metua" (i.e., Vahine Metua) (1964:64), another famous Tahitian woman whom I shall identify further. Vahine Metua was wife of Teu's second son, Ari'ipaea (Te Ari'i Fa'atou).

20 Pomare I shared his sleeping mat with a number of males as well (Jefferson, Journal, 8 June 1799, LMS Archives).

21 Gunson identified Vavea as 'Itia's father (1964:62), in opposition to the identifications made by Henry (1928:268) and Emory (Marae Traditions).

22 See also Turnbull 1813:280.

23 "Tynan with his Wives, Father and Brothers dine with me every Day. A Cannoe with a Party came over from Moreah to see the Ship, there were some Friends of Whyerreddee for whom Tynah had recourse to my lockers, to satisfy with presents. Tynah is a perfect Fool to this Woman. She rules him as she pleases, while Iddeeah quietly submits, and is contented with a moderate share of influence." (Bligh 1792:133b). 
24 In describing Teu's offspring G. Forster listed as number five " $\mathrm{T}$ '-aree-Watow [who] appeared to be about sixteen years of age [in 1776]; he told us he had another name but which I have forgotten, from whence I conclude that this which I have mentioned is only his title" (1777:II, 96). Other attempts to transcribe Te Ari'i Fa'atou were "Tarevatee" and "Tarevatou."

Adams identified Ari'ipaea as half-brother of Pomare I $(1901: 100,111,113)$ but this is confirmed by no other primary source that I know of.

25 In 1792 Bligh also included Tetaha (along with Pa'ea, his "Taaigh," and Puna'auia, his "Paterre") within the "land Division" of Atehuru (1792:166).

26 "Lycurgus" was the nickname given to Tupura'a i Tamaiti by Banks, in admiration for the effective manner in which he recovered and restored some objects stolen by his subjects from the Europeans (Beaglehole 1962:I, 255-258).

27 The Beaglehole edition reads, “... one of the Chiefs of Attahourou" (1967:198), which may be accounted for by some writers' inclusion of Fa'a'a in Atehuru.

28 Bligh 1789:II, 48-49; Bligh 1792:126b, 135.

29 Pohuetea, through this or some other Title, may also have been associated directly with the Puna'auia Point Taputapuatea marae just described, but that is not clear. In any case, his principal household was some miles away from both marae - or so one may infer from the fact that it took Rodriguez several hours by canoe to travel from one place to the other (Corney 1919:171). Anderson, writing in 1777, described Pohuetea as residing near 'Utu'aimahurau (Beaglehole 1967:979) - a somewhat puzzling circumstance inasmuch as this would have placed this Puna'auian chief's residence deep within Pa'ea.

30 It was this same Purutihara, it will be recalled, who offered her sexual favors to Cook in exchange for some red feathers - presumably before she became his "sister"!

31 Called also "Paterre." In some contexts the name Atehuru was used by Europeans to designate $\mathrm{Pa}$ 'ea specifically, rather than $\mathrm{Pa}$ 'ea and Puna'auia; but whether this was also a Maohi usage is not clear.

32 According to Emory's classification two of the enclosed units corresponded to his "inland" type and the third to his "coastal" type (1933:67-69). For a more analytical classification see Green et al. 1967.

33 In earlier writings Emory identified the marae complex described by Cook et al. and sketched by Webber as Maraeta'ata (1931; 1933; Marae Traditions); but later he joined Beaglehole (1967:198n) and Green (Green and Green 1968) and myself in identifying it as 'Utu'aimahurau. This correction has an important bearing on our understanding of Tahitian political history, and is not mentioned merely for the sake of technical accuracy.

34 Adams' designation of proprietorship referred specifically only to Maraeta'ata. But then, Adams did not even mention the name 'Utu'aimahurau, not even in his long list of marae, consequential and otherwise. From this I am led to conclude either that Ari'i Ta'ima'i was ignorant of its existence (which seems unlikely), or that she confused or lumped together the two marae (or, of course, that Adams himself misinterpreted the old matriarch's recollections).

35 There would seem to be two possible and equally plausible explanations for the close connection between Maraeta'ata and 'Utu'aimahurau marae. 
First, one of them might have been a direct offshoot of the other - say, 'Utu'aimahurau from Maraeta'ata - with the 'Oro cult having been added to the latter's other functions and buildings over the course of time. Or second, 'Utu'aimahurau could have been constructed de novo, as the tradition vaguely implies, and its proprietorship taken over (or indeed sponsored) by the chiefly dynasty already established at Maraeta'ata.

36 "E parau tupuna no Te-toofa arii no Teoropaa: Outuai te marae." (Transcribed by Emory from the Pomare genealogies.)

37 Tevahitua was a fairly common name, separately or as part of a Title - as for example, of Papara's Amo. Patea was recorded by Adams as having been connected with Fa'atoai's (Mo'orea) marae Taputapuatea (1901:38).

$38 \mathrm{My}$ basis for this opinion is the display of affection between Teri'irere and $\mathrm{Te}$ To'ofa's wife and daughter, witnessed in 1777 by Lieutenant King (Beaglehole 1967:1378-1379).

39 Explanatory notes with this genealogy add that the only offspring of Tavi and Taurua died without issue, and that Tuiterai was Tavi's "younger brother or cousin" - whatever that might signify.

40 The note recording this event, as reproduced in Emory (Marae Traditions), reads: "Maua came to Papara bringing Oro and the Maro Ura, Teraipuatata, connecting Raiatea and Atupii (Huahine)." The significance (and possible historicity) of this event will be discussed later on.

41 One of the sons was also called Aromaiterai, said Adams (1901:38).

42 For example, a great-granddaughter was Ari'i Ta'ima'i, the source of Adams' History.

43 As noted above (p. 1190) there is some question about this identification with implications which will be discussed later on.

44 Henry's Papara genealogy lists only one, Teri'irere (or Temari'i) (1928:270); but Emory (based on notes from Tati Salmon) listed nine (Marae Traditions).

45 In line with this version, of the nine offspring of Amo listed in the Papara genealogy reproduced in Emory's "Marae Traditions," only Teri'irere was borne by Purea. (Adams 1901:110)

46 Teri'irere-Temari'i was hardly the "bachelor" that Henry described him as having been, but as I noted already, he produced no publicly acknowledged progeny, and his kin-Titles and tribal office eventually passed to a collateral. According to Adams, his Temari'i Ari'ifa'ataia was at one time married to a daughter of the chief of Matarea (1901:122), a union which could not, however, have added much luster to Temari'i's own glittering kin-Titles, or much political strength to his tribal office.

47 He was a rare exception among Ra'iatean emigrees in Tahiti, for most Ra'iateans on Tahiti who are mentioned in the pages of the sources were alleged to be "princes" or "princesses" from Opoa.

48 The name Metuaro (or Motuaria, or Mahau) also figures importantly in these accounts but appears to be an alternative personal name for a holder of one of the Titles just listed.

49 "[Baldness] ... a thing rather uncommon in these islands at that age, he wore a kind of Turban and seem'd ashamed to shew his head, but whether a bald head is a Mark of desgrace with them or they thought it was so with 
us I cannot say; we judged it was the latter, as we had shaved the head of a Indian we had caught Stealing." (Beaglehole 1967:227)

50 In a footnote to this passage Beaglehole registered some skepticism, saying, “Mahine's lady may have been Amo's sister, but there is no trace of a sister in the genealogies I have seen" (1967:226n3). Evidently Dr. Beaglehole had not seen the Papara genealogy reconstructed by Emory, for this shows Amo to have had ten siblings, including four positively identified as females, and five others not identified as to sex. Also, one will recall the name of another of Amo's sisters, Tetua Unurau, who was mother of the famed Purahi.

51 According to a missionary survey published in 1818, the (usually uninhabited) islet Tupai was also "subservient" to Porapora, but who its proprietors were in 1767 I am unable to discover (Narrative of the Mission at Otaheite [London: London Missionary Society, 1818] p. 7).

52 The reference is to hogs sent by Puni to the ship, and to three young women who evidently visited the ship at Puni's command.

53 Chesneau labeled it the Battle of Ho'oroto (Ra'iatea), and asserted that it came about as the result of Mo'ohono's efforts to have his grandsons, Tenania and Mahine, vested with "sacred kingship" at Opoa's Taputapuatea marae (i.e., probably meaning, invested with a maro ura kin-Title associated with this marae). At this period the principal, locally held maro ura kin-Title of this marae was evidently that of Mato's second cousin, Vetea Uru. It is reasonable to suppose that Mato might have claimed it also, on the basis of his grandfather Ari'imao's primogenitary rights over those of Vetea Uru. (The latter's incumbency probably derived from his father.) In any case, the question of succession was evidently open enough to encourage counterclaims.

54 The account states that the location of this site on Taiarapu was near Point Ta'atua at a previously built marae called Te ahu rua tama. I am, however, unable to locate any point or marae so named. As for Taputapuatea, the name of the marae built to house the image, there was a well-known marae of that name at Tautira, which later became (or resumed being?) the principal 'Oro image depository for the whole island - but, of course, all marae serving that function were so named.

55 I called attention earlier to the peculiar discrepancy between two versions of this story. In Adams' version, which was based on Ari'i Ta'ima'i's account but translated by her daughter Marau, the lover was a shark-god of "the race of arii rani," and the girdle in question was a maro tea (1901:12-14). In the Handy version, however, which the author reportedly obtained from Marau herself, several decades later and after the death of Ari'i Ta'ima'i, the lover is specifically identified as an Opoan chief (though also a fish god), and the girdle was of red feathers - i.e., a maro ura (1930:68).

\section{CHAPTER 26}

1 The personnel of Bougainville's expedition, which anchored off Hitia'a in April 1768, were similarly unaware of what was then taking place at Papara, 25 kilometers to the west.

2 This version, which I shall label the "Adams' version," is really a hodge- 
podge of "facts" put together (and without entire consistency) from Georg Forster's journal, Wilson's "Missionary Narrative," etc., and from oral traditions said to have been transmitted - twelve decades after the events - by Ari'i Ta'ima'i herself.

3 According to the Emory genealogies, Teihotu's wife was Vavea, and this couple had only three offspring: 'Itia (principal consort of Pomare I), Pateamai (first married to Vehiatua III, later to Pomare I), and Mahau, the embattled claimant to Mo'orea's principal chieftainship. Teri'i Vaetua was one name of Teihotu's father, and may have been an alternative name for some other member of the Ahurai family, possibly for Te Pau "B" (fig. 25-1), but I can find no confirmation of this on any genealogy known to me.

4 Cook's "Tarevatoo" was indeed Pomare I's brother (or half-brother), Te Ari'i Fa'atou, and not Teri'i Vaetua.

5 Undoubtedly, a great deal of politically relevant information is encapsulated in this cryptic formula, but I shall resist the temptation to try my hand at interpreting it.

6 Beyond pointing to some traditional conflicts, such as the one between Tavi and Tuiterai (Adams 1901:22ff), I cannot account for this antagonism in specific terms. Perhaps we see here a predictable process in Maohi-like societies - namely, the typical (but not inevitable) development of friction between two more or less evenly matched tribes having a common boundary. This is, of course, far too large a matter to consign to a note, and I do so only to call attention to the question.

7 Adams quoted a dramatic song which was said to have been composed by Paparans in memory of this blow to their tribe and which identifies Purahi as the principal mover of it (1901:57-59).

8 Journal of a Voyage round the World in H.M.S.'s Ship Endeavour (Dublin, 1772) pp. 93-95. Beaglehole referred to Tupaia's intrigues against Tutaha, but provided no reference for this information (1955:117n).

9 Wilson 1799:xii-xiii; d’Urville 1834-1835:I, 544.

10 This is only one of several totally different versions for the origin of marae Teahupo'o.

11 This seems to refer to Vehiatua's part in the Papara debacle. G. Forster's error in having Tutaha view this as an insult to his family was based on his mistaken notion that Tutaha and Amo (and Teu) were brothers.

12 This refers to the time since their departure at the end of the first visit of the second voyage.

13 It will be recalled that Vehiatua I's spouse, the famous Purahi, did in fact "marry" a man named Ti'itorea after her husband's death, and that her new partner became "prime minister" to her elder son, Vehiatua II.

14 I refer here to the statement in Adams linking Tutaha with Maraeta'ata in Pa'ea (1901:74).

15 On this point Adams stated: “... Otoo was not allowed to wear the Maro without a protest. In order to receive full recognition, he was obliged to take a seat and wear the Maro-ura in the great Marae of Maraetaata in Paea. This Marae had three heads: (1) Pouira, the Tevahitua i Patea; (2) Tetooha, the 
Taura atua i Patea; and (3) Punuaaitua. Tevahitua protested, and refused to allow Otoo to take his seat and wear the Maroura on his part of the Marae. The other two made no objection, and the reason was characteristic of Tahitian society. Otoo's great-grandmother, Te-fete-fete-ui, was the daughter of Tevarua hoiatua, a chieftess of Ahurai and Punaauia, and as such had the right to a seat in Marae Maraetaata." (1901:75)

\section{CHAPTER 27}

1 In a footnote commentary on King's statement above, Beaglehole wrote: “This is not a very intelligible account. The name of the brother of Vehiatua here referred to seems to be an attempt at Teri'itetua-ounu-maona; but this person was himself Vehiatua 1775-90, and was the boy whom King has already mentioned (17 August). He never settled on Moorea. There seems to be no other reference to such a battle." (Beaglehole 1967:1382n1.) Evidently, Beaglehole missed de Barreda's and Bligh's references to "such a battle," as well as Bligh's reference to a third brother.

2 Although the actual nuptial rites formalizing these two marriages may not have been finalized for some time after the beginning of this era, the understandings regarding the alliances were probably already in effect by the time of Cook's second voyage, when the succession issue came to a head. The link between Vehiatua III and Pateamai (and hence between Vehiatua III and Mahau) is likely to have reinforced Seaward Teva's hostility toward Mahine, and was conceivably formed with that in mind.

3 See also Beaglehole 1967:977, 1064-1065, 1315-1316, 1376.

4 The situation described earlier concerning the nonhostile reception accorded some visiting Mo'oreans at Tautira could count as another example of this "Police" - although it is of course possible that the visitors in question were not from Mahine's territory. (See Corney 1919:116.)

5 See also Beaglehole 1967:214. This would appear to indicate that a Seaward Teva contingent, possibly under Vehiatua III, accompanied Te To'ofa's and Pohuetea's in the expedition against Mo'orea. This accounts for the reference to "another Chief" in Cook's passage about the expedition (p. 210), and for the reported presence of a Seaward Teva chief at the "peace" ceremony yet to be described.

6 In blaming Te To'ofa for the stalemate, Old Teu, Pomare I's father, was giving vent to a narrowly partisan sentiment, but the very exiguity of his view might indicate that his own family's interests were particularly damaged by terms of the truce. Among other things, he seems to have assumed that had Te To'ofa waited a while to attack Mahine, Cook himself might have been persuaded to intervene on the side of the Tahitians.

7 Except for the Lady Penrhyn (Lieutenant Watts, commanding), which anchored at Matavai for a fortnight during July 1788, en route to Australia.

8 According to Vancouver, Mahine was killed during the Battle of Atehuru, but this conflict took place in September 1791, three years after Bligh wrote of Mahine's death in the earlier campaign, a fact also overlooked by Adams (1901:102). 
9 This young woman, who was also called "Alredy" (Ariti?), was estimated to be about sixteen years old in 1791, and thus born circa 1775 (Edwards and Hamilton 1915:103).

10 I am somewhat puzzled by this so-called friendship between Pomare I and Te Pau "B", since Fa'a'a appears not to have aided Pomare I during the attacks of Te To'ofa, Mahine, and Vehiatua III. Actually, this seems to confirm a situation noted earlier - i.e., although Te Pau "B" had succeeded to his father's Title, de facto tribal authority had rested in the hands of Te To'ofa. Of course, with Te To'ofa dead, the friendship between Te Pau "B" and Pomare I could blossom, for the moment at least.

11 However, the Wallis maro seems to have been still at 'Utu'aimahurau marae at this time.

12 This individual was only about seven years old at the time of Bligh's Bounty visit, and he did not assume the Title of Pomare "II" for some time to come; but I shall refer to him throughout by this label in order to spare the reader some of the confusion involved in trying to keep track of Maohis' name changes.

\section{CHAPTER 28}

1 Strictly speaking Morrison was not one of the Bounty "mutineers," as he was subsequently cleared of culpability in the mutiny, but I shall continue to refer to him and all his companions by this term.

2 For example, in February 1790, Morrison witnessed a solemn ceremony at which offerings were made and shoulders bared to a portrait of Captain Cook, just as to a living sovereign (1935:85-86). One will also recall the use made of the Dolphin's pennant in the Wallis maro.

3 Henceforth for convenience I shall refer to the immediate family of Pomare I and II as the Pomares, although the Title applied only to the incumbents themselves.

4 Hitihiti's ("Odiddy," “Oedideedee," "Hedeedee") native hearth was Porapora and he claimed kinship with that island's famous old chief Puni. In 1773 and 1774 his age was put at seventeen or eighteen, and he was a useful and universally liked member of Cook's crew. After that expedition he settled at Pare in the service of Pomare I. Cook met him there in 1777, but this time he was described as "foolish," "clumsy," and kava-addicted, but evidently still skillful enough with firearms to make himself a valuable ally. According to G. Forster his original name was Mahine, but this was exchanged with a Mo'orean chief when the two became friends. As for the report that he was married to Tetupaia's sister, Te Pau, I find no such sister listed in the genealogies to which I have access, but that does not necessarily discredit this attribution. (Beaglehole 1961:lxxiii, 426n; 1967:1375, 1058-1059; Bligh 1789:II, 68.)

5 Adams reconstruction is vitiated in part by his assumptions that Temari'i and Teri'irere were half-brothers, and not alternative names for the same individual, and that Temari'i - the one under discussion — had been born about 1772 
(whereas Morrison judged him to be twenty-seven or twenty-eight years old in 1791). Moerenhout also offered a reconstruction of this complex of relationships, but it is even more ill informed and confused than Adams', and does not warrant further consideration here.

6 Adams claimed that Ari'ipaea was also Temari'i's "guardian," having been made so upon the death of Amo; but Temari'i was already about twentyfive years old when these events took place, and, as we shall see, Arno was still alive (1901:110ff.). According to Moerenhout, Ari'ipaea "betrayed his trust" as guardian to Temari'i by turning over his seat in the Papara marae to Pomare, which was tantamount to transferring the sovereignty to all Papara (1837:II, 417ff.). This account was accepted as factual by Adams, who, however, added that the transaction took place without the consent of Temari'i or the people of Papara, and was never considered by them to be binding (p. 114). I am unable to accept or reject these reconstructions written so many decades after the events they are supposed to describe, and by such partisan chroniclers.

7 As we saw previously, although Pomare II, and before him his father, had been permitted access to the Wallis maro and the Paparan image while they had been deposited at 'Utu'aimahurau, he did so only with the consent of that marae's proprietors, and subject to constraints that he evidently considered to be distasteful.

8 Thus, Arno was still alive in October 1790, contrary to Adams information (1901:111).

9 For a description of marae Tarahoi, including its new addition, see Green and Green 1968.

10 As an example, I refer the reader to Hamilton's account of his encounters with the custom of "wife-hospitality," which provides, among other things, a somewhat different view of the character of two of our leading personalities, Mahau, principal chief of Mo'orea, and his wife, Auo, who was sister of Pomare I. (Edwards and Hamilton 1915:109-110)

\section{CHAPTER 29}

1 Some idea of the nature of this expedition's relations with their hosts (and hostesses) may be gained from the information, as reported by Vancouver, that only one member of the entire company of both ships was a married man!

2 In telling Bligh about one of these vessels, in July 1792, a native informant described it as "... a Miserable vessel and the Commander as a great Rascal" (1792:168b).

3 Other members of this expedition who left accounts of some value were Tobin, Portlock, and Flinders; Tobin particularly deserves credit for the series of watercolors he produced (figs. 29-1 through 29-5).

4 See chapter 28. According to Vancouver this expedition was carried out by the mutineers themselves (1801:323-324), but if one accepts Morrison's on-thespot report, the trip to Mo'orea by some mutineers took place after Hitihiti's successful campaign, and was merely a peaceful sight-seeing tour. Vancouver 
also recorded, mistakenly I believe, that Mahine was killed in the battle of Atehuru, whereas other evidence places his death sometime earlier.

5 As I observed concerning an earlier period of this era, I am not entirely certain about the political geography of Mo'orea, or about the degree of authority exercised by its successive chiefs. Although Mahau may not have exercised the same amount of control over all parts of the island, since the defeat of Tairihamoetua (?), in 1790, Mahau and his immediate successors were undoubtedly the island's most powerful and influential tribal chiefs.

6 Vancouver's detailed amount of this event, which occurred during Mahau's visit to Pare, is one of the best descriptions we possess of an actual Maohi funeral. As most of the generalities obtainable from it have already been set forth in chapter 3, I shall not reproduce it again. The particularity about it of most present interest is the fact that Mahau's embalmed corpse, after remaining a month in state in Pare, was carried on a tour of Seaward Teva and "some of the Western districts," before being returned home to Mo'orea (Vancouver 1801:297). Another point of interest is the location of the principal funeral rites, which were at Pare's Tarahoi; in fact, no mention is made by Vancouver of Mahau's father's marae, Ahurai, although this principal Fa'a'a marae may have been included in the corpse's itinerary through "the western districts."

7 This is in disagreement with Vancouver's version, which reads as follows: "On the late decease of Mahow, his daughter by Pomurrey's sister succeeded to the sovereignty of Morea, under the supreme authority of her cousin Otoo [Pomare II]. To this young princess Pomurrey [Pomare I] became regent, and in course, the inhabitants of Morea were intirely at his command" (1801: 325-326). I am inclined to accept Bligh's version of this succession; not only was Tetuanui male, and older than his sister, but Vancouver's opinion, which was formed within days of Mahau's death, was superseded by Bligh's by several months' time. Bligh also introduced an interesting complication of this episode, in his reference to a Matuaro, which will be discussed later on.

8 I cannot definitely identify this "Matuarro" with any individual appearing on the Huahine genealogies available to us. The most likely candidate is Teri'itaria, the young boy who was ari'i rahi in Huahine during Cook's visit in 1777 (Beaglehole 1967:233), and who was the son of "Queen" Tehepapa and of either her first husband, Rohianuu, or of her second husband (and Rohianuu's brother), Mato.

9 For a description of the conclusion of this ceremony see Bligh 1792:173, which is one of the most detailed eyewitness accounts available of an actual ceremony involving a human offering. To this account Bligh also added the interesting observation that a maro ura (probably the Wallis maro) had been added to, since he last saw it, with hair from one of the mutineers - "an ostentatious mark of their connections with the English, and not of respect to the Person it belonged to."

10 Even their livestock underwent change: "It is remarkable how the Otaheite breed of Hogs is effectually destroyed. We meet with none but of the European Kind, owing to the Natives prefering them to their own, which were of 
the China sort, and another of an inferior kind because they are of a larger size." (Bligh 1789:I, 376)

11 For references to diseases allegedly introduced into these Islands during the Early European Era see the following: Beaglehole 1955:98-99; Beaglehole 1961:215; Beaglehole 1962:I, 374; J. Forster 1778:488; G. Forster 1777:I, 370-371; Bligh 1789:I, 388-389, 398, 409, 421; II, 10, 30-31, 60; Corney 1915:51; Corney 1919:30; Morrison 1935:228-230; Vancouver 1801:337; Ellis 1829:II, 272.

\section{CHAPTER 30}

1 The Spanish friars who had spent a year at Tautira had moral codes and objectives somewhat similar to those of the English missionaries, but they insulated themselves so effectively from Maohi society that they could not have produced much of an impression of any kind on their native neighbors.

2 The accounts of this encounter, mostly written by the missionaries themselves, are in places so unconsciously ironic - or poignant, or incredibly naïve, or downright hilarious - that I am often tempted to include them, if for no other reason than to lighten my own exposition; but I refrain from doing so in the interests of space. I do, however, recommend the account of the first meeting between this solemn band and a mob of Arioi on the decks of the Duff, in which the former responded to an especially lusty greeting by the untrammeled Arioi with a few tunes by Brother Bowel on the German flute (Wilson 1799:73).

3 This ritual condition of Pomare II was also mirrored in the behavior of his father, Pomare I, who at this time was still constrained from feeding himself (Wilson 1799:75).

4 Temari'i also bore the name Ari'ipaea (the missionaries' "Orypaih" or "Oripaia"), which Adams claimed was bestowed upon him as the result of his "adoption" by the late Ari'ipaea, brother of Pomare I.

5 It will be recalled that Cook's "Towha” (Te To'ofa), the great chief of Pa'ea, left as his successor his own son, who died in 1791, and that the latter was succeeded by his sister's son, whose age was about four at the time; thus he was ten or eleven in 1797, and possibly the individual in question.

6 Tutaha was an alternate name of Ha'amanemane, but appears not to be the one here mentioned.

7 The missionaries reported that Pare's principal marae, Tarahoi, was (again) "inferior" to 'Utu'aimahurau (Wilson 1799:211). During their tour of the island in 1797, the Duff's officers visited Puna'auia's marae Tahiti and reported the presence there of a small "ark" containing a god's image (pp. 208-209); the identity of the god is not given, and, although it may have been 'Oro, the image itself was evidently of less importance than the one then deposited at 'Utu'aimahurau.

8 One cannot overlook, as a contributory factor, the extent to which a successor to an important kin-Title was insulated from his parents, and particularly from his father, throughout infancy and childhood. That is to say, the lack of nurturant interaction during those formative years need not have fostered hostility 
between parent and child but by the same token cannot be expected to have fostered much affection either.

9 Further insight into Maohi social relations is provided by the fact that five other (presumably lower-class) persons were also badly burned by the gunpowder explosion, and that the missionaries were not even informed of their painful plight when first asked to treat Teri'irere-Temari'i. In fact, three of the five were not even given native medication. (LMS Transactions:I, 76-77)

10 The events were, however, not without some hopeful expectations on the part of the missionaries: "This shaking of the nation may be only plowing up the fallow ground for the better sowing the seed of eternal life: though many may fall, yet we trust the gospel will not be removed off the island, till thousands have felt it to be the power of God and the wisdom of God for their souls' salvation" (LMS Transactions:I, 84-85).

11 According to one missionary historian a contributing factor to Pomare II's hostility toward his father was the latter's action in naming his youngest son, Teri'i na Vaho Roa, to the local chieftainship of the tribal subdivision comprising Point Venus - an estate which Pomare II coveted for himself. (Thomson, History, p. 27)

12 See, for example, LMS Transactions:I, 11, 115, 120, 124.

13 The occasion of the message was the suicide - or possibly murder - of Lewis, who had been a missionary prior to his "excommunication" from the group (on account of his living with a Tahitian woman). This episode contains a world of poignant human interest, and the almost daily interchange between Lewis and the other missionaries, couched in turgidly biblical prose, reveals much about the Europeans involved. The occurrence constituted such a major preoccupation for the missionaries during so many weeks that their journal for the period contains little else.

14 In describing these events in the LMS Transactions, the missionaries provided an interesting sidelight on the degree to which Pomare I had become reconciled to his role vis à vis his son: "Pomere and Edea having been made fully sensible, that the presents sent by Governor King are for them, and Otoo not considered, began to express their fears, lest Otoo (who, by the custom of the country, is held superior in dignity to his father and mother) should take offence thereat, they expressed a wish that the scarlet dress should be given to Otoo, in preference to Pomere. Capt. Scott being informed of this, consented that it should be so, and, in order to make all things agreeable, employed his tailor to make a scarlet dress for Pomere, and another for his youngest son Teare-navo-roa; and also appointed a white shirt for each of the two chief women, Tatooa-noce, and Tooboo-iote-rye." (I, 229)

15 The missionaries' journal of the period August to January is not extant.

16 In the interest of brevity I offer no comments on the ritual aspects of this important event, and call attention only to one other feature - the fact that Pomare II had now gone beyond his father in sheer ruthlessness.

17 According to my reconstruction the image we are now concerned with was the one originally established at Papara, then taken to 'Utu'aimahurau by Tutaha et al. in 1768 , to Pare in 1792 , then back to 'Utu'aimahurau. What had 
happened meanwhile to the image called 'Oro Rahi To'o toa, the one said originally to have been at Tautira, I cannot fathom.

18 One person on the Pomares' side who was slain in Taiarapu was Mateha, a brother of Ra'iatea's chief, Tamatoa IV.

19 See also Thomson, History, p. 57.

20 According to one interpretation, Pomare I was killed by the god 'Oro to punish him for the sacrilege involved in the forceful removal of the god's image from ‘Utu'aimahurau (LMS Transactions:II, 342).

\section{CHAPTER 31}

1 In their journal entry of December 10, 1806, the missionaries requested: "If the Directors should write again to Pomare, we beg them to address him King Pomare, or Pomare King of Taheite, \&c \&c; and not chief, as it is likely to give offence, if continued." (LMS Transactions:IV, 19)

2 The reference also raises interesting questions concerning Maohi "marriage" - in this case, the nature of the relationship between 'Itia and Tenania. As we have seen, 'Itia was a loyal and helpful supporter of Pomare I to the end of his days, although she had long since had paramours, perhaps even while sharing Pomare I's mat. Tenania, however, was a somewhat different matter. Whereas 'Itia's early lovers had been toutou, Tenania held a very high-ranking Title; and his daughter by 'Itia was evidently considered of superior enough status to qualify her for the Mo'orean office of "governor." That is to say, the relationship between 'Itia and Tenania was a "marriage" in the fullest Maohi sense, and it was in effect long before Pomare I died. (See Turnbull 1813:134, 145-146.) In other words, in view of 'Itia's continuing alliance with Pomare I, and in the absence of any indications of a formal separation between the two, we are confronted in this case with still another example of the flexibility with which the Maohis defined relationships of affinity.

3 Pomare II wished himself to be called "King," but this does not imply any identity between his concept of kingship and the English one which served as his model. Nor does it imply that other Tahitians held him to be "King."

4 We do not know when or why Pomare II chose to set up a marae for himself separate from the traditional family one of Tarahoi; perhaps this had been another move in his previous effort to make himself independent of his father's control.

5 Perhaps the clearest ritual indication of the extent to which the interests of Pomare II and 'Oro had come to coincide is to be found in the account of a maeae in June 1806: "Today there was an Oroa at Pare called Ma-e-ae, this ceremony consists in offering to the god Oro Cloth, Hogs, Ava \&c. which are brought from every district in the Island. After a certain part is divided out for this purpose, the priests on the canoe (designed to carry the dedicated food \&c. to Oro who is at the Marae at Toutera) blow the conch shell, crying out at intervals Teie te ma e ae na Oro here is food for Oro to eat - supposing that the god comes and eats the spirit of the food \&c. The greater part 
of the presents brought are the Kings which he disposes of at pleasure." (Davies, Youl et al., Journal, 20 June 1806, LMS Archives)

6 A marginal comment by the missionary Nott on this passage in Davies' manuscript described the ceremony as "A kind of investing of their god oro with the royal authority, or making him their king by putting on him the royal maro ura, for which ceremony the bure is performed. Not for King Pomare." (Newbury 1961:87n2.) If Nott's identification were true - and he was undoubtedly more fluent in the language than were the other missionaries - this would constitute a most intriguing reversal of ritual roles between human ari'i and deity.

7 Fa'a'a was rarely singled out as a separate political unit in this or in other accounts of this period. Earlier it was sometimes included with Atehuru, but in later years it was included in Porionu'u.

8 According to Adams, although the land in question was in fact dedicated to 'Oro and his priests, some of its inhabitants refused to leave, thereby giving Pomare II another pretext for his next attack on the south (1901:149-150).

9 This individual is not specifically identified as a leader, but he was possibly the tribal chief of Pa'ea.

10 According to Adams the attack upon Atehuru, Papara, etc., was simply a continuation of the old feud between Purea and 'Itia which had culminated in the Papara debacle of 1768. Specifically, Pomare II's attack was viewed as a measure for wiping out the insult offered to 'Itia by Purea when the former tried to put an end to the rahui imposed by Purea on behalf of her son, Teri'irere. (1901:152.) As Adams noted, this is a "more picturesque" version of the war than others that might occur to the reader, but it is not altogether credible. For one thing, why would Pomare II include Oropa'a in his offensive action?

11 Reinforcing the missionaries' decision to withdraw was the lack of any evident sign of success in their mission, and the absence of any communication from the London Missionary Society's directors for some six years! (Newbury 1961:116)

12 Pomare II even engaged in pimping in order to obtain gunpowder: "In the evening Pomare sent 8 women to the ship to prostitute themselves to the seamen, giving them charge to get powder to bring it to him" (Jefferson, Journal, 8 April 1803, LMS Archives). This was certainly not a new tactic with the Maohis, but there is no previous record of it having been organized on this large a scale.

13 This disenchantment applied especially to the missionaries, who had few objects to give away, who had shown themselves unwilling to engage in military adventures, and whose ideology was still generally considered to be ridiculous, if not insane.

14 Newbury 1961:73; Jefferson, Journal, 12-22 September 1804; LMS Transactions:III, 43.

15 This merriment included the manufacture and drinking of an intoxicating beverage made from the root of the ti plant - an innovation introduced by the Hawaiians. 
16 Some of these chiefs may have been kinsmen, related to him through his paternal grandmother, Tetupaia, but one has the impression that Pomare II's solicitude toward those distant individuals was based more on their chieftainship than on their consanguineal ties to him.

17 One will recall in this connection that other Ra'iatean immigrant, Ha'amanemane, who made such an important place for himself in Tahitian politics.

18 I do not propose that this was a wholly new kind of development in Maohi history. In fact, similar measures seem to have been imposed shortly before this in the Leeward Islands, in connection with Poraporan conquests there, and it is likely that the same kind of development had taken place in the past on Tahiti and Mo'orea - but probably on a much smaller scale.

\section{CHAPTER 32}

1 Venus was the small schooner captured by Matavaians in September 1809. See pages 1324-1325.

2 See the strictures on missionary "censuses" in chapter 2.

3 I am not entirely sure whether Fa'a'a was an autonomous unit during this period, or was allied with Puna'auia and Pa'ea.

4 Tati and Opuhara were grandsons of Amo's younger brother, Manea, and thus legitimate successors to Teri'irere-Temari'i, who left no heirs.

With no missionaries stationed on the island during this period, such information that was recorded about events and personalities outside Pare was sparse and secondhand. However, had any of the tribal chiefs made much of a political stir, the missionaries would likely have heard of and dutifully recorded it.

5 Although humans continued to be offered to 'Oro and perhaps to other deities during this period, the sacrificial rituals evidently took place without benefit of a feather-girdle $a r^{\prime} i$.

6 These developments may perhaps represent a local manifestation of a much more generic phenomenon in Polynesian societies: that is, the ascendancy of shamanism over priestcraft in times of social disorganization.

7 It is, of course, impossible to divine all the actual motives that moved these important leaders to travel with scores and even hundreds of their followers to Mo'orea and Tahiti, and to spend so much time there. Aid to Pomare II, the announced reason, was possibly also a sincere one, but political adventuring probably figured, along with an expectation of loot. Nor should one underestimate a desire for the novelty and excitement of travel, so apparent in other situations in Maohi life.

8 Technically, inasmuch as this Uru had already sired a successor before 1777, it was the latter who held the highest-ranking Opoan kin-Titles at the time of Cook's visit - or so I assume from practices elsewhere.

9 One cause of this difficulty is Davies' apparent confusion in some passages between Tapoa and Tamatoa. For example, see Newbury 1961:137.

10 For one thing, although I do not suggest any causal connection between the two, the turn to Christianity took place simultaneously with the widespread consumption of ti-root alcohol. And Pomare II, the missionaries' premier 
convert and their proudest evidence of success, was described by some observers as having been drunk most of the time.

11 An interesting sidelight on the changes then taking place is revealed in the fact that pagan Maohis had begun to refer to their gods collectively as Tatani (Satan). (Newbury 1961:168)

12 In May of 1814 the missionaries received reports that a war had commenced in the Leeward Islands; no details were offered concerning the combatants or causes, but it is likely that this conflict was largely responsible for the return home of the Ra'iateans and Tana'ans.

13 In his more detailed (and doubtless more imaginative) account of the battle Ellis indicated that the most active leaders on the Pomare side were Mahine, "king" of Huahine, and Pomare Vahine herself - Pomare II, characteristically, having viewed the battle from the comparative safety of a canoe (1829:I, 248-249). 


\title{
BIBLIOGRAPHY
}

This bibliography contains only those items actually cited in the text. For a more comprehensive, and probably well-nigh complete, bibliography on ancient Tahiti, the reader is advised to consult the extraordinary Bibliographie de Tahiti et de la Polynésie française, critically and painstakingly compiled by Patrick O'Reilly and Édouard Reitman - perhaps the finest bibliography of its kind I have ever encountered, and one that would have shortened my labors by a year or more had it been available ten years earlier.

In addition to published works cited in the bibliography much use was made of unpublished documents and manuscripts. Text and bibliographic references should aid the researcher in the use of this material which may be found in the following places:

\author{
Alexander Turnbull Library \\ National Library of New Zealand \\ Wellington, New Zealand \\ Bernice P. Bishop Museum \\ Honolulu, Hawaii \\ London Missionary Society Archives \\ London, England \\ Mitchell Library \\ Public Library of New South Wales \\ Sydney, Australia \\ Public Record Office \\ London, England
}


Adams, Henry

1901 Memoirs of Arii Taimai E, Marama of Eimeo, Teriirere of Tooarai, Teriinui of Tahiti, Tauraatua I Amo. Paris: Privately printed.

Ahnne, Édouard

1923 “Deux légendes tahitiennes: Le grand lézard de Fautaua; histoire des Ainanu, Pipiri-ma." Bulletin de la Société d'études océaniennes 1(7): 35-40.

1924 "Le Lyrisme des Tahitiens." Bulletin de la Société d'études océaniennes 1(9): 20-23.

1925 "Mystérieuse aventure de Ariipaea Vahine, reine de Huahine." Bulletin de la Sociétéd'études océaniennes 1(10): 43-46.

1926 "De la coutume du pii et des modifications qu'elle apporta au vocabulaire tahitien." Bulletin de la Société d'études océaniennes 2(11): 6-10.

1931a "La Coutume du pii en Polynésie et le Fady de Madagascar." Bulletin de la Société d'études océaniennes 4:181-182.

$1931 b$ "Turi et Manu." Bulletin de la Société d'études océaniennes 4:168-169.

1932a "Le Déluge: version tahitienne." Bulletin de la Société d'études océaniennes 5:84-87.

1932b "Proverbes tahitiens." Bulletin de la Société d'études océaniennes 5:142-143.

1933 "Légendes tahitiennes: La légende de Ruanui; la légende de Paiheotuu." Bulletin de la Société d'études océaniennes 5:170-173.

1940 "Origine du nom de Punaauia." Bulletin de la Société d'études océaniennes 6:268-271.

Ahnne, P. (?)

1930 "L'Art du tatouage." Bulletin de la Société d'études océaniennes 4:77-80.

Alexander, W. D.

1893 "Specimens of Ancient Tahitian Poetry." Journal of the Polynesian Society 2:55-59.

Anderson, Eugene

1963 "Tahitian Bonito Fishing." Kroeber Anthropological Society Papers 28:87-119.

Anderson, William

1777 "A Vocabulary of the Language of the Society Islands." In A Voyage towards the South Pole and round the World ..., by James Cook. London: W. Strahan and T. Cadell.

Andrews, Edmund, and Irene D. Andrews

1944 A Comparative Dictionary of the Tahitian Language. Chicago Academy of Sciences Special Publication no. 6. Chicago.

Archer, Gilbert

1965 The Art Forms of Polynesia. Auckland Institute and Museum Bulletin no. 4. Auckland.

Baessler, Arthur

1897 "Marae und Ahu auf den Gesellschafts-Inseln." Internationales Archiv für Ethnographie 10:245-260.

1900 Neue Südsee-Bilder. Berlin: Von A. Asher. 
Barthel, Thomas

1961 "Zu Einigen Gesellschaftlichen Termini der Polynesien” Zeitschrift für Ethnologie 86:256-275.

Beaglehole, Ernest, and Pearl Beaglehole

1938 Ethnology of Pukapuka. Bernice P. Bishop Museum Bulletin no. 150. Honolulu.

Beaglehole, John C., ed.

1955 The Journals of Captain James Cook on His Voyages of Discovery. Vol. 1. Hakluyt Society Extra Series no. 34. Cambridge: University Press.

1961 The Journals of Captain James Cook on His Voyages of Discovery. Vol. 2. Hakluyt Society Extra Series no. 35. Cambridge: University Press.

1962 The Endeavour Journal of Joseph Banks 1768-1771. 2 vols. Sydney: Angus and Robertson.

1967 The Journals of Captain James Cook on His Voyages of Discovery. Vol. 3, 2 parts. Hakluyt Society Extra Series no. 36. Cambridge: University Press.

Bechtol, Charles

1962 "Sailing Characteristics of Oceanic Canoes." In Polynesian Navigation ..., edited by Jack Golson. Supplement to the Journal of the Polynesian Society 71:98-101.

Beckwith, Martha

1944 "Polynesian Story Composition." Journal of the Polynesian Society 53:177-203.

Beechey, Frederick William

1831 Narrative of a Voyage to the Pacific and Beering's Strait, to Co-operate with the Polar Expeditions: Performed in His Majesty's Ship Blossom under the Command of Captain F.W. Beechey in the Years 1825, 26, 27, 28. London: H. Colburn and R. Bentley.

Best, Elsdon

1917 "Some Place Names of Islands of the Society Group Supplied by Natives of Those Isles at Wellington, in 1916." Journal of the Polynesian Society 26:111-115.

Bligh, William

1789 [published in 1792] A Voyage to the South Sea, Undertaken by Command of His Majesty, for the Purpose of Conveying the Breadfruit Tree to the West Indies, in His Majesty's Ship the Bounty. Including an Account of the Mutiny on Board the Said Ship. 2 vols. London: G. Nicol.

1792 Journal of the Voyage of H.M.S. Providence. Unpublished manuscript in the Public Record Office. Reference: Adm. 55/152.

1937 The Log of the Bounty, Being Lieutenant William Bligh's Log of the Proceedings of His Majesty's Armed Vessel Bounty in a Voyage to the South Seas, to Take the Breadfruit from the Society Islands to the West Indies. 2 vols. London: The Golden Cockerel Press.

Bohannan, Paul

1955 "Some Principals of Exchange and Investment Among the Tiv." American Anthropologist 57:60-70. 
Bougainville, Louis Antoine de

1772 A Voyage round the World. Performed by Order of His Most Christian Majesty, in the Years 1766, 1767, 1768 and 1769, by Lewis de Bougainville. Translated by J. R. Forster. London: Printed for J. Nourse and T. Davies.

Bouge, L.-J.

1928 "Pêche par jet de pierres "Tautai taora ofai'." Bulletin de la Société d'études océaniennes 3:13-77.

1955 “Un Aspect du rôle rituel du 'Manu' dans l'ancien Tahiti." Journal de la Société des océanistes 11:147-149.

de Bovis, Edmond

1909 État de la société tahitienne à l'arrivée des Européens. Papeete: Published by the French Government.

Buck, Peter H. [Te Rangi Hiroa]

1943 "The Feather Cloak of Tahiti." Journal of the Polynesian Society 52: 12-15.

1944 Arts and Crafts of the Cook Islands. Bernice P. Bishop Museum Bulletin no. 179. Honolulu.

Burbidge, George W., and John F. Stimson

1930 A New Grammar of the Tahitian Dialect of the Polynesian Language .... 2nd ed. n.p. For the Church of Jesus Christ of Latter Day Saints.

Buschmann, Johann Carl Eduard

1843 Aperçu de la langue des îles Marquises et de la langue taïtienne .... Accompagné d'un vocabulaire inédit de la langue taitienne par le baron Guillaume de Humboldt. Berlin: C. G. Luderitz.

Chabouis, Louis, and François Chabouis

1954 Petite histoire naturelle des Établissements français de l'Océanie. Vol. 1: Botanique, vol. 2: Zoologie. Paris: Éditions Paul Lechevallier.

Chadourne, Marc

1922 "Le Lyrisme des Tahitiens...." Bulletin de la Société d'études océaniennes 1(6): 64-76.

Chesneau, Henri [Le Père Joseph]

1928 "Histoire de Huahine et autres îles Sous-le-Vent." Bulletin de la Société d'études océaniennes 3:57-67.

1929 "Histoire de Huahine ...." Bulletin de la Société d'études océaniennes 3:81-98.

Collingwood, R. G.

1946 The Idea of History. Oxford: Clarendon Press.

Cook, James

1784 A Voyage to the Pacific Ocean Undertaken by the Command of His Majesty, for Making Discoveries in the Northern Hemisphere, to Determine the Position and Extent of the West Side of North America, Its Distance from Asia, and the Practicability of a Northern Passage to Europe. Performed under the Direction of Captains Cook, Clerke and Gore, in His Majesty's Ships the Resolution and Discovery, in the Years 1776, 1777, 1778, 1779 and 1780. Vol. 2, book 3. London: G. Nichol and T. Cadell. 
Corney, Bolton Glanville, ed.

1913 The Quest and Occupation of Tahiti by Emissaries of Spain during the Years 1772-1776. Vol. 1. London: Cambridge University Press.

1915 The Quest and Occupation of Tahiti... Vol. 2. London: Cambridge University Press.

1919 The Quest and Occupation of Tahiti... Vol. 3. London: Cambridge University Press.

Crampton, Henry E.

1916 Studies on the Variation, Distribution, and Evolution of the Genus Partula. The Species Inhabiting Tahiti. The Carnegie Institution Publication no. 228. Washington, D.C.

Crook, William Pascoe

1826 "Extract from the Journal of W. P. Crook Containing Particulars of His Visit to the Marquesas...." Transactions of the Missionary Society, London (October): 225-238.

Cuzent, Gilbert

1860 Îles de la Société. Rochefort: Imprimerie C. Thèze.

Danielsson, Bengt

1956 Love in the South Seas. Translated by F. H. Lyon. London: George Allen and Unwin.

1957 "A Unique Tahitian Stone Figure." Journal of the Polynesian Society 66:396-397.

1962 "Étude anthropométrique des habitants de Mai'ao." Bulletin de la Société d'études océaniennes 12:46-47.

Davies, John

1851 A Tahitian and English Dictionary .... Tahiti: London Missionary Society's Press.

Dening, G. M.

1962 "The Geographical Knowledge of the Polynesians and the Nature of Inter-Island Contact." In Polynesian Navigation ..., edited by Jack Golson. Supplement to the Journal of the Polynesian Society 71:102-153.

Draper, John W.

1959 Rhyme in the Pacific. West Virginia University Bulletin, series 60, no. 2-1. Morgantown.

Drollet, Alexandre

1954 "Légende du marae de Arahurahu." Bulletin de la Société d'études océaniennes 9:336-345.

[Dumont] d'Urville, Jules Sébastien César

1834-1835 Voyage pittoresque autour du monde. 2 vols. Paris: L. Tenré.

Edwards, Edward, and George Hamilton

1915 Voyage of H.M.S. Pandora. Edited by Basil Thomson. London: Francis Edwards.

Efron, D. H., ed.

1967 Ethnopharmacologic Search for Psychoactive Drugs. U.S. Public 
Health Service Publication no. 1645. Washington, D.C.: National Institute of Mental Health.

Egler, F. E.

1941 “Unrecognized Arid Hawaiian Soil Erosion.” Science 94:513-514.

Ellis, William

1829 Polynesian Researches. 2 vols. London: Fisher, Son and Jackson.

1831 Polynesian Researches. 4 vols. 2nd ed. London: Fisher, Son and Jackson.

1844 The History of the London Missionary Society, Comprising an Account of the Origin of the Society, Biographical Notices of Some of Its Founders and Missionaries; with a Record of Its Progress at Home and Its Operations Abroad. Compiled from Original Documents in the Possession of the Society. Vol. 1. London: John Snow.

Ellis, William (Surgeon)

1782 An Authentic Narrative of a Voyage Performed by Captain Cook and Captain Clerke, in His Majesty's Ships Resolution and Discovery, during the Years 1776, 1777, 1778, 1779, and 1780, in Search of a North-West Passage between the Continents of Asia and America, Including a Faithful Account of All Their Discoveries, and the Unfortunate Death of Captain Cook. 2 vols. London: G. Robinson, J. Sewell, and J. Debrett.

Emory, Kenneth P.

n.d. Traditional History of Maraes in the Society Islands. Unpublished manuscript in the Bernice P. Bishop Museum. (Referred to as Marae Traditions in the text.)

1928 "Chant de Pai pour sa lance Rufautumu qui perça Moorea." Bulletin de la Société d'études océaniennes 3:170-171.

1931 "The Marae at Which Captain Cook Witnessed a Rite of Human Sacrifice." Bulletin de la Société d'études océaniennes 3:194-203.

1933 Stone Remains in the Society Islands. Bernice P. Bishop Museum Bulletin no. 116. Honolulu.

1938 "The Tahitian Account of Creation by Mare." Journal of the Polynesian Society 47:45-63.

1962 "Report on Bishop Museum Archaeological Expeditions to the Society Islands in 1960 and 1961." Journal of the Polynesian Society 71:117-120.

1963 "East Polynesian Relationships. Settlement Pattern and Time Involved as Indicated by Vocabulary Agreements." Journal of the Polynesian Society 72:78-100.

Emory, Kenneth P., and Yosihiko H. Sinoto

1964 “Eastern Polynesian Burials at Maupiti." Journal of the Polynesian Society 73:143-160.

Finney, Ben

1959 “Fa'ahe'e, l'ancien sport de Tahiti." Bulletin de la Société d'études océaniennes 11:53-56.

1962 "Différents noms de Mai‘ao." Bulletin de la Société d'études océaniennes 12:24-25. 
$1964 a$ "Notes on Bond-friendship in Tahiti." Journal of the Polynesian Society 73:431-435.

1964b "Polynesian Peasants and Proletarians: Socioeconomic Change in the Society Islands." Unpublished Ph.D. dissertation, Harvard University, Cambridge, Mass.

1966 “Resource Distribution and Social Structure in Tahiti." Ethnology 1:8-86. Firth, Raymond

1936 We, the Tikopia. London: G. A. and Unwin.

1940 "The Analysis of Mana: an Empirical Approach." Journal of the Polynesian Society 49:483-512.

1961 History and Traditions of Tikopia. Wellington: The Polynesian Society.

Fitzroy, Robert

1839 Narrative of the Surveying Voyages of His Majesty's Ships Adventure and Beagle, between the Years 1826 and 1836. Vol. 2. London: H. Colburn.

Foltz, J. M.

1835 Appendix to Voyage of the United States Frigate Potomac under the Command of Commodore John Downes, during the Circumnavigation of the Globe, in the Years 1831, 1832, 1833 and 1834, by J. N. Reynolds. New York: Harper and Brothers.

Forster, [Johann] Georg Adam

1777 A Voyage round the World in His Brittanic Majesty's Sloop, Resolution, Commanded by Captain James Cook, during the Years 1772, 3, 4 and $5 . . .2$ vols. London: B. White, J. Robson, P. Elmsly, and G. Robinson.

Forster, Johann Reinhold

1778 Observations Made During A Voyage round the World on Physical Geography, Natural History and Ethic Philosophy. Part 6: "The Human Species." London: G. Robinson.

Fried, Morton $\mathrm{H}$.

1968 "On the Concepts of 'Tribe' and 'Tribal Society'." In Essays on the Problem of Tribe, edited by June Helm. Seattle: University of Washington Press.

Garanger, José

1964 "Recherches archéologiques dans le district de Tautira, Tahiti." Journal de la Société des océanistes 20:5-21.

1967 "Archaeology and the Society Islands." In Polynesian Culture History: Essays in Honor of Kenneth P. Emory, edited by G. A. Highland et al. Bernice P. Bishop Museum Special Publication no. 56. Honolulu.

Gautier, Jean-Maurice

1947 "Tahiti dans la littérature française à la fin du XVII ${ }^{\mathrm{e}}$ siècle." Journal de la Société des océanistes 3:43-56.

Goldman, Irving

1960 "The Evolution of Polynesian Societies." In Culture in History, edited by Stanley Diamond. New York: Columbia University Press.

Golson, Jack, ed.

1962 Polynesian Navigation: A Symposium on Andrew Sharp's Theory of Ac- 
cidental Voyages. Supplement to the Journal of the Polynesian Society vol. 71. Wellington.

Gougenheim, André

1956 “La Marée de Tahiti; fin d’une légende.” Encyclopédie mensuelle d'outre-mer (January): 39-40.

Green, Roger C.

1961 "Moorean Archaeology." Man 61:169-173.

1967 "The Immediate Origins of the Polynesians." In Polynesian Culture History: Essays in Honor of Kenneth P. Emory, edited by G. A. Highland et al. Bernice P. Bishop Museum Special Publication no. 56. Honolulu.

Green, Roger C., and Kaye Green

1968 "Religious Structures of the Society Islands." New Zealand Journal of History 2:66-89.

Green, Roger C., Kaye Green, Roy A. Rappaport, Ann Rappaport, and Janet Davidson

1967 Archaeology on the Island of Mo'orea, French Polynesia. Anthropological Papers of the American Musum of Natural History, vol. 51, no. 2. New York.

Gunson, Niel

1962 "An Account of the Mamaia or Visionary Heresy of Tahiti, 1826-1841." Journal of the Polynesian Society 71:209-243.

1963 "A Note on the Difficulties of Ethnohistorical Writing, with Special Reference to Tahiti." Journal of the Polynesian Society 72:415-419.

1964 "Great Women and Friendship Contract Rites in Pre-Christian Tahiti." Journal of the Polynesian Society 73:53-69.

Handy, E. S. C.

1927 Polynesian Religion. Bernice P. Bishop Museum Bulletin no. 34. Honolulu.

1930 History and Culture in the Society Islands. Bernice P. Bishop Museum Bulletin no. 79. Honolulu.

1932 Houses, Boats, and Fishing in the Society Islands. Bernice P. Bishop Museum Bulletin no. 90. Honolulu.

Handy, W. C.

1927 Handcrafts of the Society Islands. Bernice P. Bishop Museum Bulletin no. 42. Honolulu.

Hawkesworth, John, ed.

1773 An Account of the Voyages Undertaken by the Order of His Present Majesty for Making Discoveries in the Southern Hemisphere and Successively Performed by Commodore Byron, Captain Wallis, Captain Carteret and Captain Cook, in the Dolphin, the Swallow, and the Endeavour; Drawn Up from the Journals Which Were Kept by Several Commanders and from the Papers of Joseph Banks, Esq. 3 vols. London: W. Strahan and T. Cadell.

Henry, Teuira

1893 "Te Umu-ti, a Raiatean Ceremony." Journal of the Polynesian Society 2:105-108.

1894 "The Birth of New Lands." Journal of the Polynesian Society 3:136-139. 
1895 “Te Parau a Honoura. The Legend of Honoura." Collected by John Williams. Journal of the Polynesian Society 4:256-294.

1897 "A War Song of the Oparaa Clan of Tahiti." Journal of the Polynesian Society 6:211-212.

1911 "More on the Ari'is of Tahiti." Journal of the Polynesian Society 20:4-9.

1912 "The Tahitian Version of the Names Ra'iatea and Taputapuatea." Journal of the Polynesian Society 21:77-78.

1913 "The Oldest Great Tahitian Maraes and the Last One Built in Tahiti." Journal of the Polynesian Society 22:25-27.

1928 Ancient Tahiti. Bernice P. Bishop Museum Bulletin no. 48. Honolulu.

Hertz, Robert

1960 "The Pre-eminence of the Right Hand: a Study in Religious Polarity." In Death and the Right Hand, translated by Rodney and Claudia Needham. New York: The Free Press.

Hervé, François

1926 "Légende des Teva." Bulletin de la Société d'études océaniennes 2:110-111.

Highland, Genevieve A., R. W. Force, Alan Howard, Marion Kelly, and

Yosihiko H. Sinoto, eds.

1967 Polynesian Culture History: Essays in Honor of Kenneth P. Emory. Bernice P. Bishop Museum Special Publication no. 56. Honolulu.

Hilder, Brett

1962 “Primitive Navigation in the Pacific - II." In Polynesian Navigation ..., edited by Jack Golson. Supplement to the Journal of the Polynesian Society 71:81-95.

Hill, S.

1856 Travels in the Sandwich and Society Islands. London: Chapman and Hall.

Hoebel, E. Adamson

1949 Man in the Primitive World. New York: McGraw-Hill.

Hooker, Sir Joseph D., ed.

1896 Journal of the Right Hon. Sir Joseph Banks ... during Captain Cook's First Voyage in H.M.S. Endeavour, in 1768-71, to Terra del Fuego, Otahite, New Zealand, Australia, the Dutch East Indies, etc. New York: Macmillan and Co.

Huguenin, Paul

1902-1903 "Raiatea la sacrée, îies Sous-le-Vent de Tahiti, Océanie française." Bulletin de la Société neuchâteloise de géographie $14: 1-256$.

Im Thurn, Sir Everard F., ed.

1925 The Journal of William Lockerby. London: Hakluyt Society.

Jacolliot, Louis

1954 “Une Genèse tahitienne." Bulletin de la Société d'études océaniennes 9:307-312. 
Jacquier, Henri

1944 "Le Mirage et l'exotisme tahitiens dans la littérature." Bulletin de la Société d'études océaniennes 7:1-27, 50-76, 91-114.

Jaussen, Mgr. Florentin Étienne [Tepano]

1898 Grammaire et dictionnaire tahitiens. Paris: Neia I Te Nenei Raa No Belin.

Kooijman, Simon

1964 "Ancient Tahitian God-figures." Journal of the Polynesian Society 73:110-125.

Koskinen, A. A.

1960 Ariki the First Born. An Analysis of a Polynesian Chieftain Title. Folklore Fellows Communication no. 181. Helsinki.

Laguesse, Janine

1945 "A propos des connaissances astronomiques des anciens Tahitiens." Bulletin de la Société d'études océaniennes 7:141-152.

1947 "Notes au sujet des phases de la lune chez les Polynésiens." Bulletin de la Société d'études océaniennes 7:292-294.

Lavaud, C. F., ed.

1928 “La Création. Hiro. Tradition diluvienne. Notice Sur Teriitinorua. Légende de Maui." Translated by Pierre Gaussin. Bulletin de la Société d'études océaniennes 3:78-80, 134-138.

Leach, E. R.

1961 Rethinking Anthropology. London: University of London, Athlone Press.

Lesson, René P.

1839 Voyage autour du monde, entrepris par ordre du gouvernement, sur la corvette la Coquille. Vol. 1. Paris: P. Pourrat Frères.

Leverd, Armand

1912 "The Tahitian Version of Tafa'i (or Tawhaki)." Journal of the Polynesian Society 21:1-25.

1918 “Notice sur la pierre 'Anave'." Bulletin de la Société d'études océaniennes 1(3): 146-147.

Lévi-Strauss, Claude

1960 “La Geste d'Asdiwal." In L'Annuaire de l'École des Hautes Études. Paris: École des Hautes Études.

Levy, Robert I.

1968 "Tahiti Observed: Early European Impressions of Tahitian Personal Style." Journal of the Polynesian Society 77:33-42.

1970 "Tahitian Adoption as a Psychological Message." In Adoption in Eastern Oceania, edited by Vern Carroll. Honolulu: University of Hawaii Press.

Lockerby, William

See Im Thurn.

LMS Dictionary

See Davies.

London Missionary Society

1821-1833 Quarterly Chronicle of the Transactions of the London Missionary Society, 1815-1832. 4 vols. London: London Missionary Society. 


\section{Lounsbury, Floyd}

1964 "A Formal Account of the Crow-and-Omaha-type Kinship Terminologies." In Explorations in Cultural Anthropology: Essays in Honor of Murdock, edited by W. Goodenough. New York: McGraw-Hill.

Lucett, Edward

1851 Rovings in the Pacific, from 1837 to 1849; with a Glance at California. By a Merchant Long Resident at Tahiti. Vol. 1. London: Longman, Brown, Green, and Longmans.

Luomala, Katharine

1940 “More Notes on Ra'a." Journal of the Polynesian Society 49:303-304.

1951 The Menehune of Polynesia and Other Mythical Little People of Oceania. Bernice P. Bishop Museum Bulletin no. 203. Honolulu.

\section{Malardé, Yves}

1930 "La Légende du Maioré (arbre à pain)." Bulletin de la Société d'études océaniennes 4:110-114.

1946 “Maeva, île de Huahine." Bulletin de la Société d'études océaniennes 77:247-250.

Malinowski, Bronislaw

1922 Argonauts of the Western Pacific. London: Routledge and Kegan Paul.

Marau Taaroa

See also Salmon, Marau Taaroa.

1937 "Légende de Hinaraurea et de la chenille de Papeiha." Bulletin de la Société d'études océaniennes 5:694-699.

March, H. Colley

1893 "Polynesian Ornament a Mythography; or a Symbolism of Origin and Descent." Journal of the Anthropological Institute of Great Britain and Ireland 22:307-333.

Marshall, Donald S.

1961 Ra'ivavae. New York: Doubleday.

Marshall, Donald S., and C. E. Snow

1956 "An Evaluation of Polynesian Craniology." American Journal of Physical Anthropology 14:405-427

McArthur, Norma

1968 Island Populations of the Pacific. Honolulu: University of Hawaii Press. McKern, W. C.

1929 Archaeology of Tonga. Bernice P. Bishop Museum Bulletin no. 60 . Honolulu.

Mead, Margaret

1928 Coming of Age in Samoa. New York: William Morrow and Co.

1930 Social Organization of Manu'a. Bernice P. Bishop Museum Bulletin no. 76. Honolulu.

Moerenhout, Jacques-Antoine

1837 Voyages aux îles du Grand Océan, contenant des documents nouveaux sur la géographie physique et politique, la langue, la littérature, la religion, les moeurs, les usages et les coutumes de leurs habitants; et des considérations 
générales surleur commerce, leur histoire et leur gouvernement, depuis les temps les plus reculés jusqu'à nos jours. 2 vols. Paris: A. Bertrand.

Montgomery, James, ed.

1832 Journal of Voyages and Travels by the Rev. Daniel Tyerman and George Bennet, Esq., Deputed from the London Missionary Society, to Visit Their Various Stations in the South Sea Islands, China, India, etc., between the Years 1821 and 1829. 3 vols. Boston: Crocker and Brewster.

Morrison, James

1935 The Journal of James Morrison, Boatswain's Mate of the Bounty, Describing the Mutiny and Subsequent Misfortunes of the Mutineers, together with an Account of the Island of Tahiti. Edited by Owen Rutter. London: The Golden Cockerel Press.

Mortimer, George

1791 Observations and Remarks Made during a Voyage to the Islands of Teneriffe, Amsterdam, Maria's Islands near Van Diemen's Land; Otaheite, Sandwich Islands; ... in the Brig Mercury Commanded by John Henri Cox, Esq. London: T. Cadell, J. Robson, and J. Sewell.

Moschner, Irmgard

1955 “Die Wiener Cook-Sammlung, Südsee-Teil.” Archiv für Völkerkunde 10:136-253.

Mühlmann, Wilhelm Emil

1938 Staatsbildung und Amphiktyonien in Polynesien. Stuttgart: Verlag Strecker und Schröder.

1939 “Das Parai-Maskenkostüm von Tahiti.” Ethnologischer Anzeiger 4:219-221.

1955 Arioi und Mamaia. Studien zur Kulturkunde vol. 14. Wiesbaden: Franz Steiner Verlag GMBH.

Murdock, George P.

1949 Social Organization and Government in Micronesia, Final Report. Washington, D.C.: Pacific Science Board, National Research Council.

Needham, Rodney

1962a "Age, Category, and Descent." Bijdragen tot de Taal-, Land-en Volkenkunde 122:1-35.

$1962 b$ "Genealogy and Terminology in Wikmunkan Society." Ethnology $1: 223-264$.

Newbury, Colin

1961 The History of the Tahitian Mission, 1799-1830, Written by John Davies, Missionary to the South Seas Islands, with Supplementary Papers from the Correspondence of the Missionaries. London: Cambridge University Press. 1967a "Aspects of Cultural Change in French Polynesia: The Decline of the Ari'i." Journal of the Polynesian Society 76:7-26.

1967b "Te Hau Pahu Rahi: Pomare II and the Concept of Inter-Island Government in Eastern Polynesia." Journal of the Polynesian Society 76:477-514.

Nordhoff, Charles

$1930 a$ "Notes on the Off-shore Fishing of the Society Islands." Journal of the Polynesian Society 39:137-173. 
$1930 b$ Notes on the Off-shore Fishing ...." Journal of the Polynesian Society 39:221-262.

Nordmann, Paul I.

1943 “Contribution à l'étude de l'infanticide, cause principale de la dépopulation à Tahiti avant l'introduction du christianisme." Bulletin de la Société d'études océaniennes 6:337-354.

Oliver, Douglas L.

1955 A Solomon Island Society. Cambridge: Harvard University Press.

O’Reilly, Patrick, and Édouard Reitman

1967 Bibliographie de Tahiti et de la Polynésie française. Publications de la Société des océanistes no. 14. Paris: Musée de l'Homme.

Orsmond, John Muggridge

n.d. Notes: Arioi, War, Dictionary. Unpublished manuscripts in the Mitchell Library.

Panoff, Michel

1965 "La Terminologie de la parenté en Polynésie: Essai d'analyse formelle." L'Homme 5:60-87. Papy, H. René

1951 "Plantes utiles de Tahiti et des Établissements français de l'Océanie." Revue internationale de botanique appliquée et d'agriculture tropicale nos. 339-340:94-113.

1954 Tahiti et les îles voisines. La Végétation des îles de la Société et de Makatéa. 2 vols. Toulouse: Les Artisans de l'Imprimerie Douladoure.

Parkinson, Sydney

1773 A Journal of a Voyage to the South Seas in His Majesty's Ship the Endeavour, Faithfully Transcribed from the Papers of the Late Sydney Parkinson, Draughtsman to Sir Joseph Banks, Esq. on His Late Expedition with Dr. Solander, round the World. London: Stanfield Parkinson.

Piddington, R.

See Williamson 1937 and 1939.

Plischke, Hans

1931 Tahitische Trauergewander. Arbeiten der Ethnographischen Sammlung der Universität Göttingen no. 2. Berlin: Weidmannsche Buchhandlung.

Pugeault, Charles

1927 “La Sceptre des reines de Huahine." Bulletin de la Société d'études océaniennes 2:219-222.

Pukui, Mary Kawena, and Samuel H. Elbert

1957 Hawaiian-English Dictionary. Honolulu: University of Hawaii Press.

Rey-Lescure, Philippe

1936 “Le Piège à poulpe." Bulletin de la Société d'études océaniennes. 5: 557-560.

1944 “Analogies dans le langage tahitien." Bulletin de la Société d'études océaniennes 6:431-441. 
1944 "Essai de reconstitution des moeurs et coutumes de l'ancien Tahiti, d'après le vocabulaire." Bulletin de la Société d'études océaniennes 7:28-34.

1945 7:77-85.

1946 7:191-195, 259-263.

1947 7:284-288, 303-307, 356-360.

1948 7:503-505.

$19518: 331-335$.

1953 9:82-83.

1946 “Le Chien en Polynésie.” Bulletin de la Société d'études océaniennes 7:266-272.

1946 “La Coutume du Tavau." Bulletin de la Société d'études océaniennes 7:196-205.

1948 “Documents pour l'histoire de Tahiti." Bulletin de la Société d'études océaniennes 7:418-422, 461-472.

1949 “La Guerre de Rooua." Bulletin de la Société d'études océaniennes 7:568-577.

1951 "De vieux gestes." Bulletin de la Société d'études océaniennes 8:220-228, 352-353.

1954 "Légende de Turi." Bulletin de la Société d'études océaniennes 9:346-349.

1955 “Le Cerf-volant.” Bulletin de la Société d'études océaniennes 9:413-414.

1956 "La Mort de Vehiatua." Bulletin de la Société d'études océaniennes 9:538-542.

Reynolds, Jeremiah N.

1835 Voyage of the United States Frigate Potomac, under the Command of Commodore John Downes, during the Circumnavigation of the Globe, in the Years 1831, 1832, 1833, and 1834. New York: Harper and Brothers.

Rivers, William H. R.

1914 History of Melanesian Society. 2 vols. Cambridge: University Press.

Robertson, George

1948 The Discovery of Tahiti. Edited by Hugh Carrington. London: Hakluyt Society.

Ropiteau, André

1929 “Légende des deux amies." Bulletin de la Société d'études océaniennes 3:289-291.

1932 “Notes sur l'île Maupiti.” Bulletin de la Société d'études océaniennes 5:113-129.

Roth, Henry L.

1905 "Tatu in the Society Islands." Journal of the Anthropological Institute of Great Britain and Ireland 35:283-294.

Roussier, Paul

1928 "Documents ethnologiques taïtiens...." Revue d'ethnographie et des traditions populaires 9:188-206.

Sahlins, Marshall

1958 Social Stratification in Polynesia. Seattle: University of Washington Press (for The American Ethnological Society). 
Salisbury, R. F.

1962 From Stone to Steel. London and New York: Cambridge University Press.

Salmon, Ernest

1937 “Les Maximes de Tetunae.” Revue de folklore français et de folklore colonial no. 1.

Salmon, Marau Taaroa [Queen Marau Taaroa]

1926 "Légende de Tariitaumatatini." Bulletin de la Société d'études océaniennes 2:119-123.

1927 “Quelques commentaires sur le Pii." Bulletin de la Société d'études océaniennes 2:260-271.

Salmon, Tati [Teura i te Rai Tati]

n.d. The History of the Island of Borabora and Genealogy of Our Family from Marae Vaiotaha. Printed manuscript in the Bernice P. Bishop Museum. 1910 “On Ari'is in Tahiti.” Journal of the Polynesian Society 19:40-46.

Sasportas, Léon

1926 "Le Miracle tahitien de la marche sur les pierres chaufées." Revue d'ethnographie et des traditions populaires 7:269-276.

Scherzer, Karl von

1861-1863 Narrative of the Circumnavigation of the Globe by the Austrian Frigate Novara (Commodore B. von Wüllerstorf-Urbair), Undertaken by Order of the Imperial Government, in the Years 1857, 1858 \& 1859. Vol. 3. London: Saunders, Otley, and Co.

Schmitt, Robert C.

1965 "Garbled Population Estimates of Central Polynesia." Journal of the Polynesian Society 74:57-62.

1967 “The Missionary 'Censuses' of Tahiti, 1797-1830." Journal of the Polynesian Society 76:27-34.

Seurat, Léon G.

1934 "La Faune et le peuplement de la Polynésie française." In Contribution à l'étude du peuplement zoologique et botanique des îles du Pacifique. Mémoires de la Société de biogéographie no. 4. Paris: Paul Lechevallier et Fils.

Shapiro, Henry L.

1930 "The Physical Characters of the Society Islanders." Bernice P. Bishop Museum, Memoirs 11:275-311.

1943 "Physical Differentiation in Polynesia." In Studies in Anthropology of Oceania and Asia, Presented in Memory of Roland Burrage Dixon. Edited by C.S. Coon and J.M. Andrews. Papers of the Peabody Museum of American Archaeology and Ethnology vol. 20. Cambridge, Mass.: Peabody Museum.

Sharp, Andrew

1963 Ancient Voyagers in Polynesia. Sydney: Angus and Robertson.

Smith, Bernard

1960 European Vision and the South Pacific, 1768-1850. A Study of the History of Art and Ideas. Oxford: Clarendon Press. 
Smith, S. Percy

1892 "The Tahitian 'Hymn of Creation'." Journal of the Polynesian Society $1: 31-32$.

1893 "The Genealogy of the Pomare Family of Tahiti, from the Papers of the Rev. J. M. Orsmond." Journal of the Polynesian Society 2:25-42.

1910 Hawaiki: The Original Home of the Maori. 3rd ed. London: Whitcomb and Tombs.

Söderström, Jan

1939 A Sparrman's Ethnographical Collection from James Cook's 2nd Expedition (1772-1775). The Ethnographical Museum of Sweden, new series, publication no. 6. Stockholm.

von den Steinen, Karl

1925-1928 Die Marquesaner und Ihre Kunst. 3 vols. Berlin: Reimer.

Stimson, J. Frank

1928 "Tahitian Names for the Nights of the Moon." Journal of the Polynesian Society 37:326-337.

Stimson, J. Frank, and Donald S. Marshall

1964 Dictionary of Some Tuamotuan Dialects of the Polynesian Language. The Hague: Martinus Nijhoff.

\section{Teissier, Raoul}

1953 "Étude démographique sur les Établissements français de l’Océanie, de Cook au recensement des 17-18 September 1951." Bulletin de la Société d'études océaniennes 9:6-31.

1956 “Île Tupuae Manu ou Maiao Iti." Bulletin de la Société d'études océaniennes 10:517-523.

1962 “A'ai no te mo'o: la légende du lézard (Ara'i Temauri)." Bulletin de la Société d'études océaniennes 12:30-34.

1962 "Note sur l'île Tetiaroa." Bulletin de la Société d'études océaniennes 12:97-102.

Teuinatua, François

1950 "Légende du cocotier et du mape ou l'histoire de l'anguille aux grandes oreilles." Bulletin de la Société d'études océaniennes 8:45-48.

Thomson, Robert

n.d. History of Tahiti. Unpublished manuscript in the London Missionary Society Archives.

Thornthwaite, C. W.

1948 "An Approach Toward a Rational Classification of Climate." Geographical Review 38:55-94.

Titcomb, Margaret

1969 Dog and Man in the Ancient Pacific, with Special Attention to Hawaii. Bernice P. Bishop Museum Bulletin no. 59. Honolulu.

Turnbull, John

1813 A Voyage round the World, in the Years 1800, 1801, 1802, 1803 and 1804 , in Which the Author Visited Madeira, the Brazils, Cape of Good Hope, the English Settlements of Botany Bay and Norfolk Island, and 
the Principal Islands in the Pacific Ocean. With a Continuation of Their History to the Present Period. 2nd ed. London: A. Maxwell.

d'Urville, Jules S. C. Dumont

See Dumont d'Urville.

Vancouver, George

1801 A Voyage of Discovery to the North Pacific Ocean, and round the World Vérin, Pierre .... Vol. 1. London: John Stockdale.

1962a "Introduction géographique et ethnographique sur l'île Mai'ao." Bulletin de la Société d'études océaniennes 12:3-16.

$1962 b$ "Prospection archéologique préliminaire de Tetiaroa." Bulletin de la Société d'études océaniennes 12:103-124.

Vincendon-Dumoulin, Clément Adrien, and César Louis François

Desgraz

1844 Iles Taïti. Esquisse historique et géographique, précédée de considérations générales sur la colonisation française dans l'Océanie. 2 vols. Paris: A. Bertrand.

Volk, Winifried

1934 Die Entdeckung Tahitis und das Wunschbild der seligen Insel in der Deutschen Literatur. Heidelberg: Kranz und Heinrichmoller.

Wales, William

1778 Remarks on Mr. Forster's Account of Captain Cook's Last Voyage round the World, in the Years 1772, 1773, 1774, and 1775. London: J. Nourse.

Walker, Orsmond $\mathrm{H}$.

1925 "Tiurai le Guérisseur." Bulletin de la Société d'études océaniennes 1(10): 1-35.

1927 "La Légende de Vei." Bulletin de la Société d'études océaniennes 2:193-218.

Wallis, Samuel

1767 An Exact Transcript of Wallis' Journal, June 5-July 29, 1767. Unpublished manuscript in the Public Record Office. Reference: Adm. 55/35.

Webster, Hutton

1908 Primitive Secret Societies. New York: The Macmillan Co.

White, Ralph G.

1967 “Onomastically Induced Word Replacement in Tahitian." In Polynesian Culture History: Essays in Honor of Kenneth P. Emory, edited by G. A. Highland et al. Bernice P. Bishop Museum. Special Publication no. 56. Honolulu.

White, Ralph G., and Ariihau a Terupe

1958 Linguistic Check-Sketch for Tahitian. Tahiti: Te Fare Vana'a. Mimeographed.

Wilder, Gerrit P.

1928 The Breadfruit of Tahiti. Bernice P. Bishop Museum Bulletin no. 50. Honolulu. 
Williams, H. W.

1957 A Dictionary of the Maori Language. Wellington: Government Printer. Williams, John.

1837 A Narrative of Missionary Enterprises in the South Sea Islands. London: J. Snow.

Williamson, Robert W.

1924 The Social and Political Systems of Central Polynesia. Vol. 1. Cambridge: University Press.

1933 Religious and Cosmic Beliefs of Central Polynesia. 2 vols. Cambridge: University Press.

1937 Religion and Social Organization in Central Polynesia. Edited by R. Piddington. Cambridge: University Press.

1939 Essays in Polynesian Ethnology. Edited by R. Piddington. Cambridge: University Press.

Wilson, James

1799 A Missionary Voyage to the Southern Pacific Ocean, Performed in the Years 1796, 1797, 1798, in the Ship Duff, Commanded by Captain James Wilson.... London: T. Chapman.

Young, J. L.

1898 "The Origin of the Name Tahiti, as Related by Marerenui, a Native of Faaiti Island, Paumotu Group." Journal of the Polynesian Society 7:109-111.

1925 "The Umu-Ti. Ceremonial Fire Walking as Practised in the Eastern Pacific." Journal of the Polynesian Society 34:214-222. 


\section{INDEXES}

For purposes of alphabetizing, the glottal stop at the beginning of a word has been ignored.

Some Tahitian words are indexed under both old-style spellings (as found in the extracts) and their modern equivalents.

The Place and Name indexes do not contain the detail found in the Subject Index, which we consider of greater importance, given the emphasis of this work.

\section{SUBJECT INDEX}

Abortion, 63, 412, 617, 713, 730, 939, 943, 1026, 1107; methods of, 411, 550. See also Contraception; Infanticide

Above-below contrast. See Upper-lower contrast

Actors, 327, 342-343, 936, 945; recruitment of, 914, 937, 945, 1106; training given, 864, 938. See also Drama; Theaters

Adoption, 230, 374, 411, 444, 455, 554, 622, $660,691,692,701,850,890,1143,1191$; rights received through, 619, 625, 626, 639, 660, 776, 1191. See also Fetchers, adoption of; Fosterage

Adzes, 135, 137, 138, 199, 255, 536, 856

Afterlife, 353, 409, 1077; activities in the, 64-65, 521-528, 820-821, 1082; for Ariois, 262, 525-526, 527, 791, 907-908, 919, 929, 960-961, 1106, 1108; nature of the, 361, 486, 557, 791, 960-961. See also Paradise; Purgatory

Age, social differentiation by, 337, 359-360, 458-459, 607-615, 689, 1110, 1112-1113, 1123,1132 . See also Aged, the; Old age

Aged, the, 387, 607, 1177, 1184; treatment of, 614-615, 724, 745. See also Age, social differentiation by; Old age

Agriculture, 44, 45, 46, 143, 149, 162, 174 , $175,234,236,248-259,272,281,430$,
541, 586, 852-855; labor used in, 125, 586, $602,971,972$; seasonal variation in, 221-222, 240-244, 245, 259-270, 305-308, $388,541,811-812,853,1148$. See also Animal husbandry

Ahi nuts, 242

Ahu, 85, 97-100, 116, 118, 178, 191, 192, 647, 668; construction of, 97-99, 177, 187, 538; names of, 1136. See also Marae

'Aito (Arioi). See Arioi sect, lodge masters of

'Aito (tree). See Casuarina

'Aito (warrior). See Warrior-champions

Albacore, 295, 296-298, 299, 304, 308; fishing for, 291, 297-298, 311-312; restrictions on consumption of, 225, 275

Albinism, 42, 161

Aleurites. See Candlenut

Alliance, political, 977, 1052, 1108, 1116; between Atehuru and Tetaha, 973; Haupahu-nui, 1052; Porapora-Ra'iateaTaha'a, 1108; Teaharoa, 832; between Te Porionu'u and Teva i uta, 973. See also Allies, political

Allies, political, 111, 267-268, 658, 973, 977, 986, 995; founding and maintaining of, 230-231, 447, 454, 465, 553, 658, 668, 704, 807, 979-980, 1006, 1009, 1099, 1100-1101, 1131, 1192, 1242, 1260, 1293, 
1315, 1326, 1337, 1338; shifting of, 976, 985, 1096, 1343; warfare supported by, 383, 386, 389-390, 505, 653, 1343. See also Alliance, political

Alocasia macrorrhiza, 43, 131, 244, 249-250, 416

Altars, 96, 97, 114, 421, 486, 533, 534, 854, 874, 888, 915, 933; construction of, 87, 399. See also Marae

Amae. See Thespesia

Amo, custom of, 1039, 1043, 1044-1045, $1162,1201,1290$. See also Chiefs, privileges of

Amo'a. See Head-freeing

Amomum, 24, 934

"Ancestor-guards," 509, 860, 862-863, 1034

Animals, domestic, 270-281. See also particular animals

Animal husbandry, 853-854, 1102, 1148

Ao, realm of, 49, 57, 66, 96, 398, 481, 536, 630, 724, 739, 982. See also Day, lunar; Po, contrasted with ao

'Ape, 43, 131, 244, 249-250, 416

Aphrodisiacs, 353

Apples, 165, 220, 228, 246, 247, 366-367

Archaeology, 46, 1121; of agricultural systems, 249,259 ; of marae, 101, 103, 178, 188, 191,534

Archery, 320-322; classes engaging in, 320, 785-786, 1144; competitions in, 319, 320 737, 878, 993, 994; ranges for, 44, 46, 104 , 320. See also Bows and arrows

Ari'i, 634, 750, 751-751, 759-765, 775, 777, 787, 791-792, 804, 805, 813, 849-850, 852, 860, 900, 935, 957, 962, 986, 991, 1047, 1050, 1062, 1066, 1080, 1098, 1117 , $1129,1134,1143,1144,1149,1155,1161$ 1163, 1167; activities of, 785, 809, 862, 877, 986, 1062, 1068-1069, 1070; characteristics of, 782, 783, 786; gifts to, 192, 770; lands held by, 969, 971, 972, 973; marriage among, 772, 773, 809, 827, 834, 846, 878, 939, 963; origins of, 53, 778-779, 1081, 1126; privileges of, 788-789, 794, 920, 939, 947, 954, 971, 1005, 1031, 1037, 1041, 1135; rahi, 260, 423, 439, 639, 677, 750, 751-751, 762, $971,1041,1061,1139,1163,1187,1191$, 1227, 1253, 1277, 1278, 1336; ri'i, 750, 751-751, 762. See also Chiefs; Classes, social

Ariois, 446, 615, 852, 878, 881, 903, 913-964, 1085, 1106-1108, 1167; activities of, 171, 226, 255-256, 262, 327, 332, 334, 337, 363, 364, 371, 421, 435, 447, 864, 909, 915-933, 1015, 1018, 1022, 1153; female,
950-951, 959, 962, 1111, 1156; grades of, 435, 921, 933-936, 944-945, 946, 947. 952, 955, 972, 1109, 1119, 1154, 1190; insignia of, 921, 933-934, 935, 936, 937, 938, 956, 962, 1108, 1119, 1140, 1284-1285; privileges of, 171, 345, 505, 924, 933, 950, 957-961, 1002, 1007, 1108; recruitment of, 768, 777, 786, 843, 936-942, 944-945, 1106, 1111; types of, 933, 939-942, 951-954. See also Afterlife, for Ariois; Arioi sect

Arioi sect, 57, 521, 666, 879, 891, 900, 906, 907, 913-964, 1131, 1132; dismissal and retirement from, 799-800, 939-942, 948, $950,1107,1108$; lodge masters of, 176, 870, 916, 922, 936, 937, 939, 944, 946, 948-949, 955, 962, 963-964, 1116, 1119, 1153, 1155, 1161; lodges of, 915, 918, 920-922, 932, 963-964, 1089, 1107, 1114-1117, 1155; origin and spread of, 738, 749, 845, 881, 894-900, 944, 954, $963,1145,1151,1207$; rule of infanticide in, 425, 619, 895, 917, 938, 939-940, 942-944, 949, 950, 953, 1107-1108, 1135, 1187, 1253. See also Ariois

Arrowroot, 149, 229, 247, 252

Art, 137, 139, 368-369, 531, 536, 592, 1151

Artocarpus incisa. See Breadfruit

Ata. See Gods, manifestations of

Atau-maui contrast, 585, 1081, 1082, 1110

Atolls, 7, 19, 35-38, 44, 281, 524-525, 529, 557,1129 ; resources of, 20, 23, 286, 853, 854; used as resorts, 35-38, 213, 435. See also Place Index: specific atolls

Atua. See Gods; Spirits

Atua-ta'ata. See Demigods

Augury. See Divination

'Aute, 143. See also Mulberry

Ava'a. See Gods' bed

Axes, 203, 497

Baldness, 1354

Bamboo, 25, 149, 165, 320; used as a tool, 134, 220, 295, 310, 415, 422, 1285

Bananas, 43, 259; cultivation of, 174, 252; forced ripening of, 252; offerings of, 260; ritual use of, 441,489

Bark cloth, 143-148, 165, 918; clothing made from, 153-157, 380; gifts of, 154, 421, 447-448, 451, 452, 453, 490, 491, 547, $587,588,806,865,928,933,948,953$, $956,958,1008,1166$; manufacture of, 112 , 125, 232, 235, 370, 371, 429, 430, 447, 537, 602, 603, 611-612, 767, 785, 856, 857-858, 903, 918, 941, 972, 995, 1000 1038, 1076, 1102; offerings of, 109, 201, 
$260,338,345,347-348,421,444,451$, $461,482,516,517,874,903,945,1003$, $1005,1007,1237,1265,1268,1307$; ritual use of, 110, 112, 396, 443, 499, 507, 508, 1016; used as money, 446, 865, 1085-1086, 1090

Barracudas, 209, 283

Barringtonia, 21, 22, 199, 284, 934

Barter, 151, 232-233, 259, 309, 588, 636, 856, 998, 1085, 1102-1103, 1115. See also Giftexchange; Trade

Basalt, 19, 135, 138, 170, 177

Baskets, 149, 244

Baths, 123, 124, 126, 153, 156, 429, 916, 1144; deconsecration through, 93, 108, $322,415,438,441,496,747,916$; given to ill, 468, 477; given to infants, 415, 416, 421, 422, 427, 550; post-paturient, 419-420, 441. See also Cleanliness, personal

Battle axes, 376

Battle shapers, 390, 393, 398, 401, 550, 876, 877, 989, 1027-1028. See also Warriors

Beaches, 19, 21

Beards, 156. See also Hair, human

Beauty: importance attached to personal, 159, 358, 1075; Maohi notion of, 159, 161, 359, 428, 436, 547, 597-598, 611, 1154

Bedding, 123, 125, 149, 165-166, 168, 171-172

Bestiality, sexual, 548

Beverages, alcoholic, 81, 1334-1335, 1364, 1365

Big-bellies, 95, 112, 114, 852, 869, 874, 957, $1027,1149,1167$

Birds, 215, 228, 893, 901; hunting of, 279-281, 814; navigation by, 215; used in fish spotting, 295, 296, 298, 299, 302. See also Feathers; particular kind of bird

Birth, 409, 413-424, 480, 550, 613, 620, 624, 626; ceremonies celebrating, 96, 108, 262, 336, 414-424, 551-552, 643, 693, 696, $928,1015,1135$; order of, 640,696 , 1024-1025, 1081, 1093, 1096, 1097-1098, $1125,1130,1182,1184$. See also Primogeniture

Blindness, 430, 467, 484, 871; of souls, 523

Blood: metaphor of, 1093; ritual use of, 107, $444,448,450,693,1220$. See also Selfbleeding

Boars, 901. See also Pigs

Boat handling, 196, 207-209, 405, 586, 1083; under sail, 207-209; while paddling, 207-209, 298-299, 401, 405. See also Boats
Boats, 194-207, 538, 556, 790; construction of, $23,69,125,199,200-205,235,259$, $310,311,327,386,388,430,602,822$, $857,859,893,989,995,998,1017,1085$, 1103; given as gifts, $260,452,461,948$, 998-999, 1005, 1008; launching new, 92, 262, 327, 398; ownership of, 309, 998-999, 1003, 1038-1039, 1046, 1219, 1291; transporting god images by, 77, 96, 101, 112, 387, 400, 902, 1020, 1265, 1307, 1316; use of, in warfare, 30, 201, 210, 382-383, 400-405, 972, 1083, 1240. See also Boat handling; Boat sheds

Boat sheds, 173-174, 201, 435

Body, human, 470, 471; odor of the, 783, 822, 1144,1154 ; relationship of, to soul, 62,64 , 409 , 526; use of, as a tool, 133-134

Bond-friendship. See Formal friendship Bonito, 225, 283, 314, 543; fishing for, 291, 295, 298-303, 304, 308, 312, 314

Boobies, 25, 215, 279, 299, 302

Boundaries: guarding of, 188, 389; marking of land, 74, 191, 625, 639, 720, 1043

Bounty mutineers, 44, 291, 328, 848, 1148, 1256-1257, 1312. See also Name Index: name of individual mutineer

Bows and arrows, 320-322, 376, 536, 544, $548,814,1038,1153$; use of, in hunting, 281. See also Archery

Boxing, 42, 133, 262, 298, 316, 318-319, 364, $381,924,950,993,1153$

Breadfruit, 4, 43, 44, 143, 223, 234-244, 291, 375, 705-706, 724, 1004; fermented, 125, 221, 225, 238-239, 243, 272, 970, 1010; mass baking of, 121-122, 236-238, 243, 789, 814-815; preparation of, 170, 220, 221, 228, 229, 234, 236-238, 274, 427; resin from, 199, 235, 279, 330, 379; ritual use of, 109, 259-262, 313, 345, 487, 489, 916,1003 ; variations in supply of, 128 , $234,259,264,268,484,541,1086$; use of, in construction, 165, 172, 199, 235

Breath, transmission of knowledge through, 54, 62, 411, 600, 721, 880. See also Knowledge, acquisition of

Broussonetia papyrifera, 143. See also Mulberry

Burial, 101, 507-511, 527, 556-557, 960; places used for, $96,110,277,507-508$, 509, 525, 747, 887, 911, 960, 1230, 1232, 1268 ; reasons for, $64,110,121$; time between death and, 468, 494, 496, 498, 556-557. See also Funeral rites; Mourning

Calendars, 54, 112, 264-270, 305-308 Calophyllum, 21, 22, 70, 146, 169, 199, 213, 
Candlenut, 24, 102, 127, 159, 170, 505, 916, 934

Cannibalism, 714-715

Canoes. See Boats

Carpenters and carpentry, 135, 166-167, 200-205, 279, 586, 635, 857, 858-859, 1103; commissioning of, $174,200,234$, 1104; payment for, $174,201,234,859$, 1103

Castanets, 328, 331, 504, 505, 506

Castaways, 35, 65, 348-349, 510, 1258, 1325

Casuarina, 21, 24, 187, 549, 1149; ritual use of, $70,94,102,109,187,510,903,1119$; tools made from, 141, 294, 302, 320, 379; wood of, used in building, 165

Cavally, 291

Caves, 53, 162, 508-509, 981

Cenchrus echinatus, 139, 140

Cerbera, 24, 328

Chants, 69, 114, 415, 416, 547, 549, 924, 928, 957, 1019-1020; creation, 49-50, $410,774,890,1134$; memorization of, 54, 429-430, 599-600, 745, 946. See also Genealogies

Checker fish, 283

Chestnut, Tahitian, 21, 22, 25, 245

Chickens, 130, 228, 272, 277-278, 430; gifts of, 447-448; ownership of, 787-788; ritual use of, 87, 109, 345, 422, 444. See also Cockfighting

Chiefs, 186, 317, 384, 393, 394, 395, 509, 532, 924, 936, 969, 990, 991, 1053-1067, 1157; authority of, 908, 971, 1010, 1140, 1164; constraints on, 761, 767, 986, 1024, 1032, 1035, 1058, 1064-1067; labor performed by, 148, 248, 281, 785, 996, 1000, 1296; households of, 860,876 $1068,1104,1147$; inauguration of, 186, 330, 364, 517, 681, 883, 929, 1049; insignia of, 82, 323, 384, 434, 536, 667, 733, 792, 817, 1017, 1020-1022, 1023, 1037-1049, 1175-1176, 1292; privileges of, $367,417,507,508,798,845,928$, 1001-1002, 1004-1005, 1018, 1023, 1035, 1039, 1043-1045, 1064, 1071, 1080, 1092, 1105-1106, 1122, 1136, $1145,1147,1162,1191,1201,1256$, 1290, 1335; redistribution by, 261, 263, 398, 652-653, 918, 927, 958, 959-960, 982, 997, 998, 1002, 1007-1008, 1013 1071-1072, 1114, 1127-1128, 1159, 1317; sacredness of, 433, 631. See also Kin Titleholders; Tribal chiefs

Childhood, 226, 427, 609-610. See also Child rearing; Children

Child rearing, 315, 409, 429-431, 598,
612-613, 694, 697, 698, 701, 717, 741, 755, 1254, 1276; permissiveness in, 609-610, 615, 699-701, 1112; sex training aspect of, 354, 368-369, 373, 430. See also Childhood; Children; Head-freeing

Children, 40, 581, 840; desire for, 807; play groups of, 697. See also Childhood; Child rearing; Parent-child relations

Chinese mulberry, 143. See also Mulberry

Chisels, 137

Christianity, 387, 955; conversion of Maohis to, $86,127,327,365,414,459,546,582$, 792-793, 884-885, 917, 1336, 1339-1349

Circumcision, see Supercision

Classes, social 65, 430, 637, 749-798, 810, 834, 921, 942, 946-947, 961-962, 992, 1058-1059, 1117-1118, 1133, 1163, 1362; boundaries maintained between, 346, 360, 390, 392-393, 454, 456-458, 554, 638, 694, 1053, 1098-1099, 1101; different activities of, 320, 327, 334, 335, 337-338, 343, 350, 429, 438, 553, 785-787, 863-864, 866, 872, 875, 923-924, 937, 961-962, 996, 1028, 1031, 1032, 1103, $1104,1144,1145,1148$; material differences between, 106, 154, 167, 170, 171-172, 187, 206-207, 223, 258, 273, 274, 319, 337-338, 381, 537, 732, 787-791; mobility between, 710, 755, 772-773, 775, 776-777, 819, 820, 862, 866, 868, 875, 877, 878, 962, 1098, 1142; origin of, 777-782, 1126, 1130-1131, 1134-1135; physical differences between, 155, 156, 157, 732, 765, 782-783, 1144; ritual differences between, 414-424, 447, 454, 462, 463-464, 468, 482, 507, 508, 552, 696, 996, 1009-1010. See also Ari'i; Manahune; Ra'atira

Cleanliness, personal, 156, 360-361, 420, 434. See also Baths

Climate, 16-19, 22-23, 242, 254, 259, 264, 304,529 ; effect of, on daily life, 127-128, 283, 535. See also Meteorology

Clothing, 152-157, 203, 432, 787; for special occasions, $261,415,420,435,448,817$, 1013; male-female contrast expressed through, 152, 602; manufacture of, 149, 152-153, 380

Clouds, time reckoning by, 128, 129; use of, in navigation, 215

Clubs, war, 376, 379, 392, 403, 417, 536

Cockfighting, 277, 322, 542, 993

Cockles, 228, 283

Coconut palms, 20, 43, 44, 45, 50, 70, 223, 234, 244-245, 305, 312, 313, 375, 693, 
1003; consumption of nut from, 125, 133, $135,220,228,229,244,427,556,1005$; cordage made from products of, 139-142, $199,289,319,390$; oil derived from nut of, $155,244,435,479,1051$; origin myths about, 708, 709; ritual use of parts of, 188, 261, 487, 510, 916, 929, 934, 996, 1010, $1032,1046,1268,1320$; use of, in construction, 149, 165, 199, 244, 379

Coffins, 507. See also Burial

Cognatic stocks, 621, 622, 655, 660-685, 1094, 1097

Colocasia antiquorum. See Taro

Colocasia esculenta. See Taro

Coming-of-age, 437

Conception, beliefs about, 63, 353, 409-413, 442-443, 550, 619-620, 1093, 1139. See also Reproduction, human

Conch-shell trumpets, 77, 328, 330, 1006; ritual use of, 261, 330, 389, 417, 909, 910, $1018,1021,1307$

Concubines, 451, 464, 833, 834, 838, 1099, 1145. See also Marriage; Semi-marriage

Conjoining, 110

Contraception, 360, 411-412, 617. See also Abortion; Infanticide; Reproduction, human

Cookhouses, 44, 162, 173, 228. See also Cooking

Cooking, 228-229, 246-247, 250, 251, 274, 276, 325, 606, 824-825; utensils for, 169-170, 221, 225, 236, 244, 245, 1038; while traveling, 196, 279. See also Cookhouses; Earth ovens

Coral, 134, 135, 177, 245

Cordage, 135, 139-143, 154, 165, 244, 294, 300; made of human hair, 139, 143, 152, 157, 320, 932, 1058, 1135; manufacture of, 140-143, 166, 289. See also Sennit

Cordyline terminalis, 108, 934, 1334

Cotton, native, 23, 530, 550

Council platforms, 46, 887. See also Tribal council

Crabs, 25, 282, 307, 308

Crataeva nuts, 535

Crayfish, 294, 308

Creation, 592, 923, 1134; myths about, 49-54, 57, 95, 188, 410, 704-705, 774, 882, 890, 1050, 1134; processes in, 49-50

Cuckoos, 26

Cultivation. See Agriculture

Cults, 57, 97, 104, 881-964, 981, 1082, 1105-1106, 1115, 1123, 1207, 1258; of Hiro, 1054-1055; of 'Oro, 57, 666, 671, 684, 909-913, 1151-1152, 1160, 1166 , 1174, 1194, 1207, 1213-1214, 1223, 1308; of Ta'aroa, 57, 882-884; of Tane, 57, 884-890, 1160

Curlews, 25

Cursing, 729, 743, 873, 908, 1314; of children by parents, 719-720, 723, 745. See also Sorcery

Cuttlefish. See Octopus

Dancing, 332-339, 364, 430, 544, 545, 603, $611,614,792,863,950,1076,1149$; costumes for, 337, 338; erotic, 93-94, 153, 332, 334-336, 338, 339, 351-352, 368, 602, 786, 924, 931, 936, 949, 1244-1245; experts at, 359, 365, 435, 864, 880, 914, 923, 937, 938, 945; group coordination required in, 584, 586, 1083; musical accompaniment to, 326-327, 328, 506; occasions for, 109, 262, 263, 336, 344, 397, $447,483,506,514,703,997,1003,1106$, 1153

Daphne, 284

Day, lunar, 128, 130-132, 264, 536. See also Ao

Death, 409, 469-472, 485-507, 620, 787; as a supernatural sanction, 594; characterization of, 56, 64; recognized causes of, 473, 555. See also Burial; Funeral rites; Mourning

Demigods, 50, 51, 53-54, 56, 62, 95, 222, 327, 412, 532, 537, 597, 648, 678, 729-730, $847,1079,1148$. See also Spirits; Name Index: name of individual demigod

Descent, 65, 688-748, 771-772, 1048, 1093-1098, 1117-1118; bilateral, 449, 454, 617, 619, 624, 694, 721, 805, 841, $1097,1100,1125,1130$; traced to gods, $49,52-53,65,442,867,901$; units of, 65 , 617-687, 1093-1098. See also Cognatic stocks; Kin-congregations; Kin-Titles, succession to; Marriage

Dioscorea alata, 1003, 1004, 1268

Dioscorea bulbifera, 541

Dirges, 491-492

Diseases, 160, 474, 484-485, 550, 583, 784; indigenous, 42, 243, 1078, 1189; induced by kava, 257; introduced, 39, 485, 1287. See also Healing; Illness; Injury

"Districts," 27-28, 30, 31, 357, 970-982, 991; activities engaged in by, 260, 261, 316-317, 322, 336-337, 435; fighting forces of, 27-28, 30, 31. See also Tribal polities

Divination, 69-71; events requiring, 188, 384, 395, 397, 488-489, 1026; methods of, 204, 219, 489, 555-556; objects used in, 108, 533; specialists in, 219, 384-385, 756, 
784-785, 879, 988. See also Dreams; Omens

Divorce. 838-841, 1147. See also Separation, marital

Dogs, 276-277; care given to, 96, 272, 276-277, 427, 430, 542; goods made from hair of, 276, 856, 921, 1148; meat from, 224, 228, 275, 276, 1005; offerings of, 87, $90,109,117,120,260,385,467,1247$

Dolphins, 291-296, 304; fishing for, 288, 291-296, 304; prohibited to women, 225 , 275; trade in, 213

Domestics, 767, 967, 1031, 1034, 1045, 1103; mahu working as, 548, 607; secular state of, 548, 601, 606, 607, 625. See also Teuteu

Drama, 339-343, 368, 863, 928, 945, 1079-1080; competitions in, 336-337; costumes for, 340, 786; satire in, 340, 462, 595, 917, 923, 924, 962. See also Actors; Theaters

Dreaming, 69, 531, 552, 875; premonitions received through, 71, 672-673, 757, 815, 875; soul's activities during, 62, 71, 470, 471. See also Divination; Omens

Dress. See Clothing; Nudity

Drills, 134

Dropsy, 485

Droughts, 254

Drowning, punishment of thieves by, 1056

Drums, 77, 169, 328-330, 365, 389, 536, 708, $817,818,1264,1291$; accompaniment to entertainment by, 317, 327, 331, 334, 335, 337, 340, 397, 451, 506, 786, 900, 932, 958,997 ; playing of, during religious rites, $81,85,87,93,109,113,117,192,370$, 417, 451, 482, 506, 512, 515, 516, 831, $874,909,910,919,981,1003,1018,1021$, $1220,1307,1308$

Drunkenness, 96, 1334-1335

Dugouts, large. See Boats; Va'a

Dugouts, small. See Boats; Puho'e

Dwarfism, 42

Dwellings, 46, 162-176, 789-790, 966-967, 1251; construction of, 166-168, 244, 388, 602, 603, 767, 804-805, 857, 972, 996-998; of chiefs, 417, 789-790, 1042-1043, 1162, 1291; public, 162, 167, $170,171,174,344,345,347,996-998$; sacredness of, 419; temporary, 173, 174, 196 279, 347, 414, 437-438. See also Households

Dyes, 20, 146, 279, 537, 934

Early European Era defined, 5 Earrings, 157, 537
Earth ovens, 126, 228, 236, 238, 250, 279, 398. See also Cooking

East-west contrast. See Upper-lower contrast

Eating, 120, 133, 159, 220-228, 230-232, 428-429, 451, 535, 721, 729, 825, 1033 , 1091; as a part of religious ritual, 911, 912, 1023; pleasure derived from, 916, 1075,1076 ; separation of sexes during, $172,224-227,230,239,374,541$, 601-602, 603, 604, 606, 809, 815, 1044, 1078, 1145, 1254; times for, 123-124, 125, 126; warriors' arrangements for, 387, 549. See also restrictions, food; Restrictions on self-feeding

Eels, 25, 283, 285-286, 918; fishing for, 291, 306; kept as pets, 286

Eleotris fusca, 25, 524

Elephantiasis, 485. See also Diseases

Embalming, 62, 489, 496, 500, 507, 508, 1300, 1360; methods used in, 498-499, 520-521; purpose served by, 64 ; specialists in, 860 , 862

Emotion as a dimension of interaction, 581, 589-591, 598, 605-607, 614-615, 632, 638-639, 725, 742-743, 795-798, 813-828, 1091-1092, 1114

Emotions, 598, 990; seat of, 63, 590, 820, 1134, 1165

Essence, 49, 63-64, 84, 409, 1038, 1047; of offerings, 90, 501, 629; receiving one's, 409, $415,426,555,557$; sorcery aimed at one's, 63, 473

Eugenia malaccensis, 246. See also Apples

Exchange contracts, 540, 593, 1053, 1115; between fishermen and farmers, 232-233, 309, 853, 854, 855, 1085, 1103, 1125. See also Barter; Gift-exchange; Trade

Exhorters, battle, 390-392, 849, 876-877, 1149; compensation of, 989; job of, 390-391, 395, 1029-1030, 1229; number of, 401, 550. See also Orators

Exile, sanction of, held by chiefs, 120, 593, 633, 640, 987, 1010, 1011, 1046, 1054 $1056,1057,1059,1065,1163,1331$; sanction of, imposed on chiefs, 761, 1025, 1032,1221 ; sanction of, in interclass marriage, $754,772,774,776,834$

Extramarital affairs, 354-358, 364-367, 464, 716, 826-827, 833-834, 837, 932, 1099, 1167; Arioi engagement in, 943, 949-951; covers for, 506; culminating in marriage, 459, 799-800, 1363; interclass, 456, 774-775, 836, 860, 1190, 1202; sanctions against, 1053, 1062, 1146. See also Prostitution; Rape; Formal friendship, wifeexchange as part of 
Eyeshades, 154, 295, 435, 763. See also Headwear

Familiars, 57, 61, 62, 286, 311, 627, 628, 880; possession by, 475. See also Fetchers; Spirits, tutelar

Farepua maro, 1234

Fattening, forced, 41, 157-159, 222, 358-359, 434-437, 550, 611, 1075; of youths, 410, 461, 553, 611, 1014; requirement of, for Ariois, 947; resorts for, 435, 1154

Fauna, indigenous, 25-26; creation myths about, 49, 50

Feather girdles, 76, 106, 620, 763-764, 883, $1041,1105,1207,1214-1216,1221,1226$, 1234-1236, 1268; red, 53, 664, 674, 675, $677,682,684,763-764,773,774,883$, 892, 903, 916, 933, 935, 962, 1017, 1019, $1039,1040,1119,1160,1191,1194,1214$, 1268, 1335, 1342, 1364; yellow, 667, 678-679, 708, 763-764, 883, 892, 903, $1120,1151,1215$. See also Feathers; Farepua maro; Kin-Titleholders; Teraiputata maro; Tetupaia maro ura; Teva maro; Wallis maro

Feathers, 49, 74-76, 865, 902-903, 906, 1020; acquiring, 75, 214, 234, 279-280, 355, $611,677,856$; clothing ornamented with, 79, 154, 381, 447, 448, 503, 506, 1022; gifts of, $79,348,490,849,893,898,1005$, 1063; ritual use of, 75-76, 84, 107, 116, $117,193,202,219,263,312,313,345$, 348, 398, 416, 417, 418, 488, 490, 510, 523, 594, 763, 886, 901, 902-903, 915, $916,1020,1023,1316$; secular uses of, 156, 157, 216, 298, 338, 380. See also Feather girdles

Feeding. See Fosterage

$\mathrm{Fe}^{\prime}$ i. See Plantains, mountain

Fenua. See "Districts"

Festivals, 127, 340, 586, 885-886, 922, 1013, 1014-1015, 1152, 1237, 1295, 1332; activities during, 361, 364; timing of, 192-193, 264, 542. See also Ghosts' night feast; Harvest festival; $\mathrm{Pa}$ iatua festival; Ripening-of-the-year festival; Taraehara festival

Fetchers, 51, 62, 71-74, 75, 77, 166, 259, 475, 533, 902; adoption of, 62, 71-74, 94, 116, $117,472,527,874,1139$; associated with shrines, 103; harming through, 472-473, 481, 555; set up along boundaries, 639, 1043. See also Familiars; Ghosts; Images; Sorcery

Ficus prolaxa, 143, 287, 999, 1018
Filaria, 25

Files, 135

Firearms, 161, 341, 848, 1266, 1284, 1310; Maohi access to, 836, 1259, 1280, 1283, 1286, 1297, 1301, 1305, 1324, 1325, 1348

Fires, 20, 110-111, 489, 494, 600; brush, 43; use of, as a tool, 138, 199

Fire-walking, 94, 108, 247

Firstborn, 357, 621-622, 651, 679, 723; privileges of, 414, 418, 439, 651, 683; respect given to, 695, 720; sacredness of, 66, 720, 794. See also Birth, order of; Primogeniture

First-fruit offerings, 93, 260, 314, 628, $629,635,721,814,883,889$, 1001-1002, 1006, 1009, 1010, 1013, 1049, 1080, 1094. See also Offerings; Ripening-of-the-year festival

Fish, 25, 247, 282-283, 543, 1086; consumption of, $220,223,224,228,788$; offerings of, $87,109,261,385,444$, 1011,1312 ; metaphor for human sacrifice, 92, 1204, 1207; trade in, 232-233, 309, 853, 854, 855, 1085, 1103, 1125. See also Fishing; particular kinds of fish; restrictions, food

Fishermen, 40, 156, 218, 327, 525, 880; as an occupational group, 852, 854, 871, 957, 1102,1149 ; clothing worn by, 153; guilds for, 313-314, 854-855, 1102, 1103. See also Exchange contracts, between fishermen and farmers; Fishing

Fishhooks, 300-301, 302, 1121; manufacture of, 139, 276, 286, 294, 295, 297, 300, 309-310, 543, 1091, 1166, 1318; ownership of, 309

Fishing, 208, 281-314, 430, 543, 584, 602, 603, 611, 814, 1076; hours for, 125, 126, 127; religious ritual surrounding, 259, 310-314, 854, 871; seasonality in, 264, 289, 294, 297, 299, 302, 303-308; sites for, 39, 186, 213, 227, 297, 305, 309, 311, 312, 396, 543; techniques of, 133, 195, 196, 284-303, 586, 999, 1079, 1159. See also Fishermen; Fishhooks; Fishing lines; Fishnets; Fish ponds; Fish weirs

Fishing lines, 142, 294, 298, 300, 309, 313

Fishnets, 151, 262, 287-289, 543, 1159; manufacture of, 995, 999-1000; operation of, 586; ownership of, 227, 287, 309, 1038. See also Fishing, techniques of

Fish ponds, 289

Fish weirs, 289, 312-313, 854

Flatfish, 283

Fleas, 162, 168

Flies, 25, 130, 151, 223. See also Fly flaps 
Flowers, 366, 501, 1013; for personal ornamentation, 40, 90, 156, 157, 421; used in time-reckoning, 130

Flutes, 328, 329, 330, 365, 921, 1264; accompanying entertainment, 331, 332, 337, 362, 900, 958; ritual use of, 397, 482, 514, 708, 919

Flute-snout fish, 283

Fly flaps, 157, 227, 1038, 1280. See also Flies

Flying fish, 283, 288, 294, 295, 299

Food, 125, 540, 636, 782, 1004-1005, 1075, 1085; circulation of, 229-234, 245, 246, 251, 253-256, 309, 636, 852, 853, 1086; preservation of, 243, 245, 263; shortages of, 243, 247, 249, 251, 383, 1087, 1334. See also Cooking; names of particular kinds of foods; Restrictions, food

Food plants, 234-253; title to, 229, 239, 254. See also names of particular food plants

Footracing, 316, 319, 322, 602, 864

Formal friendship, 455, 465, 639, 842-850, 979, 1085, 1089, 1101-1102, 1103, 1115, 1119, 1157, 1167, 1317; between different class members, 371, 795, 1143; between Maohis and Europeans, 75, 171, 361-362, 1087, 1176, 1224, 1258; ceremonies establishing, 799, 1034; as part of head-freeing process, 422, 434, 439, 440, 443-444, 465, 1147-1148; role of, in peacemaking, 335; wife exchange as part of, 604, 742, 795-798, 810-811, 825-826, 845, 848, 878, 1359. See also Friendship

Fosterage, 230, 540, 694, 697, 701-704, 727, 741, 804, 841, 842, 845-846, 938, 967, 1139-1140, 1143; distinguished from parenthood, 693; political manipulation through, 702, 1148, 1157, 1168, 1330; role of, in peacemaking, 703. See also Adoption

Fowls. See Chickens

Fragraea, 328

Free will, Maohi belief in, 523

Friendly Alliance, 909-912, 1115, 1167

Friendship, 111, 120-121, 231, 233, 342, 389, 842, 948, 1076, 1077. See also Formal friendship

Frigate birds, 26, 233-234, 299

Front-back contrast, 585, 604, 614, 634, 724, 730, 741, 742, 793-794, 809, 1080, 1081, 1082, 1095-1098, 1110

Funeral rites, 336, 501, 516, 929, 960, 1300, 1360. See also Burial; Embalming; Mourning

Furniture, 165-166, 168-170, 213, 220, 227, $551,815,1044$
Games, 315-316, 319, 323, 397, 544, 716. See also Sports

Genealogies, 54, 325, 622, 640, 661, 671, 674, 742, 760, 984, 1038, 1094, 1095, 1131, 1179; knowledge of, 599, 624, 645, 655, 656, 784, 864, 1117; of particular families, 1178, 1180-1182, 1184, 1187, 1188, 1278-1279, 1337, 1338, 1351, 1352; recitation of, 326; traced back to spirits, 65, 890

Geography of Society Islands, 7-26

Ghost guardians, 509, 860, 862-863, 1034

Ghosthouses, 493, 494, 496, 497, 498, 500, $505,507,508,556$

Ghosts, 56, 58, 61-62, 74, 92, 353, 361, 498, $524,532,556,647,648,659,694$; associated with fetchers, 71, 472, 741; fear of, $127,278,307,474,510,511,526,723$; involvement of, in human lives, 62, 65, 110 , $262,449,474,489,527,628,630,723$, 745, 819, 1077. See also Fetchers; Ghosts' night feast; Souls

Ghosts' masque. See Mourners' masque

Ghosts' night feast, 230, 510, 526, 628, 723

Gift-exchange, 146, 151, 154, 232-233, 259, 588-589, 1090, 1092, 1103. See also Barter; Exchange contracts; Gifts; Trade

Gifts, 238-239, 309, 848-849, 853, 854, 857, 861, 998, 1083, 1102. See also Barter; Gift-exchange; Trade

Ginger, native, 24, 934

Globe fish, 283, 712

Gobies, 25, 524

God houses, 77, 96, 888, 911, 1263, 1361; consecration of new, 85, 87, 92, 192. See also Images

God-image bearers. See Image bearers

God-images. See Images

Gods, 56-61, 78, 95, 327, 486, 509, 532, 535, 545, 616, 868, 871, 881, 959, 997, 1013, 1064, 1079, 1080, 1093, 1134; casting off of, 78, 1320, 1340; communication between humans and, 186, $361,547,622-623,901$; creation myths about, 49, 50, 53, 528, 648, 904-906, 1151; manifestations of, 50, 57-61, 69, 70, 85, 276, 278, 412-413, 542, 901, $1051,1055,1150$; messengers of the, $57,77,114,115-116,415,629$; participation in human affairs by, 53, 313, 317, 379, 384, 394, 411, 442, 555, 557, $624,628,648,702,713,774-775,873$, 901, 945, 946, 1016, 1021, 1043, 1062, 1163; using names of, 582, 603. See also Cults; Images; Name Index: name 
of individual god; Offerings to spirits;

Sacrifice, human, gods given to; Spirits

Gods' bed, 100, 101, 116, 885, 888

God-wakers, 852

Gongs, 328, 330, 331, 337

Gorgets, 380, 857, 877, 1005, 1148

Gossypium, 23, 530, 550

Gouges, 137

Gout, 484

Governance as a dimension of interaction, 581, 585-586, 604-605, 614, 629, 634-635, 724, 742, 751, 794, 813, 947-948, 1082-1083, 1114-1115

Grandparent-grandchild relations, 743-748

Group, social, defined, 580

Guilds, 65, 104, 200, 201, 861, 862, 878, 914, 1085, 1102, 1103, 1168; fishermen's, 313, 854,1103

\section{Ha'apori. See Fattening}

Hair, human, 156, 330, 359, 428, 492, 508, 519; caring for, 155, 602, 713. See also Cordage made of human hair

Hara, 69, 120-122, 399, 474, 489, 498, 500, 595,630

Harming. See Cursing; Sorcery

Harvest festival, 263-264, 389, 1015

Hau, 1049-1053. See also Peace

Hau Manahune, 1333-1336

Head, 445, 448; respect accorded, 62-63, 66, $133,440,638,1068,1165,1269$

Head-freeing, 409, 427, 433-434, 437-445, $552,1015,1148$; restrictions prior to, 64, 226, 437, 438-439, 466, 609, 696-697, 1135; rites for, 420-423, 437, 439-440, 443-444, 450-451, 465, 553, $809,830,843,937-938,1100$; sacredness prior to completion of, 64,439 , 441-442, 466, 474, 610, 694, 696-697, 720 ; timing of rites for, 438, 439, 628, 782, 787, 1136, 1145

Head molding, 40, 157, 359, 419, 427, 428, 597-598, 609, 698, 1290

Headwear, 154, 302, 380-381, 390, 503-504, $794,817,877,878,934,1003,1005,1240$, 1264; chiefs', 1038, 1268, 1280

Healing, 81, 156, 244, 467, 468, 474-485, 698; god of, 57, 1050; priests' role in, $96,467,512-513,514,625,1078$; specialists at, 234, 860, 875-876, 1103, 1104. See also Diseases; Illness; Pharmacopoeia

Heralds. See Messengers

Heavens: creation of, 49; levels of, 794, 896

Hedgehog fish, 283, 290

Hibiscus, 21, 22, 24, 139, 142, 149, 165, 166,
248, 289, 550; wood from, 199, 210, 286, 379

Hiva. See Tribal council

Homosexuality, 352-353, 369-374, 548, 799, 837, 863, 1091, 1111-1112,

1167-1168, 1190; as a bar to marriage, $374,446,1145$; as a facet of formal friendship, 844, 850; characteristic of domestics, 548, 607; tolerance of, 597, 603, 1111

Horizon, 539; division of, 215-216

Hospitality, 45, 344-346, 362, 794-795, 868, 926, 994-995, 1008-1011, 1088, 1176; demands of, $541,604,792,824$, 846, 959, 961, 1088, 1158; ethic of, 230-232, 347-349, 545-546, 588, 1068-1069, 1084, 1090, 1335; осcasions offered, 322, 345, 362, 916, 948, 961. See also Dwellings, public; Visiting

Households, 44-45, 65, 74, 362, 580, 968, 969, 970, 976, 1156; activities as members of, 586; composition and size of, $230,447,700-701,727,745,801,804$, 832, 860, 876, 966-967; establishment of new, 741, 801, 804; heads of, 624, 851, 878; sharing within, 205, 206, 254, 229-230, 614, 812-813, 1088, 1089, 1096, 1100, 1108, 1166-1167. See also Dwellings

Houses. See Dwellings

Humpback, 484, 871

Hunting, 276, 278-281, 320, 376, 602, $710-711,814$

Husband-wife relationships, 493-494, 524, 604, 803, 807-828, 839, 1034, 1084, 1091, $1101,1146,1254$

Hutu. See Barringtonia

'Iatoai, 634, 681, 750, 751, 761-762, 773, 775, 780, 1032, 1037, 1142. See also Tribal council

Idiots as oracles, 79, 866

Iho. See Essence

Illness, $124,186,469-472$, 525, 1015; attitudes about, 69, 161, 359, 468-469, $525,784,953,1316$; causes of, 69,432 , 469, 471, 741, 1075, 1078, 1319-1320; grief displayed about, 590; indications of, 358, 783. See also Diseases; Healing

Image-bearers, 95, 116, 852, 869, 875, 887, $1018,1027,1045$

Images, 59, 71, 421, 904, 912-913, 1021, 1150, 1151, 1194, 1234-1236, 1297, 1317, 1363; casting off of, 78, 1320, 1340; confiscation of, 398; construction of, 76, 108, 399, 857; coverings for, $66,101,116,117$, 
911; for fishing, 311-312, 313, 854; forms of, 74, 533, 664, 885, 893, 901-903, 1151; installation of, 386-387, 400, 1197,

1213-1214. See also Fetchers; Image-bearers; 'Oro of the bird feathered body image; 'Oro Rahi to'o toa; Paiatua festival; Papara image; Opoa 'Oro image

Incest, rules of, 454-455, 638, 690, 694, 695, 727, 739; Gods breaking of, 49, 50

Infancy, 226, 609

Infanticide, 63, 412, 424-426, 507, 555, 609, 696, 1079; ghosts of victims of, 474, 527; infants selected for, $39,387,423,446$, 456-457, 549, 606, 617, 619, 643, 754-755, 758, 772, 773, 775, 943; methods of, 424-426, 551, 695. See also Arioi sect, rule of infanticide in

Infants, 108; care of, 124, 165, 427, 428, 551, 1139; naming of, 581-582; souls of, 61, 63, $474,524,527,723$. See also Birth, ceremonies celebrating; Infancy

Inheritance, 105, 445, 487, 722, 729, 800, 848; loss of one's, 754, 758; of occupation, 95, 721, 761, 814, 860, 861, 862, 866, 870, 875, 907, 1032, 1102, 1103; of physical characteristics, 410-411. See also Kin-Titles, succession to; Knowledge, acquisition of; Land, rights to

Ini'a-i raro contrast. See Upper-lower contrast Injury, 69, 317, 318, 469-470, 471, 476-479, 875, 1177; accidental, 527, 555, 1075. See also Healing

In-laws, 828-833, 839

Inocarpus edulis, 21, 22, 25, 245

Insanity, 469, 484

Ipomoea batatas. See Sweet potato

Iron: Maohi desire for, 1285,1325 ; trade in 213

Ironwood. See Casuarina

Irrigation systems, 249, 541

Javelin throwing, 319-320, 381, 402

Jesters, 831, 862, 1149

Jesting, 323, 324-325, 326

Kava, 108, 256-259, 541, 602, 886, 981, 1048, 1190; cultivation of, 174,248 , 717, 853; debilitation from, 35, 213, $485,1061,1184$; drinking of, 170, 541, 602, 747, 789, 1075, 1144, 1175, 1248, 1254,1297 ; medicinal use of, 479 ; offerings of, 87, 109

Kin-congregation chiefs, 627-640, 651-652, $654,686,767,795,851,1024,1037,1109$, 1118,1330 ; obeisance to, 638-639; sanctions of, 635, 639-640; succession to, 631; rights of, 652-653. See also Chiefs; Kincongregations

Kin-congregations, 65, 622-640, 760, 890, 978, 979, 987, 995, 1073, 1088, 1089, 1094, 1104, 1105, 1114-1115, 1117, 1122, 1136, 1141, 1165; connections between, 651, 653-654, 655, 657-658, 661-685, 1095-1096, 1097; ramifications of, 649-668, 870, 979, 1095-1096, 1123, 1129, 1130, 1136; structure of, 648-660. See also Kin-congregation chiefs; Marae; Neighborhoods

Kin-congregation Titles. See Kin-Titles

Kindlers, 472-473, 481, 555. See also Sorcerers

\section{Kingfishers, 26}

Kin-Titleholders, 121, 393, 609, 659, 697, 723-724, 727, 804, 875, 943, 1027, 1037, $1039,1080,1094,1113,1132,1158$; behavior toward, 109, 595, 725, 729, 741, 992, 1193; female, 67, 604-605, 611, 644-645, 805, 827-828, 1113, 1167; investiture ceremonies for, 100, 104, 466, $904,1139,1194,1216,1221,1232,1235$, 1266-1267, 1268-1269, 1277, 1317, 1364; life crises of, 414-417, 454, 456, 494, 642, 645, 721-722, 834, 837, 838, 862, 1096, $1100,1101,1337,1339$; privileges of, 92, 225-226, 358, 766, 890, 962, 1136; sacredness of, 66, 76, 121, 720, 783-784. See also Ari' $i$; Chiefs; Kin-Titles

Kin-Titles, 627, 640-648, 686, 760-766, 783-784, 870, 1080, 1094-1095, 1165, 1207, 1279; creation of, 640-641, 659-660; Opoan-derived, 53, 57, 883, 907, 913, 1096, 1117-1118, 1119, 1160, 1191, 1207-1208, 1235; ranking of, 53, 233, 439-440, 442, 582, 583, 604-605, 606, $609,614,620,645,759,762-763,777$, 793, 805, 828, 883, 970, 1052, 1082, 1094-1095, 1096, 1105, 1109, 1111, 1183 , 1186, 1194, 1197, 1201, 1204, 1208, 1209-1210, 1219, 1225, 1226, 1330, 1337; succession to, 424, 442, 446, 447, 463, $465,466,601,606,614,643-645,682$, 694, 702, 710, 721, 739, 764, 814, 939, 1112, 1125, 1141, 1144, 1150, 1177, 1191, $1259,1295,1315$; transference of, 442 , $447,463,601,609,641-644,646,698$, 699, 700, 722, 725, 745, 773, 833, 943, 1024, 1040, 1067, 1097, 1137, 1295. See also Kin-Titleholders

Kites, 538, 984

Knives, 134, 161, 170, 220, 223, 415, 422, 434

Knowledge, 327-328, 599-600, 784, 1076; acquisition of, $48,54,62,82,85,86,126$, 
$411,487,531,600,721,879,880$. See also Sages

Kuhlia marginato, 25, 283

Labor, 125-126, 310, 315, 785, 805, 991, 995-1001, 1076, 1078-1079; corvée, 171, 174, 188-189, 767, 859, 920, 997, 999; division of, $140,245,310,447$, 537, 602, 985, 1078, 1097, 1099, 1100, 1167; incentives for, 541. See also Chiefs, labor performed by

Lagoons, 7, 15, 16, 187, 283, 288, 291, 304, $313,319,602,978$

Lakes, 283

Land: confiscation of, 991-992, 1010, $1040,1057,1061,1063,1065,1329$; disputes over, 376, 403, 1063-1064; emotional attachment to, 1164-1165; myth of fixing in place, 50-51, 53; rights to, 186, 188, 227, 254, 297, $376,398,587,624,625,633,646$, 650, 751, 765, 766-767, 769-771, 779, 792, 840, 847, 972, 992, 1035, 1076, 1089, 1094

Landscape, Maohi transformation of, 20, 43-44

Late Indigenous Era defined, 4-5

Learning. See Knowledge; Schools

Legends, 162, 235, 278, 406, 456, 457, $537,592,600,611,618,670,673,680$, 705-719, 727, 729-739, 745-748, 755-757, 760, 763, 776, 784, 801, 811-812, 813, 814-824, 835, 845, 883-884, 980-981, 1026, 1037, 1051, 1065, 1084, 1095, 1115, 1134, 1137, $1144,1149,1168$

Lese majesty, 770, 811, 1053, 1059-1061, 1065,1328

Levirate, 455, 456, 465, 729, 833, 835

Life: death contrasted with, 63; goals of, 1074-1078; restoring of, 486; signs for presence of, 426

Limbo, 65, 522, 526, 557. See also Afterlife; Souls, journey of

Limestone, 177, 187

Loans, 1089, 1115

Lobsters, 284, 305

Lockjaw, 485

Mafera, 365, 607

Magic, 83, 84, 86, 247, 339, 353, 367, 389, 476, 536, 594, 601

Mahi. See Breadfruit, fermented

Mai-atu contrast, 585

Maire fern, 109, 488

Mana, 674, 783, 859, 879, 893, 1103; concept of, 55, 58, 68-69, 93, 139, 302, 310, 312, 534, 631, 642, 1047, 1049, 1161, 1166

Manahune, 750-751, 751-751, 762, 764, 765-769, 772, 775, 777, 790, 791-792, 794, 859, 862, 1063, 1098, 1117, 1126, 1129, 1163; labor by, 637, 767, 779, 971; obligations of, 262, 767, 1047; origin of, 778, 1081, 1144; restrictions imposed on, 423, 551, 787; sacredness of, 767-768, 772, 783, 784, 866, 879. See also Classes, Social

Mango, Tahitian. See Spondias

Mangrove, 21, 759

Man-o'-war bird, 280, 503, 901, 1020, 1022

Mantas, 218

Maohi, defined, 6. See also Tahitian (language)

Māpē. See Chestnut, Tahitian

Marae, 46, 95-106, 177-193, 277, 386-387, 414, 443-444, 451, 472, 534, 538, 542, 622-624, 704, 843, 869, 870, 876, 915, 982 ; burial in, 507, 508, 525, 747, 887, $911,929,960,1230,1232,1268$; connections between, 189, 190-191, 193, 538, 640, 647, 649-651, 660-685, 979, 1196-1197, 1213; cult, 624, 869, 885, 886, 887-888, 904, 938; establishment of new, $188,602,640,653,674,776,858$, 995-996, 1012-1013, 1051, 1052, 1213, 1219, 1320; kin, 31, 44, 64, 67, 87, 162, $187,418,420-421,601,622-623,624-625$, 640, 648-649, 654-658, 693, 857, 858, 886, 996, 968, 978, 979, 1094, 1012, 1117, 1135, 1137; maintenance of, 90, 112, 113-114, 193, 314, 399, 995-996, 1017; occupational, 188, 201, 312-313, 623, 624, 854, 859, 893, 1014, 1102; sacredness of, $66,226,509,512,533,601,757$; storage in, $77,93,96,101,322,330,398,415-416$, 433, 437; tribal, 87, 187, 416, 417, 418, 434, 449, 450, 601, 623-624, 670, 671, $869,1002,1006,1027,1038,1152$; use of, as refuges, 105, 502, 505, 593, 668, 798. See also Ahu; Altars; Marae complexes; Marae-names; Marae uprights

Marae complexes, 97, 104, 685, 1193, 1196. See also Marae

Marae-names, 191, 624, 626-627, 640, 646, 648, 649, 701, 1094, 1136

Marae stones. See Marae uprights

Marae uprights, 85, 87, 97, 100, 118, 178, 535, 640, 646-648, 649, 656, 658-659, 664, 669, 742, 888, 1020, 1095, 1136. See also Marae

Maro. See Feather girdles

Marriage, 110, 111, 342, 366, 374, 409, 445-465, 552, 613, 620, 697, 698, 754, 
774, 799, 863, 1140, 1147; arranged, 453-462, 698, 721-722, 829-830; ceremonies of, $67,104,107,108,418$, 443-444, 447-453, 456, 457, 459, 461, $553,604,624,693,722,754,772$, 775-776, 805-807, 819-820, 829-830, 840, 843, 928, 950, 1015, 1022, 1082, 1100, $1115,1145,1186,1187,1189,1357$; headfreeing completed with, 434, 439, 553, 608,696 ; of chiefs, $186,553,645,824$, 1022, 1096, 1097, 1363; political motivations for, 447, 454, 465, 553, 658, 807, 979-980, 1099, 1100-1101, 1122, 1125, 1130-1132, 1157, 1192, 1242, 1260, 1293, 1315, 1326, 1337, 1338; suitable partners for, 360, 447-465, 625, 678, 729, 751-754, 755-759, 764, 770-771, 773-774, 805, 965, 1097, 1099, 1101, 1130-1131, 1166. See also Concubines; Semi-marriage; Separation, marital

Marriage classes. See Classes, social

Massage, 159, 348, 427, 480, 487, 603, 737, $755,788,1051,1144$

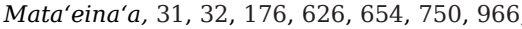
968, 969, 973-975, 976, 978, 983, 1002, 1156, 1157, 1209. See also Neighborhoods

Matahiapo. See Firstborn

Mates: primary, 464; secondary, 464, 834-838. See also Marriage

Mats, 165, 171, 340, 416, 507, 508, 856, 915; use of, as clothing, 380, 384; gifts of, 448 , $490,491,635,865$; manufacture of, 171 , $370,537,602,603$; offerings of, 109, 260, 385, 418, 635, 916, 1003, 1005

Maturity, 609, 613, 799, 1113, 1123, 1149

Measurements of distance, 585

Mediums. See Oracles

Menstruation, 353, 361-362, 554, 601, 607, 809

Messengers, 627, 761, 852, 980, 1016, 1031-1033, 1034, 1046, 1328; announcements made by, 417, 643-644, 681, 815-816, 989, 1010, 1036, 1050, 1109, $1229,1243,1245,1260,1264,1270,1321$; spirit, 57, 77, 114, 115-116, 415, 629. See also Standards

Meterology, 218, 299. See also Climate

Miro. See Thespesia

Missionaries, 4, 26-27, 46, 48; arrival in Society Islands of, 4, 26, 46, 48, 1288-1313

Mo'a. See Sacred, state of being

Mock combat, 262, 319, 379-380, 382-383, 501-502, 602. See also Warfare

Molluscs, 25, 130, 282-283, 284, 304, 602

Monarchy, emergence of, 1171, 1249, 1253 1280-1281, 1305, 1306, 1349-1350
Moon: god, 57; phases of the, 127, 264, 283, 305-308, 543

Morinda citrifolia. See Apples

Mosquitos, 25

"Mourners' masque," 501, 502-507, 798, 929, 960, 1153

Mourning, 488, 516-517, 556, 557, 590, 722-723, 725, 757, 960, 995, 1138; activities of, 226, 311, 488-494, 498-499, 501-507, 510-511, 516-517, 519, 520-521, $832,1015,1179$; symbols of, 157, 280. See also Death; Funeral rites

Mua-muri. See Before-after contrast

Mulberry, 43, 140, 248, 256, 430, 1148

Mullet, 283

Murder, 424, 468, 822, 824, 826, 830, 1053-1054, 1056-1058, 1059, 1065, 1084 1296, 1331, 1335

Musa fehi. See Plantains, mountain

Musa paradisia. See Plantains

Music, 863, 931, 938, 945, 1076, 1106. See also Musical instruments; Songs

Musical instruments, 169, 326-332. See also Music; name of particular instrument; Singing

Mussels, 283

Muteness, 484

Myths, 111, 172, 188, 219, 340, 409, 456, 552, $557,592,661,764,784,882,883$, 892-900, 903-904, 905-906, 908, 910-912, $944,954,992,1131,1140,1150,1152$ 1155, 1209, 1211, 1245; Bible-inspired, 47, 53,892 ; local variations in, 48, 530; origin, 235, 704-706, 708, 709, 724, 763, 992, 1050, 1053. See also Legends

Names, 581-583, 603, 643, 646, 668; giving of, 419, 424, 449, 581-582, 710, 717, 721, 840; personal, 424, 581, 844, 1080, 1165. See also Marae-names

Navigation, 215-218, 281, 539, 1133

Needlefish, 283, 286-287

Neighborhoods, 44-45, 65, 316, 614, 967-970, 976, 978, 979, 1061, 1108, 1156, 1208. See also Mata'eina'a

Nets and netting, 142, 151, 170; fishing with, 282, 307

Night-walkers, 869, 871-872. See also Priests

Noa. See Secular, state of being

Noddies, 215, 279

Nohora'a, 59

Noho-vao contrast, 767

Nono. See Apples

Nudity, 152, 153-154, 332, 335, 338, 339, 348, $367,368,428,432,434,484,537,1022$, 1023. See also Clothing 
$O-a$ contrast, 587, 1083, 1090

Obesity. See Fattening

Occupation, 751, 851-880. See also particular occupations

Octopus: fishing for, 283, 285, 313; metaphor of, 1119, 1204

Offerings, 66, 83-93, 108, 109, 260, 311, 312-313, 419, 488, 497-498, 510, 527, 534, 628, 629-630, 874, 916, 953-954, 1038; demanded by oracles, 80-82, rationale of giving, 234; given to chiefs, 259-260, 262, 338, 397, 398, 417, 541, 748, 916, 1001-1008, 1158, 1237, 1268-1269, 1292, 1317; given to spirits, $74,77,81,87,95$, 97, 99, 101, 109, 112, 114, 117, 118-119, $120,121,189,201,219,259-260,262$, 277-278, 313, 330, 388, 397, 398, 399, $422,474,475,479,486,481,482,525$, 526, 556, 631-632, 784, 788, 872, 876, 889, 907, 910-911, 913, 915, 917, 926, 938, 944, 1095, 1152, 1160, 1310, 1316, 1324, 1327, 1338, 1339. See also First-fruit offerings; Sacrifice, human

Oils, 201, 334, 435, 933; aromatic, 90, 109, 155, 244, 279, 366, 415, 427, 499, 935, $938,945,960,1068$; trading of, 213, 856, 1166

Old age, 466-469, 554, 609, 613, 1113. See also Age, social differentiation by; Aged, the

Omens, 69-71, 203, 204, 717, 735, 756, 870, 871, 988. See also Divination; Dreams

Ōpi'o. See Breadfruit, mass baking of Opoa 'Oro image, 1338. See also Images Opuhi, 24, 934

Ōpū nui. See Big-bellies

Oracles, 58, 78-83, 94, 487, 534, 866-869, 880, 1014, 1047, 1106, 1149, 1150, 1279, 1335, 1336, 1341, 1347; curing by, 475, 476, 513, 784-785, 875; payment of, 989; political influence of, 386, 613, 868, 901, $988,1151,1236,1318,1320,1322-1323$, 1327, 1329, 1335, 1347, 1365; sexual desirability of, 465, 774, 867, 901; recruitment of, 768, 866, 1104-1105, 1118; symbols of, 79, 81, 82, 360, 807, 867, 901, 937, 1344. See also Possession, spirit

Orators, 263, 326, 328, 365, 384, 396, 417, 869, 1007, 1013, 1027, 1069, 1227, 1279; language of, $82,176,351$; speeches by, $119,260,887,1031,1036,1051,1249$, $1268,1300,1308$; training given to, 323. See also Exhorters, battle

Ornamentation, 244, 286, 320, 330, 380, 856, $914,928,1121$; of altars, 87,399 ; of boats, 199, 200, 207; of dwellings, 165; personal,
$40,143,151,156,157,276,334,335,338$, 421, 602, 787, 865, 1075

Oromatua. See Ghosts

Oysters, 283, 284

Pahi, 173, 195-196, 200, 207, 214, 401, 539, 746, 856, 1038. See also Boats

Paiatua festival, 78, 112-120, 535, 707, 1014, $1119,1160,1316$

Pandanus, 22, 24, 149, 165, 166, 200, 244, 247, 535

Pantomime. See Drama

Papara image, 912-913, 1199, 1214, 1223, $1228,1235,1236,1265,1280,1293$, 1306-1308, 1314, 1316, 1359, 1362. See also Images

Paradise, 65, 262, 361, 522, 523, 525, 526, 557, 791, 821, 907, 938, 960, 1077, 1106. See also Afterlife

Parakeets, 26, 75, 708, 901

Parent-child relations, 431, 456, 473, 493, $515,524,590,593,604,618-619,630$ 640, 690-725, 833, 1067, 1076-1077, 1084, 1140, 1361-1362. See also Child rearing

Parrot-fish, 283, 312

Patu, 969, 973, 977

Peace, 887, 990, 1013, 1049-1051, 1082; emblems of, 385, 400, 497-498, 1031; establishing of, after war, 335, 396-400, 655, 703, 850, 930, 990, 1022, 1025, 1061, $1157,1158,1246,1264,1297,1305,1319$; offerings of, $263,345,523,720,842-843$, 1063, 1267, 1299. See also Hau

Pearls, 213, 214, 856, 1001

Pearl shell, 138, 331, 376, 390, 503, 504, 505 506, 517; fishhooks made from, 295, 297, 300; trade in, 138, 213, 214, 504, 856

Perches, 25, 283

Periwinkles, 524

Pestles, 856

Pets: cocks, 322; dogs, 276; eels, 286, 812; pigs, 273, 899

Pharmacopoeia, 257-258, 284, 479-480. See also Healing

Physical characteristics of Maohis, 40-42, 133, 352, 530, 546, 552, 597-598, 765, 782-783, 874, 1047-1048, 1144, 1175-1176, 1182, 1183-1184, 1185, 1188, 1195, 1312

Physicians, 475, 476, 875, 1104. See also Healing

Phytogeography. See Vegetation

$P i$, custom of, 533, 536, 583, 603, 1040-1042, 1044, 1149, 1162, 1165

Pigeons, 26, 279 
Pigs, 43, 70, 272, 427, 430, 542, 712, 788 1058, 1360-1361; association of, with Arioi sect, 898-899, 906, 919-920, 938, 945, 953, 956, 1152, 1153; cooking flesh of, 228; flesh of, denied to females, 224-225, 275; gifts of. 287, 421, 446, 447, 451, 452, 453, 806, 999, 1005, 1031; offerings of, 87-90, 109, 117, 120, 201, 260, 263, 345, 348, 385, 399, 422, 444, 461, 482, 513, 517, 747, 938, 1003, 1011, 1248, 1261, $1265,1267,1269,1299,1307,1312$; ownership and tending of, 787, 853-854, 1148; trade in, 232, 355, 856; wild, 248, 272, $273,278,281,710-711$

Pillows, 168, 172, 213, 1038

Pipefish, 25

Piper methysticum. See Kava

Piripiri, 139, 140, 142

Plaitware, 149-151, 152, 245

Planets, 536

Plantains, 375; consumption of, 220; cultivation of, 252; preparation of, 274, 1005; ritual use of, 107-108, 117, 261, 263, 313, $317,345,348,399,422,490,497-498$, 502, 510, 512, 720, 748, 1246, 1247, 1248, 1267, 1268, 1299. See also Plantains, mountain

Plantains, mountain, 25, 146, 247-248, 448, 934, 1003; collecting of, 125, 244, 248, $279,602,611,706,824$; consumption of, $170,242,244,247-248$; cultivation of, 43. See also Plantains

Plants. See Vegetation; name of particular plant

Play, 123, 124. See also Games; Sports

Pō, 95, 473, 487, 525, 536, 706, 724, 739, 746, 821, 982, 1041, 1077; as spirit realm, 49, $57,66,96,263,398,433,524,526,542$, 630, 892; contrasted with ao, 585, 1082; equated with night, 128, 132. See also Ao; Day, lunar

Pō tupapa'u. See Ghosts' night feast

Poetry, 326, 331, 337, 549, 864, 946

Pohue, 537

Poisons administered by sorcerers, 473, 555

Polyandry, 455, 463, 835. See also Marriage

Polygyny, 453, 455, 463-465, 642, 694, 808, 828, 833, 1189

Polynesia, comparative studies of, 12, 20, 26, $45,66,68,93,351,375,462,587,601$, 760, 780, 991, 1126-1127, 1129, 1143, 1365

Polynesians, Maohis compared to other, 41-42, 62-63, 133, 140, 211, 278, 310, 326, 794

Pooling-and-sharing, 229-230, 238, 629, 636,
637, 724, 742, 810, 812-813, 1083, 1084, 1088, 1089, 1095, 1114, 1115

Population, 26-46, 985, 1101, 1123; composition of, 39-40, 554; decrease in, 966, 968, 1143, 1286-1287, 1334; density of, 44, 45, 175-176, 254, 309, 579, 853, 966; estimates of, 26-39

Porcupine fish, 283, 284-285

Porpoise, 225, 275, 283, 299

Portage, 210-211

Possession, spirit, 58, 69, 78-83, 94, 226, 600, 937, 1107; behavior during, 512, 517, 1307, 1344; duration of, 262; individuals subject to, 469, 475, 484, 600, 866, 901, 907, 937, 1048, 1105, 1107, 1291. See also Oracles

Prawns, 25, 284

Prayers, 66, 76, 83-93, 108, 323, 326, 395-396, 411, 412, 480, 525, 599, 628-629, 632, 1095, 1321; curing through, 414, 419, 513, 517; harming through, 473, 1327-1328; manner of saying of, 85,115 , 483, 1017; occasions requiring, 69,124 , 127, 192, 311, 414, 419, 434, 444, 448, $450,474,479,481,624,1055,1322$; of atonement, 475; parphernalia associated with, 75, 534, 856. See also Priests, prayers said by; Priests, training given to

Prayer surrogates. See Priests, effigies of Prayer tallies, 109, 114

Pregnancy. See Reproduction, human

Priests, 81-83, 94-95, 148, 411, 475-476, 503, $601,627,636,653,654,679,851,858$, 864, 869-876, 878, 880, 907, 910, 924, $927,958,982,1039,1045,1111,1153$, 1213, 1335, 1342; clothing worn by, 85, $115,448,910,927,1017,1032$; duties of, 263, 389, 390, 396, 399, 475, 479-480, 487, 499, 505, 507, 519, 625, 653, 756-757, 861, 865, 868, 990, 996, 1006, 1012, 1021, 1321; effigies of, 87, 100, 109, 114, 118, 647; high, 95, 261, 416, 465, 674, 680, 707, 767-768, 820, 869-870, 892, 929, 980, 984, 1018, 1020, 1027, 1047-1048, 1054, 1066-1067, 1104, 1109, $1122,1212,1220,1248,1302$; payment of, 90, 118-119, 191, 234, 260, 490, 503, 510, 525, 526, 861, 873, 989, 990, 997, 998, 999, 1000, 1003, 1006, 1007, 1013; political power of, 201, 202, 385, 395, 505, 869-870, 874, 988, 1016, 1025, 1026, 1027, 1034, 1060, 1065, 1066-1067, 1104, 1198, 1236, 1292, 1309, 1365; prayers said by, 95, 103, 117, 118, 192, 411, 421, 444, 448, 489-490, 510, 512, 519, 647, 784, 886, 960, 1051, 1248, 1267, 1268, 
1307, 1338; privileges of, 226, 463, 613, 959; recruitment of, 631, 777, 814, 858, $962,1048,1117,1118$; training given to, 48, 86, 87, 126, 429-430, 557, 871-873. See also Divination, specialists in; Oracles; Prayers; Sorcerers

Primogeniture, 411, 631, 641-642, 643, 644, 764,1125 . See also Birth, order of; Firstborn

Profane. See Secular, state of being

Property, Maohi concept of, 848, 1120-1121; private, 1064

Prophets. See Oracles

Prostitution, 348, 354-355, 356-358, 454, 461 534, 604, 860, 863, 925, 936, 949, 962, 1146, 1257, 1364. See also Extramarital affairs

Psychic dynamism, 55

Pua, 537

Pua rata, 542

Public buildings. See Dwellings, public

Pu ho'e, 195, 196, 199-200, 205, 206, 207. See also Boats

Pumice, 134, 177

Purau. See Hibiscus

Purgatory, 61, 65, 262, 522, 525, 526, 557, 791

Pu'upu'u. See Breadfruit

Quarrying, 135, 178

$R a^{\prime} a$. See Sacred, state of being

Ra'atira, 545, 634, 750, 751-751, 762, 764, 765, 769-771, 772, 775, 777, 778, 783, $787,859,862,878,969,1039,1050,1064$, $1098,1117,1126,1129,1143,1149,1155$, 1327; authority of, 238, 385, 779, 794-795, 1036, 1057, 1308, 1314; hospitality offered by, 345, 346, 957, 961, 1034; land rights of, $187,384,639,720,779,969,1129$; privileges of, 397, 463, 653, 720, 779, 789, 828; relationship to $\operatorname{ari}^{\prime} i$ of, 201, 262, 791-792, 1002, 1034, 1063, 1322; succession among, 644, 804, 805, 1144. See also Classes, social

Racing, 262; boat, 316, 319. See also Footracing

Rafts, 286, 538

Rahui, 67, 222, 330, 632-633, 983-984, 996, 1072,1158 ; as a unit of land, 769, 969-970, 973; right to impose, 311, 652-653, 769, 770, 983, 985, 1033, 1219, 1294, 1364. See also Restrictions

Rainbows, 299, 1018, 1039

Rank, 209, 686-687, 835, 970; assertion of, 416; symbols of, 169, 207, 258, 712

Rank-status, 687, 1278, 1350
Rape, 298, 364, 365, 367, 546, 607; mass, 363-364, 367

Rasps, 135, 376, 379

Rātā, 21, 22, 25, 245

Rats, 278, 511, 540, 542

Rattles, dance, 328

Rauti. See Exhorters, battle

Rays, 283

Reefs, 8, 175, 187, 281, 402, 403; barrier, 7, 16, 19, 35; development of, 15, 16; fishing on, 130, 290, 291

Refugees, 175, 247, 399-400, 750. See also Warfare, destructiveness of

Refuges, 46, 53, 386, 398, 403, 407, 683, 888, 991, 1209, 1260, 1310, 1345; sought by criminals, 105, 106. See also Marae, use of, as refuges

Reincarnation, 61, 63, 528, 557

Relics, 313, 416, 450, 551, 854, 889, 1054 , 1055, 1117, 1136, 1223; skulls kept as, 62, $64,71,92,99,109,166,448,450,452$, 470, 472, 508, 526, 893, 1019; umbilical cords kept as, 415, 420, 421, 422, 437, 551; wearing, of ancestor, 157, 507, 722

Religious ritual, 106-122, 244, 258, 336, 361, $374,429,556,589,601,610,625,809$, 869, 882, 907, 909, 946, 954, 1011-1014, 1023-1024, 1063, 1078, 1116, 1119, 1250; accompanying construction, 174, 189-190, 201-205, 259, 996; at sports competitions, 317, 320-322; components of, 350, 368, 550, 598-599, 902, 932, 1004, 1008, 1023-1024; during warfare, 383, 385, 395-396, 397, 402, 990; errors, in, 86, 95, $120,474,707,872-873,940,984$; for food plant productivity, 259-264, 542; for traveling, 218-219, 732, 915, 916, 917, 918, 919, 927, 1152; peculiar to Arioi, 923, 932, 946, 954, 959-960; to do with fishing, 287, 310-314. See also Festivals; Head-freeing; Prayers; Priests, prayers said by; specific life-crisis events

Reproduction, human, 436, 550, 617, 642, 867. See also Conception, beliefs about

Residence, 965-976; as a factor in choosing a spouse, 458, 965; reasons for changing one's, 242, 986; rules of marital, 625, 694, 741, 800-805, 833

Resorts, 35, 213, 435, 618

Restrictions, 361, 552, 632-633, 747, 792, $799,1011,1078,1316$; during marae ceremonies, 92-93, 113-118, 189, 190, 513, 886, 910, 911, 982, 1267; food, 189, 205, 222, 223-226, 239, 275, 276, 277, 286, 412-413, 423-424, 602, 606, 787-789, 811, 813, 945, 1004-1005, 1067, 1111 , 
1136; freeing from, 78, 93; groups subject to, $369,370,601,606,625,1078$,

1134-1135, 1145; imposed for life-crisis events, 412-413, 414, 417, 418, 420, 492, $512,513,516,518-519,550,1018$; on selffeeding, 69, 133, 415, 420-423, 438, 439, 499, 551, 697, 785, 875, 1361. See also Head-freeing; Rahui

Reva tree, 24, 328

Rhetoric. See Orators

Rheumatism, 484

Riddles, 323-324

Right-left contrast, 585, 1081, 1082, 1110

Ringworm, 485

Ripening-of-the-year festival, 259-263, 389, 542, 1001, 1296. See also First-fruit offerings

Rising, time of, 123, 124

Roa, 139, 142

Rock cod, 283, 305, 311

Rock-climbing, 94

Rosewood, 21, 22, 70, 85, 106, 107, 108, 165, $187,421,444,445,448,450,452,552$, 553, 693, 873, 1013, 1046

Rumirumi. See Massage

Saccharum officinarum. See Sugarcane

Sacred, state of being, 66-69, 536, 877; association of, with spirits, 58, 66, 75, 90, 101-102, 118, 191, 277, 533, 601, 707, $875,887,902,927,931,945,946,957$; of chiefs, 414, 422, 583, 981, 1034, 1040, 1042, 1043, 1049, 1291; contrasted with state of being secular, 258, 275, 362, 600-602, 1145; danger associated with, $104,117,474,585,601,602$, 867; freeing from, 78, 92, 117, 119, 322, 441-442. See also Head-freeing, sacredness prior to completion of; Restrictions, food; Restrictions, groups subject to

Sacrifice, human, 93, 101, 109, 424, 471, 533, 551, 666, 812, 873, 908, 982-983, 1023, 1033, 1105, 1114, 1163, 1302, 1312, 1317, 1330, 1360; disposal of bodies of, 62, 70, $99,110,202,507,818,819,886,889,911$, $913,1152,1268,1296$; eyes of victims of, 92, 202, 534, 1006, 1021, 1047, 1061, $1082,1268,1269,1284,1296$; given to gods, 90-92, 107, 385, 394, 533, 666, 883, 894, 901, 906, 943, 1152, 1194, 1235-1236, 1265, 1307, 1316, 1339, 1365; kin-Titleholder's presence needed for, 1247, 1265, 1279, 1339, 1365; occasions for, $84,117,189,201,386,390,399,414$, 417, 418, 434, 449, 482, 501, 514-515, 516, 674, 869, 907, 910-911, 1012, 1017,
1018, 1036, 1061, 1160, 1247, 1268, 1284, $1295,1304,1308,1316,1320,1322$; victims selected for, $92,105,352,395,396$, 398, 399, 407, 457, 517, 636, 649, 707, 750, 755, 756-757, 768-769, 780, 812, 818, 819, 831, 832, 982-983, 984, 1005, 1016, 1039, 1040, 1042, 1044, 1046, 1056, 1057-1058, 1059-1060, 1065, 1146, 1147, $1163,1175,1190,1230,1232,1238,1244$, 1302, 1321, 1328-1329, 1345. See also Offerings

Sages, 48, 54, 268, 269, 721, 909, 910, $1027-1028,1149$

Sails, 149, 196, 200, 294

Sandalwood, 109, 155, 279, 415, 427, 477

Sandpipers, 25

Satire. See Drama, satire in

Scad, 288, 312

Scapegoating, 108, 110, 121

Schools, 54, 323, 429-430, 436, 551, 684, $745,784,865,870,871,872$. See also Sages

Scrapers, 134, 137

Screw pine. See Pandanus

Sea slugs, 284

Sea urchins, 282, 284; spines of, used as tools, 134

Seaward-landward contrast, 584, 793, 1081, 1098

Seawater, 107, 108-109, 141, 191, 490, 873, 1013,1023

Seaweeds, 25

Secular, state of being, 66, 67-68, 258, 275, $548,600-602,606,607,812,862$; of women, 104, 353, 421, 441, 601

Self-bleeding, 107, 110, 557, 589, 742, 1092; occasions for $107,416,421,444,448,452$, 483, 490, 492, 493, 511, 514, 516, 517, 519, 720, 722, 725, 1219, 1248, 1318. See also Blood, ritual use of

Self-offering, 109, 483

Semen, 351, 352-353, 371-372, 552

Semi-marriage, 457, 833-838, 1099, 1147, 1195. See also Marriage

Senility, 1184

Sennit, 170, 200, 204, 219, 320, 330, 533, 911, 1135; armor made of, 380, 390, 877; binding with, 395, 536, 871; manufacture of, $141,193,602$; metaphor of, 142; sacredness of, 69, 664, 885, 899, 901, 902; use of, in construction, 138, 165, 167, 193, 199, 328. See also Cordage

Separation, marital, 110, 453, 460, 462, 463, $581,593,607,694,721,727,805,806$, 823-824, 827, 830, 833, 835, 836, 838-841. See also Extramarital affairs 
Settlement patterns, 44, 65, 175-176, 194, 585, 1096, 1123

Sexes, the, 689, 696, 1110-1112, 1125, 1130,1132 ; contrasts between, 597-607, 1096-1097, 1123. See also Eating, separation of sexes during; Labor, division of

Sexual intercourse, 350-354, 373, 599, 603, 782, 826-827, 871, 949-951, 1076, 1081, 1149; attitudes about, 63, 409, 412, 464, 456, 599, 617, 826-827, 871, 1091, 1097, 1113; partners for, 358-361, 447, 450, 453, 614, 638, 725, 754, 799, 805, 811, 833, 845, 846-847; publicly performed, 362-364, 462, 924, 925; times and places for, 126, 361-367, 943. See also Child rearing, sex training aspect of; Homosexuality; Rape

Shaman. See Oracles

Shark-gods, 58, 81, 642, 678, 680, 814, 867, 1020, 1026, 1317. See also Gods; Spirits

Sharks, 209, 218, 225, 275, 283, 303, 312, 313-314, 889, 1230; fishing for, 282, 288, 291; teeth of, $379,380,421,434$; skin used as a tool, 134

Shells, 156, 157, 380; use of, as tools, 134, 135, 220, 236, 245, 251, 285, 309

Shell trumpets. See Conch-shell trumpets

Shoes, 154, 244. See also Clothing

Shrimp, 282, 1005

Shrines. See Marae

Siblings, 441, 613, 614; relations between, 455-456, 553, 644, 674, 697, 721, 726-743, 748, 830-831, 906, 1067, 1096, $1123,1141,1188-1189$. See also Birth, order of; Firstborn; Primogeniture

Singers, 331-332, 435. See also Singing; Songs

Singing, 326, 337, 339, 340, 430, 447, 451, 545, 603, 611, 923; accompanying dancing, 335; instruments accompanying, 330, 331, 362. See also Singers; Songs

Skin bleaching, 157-159, 359, 434-435, 537, $611,783,1154$

Sky, separation of, from earth, 51. See also Heavens, levels of

Sleep, 123, 124, 126, 127, 152, 196, 222, 598, 799,1075

Sling shooting, 319, 379, 381, 402, 477-478, 549,1282 ; stones for, 134 . See also Slingsmen

Slingsmen, 380, 392, 401, 406, 878, 989, 993, 1310. See also Sling shooting

Social relationships: definition of 579-580; pleasure derived from, 1079-1093

Soils, 8, 19, 45
Solanum repandum, 537

Songs, 326-328, 334, 365, 544, 545. See also Singers; Singing

Sorcerers, 94, 367, 880, 1103, 1162-1163; attached to marae, 103, 874, 875, 1027; fear of, 224, 226-227, 1292; payment of, 473; participation in tribal affairs by, 103, 116, 117; victims chosen by, 649. See also Fetchers, adoption of

Sorcery, 64, 471, 473-474, 481-482, 489, 527, 594, 860, 1084, 1165; effectiveness of, 555; exuvial, 63, 64, 470, 472-473, 474, 496; god of, 57; objects used in, 108. See also Fetchers; Sorcerers

Sororate, 455, 754, 833, 834

Soul, 62, 63, 470-471, 486, 582; extra-corporeal movement of, 56, 62, 71, 95-96, 470, 473; journey of, 64-65, 521-528, 1082; seat of one's, 440; survival of, after bodily death, 56, 58, 61, 62, 64-65, 74, 92, 409, 486, 487, 488, 510, 522, 523, 526, 557. See also Afterlife; Ghosts

Space as a dimension of interaction, 581, 584-585, 603-604, 614, 628-629, 634, 724, 741-742, 792-794, 809-810, 1081-1082

Spears, 379; belonging to chiefs, 1038; fighting with, 376, 379, 381, 390, 392, 402, 403, 417, 478, 1153; fishing with, 281, 288, 290-291, 313; making of, 244, 379, 549; offerings of, 109. See also Weapons

Spiders, 25

Spirits, 56-62, 132, 361, 471, 481-483, 500, 506, 511, 522, 523, 532, 536, 542, 555, 627-632, 861, 987, 990, 1006, 1007, 1009, 1015, 1016, 1079, 1082; animation of places through, 55; communication with humans by, 58, 69-71, 75-95, 104, 108, $111,116,445,472,599,763,813,815$, $816,817,851,860,861,1047,1048,1097$, 1335; fear of, 127, 172, 511, 630, 632, 725, 966-967, 1151, 1297, 1314; human relationships with, 64, 65-69, 83, 95, 107, 121, $259,353,383,385,396,526,536,601$, $606,622-623,629,632,636,642,649$, $724,800,805,866,868,875,880,1023$, 1026, 1048, 1049, 1075, 1077, 1078, 1110 , 1113; sacredness of, 66, 226, 601; sanctions held by, 593-594, 596; tutelar, 62, 66, $99,100,121,219,230,314,317,322,339$, $416,418,534,627-632,636,642,646$, $647,650,656,657,664,720,768,858$, $859,862,880,881,882,884,926,932$, 935, 961, 987, 991, 996, 999, 1000, 1002, 1012, 1013-1014, 1017, 1024, 1026, 1027, 1046, 1053, 1059, 1072, 1094, 1100, 1102, 
1105, 1118, 1159, 1160, 1167, 1235, 1317. See also Demigods; Familiars; Fetchers; Ghosts; Gods; Possession, spirit

Spondias, 24, 199, 228, 245-246, 540

Sports, 278, 315, 316-322, 376, 374, 381, 514, 544, 611, 814, 868, 1076; competitions, 260, 263, 337, 596, 599, 924, 930, 936, 993-994, 997, 998, 1145, 1164; fishing as a, 281-282, 288, 290, 303. See also name of particular sport

Standards, 417, 643-644, 1016, 1223, 1224, $1267,1270,1276-1277$. See also Messengers

Stars, 128, 264, 269; navigation by, 216-217

Sting rays, 134, 379, 390, 475

Stonework, 97, 99, 100, 134, 135, 162, $177-178,189,885,886,888$

Stories, 323, 324, 325, 350, 368, 864

Subgroup defined, 580

Subtribes, 882, 987-988, 1006-1007, 1009, 1029, 1116; chiefs of, 989, 1006, 1016, 1025, 1030, 1031, 1035, 1062, 1064-1066, 1109-1110, 1330. See also Chiefs; Tribal polities

Sugarcane, 43, 109, 228, 252, 444, 450, 452, 550, 693; cultivation of, 174, 252

Suicide, 460, 527, 593, 594, 706, 824, 830

Sun, 128, 264, 536; myth of snaring the, 51, 131-132, 705, 730

Sunrise-sunset contrast. See Upper-lower contrast

Sunshades, 154, 295, 435, 763. See also Headwear

Supercision, 64, 161, 361, 434, 551, 608, 610, $611,615,860,1012,1015$; specialists at, 861-862, 1103

Surfing, 315-316, 602, 733, 785

Surgeon-fish, 283

Sweet potatoes, 43, 244, 248, 250-251, 273, 308, 541

Swimming, 134, 315-316, 383, 602, 785

Swordfish, 209, 291

Syngnathus conspicillatos, 25

Tacca pennatifida, 149, 229, 247, 252

Taetsia, 24, 43, 189, 246-247, 535

Tahitian (language), 57, 121, 466, 583, 688, 1040-1042, 1132

Tahu'a. See Sages

Tai-uta. See Seaward-landward contrast

Tamanu. See Calophyllum

Tapa. See Bark cloth

Tapairu, 860

Тари, 66, 67, 90, 226, 310, 314, 330, 533, 536, 750

Taraehara festival, 120-122
Tāria-aro. See Battle shapers

Taro, 43, 223, 259, 273, 312, 1003, 1004, 1086, 1268; bitter, 43, 131, 244, 249-250, 416; cultivation of, 248, 249-250; preparation of, 170, 229

Taru'a, 43, 249-250

Tattoos, 159-161, 431-434, 551, 599, 817, 951-952, 1015; age of receiving, 64, 431-432, 551, 608, 610-611. 1015; differences in designs of, 433-434, 602, 645, 787, 933, 934, 935, 945, 952, 953, 1108, 1175-1176; reasons for having, 361, 433-434, 615, 951-952, 1075; specialists in giving, 433, 860, 861-862, 945, 1103, 1104

Taura. See Oracles

Tavau, 1002-1004, 1006, 1013, 1030-1031

Taxation, 191-192, 201, 202, 228, 633, 853, 770, 1001-1008, 1089, 1114, 1128, 1137; burden of, 190, 344, 770, 987, 1061; goods rendered as, $146,151,275,309,853,857,996,1000$, 1004-1006, 1102, 1128; right of, 635, 652, 794, 987, 996, 1000, 1002-1004, 1061, 1089. See also Labor, corvée; Tribute

Teachers, 337, 339, 344, 429-430, 860, 864-866, 1027-1028, 1034, 1103, 1104. See also Schools

Telegony, concept of, 353, 410, 1093. See also Reproduction, human

Teraiputa maro, 1199, 1280

Terminology as a dimension of interaction, 580, 581-583, 603, 613, 634, 691-694, 726, 729, 743-744, 749-754, 759, 765, 769-770, 791, 808-809, 828-829, 1080, 1114-1115, 1146-1147

Terns, 26, 296, 299, 302

Terracing, agricultural, 249; for dwelling construction, 162; for marae construction, 97, 178

Tetupaia maro, 1234, 1253, 1265

Teuteu, 423, 750, 751-751, 767, 768, 777, 790, 836, 859-860, 862, 1035, 1063, 1149, 1163; origin of, 773-774, 1149; work performed by, 637, 792, 859-860, 862, 972. See also Domestics

Teva maro, 1234

Thatching, 165, 166-167, 174, 202, 997, 998. See also Dwellings, construction of

Theaters, 340, 920

Theft, 61, 446-447, 746, 867, 922, 1034, 1054-1059; attitudes about, 637, 1054; fate of perpetrators of, 312, 342, 540, 556, 972, 1046, 1056-1057; from Europeans, $355,467,972,1250$; god of, 57, 61, 301, 664, 746, 1094

Thespesia. See Rosewood 
Thought, seat of, 63

Ti plant, 108, 934, 1334

Tidal waves, 242

Tides, 19, 21, 128, 130, 289, 529

$\mathrm{Ti}^{\prime} i, 966,969,976$. See also Fetchers

Time as a dimension of social interaction, 132, 580, 583-584, 603, 613-614, 628, 634, 697-698, 741, 791-792, 809, 1080-1081

Time reckoning, 128-132, 264-270, 583, 910 Titi, 768-769, 990

Titles, 581, 844, 1080. See also Kin-Titles

To'o. See Images

To'oha, 762, 767, 769, 969

Tools, 133-151, 155, 245, 255, 276, 536, 783, 1079, 1122, 1285-1286; bone, 137, 139, 309-310, 509, 543, 783, 1017, 1091, 1166, 1285, 1318; for tattooing, 159-160, 432, 433; stone, 857,1285

Torches, 290-291, 305, 306, 370, 393

Touring, 1004, 1006, 1022, 1106. See also Travel; Visiting

Toward-away from contrast, 585

Trade, 309, 354-355, 504, 811, 856-857, 1084, 1148, 1166, 1207, 1245; intra-archipelago, 213-214, 856-857; of foodstuffs, 232-234, 240, 242, 856; with the Tuamotus, 138, 151, 281, 856

Transaction as a dimension of interaction, 581, 586-589, 605, 614, 624-625, 629-632, 635, 742, 794-795, 806-807, 810-813, 957-960, 1083-1090, 1114-1115

Travel, 343-349, 480-481, 602, 721, 914, 915, 916, 926-927, 941, 958-959, 1002, 1180, 1365; intra-archipelago, 212-215, 935; modes of, 194, 207-215, 344, 447; provisions for, 208, 212-213, 236, 247, 252, 279, 540, 721, 733; restrictions on, 93, 113. See also Dwellings, public; Religious ritual, for traveling; Touring; Visiting; Voyaging

Tribal chiefs, 761, 762, 922, 1014, 1027, 1030, $1116,1118,1278$; authority of, 1005, 1027, 1035, 1053-1067, 1172, 1183, 1193, $1225,1236,1279,1330,1338,1350$; duties of, 926, 933, 946, 1064; succession to office of, 870, 1015-1027, 1109, 1111, 1160, 1258; privileges of, 795, 862, 921, 933, 946, 988, 1005, 1012, 1013, 1037-1049, 1107, 1122. See also Chiefs; Tribal polities; Tribes

Tribal council, 68-69, 758, 761, 869, 887, 988, 989, 1025, 1032, 1033, 1035-1037, 1065, $1066,1151,1161,1243$. See also 'Iatoai

Tribes, 65, 104, 653, 963, 978, 982-1037, 1070-1073, 1104, 1108-1110, 1115-1117, 1128, 1158; administration of, 1027,
1030-1031, 1034, 1060, 1064, 1104, 1109, 1122, 1160, 1163; loyalty felt to, 767, 922, 954, 956-957, 1165; metaphorical equation of, to boat, 761, 1067, 1068, 1119; structure of, 260, 634, 760, 976-977, 978, 1051, 1122, 1123-1124, 1128; territorial expansion of, 985, 1051; tutelars of, 120 , 882, 889, 890, 900, 1105, 1160, 1235-1236. See also Marae, tribal; Place Index: names of tribal areas; Tribal chiefs

Tribute, 214, 238-239, 255, 541, 587, 1001-1008, 1114, 1316, 1341; items rendered as, 154, 238-239, 240, 259, 261, 1004-1006, 1316; rendered by the defeated in war, 985, 991. See also First-fruit offerings; Labor, corvée; Taxation

Tridacna clam, 283

Trophies, battle, 101, 395, 398. See also Relics

Tropic birds, 26, 157, 279-280, 299, 503, 1020,1248

Tuna, 283

Turbos, 283

Turmeric, 43, 109, 488

Turtles, 225-226, 275, 277-278, 282, 286, $307,635,788,856,1001,1005,1136$, 1151,1328 ; offerings of, 109, 889; shell of, 1102. See also Restrictions, food

Typhoons, 18-19, 242, 254

Umbilical cord, 437, 551; cutting the, 418, 422, 551. See also Relics, umbilical cords kept as

Umu. See Earth ovens

Universe: creation of, 47-50, 56, 95, 172-173, 891; entities in, 54-65

Unu boards, 97, 100-101, 114, 399

Upper-lower contrast, 584, 604, 634, 793, 809, 891, 1081-1082, 1095, 1098, 1110

Upwind-downwind contrast. See Upper-lower contrast

Urtica argentea, 139, 142

'Uru. See Breadfruit

Uxorilocality, 803. See also Residence, rules of marital

$V a^{\prime} a, 195,196,200,207,401,654,761,1038$. See also Boats

Vārua. See Souls

Vavai, 23, 530, 550

Ve'a. See Messengers

Vegetation: human manipulation of, 20, 43-44; introduced, 20, 26, 43, 249, 252, 295; natural zones of, 8, 20-25, 530; navigation by, 215

Vehiatua's War, 405-408 


\section{Vi. See Spondias}

Villages, 44, 175, 1156. See also Population, density of; Settlement patterns

Virginity, 357, 368, 450, 537, 553, 611, 1013. See also Marriage

Virilocality, 801-804, 833. See also Residence, rules of marital

Visiting, 126, 231, 343-344, 794-795, 803, 809, 993-995, 1088, 1109, 1154, 1209. See also Hospitality; Touring; Travel

Voyaging, 186, 194, 212, 540, 738; deliberate, 211-212, 213-215, 217, 732; drift, 208, 212, 214, 539, 656. See also Travel

Walking, 133-134, 194

Wallis maro, 1215-1216, 1223, 1233, 1234 $1235,1236,1253,1257,1265,1358,1359$, 1360. See also Feather girdles

War. See Warfare

Warblers, Old World, 26

War captives, 125, 395, 396, 398, 404, 406, $462,550,750,768-769,780,849,990$, 1175

Warfare, 124, 127, 367, 375-408, 471, 548, 549, 555, 586, 648, 763, 766, 770, 780-782, 891, 894, 901, 981, 1024, $1046,1076,1079,1082,1106$, 1108-1109, 1116, 1209, 1235-1236, 1282, 1286, 1310; council for, 383-384, 548, 1264; destructiveness of, 39, 116 , $205,242,243,256,273,367,375,388$, 396, 398, 402-403, 406, 407, 424, 430, $478,509,541,549,550,598-599,649$, 779, 797, 874, 985, 990, 1011, 1050, $1217,1223-1224,1225,1227,1230$, $1246,1251,1262,1263,1264,1282$, $1283,1298,1309,1318-1319,1321$ $1344,1345,1347,1349$; female participation in, 602, 603; frequency of, 381-389; naval, 196, 999, 1083, 1228, 1229, 1263-1264, 1286; preparations for, $186,259,336,383-387,474,887$, 1013, 1036; provocations for, 83, 318, 375-376, 417, 594, 599, 628, 644, 720, 795, 796, 831, 868, 903, 930, 971, 980 988, 992, 993, 994, 1016, 1026, 1036, 1058, 1059, 1064, 1067, 1116 , 1219-1220, 1221, 1222, 1223, 1225, 1226, 1282, 1298, 1299, 1300, 1304, 1308, 1314, 1315, 1320-1321, 1329, 1343; signals of, 1261-1262; units engaging in, 655, 970, 982-985, 987-992, 993, 1061, 1107, 1116, 1117, 1123, 1162, 1310. See also Peace, establishing of, after war; War captives; Warriors; Weapons
Warrior-champions, 176, 381, 390, 392, 393, 394, 395, 404, 549, 780, 846, 876, 877-878, 990, 992, 1030, 1108, 1119 , 1149,1160

Warriors, 53, 365, 548, 549, 761, 860, 876-879, 910, 913, 914, 942, 943, 957, 962, 1028-1030, 1032, 1036, 1065, 1103-1104, 1107, 1117, 1132, 1149, 1153; clothing worn by, 154, 376-381, 390, 392, 794, 877, 878, 910, 989, $1005,1148,1240,1264$; courage of 402-404, 527; fate of, after death, 509-510, 527; numbers of, 27, 30, 387, $392,402,406$; recruitment of, 27 , 383-387, 635, 653, 767, 771, 953, 954, 956-957, 972, 989, 1030, 1070, 1117; training of, 381-383, 428, 548. See also Battle shapers; Exhorters, battle; Warfare; Warrior-champions

Water, storage of, 170. See also Seawater Wealth, 146, 149, 201, 525-526, 875, 1103 , 1136, 1165

Weaning, 427. See also Child rearing

Weapons, 134, 169, 281, 319, 320, 376-381, 390, 392, 403, 417, 536, 544, 549, 555, 1149; storage of, 416

Weddings. See Marriage, ceremonies of Weeping cloth, 483

Wet-nurses, 862. See also Child rearing

Whales, 283, 286; restrictions on consumption of, 225, 275

Whipping, 1060, 1071

Wife exchange. See Formal friendship, wife exchange as part of

Wigs, 276. See also Headwear

Winds, 15, 18-19, 248, 283, 289, 299, 304, 1133; names for, 215-216; navigation by, 217-218; travel of spirits on, 70, 77; trade, 8, 240-241, 304

Woodworking, 134, 137, 199, 1102

Wrestling, 316-318, 365, 381, 478, 544, 550, 713, 924, 993-994; competitions of, between females, 599, 785; occasions for, 262, 344, 364, 451, 932, 949, 950, 993-994, 997, 1153; vigor of, 42 , 599

\section{Xanthosoma sigittifolium, 43, 249-250}

Yams, 43, 251-252, 273, 541, 1003, 1004, 1268

Yaws, 485

Youth, 607, 609, 610-613, 799, 935, 937, 943-944, 1049, 1081, 1107, 1112-1113 


\section{PLACE INDEX}

Afa'ahiti (Tahiti), 28, 33, 34, 211, 682, 899, 984, 1116, 1155, 1259, 1267

Afa'atai marae (Ra'iatea), 662. See also Fa'atai marae (Ra'iatea)

Afaina (Tahiti), 1346

Afareaitu (Mo‘orea), 408, 685, 964, 980-981, 1121, 1182, 1151, 1204, 1309

Aharoa (Tahiti), 1138, 1317. See also Teaharoa (Tahiti)

Ahopatea (Tahiti), 30, 32

Ahui (Tahiti), 502

Ahurai (Tahiti), 1220, 1357

Ahurai marae (Tahiti), 671, 675, 684, 798, 906, 1178, 1187, 1192, 1360

Ahuroa. See Aharoa (Tahiti)

Aiatupuna (Huahine), 672

Amehiti (Mo'orea), 981

Amo (Tahiti), 681, 757

Ana. See Chain Island

Ana'a, 214, 539

Anini marae (Huahine), 662, 663, 673, 1138

'A'ou'a (Tahiti), 1196

Apayano. See Papeno‘o (Tahiti)

Apo'o-'ao marae (Fa'ana), 131

Apo'o-uhu (Huahine), 884

Apotopoto Bay (Taha'a), 170

Apuroa marae (Taha'a), 1155, 1208

Arue (Tahiti), 684, 812, 975, 977, 979, 1002, 1142, 1173, 1180. See also Pare-Arue

Ata'aroa (Tahiti), 811

Atehuru (Tahiti), 27, 30, 32, 34, 241, 242, 346, $399,481,515,517,534,684,838,904$, 906, 972, 973, 975, 993, 1151, 1173, 1193, 1194, 1197, 1213, 1221, 1231, 1241, 1244, $1245,1246,1247,1251,1252,1253,1259$, $1261,1262,1263,1264,1268,1280,1281$, $1286,1293,1301,1303,1304,1305,1307$, $1308,1310,1314,1316,1317,1318,1319$, $1320,1332,1343,1344,1347,1349,1353$, 1364

Atiapii. See Huahine Island

Atimaha (Mo'orea), 1205

Atimaono (Tahiti), 28, 34, 514, 963, 973, 977, 1003, 1116, 1155, 1198, 1293

Atimaouo (Tahiti), 1155

Atitanei (Mo'orea), 981

Atituhaui (Mo'orea), 981

Attahouru. See Atehuru (Tahiti)

Atupii (Huahine), 1354

Atutira. See Tautira (Tahiti)

Austral Islands, 909, 1122

Avea, 242

Ayautea (Tahiti), 513
Batavia, 27, 1257

Bellingshausen Atoll, 529

Bolabola. See Porapora Island

Bora-Bora. See Porapora Island

Canton Island, 20

Chain Island, 710

Cook Islands, 1122

Cook's Harbor. See Paopao Bay

Easter Island, 1126

Ellice Islands, 311

Fa'a'a (Tahiti), 28, 30, 32, 34, 242, 530, 675, 684, 707, 717, 757, 865, 963, 973, 976, 977, 993, 995, 1003, 1131, 1164, 1173, 1179, 1182, 1183, 1187, 1191-1193, 1197 , $1200,1202,1219,1237,1239,1242,1247$, $1251,1252,1255,1261,1263,1265,1290$, 1293, 1309, 1317, 1321, 1328, 1344, 1351, 1353, 1358, 1360, 1364, 1365

Fa'ahiti (Tahiti), 1182

Fa'ana Island, 131

Faanui (Porapora), 668, 892, 1009, 1030

Faarava, 979

Fa'aroa (Ra'iatea), 612, 847

Fa'atai marae (Ra'iatea), 662, 663

Fa'atoai. See Papetoa'i

Faena (Tahiti), 1322, 1333

Fahune Nui Lake (Huahine), 16, 175, 176, 289, 309, 886-889, 1159, 1209. See also Maeva settlement (Huahine)

Faina (Tahiti), 761, 1032

Fakarava. See Tuamotu Islands

Fanauaraa (Mo'orea), 981

Fare (Huahine), 477, 867, 1333

Fare Hau marae (Porapora), 190

Farepua marae (Tahiti), 675, 679-680, 681, 684, 762, 763, 764, 883, 984, 1070, 1125, 1194, 1198, 1199, 1203, 1216

Fareroi marae (Tahiti), 675, 684, 1178, 1200-1201

Farerua marae (Porapora), 667-669, 1163. See also Marotetini marae

Faretai marae (Porapora), 669

Fareteroa marae (Taha'a), 662, 663, 671. See also Onetari marae

Fatutiri, 881

Fau-roa Cape. See Venus Point (Tahiti)

Fautau'a Valley (Tahiti), 814, 815, 817, 1135

Fenua Ura. See Scilly Atoll

Fenua-ai-hua-ra'au (Tahiti), 984

Feoro marae (Ra'iatea), 892. See also Taputaputea marae (Opoa, Ra'iatea) 
Fiji, 19, 213

Friendly Islands. See Tonga

Futuna, 1126

Greater Huahine, 671-673, 884, 906, 1137, 1145,1209 . See also Huahine Island

Greater Tahiti, 8, 53, 241, 661, 681, 881, 1173, 1222, 1226, 1232. See also TahitiMo'orea

Guayari. See Vaiari (Tahiti)

Guayuriri. See Vaiuriri (Tahiti)

Ha'apaiano'o (Tahiti), 28, 33, 34, 371, 400, 479, 683, 902, 907, 926, 963, 967-968, 973, 1059, 1173, 1177-1178, 1190, 1255, 1277, 1290, 1294, 1301, 1319, 1322, 1323, 1324, 1326, 1328, 1331, 1343, 1344, 1345 , 1346. See also Papeno'o (Tahiti); Vavau (Tahiti)

Ha'apaino. See Ha'apaiano‘o

Ha'apaino'o. See Ha'apaiano'o

Ha'apape (Tahiti), 30, 32, 34, 429, 675, 683-684, 715, 745, 831, 832, 865, 917, $922,963,1155,1173,1174,1177-1179$ 1182, 1183, 1193, 1200, 1233, 1242, 1253, 1294, 1303. See also Uporu (Tahiti); Venus Point (Tahiti)

Ha'apiti (Mo'orea), 964, 980

Ha'apu (Huahine), 541

Hautaua (Tahiti), 1344

Havai'i, 53, 131, 270, 277

Hawaiian Islands, 194, 250, 276, 463, 494, 529, 539, 542, 553, 764, 779, 794, 1020, $1121,1126,1127,1150$

Hetemahana marae (Tahiti), 1316, 1321, 1323

Hitia'a (Tahiti), 3, 28, 33, 34, 423, 675, 683, 795, 824, 832, 865, 899, 963, 973, 984, $1131,1155,1173,1174,1176-1177,1190$, $1225,1283,1286,1290,1292,1294,1305$, 1306, 1320, 1322, 1351, 1352, 1355

Hitia'a marae (Tahiti), 675, 683, 1176

Hitimahana marae. See Hetemahana marae (Tahiti)

Hiti-tai, 711

Hiti-uta, 711

Hiva, 1051

Honden Island (Tuamotus), 277

Horoa-terra. See Tetiaroa Atoll

Horora marae (Mo'orea), 980-981

Howe's Island. See Mopelia Atoll

Huahine Island, 3, 16, 23, 24, 35, 38, 46, 80, $148,175,186,192,208,212,217,248$, $259,260,286,287,289,313,325,341$, 399, 401-402, 403, 452, 459, 460, 468, $486,491,541,543,663,666,672$, 673-674, 782, 824, 826, 834, 836, 867,
868, 881, 882, 884-889, 890, 894, 895, 898, 899, 914, 918, 955, 964, 966-967, 970, 972, 975, 979, 983, 994, 997, 999-1000, 1017, 1025, 1047, 1051-1052, 1116, 1138, 1149, 1152, 1155, 1159, 1164, $1207,1209,1210,1212,1213,1277,1278$, $1280,1315,1316,1319,1323,1324,1327$, 1333, 1336, 1338, 1341, 1354, 1366. See also Greater Huahine; Lesser Huahine

Hui (Tahiti), 682

Inner Teva (Tahiti). See Landward Teva Itteeah. See Hitia'a (Tahiti)

La Diadème (Tahiti), 814, 815

Landward Teva (Tahiti), 681, 780, 795, 973, 977, 1003, 1032, 1198-1203, 1214, 1317, 1319

Leeward Islands, 35, 39, 178, 187, 200, 251, $301,319,325,344,402,538,651$, 660-674, 856, 866, 927, 928, 1003, 1065, 1142, 1177, 1199, 1204, 1207-1213, 1280, 1327, 1336, 1337, 1338, 1365, 1366. See also entries for specific islands

Lesser Huahine, 673, 906, 1054, 1145, 1209. See also Huahine

Lesser Tahiti. See Tai’arapu (Tahiti)

Maeva Lake. See Fahune Nui Lake (Huahine)

Maeva Refuge (Huahine), 399-400

Maeva settlement (Huahine), 175, 176, 671, 672, 673, 970, 997, 1051. See also Fahune Nui Lake (Huahine)

Mahaena (Tahiti), 27, 28, 33, 34, 530, 683, 760, 832, 963, 973, 1148, 1155, 1173, 1177-1178, 1294, 1306, 1351

Mahaetea marae (Tahiti), 1117

Mahaiatea marae (Tahiti), 675, 681, 739, 1217,1223

Mahaiatea Point (Tahiti), 1219

Mahaitea marae (Tahiti), 99

Mahina (Tahiti), 683-684. See also Ha‘apape (Tahiti)

Mahoute, 242

Mai'ao Island, 7, 15, 22, 24, 35, 35, 38, 207, $212,251,673,881,882,883,895,955$, $964,975,999,1124,1161,1209,1280$ 1315,1316

Makatea, 40, 214, 975

Mangaia, 1126

Mangareva, 731, 1126

Manunu marae (Huahine), 662, 663, 671-674, 826, 884, 885-886

Manunu Point (Huahine), 884

Mape, 242

Mapiha'a Island, 53 
Mara Point (Tahiti), 1336

Mara'a (Tahiti), 346, 1196

Mara'a Point (Tahiti), 22, 23

Marae Point (Tahiti). See Utuhaihai Cape (Tahiti)

Maraeta'ata marae (Tahiti), 684-685, 1193, 1196-1197, 1221, 1352, 1353-1354, 1356

Marotetini marae (Porapora), 662, 663, 666-669, 671, 1138, 1338. See also Farerua marae (Porapora)

Marquesas Islands, 212, 359, 375, 533, 779, $855,1121,1126,1144,1288$

Mataea, 1199

Matahihae (Tahiti), 984, 1181. See also Teahupo'o (Tahiti)

Matahihae marae (Tahiti), 682, 943, 1137, 1174, 1181

Matahira Point (Ra'iatea), 662

Matahiraterai (Ra'iatea), 982

Mata-hiri-i-te ra'a, 1022

Matahiva, 214, 673

Mataiea (Tahiti), 538, 706, 1138, 1293. See also Papeuriri (Tahiti); Vaiuriri (Tahiti)

Mataifare marae, 772

Mata'ire'a marae (Huahine), 662, 663, 666-667, 671-673, 884

Mataoa marae (Tahiti), 675, 678-679, 680, 758, 1190

Mataoae (Tahiti), 28, 31, 34, 516, 706, 865, 963, 984, 1155, 1291

Matarea, 1354

Matarepeta, 982

Mata-tu-tahua-roa, 1021

Matavai (Tahiti), 28, 30, 32, 176, 241, 242, $372,388,400,517,538,541,594,831$, 867, 907, 956, 968, 973, 994, 997, 1061, $1134,1158,1163,1177,1179,1191,1202$, 1203, 1206, 1226, 1233, 1239, 1242, 1243, $1244,1249,1250,1251,1252,1254,1256$, $1257,1261,1262,1263,1265,1266,1270$, $1272,1277,1279,1281,1282,1283,1284$ 1286, 1295, 1297, 1299, 1300, 1303, 1304, $1310,1311,1314,1316,1317,1320,1321$, $1322,1323,1324,1331,1341,1343,1344$ $1345,1351,1357$

Matavai Bay (Tahiti), 3, 4, 27, 30, 714, 1148, 1173, 1178, 1193, 1198, 1217, 1229

Matavai River (Tahiti), 45

Matowee (Tahiti), 1291

Mattea, 1280

Maupiti Island, 8, 15, 21, 22, 23, 24, 35, 38, $53,138,170,212,215,279,301,312,529$, 669-670, 672, 779-780, 856, 881, 895, $964,999,1052,1098,1102,1108,1121$, 1136, 1168, 1208-1209, 1220

Maurua. See Maupiti Island
Mautau Point (Porapora), 667, 668, 669

Me'etia Island, 7, 8, 16, 23, 24, 34, 213-214, 856, 1060, 1280, 1281

Mo'orea Island. See entries for specific locations

Mopelia Atoll, 214-215, 279, 529, 856

Mopilia Atoll. See Mopelia Atoll

Motooroa. See Tetiaroa Atoll

Motu Iti Atoll, 7, 20, 35, 38-39, 53, 212, 524-525, 557, 856, 1220, 1355

Motu-torea (Taha'a), 899

Mouatahuhuura (Porapora), 894

Myetoo. See Me'etia Island

Nannoo Bay (Tahiti), 1331

Nanu (Tahiti), 1324

Natu'oha (Tahiti), 1196

New Zealand, 194, 375, 531, 533, 538, 539, $543,547,779,909,1121,1136,1150$

Nonohaura marae (Porapora), 669

Nu'urua marae (Mo'orea), 675, 685, 739, 980, 1003, 1138, 1178, 1188, 1204, 1205

Nu'utapu marae (Mai'ao), 673

Nu'utere marae (Tahiti), 683, 1182, 1199

Oahouio (Tahiti), 1324

Oaitepeah (Tahiti), 1281

Oaitepeha (Tahiti), 1033, 1286

Oayautea, 516

Oha aine (Tahiti), 1061, 1284

Ohatutira. See Tautira (Tahiti)

Ohitia (Tahiti), 514, 515

'Oi'o (Mo'orea), 1203

Onehoa (Tetiaroa Atoll), 35

Onetari marae (Taha'a), 662, 663, 671

One uri (Tahiti), 963

Onowhea (Tahiti), 1324

Ontong Java, 1126

O'omo'o marae (Taha'a), 662, 663, 671

Oparre. See Pare (Tahiti)

Opeimanno, 487

Opoa (Ra'iatea), 53, 115, 429, 535, 649, 657, $658,662,664,666,674,677,683,684$, $685,747,761,763,781,883,884,890$, 892-893, 897, 899, 903, 904, 907, 909, $910,911,912,929,954,963,981$ 982-983, 1016, 1017, 1039, 1048, 1052 1055, 1094, 1096, 1105, 1107, 1117, 1118, $1119,1120,1126,1131,1137,1157,1168$, 1181, 1194, 1197, 1199, 1207, 1209, 1211, 1212, 1216, 1336, 1338, 1354, 1355

Oporeeonoo. See Poreonu'u (Tahiti)

Oporenoo. See Poreonu'u (Tahiti)

Opunohu (Mo'orea), 541, 1205, 1246, 1257

Oro-fara, 714

Oro-fero (Tahiti), 706 
O-tahaw. See Taha'a Island

Otaiwyotah. See Landward Teva (Tahiti)

Otawyotah. See Landward Teva (Tahiti)

Outer Teva. See Seaward Teva (Tahiti)

Outumaoro (Tahiti), 1319

Ovai aia Lake (Porapora), 896

Pa'ea (Tahiti), 32, 675, 684-685, 821, 963, 973, 975, 1155, 1196-1198, 1213, 1214 , $1221,1231,1232,1237,1293,1304,1310$, $1352,1353,1356$

Paia, Mount (Porapora), 896

Pani, 709

Paopao Bay (Mo'orea), 406

Paorie (Huahine), 672

Papahonu, 711

Papaia (Tahiti), 28

Papaoa (Tahiti), 1321, 1344, 1345. See also Pare (Tahiti)

Papara (Tahiti), 34, 45, 99, 171, 241, 268, 328, 675, 681, 682, 739, 757, 758, 796, 865, 907, 932, 949, 963, 973, 977, 983-984, 995, 1003, 1032, 1117, 1155, 1179, 1214, $1215,1217-1225,1227,1233,1236,1257$, 1260-1264, 1269, 1270, 1283, 1284, 1286, 1291, 1292, 1293, 1295, 1296, 1301, 1303 , 1305, 1308, 1309, 1322, 1323, 1324, 1343, $1344,1346,1347,1349,1354,1355,1359$, 1364

Papararau (Tahiti), 1182

Papeare (Tahiti), 1003

Pape'are (Mo'orea), 685, 1204

Papeari (Tahiti), 538, 679, 682, 780, 795, $824,865,1155,1198$. See also Vaiari (Tahiti)

Pape'ete (Tahiti), 295, 548, 684, 814, 818, 893, $979,984,1180,1230,1338,1347$

Pape'iha Valley (Tahiti), 824

Papeno'o (Tahiti), 45, 46, 175, 548, 618, 831, 832, 968, 1155, 1173, 1323. See also Ha'apaiano'o (Tahiti); Vavau (Tahiti)

Paperipo (Tahiti), 1321

Papeto'ai (Mo'orea), 406, 899, 904, 964, 1116 , 1155, 1175, 1204, 1213, 1340, 1354

Papetoare (Tahiti), 1346

Pape'uriri (Tahiti), 708, 1003, 1155, 1198, 1291, 1293. See also Mataiea (Tahiti); Vaiuriri (Tahiti)

Pare (Tahiti), 45, 210, 240, 242, 388, 405, 487, $491,518,519,520,530,534,545,684$, 707, 820, 831, 926, 973, 975, 977, 979, 993, 994, 995, 997, 1011, 1058, 1134, 1137, 1160, 1162, 1163, 1173, 1181, 1183, 1184, 1191, 1206, 1216, 1223, 1226, 1230 , $1234,1237,1239,1240,1241,1242,1245$, $1246,1247,1249,1251,1252,1254,1255$,
1257, 1258, 1259, 1260-1266, 1268, 1275, $1276,1277,1279,1281-1282,1283,1284$, 1286, 1290, 1293, 1296, 1297, 1298, 1300, 1301, 1302, 1304, 1305, 1306, 1308, 1309, 1312, 1316, 1317, 1319, 1320, 1321, 1323, 1324, 1329, 1331, 1332, 1327, 1333, 1340, $1341,1343,1344,1345,1351,1358,1360$, 1361, 1362, 1363, 1365. See also PareArue (Tahiti); Pare Refuge (Tahiti)

Pare-Arue (Tahiti), 27, 34, 346, 501, 675, 865, 963, 984, 1002, 1039, 1040, 1131, $1177,1179,1180,1181,1182,1183$, 1186, 1188, 1191, 1192, 1193, 1194, $1196,1220,1221,1225,1231$, 1233-1234, 1237, 1253, 1277, 1294.

See also Arue (Tahiti); Pare (Tahiti)

Pare Refuge (Tahiti), 399-400

Parea, 242

Parre. See Pare (Tahiti)

Paruatetava'e marae, 322

Paterre (Tahiti), 973

Paumotu Islands. See Tuamotu Islands

Pe'eai, 711

Peihi (Huahine), 884

Pepeto‘ai. See Papeto‘ai (Mo'orea)

Peraitu, 798

Phoenix Atoll, 20

Pirepire (Porapora), 897

Pitcairn Island, 4, 802, 1256, 1257

Porapora Island, 3, 15, 22, 23, 24, 35, 38, $40,53,207,212,214,271,277,343$, $358,364,402,405,459,460,478,491$ $524,530,547,582,658,663,666$, $667-669,670,763,823,856,881,882$, $883,884,895,896,897,898,903,904$ 907, 955, 964, 1003-1004, 1009, 1017 , $1025,1030,1052,1065,1108,1109$, 1113, 1120, 1124, 1131, 1138, 1151, $1155,1157,1163,1177,1207,1208$, $1209,1210,1211,1220,1255,1278$, $1281,1333,1337,1338,1351,1355$, 1358,1365

Poreonu'u. See Porionu'u (Tahiti)

Porionu'u (Tahiti), 27, 971, 972, 973, 1003, $1174,1318,1364$

Porotonatoofa (Mo'orea), 981

Puaoa (Huahine), 997

Puarairai (Ra'iatea), 847

Puatiriura, 884

Pue (Tahiti), 1155

Pueu (Tahiti), 33, 34, 682, 1116

Pueu Toahotu (Tahiti), 28

Pukapuka, 1126

Puna'auia (Tahiti), 32, 515, 522, 675, 677-681, 722, 963, 975, 1155, 1181, 1191, 1192, 1193-1195, 1196, 1220, 1231, 1232, 1233, 
$1252,1319,1345,1346,1351,1353,1357$, 1361,1365

Puna'auia marae (Tahiti) 764, 883, 1178 , 1181. See also Taputaputea marae (Puna'auia)

Puna'auia Point (Tahiti), 684, 1194, 1353. See also Puna'auia (Tahiti)

Punaru'u Valley (Tahiti), 677, 1194

Punua, 881

Pû-'o'oro (Tahiti), 812

Pu-o-roo-i-te-ao, 523

Pu-o-roo-i-te-Pô, 523

Puppeare (Mo'orea), 254

Pupua (Ra'iatea), 892

Pupua Island. See Honden Island (Tuamotus)

Pure-ora Vale (Tahiti), 817, 818

Pureora marae (Tahiti), 682. See also Taputaputea marae (Tautira, Tahiti); Vaiotaha marae (Tahiti)

Raiamanu marae (Tahiti), 684

Raianaunau marae (Tahiti), 707, 831

Ra'iatea Island. See entries for specific locations.

Ra'iatea-Taha'a, 3, 975, 1108

Ra'i-to-moana, 1021

Rapa, 194

Rarotonga, 663, 670, 731

Rayona (Tetiaroa Atoll), 35

Rematoo (Tetiaroa Atoll), 35

Rohutu-noanoa, 523, 525

Rotu (Mo'orea), 981

Rotui, Mount (Mo'orea), 522, 557, 821, 823

Rotuma, 668

Rotuma (Fiji), 909

Ruaroa (Tahiti), 758

Rurutu, 160, 212

Samoa, 212, 311, 537, 539, 587, 804, 1126, 1127, 1135, 1144

Sandwich Islands. See Hawaiian Islands

Scilly Atoll, 529, 856-857

Seaward Teva (Tahiti), 681, 683, 795, 1032, 1225, 1234, 1237, 1291, 1292, 1312, 1317

Sir Charles Saunders Island. See Mai'ao Island

Ta‘ata marae (Tahiti), 675

Ta'atua Point (Tahiti), 1355

Taha'a Island, 7, 16, 22, 23, 24, 38, 212, 325, $452,663,671,717,780,847,856,881$, $884,895,898,899,906,955,964,967$, 1116, 1155, 1157, 1208, 1211, 1277, 1278, 1279, 1280, 1324, 1333, 1338, 1341, 1366. See also Ra'iatea-Taha'a

Tahara'a Point (Tahiti), 22, 23, 714
Tahiti Islands. See entries for specific locations

Tahiti Iti. See Lesser Tahiti

Tahiti marae. See Tahiti-Puna'auia marae (Tahiti)

Tahiti-Puna'auia marae (Tahiti), 675, 677, 679, 684, 1194, 1216, 1361

Tahiti-Mo'orea, 53, 214, 644, 674-685, 739, 882, 883, 904, 908, 909, 912, 922, 1039, 1044, 1064, 1142, 1143-1144, 1171, 1179, 1192, 1203, 1207, 1214, 1216, 1219, 1234, 1235, 1236, 1237-1255, 1265, 1295, 1307, $1314,1315,1326,1333,1337,1349-1350$, 1365

Tahiti Nui. See Greater Tahiti

Tahuea marae, 1019

Taianapa marae (Taha'a), 662, 663, 671

Taiarabu. See Tai'arapu (Tahiti)

Tai'arapu (Tahiti), 3, 8, 15, 28, 45, 53, 213, 240, 241, 360, 406, 455, 459, 488, 507, $511,517,521,681,682,710,775,881$, 893, 971, 972, 973, 978, 1108, 1173, $1174,1175,1188,1190,1192,1213$, $1214,1217,1221,1222,1223,1225$, 1230, 1232, 1237, 1238, 1241, 1243, $1244,1251,1252,1253,1257,1259$, $1267,1269,1276,1283,1292,1295$, $1300,1301,1309,1317,1318,1319$, 1329, 1333, 1343, 1345, 1346, 1355, 1363

Ta'inu'u marae (Ra'iatea), 662, 663, 670-671

Tainuu Promontory (Ra'iatea), 823

Taipoto, 772

Taohotu (Tahiti), 34

Tapaearue, 243

Tapahi (Tahiti), 1321

Tapi, 1281

Tapoohoe. See Tapuhoe

Tapuhoe, 214, 539

Taputapuatea marae (Atehuru, Tahiti), 515, 516

Taputapuatea marae (Fa'atoai, Mo'orea), 1354

Taputapuatea marae (Hitia'a, Tahiti), 675, 683

Taputapuatea marae (Opoa, Ra'iatea), 520, 535, 662, 663, 664-667, 673, 674, 892-893, 904, 1017, 1018, 1020, 1021, 1355

Taputapuatea marae (Pa'ea, Tahiti), 675

Taputapuatea marae (Papeto‘ai, Mo'orea), 1204

Taputapuatea marae (Pare-Arue, Tahiti), 675

Taputapuatea marae (Puna'auia, Tahiti), 675, $684,1231,1232,1353$

Taputapuatea marae (Taiarapu, Tahiti), 1213, 1214 
Taputapuatea marae (Tautira, Tahiti), 906, 1308, 1347, 1355

Taputuara'i marae (Tahiti), 675, 681

Tarahoi (Tahiti), 1181, 1265, 1280

Taraho'i marae (Tahiti), 675, 684, 760, 1002, $1142,1181,1182,1183,1216,1231,1235$, 1308, 1359, 1360, 1361, 1363

Taravao, Isthmus of (Tahiti), 15, 18, 45, 210-211, 780, 899, 907, 984

Tata'a Hill (Tahiti), 522, 523, 820

Tata'a Point (Tahiti), 1319

Taue Valley (Tahiti), 487

Tau i Upolu marae (Tahiti), 719

Taunoa (Tahiti), 815, 817, 818, 979, 1180

Tautira (Tahiti), 23, 28, 33, 34, 45, 175, 188, $502,512,513,545,675,682,683,756$, 781, 795, 811, 903, 906, 907, 963, 983, $984,1033,1116,1151,1155,1174,1188$, $1197,1199,1203,1226,1227,1230,1234$, 1238, 1308, 1309, 1316, 1317, 1322, 1329 , $1338,1347,1349,1355,1357,1361$

Tayarapu. See Tai'arapu (Tahiti)

Te-a'e tapu, Mount, 1021

Te Aha roa (Mo'orea), 964

Te`aharoa (Tahiti), 760, 832, 1228

Teahono'o (Tahiti), 1290

Teahu o rua tama marae (Tahiti), 893

Teahupo'o (Tahiti), 28, 33, 34, 682, 865, 963, 978, 983, 984, 1116, 1155, 1168, 1174, $1181,1182,1291,1356$. See also Matahihae (Tahiti)

Te ahu rua tama marae (Tahiti), 1355

Teahuupo'o. See Teahupo'o (Tahiti)

Te Ara e Tahiti marae (Tahiti), 1194. See also

Tahiti-Puna'auia marae (Tahiti)

Teauru, 481

Te-ava-moa passage (Ra'iatea), 910, 1018

Teavaroo (Mo'orea), 254

Tefanaautaitahi (Mo'orea), 981

Te Fana i Ahurai Tetaha (Tahiti), 684. See also Fa'a'a

Tefano marae (Mo'orea), 675, 685, 1138, 1204

Tefarerii (Mo'orea), 981

Te-hopura'a-vai-o-Hina (Tahiti), 714

Temehani, Mount (Mo'orea), 522, 523, 821, 960

Te-'ora'a-otaha (Ra'iatea), 612

Te Pari (Tahiti), 211

Teparoa marae (Maupiti), 669-670

Te piho ia teta (Tahiti), 683

Te-pori-a-tai (Ra'iatea), 899

Tepotuarai marae (Tahiti), 1182

Te Potuari marae (Tahiti), 1181

Te Puatea marae (Mo'orea), 685. See also

Taputapuatea marae (Papeto‘ai, Mo`orea)
Teraitoa, 668

Teraivetea marae (Ra'iatea), 662, 663, 1137

Terryoyootah, 973

Tetaha. See Fa'a'a (Tahiti)

Teteha. See Fa'a'a (Tahiti)

Tetero. See Tetiaroa Atoll

Tetiaroa Atoll, 4, 7, 20, 35-38, 209, 213, 240, $254,344,370,435,618,853,854,933$, 955, 956, 975, 1124, 1154, 1159, 1173, 1280, 1300, 1301, 1304, 1328

Tettahah (Tahiti). See Fa'a'a (Tahiti)

Teturoah Island. See Tetiaroa Atoll

Teva i tai. See Seaward Teva

Tevaitoa (Ra'iatea), 1019, 1207

Tevaitoa marae (Ra'iatea), 670

Teva i uta. See Landward Teva

Tiahupo'o marae (Tahiti), 1225, 1230

Tiahura marae (Tahiti), 407

Tiaraboo. See Tai'arapu (Tahiti)

Tiarapu. See Tai'arapu (Tahiti)

Ti’arei (Tahiti), 28, 683, 832, 963, 1155, 1173, 1177-1178, 1294, 1306, 1322, 1328

Tierei (Tahiti), 34, 973

Tikopia, 68, 554, 1126

Tippirreonoo, 1263

Tire (Tahiti), 1324

Tiva marae (Huahine), 1212

Tiva Point (Huahine), 673

Toa-hiva, 1021

Toahotu (Tahiti), 1155

Toareva, 1068, 1070

Tokelau, 1126

Tonga, 75, 178, 212, 257, 258, 423, 794, 1126, $1127,1144,1288$

To'oara'i marae (Tahiti), 675

To'ora'i (Tahiti), 681

Toutira (Tahiti), 514

Trobriand Islands, 1090

Tuamotu Islands, 4, 65, 138, 151, 194, 212, $214,277,348,511,677,710,856,979$, $984,1122,1136,1162,1180,1209,1272$, 1281

Tua-roa-nui-i-ao-pau marae (Huahine), 1209

Tubuai, 4, 53, 212, 539, 1256, 1257

Tuitui marae (Tahiti), 1196

Tumara'a (Ra'iatea), 1019

Tupae-mano. See Mai’ao Island

Tupai. See Motu Iti Atoll

Tupaururu (Mo'orea), 981

Tupea-mannoo. See Mai'ao Island

Tupuae Manu. See Mai'ao Island

Tyarrabboo. See Tai'arapu (Tahiti)

Uira marae (Taha'a), 662, 663

Ulietea. See Ra'iatea Island

Umarea marae (Mo'orea), 675, 685, 1204 
'Upolu Island. See Taha'a.

'Uporu (Tahiti), 683, 715, 1029. See also Ha'apape (Tahiti); Venus Point (Tahiti)

Upper Hiti (Ra'iatea), 982

Utuai marae (Tahiti), 675

'Utu-'aimahurau (Tahiti), 1213, 1214

'Utu'aimahurau marae (Tahiti), 685, 904, 1196-1197, 1221, 1231, 1232, 1233, 1234, 1245, 1247, 1256, 1293, 1296, 1304, 1307 1309, 1314, 1358, 1359, 1361, 1362

Utuhaihai Cape (Tahiti), 1183

Uvea, 1126

Vaearae. See Vaiotaha marae (Ra'iatea)

Vaearai marae (Ra'iatea), 649, 651, 662, 663, 1137

Vaearau marae (Ra'iatea), 188

Vaerai marae (Ra'iatea), 190

Vaiahu marae (Maupiti), 670

Vaiari (Tahiti), 28, 33, 34, 512, 516, 677, 679, $685,761,762,763,780,883,963,973$, $977,984,1038,1116,1120,1131,1161$, 1178, 1187, 1194, 1198, 1199, 1203, 1215 , 1216, 1293, 1303, 1309. See also Papeari (Tahiti)

Vaihiria Lake (Tahiti), 708

Vaihiria River (Tahiti), 678

Vainiania River (Tahiti), 1003

Vaiotaha marae (Porapora), 190, 662, 663, 666-667, 668-669, 671, 763, 907, 1065, 1151

Vaiotaha marae (Ra'iatea), 662-664, 763

Vaiotaha marae (Tahiti), 190, 675, 682, 683 1174
Vaiovau River (Tahiti), 1003

Vairao (Tahiti), 28, 34, 683, 1116, 1155, 1174, 1182,1199

Vaitape (Porapora), 896

Vai-tara-toa, 1022

Vai-tiare, 1021

Vaitoto (Taha'a), 719

Vaiuriri Tahiti, 27, 34, 514, 963, 973, 977, 1116, 1155, 1189, 1198. See also Pape'uriri (Tahiti)

Vaiuru-Vairao (Tahiti), 963

Vaiururi (Tahiti), 1293

Varari (Mo'orea), 685, 739, 964, 1204, 1205, $1206,1247,1252,1254,1257,1314$

Vavaara, 823

Vavau (Tahiti), 968, 1173. See also Ha'apaiano‘o (Tahiti); Papeno'o (Tahiti)

Vavau Island. See Porapora Island

Venus Point (Tahiti), 313, 715, 740, 854, 917, 1195, 1223, 1229, 1230, 1316, 1351, 1362. See also Ha'apape (Tahiti)

Vye Heereea Lake, 918

Vyeooredee, 918

Wa'ennah. See Oha aine (Tahiti)

Whahite. See Afa'ahiti (Tahiti)

Whennuaoora, 856

Whidea. See Hitia'a (Tahiti)

Whyripoo. See Ha'apaino'o (Tahiti)

Wilks Harbor (Tahiti), 1341. See also Pape'ete (Tahiti)

Windward Islands, 186, 1004. See also entries for specific islands

\section{NAME INDEX}

Adams, Henry, 674

Aheatua, 1071. See also Vehiatua II

Aimata, 452, 1180

Airoreatua, 1187. See also Purea

Airoreatua i Ahurai i Farepua, 1200. See also Purea

Aitofa, 823-824

'Aitupuai (god), 894, 897

Amo, 1179, 1190, 1199, 1200, 1201, 1202 $1205,1215,1217,1219-1220,1221,1223$, 1224-1225, 1227, 1228, 1229, 1231, 1233, $1234,1235,1237,1260,1265,1354,1355$, 1356, 1359, 1365. See also Te Vahitua i Patea (Title)

Ana, 446, 716-719, 745-747, 865

Areepaeoa Waheine. See Ari'ipaea Vahine

Arepaea. See Ari'ipaea
Aretaminu, 1345. See also Maro

Ari'imao, 1199, 1212, 1214, 1355

Ari'ipaea ("A"), 81-82, 192, 505, 511, 519, 723-724, 740, 836, 956, 1041, 1184, 1190, $1200,1254,1257,1260,1261,1265,1276$, $1277,1284,1286,1290,1292,1352,1353$, 1359

Ari'ipaea ("B"), 1202, 1361. See also Teri'irere

Ari'ipaea Vahine, 206, 486, 546, 1040, 1184, 1185, 1191, 1254, 1261, 1262, 1290, 1352

Ari'i Ta'ima'i, 1178, 1353

Aromaiterai ("A"), 984, 1025, 1199-1200, 1221,1354

Aromaiterai (“B”), 1190, 1200

Aromaitera'i i outa rau ma to'ora'i (Title), 681

Atae, 895, 899, 964, 1155 
Atea (god), 57, 203, 416, 608, 705, 724-725, 1050, 1053

Auna, 894, 1055

Auo, 1184, 1190-1191, 1205, 1206, 1242, $1252,1254,1257,1275,1290,1291,1294$ $1315,1319,1352,1359$

Auri, 408, 1178, 1179, 1187, 1192

Baessler, Arthur, 674

Banks, Sir Joseph, 28, 32, 1183

Barff, Reverend, 38, 477

Beaglehole, John C., 336, 1357

Bennet, George, 1048

Bishop, Captain, 1297, 1299, 1309 1310-1311

Bligh, Captain William, 3-4, 5, 267, 328, 535, $1111,1179,1182,1220,1250,1256,1272$, $1275,1288,1360$

Bobà, 607, 1210-1211

Boenechea, Don Domingo, 3, 28, 1227

Bougainville, Louis Antoine de, 3, 324, 363, $661,1211,1224,1351,1355$

Bourne, 38, 372

De Bovis, Edmond, 48, 1145

Broomhall, Brother, 699, 1299, 1303

Broughton, Lieutenant William R., 4, 520

Brown (seaman), 847, 1257, 1261, 1263 , 1270

Bunaruu, 895. See also Puna rua

Burkett (H.M.S. Bounty mutineer), 1261, 1263, 1264, 1265

Christian, Thursday October (H.M.S. Bounty mutineer), 1250, 1256

Churchill (H.M.S. Bounty mutineer), 848, 1158, 1258-1259, 1276

Cook, James, 3, 27, 30, 32-33, 34, 324, 355, $388,401,520,534,535,546,594,637$, 740, 748, 847, 850, 917, 1022, 1046, 1061, $1134,1207,1220,1223,1225,1226,1228$, 1238, 1258, 1265, 1285, 1288, 1358, 1365

Cox, Captain John Henry, 4, 1256, 1267

Darling, Brother, 372

Davies, John, 48

Donald, Michael, 1304

Dootahah. See Ha'amanemane; Mauri; Tutaha (Ha'amanemane)

Edea. See 'Itea

Edwards, Edward, 4

Ellis, William, 5, 38, 48, 779, 886, 1022

Erreretua. See Auo

Etari, 79, 1033, 1036

E-tee, 1176
Fa'ahoutu, 63, 557

Fa'arava'ai-anu, 708-709

Fa'atupuai i te Ra'i o Vehiatu i te Mata'i, 1182. See also Hapai; Teu

Faimano, 716, 717, 719

Fana (god), 53

Fataua. See Ari'ipaea Vahine

Fatowwa, 1262

Fatuarai, 1212, 1315, 1338

Fenua Peho, 1338, 1341

Fetefeteui, 1188, 1205

Fier re te. See Vaiareti

Firth, Raymond, 69

Flinders, 1359

Forster, [Johann] Georg Adam, 33

Forster, Johann Reinhold, 31, 343

Furneaux, Captain Tobias, 3, 849

Geronimo, Padre, 512, 515

Goldman, Irving, 1168

Great Foundation (god), 49, 604

Great Octopus (god), 469

Guatupua, 516, 517

Ha'amanemane, 85, 1255, 1277, 1278, 1279-1280, 1284, 1291-1292, 1293, 1294 1295, 1296, 1300, 1301, 1302, 1303, 1337, 1361, 1365. See also Mauri; Tutaha (Ha'amanemane)

Haggerstein, Peter, 31, 255, 968, 1272, 1294 , 1297, 1301, 1304

Hammennemanne. See Ha'amanemane

Handy, E.S.C., 55, 1126

Ha'oa'oa, 898, 906, 1150

Hāpai, 723-724, 1180, 1182, 1254. See also Teu

Hau (god), 59, 657, 1050

Hautea, 281, 287, 999

Hautia, 885, 887, 888

Hauvana'a, 786, 801-803, 810, 820, 830

Hawkesworth, John, 276, 932

Hayward, Brother, 1324

Hayward, Lieutenant, 1270

Hedeedee. See Hitihiti

Heiva, 1041, 1042. See also Teri'irere

Heiva ino, 963, 1155

Heiva (upaupa) ino, 963, 1155

Hema, 713, 730, 809-810, 1141, 1160

Hena, 672, 884

Henry, Teuira, 489, 646, 650

Henry, Brother William, 371, 696

Heywood, Peter (H.M.S. Bounty mutineer), 1256

Hidiea: See Pohuetea

Hihi-mai-vao, 814-816 
Hihira, 729-730

Hina, 708-710, 738

Hina (first woman), 433, 774

Hina (god), 49, 50, 53, 57, 132, 203, 219, 469, $591,602,664,890,892,895,1134$

Hina (Tafai's wife), 713-715, 820-821

Hina-ari'i, 702-703

Hina'ere'ere-manu'a, 53, 433

Hina-te-pipiro, 732-737

Hinatutupo, 891, 906

Hiro (god), 54, 57, 61, 305, 429, 662, 663, $664,671,673,714-719,730,746,906$, $987,1054,1087,1088,1317$

Hiro the Trickster, 429, 446, 730, 745-747, 821-822, 865, 1137

Hita, 963, 1155

Hitiea, 740. See also Pohuetea

Hitihiti, 343, 790, 836, 1241, 1259, 1260, 1263, 1264, 1275, 1279, 1358, 1359

Hoata (god), 81, 193

Hoataatama, 663, 667, 1137

Ho'ata-meamea (god), 894

Hoa-tapu (god), 894, 919. See also Hoatapuitera'i (god)

Hoatapuitera'i (god), 894, 895, 897. See also Hoa-tapu (god)

Honoura, 54, 219, 222, 359, 412, 537, 549, 553, 618, 713, 722, 737, 835, 846, 1026, 1051, 1149, 1157

Hototu, 677-679. See also Hotutu

Hotuaitu, 672, 826

Hotuhiva, 673, 826, 834, 884, 1146

Hotutu, 677-679, 1167, 1215

Hua atua, 963, 1155

Huatua, 895, 899

Huauri, 702-703, 811-812

Huiima'o (god), 1317

Huri-i-te-mono'i-a-'are-vahine, 731-737, 738, 783, 786, 792, 1134, 1148

Iddeeah. See 'Itia

Inna Madūa. See Vahine Metua

Inomedua. See Vahine Metua

'Itia, 81, 192, 327, 344, 369, 413, 423, 444, 507, 722, 725, 754, 785, 835-836, 844, 956, 993-994, 1041, 1058, 1059, 1061, $1167,1187,1189,1190,1204,1205,1206$, $1213,1220,1239,1242,1244,1252,1253$, $1256,1260,1277,1284,1290,1291,1293$, 1294, 1298, 1300, 1301, 1302, 1305, 1308, 1315, 1316, 1319, 1327, 1328, 1331-1332, 1336, 1338, 1339, 1341, 1352, 1356, 1362 , 1363,1364

Jefferson, 38, 48, 400, 491, 1303
John the Swede (beachcomber), 1294, 1297, 1301

Knott, Brother. See Nott, Brother

Lind, Andrew (beachcomber), 1294

Lycurgus. See Te Pau ("A")

Maavai (god), 886

Mae, 1175, 1230

Maemae-a-rohi, 711-713

Maeva Vahine, 673, 1025, 1209

Mahau, 206, 511, 517-521, 1205, 1206, 1238, $1239,1242,1247,1251,1252,1254,1257$, $1258,1259,1261,1266,1268,1275,1277$, 1290, 1291, 1294, 1315, 1319, 1354, 1356, $1357,1359,1360$. See also Matuaro; Metuaro Mahau; Motuaria

Maheanu'u, 1178, 1216

Maheiannoo, 451-452

Maheine. See Mahine

Mahi, 749, 897, 899-900

Mahine, 324, 782, 808, 865, 894, 949, 1036 , $1204,1220,1237,1238,1239,1242,1244$, $1245,1247,1250,1251,1252,1259,1275$, 1338, 1355, 1357, 1358, 1360, 1366. See also Mahine ("A"); Mahine ("B"); Punua Teraitua i Nu'urua (Title)

Mahine ("A"), 1188, 1204-1206, 1212, 1213, 1315-1316. See also Mahine; Punua Teraitua i Nu'urua (Title)

Mahine ("B"), 1188, 1205. See also Mahine; Punua Teraitua i Nu'urua (Title)

Mahow. See Mahau

Mahu, 846-847

Mahufaturau (god), 894, 897

Mai, 79, 365, 382, 426, 499, 547, 723, 740, $808,830-831,844,849,1033,1040,1046$, 1224, 1226, 1231, 1243, 1248, 1249, 1338

Main, Brother, 1297, 1303

Maioro, 1184. See also Vaetua

Ma'irûrû, 824-825

Manea, 1202, 1220, 1234, 1365

Manutahe (god), 193

Marama, 980-981

Marama (Hiro's son), 716, 822

Marama (Title), 739, 1137-1138, 1204

Marau Taaroa, 683, 779, 780, 1178, 1179 , 1180

Mare, 894, 1002, 1159, 1179-1180, 1278

Maro, 1344, 1345, 1346, 1347, 1348

Marore, 895, 964

Maro-'ura, 899, 963

Marremarre, 423, 1177

Mata'a, 899, 963, 1155 
Matafaahira, 980-981

Matamataarahu (god), 433, 861

Matatine (god), 311

Mato, 1212, 1278, 1315, 1338, 1355, 1360

Matte. See Pomare I

Mattee. See Pomare I

Matuara. See Matuaro

Matuaro, 847, 1277-1278, 1360. See also Mahau

Matuarro. See Matuaro

Maua, 1199, 1202, 1212, 1214, 1215, 1235, 1354

Mauaihiti, 848, 979, 1180

Mauaroa, 268, 955, 1182

Maui (god), 50, 54, 114, 131-132, 219, 412, $536,618,648,705,707-709,729-730$, 1140

Maui (the priest), 730, 908

Maui i upo'o varu, 132

Mauri, 1212, 1255. See also Ha'amanemane

McArthur, Norma, 529

Meetia. See Metea

Metea, 81, 1320, 1321, 1322, 1324, 1327

Metuaro Mahau, 1191, 1205. See also Mahau

Millward (H.M.S. Bounty mutineer), 1265, 1269

Miriama, 815

Moanarai, 822-824, 1147

Moe (chief), 706

Moe (god), 891

Moehonu, 491-492

Moerenhout, Jacques-Antoine, 48, 438, 1063

Moeterauri, 717

Moeterauri (Title), 682

Moiri, 717, 746

Mono'i-here, 714-715

Mo'ohono, 1212, 1213, 1315, 1355

Mo'o tua Raha, 550, 618-619, 707

Morrison, James, 31, 33, 48, 343, 347, 451, 1064

Mottooarro. See Mahau

Motuaria, 1205. See also Mahau

Moutahaa. See Mutaha'a

Mowree. See Ha'amanemane; Mauri

Mowroah. See Mauaroa

Mowworroah. See Mauaroa

Moyere. See Vahine Metua

Mua-va'a, 731-737

Muspratt, 1263, 1265

Mutaha'a, 895, 955, 964, 1155

Mutuarea, 1199-1200

Narcisco, Padre, 515

New, Thomas, 4, 1272

Nita, 955, 1155

Niuhi, 707, 798
Nona, 713-715

Nott, Brother, 48, 384, 400, 424, 491, 994, 1059, 1298, 1323, 1324, 1339, 1364

Nouatoua, 955, 1155

Nuatua, 955, 1155

Nuu, 677, 680

Nuutea, 677, 679, 680

Oāhīvari (god), 60

Oammo. See Amo

Obarea. See Purea

Oberreeoah. See Tetupaia

Oberreeroah. See Tetupaia

Odiddee. See Hitihiti

Odiddy. See Hitihiti

Ofeufeumaitera'i (god), 49

Oheatoua. See Vehiatua II

Omai. See Mai

Ootie, 849

Opoone, 405, 1210, 1280

Opoony. See Opoone

Opuhara, 1323, 1335, 1340, 1344-1348, 1365

Opunua (god), 517

Orea, 275, 324

Oree, 972, 1164, 1211-1212

Oreepiah. See Ari'ipaea ("A")

Oreepyah. See Ari'ipaea ("A")

Oreo, 1210, 1211

Orepia. See Ari'ipaea ("A")

Orepiah. See Teri'irere

O-Rettee. See Reti

Ori, 972, 1164, 1211-1212

'Oro (god), 49, 50, 53, 57, 59, 60, 61, 66, 74, 75, 81, 90-92, 107, 109, 110, 115, 189, 193, 273, 358, 360, 385, 386, 409, 450, $465,473,474,521-522,525,532,533$, 534, 591, 657, 662, 664, 666, 671, 673, $682,683,763,774,867,868,881,882$, 883, 884, 888, 890-913, 914, 926, 927, 929, 930, 932, 937, 938, 942, 944, 950, 954, 955, 960, 962, 981, 983, 987, 1012, $1017,1018,1019,1021,1022,1039$, 1055, 1060, 1105, 1106, 1107, 1108, $1109,1115,1119,1131,1132,1134$, $1143,1145,1150,1151,1152,1153$ $1160,1167,1174,1197,1199,1213-1214$, 1223, 1229, 1231, 1232, 1233, 1234, $1235,1236,1239,1245,1247,1279$, 1280, 1292, 1293, 1296, 1304, 1307-1308, $1309,1310,1314,1316,1317,1318$, $1319,1320,1321,1322,1324,1325$, 1327, 1328-1329, 1335, 1336, 1338, 1339, 1340, 1341, 1345, 1347, 1349, 1354, 1355, 1363-1364, 1365. See also Subject Index: Arioi sect; Cults of 'Oro 
Orotetefa (god), 895, 896, 898, 906, 915, 955, 1151

Orsmond, Reverend John Muggridge, 5, 38, 40

Ota, $1210-1211$

Oti-va‘a, 731-737

Otoo. See Pomare I; Pomare II; Tu

Otoo-nooey te Atooa. See Pomare I; Tu Nui eaa i te Atua

Otu. See Pomare I; Pomare II; Tu

Oupoufora. See Opuhara

Ouru (god), 53

Oviriau, 517, 741

Paa, 955, 963, 1155, 1266

Paheete, 1058, 1331

Pai, 537, 548, 702, 706, 719, 811, 1006, 1137

Paino, 1178, 1179. See also Poeno

Paiti, 1184. See also Vaetua

Panoff, Michel, 1138

Papa. See Stratum Rock

Papy, H. René, 20

Paraha, 1320, 1327

Paraita, 814

Pateamai, 1188. See also Vaiareti

Pateamai (Title), 1204

Pati'i, 105, 890, 1197, 1340. See also Vaetua

Pepiri, 835, 1189-1190, 1290

Pereitai, 611-612, 738, 755-757, 776, 794, $800,834,878$

Peter (Swedish beachcomber). See Haggerstein, Peter

Piddington, R. See Williamson, Robert W.

Piha, 1189-1190

Piho, 716, 822

Pipiri. See Pepiri

Poatateu. See Pohuetea

Poatatou. See Pohuetea

Poe'eno. See Poeno

Poeno, 850, 1179, 1262, 1281, 1282, 1283 , $1284,1351-1352$

Pohuetea, 355, 594, 740, 835, 838, 1194-1195, 1197, 1199, 1216, 1220, 1233, $1241,1242,1244,1245,1247,1248,1252$, 1264, 1265, 1266, 1293, 1353, 1357

Poiriri, 670-671

Polatehara. See Purutihara

Polatehèra. See Pohuetea

Polotheara. See Purutihara

Pomare, 81, 194, 272, 357, 467, 511, 517, 518, $519,520,521,545,644,754,760,782$, 868, 997, 1002, 1003, 1007, 1031, 1041, $1056,1058,1162,1163,1294$. See also Pomare I; Pomare II; Pomare III; Pomare V; Pomare Dynasty
Pomare I, 45, 102, 268, 313, 340-341, 346-347, 369, 413, 423, 442, 493, 508, $722,723-724,740,774,785,792$, 834-837, 850, 854, 856, 956, 973, 977, 993-994, 1040, 1041, 1054, 1089, 1134, 1137, 1139, 1147, 1149, 1162, 1163, 1179, 1181, 1183, 1184, 1185-1187, 1189, 1192, 1193, 1194, 1195, 1198, 1201, 1202, 1204, $1210,1212,1213,1220,1221,1222,1226$, $1227,1229,1231,1232,1233-1234,1235$, $1238,1239,1240,1241,1242-1243,1244$, $1245,1246,1247-1249,1250,1251-1255$, 1256-1257, 1259, 1260, 1261, 1263, 1267, $1268,1275,1276,1277,1278,1279,1283$, 1290, 1292, 1293, 1294, 1295-1304, 1305, 1306, 1307, 1308, 1309-1312, 1312-1313, $1315,1352,1353,1356,1358,1359,1360$, 1361, 1362, 1363. See also Tu; Tu Nui eaa i te Atua

Pomare II, 35, 82, 265, 267, 268, 269, 372, $434,452,469,483,725,748,764,774$, 777, 837, 906, 907, 992, 1035, 1039, $1044,1048,1061,1064,1136,1139$, $1148,1160,1185,1187,1206,1216$, $1230,1253,1254,1258,1260,1265$, $1266,1268,1270,1271,1275,1276$, $1277,1278,1279,1280-1281,1282,1284$, 1287, 1290-1291, 1292, 1293, 1295-1304, 1306, 1307, 1308, 1310, 1314, 1315, $1316,1317,1318,1319,1320,1321$, 1322, 1323-1324, 1325, 1326-1332, 1333-1334, 1336, 1337, 1338, 1339-1342, 1346-1349, 1357, 1358, 1359, 1360, 1361, 1362, 1363, 1364, 1365-1366. See also Tu Pomare III, 724, 1164

Pomare V, 1180

Pomare Dynasty, 511, 750, 791, 979, 1350

Pomare ("Old"). See Pomare I

Pomare, Queen. See Pomare vahine

Pomare vahine, 436, 814, 1139, 1155, 1337 , 1342, 1344-1345, 1366

Poohaitaiah, 973

Poohaitaiah Otee, 423

Popa, 607, 1210-1211

Poppo, 362-363

Portlock, Lieutenant Nathaniel, 4, 1359

Potatou. See Pohuetea

Potatow. See Pohuetea

Pottatea. See Pohuetea

Pua, 731, 736-737, 738

Puahaha, 963, 1155

Puna rua, 955, 1155. See also Bunaruu

Puni, 668-669, 1113, 1157, 1210, 1211, 1220, $1278,1337,1338,1351,1355,1358$

Punua'aitua (Title), 1196, 1357

Punua Teraitua i Nu'urua (Title), 980-981, 
1003, 1188, 1204, 1205. See also Mahine ("A"); Mahine ("B")

Purahi, 1174, 1239, 1351, 1355, 1356. See also Te Vahine Moeatua

Purai. See Purahi; Te Vahine Moeatua

Purea, 362-363, 681, 995, 1178, 1179, 1187, 1192, 1199, 1200-1201, 1202, 1215, 1217, 1219-1220, 1221, 1224, 1227, 1233, 1235, $1249,1354,1364$

Puru, 1213. See also Mahine ("A")

Purutihara, 1195, 1353

Pyetea, 867

Pyeteea, 1262

Ra (god), 881

Ra'a (chief), 1220

Ra'a (god), 52, 59, 69, 533, 657, 668, 722, 888,1070

Raatapu, 717-718

Ra'i, 814

Rata (chief), 710-713, 1051

Rata (god), 54, 56, 219, 278, 539, 544, 803, 1067, 1141

Raupa'a, 963, 1155

Raure'a, 847, 1148

Rehia, 702-703, 811-812, 1006

Reti, 1176-1177, 1190, 1225, 1351, 1352. See also Teri'itua

Rifarifa, 270-271, 277, 707

Rodriguez, Maximo, 28, 48, 343, 1163

Romatane (god), 262, 523, 915, 919, 929, 935, 938, 944, 960, 1153

Ro'o (god), 57, 85, 108, 203, 415, 672, 1151

Rooa. See Rua

Ro'otane (god), 891

Ro'oteroro'o, 108, 114, 475, 481

Roto-va'a, 731-737

$\mathrm{Ru}, 602,738$

Rua, 469, 1311

Rua-hatu, 818, 881, 1317

Rua-hatu-tini-rau, 313, 854, 884

Ruaitefa'atoa (god), 59

Ru'anu'u (god), 60, 891

Rua ta'ata, 705-706

Rua-tapua-nui (god), 523

Rumia, 49, 531

Rû-roa, 709-710

Sahlins, Marshall, 1126-1128, 1169

Schmitt, Robert G., 530

Scott, 1323, 1324, 1362

Sharp, Andrew, 539

Simpson, Captain, 1299, 1309, 1313

Smith, S. Percy, 910

Stratum Rock (god), 49, 50, 55, 57, 61, 323, 604, 670, 704, 726, 891

Sumner (H.M.S. Bounty mutineer), 1263
Ta'arei, 824-825

Ta'aroa (god), 48, 49-50, 51, 53, 56-58, 59, $60,75,77,78,93,95,96,188,202,203$, $308,382,391,416,523,524,526,531$, $542,591,604,621,657,662,664,673$, 679, 682, 702, 704, 705, 756, 763, 781, 881, 882-884, 890, 891, 892, 894, 895, 896, 904-906, 908, 923, 1029, 1050, 1141, $1143,1150,1235$

Ta'aroa-Manahune, 791, 1180, 1181-1182, 1183, 1195

Taaroarii, 460

Ta'aroari'i ("A"), 1188, 1205

Ta'aroari'i (“B”), 1191, 1205, 1206. See also Metuaro Mahau; Mahau

Ta'ata (god), 53, 894

Ta'ata Uraura. See Vehiatua II

Tabyroo, 1282, 1283. See also Tapiru

Ta'ere (god), 202, 203, 204, 433, 705, 726, 872

Ta'ero, 1050

Taerree, 836

Tafai, 523, 706, 730, 742, 780, 809, 820-821, 1160

Tafa'i. See Tafai

Taia, 831-832

Taihia, 731, 811, 1006, 1026, 1051

Ta'ihia. See Taihia

Ta'imai. See Ta'ima'i

Ta'ima'i, 267, 983, 986

Tairihamoetua, 1205, 1239, 1247, 1252, 1257, 1259,1260

Tama (god), 481

Tamatea (god), 59

Tamatoa, 1047-1048, 1341. See also Tamatoa I; Tamatoa II; Tamatoa III; Tamatoa IV

Tamatoa I, 893, 899. See also Tamatoa

Tamatoa II, 1212, 1338. See also Tamatoa

Tamatoa III, 1183, 1210, 1212, 1216, 1278, 1279, 1336, 1337. See also Tamatoa

Tamatoa IV, 1118, 1212, 1336, 1337, 1342. See also Tamatoa

Tamatoa (Title), 666, 866, 907, 1004, 1009, $1017,1105,1155,1161$

Tamera, 105, 1197

Tane (god), 51, 57, 60, 77, 80, 81, 92, 108, $115,131,193,202,203,204,205,214$, $308,382,415,416,450,536,608,657$, 671, 672, 704, 705, 724-725, 726, 774, 781, 867, 868, 881, 883, 884-890, 891, 906, 908, 987, 1017, 1019, 1105, 1106, $1107,1115,1149,1150,1151,1152,1160$, 1317

Tanihaa, 717. See also Taru'i-hau

Tanivaere, 717. See also Te-rima-'aere

Tanuta (god), 891 
Tapiru, 1282, 1283, 1284

Tapoa, 994, 1316, 1338-1339. See also Tapoa I (the Great)

Tapoa I (the Great), 872, 1212. See also Tapoa

Tapoa (Title), 1004, 1009

Taputura, 672, 884

Taraimano, 459, 460

Taramanini, 895, 897, 945, 954, 955, 1107

Taramea, 1336, 1344, 1346

T-Aree Watow, 1040. See also Te Ari'i Fa'atou

Taruia, 631, 814-820, 1142

Taru'i-hau, 746. See also Tanihaa

Taua-i-taata, 831-832

Taura'a-atua, 899, 1116, 1155

Tauraatua, 895, 955, 964

Taura atua i amo, 757-758

Taura Atua i Patea (Title), 1193, 1196

Taurua, 899

Taurua (Tavi's wife), 795-798, 1199

Taurua (Tuiaeha'a's wife), 1178

Ta'urua (Venus), 129, 1050, 1067

Taute, 868, 1322, 1323, 1330

Tavihauroa, 795-798, 983-984, 1199

Tayreede, 1291, 1293

Tayreehamoedooa. See Tairihamoetua

Te Aha Huri Fenua, 682, 683, 1182

Teano. See Vaiareti

Teare (god), 193

Te Ari'i Atua, 683, 1176

Te Ari'i Fa'atou, 1184. See also Ari'ipaea ("A")

Te Ari'i na Vaho Roa, 1137, 1184-1185, 1201-1202, 1254

Te Ari'i Nohorai, 1212. See also Tapoa I (the Great)

Te Ari'i Nui o Tahiti (Title), 675, 677, 762, 1216

Te Ari'i o Maeva Rau, 1187

Te Ari'i Vaetua (Title), 684

Te Atua Nui e Maru ae i te Rai (Title), 684, 1216

Tebourai Tamaida, 1231

Tedua Tehamai, 1184

Tedua-Towrai. See Ari'ipae Vahine

Tee (first man), 488

Tee (chief). See Tii (chief)

Teena, 722

Te'eva (Title), 1215

Te'eva Pirioi, 984, 1199, 1212, 1214

Te-fatu (god), 202, 203, 582, 658, 891

Te Fatu (Rotuman chief), 909

Teha'apapa, 1212. See also Fatuarai

Teheiura, 1213. See also Mahine ("A")

Teihamoeroa i Matahihae, 1182. See also Hapai; Teu
Teihotu, 1187, 1192, 1205, 1219, 1220, 1237 , 1239

Teihotu Matanevaneva, 668-669, 1052, 1065-1066, 1211

Teihotu Mataroa, 668-669, 1211. See also Puni

Teissier, Raoul, 555, 1209

Temaiatea, 895, 955, 964

Te Manutunuu, 677-679, 1194

Temari'i, 1202. See also Teri'irere

Temari'i Ari'ifa'ataia, 1202. See also Teri'irere

Temariotu'u (god), 219

Temeharo (god), 60, 891, 906, 1160, 1317

Te-muri, 457, 755-757, 776, 834

Tenania, 1212, 1213, 1315, 1319, 1327, 1336, $1338,1339,1341$

Teohu, 1007, 1294, 1306, 1322

Tepa (god), 81, 1320, 1329

Te Pau (“A"), 1164, 1187, 1192, 1193, 1200, $1220,1233,1237,1242,1266$

Te Pau ("B"), 1191, 1233, 1252, 1261, 1279

Te Pau (“C”), 1184, 1191, 1193, 1255, 1261, $1277,1290,1293$

Te Pau (Hitihiti's wife), 1279

Te Pau i Ahurai (Title), 1187, 1192, 1193, 1227

Tepouaru, 716-719

Teppahoo. See Te Pau (“A”)

Tepuaiti i te rau 'onini, 824-825

Tera'a roa, 955, 963, 1116, 1155

Teraimateti (god), 313

Teramanini, 964, 1117

Tereiatua, 1181

Teri'i na Vaho Roa, 1254, 1278, 1279, 1291, 1292, 1296, 1300, 1312

Teri'irere, 1041, 1042, 1117, 1139, 1169 , 1184, 1197, 1201-1202, 1219-1220, 1221, $1222,1224,1233,1234,1248,1254,1257$, $1260,1270,1271,1291,1293,1295$, 1296-1297, 1298, 1299-1300, 1301, 1303. See also Ari'ipaea ("B")

Teriirere i tooarai, 681, 682, 1032

Teri'itahi, 1025, 1199

Teri'itapu nui (Title), 1204, 1276

Teri'itapu nui ("A"), 1205, 1206, 1238, 1239. See also Mahau

Teri'itaria, 1212, 1213, 1278, 1315, 1316, 1336

Teri'i-tau-mata-tini, 814-820

Terii te Po Arei, 1212. See also Mato

Teri'itua (Title), 683, 1176. See also Reti; Vahine Metua

Teri'i Vaetua i Ahurai, 1187, 1219, 1220

Te-rima-'aere, 746. See also Tanivaere

Terito o Te Ra'i, 1336, 1337, 1338, 1339

Teroro e Ora, 1179, 1200 
Terorohiti, 673, 1209

Terraighterree, 1198

Terrano, 1193

Terrederrie. See Teri'irere

Terrerree. See Auo

Terry Derry. See Teri'irere

Terupe, 772

Te Toimata a Tuanuio Oro, 894

Te To'ofa, 30, 32, 107, 637, 877, 972, 973 1036, 1192-1193, 1196, 1197, 1199, 1233, 1240, 1241, 1244, 1245-1249, 1250-1253, 1261, 1262, 1263, 1264-1265, 1293, 1319

Te To'ofa ("B"), 1266

Te To'ofa (betrothed to Maahehanoo), 1293

Te To'ofa (father to above), 1293

Te To'ofa (Title), 1196, 1198

Tettowah. See Te To'ofa

Tetua. See Tetuanui

Tetuaehuri, 984, 1180, 1181, 1259

Tetua Nihura'i, 1184. See also Te Ari'i na Vaho Roa

Tetuanui, 669, 1199, 1275, 1290, 1315

Tetuanui e Marua i Te Rai (Title), 1194, 1195 See also Pohuetea

Tetuanui Rei i te Ra'iatea (Title), 1204, 1205. See also 'Itea

Tetuaraenui, 1178, 1179

Tetua Umeretini (Teri'itahi's wife), 1182, 1199

Tetuaunouna, 516, 517

Tetuaunumaona. See Vehiatua III

Tetua Unurau, 1190, 1200

Te Tumu O te Papa. See Stratum Rock

Tetunae, 231, 348, 595, 620, 646, 675-677 695, 759, 1030, 1037, 1067-1070, 1134, 1135,1139

Tetupaia, 1181, 1183, 1185, 1190, 1191, 1193 $1202,1210,1212,1216,1234,1235,1254$ $1255,1261,1268,1278,1279,1280,1336$, 1337

Te Tupuai e te Ra'i, 1184. See also Vaetua

Teu, 1180, 1181, 1182, 1183-1184, 1185, 1190, 1191, 1193, 1202, 1216, 1223, 1229 , 1230, 1254, 1261, 1278, 1312, 1352, 1353, 1356. See also Hāpai

Te-unu-tai-ahu, 670-671

Te-unu-tai-marae, 670-671

Teuraiterai. See Tuiterai ("A")

Te Uri, 896, 898, 906

Teva, 678-679, 680-681, 683

Te Vahine Moeatua, 1174, 1175, 1176, 1190 1200, 1221-1222, 1351. See also Purahi

Te Vahitua i Patea (Title), 685, 832, 1196, 1197. See also Amo

Tew. See Te To'ofa

Tewha. See Te To'ofa
Thompson (H.M.S. Bounty mutineer), 848, 1258-1259, 1267

Threlkeld, 38, 967

Ti'a au, 963, 1155

Ti'i (god), 50, 51-52, 53, 57, 774

Tii (chief), 520-521, 1032, 1134, 1179, 1240, 1351

Ti'ipari'i, 1178, 1179, 1351

Ti'iti'i-po (god), 433

Ti'itorea, 1174, 1175, 1227, 1232, 1351

Tina, 1185. See also Pomare I

Tina (brother to Hena), 672, 884

Tino, 1336, 1346. See also Taramea

Tipa (god), 57, 815

Tipouro. See Te Pau ("A")

Tiri, 664, 892

Titihauri, 684, 1194

Titorea, 380, 1237

To‘a-hiti (god), 276, 891

Toahitu (god), 891

Toa-te-manava, 865, 893

Tobin, 1359

Tohu (god), 81, 861, 867

To'imata, 894, 897, 906, 908

Tomārre, 973, 1199, 1261, 1263, 1267, 1269, 1284

Tomorrow-Morning, 1310-1311

Toobouratomite. See Te Pau ("A")

To'ofa. See Te To'ofa

Toota-ah. See Ha'amanemane; Mauri; Tutaha (Ha'amanemane)

Toppere, 1351. See also Ti'ipari'i

Toumata, 887, 888, 889

Towha. See Te To'ofa

T'tewha. See Te To'ofa

Tu, 107, 206, 213, 233, 256, 370, 379-380, $382-383,505,515,517,637,723-724$, 845, 847, 953, 954, 956, 971, 972, 973 975, 993, 1011, 1031, 1036, 1040, 1054, 1059, 1061. See also Pomare I; Pomare II

Tu (god), 49, 51, 57, 59, 60, 657, 781, 881 $891,893,906$

Tu (of Faarava), 848, 979, 1180, 1181

Tû (Stability), 672

Tuaroanuihau, 673-674, 1209

Tubai. See Tupaia

Tufeufeumaitera'i, 894, 897

Tuhei, 980-981

Tui-hana-taha-te-ra, 817-820

Tui-hani-potii, 731-737

Tuihiti, 786, 801-803, 810, 820, 830

Tuiterai ("A"), 795-798, 1199

Tuiterai ("B"), 984, 1025, 1200, 1221

Tui te ra'i i Taputuara'i (Title), 681

Tu Mata Riri, 963, 1155

Tu-moana-urifa, 270-271, 277, 707 
Tumu. See Stratum Rock (god)

Tumu-nui, 801-802

Tunuatefatutiri (god), 891

Tu Nui ae i te Atua (Title), 684, 774, 1002 , 1003, 1162, 1184. See also Pomare I

Tu-Nui-Paia-i-Teparoa (Title), 670

Tupaia, 27, 28, 29, 32-33, 34, 39, 212, 404, $478,508,539,790,953,971,1062,1202$, $1212,1213,1215,1222,1234,1351$

Tupaya. See Tupaia

Tupia. See Tupaia

Tupura'a i Tamaiti. See Te Pau ("A")

Turaiari'i, 1212, 1213, 1316

Turaipo (god), 433, 861

Turi (god), 846-847, 1148

Turnbull, John, 38

Tutaha (guardian of Maahehanoo and Te To'ofa), 1293

Tutaha (Ha'amanemane), 268, 540, 1177, 1181, 1182-1183, 1191, 1192, 1193, 1195, 1196, 1199, 1221, 1222, 1224, 1225-1232, 1233, 1234, 1236, 1249, 1279, 1325. See also Ha'amanemane; Mauri

Tutaha ("Old"), 1181, 1182

Tu-ta-horoa (god), 523, 821

Tutapu, 672, 731, 811, 884

Tuteha. See Ha‘amanemane; Mauri; Tutaha (Ha'amanemane)

Tuturumaa, 963, 1155

Tuturu Ma'a, 963, 1155

Tuturu Rai, 963

Tynah. See Pomare I

Upaparu, 963, 1155

Upa upa ino, 1155

Uretaetae (god), 526, 557

Uretetefa. See Urutetefa

Urripiah. See Ari'ipaea ("A")

Uru, 1210, 1365. See also Vetea Uru

Uru-o-te-oa-ti’a (god), 52

Urutaetae, 960

Urutetefa, 895, 896, 898, 906, 915, 919, 955

Vaeaiteuruoro, 894-895

Vaetua, 174, 1184, 1252, 1255, 1257, 1227, 1283, 1290, 1294, 1301. See also Pati'i

Vahine Metua, 511, 583, 956, 1190, 1200, $1290,1292,1294,1352$

Vaiareti, 171, 519, 754, 932, 1188-1189, 1190, 1205, 1207, 1252, 1290, 1356, 1357

Vaieriti. See Vaiareti

Vaira'atoa, 1181. See also Pomare I
Vairaumati, 894-895, 896-897, 898, 906, 919, 1145, 1167

Vanaama-i-terai, 831-832

Vancouver, Captain George, 4, 1179, 1272, $1287,1359-1360$

Vanu'u, 1199-1200

Varimataauhoe, 678, 1167

Vavea, 1187-1188, 1192, 1205, 1206, 1237, 1239,1352

Vehiatua, 45, 211, 408, 435, 436, 455, 488, 489, 723, 972, 983, 1011, 1033-1034, 1061, 1180, 1181, 1203, 1276, 1277, 1292, $1296,1300,1312,1351$. See also Vehiatua I; Vehiatua II; Vehiatua III; Vehiatua V

Vehiatua I, 406-408, 1113, 1174, 1175, 1190, 1199, 1200, 1220, 1221, 1224, 1225-1232, $1238,1239,1356$. See also Vehiatua

Vehiatua II, 501-502, 506, 507, 511-517, 1175-1176, 1188, 1230, 1232, 1237, 1239, $1241,1243,1249,1257,1356$. See also Vehiatua; Aheatua

Vehiatua III, 848, 1175, 1176, 1195, 1207, 1238, 1239, 1252, 1258, 1276, 1356, 1357, 1358. See also Vehiatua

Vehiatua V, 1291. See also Teri'i na Vaho Roa

Vehiatua (Title), 645, 684, 704

Vehiatua i te Matai (Title), 1174

Vete'a Ra'i Uru, 1337. See also Uru; Vetea Uru

Vetea Uru, 1210-1211, 1212, 1337, 1355. See also Uru

Vini, 814-815, 820

Wainee-òu, 355

Wallis, Captain Samuel, 3, 1220, 1224

Watts, Lieutenant John, 1357

Weatherhead, Captain Matthew, 4, 1272, 1282

Whappai. See Hapai; Teu

Whydooah. See Vaetua

Whyerreddee, 1188, 1190. See also Auo; Vaiareti

Whytooa. See Vaetua

Widouah. See Vaetua

Williams, Brother John, 38, 967

Williamson, Robert W., 1126

Wilson, Captain William, 31, 39

Wilson, James, 31, 33, 35, 424

Wowwo. See Auo

Wydooah. See Vaetua

Wyetua. See Vaetua

Wyreede. See Vaiareti 



\section{ABOUT THE AUTHOR}

DOUGLAS L. OLIVER is emeritus professor of anthropology, Harvard University, and presently occupies the Pacific Islands Chair in Anthropology, University of Hawaii. He obtained the degree of Ph.D. in Ethnology from the University of Vienna in 1935, and subsequently held a number of positions, both academic and governmental. He was a consultant on Pacific island affairs for the Department of State from 1948 to 1951 and for the United Nations in 1949. He has, during his career, carried out a number of ethnographic field studies, including one of Bougainville in the Solomon Islands and two of the Society Islands. He also planned and directed the postwar Economic Survey of Micronesia for the Naval Military Government to provide for rehabilitating the native economy in the Trust Territory of the Pacific Islands.

As a scholar on the Pacific islands, Professor Oliver is among the most distinguished. His writings are numerous, and include the following books: A Solomon Island Society (1955), The Pacific Islands (1951, revised ed., 1962) a classic in its field, Invitation to Anthropology (1964), and Bougainville: A Personal History (1973). He edited Planning Micronesia's Future (1951, reprinted 1971). 


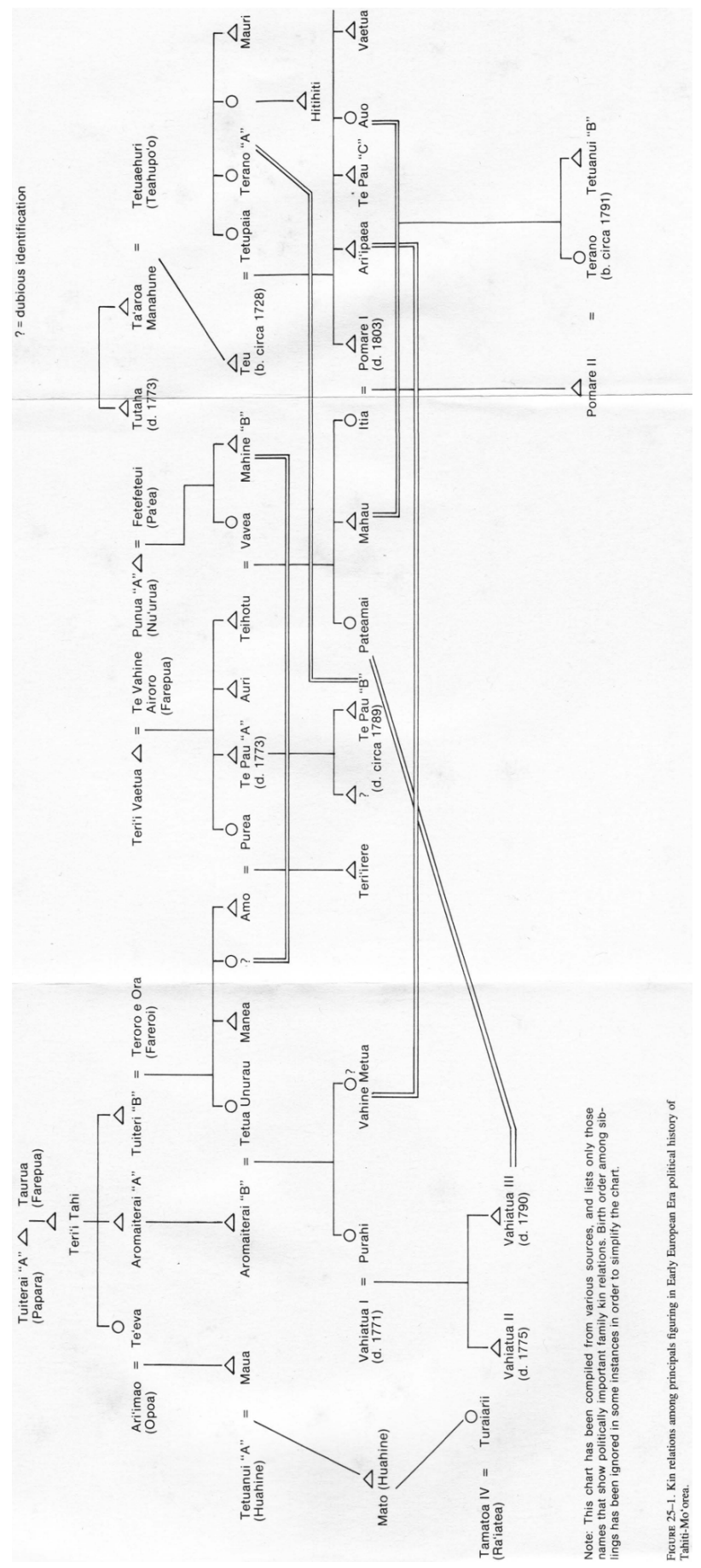



